


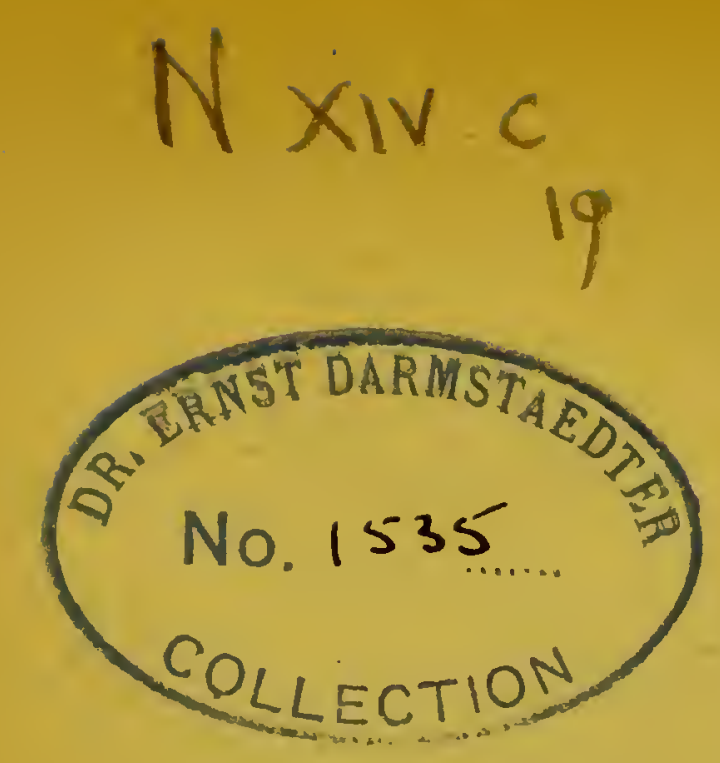

fallero

(2) $A Q$ 


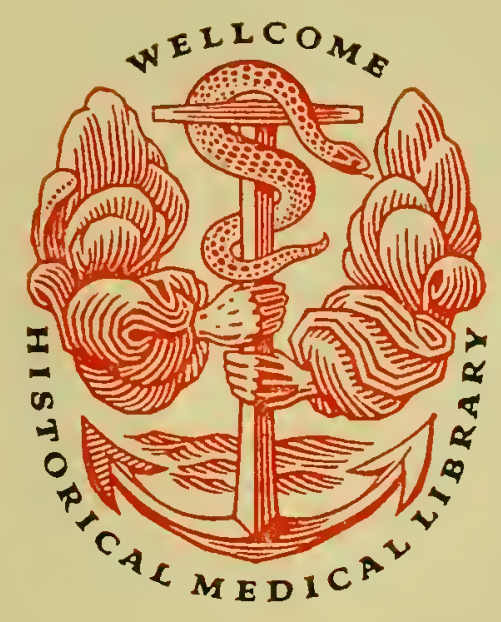

ACCESSION NUMBER

PRES S MARK 



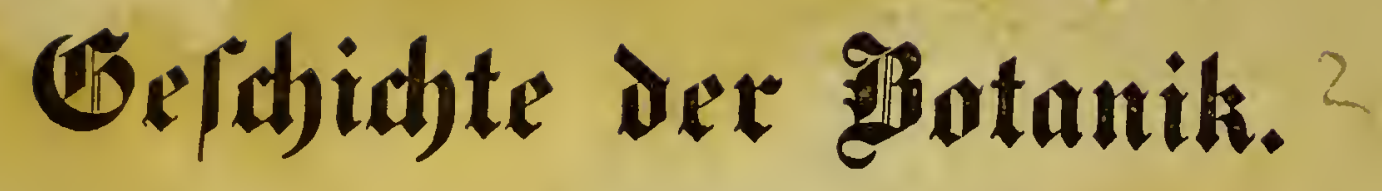




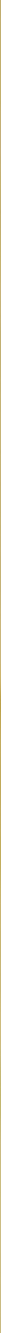




\section{(Geldidide $\mathfrak{d e r}$ isotanili.}

$\mathfrak{B} \mathfrak{n}$

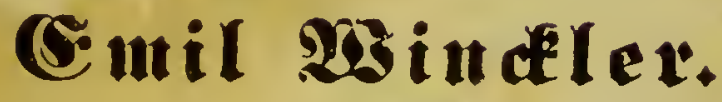

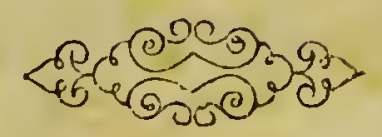

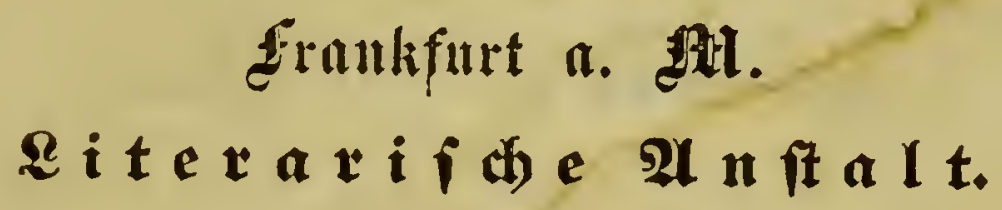

(3. SRütten.)

1854. 
Galeers

(2) $A Q$

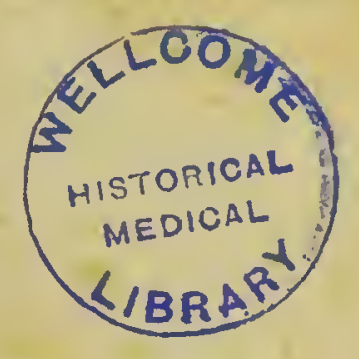

Druft von $\mathfrak{z}$ \%. v. 3abern in Minn. 


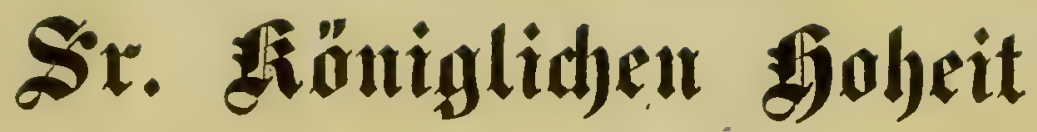 Ruswig III.,
}

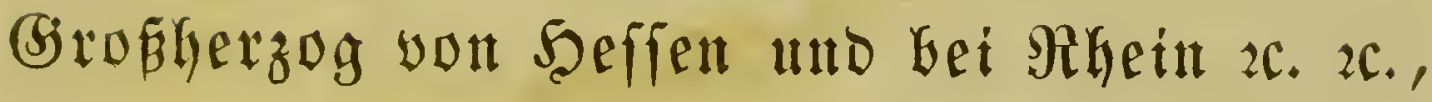

\author{
$\dot{\mathfrak{a} l g}$
}

\section{3eichen tiefiter Berebrung}

alleruntertbänigft gelviomet

dem Syerfaffer. 



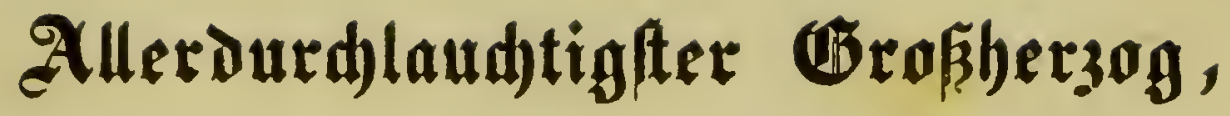

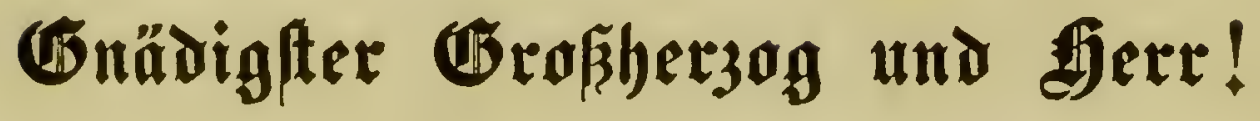

Dic thatträftige $\mathfrak{A}$ tufmcrffanteit und Iheitnahme,

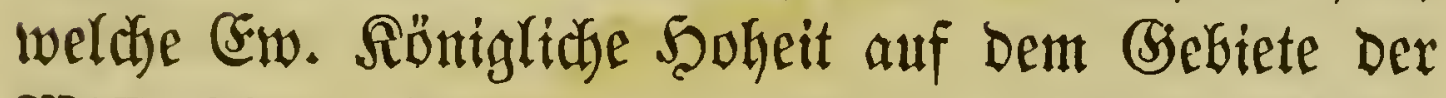

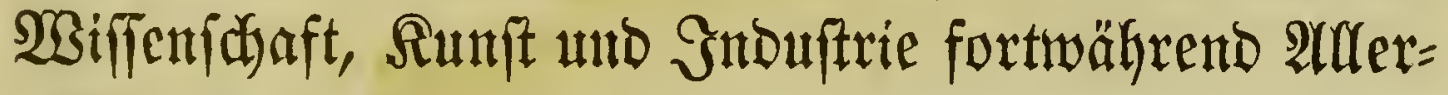

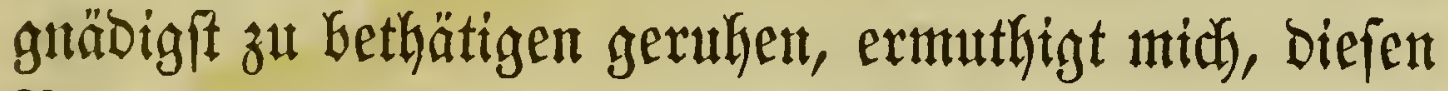

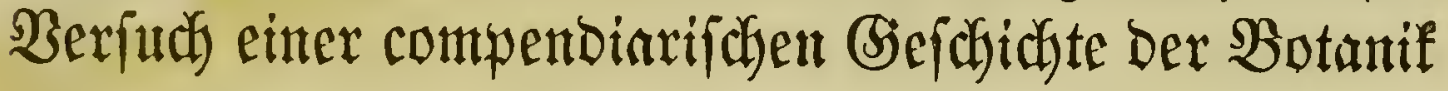

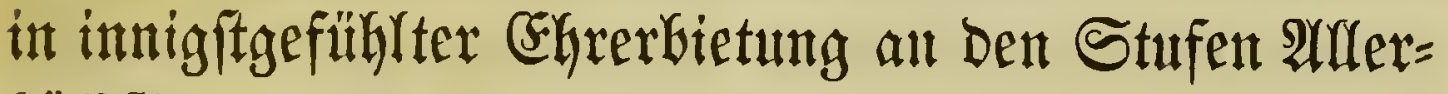
Göbjfitterent Throntez ntieberzulegen.

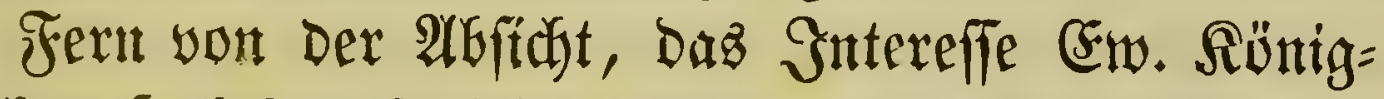

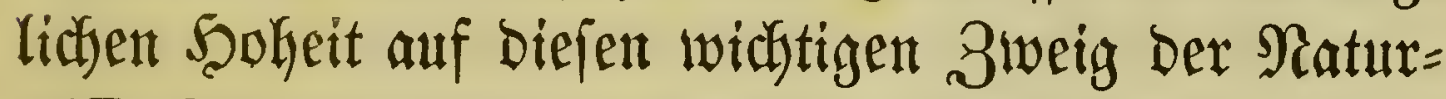
wiffertictaften lenten zut wodfent - Demt woz zu Gedarf

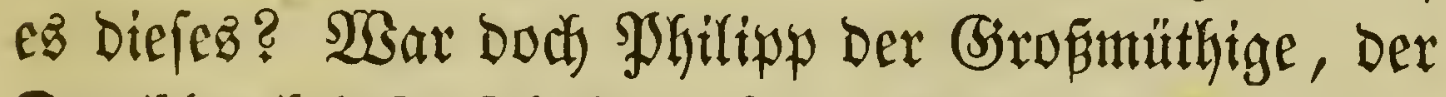

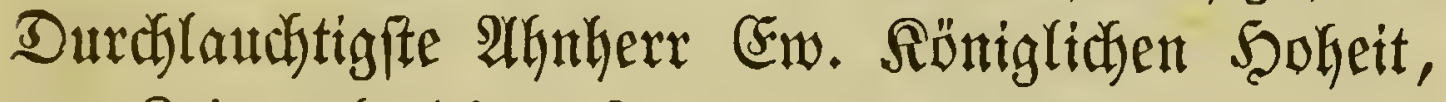

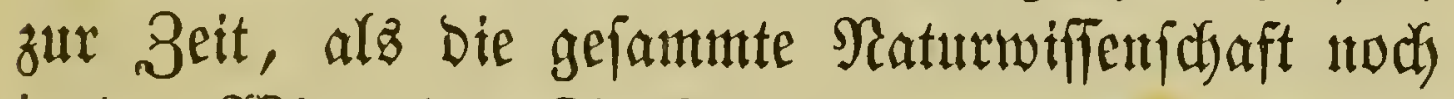
in Der 2 Siege Der Rintoheit fefflummerte, einter Der erfeten unter Den Fürrften Deutfiflands, welche, Dent

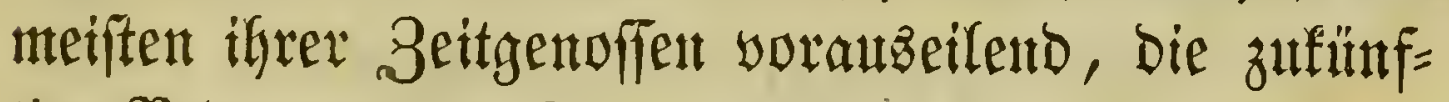

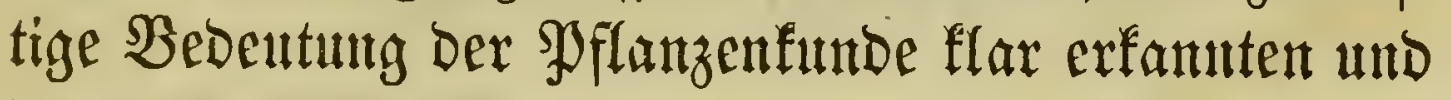

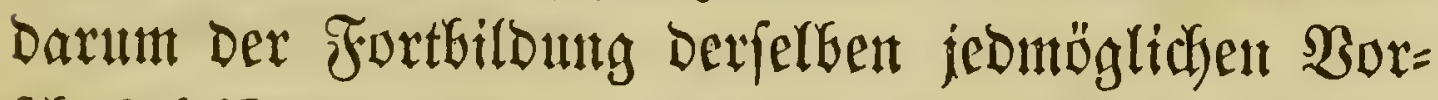

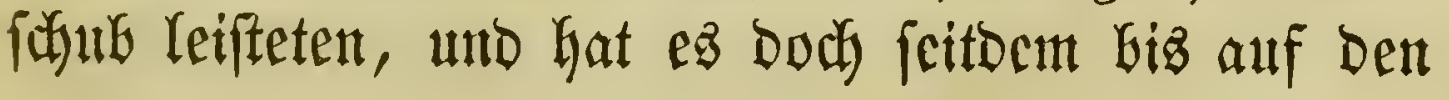


Geutigen Iag it Den heffitichent Rantoen niemalz Der Botanif an Der forgfältigiten Sflege gemantgelt hate idh Diefen Sdyritt mur Dezhalb gewagt, atm

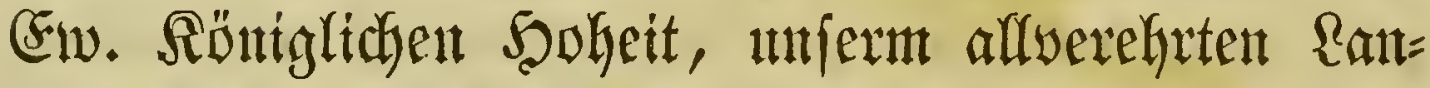

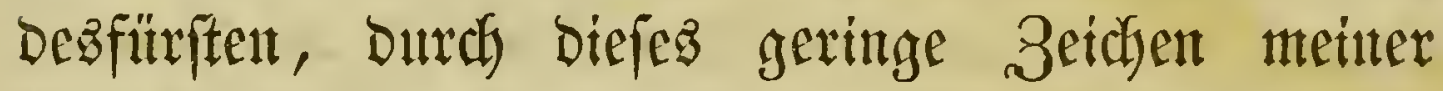
DanfGarfeit zu erfenten zat gebent, wie fegr idh Durchbrungen bin von Der tieffen Berelyutng fïr bie

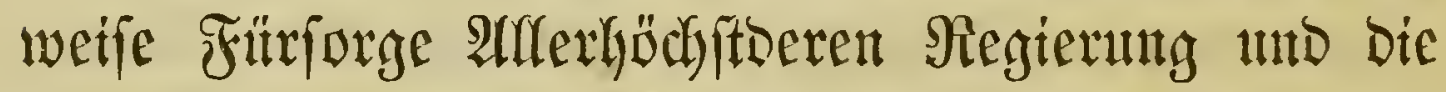

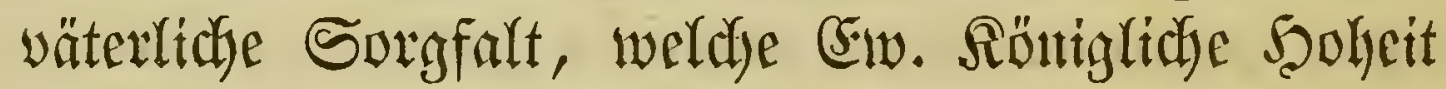

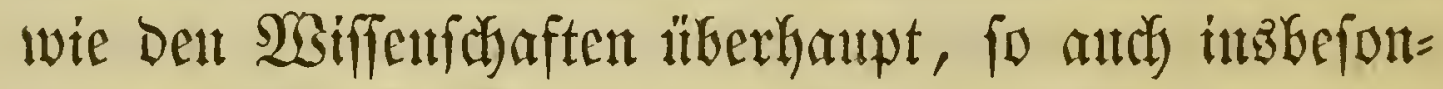

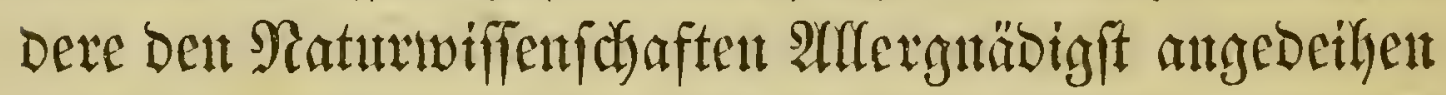

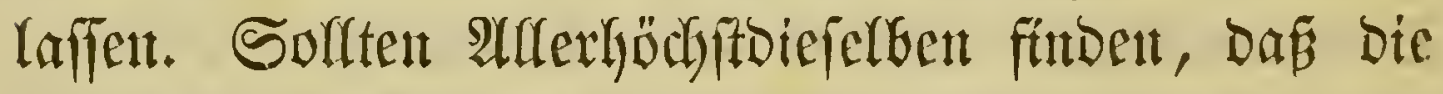
folgende Daritellunty Dent Gehandelten Stoffe nicht

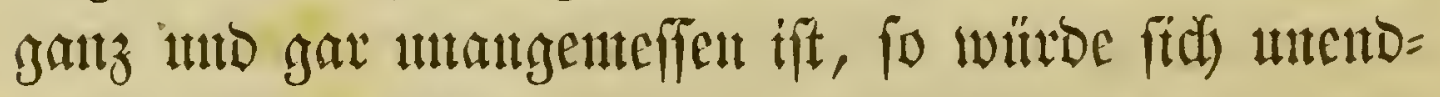
(id) beglinft füflent

(5). Röntigliden Şolgeit allertutertbänigfter

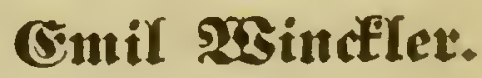




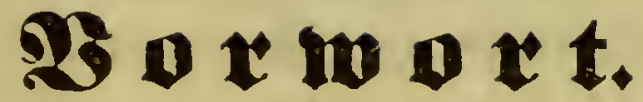

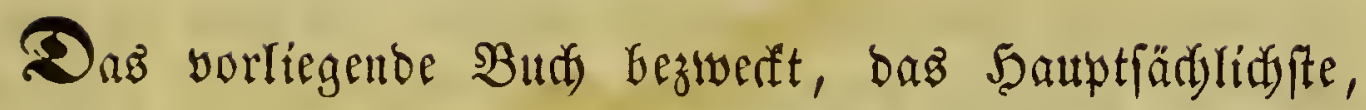

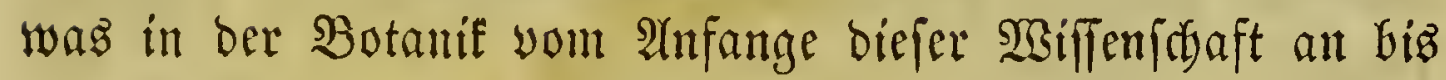
auf bie Begenwart geleiftet worben ift, in gebrängter Heber= fidjt barzuftellen. Sdjon baraus geht berwor, baf baffelse

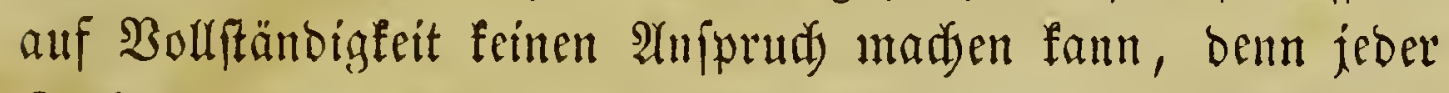

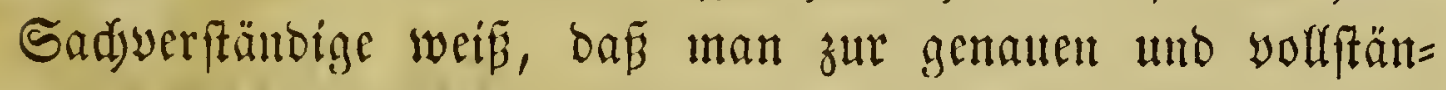
bigen Sürbigung aller Eridernumgen in ber botanifden Rite= ratur viele Bänbe nüthig haken wärbe. Bod) woirb matt

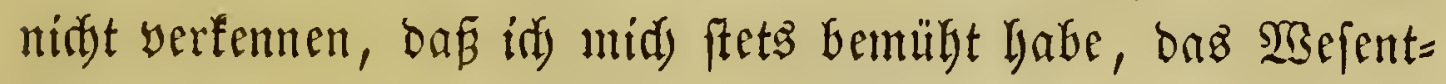
ridyite herworguheben unb namentlidy aud bei ben literarifden

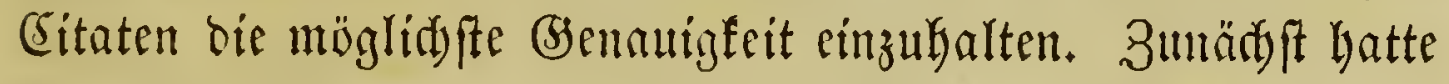

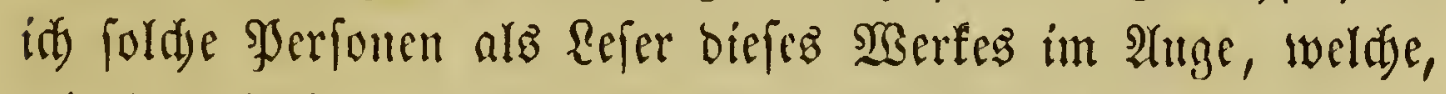
mit ben Srimzitien ber SBiflenfdraft fdyon vertraut, sinen Giftorifden Meberblide ber eniftungen berfelben fide zu verfdaf=

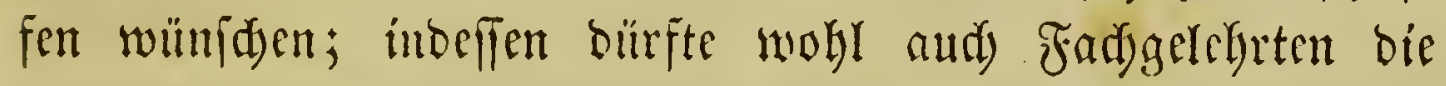
3ufammenftellung ber widjtigften Ritcratur ber cinzelnen Dis= ciplinen nidyt unwillfummen fein. Ueber fpecielle 3weige ber

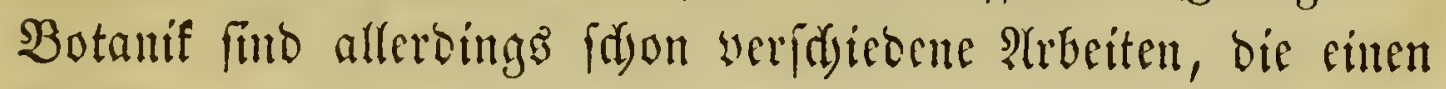
ähnlidsen 3weef wie bie vorliegende verfolgen, erfdrienen; bas gefammte liftorifde Material jener SBiffenfdyaft ift crood) nods nidst in biefer compendiarifden Form befandelt worben, wno 


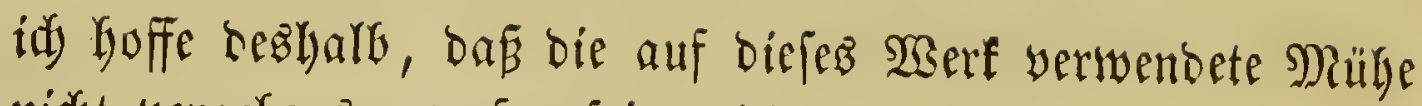
nicht vergebens gewefen fein wirb.

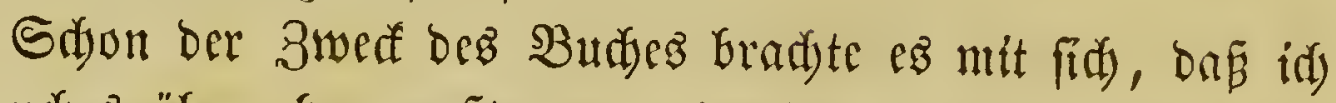
Mandyes überigelyen uñste, was in ciner ausfülyrlidyeren (bis=

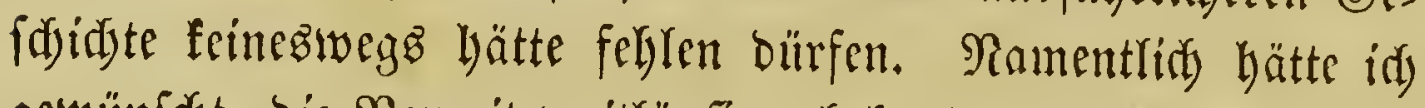

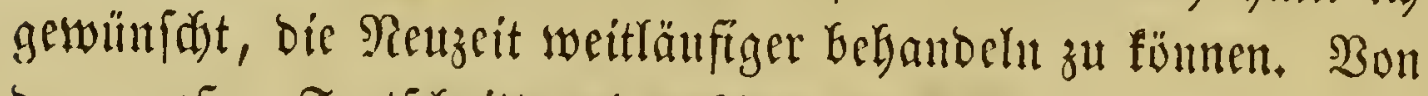
Dell grofent Fortfdritten ber Anatomic uno Sghyfiologie ber SJflanzen fomte idi) nutr eine febr gebrängte Heberfict) gebent und muste in Hebrigen auf bie fpecieflen Gabresberidste bicfer Disciplinen verweifen. Dod) glaube id, bas mir bie $3 \mathfrak{u}=$

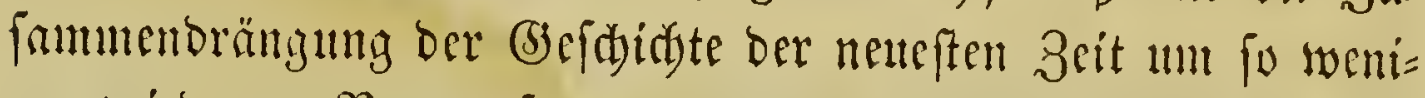
ger wirb jum Borwurfe gemadyt iverben, als man fids gerabe liber bie jüngften Erjdeimtngen ber Riteratur am Iritbeften fwecielle Raduridten werfdyaffen Eann.

(3) iefen, in Mai 1854. 


\section{Sulbalta = $\mathfrak{B e r}$ ceidunifo.}

Geite

Einleitung. . . . . . . . . . . . . . . . . . IX IX

Riteratur gum Stubium Der SSefdidte Der Botanif. . . . XVI

\section{Urfte Abtheilumg.}

3ou ben ärteften 3eiten bisz zum Biebererwaden ber

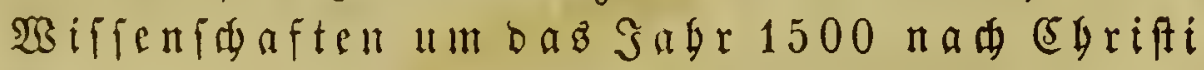
(S) c burt

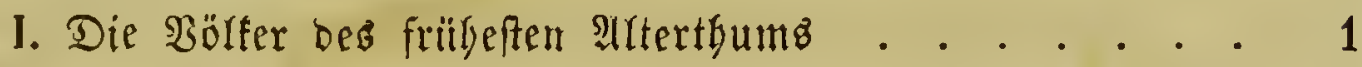

II. Die Sirieden . . . . . . . . . . . . . . . . 5

III. Die Beiten Der römifdell Weltberridaft . . . . . . 26

IV. Daz Mittelalter. . . . . . . . . . . . . . . 42

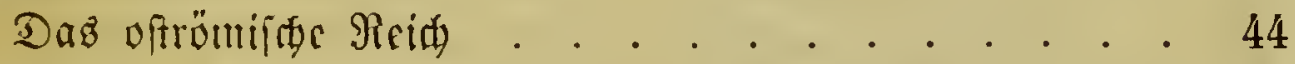

Die $\mathfrak{A}$ raber . . . . . . . . . . . . . . . . 46

Daв d)riftide 2 benbland . . . . . . . . . . 55

\section{Burite Abtheilung.}

Bon bem $\mathfrak{B}$ iebererwaden oer Wiffenfdaften bis auf Raurent 2 ntoine de Sufrien . . . . .

1. Die 3eit bes Rampfes bes nell erwatbenden wiffenidaft= linen Beifes mit bem unbebingten (S)raubeu an bie $24=$ torität der 2llten . . . . . . . . . . . . . 67

Boll ber 3eit Deg Lorenzo Medici bis auf bie Srüber saubin $(1478-1601)$. . . . . . . .

2. Sidtung ber Siefultate oer frïberen Sabrlunberte. Er= weiterung ber Seuntnis cinbeimifder uno fremblänbifdyer (Sicwädife. Berfude eines willenidnaftithen Syftems. Die erften Srumblagen zur Anatomie uno Sobyftologie Der Jflangen • • • • • • • • • • • • . .

Bon den Brüberu $\mathfrak{B}$ a ubin bis auf $\mathfrak{z}$ ournefort (1601 
3. Die 3eit ber Borbereitung zu ber gropen botanifien

Reformation . • • . • . • • . • . . . . 142

Bon Tournefort bis auf \&inné $(1694-1735)$. . 142

4. Iinné, feine (jegner und $\mathfrak{3 e r t b e i s i g e r ~ . ~ . ~ . ~ . ~ . ~ . ~} 171$

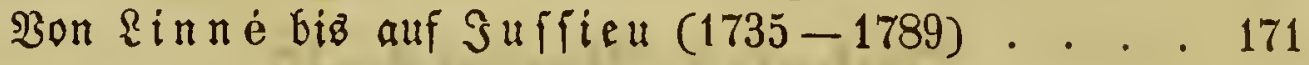

\section{界ritte Abtheilung.}

Bon \&aurent 2 ntoine be Suffieubiz auf bie (S) gen= wart . . . . . . . . . . . . . . 259

1. Das 3eitalter ber Berbreitung ber natürliden Syfteme . 261

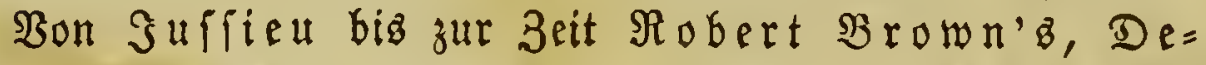
candoffe' und Afexander you Scumboldt' $(1789-1817)$. . . . . . . . . . 261

2. Die netefte 3eit . . . . . . . . . . . . . . 393 Bon $\Re$ obert Brown, Augutin gy ramus Decan= bolfe und afexander von 5̧umbolot biz auf die Segenwart $(1817-1850)$. . . . . . 393 


\section{UEinleitung.}

Pie Renntnifí Der SJflanzen Gerulyt, wie die Raturwiflen=

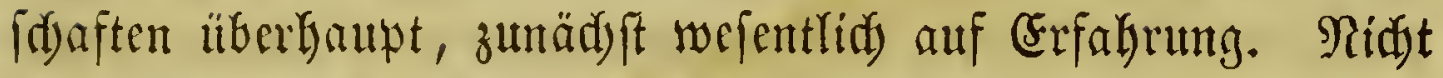
bem (Bieifte eines (simzelnen avar es möglide, aus fid) felber cin Syftem ber iln ungebenden Natur zu erjdaffen. Eine lange 3eit verflof, besor ber Menich anfing, vertrauter zu werben mit feimen Mitgefdüpfen auf ber Groe, fie von ein= anber zu fonbern uno genauer zu bezeidenen. Die meift zu=

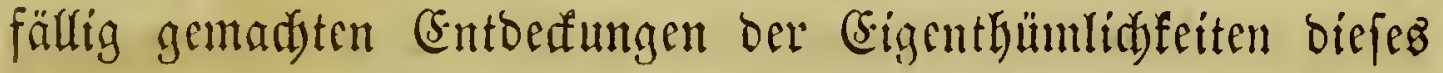

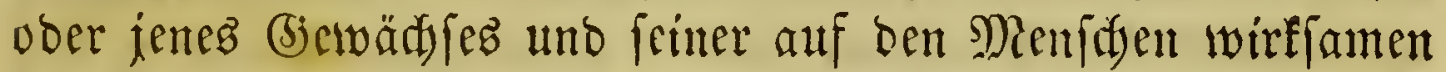
Araft wurben erfit langfam und alfmälig erweitert und yer= mebrt, uno vicle (jenerationen gingen voritber, efe man fid

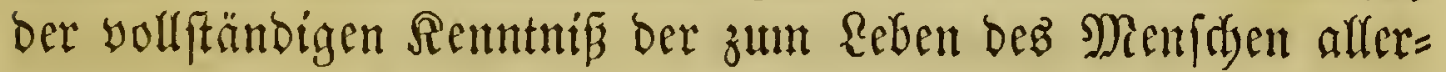
nothwonbigften Siäuter rülymen fonnte.

Aber aud) banu nod) traten ber Berbreitung botanif(aer

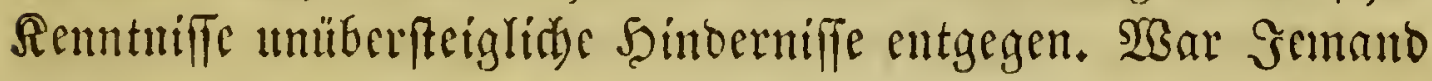

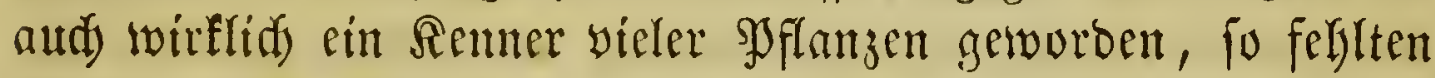

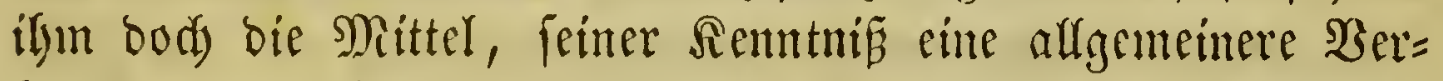
breitung zu geben; mu Sisenigen fonnte er burd) münolidye Belebrung feinen geiftigen Sidn vererben. So zeidneten fid

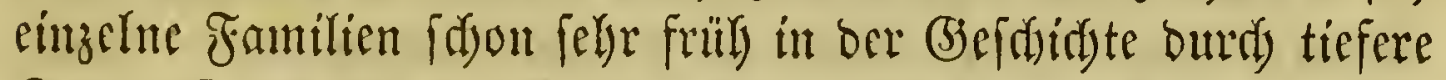

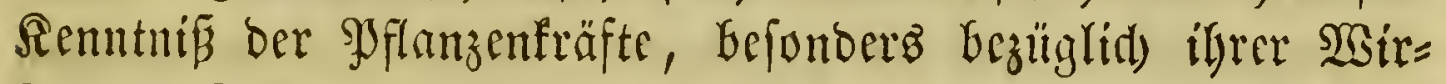

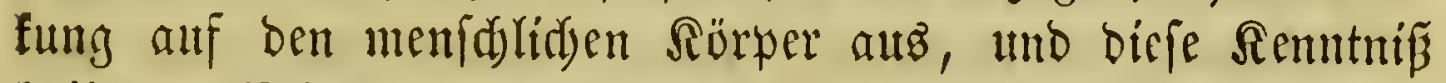
beilender Mittel ging wic ein heiliges (Erbtheil viele (s)enera= 
tionen Gindurd yom Bater auf ben Sohn über. Dod ber Mangel einer allgemeín gültigen Terminologie verbinberte,

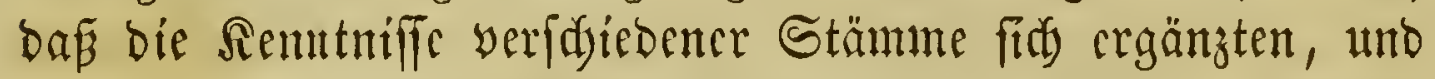
erft nadi und nadi bildeten fids für fegr verbreitete SPlanzen Ramen, beren Nlang in ben Spradyfdats beb Bolfes aufge: nommen und fo zu affgemeiner Berbreitung Geförsert wurbe. NGer felbfi biefe Ramen waren fdwanfeno unb ungenau, oft yon unbebeutenten 2 (cuperlidfeiten hergenommen, nur entfernt bie (sigenthümlidfeiten cincs (biewäb)

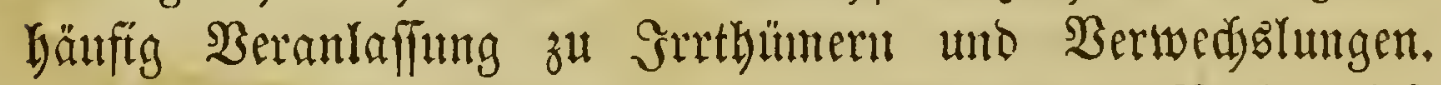

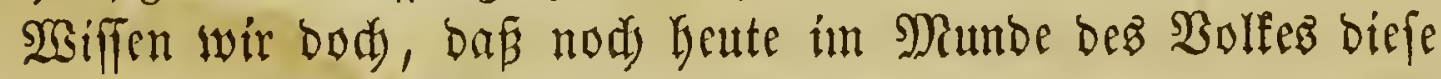

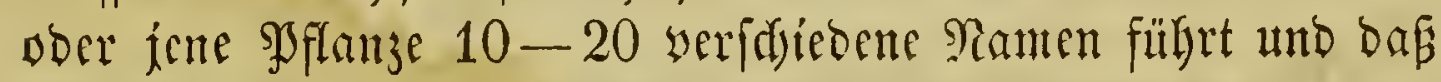

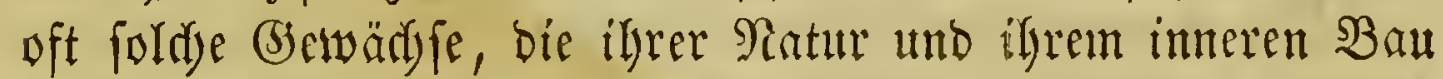
nad) grunbyerfdieden find, wegen mely ober mintor grofier

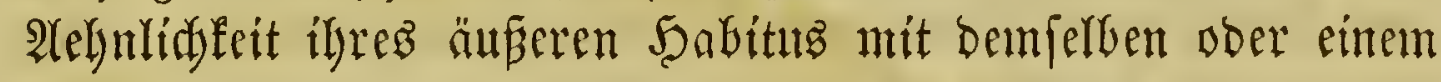

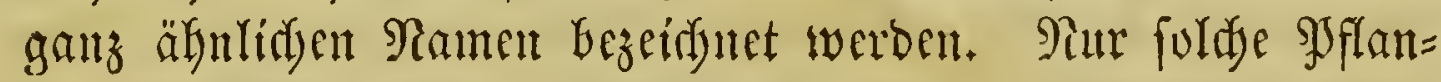
zen fomten genaut you cinander unteridjéden werben, welde fdon bei einer oberflädylidyen Beubaditung bebeutend yon ein= anoer abweidsen. Demm zur Entberang ber feineren Serfdece= benlyeitent feblten bie erforberlidyen Mittel. S(y) bie äuferen (d)

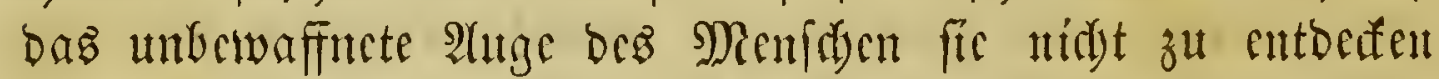

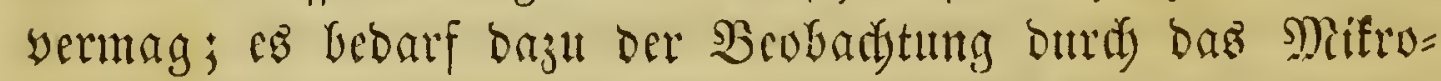
ffop; nod wicl notbuendiger aber ift baffelbe, um ben inneren Bau ber Syflanzen zut ergründen; unb unt ifre für ben $M e n=$ fden heilfaut noer fdöblidyen Sräfte gentuer zu erforfdyen,

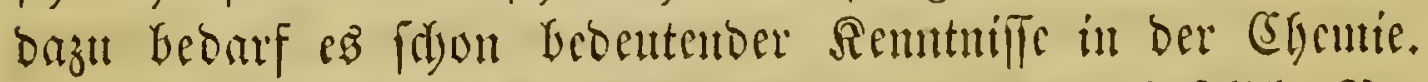

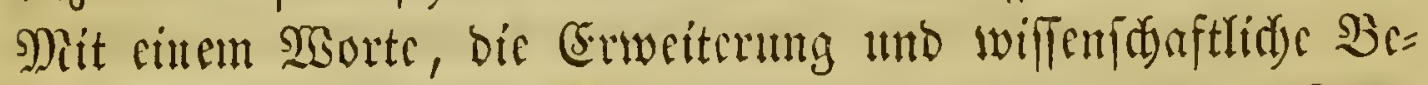

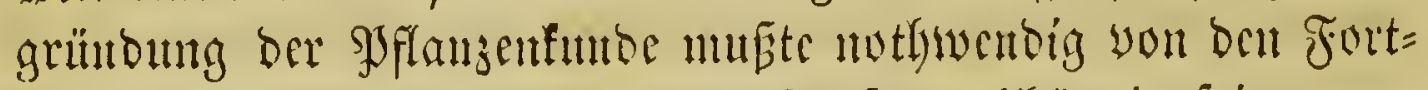

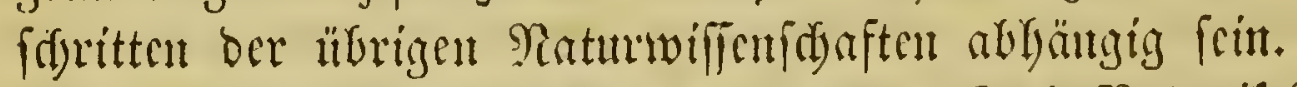

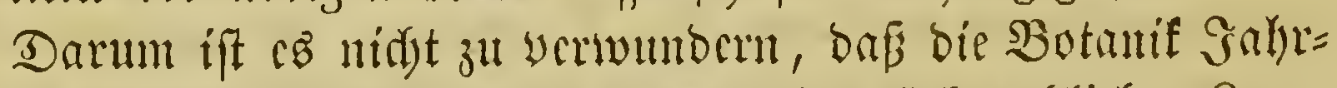

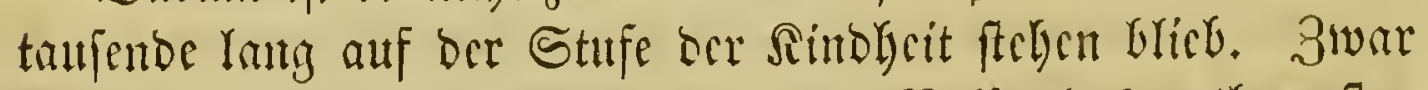

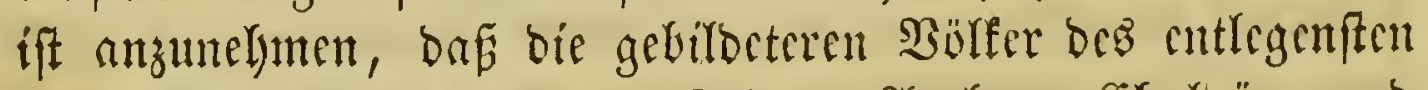

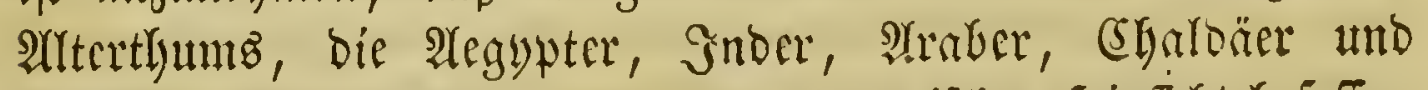

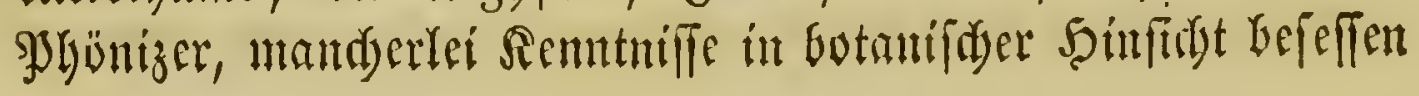




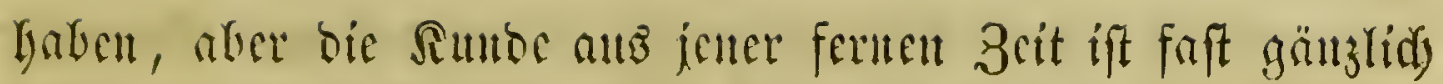

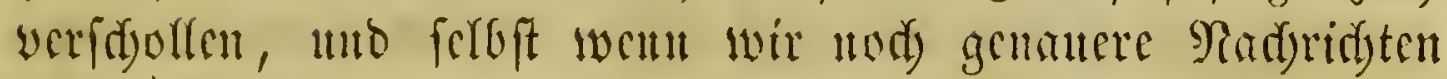

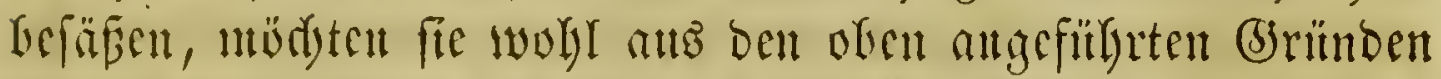

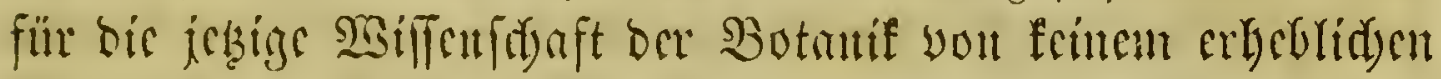

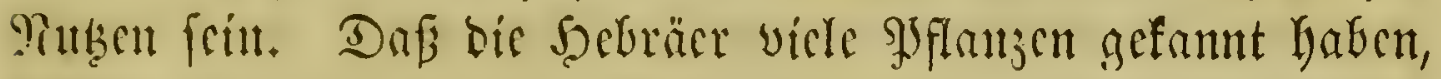
crichen wir ats ber heifigen Sdyrift; alfeit bie barin vortom=

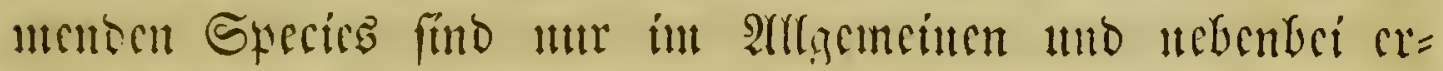

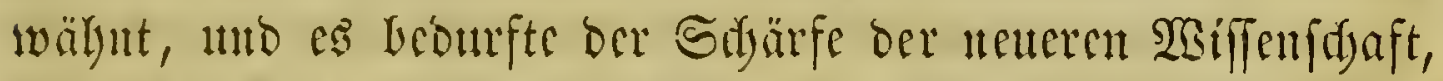
Imu feftzuftellen, weldye beftimute Bgflanjenarten unter oen (d)wanfenoen Ramen zu werffelgen fricn.

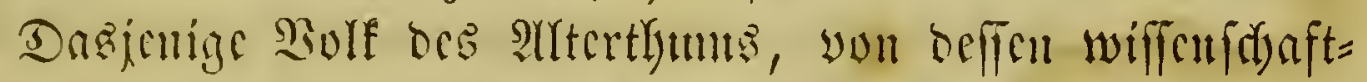

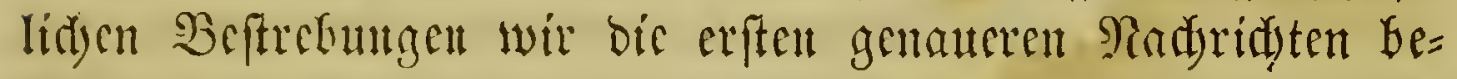

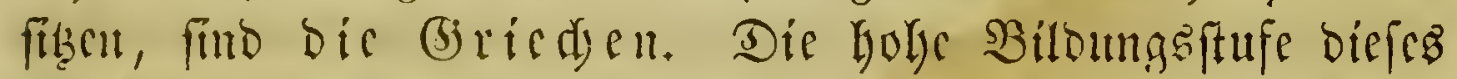
Bolfez, ber Kohe Brab ber Borfentung, weldern es in ber אumft

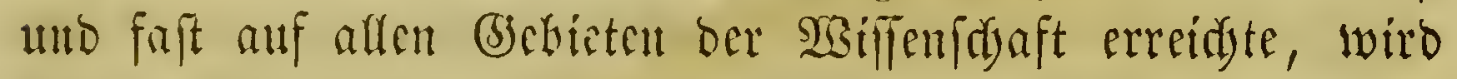

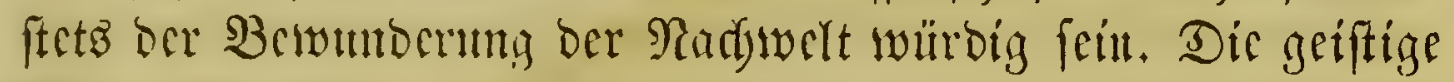
Şinterlaflenfdaft ber (Bried) gab uns bie thatfräftigften

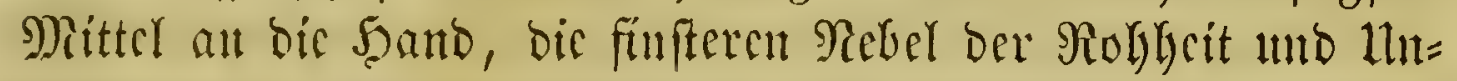

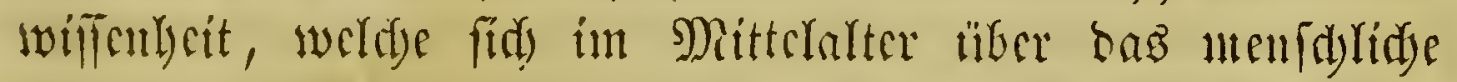

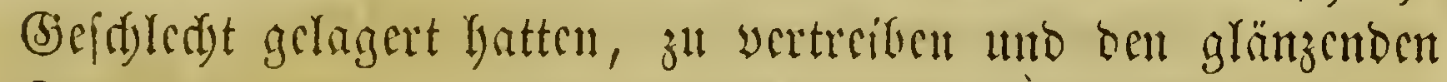

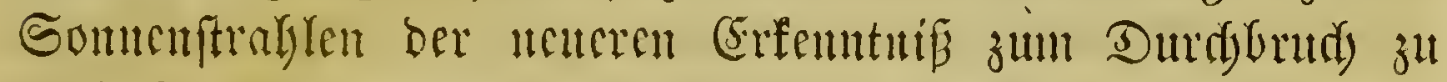

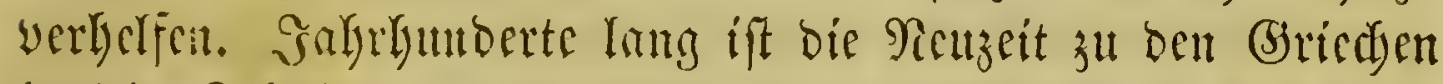
in bie Sdutle gegangen, uno auf ifren Sdyultern ftebeno,

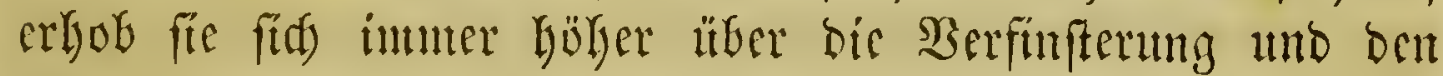

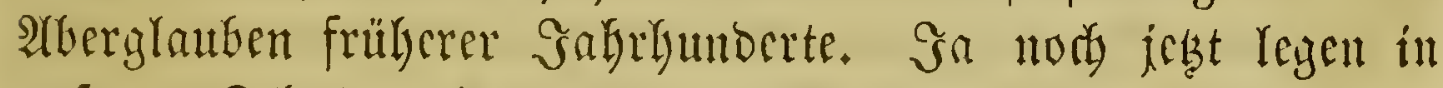
unferen Sdyuten bic Didyter, SSGilofowhen uno Riconer ber

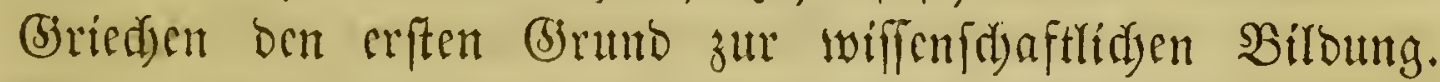

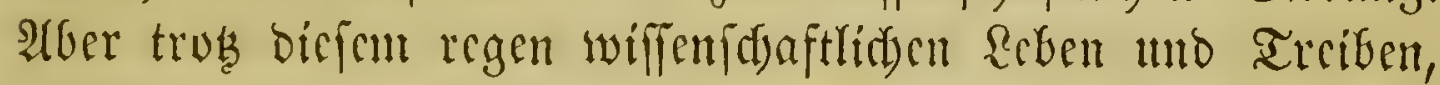
weldes in bem alten (Gried)enland geberred haben muś,

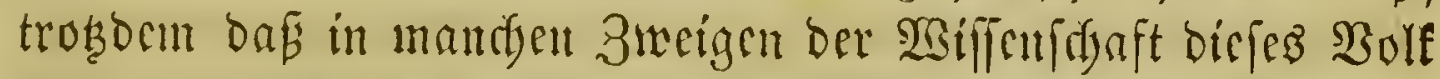
you ber Reuzeit nodil nidjt übertroffen worben ift und in ber

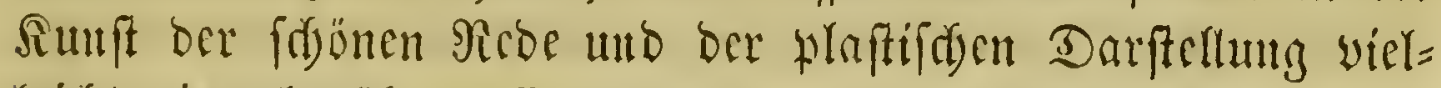
leidyt nicmals übertruffen werben wirb, truboem, ober wenn man will, gerabe barum fümen wir bebautent ber griedsijde Geift war einer rafdyen Furtbildutg Der Naturwiffenfdyaften 
nidyt günftig. Die Billbung ber (Sriedyen war eine wejentlid formale; bie (Bofecte ber äjthetifdyen Sdjünheit gingen ifnen

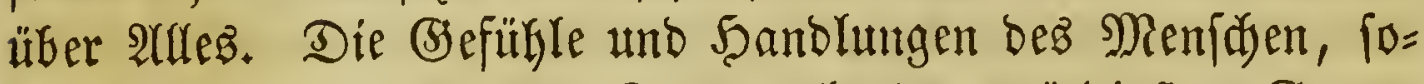

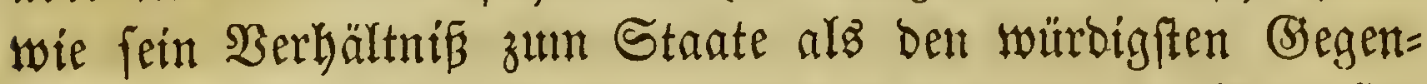

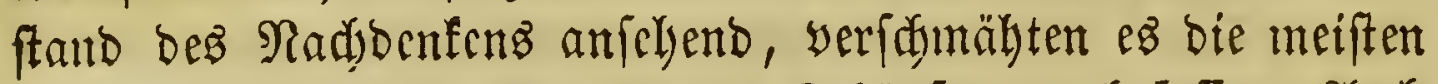
Sgrilofowhen, fid mit ber nieberen Sdyöpung zu befaffen. 2(ud) waren bie bautaligen focialen Berbältniffe nody einfad) genug,

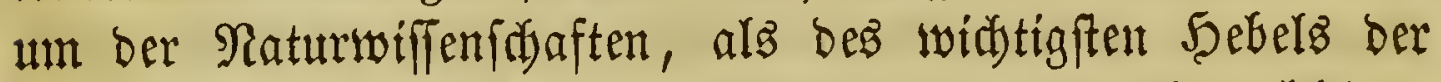
Subuftrie, nidjt jub boürfen. (Es wiberftrebte aud wohl bem griedjifdyen (Seifte, die Natur, bie er fo gern als ein grofess

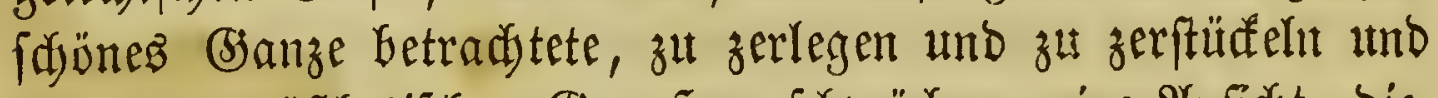
fich) fo ben äfthetifden (5)

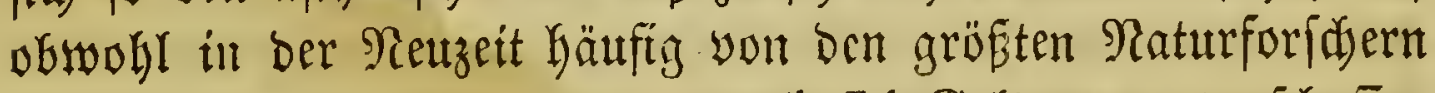
wiberlegt, Gier uno ba immer nod) fird (beltung zu verid)nffen

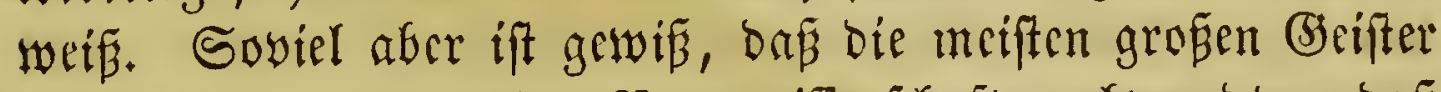
ber (Siried)en fid you ben Raturwiffenidaften abwanoten, baf nut woenige berborragente Männer mit Reigung und Eifer

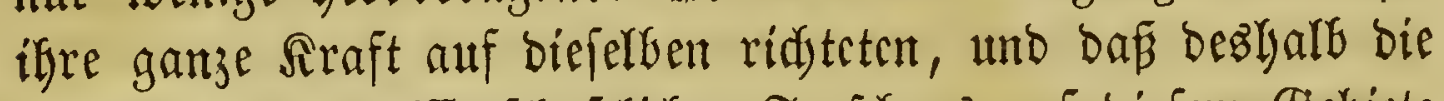

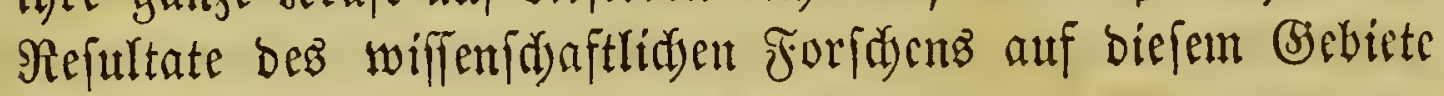
verkältnifmäßig gering, ja unbebcutend waren.

Die $\Re \ddot{n}$ uner waren bis zut Zcit ber büdyften SBlüthe

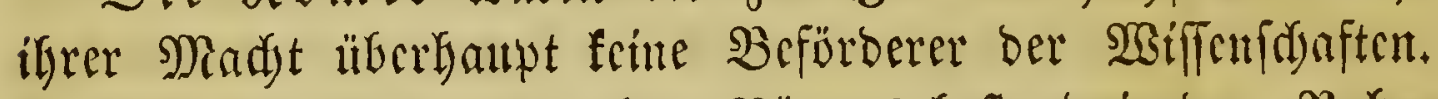

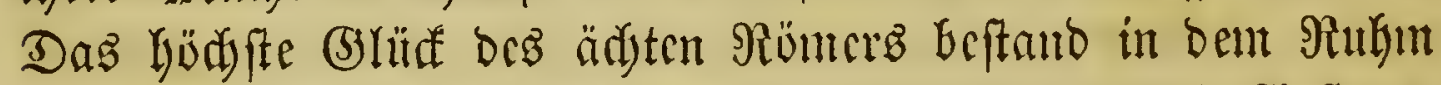

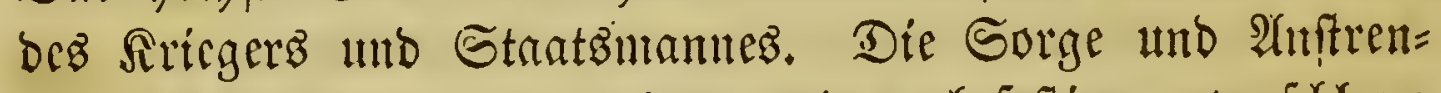
gung, bou Staat fu crweitern und ju befeftigeu, verfdilang

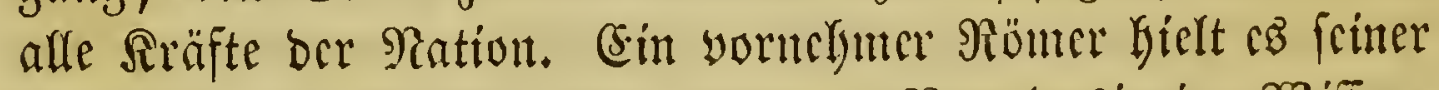

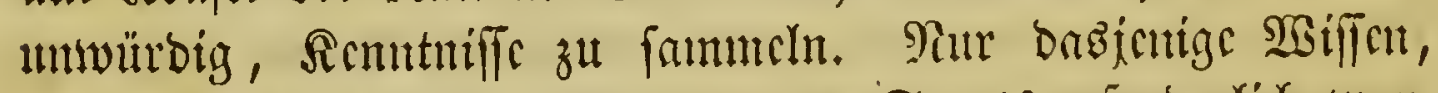

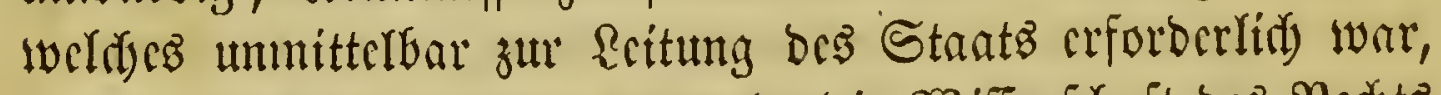

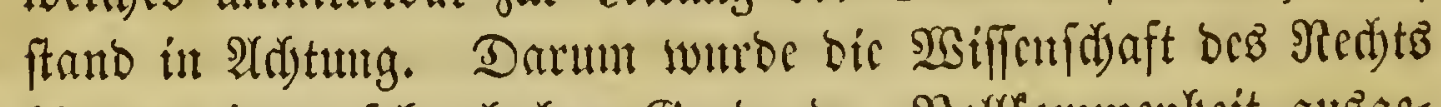

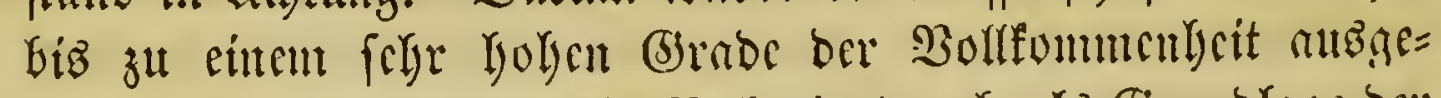

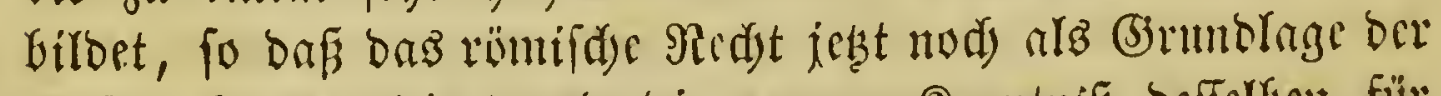

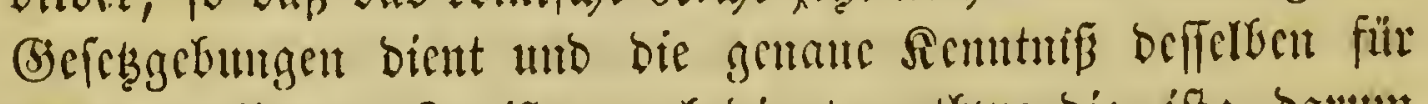

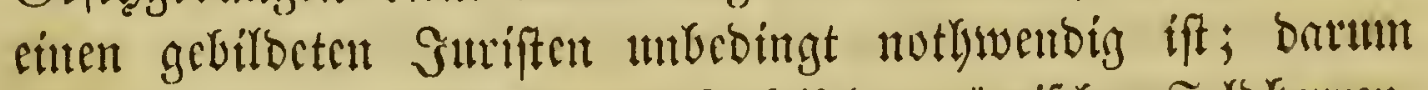

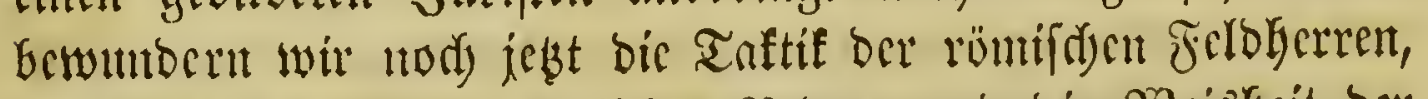

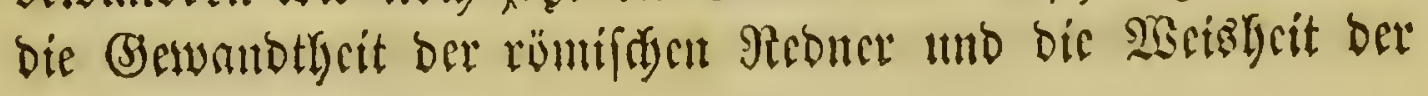




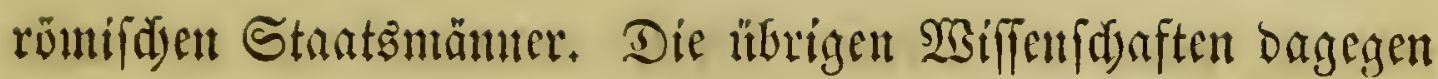

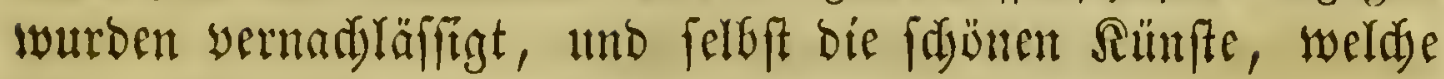

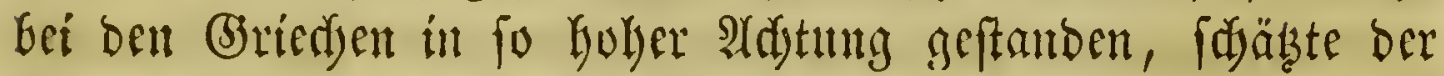

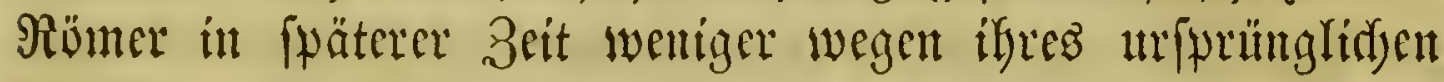

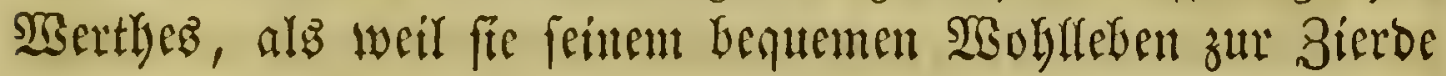
bientent.

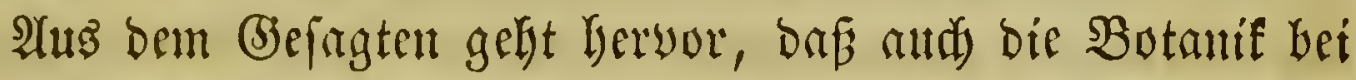

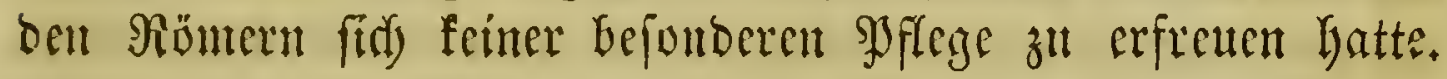

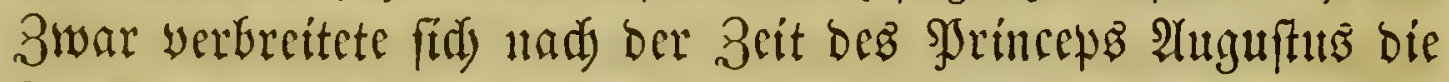
Riebe zu ben Sisifienfitaften in weitere Serife, aber audi $b a=$

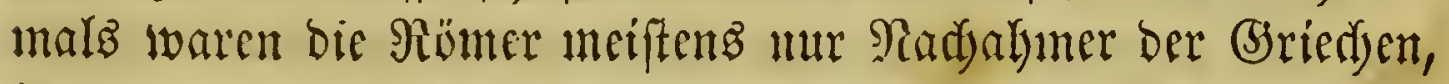
ja viele ber bebentendoften (3) elehrten ber Damaligen 3eit tuaren

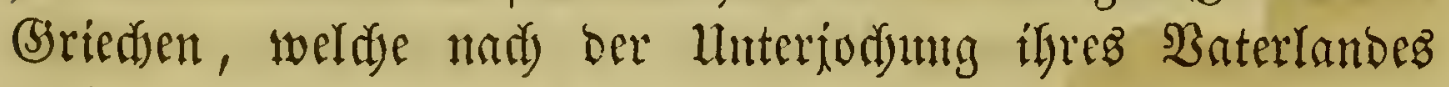
nad) Stalien fid übergefiedelt hatten. STair feben hieraus,

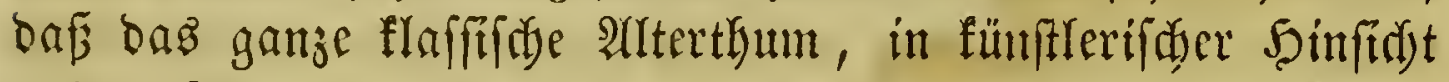
utb auf anberen (3) ebieten bes Ssiffens fo überaus merfwür=

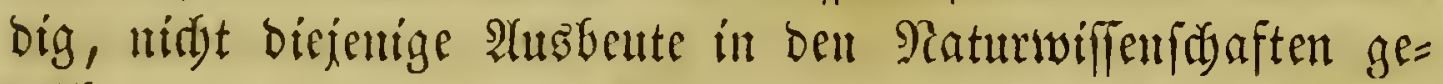
wäbrt, weldye man nad) Berbältnín ber j̈brigen Reiftungen wohl erwarten fömte.

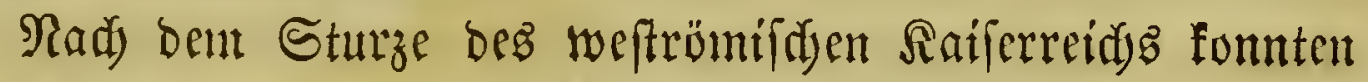
bie Sisiffenidaften nur ein fümmerlidyes Dafeit friften. Die eingebrungenen germtanif dyen Bölfer, den Reim einer böberen Billoung zwar in fid trageno, aber in ifyer roben Raturfraft

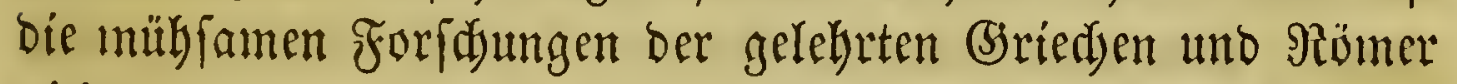
nicht verftehend, tummelten fid) unbefümmert auf ben Sdüßsen Des Arlertfums unfyer, und die Documente ber ehemaligen (5)iftesbiroung gingen zu (5runde, ober wenn fie fid in irgento

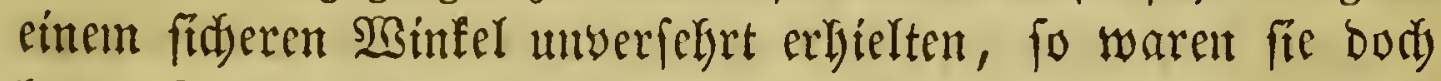
lange Zeit unbefannt und nublos. Dritben aber im oftrömi=

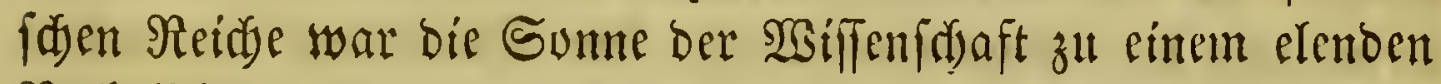

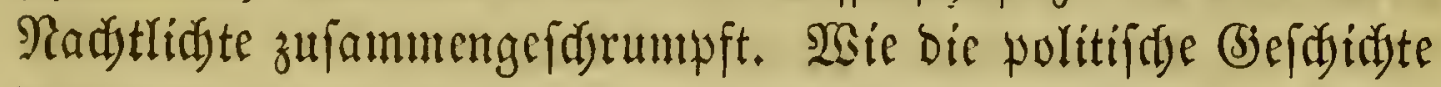
Des moridaen unb balbtobten byzantinifden Staatez troden

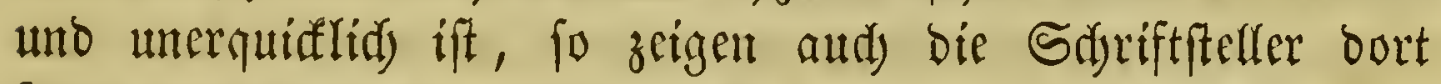
felten uriprünglícle Sraft umb Driginalität ocs (Steiftes. Die meiften waren blope Samuler und find grö̈tentbeils mur bant 
widytig, wein fie in ihren Siserfen Cingelnes aus ben alten flaffifich Sdgriften aufbewalyrt haben.

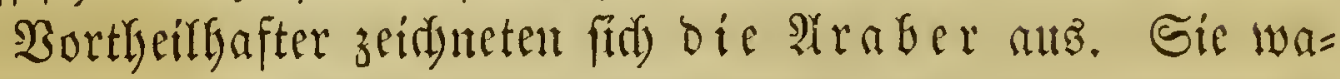
ren eine 3rit lang faft bie einzigen wïrsigen aräger befontor's

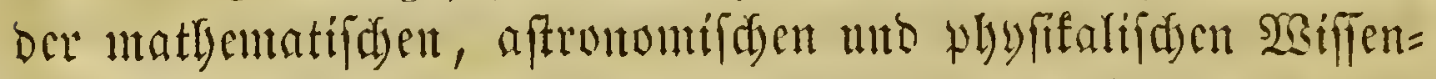

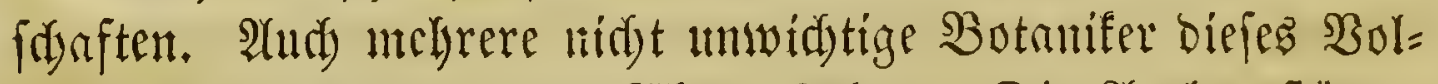

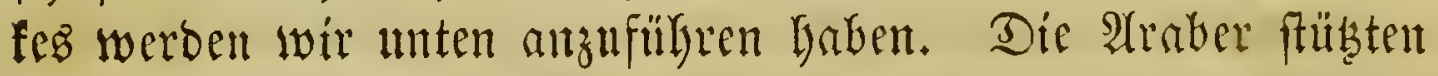

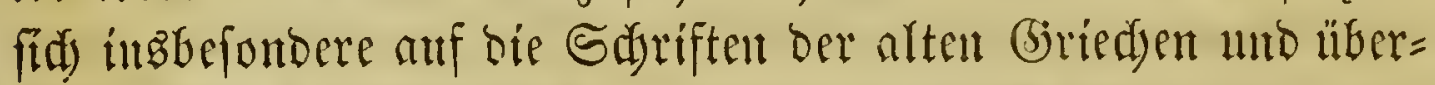

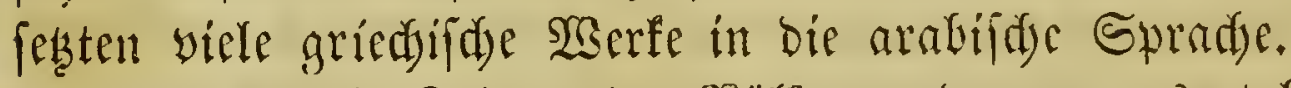

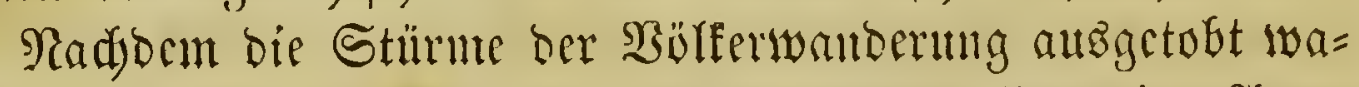
ren, und in atbentande bas Bgriftenthun allgemeine 2Aner= fenumug erlangt lyatte, fing man nad) unb nad wieber an, bie Bildoung Des Geiftes zu fultiviren. Dies ging jebody ber Ra= tur ber politifityen 3uftäld we wegen nur forkr langfaul yon Statten. Die Didutfunft gelangte in Dentidyland nidjt lautge nad) Dem Salgre 1100 nad) (Shrifto zu cinem hoben (Grabe Der

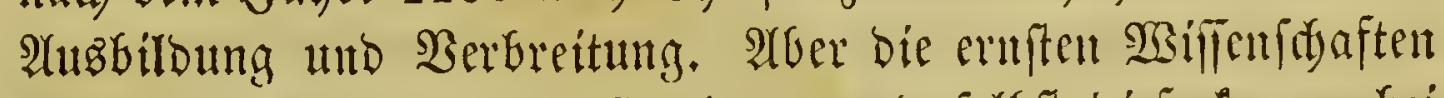

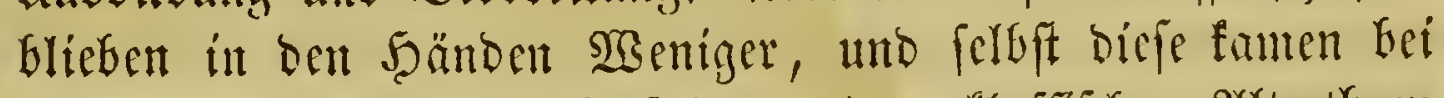

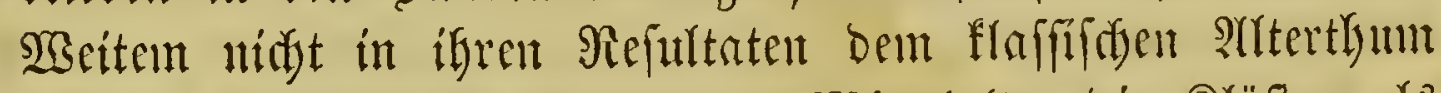
gleid). Şauptfäd)lidid müffent int Mittelarter bie SYüfter als

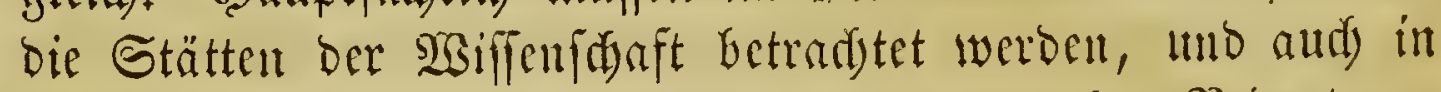
Der Botanif find eintige Miönde nidgt ganj obue Bebentung.

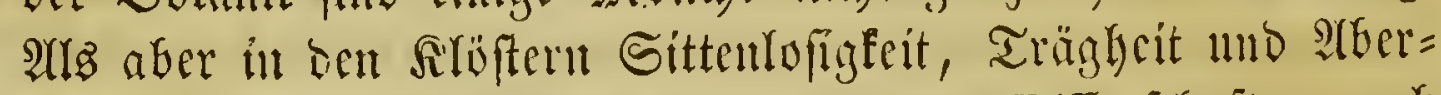

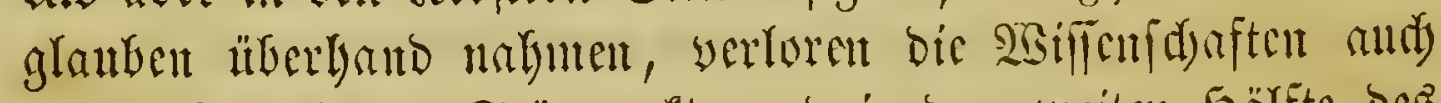

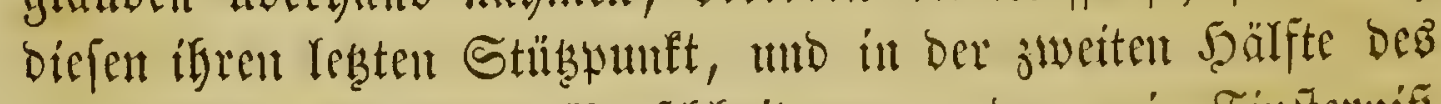

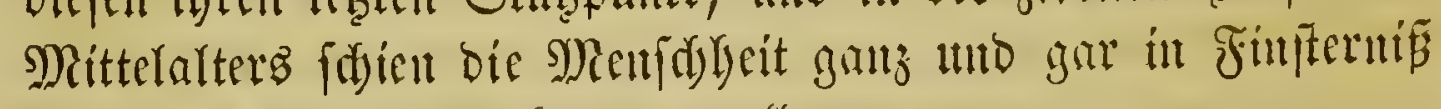
und Dummerit verfinten zul wollen.

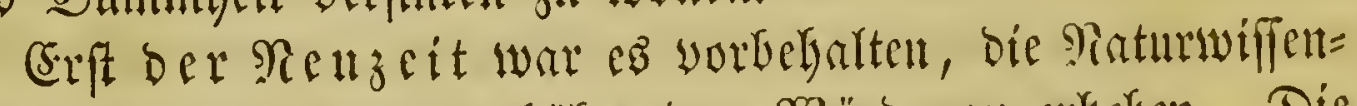

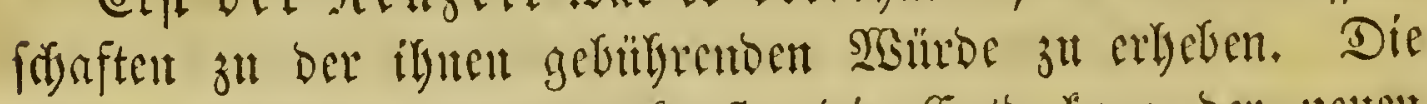
Erfindung Der Burborutertumf, bie Eintbefting ber meten

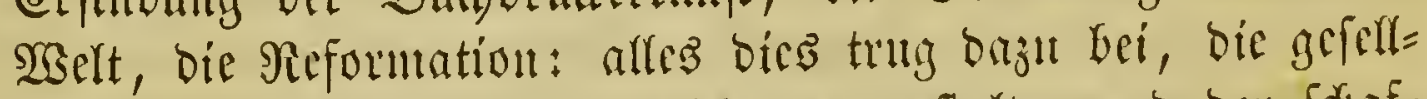

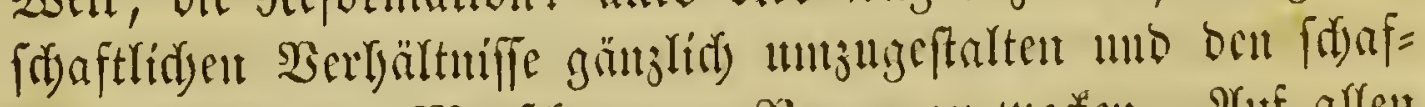

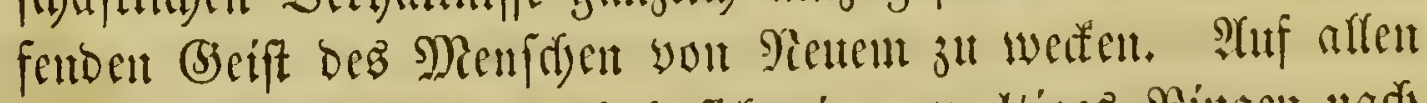

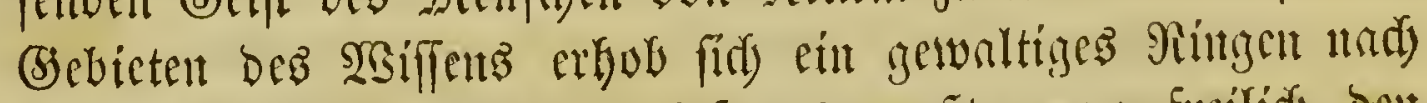

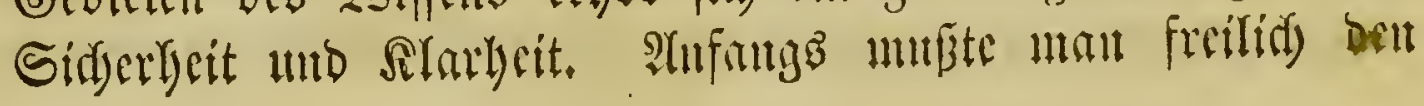


alten Slaffifen Sdyritt yor Sdyritt folgen, aber nadyocm man

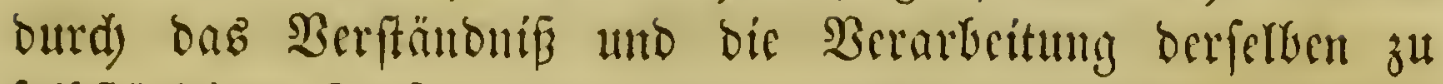
felbftäntiger Rraft grlangt war, nafm dic geiftige Bilbung

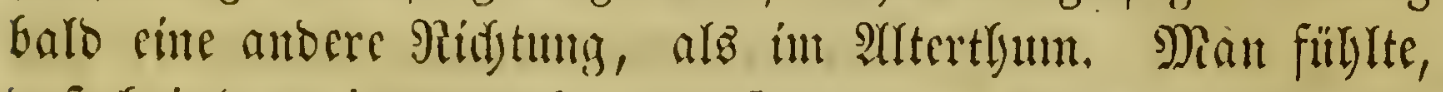

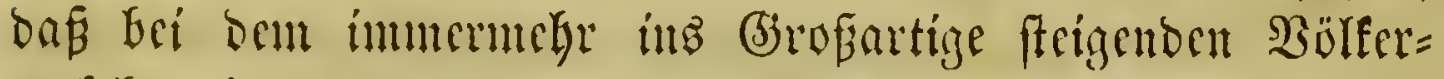

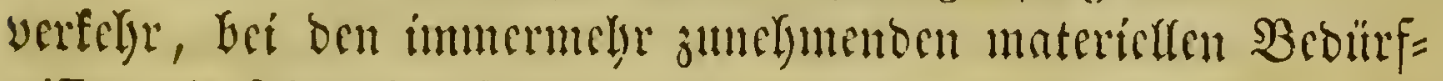

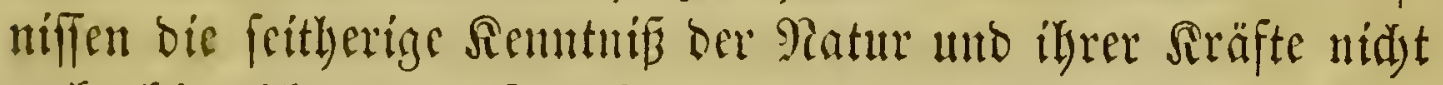

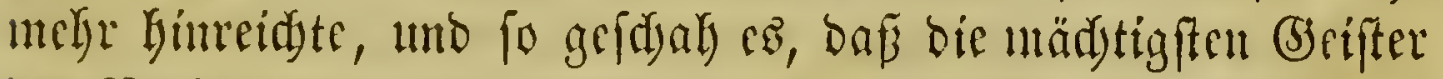

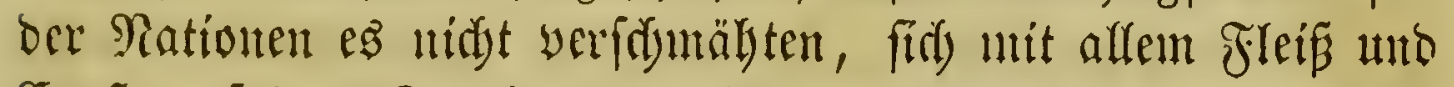
Gruft auf baz Stubium ber Raturwiffenfdyaften zu werfen;

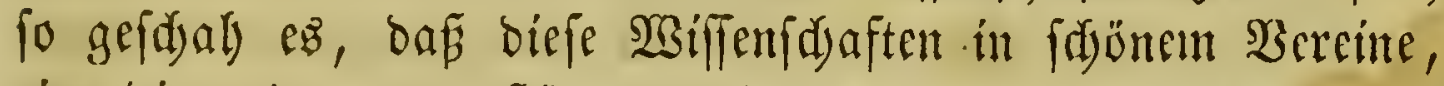
eine bie andere unterftütseno, inmer weiter fortftrebten uno enolid) in ber neueften 3rit গefultate ergielt haben, wie fie

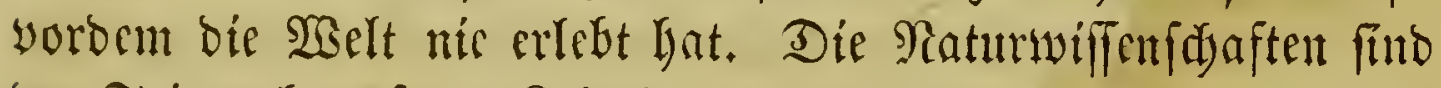
ber Triumph unferes Zritulters. - Alud bie Botanif erlebte in ber Neuzcit cinc volffänoige unngeftaltung und gelangte jest erft zu einer fidyeren Feffiteflung uno zu cigentlid wiffen= fotaftlíder Begrünoung.

Wir glauben nadj bem Drigen naturgemäp zu verfalgren, wenn wir bie (Befidsidste ber Botanil in brei abtheil ungen zerlegen. Die erfte albtheillung beginnt mit ben eriten 2 nnfän= gen ber Sisifenfidyaft uno reidyt bis zur SBiebererwadjung oer

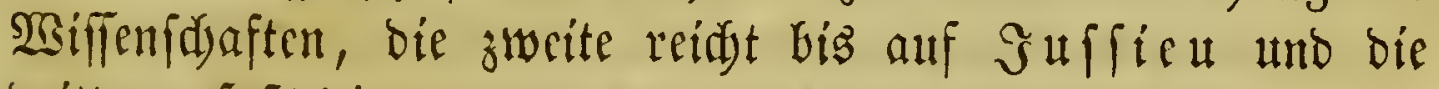
oritte umfast bie ganze neure 3rit bis auf bie Gegentwart. 


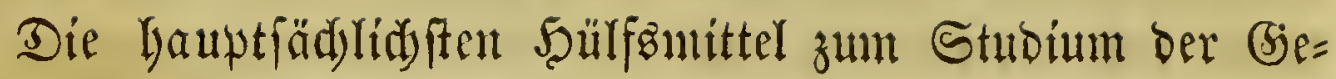
fdidite ber Botanif finto:

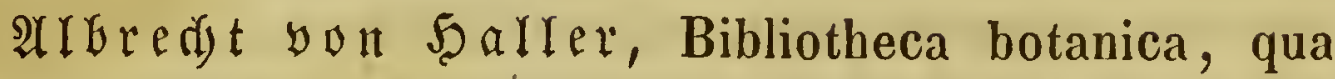
scripta ad rem herbariam facientia a rerum initiis recensentur. Tomi II. Tom. I, tempora ante Tournefortium; Tom. II, a Tournefortio ad nostra tempora, Tiguri 1771-72. 4:

(5 $\mathfrak{a t} \subseteq \mathfrak{S} \mathfrak{e} \mathfrak{n g e l}$, Historia rei herbariae, 2 voll. Amsterd. 1807 -8. 8.

Deffen (sefditdte ber Botanif, neu bearbeitet, 2 Ifle. Altenburg und Rcipzig 1817-18. 8.

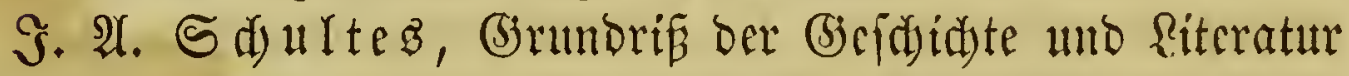
Der Sotanif yon Theophraftos Crecfios bis auf bie neuteften 3eiten. 2Sicu 181\%. 8.

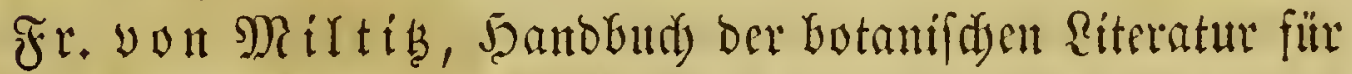

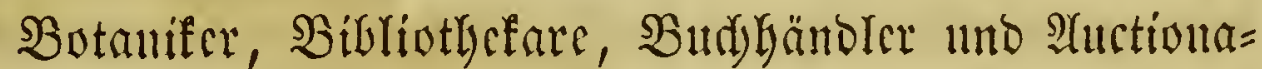
toren mit 2 ngabe ber $\mathfrak{S} r$ cife uno Recenfonen. Mit

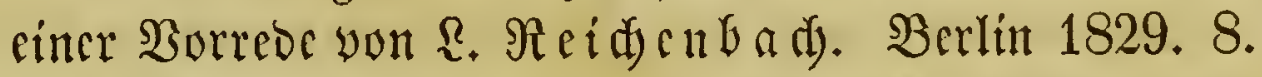

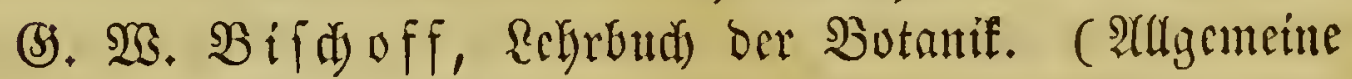
Botanif.) II. Bסo, 2, IGl. Stuttgart 1839, gr. 8.

M. S. $\mathfrak{R} \mathfrak{r} \ddot{g} \mathfrak{f r}$, Bibliographia botanica. Şanobud) Der botanifden Riteratur in fyftematifacr Dromung, nebfe furzen biographifden Rotizen über bie botanifden Sedjriftifterler. VBertin 1841. 8.

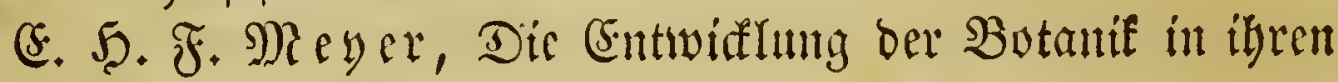
Sauptnwomenten. Rinnigsberg 1844. 8.

(5). A. $\mathfrak{Y} \mathfrak{r} \mathfrak{i} \mathfrak{e l}$, Thesaurus literaturae botanicae omnium gentium inde a rerum botanicarum initiis ad nostra usque tempora quindecim millia operum recensens, Lipsiae 1851, 4.

(5. $\mathfrak{A}, 3 \mathfrak{u}$ d) $\mathbb{I}_{\delta}$, Additamenta ad G. A. Pritzelii thes. literatur. bot. Halis 1853. gr. 8. 


\section{Erlte exthoilumg.}

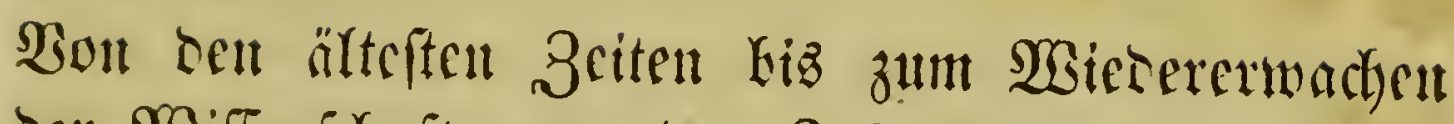

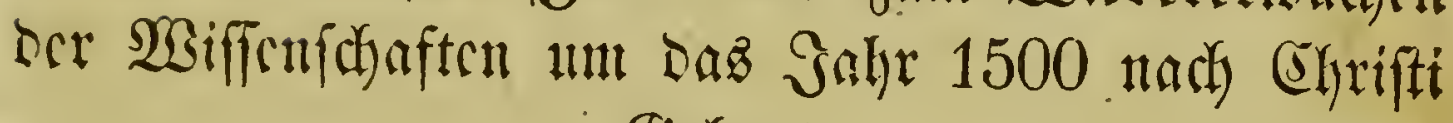
(3ieburt.

\section{Die Bölfer bes früheften 2ultertbums.}

Die ălteften Sxuren ber menidhliden Rultur gehen zu bem

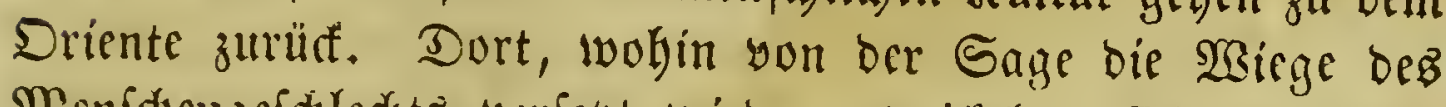

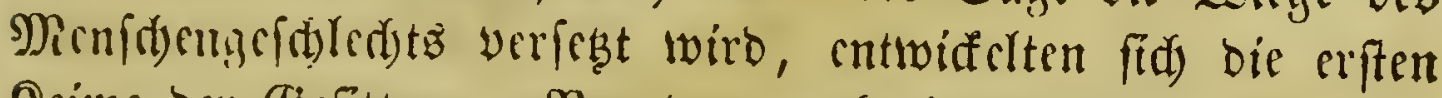
Serime ber (5iefittung. Bon sort verbreiteten fie fid in immer weiteren Sereifo, ullo erft nadjocm die Bewohner ber mitt= leren uno füolidyen Thrile Afienz vielleidst Gahrtaufenoe lang auf ciner zicmlid holden Stufe der Rultur geftanben batten, zeigten fid) an ben mittellänbifden Rïifen Europa's bic erften Merfmale cincs emporftrebenoen Bsifteg.

Gnbien insbefonocre, burd) frite Rage in jeber binfidst frhr gcidjükt, jecod) nidst abgefperrt gegen bon Berfergr mit anberen Rationen, zcidyute fid fdon felyr frülge burdj feine Madjt uno frine Ssciftebbilloung unter ben Ränoern 2lfiens aut?. (5.s mag foon im graucften Alterthum zwifd)en bicfern \&anbe uno bein innern Afien, Shina unb Arabien cin Tebhafter Şan=

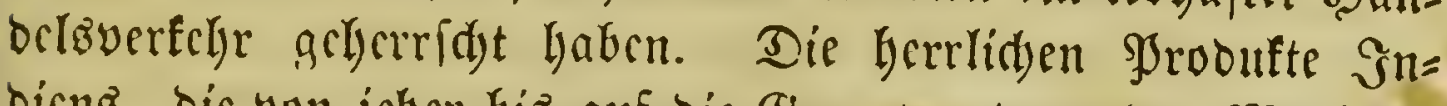

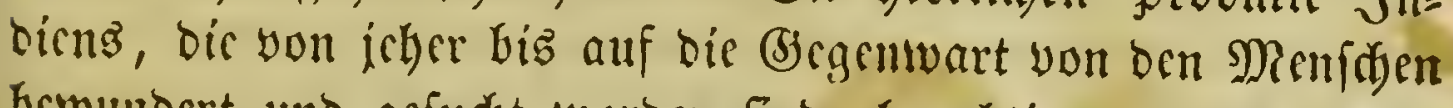
bewundert uno gefudit worben find, beredtigen uns zu biefer

E. $2 B$ in a le r, Brif D. Bo Botanit. 
Innahme, Bei ber mannidjaltigen und pradjtyoden $\mathfrak{B e g e}=$ tation bes Ralloes und ber Reigung dez Gnocrs zun Rary= benfen itber bie Natur, wie fie fid fdoun in ben älteften pee=

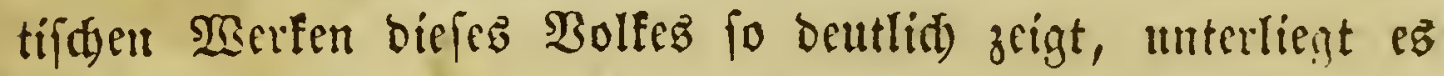

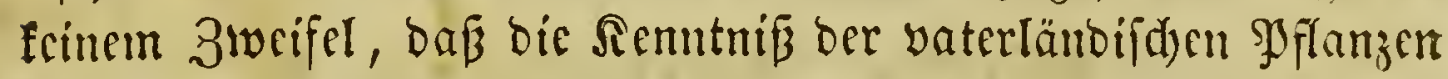

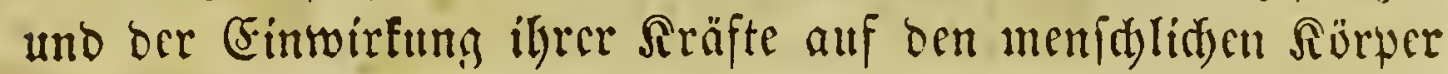
in alten Snoien weit verbreitet war; allein es fel)len uns afle

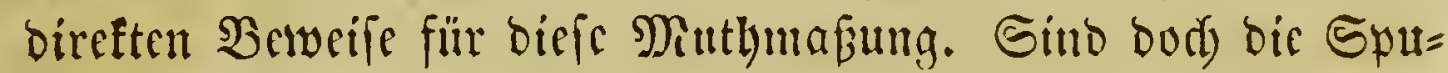

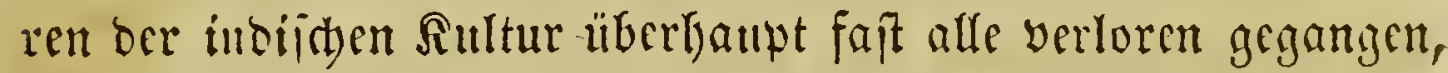

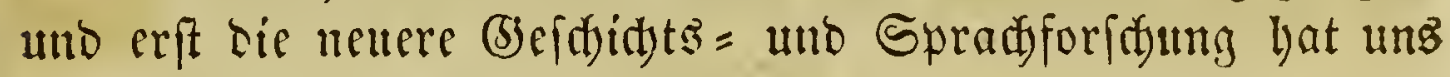
mit bem \&eben ber alten Gnoer cinigermaben befamt gemad)t. ")

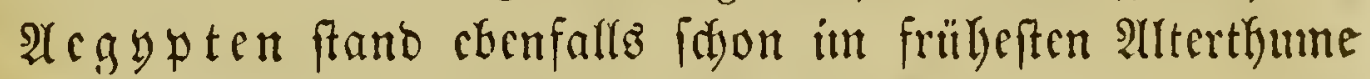
auf einer nidjt unbebeutenden bु̈̈ke ier Sultur. Dic Subent fanten, alsz fie zut Zeit Sofephos bortbin famen, foun cinen

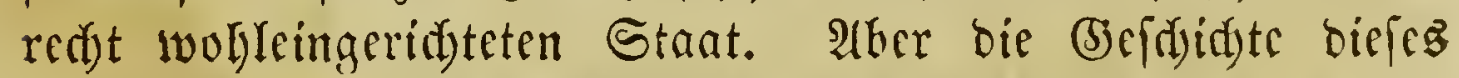

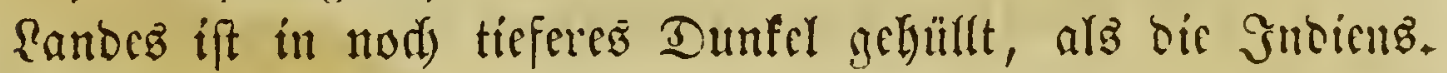

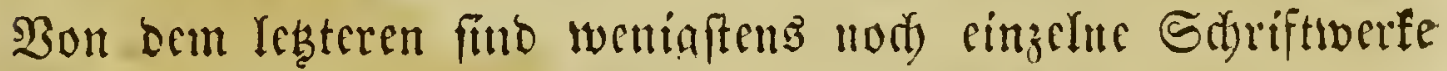
übrig, aus benen wir in פ̧ezichung auf foine geiftigen $\mathfrak{B} e=$

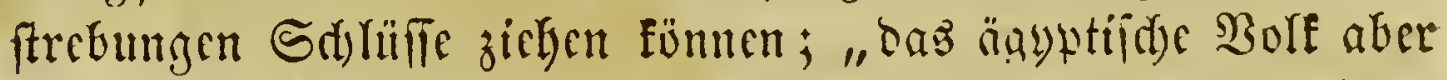

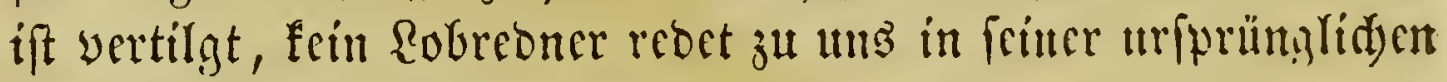
Spradje, frin $\mathfrak{B u}$ ib uberliefert uns feine Echren." ${ }^{2}$ ) -

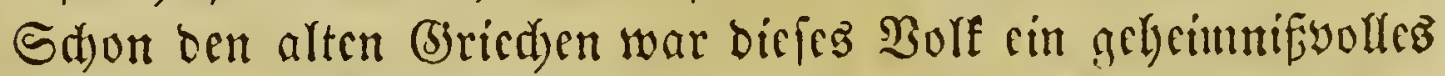
Räthjel. Sic fdurieben ben ägyptifden prieftern dic grüfite

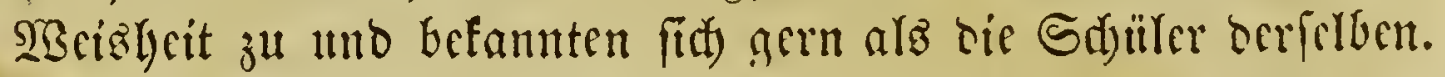

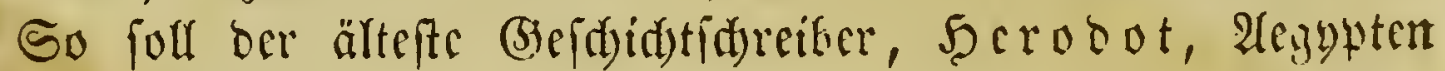
burdereif baben; Solon, Sygthagoras unb gr laton follen cbenfalrs mit ben ägyptifden \$̧rieffern in Berübrung gefom=

1) Dis unterfuchung ïber bie Eitten uno 3uftänbe ber alten Snber fino nod) zu neu, um zu volftänoigen Sicfurtaten gelangt ju feill. Ratürid baben bie Englänoer sie befte Belegenbeit zu folden Unterfudungen. In Den Transactions of the rnyal asiatic society of Great Britain finben fid lier uno ba aud cinjelne Bemerfungen über bie glfanisentenntnib ber alten Sntel.

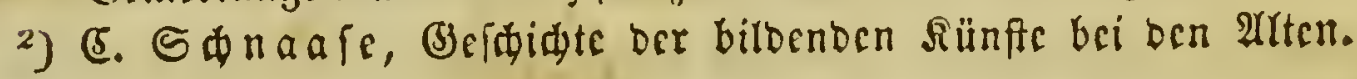




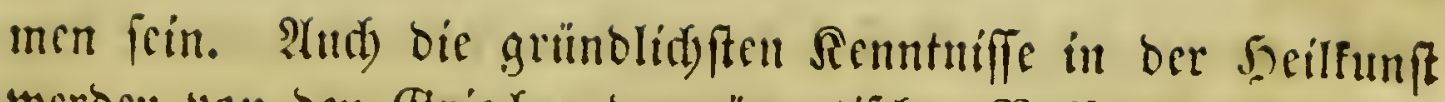
werben you ben (Stredsen bem ägyptifdyen Bolfe zugefdrtieber. So fagt ;. B. Şomer, Do. IV. 229 ff.:

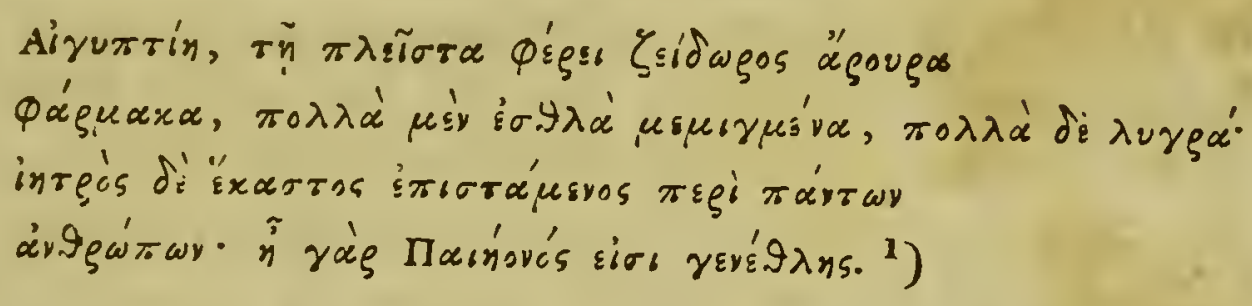

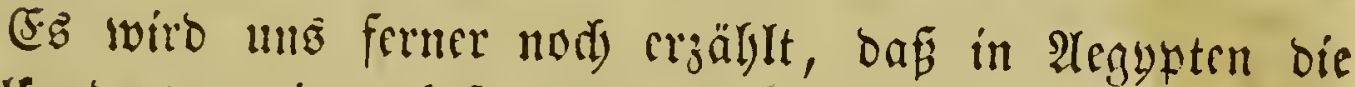
Sreilfunto von cincm befonderen Stanbe ausheübt worben fei,

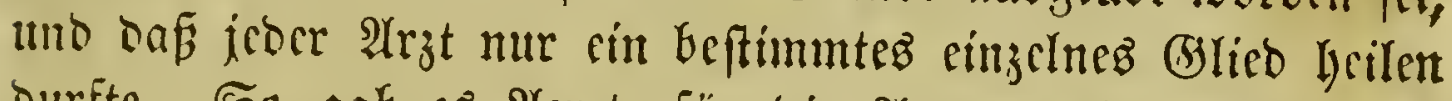
surfte. So gab es Aerzte für bie 2 tugen, die Zähne, bent

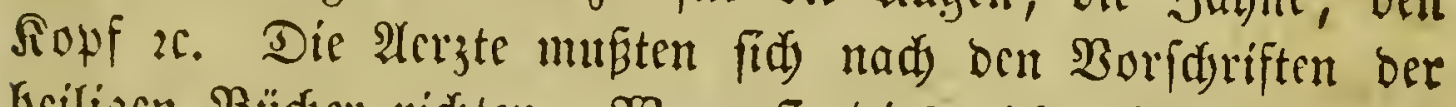
Gciligen Bädyer ridjten. SGem fie bies nidyt thaten, waren fie für ben 2 (uвgang oer Sur verantwortlidy. ${ }^{2}$ )

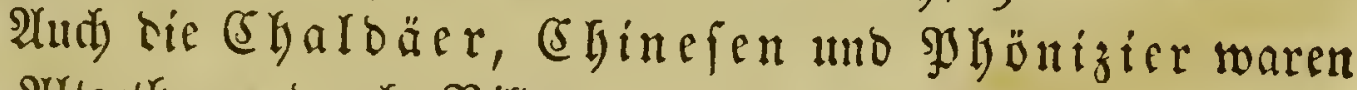
in Altertlyume burdi Biloung uno Renntniffe ausgeseifinet. Der Şandel oer \&ç̧teren war über dí ganze bamals bclannte

1) $\Re a \mathfrak{A}^{2} \mathrm{OB}:$

Dort (in $\mathfrak{A}$ (egypten) bringt bie frudtbare (5rbe Danderlei Єäfte berbor zu gutter und fđäbliđer Mif币ung; Dort if jeber ein $\mathfrak{2} \mathfrak{r}_{\mathrm{g}} t$ und übertrifft an Erfabrung Utue Renfden; benn wabrlid fie finb vom (B)

$\left.{ }^{2}\right)$ Bonastre, Notice sur quelques végétaux représentés sur les anciens monumens de l'Egypte in ben Journal de Pharmacie, Octbr. 1830, pag. 642.

Kunth, Recherches sur les plantes trouvées dans les tombeaux égypliens par M. Passalaqua in ben Annales des sciences naturelles, t. VIII. Août 1826, p. 418-423. II. R aspail, Notice sur la détermination spécifique des Céréales trouvés par M. Passalaqua dans un tombeau égyptien in ben Mẻmoires du Mus. d'hist. natur. $8^{\mathrm{mo}}$ ann., $10^{\text {me }}$ cah., t. XV, p. 145 etc.

2Huh in (5) eiger'z Ragajin, Febr. 1827, S. 115 u. 167,

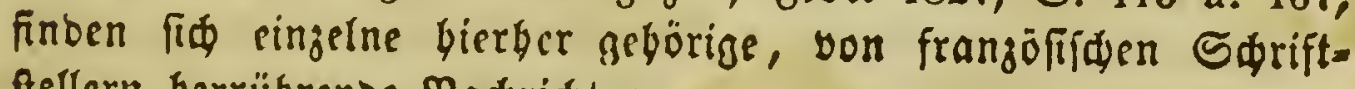
fellern berrübrende Radridten. 
(Evo aughebreitet. (5) wis waren ihnen beghalb aud bie Pro= Dufte ber Ränoer, an beren Rüften fie oftmals lanbeten, genau

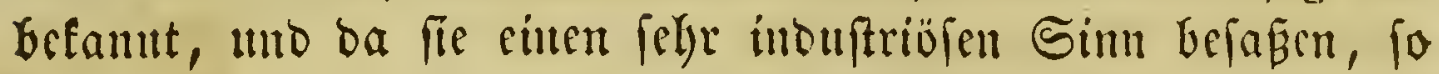

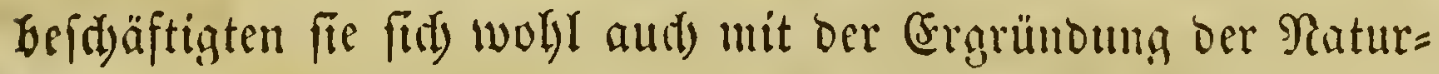

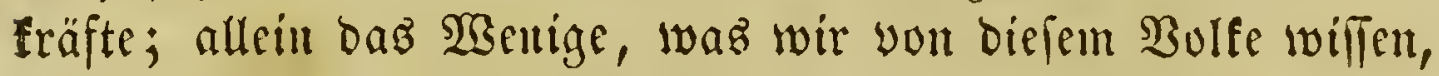
ift uns ourd) bie Trabirion ber (Briect)en und Römer zugefom= men, wou bem Bolfe felbft fitto feine Denfmale übrin geblieben.

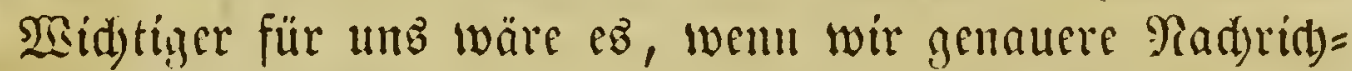

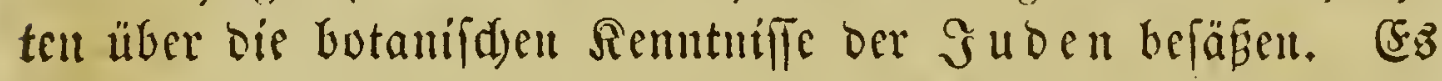
fommen in ben heiligen Sdyriften biefes, für bie driftlidye

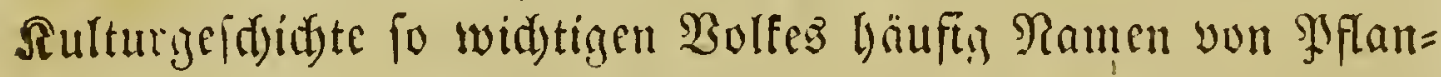

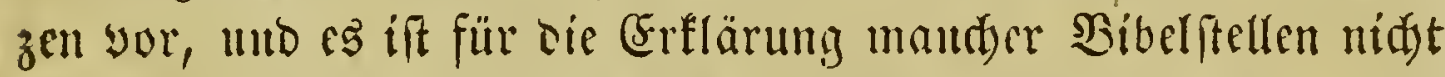

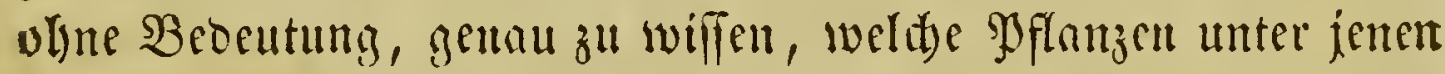

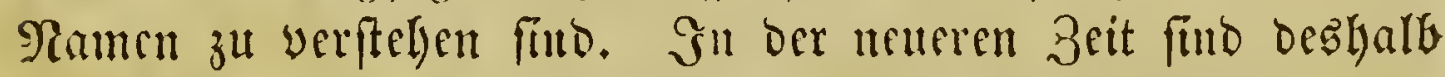

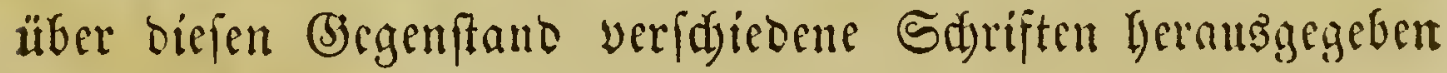
soorten. ${ }^{1}$ )

1) 01 . Celsius, Hierobotanicum. Upsal. 1745-47. 8.

J. Gesiler, Phytographia sacra. Tigur. 1759-1773. 4.

W. Carpenter, Scripture natural history. Lonilon 1828. 8. Bergleidye Eeoulgarti $\mathfrak{R}$ auwolfell, ber Arjney Doctorn,

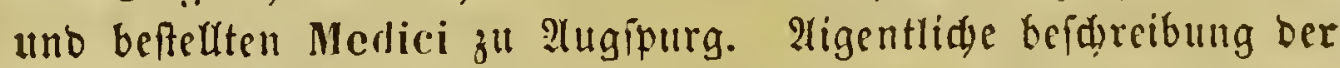

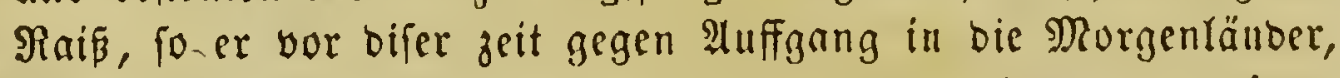
fürnefymlich Syriam, Judaeam, Arabiam, Mesopotamiam, Bahyloniam, Assyriam, Armeniam etc. nid)t ofme geringe mübe unno große gefabr fertho volfradyt: neben vermeldung vil altberer fert $j_{j} a m e r$ und brufüübiger fadicn, bie alle er auff folder erfundiget, gefeben und obseruirt yat. 2tlles in brey unberidiblidye Thail mit fonberem fleis abgethailet, unb cint jeber weiter in feine fonbere sapitel, wie bero inuluglt in ju end gefeßtem Siegifter zufuben. Betrudt zu Rauningen, Durd Reongart Reinmidel 1582. Duarto. - Daffelbe Siserl, zweite 2luflage, ourd cincu vierten Theil uno 5oljidjuitte ver= melyrt. - Eprengel, llistoria rei herbariae, t. I. Cap. I: Flora biblica; uno inglecionbere $E$. $\Re$. Siofenmülter,

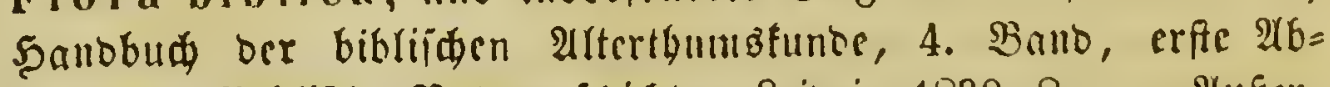

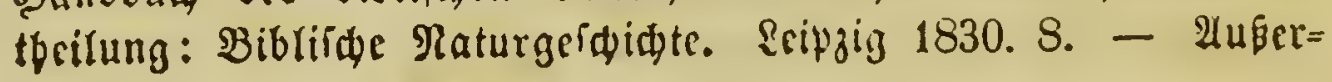




\section{Die Griechen.}

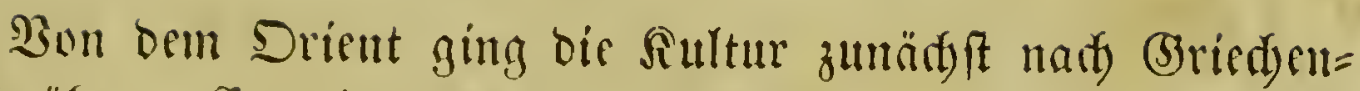

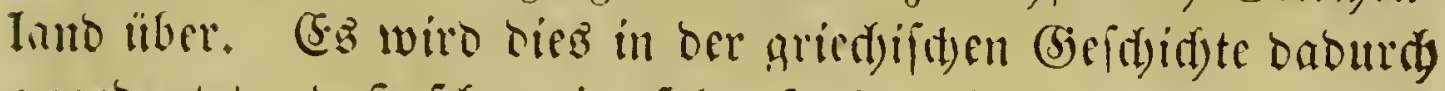

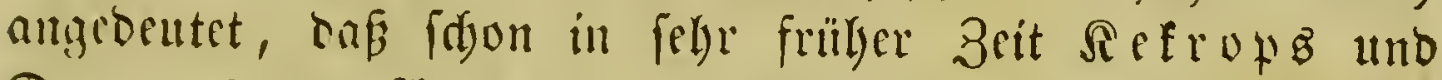

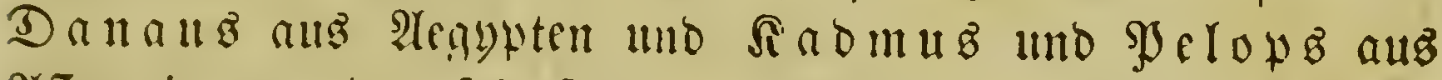
2ffer eingewantiort fein fullen. Die Sage bejeidnet mit biefen Tamen eingelner herworragender Männer jebenfalls gröpere 3ïge won Eimwanoerern, weldye unter ben in (5ried)enlant cin=

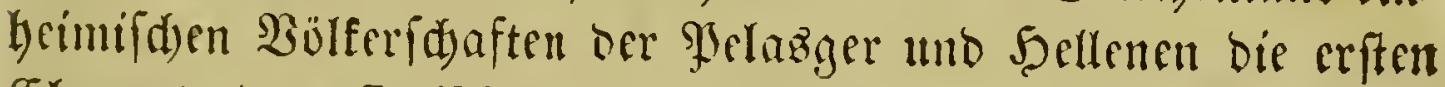
(5. Temente ber afiatiiden Gisifesbiloung verbreiteten.

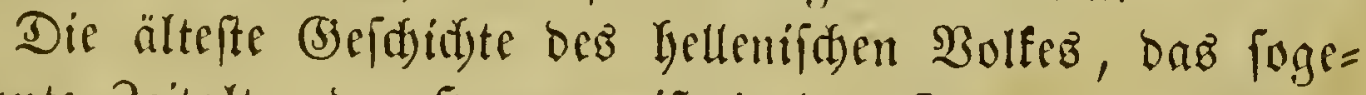
nannte Britalter ber Seroen, ift in bas (Jicwand oer Mythe

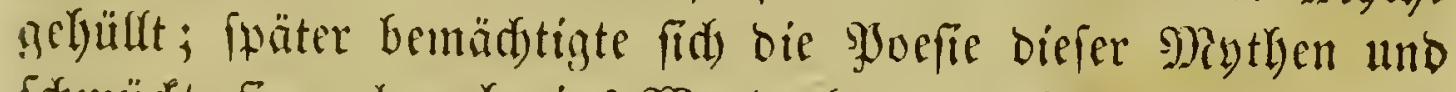

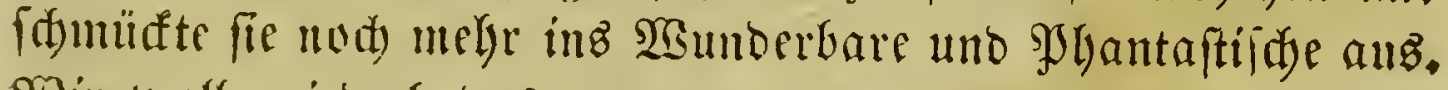
Wir wollen jebods bas, was uns am widjtigften für unferen

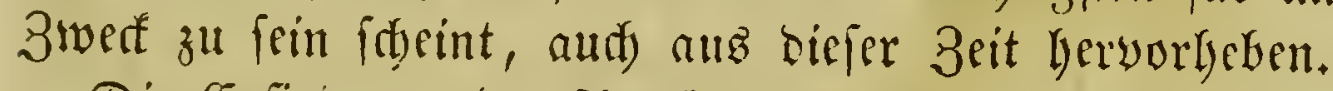

Die Erfinoung ober Anfflnuzung oer nüblichften (J)wäad)

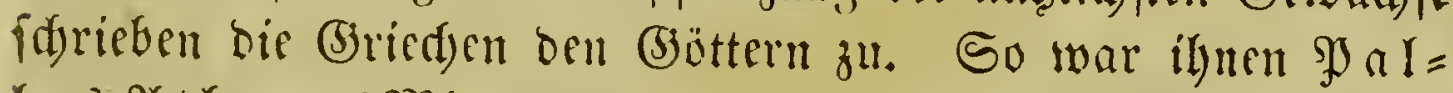
las $\mathfrak{A}$ the ne (Minerva) die Erfinberin bes Delbaues, einez

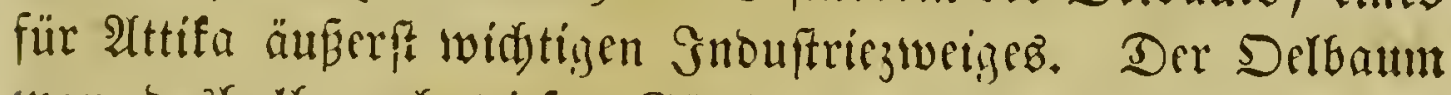
war beshalb aud defer (Ssüttin geweiht uno bient bei oen A्lten oft als Sinnbild Derielben.

Demeter ( (Seres ) Iefrite oen Siöniz Iriptoremus zu

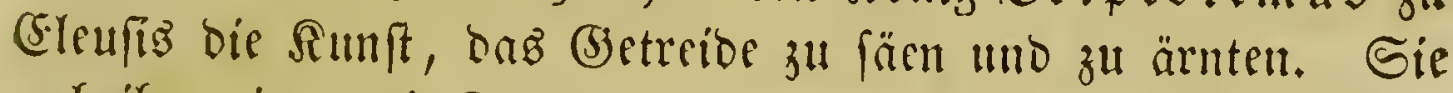
gab ifm cinen mit Dradjen beffannten Sigagen unb befahl ifm, Das Bsetreide auf ber ganzen (Erbe zu verberten. Dies that Triptolcmus, uno yon ilym lernten bic Menf(d)en zuerfit bie für ifr Reben aviditigften Şflanzenarten zu bauen; fie Iernten ben

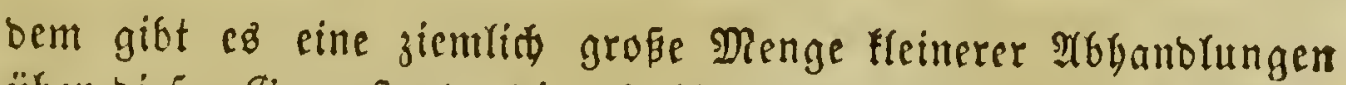
über biefen Begenftant, bie wir bier niđt näher anfübren wollen. Bergl. Darüber ßrüger'z Bibliographia botanica. Berlin 1841, S. 33, und $\mathfrak{x}$ ripet S. $362-63$. 


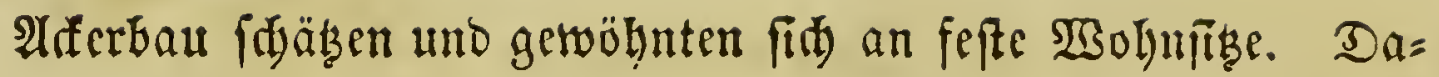

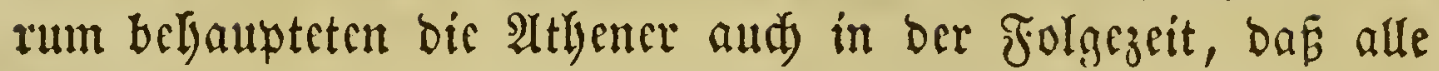
Bülferfdaften ber Erbe yon ilyrem (Serftenfeloe nabe bei Der Stabt (ercufis (bom ager Rharius) den (Jictreibefamen er= halten hätten. - Seljr befaunt ift dic Sage yon $\mathfrak{B} a c d u s$,

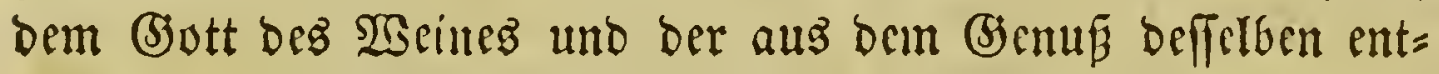
ftelenden Freude. Sin Den Sändern bes Dftens überall um= berzichento, verbreitete er balo burd) (j)üte, bald burd (b)e

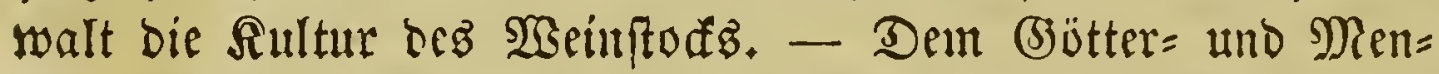

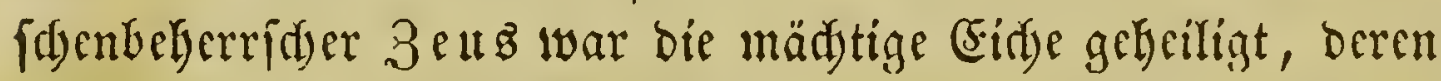
Frü(fte vielfad) zur Rahrung bienten; und alş Ricblingsłplanze Itporlo's galt ber Rorber, weil bie won iflm geliebte Rymphe Baplute in cinen foldyen verwandelt worben war. Seifpicle

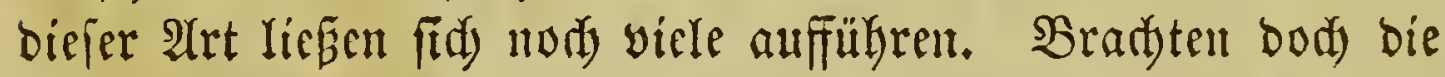

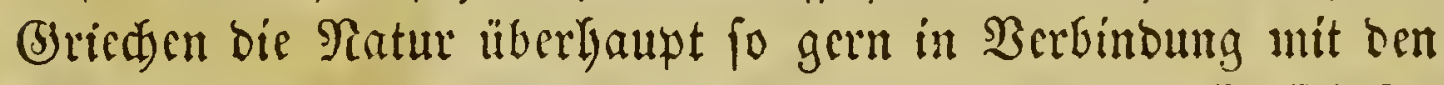

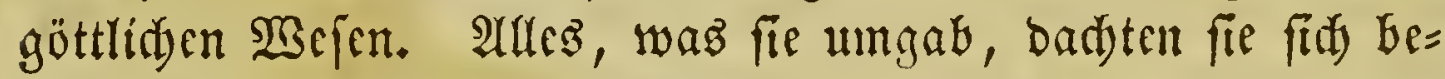
Iebt. Şainen, Duellen, Thailern uto $\mathfrak{B e r g e n}$ fdrieben fie

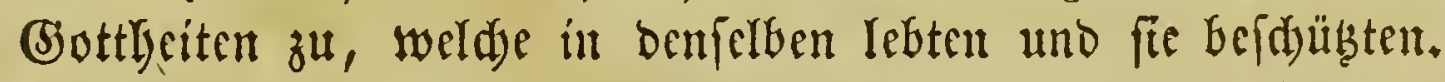

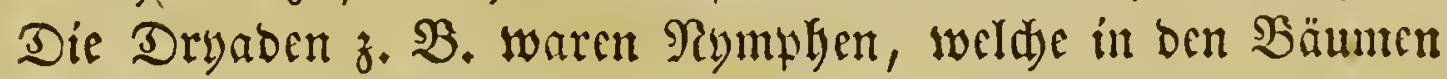
Iebten, mit oenjelben entftanden and mit ifnen wieber zu Grunde gingen; Darum flagten fie oft, wenn ber Bam, mit Dem fie

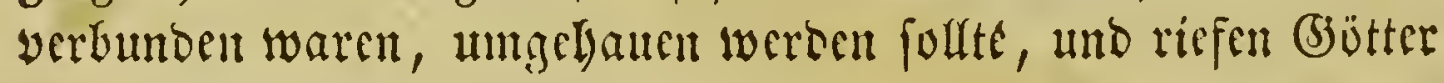
unto Menfd)en zum $\mathfrak{B}$ eiftant an.

Bei Şomer foummt aud) cin Gefonderer (bott ber Şcilfunbe, গু ä on genaunt, yor, bem man bie Senntnif ber lecilenten Sräuter juîdrich, utb ber bei ben Giöttern bie Stelle des

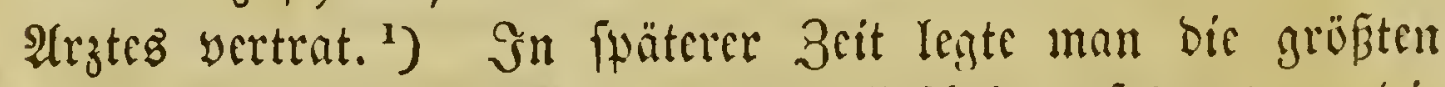

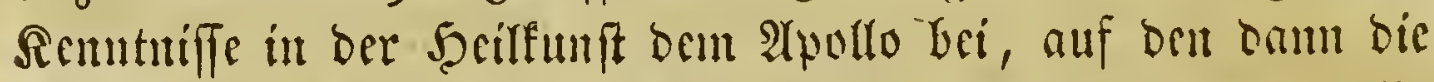

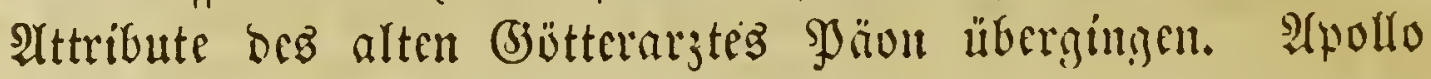
felbit aber erlernte einizen Sagen ju Folge bie Jaciffunbe you bem Eentauren Ebiron. Diefer, cin Sulgn bez Saturn mo

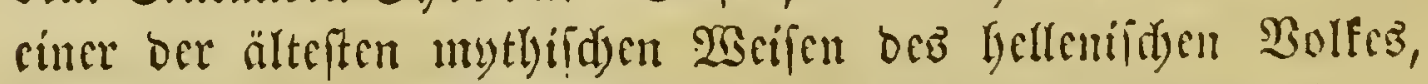

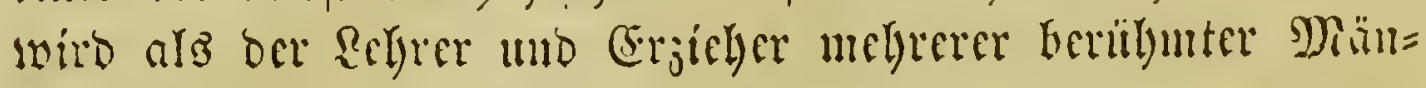

1) Ilias V, 400, 900 . 


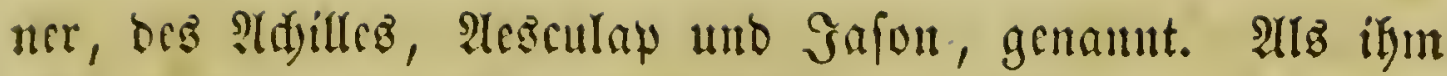
cinft cin wergifteter gfoil in ben Fun gefallen war, fand er ein Sarilmittel bagegen in bem bitteren Safte siner glflanze, weldye undi) if) m- Sentanremm vorr (Shironiwn (Gentiana Centaureum, L. Chironia Centaureum, Willd., Tanfertboyntoens fraut ) gुctaunt wurtoe.

Ars cin Saciffmoinger bes loben Altertfyms wirb audd)

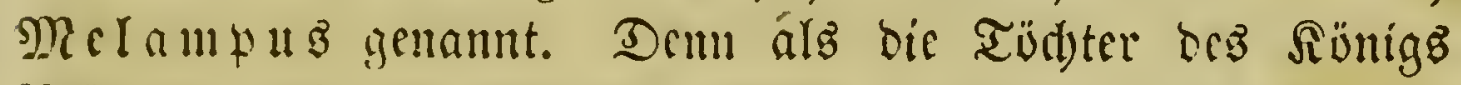

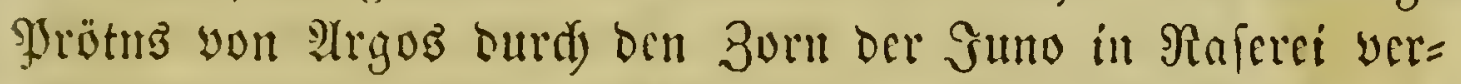

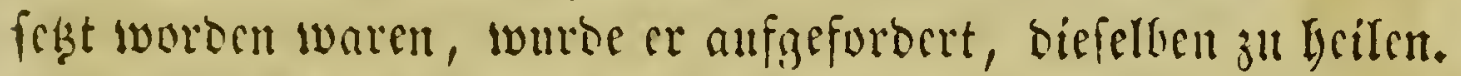

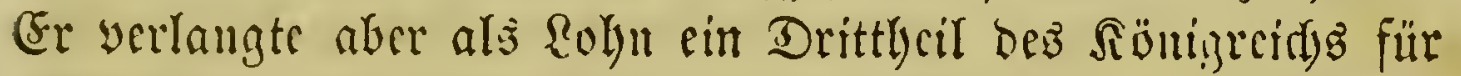

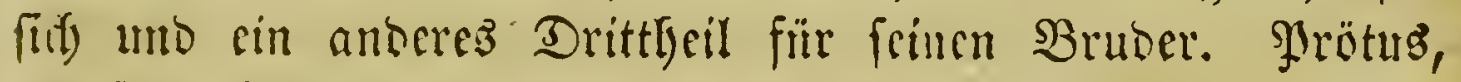

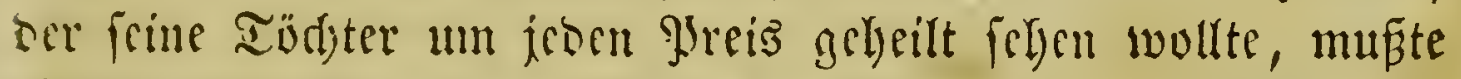

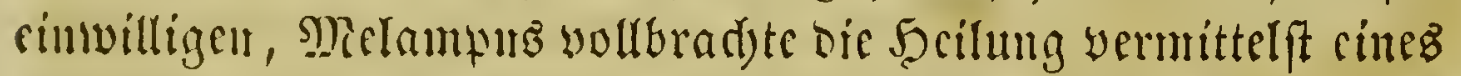
Srautcs, bas Mad) ifm ten ?amen Melampodium (Vera-

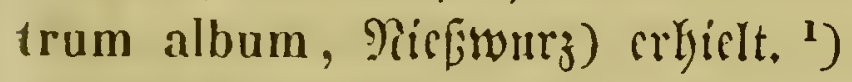

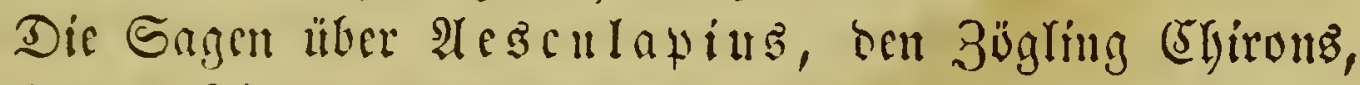

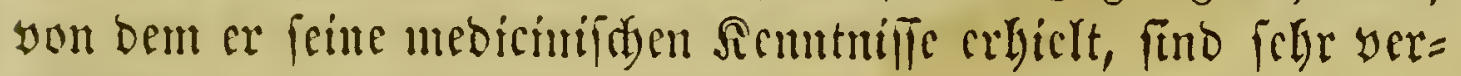

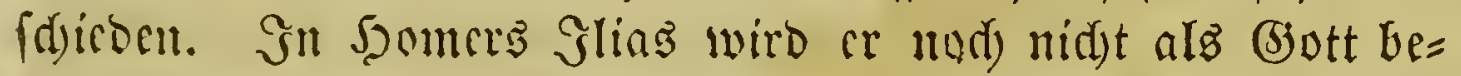
tradjtet, fonbern er gilt bort als cin ielye erfalfrentr $\mathfrak{A r}_{\mathfrak{z}} \mathrm{t}^{2}$ ),

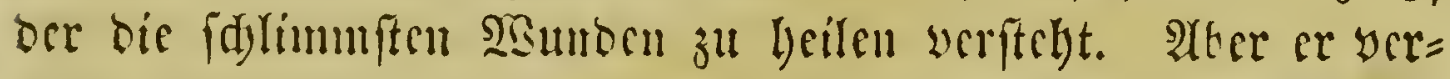

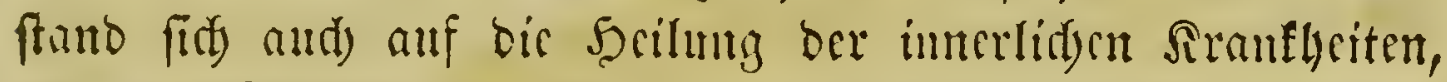

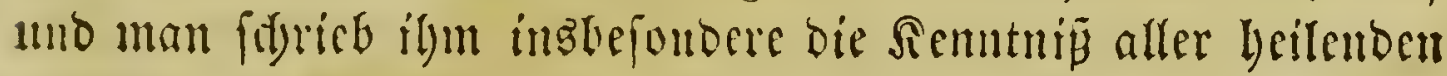

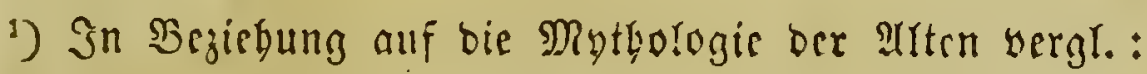

G. R. Bo ehmer, Plantae fabulosae impr. mythol. specim. $1-5$. Witlenberg. $1800-18013$. 4.

3. 5. (5. Sd) weigger, cinleitung in bie Rytbulogic allf bem Stanbpunte ber Raturwilfenid)aft. (Fin 2Hhang juber in ben Sabren 1824-1828 eridjiencuen 3citidrift bes $\mathfrak{3 e r c i l l}$ für $\mathfrak{B e r}=$

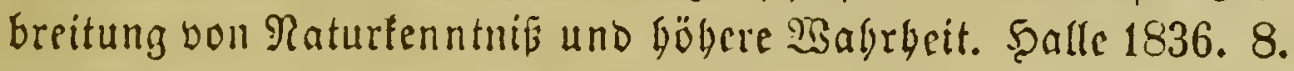

Heber berfdicdene bei ben gricdifduell Didtern vorfommende Şlfanzenarten fuben fid audd sinzelne $\mathfrak{S}$ smerfungen in (5. Spren= gel'z Antiquitatum botanicar. specim. I. Seipzig 1798. 4. Sergl. über dic zablreiden bierber gebörenden Edyriften 9 ribel ธ. $366-67$.

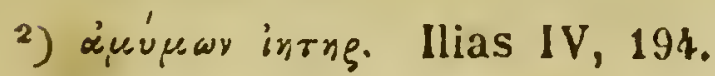


Sräuter zll. Seine Rumft ging ber Saģe nadi fo weit, tak er ferbft Todte wieder zmm Reben erweden fonnte. Darum be= fdyerte firs einft Sুluto, ber bott Der Unterivelt, bci Zcus,

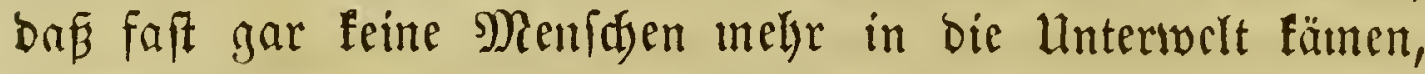
woil $\mathfrak{A}$ esculap fie yon ben frither für unthrilbar grbaltenen Sranffeiten befreite und bie Beftorbenen wieber burd) feine Sunft in's Rebell zurüfơnädyte. Zeus ergrimmte über biefe Bermeffenbeit einca Sterbliden uno erfdulug ben Aeżculap mit bein 3̧lize. Später wurbe 2lesculap alz bem Erfinder ber Arzucifunde göttlide (E)gre crwiejen. Man betradtete ifn

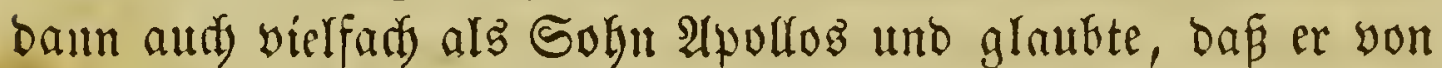
siefen felbft in ber Sceilfunde unterrinjtet worben fei. An ver= fdiebencm Drten (briedjenlanos wurben ilym Tempel erbaut, her berïlymtefte aber befand fiti in ber Rähe ber peloponneft= fdien Stabt (Epionurus in cinem grofien gelsciligten Saaite. Bie 2 ttribute, mit benen man bicicn (5ott gewöhnlids onrgefteilt erbliat, fino bie Shlange uno ber 5alnn. Die erftere foll bie

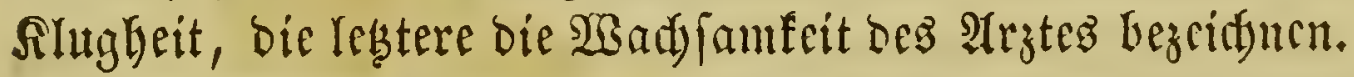

Die Renntuiffe 2(esculaps gingen auf frine Rad)fommen,

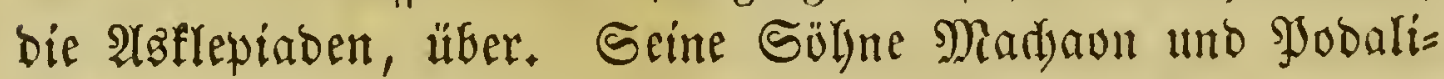
rinz zogen mit yor Troja uno werben won jouner als bie yor=

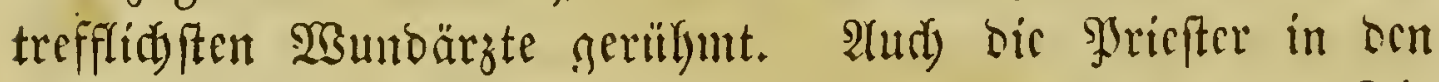

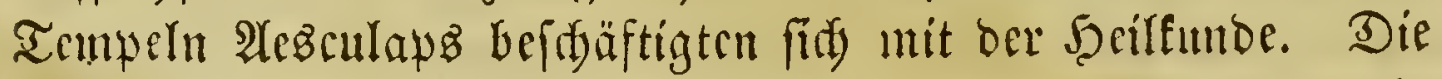

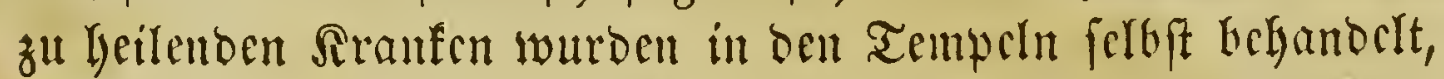
uno wocun fie swiebcr genafen, fo musten fie ilyre Sranfleit unb bie Mittel, burd) weldye fie bie (Sefundheit wicber erlangt

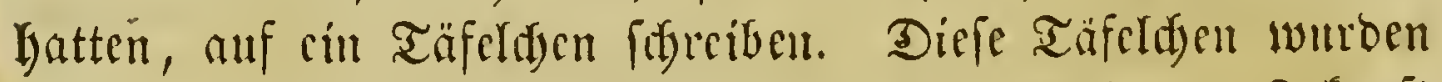
bann in ben Tempeln aufgelyängt uno bicuten in oer $3 u f u n f t$

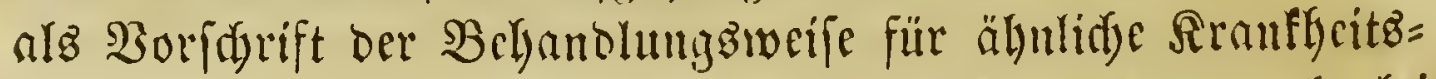

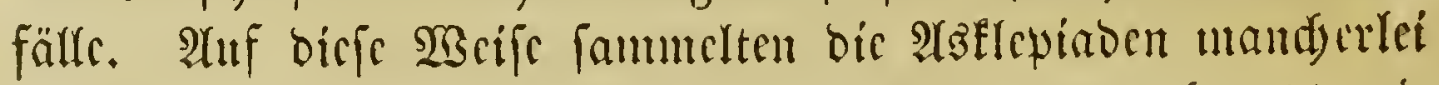

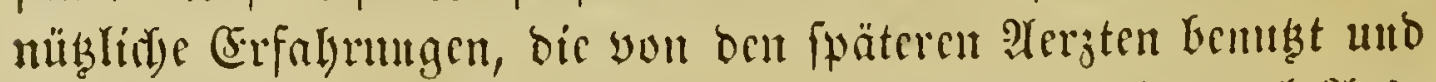
wervolftämbigt werben founten. So wurben bie Temper Ares=

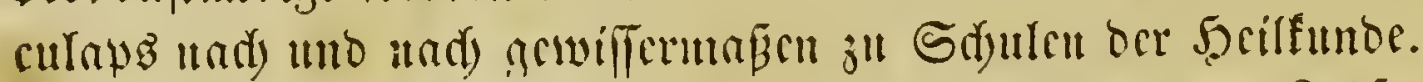

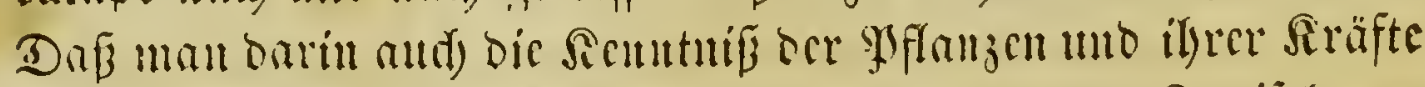

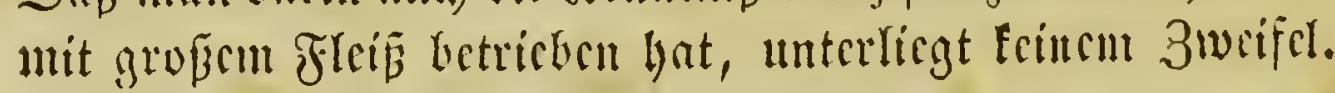




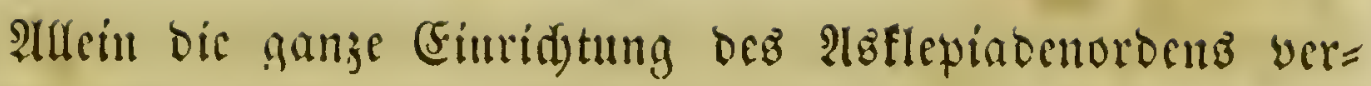

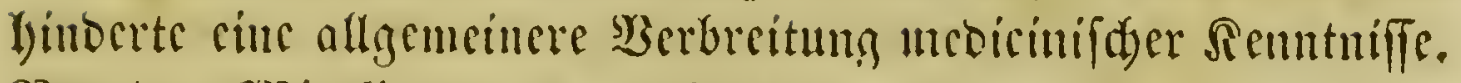

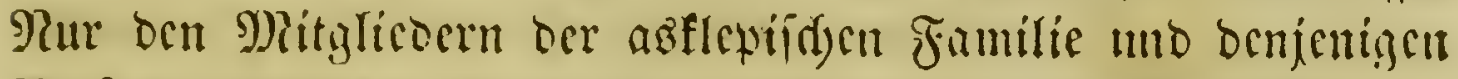
Sorjoun wurben bic heiligen (5) beimuiffe mitgetbeilt, weld)e

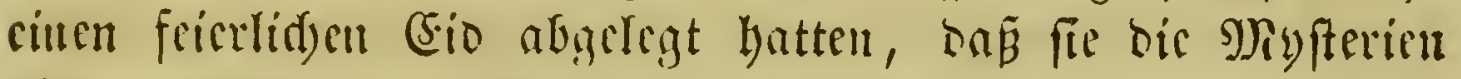
nid)t entweifsen, nod) siciclben cincu Ridstcingewsibten mit= theilen wollten. Daun funnte bie Micoicin aud) f(d)on aus Dem Grunde unter ben 5ellenen feine bereutenten Fortid)ritte

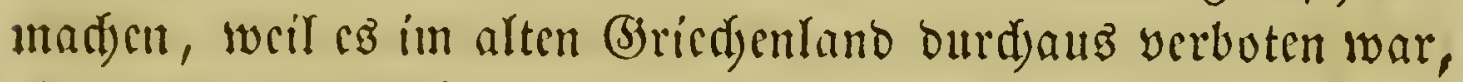

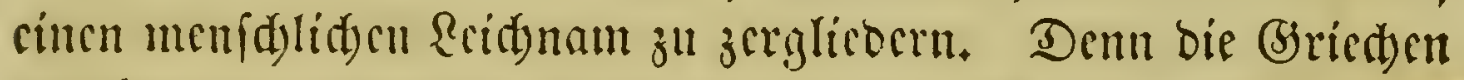
glaubten, die Serlen füunten nady bem Tobe nidyt elder an

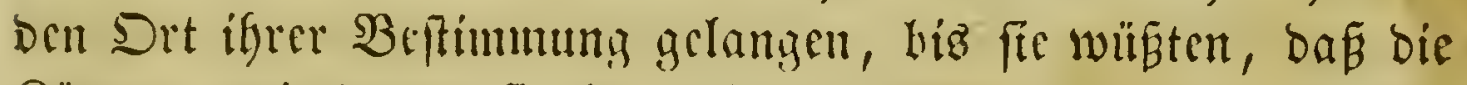
Sürwer, mit Denen fie in bicjem seben verbunben getvefen, woirflich becroigt ober verbramnt worben wäreı. Berlebungen menidylid)er Reidyame wuroen beshalb freng beftaft. So

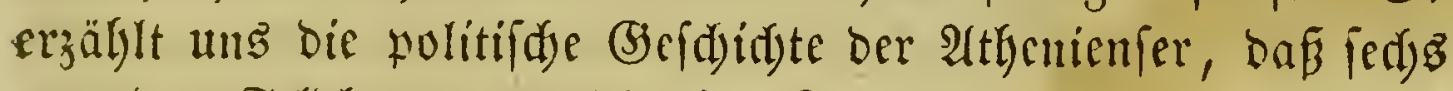
yon ben forbheren, woldye im Sabr $406 \mathfrak{v}$. (5h). bei ben argimulfidsen Infelu über die Spartaner gefiegt hatten, beshalb (wenigftens bein Sorwande nad) ) zum Tooe verartheilt wwr= oen, weil fee, burw cinen beftigen Sturm verbinbert, baz

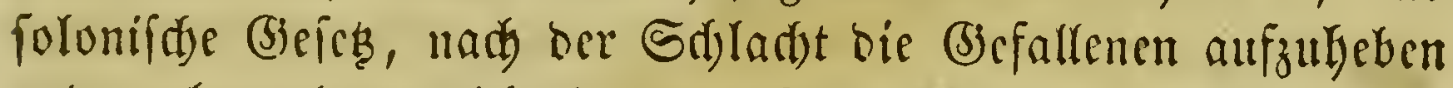
unb zu begrabon, nidjt hatten befolgen fünnen. - 2 (lle neuen Renntniffe in oer Şrilfumbe mufiten Darum burd) mübfames Srobiren gefunden werben, und ca ift beshalb nidyt zu ver= wwunbern, wenn bie Fortfdritte mur äuferft langlam vor fid gingen. A(ud) bie Siflanjenfunte founte oarmm nur langfau sweiter gedeilfen; Deun fie surbe in jeuen 3eitcu nur ill ifger

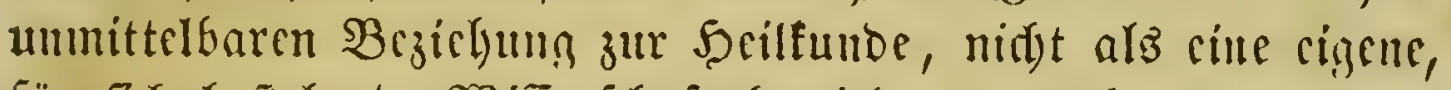

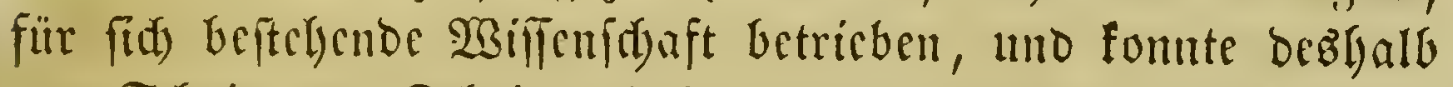
эur Sdyritt yol Sd)ritt mit jence cincr grö̈eren Grweiterung entyegengelen.

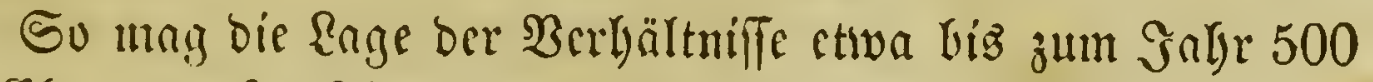
v. Shr. seweien fein. Ulm bicje Zeit aber erwadjte ber bent= Eembe (Bscift crift red)t in (5risd)enlant. Bejonters waren

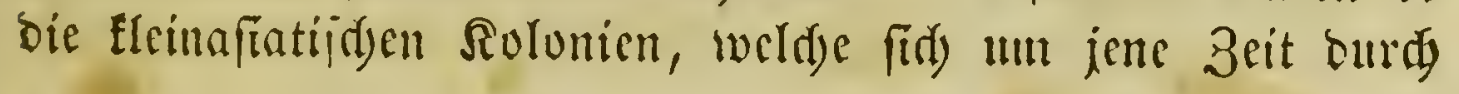




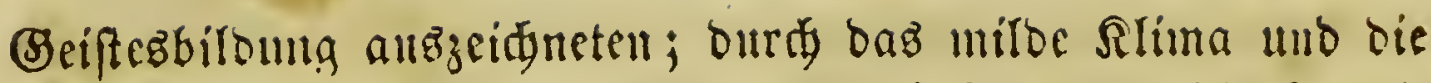
iiberaus günftige Rage igres Ranbes geboben uno nidgt io wie

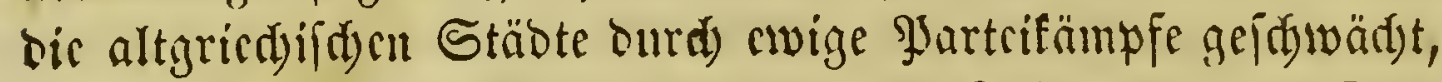
gingen fie felbfit bem Mutterlanoe in oer Sultur voran. Dort crwadyte autg zuerft bie Riebe zum fhifo[uplifdyen Forfden. Die älteften grierdifdyen Didyter, wie oer unferblidye Şomer, blülyeten in ben griedifiden Sulonien SIcinafiens, uno soar in bod) aud $\mathfrak{T h}$ ales, beim wir bie erfen Furfdungen ïber bas

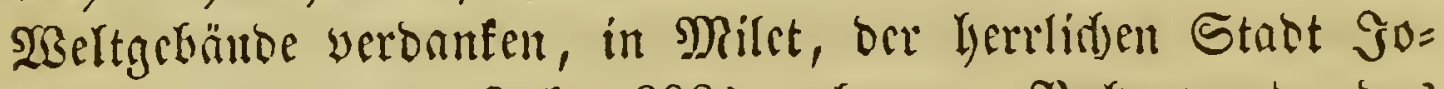

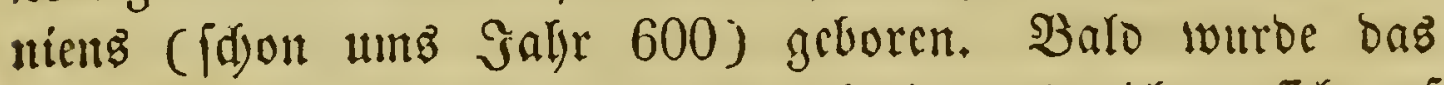

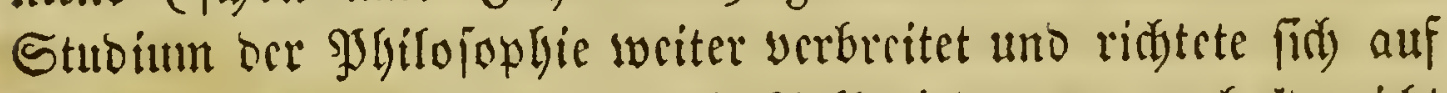

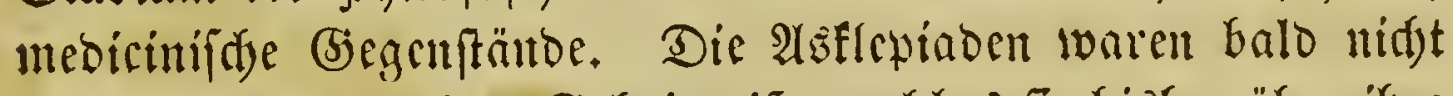

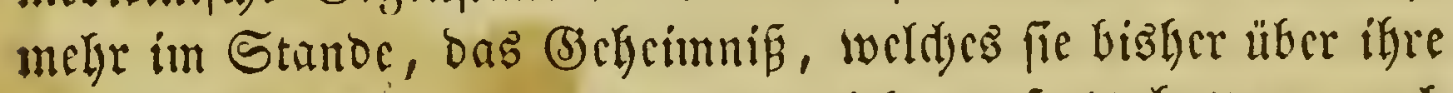

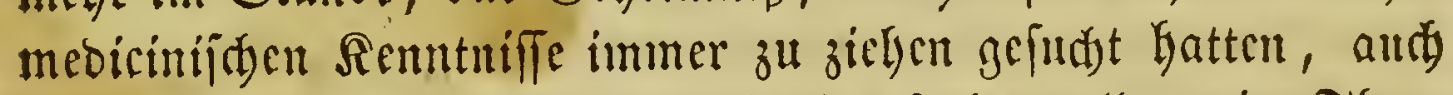

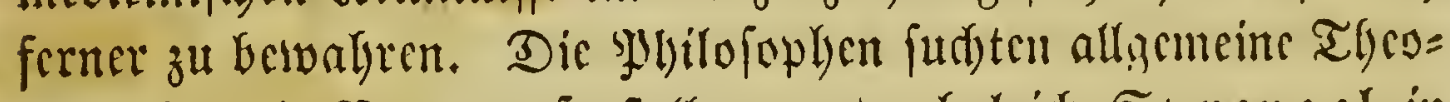
rien über die Natur aufultellen, mo obgleidy Sprengel in

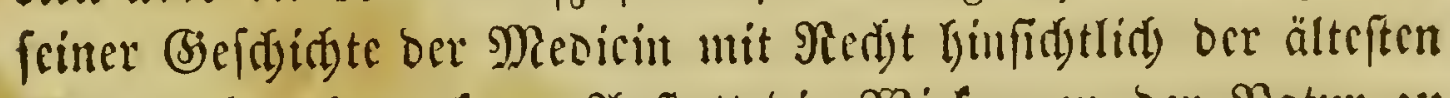

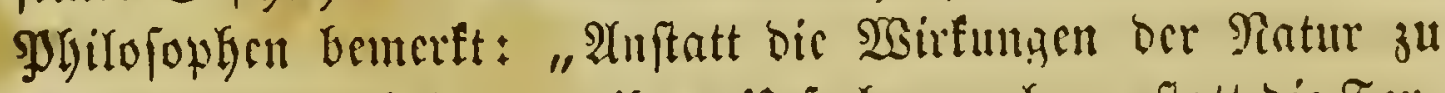

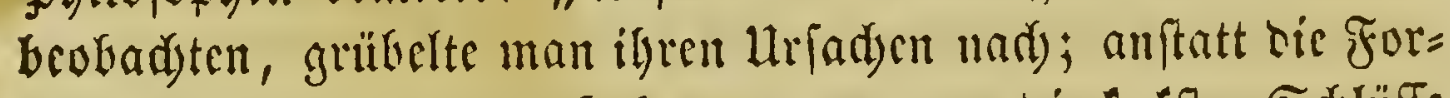

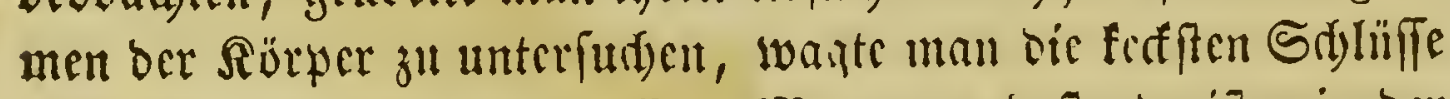
über bie affgemeinen urftofie. Man war befto breifter in ber

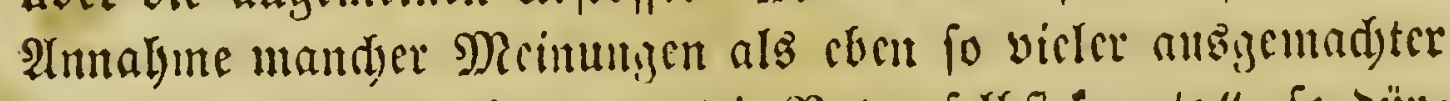

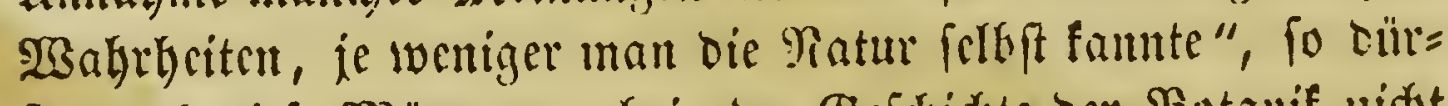

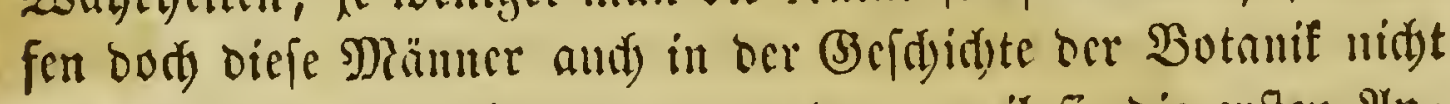
mit Stillfwweigen überga:igen worben, weil fie bie crffen $\mathfrak{A} \mathfrak{h}=$

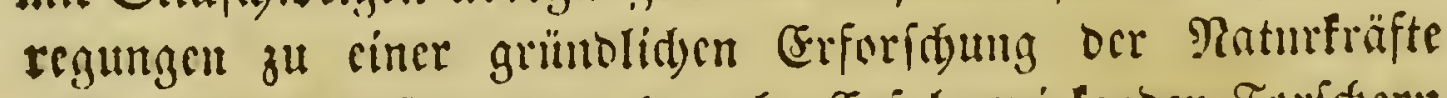
gaben unb ben fpäteren mit mebre Erjoly swinfenben Furfacen zur (3rundinge dienten.

\section{$\mathfrak{P}$ 4) $\mathfrak{t} \mathfrak{l} \mathfrak{a} \mathfrak{g} \mathfrak{O} \mathfrak{x} \mathfrak{a} \mathfrak{B}$}

war ume Saly 550 nulf ber Snfel Samod getoren.

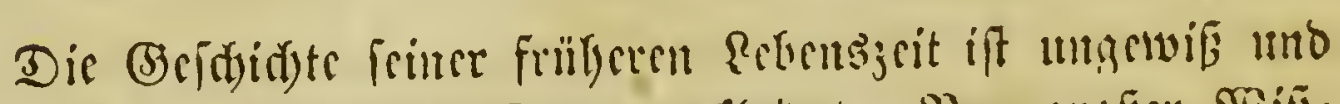

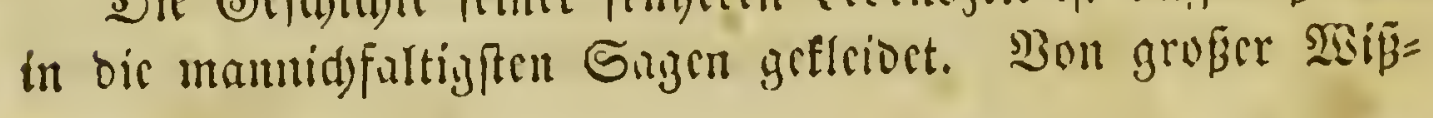


benierbe getricben, foll er auf ben Rath bes weifen Thalez fing

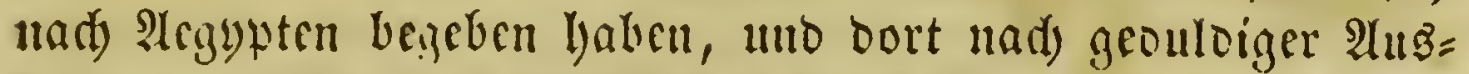

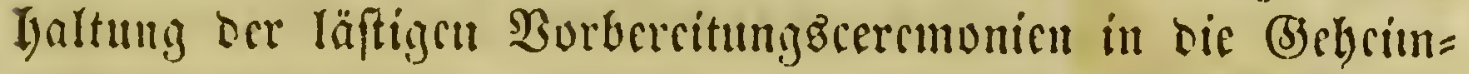

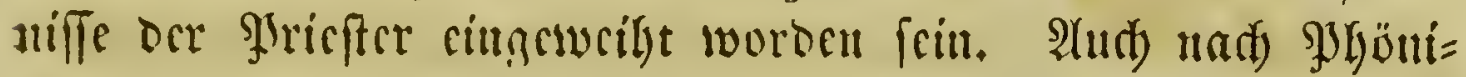

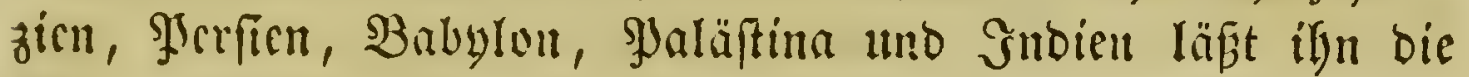
Gage reifen mb bort alle Senntuife ber bamaligen Menfdybeit

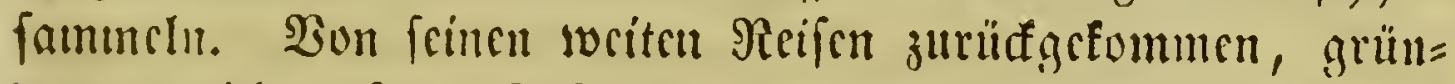
bete er nidjt auf orr Snjal Samus, mit beren bamaligen poli= tifdsen Berbältuiffen er nid)t zufricten war, fondern in ber unteritalifd)en Stast Srotun, cbenfalla cincr gried)ifden నolo=

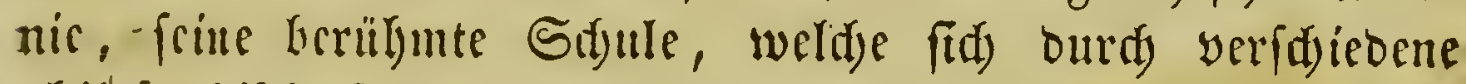

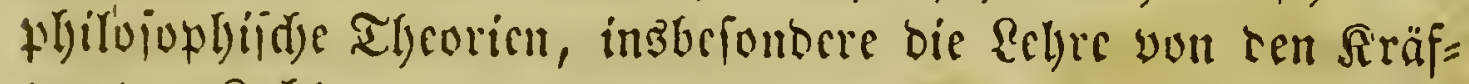

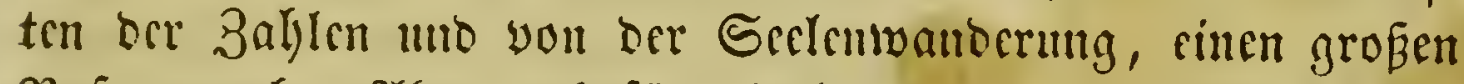

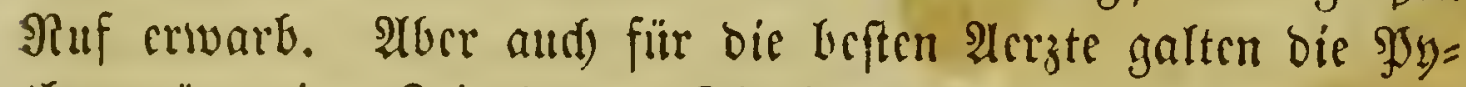
thagoräer cine 3rit lang. Sic bebienten fich bei igren b̧ci= Iungen magiidser Furmcln unb anderer Gianfereirn; Cancben

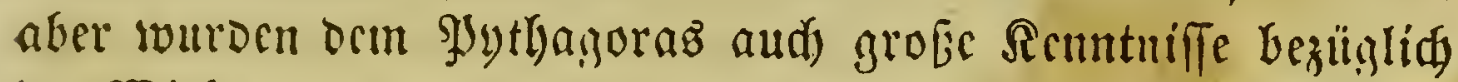
ber $\mathfrak{S i r f u n y e n ~ o r r ~ \Re i r a ̈ u t e r f r a ̈ f t e ~ z u g e i d ) r i e b e n ; ~ f o ~ f o l l ~ e r ~} \mathfrak{B r c i =}$ amidjläge, bic Miccrivictel, ben Senf uno mohrere andere Şlanjen in magiider arbfityt angervand haben. ${ }^{1}$ )

Die (Bscicke tor pythayoräifden Sdyule waren fehr frenge. (5rft nad) viclfad)en Şrüfungen fonnte man in bas inucrfte

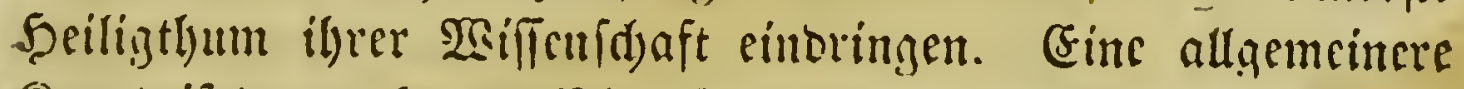

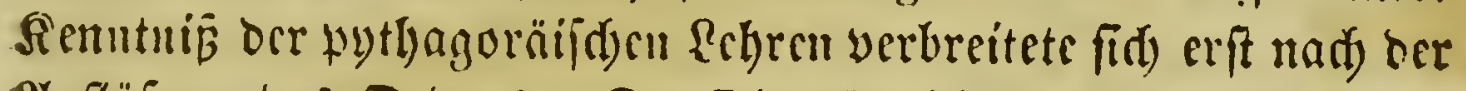

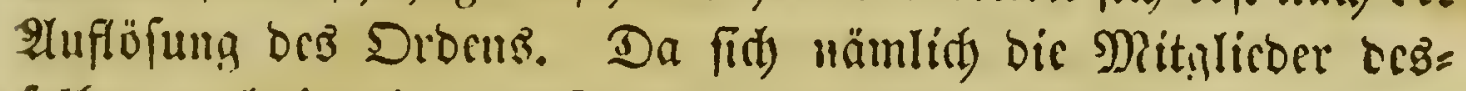
frlben aud) in ric pulitifden $\mathfrak{B}$ crbältuilie orr Stabt mifdsten, fo cutffano unter ocm nicberen Bolfe cin groper llnwillen woiber

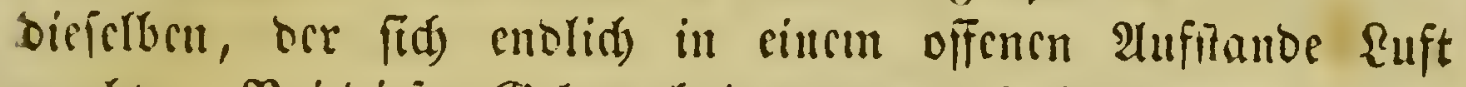

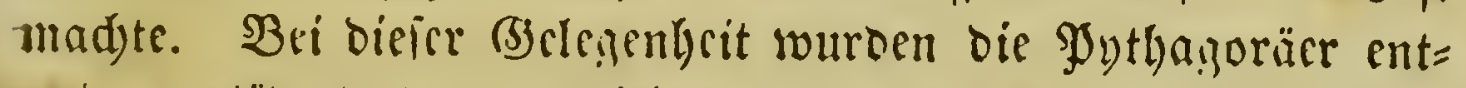
wober setüotet oocr yertricben. Die Bertricbenen aber, num nidjt inclyr all bie (Bseicte ors Drbens gebunden, verbreiteten ifre Senutuiffe in tocitcre 尺reife.

1) Bergl. Sprengel's pragmat. (3ef́didte ber Med. und bie bort citirten Stellen von prinius. 


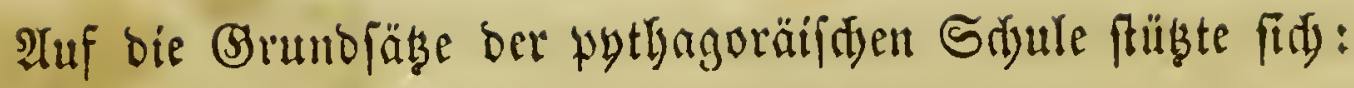

\title{
(E) MPDDUE
}

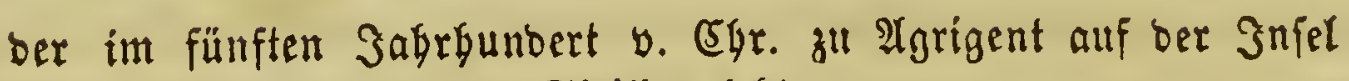
Sicilien lebte.
\end{abstract}

2(ud) yon feinen Rebensumftänoen if wenig befannt. Fr

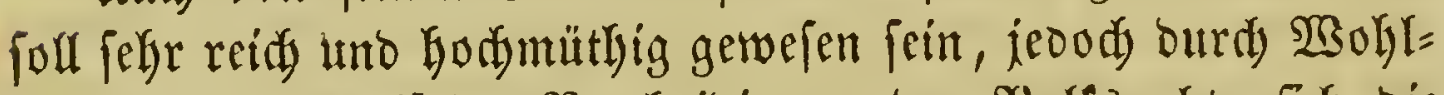

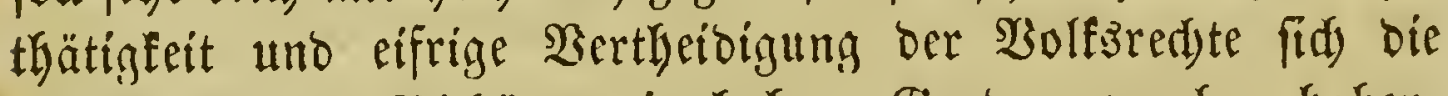
2ldtung feiner Mitbürger in lohem (brabe erworten haten.

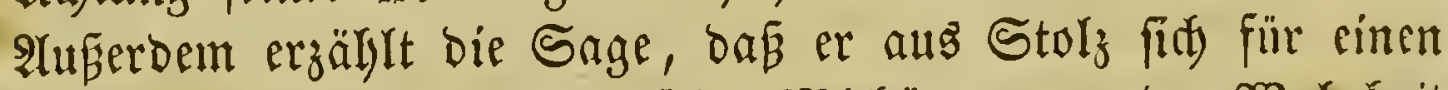
(3)ott ausigegeben und, um feine Mitbürger von ber $\mathfrak{B a h r h e i t}$

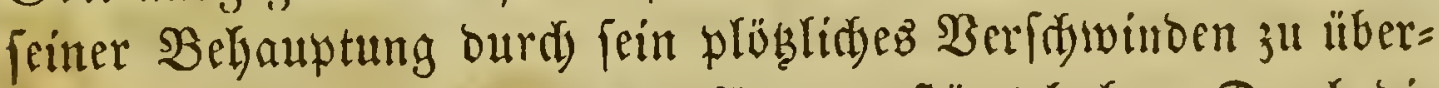
zettgen, fid in Den Arater bes \&etna geftürgt habe. Durd bie Altabiloung ber Regre yon ben vier Elementen ift er bejonberz befannt. Seine Sariften aber fint verloren gegangen ober

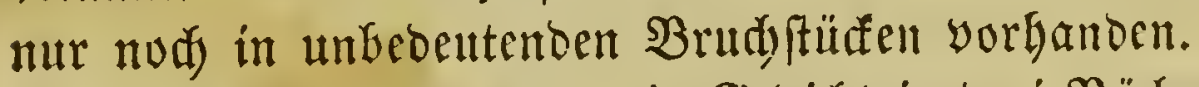

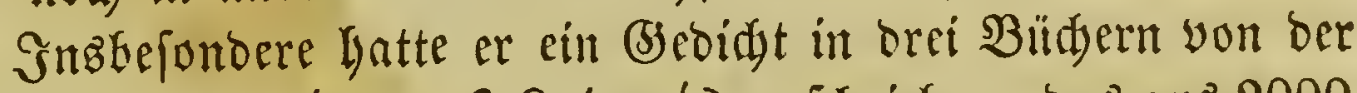

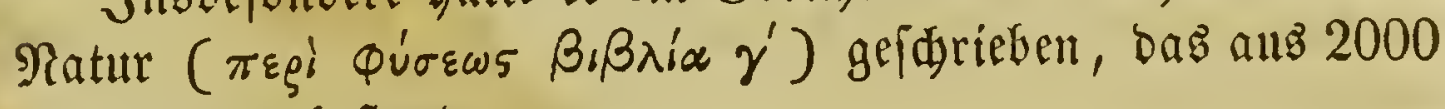
Sexametern Geftano.

Nady biefent Shillofophen find bie Sylamjen nody yor bem Arcizlaufe ber Sonne fur vor ben Thieren entftanocu. Sie

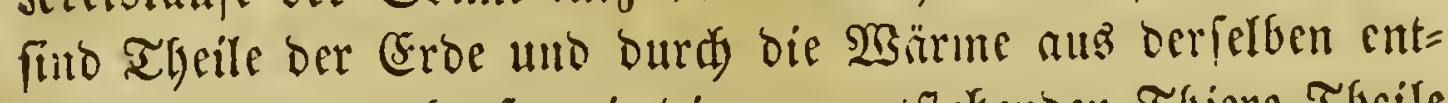
wiafelt worben, ebenjo wie die neu entfegenden Thiere Theile Dez mütterfiden Rürpers fino. Die Früdste oer syllanzen find

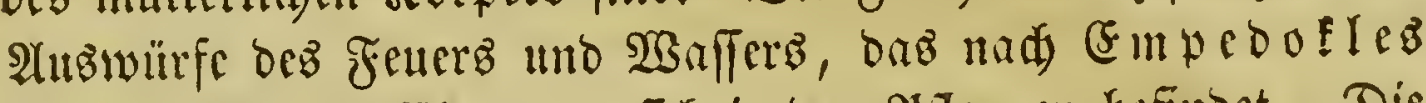
Theorie von ben (Elementen fid) in ben Planjen befurbet. Die

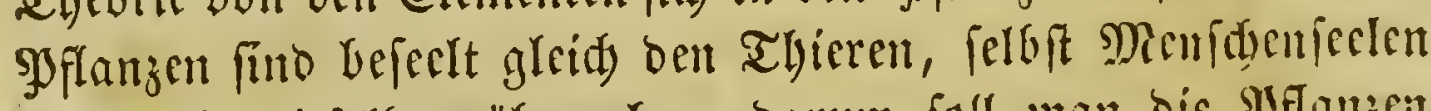
fönnen in bieferben lübergeben; Darum foll man bic Syftangen nidyt verlesen. Sie unterfdyciben fids aber yon ben Thieren

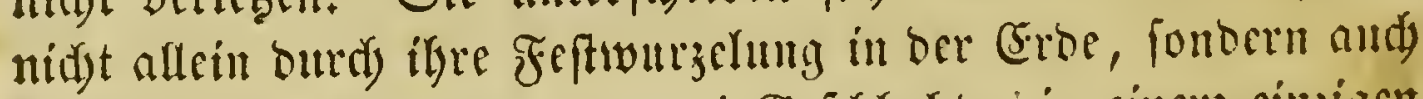

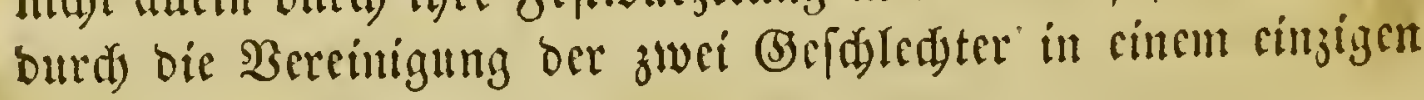
Snoivioumm. ${ }^{2}$ )

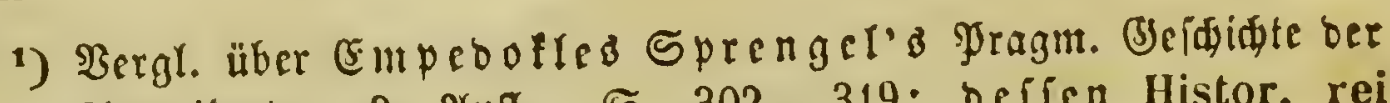
\{francifunde, 3. 2(ufl., S. $302-319$; beffen Histor. rei 


\section{$\mathfrak{A} \Perp \mathfrak{a} \times \mathfrak{a} \mathfrak{g} \vee \mathfrak{r a z}$,}

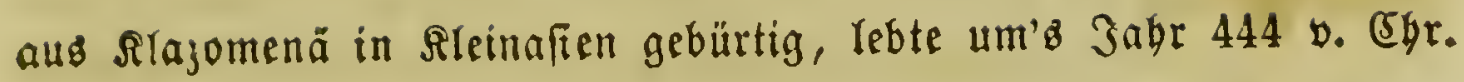

(er gebörte zu Der won Ihales geftifteten jonifden Philo=

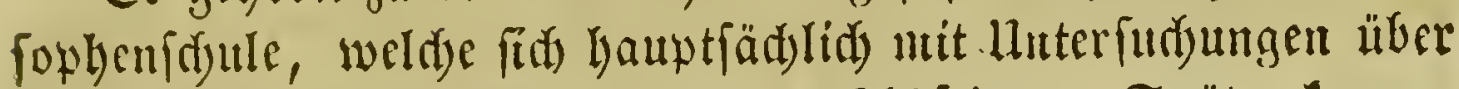

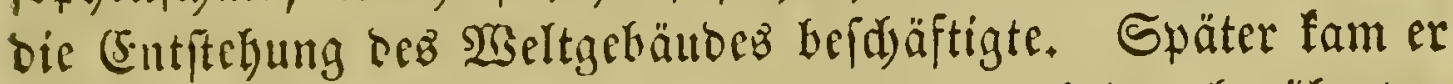
nad) $\mathfrak{A}$ then utd zäblte bort unter andern aud ben berühmten Staatsmann Sperifles zu feinen Sdütlern, wurbe jedod ma(t) trieben.

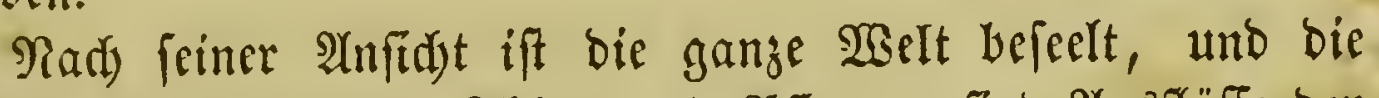

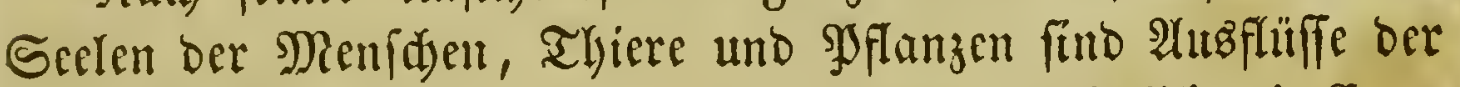

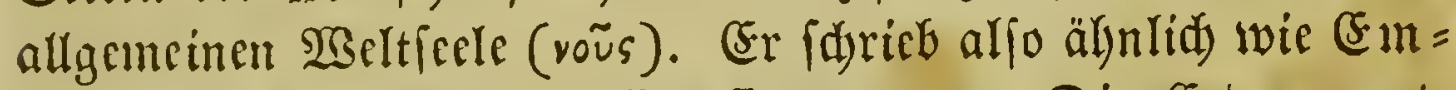
ped oflez den SPflanjen Empfinoung zu. Die Eroe nannte er bie Mutter, Die Sonne Den Vater Der Mlanzen. Ferner inag nody

\section{Dcmofritoz}

auz शtbbera in Thrazien, um's Sahr 430 v. ç̧r.,

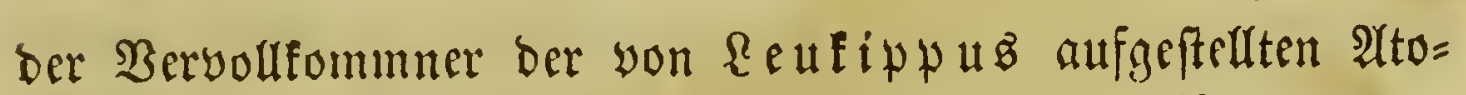
menlebre, getrannt werben. (5r madyte weite Reifen und er= warb fids auf benjelben vielfade Renntniffe. Gm alterthme wourde er für einen gründliden Renner ber Ratur gebalten; man fduricb ifm viele 3auberfünfte, fouvie aud) bie vollftänoige

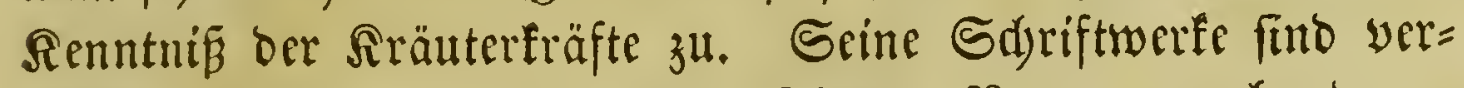
loren gegangen. Die unter feimem Ramen yorbanbenen

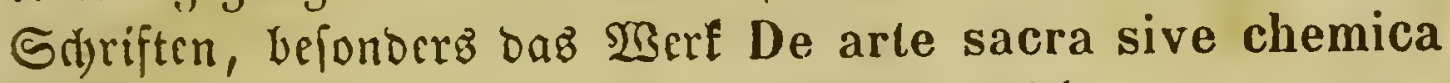
(

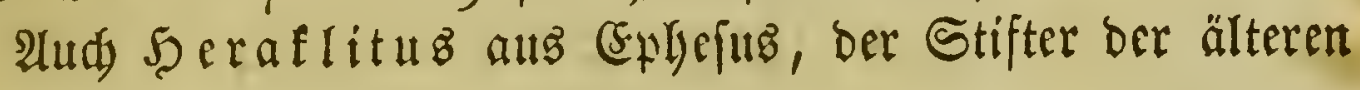

herbar., lib. I, cap. V. Empedocles Agrigentinus: De vita et philos. ejus exposuit etc., Fried. Guil. Sturz, Leipzig 1805. Empedoclis et Parmenidis fragmenta ed. A mad. Peyron, Leipzig 1810. 
cleatifden Soljule, befdaftigte fith mit ber Ergrüloung ber Naturfiäfte. Er ift befonbers baburd) befannt, bafi er bas Fener alsz baz bewenende Srincip in ber Ratur anjah. Sdjon bie Alten befdwerten fid) liber bie Unflarlyeit feiner (s)runb=

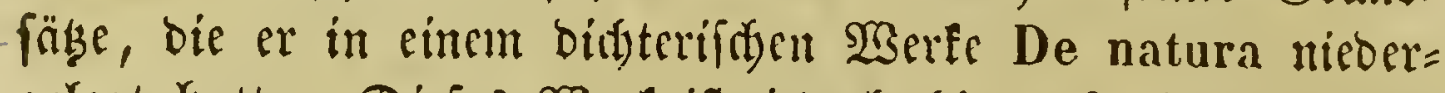
gelegt hatte. Diefes SBerf ift jedudf) bis auf einige wenige Brudffiture werloren gegangen.

$\mathfrak{Z}$ enn num aud bie theoretifdsen Speculationen biefer ŞGi= Iofophen für bie Ratumwiffenfdyaften wening Erfprieflidjez leifte= ten, fo regten fie bod) das Radoenten über Raturgegenftänbe an und verlinberten baburd), Das eine Elcine RTafle yon Sorie=

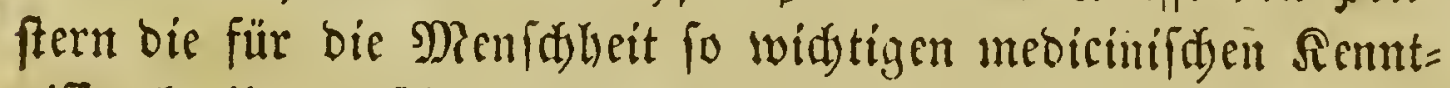

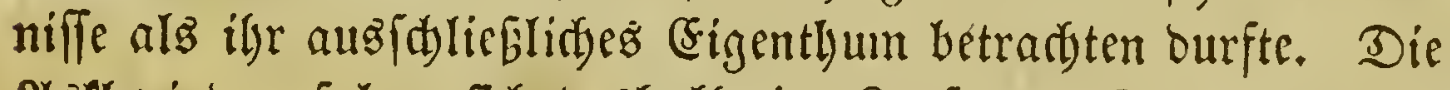
Asflepiaben faljen fich reshalb in Raufe ber 3eit genötligt, yon ifren ftrengen Sagungen bez̧igglidi) oer (5elyeimbaltung ibrer Tempelweisheit abzulaffen. Bwar mur mit $\mathfrak{2}$ Boberwillen

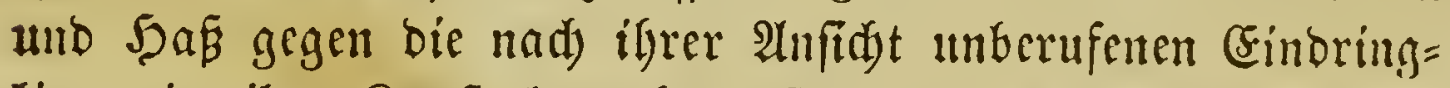
linge in ibre Sunft beraubten fie fidf bes feither um inre Şäuter gegoffenen myfteriöfen Sceiligenfdeins, aber ijre Sräfte waren zu gering, beut fortorämigenoen (Jieifte ber 3cit

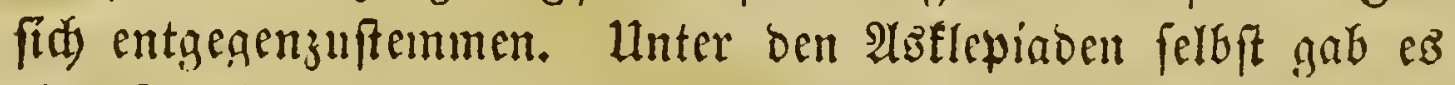

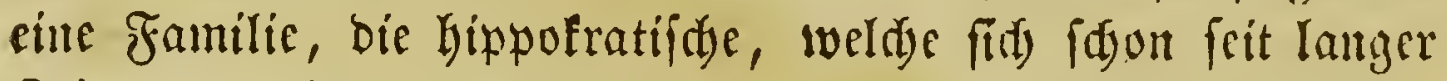
3rit ausgezeidynet uno allmälig baju brigetragen hatte, die

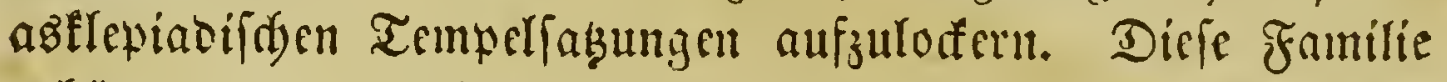
gebörte zut ben গुrieftern bes äsculapifden Tempels auf ber

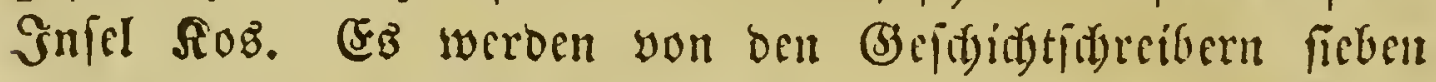

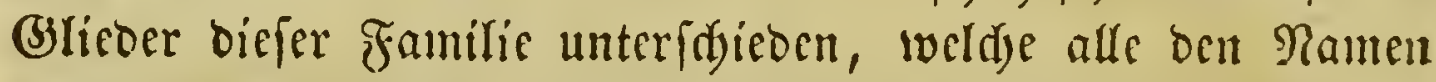
Sippofratę fübrten. Der berillymtefte berfelben aber swar

\section{Sip}

ber Solgn bes 5eraflides und ber Yygänarete, werdacr ungefägr un's Sabr 460 v. (5)r. geboren wurbe unt etwa 370 v. 厄)r. farb.

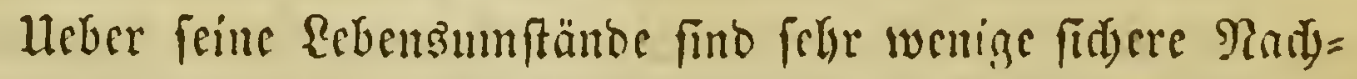
ridjen vorbanben. Sen crften Unterridjt, bejonberb in ber 
Irzueifunde, erbielt er yon feinem Bater Serafliofs; auberbem aber foll er vou 5erobifus aus Eelymbrien und

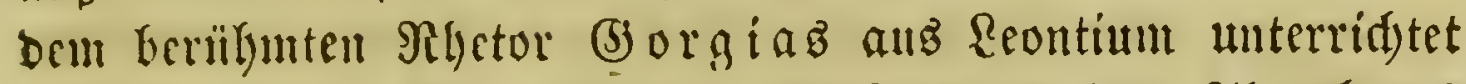

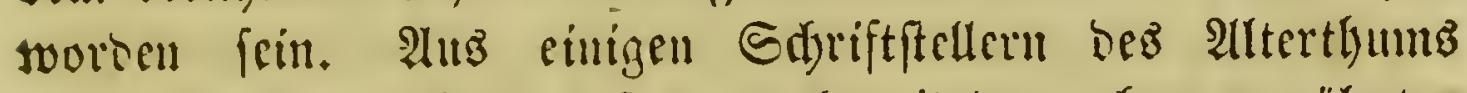

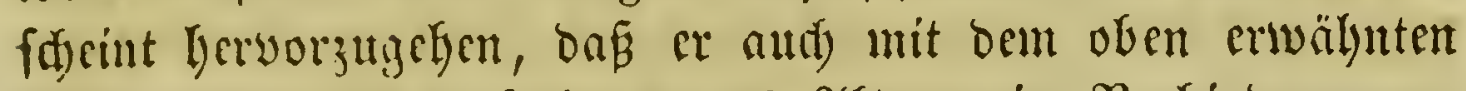
Jjhilofort)en Demofritus aus aboera in Berbinoung ge=

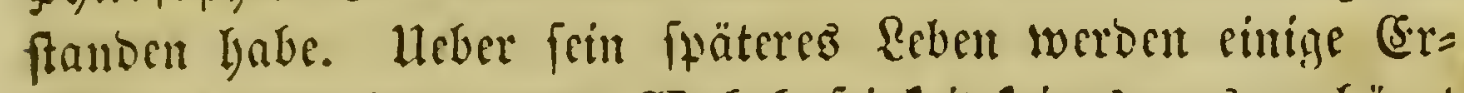

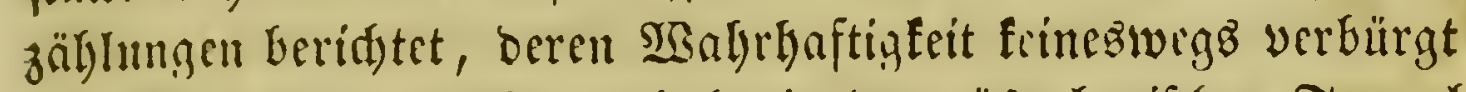

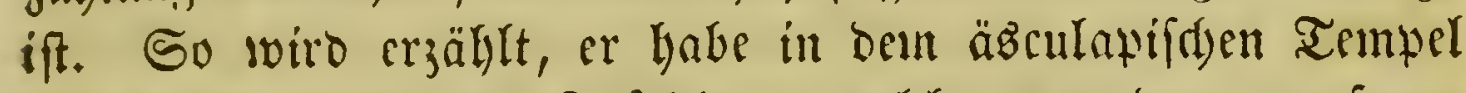
feiner Baterfadt die Täfeldsen, welde von ben genefenen Sranfen aufigriängt worden waren, abgeddrieben uno bann Sen Tempel felbft angezünoet, Damit er als ber Entoeffer ber barin aufbewahten (Erfabrumisen angefefen werbe. Aud) foll er an ben Şüfen verfirtidener Şerrfiner ber bamaligen 3eit grofic Sitren verridytet uno inefrere Stäbte, unter anbern aud) Pltben, yon ber lyeft befreit baben. 2uf feinen Fall mördete unter ber athenifichen Peft die zur Zeit bez Periflez in ben Gahren 430 und 429 zu Athen Gerridsende Seuthe verftandon fein, ba you cinem glaubuäroiģen Sdyriftfefler ber bamaligen

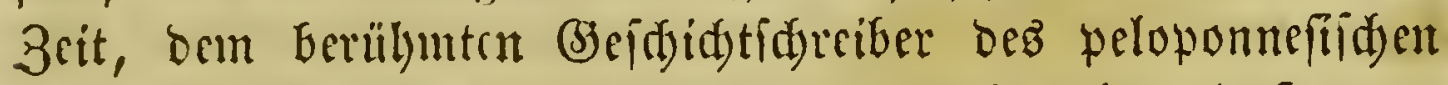
Siriegez, Ilyufybioez, ausbrüflid bemerft wiro, baß́ gegen

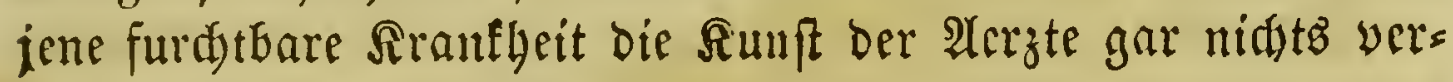
modyt bätte.

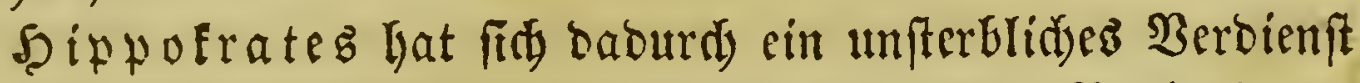

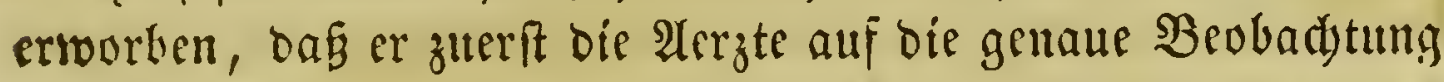
ber Sranfbriten himviez. Die Ażlepiaden hatten immer mur empirita verfalren; igre Erfagrungen hatten fie meifens burd) 3ufall oder sprobiren gẹ̣unden. Die ghilviopken yer= ficlen in bas gerabe entgenengeieste (sxtrem. Sie glaubten unbefiummert um alle Erfabrung ourd) allgemrine $\mathfrak{T}$ beorient zum Bicle grlangen zu tüment. Şip fofrates aber ftüthte fid) auf ber cimen Seite auf bie (Erfabrungen ber Asflepia= ben, antererieits afer war er auds burd) philofoplyifdes

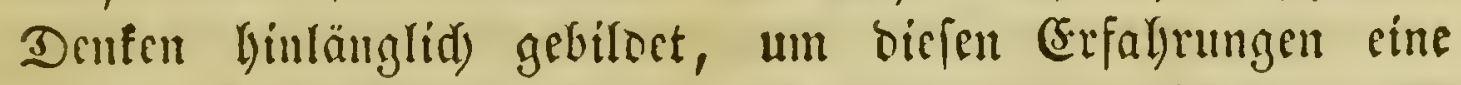
alfgemeinere Brunblage zu geten unto ilgre Begrünoung 
tiefer, als in ber zutäd) in bie 24ugen fpringenden $\mathfrak{u r}_{r}=$ fadje, zu judyen.

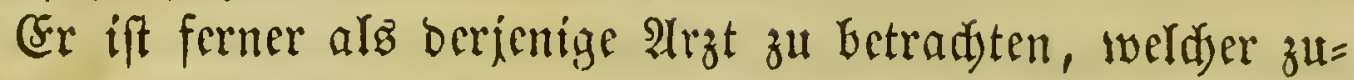
erft auf bie sididigfeit einer geregelten \&ebenzoromung hin=

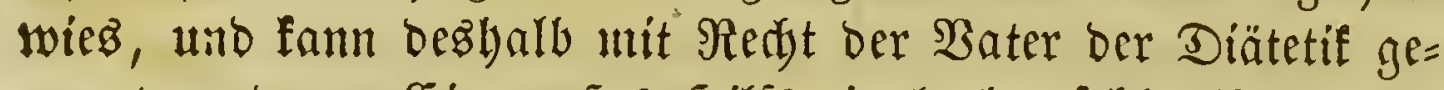

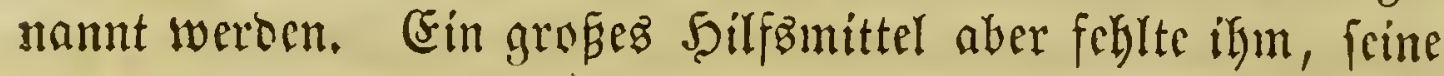

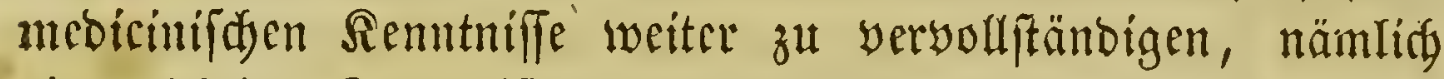
cine ridjtige Renntnif des menid)lidien Rürperbaues. Şätte

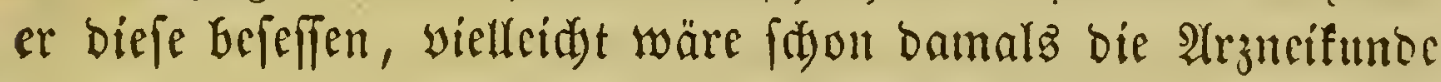
zu berienigen Şöheftufe ber Aluzbil bung gelangt, weldye fie erft viele Gahrhumberte fpäter zhl erreidyen in Stanoe war.

(5:B werben bem 5̧ippolrates 70-80 Sryriften zuge= fdrieben. (Es ift jebod) anzunehmen, bas man auf ifn, als Das berülumtefte Mitglied feiner Familie, aud alles bas zurüđ = zufüfren gcfudyt hat, was yon feinen fedjs Ramensigenoflen berrïlyrt. Sdjon in a(ttertl)um hat man fid barum Mühe gegeben, diefe vielen Sdyriften auf bie einjelnen (s)lieber ber Giwpofratifigen Familie zu vertbeilen. Die nodj workandenen Sriviften finto aud) in fpäterer 3eit viclfad) verändert uno ver=

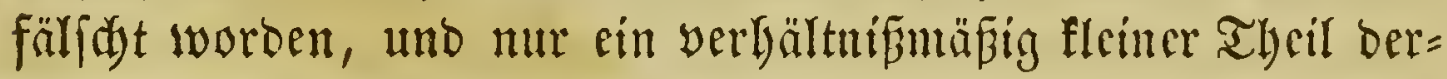
felben mag wirflidy yon ber biptofratifiden Familie berrübren.

bipuofrates bebiente fid bei ben Scilumgen meifens foldjer Mittel, weldye aub bent grflanjenreidye lyergenummen

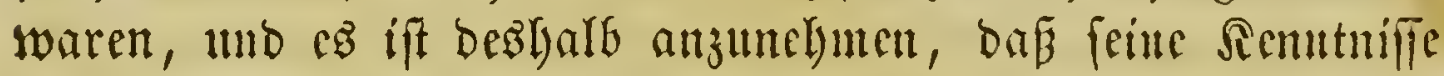
in ber \$gflanjenfunde nidyt unbebeuteno gewejen fund. Seine Sdyriften fmo aber auds fisun beshalb für bie Butanif widyti?,

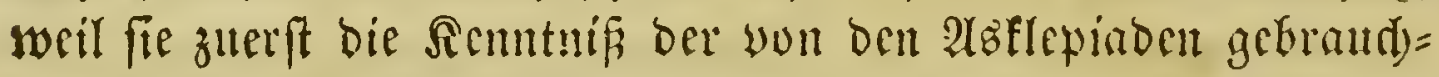
ten PJflanzen weiter verbreiteten. Es werben in sen siserfen

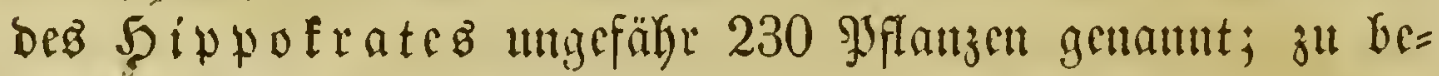

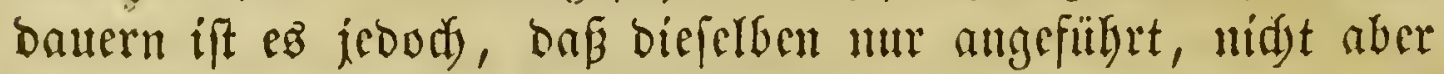
näber befduricben fint.

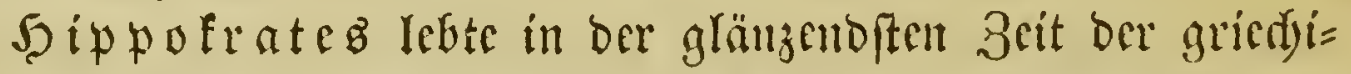

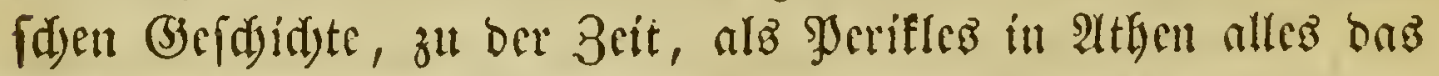

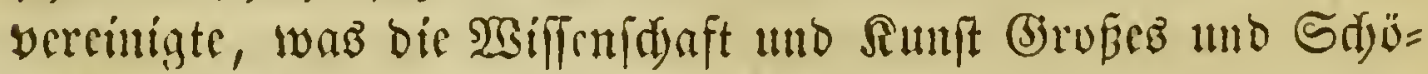
nes aufjurucifen vermodyte, zu ber 3eit, als bic berillymteften 


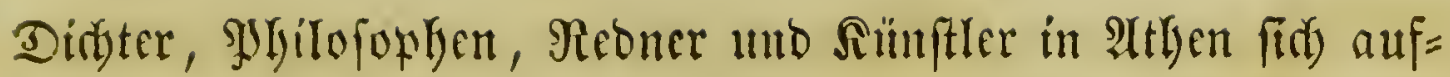

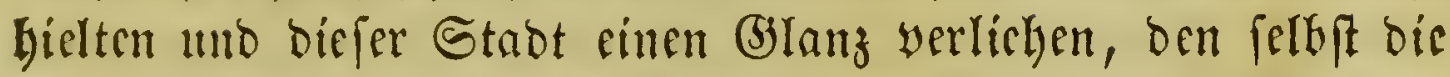

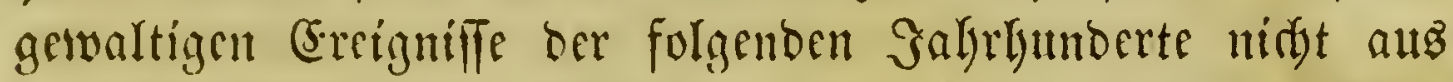

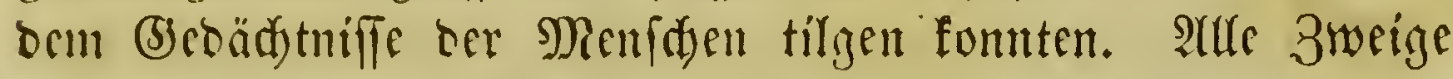
bre menf(d)liden 2 siffenz wetteiferten bamals miteinnoner um

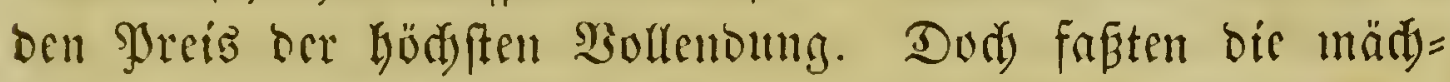
tígfen (Jeiffer ber bamaligen 3eit ben Menidsen melyr you ber

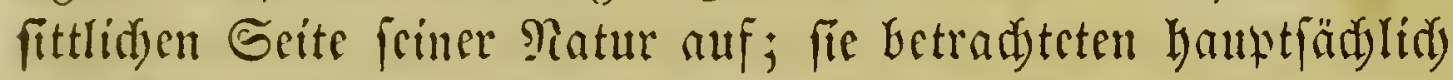

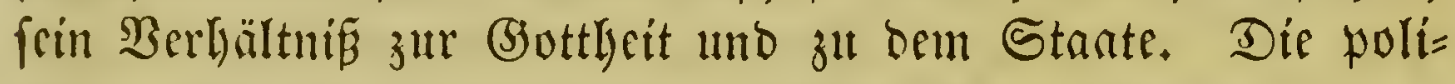

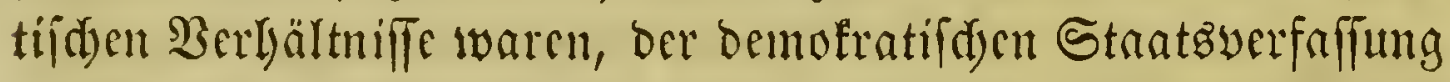

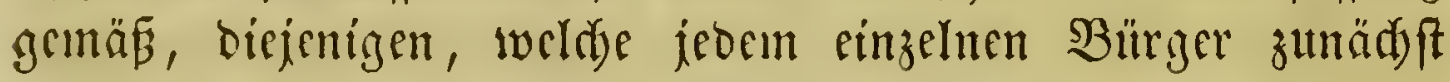
am Serzen Yicgen musten. Die Recligion aber war mit bem

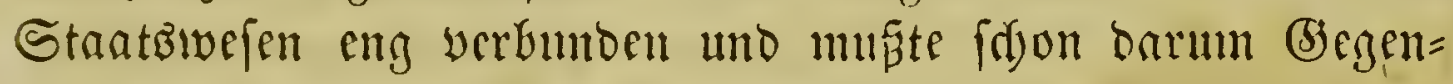
ftand der ernfteften Betraditung werben. Bie 3erglieberung

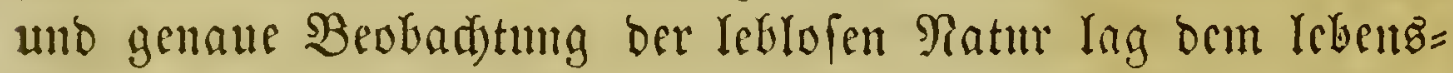

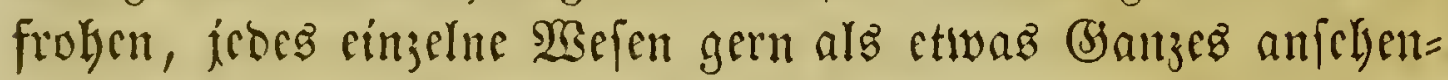
Den Griedjen zu fern, als bas er fie zum Bregenftand feines

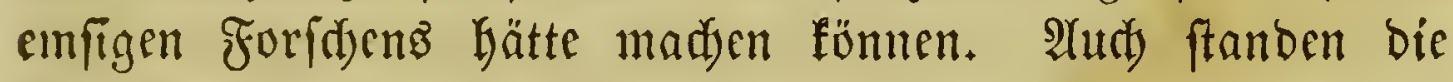

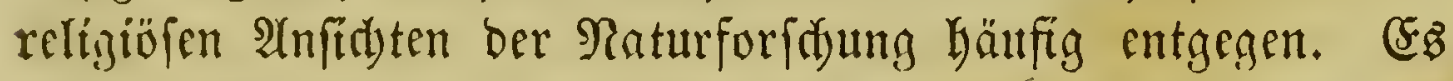
war 子. $\mathfrak{B}$. burdyaus verpönt, ben Rcídynain cines Menfdgen

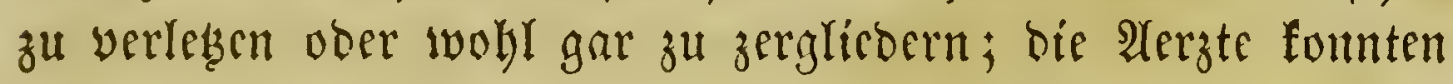
mur aus bem $\mathfrak{B a u c}$ ber Thiere auf bie Drganifation bez

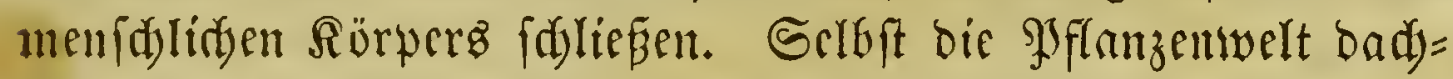

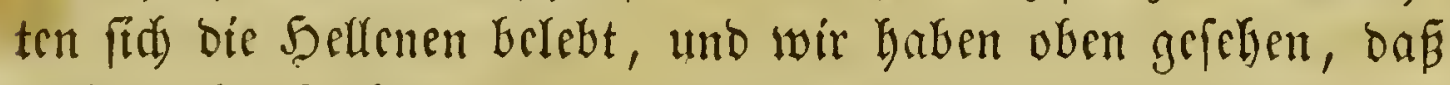

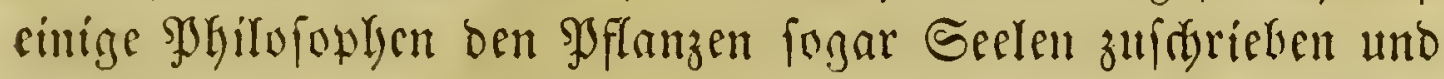
Den llcbergang menffhlidgre Seclen in biejeltern für müglids Jiclten. So verbot z. B. E m medofleb, die Brätter yon

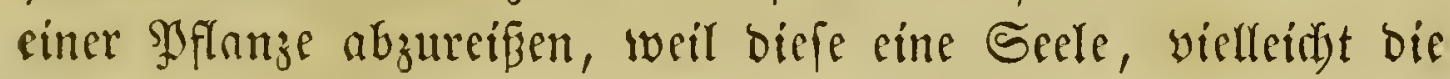

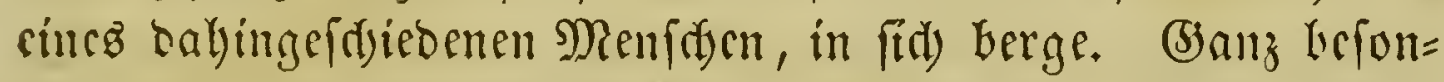

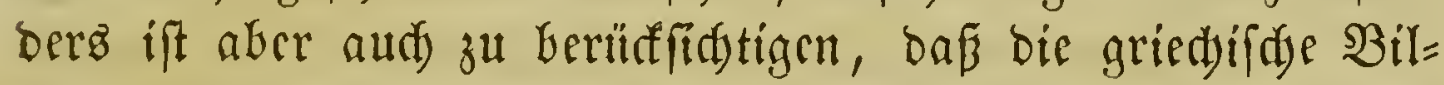

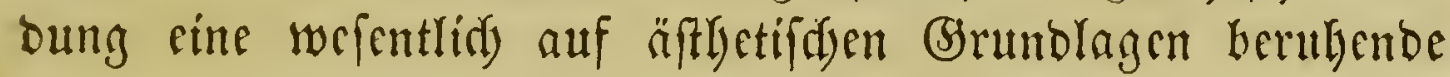
wwar, uno baj inzbefonoere in ben Beiten nady bem pelopon=

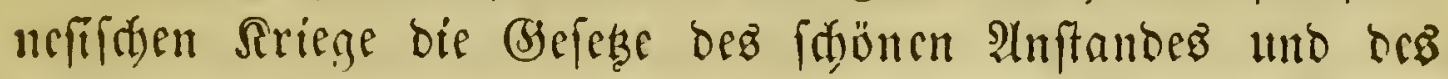

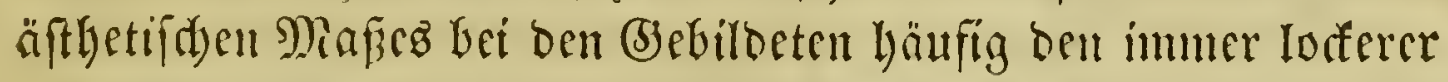

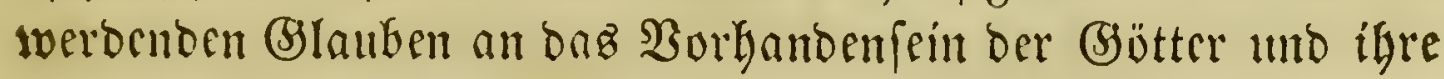


Matht über ben Menfden vertreten musten. Die äfthetifde Biloung, wenn fie fo allgemein werbrcitet ift, wic zu jenen 3eiten ocs alten (S)richenlantz, ift aber ocr Jortbiloung oer Raturwiffard)aften nidjt günftig. Shr ift eine funftyolle $\Re e=$

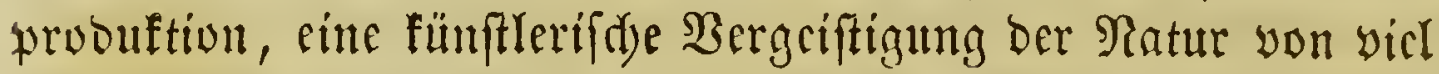

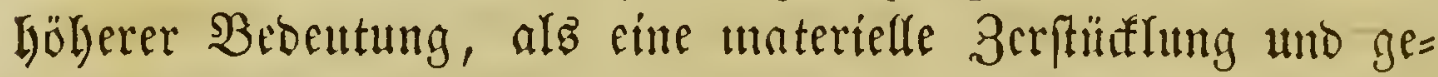
naue Darlegung ber einzelnen Altome, auts weldyen biefcrbe

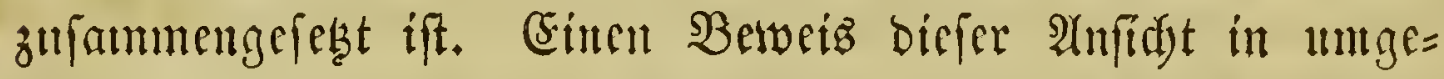
feljrter SAseife licfert bie Gegemwart. Sest, wo die Ratur=

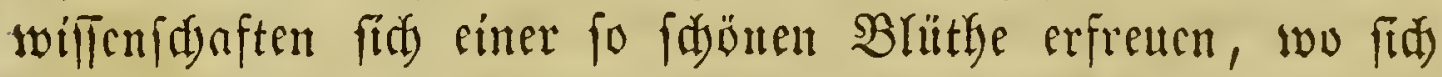
bic 2mwenb fiarfeit berfelben auf bas gemeine Reben it ben ge= woltigften Unternelymutgen jebem SMenityen flar vor Angen ftellt, tritt bie produltione Siraft bes Didsters uno Sïuftlers, man fann fagen in allen Rändern Europa's, zurüñ uno gibt

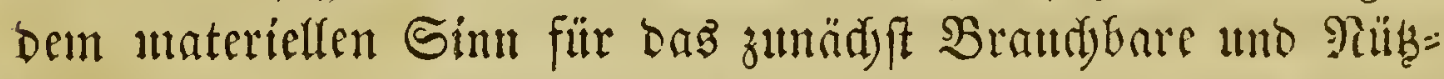

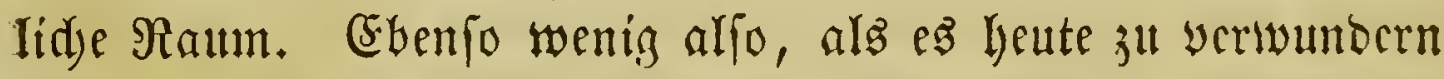
ift, swenn neben ben bedcutenoen Reiftungen ber materielfen

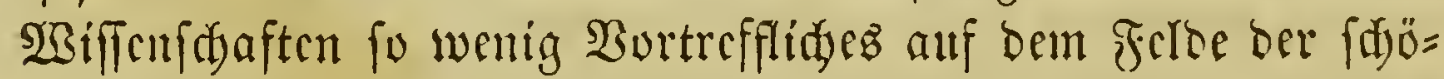

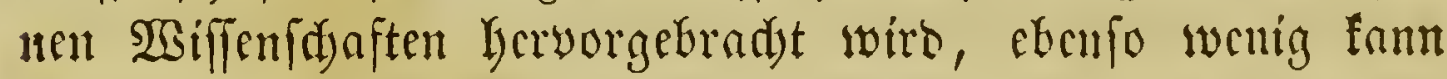

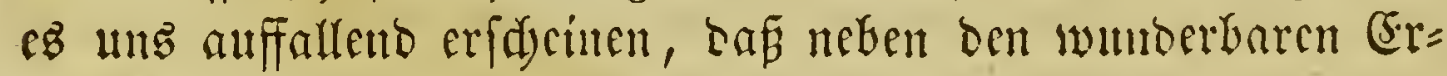

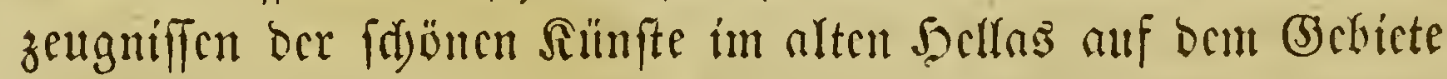
ber Raturwiffenfdsaften verfältnifmäsig fo wentig gelciftet worben ift.

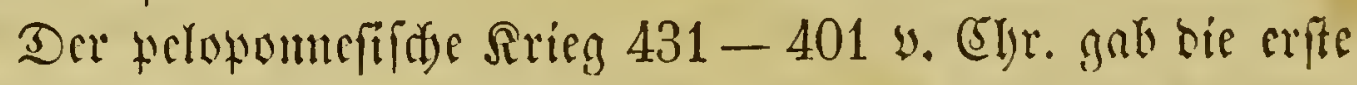

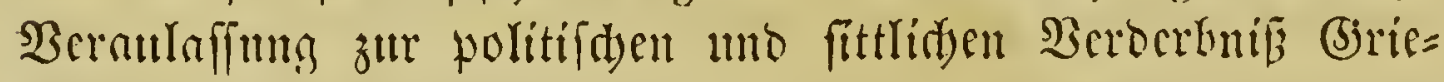
d)enIanda. Die zwei mädytigften Stanten, âtben uno Strarta, befämpften éntuber über bic Frage, wer won ihuen ben crifen

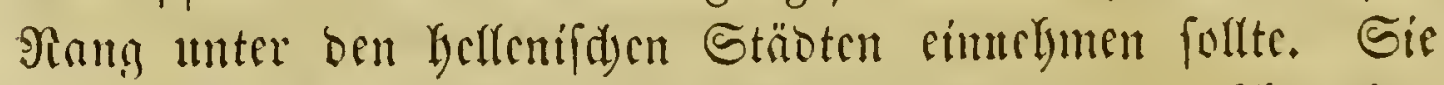

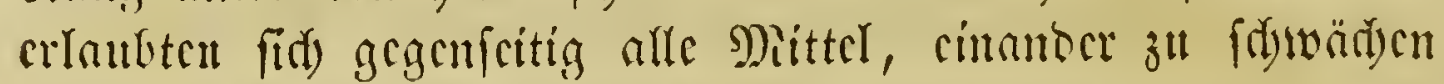

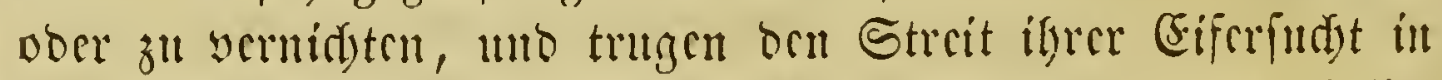

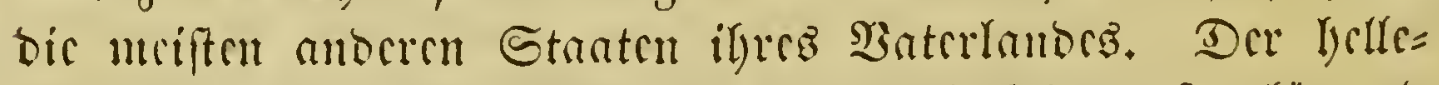

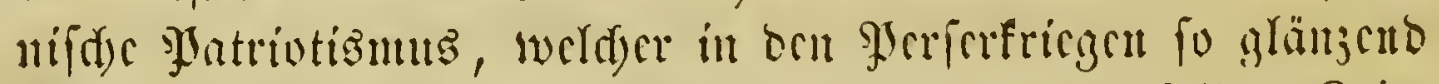

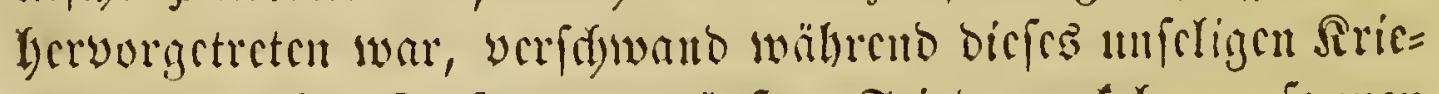

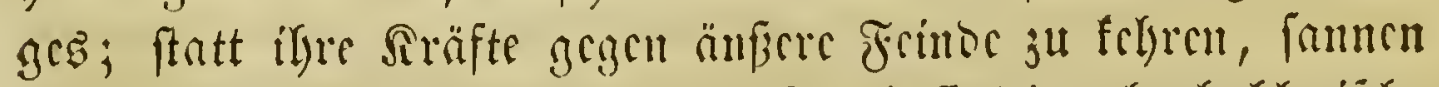

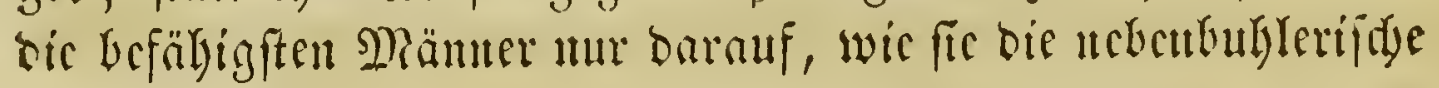


Stabt bes cigenen Baterlandez am fduellften zu (5)runde ríd)=

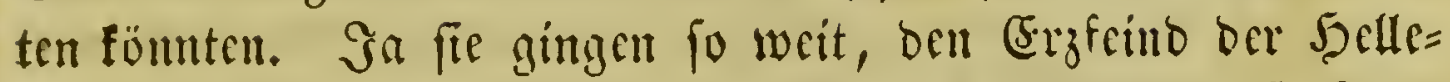

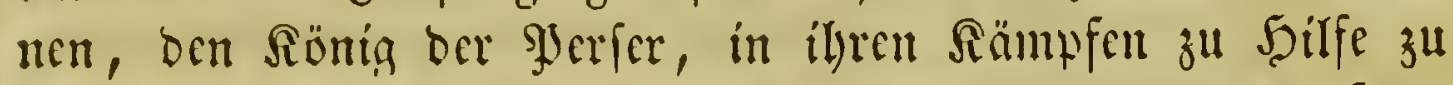
rufen uto un feinen Sisiftand ju bulylen. Daju famen fort= wäbrente Befelboungen ber grarteien ferbft im Edjofie ber rigenen Stäbte. Der frillyer fo eble Gharafter Der Jellenen

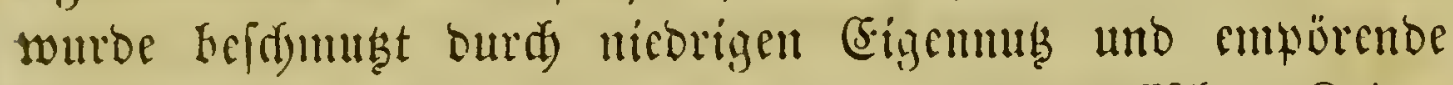
(5)raufamfeit. Die 3eit nad) bem felopounefifiden Sriege Ivar Die fidumflidyfe, bie (biried)enland jemals erlebt hat, uno ferbft oer rulymyolle Glanz ber tyebanifden Sieger in ocn Sd)Indeten bei Renftra uno Mantinea erfidecint bem unbefange=

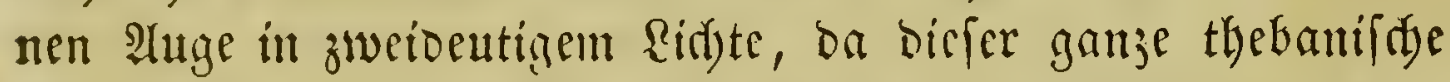
Sricg bod eigentlidy nur cin Sampf ber Sïrger gegen illue

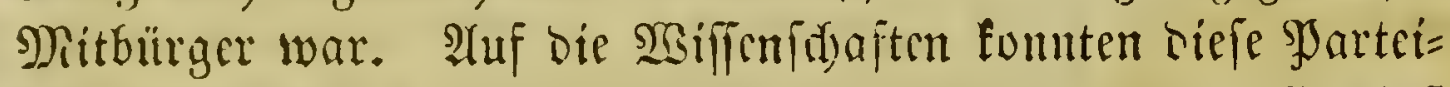
fämpfe allerbingz nidht fo raid) ifgren verberblidsen (sinfluf äıbern; nod) eine Zcit lang blieben jene in SBłüthe, aber bald nadyer madten fid aud lier bie jerrütenoen Pidftungen ber

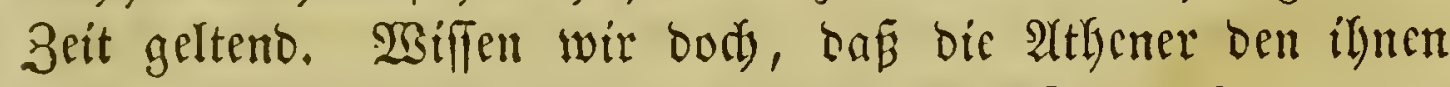

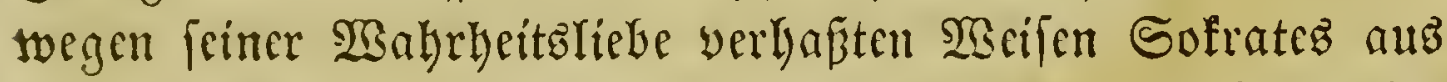
nidatigen Gründen jum Iobe verbamunten, uno baf felbft cin= flufreidye Sd,riftiteller fid) you ben Feinoen oer griedsifdsen Frcilycít befted)en liefen uno in Solde berfelben an bem hnt= tergange ilyres eigenen Baterlandes arbciteten.

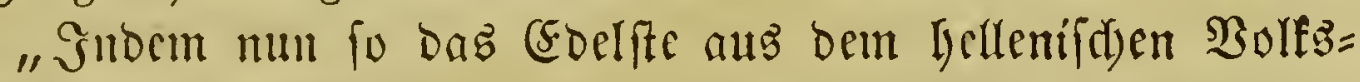
thum entwidy, öfincte ber entartete Simu un fo Ieid)ter fid ben Rodungen nidytsmüroiger Barbaren, und die herrlidye Manngeit Der Sellenen gab fith lyin für binterliftig baracbo= tencs (5iclo." I) - Darum war es möglid), Ea jo ber tapfere,

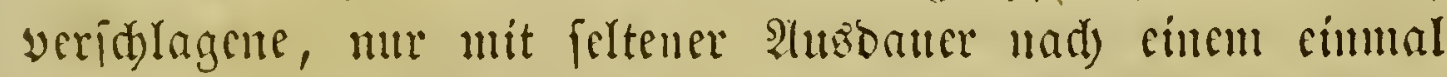

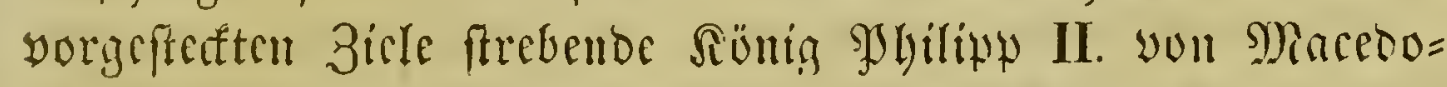

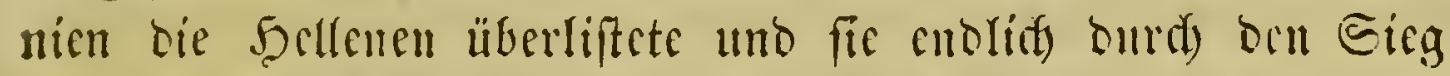

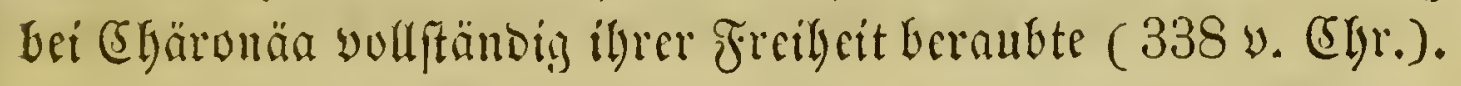

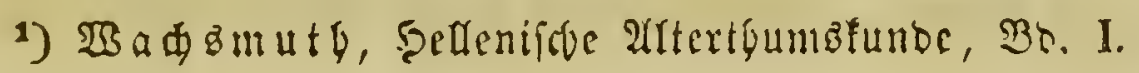




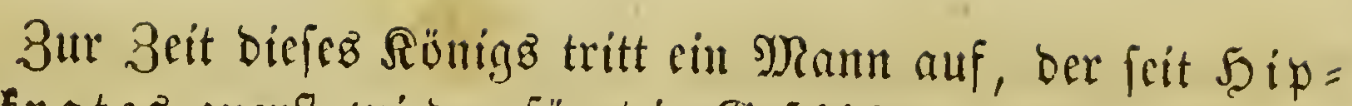

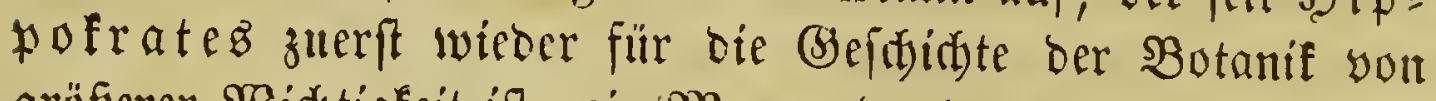

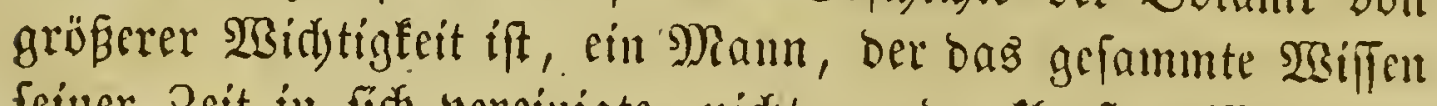
feiner 3eit in fid vereinigte, nidjt mur ber flarfte wiffenfdyaft= lidbe Denfer in ganzen hellenifden alltertlyume, fonbern aud

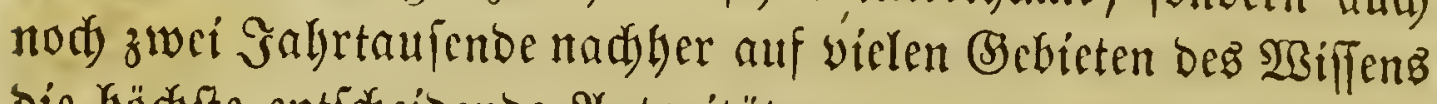
bie hödffe entfocidonde 2 hutorität.

Diejer Mann war

\section{$\mathfrak{A} \mathfrak{i}$ 代 otelc $\mathfrak{c}$,}

geboren in ber thragifwen Stabt Gtagira im Jagre 384 y. (5Gr.

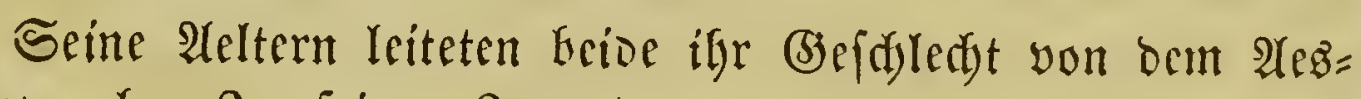
culap ab. Sn feiner Jugent war er gryarmafopol, b. h.

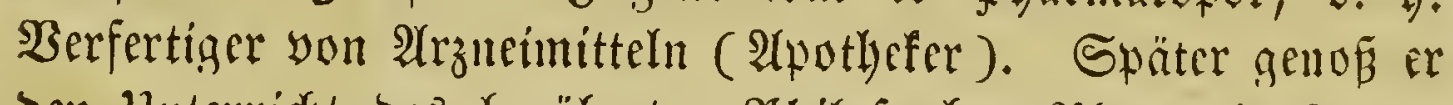

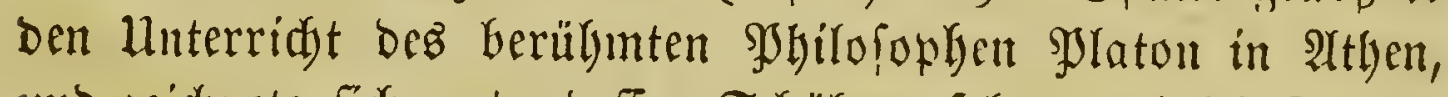
und zeidunte fid unter beffen Sdüllern fegr vorthcillaft aus.

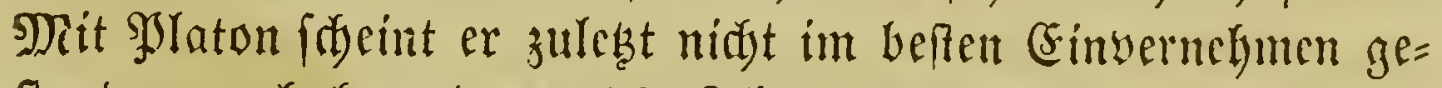
ftanden zul haben, ba er bie Relien befferben nidjt alle unbe= bingt alz $\mathfrak{w a h y}$ annalym.

(Er war jedon burd) feine (jeldyrfamfeit in (Striedyentant

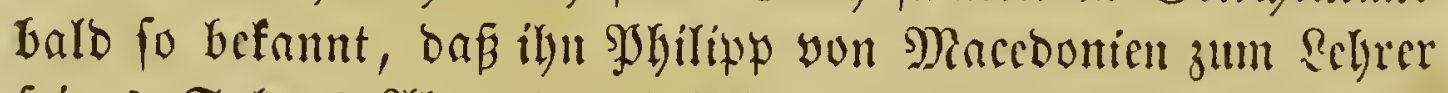

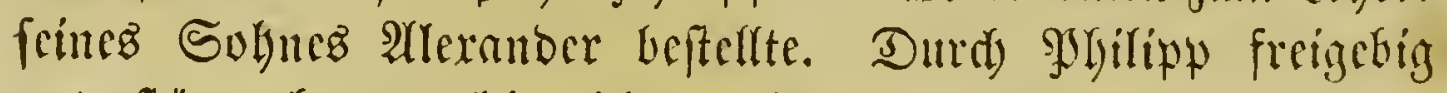
unterftübt, batte er biutreidsente Mittel, feine wiffenfdyaftlidyen Foridumgen zut erweitern. Nody melyr aber war bicz der Fall,

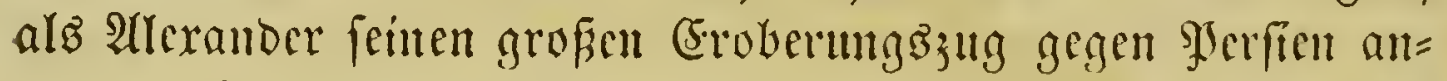
getreten hatte. Dicfer Rünig folbenfte ily cin Ranbgut, unter=

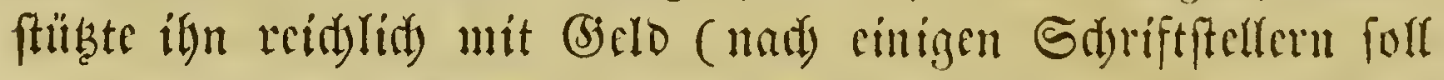
cr ifm die ungefenere Summe von 800 Talenten zแm (5)e=

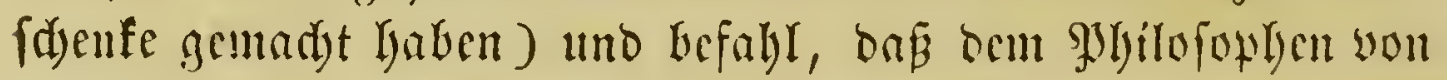
allen Thieren in ben croberten Ränocrn cin Exemprar 3migedsiftt werbe. - Ariftoteles war and ber Stifter ber peripateti=

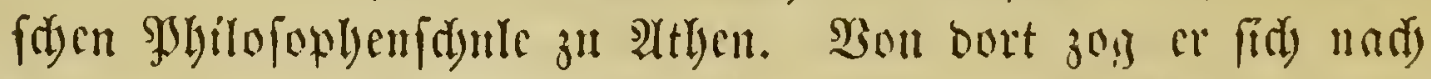

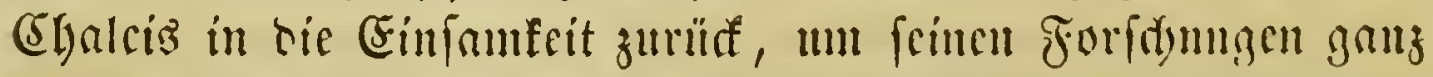

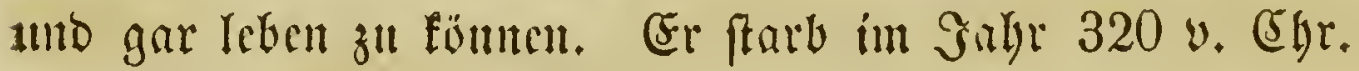


Son ben grofen Berbienfen biejes Shbitufophen um bie Sisifenfdyaften überlyant unb von feinen zablreidjon, faft alfe Theile bes $\mathfrak{B}$ ill die Nede feill. (5r felteft gibt in melyreren Stellen feiner Sdyrif= ten an, baf er ziver Bäd)er über die sfflnuzen gefdrieben habe.

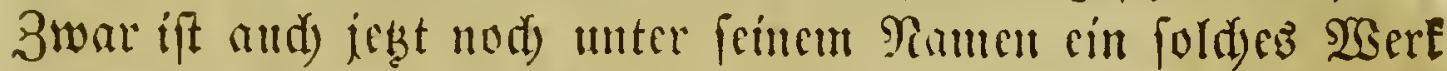
unter bem Titel $\pi \varepsilon \rho_{i} \phi \cup \tau \tilde{\omega} \nu \beta, \beta \lambda_{i}^{\prime} \alpha \beta^{\prime}$ (de plantis libri II)

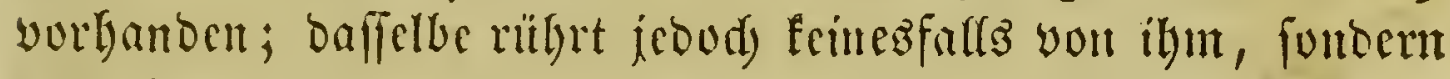
you cincm fpäteren $\mathfrak{B e r f a f f e r ~ h e r . ~ U e b e r ~ b i e ~ S r u ̈ n d e ~ b e r ~} \mathfrak{U n}=$

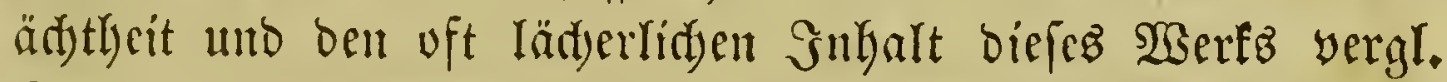
Sprengel's histor. rei herb. lib. I, cap. VI bon Affdunitt: Pseudo-Aristoteles de plantis. $\mathfrak{Z a g} \mathfrak{A}$ riftotele $\mathfrak{B}$ felbit yon oen Pflanzen gewurist uno geondid, fann man nur feljr

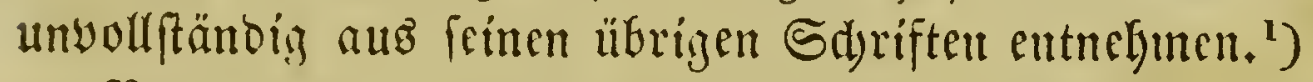

Bon größerer Bebeutung für die gुflanzenfunde war

\section{$\mathfrak{I b} \mathfrak{p} \mathfrak{p b} \mathfrak{x}$ it}

Der Sdjuller und Rartyfolger Des Ariftotelez in ber peripateti=

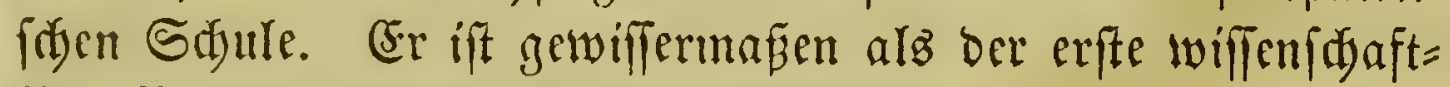

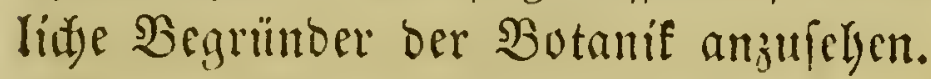

(Er war aus ber Stadt Erefus auf ber Gnjer Reghob ge= bürtig unb wurbe von feinem Bater foun fehr frillyzeitig zu ben Sturien angehalten. Scin erfter \&elgrer foll oer Sghilofoph Eeufippuz aus Erejuz gewefen frin. Später ging er tady

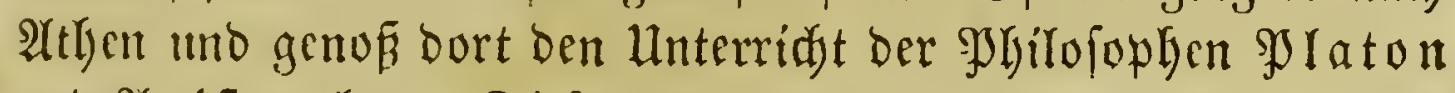
uno $\mathfrak{A}$ riftuteles. Diefer gewann zu ifm wegen feiner grofent

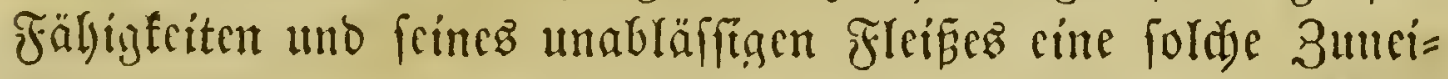

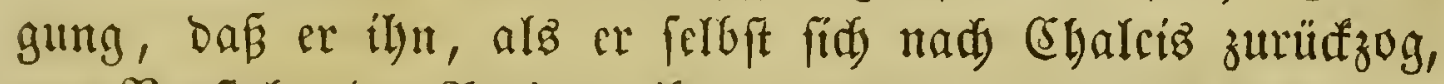

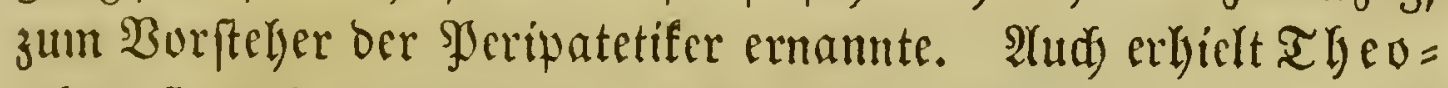

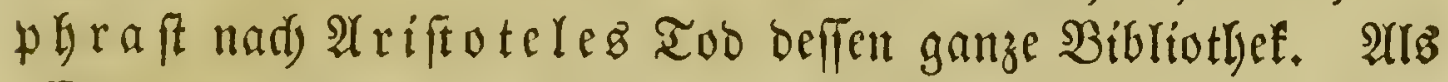

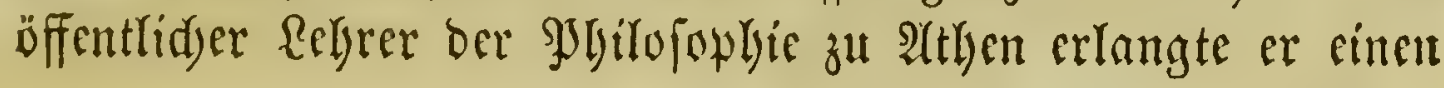

1) Henschel, Coniment. de Aristotele bot. philosopho. Vratislaviae 182\%. 4. 
groficn Ruf. Die Zahl feincr Sdyuller foll bis auf $2000 \mathrm{ge}=$ ftiegen feil. 3rwar wurte er burd oen in oer Bolfsecriamm= lung burdgegangenen Antrag eincs gerwiाlen Sophofles,

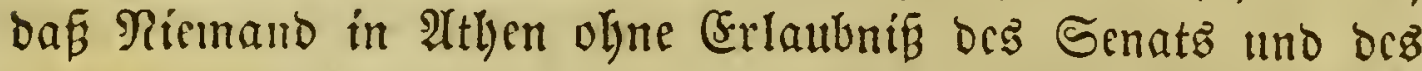
Bolfe öffentlidy Ichren follte, cine 3eit lang nebft anderen $\mathfrak{B h} i=$ Iofowhen aus Altben vertrieben, jeood nad balo erfolgter 2 luf= hebung biefes Biefckes wiebrr zurüdgerufen. Bei ben Athenern ftand er wegen feiner grofien (jelebrjamfcit und feines colen

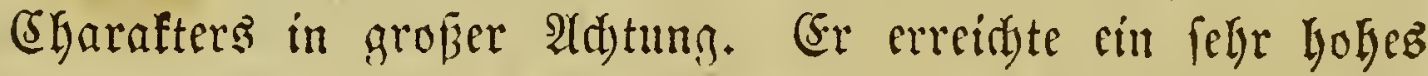

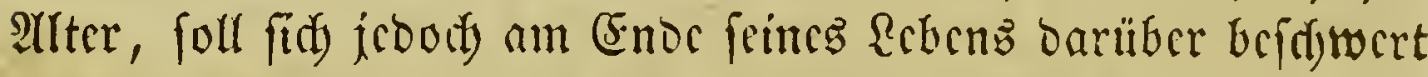
Gaben, baß bis bem Menidyen zugcmeffenc \&cbengoauer für bas wifferidyaftlide Forfdyen fo furz und unjureidyend fei. Sein Tob wurbe von feimen Mitbürgern tief betraucrt, unb gan; Athen foll feincm Roidyenbegängniffe beigewohnt haben.

Theoplyaft hat feldr viele SGerfe geidurieben. Man zäbrt twenizffens über 200 Titel feiner Surfiften auf. Dod fino feine Arbeiten bei woitcm nidjt alle auf uns gefonmen. ScineBibliothef, in welder fidy aud Ariftoteles binterlaffene Werfe befanden, hatte ein eigenthümlides Sdyiafar. Fr felbla

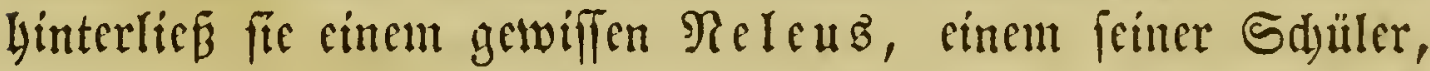
ber fie feinen Grben, unwiffenden Misnidyen, binterliç, bie nidyt wubten, was fie mit berjelben anfangen follten. Âtus

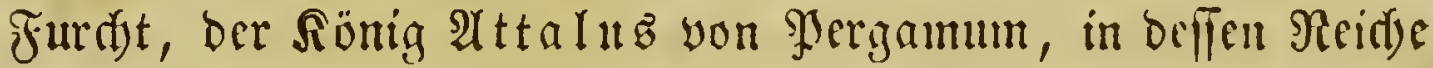

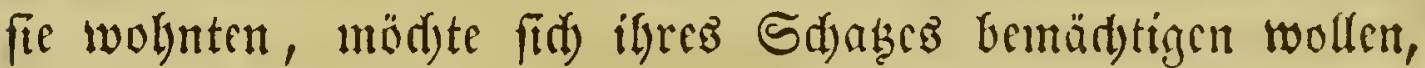

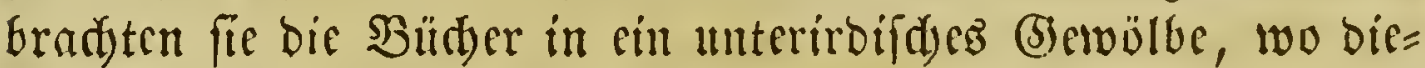

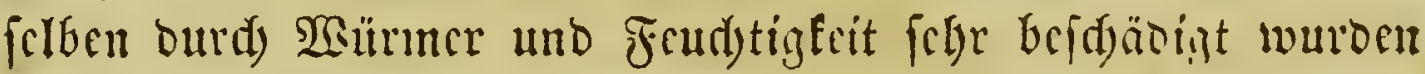

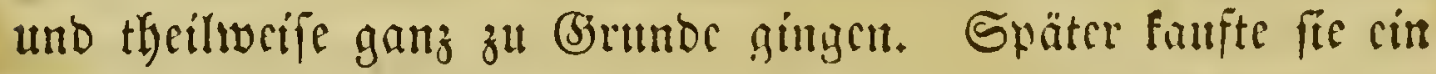
Büderliebhaber, Ramens atpellifon, mo fudte fie wicoer ju veryollfänoigen, was ilym jebod) bei feiner geringen (5)clebr= faunfeit fobr folledyt gelang. Errf zur Zeit, als ber römilife Dictator $\subseteq$ ulla 2 then cimahm, wurben die nody yorban= benen $\mathfrak{S e r f e}$ wicber allgcmeiner befannt und theils nady $\Re$ tom, theils nary Alexanbricn berfauft.

Bon Thcophraft find nod) fwei WBerfe über bie \$flanjen

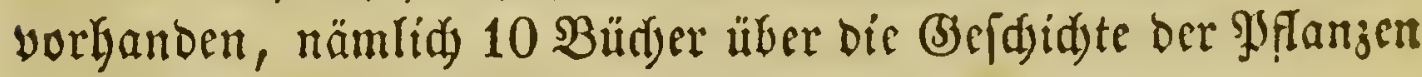




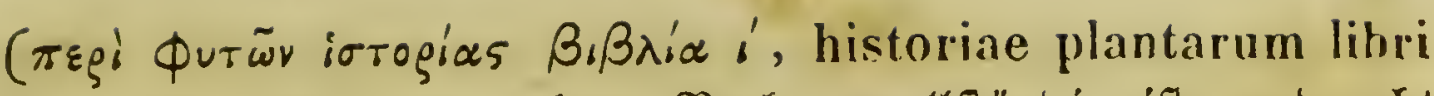

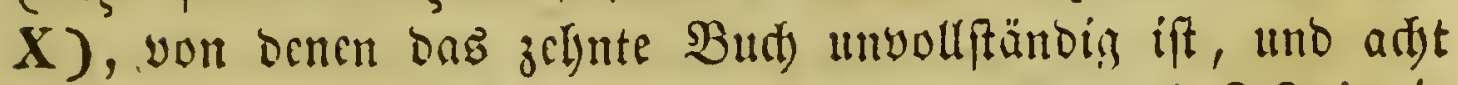

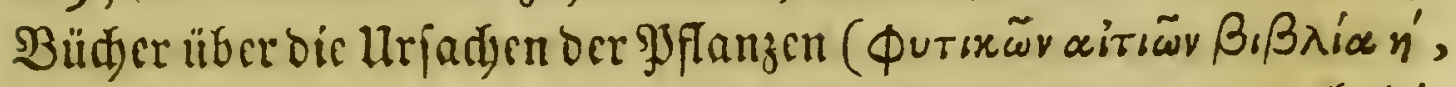
de causis plantarum libri VIII), von benen num nod) bie

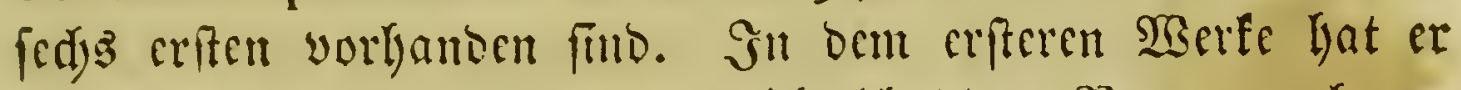
ungefïlyr 500-600 \$yflanjen nidjt blos bom Tamen nad) ant=

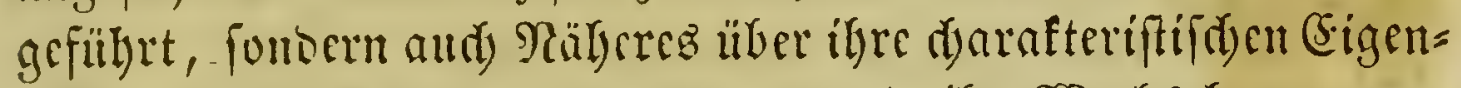

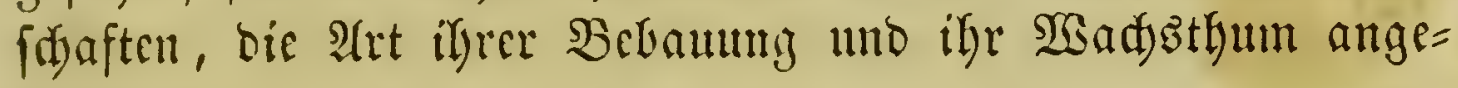
geben. ${ }^{1}$ )

2unerbem werben nody vicle Ramen fold)er Reute aufges

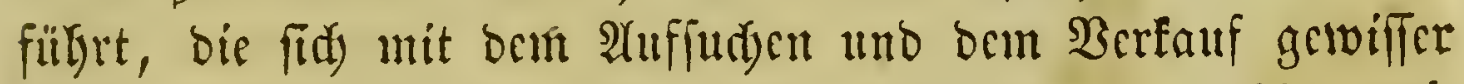

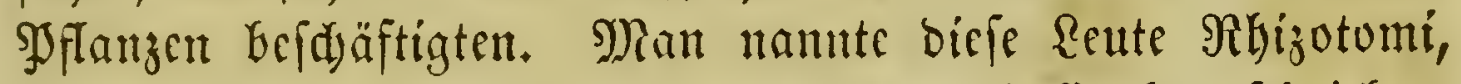
İurzelgräber. Einige bericlben lyaben aud) Werfe geidricben, uno you cinjelnen bicier Sdyriften Hefizen wir nod Fragmente. Diefe fino jeoder ziemlidi unbebcuteno. Sic führen meift nur Die Ramen ber Yjflanzen auf, geben aber feine nälyere $\mathfrak{b} e=$ (d)reibung oerjelbert.

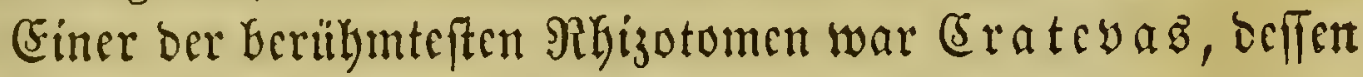

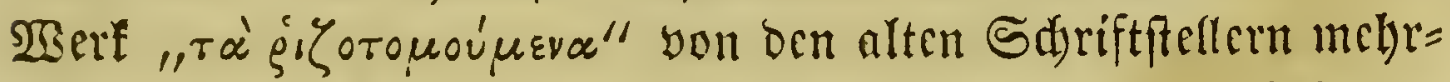

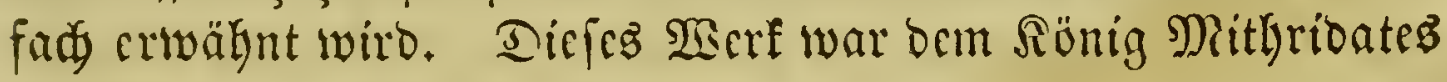

1) Die Irbiner Ausgabe ser bierber gebörenten Edriften Theoptraftz ifit in Berbindung mit megreren Werfen bes 2riftoteles 1497 zu Renebig eridienen; zu $\mathfrak{B a j e l} 1541$ mit lat. Heberiegung. Ferner:

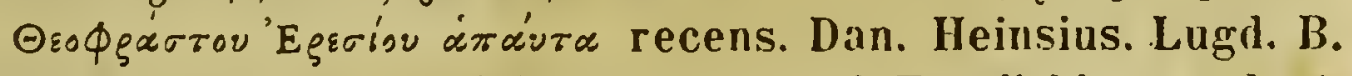
1613; griechifd=lateinifa. Theophrasti Eresii histor. plant. libri IX cum notis Jul. Caes. Scaligeri et. Rob. Constantini ed. J. Bodaeus a Stapel. Amsterd. 1644. fol.; mit einigen Hebitoungen. Die in biefer $\mathcal{A}$. Ecaligers und 5onfantin's find aud felbftänoig 1566 und 1584

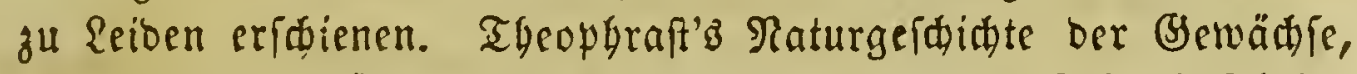
überiét uno erläutert von $\mathfrak{R}$. Sprengel. Artona 1822. 2 Theile.

Ueber bie einzelnen bon Ibeophraft aufgefübrten Sfflangen vergl. Sprengel, histor. rei herbar. Lib. II, cap. I. Die Aubabe bon Stafyoufe, Dxforb $1813-14$, obne lat. Ueber = fezung, entbegrt nad Sprengel eimer fideren Rritit. 
(5upator yon Sontus, oer im Alterthume wegen feiner Pुflan= zenfenntniffe fehr berüfmt war uno ein allgemeines (segengift (Mitfribat) erfand, gewiomet. ${ }^{1}$ ) (58 zeitinete fid you andern baburd) aแs, bas es Albbiloungen ber befthricbenen Syflanzen enthielt, obgleidy Diosforibes behauptet, Dás Eratevas zu= weilen nidyt nad) ber Yatur, fondern nach Dem, waz er yon anderen SJerionen gebört, Geidurieben habe.

Von $\Re$ if ander aus Solophon fino nod einige Sryriften

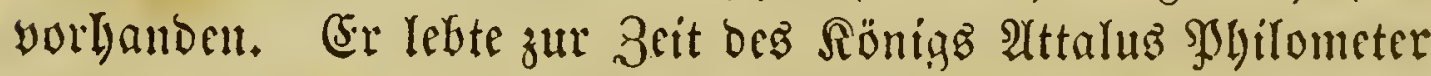
(134 y. (5hr.), ber weizen feiner \$flanzenfenntnis in Âtrer= thum febr berülynt war. So wiro ung erzäblt, daßj riefer

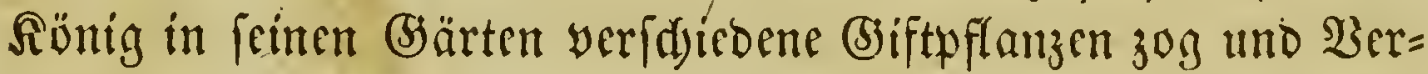
fudse mit ifnen anftellte, um bie SBirfung ifres Bsiftes uno biejenigen Mittel zu ergrünoen, weldye dieje : Sirthung wicoer auflyeben. Nifanoer befdäftiǵte fid) ebenfallz lyautfärblidy mit (3)iften, fowohl animalifden als vegetabilifiden, wo Iegte

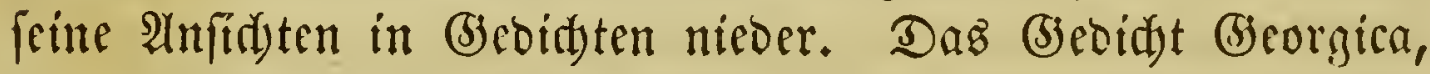

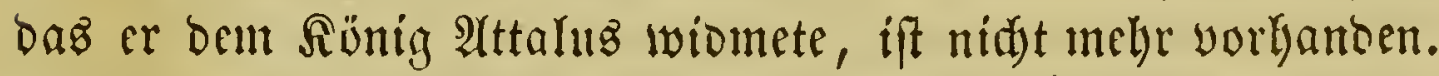

Die beioen (jebidgte Theriaca uno Alexipharmaca ban= beln hauptfäd)lidy won ben SBirfungen ber (Siffe und yon ben (Segengiften. In bem lezteren $\mathfrak{W e r f e}$ befdreibt er z. B. bie Wirfun! bes Aconitum lycoctonum, oes Sdjirlinilz, ber illyrifden 3citlofe, bes Solanum insanum, bez Bilfentrautż, bes Miohnlafts und ber Sdymä!nme. ${ }^{2}$ )

Radjoem bas eigentlidye (striedyenlano fowobl an wolitifacer Madyt wie an Rraft bes (5eciftes immer tiefer gefunfen war,

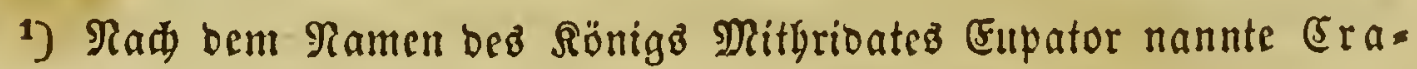
teva ze cine Yflanje Eupatoria.

2) Rifanoer's Sdyriften finb in ber arbiner 2 augabe mit ben alten

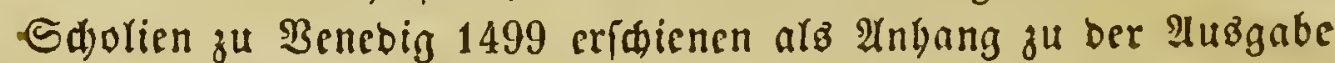

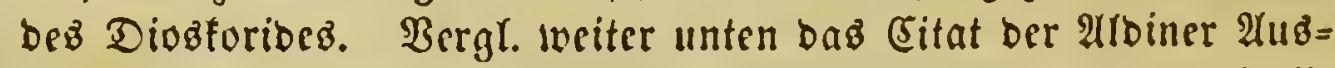

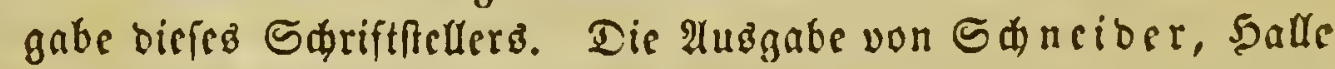
1792, entbält nur bie Alexipharmaca mit Barianten unb ভథlo= lien, nebft einer profaifden lat. Leberię̧ung. 
wurbe aud) Atthen, frülycr ber Mittelpunft aller wifferfdjaft= lidjen uno fïnflerifden $\mathfrak{B e f t r e b u n g e n , ~ i m m e r ~ u n b e b e n t e n d e r . ~}$ Die Bertreter ber Siffenfdjaften zougen fid allmälin nady

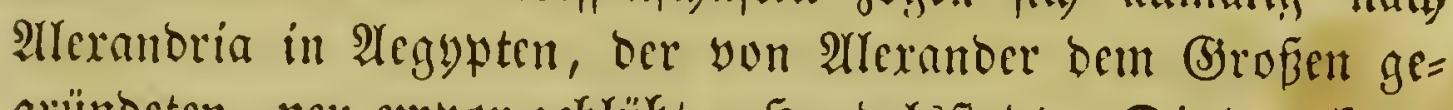
gründeten, neu empor geblülten Sandelsftabt. Die bort berr=

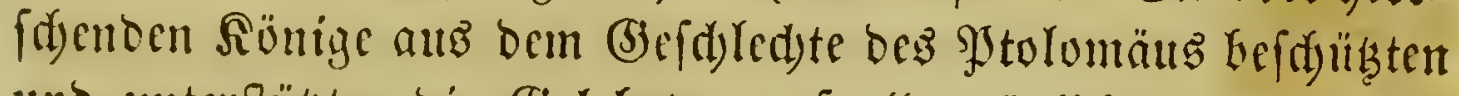
und unterfühten bie (S)lehrten auf alle möglidye $\mathfrak{B}$ eife. Sie brad)ten eine grofie $\mathfrak{B}$ ibliothef zufammen und erridjteten eín umfangrcidyes Miufenm. Die Belebrten felfit wurben auf Staatofoften verfiftigt und leben in ber forgenfreieften Rage.

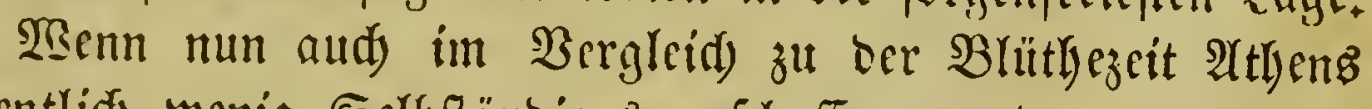
eigentlify wenig Selbfääbiges gefdaffen wurbe, wenn mant fid) auth meiftens auf bie Erflärung ber alten Rlaffifer $\mathfrak{b} e=$ fdrünfte uno felhft bäufị in gelehrte Spibfindigfeiten uno (3rübeleien fid) verlor, fo wurbe bod) aud) sann unb wamn auf

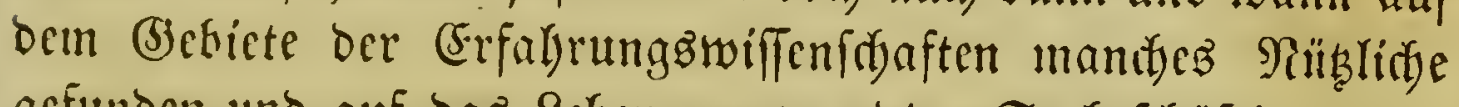
gefunden und auf bas Reben angewant. So befdjaftigte man fid) hier ztterft in Gökerem Mafiftabe mit oer Anatomie; bemt die Sgrolomäer waren in religiöfen $2(n$ fid)ten fehr tolerant und fegten bem gelchrten Forfiden feine Şimberniffe entgegen.

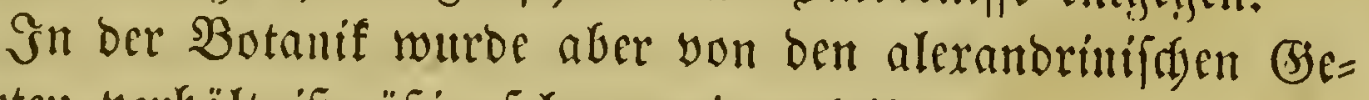
lehrten verhältniésmäßig felgr เvenig geleiftet.

Sd) ultes in frimem "(Srunbrif einer (Befdjidjte und Rite= ratur ber Botanif" meint, bie Botanif fei ben ArTeranbrinern

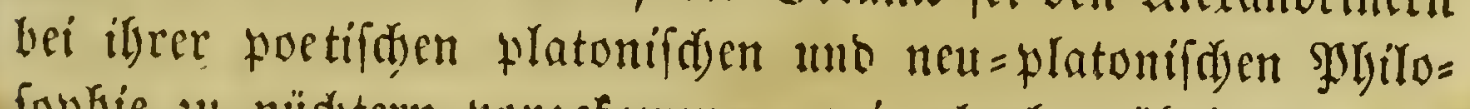
fophie zu nüd)tern vorgeformmen; wir glauben übrigens, bas bie aleranbrinifden (Selelgrten felbft nüdern genug waren, un bie Sotanif nidgt gerabe nüd)terner als fid) felbft zu finden; benn ifgre (sicbidste und bie meiften ifgrer $\mathfrak{B}$ emerfungen zu ben Edriftetellern Des alten Sried)enlando entbelyren fo fehr alfer

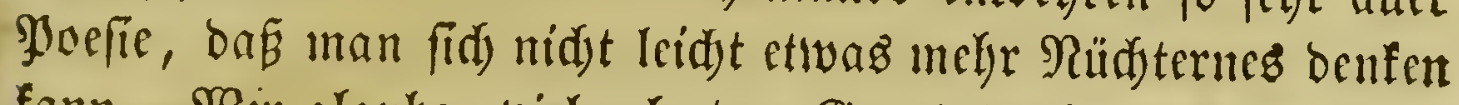
fann. SBir glauben viclinebr ben Grunb barin zu finben, baß

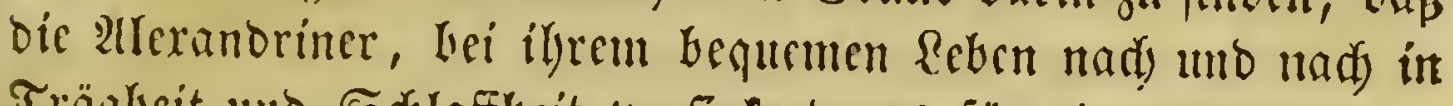
Träglyeit uno Sdblaffleit verfinfeno, $\mathfrak{3}$ für cine angenelymere Befduätigung hiclten, ben alten Alutoritäten aut jebem Sdbritt 


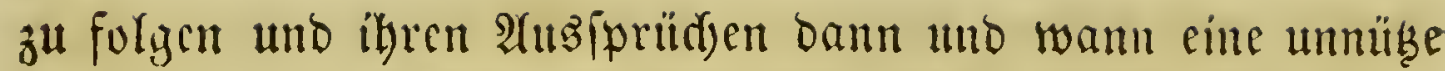
woer läd)erlide Eretärung beizufügen, alz burdy baz 2Anftrengen

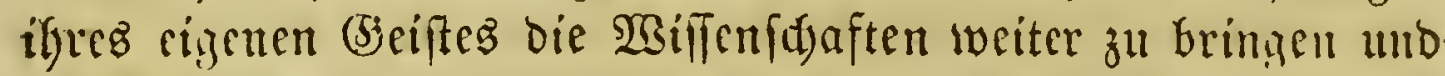
Die Srrtfümer ifrer Borgänger zu verbeffern. Darum waren grammatifde Stubien, weldye unferer $2(m$ fid)t nad) nüdsterner als bas Betreiben Der Botanif find, in Allexantria bie Şaupt=

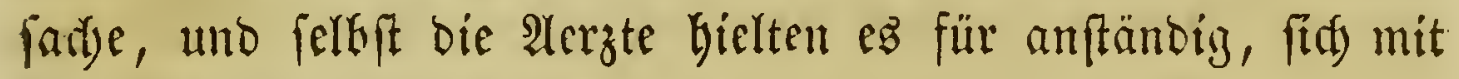
Denjalben zu befafien.

Sprengel fülytt in fciner Historia rei herbariae eine

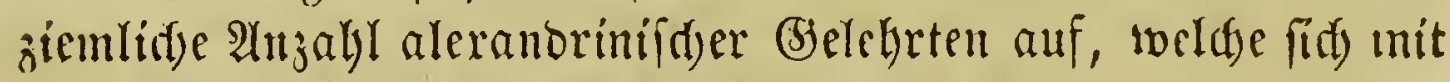

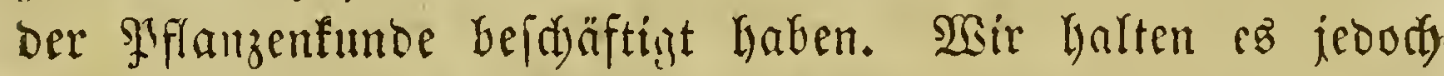
nid)t für nötbig, bie Ramen berfelben aufjufül)ren, umb ver= werifen beshab auf ben angefülyten Srbriffteller t. I, lib. II, cap. 2.

\section{Die Beiten ber römifhen}

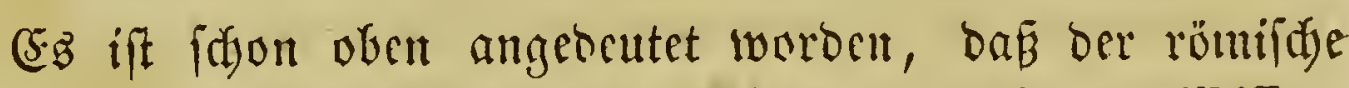
(SGarafter überhaupt veber ben Rünften, nod) ben Sillen=

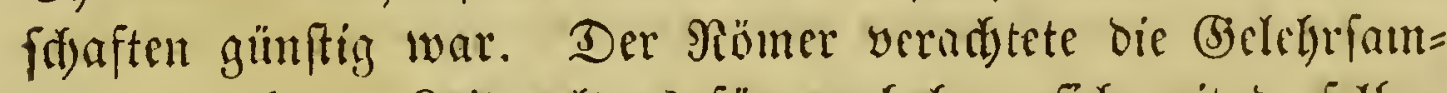
frit, uno range Zrit galt es für unelyrbar, fiti) mit berfelben

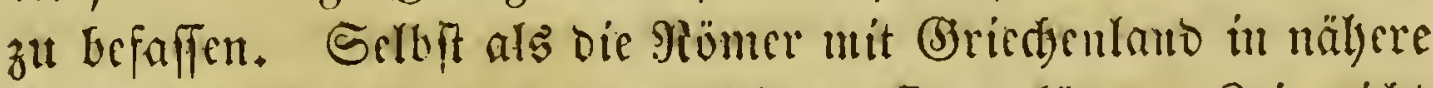

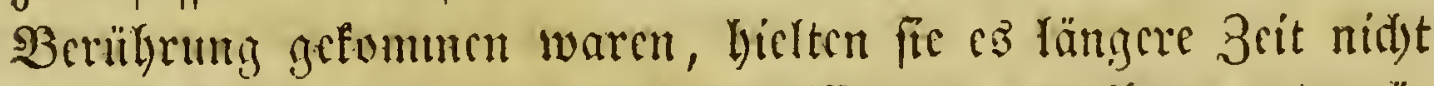

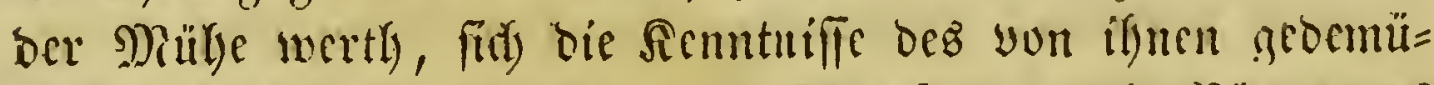

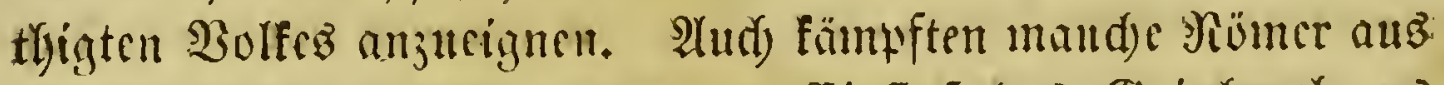

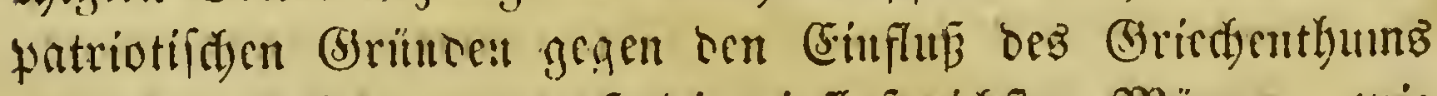

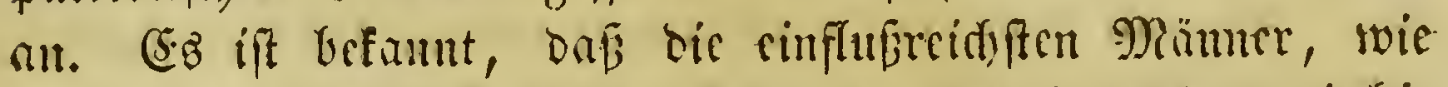

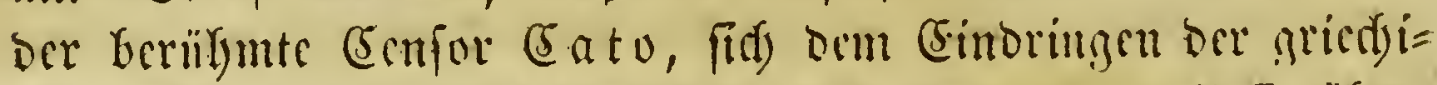

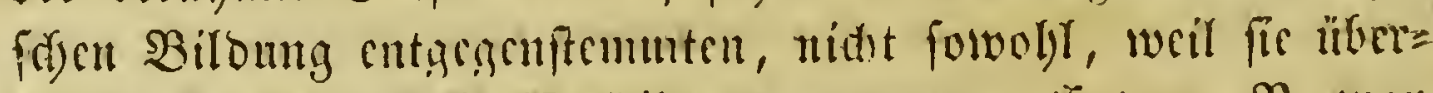

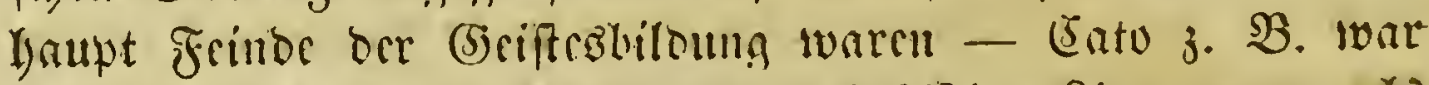
forbft cin Fremo uno אemter ber gried)ifd)en Ritrratur - afs:

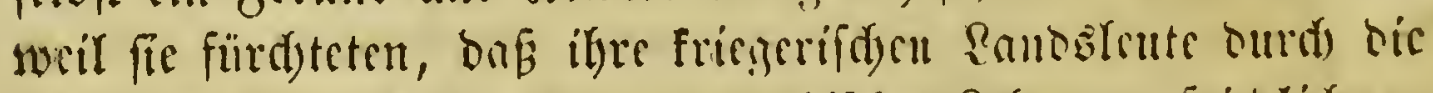

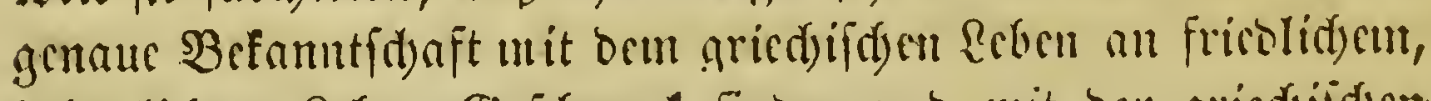

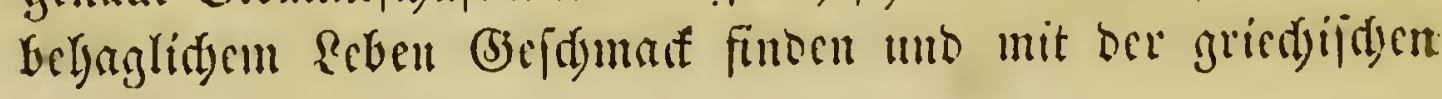




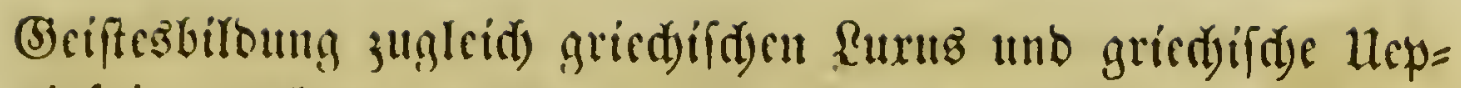
pigfeit autelymen müd)ten. Denn fdon Damalz fing baz fitt= lidje Eecuen ber $\Re$ ümer allülig an Iaxer uno loferer zu wer= ben unt zcigte bom aufmerfanten $\mathfrak{B a t e r l a n d g}$ freumbe bie Seime or fpäteren Unfittlidsfeit uno $\mathfrak{B}$ erworfenkeit.

Dic Nidutigfeit oer 2mfidsten jencr alten Patrioten hat fids

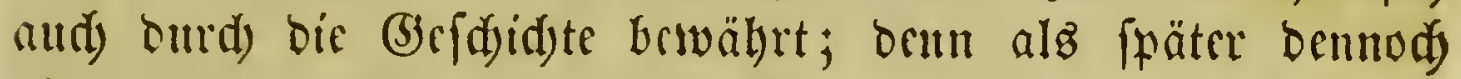

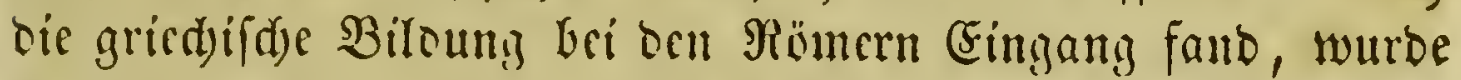

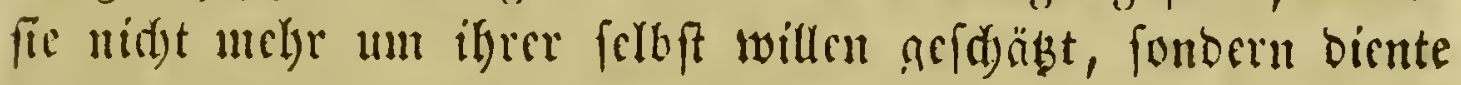

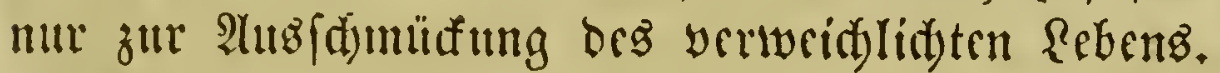

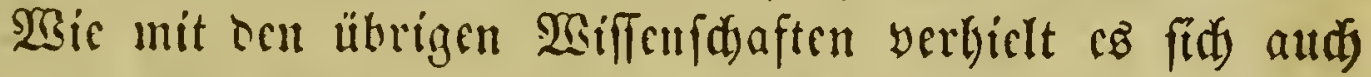
mit ber Argncifuttoe. "Dicfe Runft", fagt Sprengel,

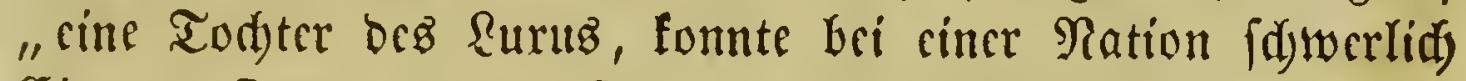
Eimgany futocu, beren Bilicber, you lyödften bis zum nicb=

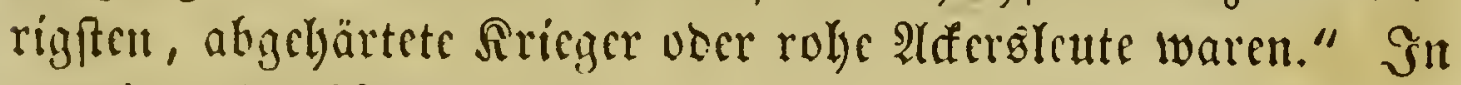
ctwaigen SWuthfällen half man fid) mit gowiffen baaşmitteln oocr glaubte ourd) gewiffe Furmeln und $\mathfrak{B}$ efdwwörungen ber (3)̈tter bie Siranflycit entfernen zu fïnnen. Die erften rigent=

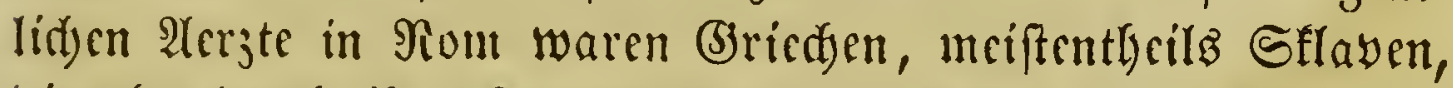

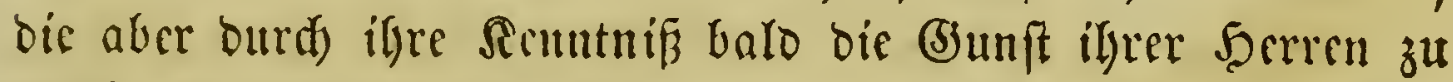

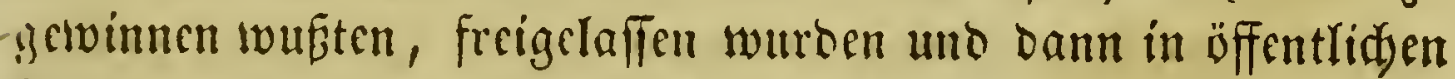
Euben (medicinae) ihr (bejdanft betricben.

Son cigentlidjen botanifden Senntniffen fonnte in jenen 3citen natürlid) gar nidyt bie Reos frin. Die Renntnif́ ber Syflanjen hatte nur infofern SBerth, als fie zur 2ubübung ber Scilfunde bienen fonnte, und ba bie Scilfunde felbft febr un= bcocutcno war, fonute and bie glanzenfenntuís nur firgr ge= riitg fcill.

Man fünnte freilid) crwarten, bafi in Nom fdyon wergen

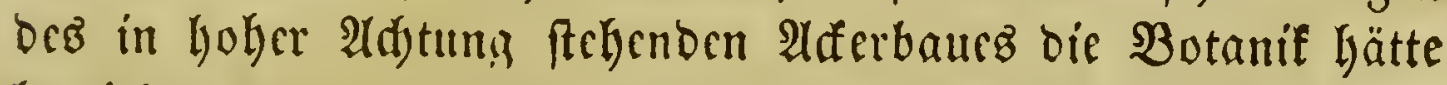
betricben weresu müffen, allein $\mathfrak{e B}$ wirb wohl bamals ebenfo in bicfer Şinficht grovefen frin, wie heute; ber ungebilbete fanbbaucr lernt gern nur bag, twas feine Borfaliren geivufit haben, uto begt gegen neue 2 nifdeten ein uniberwindidjes গ⿻ín traucu. 
Der oben erwälinte

\section{Mian $\mathfrak{A} \mathfrak{B}$ Porciub cato, geb. 235 , geft. 150 У. (5) r.,}

cin grofer Freund bes Afferbaues, fdricb unter anbern aud)

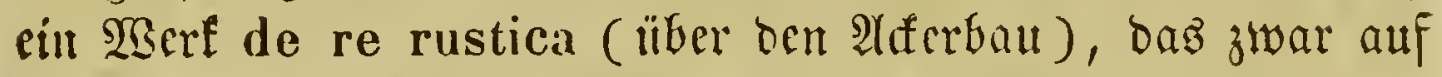

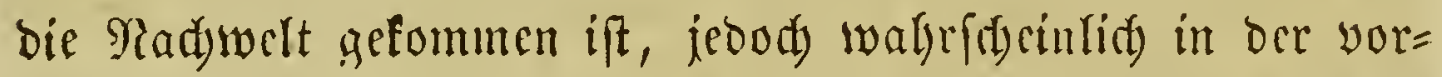

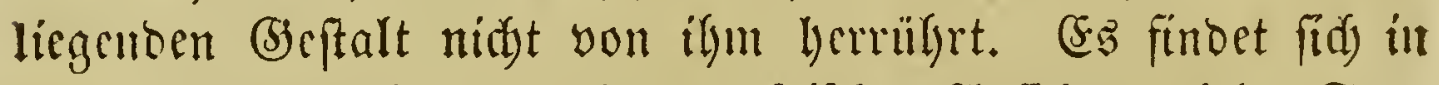

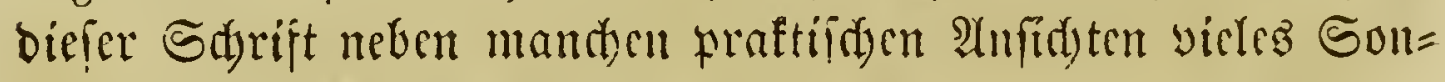
berbare und 2(berịläubijd)e. Es wiro baril aud von ber

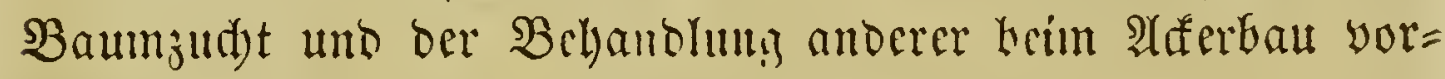
fummentrer (5iswärbje gehanoelt. ${ }^{1}$ )

Später idrieb über denfelben (Bergenftrono

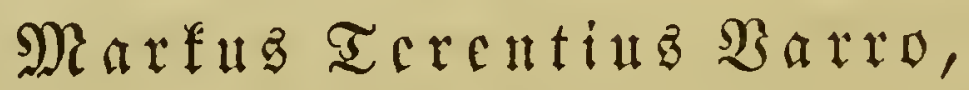
geb. 117 , gef. 27 y. (S) r.

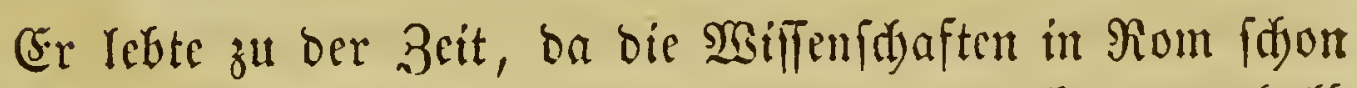
allgemeincre Berbrcitung gefunoen hatten, uno hatte beshalb

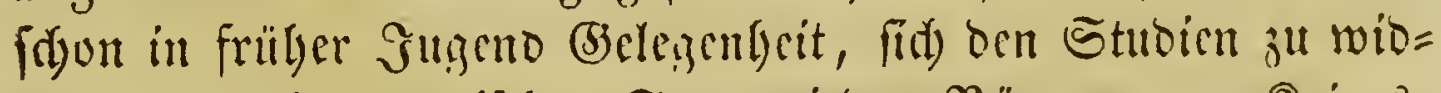
men. Da im römifden Stante jeber Bürger zแm Rriegg =

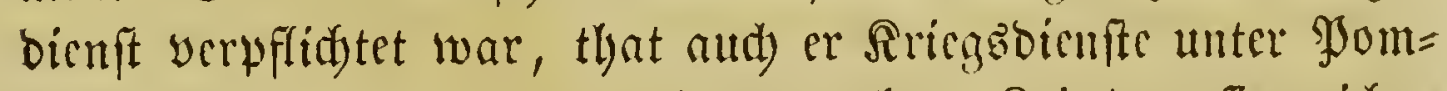
fejuB, wuBte fiel) jebod) nod) jur redjten 3eit ocm fegreidyen

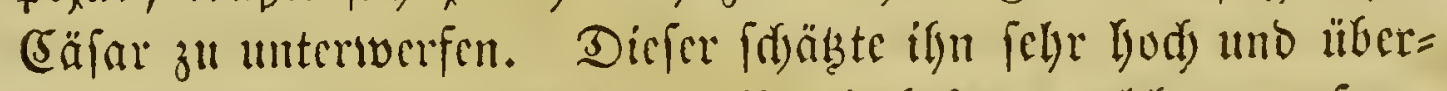
tru! ilym bie âfufficht niber bie Bibliothefen, weld)e er gefam=

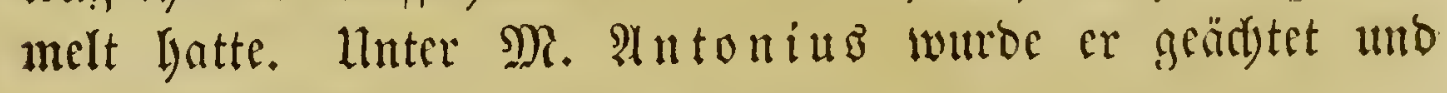

1) Bergleide Sprengel, Hist. rei herbar. lib. II, cap. 3. M. Porcius Cato de agricultura sive de re rustica liber. Venetiis 1472. Fol. Basil. 1535. 4. Antwerpiae 1590 u. 1598, cum notis A usoni Pompae. J. M. Gessner, scriptores rei rusticae, Lipsiae 1735 . 4. - Scriptores rei rusticae cur. J. G. Schneider. Lipsiae 179'. 8. 


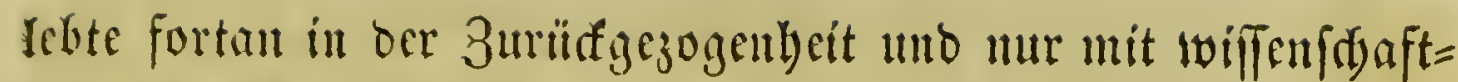
lidyen ?reciten bejuaftigt.

Barro war viellidyt ber gclebrtefte alfer Röncr. Aluf

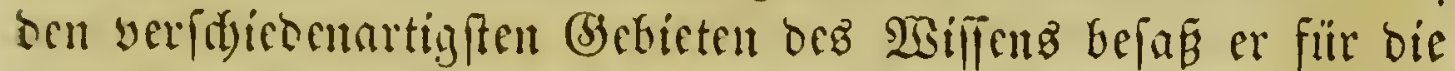
Damalige 3rit febr brocutento semntniffe. Fr foll umgefähr 500 Sndriften verfabt haben, von benen jebod) aufer einigen

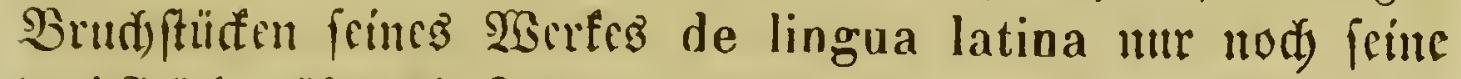
brei Bïder über bic Ranbwirthidjaft (de re rustica libri III)

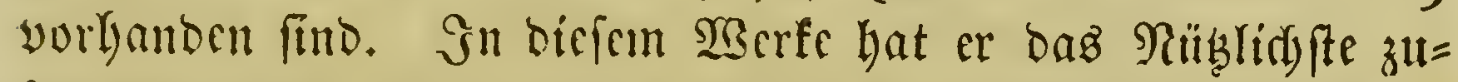
fammengeftellt, was bor iflu, befonbers yon griedyifdyen Sabrift= fecllern, gefdriben worben war. Altd) bei ifm, woie bei (5ato, finden fit) ncten viclem Braudbaren, Gejonocrs im brit= ten Buble, mandise fonderbare und eigenthünlidye $\mathfrak{B e m e r}=$ fungen. ${ }^{1}$ )

Der Gerilfinte Didyter

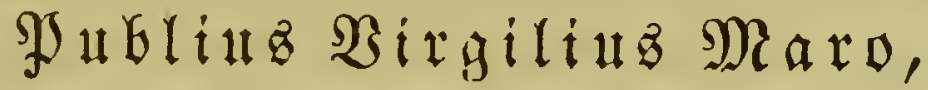 geb. 71 , geft. 19 y. (5gr.,}

hat ebenfallz ein Sart gefdrieben, bas in gewiffem Simu

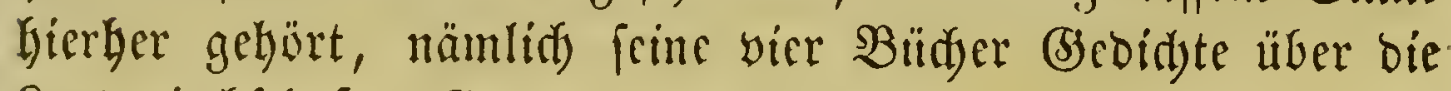
Ranowirthidaft (Georgicon libri IV). (Es hanoclt liber Den Aferbau, bie Baumpflanjung, die Biel $=$ uno Bienen=

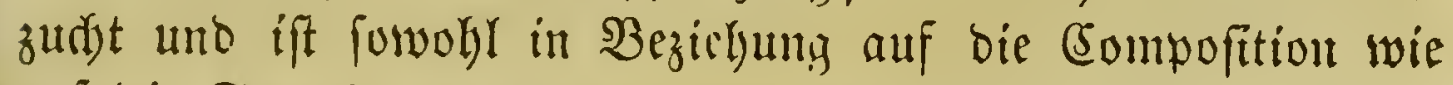
auf bie Spradje cin gleid) vortrefflides Mcifterftül. Ratür=

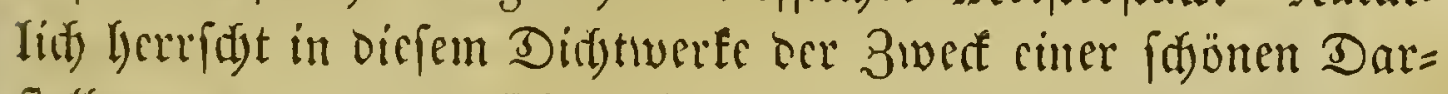

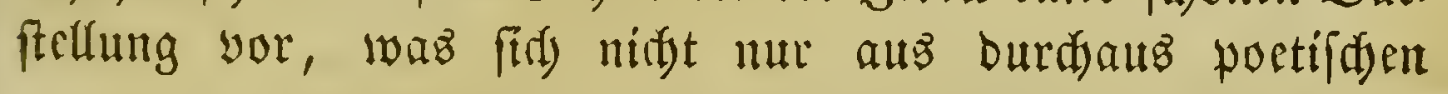

1) M. Terentius Varro, De re rustica in ber oben erwägn. ten $\mathcal{A}$ tügabe Eato's. Bas. 1521; 1576. Par. 1515; 1569; 1533; 1581. 8. mit Scaligerg 2(mmerkungen. - Amstelod. 1623. 8. Lugd. 1601; cum A usonii Pompae commentariis. 8. 
Stellen, wie I. 467 , II. 458 , III. 474 2c., fondern aud) aus

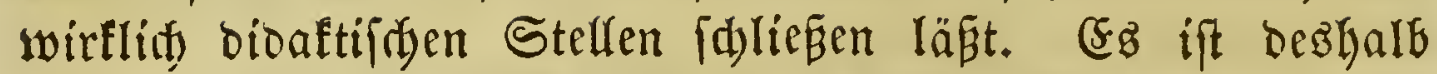
nid)t zu erwarten, baßj bie vorfoumenoen gy flanzen mit wif=

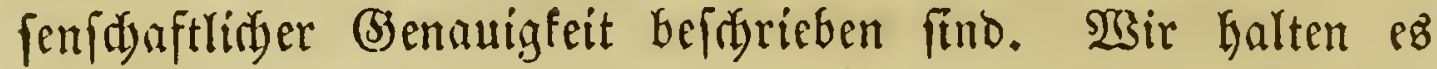

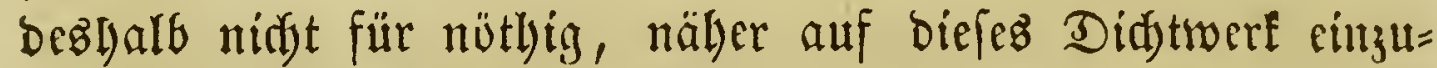
geben, und verweifen Denienigen, dem es darum zu thun ift, bie von Birgil erwälynten SDflanzen zufammengeftellt zu fehert, aufer Sprengel, Histor. rei herbar. tom. I, lib. II, cap. 3, auf bie unten verzeirineten Wrerfe.")

3u berfelben 3eit full fid aud ber Freigela flene $\mathfrak{A}_{\mathfrak{n}}$ to $=$

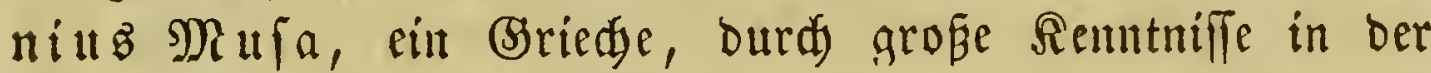
Scil = und Spftanzenfunde ausigezeitymet haben. Er befreite ben Srinceps ÂAguftus von einer laniswierigen Rrantlyeit, an

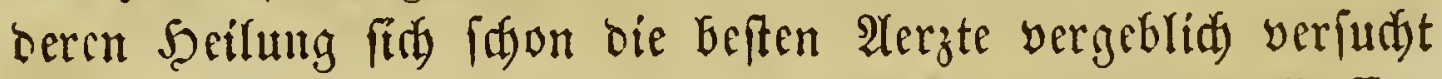
batten, Durdf falte $\mathfrak{B a ̈ b e r ~ u n d ~ b a s ~ T r i n f e n ~ v o n ~ f a l t e m ~} 2$ Sa fler.

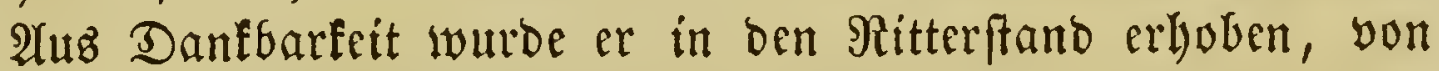
Aluguftus und bem Senate reidylid) befdenft und burdy bie Alufftellung einer ebernen Bildfäule in Tempel Aležculaps ge= elyrt. Er foll über bie Bereitung ber Argneimittel gefdrieben

') A. J. Retzius, Flora Virgiliana. Lund. 1809. 8.

A. L. A. F ée, Flore de Virgile ou nomenclature méthodique et critique des plantes, fruits et produits végét. mentionés dans les ouvrages du priuce des poëtes latins. Par. 1822. 8. 1 tab.

Tenore, Osservat. sulla flora Virgiliana. Neapel. 1826. 8. Paulet, Flore et Faune de Virgile. Par. 1824. 8. 4 tab. Virg. Mar. Georgicarum L. 4. with an english translation and notes by John Martyn. London 1741. 4. 1746. 8. mit einigen abbilbungen verfegen.

Bon Demfelben Berfaffer Virg. Mar. Buccolica sive eclogae with an english transl. and notes. London 1749. 4. Bon bem erferen 3 erfe if 1759 zu Samburg cine Deutide Heberfectung boul Dufd arfdicnen.

Die befte deutidae Heberietzung der Berte Birgits if bie yon $\mathfrak{B}$ of 


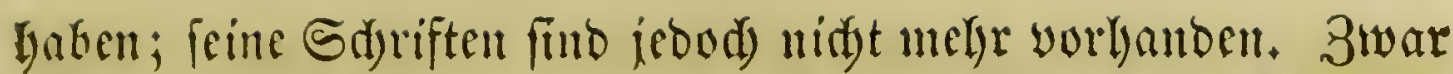
gibt eg unter feincm Ramen nod) zuei Sdriften: Libellus de tuenda valetudine unb de herba betonica (vettonica),

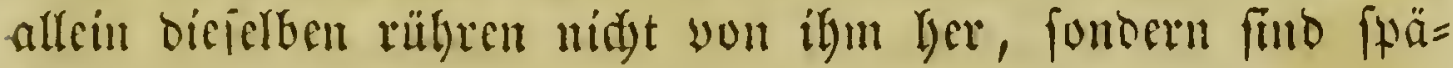
teren llriprungs. ${ }^{1}$ )

(5) bes Rönigs Guba won Mauritanien. Radf feinem Ramen ift bif glflanje E uphorbia benamt.

Beibe lebten um's Galyr $50 y$, (Shr. (3ebutt.

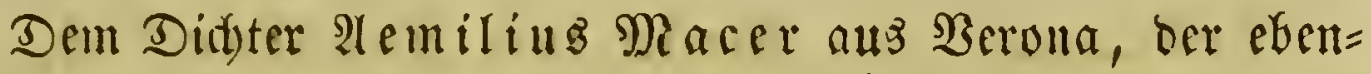

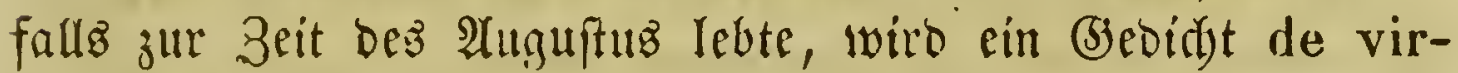
tutibus herbarum, weldyes yon den (biften uno Rräften ber

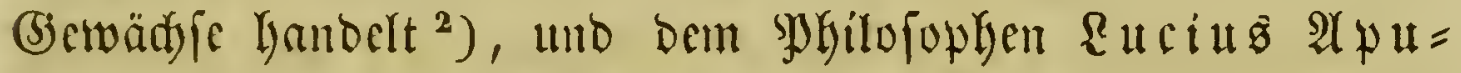
Iejug cin $\mathfrak{\text { Serf }}$ de herbis zugeidrieben. ${ }^{3}$ )

SBidtiger als bie eben (Erroälynten ift

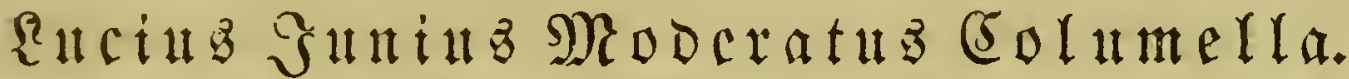

(5x war aus (j)abez in Spanien gebürtig unb rebte unter ben Raifern

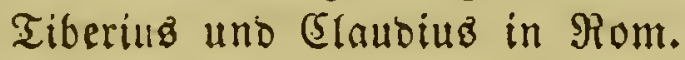

Bon feinen übrigen Rebensumfänoen ift nidyts Räheres befannt. Scin SBert über bic Ranbivirtbidyaft (de re rustica)

1) Ant. Mlusae, De herba vetonica. Tigur. 153\%. 4. Mit (5ommentar.

J. G. Ch. Ackermann, De Ant. Musa et libris, qui illi adscribuntur. Altorf 1786. 4.

$\left.{ }^{2}\right)$ Macer Floridus, De virtulibus herbarum una cum Walaf idii Strabonis, Othonis Cremon. et J. Folcz carminibus similis argumenti quae sec. cod. ms. et vett. edit. recensuit, supplevit et adnotatione critica instruxit L. Choulant. Lips. 18:32. 8.

F. Boerner, De Aem. Macro ejusque rariore hodie opusculo de virtulibus herb. Diatribe. Lips. 1754. 4.

3) Herbarium Apulei Platonici ad Marcum Agrippam. Romae s. a. 4. Paris. 1528. Fol. Bon Ga abriel şummelberg ebirt. Tiguri 1537, 4 . 
iu zwörf Bädern ift nod vorbanden. Dab zelynte $\mathfrak{B}$ ud biefes $\mathfrak{3 e r f e s}$ enthält ein Rehrgedidyt über den (5)artentau, in weldfem ber Berfaffer verfudt, ben Birgil zu ergänzen.

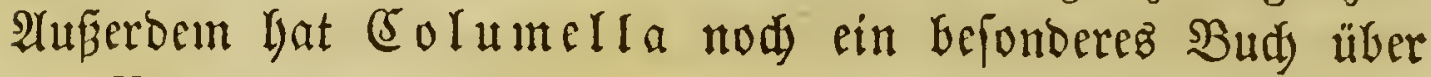
bic Baumgudt gefdrieben. ${ }^{2}$ ) -

Der für die Pflanzenfunde bebeutendfte Sdyriftifteller bes ganzen âtertbuns aber ift

\section{Hedanius ober Hedacius Dioßforibeg.}

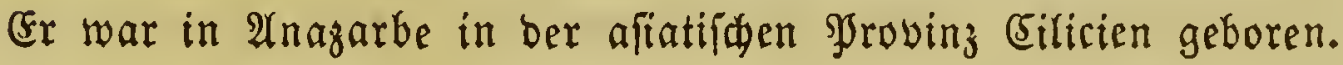

Ueber bie Zeit, in weldyer er lebte, ift fijon wiel geftritten worben. Sbgleidy aber Slinius trobsem, baj er iljn oft

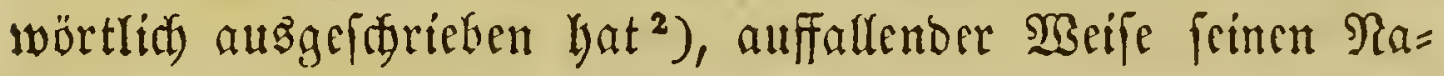

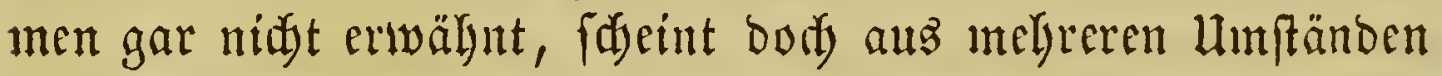
berborzugehen, Daßj er zur Zeit bez Raifers Rero, umgefälr

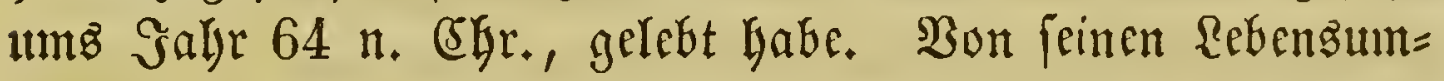

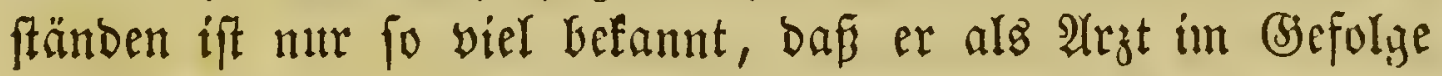
ber römifden Scere weite Reifen unternommen uno Dabei bie für bie $\mathfrak{A}$ rgneinittellegre widjtigen Stoffe mit groferem Eifer fcrbfändig unterjudt hat. Scine Sdyriften find in griedyi=

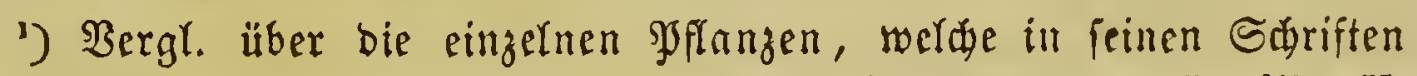
vortommen, Sprengel, Hist. rei herb. tom. I, lib. II, cap. 3. - L. Jun. Mod. Col., de re rust. libri XII. Bononiae 1520. Fol. Argentorati 15\%3. 8. Lugd. 1548. 8. Par. 1543. 8. - Schneider, Script. rei herb. fielye oben

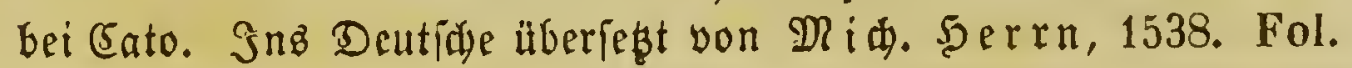
Bon $\mathfrak{T}$ geod. $\mathfrak{R} a \dot{j}$. D a g b, Migbefurg 1612. Fol. Beroaldi notae in Columellam, im 16. Sabrgundert an veridjedenen Drten erícienen, guerti Bononiae 1514.

2) SIinius fönnte itbrigenz aud biefelgen, unz unbefannten Sueflen, nady benen Diosforibes arbeitete, benubt baben, und feine vftmals wörtlide Hebereinftimmung mit ciefent bager jul erffären feill. 
fder Sprade verfapit. Sie zeidunen fid jebod nidjt burdy cine fduoue Sdureifart aub, waz er felbft jugeftelyt. (5) a len

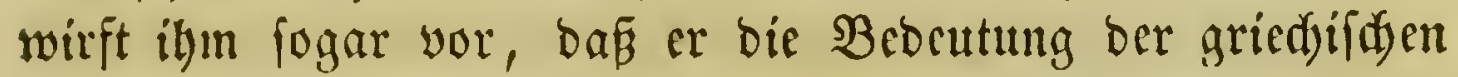
șorte nidjt verftanoen habe. (E) ift bies übrigens leidjt Daraus zu erflären, baß in feinem Baterlande Silicien nídst bie reme griedifde Spradje, fondern sin (semifa mefrerer Sprad)en geredet wurbe.

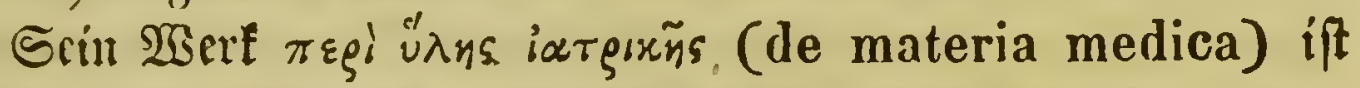
freilidy feine Botanif, fonbern cine $\mathfrak{A r}_{\mathfrak{g}}$ meinittellehre, was

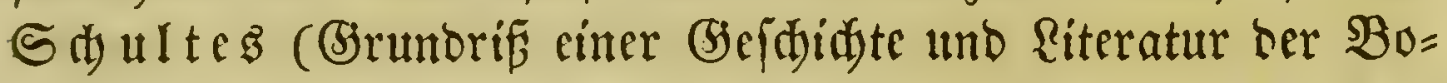
tanif) fehr hod anjuldjlagen fodeint. Die Alten trieben über=

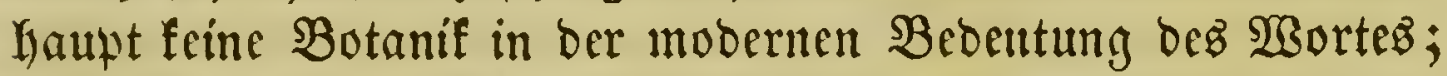

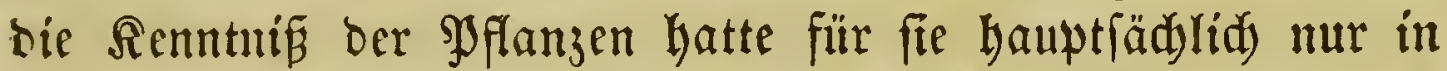

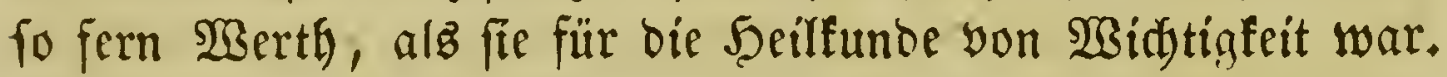

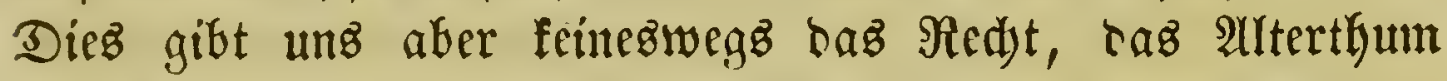

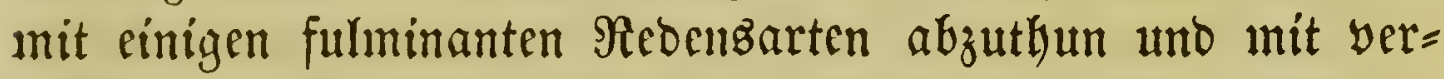

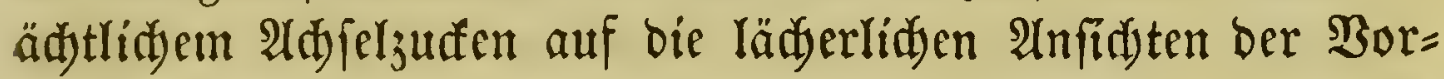
zeit Gerabzublifen. Die (Sefdidite eimer Biffenidyaft muß auts bie geringften 2 nfänge Dez Forfdens zu würbigen verftelen,

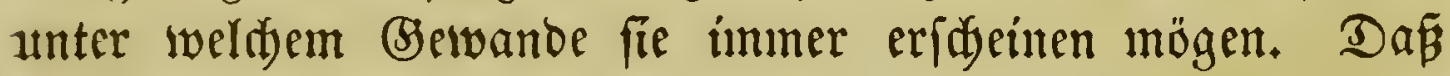

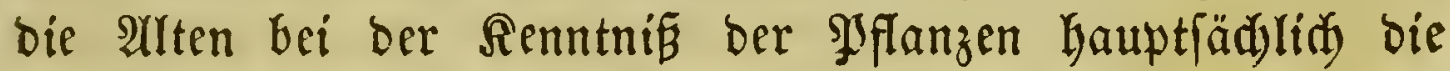

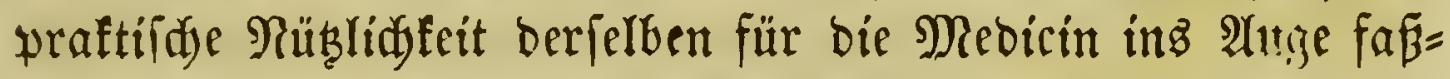
ten, fommt uns burdjaus nidjt fo fonberbar vor, wie biez bei Sdultez ber Fall zu fein fdeint. 2udd heute nod) ift

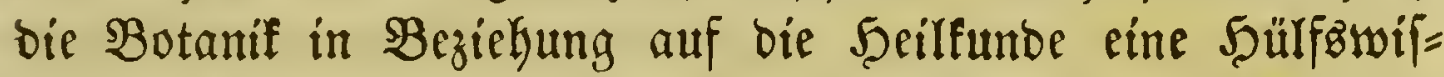
fenfdiaft und wird ftetz eine folde bleiben. Die Anlegung yon botanifaten (s)ärten, weldye Sdyultez für fo woidtig hielt,

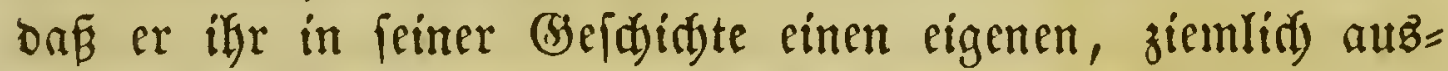
fübrlid)en 2(bfdnitt wiomete, währeno er bie Reiftungen ber grö̈ten SThyftologen nur in Borbeigehen erwähnt, wäre an fid) eine blope Spielerei, wenn ihr nidft bie tiefere Sbee zu

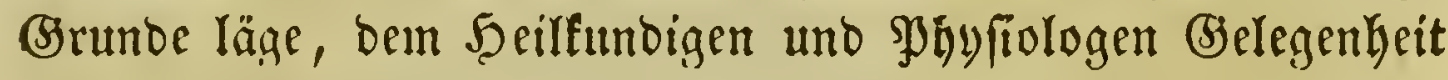

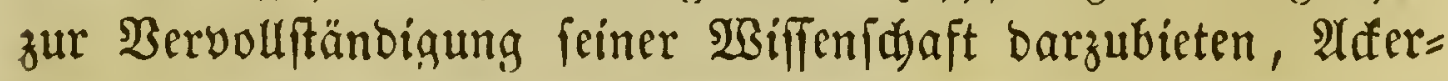
bau, Şandel uno Jnouftrie zu fürbern. Mag nun auti) Diobloribez nur eine $\mathfrak{A} r$ neimittellebre uno feine Botanif ge=

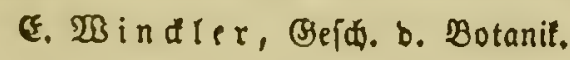


fdrieben Gaben, feine Berbiente un bie Shflanjenfunte finto genugiam auterfannt worben. Faft fedsszehn Galjrhunberte

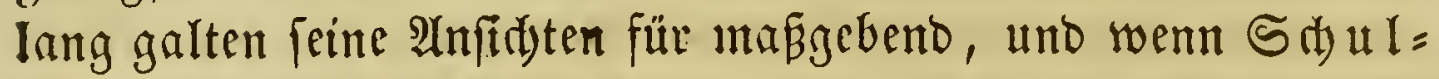
tes gerade barin eine Sdmälerung der Berbienfte jenes Man=

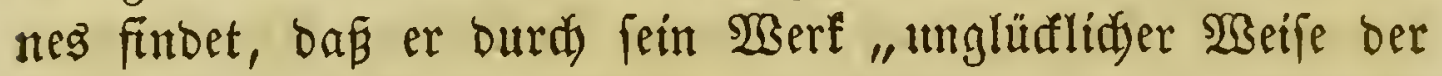

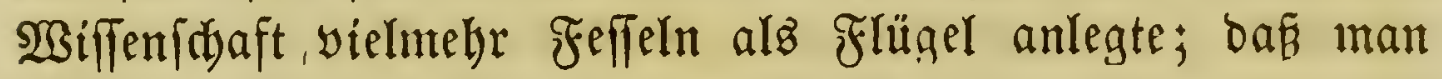
burd) 1500 Sahre feín beflerez $\mathfrak{B e r l}$ fand, alz oaz feinize, uno folglid) bei ifm ftehen geblieben ift," fo fönnen wir bies nur für einen nod) tieferen Berveggrumb zur SBürbigung bes Díbloribes betrad)ten und find weit bavon entfernt, ifm bie Dummbeit feiner $\mathfrak{R a d}$ folger zun Bormurfe zu maden.

Diobloribes führt in bem oben ertwälnten $\mathfrak{B}$ erfe ungefähr 600 syflanzen an, yon benen er etwa 400 furz befibrieben ober imit anberen befannten Syflanzen vergliden hat. (Er bält fid feinem Ziverfe gemäß bei feinen Unterfideibungen ber ein= zelnen Species bauptfädblid an bic Birfungen ibrer ßräfte, und ba er bierbei nad feinem flaren und beftimmten Syfteme verfäbrt, fo find viele fainer Befdreibungen fïr unz ganz $u$ =

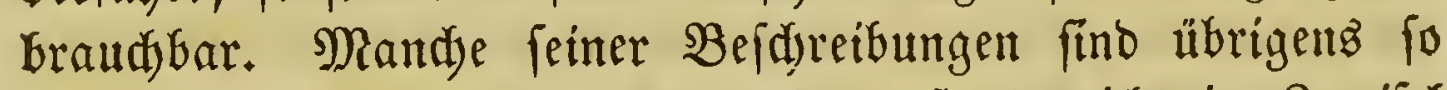

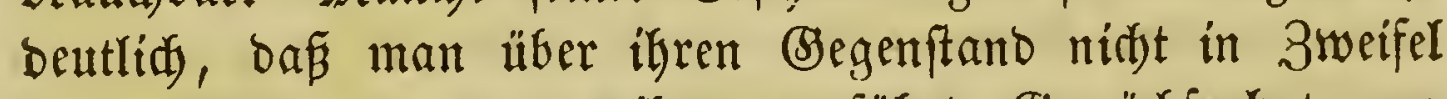

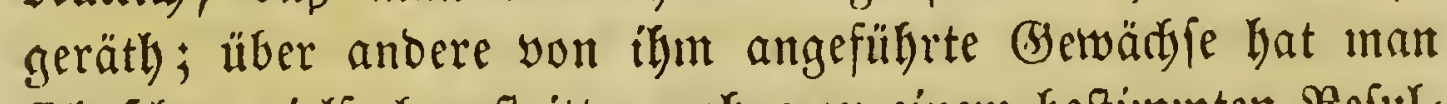
fid) fidon vielfad geftritten, ohne zu einem beftimmten $\Re$ eful= tate gelangt zu fein. Sinige ந̧andidriften feinez 2 Zerfez find zwar mit abbiloungen verieben; biefe fino jebod felbit fo

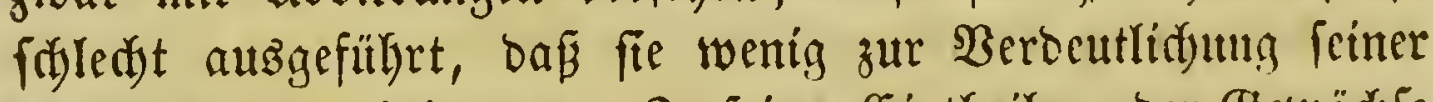
Beforetbungen beitragen. In feiner (sintheilung ber (Sewädble bringt er oft bie verfdiebenartigften Spflanzen zll fammen, bei

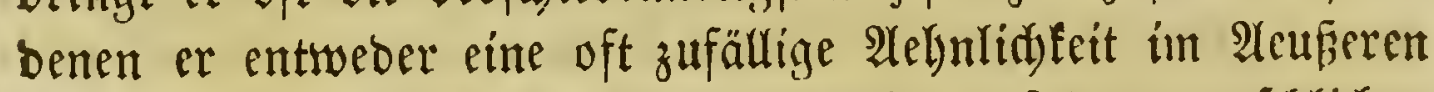

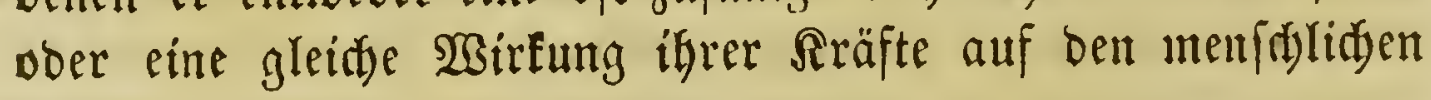
నörper findet. ${ }^{1}$ )

2) Heber bie 2lrgneipflanzen, weldeer fuerferwähnt bat, vergl. Spren= gel'g Berfud einer pragmatifden (sefdidte der Argneifunbe, 2. Thl., \$. 44, unb über bie von igm bef(briebenen \$flanjen über= baupt, Sprengel, Histor. rei herbar. tom. I, lib. II, cap 3. 
Bon feinem berillymten serfe befinden fid auf ber Siete ner Bibliothef zivei Subices; oer cime, weld er von Conftan= tinopel bortlin geforad)t wutbe, foll aus bem 5 ., nad) Alnoern

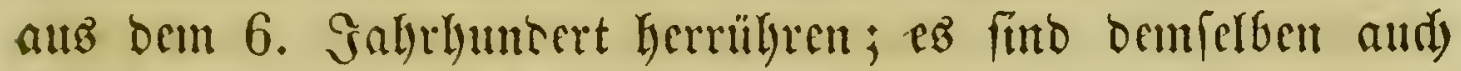
Abbildungen brigefügt; ber fith ebentoafelbit befundidge Reapo= Yitanifde (Soder foll nod) älter fein. ${ }^{1}$ )

Ferner befintet fid) einer in Shariz, ebenfallz mit 2 (bbil= Dumgen yerfeken, und brei in Reiben. ${ }^{2}$ )

2) Diefe Scanbidriften find auf Pergament, bas erfere in Şalb= folio, mit gleidjeitig gemalten Syflanzen, angeblid berfäst auf Befebl ber Suliana $\mathfrak{A}$ nicia, einer Todter bes im Sabre $472 \mathrm{im}$ Dccibent berridenben Raifers Flavius 2 nicius DIy= brius, welde nad 5onftantinopel an $\mathfrak{A r e o b i n o u s , ~ b e n ~ b a s ~ B o l f ~}$ an bie Stelle bez Raifers 2lnaftafü Dicoruz fetzen wollte, ver= eberidyt wurbe. Sie foll bies Berf zum (5ebraude eines in Son= fantinopel von ibr geftifteten Spitals baben fdreiben laffen. Die sweite, in Suartform, iheint ber Sdrift naw älter; allein bie Syflanzen zeigen fid ungleid fpäter binzugemalt.

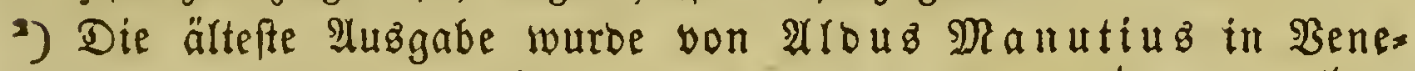

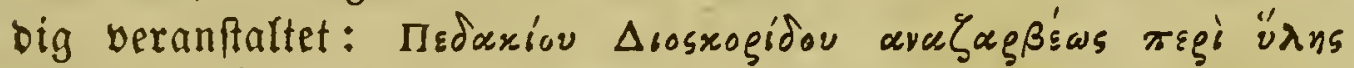
iar Ausigabe im Jabr 1518.

Feblerfreier aber ift forgende 2luzgabe:

Пedariov etc. Pedacii Dioscoridis Anazarbei npera, quae extant, omnia. Ex nova interpretatione Jani Antonii Sarraceni. Frcf. 1598. Fol.

Die Ausgabe von (3) pupylus, Jaris 1549, 8., if am Rande mit vielen Reżarten auz 5̧aubidriften unb Alügaben ver= feben. Die bem Diogtoribes untergefdobenen Stellen find am Enbe beigebruat.

Fine neure 2 usigabe von Diostoribes werfen mit Heber= fesung uno Sommentar ift forgenbe:

Pedanii Dioscoridis Anazarbei de materia medica libri quinque. Ad fidem codicum manuscriptorum, editionis aldinae principis usque quoque neglectae, et interpretum priscorum textum recensuit, varias addidit lectiones, interpretationem emendavit, commentario illustravit Cur= tius Sprengel. Lipsiae $1829-1830 ; 2$ Ible. in Duart. 
Diokforibes $\mathfrak{W}$ erfe find auberorofntlid bäufig commentirt worben. Scton im Jahre 1529 erfidien eine 2luşgabe ber= felben mit Sommentar: Dioscorides Graece et Latine, ex versione et cum commentariis Marcelli Vergilii. Colon. 1529.

Bon ben übrigen Gommentatoren wollen wir nur nemmen: Matthioli,

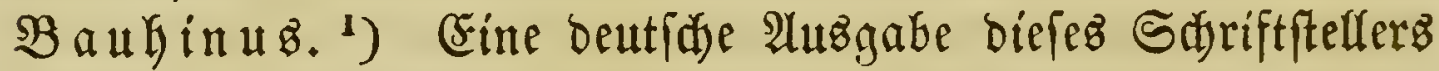
rrjđien zu Franffurt a. M. 1546: Dioşforibez Sräuterbud,

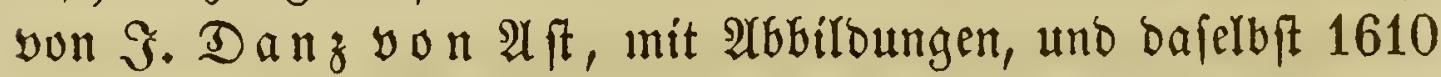

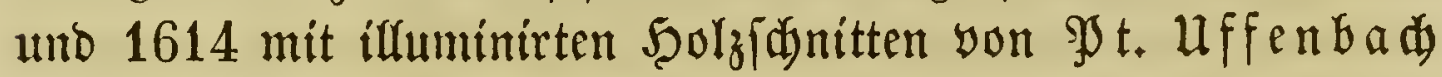
herauzgegeben.

2(ud) in andere neure Spradyen find bie $23 e r f e$ des Díos= furibes überjegt worben. ${ }^{2}$ )

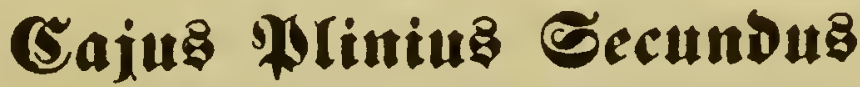

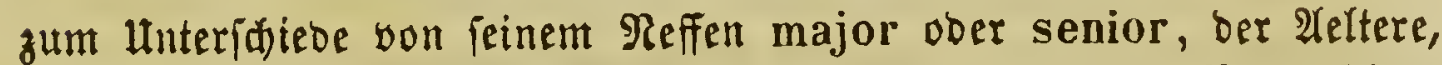

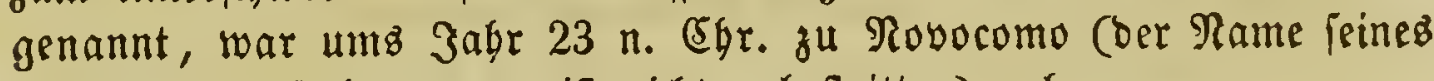
(seburtzortez if nidit unbefritten) geboren.

Er that Rriegabiente in Sermanien, wurbe unter Nero zum Âugur ermälylt uno unter Befpaftan, bei bem er in grofier 2 datung frand, Srocurator in Spanien, fpäter wurbe er 2 nfülbrex einer rümifden Flotte. Es ift wumberbar, wie

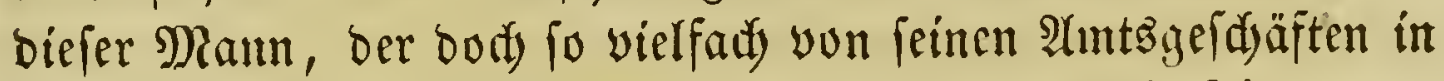

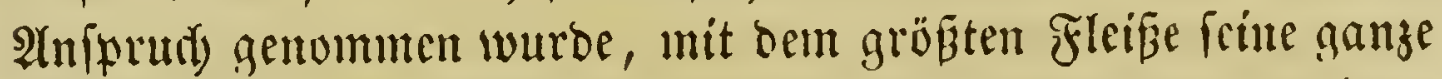

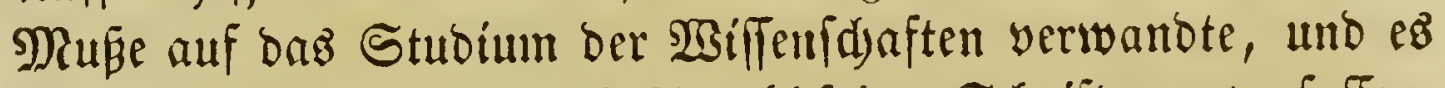
fid) fo ermöglidyte, dic grofie 2 (nzahl feiner Sdyriften zu verfaffen. (5x fand einen feldr tragifdelt Tod. Sndem er fidi) näm=

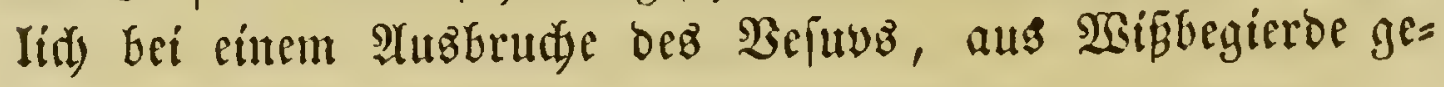

1) Hebcr bie anberen vergl. Sprengel, Histor. rei herbar. lib. c. und Schultes S. 48 .

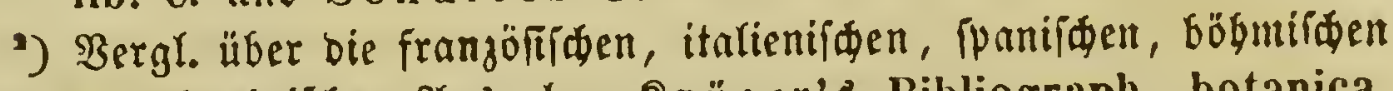

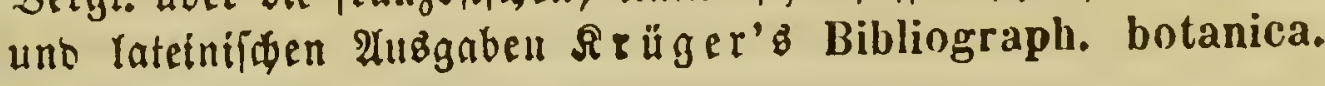
S. 25 น. 26. 


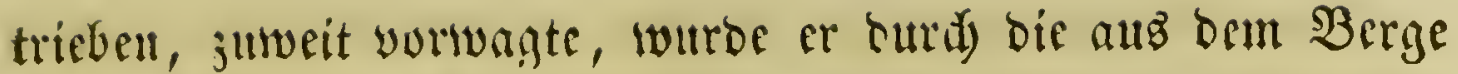
Lerworftrümenoen Dämpfe erffift (79 n. (Shr.).

Das Berzsidynif feiner Sdyriften ift uns in feines Reffen, Şlinius bes S̈̈ngeren, Briefen lib. III, ep. 5 aufbetwalyrt. Aber nur frine Rattrigefdidte in 37 Bäd)ern (naturae historiarum libri XXXVII) ift auf bif Radibelt gefoumnen.

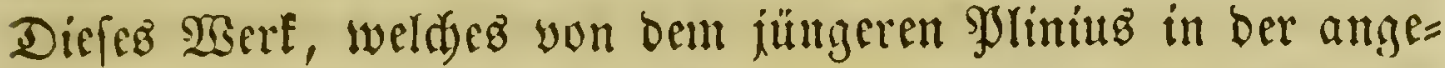
fülyrten Stelle ein opus diffusum, eruditum, nec minus varium, quam ipsa natura genannt wirb, ift cine 3 ilam= menfteflung won Excerpten auz melyr als 2000 Sdyriftifellern. In bem 11. - 19. Butbe ift von ber Srflanzenfunde, und in 12. - 32, von ben $\mathfrak{A}$ rzmeimitteln aus bem $\mathfrak{T h i e r}=$ uno $\mathfrak{P}$ flanzen=

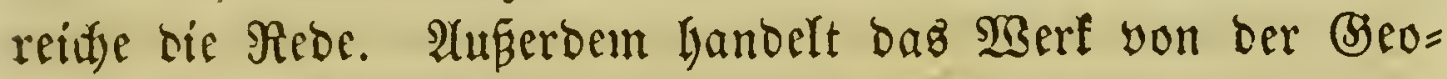

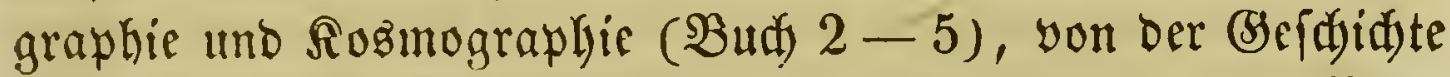
ber Tlyiere (Bud) $6-10$ ), yon ben Mineralien, ber $\mathfrak{B i l}=$ yauerei und Malerei (Bud) $33-37$ ), und verbreitet fid) nebenbei aud über ben Şandel, bie Shifffahrt, פghyfit und

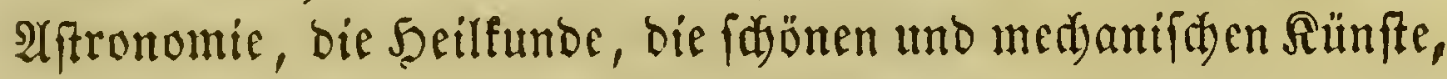

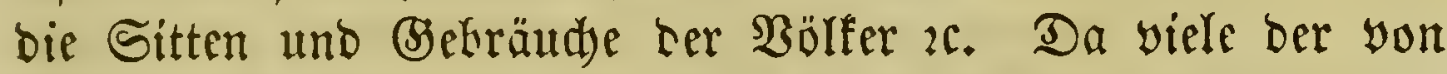

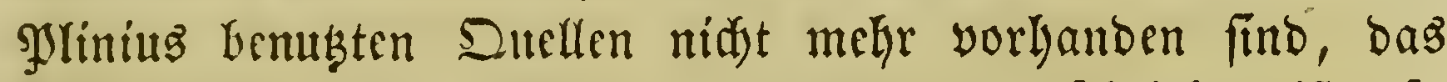
Bert felbft audi geiftsoll und originell gefdrieben ift, fo funnte ifm bie A2nerfenmung ber Nadunelt nidst entgehen.

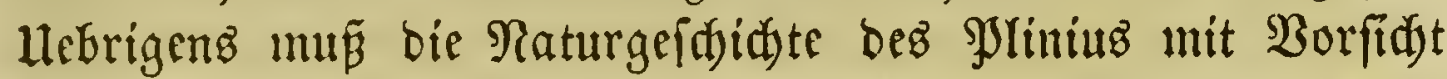
benubst werben, sa firh zuweilen cine flitdtige Bearbeitung und eine gewiffe Reidytgläubigfeit beg Berfalfers nid)t verfennen läßt.

Wie faon oben bemert, hat glinius den Dioztoribes wabr= facinlid febr ftart bemubt, ebenjo bie übrigen Sdariftfteller, welde vor iGm über bie syflanzenfunbe gefdrieben haben, bejon= berz aud) Den Theophraft. Die Bejdreibungen ber Syflanzen

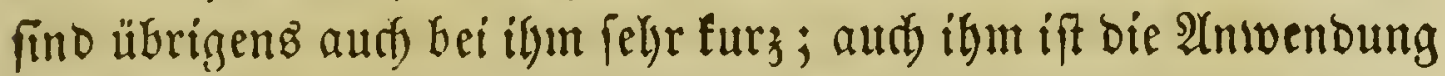

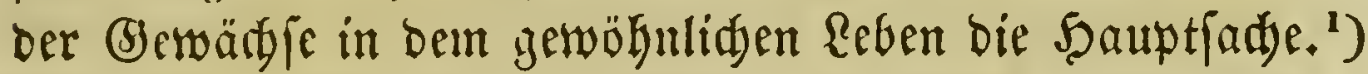

1) Bon Plinius' binterlaffenen Sdriften gibt ев viele Şanbidriften

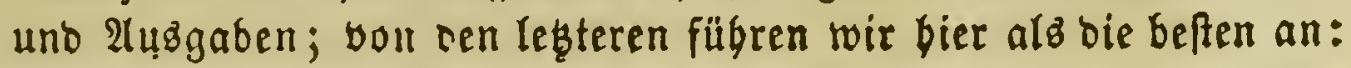
C. Plinii Secundi historiae naturalis libri XXXVII, quos 
Bon Slinius wirb lib. 20, cap. 17 und lib. 25, cap. 2 ein getwilfer Autonius (5aftor erwälnt, der felbit einen grobern Garten befeffen und viele feltenen Sylanzen barin ge=

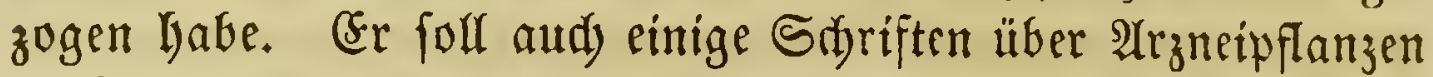
yerfajt haben.

Scribonius Rarguz Defignatianus, Reibarzt bez

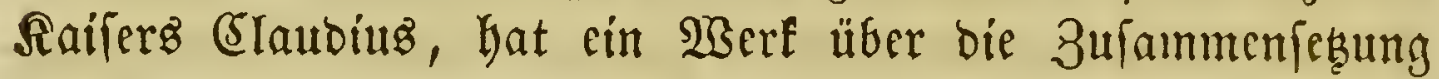
ber $\mathfrak{A} r$ zaneimittel hinterlaffen. Er bemuste inztefondere ben oben erwäbnten Nifander und außerbem melyrere andere Sdrift=

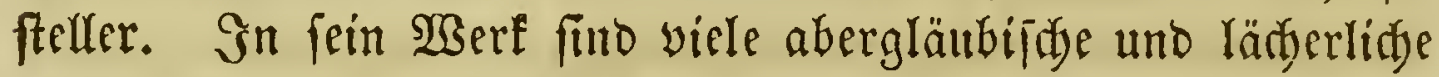
Anfidten aufgenommen. ${ }^{1}$ )

interpretatione et notis illustravit Joannes Harduinus. Jussu regis christianissimi Ludovicii magni in usum serenissimi Delphini. Editio altera emendatior et auctior. Tom. I-III. Parisiis, typ. Ant. Urb. Caustellier, 1723. Fol. Die erfte $\mathfrak{A}$ ugigabe war im Sabr 1685 in fünf Suartbämben berauşzefommen.

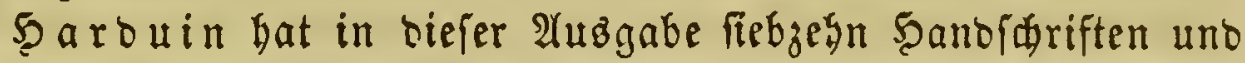
auser Daledamp's zu (Senf 1631 exfdienenen C. Plinii Sec. historiae mundi libri XXXVII nod mebrere anbere 2 (ug̊gaben benust. Sgitniug' Raturgeididte wurbe idon 1565 ing Deutide

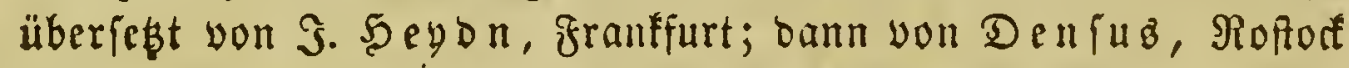
1764. Sime andere Heberiegung erfdicn zu Franffurt im Sabr 1618: C. Plinii $\mathfrak{B u ̈ h e r ~ u n b ~ S h r i f t e n ~ y o n ~ \Re a t u r , ~ A r t e n ~ u n o ~}$

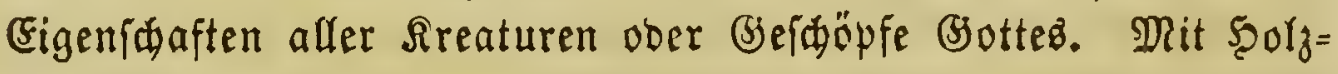

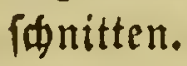

Fine neutere Ueberiełung von $\mathfrak{R}$. Frit Heber bie franzöfifden, italieniiden uno fpaniīen Ueberiebungen Diefez Sdyriftfellers vergl. Sr üger' Bibliograph. botanica. S. 31 .

Uleber bie einjelnen von $\mathfrak{g}$ riniuz neu befdriebenen ober an= gefülrten Sglanjen vergl. Sprengel, Hist. rei herb. Tom. I, lib. 2 , cap. 3.

) Scribonii Largi de compositionibus medicamentorum liber unus antehac nusquam excusus, Jnanne Ruellio castigatore. Paris. 1529. Fol. Bas, 1529. 8. 5erauzgegeben bon J. Rhodius, Batavii 1655. 4.; von J. Mich. Bernhold, Argentor. 1786. 8. 


\section{Claudus Gaalcnus,}

geb. 131 zu Wergamuz in RTcinafien, geft. 200 n. (5)r.

Sein Bater Rifon, ein Baumeifter, gab ifm von früber Sugeno auf cine vertrefflitise Erziegung. Balen ftubirte an= fangz bie shilofophie, befonoers die ariftotelifitse unt bie flatonifide; in fiebzeluten Gahre aber wiomete er fid auf Beranlaffung cines Traumes bein Stubium ber Mebicin. 21 Sahre alt begab er fidy nady Simyrna, uno yon oa nady $\Omega$ rinth, um in viejen Stäbten einige auszgezcidynte \$Jhilofophen

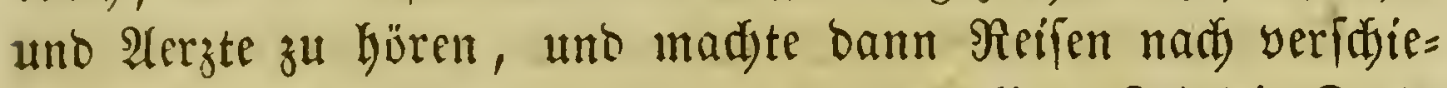
benen (S) Alleranorien für oen Bereinigungapunft aller $\mathfrak{W i} i$ enidjaften galt, und es inzbefondere für 2Aerzte eine groß̧e Empfehlung war, bort ftubirt zu haben, fo begab fidh aud (bjalen brrtbin, um fid bauptjäd)lidi mit ber Aluatomie, bie befonoers in Alexanorien betrieben wurbe, zu befdäftigen. Dann Eelirte or in feine Baterftabt zurüf. Sn Folge eines bort ausgebrodte= nen $\mathfrak{A} u f i f a n b e z$ verließz er biefelbe jedod) wieber unb begab fid in feinem 34. Sahre in bie $\mathfrak{S e l t f t a d t ~ \Re o m . ~ S T i e r ~ w u r b e ~ e r ~}$

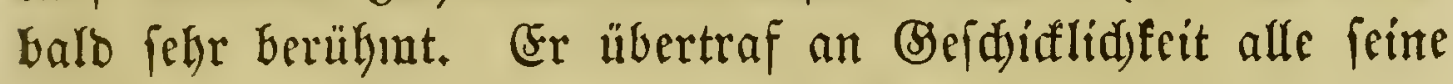
Eollegen, werhalb ifm bieje auf alle müglithe Meife nad)= freflten, fo bafi er ain Einde, jogar verhindert wurbe, feine offentlidyen anatomifuen Borlejungen fortzuiezen. In Folge biefer unaugenehmen Berbältniffe, une weil bamals eine $a c=$

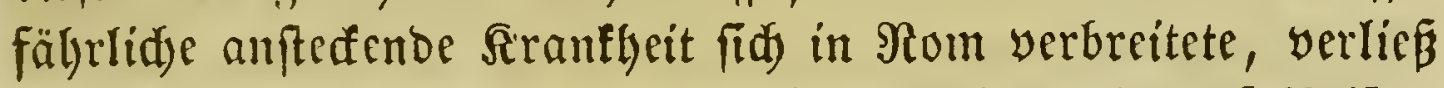
er Diefe Stabt wieber uno begab firf abermals auf Reifen.

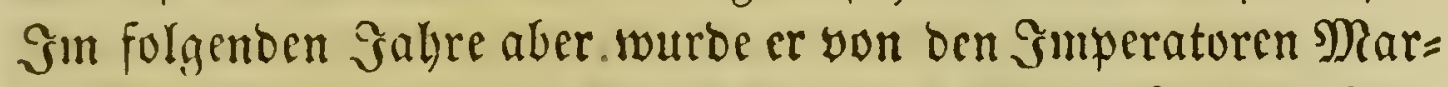
fus Aurelius und \&ucius $\mathfrak{B a r u s}$ ivieber zurïđgerufen uno blieb wahrideinlidy alz Reibarzt bez jüngeren (säfor Commodus längere 3eit in Rom. Ueber fein fpäterez Siben liegen feine gemiffe Radjridsten vor; $e B$ ift nidbt eimual befannt, ob er wieber in fein Baterlano zurüffebrte. Nady Subag erreidte 
or Daz 70. Sebensiafir uno farb alfo im Jabr 200 ober 201 nach (5hr. (s)eb.

(3)alenus wird als ber gröfte und berüfmtefte $2 \mathfrak{A} z$ t bes A(tterthums betradjtet, ber mit feinem medicinifjen $\mathfrak{B S i f f e n}^{2}$ cinen groß̧en Sdyag anderer Renntniffe verband. Er bradyte bie Seilfunde, welde fidy nady uno nady in ben veridjedenen mebicinifdyen Sdyulen in unnitge (Srübeleien uno Spibfindig= feiten berloren hatte, zuerfit wicber auf ben natürliden $\mathfrak{B}$ eg

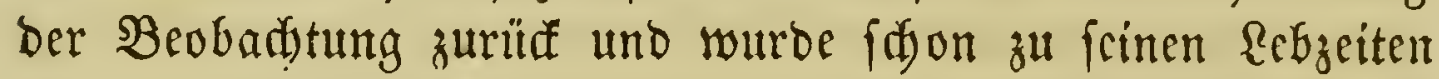

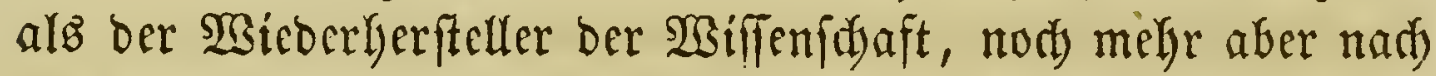
feinem Tobe als bas yortrefflidfte Mufter und faft unerreid)= bare Borbilo eines tüdytigen $\mathfrak{A} \mathfrak{r} z$ tes angeílyen.

(Er hat feldr viele Wrerfe gefdrieben; bie meiften ber nudi sorbanoenen find medicinifden Inhalts. In ocnielben fino

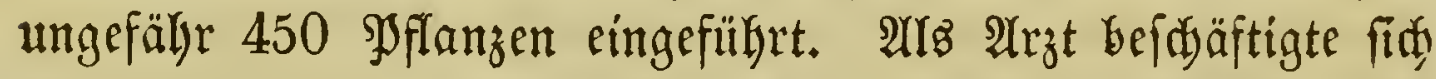
(J)alen, ebenfo wie feine Borgänger, hauptfädlíd, mit bent Rräften ber Splanzen und folgte Gierbé meiftens bem Dios=

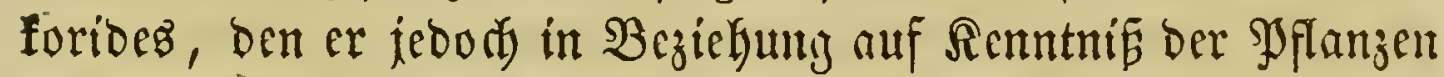
nidjt erreidft fat liaben (d)cint. ${ }^{1}$ )

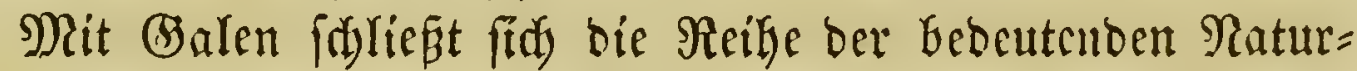

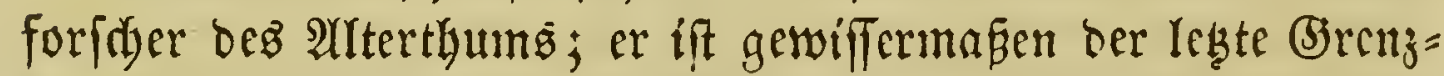

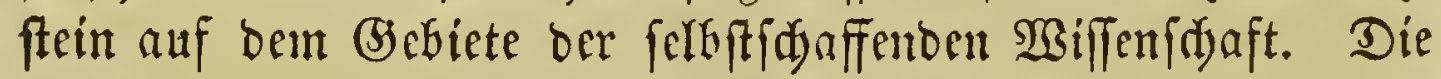

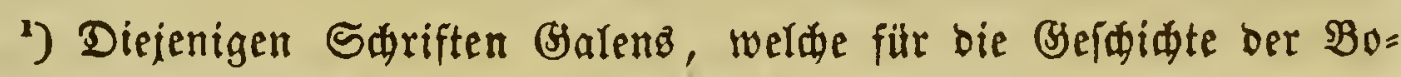
tanif $\mathfrak{B}$ idtinfeit baben, find folgende:

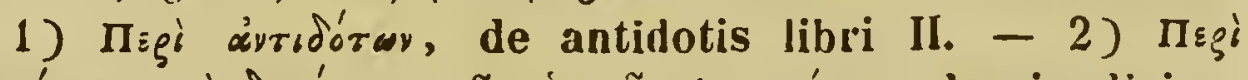

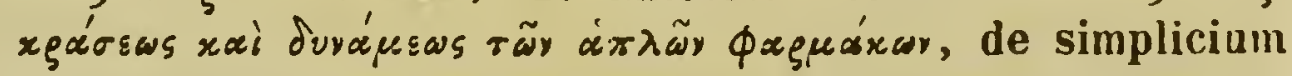
medicamentorum temperamentis et facultatibus libri XI.

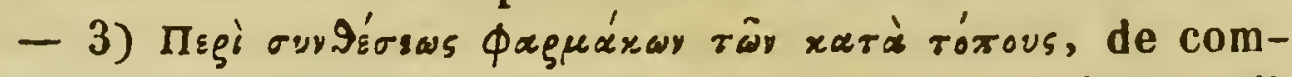
positione medicamentorum secundum locos libri $X .-4)$

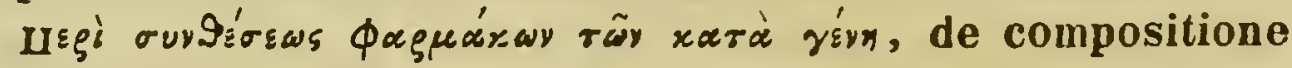
medicamentorum secundum genera libri VII.

Seine Sdyriften wurben mit benen bes Sippofrated zu Paris im 3abr $1679-99$ in 13 Foliobänben von $\Re e n$. Shartier, und ill ber neueren 3eit voll 5. (5). Sulnn, Reipjig 1821-1825, 10 Bänbe in 8., Gerautgegeben. 
madjfolgenden Srgriftifeller waren unbebeutende, ia oft ganz cinfidstalufe Sammiter mo (Excerptemmadier.

Marcellus (Empiricus aus Borbeaur, Reibarzt bez

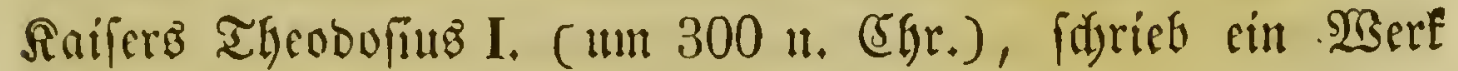

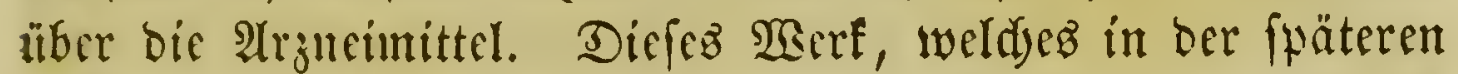
3 cit burd) cinen anberen Sammler walgrdyeinlidy verberbt und verftümmelt worben ift, jeidnet fid burd den wahnoigigften Aberglauben auz. ${ }^{1}$ )

Dribafius, uns Salj 400, aus Şergamus gebürtig, Reibar medicinifiden Sdyriftitellern, weldye vor ibm gelebt hatten, it 70 Bürdern, von benen nodj 14 erhalten frtto. Borzüglid)

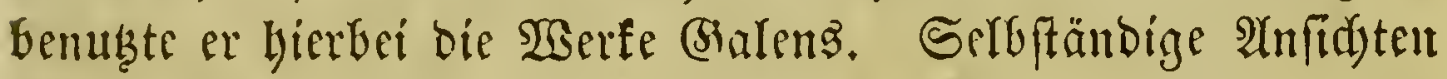
futben fids in biefem Siserfe felten; baffelbe ift jeoons barum für uns midytig, weil barin bie Sdyriften manther (jolfebrten

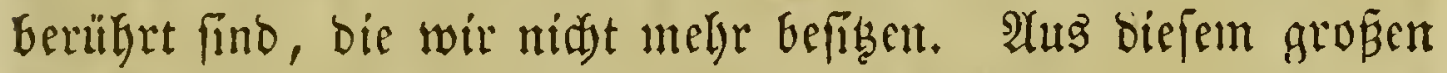

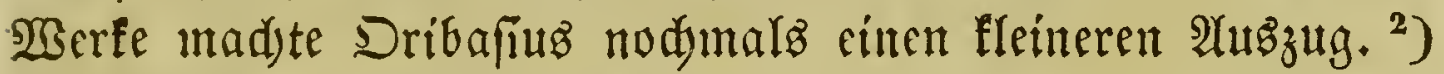

Bebeutend fpäter und fdon in ber 3eit, als baz weit = römifde Saiferthum bereitz aufgelöft war, arbeiteten einige Sdyriftíteller in ganz ähnlidjem Sime, wie bie vbengenannten.

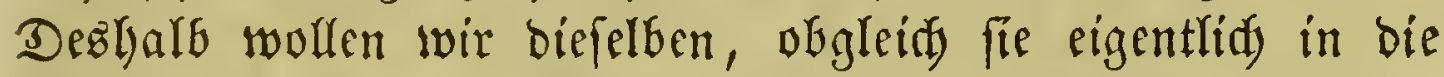
nadjolgende gyerivoe gebören, gleidy hier beiläufig erwälnen.

श्e tius verfertigte cin äbnlides Sammelwerf, wie Dri= bafus. Sn ber materia medica fulgte er burdjaus ben $\mathscr{A}(n=$

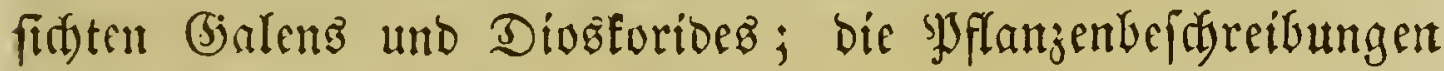
Dez (escteren liéz or immer weg. ${ }^{3}$ )

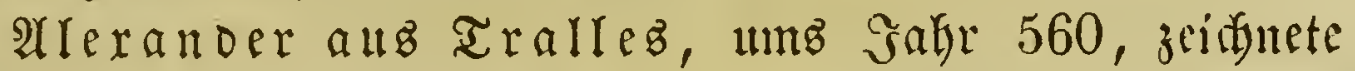
fid) unter ben gleidzeitigen 2 lerzten vortheilfaft als Seloft $=$

1) De medicamentis, ed. Janus Cornarius. Basil. 1536.

2) Oribasii euporista ar Eunapium, libri 4. Basil 1529. Fol. ed. J. B a p t. Rass arius, Venet. 1558. 8.

3) Aët i Amideni librorum medicinalium tomus primus, primi scilicet lihri octo nunc prinum in lucem editi. Venet. 1834. Fol. in grierbiføer Sprade. Sateinifde $\mathfrak{A}$ uzgaten find ju $\mathfrak{B a f e r}$, Benedig und anderen Srten erfoienen. 
Denfer aus. Er folgte nidgt blinb feinen grofen Borgängem, fonbern verglid) ftetz die anfidten berfelben mit feinen eigenen Erfabrungen und wagte es fogar zuweilen, (3)alen offen zu tabeln. ${ }^{3}$ )

J a ul von $\mathfrak{A}$ e gina, ums Gabr 640 , hat ebenfalla sinen

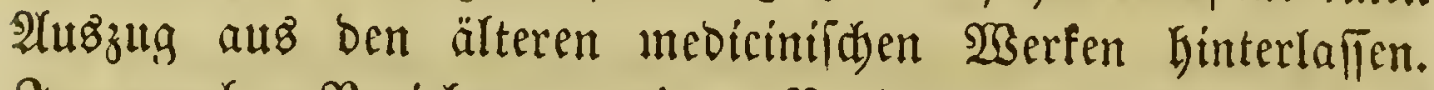
In mandyer $\mathfrak{B} e z i e l u n g$, wie 3. $\mathfrak{B}$. in ber (Shirurgie, ift er felbftändig. ${ }^{2}$ )

\section{Das Mittelaltet.}

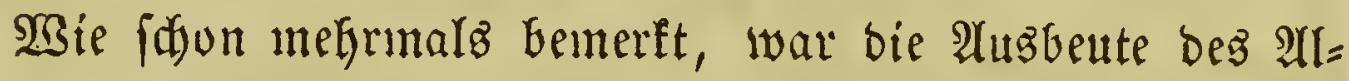
tertl)uns in ber $\mathfrak{B}$ otanif nidyt bebeutend. Man hat alle $\mathfrak{P}$ flan= zen, bie von ben Alten befdrieben ober erwähnt fins, zulain= mengezäblt uno nidgt inelgr als 1200 gefunoen. Das Mit= telalter aber hat hiergu nur eine fleine $\mathfrak{A n}_{\mathfrak{j}}$ abl hinjugefügt, ia fid nidgt einmal immer beftrebt, bie wenigen naturwiffenfidaft=

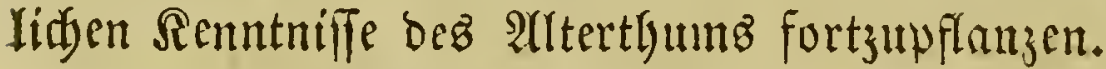

Sdyon währeno ber Raiferzeit ging ber wiffenfdaftlide

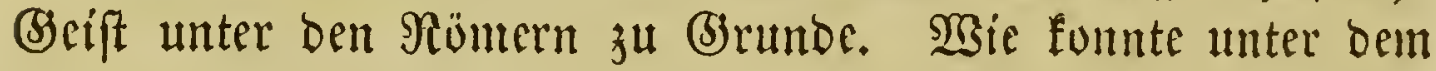
Dructe biefer meiftentheils roken, graufanen uno wollüftigen

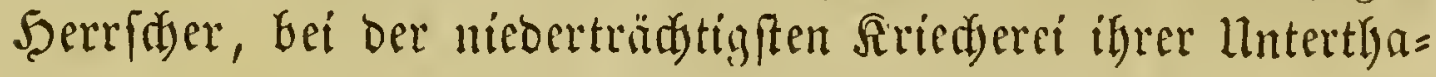
nen und bei ber ins Maflofe geluenoen Sifivädse uno Sit= tenlofigfeit ber Bewohner Jtaliens ein neter, fülner (Sedanfe geforen werben, oder wenn er geboren wurbe, wie lomite er unter foldsen Menidjen atnerfeunung funden?

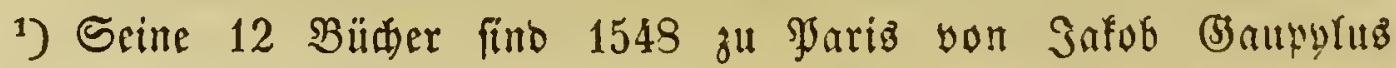
herausgegeben worben. Später now einige alloere Atugaben.

$\left.{ }^{2}\right)$ Pa ul i A g inetae de re medica libri septem. Venet. 1528. Basil. 1538. Fol.; in griedifder Sprade. 2ha in lateinifider Sprade find mebrere 24uzgaben vorballoen. Daz fiebente Buth, weldes von ben Arzmeimitteln banbelt, if auch befonders erídies nen: Pauli Aeginetae pharmaca simplicia 0thone Bruntelsio interprete. Argentorati 1531, Paris 1532. 8. 
Die Sceilfunoe fant berab zu ber geoanfenlofeften (s.me firie; Der wahnfunigfte atberglauben madyte fid) breit bei Der Bebanolung oer Sranfleiten. Durd) einfältige Formeln, Berufungen uno Beftreidyungen glaubte mau bie hartnädigften llebel furiren jut fünnen. Die Sdyriften ber alten Alergte fannte man niabt inchr, ober man nalym aus benfelben $\mathfrak{g}^{\mathfrak{e}}=$

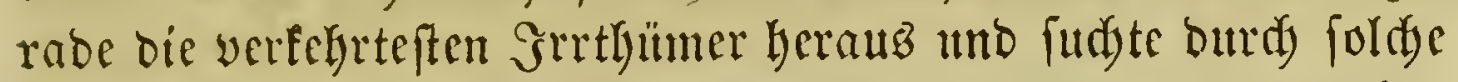
Autoritäten ben immer woiter um fî̀) greifenden 2 (berglatben nody zu beftärfen. Dẩ man barum aud) bie (Erforjdung ber Sirütterfräfte bei Scite legte, war natïllid). STgqu follte man milh jam bie grofie Menge yon gुflanzen femen Yernen, wenn man burd cine cinfad) Bef(d)wörung ober burd) ein

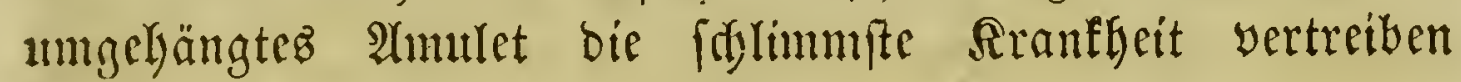
fonnte?

Selbft die 2(nnatyme des Shriftenthums als Staatsereli= gion betwirfte feine günftige $\mathfrak{B e r a ̈ n b e r u n g ~ i n ~ b i e f e n ~} \mathfrak{B} e r h a ̈ l t=$

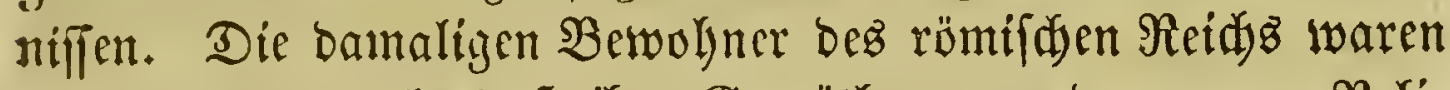

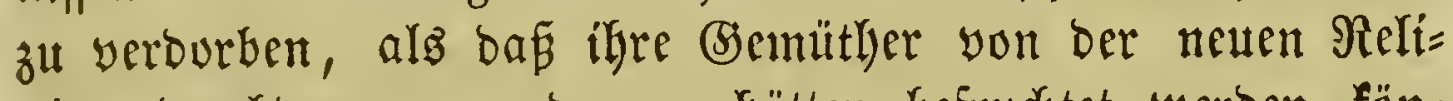
gion Durdorungen und, neu bätten befrudytet werben fön $=$ nen. Sm Begentheil binberten vicle 2 ntlyänger ber neuen Rebre Den Fortfdritt ber : 2 iffenfdaften. In ifyrem zelotifden

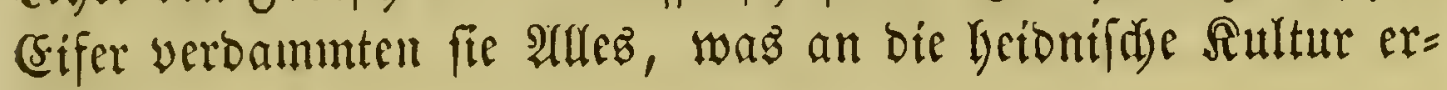
innerte.

Die germanifdent Bülferftämme, weldye verheerend üfer bas weptrömifde Reid) Lereinbradyen und es entolid) über Den

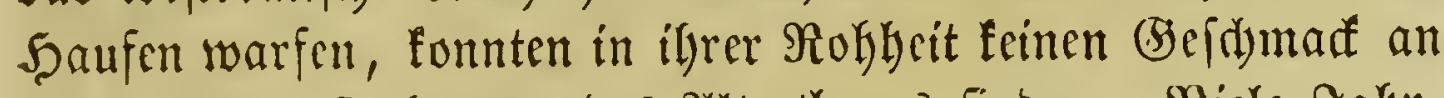
ben (3) ciftesheftrebungen bes Alterthumb finden. SBiele Gabr= hunberte musten erft vorübergehen, che fie anfingen, bie

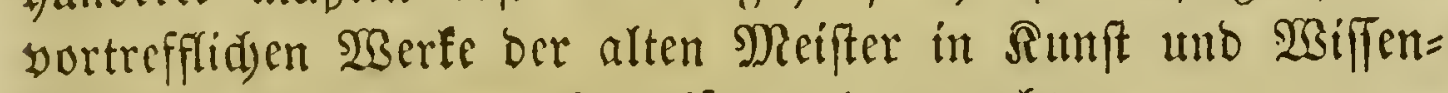
1daft cinigermaêen zu begreifen und zu adjten.

Die wenigen Sdriftfteller bes europäifłen Decioentż zur Zeit ber grobien Bölferwanderungen unb nady benfelfen waren meiffenz unfeleftändige Sammler, bie oft felbft bas, wos fic aus früheren Sdjriftfellern zufammengefdrieben, nicht redjt yerftanden. Eintige yon ifnen, bie eigentlidy bierher gebören, 
Gaben wir bei (Selegenlyeit fdyon oben aingefüfrt. (5: tönnte allenfalls hier nod) der Spanier S fib or us aus (Sarthagena, Biffof zu Sevilla, geftorben 636 nady (Shr., erwähnt warden, weil er unter allbern auth ein $\mathfrak{W}$ erf, Origines betitelt, $\mathfrak{g}=$

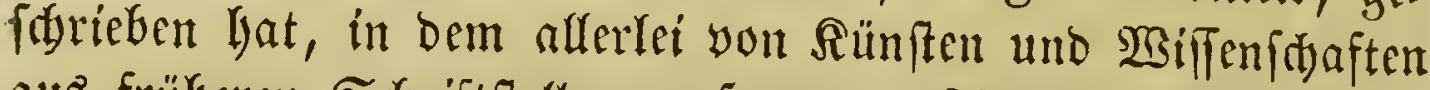
aus frülyeren Sdyriftitellern zufammengefdrieben ift. ${ }^{1}$ )

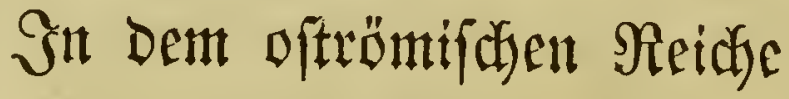

fonnte mant fids zwar in bem Streite itber sie Berelyrung oer Sceiligenbilder, fo felyr

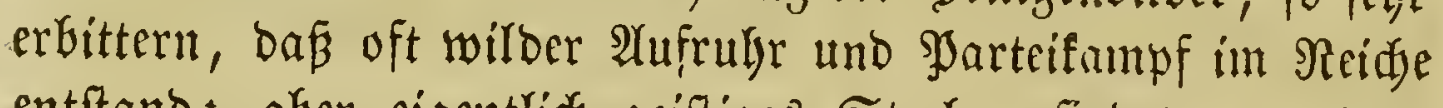
entftand; aber eigentlidy geiftiges Streben finbet man bort felten. Mandye Raifer, von Sülonerfdnaren auf ben Thron erboben, robe umwilfende Meniden, veradteten gerabezu bie

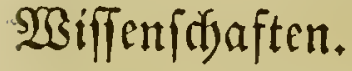

So verbot z. B. Midyal II, alfen Sdultunterridyt, inbem

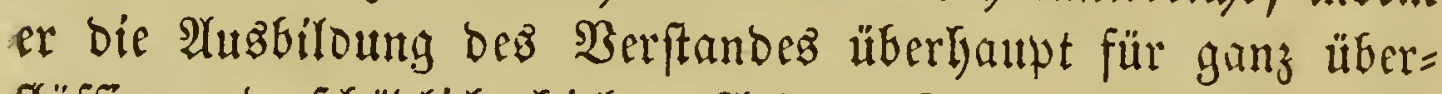
flüffig uno fdäblid bielt. Anbere Raifer bagegen waren Freunde der wiffenidsaftliden $\mathfrak{B}$ ildung unb unterfitibten bie Bertreter berfelben. SBir brautben mur an ben befannten

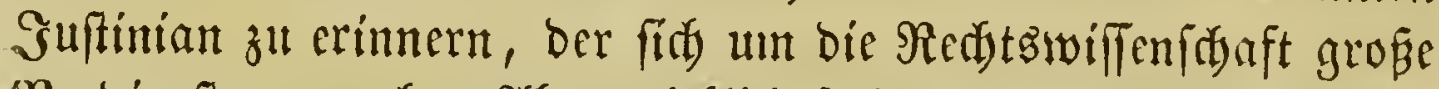
Berbienfte erwarb. A(ber wilflid) felbftänoige (S)eiftesprobutte Haben unz die Sfrrömer nidjt Ginterlaffen. Glyr bödjftez Streben ging barauf linaus, bie $\mathfrak{B s e r f e}$ bes arterthums zut fammeln, zu excerpiren ober nadi ifrer 2 Beife zu erflëren.

3u ben Raifern, weldye fids für bie \$siffenfidaften interes= firten, geförte aud) (5ouftantin VII. (unts $\mathfrak{F a h r} 912$ ), ber

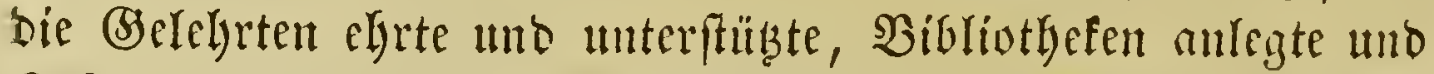

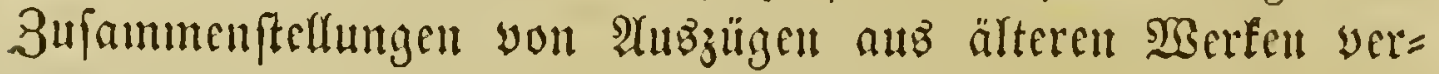
allftaltete.

1) Isid. Misp. orig., ed. Vulcan. Basil. 1577. Fol. 
Wabrid) cinlid) aus feiner 3eit ftamme cine berartige Samm= lung, bie cinem gewiffen $\Re$ ou genannt, zugeid)rieben woirb. Sie ift meiftenz aus ben 2 serfen

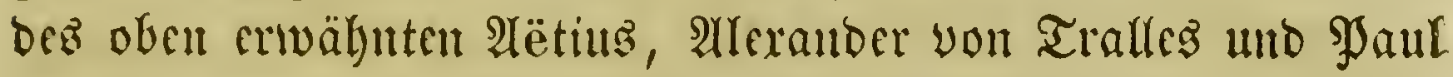
you Aegina, und jwar oft wörtlids ausigefdyrieben.

3 3il 3eit ocs Saifers Midjacl Ducas (1071 - 1078)

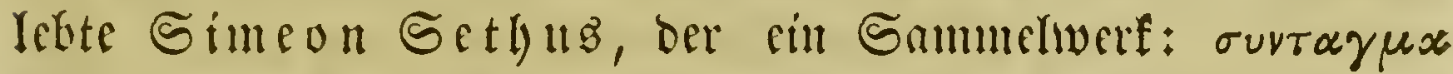

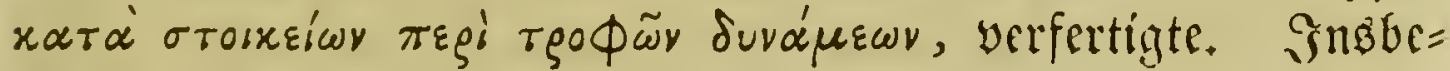
fondere foll er hierbei die Sdyriften bez Midja el MJ fellus, weldyer un biefelbe Zeit lebte, bemmbat haben, weshalb auty

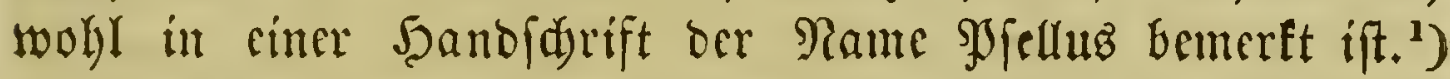

Gohamnez, yon bem 2unte, bas er an bem 5yufe des Saiferş Âtnoronicus II. (in ber Ießzten Shälfte bez 13, Jal)r= hunbertb) beteidete, Actuarius genannt, handelte in feinent Sistf: : De actionibus et affectibus spiritus animalis ejusque victu ac nutritione, libri II ${ }^{2}$ ) aud yon ben $\mathfrak{R a l}=$ rungsinittelı.

গif im 13. Эabrlumbert. (Er fdyrieb aud) über bie 2 rancimittel und bemuste insbefondere die arabifduen Sariftiteller, mit

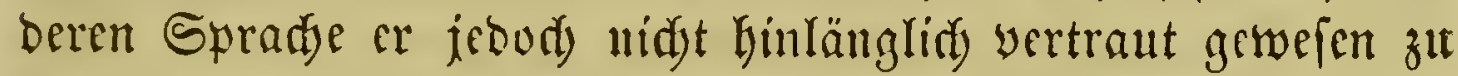

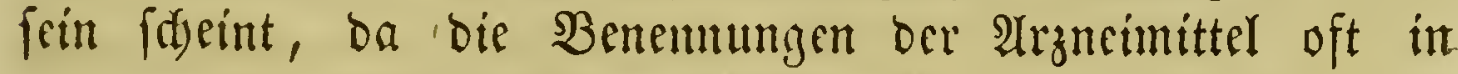
verberbter form ket ím vorfommen. ${ }^{3}$ )

1) Sime onis Sethi Syntagma per literar. ordin., de cibariorum facultate, gr. et lat. Sil. Greg. Gyraldo interpr. Basil. 1538. 8. - Volumen de alimentorum facultatibus etc. a Martio Bogdano. Paris. 1658. 8. - Bergl. Sprenge l, llist. rei herb. lib. III. cap. I.

$\left.{ }^{2}\right)$ Joan. Actuarii de medicamentorum compositione libri II, ed. Dionys. Corronius. Paris. 1539. 8. S5rrauzgegeben

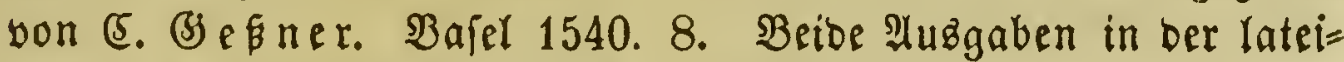

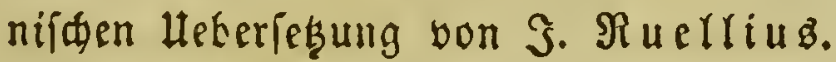

3) 2(uळ biefez Nic. Myrepsi Alexandr. Medicamentorum opus in sect. 48 digest. efc, a Leonh. Fuchsio e graeco in 


\section{Dic $\mathfrak{A r a b e r}$.}

Radbem bas abendländifdye Raiferreid) yon ben einbrin= genocn Barbaren yernidtet worben, biefe Barbaren aber felbfí allmälig an eine frieblidse Rebensiveife fid gewölynt hatten uno

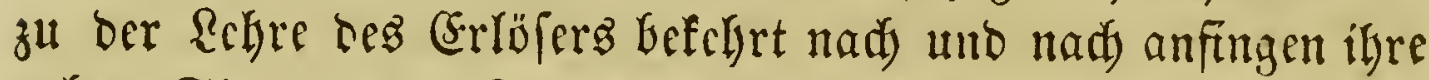
roben Sitten zu verfeinern, unb währeno $e \mathfrak{B}$ aljo fdjien, als follte bab Clyriftentlum auf oer ganjen brfauten Eroe ben Sieg Dawon tragen: Da erbob fid plüglid, in bem fernen Alafien cin Mann voll glühender $\mathfrak{B}$ egeifterung uno thatfräf= tigem Muthe und verfundete cine neue \&efre, die von nun

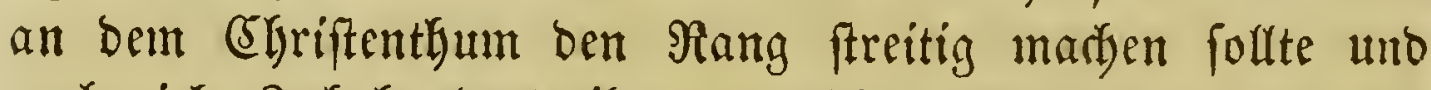
aud) viele Gabrhumberte ihm gegenüber geftanoen hat als ber fiblimmfte und trobigfte Feino. Nafd vermelyrte fity bie Zabl Der $\mathfrak{B}$ ffeuner $\mathfrak{M a h o m e d s , ~ u m b ~ u n t e r ~ f e i n e n ~ \Re a d f o l g e r n ~ f t r o ̈ m = ~}$ ten fie berwor über Syricn, Saläftina, Mefopotanien, Socr= fien, Armenien, Alegypten uno Rorbafrifa, ja fie orangen

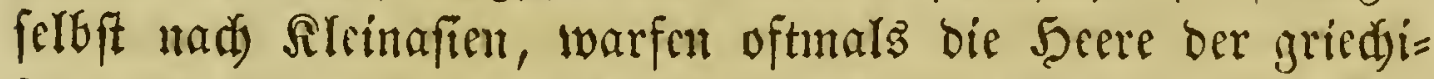
fden Raifer vor fid nicoer, eroberten endlidy ben gröften Theil Spaniens, uno viclleicht hätte bie Rebre bez Sprowheten

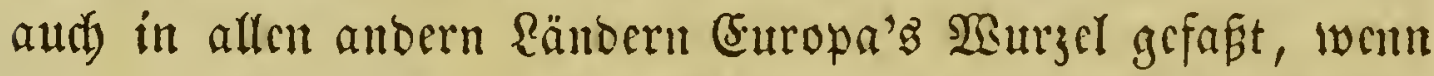
nid)t Der tapfere Rarl Martel bie nad) Franfrcid) yororingen= ben Mauren bei Şoitierz büllig aufz Şaupt gefd)lagen bätte.

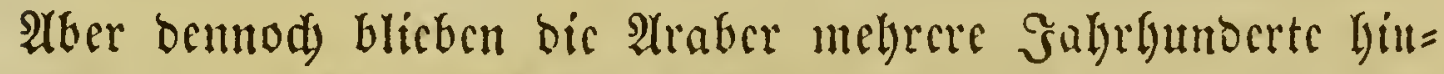

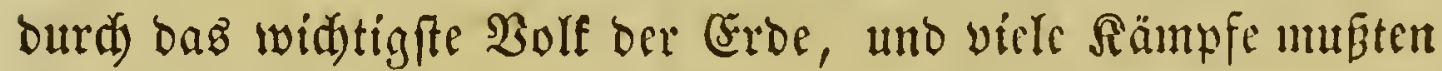
bie driftliden Sationen beftefen, un fid) wor ifrem wiloen

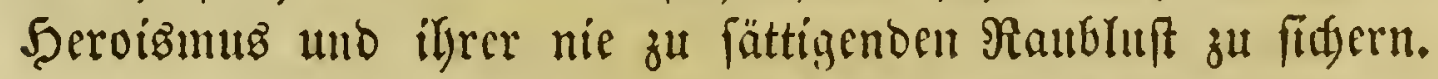

Dic Araber, einer ed len Menfidenraçe angebüreno, waren an uno für fíd nid)t rol und biloungsunfälig. Sd)on als

latinum recens conversum lucu lentissimeque annotationibus illustratum. Basil. 1549. Fol. - Sceraugigegeben bon 3. Agrilora $\mathfrak{A}$ m monius. Sngolfabt 1541. 4. - $\mathfrak{B e r}_{\mathrm{r}=}$ gleide Sprengel, Histor. rei herb. lib. III, cap. I. 
fie nody auf ben Stewen iffes Saterlaubez fid unbefannt

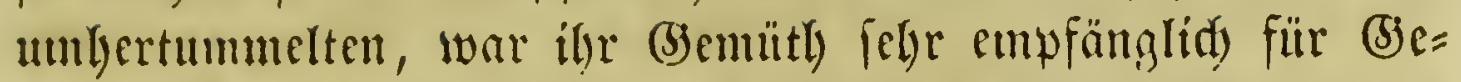
fang und Didytfunft, uno wohl miggen fie fdoun bamals man= d)erlei fienntuiffe erworben uno gexflegt haben. Freilidis als fie von ifren (5halifen aufgeforbert wurben, liberall hin mit Dem Sdywerte bie Eefhre Mahjomedz zu verbreiten, mußten fie längere Zeit hinsud die Beftebungen des Friedenz bei Seite

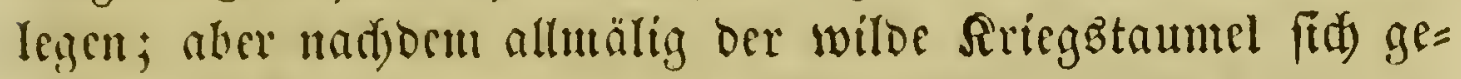
legt uno bie cinzeluen arabifden Staaten eine fefte Brundage gevonnen hattin, blïlten, befonders nadjoem ber Stamm ber Qlbbaifioen fid) jur Scerridjaft emporgefdroungen, gebildete

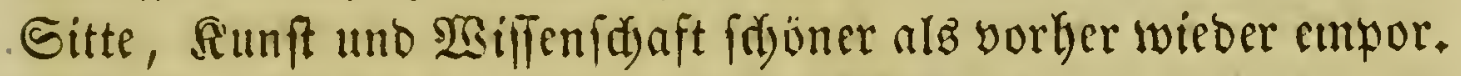
In viclen Stäbten wurden grofe sbibliotlefen angelegt, uno bie Sifulen zu Bagbad, Baflora, Alexanbrien, Evorboya uno anoeren Stäbten waren ferbft in d)riftliden Albendande weit= lyin berüh)ut.

Beffentmeneadytet ınus man fid Güten, bafi man bie bama= lige arabijde Sultur nidt überfdäbe. Sie erfdeint uns haupt= jädblid) nur beşbalb fo gläuzeno, weil bie dyriftiden Ränoer Damals in tiefe SBarbarei verfunfen waren. (Eigentlid) Neues

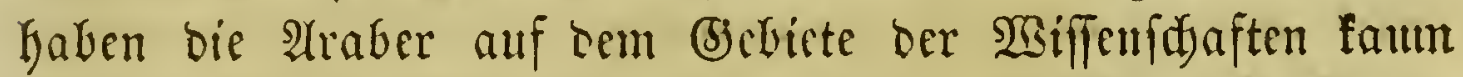
herworgebradyt. Dirjenigen Dizciplinen, weldye im flaffict)en

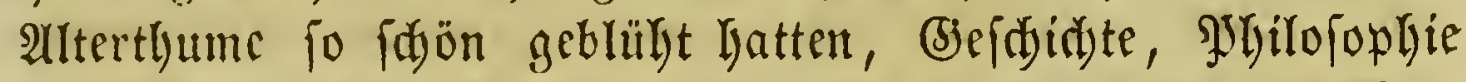
uno BBereofamfeit, founten bier unter bem burdjaus willtür=

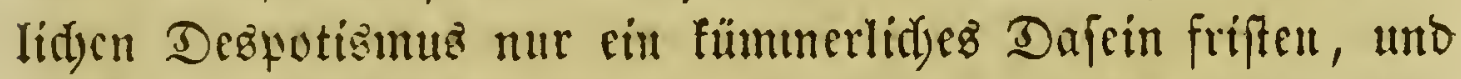
felbft ill ben Realoisciplinen, bie von ben Scerridern als nidjt

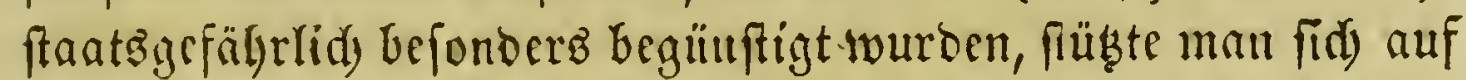
bie alten griedsifden Sdyrifteteller, infurweit man fie fannte; insbejontere war ez striftutelez, sen man ars umilertrefflidjes Borbilo Eetradytete.

SWir wollen nun biejenigen arabijden Sdyriftiteller furz erwäluten, sveldye für bie (sefdyidste Der Botanif von einiger Wintigfeit find. 2(ud) bie arabifden Sflangenfenuer betrad)=

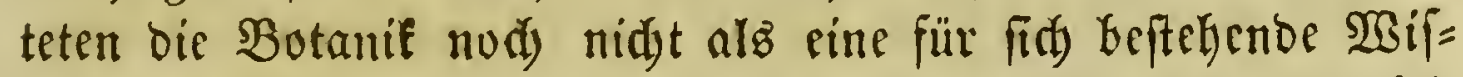
fenfdjaft, fondern Fetrieben fie uur wegen ibrer Woidjtigfeit 


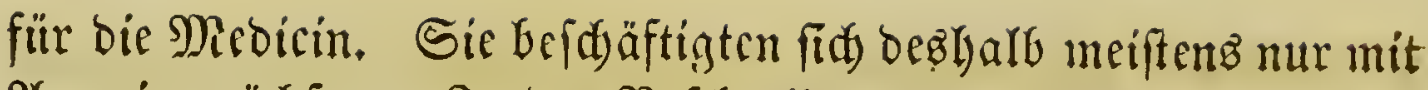

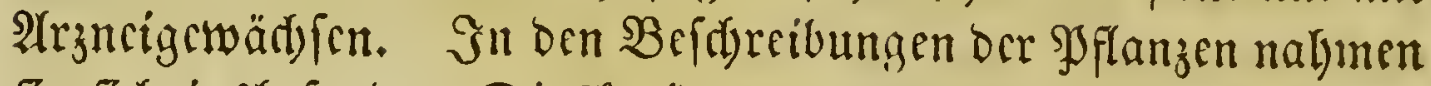
fie fid inserfondere Diosforibes zun Mufter, oeflen Gdyriften fie übrigcns oft nidgt redyt verftanden zu haben fdecinen.

Den erften 2uftop zur Betreibung oer SBiffenfdyaften unter ben 2 rrabern gab die Groberung yon Aegypten. Denn Alle=

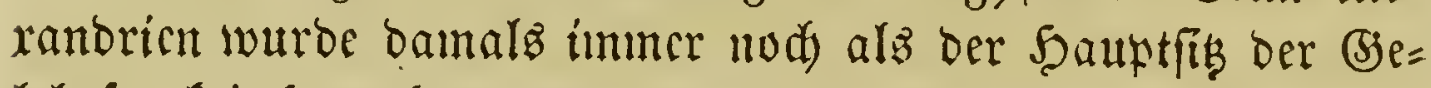
Iebrjanfeit betradjtet, wuo von bort verbreiteten fid insbejon= Dere medicinifde Renntmiffe in ben Drient. Die Reftorianer,

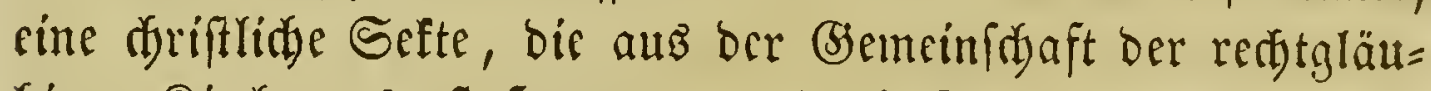
bigen Sirtbe ausgeftofen war, uno bie Juben waren anfangz

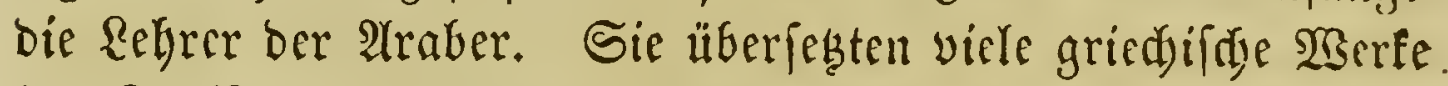

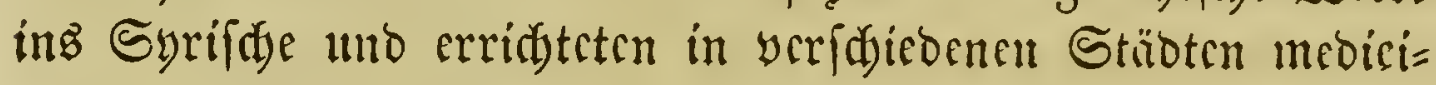

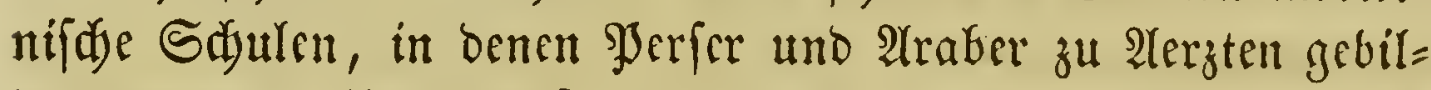
bet wurben. Unter biefen Reftorianern jeidinete fid feit bem 8. Gahrhmoert eine Familie, "Snedte (Shrifti" genannt,

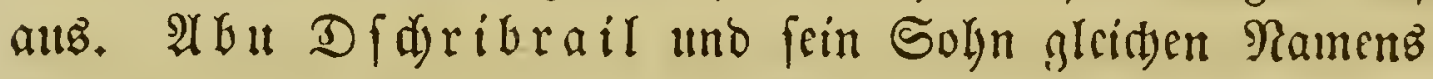
Iebten zur 3cit bes (Shalifen 5̧arun 2(rrajdjio uno erwarben

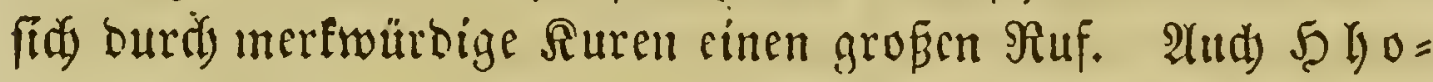

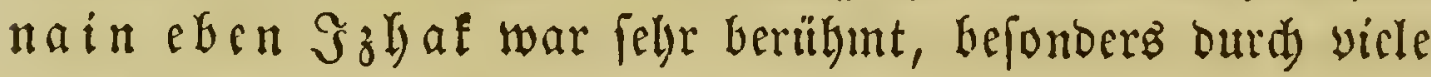
Ueferfegungen aus bem (striedsifdsen. -

Für die gJharmacie haben die 2 traber aum meiften gethan.

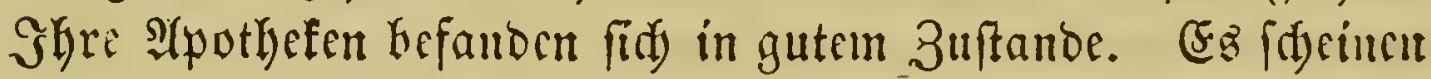
fdyon yon ber Sbrigfeit Borfdriften zur Bercitung oer 2 liğnei= mittel erlaffen worben z"l fein; wenigftens ftanoen bie $\mathfrak{2} p 0=$ thefer unter ftrenger Aluffidyt ber vorgefesten 2 eljüroen. Biele Arzneinittel haben bie 2 laber zucrft bersitet, und bager foumnt ez aud), bafi nod) jest fo vifle arabijac Benennungen in un=

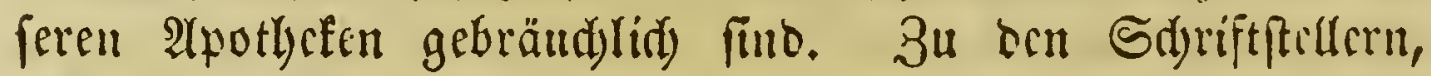
Iweldje über Die materia medica gefdricben haben, gebört

\section{$\mathfrak{A} \mathfrak{b} \mathfrak{c}$ (j) $u \in f i t$,}

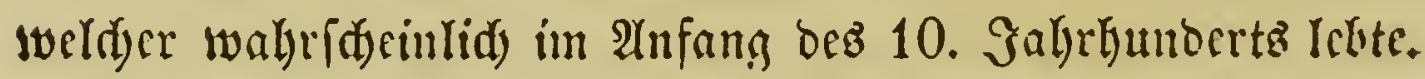
Bon feinen Rebengeverbältniffan iff nidjts Räheres befaumt. Er 
bat ein $\mathfrak{B e r f}$ von ben Rräften und Wirfungen ber $\mathfrak{A}$ rzneis mittel geidrieben. ${ }^{2}$ ) -

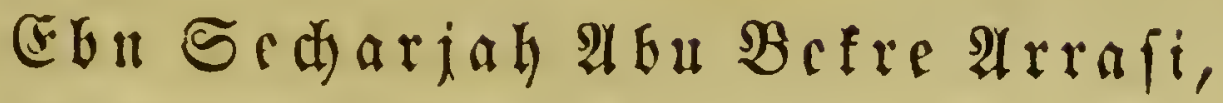

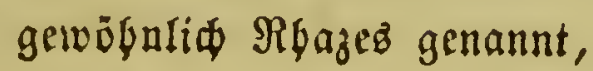

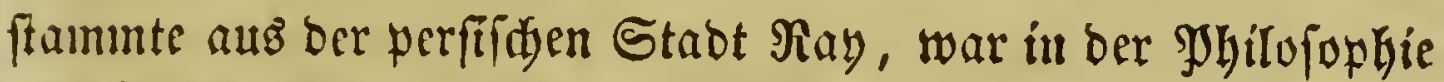

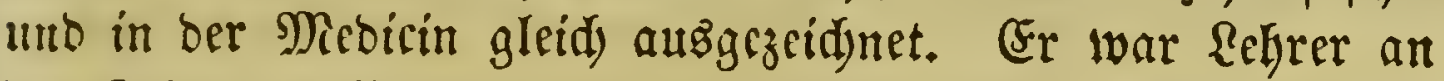
ber Sdyule zu $\mathfrak{B a g b a b}$ uno erwarb fid) einen aużgezeidyneten Ruf. Er ftarb in Gafir 923. Sein 5auptwerf Hhawi

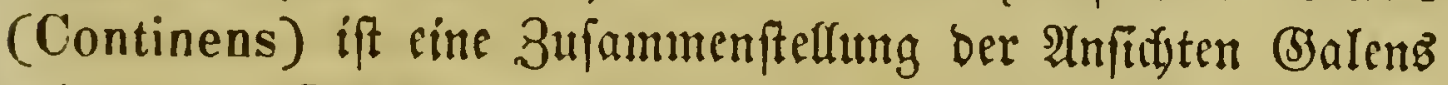

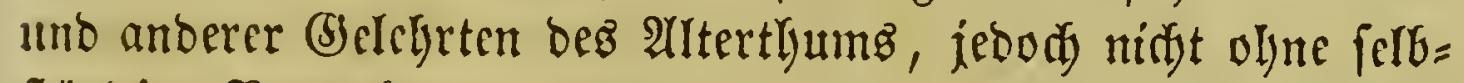

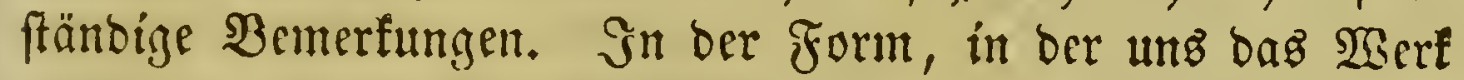
yorliegt, if zwar feine aledtheit beftritten; weun man jebods

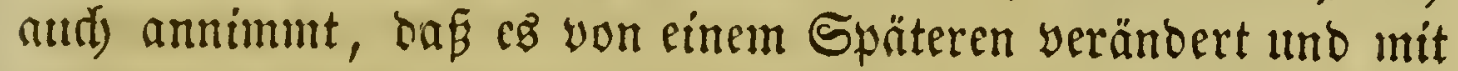
3 ufägen verfefien worben fei, fo ift bod ber eigentliche Sern

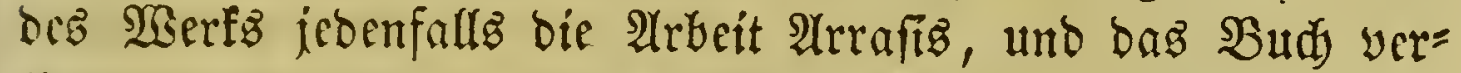
liert baburdy nidjte an feiner Widjtigfeit für bie (Sefdidjte ber arabifdyen Belehriamfeit.

Sn bem 21., 22., 23. uno 24. Sudje biefes 2 erfs witb yon ben 2 ranneifräften unt ber. Diätetif gerjanbelt, uno es find

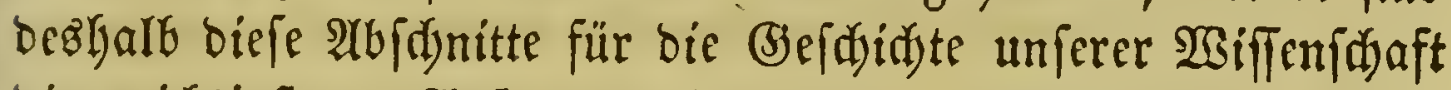
dic widtigften. 2Auberbem hat 2 rrafi nod mehrere andere

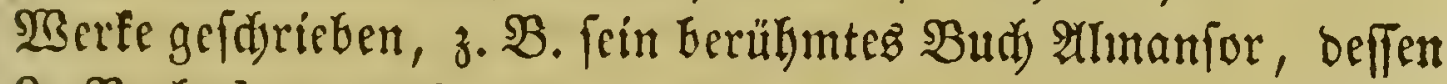
9. $\mathfrak{B}$ udi) de curatione morborum lange 3 eit bent (Segenftand von Borlefungen auf Univerfitäten bilbete; biefelben find jeborh

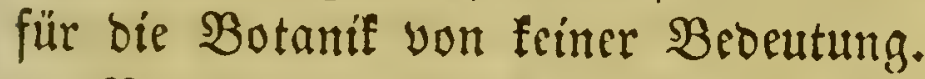

Bon $2 \mathfrak{b u}$ 'l Fabli Sdierzita, ber im 10. Jahr= bunberte Icbte, foll cin nody ungeoruftes $\mathfrak{B}$ erf, de re herbaria et medica, vorkanben fein.

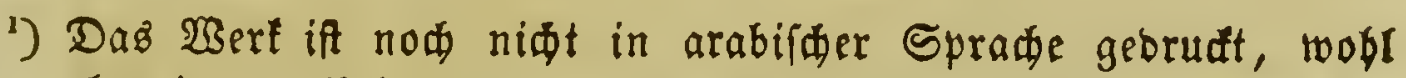
aber in ber $\mathfrak{H}_{e}$ eerfétung: De virtutibus medicinarum et ciborum. Argentor. 1531. Fol.

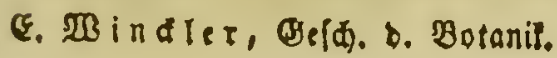




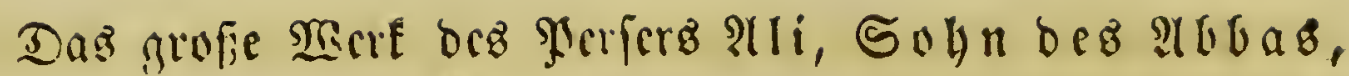
gefforten 994, tas fintiglidse senamt, Gantelt you allen

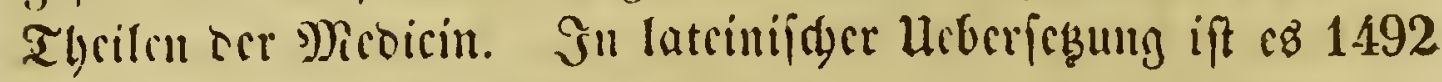
3u Bencrig lycraniggfomuten.

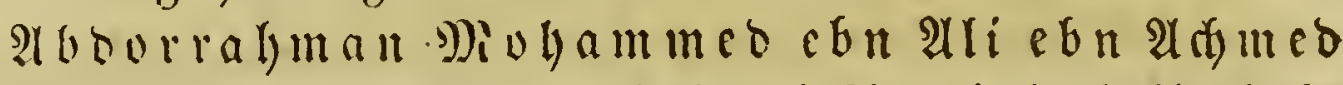

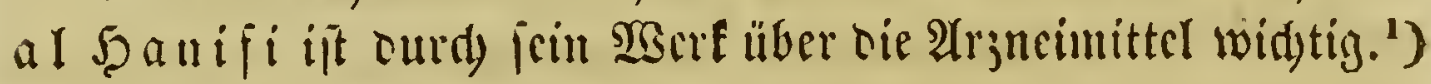

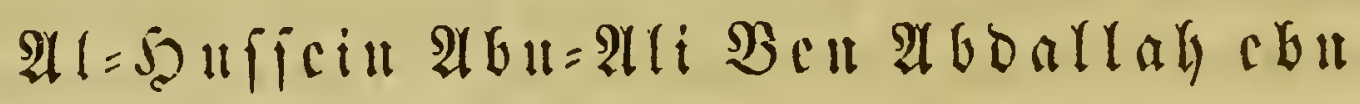 Silla,}

gemöbntid Avicenna genannt, war umb Эałr 980 ju Bofbara geboren.

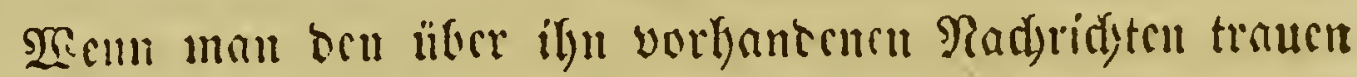

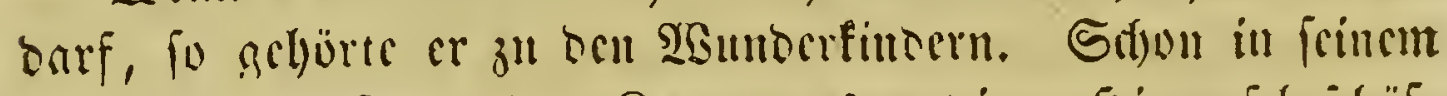

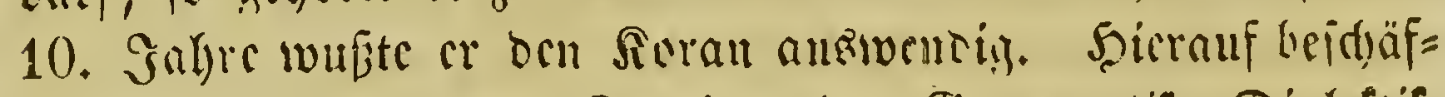
ti!nte $\mathrm{cr}$ fid) mit ocm Stubimm ocr (Strammatif, Dialctif, Matbematif uno 2iftronomic, verlicis aler balo ben Unterridyt

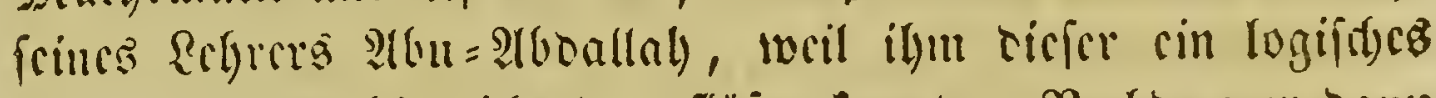

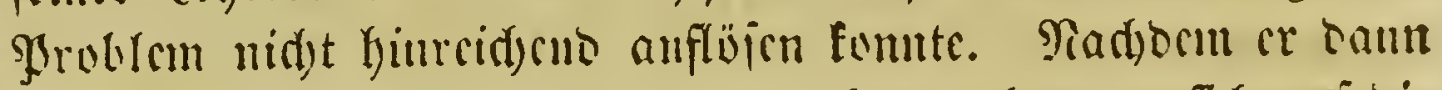

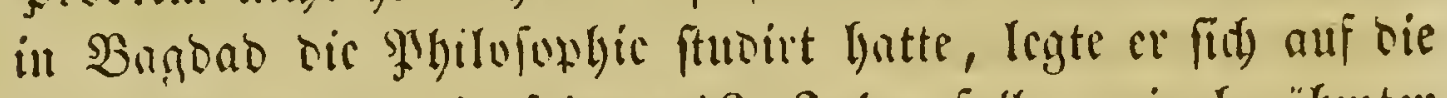

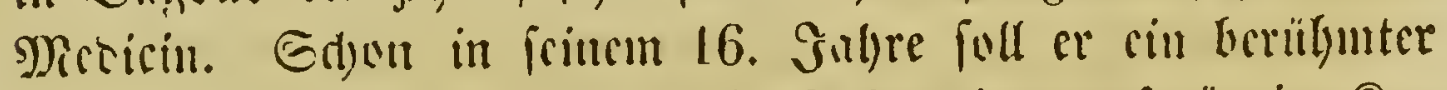

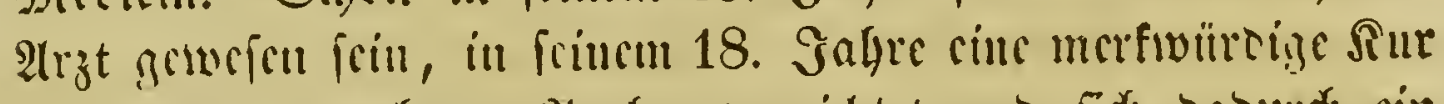

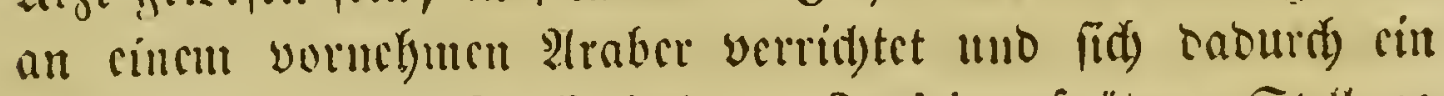

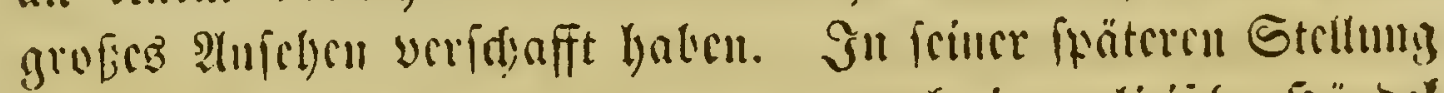

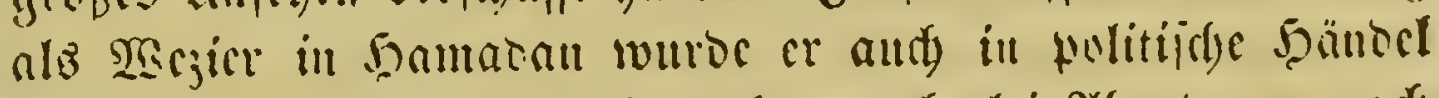

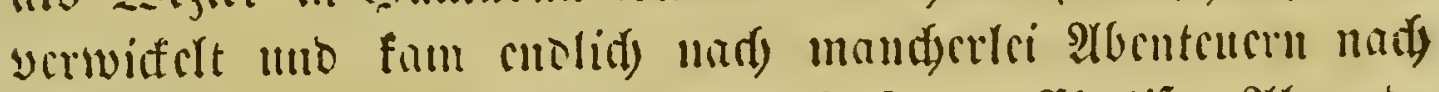

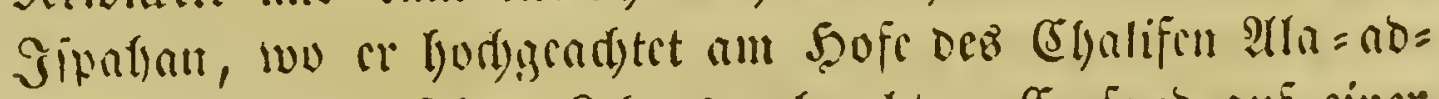

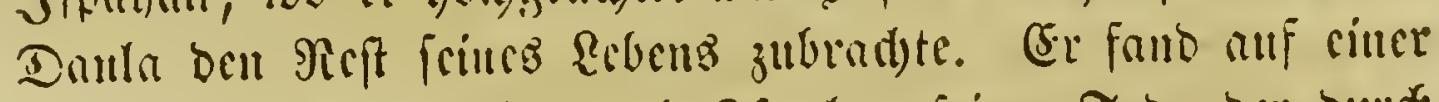

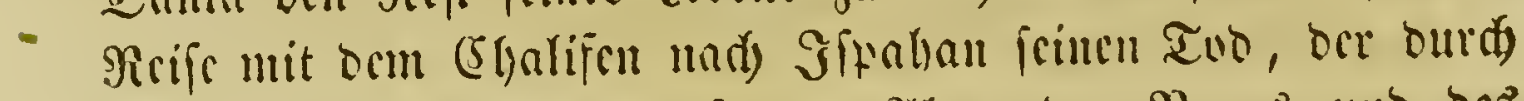

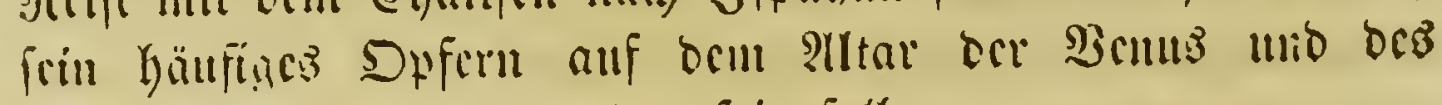
Bacd)us befdylcunigt worben frin foll.

2) De proprietatibus ac virtutibus medicis animalium, plantarum ac gemmarum tractatus triplex nunc primum ex arabico idiomate latinitate donatus ab Abrah. Ecchellensi, Maronita. Paris 164.8. 
Aviccma bat mebrere Gabrhunderte bindurty in bem Reidje

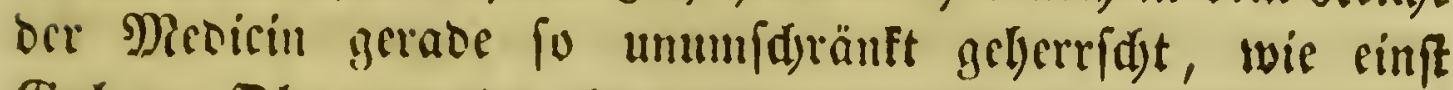

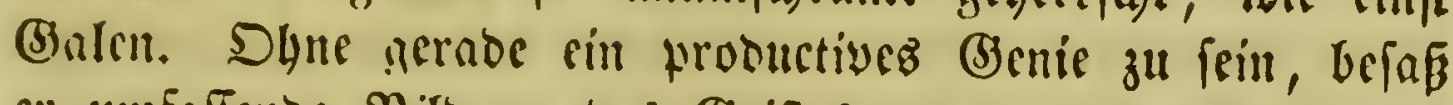

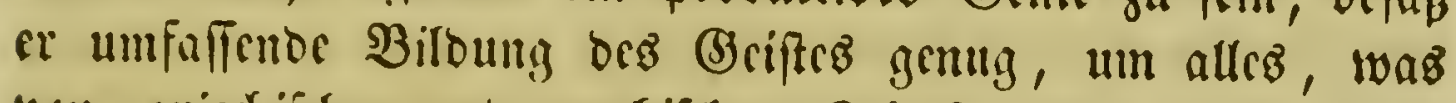

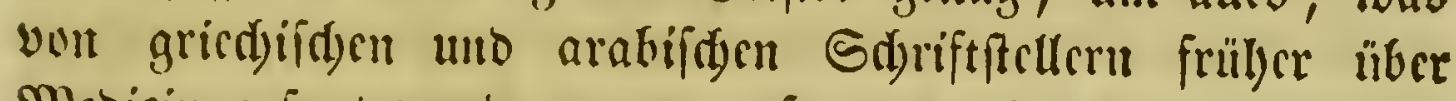
Medicin gejagt worbcn war, zufammenzufteflen und fuftema=

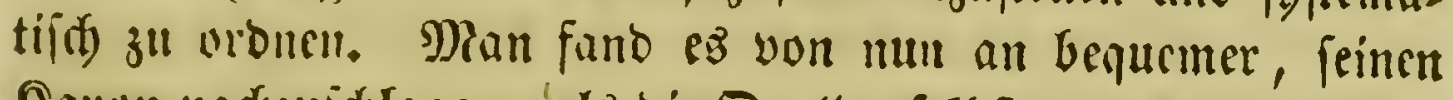
Ranun narbiuidylagen, 'alis bie Duellen felbft, aus benen bicfer

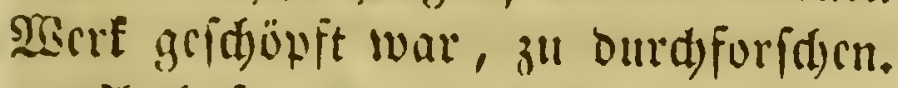

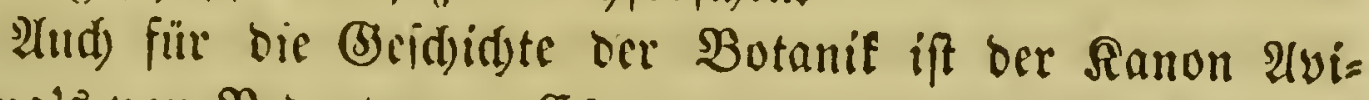

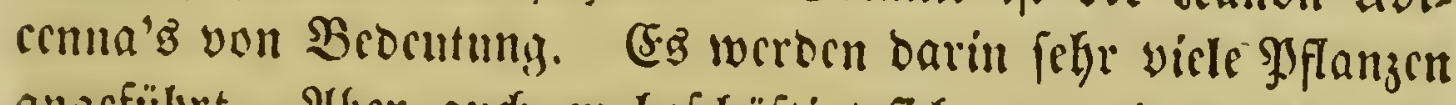

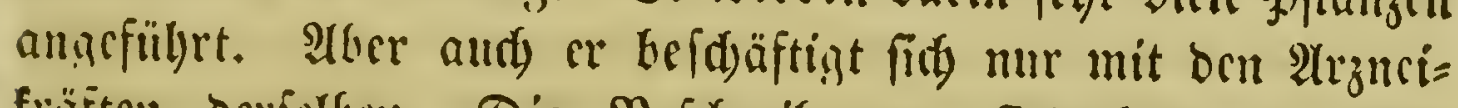

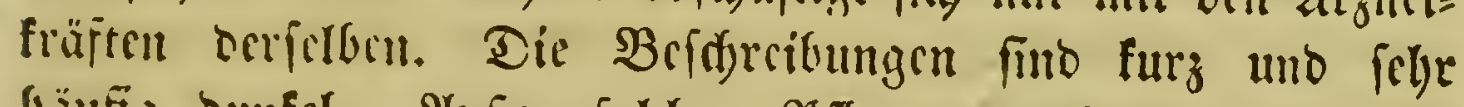

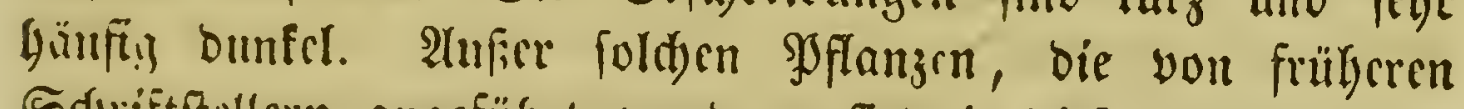

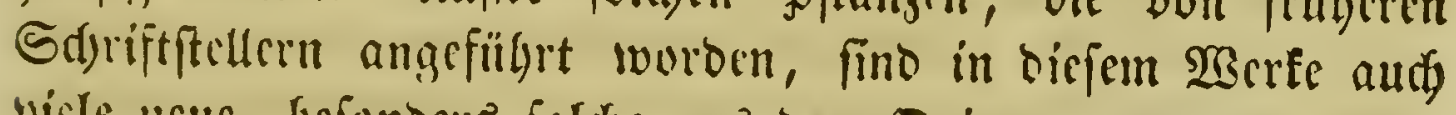
vicle ncue, befoncers foldbe aus ocm Driente, erwälynt. Ber=

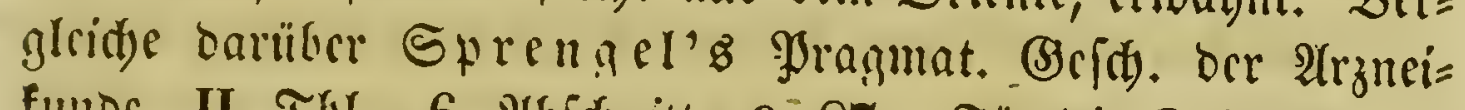

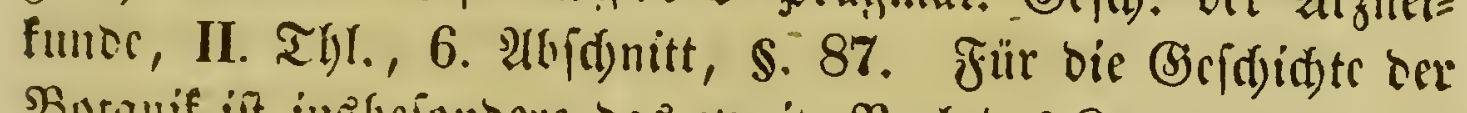

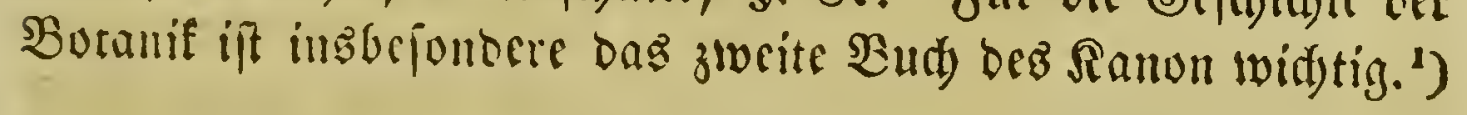

\section{Scrapiou dex Gülngere, \\ Icbte wabríceintid ums Sabr 1000;}

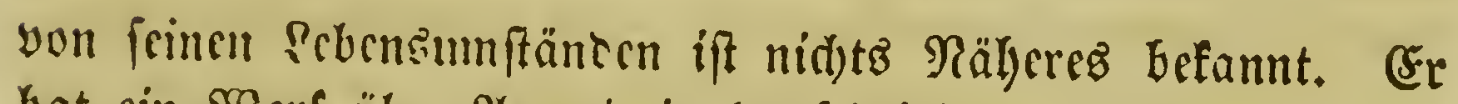

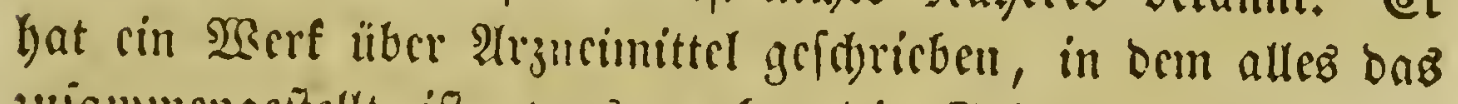
julammengefiellt iff, was worber bie Biridden unb Araber

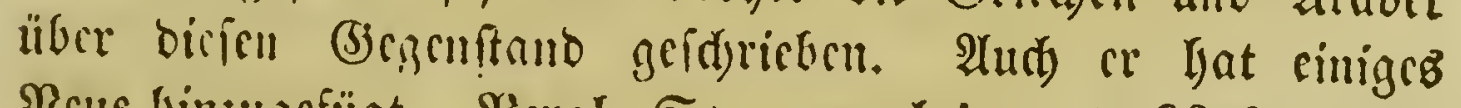
Rcue binjugefügt. Sicrgl. Sprengel I. c. \&. 90. ${ }^{2}$ )

1) In arakifipr Spradie if ber Canon medicinae 1593 Fol. zu

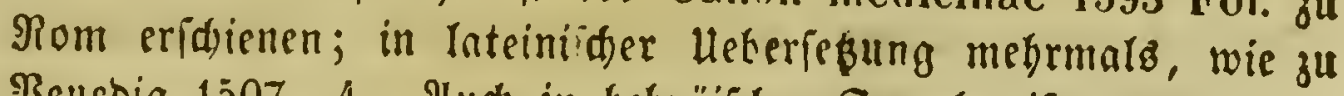
Bencbig 1507. 4. Alud in behräidaer Spradte if berfelbe vor= banten; erifdienen zu Meapel 1492.

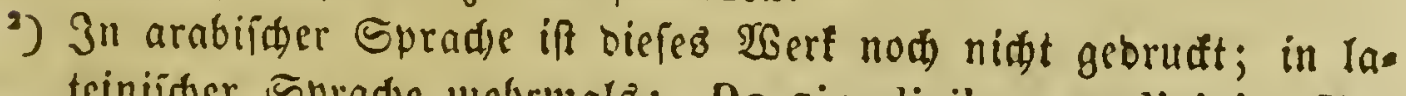
trinifacr Sprad)e mebrmalb: De simplicibus medicinis. Mediulani 1473. Fol. Lugd, 1525. Venet. 1550. 
(5twa um rieferbe 3eit lebte Ma jawaih ben f̧amed, gewölnlid Difiue der Süngere genant. Er foll ein

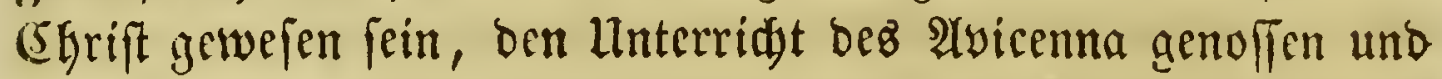
fid) Dann an bem $\mathfrak{b}$ ofe bes (Shalifen zu Rabira aufgehalten baben. 2ludy er bat über 2 rrzmeimittel gefdrieben, uno feine Sidriften fanden lange Zeit in gropem Anieben. $\left.{ }^{1}\right)$

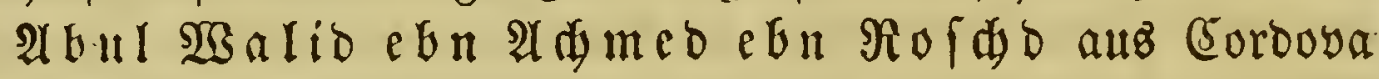
in Spanien, gewöhnlid 2 verrloo ëes genannt (geft. 1206), cin gruß̧er Berehrer dez Ariftotelez, fünnte wegen feinez Mertes über Die Medicin einigermá̧en aud hierber gezojen Iverten. ${ }^{2}$ )

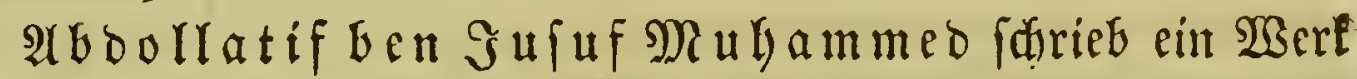
iiber die Denfwürdigfeiten Aegyptenz, in Dem verffriebene Şflanzen befdrieben fmo. ${ }^{3}$ )

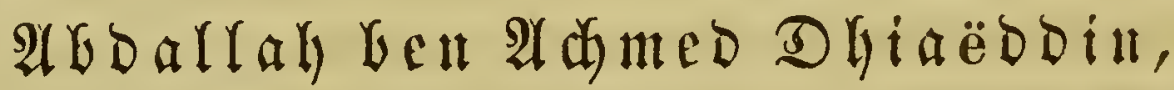

gewögntid e $\mathfrak{b} \mathfrak{n}$ beit $\mathfrak{a r}$ genannt,

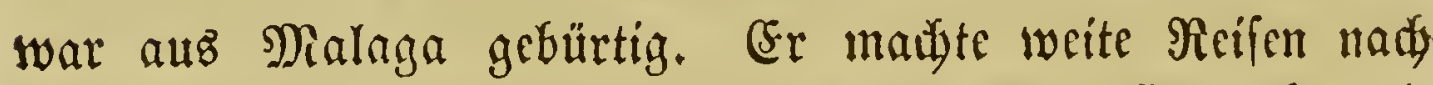
(Sried)enland und in ben Drient und fdyrieb ein Șert über bie

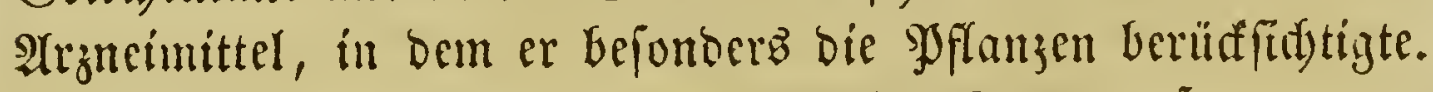

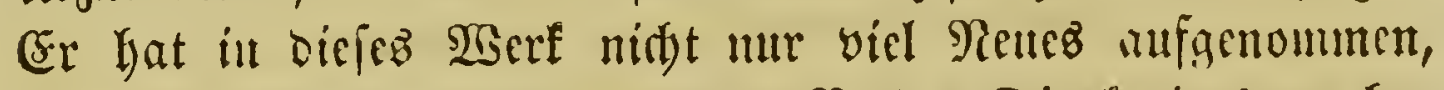

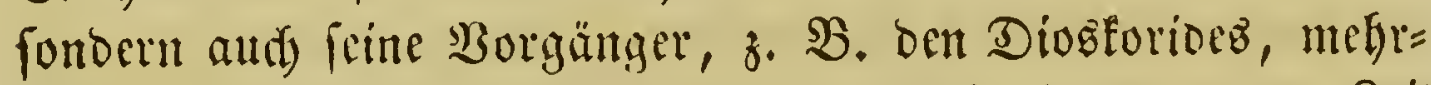

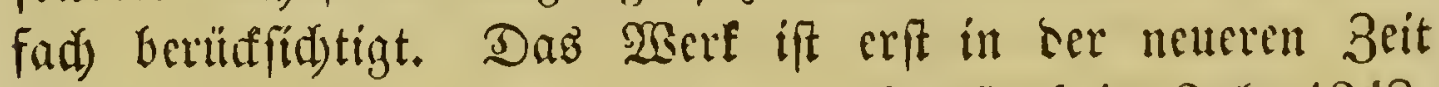

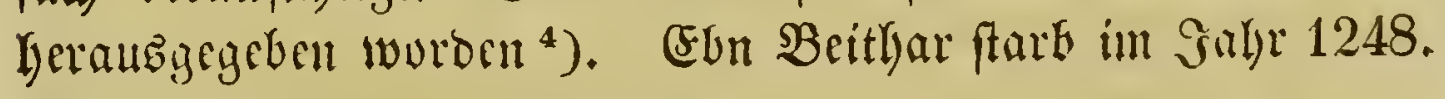

1) Sn Vateinifder Heberifteung: De re medica libri III, Jacobo Sylvio interprete. Paris 1542, 1544. Fol. Stalienifide Hebcrfeçung öl Bencbig 1475, 1487 Fol. 26.

$\left.{ }^{2}\right)$ Liber de medicina, qui dicitur Colliget. Venet. 1514; unb ebendafelfft 1549.

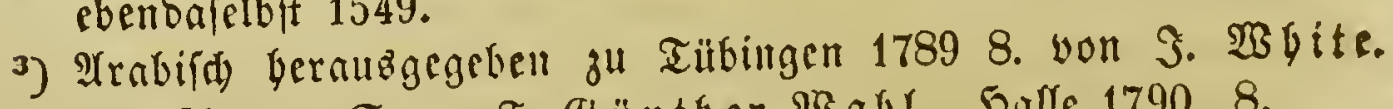

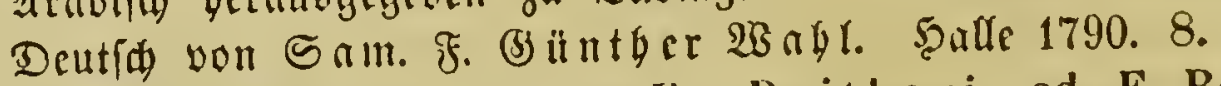

*) Elenchus materiae medicae Ibn Beithari, ed. F. Reinh. Dietz. Lips. 1834. 8. 


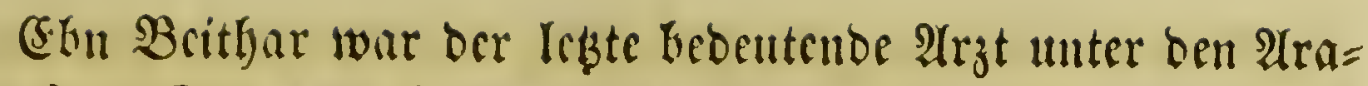

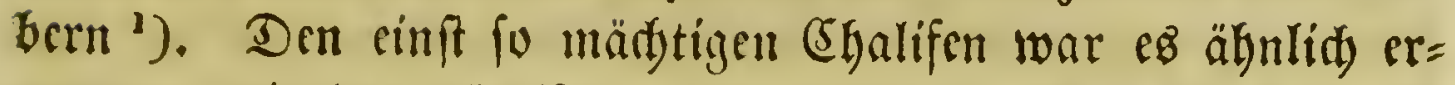
gangen, wie ben rümiften Smperaturen. Die Atraber, bie frilher ber Sdgrefen won ganj Suropa geweien waren, ver= fanfen nady uno nadi in lleppigfeit uno Irägleit, ja fie ver= loren felbft ibre fonft to gerülunte Tapferfeit, fo bafi fid bie Serrider genöthigt faben, zu ihren eigenen Sduke fid mit fremben Sülonerfidaaren ju umieben. Diefe Söldner abel

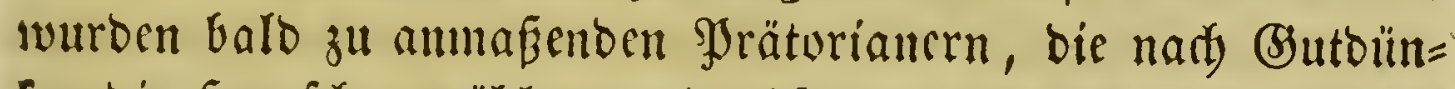
fen bie Serrfater wählten unb abjeb̧ten. Dazu famen bie öf= teren Ângriffe wilber Barbarenborden, uno wenn aud) bie

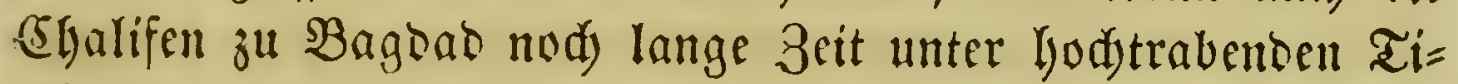

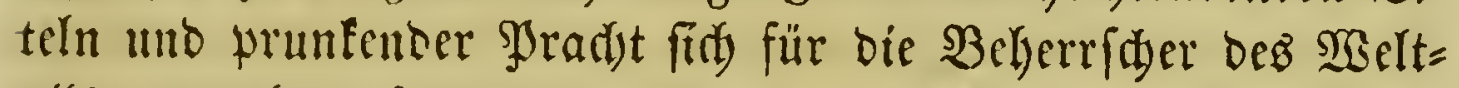
alls autigaben, fo waren fie bed) weiter nithts, als bie elen= ben Sdyatten ibrer gewaltigen Borfahren. (Endidy im Gabr 1258 fübrte Shulagu, Der (Enfel Didenges=-(5)ans, feime mon= golifden Sorben gegen Bagbad uno sernidtete mit ber Serr=

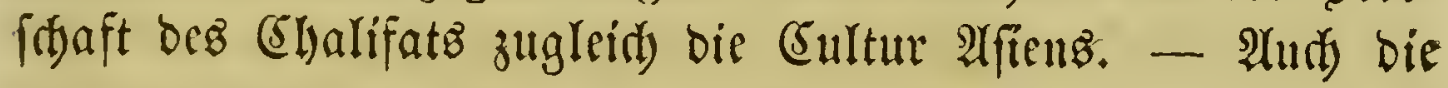

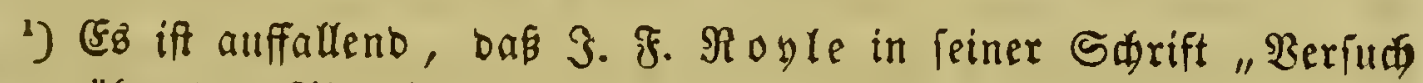
ilber baz 2lltertbum ber indifaen Mebicin ac." fagt, bás in ber

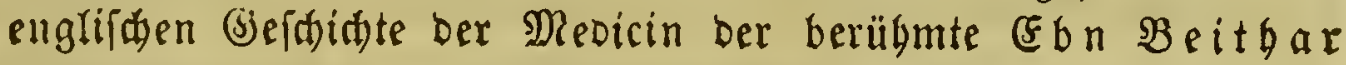
gar niđt erwäbnt fei, wälurend bod fajon 5amberger in fei=

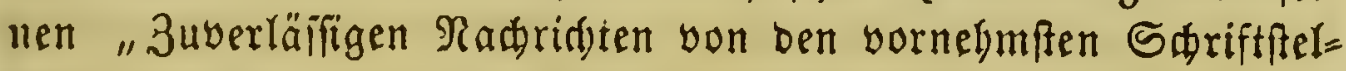
lern 2c. 1764" von ifm rebet und angibt, ez fei Beithar'z Tractatus de limoniis malis 1583 z

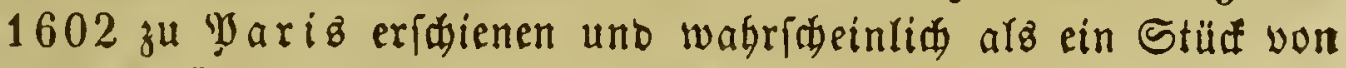
beffen gröferem $\mathfrak{B}$ erfe zu betrad)ten. 2(uळ SprengeI in fei= ner Histor. rei lierbar. 1807 rebet von biefem Sdyriftfeller uno bebauert nur, bafi er ign nidet babe benugen fönnen. Sn Sprengel'z Befđidte der Arzmeitunbe ift er ebenfallz rühm: lidft ermägnt. Die oben errwäbnte 2rbjanblung von Royle, ins Deutfide überiegt von 3. פsalla d, mit ciner Eimteitung uno

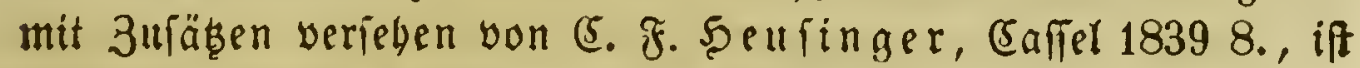
übrigenz für bie Beididate ber arabifden Raturfunde und bejon= bers in Beziegung auf ihren 3ufammentang mit ber inbifwen (Sultur von $\mathfrak{3 i d}$ idigteit. 
Mauren in Spanien erreidte balo tas Berbän!nní́. Daz

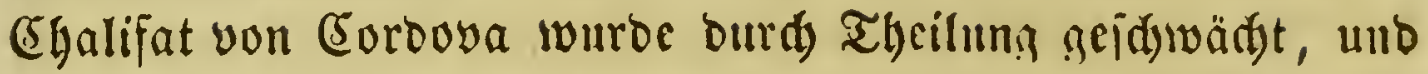
zu gleidyer 3eit erbuben fith brobent neben itgm mebrere darifs. lide Straten. Dic italieniidyen Freiftäote zọen nad) uno nad

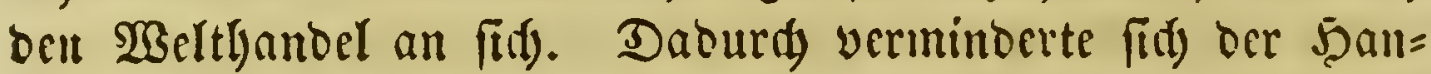
belzyerfegr ber fpaniiden $\mathfrak{A}$ raber, ifr $\mathfrak{B o h l p t a n d}$ und mit illu ifre Madjt fanf immermegr, während bie dyriftliten 2Bülferida aften Spanienz fiegreid) genen bie Un!̣läubigen vor=

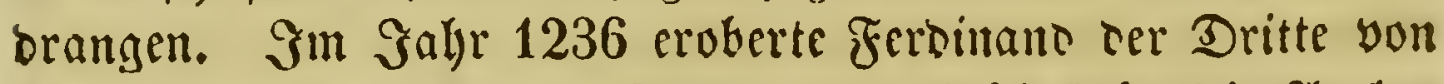

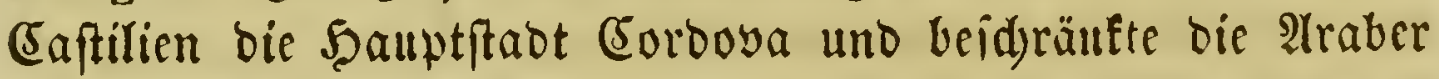

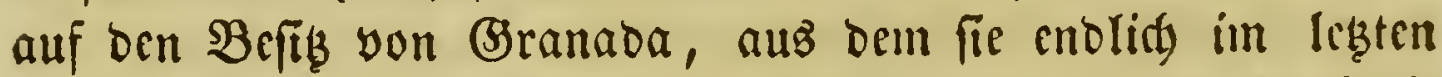
Biertel bes 15. Gahrhutocts von Froinato bem Ratholi= (d)en ebenfalls vertrieben wurben.

Benn aud) bie Araber auf bem (Gebicte ber Mechicin z"t

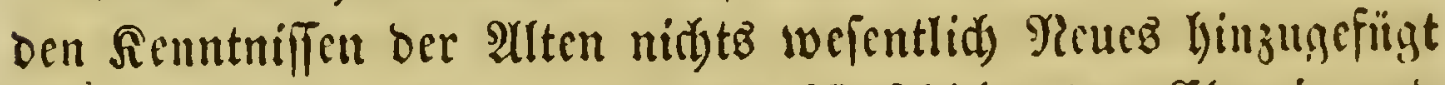

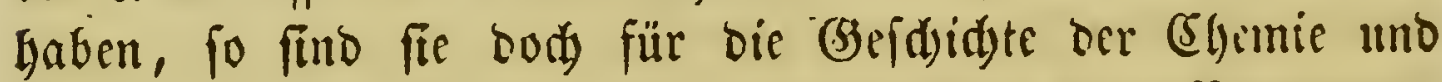
bie Refre von ben $\mathfrak{A r g n c i m i t t c l n}$ von nidbt geringer Bebcutuns. Die (potheferfumit baben fie cigentlid) ucu geid)affen, wic wir fdyon anzegeben baben. Alud mandye SPlanzen wurben ourd fie ill Europa zuerft befannt; Surd) ilsen weit verbreiteten Şandel famen fie namentlid) mit oen \&äubern bes Drients

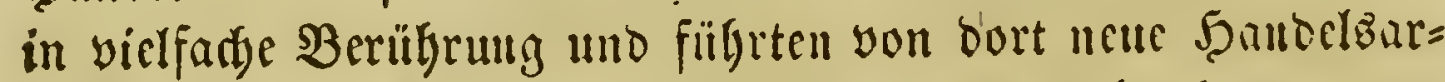
tifel nad) (5uropa. Bejonders incifide yrodufte lernte man burdy fie zuerit genauer fennell. Auth verbanfen wir ifnen die Einfü̆rung abfübrenter Planzen, wie oer Saffia, Senna

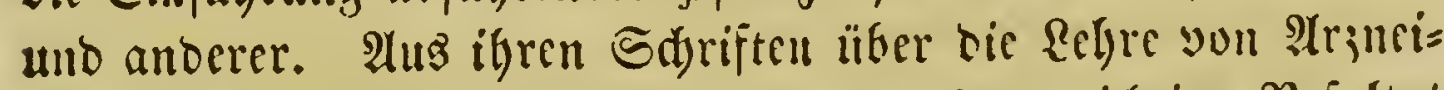
mitteln tönnte man viel(reid)t nodi mand)es widjtige Reilultat

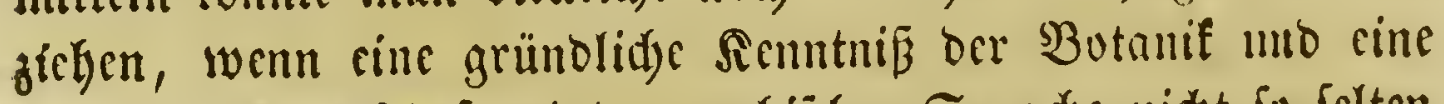
genaue Befanntidsaft mit oer arabijoen Spradje nidyt fo felten vercinigt anzutreffell wären ${ }^{1}$ ).

1) Bergl. über bie cingelnen Fflanzen: Sprengel'z Wragm. (S) ber $\mathfrak{A}$ rgueifunde II. BD. 6. 2bid. 9. 87, uno inzbeionbere beffen

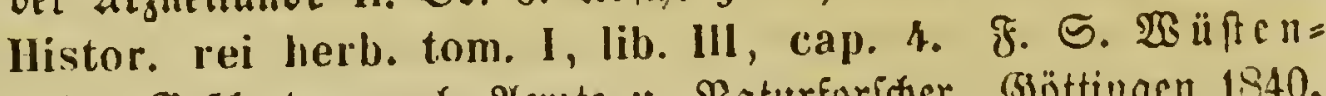
ferd, Befd. ber arab. Aerjte u. Raturforider. (3)öttingen 1840. 


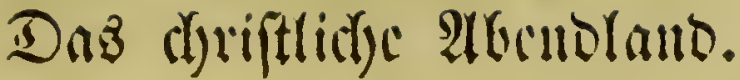

Die lang bauternben Ueberfluthumgen ber Bülferwanberung

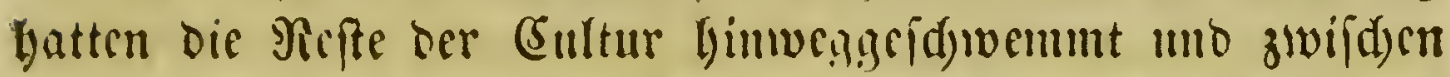
oen verizanyenen 3riten uno sen nen entfanoenen Bicneratio=

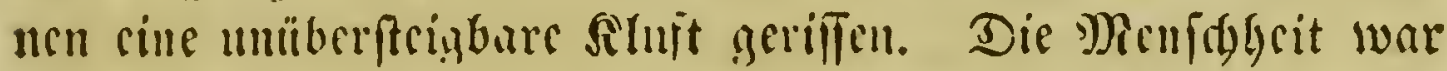

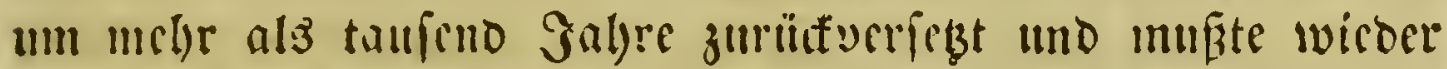

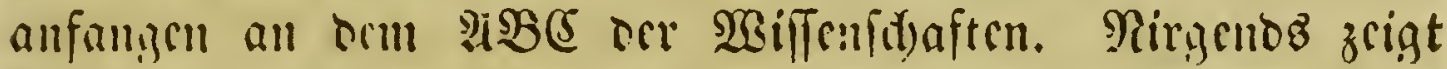

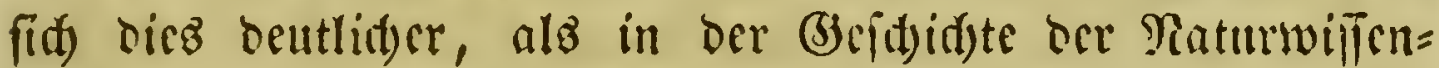

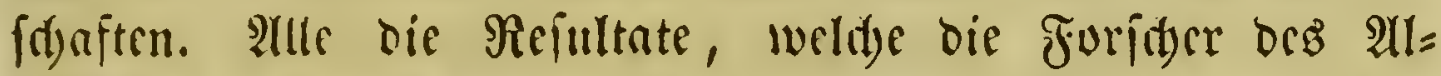
tertlyums milb fam ergeniyt batten, wiren toot uno fruddtloz für bie neucn, (b) f(d)led)ter, tie ez nifst verftanten, bie auf

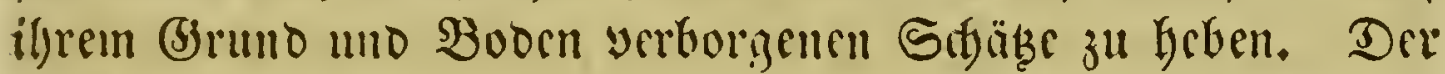

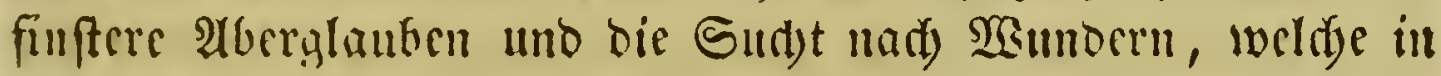
ewigem Strcite liegen mit bem lyclen Tagezlidyte beg $\mathfrak{B e r}=$ ftandes und, fobalo dieicr eridslafft, broheno igr baant erhe= ben, Ingen aud) bamalz mit blcicrnem (Sicudidyte auf ben (5)= müthern oer Menidsen. Mit Znuberformeln, Bannfrrïd)en,

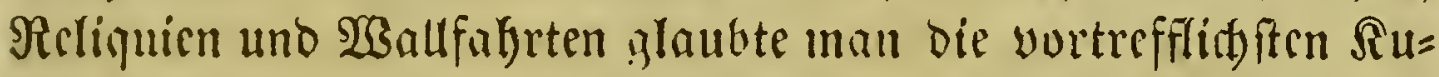
ren verridyten zu fünnen. Dicicnigen Männer aber, weldbe durd) natürline Mittel bis Rranflgsiten ju bsilen werfut)ten, verad)= tete man, uno cs bätte nid)t vid gefellt, fo wären fie gleids ben Barbieren für igrluz gehaltin worben; ober man fürd)tete fir, wril man ilbr Treiben nidyt verftand, man betrad)tete fie

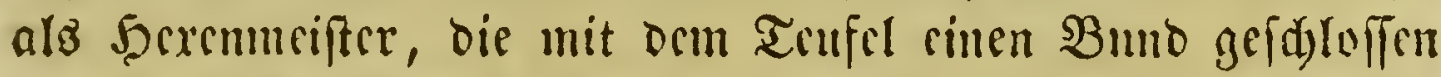
uno bie Siranflgeiten, Die fie vertrieben, aud seren fo gut mirber berbcizaubern fümnten. Sisie wenig man tie Scilfunce

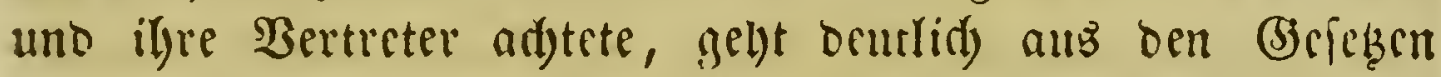

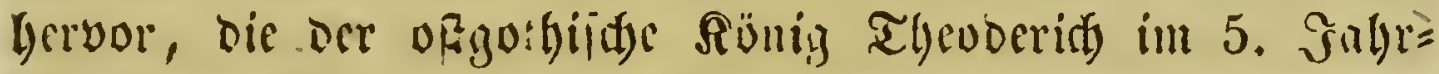

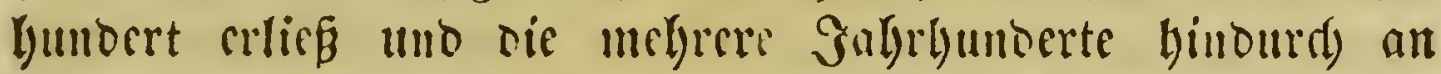

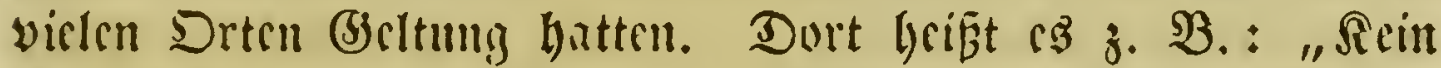

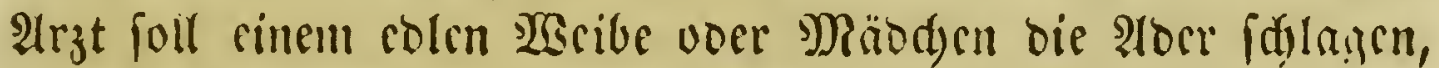

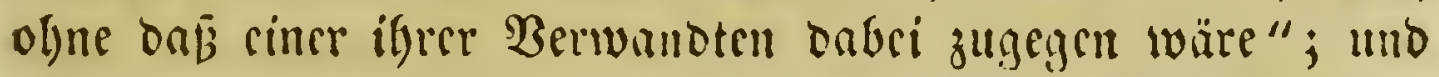
als (3) runo ricjez Gefézez woiro angegeben: quia difficilli- 
mum non est, ut sub tali occasione ludibrium interdum adhaerescat.

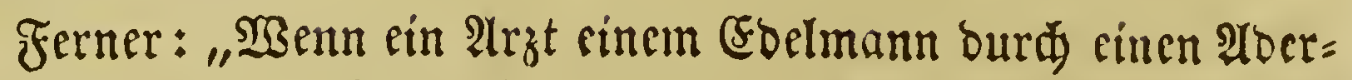
Ia Sadaben zungefügt, fo verfällt er in cine (5eloftrafe, unto wenn ber (Edelinann nad) oer Speration firtbt, fo wiro ber

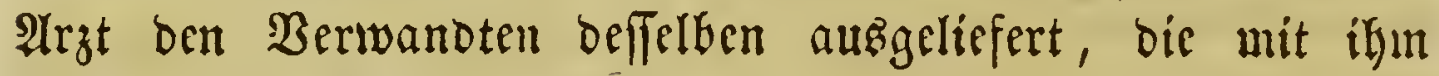
mad)en fünnen waz fie wollen."

Dap burd) folthe uno älynlidje Beroronungen ber Scilfunde nidit auffeholfen wurbe, verftegt fid von felbit.

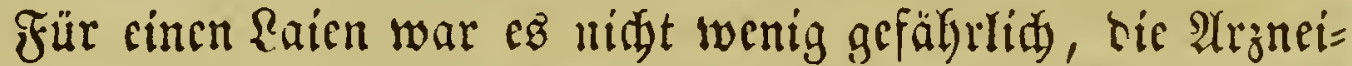
funde zu treiben. Den Beiftliden geftano man es eher zu,

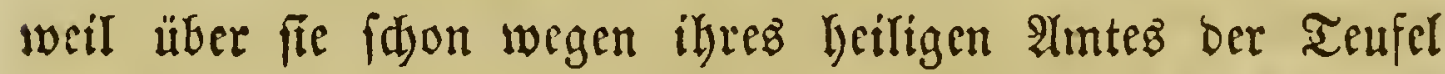
feime Gervalt hatte. Snzbefondere waren die Rlöfter bieje= nigen Stätteu, wobiu fid) bie geringen Ueberrefte ber Sisiffen= fdaften flüdteten. 3war wures auf metreren Concilien ber

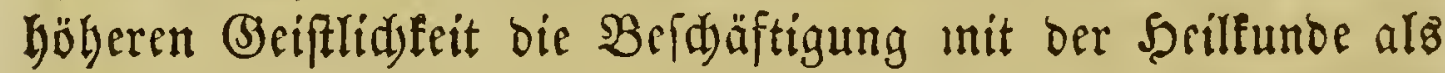

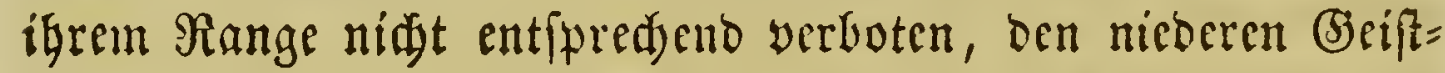
Iíden bagegen war $\mathfrak{c}$ ge geftattet, Die Syflege Der Rranfen als

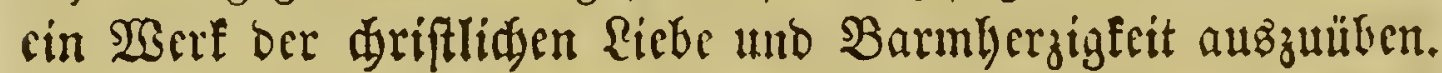
Man thut aber ben Rlöftern gewis Unred)t, wenn mant ifnen

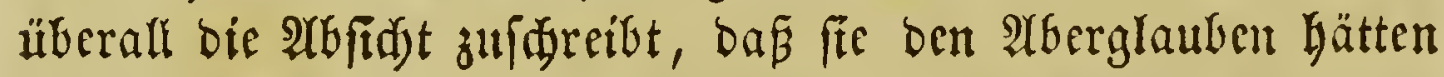
sermebren wollen. Standen bodh bie (Seiftidjen auf einer

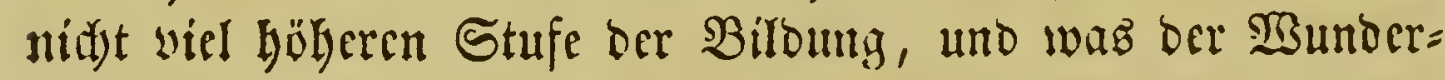
und Afberglauben bei been ungebildocten Bolfe verma , davon

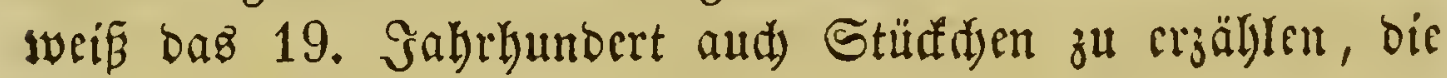
Denen bez Mittelalterz nidjt viel nadjitchen.

Rur wer ben Flammberg geljörig fdiwingen founte, ber war cin gemadyter Mann; alle Rünfte uno Rentniffe, bic fids

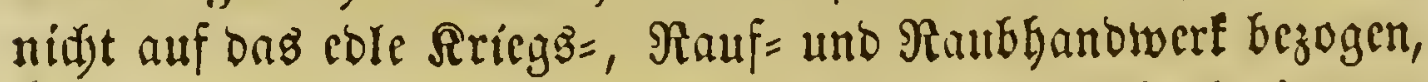

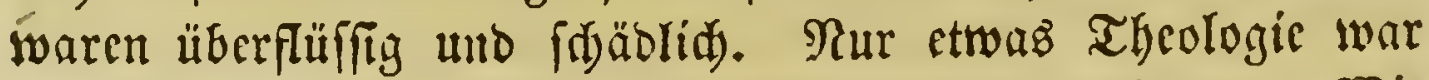
sommöthen, um die Eroe mit bem Şiumel zu verbinden. SBic

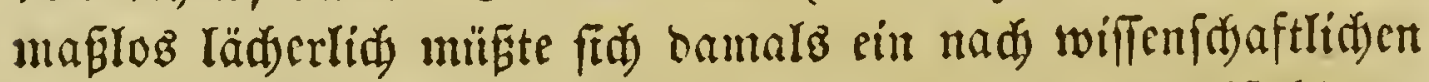
Regeln verfabrender $\mathfrak{B}$ otumifer gemnd)t haben! Browís bätten die aläubigen Seclen ein Paternofter fïr feinen verriaten Berftanto gehetet. 
Die materia medica unb fomit aud bie Sräfte ber $\mathfrak{g}$ flan= zen braudjte man bamalz nid)t zแ fennen, bem cin Spändyen

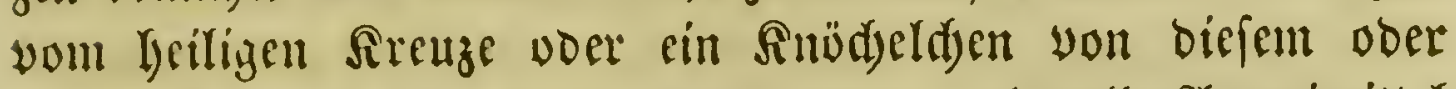

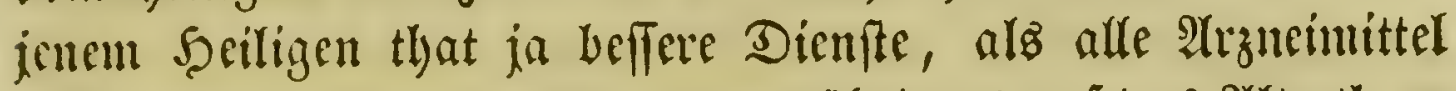
zufaumengenommen. $\mathfrak{x e n u}$ man übrigens auf bas Altertl)um

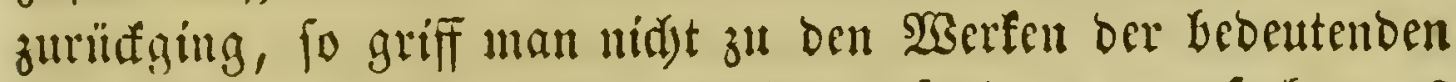
Sdjriftifeller, bie man nidyt verftand, fondern man fudjte aus

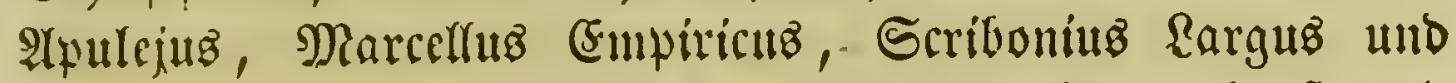
andern berartigen Srariftfteffern gerabe bas $\mathfrak{B}$ unberbarfte und

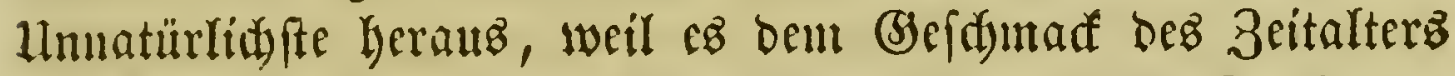
am meiften zufagte. (Salen's und Diosturibeg' Sdyriften fante man nur hier und ba in fdiled)ten Heberfebungen.

Rarl ber (Brofe jwar, cin Mann, ber feinem Jahrlyunbert

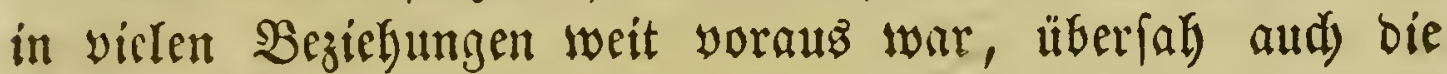
Widitigfeit ber Şeilfunbe nidyt und befahl, bas in ben yon ifm in veridjebenen Stäbten geftifteten Sdyulen neben ben gewöhnliden fieben Sdullwiflenidaften (Grammatif, AYrith= metif, Mufif, Dialeftif, Mbetorif, Beometrie und Affrono= mie) aud bie Arzneifunde gelehrt werbe. (sin Berzeidnif Der zu Siarlz zeit am meiften verbreiteten 21 rzneimittel geben Eckard's Commentarii de reb. franc. orient. vol. 2. Heber bie bort angeführten yergl. Sprengel, Hist. rei herb. tom. I, lib. III, cap. 2. A(ber unter Sarls (d)wad)en

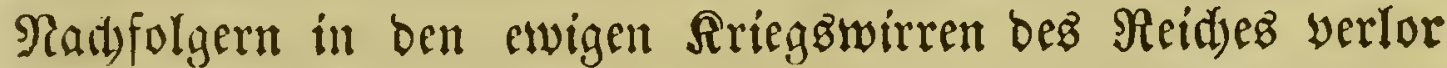
fid) bald wieber bie faum erregte Riebe zu ben 2Biffenidaften, und bie frillyere Barbarei brad) wicber hereit.

Um diefe 3rit Iebte $\mathfrak{B}$ a lafried Strabo, geb. 807, geft.

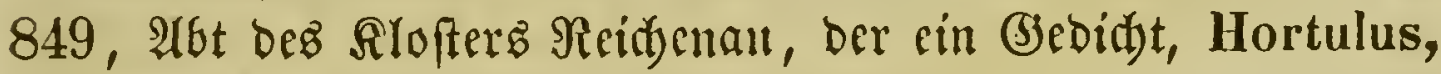
yerfertigte, eine Befdreibung Des Bartens, den er felbft bei

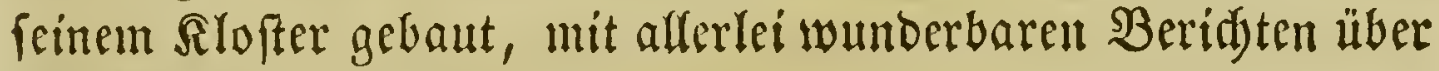
Die Nräfte ber Niäuter.²)

2) Der Hortulus erfetien int Druf 1512 zu Rürnberg in 4. unb 1530 zu freiburg 8. 
Şirbenardis, Aebrifin des STlofters auf ocm Nupperta berge bei $\mathfrak{B}$ ingen (umb Gahr 1100) bat cinc Sryrift binter= Iaffen, in ber von ben $\mathfrak{a}$ rgncimittrln gercoct mo unter allocrn 3. $\mathfrak{B}$. angegeben wird, Daß bas yemcine Farrentrant gegen alle

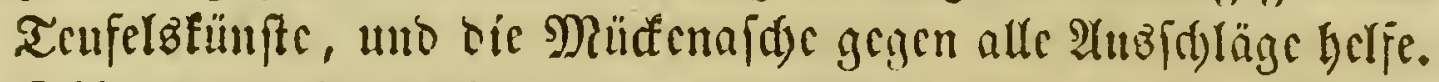

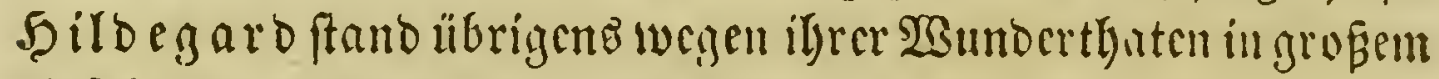

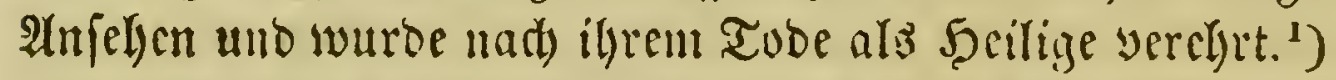

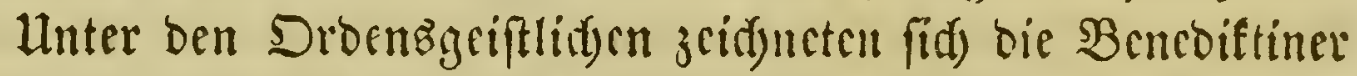

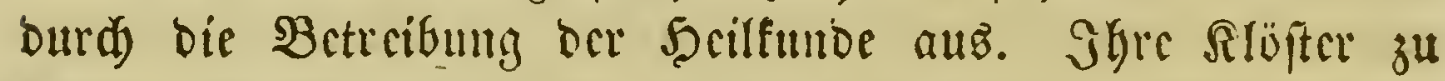

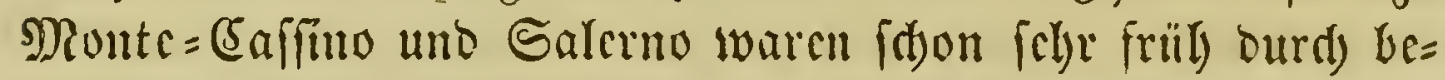
bcutcmbe Suren weit berillymt, bas crftere insbefondere ourds

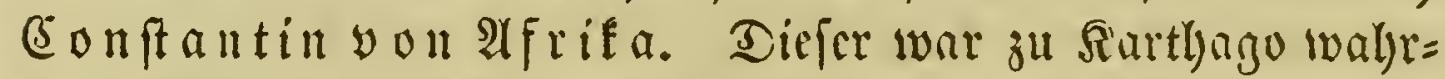

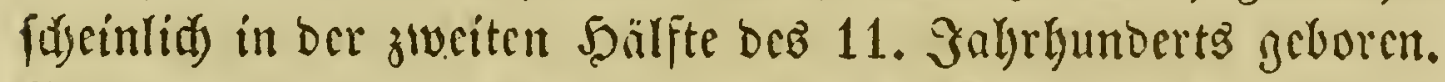
(5e mad)te weite Reifen in bon Drient, und als or nady 39

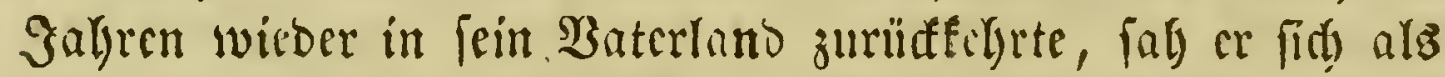
3auberer verfolgt, fallo jeoud) Sigul bei rem Şerzog Rubert

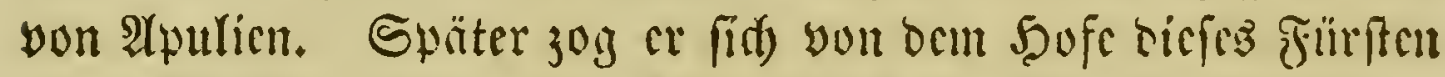

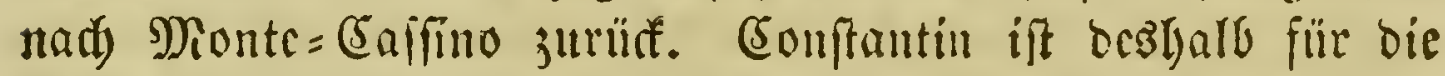

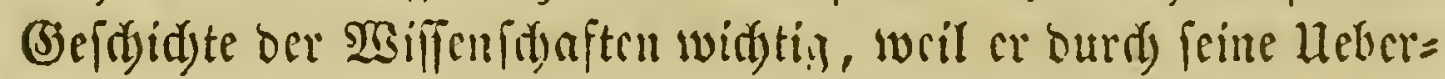
feşungen arafifd)er Sd)riften bic $\mathfrak{B}$ (funntid) nft mit ben $2(r a b e r n$

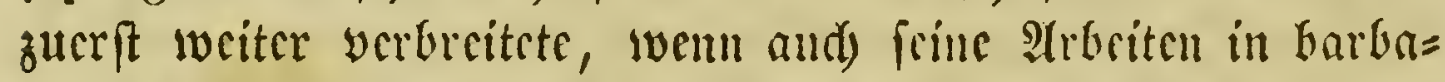
rifden Ratcin gefdricben uno bic Driginale frincsivegg getren wiebergeycben finto. In ocm tractalus de gradibus medicinarum banbelt or yon ocn $\mathfrak{A r}_{j}$ ucimitteln, die yon ben $\mathfrak{A}$ ras bern altycivant wutroen. $\left.{ }^{2}\right)$

(5twas fläter $(1114-1187)$ Iebte (5) crard yon (5rc=

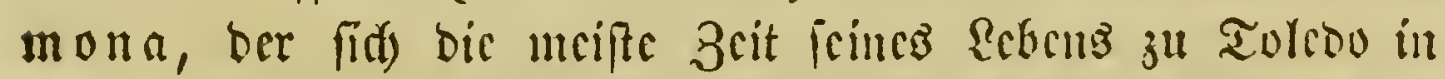
Spanien nufliclt unto bort fowogl vicle von ben arabifden Aergten, wie andi) bie :

4) St. Hildegardis, De simplic. medicamentis lib. I; de comp. medic. I; physica. Argentor. 1533 uno 157\%. Fol. -

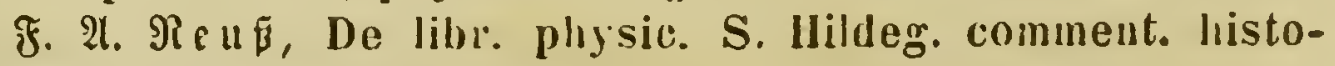
rico medic. Wirceburgi 18:35. 8.

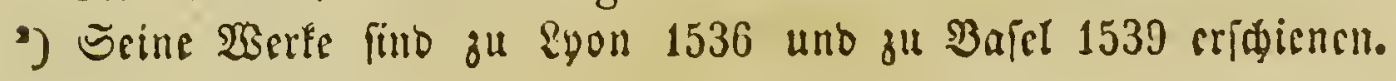




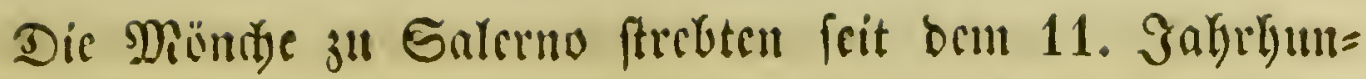

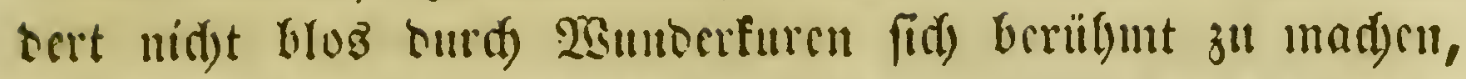
fontern and wirtlid) wiffenithaftlitye Semutnifie zu cruverben. So bilocte fid ju Salcrno rine Sithle ber Mericin, zu woddace Ed)üler uno אiranfe aus allen Ränocrn pilyerten.

Baz Regimen sanitatis Salerni gibt bon beften Begriff

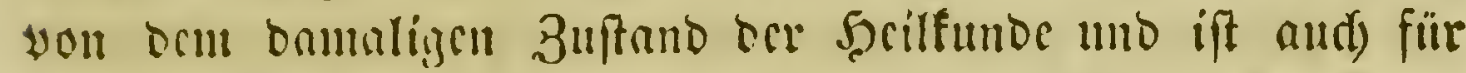

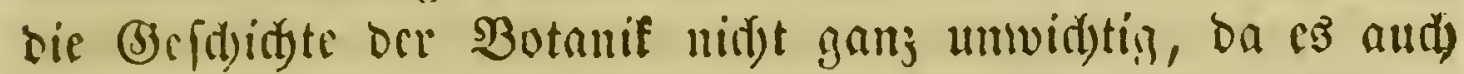

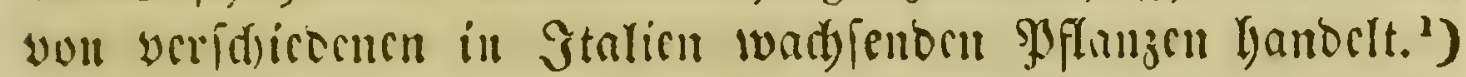

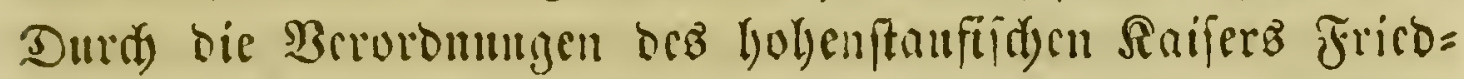
rid) II. (1238) warbe die falernitanifite Sefule gewilfer=

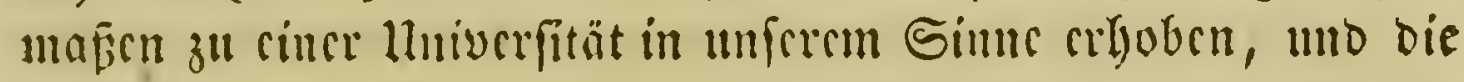

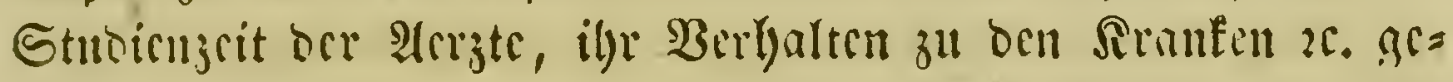

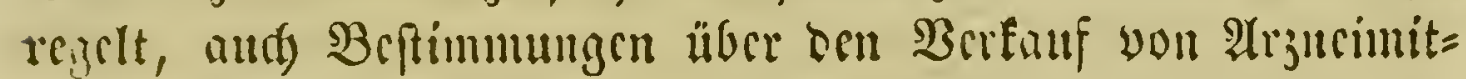
trlin fritigriezt.

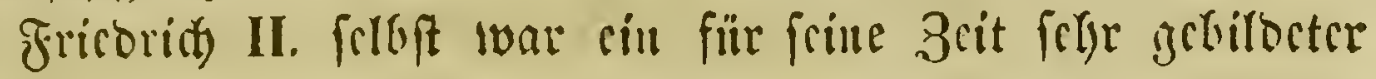

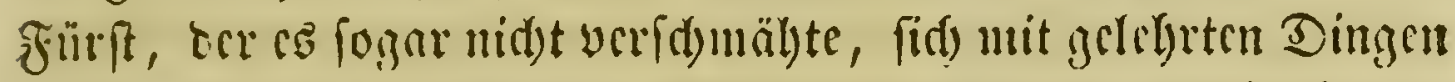

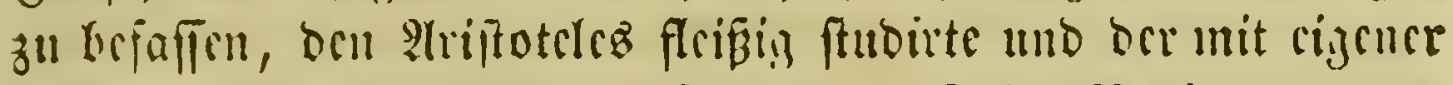

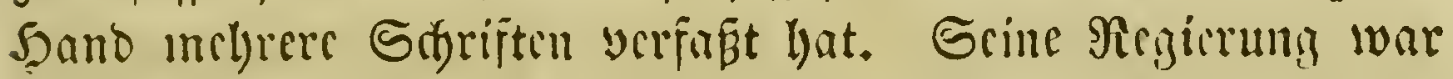

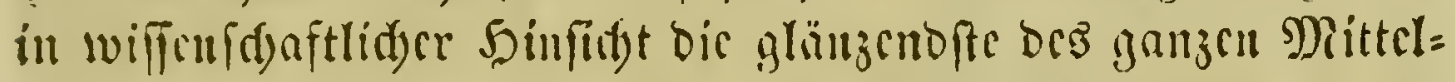

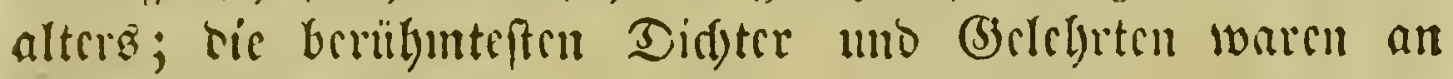
frincm 5̧ofe verfaumuclt. 3n frincr 3rit (1230) wurbocn and

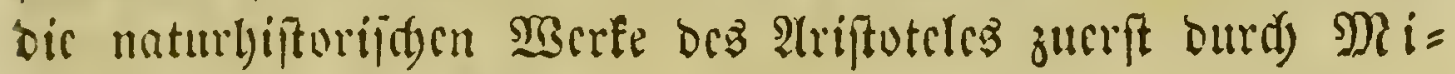
d) nel Scotus befunnt.

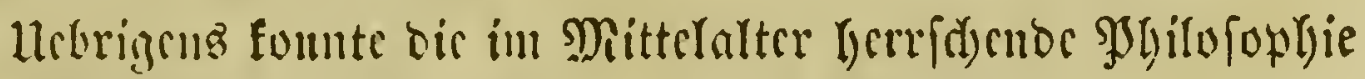

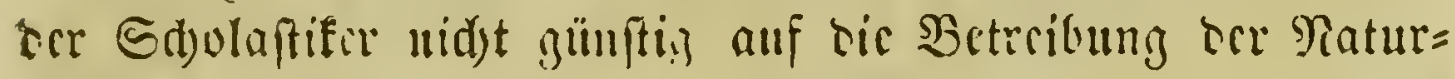

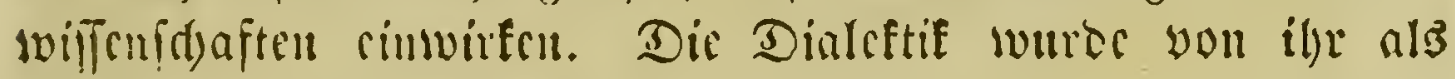

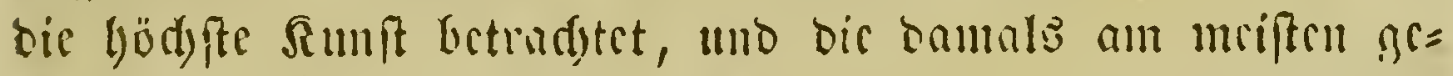
fricrten Denfer verloren fid in sie fubtilfen Spibfintigfsiten.

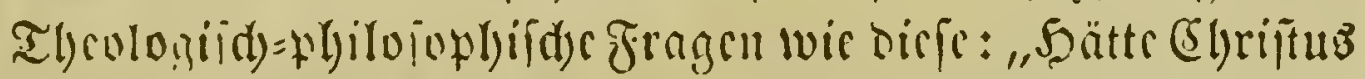

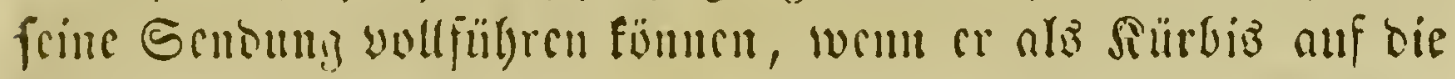

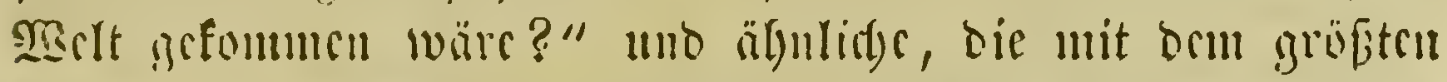
Gruffe für uno wiocr beantwortet spurben, muften natüllid)

1) Serauggegeben yon 2termann. Stenoal 1790. 
Die (5eifter you bem realen Wiffen abzielyen, unb wir finden

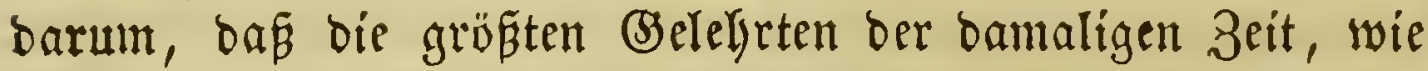

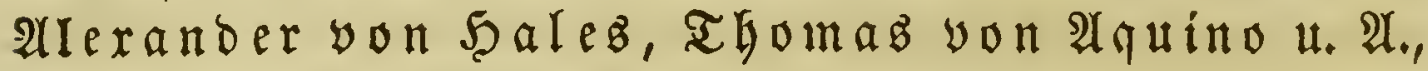
yon bergleiden (B) rüteleien nidjt frei fint.

Bincenz, zum Droen ber Dominifaner gebörent, Sub= prior in bem Slofter zu Beauvaiz, wahrideinlia in Jalir

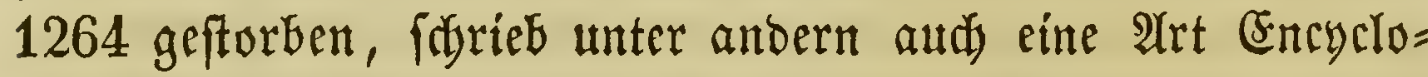

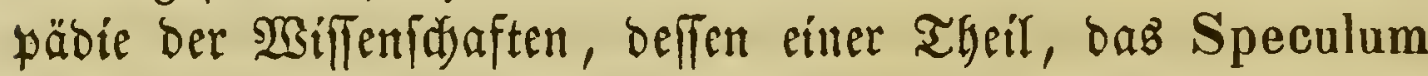

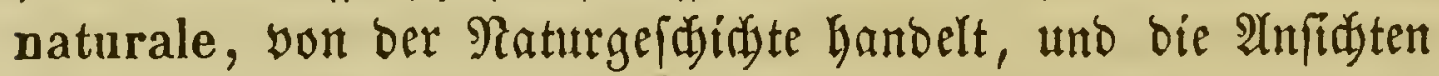
griedijder, lateinifider unb arabifder Sdyriftifeller zujammen= fteflt. ${ }^{1}$ )

Uhin bicfe 3eit rebte aud Syeter yon (eresentia, ber cin $\mathfrak{B u d y}$ über die Ranbwirthjdaft hinterlaflen hat. ${ }^{2}$ )

\section{Albertuz $\mathfrak{M} \mathfrak{a} \mathfrak{g} \mathfrak{u} \mathfrak{z}$}

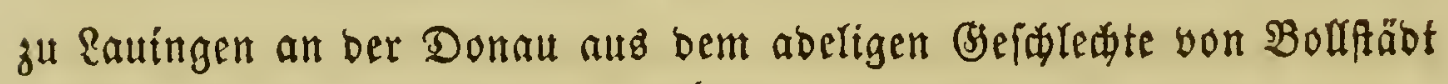
geforen.

ein Dominifaner, Iebrte in mehreren Stäbten Deutfdlando

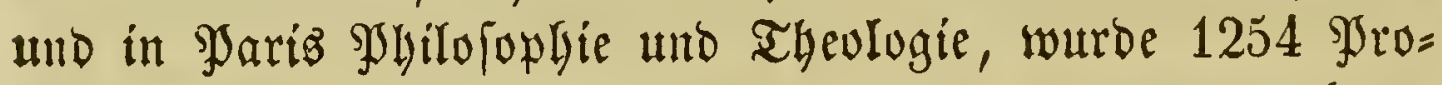
vinzial feines Drbenz uno 1260 Bifdo of yon Regensburg,

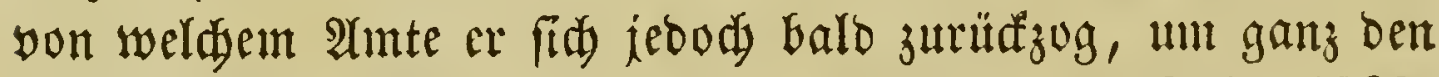
Biffenidyaften leben zu Eünnen. Er ftarb im Gahr 1282. ATbertus Magnub war wegen feiner plyyftellifden und medanifden Renntriffe febr berilgmt. Befrumt find bie Er=

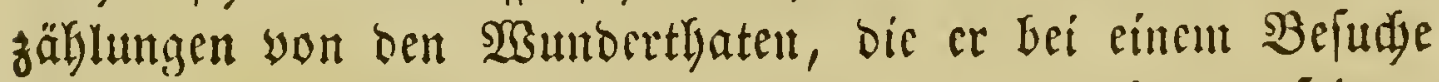

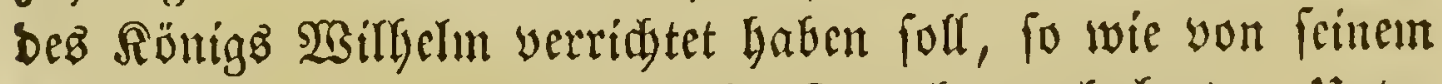
Automaten, ber bie menidglidye Spradje nadyalymte. Unter feinen vielen Sdyriften ftiloen fid and einige, weld)e für bie

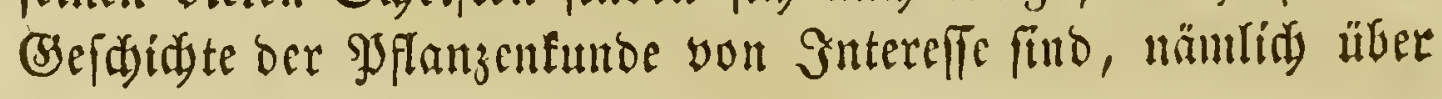

1) Speculum quadripartitam. Lugduni 1494. Fol.

2) Opus ruralium commodorum. Lovan. 1474 unb anberivãrt ; zu Bafel mit arbbild. 1548. SBergh. über benfelten Sprengel, Histor. rei herbar. tom. I, lib. III, cap. 5, S. 281. 


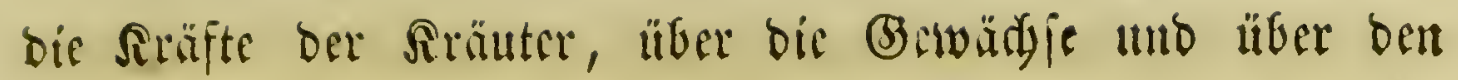
A(ferbau. $\left.{ }^{1}\right)$

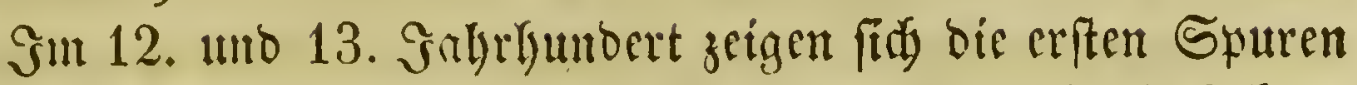

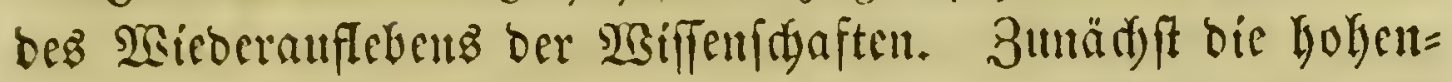
ftalfifden Raifer, bann melgrere Rünige von Englanto unt

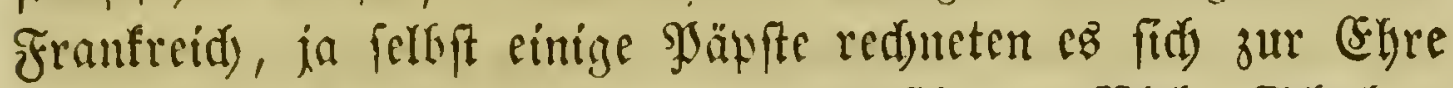
an, die gelefhrten Stubien zu begünttigen. Biele. Sd)ulen, unter benen bie won Bologna uno \$ariz die herworragenoften Ivaren, zogen buras die Freigeiten, welde ifnen yon Fürften uno Säpften verlielsen swurben, aus allen Theilen (5แropa's grop̧e Sđaaren yon Yernbegierigen Männern heran. 2(ud) ber weit verbreitete 5̧andeläverfegr ber italienifiten freiftäbte trutg viel zur Bermelyrung Der geographifden und naturbifto=

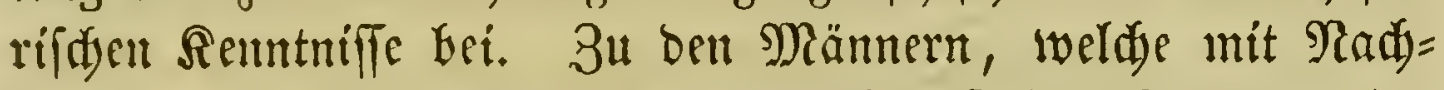
brữ auf cin verminftiges, yorurtheilbfreicz Stubium ber

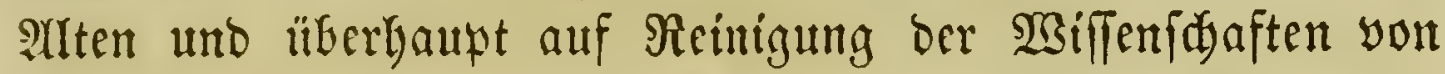

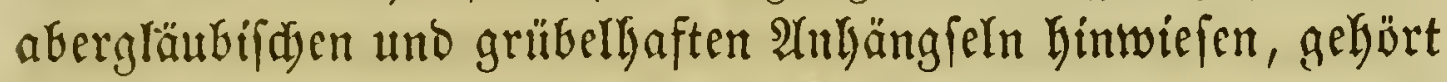
inzbefonoere ber englifte Franzisfaner $\Re$ oger $\mathfrak{B a c o}$ ( $g e=$ ftorben zu Drforo 1294), ber afer efen wegen feiner Reue= rungen viele Berfolgungen erdulden muste.

Die berübmteften Sdjriftfeller aub diefer 3eit, welde bierlier gehören, fint:

\section{SiII DNDE GDTDD,}

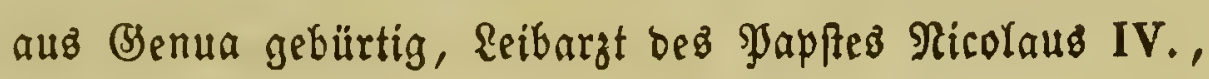

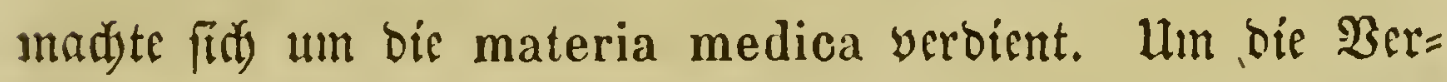

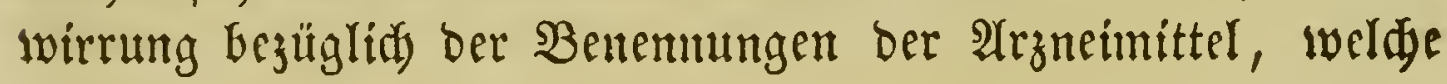

1) Seine geiammten Berfe, unter benen bie oben genannten Sarif= ten de virtutibus herbarum, do vegetabilibus unt de agri-

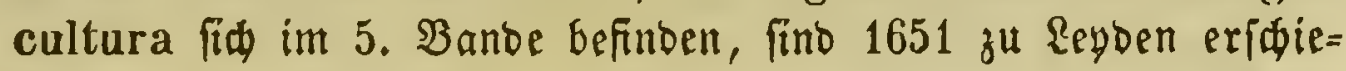
nen. - De virtutibus herbarum, animalium et lapidum. Argent. 1497. Lips. 1505. 4. Amstelod. 1643. 8.; beutí, Strapburg 1549; Rürnberg 1731. 4. 
Durd) die Sifriften ber Araber uno die Meberieger Derfelben hervorigebrant worben waren, zu entfernen, burdireifte or

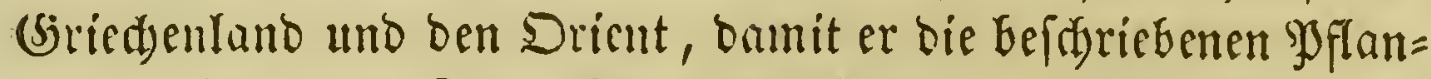
zen an Drt uno Stelle betradyten fünnte. Altein leiber fam

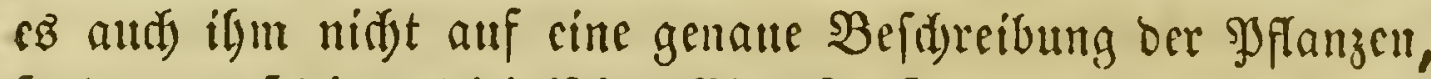
fonbern auf bie medicinifden (sigenfdunten berjelben, wie man fie einmal nady ben herridsenden Theorien feftgeftellt hatte, an, uno fein $\mathfrak{B}$ erf Clavis sanitatis if bezhalb weiter nidft

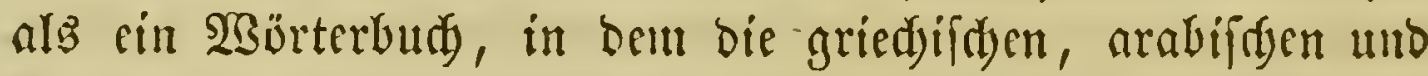

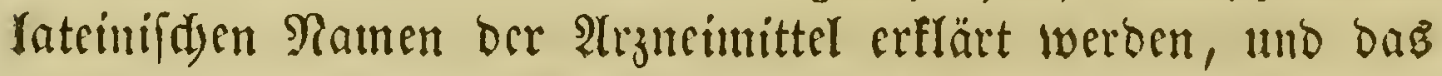
yon Spradjeblern und fadjlidjen Mifuerftänonifien eine grufe Mienge aufjutweijen hat. ${ }^{1}$ )

\section{Matthä $\mathfrak{a}$ Sylvaticuz}

aแz Mantua, lebte 'umb Sabje 1317.

Seine medicinildy Pandeften haben cinen ähnliden 3weat

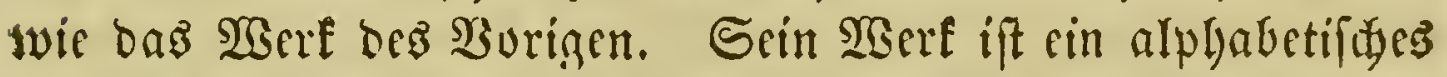
SBörterbud) yon Benemunugen mebicinifder und naturlifito= rifd)er (segenftäube. (5:z feblte jebod) aud) ifm an ber nüthigen Semutnis ber grierdifiden und arabifdyen Spradye. Matthäแs batte in Salerno cinen eigenen (Sarten, in bein er ägyptiidge

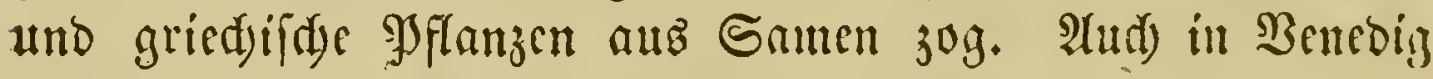
wurbe um bicie 3eit ein offentlidjer mebicinifyer (5)arten an= gelegt, oeffen Sylanjen yon Anor. Ä in a bei gemalt wurben. ${ }^{2}$ )

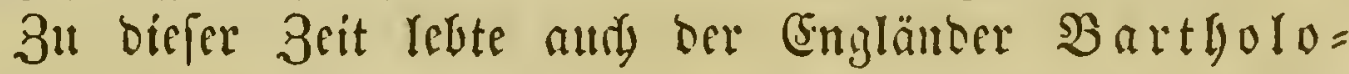

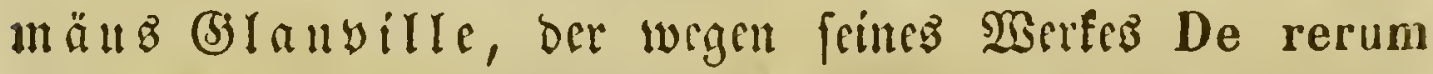
proprietatibus bierlier geljürt. ${ }^{3}$ )

1) Simon Januensis, Clavis sanitatis. Venet. 1514. Fol.

$\left.{ }^{2}\right)$ Matthaeus Sylvaticus, Pandectae medicinae. Lugd. 1534. Fol. Sicrgl. Sprenge l, Hist. rei herb. tom. I, lib. III, cap. 5, S. 286 ff.

3) De rer. prop. Argentor. 1491. Norimberg. 1519. Fol. Sns

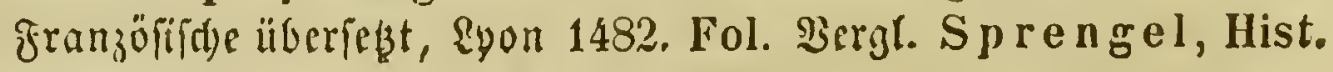
rei herb. l. c. 


\section{GaFob De DOUdi}

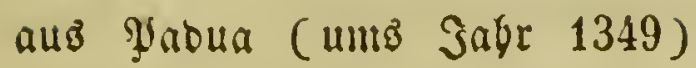

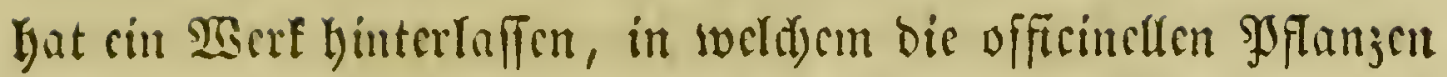

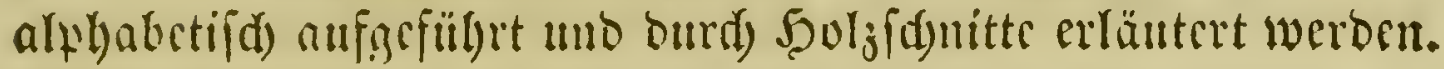

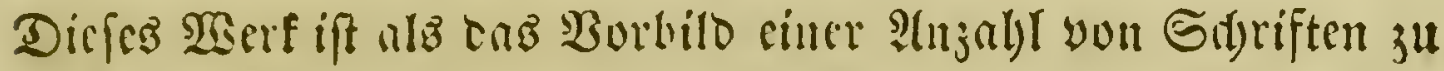
betrad)ten, welde unter bem Titcl Ortus sanitatis vocr Fräut= terbud) im 15, und and nody im 16. Salyrtumbert an veridsie= Denen Drten, wis z" Nani 1485, 1491 ; Nugghurg 1486, 87, 85, 96; ulm 1487; $\mathfrak{B}$ enedi] 1511, 17; \{übeff 1492, erf(j)imen. ${ }^{1}$ )

Frnoes, Bürgermeifter yon Rübef, hatte in bem Drient gercift uno bort yon cinem mitgenummenen Maler bie von

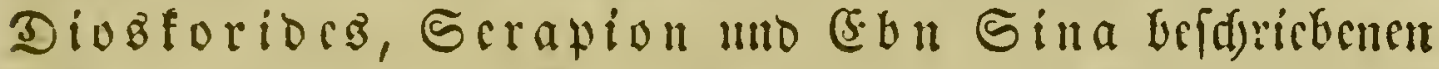

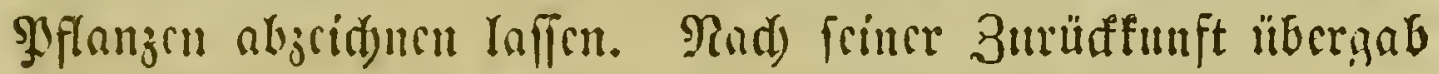
er bic 2(hbilomingen, bie mur jum Theil naturgetten find, bem

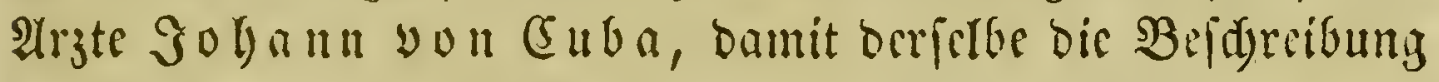
saju licfere. Bicfe $\mathfrak{B c}$ cdyrcibung bandoclt bautptiärblich yon bem Nutgen ber abgebiloeten splanzen, zcidynet fidj jedod) nid)t be= fonbers vorthcillyaft atts.

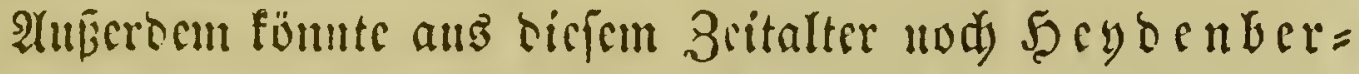

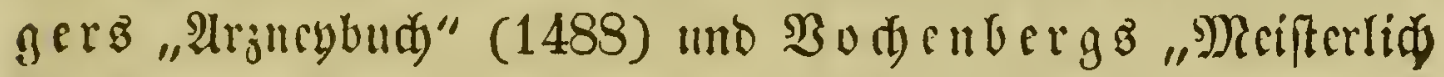

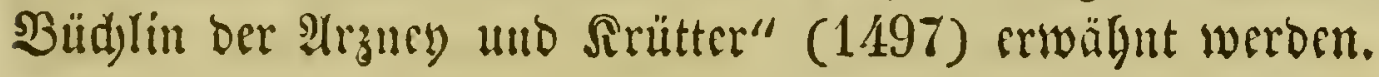

1) Sacob be Dondi, Aggregator practicus de simplicibus. Venet. 1'199. 4. Bergl. Sprengel, 1. c. S. 289 ff. 


\section{Bweite Xutbeilung.}

Bon Dem Wistederwadhen ber Wiffenifhaften bis auf $\mathfrak{R} \mathfrak{a}$ rent $\mathfrak{A}$ toine De Guffieu.

Mebrere Umftänbe vereinigten fidy im \&aufe bes fünfzefnten Galgrhumbertż, um ben Berbältniffen Europa's eine ganz an= bere (3)eftaltung zu geben. Sater biefe llingeftaltung sefdab nidit plöblid), gleidusie ber unauflyaltfame 3ug eines witoen Eroberers ganje Staaten und Bölfer vernidjtet, fontern all= mälig feimte fie hervor, genälyrt yon ber belebenten $\mathbb{R}$ raft bez (Seiftes, unt eben barum brang fie ein in bie innerften Sdjidten

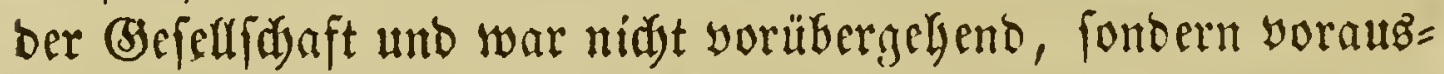
beftimmeno für alle zufiunftigen 3eiten, fo lange sie Sultur nicbt wweber yon ber Finfterní̄ ber $\mathfrak{B a r b a r e i ~ v e r b r a ̈ n g t ~ f e i n ~ w i r b . ~}$

Die $\mathfrak{B} u d$ boruderfunft war erfunden worben. Alber für eine lange 3eit hätte fe wohl ber Menfdabeit wenig gentït, wenit

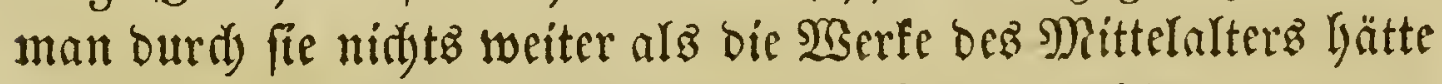

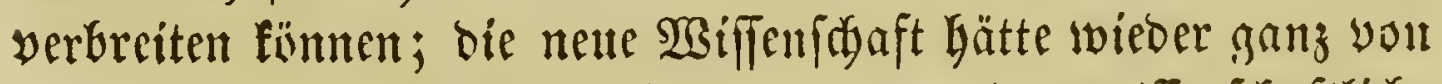
vorn anfangen, alle Srrthü̈mer, benen ber wiffenfdjaftlidye

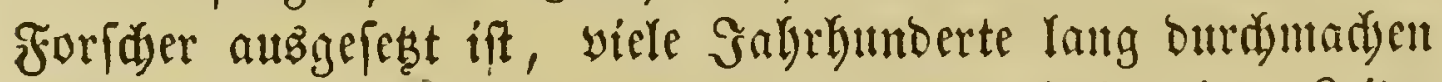
mitffen, wenn fie nidyt yon cinter anderen Seite einen Reiter

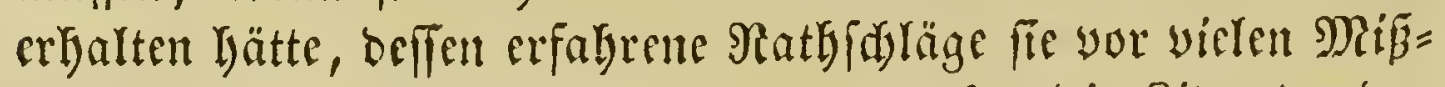
griffen bewalyrten. Diefer Reiter war aber bie Riteratur ber Alten, inzbejondere dí ber (3ried)en. Artz int Sabr 1453 Gonftantinopel von ben Türfen éngenomnen $\mathfrak{x m b e}$, flüdteten 


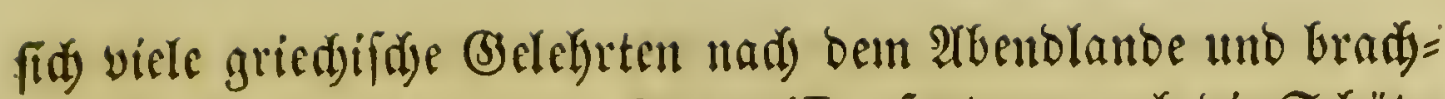

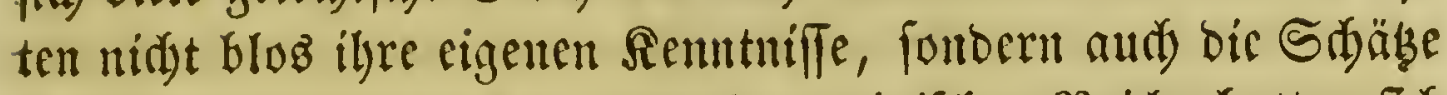

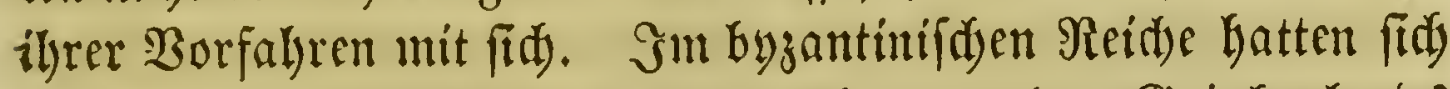
viele ber yortrefflidyfen Sd)riftwerfe bes alten (Briedsenlands

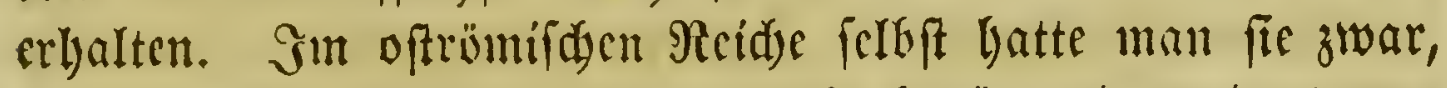
wic wir when gefehen lyaben, wenig benübt; benn bort war ber (Seift erfdylafft unt zum felbitthätigen Sdyaffen untlätig $g e=$ worben. (Sanz andere Erfulge aber gewann bie frifdye Siraft feg abenbländifiden Strebens.

In Stalien bauptä̈dylidy war fdon ein Sabrhumbert früher bie Riebe zu ben alten Rlaffifern mit neuer Stärfe erwadit. Dort hattent fifon bie grofien Diffter Dante, Setrarea ano

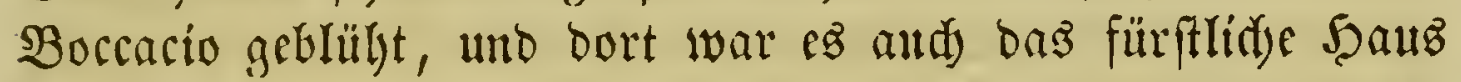
Der Mcoiecer, bas zuerft twicher feit tem Raifer Fricoridy II.

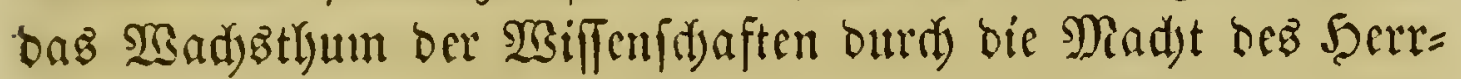
fajers befürberte. Balo eiferten aud) bie Sberbäupter ande= rer \{änocr ben Mebiceern nad), uno wir fehen in biefem Zeit=

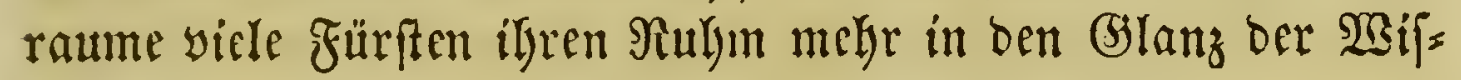
fenfdaften, als in bie Berwalt ber waffen ieken.

Şierzu fam am Ende bez fünfzelynten Jahrhundertz die

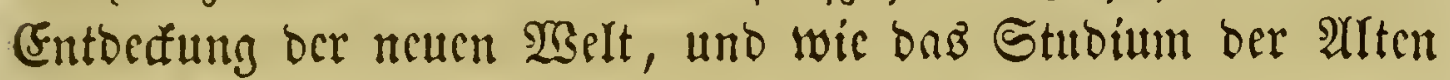
ber Begenwart eine thatenuolfe Bergangenbeit auffdilofi, fo

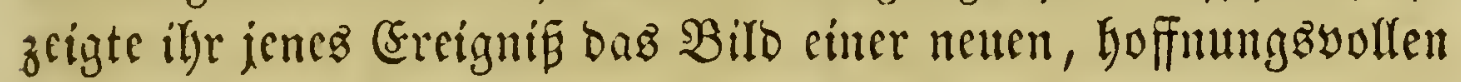
3ufunft, in ber fie bişuer ungeafnte Frïdte ärnten wärbe.

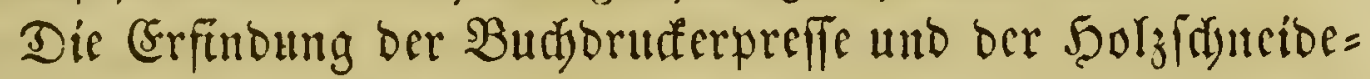

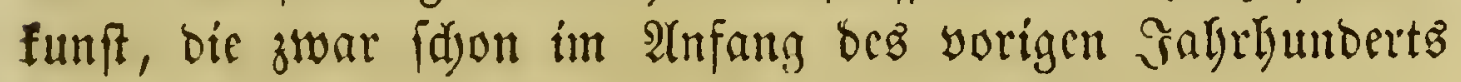
befannt war, jest aber crft allmälig verwolfommuct warbe, bie Burdforddung ber alten Dueflen uno die Entoefung ber

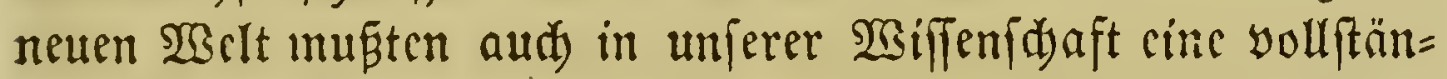
bige llmwandlung lerborbringen. 3war traten bie Realdis=

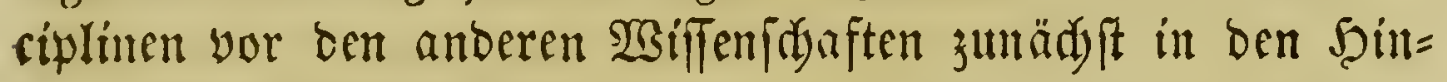
tergruno; benn bei ifnen war es nidjt bamit gethan, oap ber menfolidse (Geif mit neten Goeen befrudstet wurbe, ifnen war aud) bie eigene (Erfahrung unbebingt nothwentig; fermer boten

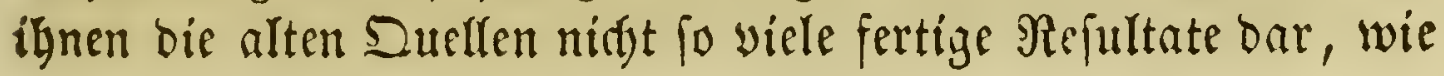

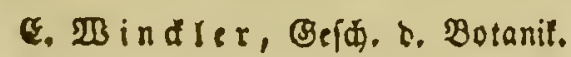




\section{6}

ben anberen Dizciplinen, ba, wie wir oben geieben baben,

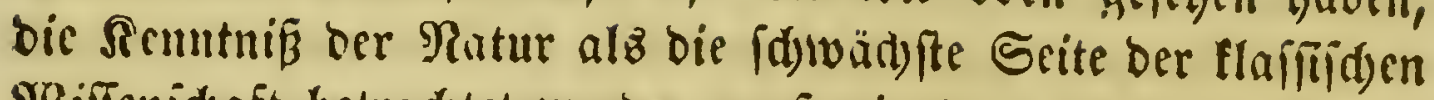
gisiffenid)aft betrad)tet werbell muf, ja ber unbedingte (Slau= ben an bie Autorität ber (Sried)en uno Nümer fojabete fegr büufig Den Forfdoungen Der neueren Raturforfder ; deffemun= seadytet war aber aud bier bas Ducilenftudiun befrudteno unt anregeno uno fildete bas funbament alles ferneren fort= fdritts.

$3 \mathfrak{u}$ zrigen, wie biefer Furtfdritt fi由 allmälig geftaltete, ift 3ived ber folgentoen Barftellung. 


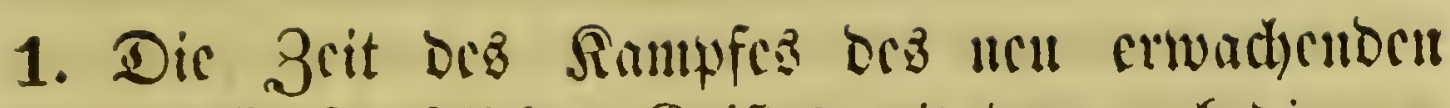
mifferifchaftlichen Griftes mit bem mubcoingtut

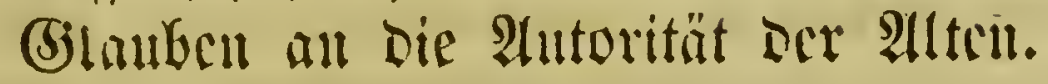

Bon der 3rit beg Qorenjo Medici biz auf bie $\mathfrak{B}$ rübre $\mathbf{3 a u b i u}(1478-1601)$.

Die crifte Alufgnbe ber Botanifer biefes 3citraumes war die, den Theuphraft, Diostorioes und glinius belfer zu überiesen - bcum bis̆her lyatte man winigftens bie Sdjrif= ten ber beioen (Erften nul surd) fdslcăte Ucbertragungen aus beun Arabifden gefaunt, - zu commentiren und rie burd bab

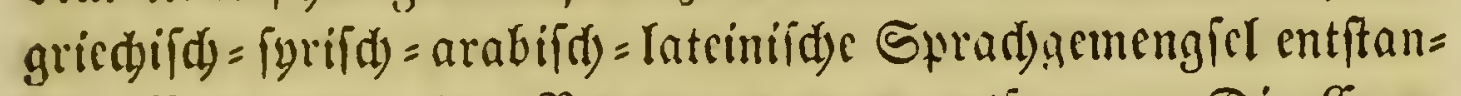
sene Berwirrung ber Benennumgen zu entfernen. Die Coms

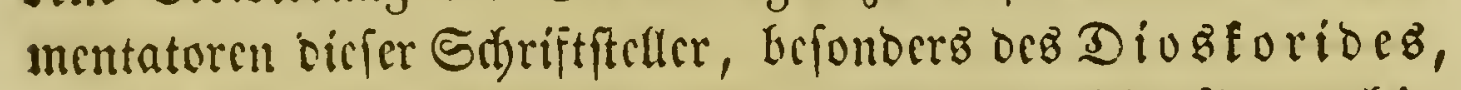

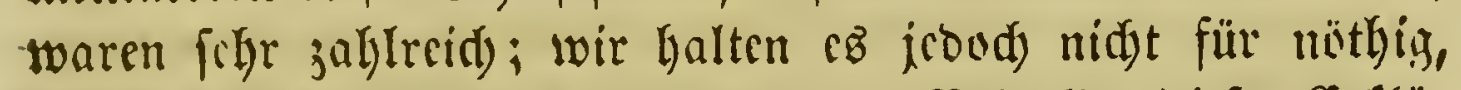

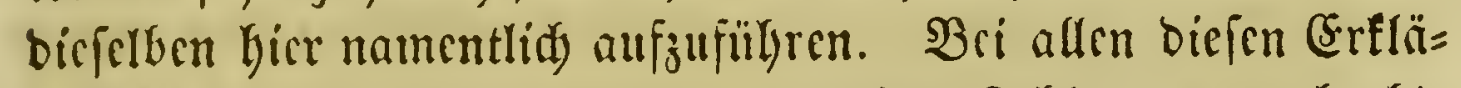
rungen abor beging man cincn gewaltigen fobler, man glaubte nämlity, rafi in ben Serfen bes Diustoriocs ze. alle SFlanjen bes Erobodens cntbalten feicu, fo wie baf man dic= felfen auds alle in bemienigen Sanbe, worin man fich gerabe

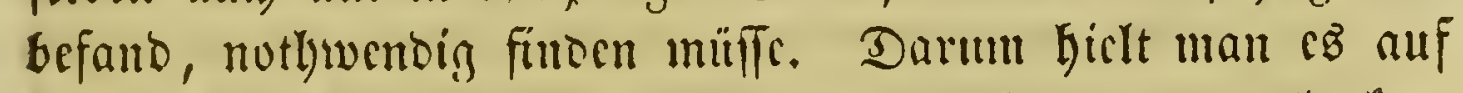
ber cincn Ecite nid)t für nötbig, ncue \$ुflanjcn ju entbcten, anbercrfeits müfte man fid oft verigcbens ab, ric beidsrie= benen Pflanzen aufüfinocn. Diciar Srrthum verbintorte auf

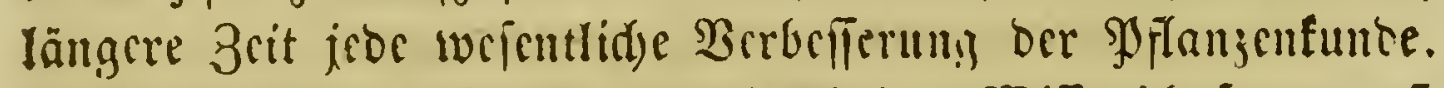

Sn ocmicnigen Rande, wo sic übrigen 2 Sill zu blïlyen anfingen, lebten aud bie erfen nemensuwertben SPflanjenfinner tor Reujcit.

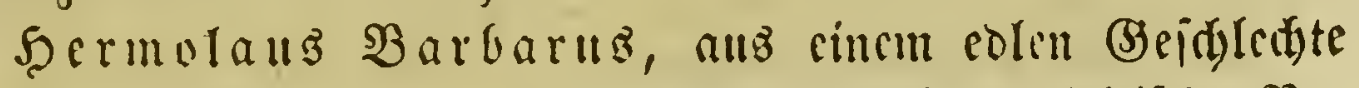
Benedigs ftammeno, gefturben 1493, verfä̈te fritifitge $\mathfrak{B} e=$ 
merfungen gegen Plitilus, worín er fid rïlyut, mefr als 5000 Grrthiumer biefes Sdriftifellers nadgewiefen zu haben. $\left.{ }^{1}\right)$

Der Bicentiner Ricolaus Reonicenus, geftorben 1524, ftubirte forgfältig bie alten Duellen uno fudste barzu=

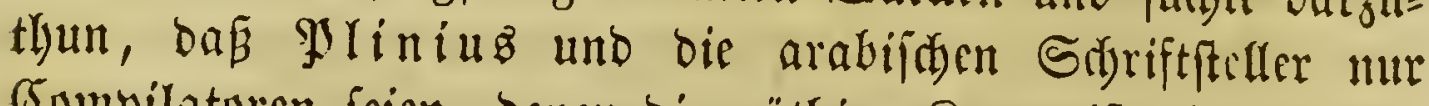
(Sompilatoren feicn, oenen bic nüthige femtnif abgehe. ${ }^{2}$ )

(Begen ily trat Sandolfo (5ollenucci (auf Befegl Sfor $\mathfrak{a}^{\prime} \mathfrak{B}$ lingeridetet 1504) auf, indem er bie Beflauptung

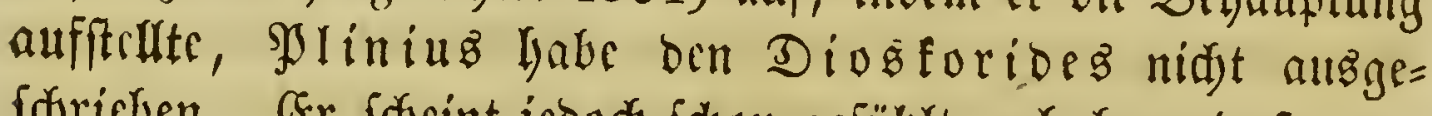
fdrieben. Er foreint jeood fdoun gefüblt zu haben, bas man,

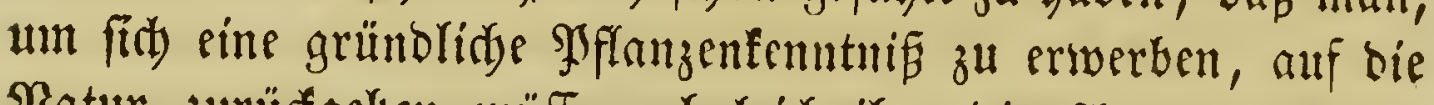

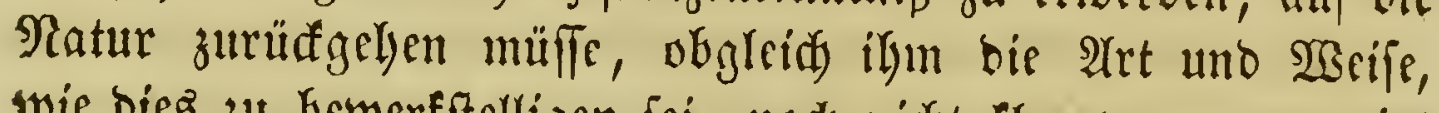
woie bies zu bewerfftelligen fei, nod nidyt flar war; or meint nämlid, man folle fid) nicht mit ser Riteratur, fondern mit Dem Erbboben befdäftigen, uno nidgt fowohl bie alten Sibrift= fteller lefen, gemalte Şflanzen betrad)ten uno auf bie griedfi=

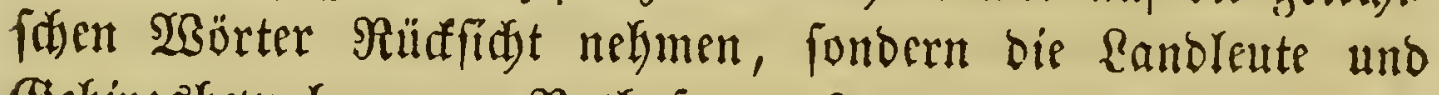
(B) birgaberwolner um Rath fragen. ${ }^{3}$ )

1) Castigationes Plinianae. Romae 1492. Fol. Secundae castigationes. Romae 1493 Fol. Diejer Sđriftteller geyört auळ ju ben Conmentatoren bes Diozloridez: Corollarii in Dioscoridem libri $V$ non ante impressi. Impr. cum Joall. Bapt. Egnatii in Dioscoridem annotamentis. Venet. 1516. Fol.

2) De Plinii aliorumque in medica erroribus etc. Ferrar. 1492. 4. - De Plinii aliorumque medicar. erroribus liber. Cui addita sunt quaedam ejusdem autoris de herbis et fructibus, animalibus, metallis, serpentibus tiro seu vipera. Basileae, excudebat Henricus Petrus. 1529. 4.

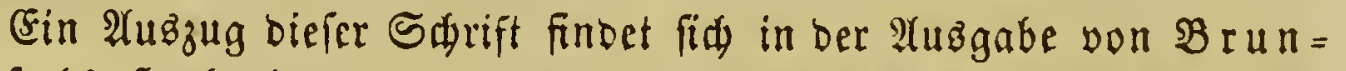
fers Serbarium von 1531, Thl. II in 2 nhbang S. $44-89$; ebenio in ber 2 usgabe von 1536 S. $140-205$.

Nic. Lenniceni, philosophi et medici clarissimi opuscala etc. Per D. Andr. Leennium Medicam. Basil. 1532. Fol.

3) De interpretatione simplicium, quae sunt apud Plinium, calumniis Leoniceni responsio in $\mathfrak{B}$ runfelg 5 crbarium, $2 \mathfrak{r}$ Ifl. 1531. 
Marcellus Bergilius aแs florenj (geft. 1521), ber ben Diosforio es unit grofen freipe cummentirte, trat eben=

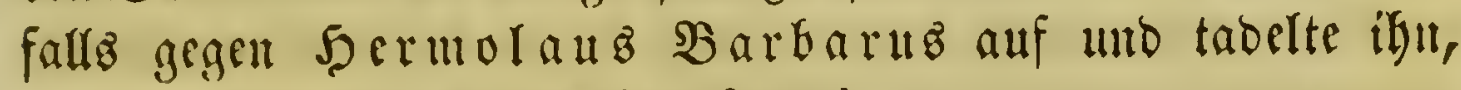
wo ar nut baju (5elegentheit fand. ${ }^{1}$ )

Gubaunez Ma naroub auz Ferrara bagegen (14621536) nennt ben Borigen wieberum einen Maun, oer mehr

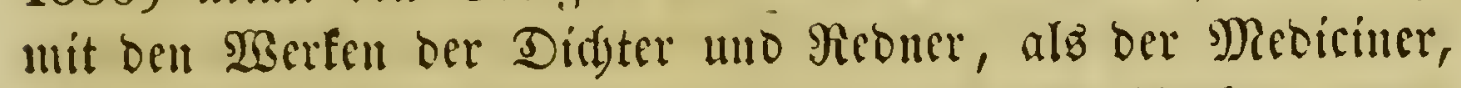

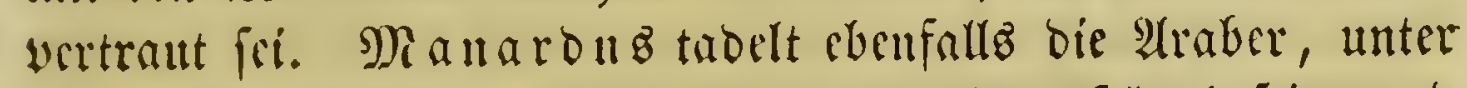
benen er namentlid) ben Mefue cummentirte, fehr beftig, und

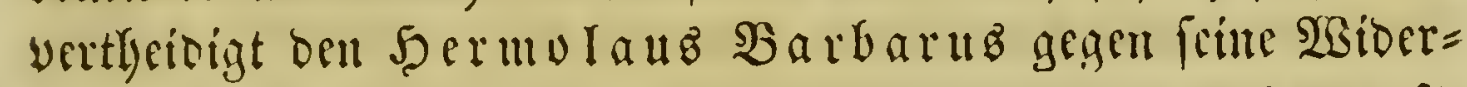
fad)er. Audy war er felbft ein grünblidyer SPlanjenfeuner. ${ }^{2}$ )

Alus biefen Streite wiro flar, daß̧ man in Stalien fdon anfing, bie unbebingie âtorität ber 2 (rten leife zu bez̧weifelut. Der erifte Staliener aber, wilder frine Ranbsleute mit Rady= bruf́ nuf baz Stubium ber baterländifden (J)erbäd)fe auf= merfiam madete, war

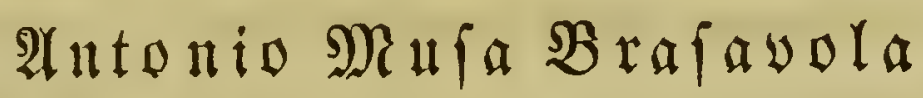 \\ aus ferrara, geftorben 1555.}

(Er war ein grünblidjer Sienner ber Arten, fudte aber auds zugleid) auf mehreren Reifen bie \$Jflanzen in Der Ratur felbit

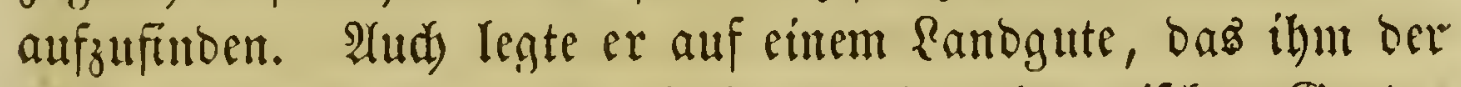
FFiirft von Ferrara gefdenft hatte, einen botanifden (S)arten an uno veranlaß̧te ben Scerzog Alfons von Efte zu Ferrara,

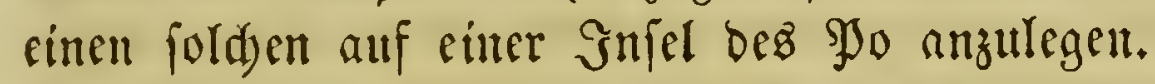

1) In Dioscoridem Corollariarum libri V. Adjectus est index eorum, quae hisce libris explicantur etc. Impr. cum Dioscoride, interprete $\mathrm{Mlarcello}$ Vergilio. Colon 1530. Fol.

') Epistolarum medicinalium libri XX. Ferrar. 1521; ad autographum collati et editi. Ejusdem in Mesue simplicia et composita annotationes et censurae. Basil. 1540. Fol.; 1549. Fol. Venet. 1542. Fol. - $\operatorname{Sin} 24$ zzıg bieire Sdrift

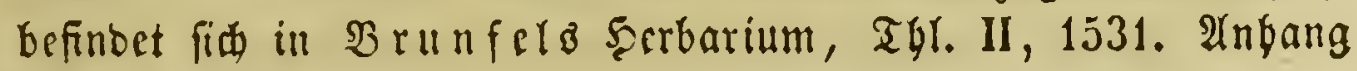
ธ. $32-43$. 


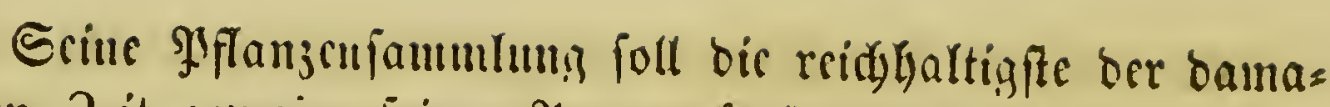

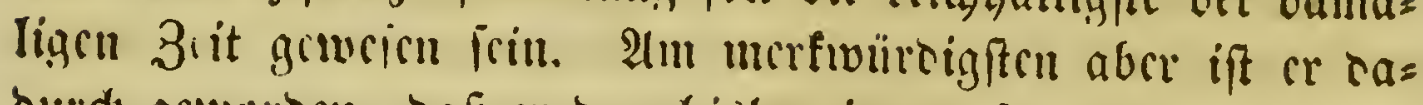

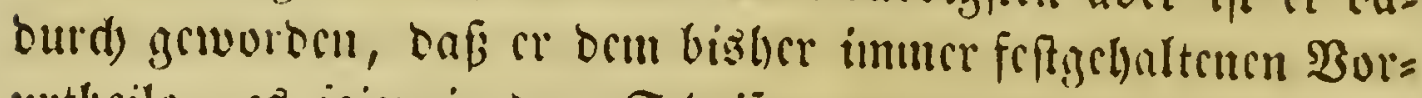

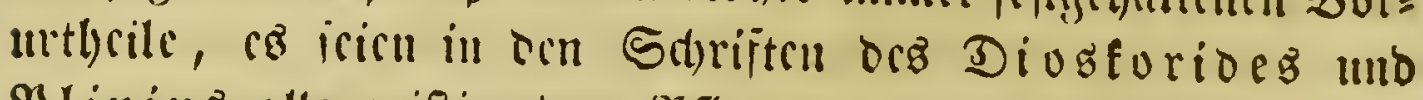

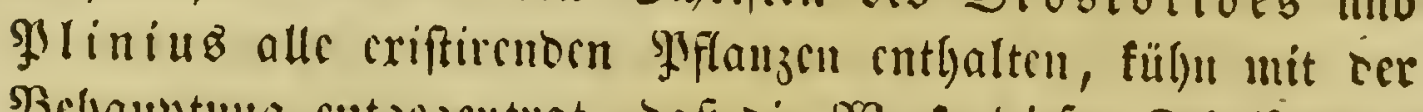

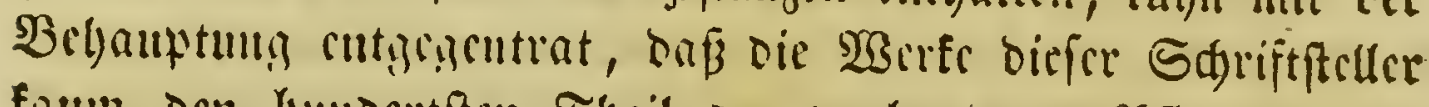

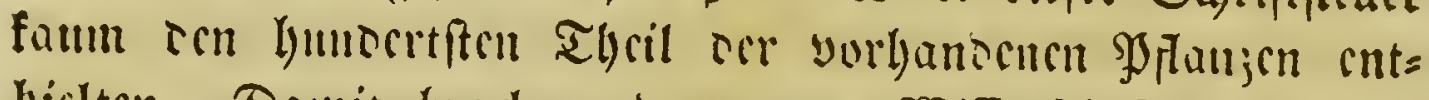
biclten. Damit brad) or bor ucuen Sillendaft in Gtalien

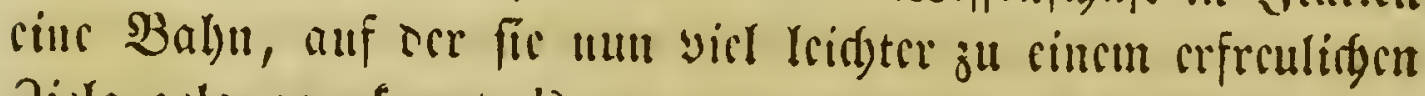
3iile gilanigen fountc. ${ }^{1}$ )

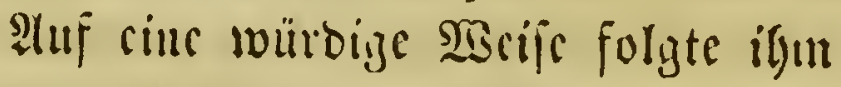

\section{Bartolomed Maranta,}

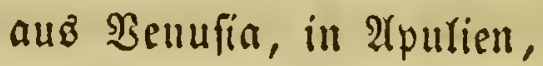

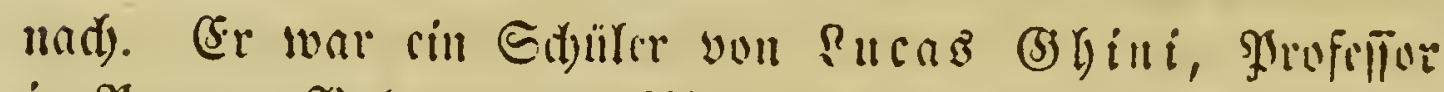

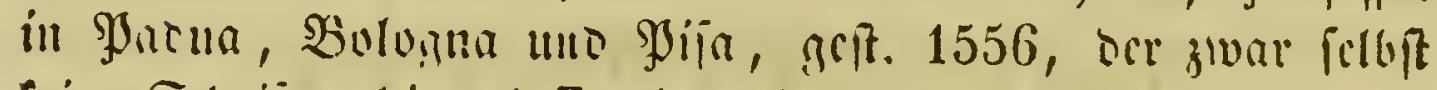

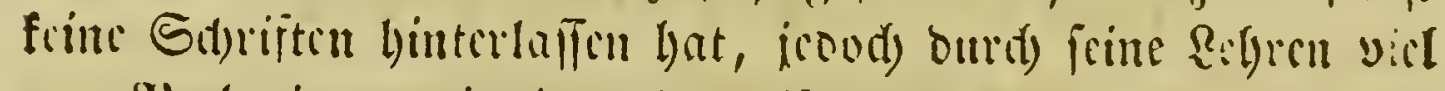

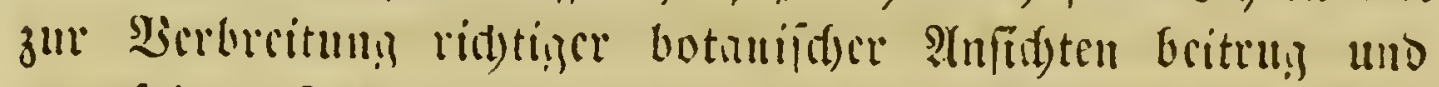

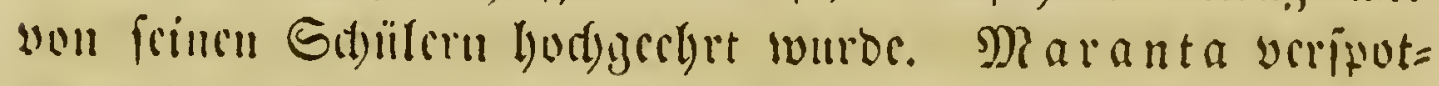

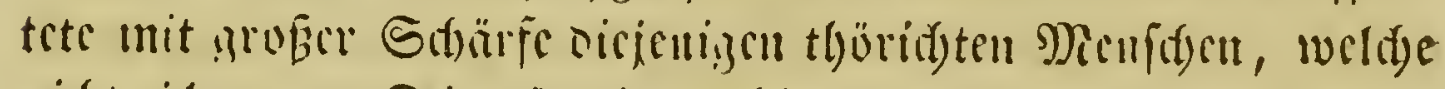

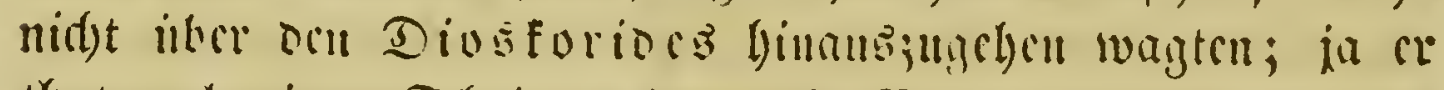
that mat) cimen Sderitt writer, als $\mathfrak{B}$ rafavola, indorm

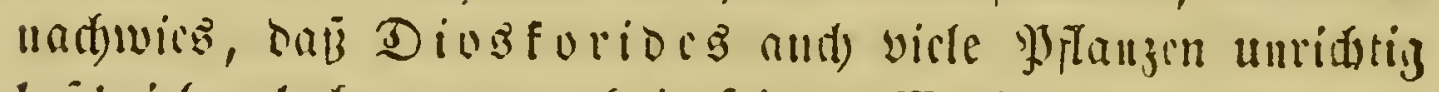
beidricten batic, uto ginb in fritcul siserfe Methodus cognoscendorum simplicium, Ventet. 1559, 4., an, wic man

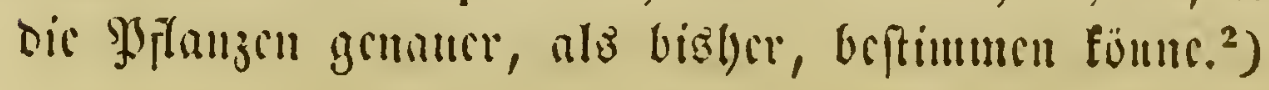

1) Examen nmuium simplicium medicamentorum etc. TRabr= (d)cinlid) f'creft in Rom 1536. Fol. Lugduni 1536. 8. Dufect6ft 1.537. 8. 1.514. 8. Venet. 1539. 8. 154.5. 8.

$\left.{ }^{2}\right)$ Norum herbarium s. methorlus congnoscendorum omnium simplicium etr. Venet. 1581, r.

Nella lleriaca e del mithridato. Vinegia 1572; fat. Francolurti all M. 1536. 


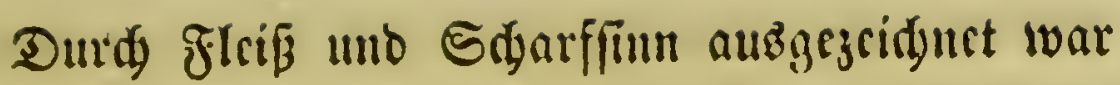

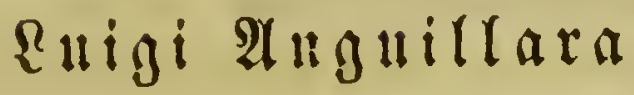 aนs Rour,}

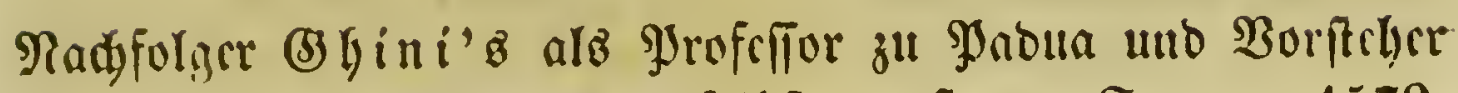

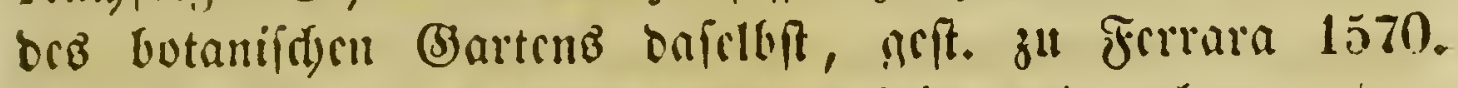
Ex batte Stalicu, Eurfifa mo Sarbinisu unb mibrere anbere

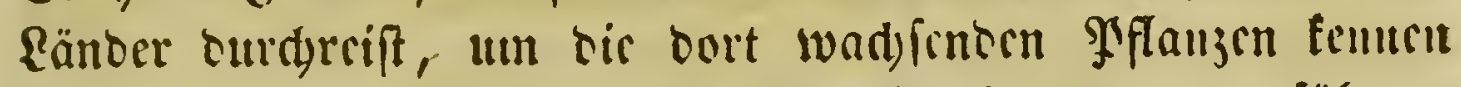
zu Icruch und fie mit sen bon Div zul verglcidsen. A(t) bat er nidyt weuige neue Pflanjen auf= g(junceri. $\left.{ }^{\prime}\right)$

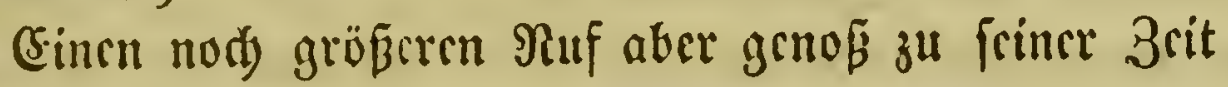

\section{Pietro Allica Matthioli,

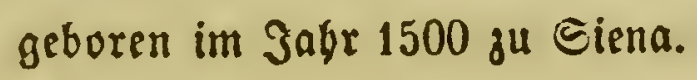

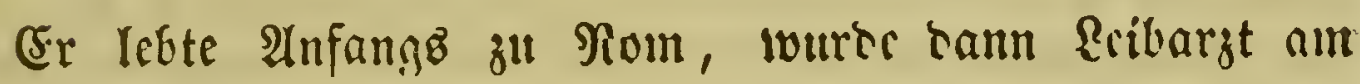

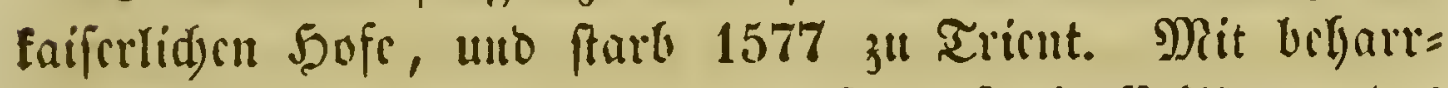

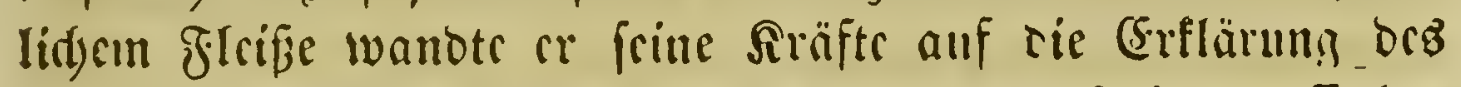

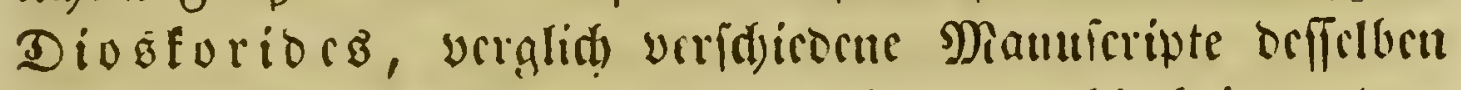
uno verbefferte bie Hebrifesungen, intem ar licrbci von bout

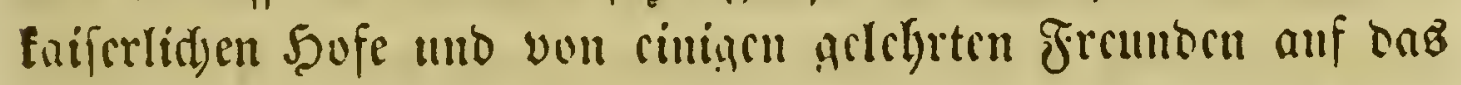

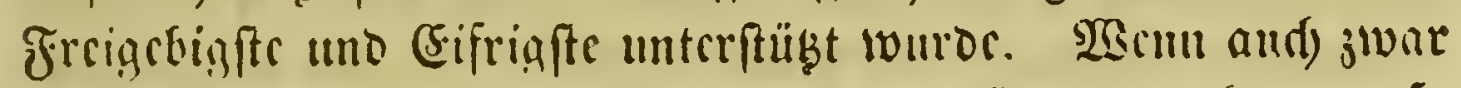

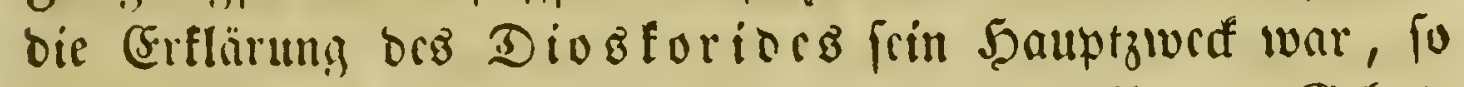

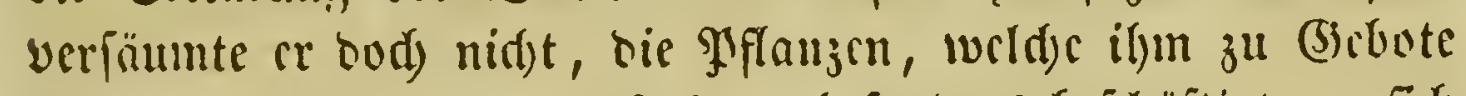
ftantocn, scuaucr zu unteriud)en; befonters befdyäftigte or fid mit orn (5)

1) Semplici dell' eccell. M. Luigi Anguillara, mandati in lure da Giov. Marinello. Vinrgia 1561. Cine lat. ueberr. veranfaltete $\Re$. Ballgin. Bafer 1593 . Rergl. Hilkr bicfen Edriffifeller Eprengel, Geididete ber Botanif, I. Thl., S. $289-93$. 
Deftreidy. Die von ifm neu aufgefundenen oder bow befler als feither beidriebenen Pflanzen fino in Sprengel's Histor. rei herbar. S. 337 ff. yerzeidinet. 3u bebauern ift

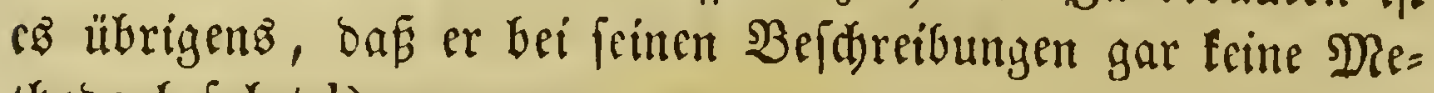
thooe befolgt. ${ }^{1}$ )

(banz cimzig in feille 2 rt war in biefer Periode

\section{Antrea Geialpini,}

geboren in Sabr 1519 zu 22rezzo,

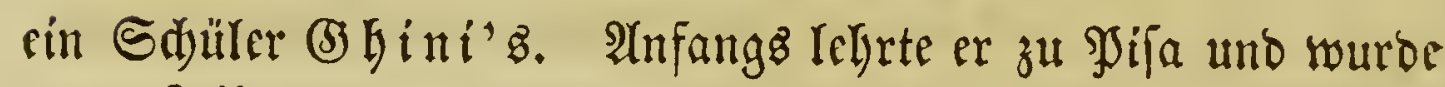
rann Reibarzt bes Sapfez SIcmenz VIII. Gr befás aubze= breitete Sinntuiffe nidst nur in alfen 3iveigen ber Ratur= viffenfdaften, fontern auty in Der Shbilofophie, uno Gatte fid) Durd) bas Stubium von 2 r ift o tele $\mathfrak{B}^{\prime}$ Merfen grünolid worgebildet uno fid an cin fiarfez, logiid georonetez Denfen

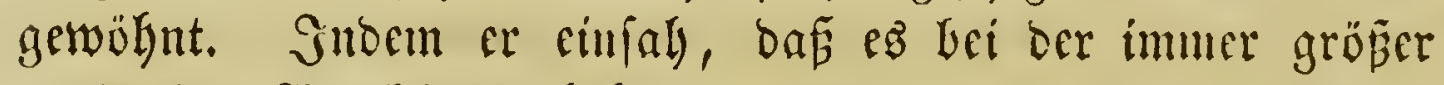

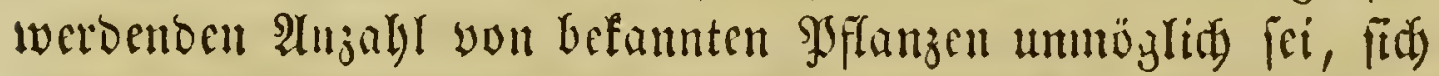
cine genaue Ueberfidst zu verid)affen, uno baß barum bie ofue

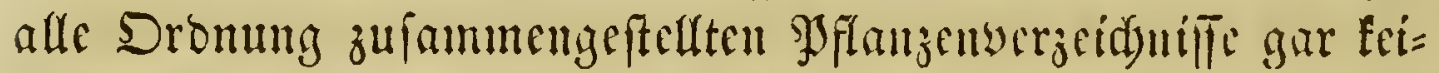
nen Nuken getwähren fönnten, faul er auf bic Goee, bic yor

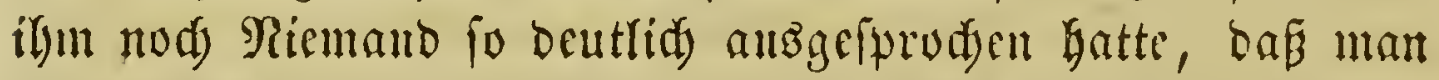

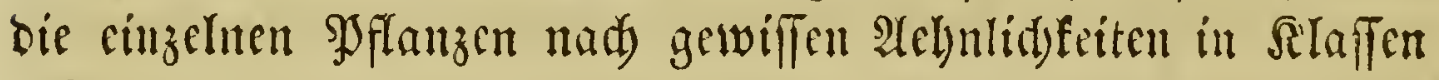
zufammeniteflen müife, uno cutwarf, yon decjer Goee aus= gehend, cin Syftem, bas zwar bas bejte 3cuzniz you feinen

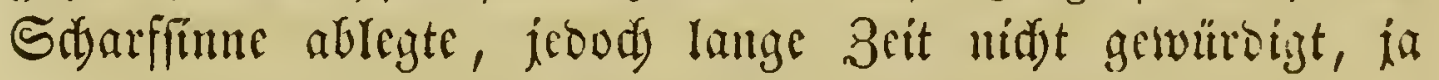

1) Scine (5ommentarien baben febr viele $\mathfrak{A}$ uflagen in mebreren Spraden erlebt. Stal. zu Siencoig 1544, Rat. bafelbit 1570 und Francolurti 1598. - Epistolar. medicinal. libri V. Pragae 1561. Fol. uno anderwärti. - Opusculum de simplicium medicamentorum facultatibus. Venet. 1569. 12. - Compendium de plantis onmibus etc. Venet. 1571. 4. - De plantis epitome utilissima etc. Fraucof. ad M. 15S6. 4. Bergl. $\mathfrak{g}$ rife $\mathfrak{l}^{\prime}$ Thesaurus literaturae botanicae 5.186 น. 334. 
Fogne ganj

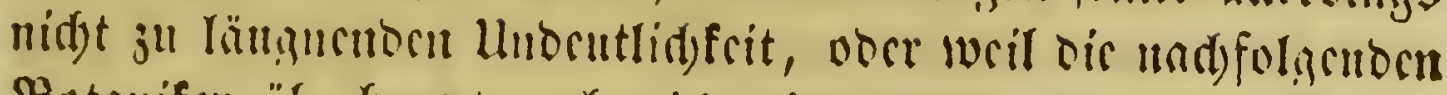

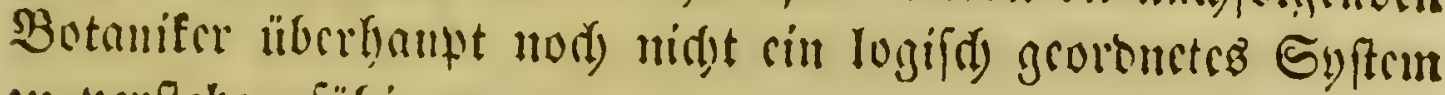
zu verftrlyen fälig weren.

Srin Syftem bat ar in boun SErrfe de plantis nicoce =

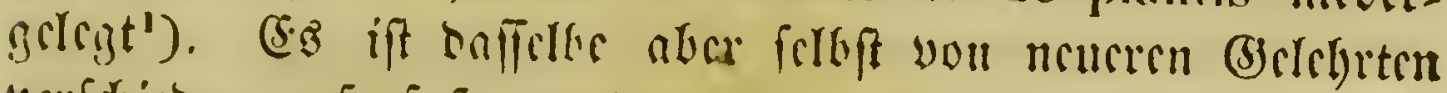

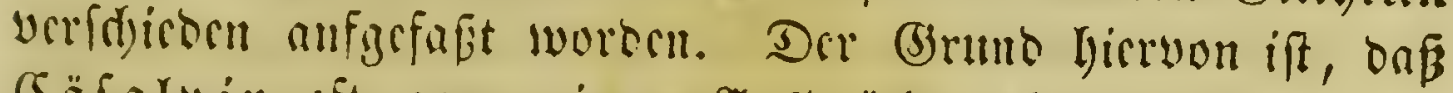

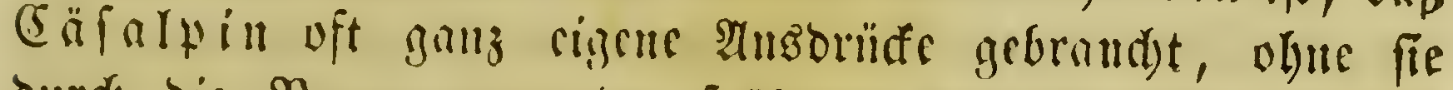

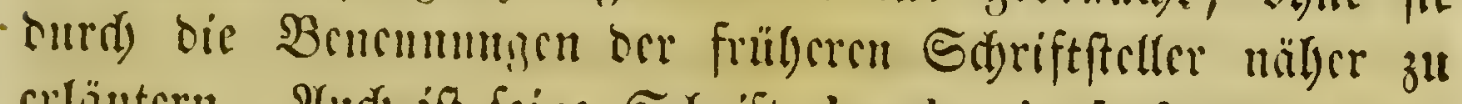
crläutern. 2(tud) ift frime Sd)rift de plantis fo folten grovor=

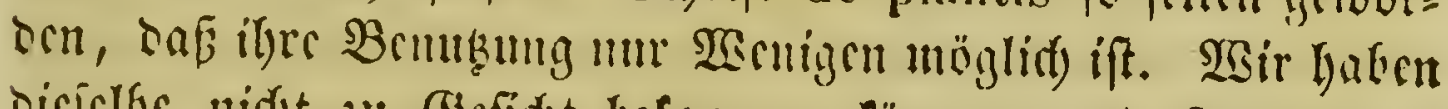

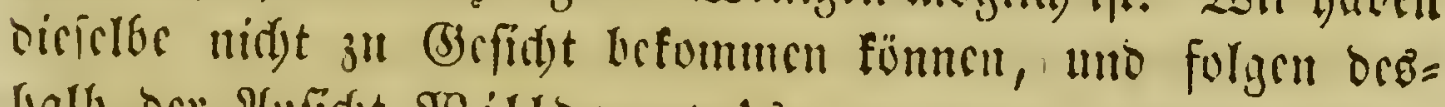
lyalb ocr sufidyt Silloc now'

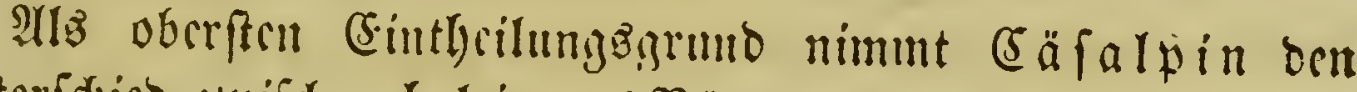

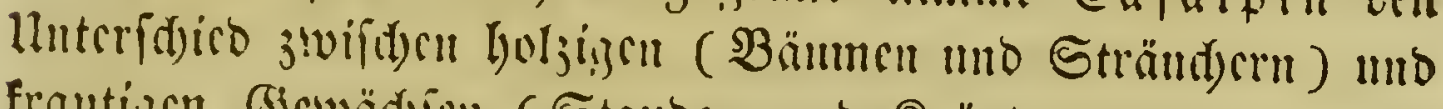

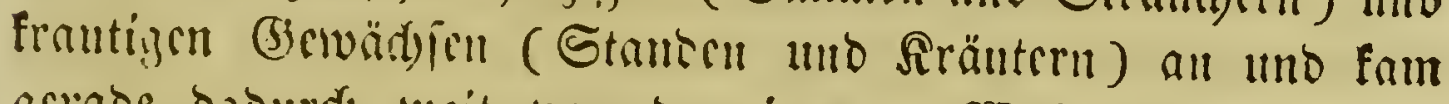

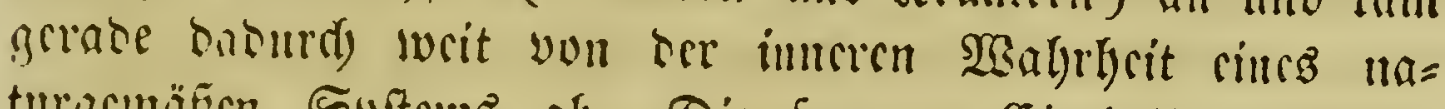

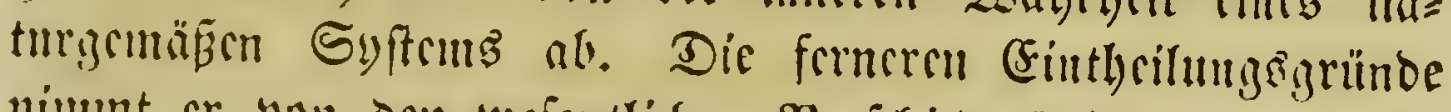

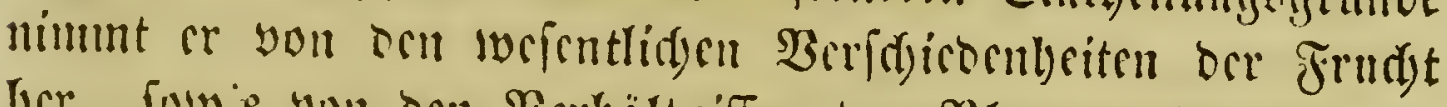

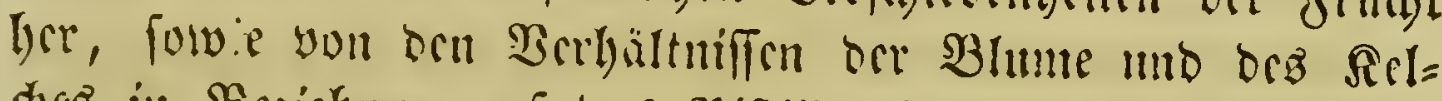
d) fityt anf rí 3abl unt Stcllming orr Samen unt bie Rage

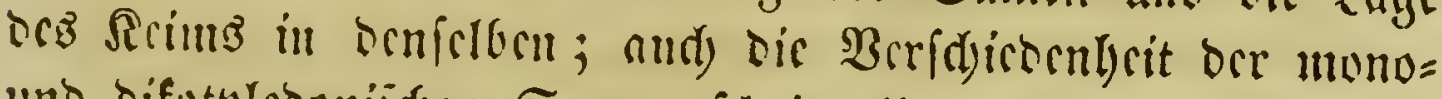

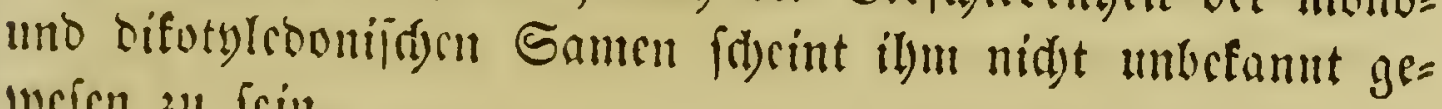
iveirn ful frin.

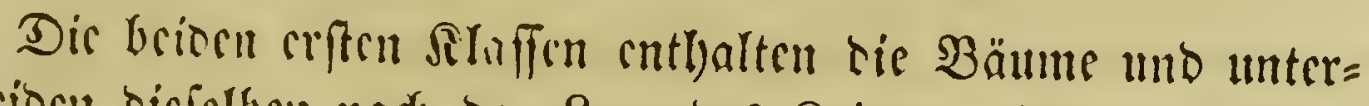

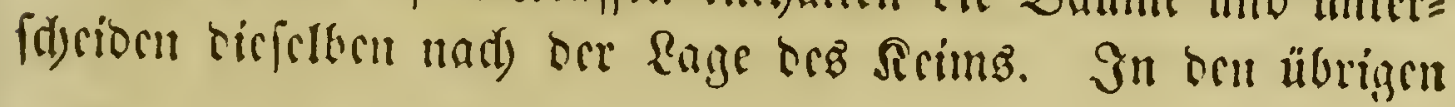

') De plantis libri XVI. Ad serenissimum Franciscum Medicem, Mlagnum Actruriae Ducem. Florentiae, 1583. 4. Appendix ad libros de plantis et quacstiones peripateticae. Rom. 1603. 4. - Diefer Itppenbix befinbert fid aud) in $\mathfrak{B} 0 \mathrm{c}=$ cone's Nuseo di piante rare della Sicilia etc. Venet.

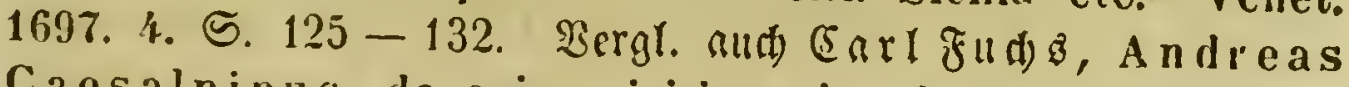
Caesalpinus, de cujus viri ingenio, doctrina et virtute. Marburgi 1798, 4. 


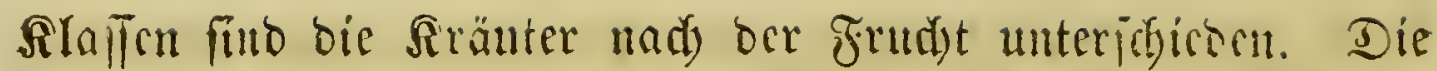

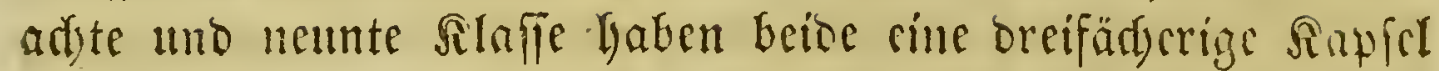
uno fint sanad) unterfdicoen, of fie faferige ober ziviebel=

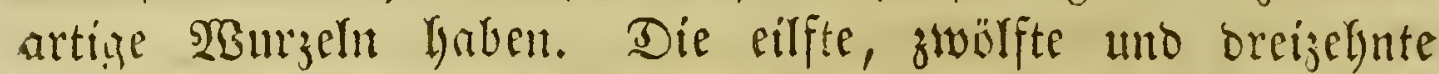

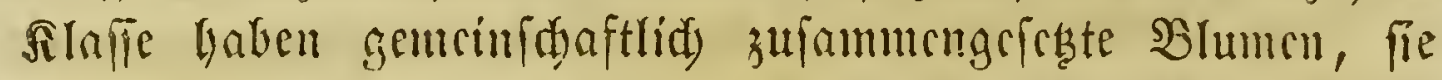

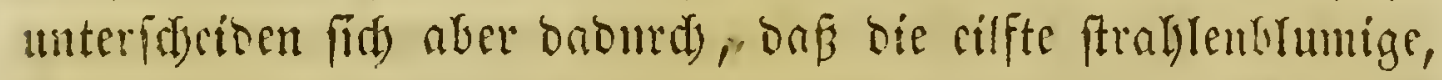
bie jwilfte geftreiftblumige uno bie breizchute fdeibenartig= blumize Pflanzen enthält. Sn tie vierzelnte Silaffe gehören

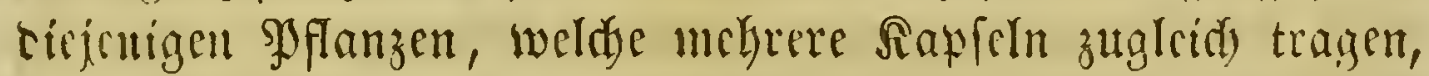

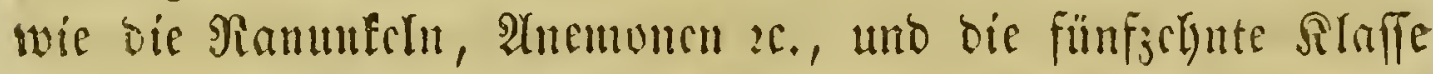

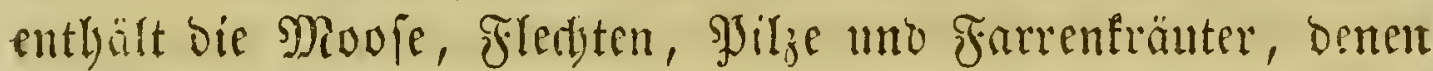

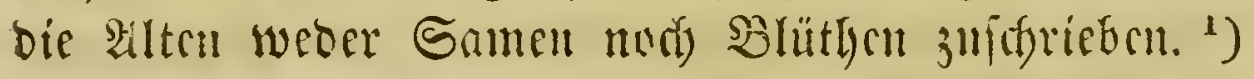

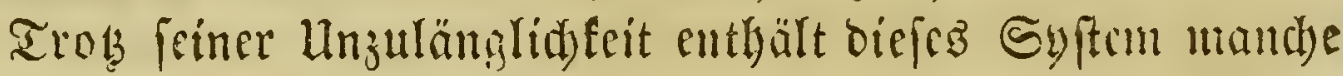

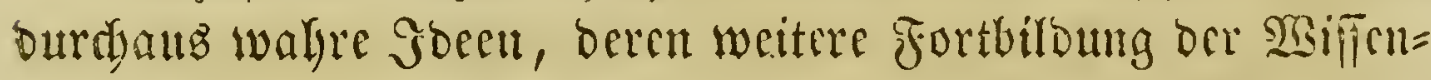

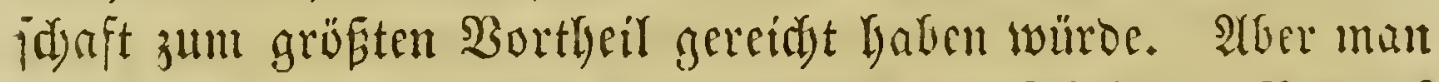

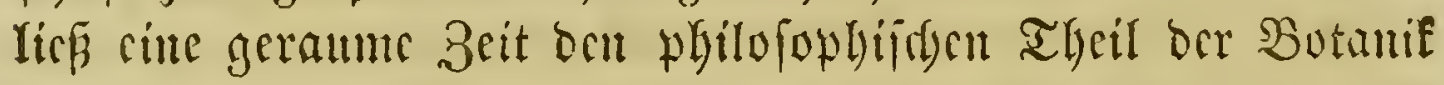
yanj unbeadjet, incem man es für lyimeidyent liclt, die

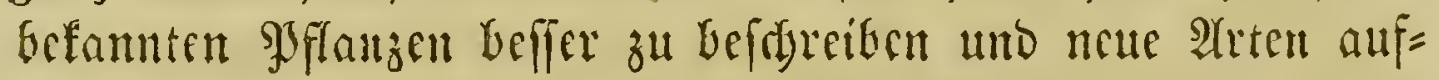
zufinoen.

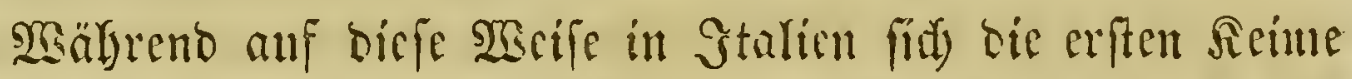
ocr neuen $\mathfrak{B}$ iffenjdaft entwiffelten, wav man aud in Doutid)=

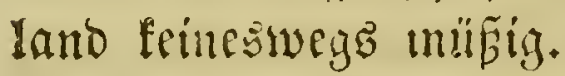

Unter ocn Bätern Der beutidyen Sotonif ift juerit

\section{Dtto $\mathfrak{B} \mathfrak{i} \mathfrak{u}$ fla}

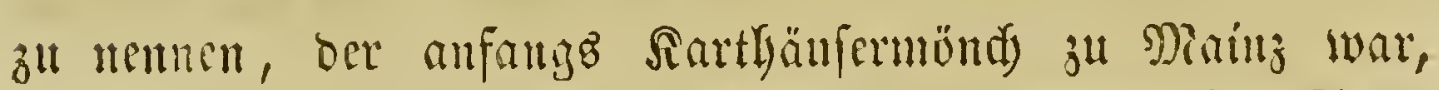

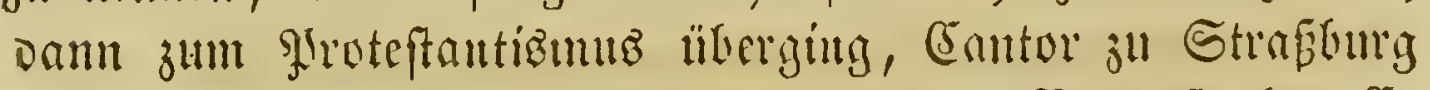

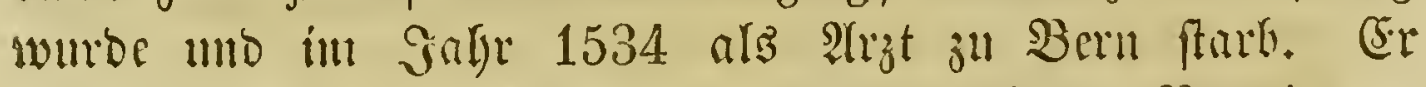

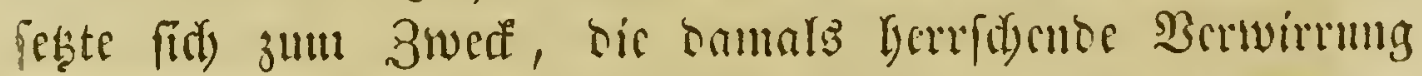

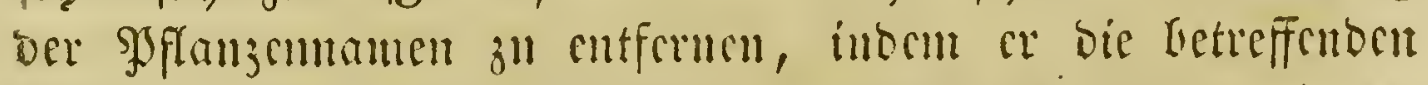

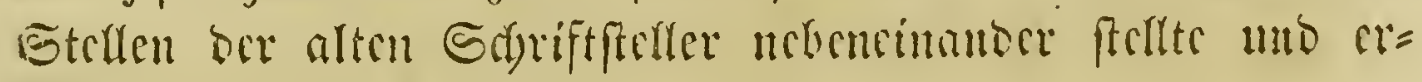

3) Bergl. Sprengel, llist. rei herbar. S. 426 זr. 


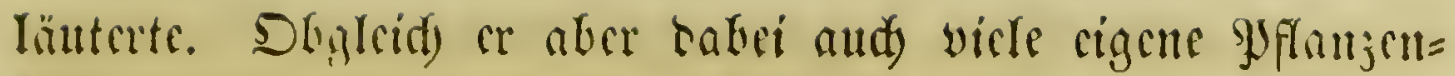

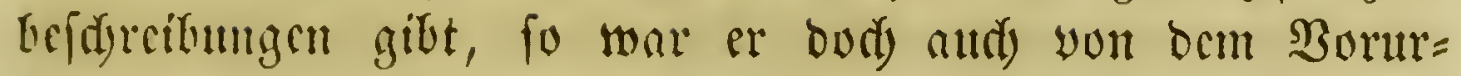

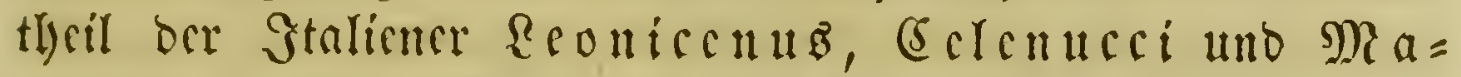
narbus, beren Sdjriften or befonters ftubirt batte, ange=

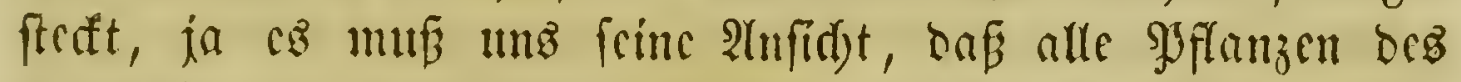

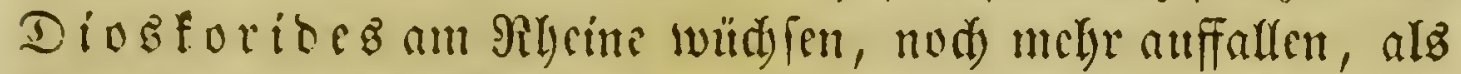

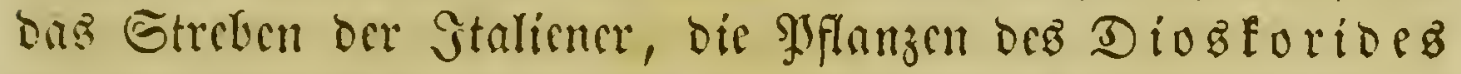

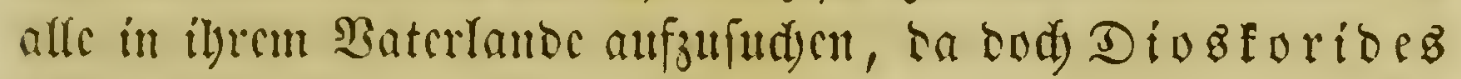
ferbft in Stalien selebt umb gefdricben hatte. F(t)er yon ber SPlangengcugraphie hatte man ramalz nod) fcimen $\mathfrak{B} e g r i f$.

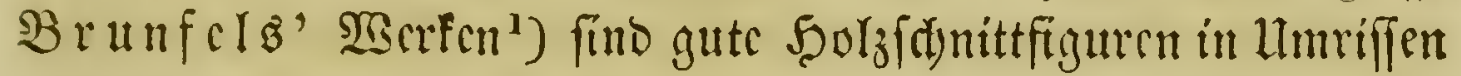
Lrigegeten, zunveilen aber am unredgten Drte angefügt.

IIm dicfrlbe Bcit lebte

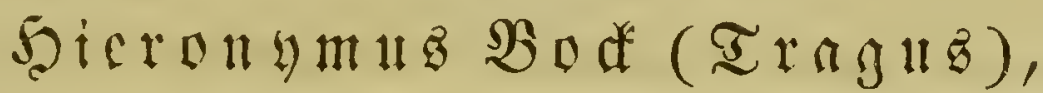

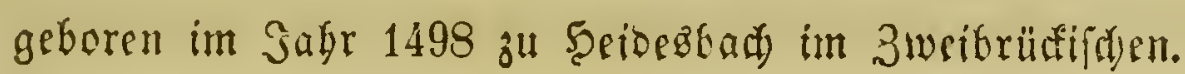

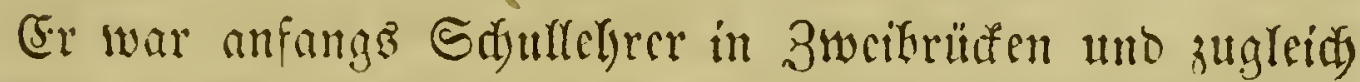

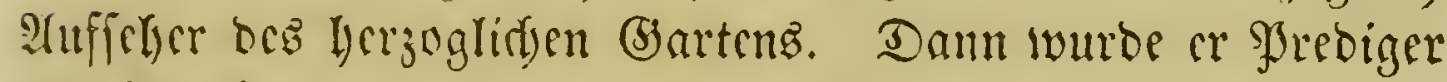

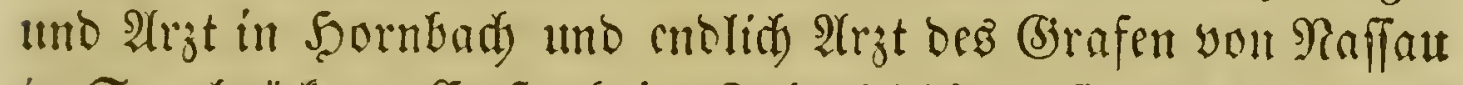

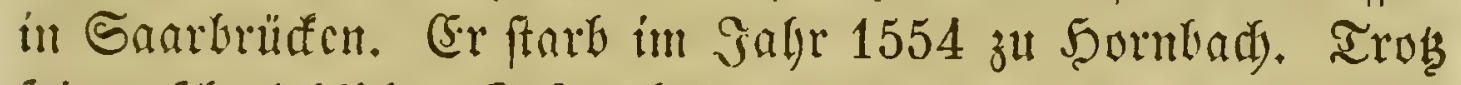

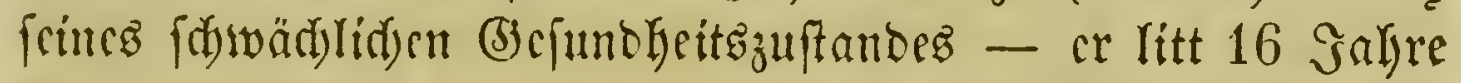
an ber Edywinbfudyt - war er ciner ber cifrigften Pflanzen= forfdyer, bic jemals gelebt baben. (Se Durdywanderte bent

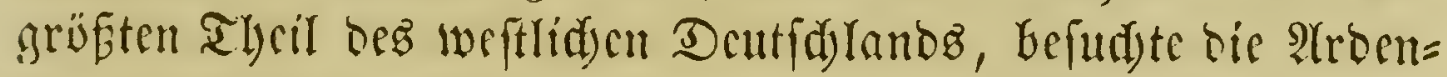
nen, ben Gura mo bic Edyucizeralpen. Befonters madyte

1) Herbarum vivae icones ad naturae imitationem initalae, et Appendix de usu et administratione simplicium. Argentor. 1530. Tom. I. 1530, 31, 32, 37, 39. Tom. II. 1530, 36, 39. Tom. III. 1536, 39, 40. Fol. Deutid): (5ontrafayt Sräuterbuch neulia befdrieben. Strapburg 1532. Fol. II. Thl. 1537. 2(ud) 1546 in Franffurt. Fol.; 1537 Fol. in Gtraffurg. 2lle 2usgaben find felten. Heber Die ürrigen Echriften biffez (Selefrten vergl. Srigel's Thesaurus 5.37 แ⿰ 334. 


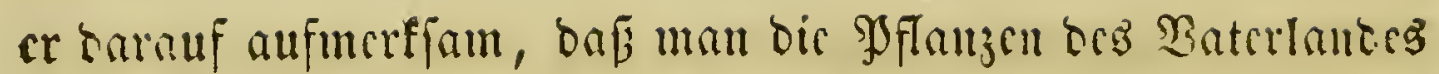

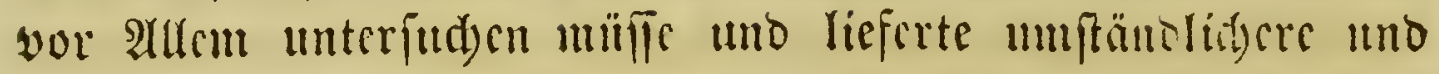

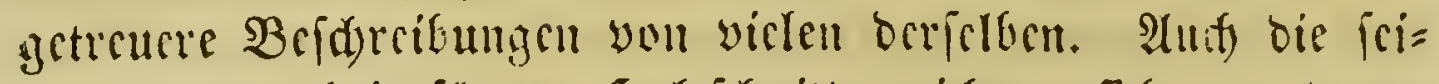

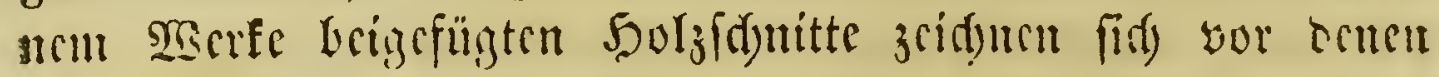

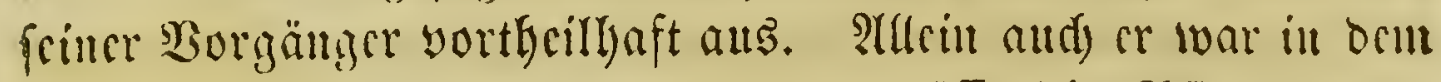

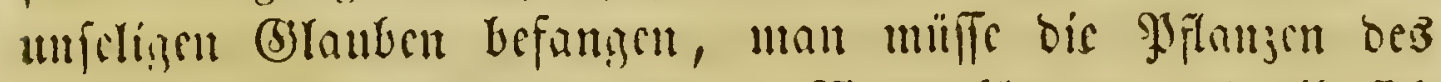

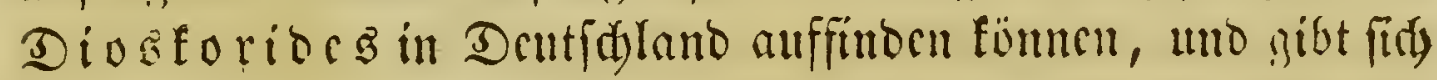

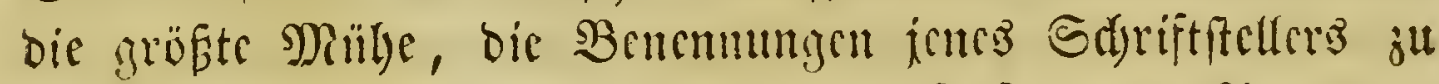

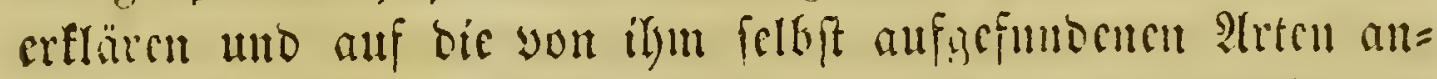

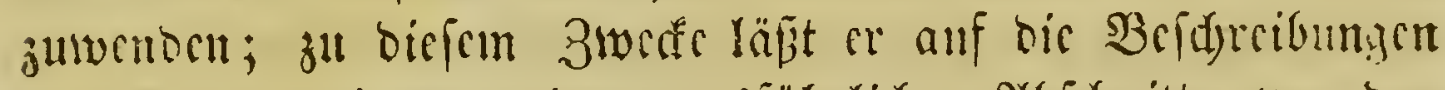

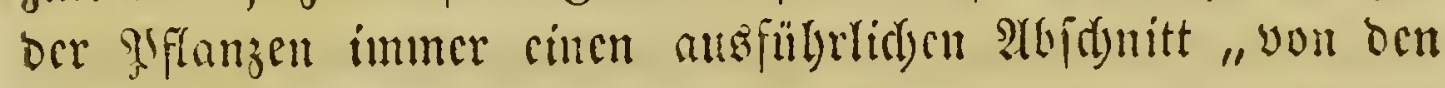
গanten" folgen. ${ }^{1}$ )

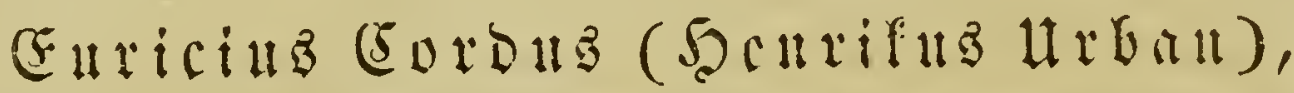

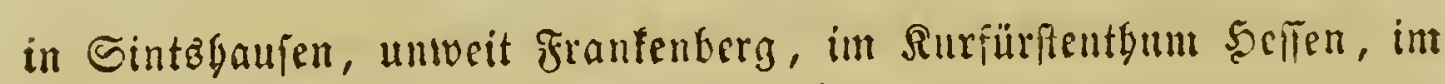
Sagr 1496 getoren,

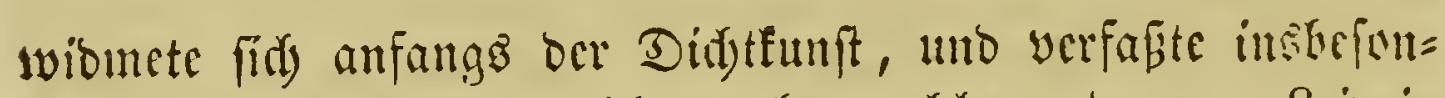

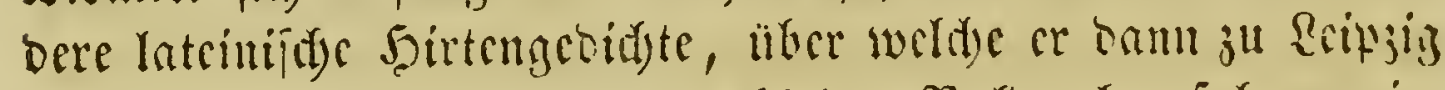

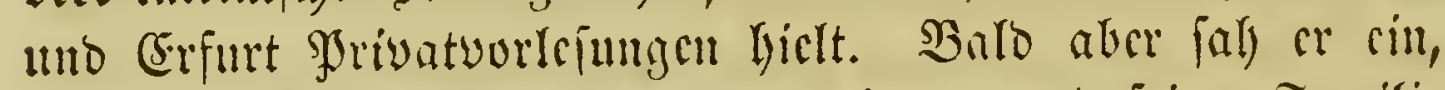

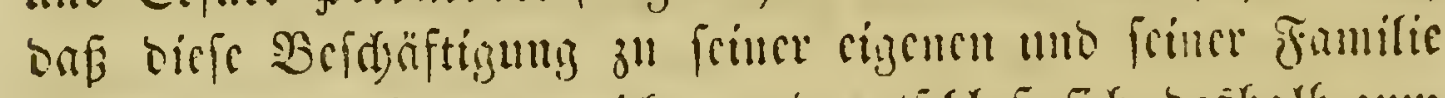

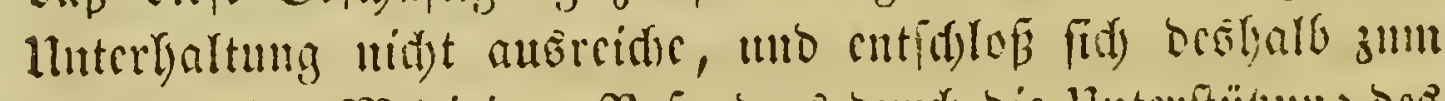

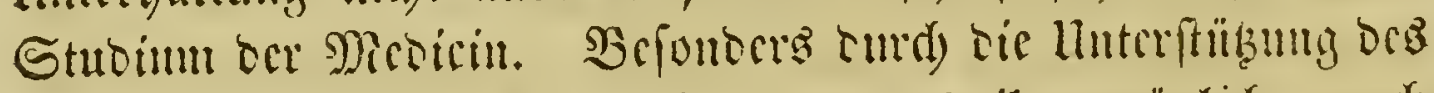
(Erfurtifd) ân

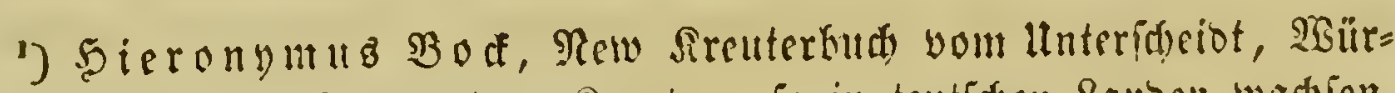
fung utu Ramen ber Sreuter, fo in teutfden Samben wadicn. Strapsurg 1539, ogne 5odzidnitte, fpater mit Jigurel 15 16 , 1595, 1630. Fol. Qateinifh: De stirpium maxime earum, quae ii Gerrania nostra nascuntur, usitatis nomenclaturis, propriis differentiis etc. ex lingua germ. in lat. convers. per D a vid Ky heram. Argentor. 1552. 2 Bor. 4. Die $\$$ ith bitongen befonbrib: Verae atque ad vivum expressae imagines omnium herbarum in H. Bock herbario depictarum: Ibid. 1550. 1553. 4. 


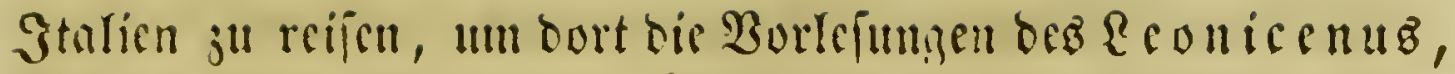

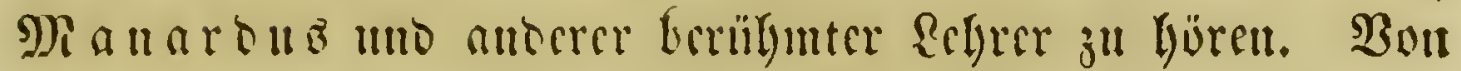
Eeonicenus, oer tamale fdou 94 Gabre alt war, crbiclt cr z"l Ferrara 1522 sen Doctorbut. Rad) frinte Zurtidfunft

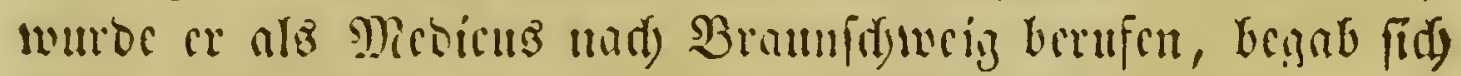

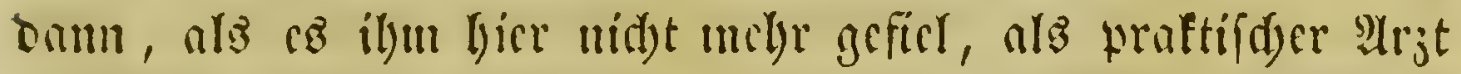

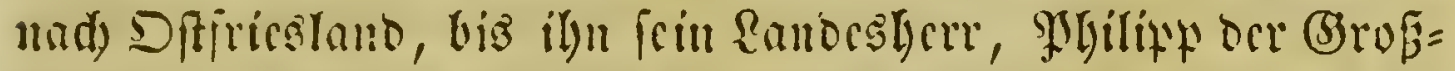

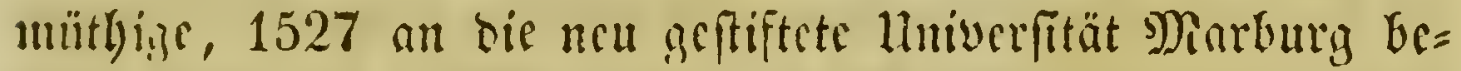

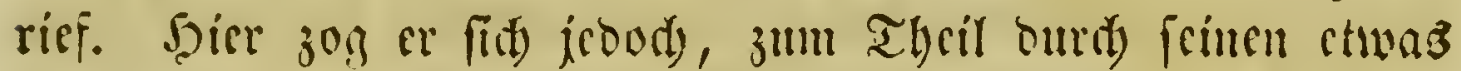

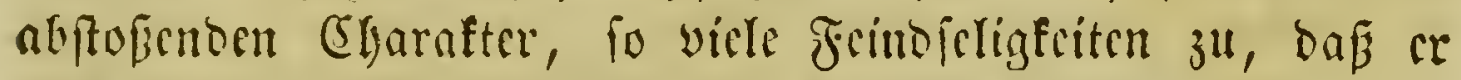
frol war, ars ilyn ber Magiftrat yon Bremen in Snly 1534 ars orbentlityen Mcbicus uno Mrofeffor des (s)ymafums in ricic Stad bericf.

Dort frarb or inl Gafre 1534.

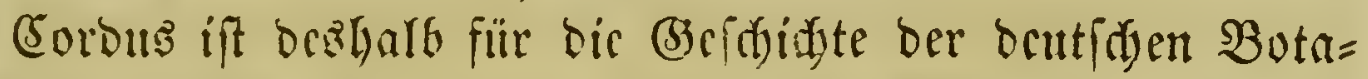
nif yon grofer SBidytigfeit, weil or ber (Erfte war, ber fid

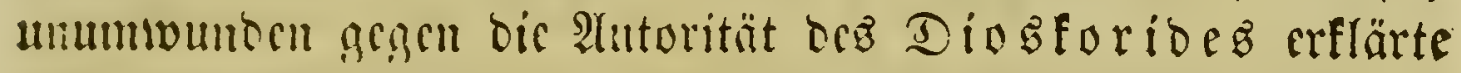
und barjutgun fudste, baßs as unmöglidi fei, dic von jenem

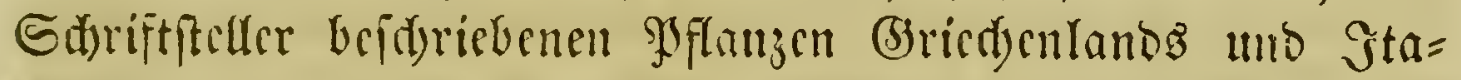
Jiens in Dentidjland alle zu fmorn. Er: watre baburd $\mathfrak{B} \mathfrak{r} \mathfrak{a} \mathfrak{n}=$ fels offener (5isgncr. ${ }^{1}$ )

Sein Sohn Barcring Gorous, ber in frincm 29.

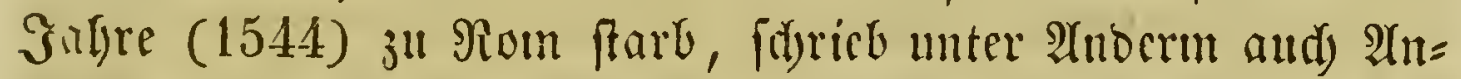

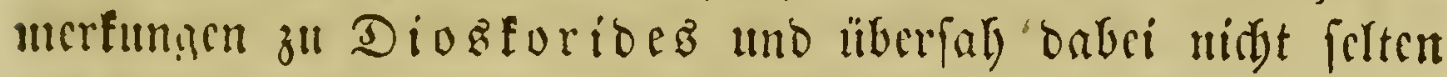

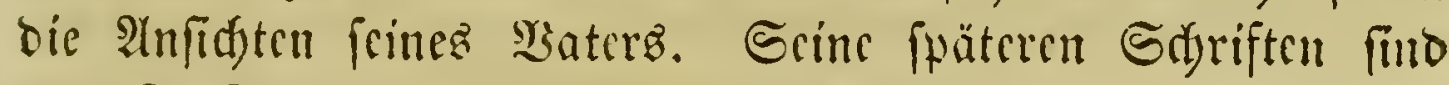
you $\mathfrak{R}$. (5)

1) Botanologicon, sive colloquium de herbis. Colon. 153\%. 12. - Paris. 1551. 12.

3) Valerius Cordus, Adnotationum in Dioscoridem libri V. Francof. 1549. Paris, 1551. - Argentor, 1561. Fol. Stirpium descriptionis liber quintus qua in Italia sibi visas describit; in praccedentibus vel omnino intactas, vel parcius descriptas. Hunc autem morte praeventus, perficere non potuit. - In Dioscoril, adnot. - Historiae plantarum libri IV. Sylva observationum variarum, qua inter pe- 


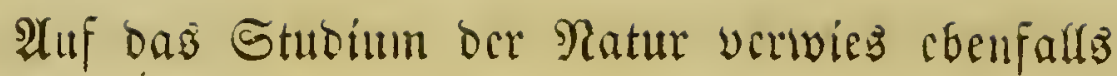

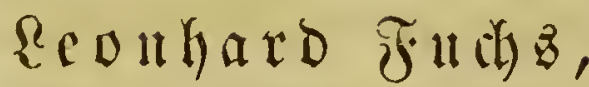

孔แ $\mathfrak{B e n b o i n g e n ~ i n ~} \mathfrak{B a t e r n} 1501$ geboren.

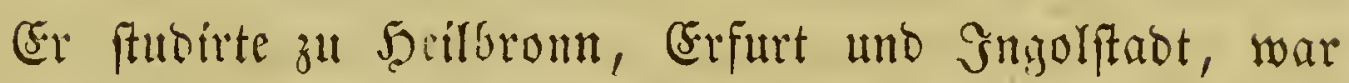

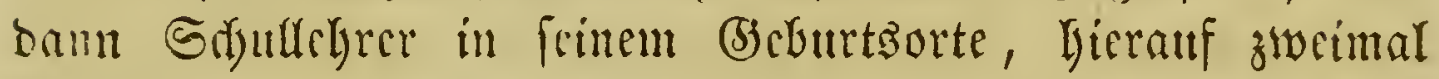

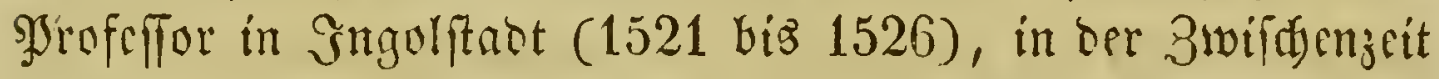
cimmal zu 2tnsbad), unb fam bann als grofeffor nady Iübingen. Bafrbft ftarb or im Galdr 1565.

Peten feinen Berticnften um bie Crrforfdung ber vaterläl=

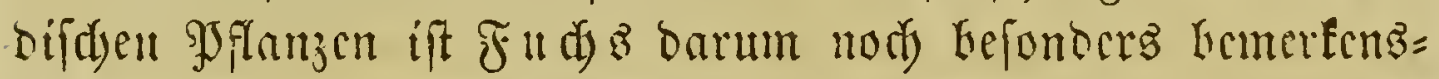
werth, weil er jucrit gुflanjen in Rebensyröß̈e in treffliden

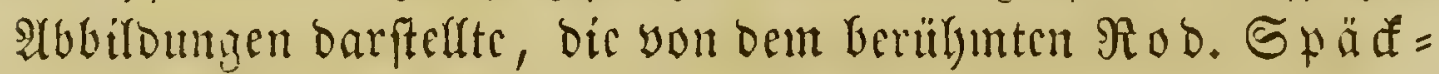
lin in 5 oly gefdutten wurben und fo gelungen fino, dab fie

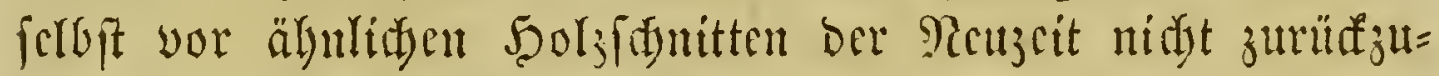

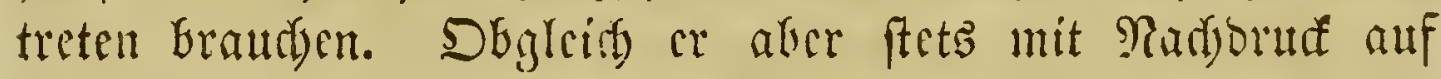

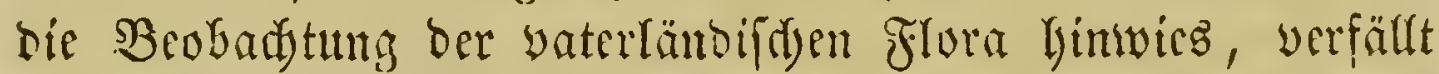
et bod bänig an folden Stelfen feiner Commentarien, wo $\mathrm{kL}^{2}$ auf Diostorioes zu reden foumt, in ben alten Jrethum uno gibt bann viclfadye Unridstigleiten. Bon feincm unten

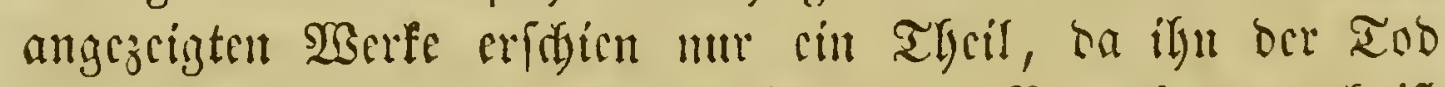
an ber Bulfendung beffelben werbittocrte. Bemerfensiverth) ift

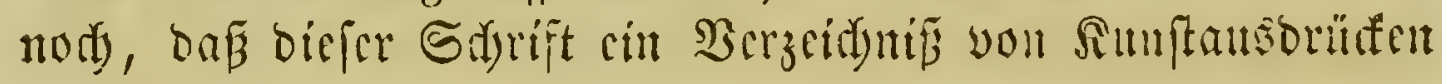

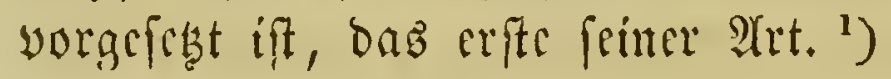

regrinandum brevissime notavit, primum de rebus fossilibus, ut lapidihus, metallis etc. deinde etiam plantis. ed. Cr. Gesner. Argentor. 1563. Fol.

1) De stirpium historia commentarii insignes. Basileae $15 \% 2$. Fol. - Paris. 1546. 12. - Lugduni 1547. 12. - Ibid. 1549. 8. - Ibid. 1555. 12. - Deutid : Rcw Sireuter=3ud) von \&congarb

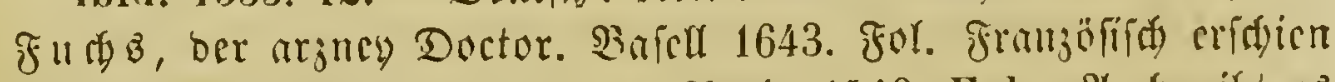

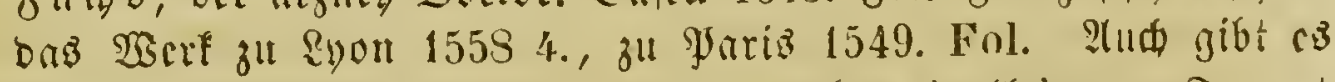

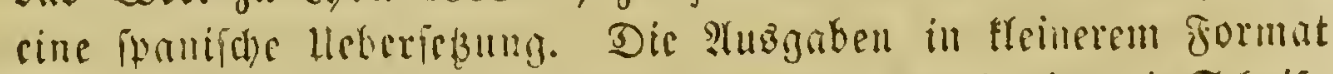

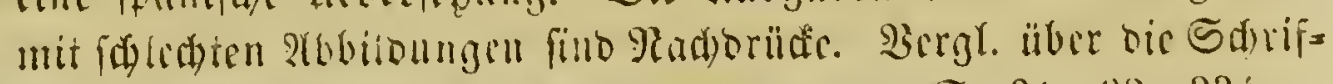

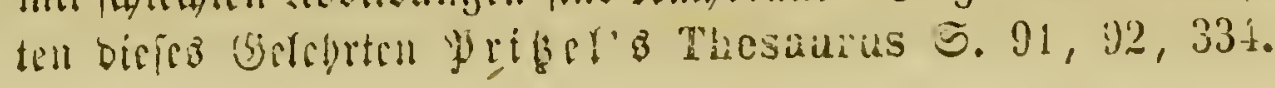




\section{Fonrad Gestler,}

iin Sabr 1516 gu 3üridi) geboren,

war cin Mann bon umfa fenben Rentuiffen mo uncrmulo= rityer Thatigfrit, weshals man ifn nidgt mit llned)t ben

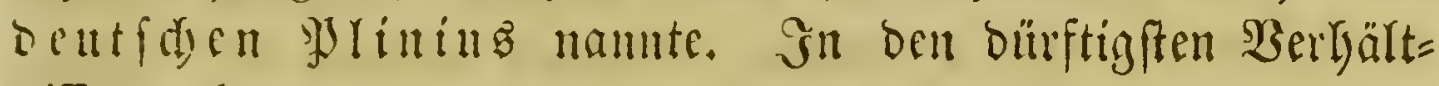
niilen geboren umb ergojen - er twar oor Sofn cines armen Sïrfduers - mufite er anfangs feinen Luterhalt als Famulno

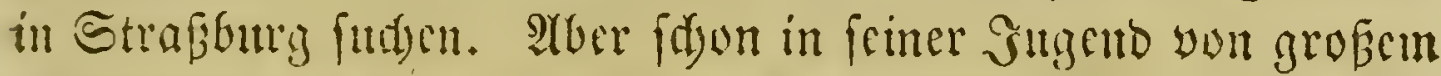

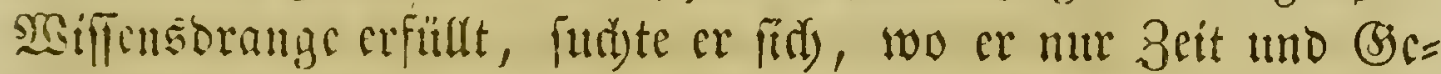

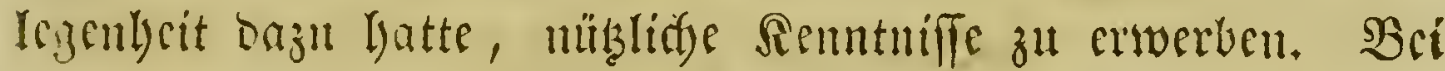
fciner 3urüfumft in feine Baterifast warf igm bie bortize Stfabcute cine Jemfion aus, damit er in den Stand gefest

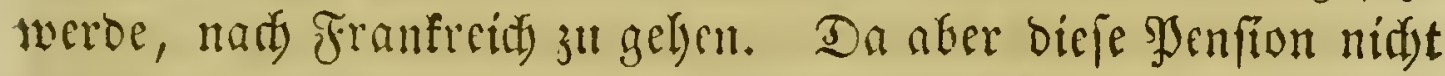

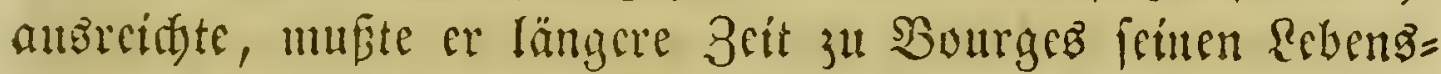

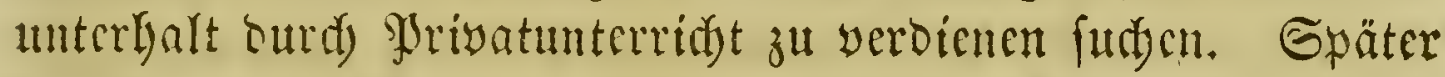

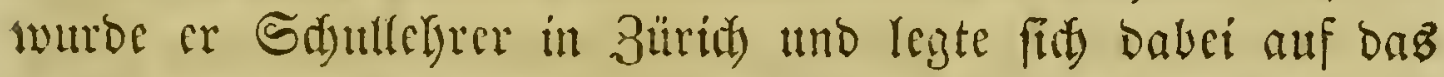
Etubium ter Miedicin. Dann befudse er nody inchrere an= ocre llniverfitäten und farb cnolit) in feiner Baterftadt als

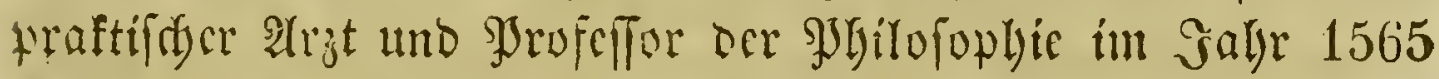
all ber Deft. Durdy feinen unnbläffigen Sifer hatte er es

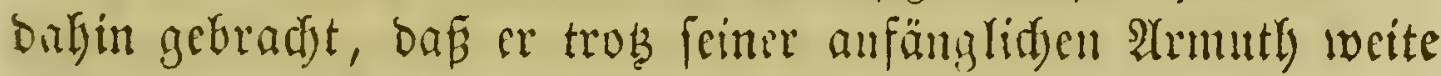
Réfen unternebmen, cine foüne Raturalienfammlung anlegen

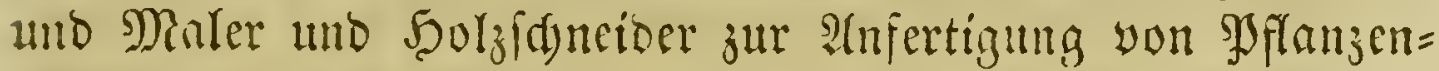

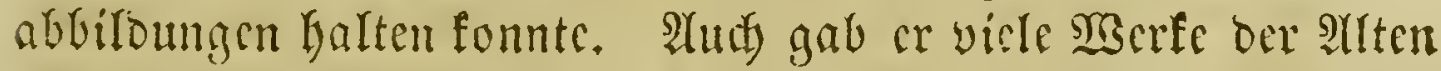

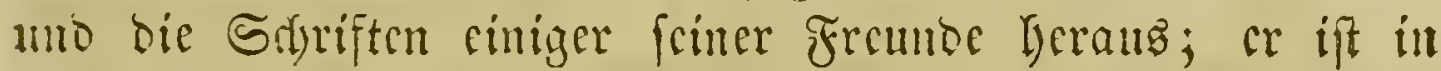
bicfer SBezicl)ung fidjon melgrmals erivälynt worben.

Áter aud nod) wergen eines anderen Umiftandes ift er für bie (Bcfdrid)te bor Botanif von Bcocutung. Ser war nämlid

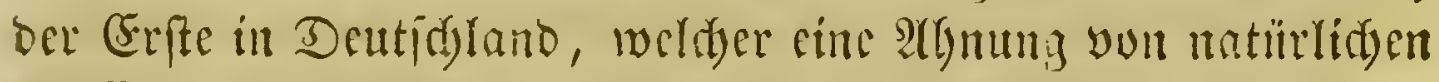
Slaflen uno (5)attumgen hatte uno die Merfmale ber $\mathfrak{B e r}=$ wantifdaft yon ben Blumen und Samen Gernalym. Salein

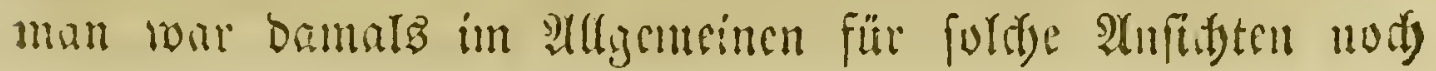




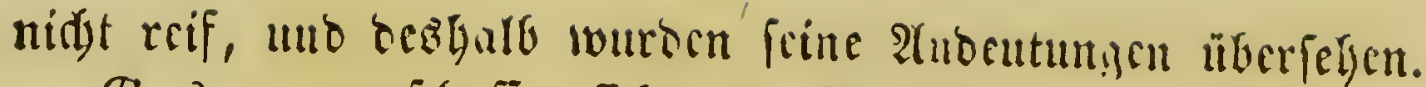

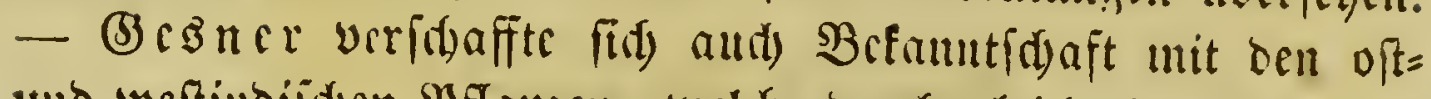

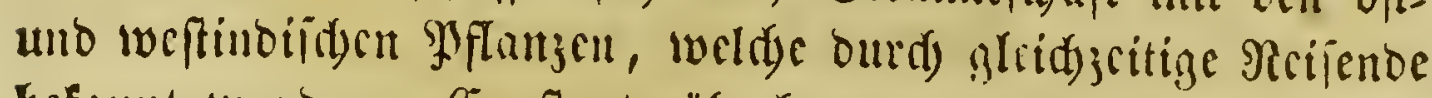

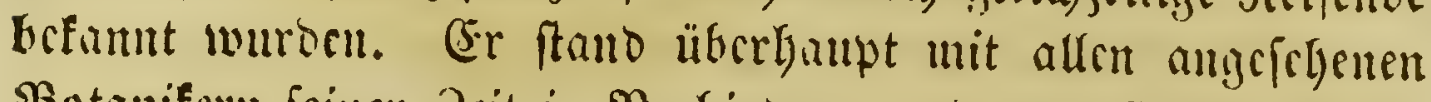
Botruifern frincr Brit in Berbinoung uno unterftügte uno be= forberte die Silfenfidsaft, wo ar mur founte. Er felbft gab

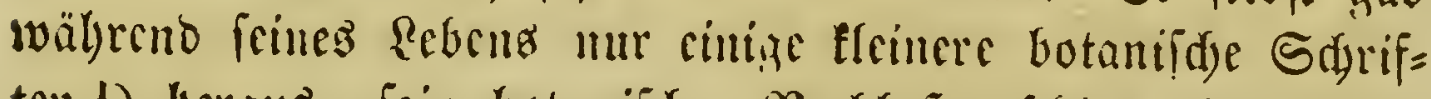

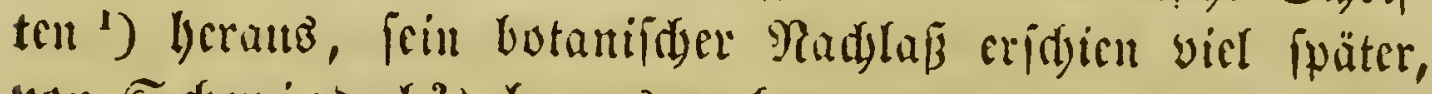

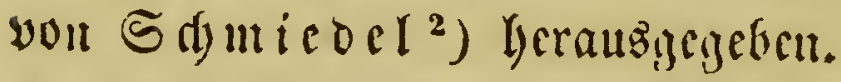

\section{Sond) geboren 1534 gu গürnberg,}

wurte son Milanibthon erjogen, reifte bonn mads Stalien, svurbe it Rom zum Doctor crmant uno wirte bann in feince

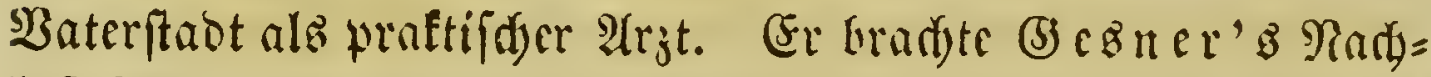

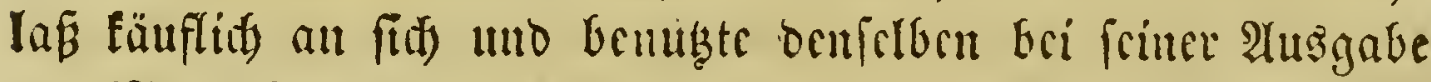

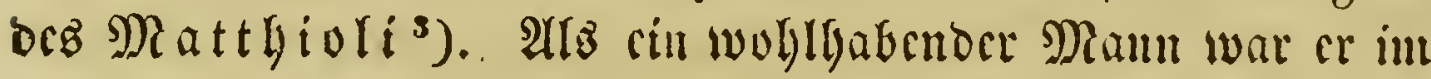

1) Enchiridion historiae plantarum etc. Basel 1541. 8. De plantis hactenus ignotis obne Drt und Gafr. Catalogus plantarum nomina latine etc. praeponens. Tiguri 1542.4. Tabulac collectionum in genere et particulatim per XII menses in usum pharmacopolarum. Argentor. 1553. Tig. 1587. - De raris et admirandis herbis quae etc. Lunariae nominantur. Tig. 1555. - De stirpium aliquot nominibus vet. et nov. Basel 15.57.8. - Epistola ad Ca sp a rum

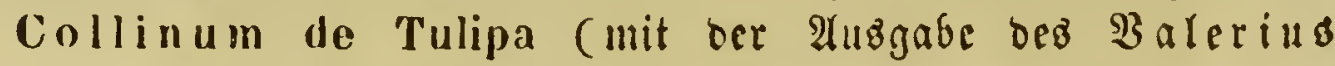
(5orou d). Argentor. 1561. Fol.

-) Opera botanica Conr. Gesneri per duo saecula desiderata, nunc primum in lucem edidit C. Cl. Schmiedel. Norimbergae 1751 - 1781. 2 I I geife. Pol. - Historiae plantarum fascirulus. Heid. 17.59. Heber bie zablreidyen Edfriften

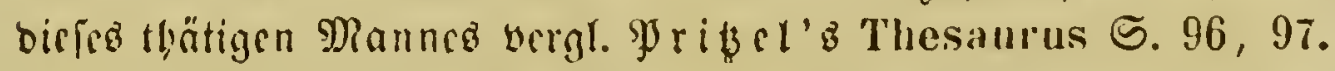

3 P. A. Mallhioli, De plantis epitome utilissima, nor'is iconibus et descriptionibus aucia at Joacho Camerasio. 
Stanoc, fiti) cince reid) ausigeftatteten (Sarten zu halten, Den cr ands in cince Sifuift befdrieben hat, bie als bie erfe

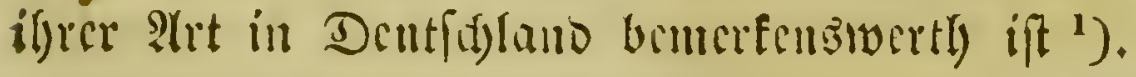

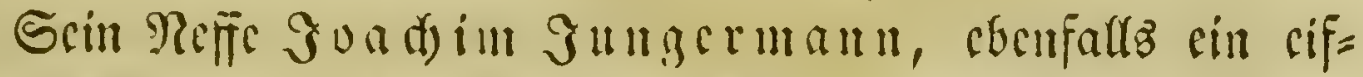

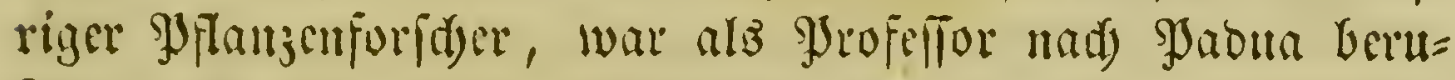
fen, ftarb aber auf citter Reife in ocn Drient ju Sorintl) in Zable 1591.

\section{Soha}

2rrat ợ Rorbyaufen, geftorben im Sabr 1587,

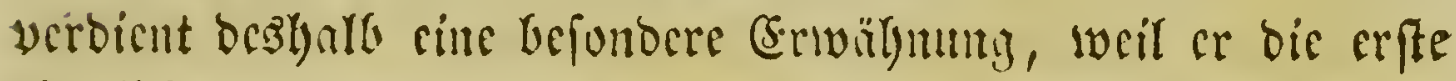

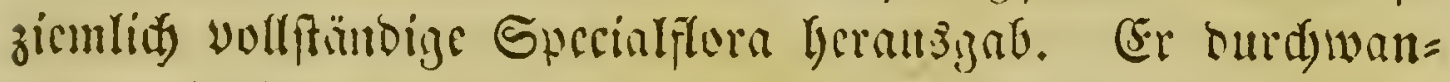
berte nämliti) ben Sarz, um bie bort wadbjenton Planjen

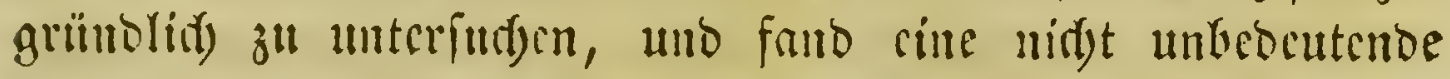

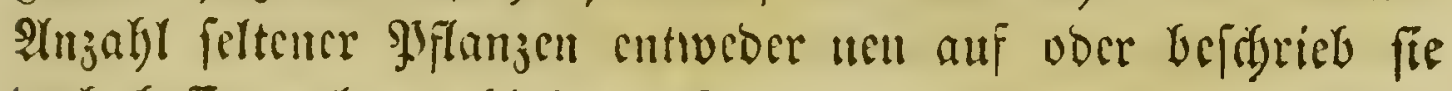
bod befler, als ca bialder gefdyelyen war. ${ }^{2}$ ) -

\section{Sacob Theodi,}

aนв Bergácen gebiirtig (barum Tabernaemontanus genannt),

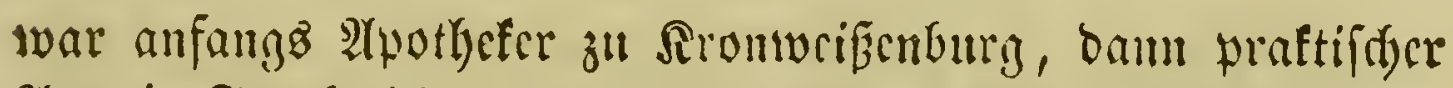

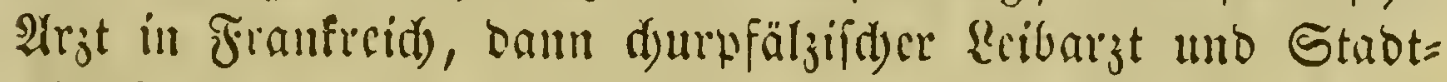

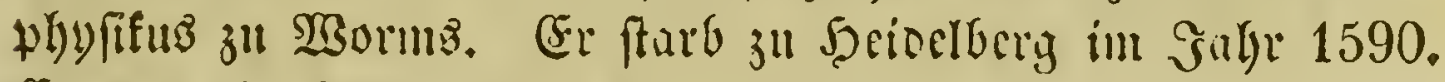

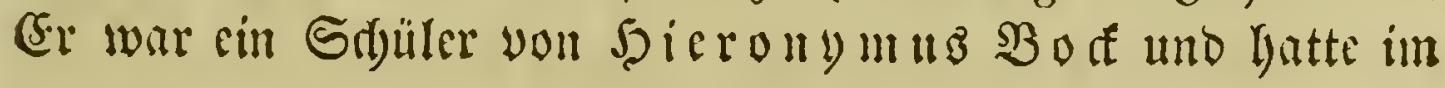

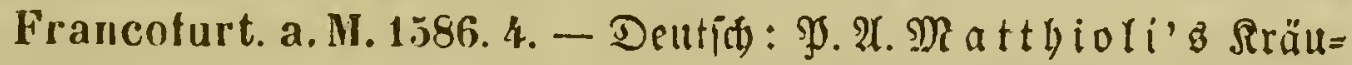
terbud) burd $\$$. (5 a merarium. Franff. 1590. Mit 1069 Figuren.

b) J. Camerarii hortus medicus philosophicus. Francofurti 1.588.

2) Sylva hercynica s. catalngus plantarum sponte nascentium in montibus et locis vicinis IIercyniae, qua respicit Saxonians, ad J. Camerarium, zuerit 1588 4. in Frantfult a. M. mit bes (5 amerariub Inetus, bann allein ju Rurbgaujen 1654 ober 1674. Die restere Ausizabe yat sy rizgel nirgenos auffinoen fönnen.

E. $2 B$ indeter, Brifi) s. Butanit. 


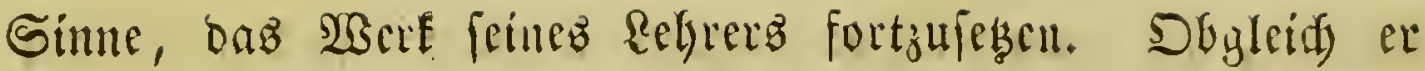

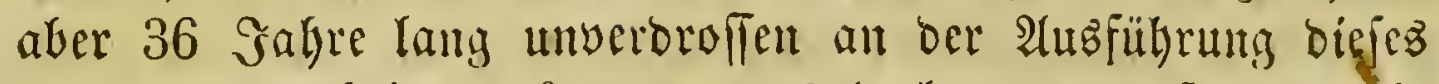
Borbabens arbeitete, toute cr ca bod) mur zur Şcrausgabe Des erften Theils bringen. Die Seraugigabe ber beiben ande= ren Theile übernafm Rifolaus $\mathfrak{B} r a n$ in Marburg. Sprengel behauptet, oẩ in biefem Werfe mefre alz 5800 פyflanzenartent entfalten feicn. 2480 oer felben fint abzebiloct. Die Figuren fino jebod) meiftens aus früberen alutoren ent=

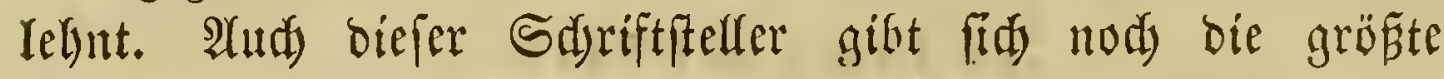

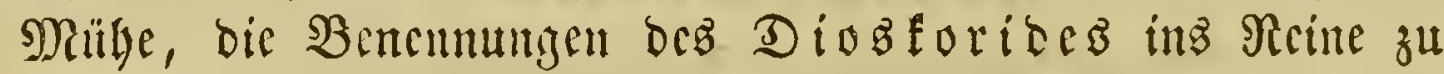

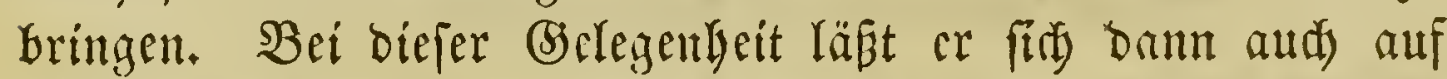
bie Ramen ciniger anberen Sprargen cin. Dic Sceilfräfte Der Spflanzen werben mit grof̧er Uumftänolidefeit angegeben ${ }^{1}$ ).

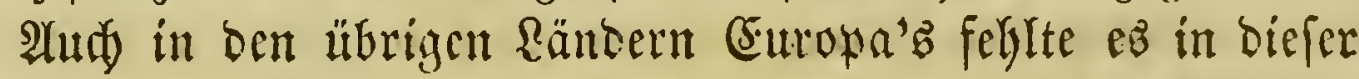

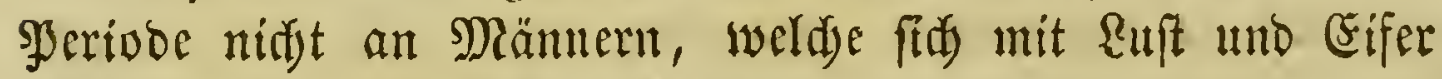
Dem Studium ber Planjentulloe wibmeten.

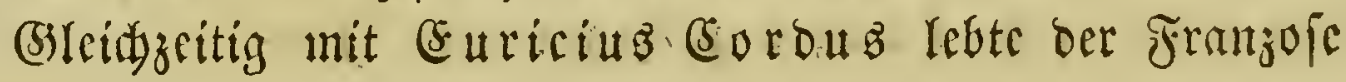

\section{Gean Ruelle,}

3u. Soiffong 1474 getoren,

anfangs Reibargt bes Rünigz, bann Domberr zu Jariz, ge=

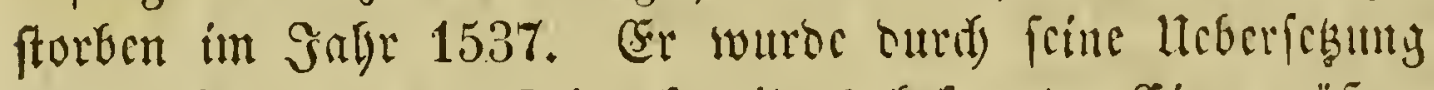

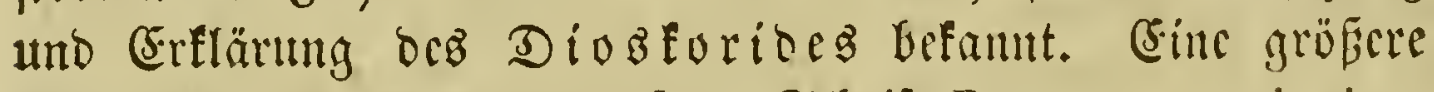
Alufmerffamfeit hätte wobl frite Sdyrift De natura stirpium verbient, fie watrbe aber zul ifrer 3rit faft gar nidyt readytet. Diefclbe entlält eine arbanolung liber bic Bencmuntigen ber

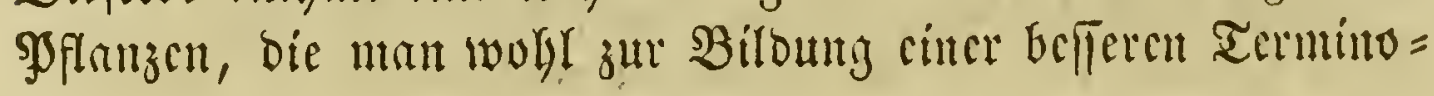

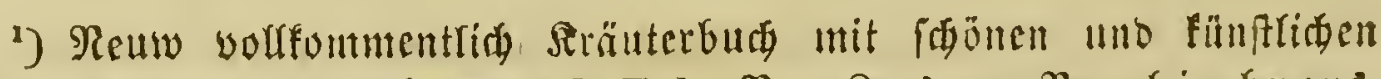

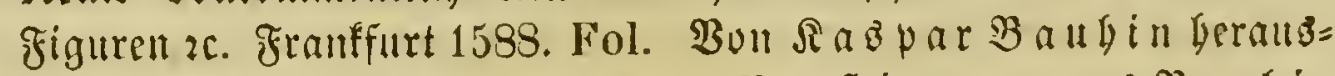

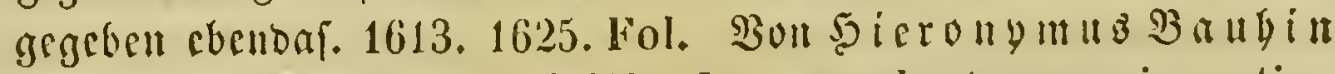
Bafel 166\%. Fol. - Rateinifa): Icones plantarum sive stirpium tam inquilinarum quam exoticarum. Francof. 1588. 1590, 4. obliquo; 2225 2tbbildungen. 


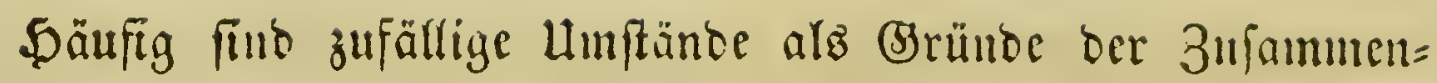
ftedung angenommen. Er unterfdecibet 3. B. TSalobäume, Gefträudge, frudttrajende Bäume, fdönthlïlecube, wohlric= dende Planjen, foldee, bie an fteilen und felingen Drten, an Sümpfen 3 . Wadjien 2 ., oblue auf ilgre natürlidye Berwanot=

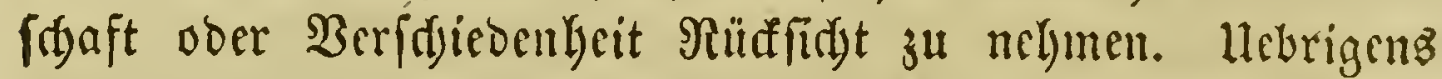
bat Da le d) a mp aud) ausläubifde Pflanzen in fein SSerf auf= genummen. ${ }^{1}$ ) lleber bie yon iflu neu aufgefumbenen ober beffer beffricbenen $\mathfrak{P}_{f l a n} e n$ yergl. Sprengel, Hist. rei herb. libr. IV, cap. 5, Scite 433 fr.

Melgr alz bie franjofen zeidyneten fid in biefer Mgeriobe

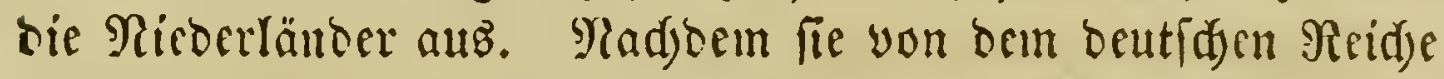
getrennt und unter bie Serridaft bes graufanen gybilips II. von Spanien gefommen waren, befreiten fie fids enclids, Durd) ben politifiden und religiöfen Druaf zum Areuferften ge=

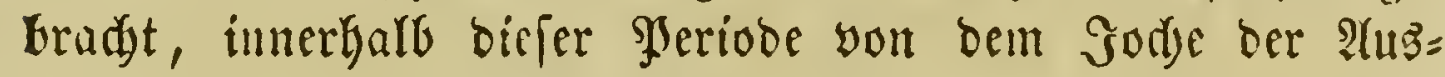
länber. Der melle Staat fam balo zu grof́cr Marbt uno serbreitete feine Colonien uno feinen 5 ander in rie entfernteften

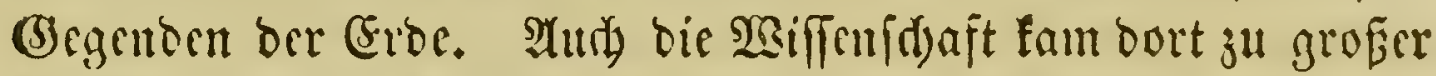
Shlithe, uno baf andi tie Şutanif insbefonbere burdy bas Befauntwerben unit ocm Pflanjenteidythm ber nencu Sart geförtert wurbe, ift leidyt begrefflidy. Alus tenjenigen Mäu= nern, weldye fid un bie siiflenidyaft serbient madyen, fint bauptjädslidy orei bervorbulgeben:

\section{Rembert Dodocus (Dodonacus ),}

geboren zu Redeln iut 3agr 1517,

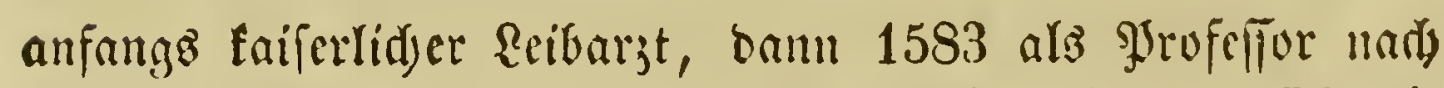
Reiber berufen, geftorben im Gngre 1586. (5r tegte fids mit

1) Historia generalis plantarum in libros XVIII per classes arteficiose digesta etc. Lugduni 1586. 1597 Fol. mit 2696 Fig. II Thle. Der Rame oca Sierfaffers feglt auf sem Titel.

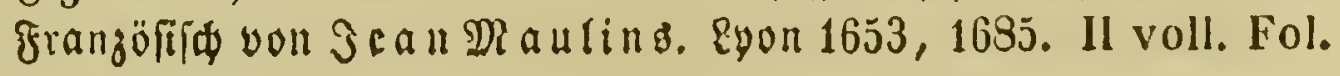




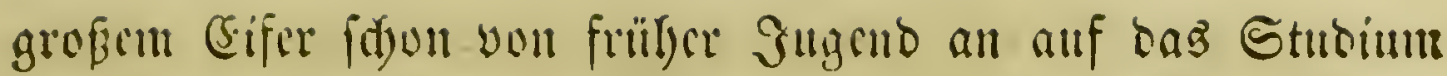

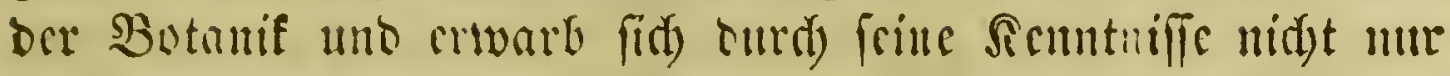

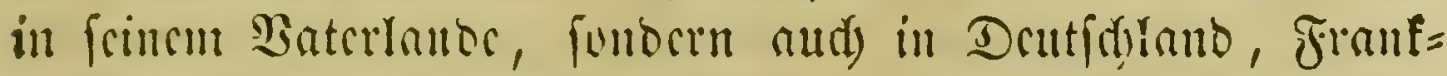

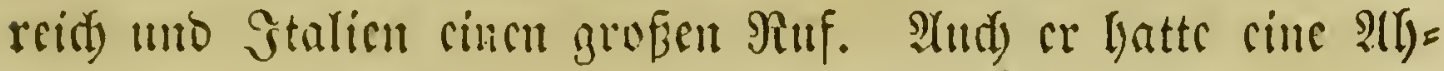

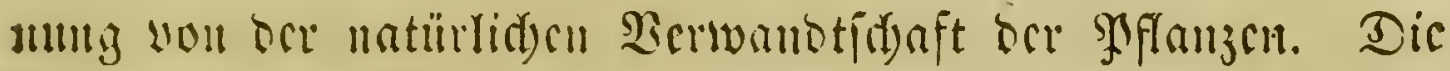

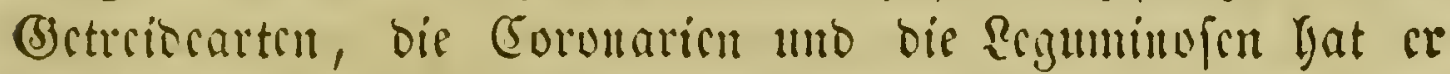

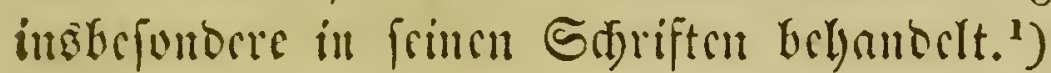

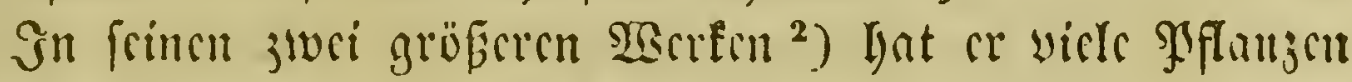

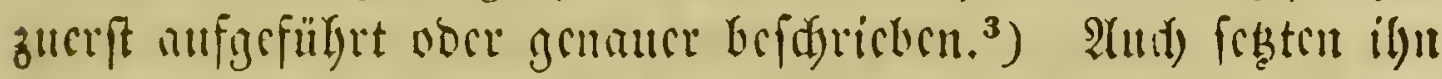
frite günftị\}n Berbältniffe in ocn Stant, beffere Abbildungen, alßz frine Borgänger, ju Viefern. Scincm Sisrfe stirpium historiae etc. find 1330 \$ृoljidnnitte brigsfügt. ${ }^{4}$ )

\section{Matthiaz de R'D bal ( Robcliub),}

zu Ryffer in Frandern 1538 geboren und geftorben alz scoffotanifer

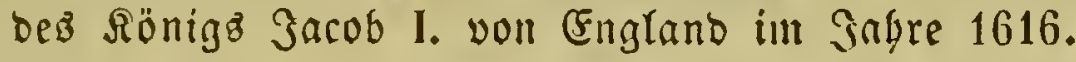

(5.r lyatte Deutidyland, bie Sdjwciz, Jtalicn und Jrane=

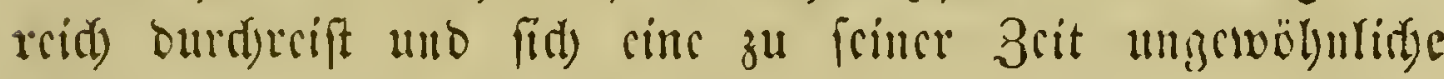

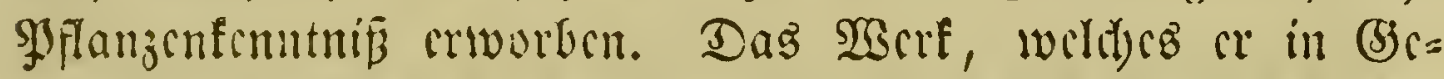

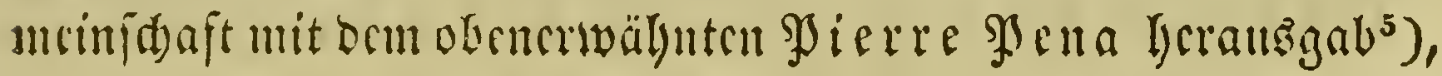

') Frumentorum, leguminum, palustrium et aquatilium herbarum lisistoria. Antv. 1566. 8. - Florum et Coronarium odoratarumque nounullarum herbarum hist. Antv. 1568, 1569. 8.

$\left.{ }^{2}\right)$ Cruydeboeck. Antv, 1563. Fol. Stirpium historiac pemptades sex, sive libri XXX. Antv. 1583. Fol. Sion $\mathfrak{L} \mathfrak{o b} \mathfrak{b}$

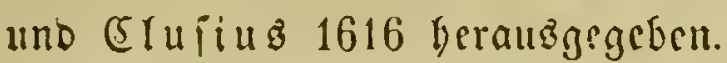

$\left.{ }^{3}\right)$ Siebe Sprengel, Histor. rei herb. lib. IV, c. 5, S. 395 fi.

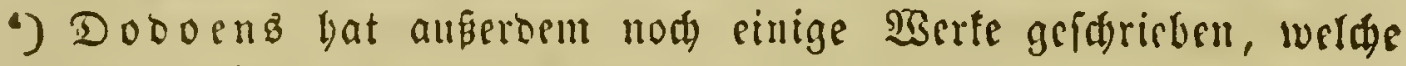
man nebft ben Heberişzungen feines Srubdeboef bei $\mathfrak{s} r$ üger,

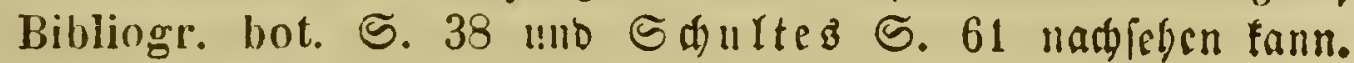
Bergl. and 9y rifel'z Tliesaurus S. 71.

b) Petri Penae et llatthiae de L'Obel, Nova stirpium adversaria etc. London 1570, 71, 72. Antv. 1576. Mit cinem ?ngange: Rariorum aliquot stirpium appendix. $\mathfrak{S}$. Srizel's Thesaurus S. 65. 


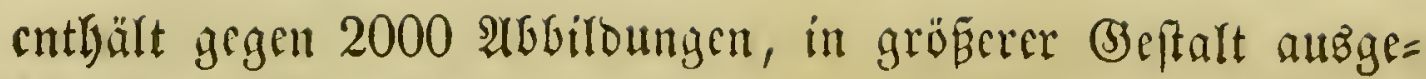
führt, als es bisher gridychen war. 2(ud) in feimen 2 Berfen

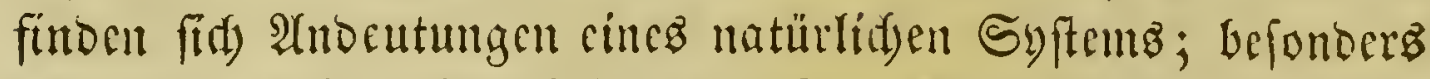
hat ar bie meifen ibm befannten Monofobyletonen zufammen=

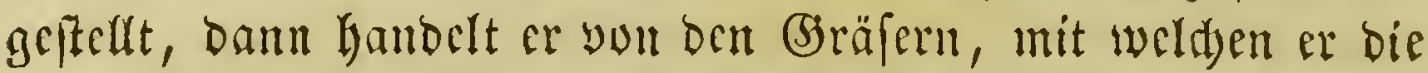
(3)treibe= und Sidiffarten zufammenbringt, fommt bann zu Den Gribeen und Scitamineen, zu ben Binfen und Syperoibeen

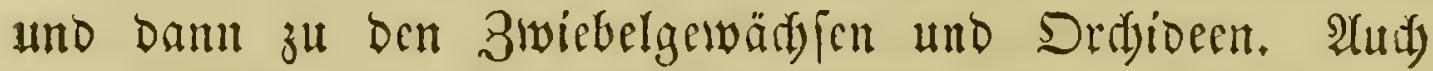
anbere Sflangenarten ftellte er nad, Berivandtidjaftsmerfmalen zufammen, jeood 1 ar ifm bie Goee eincs natürliden Sy ftems

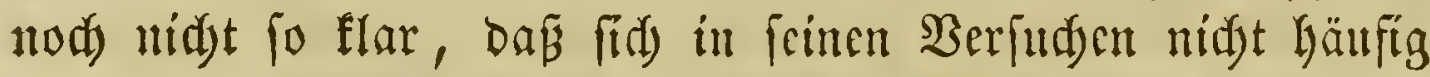

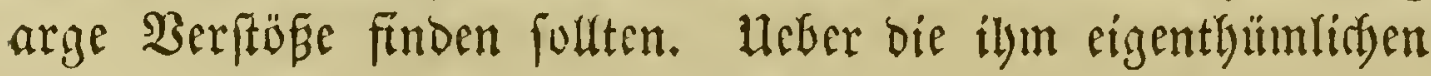
SJflingen vergl. Sprengel, Hist. rei herb. lib. IV, cap. 5, S. $400 \mathrm{f.}^{1}$ )

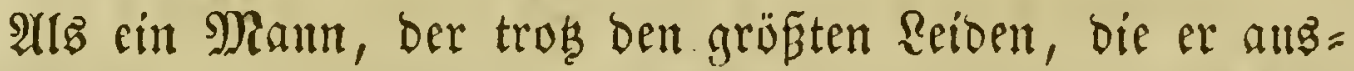

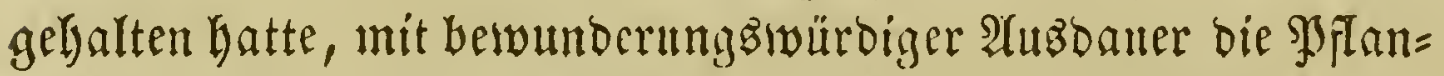
zenfunbe betricb uno ju bicfem 3weffe grofe und befduerlidse Neifen unternalym, zeigte fid

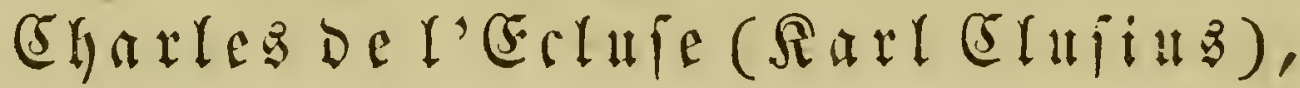
geboren in ber (Srafidaft $\mathfrak{A}$ rtoiz in Sabre 1526.

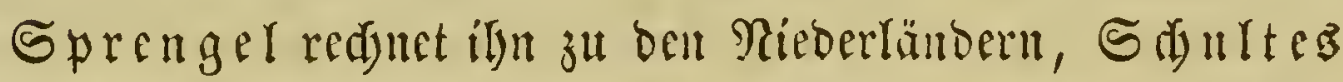

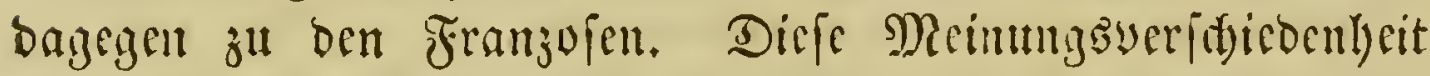

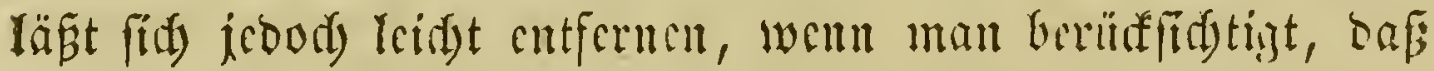

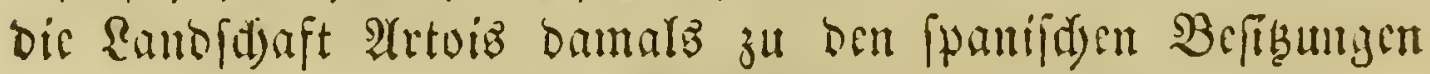
in ben Riederlanden gehürte.

1) Seine übrigen $\mathfrak{B e r f e}$ fino: Plantarum sive stirpium historia, cui annexum est adversariarum volumen. Antv. 1576. Fol. Plantarum s stirpium icones. Antv. 1581 - 91. 2 part. 4. obl. - Stirpium illustrationes a Guil. Howe, nad frinem Tube exflyiencn, Ronb. 165j. 4. - Kruydtboeck olt Beschryvinghe van allerleye Ghewassen, Hesteren ende Gheboointen. Antv. 1581. Fol. 


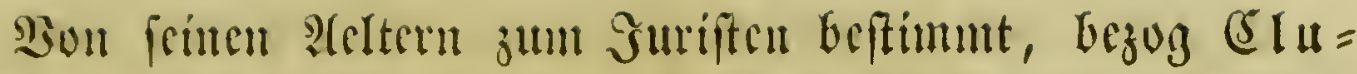
fius dic Univerfität Rüwen. (5r fand jeoud) bald, bar die

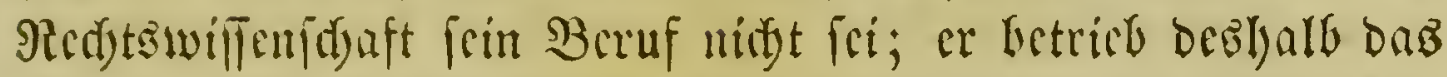
Stmbium bor damals notlywembigften Spradien mo befdäftigte

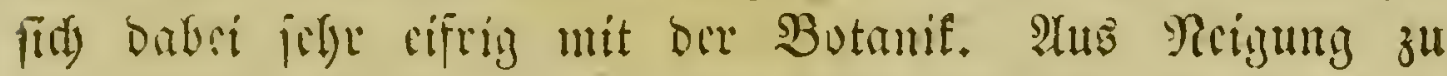

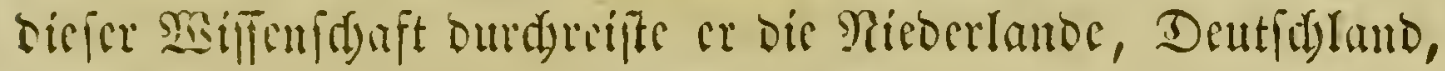
Franfreid, Englimo, Hnyarn, Spantion mo Jortugal uno

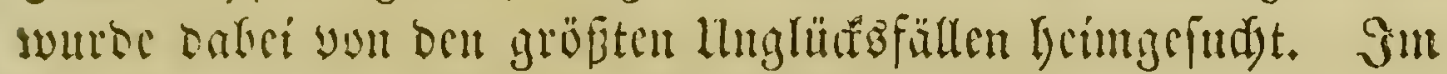

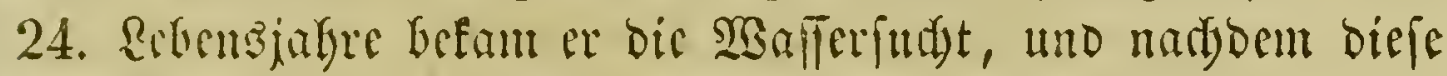

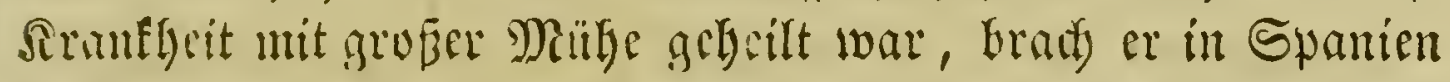

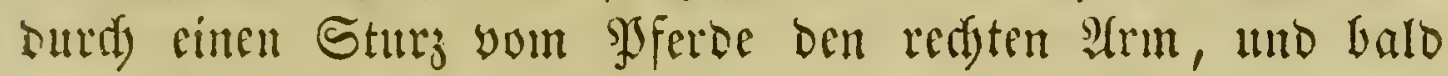
barauf widerfugr ijm berfelbe lufall an bem rediten Sijenfel.

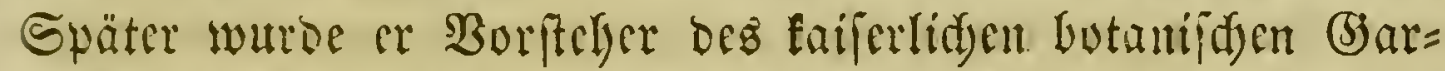
tens zแ : frinem 55. Rebensialite verrente er fid) Den linfen Juf uno

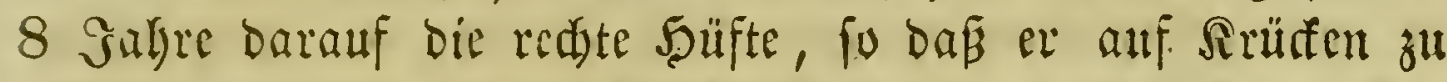

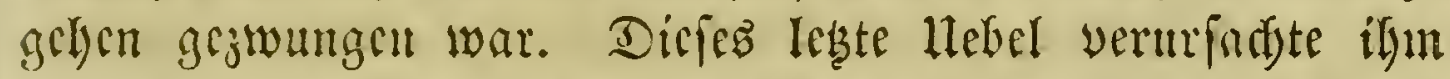

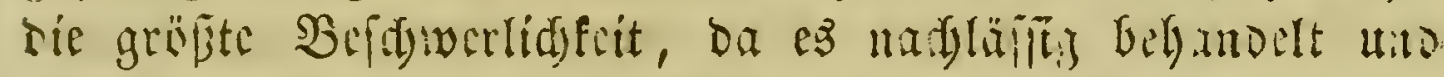

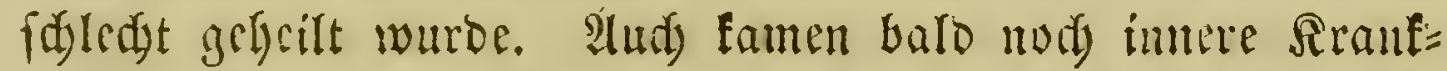

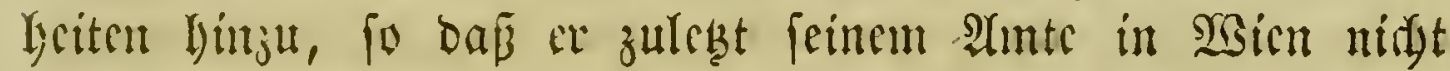

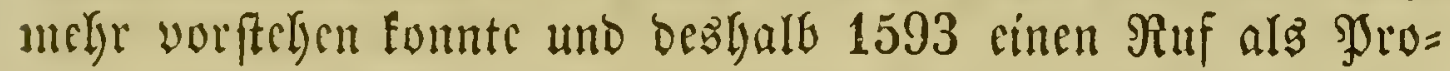
feffor mady Reioen amahm. - Dafelbft ftarb er im Sahr 1609. Alfe jene Reiben Des Rörpers waren aber nidst im Stante, bie Sraft frites (5) ciftes zu fdwäd)en; mit uncrmüblid)er $\mathfrak{A} u s=$

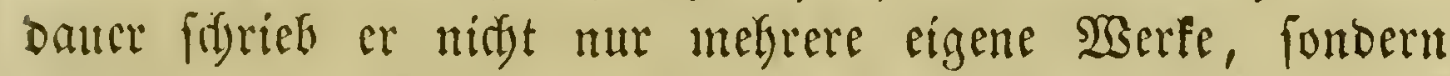

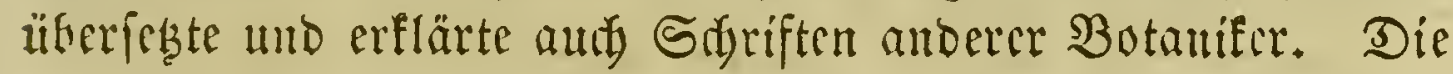
won illu ren aufigefundenen uno beffer, als früfer, bejdrie= benen glflanzen fint felfr zalylreidy. Bergl, barüber Sprengel, Hist. rei herb. lib. IV. cap. 5, S. $410-422 .{ }^{1}$ )

1) Scine Şauptwerfe fino: Rariorum aliquot stirpium per Hispaniam observatarum historia. Antv. 1576. 8. Rariorum stirpium per Pannoniam, Austriam et vicinas quasdam provincias ubservatarum hist. Ibid. 1583. 8. Bribe zแfammen: Rariorum plant. hist. Antv. 1601-1633. Fol. - Curae 
Einglano war in biefom 3citraume viclfady von blutigen Büligerfirgen zerriffen; nur wemige feiner Rünine batten Sim

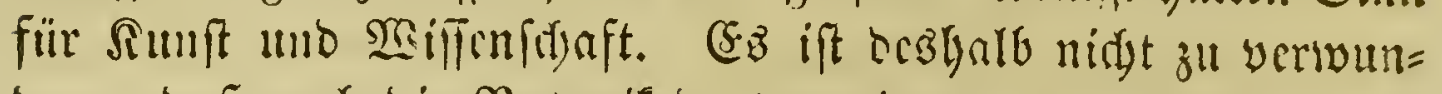
bern, baf and die Sotanif bort weniyer, als in ocn übriyen Sünoern Furowas, hetrieben wurbe. Bon ben englifiden $\mathfrak{B}$ ota $=$ nifern in bicfer slserivoe ift mur

\section{William $\mathfrak{I} \mathfrak{u} \mathfrak{i} \mathfrak{c}$}

berworguleben, ber in ber (5)afidafit Rortgumberlano geboren,

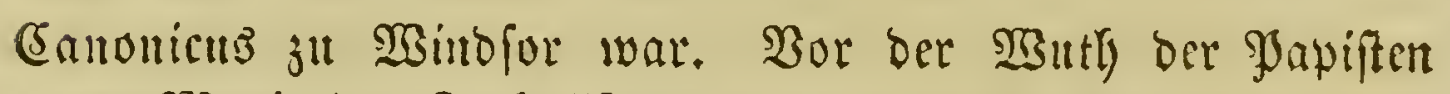

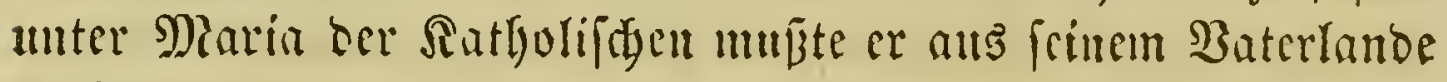

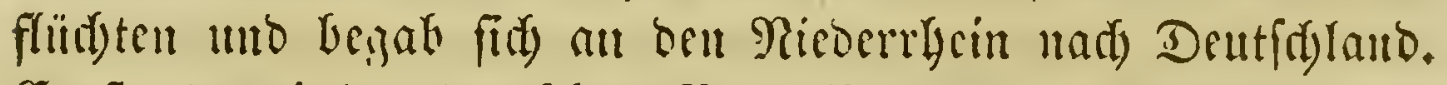
Er ftant mit ben oentid)en Botanifern in mager Berbindung

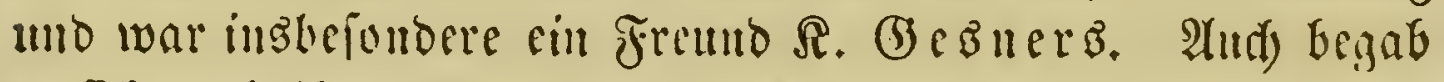
er fid) nad) Sadua, um die Borlepumigen ber bortigen berilym=

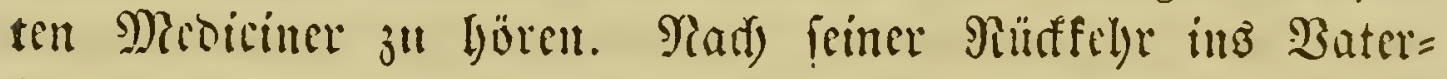

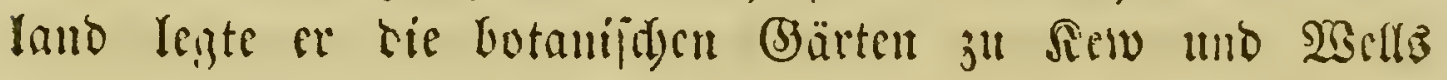
alt $^{1}$ ). Er ftarb im Gabre 1568. Das von ifm beraugegs=

posteriores. Antv. 1611. Fol. Exoticorum libri $\mathrm{X}$, quibus animalium, plantarum, aromatun, aliorumque peregrinorum fiuctuum listoriae describuntur: Item Petri Belloni observationes C. Clusio interprete (worin llefer= fekungen won nod vier anberen Sdariftitellern enthalten find). Antv. 1605. Fol. Bergl. Jgribel' Thesaurus S. 64.

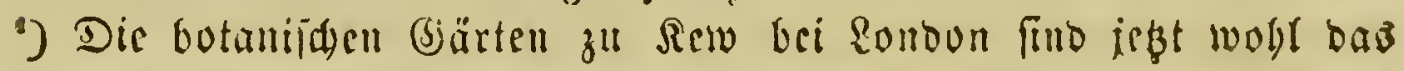

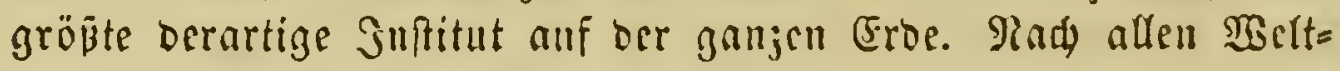

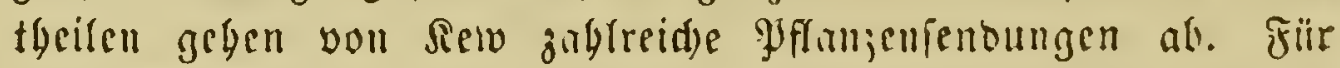
bie Unterbartung Des Gartenz fino 7000 Pfo. Sterting iäbrtiá

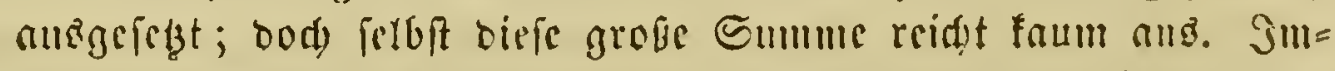

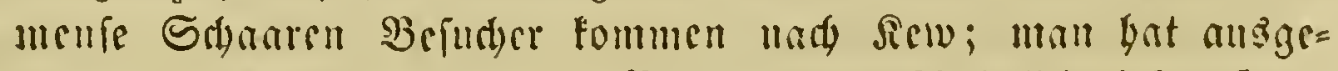

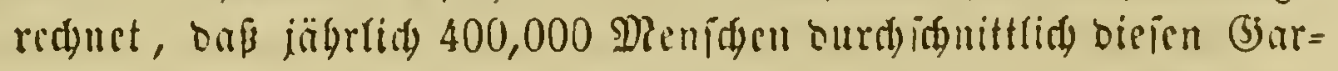
ten bejudyen, und es fdyeint, alo wolte tieje $3 a b t$ immer nod zunclumen. 


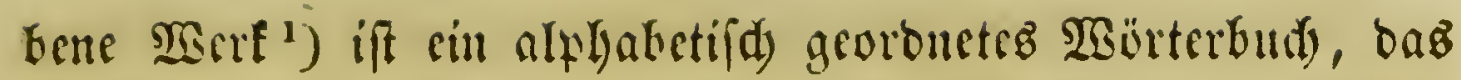

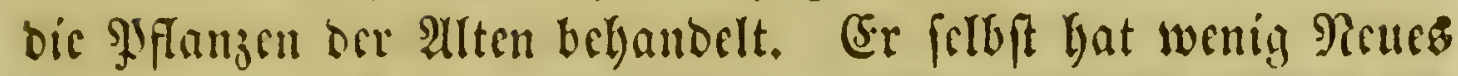

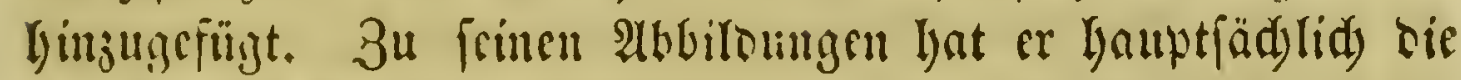
von $\mathfrak{F} u$ (d) benแbt.

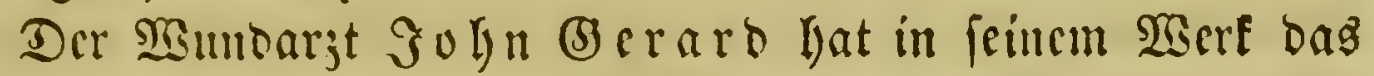

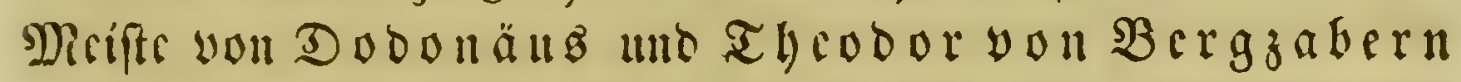
entlebut. ${ }^{2}$ )

Bon ben fpanifiden uno portugiefiduen Srbrifteftlern, wcldye in biefan 3ritraum - sinigez gelriftet haben, find bier ju nernen:

Rorenzo Syerez, Apotyefer in Tulcoo, bar cine Rrife

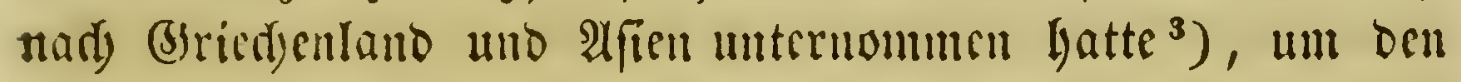
Diveforibes gründlid) commentiren zu fümen.

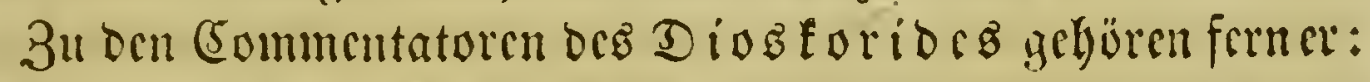
Fndr. Rucana, Jroffifor in Salamanfa ${ }^{4}$, uno ber Sortugicic

Sol. Roderic de (saftello $\mathfrak{B} \mathfrak{l}$ anco, ober $\mathfrak{A}$ matub

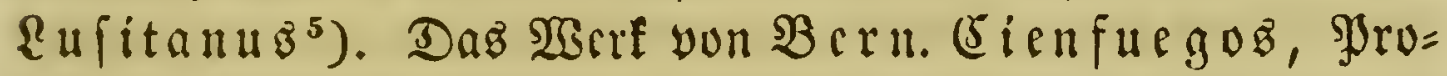

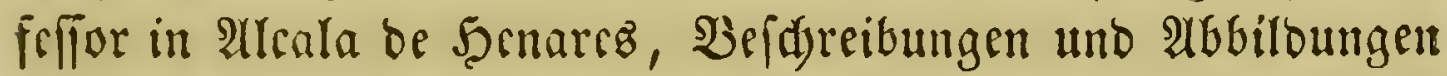

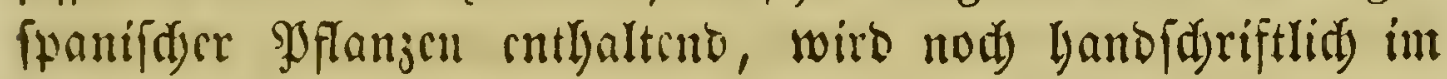
Escurial aufbctwahrt.

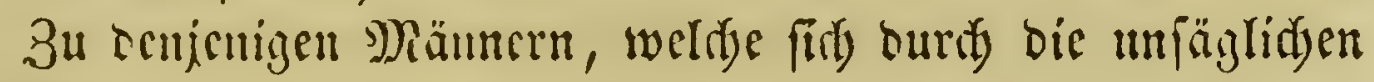
Beid)werben, weldye ju bamaliger Zcit mit bem $\Re$ eijen in uncultivirte Ränocr verbunben waren, nidgt abjdyeden lisßen,

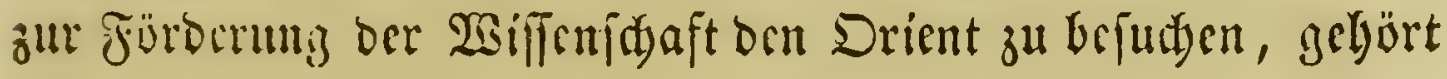

1) A new lierball, book I. London 1551. Fol. - Sn brei Bänben. Collen 1568. Fol.

2) The herhal, or general history of plants. Lond. 1597. Fol.

$\left.{ }^{3}\right)$ De la Teriaca. Toledo, 1575. - De medicamentorum. Toledo 1599.

4) Eeine Heberfegung mit ausfübrtidem (5ommentar eridien $j^{u}$ $2 \mathfrak{2 n t w e r p e n ~ 1 5 5 5 . ~ S e i n e ~ a n n o t a t i o n e s ~ i n ~ D i o s c o r i d . ~ L u g d . ~}$ B. 1554 .

s) In Dioscoridis de mat. med. libros II enarationes. Venet. 15.53, 1.558. Argentor. 155\%. 
Piere $\mathfrak{B}$ clon ats Manz, geboren 1517, ermorbet in Jabre 1563, ber in Den Gabren 1546-49 (Sriedyenland,

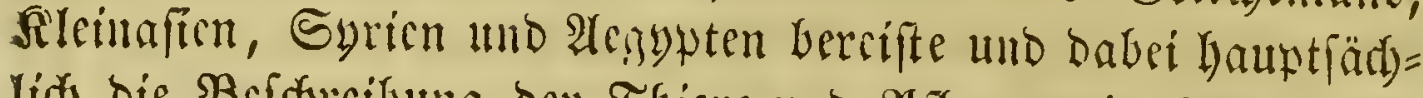
lid) bie Beffereibung Der Thiere und SPflanzen in Auge hatte.

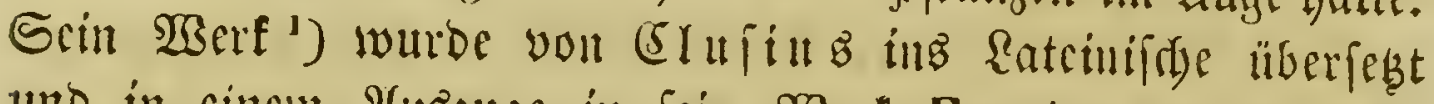
und in eincm $\mathscr{A} แ g_{z} u g e$ in fein $\mathfrak{S e n t}$ Exoticorum libri $X$, fammt ben Sibriften von (S) arcias ab Dita und Acofta, über insifde SPlanzen, und von $\Re$. Mo nardes, über weft= indifche ysflanzen, aufigenomunen.

Reonliar Rauwolf aus Flusburis, geftorben 1596, reifte in Drient in ben Gahren 1573-76. Die von ifin

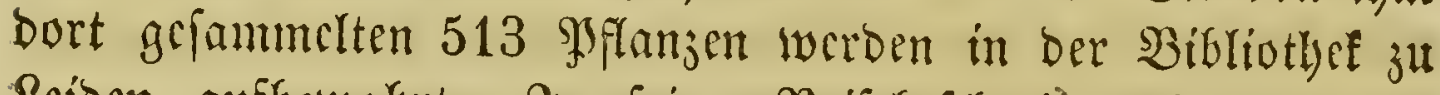
Reiben aufbewalyet. In friter Reifebefdreibung ${ }^{2}$ ) find mur

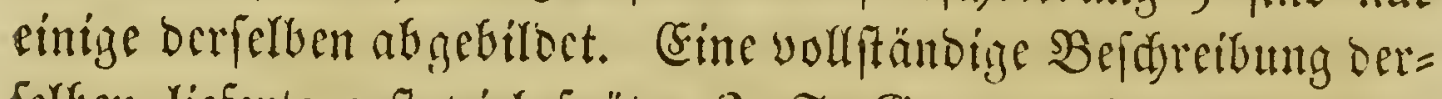
forben lieferte erft wid fpäter $\Im$. F. (B) ronovilt $B^{3}$ )

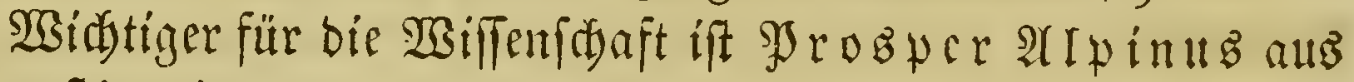
Mareftica in venctianifden Gebiete, geboren 1553, ocr it

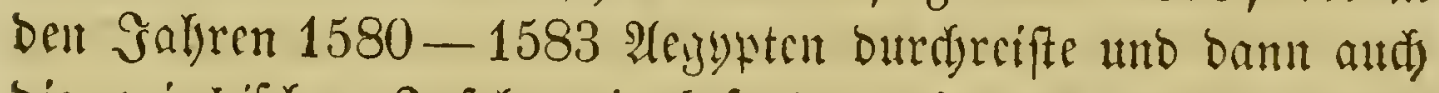

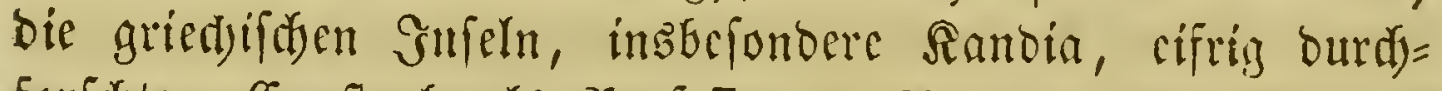
forfdyte. Er ftarb alb grofelfor zu gुabua im Jahr 1593 ober 1617. ${ }^{4}$ )

1) Les observations de plusieurs singularités et choses mémorables, trouvées en Grèce, Asie, Judée, Egypte, Arabie. Paris 1554. 3 Thl. 4. 1598. 4. Anvers 155. 8. (5r

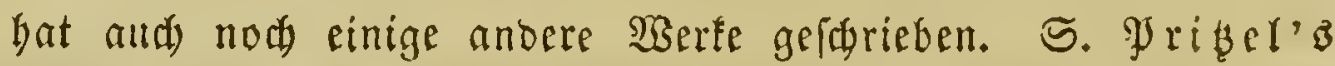
Thes. S. 18.

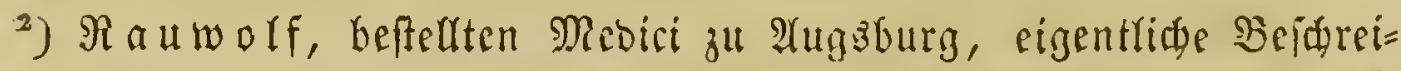
bung oer Raif, fo er in bie \$lorgentänder voubradyt 2 . Frant= furt 1582. 4.

3) Flora orientalis, s. recensio plantarum, quas L. Rauwolf in Syria, Arabia, Mesopotamia, Assyria et Judaea collegit; ed. A. J. F. Gronovio, Leidae 1755. 8.

4) De plantis Aegypli liber. Venet, 1592. 4. Patavii 1640. 4.; Leidae 1735. De plantis exoticis libri II, Meldes $25 \mathrm{sen}$ von feinem Sobue 1629 4. zu Benedig Gerausgrgeben wurbe. - 


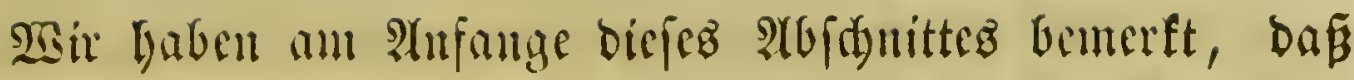
bie (sutbefung ber neten Welt wejentlid) zur Fürberung ber

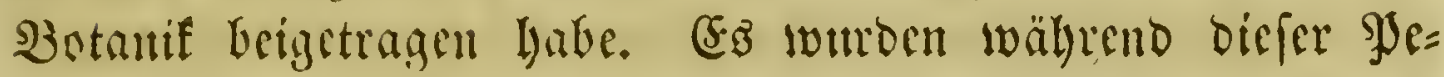

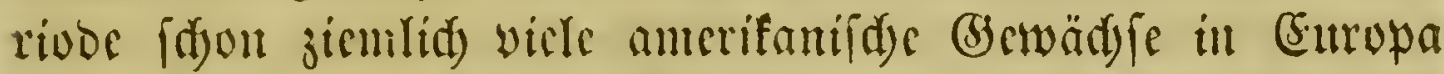
befant. Frrilidy hatte man bei ber erften Befauntidjaft mit

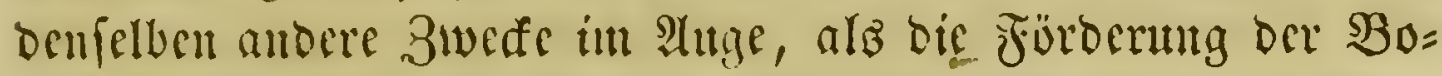
truif; man batte es zunäd) at af foldye splanzen abgefeben,

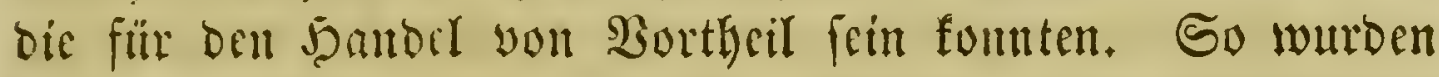
buld verfdicbene Färbipfanjen, Groürze, bie weftindifige

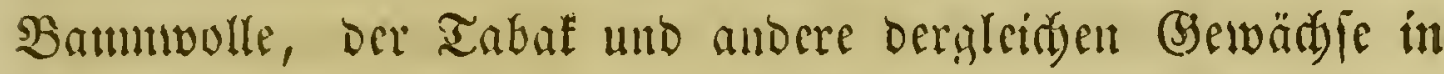
(5mopa befannt. Die erften Botanifer aber, weldbe nad). Atme=

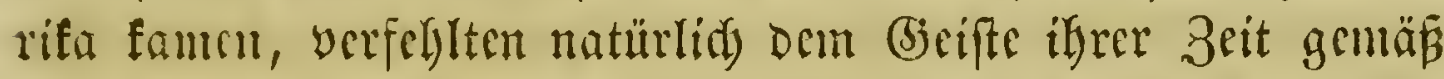

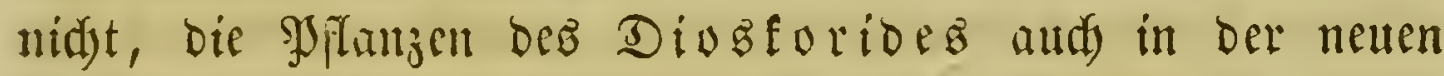
2 iselt anfulution. -

(5) Jijalo Fernandez De Dyidoy Baldeb, Statt= balter in Stispaniola, gab im Gabr 1525 genauere Befdrei= bungen amerifanifder Syflarzen, ${ }^{\text {) }}$ )

$\mathfrak{N}$. Monardes, Mrofeffur in Sevilla, fammelte alles Daşenige, waz bisher ïfor bie Pflanzen Amerifa's befannt getworden war. ${ }^{2}$ ) Der $\mathfrak{A}$ rzt

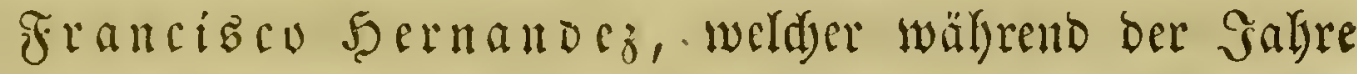

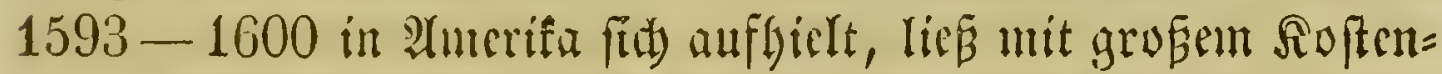

De balsamo dialogus. Venet. 1591. 4. - De Rhapontico disputatio. Patavii 1612. 4. Lingd. Bat. 1718. 4.

1) Sumario de la natural y general istoria de las Indias. Toledo 1526. Fol. - Primera parte de la historia nat. y gener. de las Indias, yslas y terra firme del mar oceano. Sevilla 1535. Fol. Franzöfíi : ஒJariz 1555.

2) Historia medicinal de las cosas que se traen de nuestras Indias occislentales, que sirven en medicina. Sevilla

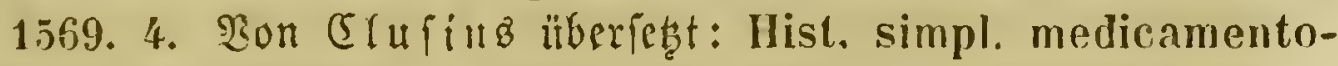
rum ex novo orbe delatrium, quorum in medicin. usus est. Antv. 157k, 79, 93. Moularoes bat nod melyere andere Erfriften veriast, bie wir bier nid)t anfübren. Viergl. Darüber Ps rizer's Tinesaurus 5.198. 


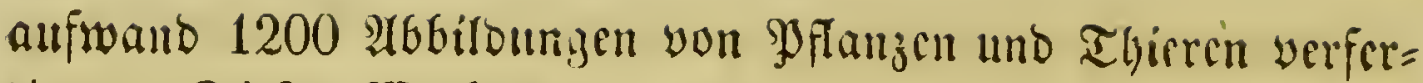

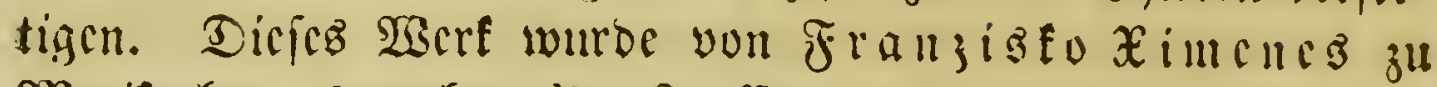

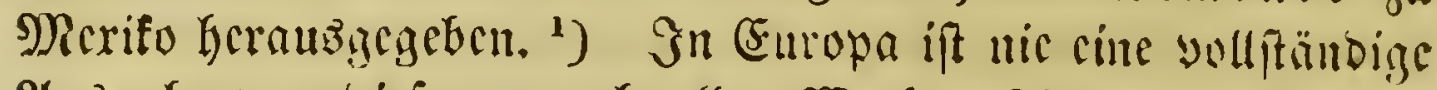

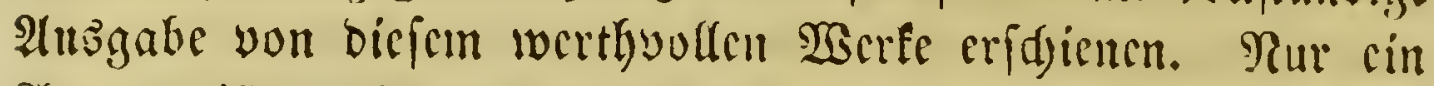

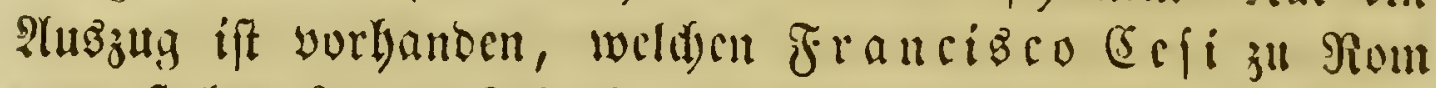
veramftaltete ${ }^{2}$ ); berfelbe ift jeood) äuferft unvollfänoig.

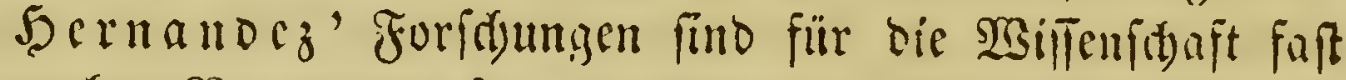

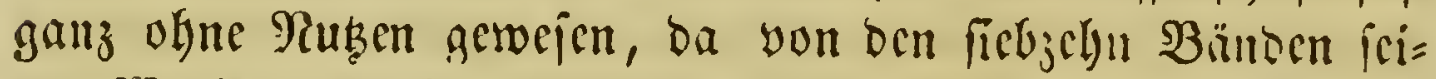

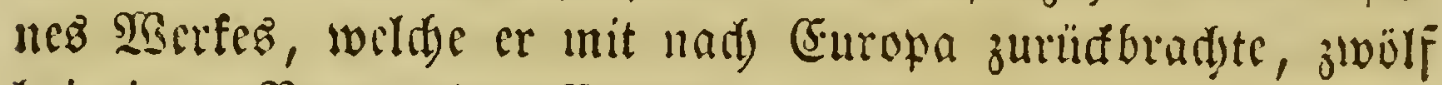
bei cinem Biande bes (siscurial yernitytet wurben.

In bicfer SPeriobe wurbe man audi) jucrft mit jube ans: lämbifden Syflanzen befaunt, weldse gegentwärtiy cine fo be=

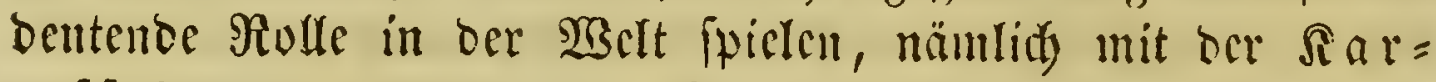

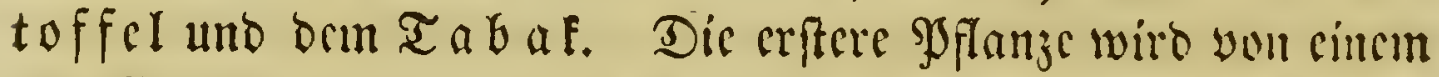
gewiffen Çarate muter ben (Sewäd)fon Sorm's mit bem Ramen

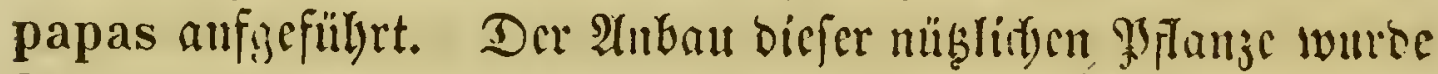
freilidi erft vicl fwäter cultivirt. - Der Taluat wuroe juerft

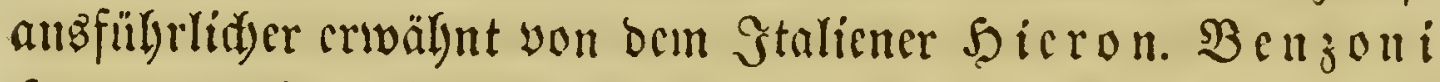
(nova novi orbis historia, Genev. 1578. 8.), bcr fith in ben Gabren 1542-65 in 2merifa anfigelyalten hatte. Hebri=

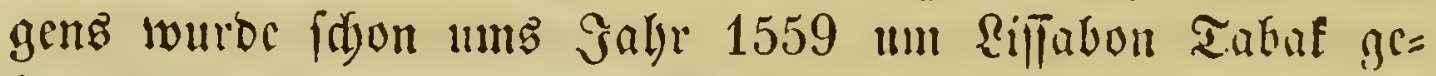

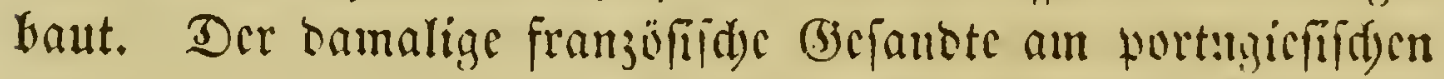
Sofe, Gean Ricot, futcte den Rünig von Franfrrid) zur Berpflanjung bez Tabafz in bicies Rnno ju bewergen, mo

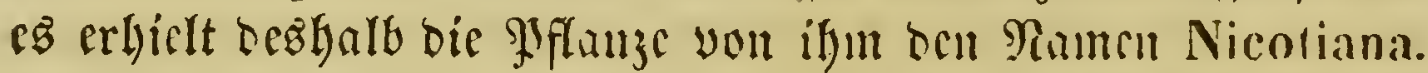

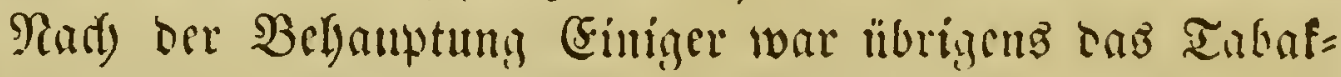

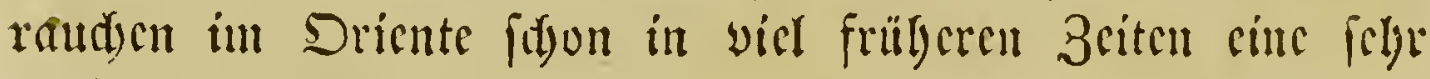
verbreitcte Sitte.

1) Francisc. Hernandez, De la naturaleza y virtudes de las plantas y animales de la nueva España, en especial de la provincia de Mexico, de que se aprovecha la Medicina. Mexico 1615. \%.

2) Nova plantarum animalium et mineralium regni Mexicani historia. Rom. 1651. Fol. 


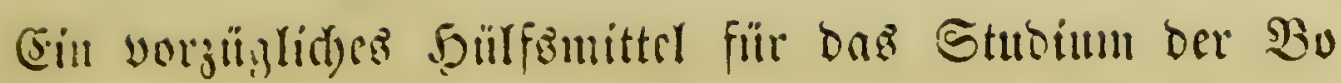
timif gemälyecn bic botanifd)en (b)ärten, intocm man in ben=

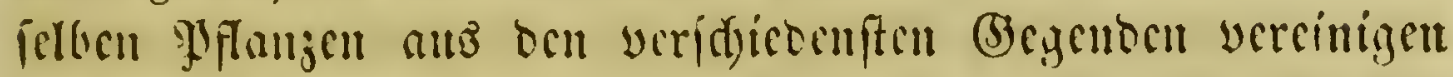
fann. (5.z founte barmu nid)t foblen, baj, fobalo die $\mathfrak{B} v=$

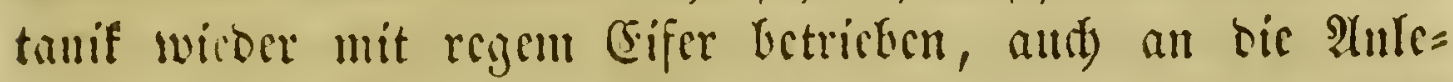
gum! fold)er (Gä̈ten wicter geondjt wurbe. Sn Gtalien, als bom Ranbe, wo, wie wir cben gejelen laben, zuerft wic=

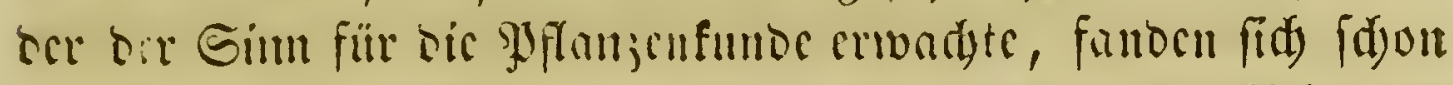

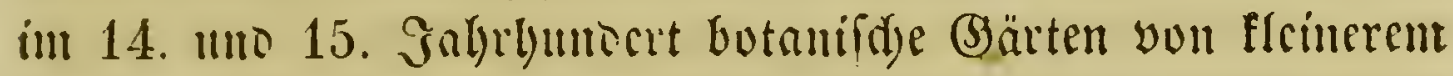

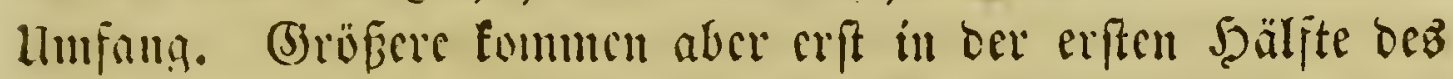
16. Gabrlumoerts auf.

Mrfunfo, ber Fürft yon Effe, Gatte um dicje Zcit brei Gotanifdi (s)ärten am \$ुo; aud) haben woir $\mathfrak{o b e n}$ bemerft, bas Brafuyola cincu cigenen butanifiden (jarten bei bicjer Stabt

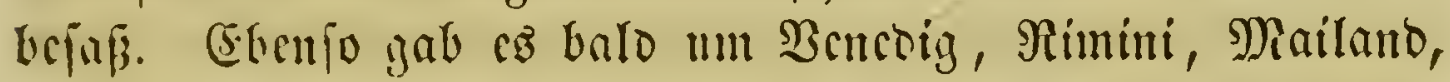
(Jimua, Rucca, Rom und Reapcl, balo audi) in Deutfifland,

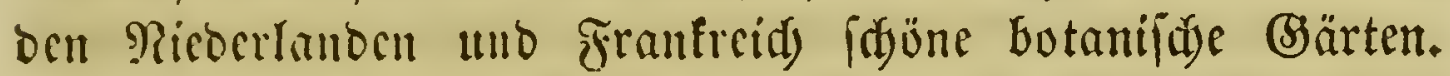

Balb fum $\mathfrak{c}$ aud auf, ben llniverfitäten botanifde, f.g. af a d wifd)e (s) ärten zujutbcilcu. Goldye (5ärten wurben

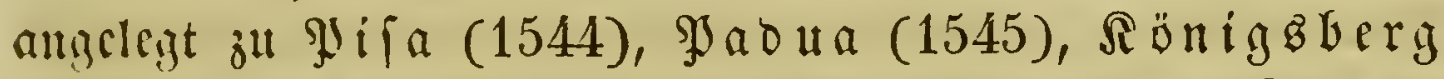
(1551), Florej (1559), Bologna (1568), Reiten

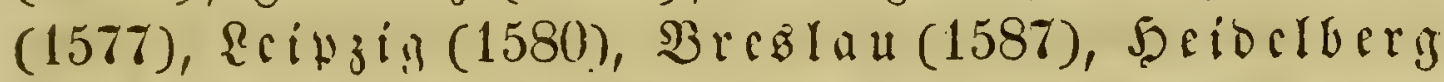
(1597), Montpellicr (1598).

Ulber rie berülyuteften Borftelyer bicjer (Gärten uno bic

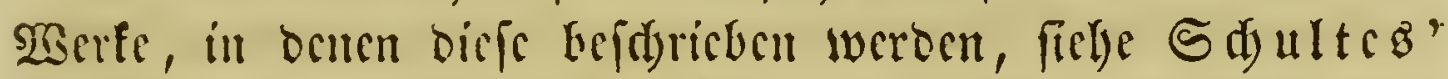

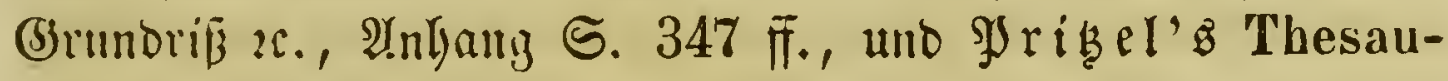
rus 5.379 ff. 
2. Eichtung Ior Picfultate Der früheren Gafyrfun= Drrte. Erweitcrung Der Semutnif ciulgcinifder

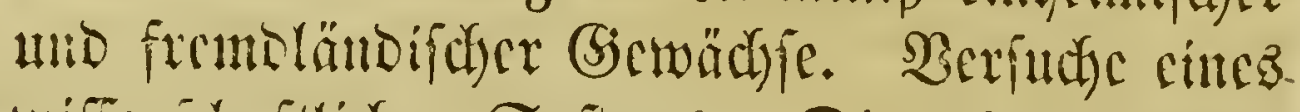

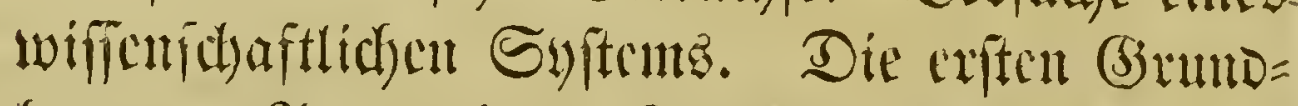

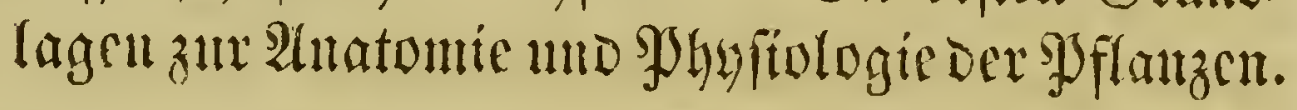

\section{Bon ocn $\mathfrak{B}$ rüorn $\boldsymbol{B} \mathfrak{a b}$ in bis auf (1601-1694).}

In bem worigen 2 bfditte founten wir bie Sdrifteftefer nad) Ränocrn orbucn, da fie faft alle einen uno benfelbent

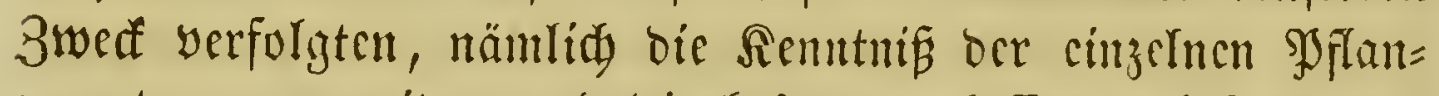

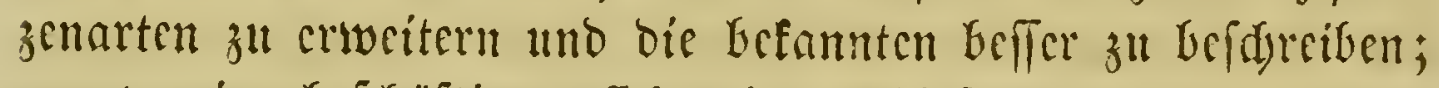
nur wentige befdäftigten fid mit oer Aluffellung ciner geors: neten Methooe ober mit oer Errforfdung oer cinjeluest

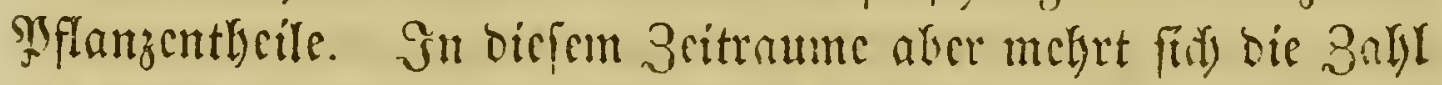

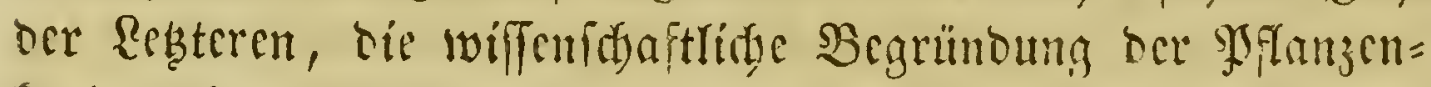

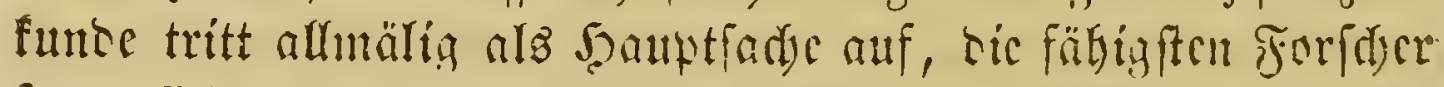
fescut fith bic Feftftellung cincs Syftems zum Bicle uno frellen anatomifas and phyfologifdye Beobadytungen an. Danebra

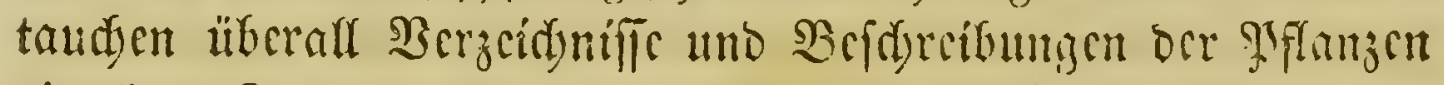

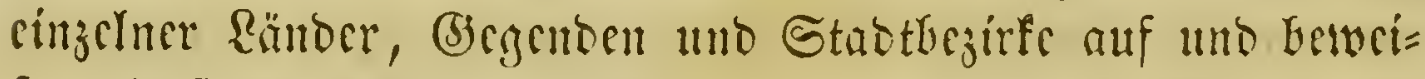

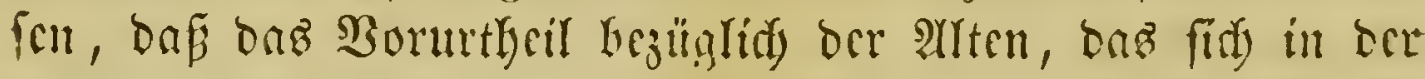
vorigen Prriobe fo hartnäefig ju erbalten wufte, mun cnolidy ganz verfdumben ift. Die nodi im vorbergegangenen Gabr=

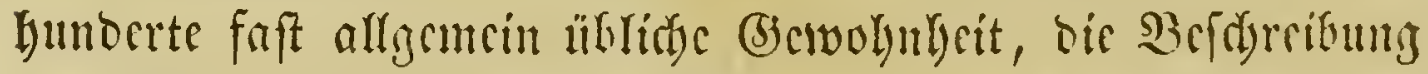
ber Şflanzenfräfte mo ilyrer Sairfungen als cinen we wentfityen Theil ber botanifden Sedriften ju betradjten, bört it biefer

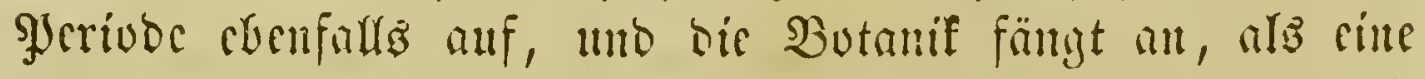

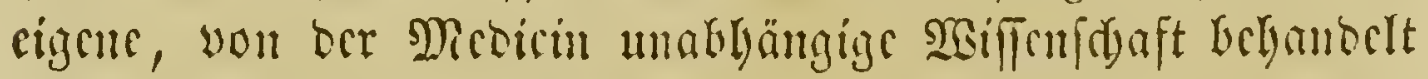
zu werbert. 


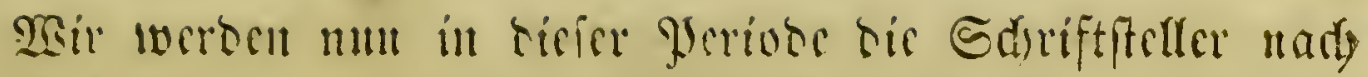
ocu Pidjtungen, weldye fie hauttiddlid) verfolgten, zufammen=

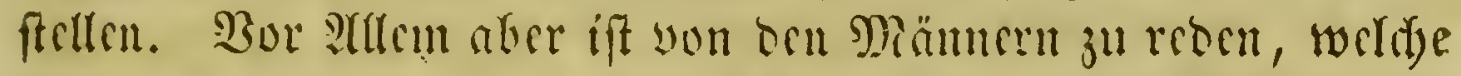

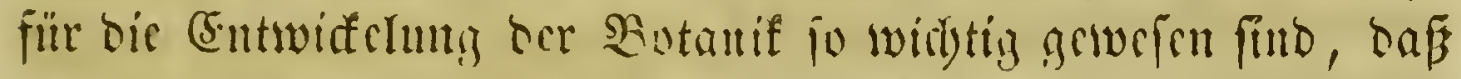

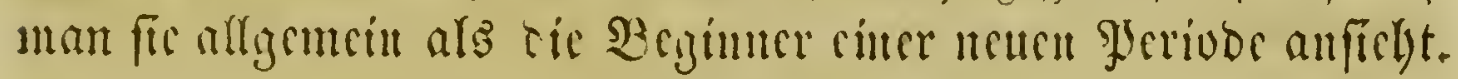

\section{Sobam Sambin,}

geboren im Sald 1541 zแ $\mathfrak{B}$ rifel,

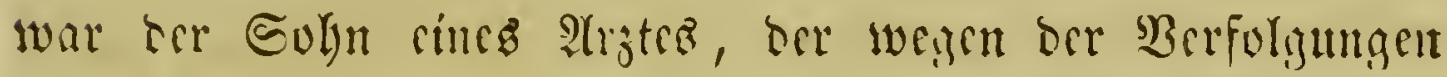
gegen bic Şugenotten in Franfrrid) auz friner Baterftad

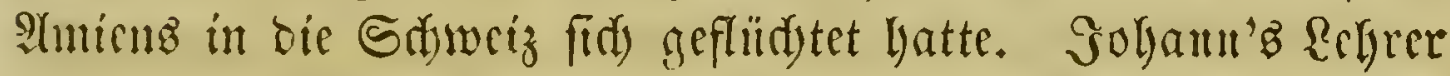
war ber berillymte Reongaro Fudjs. Später fam cr. mit

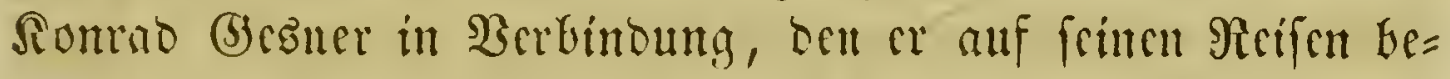
gleitcte. (Sr madjte Reifen in bie Sd)weiz, ben Sramarzwald, dab (s.liaf, nady Surgumo, Frantreid) und Stalien.

Sfäter lebte or cinige Zcit in Yyerbun am Mcuenburger =

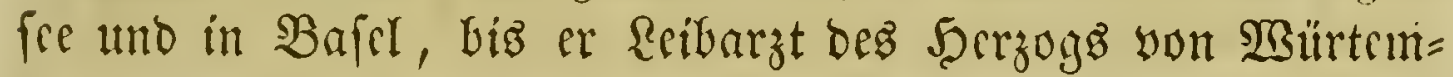

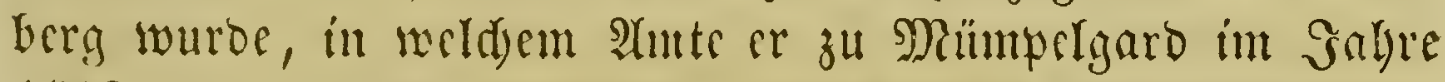
1613 ftarb. Soron in frimer Jugetio hatte er ben Pran ge=

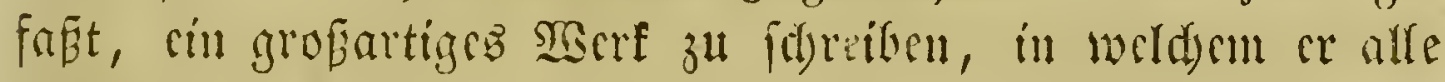

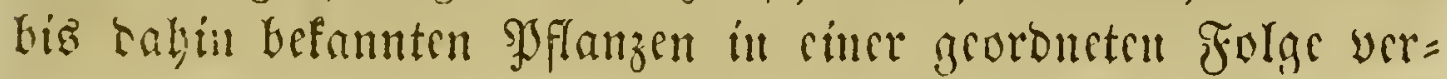

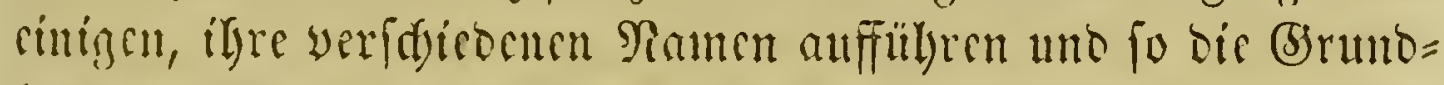
lage ju ciner feften Terminolugie Irgen wollte. Sm gabro

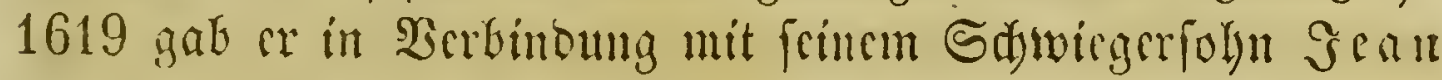

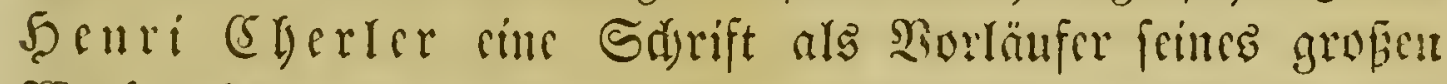

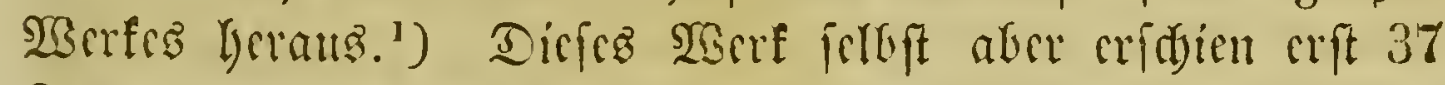

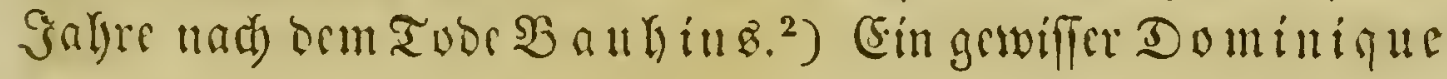

') Jol.. Ba uh in i et J. Hi enrici Cher leri Historjaegeneralis plantarum novae et absolutae prodromus. Ebrorluni 1619.4.

2) Joh. Baulini plantarum historia universalis nova et absolutissima cum auctorum consensu et dissensu rirca eas. Ehrod. $1650-51.3$ פobe in Fol. H4d erfdiell bas Wert mit 3600 Solzid)nitten 1661 zu (5enf. 


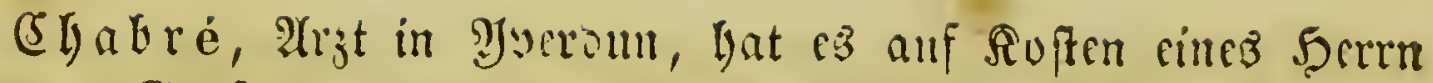

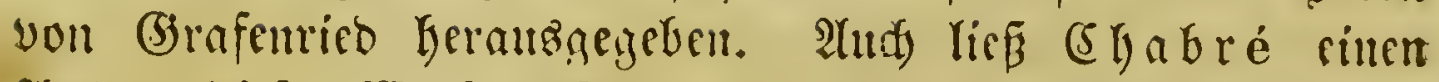

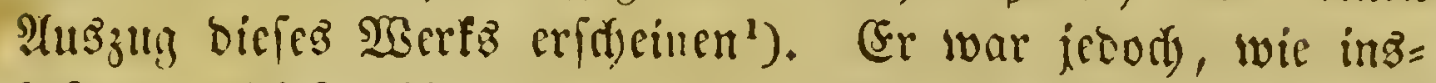

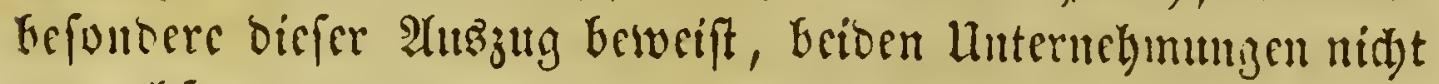
gewadyjen.

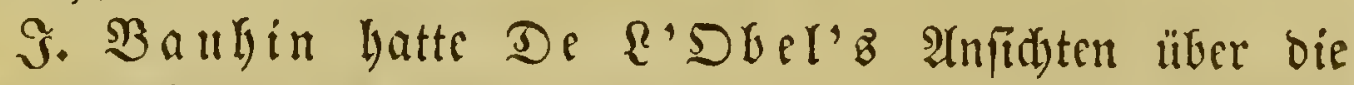

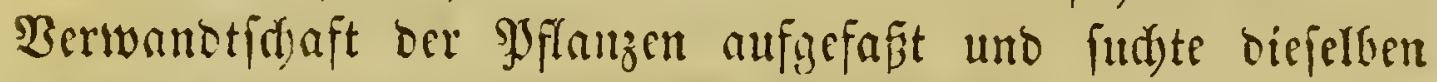
weiter angantiloen; und obgleidy er wegen ber banals nod fel)r geringen Nemtnif ber feineren Solangerorgane cin natür= lides Syftent unmöglid confequent burdfülyren fonte, fo

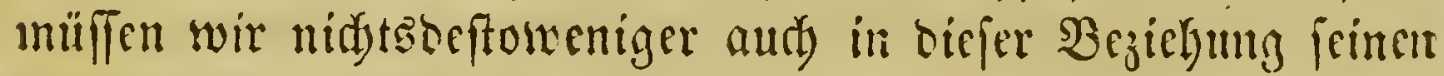
Styarffurn betwumbern.

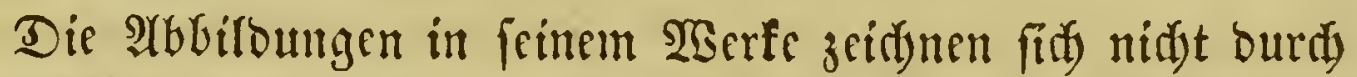
Bierlidsteit aus; audy finto fie nidst felten aum unred)ten Drte angefïgt, was ïbrigens wobl nifit bem Berfaffer, fonbern bem Sorausgeber zuzufireiben ift.

Dhne allen Bweifel aber waren die Beftrebungen $\mathfrak{V}$ a uI ing für bie Entwiffelung oer Siffenfdiaft von grofer $\mathfrak{B}$ ebeutung.

\section{Saริpar Saubit,}

ter Bruber Dez Borigen, war im Gabr 1550 ober 1560 z̆ Bajel gevorea.

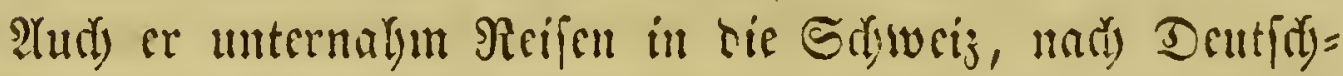
lano uno Stalien, uno fammelte alfe grftanjen, bic er mur

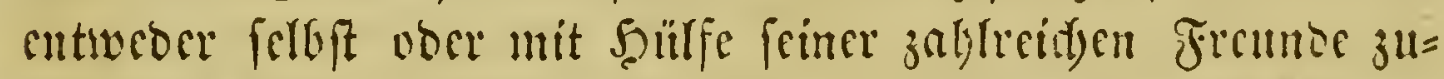

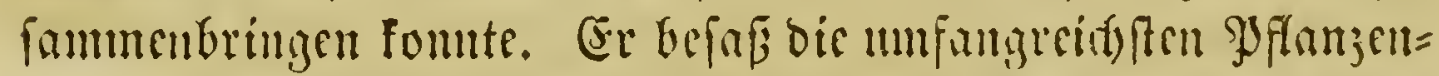

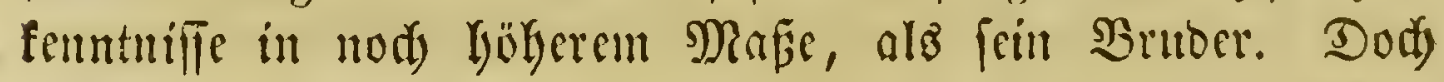
barf man wobl behaupten, baf er jenem an wiffenidsaftlidsem

1) Omnium stirpium Sciagraphia et Icones etc. authore Dom. Chabraeo. Genev. $1666-1677$.

Heber Sobann Baubinz Entbectungen in ber şflanjen. welt vergl. Eprengel, Gej巾. ber Botanif, S. 365 f. im 1 ten Bb. 


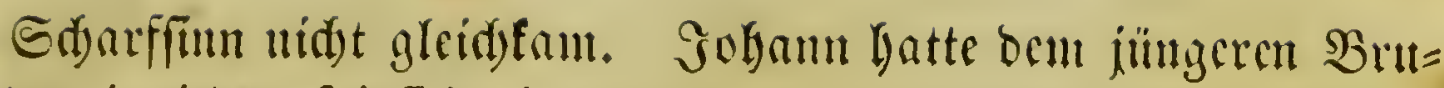

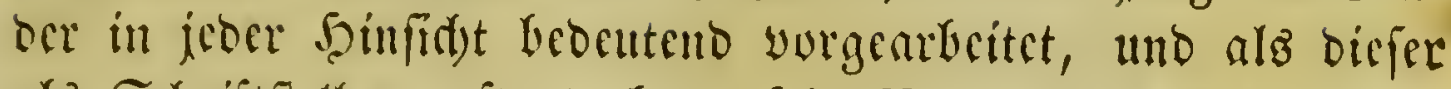

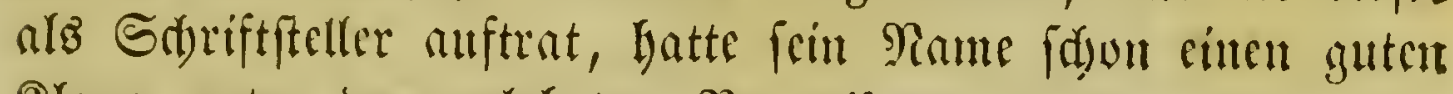
Silany unter ben gelebrten Butanifern. Barmu ftand $\mathbb{R}$. Baulin mit allen bamalizen Saturforidern bald in maber Befonntfdaft uno burfte fid) bei frimen $\mathfrak{A}$ rbeiten allestiger Sülfeleiftung erfreuen. Faft alle \$sflanjemfammlunigen Euro=

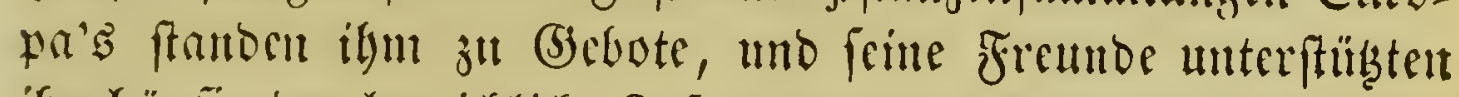

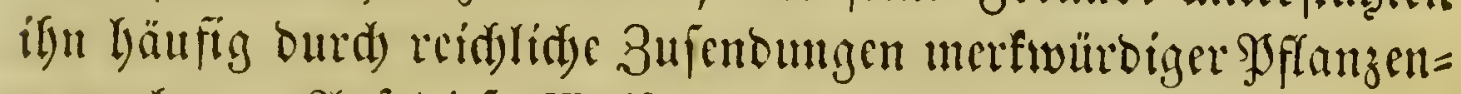
exemplare. 2huf biefe 2 seife war er elder, als alle feine $\mathfrak{B}$ or $=$

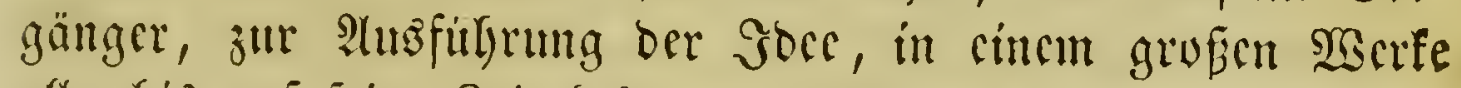

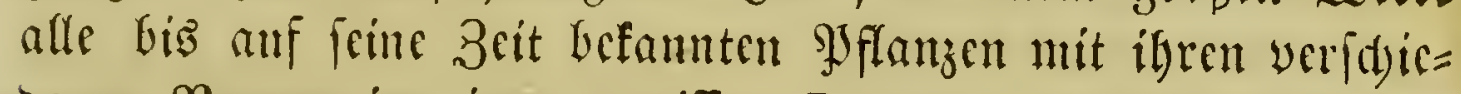
benen Ramen in einer getwiffen Dromung jufammenjuftellet,

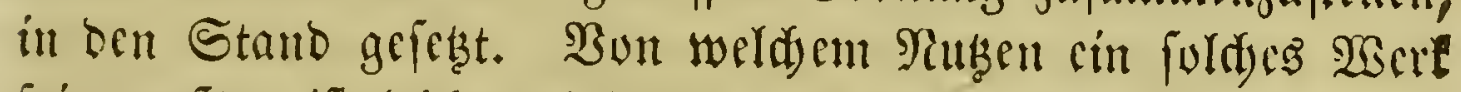

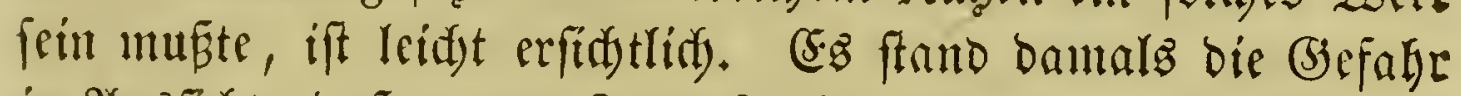

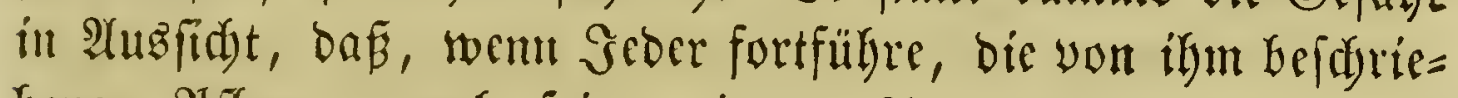
benen BSflanzen nad) feiner cigenen 2 it ful benennen, zulest

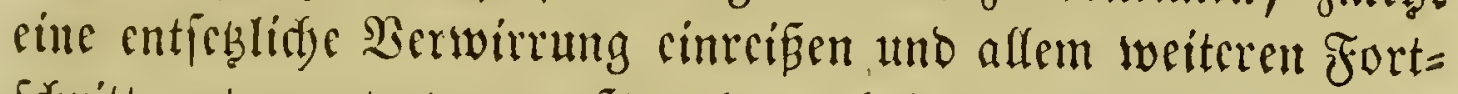
fdritt entigegentreten mufte; benu bei feiner Siffenidyaft ift wohl cine genaue uno allgemein anerfannte Romenclatur ers forberlidyer, als bei ber Botanif. (5:B fann besharb bas $\mathfrak{B e r}=$ bienft $\Omega$. $\mathfrak{B}$ a uhin's, biefer Berwirrung ein Biel gefest und für bie Dauer eines ganzen Gabrhumberts bis anf ben Refor= mator Rinné cine zínlid) beftimmte Ierminologie gefdaffen zll haben, nidjt genug hervargeloben werben. Selbft Rinté

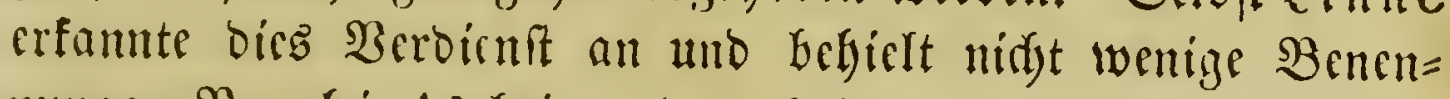

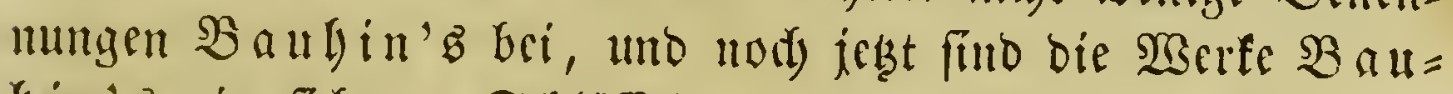
hin's cin fidserer Sdlüflel zu allen Edyriftiftlern, welda yor ifm liber Botanif gefdrieben baben.

Saspar $\mathfrak{B}$ a ulin ftarb in Sabre 1624 alz STrufeffor zut Bajel, nadjocm er 40 Jabre lang an feincut Siste gear= beitet batte. ${ }^{1}$ )

1) Die erfte Edjrift R. $\mathfrak{B a}$ a Phytopinax sive enumeratio plantarum nostro seculo

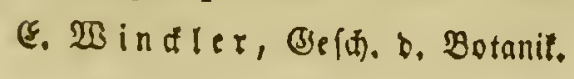




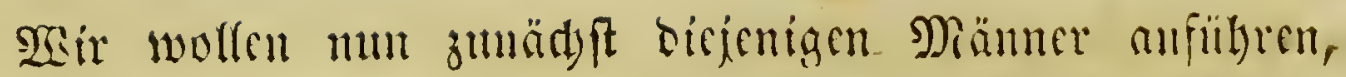

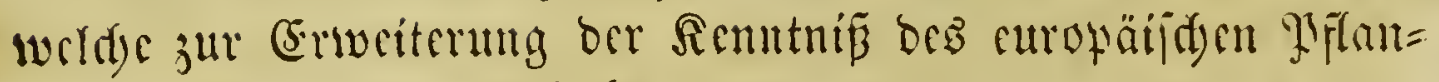
jenidjakez beigetragen haben.

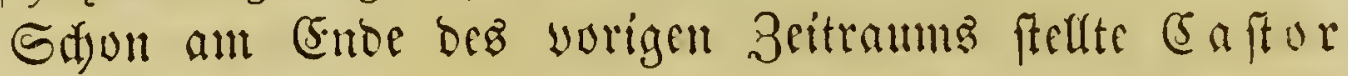
Durante (gefturben 1599) aus älteren Edrrifteftlern rin

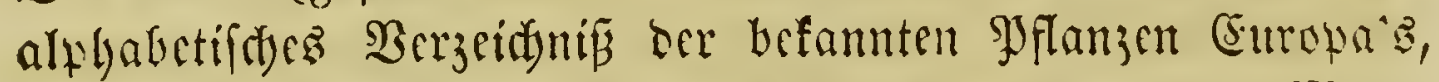

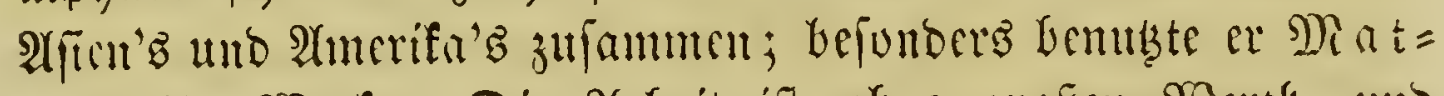

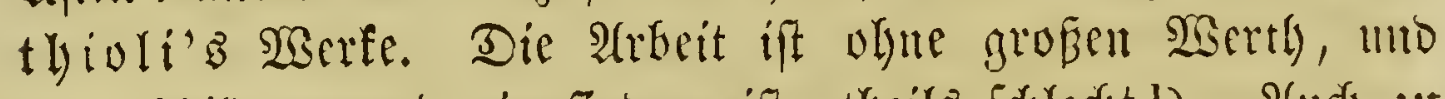

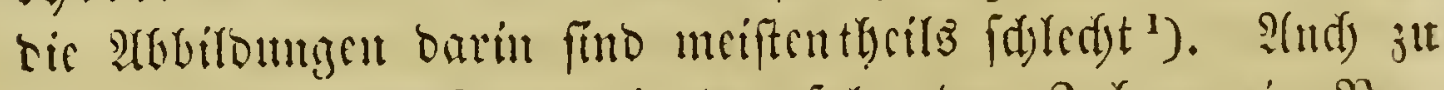

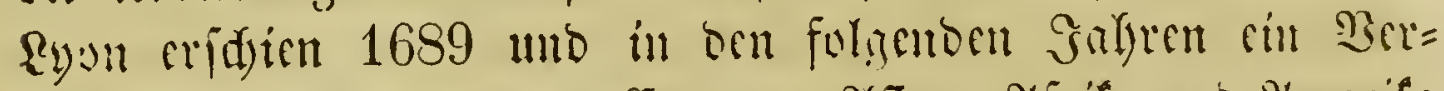

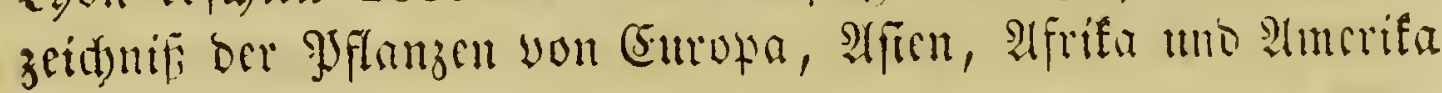
you cincur lubefannten. ${ }^{2}$ )

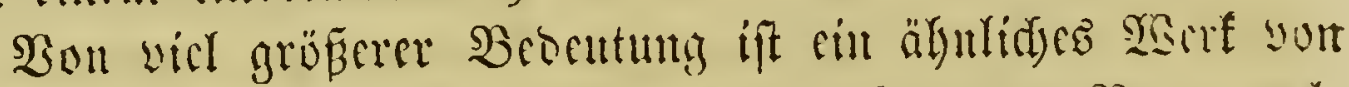

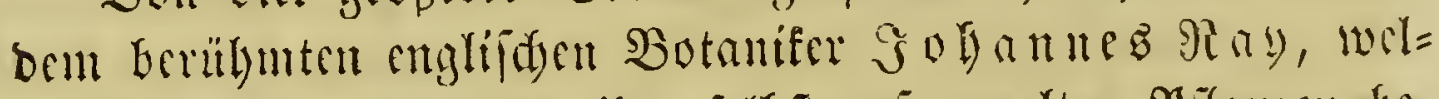

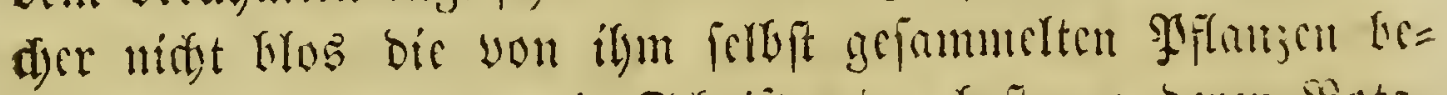

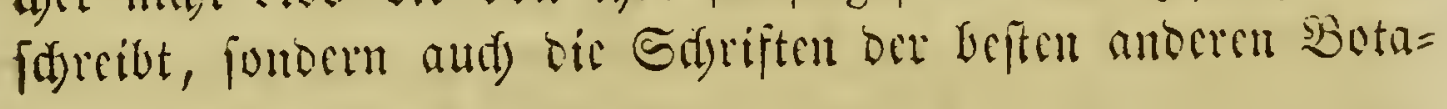

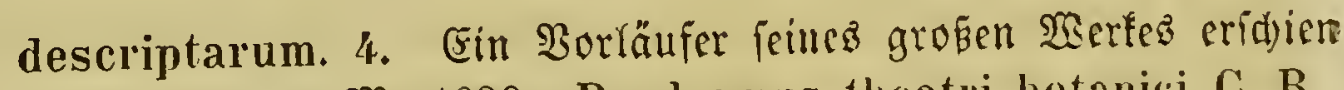
zu Franffurt a. SR. 1620: Prodromus theatri botanici C. B., in quo plantae supra sexcentae ab ipso primum descriptae cum plurimis figuris proponuntur. 4. - Esin Pinax theatri botanici etc., welder 1623 uno 1671 ju Bafel berat: $=$ fam, forlte nur als eine vorläufige Alusfübrung bes won ibm proffirten gropen theatrum botanicum gelter. 2 ber nur cin Band von bicfem lesteren siserfe wube von feinem Sobne 1653

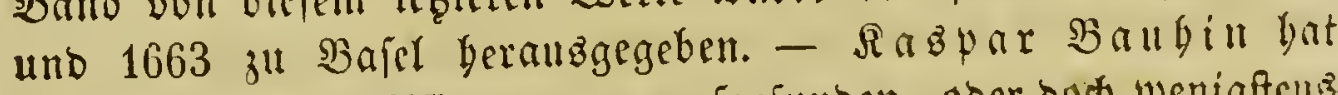

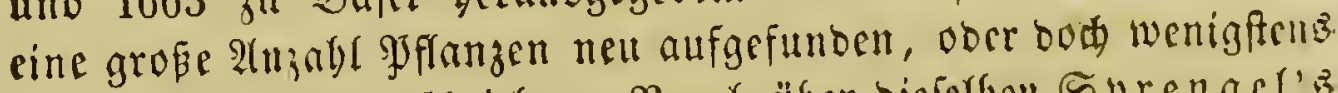
beffer, als feityer beftriebel. Bergl. über bielelben Sprengel'z (3) $\{$ f d. D. Bot. 1. Thl. S. 370-377.

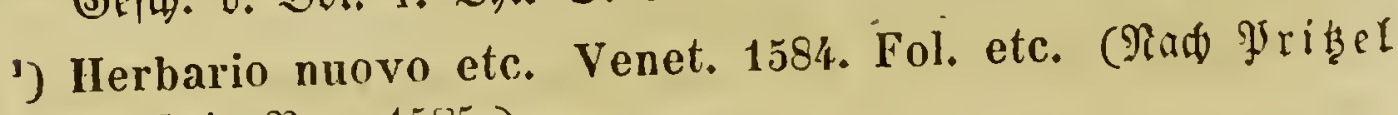
juerfit in গom 1585.)

*) Histoire des plantes de l'Europe et des plus usitées qui viennent d'Asie etc. rangée selon l'ordre du Pinax de

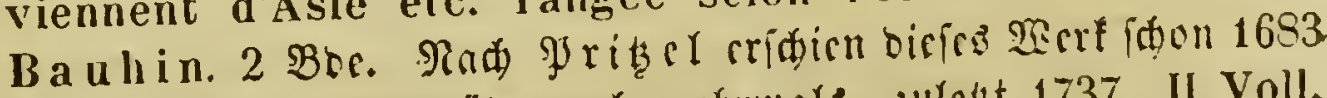
in 8. zu Syon, und päter nod mebrmals, julept 1737, II Voll. iil 8. 


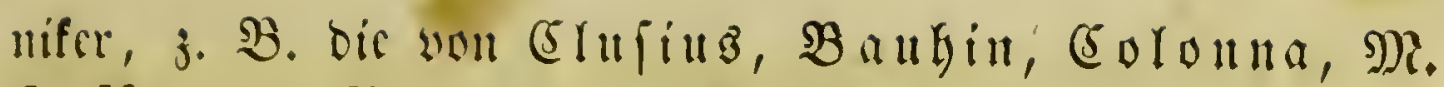
நoffunan, Bocconi ic. beritifidstigt. ${ }^{1}$ )

3uglcid) fom aber am (5noc bes vorigen unt im 2urfange

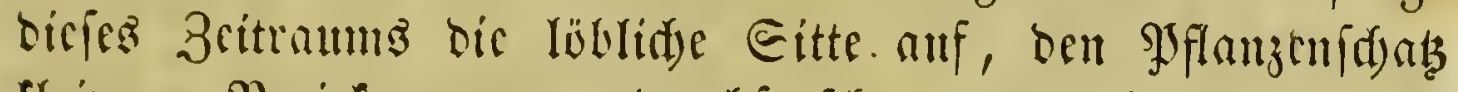
flcinerer $\mathfrak{B}_{\mathrm{j}}$ irfe genau ju burdforidjen; es entftanoen in ben

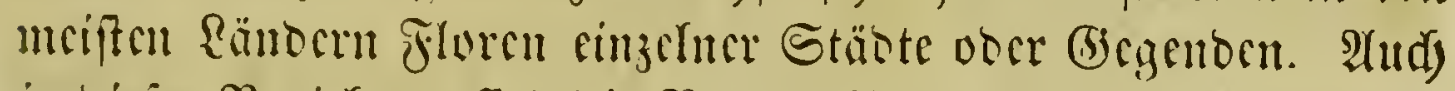

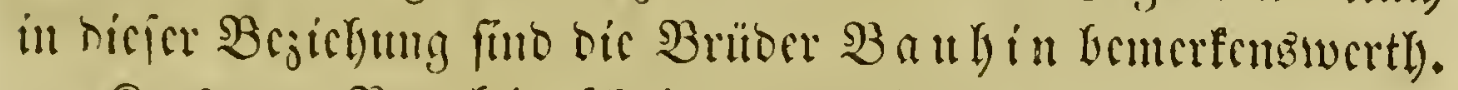

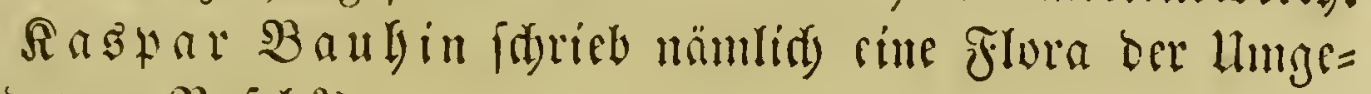
geno won $\mathfrak{B} a \mathfrak{c l} .^{2}$ )

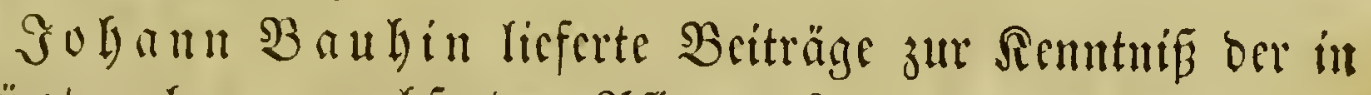

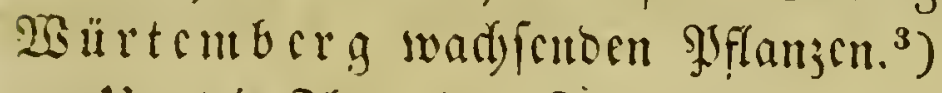

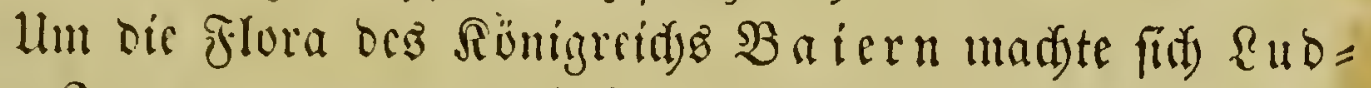
wig Sungerman burd) frin Bergeiduif Der un artorf

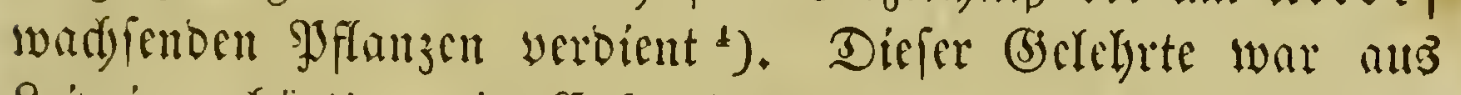

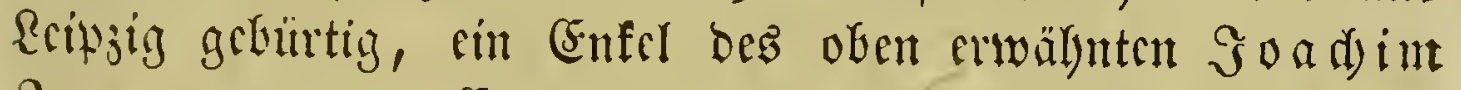
Gungermann. Gr war in oen Jahren 1614-25 Refrer

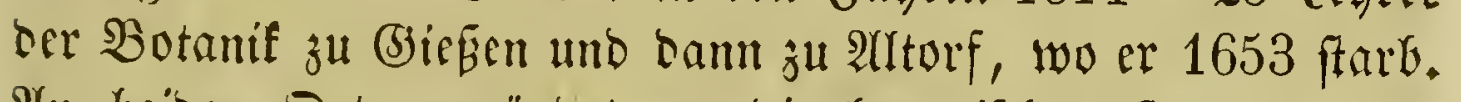

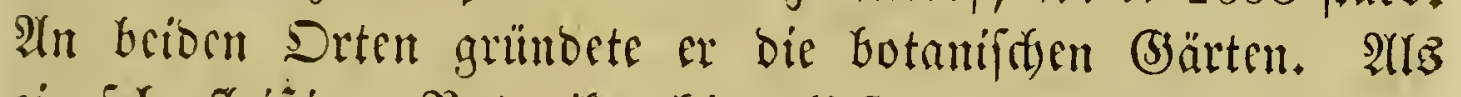
ein febr fleibiger Botanifer Ginterliés er cin Jerbarium won

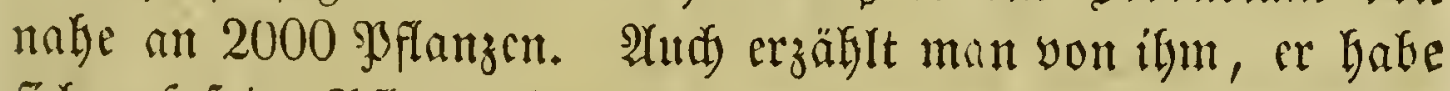

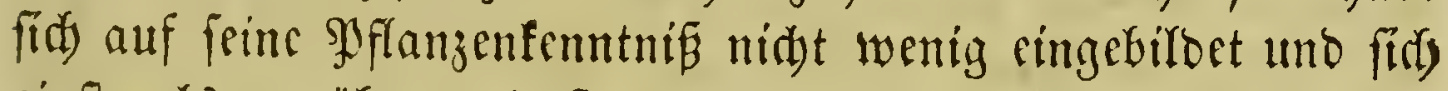

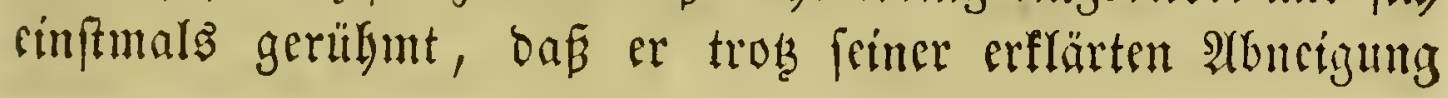

1) Stirpium Europ. extra Britannias nascentium Sylloge etc. London 169'. 8.

$\left.{ }^{2}\right)$ Catalogus plantarum circa Basileam sponte nascentium, cum earum synonymis et locis in quibus reperiuntur. Basil. 1622.

$\left.{ }^{3}\right)$ Histor. novi et admirab. fontis balncique Bollensis in ducatu Wirtemb. Montisbelg. 1598. 8. Deutid yon Davi Forfter, Stuttgart 1598. 4. Unter Dem Iiter: De aquis medicatis nova methodus erfdien nact $\mathfrak{g}$ ritel bieferbe Sdrift 1605,1607 und 1612.

4) Catalogus plantar., quae circa Altorffinum Noricum et vicin. quibusd. locis proveniunt, recensitus a C a s p. Ho ffmanno. Altorff. 1615. 4. 


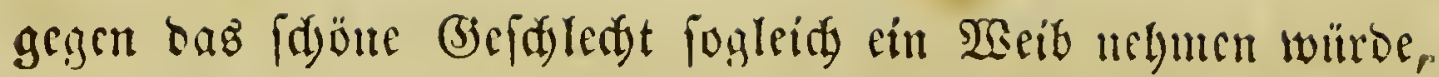

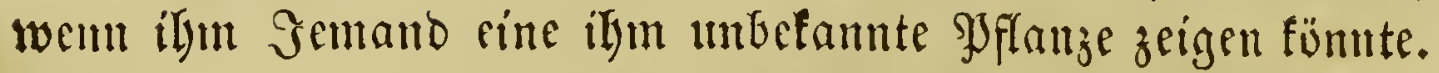
An ber bem oben erwäbuten $\mathfrak{W e r f e}$ bearbeitete er aud eine

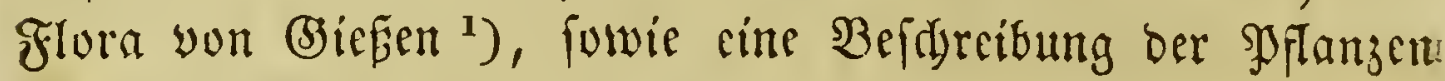
bes medicinifyen (Sartens zu âturf. ${ }^{2}$ )

Seine Sdyriften zeidnen fid jeodd nidyt burd Sromung: unt Rlarbeit in ber 3ujammenfeftung aus.

Scin Rardfolger als Rehrer za Artorf war Morig $50 f f=$ mann (geb. 1621, geft. 1698), welder ebenfafle bie in Der Uningegent unt in bem mebicinifiden (b)arten von Artori wad)= fenten Pflanzen befdrieb. ${ }^{3}$ )

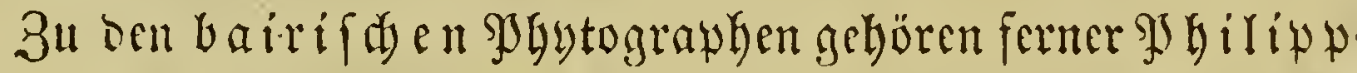
uno Albert Menzel, wegen ifrer Flura yon Jingulftadt. ${ }^{4}$ )

Solyan (5)erg Boldamer $(1616$ - 1693), Stadt= argt fu Nürnberg, ftano in fleifigem. Berfelgr mit ben meiften

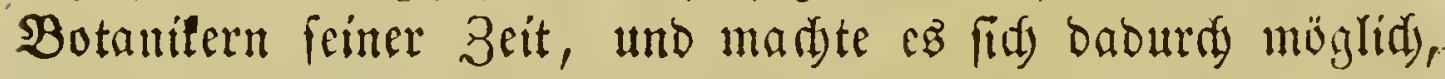

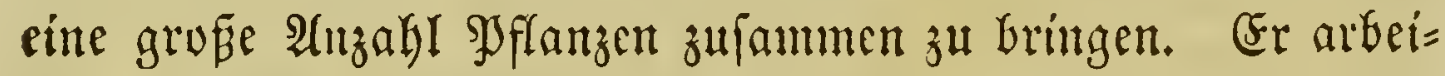
tete eine Flora von Rürnberg aus, bie zwar in alphabetif ter Sronung abgefafit, jeburb mit viclen $\mathfrak{B e m e r f u n g e n t}$ über bie in biejer Serivo auftaudenden Syfteme verfehen ift. 2udy

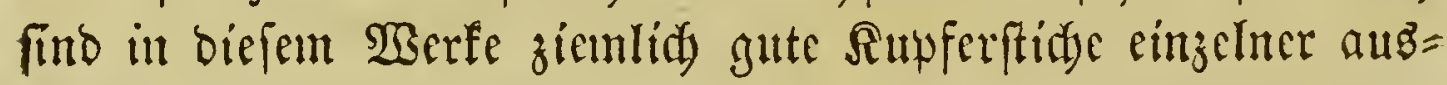

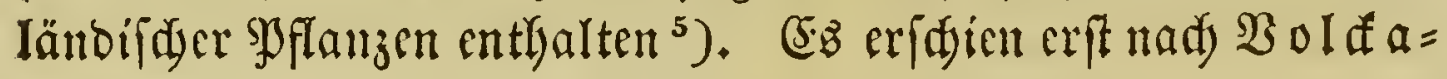
mer's Tode.

Unter ben badifden Sootanifern ift (b) eorg Frant yon Fraulenau (geb. 1644, geft. 1704) za nemnen, ber

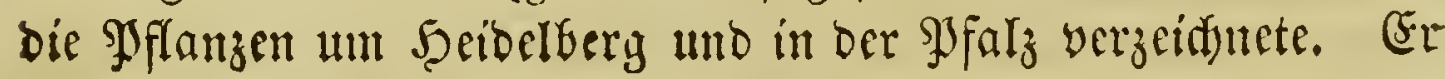

1) Cornucopiae florae Gissensis. Giessae 1623. 4.

$\Rightarrow$ Catalog. plant. horti et agri Altorf. Altorf. 1646. 8 .

3) Florilegium Altorf. etc. Altorf. 1676. 4. - Florae Altorf. deliciae sylvestres etc. ibid. 1662. - Florae Altorf. del. hortenses, ibid. (1637.) 4. - 2 (4u nod einige anbere Sdrif= ten bat er verfapt. Bergl. Pr ritgel's 'Thesaurus S. 122.

-) Synonyma plantarum etc. circa Ingolstadium sponte crescent. etc. Ingolst. 1618. 8. -1654.8.

$\left.{ }^{3}\right)$ Flora Norimbergensis. Nor. 1700. 4. - 1718. 4. 
Jwar in ben Gabren 1670 - 90 Srofeffor in Jectoelberg, bamn

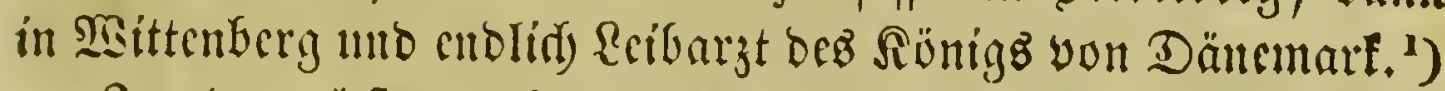

Sn ben öferreidifden Stanten gab es in biefer

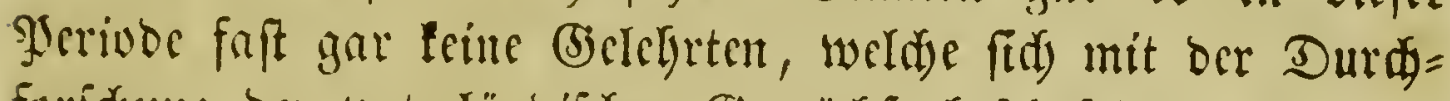

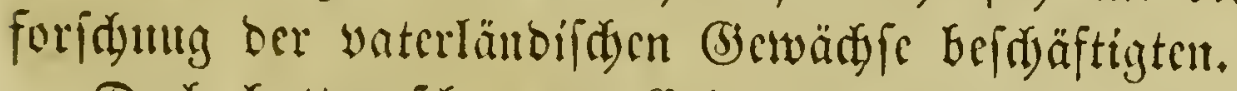

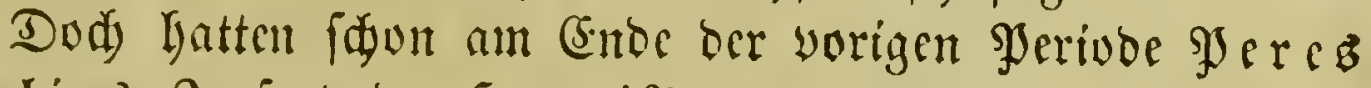

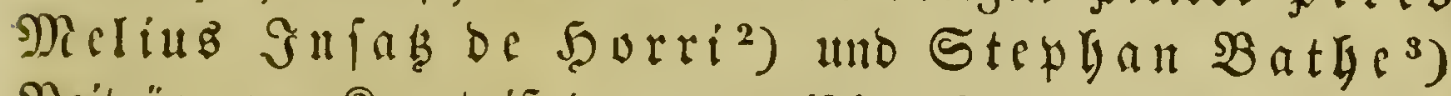

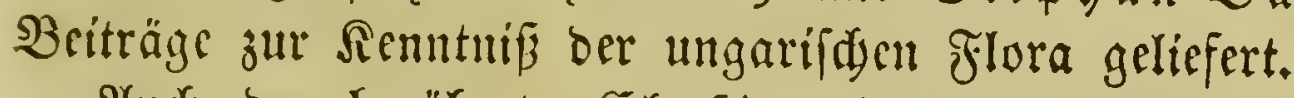

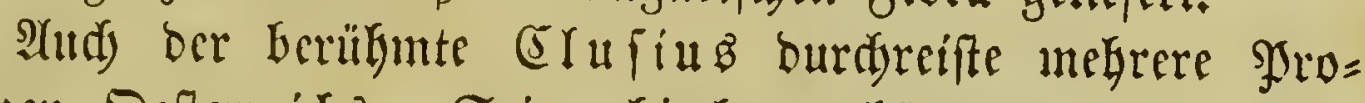
vinzen Defterreidts. Seine Gierber gehörenden $\mathfrak{Z}$ erfe fino f(d)on oben angeführt. ${ }^{4}$ )

lleber bie Flora Mitteloeutfdiando eridien auber

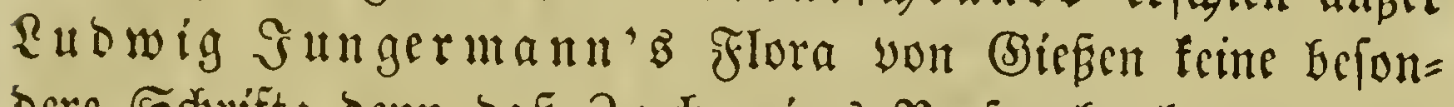
bere Sdifift; benn baß $3 \mathfrak{a}$ darias $\mathfrak{N}$ ofenbad, ber $\mathfrak{B e r}=$ faller Dez "Sarabiezgärttcin, barin bie ebelften Rräuter ab. conterfeytet uno befdrieben furt "(Franffurt a. M. 1588),

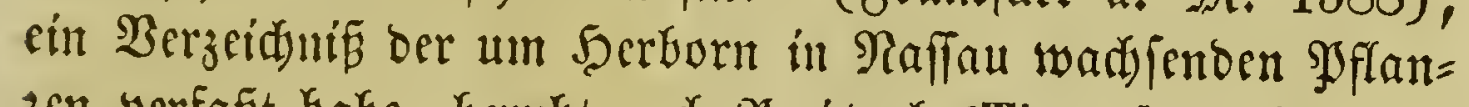

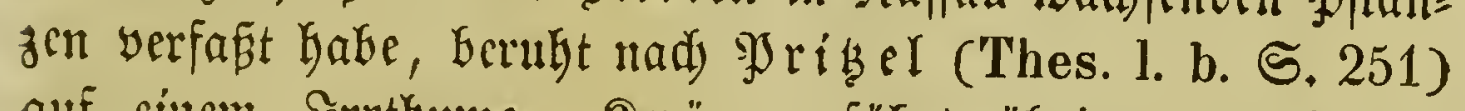
auf cincm Jrrthume. N $\mathrm{rüger} \mathrm{fübrt} \mathrm{übrigens} \mathrm{nod} \mathrm{cine}$ Srifrift yon einem gemiffen (E)

2) Lexicon vegetabilium usualium, Argent. 1672. 12., welde Werf 1685 unter bem Titel: Flora Francica s. lex. plant., in quo nomina, vires, praeparata plant. etc. 12. eríien.

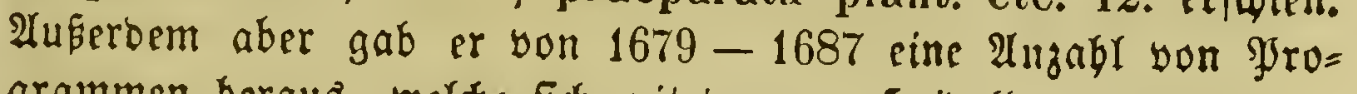
grammen beraus, welde fid mit ben um Spibelberg uno in ber

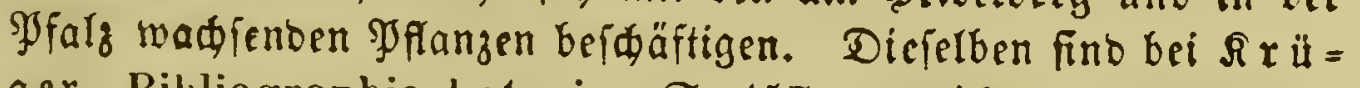
ger, Bibliographia botanica S. 157 , werzeidnet. Jy ripel's Thesaurus S. 88 u. 89.

3) Debrecinens, herbarium. Claudiopoli Transilo. 1578. 4.

3) Castriferensis herbarium hemerii varitii. 1595. 4. - $\mathfrak{R} a \Phi$ Rrüger S. 153.)

4) In bem angefübrten BBerfe Rariorum aliquot stirpium per Pannoniam etc. observatarum historia befindet fid aud ein stirpium nomenclator Pannonicus von $B$ ejtbe.

3) Botanicum Francofurtanum etc. Franffurt a. $\mathfrak{R}$. 1546. For. 


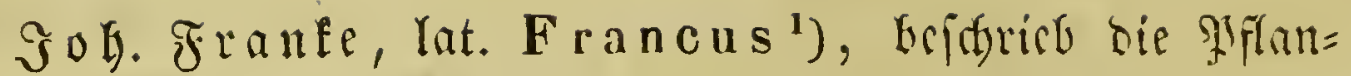

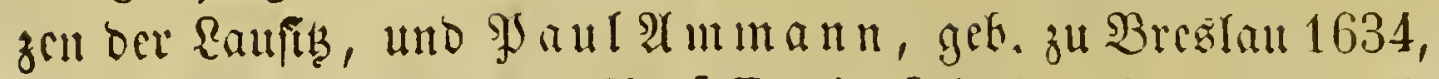

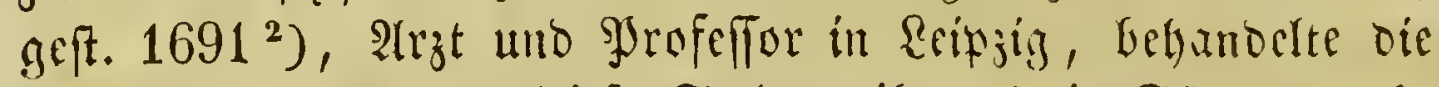

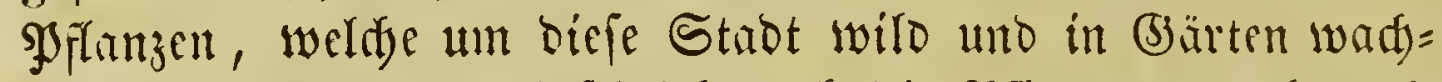

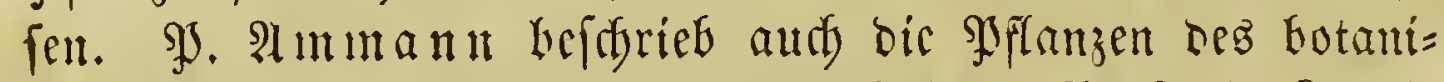
fiden (Sartenz, weldy you bom Ratbaherrn $\mathfrak{B}$ ofe in Reipziq angelegt worben war und fit bamals burdi finen Syflanzen= reidythuin auşzeiduntc. ${ }^{3}$ )

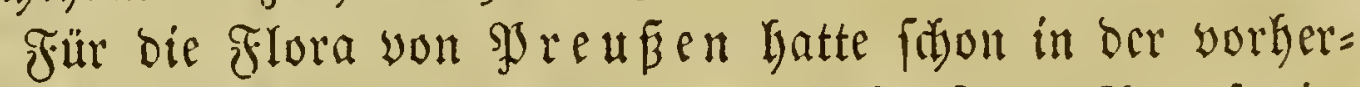

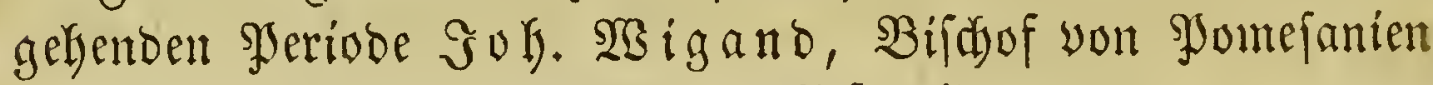
in Ditprentien, eintige Rotizen geliefert. ${ }^{4}$ )

SBidytiger aber if Ricol. Delgafen, Stabtrath in Danzig, ber ein Berzeitunis won 348 Arten um biefe Etabt wilowad) fender gyflanzen lieferte. ${ }^{5}$ )

(sinen Anbang zu Derhafens Srbift Yieferte (shriftian פenticl, won bem weiter unten die Rede fein wirb. ${ }^{6}$ )

Sohann Röfel $(1607$ - 1656), Jrofeffor in Rönigg = berg, ein tǚtiger Botanifer, bearbcitcte cbonfallè bie Flora

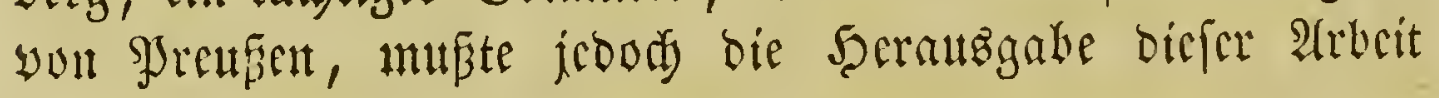

1) Hortus Lusatiae, baz if: lat., beutifle und etglide mentifice

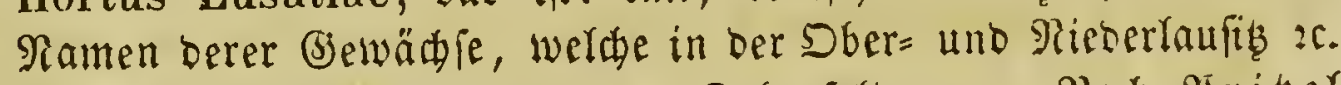

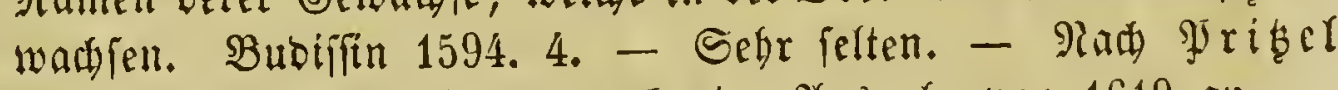

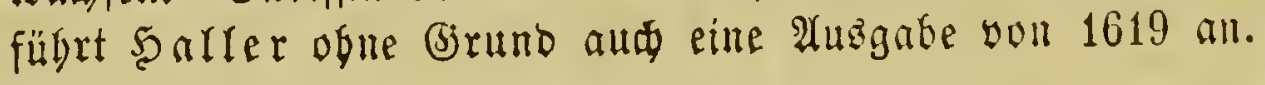

$\Rightarrow$ Supellex botanica, h. e. enumeratio plantarum, quae non solum in hort. med. Lips., sed etiam in aliis circa urbem viridariis, pratis etc. Lips. 1675. 8.

3) Hortus Bosianus, quoad exotica solum descriptus. Lips. 1686. 4.

2) Vera hist. de succinio Borrussicn etc. et de herbis in Borussia nascentibus. Jenae 1590. 8.

s) Elenchus plantarum circa Dantiscum nascentium etc. Dantisci 1643. 4. 1656. 8.

$\left.{ }^{6}\right)$ Centuria plantarum. circa Gedanum sponte nascentium etc. Dantisci 1650. 4. 


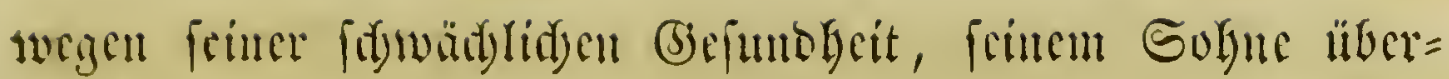

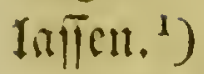

lleber bie Flora won 5 alle eridsienen in biefem Zeitraume

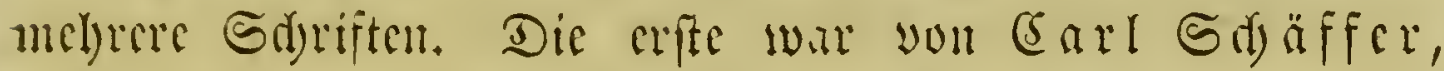
gek. 1613, geft. 1675, Stnotnigt bafelbit, werfät. Er be=

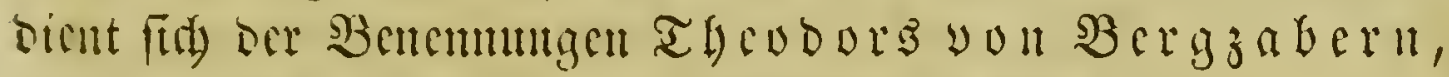
gibt aber bie Standorte ber gyflanzen nidjt an. ${ }^{2}$ )

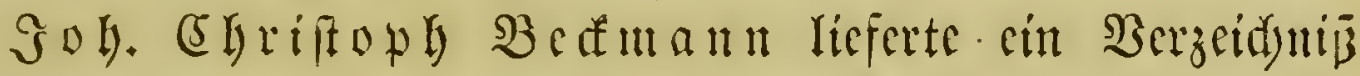
fer um Franfurt an ber Doer wadjenden Srflanzen. ${ }^{3}$ )

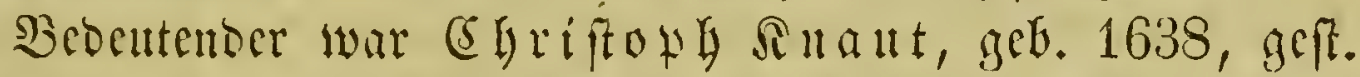

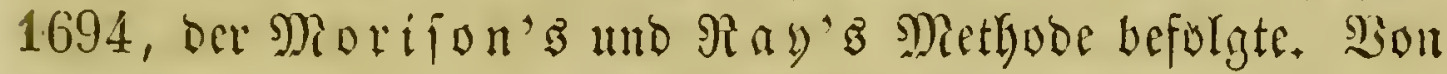
ify wirb weiter unten wow bie Rebe fein. ${ }^{4}$ )

Gobaun (5) otfiricb Dlearits, geboren 1635, ge=

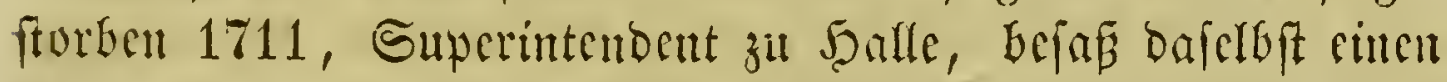
Gotunifden (3arten, yon beffen Syrlanzen el ein Berzeidynif

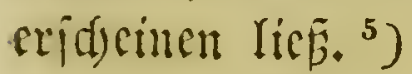

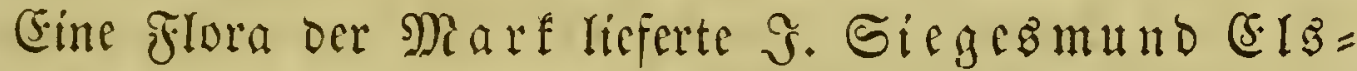
bolg, furfürftlider Reibarzt zu Berlin, geboren 1623, ge= fturben 16s8, worin $\mathfrak{\Omega} \mathfrak{a}$ f. genommen futb. Diefe ârbeit if jedod unbedeuteno, da fie

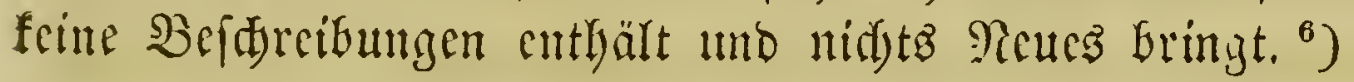

1) Plantas in Borussia sponte nascentes e manuscriptis parentis mei divulgo, Johan. Loeselius, Johannis filius. Regiomont. Borus, 1654. 4. - Die $\mathfrak{A}$ us̉gabe von 1673 fomte gr risel nidit auffinden. (Frf 1703 murbe biefe Edrift

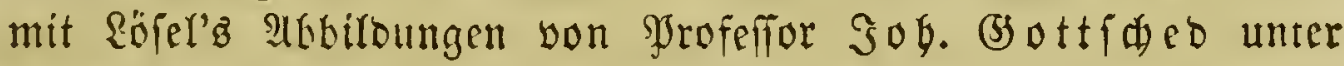
bem Titel Flora prussica zu Rönigäberg in 4. Gerauzgegeben.

2) Deliciae botanicae Hallenses etc. Hallae 1662. 12.

3) Memnranda Francofurtana etc. Francf. ad Oderam 16 iz6. 4. 1706. Fol.

4) Enumeratio plantarum circa Halam Saxonum et in ejus vicinia etc. Lips. 1688.8.

5) J. G. O l e a ri i specimen florae Hallensis s. designatio plantarum hortuli sui. Hal. 1668. 12.

-) Flora Marchica. Berol. 1663. 8. Reuangelegter (3)artenbau 2 . (Söln a. b. Spree 1666. 4. u. melrmals. - Irnuci= ઉarten

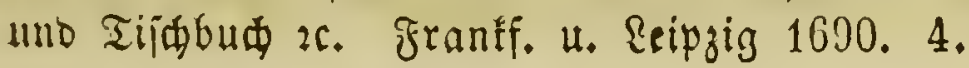




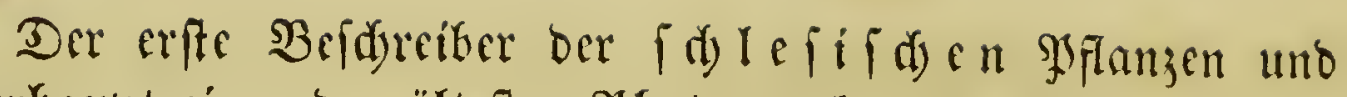
überlyaupt ciuter ber ältefen $\mathfrak{s}$ bytograplen Doutichlando war

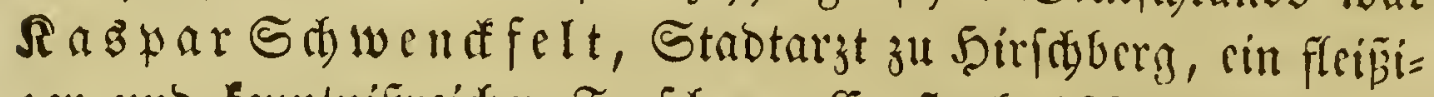

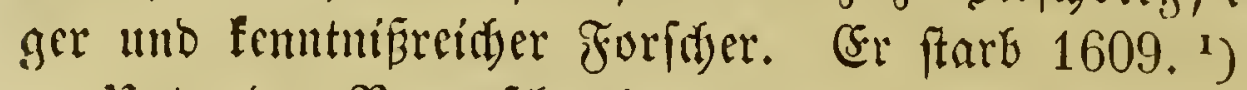

Unter ben Braumfduweigern fint zu erwälnen $\Im$. (5) $\mathrm{cm}=$

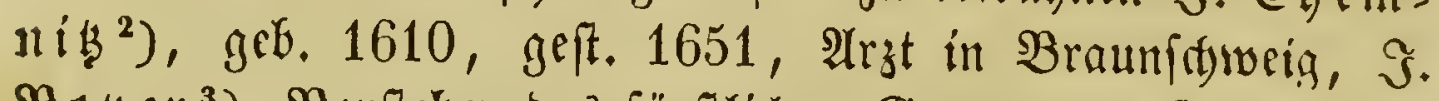

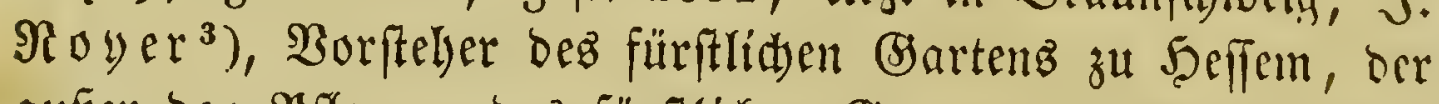

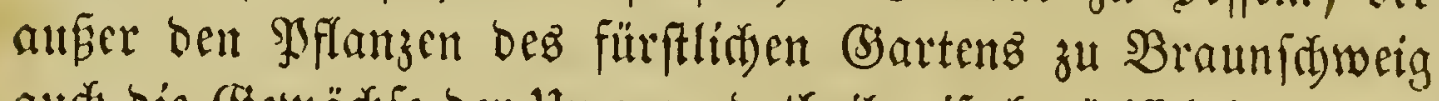
aud) bie (5scwäd) ber Ungegent theilweife berüafidytigte, uno

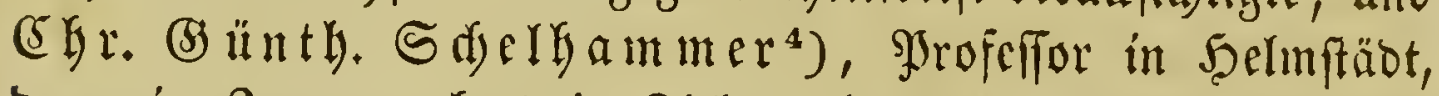
bann in Fena, zulegest in Rid, geb. 1649, geft. 1716, ber audi weiter unten zut eriwälynen ift.

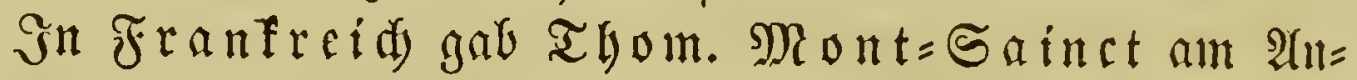

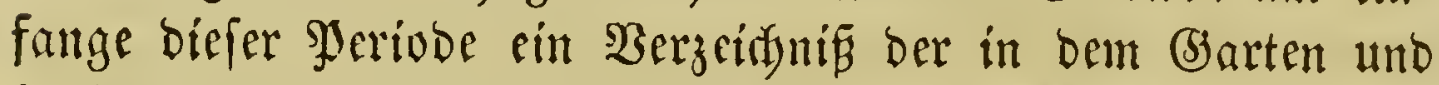
in ber Umgegend yon Sens wadfentorn Bjflanjen herauz. ${ }^{5}$ )

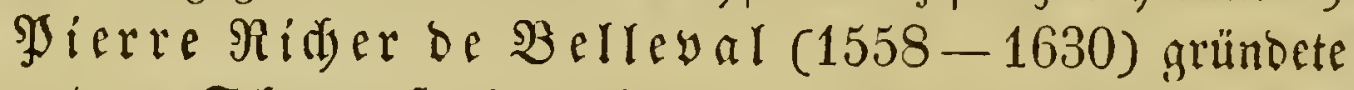
unter bem Sdyutse Seinrid) IV. Den Fotanifden (Jarten

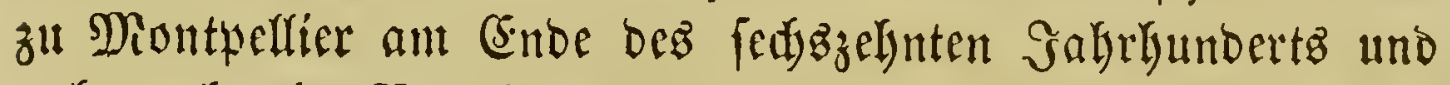

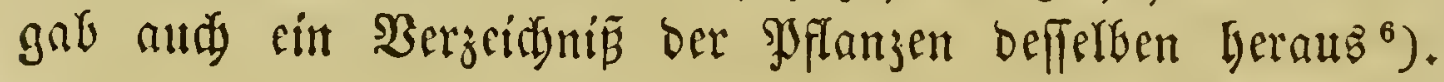

3) Stirpium et fossilum Silesiae catalogus etc. Lipsiae 1600.

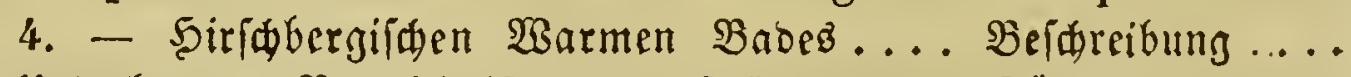

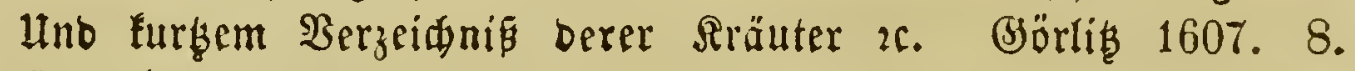
5̧iriaberg (1619), 8.

2) Index plantarum circa Brunsvigam trium fere milliarium circuitu nasc. c. append. iconum. Brunsv. 1654. 4.

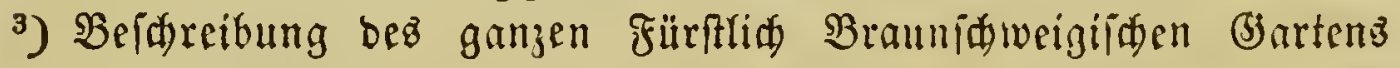

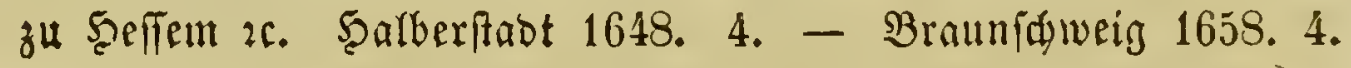

-) Catalogus plantarum maximam partem rariorum, quas per hoc biennium in hortulo domestico aluit et, paucis exceptis, etiam his vernis vestivisque mensibus poterit exhibere. Helmst. 1683. 4. Heber befifen übrige Sdrifsen vergl. Yritger'Thesaurus S. 261, 262.

s) Le jardin Senonois cultivé naturellement d'environ 600 plantes qui croissent à moins d'une lieue de la ville et cité de Sens, 1604. 12. Sebr felten.

-) Onomatologia s. nomenclatura stirpium, quae in horto 


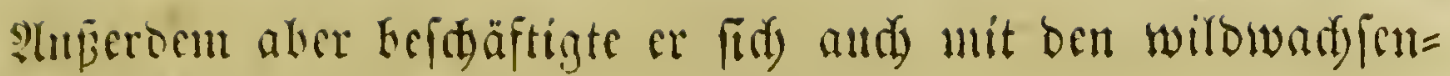
oen Syflunjen der Srovinz Ranguedoc. ${ }^{1}$ )

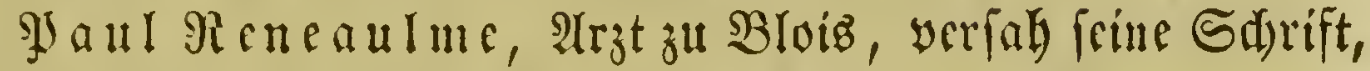
soclde theils yon wilowadjentorn, theils yon (5artenpflangen Lanbelt, mit guten Abbiloungen. E.r hat übrigenz bie Eigen= thümlidfeit, bie \$yflanjen mit griedsifden Ramen, bie er felbft erfunocn bat, zu belegen. ${ }^{2}$ )

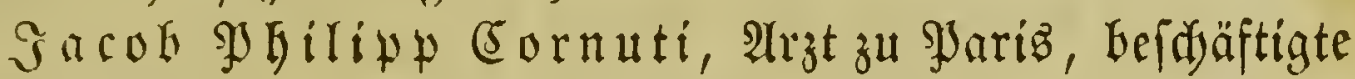

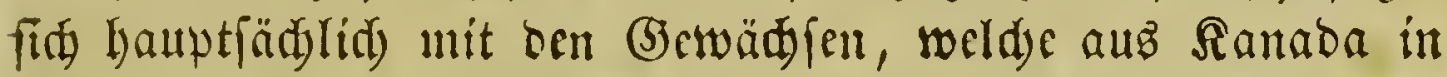
Die parijer (5)ärten verpflanzt worben waren, fügt jebord feinem

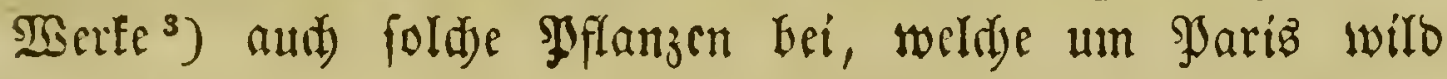
twarfjen.

Ilm siefe Bcit lebte aud Ricolaus Mard)ant, ber in ben Jahren 1649 biz 1659 mefrere, nor) ungebrufte Ber= zeidniffe franzöfifder gJflanzen, namentlidy oer lungegeno yon Şaris, geidrieben baben foll. ${ }^{4}$ )

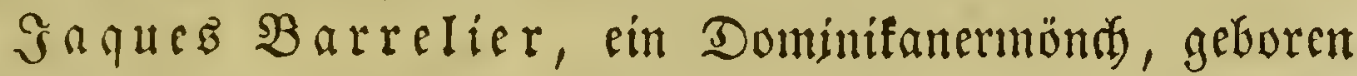
1634 zu SJaris, geftorben bajelbft im Sahr 1673, unternahm

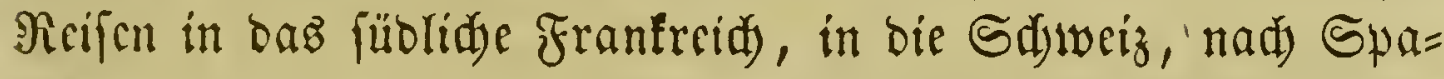
nicn unb Jtalien, oft in (3emeinidjaft mit bem Staliener $\mathfrak{B}$ oc $=$

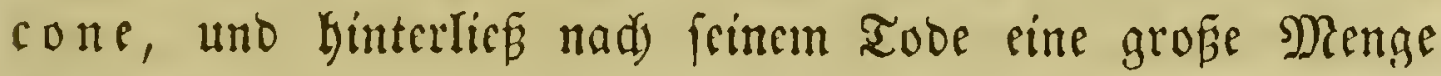
Iुjtanzenabbiloungen. (5r fand aud) eine nidjt unbebcutente

regio Monspeliensi recens constructo coluntur. Monspelii 1598. 12.

1) Dessein touchant la recherche des plantes du Languedoc. Montp. 1605.8.

2) Specimen historiae plantarum. Plantae typis aeneis expressac. Paris. 1611. 4.

3) Canadensium plantarum aliarumque nondum editarum historia etc. Adjectum est Enchiridion botanicum parisiense. Paris. 1635. 4.

4) Rrüger fübrt voul ifm folgenoe Sarift an: Index stippium ducis aurelianclisis, Gastonis jussu et largitione in Gallia conquisitarum. (s. l.) 1659. Fol. Sy rifel fïlyrt bicfe Sdrift nidat an, aud Sprengel nidt. 
Anzahl vor feiner 3rit nidyt befunnter Softangen auf, wilde in Sprengel's Histor. rei herb. tom. II, S. 174-176 wergeidnet fint. Seine 2 rbeiten wurben cinige 3eit nad) fei= nem Tobe von âtun be Guffie nad Tournefort's Syfem georbnet heraugigegeben. ${ }^{1}$ )

Der in anderer $\mathfrak{B}$ czielung weiter untell zu errwähnende

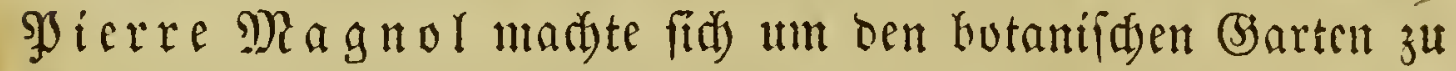

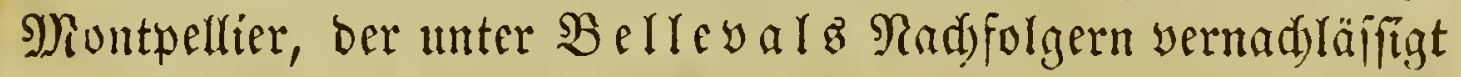
worben war, werbient ${ }^{2}$ ). ATber er bearbeitete auth eine Srbrift über bie in ber (Segento yon Montifllier wildwadjendent Ifflanzen. ${ }^{3}$ )

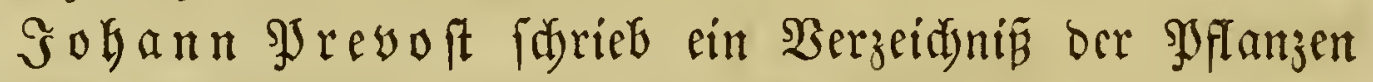
yvn Béarn und ber angrenjenden frovinjen. ${ }^{4}$ )

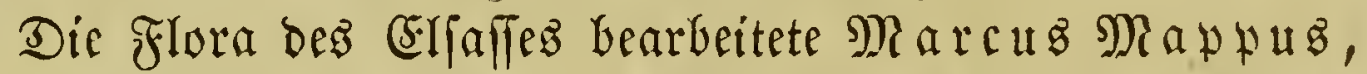
2iž zu Strafiburg, geb. 1632, geft. 1701, ber als Sryuller

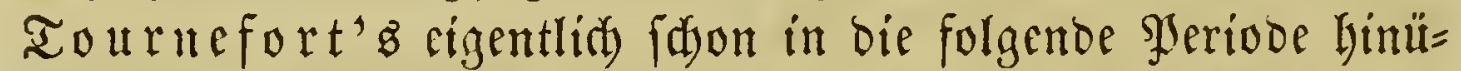
berfitreift. Sein $\mathfrak{B e r l}$ enthält zwar wenig ueur Syflanzen, ift

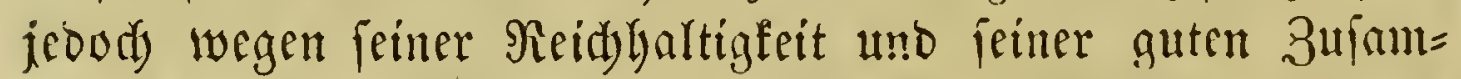
menfterlung ber Synonymen bemerfenswerth. (s:s ift übrigens

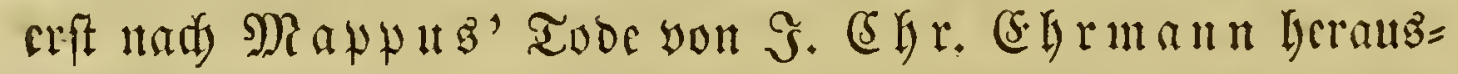
gergeben woroen. $2(u d$ - s) Des botanifiden (G)artens zu Strab̧urig entlyält zum Theil swilnawadj[ende syflanjen. ${ }^{5}$ )

1) Plantae per Galliam, Hispaniam et Itaiiam observatae. Opus posth., cur. Ant. de Jussieu. Par. 1714. Fol. Mit 1324 2lbsifoungen.

2) Hortus regius Monspeliensis. Monspelii 1697. 8 .

$\left.{ }^{3}\right)$ Botanicum Monspeliense, s. plantarum circa Monspel. nascent. index, cum appendice, quae plantas de novo repertas continet. Monspel. 1686. 8. - Eime frithere $2418=$ gate: Lugdun. 1676.8.

4) Catalngue des plantes qui croissent en Béarn, Nararre et Begorre et es Costes de la mer des Basques. Pau, 1655. 8.

$\left.{ }^{5}\right)$ Histor. plantar. Alsaticarum posthuma opera et studio $\mathbf{J}$. Chr. Ehrmanni. Argent. 1742. 4. - Catalogus plant. 
Unter ben italienifiden Botanifern biefez Beitrama find

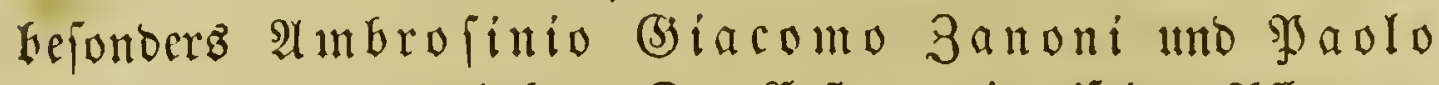
$\mathfrak{B o c c o n e ~ G e r b o r z u l y c b e n . ~ D e r ~ G r i f t e r e , ~ e i n ~ e i f r i g e r ~ S i f l a n z e n = ~}$ forfder uno guter 3ciduner, war Sorfteher bes botanifden

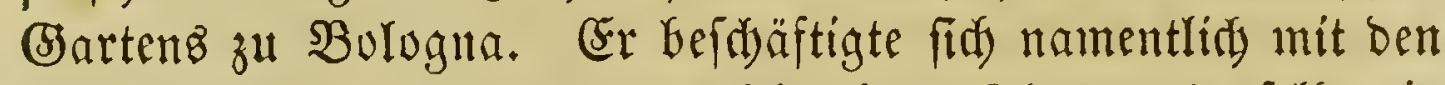
Şflanzen feiner Biegend und beforich bie feltneren berjelben in

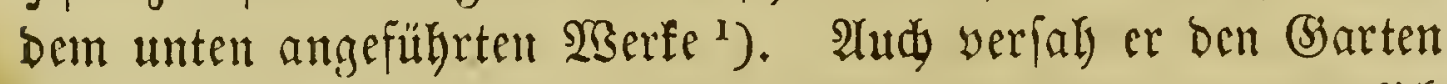

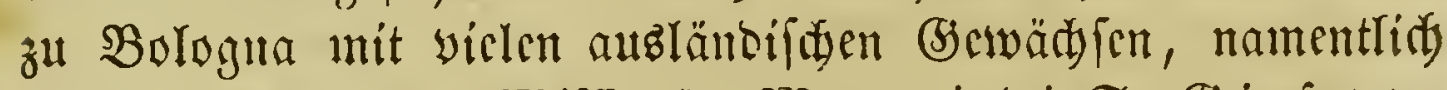

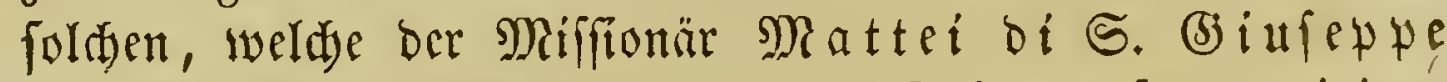
aus Malabar mitgebradjt batte. Diefe hat er fammt cinigent Şflanzen ber füblíden Sdyweizeralpen uno ber Apenninen eben= farks befdrieben ${ }^{2}$ ). 3anoni lebte yon 1615 bis 1682.

\section{$\mathfrak{P} \mathfrak{a} \mathfrak{O} \mathfrak{d} \mathfrak{B} \mathfrak{o} \operatorname{ccone}$,}

geboren zu Sayona 1633, gefturben zu গ̧alermo 1704,

gerwöhnidy Sylvius genannt, ein (Siftercienier Möndy, burd)=

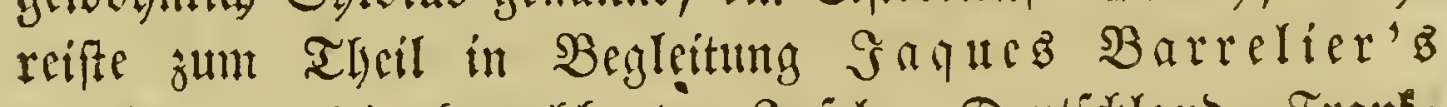
Stalien und bic benadjbarten Snjeln, Deutjoland, Frant= reid), Solfand atmo England, umb famunclte auf feinen $\mathfrak{S a n}=$

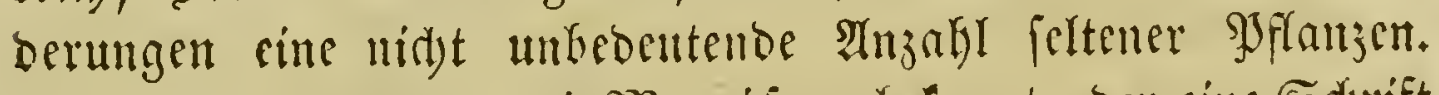
In England wurbe er mit \$i orifo n befannt, ber cine Sdjrift

Amstel. 1689. 12. - Paradisus Batav. etc. Opus posthumum. Ed. William Sherard. Lugd. Batar. 1659. 4. Ibid. 1705.4 .

1) Indice delle piante portate nell' anno 1652 nel viaggio di Castiliglione ed altri monti di Bologna. 16.52. Fol.

${ }^{2}$ ) Istoria botanica. Bologina 1675. Fol. mit 80 Sutpfertafern.

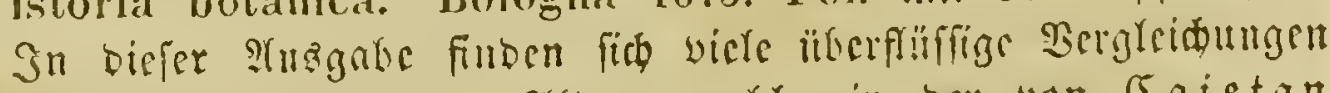
mit bell grffanzen ocr aften, werde in ber won bajetan D2ontiu (Rariorum stirpium historia ex parte olim edita.

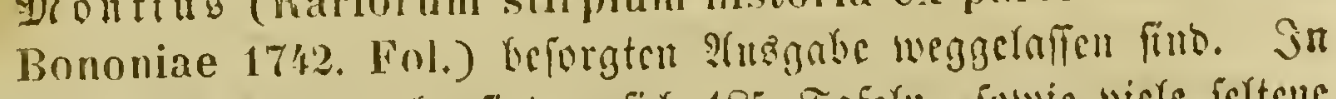

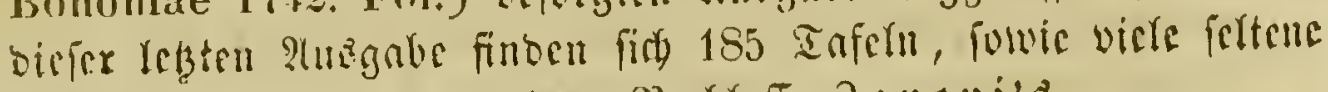

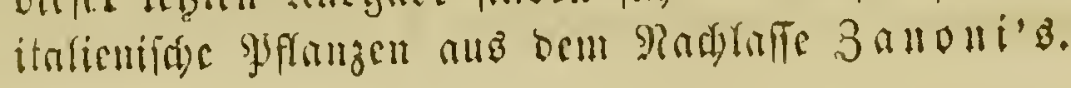




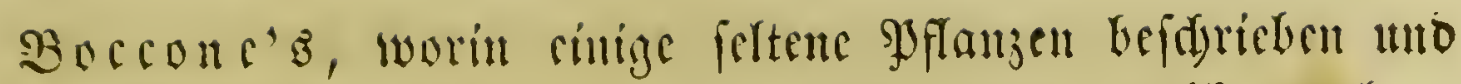
afigebiloet find, berauzgab ${ }^{1}$ ). (Einige Gabre mablyer gab er mif 3uroen 2 . Sherard's zat Benedig fein Mufum Gernus ${ }^{2}$ ). Die Abbillongen $\mathfrak{B}$ occone's futo vft zu flein, meifens nidyt befonders ausgezeidunet; mehrere berfelben foll er yon $\mathfrak{B a r r e l i e r}$ entlebint haben.

Auper biefen wollen wil nod) erwähnen (3) iovanni

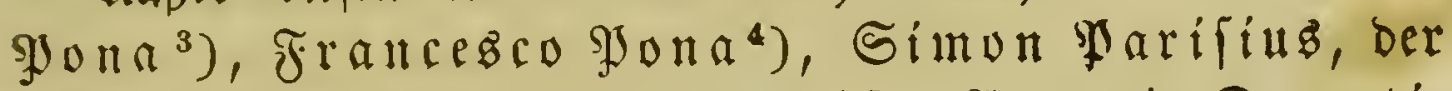
cinize Prflanjen auf Sicilien befdrieb ${ }^{5}$ ), Antonio Donati,

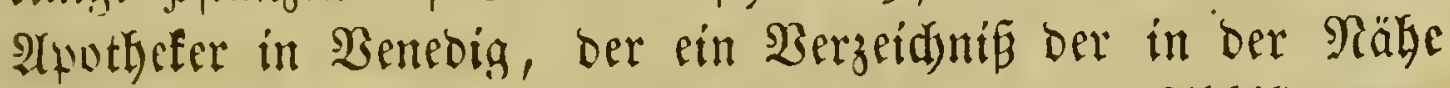

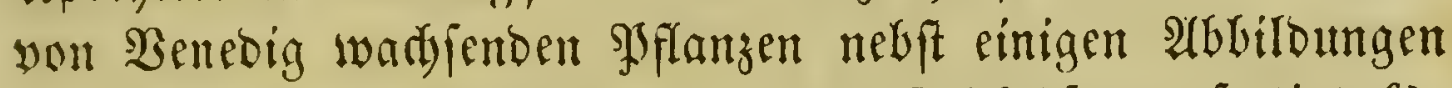
unto Befdyrcibungen uno 2 ngabe ber 5eilfräfte verfertigte ${ }^{6}$ ). (3)iufepte Bonfiglioli aub Incona, ber bie auf bem Actna wadjfenden Syflanzen unteriud)te ${ }^{7}$ ), Dominicus $\mathfrak{S} \mathfrak{a}=$ narolus als Bergeidyer ber in bem rümifiden Amphitheater

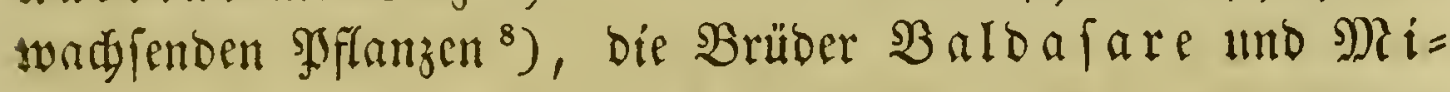

9) Icones et descriptiones rariorum plantarum Siciliae, Helitae, Galliae et Italiae. Oxonii 1694. 4. mit 52 Iafern.

$\left.{ }^{2}\right)$ Museo di piante rare della Sicilia, Malta, Corsica etc. Venezia, 1697. 4. mit 131 Tafeln. - Bofcone idrieb nod

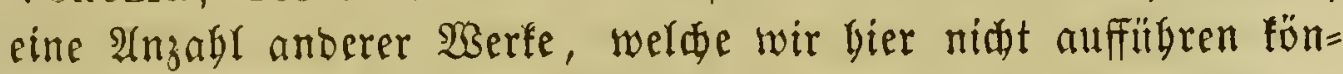
nen. 2Bir verweifen auf 9ribel's Thesaurus S. $24 \mathfrak{u} .25$.

3) Plantae s. simplicia, ut vocant, quae in Baldo monte et in via ab Verona ad Baldum reperiuntur etc. Verona 1595. 4. Antverp. 1601. Fol. Basil. 1608. 4.

4) Il paradiso de fiori, overo lo archetypo de giardini discorso. Con il catalogo delle piante che si possono avere del monte Baldo nel mese di maggio. Veron. 1622. 4.

๖) Descrizione o piante della Sicilia. Panorm. 1610. (₹̈erlt

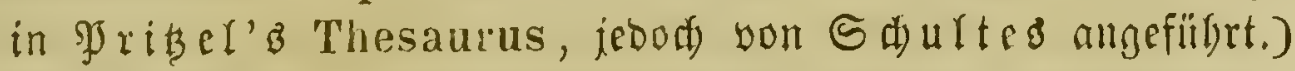

-) Trattato de semplici, pietre e pesce marini, che nascono nel lito di Venezia. 1631. 4.

") Sefindet fith in gyietro (Earrera'b "il Mongibello descritto." Catan. 1636. 4..

8) Plantarum amphitheatralium catalogus in beffen medic. observat. pentacost. quinque. Rom. 1652. 4. 


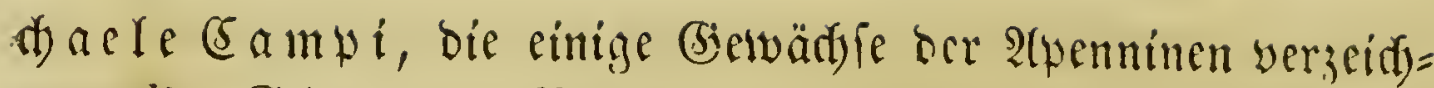

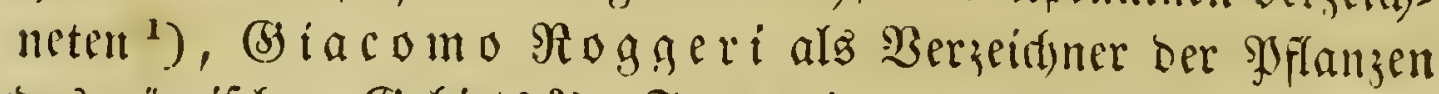

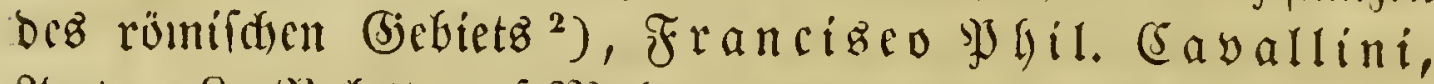

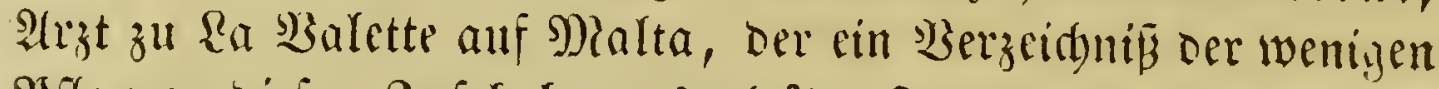

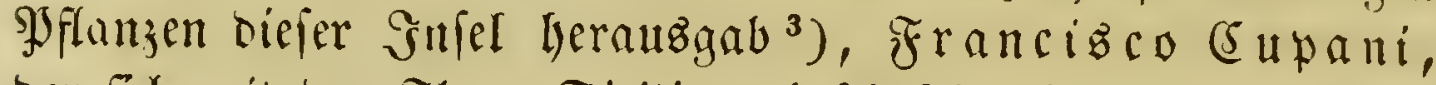
ber fid) mit ber Flora Giciliens bejuaftigte ${ }^{4}$ ) uno ben (Eng= ränoer Sacob $\mathfrak{S e t i v e r ~ w e g e n ~ f e i t r e r ~} \mathfrak{B e m u ̈ l}$ jutgen um die italienifde Flora, obgleidy er ber Zeit nady in bie folgende গJerivoe gelgört. ${ }^{5}$ )

Die Spanier uno Portugicien waren in biejent 3eit= raume auf bem (B)biete ber Botanif faft ganz unb gar un= thätíg. Die wenigen Männer, welthe über die Flora ber

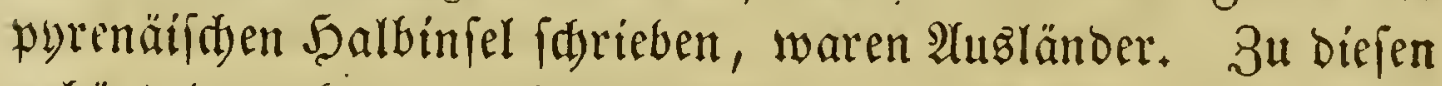

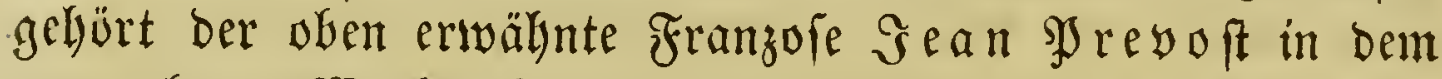
angegebenen $\mathfrak{W e r k e , ~ f o w i e ~ ( 5 ) ~ a ~ b r i e l ~ ( J ) ~ r i b l e y , ~ w a h r i d e i n = ~}$ lidy ein Engländer, ber 30 Jahre lang bie Flora sortugals ourd)forfote. Seine Sdyrift ift aber nur ein reidibaltigez

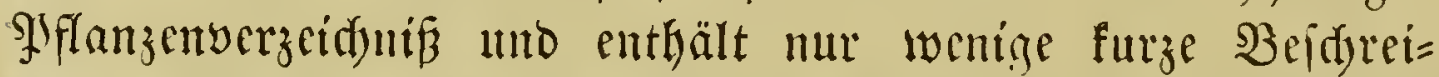
bungell. Später wurbe fie von Dom. Ba no elli nady bem Rinnéf

1) Specilegio botanico, Dialogo, nel quale si manifesta lo sconosciuto cinnamomo delli antichi. Lacca 165\%. 4.

2) Cataloge delle piante native del suolo Romano. Rom. 1677. รn $\Re$ ay's Sylloge aufgefülurt.

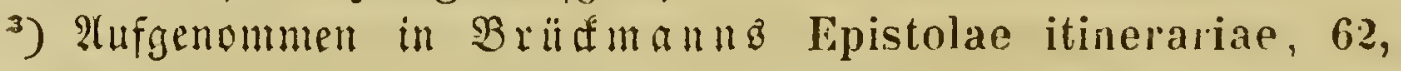
Cent. II. p. 674-691, unter bem Iiter: Pugillus meliteus s. omnium herbarum in insula Nielita ejusque districtis enascent. perbrevis enarratio.

4) Catalog. plantar. sicularum noviter adventarum. Panormi. 1692. Fol. Siermefret uno verbeffert unter bem Ritel: Syllabus plantarum siciliae nuper detectarum. Panormi. 169\%. 16.

$\left.{ }^{5}\right)$ Plant. Ilaliae marinarum et graminum icones et nomina. Lond. 175. Fol. Plantarum Ehuriae rariorum catalogus e Caesalpino, Boccone, Menzelio, Rajo. Lond. 1715. Fol.

-) Viridarium lusitanum etc. Ullyssipone 1661. 12. - Son Dom. Ba a derfi beraubegegen im Sagr 1789 in 8. 


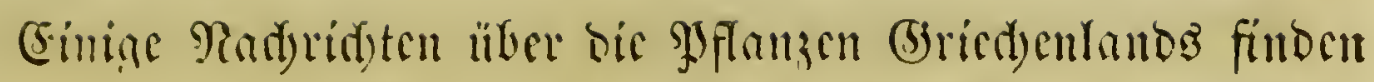

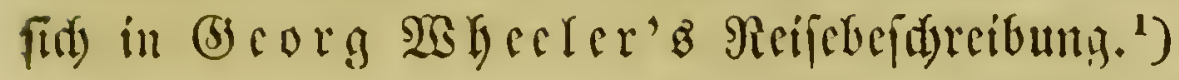

In (3) rofibritannien war man in bicfem Zeitranme

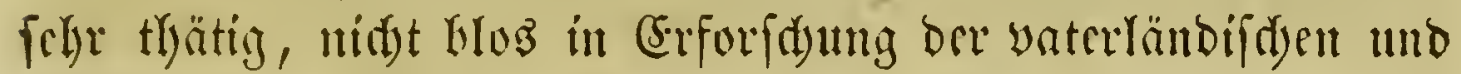

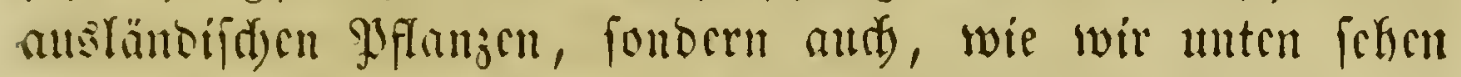

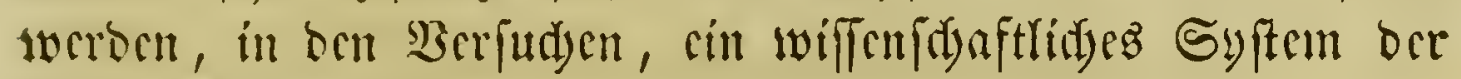
Botanif aufjutellen.

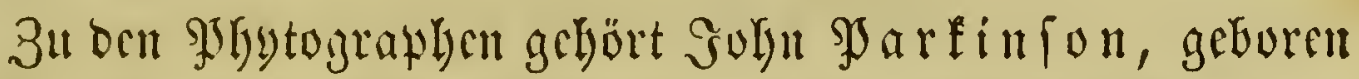

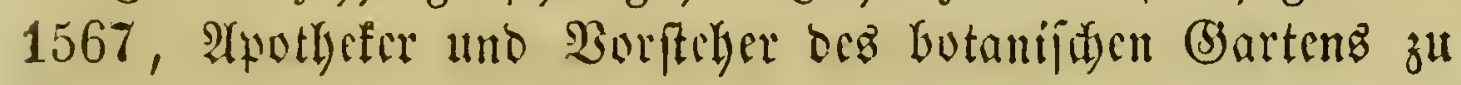

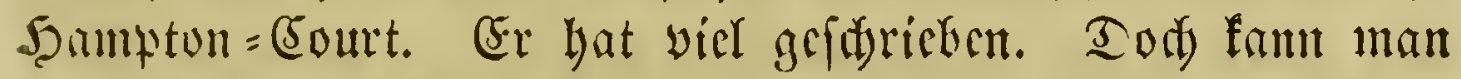
feinen Sdriften fiumen großen $\mathfrak{B e r t h}$ beilegen, ba er meiftens

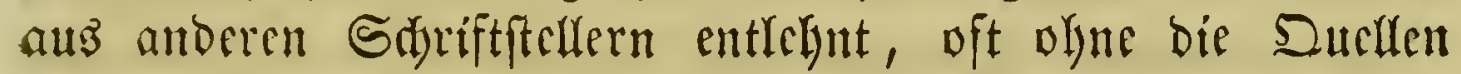
anjugeben, und bie Prflangen olgne Sromung willfürlidi balo nadi) bem Standorte, balo nad) äußeren Formen, balo nads

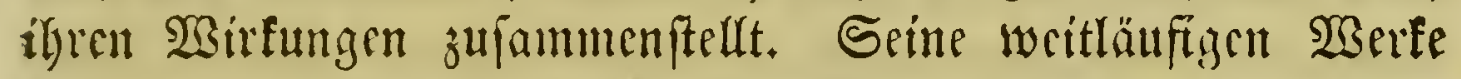
fügten zu bom bizlyer befannten গyflanzenidange nur wenige neue (sewädsarten binzu. Bergl, darilber Sprengel'g (5erid. D. Bot. S. 97 แ. $93 .{ }^{2}$ )

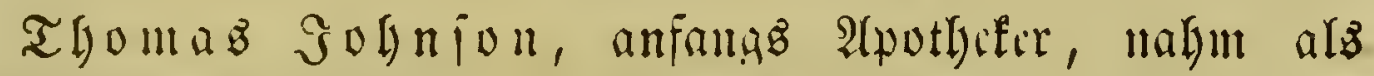
Freibilliger an ocn Bürgertriegen Theil uno fticiz bis zu be!n (brade cines Sobrlicutcmantz, wurbe aber bei ber $\mathfrak{B}$ elagerung yon $\mathfrak{B}$ afuth int Jahre 1643 getübtet. Er ftand wegen feiner

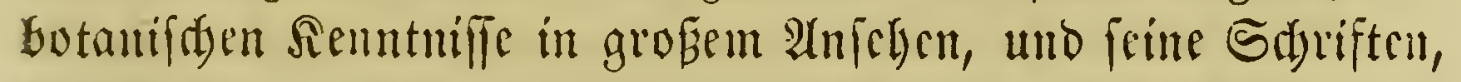
bic cr in ben Galjen 1632 bis 1641 beraugagab, haben vid

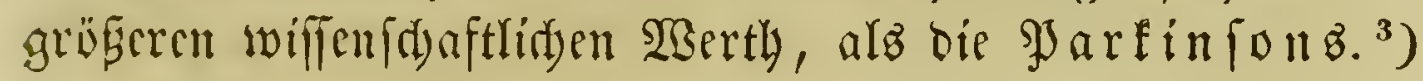

1) A journey into Greece. Lond. 1682. Waris 1689. Wmiter= Dam 1722.

$\left.{ }^{2}\right)$ Theatr. bot., or a herball of a large extent. I.ond. 1640. Fol. - Paralisi in sole paradisus terrestris. Lond. 1629. Fol. 1656 Fol.

3) Descriptio itineris investigationis plantarum causa in agrum Cantianum suscept. Lond. 1632. 8. Ericetum Hamstedianum. Lons. 1632. 4. Mercurius bot. s. plantar. gratia suscepti itineris anni 163't descript. Lond. 163\%. (4.) 16'1, 
Der als Syftematifer berülmte $\Im$ oly n $\Re$ ay war aud als Shbytograwh ungemein thätí. Daz Räbere über ign woiro woiter unten angegeben twerden. ${ }^{1}$ )

Bon nidjt geringerer - $B$ ebeutung für die $\mathfrak{B}$ iffenfdyaft ift

\section{Reonard SHafenet,}

geboren 1642, geftorben 1706.

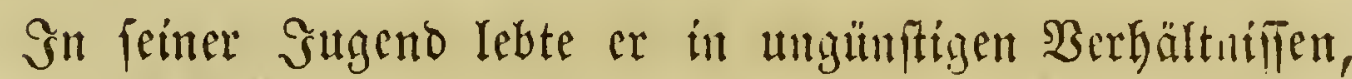
att benen er erfit burdi bie Unterftühung oer Rünigin Auna herausfam. Später wurbe er zum Borfteher ber fönigliden (S)ärten ernannt. Das yon ifm gefamunelte Şerbarium ent=

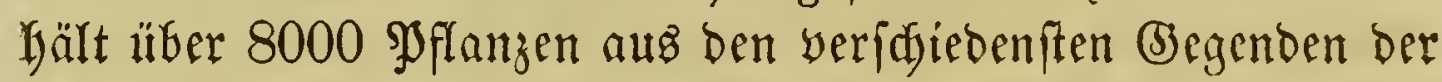
(5rbe uno wiro nod) jest im britifsen $)$ Rufeum aufberbabrt. SOlufenet war aber aud ein äuberft thätiger Sdyriftitefler, and feine 2 serfe find bejonbers wegen ber barin enthaltenen zaljlreiden arbiloungen nod) jegt für ben Botanifer von

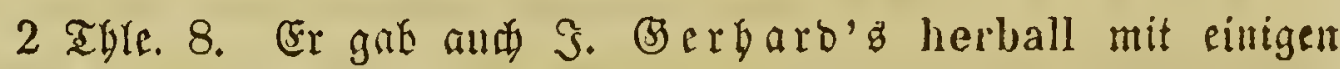
Bereidyerungen 1633 za Ronbon beraus.

1) Seime fierber gefürenten Sariften find: Catalog. plantar. Angliae et insular. arjacentiam. Lond. 1670. 8. - Fasciculus stirp. britannicar. post editum plantar. Angliae catalogum observatar. Lond. 1688. 8. Diefe beioen Sđ̣if= ten zufummen unter orm Titel: Synopsis methodica stirpium Britanuicar: etc. ibid, 1690. 8., uno melyrmita, worin er bie früber angenommene arpbatetifdye Sronung verläst und feime eigene Metlobe befolgt. - Catalogus plantarum circa Cantabrigiam nascent. Cantahr. 1660. 8. uno mebrmalb anonym. - Stirpium europaearum extra Britannias nascent. sylloge. Lond. 169\%. S. in alpbabeticher Dronung. Travels through the Low-countries, Germany, Italy and France etc. Lond. 1673. 8. - Ein wichtiges $23 \mathrm{er}$ if aud bie Historia plantarum etc. in 3 Igeifen, sonbon 1686, 3 shle., 1704, worin auf bie feit $\mathfrak{B}$ aubin gemadsten Entberfungen forgfältige siiuffidyt genommen ift. 


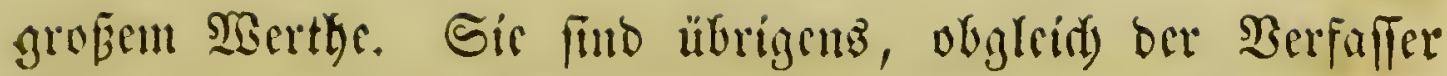
mit ben bamaligen Syftemen wolyl befannt war, in alphabe=

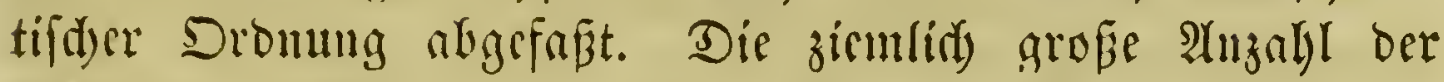

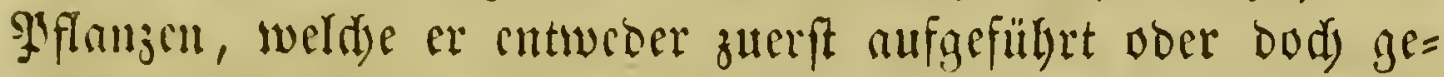
muter, als feitler, befdricben hat, fund in Sprengel's Histor. rei herb. S. $147-161$ angegcben, ${ }^{1}$ )

(5) Genfalls wegen frinter ssflangenjammlungen unt abbit= Dunigen ift

\section{Sames Wetiver,}

Ifpotgefer in Ronbon, geftorben 1718,

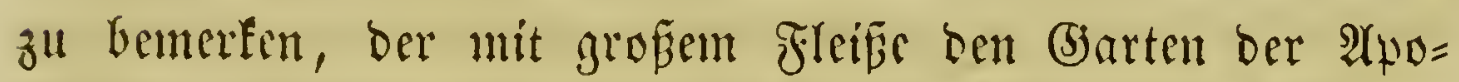

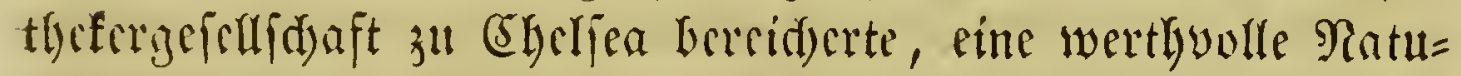
ralicufammlung anlegte und vicle Sd)riften Griauggab. (Er war,

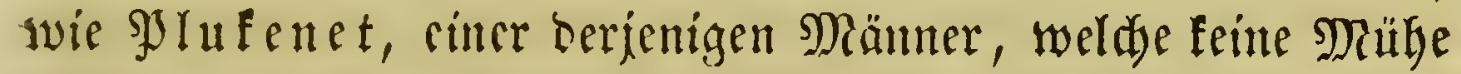

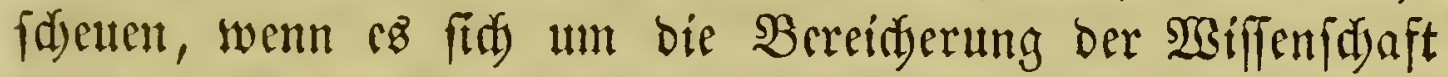

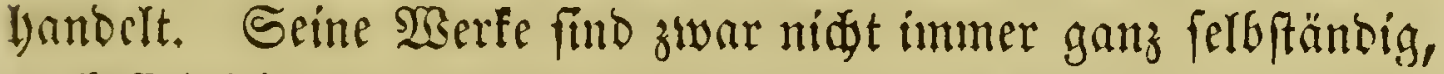
and) find bic barin entbaltencu abbildungen wegen ibrer Rlsin= heit nidt fo vortrefflid), wie bie $\mathfrak{g} l$ ufenct's, bod) finden fid

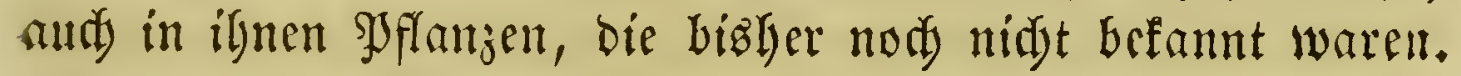

Siefe hicrüber Sprengel l. c. S. 163 bis $165 .^{2}$ )

2) Scine Merfe: Phytographia, London 1691 - 93, Almagestum botanicum, ibid. 1692-1693, Almagesti botan. mantissa, ibid. 1700, Amaltheum botanicun, ibid. 1705, find unter bem Titel: Leon. Plukenetii opera omnia zu \&on= bon 1720, VI Voll. in 4. eriftienell; 2. Alufl. in 4 Thln. 1769. 4.

2) Einige Edriften Petiber's find fwon oben, wo bie Rroe von Der italieniiden flora war, angegeben worbell. Alle zufammen fino 1764 zH Sunbon unter bem ritel: Jac. Petive ri opera omnia ad historiam naturalem spectantia in $3 \mathfrak{T}$ gln. erfdic=

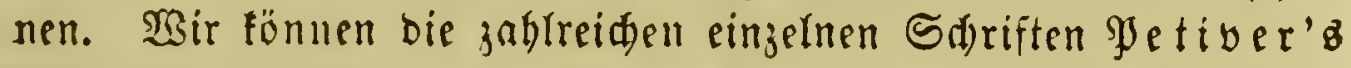

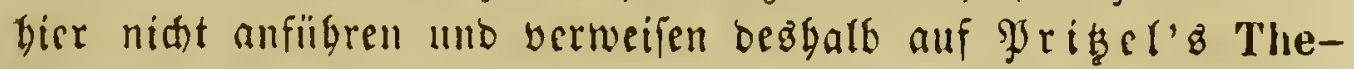
saurus S. 225 u. 226.

๔. BBindter, Beid. b. Botanil. 


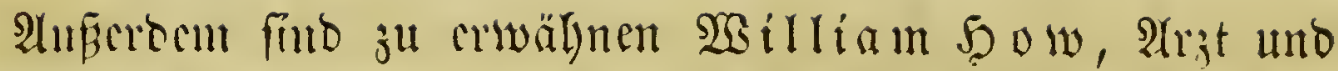

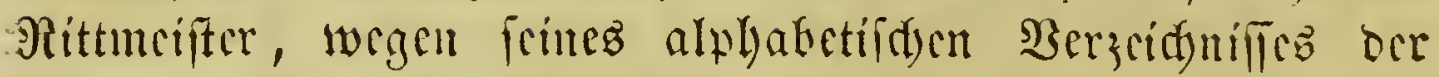
Sflanzen Englanoz mit Angabe ber Standörter ${ }^{1}$ ), Robert

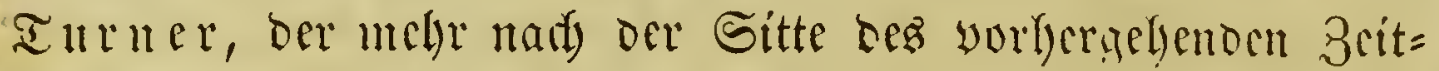

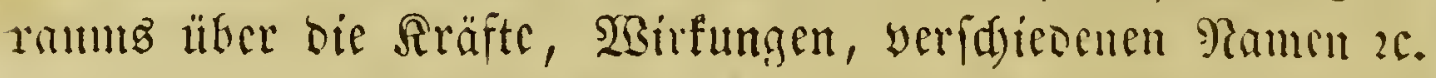

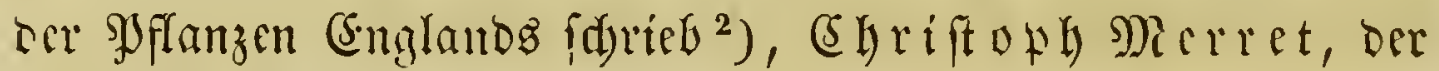
chenfalls einige Soflanzen (Englands fammelte ${ }^{3}$ ), $\mathfrak{F}$. $\& a n g=$ ford wegen feiner Sdruft über die Dbftbämme, weldye in England gebeifen ${ }^{4}$ ), Nobert Sibbalo, inegen feitrs

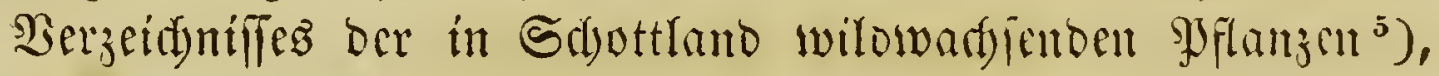

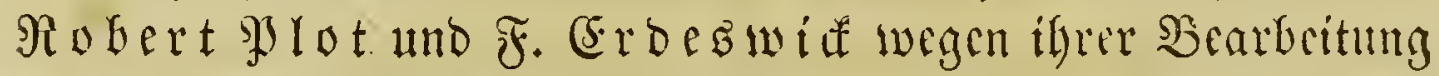

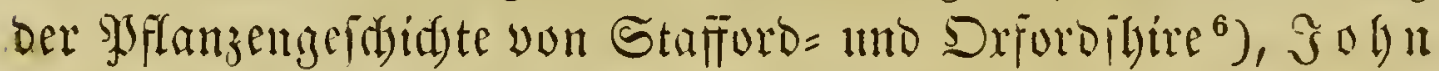

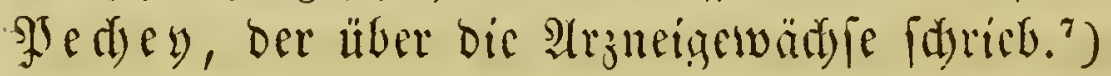

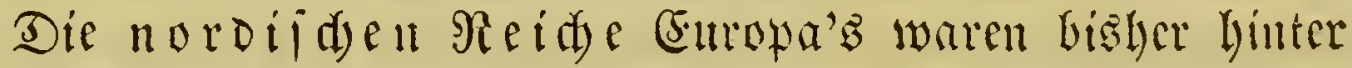
son Sübläntoen weit zurüdgeblieben; woir hatten in ser yorigen

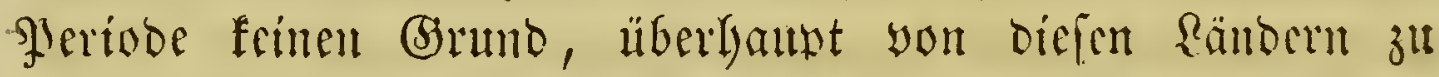
reben; bemn, wenn man baв yon Srüger $\subseteq .125$ anıefülyte,

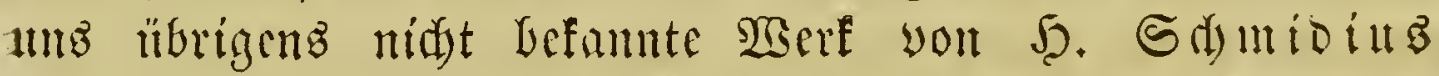
(Herbarium Danicum. Hafn. 155j) altanimunt, fo fann man

1) Phytologia britann. etc. London 1650. 8. (Er gab auth ¿obel's Stirp. illustrat. bermiz.

2) Botanologia, the british Physician etc. Lond. 1664. 8.

3) Pinax rerum naturalium britann. Lond. 1667. 8.

4) Plain and full instructions to raise all sorts of fruit-trees that prosper in England. Lond. 1681. 8. - 1696. 8. - 1699. 8.

$\left.{ }^{5}\right)$ Scotia illustrata s. prodromus rerum naturalium etc. Edinb. 168\%. Fol. - History ancient and modern of the Sherisdom of Fife. Lond. 1710. Fol. - History of Linlinthgaw. ibid. 1710.

*) Natural history of Oxfordshire. Oxford. 1677, 86, 95, with additions of Burmann 1705. Fol. Natural history of Staffordshire. Oxf. 1679, 86. Fol. F. Erdes wick, nat. history of Staffordshire. Lond. 1686. Fol.

${ }^{7)}$ The compleat herbal of physical plants etc. Lond. 1694. 8 - 9ritger fübrt anferbem nod an: Hugh Plat, the garden of Eden, or a description of all flowers now growing in England etc. Lond. 1660. 8. 
redyt mobl behateten, baj in bem vorkergehenden 3eitraume feine botanifde Sd)rift won ben noroifden Reiden ansge= gangen fei. Sn biefer gुeriobe bagegen zeight fid) aud lyier ong riifyulid)e Streben, die vaterländifd)e fylora zu burd)foridsen.

(5) $\mathfrak{d} \mathfrak{i g}$ Fuir - 162S) Durdireifte Dänemarf, Sdymeden mo Rorwegen, ant fanmelte die in biefen Rändern wilowady fenton gुflrmzen. ${ }^{1}$ ) 2uds Dtto Sperling, ein Şanburger (1602-1681), ber Sorfeber bes botanifaen Gartens zu Sopentyagen war, matyte fid un die norbifdue Flora verbient. ${ }^{2}$ )

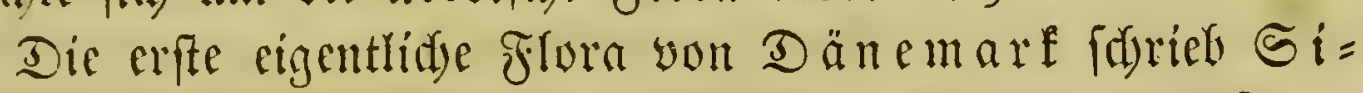
man gy a ulli aus Proftod (geb. 1603, geft. 1680), anfangz

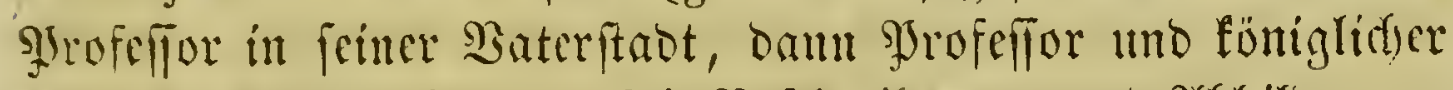

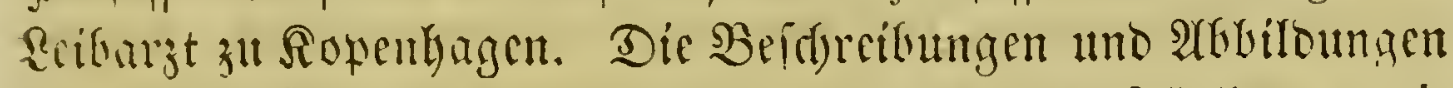
frites Siserts furo meifens aus aneren Sdyrifteftern, wie Matthioli, Robel und Dodanaeus, entlefnt. Die Wrfanzen fino in alwhabetifider Dromung mit âtgabe ber Secil= fräfte nach Den Sahregzeiten georonet. ${ }^{3}$ )

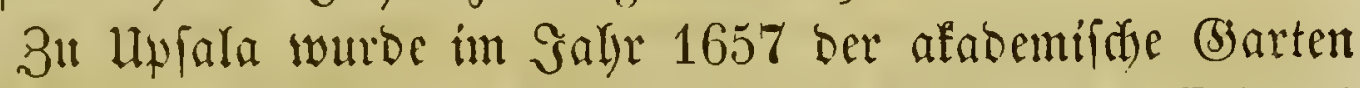
angelegt; rie 2uffidst über bonflelben führte zuerft Dlaus $\Re$ uobed , geb. 1630, geft. 1702, weldyer mefrere Suriften ither benjelbon Germiggab. ${ }^{4}$ )

1) Index plantar. indigenar., quas in ilinere sun observavit, quae circa Nidrosiam reperiuntur. In $\mathfrak{Z}$ gom. Fiartorin' Cista medica Hafniensis. Hafniae. 1662. 8. ऽ. $278-293$.

2) Hortus Christianaeus s. catalngus plantar., quibus Christiani iV. Daniae regis virilariun Hafniense anno 161 .? et superinre adornatum erat. Hafn. 16'2. 12. - 3u finden in Sillon $\mathfrak{g}$ aulli's Viridaria varia, S. $1-80$.

$\left.{ }^{3}\right)$ Flora danica, det er: Dansk Urtebog. Ropenlyagen 1648. 4. Dieielfe Sronung befolgte er in feinem Quadriparlitum botanic. Rostock 1639. 4. Strabburg 1667. 4. Jranffurt a. MR.

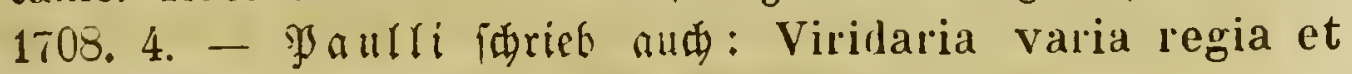
academica publica etc. Hafniae 1653. 12

-) Catalig. plantar., quibus hortum acaremirum Upsaliensem primum instruxit anno 1657. Upsaliae 1658. 12. 
Ferner find nodi) zul erwähnen Golyann Franfe (lat. Frankenius), \$rofefior zu Uxiala, geboren 1590, geft. 1661, ber fith mit ben lateintifyen uno fduwedifden Pflanzen=

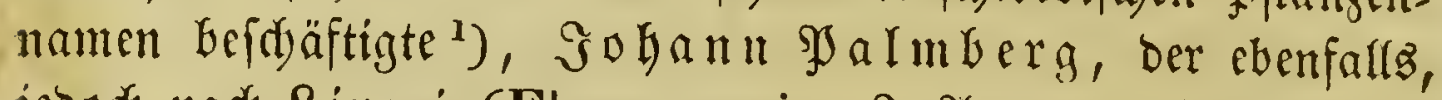
jebori) nad) Riun é (Flora suecia, 2, 2(ubg., p. IX) in fehr

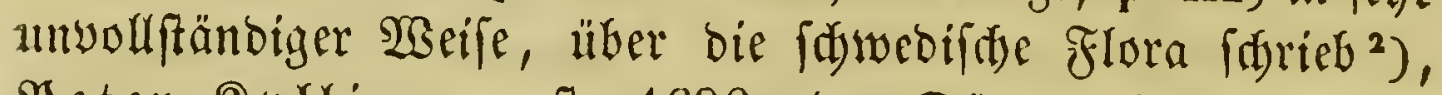
Speter Rylling, geft. 1696, Der Dänemart, Sorwegen

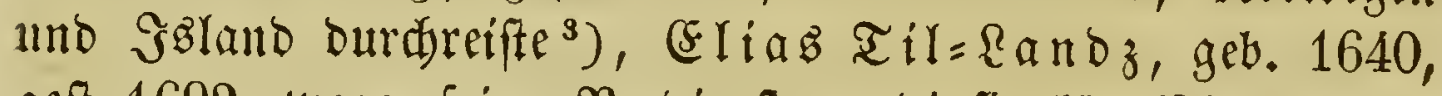

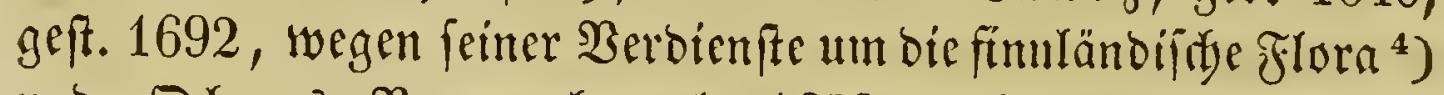
und $\mathfrak{D} \mathfrak{l} \mathfrak{a} \mathfrak{s}$ Bromel, geb. 1639, geft. 1705, Der eine Specialflora yon (jothenburg yerfajite. ${ }^{5}$ )

IBälyrent nun fo tuberall ein reges Streben in ber Erfor=

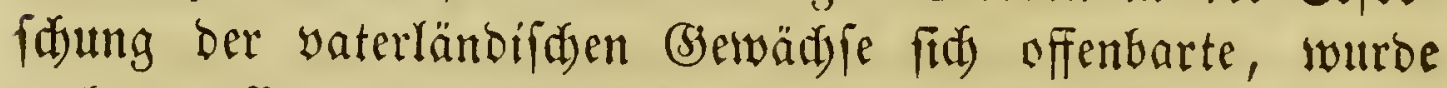

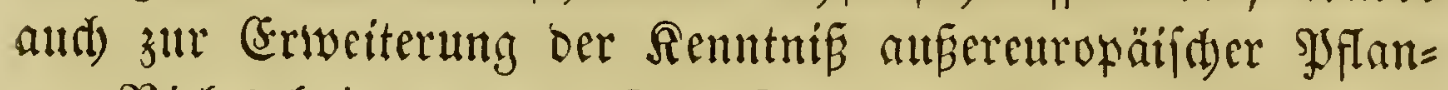
zen Sieles beigetragen. Der Jandeläverfelyr mit Sftindien uno ber neten SEelt wurbe in biefer Deriobe immer aubgebrei=

Hortus Upsaliensis academiae etc. Upsal. 1666. 12. Hortus botanicus variis exoticis indigenisque plantis instructus. Upsal. 1685. 8. --

Horticultura nova Upsaliensis. Upsal. 1764. 4. - 2u出 \{brieb er: Deliciae Vallis Jacobaea etc. Upsaliae 1666. 12. - Sn Bremeinidaft mit feinem Sobne arbeitete biefer Belegrte an einem gröberen phytograpgifden $\mathfrak{B}$ erfe, woyon im näd)ten $\mathfrak{A}$ bidjnitte bie $\Re$ ede fein wirb.

i) Speculum bot. cont. herbar. vocabula latina et suecica. Upsal. 1638, 59. 4.

2) Serta florae suecanae. Stregnes. 168'. 8. 1738. 8.

3) Viridarium Danicum etc. Ilafn. 1688. 4. Bergleide aud Bartholini Act. Hafn. T. II. No. 130.

-) Catalog. plantar., quae prope Ăboam tam in excultis quam incultis locis inventae sunt. Ăbo. 1673, 1683. 8. - Dieץe

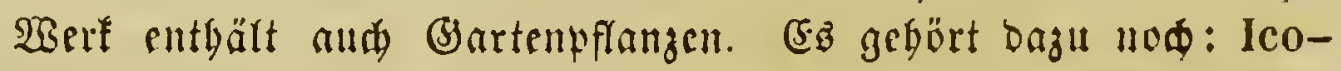
nes novae in usum selectae et catalogo plantar. promiscue appensae. Ăboae. 1683. \&.

5) Chloris Gothica, s. Catalogus plantar. circa Gothenburgum nascent. Gothenb. 169\%. 8. 
teter, uno an viclen gJunften oer fremben Welttheile erhoben fid blïhente curopäifdye Solonien. Fatd fudjte man bort in biefent

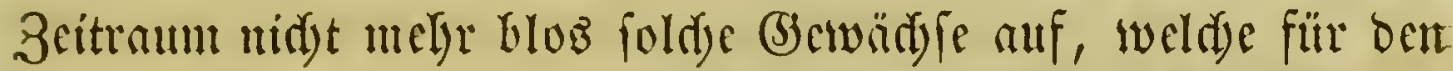
5ander won wejentlidsm ?inken waren, fondern man botani= firte jest aud) un ber Pfflanjen felber willen, umb mand)er

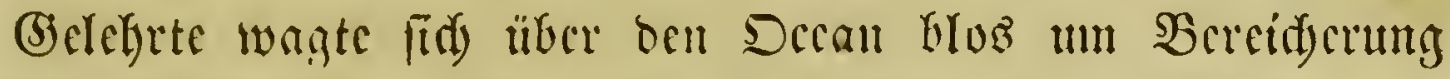

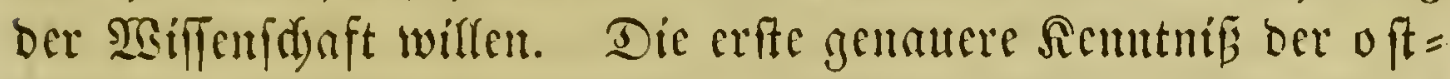

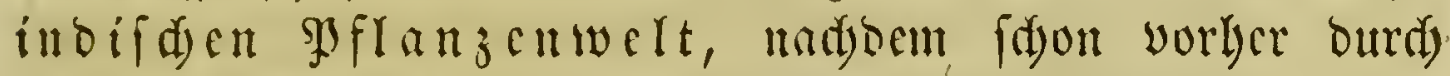

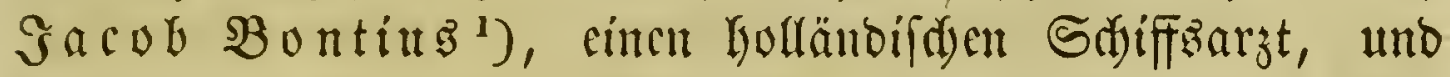
bermanu Rifolaub Brimm, geb. 1641, geft. 1711,

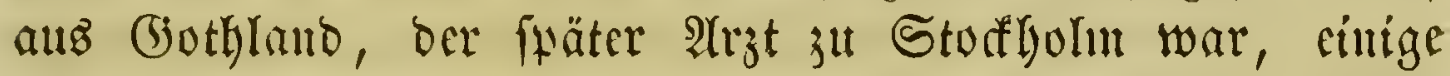

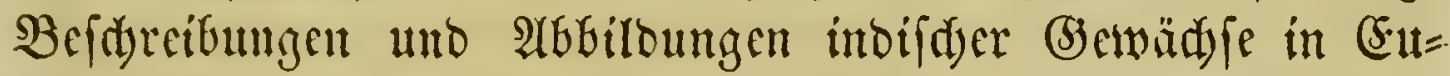
ropa befaut geworben waren, verbanfen wir bem Stattbal= ter ber Golländifd)= oftinbijan Rompagnie auf Malabar,

\section{Seentid vau Rhede tot Drafenteen,} geboren 1635, geftorben 1691,

ber von cinigen Braminen bie SPflanzen benennen, Dann ibre Bemerfungen überfesen uno mit abbiloungen verjeben ließ̧. Die lateinifde Heferjebung rülyrt yon $\Im$. (5 a fearius,

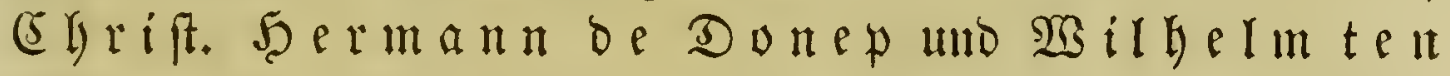

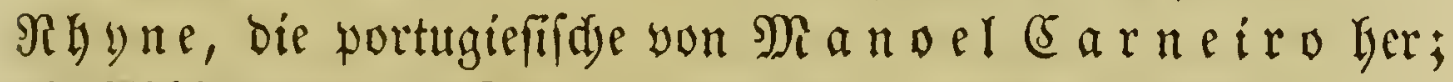
Die Abbilloungen verfertigte fun Iheil oer Jater $\mathfrak{R a t t e i}$ of (5. (5) uifeppe. Das mit grofiem Roftenaufiwande vollenoete Saerf wurbe baun in 2 (mfterbam von megreren Belchrten, wie Arnold Sycu, Soliann Eommelyn, Munnif, Th. Sanfon ab atmeloyeen mo $\mathfrak{A} \mathfrak{b} \mathfrak{a}$. a Soot,

1) De medicina Indorum libri IV. Lugd. Batav. 1642. 12. -

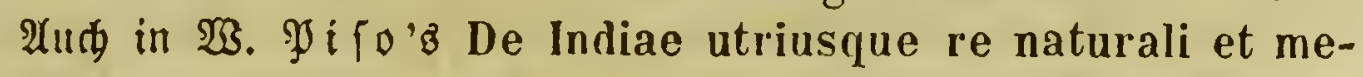

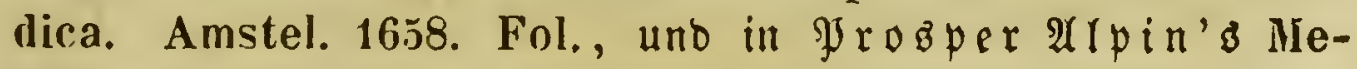
dicina Aegyptiorum. Lugd. B. 1718. 4., zु finben. 
mit 700 Abbildungen in zwölf Ihcilen und cinem Regifter= band von 1678 biz 1703 herauzgegeben ${ }^{1}$ ). Der vorbin er=

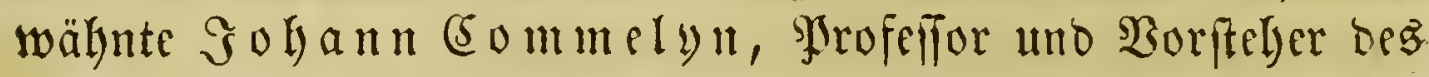
botanifden (s)artents zu Amfterbam, geft. 1698, war ein thä:=

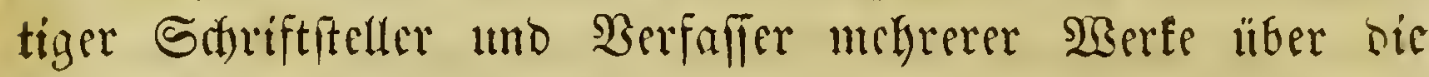

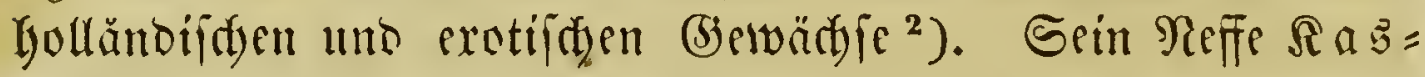
far commelyn, geb. 1667, geft. 1731, eiferte ifm auf

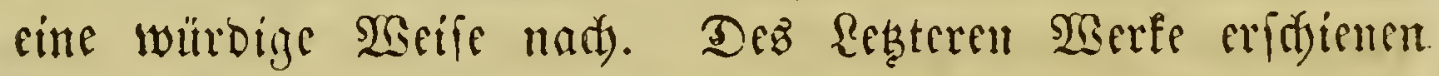
zwar erft int folgenden 3eitraume, wir fillfren biefelben je= Dorf) hicr gleich in 3ufammelibange an. ${ }^{3}$ )

Nidst weniger bemerfenswerth find bie Reiftungen tes Şanauers

') Hortus malabaricus indicus, cum notis et commentariis Joh. Commelini, Amstelod. 1688-1703. Fol. Serais= gegeben von 5eill. Ronbon 1774. 4. Pars I.

2) Nederlantze Hesperides; dat is, Oeffening en gebruik van de Limoen- ell Oranje-boomen; gestelt na den aardt en climaat der Nederlanden. Amsterd. 1675. Fol. - Catalog. plantar. indigenar. Hollandiae, cui praemissa Lam berti Bidla o dissert. de re herb. Amstelod. 1683. 12. - Lugd. B. 1709. 12. - Catalog. plantar. horti med. Amstelod. Amstelod. 1689. 8. - 1702. 8. - Horti medici Amstelod. rariorum tam orientalis, quam occidentalis Indiae, aliarumque peregrinarum plantarum etc. descriptio et icones, ed. a Fr. Ruyschio et Franc. Kiggelario. Pars prima. Amstel. 1697. Fol. Pars altera, auctore Caspare Commelino 1701.

3) Flora Malabarica s. horti Malabarici catalng. Lugd. B. 1696. 8. - $\mathfrak{A}$ (ud unter bem Iitel Botanographia etc. Lugd. B. 1718. Fol. - Plantar. usualium horti med. Amstel. catalng. Amstel. (1698). 8. (1724). 8. - Horti med. Amstel. plantae rariores et exoticae ad vivum aeri incisae. Iugd. B. 1706. 4. 1715. 4. - Praeludia botanica ad publicas plantar. exoticar. demonstrationes. Lugd. B. 1703. 4. -1715 . 4. 


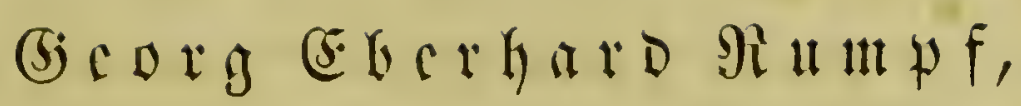 geb. 1637, geft. 1706,}

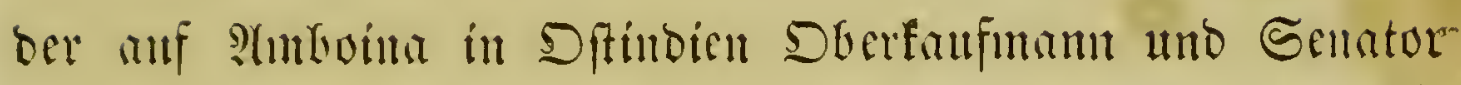

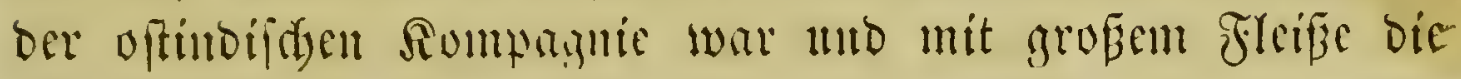

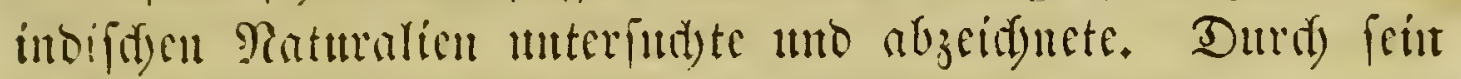

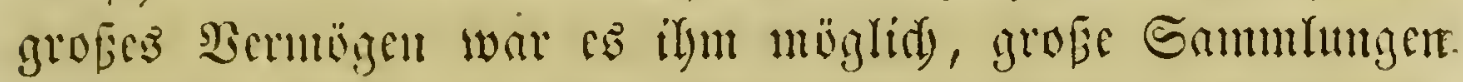
anjulegen, welde er aber famm feincu glatieren burds cine

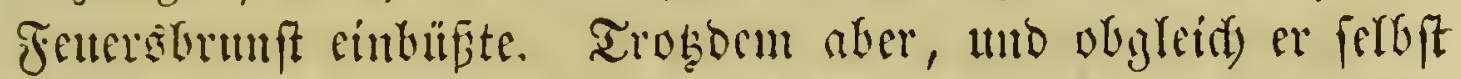
fwäter erblintete, gab er feir lluternelymen nidyt auf, fonoern

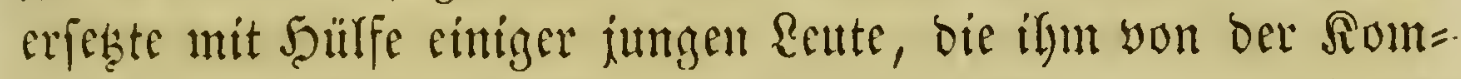
pagnie beigegebent wutden, ons Berlorene wieber, fo baj bas.

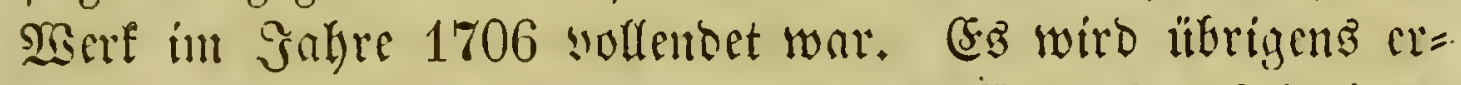

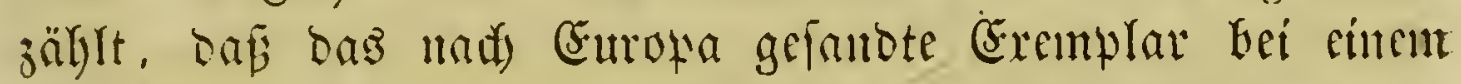

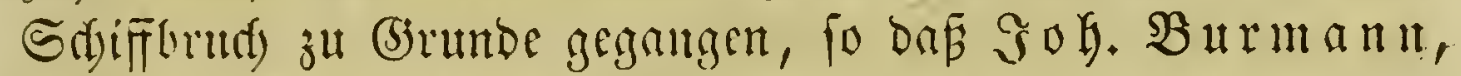
ber bas șerf mefr als 30 Gahre nadher herausgab, mut

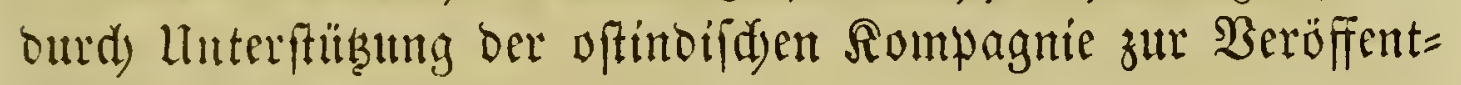
lidfung befähigt worden jci. ${ }^{1}$ )

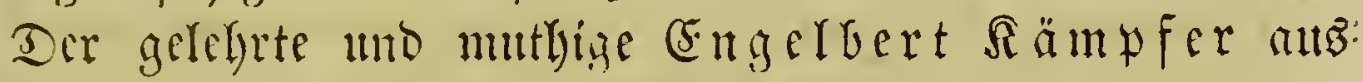

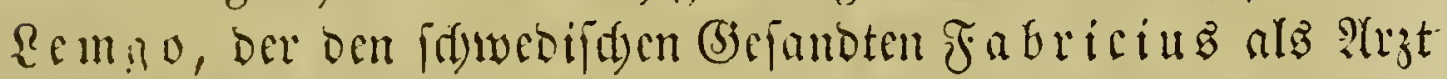
nad) 羽erfen begleitete, unternithm in ben Gabren 1683 rib

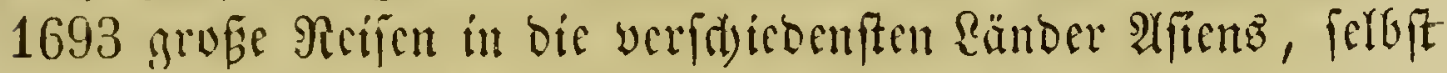
bis in bas ferme Gapan hinein uno bradste eine reidbaltige

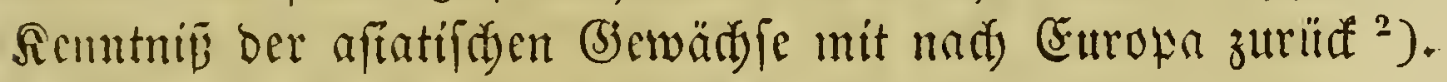
Er ftarb als Reibargt brs Grafen Riphe im Jalre 1716.

1) Herbarium amboinense etc. Tom. I - VI cum Auctuario C. J. Burmann. Amstelod. 17h1-5.5. Fol. Joh. Burmann, Flora amboinensis, sive index in omnes icones Herbarii Amboin. Amst. 1769.

2) Amoenitatum exoticarum politico-physico-medicarum Fasciculi V. Lemgov. 1712. 4. -

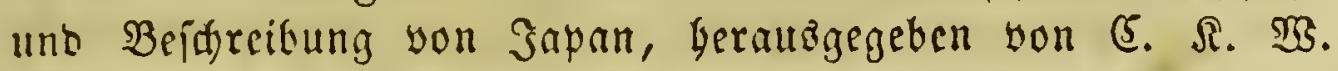
Dob $m$. Remgo $1777-79$. 4. - Die von ibm binterlaffenen 2lbbiloungen find yon $\mathfrak{B a n f} 1791$ z̆l Rundon edirt worben. 


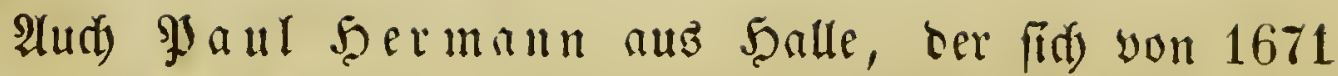

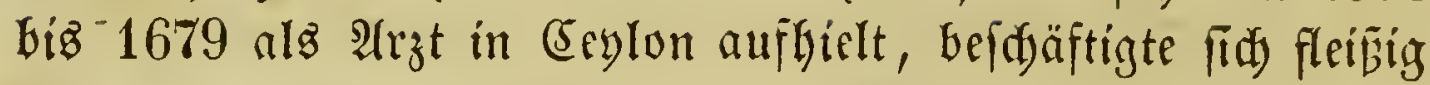
unit ben intifdyen SDflanzen, feine Manujeripte wurben aber nad) frinem Tode (1695) meiftentheils zerftreut. Nur einige Brudftüfe berfelben fint won anderen (belelinten herausgege= ben worben. Ilnten wirb you Sermann nod weiter bie Rede (rin. ${ }^{1}$ )

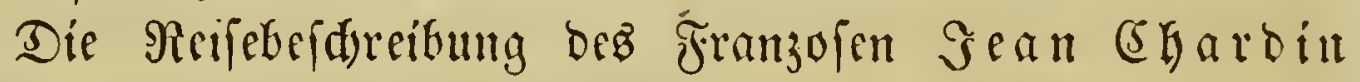
enthält nul wenige perfifde und vitindifde syflanzen. ${ }^{2}$ )

Heber (şina gab zuerft ber Gefuitemmiffonär $\mathfrak{M}$ id)ael Boym Radyridt. Seine Sdurift ${ }^{3}$ ) enthält robe Abbildumgen, mangelbafte Befdreibungen, forwic aubs cinige Unwabrheiten.

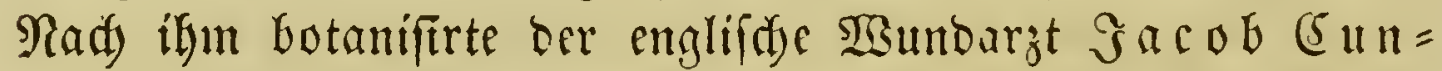
ningham alf ben dinefifden Rüften uno Snifln. Seine

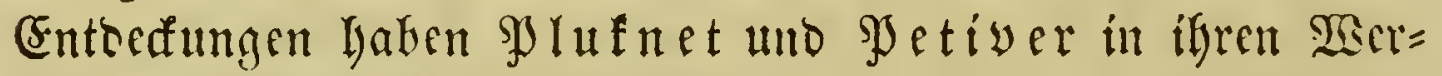
fen zun Iheíl befaunt gemadyt.

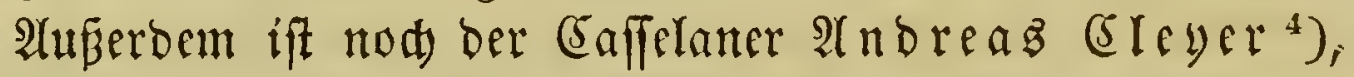

1) Paradisus Batavus etc. Opus posthumum curante Guil. Sherard o. Lugd. Batav. 1698, 1705. 4. - Die Ramen Der Yflanzen, welde Şermann auf 450 Tafeln abgebilbet lin= terlafien batte, fint im Musaeum Ceylanicum, ibid. 1814, aufgezeidnet. - Paradisi batavi prodromus. Ed. Simon W a r to $n$ in ejus schola bot. Amstel. 1689. 12. - $5 \mathfrak{e r}=$

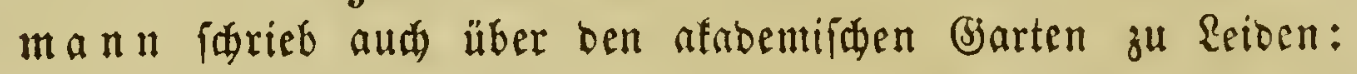
Horti acad. Lugd. Batav, catalog. etc. Lugd. B. 1687. 8. Florae Lugd. Bat. flores s. enumeratio stirpium horti Lugd. Bat. etc. Lugd. B. 1690. 8.

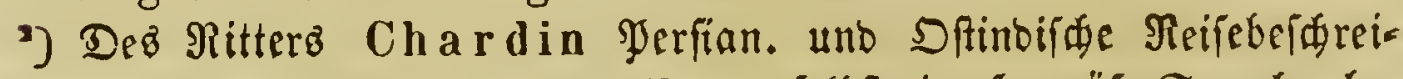
bung 2c. Erfftid bom Authore felbft in frambör. Spradje be=

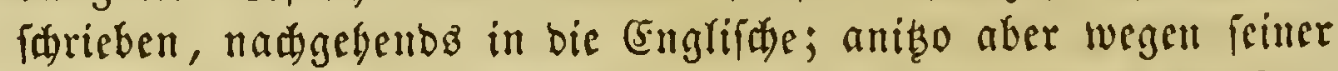

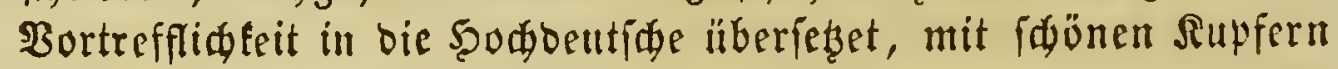
gegieret, uno nütbigent Regiffer veriegen. Seipsig 1687. 4.

3) Flora Sinensis. Videbon. 1656. Fol.

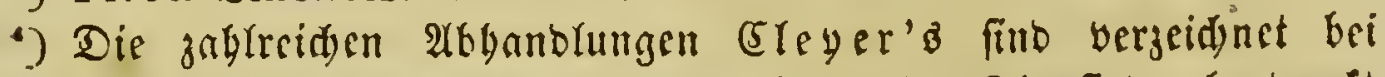
Rrüger, Bibliograph. botan. S. 175. Sie fino abgedruft in Miscell. Act. Nat. Curios, $1685-98$. 


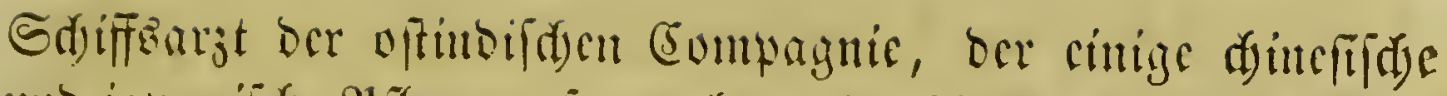

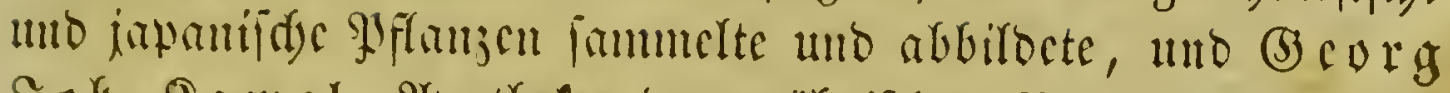

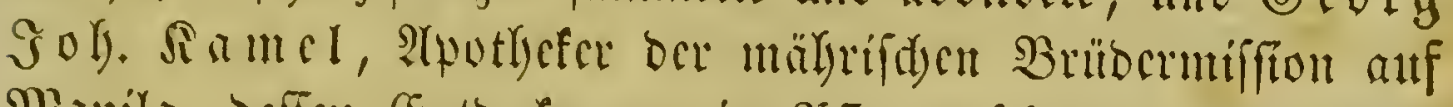

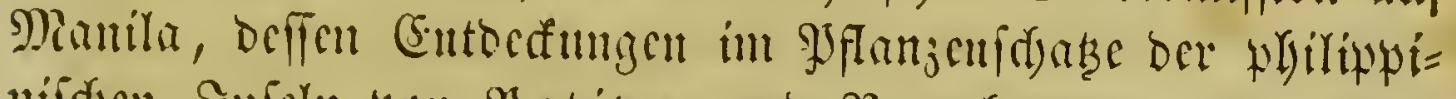

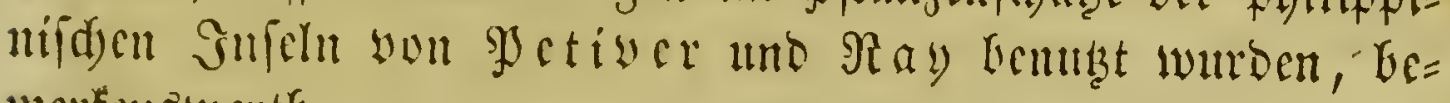
merfonswerth.

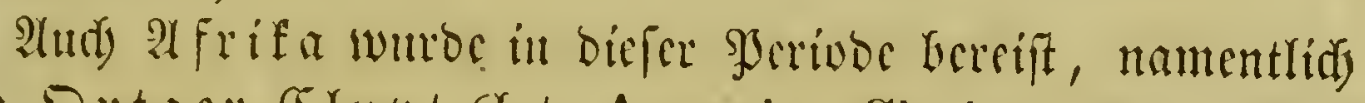
won Dutger Gluyt (lat. Augerius Clutius) ans Reibent,

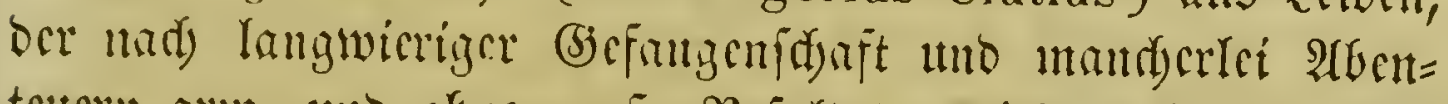
teucrit arm, uno ohne grope Refultate crjielt zu haben, nady

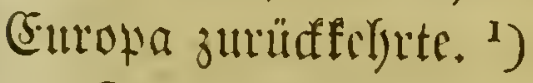

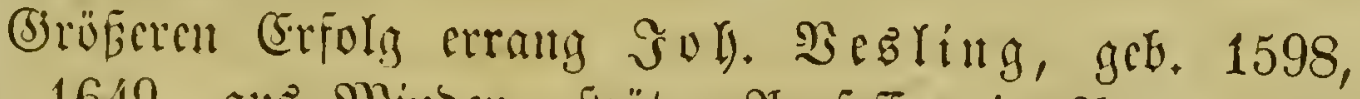
geft. 1649, aus Shinbcu, fpäter Srofeffor in SJabua, bci nancutlid) $\mathfrak{A}$ egypten bercifte $^{2}$ ). - Heber die Gunel $\mathfrak{M} a=$ bagascar gab ber bortige framjöfidyc Stattjalter (Fticnue o e flacourt bie crften Raduriden in feiner Jisfdidte biefer Infel. ${ }^{3}$ )

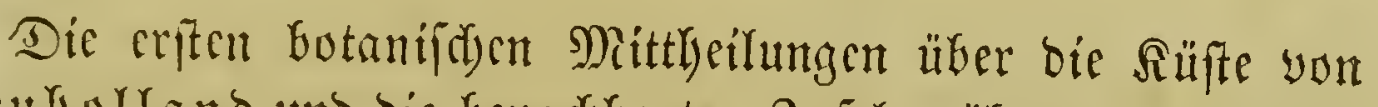

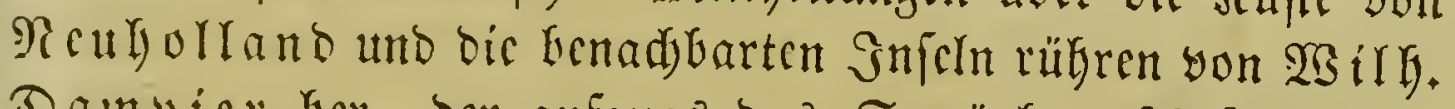
Dampier her, ber anfangs baz Seräubergefdäft betricb,

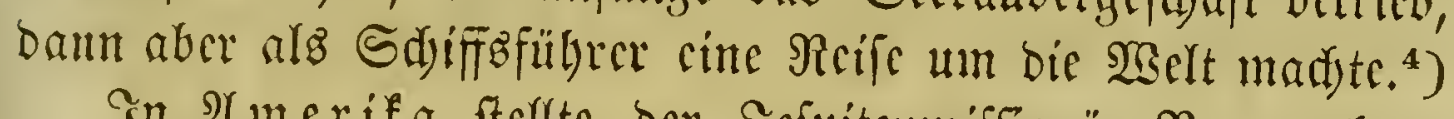

In $\mathfrak{A}$ merifa ftellte ber Gefuitemmiffunär $\mathfrak{B} a \mathfrak{r} \backsim \mathfrak{a b} \mathfrak{a}$ Sobo, geb. 1570, aus Spanien, oer fint yot 1596-1653

1) Memorie der vrcmder blom-bollen, wortelen, kruyden, planten, struycken, zaden ende vruchten etc. Amsterd. 1631. 8. - Historia cocci de Maldivia Lusitanis, s. nucis medicae Maldivensium. Amst. 1634. 4.

2) De plantis aegyptiis observatt. etc. Patavii 1638. 4. -

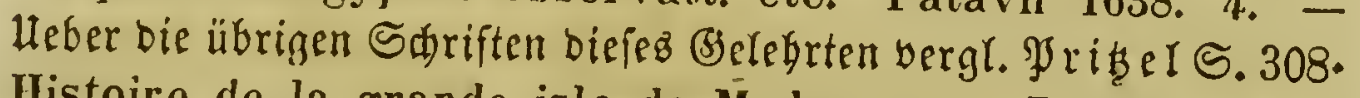

3) Histoire de la grande isle de Madagascar. Paris 1661. 4.

4) A new voyage round the world. Lond. 1697. 8. - 1729. 8. - A supplement to the voyage round the world it eiller Sammlung bon Rei

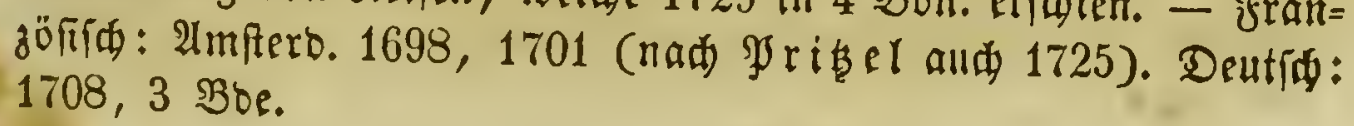


auf ben 2 ntiflen, in Mexifo und Seru aufgiclt, wicle naturs

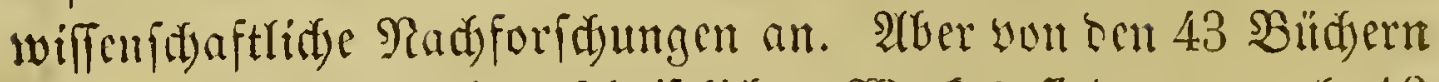

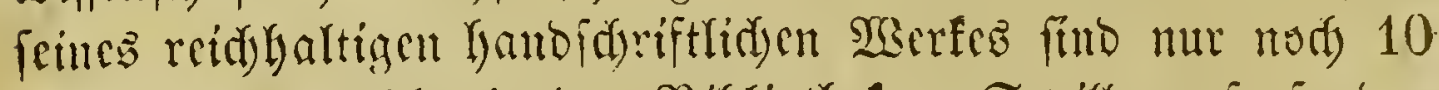

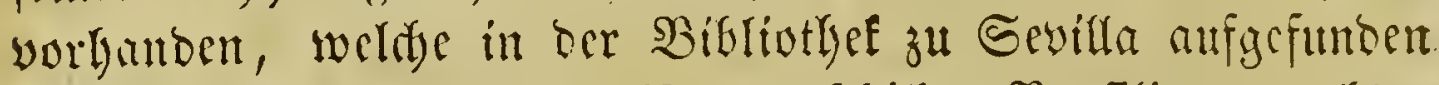

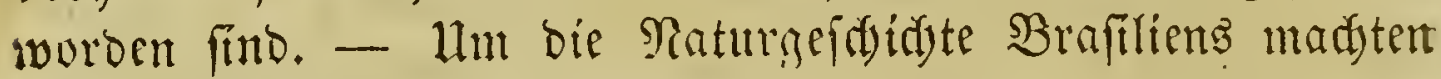

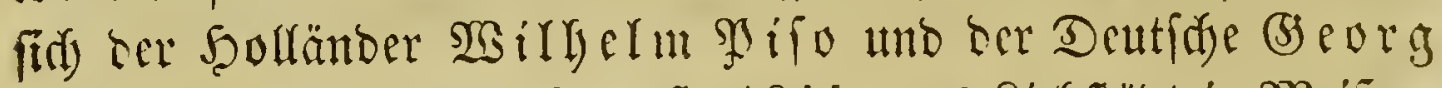
Miarcgraf, gef. 1610, geft. 1644, atts Richftät in Meizert, yeroicut, weldye ben Brafen Moriby yon Raffau auf friner

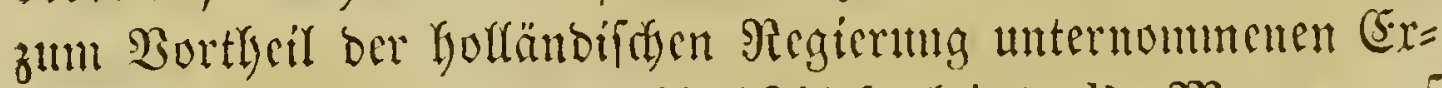
perition in oen Galden 1636 biz 1641 Gegleiteten $^{1}$ ). Maregraf

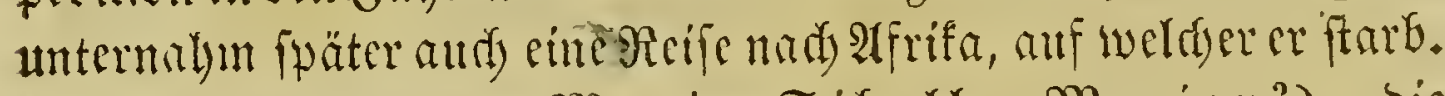

Aud cime Fran, Maria Sibylla Merian²), bie

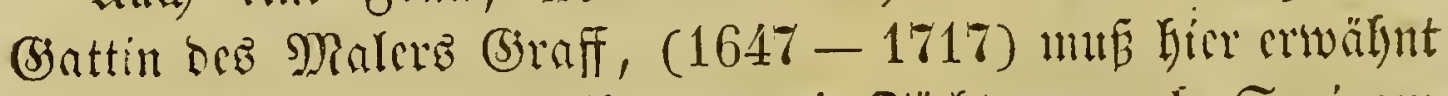

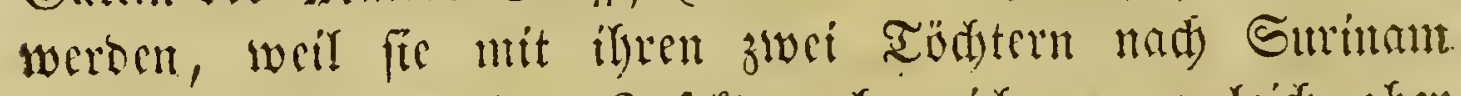
reife, um bic bortigen Snfetten abjujcidyun, jugleid aber aud einize Shflanzen malte.

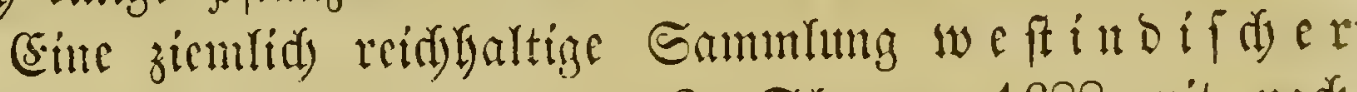
Pflanjen Gradte ber Grlänoer $\Im$. Elvane 1689 mit nady Eurota. Er war fpäter füniglider Ecibarjt unto Dräfioent ber füniglidyen Societät zat Ronbon und vermadyte frinen ganzen

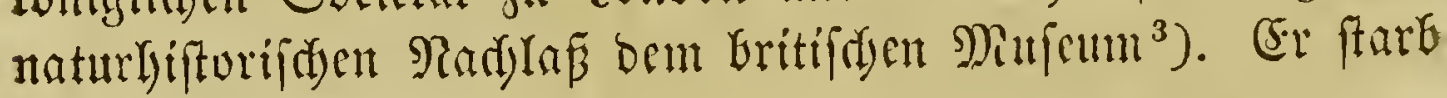
in $\mathfrak{s}$ algr 1753.

1) Histor. natural. Brasiliae, ed. Joan. de La et. Amstelod. 1648. Fol.; mit $\mathfrak{M a r c g r a f}$ ' nad ber $\Re a t u r$ aufgenemmenert Abritbungen. Bweite Auzgabe: Guil. Pisonis de Indiae utriusque re naturali et medica etc. Amstel. 1658. Fol. Accedil: G. Mar c g r a vii tractatus topograph. et meteorol. Bras. et J ac. Bontii histor. nat. et med. Indiae. - G. P is on is llist. med. Bras. ed. Jos. Eques de Vering. Vindob. 1817. 8.

$\Rightarrow$ De generatione et metamorphosi insectorum Surinamen-

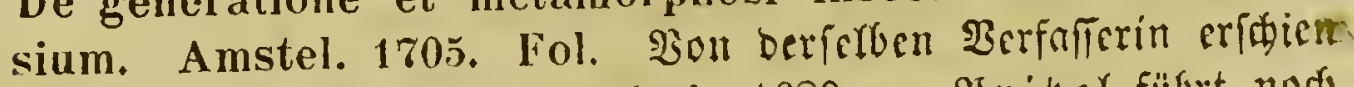

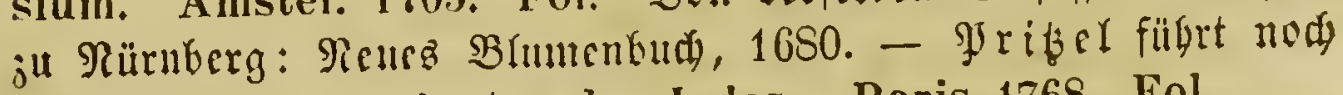
an: Recueil des plantes des Indes. Paris 1768. Fol.

3) $\Lambda$ voyage to Madera, Barbados, Nieves, St. Christophers and Jamaica, with the natural history of the herbs etc. 


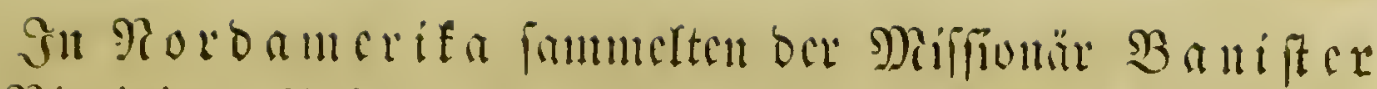

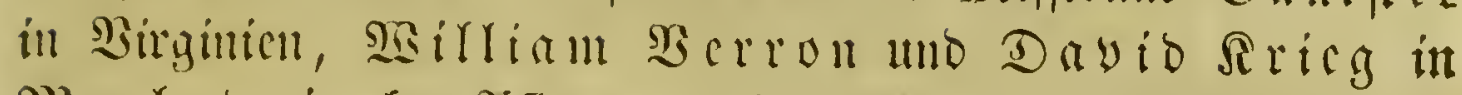

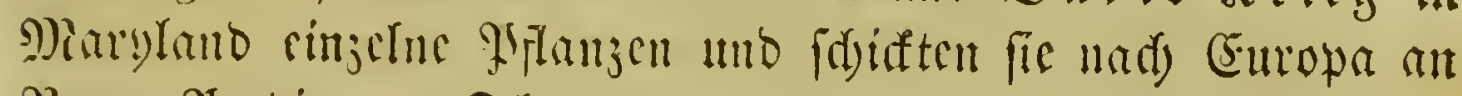
Ray, Petiver, Gloane n. F.

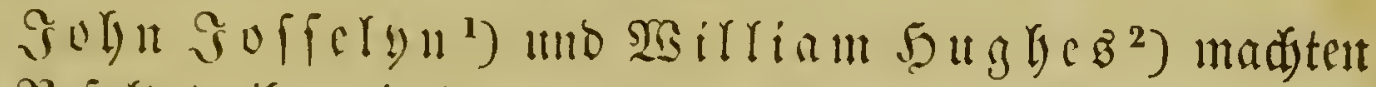

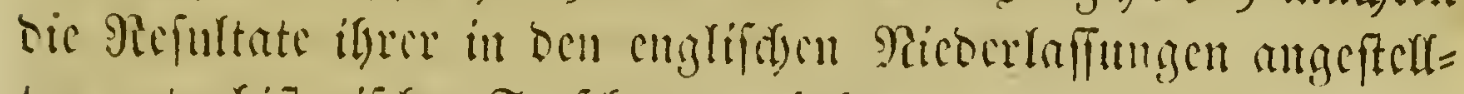

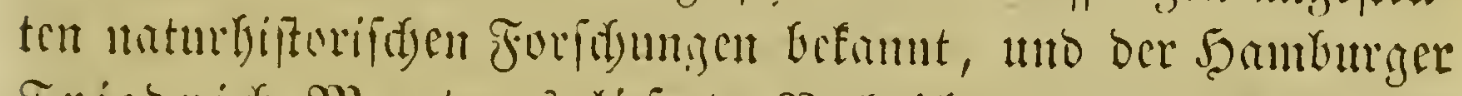

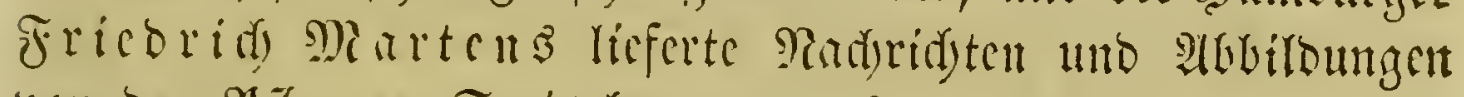

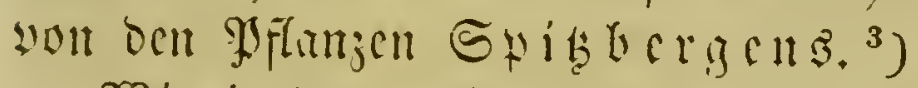

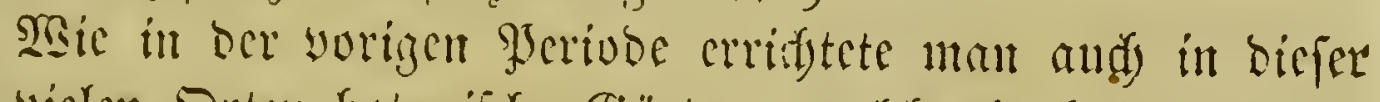

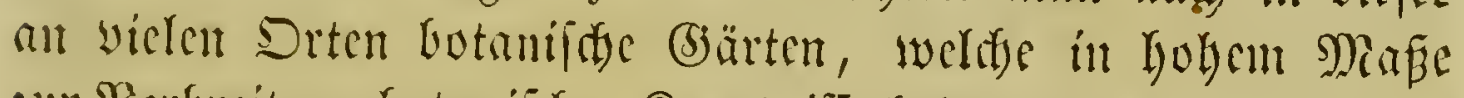

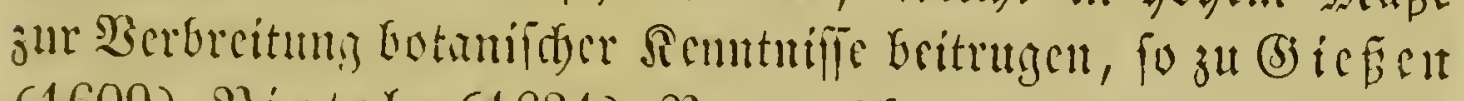
(1609), Rinteln (1621), Regensburg unt urm (1622), S)aris (1626), Artorf (1626), Gena (1629), Dxioro (1632), Meffina (1636), utredt (1638), Ropenlagen (1640), Rille (1644), atmfterdam (1646), Gröningen

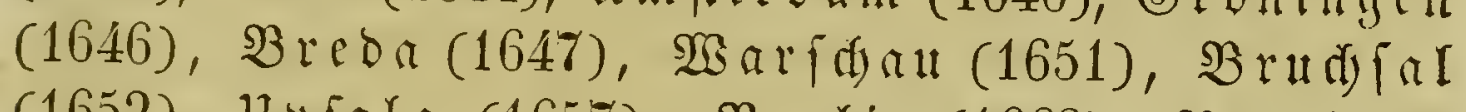
(1652), Mnfala (165\%), Berlin (1663), Prezbutg

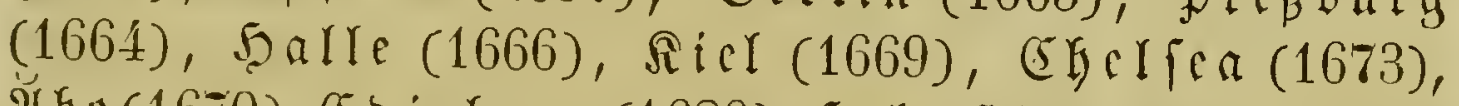

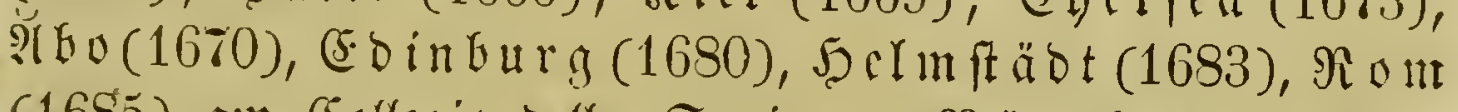

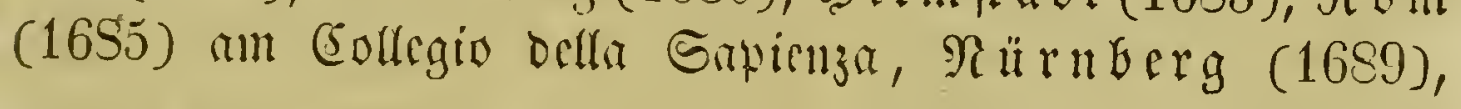

London 1707-1727. Fol. - Catalog. plantar., quae in insula Jamaica sponte proveniunt etc. adjectis aliis quibusdam, quae in insulis Maderae, Barbados, Nieves et St. Christophori nascuntur. Lond. 1696. 8.

1) New-Englands rarities discovered in birds etc. and plants. Lond. 1672. 12. - An account of two voyages to NewEngland. Ibid. 167\% 8.

$\left.{ }^{2}\right)$ The american physician, or a treatise of the roots, plants etc. London 1672. 12. - Derictbe fifrieb aud: The compleat vineyard, or an excellent way for the planting of wines etc. Lond. 1670. 8. - The flower-garden enlarged shewing how to order and increase all sorts of flowers. Lond. 1677. 12.

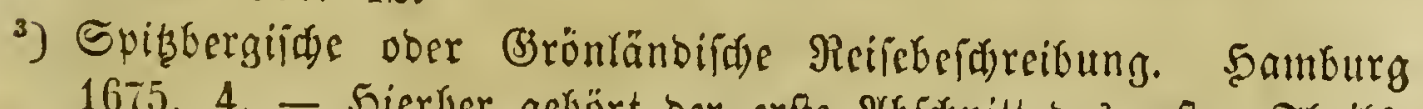

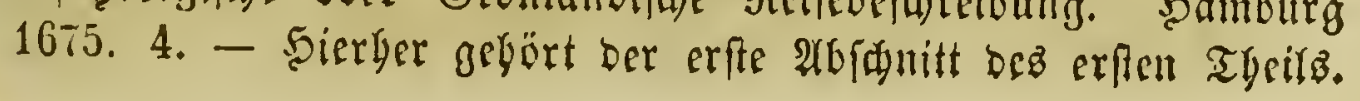




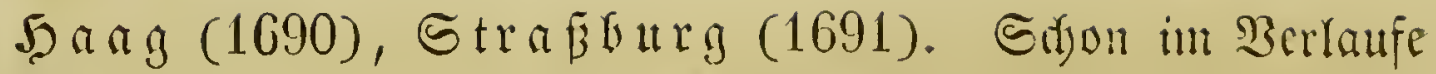
ber obigen Darftellung fint Notizen liber cinjelme Befdreiber

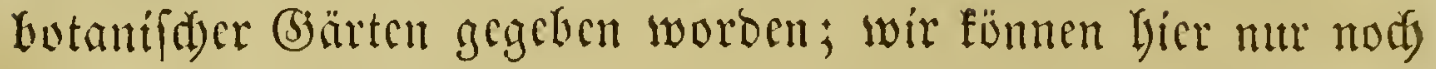

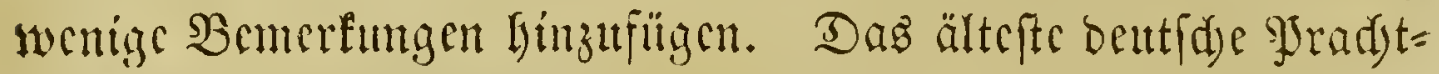
werf yon SPflangenabildumgen ift ber Hortus Eystettensis yon

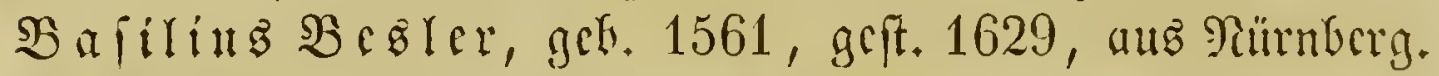

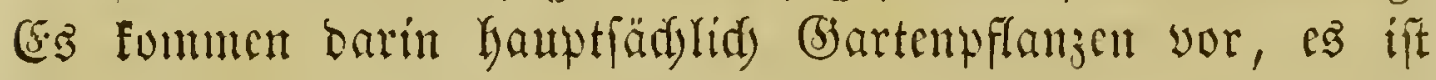
aber fonberbar, bafi yon ber Exiften cincs bartens bes $\mathfrak{B} i=$

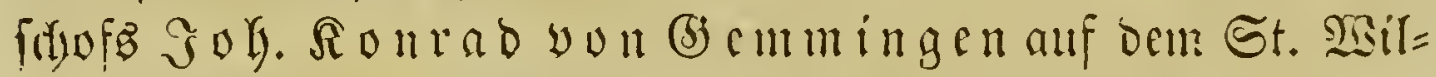
litalosberge nirgenos eine Simbe vorbanden ift ${ }^{1}$ ). Sb die

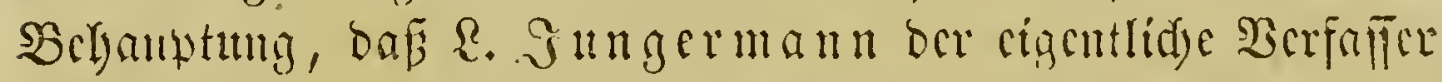

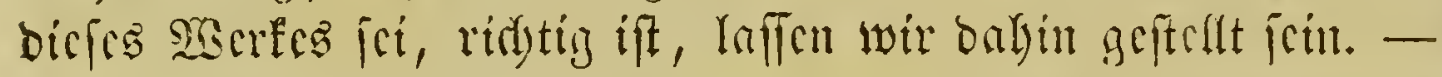

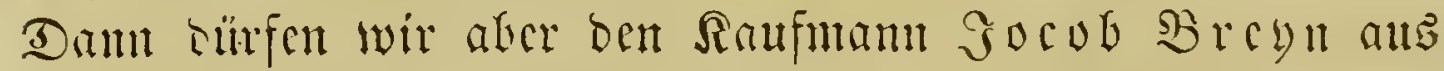
Danjig nidst zu erwähnen vergeffen, oer vicl zat Grweiterung,

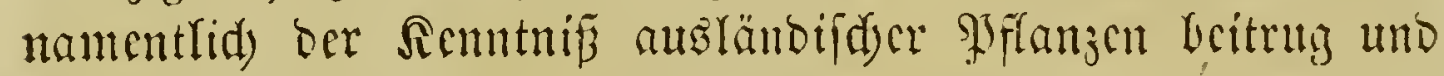
nod) in fpätcrem âtter nad) 5ुoffand reifte, unt bic burtigent

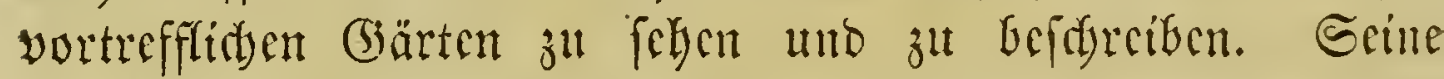

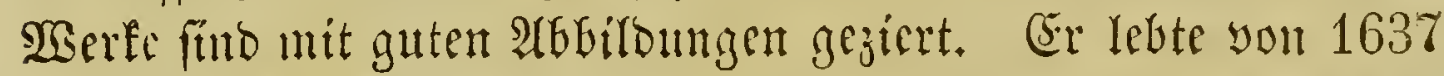
bis $1697^{2}$ ). Gm Ucbrigen muilicn wir alf Sdultes" Berfud 2c. im Antyang S. 357 - 385 verwoifen.

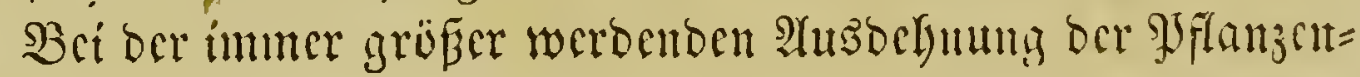

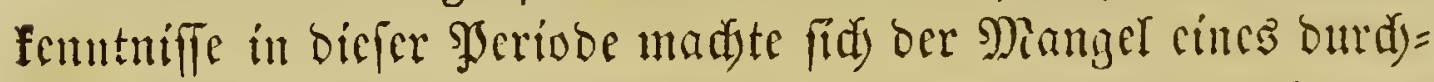
grcifonden Syftems redt fülylbar, uno es war beshalb gans,

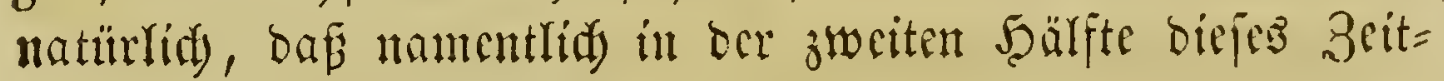

1) Hortus eystettensis, s. 1. 1613. Fol. Wi demann, catalog. systemat. secund. Linnaei systema vegetabile adornatus arbor., frutic. et plantar. celebrior. horti Eichstettensis. Sürnberg 1805. Bergl. über biefen Sdriftiteller गुritiel's Thesaurus 5.21.

2) Exoticar. aliarunque minus cognitar. plantar. centuria prima. Gedani 1678. Fol. Prodromus fasciculi plantar. rarior. primus etc. Ibid. 1680. 4. - Prodromus fasciculi plantarum secundus etc. Ibid. 1659. 4. - 1739. 4. Die beiben Ietateren Sariften wurben von Breyn's Solne 306. Whifipp, argt zu Dangig, fpäter nochmals berauşgegeben. 


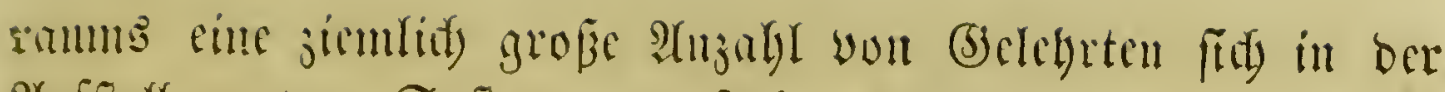
Sheftellung von Gyftemen verfudyte. SBarum man aber zu=

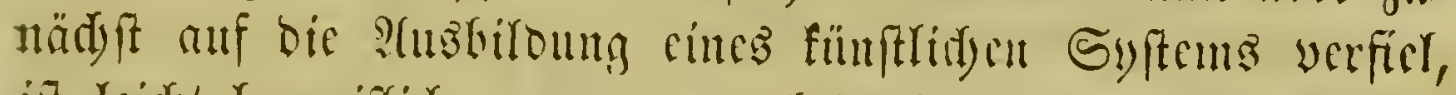

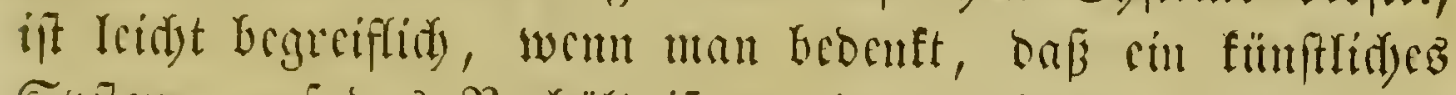
Syltem, auf bas Berbältmís wenizer cunfadyer Drgane $g e=$

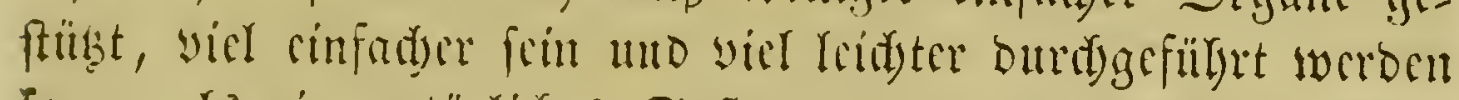
fam, als cin natürlitycs Syltem, bas notlywentiger Wasije fidjon feiner Ratur mady auf verwictelteren Berbälniffen be:

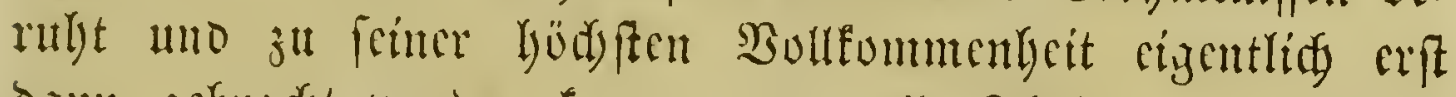
baun gebradyt werben faum, wem alle Theile ber Botanif

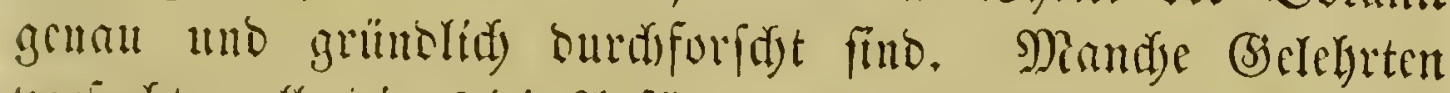

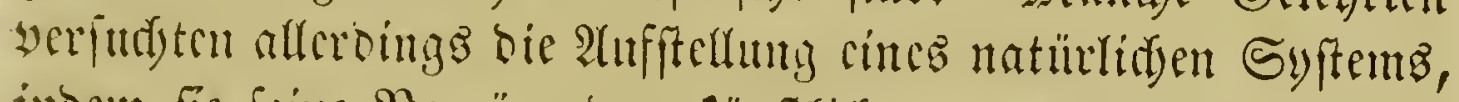

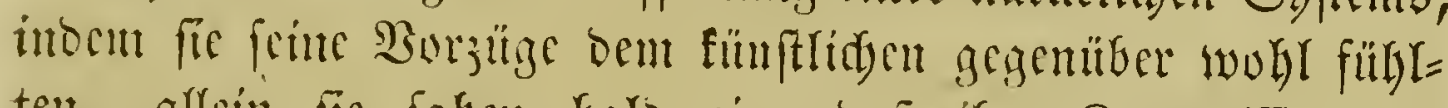

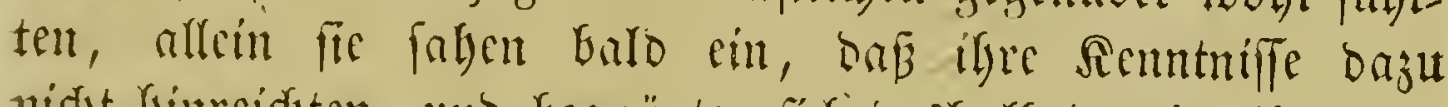

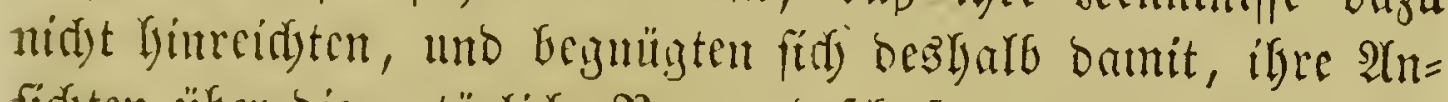
fid)ten

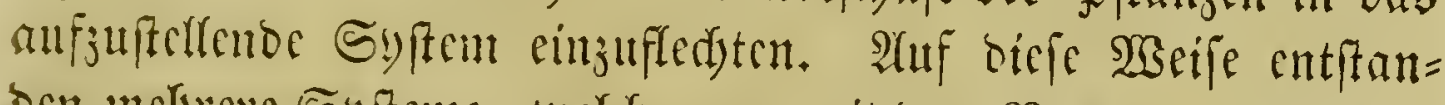
ben melirere Syfteme, weldbe man mit bem Ramen "gemijigte" brjcirducn faum.

Rad) Cäfalwin ber crite, ber bie ahfifelfung cints

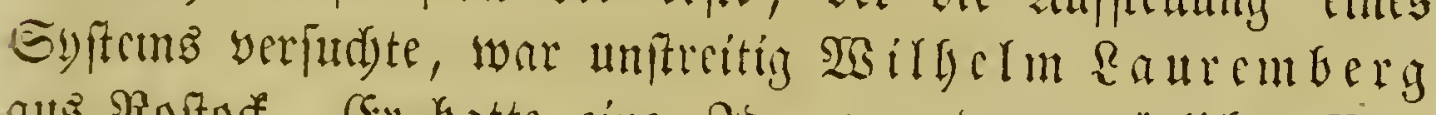

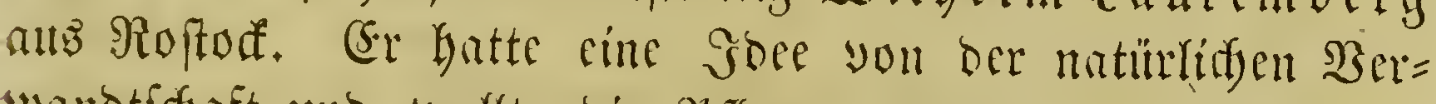

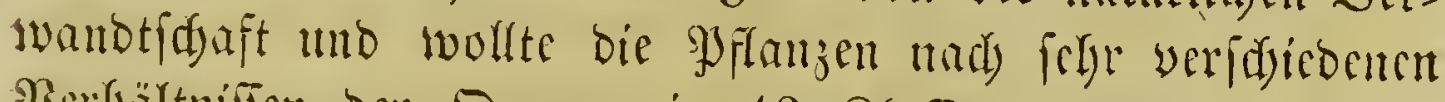
Berbältniffen Der Drgane in 12 Rlaffen brimzen. (5.g if aber offenbar, baj zut 3eit Raurember!s - die Sarift,

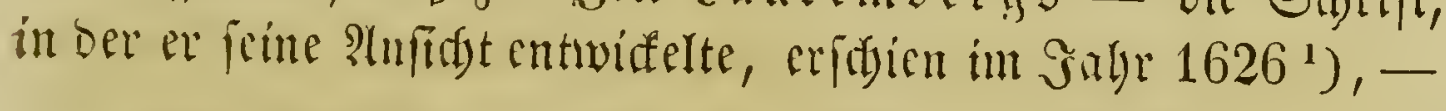

1) Botanotheca, s. method. conficiendi herbar. vivum. Rostock 1626. 12. Bon Morits Soffmann leraubegeben, Attorf 1662, 1693. 4. - - 2uch zu finden in Sim on $\mathfrak{s}$ aurlt' daria. Ropentagen 1653. 12., S. $731-799$, und in Deffen Quadripartitum hotanicum. Strabsurg 1667. 4., S. $635-$ 660. Franffurta. $\mathfrak{T} .1708 .4$. , S. $668-690$. - Stwaz. Fäter erichienen zwei Sdbriften von gieter a a uremberg, nämlid: Horticultura libri II comprehensa etc. Francof, ad M. (16:32) 4. 165\%. 4. - Apparatus plantar. prim. etc. Fran- 
wo faum bas Mifrostop crfunden war, uno aljo bic feíncen Syflumjentigane nod) gar nidst befant fein funnten; cin eini= germáäen yollftändiges natïrlides Gyftem cine reine llumüg=

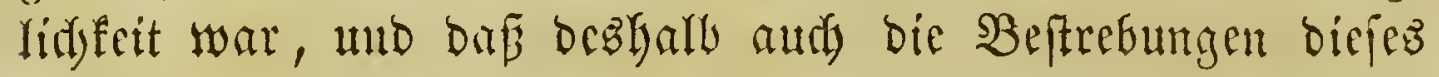

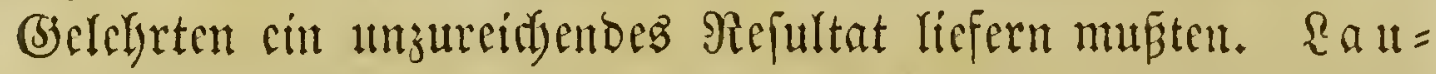
remberg's 2 tuffidt fand barum aud feinem allgemeinen Ein= gang.

Bon gröferer Siditigfert war

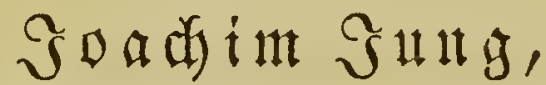

geboren z̆u Rübef im Saghr 1587,

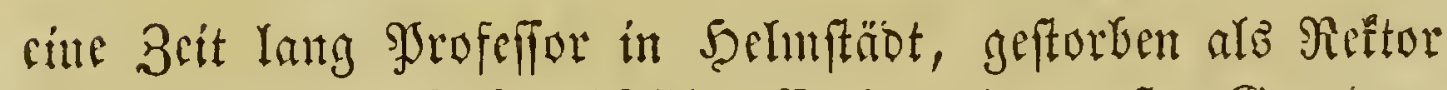

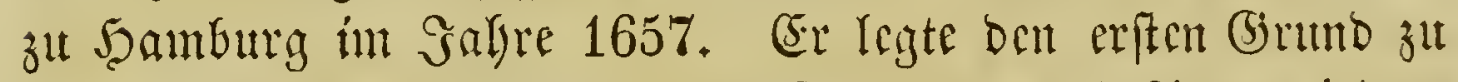

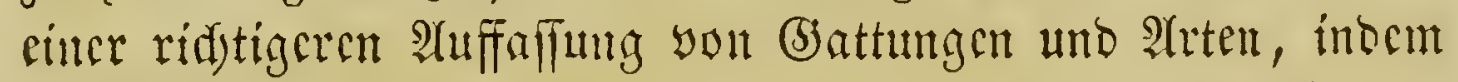

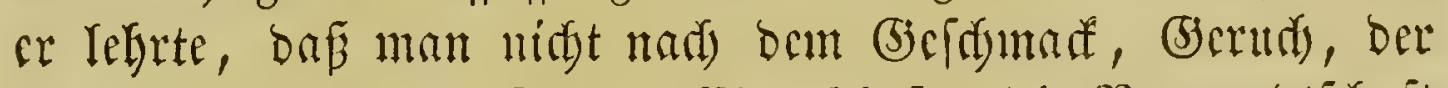
Farbe vocr andern zufälligen Eigenfdaften bie Berwantfidaft

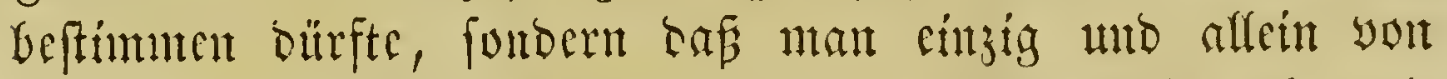
foldyen Sicrfmalen ausgehen mullfe, welide wefentlidy unto

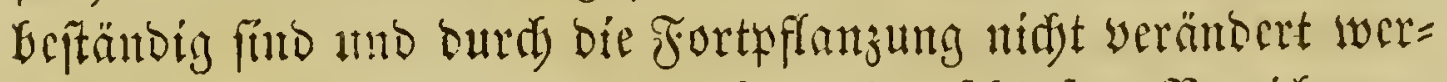

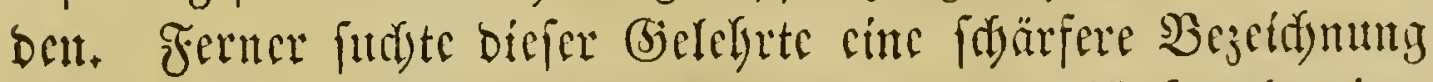

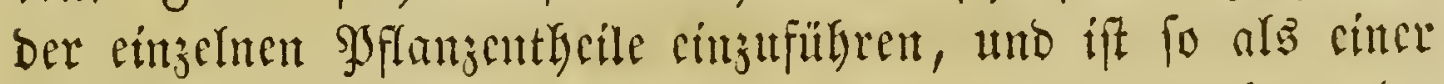
Der Sdjöpfer Der butanifian Sultefpraride zu Getradjten, ba frine $\mathfrak{B}$ enemungen, woun aud nidyt burd) frime eigenen, fo bod

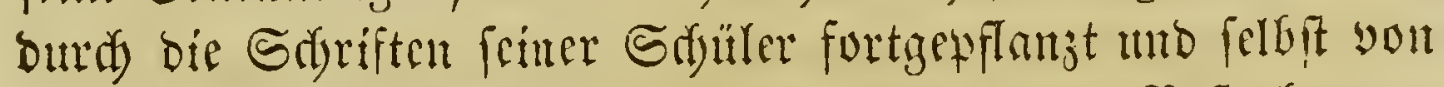
Rinné, obgleidy) biefer längere 3eit yon bon Beftrebutgent

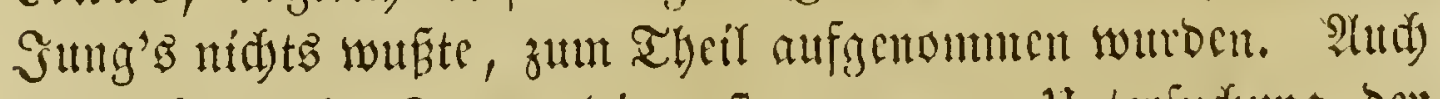

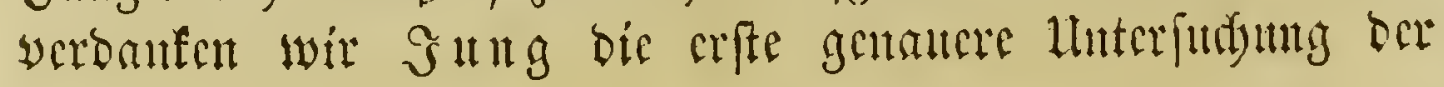

cof. ad M. (1632) 4., uno 1654. 4, Bifaoff bebautet, in ber Borrebe zul biefent lebteren Werfe feien bie oben beriflyrten Alubeutungen entbalten; $\mathfrak{A}$ no ere bebauten, biefelben befänden

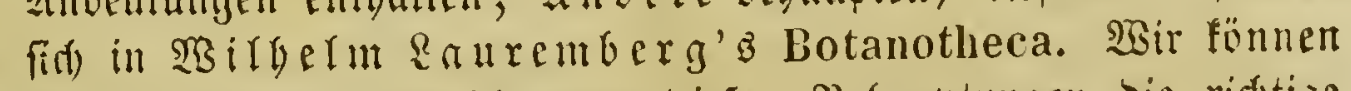

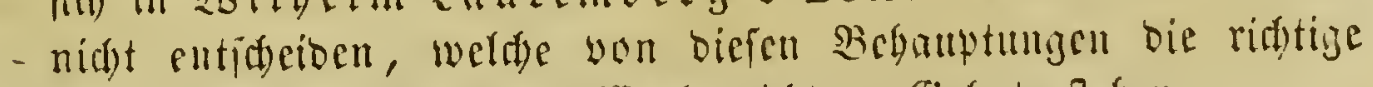

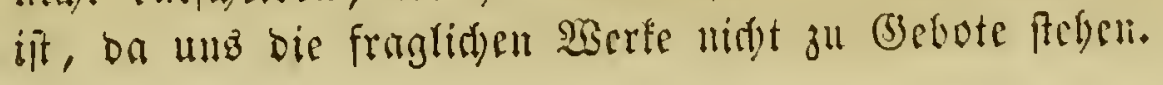




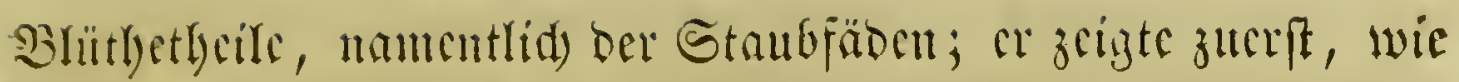

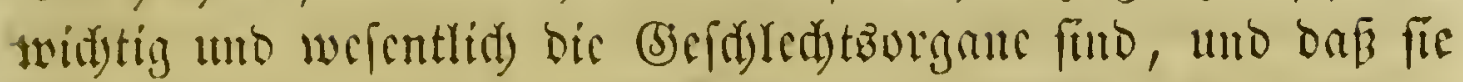

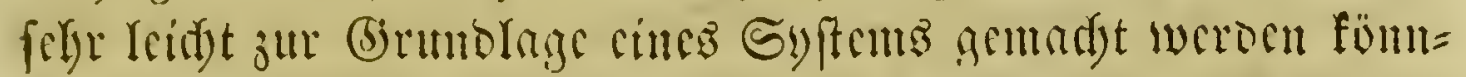
ten. (5r gab aber wälyeno frines Rebens feinc Sidriften

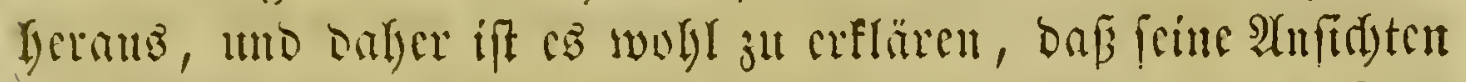
in Sallyemrinen wenig beardet watroen. Dody trugen feine

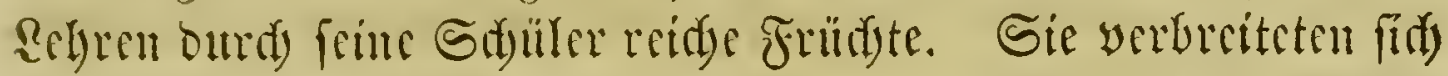

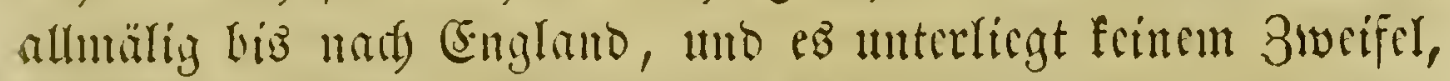

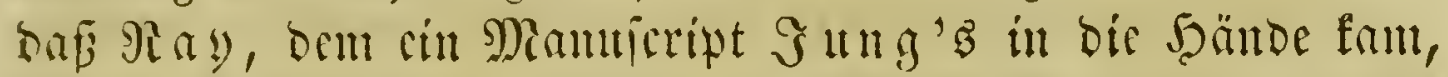

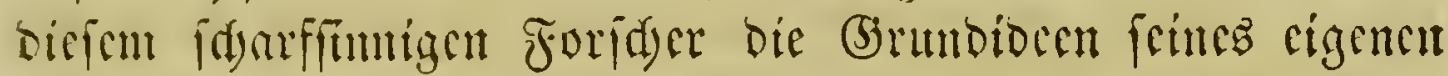
Sy) ftemis verbante. ${ }^{1}$ )

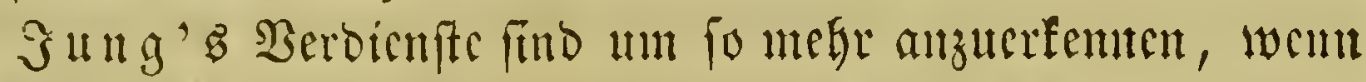

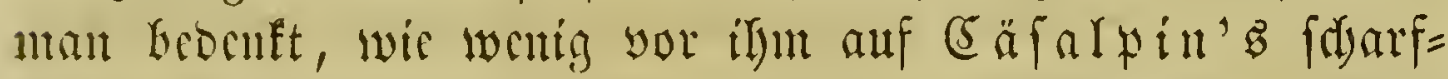

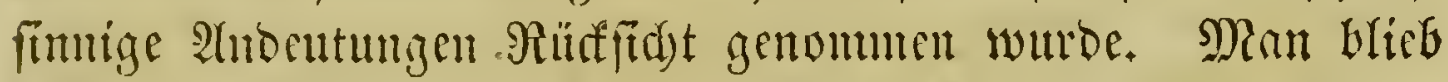
entweder halgztarrig bei Der alphabetioden Dromung ftelen, oocr - was nody fdylummer $\mathfrak{w a r}$ - mant ging yon ganz 1 the

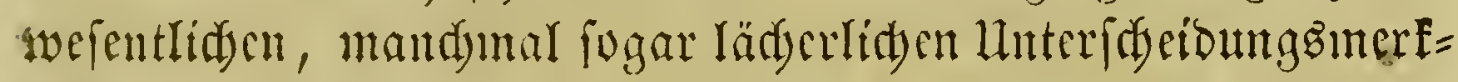
malcn, wie yom (5orud), Gridjmad, Stanoort, Farbe, ja fogar yon aftrologifdon Signaturen aus.

Der Erife, defīen Syftem cine allgemcincre Ancrfenuming farto, war

\section{Mobert Miorifon,}

geboren 1620 zu Herbeen in Sajuttrand.

Sn ben Bürgetfriegen crgriff er bie Sartei ber Stunt

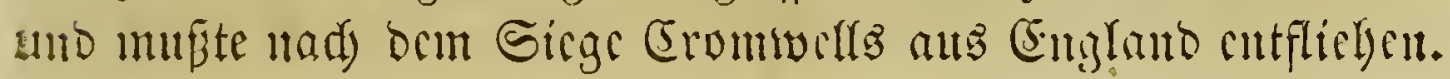

3) J. Jungi i, Doxoscopiae physicae minores, cura M. Fogelii. Hamb. 1662. 4. - Isagoge phytoscopica, ut in collegiis privatis ab ipso tradi auditoribus solita, recens. J. Vagetio. Haunb. 1678. 4. Die erfie Sdrift erifien nod)=

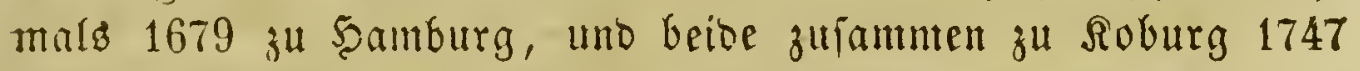
unter bem Titel: J. Jungii Opuscula botanico-physica etc. 4 . 


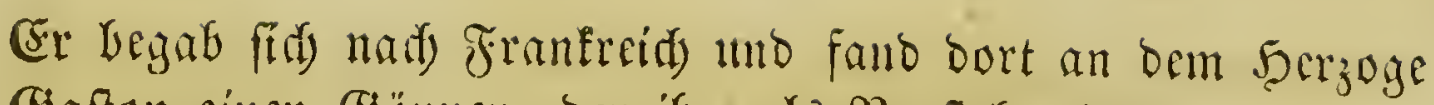

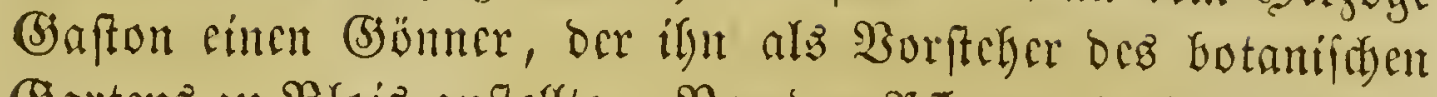
(5) artens zu Bloiz aulfellte. Bon ben Pitanjen dicfes Grartens

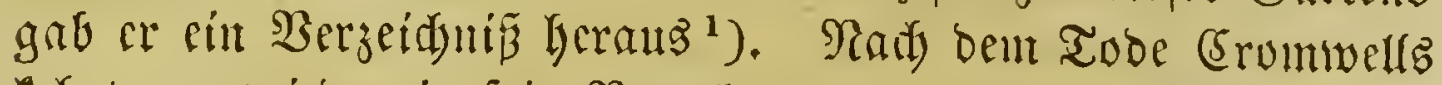

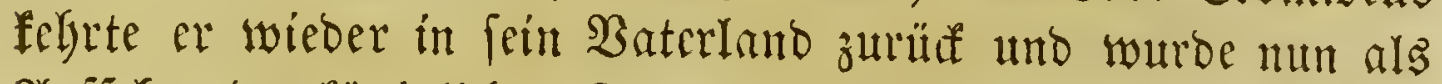

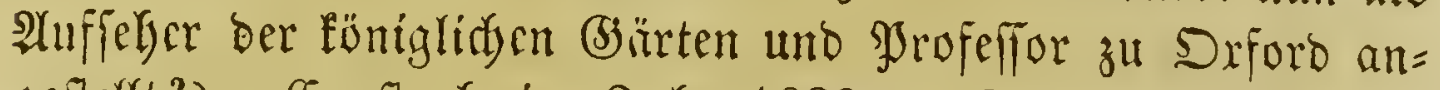
geffellt ${ }^{2}$ ). (Er ftarb im Gafr 1683 zu Eonoon, yon einem SGagen überfahren.

Morifon's Syftem iff èn gemídes, inbem er nament=

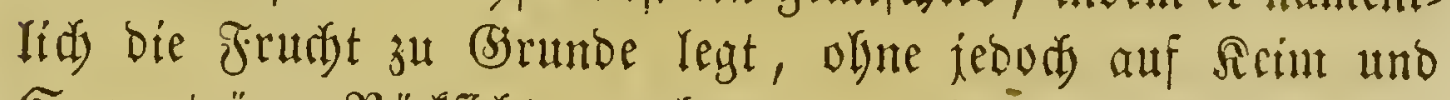

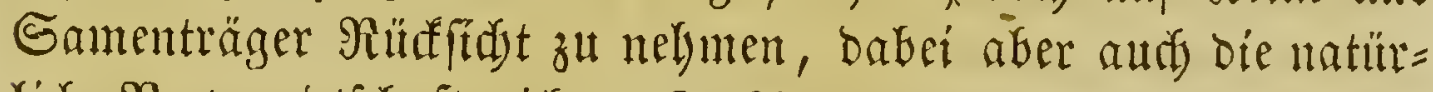

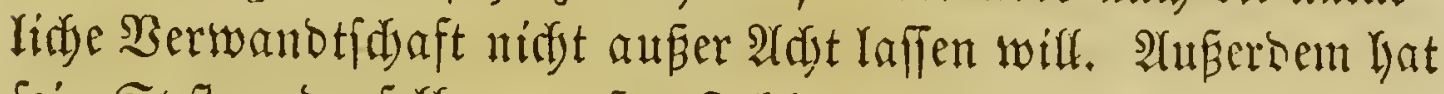
feill Syftem benfelben grofen Febler, wie bas (Säfaltin's,

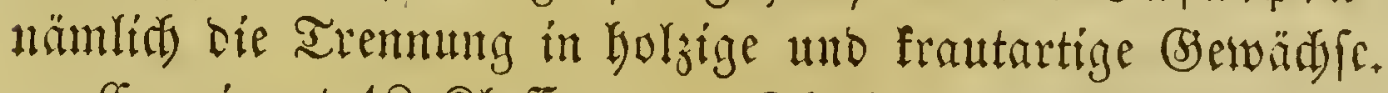

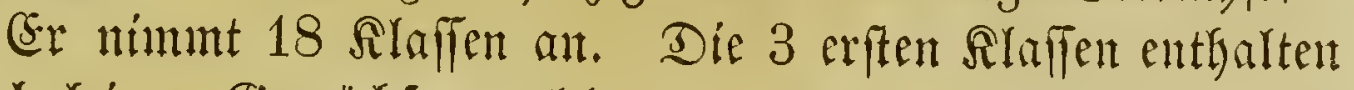

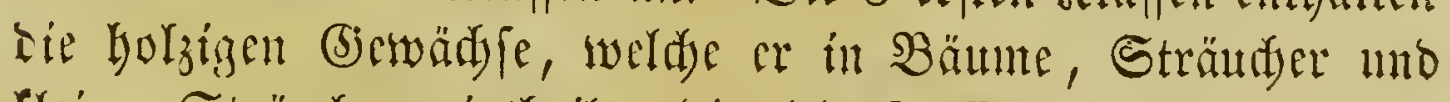
frcime Sträuder éntheilt; die 15 నiaffen ber frautartigen

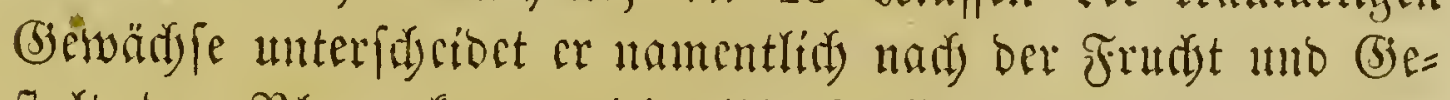
farlt ber Brumenfrune; die 17. Sraffe cutbălt bie Farren= fräuter, weld e cr Capillares nennt; die Jjflanzen ber 18. Alaffe nemt er Heteroclytae, unt reifnet Dahin bie Moofe,

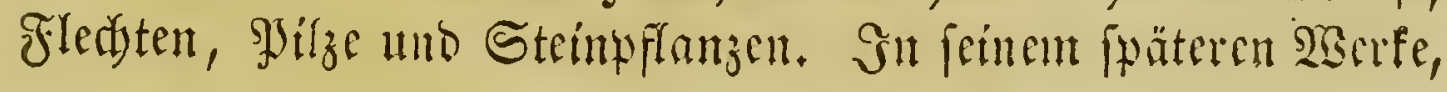

1) Hortus regius Blesensis. Paris. 1635. Fol.

$\left.{ }^{2}\right)$ Hallucinationes in C. B a uhini pinace, item animadversiones in III tom. historiae plantar. J. Bauhini. Lond. 1669. 12. $\mathfrak{A}(\mathfrak{z} \mathfrak{2} \mathfrak{2}$ thyang: Dialogus inter socium collegii regii Londinens. et botanographum regium. Diefe beiocul Swrif= ten bifben oen II. Theil ber Praeludia botanica. - Plantarum umbellifarum distributio nova per tabulas cognationis, ex libro naturae delecta. Oxon. 1672. Fol. $\mathfrak{B o n}$ bem 5raupt= werfe: Plantarum historia univers. Oxoniens. etc. wurbe mur ber ziveite Theil wom Berfoffer 1650 z" Drford in Fol. ebirt. Der erfe Theil, welder von ben Bäunten yanbefn fulfte,

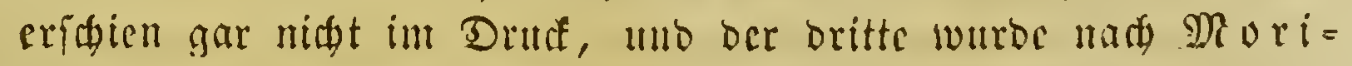
fon' adobe von Sacob Bobart 1699 bermagrgelen. Beide Tycite zufmunen eridgienen ju Srforo 1715 in Fol. 
Dir Historia plantarum universalis etc., futd)

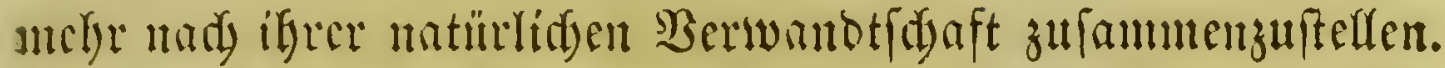

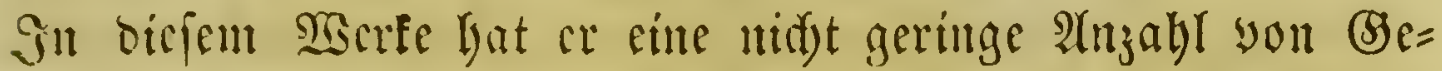

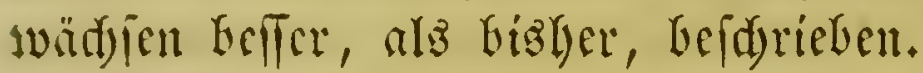

D) orifon's Syftem wmbe yon bem Rripziger Profeffor

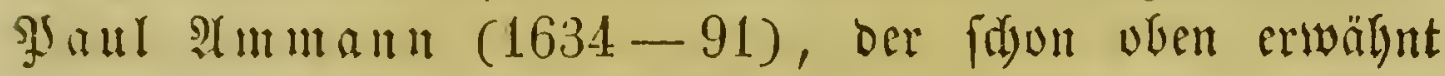
sworben iff, angenommen. Diefer judte es jcodd zu verein= farden, inocm er yon oen megr univefentlidaen Merfinalen

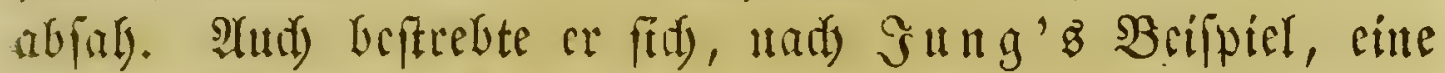

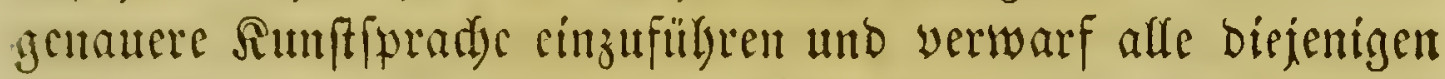

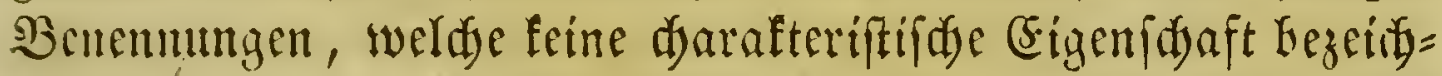
nen. Seine darafteriftifden Merfmale malym er Galiptiäalid yon bon Befrudgtungaiverf zcuzen her. ${ }^{1}$ )

Ein allerer Madjfolger Morifon's bar

\section{$\mathfrak{A} \mathfrak{a} \mathfrak{l} \mathfrak{S} \mathfrak{e} \mathfrak{m a n n}$}

aแz Şalle, geboren 1640, geftorben 1695.

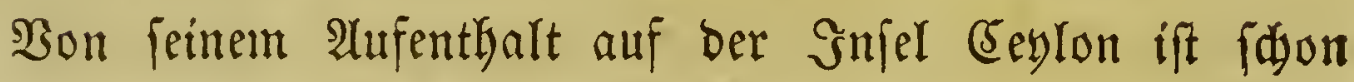
gerebet worben. Rady feiner Rüffehr warbe er Syrofeffor in Reiben unb oronete ben bortigen botanifden (Sarten nad) Dem Morifon'fden Syftem.

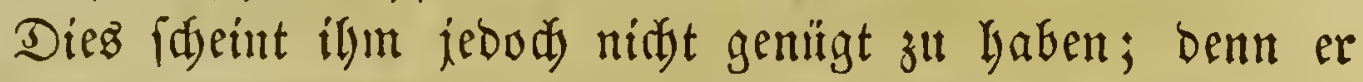
entwarf cin Syftem nadj eignem Wlane, Das haupt fädlid) auf ben Samen uno bie Frudyt grgründet ift, jebod bie und ba

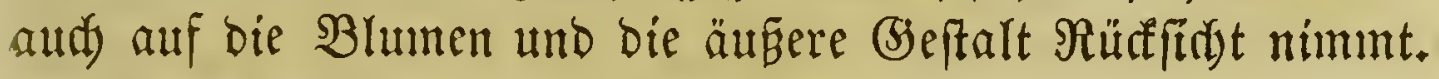
Sein Syftem, bas nidyt unter frinem eigenen $\Re a m e n$,

1) Character plantar, natural, a fine ultimo videlicet fructificatione desumptus ac praemisso fundamento methodi genuinae cognoscendi plantas per canones et exempla digestus. Lipsiae 1676. 12. - Francf. ad M. 1700. 12. Curae secundae, quibus character plantar. natural. anno praeterito 168.5 vel auctior vel correctior redditus fuit. Lipsiae 1686. 12.

(5. BBind 


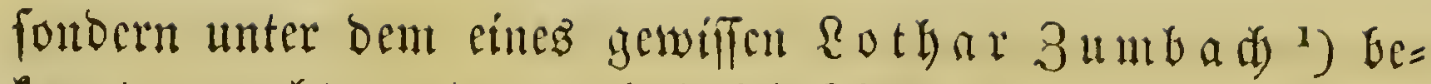
frunt gemadyt wurbe, entyält 25 Silalfen. Die oberfte (5in= theillung ift die in Firäuter und Bäume. Die Siräuter zerfallen in 3 Arbtheílungen, nämlid) 1) nad̛t 3) SSflanzen obne Bhmmentrone; efrenjo bie Bäune in 1)

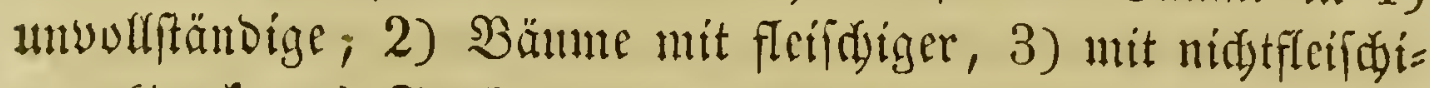
ger (trofener) Frudt. Baz Syftem ift alfo rein auf bie Frudjt bafirt.

Albgefchen yon ber Unyolftändigfeit bicję Syftemz lcioet c8 bauptiäd)lidy an ber verfeglten (sintleilung in Rräuter und Bäume, uno bann baran, baje bie conjequent auf die Frudt

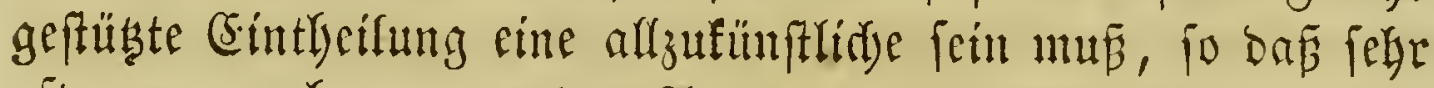
oft ganz nahe verwande Arten ber cimmal angenommenen Unteridyeidungimerfmale wegen getrennt und nidjt verwandte in eine Slaffe zufammengeftellt werben.

Scermann folbit fah einige Mängel feines Syftems cin und beabfititigte, biefelben zut entfernen, wurbe jebod babei yon bem Tobe überrafd t ${ }^{2}$ ). Sein Syftem fant, obgleidy

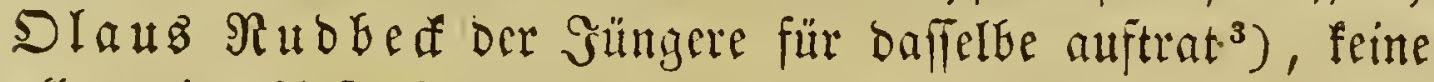
allgemeine $\mathfrak{A} u$ fnahme unter ocn $\mathfrak{B}$ otanifern.

Befannter wurbe has Syftem yon

\section{Swlyn Mara oDcr May (Majug),}

zu $\mathfrak{B l a t a}=$ Rottey in Efiter 1628 geboren.

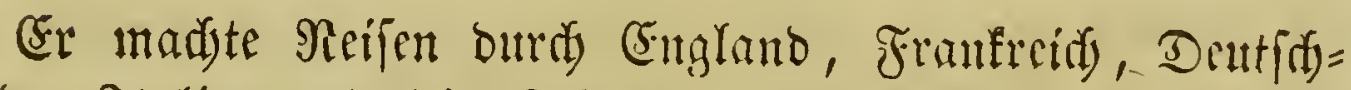
land, Stalien und bie Sinweiz, und farb zu Ronoon im

1) Florae Lugduno-Batavae flores s. enumeratio stirpiun horti Lugduno - Batavi methodo naturae vestigiis insistente dispositarum et anno 1689 in lectionibus expositarum a P. Hermanno, nunc vero primum in lucem editar. opera Lotharii $\mathrm{Zumb}$ ach. Lugd. - Bat. 1690. 8.

$\left.{ }^{2}\right)$ Flora Lugduno - Batava (altera) etc. Leid. 1695 .

3) 0I. Rudbeck fil., Dissertatio de fundamentali plantar. notitia recte aquirenda. Traject. ad Rhen. 1690. 4. 


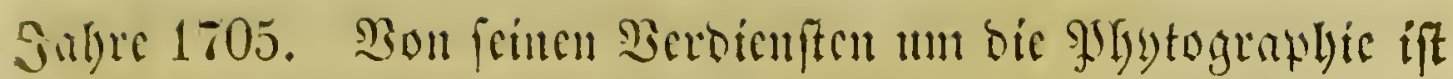

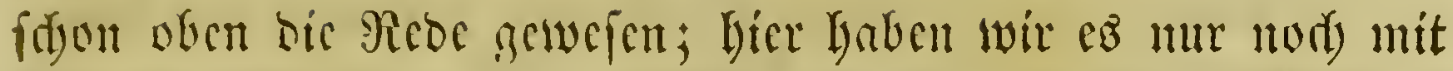
frincm Syfteme zu thutn. Diefes grindet fid) unserfembar

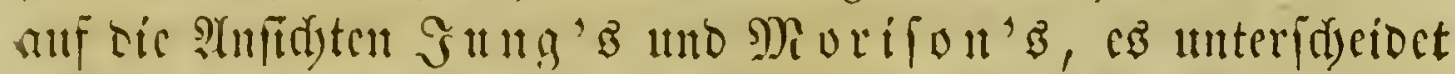

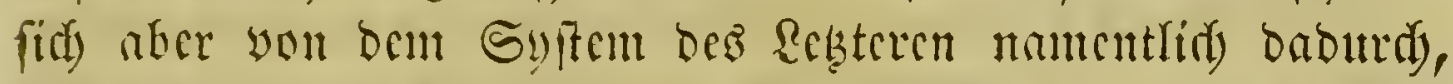

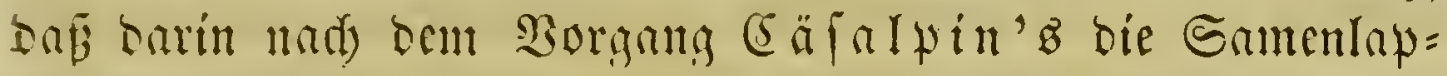

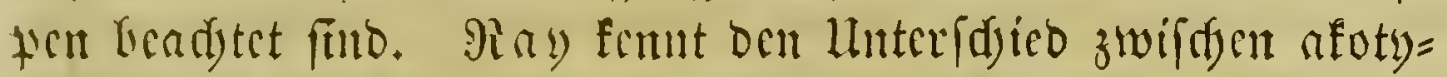

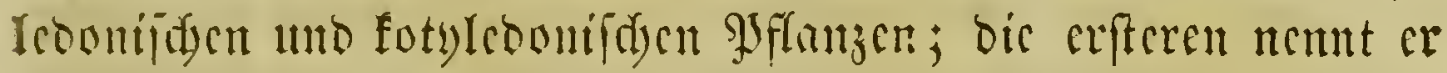

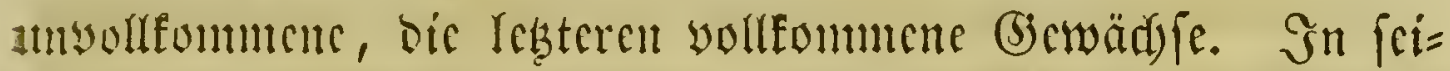
sten fräteren 2 erfen nannte or aber bie Alfotylebonen nicbere

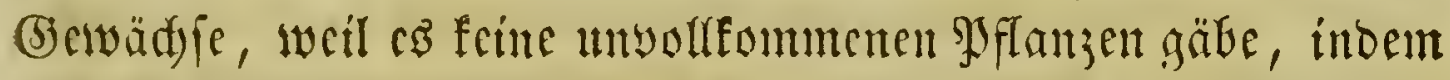

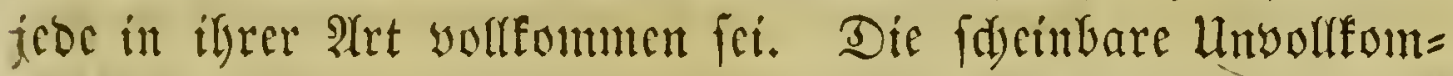

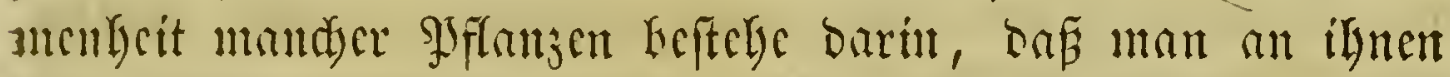
fcine Blüthon bemerfe. Darum fönne man bie grflanjen cin= theilen in foldse, bie Ghüben, und folde, die nidyt blühen. 3u ben lcşteren redjnet er bann bie Srivämme, Mooje, Sornllen, Argen u. f. w. ; in $\mathfrak{B}$ çiekung auf bie Frarrenfräuter

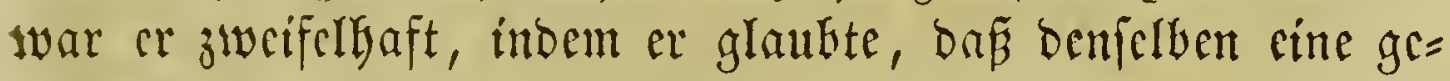

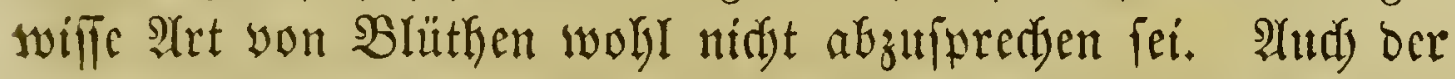
IInteridsieb zwifden monofotylebonifden uno bifotyledonifden Jyflanzen war ifm nidgt unbefannt. 3u ben erfteren redbnet cr aud) (djon bie \$almen.

Scin Syftem ift aber ebenfalls cin gemifdetes, ba er melyr

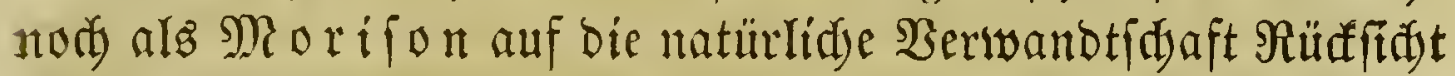
stimmt. A(ud) Gat er nod) bie alte Şauptcintbcilung in Rräu= ter und Bäume. Daß̉ man bí Frudtst zur (5rumblage einez Syitems madyen bürfe, wollte cr burdjans nidgt anerfennen.

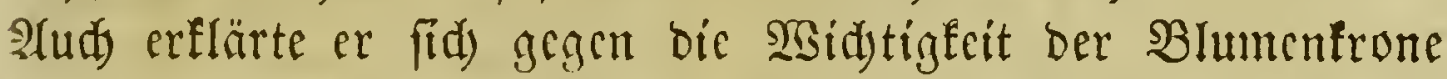
bci 2uffellutg cincs Syiftemz uno fam baburd) namentlid) mit Rivin und Tourncfort in Streit.

llıgcfäly 18,000 sुfflanjenarten lyat er nad) feincm Syfteme

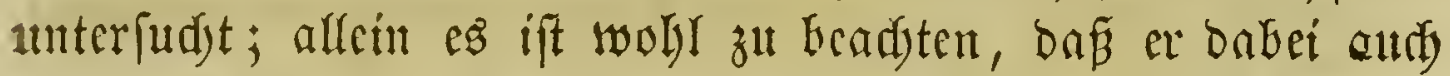

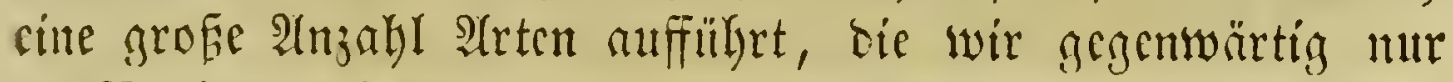
alı̉ Barictäten betradjten. Scin Syftem zerfällt in 33 Rlaffen.

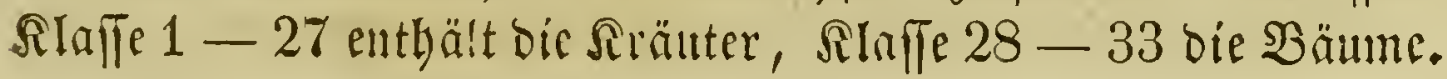


Bemerfenzwerth ift nudy, baf cr fowohl für bie Siräuter wie für bie $\mathfrak{B a ̈ u n c ~ e i n e ~ b c f o n d e r c ~ S l a f l e ~ v o n ~ A n o m a l a e ~ a u f f e c l t e , ~}$ zut benen er alfe bicjenigen Pflanzen zälylte, weldye er in ben übrigen RTaffer nidjt hatte unterbringen fönnen. ${ }^{1}$ )

(5hriftoph $\Re$ naut fudte $\Re a y)^{\prime}$ Syftem zu versinfaden, intem ar bie 33 Slaffen beffelfen auf 17 reducirte. (Sr wande. biefe Metfode in feiner Flora ber Unyegento von Saalle an²). Sie wurbe jebod) wenig-befannt. - 2 Is gegen das Enbe

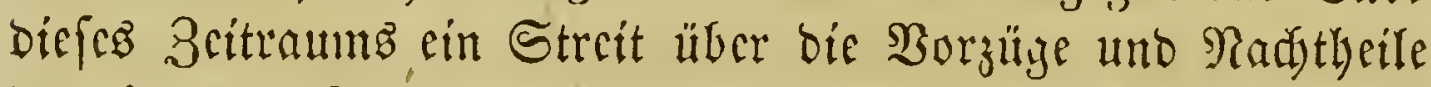
Der einzclnen Syfteme entifanto, trat ber Selmitäbter Profefor (3) ünther (5hriftoph Sdergammer, geb. 1649, gefí. 1716, auf die Srite $\Re \mathfrak{a} y$ 'B und verthrioigte namentlid) die alte Eintheilung in $\mathfrak{B a ̈ u m e ~ u n o ~ R r a ̈ u t e r , ~ b i e ~ v o n ~ \Re i v i n ~}$ angegriffen worben $\mathfrak{w a r}^{3}$ )

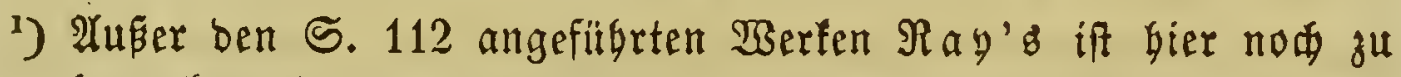
bemerfen: Methodus plantar. nova, brevitatis et perspicuitatis causa synoptice in tabulis exhibita; c. not. generum tum summorum tum subalternorum characteristicis, observationibus nonnullis de seminibus plantarum etc. Amstel. 1682. 8. Ibid. 1710. 8. Lond. 1733. 8.

2) Enumeratio plantarum circa Halam-Saxonum et in ejus vicinia ad trium fere milliarium spatiun provenientiun, cum earum synonyniis, locis natalibus etc. Additis characteribus generum summorum atque subalternorum. Lipsiae 1687.8.

$\left.{ }^{3}\right)$ De nova plantas in classes digerendi ratione ad Joan. Rajum et Aug. Quirin. Rivinum epistolica dissert. Hamburgi 1695. 4. - De nova plantas cognoscendi me-

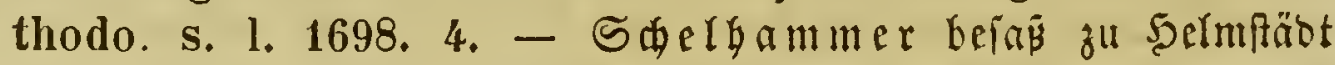

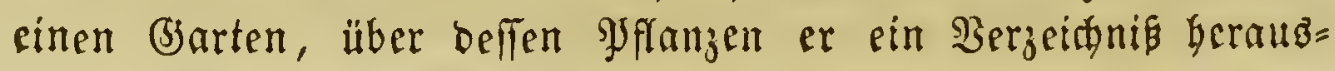
$\mathfrak{g a \mathfrak { b }}$ : Catalogus plantar. maximam partem rariorum etc. Helmst. 1683. 4. - Heber feine übrigen Sdiriften (Эrogramme)

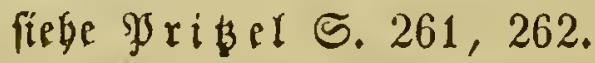


S(ud)

\section{Şiere $\mathfrak{M}$ agnol,}

geboren 163S, geftorben 1715 atż Profelīor zu Montpellier,

entwarf ein cigenez Syftem, worin or auf ben Mnteridsed Ier Sotylesonen uno alfotyleoonent und auf natürlidye Ber=

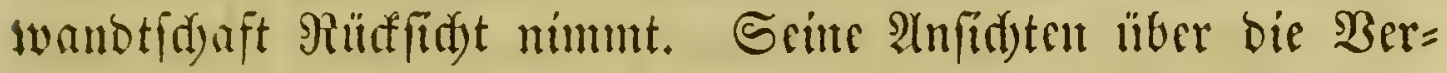

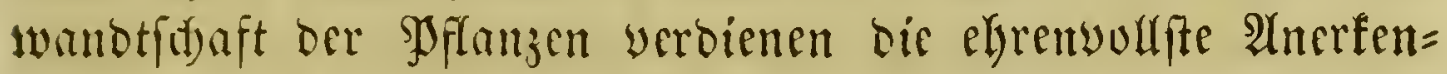
mung, zumal fie zur bamaligen Zeit ganz cinjig in ihrer AYrt avaren. WBir werben biefelben in ber nadgfoligenton Periode

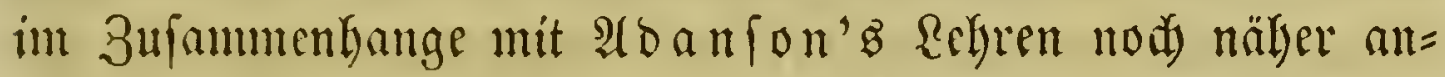

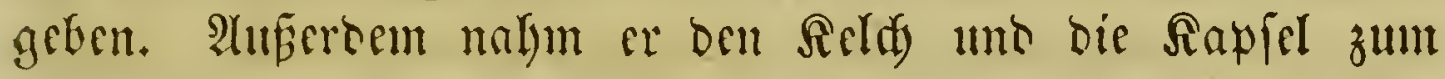

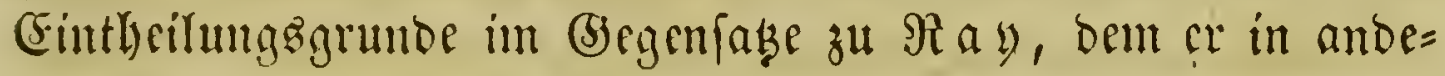
ren $\mathfrak{B e z i e h u n g e n ~ f o l g t . ~ S c i n ~ S y f t e m ~ i f t ~ u ̈ b r i g e n s ~ w e n i g ~}$ benditet worben.")

Der legte uno bebeutendfte Syftematifer biefes Bcitraums ift

\section{1uguit Suirin Rivinus (B̧adyman),}

geboren zu Reipzig 1652 uno geftorben alz 9rofeffor baferbet im Sabre 1725.

Er ift in melyreren $\mathfrak{B} e z$ ziefungen für die $\mathfrak{B}$ otanil yon $\mathfrak{B} e=$

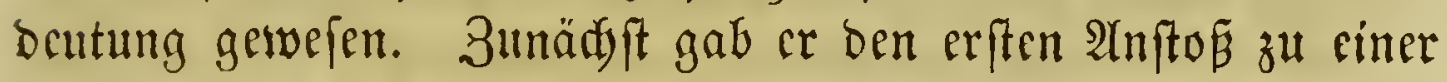
metbodifden Romenclatur und bildocte bie erften Gattungs: namen, bie zum Theil norb beute gebräudylid find. Ferner gab er zuerft bie alte cingeroftete eintheilung ofr sfflanzen in

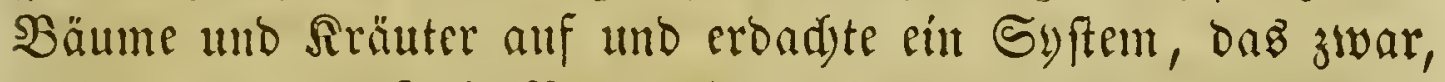
wril as ganz auf bie Blumenfrone bafirt ift, an csinfeitigfrit

1) Prodromus historiae generalis plantarum, in quo plantae per familias disponuntur. Monsp. 1689. 8. - Novus character plantar. in II tractatus divisus, opus posthumum ab auctoris filio Antonio editum, ibid. 1720. 4. 
Iribet, trobocm aber wegen feiner (5oniciluenz amo weil es nid)t

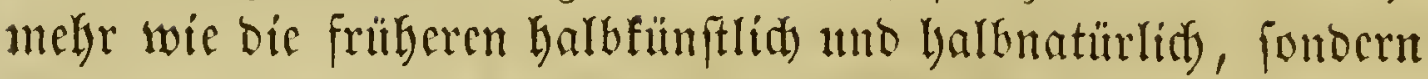

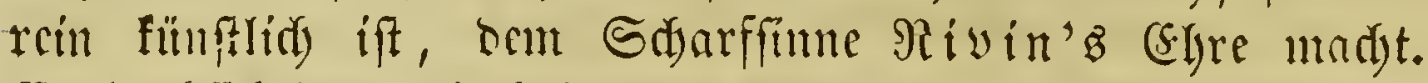

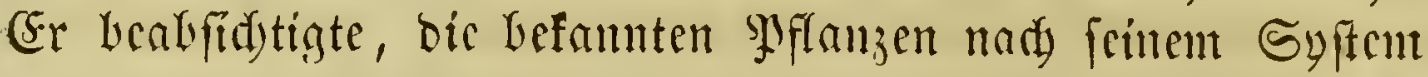

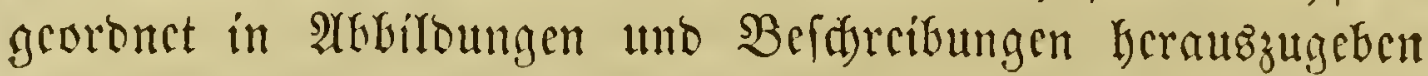
unb verwanote auf biefes Unternchmen fein ganzes $\mathfrak{B e r m o ̈ g e n ~}$ (cas 90,000 fl. Getragen hatien foll), fonte aher bod) feincm Şlan nidyt ganz ausfülyen; bie Sुflanzen breicr Dromungen twutben von ihut felbft, und bie Arkfildungen cincr sicrten Dromung uad) frinem Tobe herauggegcben ${ }^{1}$ ). Saie fdon be= merft, ftülite $\Re i$ in fein Syftem auf bie Błmmentrone, ings=

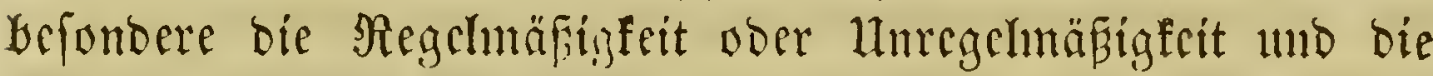

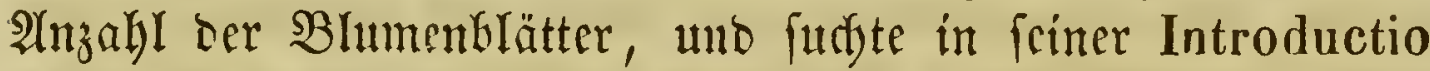
generalis in rem herbariam (Rcifzig 1690, Fol. - 1696, 12. - Lips. 1720. 12.; Die Ieste 2 tuşgabe enthält audi Dillen's (sinwürfe uno $\Re i v i n ' s$ Antwort auf bicfelect) barzutlyun, bas bies beffer fei, als bie Unterfacioungsunerf= male yon ber Frudjt Gerzunchmen. Baburd) aber uno weí cr bie Eintheilung in Bäume, Sträuther uno Rräuter verwarf,

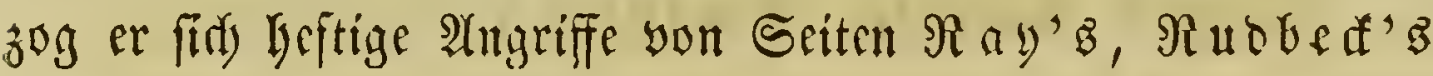

') Ordo plantar. quae sunt flore irregulari monopetalo. Lips. 1690. Fol. mit 126 Ipfrtfln. - Ordo plantar., quae sunt flore irreg. tetrapetalo, ibid. 1691. Fol. mit 119 Tfln. - Ordo plantar., quae sunt flore irreg. pentapetalo, ibid. 1699. Fol. mit $140 \mathfrak{T f l n}$. Rad feinem $\mathfrak{T}$ obe gab \&ub wig bie 2(bbitoungen ber irregulares hexapetalae obne Tert Geraus.

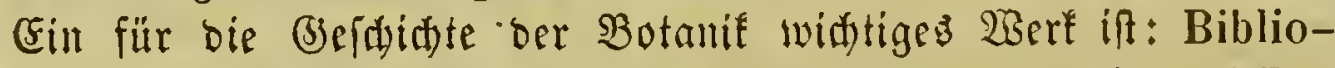
theca Riviniana, sive Catalog. librorum philologico-philosophico-historicorum, itinerariorum, inprimis autem medicorum, hotanicorum et historiae naturalis scriptorum etc. rariorum, quam magno studio et sumtu sibi comparavit D. A ugust. $Q$ u irin. Rivinus etc.; praemissa est vita Rivini descripta per M. G. Sam. Hermann. Lips. (1727). 8. - 6:3 entbält sin Berreidnís ber meifen älteren Botanifer unt ifgrer Sorjifter. 


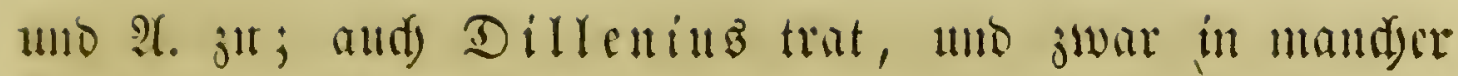
Bejichung nidjt mit umedst, gegen ilin auf.

Die Doromungen ber 18 STaffen feines Syftems fint auf Die Frudyt bafirt. Dicje ift nämlit) entweder frei (fructus nudus), voer in cinen Frndytbelyalter (pericarpium) einge= (d)luffen; biefer Frudetbebäler befergt entweber aurs einer troffenen (pericarpium siccum), ober ahs einer fleifdrigen Subftint (pericarpium carnosum).

Mit bent Shrang biefez Bcitraums begannen aud bie

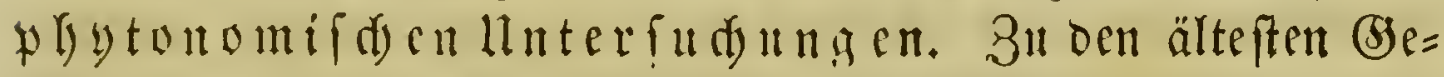

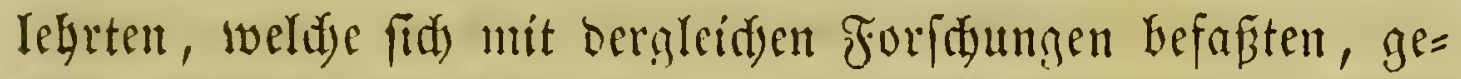

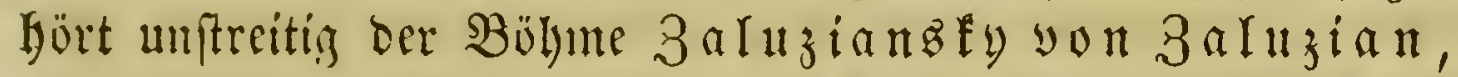
ber fdon eine ziemlidi beftummte Goee yon ben Sexualver = bältniffen ber Syflanzen gebabt haben mú, on er ben Staub= faben, Staubteutel uno Staubweg unterideibet uno won Saer= maphrobiten, Anorogynen unt getrennten (Sefidedytern rebet. ${ }^{1}$ ) Faft zll berfelben 3eit lebte ber Staliener

\section{J゙áfinz colonna,}

geboren 1576 ju Reapel, geftorben im Salye 1648.

Gr war anfangs Surift, lwurbe aber burd) feine Srant= Geit, bie Fallfudt, zum Stubium ber Botantif Gerwogen, in= Dem er in ben Sdyriften ber alten spflanzentenner ein Mittel

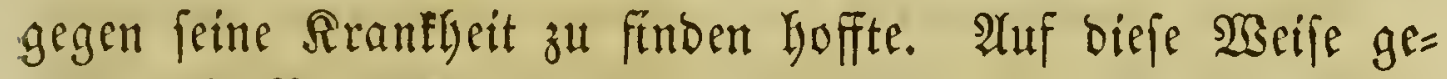
twann bie Botanil einen igrer fdarffunigften Bertreter, Dem fie fegr wiel zu verbanfen bat. Er war ber (Erfte, oer bie

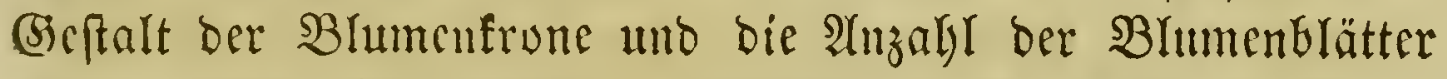
einer genauen $\mathfrak{B}$ etrad)ung unterwarf. A(ud) befdrieb er ben (brifiel uno feine Zertheillungen, bie Stautbä̈on, Staub= beutel uno Staubwege, uno war mit ber Berfidiebentyeit ber

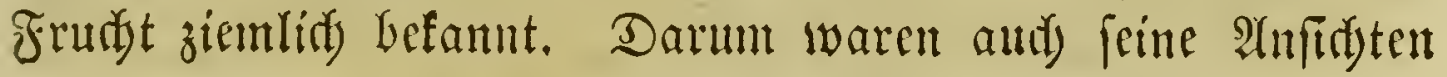

1) Methodi herbariae. Prag. 1592. 4. - Francf. 160\%. 4. 


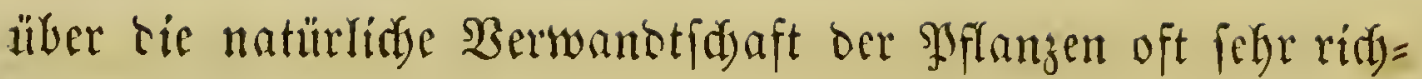
tig, obgleidy er firi) nidyt bazu verftant, eín volffändiges

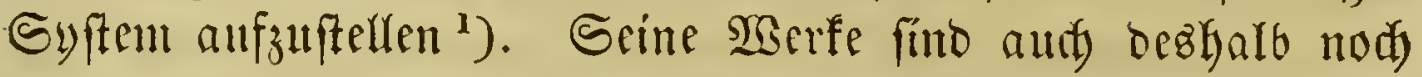
Gemerfensuberth, weil fie bie älteften splangenabbiloungen in Supferftidsen enthalten.

Norian Spiegel aus Brüfel, geb. 1578, gefít. in Jaljre 1626 als grofeffor in \$aoua, war ebenfalls ein fodarf=

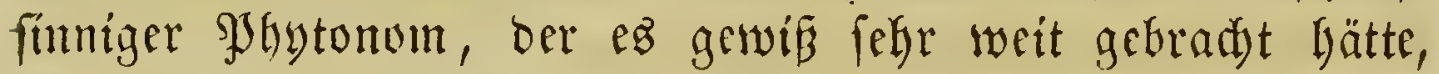
toenn ihm nidyt bas nothiwentigfte Şülfamittel zu berartigen

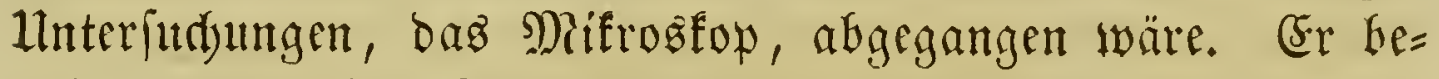

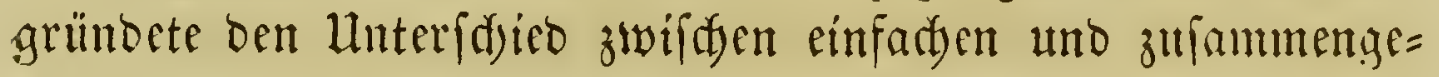
festen Drganen uno hatte foron ziemlidy ridytige Anfedten über die 3wifdenzellengänge-uno die in ifnen enthaltene Subftant. ${ }^{2}$ )

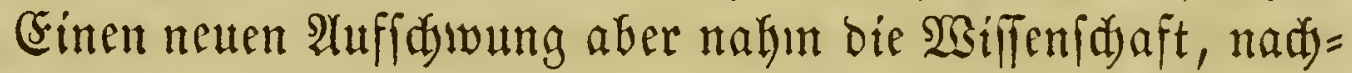
Dein aun 2 nfang bez frebzebnten Galyrhundertz burdi corn. Drebbel, bans uno 3adyarias Sanien die Giraz=

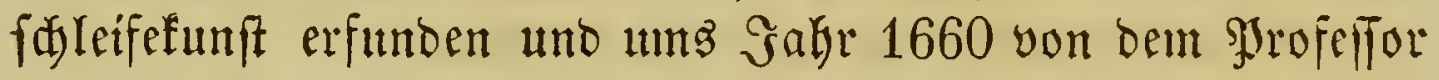
Robert 5 o of , geb. 1635, geft. 1702, in Rundun bas erfte, zu naturwiffenfdyaftlidyen Unterjudyungen tauglidye Mifrosfop lergeftellt worben war. Diefer (Gelehrte gab felbit balo barauf cine Sammlung mifrosfopiforer Unter futyungen heraus, unter

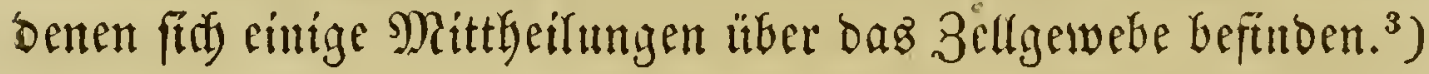

$\left.{ }^{2}\right)$ Phytobasanos, s. plantar. aliquot historia etc. Neapol. 1592. 4. Florent. 1744. 4. - Minus cognitarum rariorum-

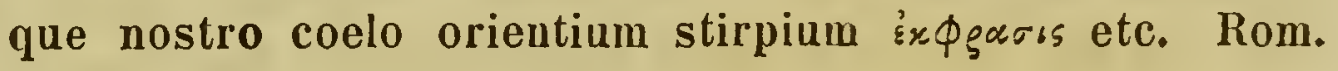
1616. 4.

2) Isagoges in rem herbariam. Patavii 1606. 4. - Leid. 1633. 12. - Helmstaedt 1667. 4. $-\Lambda \mathrm{d}$ r. S p ie gelii opera omnia, ed. Vanderlinden. Amstelod. 16'5. Fol. SBergl. Charles Morren: Adrien Spiegel, Extrait d'une histoire inédite de la botanique belge. Bruxelles 1838. 8.

3) Micrographia or some physiological descriptious of minute bodies, made by magnifying glasses, ' with observations and inquiries thereupon. Lond. 1665, 1667. Fol, Mit $\mathfrak{A} 6=$ bilbungen. 


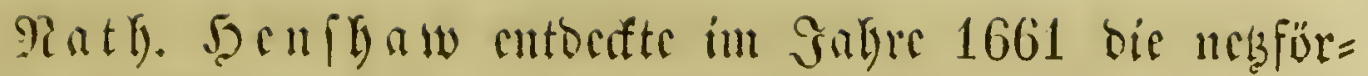

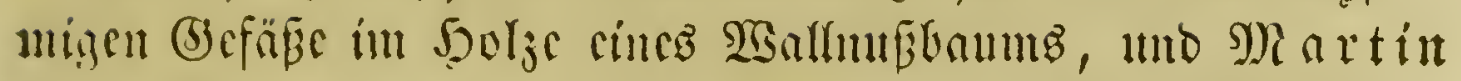

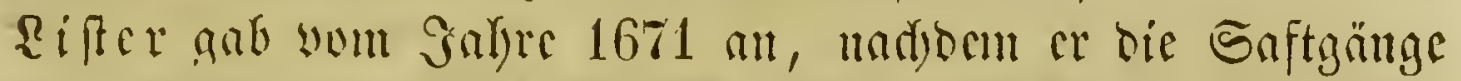
in ber Rimos uno im Siarfe anfgefunoen hatte, feine For= fdumgen liber bie Barwenumgen ber Gäfte berans. ${ }^{1}$ )

Bwei Männer aber waren es namentlid), dic ben (5) rumb

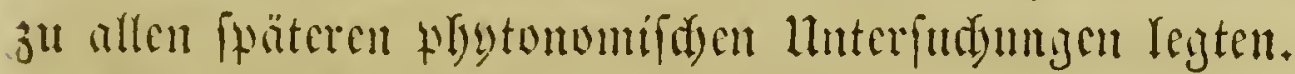

șir nemen juerift ben Einglänorr

\section{Mehentias Grew,}

Sefretär ber fünigliden Societät in Lonbon.

Sdyon fain Rebrer $\mathfrak{x h o m a s ~ M i l l i n g t o n , ~ S h o f e f f o r ~ i t ~}$ Drford, hatte cine, wenn and) grobentlecils uncidgtige Goce über bic fomftionen ber Strubgefäbe gehabt. Er ferbit aber, unterftügt burdy gute Mifrogfope, madjte yon 1661 an cine

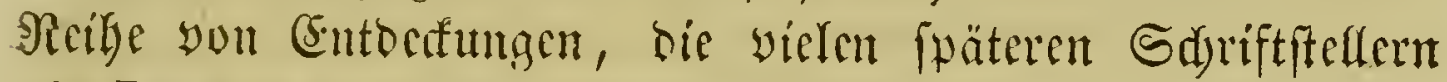
als 5 uelfen neuer Soent dienten. Neben feinen anatomifden Ilnterfuthungen ftellte (5) rew aud über bie Berridtungen ber SIflanjenorgane Beobadjtungen an. Ramentlid verbantt ifm bie Eefre von ben Sexualberbälnififen mandye vortefflitye

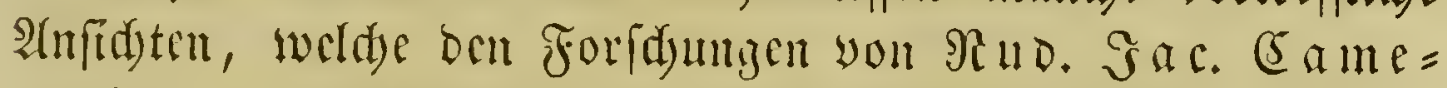
rarius, der gewöbnlidy als der Begründer oer Sexuartgecrie betraidet wiro, bedentend vorarbciteten. Er ftarb im Gabre $1711 .{ }^{2}$ )

$\left.{ }^{1}\right)$ Philosophical transactions. Vol. 6, No. 70, 79. Vol. 7, No. 90 etc.

$\left.{ }^{2}\right)$ The anatomy of vegetables begun etc. Lond. 1673. 8. An idea of a phytological history propounded, together with a continuation of the anatomy of vegetables, partirularly prosecuted upon roots. Lond. 1673. 8. - The comparative anatomy of trunks, together with an account of their vegetation grounded thereupon. Lond. 1675. 8. - The anatomy of plants etc. Lond. 1692. Fol.

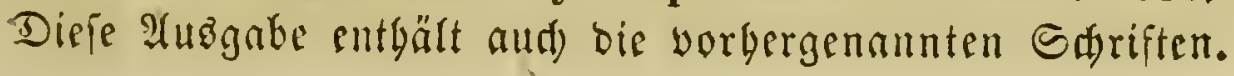




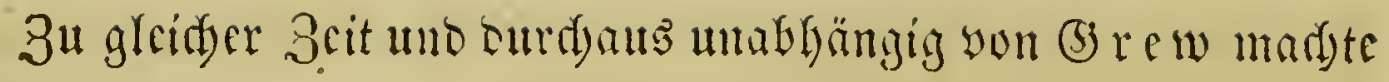

\section{Mraxcelfo Mralpighi,}

Srofefior in Bologna, geb. 1628, geit. 1694,

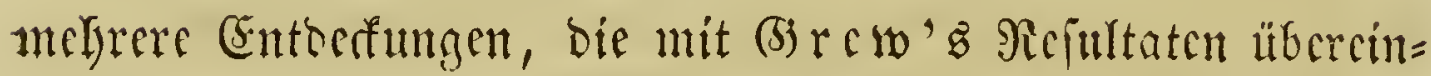
ftimmten. Sm Salyre 1671 überfande er feine Schrift ${ }^{1}$ ) ber föniglidjen Societät zu Sonoon; zu biefer 3cit latte aber

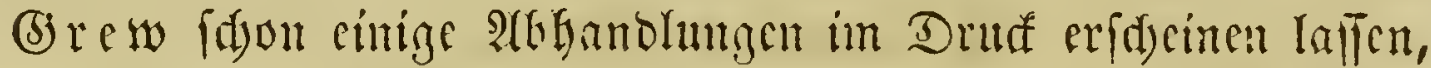
unto obgleidy Malpighi nidyts liervon gewubt hatte, fo twurbe bod) ber (Erfitere von mut an inciftens für oen erften Segrünocr ocr Şbytonomic angefefen.

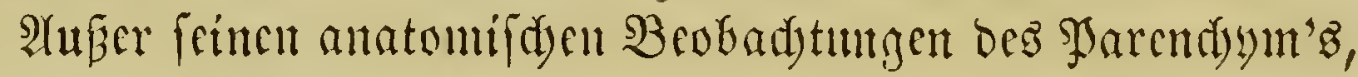

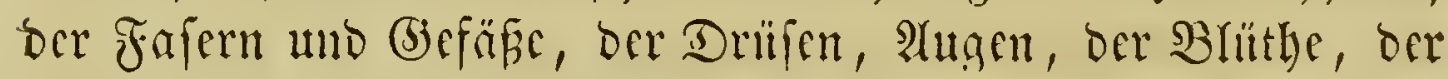

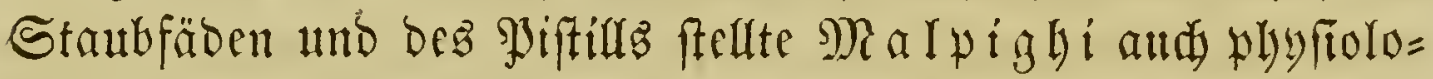
gifde Unterfudumben an, namentlid) lüer bie Entwiffelung

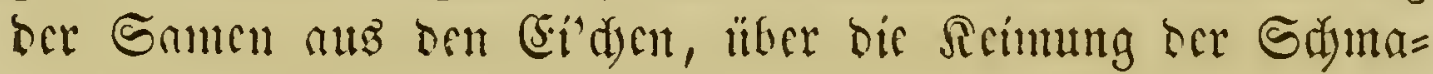

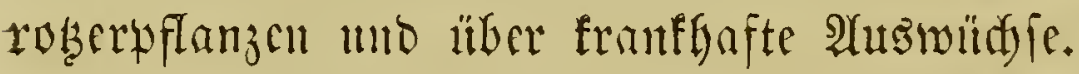

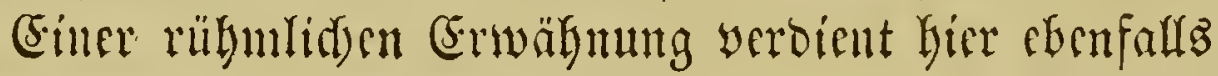

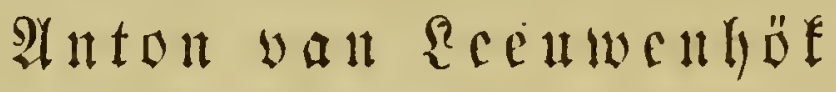 aus Delft, geb. 1632, geit. 1723,}

Ser mit ben won ifm feldft verfertigten trefflidyen Mrifrosfowen

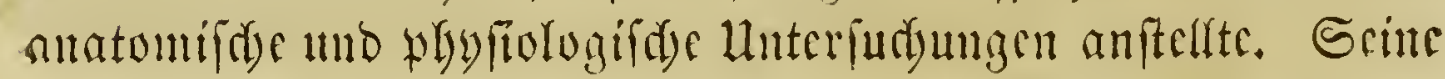
gefultate gab er in ber form von Briefen an bic füniglidje

1) Anatome plantarum. Lond. 1675. Fol. Tom. II. ib. 1679. Fol. M. Malpighi i Opera omnia. Lugd. Batav. 1657. 4. Lond. 1686. Fol. - 0pera posthuma etc. Lond. 169 . Fol. - Amstel. 1698, 1700. 4. - Venet. 1698, 1743. Fol. - Amsterd. 1755. 4. 
Socictït 3u Ronoun heraus. Sic fint meiftentbcils in bon Philosophical transactions erfidicuch. ${ }^{1}$ )

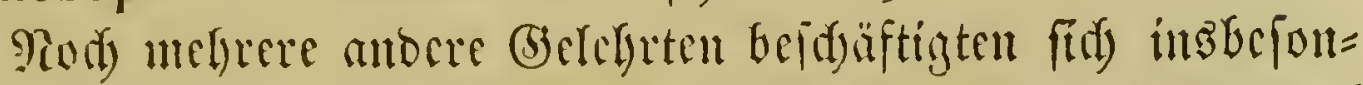

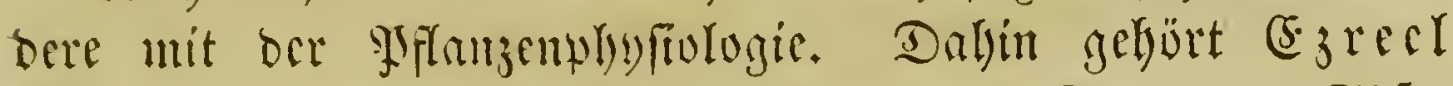
Tougue wegen feincr Berfudye über die aufferigendon Säfte

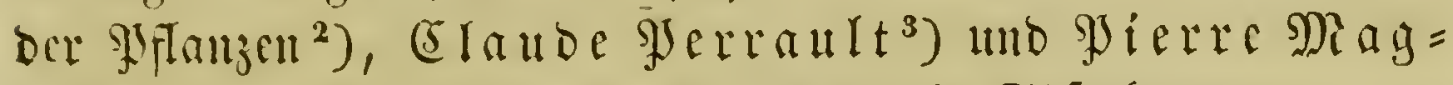
nols), weldye Unterịnd ${ }^{*}$ )

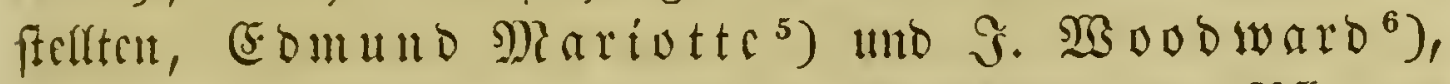

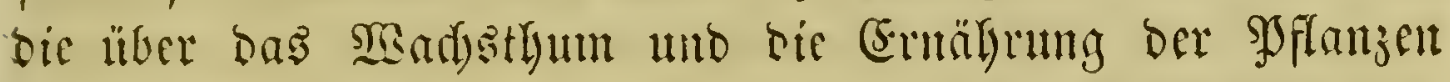

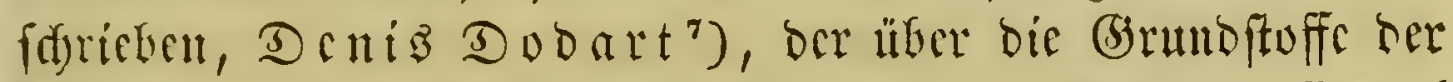

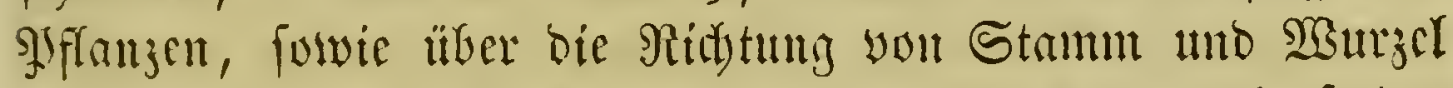

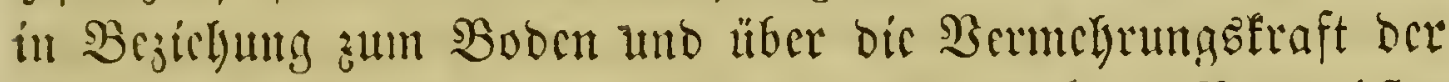

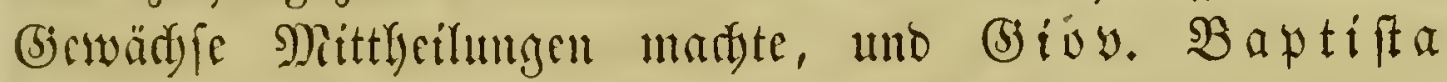

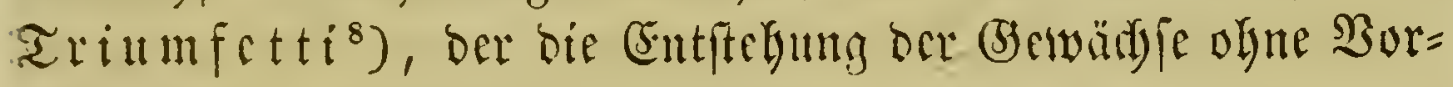
bambchicin bes Samchs zu bewcifen futite.

1) Seierger gegüren namentfit): De vasis triplicibus in variis plantis visis maximis $s$. tracheis, parvis et transversis s. ex medulla in corticem euntibus etc. Philos. transact. No. 127. - De ligno ejusque vasis, No. 148. - De cortice plantarum cum cute animalium comparato, No. 201. - De fabrica seminum et umbillicari funiculo, No. 297. De seminali fabrica polypodii, annulo elastico, capsula, polline etc., No, 297. - Arcana naturae etc. Delphis 1695. 4. - Lugd. B. 1722. 4. - Continuatio arcanorum etc. Delphis Bat. 1697. 4. - Opera omnia. Lugd. B. 1715-1722.

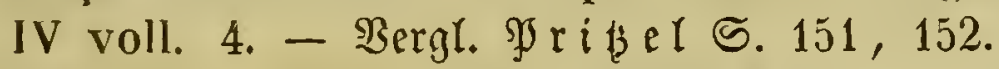

$\left.{ }^{2}\right)$ Phil. transact., vol. 6 , p. 2063 If.

3) Wémoires de l'Académie des sciences 1667 unt 68.

4) Magnor's Sdyriften find oben S. 133 augefïlyrt.

5) Premier essay sur la végétation des plantes. Paris 167f, 79. 12. - Seine gefammetten $23 e r f e$ fino 1717 zu Seiben eridjienen.

6) Philos. transact., Vol. 21, No. 253.

') Mémoires pour servir à l'histoire des plantes. Paris 1676. Fol. 1679. 12. - 2Ampterdant uno Reipzig 1758. 4.

$\left.{ }^{3}\right)$ Observationes de ortu et vegetatione plantarum. Romae 1685. 4. Derietbe yerfapte nod) einige anocre Edyriften; fiebe gyriel S. 301. 
Am Shlufle biefer Pleriode ift nod

\section{(Sh)riftian Mentad}

als Derienige anzufïhren, weldyer ben eriten Begriff yon

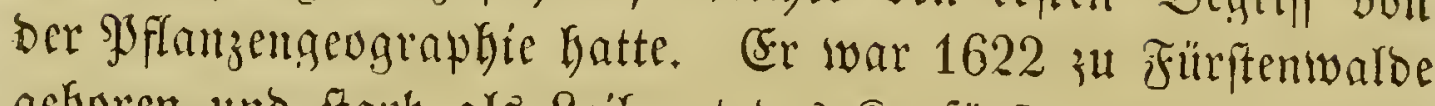
geboren unb ftarb als Reibargt bes Rurfürfen won 3 randen=

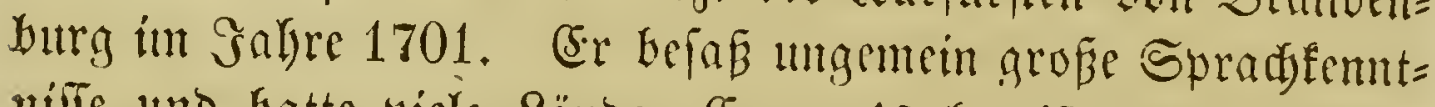
nilife uno batte viele Ränoer (Emopa's bereift. Durd) feine

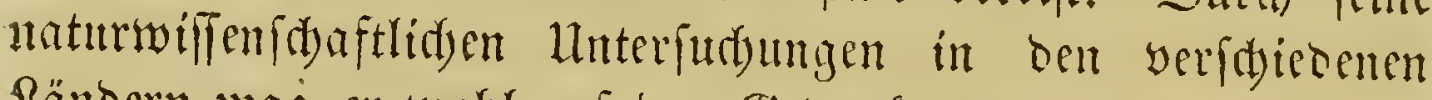
Ränoern mag er wohl alf ben bicoanten gefommen fein, baz

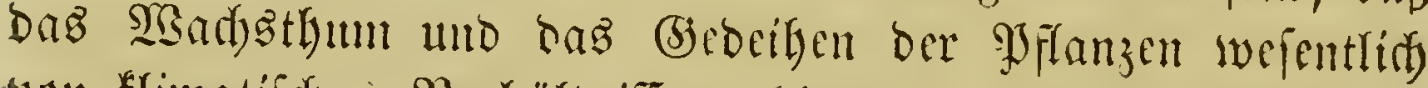
yon frimatifden Berbältuiffen abbäugt, cine Thatiadye, die

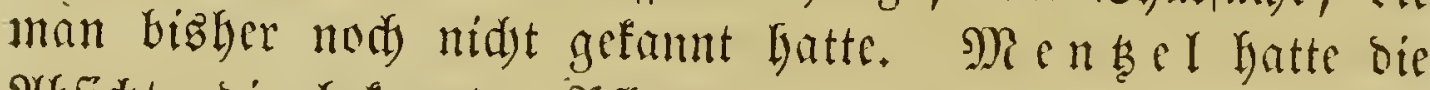

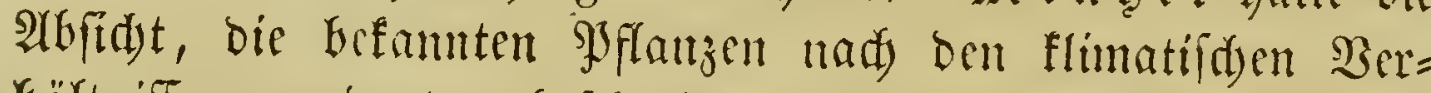
bältuiffen georonet zu beforeiben, allein er verlor fritue meite

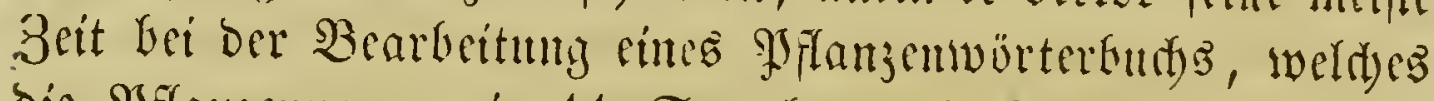
sie SPflanjennamen in 11 Spradjen mit furger alnjabe ber Secilfräfte entbailt. ${ }^{1}$ )

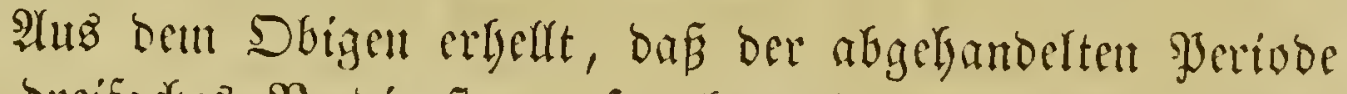

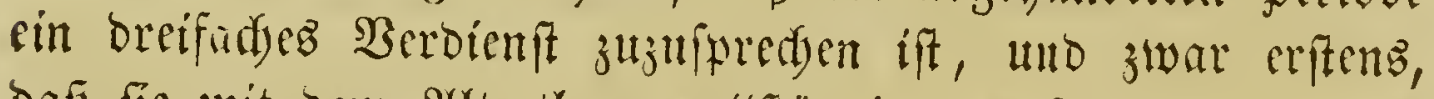
Dafi fie mit bem altertlym vollftünoig uno für immer abge= redynet, bamn, bẩ fie in allen cistlifirten \&änoern Europa's

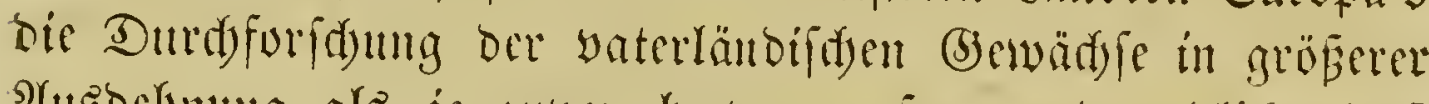

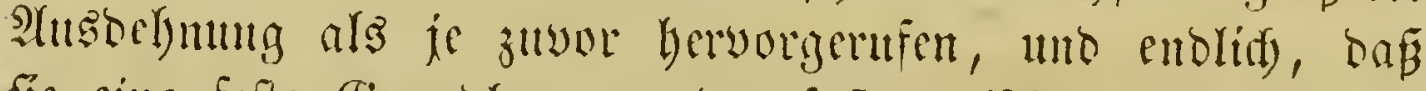
fie eine fefte (brundage zu ber fyftematifiden anatomifich

$\left.{ }^{2}\right)$ Index nominum plantar. multilinguis. Berol. 1652. Fol. Ibid. 1696 uno 1715 unter bem Titer: Lexicon plantar. polyglotton universale. Fol. Sn den beiben Yekteren 2 tubagnen befindet fith als $\mathfrak{A}$ (nf)ang: Ad indicem universalem nominum plantarum et pugillum corollarium, worin über bie von

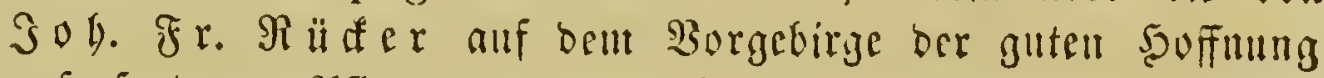
anfgefunbenen Pflanzen gerebet wirb. 


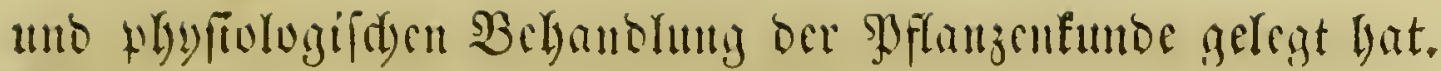
Dic Reifungen ber cinjelnen (belchrten haben wir angefülyrt, aber auber ifuen trugen and) bis an melyeren Drten geftif $=$

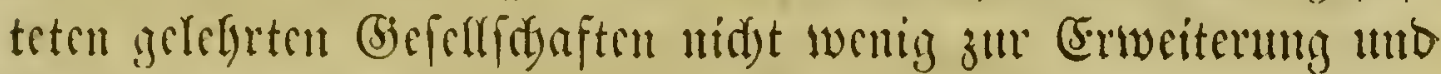
Itubercitung oer Syflanjenfenntuiffe bei.

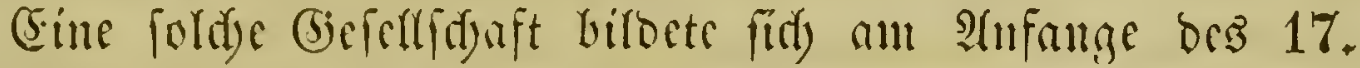
Gabrhumberts ju giom auf Sirranlaffun! bes Fïrften Fed $F=$ ricu Sefi. Dies war bic Academia de' lincei, fo $\mathfrak{g}^{E}=$ namt, wril fir in ifrem Sapapen als Sinnbilo dra Srbarf=

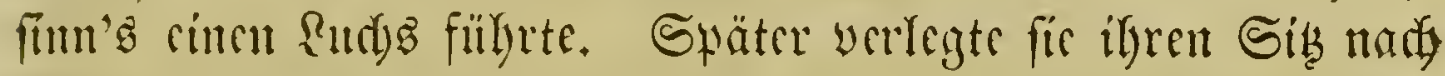
Rrapel, wo fie balo burd) ben Rünig yon Spanicn aufgelöf wutrde. - Der englifde Sünig Sarl II. ernante eine fordon

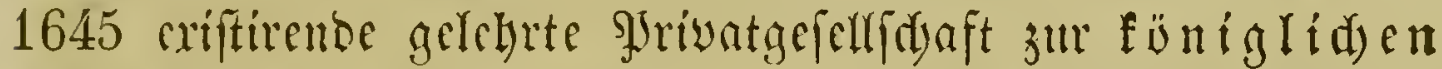
Societät ber $\mathfrak{W}$ iffenfd aften, unter weldem Titel fie fis auf unicre Bsit lyerab wirfte.

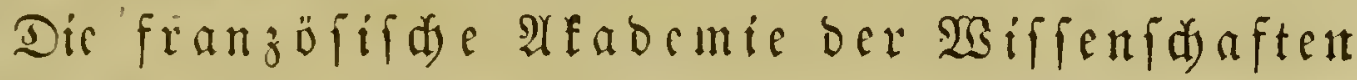

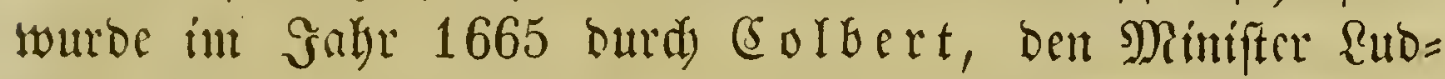
wigg XIV. gegründet und hat biz zur (S)egenwart viel zur

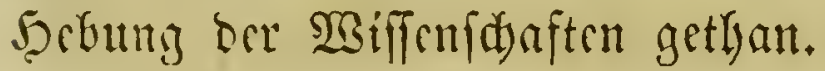

Der boutidye Raifer Reopold I. ernannte bie naturforidyente

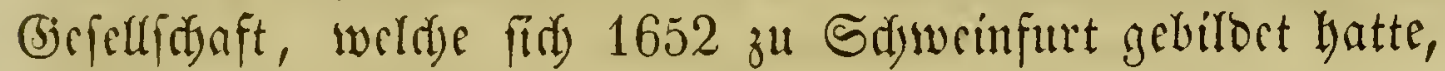

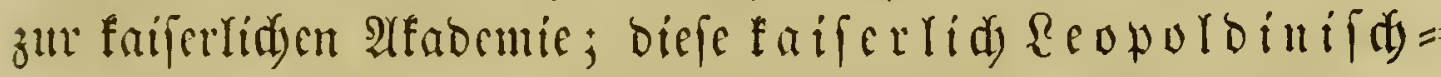

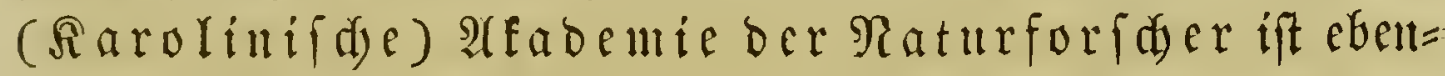
falls nod jest in allen Bweigen ber Raturwifferidgaften thätig. 


\section{Die 3cit ber Borbereitumg zu Der gropecu bota= nifben Reformation.}

\section{Bon Sournefort big auf Rinné, $(1694-1735)$.}

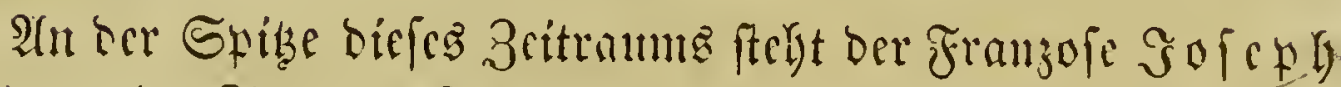
Sitton be Tournefort. (5e if barum als epodsmadsent

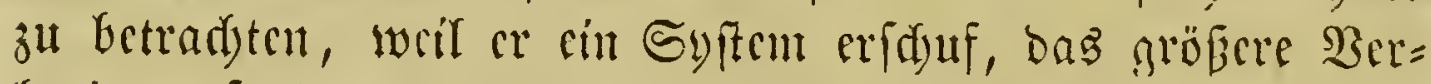

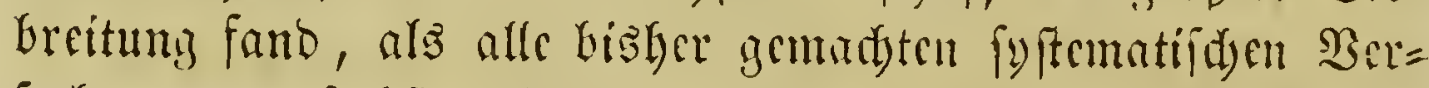

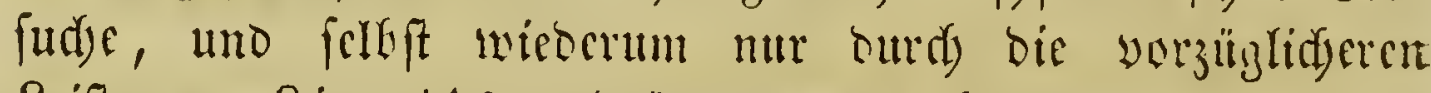
Reiftungen Rinn é' verbrängt werben founte.

\section{Soienh Pitton De Sournefort,}

im Sabre 1656 auf bell (3)ütern feiner gamilie nalye bei $\mathfrak{2}$ (ix in ber Provence geboren,

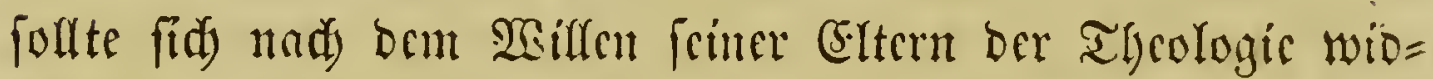

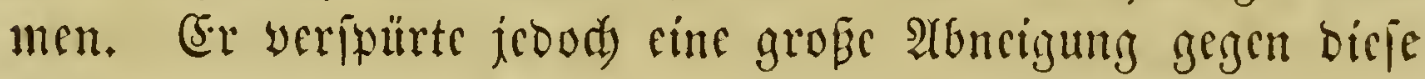

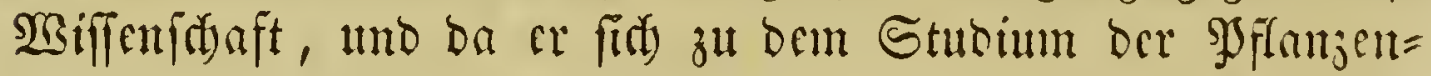
funbe befonders bingejogen fülylte, fo begab or fid uad Miont=

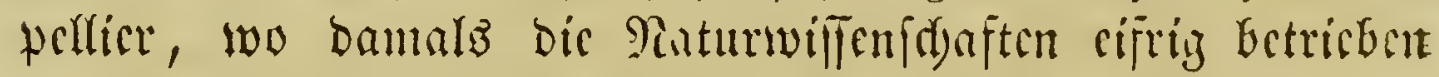

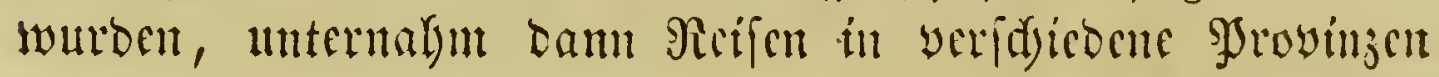
Franfreids und Spanicus unt burdywanderte cinen Theil ber

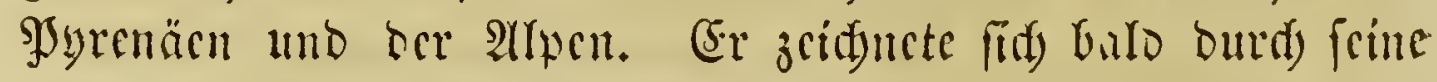

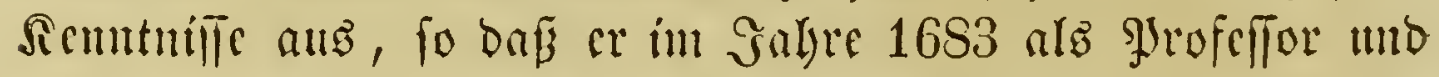

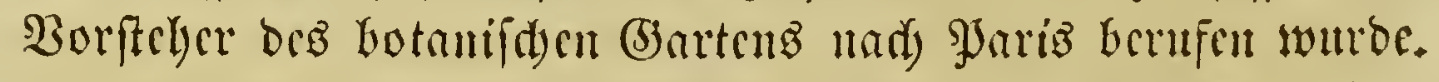

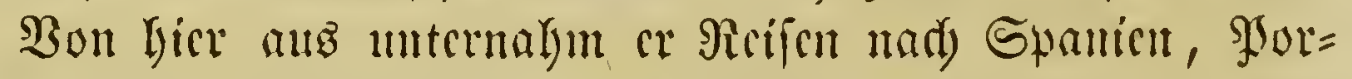

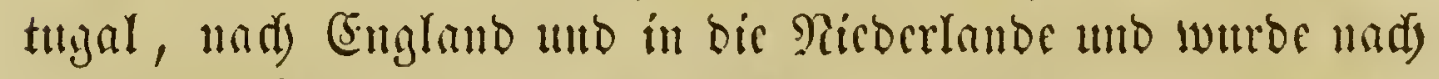

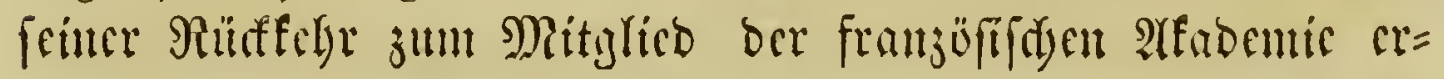


namut. Balo nad)her begub er fith in Begleitumg bes bent=

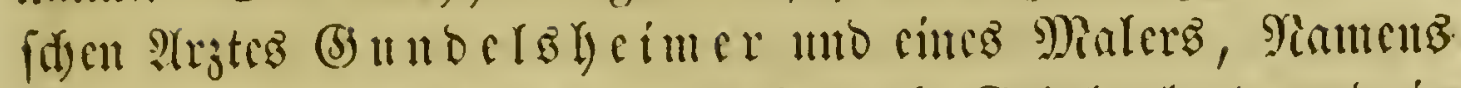

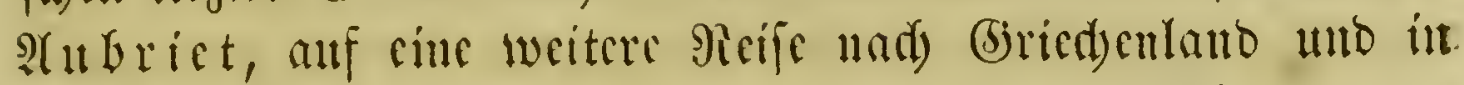
ben Drient mo fan mit viclen Semtitiffen bereidyert - et Gatte etwa 1300 uene Pflanjenarten gefaumelt - mad) Parią

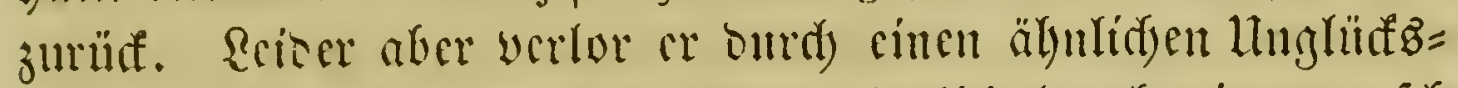
fall wie Miorifon - er erbiclt nämlid) burdi cincu rafd

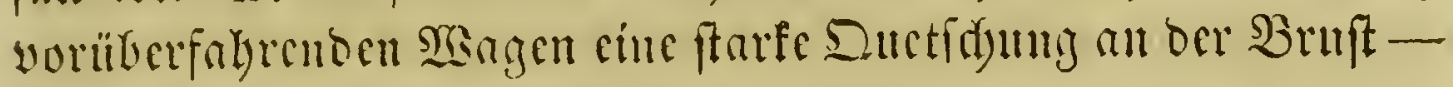
fidou int 52. Jafire bas Rebent (1708).

SEorin beftert ber Burjuy von Iournefort's Syftem wor anberen gleidyzcitigen $\mathfrak{B e r}$ fudyen? (E) ift feinem Srincip nad) cin fünftlidyes Syftem uno follte nad) $\mathfrak{T}_{\mathrm{v}}$ uruefort's

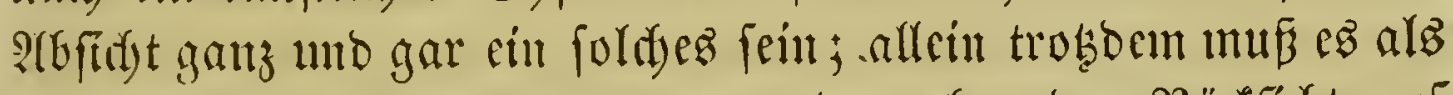

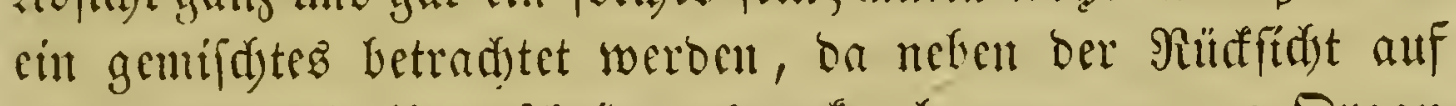
bas cimmal als Unterfdeciomngamerfunal angenommene Drgan aud) bic natürlidye Berwandtid)aft beadjet wird, insbejondere

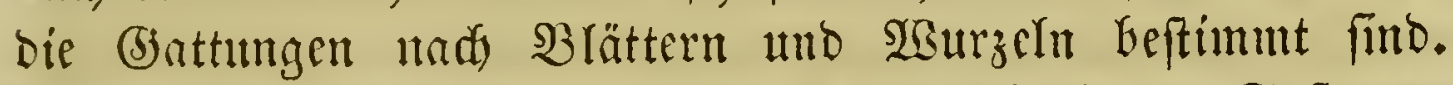
Die oberfe Eintheilung ift wic bei oen friberen Syftement (mit Altsnafme bes rivinifden) bie in Sräuter uno Stanben (herbae et suffrutices), uno in $\mathfrak{B}$ n̈mme แmo Sträıd)er (arbores et frutices). Dann foumt $\mathfrak{c} b$ baramf an, ob cime Blumenfrone (Gorolle) vorbanten ift, ooer nidst. Gin erite= ren Falle ift die Einblättcrigfeit oocr Bielliättcrigfeit oer

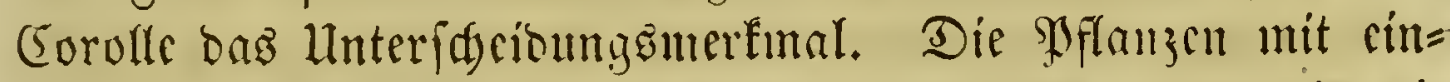
blätteriger Sorolfe mad)en Die vier erften Alaffen ans, bie mit vierblätteriger Borolle zerfallen in cinfadtblïtligge (simplices,

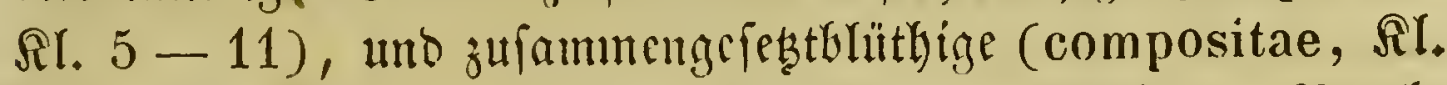

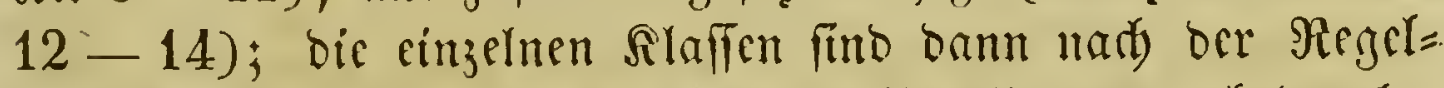

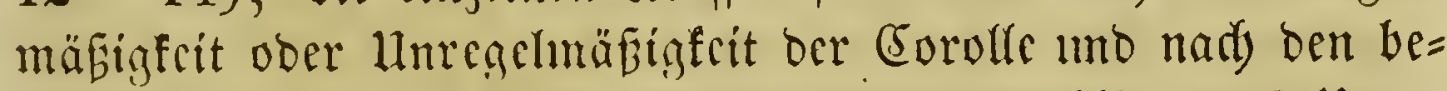
fonberen djarafteriftifden Formen berfelben gebildot. - Unter

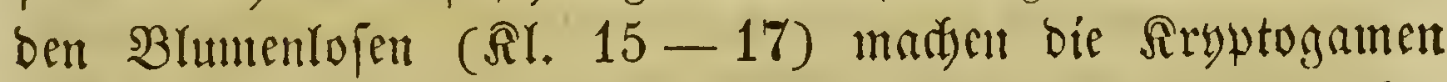
cime bcjonbcre Slaffe aus. - Dic Bäunte tuto Sträudjer

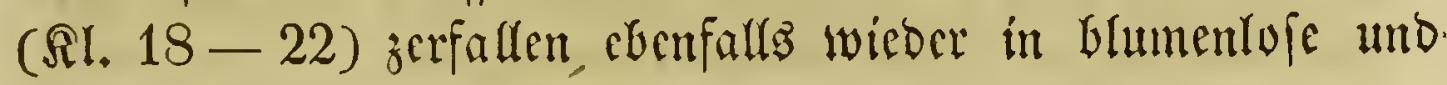
mit ciner Sorolle veriebcue.

Die Slaffen zerfallen wieber in Drountigen, uno zivar bei. 


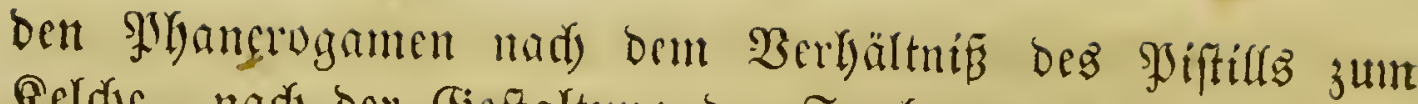

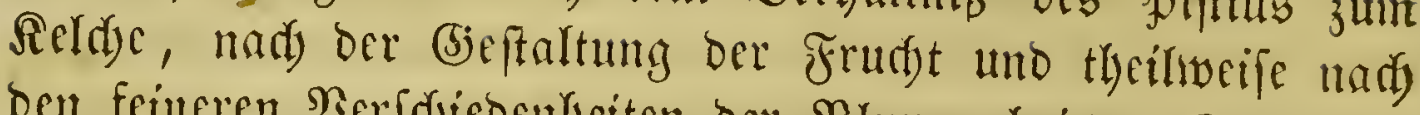
Den feineren Berfdiebenlyeiten ber Blume, bei ben Aryptoga= men aber nad) ber Stellung ber Früd) te und banad), ob fie auf bem Ranbe ober im Saffer vorfommen. - 2Am meiften mag lovbl jur Berbreitum beg Tournefort' foen Syltems bie fit)arfe Unterfdeisung zwifden (jattung uno atrt beige= tragen baben. Sine grob̧e Anzabl (Sattungen bat er zucrit feitgefterlt, uno viele berfelben futo auth von sinné beiber)al= ten worben, obgleids er ifhen oft andere Ramen gegeben Gat. Tourncfort lat in fein Syftem mingefäly 10,000 9Jflanjen= arten untergebrad)t, beinake um dic Şälfte wentiger als $\Re$ ay,

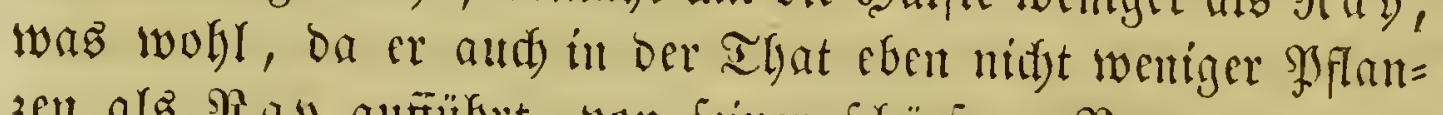
zen als $\Re$ ay aufiught, yon finer foüarferen Begrenjung ber (5attungen mo atren herriliz)en mag. Er fiscint auf ben

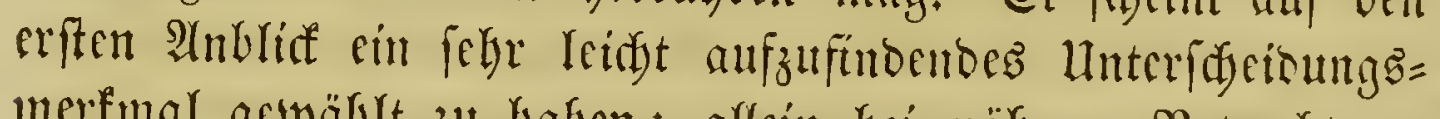
merfmal grwälyt zu haben; allén bei näberer Betraditums

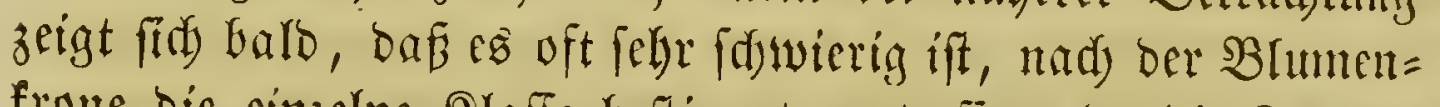
frone bie einjelne Slaffe beftimm zut treffen, ba bie Formen ber (Sorolfe oft ganz ummerflidy incinanber übergelyen. ${ }^{1}$ )

llebrigens wurbe $\mathfrak{I}_{0}$ urnefort'B Syftem yielfad) uno jum Theil mit guten (Siünden anjegriffen, namentlid) yon bemínt= gen, weld)e bie Fruddst als bas wefentlifye Unteridseioungs = merfmal angenommen haben worten. In $\Re$ a $)^{\prime}$ b oben 5.112

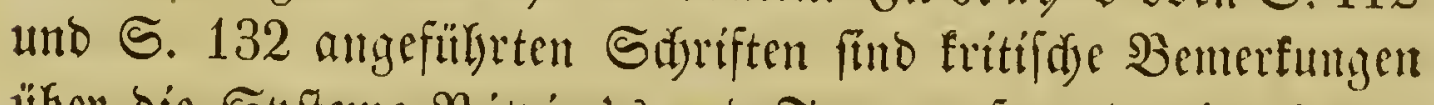
liber bie Syfteme Rivin's und Iournefort's eingeftrent.

1) Eléments de botanique ou méthode pour connaitre les plantes. Paris 1694, III voll. gr. 8. mit 451 §pfrtfln., weldse bie (Battungsdaraftere barfellen. - Fine voll 3erf. beforgte mob vermegrte lat. 24 sagabe: Institutiones rei herbariae, edi-

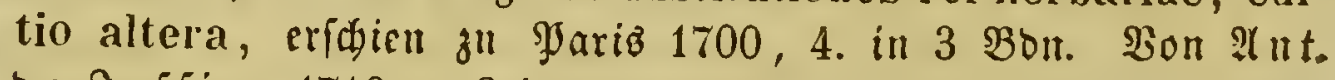
De Sufficu 1719 zn \&eiben mit 3ufäłen unb eincr 2tbbanblung über baß Dournefort'f fortii de optima methodo instituenda in rei herbaria ad Guil. Sherard epistola (Paris 1697). 8. 
S(ud) ber berilfute $\mathfrak{D}$ irfe

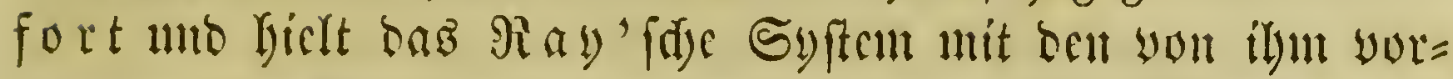

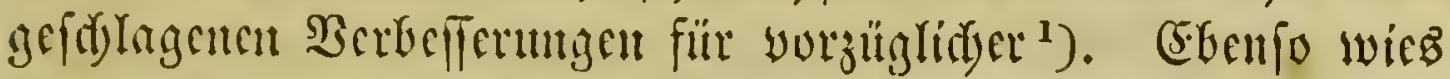
Jatriaf BIair, ber fid überbaut gegen bie bamals über=

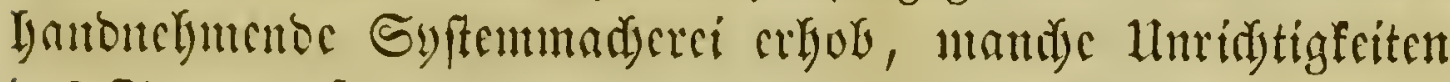

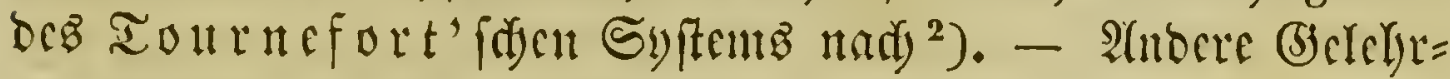

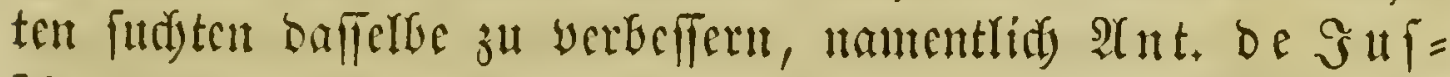
ficu (fiche ober Tourncfort's Sdjriften), (5) iuglio Soutedera ${ }^{3}$ ) unb insacjonbere $\mathfrak{B} a$ illant.

Rody in ber nemeren Zeit hat ber Srofeffor (b) thint in Srario bas Tournefort'fue Syftem zu verbeffern mo fo wicocr in 2 (tufuntute zut bringen gefutht ${ }^{4}$ ). (5r hat baffelbe

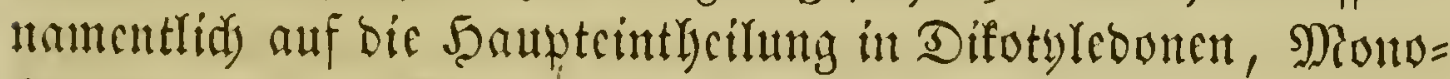

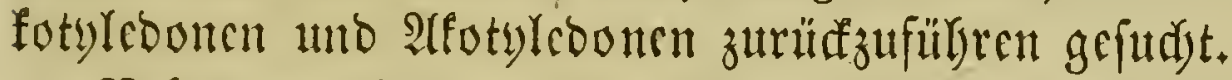

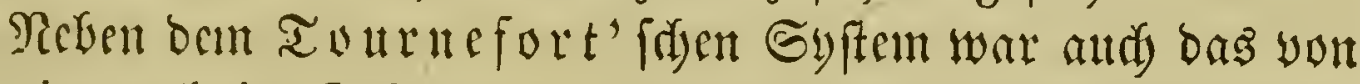

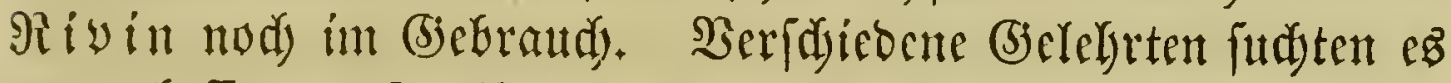

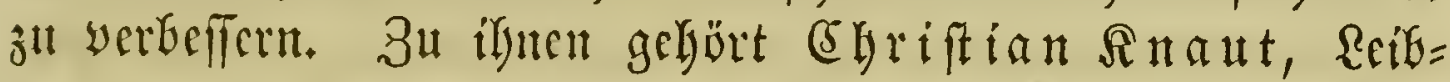
argt bez Fürften won Röthen uno Biblivthefar in 5̧alle, geb.

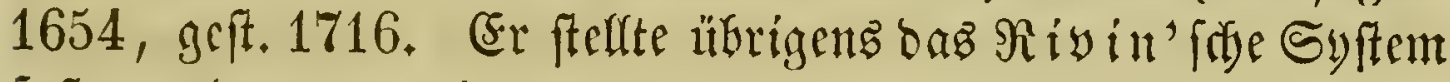

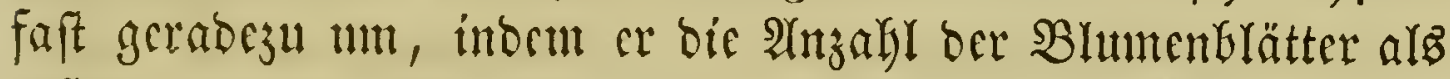

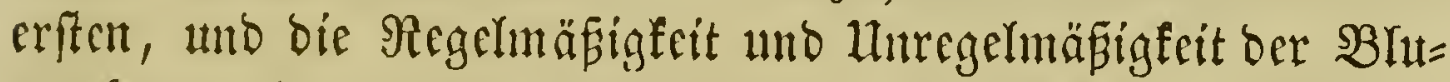

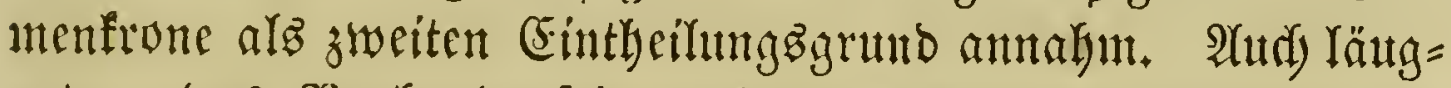

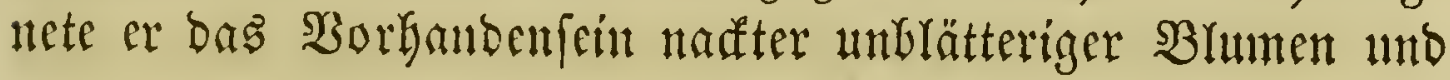

1) Catalog. plantar. sponte circa Gissam nascentium cum appendice etc. Francf. 1719; mit 16 Sipfrtfin., auf weldett bie yon ifm neu aufgeftellten Brattungen warafterifirt finb.

$\left.{ }^{2}\right)$ Botanick essays. Lond. 1720. 2 voll. 8. 4 Ifln.

3) Anthologia, s. de floris natura libri III etc. Patav, 1720. 4. $12 \mathfrak{I f f r}$.

4) Classification végètale, ou exposé d'une nouvelle méthode calquée sur celle de Tournefort, d'après laquelle sont rangées les plantes du jardin de l'école spéciale de Pharmacie à Paris. Paris 1807. 12. - Nouvelle méthode calquée sur celle de Tournefort etc. Paris 1823. 8.

(5. Wintrer, Befid. b. Botanit, 
naderter Samen und nahm eine ben Samen bebefonbe Frudte bülle, bie er in affen Fä̈lfen Sapfel namte, ant. ${ }^{1}$ )

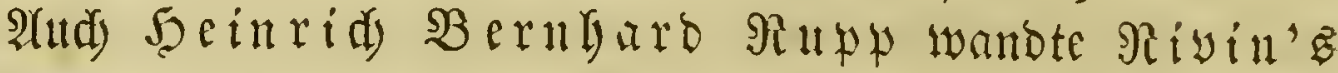
Syftem, jedod mit einigen $\mathfrak{S e r a ̈ n}$ erungen, die fid meiftens auf bie Synantheren begogen, in feiner Flora yon Gena $a n^{2}$ ). Johann (Eraft bebenftecit, geb. 1702, geft. 175\%, ba=

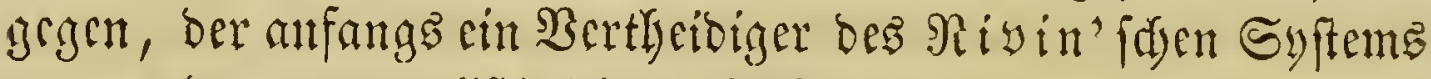

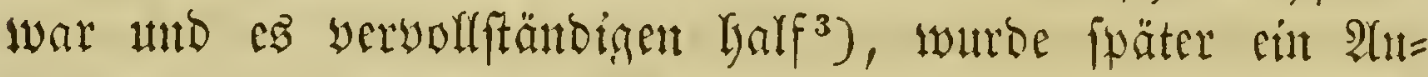

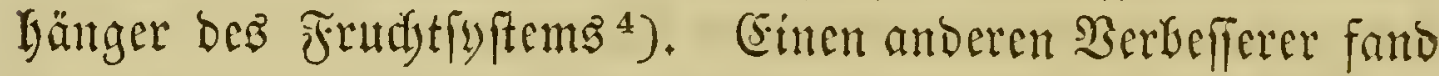
Das Rivin'fde Syftem an (Elyift. (b) ottlieb Rubuig, geb. 1709, geft. 1773, fpäter झुrofefior in Reiszig, ber bie

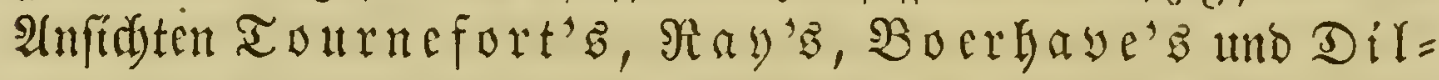
Ien's Damit zu berbinten furbte uno es um zuei Silaffen ver= medirte. ${ }^{5}$ )

2(td) Solann beinridi Srainer wollte bas Syftem Rivin's uno Tournefort's vereinigen und läugnete bie

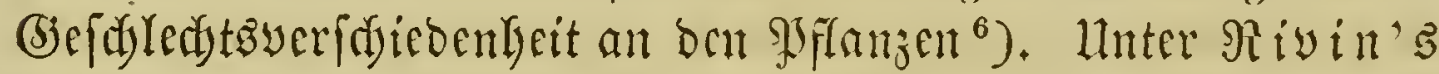

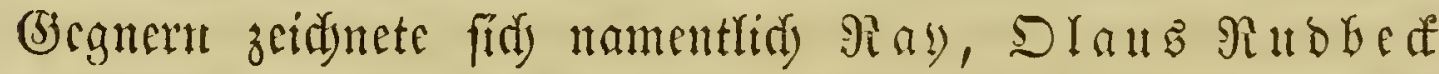
und Diflen aus. - Selbft Jermann's Eyftem fanb nody in biefer \$Jeriobe 2(nryänger.

1) Method. plantar. genuina, qua notae characteristicae tam summae quam subalternae ordine digeruntur et per tabulas synopticas delineantur. Lipsiae et Halae 1716. 8 . Bergl. aud beffer Dissertatio praeliminaris, qua de variis doctrinam plantarum tradendi variorum methodis disseritur, veraque ac genuina methodus indigitatur. Halae 1705. 4.

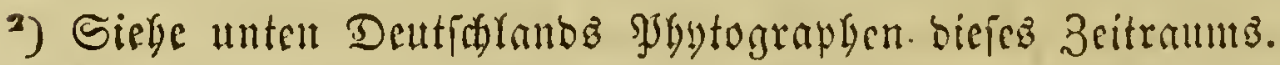

3) De continuanda Rivinarum industria in eruendo plantar. charactere. Lipsiae 1726. 4. - Definitiones plantar. Lips. 1731. 4.

4) De methodo plantar. ex fructu optima. Lips. 1740. 4.

5) Definitiones plantarum. Lips. 173\%. 8.

-) Tentamen botanicum auctum et emendatum. Vienn. 174\%. Fol. (Ŝf in sgripel Thesaurus nidgt aufgefügrt.) 
Der berillynte Miediciter

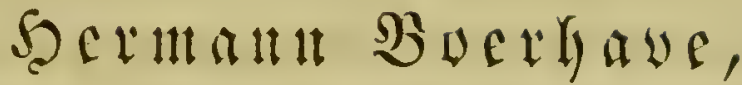 \\ geborell ju Eciben 1668, jeftorben 1738,
}

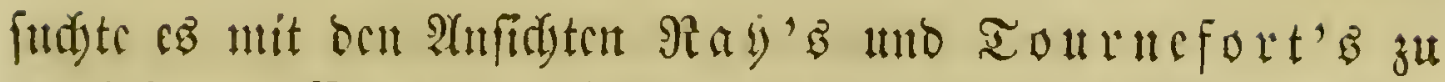

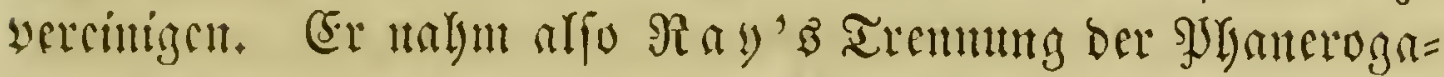

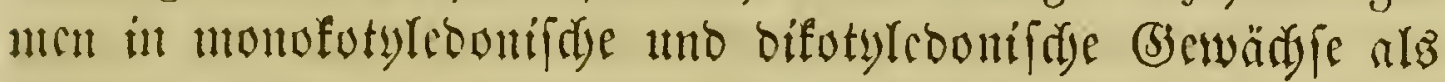

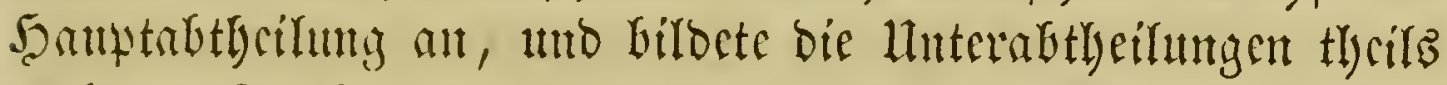

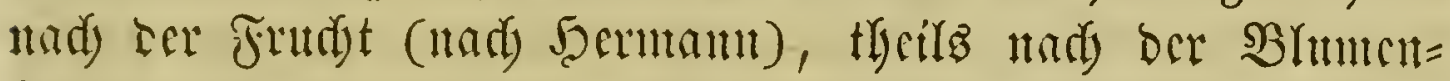
frome (Had) Touncfort). Die Sryptogamen tycilte er in bret SIa unb S(y) äuntr; 3) Farrenfräuter.

SAf dicfe Sasife crficlt er 34 STaffer. ${ }^{1}$ )

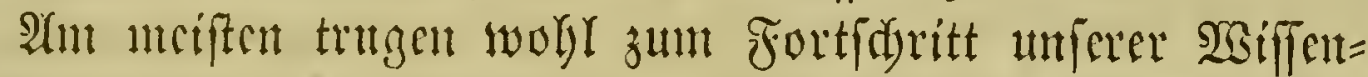

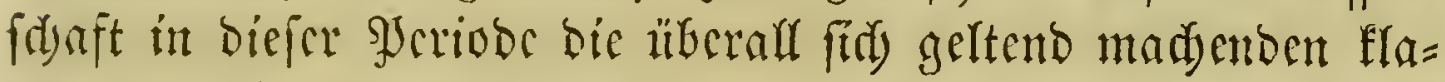

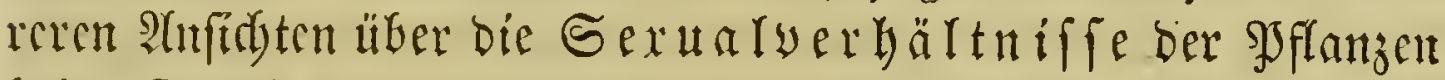
bei. Sor Erffe, ber bicje Sadje mit Radorud und Erfolg in Ânregung bradjte, swar

\title{
Mubolph Sacob Gamerarits,
}

geboren 1665, geftorben ałв গুrofeffor zu Tübingen in Sabre 1721 .

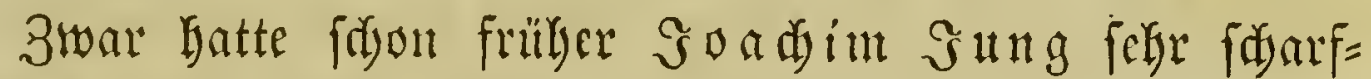

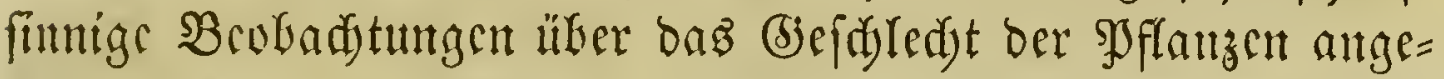
ftellt, ebenjo ber Engländer (B) $r e w$, alfein beibe hatten bod nidyt mit folder Beftimutheit, wie (sameraritso ${ }^{2}$ ), yon

1) Heber Boerbave'z bierber gegörenbe Sariften fiebe unten bie Jgytograplen ber Rieberlalloe.

2) Epistola de sexu plantarum. Tubing. 1694. 8. - De plantis vernis. Tubing. 1688. 4. - De herba Mimosa s. sentiente, ib. 1688. 4. - De convenientia plantar. in fructificatione et viribus, ib. 1699. 4. - De Scordio, ib. 1706. 


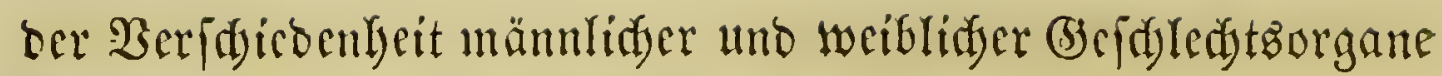
unto ifrer Funtionen gersoct.

Die botanifdyen Sdyriften (5amerar's, worldye auts einer

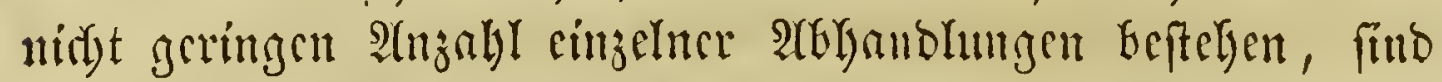
erft längere 3eit nad) feinem Tobe grfammelt herautägegrben worben. ${ }^{1}$ )

Heber die you Cramerariuz angeregten Forifungen

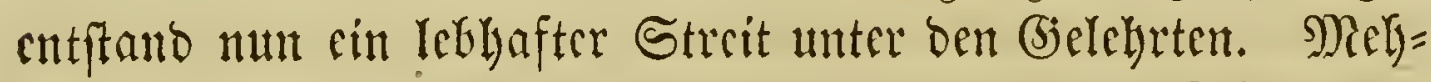
rere ber bebentenoften Botanifer ber bamaligen 3eit traten auf frine Seite und führten feine 2 (nffedten weiter aus. 3 th

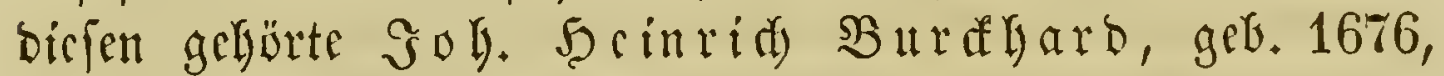

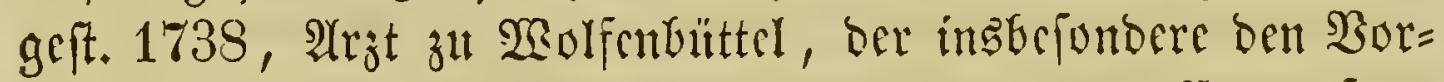
zug, weld)en bie Befrudjtungsorgane bei ber Entwerfung cines Syftems yor allen anderen SJflanzenthcilen yerbienen,

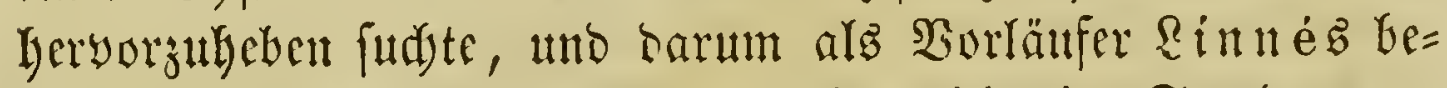
tradjet iverben famn, troboem aber nidyt im Strnoe war, bie alte Eintheilung in : Borb zu werfen ${ }^{2}$ ). Ferner Samuel Morland, ber zut beiveifen fudste, baj ber Staub ber antheren bic sigentlide Befrudytung herbeifüfle, und bapi diejer Stautb yon ben $\mathfrak{f l e}=$ Gerigen Saaren ber Rarbe feftgehaltut werbe uno bamt burd

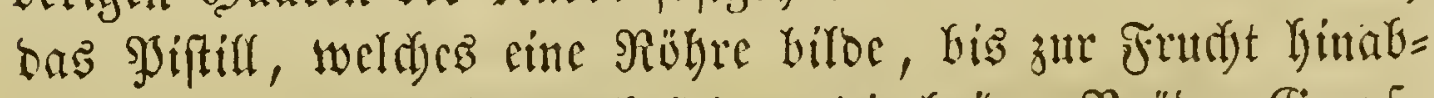

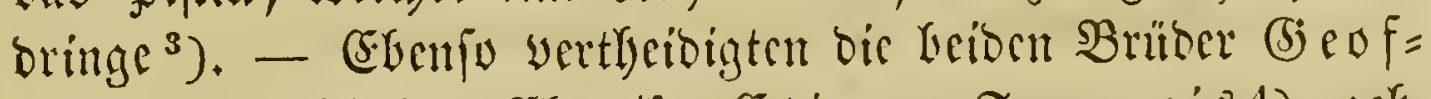

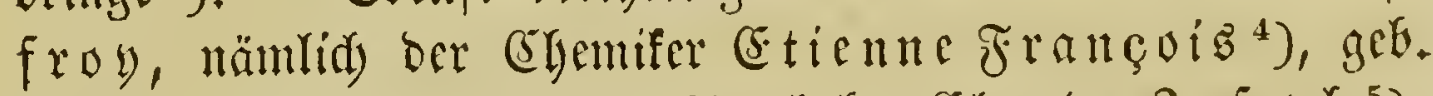
1672, geft. 1731, uno ber apothefer (Elaude gofewl ${ }^{5}$ ),

4. - De ustilagine frumenti, ibid. 1709. 4. - De Lolio temulento, ib. 1710. 4. - Biga botanica sc. Cervaria nigra et Pini coni, ib. 1712. 4. - De Ulmaria, ib. 1717. 4. - De Fumaria, ib. 1718. 4. - De Rubo idaee, ib. 1721.4.

1) Rud. Jac. Camerari Opuscula botanici argumenti collecta, ed. J. Ch. Mikan. Pragae 1797. S.

2) Epistola ad Le ibnizium etc. Wolfenbüttel 1702. 4.

3) Pliilos, transact. V. 2, 3, No. 2S7.

4) Theses crgo hominis primordium vermis. Paris 170\%. 4.

5) Mémoires de l'Académic des scienc. 1711. 


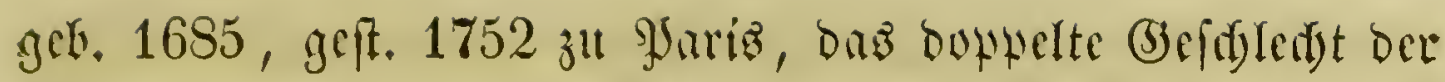
Byflaugen; ber (erfere fterte aud zuerft lluterjudsungen itber die Farben ber Grivädje an.

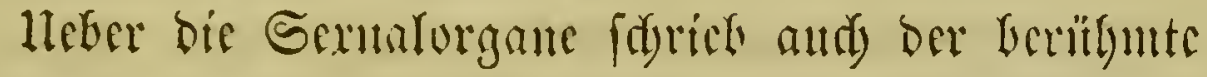

\section{Gebatian Baillant,}

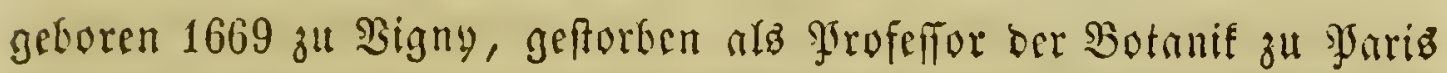
iin Salgr 1722.

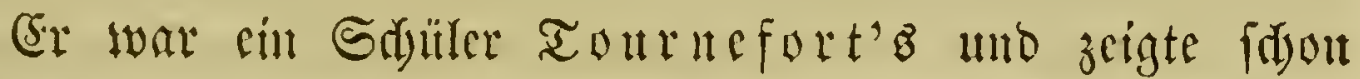

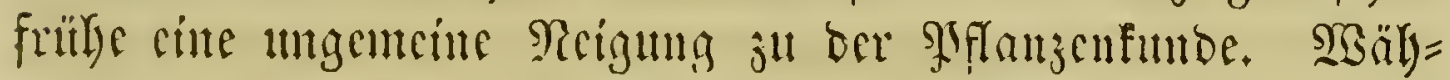
rend femes ganjen Rebens hat er bie Botanif ju fürbern ge= fudt und faft un affe Theile ber Tsiffenfidaft fid werbient

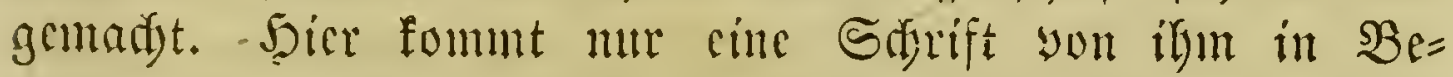

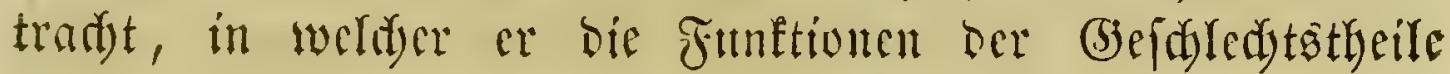

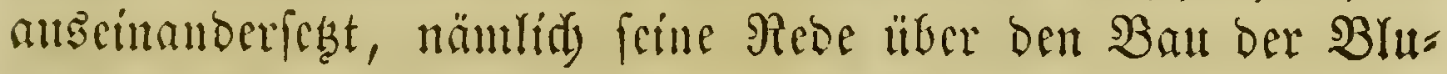

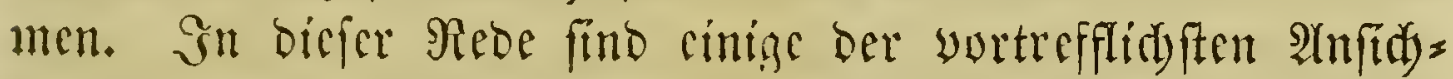

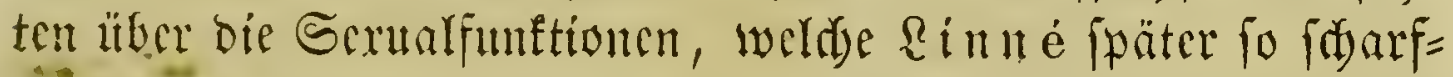

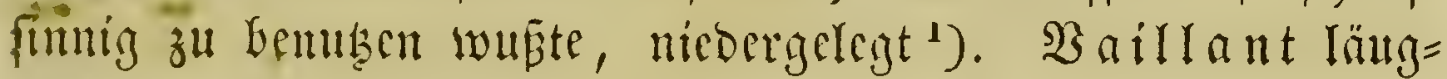
nete Den matericten llebergang bez Jolfens, indem er mur yon cinem befruditenocn Jeaudye wiffen wollte, nalym afer

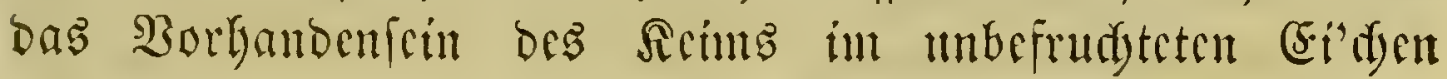

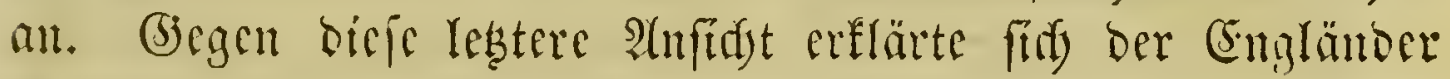

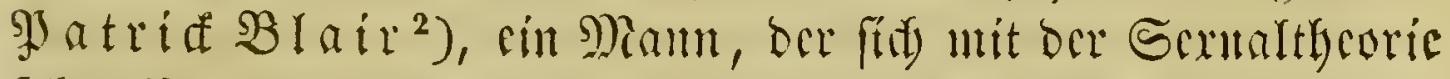

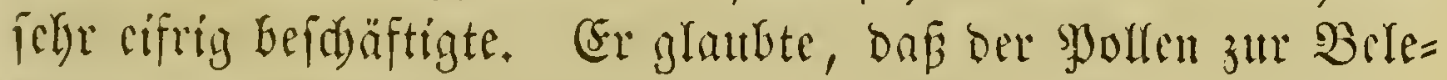

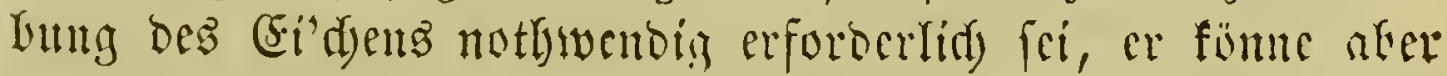

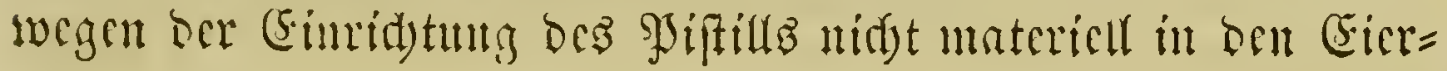

$\left.{ }^{2}\right)$ Sermo de structura florum, horum differentia usuque parlium eos constituentium. Lugd. Batav. 1718. 4. - 1727. 4. - 1728. 4. Sont. und franjö. Jranjöf. in bemfetben Galre.

$\left.{ }^{2}\right)$ Botanical essay's in 2 parts. Lond. 1720. Sergl. aud) Defiert Miscellaneous observations in the practice of physic, anatomy and surgery, with remarks in botany. Lond. 1718. 8. 2 Iaf. 


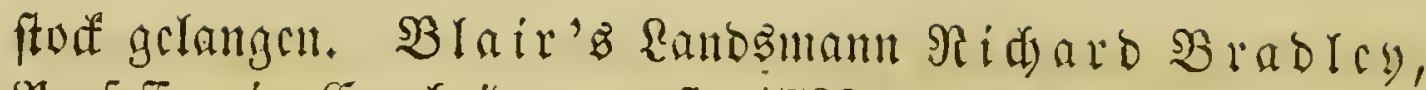
shofeffor in Sambrioge, geft. 1732, Lat cbenfalls über bie

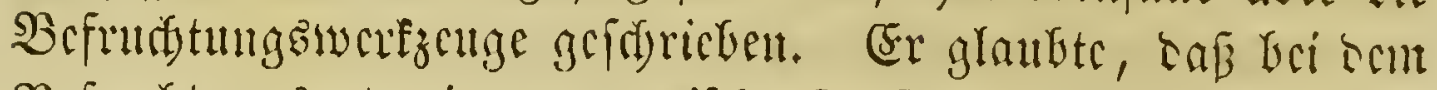
Befrudytungäacte cine magnetifdye Siraft thätig fci, indom bel

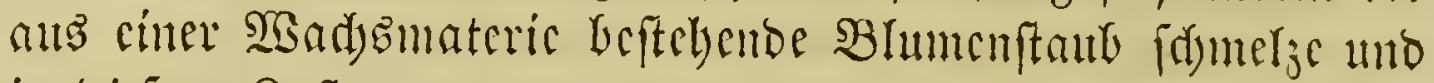
in bicfon 3uftanoc angezogen warbe. ${ }^{1}$ )

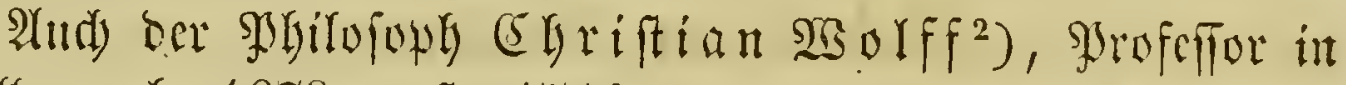
Salle, geb. 1679, gcft. 1754, der nebcubci mandye Cxperi=

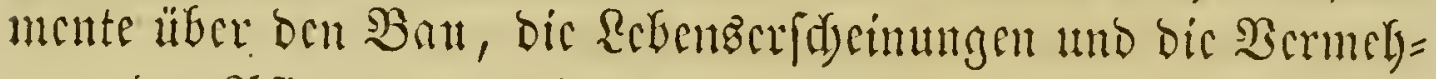
rung bor gyflanzen anfellte, aud ciner ber (Erfiten war, weldye

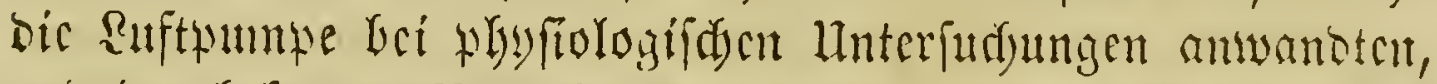
uno Der befannte Raturforfder $\Re$ éné $\mathfrak{A} n t$. De $\Re$ éaumur

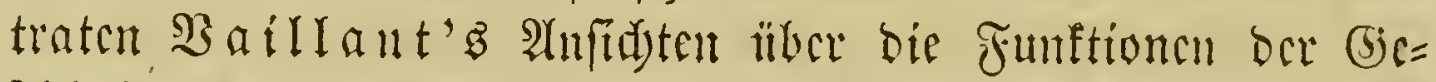

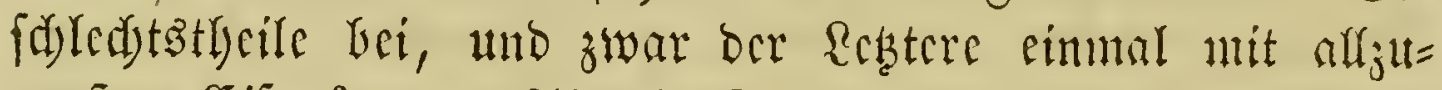
brofacm (sifer ${ }^{3}$ ). —

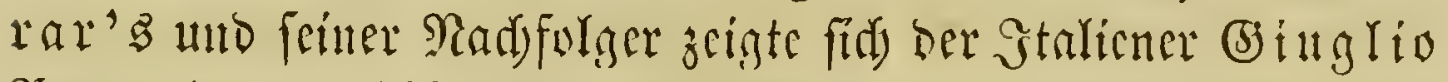

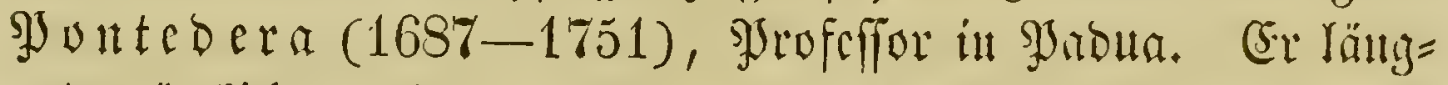

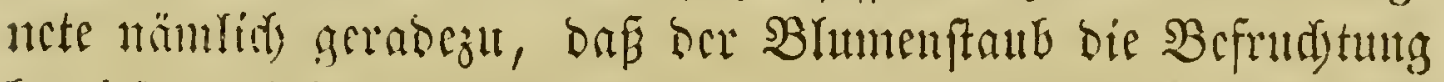

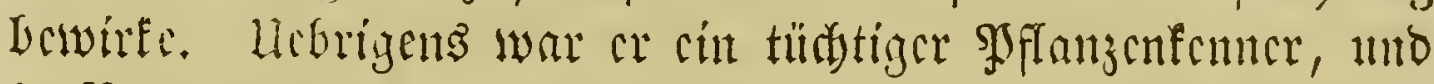

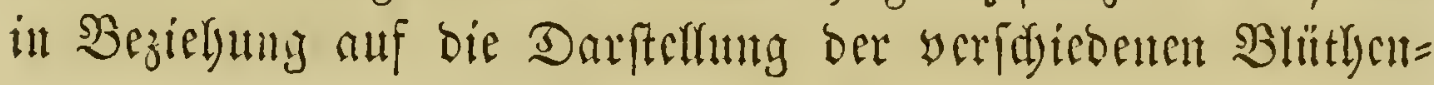

1) A new improvement of planting and gardening both philosophical and practical. Lond. 1717. 8. Sethfte ?fuşgabe in $3 \mathfrak{I} \mathfrak{I} \mathfrak{I n}_{1}$, Lond. 1731, 8. New experiments and observations relating to the generation of plants etc. Lond. 172\%. 8. 2Uแ

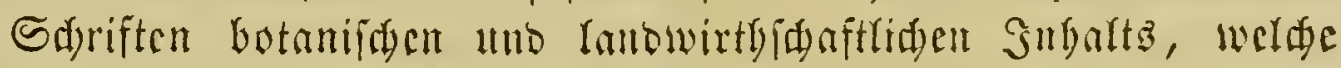

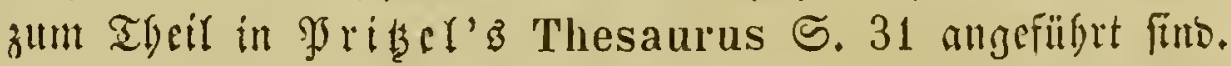

2) Christ. Wolff et Adam Ixstatt, De malo pomifero absque floribus ad rationes physicas revocato. Marbg. 1727. 4. Entrefimg Der wayrell Hrfade von ber wmberbaren פermegrung dos Bjetreides. Salle 1718, 4.; 1725, 1750, 4. -

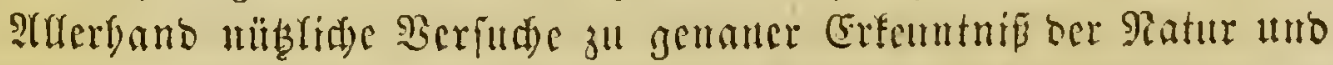

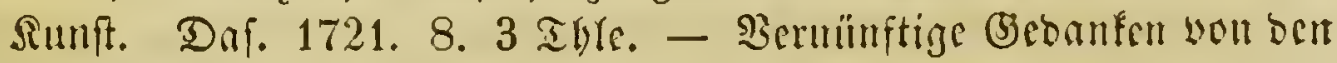

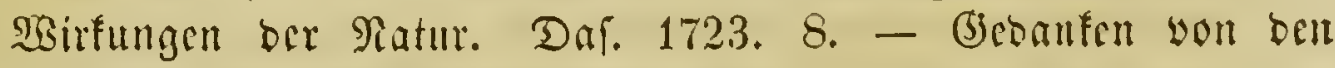

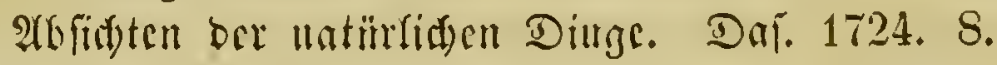

3) Mémoires de l'Académ. des scienc. 1711. 


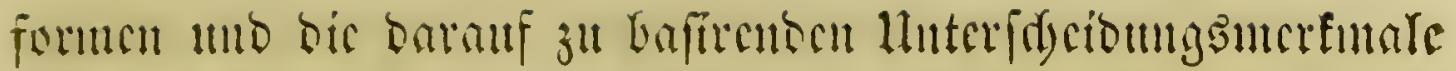

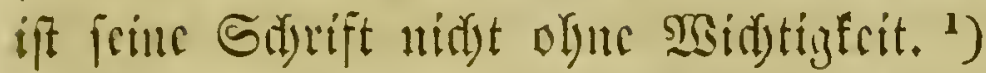

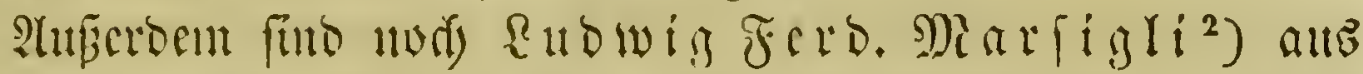

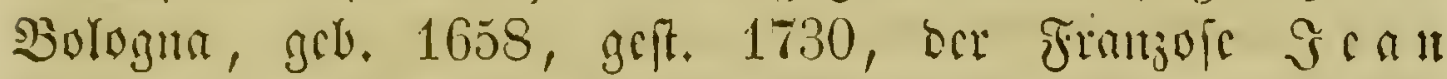

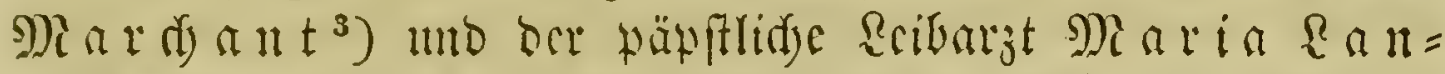
cif $\left.i^{*}\right)$, geb. 165-1, geft. 1720, wegen iffer Bemerfungen

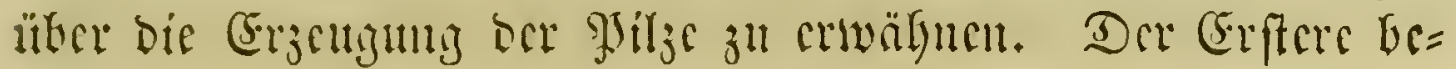

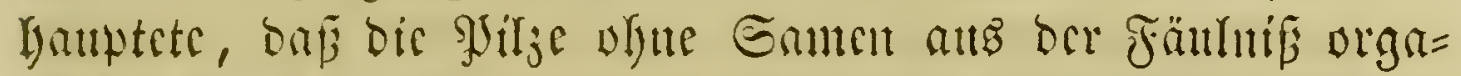
miid)er Stoffe cutfiänocit, and bcobad)tete or in Mebercinftint=

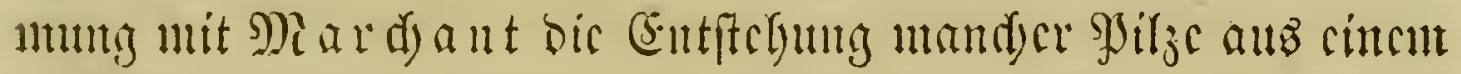
floctigen, swmerlälutidyen (s) swebe.

Sincr ber bebcutendfen gsflanjenthyfulogen aber war ber englifdre (jociftidye

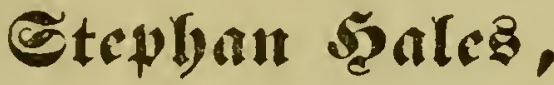

geboren 1677, gefturben 1761,

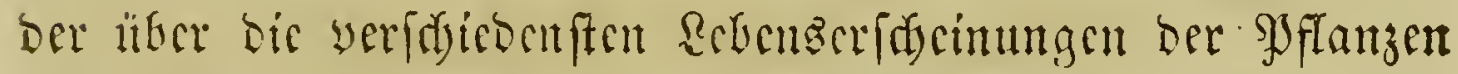

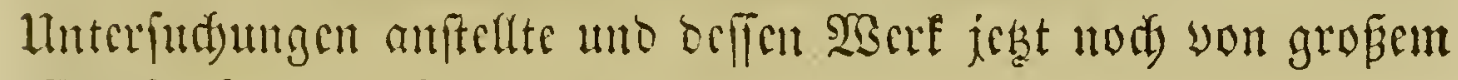
Serthe für ben Botunifer ift.

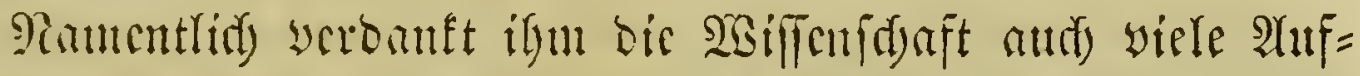

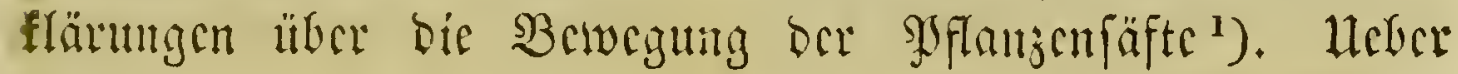

1) Anthologia, s. de floris natura libri III. Accedunt dissertationes XI ex iis, quas habuit in horto publ. Patar. anno 1719. Patav. 1720, 4., mit 12 Supfertafelu.

$\left.{ }^{2}\right)$ De generatione fungorum epistola ad Lancisium. Rom. 171/. Fol. 31 Iaf.

3) S. Mardant' \& Edriften eridienen in ben Sngren 1692-1735 in Den llémoires de l'Acad.

$\left.{ }^{4}\right)$ Dissertatio epistolaris de ortu, vegetatione et textura fungorum ad comitem L. F. Marsilium. Rom. 1714. Fol.

$\left.{ }^{5}\right)$ Vegetable statics or an account of some experience on the sap of vegetables etc. Lond. 1727. 8. 19 Taf.; 1731

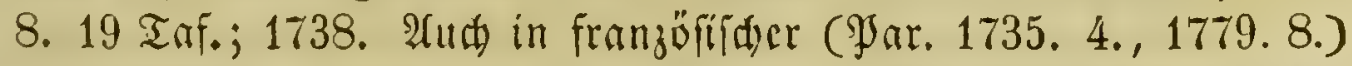
und beutfder (5̧afle 1748, 4. 11 Iaf.) Heber fęung vorbanden. 
biefe Rebre madyten audi die fdon angefüfrten Engländer Bradrey uno Blair, fowie der franzöfide Jefut De Ia $\mathfrak{B} a \mathrm{i} f \mathrm{fe}^{1}$ ) (cigentlid) $\mathfrak{S}$. Sarrabat) Mittbcilungen.

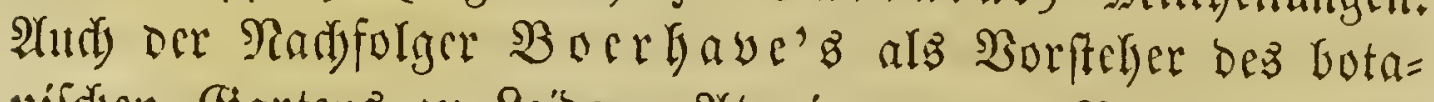

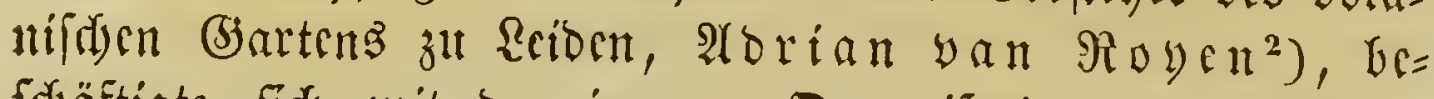

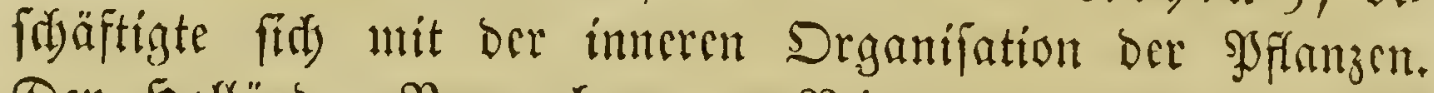

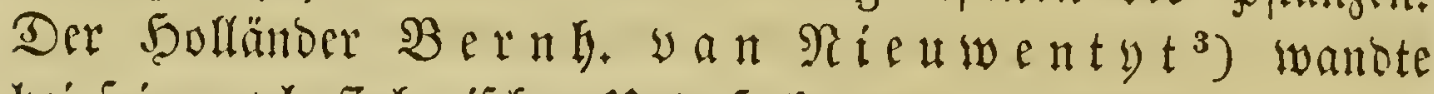

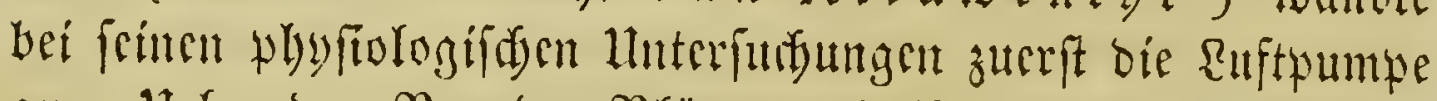
an. Ueber ben Ball ber B̧ätter uno igre Funtionen bei ber

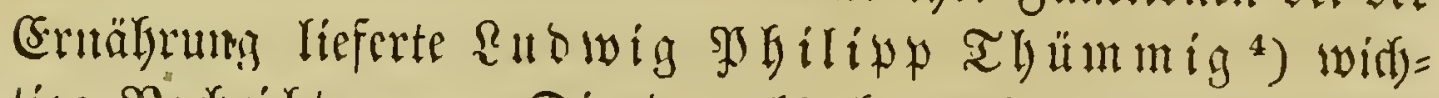
tige Radridsten. - Die Damals beziwerten Refultate ber SJflanzenantatomic uno Why fiologic wurben won Dem Reipziger

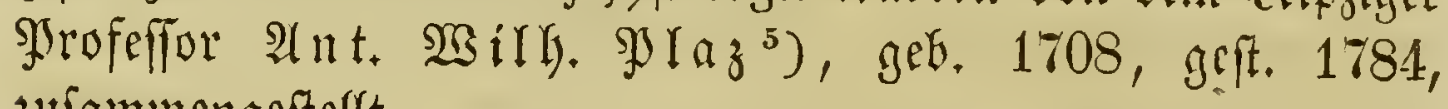
zulammengrfteft.

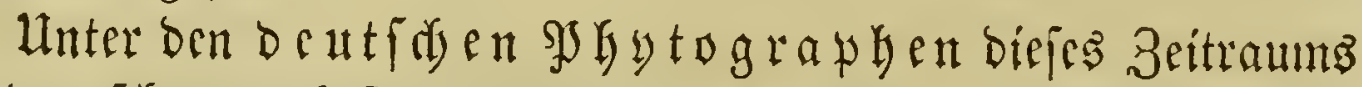
ift der fodon merrfad erwäbnte

\section{Soldant Safob Dillenius}

aนธ Dormftadt ber berübmtefte. Er wutrbe 1687 geboren.

Srfon frïgseitig legte er fid) mit befonocrer Borliebe auf bas Stubium ber Botanil und Gradste es Darín balo jo weit,

1) Dissertation sur la circulation de la sève des plantes etc. Bordeaux 1733. 12. Eine von ber sifabemie zu Borbeal gi: frönte STreişidrift.

$\Rightarrow$ De anatome et oeconomia plantar. Lugd. Batav. 1728. \%.

3) Regt gebruyk de weereld beschouwingen. Amsterd. 1716

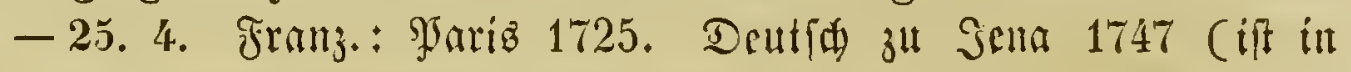
9ridel's Thesaurus nidit enthalten).

4) De arboribus ex folio educatis. Halae 1721. 4. Deutifid:

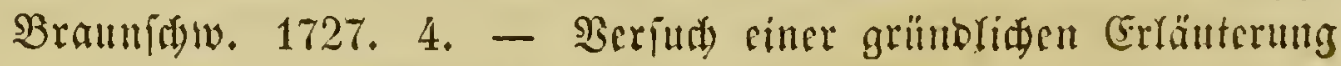
ber merfuüroigften $\mathfrak{S e g e b e n f e i t e n ~ i n ~ b e r ~ \Re a t u r . ~ S a l f e ~ 1 7 2 3 . ~} 8$. Marburg 1735. 8.

${ }^{5)}$ Organicarum in plantis partium historia. Lips. 1751. "4.

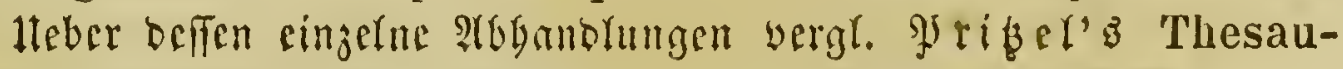
rus S. 230. 


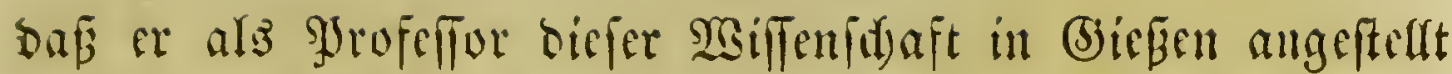

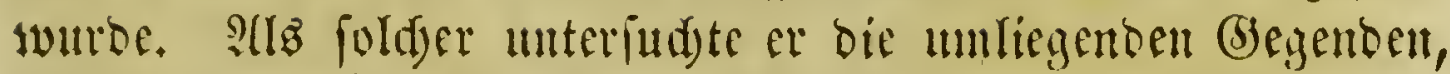

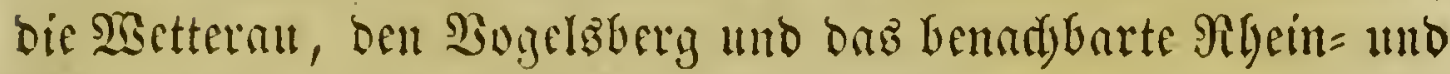

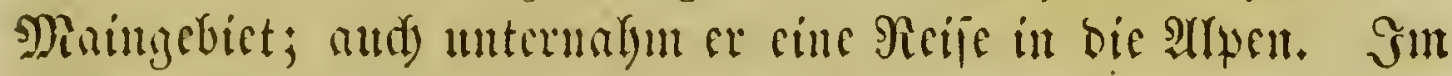

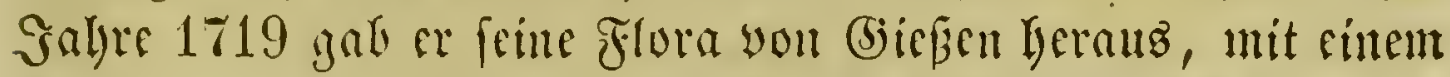
Alnfanje, in ocm er unter Anderm aud) eine Bejdreibung ber Iुflanjeriynttungen lieferte. ${ }^{1}$ )

Bou (jiefenen wurde er 1721 von $\mathfrak{X}$. Sherard, ber mit grofem Softruafwanto visle Botanifer unterftübte (weiter unten wirb yon ifm nod bie Nebe fein), nadi England mit= genommen und blicb bei feinem Befdultser bis zum Gabre 172S. In Dicjem Jabre aber erbielt er einen Relyrftubl ber Botanif ju Srford, ben Sherard cigends für ijn erridjtet

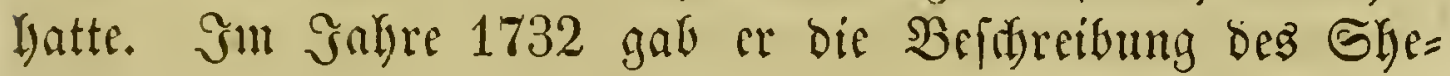

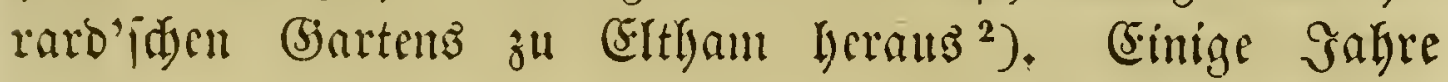

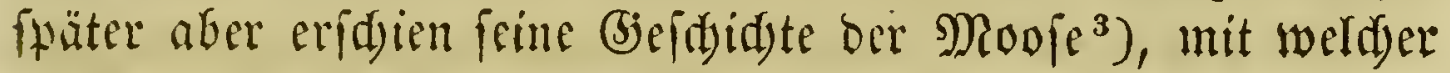
er fid Jwanjig Gabre lang befdäftigt hatte. Diefes Werf, Das̉ ungefähr 1000 strten mit arbbilouitgen entbält, begrün=

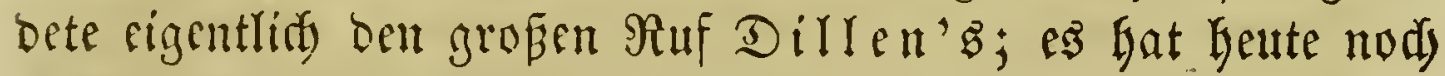
nidfts you feinem $\mathfrak{B}$ erthe verloren.

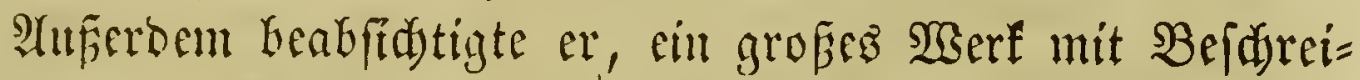
bungen und Abbiroungen Der befaunten SFlanjen zu bearbei= ten, ber Tod aber verhinderte ifn baran (1747).

1) Joa. Jac. Dillenius, Catalogus plantarum sponte circa Gissam nascentium, cum appendice, qua plantae post editum catalogum circa et extra Gissam observatae recensentur et specierum novarum vel dubiarum descriptiones traduntur, genera plantarum nova figuris aeneis illustrata describuntur: pro supplendis institutionibus rei lherbariae J. P. Tournefort. Francof: 1718, et novo titulo 1719. 8. c. tab, aen. XVI.

$\left.{ }^{2}\right)$ Hortus Elthamensis Jac. Sherar d, fratris Guilelmi. Lond. 1732, II voll. Fol. Mit 324 Supfertafirn.

3) Ilistoria muscorum. Oxon. 1741. 4. Mit 85 raf. Englifa 子แ Sonbon 1763. 4. 
Gine weniy befomte Flora yon ganj Deutidland wurbe in biefem 3eitramme won Mida el Bernharo $\mathfrak{B a l e n =}$ tini ${ }^{1}$ hernubgegeben. Der Nürnberger $\mathfrak{K a n f m a n n}$ Solyann

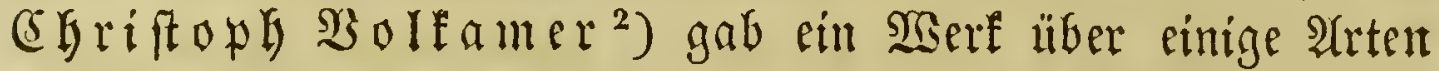
exotifder SPflanzen am Anfange biejer Seriobe heraus, welde er zum Theil in feinem (5)arten gejogen hatte.

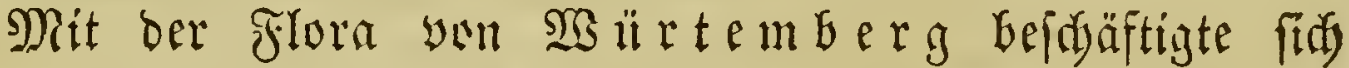
(3) eorgDuyernoy, Srofeflor in Tübingen, in feinem ziem=

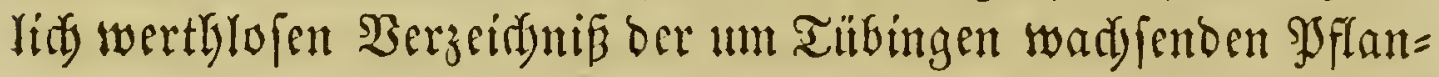
zen ${ }^{3}$ ) und $\Im$. Dietrids Reopold in feinem Berzeidnifs

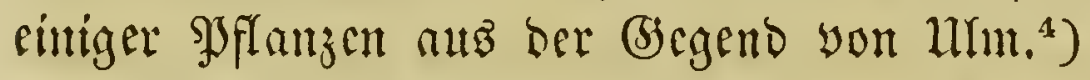

(5)riftian 5̧einria) Ernotel, geft. 1734, Reibarzt bes

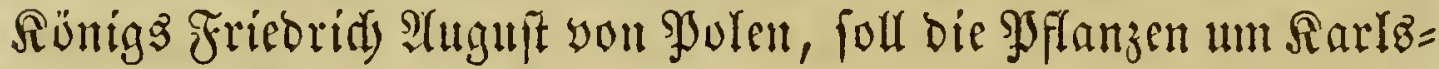
bab und Seiblis und einiger anderer Bäber verzeifinet haben. ${ }^{5}$ )

1) Mich. Bernh. Valentini, Viridarium reformatum seu regnum vegetabile Germaniae. Francof. ad. II. 1719. Foi. II tom. c. 384 Fig. (Er idrieb now einige andere $\mathfrak{3 e r f e}:$ Museum museorum. Francf. 1704-14, 3 voll. Fol. Prodromus historiae naturalis Ilassiae. Gissae 1707. 4. Bergl. Wrizel S. 305, 306.

2) Mürnbergifac SacBperiben ober Bejdreibung Der eblen Sitronat=,

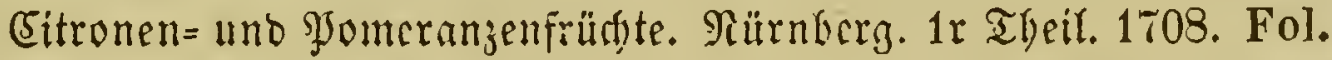
mit 115 Rpfrtfln. 2r Ifeil 1714 mit 126 Ifln. 3merfen Theile befindet fí S. $209-243$ : Rürnbergifale frora; im zweitcr

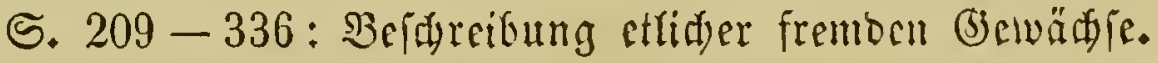

3) Joa. Georg Duvernoy, Designatio plantarum circa Tubingensem arcem florentium. Tubing. 1222. 8.

4) Joh. Dietr. Leopold, Deliciae sylvestres florae Ulmen-

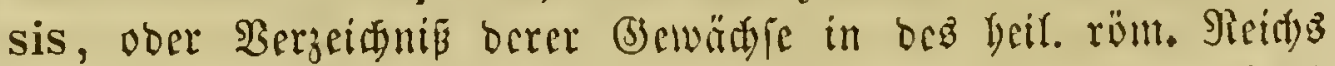

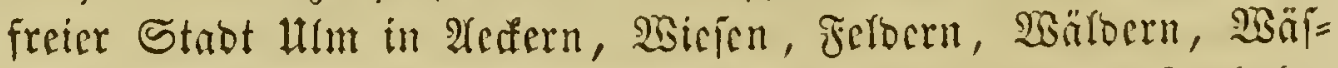

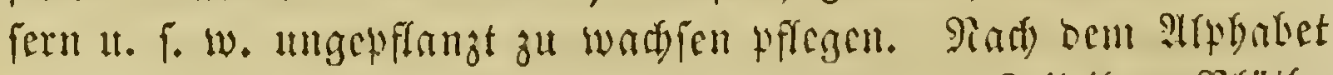

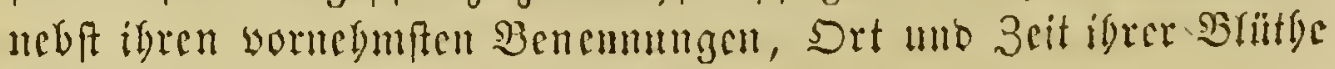
z̆tfanmengetragen. Htm 1728. 8.

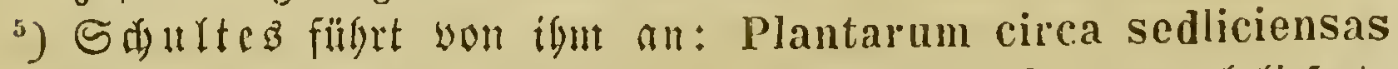
thermas elenchus. Norimb. 1723. গard Sprengel lieferte

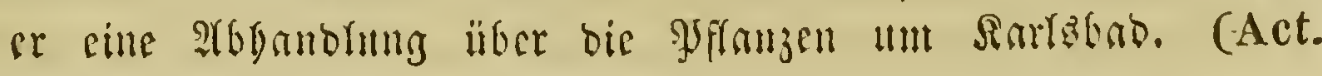
nat. cur. 3 app. p. 135 , seq.) 


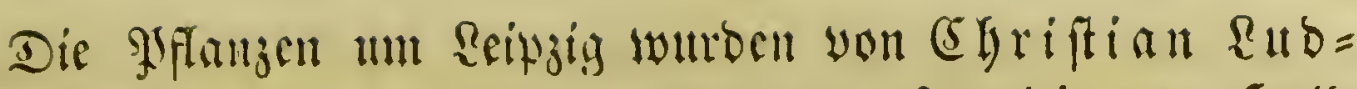

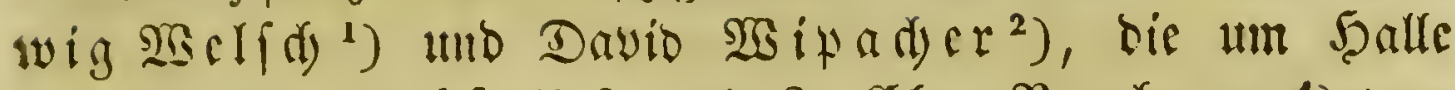

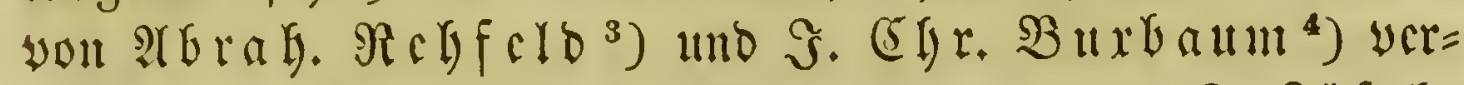

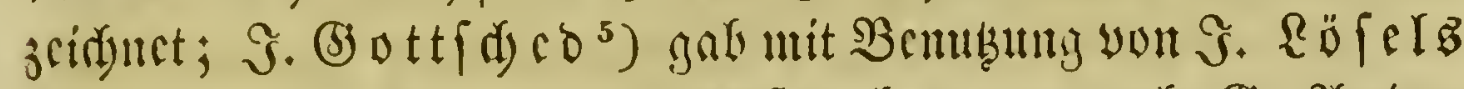

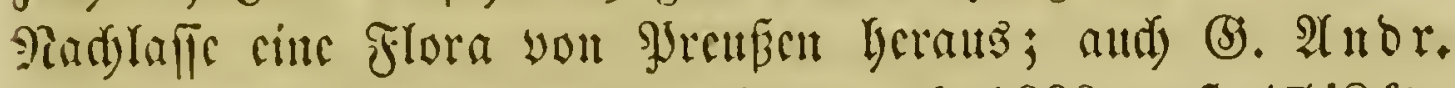
Scclrwing, SHediger ju Angerburg, geb. 1666, geft. 1748 ${ }^{6}$ ), zählte cinige in becicm Ranbe wadjpende Spfanzen allf.

Dic Florit won Franffut an ber Doer, welde yon bent burtigen \$rofeffor Martin Daniel (nai) Şalfer Sumad) Gohecuills, geft. 1718, werfafit wurbe, ift beshalb be= merfenstwerth, weil fidy in igr bic erfite Spur-ciner analyti=

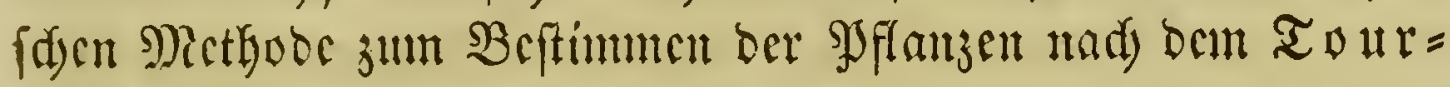
ucfort'fden Syfteme befindrt." )

Eine bejondere Grwähnuth verbicut ber arme Stubent

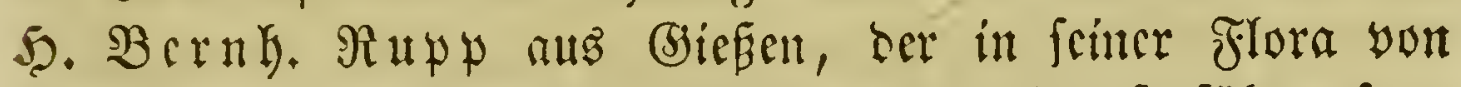

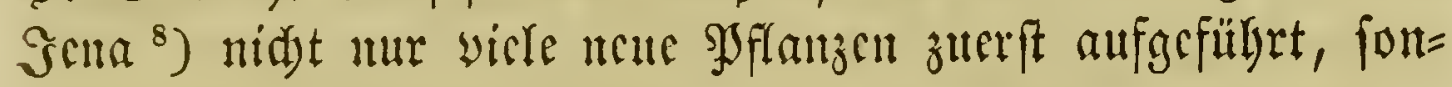

2) Ch. Ludw. Welsch, Basis botanica s, brevis ad rem herbariam manuductio, cum onomastico plantarum in climate Lipsiensi crescentium. Lips. 1697. 12.

$\left.{ }^{2}\right)$ D a v. W i p a che r, Flora Lipsiensis bipartita. Lips. 1726.8.

$\left.{ }^{3}\right)$ Abrah. Rehfeldt, Hodeg. botanicus menstruus, praemissis rudimentis botanicis, plantas quae potissimum circa Halam vel sponte proveniunt vel studiose nutriuntur enum. Halae 1717. 8.

-) Joa. Christ. Buxbaum, Enumeratio plantarum accuratior in agro Ilalensi locisque vicinis crescentium. Cum praefat. Fr. Hoflmann de methodo compendiosa plantar. vires et virtut. in medendo indagandi. Hal. 1721. 8.2 Iffli.

s) J. Goottsched, Flora Prussica. Regiomont. 1703.4. $85 \mathfrak{T}$ flıt.

5) G. A. Hellwing, Flora quasimodo genita sive Enumeratio plantarum aliquot Prussiae. Gedani 1712. 4. 3 IFfn. Supplementum flor. Pruss. ib. 1726. 4. 3 T fftr.

") Vademecum botanicam etc. Colh. 1710. 8.

3) Henr. Bern. Ruppius, Flora Jenensis, sive enumeratio plantarum tam sponte circa Jenam, et in locis viciuis 
bern aiti) melyrere nete (b)attungen feftgeftellt hat. (Er farb

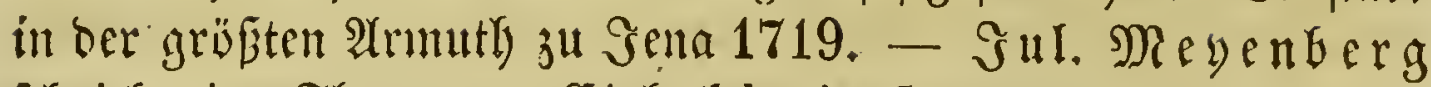
fdrieb eine Flora von (sinberf ${ }^{1}$ ) in Scannover.

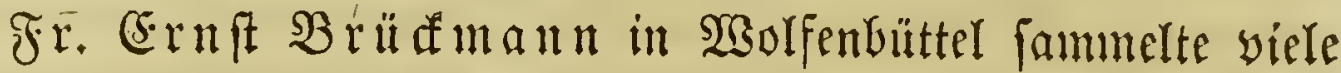

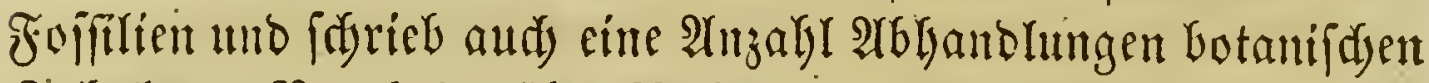

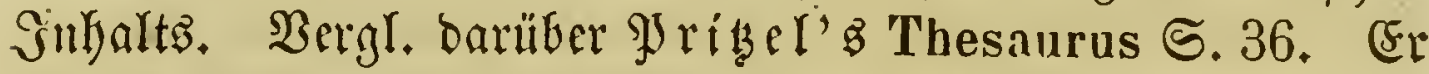
fdecint zuerif wieber bie von ar nor. Spiegel erfundene

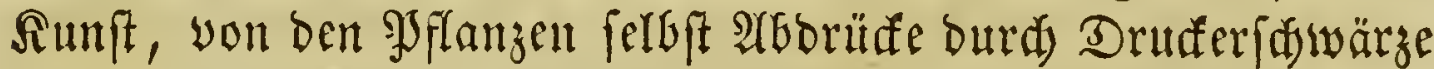
zu verfertigen; in Ânregung gebrargt zu haben. ${ }^{2}$ ) Solde

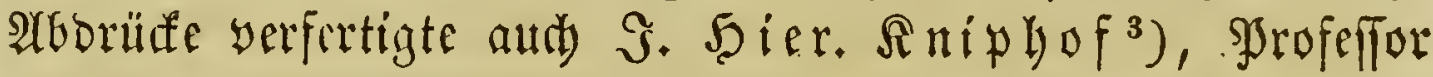
zut Erfurt, gef. 1704, geft. 1762.

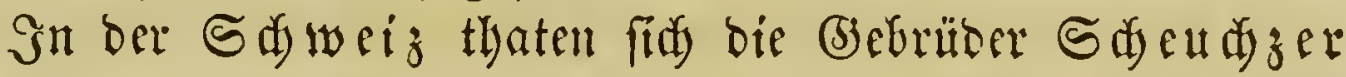
herbor. Gohann Gacob S dyeudjer, geb. 1672, geft. 1733, Shrofeffor in 3üridy, madyte melyrere Reifen in bie

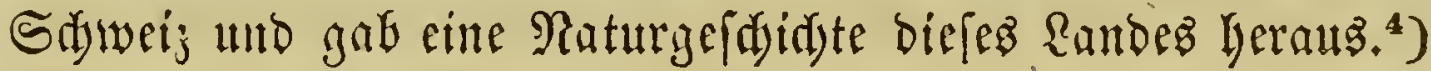

nascent. quam in hortis obviarum methodo conveniente in classes distributa figurisque rariorum aeneis ornata in usum botanophilorum Jenensium edita a J. H. Schulteo. Francof. et Lips. 1718. 8. c. tab. aen. III. - ibid. 1726. ibid, $17 / 5$ c. tab. aen. VI; ed. a A. Hallero.

1) Henric. Meyenberg, Flora Eimbeccensis. Göttingen 1712. 8.

2) Senbidreiben an Serrn S. Sier. Rnipgof, bie bequeme uno

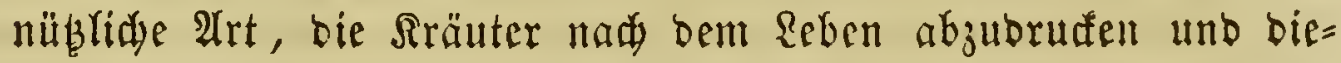

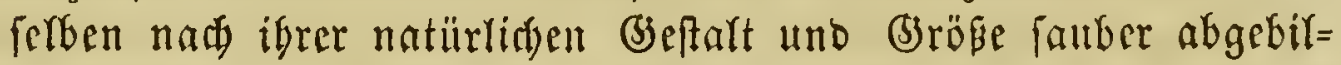
bet barzulegen, unb alfo febr compendiöfe Herbaria pieta zut แad)en. W3olfenbüttel 1733. 4.

s) J. II ier. Kniph of, Botanica in originali, s. herbarium

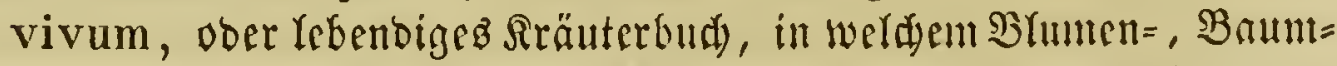

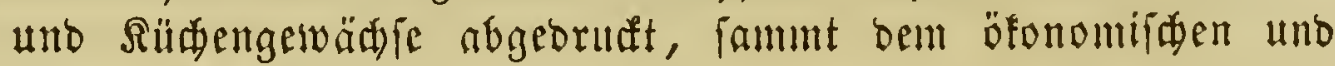

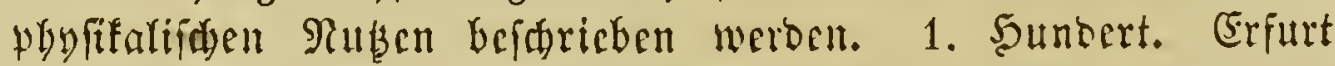
1733. Fol. Studio G. F. Trampe. Hal. 1757-64. Index 1767. Rebentig Dfficinal= §räuterbud. Erffurt $1733-34.4$ BDbe. Fol. 1. 11. 2. 5aumbert. Heber feine übrigen Edjriftent vergl. פr

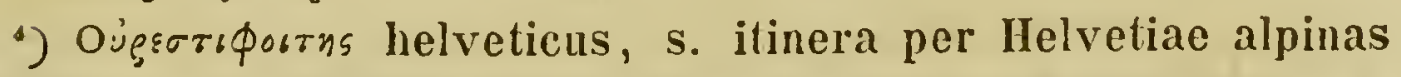
regiones facta annis $1702-11$. Lugd. Batav, 1723. 4. 


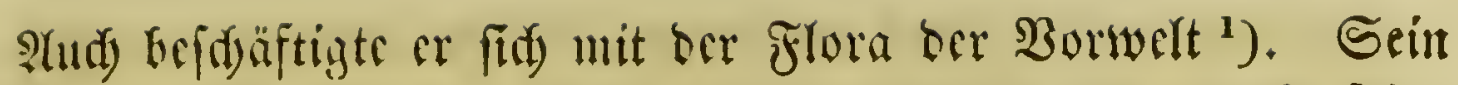
Bruber Gokanı (16S4 - 1737) madjte firi) butd) feinte

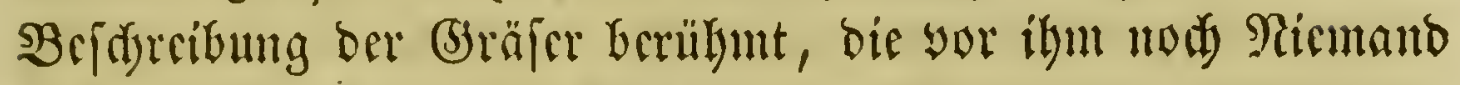
fo yorzüglidi bearbeitet hatte. ${ }^{2}$ )

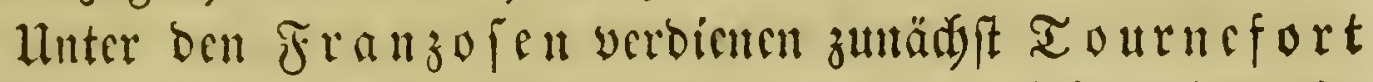
unb Bairrant als Sghytographen unfere Aufmerfamfeit. Bribe forrieben eine frlora ber ltmgegeno von SyariB. Die

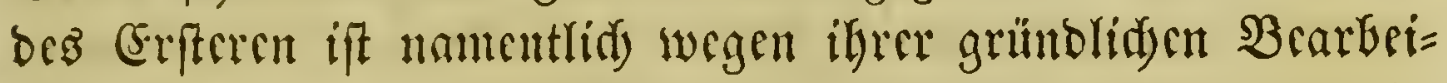

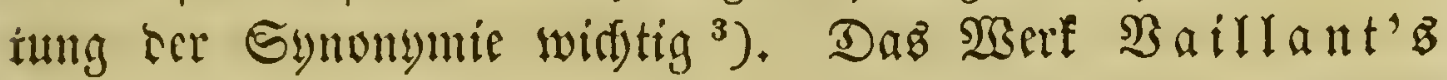
if aber wohl nodj yorzüglidyer. Sn bemfelben fund aud bie

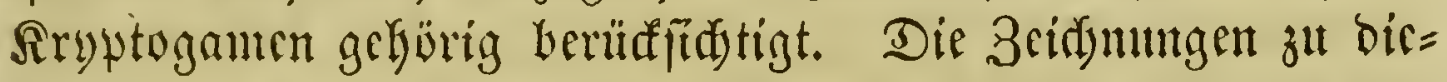
fer $\mathfrak{A}$ rbeit lieferte ber Maler $\mathfrak{A}$ ubriet. Dả 2 serf wutroe erfit nad) ors Berfalferz Tode you $\mathfrak{B}$ oerlyave heraub= gegeben. ${ }^{4}$ )

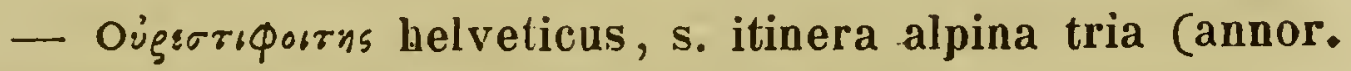
$1702-4)$ etc. Lond. 1708. 4.

1) Herbarium diluvianum. Tiguri 1709. Fol. - Herbarium diluvianum. Lugd. Bat. 1723. Fol. mit ßupfertafeln. - Phy= sica sacra iconibus illustrata, in qua de variis Scripturae sacrae plantis, procurante Andr. Pfeffel. August. Vindel. 1732 - 35. 5 voll. Fol, mit 650 Tafeln.

2) Agrostographiae helveticae prodromus. Tiguri 1708. Fol. 8 Iafefı. - Operis agrostographici idea, seu Graminum, Juncorum, Cyperorum, Cyperoidum iisque adfinium method. Tigur. 1719. 8. - Agrostographia s. Graminum, Juncorum, Cyperorum, Cyperoidum atque adfinium histo-

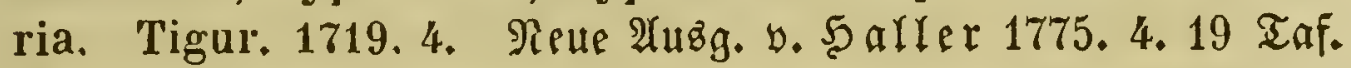

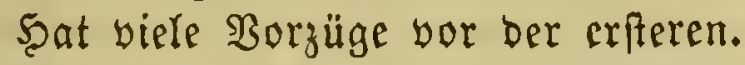

$\left.{ }^{3}\right)$ Histoire des plantes qui naissent aux environs de Paris, avec leur usage dans la médicine. Paris 1698. 12. History of plants growing about Paris. London: 1736. II Tom. 8. - Eine zmeite $\mathfrak{A}$ (uzgabe bejorgte $\mathfrak{B}$ erngarb yon Sulfieu, গ⿴aris 1725, in 2 Bänder. 12. -

4) Botanicon Parisiense. Operis majoris prodituri prodromus. Lugd. B. 1723. 8. - Lugd. B. et Paris 1743. 8. - Botanicon Parisiense, ou Dénombrement par ordre alphabétique des plantes, qui se trouvent aux environs de 
Baillant werfapite aud eine fritifide Bearbeitung ber Synantheren uno Dipfaceen, ullo ez fint yon ihum nidyt wenige SPflinzengattungen zurrit feftgeftellt worben. Seime Gierauf bejüliliden Sdyriften fino in ben Memoiren ber franjöfifden Ufarmic ber Saifenjaften yom Gahr 1718 bis 1722 ent= Galten.

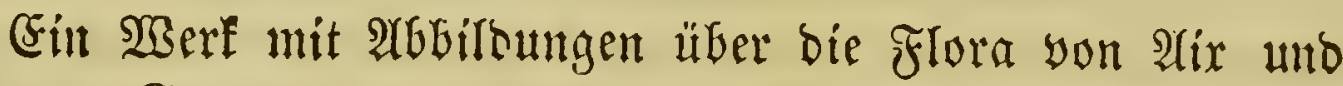
anderen Gegenden ber Jrovence werfapte Gofepl (Sari=

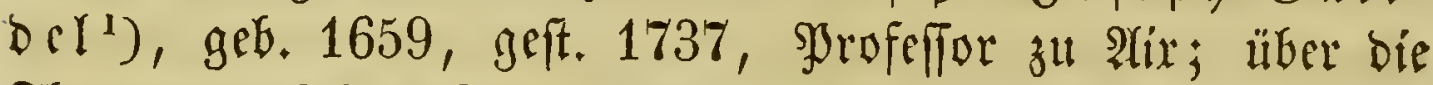
Flura yon Dijun fdrieb Soldilib. (5orret ${ }^{2}$ ), luber bie ber Aluvergne Sierre Gean (5homel ${ }^{3}$ ). Die Arbeiten yon $\mathfrak{M a r l}$. Ma biefem Zeitraum won $\mathfrak{F} \mathfrak{r} \mathfrak{n}$ c. $\mathfrak{B} \mathfrak{a} \mathfrak{l}$ th. Sindern veryolfftän= bigt ${ }^{4}$ ). Dann aber barf hier aud a lutoiut be Guffieu,

Paris etc. Enrichi de plus de trois cents figures, dessinées par le Sieur Claude Aubriet, peintre du cabinet du Roy. Leide et Amsterd. 1727. Fol. 33 Iaffefn.

') Jos. Garidel, Histoire des plantes qui naissent aux environs d'Aix et dans plusieurs autres endroits de la Provence. Aix 1715. Fol. avec $100 \mathrm{pl}$. - Paris 1719. Fol. Par. 1723. Fol.

$\left.{ }^{2}\right)$ Phil. Collet, Catalogue des plantes qui croissent autour de la ville de Dijon. Dijon 1702. 12. - Lettres sur la botanique. Par. 1697. 12.

$\left.{ }^{3}\right)$ Pierre Jean Chomel, Histoire des plantes d'Auvergne.

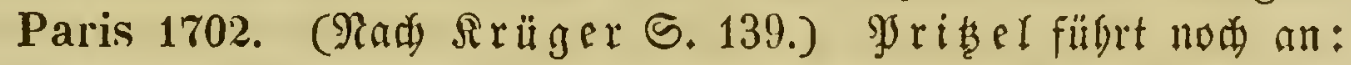
Reponse à de lettres écrites par Mr. Collet sur la botanique. Paris. 1697. gr. 8. - Catalog. plantar. officinal. secund. earum facultates dispositus. Paris. 1730. 8. Abrégé de l'hist. des plant. usuelles. Par. 1712. 8. uno $\ddot{p} f t e r$.

*) Tournefortius Alsaticus, cis et trans Rhenanus, sive opusculum botanicum, ope cujus plantarum species genera et different. circa Argentorat. tiro dignoscere possit. Argentor. 1728 c. tab. aen. 5. 8. - Hortus Alsaticus. Argent. 1747. 8. 12 Iaf. 


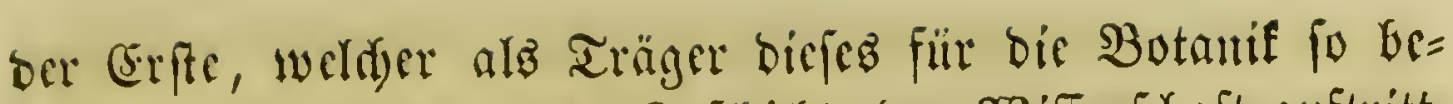

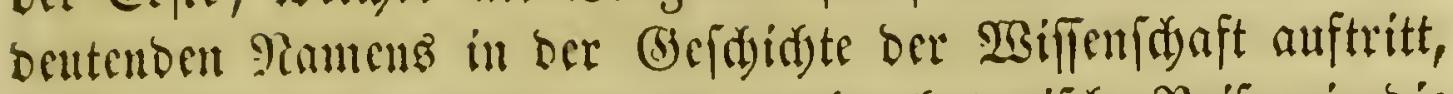

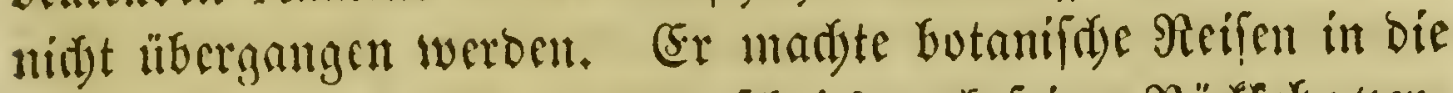

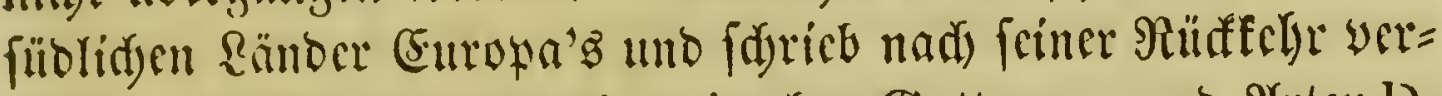

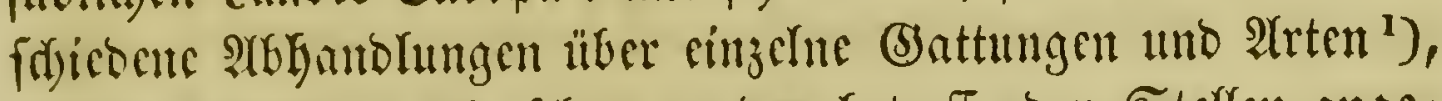
madyte fidi) autif, wie foon an ben betreffenden Stellen ange=

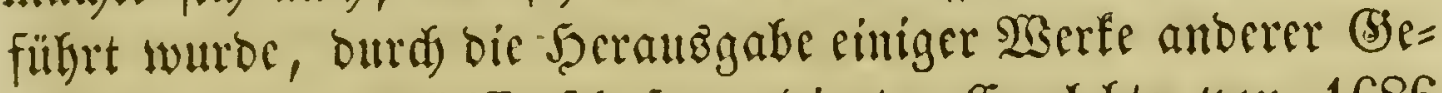

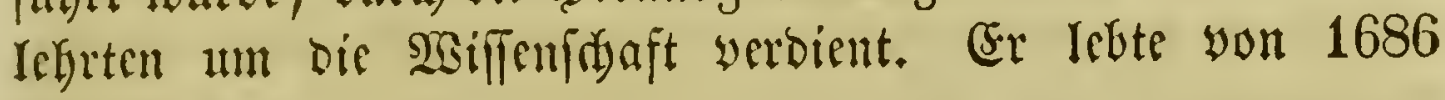
bi⿱ 1758.

Jn (S) robritannien jeidjnetefidy auperDillen, beflen

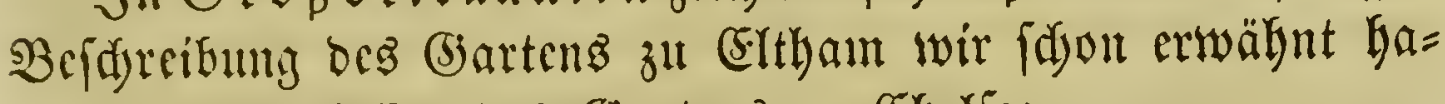
ben, Der Borféter des Gartenż zu Ehelfea,

\section{Philipg Miller, \\ geboren 1691, geftorben 1771,}

wortheilfaft auz. Namentlid burd) fein (särtnerlexifou, baz fowobl wegen bes Textes alz ber A(bGildungen bauernoen

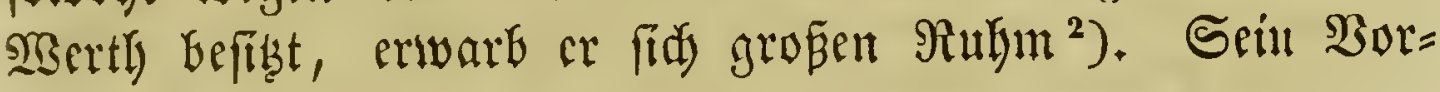

1) Mémoires de l'Académie des sciences. Sał̧rg. 1711 u. 1712. - Discours sur le progrès de la botanique au jardin royal de Paris. Par. 1718. 4. - Dissertatio de analogia inter plantas et animalia. Lond. 1721. 4. - Traité des verdus des plantes, ourrage posth. de Ant. de Jussieu par Ga ndoger de Foigny. Nancy 1771. 8. Par. 1772. 8. - Eloge de Mr. Fagon, avec l'histoire du jardin royal de Paris et un introduction à la botanique. Paris 1718. 4.

$\left.{ }^{2}\right)$ The Gardeners and Florists dictionary. Lond. 1724, II voll. 8. - The gardeners dictionary etc. Lond. 1731. Fol.

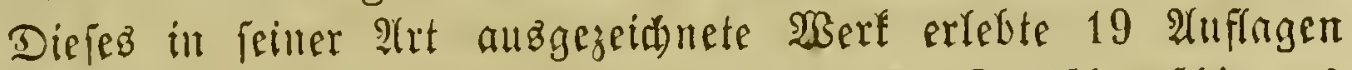

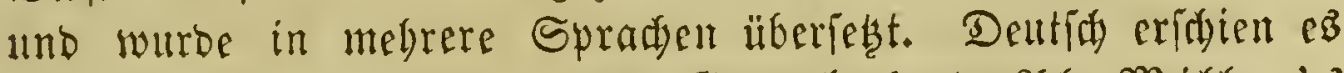

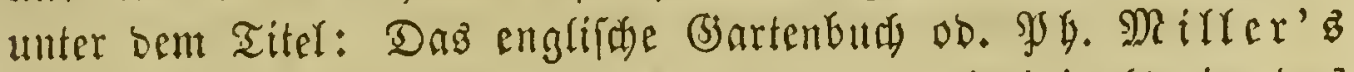

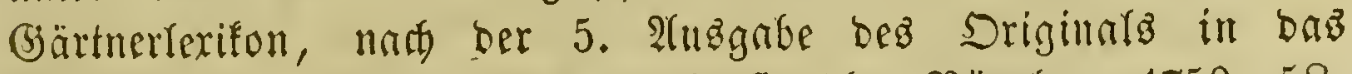

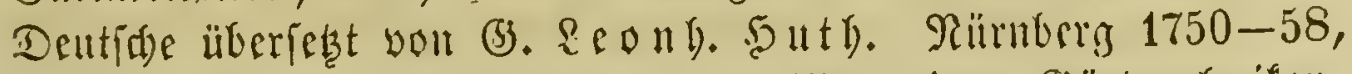

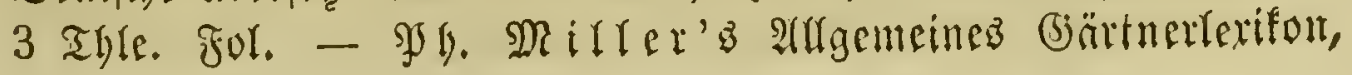


gänger in ber Alufint liber ben Giarten zu Shelfea, Jofeph

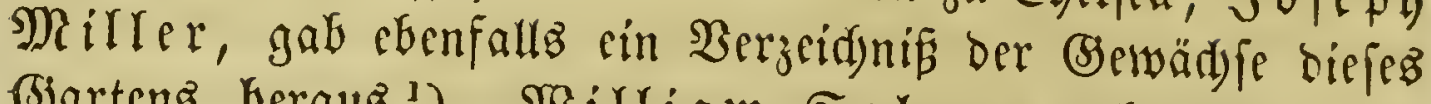
(J)artens heraus ${ }^{1}$ ). SGilliam Salmon gab cine Flora

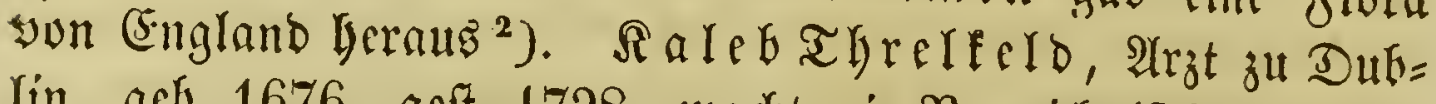

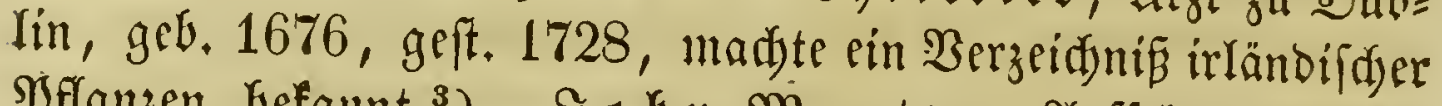

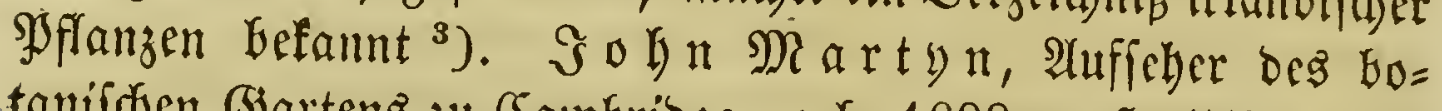
tanifden (5)artens zu (Sambribge, geb. 1699, geft. 1768, ver=

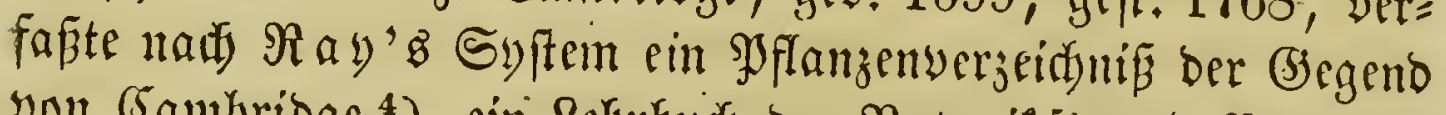

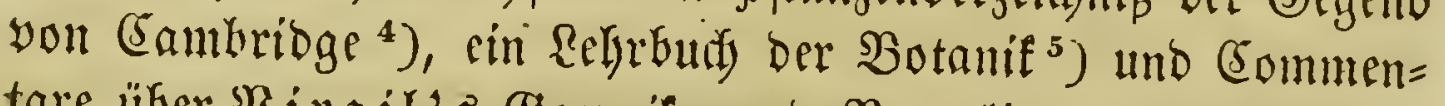
tare lïber siagil'b Beorgifa uno Buccolica; aud liberfegte

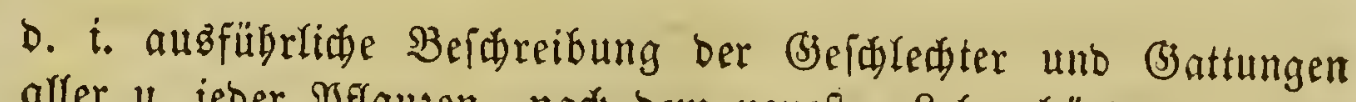

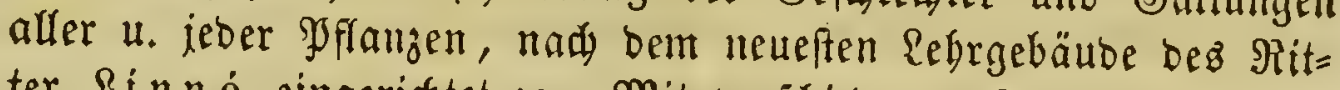
ter Li nné eingeridtet 2c. Mit yeridiebenen Supfern nad ber 8. 2Atıgabe aus Dem Englif由en überiest. Riirnberg 1769-76,

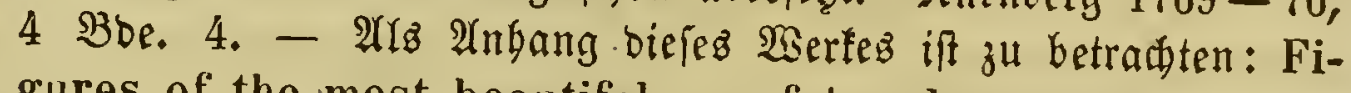
gures of the most beautiful, useful and uncommon plants described in the Gardeners dictionary; to which are added their descriptions. Lond. 1760, II voll. Fol., mit 300

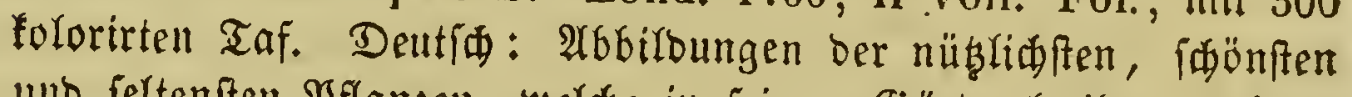

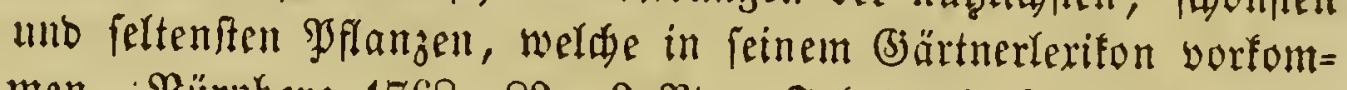

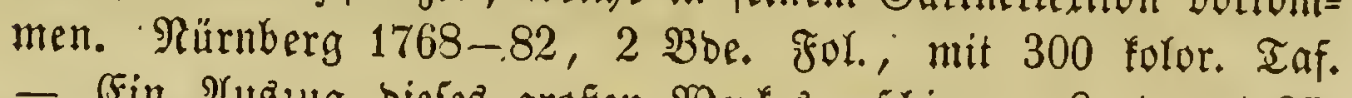

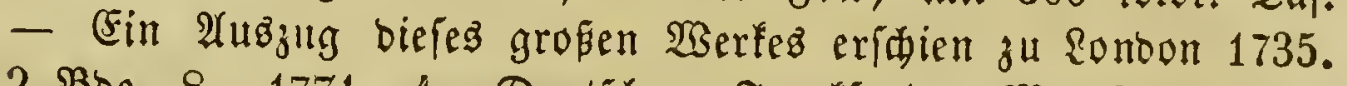
2 Bbe. 8. 1771, 4. Deutif fu Franffurt a. M. 1802-3,2

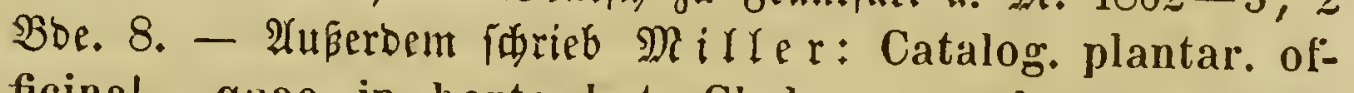
ficinal., quae in horto bot. Chelseyano aluntur. Lond. 1730. 8. - The Gardeners Kalendar; with a short introduction to the science of botany. 15. भIแzg. Ronb. 1769. 8 .

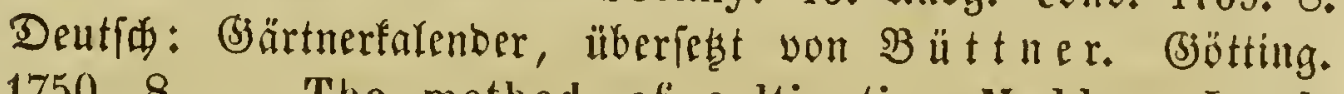
1750. 8. - The method of cultivating Madder. Lond.

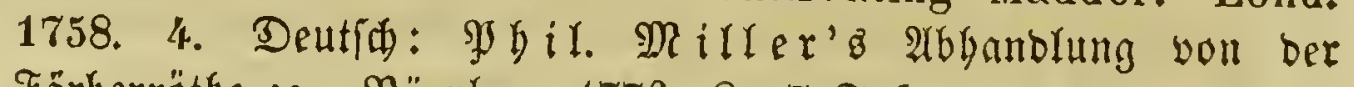
Färberrötbe zc. Rürnberg 1776. 8, 7 Taf.

1) Philos. transact. vol. 43, n. 474,476 , vol. 44, n. $480,484$. IUdf (4)rieb er: Botanicum olficinale. Lond. 1722. 8.

$\left.{ }^{2}\right)$ Will. Saimon, The english herbal. Lond. 1710. Fol. I. vol. p. 680 , II. vol. p. $671-1296$, c. fig. lign. inc.

3) Synopsis stirpium hybernicarum. Dublin 1727. 8.

4) Hethod. plantar. circa Cantabrigiam nascent. Lond. 1727. 8.

${ }^{5}$ ) First lecture of a course of botany. Lond. 1729. 8. 


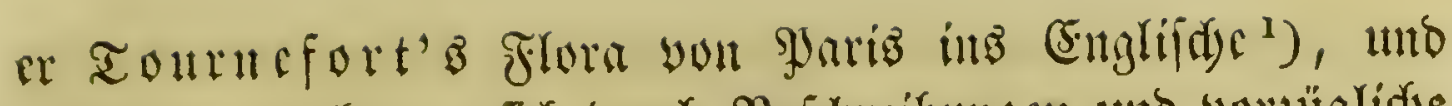

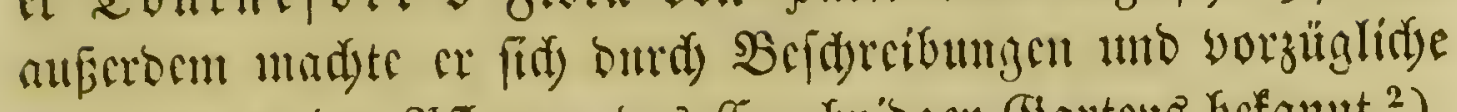

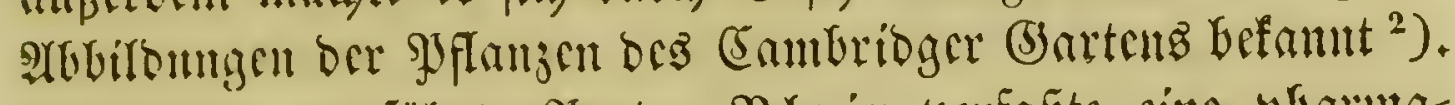

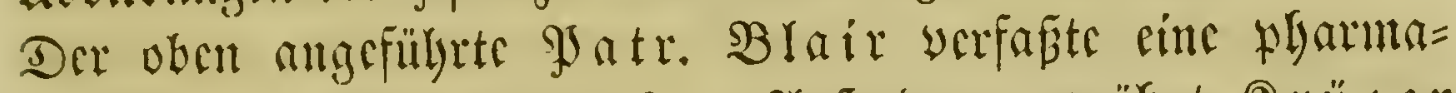

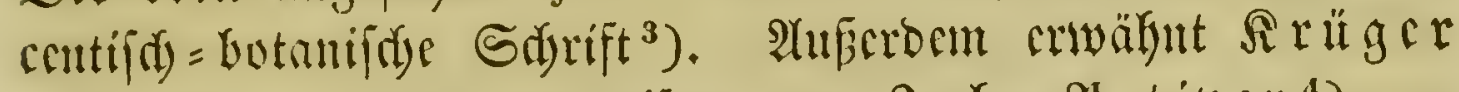

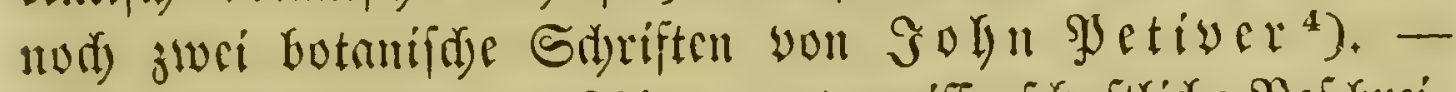

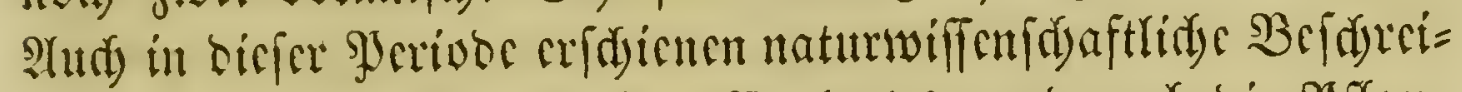
Eungen cinjcher (sraffdaften Englanbs, unb aud) bie Syflan=

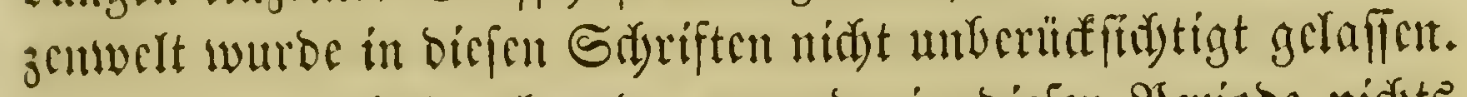

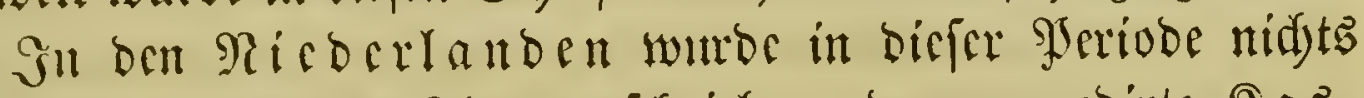

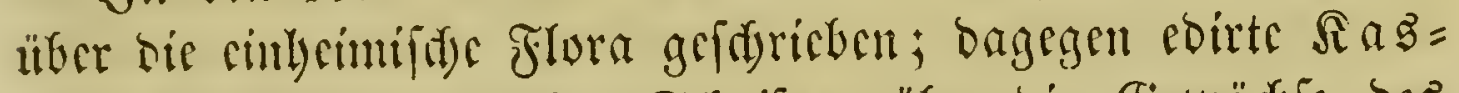

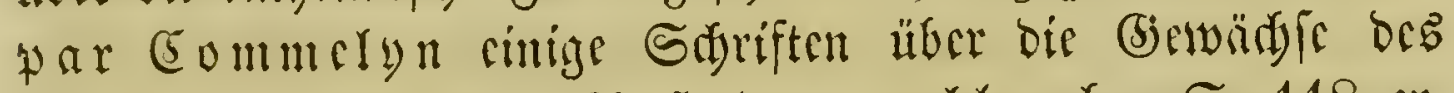

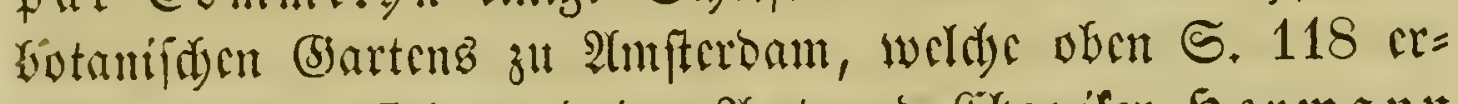

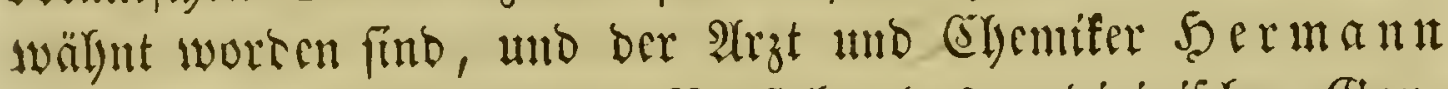

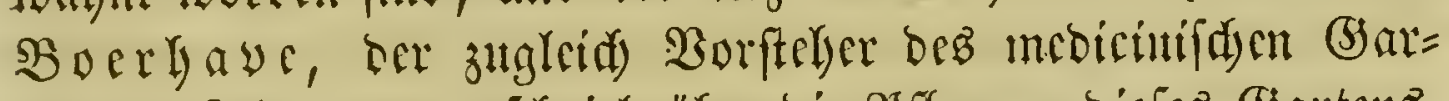

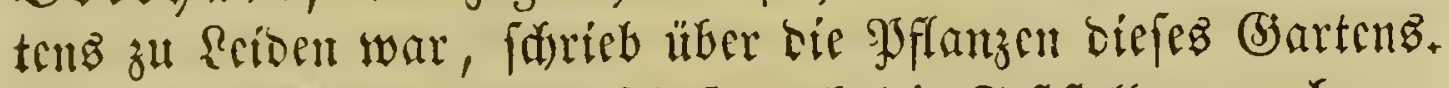

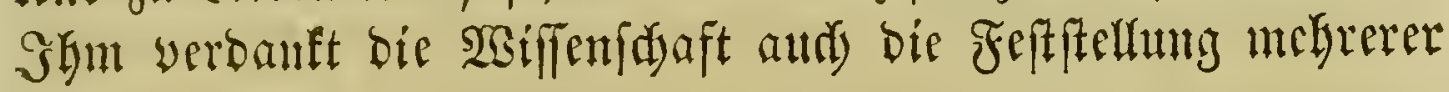

1) John Martyn, Tournefort's history of plants growing about Paris, translated in the english with many additions, and accomodated to the plants growing in Great Britain. Lond. 1732. 8. Vol. I, pag. 311 , vol. Il, p. 362. - $\mathfrak{A} u$ perbem iffricb $\mathrm{er}$ : Tabulae synopticae plantar. officinal. ad method. Raja nam dispositae. Lond. 1726. Fol. - A short explanation of the technical words made use of in botany. s. a. 4 .

$\left.{ }^{2}\right)$ Ilistoriae plantar. rarior. decad. V. Lond. 1728. Fol.

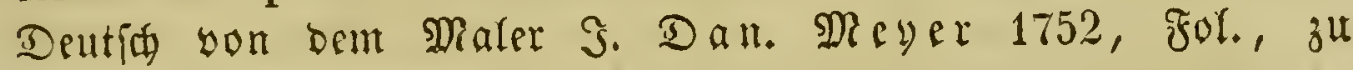
Rürnberg beraużgegeten.

$\left.{ }^{3}\right)$ P a tric. B la ir, Pharmaco-botanologia, or alphabetical and classical dissertation on all the british indigenous. Lond. 1723-28. 4.

4) John Petiver, Herbarii britannici catalogus. Lond. 1702. Fol. - A catalogue of M r. R a y english herbal illustrated with figures in folio. London 1713, 17151732. Fol.

๔. $\mathfrak{B}$ ind 
BSflanzengattungen. Bon frinen lürigen $\mathfrak{B e r b i e n f e n ~ u n t ~ b i e ~}$ Sotanif iff foron oben gerebet worben., ${ }^{1}$ )

lunter ben italienifden gुbytogration fino zu nennen:

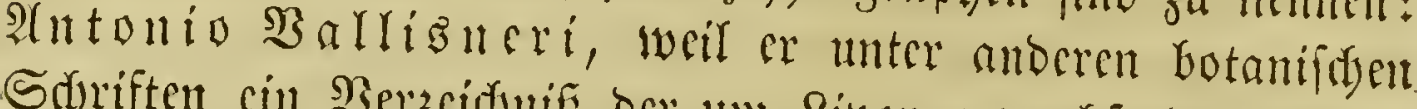

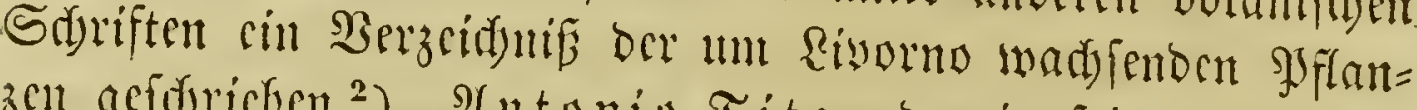

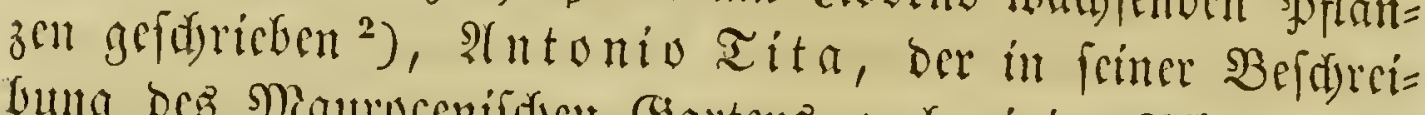

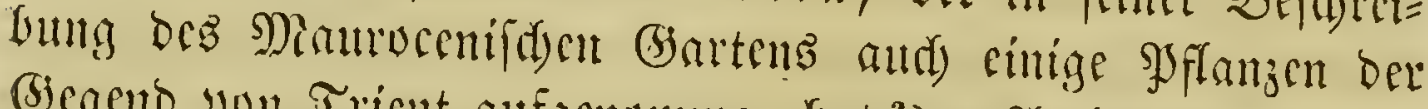
(biegento von Iricut aufigenummen bat ${ }^{3}$ ). Alud Pontebera ift als gryytograply frincs Baterlanbs zu merfen ${ }^{4}$ ). - (5in

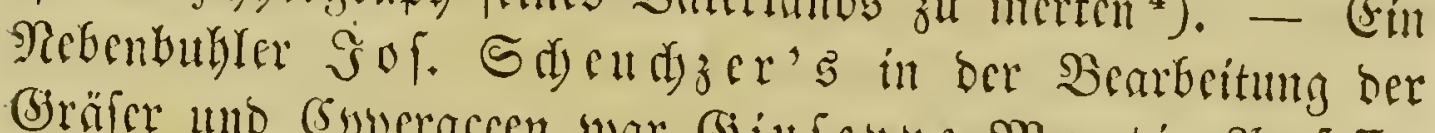

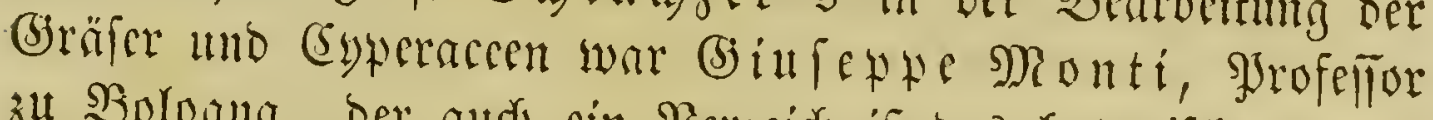

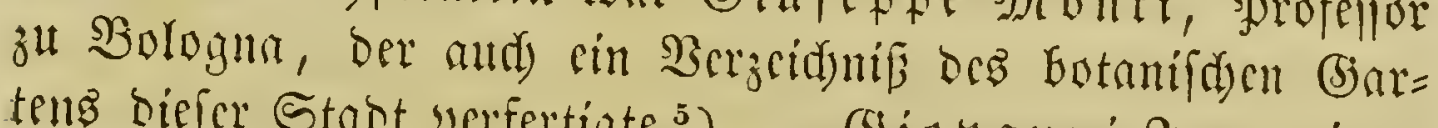
tens diefer Stabt werfertigte ${ }^{5}$ ). - (S) ioyanni Geronimo 3aniderli, ger. 1662, geft. 1729, S(pothefer zu Wenebig, unterfutste die Flora fémer Baterftabt, Bernna's, Sitriens

1) Index plantar., quae in horto Lugduno-Batavo reperiuntur. Lugd. Batav. $1710-1220$. 4. - Index alter etc. Ibid. $1720,27.2$ B̊P. - Historia plantarum, quae in horto acad. Lugd. Bat. crescunt, cum earum characteribus et medicinal. virtutibus. Romae (revera Lugd. B.) 1722. 8. Lond. 1731, 1738. 8.

2) Prima raccolta d'Osservazioni et Esperienze. Venez. 1710. 12. - Opere diversi. Venez. 1715. 4.

$\left.{ }^{3}\right)$ Catalog. plantar., quibus consitus est Patavii amoenissimus. hortus Joan. Fra nc. II a u ro ceni. Accedit iter per alpes tridentinas etc. Patav. 1713. 8.

4) Compendium tabularum botanicarum etc. Patav. 1718. 4. - Epistolae II de horto Patavini. Venet. 1726. Fol, Bergl. nud beffen: Epistolae ac dissertationes. Opus posth. in II tom. distrib. etc. Patav, 1791. 4.

$\left.{ }^{5}\right)$ Gius. Monti, Catalogi stirpium agri bononiensis prodromus gramina et adfinia complectens. Bononiae 1719. 4. 3 Inf. - Indices horti Bonon. ad usum demonstrationum, quae in horto bononiensi quotannis habentur. Bonon. 172\%. 4. 1 Taf. - Exoticorum simpl. medicamentor. indices. Bonon. 172\%. 4., 1753. 4. 


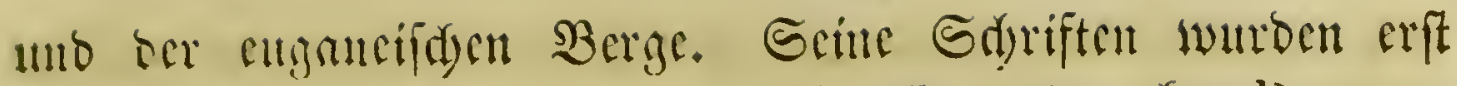
nad) feincm Tobe won feinem Solgne hermigegeten ${ }^{1}$ ). Der whidjtigfte Sybytograwh Stariens in bicfer Seriobe aber Jyar

\section{Piet Hutouid Mideli

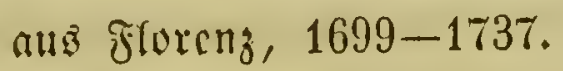

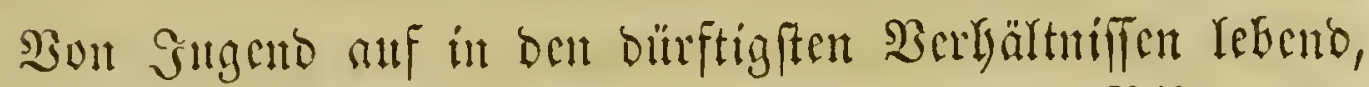

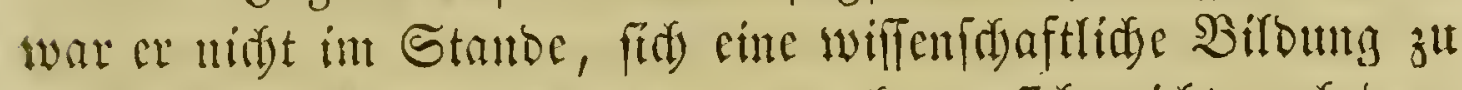

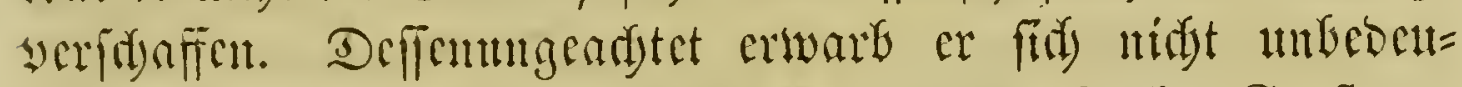

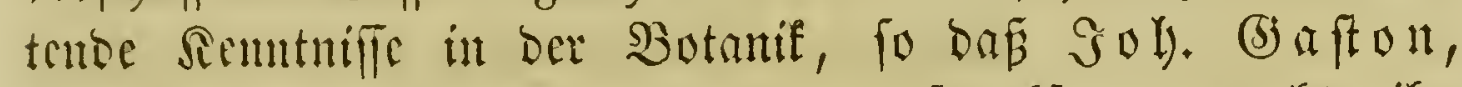

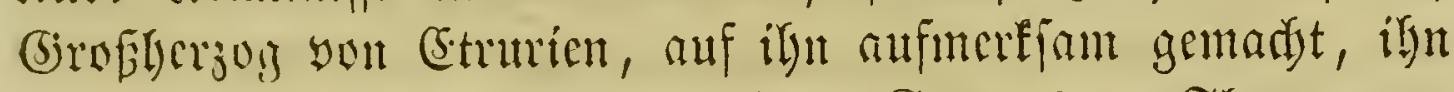

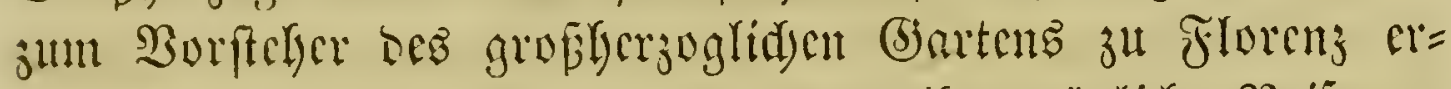

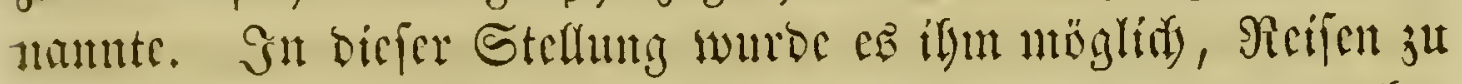
unternefincn. So burdwanderte er faft ganz Stalien und be=

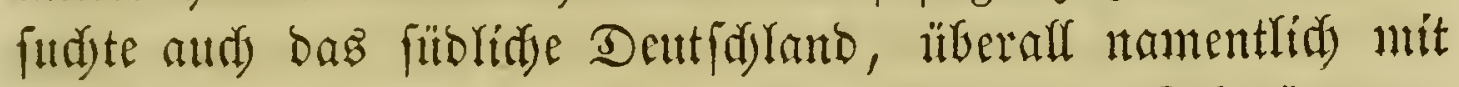

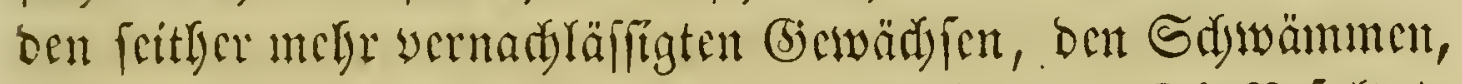

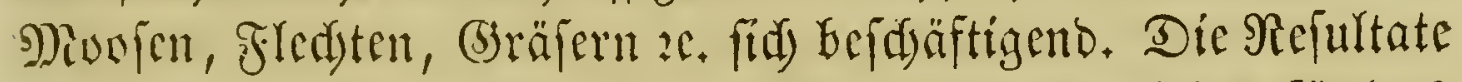

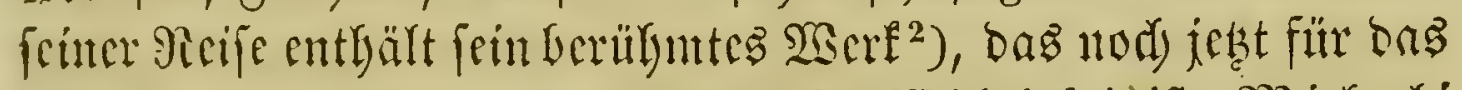

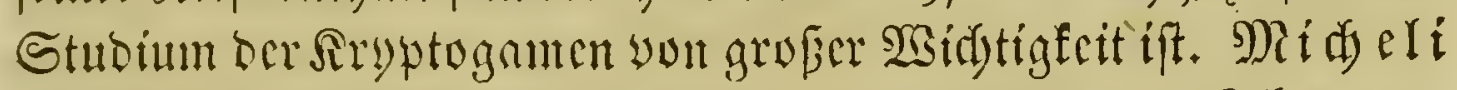
ift als ber cigentlidf wiflenfdaftlidje Begrüntor ber Rebre you

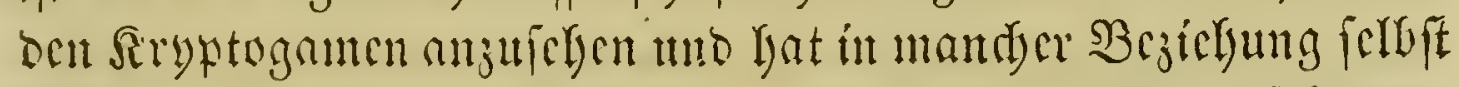
Dirren's (jejdidyte ber Mrove writ übertruffen. Die won

.') Istoria delle piante che nascono ne Lidi itorno a Venezia. Venez. 1735. Fol. (Op. posth.) c. 311 fig. - Opusc. botan. posthuma. Venet. 1730. 4.

2) Nova plantarum genera juxta Tournefortii methodum disposita, quibus plantae 1900 recensentur, scilicet fere 1400 nondum observatae, reliquis suis sedibus restitutae etc. Florentiae 1729. Mit 108 §upfertafén. gr. 4. - $2(1 \mathfrak{B}$

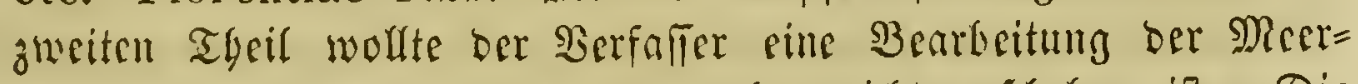
gewäd)je nadforgen laftert, waz aber nidyt gridelyen iff. Die

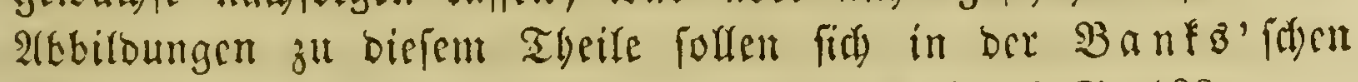

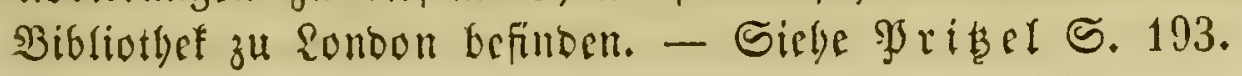




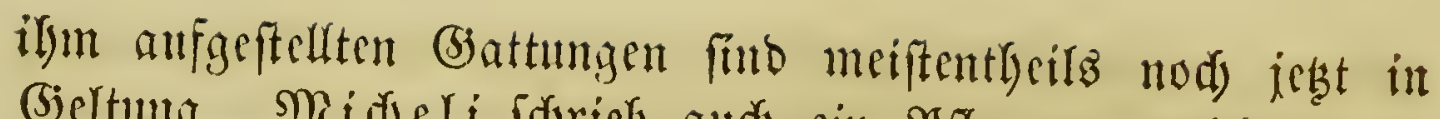

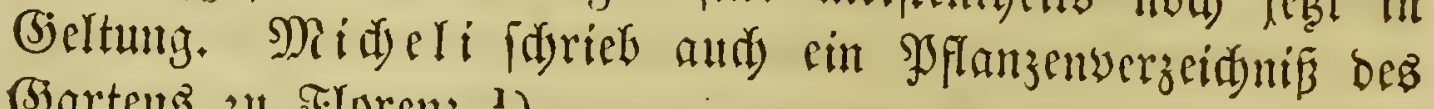
(3artens z" Florenj. ')

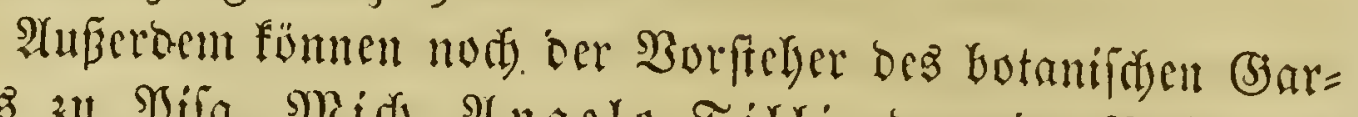

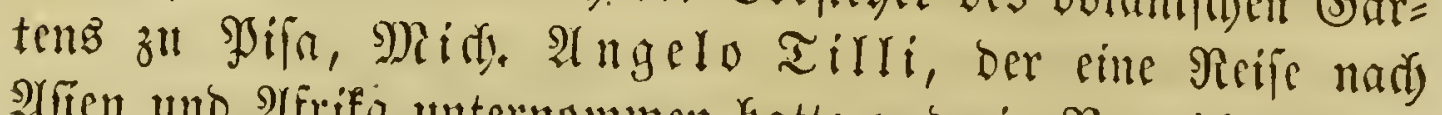

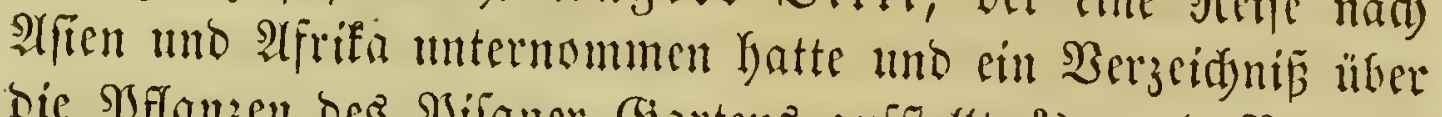

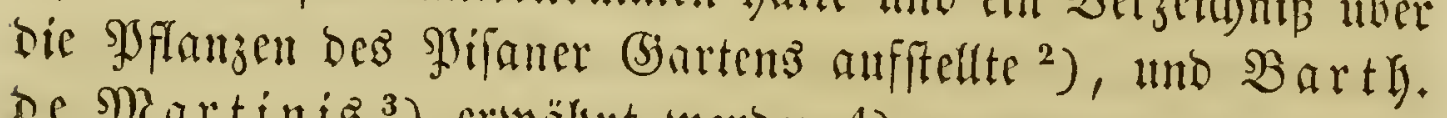
ae Miartinis ${ }^{3}$ ertwälut werben. ${ }^{4}$ )

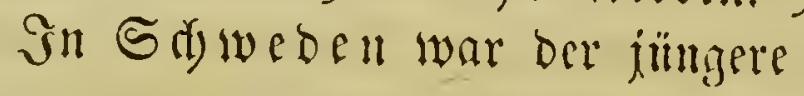

\section{Ia geb. 1660, geft. 1740 ,}

Der oben als âthänger beB Şerman

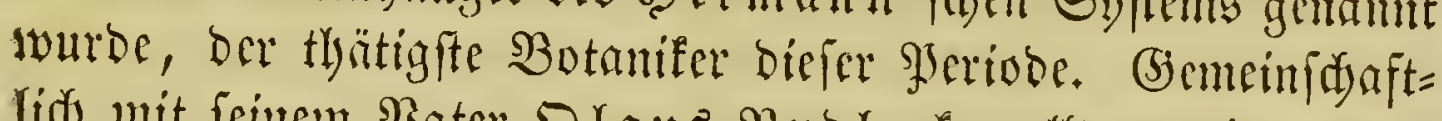

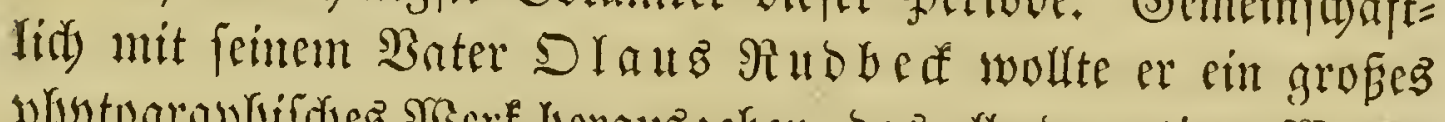

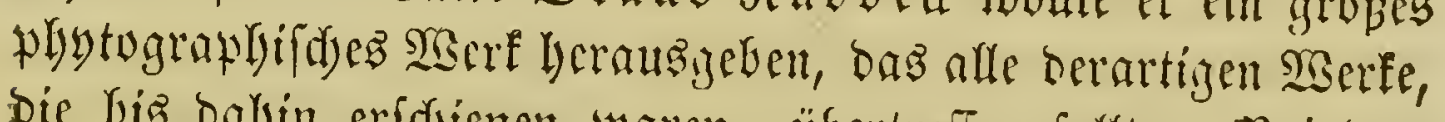
bie bis bahin erfáienen waren, ribertieffen follte. Bei bem grofen Branoe zu Hpfala im Gafire 1702 yerbrante jebod bie ganje $\mathfrak{A}$ uffage bes erften Bandes bis auf brei (xemplare mit ben $10-11000$ 5ुulzfdutten zu ben übrigen Iheilen ${ }^{5}$ ).

') Catalogus plantarum horti Caesarei Florentini, opus posthumum. Florent. 1748. Fol. 7 Taf.

2) Catalogus plantarum horti Pisani. Florent. 1723. Fol. 50 Taf.

$\left.{ }^{3}\right)$ Barth. de Martinis, Catal. plant. invent. in itinere ab urbe Verona ad Baldum montem. Verona 1707. 4.

$\left.{ }^{2}\right) \operatorname{Rr} \mathfrak{i} g \mathfrak{c r}$ fülgrt nod) an: J. M. Lancisius, De herbis et fruticibus in recens aggesto littore Tiberis suborientibus, extat ad calcem physiol, animadvers. in Plinii Villam. Romae 1717.

5) Campi Elysii liber II. Upsal, 1701. Fol., worin bic Drdji= bren unb urbrere 3wisbergewäd) fe cntfarten fint. Campi Elysii liber I. etc. ibid. 1702. Fol. Der erfie Their murbe fan̈ter won S. E. S. Smith gerausgegeten: Reliquiae Rudbeclianae, 


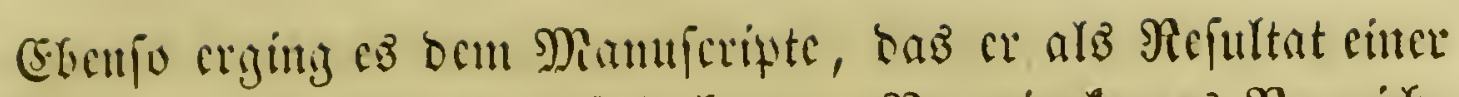

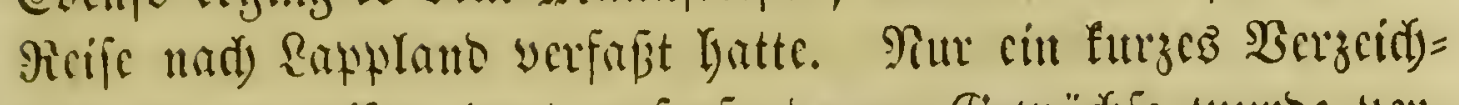

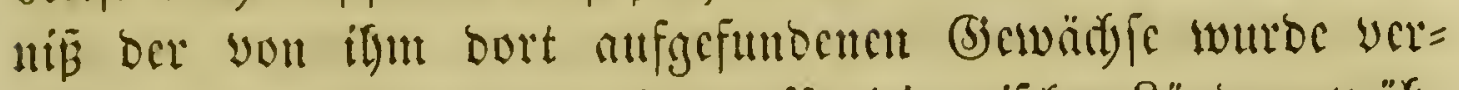

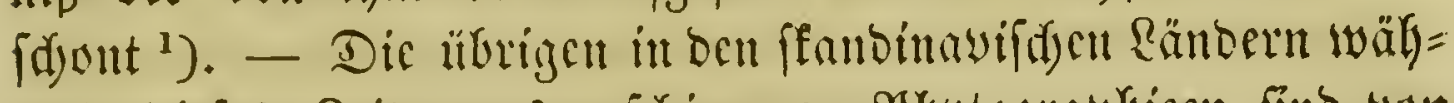

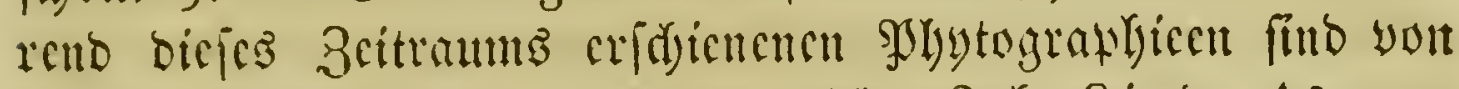

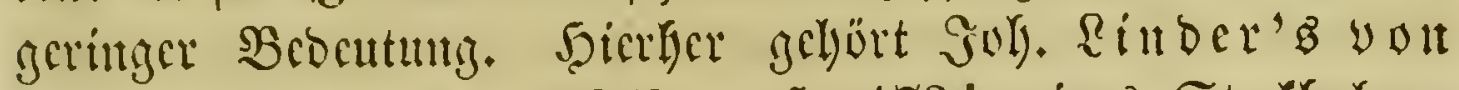
Rinberfolfe, geb. 1678, geft. 1724, cimes Stodfulmer

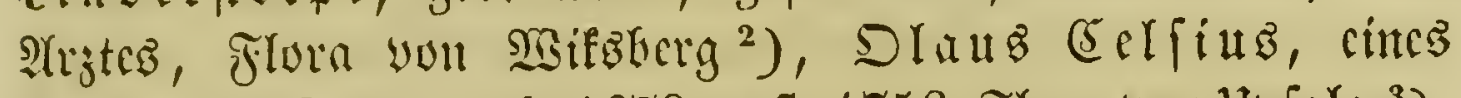

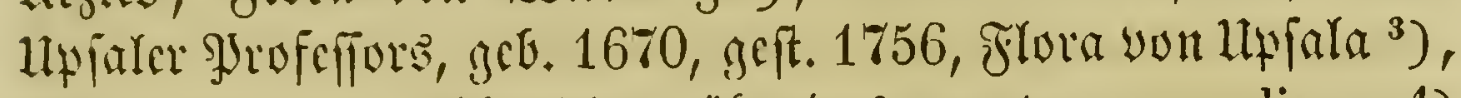

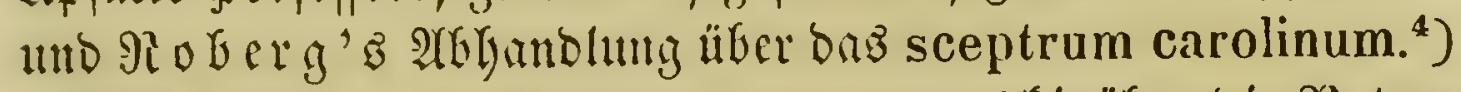

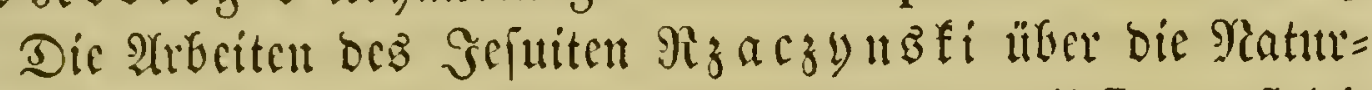

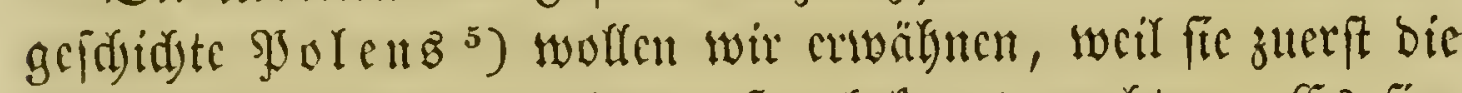

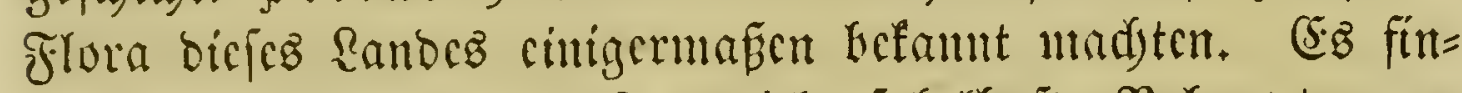
ben fiti in feinen Sibriften vicle fabergafte Belyauptungen. Unter ben Männern, weldye fid) un bie Erforidyung ber

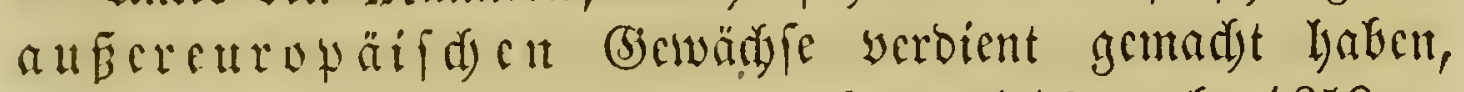

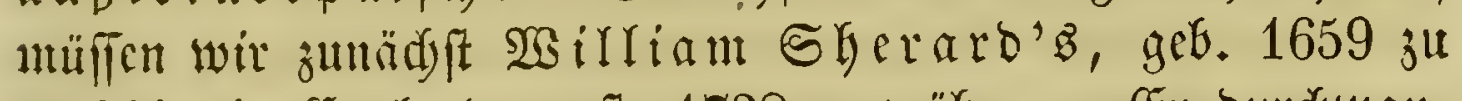
Bufdjoy in England, geft. 1728, crwähnen. (Fr Durduwan=

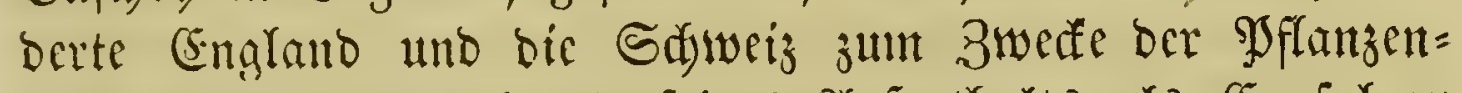
fammlumb, und wälerend feines Alufenthalts als (5onjul zu

sive camporum elys. libri primi quae supersunt, adject. nominib. Linn. Lond. 1789. Fol. Seine übrigen Sdyrifter (meift Difertationen) förnen wir bier nid)t anfübrenen. Siebe gु ritel $\subseteq .254,255$.

1) Nora Samolad, s. Laponia illustrata, et iter per Uplandiam etc. Upsal. 1701. 4. $\mathfrak{B}$ ergh. Act. liter. Sueciae. 1720.

$\left.{ }^{2}\right)$ J. Linderstolpe Lindern, Flora Wiksbergensis. Holm. 1716. 8. 1728.8.

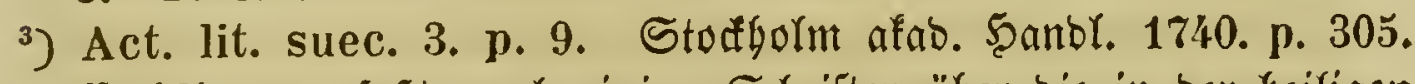
cerfiu z werfapte all cinige Sdriften über bie in ber beiligen

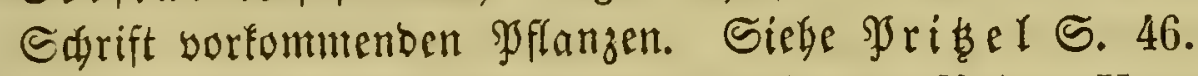

4) Dissert. de planta Sceptrum Carolinum dicta. Upsal, 1731. 4. Deffen übrige Sdriften fiebe bei গjritel S. 248.

$\left.{ }^{5}\right)$ Ilist. nat. Polon., Lithuaniae. Sandomir. 1721. 4. Auctarium. hist. natur, etc. Gedani 1745. 4. 
Smyrua $(1703$ - 1721) regte er Dort eimen botanifocn (bar= ten mit vrientalifien Soflanzen an und verforgte vicle nam=

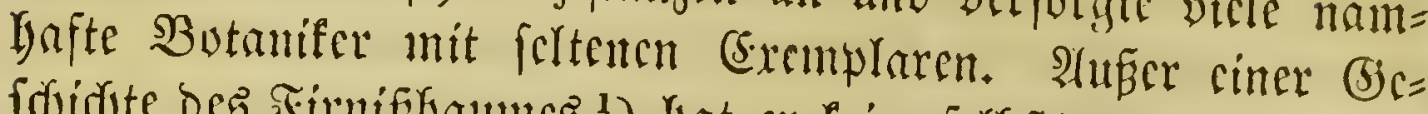

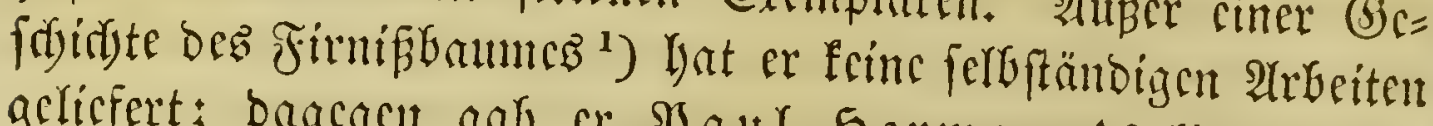
gelicfert; Dagegen gab er $\mathfrak{g}$ aul bुermann's literarifden

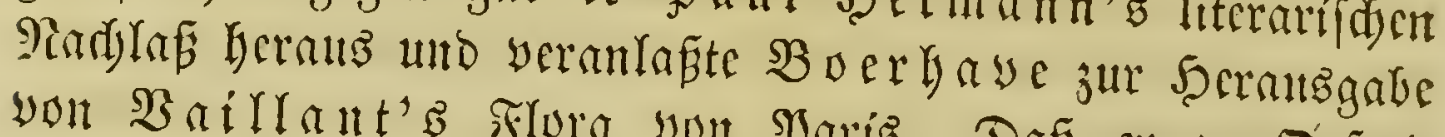

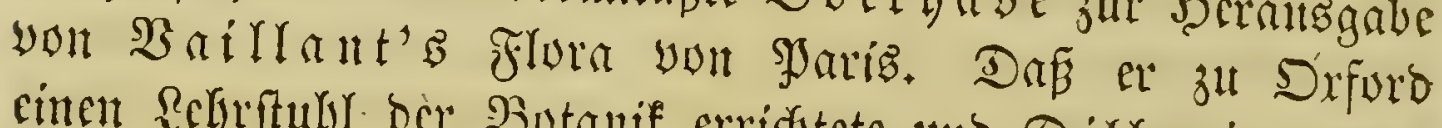

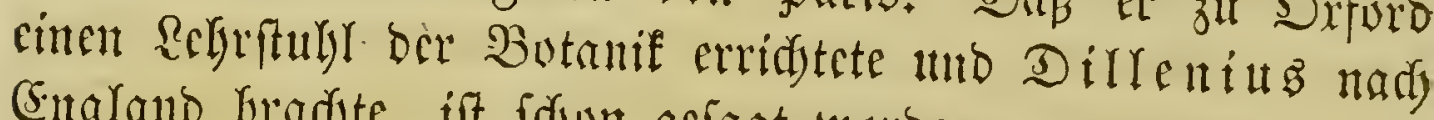
Einglano bradite, ift fidun gejagt worbcit.

Tournefort bereffe 1700 bis 1702 STeinafien, und

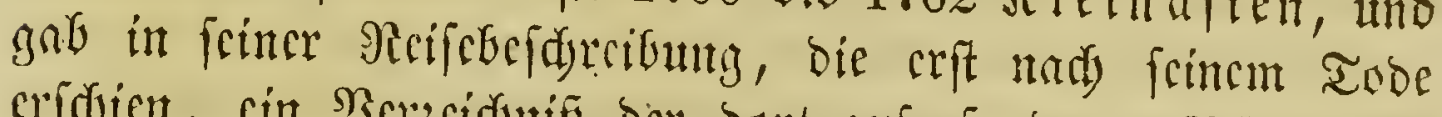

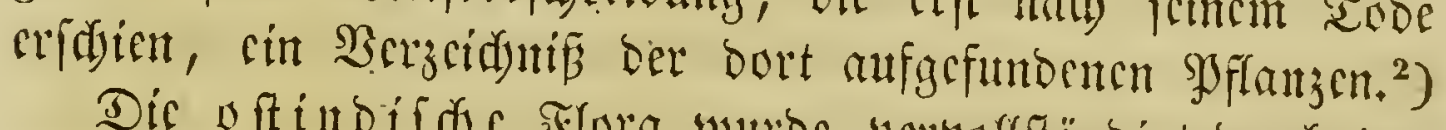

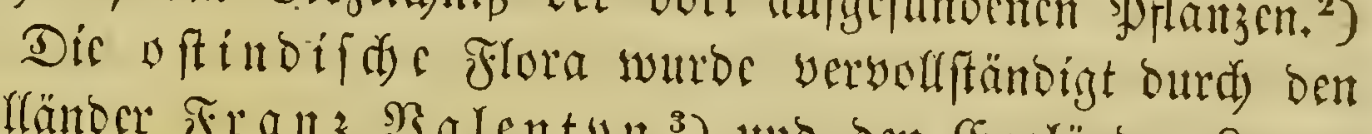

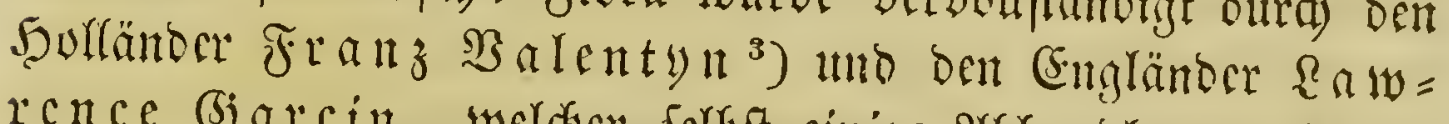

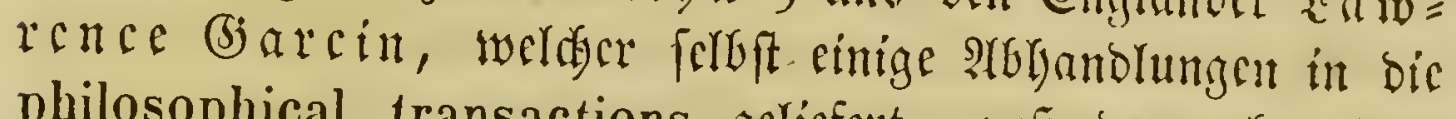
philosophical transactions gclicfert, aufecrocm aber bem

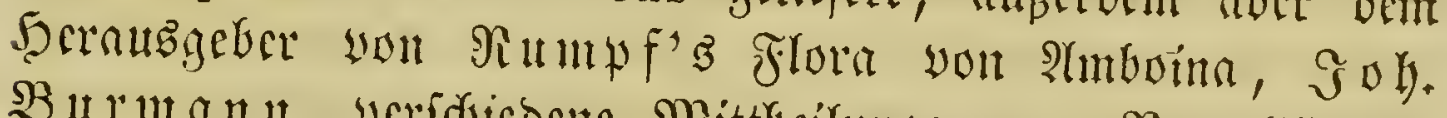

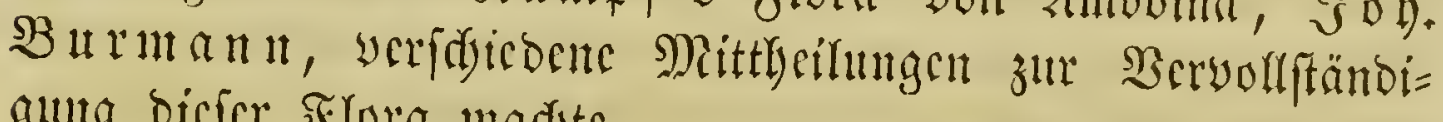
guitg bicfer Flora madjte.

De Ia Roubere gab cintige Rotizen über bas $\mathfrak{R}$ ütig=

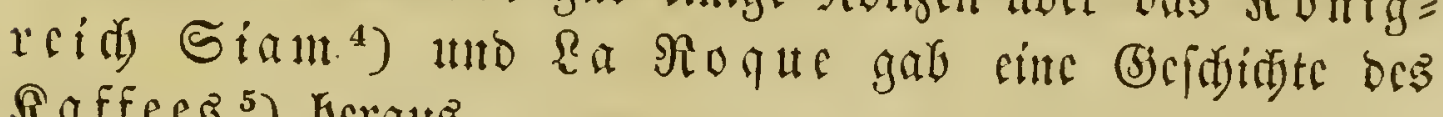
$\mathfrak{R} a f f e \mathfrak{G}^{5}$ ) Geraus.

1) Philos. transact. vol. 31. No. 367.

$\left.{ }^{2}\right)$ Corollarium institutionum rei herbar., in quo plantae 1356 in orient. regionib. observat: recensentur et ad genera

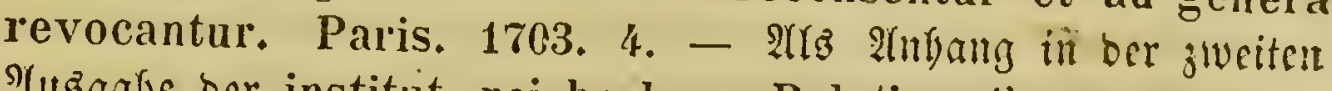
$\mathfrak{A}$ แร̧galle ber institut. rei herb. - Relation d'un voyage du Levant lait par ordre du roi. Paris 1717. 2 voll. 4. Lyon 1717. 3 voll. 8. Amsterd. 1718. 2 vol. 4.

$\left.{ }^{3}\right)$ Oud - en nieuw Ostindien - noauwkeurige verhandelingen van Nederlands Morgenthey'd in die gewesten. Amsterd. 1724-26. 5 Bb. Fol.

4) Description du royaume de Siam. Amsterd. 171\%. 2 vol. 12.

5) Voyage de l'Arabie heureuse par l'Ocean oriental, fait en 1708-10. 12. Amsterd. 1816, 12. 


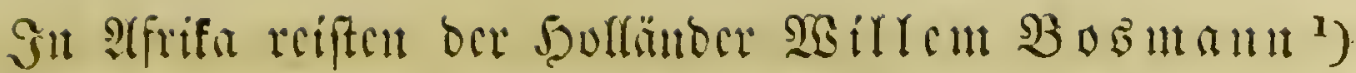

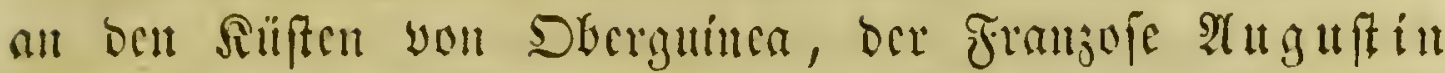

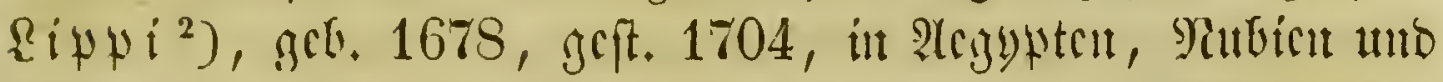

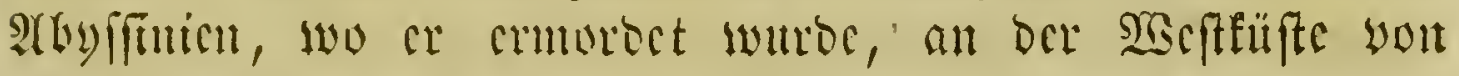

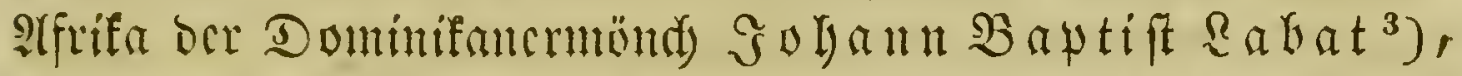

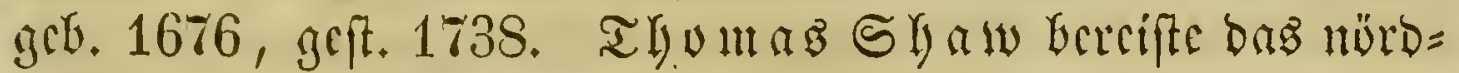
lidje $\mathfrak{A f r i f i}$ utto $2\left(\right.$ cogypten. ${ }^{4}$ )

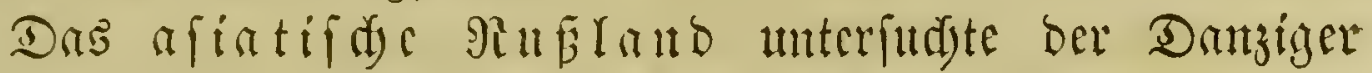
Dau. (3)ottlob Mefferfdumio, ged. 1685, ber. 1730

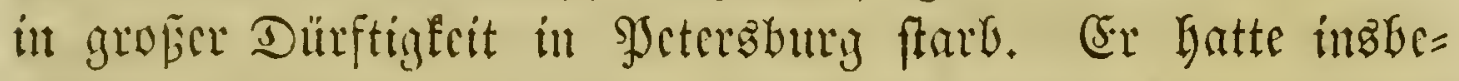

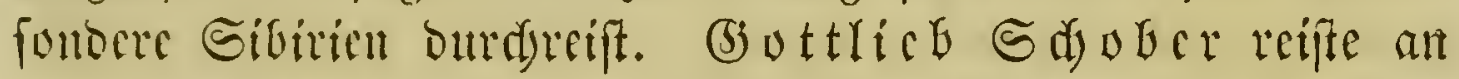

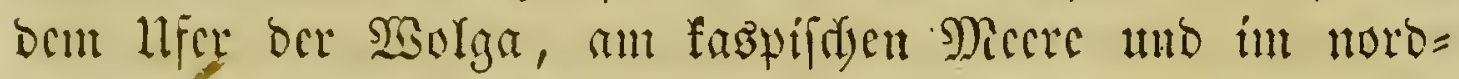

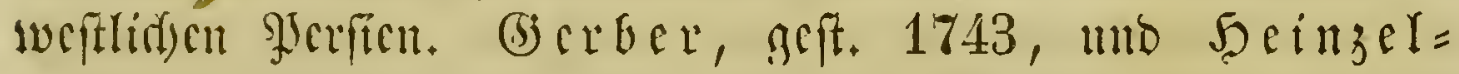
ma n

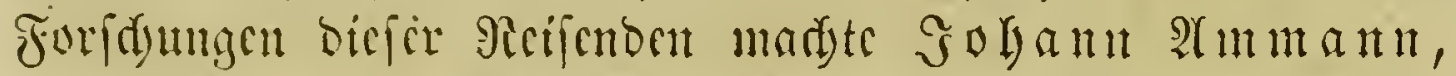

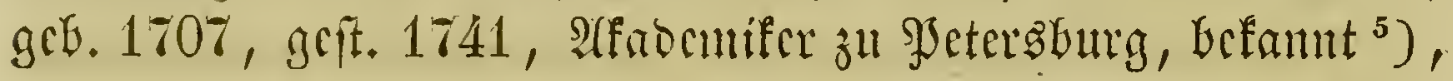

1) Noauwkeurige beschryving van de Guinea-Goud. - Sier=

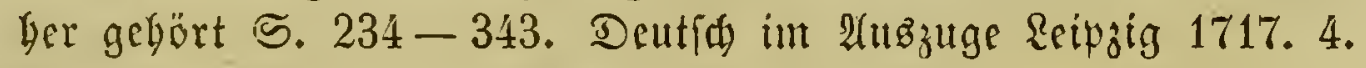
Salnnover 1771. 8. - Sand - en Slavenkust. Utrecht 1704.

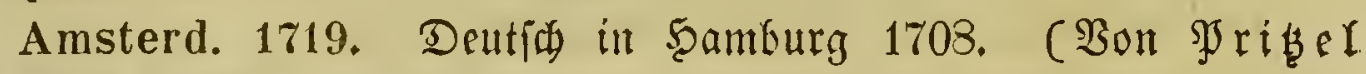
nidit eriväbut.)

$\Rightarrow$ Die Sammlungen Rippi's befinben fï in Yaris.

$\left.{ }^{3}\right)$ Nouvelle relation de l'Afrique occidentale. Paris 1728. 5 Boe. 12. - Nouveau voyage aux isles de l'Amérique, contenant l'histoire naturelle de ces pays. Paris 1722. 6 voll. 12.1742 .8 voll. 12.

4) Travels or observations relating to several parts of Barbary and the Levant. Oxford 1738. Fol. Supplentente bazu eridienen ibid. 1746. Fol. uno (1747) Fol. Deutid: Reifen, ober 2 nnterfungen beridicbene Theife ber Barbaref und Reyante betreffend: Rady ber 2. engl. 2luşgake ins Deutide überichtet. \{eipzig 1765. 4. 62 Tafeln. - Catalogus plantar. quas in variis Africae et Asiae partib. collegit Th. Shaw. Oxonii 1738. Fol. Accessit appendix de coralliis et eorum affinibus. Opera J. J. Dillenii.

s) Stirpium rarior. in imperio rutheno sponte provenientium 


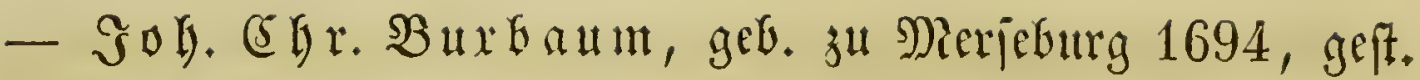
1730, ein Sadje, begleitete ben Grafen Romanzow mady Gonftantinowel und befudte bei biefer (5)elegenheit Rlein= afien uno $\mathfrak{A}\left(\mathfrak{m e n i e n}{ }^{1}\right.$ )

Die widftigften Radyridten über bie amerifanifde

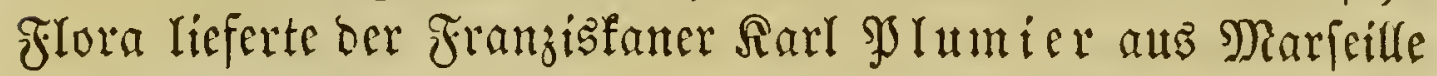
(1646-1704). (5r Ginterliés gegen 10 Bänbe mit 1400

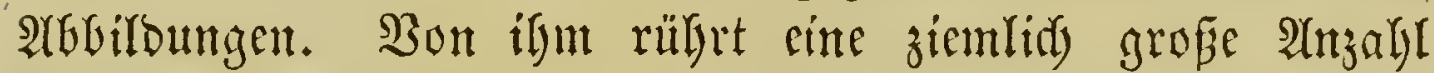

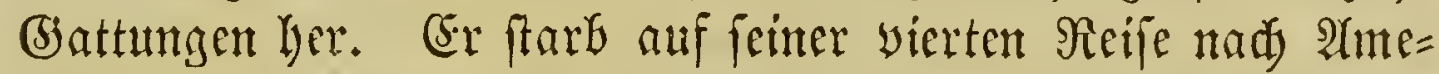
rifa auf der Şalbinfel yor Eadir. Die meiften feiner Shrifter erfdenen erft nad) feinem Iobe ${ }^{2}$ ), - \&uuis F̌suillée, get. in Der Srowente 1660 , geft. 1732 , bereife fulwohl ben Drient

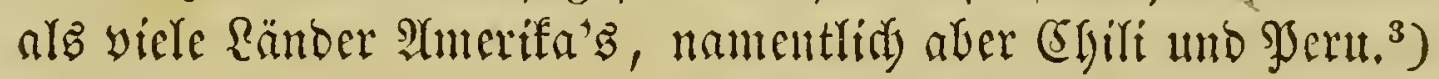

icon. et description. Petropol. 1739. 4. 35 Tafern. $\mathscr{A}\left(\begin{array}{l}\text { a } \\ \text { in }\end{array}\right.$ Act. Petropol. T. 3, 10, 11, 12.

1) Centuria I. plantarum minus cognitarum circa Byzantium et in Oriente observatarum. Petropol. 1728. 4. 65 I afellt. II. Cent. 1728. 8. $50 \mathfrak{T} \mathfrak{a f}$. III. Cent. 1729. $74 \mathfrak{T} \mathfrak{a f}$. IV. Cent.

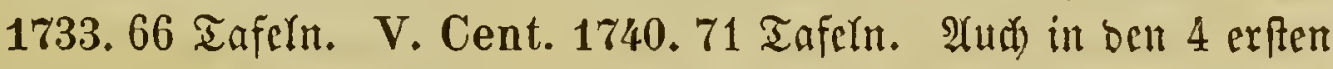

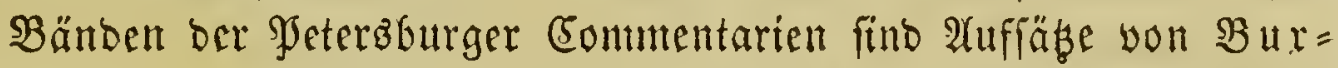
baun. Die lesten Centurien bejorgte (j) nelin. S. beffen Enumerat. plant. Italiae. Magdeb. 1721.

$\left.{ }^{2}\right)$ Description des plantes de l'Amérique. Paris 1693 mit 108 Iafeln. Fol. - Nova plantar. Americanar. genera. Paris 1703. 4. 40 Iaffeltr. - Traité des Fougères de l'Amérique. Paris 1705. Fol. - Filicetum Americanum, s. filicum, polypotiorum, adiantorum etc. in America nascent. icones. Paris 1703. Fol. 222 Iafeln. - Plantar. Americanar. fasciculus I. $(-X)$ continens plantas, quas olim $\mathrm{C}$. Plumier depinxit; ed. J. Burmann. Amstelod. 17551760. Fol. 262 Iafein.

3) Journal d'observations physiques, mathématiques et botaniques faites sur les côtes orientales de l'Amérique méridionale. Paris 1714. 3 tom. 4. - Journal des observations faites en la nouvelle Espagne et anx îles de l'Amérique.

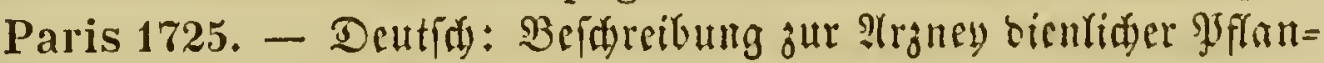

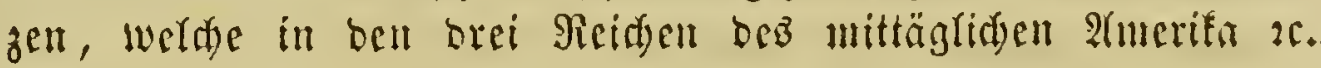

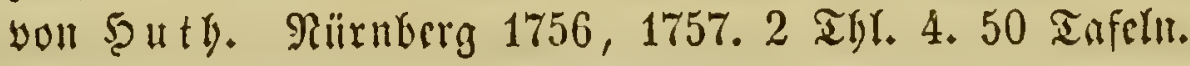




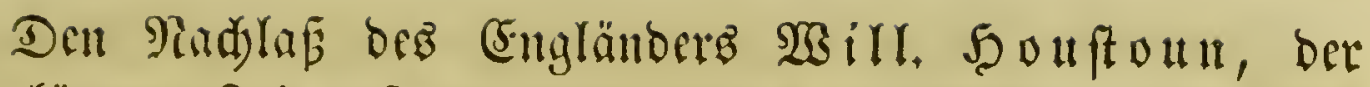
fid) längere Zcit auf ben 2Yutillen unb in Reurpanien aufbielt

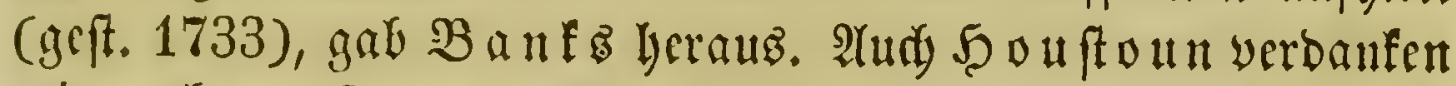
wir melyere (5iattungen ${ }^{1}$ ). Fermer madjten nod) $\mathfrak{A}$ mab éc

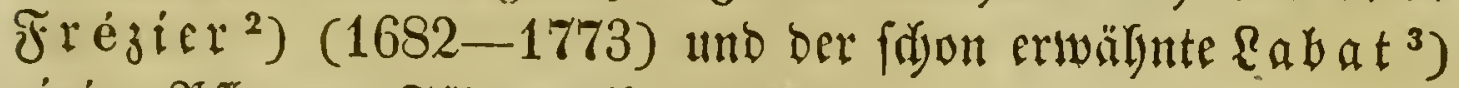
einige Pfflanjen Silbanterifa's befannt.

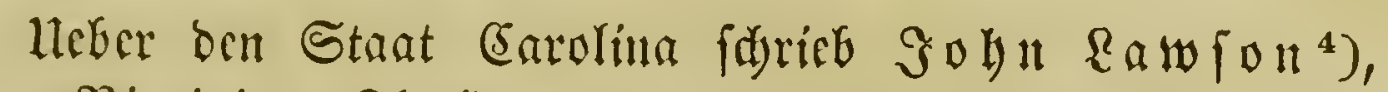

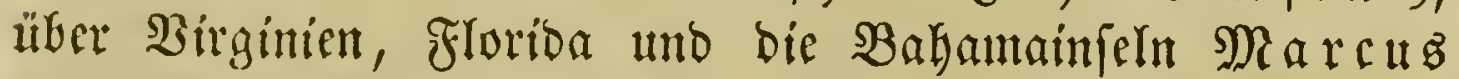
$\left(5 a \operatorname{teb} y^{5}\right)(1680-1749)$, über (jrönland ber bänifdye

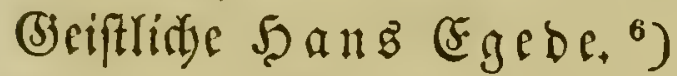

1) Reliquiae Houstounianae s. plantar. in America meridionali collectarum Icones manu propria aeri incisae, cum descriptionib. e schedis ejusd. in Bibliotheca Jos. Banks asservatis. Lond. 1781. 4. 26 Taf. - Juxta exemplar Londinense. Ed. in Germ. I. Norimb. 1794. 8, 15 Taf.

2) Relation du voyage de la mer du Sud aux côtes du Chili, du Pérou et du Brésil, fait pendant l'années 1712,1714 . Paris 1716 und 1732. 4. $37 \mathfrak{T a f}$. Lond. 1717. 4. Amsterdam 1718. 4. Deutfd: Samburg 1745. 8.

3) Siebe oben S. 167.

4) History of Carolina, containing the exact description and natural history of that country etc. Lond. 1709. 4. Deutfi yon $\mathfrak{B}$ iffer: Şamburg 1722. 8.

$\left.{ }^{5}\right)$ Natural History of Carolina, Florida and the Bahama islands. Lond. 1731 - 43. 2 voll. Fol. Append. Lond. 1748. 2. ed. Lond. 175\%. Fol., 1771. Fol. - Catesby, Hortus Europae americanus or a collection of 85 various trees and shrubs, the produce of North America, adapted to Great Britain, Ireland and most parts of Europe. London 1767. Fol. 17 Taf. - Hortus britanno-americanus, or a curious collection of trees and shrubs, the produce of the british colonies in North America etc. Lond. 1763. Fol. 17 tab.

-) Det gamle Groenlands nye perlustration, eller naturalhistorie etc. Kiöbenhav, 1741, 4. Deutid: Franffurt 1730. Berrin 1763. 8. 
Botanifje (Särten wurben in biejer Sheriobe angelegt: fut Sugorftabt (1700), 5̧arlem (1702), cambribge (um 1702), $\mathfrak{B} \mathfrak{u} \mathfrak{r} \mathfrak{b} \mathfrak{b} \mathfrak{r g}(1709), \mathfrak{g} \mathfrak{a} \mathfrak{b} \mathfrak{a} \mathfrak{g}(1710), \mathfrak{S}$ it ten= berg (1711), Şetersburg (1725), אarloruge (1733).

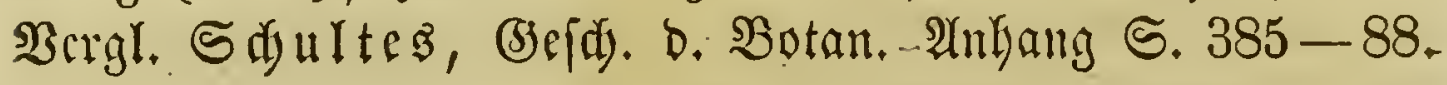




\section{Rinné, frine Gifgntr uno Bertfribiger.}

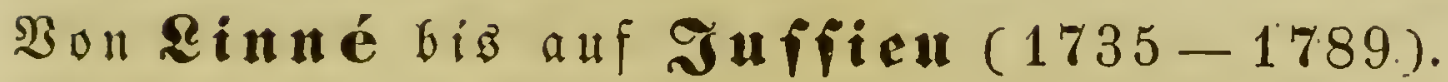

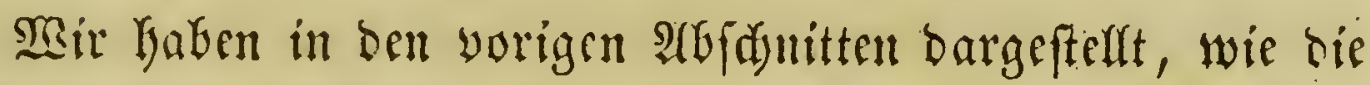
neut erwadyte Wifienfdaft, anfangs nod fdwad) uno unjelb= ftänoig, fids won ben alten Edriftefeflern gebulbig muste am (bäungelbanoe fübren laflen, wie fie aber allmälig erftarfte

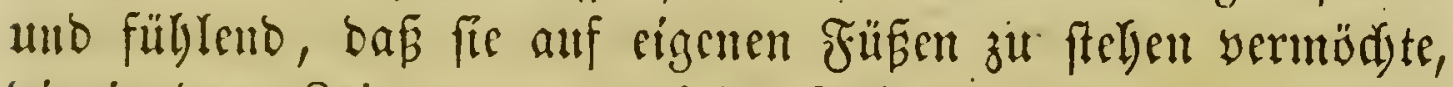
bie in bem Beitraum you vielen Gahrbumberten fereotys ge= worbene Alutoritätştyramei enolid) zerbiad, wie fie inşberon= Dere burd) bie llnterfudung bes vaterlänoifden $\mathfrak{B}$ obens fid

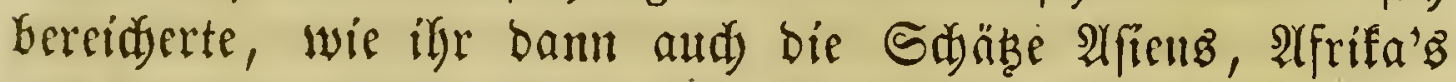
unb ber neuen Siselt zufloffen, wie man enolid), feleft erftaunt über bie Maffe bev vorbandenen Materialien, barauf fant, fie zu fidteh uno zu orbnen, wie man aber sinfah, bafi zu biefem 3twefe die Remtnif ber einzelnen Drgane erforberlid fei, unb wie man bann namentlici) nady Erfindung bes $\mathfrak{M i}=$ frobfopz aud den immeren $\mathfrak{B a n}$ ber (betwädjfe nad) alfen Seiten

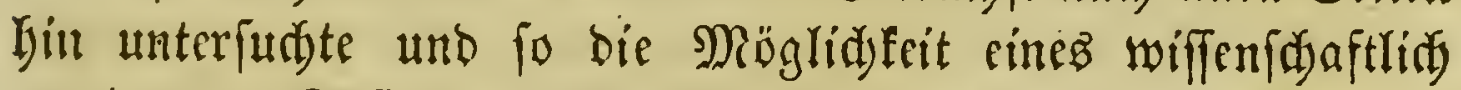
georbuten Syftems eriduf: Âthes bies war am 2 mfange biefer Syeriobe fdon gefdelen, ja $\mathfrak{e B}$ ljatten fdon Männer wie Nay, Nivin uno Tournefort u. a. Befche aufgeftefl, bie yon wiclen ifyer Zeitgenoffen als ridytig erfannt wurben;

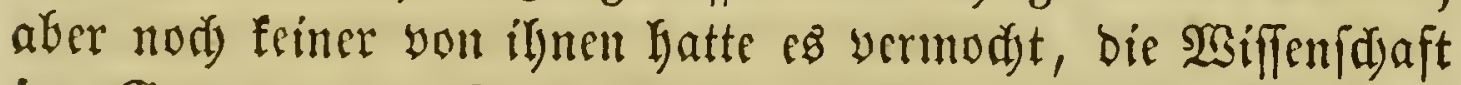
iun Banjen ullo Grofen unzugeftalten; bie Fefler ifrer Syfteme lagen zu offen am Tage, fie hatten bie an einzelnen SJflanzen bezüglids bes inneren Saute gemarten Entbefungen zu wenig auf cimen alfgemeinen Stantpunft zu erheben ver= modyt, fie hatten von vielen (battungen bie dyarafteriftifden

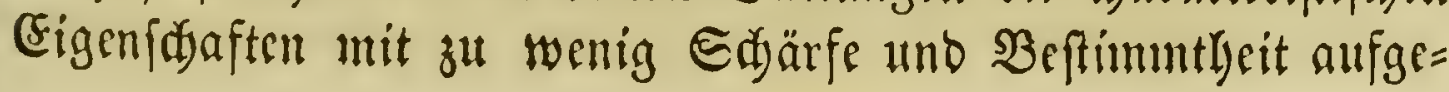




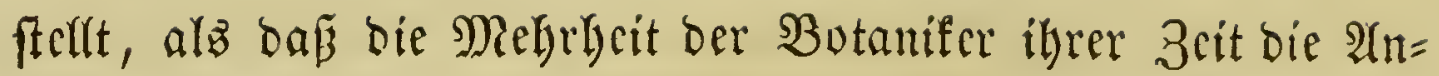
firdenten bes sinen ober bes anderen ju ben ibrigen bätte

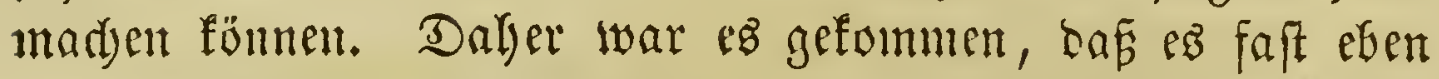
fo vicle Syfteme und Methoden als nambafte Mflaubenfenner

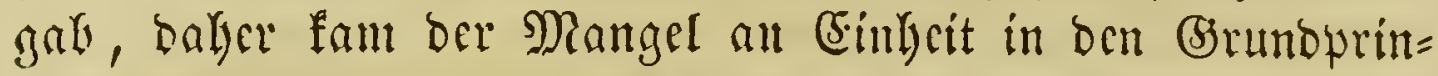
cipien ber $\mathfrak{B}$ iffenfdaft, cin Mangel, ber Dem weiteren Fort= fdyeiten äuserft gefälyrlidy zu werben brohte. Sin jeber, ber fid als felfftämbiger Denter zeigen wollte, glaubte boi diefer Berwirrung am Ende mur feine eigene (sinfludt als ridytig aueremen zu bürfen, und jo entftand namentlid in ber zu=

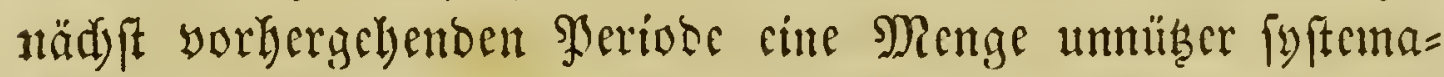
tifder Spefulationen, wolde wir, ba fie unfudjtbar für bie

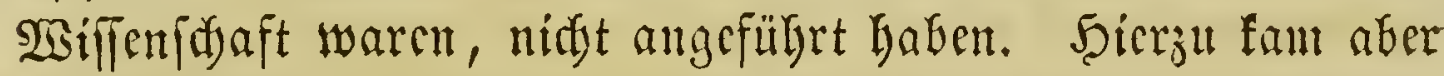
nod) Der Mangel einer alfgemcin antgenommencu Terminologie. Sian unußte, um eine SJflanj fenntlid ju beftimmen, oft ju

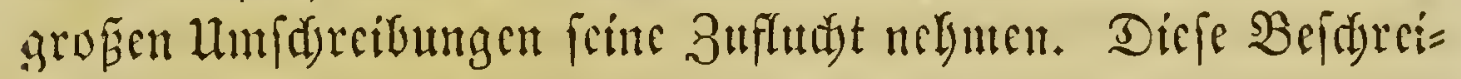
buthen muEten aber bei ben veridfiedenen Sdriftitellern von cimander abweidyen, indem ber (sine auf biefe, ber sindere auf

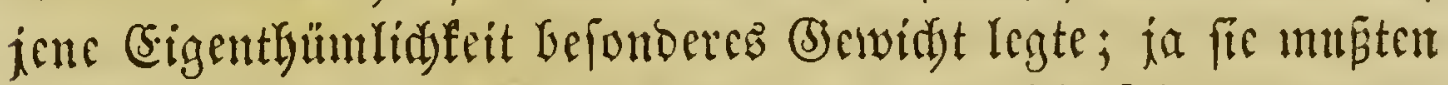

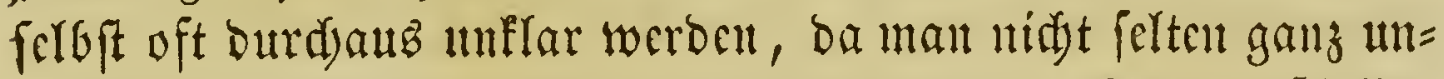

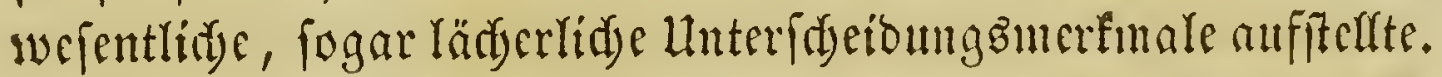

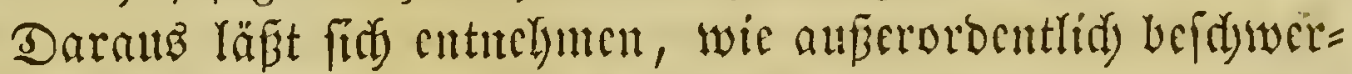
Iid) bas Stubium ber Butanif, und weie bringeno ju ber ba= mtaligen 3cit bas Berlangen frit muste, oafi dicfem fduman=

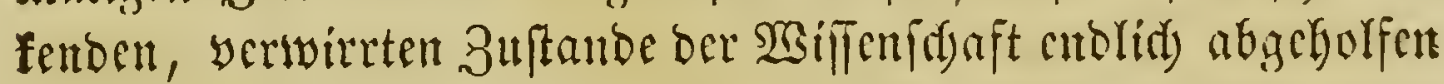

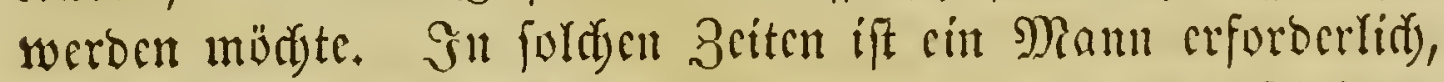

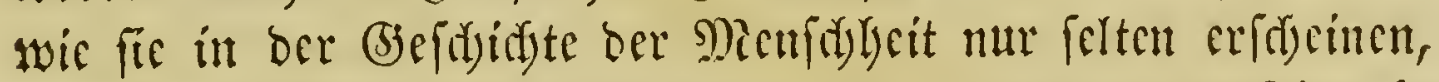

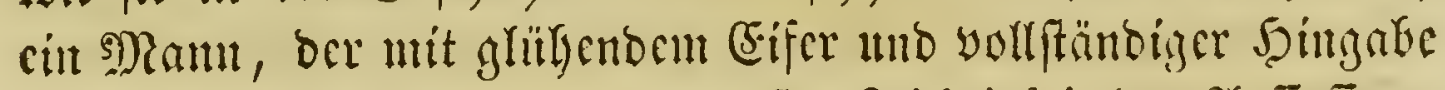

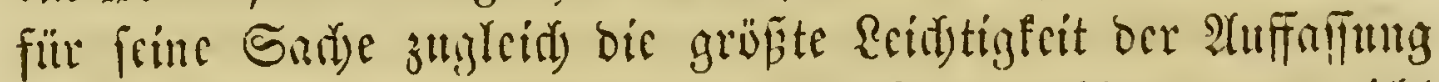

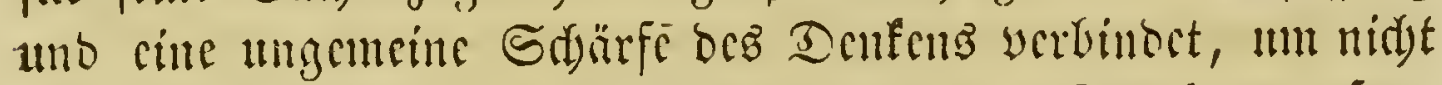

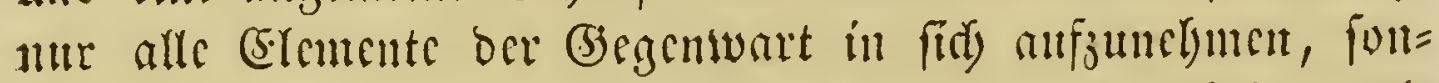

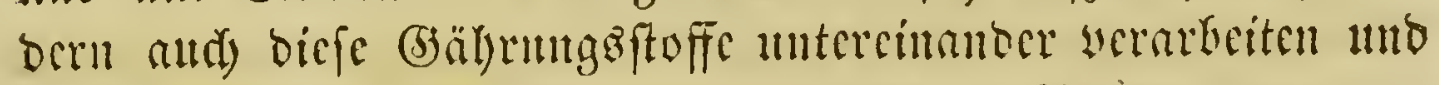

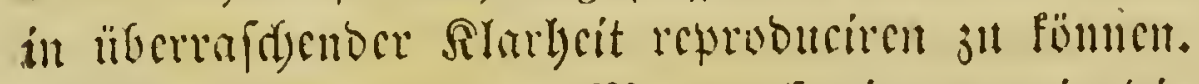

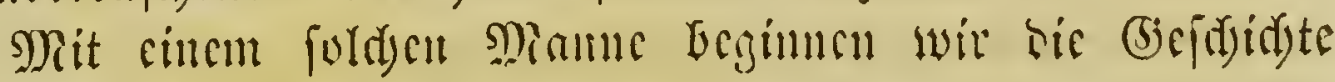
Dicfez 3ritrammes. 


\section{Ratr $\mathfrak{a} \mathfrak{i n e ́}$}

swurbe als ber Sogn cines unbemittelten Bseiftiden zu $\Re$ ăzgult in Der falwebifacu Proving Eefland ant 23. Mai 1707 geboren.

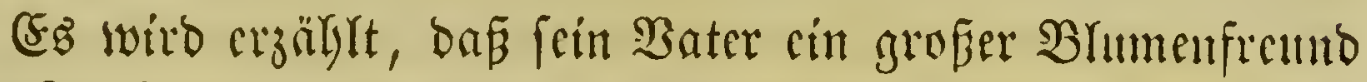
getwefen fei, und ç ift wobl nitbt zu bezlveifeln, bafi biefe

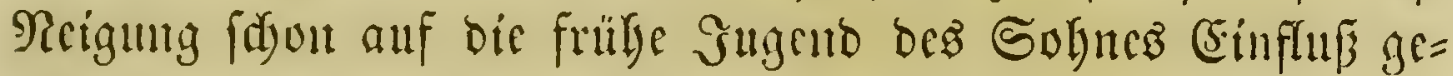

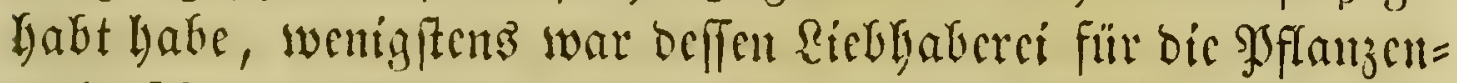
welt fdoul in fritem zcluten Rebcnsialre ftart ausgeprägt.

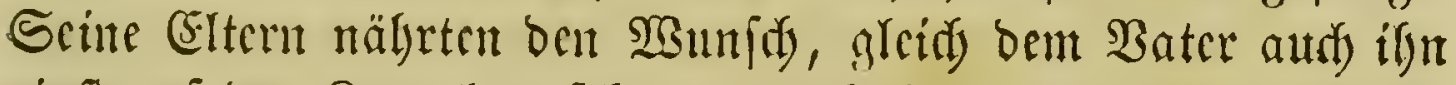
ciuft auf ber Ranjel zu felyen, und fdiffen ifn beshalb in die

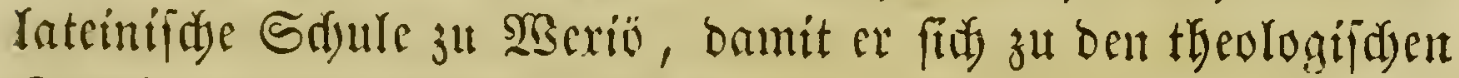

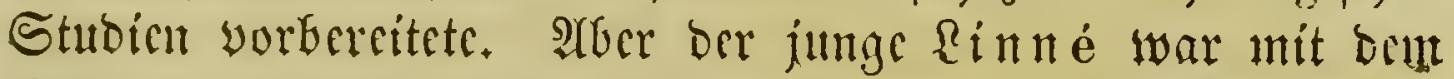

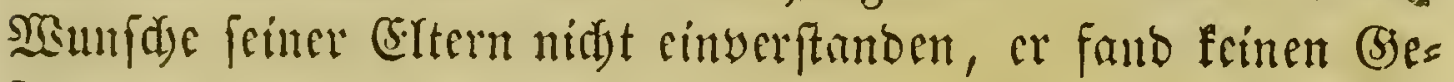
fallen an Dem Spradjfubium und ging gar zut gern neben

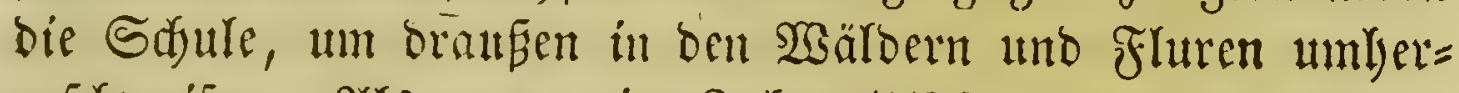

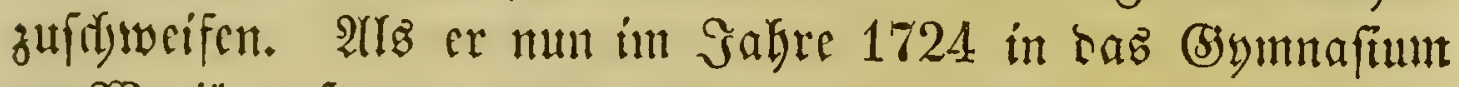
zu $\mathfrak{S}_{\mathrm{a} x}$ iö aufgenommen worben war, erflärten feine Rebrer,

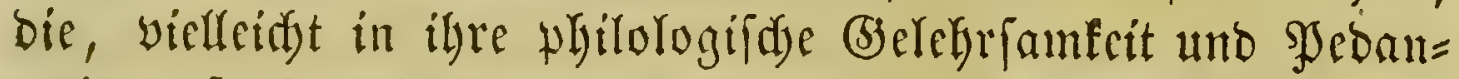
terie verfunfen, jebes andere geiftige Streben nidft zu würbigen verftanoen, bem armen $\mathfrak{B a t e r , ~ d a j z ~ f e i n ~ S o l j n ~ z u m ~ S t u b i r e n ~}$ nifft tauge, er werde ifn beffer ein J̧andwerl crlernen laffert. So friner fdönften 5̧offmung beraubt mo über dic Träghcit frines Rimbes erbittert, fafite ocr alte Rinnè ben Sintid)lub,

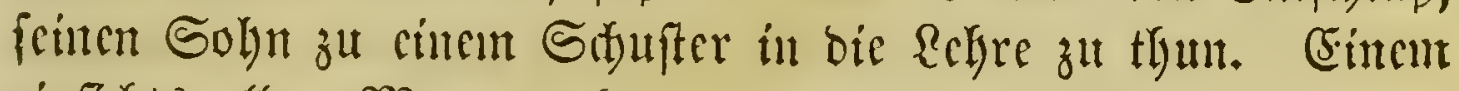
cimfid)tgvollen Manme aber, bem Provinzialarzte Gobann

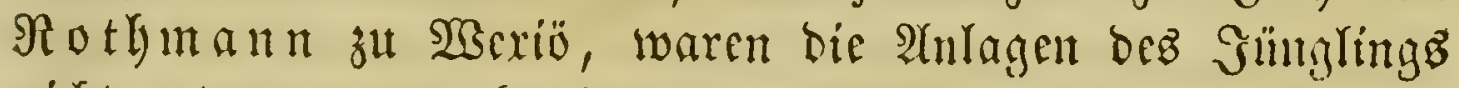
nidyt entgangen, cr beredete ben $\mathfrak{B a t e r}$ zur $\mathfrak{A}$ cnoerung feincs

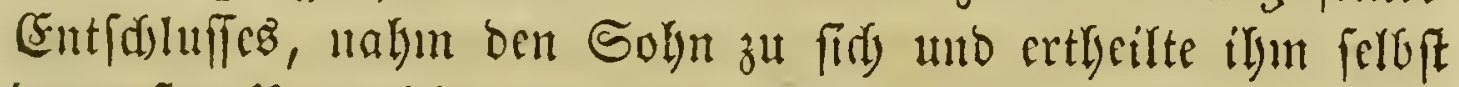

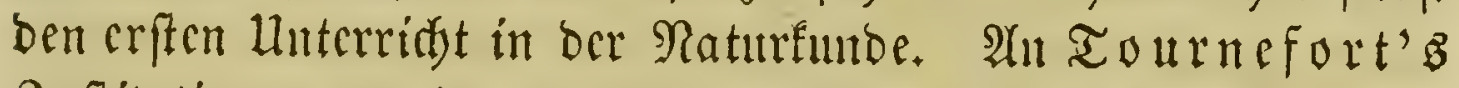

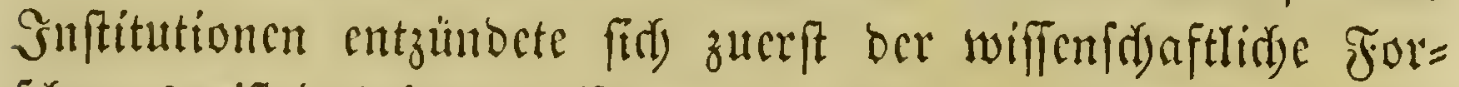

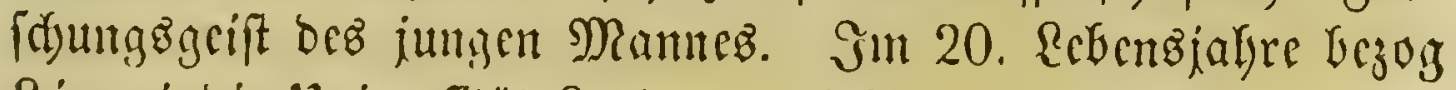
Rinแ é die lnniverfität \{uno, un fiff bafelbft ber Mesicin zu wiomen. alber er befand fid, bort in sen bürftigften Berbält= 
niffen, uno mur burdi) bie vätcrlidye Unterftülung beB bortigen

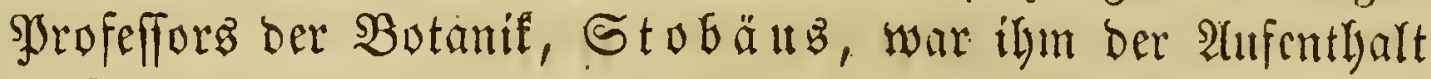
zu \&uto übcrhaupt möglidi). Bald barauf begab er fid nadi Ilpfala und fetste burt in ber brïfendften Rage, oft ofme bie

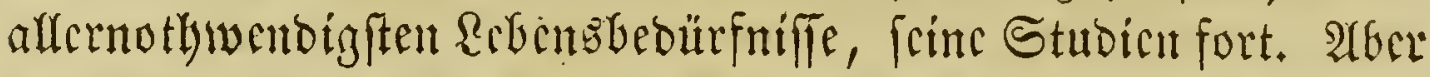

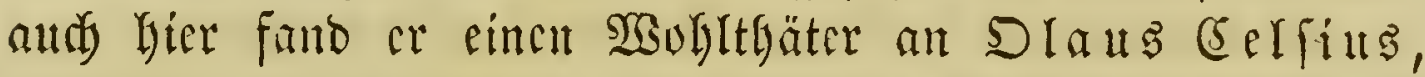
sprofeffor ber Theologie, ber als botanifder Sdyriftiteller in ber vorbergehenoen Seriode crwälnt warbe. 3u bicier 3cit

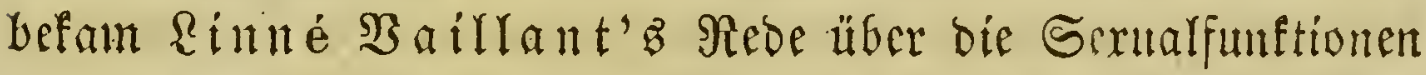

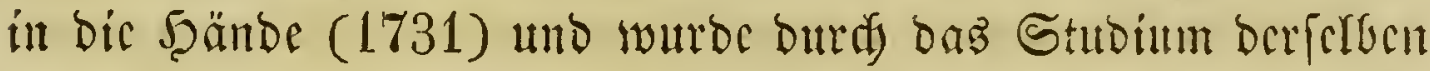

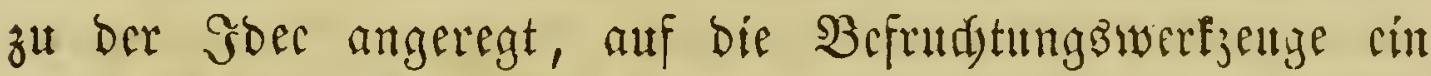
nettez Syftem zu grïltocn.

Die erften Spuren biefer Goee fint in frinem Hortus uplandicus (1731) nicbergelegt. Diefe Serrift zog bie $\mathfrak{A} u f=$

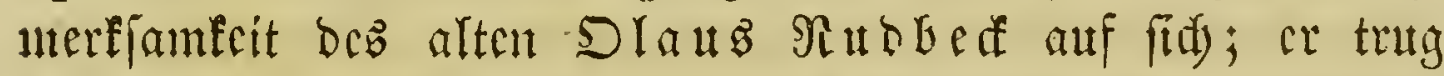
Rinné auf, ben Stutoirenden bie syflangen in bem botanifden

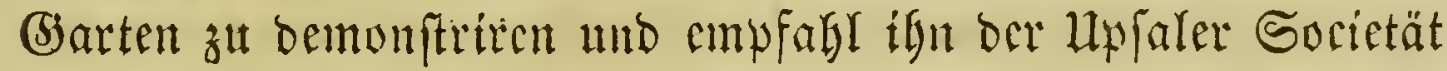

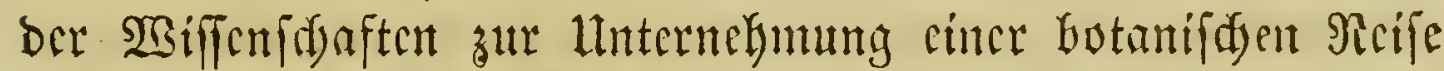

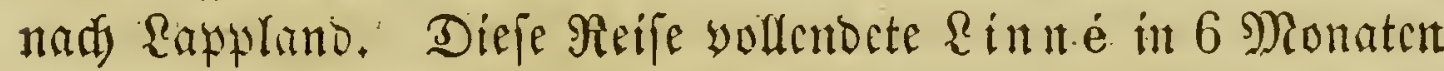
uno Yegte die Refultate berjelben in feiner Flora lapponica

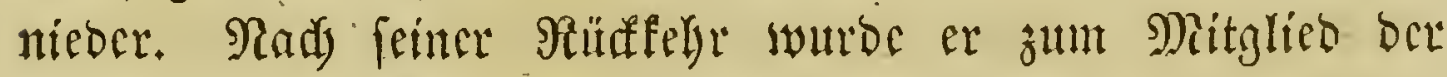

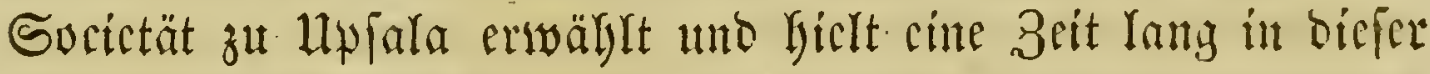
Stabt Borlejungen über Botantif. Da er jcouts nod feitcut

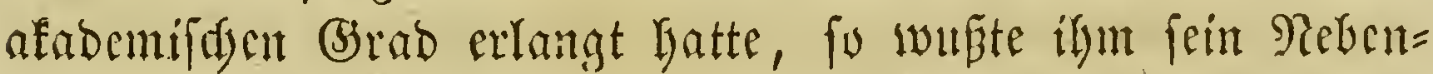

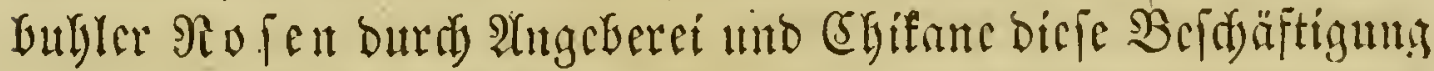
zu verlciben; er unternalym beshalb cite Reife mady Dalcfar= rien, unb lychlt bant fut Fablun Borlefungen über Mincralogie.

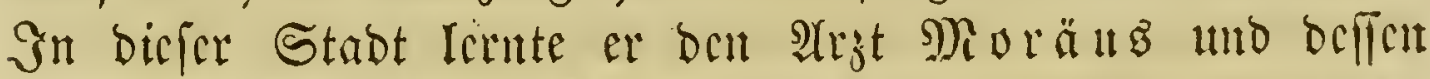

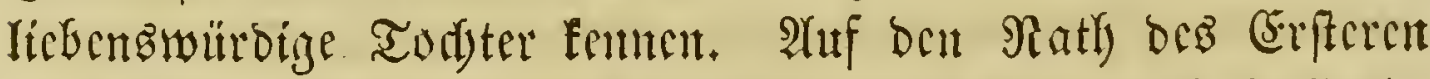

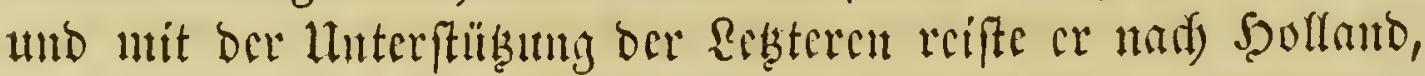

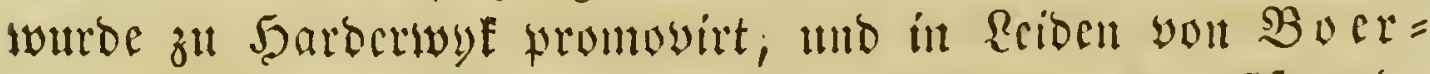

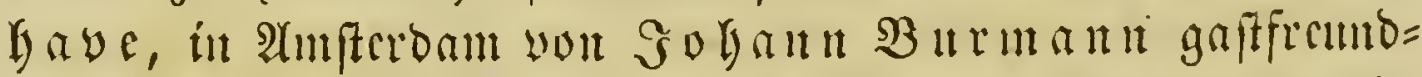

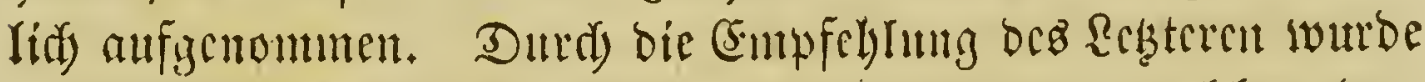

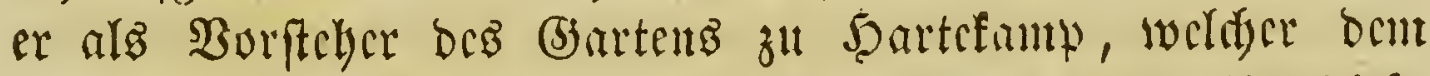

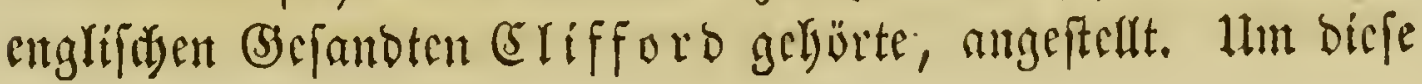


3eit (1735) forrieb er fein Keruilymtes Syftem ber Ratur uno

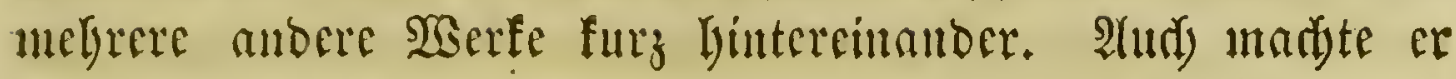

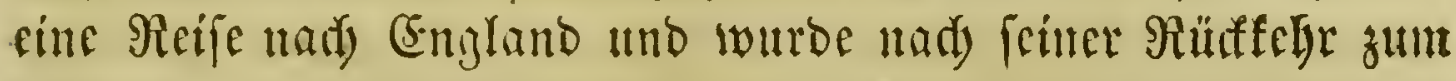

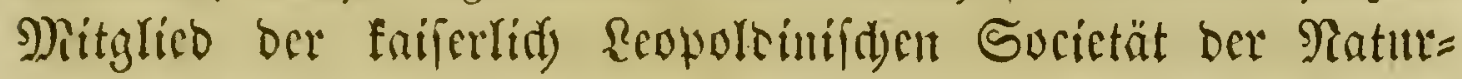

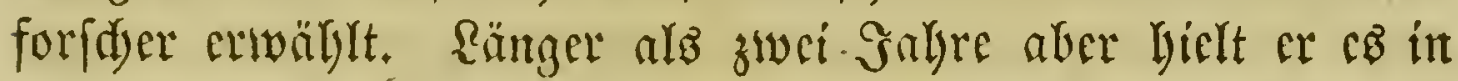

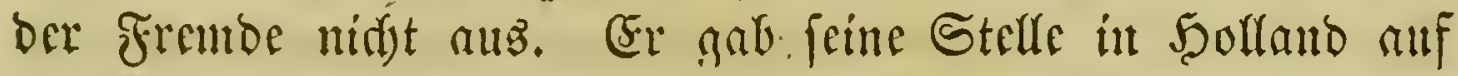

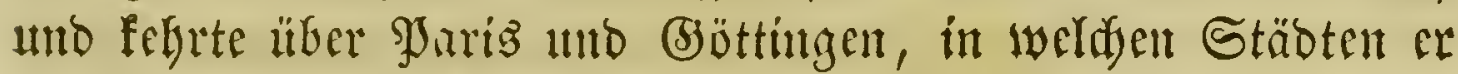

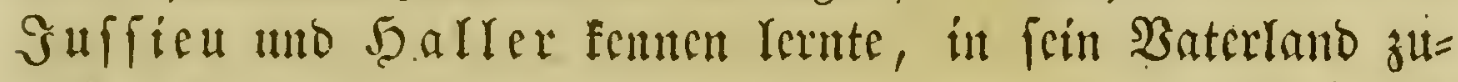
riide. Dort aber erwarteten ify anfangs feine glänzentent

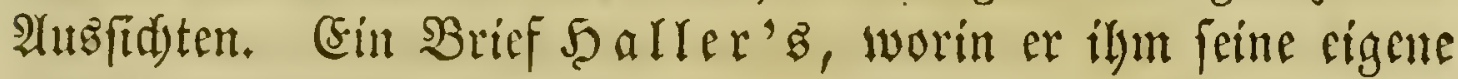

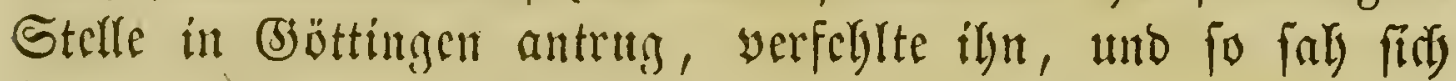

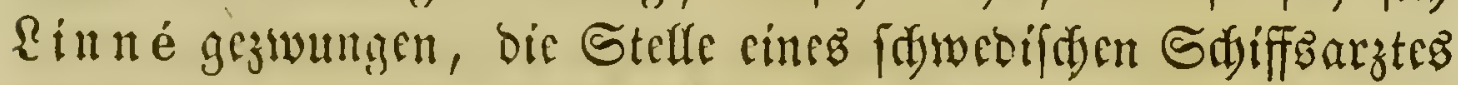

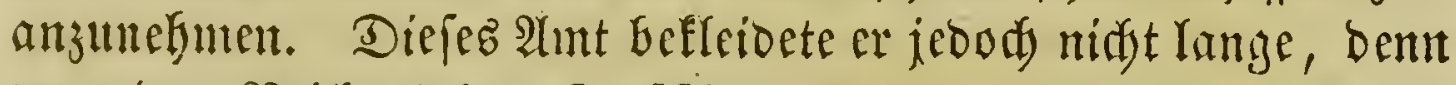

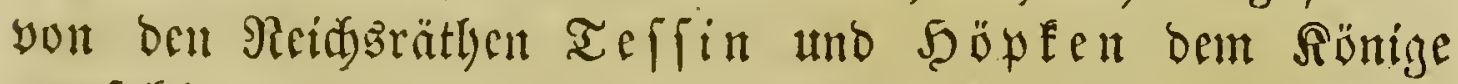
empfolilen, warbe er von bicfent zum fünigliden $\mathfrak{B}$ otanifer

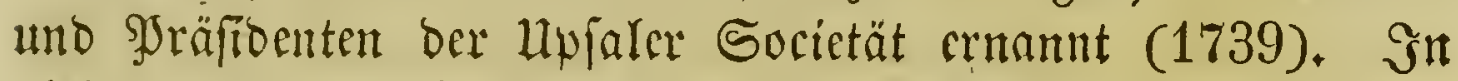

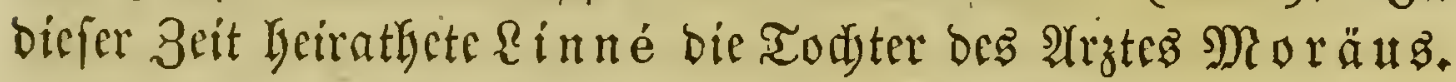

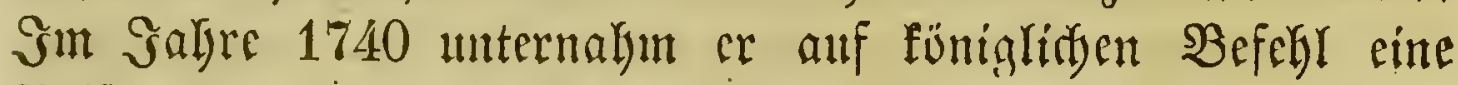

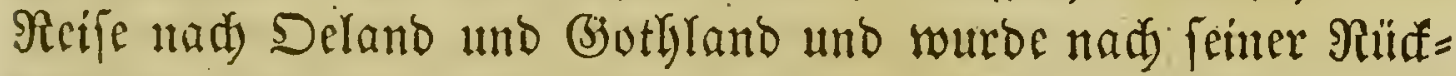
felyr zum Srofeffor ber Medicin und :Nnatomic zu ltwfala er=

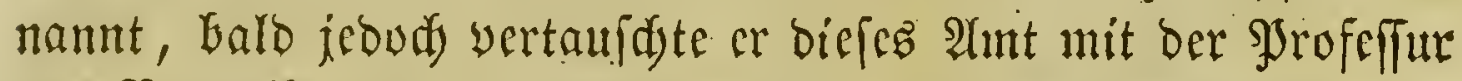

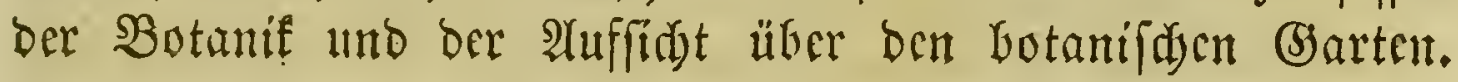
Ber alte Rinnè erlebte diez Giliä feinez Sognez uno fonnte

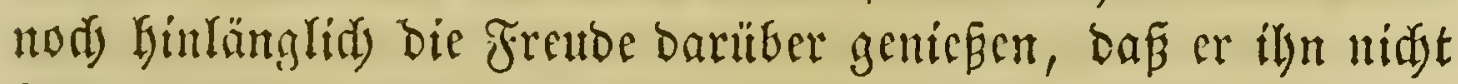
lyatte Schufter werben laffert. 36 Salje lang warr sinné Jrofeffor in Mpfala. Sein Rünig fowolgh wie bie gelelyrten

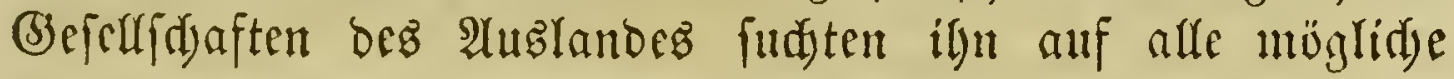

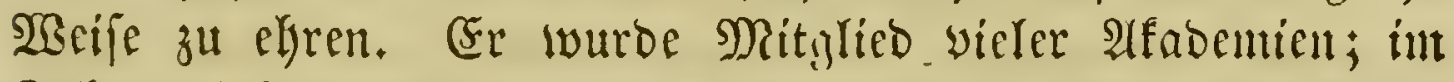

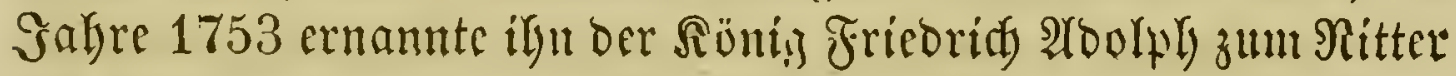

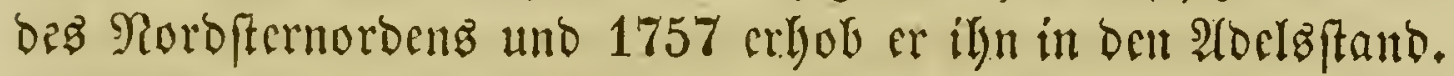

Rinné ftarb am 10. Sanuar 1778.

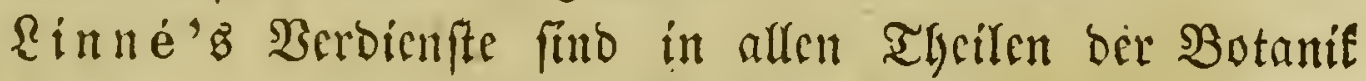

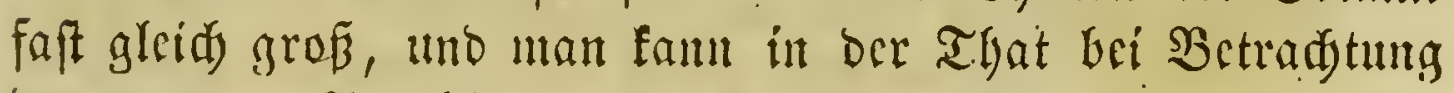

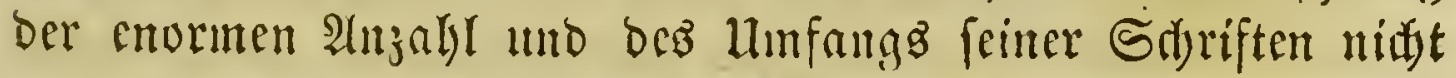
genug ben eifernen flcíp biejez Mannez Griwundern. 
Sdyon in feinem 24. Secbengialyre fam sinné - wie oben crwähnt - auf ben (scoanten, bie Befruditungsiwerf zeuge zur (S)runblage cincs Syftems zu nelymet. (Er wurbe zu biejer Foee zunädyft burdi $\mathfrak{Y}$ aillant's Sermo de structura florum, bann aber aud) fiderlid) burd Sy a trif $\mathfrak{B}$ Iair' $B$ und

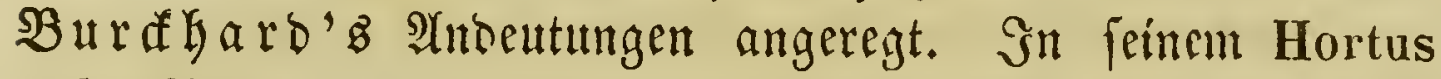
uplandicus (1731) beutcte cr zuerft auf diefe Goee lin. Bon mun aber wante or alle frine 2 ufmerf famfeit auf jene widytigen Drgane uno in feinen Sibriften, bie in ben Jabren 1735-38 erfdienen, fübrte or fein Syftem wciter aus. ${ }^{\text {) }}$ )

') Die baupträbliditen Shriften Rinnè's find folgende:

Systema naturae, sive regna tria naturae systematice proposita per classes, ordines, genera et species. Lugd. Batav. 1735. Fol. max. Die 13. 2(uzggabe wurbe von Sof. Friebr. (5) melin, Reipzig $1788-93$ in 3 Theilen 8. bejorgt.

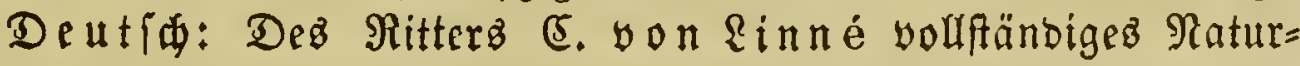

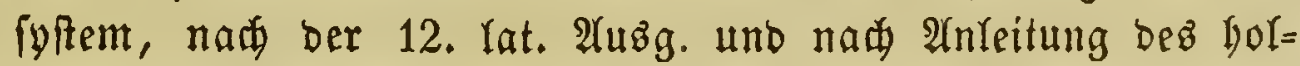

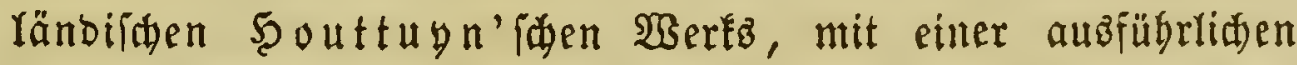

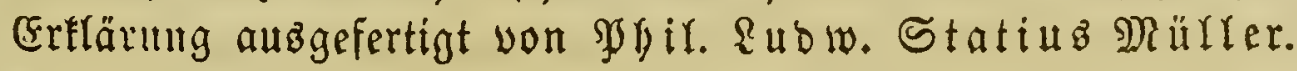
Rürnberg 1773 - 77. 7 T geile ober 9 Boe. 8. - Das Systema vegetabilium 1vuroe fpäter melgrmalż befonderż Geraużgege= ben, zulez̧t von Eurt Sprengel. (3öttingen 182j-28. 8. Fundamenta botanica, quae majorum operum prodromi instar theoriam scientiae botanices per breves aphorismos tradunt. Amstelod. 1736. 8. Zulcht Gerauzgegeben won Jean Emanuel Gilibert, Coloniae Allobrogum 1786. 8.

Bibliotheca botanica. Amstelod. 1736. 8. Halae-Salicae 17'17. 8. Amstelod. 175̌1. 8.

Musa Cliffortiana. Lugd, Batav. 1766. 4. - Hortus Cliffortianus. Amstelod. 1737. Fol. - Viridarium Cliffortianum. Amstelod. 1737. 8.

Flora lapponica. Amstelod, 1737. 8. Sim Salgre 1792 vout

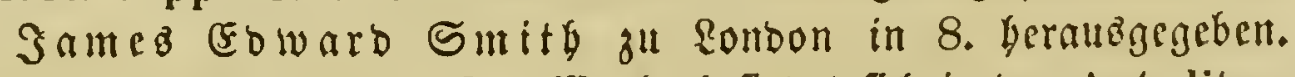
Der $\mathfrak{B}$ orläufer zu biefem $\mathfrak{B}$ erfe befindet fid in ben Act. liter. et scient. Sueciae 1732 p. $46-58$. 1735. p. 12-23.

Genera plantarum eorumque characteres naturales secundum numerum, figuram, situm et proportionem omnium 
Dicjes befteht aus 24 Rlaffen, welide mady folgendon Merfmalen unterfdicoen funo:

\section{Itnterideibungsmerfmale bes erfiten Grabes.}

Die Befruditungäwerf $f_{j}$ enge fulb:

I. $\mathfrak{w a b r n e f} \mathfrak{m b a r e}$,

II. verborzene.

fructificationis partium. Lugd. Batav. 1737. 8. Reuefte 2uşgabe: Edit. nova, curante Curtio Sprengel, Goettingae $1830-31.2$ voll. 8. Deut (4): (J)attungen ber Wflanjen und igre natürliden Merfmale. Rady ber 6. Alusg. uno ber exfen ullo jweiten Mantiffe überfest bon 30 . Jac.

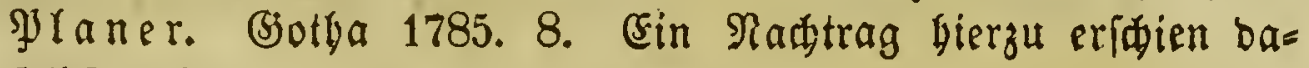
Feloft 1785.

Corollarium generum plantarum, exhibens genera plantarum sexaginta, addenda prioribus characteribus expositis in generibus plantarum. Accedit methodus sexualis. Lugd. Batav. 1737. 8.

Classes plantarum, s. Systemata plantarum omnia a fructificatione desumta etc. Fundamentorum botanicorum pars II. Lugd. Batav. 1739. 8. Halae, 1747. 8.

Critica botanica, in qua nomina plantarum generica, specifica et variantia exanini suhjiciuntur etc. Seu fundamentorum botanicorum pars IV. Lugd. Batav. 1737. 8. Flora suecic:a. Stockliolm. 1745, 1755. 8.

Öländska och Gnthländska Resa på Riksens Högloflige Ständers befallning förröttad åhr 1741. Stocklıolm och Upsala 174.5. 8. Dentid: Serrn Çarl'z yon Rinné Sieifen burd Deland und Gothland. Şatle 1764. 8.

Wästgöta-Resa, på Riksens Höglonige Ständers Befallning lörrättad ăr 17r6. Slockholm 1747. 8. Deutid: Sorrn (5arl's yon \&innè Reifan burd Weftgotgland. Şalle 1765.8.

Flora zeylanica. Ilolmiae 1717 et $\Lambda$ mstelod. 1718. 8. Hortus upsaliensis. Stockholmiae 17:8. 8.

Materia medira, liber I de plantis. Ilolmiae 17498.5. 2usg. von 3. (S. D. Sdic ber, Scipzig und Ertangen. 1787. 8. ๔. Bindler, Brff. B. Bstanil. 
Interfacioungsmerfmale bes z weiten Grabes.

I. Die walginelinbaren Befrudtungsiverfyeuge beftelyen:

A. $\mathfrak{a} \mathfrak{u} \mathfrak{B}$ 3witterbläthen, b. h. männlidye und weiblide (sefdiledytsorgane find in einer Blüthe vereinigt; oder

B. bie männliden und weibliden (s) $e=$ fidedisorgane find getrent, b. h). auf veridiedenen Frudjetbon befindlidy.

Amoenitates academicae. VII voll. Holmiae et Lipsiae 1749. 8. Vol. VII - X. Erlangen 1789-90. Zum Theil ins

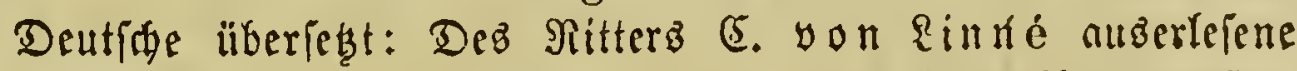

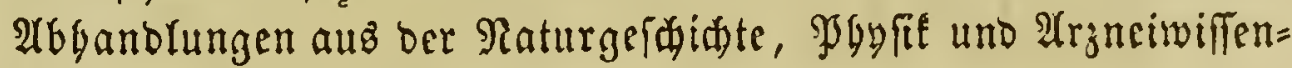
任aft. Reipzig $1776-78.3$ Tble. 8.

Philosophia botanica. Stockholmixe 1751. 8. Die neuefte 2(uøgabe: Caroli Linnaei philosophia botanica, studio Curtiis Sprengel. Tornaci Nerviorum 1824. 8. Deutf Species plantarum. Holmiae 1753. 2 voll. 8. Reueite $2483=$ gabe won carl \&ubivig $\mathfrak{B}$ illo enow. Berlin $1831-33.8$. Mantissa plantarum. Holmiae 1767. 8. 1771. 8.

Termini botanici, classium methodi sexualis generumque characteres compendiosi. Ed. Paul Dietr. Giseke. Hamb. 1781. 8. 2. Auflage 1787. 8.

Praelectiones in ordines naturales plantarum, ed. Paul Dietr. Gies eke. Hamb. 1792. 8.

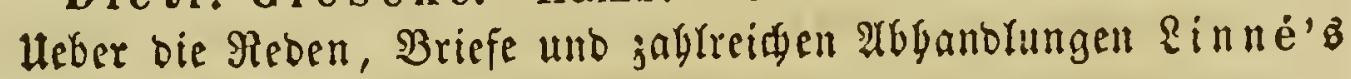
bergleide $\mathfrak{P r}$ izel S. $164-169$.

Heber \&inné'z Ibätigfeit überbaupt:

Orbis eruditi judicium de Caroli Linnaei scriptis. (Hol-

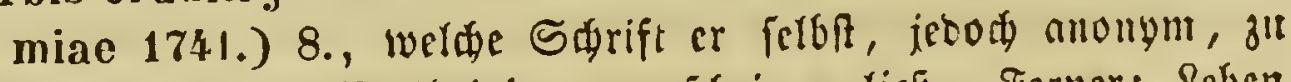
feiner cigenen Bertbeidigung erfocinen liés. Ferner: \&eben

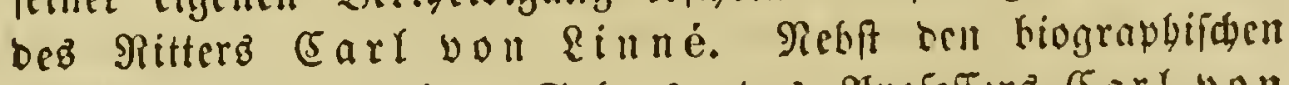

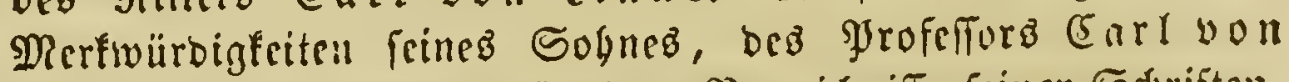
\&inné, und eincm vouriändigen Berjeichniffe feincr Schriften,

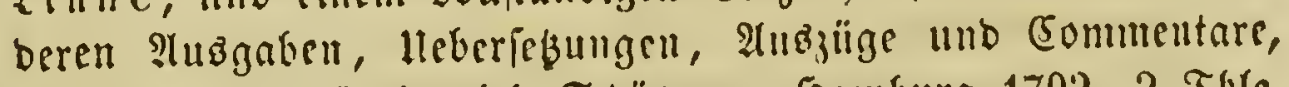
bon Dietrid Şeinrids Stöver. Samburg 1792. 2 Igle. 8. Nadtrag Daf. 1793. 


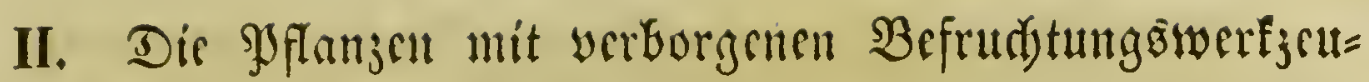
gen madyen mit cille Silaffe att?

\section{Itnterfacibungsmerfmale bes sritten Grabes.}

I. A. Dis Zuvitterblütlyen entlarten

1) frsis $\subseteq$ taubgefä $\mathfrak{B} 6, b$. h. foldse, bie weder unter fids, nod) mit ben Shiftillen verwad) fen fint; ober

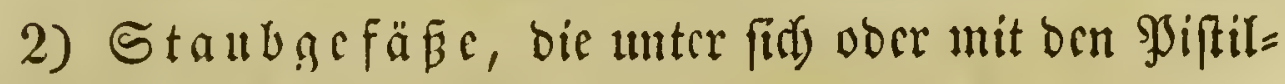
Ien verivadja fant.

I. B. Die ssflanzen mit getrennten (befdyledetern find entiveber

1) einläufige, b. h. foldbe, bei benen fid die männ=

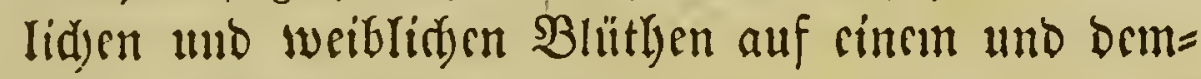
frlben spflaugencxemplare befulden, voer

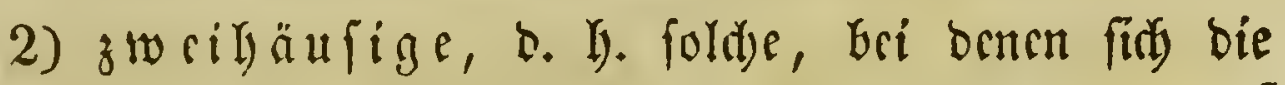

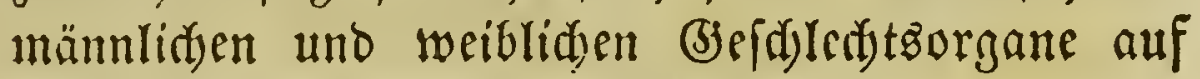
z'vei Syflanzenercmplaren befunten, ober

3) vielehige, b. h. SPlanzen mit 3ivitterblüthen und getrennten (scifbleditern, bie fid) bald auf cinem, bald auf veriduicoenen Gremplaren befinden.

\section{Unteriacioungemerfmale bes vierten Grabes.}

A. 1). Die frsicn Staubgrääe find:

a. gleid)lang, oder

b. unglcid)lang.

A. 2). B̧si ben unfrcien Staubggefäßien fünmen

a. Dis Staubfäten unter fira,

b. Die 2 utheren unter fids,

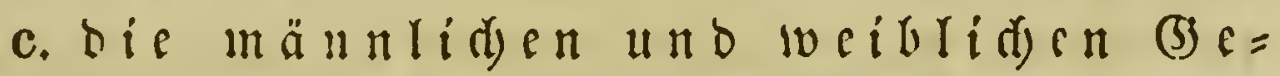

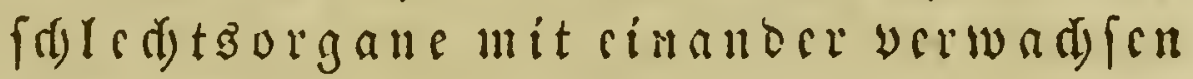
frin.

B. 1, 2 uno 3) unterliegen friner weiteren STafrncin= theillung. 
Itnteridheisungsmerfmale bes fünften Grabes.

I. A. 1) a. Bei ben gleidglangen Staubfăben mađ̆t entrueder

a) ihre $\mathfrak{A} \mathfrak{i} z \mathfrak{b} \mathfrak{l} l$, obcr

b) ifre $\mathfrak{A} \mathfrak{z}$ abl and ihr Standort

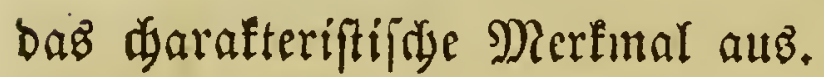

I. A. 1) b. Bei ben ungleid)langen Staubfädon fommt eż auf baz 3ablenverbältnís oer längeren zu ben fürrgeren an.

I. A. 2) a, b unb c. unterliegen feiner weiteren Rlaffen= cintheilung.

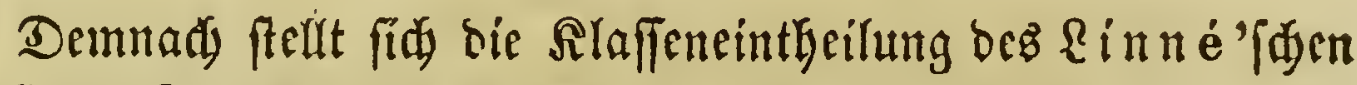
Syftems folgenoergeftalt bar:

\section{Pfingen mit wabrnebmbaren :Befruchtungs: werf́zugen, Plianerogrmia.}

A. Mit $3 \mathfrak{w}$ itterblüthen verfelen, monoclinia.

\section{1) MRit freien Staubgefäpen.}

a. Staubfäben gleidglang. Dic Drbmungen in

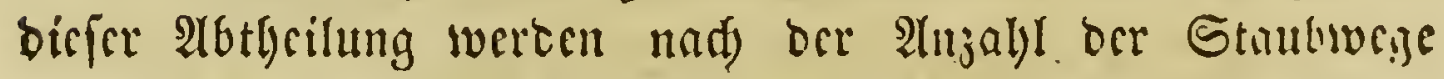
unterfosicoen, wobei jrood zu bemerfen ift, baj bei worfoul=

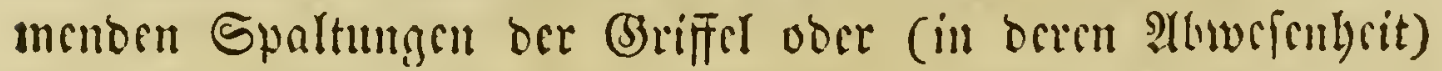

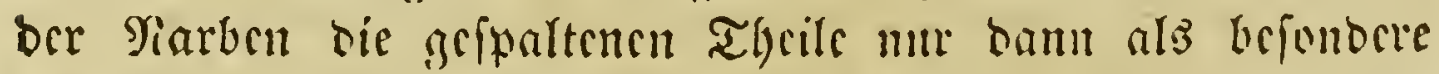

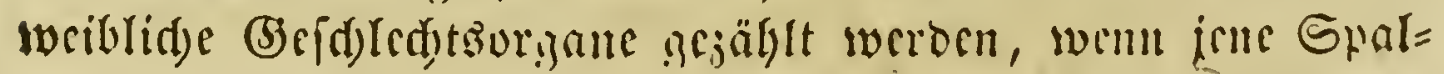

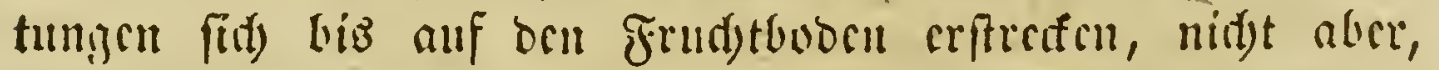

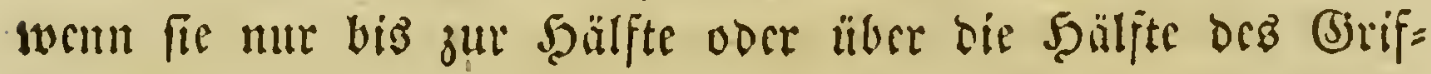
frls gellyet. 
a. Mad Der Aurzabl Der Staubgefäke.

\section{Erifte Rlaffe,}

mit cincu Staubgefäre:

Ginmännige, monandria.

Diefe Alaffe hat ziwci Dronumgen:

Er fite Dronung, monogynia, mit cinem Siftilfe. 3weite Dronung, digynia, mit zivei Siftillen.

\section{3wcite Silaffe,}

mit zivei Staubgefäfen:

3weimännige, diandria.

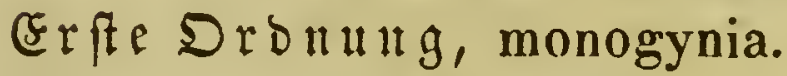
3weite $D$ rounng, digynia. Dritte $D$ ronung, trigynia.

\section{Dritte Rlaffe,}

mit orei Staubgefä $\tilde{B} \mathfrak{e}$ : Dreimännige, triandria.

Erfte Dronu $\mathfrak{3}$, monogynia. 3iveite Dronung, digynia. Dritte Dronung, trigynia.

\section{Bierte Sitafie,}

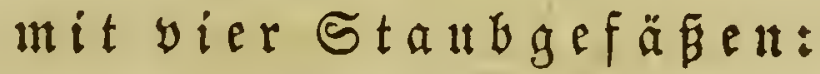
Biermännige, tetrandria.

Erfte Dronung, monogynia. 3 wcite Dronung, digynia. Dritte Dronung, trigynia.

\section{Fünfte $\mathfrak{i l a f l e , ~}$}

mit fünf $\subseteq$ ta $\mathfrak{u} \mathfrak{b} \mathfrak{g} \in \mathfrak{f} \mathfrak{a} \mathfrak{B} \cdot \mathfrak{e} u$ :

Fünfmãnnige, pentandria.

Crefte Dronung, monogynia. 3 weite $D$ rou $u$ n, digynia. 
Dritte Dronung, trigynia.

Bierte Dronung, tetragynia.

Fünfte $D \mathfrak{r} \mathfrak{n} \mathfrak{n} \mathfrak{j}$, pentagynia.

Sed) te Dronuแ , polygynia.

\section{Scchiste Slaffe,}

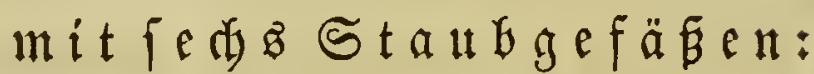

Se๘๋̋männige, hexandria.

Frfe Dronung;, monogynia.

$3 \mathfrak{w e}$ ite $\mathfrak{D} \mathfrak{r} \mathfrak{n} \mathfrak{u} \mathfrak{g}$, digynia.

Dritte $D \mathfrak{r} \backsim \mathfrak{d} g$, trigynia.

Bierte Dronung, tetragynia.

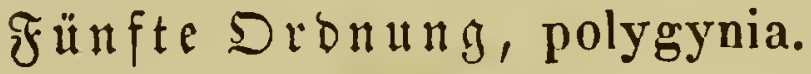

\section{Sickente Silaffe,}

mit fieben Staubgefä źn : Siebenmännige, heptandria.

(5) ffe Droukng, monogynia.

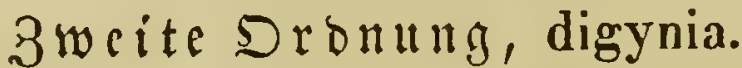

Dritte Dronung, trigynia. Bierte Dronung, tetragynia.

\section{Aldyte Slaffe,}

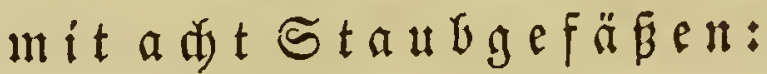

$\mathfrak{A}$ tmännige, octandria.

Erfte Dronung, monogynia. $3 \mathfrak{n e i t e}$ Dronung, digynia. Dritte Dronung, trigynia. Bicrte $\mathfrak{D}$ ronung, tetragynia.

\section{Remute RTafie,}

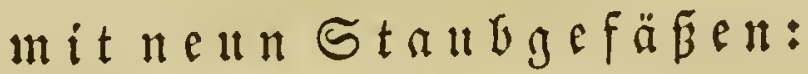

Reunmännige, enneandria.

(F) f f $\mathfrak{c} \mathfrak{D}$ rounn, monogynia.

3 weite Dronung, trigynia.

Dritte $D$ romung, hexagynia. 


\section{3rhute Slaffe,}

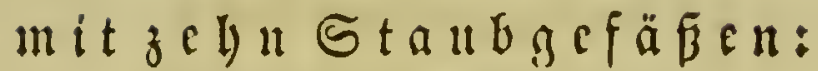

3egnmännige, decandria.

(E) fte Drou un, monogynia.

$3 \mathfrak{w e}$ ite Dronung, digynia.

Dritte Drouung, trigynia.

Bierte Dronung, pentagynia.

Fünfte Dronun\}, decagynia.

Gilfte Slaffe,

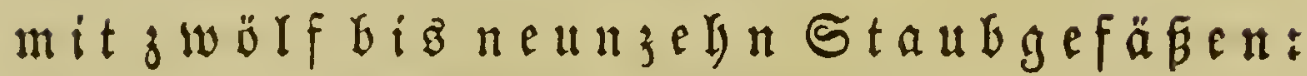

3 wölfinännige, dodecandria.

Erfte Dronu

3 weite $D$ ronung, digynia.

Dritte $\mathfrak{D}$ ronung, trigynia. -

Bierte Dronung, pentagynia.

Fünfte Dronung, dodecagynia.

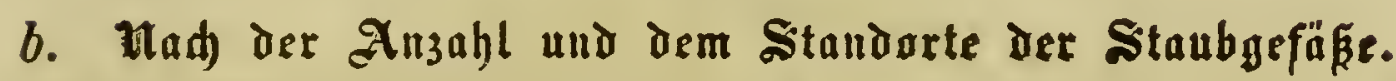

\section{3ivolfte Silaffe,}

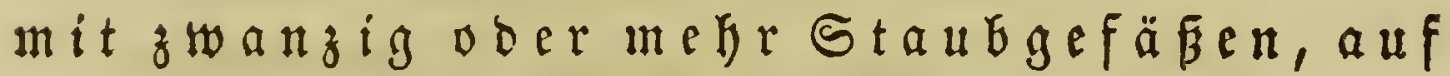

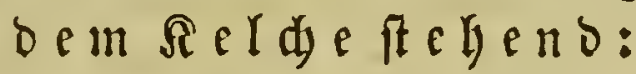

3wanzigmännige, icosandria.

Erfte $D \mathfrak{r} b \mathfrak{n} u \mathrm{~g}$, monogynia.

3ivcite $D$ ronung, digynia.

Dritte Dronung, trigynia.

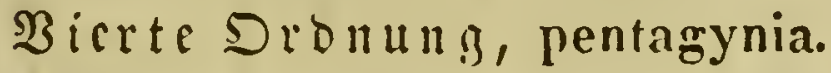

Fünfte $D$ ronun!, polygynia.

Drcizclinte Rlaffe,

mit zwanzig ober meld Staubafefäben, auf dem

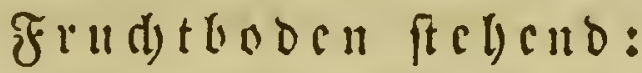

Bielmännige, polyandria.

Frfte Dronung, monogynia.

马ueite Dronung, digynia. 
Dritte $\mathfrak{D}$ onung, trigynia.

Bierte Dronung, tetragynia.

Fünfte $\mathfrak{D}$ rounis, pentagynia.

Sedite Dronung, hexagynia.

Siebente Dronung, polygynia.

b. Staubfäben ungleidlang. Dí Syflanjen bie= fer arbtheillung lyaben alfe nur ein Siftill. Darum fübrt Linné zul Unterideibung ter Dronungen bie Beidaffenleit ber Früdte alz Merfinale an.

\section{Bierzchute Rlaffe,}

mit zuei längereu uno zivei fürzeren Staubfäben: 3 weimäntige, didynamia.

(Erfte Dronumg, naftfaunige, gymnospermia. 3weite Drbung, bededtfamige, angiospermia.

\section{Fïnfzchute Slaffe,}

mit yier längeren und zwei fürzeren Staubfäben: Biermäntige, tetradynamia.

(Erfe Dronung, siliculosa, fdötdyenfrïdtige. 3twe ite $D$ ronun 马, siliquosa, figoterfrüditige.

2) Staubgrfäßze unter fịh oder mit sem

a. Staubfäben unter fid verwad fen. Sn biefer 2(bthcilung werben Die Dronungen mad) Der $\mathfrak{A n}_{j}$ abl ber Staub= fäben beftimunt.

\section{Srafizzclynte Slaffe,}

bié Staubäben find in ein $\mathfrak{B}$ ünof verwaden:

Einbrïberige, monadelplia.

(Erfte Dronung, triandria.

3weite Dibung, pentandria. 
Dritte Dronung, octandria. Bierte Dronung, endecandria. Füufte $D \mathfrak{r} \backsim u n g$, dodecandria.

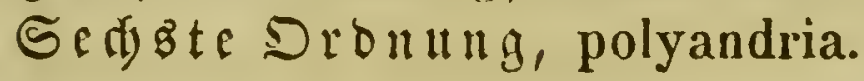

\section{Siekoughnte Rlaffe,}

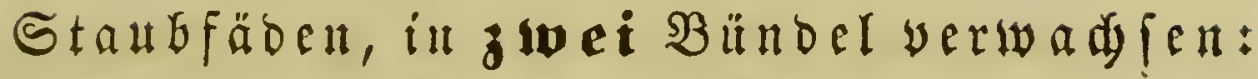
3weibrüberige, diadelphia.

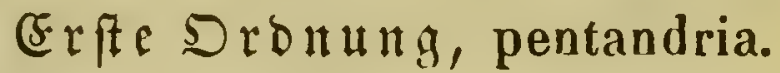
3iveite Dronung, hexandria. Dritte Dronung, octandria. Bierte Dronung, decandria.

\section{2(d)tzelyute אIaffe,}

Staubfäben in Drei voer mebrexe Bändel werwadif $\{$ :

Siefrrüberige, polyadelphia.

(E) $\mathfrak{f t e} \mathfrak{D} \mathfrak{r} \mathfrak{d} \mathfrak{u} \mathfrak{g}$, pentandria.

$3 \mathfrak{w}$ ite $D \mathfrak{r}$ nung, icosandria.

Dritte $D \mathfrak{r} \mathfrak{n} u \mathfrak{g}$, polyandria.

b. Die Antheren find unter fidyerwaden.

\section{Neutzehute Rlaffe,}

mit fünf verwadifenen atheren:

Mitzeugenbe, syngenesia.

Eine fermere sigenthiumlidefeit biefer Rlaffe ift, bả fie

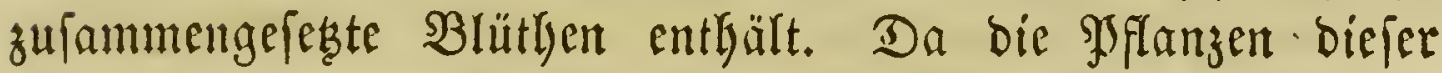

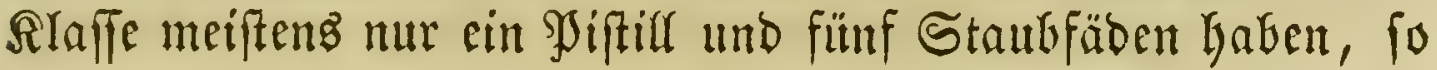
fonnten biefe beiben Digane bei ber Eintbeilung ber Dro= nungen nid)t alo Interideibungsimerfmale angenomment wer= 
ben. Rinné theilte beşhall alle SPflanzen biefer. (Sattung in zivci Âtbtheilungen:

A. M o n o g a m i a, b. h. Sflanzen mit einfadjen $\mathfrak{B l u ̈ t h e n . ~}$ B. P oly g a mia, D. G. Pllangen mit zufammengeferstent Brüthen.

Die Ietitere Abthelung theilte er wieberum:

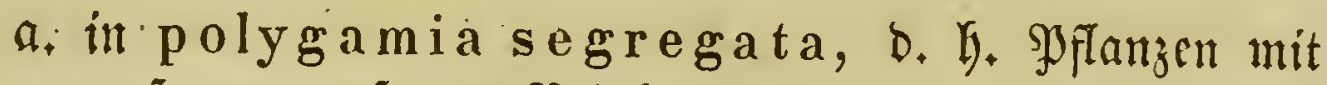

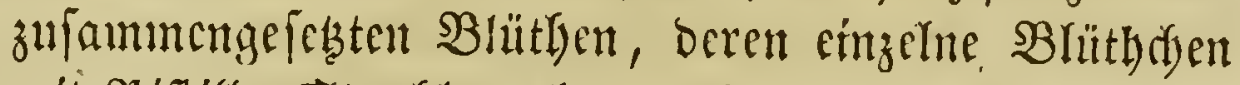
mit Siftill, Staubbeutel und cinem bejonderen Reldye werfehen fino;

b. polygamia simplex, D. h. STflanzen mit zut faumengeferten $\mathfrak{B l u ̈ t h e n , ~ D e r e n ~ e i n z e l n e ~ B l u ̈ t h d j e n ~}$ bon einem gemeinfdyaftlidjen âdde umfdloflen find.

Die abtheilung $\mathfrak{b}$. zerfpaltete er in

aa. polyg a mia a equalis, D. G. Sglanzen mit zu=

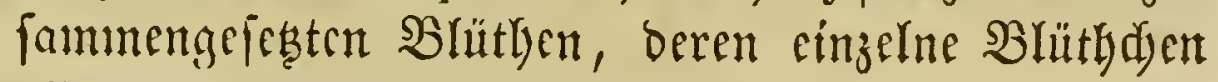
alfe 3witterblütten find;

b6. polyga mia spuria, b. h. Şflanzen mit zulam=

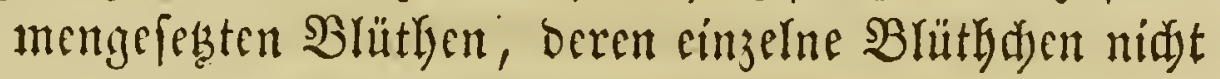
alle Ziwitterblüthen find.

Diefer 2 btheilungbr. gab er brei Dronungen: aan. polygamia superflua, b. H. Pflangen mit zulammengeferten SBlüthen, weldye in ber Sdjeibe 3witterblüthen und in Stragle ober am Pande

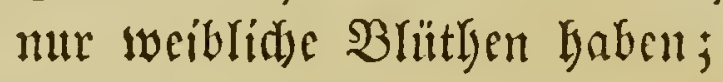

bbG. polyg a mia frustranea, D.h. Pflangen mit $\mathfrak{u}=$

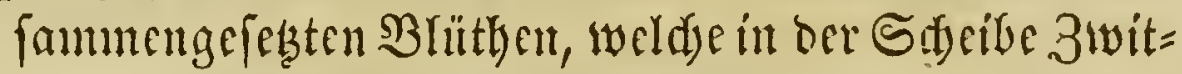

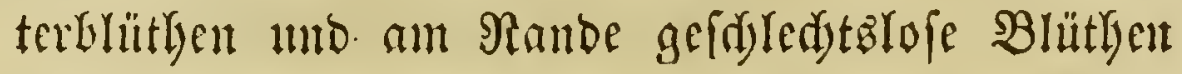
laken;

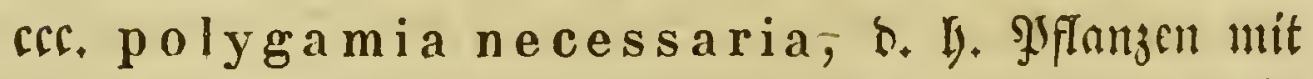

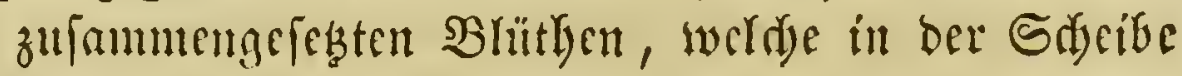

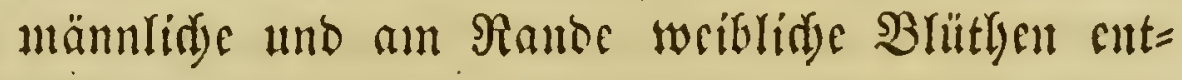
Lalten. 


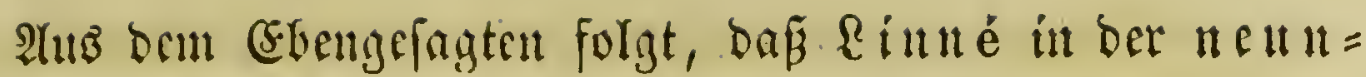

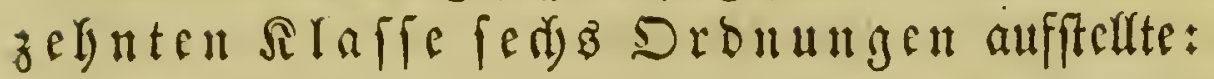

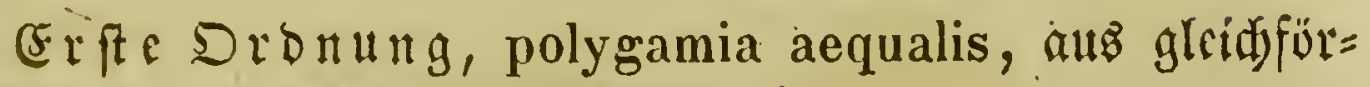
mig wielehigen Syflangen befteheno.

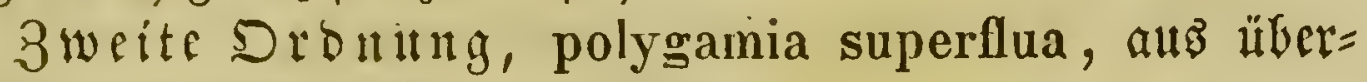
flüffig vieleligen Syftangen befteleno.

Ditte Dronıng, polygamia frustranea, aub ver= geblid) wiclerigen SJflanzen beftehend.

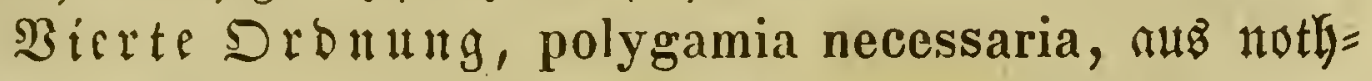
wendig vielebigen Sfflangen beftelgeno.

Fünfte Dronung; polygamia segregata, aus $g e=$ trennt vielefigen Jflanjen Keftelyent.

Sed ste Dronung, monogamia, auts cineligen Syllan= zen beftelient.

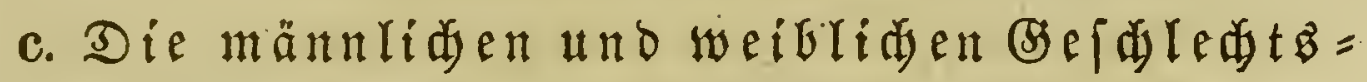
organe find mit einander verivad fen.

\section{3wanzigfte Rlaffe,}

Gynandria.

(Eine gemeinfdaftlide Säule trägt die mit einander yerwad) fencumäntiden uno weibliden (be) dedetiorgane.

Diefe Srafie bildet ifre Dronungen and ber Anzal ber Staubbeutel.

(Erfte Dronung, diandria.

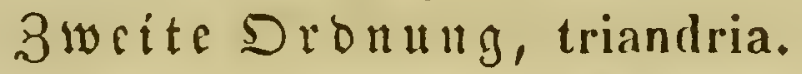

Dritte Dromung, tetrandria.

Bierte Dronung, pentandria.

Fünfte $\mathfrak{D}$ ronung, hexandria.

Sediste Droulng, octandria.

Siebente Dionung, decandria.

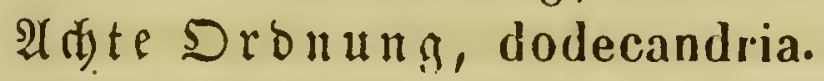

$\mathfrak{R} \mathfrak{u n t e} \mathfrak{D} \mathfrak{\mathbb { D }} \mathfrak{u} \mathfrak{n} \mathrm{g}$, polyandria. 
B. Syfanzen mit getrenten (5) efdredtern, diclinia.

\section{Giunnozivanzigfte Rlaffe, \\ 1) einläufige, monoecia.}

Die Dronumgen biefer Rlaffe werben nad ber

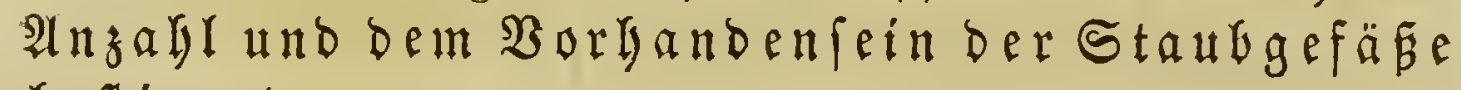
beftimat:

Erfte Dronung, monandria. 3weite Dronung, diandria.

Dritte $\mathfrak{D}$ ronung, triandria.

Bierte Dronung, tetrandria.

Fïnfte $D \mathfrak{r} \mathfrak{n} \mathfrak{n} \mathfrak{g}$, pentandria.

Sedgte Dronung, hexandria.

Siebente Dronung, heptandria.

$\mathfrak{A}$ d) te $\mathfrak{D}$ onung, polyandria.

$\mathfrak{N u n t e} \mathfrak{D r b} \mathfrak{n} \mathfrak{n}$, monadelphia.

$3 \mathfrak{c h n t e} D \mathfrak{r} \mathfrak{n} \mathfrak{n} \mathfrak{n}$, syngenesia.

(Eilfte Dronung, gynandria.

\section{3weiundzwantigfte Rlaffe,}

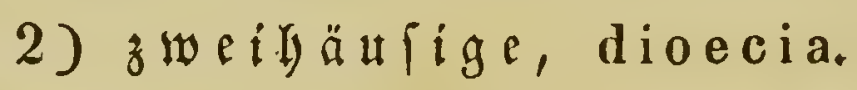

Die Dronungen in biefer Rlaffe find biefer = bente in fer vorigen.

Dreiultozuanzigfte Alaffe,

3) vifelebige, polygamia.

Die Dronungen biefer alaffe werden nad ber berfdedenen bertheilung ber (Befdeleder be= ftimint:

(E) r fte Droutng, monoecia, cinthäuft\}e. 3we ite Dronung, dioecia, zweifäu低e. 
Britte Dronung, trioecia, oreifäuftge, D. G. folde şflanjen, bei benen auf bem cinen Stamm bloz mämnlidje, auf bem nicberen Glos weiblidue uno anf Dem britten 3witter= blüt)en worfommen.

\section{II. \$flanjen mit verborgenen Befruchtung werf zeugen, Cryptogamia.}

\section{Sierundzwanzigfte Slaffe.}

Die Drounngen biefer Rlaffe werben nady

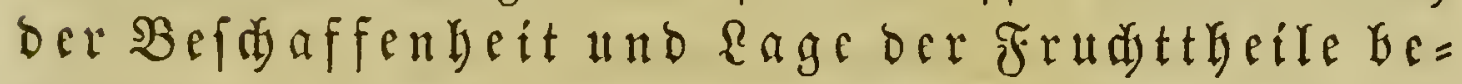
ft imut.

(Er fte Dronung, Farrenträuter, filices.

3weite Dronung, Moofe, musci.

Dritte Dronung, Algen ober Fledten, algae.

Bierte $\mathfrak{D}$ d nung, Srawämme, fungi.

Die Salmen befandelte Rinné in eitnem befon= beren $\mathfrak{A} \mathfrak{n} \mathfrak{l} \mathfrak{a} \mathfrak{g}$.

Eine grofe (5rleidyterung in ber Darfteffung ber (Setwädy fe fülyrte er aber nodj badurdy ein, bạ ar jeber Sfflanze einen (j)attungs = tmb cinen Trivialnamen gab. Durdi) Diffe zwet Bezeidunungen iwar mun die SSflanze volftändig genau bezeid)= net, uno alfe Umidreibungen wurben ïberflüffig.

So groß̋e $\mathfrak{B e r a ̈ n d e r u n g e n ~ m u f i t e n ~ n a t u ̈ r l i d ) ~ g e w a l t i g e ~} \mathfrak{A} u f=$ regung unter ben Botanifern herworbringen. Man hatte zwar feither hier uno ba won ben zwei (befd)ledstern ber glflanzen gerebet, überallbin war feit $\mathfrak{B a}$ all a nt eine gewifle 2 llynung yon ber ridytigen $\mathfrak{B} e$ fruddtungsthecrie gebrungen, aber baf ein Botanifer, uno zwar cin nodi) fo junger Mann, wie \{inné, es wagte, mit ber föärfíten (Sonfequen die mäm= lidjen und weiblidjen Serualien von einander zut tremen uno. 
Die Berfdyiedenheit biefer Trennung zur B̧nfis eines neuen Syftems zu mad)en, bas war unerbört. 2(tber Rinné trug feine Rebren fo flar uno übergengeno vor, dap balo cin grofer Theil feiner. 3eitgenollen fït ilgn getwonnen war. Dod

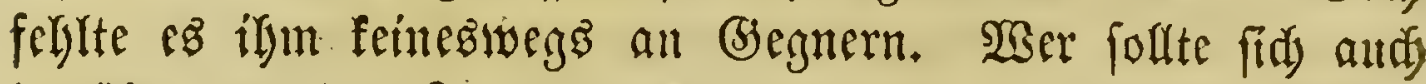
barüber twutuern? Reue A(nfidjten, die bebeutende Folgen mari) fid zu zielyen verfpredyen, ftopen oft ferbfi bei Männern,

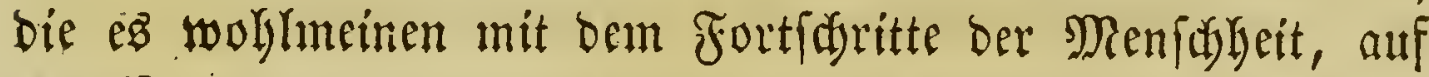
Ziweifel und harte $\mathfrak{B}$ iberfprithe, zumal wenn biefe Amfinten nod) nidst erftarft genutg find, am jeben Feind fiegreid zu be= fämpfen. Sat es ja bod felbft in unferem Sahrthuderte, Das alfe biejenigen Betweife, weldibe sinné felbft für bie Wabrheit feines Eyftems nidyt beibringen fonnte, nachgebult hat, seute gegeben, bie hartnäfig uno harthürig gemug waren, un bie neue Serualtheorie überbaupt für unftattbaft zu Galten, yiefleid)t aus einem ägnlid)en (Jirunbe, wie jone grofe PJarté

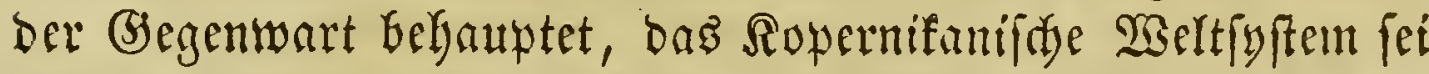
unwahr, weil es ben 2 nfideten ber biflifden $\mathfrak{A}$ tutoren wiber= fpredje.

Raum war bas Rinne' fibe Syftem befannt getworben, fo

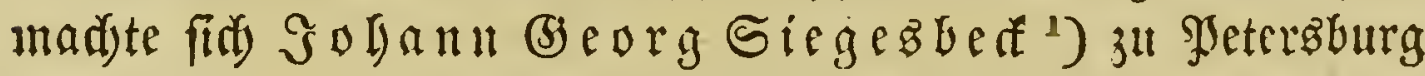
Dariber her. Sein Şauptgrumb gegen baffelbe ift originet gemuj. (Er Gebauptete nämlid, bie ganje Regre yon ber $\mathfrak{B} e=$ frudtung fei verwerflid, weil fie gegen bie Sittridjeit an= fämpfe. 2(ber er werwarif audi alle übrigen Berbefferungen Sinne's, biefleidy weil er biefen groben Mann überheut als eine umreine Duefle anfah, mit beren trïbem salfer er feine unfdurbigen Sä̈nde nidyt beflefen wodtè. Şätte Sie=

.) Botanosophiae verioris brevis sciagraphia. Petropoli 1737. 4. Im 2(nyange: Epicrisis in Linnaei systema plantar. sexuale et huic superstructam methodum botanican. -

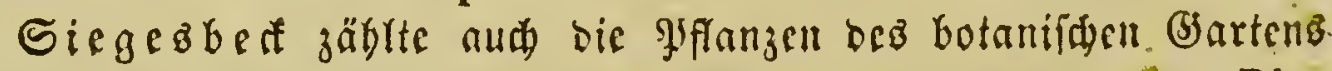
zu gfeterşburg auf: Primitiae florae petropolitanae. Rig. 1736. 4. Suppl. ib. 173\%, 4. 
geBbef zu utrerer Beit getebt, wo fo viel über bie ernt=

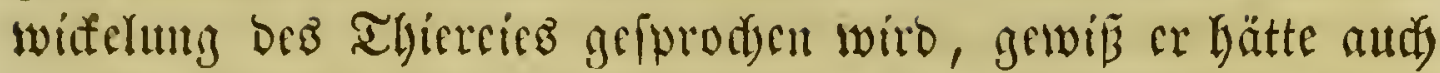

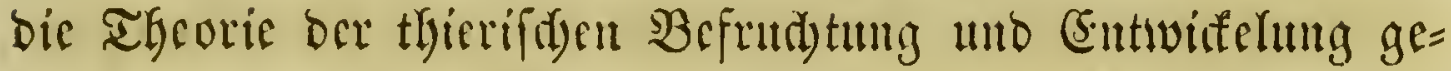
läugnet wnd aus fittlidgen (S)ründen belyauptet, bie jungen Sindcin whirben von ber \$̧ebanme aus bem Brumen geljolt Dber you bem Storde durd) Den Sryormftrin gebradjt. Gegen Siegeb f a traten $\mathfrak{g}$ obann $\mathfrak{B}$ roival ${ }^{1}$ ), geb. 1707, geft.

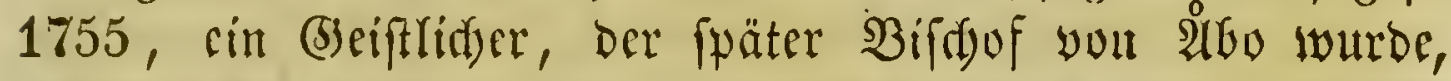

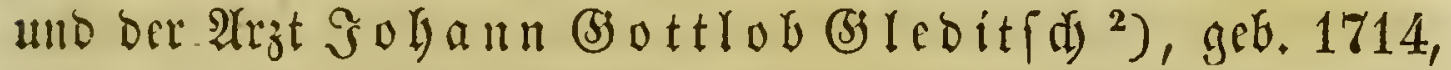

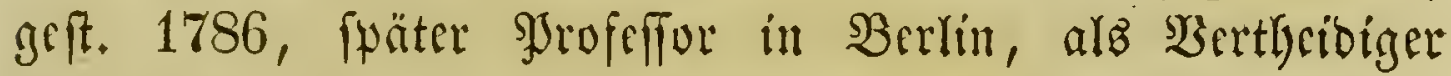
Rinné's auf. In friner (Erwiorung ${ }^{3}$ ) auf bie Sityrift bes

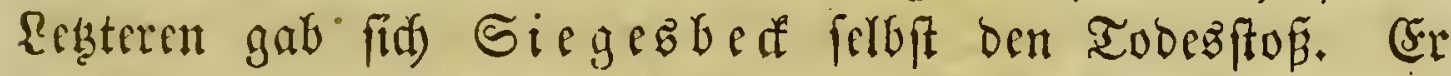
brad) Darin mämlidy in cinem fo tutwürbigen Tone gegen feine

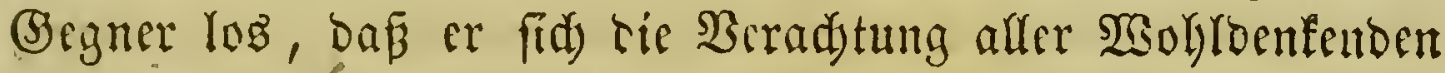

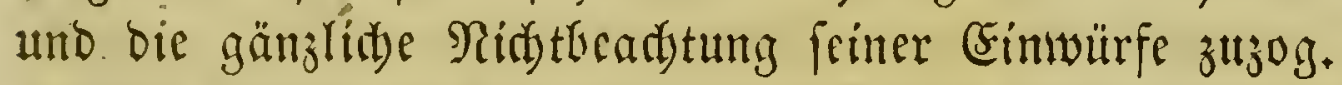

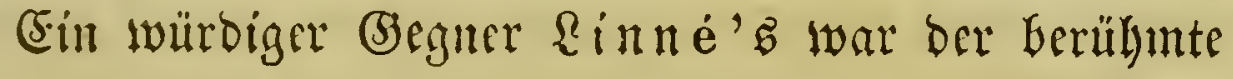

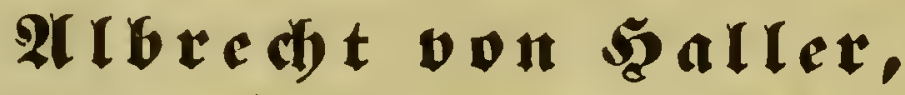

geboren 1708, geftorben 1777,

ein Mann, der faft auf alfen Giebieten des Wriffens gleida alszgejeidynet war; wir brauden hier nur an feine Berbienfte unt bie Anatomie und Shyfiologie, um bie beutfde Spradye und Didjtfuntit zu erimern. Er Gürte in Sciben Den grofen $\mathfrak{B} \cup \mathfrak{e r h a v e , ~ D u r d y a n d e r t e ~ f d o n ~ f r i b e ~ f e i n ~ B a t e r l a n d , ~ b i e ~}$

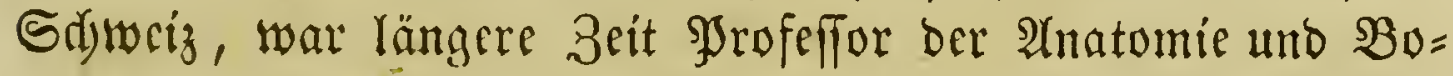

1) Examen epicriseos in systema plantar. sex. Linnaei, anno 1737 Petrop. evulgatae, auct. J. G. Si e g e s b e ck. Jussu amicorum institutum. Ăboae 1739. 4.

$\left.{ }^{2}\right)$ Consideratio epicriseos Sie ge sbe ckia na e in Linn. syst. plant. sex. et methodum botanicam. Berol. 1740. 8.

3) Vaniloquentiae botanicae specimen a J. G. Gleditsch etc. Petropol. 1741. 4. 
tanif in (S)öttingen, und ftarb zu $\mathfrak{B e r n}$ als Şräfioent bez

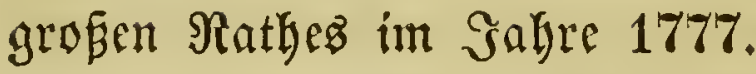

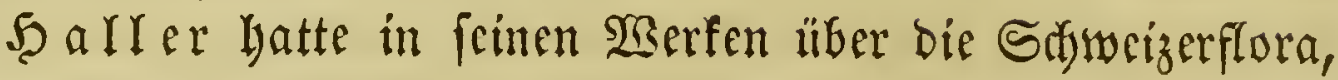
yon benen unten dic Rede fein wirb, fidi eines gemifdeten Syftems bedient, bas auf yiel complicirtere Berhältniffe als Das Rinné fdye gebaut ift.

(J)egen Das \&innéfide Gyftem madte er Den Einumr,

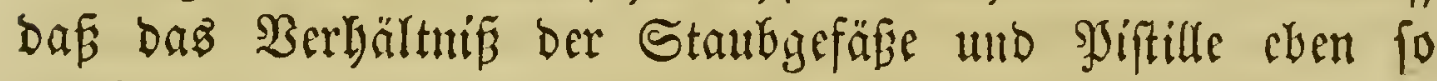
wenig, wie jebes andere Drgan, an und für fitid als (srund = lage eine Syftems angenoumen twerben fünnte. ${ }^{1}$ )

Diefe Beflauptung mag aus bem Streben 5 aller'B, fo yiel als müglid ein natürlides Syftem zu fdaffen, herbor= gegangen feill; es fducint, als labe er in jeinem Streite gegen feinen grofen (j)egner den Unterforied zwifden einem wejent= lidi fümftliden und einem uatïrliden Syfteme nidyt gehörig

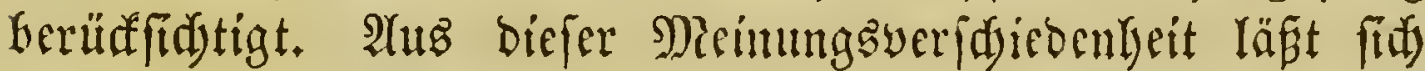
übrigens feineșwegs die Sceftigfcit biefes fonft fo umftrtigen

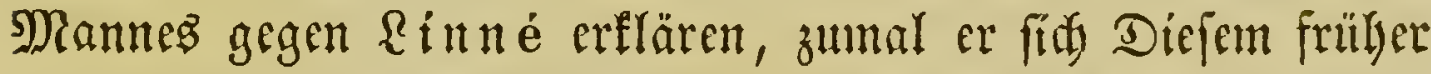

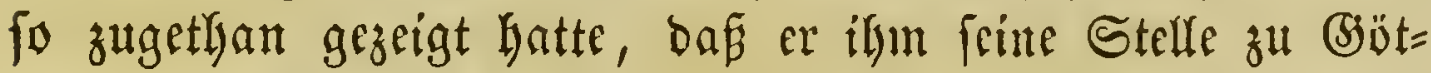
tingen überlaflen wollte. Seine Jeftigfeit trieb ifn fo weit, saf er unter Dem Ramen feimes Sohnes Emmanuer, eines Snaben yon fünfzenn Jahren, mehrere 2ingriffe gegen beit grofen Reformater ber Raturwiffenidjaften fidleuberte ${ }^{2}$ ).

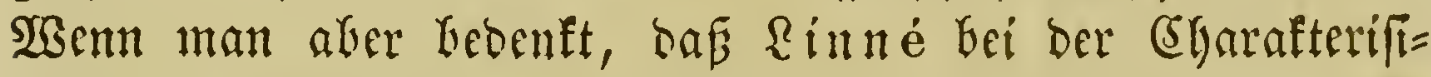

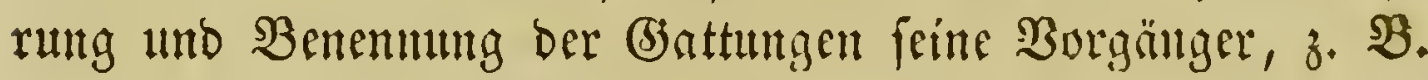

1) Эergl. Deffen De methodico studio botan. absque praeceptore. Göttingen 1736. 4. 1 Iaf. (Opuscula botan. S. 43.)

$\left.{ }^{2}\right)$ Epistola qua patri A. de Haller de natalibus gratulaturus dubia quaedam ex clarissimi Lin n a e i fundamentis hausta offert. Goetting. 1750. 4. - Dubia ex L i n $n$ a e i fundamentis botanicis hausta tradere pergit. Goetting. 1751. 4. - Nuper proposita dubia contra ill. Carol. Linnaeum illustratus etc. Goetting. 1752. 4. - Dubiorum contra sectionem septimam fundamentorum ill. Linn a e manipulus primus et secundus. Gotting. 1752. 4. II fasc. 
Touruefort, oft nidyt genug fieriffidytigte mo oft cine

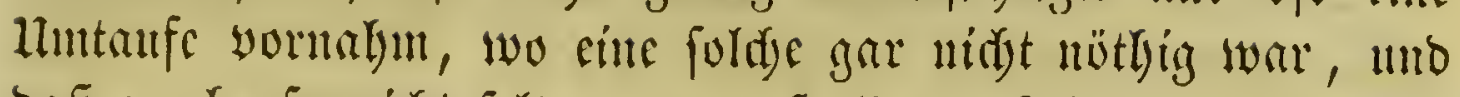

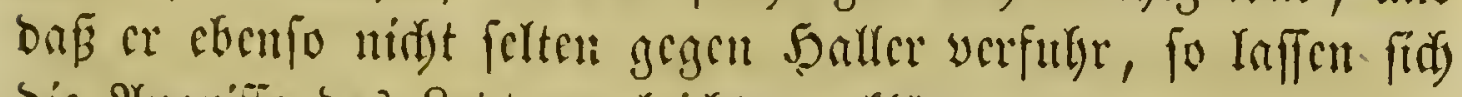

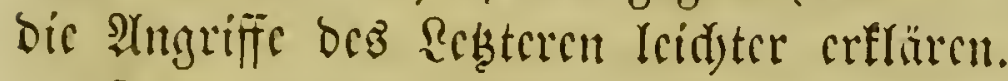

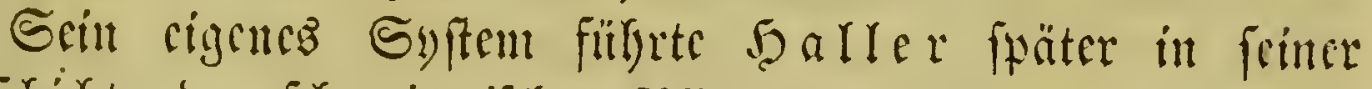

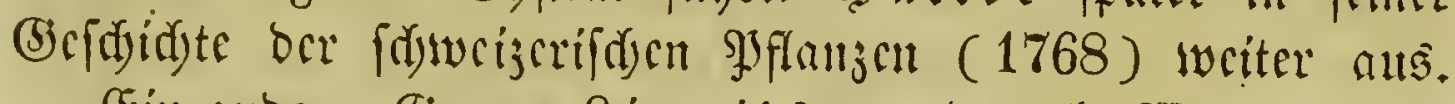

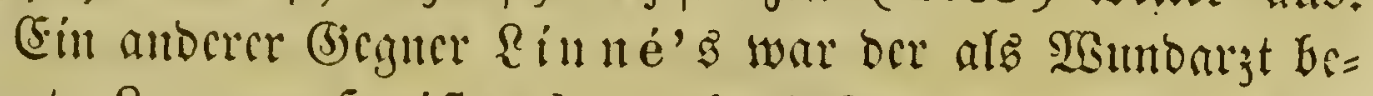
rillunte Rorenz Şeifter ${ }^{1}$ ), geb. 1683, geft. 1758, JJro=

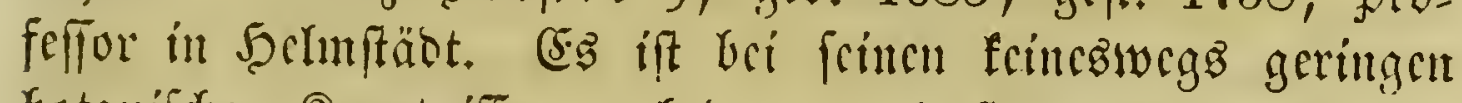
botnnifden Senntniffen zu bebauern, baj er fid auf cine bes

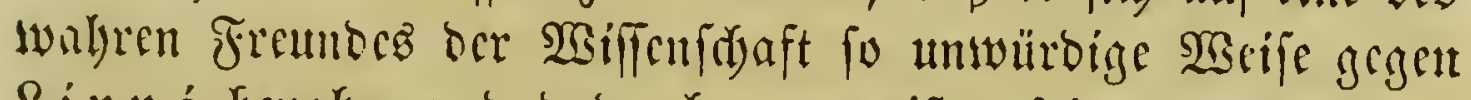

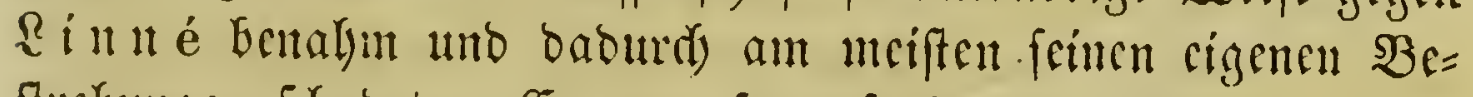
ftrcbungen fonocte. Er war fo aufgebradyt gegen Rinné,

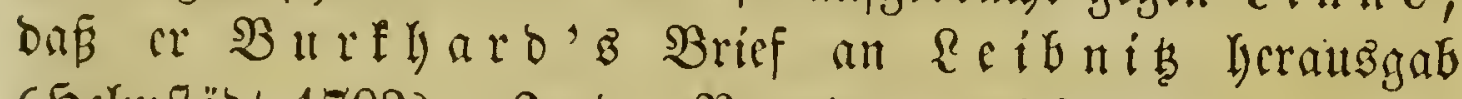

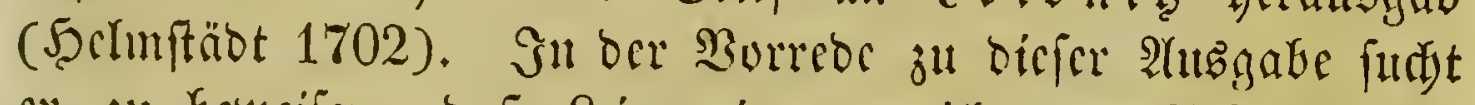

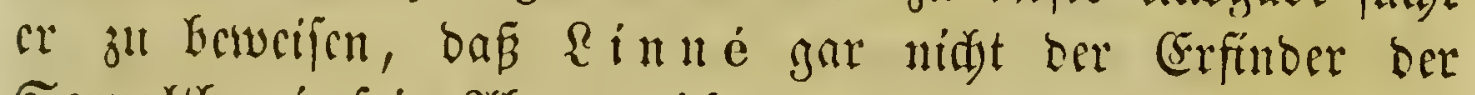
Scxunltheorie fei. 2(ber er ridftete Samit midt siel aub. Denn

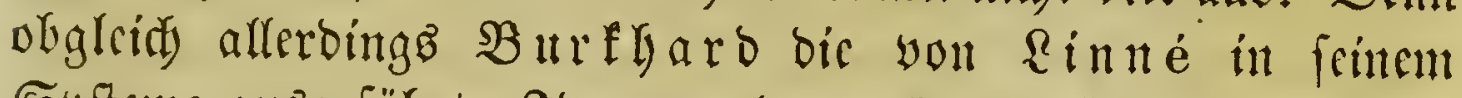
Syftcme ausgrfithrte Soee angcbcutet lyatte, fo fah man bods

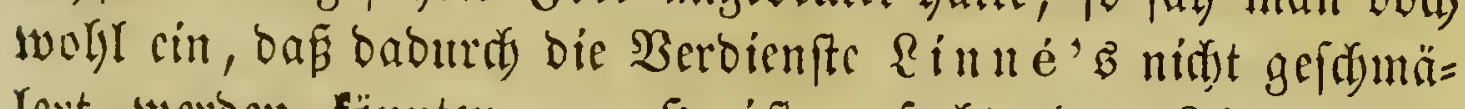

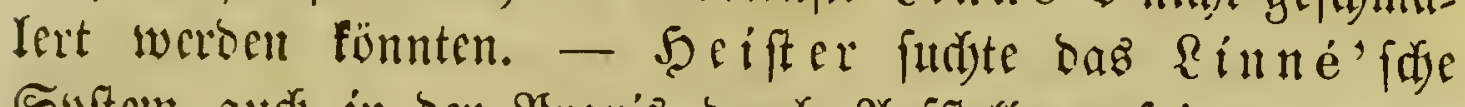

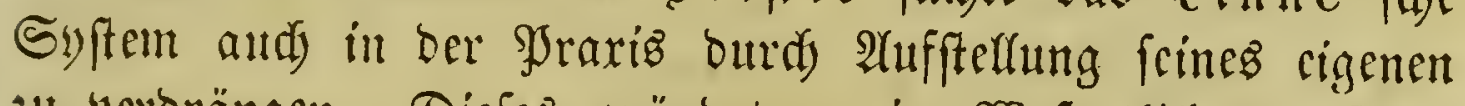
zu verorängen. Diefrs grünbete cr im $\mathfrak{S e}$ entlict)en auf bie

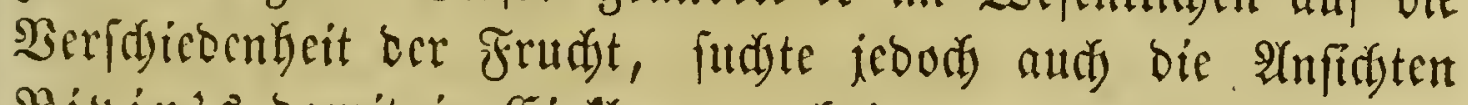
Rivin's bamit in Einflang zu bringen. Daffrlbe fano $j e=$ Dor) feine Berbreitung. ${ }^{2}$ )

3) Meditationes et animadversiones in novum systema botan. sex. Linnaei. Ilelmst. 1741. 4. - De nominum plantar. mutatione utili et noxia; ibid. 1741. 4. - De gerieribus plantarum medicinae causa potius augendis quam minuendis; ibid. 1751. 4. - Bergl. aud: Programma de studio rei herb. emendando. Helmst. 1730. 4. Deffen ilbrige

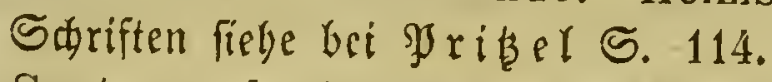

$\left.{ }^{2}\right)$ Systema plantarum ex fructificatione, et regulae de nominibus plantar. a Lin na eis longe diversae. Ilelmst. 1748.8. હ., $\mathscr{B B}_{B}$ ind fer, Befक, B. Botanit, 
Şeifter forsent ziemlidid ridytige Begriffe yon ber natür= Iidjen Berwandfidjajt befeffen zu Laben.

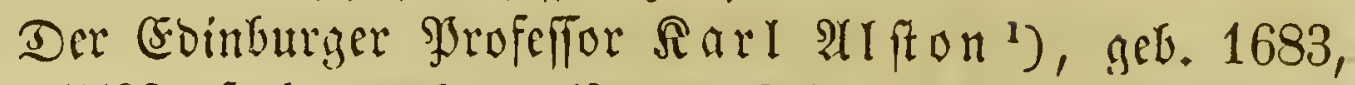

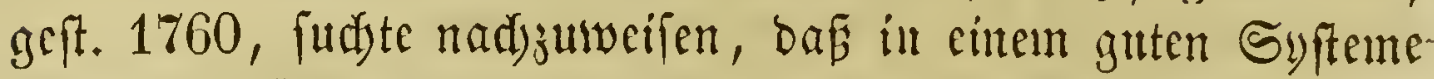

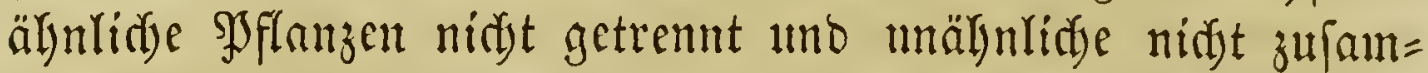
mengeftelut werben bürften. - Diefe anffityt ift allerbings anf ein matürlidjes Syftem antwenobar, fällt aber in $\mathfrak{B} e$ zieryung auf cin fünflidies Syftem in fid felbft zuammen.

Arfon gab Tournefort's Syftem yor bom Rinné= fden ben Borzug.

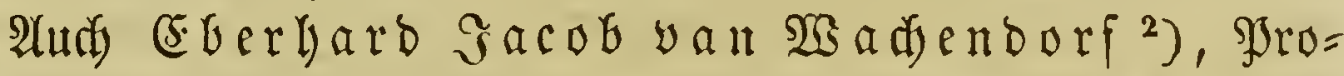
feffur in lltredt, geb. 1702, geft. 1758, war mit bem sinn $^{2}=$ fden Syfteme nidyt zufrieden und verfertigte deshalb cin

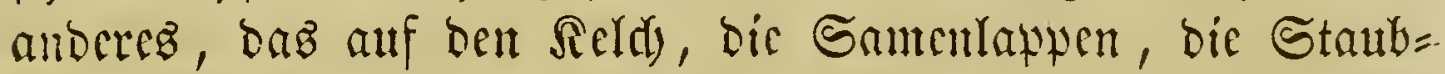

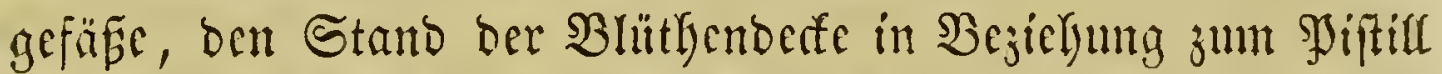

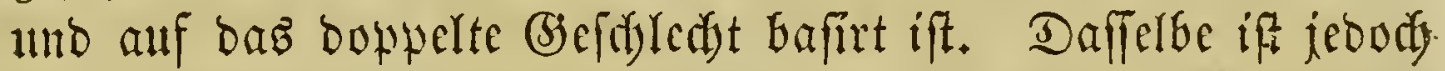
fo in eitantor gefdjadytelt uno mit fo fdanderlyaft flingendent $\mathfrak{Y}$ iamen, wic $\mathfrak{z}$. $\mathfrak{B}$. scheseopetalostemones, pollaplostemonopetalae, eleutheromacrostemones etc., gefpifft, $b \cap \tilde{B} \mathfrak{P B}$ unnüglidy cinte günftige 2 (ufnalime finden fonntc.

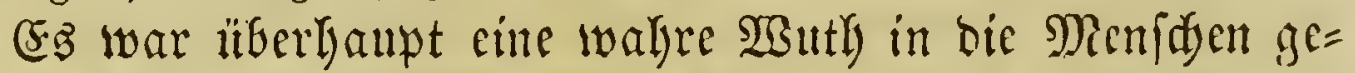
fahren, ueue Sylfeme zu fdimicoent.

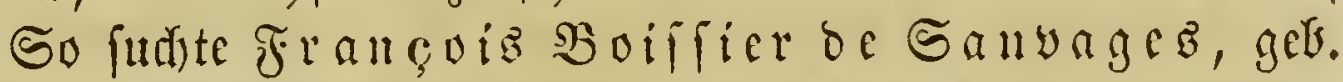
1706, geft. 1767, Mrofeffor in Montpellier, fein Syftem gans auf bie $\mathfrak{B e r f d j e b e n t}$ eit ocr $\mathfrak{B}$ lätter ju grünoen, éit $\mathfrak{B e r f u d}$,

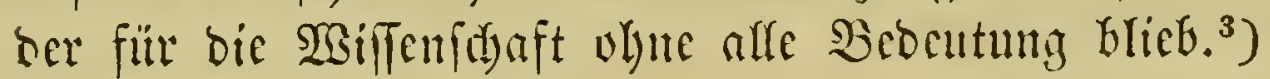

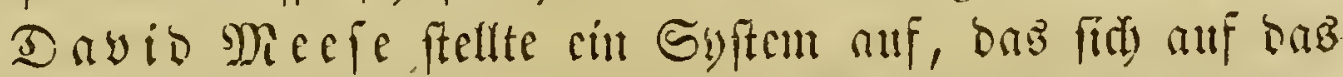

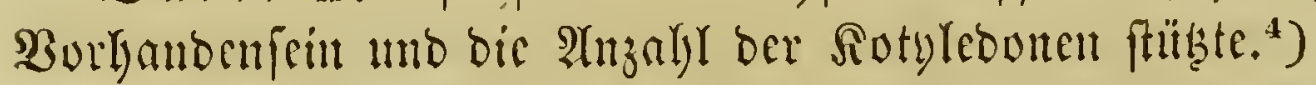

1) Tirocinium botan. edinburgense. Edinburg. 1753. 12.

$\left.{ }^{2}\right)$ Horti ultrajectini index. Ultraj. 1747. 8.

${ }^{3}$ ) Methodus foliorum, s. plantae florae monspeliensis juxta folior. orig. Hag. 1751. 8 .

4) D. Meese. Het XIX Classe van de genera plantarum van Linnacus, Syngenesia genaamt, opgeheldert en 


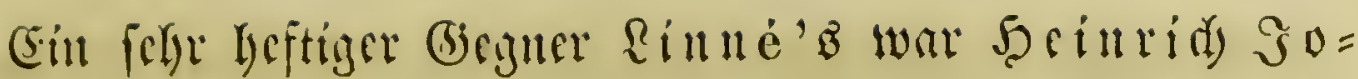

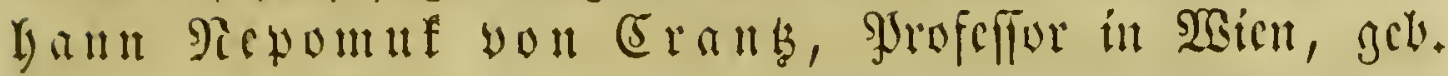
1722, geft. 1800. Ein guter Beobadter unb grofer Seumer ber ifferreidyifden Florm, madyte cr aflerbings auf mantbe

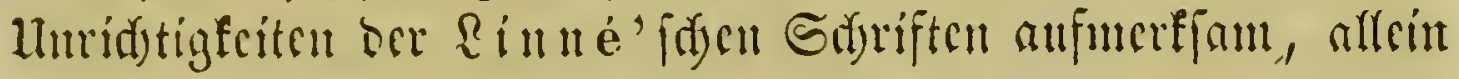

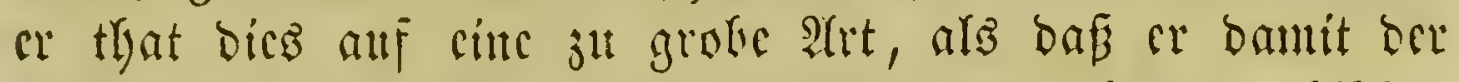

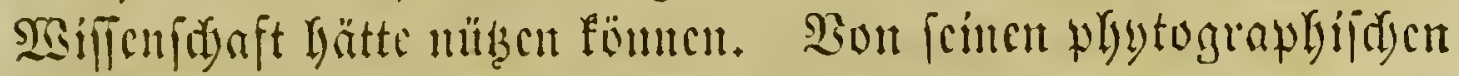

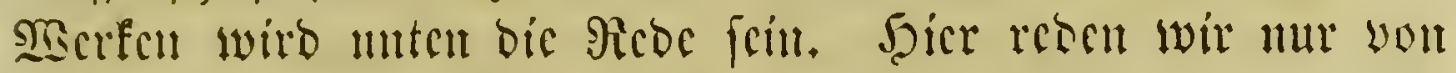
fcincn Institutiones rei herbariae (TSien 1766. 8.), in twcl= (d)

(5: is if bicz Syftem hauptfärylify auf bas Borbandenfein,

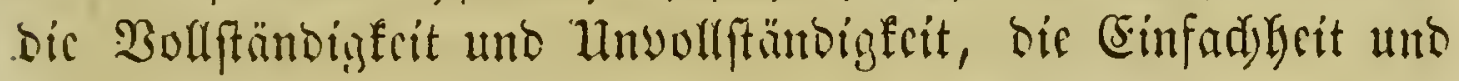

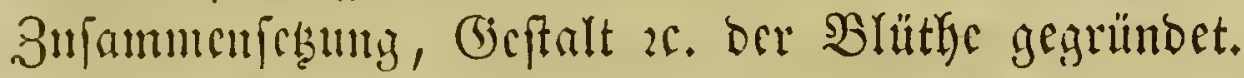

Der fodon in ber vorigen gaeriod (S. 146) erwähnte (E) rift. (5) ottr. Rublvig war cincr ber Erften, weldye bie anfiduten Rinné's vertlycibigten uno verbefferten. ${ }^{1}$ ) Spröter

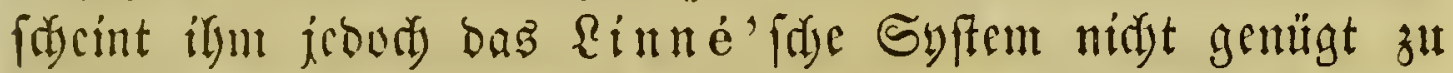
baben, Dem cr cutwarf sin eigenes Syftem ${ }^{2}$ ), bas fid theils auf bic Şluncufroue, thcils auf bie (Gejd)lchtöorgane grün=

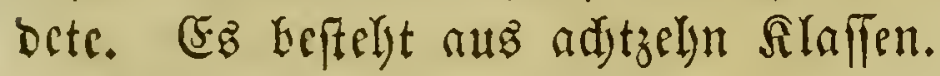

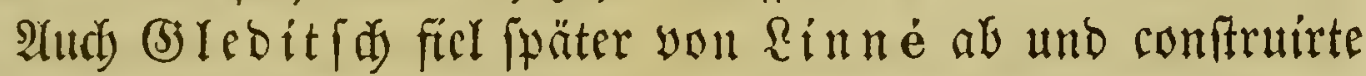
cin rigenes Syftem ${ }^{3}$ ). Die \$Jhancrogamen thrilte er in vier

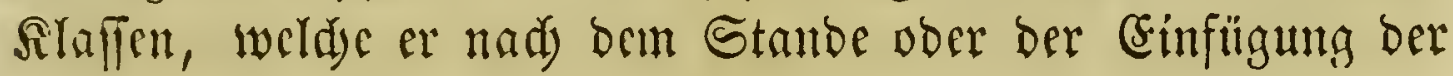

vermeerderd. Leeuwarden 1761. 8. - Plantar. rudimenta, s. methodus ducta ex differentiis seminum, Cotyledonum. Leovardiae 1763. 4. Diefés $\mathfrak{B}$ erf wurbe nid)t yolfendet.

1) De sexu plantarum, Lipsiae 1737. 4. Observationes in methodum plantar. sexualem Linnaei. Ibid, 1739. 4.

$\left.{ }^{2}\right)$ Institutiones historico-physicae regni vegetabilis, Lips. 1742, 57. 8. 2(ußserbem farieb er: Definitiones generum plan-

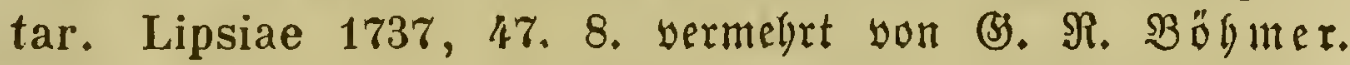
1760. 8. Prog. de minuendis plantar, generibus 1737. 4. Aphorismi botanici, 1738. 8. De minuendis plantar. speciebus. 1740. 4. Heber beffen übrige Sdriften wergl. Sr rizel S. 175. $\left.{ }^{3}\right)$ Systema plantar. a staminum situ. Berol, 176\%. 8. 


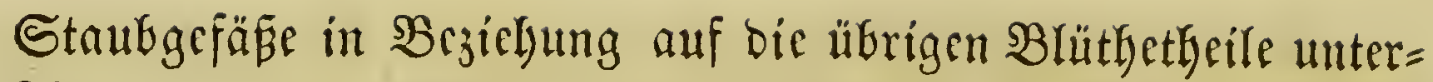
fdied. Die zweiunbvierzig Dromungen ber \$Jbanerogamen

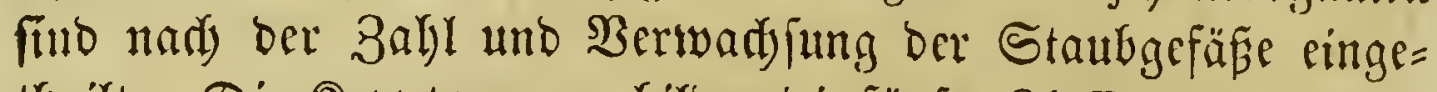
theilt. Die Iryptogamen biloen bie fünfte Alaffe, Deren Dro= nungen im aldyemeinen benen ber vierundzwanzigften Slaffe Rinnés entipredien.

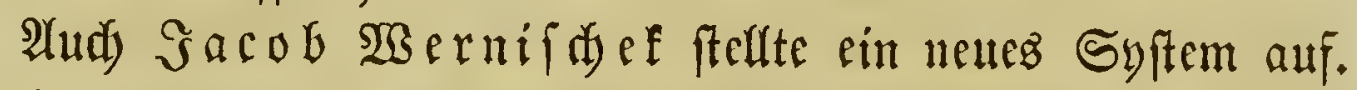
(5:s hatte zwanzig Silaffen uno grïnoete fid namentlid) auf bie 2(nfidten $\Re$ ivin's uno Tournefort's; niemals if es jebody fut einigem $2\left(n\right.$ felen gefommen ${ }^{1}$ ). Faft gleidyzeitig bradten Şaul Dietr. (B) iefefe ${ }^{2}$ ) und Sohann Ititus $^{3}$ ), 1729, geft. 1796 als Srofeffor zu Swittenberg, einzelne $\mathfrak{A}$ enderungen dez Rinné (d)en Syftems in Borfd)lag.

(Jiegen das Ende diefes 3citraums wande ber Staliener Rarl $\mathfrak{A}$ llioni, geb.1725, geft. 1804, Shofefior in Turin, ein Syftem an ${ }^{4}$ ), baz yon ber Beridjicoenheit ber Blunen= frone Gergenommen war, in feinen Unterabtbeilungen aber fid

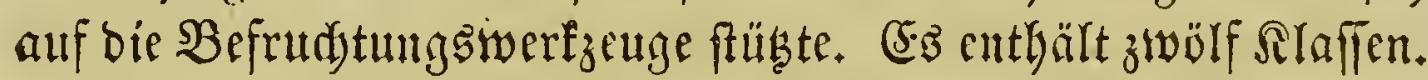

(Ein äuperft grober (Stegner Rinne's war $\mathfrak{F}$. Safimir Medicus, geb. 1736, geft. 1809, Borfteker des Grjwe $=$

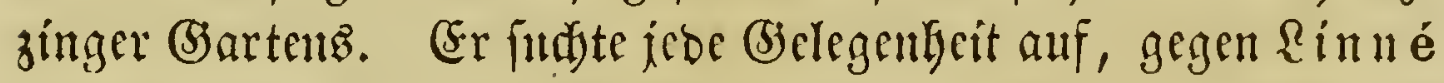

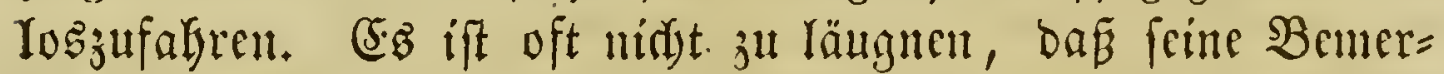
fungen ridytig find, allein burdy feine alfugrofie Reidenfdyaft=

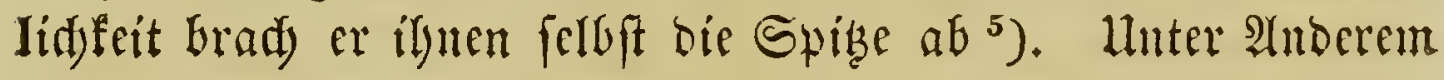

5) Genera plantar. etc. Vindebon. 176\%. 8.

3) Systemata plantarum recentiora instar speciminis. Gotling. 1767. 4.

3) Syst. plantar, sex ad naturam composit. Wittemb. 1767.

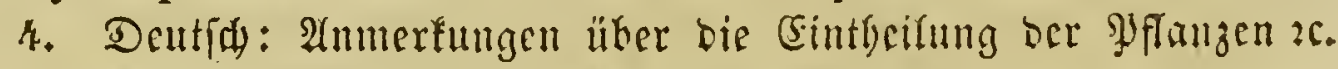
Reues 5amb. Magaj. Stüa 90 , S. $483-517$.

*) Flora pedemontana. August. Taurin. 1785, mit 92 Supfern. 3 voll. Fol.

5) Botanifac Beobaditt. Mamngrim 1783, 84, 2 S3be. 8. Heber einige fiunfticte (3)

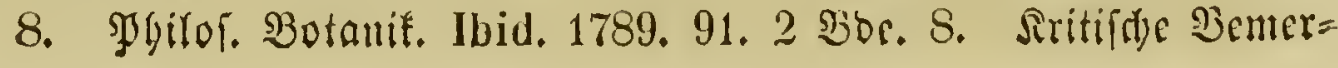


bebautete er audy, bie eilf erften Siraffen bes Rinné fusen Syftems feien verfeblt, weil bei ifuten feine Rüffidjt barauf genommen twerde, wb bie Stautfäben an ber S3lume ober auf bem Frudjetroden eingefügt feien. (Fr fdultug beshalb sor,

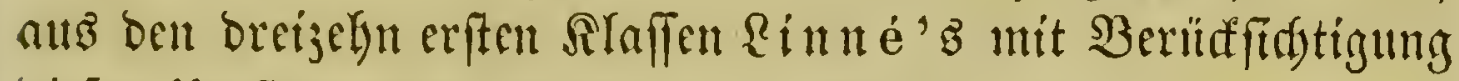
biefé 1 mftandes vierumbjwanjig andere zu madjen.

3ur Berbreitutig bes Rinnéfren Syftems trug bald

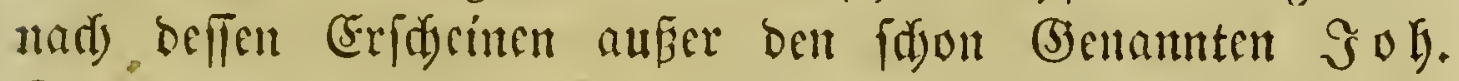

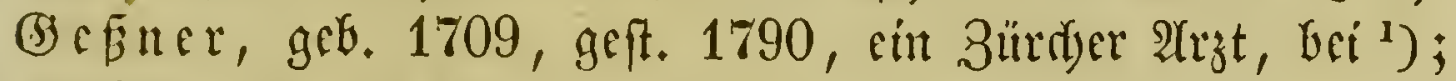

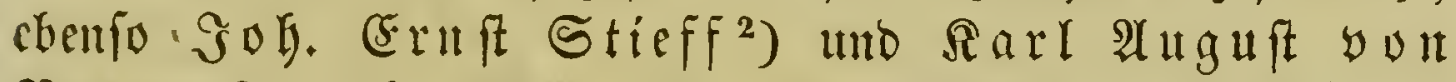
Bergen ${ }^{3}$ ), geb. 1704 , geft. alB \$rofeffor zu franffurt an ber Doer 1759. SুJilipp Ronrad Fabricills ${ }^{4}$ ), geb.

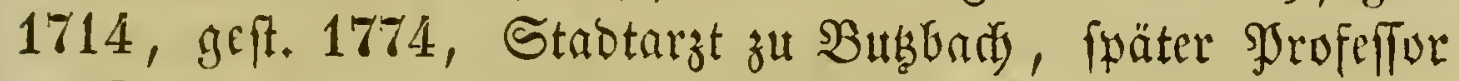
zu Sclmftäot, war nidjt in allen Shunten mit Rinné ein= werftanten; fein Tabel hält fid jebod) ftets in ben Sdyranfen Der Mäß̈igung.

Alud) Sacob (Shrift. Sdäffer ${ }^{5}$ ), geb. 1718, geft. 1790, Superintentent in Regensburg, madyte fid um bie

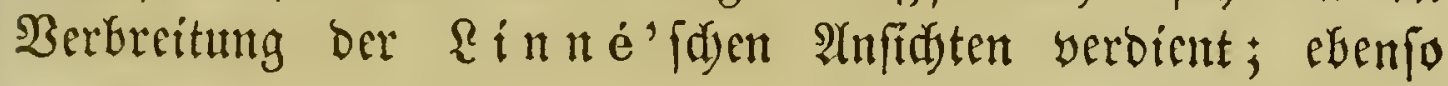

fungen über Begenftänbe auz ber $\mathfrak{s f l a n z e n f u n b e . ~ I b i d . ~ 1 7 9 3 . ~} 8$. Die meiften feiner Sthriften gegören in bie folgende Yeriobe.

$\left.{ }^{2}\right)$ Dissertationes de partium vegetationis et fructificationis structura, differentia et usu. Lugd. Bat. 1743. 8. Heber bellen übrige Sđriften vergl. $\mathfrak{s}$ riţel 5.97.

$\left.{ }^{2}\right)$ De vita nuptiisque plantarum. Lipsiae 1741. 4.

$\left.{ }^{3}\right)$ Utri systemati Tournefortiano, an Linnaeano, primae partes deferendae sint? Francof. ad Viadr. 1742. 4.

4) Primitiae florae butisbacensis. Wetzlar. 1743. 8. Enumeratio methodica plantarum hort. med. Helmstadiensis. Helmst. 1759, 1763. 8. Drimborn 1776. 8.

5) J. Chr. Schaeffer, Epistola de studii botanici faciliori ac tutiori methodo. (Ratisb.) 1758. 4. Isagoge in bot. expeditiorem. Ibid. 1759. 8. Botanica expeditior, genera plantar. in tab. sexual. et universalib. exhibens. Ibid. $1760,62.2$ Bnde. 4 . 


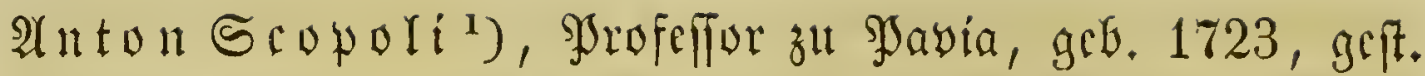
1788, ber ziwar allfanjo ein cinenes auf bie Corolfe geftulbęs

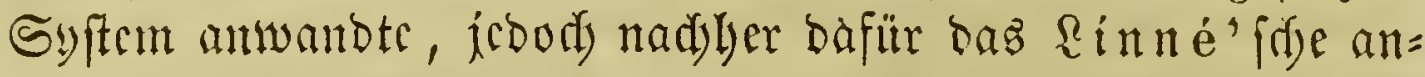
malym. Bon ifm wirb nod) water die Rebe frim. - Mnter

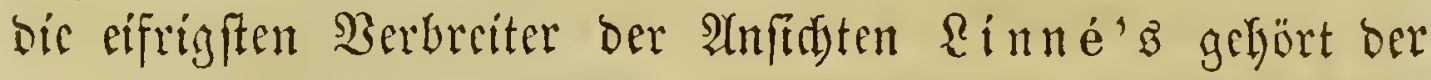

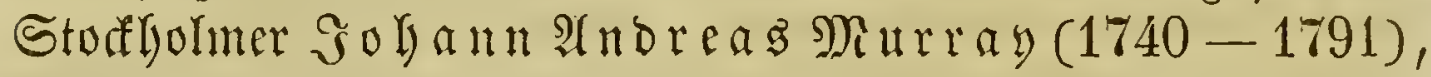

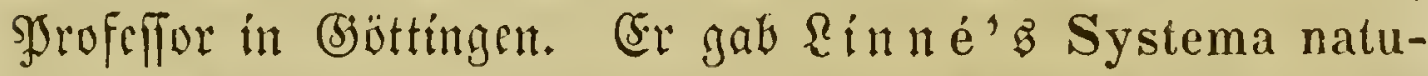

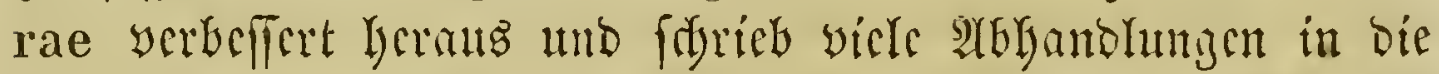
(5)öttinger (Sommentarion ${ }^{2}$ ). - (Gine vermelrte 2 (uşabe Der Genera plantarum beforigte Golj. 'Shrift. Daniel $\mathfrak{B}$. Sificber, geb. 1739, geft. 1810 als Srofefifor ju Erlangen,

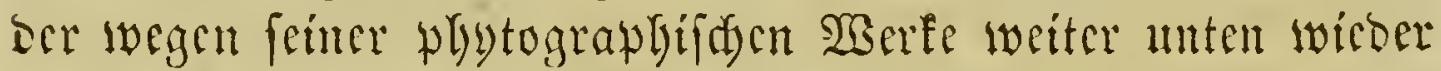

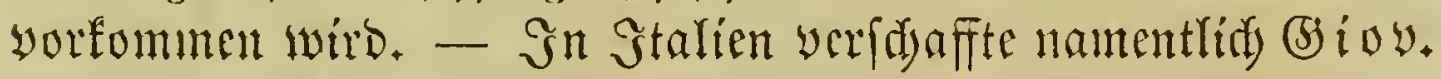

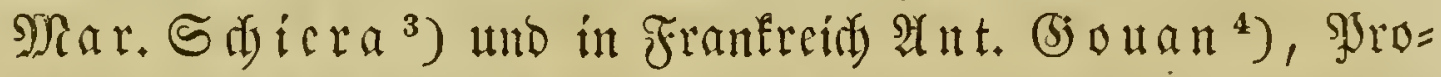
feffor in Miontpelficr, Dem \&innéfiden Sylteme Eingang.

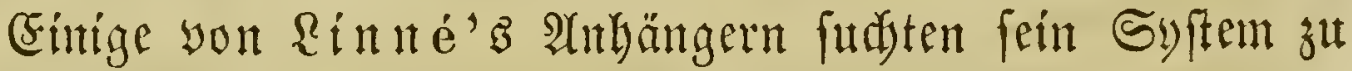
yerbeffern. Namentlid beabfidtigte bies $\mathfrak{i}$ ard berg, grofeffor in lupfala. Er liefi bie zwanzigfte, eimutn= ziwanjigfte, ziveiundzwanzigfte uno trciundziwanzigfte filaffe ausfalfen und bradyte die barin aufgefülyrten \$oflantsen nad) ber

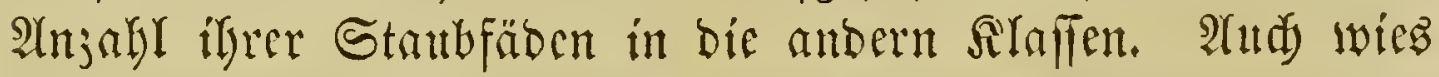

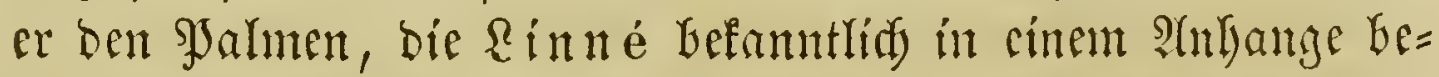
Gandelt fatte, ifre gebübrende Stefle an. Dicfe Berände=

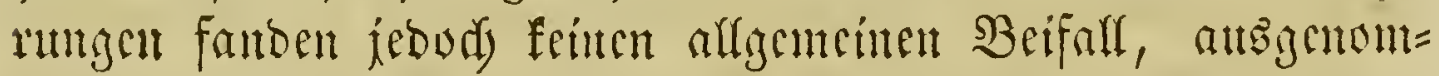

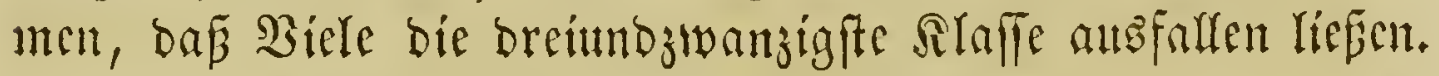

1) J. A. Scopoli, Anni historico-naturales. Lips, 176972. 5 Bobe. 8. Deutid: Wrien $1770-1781$.

$\left.{ }^{2}\right)$ Opuscula, in quibus commentationes varias tam medicas quam ad rem natural. spectantes retractavit. Goetting. 1785. - 1786. 2 voll. 8.

$\left.{ }^{3}\right)$ Dissertationes II, quar. altera de plantar. sexu etc., altera de natur. et constante plantar. adfectione ad perpendiculum. Mediolan. 1750. 8.

') Explication du système botanique du chevalier v o n Lin n é. Montpellier 1787. 8. Par, 1795. 8. 


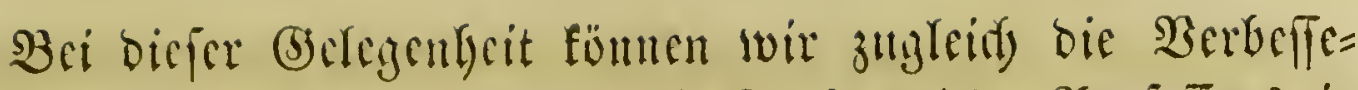

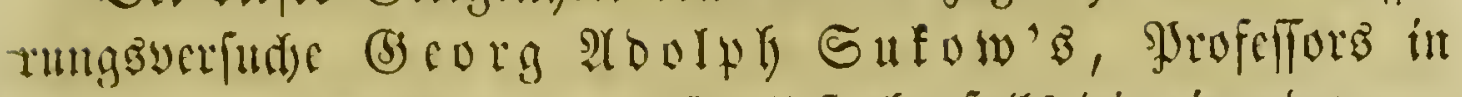

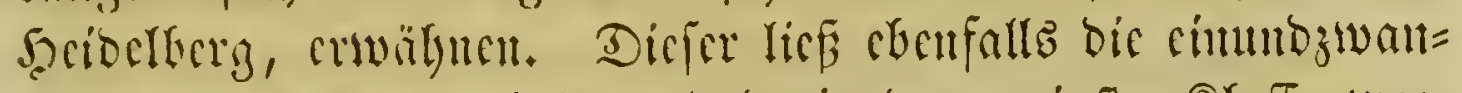

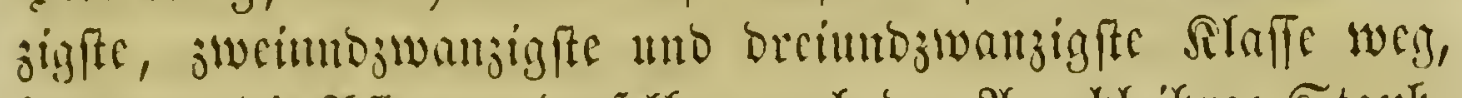

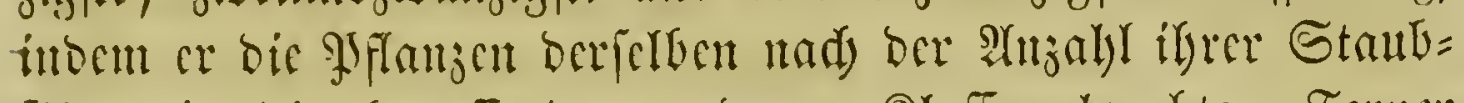
fäbon in bie betreffertom anderen Silaffen bradjte. Ferner

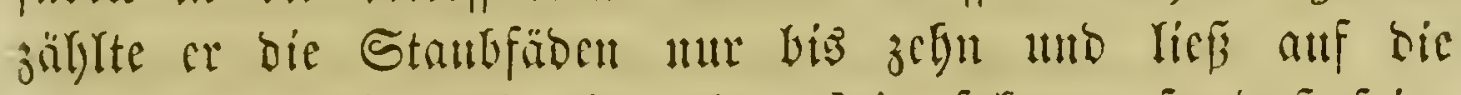

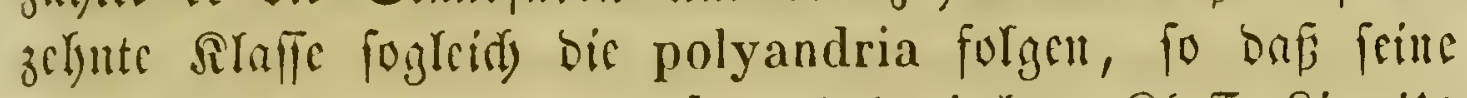

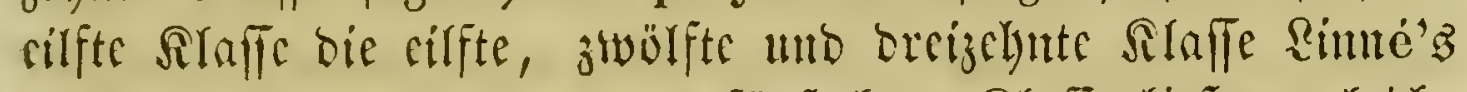

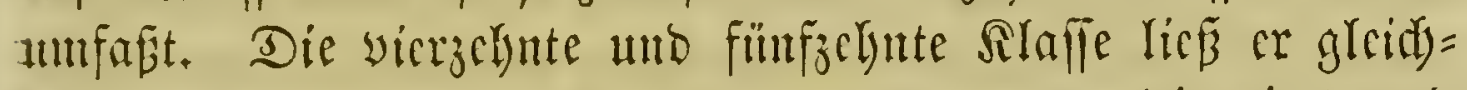
falls weg unb bradjte fie als Dronungen anter bie vierte und

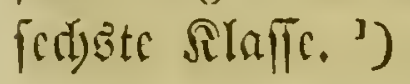

Samul el Riljeblad, geft. 1815, dent wir, ob=

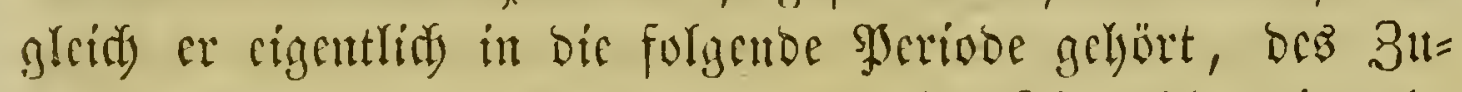
fammenlyangs wegen ficr nemen, woldte Rinnés vietunt=

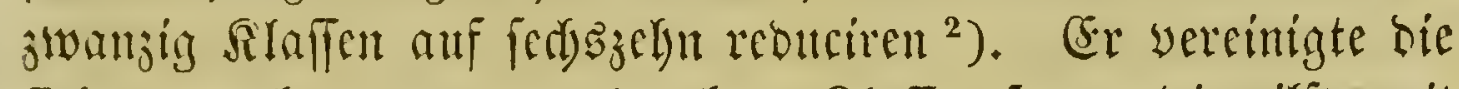
fiebente, adyte, neunte und jelyute Silafle, ferner bie eilfte mit

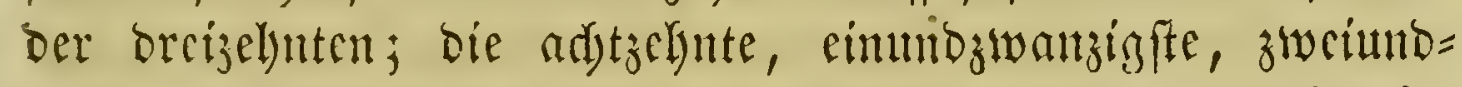
zwanjigfte und breinnojwanzigfte liés cr ausfallen und bradyte bie barin alfgefübrten (5)cuäd) in ben übrigen Rlalfen unter.

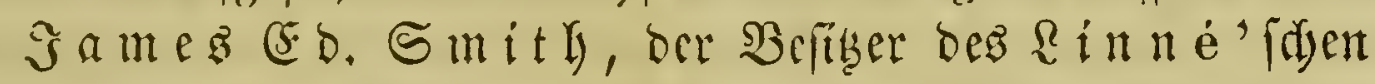
berbariums, beliclt zwar bie vierumbjwanzig Silrffen bei,

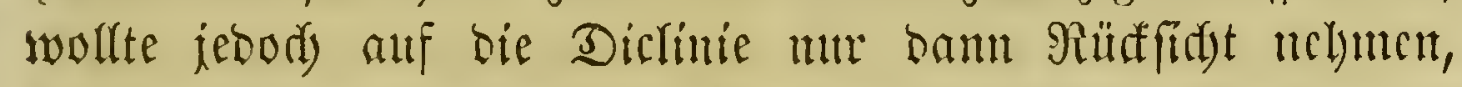

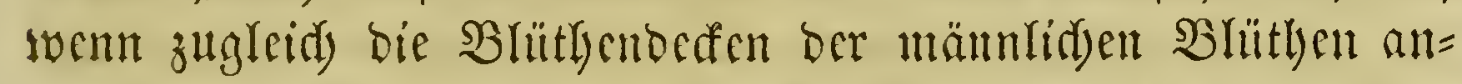
bers formint feien, als bie ber weiblidsen; im entigegengefes =

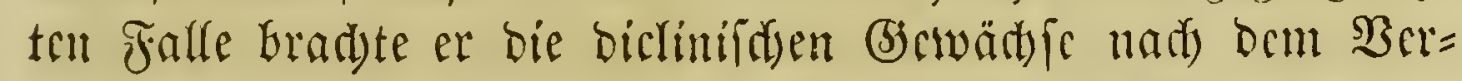
bältnifi igrer Staubgefäpe unter die anderen Slnffen.

1) Seine $\mathfrak{B e r f e}$ fint: Defonomiifa Botanif. Mannl. 1777. 8. Berfudje üfer bie $\mathfrak{B}$ Brfungg. weridied. Suftarten auf bie $\mathfrak{B e g e =}$ tation 2c. Mündyen 1782. gr. 4. - 2tufangägründe ber theoret. u. angewanbten Botanif. Reipzig 1786, 2 I Ille. 1797. 8. Diagnofe ber \$flanzengattungen nad ber neteften 2Auzgabe bes Linné'fden Scrualiyftems. Reipzig 1792.8.

3) Ratio plantas in XVI classes disponendi. Upsal. 1796. 4. 
Alle bicfe ßeränberungen fanden jedodi twenig Beifall.

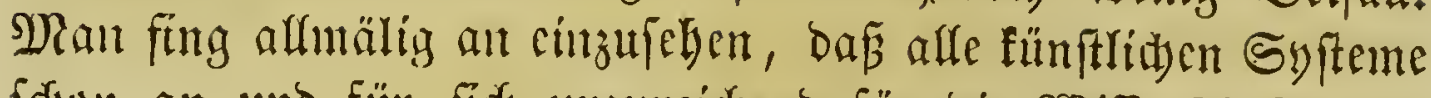

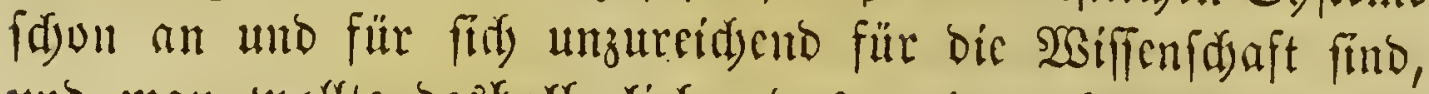
und man wolfte deblyalb lieber baz weit verbreitete Syftem Riune's in feiner urpriingliden Bseftalt beibebalten anto bie burd) bie (srfabrung beftätigten Mänger beffelben gewiffen= baft ammerfen, als fiti) auf weitere Berbefferungsfpefulationen ciulaffer, bie an (snoe bod) mur wiederum cin mangelfaftes

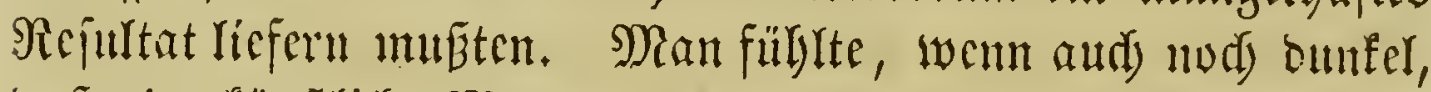

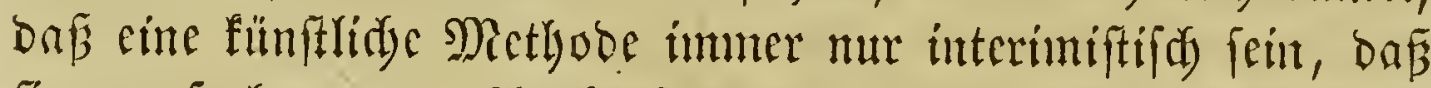

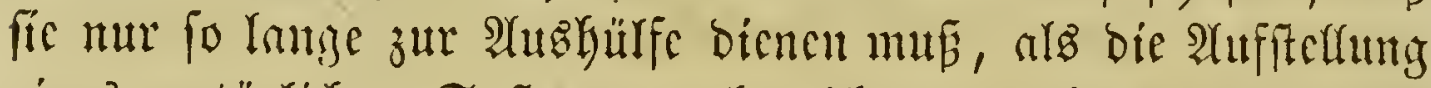
cincs natïrlidyen Syftems noid) nidjt möglid gewoorben ift; Daß bas fünftlidye Syftem mur zur Errteidyterung Des Stubiums

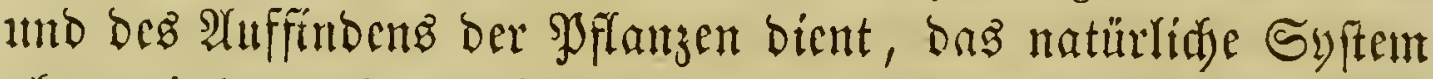
aber mit bem cigentlidyen Wefen bes SYflanzenreids nothwen= Dig zu[ammenlyängt.

Man liatte bas Bebürfnín cines natürlidyen Syftems fdon Innge gefühlt. Sidon ber gewühnlide Menid, Der burdyaus

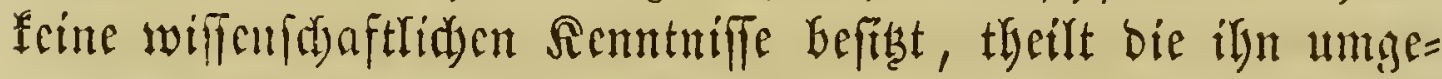

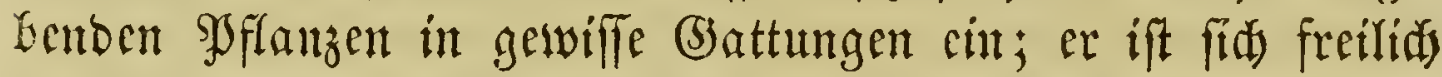
vft bes Brumbes bicier ceintbeilung nidjt elar bedwät, aber sicfe ober jene Sffanzenartent lïben einen fo werwanden Csit =

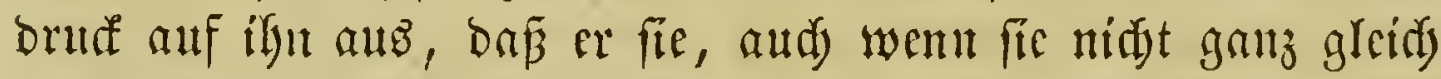

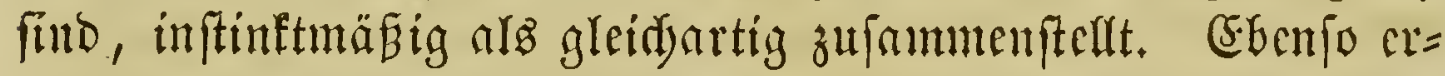

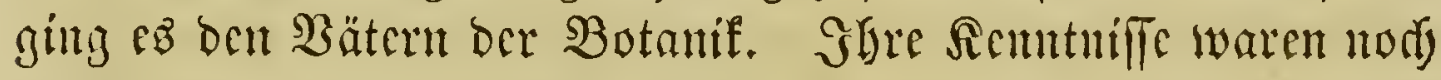

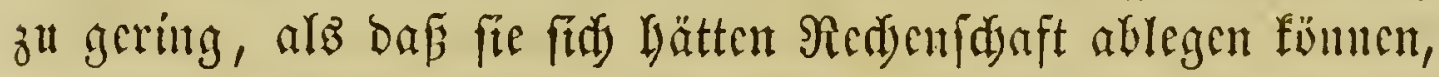
warmm dicfe voer jene (5)cwärje mit cinatber verwant feicu; aber dafi diefelben verwand feien, daz merften fie.

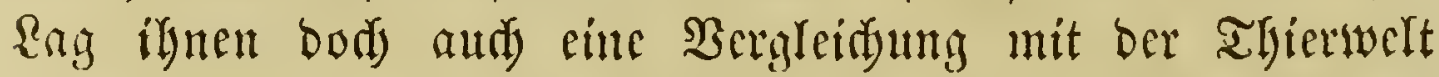

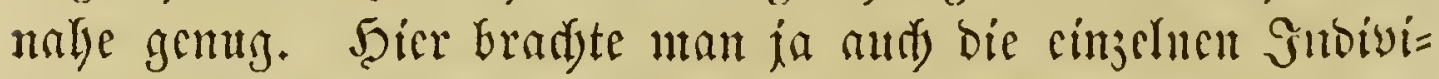

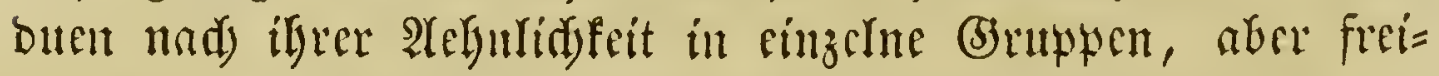
lid) waren hicr attd bie Interfdeidungemerfunale viel herwor= tretendoc, als bei bem Syflantsemreidse. So futrg man bemt fwäter an, nach cincm Drganc zu fudyen, bas allen Şflanjen

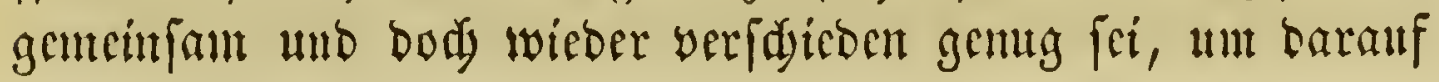




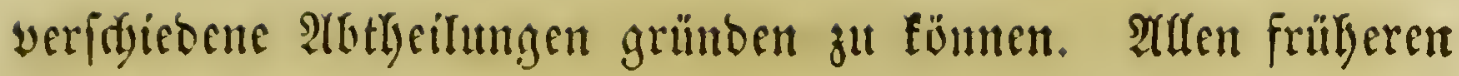

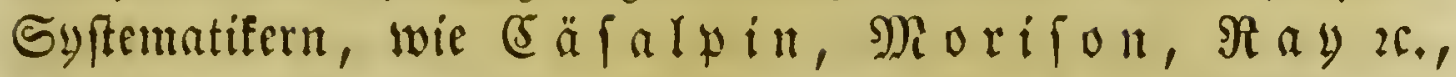

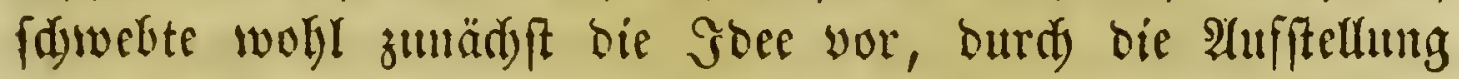
ifrer Syfteme bie Grunblage zu einer natürliden Metlyode zu Iegen, unb fie algnten babei wohl faum, bas ifnen bie Remnt= niß̧ gerabe berienigen Srgane abginge, weldye bei ber Feft= feffung ber Syflangenvermantidjaft bie allerwe fentlidsten fint. Man hatte fcine flare $\mathfrak{B}$ orfteflung yon bem Unterfdrebe einez fünflidyen umb eines natürliden Syftemb. Daher entftanben bie Iangwierigen Streitigfeiten barilber, weld)ez Drgan man als bas Şauptunterfdeioungsmerfual annelmen miiffe. Diefe Streitigfeiten bauerten biz zum Ende diejez Zeitraums und nod) bariber linaus.

Bodh haben wir foun melyrmals (G)elegentyeit geljabt, auf cinzelute $\mathfrak{M a ̈ n n e r ~ a u f m e r f f a m ~ z u ~ m a d j e n , ~ b i e ~ r i d j t i g e r e ~} \mathfrak{B e}=$ griffe von oer natürliden Berwandef(d)aft hatten. But biejen gelgüren namentlid) Raurembergund Magnol. Der $\mathfrak{R e g}=$ tere fagt in erften $\mathfrak{B}$ ante feine 3 Prodromus historiae generalis plantarum: "Jith labe in ben Pflangen eine $\mathfrak{B e r w a n d t =}$ fidaft zu bemerfen geglaubt, madj Deren Graben man bie SJflnuzen in ver fdjiebene Familien oronen fünnte, wie man bie Thiere vronet. Diefe Aebulidfeit zwifden Thieren unb Soflan= zen bat mir (5elegenlyeit gegeben, die $\mathfrak{P f l a n z e n ~ i n ~ b e f t i m m t e ~}$ Familien, äbnlid ben Fantilien ber Menfaen, zu bringen, und da es mir unmöglid) (d)ien, bie Rennzeident biefer $\mathfrak{F} a=$ milien blos aus ben Fruddttheilen zu entmelymen, fo wählte id) bie Iyeile ber Splanzen, weldye die vornehmften djarat=

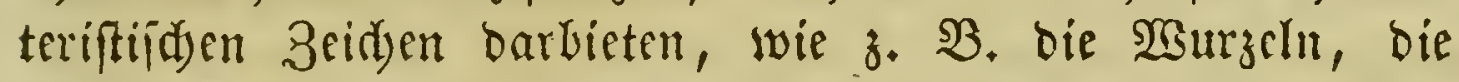
Stengel, bie Blätter und bie Sainen; ja es funbet in felyr

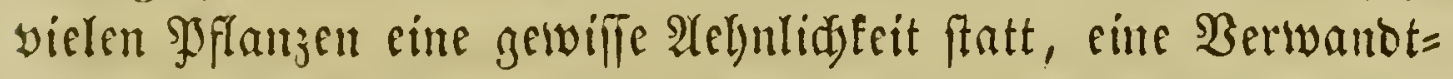

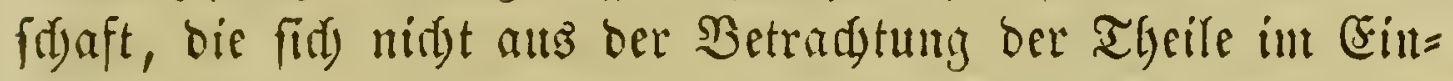
zelnen ergibt, fondern aus bem (b) efmunteinoruta, eitre fügl=

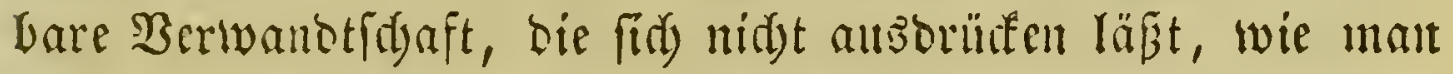
dies in ben Familien ber alyrimonien und ber Stotentiffent fielyt, bie jeoer Botanifer für verwand erflären wirb, $v b=$ 


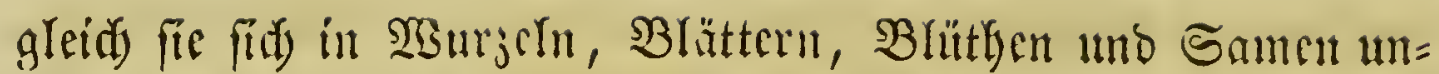

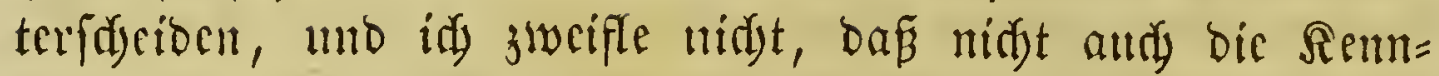
zeíd)en ber Famílín yon den erften $\mathfrak{B r a ̈ t t e r n ~ d e s ~ R e i m s ~ b e i ~}$ frincm Atustritt aแt sem Samen entnommen werben fünnten. Jd) habe baher sic Drommng ber Spflanjentheile befolgt,

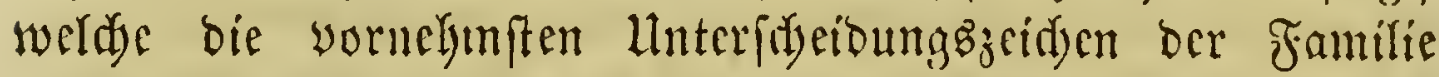
zcigen, uno vbne mid) auf cincu cinzigen I

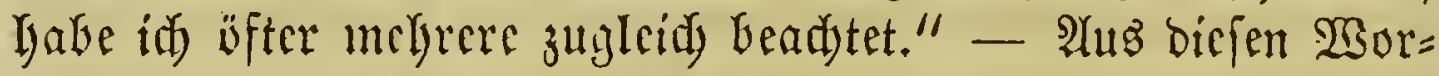

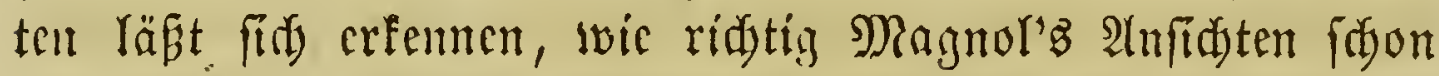

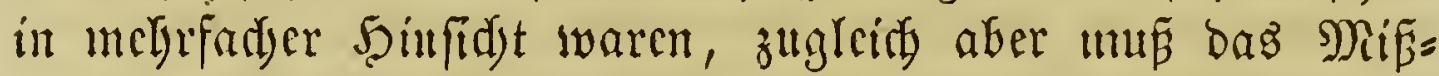
verbältnif zwifdyen dicjen 2Anfinten und ber bamals vorhan=

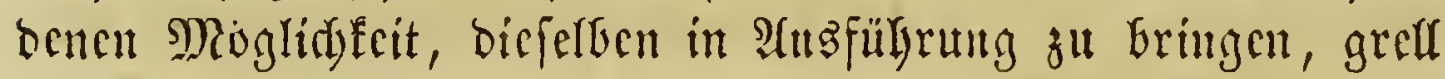
auffallen. Șis wenig wufte man bamnlz z. $\mathfrak{B}$. yon ber

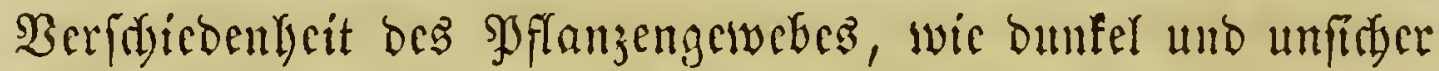
waren bie Mcinungen $\mathfrak{i} b$ er die Scrualwerbältmiffe!

Man lat nidst ferten bic Frage aujgeworfen, warmm wogl

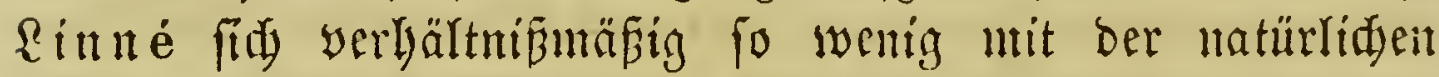

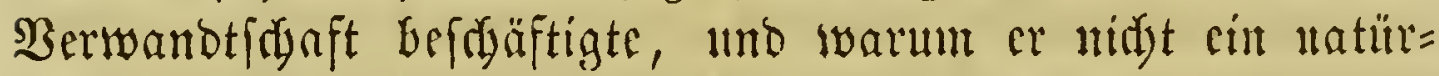

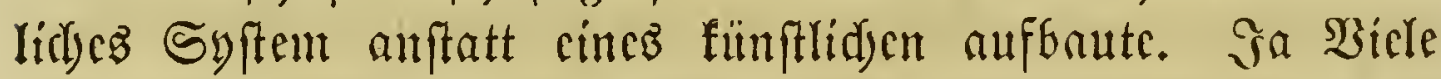
laben fogar beljauptet, er fei cin Frino ber natürfitycu Rlaf= fifitation getwefen mo labe fie, two cB mur müglids geswerent fei, ftetz zu vermeiben gejurbt. Sene Frage aber läpt fids

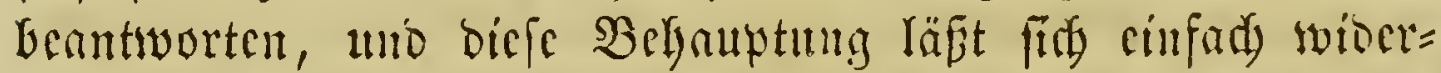

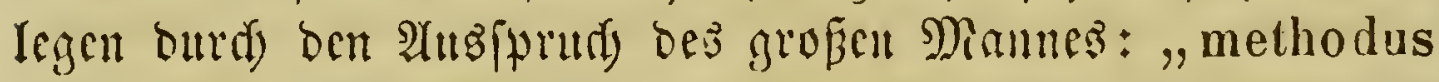
naturalis primus et ultimus finis botanices est et erit." Ilber eben barum, weil bic natïrlide. Siraffififation fo chg

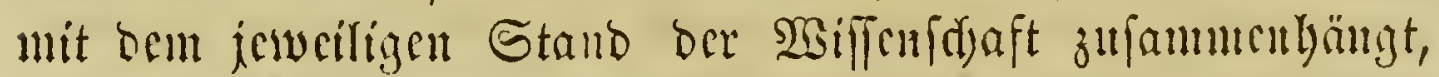

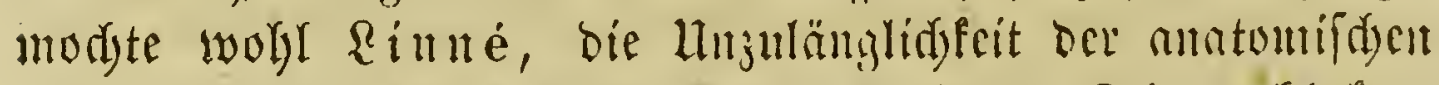

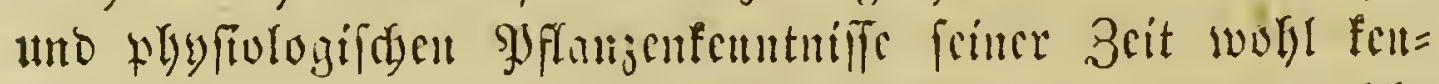

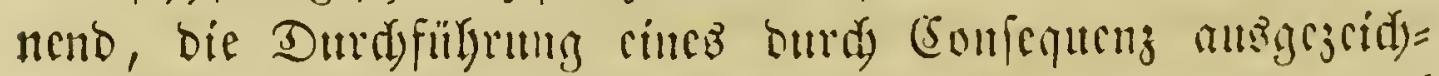

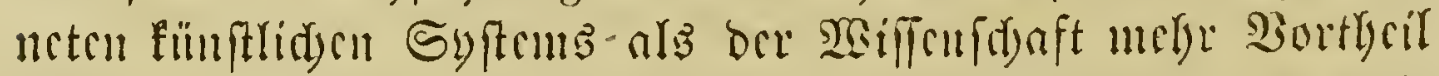

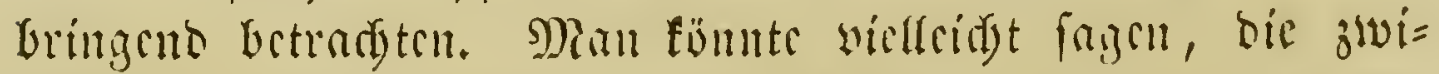

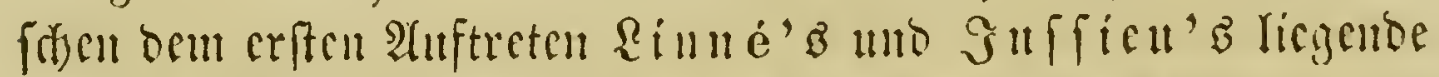

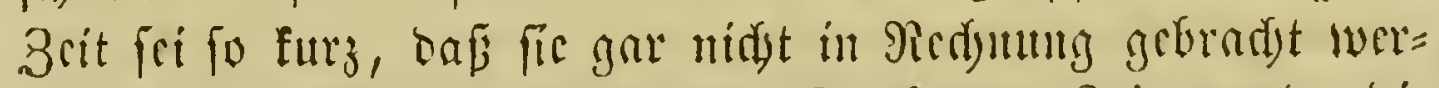
ben füme. Allein gerade in biefer furjen 3eit wurte bie 


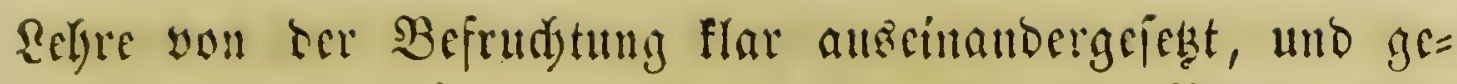
rabe in biefer 3eit war ber Rampf liber bie Vorgüge ber einjcluen Drgane am lyeftigiten, gerabe biefe Zcit war $\mathfrak{c B}$,

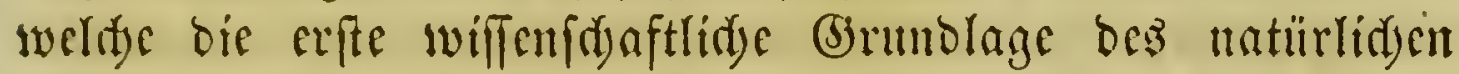
Syftems möglidy madjte. Rinné fudite ilberbies in feinem Gyfteme bie verwanten (semädyfe möglidyft zufanmenzilfel= Ien, ebenjo in bem won ilym herrifyectioen Syfteme, oas unter

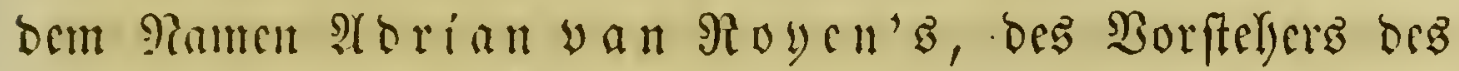
Reibencr (bartenz, befaumt gemadyt avmbe ${ }^{1}$ ). IAm bentlid) fent aber (prad) er fid) int fpäteren Rebensalter itber bie Serwandt=

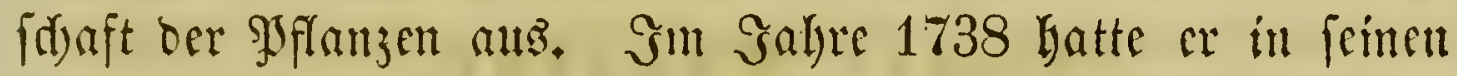
Classes plantarum (p. 489-541) 65 matïrlidje Drommgen angenommen, in ben Sriwatyorlefungen aher ${ }^{2}$ ), bie er itl ben Gabren $1764-1771$ feinen yorzüglideften Sdjülern biclt, reoucirte er bie $2(n j a b l$ berjelben auf 58.

aber obglcidy (b) iefe ffe, eimer ber vertranteften Sdyüler

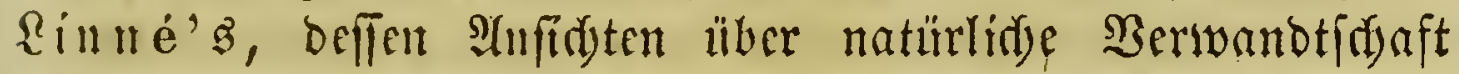

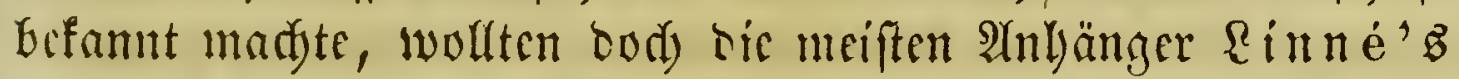
nidjts bavon hüren. Man glanbte fain redjter Rimnéaner zu fein, ivenn man nidgt gegen bie natïrlidyent Syfteme fid aแเริโräd)e.

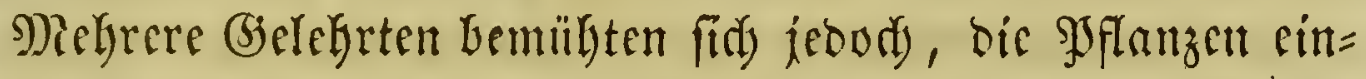

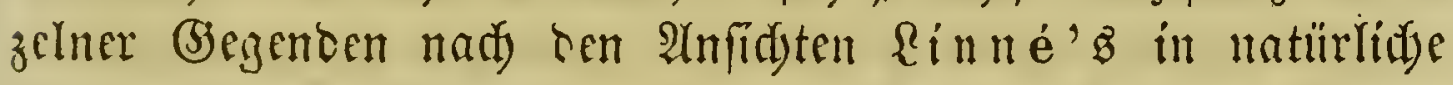
Dromungen zu Gringen. Seierber gebürt namentlidy soltis

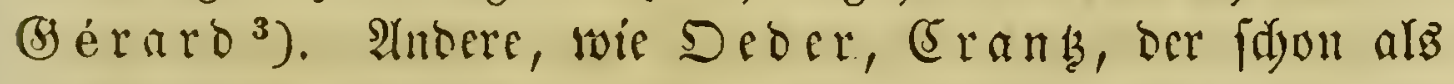

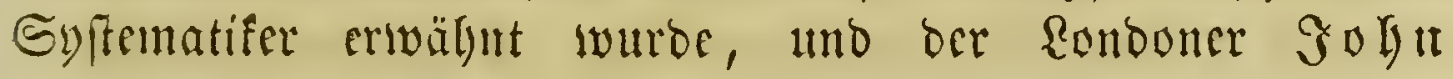

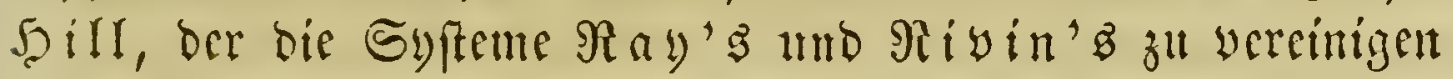

1) A dr. va n Royen, Flor. Leydens, prodromus. Lugd. B. 1 \% 40.8.

$\left.{ }^{2}\right)$ Praelectiones in ordines natura!es plantarum. E proprio et J. Chr. Fahricii manuscripto edidit Paul Dietr. Gicsecke. Hamburgi 1792.

$\left.{ }^{3}\right)$ Flora gallo-provincialis. Paris 1761. 8. 


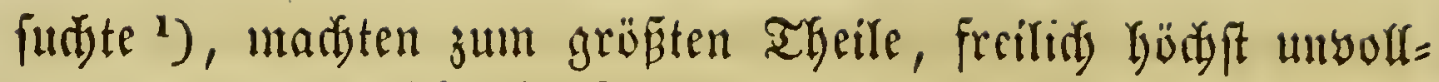
fommene, natürlidye Rlaffififationen.

Thud) Scopoli fam gleid, Rinne in frinen fpäteren Rebensialsen auf bie natürlidge Rlaffififation zurüd. Er nahin 36 3ünfte alt. Geber 3unft feste er ben Namen eines be= rübutten Botaniferb $\mathfrak{b e i .}{ }^{2}$ )

Einen Sdyritt weiter, alB feine Borgänger, bie immer mur nad) benjenigen Drganen, bie ilynen gerabe befannt waren, voer bie fie für bie iwefentlidften bielten, flaffificirt Gatten, ging

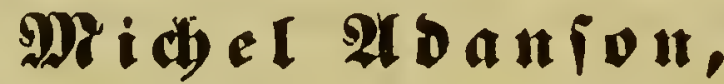

geboren 1725 zu $\mathfrak{A}$ ix in Der Srowence, geftorben 1806 ,

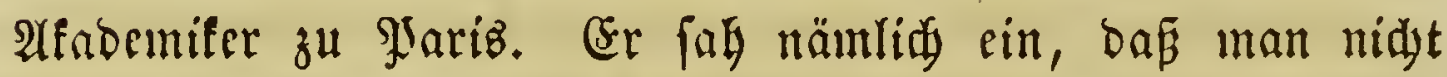
nad) cinem Drgane, fonocrn nur nady siclen zuammengenom=

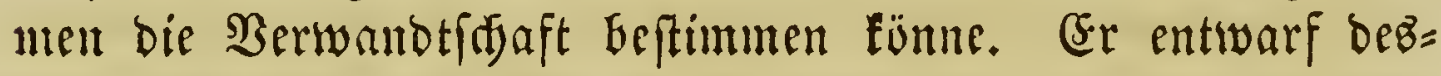
Jalb mit großjer 2 lusobauter für jebez Drgan und frine $\mathfrak{B e r}=$ bältnifie zut ben anbern Syflanjentbeilen, cin Syftem, in wet= dem er alfe in Befieljung auf Das als $\mathfrak{B a f i z}$ angenommene Drgant ähulidye Plflanjen zufammenftelfte. So erbielt er 65 verfdicdene Syfteme. Diefe verglidy er mun uno bradjte bie= jenigen (belvädsfe, weld)e find in ben meiften jener Syfteme

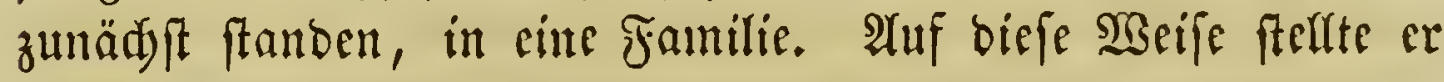
58 Fantilien auf.

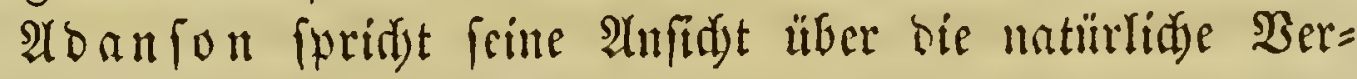
wamotfduft felgft in ben SBorten aus: ${ }_{n}$ La méthode natu-

1) The vegetable system etc. Lond. $1761-75.26$ Bbe. mit 1442 Rupfertafcin. Fol.

2) Methodus plantar. enumerandis stirpibus ab eo hucusque repertis destinata. Vienu. 175\%. 4. - Introductio ad histor. nat. sistens genera lapidum, plantarum et animalium hactenus detecta, characterib. essentialibus donata, in tribus divisa etc. Pragae 1777. 8. Bergl. aud beffen Fundamenta botanica etc. Paviae 1783. 8. c. $X$ tab. Vienn. 1786. 8. c. $X$ tab., ib. 1802.8 . 
relle doit être unique, universelle ou générale, c'està-dire ne souffrir aucune exception et être indépendante de notre volonté, mais se régler sur la nature des êtres, qui consiste dans l'ensemble de leurs parties et de leurs qualités; il n'est pas douteux qu'il ne peut y avoir de méthode naturelle en Botanique que celle qui considère l'ensemble de toutes les parties des plantes ${ }^{1}$ ).

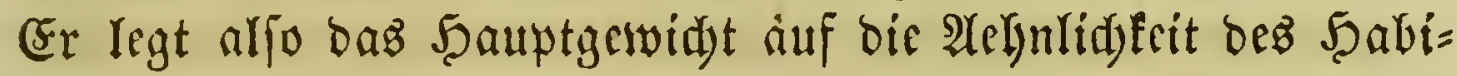
tus, b. h. bic (Erfdycinung alfer Drgane in ibrer (5efammtheit (l'ensemble de toutes les parties des plantes). Diefe

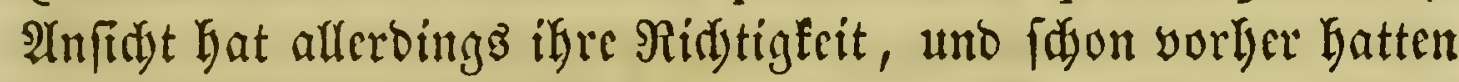
anocre Männer, z. $\mathfrak{B}$. Rinné, bloz igrem Inftintte uno

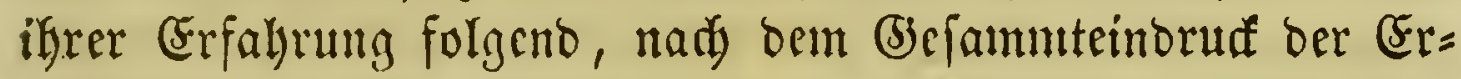
低cinung ber Syflanzen fie oft in gant ridjtige verwande Grup= yen gebrad)t. AUtein wenn man über bieje Uebereinftimmung

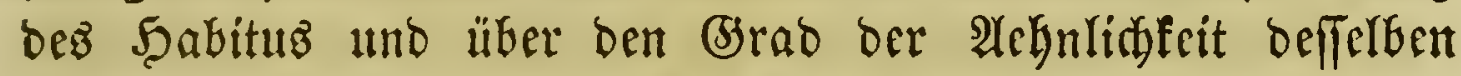

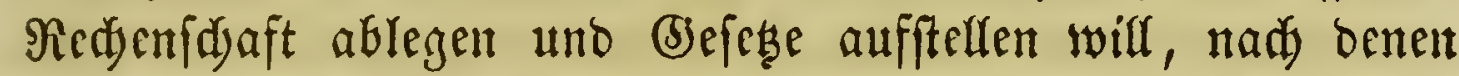
eine natürlide Rlaffififation vorgenommen werben folf, fo mus man bic einjelnen Drgane ber SPflanzen vergleiden. $2(b \mathfrak{a} n=$ fon that biefes und libertraf baburd) alle frine Borgänger. (Fir Teftimute aber ben (Grab ber Berwandtidaft blos nad

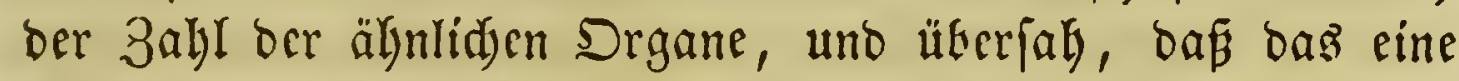
Drgan von ungleid) gröferer $\mathfrak{B e b e u t u n g , ~ a l s ~ c i n ~ a n c e r e s , ~}$ fein fann. 3ur Entfermung dirfes Felylers waren bie beiben

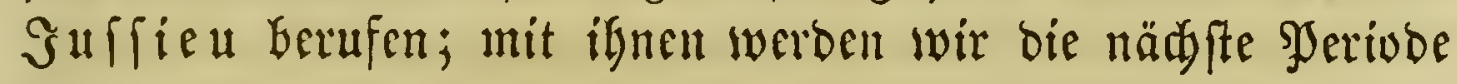
begimen.

A baju wobl auber ber bamntigen Ricblaberci fül tümftlidye Syfteme foine oft jonderbare Romenclatur und bie auperorbent=

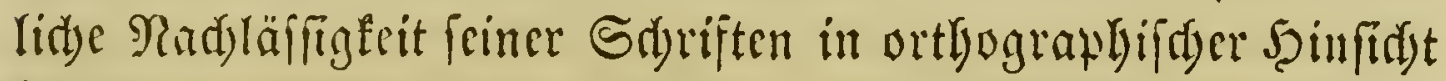
beigetragen $\mathfrak{h a b e n} .{ }^{2}$ )

1) Les familles des plantes. Par. 175\%. Préface CIV. 1 Art.

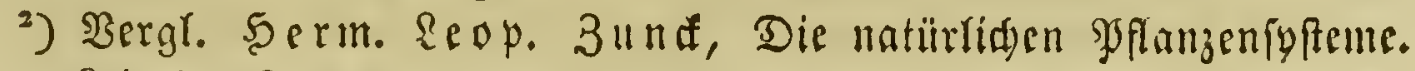
Seipjig 1840. 8. 


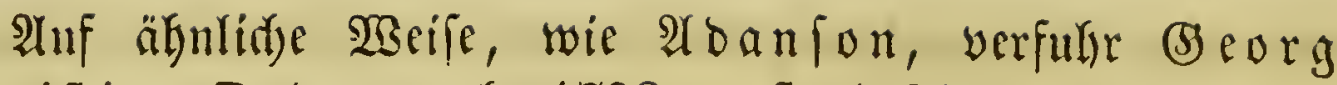
(G) hiftian Deder, geb. 1728, geft. 1791, bei Aluffellung feines Syftems. Diefes ift jebod) fein rein natierlides, weil

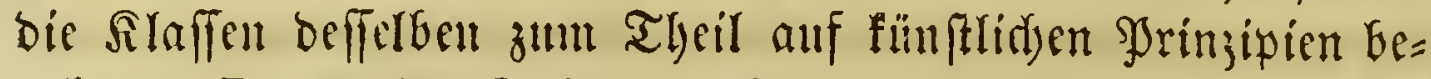
ruben. Deder's Syfem entbält 8 Rlaffen, weldye in 34 Familien zerfallen. ${ }^{1}$ )

Man follte glauben, bafis bie Erfintoung bes Mifrueflops zu genaueren lluteriudungen allgemeín uno mädtig bätte auf=

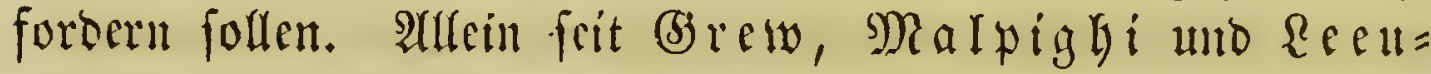
wenh ö war cine geraume Zeit verfloffen, in ber bie Ratur= Ielyre nidjts şejentlidjeg zu Tage förberte, ja in ber felbft bie Refultate ber obengenannten Foridjer wenig gefannt uno

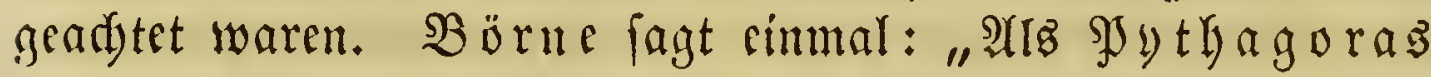

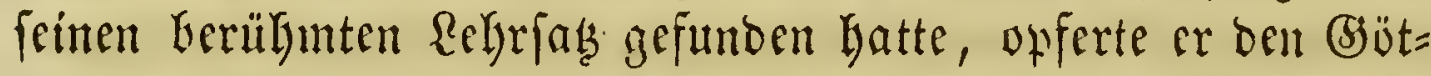
tern eine befatombe; feitben zittern bie Ddy fen, fobald eine

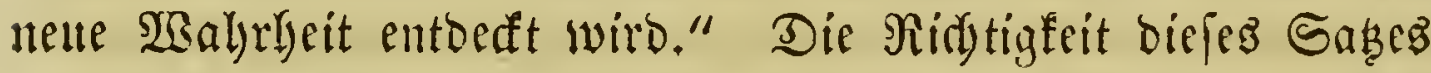
zeigte fid aud) wieber nad) Erfutomi ber Mifrobfops. Die Ritter Der Stabilität erboben fid gegen feine 2rnwentoung,

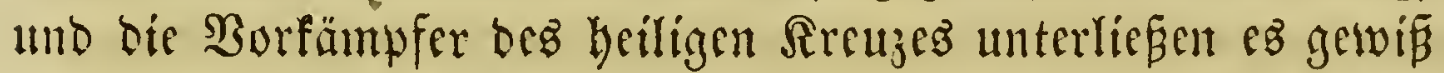

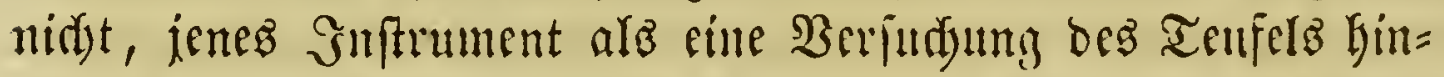
zuftellen. - G iov. Geron. Sbaraglia namentlid, SJro= feffor zu Bovlogna, erfläte in ber yorigen Syeriode ben (5)e= rrandi) bes Mifrogetupz für unftatthaft; er läuynete bemgemä audl) bie (Exiftenz ber Spiralgefäße uno ber Marfitrablen ${ }^{2}$ ).

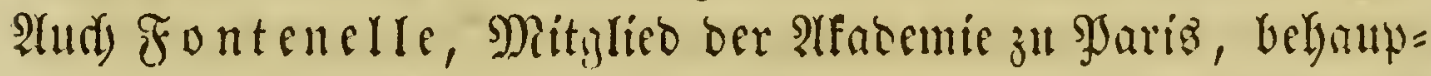

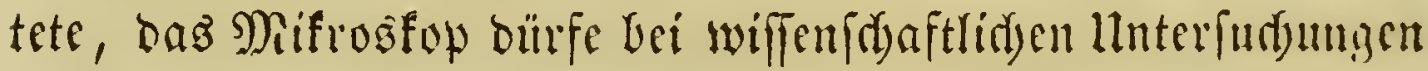
nidyt angewantot werden, weil es bem $\mathfrak{S}$ evbadjer oft mir daz

1) Elementa botanica. Pars I. IIafnize 176\%. Pars II. 1766. 8. Deutfis: Ropengagen 1764-66. 8. - Nomenclator botamicus etc. Ihid. 1769. 8. - Enumeratio plantar. Danicae et Norwegicae cryptantherae. Ibid. 1770, 8. Deutfíd baf. 1770. 8.

2) Oculorum et mentis vigiliae. Bonon. 170r. 
zrige, was er gerabe fehen lvulfe; bic ganze Relfre von ben

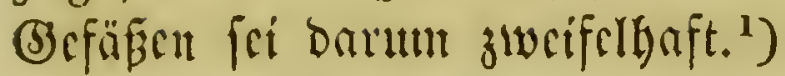

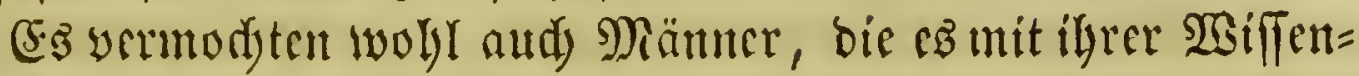

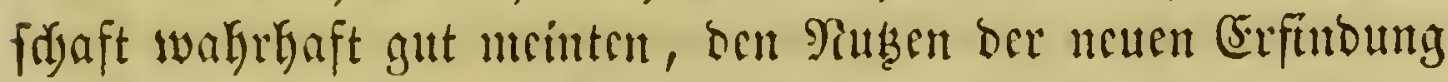
nidyt wedyt cinjufhen. Sie hielten bie mifrobtopifdyen unter= furdungen 'melyr für bilettruttifye Spiclereicu. Die Semtutís

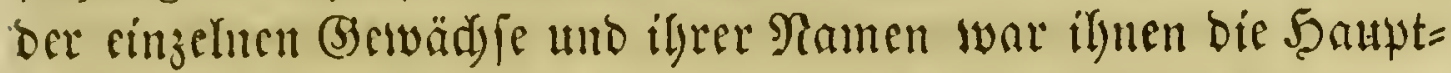

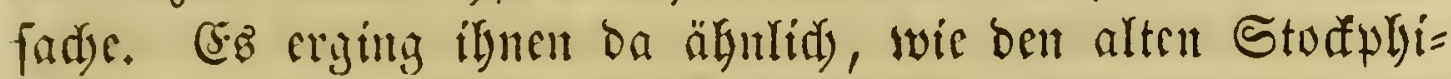

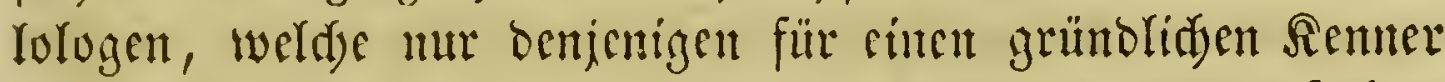
bes Alterthums balten, ber redst viele gjhrajen int Ropfe hat, bamit er alle Blugenbliffe fagen fann: ut Horatius dixit, ober inquit Cicero de off. lib. I. cap. 3 etc., bagegen vor alfen-Sdyriften, die in ben (Bsift bez Artertlums einjufülyren fudjen, brei Areuje madyen. Zu biejen Stofbotanifern ge= yörte aud sinne in grwiffem (Srabe; fagt er bod in feinter Philosophia botanica $\$$. 43: „Botanophili sunt qui varia de vegetabilibus tradiderunt, licet ea non proprie ad scientiam botan. spectant, ut anatomici, hortulani, me-

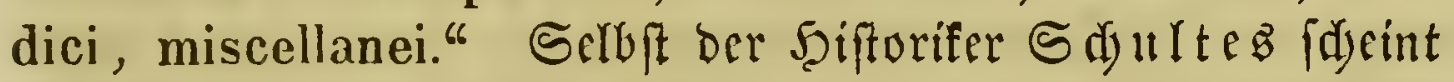

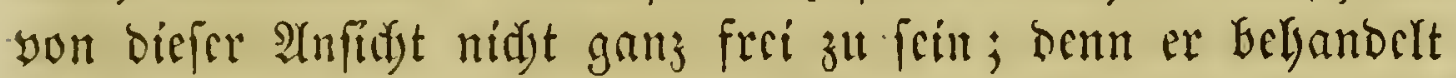
Die gröften Âtutumen uno \$shyfulogen oft nur im Borbei= gebcr, insem or zuweilen als Entritulbignng brifügt: "Er war cigentlid) melgr Jjhyfologe als Sotantifer."

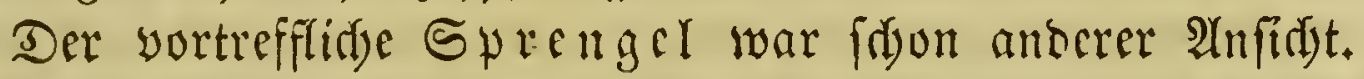

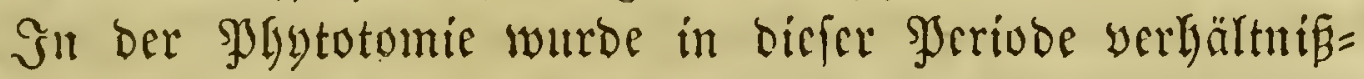

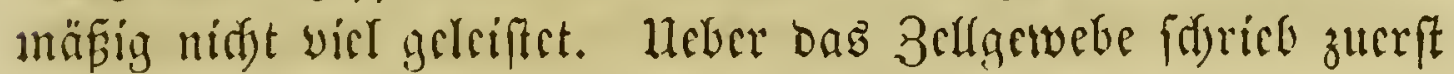

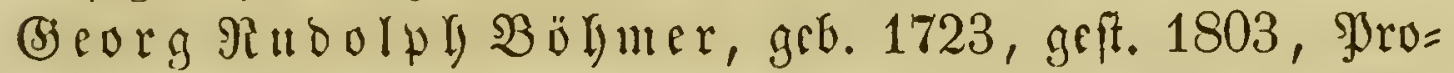

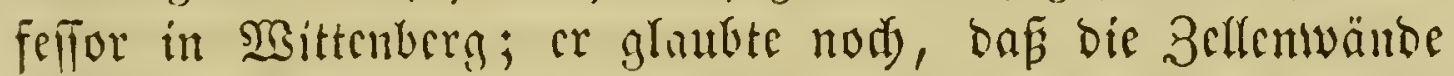
aus Faferil gebiloet (cicn. ${ }^{2}$ )

1) Ilist. de l'Académie des sciences de Paris, 1711. p. 43.

2) De vegetahilium celluloso contextu. Wittenb. 1753. 4. 3irgl. aud Deflet Spermatologiae vegetabilis pars I - VII. Wittenb. 1777 - 8\%. 4. Heber feine Srogramme und Differ= tationen vergl. IJ ribel S. 26. 


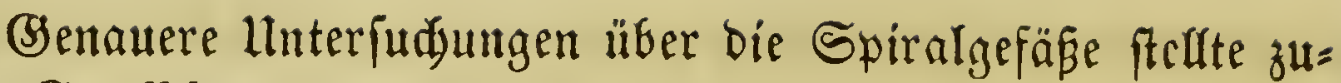
erft (3). Ehr. Neidil, Srofeflor in Ecipzig, geb. 1727, geft. 1771, an. (5rentbedte, bafí die yon Marpigly $\mathfrak{g e}=$

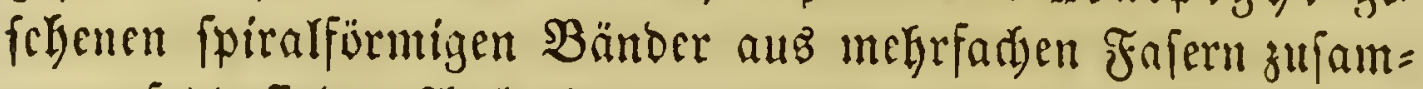
mengefest find. Aludy läugncte er baz Vorbandenfein yon Rlappen in biefen Befäfen; diefe entbielten nidjt blos \&uft, fonbern bienten aud) zur Führung ber Spflanzenfäfte. ${ }^{1}$ )

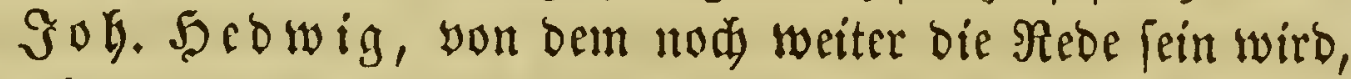
betradytete bie Spiralgefäfe als häutige $\Re$ öhren, um die fids

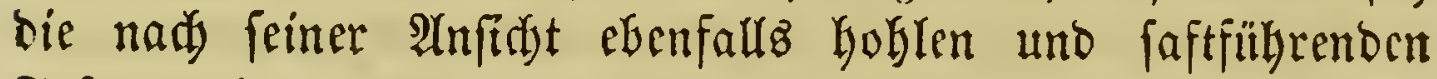
Fafern twinden. - Seinrids Dan. Moldentyatwer, ber Die Spiralgefäßze unmftändlider befdrieb, läugnete die Ber= zweigung Dericlben. ${ }^{2}$ )

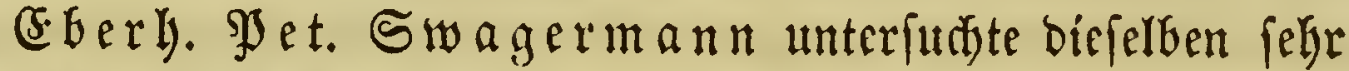

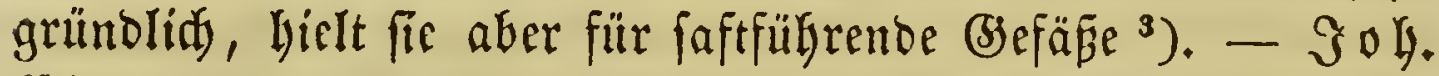

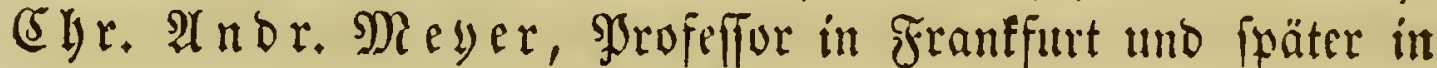
Berlin, geb. 1747, gcit. 1799, ber in feiner Sdyrift itber bie (Sefäße nidjtz wejentlid) Reuez bringt, hielt bie 3ivifden=

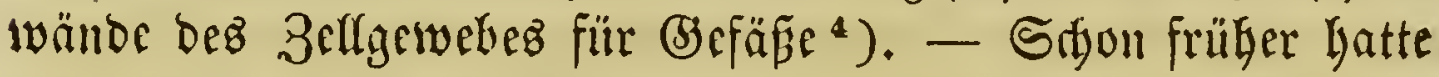
ber Nürnberger $\mathfrak{A} \mathfrak{z}$ t (Shrift. Sac. Trew, gcb. 1695, geft.

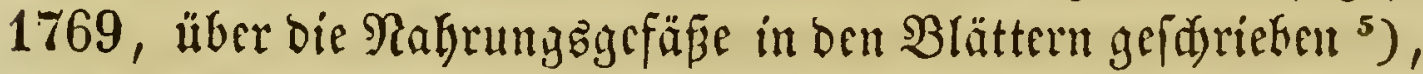
weldye Sdyrift won sincm gewiflen $\mathfrak{~}$. 2 . Seligmann

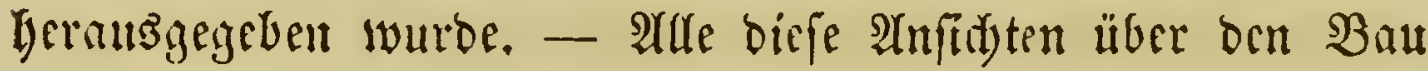

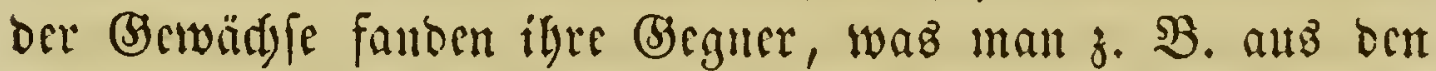

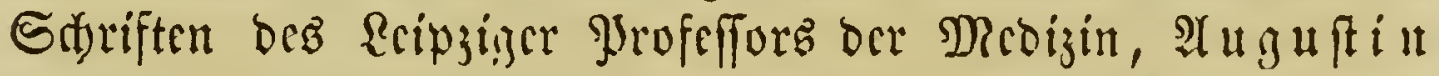
Friedrid) $\mathfrak{B a l t h e r}{ }^{6}$ ), geb. 1688, geft. 1746, und bes

') Diss. de vasis plantarum spiralibus. Lips. 1753. 4.

2) Diss. de vasis plantarum. Traj. ad Viadr. 1779. 4.

$\left.{ }^{3}\right)$ Verhandel. van de holl. matschappy te Harlem 20, u. 21. Deel. 1782.

-) Sur les vaisseaux des plantes (Mém. de l'Académ. roy. des sc. de Berl. 1788 -- 89).

s) Die Rabrungaggeä̧̧ in ben $\mathfrak{B}$ lättern. Rürnberg 1749. Fol.

-) De structura plantar. programma. Lips. 17\%0. 4. 


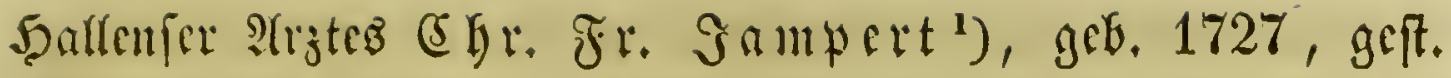
1758, follon faum.

Mlefer dic Epibermis und bie Spaltüfrnungen fadrieb $500=$

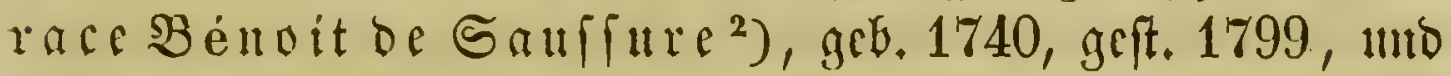

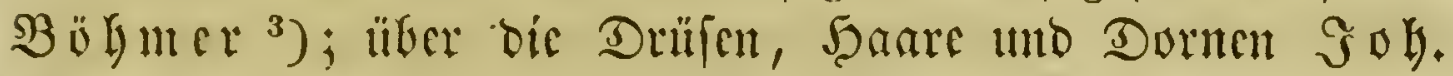

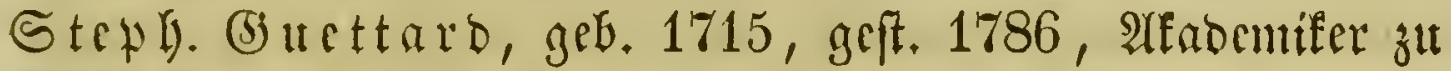
Parib. $\left.{ }^{4}\right)$

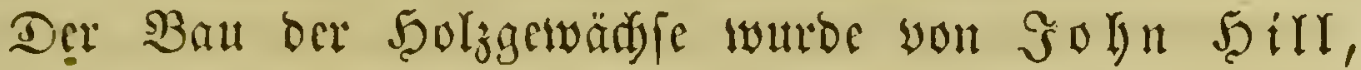

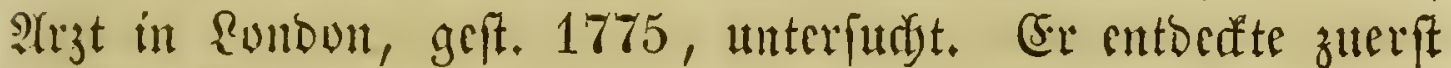

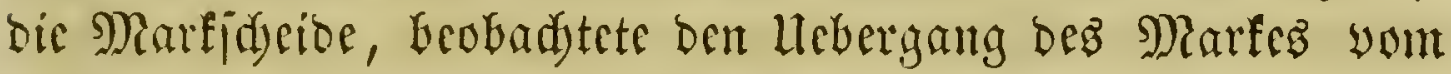

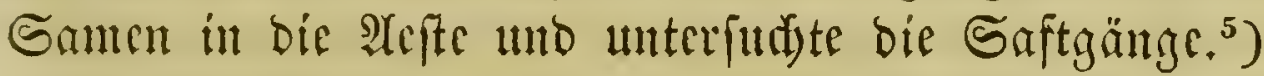

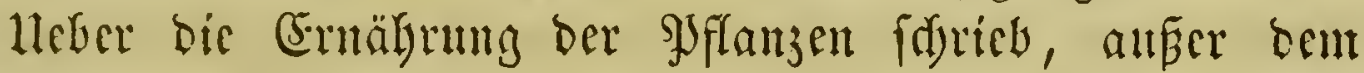

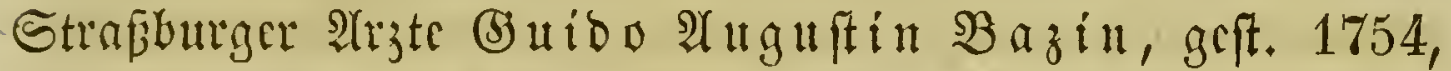

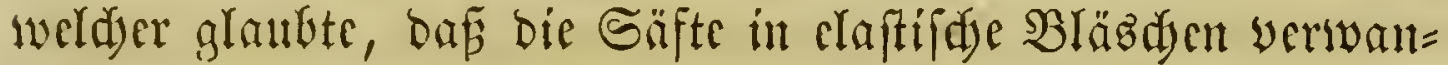
Delt würden unt fo vermittelft ber Spiralgefäpe in ben Sfftan=

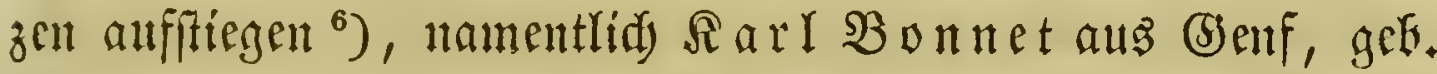

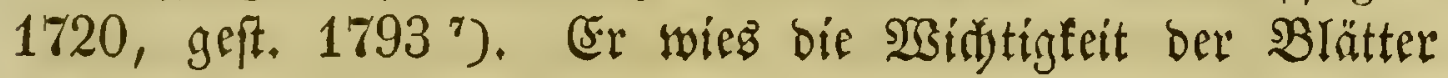

1) Specimen physiologiae plantar, contra vasorum in plantis probabilitatem. Hallae 1755. 4.

$\left.{ }^{2}\right)$ Observations sur l'écorce des feuilles et des pétales. Genève. 1762.8 .

$\left.{ }^{3}\right)$ De plantarum superficie exercitatio 1 - 4. Wittenberg. 1770. 4 .

4) Mémoir. sur différentes parties des sciences et arts, tom.

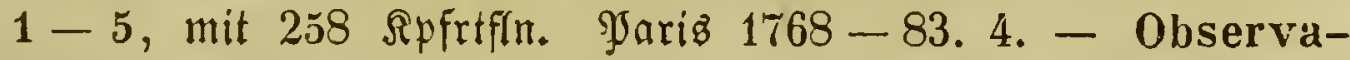
tions sur les plantes. Paris 1747. 2 tom. 8.

$\left.{ }^{5}\right)$ The construction of timber, from its early growth, explained by the microscope. Lond. 1770. Fol. 43 Iafelm. 1774. Fol. 44 Tafeln.

-) Observations sur les plantes, et leur analogie avec les insectes. Strasbourg 1741. 8. Deutfø im Samb. Mag. Bb. 4 u. 9.

7) Charl. Bonnet, Recherches sur l'usage des feuilles dans les plantes. Goetting. et Leide 1754. 4. 31 Tafeln. Deutid:

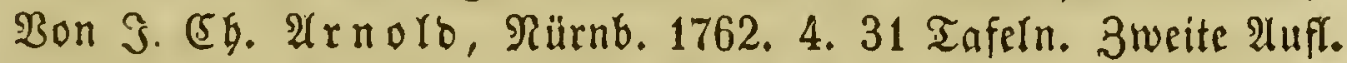

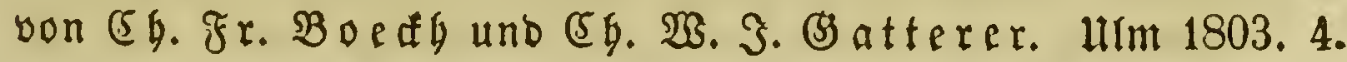
E., Bind le r, Befक. b. Botanit. 


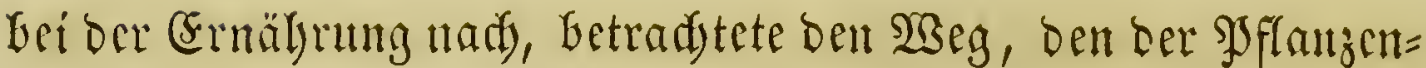

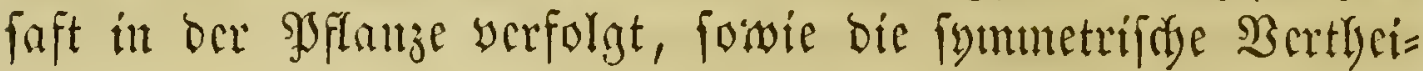
rutg ber Blätter an ben Stengeln und Zlweigen, Frad) son

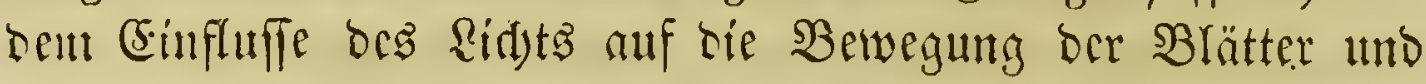
madte auserbem nod mandye intereffante Beobartungen.

Der franjöfifde Sfftzicr Muftel futde dic befannten

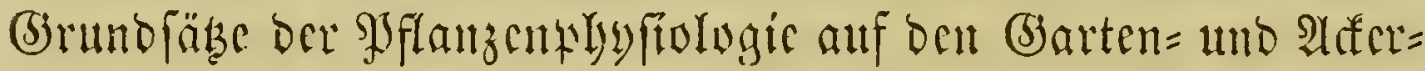

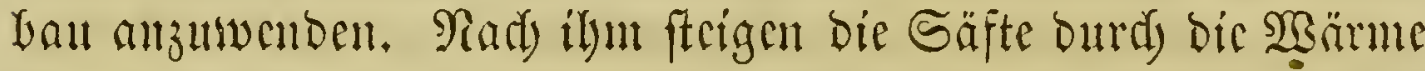

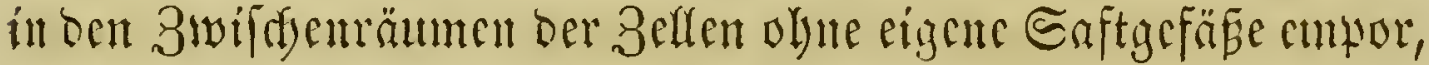

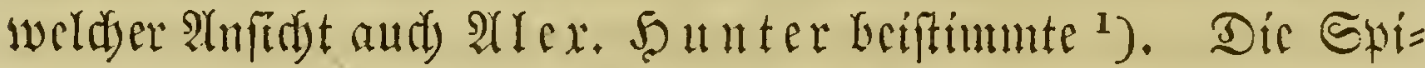

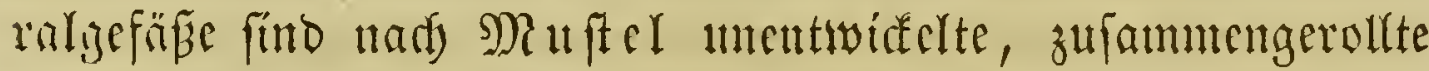
Fajern; bie Şlätter fallen ab burdy bas 2 (njidyellen ber

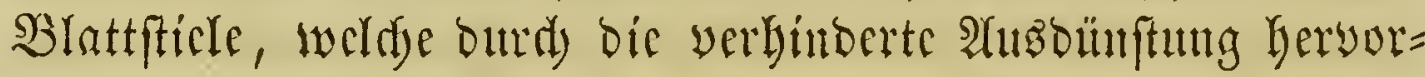
schradjt iwird. ${ }^{2}$ )

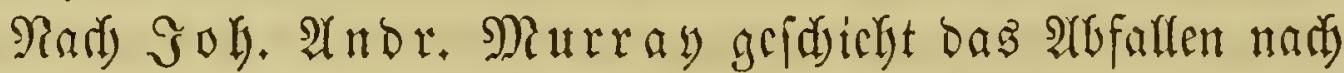
bem $\mathfrak{A}$ (uftreten ber Snospen in ben BIattwinfeln, woburd) bie SIattfiticle verorängt weroen. ${ }^{3}$ )

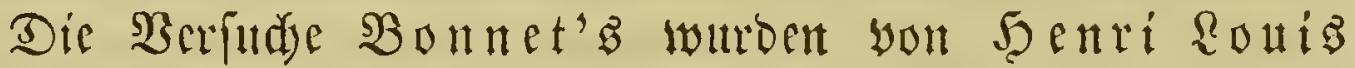
Bulyamel bu Monceau, geb. 1700, geft. 1782, Átuferyer

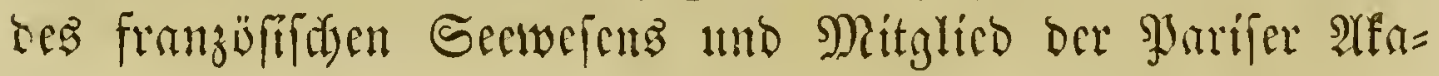
bente, weiter ausgefügrt. Seíte Unterfutyungen über bas

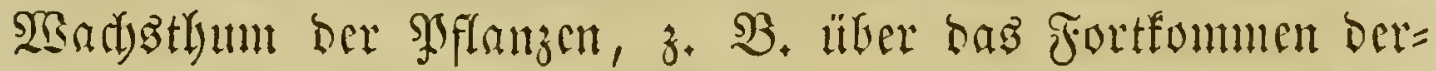
farben in gewibnlidyen Trinfivaffer, crregten nidyt geringes Fufflyent. Scine Bemertungen über ben Ragrumgsajaft, bié

- Parallèle des plantes et des animaux (Contemplation de la nature. Amsterd. 1764. 2 tom. 8. Hamb. 1782. 3

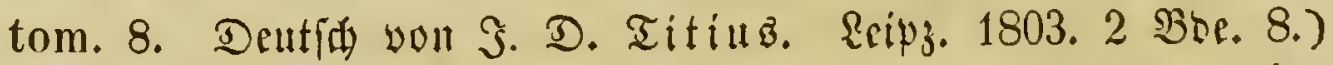

1) Georgical essays, vol. 1. p. $170 \mathrm{ff}$ - - Bergl. aud: Heber

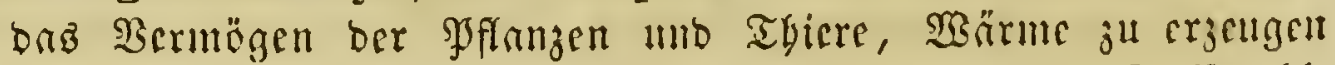

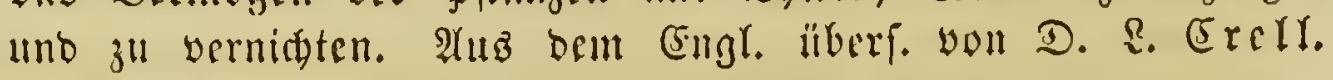
Şelmft. 1788. 8.

2) Traité théorique et pratique de la végétation. Paris et Rouen, 4 voll. 8.

3) Opuscula. Böbttingen $1785-86.2$ Bbe. 8. TÝ. I. S. 138. 


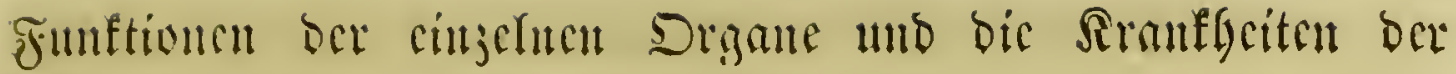

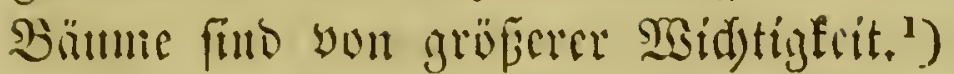

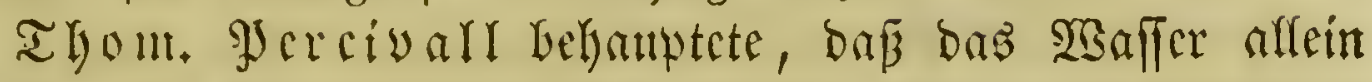

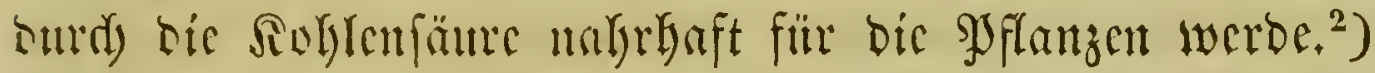

Heber sas $\mathfrak{A}$ tuathmen yon Saucrituff in Somenlidyte

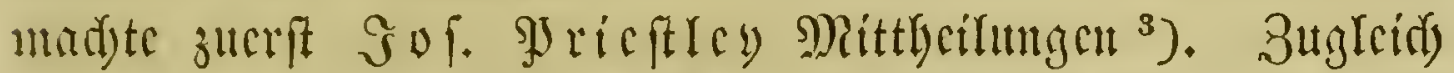

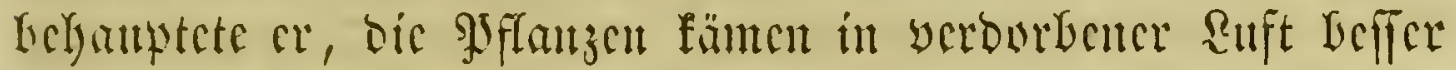
als in gemeiner fort uno reningten jene fogar. (5)

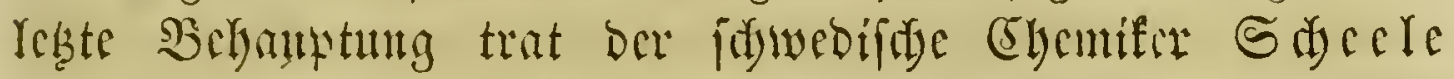

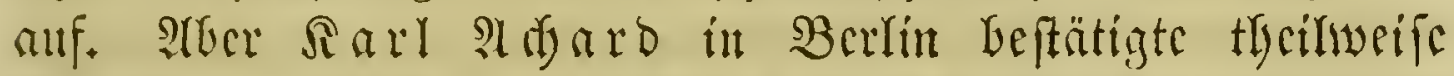

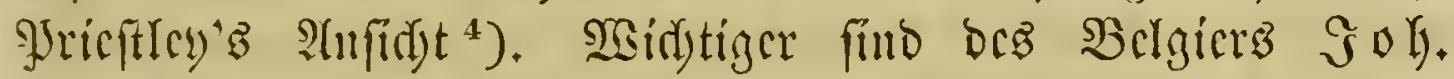

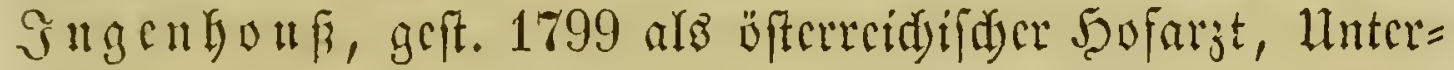

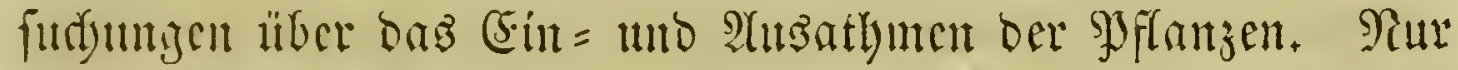
sie 3 lätter mo grünen Stringl atfmen int Sonnenlicht Gancrituff aus, zur Radytzcit und im Sdjatten bagegen ver=

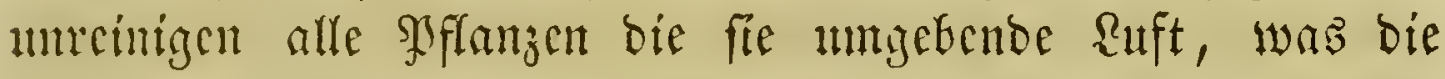

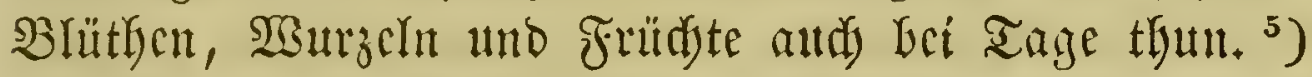

Díc Yebstere âtud befämpfte Gean Senebier, geb. 1742, geft, 1809, Socbiger und Bibliothefar zat Benf, in=

$\left.{ }^{1}\right)$ De la physique des arbres, de l'anatomie des plantes et de l'oeconomie végétale. Paris 1758.2 voll. 4. $\mathfrak{A} u 8$ bent

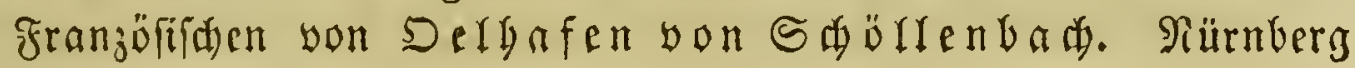
$1764-65.4$.

2) Hunter's Georgical essays. vol. 5. p. 17. (1775).

$\left.{ }^{3}\right)$ Experiments and observations relating to various branches of natural philosophy. Lond. 1779. Deutidy: Reipjig 1780.

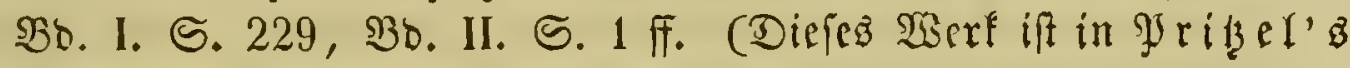
Thesaurus nidt aufgefülyrt.)

") Mlémoir. de l'académ. de Berlin, 1778.

$\left.{ }^{5}\right)$ Experiments upon vegetables. Lond. 1779. 8. Deutfd): Berfude mit sfflanzen, woourd entbeft worben, onfi fie bie Sraft befizen, bie atmogplyärifase Ruft beim Somrenfacill zut reinigen und im Sdhatten uno bes Radts über zu verberben. 2. D. Engl. Seipzig 1780. 8. Bergl. aud Deffen Bermifidte Sdyriften phyfifd =mebicimifden Sngaltz. Heber u. Herauzgegeb. ๖. Molitor. 2. Auflage. Mien 1784, 2 Bbe. 8. 5 Taf. 
bent er behauptete, bafi bie Pflanzen in Sdjatten uno bei Nadyt gar nidyta ausatlymeten. Die Trübung yon Rale= waffer burd) bie im Sdyatten ausigelyaudite Ruft fidrieb er

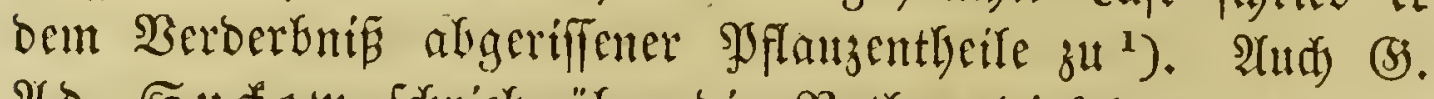

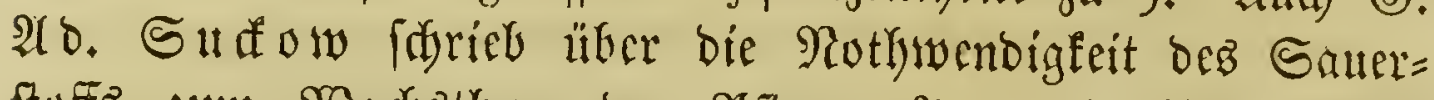
ftuffs zun Wadjathum ber SPflanzen ${ }^{2}$ ), und (5hriftowh (B)irtanner behauptete Darauf, daf ber Gauerftoff daz cigentlide Rebentoprinzip affer vrganifreten Rörper fei. ${ }^{3}$ )

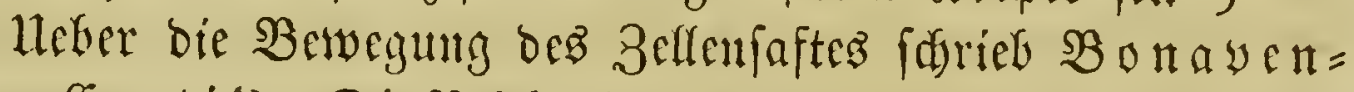

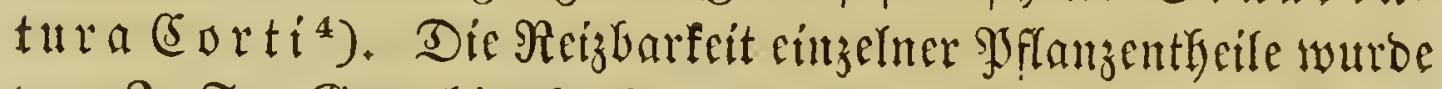

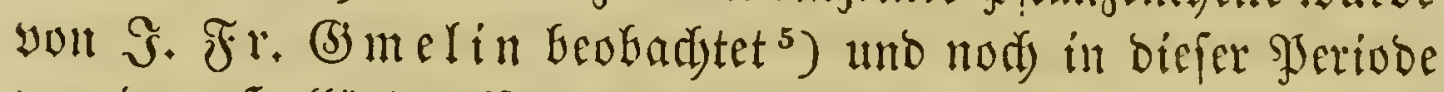
yon bem Şuflüber Martin yon Marnm ausefǘrt. ${ }^{6}$ )

Sob. Ant. Nollet uno Runeberg ftellten Beobad)= tungen über Den Cinfluß

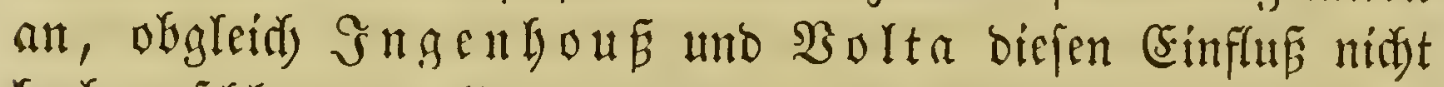
lyod) anfdragen wollten. Anbere, wic (3) iulio, $\mathfrak{B} a f f a l i=$

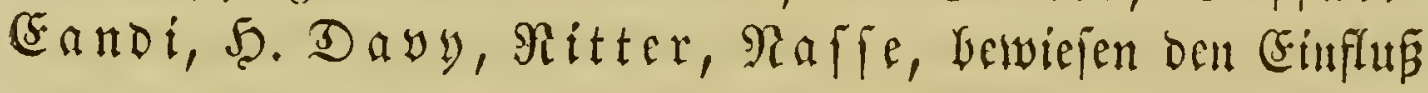

$\left.{ }^{2}\right)$ Expériences sur l'action de la lumière solaire dans les vẻgétaux. Genève 1788. 8. Bergl. au由 Defîen: Mémoir. physico-chimiques sur l'influence de la lumière solaire etc. Genève 1782, III voll. 8. Deutfad: Reipjig 1785, 4 Thfe. 8. Recherches sur l'influence de la lumière solaire pour métamorphoser l'air fixe en air pur par la végétation. Genève 1783. 8.

$\left.{ }^{2}\right)$ Act. academ. Theodor. palat. 5. p. 165 ff. - Serín üb. b. 2Birfigg. veridied. Suftarten auf o. Begetation. Münden 1702. gr. 4.

$\left.{ }^{3}\right)$ Journ. de phys. 36. p. $422 \mathrm{ff}$.

4) Osservazioni microscopiche sulla Tremella e sulla circulazione del fluido in una pianta aquajuola (Chara). Lucca 1774. 8. 3 Iaf. - Lettre anressée à Mr. le Comte Paradisi: sur la circulation d'un fluide, découverte en diverses plantes. Journ. de phys. par Rozier. Paris 1776. t. VIII. - Letera sulla circolazione del fluido scoperta in varie piante. Modena 1785.

$\left.{ }^{5}\right)$ De irritabilitate vegetabilium etc. Tubing. 1768. 4.

-) De motu fluidorum in plantis, experimentis et observationibus indagato. Groning. 1773. 4. 


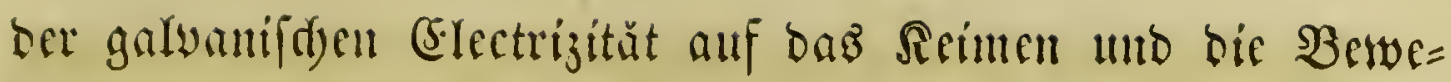
gumben ber (G) elväd)

Auf Den fogenanuten Şflanzenjdalaf wurbe Şill zuerft aufmerfan ${ }^{1}$ ). Dí erften aแ8fülyrlidyen Radyridten barüber

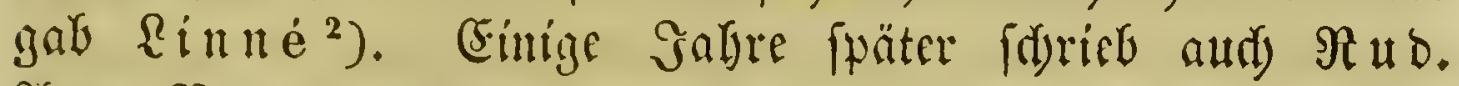
I(ug. $\mathfrak{B}$ og el baruber. ${ }^{3}$ )

Uleber bas. (befdeledit ber Syflanzen fand, wie wir fidjon

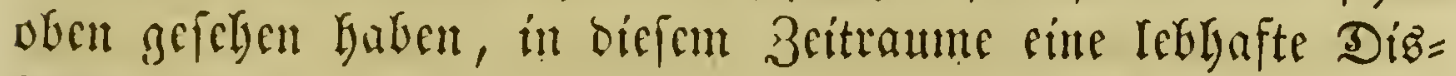

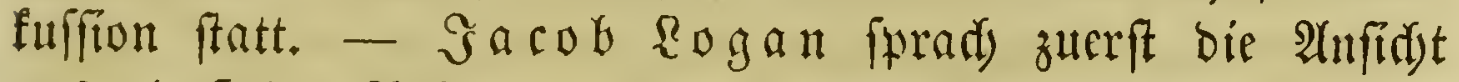
nus, baß ocr Solfen nidjt in oen Griffel cinbringe, fondern yon ber fliffigfeit oer Rarbe aufgejogen werbe ${ }^{4}$ ). Diefe $\mathfrak{A} n=$ fint wurbe yon Rimé aboptint uno vertyeidigt. ${ }^{5}$ )

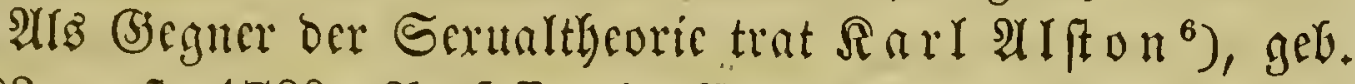
1683, geft. 1760, Srofeflor in Erinburg, uno (5) e org $\mathfrak{F}$.

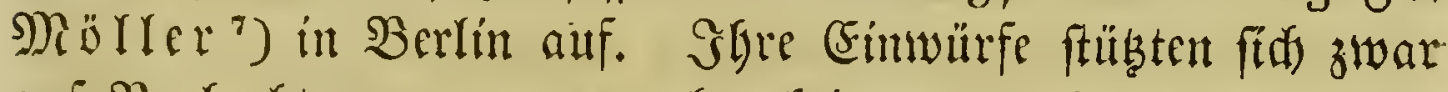
auf Beobadytungen, waren aber feincsinegz in Stande, be= bcutende 3wcifel rege zu marden, ba fie burd) gründlide (5r= flïrungen befeitigt wurben. Ramentlid $\mathfrak{A} \mathfrak{b} r$. (5) ot $t \mathfrak{b}$. Säfiner ${ }^{8}$ ), geb. 1719, geft. 1800, Srofeffor in 5öttingen,

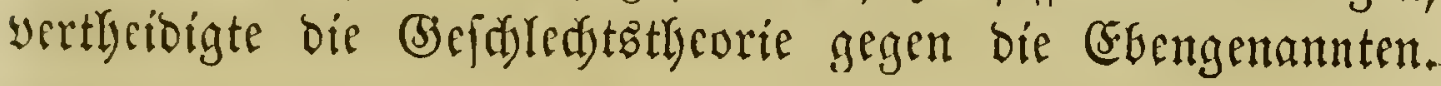

1) The sleep of plants and cause of motions in the sensitive

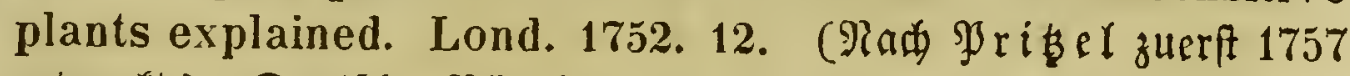
gebruft.) Deutf : Rürnferg 1768. 8.

$\left.{ }^{2}\right)$ Somnus plantar. praeside C. Linnaeo propositus a P. B r e mer. Ups. 1755. (Amoen. acad. vol. IV, p. 333-350).

3) De statu plantar., quo noctu dormire dicuntur. Götting. 1759. 4.

") Philos. transact. 1736. No. 4/1. Writer fillgrt aud an: Experimenta et meletemata de plantar. generatione. Lugd. B. 1739. 8. 1 Taf. Deutfd: Berfude u. Bebanfen you b. Erjeugung Der SPflanzen. Sggyfit. Boluftigungen, vol. III. p. $1088-1102$.

5) Disquisitio de sexu plantar. etc. 1760.

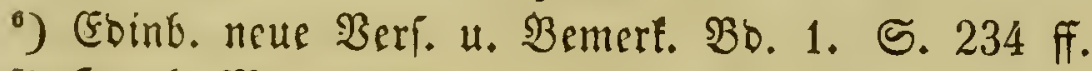

$\left.{ }^{7}\right)$ Scamb. $\mathfrak{M a g a}$. Bo. 2. S. $454, \mathfrak{B}$ b. 3. S. 410 , Bb. 7. S. 428 ff-

') Şamb. Magaz. BD. 3. S. 11, B̉b. 6. S. 529. 


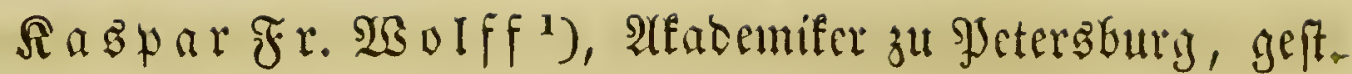
1794, befdäftigte fid) lyattptfäd)lidy mit ber Drganifatiun bes Embryo und mit don unbefrudteten (Sicri, $\mathfrak{B}$. Fr, von

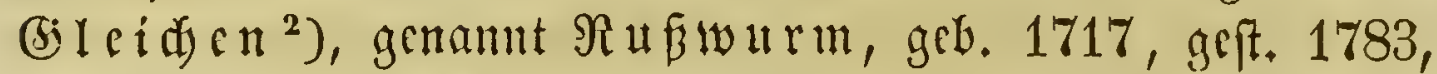
ber vielfadye mifrogitopifdye Unterfudungen anfellte, belyauptete, Daß Der SSoulen nidyt ummittelbar jut ben Eiern gelangen tönne, wail bie Şaare und \$apillen ber Rarbe geferloflen feien, uno yertheibigte bic Eaxualtheorie gegen ibre Frinbe. - Eafen=

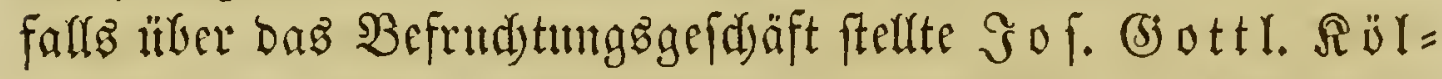

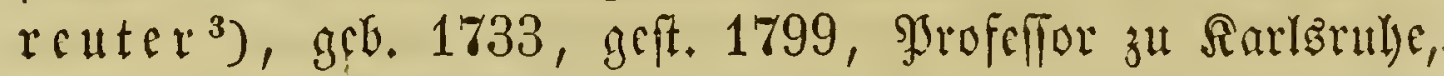

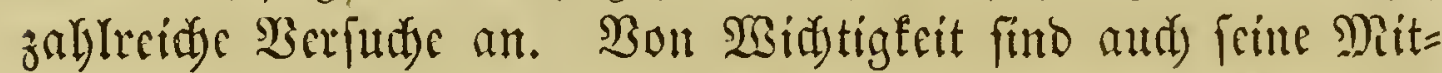

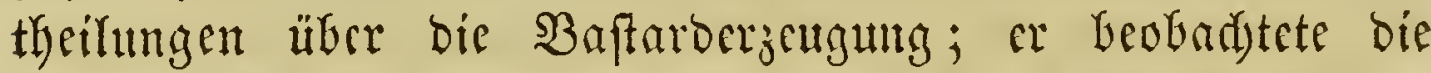

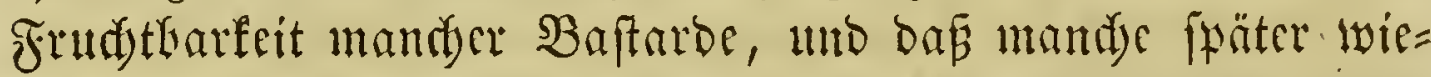
ber zu ber atriprïnglidyen Form zแriaffetgren, Yängncte aber, Dá̧ SBaftarde you felbft entftelyen tönntent.

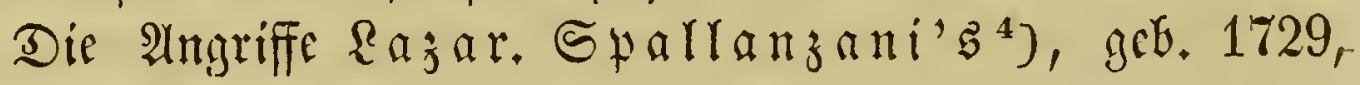

1) Theoria generationis. Hal. 1759. 4. 2 Taf. - Ib. 1774. 8. 2 Iaf. - Deutfit: Ilgeorie von Der Beneration. Bertin 1764. 8.

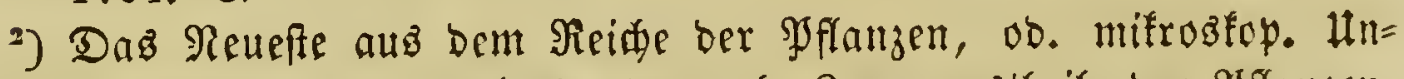

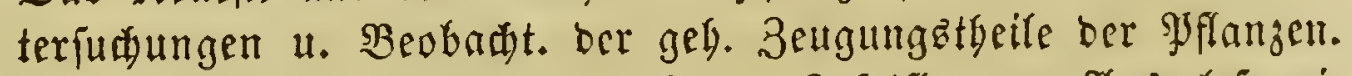

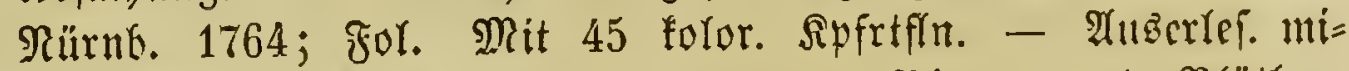

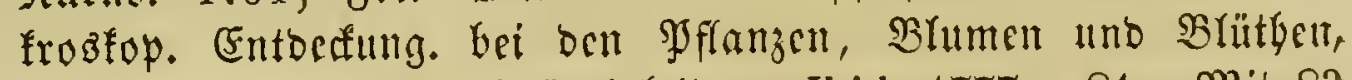
3njeftert u. and. Rerfwürbigfeiten. Ibid. 1777-81. Mit 83 folor. Spfrtfln. 6 Şfte. gr. 4.

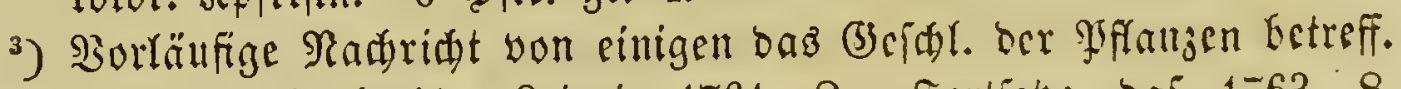

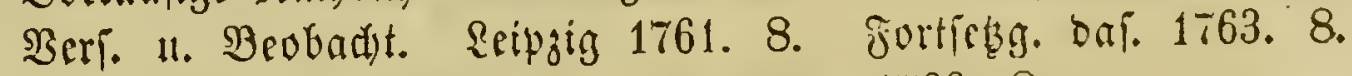
2. Fortferg. baf. 1764. 8. 3. Fortfeigg. 1766. 8.

4) Della generazione di diverse piante nella fisica animale e vegetabile. Modena 1776. 2 voll. 8. Dcutids: Reipsig 1786. Sergl. nud beffen: Opuscoli di fisica animale e vegetabile. Moden. 1776. II voll. 8. - Fisica animale e vegetabile. Venezia 1782. III voll. 12. - Experiences pour servir à l'histoire de la génération des animaux et des plantes. Genève 1786. 8. Dentíd: 1. Afbtheifung, Reipziga 1786. 8 . 


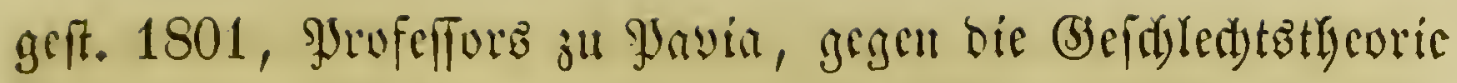
lyatten feineil Grfolg.

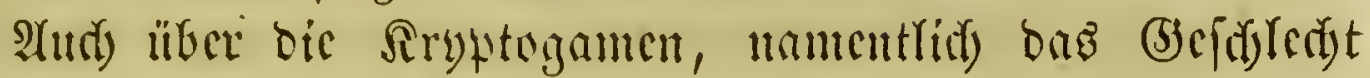

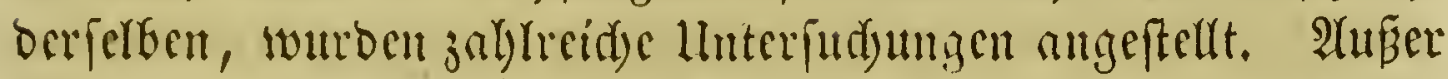

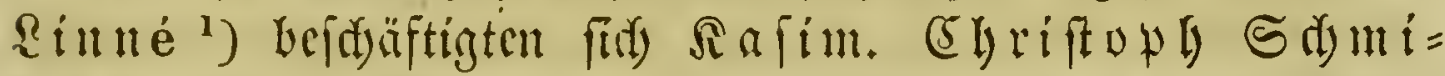

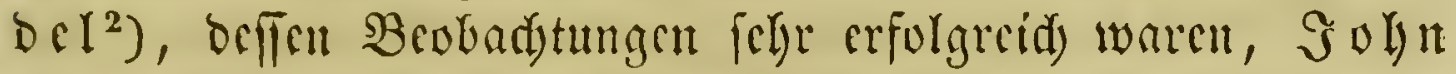

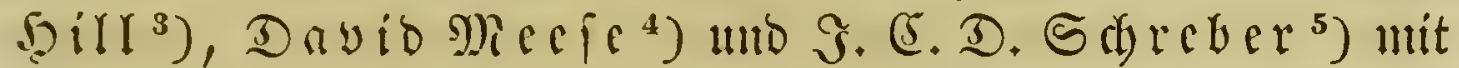

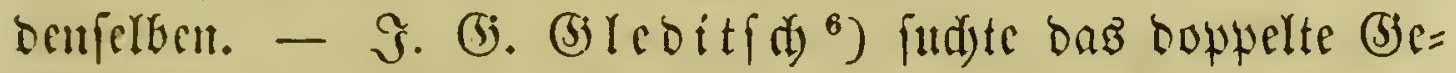

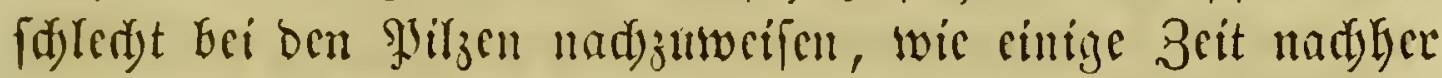

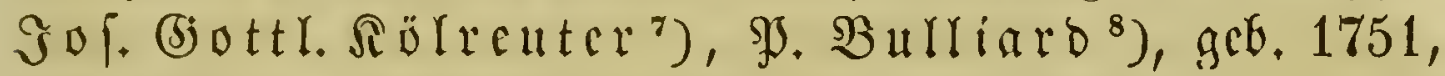
geft. 1793, uno beebwig. ${ }^{9}$ )

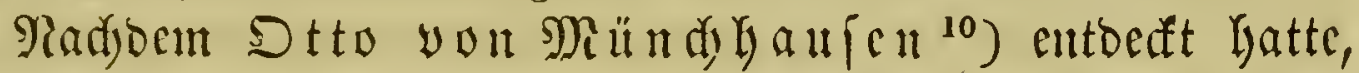

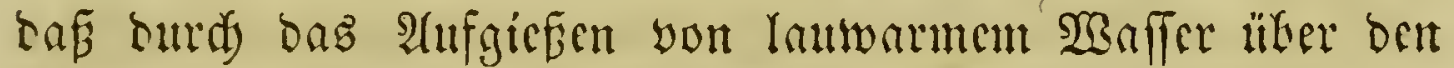

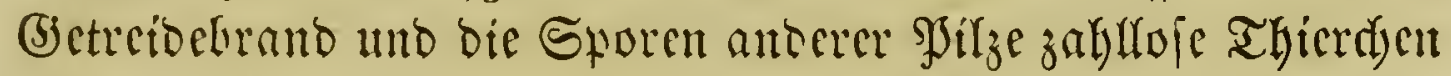
fid) entwiffeln, uno Rin ne ${ }^{11}$ ), Gicrauf geftutgt, you ben Santen=

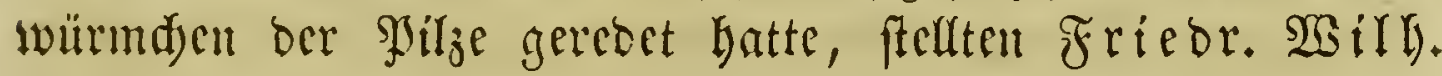

1) Semina muscorum praeside C. Linn a e etc. Ups. 1750 .

$\left.{ }^{2}\right)$ De buxbaumia. Erlang. 1758. 4. De Blasia. Ib. 1759. 4. De Jungermannia. Ibid. 1760. 4. 3uglei mit melgreren anderen Ilbyanbl:: Dissertationes botanici argumenti revisae et recusae. Ibid. 1783. 4.

$\left.{ }^{3}\right)$ The british herbal etc. Lond. 1756. p. 99.

$\left.{ }^{4}\right)$ Acta societ. scient. harlemens.; tom. X, p. II. p. 171.

$\left.{ }^{5}\right)$ De Phasco. Erlang. 1770; mit 2 Tafern.

6) Mém. de l'acad. de Berlin. 1748. p. 60.

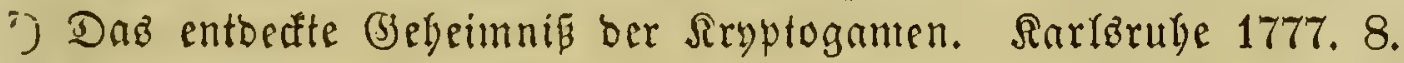

$\left.{ }^{8}\right)$ Histoire de champignons de la France etc. Paris an VI (1791-1798). Fol. 4 tab. Siebe bic Borrebe.

${ }^{\circ}$ Theoria generationis et fructificationis plantar. cryptogamicarum Linnaei etc. Petropol. 1784. 4., mit 37 Spfrtffl. Reipzig 1798, mit 42 ßpprtffin. 4.

10) Der Saatsyater, 5annoyer 1765-74. 8. 6 Bbe.

11) Mundus invisibilis, quam praeside C. de Linné propos. etc. Ups. 1767. Amoen. acad. ed. cur. Schreber, tom. VII. p. $385-408$. 


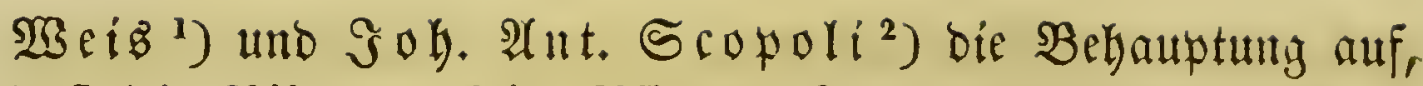

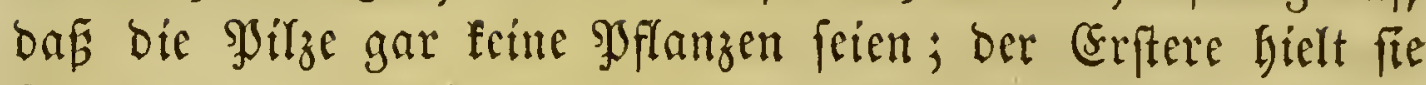

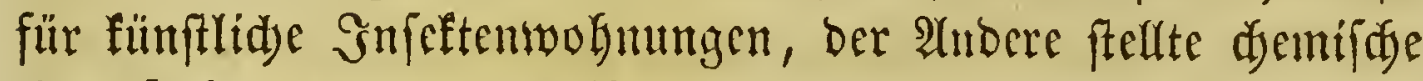
Unterfudutugen an, un igre thierifde Ratur zu betweifen. -

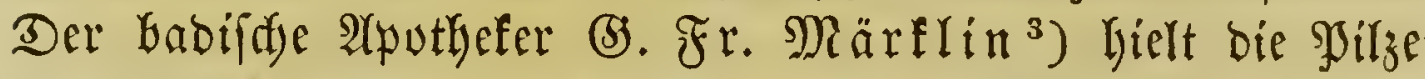

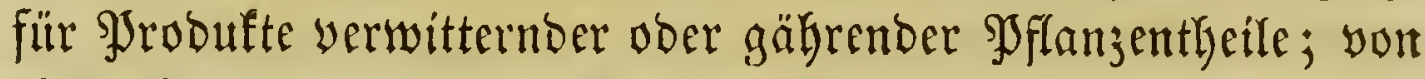
einer fortiflangung Durdh Samen fünne aljo bei ifnen gar fcine Rebe fein.

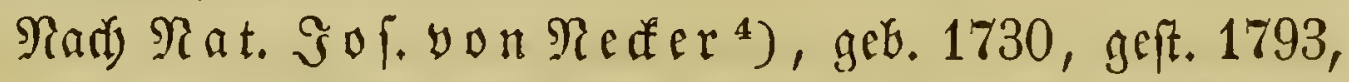

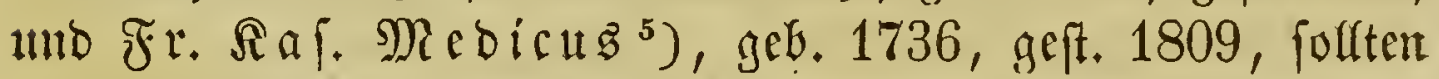

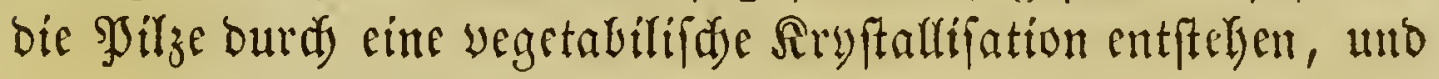
Stt o Fr. Mür(er ${ }^{6}$ ), Shrofeffor in Ropenthagen, geb. 1730, geft. als bänifder Stantarath 1784, hielt fie für 3oophyten.

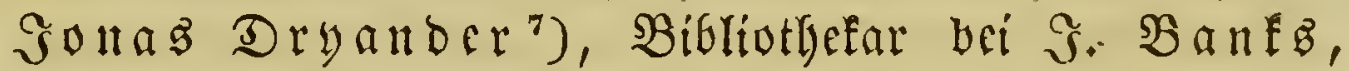

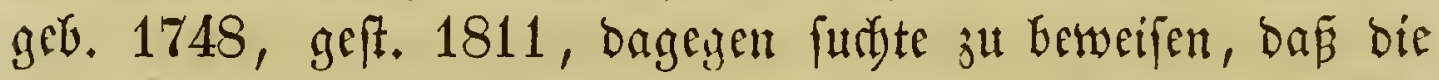

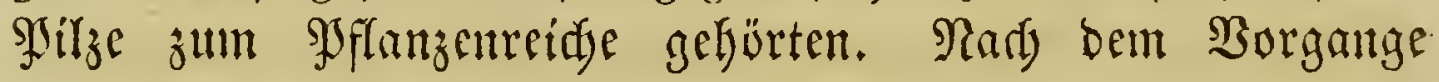

1) Plantae cryptogamicae florae Gottingensis. Gotting. 1770 . 8. mit 1 for. Tafer.

$\left.{ }^{2}\right)$ Deliciae insubricae. Ticini $1786-88$. Fol. 75 tab. Vol. I. p. $41 \mathrm{ff}$.

3) Ilfteri'b Maga. fïr Bot. Bb. 3. S. 137.

4) Traité sur la Mycitologie ou discours historique sur les Champignons. Mannh. 1783. 8. 1 Tafel.

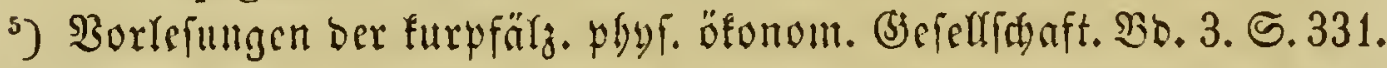

${ }^{\circ}$ ) Prodrom. zoolog. dan. p. 256. - Beidäftigung ber kerl.

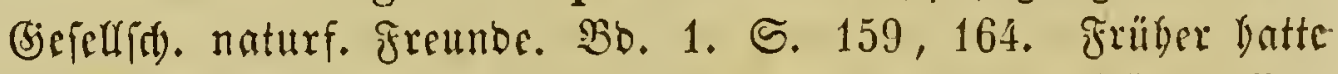
or fid gegen bie thierifale Siatur ber gitziporen crflät: PileLarven met dobbelt hall. Kiobenh. 1722.

7) Dissert. fung. regno vegetabil. vindicans. Lond. 1776. Bon bicient Edriffferffer rübren aud bie folgenden Sdjriften iwer

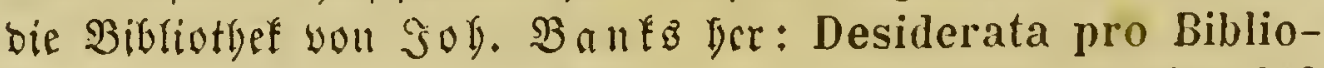
theca Banksiana. Lond. 1790. 8., in wrider Edirift 1343

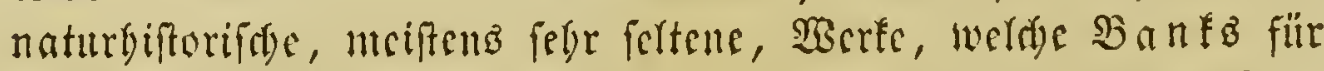
feine Bibliothef anzufdaffeu fudte, aufgefiürt fiub. - Catalog. bibliothecae historico - naturalis Jo S. Banks. Lond. 1796 -1800 . V voll. 8. III, vol, Botanici. 


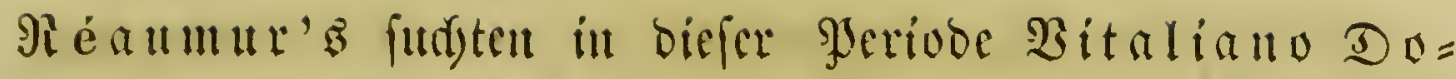

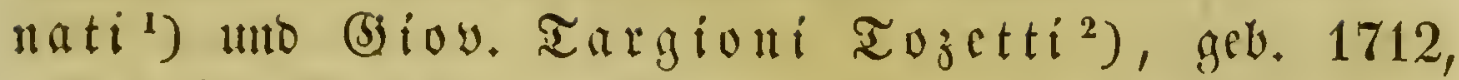

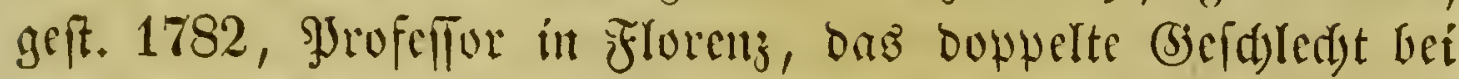

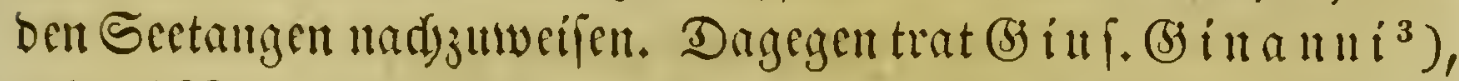
geb. 1692 , geft. 1753, auf, fowie audi $\subseteq \mathfrak{a m u} \mathrm{el}$ (5) ott $=$

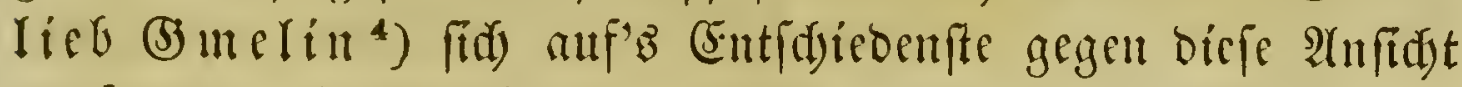

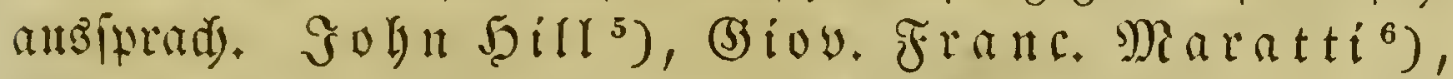

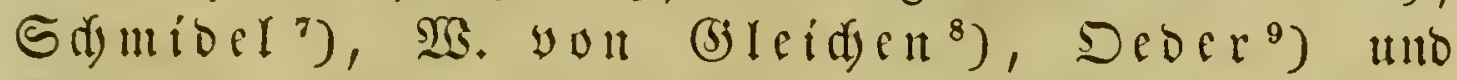

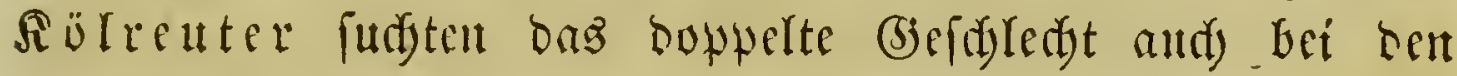
Farrenfräutern undjulweifen, inbem ber eine diefes, ber andere

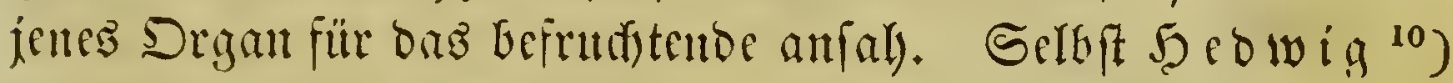

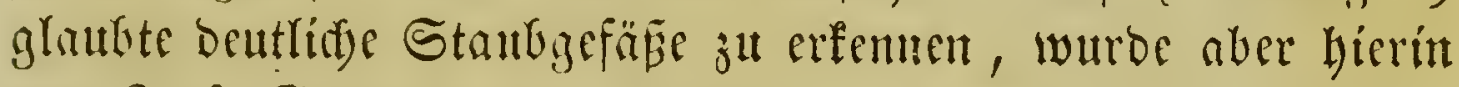

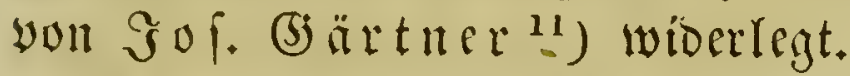

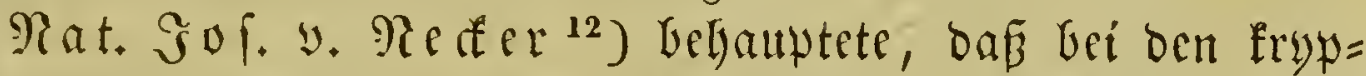

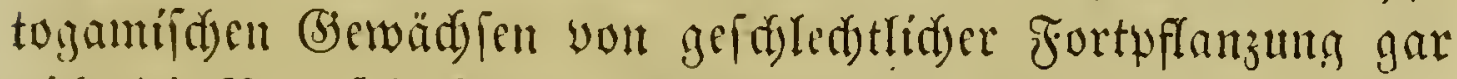

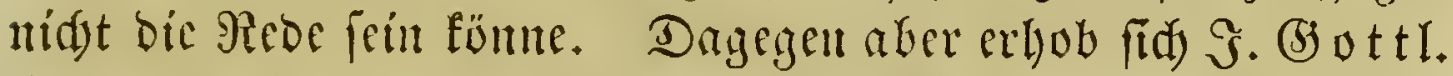

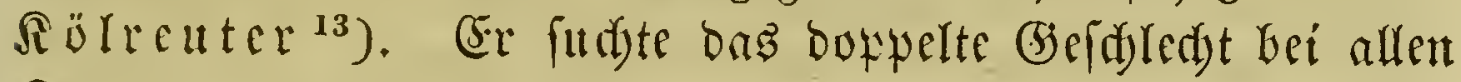
Siryptoganten nadjutweifen.

1) Saggio della storia naturale marina dell' Adriatico. Venezia 1750. 4. 10 Tafeln. Deutifi: Şalle 1753. 4. 1 Tafer.

$\left.{ }^{2}\right)$ Relationi d'alcuni viaggi fatti in diverse parti della Toscana. Firenze $1768-1779.12$ BDe. 8.

3) Opere postume. Venezia 1755-57. 2 Bod. Fol. 55 Tafelit.

4) Historia fucorum. Petrop. 1768 mit $33 \Omega$ $p$ frtffn.

$\left.{ }^{5}\right)$ The vegetable system. etc. Lond. $1759-75$. p. 14/4.

$\left.{ }^{6}\right)$ Atrorga $\phi_{n}$ s. descriptio de vera florum existentia etc. Romae 1760. 8. 1 Tafel.

') Icones plantar. etc. Erlang. 1762-94. p. 47, 48. tab. 73. f. 4. 6. 9 .

8) Daz Reucfte 2c. S. 24. tab. 3. fig. 6. S. 31. tab. 24. fig. 9.

') Elementa botanica. Hafn. 1766. vide P. II. p. 269.

$\left.{ }^{10}\right)$ Theor. generationis p. $87 \mathrm{ff}$.

$\left.{ }^{11}\right)$ De fructibus et seminib. plantar. Stuttgart 1788-91. 4. pag. 36.

12) Physiologia muscorum etc. Mannh. 1774. 8. 1 Iafer.

13) Das entoefte Bjegeimni ber Siryptogamen. Sartärube 1777. 
Die gründlidften lnterfudumgen üßer die Rryptogamen fitcllte $\mathfrak{a b c r}$

\section{Sobanu Sedwig,}

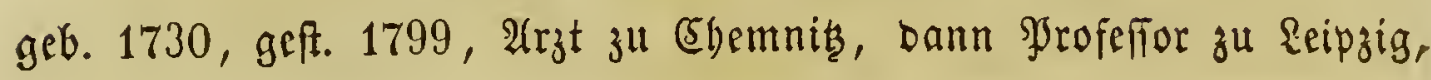

an. (5r war überbaupt cincr ber thätigften und fdarffint=

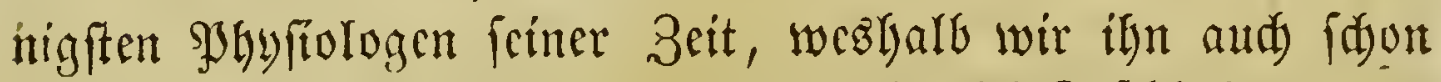

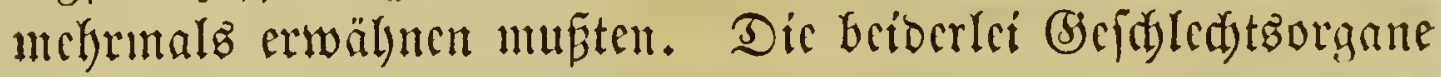
ber Moofe, Rebcrmooje uno Sharaccen lat er zum grö́ten Theife fo crfant, wie fie lycutzutage angenommen werben;

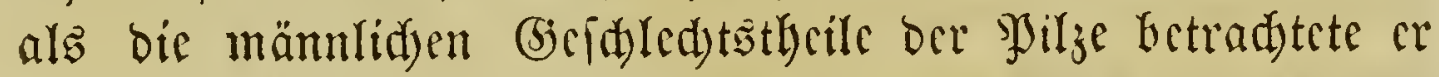

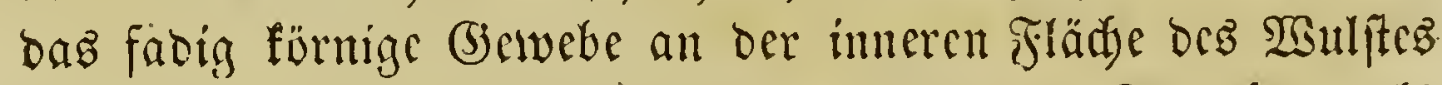

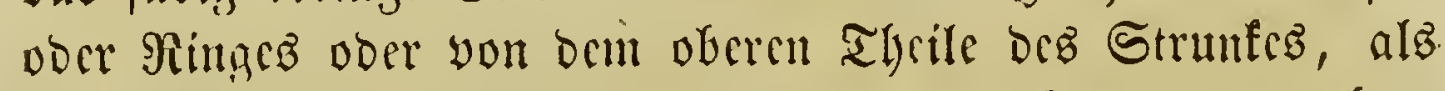
bie ber Sdyafthalmen bie claftifden, Die Sporen ungeben= ben Fäbon; für die mämlityen Scrualien bor Farrenfräuter

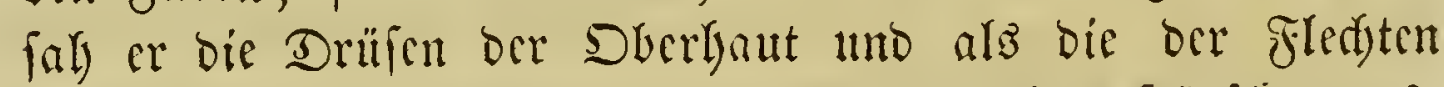

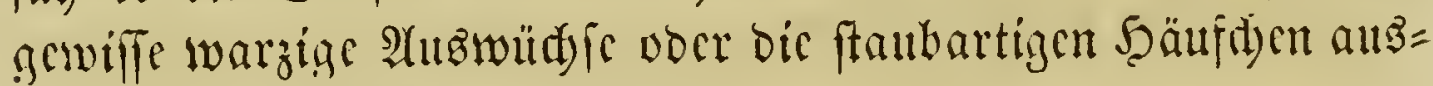
gewitterter $\mathfrak{B r u t z}$ ellen an. ${ }^{1}$ )

Der $\mathfrak{B} h y$ tograplen und Floriften gab es in biciont

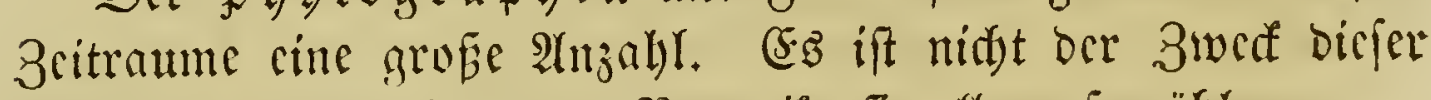

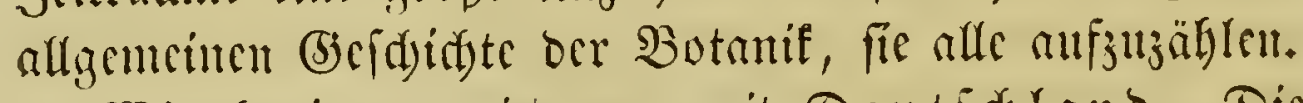

Wir feginuen wicocrum mit Deutidgland. Die crite eigentlidye Flora von ganz Dentid)lano verfapte Albert

') Theor. generat. etc. 2. ed. Lips. 1798. 4. - Fundam. hist. nat. muscorum frondosorum etc. Lips. 1782. II voll. 4. 20 Iafeln. - Descriptio et adumbratio microscopico - analytica muscor. frondosor. etc. Lips. 1787-97. IV voll. 160 Iafeln. - De fibrae regetabilis et animalis ortu. Lips. 1789. 4. -

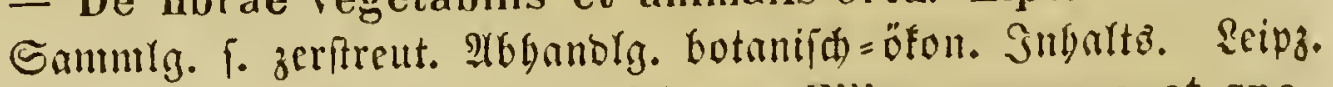
1793 - 97. 2 Boe. 8. 6 Iafeln. - Filicum genera et species recentiori methodo accomodatae analytico descriptae. Lips. 1799 - 1503. IV Fasc. Fol. 24 Iafeln. - Species muscorum frondos. etc. Op. posth. Lips. 1801. 4. 77 Infeln. Supplement. I - IV. $1811-42.325$ Inffin. 


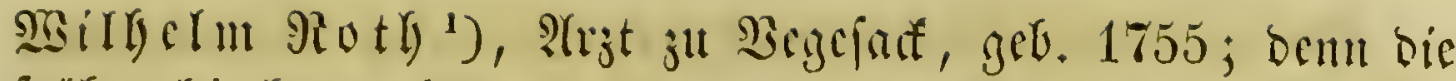

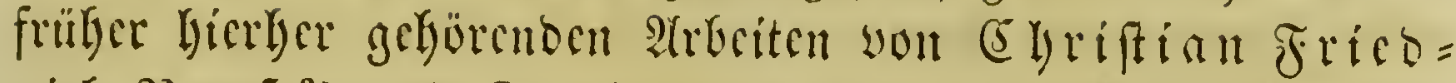
rid) $\mathfrak{A} \mathfrak{c} u \tilde{B}^{2}$ ) แno (5)

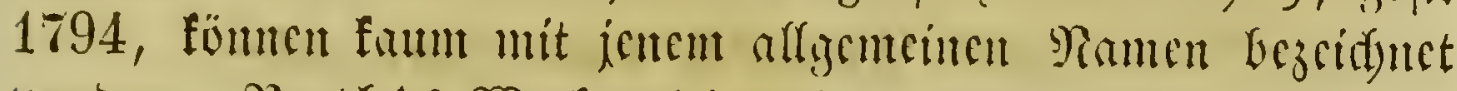

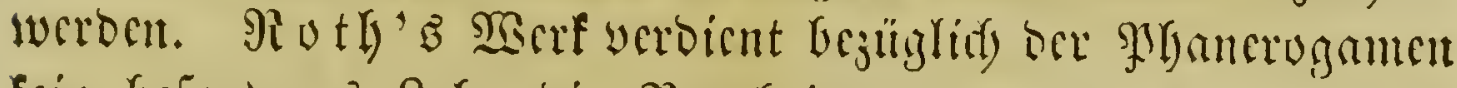

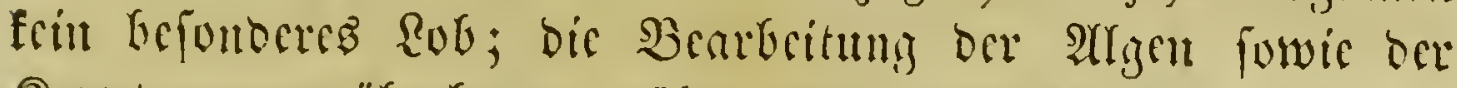

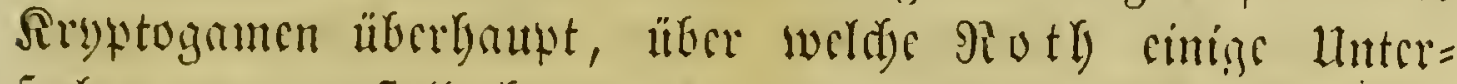

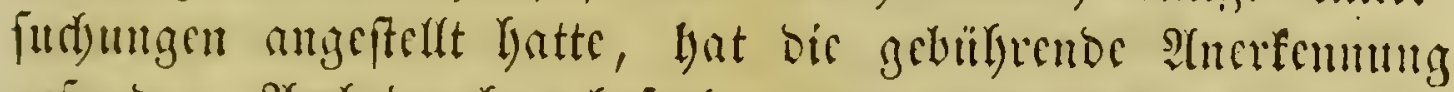

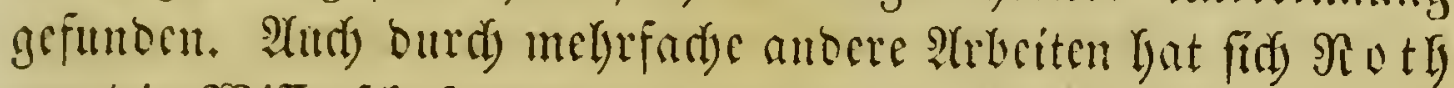
un rie Silfinidjaft yerbicnt gemadyt.

2太. 5 . Framer forteb in biefem Zeitraume zuerfit liber

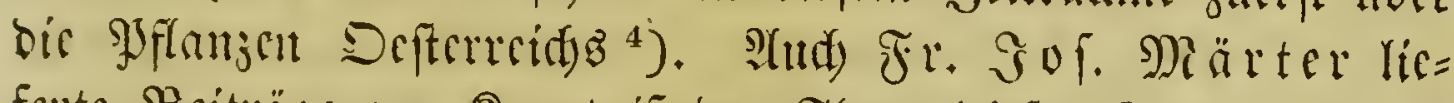
frrte Briträge zur fenmtnif orr Flora biefez Randes. ${ }^{5}$ ).

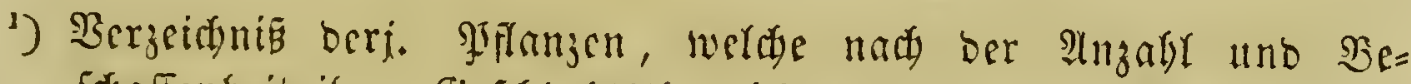

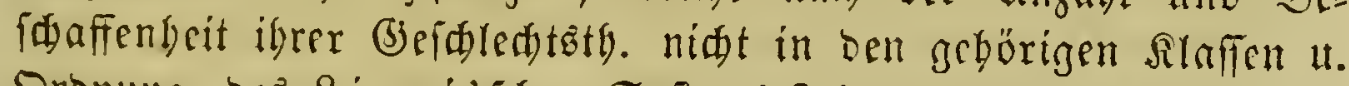
Sronung. Des \& in biciç Syftem. Altenburg 1781. 8. - Beiträge z. 30t. Brem. 1782 - 83. 8. - Bot. 2lbbanor. u, Beobadtungen. Rlïrnberg 1787. 4. 11 Tafeln. Seime Thätigfsit reidste noch woit in bie

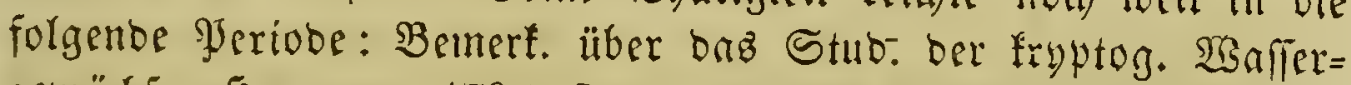
gewädje. Sannover 1797. 8. - Catalecta botan. quib. plantae novae et minus cognitae describuntur atque illustrantur. Lips. 1797 - 1806. S. - Reue Beitr. zur Botanif. Franff. 1802. 8. - Bot. Bemerk. u. Beridtig. \&eip. 1807. 8. Tentamen florae Germanicae. Lipsiae 1788 - 1800. 3 voll. 8.

$\left.{ }^{2}\right)$ Compendium botanices systemat. Linné. conspectum ejusdemque applicationem ad selectiora plantar. German. indigen. usu medico et oeconomico insignium genera, eorumque species continens. Ulm 1774. c. 10 figg. 8. 1785.

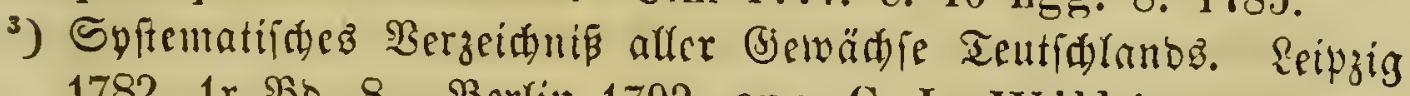
1782. 1r SBb. 8. Berfir 1792. cur. C. L. Will de now sub tit. Synopsis plant. german. cont. plantas in German. sponte proven. II Tom.

4) Elenchus vegetabilium et animalium per Austriam inferiorem observatorum, sistens et in classes et ordines genera et species redacta. Viennae 1756. 8.

3) $\mathfrak{B}$ erzed

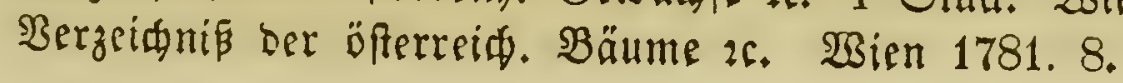


Der widtigfte unter ben öfterreid if den Shytographen Diejer Seriobe aber war

\section{Pricolaus goienb von Sacquin,}

Srofeffor ber Botanif in $\mathfrak{B i e n , ~ g e b o r e n ~} 1727$ zu Retben.

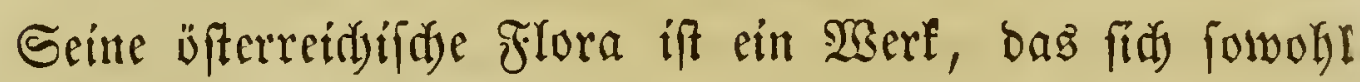
burd) (bründidfeit wic burd) pradtyolle 2 (usfübrung aus= zeidynet ${ }^{1}$ ). 2(ud) nod burd 'melyrere andere Sdyriften madyte er fid namentlidi) um bie Flora 2 wiens werbient ${ }^{2}$ ). Bon fei= nen $\mathfrak{2}$ erfen über bie außereuropäifden Giewäd) fwiro unten

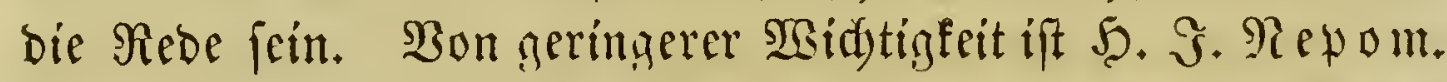

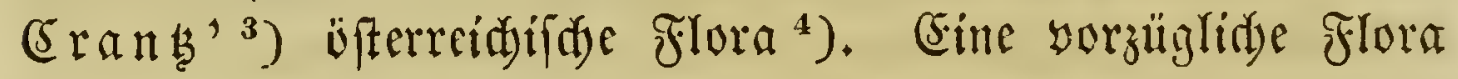

1) Florae austriacae seu plant. selectarum in Austriae archiducat. sponte crescentium icones etc. Vindob. 1773- 78 . V voll. Fol. c. 500 tab. col.

$\left.{ }^{2}\right)$ Enumeratio stirpium plerarumque, quae sponte crescunt in agro Vindobonensi montibusque confinib. Vindobon. 1762. 8. 9 Iaf. - Hortus bot. Vindobonens. Ibid. 1770-76. III voll. Fol. 30 tab. col. - Index regni vegetabilis qui continet plantas omnes, quae habentur in Linnaeani systematis edit. novissima XII. Vienn. 1770. 4. - Miscellanea austriaca ad botanicam, chemiam et histor. naturalem spectantia, c. fig. partim col. Vindob. 1778-81. 4. 2 voll. 4.4 tab. Sn bein Yekztgenamten 2 serfe fino aud bie forld ungen,

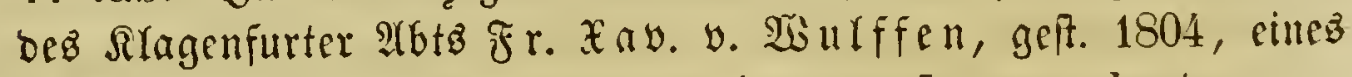
fegr fleifigen Botaniferz, nicbergelegt. - Icones plantar. rariorum. Vind. 1781-93. III voll. Fol. c. 618 tab. col. -

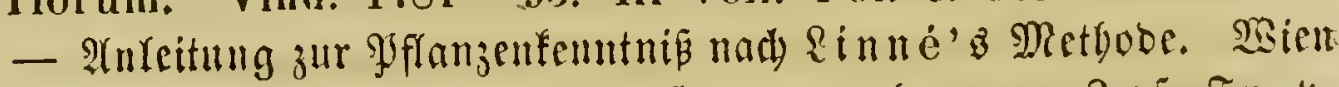
1785. 8. 11 Taf. 1800,8 . Serrusgegeben yon 3o\%. is $\mathrm{r}$.

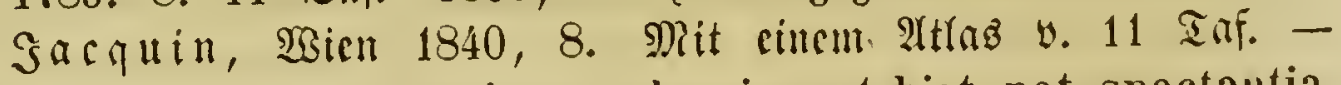
Collectanea ad botanicam, chemiam et hist. nat. spectantia. c. 106 tab. col. V voll. 4. Vienn. 1786-96.

3) (E $x$ ant emendata. Vindobon. 1767. 8. c. 6 tab. - Classis cruciformium. Lips. 1769. 8. c. 3 tab.

4) Stirpes Austriacac. III fasc. Viennae et Lips. 1762-67. c. 15 tab. - Vienn. 1769. II part. 4. c. 18 tab. 


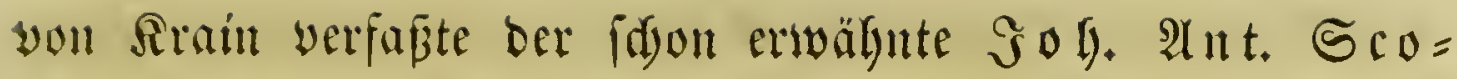
woli $i^{1}$ ), oer bie biferrédyifde Flora ${ }^{2}$ ) überbaut fleisin ut=

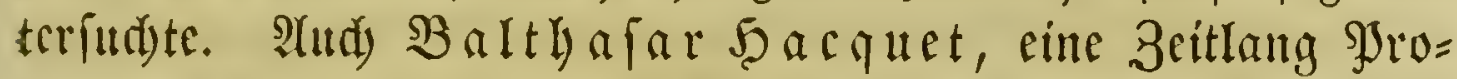
fejlor in Remberg, geb. 1740, geft. 1814, befduätigte fits

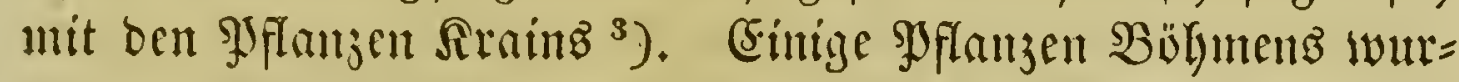

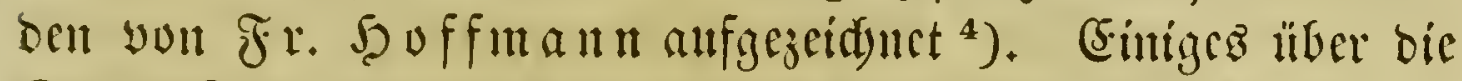

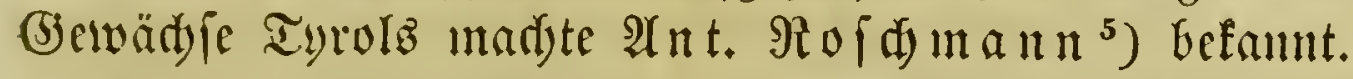

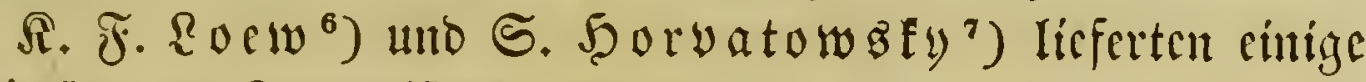

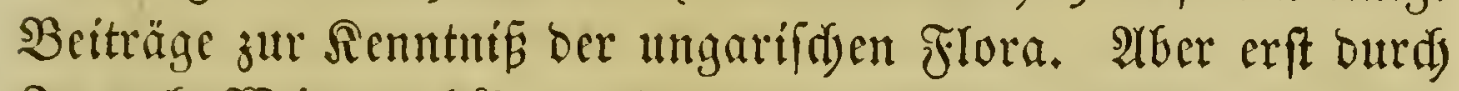
Sacob $\mathfrak{B}$ interl ${ }^{8}$ ) wurben genauere (addridjten über $\mathfrak{U n}=$ gaing Flora mitgetbeilt; berfelbe fdrieb audy ein Vergeidunif bez Gotanifaen Gartens zu Sefth. Wrizel erwähnt auper= Dcm nod) jwei Sdyriften über Hıgarns Jlora yon $\mathfrak{B} e \mathfrak{n} \mathfrak{b}$ (1778) uno $\mathfrak{B a l o g}(1779)$.

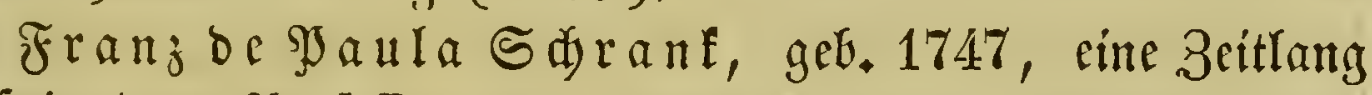
Scluit, bann Wrofeffor an veridfiedenen Drten, zulegt in Mün=

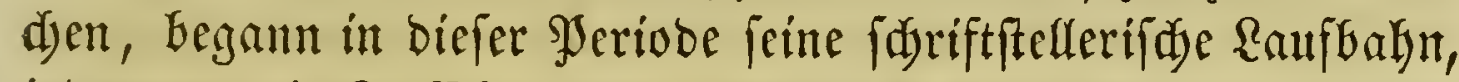
indem er mit $\Re$. Ehrenbert Frlara. $\mathfrak{y}$, Moll naturbifto=

1) Flora carniolica, Viennae 1760. I tom. 8. Ibid, 1772. c. 65 tab. II voll, 8.

$\left.{ }^{2}\right)$ Deliciae florae et faunae Insubricae. Ticini 1786-88. Fol. P. I. c. tab. I-XXV. P. II. c. tab, aen. XXV. P. III. c. tab, aen, XXV.

$\left.{ }^{3}\right)$ Plantae alpinae Carniol, Viennae 1782. 4. c. V tab. Heber feine Reifen in Rrain uno ben benabbarten Rändern vergleide Jjorigel S. 107.

4) Dissertatio de plantis et generatim et in particulari de quibusdam rarioribus regni Bohemiae vegetabilibus. Pragae 1748.

$\left.{ }^{5}\right)$ Regnum animale vegetabile et medicum Tyrolense. Oenipont. 1738. 4.

6) Epist. ad botanic. quae de flora Pannonica conscribenda consil. cum ipsis communicat. Sempronii 1739. 4.

') Florae tyrnaviensis indigenae pars I. Tyrnav. 1774. 8.

$\left.{ }^{3}\right)$ Index horti bot. universitatis Hungariae, quae Pesthini est. Pesth. 1788, 8, 26 tab. 


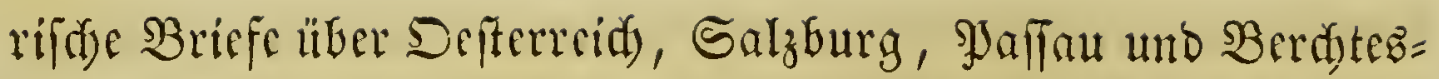
gabcn lycrausgab. (Suljburg 1785. 2 BDe. 8. Mit 3 Taf.) ${ }^{1}$ ) Unter ben baierifon 3 bytograplen biefes Zeitraums nimmt

\section{Sai. Chr. Sdymieder,}

get. 1718, geft. 1783, Frofefitor in Grrangen, bann Reibarzt bes Marfigrafen zu $2(n s \mathfrak{b a}$,

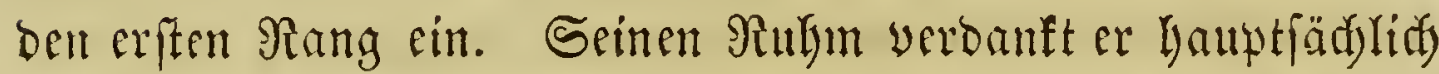
bem vorzüglíden $\mathfrak{S e r f e : ~ I c o n e s ~ p l a n t a r u m ~ e t ~ a n a l y s e s ~}$ partium etc. (Nürnberg 1747. Fol. mit 50 folor. Taq. Ibid. 1762. Fol. 50 lolor. Taf. - Erlnngen 1793-97, 3 manipuli. 75 folvr. Taf. Fol.), bab ingbefonoere bie beut=

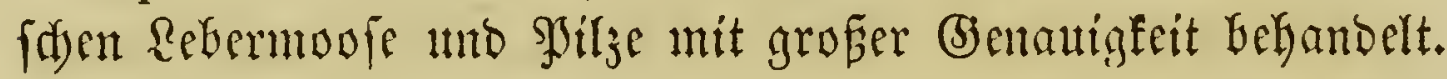

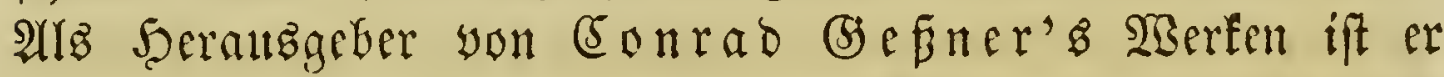
\{don oben genannt worben. Seine Monographien über ein=

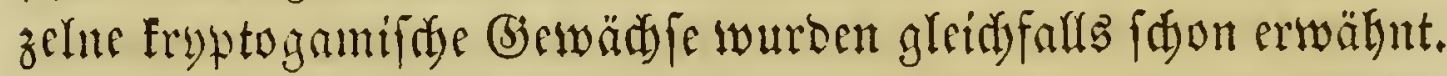
Sat. (Shr. Sdäfer, geboren 1718, geftorben 1790,

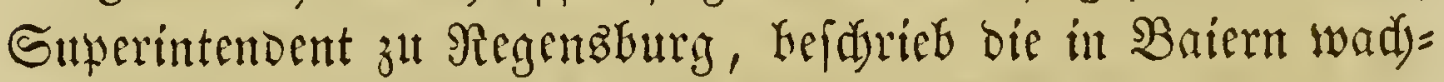

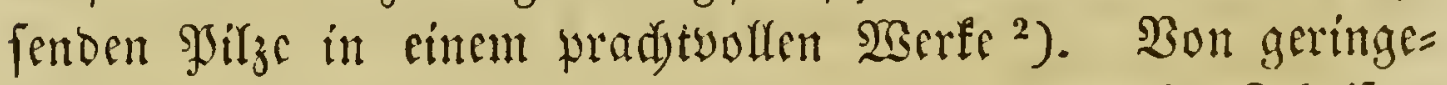
rer $\mathfrak{B}$ edeutung für die baierifde Flora finto bie Srariften

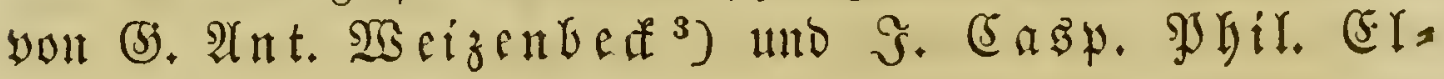

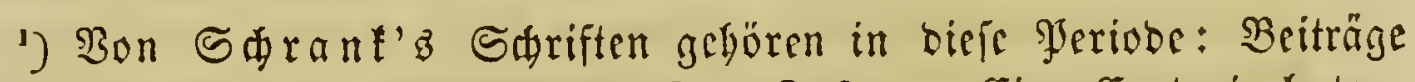
3. Raturgeín. Reipz. 1776. 8. 7 Taf. - Cine Senturie botan. Anmerfgg. ă Simné Species plantar. Erfurt 1781. 4. -

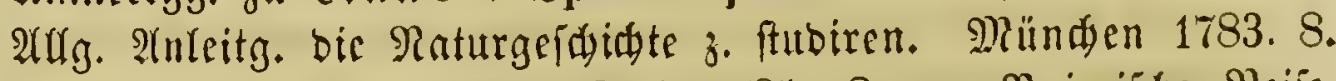
- $\mathfrak{A}$ nfangågr. ber Bot. Daf. 1785. 8. - Baierifde Meije. Daf. 1786. 8. 3 i $\mathfrak{a f}$.

2) Fungorum, qui in Bavaria et Palatinatu circa Ratisbonam nascuntur, icones nativis coloribus expressae. Ratisbonn. 1762 - 74. 4 voll. 4. - Errangen 1800. 5 Bof. mit 330 for.

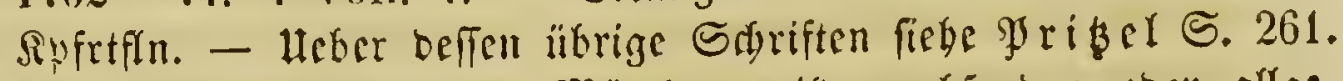

3) 2 (nzeige ber meifen um Münden wito wadjenben ober allge-

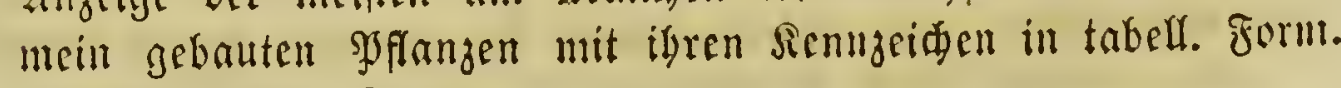
Münd)ท 1786. 8. 


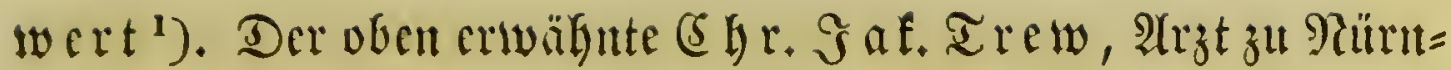
berg, gab in (5) ementrdaft bes Malers (5). D ionyl. (5) het, geb. 1708, geft. 1770, cin befdreibendes 9jradjtwerf heraug ${ }^{2}$ ).

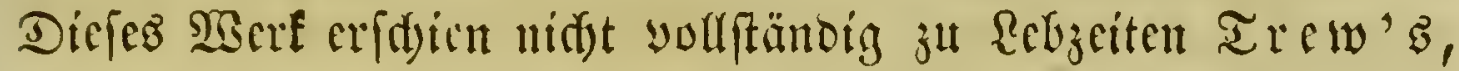
fondern wurbe erit nad) beffen Tode yon $\mathfrak{B} e n e d$. (5) rift.

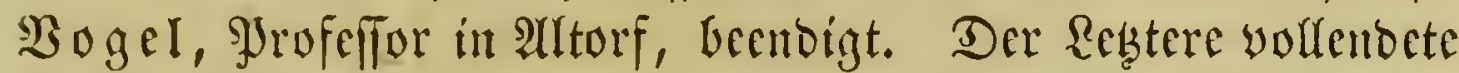

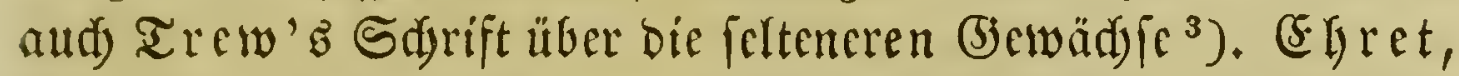
ber fpäter in (Englano lebte, gub bort cbenfallz cin befferei= benbez $\mathfrak{B e r f}$ heraus. ${ }^{4}$ )

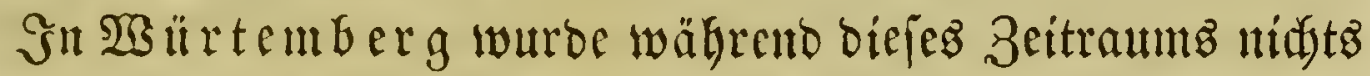
Sonberlides für bie Jjhytographie geleiftet. Die lierber ge=

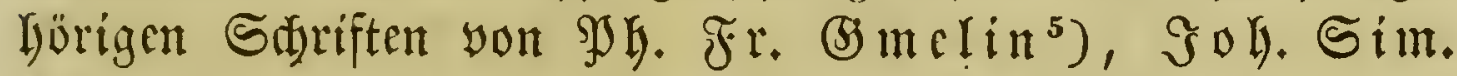

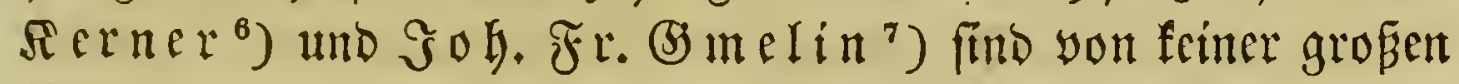
$\mathfrak{B}$ rocutung.

1) Fasciculus plantarum flora Markgraviatus Baruthini. Erlang. 1786. 4.

2) Plantae selectae. Norimb. 1750-73. Fol. mit 100 folor. $\mathfrak{T} a f$. - Plantae rariores, quas maximam partem in horto domestico coluit etc. Norimb. 1763. Fol. Mit 10 folor. Iaf.

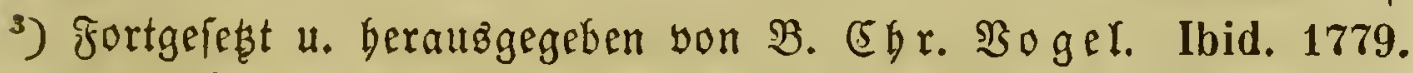
Fol. Mit 10 folor. Taf. - Trew fdrieb ferner: Hortus nitidissimus etc. Rürnberg 1750-86. III voll. Fol. Mit 180 folor. Taf. - Beiđreibg. Der grop̃en amerifan. Alloe. SRürnt. 1727. 4. $1 \mathfrak{T} \mathfrak{d} f_{0}$ - Cedrorum Libani historia eorumque character botanicus etc. Norimb. 1757 et 1767. 4. $7 \mathfrak{T a f}$.

4) Plantae et papiliones rariores depictae et aeri incisae. Lond. 1748 - 59. Fol. 15 folor. Taf.

$\left.{ }^{5}\right)$ Fascicul. plant. patriae urbi (Reutlingae) vicinarum sponte crescent. cultarumq. cum usu earum plebejo adject. observat. etc. Tubing. 1764. 4.

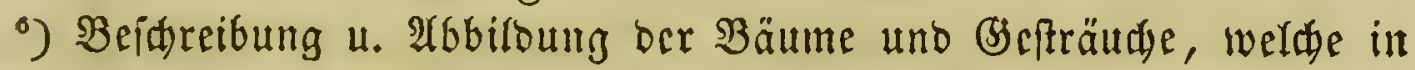
bem 5erzogthum 23ürtemberg wirt wadijer. Stuttg. 1788. 4.

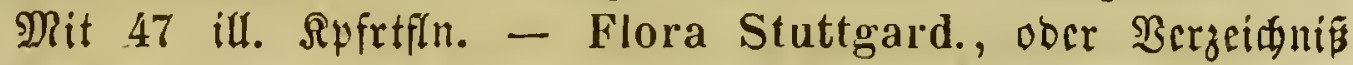
Der um Stuttgart wilt wadifenden gyflanjen. Stuttg. 1786. 8.

") Enumeratio stirpium agri tubingens, indigenarum. Tubing. 1772. 8. Derielbe idrieb aud: Onomatologia bot. completa.

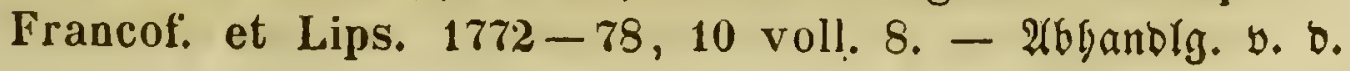




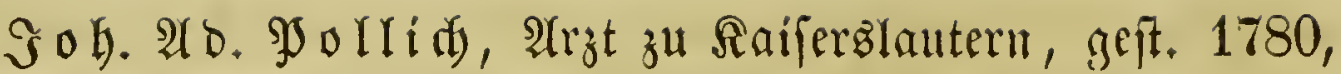
madyte fid $u$ m bie Flora ber $\Re$ beind falz verbient ${ }^{1}$ ). (5). M. (3) a ten nof lieferte cin Berzeidunif ber (B)egend und beß (5)artenz yon Seibelberg. ${ }^{2}$ )

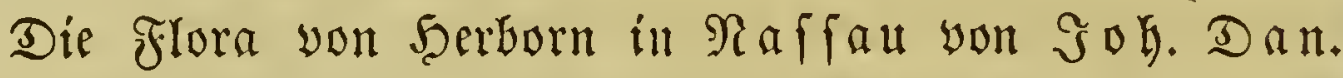
Reers ift wegen ifrer genauten Darfteflung ber Gräjer be= merfenswerth). (Herbon. 1775. 8. Mit 16 Inf. Berlín

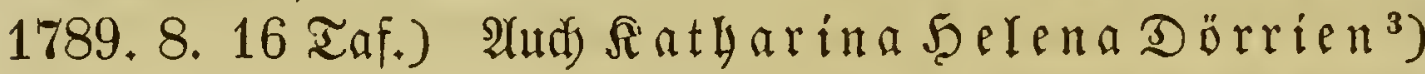
uno Shlilipp Miller ${ }^{4}$ ) befdrieben bie spflanzen Maffan's.

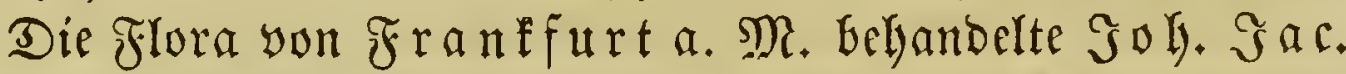

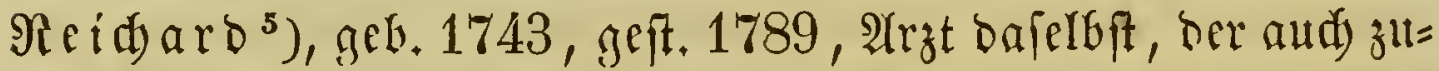
erft Rinné Species plantar. nady befien Tobe heraugant. ${ }^{6}$ )

Uum bie heffif dise flora madyte f(id) namentlid (5onr. Münd, Srofeffor in Marburg ${ }^{7}$ ), geb. 1744, geft. 1805,

giftigen Bewähjen, welde in Dettifland unb vornebmlid in

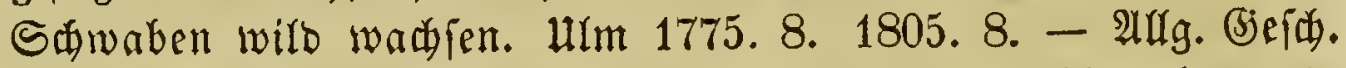
D. Pflanzengifte. গürnb. 1777. 8. 1803. 8. - Abbanblg. v. D. Arten bes Hntrautz auf D. Aectern in Shwaben u. von beffen Benubung. Rübed 1779. 8.

1) Historia plantarum in palatinatu electorali nascentium incepta secundum systema sexuale digesta. Manheimi 1776-77. 3 tom. 8. 4 tab.

$\left.{ }^{2}\right)$ Stirpes agri et horti Heidelbergensis ordine Ludwigii c. characterib. Linnaean is, Hallerianis aliorumque. Heidelb. 178?. 8.

3) Berzeidnife u. Befdretbung ber in ten Sraniell = Raffauifaen Rant= ben wílwad fenden (jewäaje. Seerborn 1777. 8. Rübed 1779. 8.

4) Flora Herbornensis. Giessae 1775. ( (D. 2A.) - Berlin 1789 cur. G. L. Willde now c. XVI icon. col. (Siebe Rrüger

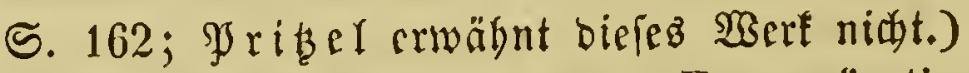

${ }^{5}$ ) Flora Moeno-Francofurti. Francofurti ad Moen. 1772. P. I. P. II. 1778. c. tab. aen. I. 8. - Enumeratio stirp. horti bot. Senkenberg. Ibid. 1782. 8.

-) Systema plantarum, edit. novissima, p. 1-4. Frankfurt 1779 - 80 .

$\left.{ }^{7}\right)$ Enumeratio plantar. indigen. Hassiae, praesertim inferior. secund. method. sexual, dispositar. Casselis 1777. P. I. 8. 


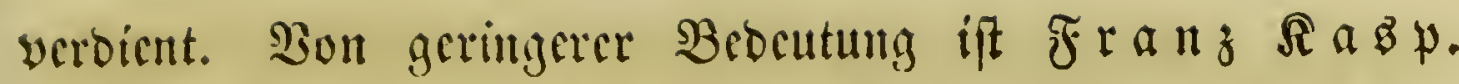
Ricblei nz Flora yon Fullor. ${ }^{1}$ )

Unter ben He

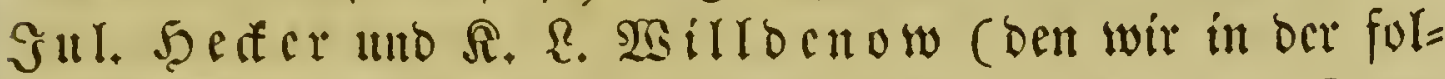

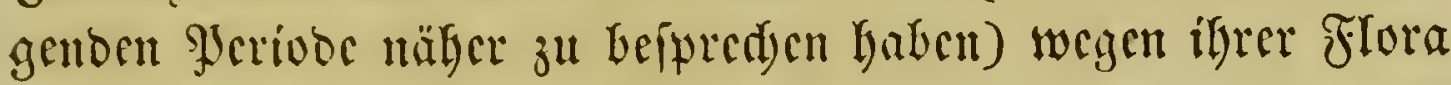

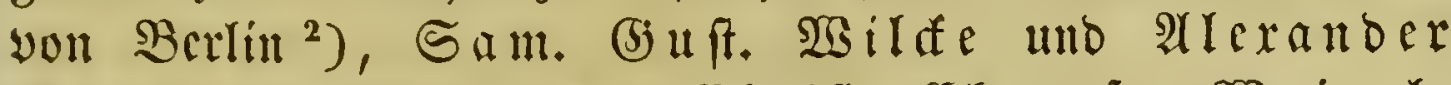

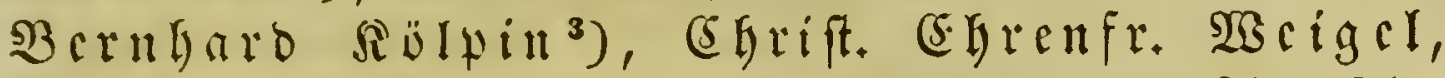

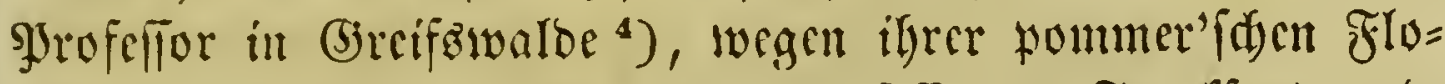

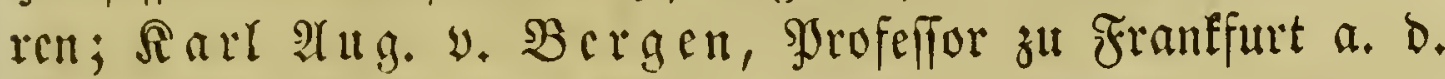
Docr, gch. 1704, geft. 1759, uno $\mathfrak{g e t} . \Im \mathfrak{m m a n}$. $\mathfrak{S} \mathfrak{a} \mathfrak{r} t=$ ma $\mathfrak{n}^{5}$ ) bearbeiteten bie Flora yon Franffurt an ber Socr;

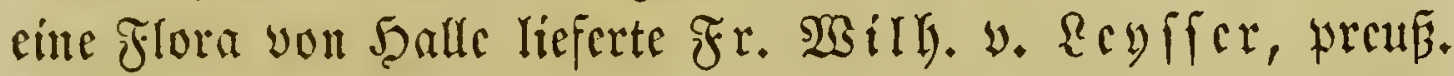

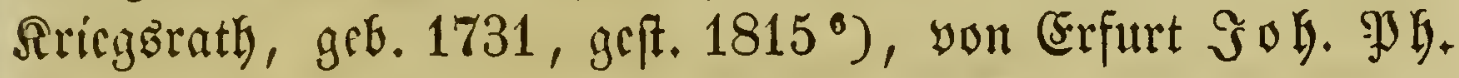

- Method. plantar. horti bot. et agri Marburgi a stami-

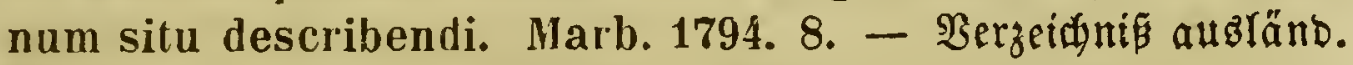
Bäume u. Stauben bez Sdloffez खeiffentein bei Raffer. Jranff. u. Seipq. 1785. 8. Mit 8 Taf.

2) Flora Fuldensis, ob. Berg. ber in bem fürftentf. Fulda willo = wadfenben Bäume, Sträuđer u. SPflanzen. Franf. a. M. 1784. 8.

2) Flora Berolinens, , ๖. i. Afor. Der Siräuter. Berlin 1757-58. I - III Cent. Fol, $300^{\circ}$ Taf. - Specim. flor. Berolinens. Berolini 1742. Fol. - Willdenow, Florae Berolin. prodrom., secund. system. Linneanum a Thunbergio emendat. conscript. Berol. 1787. 8. c. VII tab.

3) Wilcke, Flora Gryphica, exhibens plantas circa Gryphiam intra milliare sponte nasc. Gryph. 1765. 8. - Ko elp in, Supplem. flor. Gryph. Ibid. 1769. 8. - Wilcke, Hortus Gryphicus etc. Ibid. 1765. 8.

4) Flora Pomerano-Rugica, exhib. plantas per Pomer., Suev. et Rugiam sponte nasc. Berol. 1769. 8. Suppl. Gryphiae 1773. 8. - Index seminum et plantal. horti Gryphici systematicus. Gryphiae 1773. 8.

3) Flora Francofurtana. Francof. ad Viadr. 1750. 8. - Catalog. stirp. indigenar. aeque ac exterarum hort. med. Viadrin. Ibid. 1744. 8. - II a rtmann, Plantarum prope. Francof, ad Viadr. 1767. Fasc. I. 4.

') Flora llalensis. Halae 1761. Ibid. 1783. 8, 1 Taf.

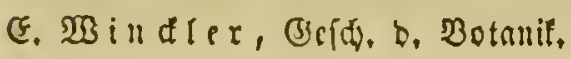




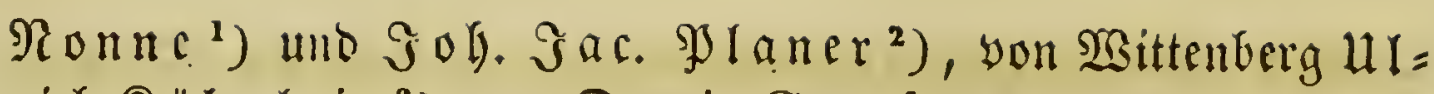

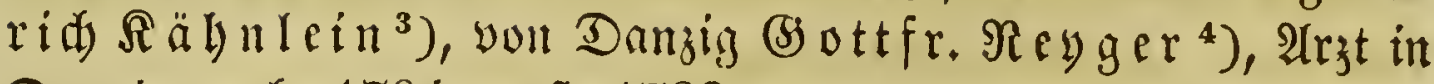
Danzin, geb. 1704, geft. 1788, yon Barby F. A. y. Skol= $\mathfrak{I e r}^{5}$ ), geb. 1718, geft. 1815. Lleber bie preufíf fo flora über=

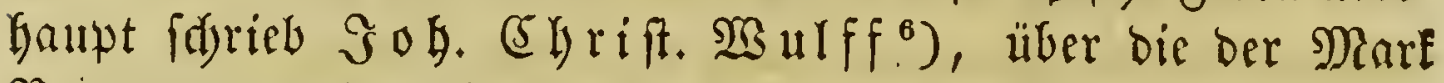

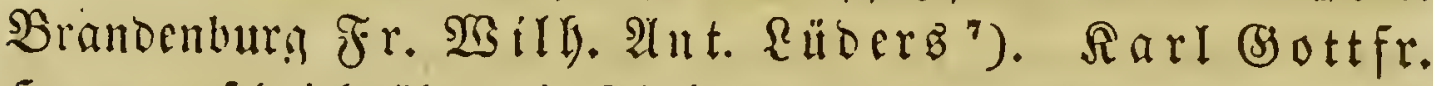

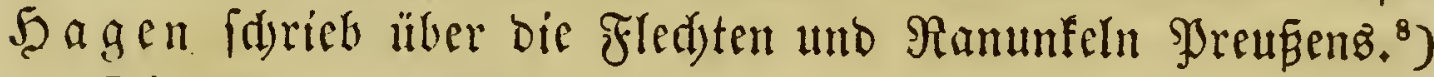

Die Flora yon S dif efien wurbe zwar bearbeitet, jebod nicht vollfämsig, von bem (brafen Jeinr. (5) ottfr. Mat=

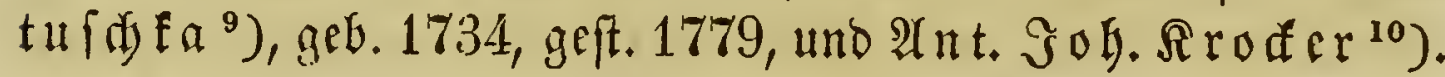

1) Flora in territorio Erfurtensi indigena. Erfurt 1763. 8.

$\left.{ }^{2}\right)$ Index plantarum, quas in agro Erfurt. sponte provenientes olim J. Ph. Nonne, deinde J. J. Planer collegerunt. Gothae 1788. Suppl. 1788. 8.

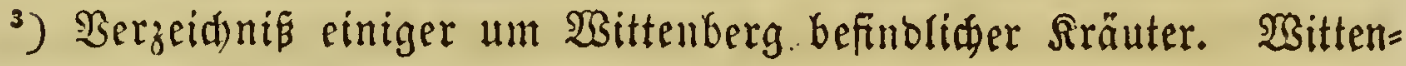
berg 1763. 8.

4) Tentamen Florae Gedan. methodo sexuali accommodatae (cont. 736 gen.). Dant. 1764-66. II voll. 8. Accedit J. Ph. Breynii vita et Chr. Menzelii centur. plantar. Gedanens. Dentid 1786. 8. Bermebrte und ganz umgearbei=

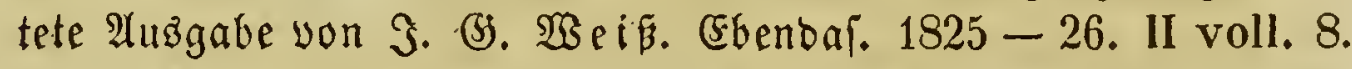

$\left.{ }^{5}\right)$ Flora Barbyensis renov. J. Ch. Schreber. Lipsiae 1775. 8. Suppl. Barby 1757. 8. 1 Tafer.

$\left.{ }^{\circ}\right)$ Plantae XXIII in Borussica repertae. Regiomont. 1744. 4. Flora Borussica denuo efflorescens auctior. Regiomont. et Lips. 1765.8.

$\left.{ }^{7}\right)$ Nomenclator botaaicus stirpium Marchiae Brandenburgicae secundum systema Gleditschianum a stamin. situ digestus. Berol. 1786. 8. Ibid. 1788.

$\left.{ }^{8}\right)$ Historia lichenum Prussicorum. Regiomonti 1782. 8. 2 for. Iafeln. - Commentatio bot. de ranunculis Prussicis, Regiomonti (1783) 1784. 4.

9) Flora Silesiaca. Breslau Th. I 1776. Th. II 1777. 8. Enumeratio stirpium in Silesia sponte crescentium. Ura-

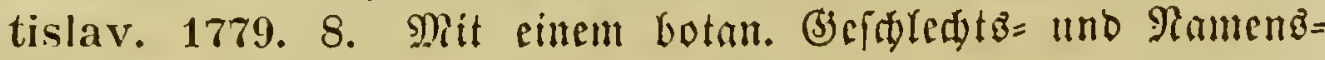
regiffer. Brealau 1789. 8.

10) Flora Silesiaca renov. Uratislav, 1787, V Tom. in V Vol. c. 110 icon. color. 
Dic um Reipzig wadjenben Prflangen watroen in biefent 3citraume mebrmals vergeidunet uno bejdrieten, fo von (5).

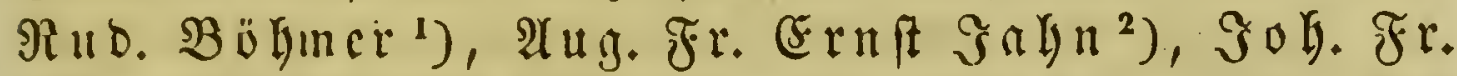

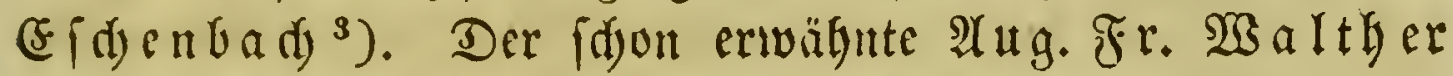
fdrieb über bic SPFlanjen feines (B)artens in Reipjig. ${ }^{4}$ )

Die befte Reipziger Flora aber lieferte

\section{Sol, (Ehrift, Dan, von E(freber ${ }^{5}$ ),}

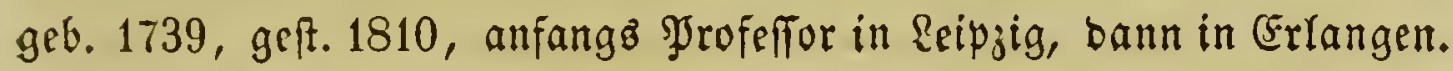

Err gehört zu ben yorgüglidgften shytographen biefes 3eit= raums. Namentlid) burd) einige Monograplien, z. $\mathfrak{B}$. über die (5räfer uno bie (5)attung Phascum ${ }^{6}$ ), fowie burd) bie Scrausgabe yon $\mathfrak{R}$ inne's Genera plantarum ${ }^{7}$ ) hat er feine beocutenden botanifden Renntniffe und feinen fdjarfent Beobadjtungägeift gezeigt.

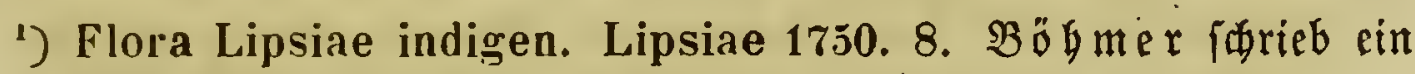
literarbifforif turalis. V voll. Lips. $1785-89.8$.

$\left.{ }^{2}\right)$ Plantas circa Lipsiam nuper inventas describit. Lips. 1774. 4.

$\left.{ }^{3}\right)$ Observationes botanicae. Lipsiae 1784. 4.

4) Plantar. exoticar. indigenarumque index tripartitus. Lips. 1732. 8. - Designatio plantar., quas hortus A. F. Walthe ri complectitur. Accedunt novae plantar. icones 24. Lips. 1735. 8. $24 \mathfrak{T} \mathfrak{a f e l n}$.

$\left.{ }^{5}\right)$ Spicilegium florae Lipsicae. Lips. 1771. 8. Ibir. 1775.

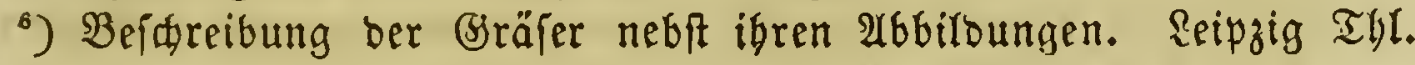
1 - 3. 1769, 1810; mit 54 §pfrtfln. 3 agle. Fol. - De phasco. Lips. 1770. 4. mit $2 \mathfrak{I} a f e \mathfrak{n}$. - Icones et descript. plantar. minus cognit. Decas. I. Halae 1766. Fol. c. X tab.

${ }^{7}$ ) Francof. ad Moen. 1789 - 91. 2 BDe. - Plantar. verticillatar. unilabiatar. genera et species. Lips. 1774. 4. Unter feiner ?afufidt geidrieben: Wilh. Dresky, De Valeriana officinali. Erlangen 1776 ; Andr. E. Etlinger, De Salvia, Ibid. 1777; J. L. Chr. Kölle, Spicilegium observationum de Aconito. Erl. 1788; J oh. Alb. Frölich, De Gentiana libellus. Erlang. 1796. 


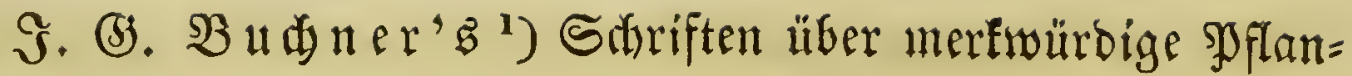
zen bes Soigtlandes und Tobias Rour. Şoppe's Flora voll (jera find von geringer Bcbeutung ${ }^{2}$ ). - Şaller gab $\Re$ upp'z Flora yon Gena vermehrt und verbeffert heraus, ${ }^{3}$ )

Die Sflanzen um Sena wurben ferner yon $\mathfrak{s}$ h. Seinr.

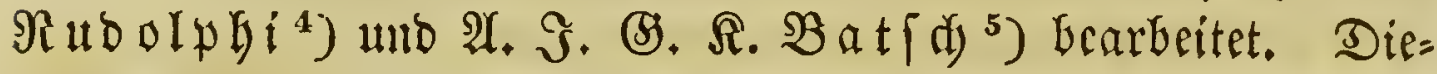
fer Belelirte lebte yon 1761 - 1802 uno ftarb als Syrofeffor

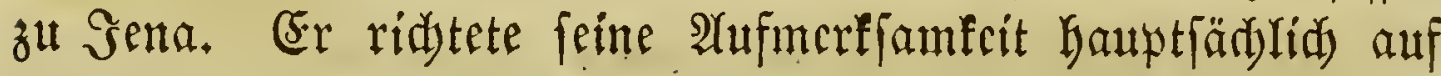
bie un Senta wadjenden Sjifze und Srawänme uno licferte yortrefflide abbildungen won benfelben. ${ }^{6}$ )

Die Flora von (s) öttingen worbe efenfalle megrfach be=

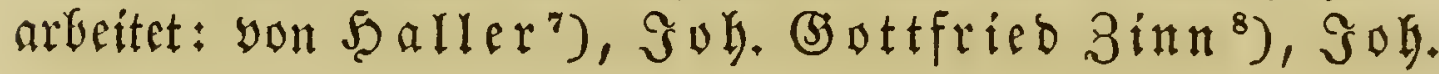

1) De memorabilibus Voigtlandiae ex regno vegetabili (s. loco) 1743. 4. 1 fasc. - Descript. epist. de rariorib. quibusdam plantis et fructibus, in Voigtlandia natis. Giezae

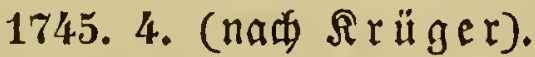

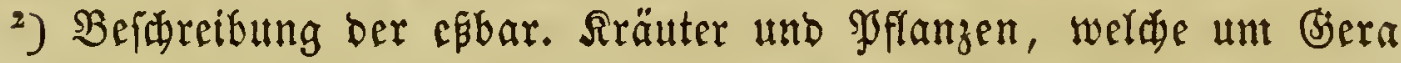
wadfen uno bei theurer 3eit gut ju brauden find. Giera 1773. Deffen (3era'fae frlora; mit einer $\mathfrak{B o r r e d e}$ yon $\Im$. $3 \mathfrak{m m a n}$. Bald. Sena 1774. 8.

$\left.{ }^{3}\right)$ Flora Jenensis Henr. Bernh. Ruppii ex posthumis auctoris schedis et propriis observationibus auct. et emend.; accesserunt plantar. rarior. novae icones. Jenae 1745. c. tab. aen. VI. 8 .

4) Diss. Florae Jenens. plantae ad polyand. monog. Linn. pertinentes. Jenae 1781. 4.

s) Dispositio gener. plantar. Jenensium secund. ordinem Linn. et fam. naturales. Jenae 1786. 4.

-) Elenchus fungor, lat. et german. Halae 1283-89; mit 42 col. Iafeln. 4.

7) Enumerat. plantar. horti regii et agri gott. Gotting. 1753. 8. Brevis enumeratio stirpium horti goetting. Ibid. 1743. 8. 1 tab. 1753. Gr färieb and iiber bie Bffanjentycinnitter: De praestantia remediorum vegetabil. Goetting. 1752. 4. Ex itinere in silvam Hercyniam etc. Ibid. 1738. 4. 1 tab. (Opusc. p. $75-152$ ).

3) Catalog. plantar. hort. med, et agri gott. Gotting. 1757. 8. 
A( (G)artent bafelbft, geb. 1740, geft. 1791, ber audi) burd) feine

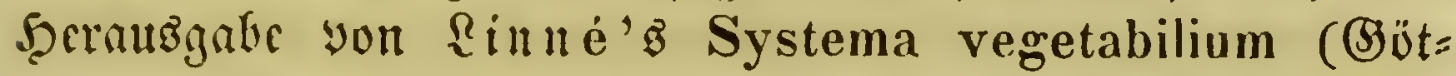

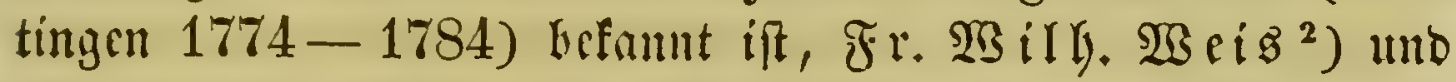

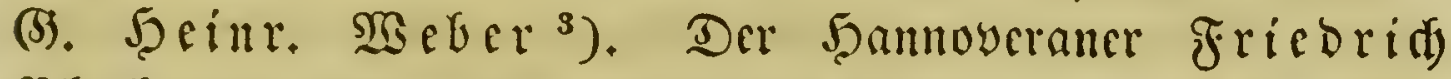

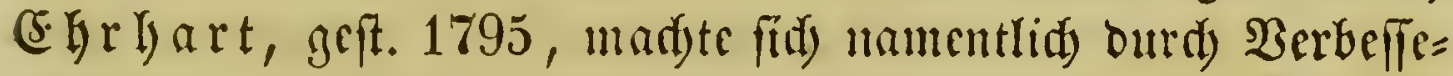
runy bor Rinnéfiden (Gattungsed)araftere um bie Botanif serbient ${ }^{4}$ ). (sir ift aud) beshalb nod zu erswälnen, weil er zuerft verfäuflidye Sammlungen getrofneter SIflanzen veran= ffaltetc.

Die Flora you belmftäbt wutbe yon Sour. Fabri=

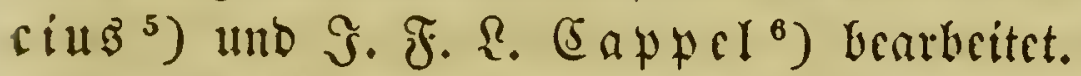

Sn Me fflenburg fint R. ( (Shr. $\mathfrak{i} \mathfrak{i} m{ }^{8}$ ), Bürthermeifter zu. Maldsin, als floriften

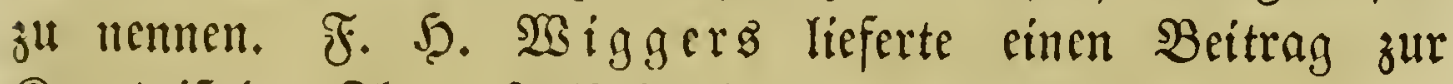
Remutnís ber Flora Solfteins. ${ }^{9}$ )

Unter ben Sdj weizern ift yor affen zunäd) ber fidout

1) Prodrom. designat. stirpium Gottingens. Gotting. 1770. 8.

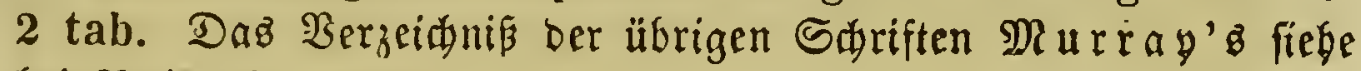
bei gritiel S. 206.

2) Plantae cryptogamicae florae gott. Gotting. 1770. 8. $1 \mathfrak{T a f e r}$. Entwurf einer Forftbotanif. 1 Bob. (jötting. 1775. 8. 8 Tafern.

3) Spicileg. florae Goetting. Gothae 1778 c. V icon. col. 8. - Plantar. minus cognitar. decuria. Kilon. 1784. 4.

-) Beiträge zur Raturfunde 2r. Şannoyer 1787 -92. 7 BDe. 8.

$\left.{ }^{5}\right)$ Flor. Helmstaedt. rariores et utilior. plantae. Helmstaedt 1759. Ibid. 1763. Ibid. 1776. 8.

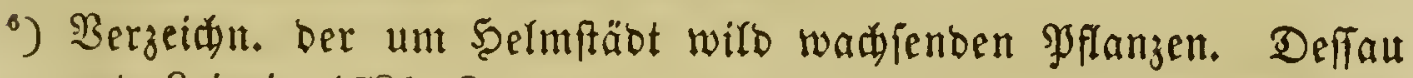
unb \&eipzig 1784. 8.

$\left.{ }^{7}\right)$ Enumerat. systematic. stirp. per Ducat. Megapolitan. Strelizensem observatar. Trajecti ad Viadr. 177\%. (Rad) $\Re \mathfrak{i} g \mathfrak{e r}$ ).

$\left.{ }^{8}\right)$ Flor. Megapolitanae prodromus. Lipsiae 1788. 8. 1 Tafer.

$\left.{ }^{9}\right)$ Primiliae florae Holsaticae. Kiel 1780. Diefe Differtation

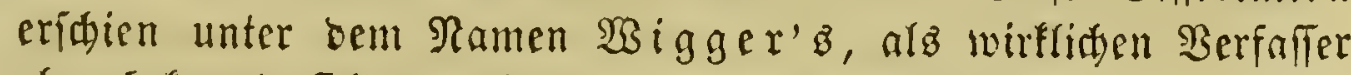

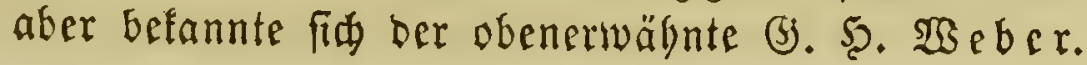




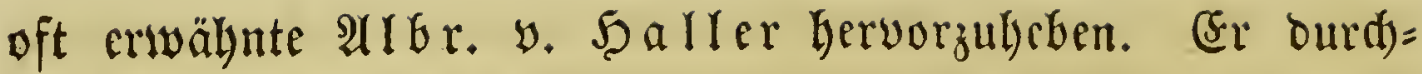

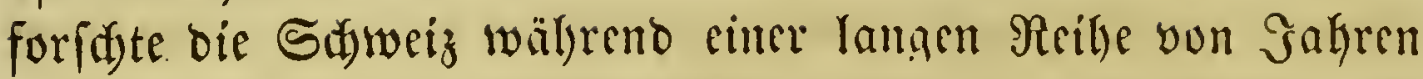

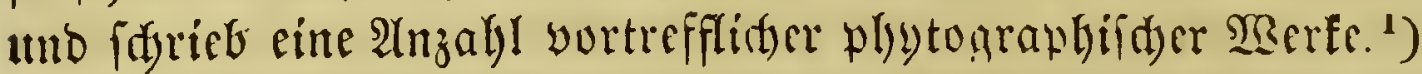

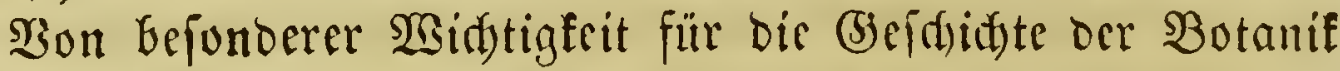
ift feine Bibliotheca botanica. Tiguri 1771 - 72. 2 voll. 4. ${ }^{2}$ ). - Auferdem nennen wir von ren Gdweizern nod)

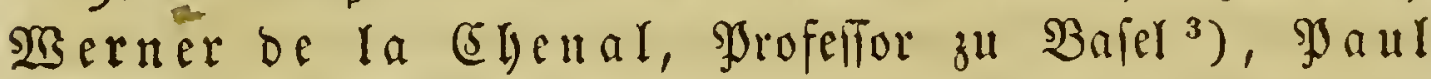

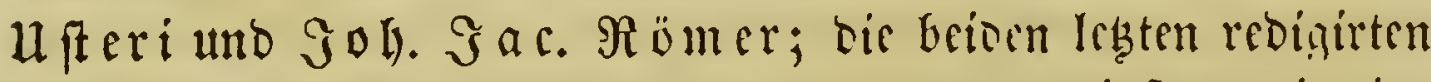
mebrere botanifbe Zeitictriften, won benen wenigftens die eine zum Iheil in biefer Sperivoe erfdjien. ${ }^{4}$ )

Alud in Franfreidh feblte es nidst an Floriften $\mathfrak{b a ̈ l}=$ rent biejes 3eitraums. Die un Praris wadjienten shflumjen wurben bearbeitet yon $\mathfrak{T h}$. $\mathfrak{F}$ r. Dalibard ${ }^{5}$ ), $\mathfrak{O}$. $\mathfrak{B}$ arbea

2) Iter alpinum anni 1731. - Iter helvet. anni 1739. - Enumeratio methodica stirpium Helvetiae indigen. Gott. 1742. Fol. Tom. I. II. Fol. c. 24 tab. aen. Die 2te 2 tuff. bieier Sdrift erífien fpäter unter bem Titel: Historia methodica stirp. indigen. Helvetiae inchoata. Bern 1768. Fol. III Tom. c. tab. 48 aen. - Enumerat. stirp. quae in llelvet. rarior. proveniunt. s. l. 1760. 8. - Ad enumeration. stirp. Helvet. emendationes et auctuaria. (Bern) 1759. 4. P. I - IV. - Nomenclat. ex histor. plantar. indig. Helvet. excerpt. Bern. 1769. 8. Dic âtbildungen ber 2ten $\mathfrak{A}$ uff. eridienen aud unter bem Titel: Icones plantar. Helvet. denuo recusae c. descript. et praefat. auctor.; notas addid. J. S. Witte n b ach. Bern. 1795. c. 52 icon. Fol. 1813. Appendices in J. Scheuchzeri agrostographiam. Tiguri 1775. 4. Befonbers auf $5 \mathfrak{a l l e r}^{\prime}$ Edyriften über bic

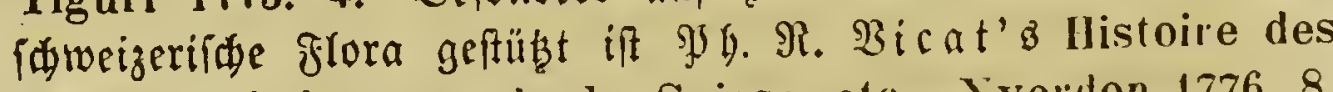
plantes vénéneuses de la Suisse etc. Yverdon 1776. 8. $3 \mathfrak{T a f f} \mathfrak{i n}$, unb befien Matière médicale. Berne 1791. 2 voll. 8. Dentid yon Sam. Şa

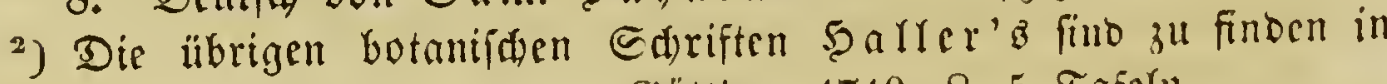
fcimen Opuscula botan. (3)ötting. 1719. 8. 5 Tafeén.

$\left.{ }^{3}\right)$ Observationes botanico-medicae. Basil. 1776. 4. 1 Infér.

+) Magagill für bie B̧otanif. Bürid $1787-90$.

$\left.{ }^{5}\right)$ Florae Parisiensis prodromus, suivant la méthode sexuelle de Linné. Paris 1749. c. aell. tab. IV. 8. 


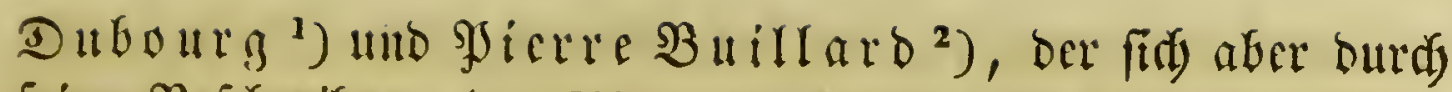

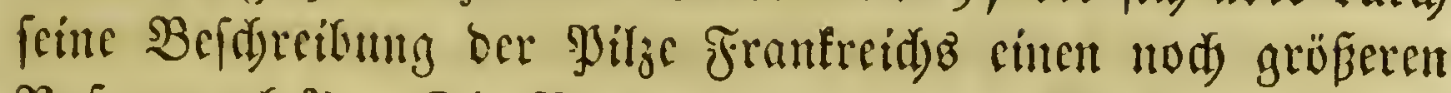

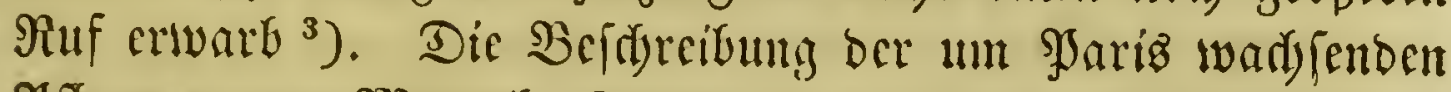
SSFlanjen you Datth. Fabregou ift fegr unbedcutend. ${ }^{4}$ ) Heber dic flora vou Muntpellier fortieb Fr. Boiffier

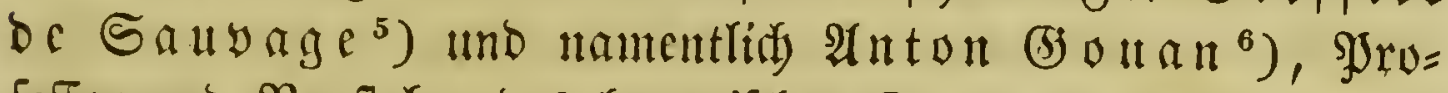
feflor uno Borftelyer bes botmifdsen (5artenz zu Montpellicr, ber aud) über Die \$Pflanjen Der \$Jyrenäen fdrieb. ${ }^{7}$ )

Dic Flora yon Strafburg benbeitete ein 1 ngenann= ter $^{8}$ ) ( $\mathfrak{\text { al }}$. Reinbolo Spielmann nad) (Srell, (She= mifde Almalen, 1784. I. pag. 579), bie yon Eyon (Slaret

1) Botaniste français. Paris 1767. 8.; im zw weiten Igeit.

$\left.{ }^{2}\right)$ Flora Parisiensis. Paris $1776-80$. V voll. 8. avec 640 pl. col. - Introduction à la flore des environs de Paris suivant la méthode sexuelle de Linné et les démonstrations botaniques du jardin du roi. Paris 1776. 8. 2 tab. col. - Herbier de la France. Paris 1780 - 95. XII voll. Fol. 600 tab. col.

3) Herbier de la France. Paris $1780-1812$. Die erfte $\mathfrak{U b}=$ theilung entyält bie Biftgewä山ie; bie zweite bie Silze Frant=

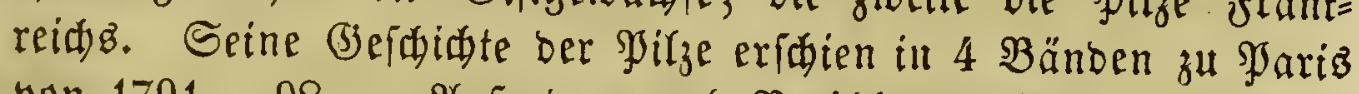
yon 1791 - 98. - 2fuferdem gab $\mathfrak{B} u$ ilfard ein Dictionnaire élémentaire de botanique, Paris 1783, Geraus.

4) Description des plantes qui naissent aux environs de Paris, avec leurs usages dans la médecin et dans les arts. Paris 1740 . VI voll. 8.

$\left.{ }^{5}\right)$ Method. folior. s. plantae Monspel. juxta folior. originem ad juvandam specierum cognitionem digestae. La Haye 1751. c. tab. aen. I. 8.

$\left.{ }^{6}\right)$ FInra Monspeliaca sistens plantas No. 1850 ad sua genera relatas et lybrida methodo digestas. Lugd. Batav. 1765. 8. 3 tab. - Herbarisations des environs de Montp. 1796. 8. - Hortus regius Monspeliensis. Lugd. 1762. 8. 7 tab.

') Illustrat. et observation. botanicae ad specier, histor. facientes; s. rarior. plantar. indigenar. Pyrenaicar. adumbrationes synonymor. reformation. Tiguri 1773. Fol. 26 tab.

$\left.{ }^{8}\right)$ Prodromus florae argentoratac. Argent. 1766. 8. 26 tab. 
de Ia Tourette ${ }^{1}$, die ber Gegend yon Srleans und Eftampez $\Im o \mathfrak{l}$. Steph. (s) uttard ${ }^{2}$ ), bie yon Rantez

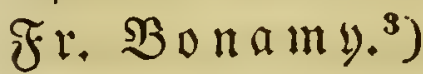

Die Soflanzen einzelner Srovinzen wurben Kearbeitet: you R. (5) é rarb bie ber \$rovence in einem yortreffliden $\mathfrak{S}_{\text {erfe }}{ }^{4}$ ),

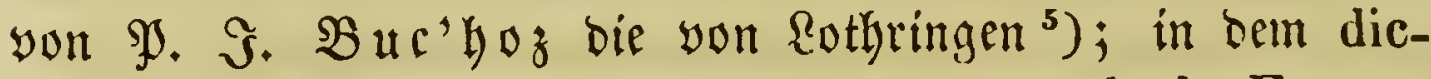
tionnaire raisonné universel des plantes de la France. Paris 1770 - 71. IV voll. 8., baz biefer vielfdrcibende Berfaffer neben vielen anberen hier nidjt zu erwähnenden 2 Ser= fen compilirte, finden fid̄) Beiträge anderer Botanifer zu Den Floren verfdiebener Şrovinzen.

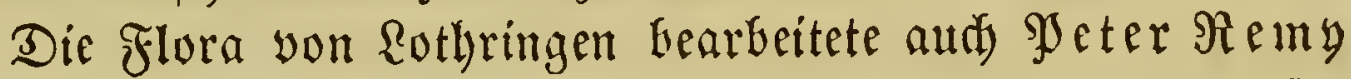

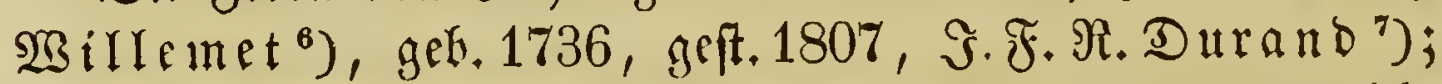
bie von $\mathfrak{B u r g}$ umb bie Der Dauphiné fand cinen auzgezeid $=$ neten Bearbeiter an. Dan. Billar ${ }^{8}$ ), Die erfte yollftän=

1) Chloris lugdunensis, 1785. 8. Botanicum Pilatense or catalogue des plantes qui croissent au Mont Pilat, in beffen Voyage au Mont Pilat dans la province de Lyonnois. A vignon 1770.8.

$\left.{ }^{2}\right)$ Observations sur les plantes. Vol. 1. 2. Par. 1747. 2 voll. 8. 4 tab.

$\left.{ }^{3}\right)$ Florae Nannetensis prodrom. Nantes 1782, 12. Addenda ad flor. Nannetens. prodrom. Nant. 1785. 12.

4) Flora Gallo-Provincial. Par. 1761. c. XIX icon. 8.

5) Traité historique des plantes qui croissent dans la Lorraine. Paris 1770. X voll. 12. - Tournefortius Lotharingiae ou Catalogue des plant. qui croissent dans la Lorraine et les trois Evêchés. (Nancy 1764.) 8. Heter bie

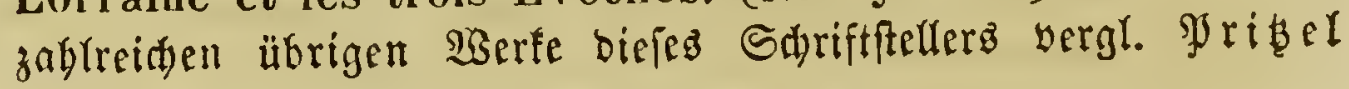
ভ. 38,39 .

-) Phytographie économique des plantes de Lorraine. Nancy 1780. 8.

7) Flore de Bourgogne. Dijon 1782. II Tom. 8.

${ }^{3}$ Prospectus de l'histoire des plantes du Dauphiné et d'une nouvelle méthode de botanique etc. Grenoble 1779. 8. - Mistoire des plantes du Dauphiné etc. Ibid. 1786-89.

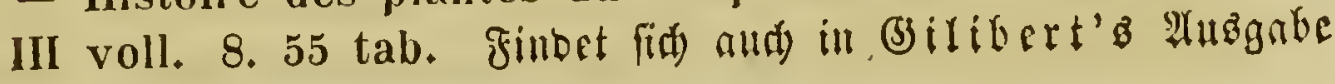




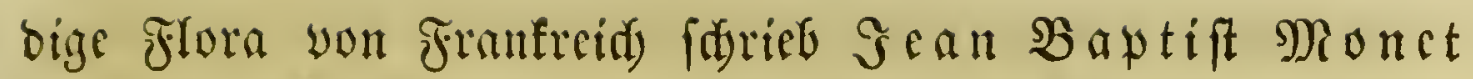
be $\mathfrak{R} a$ u a $f$, Profeffor am uaturbifturifdyen Mufrum zu Pariz. Ev wante in biejem Siserfe juerft bie analytifde Methode bes Mflnuzenbeftimmens an, cine Methode, die beun 2 nfänger alferbing grofe Reidjtigfeit gewährt. STit werben auf biefen (5)efebrten und fcine Metloobe in ber näd)fen \$eriobe zunüat= founne1t. ${ }^{1}$ )

P(uber ben (Benannten erwähnen wir nod) (s)iraub Soulavie, ber bas fïblidye Frantreid, namentlid) in pflanzen=

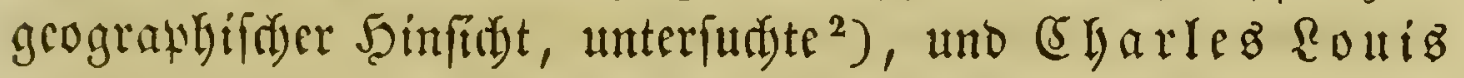
De l'beritier of Bratelle (geft. 1800), ber viele Mid=

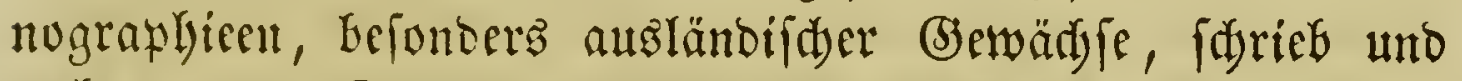
meljrere neue (Siattumgen aufitellte. ${ }^{3}$ )

Ueber bie Rultur Der Bäume in Franfreidi madjte $\mathfrak{B} \mathfrak{u}=$ hamel bu Monceau, bon bem fdon oben bie Rebe war,

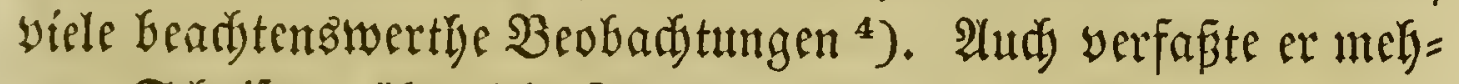
rere Sdyriften über die Ranbwirthidaft.

von $\{$ inné's Systema plantarum, Colon. Allabrog. $1785-$ 87. VII voll. 8. Biffarz gab aud ein Berzeidnis bez (bar= teng yon Strap̃burg herauz. Strap̧burg 1807. 8, 6 Tafeln. Heber feime übrigen Sdriften vergl. Sribel S. 309.

1) Flore Française. Par, 1778. III Tom. 8. Ibid, 1793. Ibid. $1805-15$. V Tom. en six vol.

$\left.{ }^{2}\right)$ Histoire naturelle de la France méridionale. Par. 1783. 2 tab.

$\left.{ }^{3}\right)$ Stirpes novae aut minus cognitae iconibus illustratae. Paris 1784-85. 6 fasc. Fol. 84 tab. - Geraniologia etc. iconibus illustrata. Ibid. 1787 - 88. Fol. 44 tab. - Sertum anglic., s. plantae rariores quae in hortis juxta Londinum inprimis in horto regio excoluntur. Par. 1788. Fol. 34 tab. Ferner farieb er über viele eingelne (5)attungen. Siefe Britiel S. 157.

*) Physique des arbres (ङ. 210). - Traité des arbres et arbustes, qui se cultivent en France en pleine terre. Paris 1755. 2 voll. 4. 250 Iafeln. $1801-19$. VII t. Fol.

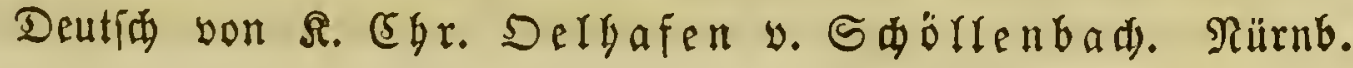


Bie befte Flora yon altenglano farieb in biefem Zeit=

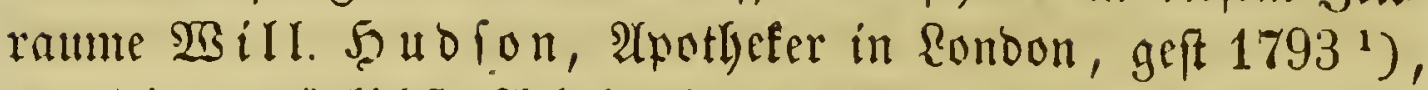

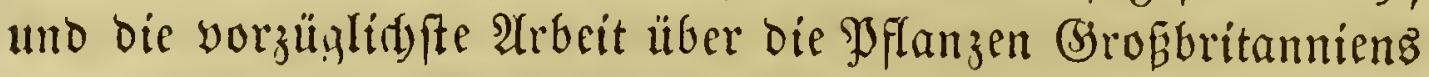
ülerbaupt licferte $\mathfrak{B}$ ill. $\mathfrak{B}$ ithering, $\mathfrak{A}$ r geb. 1741, geft. $1799^{2}$ ). 2 Uaperdem aber lieferten nody viele

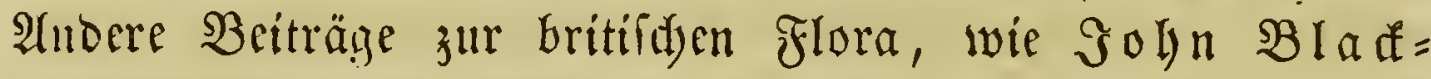

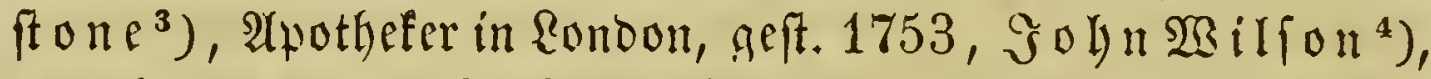

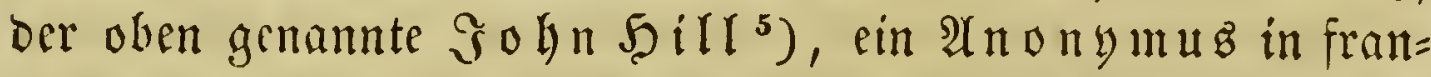

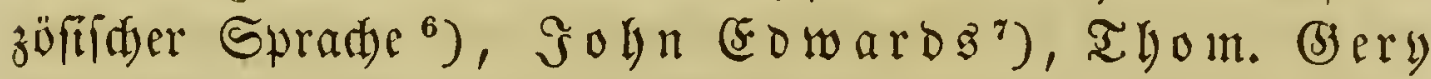
(5ullum ${ }^{8}$ ), Sames Sentinfon nad) Rinnés Flora

1763. 4. - Des semis et plantations des arbres et de leur culture. Par. 1760. 4. 16 Iaffefn. Deutíf: Rürnb. 1763. 4. $16 \mathfrak{I a f e t n . ~ - ~ T r a i t e ́ ~ d e s ~ a r b r e s ~ f r u i t i e r s , ~ c o n t e n a n t ~ l e u r ~}$ figure, description, culture etc. Par. 1768. II voll. \%) 1782. III voll. 8. - (1808) - 1835. VI voll. Fol. Deutíl:

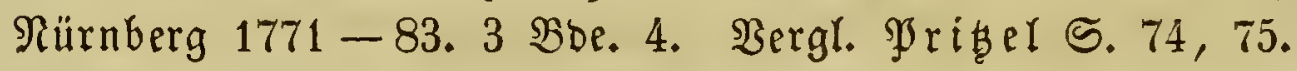

1) Flora Anglica. Lond. 1762. 8. Ibid. 1778. 8. 1798. 8.

$\left.{ }^{2}\right)$ A botanical arrangement of all the vegetables naturally growing in Great-Britain. Birmingh. 1776. c. tab. aen. XII. 8. Edinb. 1835.8.

$\left.{ }^{3}\right)$ Fascicul. plantar. circa Harefield sponte nascent. Lond. 1737. 12. - Specimen botanic. Lond. 1746. c. tab. aen. I. 8.

4) A synopsis of british plants in Mrs. Ray method. Newcastle 1744. c. tab. lig. inc. II. 8.

$\left.{ }^{5}\right)$ British herbal. Lond. 1756. c. 75 icon. Fol. - Herbar. Britannicum, secund. metliod. floral. nov. Lond. 1769. c. 195 tab. aen. 8. Flora Britannica, secund. systema sexuale. Lond. 1760. 8. Heber bie bier niđt crwägnten 23 erfe 5̧ill's vernl. Pritgel S. 119.

-) Flora anglira, nu flore anglaise contenant les plantes, qui croissent naturellement dans le rnyaume d'Angleterre distribuée suivant le système sexuelle. Lond. 1764. S.

${ }^{3}$ The british herbal. Lond. 1730 . Fol. 100 folor. Taffrn. Select collection of one liundred plates (iibcr cngl. unb aแถ่ไäıb. B(umen). Sonb. 1775. Fol. 100 Tafıln.

s) Flor. Anglicae specim. imperfect. inchoatum. Lond. 1784.8. 
anglica ${ }^{1}$ ), Rid . S

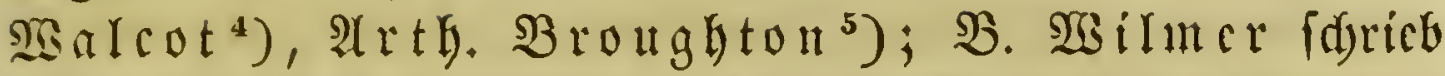

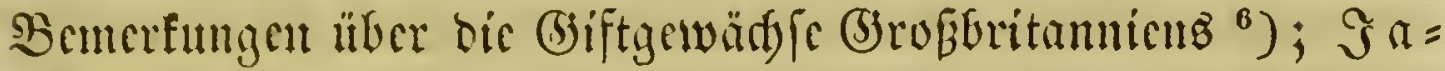
mes Borton luber bie Farren uno Jjil $\mathfrak{z}^{7}$ ); $\mathfrak{G}$ ame Diffon üter yeridjiconte fryptogamifde (bowädje. ${ }^{8}$ )

Dic vorgüglidjfe und pradytwollfte Specialflora diefes Zeit=

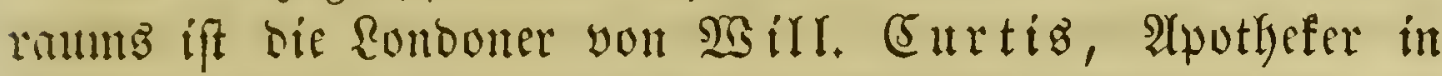

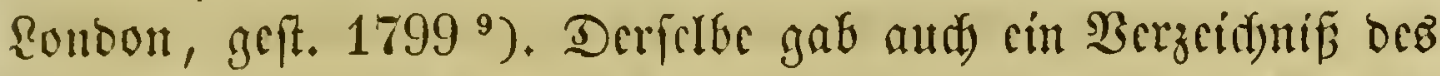
Ronbonter botan. (Sartens hernus ${ }^{10}$ ), yerfajite die 14 erften

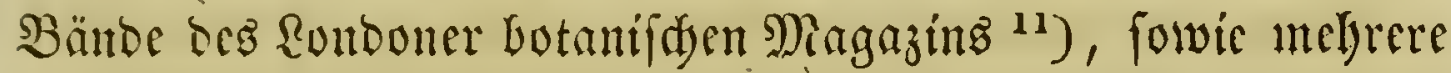

1) Description of british plants. Kendal 17\%5. c. tab. aen. V. 8 .

$\left.{ }^{2}\right)$ The english flora. Lond. 1775. 8. - Suppl. 1780. 8. Botanicus universalis et hortulanus etc. London $1770-77$. IV voll. 8.

$\left.{ }^{3}\right)$ The british Flora. York 1777. c. tab. aen. V. 8.

4) Flora Britannica. Bath. 1778. c. tab. aen. 168. 8.

$\left.{ }^{5}\right)$ Encheiridion botanicon. Lond. 1782. 8.

$\left.{ }^{6}\right)$ Observat. on the poisonours vegetables which are either indigenous in Great-Britain, or cultivated for ornement.

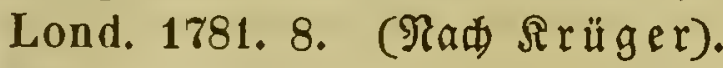

7) Filices Britanniae etc. Lond. 1785-90. 2 Boe. 4. mit 46 Ipfrtfln. - History of Fungusses growing about Halifax. Hudderstield 1788 -- 91. 3 BBbe. 4. mit 182 folor. Tafelr.

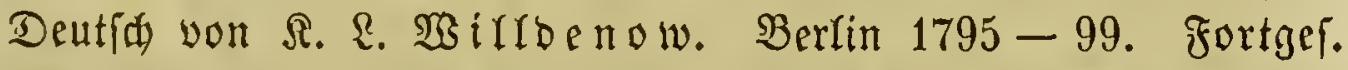
yon (5) 8. 4 Bop.

$\left.{ }^{8}\right)$ Plantar. cryptng. Britanniae fasc. IV. Lond. 1785- 1801.

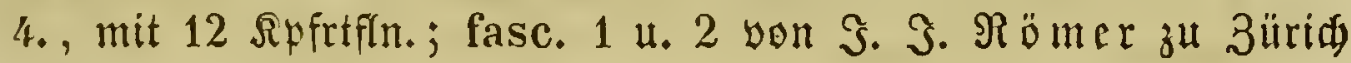
1788 Geraużgegeben.

$\left.{ }^{9}\right)$ Flora londoniensis etc. Lond. 1777 - 87. 70 Fasc. Fol.

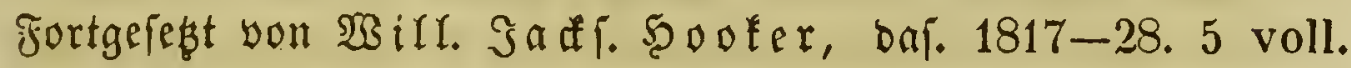
Fol. Mit 702 for. $\mathfrak{T} a f$.

$\left.{ }^{10}\right)$ Catalogue of british etc. plants cultivated in the London botanic garden. $\mathfrak{D a}$ 的 1783. 8.

11) Botanical Magazine or Flower-Garden displayed. London yon 1774 an. Defifen übrige Sdariften fiege bei PJ ritzel S. 55. 


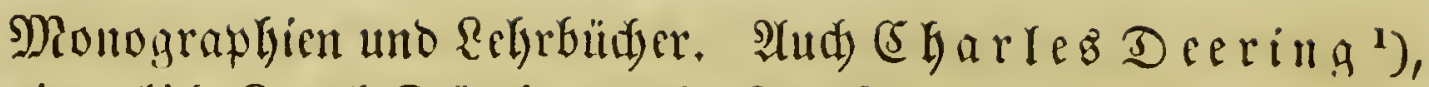

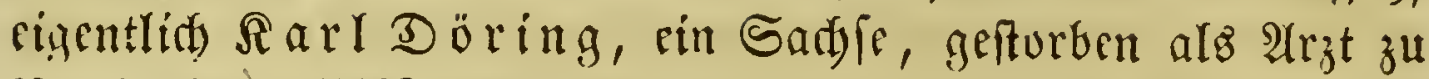

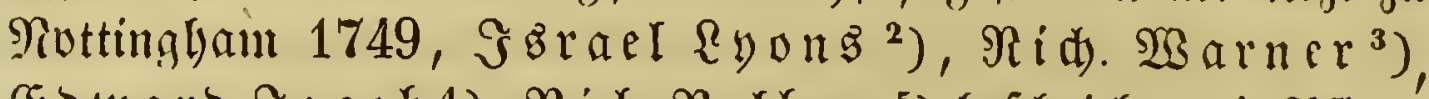

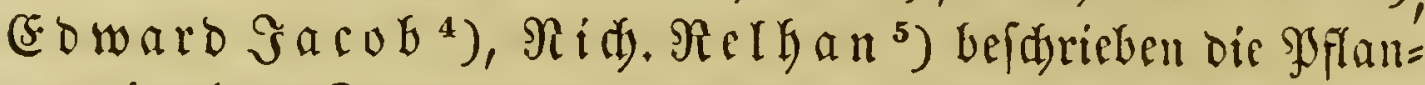
zen einzelner Gegenden.

Die Flora yon Sdiottland bearbeitete ber (Bseiftlidje Gohn Rightfoot, geb. 1735, geit. 1818. Fr zeidunet fid) Durd) mandise nete (Entocfungen uno burd) eine grülto= lidbe Bearbritung vortheilhaft aus. ${ }^{6}$ )

Unter den nieberlänoifden Floriften ift Ratalis

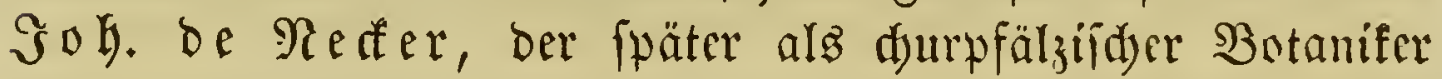
zu Mannbein lebte, ber beocutenofte. (Sr farieb sine flora Der belgifden Srovinzen ${ }^{7}$ ). Außerdem aber verfaß̧te er mrh=

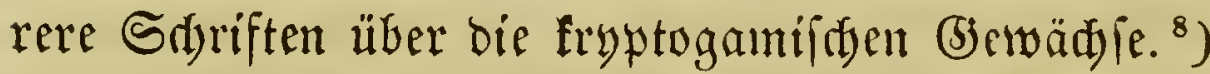

David Meeje, (Särtmer zu Franeffer, verfagte cine Flura yon Friesland ${ }^{9}$ ), fowie cine Monographie ber 19.

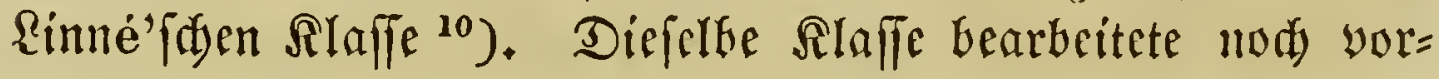

1) A Catalogue of plants naturally growing in England, more specially about Nottingham. Nottingh. 1738. 8. Nottingh. vet. et nova. Nott. 1751.

$\left.{ }^{2}\right)$ Fascicul. plantar. circa Cantabrigiam. Lond. 1763. 8.

$\left.{ }^{3}\right)$ Plantae Woodfordienses. etc. Lond. 1771. 8.

$\left.{ }^{4}\right)$ Plantae Favershamienses etc. Lond. 1777. 8.

5) Flora Cantabrigiensis. Cantabr. 1785. 8. 7 tab. Suppl. $1786,1788,1793$.

') Flora Scotica etc. Lond. 1777. 2 voll. 8. 35 tab.

7) Deliciae gallo-belgicae silvestres etc. secund. principia Linnaei. Argentor. 1768. 2 voll. 8. 1773.

8) Atufer ben fiton oben genannten: Method. muscor. per classes, ordines, genera ac species c. synon Mannh. 1771. 8. 1 tab. - Eclaircissement sur la propagation des Filicėes en général. Ibid. 1775. 4., uno verítiedene fleinere Ablanbr. in ben Denfifariften oer pfälg. 2lfabemie.

จ) Flora frisica. Franecker 1760. 8. 2 Taf.

$\left.{ }^{10}\right)$ Het XIX Classe van de genera plantar. van Lin naeus, Syngenesia genaamt, opgeheldert en vermeerderd. Leeu- 


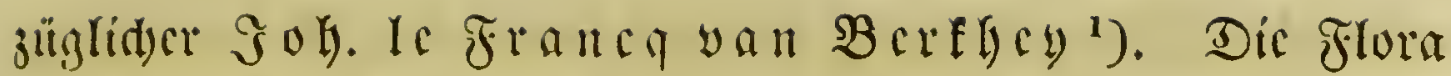

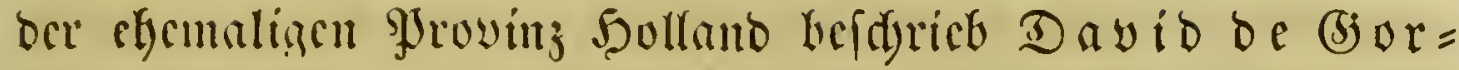
ter, Srofeffor zu Sarbcrwye ${ }^{2}$ ), geb. 1717, geft. 1783, uno Stcph. Fol. van (S)

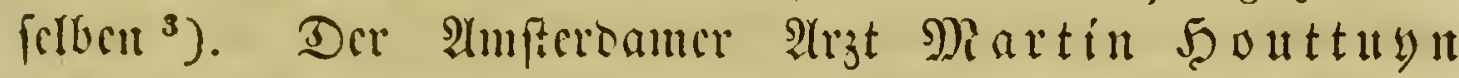

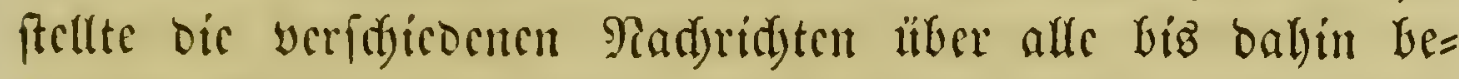
faunten Syflanzen zufammen uno lieferte fo cine volffänbige SSflanjengeid)idste. Dicfalbe wurbe von (Shriftuann und Bjanzer ins Drutfide überfest. (Nünberg $1777-78,14$ Thle. 8.) ${ }^{4}$ )

Dic Flora Gtaliens wurbe audi in biefom Beitraum fleifin Durdyforidst. Der Franzufe Fr. Seguier, ber fdon frither cin butanifdes 2 serf herausigegeben hatte ${ }^{5}$ ), burd)= fudyte $D$ beritalien, namentlidy aber bie (jezzento um $\mathfrak{B}$ erona. ${ }^{6}$ )

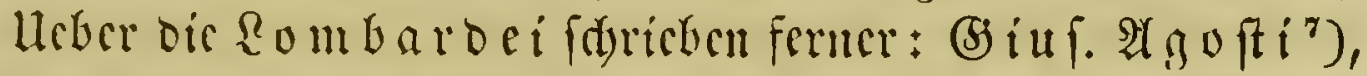

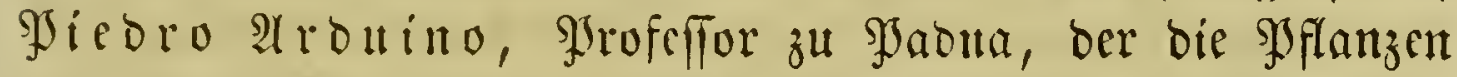
bes botanif(t)en (barteng und Der Hungegend diefer Stadt be=

warden 1761. 8. 8 Taf. Bergl. aud beffen: Plantar. rudimenta, p. 1, No. 1 et 2. Leovard. 1763. 4. 7 folor. Taf.

$\left.{ }^{1}\right)$ Expos. characteristica florum, qui compositi dicuntur. Leid. 1761. 4. 9 tab.

2) Flora Gelın-Zutphanica. Harderov. 1745. 8. Append. 1757. - Flora belgica. Ultraject. 1767. 8. Suppl. 1768. 1777.

3) Plantar. Belgii foederati indigenar. spicilegium. Harderov. 1788. 8.

$\left.{ }^{4}\right)$ Naluurlijke historie, oft uitvorige beschrijving der dierell, planten en mineraalen. Amsterd. 1774-83. Deel II. Stück 1-14.

$\left.{ }^{5}\right)$ Bibliotheca botan. Hag. Comit. 1740. 4. Lugd. B. 1760. 4. Auctuarium bazu, ibid. 1760. 4.

-) Catalng. plant. quae in agro Veronensi reperiuntur. Veron. 174.5. 8. Supplementum. Veron. 1754. 8. 8 tab. - Plantae veronenses. Veron. 1745. 2 voll. 8. 17 tab.

$\left.{ }^{7}\right)$ De re botanica tract., in quo eae stirpes peculiariter recensentur quae in agro Belunensi et Fidentino vel sponte nascunt, vel arte excolunt. Belluni 1770. gl. 8. 


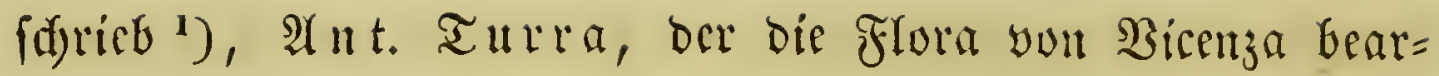
britete $^{2}$ ). - Die Flora von So iemont wurbe yon $\mathrm{farl}$ Allioni ${ }^{3}$ ), Srofeffor in Turin, geb. 1725, geft. 1804, yon

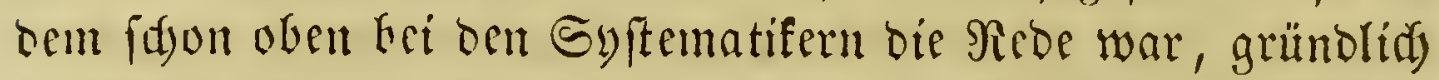
unteriudst. - Fulgentiub Bitmann beforicb bie Spflan=

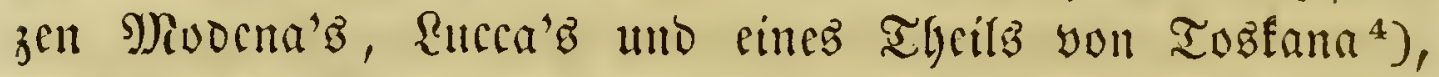

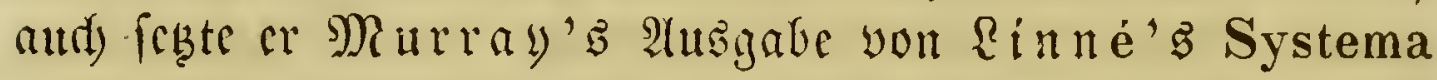
vegetabilium (Summa plantar. quae hactenus innotuerunt, t. 1-6. Mediol. 1789-92. 8.) fort; Ferd. Baffi beidrieb thailweile bie Flora ber 2 (penninen. ${ }^{5}$ )

Die tosfanidse Bfflanjemwelt aber wurbe von $\mathfrak{B} i$ agio Bartalint in feiner Flora yon Siena ${ }^{6}$ ) tho von (b) ioy. Targioni= Iozetti bearbeitet ${ }^{7}$ ). Wut befien Sohn $D t=$

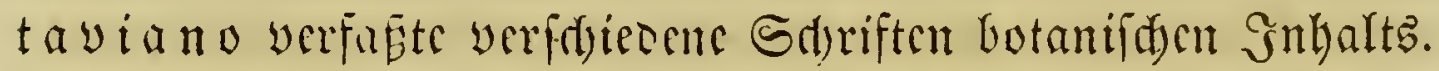

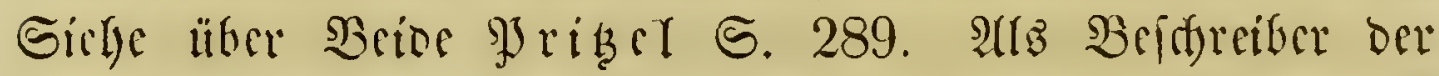
Flora des Rirdyenizantes if́t Riberato Sabbati zu nemen,

') Animadversion. botan specimen. Patavii 1759. Mit 12 Ipprtfln. 4. - Animadver's. bot. spec. alter. Venet. 1764. 4. 20 tab.

$\left.{ }^{2}\right)$ Florae Italiae prodromus. Vicent. 1780. 8.

3) Rariorum Pedemoulii stirpium specim. primum. Taur. 1755. c. tab. aen. XII. 4. -- Stipium praecipuar. Jittoris et agri nicaeensis enumeratio methodica cum elencho aliquot animalium ejusd. maris. Paris. 1757. 8. - Flora Pedemontana. Turin 1785. t. I-III, c. 92 icon. Fol. Auctuarium ad floram Pedemontanam. Taur. 1789. 4. 2 tab. - -ynopsis methodic. stirpium horti Taurinensis. 1760. 4.

4) Saggio dell istoria erlıaria delle Alpi di Pistoja, Modena, Lucca etc. con nuove observat. botan. et mediche. Bolog. 1773. 8.

5) Commentat. instit. Bonou. T. IV, p. 296 seq.

-) Catalogo delle piante che nascono spontaneamente intorna alla citta di Siena etc. Siena 1776. 4. - Ragnaglio di alcune produzione naturali dell' agro Senese. Ibid. 4.

7) Relationi d'alcuni viaggi falti in diverse parti della Toscana. Firenza $1768-79.12$ פboc. 8. 


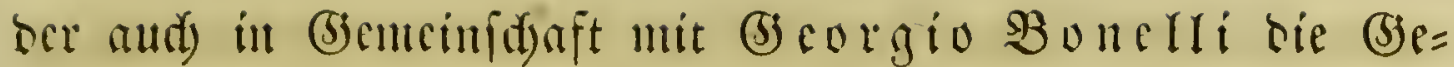
wäd) je bes botaniftyen (bartenz in Rom ju befdreiben an=

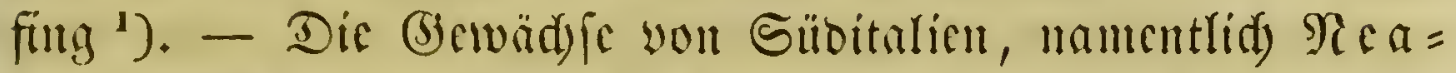

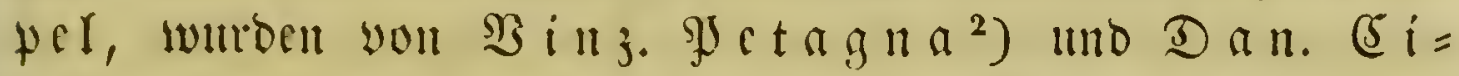
rifl $0^{3}$ ), gronfeffor in scapel, geft. 1799, uno bie Sici=

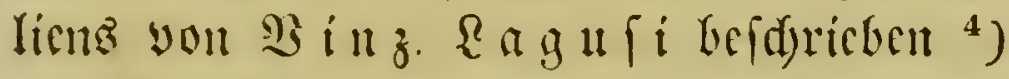

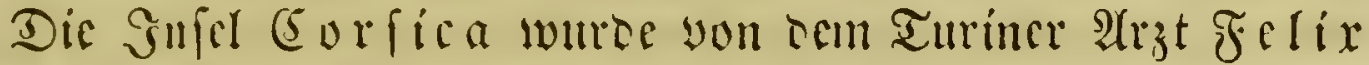
Balle im Gabr 1747 bercift. Dis Rejultate friter Foridyut=

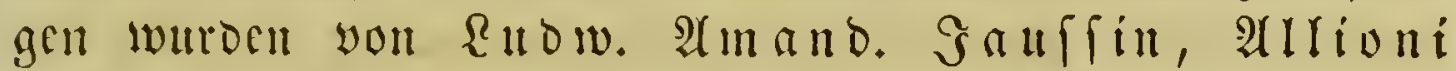

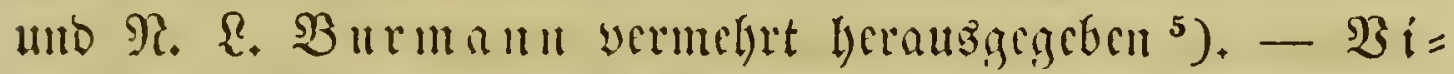

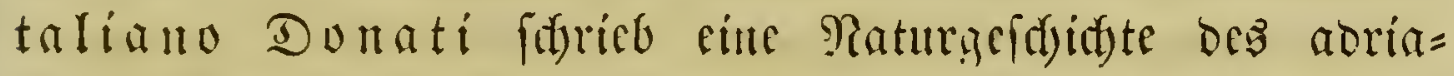
tif(t)en Mecres, in welder er befonders ïler bic alyen uno 30owhyten redet $^{6}$ ). (3) iovanni a ntonio Battarara ${ }^{7}$ ), geft. 1789, lieferte $\mathfrak{B e f d r e c h u n g e n ~ u n d ~ A b b i l s u n g e n ~ b e r ~ u m ~}$

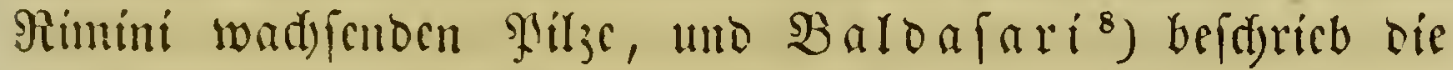
Mierrgcwäd) ye yon Sicna.

Dic pyrenäifde Şalbinfel blieb in dicfem 3eit=

1) Synopsis plantarum quae in solo Romano luxuriantur, juxta method. Toul'nef. Ferrar. 1745. c. tab. aen. II. 4. Rom. 1754. 4. - Hortus roman. juxta systema Tournefortii A. G. Bonelli, specierum nomina suppeditante Liber. Sabbati. Tom. I-V. Rom. 1772-78. Fol. Fort= gefert von (sonftantin Sabbati und Ricol. Martelli. $\Re o m$ 1780. Sm (janzen 700 Tafeln.

$\left.{ }^{2}\right)$ Institutiones botanicae. Neapoli 1785-87. 5 voll. 8 .

$\left.{ }^{3}\right)$ Plantar. rarior. regni Neapolit. Neapoli II fasc. 1788-92. c. XII tab. aen. Fol.

4) Erbuario italo siculo di moltissime piante. Palermo 1743. 4.

${ }^{5)}$ Mémoires du royaume de Corse, vol. 1. 2. Lausanne 1758. 12. - Florula Corsicae. Misc. Taur. II. p. 201-218. 1 tab. - Nov. Act. Acad. Nat. Cur. IV. A ppend. p. 205-254.

$\left.{ }^{6}\right)$ Saggio della storia naturale marina dell' Adriatico. Venezia 1750. 4. 10 tab. Deutfid: Salle 1753. 4. 1 Iafer.

$\left.{ }^{7}\right)$ Fungos. agri ariminiensis historia. Faventiae 1755. 4. 40 tab. 1759.4.

•) Act. Senensia. Tom. II. 
raume gar febr lyinter Dèt übrigen civilifirten Rändern zurǚt. 3u ben wenigen Botanifern Spaniens gehört ber $\mathfrak{X}$ Sund $=$ arzt uno Srofeffor zu Mabrí Sofeph Duer $\mathfrak{M a r t i}=$ nez, geb. 1695, geft. 1764, ber eine allgemeine Flora yon Spanien mit ciner gerabe nidyt biel Rettes bringenden Rritif bes Rinn éfden Syftems zu fdreiben anfing. ${ }^{1}$ ) Diefe Flora wulde fortgefert yon (5afim. (bo omez Drtega ${ }^{2}$ ), Bor= felher bez botanifden (bartens zu Mabrio, ber auth über bie

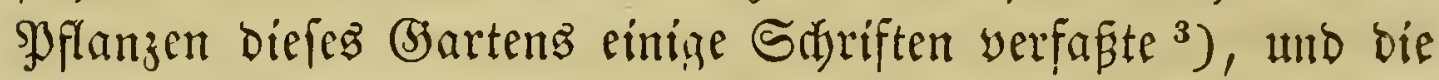
SJflanzen ber $\mathfrak{B a ̈ t e r ~ y o n ~ T r i l l o ~ v e r z e i d n e t e . ~}$

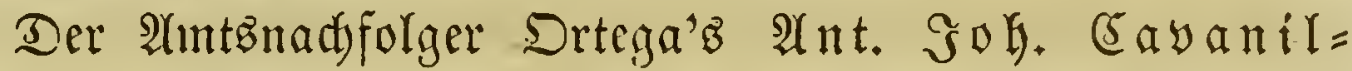
$\left.\mathfrak{I}_{\mathfrak{B}} \mathfrak{B}^{4}\right)$, geb. 1745, geft. 1804, ein Эefuit aแb $\mathfrak{B a l e n c i a , ~ f i n g ~}$ am Ende dicfes 3eitraums feine literarifuse Raufbahn mit eincr trefflitien SBearbeitung ber Montadelphiften au. Bon feiner weiteren $\mathfrak{I}$ yätigfeit wird in ber folgenden gleriobe $\mathfrak{g e}=$ redet werden. - Der Sifwede gateter Röfling ${ }^{5}$ ), geb.

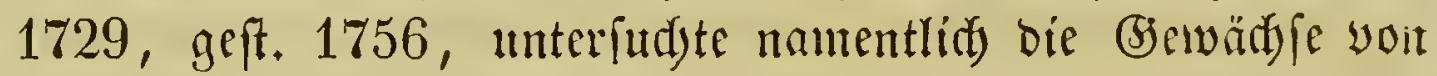
Saftilien; unter ben yon inm verzeidyuten 1300 arten funden

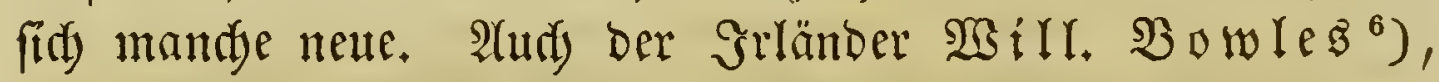

1) Flora española et historia de las plantas que se crian en Espan. Madrid. Tom. VI. 1762-84. 4. 212 tab.

2) Continuacion de la flora española par Casim. Gomez de Ortega. Madrid 1784. 4.

3) Elenchus plantar. horti regii madritensis. Madrid 1796. - Novar. aut rarior. stirpium horti reg. madrit. description. decades X. Ihid. 1797 - 1800. 4. 18 tab. - Tratado de las aguas termales de Trillo. Madr. 1778. S. Drtega

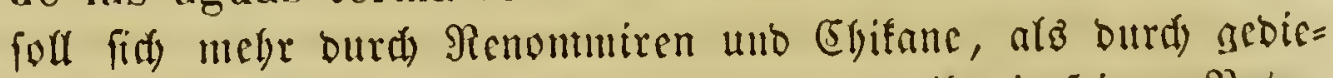

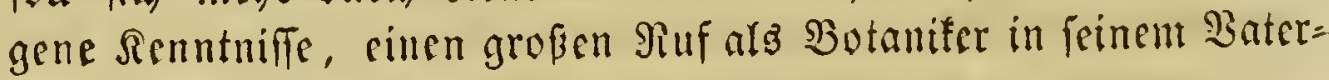
lanbe erworben baben.

4) Monadelphiae classis dissertationes decem. I - VIII, Par. $1785-89$. IX u. X, Mabrib 1790 ; mit 296 Sipfrtfin. 4.

$\left.{ }^{5}\right)$ Iter hispanicum etc. Stockh. 1758. 8. 2 tab. Deutifi yon $\mathfrak{R o ̈ r p i n . ~ B e r r i u ~ u . ~ S t r a l f u m b ~ 1 7 6 6 . ~ 8 . ~} 2$ inafeln.

-) Introducion a la historia natural de Espagna. Madr. 1785. 4. 1789, 4 . 
geft. 1780 , ber längere 3eit fît) in Shanien auflielt, uno Э. Talbot Dillon ${ }^{1}$ ) auf frimer Reife burd) Spanien lie= ferten mandye widytige Notizen über sic Flora Spaniens. -

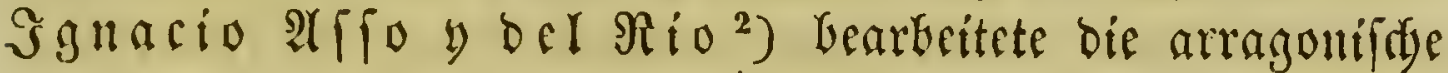
Flora.

Meter bie flora gortugals fdrieb cinzig unb allein ber

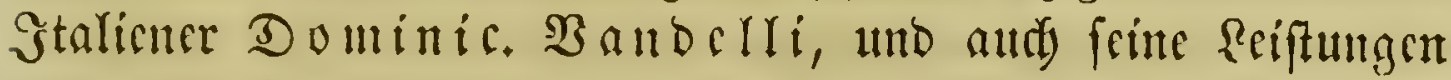

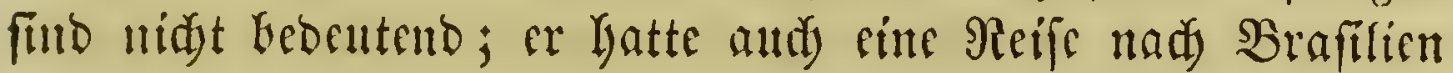
gemadit. ${ }^{3}$ )

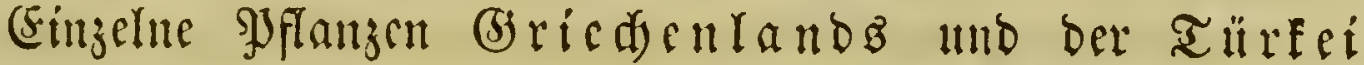
wurben jwar in verfdyebenen Rrifebefdreifungen erwägnt, ofr

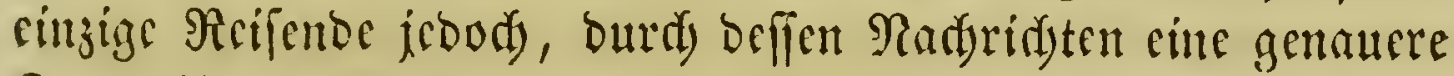
Renntmí̄ ber Spflanjen jener Ränder verbreitet wurbe, war Soln Sifthorp, Srofeffor in Drford, geft. 1796, ber gegen das (5nbe biefes und an 2nfanye des folgenten 3eit= raums bie vlympifde Şalbinfel und Rleinafien bereifte. Seine

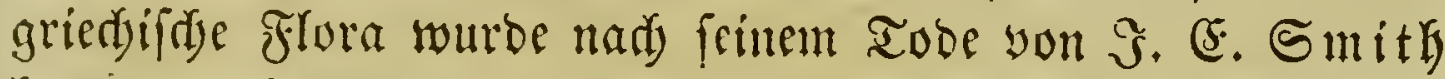
lerauggegeben. ${ }^{4}$ )

Un bie bänifde flora (Norwegen, Galand, die Faröer und (5) rönland gelörten baunals nod zu Däne= marf) madte fid zunäd) for fdon oben erwälnte (5) eorg Shriftian von Deber, Sorofeffor in Sopentagen, yer= bient. Er gab bie brei erften $\mathfrak{b a ̈ n t}(1761-70)$ ber yor $=$ trefflityen Flora danica heraus. Die zu biefem $\mathfrak{X}$ erfe $\mathfrak{e r}=$

1) Travels through Spain. London 1780. 4.

$\left.{ }^{2}\right)$ Synopsis stirpium indigenarum Arragoniae. Massil. 1779. c. tab. IX. 4. Mantissa (s. a.) 1781. Tom. I. 2 tab. Enumer. stirpium in Arrag. noviter detectar. (s. 1.) Tom. I. 178\%. 3.

3) Florae lusitanicae et brasiliensis specimen etc: Conimbricae 1788. 4. 5 tab. - De arbore draconis s. dracaena Ulysspon. 1768. 8. 1 tab. - Fascicul. plantar. c. nov. generib. et speciebus. Olisip. 1771. 4. 4 tab.

*) Flora graeca etc. Lond. 1806 - 13. II voll. 8. $1806-$ 1840. X voll. 966 col. tab. (250 E.) 
forberliden Sammlungen und Tbbilloungen wurben näılid auf $\mathfrak{N o f t e n ~ b e r ~ b a ̈ n i f d e n ~ \Re e g i e r u n g ~ y e r a n f t a l t e t , ~ u n o ~ y o m ~ J a k r ~}$ 1761 an wurden bie eimzelnen Bänoe herauzgegeben. Den 4. und 5. Bant (1770-82) beforgte $D$. F. Mïller, ben 6. und 7. (1786-94) $\mathfrak{M a r t} \mathfrak{B a h l}$, oen 8, und 9. $\mathfrak{W}$.

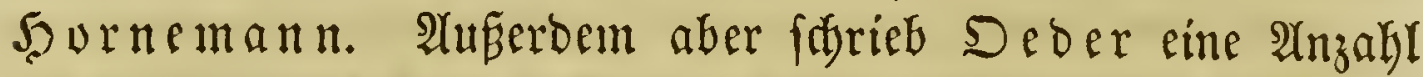

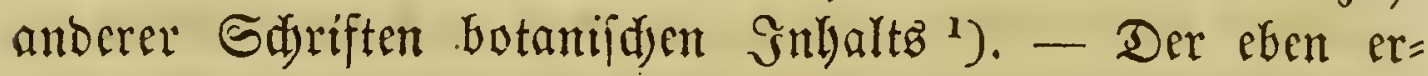

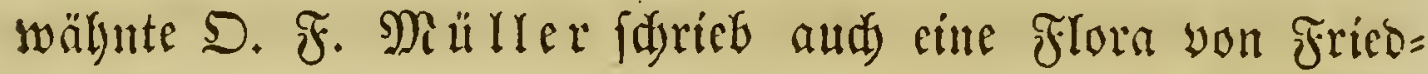
ridisthal. ${ }^{2}$ )

Beiträge zu ber flora Norwegenz lieferte Gonaz

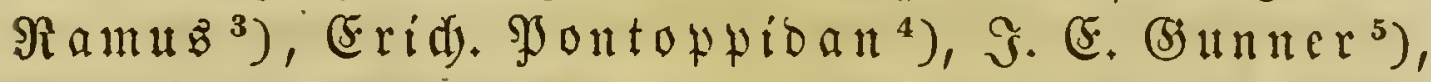
Sifft of yon Drontleim, geb. 1718, geft. 1773, 5.. Ton=

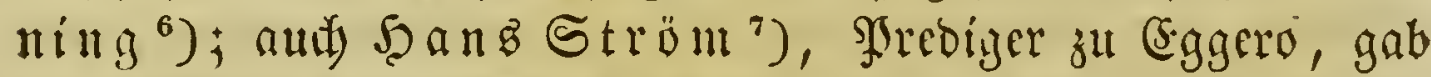
cuitige গaduträge zu berfelben.

Giner ber frudutbarften Dänifden Sotanifer diefes 3eit=

') Nomenclator botanicus. Kopenh. 1769. 8. - Enumerat. plantar., florae Danicae id est sponte nasc. in regnis Danicae et Norweg. ducatibus Slesvigi et Holsatiae; Comit. OIdenburgi et Delmenhorstiae. Hafn. 1770. 8. Deutiø: Berjei

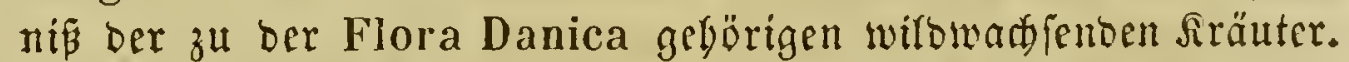
Sopenlagen 1770. 8. - Enum. plant. fl. Danicae Cryptantherae. Hafn. 1770. 8.

$\left.{ }^{2}\right)$ Flora Friedrichsdalina. Argent. 1767. c. II icon. 8 .

$\left.{ }^{3}\right)$ Norriges beskrivelse. Kiobnh. (1735). 4.

4) Förste forsög paa Norges naturlige historie. Kiöbnhavn. $1752-53.2$ voll. 4. Deutf yon Sqeibe. Sopengigen 1754. Scipzig 1769. 2 ז́le. 8.

5) Flora Norwegica. Hafin. $1766-72$. II tom. c. tab. aen. IX. Fol.

-) Norsk medicinsk och oeconom. Flora I. Deel. Kiöbnh. 1773.4.

$\left.{ }^{7}\right)$ Danske Videnske Selsk. Scrift. 3, p. 348 seq. 4, p. 369 seq. 10 , p. 249 seq. 12 , p. 299 seq. Naturhist. Selsk. Skrift. B. 1. H. 2, p. 30 seq. Norsk. Vidensk. Selsk.

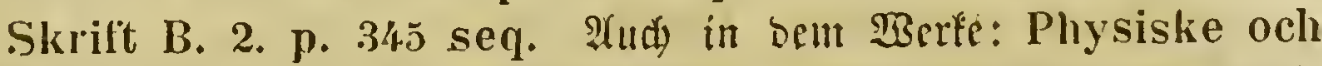
öknnomiske beskrivelse över Söndmöl Soröe $1762-66$. 4. finoet fid ein :ergeidnis bon PJflanzen. 


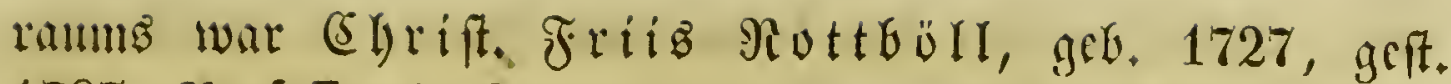

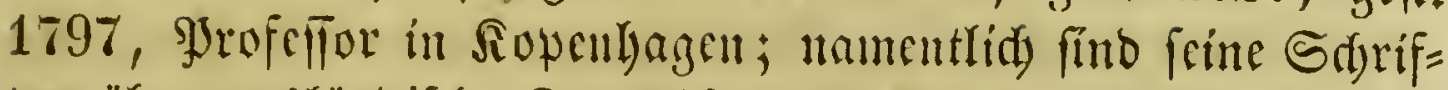

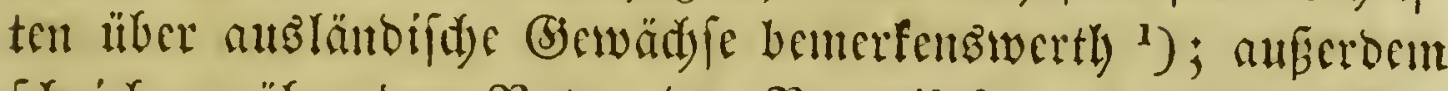

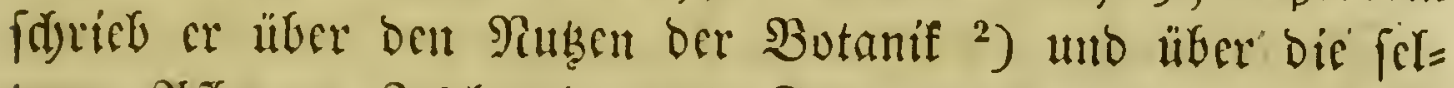

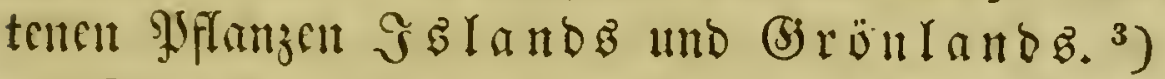

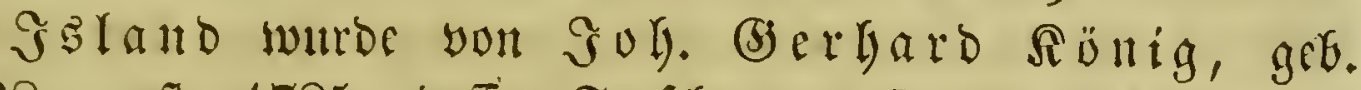
1728, geft. 1785, beffut Forfdungen D. F. Mulfer be=

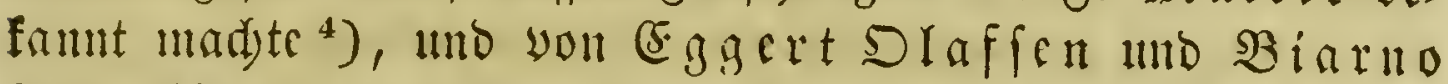

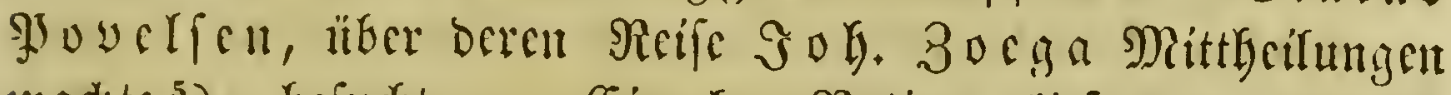
mad)te ${ }^{5}$ ), befudst. - Einzelue Rotizan licferten aud $\Im$.

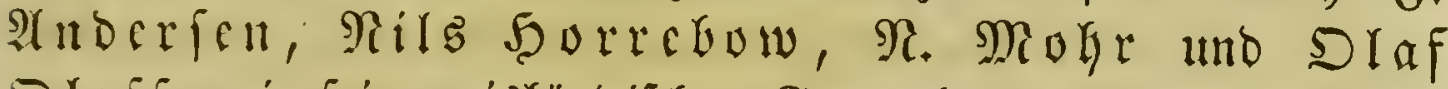
Dlaffen in feinem isländiforn (Gartenfud)e. ( (Rampmanna= Gibn 1760. S. 5 tab.)

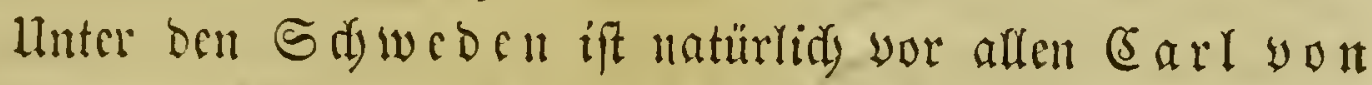
Rim é ałs. WJyytwgrawh zu erwähnen wegen feiner lapplän=

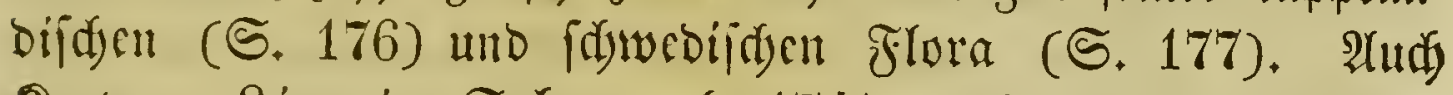
א. von Rinné, Sofn, geb. 1741, geft. 1783, madj bem AGfterben feimes Baters Jrofeffor in Mpfala, war ein nidyt

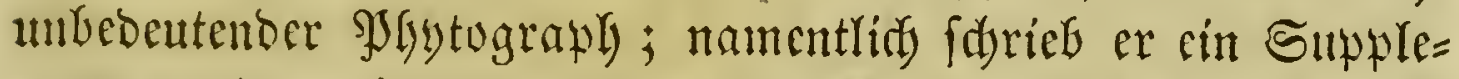
ment ju ben plyytographifoen SGerfen feinez Baterz, fowie

1) Description, et iconum rariores et pro maxima parte novas plantas illustrant. Lib. I. Hafn. 1773. Fol, 21 tab. Descriptiones rarior. plantar. surinamensium. Ibid. 1776. 4. 5 tab. 1798. Fol. 5 tab. - Descriptiones et icones rarior. pro maxima parte novar. plantar. Ibid. 1786. Descriptiones plantar. quarundam surinamens. c. fragmentis mater. medic. et oeconomicae surinamens. Ibid. 1798. Fol. 5 tab.

2) Botanikens udstrakte nytte. Kiöbnh. 1771. 8. 1 tab.

$\left.{ }^{3}\right)$ De plantis novis vel rariorib. Islandiae et Groenlandiae, c. introitu de bot. incremento apud Danos. (Act. soc. reg. havn. X. p. 393.)

4) Nov. Act. Nat. Cur. Vol. IV. p. 203.

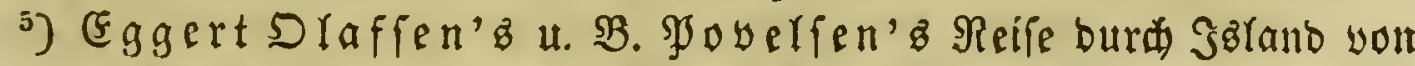

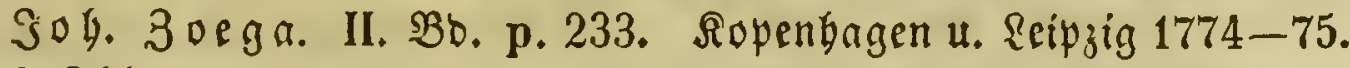
2 IGle. 4. 44 Tafeln. - Povels. Spec. obs. Havn. 1749. 4. 
cinige Sdyriften über ben fotanifiden (B)arten zut Uplala uno énige Monograplien ${ }^{1}$ ). Nadjträge zu \&inn e's flora yon Sidueben lieferten nod Speter $\mathfrak{\Omega} \mathfrak{l}_{\mathfrak{m}}^{2}$ ), geb. 1715, geft.

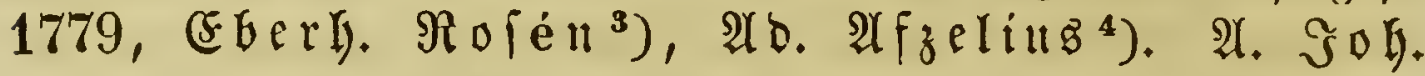

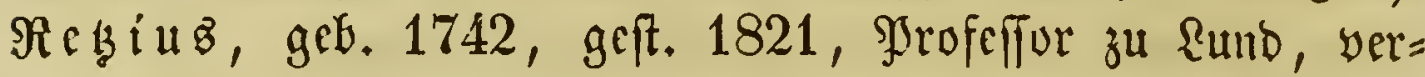
fapte in biefam 3eitraume eine fynoptifde Flora yon Sfan= Dinavien ${ }^{5}$ ); aud gab er cínen Nomentlator (Reipzig 1772)

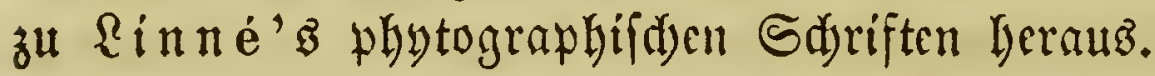

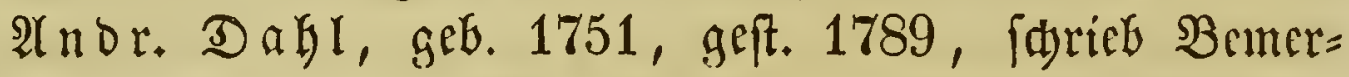

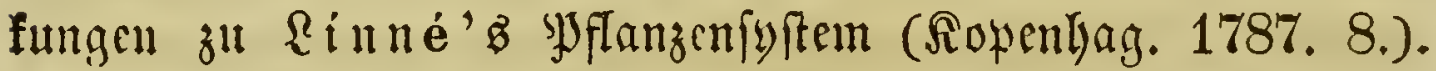
Der bebeutenofte fawedifde Botanifer nadi Rinné war in biefem 3eitraume

\section{$\mathfrak{A a r l} \mathfrak{S} \mathfrak{e t e r} \mathfrak{I} \mathfrak{h} \mathfrak{u} \mathfrak{b} \mathfrak{e} \mathfrak{d}$, geb. 1743 , geft. 1828 ,}

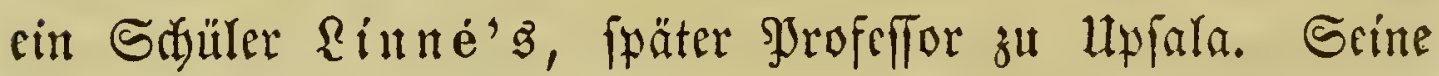

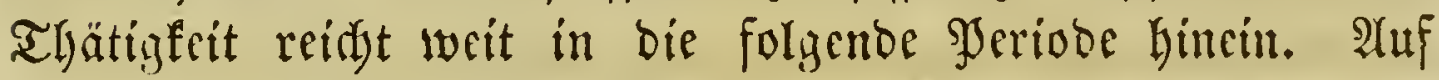

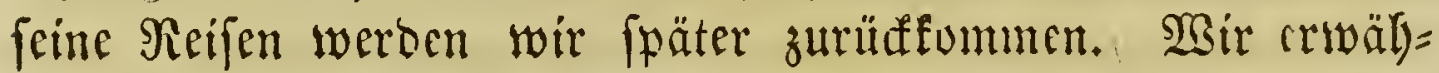
nen bier nur, bafi er fefr viele atbhandlungen botanifden

1) Supplement. plantar. Brunsvicae. 1781. - Decas I et II plantar, rarior. hort, upsaliens. Stockh. 1762-63. Fol. 20 tab. - Fasc. I plantar. rarior. h. upsal. Lipsiae 1767. Fol. 10 tab. - Seine teeineren 2(bbandlungen finden fid int bent Amoen. acad, vol. $X$. in fine.

2) Florae fennicae p. I. Ăboae 1765. 4.

$\left.{ }^{3}\right)$ Observationes botanicae circa plantas quasdam Scaniae non ubivis obvias et partim quidem in Suecia hucusque non detectas. Lund. 1749. 4 .

4) A. A fzelius et A. M. Waldström, De vegetabilibus sueranis etc. Sect. I. p. I. Ups. 1785. 4.

$\left.{ }^{5}\right)$ Florae Scandinaviae prodromus etc. IIolm. 1779. 8. Lips. 1795. 8. Suppl. et emend. Lundae 1805. Suppl. secund. et emend. Ibid. 1809. 4. - Fascic. observatt. bot. Lund. 177\%. 4. 
Sullalts verfafit hat, welde zum Igeil in ciner Sammlung eridienen find. ")

Aud) $\Re$ u fad) in botanifder Şinfidst burdjforidst. Der vfen erwäbnte

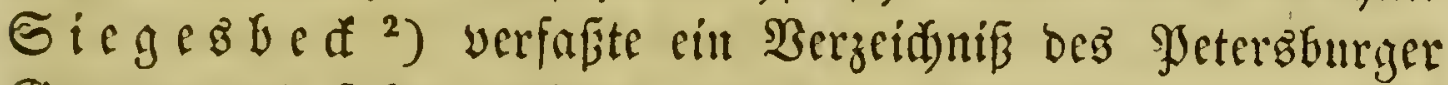
(3)artents unt fülyrte babei audj sinige wilowadjente Pflanzent an. Daum wurbe bie Flora yon Setersburg yon $\mathfrak{D} a y$ ib $D$ e (5) orter ${ }^{3}$ ) bearbeitet. Sean (Em. (B) ilibert befdäftigte

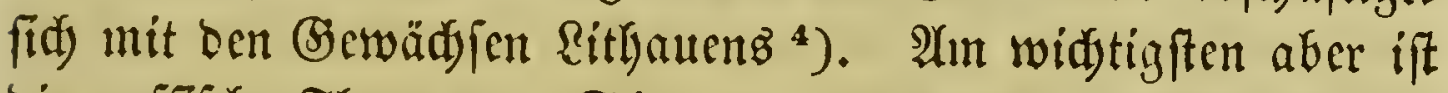

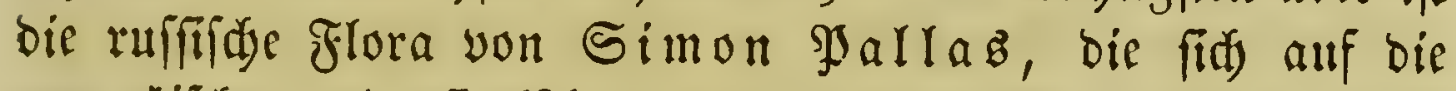

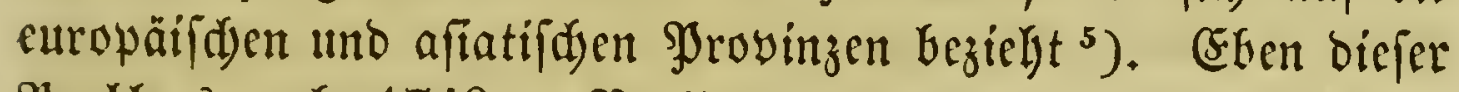

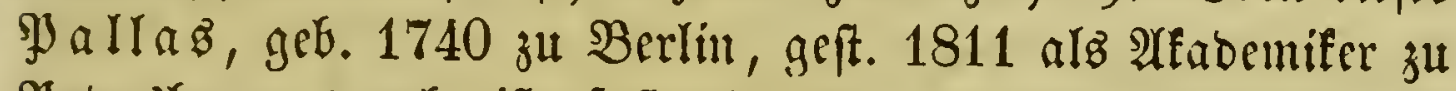
Beterzburg, Durdareifte faft alle ßrovinzen bez grofen rufft=

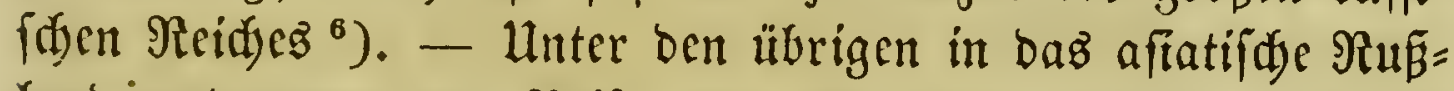
land unternummenen Reijen war biejenige, weldye $\mathfrak{S}^{\circ}$ h. (J).

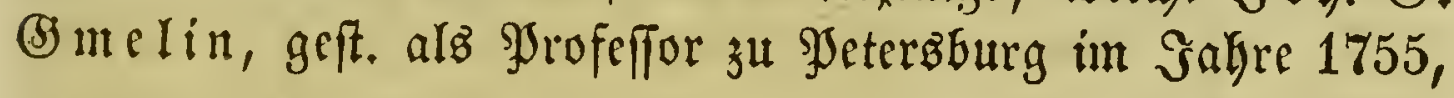

1) Dissertationes acad. Upsaliae habitae sub praesidio C. P. Thunberg. Ed. Chr. H. Persoon. Goetting. 1799-1801. 3 voll. 8.

$\left.{ }^{2}\right)$ Primitiae florae petropolitanae. Rigae 1736. 4. Suppl. 1737.

3) Flora ingrica ex schedis Steph. Krascheninikow confecta et propriis observat. Petropol. 1761. 8. - Appendix ad floram ingricam. 1764. 8.

4) Flora lithuanica inchoata etc. Grodnae 1781. 8. Entbălt aud befien: Chloris grodnensis etc. ordine Linnaeo. Supplementum. Vilnae 1782. - Calendrier de Flore pour l'an 1778 , autour de Gradno, et 1807 , autour de Lyon. Lyon 1809. 8. tab. Bitlibert, ber früber Mrofeffor in MBitna war, zulefet aber in Eyon lebte, idrieb aud einige $23 e r f e$ über bie europäif́de flora: C. Lin naei systema plantar. Europae. Lugd. 1775. - Histoire des plantes d'Europe, ou éléments de botanique pratique. Lyon 1798,1806 . 8. Bergl. Ş rifiel S. $97,98$.

$\left.{ }^{5}\right)$ Flora rossica etc. Petrop. 178\%-88. 2 Bbe. $\mathfrak{R}$ it 100

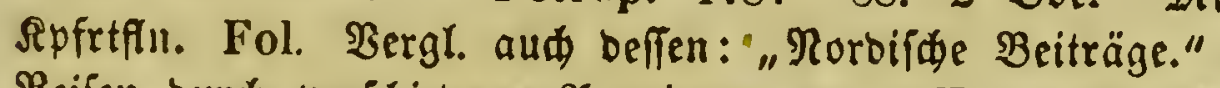

-) Reifen burd verídiebene Mrovingen bes ruffif Ben Meids. Wex tersburg $1771-76.3$ Thle. 4. 


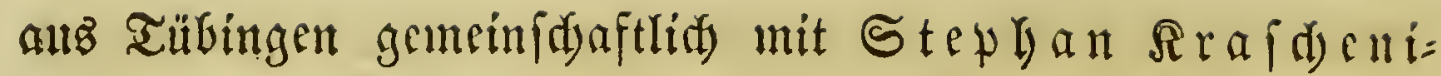
nif ow, (5). SB. Steller aus SBeingheim, geft. zut Şeterb= burg 1746, und einigen 2 noern unternahm, für bie Botanif

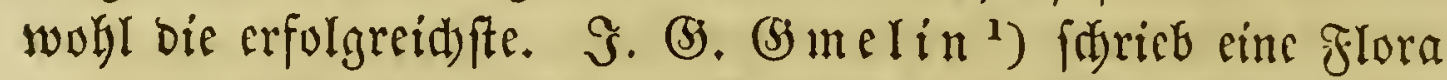

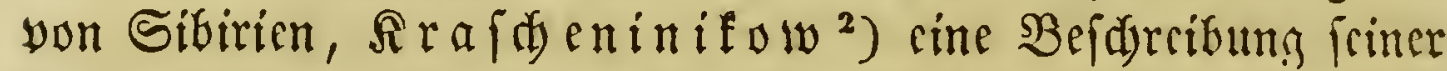

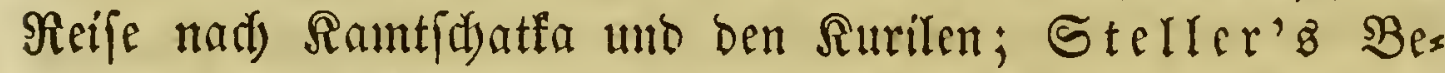
fdreifung ber Beringsinfel - bort war ber auf einer wiffer=

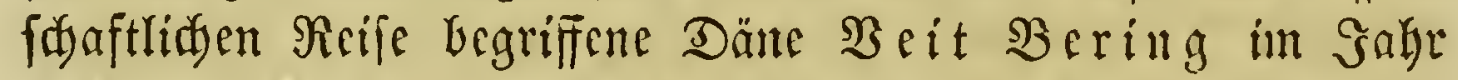
1741 umgelommen - burbe von $\mathfrak{g}$ arras herausgegeben ${ }^{3}$ ). Bon geringerer $\mathfrak{V}$ cbeutung für unfere 2 iflfend aft war bie Reife Samuel (5) ottlieb (5) meliu's, bez vorbingenant= ten Reffen, geft. im Rerfer zu Derbent an faspifduen Merre

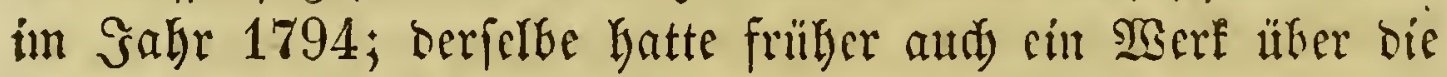
Tangalgen gefdrieben, bas Gier eine lobende (srwälgum ver=

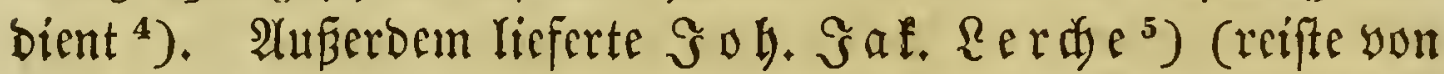
1737 - 47) einige Notizen über Sübrupland, Erid) $\mathfrak{R}_{\mathfrak{a}} \mathfrak{m a n n}^{6}$ ), geft. 1796, hiber bie Flora Sibiriens,

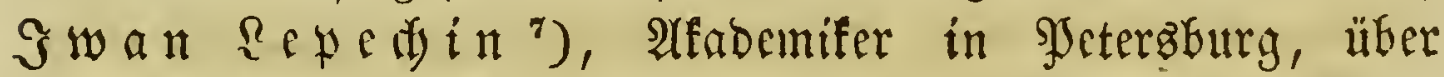
Nororugland, S. (5) ottl. (5) eorgi, ber in (sefelfidaft

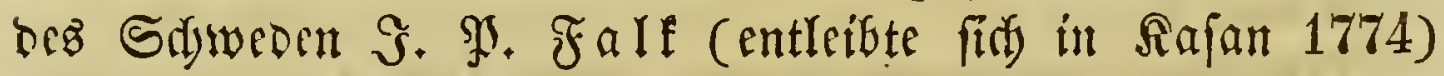

1) Flora sibirica s. historia plantar. Sibiriae. Petrop. 1747 -69. 4 Bbe. Mit 217 Spfrtfln. 4. Bergleide aud berifen

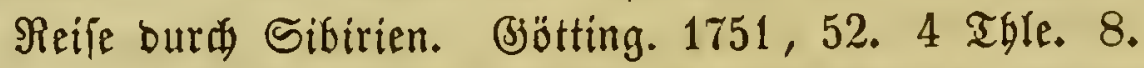

$\left.{ }^{2}\right)$ Opisani Zemli Kamschathi etc. Petersb. 1755. 2 voll. 4. Deutfil : Eemgo 1766. 4. 1789.

3) Reue norbifđe Beiträge. Bo. 2. S. 255 fi.

4) Historia fucorum. Petropol. 1768. Mit 35 Spfrtffn. 4. -

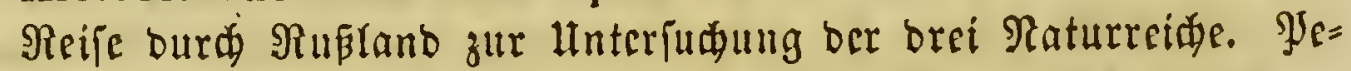
terzburg 1774. 3 I ble. 143 Taf. 4.

5) Nov. acta nat. curios. Voll. V. p. 161 seqq.

6) Sibirifate Briefe. (3)̈̈ttingen 1769. 8. Nov. comment. petrop. Bb. $15,16,18$.

7) $\mathfrak{A}$ (nz bem $\mathfrak{R}$ uffifinen yon

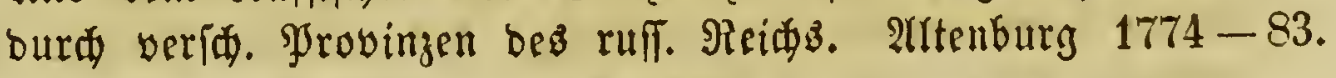
3 Thle. $4,17 \mathfrak{T} \mathfrak{a f}$. 
reifte, über ben llral und Sïbjibirien ${ }^{1}$, ber Riefländer Э. Ânt. (5) it (benftäb ${ }^{2}$ ), geb. 1745, geft. 1781, über

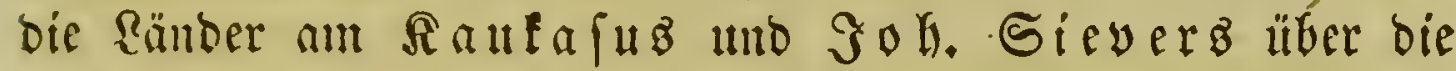
Rongolfi. $\left.{ }^{3}\right)$

Ueber $\mathfrak{g}$ erfien funben fith in S. (5), (5) melin's Reife=

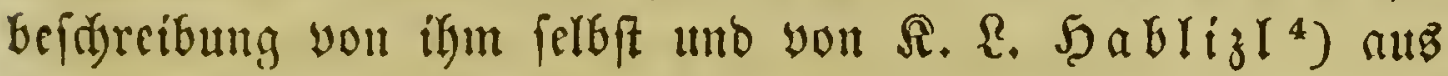
Soreufen sinige Radyridten.

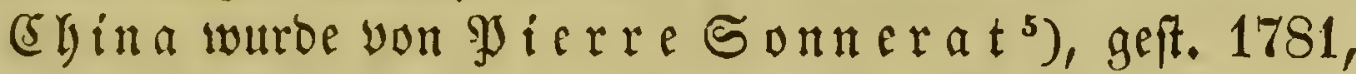
ber aud Dftindien uno die Shilippinen bejudt hatte, und yon Macartney ${ }^{6}$ ), (Sodindina von bem Miffionär Soh. be Roureiro, ber fid einige 3eit aud in (Elina und Mojambique aufgehalten hatte, Gereift. ${ }^{7}$ )

Ueber bie japanefifde flora gab ber oben erwähnte,

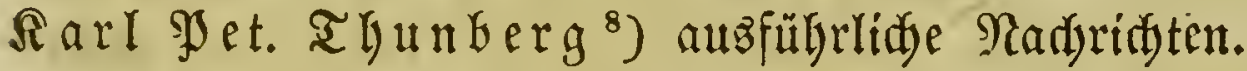

Friedrid Şaffelquift ${ }^{9}$ ), geb. 1722, geft. 1752 zu Smyrna, befudte Syrien, Rleinafien, sypern mo

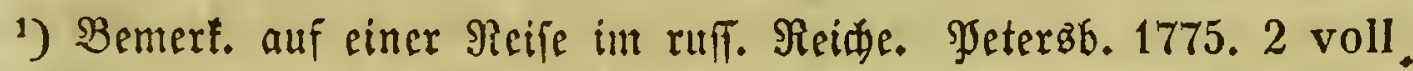

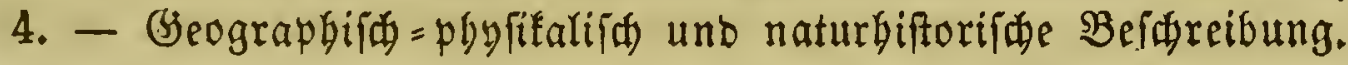

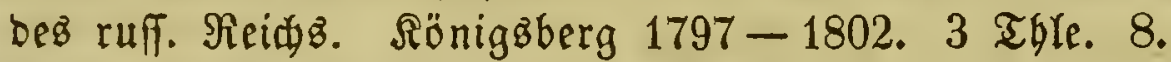

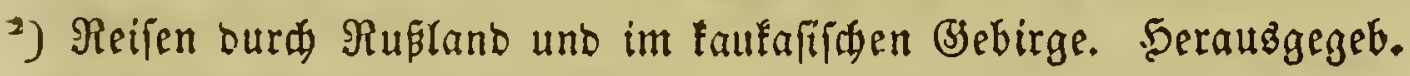

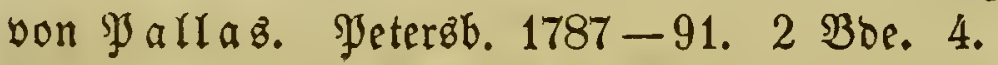

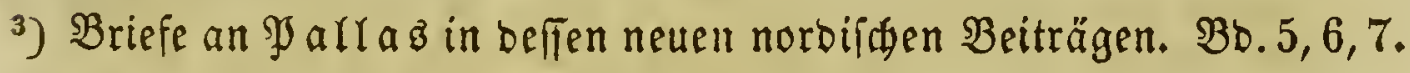

*) Siege aud beffen phyfifarijale Beidreibung ber taurifden Statt= balteríaft. Şannober 1789.

5) Voyage aux Indes orientales et à la Chine. Par. 1782. 4. 2 BDe. Mit 140 Rpfrtfln. Deutfd: 3üri申 1783. 2 voll. 140 Iaf.

6) Seine Reifebemerfungen wurben 1796 u. 97 von $\mathfrak{A}$ en. $\mathfrak{A} \mathfrak{n} \triangleright$ fon und (S. \&. Stallnton berauzgegeben.

7) Flora cochinchinensis etc. Ulissipon. 1790. 2 Boe. 4. Cum notis C. L. Willdenow. Berol. 1793. 2 voll. 8.

8) Flora japonica. Lips. 1784. 8. 39 tab. - Icones plantar. japonicar. Upsal. 179t-1805. Fol. 50 tab.

3) Seine Sdriften wurben yon $\mathfrak{g}$ inve ebirt. Iter palaestinum etc. Stockh. 1757. 8. Deutif yon Bsabebuf 1762. 8. 
A(egypten. (B) iov. Mariti $i^{1}$ ) bereifte diefelben Ränder (1760-63). Um biefelte 3eit begab fid aud eine bänilde Expedition unter $\mathfrak{A} \mathfrak{a}$ ften $\mathfrak{R} i \in \mathfrak{b} \mathfrak{u} \mathfrak{r}$ mad bem Srient, bei

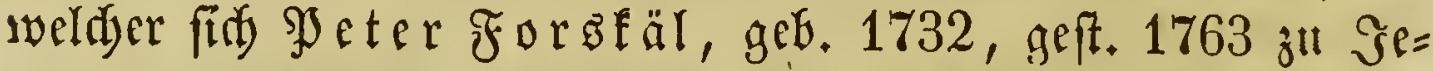

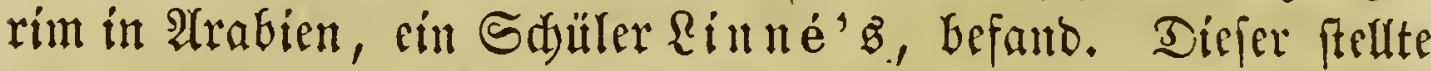
in $\mathfrak{A} \mathfrak{r a b}$ ien Gotanijde Unterjudungen an ${ }^{2}$ ). Heber bie Flora

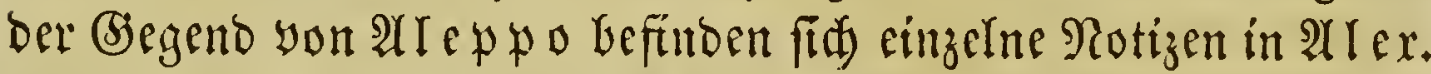
$\Re$ uffer's (geft. 1768) Raturgefdidte diefer (jegend. ${ }^{3}$ )

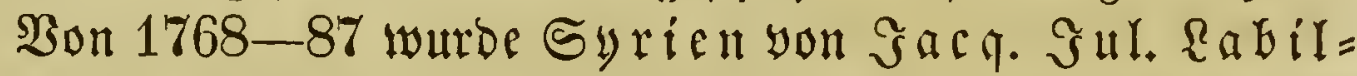

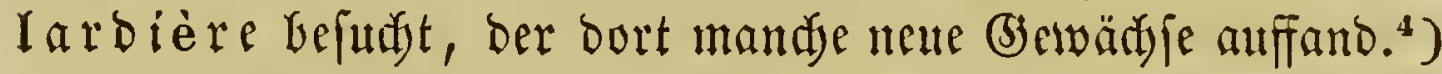

Die Flora Ditindiens whor namentlid yon $\Re$. ?. $\mathfrak{B} \mathfrak{u} \mathfrak{i n a} \mathfrak{n}^{5}$ ), geb. 1707, geft. 1780, Şrofeffor in $2(m$ fter= bam, bearbeitet. Er jelbft hatte Dftindient nidjt bejudd, aber er wurbe bei feitem Unternefinen fowohl burd ben reiden

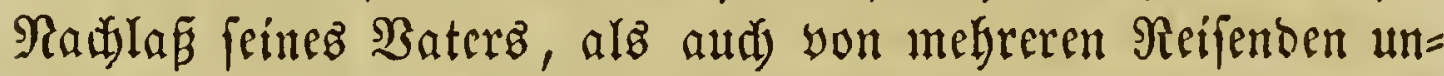
terftübt. - Sin fleifigiger Reifender war Der fdjon oben er=

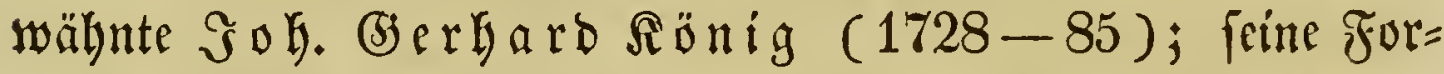
fdungen über bie indifde Flora wurben yon (Shr. Fr. $\Re$ ott $=$ $\mathfrak{b}$ öll befannt gemadyt ${ }^{*}$ ); feine Unterfudungen über bie Sci=

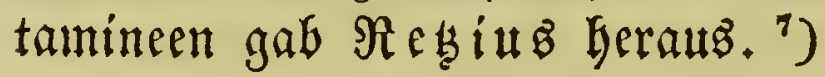

1) Viaggi per l'isola di Cipro e per la Soria e Palaestina dall' anno $1760-68$. Torino $1769-70.5$ Bbe. 8.

2) Flora aegyptiaco-arabica ete. 5eeraubigegeb. von $\Re$. Ri $=$ $\cdot{ }^{b} \mathfrak{u} \mathfrak{y}$ r. Havniae 1775. 4. - Icones rer. nat. quas in itinere orient. depingi curavit. Ibid. 1776. 4. 43 tab. 2(ud

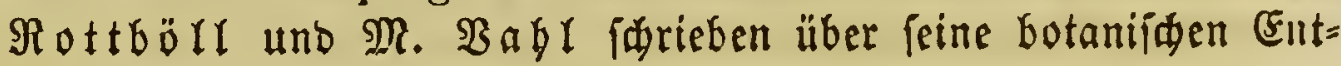
bectungen.

3) The natural history of Aleppo and parts adjacents. etc. Lond. 1756. 4. 16 tab. Deutfi von 3 . F. (3) melin. (3)̈̈ts tingen 1797-98. 2 voll. 8. 15 Taf.

4) Icones plantar. Syriae rarior. Paris. 1791-1812. V decad. 4. 50 tab.

s) Flora indica etc. Lugd. Batav. 1768. Mit 67 Spfrtffin. 4.

-) Descriptionum et iconum lib. I. Havniae 1773. 8.

') Fasciculi observationum bot. I-VI. Lips. 1779-91. Mit 19 folor. $\mathfrak{T a f}$. Fasc. III. p. 45-76. Fol. 


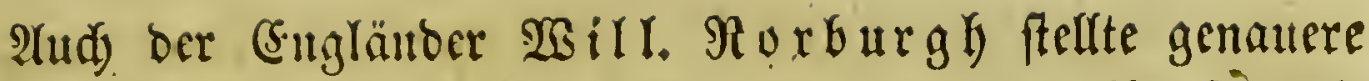
Radjorfdungen über die indifde Flora an. Bon ifm ${ }^{2}$ ) und

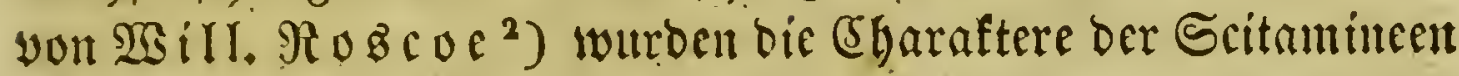

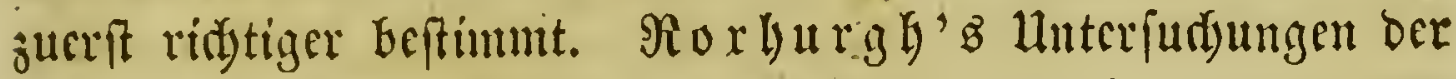
Syflanjen auf ber Rilfe yon Rotomandel wurben bout Sof. Bants yeröfentlidt ${ }^{3}$ ). Aud) Siere Sonnerat

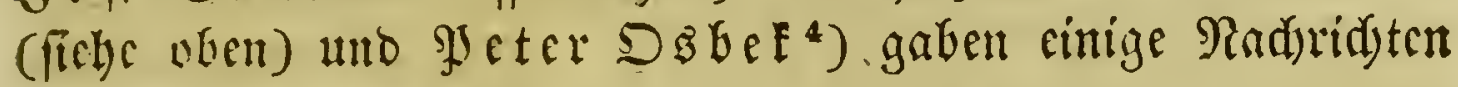

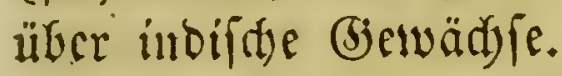

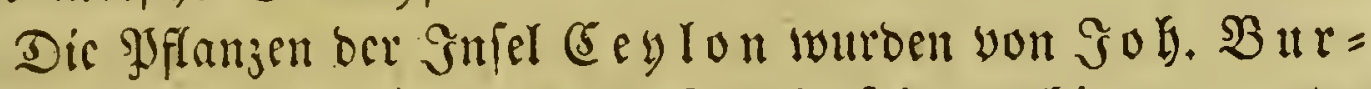
In ann $n^{5}$ ) befdrieben, Ier ebenjo wie fein vorbin genannter

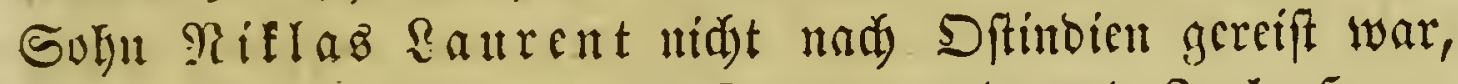

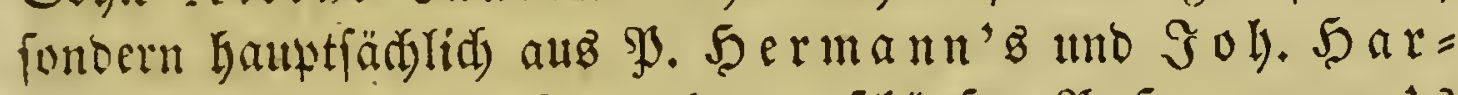
tog's nadygelaffenen Sammlungen foüpfte. Sg. Ş er ma n't Scerbarium wurte aud yon \&innè in feiner flora yon (Eey)=

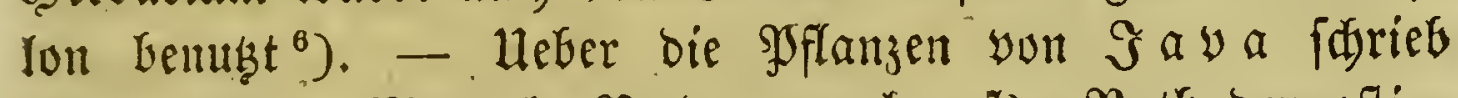

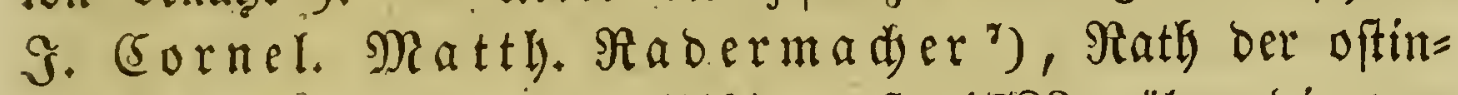
bijiden (Sompagnie, geb. 1741, geft. 1783; über bie yon Sumatra $\mathfrak{Z} i l l . \mathfrak{M} \mathfrak{a} \mathfrak{a} b \mathfrak{e n} .{ }^{8}$ )

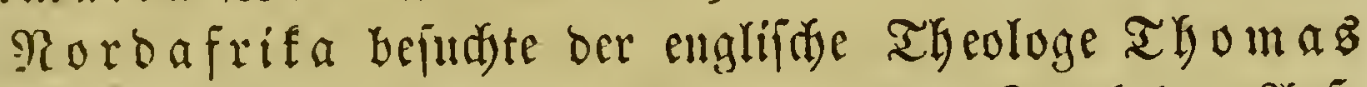
Shaw am Anfange biefes 3citraumes jum 3wed ber 24 f $=$ furdung von Âttertlyümern; cr fammelte aber aud siflanjert auf feimen. $\mathfrak{B a n d e r u n g e n , ~ b i e ~ f i t h ) ~ b i s ~ n a d ) ~ A l e g y p t e n ~ u t m o ~}$ Syricn erftrecten ${ }^{9}$ ). Norbafrifa wube forner yon $\Re$ ené

2) Asiatic. researches. Vol. 11. p. 200 seqq.

$\left.{ }^{2}\right)$ Transact. of the Linn. soc. Vol. 8. p. 330 seqq.

$\left.{ }^{3}\right)$ Plants of the coast of Coromandel etc. Lond. 1795- 1819. 3 voll. Fol. max. 300 Folor. Tafeln.

i) Dagbok öfwer en ostindisk resa etc. Stockholm 1757. 8. 12 tab. Deutfa: গoftod 1765. 8. 13 Tafeln.

s) Thesaurus zeylanicus etc. Amstel. 1737; mit 110 నpfrtfln. 4.

-) Flora zeylanica. Holmiae 1747.

") Naamlyst der planten, die gevonden worden op het eiland Java. Bataria $1780-82.4$.

8) The history of Sumatra. London 178\%. 4.

-) Travels and observations relating to several parts of Barbary and the Levant. Oxford 1738. Fol. Deutfif: Reipzig 
Itid) Desfontaites ${ }^{1}$ ), Srofelfor in Syariz (reifte

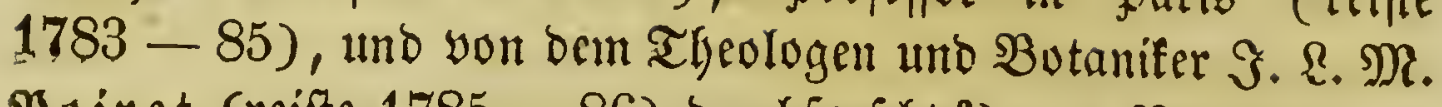

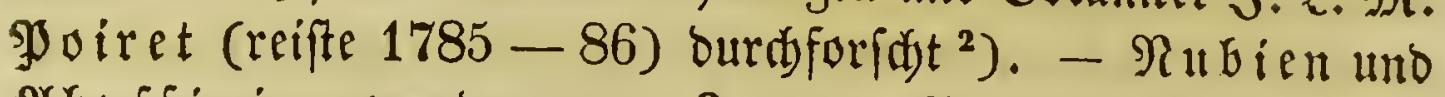

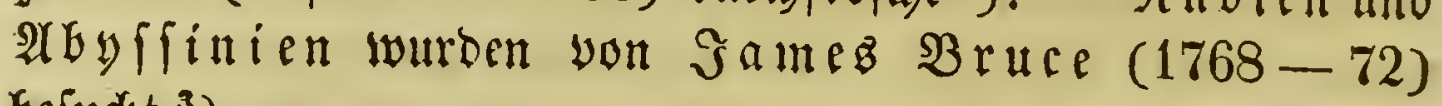
be $\left[\right.$ ud)t. ${ }^{3}$ )

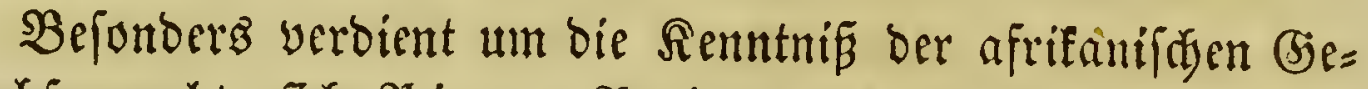

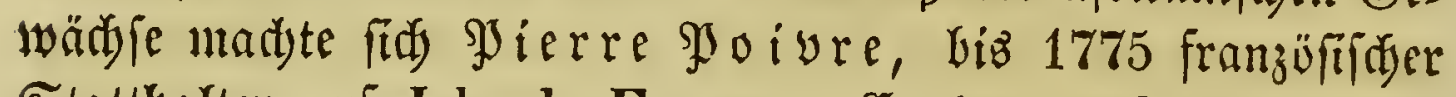
Statthalter auf Isle de France. (Fr Iegte auf biefer Jnjel einen botanifden (Sarten für tropifd)e (5sewäd) fe an uno unter= ftühte gaftreundlicy oen fleifigen Botanifer Ş hilibert 5 o m $=$

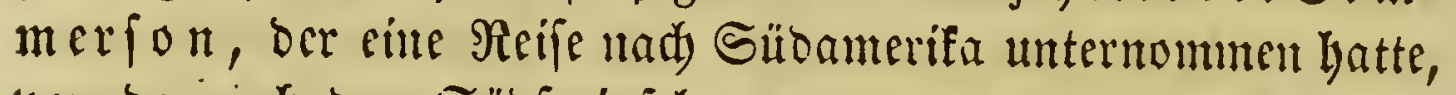
yon ba nad ben Silbjecinfeln gegangen war, แmb 1773 auf Isle de France ftarb. Die vou Diefeul gefammelten gyflanzen, welde fid auf 25,000 Arten belaufen follen, wurben nad) Maris gebradjt, feine Mamujeripte aber fino verloren gegan=

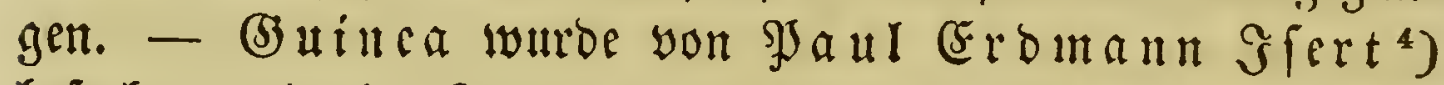
befudit, uno in Senegambien bielt fith der berülynte Midjel $\mathfrak{A} b$ anjon vier Jahre lang $(1749-53)$ auf $^{5}$ ). Namentlid) aber bas $\mathfrak{A} a \mathfrak{l} \mathfrak{l}$ and wurbe vielfad) ju botanifjed

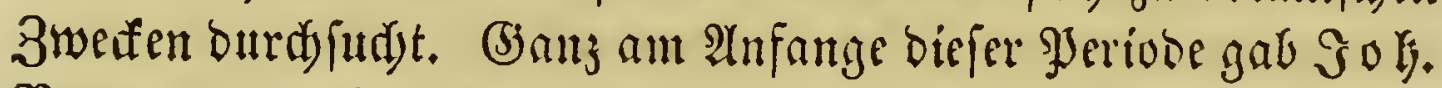
$\mathfrak{B}$ urutan eine $\mathfrak{B}$ efdrcibung feltener Sappflanzen beraus,

1765. 4. $32 \mathfrak{T} \mathfrak{a} \mathfrak{f} \mathfrak{f}$. - Catalog. plantar. quas in variis Africae et Asiae partibus collegit etc. Accessit appendix de coralliis et eorum adfinib. opera (J. J, Dillenii). Oxon. 1738. Fol.

1) Flora atlantica, s. hist. plantar. quae in Atlante agro Tunetano et Algeriensi crescunt. Paris $1798-1800$. 2 voll. 4. 261 tab.

2) Voyage en Barbary etc. Paris 1789. Deutif): Straøburg 1789.

$\left.{ }^{3}\right)$ Travels to discover the source of the Nile. Edinburgh

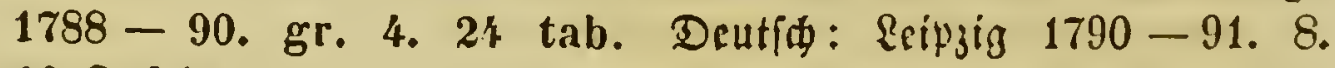
46 Iafeln.

-) Reíe nad (suinea. Ropenbagen 1788. (Rürnberg 1789.) 8.

') Histoire naturelle du Sénégal avec la relation abrégée d'un voyage fait en ce pays. Paris 1757. 4. 20 tab. Dentifi: Branbenburg 1773. 8. Esipjig 1773. 8. 
weltae er aนs ben Sammlungen mebrerer Reifenden erbaltent hatte.')

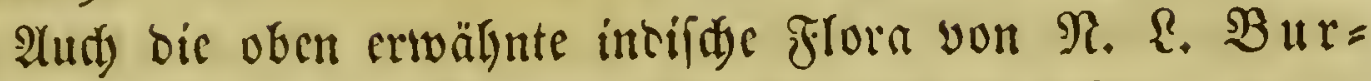
$\mathfrak{m} a \mathfrak{n}$ entlyält cincn Prodromus florae capensis.

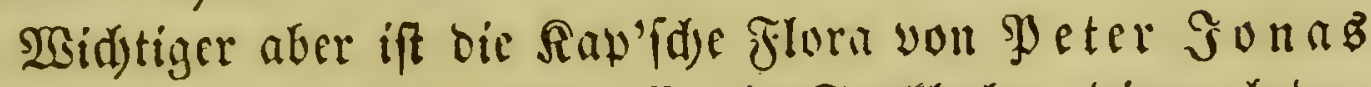
Bergiuz, grit. 1790, grofeffor in Storflyolm, bic nad) ben

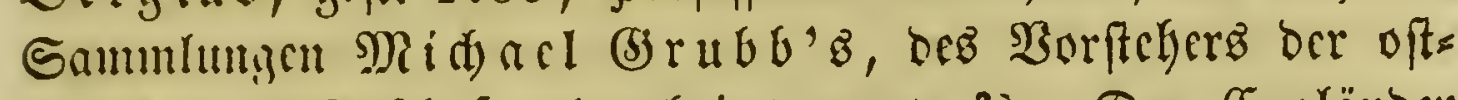

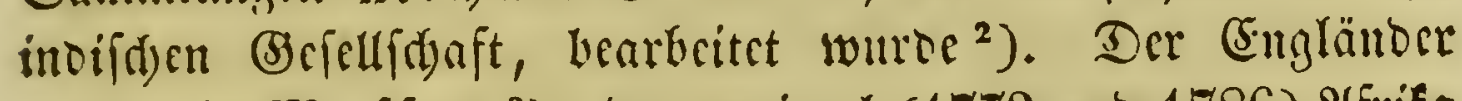

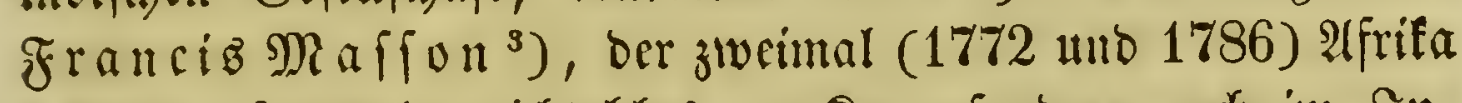
fefud)te, fammelte nidyt bloz am siap, fonbern aud in $\Im_{n}=$ nerı $\mathscr{A}$ frifa's. An widstigften aber fund bie Foridsungen Aarl $\mathfrak{J}$ et. $\mathfrak{X}$ unberg's, Der yon $1772-75$ am $\mathfrak{i a l}$ verweille. ${ }^{4}$ )

DeB Srberen Anor. Sparrmann Befdreibung beb

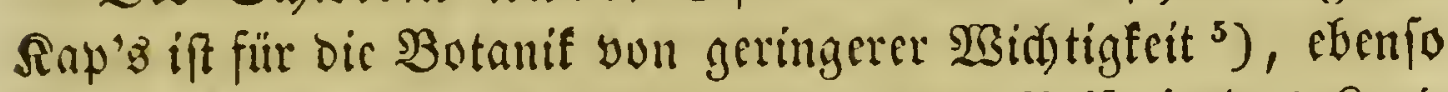

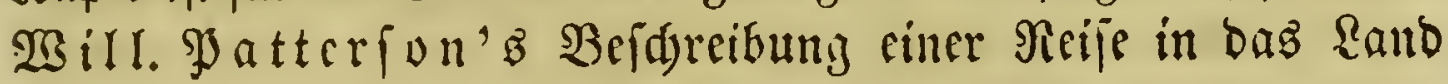
Der Sottentoten und אaffern. ${ }^{6}$ )

Die in bieien 3eitraum fallenden Sdyriften über bie zllora $\mathfrak{A}$ merifa'b fint fehr zahlrcid). - Sdjon am Anfange biejer

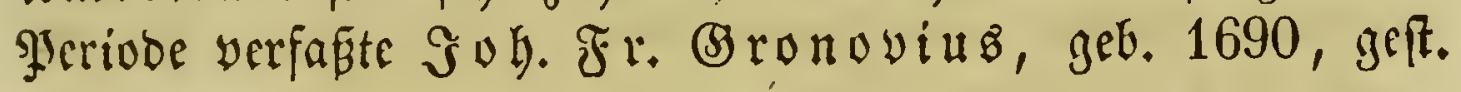

1) Rarior. africanar. plantar. decas I ( $-X)$. Amstelodami 1738 - 39. 4. 100 tab.

$\left.{ }^{2}\right)$ Descriptiones plantar. ex capite bonae spei. Holmiae 1767. 8.5 tab.

-) Stapeliae novae, or a collection of several new species of that genus discovered in the interior parts of Africa. Lond. 1796. Fol. mit 41 folor. Spfriffn.

-) Prodrom. plantar. capens. etc. Upsal. 1794-1800. 8. 3 tah. 2 Thle. - Flora capensis etc., secund. systema sexuale emendatum, ibid. $1807-13.3$ Rieferungen in 8 . Hafn. 1818-20. 8. Stuttgart. 1823. 8.

3) Resa til godla Hopps-Udden. Stocklı. 1783. 8. 10 tab. Deutíd: Brrlin 1784. 14 Tafeln.

6) A narrative of a journey into the country of Hottentots and Caffraria. Lond. 1789. 4. 17 tab. col. Deutfid: Berlin 1790. 8. 15 Tafeln. 
1762, Senator in Reiocn, cine flora you Birainien,

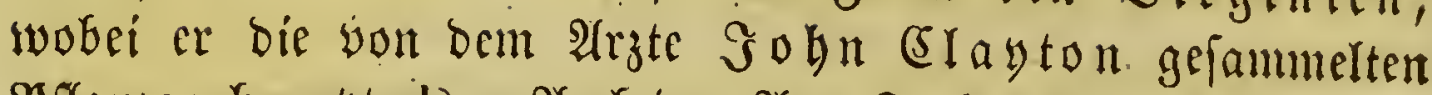

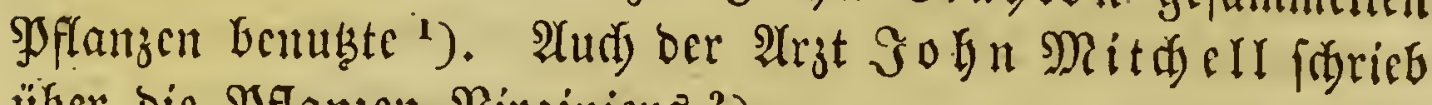
iiber bic SPflanzen $\mathfrak{B}$ irginiens. ${ }^{2}$ )

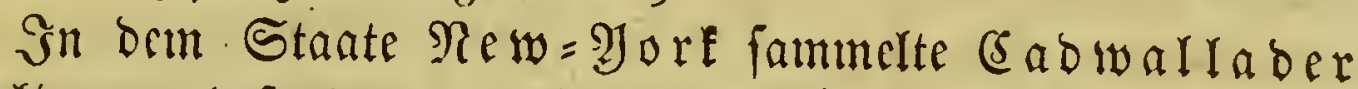

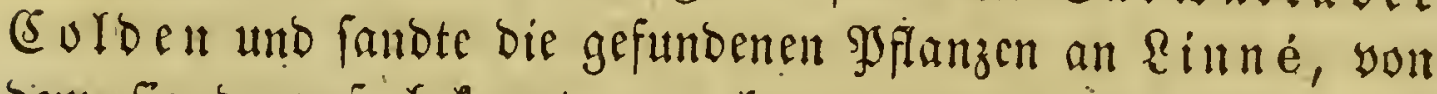
bein fie barnuf befannt gemadist wurben ${ }^{3}$ ). "2ud $\mathfrak{T}$ enny (Solden, bie Toditer bes obengenaunten, befdäftigte fin mit

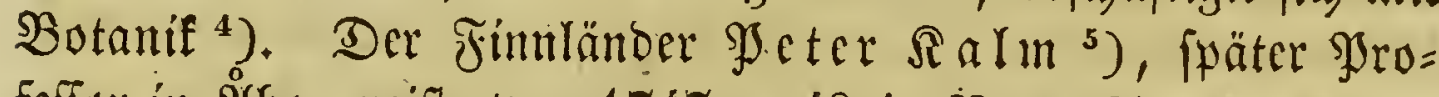

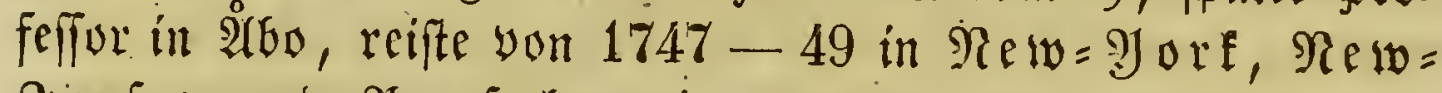
Gevfey uno IJenfylyanien, mo fante ebenfalls siele Sflanjen an Rinné. - Heber tic fïbliden \$orovinjen ber

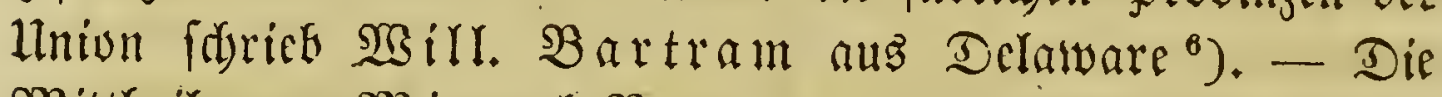
Mittyeilungen Miguel $\mathfrak{B}$ en egas über die Mflunzen Cal $i=$

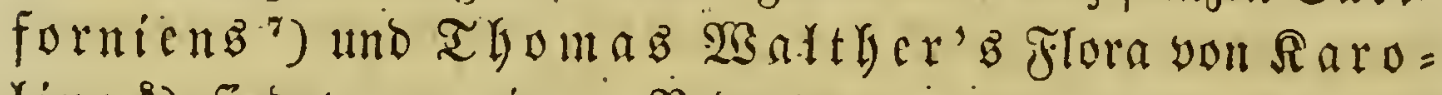
Iina ${ }^{8}$ ) furd voll geringer $\mathfrak{B}$ cocutung.

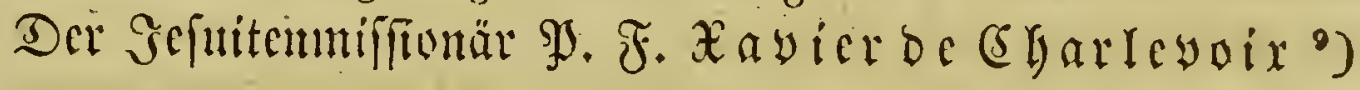

1) Flora virginica etc. Lugd. Batav. 1739-43. 2 Boce. 8. 2te 24แzg. von Th. \&. (5) ronoviub. Ibid. 1762.

$\left.{ }^{2}\right)$ Act. nat. curios. Vol. 8. app. p. 187.

8) Act. soc: Upsal. 17'3, 1744-50.

4) Eine Beffreifung bos hypericum virginicum in bon essays by a soc. in Edinb. Vol. 2. p. 1. Shre Flora bon Rew = Mork

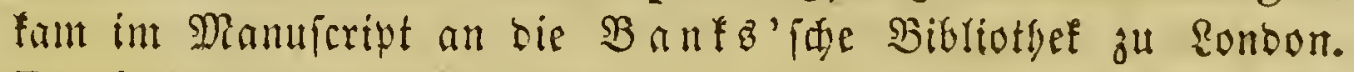

$\left.{ }^{5}\right)$ En kort berättelse om natürliga stället nyttan samt skötsel of några wäxter hembragt från Norra America. Stockh. 1751. 8. - En resa til Norra America. Ibid. 1753 - 61. 3 פBoe. 8. Deut (j) : (jötting. 1754 ff. - Heber ben rotgen Maulbcerbaum. Stockh. acad. handl. 1776. p. 143.

$\left.{ }^{\circ}\right)$ Travels in the interior parts of North-America. Philadelph. 1791. Lond. 179\%. 8. 8 tab. Drutfdy: Şrtin 1793. 8. 8 Iafern.

$\left.{ }^{7}\right)$ A natural and civil history of California. Lond. 1759. 8.

$\left.{ }^{8}\right)$ Flora caroliniana. Lond. 1788. 8. 1 tab.

$\left.{ }^{9}\right)$ Histoire et description générale de la nonvelle France. Paris 174'. 3 B̧br. 4. 
fdrieb bie Lluterfudfungen $\Im$ ohn $\mathfrak{B}$ artram' auf feincr- Reife yon Jenfylyanien zu ben fanabifd) Scen. ${ }^{1}$ )

Der Sdjotte Ardibalo Mengieb botanifirte an ber

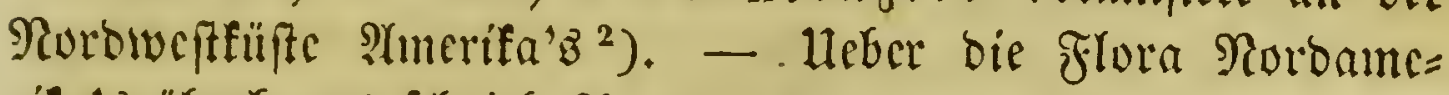

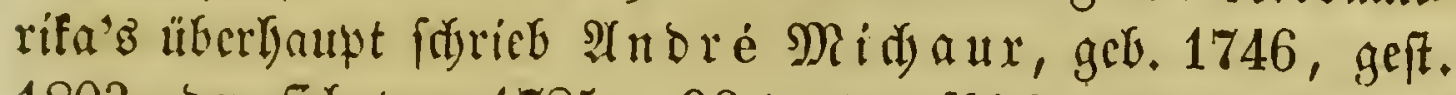
1803, ber fid yon 1785 - 96 bort aufbiclt; audi) lieferte er cine Befdrcibung ber norbamerifanifden (Fidjen ${ }^{3}$ ). - Die

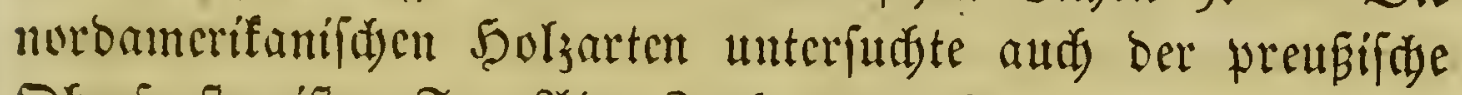

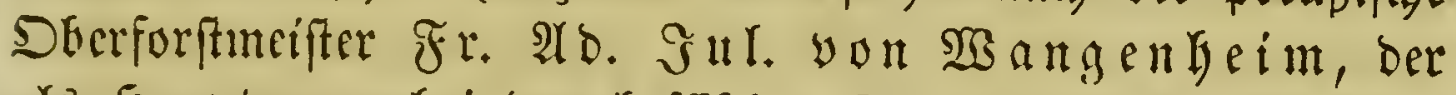

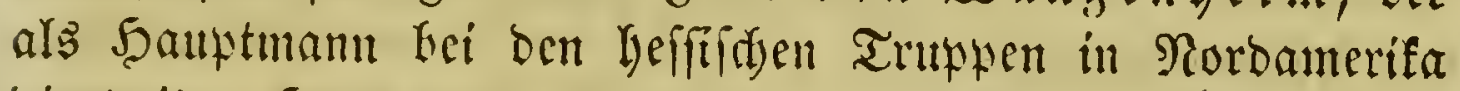
biente $^{4}$ ). J

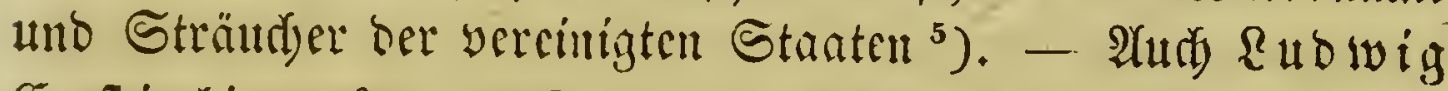

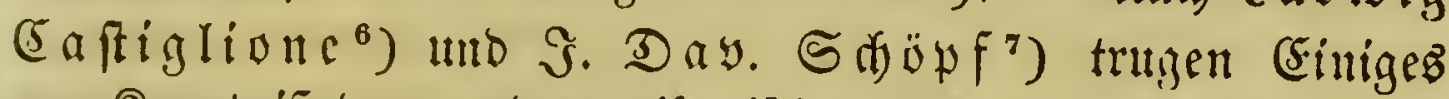
zat Remtnif ber nurbamerifanifiden Syflanzenwelt bei.

Einiges über die STflanjen ber Snlel $B a r b a b o s$ findet

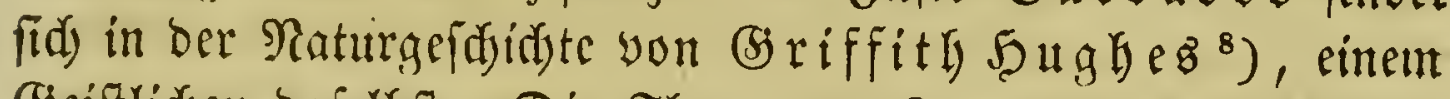
(S) riftidyen baferbft. Die Flora yon $\Im$ ama if a aber wurbe

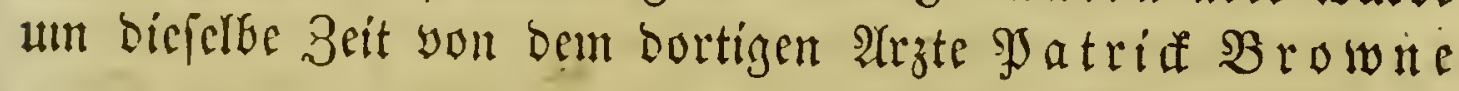

1) Observations etc. made in his travels from Pensylvania to Onondago, Oswego and the lake Ontario. Lond. 1751. 8.

$\left.{ }^{2}\right)$ Transact. of the Linn. soc. Vol. 4. p. 63.

$\left.{ }^{3}\right)$ Iristoire des chênes de l'Amérique septentrionale. Paris 1801. Fol. 36 tab. Deutich: Stuttgart 1802-4. 4. - Flora boreali-americana etc. Par. 1803. 8. 51 Taf.

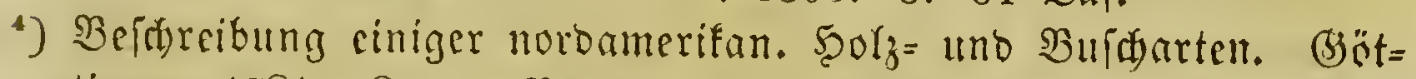
tingen 1781. 8. - פecitrag zur beutid. Golzgeréden Forfwit= fenid)aft, bie 2(npflanzung norbamerifan. Solzarten mit $2($ nwen= bung allf beutide fourfe betr. Daf. 1787. Fol. 31 Taf.

5) Arbustum americanum ete. Philadelph. 178.5. 8. Dentif: Reiping 1788. 8.

$\left.{ }^{6}\right)$ Viaggio negli stati uniti dell' $\Lambda$ merica settentrionale fatto negli anni 1785-87. Nilano 1790. 2 voll. 8. 14 tab.

5) Nateria medica americana. Erlang. 1787. S. - Reife burd bie norbamerifan. Stanten. Dar. 1788.

$\left.{ }^{8}\right)$ The natural history of Barbados. Lond. 1750. Fol, 29 tab. 


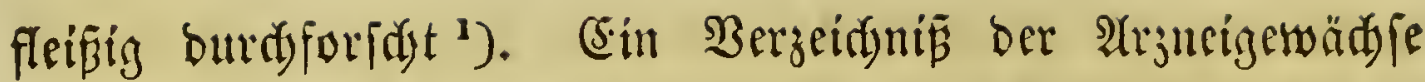
yon St. Domingo gab Sol. Bapt. René Souppé=

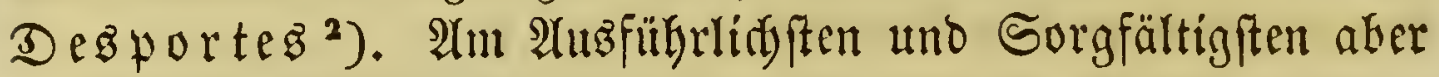

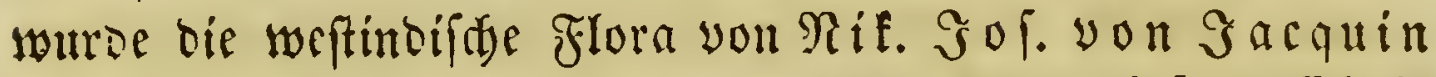
und DIaf Swarts bearbritet. Ber Erftere befand fidi) in ben Sahren 1754-59 in Weftindien unb madyte nady feimer

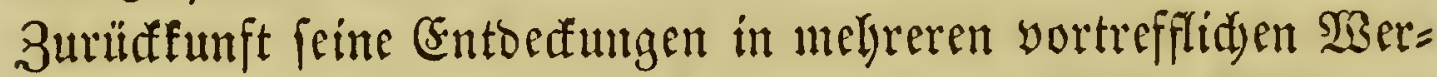
fen befamt ${ }^{3}$ ). $D$. Swark (verweilte yon 1783-87 in Sisftindien) crweiterte uno vervollfändigte dic Foridungen Gaequin's. (Er hat 850 neue Spflanzenarten aufgefunden uno befannt gemard.t. ${ }^{4}$ )

Silb amerifa zog Durd bie wullorbare Pradyt uno ben Reidythum feiner Begetation viele Freunde ber Botanif an. - Für die Flora von (5) uana fund die Entoefunaen bez

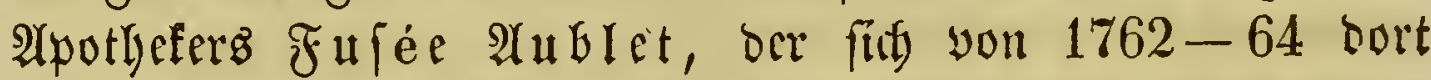

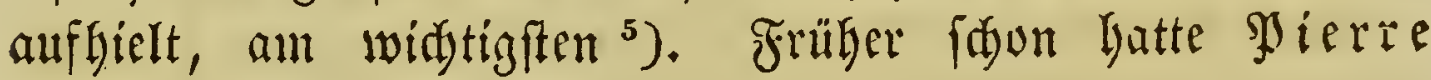

1) Civil and natural history of Jamaica etc. Lond 1756. Fol. 50 tab. 1789. Fol. 50 tab.

$\left.{ }^{2}\right)$ Histoire des maladies de St. Domingue. Paris 1770. 3 voll. 12.

3) Enumeratio systematica plantar., quas in insulis caribaeis detexit. Leidae 1760. 8. - Selectarum stirpium american. historia. Vindobon. 1763. Fol. $183 \mathfrak{T} \mathfrak{a f}$; 1780 mit 264 gemarten $\mathfrak{T} a f e l n$, gr. Fol. - Observation. botan. iconilus ảb autore delineatis illustratarum part. IV. Vindobon. 1764-71. DRit 100 ßupfrtin. Fol.

- Nova genera et species plantar. etc., quae sub itinere in Indiam occident. digessit. Holm. 1788. 8. - Observationes botanicae quibus plantae Indiae occidentalis etc. illustrantur. Erlang. 1791. Mit 11 $\mathfrak{f}$ frfffln. 8. - Icones plantar. incognitarum quas in India occident. detexit, delineavit. Ibid. 179\%. Fol. 13 tab. col. - Flora Indiae occident. aucta atque illustrata etc. Ibid. 1797-1806. Mit 29 Spfrtflu. 3 voll. 8. Iteber feime übrigen Sariften fielye Syripel S. 287.

-) Histoire des plantes de la Guiane françoise, rangée suivant la méthode sexuelle etc. Par. 1775. 4 Bbe. Mit 392 
Barrere, fräter Wrofeffor in Serpignan, geft. 1755, bie Syflanjen (S)tiana's in alphabetifduer Dronung aufgezeidjnet ${ }^{1}$ ). Jeter \&üfling, geft. in (3)uiana 1756, fano mande neue PJflanjen in biefm Ranbe. Srin Tagebud) wurbe von \&i tu é herauggegeben ${ }^{2}$ ). Heber bie medicinifden, (S)

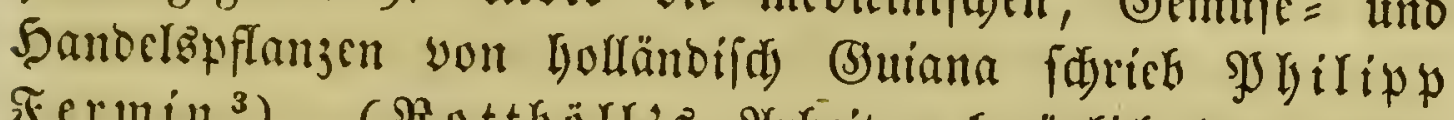

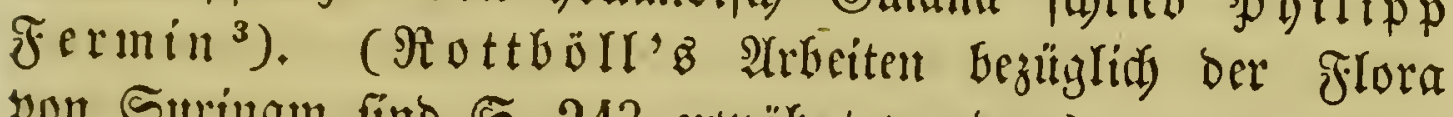
won Siminam find S. 243 erwähnt worben.)

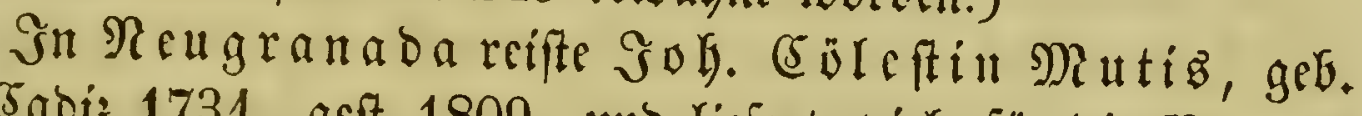
ill Eabij 1734, geft. 1809, uno lieferte vicle für bie Botanif, nautentlid) die Renntnis ber (Shinaarten, widstige Radridyten; er legte zu Santa Fé be $\mathfrak{B o g o t a}$ eimen botanif́chen (Farten an. ${ }^{4}$ )

Ueber die (5ewäd) $\mathfrak{B r a f i l i e n s}$ licferte Dominico

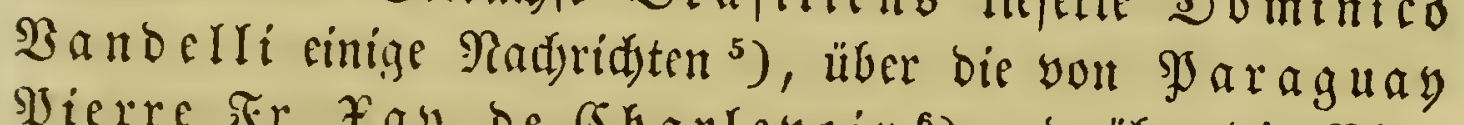

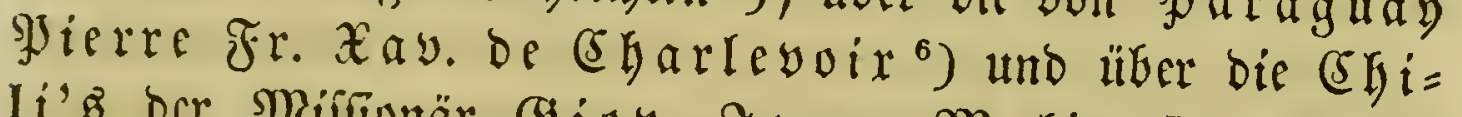
li's bor Miffunär (5) $i \mathfrak{b}$. Fgnaz Molina ${ }^{7}$ ). - Die Spanier Sippol. Ruiz und Gof. Savon reiften itt bent

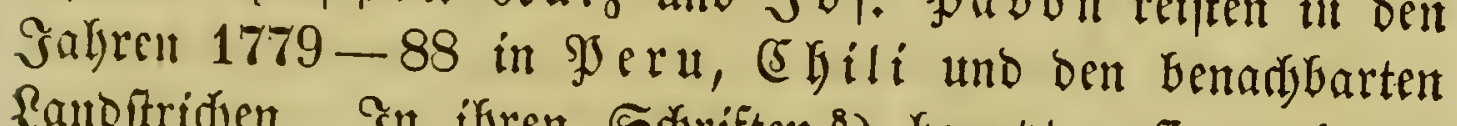
Rambfridien. In ifren Sdriften ${ }^{8}$ ) bemuten fie aud bie

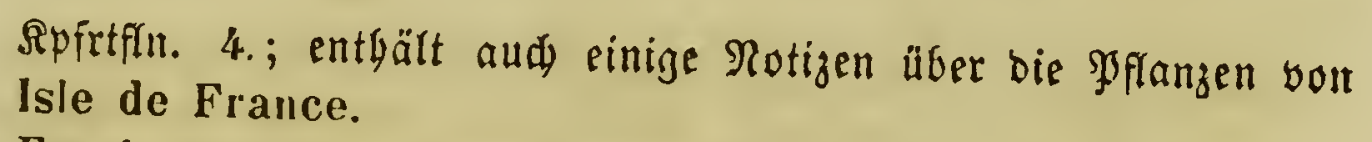

1) Essai sur l'histoire naturelle de la France équinoxiale. Par. 1741, 1749. 8.

2) Siebe oben S. 240.

3) Histoire naturelle de la Hollande équinoxiale. Amsterd. 1765. - Description générale historique et géographique de la colonie de Surinam. Ibid. $1768,1769.2$ Boe.

*) Nov. act. soc. upsal. Voll. 5. p. 120. - Stockh. acad. handl. $178 \%$, p. 290. - Instruccion relativa de las especies y virtutes de la Quina. Cadiz. 1792. 4.

5) Fasciculus plantarum. Ulissipon. 1771. Wit 4 Spfrtfn. Eielye aud S. 241.

-) Histoire du Paraguay. Paris 1756. 3 Bbe.

7) Saggio sulla storia naturale del Chili. Bologna 1782. 8. 1810. 4. Deutín: Reipzig 1786. 8.

-) Florae peruvianae et chilensis prodromus etc. Madrid 
Foridyungen des unglürliden Franjofen Sof. Dombey; geb. 1742, geft. 1795, Der ilyr Reifegeführte gewejen wwar: Die yon Gofeph be $̧$ ufficu, ber fid einer zun Jived grographifder Unterfudumtgen nad Sibamerifa abgelyenoen (Befellfdaft yon (Gelebrten unter ber Fülyrung bes Grafen Mo.urepa angejdloffen hatte, in jenem Ranbe gefanmelten Sflanzenfdäge famen al feinen Neffen, ben berilhmten $\mathfrak{A}_{\mathfrak{n}}=$ toine Raurent de Guffien. - Die Spanier (5). Juan uno $\mathfrak{A} n t$. Urloa gaben wenige Rotizen über bie Pflangen

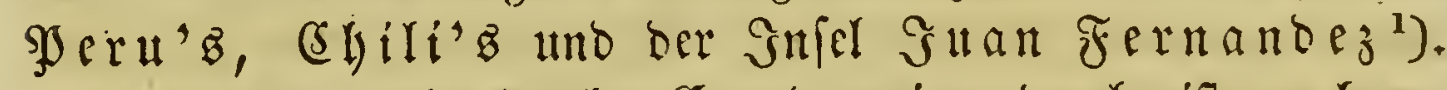
- Sarl Maria de la C ond amine burdyreifte mebrere Räuber Silbamerifa's ${ }^{2}$ ) uno theilte unter andern bie erfte Radridit ïber bie Cinchona Condaminea Humb. und bic Siphonia elastica Pers. mit. ${ }^{3}$ )

Heber bie splanzen ber Falflandsinfeln, ber $\mathfrak{z} a=$ wlataüubung uno ber Snfel S.t. Satharina madyte $\mathfrak{A} n$ t. Jof. Soernetty einige Mittheilungen. ${ }^{4}$ )

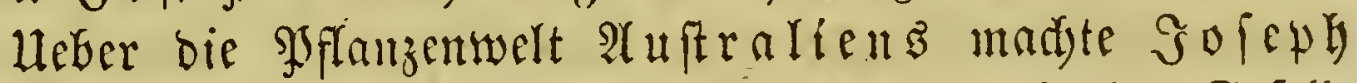
$\mathfrak{B a n f} \mathfrak{B}^{5}$ ); geb. 1743, geft. alz SJräfioent ber fönigl. (Befell=

179\%. Fol. 31 tab. Romae 1797. gr. 4. 31 tab. - Flora peruviana et chilensis. Madr. 1798-1802. 4 gbbe. Fol. 425 tab. - Systema vegetabilium florae peruv. et chil. Ibid: 179s. gr. 8. - Quinologia, s. de arboribus Kinae Kinae, h. e. de speciebus Cinchonae. Ibid. 1792. 4. Dentifit: (3) ötting. 1794. Supplemento al Quinologia. Madi. 1801. 't. 1 tab. Bergl. STritel' Thesaurus S. $255,256$.

1) Relacion historica del viage de la America meridional. Madr. 17!8. 4 Bbe. 4.

2) Relation d'un voyage fait dans l'intérieur de l'Amérique méridionale. Paris 174.5. 8.

s) Mémoir. de l'acad. de Paris 1738, p. 323; 1751, p. 4SS.

-) Journal historique d'un voyage fait aux îles Malouines. Berl. 1769. Par. 1770. 2 Sbre. 8.

3) Bergl. Duncan, A short account of the life of the right honourable Sir Jos. Banks. Edinb. 1821. 8. - Eloge de Sir Jos. Banks. (Cuvier, Recueil.) Paris 1827. 8. 


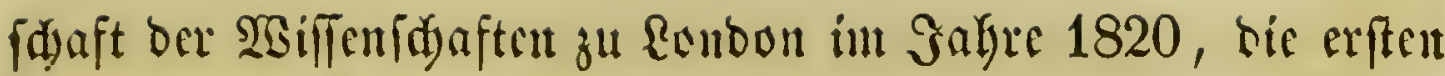
Rarbrid)ten befannt. Er begleitete näullidy ben (Sapitän (5 o of auf feiner crften Reife un bie Melt uno unterftühte uad)

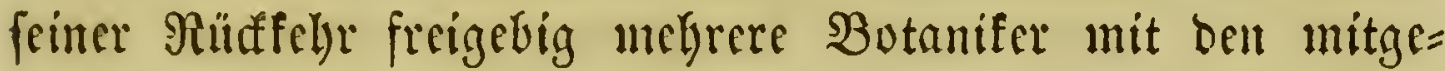
brad)ten Sdyäzen. Ueberfaupt zeidjnete er fid ftets burds

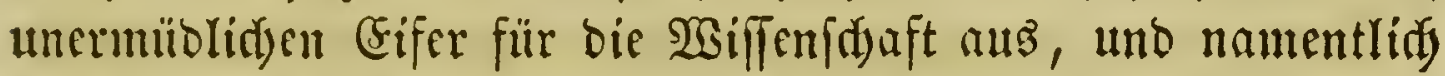
bie Botanif unkm or in befonderen Sryub.

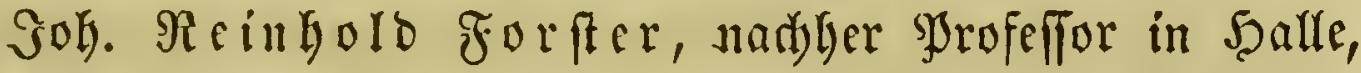
geb. 1729, geft. 1798, uno beffen Solyn (5) org Forfter, fwäter Şrofeffor in SBilna, geb. 1754, geft. 1794, begleiteten

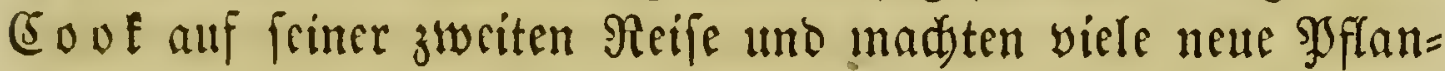
zenarten Aufraliens befunnt ${ }^{1}$ ). - Neuguinea wurbe yout Sierre Sonncrat ${ }^{2}$ ) und $\mathfrak{T}$ gom. Forreft ${ }^{3}$ ) befudst. -

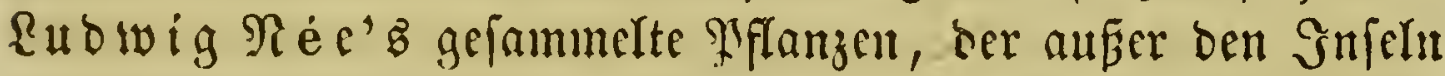
ber Süb fee aud Mittel= unb Sildamerifa bejudt hatte, madjte (ธaทanilleb befannt. ${ }^{4}$ )

Die gyfratzengeographie befand fid in biefem Zeit= raum nod in igrer frübeften Rinobeit. Die meiften Botanifer

3) J. Reinhold et Georg Forster, Characteres gener. plantar., quas in itinere ad insulas maris austral. collegerunt etc. Lond. 1776. 4. 75 tab. 1776. Fol. - Deutifi: Stuttgart 1779. 4. $18 \mathfrak{T a f e l n}$. - G. F' or s ter, Florulae insular. austral. prodromus. Götting. 1786. 8. - De plantis esculentis insular. Oceani austral. commentatio. Berol. 1786. 8.

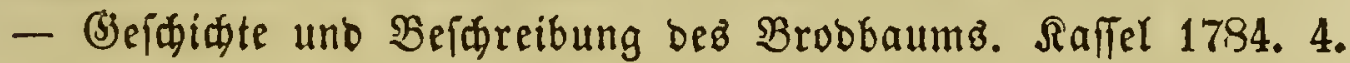
$2 \mathfrak{I a f}$ - - Bon beiben: A voyage round the world with $C$ apt. Cook. London 1777. Deutfí: Berliu 1778. - S. R. Forfter Bemerlgg. üb. Begenft. Der phyfi

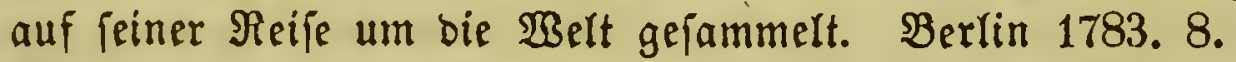

2) Voyage à la nouvelle Guinée. Paris 1776. 4. 120 tab.

$\left.{ }^{3}\right)$ A voyage to New Guinea and the Moluccas. Lond. 1779. 4. 27 tab. Deutíl: Şamburg $1782-93.8$.

-) Icones et descript. plantar. quae aut sponte in Hispania crescunt, aut in hortis hospitantur. Madr. $1791-1801$. 6 Bbe. Fol. 600 tab. Bei ben brei Iep̧ten Bänden bat er bez

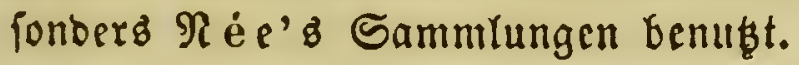

E. Bindter, Befd. b. Botanit. 
Latten gar fcinen Begriff bawon. Sịné gab übrigenż in verfdricbenen 2(kbandlungen mandye Andeutungen. ${ }^{1}$ )

Ferner verjudte Soulavif in Der S. 233 angeführten Sdirift cine geograplifide Darftellung ber Syflanzen Süb= frantreidys.

2lud über bie Metamorwhofe ber SJflanzen fdrieb

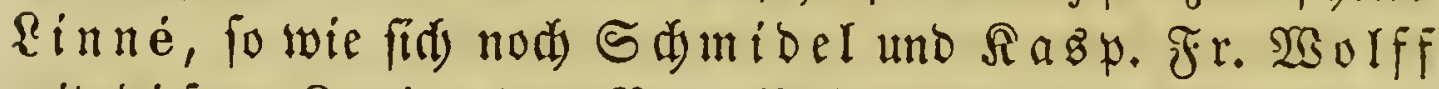

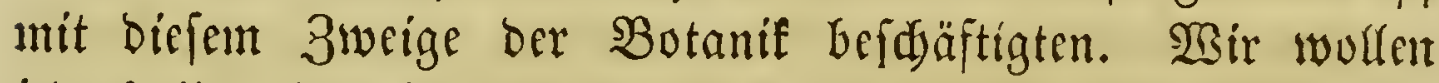
jecod) ilyre Anfiteten in ber nädyften Seriode im 3urammen= bange mit (s)

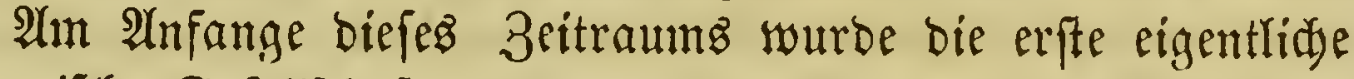

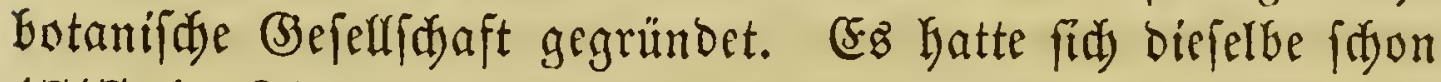
1717 in Florem gebildet, fie wurbe aber erft 1739 yom

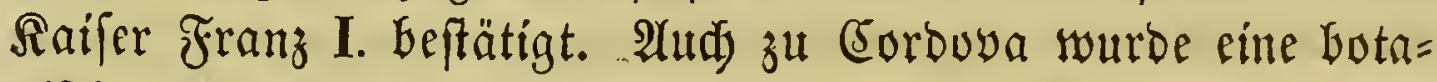
nifde âfabcmie gegründet.

Botanifde (Särten wurben während diefes 3eitraums er= ridutet zu (5) öttingen (1737), Turin (unter Bictor $\mathfrak{A} \mathfrak{m} \mathfrak{a} \mathfrak{e} \mathfrak{u} \mathfrak{B}$ ), (Erlangen (bielleid)t 1743), Franf a. D. Doer (1744), Madrio (1753), SE i en ber (Barten Der Utniverfität uno ber (s)arten 子u Sdjönbrnnn (1753), 3 ürid), (5ireifsivalde (1765), Amienz (1770), Mann= beim (1771), (Soimbra (1773), Mantua (1780), Franffurt a. M. (1782), Marburg (wabridseinlidy 1786), Saljburg (1786).

2) Oratio de telluris habitabilis incremento, 1743. (Amoen. acad. Vol. IV. p. 64. Erlang. 1788.) Stationes plantarum, 175 \%. 1. c. ed. 3. vol. II. p. 430,444 seq. - Coloniae plantarum. 1768. (Ibid: Erlang. 1785. vol. VIII. p. 1.) 


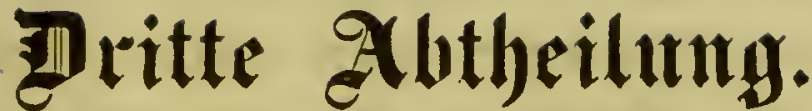

\section{Bou Rautent 2tutoine De Surfiten biz allf Die}

(Gegemwart.

Rady ber vou uns angenommenen (Eintl)eilung zerfällt bie

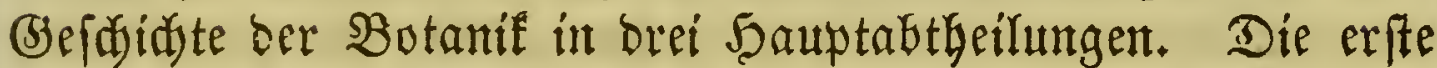
umfaft bas 2्(tterthum und Mittelalter, bie zweite beginnt

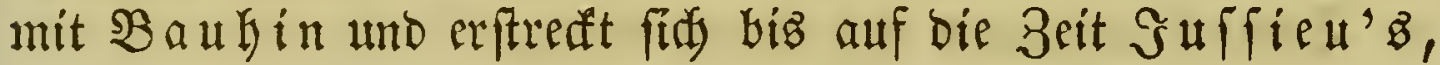
bie britte geht yon ba bis auf bie (S)egenwart. Hnierer $\mathfrak{A}_{n}=$

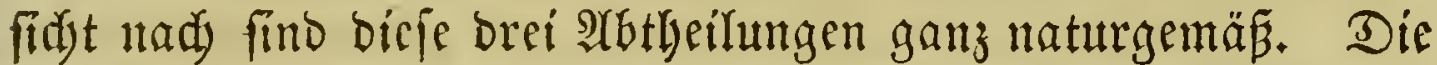

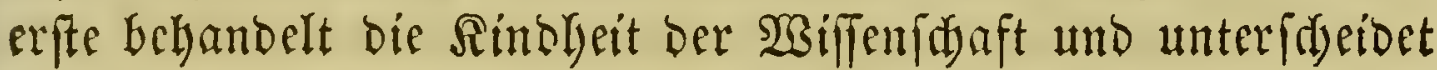
fidi) yon ben beiben anderen wejentlid) baburd), bar bie zu

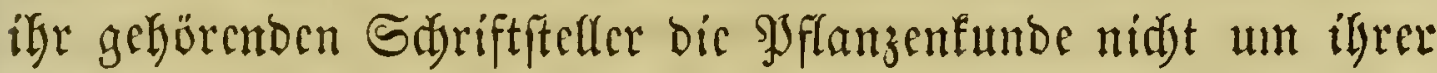

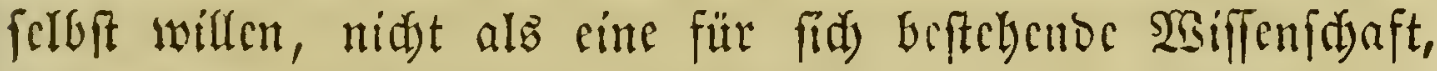
jonoern nur in $\mathfrak{B}$ egiclutug auf bon Nuben, oen fie ber memid)=

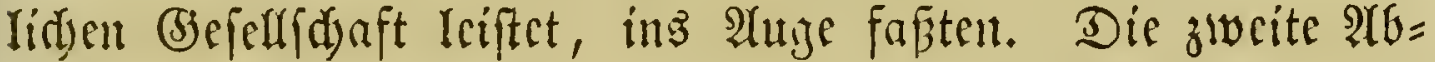
theilung behandelt gewilliermaß̧en baz jugendide âter ber Botanif, bie 3eit, wo bicfe SBiffenfd)aft aus ber fintifden

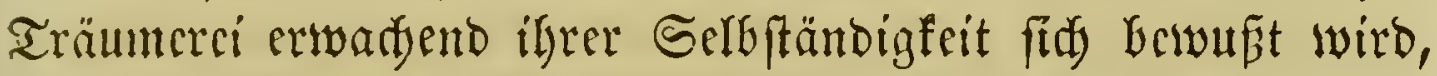
über igr bisheriges Berbalten nadbocult, bann zแnäd)ft auf

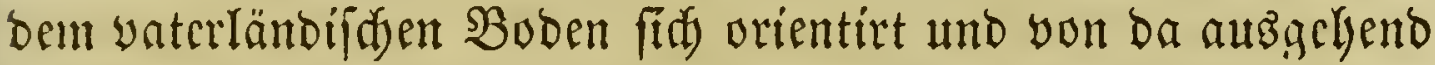
fart burdi) alle Theile ber befannten Eroc wandert, überall

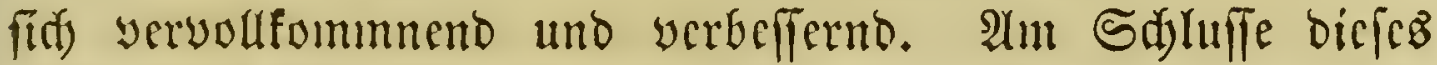
3citraums ftebt der geswaltige sinné. 3wei Dinge waren 


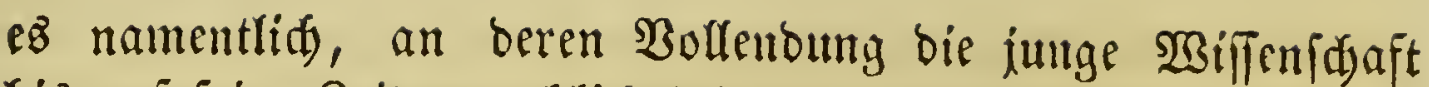
bis auf frine 3eit vergeblid fid) abgemübt hatte, nämlich bie Aufitellung eines Syftems, bas burd) frine Bortrefflidfeit

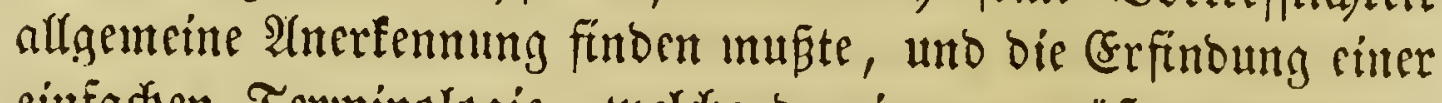

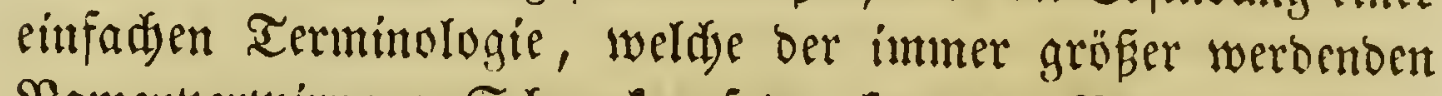
Ramenyerwirrung Sdbanten fegen fonnte. Beibe Brobleme lïfte Rinné unb bewoirfte to eine heilfame Reform, aber

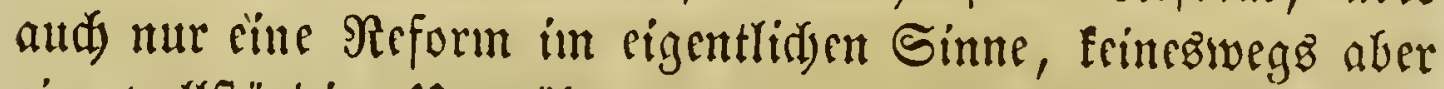

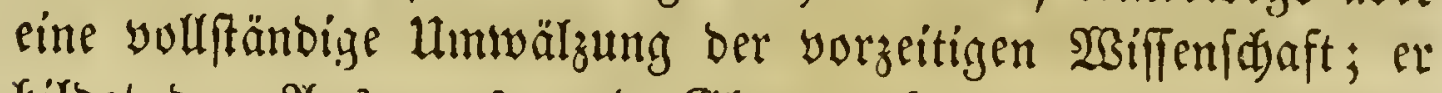

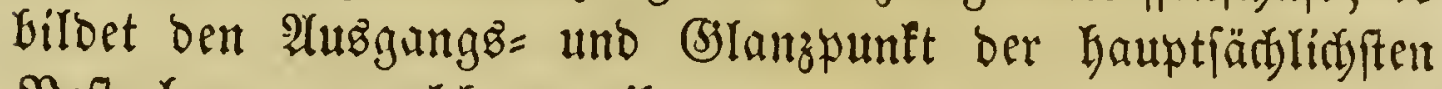
Beftrebungen, weldye vor ifin gang uno gebe waren. (Fegen bie zu feiner 3eit hervortretenben, freilid nody yerworrenen, neuen 2 mfidten zeigte er fid bagegen ziemlid unempfindid,

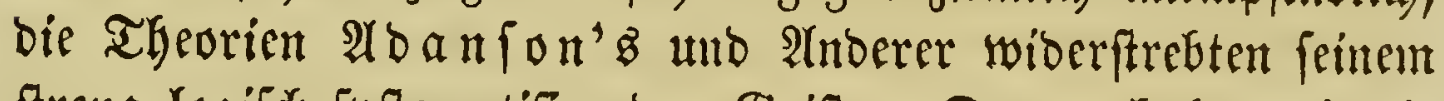
ftreng logiid fyftematifirenoen Beifte. Darum lyaben wir bie Reiftungen \&inne' 8 in ber vorigen Abtheilung befproben unb

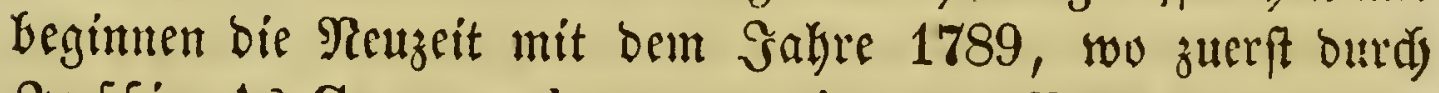
$\Im \mathfrak{u}\left\{\mathfrak{i}_{\mathfrak{e}} \mathfrak{u}^{\prime} \&\right.$ Genera plantarum eine neut $\mathfrak{B}$ etradytungşweife Der Botanif allgemein fid $\mathfrak{B a b n}$ brad). 


\section{Daz Zcitalter Der Berbreitumg Der untürlident Syfteme.}

\section{Bon Iufieu bis zur 3eit Robert 3 roun's, Decandorfe's unb Altexáder von sum: bold's $(1789-1817)$.}

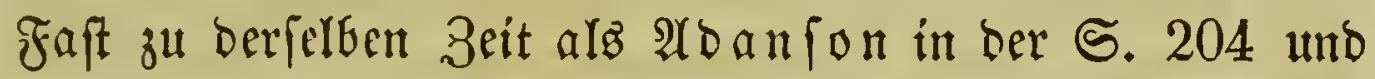
205 angegebenen $\mathfrak{B}$ eife Durd) alfgemeine Bergleidung Der einjelnen SPflanjenorgane ein natürlides Syften zu begründen fitchte, war

\section{Bernard פe Suffieu}

Darauf bebadt, biejelbe Goee, jedod auf cine mekr logifde und naturgemäpe 2 rrt, zu verwirflichen. Diefer Mann, oem

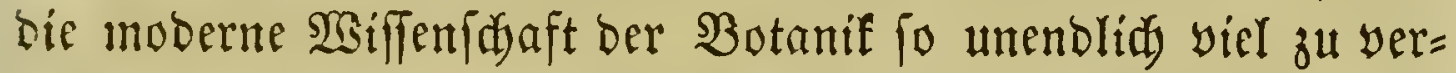
Danfen hat, wurbe in Gabre 1699 zu Ryon geboren. In boin Gefuitencollegium bafelbft legte er ben Girumb zu feiner wiffenfdaftliden $\mathfrak{B}$ ildung, begab fid baun zu feinem älteren

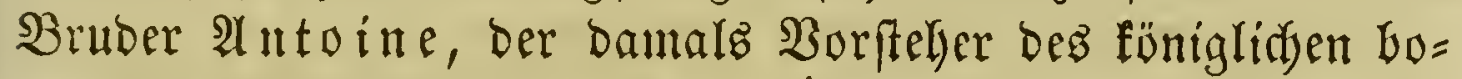
tanifden (5artens zu Waris war, und begleitete Denfelben auf feituer botanifden Reife nadi Spanien uno \$ortugal. Rad feiner Zurülffunft begab er fid nad Montpellier, um Mebicin zu ftubiren, und promovirte auf biefer 5odjithule im Sakr 1720.

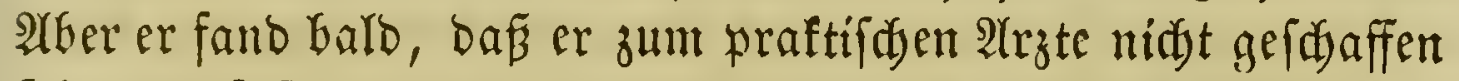

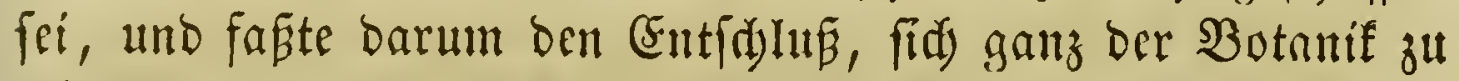
wiomen, zu welder $\mathfrak{B i f f e n d}$ aft er fdon früber grofe Rei= gung gefapt hatte. (5r begab firi beghalb wieberum nads SJaris und war als Unterbemonftrator feincm Bruder bei beffent Borlefungen befülflid), Rubwig XV. ernannte ifn fpäter zunt 


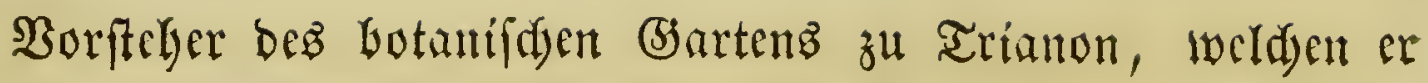
f(t)on vom Galire 1774 an nady ber you ifm gefaften Soee sines natürlicten Syftems cinzurifyten begann. Dort bejudste ifn aud) Linné, als er nad) Dem 2 ufgeben finer Stelle zu Şartcfamp int fein Baterland zurürffehrte, und yon bicjer Zeit an ftanden bie beiben Mämer in beftändigem freumbidsaft=

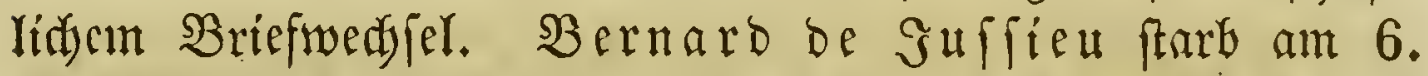

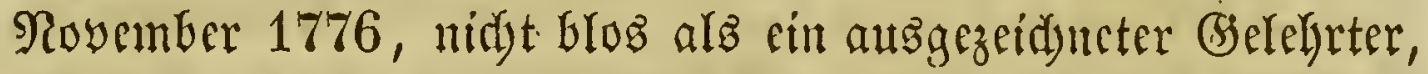
fonbern audj als yorzüglidjer Manfdy yoll alfen, bie ifn fann= ten, hod) geehrt. (sir hat wenige Sdyriften verfapt; audi

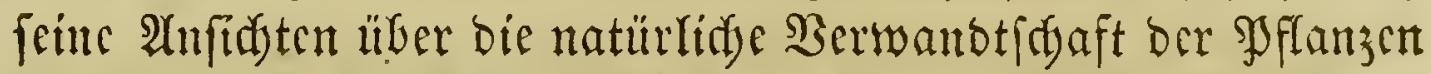
hat er nidyt im Drucfe befannt gemadjt ${ }^{1}$ ). Dic Sicröffent= lidung und weitere $\mathfrak{A}$ ušbirdomy berfelben war vielmely feinem Reffen

\section{Rautent Antwine be Suffieu}

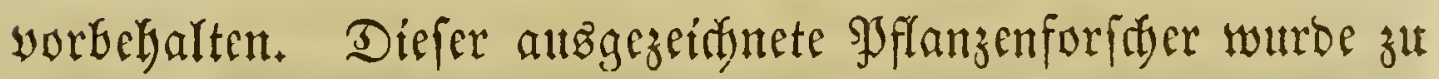
Ryon im Galje 1748 geboren. Er ftudirte ebenfalls Mcoicin,

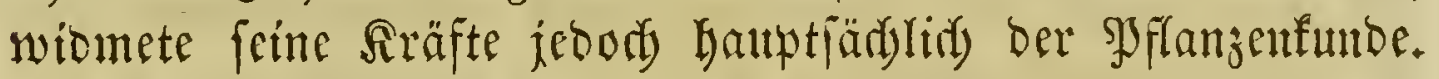
Jim Jahr 1773 wutrbe er zum Sorofefior ber Sotanif utro

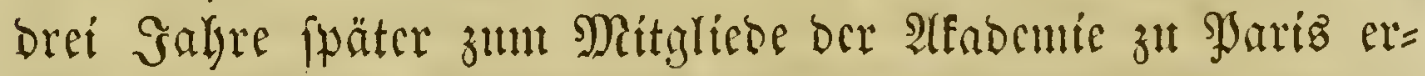
naunt. Rapalcon beefrte ihn mit bem Titel eines Rathes

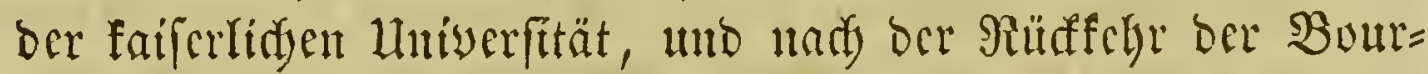

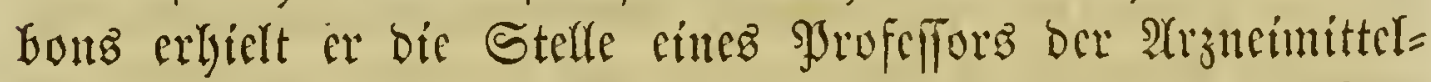

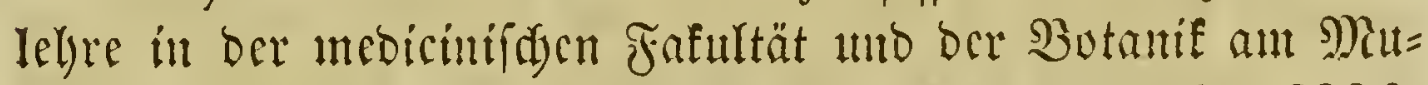

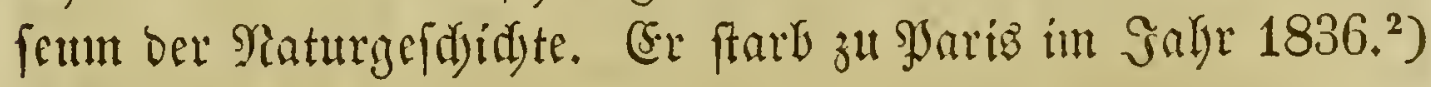

1) Heber bie 3ooplyyten in ben Mém. de l'Académ. de Paris 17.'2. p. 392.

Heber Pilularia uno Marsilea. Ibid, 1739. p. 240 seq. 1740. p. 263 seq.

Bern. de Jussieu, Quaestio medica, an compar animantium et vegetantium perspiratio? Paris 1777.4.

2) Heber bie Ranunfulaceen, Mèm. de l'Acadẻm. de Paris 1773, 


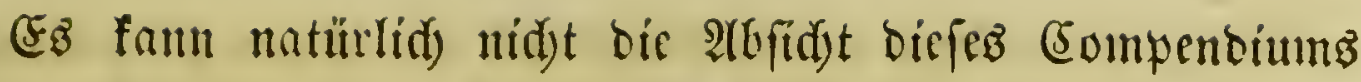
frin, genau zu erürtern, weld)er 2 (nth)eil an ber Aluffellung

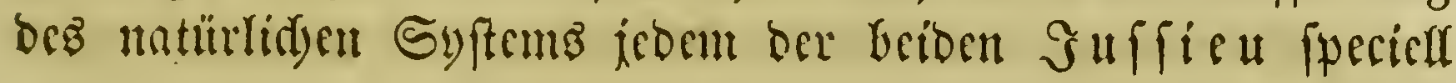

p. 214 seq. - Heber Die 2 noronung ber Pfflanzen im Barten zu Irianon. Ibid, 177\%. S. 175-197.

Genera plantarum secundum ordines naturales disposita, juxta methodum in horto regio Parisiensi exaratam anno 1774. Paris. 1789. 8.

Mémoires sur les caractères généraux de familles tirés de graines et confirmés ou rectifiés par les observations de Gaertner. - Premier mémoire: Aristolochiées-Plumbaginées. (Ann. V. 1804.) Suppl. (Ann. VII. 1806.) - Second mémoire: Monopétales hypogynes. (Ann. V. 1804.) - Troisième mémoire: Monopétales perigines. (Ann. V. 1804.) - Quatrième mémoire: Monopétales epigynes à anthères réunies. Première partie. (Ann. VI. 1805.) - Cinquième mémoire: - Deuxième partie. (Ann. VII. 1806.) - Sixième mémoire: - Troisième partie. (Ann. VIII. 1806.) - Septième mémoire: Monopétales epigynes à anthères distinctes. (Ann. X. 1507.) - Huitième mémoire: Caprifoliées-Loranthées (Ann. XII. 1808.) - Neuvième mémoire: AraliacéesOmbellifères. (Ann. XVI. 1810.) - Dixième mémoire: Renonculacées-Malpichiacées. (Ann. XVIII. 1811.) - Onzième mémoire: Hypericées-Guttifères. ( $\Lambda n n$. XX. 1830.) - Douzième mémoire: Aurantiacées-Théacées. (Mém. II. 1815.) - Treizième mémoire, première partie: Meliacées-Geraniacées. (Mém. IIl. 1817.) - Treizième mémoire, deuxième partie: Meliacées-Tiliacées. (Mém. V. 1819.)

Mémoires sur les genres de plantes à ajouter ou à retrancher à diverses familles connues, premier: Primulacées, Rhinanthées - Acanthées - Jasminẻes - Verbenacées - Labiées - Personées (Ann. XIV. 1809.); deuxième: Solanées - Borraginées - Convolvulacées Polemoniacées - Bignoniées - Gentianées - Apocinées - Sapotées - Ardisiacées. (Ann. XV. 1810.)

Mémoire sur la réunion de plusieurs genres de plantes en un seul dans la famille des Laurinées. (Ann. VI. 1805.) 
gebührt; wir müffen uns vielmelgr mit ben obigen 2 noeutungen liber ifre gemsinfdaftlicten $\mathfrak{B e r b i e n f t e ~ u n ~ b i e f e l b e ~ b e g n u ̈ g e n ~}$ uno gehen nun zu ciner furzen Darftellung bes Syftems felber ilber.

Observations sur la famille des Amarantacèes. (Ann. II. 1803.) - Observations sur la famille des Nyctaginées. (Ann. II. 1803.)

Mémoire sur le Dicliptera et le Blechum, genres nouveaux de plantes composés de plusieurs espèces auparavant réunies de Justicia. (Ann. IX. 1807.)

Observations sur la famille des Verbenacées. (Ann. VII. 1806.)

Sur le Curanga, genre nouveau de plantes de la famille de Personées. (Ann. IX. 1807.)

Mémoire sur le genre Phelipaea de Thunberg et sur d'autres plantes qui portent le même nom. (Ann. XII. 1808.) Mémoire sur le Cantua, genres de plantes de la famille des Polemoniées. (Ann. III. 1804.)

Sur le Solanum cornutum du Mexique. (Ann. III. 1804.) Sur le Petunia, genre nouveau de la famille des Solanées. (Ann. II. 1803.)

Sur la plante nommée par les botanistes Erica Daboecia, et sur la nécessité de la rapporter à un autre genre et à une autre famille. (Ann. I. 1802.)

Mémoire sur les Lobeliacées et les Stylidiées, nonvelles familles de plantes. (Ann. XVIII. 1811.)

Mémoire sur l'Acicarpha et le Boopis, deux genres nouveaux de plantes de la famille de Cinarocephales. (Ann. II. 1803.)

Mémoire sur le Kleinia et l'Artinea, deux genres nouveaux de plantes de la famille des Corymbifères. (Ann. II. 1803.)

Sur le Gymnostyles, genre nouveau de la famille de Corymbifères. (Ann. IV. 1804.)

Mémoire sur l'Opercularia, genre de plantes voisin de la famille des Dipsacées. (Ann. IV. 1804.)

Sur la famille des plantes Rubiacées. (Mlèm. VI. 1820.) Mémoire sur quelques nouvelles espèces d'Anémones. (Ann. III. 1804.) 
Fl anfon hatte bei feiner mit betwunderunggiwürbigem

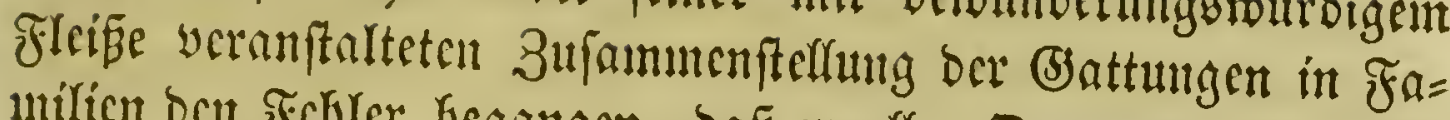

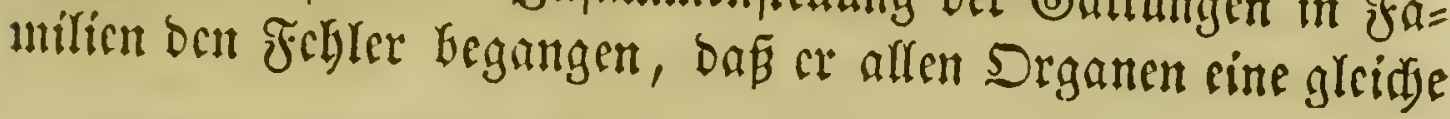

Mémoire sur le Paullinia, genre de plantes de la famille des Sapindacées. (Ann. IV. 1804.)

Mémoire sur le Melicocca et quelques espèces nouvelles de ce genre des plantes. (Mém. III. 1817.)

Sur quelques espèces du genre Hypericum. (Ann. III. 1804.)

Mémoire sur une nouvelle espèce de Marcgravia et sur les affinités botaniques de ce genre. (Ann. XIV. 1809.)

Mémoire sur le Grewia, genre de plantes de la famille des Tiliacées. (Ann. IV. 1804.)

Mémoire sur la famille nouvelle de Polygalées. (Mém. I. 1815.)

Exámen de la famille des Renoncules. (Mém. de l'Acad. des sc. 1773. p. $214-240$.)

Note sur le genre Hydropityon de Ga ertner fils et sur ses affinités avec d'autres genres. (Ann. $X .1807$.

Sur la nouvelle famille des Paronychiées. (Mém. II. 1815.) Mémoire sur le Loasa, genre de plantes qui devra constituer avec le Mentzelia une nouvelle famille. (Ann. v. 1804.)

Observations sur la famille des plantes Onagraires. (Ann. III. 1804.)

Mémoires sur les Passifforées, - premier mémoire: Sur quelques nouvelles espèces du genre Passiffore, et sur la nécessité d'établir une famille des Passifforées (Ann. VI. 1805.); - seconde mémoire: Sur la famille des Passiflorées et particulièrement sur quelques espèces nouvelles du genre Tacsonia (Ann. VI. 1805.) Mémoires sur les Monimiées, nouvelle ordre des plantes. (Ann. XIV. 1809.)

Sur quelques genres de la Flore de Cochinchina de Loureiro, - première note: Aubletia. Aglaïa. Citta. Knema. (Ann. XI. 1808.); - deuxième note: Tetradium. Gonus. Limacia. (Ann. IX. 1808.); - troisième note: $\Lambda$ denodus. Reflexions sur l'Elaeocarpus. Gemella. (Ann. Xl. 1808.); - quatrième note: Anoma. 
TSidtigfeit beilegte, uno die Rähe ber Berwandtadjaft nur nady ber Zahl ber gleiden ober ähnlidyen Drgane beftimmte.

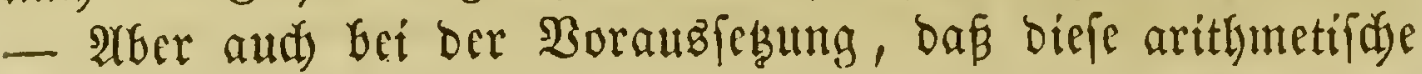
Beftimumng ber Berwandtidjaft naturgemäß fei, wïrbe jene Methoobe bod an einem grofen Mangel leiben. Denn ber lurkeber berjelben fonnte bod nur nad) bem Stande ber Wiffen=

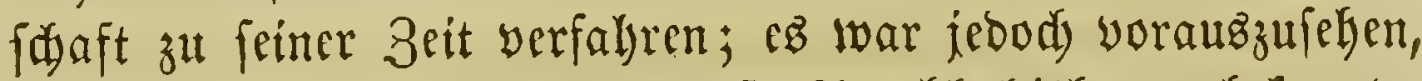
cafa fehr balo folwohl eine arofe Atnzahl bisher unbefannter

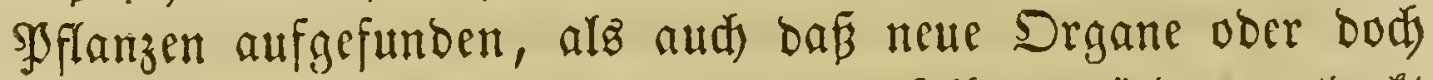
bisher nidyt gefannte Funftionen Derfelben würben entoeft werben, fo bafi man bei ber sinreilyung einer jeben neuen Grattung ober ber $\mathfrak{B}$ erürfidstigung eimes jeben Fortiduritts in Der Anatomie uno Shypiologie ber Syflangen bie herfulifde 2hrbeit $\mathfrak{A}$ banfon's wieber yon yorn beginnen uno alf bie

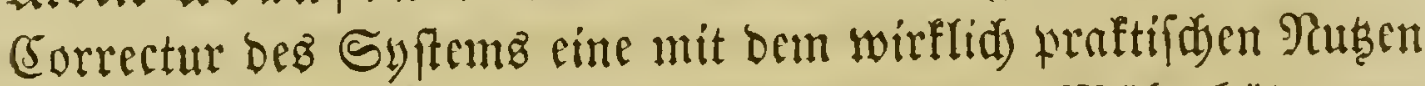

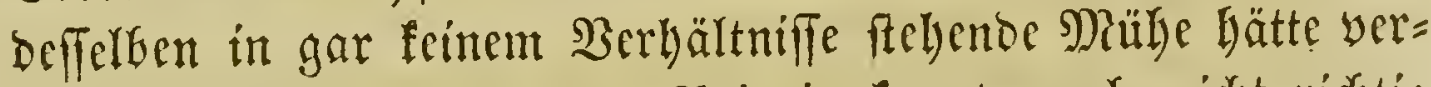
wenben müffen. 2 (ber bas Sgrincip fonnte aud nidjt rítig fein; benn es gift gewiffe Scautorgane, beren Borfandenjein bas einer grofen Menge anderer nothwendig zur folge bat, uno biefe Yestere gleid) ben erfteren als Soften Der 2 boition fämmntlidjer Drgane zu betradyten beifít nidjts 2 nnoerez, als

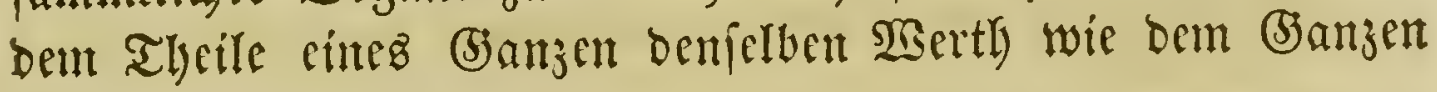
ferbif beilegen.

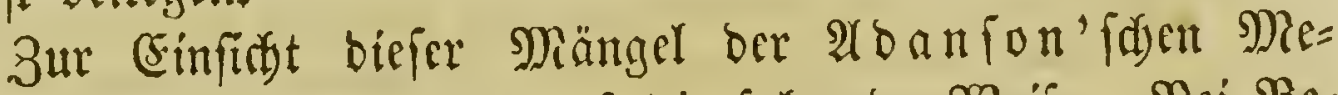
thobe gelangte $\mathfrak{S} u f f i c u$ auf bie folgenbe $\mathfrak{Z}$ eife. Bei $\mathfrak{B} e=$

(Ann. XI. 1808.); - cinquième note: Nephroia. Pselium. Thilachium. ( $\Lambda$ nn. XII. 1808.); - sixième note: Melodorum. Desmos; - Note sur les genres de la famille des Anonacées. (Ann. XVI. 1810.); - septième note: Physkium. (Ann. IX. 1807.); - Note sur le calice et la corolle. (Ann. XIX. 1812.)

Extrait d'une Mémoire de M. Cuss on sur les plantes ombellifères. (llistoirc de la société royale de médecine 1782 - 1783.) Bcrgh. आud giribel's Thesaurus $\mathfrak{S}$. 135 - 136, Rr. $5029-5068$. 


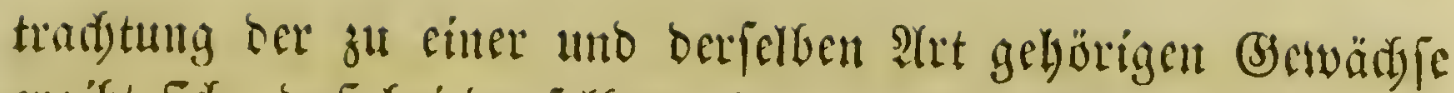

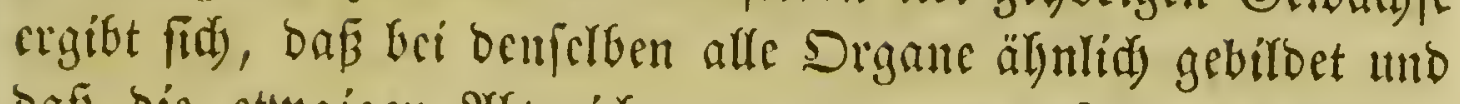

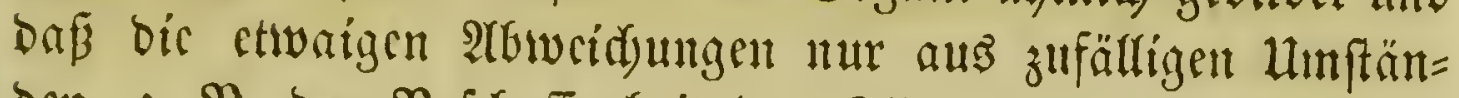

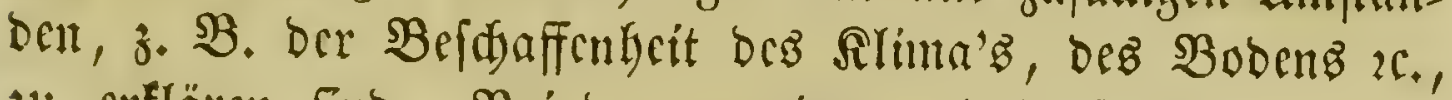
ju crflären fino. Şci beat zu einer 4 mo berfelben (B)attung gehörigen 3ुflanzen wiro aber bie 3ahl ber älynlidan Dre gane bei lveitem gerínger; es ift jebod) auzunchmen, bas bie

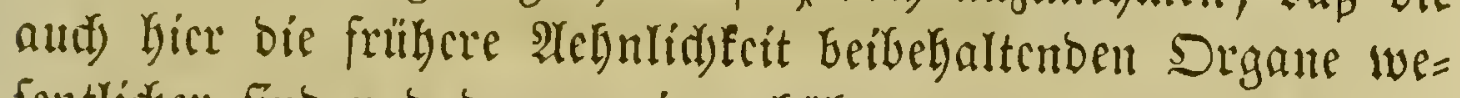

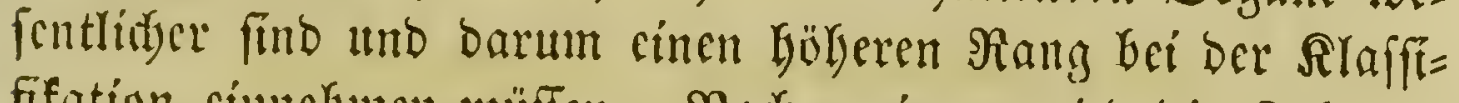

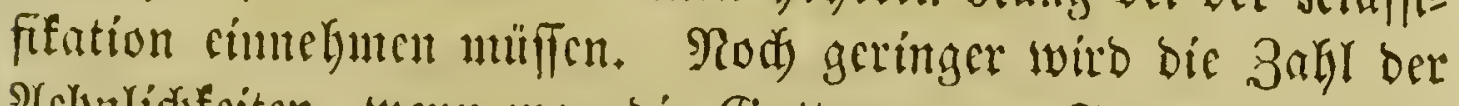

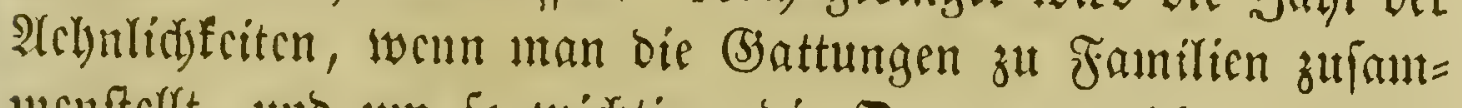
menfellt, und un fo widjtiger bie Drgane, weldye audi hicr

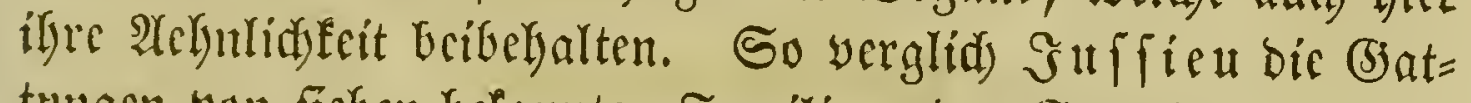
tungen you fieben bchanten Familien, ben (J)ramineen, Rilia= ccen, Labiaten, Sompofiten, Ulmbelliferen, Gruciferen und $\mathfrak{R}=$ guminoien, und nadjocun er bei bicfen bíc melyr ober weniger wefentlicten Merfutale yon einauber gefondert und feftgeftellt hatte, erbielt $c r$ auch für anbere minoer befannte Familien

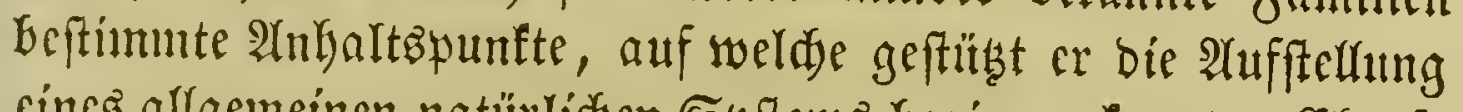
cincs alfgemeinen natürliden Syftems beginnen fonnte. Ebenjo

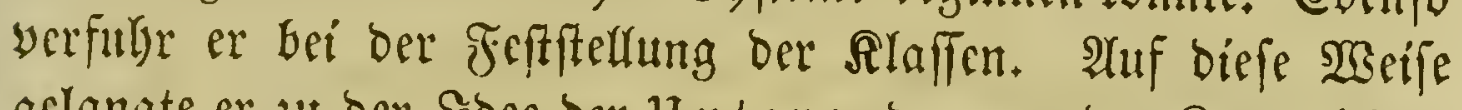

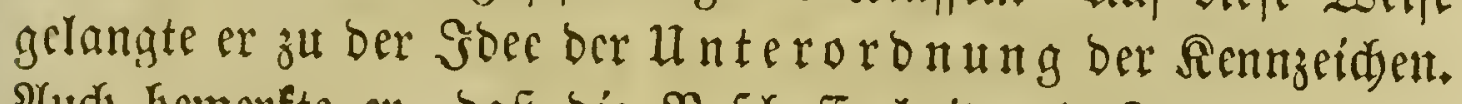

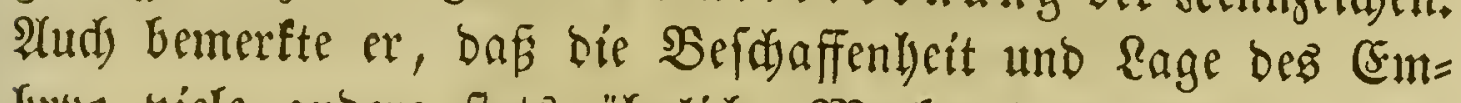
bryo vicle andere ftcts äfnlidje Merfmale burd) bie ganze STflanzentwclt in Sefolge hat, und theilte barum bas ganze SJflanzenreid in brei grofe Abtheilungen: Afotylebonen, $\mathfrak{M N}_{0}=$ nofotylcoonen uno Difotylcoonen. Die Afotyledonen umfaffen

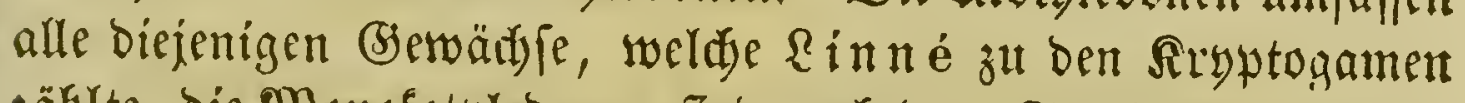
zäGlte, bic Monototylebonen find nady ben Stanoe ber Staub. fäben unterfdiebon; bie Difotylebonen zerfallen in folde, weldye

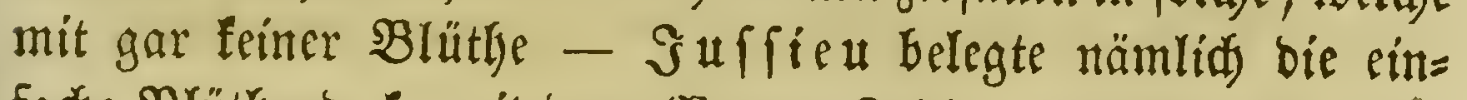
fadje Blüthendede mit bem samen Reld), - welde mit einer cinblättcrigen, wcldhe mit einer mebrblätterigen Blume ver feben find, und in foldse, bei benen bic Staubgefäßze yon bem Siftille getrennt find. Demgemäв ftcllte fid bas urfprüng= 
lidje Sdjema ber vierzeln SIaflen, nadj welden Bernar De $\Im \mathfrak{u} f\{i \in \mathfrak{d}$ den Garten zu Trianon oronete, folgender= geftalt bar:

\section{Siaffe I: StEotylebonen.}

\section{MRonofotyledonen.}

III: a. Staukfiäben auf bein Frudtboben.

"III: b. Staubfäben auf bem Sieldie.

"IV: c. Staubfäben auf Dem şiftill.

\section{Difotyledonen.}

a. $\mathfrak{B} \mathfrak{H}$ menlofe.

" V: a. Staubfäben auf bem Reldye.

"VI: $\beta$. Staubäben auf Dem fruttboben.

b. Mit einblätteriger $\mathfrak{B} \mathfrak{l}$ me.

"VII: $\alpha$. Borolfe auf bem Frudtbober.

"VIII: $\beta$. Eorolle auf Dem Reldye.

$\gamma$. Sorolle auf bem Shiftill:

"IX: a. mit verwadj jenen Ântlyeren,

" $X:$ b. mit freien âththeren.

c. Mit vielblätteriger Blume.

"XI: a. Staubfäben und Sorolle auf bem Ssiftill.

"XII: $\beta$. Staubfäben und Gorolfe auf bem Frudtetboben.

"XIII : $\gamma$. Staubfäben und Sorolle auf ben Sieldye.

"XIV: d. Mit getrennten (B) efdedern. 


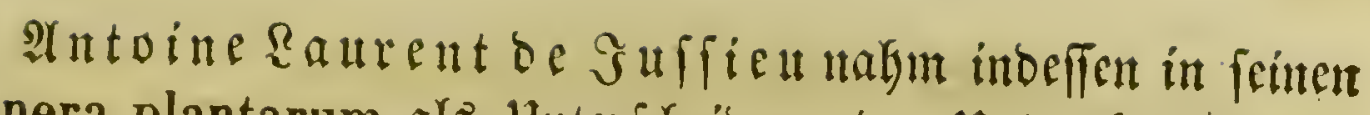
Genera plantarum als Unterid)eibung ber Unterabtheílungen burdygängig bas Berbältniñ des Stanbez ber Staubfäben zum Jifitille an; ftelyen bie Stanbfäben auf bem Siftille, fo rebet el yon Exigynie, entfechen fie auts bem Frudjtboben, yon Sypogynie, uno fommen fie atts ber (Sorofle ober bem Reldje

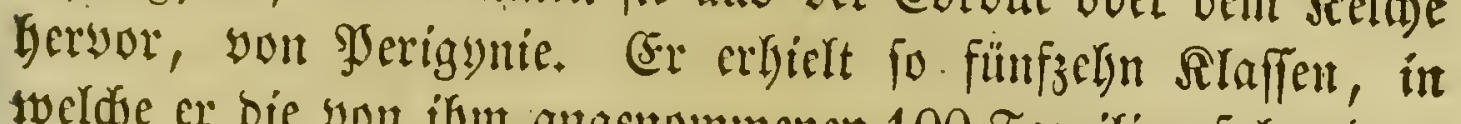
twelde er bie yon ifm antgenommenen 100 Familien folgender= mafen eimreifte:

\section{Acotyledones.}

1) Fungi.

2) Algae.

3) Hepaticae.

Exife Siffe:

II. MIonocotylediones.

3 weitc $\mathfrak{A}$ affe:

Monohypogynae.

7) Aroideae.

8) Typhae.
4) Musci.
5) Filices.
6) Najades.

9) Cyperoideae.

10) Gramineae.

Dritte $\mathfrak{N} \mathfrak{L} \mathfrak{a}\{\mathfrak{e}$ :

Monoperigynae.

11) Palmae.

12) Asparagi.

13). Junci.

14) Lilia.
15) Bromeliae.

16) Asphodeli.

17) Narcissi.

18) Irides.

Bierte $\mathfrak{R} \mathfrak{l} \mathfrak{a} f \mathfrak{e}$ :

Monoëpigynae.

19) Musae.

20) Cannae.

21) Orchideae.

22) Hydrocharides. 


\section{Dicotyledones.}

A. Monoclinae.

a. Apetalae.

Fillfte Rlaffe:

Epistamineae.

23) Aristolochiae.

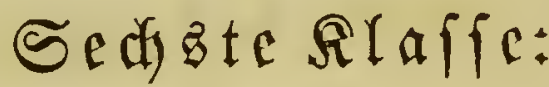

Peristamineae.

24) Elaeagni.

25) Thymeleae.

26) Proteae.
27) Lauri.

28) Polygoneae.

29) Atripliceae.

Siebente Rlaffe:

Hypostamineae.

30) Amaranthi.

31) Plantagines.
32) Nyctagines.

33) Plumbagines.

b. Monopetalae.

\section{$\mathfrak{A}$ d $t \mathfrak{e} \mathfrak{A} \mathfrak{a}\{\mathfrak{f} \mathfrak{c}$}

Hypocorolleae.

34) Lysimachiae.

35) Pediculares.

36) Acanthi.

37) Jasmineae.

38) Vitices.

39) Labiatae.

40) Scrophulariae.

41) Solaneae.
42) Borragineae.

43) Convolvuli.

44) Polemonia.

45) Bignoniae.

46) Gentianac.

47) Apocyneae.

48) Sapotae. 


\section{Nallte Raffe:}

Pericorolleae.

49) Guajacanae.

50) Rhododendra.
51) Ericae.

52) Campanulaceae.

\section{3egite Rifaffe:}

Epicorolleae.

. SYNANTHERAE.

53) Cichoraceae.

54) Cynarocephalae. 55) Corymbiferae.

\section{Eilfte Rifafe:}

Epicorolleae.

ß. ChorisantherAe.

56) Dipsaceae.

58) Caprifolia.

57) Rubiaceae.

c. Polypetalae.

$$
\text { 3wölfte } \mathfrak{R} \text { taffe: }
$$

Epipetalae.

59) Araliae.

60) Umbelliferae.

\section{Dreizelite Rlaffe:}

\section{Hypopetalae.}

61) Ranunculaceae.

62) Papaveraceae.

63) Cruciferae.

64) Capparides.

65) Sapindi.

66) Acera.

67) Malpighiae.

68) Hyperica.
69) Guttiferie.

70) Aurantia.

71) Meliae.

72) Vites.

73) Gerania.

74) Malvaceae.

75) Magnoliae.

76) Anonae. 
77) Menisperma.

78) Berberides.

79) Tiliaceae.
80) Cisti.

81) Rutaceae.

82) Caryophylleae.

\section{Bierzefute Rlaffe:}

Peripetalae.

83) Sempervivae.

84.) Saxifragae.

85) Cacti:

86) Portulaceae.

87) Ficoideae.

88) Onagrae.

89) Myrti.
90) Melastomae.

91) Salicariae.

92) Rosaceae.

93) Leguminosae.

94) Terebinthaceae.

95) Rhamni.

B. D i clin a e.

Fünfehute Rlaffe.

Diclinae.

96) Euphorbiae.

97) Cucurbitaceae.

98) Urticae.
99) Amentaceae.

100) Coniferae.

Einer ber farffintigften Botanifer Frantreids war

Gean Baptife Monet de Ramati,

Der burd feite treffliden SPlanjentefdreitungen in ben weiter unten anzugebenden SBerfen fowohl zur Berbefferung bes tïmft= lidyen wie bes natïlliden Syftems nidet wenig beitrug. $3 \mathfrak{t t}=$ gleid) aber ift er bier als (orünter eimer cigenct Methobe, ber f. g. analytifden ober bidjotomifden, zu uennen. Sin Syltem fann biefe Methobe nidjt genamnt werben, fee ift vielmegr 


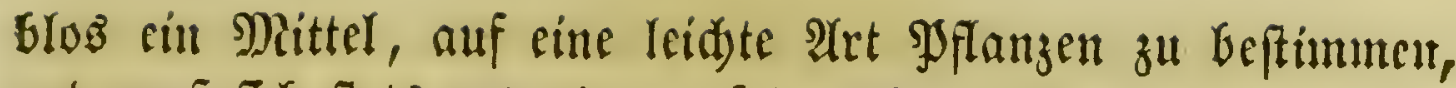
umb mus fidy ftets entiveder auf bas fünftidye ober natürlidje Syftem ftüken. Dem Anfänger gewälyrt $\mathfrak{R} a m a r$ af' $\mathfrak{B}$ De= thode ber SPfangenbeftimmung grope Erleidsterung, fie bat

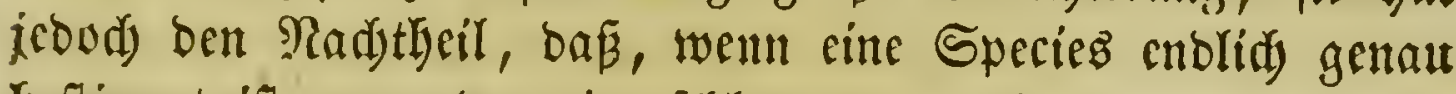

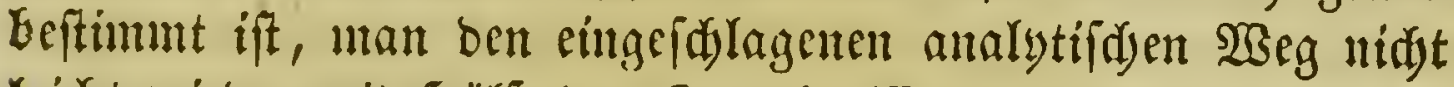
leidjt wieber mit Şülfe bes (B)ebäd)tniffes zurüdverfolgen famm ant fo aun Ento nidjts weiter alz bon Ramen ber SPflanze übrig bebält. Diefer Mangel ift audi wohl fidulo baran

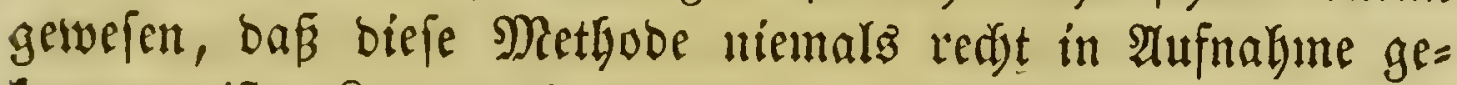
fommen ift. \&amarf entwicfelte feine Anfidsten über bie= felben in ber sinleitung zu feiner frar:zöfifiten flora (fiebe unten bie SJytographen Franfreid)s ), in ben Mémoires de l'Académie de Paris yom Gafre 1785, p. 437 ff. und im Journal d'histoire naturelle, tom. I. p. 9 ff., 81 ff., $136 \pi_{0}, 300 \pi_{0}, 361$ ז.

3ur Berbreitung bes natürlidien Syftems trug Etienne Sg ierre $\mathfrak{B}$ entenat ${ }^{1}$ ), SJrofeflor zu SJarí, geb. 1757, geft. 1808, burd) feine ausfülyrlidse (Erläuterung bes $\Im \mathfrak{u}$ ffieu= fden Syftems nebft ber Darftellung ber Sattung $b=$ und $\mathfrak{F a}=$ miliendjaraftere nitjt wenig bei. - Denfelben Begenitano belandelte einige Gakre fläter Gaume Saint= J̧ilaire ${ }^{2}$ ),

1) Tableau du règne végétal selon la méthode de Jussieu. Paris an VII. 1794. IV voll. 8. 24 tab. - \$ुergl. aud beffent Principes de botanique. Paris an III. (1795.) 8. 14 tab.

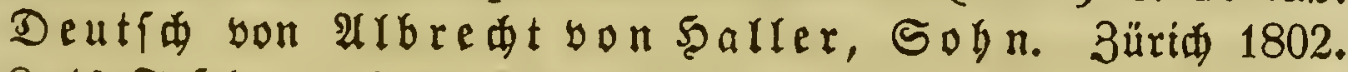
8.14 $\mathfrak{T a f e l n}$. - Decas generum novorum. Parisiis 1808. 4.

2) Exposition des familles naturelles et de la germination des plantes; contenant la description de 2337 genres et d'environ 4000 espèces les plus utiles et les plus intéressantes; 117 planches, dont les figures ont été dessinées par l'auteur, représentant les caractères des familles et les différents modes de germination des plantes monocotyledones et dicotyledones. Paris an XIII. 1805. II voll. 8. 112 tab. 
beflen feiftungen indeffen weit hinter beuen $\mathfrak{B e n t e n a t ' z ~}$ Jurülffelyen. - Ferner waren bie Forfdungen von Sof. Franz Sorrea de Serra, Secretär der alfabemí del Wiffenidjaften zu Riffabon, alsbann burds bie Berfolgungén ber Jnquifition aus feinem Baterlande vertrieben, Befandter in Ronoon unt in bent vereinigten Staaten, geftorben in fei=

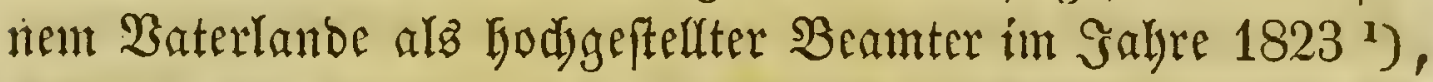

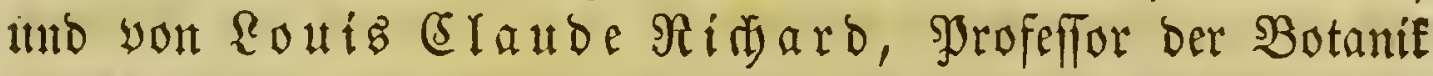

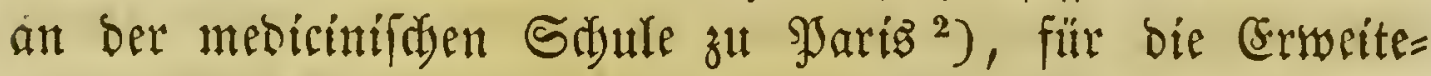
rung und Berbefferung oes. natürlidyen Syftems yon nidjt geringer Şididtigfeit.

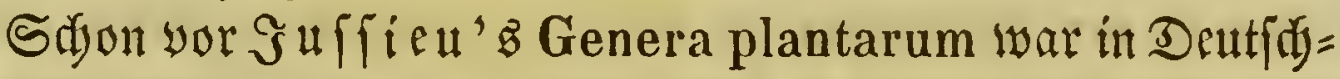
lanto

\section{Soieph (5) ät tuex's,}

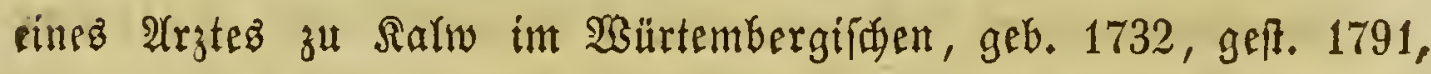

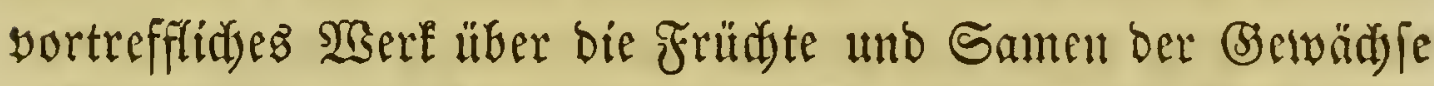
erforienelt ${ }^{3}$ ). Diefe Sifrift, welde baburd), Dnfi fie nuf cit

') Ann. du mus. 8, 59,69, 389. tom. IX. p. 283. 288. ff. tom. XVIII. p. 206, über ben Fimeifförper uno ben Samen; über bie Familie Der 2Yurantieen: Ann: du mus. 6. p. 376 ıno Transactions of the Linn. society. 5. p. 218.

3) Demonstrations botaniques, ou analyse du fruit, considéré en gènéral. Paris 1808. 8. Annal. du mus. tom. XVI. p. 296. tom. XVII. p. 223 ff. 442 ff.

s) De fructibus et seminibus plantarum. Stuttgardiae et Lipsiae 1788 - 1807. 3 voll. 4. - I. Stuttgardiae 1788. Accedunt seminum centuriae quinque priores. 79 tab. II. Tuebingae 1791. Continens seminum centurias quinque posteriores. $101 \mathrm{tab}$ - - III. Lipsiae 1805-1807. Supplementum carpologiae, seu continuati operis Josephi Gaertner de fructibus et seminibus plantarum voluminis tertii centuria I et II, auctore. Karl Friedrich Gaertner. $4+$ tab. 


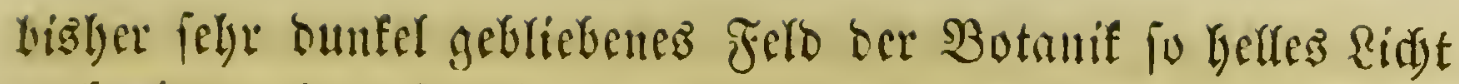

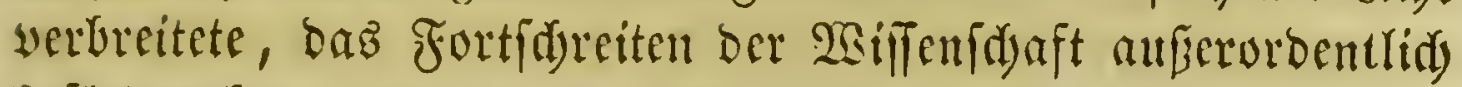
befürtert bat, wurbe lange 3eit in Beutfdyland nidyt redjt aner= fant. (sinen viel fruddtbareren Boben aber fanden (s) är tucr ss

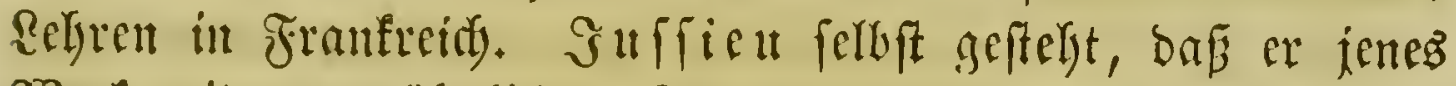

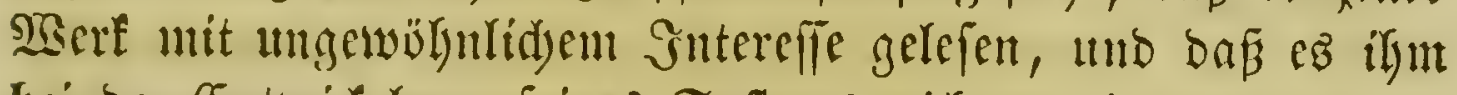
bei ber Sutwiffelung feines. Syftems nidyt wenig genübt habe.

Der (Frfte in Dentidland, ber fids etwas weiter in bas

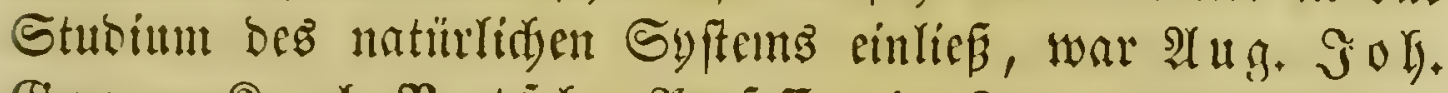

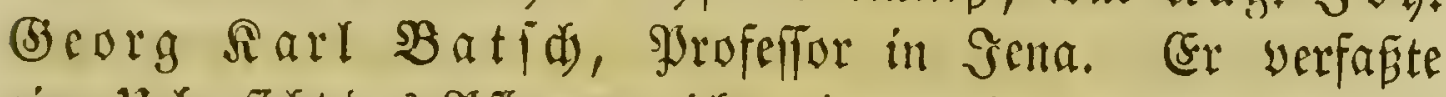

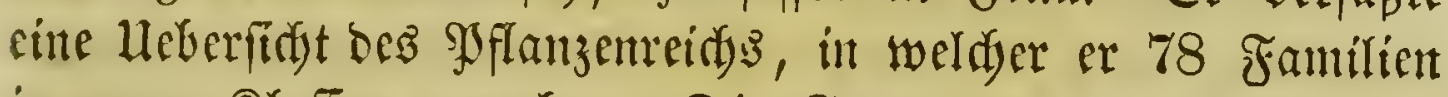
in neun Rlaflen amnahm. Die Giattungen tharafteriferte $\mathfrak{e r}$ nidyt, bie Bgaraftere ber (Sruppen und Familien bagegen be=

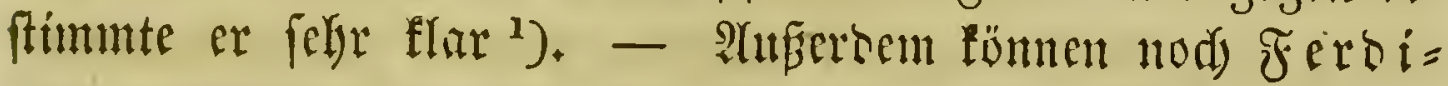

1) Dispositio generum plantarum Jenensium secundum Linnaeum et familias naturales. Jenae 1786. 4. - Tabula affinitatum regni vegetabilis, quam delineavit et nunc ulterius adumbratan tradit. Wimariae 1802. 8. 1 tab. Bergleitie aud beffen: Analyses florum e diversis plantarum generibus omnes etiam minutissimas eorum externas partes demonstrantes, et earundem harum partium characterem genericum, philosophiam botanicam, et generum intimiores affinitates a natura statutas. (Blumenzergliede= rungen 2c.) Halae 1790. 4. Vol. I. fasc. 1 et 2. 20 tab. col. (latine et germanice). - Botanif (und cinzigę) Stüt. Şalle 1791. 8. 6 Tafeln. - Synopsis universalis analitica generum plantarum fere omnium hucusque cognilarum quam secundum methodum sexualem, corollinam et carpologicam adjunctis ordinibus naturalibus exaravit. (P. I et II.) Jenae 1794. 4. - Dispositio generum plantarum Europae synoptica secundum systema sexuale emendatum exarata adjunctis ordinibus naturalibus. Jenae 179\%. 4. - - Seiträge unb Entwürfe zur prag-

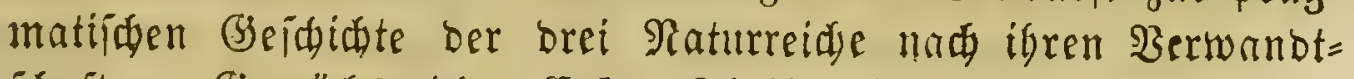

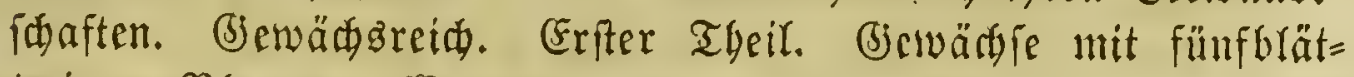
terigen Blumen. Wseimar 1801.4. 1fre Ricferung. Heber bie

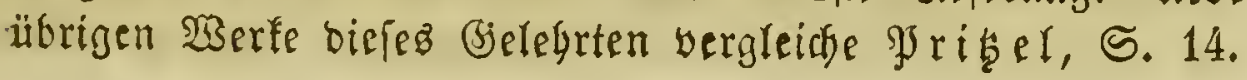




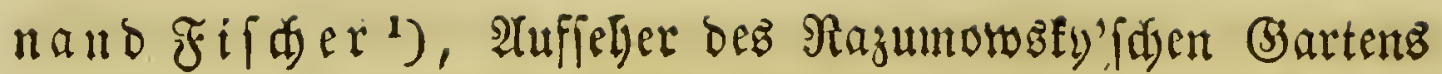

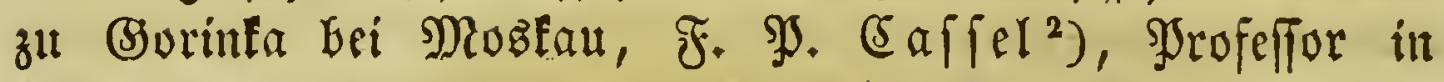
Rüln, Reopolo Irattinia ${ }^{3}$ ) und Iurt Sprengel erwälynt werben.

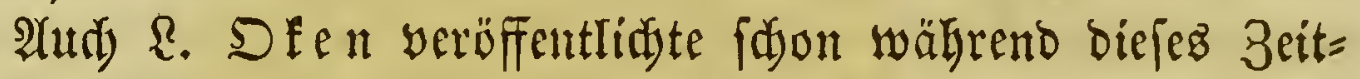

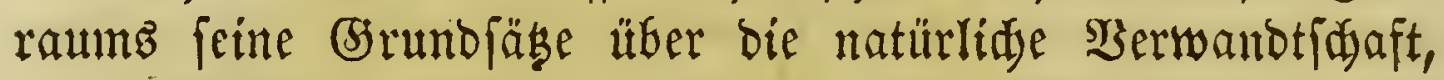

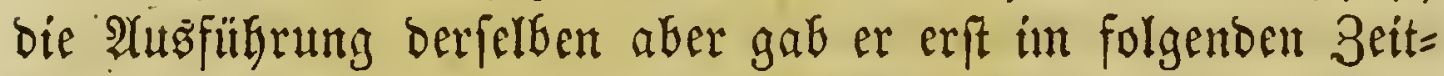

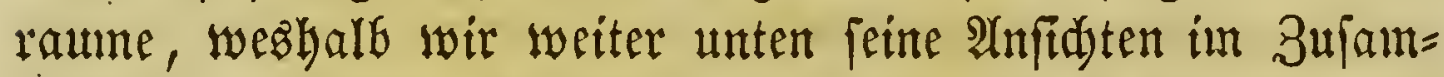
mentange barftellen werben.

Sn (England trug auper $\Re$ id. Ant. Salisbury ${ }^{5}$ ), ber namentlid bie Syerigynie der Staubfäben unterjunte, haupt= färlidf) Robert Brown zur Berbreitung oes natürlident Syftems bei. Die Thätigfeit biejes berüfymten Beleyrten wollen wir indeffen in ber näbjen Seriode in 3 ua ammen= bange barftelfen.

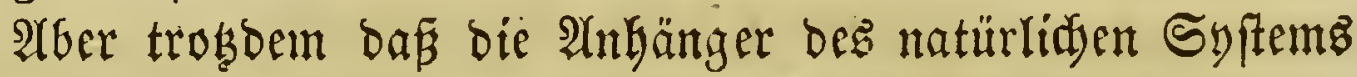
inmer zallreider wurben, fo gab es bod nod) Botanifer ge= nug, weldye unerjdütterlid fefthielten an bem von $\mathfrak{R} i n n e$ é aufgeftellten Syjteme uno mit aller Araft gegen bas $\mathfrak{B o r}=$

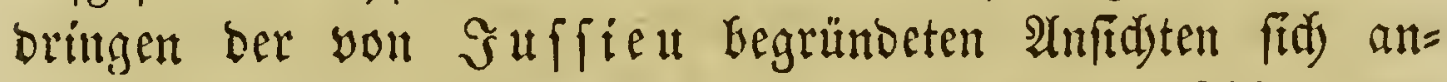
ftemunten. Sam meiften wohl war biez in Deutidslanto ber Falf, und barum futtoen wir, wälyrento man fid in frant= reidi inmer affgemeiner Der $\mathfrak{B}$ ervolffummunung bes natürlidyent Syftems zumandte, in unjerent Baterlanbe währeno biejes

a) Commentat. societ. phys. med. Mosq. vol. I. p. 12 seq. -

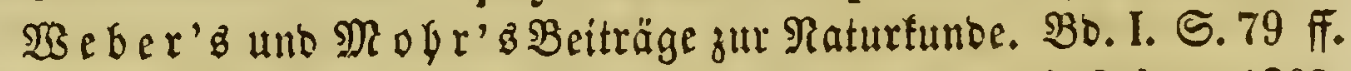

$\left.{ }^{2}\right)$ Genera plantar. methodo naturali disposita. Vindobon. 1802.

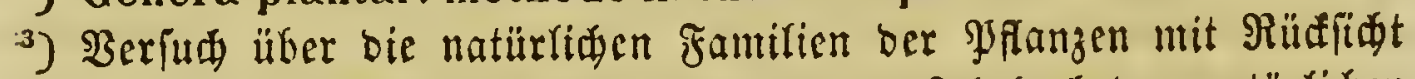

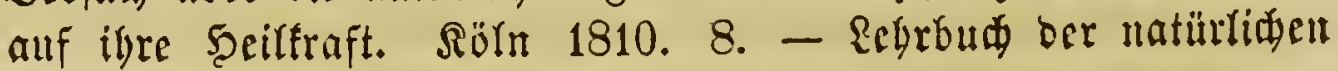
Yjflanzenorbinung. Franffurt 1817. 8 .

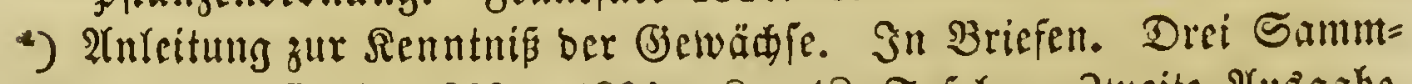

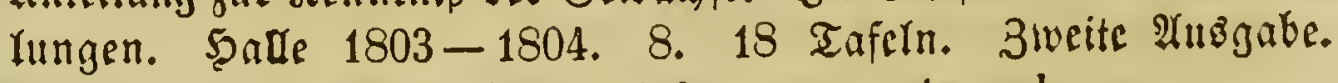
3 Bbe. 1817 - 1818. 8. 25 tab. pro parte col.

s) Transact. of the Linn. soc. vol. VIIl. p. 1. seq. Sicrgl.

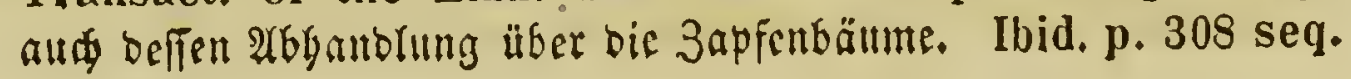




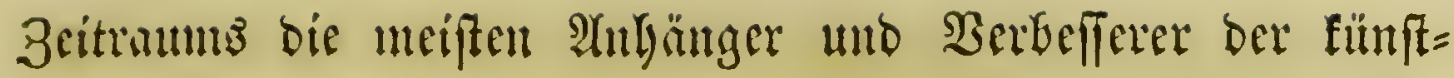
lid)en Miethode.

Selbft fout gans vortrefflidje Botanifer bielten $\mathfrak{e B}$ für rathjamer, an bem berigebradjten feftzulyalten, als ben ueue=

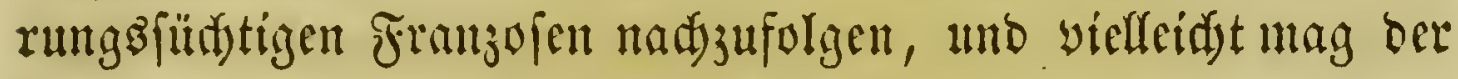

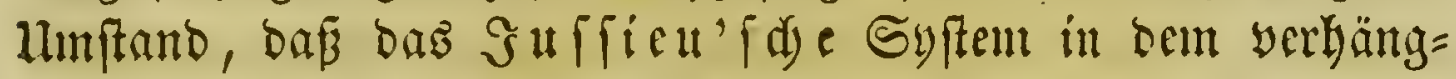

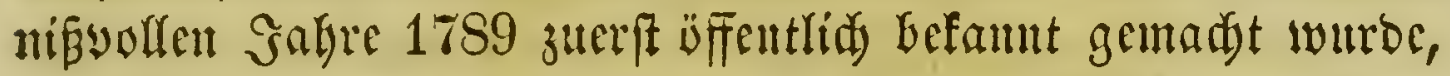
ors Míptranen, oem liberhaupt jede neue Entoefung anfäng=

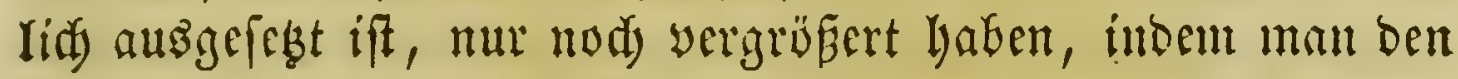

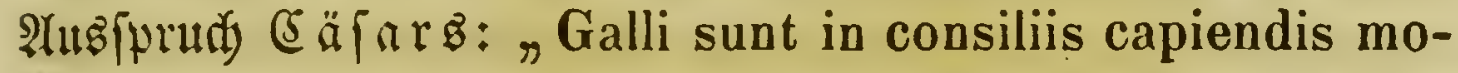
biles et novis plerumque rebus student " iegt nifjt $\mathfrak{b l o b}$ auf bie politijacn, fontern aud auf bie wifienidjaftlidsen $\mathfrak{B} e=$ ftrebungen ber Franjufen anwandte. Bielen mag aud) wohl

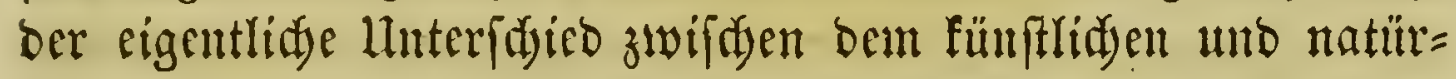

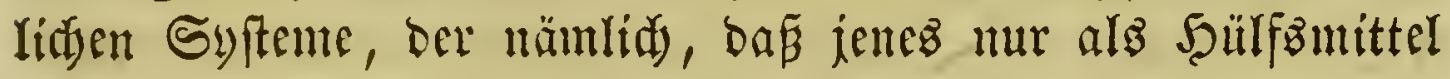
jum $\mathfrak{B}$ eftimmen und Befdyeiben ber SPflanzen bient, biefes

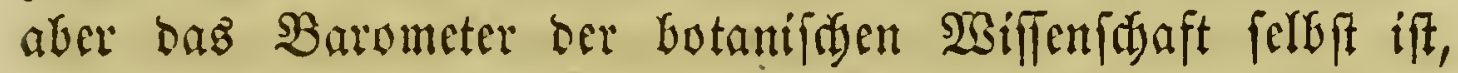

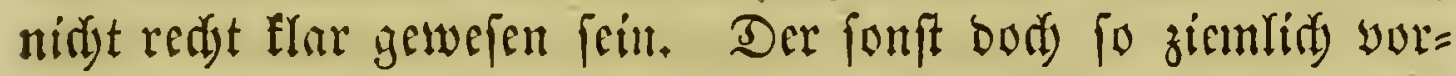
untlyeilsfreie Sdultes fagt in feiner (Befdjidjte ber Botanif, S. 211: "Sisenn Rinné'Syftem ber Iriumph ber $\mathfrak{B e r}=$

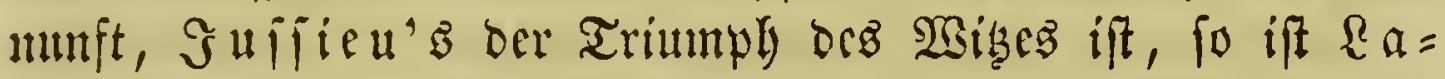

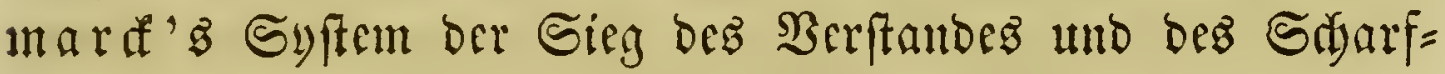

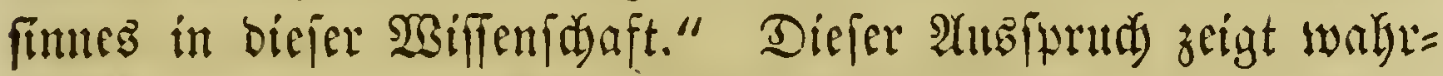

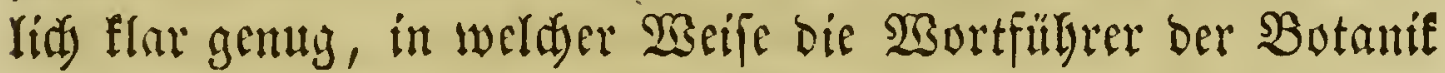

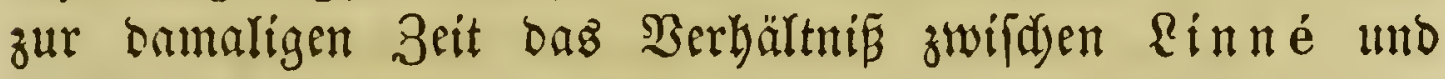

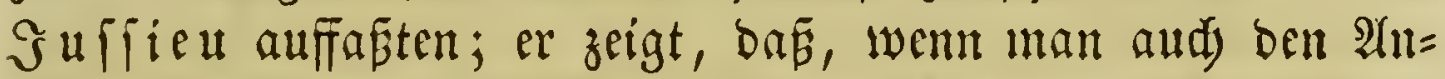

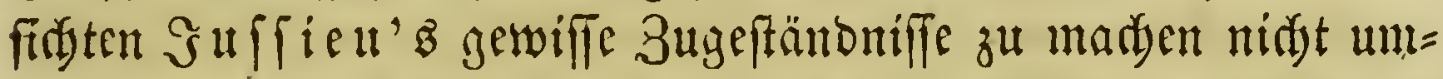
bin founte, man biefelben bod) mur als geiftreidye Spiele bes Şi emft genuy frien, um yon cinem $\mathfrak{B v t a n i f e r ~ y o u ~ a ̈ d r t e m ~ S d y r o t ~}$ unb Rorn aboptint swerben zu fünnen.

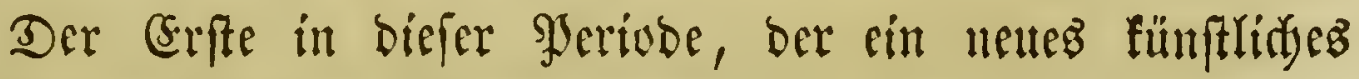
Syiftem auffitelte, wat 


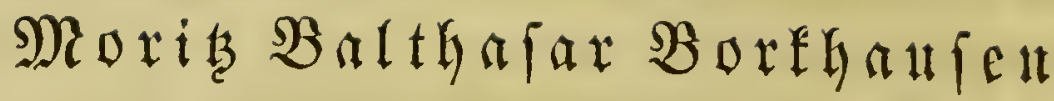 \\ zu Darmftabt.}

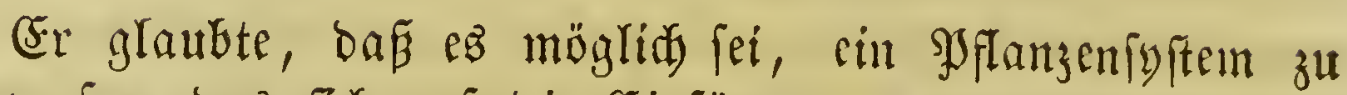
entwerfen, bas fids auf bie (sinfügung, oas Berbältníp und bie Berbindung der Staubfäben grünbe, ofne die 3ahl ber

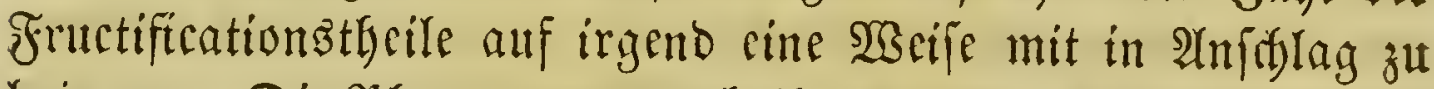
bringen. Die Mhancrogamen theilte er nad diefen Unterfaci= Dungsimerfmalen in 4 Slaffen; Die Aryptogamen aber zerfälfte

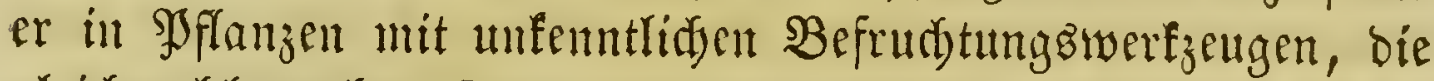
gleidyobl walje Samen bringen (filices, rhizospermae,

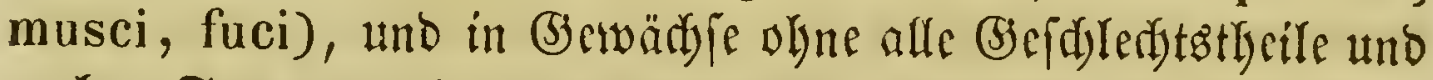
wabre Samen, bie fid bloz burd) fancnähnlidye Sürperdyen oder Snosjen fortpflanzen (algae, fungi). Die unter biefe werfdiebenen Abtheilungen gebürigen Soflangengattungen zer= Iegte er auf analytifde SBeife nady ber Berfdiebenteit ber Şlüthe uno ber Frudgt in weitere IInterabtheilungen. Rady

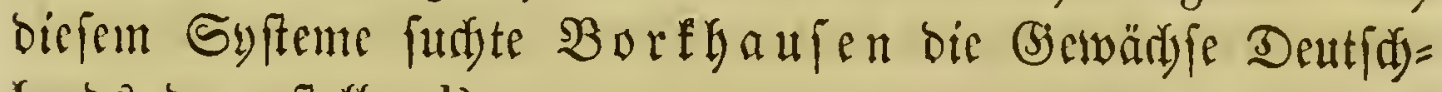
Innos barzufteflen. ${ }^{1}$ )

Auf ähnlidye Saseife verfulgr

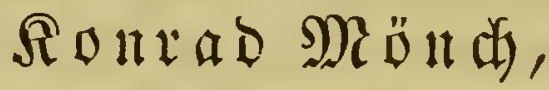

geb. 1744, geff. 1805 alż \$̧rofeffor 孔̆ $\mathfrak{M a r b u r g}$.

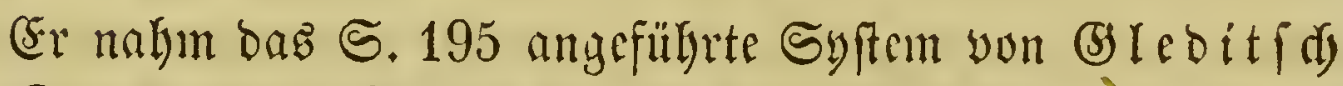
zut (5) runolage, fillyrte jebod) aufer ben you (s) rebitfd) an=

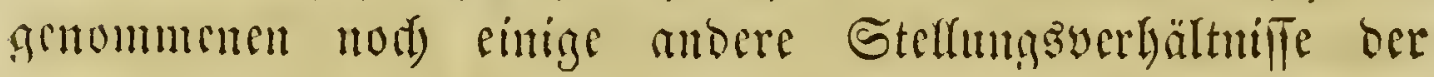

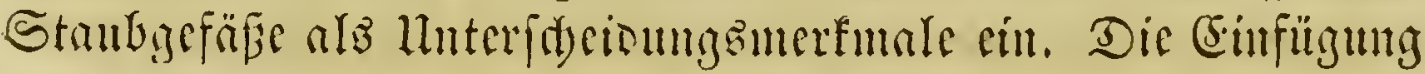

d) Tentanen dispositionis plantarum Germaniae seminiferarum secundum novam methodum a staminum situ et proportione cum characteribus generum essentialibus. Opus posthumum. Darmstadt 1809. 8. Dic crite 24ugnte eridien 1792. 
Der Strulbfäben in bie Rectrricn (parapetalostemones), die abwedjelltoe Steflung alf bem fieldje und ber Gurulle (allagostemones) unt bif (Einfügung anf bem Stigmn (stigma-

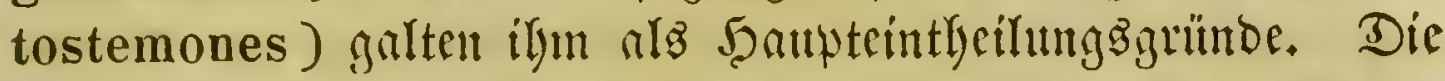

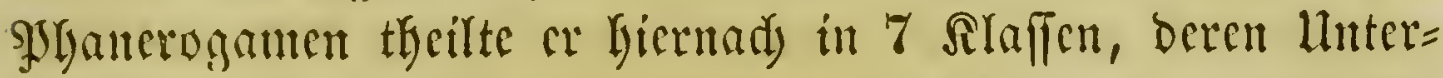
artheilungen won ben fructificationsthcilen uno zivar zunä(t) ft yon ber Frudjt und baun von ber Blüthe herizenommen find. Die Siryptogamen zerfälte er in 6 Dromungen. Radj bicfer Methode georonet fübrte er bant bie (S) wäd) fe des botanifden (5) artens uno ber lumgegeno yon Marburg auf. ${ }^{1}$ ).

Sdyon cine vberflädylidje $\mathfrak{B}$ etradjtung biejer Syfteme genügt inbeffen, un bie Sinfidyt zu erlangen, dafi fie hinter ber logi= fden Sdjärfe und Sonjequenz dez $\mathbb{R}$ inn é fden Syftems woit zurühblicben, umb $e B$ bebarf barmm feines befonderen Rad $=$

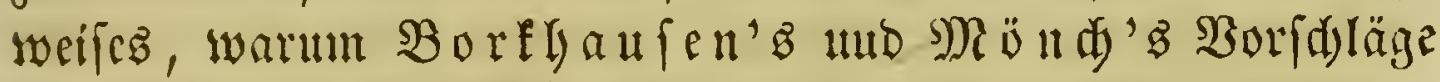
fein (3) Györ bei ben Britanifent fanden.

Das Rinnéfde Syftem blieb jebod) feinesmegs unge= fdoren. Sdyon in ber vorigen seriobe ( $5.198-199$ ) hatten wir (jelegenfeit, bie Beränberungen, theifweife aud $\mathfrak{B e r b e f f e}=$

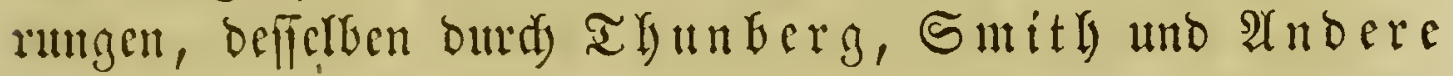
ju berülyen. Atud) wälrend biejes Zeitraums twurden einige

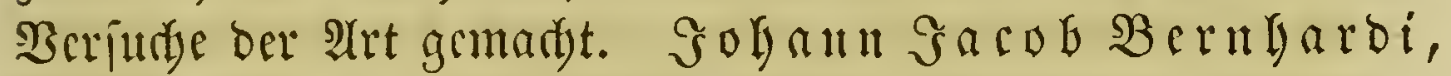
Sjrofefior in (Erfurt, nahm mur 12 Siaflen an, bie er nad)

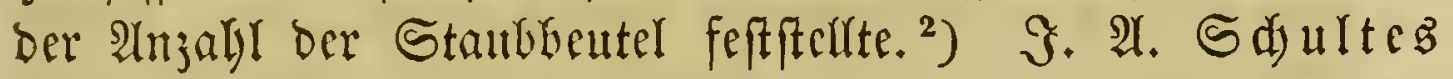

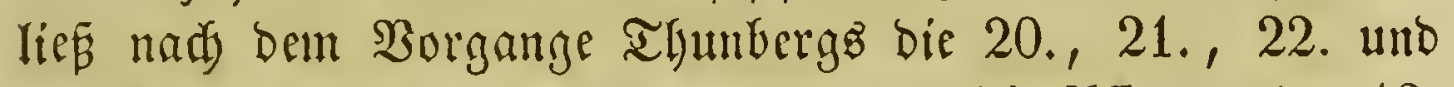
23. Slaffe auşallen. Ferner bradjte er bie syflanzen ber 12. SInfle in bie breizelnete unb belielt aljo nur. nod) 19 Slaffen

') Methodus plantas horti botanici et agri Marburgensis a staminum situ describendi. Marburgi Cattorum 1794. 8. Suppl. 1802. 8.

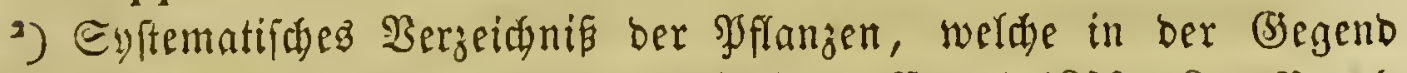
won Erfurt gefunden worben. Thl. 1. Erfurt 1800. 8. פBergl.

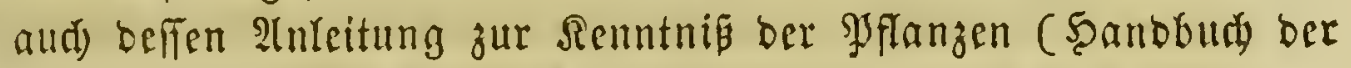
Botanif). 1. BDD. Ibid. 1804. 8. 


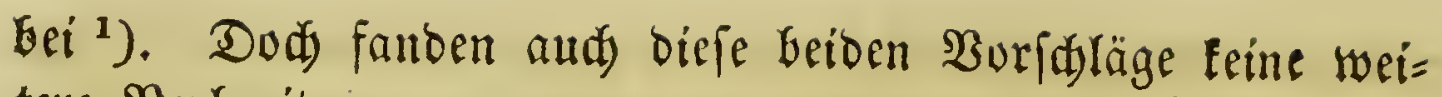
tere $\mathfrak{B e r b r e i t u t g . ~}$

Die Anatomie uno gloy fiologie ber (sewädje fanto

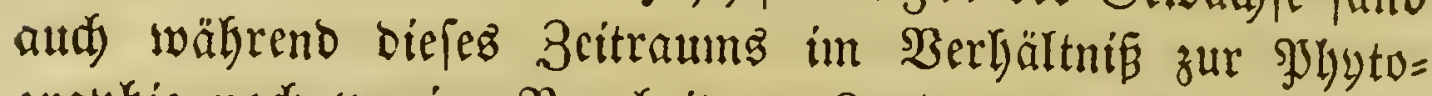
grawhie nod) wenige Bearbeiter. $3 \mathfrak{u}$ ben S. 208 uno 209 angefülyrten Sdriftftellern, weldje bas Dafein ber Şflanzen= gefäße läugneten, gebörte aud Friebrid $\mathfrak{R}$ afiutir $\mathfrak{M}_{\mathrm{e}}=$ bicub, befien $\Im$ S. $196 \mathfrak{u}$. a. in anderer Beziehung fron $g e=$ badjt worben iff ${ }^{2}$ ). 2udd Gean Senebier fonnte bie Spaltüffnungen nidst auffinden uno fłrah unriatige Anfteten über die Spiralgefäße auz (Phys. vég. Tom. I. p. 91,

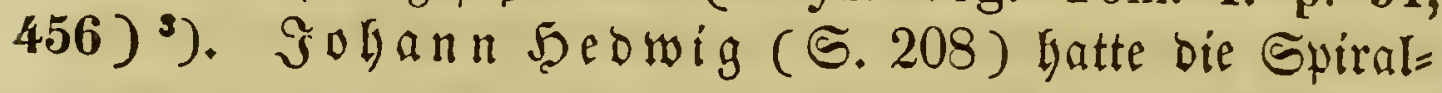

2) Baiernz Flora. Grfte Genturic, Randz̧ut 1811. 8. - Soft=

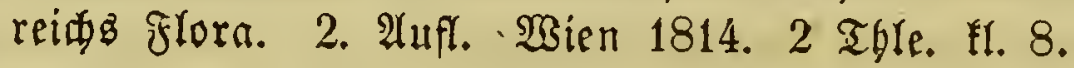

2) Beiträge zur $\mathfrak{P f l a n z e n a n a t o m i e , ~ P f l a n z e n t g y f i o l o g i e ~ u n o ~ e i n e r ~}$

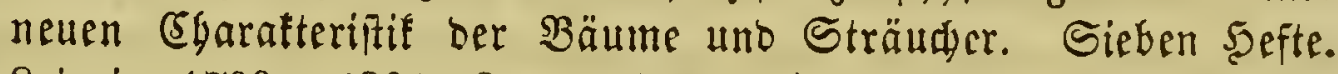
Eripzig 1799-1801. 8. - Diefer Bjelegrte verfapte aufer ben

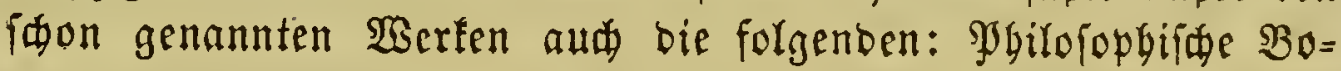
tanit mit fritifhen Biemerfungen. 2 Serfte. Mannbeim 1789 - 1791. 8. - Mflanzengattungen naw bem Snbegriffe fämntt= lider Fruftififationstheile gebirbet und na由 bem Serualpflanzen= regiffer georonet mit fritif beim 1792. 8. - Biei ididte Der Botanif unjerer Beiten. Mann= Geim 1793. 8. - Rritif Dem $\mathfrak{Y l a n j}$ enreidfe. 1. Bandes 1, und 2. Stürt. Mannbeim

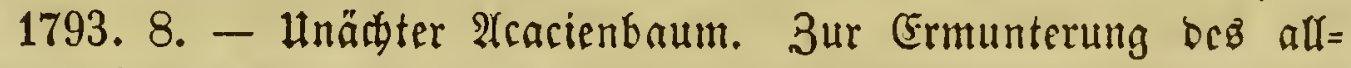
gemeinen 2 (n)

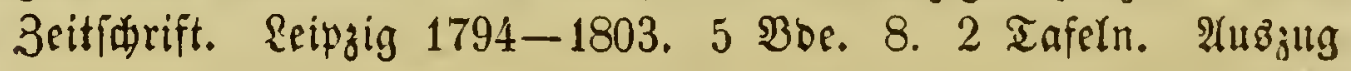

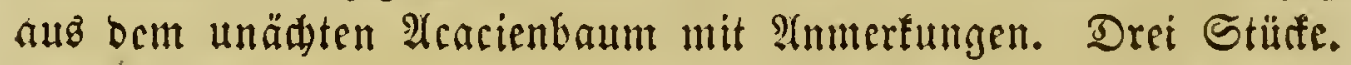
Düffertoorf 1798-1802. 8. - Beridit über bie in ben Surgen 1800 bis 1802 gefübrten Salläge in ber furfürffriden $\mathfrak{A}$ cacien=

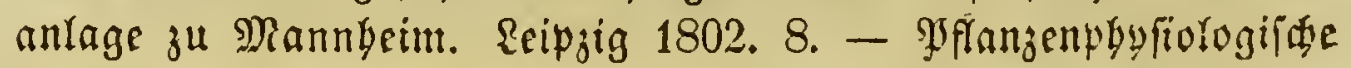

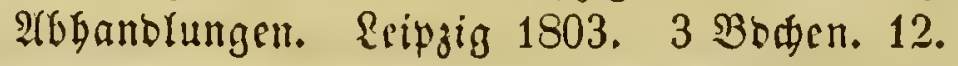

3) Physiologie végétale, contenant une description des organes des plantes et une exposition des phénomènes produits par leur organisation. Genève 1800. 8. 


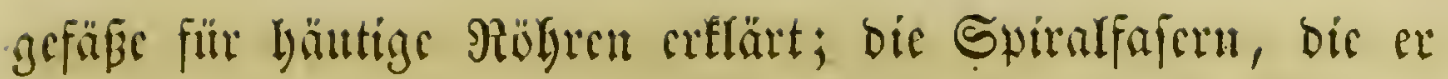

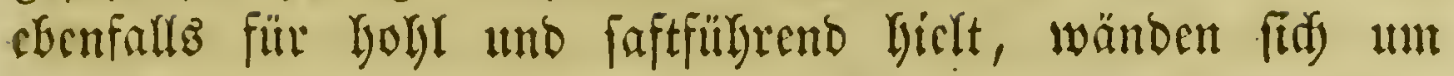
jene Germ, dic Sdyeidewände ber Dberbautzellen betradfete

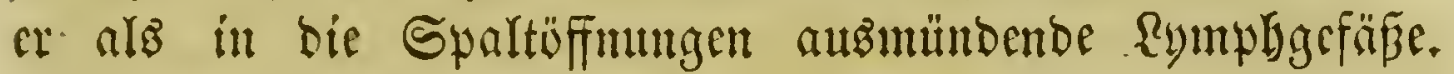
Alubrea Eumparetti, Srofeffor ju Sabua, bebautete

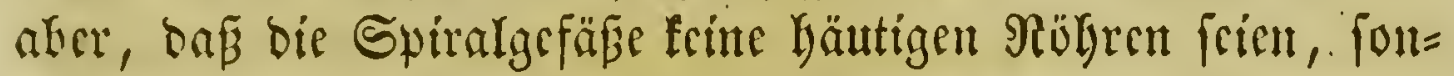
bern cinjig und affrin burtis die Sindungen ber Fafern ge=

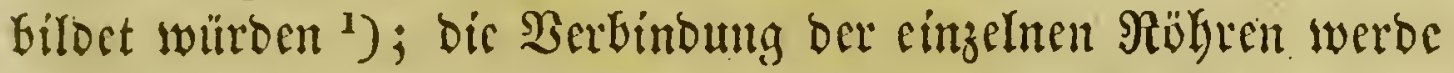
Durd) Duerfäbon lycrgeftellt ; er nahm audi) cine Beräftelung ber Spiralgefäfe an. Somparetti war überhaupt ein

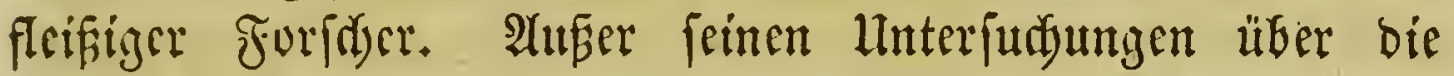

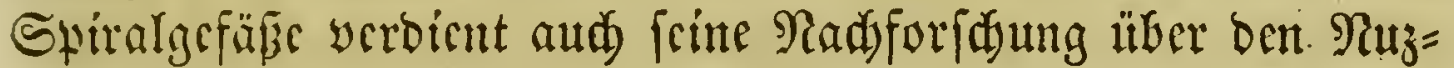
jen, weld)en bie Rutyledonen bei ber Ernährung ber jungen

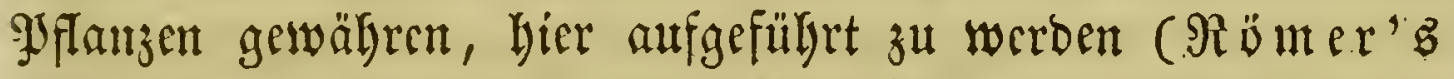

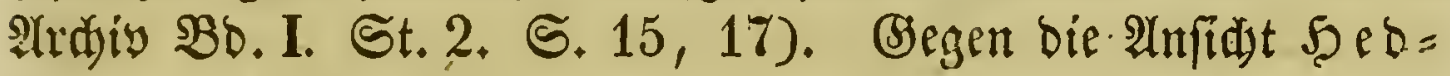
wig's, baf die Sheiberwände ber Sberbaut aus Rgmphge=

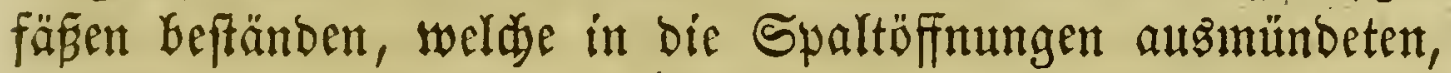

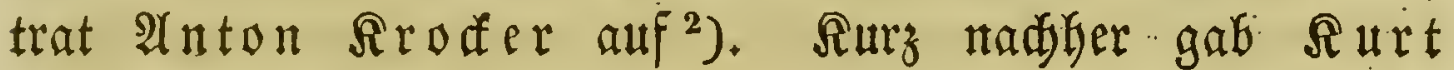

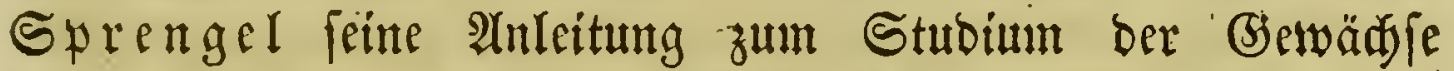
beraus, worin er melyrere feither herridyento getwejene $2 \mathfrak{n}=$

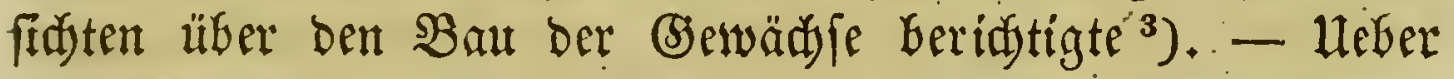

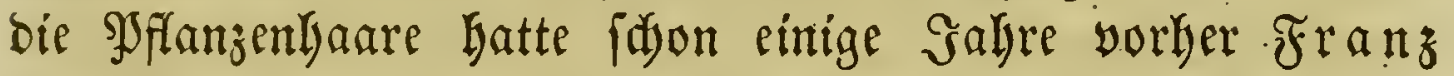

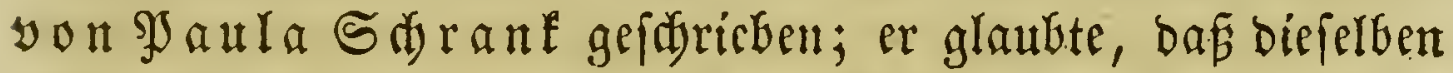

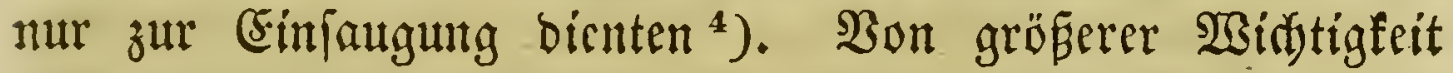
aber waren beg berülymten $\mathfrak{A} \mathfrak{u g}$. Sy yram. Decandorle Interfudjungen über ben $\mathfrak{B a u}$ ber Epibermis und feinte $\mathfrak{B} e d=$

1) Prodromo di fisica vegetabile. Padova 1791-1799. II vóll. 8.

$\left.{ }^{2}\right)$ De plantarum epidermide. Cum praefatione Curtii Sprengel. Halae 1800. 8. 3 tab.

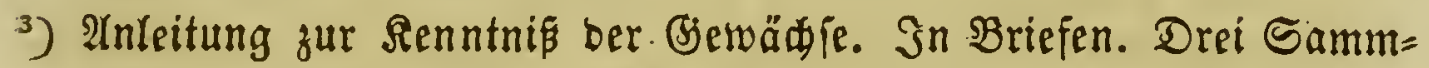
lungen. 5̧alle 1802-1804. 8. 18 Tafeln. 2. 2ُuß̈g. 1817 u. 1818. 2 Thle. ob. 3 Bbe.

4) Bon ben Rebengefäpen ber \$flanzen uno ibrem Ruąen. Salle 1794. 8. 3 Tafeln. 
badytumigen üfer die Seçelväbje ${ }^{1}$ ). Soljann Gacob Bernhardi unterfurbte die SPflantzengefäfe und ftellte zum

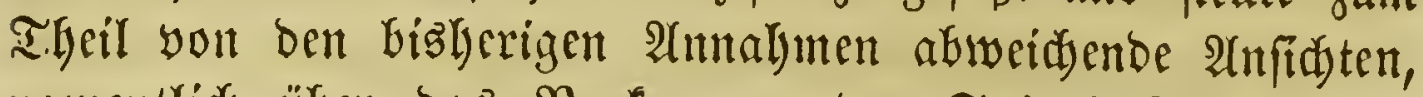
namentlidy über bas Borfommen der Spiralgefäße in ber Rähe des Marfes, die inmere 5̧aut uno die Hebergänge der= felben in Ringgefäße, Treppengänge uno punftirte Röhren

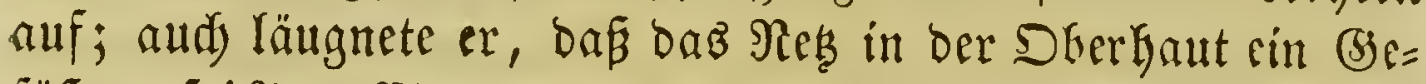

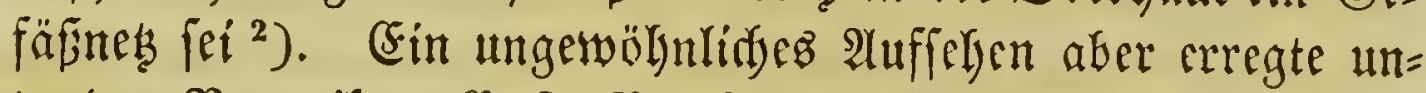

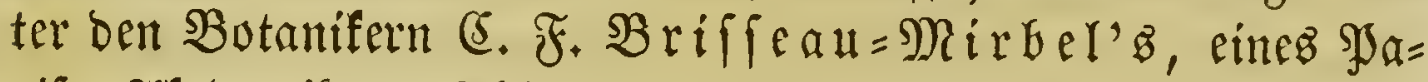
rifer Affabemifers, A(bhanolung über bie 2 natomie uno ŞGyfio= logie ber (Sewäbje; benn er wids in viclen shunten ganz uno

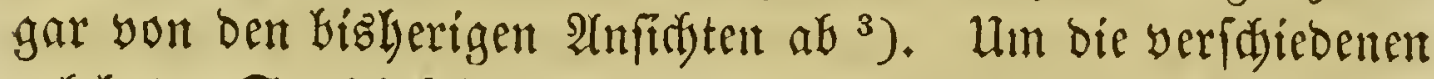

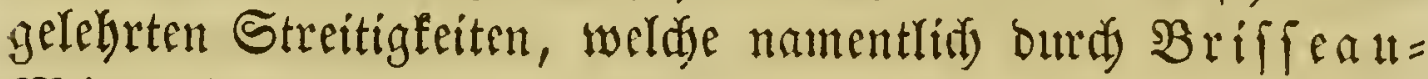
Mirbel waren herborgerufen worben, ju beendigen, ftelfte

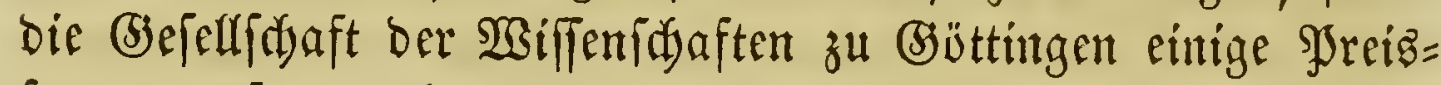
fragen auf, weldye bis zum November 1805 gelöft fein forle ten. Der Shreis wurbe ben Berliner Srofefforen be Friebrid Rind uno $\Re$ arl $\mathfrak{A}$ smund $\Re$ uborphi zuer= fannt. Der Creftere fdrieb namentriaty über das Zelfyewebe und zeigte, bafi balfelbe aud) in unvolftummenen (s)ewväb) jen vorfommt, über bie Spiralgefäß̈e, die 3ivifdyenjellentgätge,

') Observations sur les plantes marines. (Extrait: Bull. soc. phil. de Paris 1799. p. 171. 1 tab.) - Mémoires sur les pores de l'écorce des feuilles. (Bull. des sciences par la soc. philomat. 1797. No. 4i.)

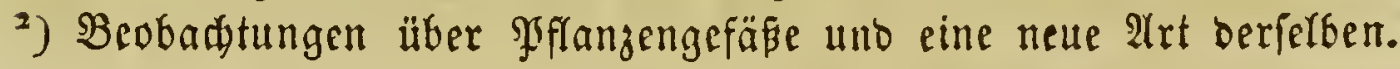

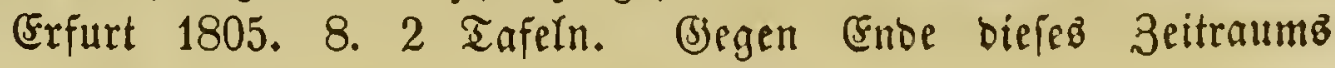
(1805) begann er baz von 3. 3. R. Siafler in ben Gabren $1804-1810$ rebigirte allgemeine beutfine Gartenmagajin (25ei= mar) Kerauģugeben.

3) Traité d'anatomie et de physiologie végétales suivi de la nomenclature méthodique ou raisonnée des parties extérieures des plantes, et un exposé succinct de systèmes de botanique les plus généralement adoptés. Ouvrage servant d'introduction à l'étude de la botanique. Paris an $\mathrm{X}$. II voll. 8. et un tableau. 


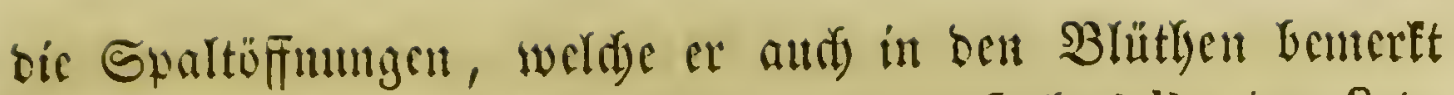

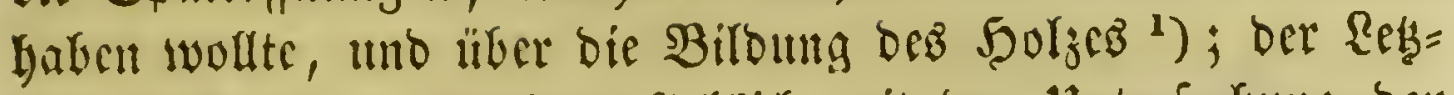

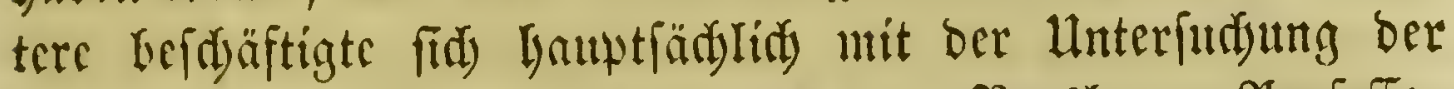
Spaltïffmmgen ${ }^{2}$ ). - 2 (ber aud ber Breslauer Srofeflor R. 5. Treviranus hatte in Folge der yen ber (jöbtinger

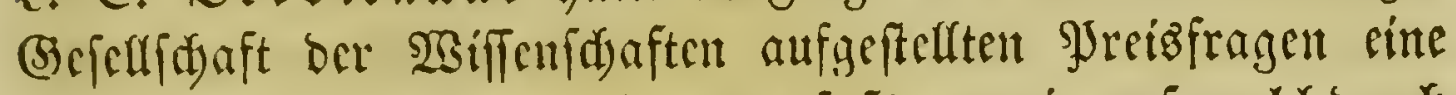

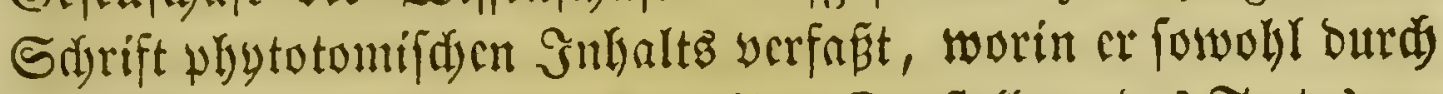
gute AGbildungen, wie burd die flare Darftellung bes Textes zur

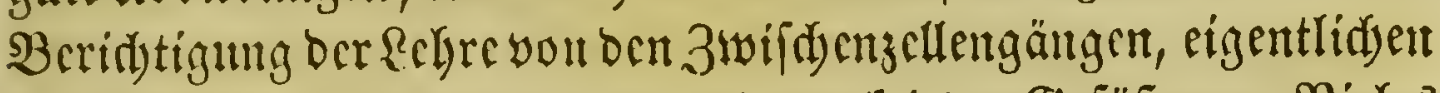

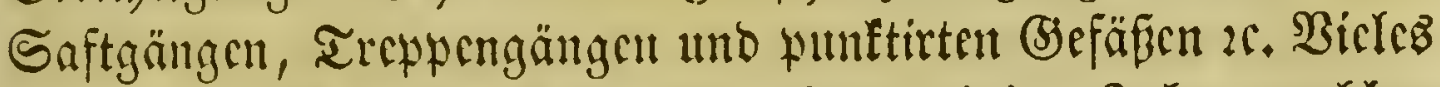

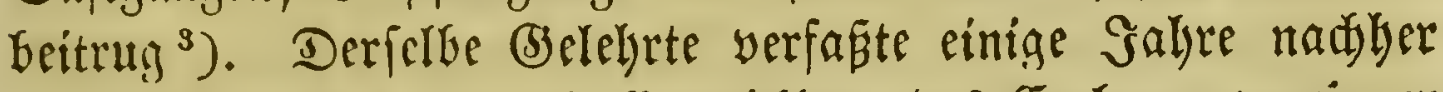

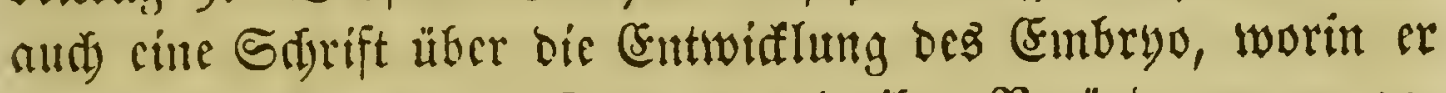

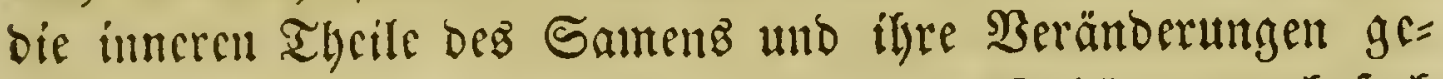
mau unteriudste ${ }^{4}$ ). So von ben beutiden (jelebrten megrfad

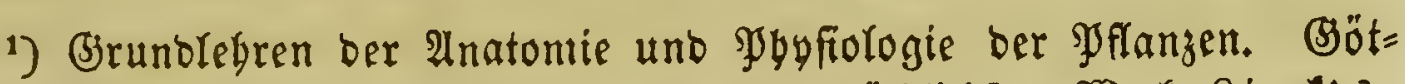

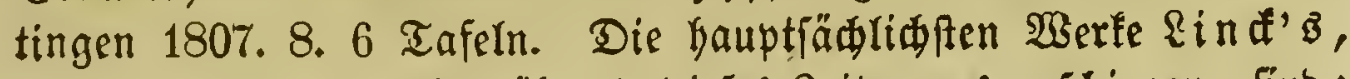
welde auperbent now wäbreno biefé Beitraumb erítienen, fint:

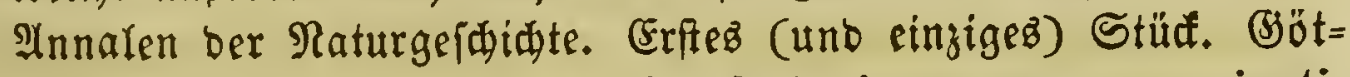
tingen 1791. 8. - Philosophiae botanicae novae seu institutionum phytographicarum prodromus. Göttingae 1798.

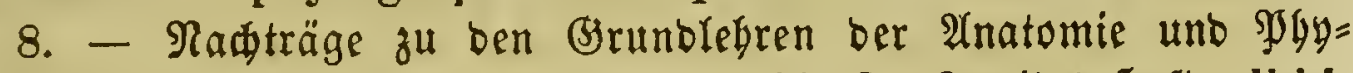
frologie ber Yfflaurzen. Büttingen 1809. 8. 3weitez Sefft. Ibid. 1812. - Rritifde Bemerfungen uno $3 u[a ̈ b e$ zu $\Re u r t ~ S p r e n=$

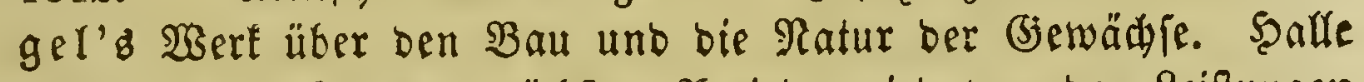
1812. 8. - Sn ber nädffen Seriode wirb yon ben Reiftungen biefez Bjeleyrten now öfterz bie Rebe fein.

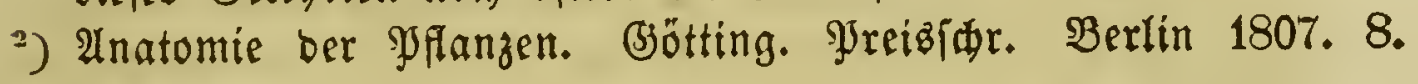
6 Tafelin.

3) Bom inmenbigen Bau ber Berwäble uno yon ber Saftbewegung in Denferben. Esine Sdurift, welder bie föniglide Societät ber

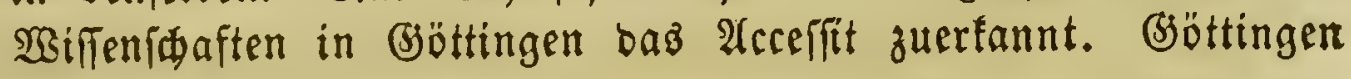
1806. 8. 2 Iafeln.

4) Bon ber Entwidelung bes Embryo unb feiner $\mathfrak{H m g}$ ällungen im Yjfanzenei. Berlin 1815. 4. 6 Tafeln. 2luperbem gab er in biefer Weriode now Geraus: Observationes, quibus stirpes quasdam germanicas illustrare conatus est. Rostockii 1812. 4 . 


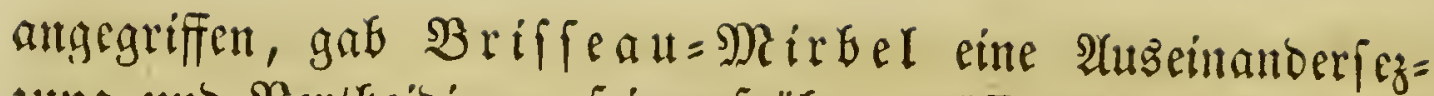

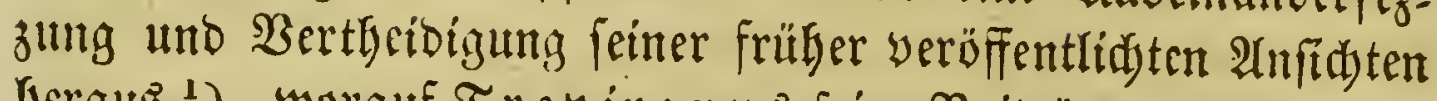

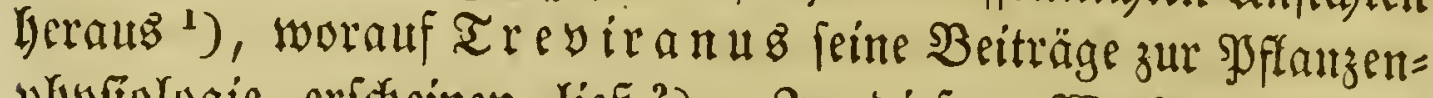

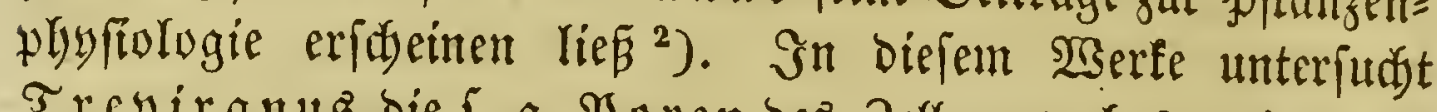
Treviranus bie f. g. Soren bes 3ellengewebes, mit benen er fid folon in feimer vorbin erwähntent Sdirift befdäftigt hatte; auth ift baffelbe nod) barum bejonbers bemerfenstwerth, wril barin zum eritemmale auf ben. Unterfated ber beiben Blattfläden aufmerffam gemadyt wirb. 3u berfelben 3eit

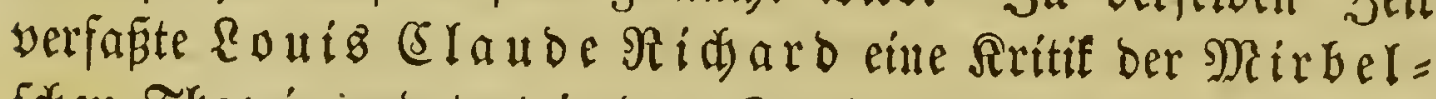
fdjen Iheorie und trat in bem Streite zwifden frinem \&anos= maune uno ben beutiden (Felegrten bezüglid mebrerer Fragen auf Die Seite ber Regteren. ${ }^{3}$ )

Jim folgenton Jahre erfodien bas für bie SPlamjentanatomie

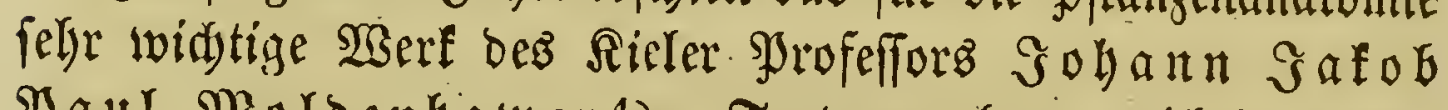

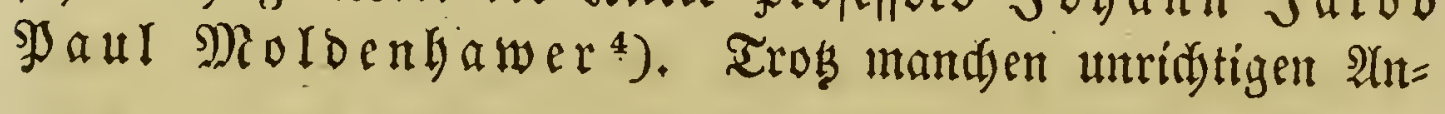

1) Exposition et défense de ma théorie de l'organisation végétale. Publiée pár le Dr. Bilderdyk. A la Haye 1808.' 8. 3 tab. - Zweite $\mathfrak{X}$ (uzgabe : Exposition de la théorie de l'organisation végétale servant de réponse aux questions propiosées en 180' par la société royale de Göttingue. Paris 1809. 8: 9 tab. - Bergleide aú beffen: Eléméns de physiologie végétale et de botanique. Paris 1815. 3 voll. 8. 72 tab. - Histoire naturelle générale et particulière des plantes; ouvrage faisant suite aux oeuvres de Leclerc de Buffon et partie de cours complet d'histoire naturelle rédigé par. C. S. Sonnini; continué par. N. Jolyclerc. Paris $1800-1806$. XVIII voll. 8. 142 tab.

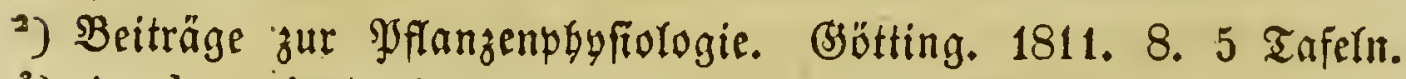

$\left.{ }^{3}\right)$ Analyse botanique des embryons endorhizes ou monocotylédonés, et particulièrement de celui des Graminées: suivie d'un examen critique sur quelques mémoires anatomico-physiologico-botaniques par Mir bel. Paris 1811. 4. 6 tab.

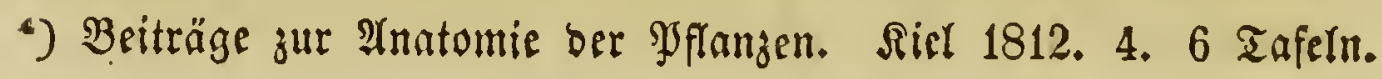


fideten ilber dic Spiralgcfäfic uno dic Spaltüfinungen hat Moldenhater burdi feine Unterfutdungen ber fibrüfent

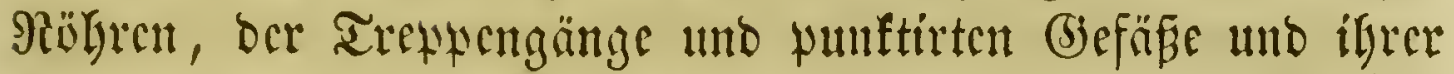
Entfelyung, fowie ber 3clfen bic Silf

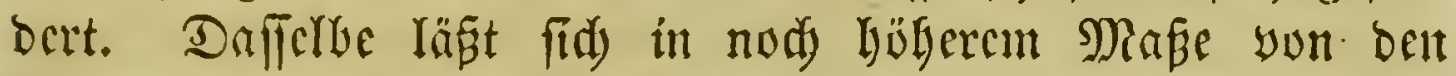
Eciftungen bes Jenner grofeffors Dictrid) (J) eorg $\mathbb{A}$ iefer Gehauptell ${ }^{1}$ ). Scinc yon ber Saramer Socictät gefrönte

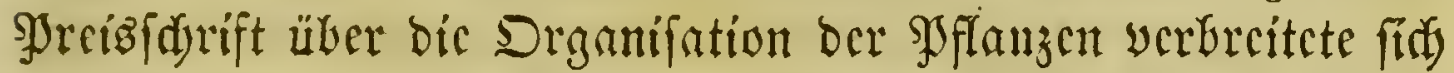
yolffäntoiger, alz $\mathfrak{c B}$ bishcr gejdychen war, über ben ganzent

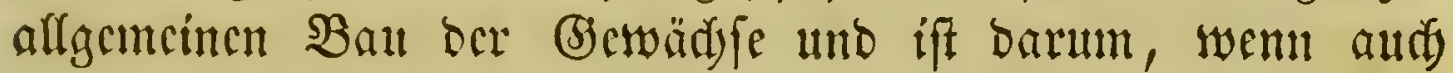

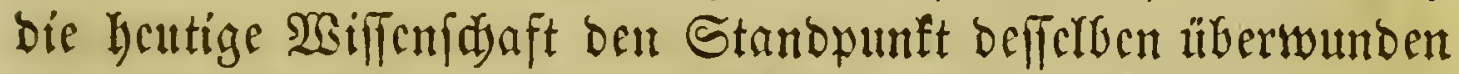
hat, für bic (befordidte der Sfflanzenanatonie von nidyt ge= ringer $\mathfrak{B}$ edcutung.

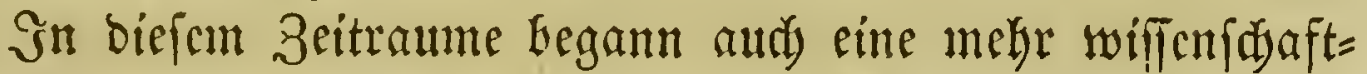

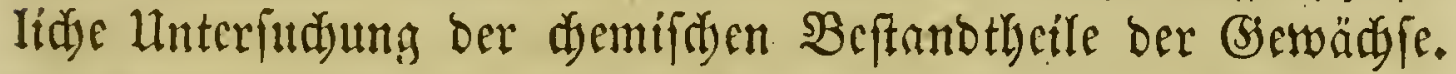
Inter bon (bielehrten, welde fid zuerft mit biefem 3iwcige ber Ratumiffenfdaften befdäftigten, if Theobor von Sau \{ fure zu nenten; er bielt fid indeffen nod ziemlid) allgemsin. ${ }^{2}$ )

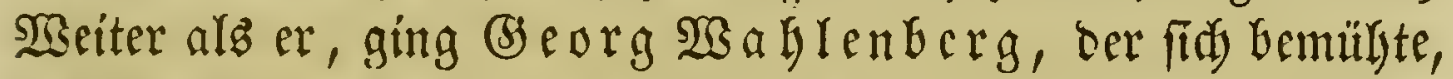
bas $\mathfrak{B o r b a n d e n j e i n ~ b e r ~ y e r f d i e b e n e n ~ d y e m i f d e n ~ B e f t a n d t h e i l e ~}$ in ben eingelnen Drganen nadysuwcifen uno bie Erzcugung Derfclben zu ergründen ${ }^{3}$ ), Uum biẹclbe Zeit zeigte ber $\cdot \mathfrak{B e r}=$ Jiner Srofeflor Siegmun Friebrid J̧ermbftäd, wie man bie \$oflanzen demifd zergliebern fönne, uno wies in fei=

1) Mémoire sur l'organisation des plantes, qui a remporté le prix en 1812. Harlem 1812. 4. 22 tab. - Bergleiđe aud beffen: Apborismen auz ber SJgyfiologie ber SPflanzen. (S)öttingen 1808. 8. - Grunbzüge ber Ânatomie ber SJflanzen. Sena 1815. 8. 6 zafeln.

2) Recherches chimiques sur la végétation. Paris 1804. 4. 16 schemata. 1 tab. - Deutid von Friebrid Sigmuno

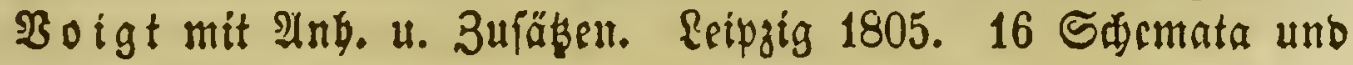
1 זafel.

3) De sedibus materiarum immediatarum in plantis tractatis. Upsaliae 1806-1807. 4. 


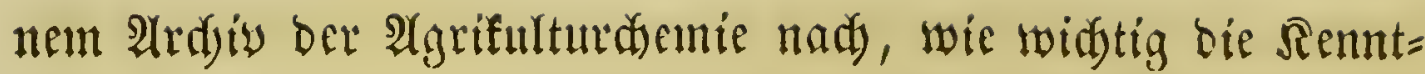
nif ber damilden Beftandtheile ber (Setwäd) fe für bie Rand=

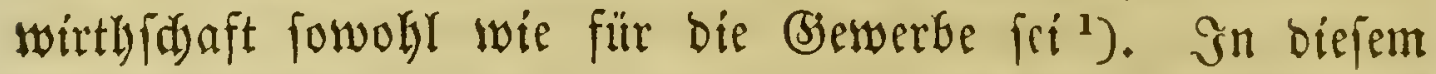

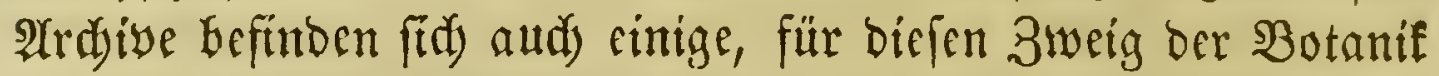

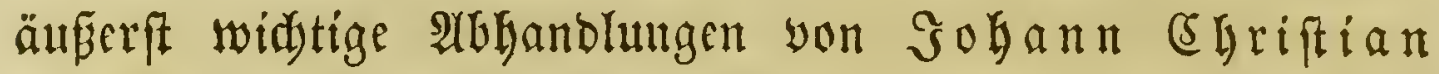

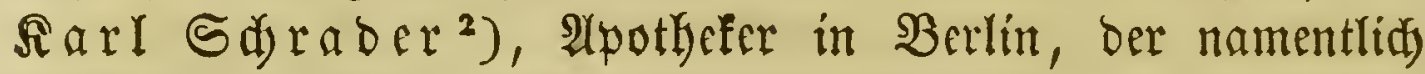

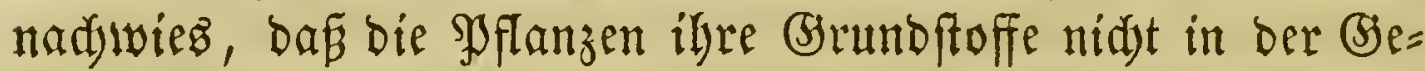
ftalt, wie fie biefelben nüthig haben, aus bem Boben auf $=$ faugen, fondern biefelben aus den sirementarftoffen felbit, mittelit Cinwirfung des Sonnenlidts, in fid exzeugen, und

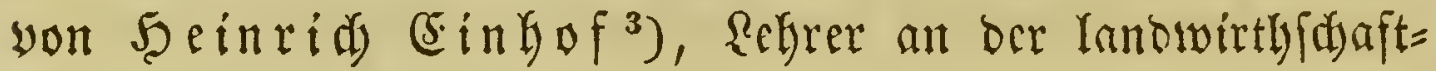
rifuen Sidule zu Möggelin, geftorben 1810, ber über bie in

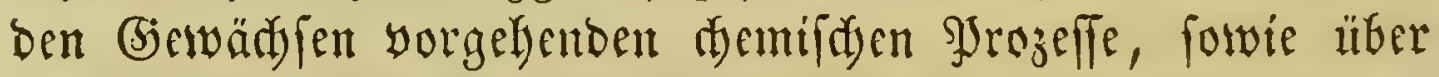

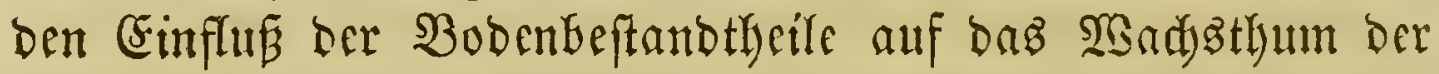
SPflanzen intereffante Mittbeilungen madyte, - Mit ber praf=

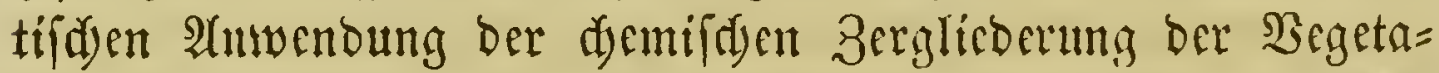
Gilien berdätigte fid namentlid) aud ber englijas (Shemifer

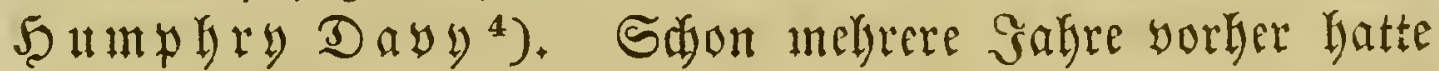

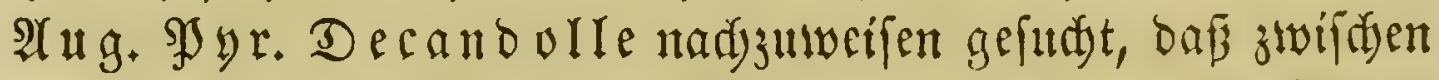
ben auf geviffen Beftandtheilen ber gpflanzen berulyenden

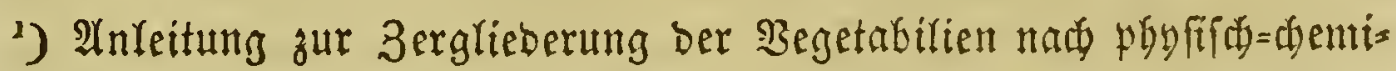

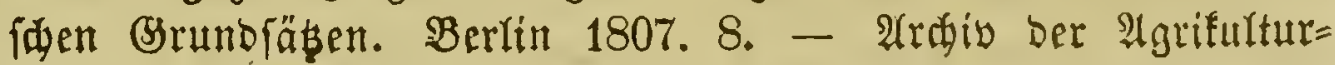
(5Gentic. Berlin 1803. 6 Thle. - פriagel erwäbnt bicie

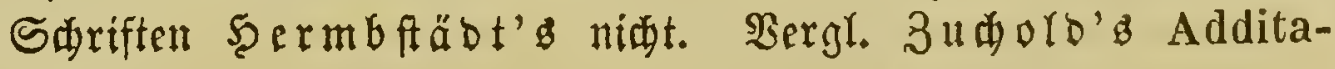
menta S. 21, 22.

2) Ardiv, $\mathfrak{B b}$. 1, S. 85 ff.; Bb. II, S. 189 ff.

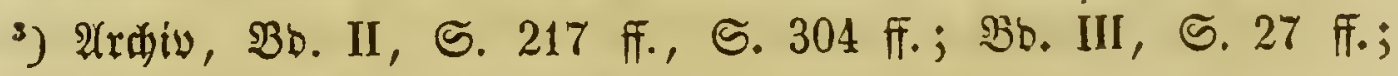
SB.. IV, S. 1 ff., S. 275 ff.

-) Elements of agricultural chemistry, in a course of lectures for the board of agriculture. Lond. 1813. 4. 10 tab. with an Appendix : Account of the results of experiments on the produce and nutritive qualities of different grasses and other plants, used as the food of animals, instituted by John Duke of Bedford. - New edit. with notes by Dr. Jolın Davy. London 1839. S. 
Seilfräften uno ber natürliden Berwandfidjaft mebr ober minber cine werbärtnifmäpige Uebereinftimumung herride ${ }^{1}$ ); cine genauere Aubfülyrung bicfer. Anfirdst wurbe jedod) erft fpäterlin von $\mathfrak{F r}$. $\Re u n g e$ gegeben, deflen wir in ber fol=

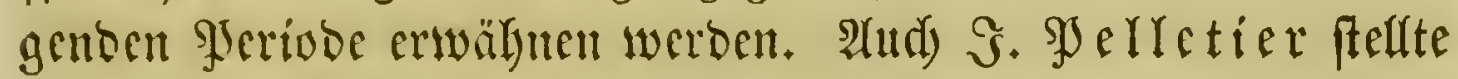

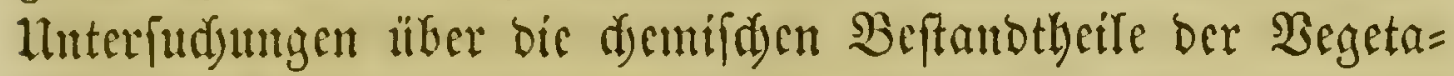
bilien an. ${ }^{2}$ )

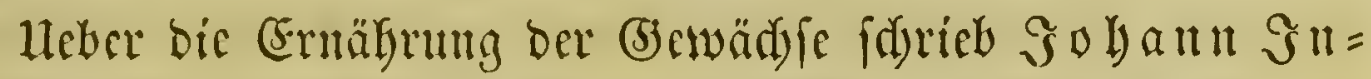
genloun

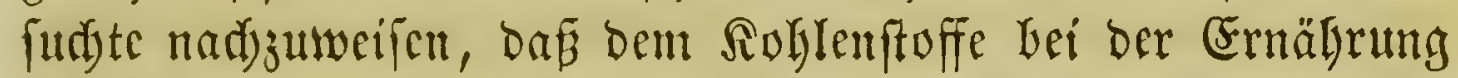
Der Şflanjen Der widjtigfte ântheil gebübre, ftellte jebods nid)t in H(brcoc, onf Stiffituff und andere, namentlicis fal= zige, eroige uno metallifde Subftanzen zum Fortfummen ber

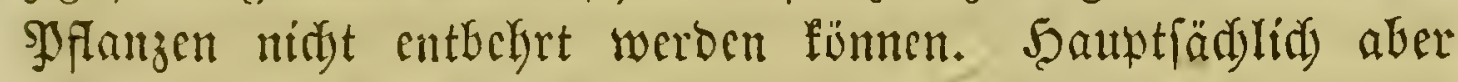
mad)te er fid burd bie Almwendung feiner Forjdjungen alf bie Ranbwirthfdaft, namentlid) auf bie Berbefferung bes $\mathfrak{B o b e n s}$ werbient. Die unten angeführte Sdjrift diefes Gelegrten wurbe won (5) ot thelf Fifder überfest und von $\mathfrak{F}$. 2 . yon Sambold mit eincr Einleitung verfehen, worin biefer fpä= ter fo berüfmte Forfder burd Dargeftellte $\mathfrak{B e r j u d y e ~ z u ~ b e g r u ̈ n = ~}$

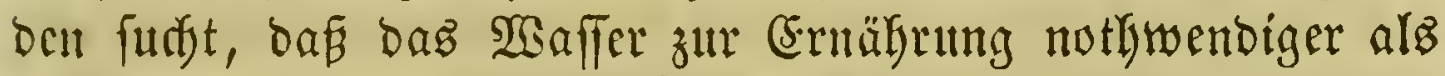

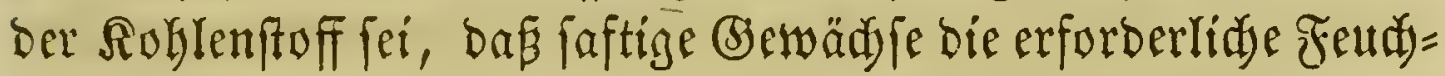

1) Essai sur les propriétés médicales des plantes comparées avec leur classification naturelle. Paris $1804.4 .-2^{\circ}$ éd.

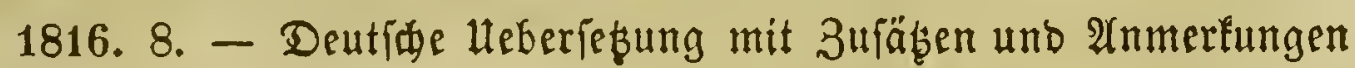
begleitet yon $\Re$. J. YJorlet. Aarau 1818. 8.

${ }^{2}$ ) Essai sur la nature des substances connues sous le nom de gommes résines. Thèse. Paris 1812. 4.

3) Proeve over het Voedzel der Planten, en de vrugtbaarmaking van Landereijen. Uit het engelsch vertaald door J. va n B reda. Deft 1796. 8. - Deutí : Heber Ernäbrung

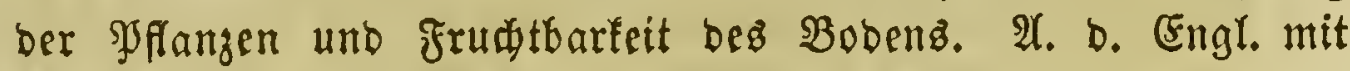
Ammerfungen yon (B) ottberf Fifder. Rebft einer Cinteitung über cintige Begenftände ber şflangenpgyfioloğie von $\mathfrak{F}$. $\mathfrak{A}$. yon scumborst. Seipzig 1798. 8. 


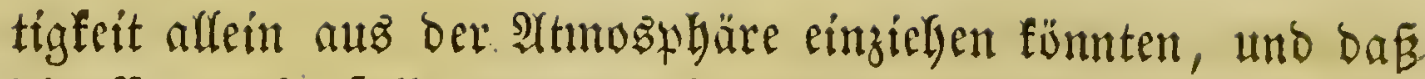
die Croe ebenfalls zu ben eigentlidsen Rahrutgsimitteln ber (Gewädje zu zählen fei; überbaupt bürfe man bei ber phy = frologifden Betradytumg der Sflanzen nidyt cinjeitig verfakren,

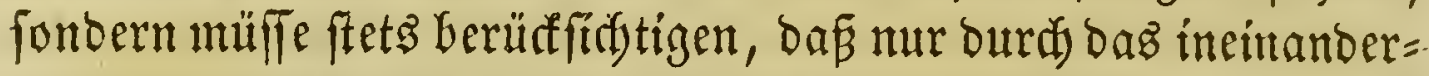
greifende 3ufammenwirfen vieler Sräfte unb Beftandtheíle bas Reben ber SJflanje erzeugt und erbalten werbe. 2lud (5) ottfr.

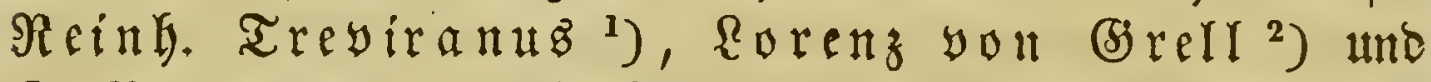
S马. $\mathfrak{B}$ raconnot ${ }^{3}$ ) Gefdäftigten fid mit lunterfudungen über bie Srnährung der Pflanzen. Die biz bahin gemadten $\mathfrak{B e o}=$ Gartungen ïber diefe Materie ftelte CEriftian Friebrid Sarles im 3ufammentange bar. ${ }^{4}$ )

Wie bie S. 212 genannten (Belegrten judte jest aud Rarl (S) ottlob $\Re a \mathfrak{f n}^{5}$ ), Srofeffor in Ropentagen, bie Nothwendigfeit tes Sauterftoffz für bie Erhaltung ber (bie= wäd) barzuthun; aud yerbreitete er fid über bie șidtigfeit bes Ridjtes und wies ben Einflus einiger giftigen Stoffe auf

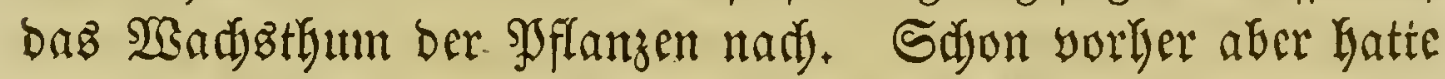

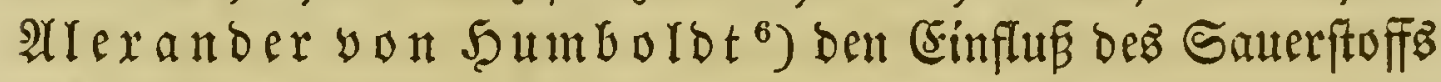
auf bas Reimen ber Samen madgemiefen uno $̧ o h a n n$

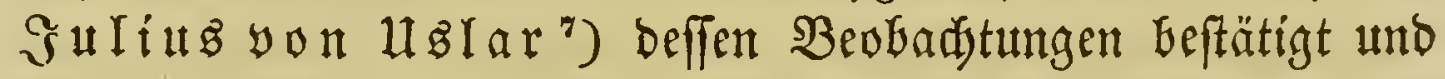

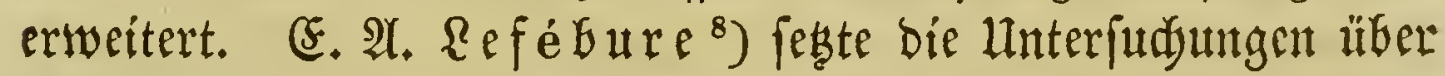
biejen (s)egenfand fort, and Franz Şuber tmo Geat

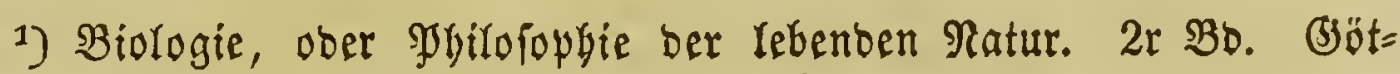
tingen 1803. 8. S. $31-137$.

2) (5) ebrenz Journat. BB. 9. S. 100.

3) Ranowirtbidaftide 3eitidrift. 1811. S. 13.

4) Opuscula academica. Lipsiae 1815. 8.

5) Danmarks og Holsteins Flora, D. I. 1796. 8.

') Magas. encyclop. 6 p. 462 ff. - $\mathfrak{A}$ (plyorisimen aus ber denti= fien Jjgyfiologie ber Syflanzen. Reipzig 1794. 8.

7) Fragmente neuerer Sfflanzenfunde. Braunidw. 1794. 8.

3) Expériences sur la germination des plantes. Strasbourg an IX. (1801.) 8. 


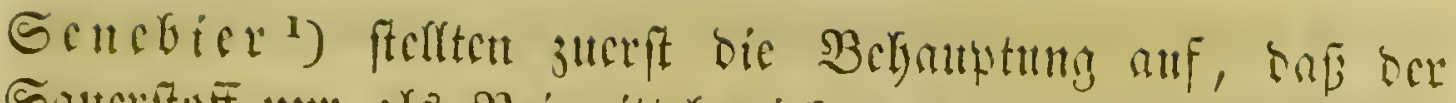

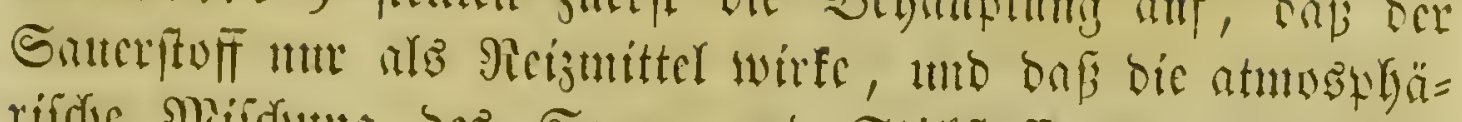

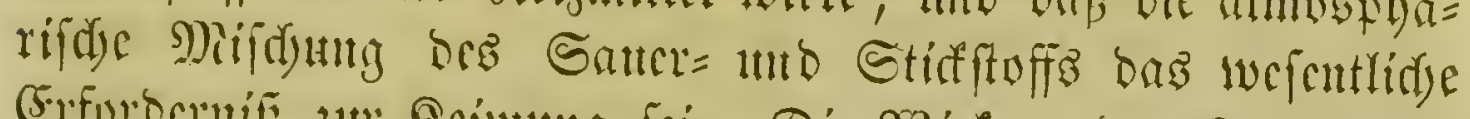

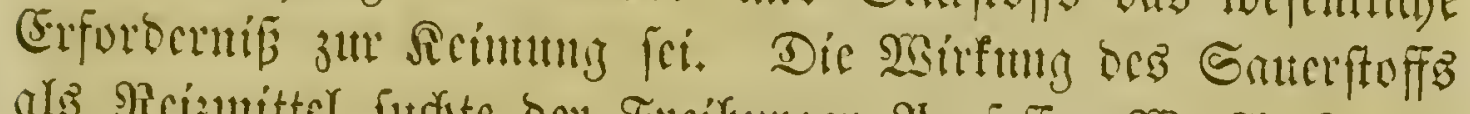

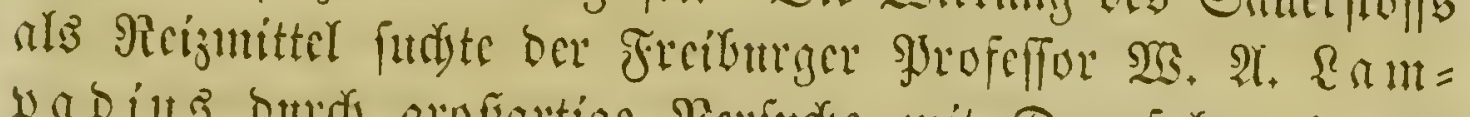

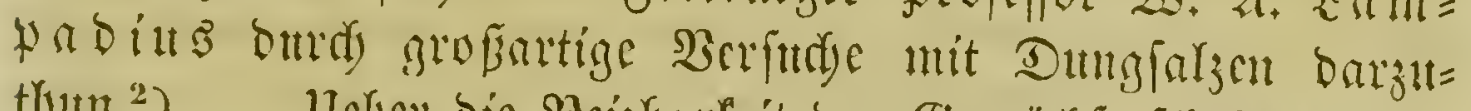

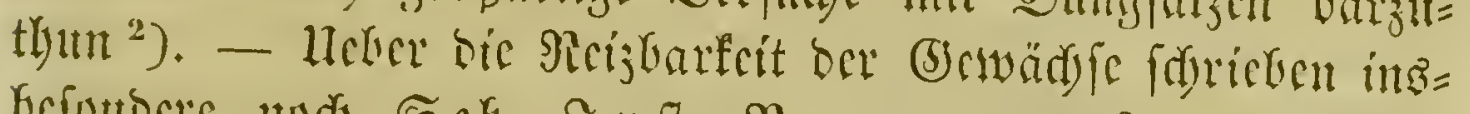

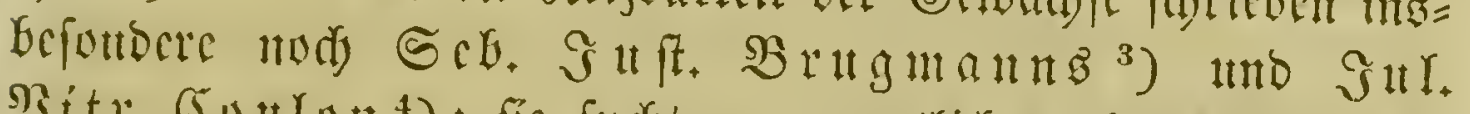
Bitu. (5otlon ${ }^{4}$ ); fie futden namentlidy nadyztwecifon, Saf

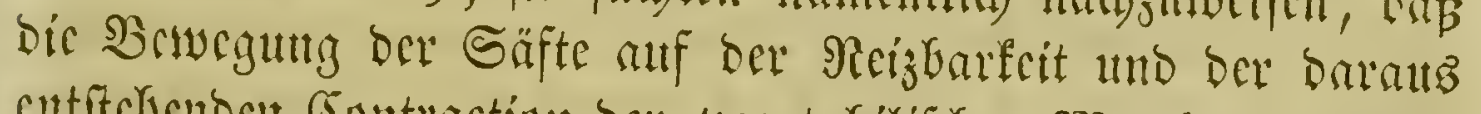

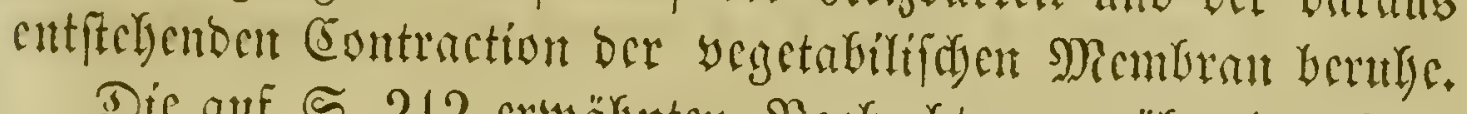

Die anf S. 212 crwäbnten Bcobadytungen liber bon Eint

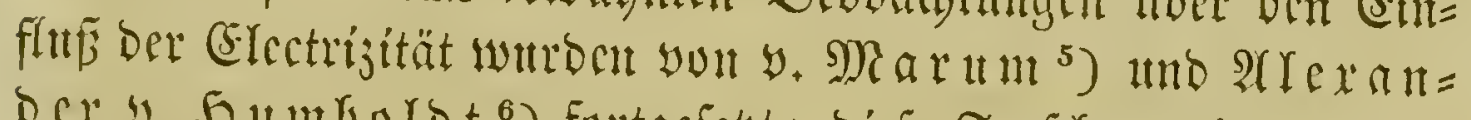

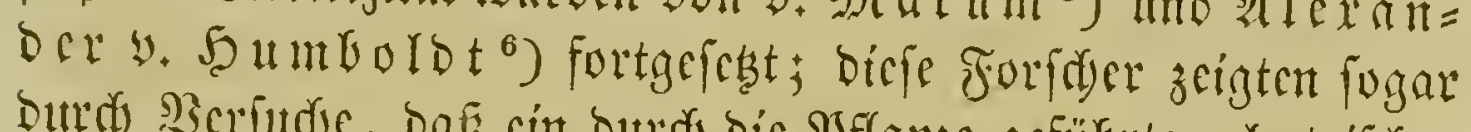

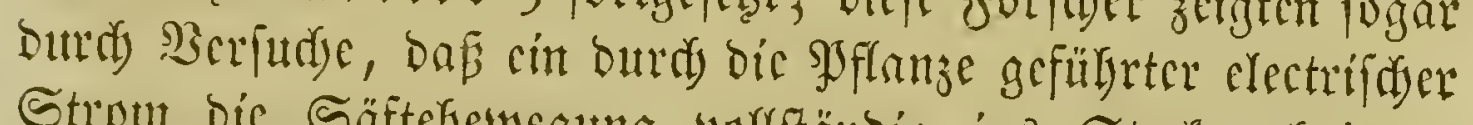
Strom bic Safteberwegung youftändig ins Stoden bringen füunte. - Dic Sacwegung ocr Spflanzenfäfte madjte Frans

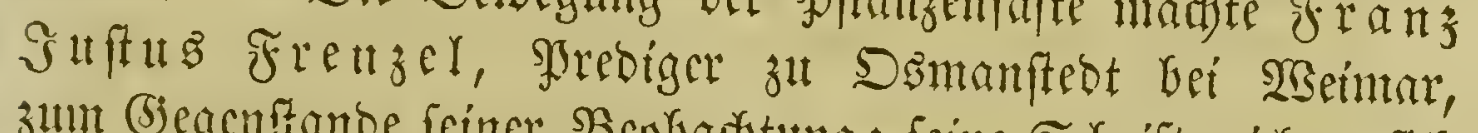

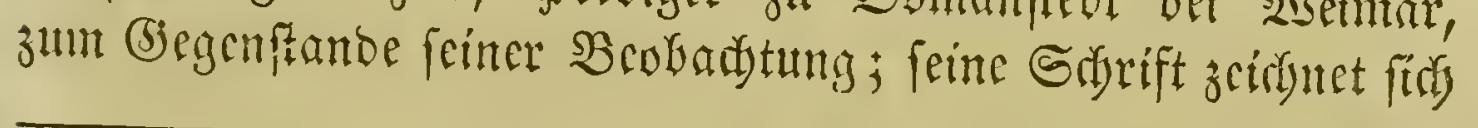

1) François Huber et Jean Senebier, Mémoires sur l'influence de l'air et de diverses substances gazeuses dans la germination de différentes graines. Genève 1801.

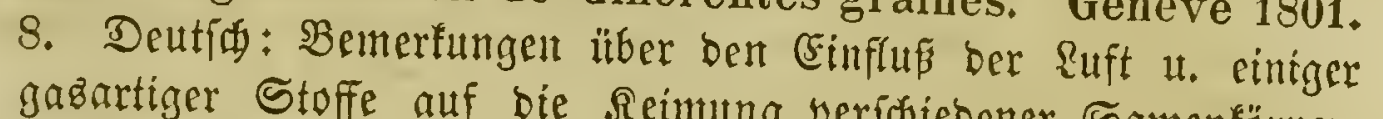
gazartiger Stofe auf bie Reimung veridiebener Samenförner.
Sannover 1805.8 .

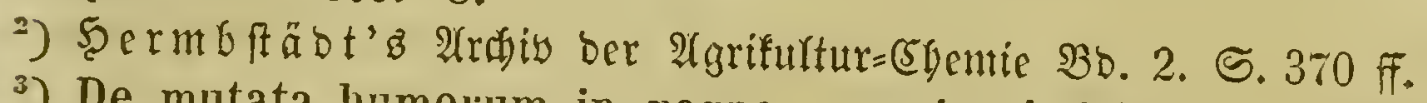

$\left.{ }^{3}\right)$ De mutata humorum in regno organico indole a vi vitali vasorum derivanda. Lugd. Batav, 1789. 8.

4) De mutata humorum in regno organico indole. Lugduni Batav. 1789. 8.

5) Lettre de Mr. van Marum à Mr. Ingenhousz contenant des expériences sur l'action des vaissaux des plantes etc. (Journ. de physique de Mr. Lametherie pour l'année 1792.)

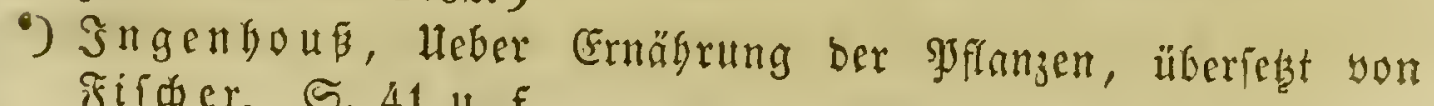
Fifder. S. 41 u. f. 


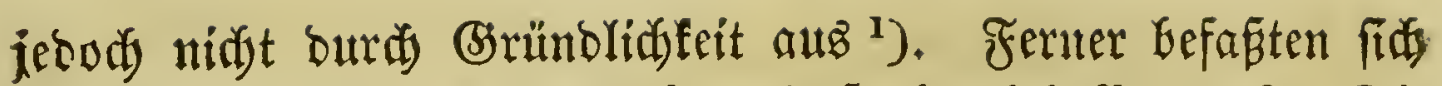

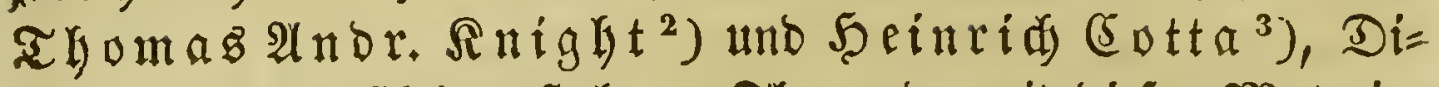
rector ber Forftlelyranftalt zu Tharand, mit biefer Materie;

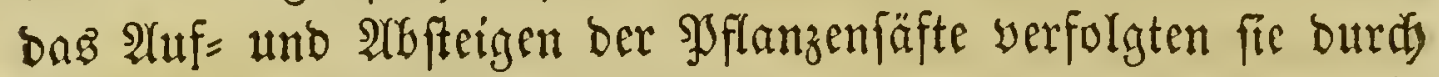
bie Anwendung gefärbter Flüffigfeiten; audi madten fie widh= tige Bedbadjtungen über bie Entftelyung bes Splintes, ber

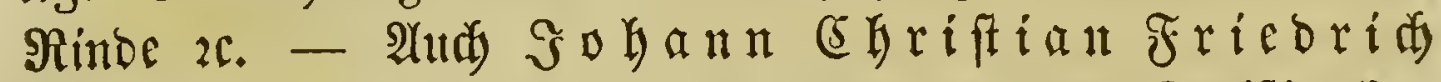
Meyer ${ }^{4}$ ), Eefrer an ber Forftlebranftalt zu Dreifigader, $\mathfrak{A}, \mathfrak{A} \mathfrak{u} \mathfrak{b} \mathfrak{i} t$ bu $\mathfrak{g}$ et $\mathfrak{i t}=\mathfrak{T} \mathfrak{L} \mathfrak{o} \mathfrak{a} \mathfrak{a} \mathfrak{b}^{5}$ ), eine 3eitlang Snfanteriebauptmann, fpäter Dírector ber finigliden $\mathfrak{B} a u m=$

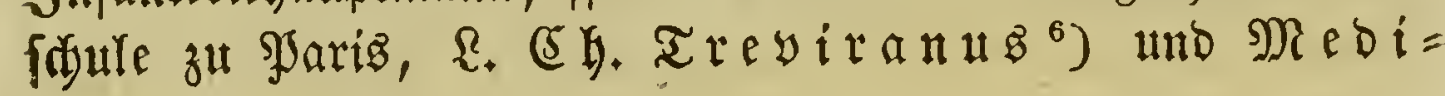

1) Shyfrologifwe Beobawtungen über ben Itmlanf bes Saftz in

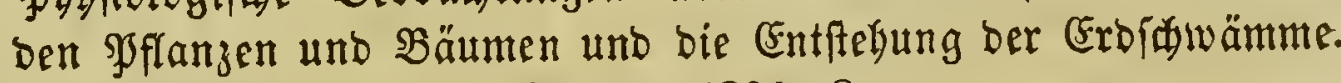
Jjeizfđar. 2A. b. Rat. Weimar 1804. 8.

2) Philos. transact. 1801. p. 33 ff. -1803 . p. 277 ff. -1804. p. 183 ff. -1805. p. 88 fi. 257 fi. -1806 . p. 99 ff. 293 ff.

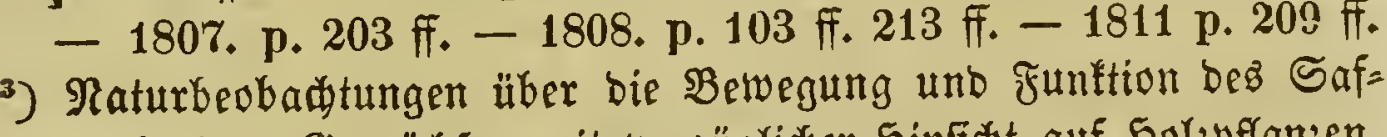

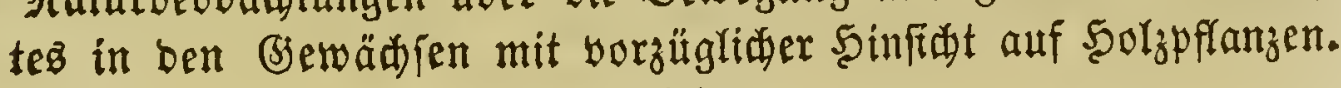
Weimar 1806. 4. 7 folor. Tafelm.

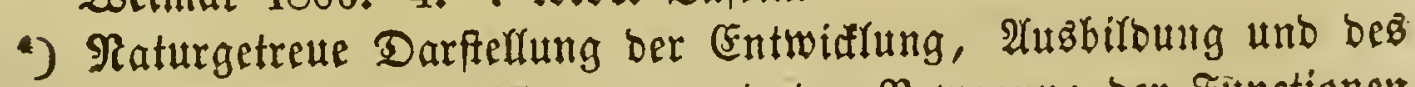
Wadattums ber Yjfanzen, unb ber Bewegung ber Füunctioner

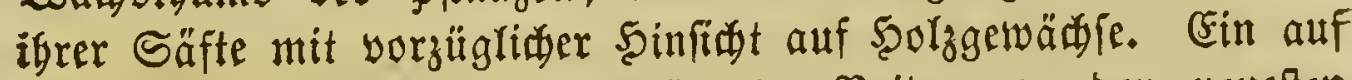

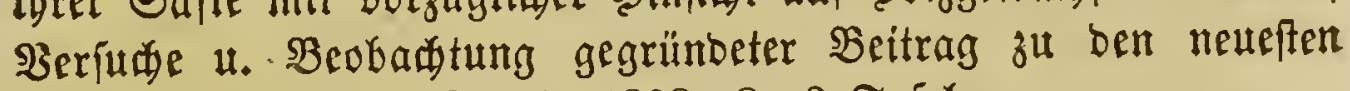
2̂nfidten Gierüber. Reipzig 1808. 8. 2 Tafeln.

5) Essais sur l'organisation des plantes, considérée comme résultat du cours annuel de la végétation. Paris 1806. 8. - Mélanges de botanique et des voyages. Premier recueil. Paris 1811. 8. 1 carte. 18 tab. - Essai sur la vẻgétatiou considérée dans le développement des bourgeons. Paris 1809. 8. 2 tab. - Histoire d'un morceau de bois, précédée d'un essai sur la sève considérée comme résultat de la végétation; et de plusieurs autres morceaux tendant à confirmer la théorie de physiologie végétale. Paris 1815. 1 tab.

-) Som inwendigen Bat ber (becwảdje unb von ber Saftbetweguta in benfectbert. Büttingen 1806. 8. 2 Taf. 


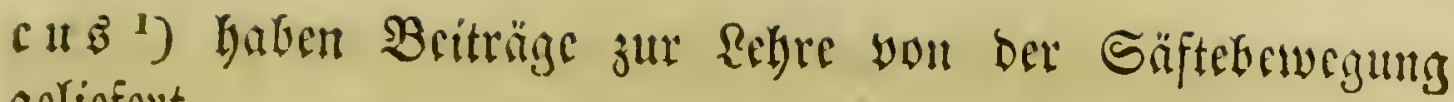
geliefert.

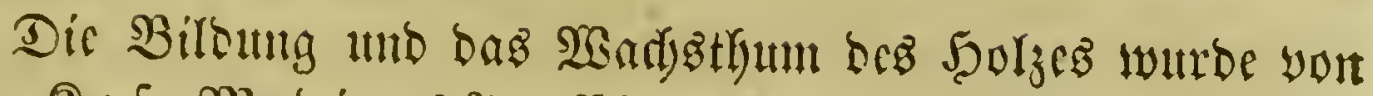

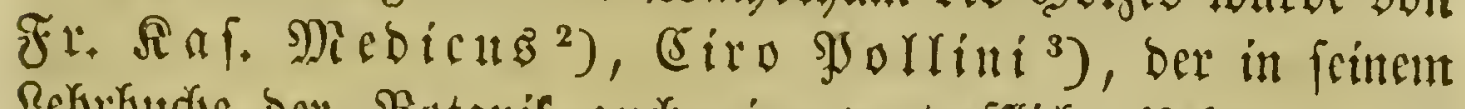
Reflebudje ber Botanif audi cine yortrefflide laberfictst ber

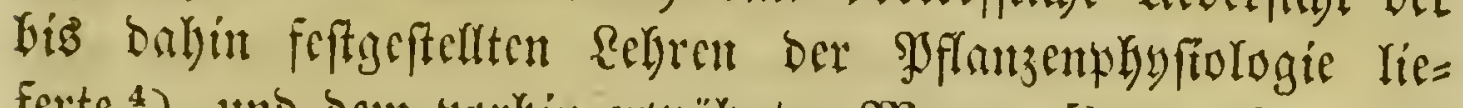

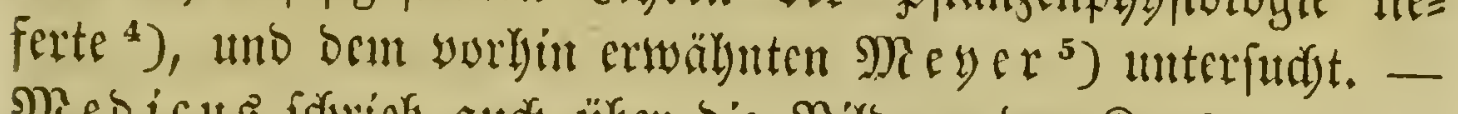
Me

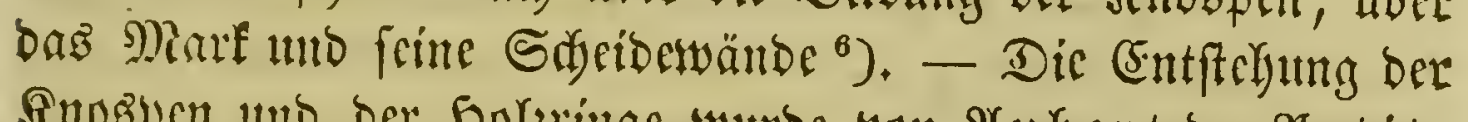

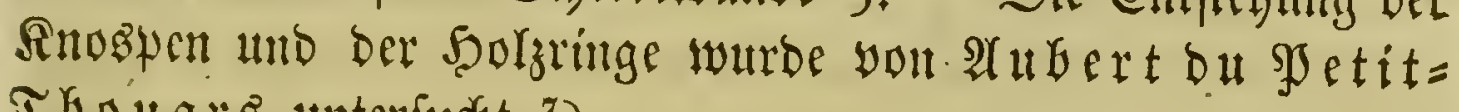
Thouar unterfudft. $^{7}$ )

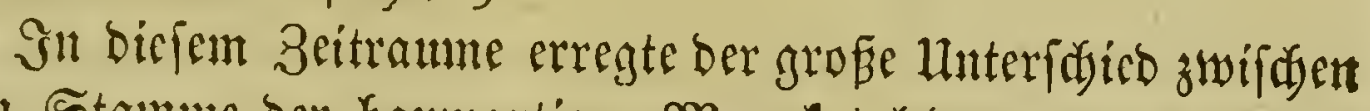
bem Strmume ber Gaumartigen Monofotylcoonen und Difoty=

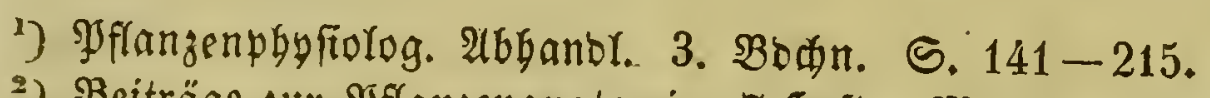

2) Beiträge zur \$fFanzenanatomie. 7 Sefte. Mannt. 1799-1801. 8.

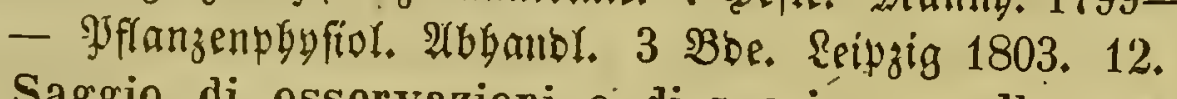
3) Saggio di osservazioni e di sperienze sulla vegetazione
degli alberi. Verona 1815. 8 .

4) Elementi di botanica compilati. Verona 1810-1811. II voll. 8. 20 tab.

5) ธ. vben ธ. 290 .

$\left.{ }^{6}\right)$ S. when Rote 2.

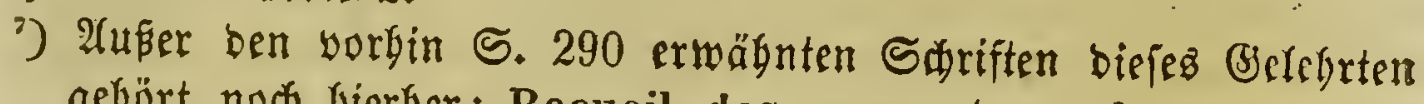
gegört now Gierger: Recueil des rapports et des mémoires sur la culture des arbres fruitiers, lus dans les séances particulières de la société d'agriculture de Paris. Paris 1815. 8. 8 tab. - Bibliothèque chronologique. VII. p. Sn ber folgenben अeriobe erífienen nod: Revue générale des matériaux de botanique et autres, fruit de 35 années d'observations, dont dix passées sous les tropiques; servant de prospectus pour les ouvrages qu'il est prêt $\dot{a}$ publier et qu'il propose par souscription et d'annonce pour ceux qu'il a publiẻs devant seize ans quill est de retour en Europe. Paris 1819. 8. - Cours de phytologie, ou de botanique générale. Première séance. Paris 1819. 8. - Seconde séance: Phytognomie. Paris 1820. 8. 


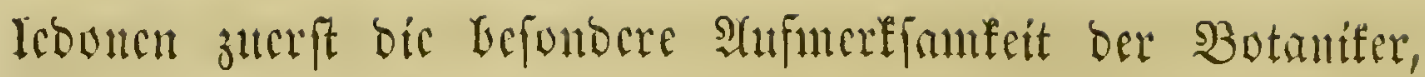

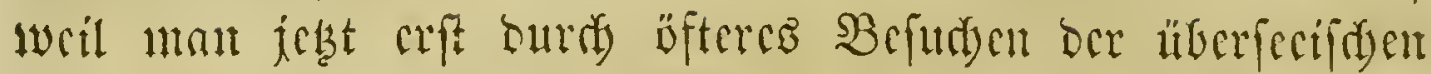
Ränock mit ben grüferen Monofotylebonenarten gemuler be=

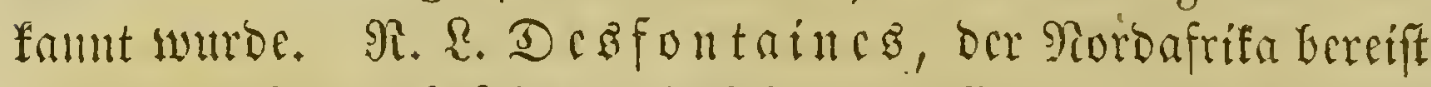

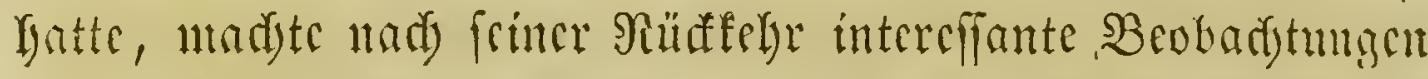

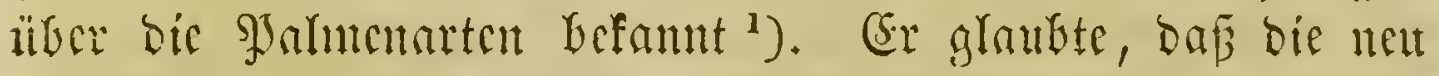
cntfifandoucn Fafern burd) bic Mitte bre Stanumes burdjzögen

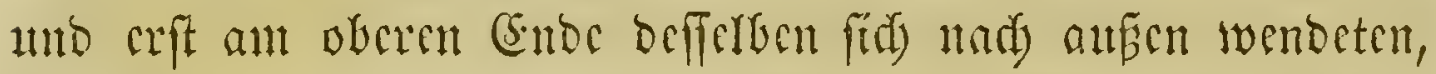
fo bafí bie mit ifnen in Servindung ftehenten Blätter anf ber

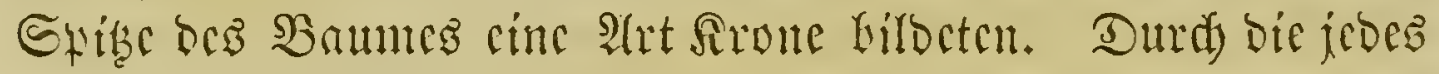

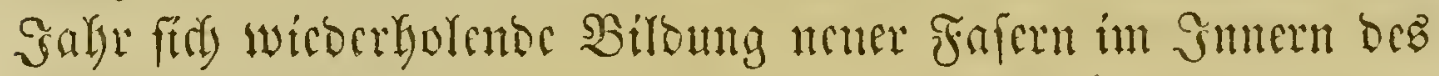

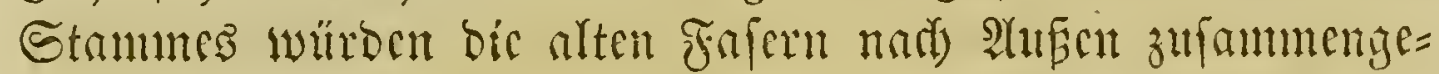
brängt, woraus bic größ̄ere (5)corängtheit berfellocn nady ber

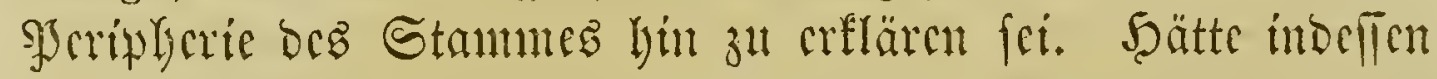

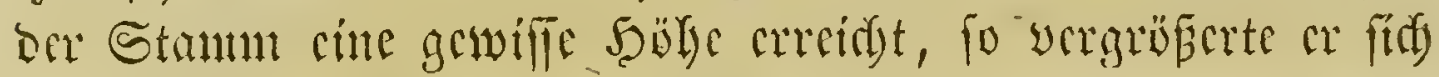
nidjt mefre in bie Diffe, fondern mut in bic Şöhe, amb bafer

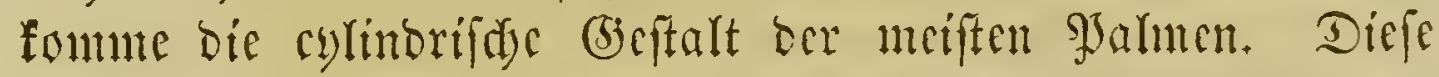
Ilyerie wurbe faft alfgemcin angenomum, mo felbit ars

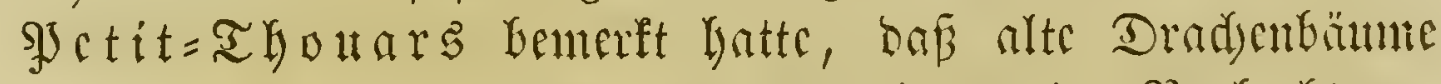

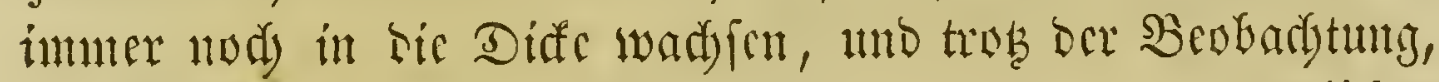

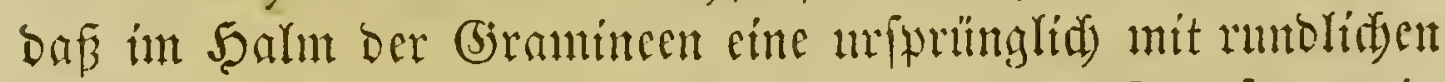

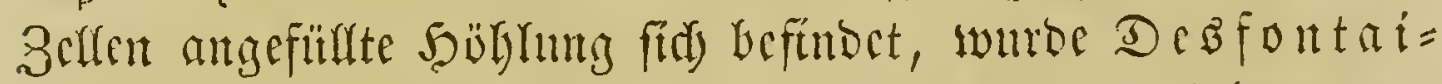

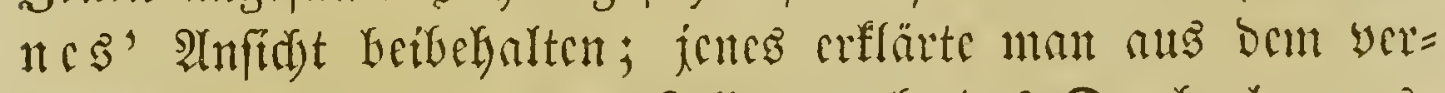

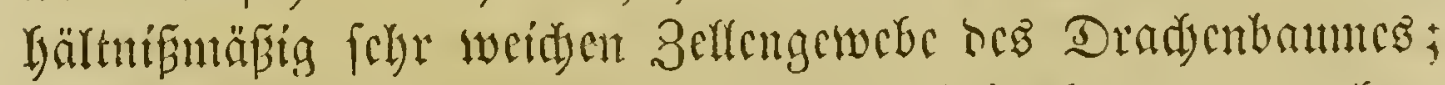

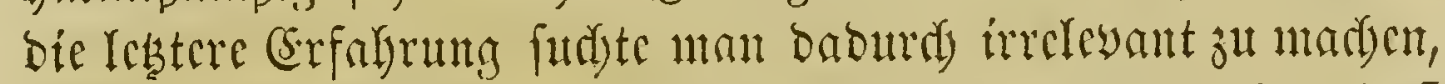

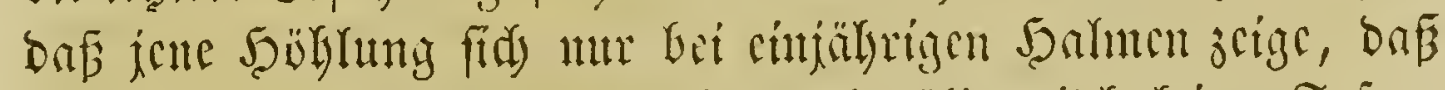
bei perentrircuben bagegen biefelbe aflutälig mit lyoljigen Fafert

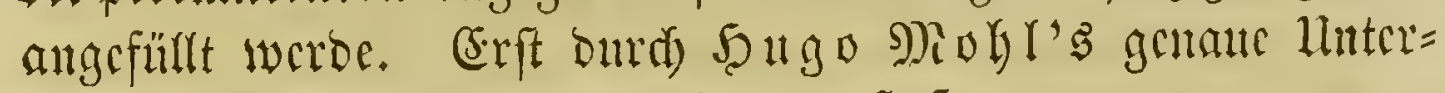
fitd)ungen warbe jenc Theoric umgeftefen.

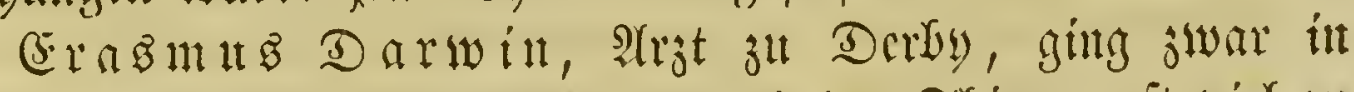

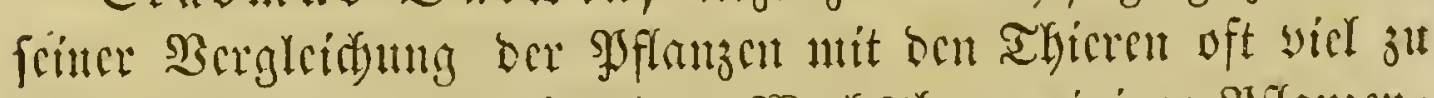

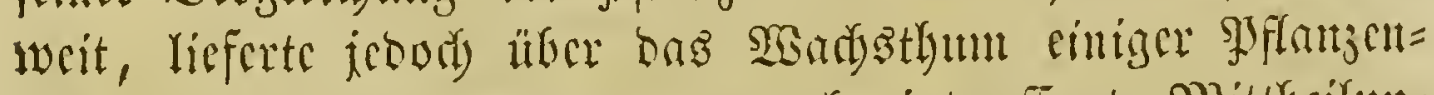

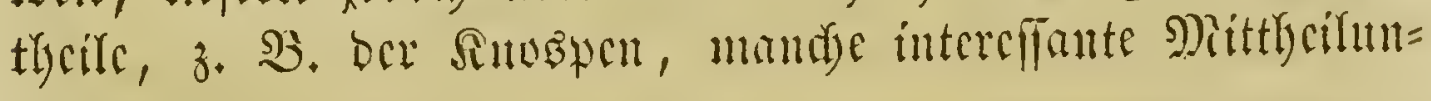

1) Mém. de l'inst. sc. phys. et math. I. p. 478. 


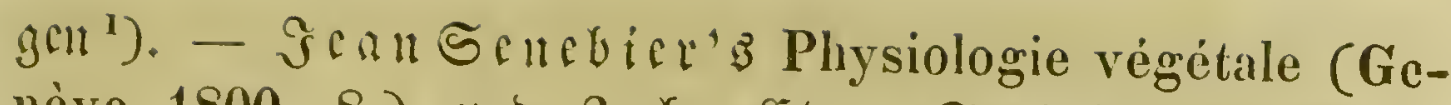

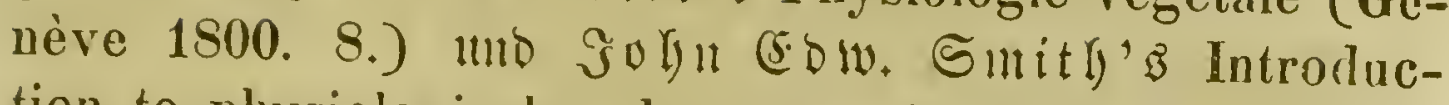
tion to physiological and systematical botany (London

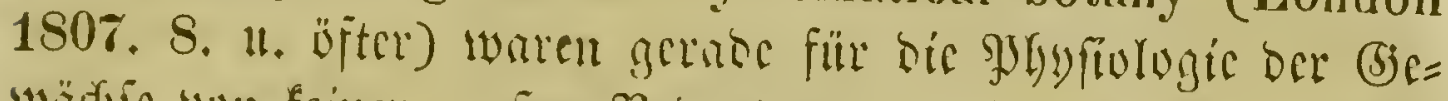

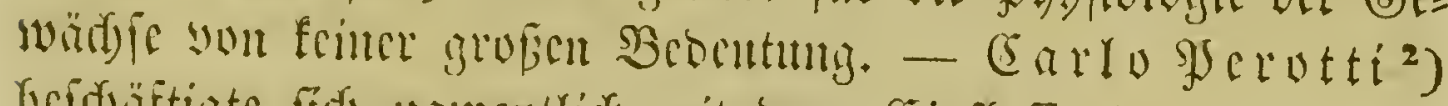

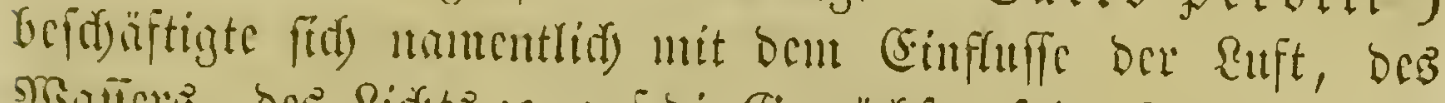

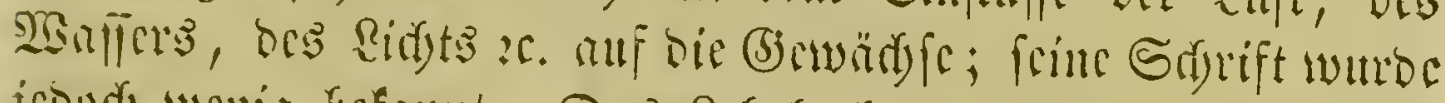

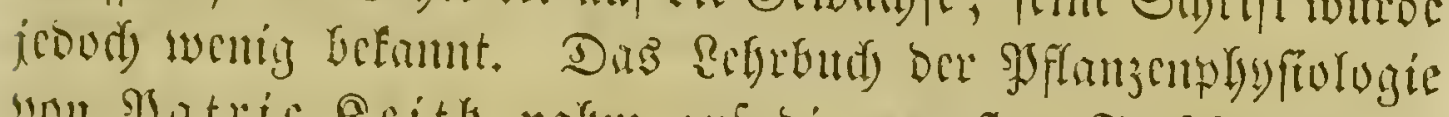

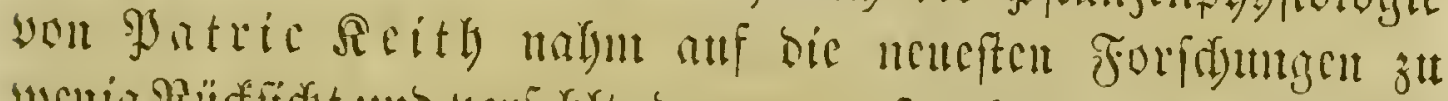

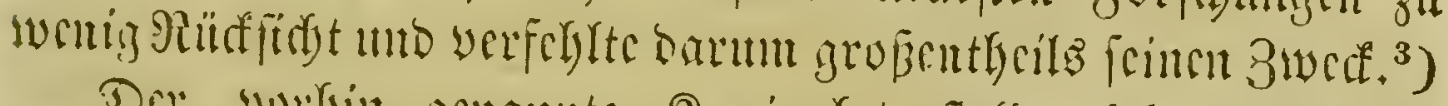

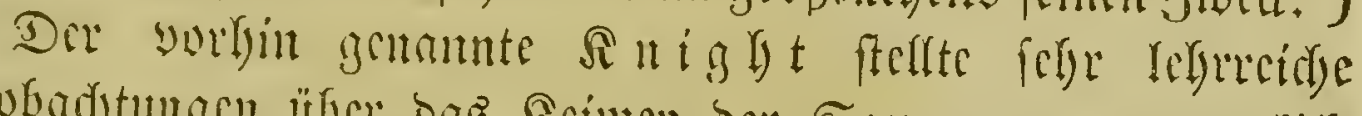

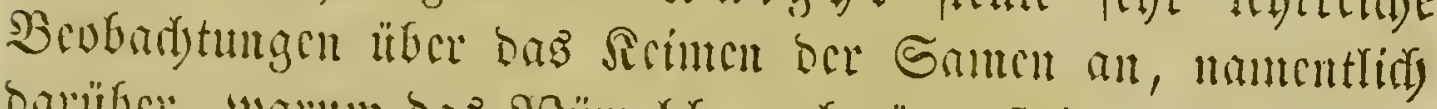

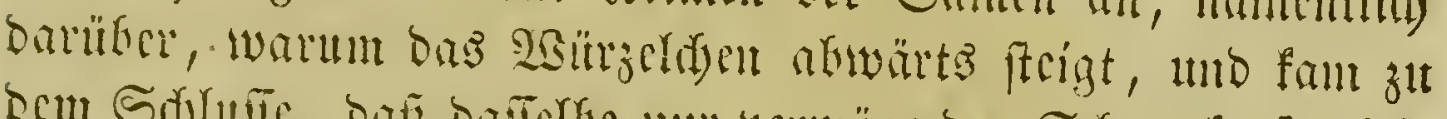

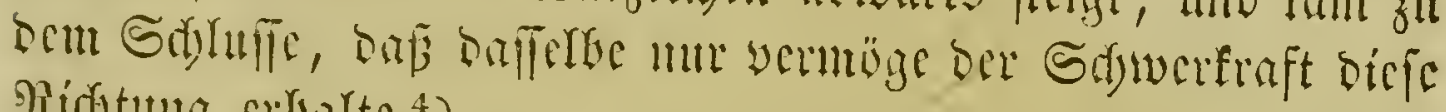
Ridutung crigaltc. ${ }^{4}$ )

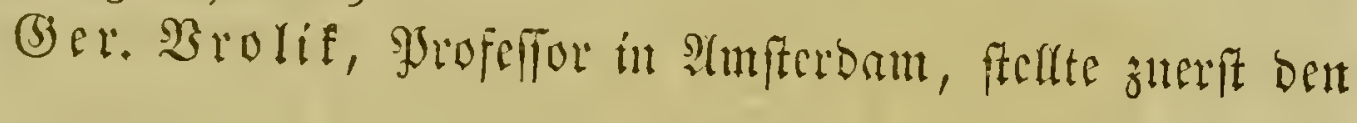

1) Phytologia or the philosophy of agriculture and gardening. London 1500. 4. 12 tab. - Deutfit: won Dr. 5eben= freit. Eeipjig 1801. 2 Boe. 8. 6 Tafeln. Sergl. aud Deffen: Zoonomia or the laws of organic life. Ed. II. corrected with plates. London 1796. II voll. 4. - Deutid): 5aan= irover $179 \vec{\jmath}-1799.3$ Bjoe. 8.

$\left.{ }^{2}\right)$ Fisiologia deíle piante etc. (Barge) 1810. 2 voll. 8. Bergl. aud befien: Observations physiques sur les inconvénients de plantêr des arbres fruitiers dans les prairies et de la meilleure manière de les tailler et des avantages de cette opération; ouvrage rédigé d'après l'état actuel des connaissances de physique et de physiologie végétale. Seconde édition revue et augmentée par l'auteur. Carmagnole 1812. 8.

3) A system of p!lysiological hotany; illustrated by nine engravings. London 1816. II voll. 8. 9 tab.

4) Philos. transact. 1806. vol. I. pag. $99-108$. Borgl. and)

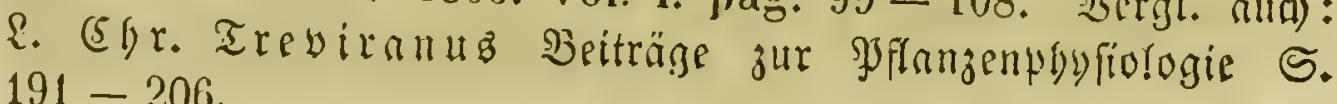
$191-206$. 


\section{4}

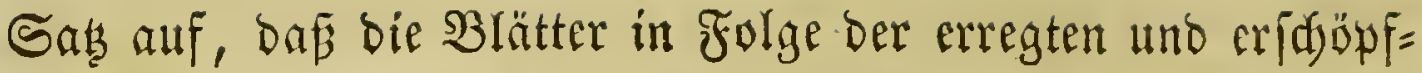
ten $\Re$ eizbarkeit auşdylügen unto abfielen. ${ }^{1}$ )

Heber die Funftionen ber Spaltöfnumgen, namentlidy über

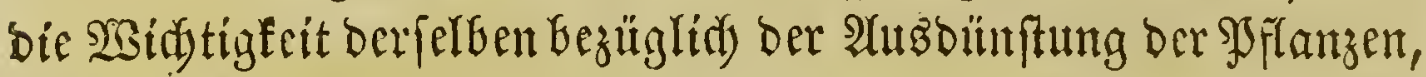
fdrieb Rubolf Ehriftian Treviranub.

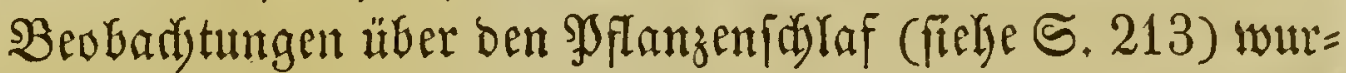

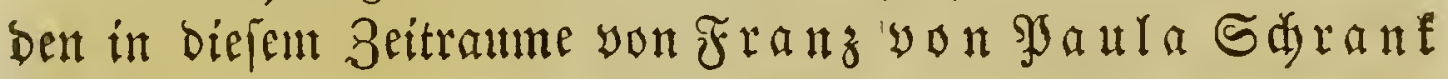
angejteldt. ${ }^{3}$ )

Der Streit über die Sexuarien und beren Funttionen in ber yorigen socriobe fo ziemlid zu ende gefullyrt worben, wbgleidi) wir bamit feineswegs belaupten wolfen, bas biejer Segenftand foon bamals gans ins Rlare gefradjt worben

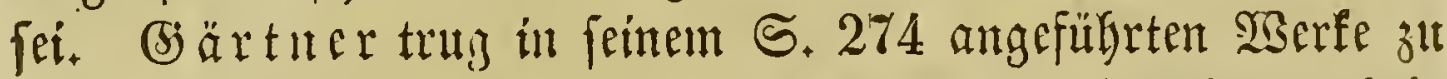

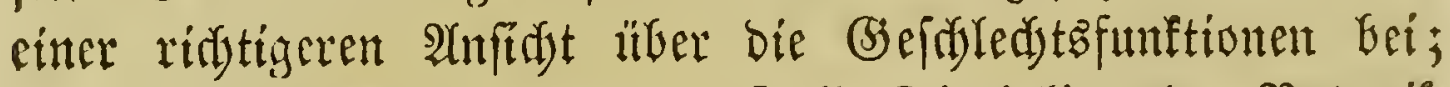
überhaupt wirte biefes Wert auf alle Dißsciplinen ber Botanif

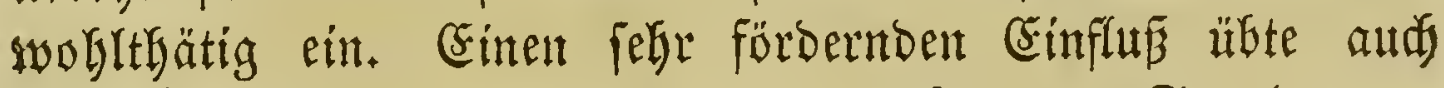

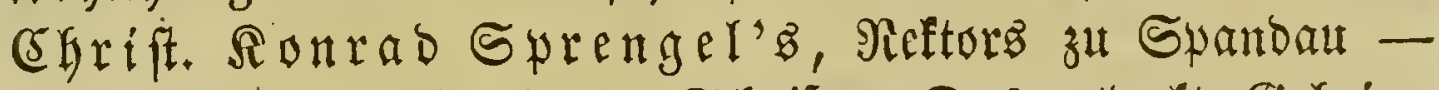
fwäter lebte er in Berlin - Sarift: "Das entbefte (sebeim=

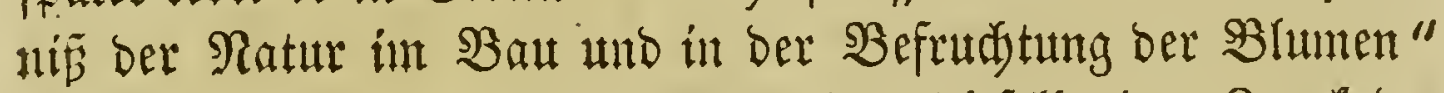
auf bieic Regre ausi ; namentlid flärte biejelbe ben 3 wed ber Seftarien auf unb zeigte, bas im Falle einter Didsugamie bie

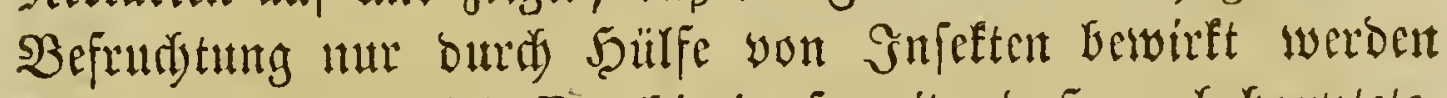
lünne. (5r ging indeffen bierin joweit, baj er behauptete,

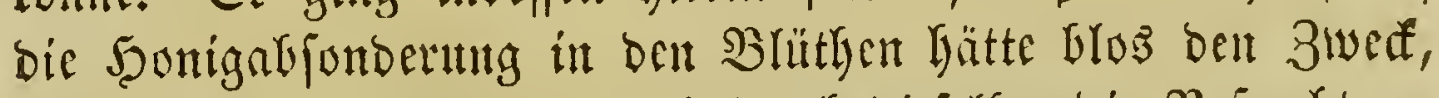

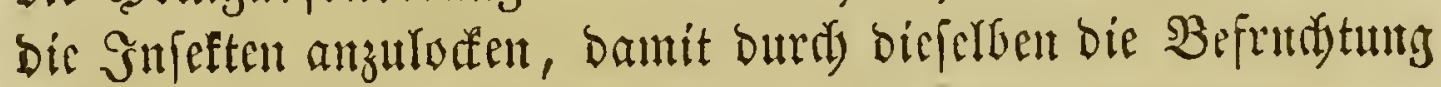
sermittelt warben fönute.

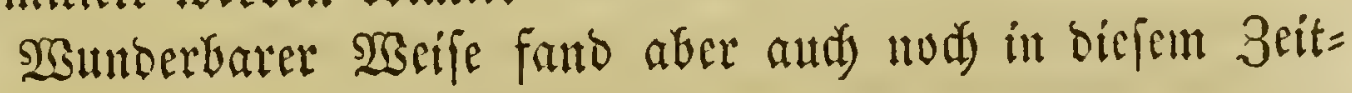

1) Dissertatio sistens observationes de defoliatione vegetabilium nec non de viribus plantarum ex principiis botanicis dijudicandis. Lugduni Batav. 1796. 8.

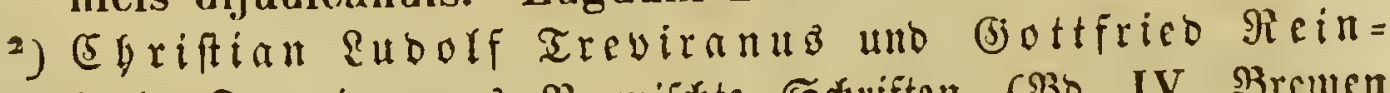
bold Treviranuz Bermifate Sdififten (B্b. IV. Bremen 1821. 4. 6 Iafeln.) S. 173 ff.

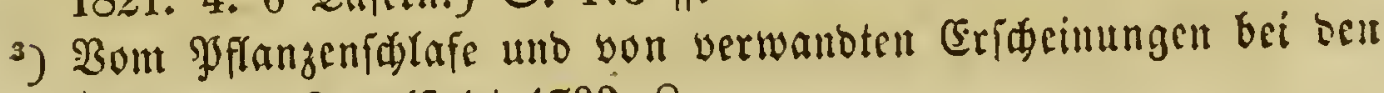
Syflanzen. Sulgorltadt 1792. 8. 
raume bie Befrudjtungstherie ifren beftigen (J)egner an

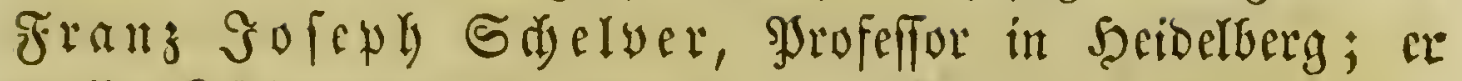

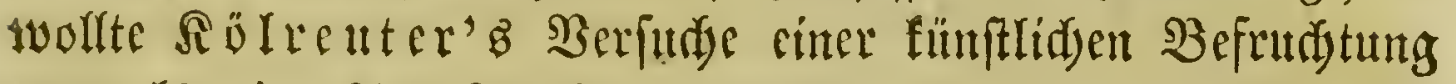

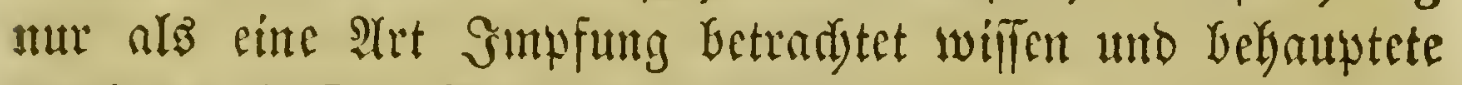

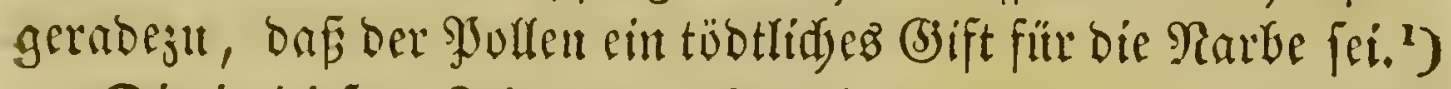

Die in bicfem 3eitraume über bie flora yon (3) efa mm $t=$ europa exfdyimenen Sdyriften find yon feiner befonderen

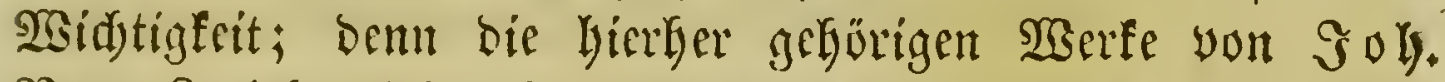

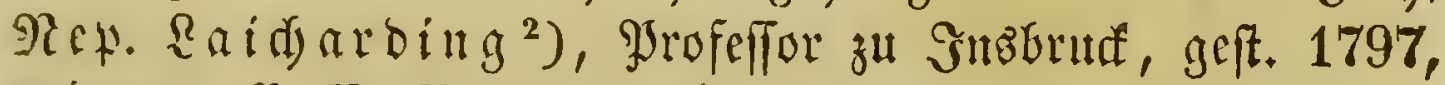

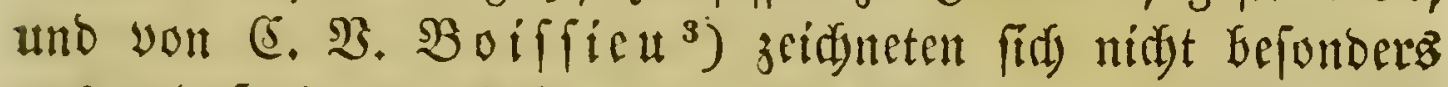

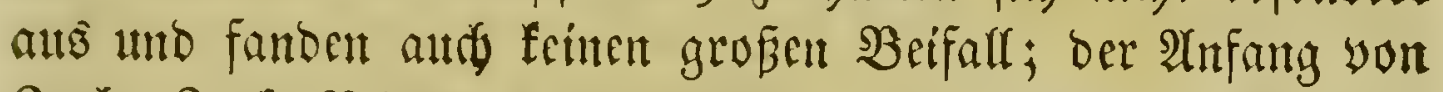

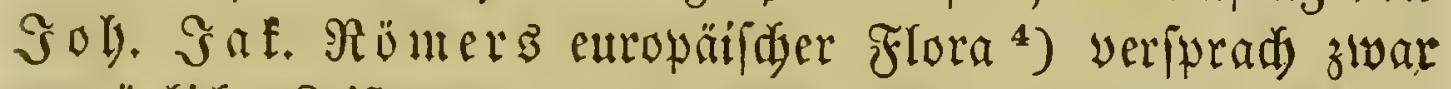
yorjügliffe Reiftungen, namentlidy aud bežïglid. Der Albbil= bungen, allein nad) bent (Erid)einen ber erfen 14 Sefte wurbe

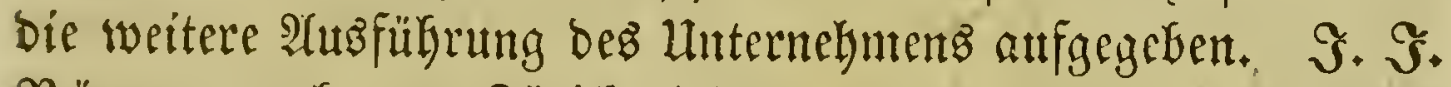

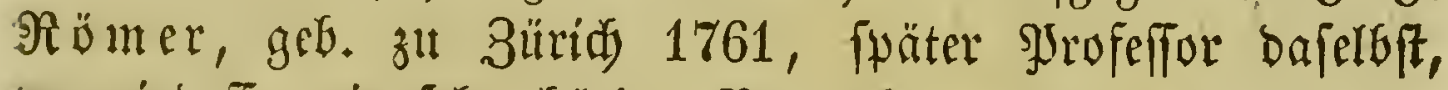
war indeffen ein felgr thätiger Botanifer. Sdyon in ber yor $=$ Gergebenden Seriode haben wir erwäbnt, bá er mit $\mathfrak{s} a \mathfrak{u l}$

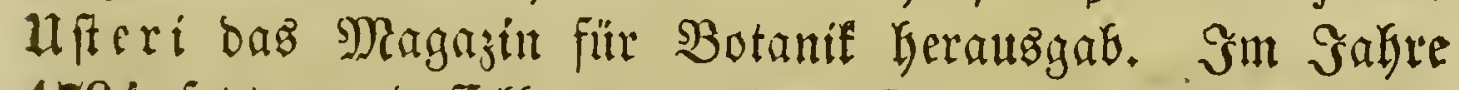
1794 feste er baffelbe unter dem Iitel "Neues Magazin

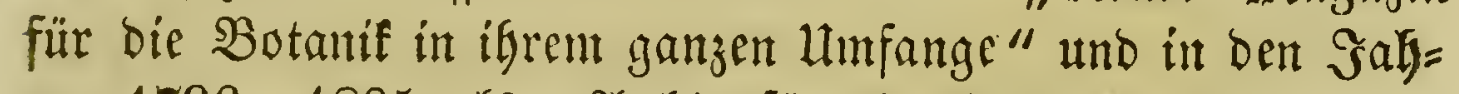

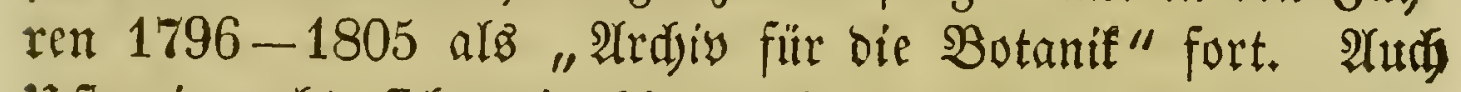

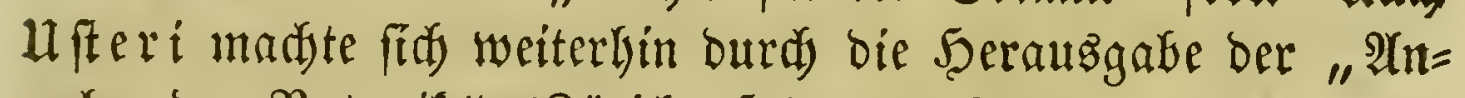
nalen oer Botanif" (Zürid, fpäter zu Reipzig, 1791-93) uno ber "Neuen $\mathfrak{A n n a l e n ~ b e r ~ B o t a n i l " ~ ( R e i p z i g ~ 1 7 9 3 - 1 8 0 1 ) ~}$

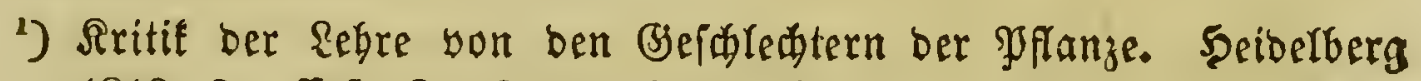
1812. 8. Erfte Fortfetung ibid. 1814, 8. - 3weite Fortfegutig Sartårube 1823. 8.

2) Vegetabilia europaea. Oeniponte 1770-71. 2 voll. 8. Manuale botanicum, sistens plantar, europaear. characteres gener., specier. differentias, nec non earum loca natalia. Sectio I u. II. Lipsiae 1794. 8.

3) Flore d'Europe. 3 voll. 8. 240 tab. Lyon 1805-1807.

*) Flora europaea inchoata. Fasc. I-XIV. Norimbergae 1797-1811. 8. 112 tab. col. 
14nt bie Saif

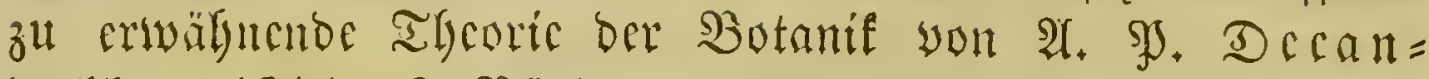
Dolf $(1815,2$ Vänte) uno gab dí Flora britannica

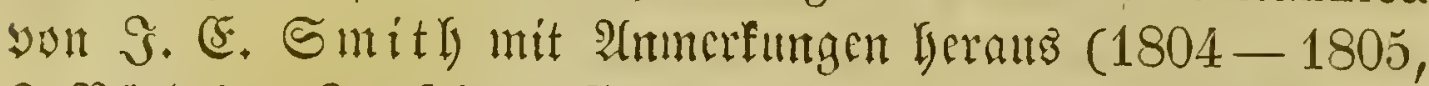
3 Bänoe). Sn fritch Collectaneis ${ }^{1}$ ) bcfindon fid mand

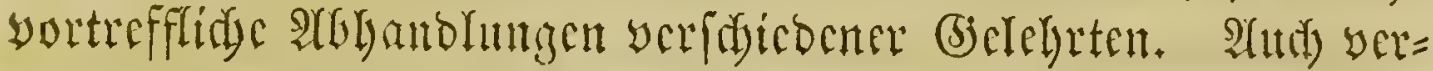

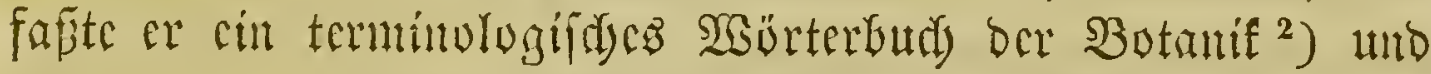
fanmelte bic Sdyriften viber fpanifdse, portugieffide unb bra= filianifde Sflanzen. ${ }^{3}$ )

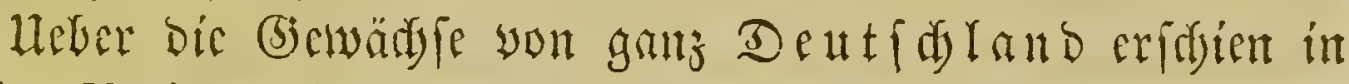

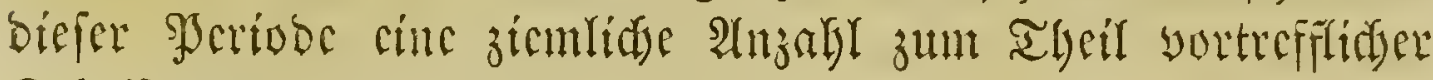
Edyriften. Dic ältefte berfelent watros von (b) is. Franz

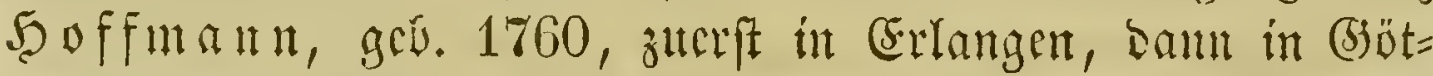

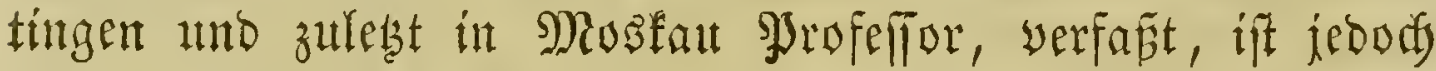
ofine Gefondere Sorzüge ${ }^{4}$ ). Şoffmann fdricb auperbcut

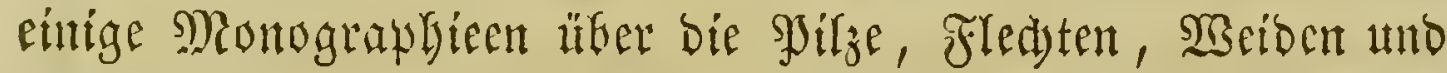

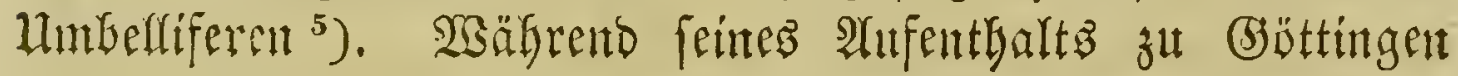

1) Collectanea ad omnem rem botanicam spectantia. Turici 1809. 4 tab. 4.

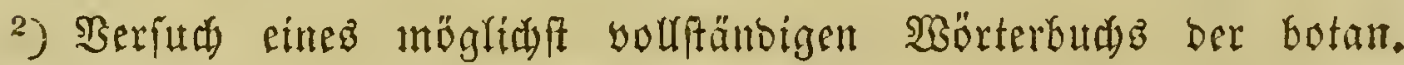
Terminulogie. 3üridy 1816. 8.

3) Scriptores de plantis hispanicis, lusitanicis, brasiliensibus etc. Norimbergae 1796. 8. 8 tab. - Catalogus horti botanici societatis physicae Turicensis. (Turici) 1802. 12.

4) Deutfdilanda Frora. Grifangen 1791. 12. 12 tab. col. Reure Aufl. baf. $1800-1804.2$ sbdm. 12. 2't tab. col. 2. Thl. 1795. 14 tab. col.

$\left.{ }^{5}\right)$ Syllabus plantar. Umbellifar, denuo disponendarum, exhibens enumerationem omnium specierum etc. Mosquae 1814. 8.

Hortus Gottingensis, quem proponit simulque orationem inchoandae professioni sacram indicit. Goettingae et Lipsiae 1793. Fol. 1 tab. col.

Vegetabilia in Hercyniae subterraneis collecta iconibus descriptionib. etrobservationib. illustrata. Norimbergae 1797. Fol. - 1811. Fol. 18 tab. col. 


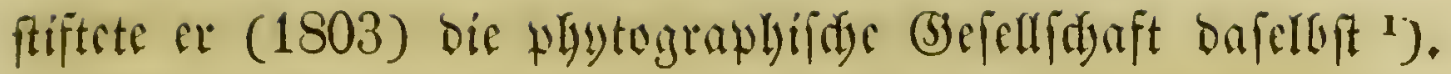

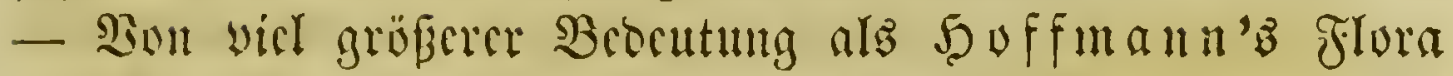

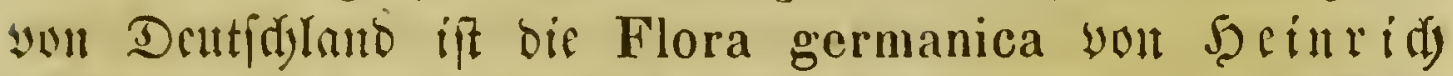

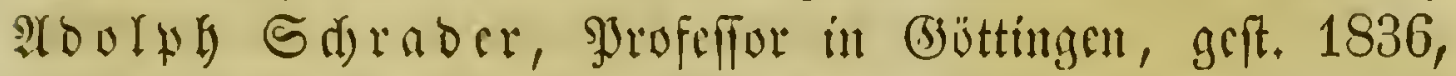

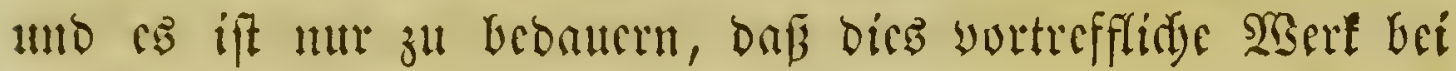
weitem nod) nidst yollenoet ift, fonbern mut die brei erfect

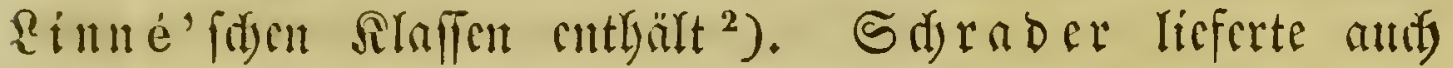
mehrere Mionogratbiem ${ }^{3}$ ), fortieb liber oen botanifden (bar=

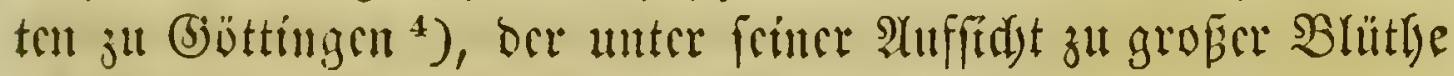

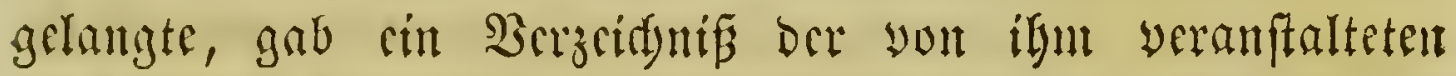

Syllabus plantar. officinal. (3) öttingen 1802. 8.

Hortus Mosquensis. (Mosquae) 1808, 8, 1 tab.

Genera plantar. Umbellifar. eorumque characteres natarales secundum numer., figuram, situm et proportionem omnium fructificationis partium. Mosquae 1814. 8. 3 tab. Ed. II. Ibid. 1816. 8. 6 tab.

Nomenclator fungorum. P. I. Agarici. $\mathfrak{B e r l i n} 1789.8 .6$ tab. Continuatio. Berfin 1790. 8.

Plantae lichenosae. Lipsiae $1789-1801$. III voll. Fol. 72 tab. col.

Enumeratio Lichenum iconibus et descriptionibus illustrata. Erlangae 178\%. 4. 22 tab.

Historia Salicum iconib. illustrata, Lips, 1785-91, 2 voll. Fol. 31 tab. col.

De vario Lichenum usu. Sect. I. Erlangae 1786. 4.

Observationes botanicae. Erlang. 1787. 4.

Vegetabilia cryptogama. Erlang. 1787-90. II fasc. 4. 16 tab.

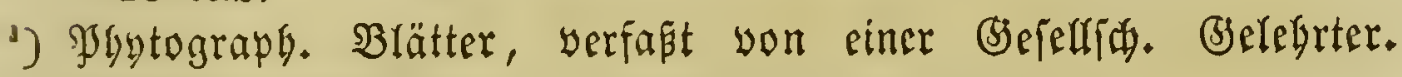
(j)̈̈ttingen 1803. 8.

2) Spicilegium Florae germanicae. Pars prior. Hanoverae 179\%. 8. 4 tab. col.

Flora germanica, Tom. I (unicus). Goetting, 1806. 8. 6 tab.

Catalogus horti Goettingensis. (Goettingae) 1806. 8.

3) Bergl. Yritiel S. 267.

4) Hortus Gottingensis. Goetting. 1809. Fol, 16 tab. col. 
Sammlung froptogamifjer (F) bon Gabra 1799-1803 bas " Journal für bie Botanif"

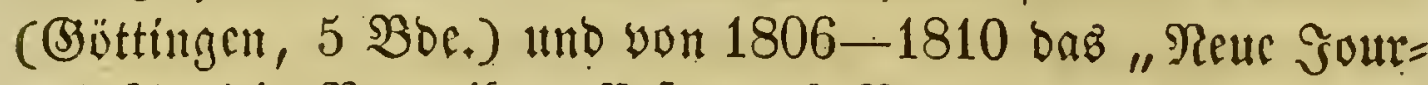
nal für bie Botanif". (Erfurt, 4 Bänbe). - Dic beutjde

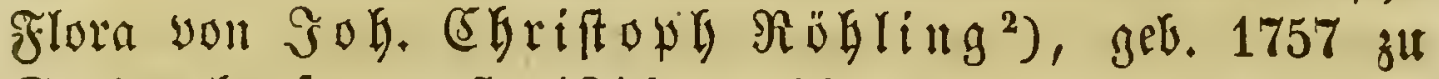

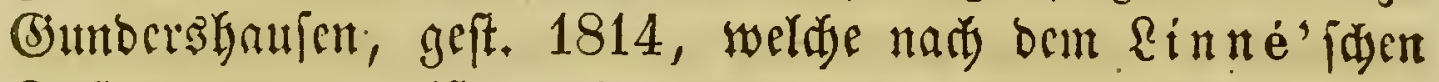

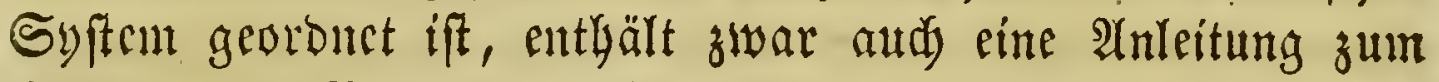
Stubium ber Botanif, zeitunet fith jebod) nidjt wejentlidy aus. Rübling lieferte auberbem eine Bearbeitung. von Deutid =

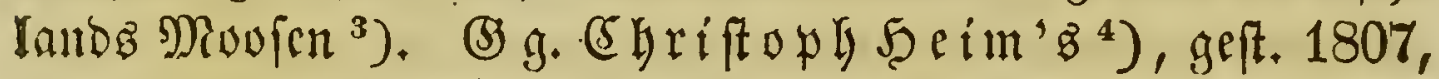

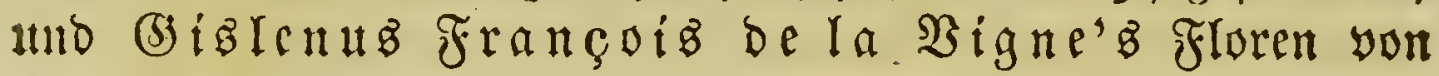
Deutichlano ${ }^{5}$ ) find wenig befant geworden. Der oben er=

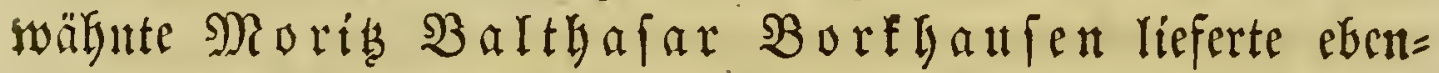
fallz $\mathfrak{B}$ riträge zur beut foden Flora, fowohl in $\Re$ ö mer 'B neuem Magazin ( $\mathbf{I}, 1-34$ ), wie audy in bem fijon citirten Tenta-

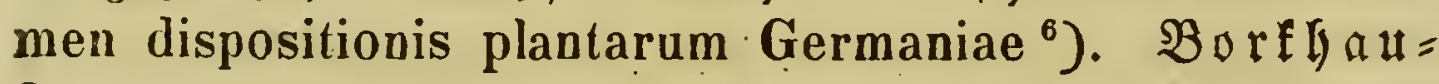
fen. befaiste fid namentlid) mit ber Forftootanif ${ }^{7}$ ). Ferner

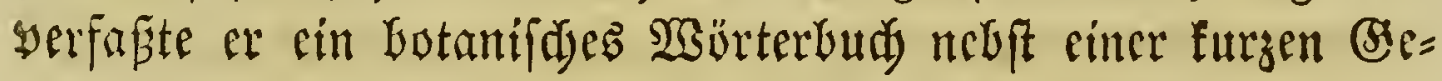

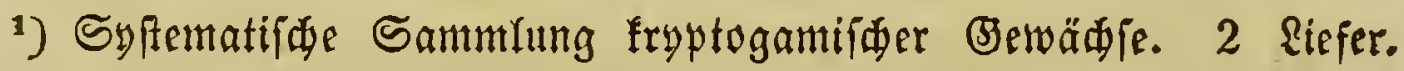
(5)̈̈ttingen 1796-97. 8. - Nova genera plantar. P. I. Lips. 1797. Fol. 6 tab. col.

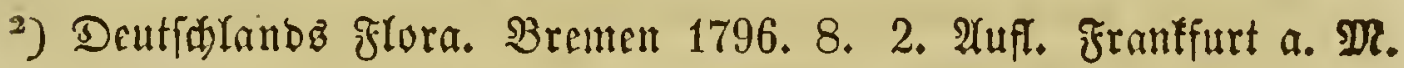

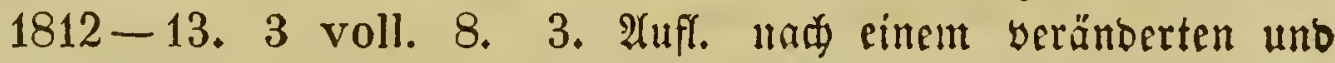

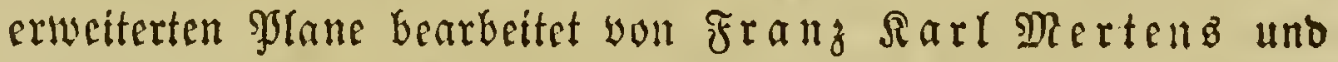

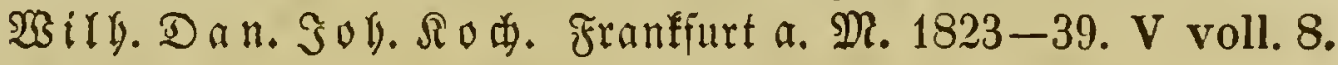

3) Deutfallanto Moofe. Bremen 1800. 8.

4) Deutifide frora. Scalle 1799. 2 Thle. 8.

$\left.{ }^{5}\right)$ Flore germanique. Erlang. $1801-1802.4$ cahiers. 12. 64 tab. col.

$\left.{ }^{6}\right)$ Darmitad 1809. 8.

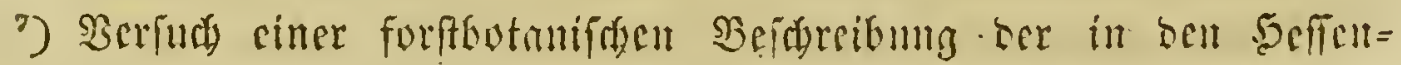

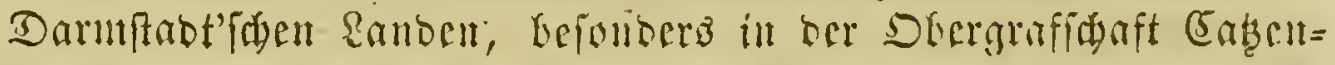
eflenbogen in Frcien wachjenben 5orjarten. Franffurt a. $\mathfrak{M}$.

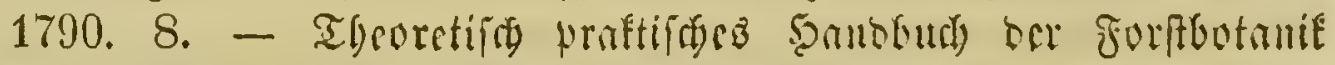
und forftedentlogie. Biesen 1800. 2 Thle. 8. 


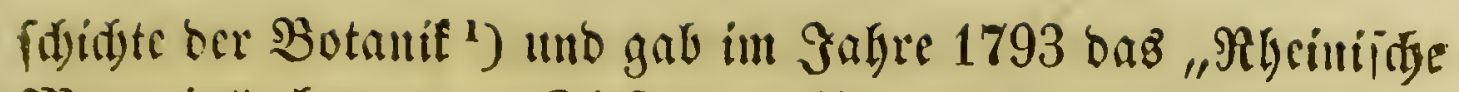

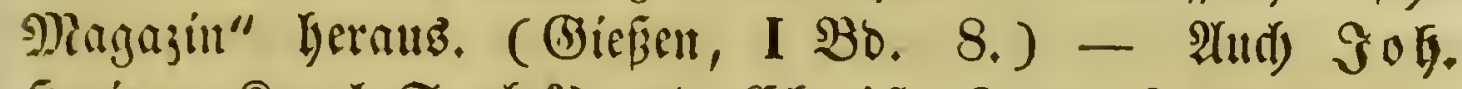
Sciur. Sarl $\mathfrak{S a d}^{2}$ ) uto (5hrift. Rubolf Trevira=

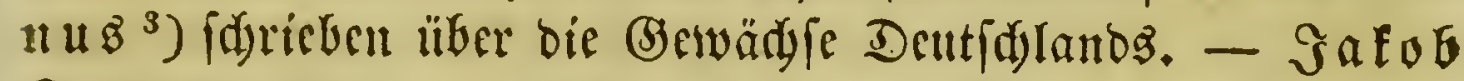
Sturm, Maler und Supferftedyer zu Rürnberg, begrun

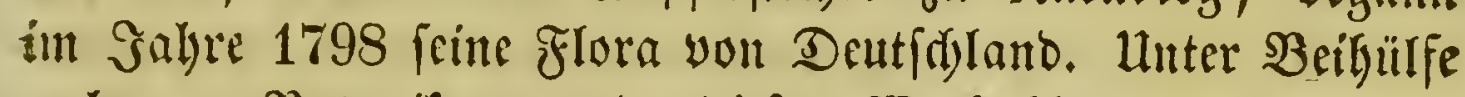
melyerer Botanifir wurbe biefes 2 Bert bis in bie neuefte 3 cit fortgefest. (Es zeidnet fid) naunentlid) burdi feine meift felle maturgetreuen $26 b$ bilbungen aus ${ }^{4}$ ). Die Şefdreibung

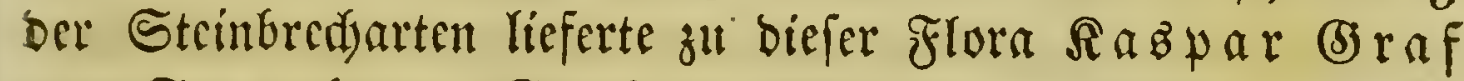
you Sternberg, Giutaherr zu Brzezina in Böhmen, Diret=

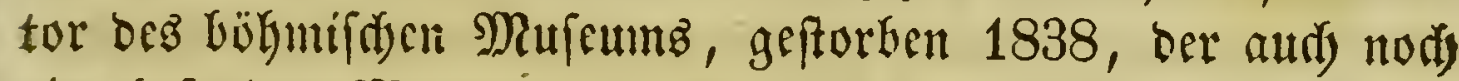

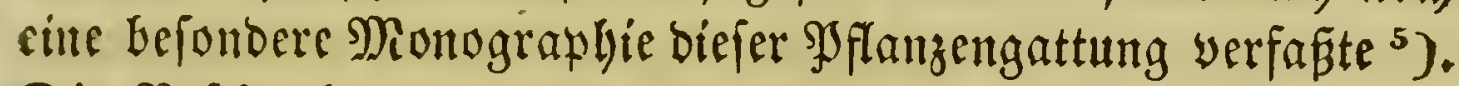
Die Sefdreibung ber Algen in Sturm'B Flora rübrt von

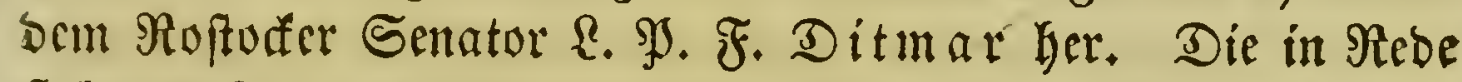
ftebenoc flora zerfällt in brei arbtheilungen: bie erfte atbethei=

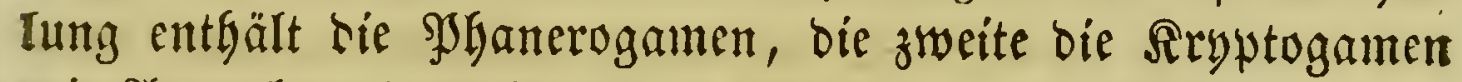
mit AYtsnahme ber piljartigen (Getwädje, in ber britten wer=

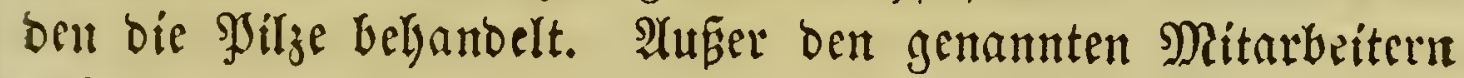
licjerten aud Bciträge: Sdjeber, ber bie Monograwbie ber Rleearten verfafte; ந̧oppe, von beim namentlida bie Befdreibung ber $\mathfrak{X}$ Bifen und zun Theil ber Riebgräjer her=

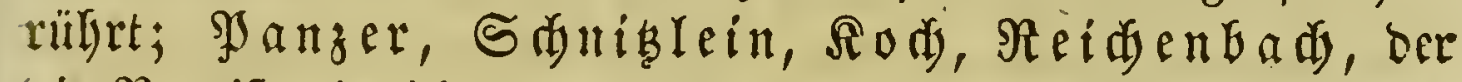
bie Bergifmeinnidatten befdrieb; Fieber, $\mathfrak{B}$ oit, $\mathfrak{B l a} n=$

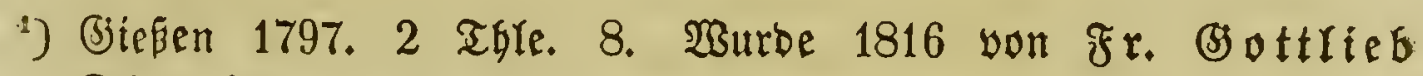
Dietrí berausgegeben.

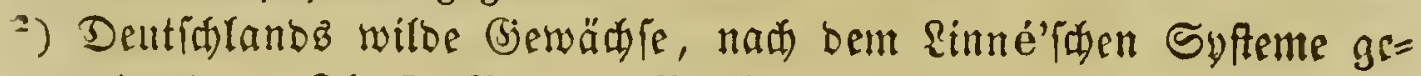
orbnet 2c. Th. I. SBo. 1. Berfin 1804. 8.

$\left.{ }^{3}\right)$ Observationes botanicae, quibus stirpes quasdam germanicas illustrare conatus est. Rostockii 1812. 4.

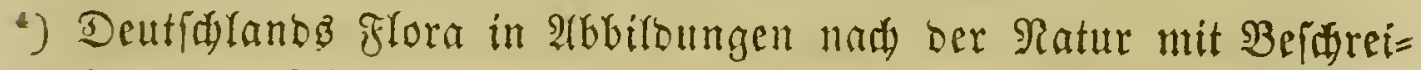
fungen. Fiürnterg 1798-1848. 149 5efte. 12. 2200 for. Taf.

5) Revisio Saxifiagarum iconibus illustrata. Ratisbonae 1810. Fol. 31 tab. Suppl. I. 1822. 10 tab. col. Supl. II. 1831. 16 tab. col. 


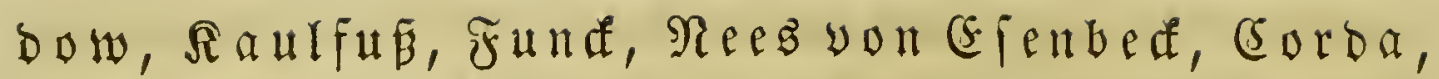
Rauler mo Rostoyius. - Beorg

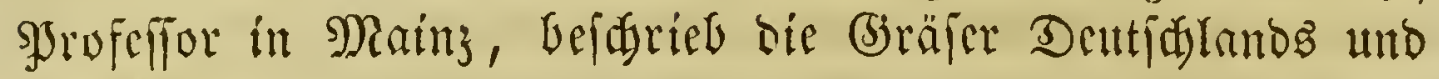

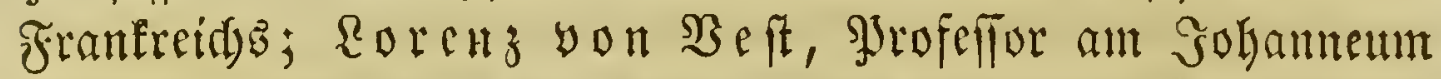

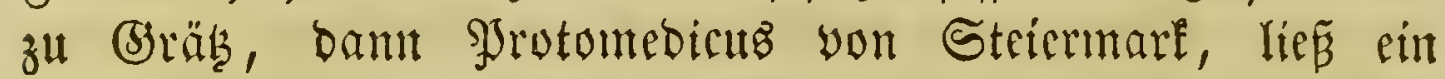

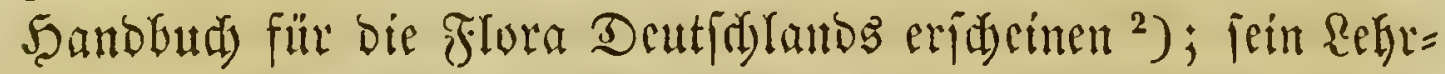

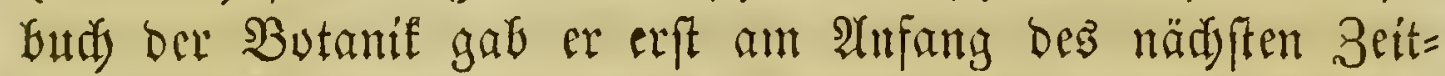
raumb Geraus. ${ }^{3}$ )

Mrbert $\mathfrak{Z}$ irgelm $\Re$ oth feste in biejer Periobe feine

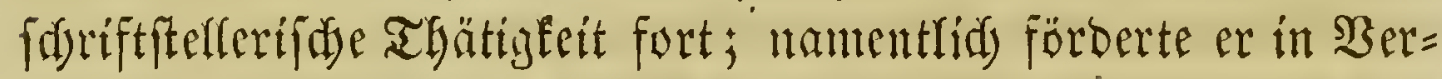
bindung mit Franz $\mathfrak{A} a \mathfrak{L}$ Mertens, Srofeffor in Bremen,

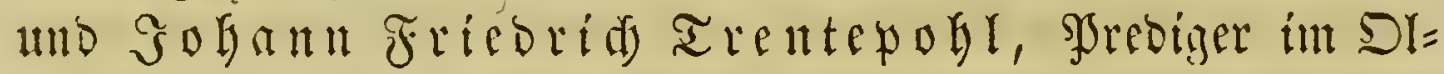

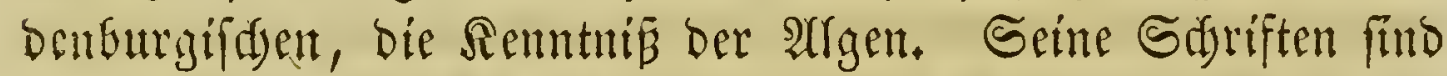
S. 219, Pote 1, angefüfrt worben. - Bon bejonderent

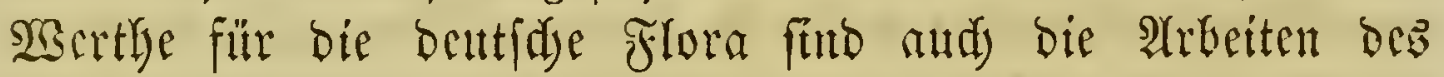

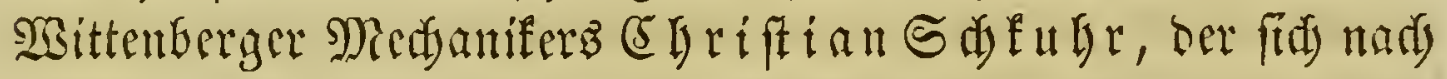

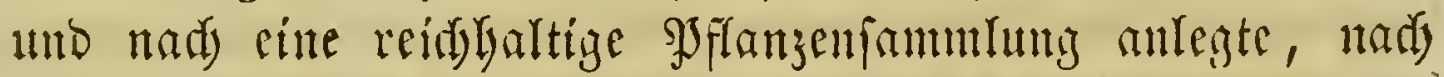

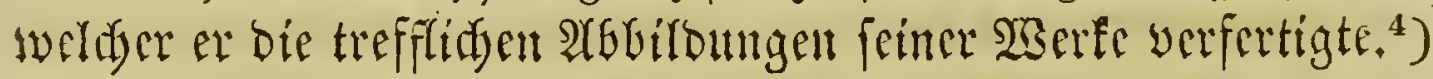

1) Descriptio graminum in Gallia et Germania tam sponte nascentium quam humana industria copiosius provenientium. Frankf. a. M. 1802. 12. 10 schemata.

2) Manuale botanicum. Klagenfurti 1805. 8 .

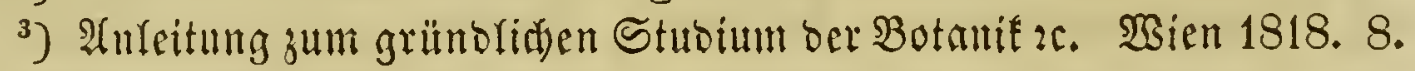

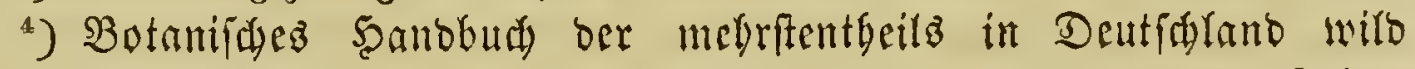

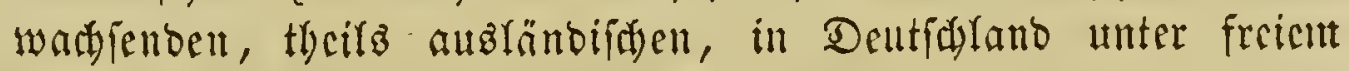

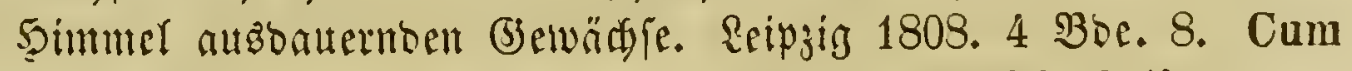
$400 \mathrm{tab}$. col. - Enchiridion botanicum. Editio latina (curante Friedrich Schwaegrichen). Lipsiae 1806. 8. 88 tab. col. - Befdreifung uto athbirbung ber theils befautu= ten, theilz nod nidyt befdriebenen STrten von Nicogräfern, nady

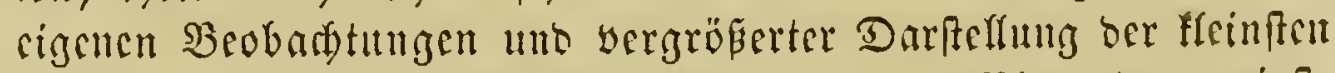

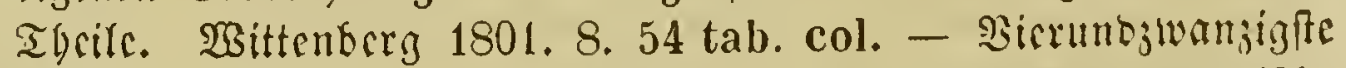

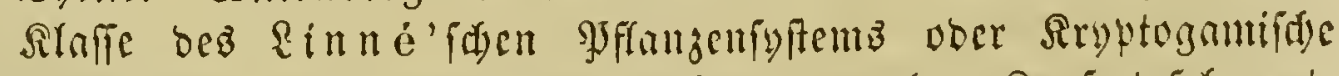

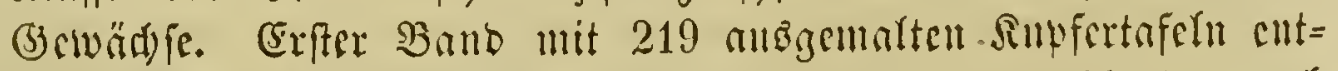

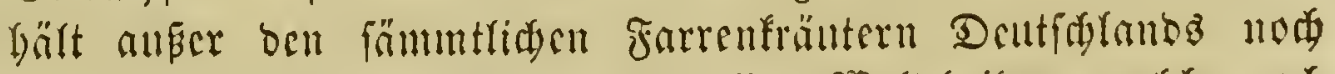

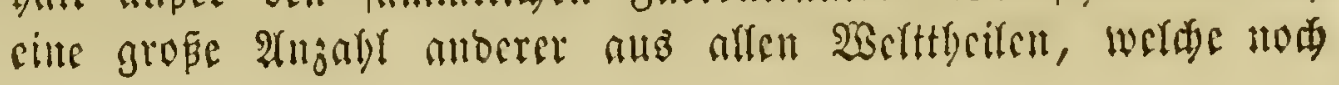


3u לen einjelncu Rümbern Dentjulanoz übergebeno went=

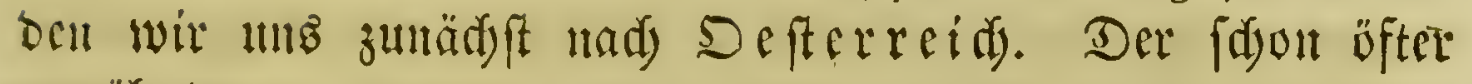
crualgnte

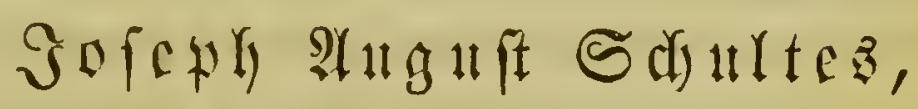

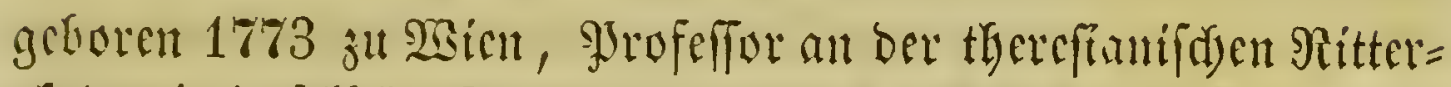
afabcmie bafelbft, fräter an ber Univerfität zul Rirafau, bam

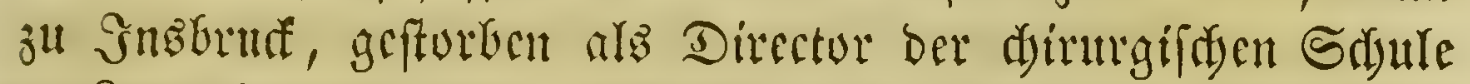

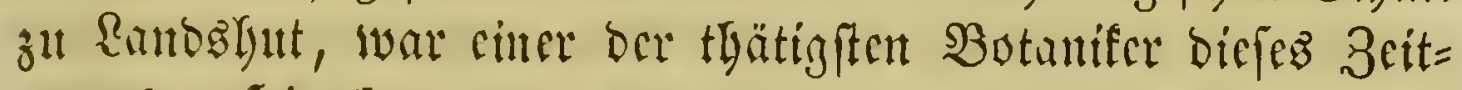

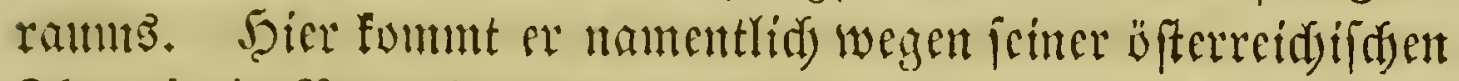

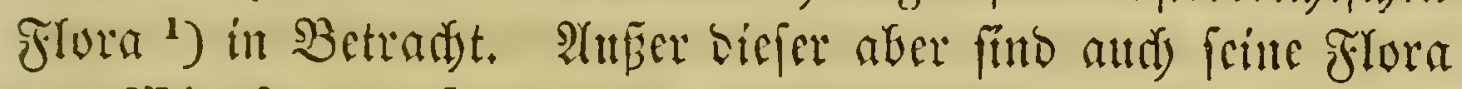

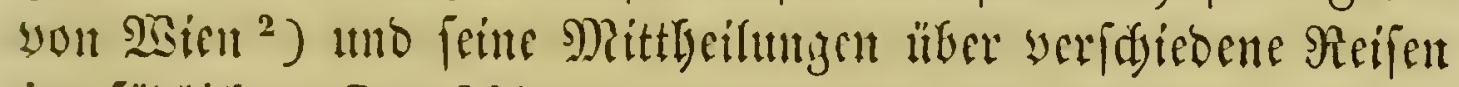
iun fübliç) Dent für bic Senntnis ber (S)

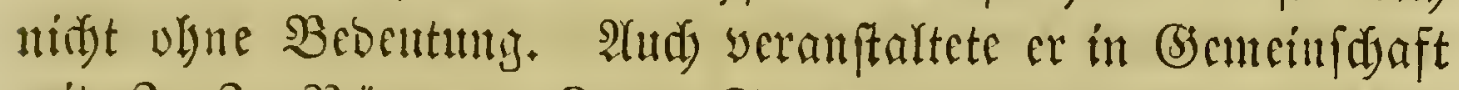

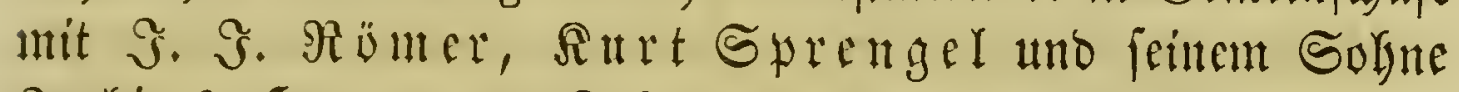

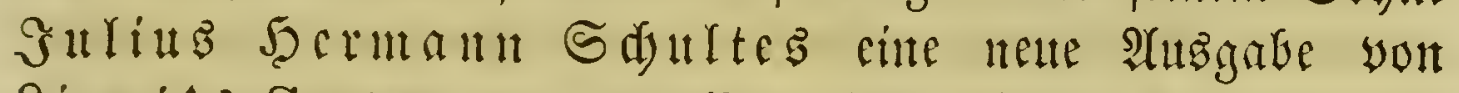
Rinn é $\$$ Systema vegetabilium ${ }^{4}$ ), lieferte cinte verbefferte

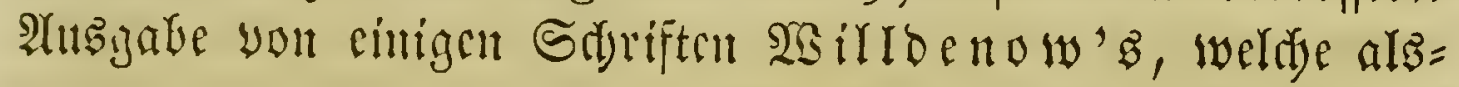

nidst ober zum Theil unvolfommen, all nur in fertenen 20 erfen abgebilbet fint. Wittenberg 1809. 4. - Deutidlands fryptoga=

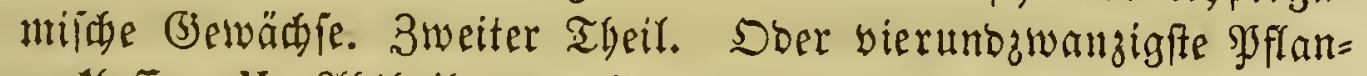
jentlalle. II. Albtbeilung, die beutiden Mooje entbaltend. In 3 Seften. Reipzig $1810-1847$. 4. 42 tab. col, - Supple= ment. Reipzig 1847. 4.

1) Defterreiđz Flora. Ẇien 1794. 2 voll. 8., Edit. II. Viennae 1800. 8. 2. Aluft. Wien 1814, 2 voll. 8.

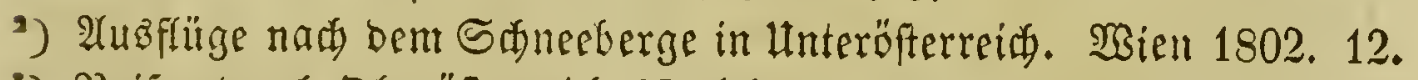

3) Sieifen burd Sberöfterreiø (Salzkammergut) in ben Jahren 1794, $95,1802,1803,1804$ unb 1808. Tübingen 1809. 2 Bbe. 8.

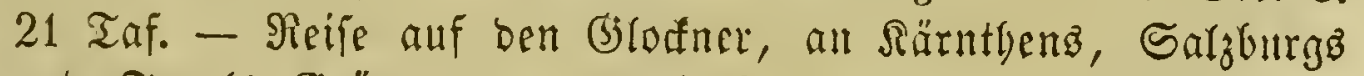

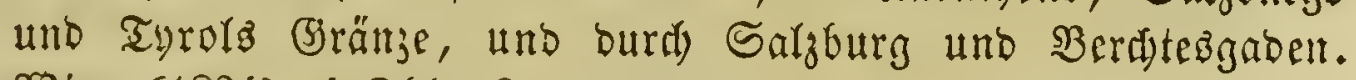

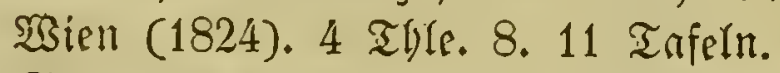

4) Stuttgart 1817 - 30. 8. 10 şbe. (Entbält die erften feds

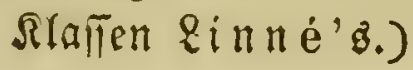


balb zu erwähnen find, und farieb itber ben botanifden (3)arten zu Rrafau ${ }^{1}$ ). Diejemigen Sdjriften bon S weldye bie flora Baaiern's behanbeln, werben unten ange=

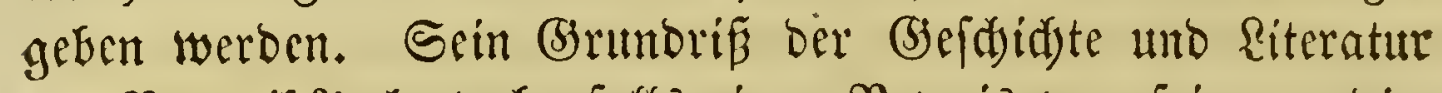
ber Botanif ${ }^{2}$ ) legt ebenfalls cinen Basweis yon feinen gedie= genen Fadffentmilfen uno feiner mäheren Befannt (d)aft mit

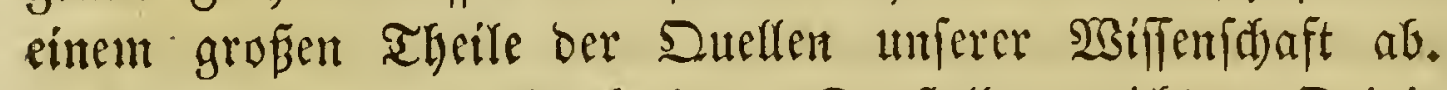
A(ud) fehlt es biefem $\mathfrak{W}$ erfe in ber Darftellung nicht an Drigi= ualität, oft ftöst man felbit auf eine gewwiffe humbriftifese Frifde, mit welder ber Berfalfer bie oft allzupröbe Troden= Leit des Stoffis etwas anfeudten zu wollen idyeint. Mit

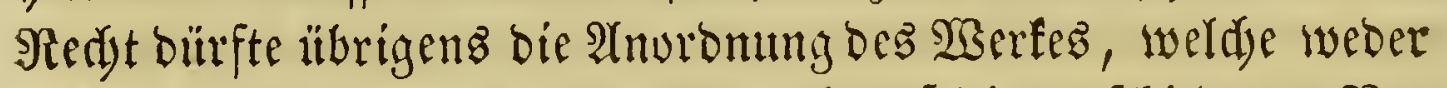
auf bie einzelnen Disciplinen, nod) auf dic veridjicbenen $\Re a=$

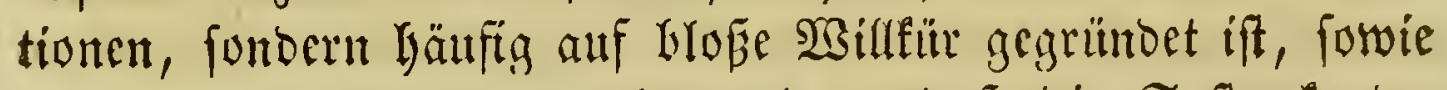
audi) ber Ulmitant getabelt werben, baj bie Syftemfunde,

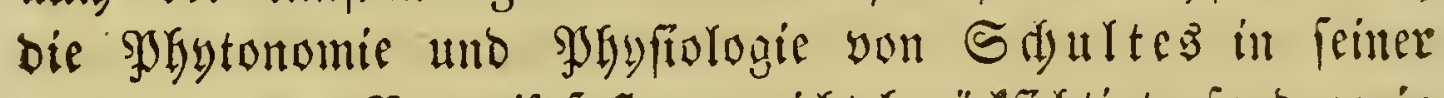

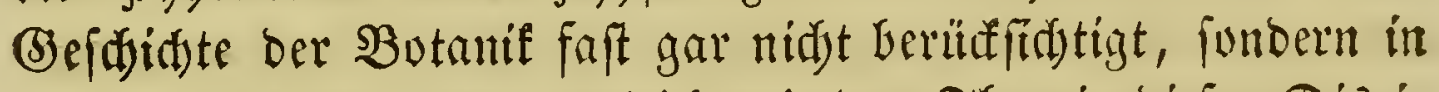
befonderen abfdnitten zugleid) mit ser Theorie bicfer Disci= plinen Gebandelt wird, fo bap bie Erfolge, welde burdy diefe beiben 3weige herworgebradytwurben, in bem crwälnten Siserfe feinesivegs gemtugfam herwortreten. Eine befonbere Bardtung verbient ber anbang zat bicjent (jefdridstaiverte, weldyer bie

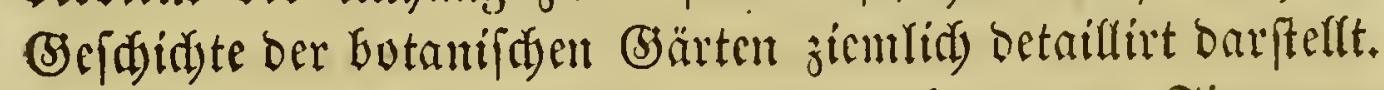

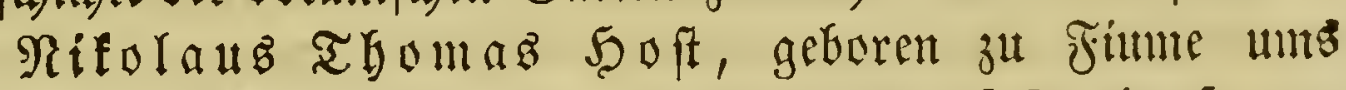

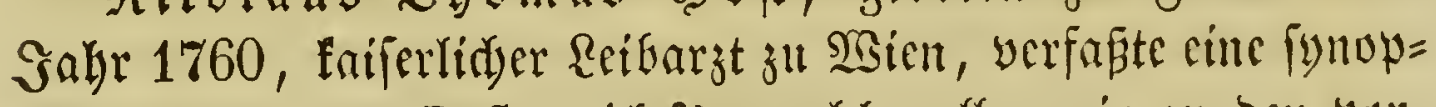

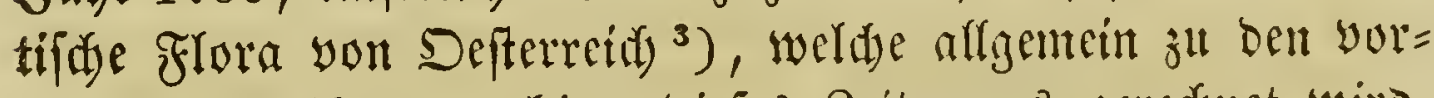

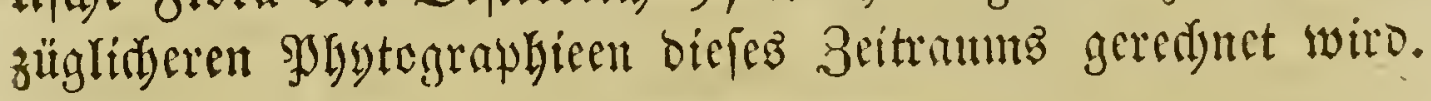

1) Catalogus primus plantar. horti botanici C. R. Universitatis Cracoviensis anno 1806. Cracoviae 1807. 12. Catalog. II. ibid. 1808. 12.

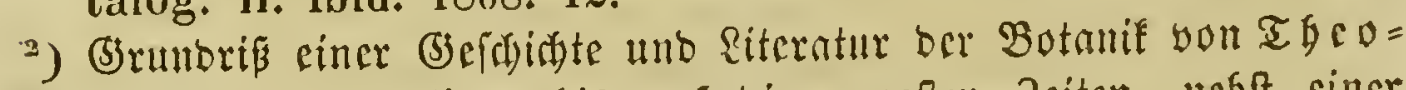
proftos Grefios bis auf bie neueften 3riten, mebt ciner

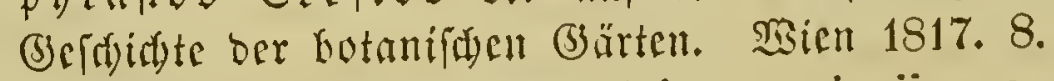

$\left.{ }^{3}\right)$ Synopsis plantar. in Austria provinciisque adjacentibus sponte crescentium. Vindobon. 1797. 8. 


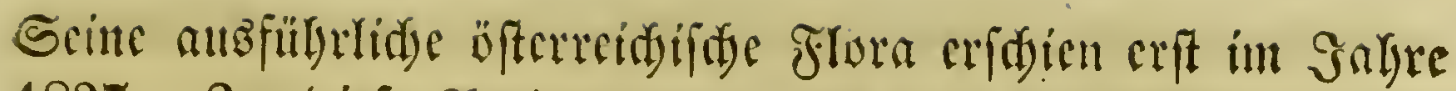

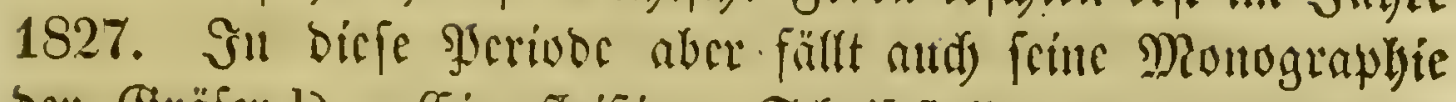

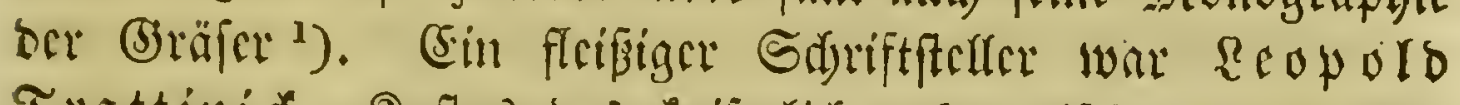

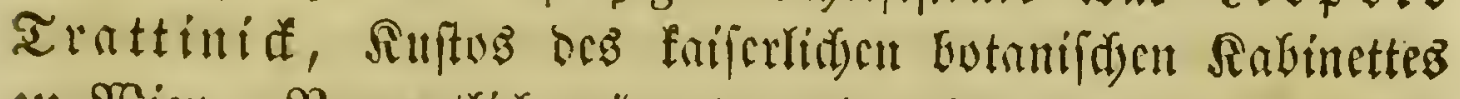
ôt Sisin. Ramentlid) wiomete or bon im Raiferftante wad)=

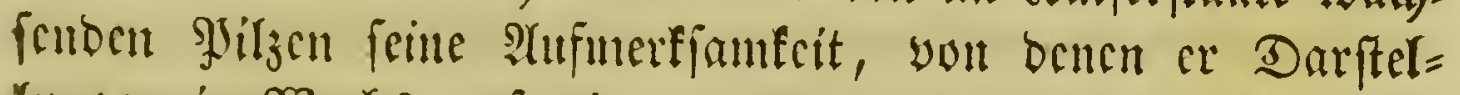

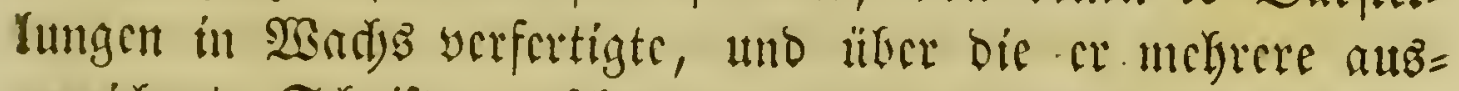

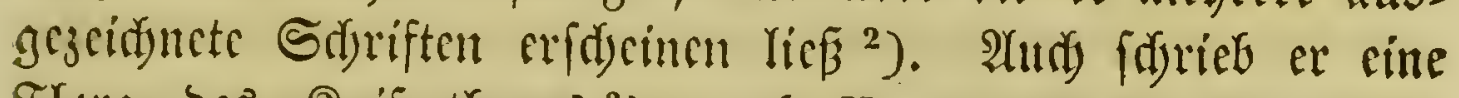

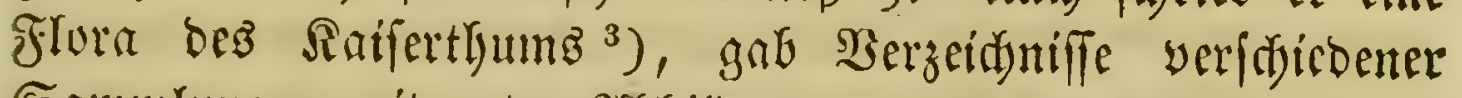
Sammlungen mit guten abbiloumgen verferyen beraus ${ }^{4}$ ) unb werfäte anferbem cinige Sduriftent allgemcineren botantiduen

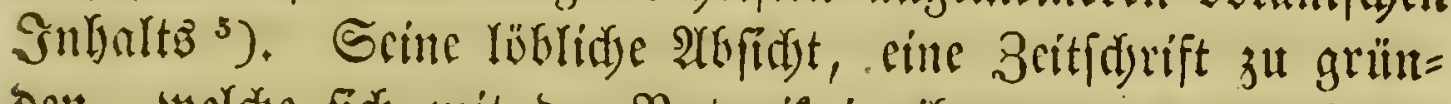

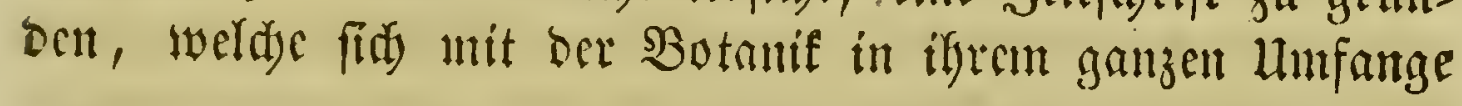

1) Icones et descriptiones graminum austriacorum. Vindobonae 1801-1809. IV voll. Fol. 400 tab. col.

${ }^{2}$ ) Fungi austriaci ad specimina viva cera expressi, descriptiones ac historiam naturalem completam. Manipul. I-V. Vienn. 1804-1806. 4. 18 tab. col. Edit: nova. Vienn. 1830.

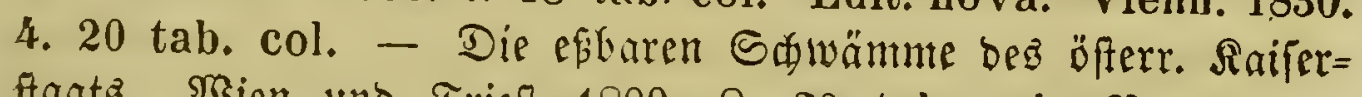

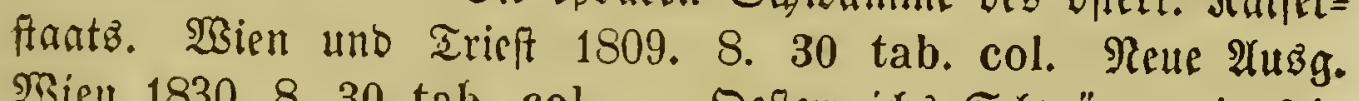
Wien 1830. 8. 30 tab. col. - Sefterreinfo Sdjwänme in frin

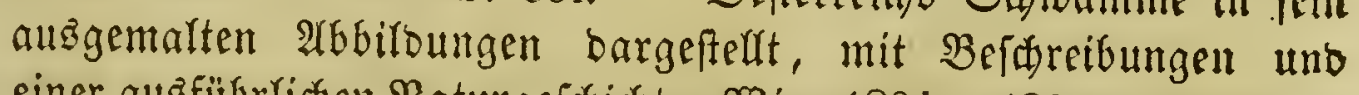

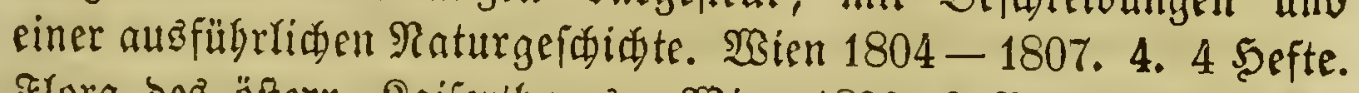

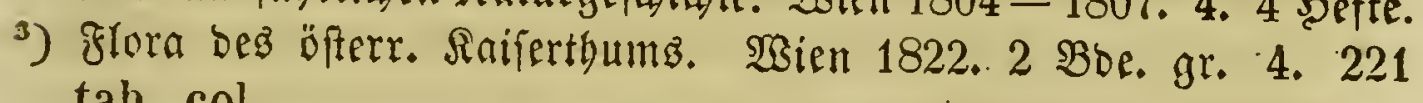
tab. col.

4) Thesaurus botanicus (Fasc. I - XX). Viennae (1805-) 1819.

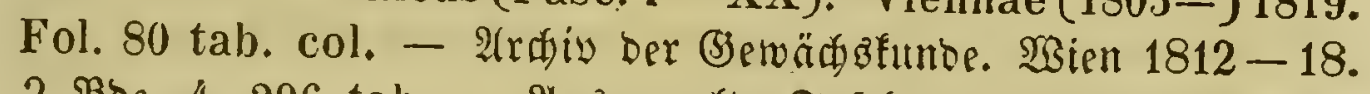

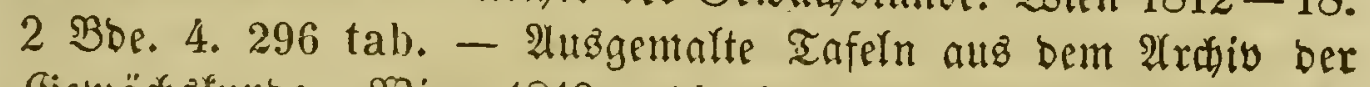

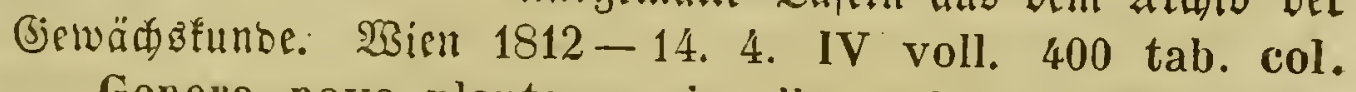
- Genera nova plantarum iconibus observationibusque illustrata. Fasc. I u. II. Viennae 1825. 4. 24 tab.

$\left.{ }^{5}\right)$ Gencra plantarum methodo naturali disposita. Vindobonae 1802. 8. - Observationes botanicae tabular. rei herbariae illustrantes. Fasc. I - III. Viennae 1811-12. 4. - Rosacearum Monographia. (Synodus botanica; omnes familias, genera et species plantarum illustrans.) Vindobonae $1823-2$ \%. IV voll. 8. 
befdaftigen jollte, wutbe nut auf furge Zeit in ber folgenden Şrerivor ausgeführt. ')

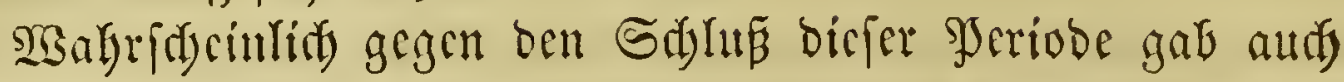
Golann, (Erzherzog. yon Defterreid, atboiroungen

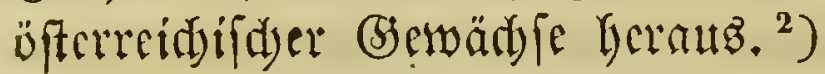

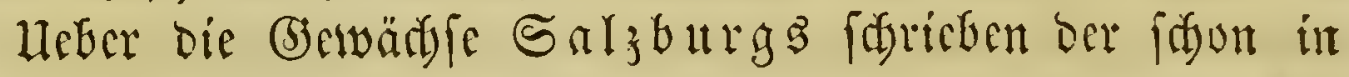

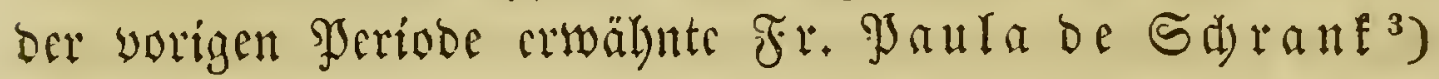
und Fr. Anton you $\mathfrak{B} r \mathfrak{n} u e^{4}$ ), geb. 1767; Hiber bie ber Steiermart Franz Sartoris) und liber bie Tyrol's

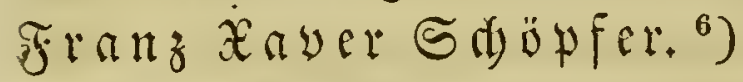

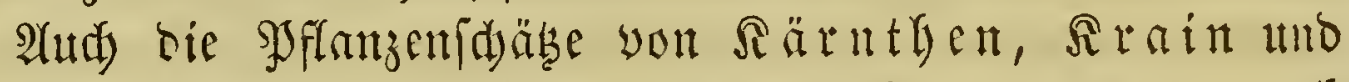

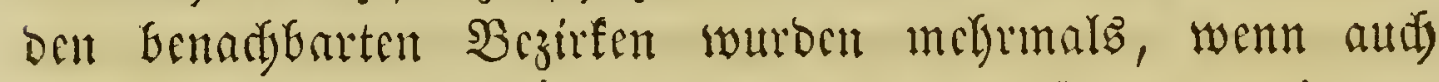
nidst befonsers grüntolidy, von cinigen Reijenten, wie yon bem Marnuis de Suffen ${ }^{7}$ ), won Jofeph Reinct

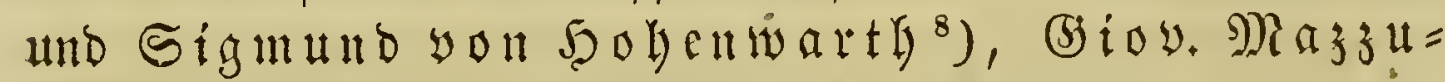
cato ${ }^{9}$ ) unb (5ioy. Brignoli ${ }^{10}$ ) unterjudyt.

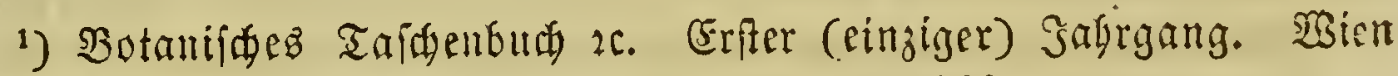
1821. 8. 3ergl. auperbem 习ritiel S. 299.

3) Solann, Fraberog you Deferreid: Icones plantarum austriacarum ineditae. (Vindobonae) s. a. Fol. 92 tab. aeri inc.

$\left.{ }^{3}\right)$ Primitiae florae Salisburgensis. Francofurti ad M. 1792. 8. 2 tab.

*) Saljburgifide Flora. Saljburg 1797. Ill voll. 8. 6 tab.

$\left.{ }^{5}\right)$ Specimen nomenclatoris plantar. phaenogamar. in Styria sponte crescentium, adjunctis adnotationibus. Viennae 1808. 8.

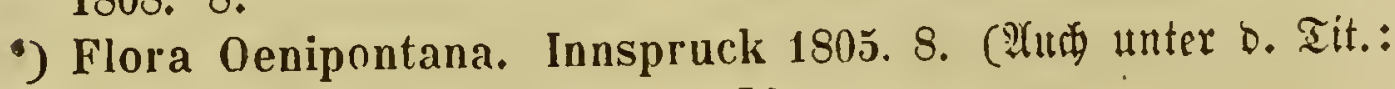
"Flora tyrolensis " volumen I.)

$\left.{ }^{7}\right)$ Principes de botanique. Venise 1802. 8.

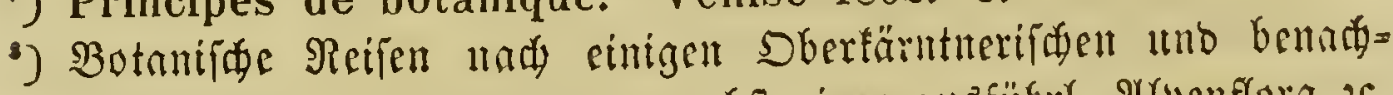

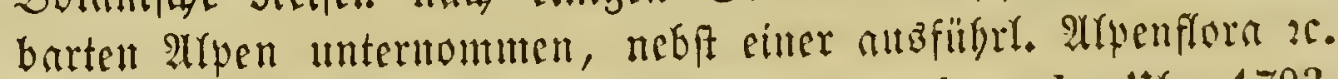

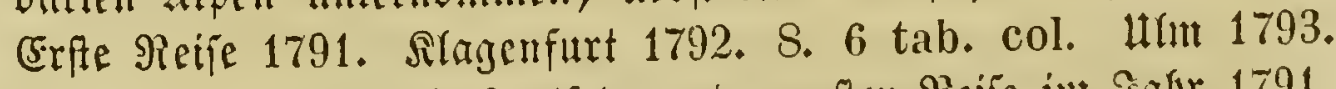
8. 3weiter Band nla Fortfebung oer erften Seife im Sabr 1791. Rlagenfurt 1812, 8. 10 tab.

9) Viaggio botanico all' alpi giulie. Udine 1811. 8. $33 \mathrm{ergl}$. altid) Syrizel S. 187.

so) Brignoli a Brunnhoff, Fasciculus rarior, plantar. 


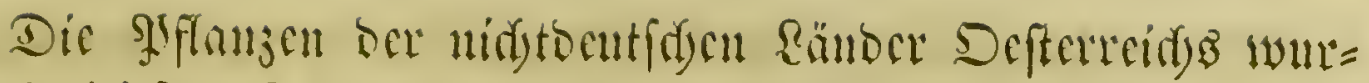

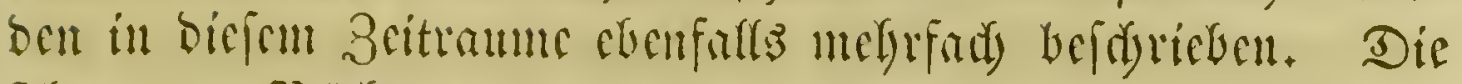

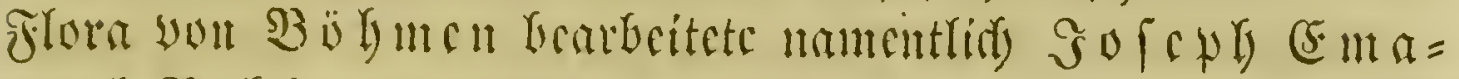

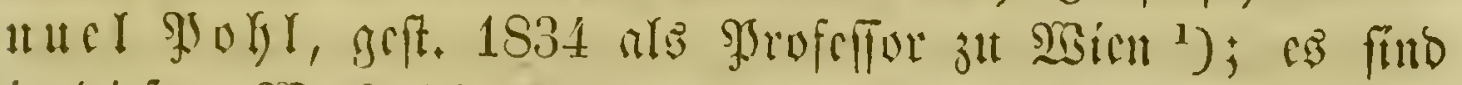

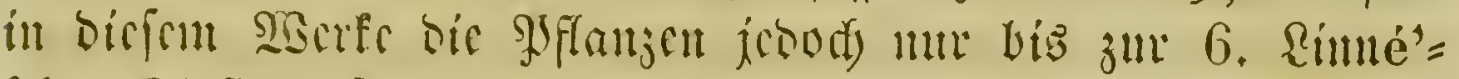

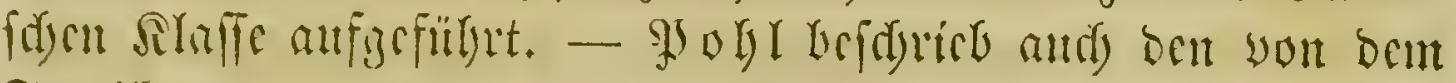

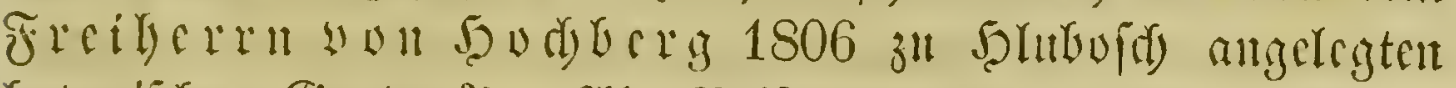

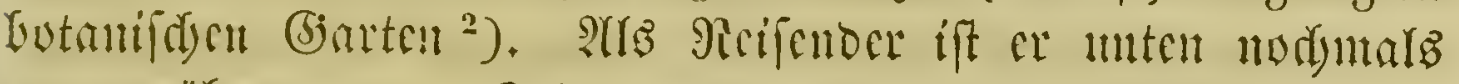

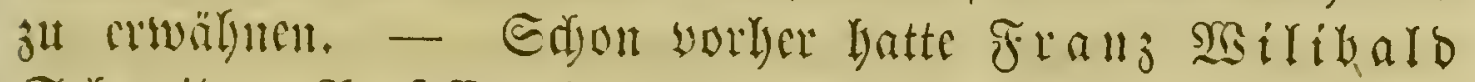

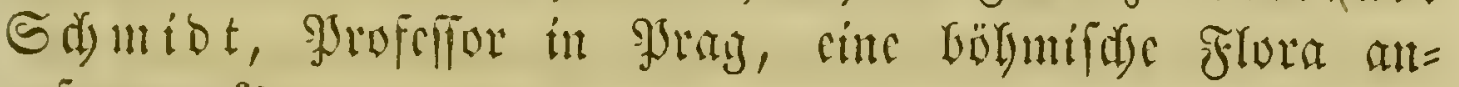
gefangsut. ${ }^{3}$ )

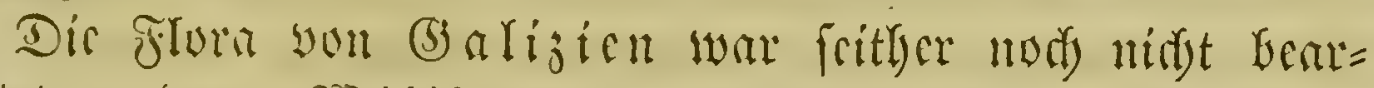

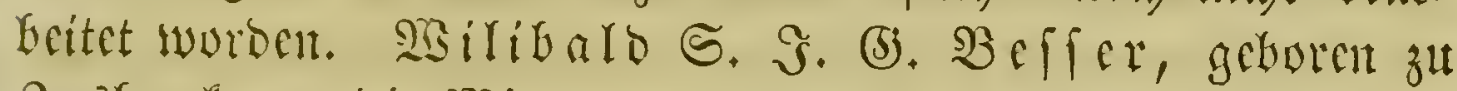

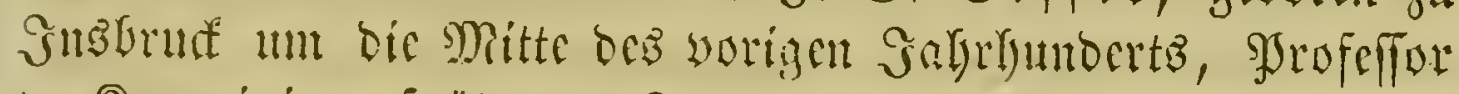

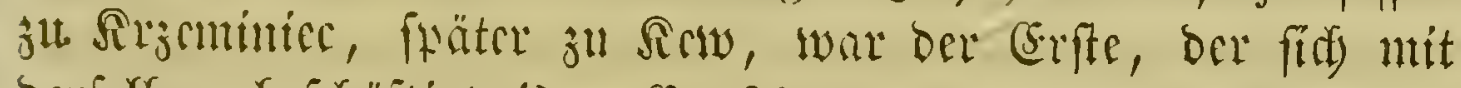
berfelfen befdaftigte ${ }^{4}$ ). (Er fdrieb aud cinige Monograt whieen über bis Giattunty Artenisia. (Nouv.', mém. de la soc. des natural. de Mosc.)

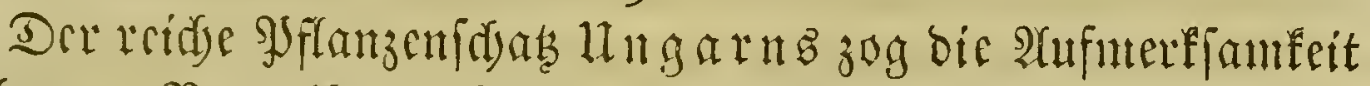
mefrerer Botanifer auf fids. Die Beitringe von Stephant

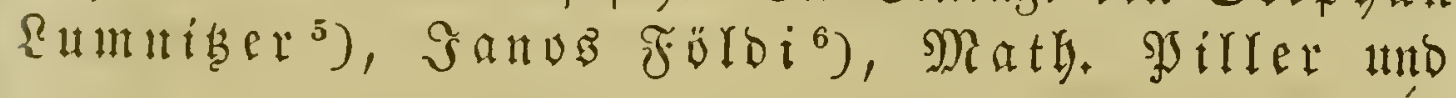

Forojuliensium. Urbini 1810. 4. - Derierfe verfäte attd: Catalogus plantar. in horto botanico Archigymnasii liutinensis cultorum. Mutinae 1817. 8. - Ibid. 1836. 8. 1S42. 4. 2 tab. Sergl. Is

1) Tentamen Florae Bohemiae. Prag. 1810-15. $2 \mathfrak{3}(\mathfrak{b t}) .8 .1 \mathfrak{T} \mathfrak{a}$.

$\Rightarrow$ Frag 1812. 8.

3) Flora boëmica inchoata. Tom. I. Cent. 1-4. $\mathfrak{I} \mathfrak{r a g} 1793$ -94. Fol. - Reue und feltene SPflanzen nebfét einigen anbern

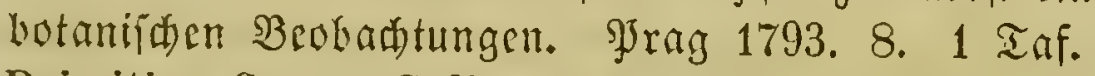

4) Primitiae florae Galiciae Austriacae utriusque. Viennae 1869. II voll. 12.

5) Flora Posoniensis etc. Lipsiae 1791. 8. 1 tab.

') Rövid kritika és rajzolat a' Magyar füvésztudományról (i. e. Brevis critica et delineatio botanicae hungaricae). Bétshen (Viennae) 1793. 8. 


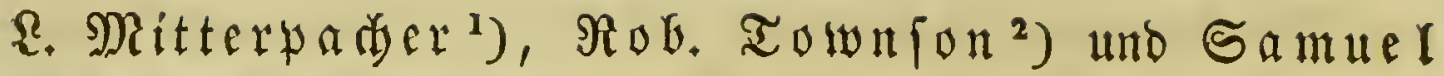

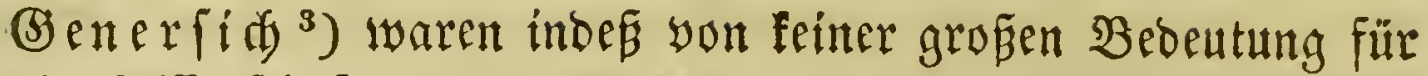

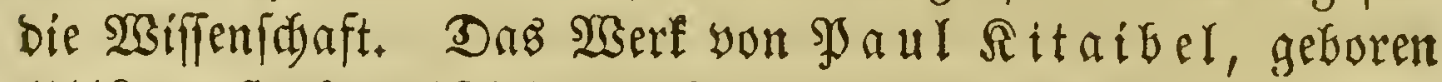
1759, geftorben 1817, Srofeffor und Borféter bez botani= fdyen (Sartens in Shefth, ift unftreitig am widtigften für bie Renntnís ber ungarifaen Flora ${ }^{4}$ ). Diejer Gelehrte Durd = forfdite nidst blos llngarn nad) allen Riditungen, fonbern Durdwanterte aud bas Sanat, Rroatien, Slawonien uno Dalmatien. . Durd die Huterftühung des (b) rafen Franz

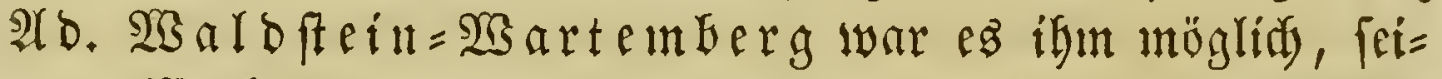

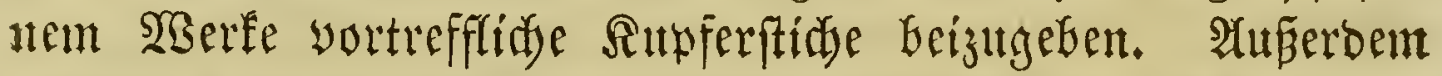
forieb er aud über Den botanifden (biarten zu গুSefth ${ }^{5}$ ). -

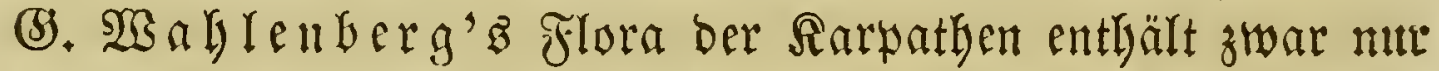
wvenige neue Beitrïge zur Flora biefes (5ebirges, ift jebod wegen ifrer Alngaben über bie geographifde Berbreitung ber Sflanzen zat beadjten. ${ }^{6}$ )

Sine Flora yon Siefrenbürgen verfafte der Sdjäsbur=

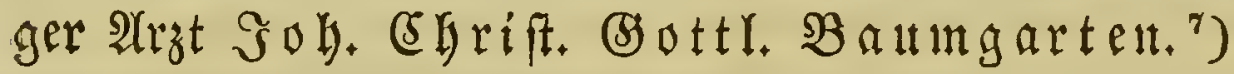

Unter ben bairifden sogytographen ift ber fdon früber (ङ. $221 \mathfrak{u}$. a.) genamute

1) Piller et Mitterpacher, Iter per Poseganam Slavoniae provinciam mensibus Junio et Julio 1782 susceptum. Budae 1782. 4. 16 tab.

${ }^{2}$ ) Travels in Hungary. London 1797. 4. 16 tab.

$\left.{ }^{3}\right)$ Florae Scepusiensis elenchus. Leutschoviae 1798. 8.

4) Descriptiones et icones plantar. rarior. Hungariae. Viennae 1802-12. III voll. Fol. 280 tab. col.

5) Plantae horti botanici regii universitatis Hungaricae (Pesthini) 1809. 8. 1812. 8.

-) Flora Carpatorum principalium. Goetting. 1814. 8.

7) Enumeratio stirpium Magno Transilvaniae principatui praeprimis indigenarum, in usum nostratum botanophilorum conscripta inque ordinem sexuali-naturalem concinnata. Vindobonae 1816. 3 voll. 8. 


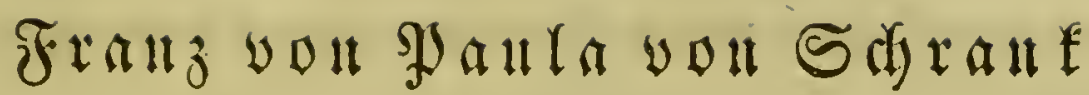

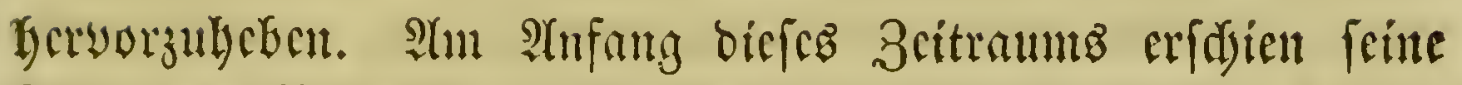
Flora yon Baicrn ${ }^{1}$ ), tann fdricb cr cite bejonocre Sdurift über bie faljburgifde frora ${ }^{2}$ ), gab bie Befdureifung feiner

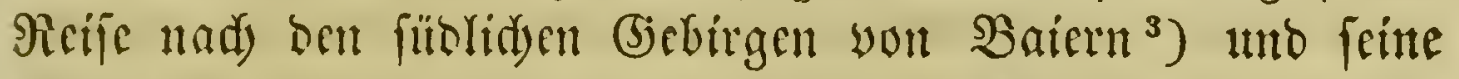
Brieffe über bas Donaumvos ${ }^{4}$ ) heratts. Audy licferte cr ben

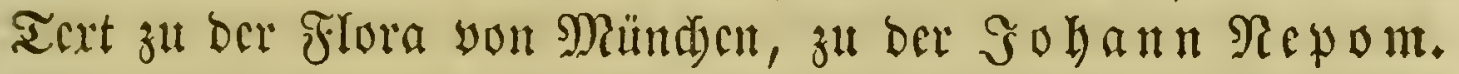
Mayrlyoffer bie A(bbildungen verfertigte ${ }^{5}$ ), uno forieb

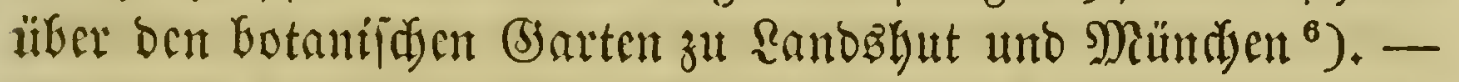

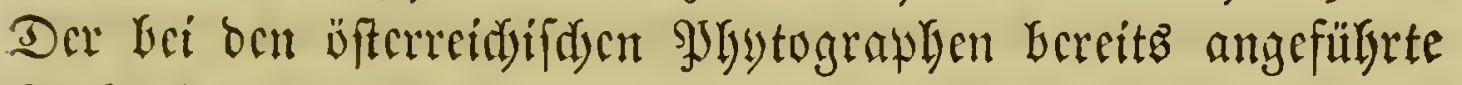

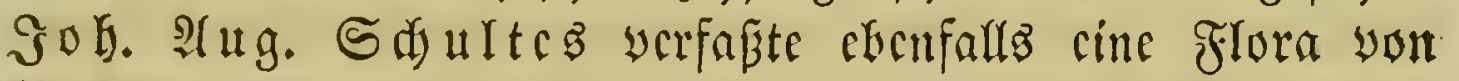

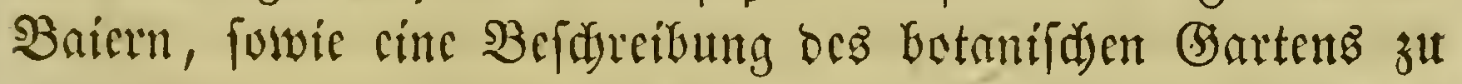

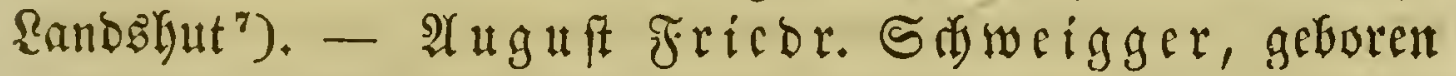

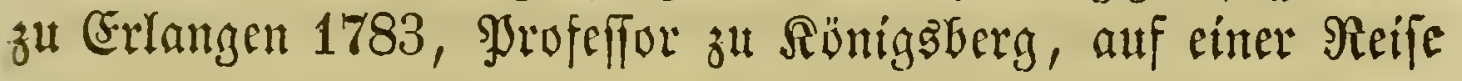

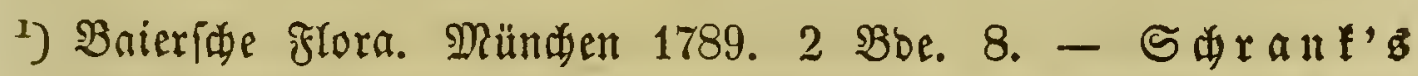

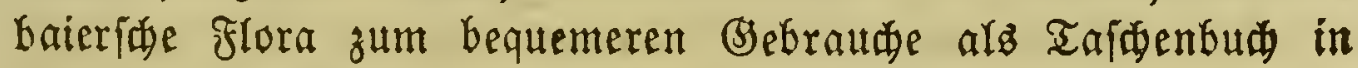
bequemere Form gebradit. Regensburg 1793. 8.

$\left.{ }^{2}\right)$ Primitiae Florae Salisburgensis cum dissertatione praevia de discrimine plantar. ab animalibus. Francof. a. M. 1792. 8. 2 tab.

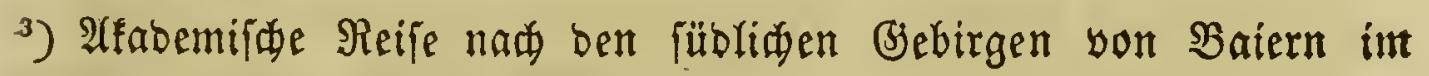
Sabr 1788. Münden 1793. 8.

4) Raturbiftorifale und öfonontifá Briefe über baz Donaumooż. Mannbeim 1795. 4.

5) Flora Monacensis, s. plantae sponte circa Monachium nascentes, quas pinxit et in lapide delineavit $\mathbf{J}$ oh. Nepom. II a y h of fer. Monachii $1811-18$. IV voll. gr. Fol. 400 tab. col.

6) Catalogus plantar. horti academici Landishutani. Landishuti 1807. 4. - Plantae rarior. horti academici Monacensis descriptae et iconibus illustratae. Monachii 1819. II voll. Fol. 100 tab. col.

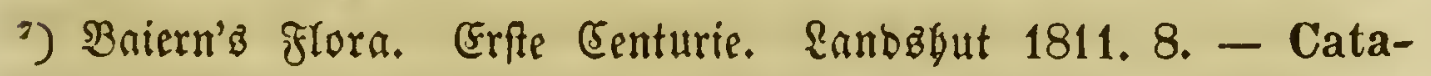
logus horti regii botanici Landishuti Bojorum. Landishati 1810. 8. Suppl. I-III. ibid. $1811-13.8$. 


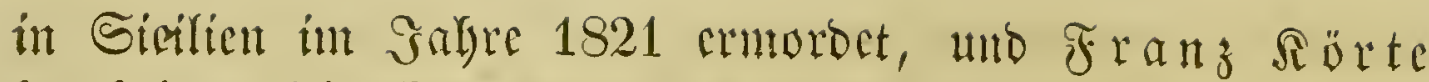

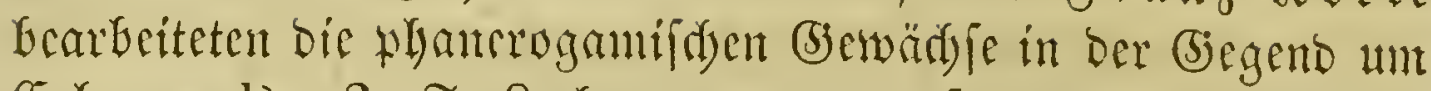

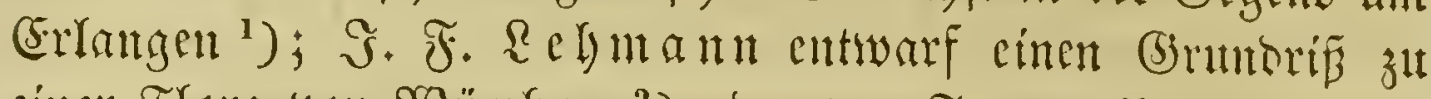

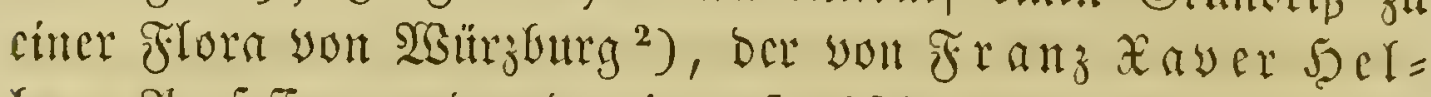
Ier, Frofeffor an ber bortigen J̧odydulte, weiter atsgefübrt

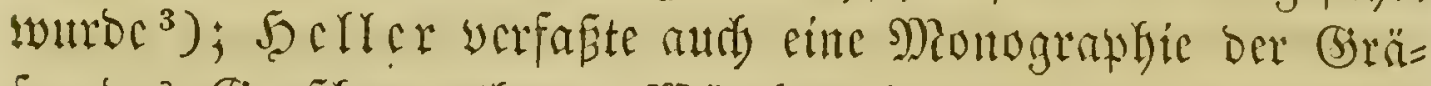

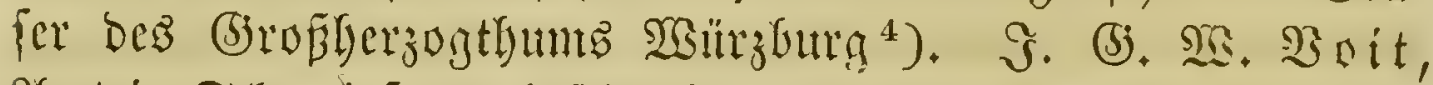
Argt in Sdycinfurt, befdricb dic Movfe ${ }^{5}$ ) und $\mathfrak{A}$ mbrofius

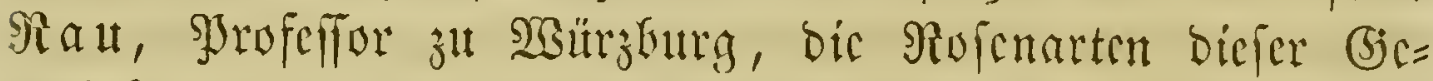
gent ${ }^{6}$ ). Gofann Rubw. Shrift. Sörle yerfafite cine

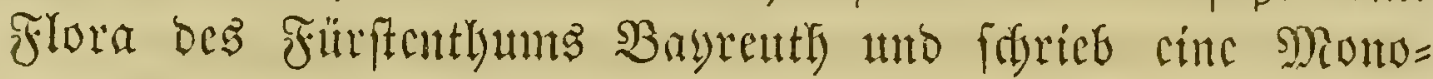

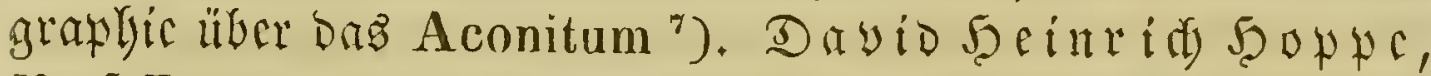

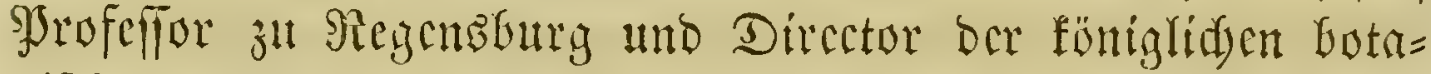

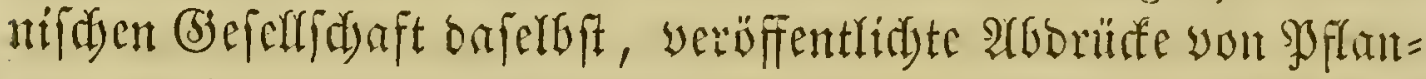
zen aus der Unigegento yon Regensantrg ${ }^{8}$ ), gab cin Herba-

1) Specimen florae Erlangensis. P. I. Classis 1-13. Erlangae 1804. 8. - Flora Erlangensis. Pars II, autoribus A. F. Schweigger et Franz Ko erte. Classis 14-23.

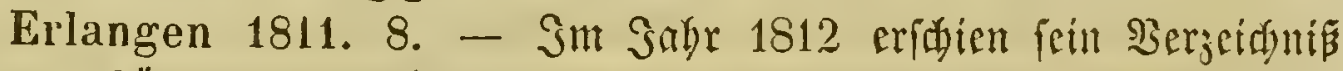

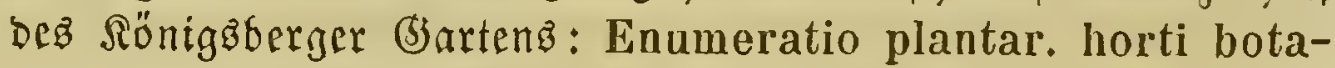
nici Regiomontani. Regiomonti 1812. 8.

$\left.{ }^{2}\right)$ Primae lineae Florae Herbipolensis. Ilerbipoli 1809. 8.

$\left.{ }^{3}\right)$ Flora Wirceburgensis. Wirceburgi $1810-15$. II voll. $S$. Supplement. 1815.

4) Graminum in Magno Ducatu Wirceburgensi tam sponte crescentium quam cultorum enumeratio systematica. Wirceburgi 1809. 8.

$\left.{ }^{5}\right)$ Historia muscorum frondosorum in Magno Ducatu Ilerbipolitano crescentium. Norimberg. 1812. 8. 1 tab.

$\left.{ }^{6}\right)$ Enumeratio Rosarum circa Wirceburgum sponte crescentium. Norimbergae 1816, 8. 1 tab.

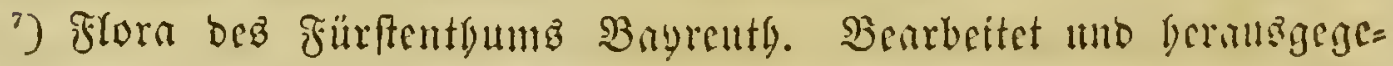
ben you Th. Egrift. Eirrobt. Bayrentí) 1798. 8. - Spicilegium observation. de Aconito. Erlang. 1758. S. 1 tab.

$\left.{ }^{8}\right)$ Ectypa plantarum Ratisbonensium. গiegenzburg 1787 -93. 8 voll. Fol. 800 tab. 


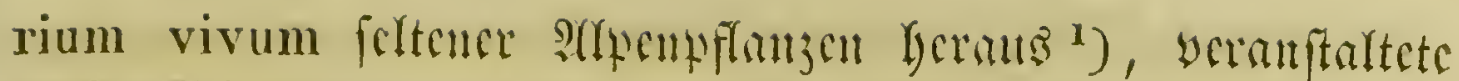

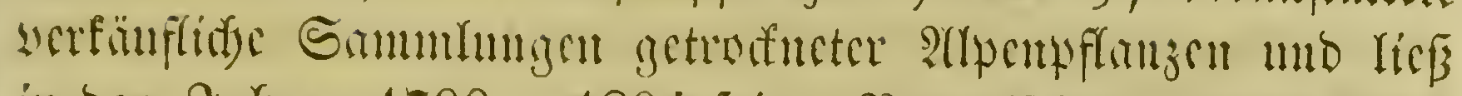

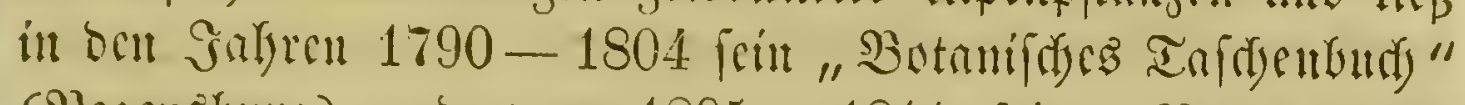

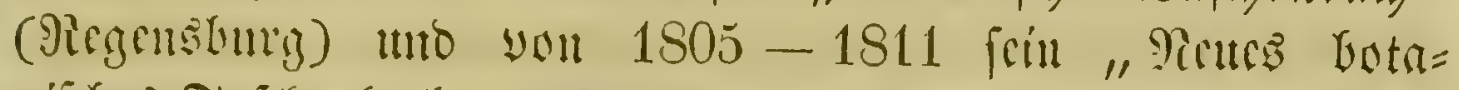

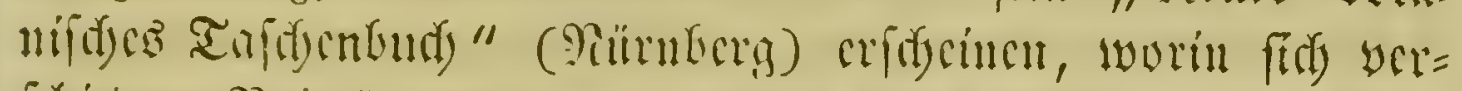

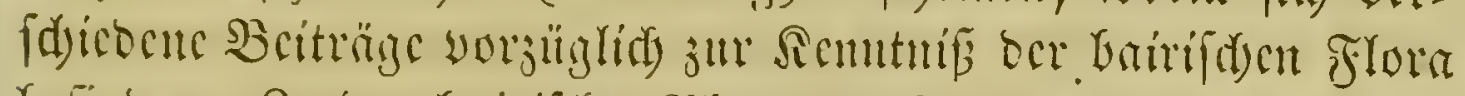

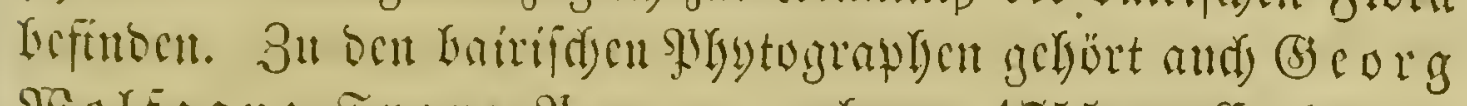

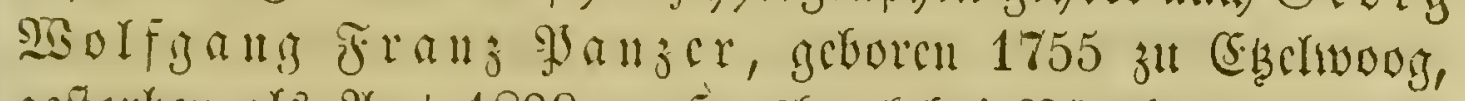

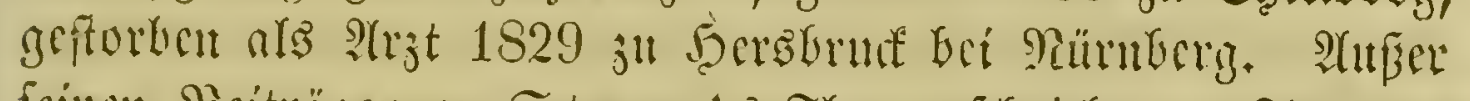
frincu Bciträgen zu Sturm'

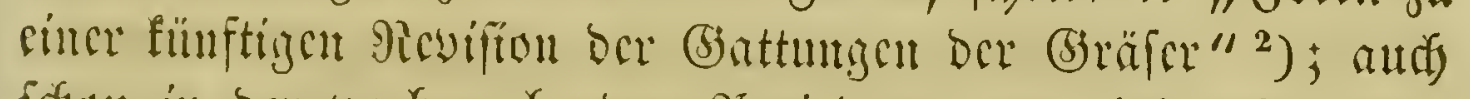

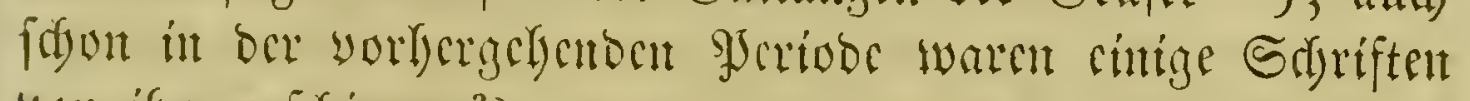
you ifu crichicucu, ${ }^{3}$ )

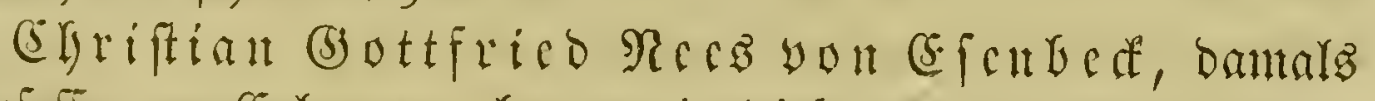

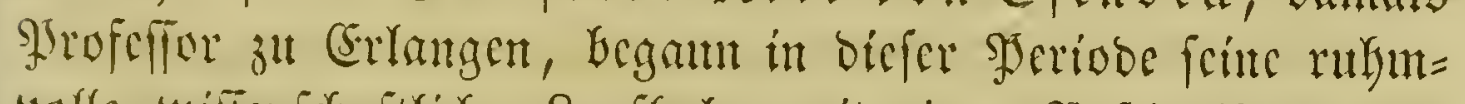

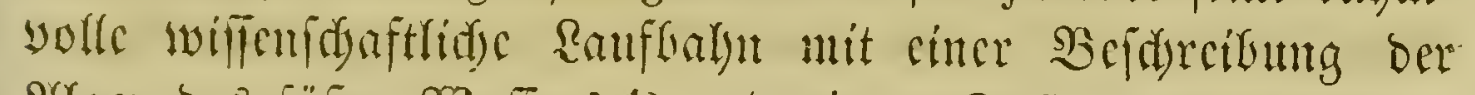

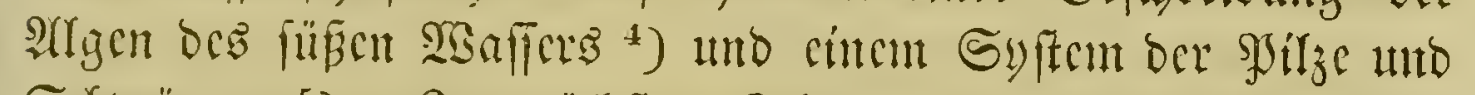

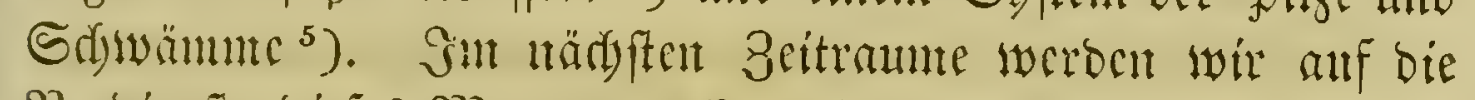

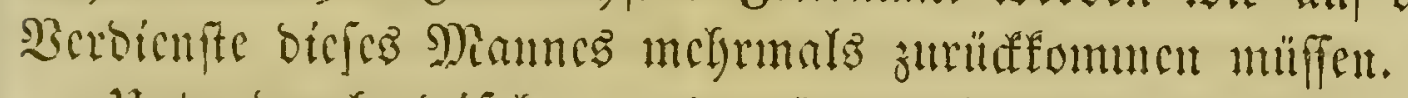

Unter bat badifden unt wärtembergifden Floriftent if yor alfen inal (Shriftian (b) melit, babifder Reibarzt, Jjrofeflor und Dircctor brs botanifden (5artens zu Sarts= rube, geboren 1762 zu Babcnweíler, geftorben 1837, wegen feimer fely forgfältig gearbeiteten Flora yon Baben umb bem

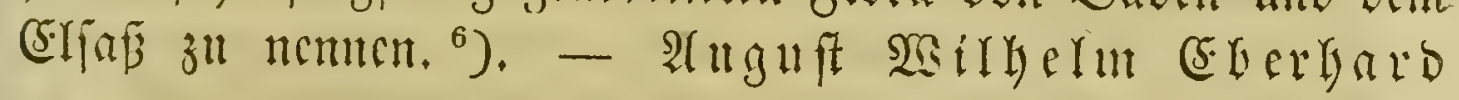

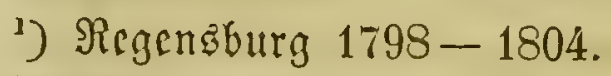

$\Rightarrow$ Mündfen 1813.4.6 Tafern.

$\left.{ }^{3}\right)$ Observationum botanicarum specimen. Norimbergae et

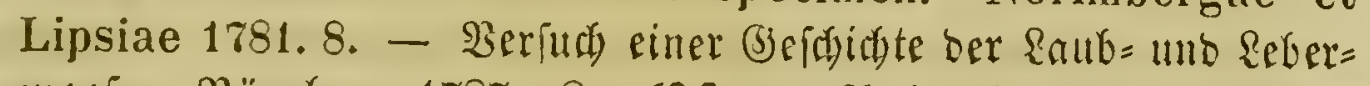

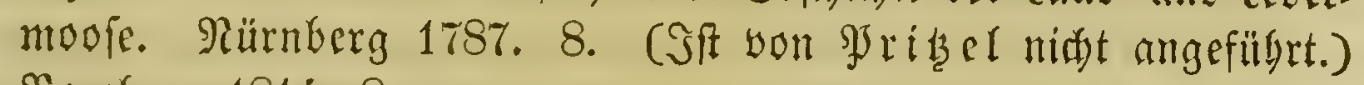

4) Bamberg 1814. 8.

5) $\Re$ Bürburg 1816. 4. 44 tab. ad nat. col.

$\left.{ }^{6}\right)$ Flora Badensis. Carlsruhae 1805-26. IV voll. 8. 24 tab. - Heber ben Sartaruther barten faricb er: Hortus Magni Ducis Badensis Carlsruinanus. Carlsrulıac 1811. 8. 


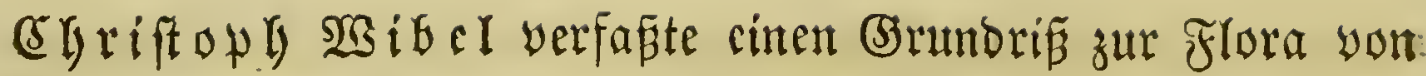

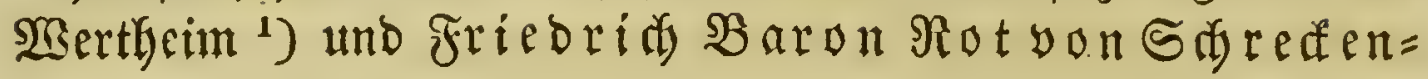
ftein eine Flora ber Begent um ben Uriprung ber Donau und bes Redfars ${ }^{2}$ ), Эahre yorher eine anonyme Sdrift erfdienen war ${ }^{3}$ ), Sobann Simon von aerner, 5ofrath und Sorofeljor zu Stuttgart, gefturben 1830, gab melyere $\mathfrak{W e r f e}$ mit $\mathfrak{g e}=$ malten $\mathfrak{A b}$ billoungen heraus ${ }^{4}$ ). (Das aud fïr bie Sjhytogra= phie äuferft twidtige $\mathfrak{W e r f} \mathfrak{S}$. (5) ärtner's über bie Früdyte unb Samen ber (Selvädje, weldjes yon feinem Sohne (S. F. (5) ätner fortgefest witroe, ift oben fodon angefübrt worbent.

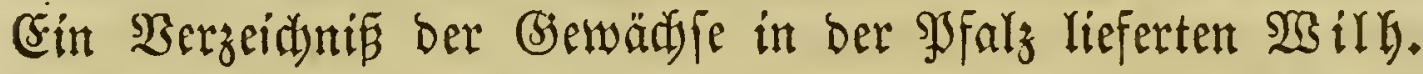

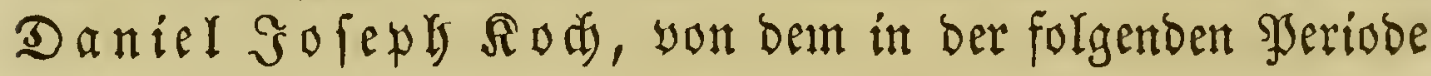

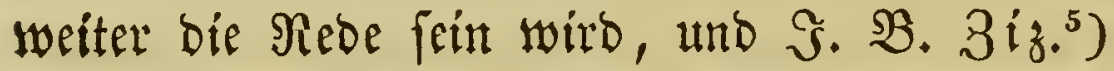

3ur heffifden flora lieferten $\mathfrak{B}$ orfha a

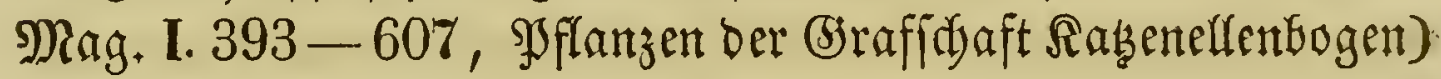

1) Primitiae Florae Werthemensis sistens Prodromum. Jenae 1799. 8. $\mathfrak{B e r g l}$, aud 9 ritel, S. 321.

2) Flora ber (jegeno um ben Hrfprung ber Donat unb bes Reafarä; bann yom Einfluf ber Sduffen in ben Bobenfee bis zum Ein= flué ber Ringing in ben $\Re$ bein. 18 Bodn. (Monandria-Tetrandria.) Donaucidingen 1804. 8.

3) Winterthur 1799. 8.

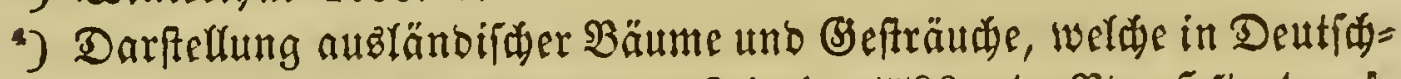
land im Freien auşbauern. Seipjig 1796. 1r Bro. Saft. 1-4.

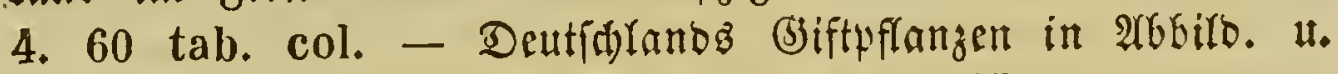
Erfflärungen. 18 Seft. Şamnower 1798. 4. - Hortus sempervirens', exhibens icones plantarum selectiorum quotquot ad vivorum exemplorum normam reddere licuit. Stuttgardiae 1795-1830. LXXI voll. Fol. eleph. 851 tab. col. manu pictae. - Icones plantar. selectior. Fasc. I. Stuttg. 1802. Fol, it tab. col, - Genera plantar. selectar. specier. iconib. illustrata. Stultgardiae et Mannheim $1811-28$.

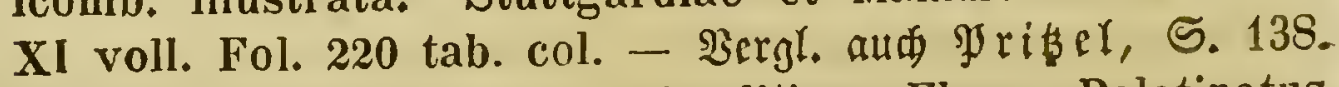

$\left.{ }^{3}\right)$ Catalogus plantarum quas in ditione Florae Palatinatus legerunt, in amicorum usum conscriptus. Phanerogamia. Moguntiae 181\%. 4 . 
unb (3), (3) ärtuer (

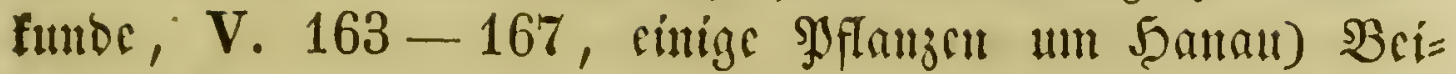

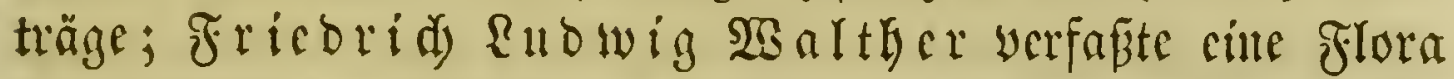

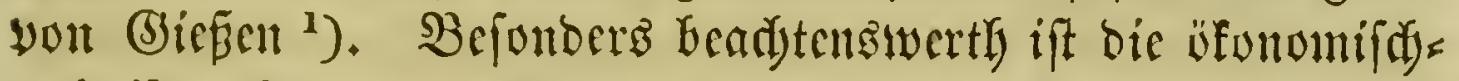

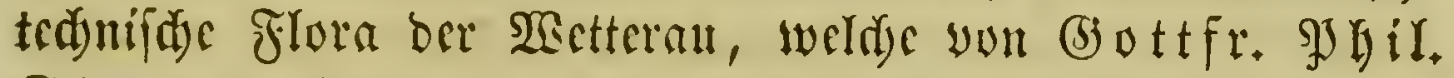

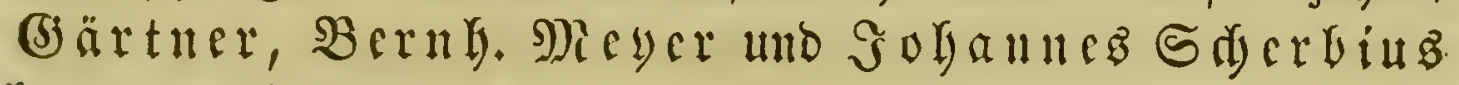
herauḃgegeben wurbce. ${ }^{2}$ )

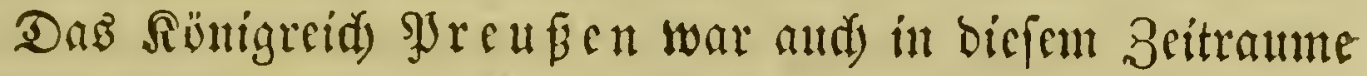
ziemlid) reidy an Botanifern. WSir nemnen zuerft

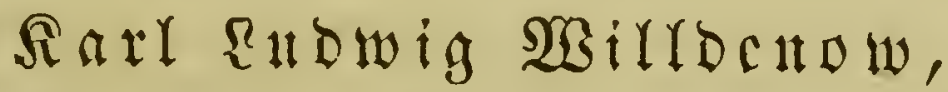

geb. 1765, geft. 1812 ałz Srofefior und Borfeber bes botanifden (3iartenz zu Bertiin. ${ }^{3}$ )

Seine Flora yon Berlin ift fodon 5.225 erwälynt wor $=$

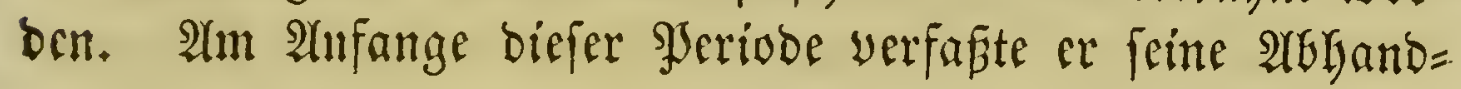

1) Flora yon (się̄en und ber umliegenden siegento. Mit einem SJlame bes botan. Uniberfitätżgartenz. Bießen und Darmftabt 1802. 8. $\mathfrak{M}$ it $1 \mathfrak{f o l}$. Tafel.

2) Scfonomifat=tednifde Flora ber SBetterau. Franffurt a. $\mathfrak{M}$. 1799 - 1802. 3 Bbe. 8. 1 mappa geographica.

$\left.{ }^{3}\right)$ Tractatus botanico - medicus de Achilleis, cui accedit supplement. generis Tanaceti. Halae 1789. 8. 2 tab. - Historia Amaranthorum. Turici 1790. Fol. 12 tab. col. - (3rumb= rí̈ der Irräuterfunbe. Berfin 1792. 8. 9 Taf. Die 6. úmb 7.

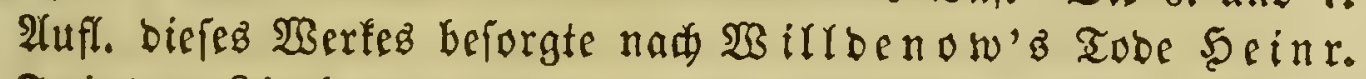
griebr. Rin unb exífien erfere 1821 unb lestere 1831 in 8. mit $11 \mathfrak{I} \mathfrak{a f e} \mathfrak{f n}_{\text {. }}$ - Phytographia seu descriptio rariorum minus cognitarum plantarum. Fasc. I. Erlangen 1794.

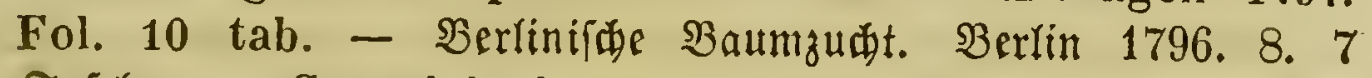
Tafeln. - Geraniologia in amicorum usum seorsim impressa. Berolini 1800. 8. - Wirroenow unb 2 . 5.. $50=$

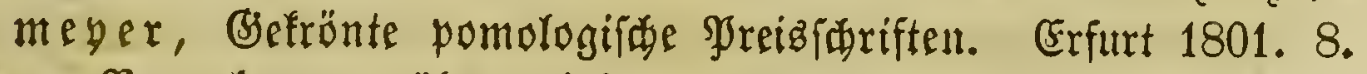
- Benterfungen über einige feltene farrenfräuter. Erfurt 1802. 8. 3 Taf. - 2fuleitung zum Selffflubium ber Bota=

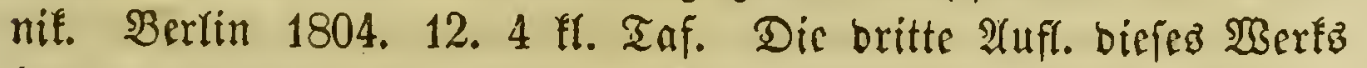
beforgte Sacinr. Friebr. Rinf, Berlin 1822 mit 4 fol. Tafeln, 


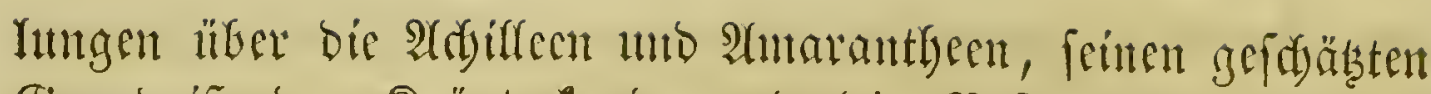

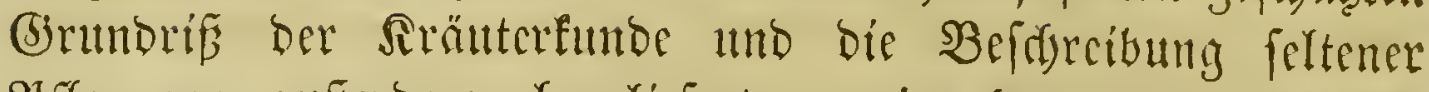
ŞFlanzen; auferbent aber licferte er eine beträdytlidge $2(n z a b l$

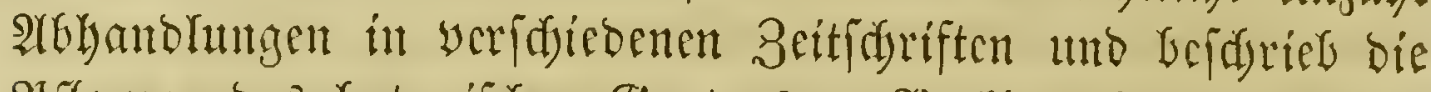

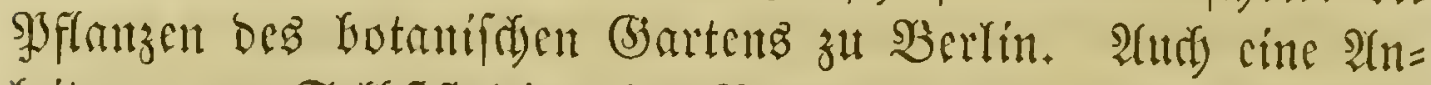
Yeitung zum Sclfftftudum ber Botanif lief er eridyeinen; bas =

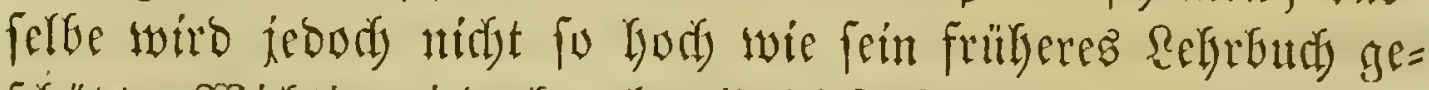

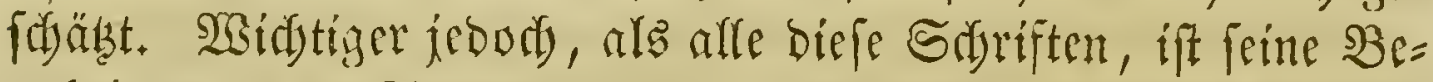
arbeitung yon Rimne's Species plantarum, weldye fidy fo= wohl burdy ifre Sorgfalt, wie Durdi ifren Rcidythum aut neuen Arten auszeidynet. Das Siserf erfdrien von 1797-1810

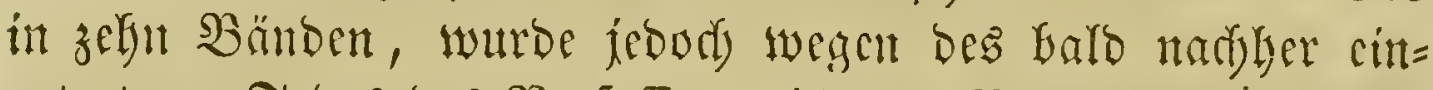

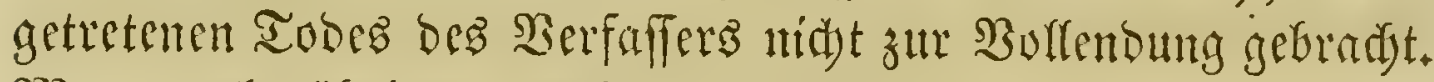

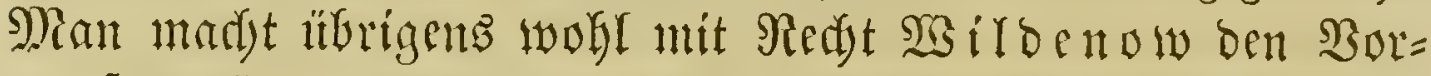

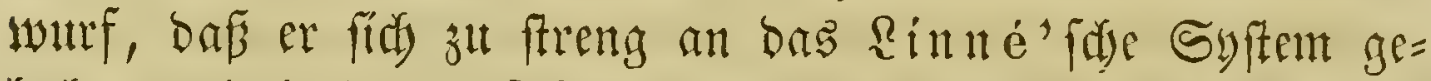
lyalten uno in ber atnfübrung ber Synnente ju unfeleftändig

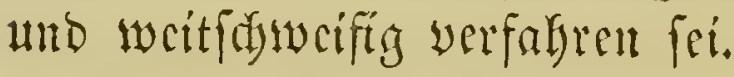

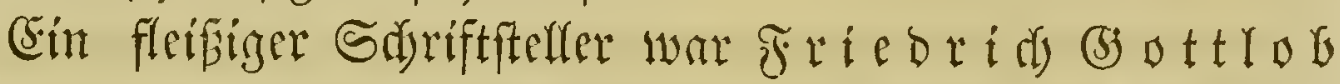

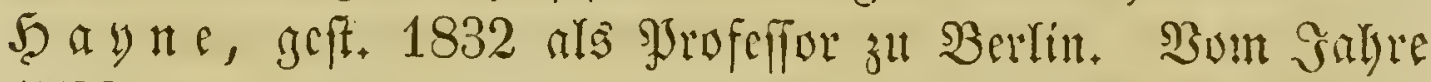
1799 an $\mathfrak{g a b}$ er feine butd) A(bGildungen erläuterte Termino=

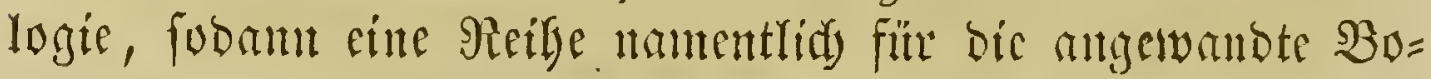

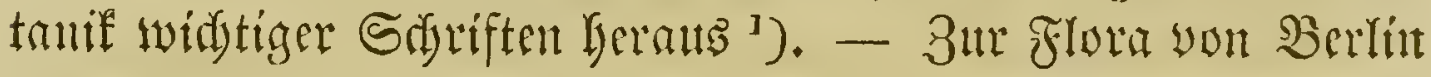

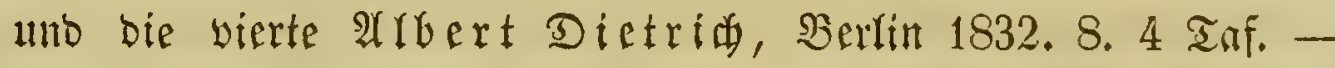
Caricologia, sive descriptiones omnium specierum Caricis etc. Berolini 1805. 8. - Enumeratio plantarum horti regii botanici Berolinensis, continens descriptiones omnium vegetabilium in horto dicto cultorum. Berolini 1509-13.8. - Hortus Berolinensis, sive icones et descriptiones plantarum rariorum vel minus cognitarum, quae in horto regio botanico Berolinensi excoluntur. Berolini 1816. Fol. 110 tab. col.

1) Termini botanici iconibus illustrati. Berolini 1807. II voll. 4. 69 tab. col. - Betreut Darfteflung uno Beffreibung Der

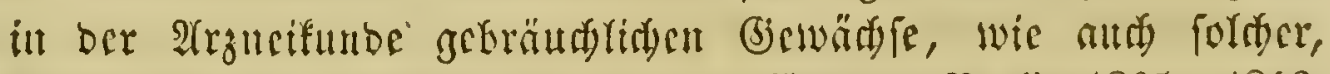
werdye mit ignen verwed) felt merben fümen. Sorrtin 1805-1846. XIV voll, 4. 648 tab. col, - Sergl. Writicl S. 112. 


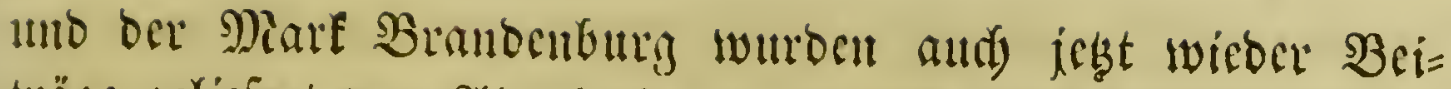

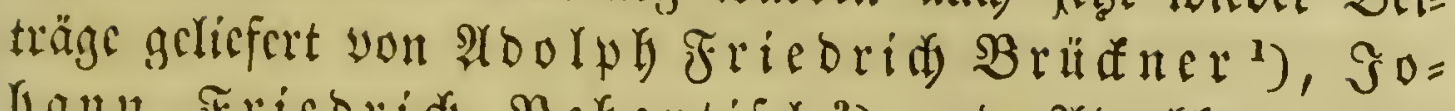

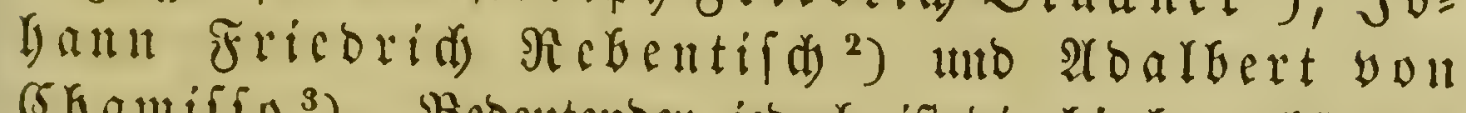
(5hamiffo ${ }^{3}$ ). Becocutember icbody ift bie hierher gebörende

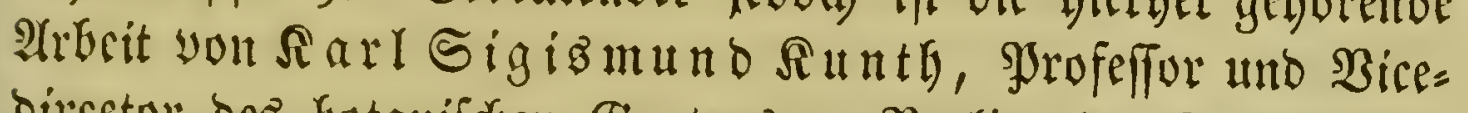
birector bes botanifda (5artenz ju Berlin, Der fpäter und) = mals ju ertwälucn ift. ${ }^{4}$ )

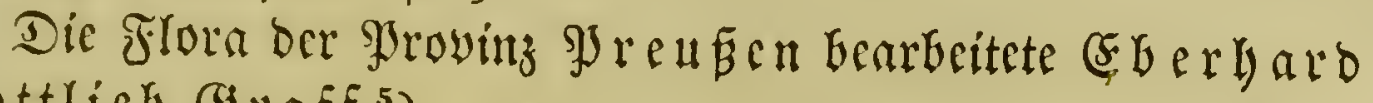
(j) ottlieb (a) $\mathfrak{a} \cap f .^{5}$ )

Mit ben un Sittenberg wadjenben Pflanzen befdäf=

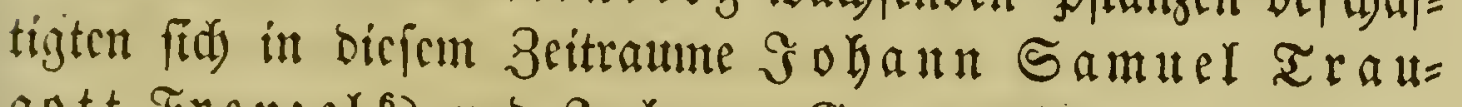
gott Frenzel ${ }^{6}$ ) uno Gohaun (5)org $\mathfrak{B}$ ün $\left\{d e^{7}\right.$ ), mit ber Flora von Salle Gohann Friebrid $\mathfrak{B}$ ohlleben ${ }^{8}$ ),

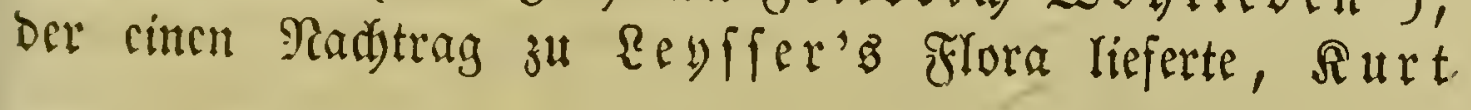

1) Florae Neobrandenburgensis Prodromus. Jenae 1803. 8.

$\left.{ }^{2}\right)$ Prodromus Florae neomarchicae. Berol. 1804. 8. 4 tab. col. - Index plantar. circa Berolin. sponte nascentium. Berol. 1805.8.

$\left.{ }^{3}\right)$ Adnotationes quaedam ad Floram Berolinensem Kunthii.

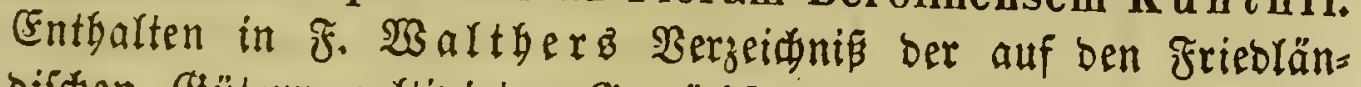
Difめen Büütern cultibirten Getwädie, nebft einem Beitrage ber Flora ber Mittelmarf. s. 1. 1815. 8. - Heberfidt ber nußbarfen

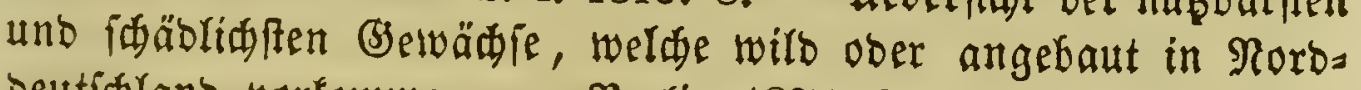
Deutidlanb borfommen 26. Berlin 1827. 8.

") Flora Berolinensis. Berolini 1813. 8. - 1838. 2 voll. 8. - Adnotationes de Adalb. de Chamisso.

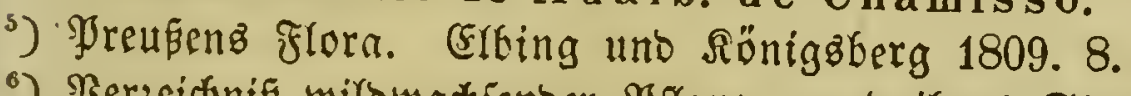

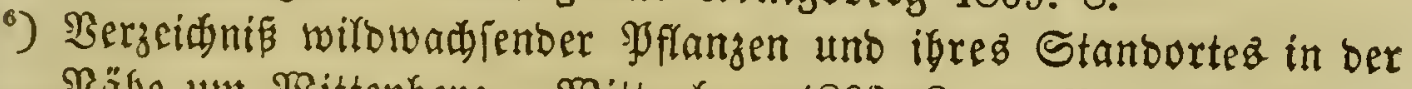

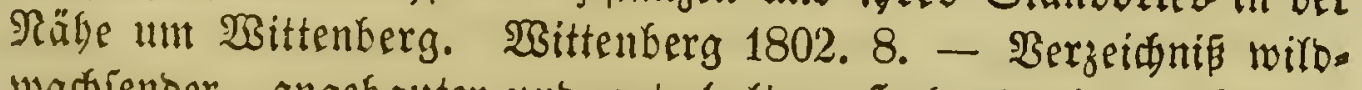
wadjender, angebauter und unterfaltener 5̧orgarten in ber Biegento yon $\mathfrak{W}$ Bittenberg. Wittenberg 1801. 8.

7) Enumeratio plantar. circa Vitebergam in aquis, locis paludosis et humidis praecipuar. necnon officinal. sponte crescentium. Wittenbergae 1804. 8.

$\left.{ }^{8}\right)$ Supplementi ad L ey's S eri Floram Halensem fasc. I. Halae 1796. 8. 1 tab. 


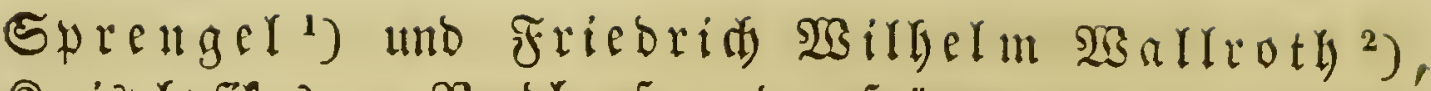
Rreisplyyfifus zu Rorblyaufen, ber [̣äter nod zu erwähnen iff; - yon ber (Erfurter Flora werfafte Gol. Jacob

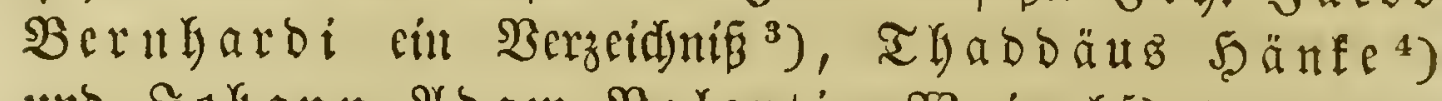

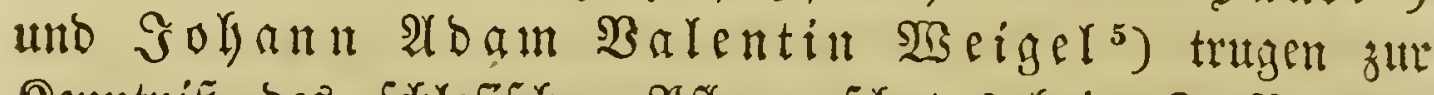

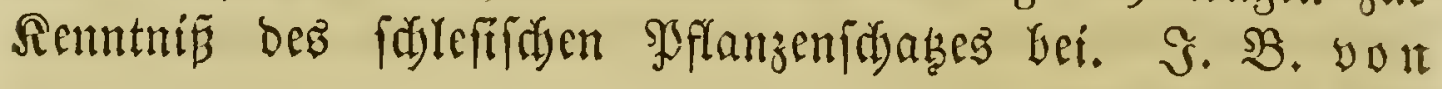

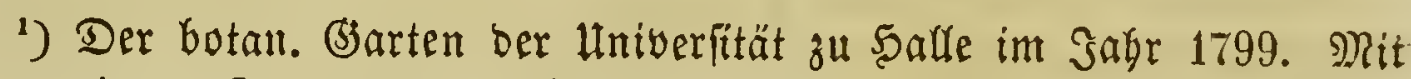
einem Brandrís bez botan. Bartenछ. Şalle 1800. 8. 1 Tafel.

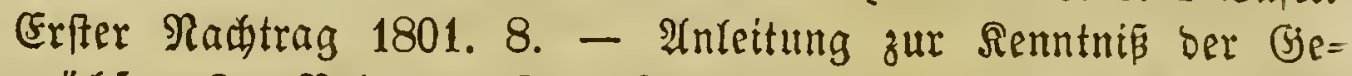

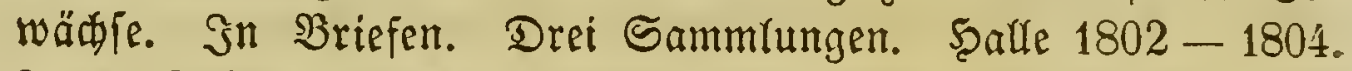

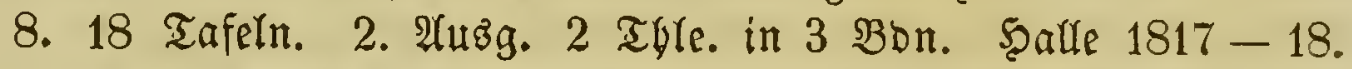
8. 25 tab. pro part. col. - Siartenzeitung mit idCuminirten 爪upfern. Salle $1804-1806$. 4 Bbe. 4. - Flora Halensis tentamen novum. Halae - Saxon. 1806. 8. - Mantissa prima Florae Halensis, addita novar. plantarum Centur. ibid. 1807. 8. - Mantissa altera. ibid. 1811. 8. - Flora Halensis. Ed. II. ibid. 1832. 2 tom. 8. - Index plantarum, quae in horto botanico Halensi anno 1807, viguerunt. Halae 1807, 1808. 8. - Historia rei herbariae. Amstelodami 1807-1808. 2 tom. 8. - Gefammelte Rachridten yon ber

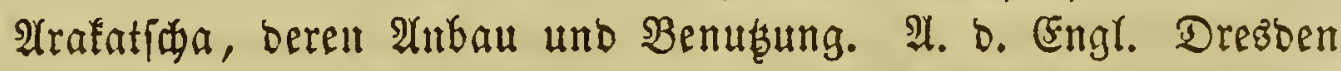
1808. 1 fol. Tafer. - Plantarum Umbellifarum, denuo disponendarum Prodromus. Halae 1813. 8. 1 tab. - Plantarum minus cognitarum pugillus I et II. Halae $1813-15$. 2 voll. 8.

$\left.{ }^{2}\right)$ Annus botanicus, sive Supplementum tertium ad C. Sprengelii Floram Halensem. Halae 1815. 8. 6 tab. -

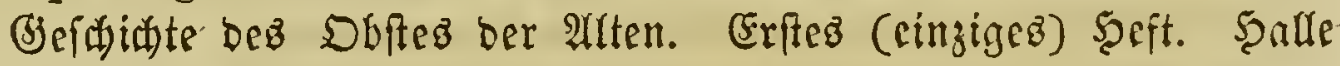
1812. gr. 8.

3) Syftematif um Erfurt gefunden werben. 1r $\mathfrak{x}$ gl. Erfurt 1800. 8. - Catalogus plantar. horti Erfurtensis. 1799. 8. - Suppl. I-VL.

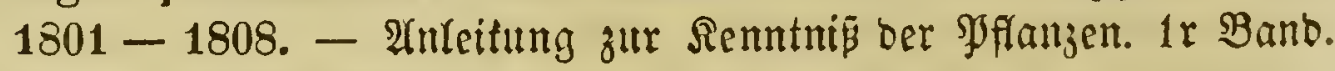
Exfurt 1804. 8. 5 Tafeln.

*) Beobadtungen auf Neifen. (1791.)

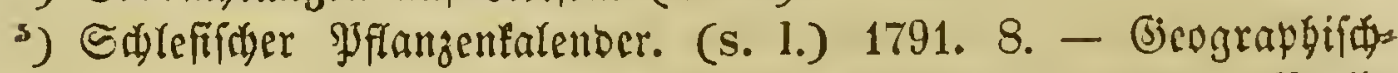

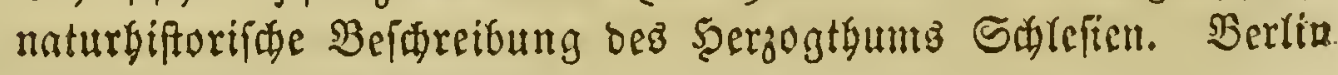
1800 - 1806. 10 Bber. 4. 


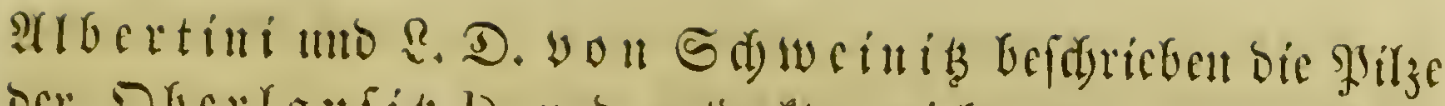

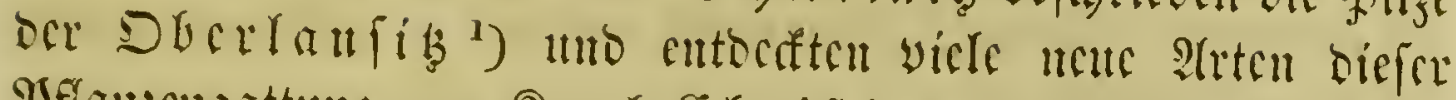

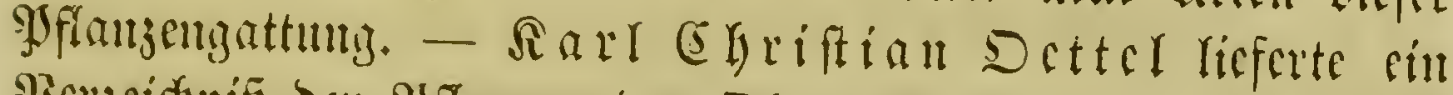

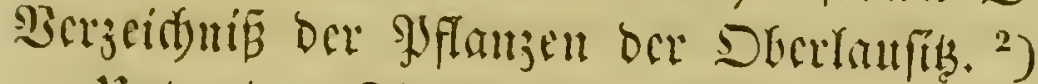

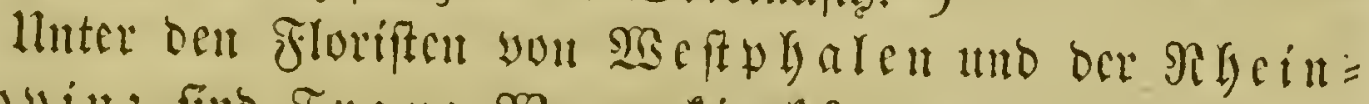

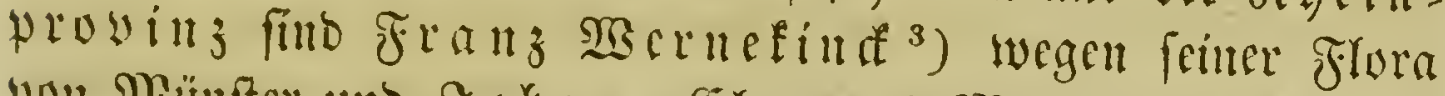

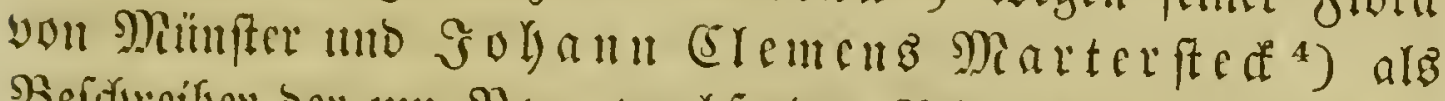

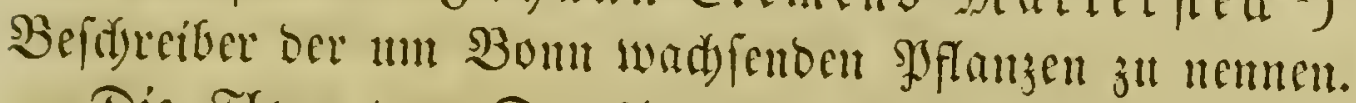

Die Flora yon Deseden wabe in biefan Zeitramme

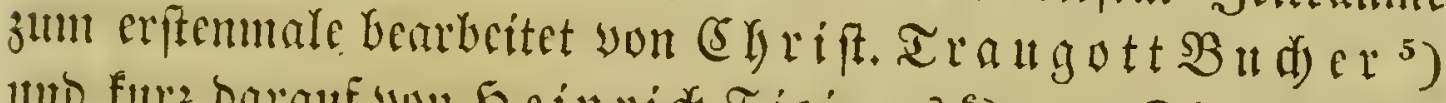

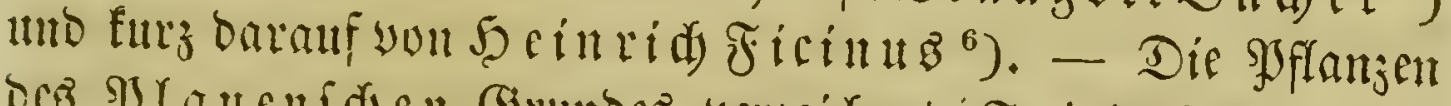

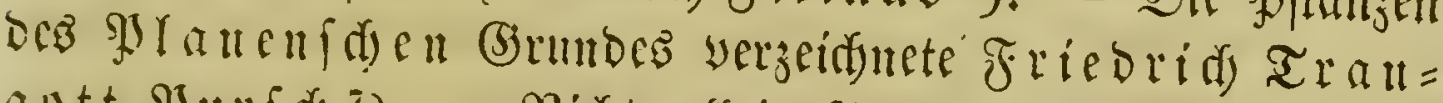

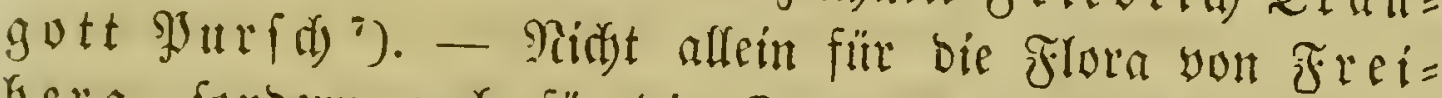
berg, fonbern andi) für bie Renutuif ocr fryptogamifden

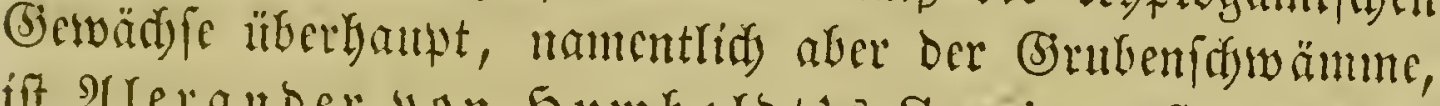

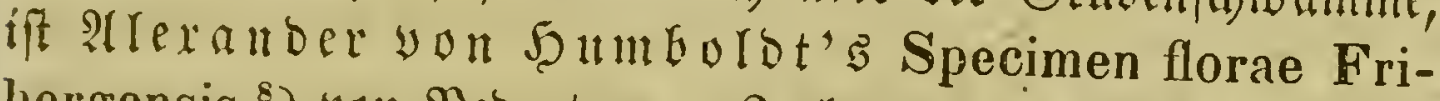
bergensis ${ }^{8}$ ) von $\mathfrak{B}$ cocutung. Fol)ann (Shliftian (5jott= lob $\mathfrak{B a u m g a r t c u}$ yerfápte cine Flora yon ecipzig ${ }^{9}$ ).

1) Conspectus fungorum in Lasatiae superioris agro Niskiensi crescentium etc. Lipsiae 1805. 8. maj. 12 tab. col.

$\left.{ }^{2}\right)$ Syftematifaes Ber Yflambrt. Bürlit 1799. 8.

3) Icones plantarum sponte nascentium in Episcopatu Morasteriensi, additis differentiis specificis, synonymis et locis natalibus. Vol. I. contin. tab. 1-100. Monašterii 1798. Fol.

4) Bonnifue flora. Erfter Theil. Bonn 1792.8.

$\left.{ }^{5}\right)$ Florae Dresdensis nomenclator. Dreß̧ben 1806. 8.

$\left.{ }^{6}\right)$ Flora ber (jegello um Dresben. Drešben 1807-1808. 8. 1 fol. Tafel. - 2. 2lufl. Daf. $1821-23.2$ Thle. 8. 3 I rnfeln. - 3 . Aufi. Dresber 1838 yon Ficinus uno (3) uftay seyngolo, mit eincr Sarte.

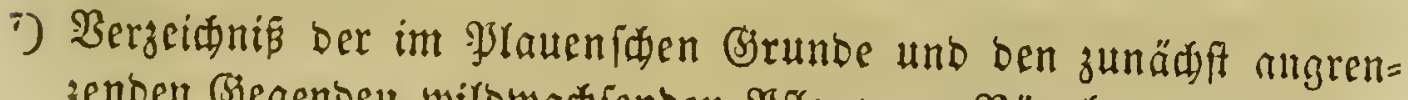
zenben Gegenden wildwatienben Pflanzen. Rürnberg 1799. Fol.

$\left.{ }^{8}\right)$ Berolini 1793. 4. it tab.

9) Sertum Lipsicum. Lipsiae 1790. 8. - Flora Lipsiensis. Lipsiae 1790. 8. 4. tab. 
Sn biefer Stabt lebte fur bantaligen Beit auth $\Re$ omanuz

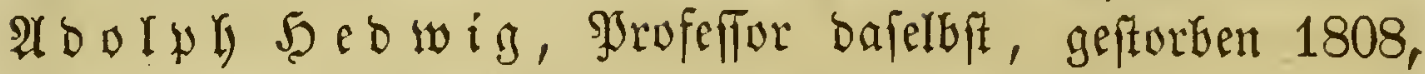

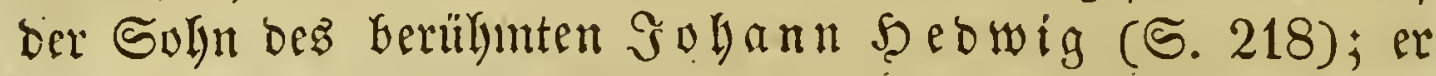

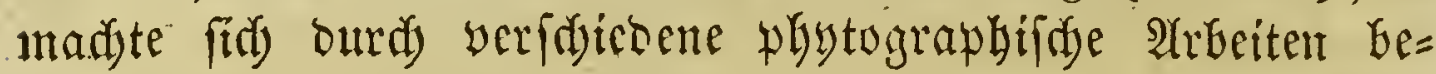
$\mathfrak{f a n n t .}^{1}$ )

(El)riftian Friebrid) Sdy ägriden, Relyer an ber= felben Sodjidule, war ebenfalls eint fleifigiger Sdyriftiteller.

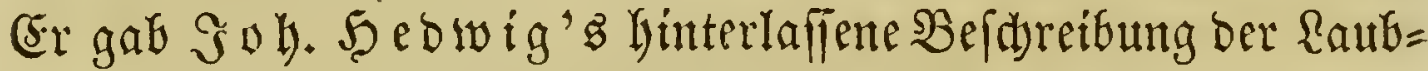
moofe heraus und farieb Supplemente bazu, fetste die Dar= ftelluing ber Moofe in ber von $\mathfrak{S}_{\mathrm{B}}$ ill be nu wo veranftalteten

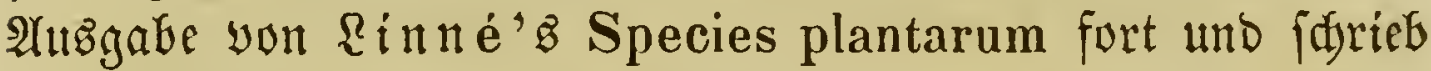

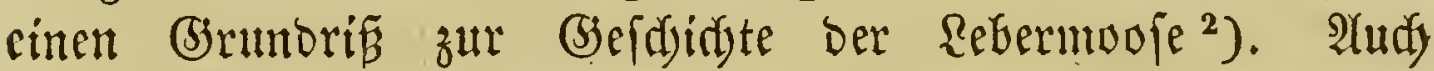

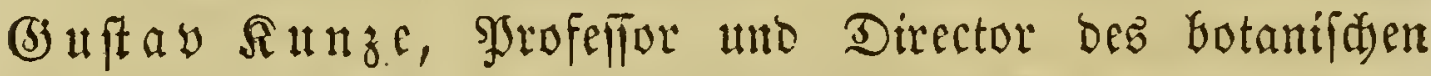
(5artens zu Reipzig, war ein tübtiger Mylulog. (Er veran= ftaltete bertäuflidye Sammlungen von Sdyännmen unb gab

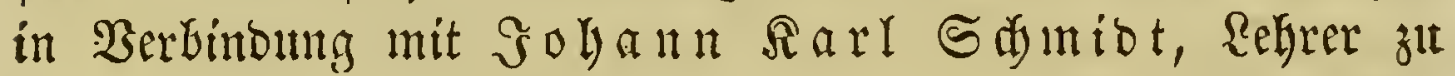
Tieffurth, banu zu Sofiwgl und zuleşt zu Renzburg in ber

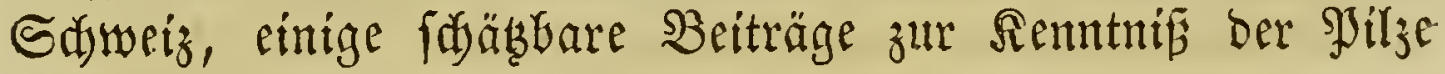
lyeraus. ${ }^{3}$ )

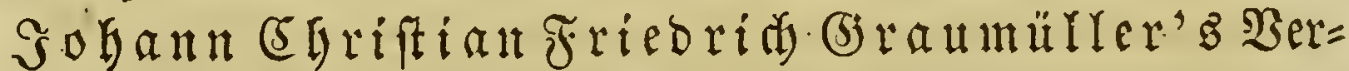

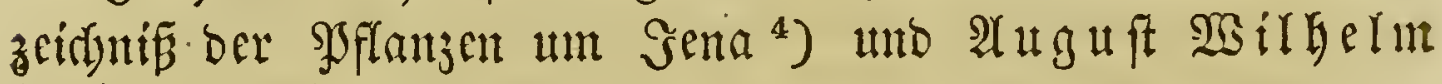

1) Tremella Nostoch. Commentatio. Lipsiae 1798. 4. 1 tab. col. - Sporarum catalogum offert. Lipsiae 1799. 8. -

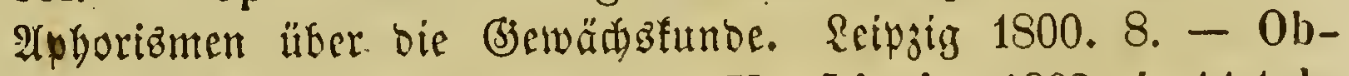
servationum botanicarum fasc. V. Lipsiae 1802. 4. 11 tab. col. - Genera plantar. secund. characteres differentiales ad Mirbelii editionem revisa et aucta edenda curavit. Lipsiae. 1806. 8. (Entyält die erffen 10 Rlaffen \&inn é'B.)

3) Topographiae botanicae etc. Lipsiensis. Lipsiae 17991806. 4. - Historiae Muscorum hepaticor. Prodromus. Lips. 1814. 8. 1 tab. col.

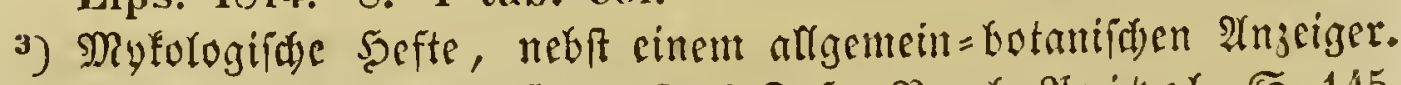

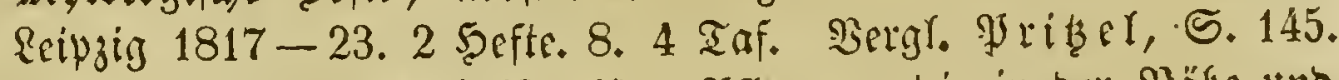

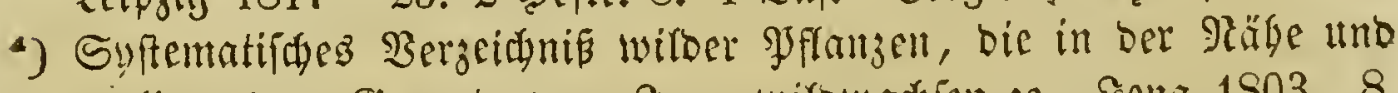

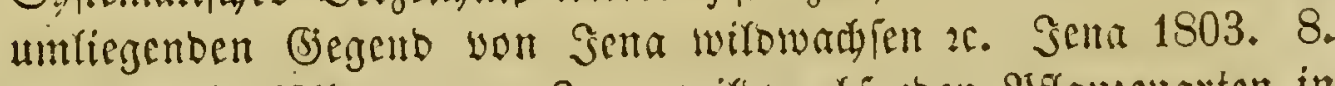

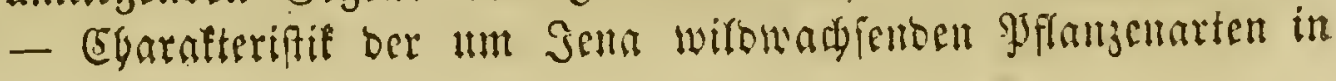


Denuftet's Flora you SBrimar ${ }^{1}$ ) find wou geringer $\mathfrak{B} e=$ Dentumi.

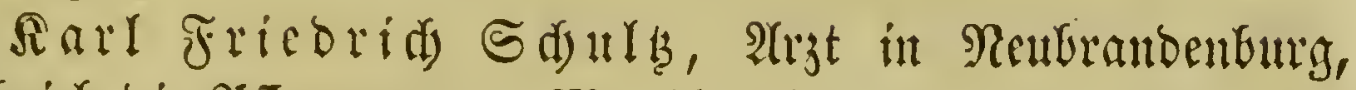

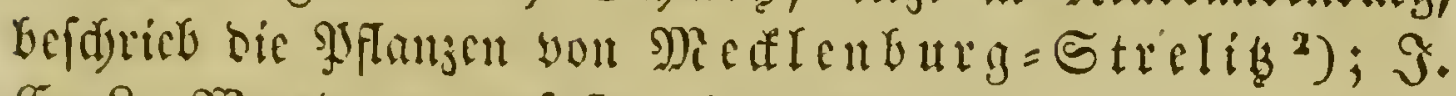

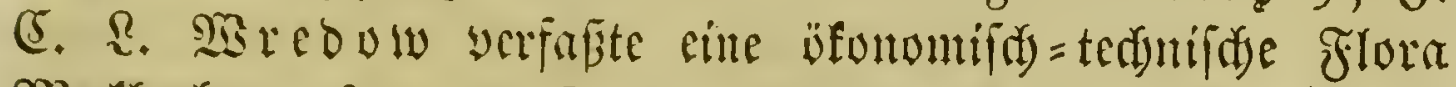

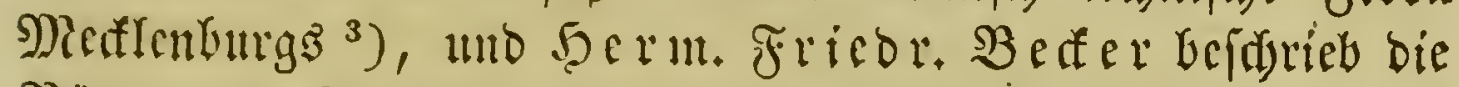

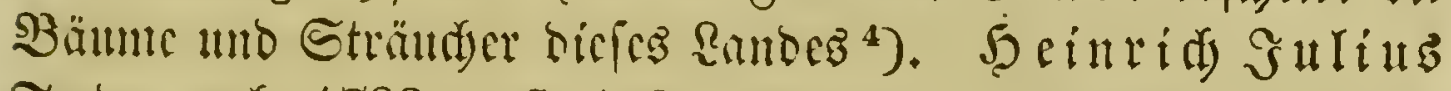

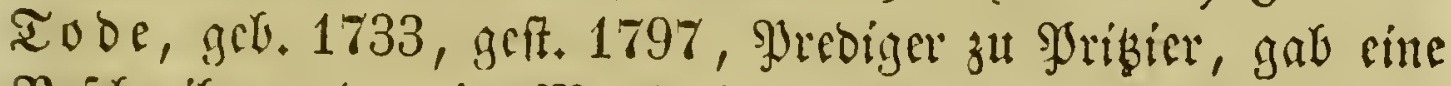
Şcidyreibung ber it Mefflenturg wadjenden Pilye herauz

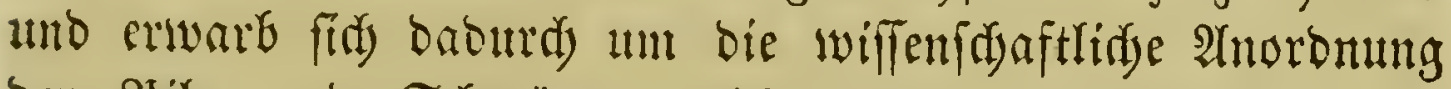
ber SJilje und Sdytuämme nidyt geringes Berbienft ${ }^{5}$ ). -

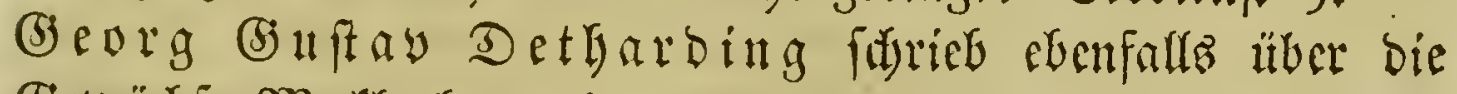

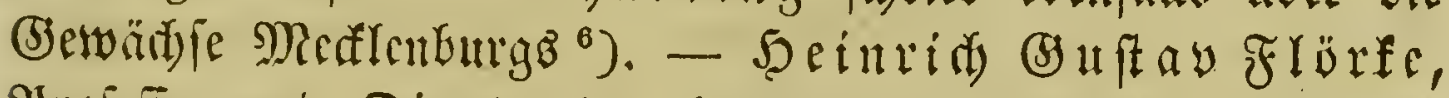
SJrofentor uno Director bes botanifaen Gartens ju Noftoć,

tabelfarifder Form. Sena 1803. S. - Reule Methode von na

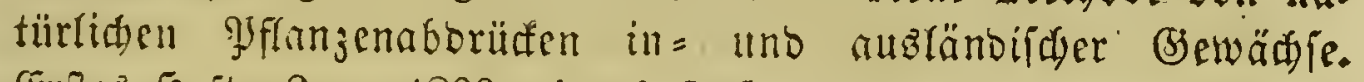
Erffes Seft. Sena 1809. 4. 10 Taf. - Flora pharmaceutica

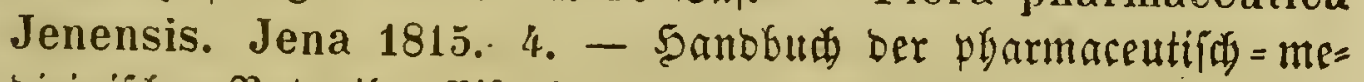
bicinifaen Botanif. Eifenterg $1813-19.6$ Bbe. 8.

1) SBeimarz Flora. 1. Afbth. (PJganerogamen.) Sena 1800. 8. -

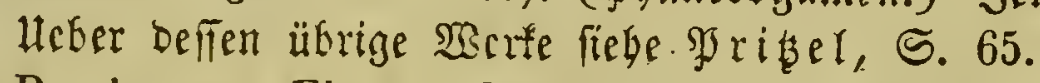

$\left.{ }^{2}\right)$ Prodromus Florae Stargardiensis. Berolini 1806. 8. Suppl. Neobrandenburgi 1819. 8.

3) Tabeularifhe Heberfidyt ber in Meălenburg witowadjenben pgä

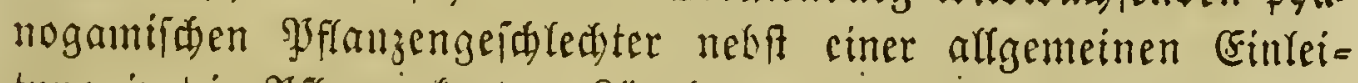
tung in bie Pflanzenfunoe. Rüneburg 1807. 8 . - Defonomifis tednifde Flora Meftenburgo. Rëneburg $1811-12.2$ Sobe. 8.

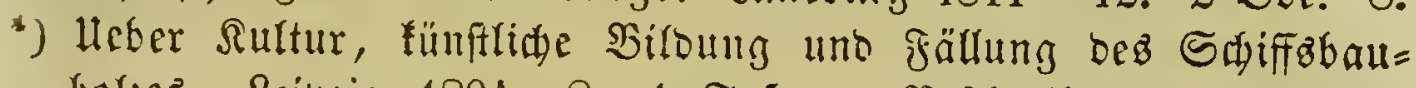

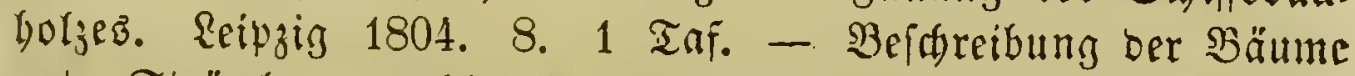

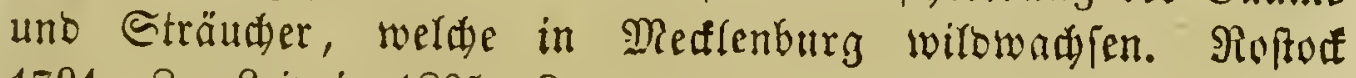
1791. 8. Reipzig 1805. 8.

5) Fungi Mecklenburgenses selecti. Lüneburgi 1790-91. Il fasc. 8. 17 tab.

-) Berzeidni einer Sammlung von getrofineten medtenburgifden

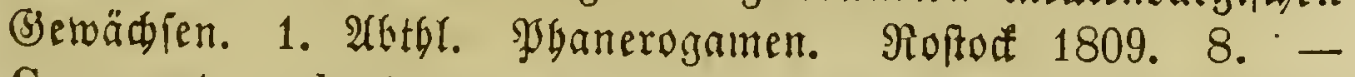
Conspectus plantarum magniducatuum Megalopolitanorum phanerogamar. Rostockii 1828. 8. 2 tab. Fol. 
geft. 1835, war cin grünblidjer Remmer Der Flcdjen, lïber weldye SPflanzengattmingen or verifdicoene Alblanthlungen ver= fante. ${ }^{1}$ )

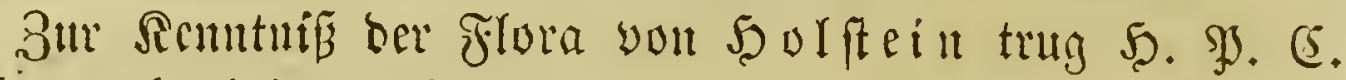

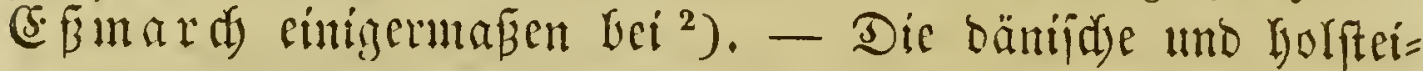
mifdye Flora von farl bottloh Rafn wird weniger in whytegraplificher biuficht, als wegen ber in ifre entbaltenen

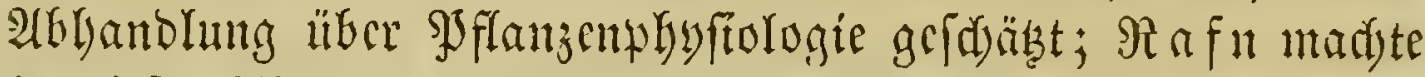
in biefer 2lbhandlunt widjtige Beobad)tungen über ben Ein=

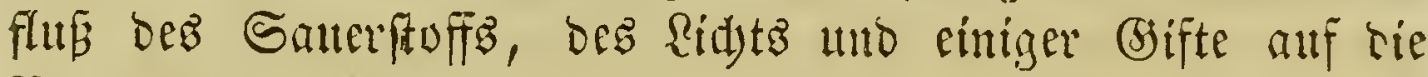
Begetation befamt ${ }^{3}$ ). Der Rieler Jrofeffor Friebrids Sigerr, geft. 1823, gab in Serbintung mit Danicl

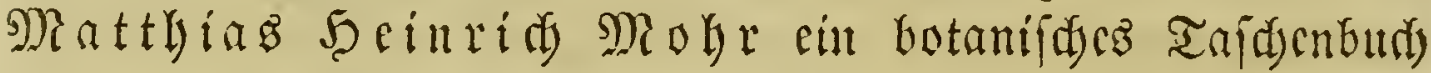

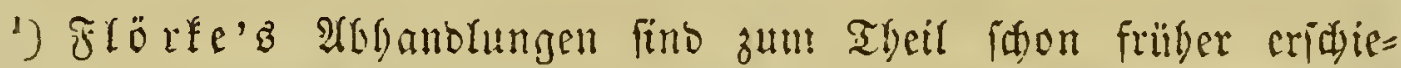

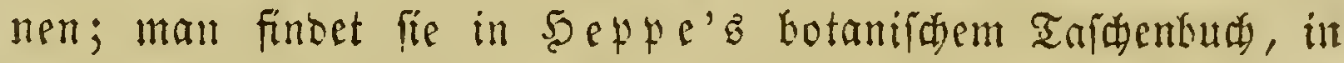
Squraber'z Sournal für die Botanif und in bem Berliner Magrain. - De Cladonis, difficillimo Lichenum genere, commentatio nova. Rostockii 182S. 8. - Bon feinen ver= fäuffiden "Dentiaen Siffenen. Berlin." fino von 1809-1815

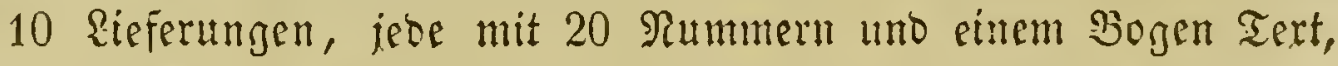

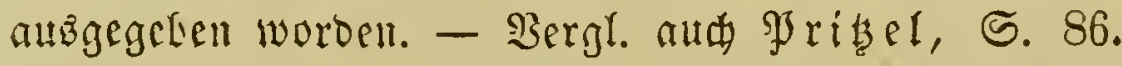

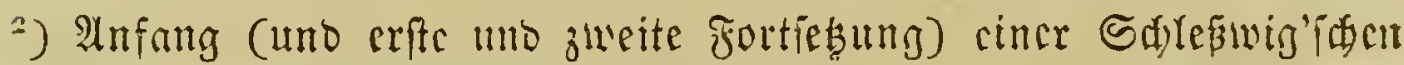

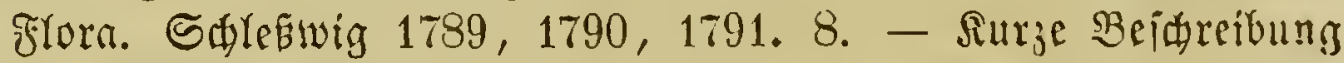

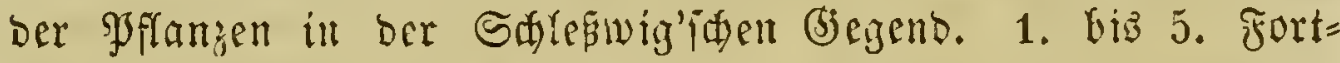

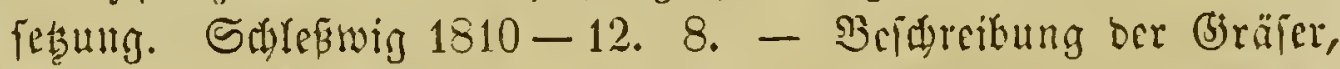

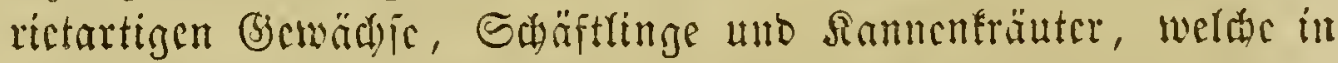

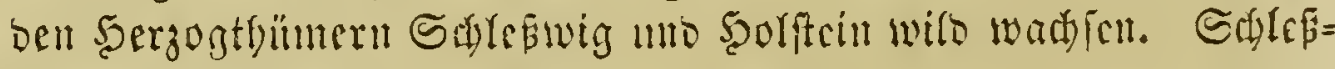
wig uto Reipzig 1794. 8.

3) Danmarks og Iolsteens Flora, systematisk, physisk og ökonomisk bearheydet. Kiobenhain, $1796-1800$. II voll. 8. - Udkast till en Plante-Physiologie, grundet paa de nyere Begreber i Physiologie og Chemie. Kjöbenharn 1796. 8. - Doutial): Entwurf ciner giflanjenplygfologic, auf

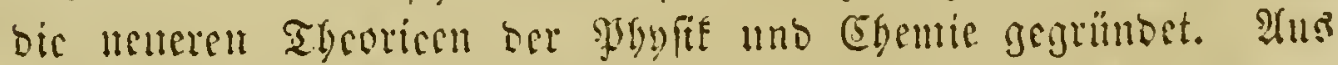

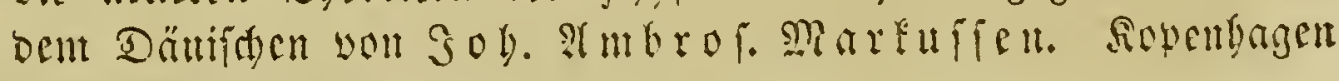
uno Scipjig 1798. 8. 
auf bns Salyr 1807 Keraus, wurin Dentfdalanbs Fantu,

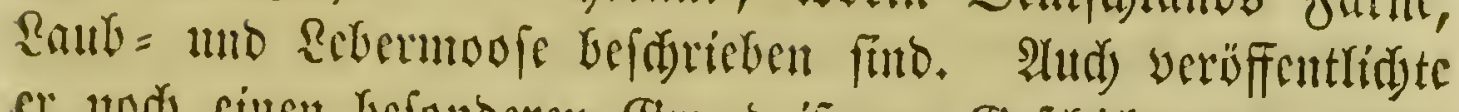

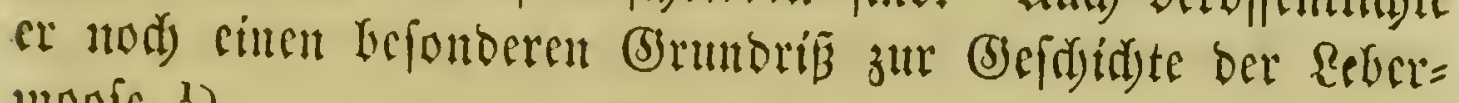
moofe. ${ }^{1}$ )

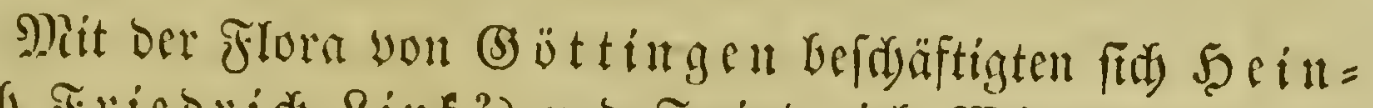

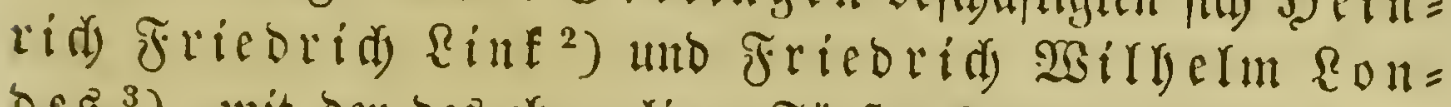

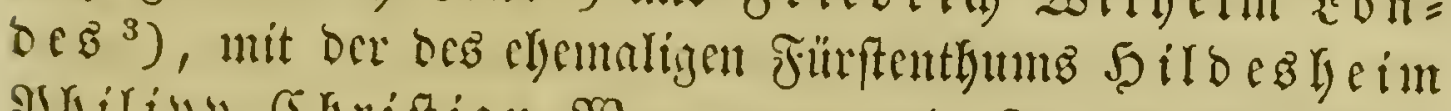

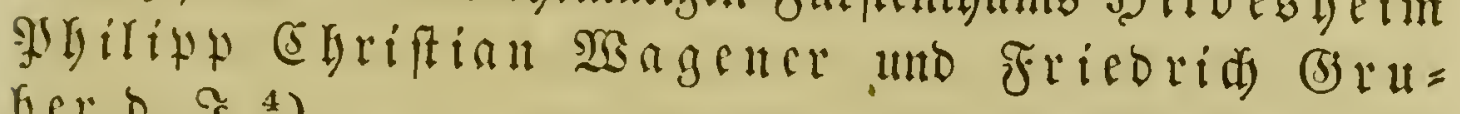
Ger ฉ. $\left.\Im{ }^{4}{ }^{4}\right)$

Dis llnterfutdyung ber fdyerizerifden flora warbe in

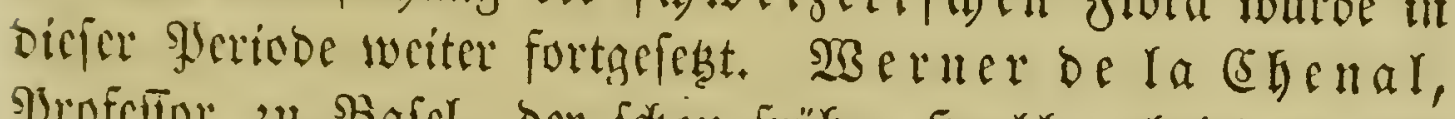

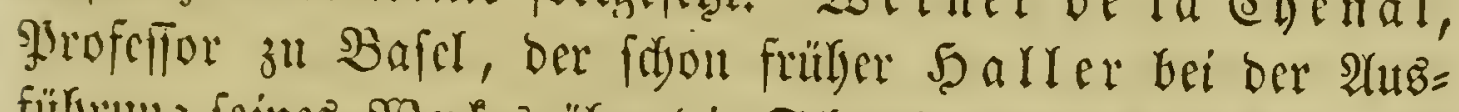

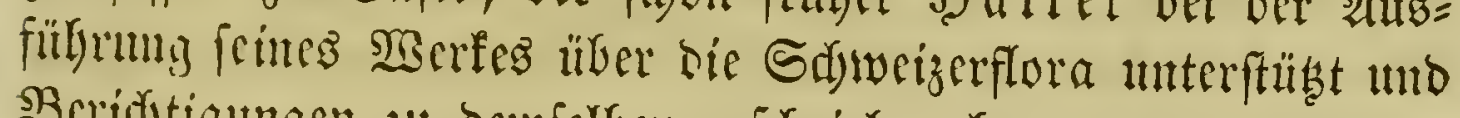

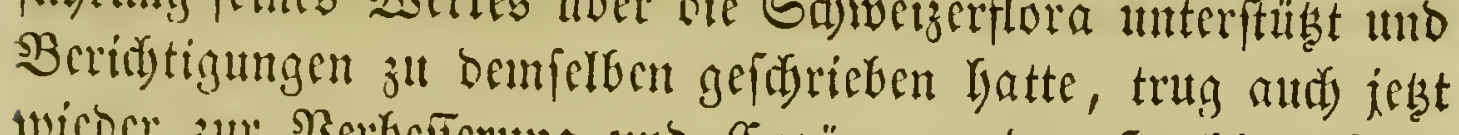

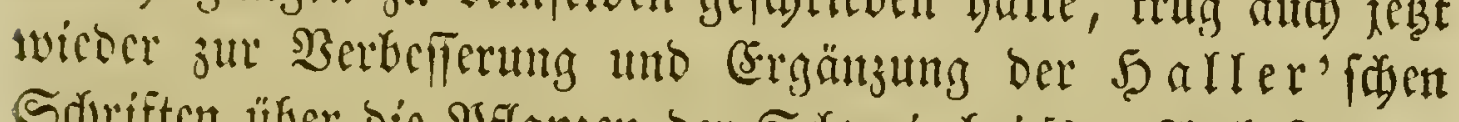

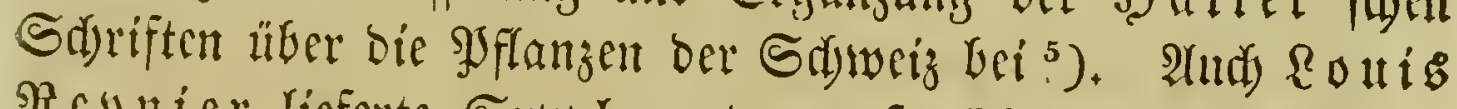

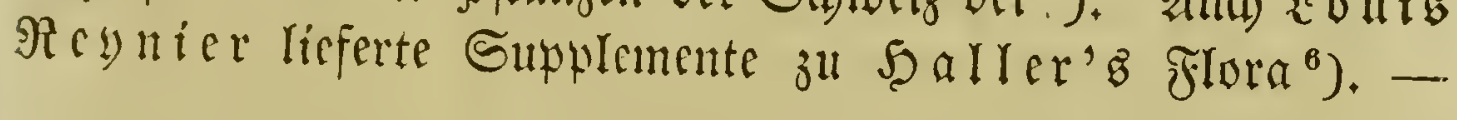

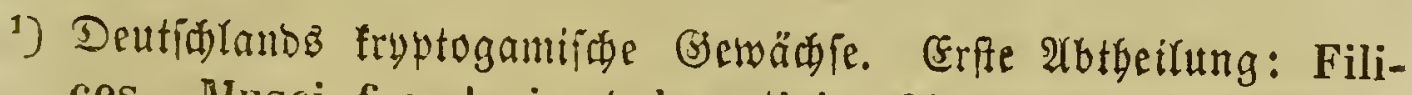
ces, Musci frondosi et hepatici. Siel 1807. 12. 12 Taq. Historiae Muscorum hepaticorum Prodromus. Kiliae 1815.

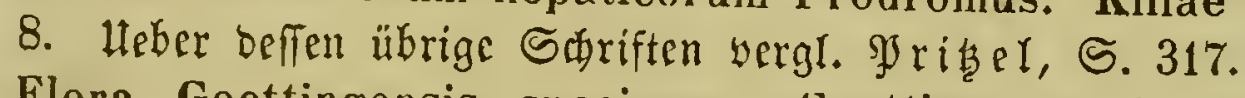

2) Flora Goettingensis specimen. Goettingae 1739. 8. -

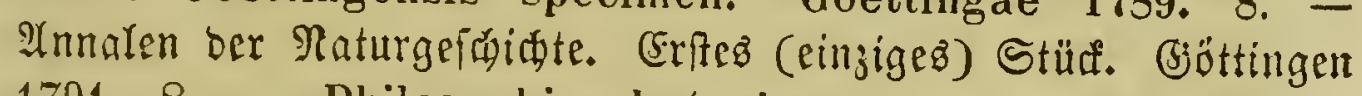
1791. 8. - Philosophiae botanicae novae sen institutionum phytographicarum prodromus. Goettingae 1798. 8.

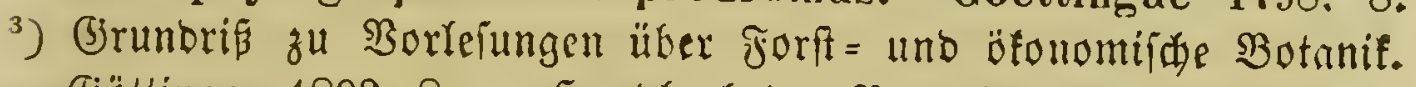

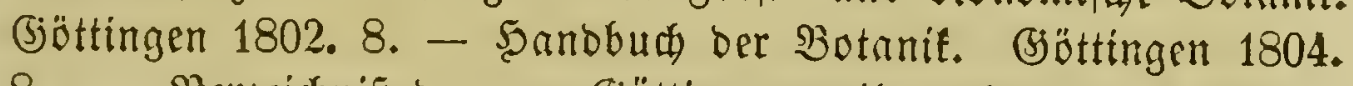

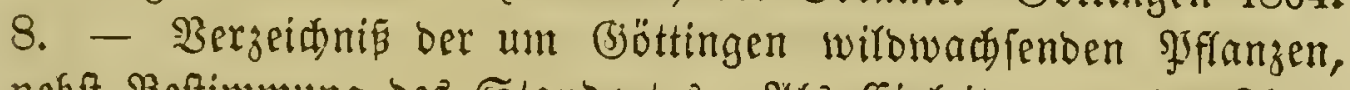

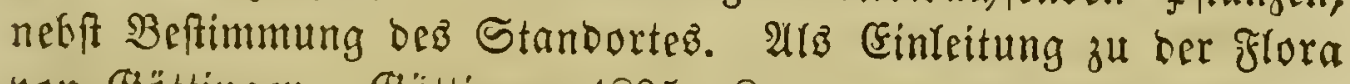
yon Gättingen. अ3öttingen 1805. 8.

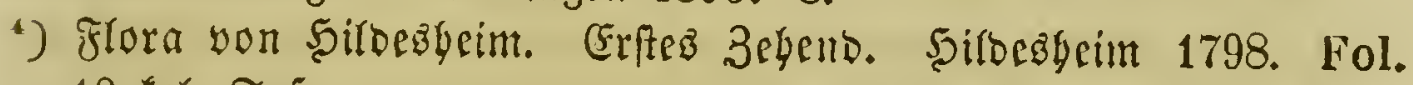
10 fol. $\mathfrak{T a f}$.

5) Observationes botanico-medicae. Basileae 1776. 4. 1 tab.

6) Mémoires pour servir à l'histoire physique et naturelle de la Suisse. Tom. I. Lausanne 1788. 8. 2 tab. (Fr ver=

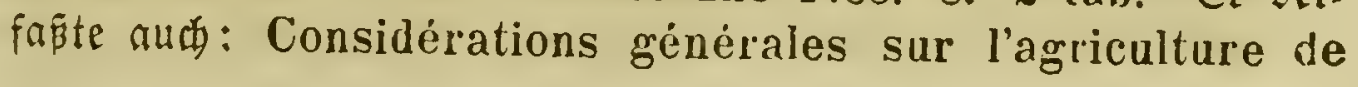




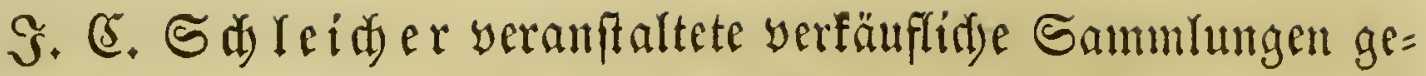
trofneter feltener Sdyeizerpflanzen und gab ein Berzeidjnís feiner Sammlungen beraus, weldyez als überfidytlidjer Rata=

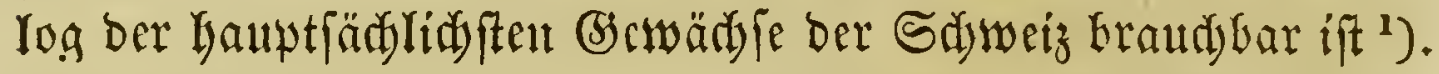

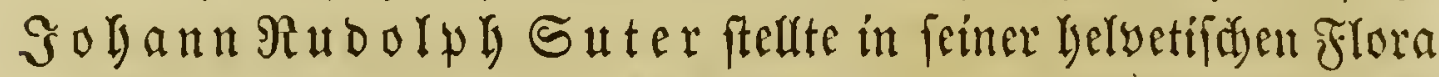
bie biz auf feine 3rit entbeften Spflanzen ber Sdjweiz nadi) Dem Rinnéfden Syftem georbnet zulammen ${ }^{2}$ ). (Fine funop= tijide Flora ber Sidweiz yerfapte De (STairville ${ }^{3}$ ), ber

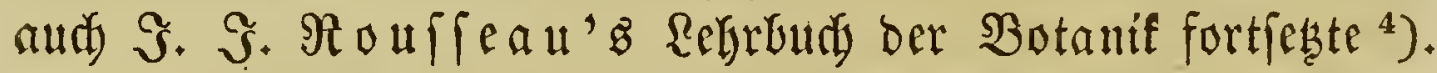

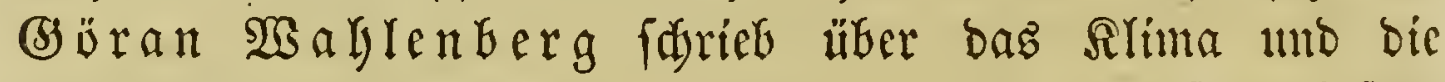

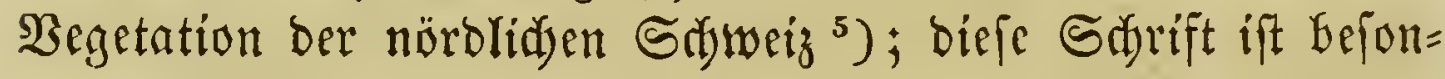
berz in Hflanzengeographifder Şinfidyt yon Şidjtigleit. Einige Seiträge zur Renntní ber Sdiweizerflora lief̣ertent

l'Egypte et sur les améliorations dont elle est susceptible, et observations sur le Palmier-Dattier et sur sa culture. (Paris 1802.) 8.

') Catalogus plantarum in Helvetia cis - et transalpina sponte nascentium, quas in continuis fere itineribus in usum botanophilorum collegit et summo studio, collatione cum celeberrimorum autorum descriptionibus et iconibus facta, rite redigit. Bex Helvetiae (1800) 8. - 180\% 8. - et catalogus Salicum. 1815. 8. - 1821. 8.

$\left.{ }^{2}\right)$ Flora helvetica, exhibens plantas Helvetiae indigenas Hallerianas et omnes, quae nuper detectae sunt ordine Linneano. Turici 1802. II voll. 12. Editionem alteram ed. et aux. Joh. He get s chwe il e r. Ibid. 1822. II voll. 12.

3) Manuel d'herborisation en Suisse et en Valais, rédigé selon le système de Linné, corrigé par ses propres principes etc. Winterthur 1811. 8. - Genève et Paris 1819. 8.

*) Le Botaniste sans maitre, ou manière d'apprendre seul la Botanique au moyen de l'instruction commencée par J. J. Rousseau, continuée et complétée dans la même forme. Paris et Winterthour 1805. 12.

$\left.{ }^{5}\right)$ De vegetatione et climate in Helvetia septentrionali inter flumina Rhenum et Arolam observatis et cum summi septentrionis comparatis tentanien. Turici 1813. 8. 3 tab. 


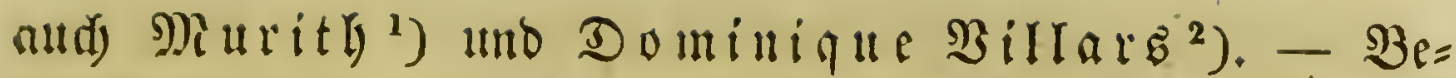

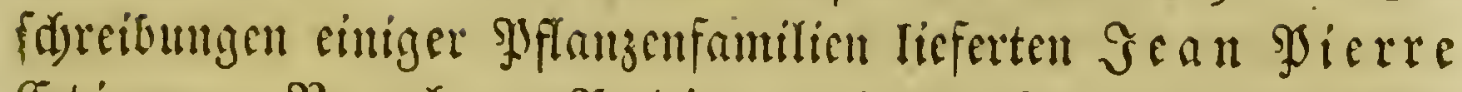

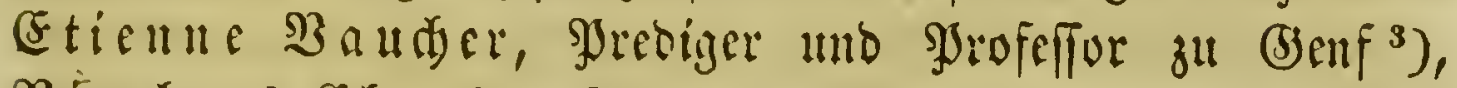
Ricolaub (Eharles Seringes), yon dem unten nod die Pede fein wirb, und Jean François (jottlieb gुh $i=$

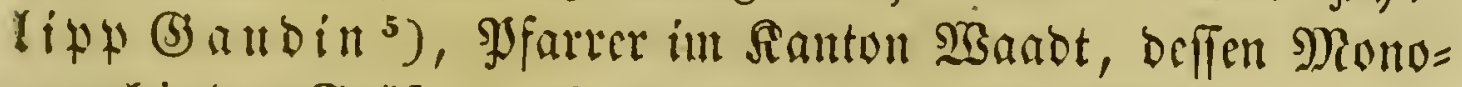
grathic ber (5) räjer grofe 2 (nerfenum gefunden hat.

Fin gchorner Sidweijer war aud) Samuel Elias yon

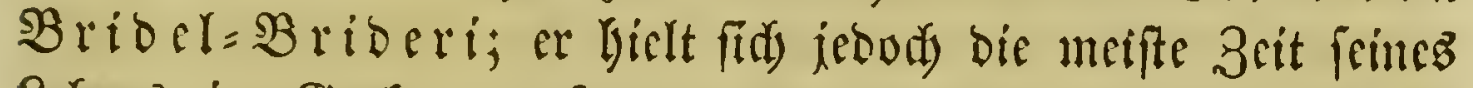
Rebens in (5otha, anfangz als (Erzielder des berzoglidjen Şrinjen, tamu als geh̆. Regationsirath auf uno farb $b a=$ felbft in Gabre 1828. 3um Theil in biefe. Sorivore fallen feine treffliden $\mathfrak{B a r f e}$ über die Movfe. ${ }^{6}$ )

1) Le guide de botaniste, qui voyage dans le Valais, avec un catalogue des plantes de ce pays et de ses environs, auquel on a joint les lieux de naissance et l'époque de la fleuraison pour chaque espèce. Lausanne 1810. 4.

$\left.{ }^{2}\right)$ Mémoires sur la topographie et l'histoire naturelle, extraits du cours de l'école centrale du département de I'Isère etc. Lyon 1804. 8.

$\left.{ }^{3}\right)$ Mémoire sur les graines des Conferves. (Paris) 1800. 4. 2 tab. - Histoire des Conferves d'eau douce, contenant leurs différens modes de reproduction et la description de leurs principales espèces, suivie de l'histoire des Trémelles et des Ulves d'eau douce. Genève 1803. 4. 17 tab. Monographie des Prêles. Histoire générale et physiologique du genre. Genève 1822 4. 13 tab. - Monographie des Orobanches. Genève et Paris 1827. 4. 16 tab.

") Essai d'une monographie des saules de la Suisse. Bernae 1815. 8. 2 tab.

5) Etrennes de Flore. No. I. Lausanne 1804. 16. - Agrostologia helvetica, definitionem descriptionemque graminum et plantarum eis affinium in Helvetia sponte nascentium complectens. Parisiis et Genevae 1811. 2 voll. 8.

s) Muscolngia recentiorum seu Analysis, historia et descriptio methodica omnium muscorum frondosorum hucusque cognitorum ad normam Hedwigii. Gotha 1797-1822. 4. Suppl. $1807-1822$. 
Unter Denienigen Bstanifern, welde liber bie Flora bez Rünigreidys Frantreid) gefdrieben lyaben, ift yor allen Sean $\mathfrak{B a p t i f t e}$ Monet be la Mar fe Gervorzukeben. Ramara ift ber Berfaffer ber erften yollftänbigen Flora yon

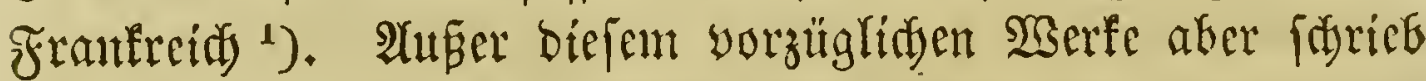
er aud bie vier erften SBänto ber Encyclopédie méthodique, einer für bie șflanjenbefd)reibung äunerfít widjtigent Duelle ${ }^{2}$ ). Ein ipeciefles Syftem ift übrigens barin nidyt befolgt, vielmehr ift bie alphabetifade Dromung feftgelalten. Die Fortfetsung zu biefer Encyclopäbic twurbe yon $S$. $\mathfrak{R}$. SR. Soiret bearbeitet. $\quad \Im n$ Berbintung mit $\mathfrak{B}$ riffeau= $\mathfrak{R} i \mathfrak{r}=$

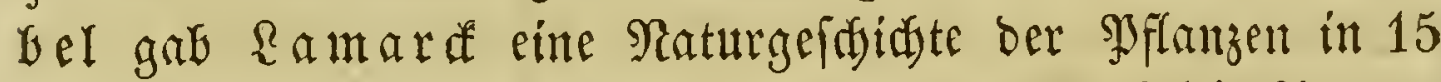

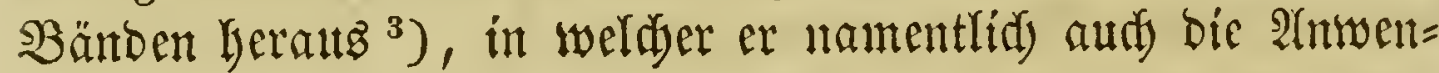

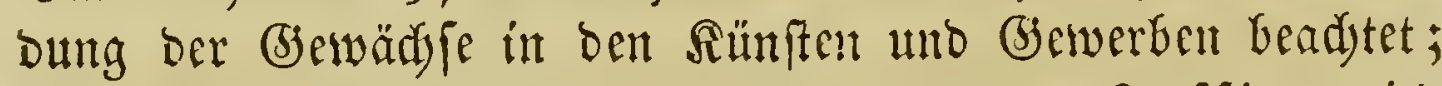
fowolyl baz Syftem Rinnés wie baz yon Suffieu twirb in biejem $\mathfrak{B e r f e}$ berüafidstigt. Ferner gab $\mathfrak{a} \mathfrak{m a r}$ af in

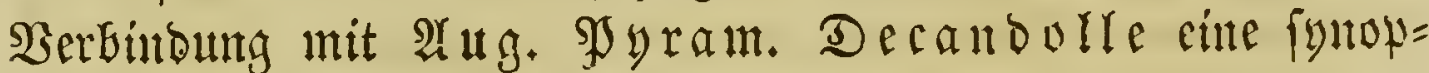
tifád Flora yon Franfreid beraus. ${ }^{4}$ )

Sean Şenxi Saume Saint= Şilaire, arfate=

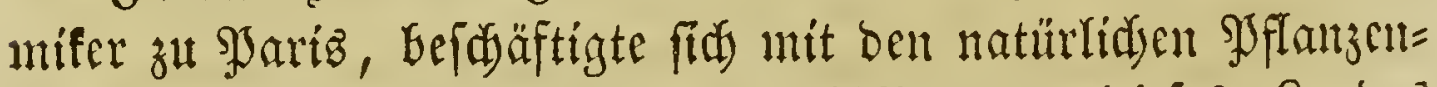
familicn Frantreidjo und gab abbiloungen biejes santos

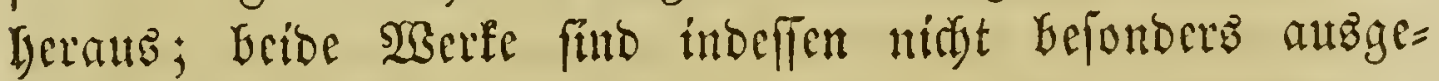

1) Extrait de la Flore française. Paris 1792. 8.

2) Encyclopédie méthodique. Botanique. Paris 1783-1817. XIII voll. 4. - Atlas gr: 4. 900 tab. - Tableau encyclopédique et méthodique des trois règnes de la nature. Botanique. Illustrations de genres. Paris $1791-1823$. III voll. 4.

$\left.{ }^{3}\right)$ Histoire naturelle des végétaux classés par familles, avec la citation de la classe et de l'ordre de Linné et l'indication de l'usage qu'on peut faire des plantes dans les arts, le commerce, l'agriculture, le jardinage, la médecine etc. Paris 1802. XV voll. 12. $-1830 . \mathrm{XV}$ voll. 12. 120 tab.

4) Synopsis plantarum in flora gallica descriptarum. Parisiis 1806.8. 


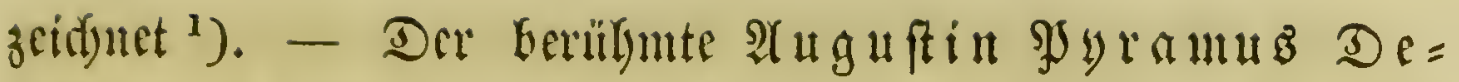
canbolle war aud cin yorzuliglider Sbytograph, wir

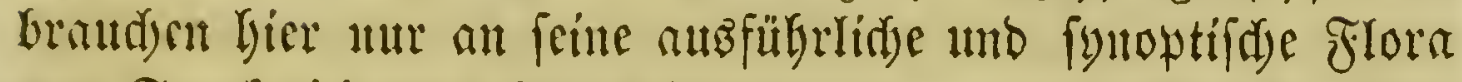

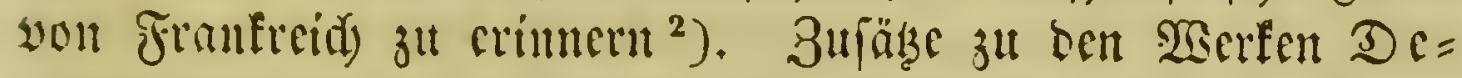

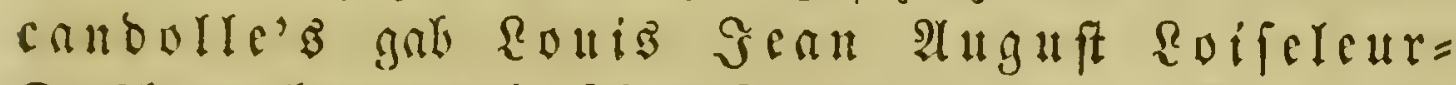

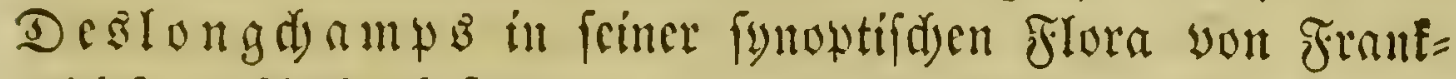

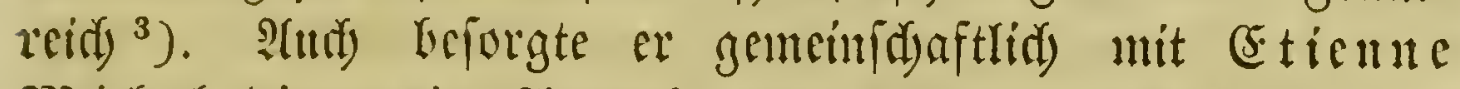

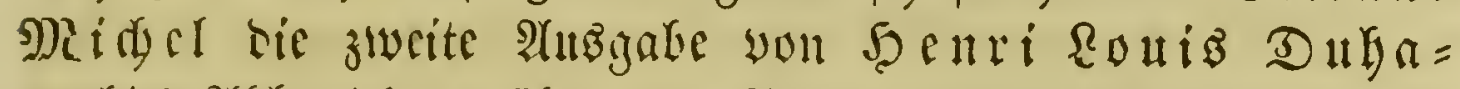

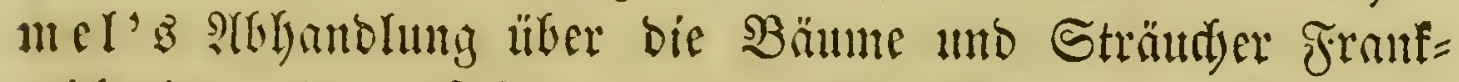
rcidys ${ }^{4}$ ) unb werfapte nody sinige andere phytographifde

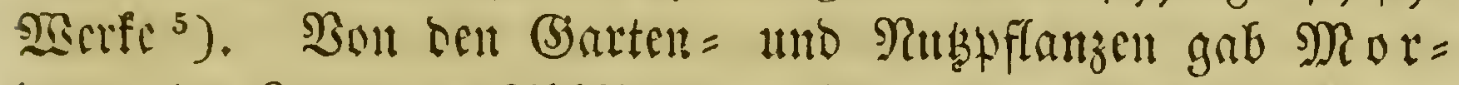

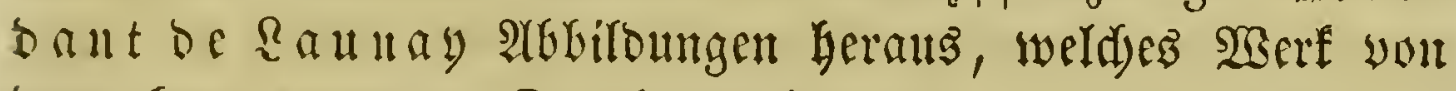
som eben gennuten Deglong dis amps fertgeicist wurbe. ${ }^{6}$ )

2) Exposition des familles naturelles et de la germination des plantes; contenant la description de 2337 genres et d'environ 4000 espèces les plus utiles etc.; 117 planches représentant les caractères des familles et les différents modes de germination des plantes monocotylédones et dicotylédones. Paris an XIII. 1805. II voll. 8. 112 tab. - Plantes de la France décrites et peintes d'après nature. Paris (1805 -) 1822. X voll. petit 4. 1000 tab.

$\left.{ }^{2}\right)$ Plantarum historia succulentarum. Histoire des plantes grasses, avec leurs figures en couleurs, dessinées par P. J. Redouté. Paris 1799-1821. XXXI fasciculi. Fol. (185 tab. col.)

3) Flora gallica. Lutetiae 1806-1807. II voll. 8. 21 tab. Paris 1828. II voll. 8. 31 tab.

*) Traité des arbres et arbustes que l'on cultive en France en pleine terre. Seconde édition. Paris 1801-19. VII voll. Fol. 488 tab. col.

\$) Notice sur les plantes à ajouter à la Flore de France (Flora gallica), avec quelques corrections et observations. Paris 1810 . 8. 6 tab. - Recherches historiques, botaniques et médicales sur les narcisses indigènes, pour servir à l'histoire des plantes de France. Paris 1810. 4.

-) Herbier général de l'amateur, contenant la description, 
Mit ber Flora yon $\mathfrak{J} a r i s$ bejoäftigten fid in biejem

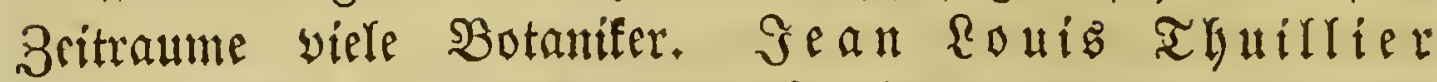

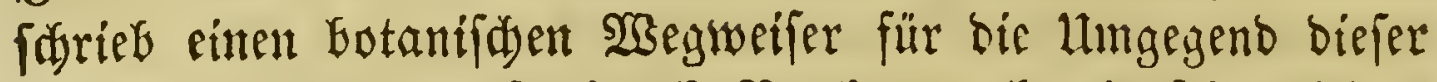

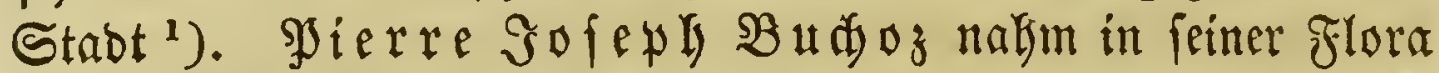

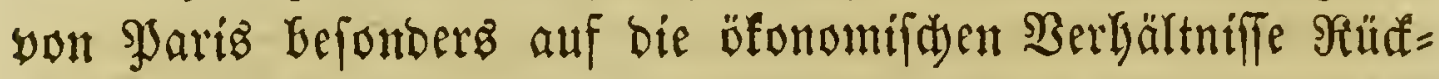

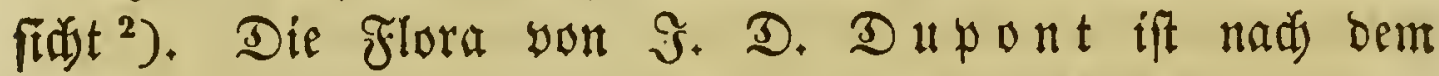
Syfteme Rinnés und Suffieu's bearbeitet ${ }^{3}$ ). S(udf

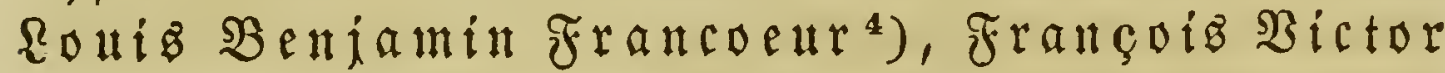

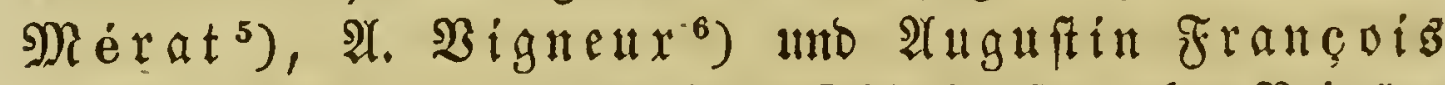

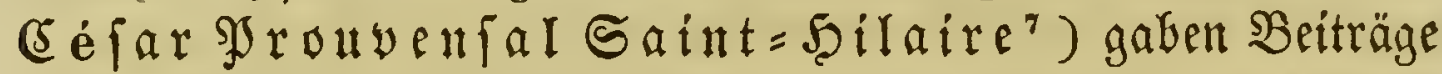

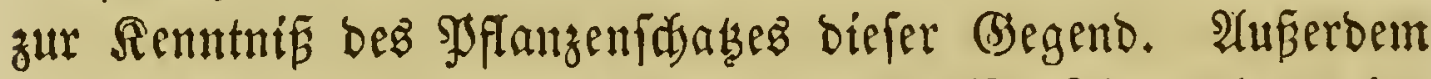

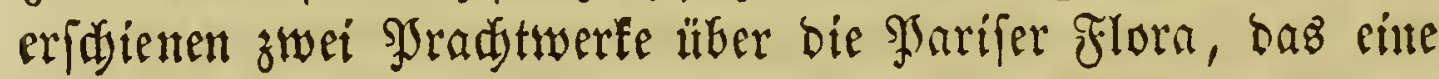

l'histoire, les propriétés et la culture des végétaux utiles et agréables, dédié au Roi par feu Mordant de La unay; continué par J. L. A. L o is eleur-Deslongch a mps. Paris 1816-1827. VIll voll. Livraison 1-96. 570 tab. col. et text.

1) La Flore des environs de Paris. Paris 1790. 12. - 1799. 8.

2) Flore économique des plantes qui croissent aux environs de Paris etc. Paris 1797. 8. - $\mathfrak{B e r g l . ~ u ̈ b e r ~ b e f i f e n ~ a n d e r e ~}$ Shriften 9ritiel, S. 39.

3) Double Flore Parisienne. Paris 1813. 8.

4) Flore Parisienne. Paris an IX (1801). 12.

$\left.{ }^{5}\right)$ Nouvelle Flore des environs de Paris. Paris 1812. 8. 1821. 8. - 1831 - 183\%. II voll. 12. - 1836. II voll. 12. 1837-1838. II voll. 12 .

-) Flore pittoresque des environs de Paris. Paris 1812. 4. 6 S tab. col. 1 carte col. Suppl. 1814. 4. 1 tab. col.

") Observations sur le genre Hyacynthus. Orléans s. a. 8. - Notice sur 70 espèces et quelques variétés des plantes phanérogames trouvées dans le Département du Loiret, depuis la publication de la Flore Orléanaise de M. l'abbé Dubois. Orléans s. a. 8. - Mémoire sur les plantes auxquelles on attribue un placenta central libre et sur la nouvelle famille des Paronychiées; suivi d'une note sur la même famille par M. Ant. Laur. de Jus sieu. Paris 1816, 4. 1 tab. 


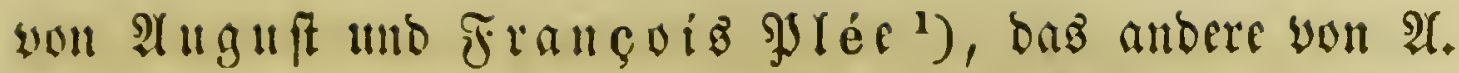

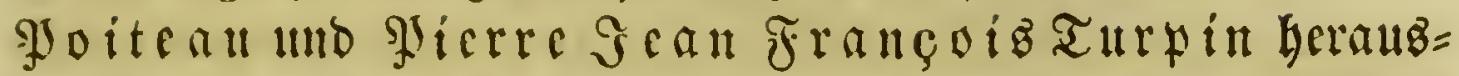

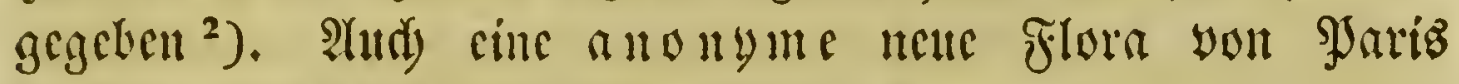
wurbe um biefe Zeit befaunt gemtadt. ${ }^{3}$ )

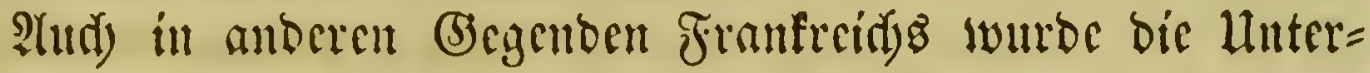

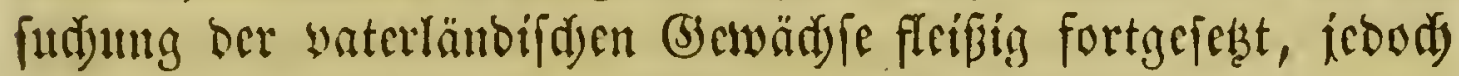

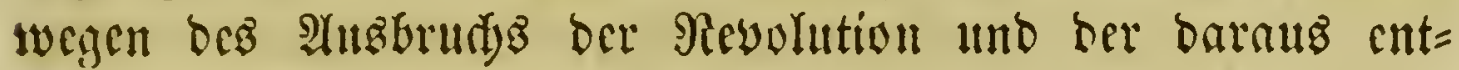

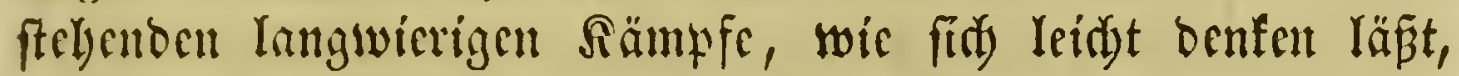

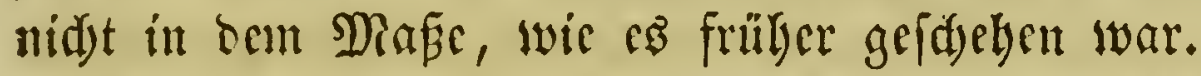

Dic Flora ber Rormandic bearbeiteten Schri Fran=

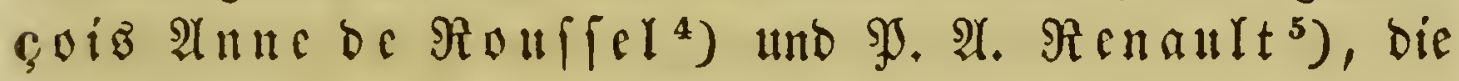

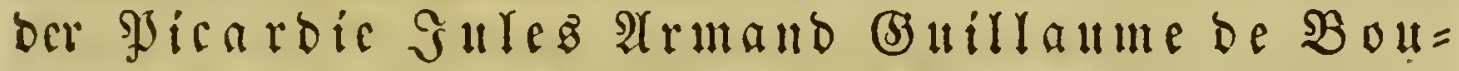

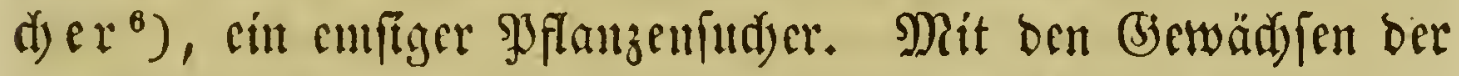

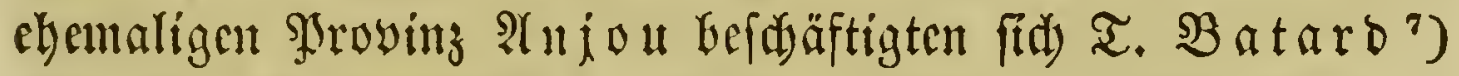
unb (3) abricl Eléonor Merlet be la $\mathfrak{B o u l a y e}{ }^{8}$ ), bie ber groving Soitou wurben yon Scan Rouis Marie

1) Herborisations artificielles aux environs de Paris. Paris 1811. 8. - 40 tab. col.

$\left.{ }^{2}\right)$ Flore parisienne. Paris 1813. Fol. 45 tab. col. - Le jardin botaniq. de l'école de médecine de Paris. Paris 1816. 12.

3) Nouvelle Flore des environs de Paris. Paris s. a. 12.

4) Tableau des plantes usuelles rangées par ordre, suivant les rapports de leurs principes et de leurs propriétés. Caën 1792. 8. - Flore du Calvados. (Caën 1796.) 8. 1806. 8.

3) Mlémoire sur la culture des pommiers dans toute l'étendue de la république française. Rouen an III (1795). 8. - Flore du Département de l'0rne. Alençon 180r. 8.

$\left.{ }^{6}\right)$ Extrait de la Flore d'Abbéville et du Département de la Somme. Paris 1803. 8.

") Essai sur la Flore du Département de Maine-et-Loire. Angers 1809. 8. - Supplém. 1812. 8. - Notice sur les végétaux les plus intéressans du jardin des plantes d'Angers. Angers 1810. 12.

3) Herborisations dans les dép. de Maine-et-Loire et des Deux - Sêvres. Angers 1809. 12. 


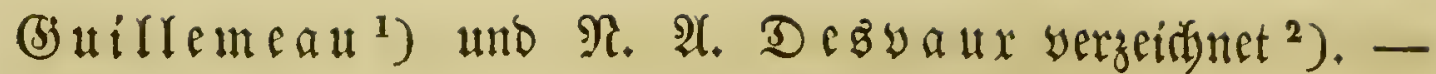

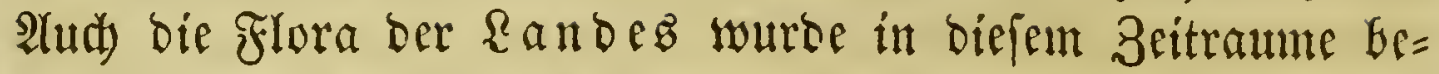
arbeitet yon $\mathfrak{S}$ an $\mathfrak{T}$ bre. ${ }^{3}$ )

Sn Rothringen butanifirten Remi 2 irlemet (ber (Aeltere) ${ }^{4}$ ), ber aud surd feine Mlonographie Der fternblüthi=

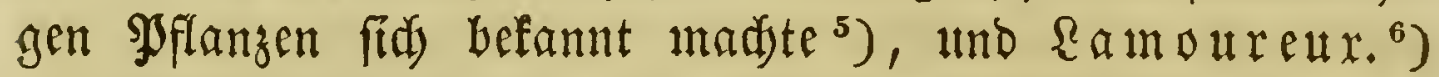
Einiges üfer die Flora ber begeno yon Drleans lieferte

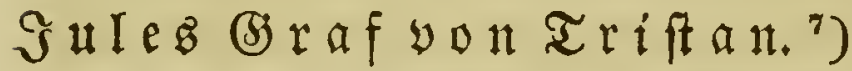

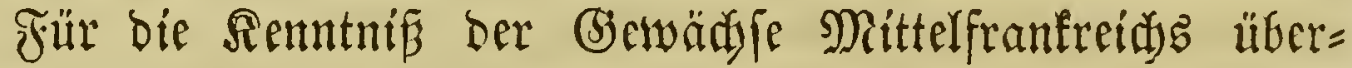
Lautpt ift die yon Dabois verfafte Methobe, bie Msflanzen

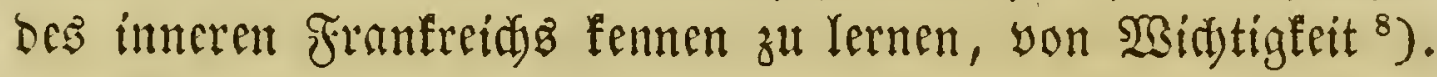

1) Histoire naturelle de la Rose, où l'on décrit ses différentes espèces, sa culture, ses vertus et ses propriétès etc. Paris 1800. 12. 1 tab. - Calendrier de Flore des environs de Niort. Niort 1801. 8.

$\left.{ }^{2}\right)$ Journal de bot. 2. p. 307 .

$\left.{ }^{3}\right)$ Essai d'une Chloris du Département des Landes. Dax (1803).

4) Phytographie économique de la Lorraine. Nancy 1750. 8. - Phytographie encyclopédique, ou Flore de l'ancienne Lorraine et des départements circonvoisins. Nancy 180 . III voll. 8.

s) Monographie pour servir à l'histoire naturelle et botanique de la famille des plantes ètoilées. Strasbourg 1791.

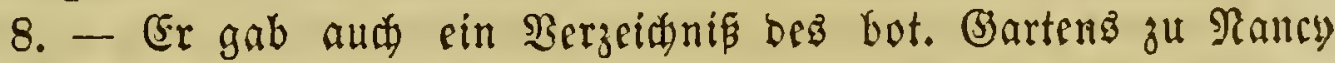
Geraus : Catalogus plantarum horti botanici Nanceynensis. Nancy 1802. 8.

-) Mémoire pour servir à l'bistoire du dép. de la Meurthe. Nancy 1803. 8.

7) Mlémoire sur la situation botanique de I'Orléanais et sur les caractères de la Flore Orlèanaise. Orléans 1810. 8. - Tableau des époques de la végétation observées aux environs d’Orlẻans anné 1817 et 1818. (Orléans.) 8. 3 tableaux.

- Méthode èprouvée, avec laquelle on peut parvenir facilement et sans maître à connaître les plantes de l'intérieur de la France et en particulier celles des environs d'Orléans etc. Orléans an XI (1803). 8. - 1825. 8. - 1833. 8. 18\%0. 8. 


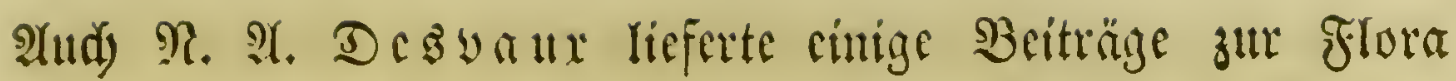
Dittelfrumfrcidys ${ }^{1}$ ).

Unter ben Stäoten Gildfrantreidjs jog von jeler Mlont= wellier mit feiner fflanjenreiden llmgetung bie Blife ber Sotanifer nuf firty. Stud) in biefer Periobe wurbe bie Flora

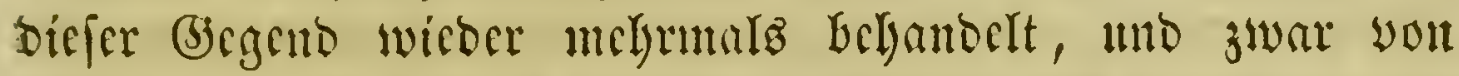

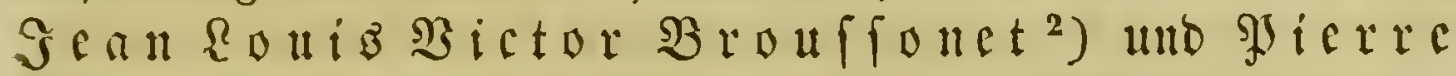

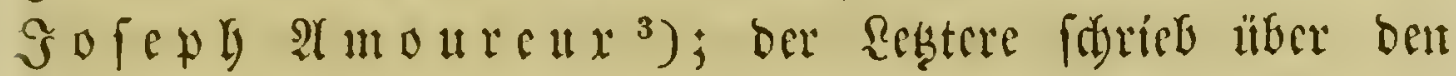

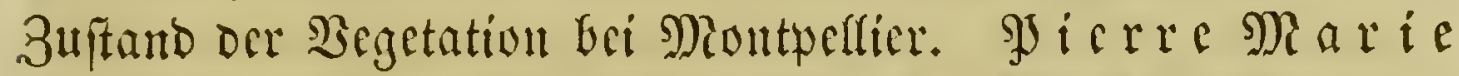

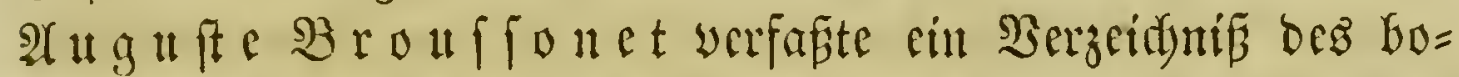
truijiden (3)artens z" Montwellicr ${ }^{4}$ ). - Mit ben in ber Uum= gegent dicfer Stabt yorfoumenten (Conferyen befoüftigte fids

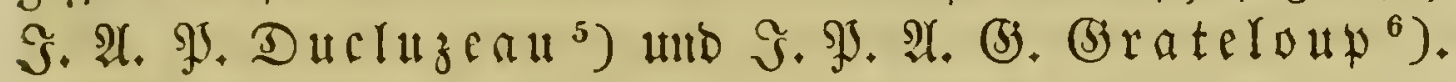
- Dí Flura ber $\mathfrak{A}$ uergae befruricb Antoine De= Iarbre ${ }^{7}$ ). (5r Iebte yon 1724 biz 1813. - Der Pfflanzen= (d)

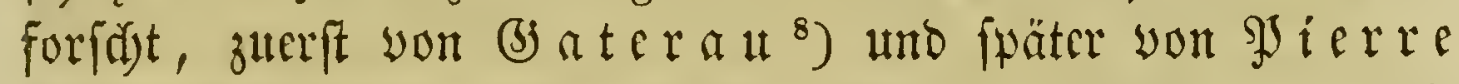

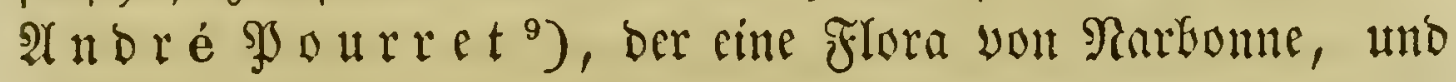

1) Journal de botanique 2. p. 145.

2) Corona Florae Monspelieusis. Monspelii 1790. 8.

3) Etat de la végétation sous le climat de Montpellier ou époques des fleuraisons et des productions végétales. Nontpellier 1809. 8. - Hteber befifen Differtationen vergleide IJrifel, S. 6.

4) Elenchus plantar. horti botanici Monspeliensis anno 180\%. Monspelii 1805. 8. - Appendix 1806. 8.

3) Essai sur l'histoire naturelle des Conferves des environs de Montpellier. Montpell. (1805). 4.

6) Observations sur la constitution de l'été 1806, avec un appendix sur les Conferves. Montpellier 1806. 4.

7) Flore d'Auvergne. Clermont-Ferrand, 1795. 8. - Paris et Clermont-Ferrand. 1797. 8. - Riom et Clermont 1800. II voll. 8.

-) Description des plantes qui croissent aux environs de Montauban etc. Montauban 1789. 8.

') Extrait de la Chloris Narbonnensis, renfermée dans la 


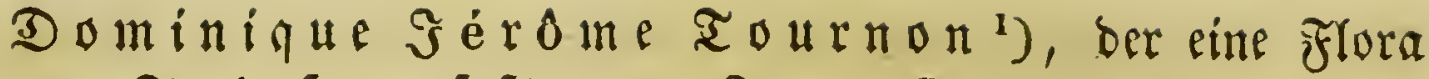
yon Touloure yerfáte. - Gean (S) uérin verzeidnete

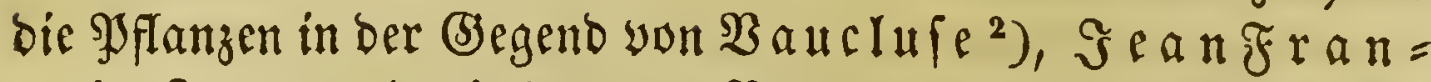

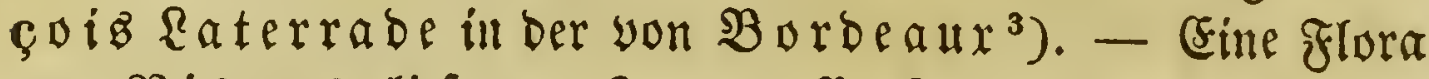

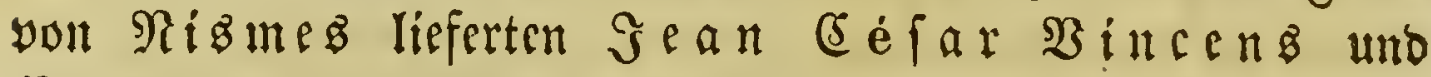

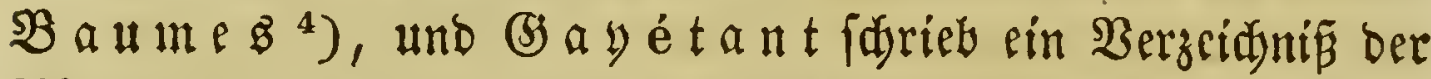

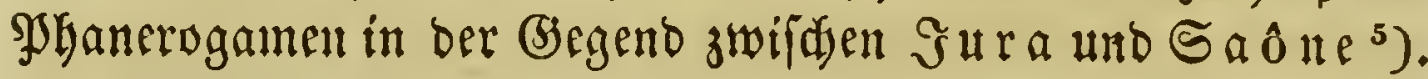
- Die Bewädje des Departements Rot werzeidnete $\Im$. $\left.\mathfrak{B} \mathfrak{u} \in \mathfrak{l},{ }^{6}\right)$

Die yortrefflidyfte $\mathfrak{A r b e i t}$ über bie in ben Syyrenäen fort=

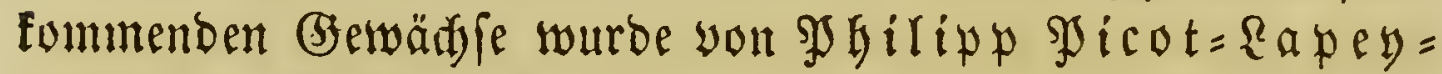
roufe verfajt" ${ }^{7}$, auferbem aber idrichen Gean grori=

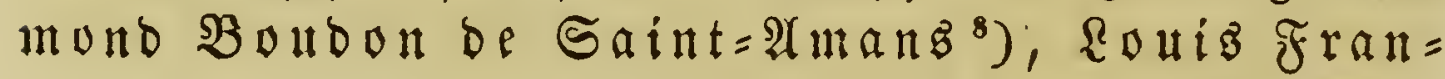

relation d'un voyage fait depuis Narbonne jusqu'au Nontserrat, par les Pyrénées. 4. (Aُug̊z. a. D. Mém. de Toulouse. vol. III.)

5) Flore de Toulouse. Toulouse 1811. 8. - 1827. 8.

2) Description de la fontaine de Vaucluse. Avignon 180\%. 12. - 1813. 12. - Fragmens d'une topographie physique et médicale du département de Vaucluse. Montpellier (1807). 4.

$\left.{ }^{3}\right)$ Flore Bordelaise. Bordeaux 1811. 12. - 1821. 12. - 1829. 12. - 4 édit. par J. E. Laterrade. Bordeaux 1846. 12.

") Topographie de la ville de Nismes et de sabanlieue. Nismes 1802. 4.

$\left.{ }^{5}\right)$ Catalogue des plantes à fleurs visibles, qui croissent dans les montagnes du Jura et dans les plaines qui s'étendent depuis ces montagnes jusqu'à la Saône. Besançon 1809. 8.

-) Catalogue des plantes qui croissent dans le Département du Lot. etc. s. l. et a. 8.

') Figures de la Flore des Pyrénées, avec des descriptions, des notes critiques et des observations. Tom. I. Clivraison 1-4.) Paris 1795-1801. Fol. 43 tab. col.

$\left.{ }^{3}\right)$ Fragments d'un voyage sentimental et pittoresque dans les Pyrénées, ou Lettre écrite de ces montagnes. Metz 1789. 8. 


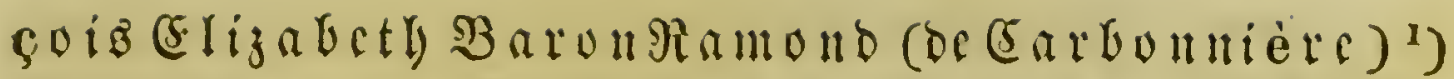

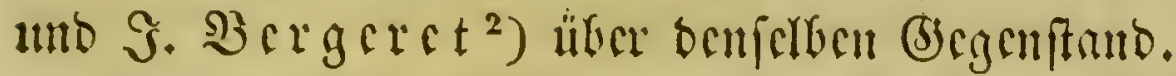

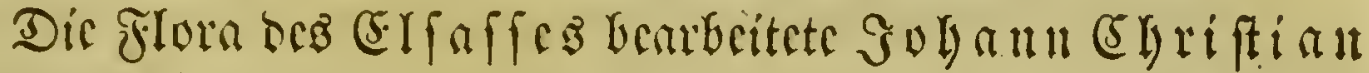
Stol $\left(3,{ }^{3}\right)$

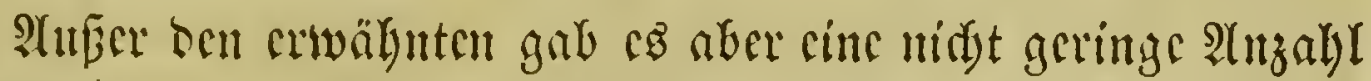
Botnuifer in Fronfreidy, welde fidy nidst mit ber FTorn ein= zelner Gegentorn, fontorn mit alfgemein whytugraphif beiten ober mit ber Erforfdyung uno Bejorcibung fpecieffer

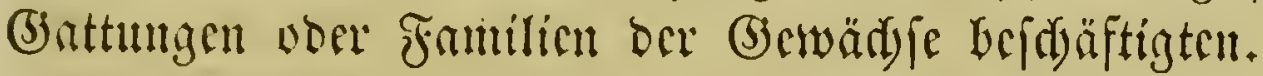

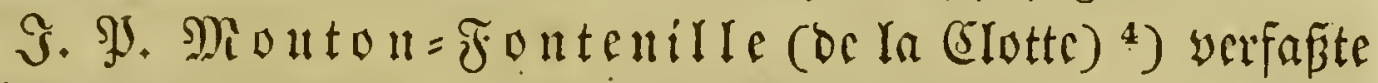

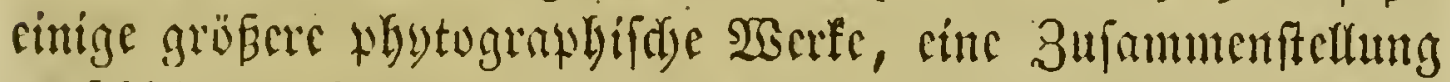
werfodicoener Syfteme unt ein Rerifon ber in ber $\mathfrak{B}$ otanif ge=

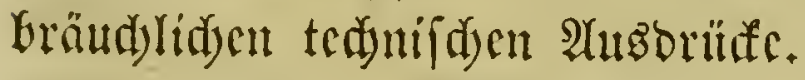

Borjüglide Arbeiten licferte \&vuis Çıube Marie

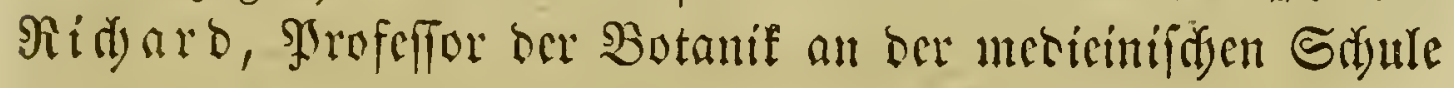

1) Observations faites dans les Pyrénées, pour servir de suite à des observations sur les Alpes, insérées dans une traduction des Lettres de W. Coxe, sur la Suisse. Paris 1789. 8. 3 tab. - Voyages au Mont-Perdu et dans la partie adjacente des llautes-Pyrénées. Paris 1801. 8. 6 tab.

${ }^{2}$ ) Flore des Basses-Pyrénées. Pau an XI (1803). II voll. 8.

$\left.{ }^{3}\right)$ Flore des plantes qui croissent dans les départements du Haut - et Bas-Rhin, formés par la ci-devant Alsace. Strasbourg 1802. 8.

4) Tableau des systèmes de botanique généraux et particuliers. Lyon 1798. 8. 100 tableaux synoptiques; et deux mémoires. - Lyon an IX. 1801. 8. - Dictionnaire des termes techniques de botanique à l'usage des élèves et des amateurs. Lyon 1803. 8. - Système des plantes, contenant les classes, ordres, genres et especes etc. extrait et traduit des ouvrages de Linnaeus. Lyon 1804-1805. V voll. 8. - Tableaux de concordance des genres d'un Pinax des plantes Européennes. Paris (Lyon). (1814-1815). 8. 


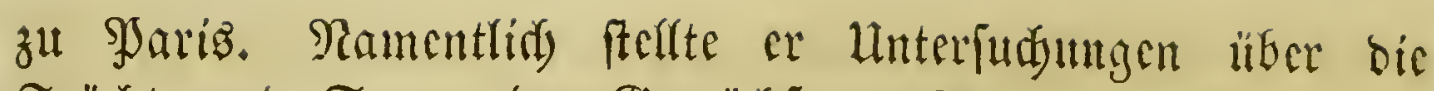
Früd) uno Samen ber (SPlväd) an an. ${ }^{1}$ )

Einer ber frudjtbarften Monograwliften Frantreids wa

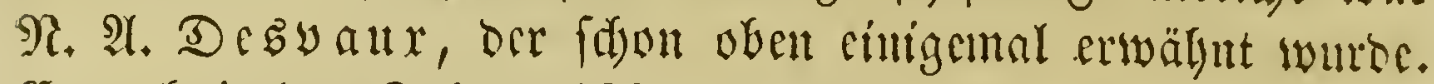
Er gab in ben Jabren 1808-1814 bas Journal de botanique lyerans und lieferte anserbem viele Beiträge in andere Gotanifac 3eitfariften. ${ }^{2}$ )

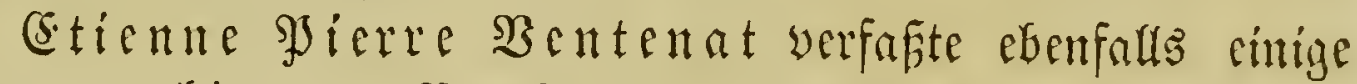
Monograwhicen, 3. B. hiber bie (5)attumig Arum und Tilia.

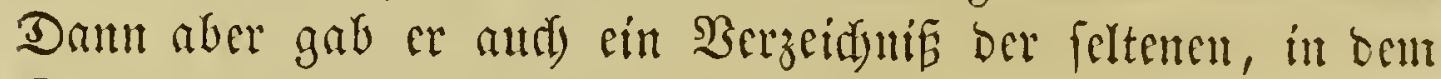

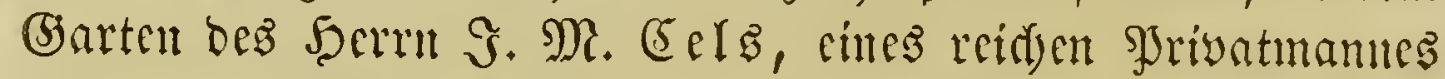
zu Sharis, gezogenen STflanzen heratz und befdrieb ben (biar=

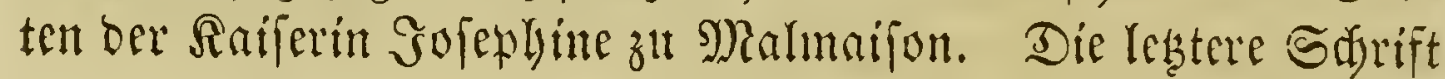

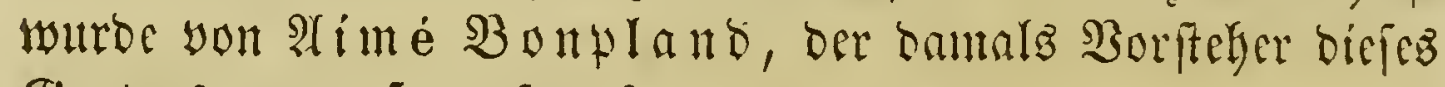
(Bontens war, fortgefert. ${ }^{3}$ )

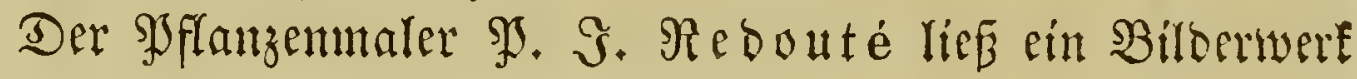

J) Démonstrations botaniques, or Analyse du fruit considéré en général. Publiées par Henry A uguste Duval. Paris 1808. 8. - Deutif: Reipzig 1811. 8. 1 Tafel. Analyse botanique des embryons endorhizes ou monocotylédonés, et particulièrement de celui des Graminées; suivie d'un examen critique sur quelques mémoires anatomico - physiologico - botaniques par MI ir bel. Paris 1811. 4. $6 \mathrm{tab}$.

$\left.{ }^{2}\right)$ Notice sur un nouveau genre des plantes de la famille des Cypéracées. s. l. 1805. 8. - Phyllographie ou histoire naturelle des feuilles, peintes par Bonnet père et fils. Paris 1809. 8. 22 tab.

3) Description des plantes nouvelles et peu connues, cultivées dans le jardin de MI. J. Cels. Paris an VIII. 1800. 4. 100 tab. y. Redouté gcseidfuct. - Monographie du genre tilleul. Paris an $X$. 1802. 4. 5 tab. - Choix des plantes, dont la plupart sont cultivées dans le jardin de Cels. Paris an XI. 1803. Fol. 60 tab. - Jardin de Malmaison. Paris 1803-1804. II voll. Fol. 120 tab. col. Decas generum novorum. Paris. 1508. 4. 


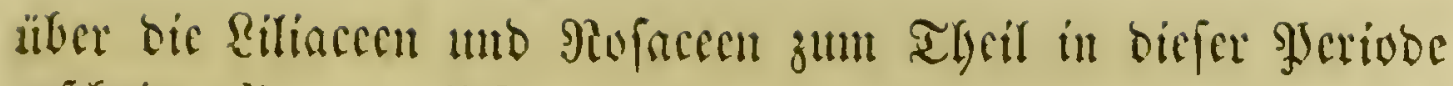

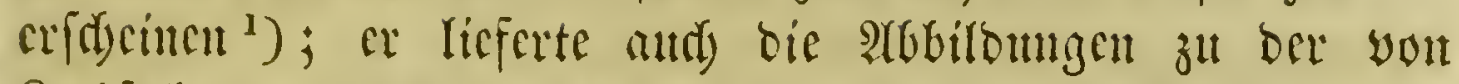

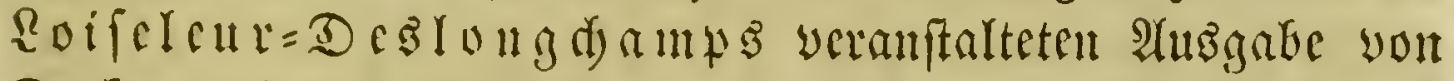

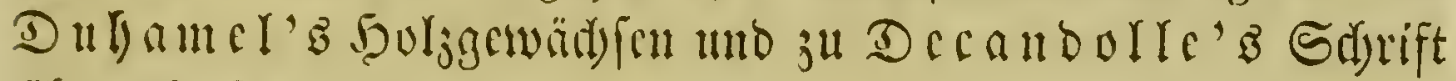
liber bic Fettiflanzen.

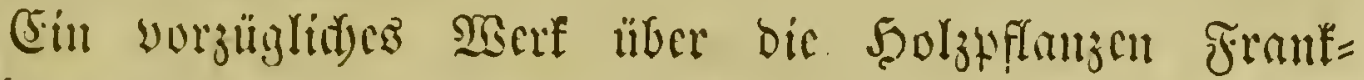

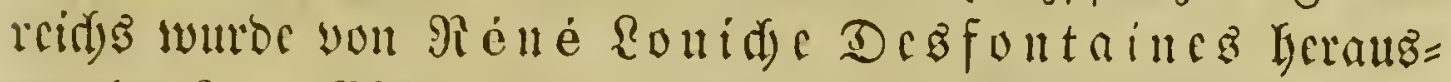

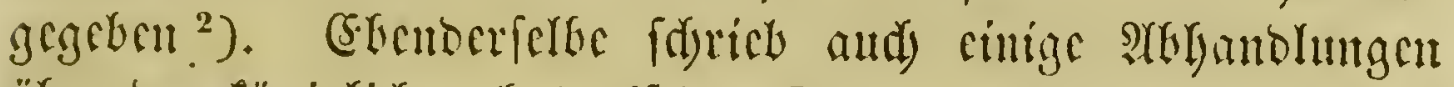

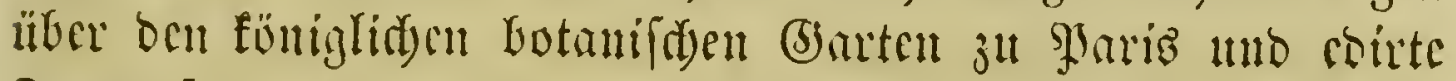
Toumefort's Corollarium.

Die veridficbenen ATrten ber Sacimeben uno ber (sid)en

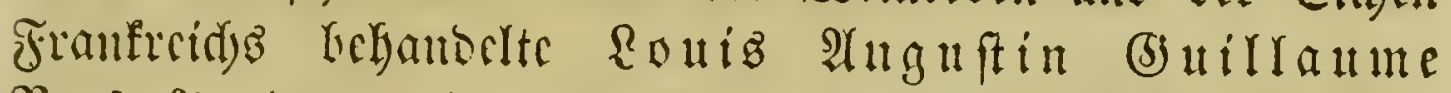

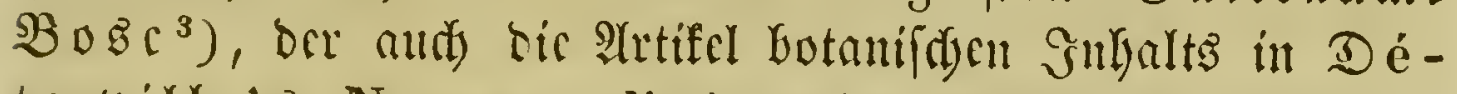
terville's Nouveau dictionnaire d'histoire naturelle (Paris 1801 - 1819) verfifite.

') Les Liliacées, peintes par P. J. Redouté. Paris $1802-$

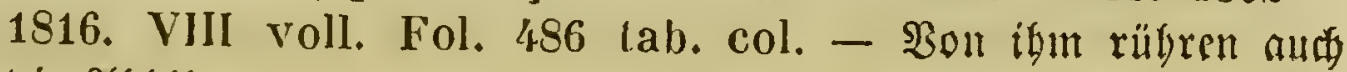
bie Abbildungen in Э. S. Rouffea u'z Botanif Ger: La botanique de Jean Jacques Rousseau etc. Paris an XIV. 1805. Fol. 65 tab. col. - Les roses. Prospectus. Par. 1816. 4.

2) Histoire des arbres et arbrisseaux, qui peuvent être cultivés en pleine terre sur le sol de la France. Paris 1809. II voll. 8. - Description d'un nouveau genre de plante: Spaendoncea. (Paris 1795.) 8. 1 tab. - Tableau de l'école de botanique du Muséum d'histoire naturelle Paris 1804. 8. - Edit. II. 1815. 8. - Catalogus plantarum horti regii Parisiensis. Edit. III. Paris 1829. 8. - Adlitamentum ibid. 1832. 8. - Choix des plantes du corollaire des instituts de Tournefort, publiées d'après son herbier et gravées sur les dessins originaux d'A ubriet. Paris 1808. 4. 70 tab. col.

3) Exposition du plan de travail adopté pour étudier et classer les diverses variétés de vignes cultivées dans les pépinières $d u$ Luxembourg. Paris s. a. 8. - Mémoire sur les différentes espèces de chênes qui croissent en France, et sur ceux étrangers à l'empire qui se cultivent 


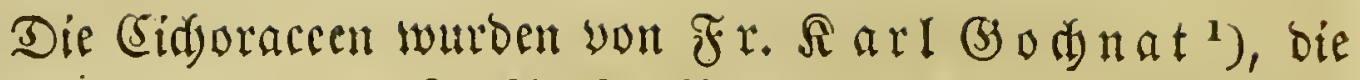

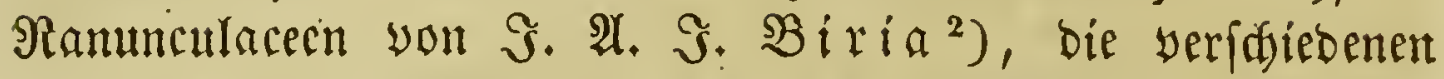

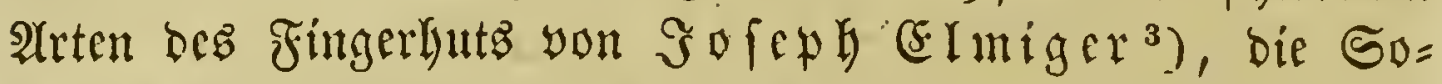
Ianeen und $\mathfrak{A}$ nonaceen yon Midal Félix Duna ${ }^{4}$ ), die Gaffen yon Rouis Thédore Fréberic (solladon ${ }^{5}$ ) mo die Sotentilfen yon (Shriftian (5) ottfrieb Refter ${ }^{6}$ ) bearbcitct.

Mmbroife Marie François Gofenh Syalifot=

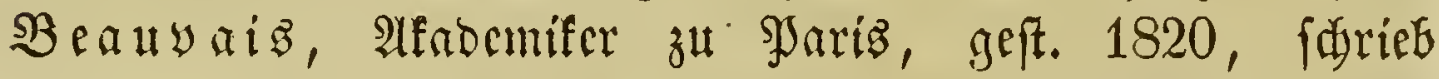
mefrere Büdyer und $\mathfrak{A b h a n d l u n g e n ~ u ̈ b e r ~ b i e ~ M o p l e , ~ B a ̈ r = ~}$

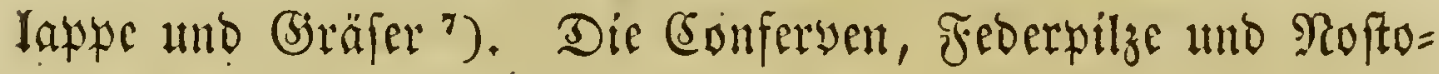

dans les jardins et pépinières des environs de Paris, ainsi que sur la culture générale et particulière des uns et des autres. Paris 1808. 4.

1) Tentamen medico-botanicum de Cichoraceis. Argentorati 1808. 4. 3 tab.

$\left.{ }^{2}\right)$ Histoire naturelle et médicale des Renoncules, précédée de quelques observations sur la famille des Renonculacées. Montpellier 1811. 4. 2 tab.

$\left.{ }^{3}\right)$ Histoire naturelle et médicale des Digitales. Montpellier 1812. 4. 2 tab.

*) Histoire naturelle, médicale et économique des Solanum et des genres, qui ont été confondus avec eux. Montpellier 1813. 4. 26 tab. - Solanorum generumque affinium Synopsis seu Solanorum historiae editionis secundae Summarium, ad characteres differentiales redactum, seriem naturalem, habitationes stationesque specierum breviter indicans. Monspelii 1816. 8. - Monographie de la famille des Anonacées. Paris 1817. 4. 35 tab.

$\left.{ }^{5}\right)$ Histoire naturelle et médicale des Casses et particulièrement de la Casse et des Sénés employés en médecine. Montpellier 1816. 4. 20 tab.

-) Monographia de Potentilla, praemissis nonnullis observationibus circa familiam Rosacearum. Parisiis et Argentorati 1816. 4. 12 tab. (Tabulam primam analyses sistentem curavit Louis Claude Richard.)

') Prodrome des cinquième et sixième familles de l'Aethéo- 


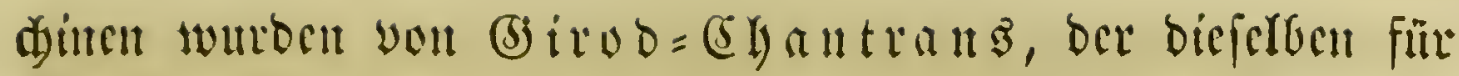

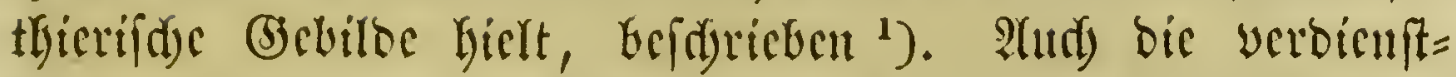

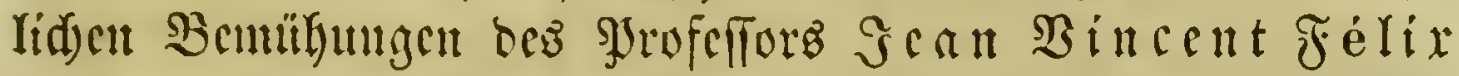

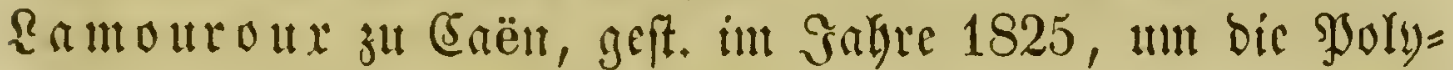
fen utto Mecralgen wurben während biefes Britrauns fowohl in Gefontoren Siserfen, als audi in bem Journal de bot. (P. II. p. 38, 129, 156 ரि.) befannt gemadjt. ${ }^{2}$ )

Der bebententofte Botanifer England raune $\mathfrak{w a r}$

\section{Sames Obmard Smith,}

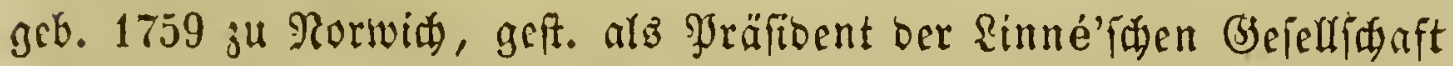
ju Ronoon int Salyre 1828.

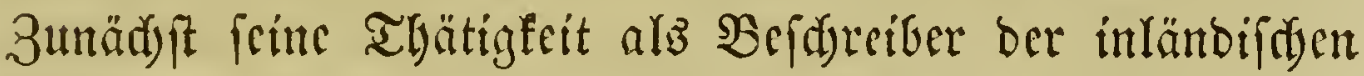

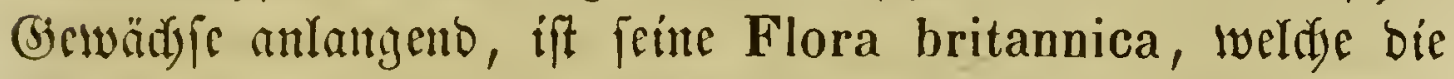
SJaneroganten, bie Farrenfräuter und Movfe entbält, uno

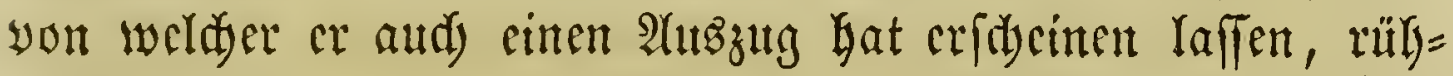

gamie. Les Mousses, les Lycopodes. Paris 1805. 8. Nouvelles observations sur la fructification des Mousses et des Lycopodes. (Paris 1811.) 4. 1 tab. - Premier (et second) mémoire et observations sur l'arrangement et la disposition des feuilles; sur la moëlle des végétaux ligneux et sur la conversion des couches corticales en bois. Paris 1812. 4. 4 tab. - Essai d'une nouvelle agrostographie; ou nouveaux genres des Graminées, avec figures représentant les caractères de tous les genres. Paris 1812. 8.; et Atlas in 4. 25 tab. - $\mathfrak{B e r g l}$, aud $9 \mathfrak{r}$ rifel' Thesaurus etc. 5.218.

1) Recherches chimiques et microscopiques sur les Conferves, Bisses, Tremelles etc. Paris 1802. 4. 26 tab. col.

${ }^{2}$ ) Dissertations sur plusieurs espèces de Fucus, peu connues ou nouvelles, avec leur description en latin et en français. Premier fascicule. Agen, an XIII (1805). 4. 36 tab. - Exposition méthodique des genres de l'ordre des Polypiers. 1811. 4. - Essai sur les genres de la fa- 


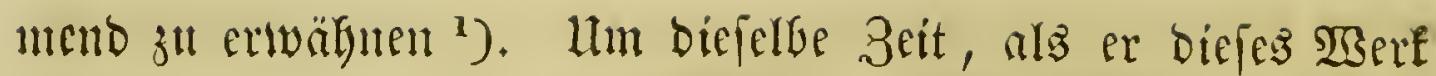
bearbeitete, hatte Games Sowerby eil Bilderwert ber englifiden Flora begonnen, zu weldem anfangs ber früher erwähnte $\mathfrak{B}$ illiam $\mathfrak{B}$ ithering ben Text lieferte. Diefe olye fyftematifide Dromung in cinzeluen Rieferungen erfidei= nenbe $\mathfrak{A}$ rbeit verfprad), ba bie Abbildunate theilmeife folledt ausgefulfyrt waren, anfänglid nidyt viel. Sritoem aber ভin ith Die Befdreibungen bazu lieferte, ergielt bas 2 Bert burd bie

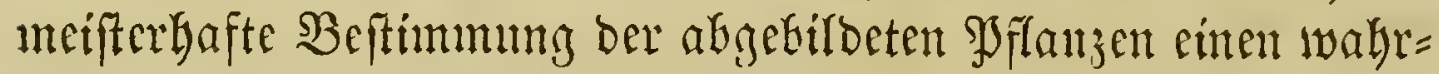

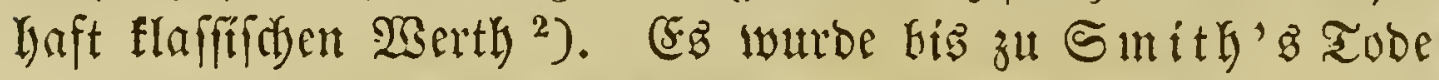
fortgefegt, tutb in Gahre 1832 wurbe eine zweite 2 tusgabe, mady bem Syfteme Rinne' B georonet, begonnen. Rint we= niger, als um die Flura feittez Baterlanbes, madyte fith

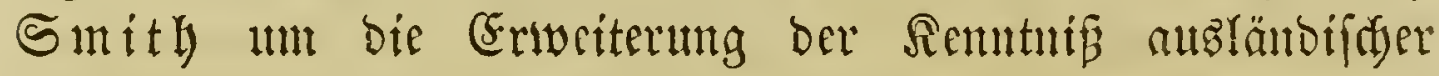

mille des Thalassiophytes non articulées. Présenté à l'Institut dans la séance du 3 février 1812. Paris 1813. 4. 7 tab. - Rapport sur le blè Lammas. Caën 1813. 8. Histoirc de polypiers corolligènes flexibles, vulgairement nommées Zoophytes. Caën 1816. 8. 19 tab.

1) Flora britannica. Londini $1800-180 \%$. III voll. 8. Compendium Florae britannicae. Londini 1800. 8. Editio in usum Florae germanicae a Georg Franz. H offm a nn. Erlangae 1801. 12. - Edit. II. London 1816. 8. - Edit. III. London 1818. 12. - Edit. V. London 1828. 12.

$\left.{ }^{2}\right)$ English Botany, or coloured figures of british plants with their essential characters, synonymes and places of growth. To which will be added occasional remarks by James Edward Smith and James Sowerby. The figures by J ames Sowerby. London $1790-1814$ : XXXVI voll. 8. 2592 tab. col. - Supplement to the English Botany, by William Jackson Hooker and other eminent botanists; the figures by James de Carle Sowerby No. I - LXV. London 1831. 313 tab. col. General indexes to the thirty-six volumes of English Botany to which is added a alphabetical index to english fungi; making together a catalogue of indigenous british plants. London 1814. 8. 


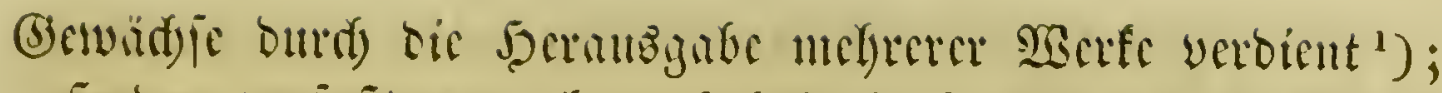

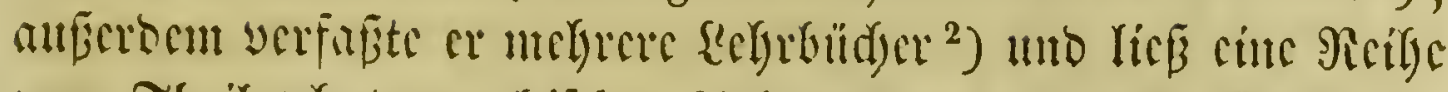

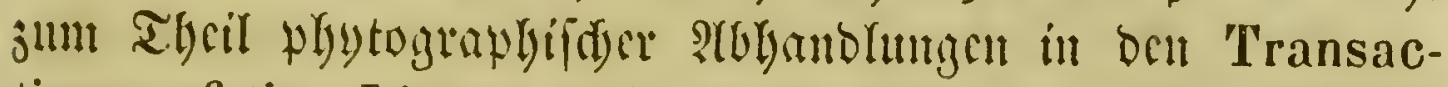
tions of the Linnaean Society cridsciten. Attd) nuf bcut anberen (Srbicten ber $\mathfrak{B}$ stanif werocn wir bicfem umermultolid)en Forid)er mody mebrmals begegnen. Seine fdrifteftellerifde

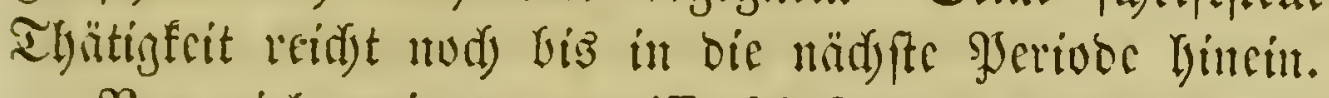

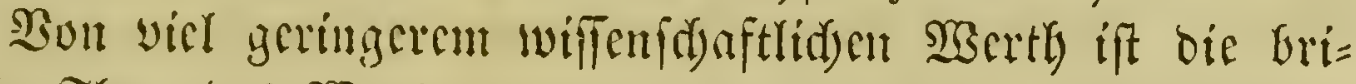

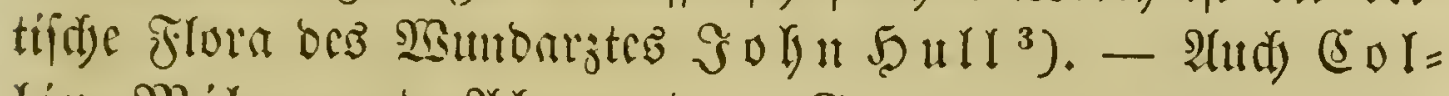

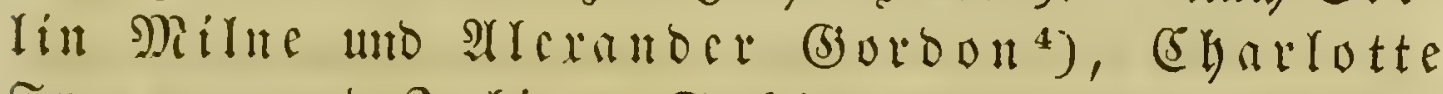

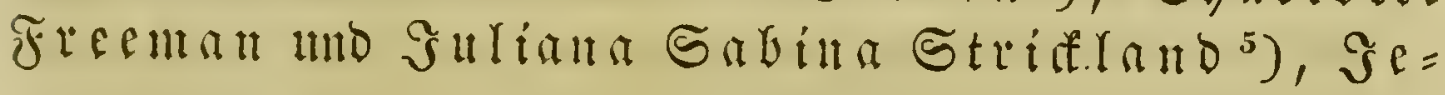

1) Plantarum icones hactenus ineditae, plerumque ad plantas in herbario Linneano conservatas delineatae. Fasc. I - III. London 1789-1791. Fol. 75 tab. - Icones pictae plantarum rariorum. Londini $1790-1793$. Fasc. I - III. Fol. max. 18 tab. col. - Spicilegium botanicum. Fasc. I et II. London 1791-1792. Fol. 24 tab. col. - Tentamen botanicum de Filicum generibus dorsiferarum. (Turin 1793.) 4. 1 tab. - Fxotic Botany, consisting of coloured figures and scientific descriptions, of such new, beautiful or rare plants as are worthy of cultivation in the gardens of Britain. London 1804-1805. II voll. gr. 8. 120 tab. col.

2) Syllabus of a course of lectures on botany. London 1795. 8. - Tracts relating to natural history. London 1798. 8. - An introduction to physiological and systematical botany. London 1807. 8. - Ibid. 1809. 8. - Ibid: 1814. 8. 15 tab. - Ibid. 1819. 8. 15 tab. - Ibid. 1825. 8.

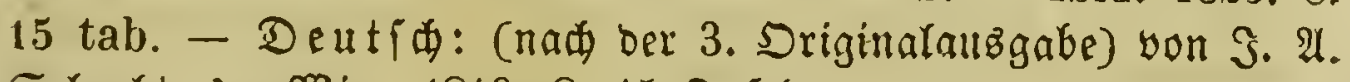

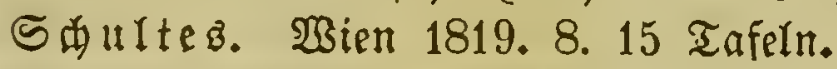

3) The British Flora. Manchester 1799. II parts. 8. -

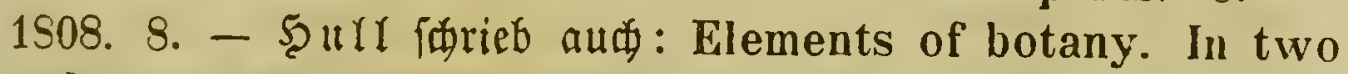
volumes. Manchester 1800. 8. 16 tab.

4) Indigenous botany, or habitations of english plants, containing the result of several botanical excursions etc. London 1793. 8.

3) Select specimens of British plants. Il voll. Fol. London 1797-1809. 5 tab. col. 


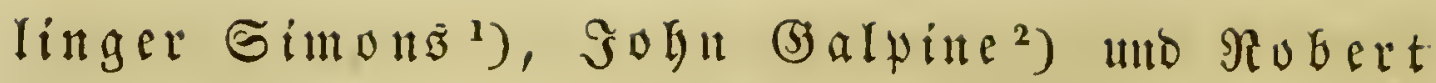
Sohn :hornton ${ }^{3}$ ) behandelten denfelben Begenftand. Ihomab Martyn, Srofelfor in Sambribge, lieferte $\mathfrak{A} b=$ bildungen ber für ben Ranbbau ind bie Gerwerbe widutigen

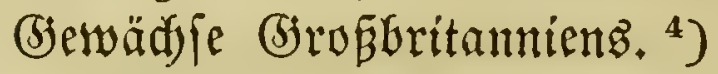

Mit ber AbGildung unb $\mathfrak{B} e$ fdreifung feltener, namentlid)

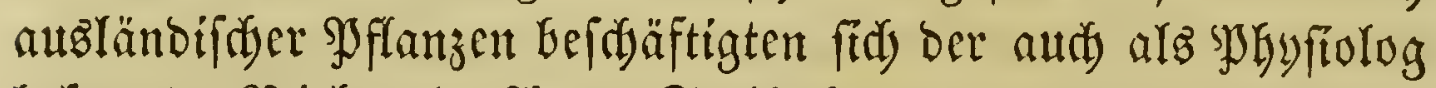
befamte $\mathfrak{a}$ idarb $\mathfrak{A}$ t. Salibbury ${ }^{5}$ ), ber indeffen in

1) Synopsis plantarum insulis britannicis indigenarum; complectens characteres genericos et specificos secundum systema sexuale distributos. Londini 1798. 8.

$\left.{ }^{2}\right)$ A synoptical compend of british botany. London 1806. 12. - 1813. 8. - 1820. 8.

3) The British Flora. London 1812. V voll. 8. - $B o n$ bem= felfen $\mathfrak{B e r f a f f e r : ~ A ~ n e w ~ i l l u s t r a t i o n ~ o f ~ t h e ~ s e x u a l ~ s y s t e m ~}$ of Linnaeus. Vol. I. London (1799-1809) imp. Fol. 66 tab. - Select plants. The temple of the Flora. London 1799 imp. Fol. 31 tab. col. - Elements of botany. London 1812. II voll. rep. 8. - Practical botany. London s. a. 8. vol. I. 85 tab. - An introduction to the science of botany. London 1833. 12.

4) Flora rustica, exhibiting accurate figures of such plants as are either useful or injurious in husbandry, with scientific characters, popular descriptions and useful observations. London $1792-1794$. IV voll. 8. 144 tab. col.

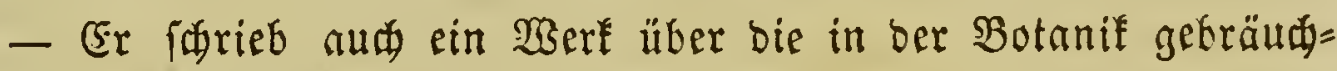
liden $\mathfrak{A}$ usbrinfe: The language of hotany: being a dictionary of the terms made use of in that science, principally by Linnaeus, with familiar explanations and an attempt to establish significant english termes. The whole interspersed with critical remarks. London 1793. 8. Ed. II. London 1796. 8. - Ed. III. London 1807. 8. (Deffen „Observations on the language of botany" finten fiti iil b. Transact. of the Linnean Society, vol. I. p. 147-15\%.)

$\left.{ }^{5}\right)$ Icones stirpium rariorum descriptionibus illustratae. Londini 1831. Fol. max. 10 tab. col. - The generic characters in the English Botany collated with those of Linné. London 1806. 8. 


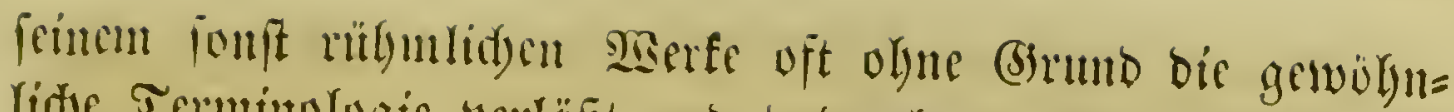

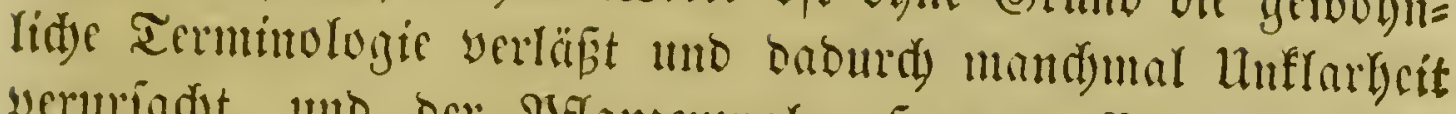

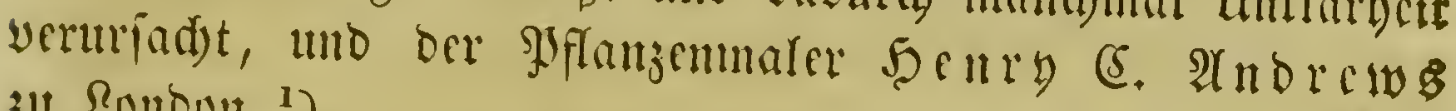
3u Ronoun. ${ }^{1}$ )

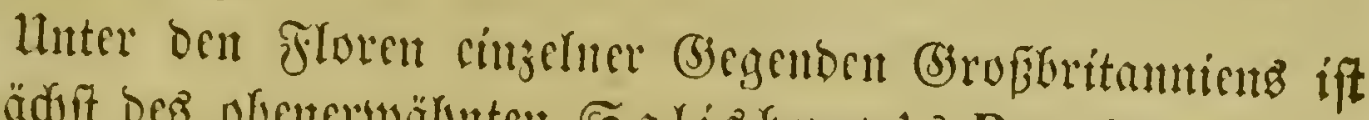

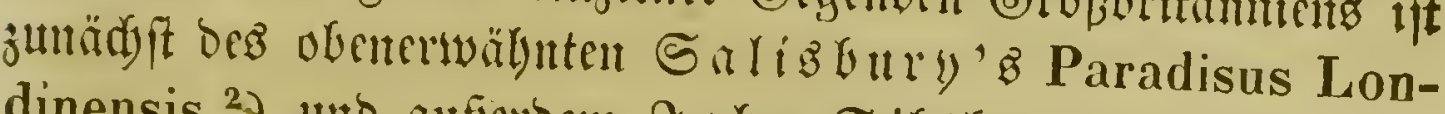
dinensis $\left.{ }^{2}\right)$ uto anferbem $\Im$ obn Sibthorp'B, Srofeffors in Drfurb, igeft. 1796, Flora oer llnigegend diefer Stabt ${ }^{3}$ ), (6) arleb albot's flora von Bebforb ${ }^{4}$ ), SWalter

1) Coloured nngravings of Heaths. The drawings taken from living plants only; with the appropiate specific character, full description, native place of growth and time of flowering of each; in latin and english etc. London $1802-$ 1809. IV voll. Fol. 288 tab. col. - The Heathery; or a monograph of the genus Erica, containing coloured engravings with latin and english descriptions, dissections etc. of all the known species of that extensive and distinguished tribe of plants. London 1804. VI voll. gr. 8. 300 tab. col. - Geraniums; or a monograph of the genus Geranium, containing coloured figures of all the known species and numerous berutiful varieties, drawn, engraved, described and coloured from the living plants. London 1805. II voll. 4. 124 tab. col. - Roses; or a monograph of the genus Rosa, containing coloured figures of all the known species and beautiful varieties, drawn, engraved, described and coloured from the living plants. London 1805 - 1828. II voll. 4. (129) tab. col.

$\left.{ }^{2}\right)$ The Paradisus Londirensis: containing plants cultivated in the vicinity of the Metropolis. The description by Richard Anthony Salisbury; the figures by Will. Hooker, pupil of Francis Bauer. London 1806 1807 (nab) E. A. Z u chold 1805-1807) II voll. 4. 117 tab. pulcherr. col. (nad) Zuchold 105 coloured plates). Bergleide ald barüber: Additamenta ad G. A. Pritzelii thesaurum literaturae botanicae colleg. et composuit $\mathbf{E r}$ nestus A mandus Zuchold. Halis 1853. S. 24. No. 203.

3) Flora Oxoniensis. Oxonii 1794. 8.

4) Flora Bedfordiensis. Bedford 1798. 8. 6 tab. col.

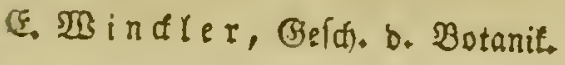




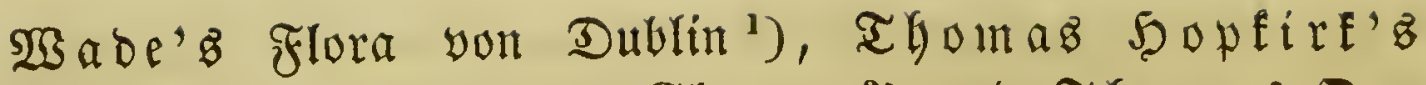
Flora ber Humgegeno, yon (Glasgow ${ }^{2}$ ) uno $\mathfrak{T}$ homaz $D r=$ Doynd Flora yon Rottinglyam ${ }^{3}$ ) zu erwähnen. Tho

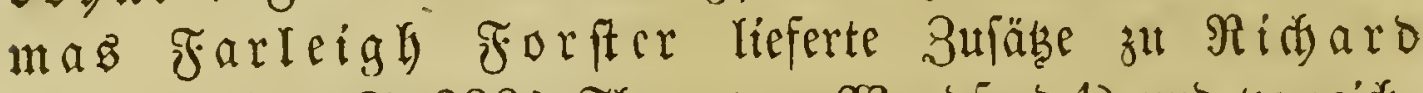

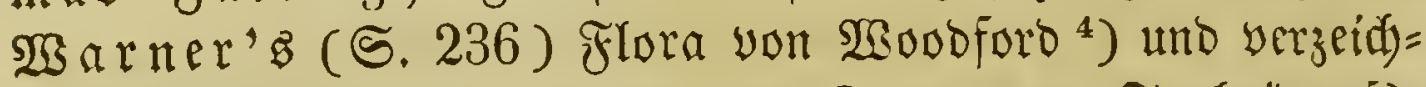
nete die felteneren SPflanjen in ber (Segent yon Tonbribge ${ }^{5}$ ).

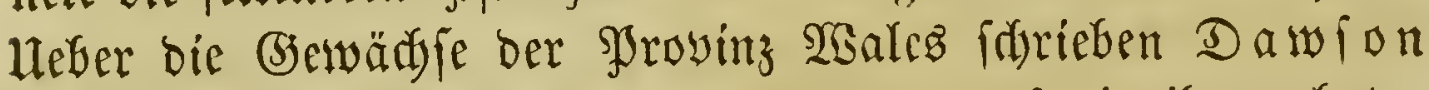

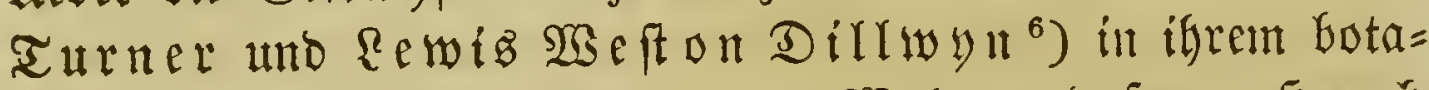

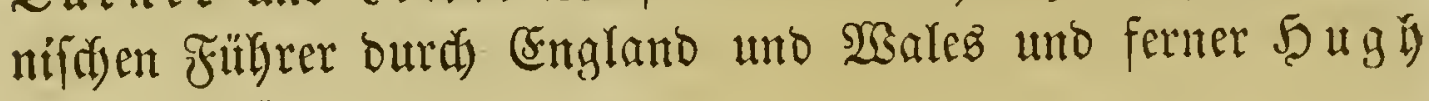
Davies. ${ }^{7}$ )

Der (b)arten zat Rew fand aud in biefer Sheriobe feine. Befdreiber. Der Borfteher beffelben, Satlliam Al iton, fübrte in feiner Befdreibung biefes Gartens viele nelle.

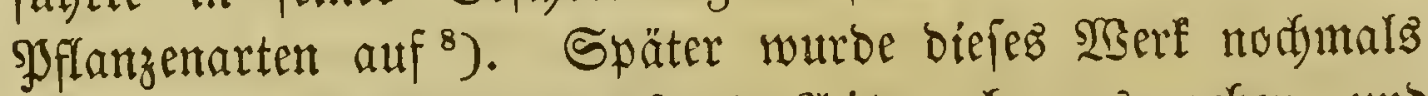
bon feincm Solye Toinnfeno Alton heraugegeben, tmo

1) Catalogus systematicus plantarum indigenarum in Comitatu Dublinensi inventarum. Pars I. Dublin 1794. 8. WSade inrieb aukerbem: Syllabus of a course of lectures on botany. Dublin 1802. 8. - Plantae rariores in Hibernia inventae. Dublin 1804. 8. - Salices or an essay towards a general history of sallows, willows and osiers etc. Dublin 1811. 8. 1 tab. col.

$\left.{ }^{2}\right)$ Flora Glottiana. Glasgow-1813. 8. - Flora anomala. Glasgow and London 1817. 8. 11 tab.

$\left.{ }^{3}\right)$ Flora Nottinghamiensis. Newark 1807. 8.

$\left.{ }^{4}\right)$ Additions to Warner's Plantae Woodfordiensis s. l. 1784. 8.

$\left.{ }^{5}\right)$ List of the rare plants found in the neighbourhood of Tonbridge Wels. London 1801. 12. - Flora Tonbrigensis. London 1816. 8. 3 tab. col.

$\left.{ }^{6}\right)$ The botanists guide trough England and Wales. London 1805. II voll. 8.

$\left.{ }^{7}\right)$ Welsh botanology. London 1813. 8. 1 tab.

$\left.{ }^{8}\right)$ Hortus Kewensis; or a Catalogue of the plants cultivated in the royal botanic Garden at Kew. London 1789. III voll. 8. 13 tab. - Ed. II. enlarged by William Townsend Aiton. $1810-1813 . \mathrm{V}$ voll. 8. 


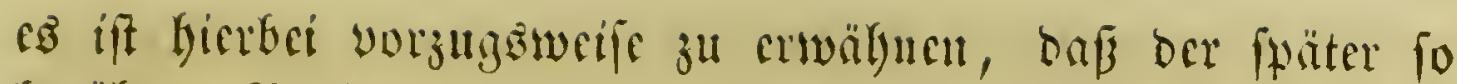

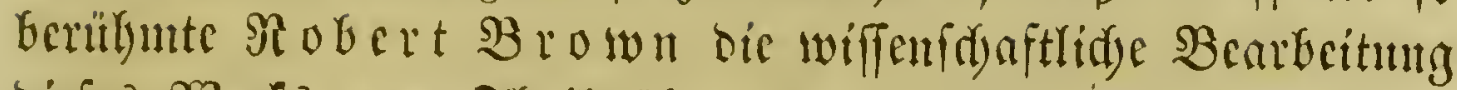
biefes :

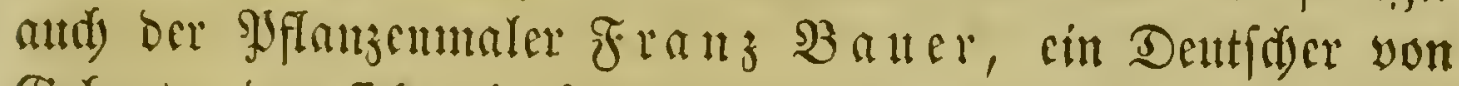

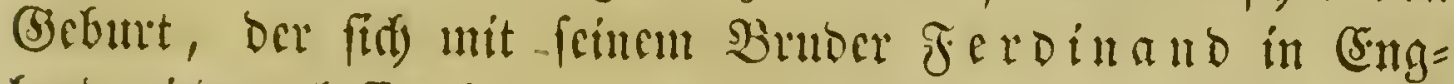

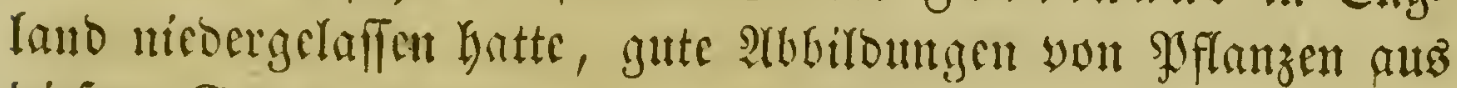
Diefeul (Sarten. ${ }^{1}$ )

Aluper ben bereits erwälnten Sdyrftfellern lebten aber

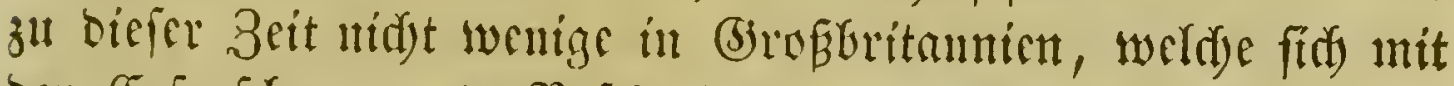

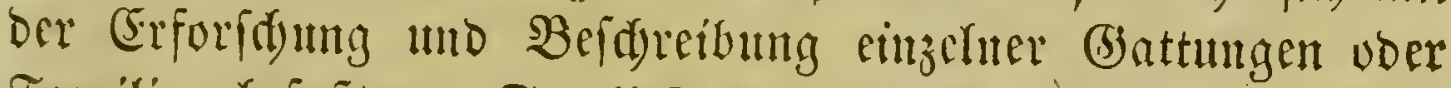

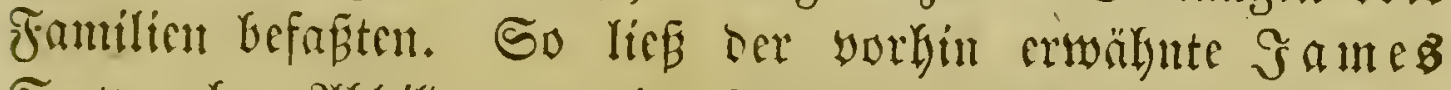

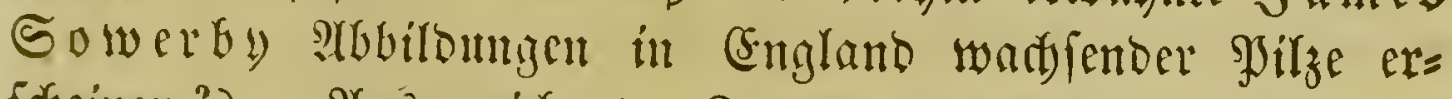
fdocinen ${ }^{2}$ ). A(uşgezeiducte Semer Der Algenarten waren Retwis TBefton Dillwy $\mathfrak{n}^{3}$ ) und Daw (un Turuer ${ }^{4}$ ), yon benen ber Erftere die Conferyen, Turner bagegen die Tangarten bearbeitete; einer befonoeren ruldenliden (Erwäh= numis verbient nod) oes Regteren Befdreifung oer in $\Im_{r}=$

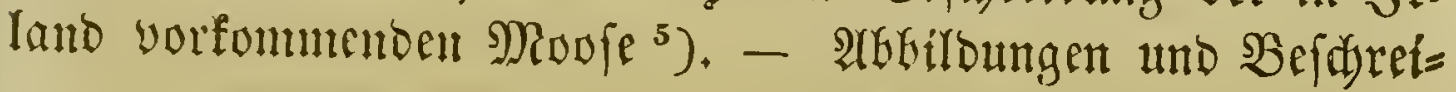

1) Delineations of exotick plants cultivated in the royal garden at Kew. Drawn and coloured, and the botanical characters displayed according to the Linnean System. Published by W. T. A iton. London 1796. Fol. 20 tab. col.

2) Coloured figures of english Fungi or Mushrooms. London 1797 - 1809. Fol. and Suppl. $440^{\circ}$ tab. col.

$\left.{ }^{3}\right)$ British Confervae; or colored figures and descriptions of the british plants referred by botanists to the genus Conferva. London 1809. 4. 115 tab. col. - Deutf Diflwyn für Deutide Botanifer bearbeitet von Friedr. und Dan. Mattb. Şeinr. Mo obr. 4 Sefte. (jöttingen $1803-$ 1805. 8. 37 Tafeln.

*) A Synopsis of the British Fuci. London 1802. II voll. 8.

5) Muscologiae hibernicae spicilegium. Yermuthi et London. 1802. II voll. 8. - Difrwy und $\mathfrak{T} u \mathfrak{r}$ er bearbeiteten au币 nacholgendes Mert gemeinfaftida: Fuci, sive plantarum Fucorum generi a botanicis adscriptarum icones, descriptiones et historia. (Aud) englifd unter b. Tit.: Fuci, or 
bungen Der englifden Algen lieferte aud) $\Im o b n$ @tadt= ho $\mathfrak{u}\left\{e^{1}\right.$ )

Der in ber nädyften Jeriode augfiülyrlidyer zu bebandelnde

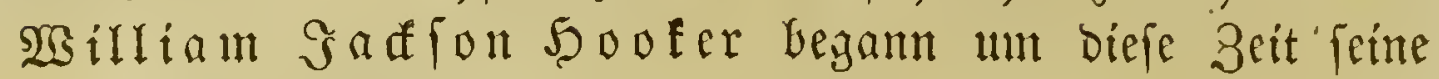
literarifde Saufbahn. (s) verfabte eine Sdyrift liber bie Sungermannien'(Srofibritamiens ${ }^{2}$ ), hatte aber fadon früber Die $\mathfrak{A} b$ billoungen $\mathfrak{z} \mathfrak{U} \subseteq \mathfrak{a} \mathfrak{I} \mathfrak{B} \mathfrak{b} \mathfrak{u} \mathfrak{r} y^{\prime} \mathfrak{z}$ Paradisus Londinensis bejorgt; in ben Gafren 1812-1816 fegte er bie Rondoner Flora von 2 Birliam (S artiz (S. 235 ) fort.

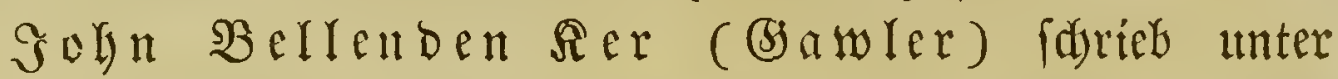
2(nderm aud) über bie Griben ${ }^{3}$ ); feine abghandhungen find in veridsebenen 3eitidyriften zerftreut.

$\mathfrak{A}$ brian $\mathfrak{S}$ aroy $\mathfrak{S} \mathfrak{a}$ worth, beffen $\mathfrak{T}$ bätigfeit fid weit in bie fulgende Weriode hinein erftreft, lieferte fdon währent

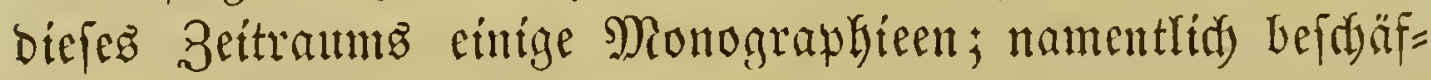
tigte er fid mit ben Saftgewädjen ${ }^{4}$ ). - Der Bicepräfibent

coloured figures and descriptiones etc.) London 18081819. IV voll. gr. 4. 258 tab. col.

1) Nereis britannica, continens species omnes Fucorum in insulis britannicis crescentium (descriptione latina et anglica, necnon) iconibus illustrata. Bathoniae 1801. Fol. - Append. 24 tab. col. - Ed. altera: Oxonii 1816. 4. 20 tab.

2) British Jungermanniae: being a history and description with coloured figures of each species of the genus and microscopical analyses of the parts. London 1816. Fol. 88 tab. col.

3) Ramentfid in ben Annals of botany unto im Journal of science and the arts.

4) Observations on the genus Mesembryanthemum in two parts, containing scientific descriptions of above one hundred and thirty species. London 1794. 8. - Miscellanea naturalia sive dissertationes variae ad historiam naturalem spectantes. Londini 1803. 8. - (Agitur: praesertim de Mesembryanthemi, Tetragoniae, Portulaceae et Saxifragae generibus.) - Synopsis plantarum succulen- 


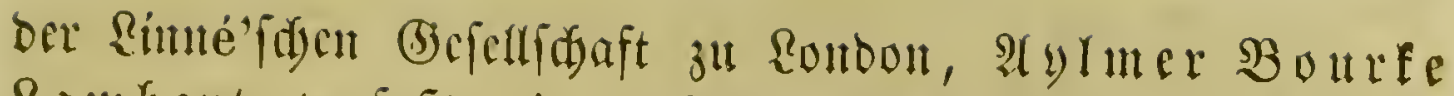
Rambert, verfaste cine trefflidye Befdrecifumg oer Gattumg

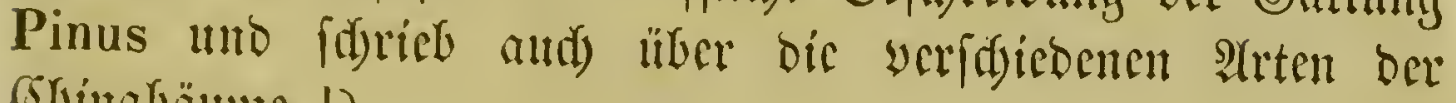
(E) inn

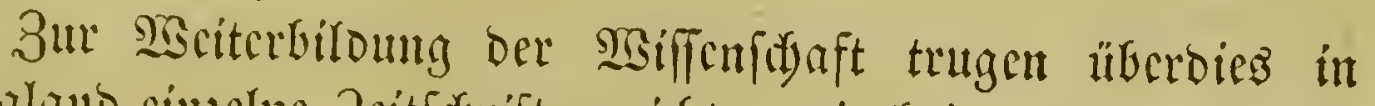

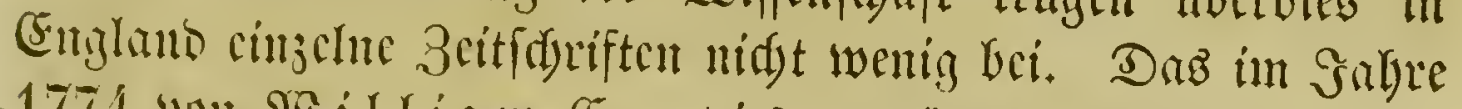

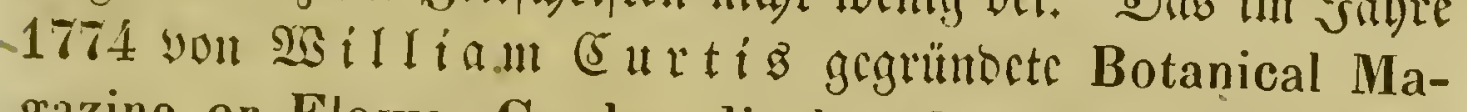
gazine or Flower-Garden displayed wurbe in bicfer \$ge

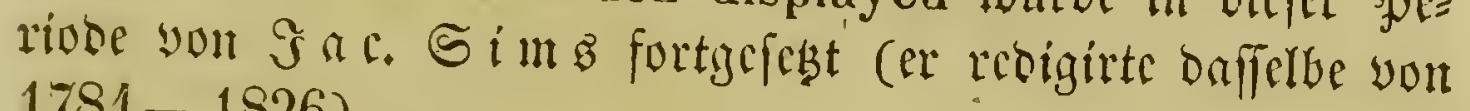
1784-1826).

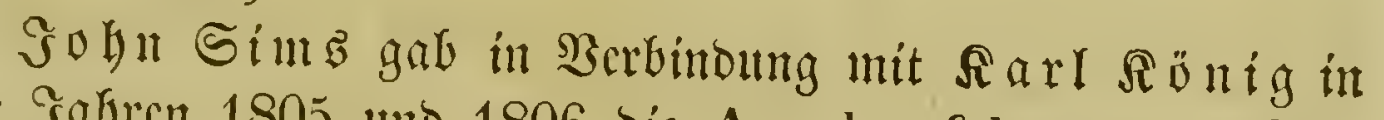
ben Gagren 1805 und 1806 bie Annals of botany fu Ront= bon herrats. Begen Ende diefes 3eitraums (1815) begrün=

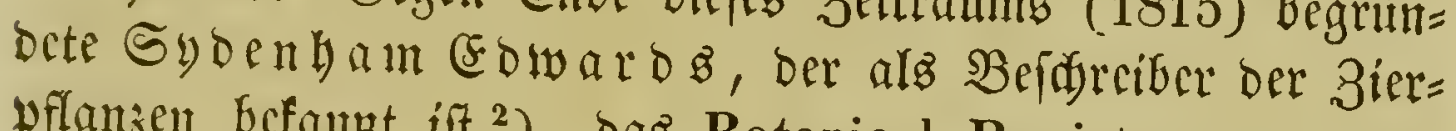
pflanjen befannt iff ${ }^{2}$ ), das Botanical Register or ornamental Flower - Garden, weldye 3eitfdrift in ber folgenden Jerivoe fortgciegt warbe.

tarum cum descriptionibus, synonymis, bocis, observationibus anglicanis, culturaque. Londini 1812. 8. - Editio usui hortorum Germaniae accomodata (curavit Franz von Paula Schrank). Norimbergae 1819. 8.

1) A description of the genus Cinchona, comprehending the various species of vegetables, from which the Peruvian and other barks of a similar quality are taken. Illustrated by figures of all the species hitherto discovered. To which is prefixed Prof. Vabl's Dissertation on this genus etc. London 1797. 4. 13 tab. - A description of the genus Pinus, illustrated with figures, directions relative to the cultivation and remarks on the uses of the several species. London 1803. Fol. max. 44 tab. col. (tab. 10, 12, 33 et 34b sunt nigrae.) - Vol. II. (to which is added an appendix containing an account of the Lambertian Herbarium by Mr. David Don.) London 1824 . Fol. 10 tab. col.

2) 61 plates representing about 150 rare and curious ornamental plants. London 1809. 4. - Diefé $\mathfrak{B e r f}$ if weder

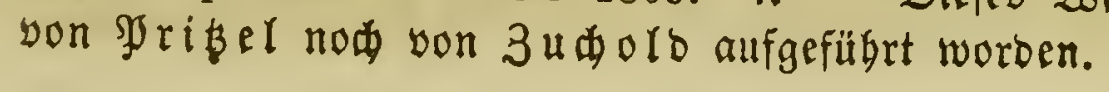


(3rope $\mathfrak{B e r d i e n f t e ~ h a t ~ f i t h ~ d i e ~ v o n ~ D r . ~} \mathfrak{B} \mathfrak{r}$ th gegrünbete

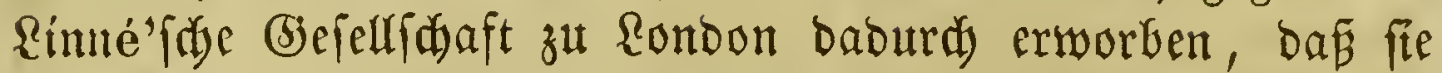
yom Jalire 1791 an bie Transactions of the Linnaean Society heratiggab, in welden fidy vicle vortrefflide $2(65$ and $=$ lungen über alle Theile ber SPflauzenfunde befinden.

Unter ben niederlän dija en Shytographen nennen wir zunädýt die beisen Reftiboubois, nämlid den Bater Jean $\mathfrak{B a p t i f t e , ~ g e f t . ~ 1 8 0 5 , ~ u n d ~ D e n ~ S o h n ~ F r a n c ̧ o i z ~}$ Gofeph, geft. 1815, beibe Segrer ber Maturgefdidyte zht Rille. Sie bearbeiteten zujammen eine belgílde flora, weldae zwar fidon in ber vorigen Seriobe in ber erften 2 luggabe er= fdien, in ber jekigen bagegen zweimal vielfad vermegrt uno verbeffert herauggegeben warbe. ${ }^{1}$ )

F. Rouçel verfaß̧te zwei Srrriften über die Pflanzen

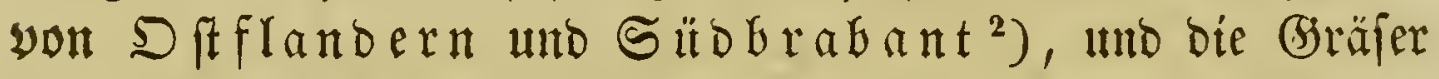

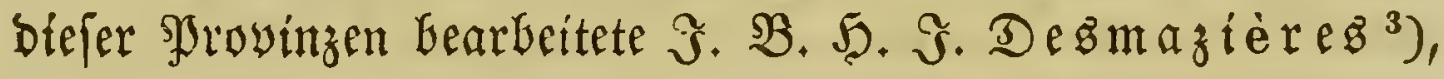

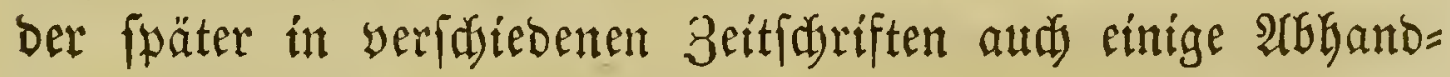

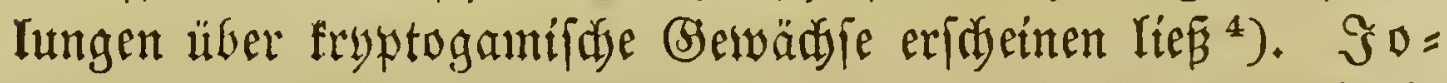

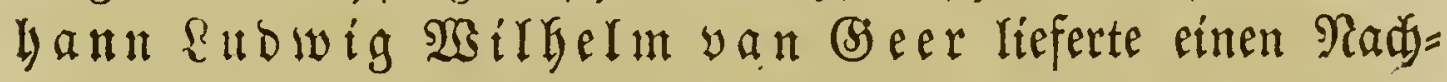

1) Botanographie belgique, ou méthode pour connaitre facilement toutes les plantes, qui croissent naturellement dans les provinces septentrionales de la France. Lille 1781. 8. tab. - Seconde édition, corrigée, augmentée et divisée en trois parties. Lille an VII (1799). III voll. 8. - Ed. III. Ibid. an XII (1804). 8. - Bergl. au由 ஒrifel's Thesaurus S. $155-156$.

2) Traité des plantes les moins fréquentes, qui croissent naturellement dans les environs des villes de Gand, d'Alost, de Termonde et Bruxelles. Paris 1792. 8. Flore du Nord de la France. Paris 1803. II voll. 8.

3) Catalogue des plantes omises dans la botanographie belgique et dans les Flores du Nord de la France. Lille 1823. 8. - Agrostographie des départements du Nord de la France. Lille 1812. $\delta$.

*) Mém. de la soc. Linn. de Paris. - Ann. des sc. nat. etc. 
tray ju (5) orter's flora (S. 237) '), Die grflanzen ocb

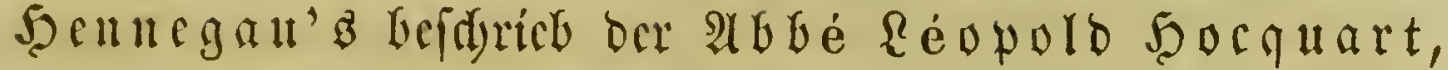
Borfecher bes Rollegiums zu $\mathfrak{a t h}^{2}$ ), 一 2 (m widtigften aber

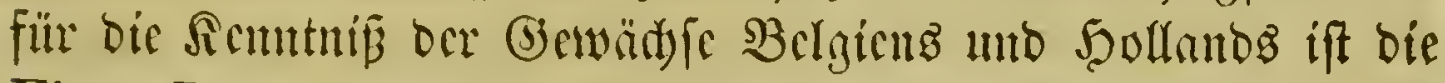
Flora Batava, weldje im Sagre 1800 begunnen warbe; Den

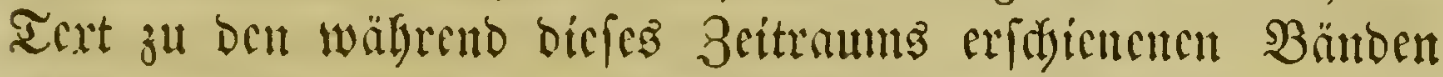

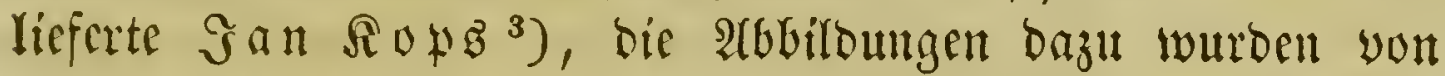

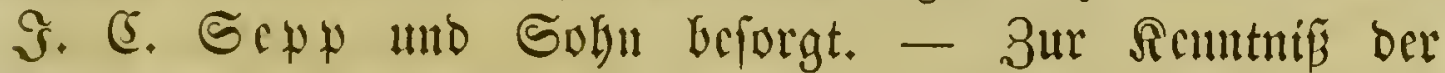

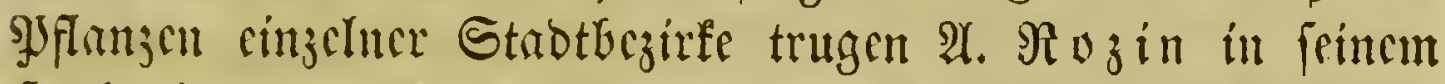
Scrbariun getrofincter sfflanzen aus oer llmgegend yon Rüt=

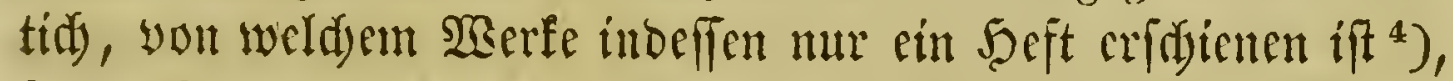

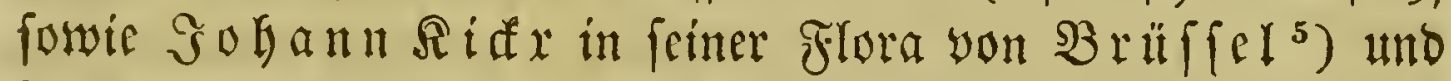

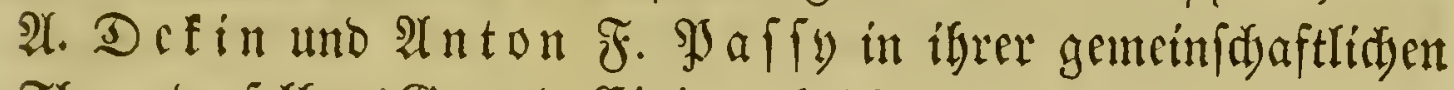

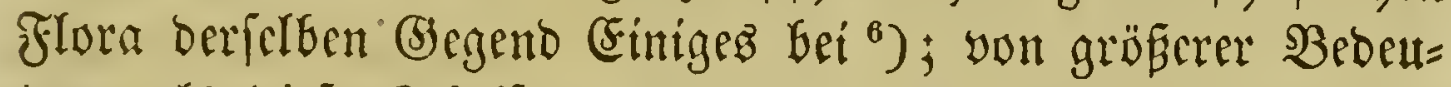
tung als biefe Sdriften aber ift 2 . \&. S. Rejeune's,

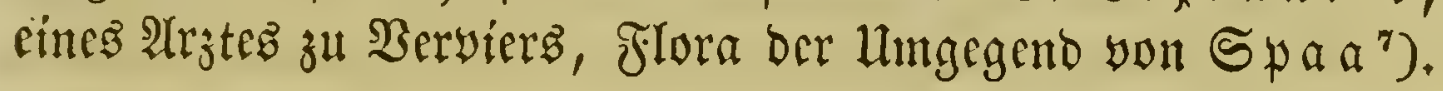

1) Plantarum Belgii confoederati indigenarum spicilegium alterum quo Gorteri Flora VII provinciarum amplificatur et illustratur. Trajecti ad Rhenum 1814. 8.

$\left.{ }^{2}\right)$ Flore du Département de Jemappe, ou définitions des plantes qui y croissent spontanément, faites d'après le système de Linné à l'usage des élèves en botanique. Mons 1814. 8.

$\left.{ }^{3}\right)$ Flora batava, of Afbeelding en Beschrijving van Nederlandsche Gewassen. Amsterdam 1800-1847. IX voll. 4. 730 tab. col. - Index plantarum quae in horto RhenoTrajectino coluntur anno 1822. Trajecti ad Rhen. 1823. 8.

4) Herbier portatif des plantes qui se trouvent dans les environs de Liège, avec leur description et classification selon le système de Linné. Premier cahier. (Liège) 1791. 8.

s) Flora Bruxellensis, exhibens characteres generum et specierum plantarum circum Bruxellas crescentium etc. Bruxellis 1812. gr. 8.

-) Florula Bruxellensis. Bruxellis 1814. 8.

') Flore des environs de Spaa, ou distribution, selon le système de Lin naeus, des plantes qui croissent spon- 
(3) egen bas (5nde biefer Seriode erfdien ber erfte die Syane=

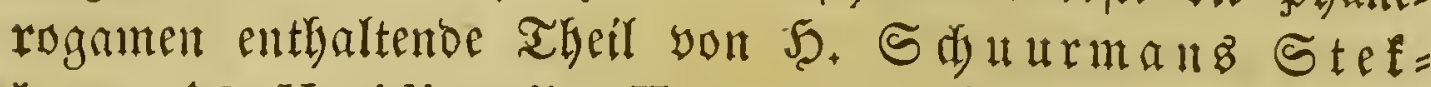
Hoyen's Kruidkundig Handboek, in weldem fith audd

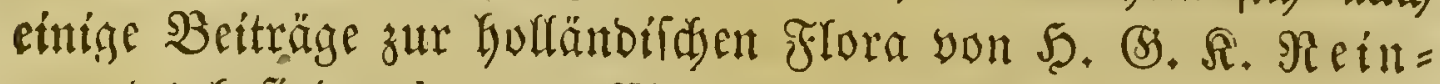

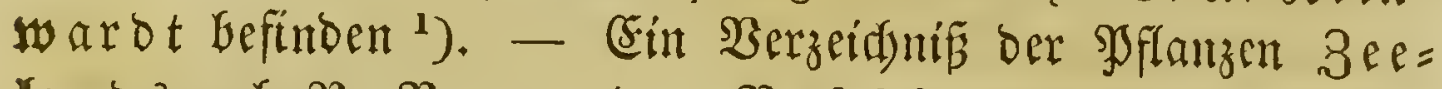

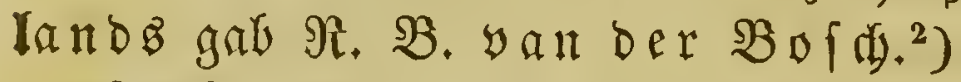

Sn Stalien, namentlid) in ben nöroliden Staaten ber Salbinfer, wurbe die Splanzenforidung fleisig weiter betrie= ben. Domente Noeca, Drofeffor umb Borfeber bes bo=

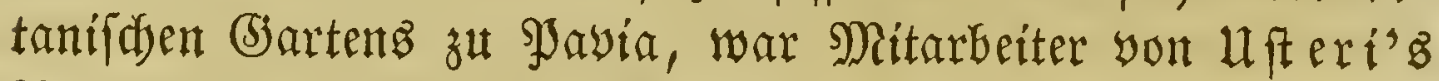
Annalen, in weldye er verfdiedene Albgandungen liber die italienifdse Flora unto den botaniforsen (5arten zu Mantua lie=

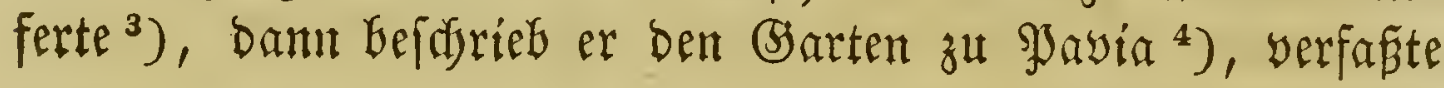

tanément dans le département de l'Ourie et dans les départements circonvoisins pour servir de suite à la Flore du Nord de la France de Mr. Ro u cel. Liège 1811-1813. Deux parties. 8. - Revue de la Flore des environs de Spaa. Liège 1824. 8.

") Kruidkundig Handboek, bevattende eene systematische beschrijving van alle in de Nederlanden, in hed wild groeijende boomen, heesters en kruiden. Amsterd. $1815-$ 1818. II voll. 8.

$\left.{ }^{2}\right)$ Enumeratio plantar. Zeelandiae belgicae indigenarum tertia. s. 1, et a. 8 .

3) Horti botanici Mantuani historia, descriptio. (Turici 1793). 8. 1 tab. - Illustrationes nonnullarum plantar, horti botan. Mantuani (Turici 1793). 8. -- Scenographia horti botanici Mantuani. (Turici 1796). 8. 1 tab.

4) Ticinensis horti academici plantae selectae, quas descriptionibus illustravit, observationibus auxit, coloribus ad naturam prope reddidit. Fasc. I. Ticini 1800. Fol. 6 tab. col. - Synopsis plantarum horti botanici Ticinensis anno 1803. Papiae (1803). 8. - Synonymia plantarum horti botanici Ticineusis. Papiae 1804. 8. - Nomenclatura stirpium horti botanici Ticinensis, juxta species plantarum a Cl. Will de now hucusque evulgatas. Papiae 1807. 8. - Onomatologia seu nomenclatura plantarum, quae in horto med. Ticinensi coluntur anno. 1813 etc. Pap. 1813. 8. 


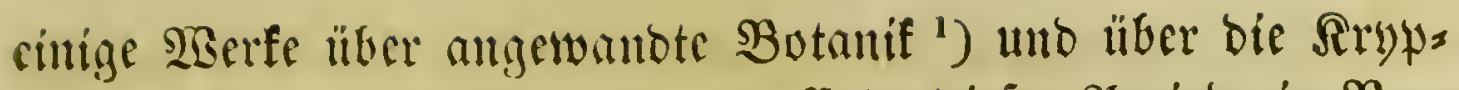
togamenfunbe ${ }^{2}$ ) uno begam am (5nbe diefer Periobe in $\mathfrak{B e r}=$ binoung mit (B) iovanni Battifta $\mathfrak{B a l b i B}$ eine aubfübr= lidje Flora oer llmgegeno yon gs a via herruszageben. ${ }^{3}$ )

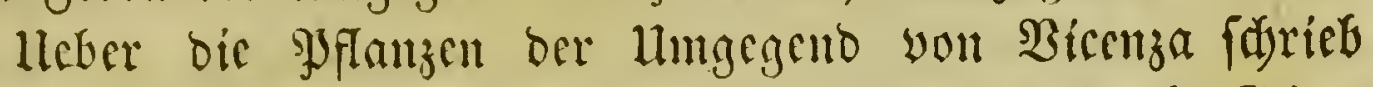

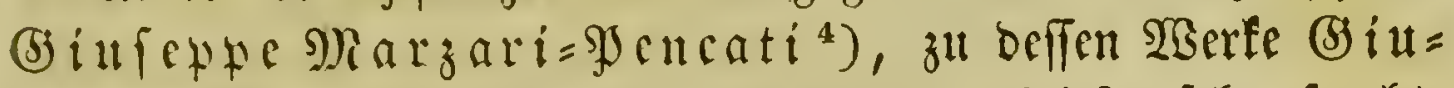
fephe Moretti Radträge lieferte ${ }^{5}$ ). Dicier febr frudt= bare Sduriftiteller, beffen mrifte Srbriften indeflen erft im foll= genoen 3citraume erfdoienen, war \$rofeffor zu \$gavia. - Ein

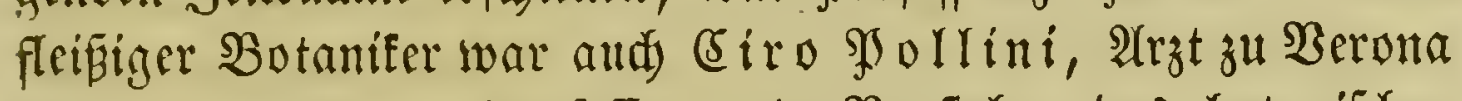
und cine Zcitlang \$rofeffor und Sorftelyer bez botanifden (3)artens bajelbft. 2(ußer einigen SBerfen alfgemein botani=

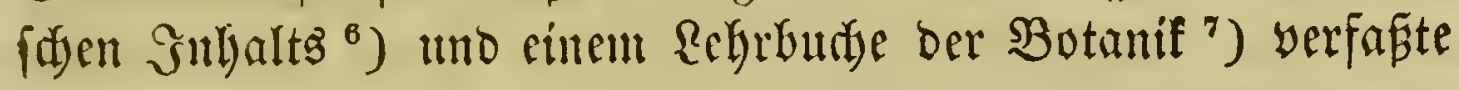

') Elementi di botanica. Pavia 1801. 8.4 tab. Ed. II. Ibid. 1805. 8. 5 tab. - Instituzioni di botanica pratica applicabili alla medicina, alla fisiologia, all' oeconomia ed alle arti. Pavia 1808 - 1809. III. voll. 8.

$\left.{ }^{2}\right)$ Termini botanico-cryptogamici ad normam recentiorum definiti necnon exemplis e classe XXIV systematis Linneani desumptis iconibusque 218 illustrati. Papiae 1814. 8. 4 tab.

3) Flora Ticinensis. Ticini $1816-1821$. II voll. 4. 27 tab. -

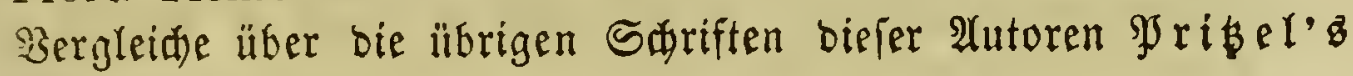
Thiesaurus S. 212.

* Elenco delle piante spontanee fino ad ora osservate nel territorio di Vicenza. Milano 1822. 8.

5) Noticia sopra diverse piante da aggiungersi alla Flora Vicentina. Pavia 1813. 4. 1 tab. - Continuazione ibid. 1820. 4.

6) Synonymia hotanica moderna. Milano 1804. 8. - Succinto esame degli Elementi di hotanica del Professore Pa olo Sangiorgio. Verona 1809. 8. - Dell' influenza delle scienze naturale sull' agricoltura. 'Verona 1809. 4. Discorso istorico sulla botanica. Verona 1812. 8.

7) Elementi di botanica compilati. Verona 1810 - 1811. II voll. 8. 20 tab. 
er eine Flora ber Uungegend von Berona ${ }^{1}$ ), worin er zugleid Die Sflanzen bes Beronefer Bartenz befinrieb, dann aber unterfudyte er aud bie am (5arbafee ${ }^{2}$ ), auf bem Monte Baldo und an ben cuganeifiten $\mathfrak{B} e r g e n$, namentlíd bei 2 (bbano

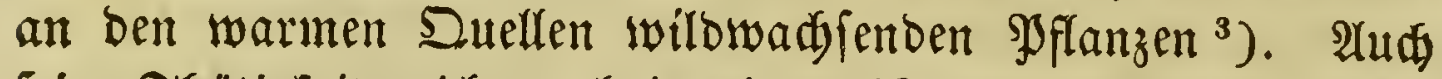
feine Ihätigfeit reidyt nody in bie nadjfolgende Seriobe hinein. - Die Flura ber Stadt (5.te bearbeitete Filinpo $\Re e^{4}$ ), ber Berfaffer mehrerer Sariften lanbwirthfdaftliden $\Im_{n}=$ Galts ${ }^{5}$ ). - Für die Renntnis Der oberitalijden Flora iiber= Gaupt, inbefondere aber ber in ben norifiden uno rhetificen

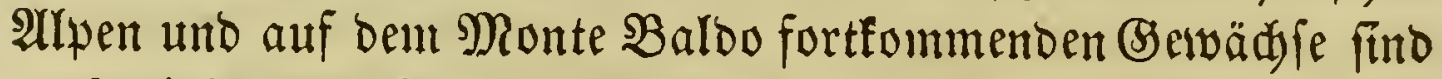
aud einige Berfe des (Srafen $\Re \mathfrak{a} \mathfrak{y a r}$ von Sternberg nidjt obne $\mathfrak{S i d h t i g f e i t}^{6}$ ). - Uefer bie Flora ber julifden

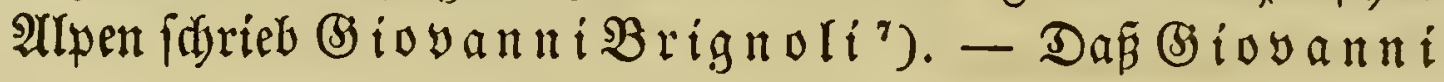

1) Horti et provinciae Veronensis plantae novae vel minus cognitae, quas descriptionibus exornavit. Fasc. I. Ticini 1816. 4. 1 tab. - Catalogus plantarum horti botanici Veronensis. Verona 1812. 8. - 1814. 8.

$\left.{ }^{2}\right)$ Viaggio al Lago di Garda e al monte Baldo in cui si ragiona delle cose naturali di quei luoghi aggiuntovi un cenno sulle curiosita del bolca e degli altri monti veronesi. Verona 1816. 8. 1 tab.

3) Osservazioni intorno al Viaggio al lago di Garda e al Monte Baldo. s. 1. 1817. 8.

-) Florae Atestinae Prodromus. Mutinae 1816. 8.

5) Saggio di bibliografia georgica, ossia indice ragionato delle principale opere di agrieoltura si antiche che moderne. Venezia 1802. 8. - Saggio teoretico-pratico sulle malattie delle piante. Venezia 1807. 8. - Ed. II. 1817. 8.

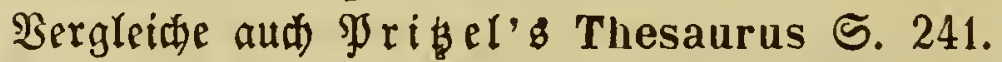

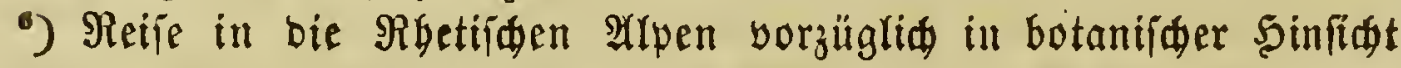
im Sommer 1804. Rürnberg 1806. 8. - Reife burø Tyror

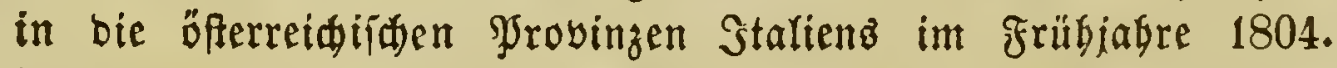
Regenzburg 1806. Fol. - Revisio saxifragarum iconibus illustrata. Ratisbonnae 1810. Fol. - Suppl. 1822, 1831.

") Fasciculus rariorum plantarum Forojuliensium. Urbini 1810. 4. 
beften Botanifer Stalienz wälrend diefes 3eitraumez war

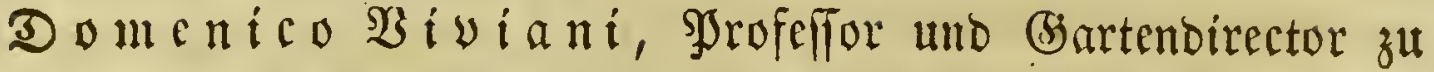
(S) emua, befien vorzüglidyfte Sdyriften übrigens erfi in ber

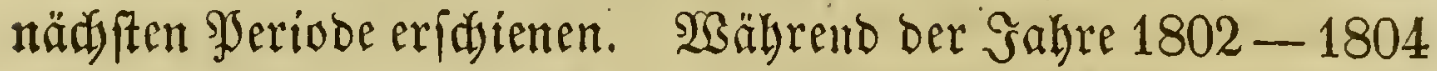
gab er bie Annali di Botanica herauz '): Ferner beidrieb er feltentere $\mathfrak{p f l a n z e n ~} \Im$ talienz ${ }^{2}$ ) mo feine zu naturwiflen=

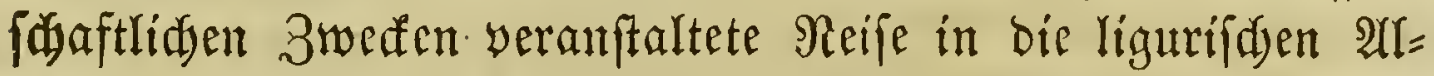

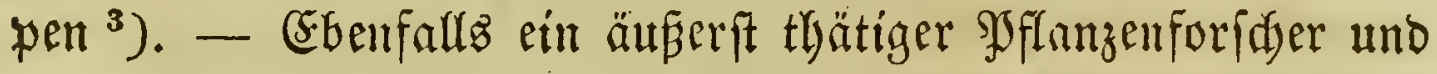

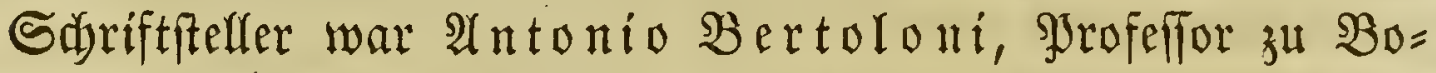
logna, ber in biejer Seriobe indeffen erft feine literarifaje Ihätigfeit begann; er fdrieb nämlid l̈bek die feltneren

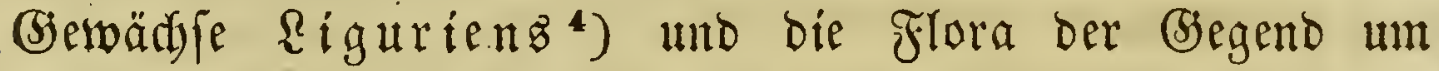

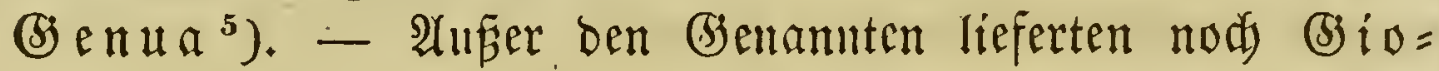

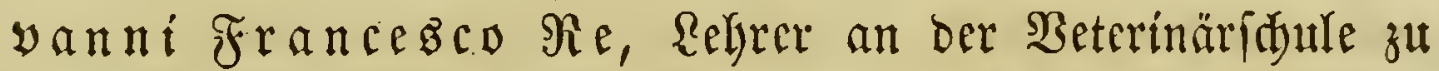
Turin ${ }^{6}$ ), (sarlo Antonio Rodovico Bellardi, der

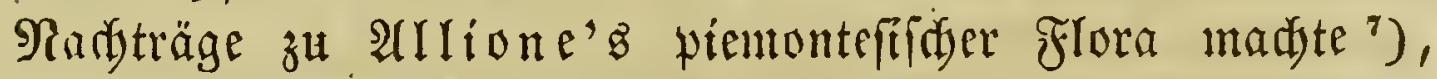
Midele $\mathfrak{F r a n c e g c o ~} \mathfrak{B} u \mathfrak{i v a}{ }^{8}$ ) uno $\mathfrak{s e a n}\left(\mathfrak{a v y}{ }^{9}\right.$ ) zur

1) Annali di botanica. Genova 1802. 4. - Annales botanici redacti curà Dom. Viviani. Vol. I. p. II. Genuae 1804. 4. 5 tab.

2) Flórae italicae fragmenta. Fasc. I. Genuae (1803). 4. 26 tab.

3) Voyage dans les Appenins de la ci-devant Ligurie pour servir d'introduction à l'histoire naturelle de ce pays. Gênes. 1807. 4.

4) Rariorum Liguriae plantarum Decas I. Genua 1803. 8. Decas II. Pisis 1806. 8. Decas. III. Pisis 1810. 8.

s) Plantae genuenses, quas annis $1802-1803$ observavit et recensuit. Genuae 1804. 8.

-) Flora legusiensis. Taurini (1805). 8.

\%) Appendix ad Floram Pedemontanam. Augustae Taurinor. 1792. 4. 7 tab. col.

8) Nomenclator Linna eanu Florae Pedemontanae. August. Taurinor. 1790. 12.

9) Stationes plantarum Pedemontio indigenarum. Taurini auno IX. 1801. 8. - Genera plantarum subalpinam regio- 
Remmtnif oer fiemonteffidyen Flora einige Beiträge. - Die SPlanzen ber Gnjel Sardinien wurben in biefem Zeitraume nod) wenig unterfutit; ; mr Arrlione (Misc. Taur. I, 88103) uno Domcnico Arberto 2 zuni madyten Einiges in bicfer Simfidst bcfinut. ${ }^{1}$ )

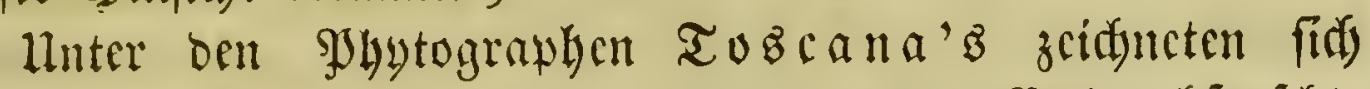

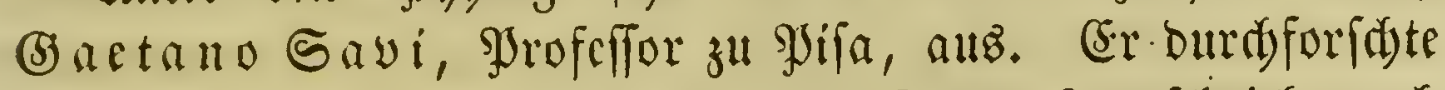
mit gropem Flripe dic Flora dicfes Randes ${ }^{2}$ ), fidricb aud

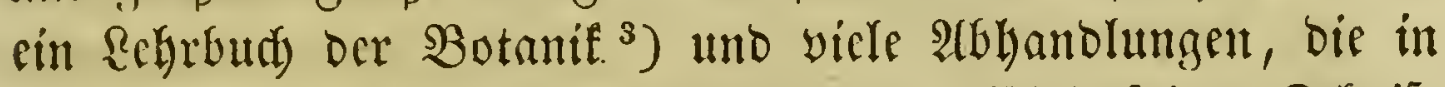
weriduiebenen 3citfdriften zerftrent find. Wiele feiner Sibrif= ten fallen indeffen crit in bic nadbfolgente sjerivbe. (5) Teid)= rübmeno hervorzuheben ift Dttayiany Targioni=Toz= zetti, Shrofelfor und Brartendirector zu Florenz, geftorben

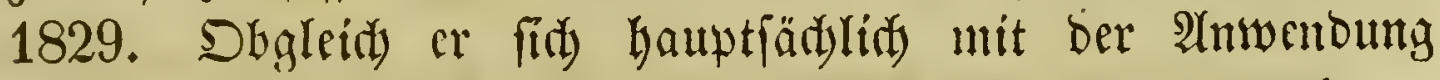
ber Botanif auf bie 2 gricultur befdjäftigte, hat er body zur :Beiterbiloung bor rein wiffenfdaftlicten Botanil ebenfalls beigctragen, namentlid) Durdi fein Refrbud der Botanif,

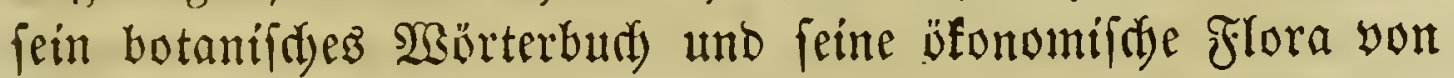
Flarenz. ${ }^{4}$ )

nem exornantium earumque characteres naturales secundum numerum, figuram, situm et proportionem omnium fructificationis partium. Taurini, anno X. (1802.) 8. Phyllographie piémontaise. (Turin. 1816.) III voll. 8.

`) Histoire géographique, politique et naturelle de la Sardaigne. Ed. II. Paris 1802. II voll. 8. 1 charte.

2) Flora Pisana. Pisa 1798. II voll. 8. - Enumeratio stirpium in horto Pisano. Pisis 180\%. 8. - Trattato degli alberi della Toscana. Pisa 1801. 8. - Firenze 1811. II voll. 8. - Due centurie di piante appartenenti alla Flora etrusca. Pisa 1804. 8. - Materia nedica vegetabile toscana. Firenze 1805. Fol. 60 tab. - Botanicon etruscum, sistens plantas in Etruria sponte crescentes. Pisis $1808-$ 1825. IV voll. 8.

3) Lezioni di botanica. Firenze 1811. II voll. 8.

4) Institutioni botaniche. Firenze 1794. II voll. 8. - 1802. III tomi. 8. 12 tab. - 1813. III voll. 8. 17 tab. - Lezioni 


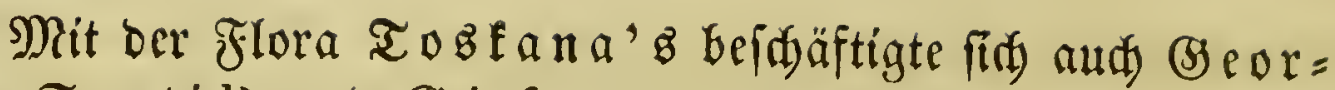
gio Santi $i^{1}$ und (S) iufeppe $\Re a d b i$, ber eine Zeitlang Borfteher bes Mureumb zu Florenz war, fpäter aber auf ciner Reife in 2 eggpten ftarb (1829), Befdrieb die Rrypto=

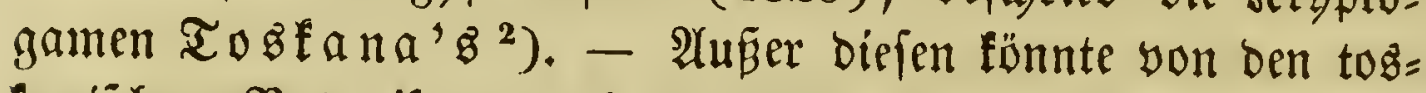
fanijaen Botanifern nod attilio 3 uccagni, Brofeffor

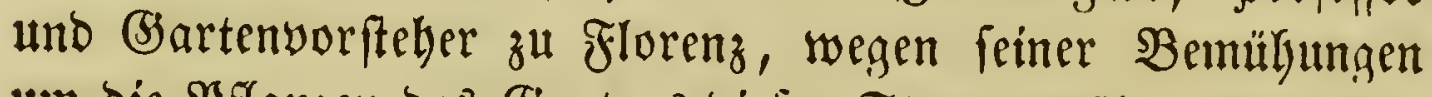
un die Syflanzen bes (jartenz biejer Staot erwähnt werben. ${ }^{3}$ )

Sm Rirdenftaate wurbe wälrend diefes Zeitraums

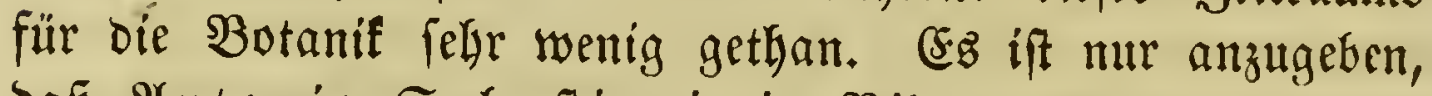

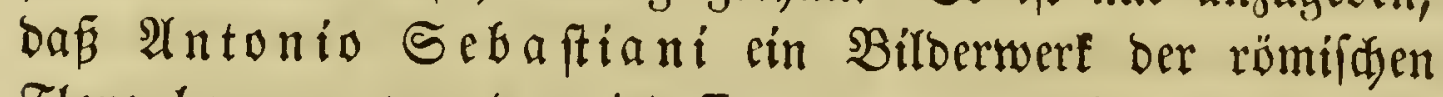
Flora begann, yon bem indeffen nur zwei Sefte eridjienen."

di agricoltura specialmente toscana. Firenze $1802-1804$. VI voll. 8. - 'Sopra alcuni funghi ritrovati nell' apparecchio di una frattura complicata d'una gamba umana. Modena 1805. 4. 1 tab. - Prospetto per la Flora economica florentina. Verona 1803. 4. - Dizinnario botanico italiano che comprende i nomi volgari italiani specialmente toscani, e vernacoli delle piante raccolti da diversi autori e dalla gente di campagna col corrispondente latino Linneano. Firenze 1809. II part. 8. - 1825. II voll. 8. Observationum botanicarum Decas I - V. (Florentiae $1808-1810)$. 4. 13 tab.

1) Viaggio al Montamiata e per le due provincie Senesi. Pisa $1795-1806$. III voll. 8, 24 tab.

2) Di alcune specie nuove e rare di piante crittogame ritrovate nei contorni di Firenze Memoria. s. I. et a. 4. 3 tab.

3) Centuria prima observationum botanicarum, quas in horto regio florentino ad stirpes ejusdem novas vel rariores illustrandas instituit. (Florentiae 1806.) 4. 1 tab. - Synopsis plantarum, quae virescunt in horto botanico Musei R. Florentini hoc anno 1806. (Florentiae 1806.) gr. 8. (Er faricb aud: De naturali liliorum, quae ante simulacra Deiparae locantur, fructificatione, veluti prodigium evulgata. (Florentiae 1796.) 8.

t) Romanar. plantar. Fasc. I. Romae 1813. 4.4 tab. Fasc. II. Romae 1815. 4. 6 tab. 
Aud in unteritalien war die 3abl ber spflanzen= forfder nidyt grof. (Es eridjienen zwar meldere Sdyriften über die Flora yon $\mathfrak{R}$ enel uno Sicilien, die meiftent berfelben lieferten jebod nur geringe $\mathfrak{B}$ citräge zur $\mathfrak{R e n n t n i \beta}$ ber

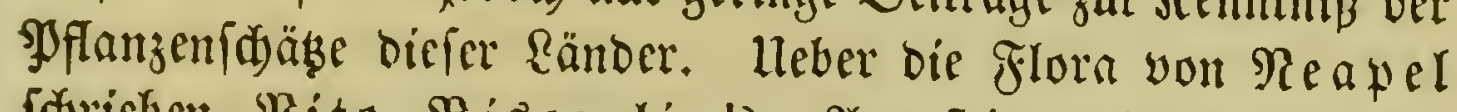
daricben Sito Bisceglie ${ }^{1}$ ), Agoftino Ronconi ${ }^{2}$ ), Bincenjo 2 riganti ${ }^{3}$ ), ber aud in ber nädyften $\mathfrak{d e}=$ riobe ju erwälnen ift. - Der bebeutenofte unter ben neapulitanifden Botanifern war aber Midele Tenore, Srofeffor und Bartendirector zu Nerpel, beffen literarifye Ihätigfeit biz in bie ncucfte 3eit hincinteidyt. Sn ber vor

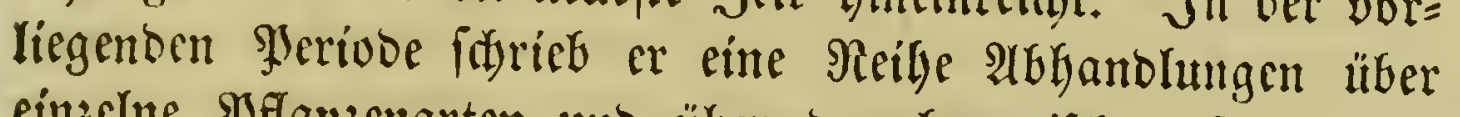
einzelne Spflanzenarten und über Den botanilden Garten zu Reapel ${ }^{4}$ ); Daneben aber befdäftigte er frd emfig mit ber Flora feines Baterlandes unb begann in Gahre 1811 feine

1) Flora della provincia di Bari. Napoli 1809.8.

2) Osservazioni del Dottor Agostino Ronconi su la Flora napolitana. Lettera prima. Napoli 1811. 8. - Analisi delle Osservazioni del Dottor Agostino Ronconi su la Flora napolitana del Dottor Giovanni Gussone. Napoli 1811.8.

3) Stirpes rariores quae in regno Neapolitano aut sponte veniunt aut hospitantur. Neapoli 1816. Fol. 5 tab. - De nova Pimpinellae specie cui nomen Anisoides dissertatio. Neapoli 1805. Fol. 1 tab. - Clavis systematis sexualis Linnaei sistens plantarum classes, ordines eorumque animalias, in tres tabulas synopticas distributa atque iconibus aeri incisis illustrata. Neapoli 1804. Fol. 1 tab.

-) Catalogo delle piante del real giardino botanico di $\mathrm{Na}$ poli. Napoli 1807. 16. - Memoria sull Arachide americana. Napoli 1807. 4. - Catalogo delle piante del giardino botanico del Signor Principe de Bisignano. Napoli 1809. 8. - Catalogus plantarum horti regii Neapolitani ad annum 1813. Neapoli 1812. 4. - Append. Ibid. 1815. 8. - Ed. II. Neapoli 1819. 8. - Catalogo della collezione agraria del real giardino delle piante. Napoli
1815. 8 . 
ausfübrlidge neapolitanifde Flora ${ }^{1}$ ), welde aber in biefem Zeitraume nidyt yollendet wurbe; audi) verfä̧te er ein Rebr= bud Der Botanif. ${ }^{2}$ )

Heber bie Gewädje ber Jniel Sicilien fdrieben 2 nt nio $\mathfrak{B a r o n e} \mathfrak{B i y o n a}=\mathfrak{B}$ ernarbi ${ }^{3}$ ), geit. 1837, uno

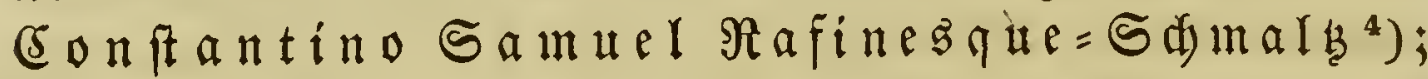

1) Saggio sulla qualita medicinali delle piante della Flora Napolitana, et sulla maniera di servirsense per surogarle alle droghe esotiche. Napoli 1808. 8. 1820. 8. Flora Napolitana. Napoli $1811-1838$. V voll. Fol. Icones in Fol. max.: 250 tab. col. - Raccolta di viaggi fisico - botanici effetuiti nel regno di Napoli dai collaboratori della Flora Napolitana. Vol. I. Napoli 1812. 8.

2) Corso delle botaniche lezioni. Napoli 1806. II voll. 8. Ed. II. Napoli $1816-1823$. IV voll. 8 .

$\left.{ }^{3}\right)$ Sicularum plantarum Cent. I (et II). Panormi 1806. 4. min. 13 tab. - Monografia delle Tolpidi. Palermo 1809. 5 tab. - Stirpium rariorum minusque cognitarum in Sicilia sponte provenientium descriptiones nonnullis iconibus auctae. Manipulus I-IV. Panormi 1813-1816. 4. 14 tab. - Scinaia, Algarum marinarum novum genus. (Palermo 1822.) 8. 1 tab.

-) Caratteri di alcuni nuovi generi e nuove specie di animali e piante della Sicilia ete. Palermo 1810. 4. 20 tab. - Specchio delle scienze o giornale enciclopedico di Sicilia sopra la fisica, la chimica, la storia naturale, la botanica, l'agricoltura, la medicina etc. Tom. I. Palermo 1814. Il voll. 8. 2 tab. - Précis des découvertes et travaux somiologiques entre $1800-1814$, ou choix raisonné de ses principales découvertes en zoologie et en botanique etc. Palerme 1814. 12. - Principes fondamentaux de somiologie, ou les lọis de la nomenclature et de la classification de l'empire organique ou des animaux et des végétaux. Palerme 1814. 8. - Analyse de la nature, ou tableau de l'univers et des corps organisés. Palerme

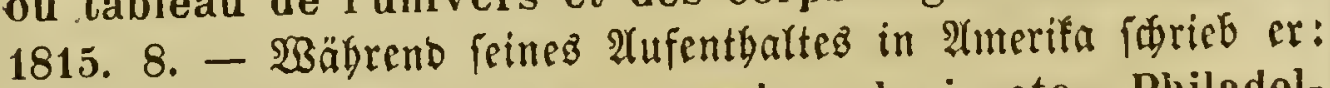
Circular address on botany and zoologie etc. Philadelphia 1816. 8. - Rafinesque-Schmaltz et Giuseppe 


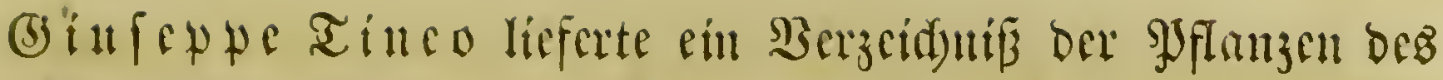
afabcuifden (bartens zแ

Unter ben fis anif d) en Botanifern diejes Zcitraums

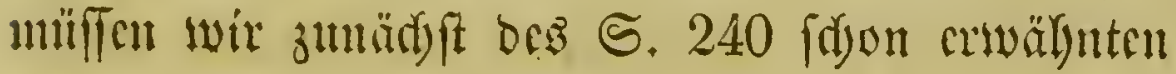

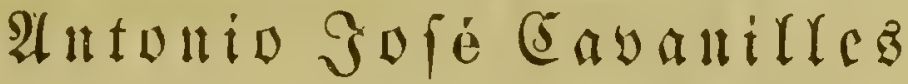

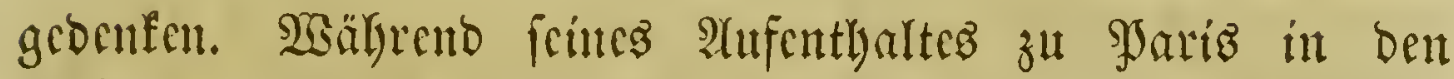

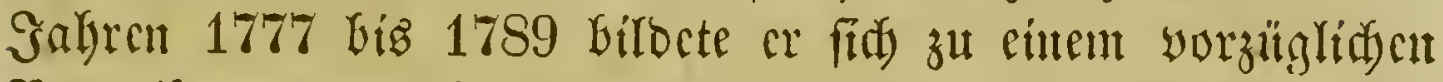
Botanifer aub und bearbeitetc bic Maryacen, Mclicen, Maffe floren und Malpighicn in feiner ausgezcidjneten Monographie

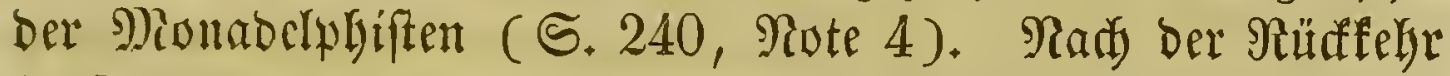
in feit Baterland unterfutede er bie Flora Spaniens; in bent

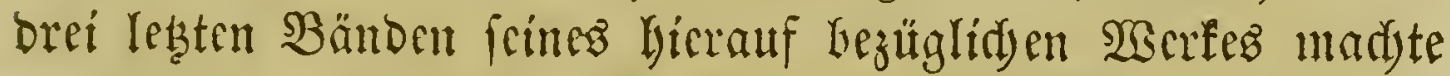

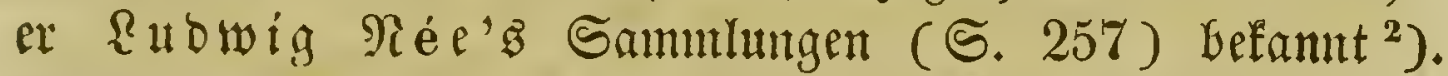
Bon nidjt geringerem Snterefle ift fcine naturhiftorifde $\mathfrak{B}_{\mathfrak{e}}=$

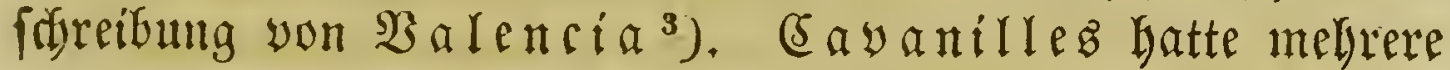
Streitigfciten mit cinigen feiner Fadfgenoffen auşufediten,

Emmanuele Ortolani, Statistica generale di Sicilia. Parte I. Fisica della Sicilia. Palermo 1810. 8. 2 tab.

') Index plantarum horti bolanici Academiae regiae Panormitanae una cum nominibus pharmaceuticis atque vernaculis in usum medicae juventutis. (Panormi) 1790. 8. Synopsis plantar. horti academici Panormitani. Panormi $1802-1807$.

$\left.{ }^{2}\right)$ Icones et descriptiones plantarum, quae aut sponte in Hispania crescunt, aut in hortis hospitantur. Matriti 1791-1801. Vl voll. Fol. 600 tab. col.

3) Observaciones sobre la historia natural, geografia, agricultura, poblacion y frutos del reyno de Valencia. Madrid 1795-1797. II voll. Fol. 54 tab. col. - Suplemento a las observaciones sobre e cultivo del arroz en el reyno de Valencia, y su influencia en la salud publica, en respuesta a la contestacion de D. Vicente Ignacio Franco. Madrid 1798. 8.

E. SB ind rer, Beld. b. Botunit. 
wobei ez zutweilen fararf berging. Sabon wäbreno feines Aufentbaltz zu Sariz fam er wegen feiner 2 bbandlung über Die Monadelphiften mit I'\$̧eritier ( 5.233$)$ in Streit ${ }^{1}$ ), in weldem eB fidf am die Sriorität oer benfelben Segenftand beleudtenden Sifriften beiber (Selebrten Gandelte. Sn Ma brio entzweite er fid mit dem (Gartenvorfeber Drtega ( 5.240$)$, truig jeovd) in diefem Streite zulegt ben Sieg bayon, indem er im Sable 1801 die Stelle feineb in den

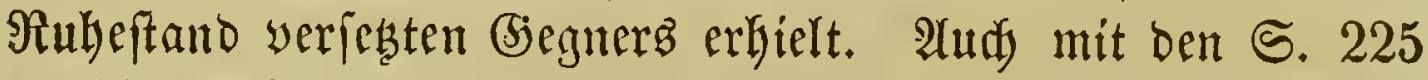
erwälynten $\Re$ eijenden $\Re u i z$ und $\mathfrak{S}$ a v n gerieth er in Streit, burds welden er indeffen bei ben competenten und unpar= teiifden Beurtheillern burdyans leine günftige Neinung yon feinem Elyarafter, erregte. oon 1799-1804 gab er, an=

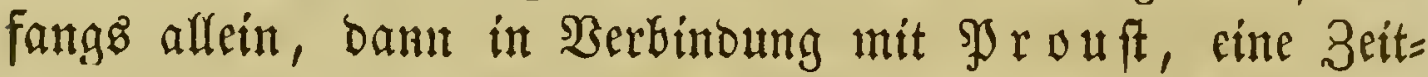
forift naturwiffenidyaftiden Эnbalts heraus ${ }^{2}$ ). - Ueber die Flora Spaniens uno dell Mabriber (Sarten verfabite Ma= riano $\mathfrak{a g a b c a , ~}$ Borfteber des botaniffen Gartenz zu Mabrio, mefrere Werfe $^{3}$ ). Ferner lieferten (5)rifian

') Observationes in quintum fasciculum de l'Heritier. s. I. et a. 4. Bergl. aud: Colleccion de papeles sobre controversias botanicas. Con algunas notas del mismo a los escritos de sus antagonistas. Madrid 1796. 8. थuperbent farieb er: Carta.de D. Antonio Cavanilles en respuesta a la que se insertó en la segunda parte del memorial literario del nes de Septiembre de 1788, donte se hace critica de sus disertaciones botánicas por une que se titula vecino de Linna. (Madrid 1789.) 12. Descripcion de las plantas, que demostró en las lecciones publicas del año 1801, precedida de los principios elementales de la botanica. Madrid 1802. 8.

$\left.{ }^{2}\right)$ Anales de historia natural. Madrid 1799, - Anales de sciencias naturales. 1800.

3) Amenidades naturales de la Españas: o bien disertaciones varias sobre las producciones naturales espontaneas o conaturalizadas en los dominios españoles. Tomo I (num. I). Orihuela en la imprenta de la muy illustre 


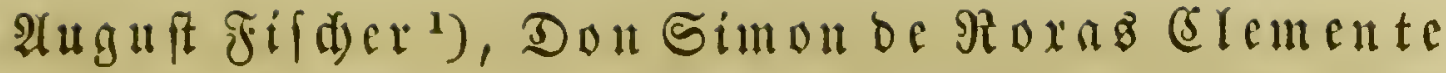

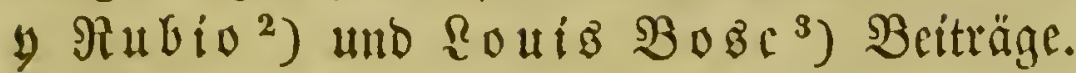

Rod) tweniger Botanifer als Spanten hatte Syortugal

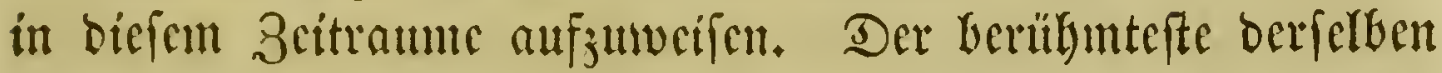
war Felix ayellar Şrotero, Srofeffor ju Coimbra,

Junta. 1811. 4. - Genera et species plantarum, quae aut novae sunt aut nondum recte cognoscuntur. Matriti 1816. 4. 2 tab. col. - Instruccion sobre el modo con que pueden dirigir sus remesas y noticias al real jardin botanico de Madrid los que gusten concurrir a la perfeccion de La Ceres Espa ĩola, ó tratado completo de todas las plantas, e specialmente de las cultivadas en España cujas semillas pueden convertirse en pan. (Madrid 1816.) 4. - Elenchus plantarum, quae in horto regio botanico Matritensi colebantur anno 1815 , cum novarum aut minus cognitarum stirpium diagnosi, nonnullarum descriptionibus contractis. Matriti 1816. 4. - 2 (u山 in in ber folgenden YJeriobe eridienen now einige 23 erfe yon bemiflben: Memoria sobre las plantas Barrilleras de España. Madrid 1817. h. - Amenidades naturales de las Españas. Tom. I. número segundo. Madrid 1821. 4. - Observaciones sobre la familia natural de las plantas aparasoladas (Umbelliferae). Londres 1826. 8.

1) Description de Valence ou Tableau de cette province, des ses productions, des ses habitans, de leurs moeurs, de leurs usages etc. Pour faire suite au voyage en Espagne du même auteur par Chr. Fr. Cramer. Paris 1804. 8. S. $393-418$ entbalten: $\mathfrak{B e r}$. Balencia.

2) Ensayo sobre las variedades de la vid comun que vegetan en Andalucia, con un indice etimológico, y tres listas de plantas en que se caracterizan varias especies nuevas. Madrid 1807. 8. - Deut

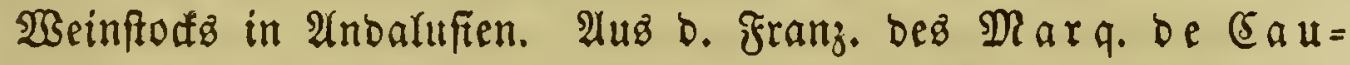
melz ins Deutfde überf. Durd $\mathfrak{A}$. $\mathfrak{A}$, Frbrn. y. Mascon. (3rä 1821. 8. 1 Eafel. 6 Sdemata.

2) Voyage en Espagne à travers les royaumes de Galice, Lèon, etc. Paris. 8. 
nad)her (Gartenoirector zut Riffabon, geftorben 1829, oeffen literarifde Thätigfeit nod in bie folgende Periobe Liméntreidyt ${ }^{1}$ ). 2lud ber S. 274 erwälynte (Sorrea de Serra liejerte einige

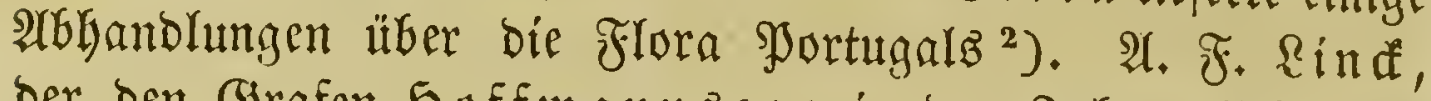
Der ben Grafen 5 offmannzegg in Den Gahren 1798 und 1799 auf ciner $\Re$ cife in bie pyrenäifdye Salbinfel begleitete,

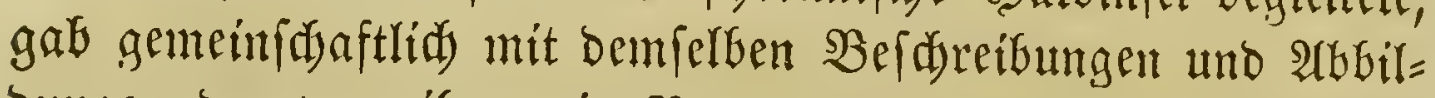
bungen ber von ifnen in Sortugal aufacfundenen (S)ewädfe

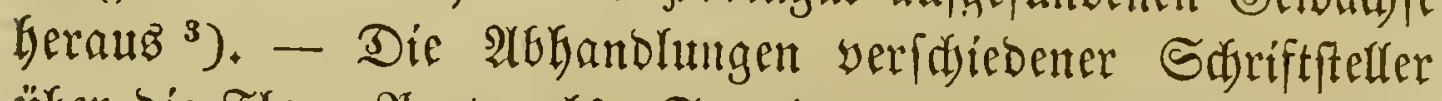
über bie Flora Jortugals, Spaniens unb Braftliens watroen

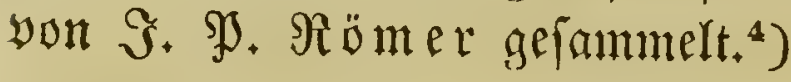

1) Compendio de Botanica. Paris et Lisboa 1788. II voll. 8. 31 tab. Edit. II. Compendio de botanica do Doutor Felix de Avellar Brotero, addicionado e posto en harmonia com os conhecimentos actuaes desta sciencia, segundo os botanicos mais celebres, como Mirbel, De Candolle, Richard, Lecocq e outros. Por Antonio Albino da Fonseca Benevides. Lisboa 1837 1839. II voll. 8. 37 tab. - Principios de agricultura philosophica. (Livro I: Anatomya e physiologia dos vegetaes). Coimbra 1793. 4. - Flora lusitanica, seu plantarum quae in Lusitania vel sponte crescunt, vel frequentius coluntur ex florum praesertim sexubus systematice distribuarum Synopsis. Olissipone 1804. II voll. 8.

$\left.{ }^{2}\right)$ Philos. Transact. 1796. - Transact of the Linn. soc. Vol. V and VI. - Ann. du Mus. vol. VI, VIII, IX, X et XIV. Bullet. de la soc. philomat. vol. XI.

$\left.{ }^{3}\right)$ Flore portugaise, ou description de toutes les plantes qui croissent naturellement en Portugal, avec figures coloriées, cinque planches de terminologie et une carte. Berlin 1809-1840. II voll. Fol. 114 tab. col. - Sm Sabre

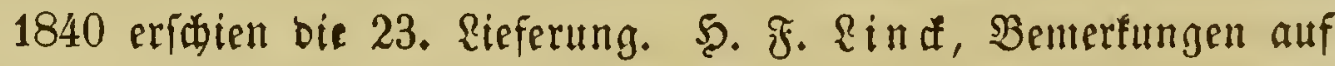

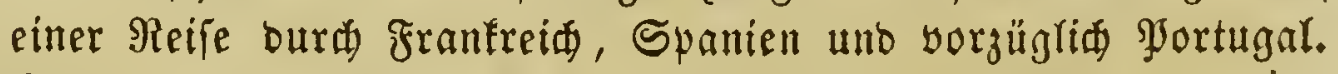
Riel 1799 - 1804. 3 Thle. 8.

*) Scriptores de plantis hispanicis, lusitanicis, brasiliensibus adornavit et recudi curavit J. J. Roemer. Norimbergae 1796. 8.8 tab. 


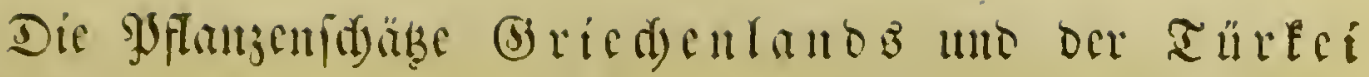

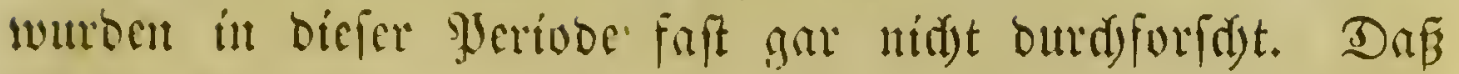

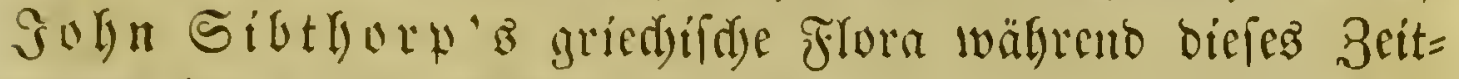
ramms im Drute eridjen, ift fodon S. 241 angegeben wor=

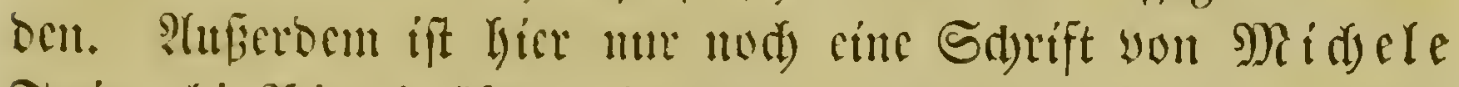

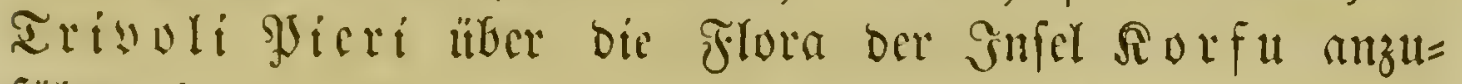
fïllyen. ${ }^{1}$ )

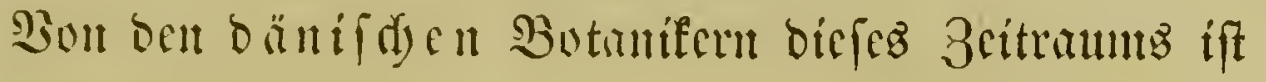

\section{Martin $\mathfrak{B a h l}$}

getworen 1749 j̆ Bergen in Rorwegen, geftorben im Sahre 1804 arz Wrofefior ju Ropentaget,

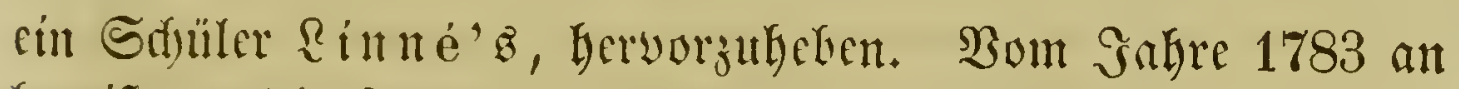
bereifte er bie füblidyen und weftlidyen Ränder (Furopa's anto cimen Theil yon Torbafrifa uno erwarb fid) baburd eine fehr

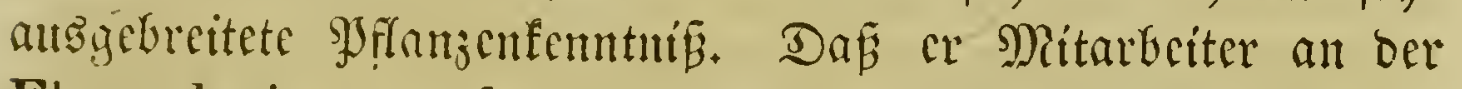
Flora danica geweien, iff fidon S. 242 crwähnt worten. Bon großjer Sisidytigfeit hätte feine Enumeratio plantarum, bie alle onmals befannten \$Jfanzen umfnffen follte, für bie Botunif werben mitffen, wäre er midst an ber Boffendung

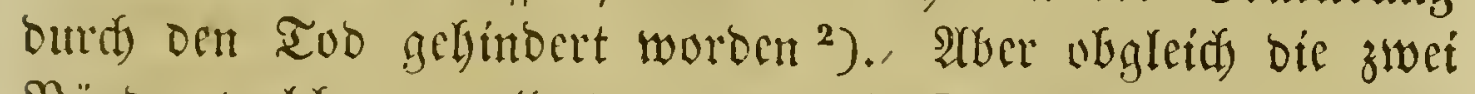
Bämbe, welde er vollendete, mur bie (jierwädje bis zur zwei= ten Drommig oer britten Silaffe entbalten, reiden fie bod

1) Della Corcirese Flora Centurie prima, seconde e terza, ossia storia di piante trecento, appartenente al suolo dell' isola di Corfu. Corfu 1814. 4. max. - In ber forgen= den Seriube eridien nod: Flora Corcirensis Centuriae I et II, sive enumeratio 200 plantarum, quas in insula Corcirae invenit. Corcirae 1824. 8.

$\left.{ }^{2}\right)$ Enumeratio plantarum vel ab aliis, vel ab ipso observatarum, cum earum differentiis specificis, synonymis selectis et descriptionibus succinctis. Havniae 1804-1806. II voll. 8. 


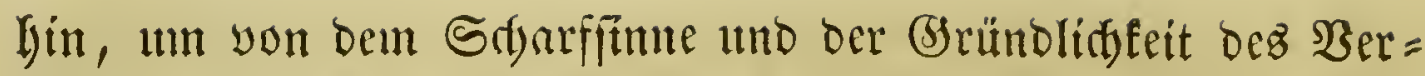
falfers Zeutgniß̧ abzulegen. $\mathfrak{B a h l}$ beförderte auth bie Rennt=

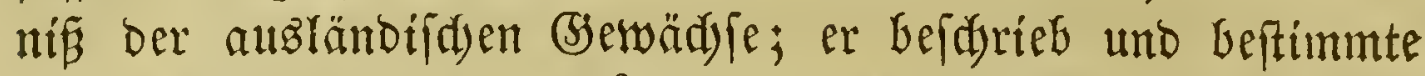
díe yon Seter Forzål (S. 248) in alegypten und

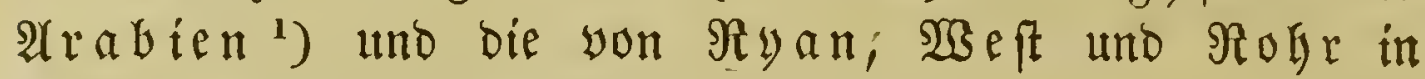
SBeftind $i \in n^{2}$ ) gefammelten Sflanzen.

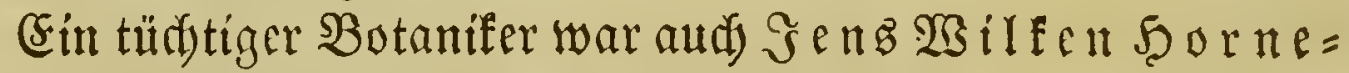
mann, Shrofeffor und Bartendirector zu Ropentyagen, ber als Bearbeiter oes 8, uno 9, SBandes oer Flora danica ebenfalls S. 242 fidon genant worben ift. Seime üfonomi=

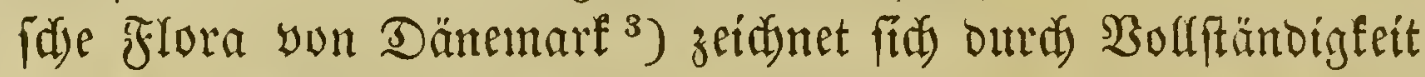

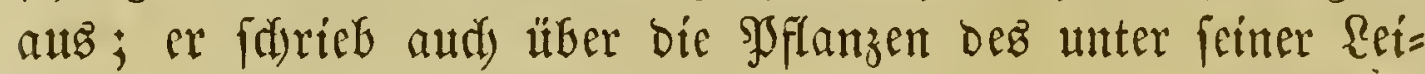
tung ftekenden (5artens ${ }^{4}$ ) uno gab nody in oer folgenden Seriobe eintige Sryriften botanifden Snhaltz heraus. - - $\mathfrak{R}$ arl

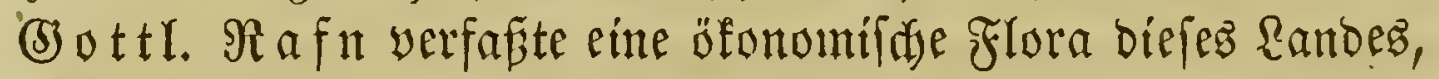

1) Symbolae botanicae, sive plantarum tam earum quas in itinere imprimis orientali collegit Petrus Forskål, quam aliarum recentius detestarum exactiones descriptiones, necnon observationes, circa quasdam plantas dudum cognitas. Havniae $1790-1794$. III partes Fol. 75 tab.

$\left.{ }^{2}\right)$ Eclogae americanae, seu descriptiones plantarum praesertim Americae meridionalis nondum cognitarum. Fasc. I - III. Havniae 1796-1807. Fol. 30 tab. - Icones illustrationi plantarum americanarum in Eclogis descriptarum inservientes edidit; M. V. Decas I - III. Havniae 1798 - 1799. Fol. 30, tab.

$\left.{ }^{3}\right)$ Forsog til en Dansk oekonomisk Plantelaere. Kjobnhavn 1795. 8. - Ed. II ibid. 1806. 8. - Ed. III ihid. 1821 - 1837. II voll. 8. 2 tab.

4) Enumeratio plantar. horti botanici Hafniensis. Hafniae 1807. 8. - Hortus regius botanicus Hafiniensis, in usum tironum et botanophilorum. Hafniae $1813-15$. II voll. 8. - Supplementum horti botanici Hafniensis in usum tironum et botanophilorum. (I - III.) Hafniae 1819. 8. 


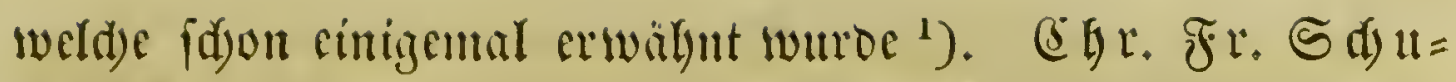
ma d) er, geftorben 1830 als Brofeffor oer 24natomic zu אopen=

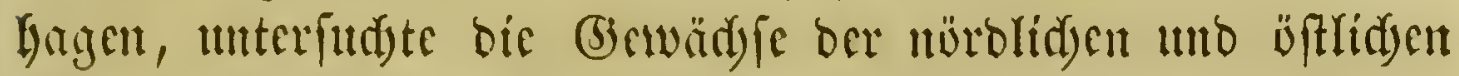

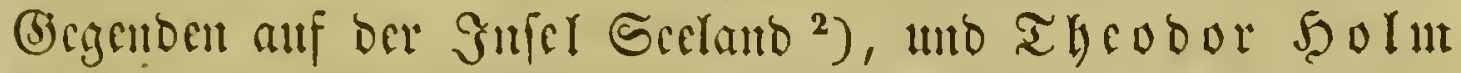

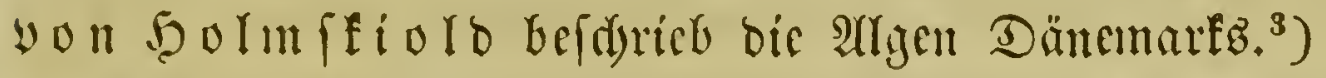

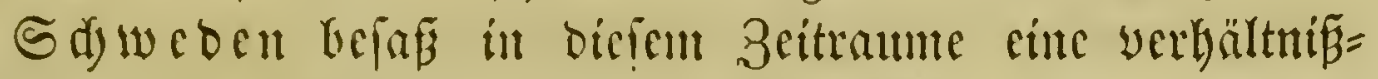

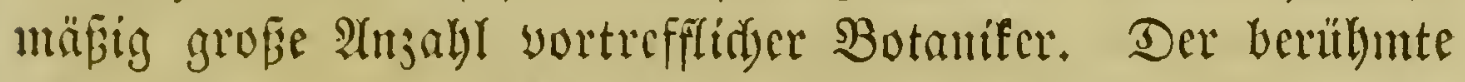

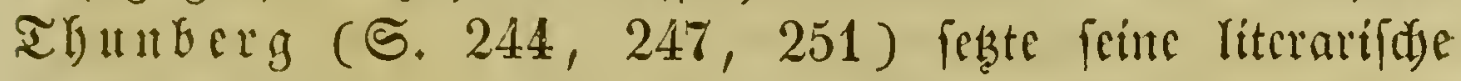
Ilyätigfeit fort. ${ }^{4}$ )

1) Danmarks og Holsteens Flora, systematisk, physisk og ökonomisk bearbeydet. Kjobenhavn $1796-1800$. II voll. 8 .

2) Enumeratio plantarum in partibus Saellandiae septentrionalis et orientalis. Havniae $1801-1803$. II voll. 8. -

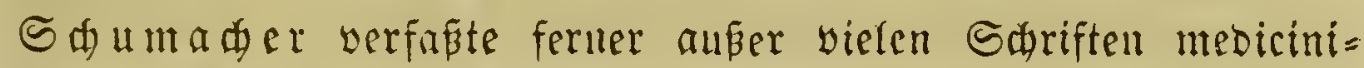
低en Sulgurtz: Den Kjöbenhavnske Flora, Planterne med tydelige Befrugtningsdele, overs. og foröget med danske Trivielnavne og Register ved F. C. Kiels en. Kjöbenhavn 1804. 8. - Sch u macher og J. D. Herholdt, De officinelle Laegemidler af Planteriget, som voxe vildt oller kunne dyrkes i de danske Stater. Kjöbenhavn 1808. 4.

3) Beata ruris otia fungis danicis impensa. (Hafniae 17901799.) II voll. Fol. 75 tab. col. - Die 5eraugagabe bez zweiten Theilz beforgte Erif Biborg. - Coriphaei Clavarias Ramariasque complectentes cum brevi structurae interioris expositione. Denuo cum adnotationibus editi necnon commentatione de fungis clavaeformibus aucti a Christ. II enrico Persoon. Lipsiae 1797. 8. 4 tab. col.

4) S(ǘer ben bereits angefïlgrten Sd)riften if nod zu erwägnen: Resa uti Europa, Africa, Asia, förrätad åren 1770-1779. Upsala 1788-1793. IV voll. 8. 6 tah. - Deutfid yon (s) $r o s=$

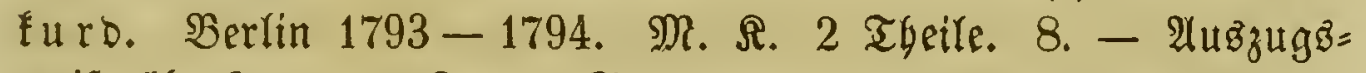

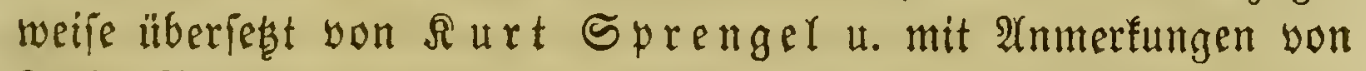
So\%. Reing. Forfter. Berlin 1792. 8. - Die afabem. 2tbgandlungen, welde unter feiner Reitung verfapt wourben, ver=

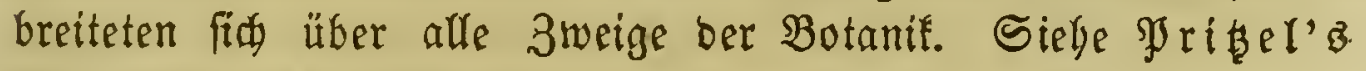
Thesaurus, S. 194, 195. 
(Sin gleid) unermidider SPlanzenforider war

\section{Slof $\widetilde{G} \mathfrak{a} \mathfrak{x}$ 急,}

gef. 1760 , gef. 1818 alz grofeffior zu Stodform.

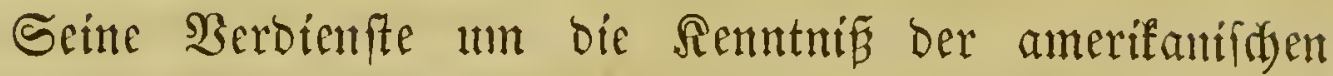
Flora find S. 254 fdyon erwälynt worben; nidyt weniger aber ift er wegen feiner zahlreidyen Sdyriften l̈ber die Getwädje feines Saterlandes Gemerfenzwerth; namentlid) fdrieb er liber die Mvofe, Srdjibeen ${ }^{1}$ ) tuto Farrenfräuter ${ }^{2}$ ). - Samuel

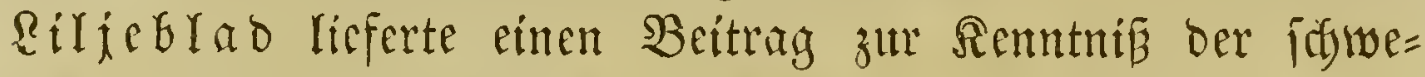

1) Act. soc. scient. upsal. VI, p. 59 seq. - Stockholm.

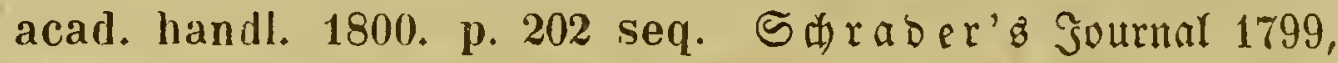
St. 2 , S. 201.

$\left.{ }^{2}\right)$ Methodus muscorum illustrata. Upsal. 1781. 4. 2 tab. Dispositio systematica muscorum frondosorum Sueciae. Adjectis descriptionibus et iconibus novarum specierum. Erlangae 1799. 12. 9 tab. col. - Genera et species Orchidearum systematice coordinatarum. s. 1. 1805. 8. 1 tab. Diefe Sdurift finbet fid, aud in Saraber's nettem Sournal $I$. ऽ. 1-108. Synopsis Filicum, earum genera et species systematice complectens. Adjectis Lycopodineis et descriptionibus novarum et rariorum specierum. Kiliae 1806. 8. 5 tab. - Lichenes americani, quos partim in Flora Indiae occidentalis descripsit, partim e regionibus diversis Americae obtinuit, iconibus coloratis illustravit $\mathbf{J}$ acob Sturm. Fasc. I. Norimbergae 1811. 8. 18 tab. col. Grunderna till Läran om Djur och Växter. Stockholm 1813. 8. - Summa vegetabilium Scandinaviae systematice conrdinatorum. Holmiae 181\%. 8. Seine literarifde Sinter=

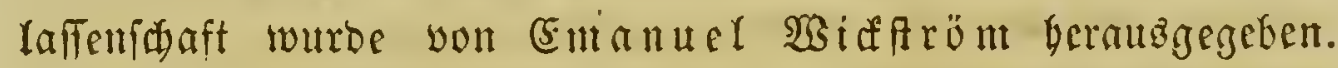
Adnotationes botanicae quas reliquit 0lavus Swartz. Post mortem auctoris collectae, examinatae, in ordinem systemáticum redactae atque notis et praefatione instructae a Johanne Emanuele Wickström. Accedit Biographia Swartzii, auctoribus Curtio Sprengel et Carolo Adolpho Agardh. Holmiae 1829. 8. It tab. 


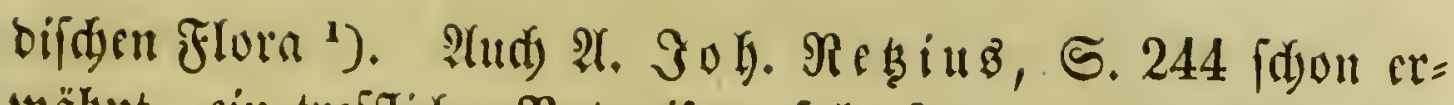
Ivähnt, , cin trefflidyer Botanifer, fubr fort, bie botanifde \&ite=

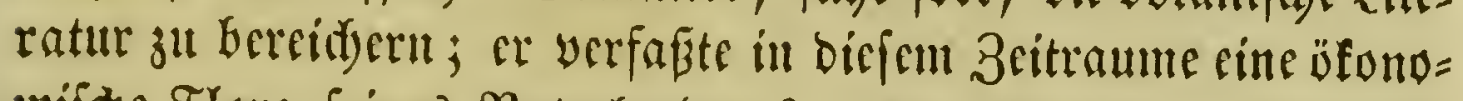
míde Flora (cimes Baterlandes ${ }^{2}$ ), cine Birgilifde Flora ${ }^{3}$ ),

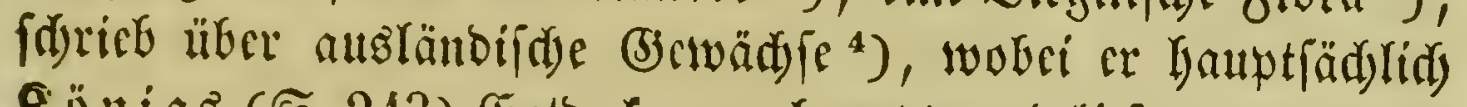

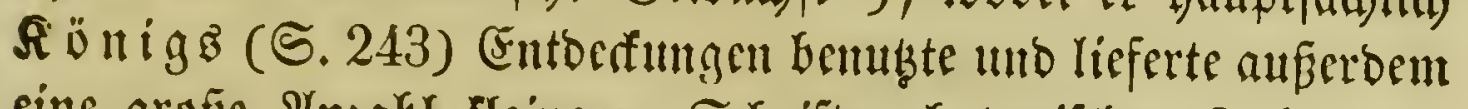

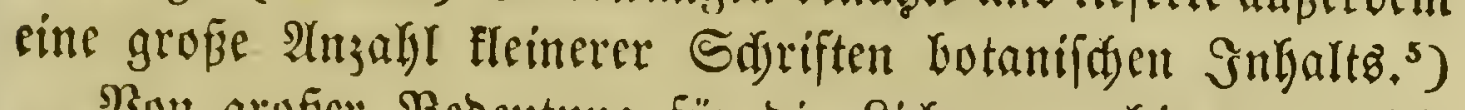

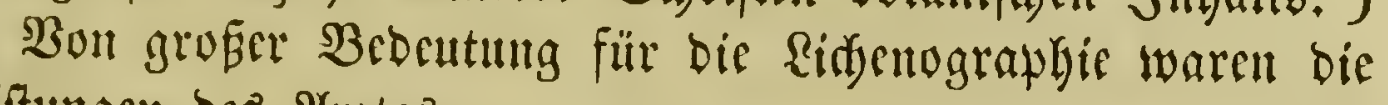
Reiftungen brs 2 trötes

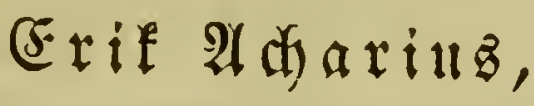

aนв Sftgotblano, gefturben im Sabre 1819.

Er if als ber eigentlidje Begrünoev oer fyftematifden

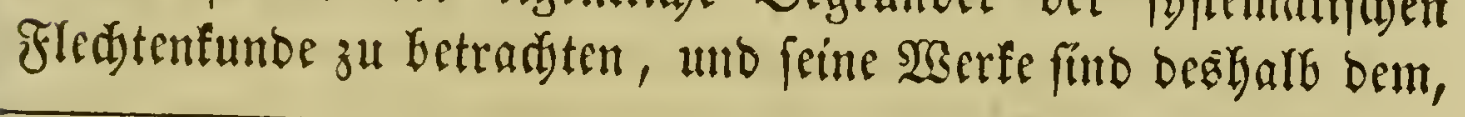

1) Utkast til en Svensk Flora, eller Athandling om Svenska Wäxternas väsendteliga kännetekn och nytta. Upsala 1792. 8. 2 tab. - Ed. II ibid. 1798. 8. 2 tab. - Tredge uplagan, med Norska Wäxter lillökt efter Författarens död utgifven. Upsala 1816. 8. 2 tab. - Svenska Oertslagen, eller kort afhanding om sattet at efter botaniske grunder urskilja svenska växterna, til classer ordningar och slägter, af S. L. Upsala (1792). 8. 1 tab. - Coloniae plantarum in Suecia. Pars I-II. Upsaliae 1809. 4.

2) Försök till en Flora oeconomica Sueciae, eller Svenska Wäxters Nytta och Skada i Hushällningen. Lund. 1806. II voll. 8. - Bihang till Flora oeconomica Sueciae. Lund. 1812. 4.

3) Flora Virgiliana, oller Försök at utreda de Wäxter som anföras uti P. Virgilii Maronis Eclogae, Georgica och Aneides, jämte Bihang om Romarnes Matwäxter. Lund. 1809. 8. - De plantis cibariis Romanorum. Lundae 1808. 4.

4) Observationes botanicae, sex fasciculis comprehensae. Quibus accedunt Joh. Gerardi König Descriptiones MIonandrarum et Epidendrorum in India orientali factae. Lipsiae 1789 - 1791. Fol. 19 tab. col.

s) Nergleide Prifel's Thesaurus S. 244. 
Der fidt) mit biefem 3weige ber Botanif bejdäftigt, burdjaus

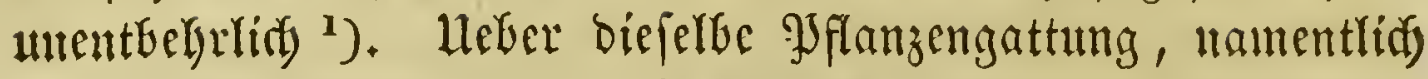

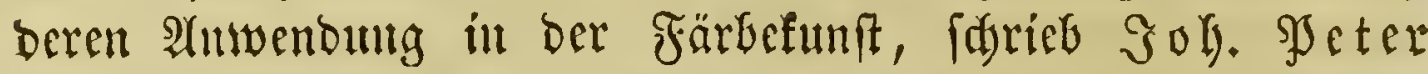

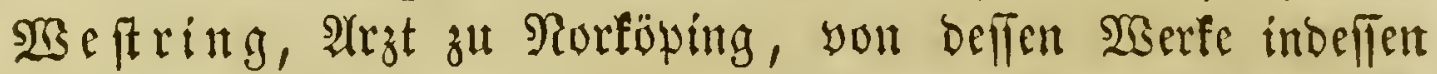
nur cin Jazcifel erjdien ${ }^{2}$ ); er lieferte aud verfdiebene $2(b=$ battolungen in 3eitfdriften. ${ }^{3}$ )

Einer ber unermiblidjften Botanifer feiner 3eit wat

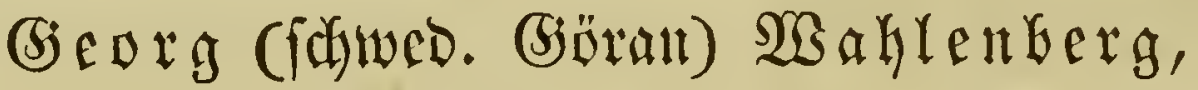

Srofeffor zu $\mathfrak{u}$ plala.

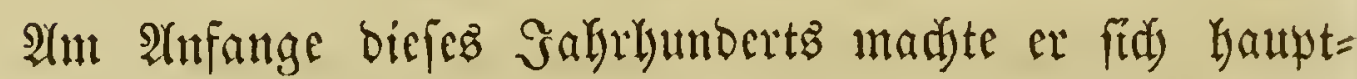

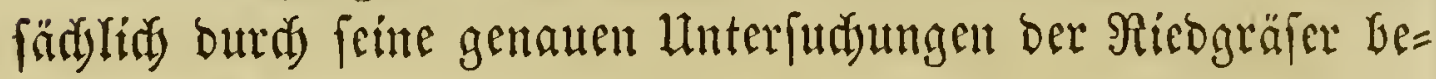

1) Lichenographiae Suecicae Prodromus. Lincopiae 1798. 8. 2 tab. - Methodus, qua omnes detectas Lichenes secundum organa carpomorpha ad genera, species et varietates redigere atque observationibus illustrare tentavit. Stockholmiae 1803. II sectiones et suppl. 8. 8 tab. Lichenographia universalis in qua Lichenes omnes detectos, adjectis observationibus et figuris horum vegetabilium naturam et organorum carpomorphorum structuram illustrantibus, ad genera, species, varietates differentiis et observationibus sollicite definitas redegit. Goettingae 1810. 4. 14 tab. col. - Synopsis methodica Lichenum sistens omnes hujus ordinis naturalis detectas plantas, quas secundum genera, species et varietates disposuit, characteribus et differentiis emendatis definivit necnon synonymis et observationibus selectis illustravit. Lundae. 1814. 8.

2) Svenska Lafvarnas Färghistoria, eller stättet att använda dem till färgning och annan hushållsnytta. Första bandet. (Häftet 1 - 7.) Stockholm 1805. 8. 21 col. tab. -

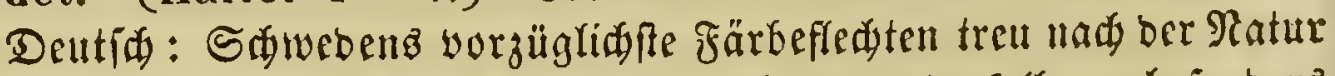
abgebilbet, mebft ber demifaen Berrbeitung berfelben, bejonberz

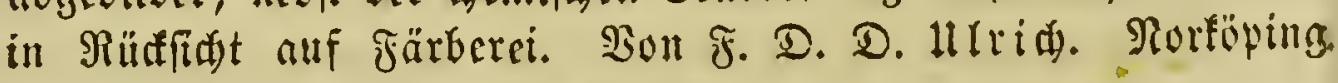
unb Reipzig 1805. 8. 3 for. Tafeln.

3) K. Wet. Acad. Handl. ilt ben Sngren 1791- 1807. 


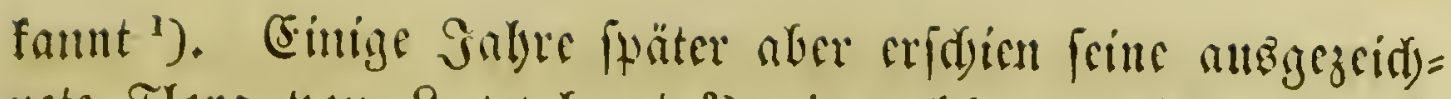
uete filora yon Raphlano ${ }^{2}$ ), in welder cr viele wählent bes Sommers 1S00, 1802, 1807 uns 1810 won ifm in jentem Ennoe gemadyten Eintoefungen verüfentlidste. Son frimem

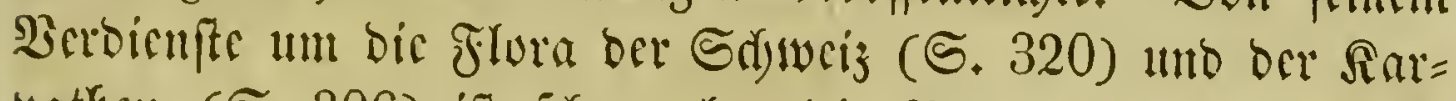

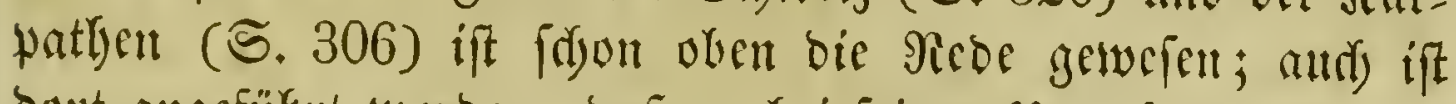
bort angefülynt worben, oaf er bei feitren Huterfudungen auf bie geographifiden \$erbältnifle ftets Gefondere Rürfidit nahm.

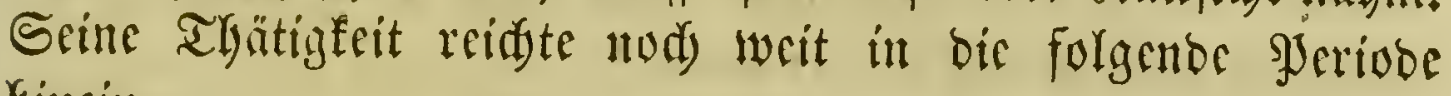
binciin.

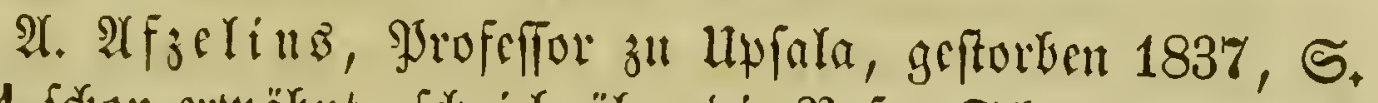

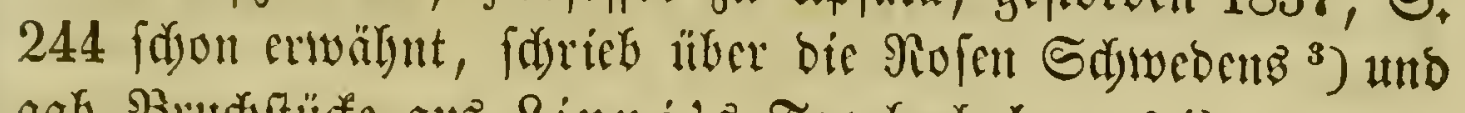

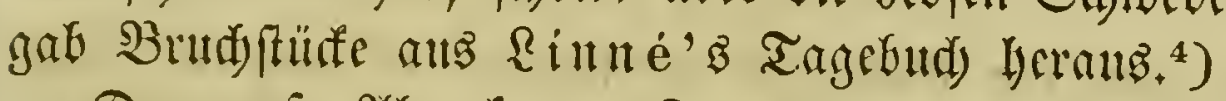

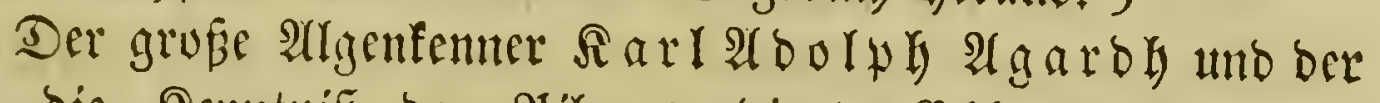

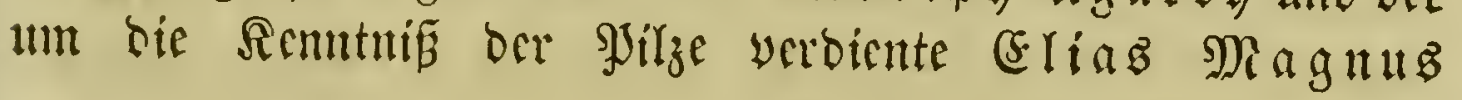

1) Stockh. acad. Handl. 1803. p. 138, seq. Annals of botany. vol. II. p. $112-144$.

2) Flora lapponica, exhibens plantas geographice et botanice consideratas in Lapponiis suecicis, scilicet Umensi, Pitensi, Lulensi, Tornensi et Kemensi necnon Lapponiis norvegicis scilicet Norlandia et Finmarkia utraque indigenas et itineribus annorum 1800, 1802, 1807 et 1810 denuo investigatas. Cum mappa botanico-geographica, tabula temperaturae et tabulis botanicis XXX. Berolini 1812. 8. 30 tab. - Berättelse om mätningar och observationer för att bestämma Lappska Fjällens höjd och temperatur vid 67 Graders Polöjd, förrätade år 1807 af Göran W ahlen berg. Med charta och 3 utsigter. Stockholm 1808. 4. 4 tab.

3) De Rosis suecanis. (Tentamen I-XI). Upsaliae 18041813. 4.

4) Egenhändiga Antekningar af Carl Linnaeus om sig sjelf. Med Anmärkningar och Fillägg. Upsala 1823. 4. - Rinné's eigenbänbige $\mathfrak{A n}_{\mathfrak{z}}$ eidnungen über fí felbft mit

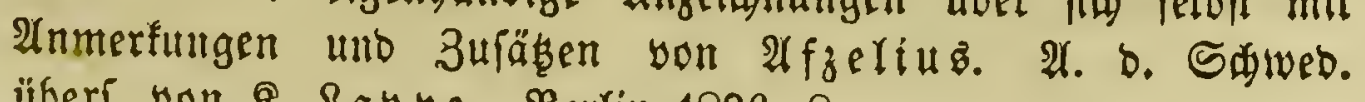
über. von R. Iappe. Berlin 1826, 8. 


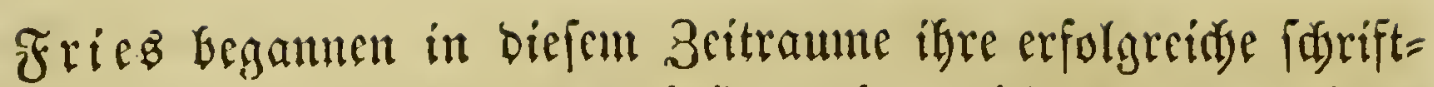

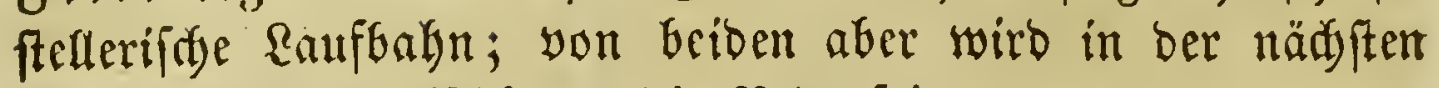
\$eriobe nod im Räheren bie Rebe fein.

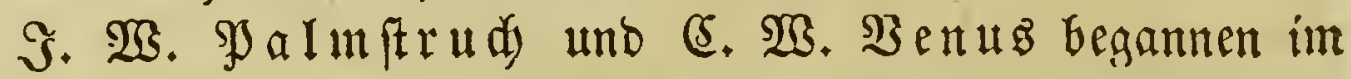
Jahre 1802 bie Svensk botanik heraużugeben; ben \%. uno 8. Bano fejorgte (5) F. Billberg, ben 9, , 10, uno 11 . bie Stodflolmer Afabemie ber Siffenfdaften; an ber $\mathfrak{B e a r}=$ beitung bes Textes betheiligten fidi audi (5. Duenier, D. Swarts und (5) Wahlenberg. ${ }^{1}$ )

$\mathfrak{F} \mathfrak{r}$. $\mathfrak{B} \mathfrak{e b} \mathfrak{e r}$ und $\mathfrak{M}$. 5 . Mohr lieferten einige Beiträge zur fduedifden ${ }^{2}$ ), (Shrift o wh 5 a muer zur norwegifden ${ }^{3}$ ) Flora.

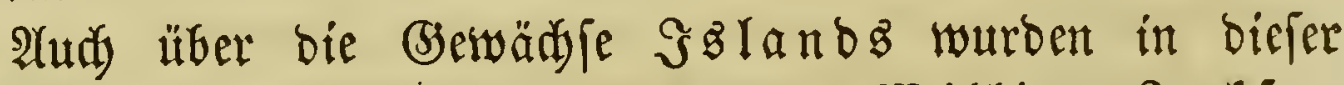

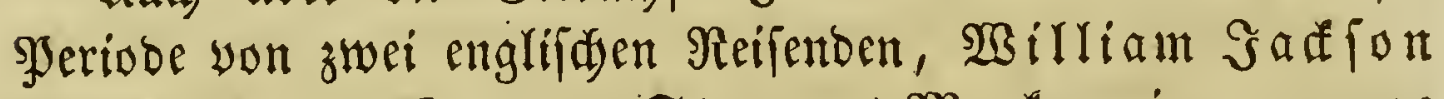

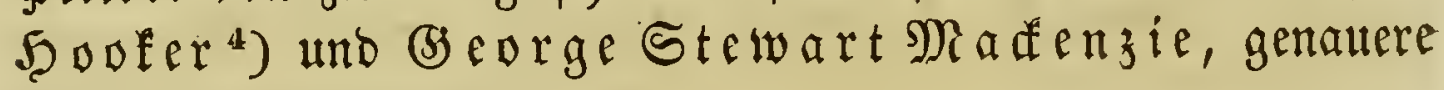
Notizen verüffentlidyt. ${ }^{5}$ )

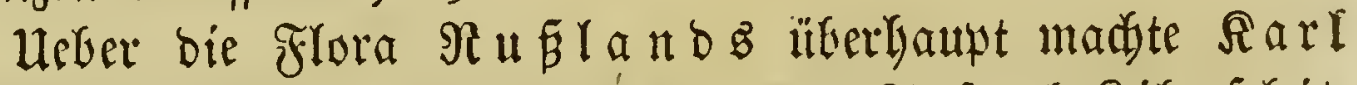
Fr, yon Rebebour Mittlerilungen ${ }^{6}$ ). Jofeph Ribofitis

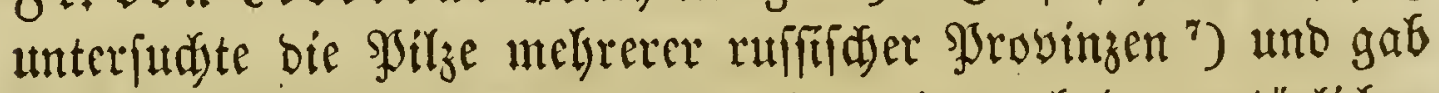
in $\mathfrak{B e r b i n d u n g ~ m i t ~} \mathfrak{R}$. $\mathfrak{B}$, Iriniu eit nad) Der natürlidsen

1) Svensk ,Botanik. Stockholm 1802-1803, 11 Bbe. 8. 792 folor. Sipftflit.

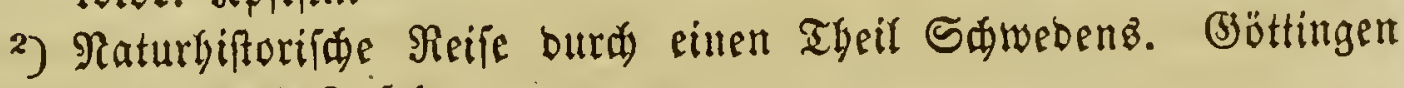
1804. 8. 3 Tafetn.

3) Flora Norvegicae Prodromus. Forlöber af norske Flora eller Planterige. Udi systematisk og Linnaeisk Dragt efter Sexualsystemet. Kiöbenhavn. 1794. 8.

$\left.{ }^{4}\right)$ Journal of a tour in Iceland. Yarmouth 1811. 8. - Ed. II. Lond. 1813. II voll. 8.

${ }^{5}$ ) Travels in the island of Iceland during the summer of the year 1810. - Ed. II. Edinb. 1812. 4. 15 tab.

$\left.{ }^{6}\right)$ Observationes botanicae in floram rossicam. Petropoli 1814. 4.

7) Enumeratio fungorum quos in nonnullis provinciis imperii ruthenici observavit. (Mém. de la soc. des Nat. de Moscou V, p. $75-83$.) 


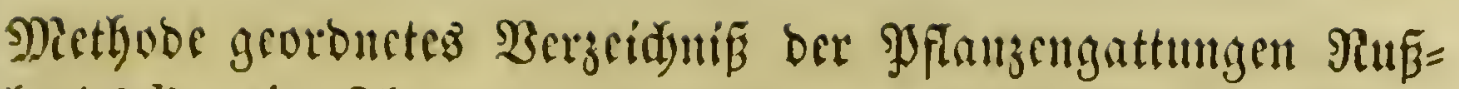

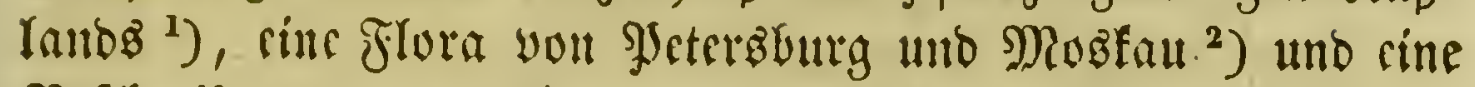

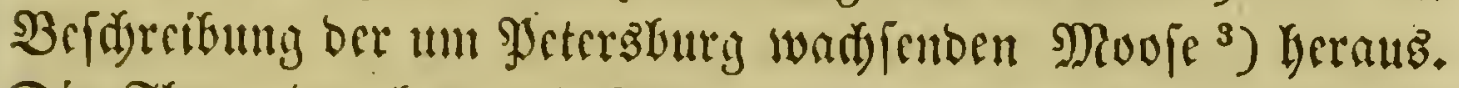
Dí Flora ber letgtereit Stadt wurbe fanct won (j) regor Sobolewaty), bie ber Dftecprovingen überbatpt yout Day ib 5einridy (5) rinbel ${ }^{5}$ ), Shrofeffor in Dorpat, $\mathfrak{E}$ :

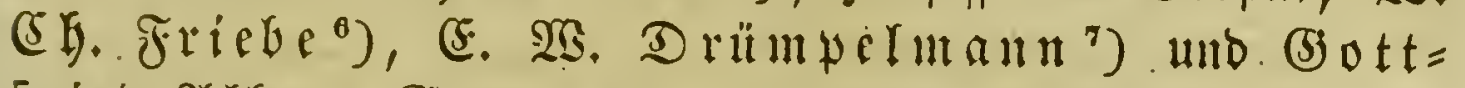
fricb albert. (S) yorfoumenoen (bswäd fe befdrieben Fricbrid Stewhan ${ }^{9}$ ), Swan Dwiguboly ${ }^{10}$ ) unt Seinridyon Martius ${ }^{11}$ ),

1) Tableau botanique des genres observés en Russie et disposés selon la méthode naturelle. Wien 1814. Fol.

2) Flore des environs de St.-Pétersbourg et de Moscou. Tom. prem. St. - Pétersbourg 1811. 4. 40 tab. col.

3) Description des mousses, qui croissent anx environs de St. - Pétersbourg et de Moscou. St. - Pétersb. 1811. 8.

-) Flora Petropolitana. Petropoli 1799. 8.

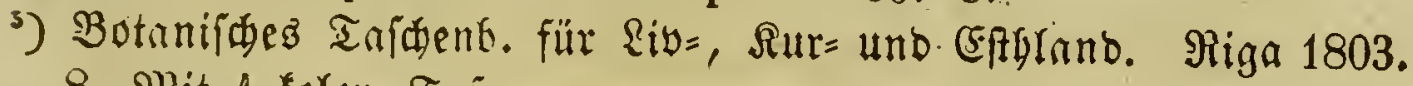
8. Mlit 4 folor. $\mathfrak{x}$ nf.

-) Sefonomifd=tednifde Flora für Rieflano, CFflgland und Rurlanb. Riga 1805. 8.

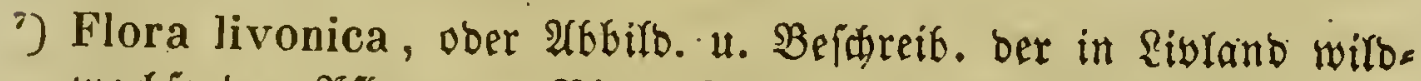

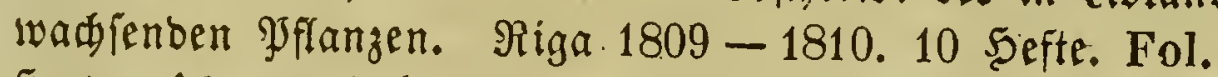

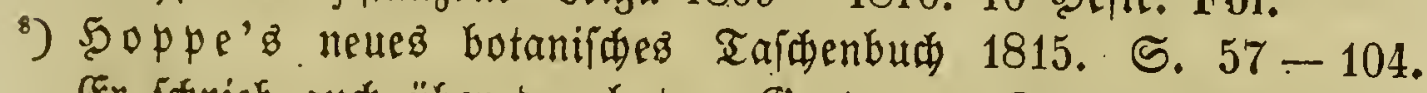
(Er 低rieb aud über ben botan. Barten zu Dorpat: Berzeidni

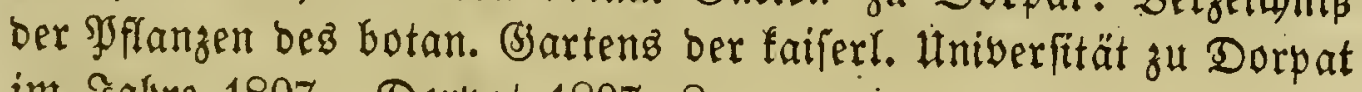
im Jabre 1807. Dorpat 1807. 8.

9) Enumeratio stirpium agri Mosquensis. Mosquae 1792. 8. - Icones plantarum Mosquensium ad historiam plantarum sponte circa Mosquam crescentium illustrandam pinxit et in aer. incidit. Decas 1. Mosquae 1795. Fol. 10 tab.

${ }^{10}$ ) Prodromus Florae Mosquensis. Mosquae 1802. 8. - $\mathfrak{3 a ̈ h}=$ renb biefer Seriode verfapte er aud: Fundamenta botanica Linnaei. Mosquae 1805. 8. - Elementa historiae naturalis vegetabilium. Pars I. Mosquae 1811. 8. - Ibid. 1823. 8. - Später if er nowmalz zu erwäğnert:

11) Prodromus Florae Mosquensis. Mosquae 1812. 8. - Edit. II. 1817.8. 
Die Flora Rithauens wurbe yon $\mathfrak{x}, \mathfrak{B}$. S. Sundzill, Şrofeffor in $\mathfrak{Z s i l n a , ~ u n t e r f u d i t . ~}{ }^{1}$ )

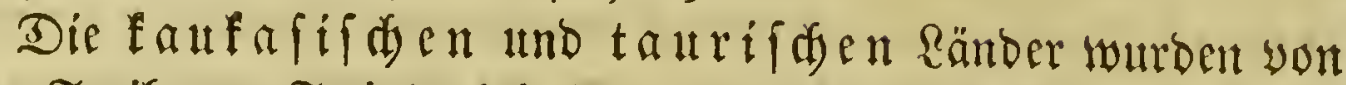
Dem Freiferm Friebrid) 2 uguft $\mathfrak{M a r}$ dall yon $\mathfrak{B} \mathfrak{i}=$

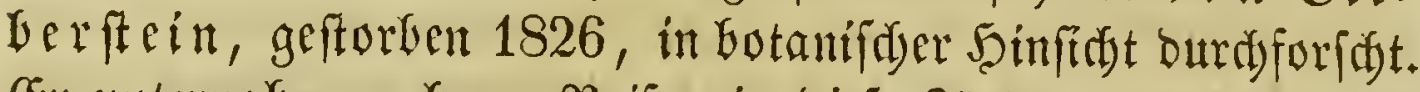

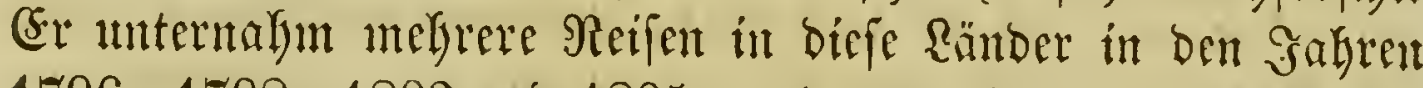
1796, 1798, 1802 und 1805, uno entoefte vicle neute şflan= zenarten ${ }^{2}$ ). Diefelben (Segenden Gereifte ber ruffifde Staats= rath (Elyiftian $\mathfrak{y} \mathfrak{n}$ Steyen, beffen Entbefumgen in ben S3etersburget unt Mosfauer gelebrten 3eitfdriften veröffent=

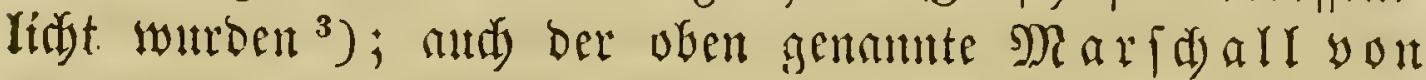

1) Opisanie roślin litavskich wedlug ukladu Linneusza W. Wilnie 1791. 8. - Ed. II ibid. 1811. 8. - Index plantarum horti botanici universitatis Vilnensis. Vilna 1814. 8. -

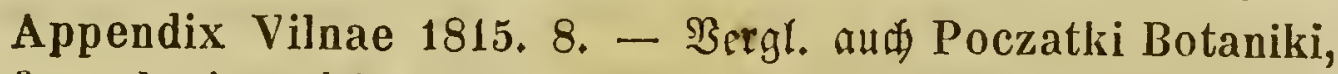
fyzyologia roślin, nauka wyrazów. W. Warszawie 1804. II voll. 8. - Ed. II. W. Wilnie 1818. 8.

$\left.{ }^{2}\right)$ Tableau des provinces situées sur la côte occidentale de la mer Caspienne. St. - Pétersbourg 1798. gr. 4. - Be=

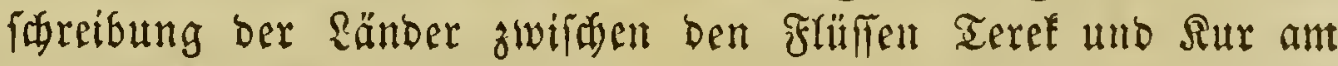

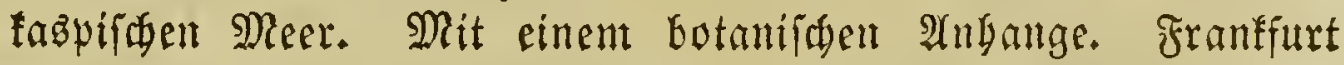
a. $\mathfrak{M}$. 1800. 8. - Flora taurico-caucasica, exhibens stirpes phaenogamas in Chersoneso taurica et regionibus caucasicis sponte crescentes. Charkoviae 1808-1819. III voll. 8. - Supplementum, continens plantas phanerogamas per Tauriam atque Caucasum post edita priora volumina detectas et in pristinas animadversiones. 1819. Centuria plantarum rariorum Rossiae meridionalis, praesertim Tauriae et Caucasi iconibus descriptionibusque illustrata. P. I. Charkoviae 1810. Fol, 50 tab. col. P. II. Decas I - III. Petropoli 1832-43. Fol. 30 tab. col.

3) Observationes in plantas rossicas et descriptiones specierum novarum (IIém. de la soc. des Nat. de Mosc. T. V, VII, IX, et Bullet. de la soc. des Nat. de MIosc. T. IV.) - Decas plantarum nondum descriptarum Iberiae et Rossiae meridionalis (1. c. Tom. II). - Cataloǵue des plantes rares ou nouvelles, observées pendant un voyage 


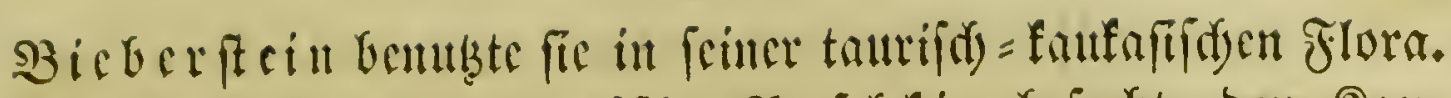

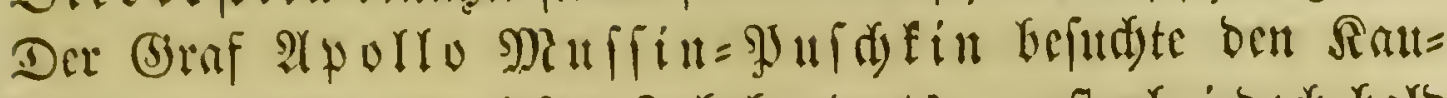

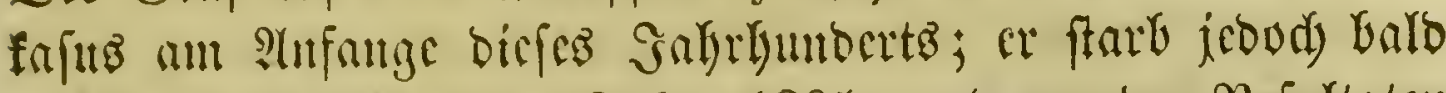

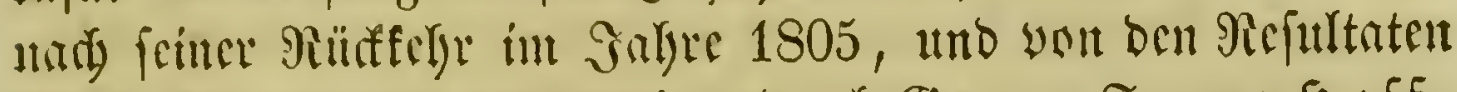

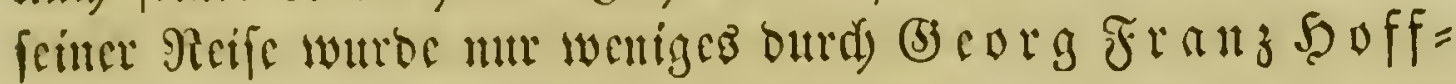
ma

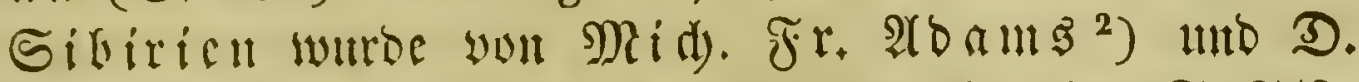

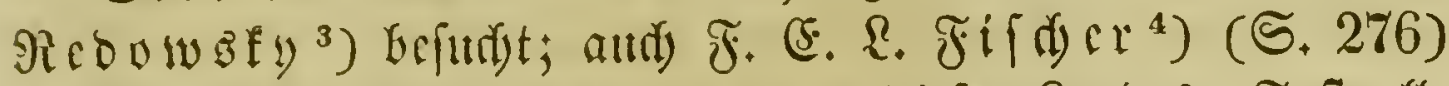

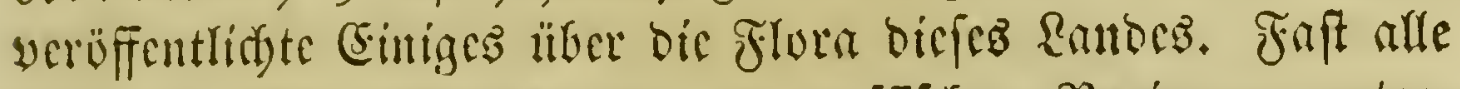
biefe gecifentoen warben you ber ruffifden Regierung unter" =

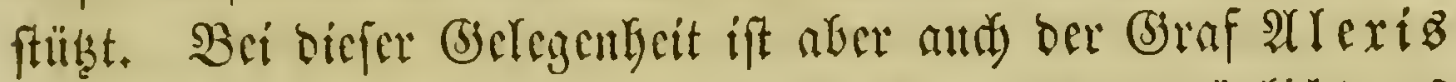
$\Re$ a zum of

autour du Caucase oriental (1. c. Tom. III et IV). Observationes in Saxifragas taurico-caucasicas (l. c. Tom. IV). - Monographia Pedicularis (1. c. Tom. VI). Alyssi rostrati et Erodii serotini descriptio (Mém. de l'acad. des sc. de St. - Pétersb. Tom. III. 1810 - 1811. - De Pinubus taurico-caucasicis (Bull. de la soc. des Natur. de Mosc. 1838. No. 1).

1) Commentationes societatis physico-medicae apud universitatem litterarum caesareum mosquensem institutae. Vol. I. P. I. 1808. Dieferfe Beitfinrift fübrte von 1809 an ben Titer: Mémoires de la société impériale des Naturalistes de Moscou.

$\left.{ }^{2}\right)$ Descriptiones plantarum minus cognitarum Sibiriae praesertim orientalis etc. (Mém. de la soc. des Natur. de Mosc. Tom. V et IX.) Descriptio novae speciei Azaleae (Mém. de l'acad, des sc. de Pétersb. Tom. II. 1807-1808). 1 infert.

3) Sur quelques plantes de Sibérie. (Mém. de la soc. des Natur. de Mosc. T. I.) S. S. Rubolph madte Einiges von ben Entbefungen biefez Reifenben befannt: Dissertatio exhibens novissimas plantas Sibiriae orientalis (Mém. de l'acad. des sc. de Pétersh. T. IV. 1811). 3 Taffeln. 2(u币 \{tolbert (5yamiflo benute fie zum Theil.

4) Descriptio plántarum rariorum Sibiriae. (Mém. de la soc. des Natul. de Mosc. Tom. III.) 5 Tafeln. 
Durd) freigebige Unterftülsutgen veridsiebenen $\mathfrak{3 o t a n i f e r n , ~ b i e ~}$

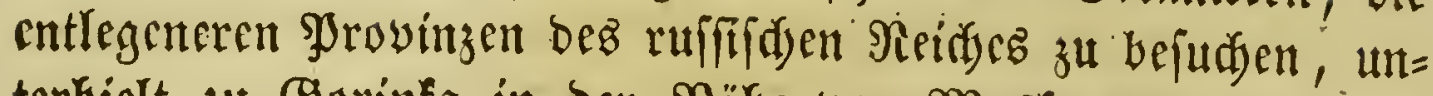

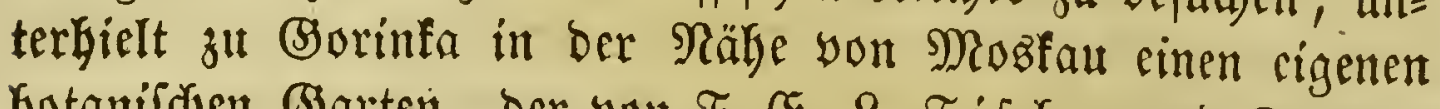

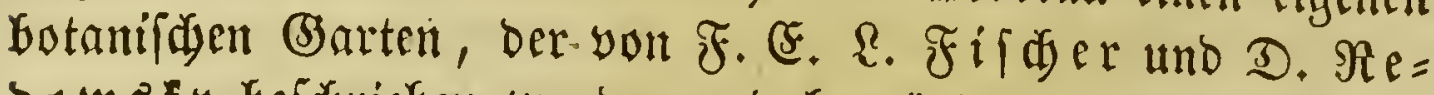

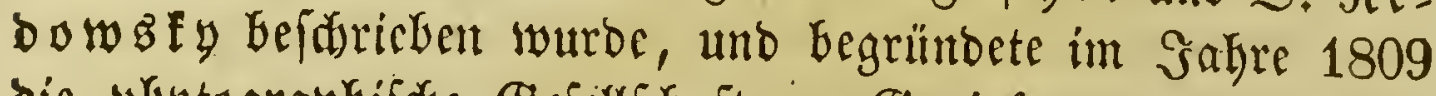
bie whytographifde (sciellidaft zut Brorinfa; er felbft war

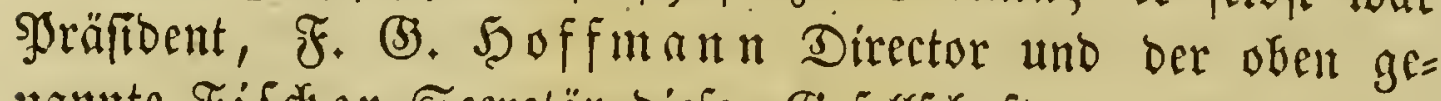

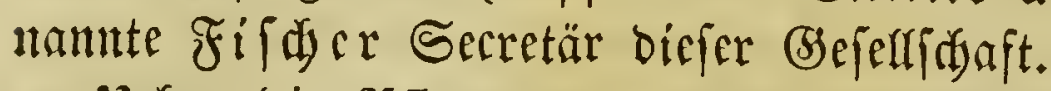

Ueber bie SJflanzenwelt Alfienz. find aus diefem Zeit= raume mur wenige Sdriften anzufüfren. (5s wurben aller=

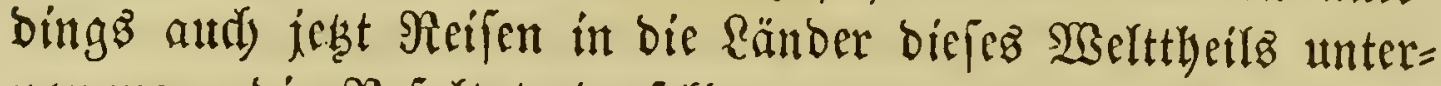
nommen, bie Refultate berfelben wurben jebodi meifens erit fwäter befannt gemadyt, wesgalf wir aud in ber folgenden Sheriobe barauf juritiffominen werden.

Ueber $\mathfrak{J}$ erfien gab (5). A. Drivier, ber 1792 im $2 \mathfrak{H}=$ trage Der franzüffiden Regierung gemeinfdyaftlidy mit $\mathfrak{B} \mathfrak{r} \mathfrak{u}=$

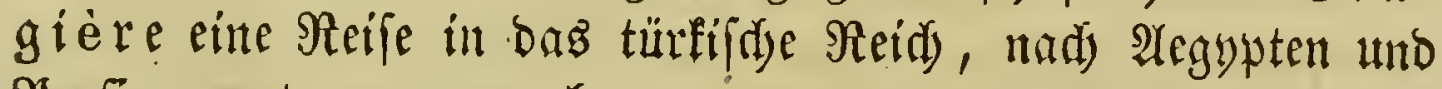
Serfen unternommen hatte, mur wenige für bie Botanif widytige Radyrifiten.

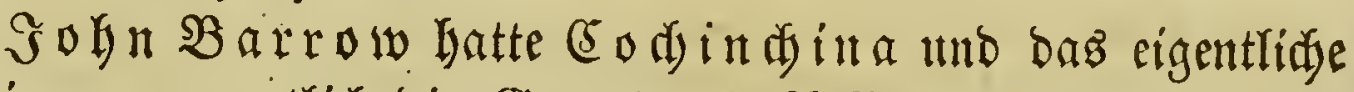
(5) ina, mamentfid bie (Segento um SJefing uno Santon, be=

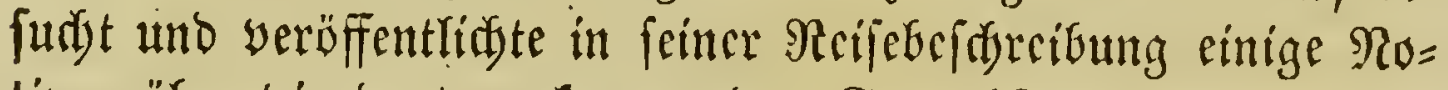
tizen über bie bort vorfommenoen (अ)

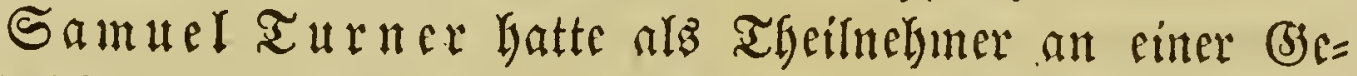

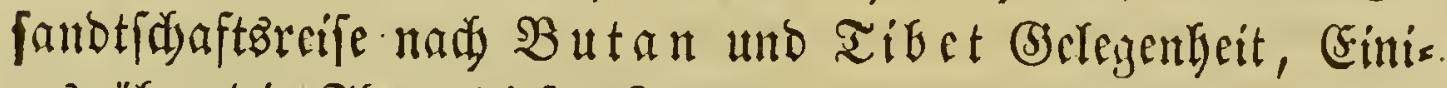
gez über bie Flora biefar Ränder aufajeitgnen. ${ }^{2}$ )

1) A voyage to Cochinchina in the years 1792 and 1793 etc. London 1806. 4. 21 tab. col. - Travels in China. London

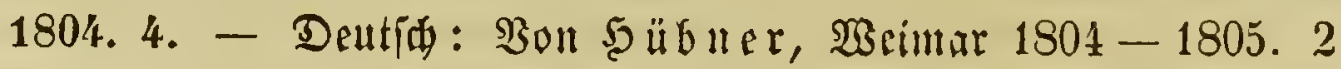
Theile. 8. Mit 7 Iafeln.

2) An account of an embassy to the court of the Teshoo Lama in Tibet; containing a narrative of a journey through Bootan and part of Tibet. London 1800. 4. 14 tab. Heber. feßt yon Sprengel. Weimar 1801. 8. 


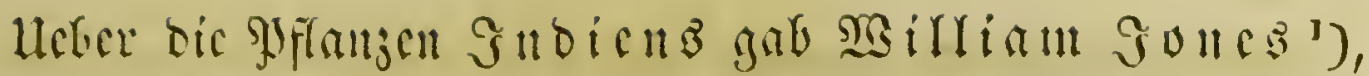

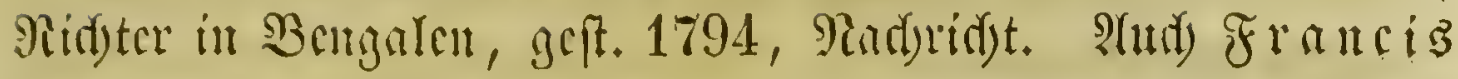

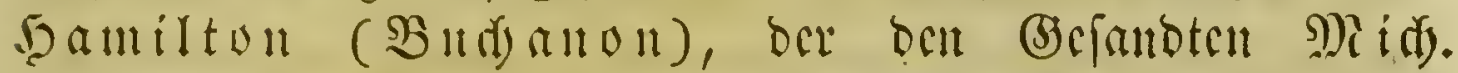

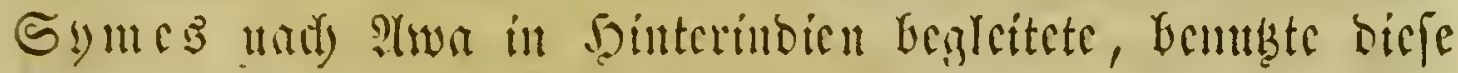
(biclegenlycit jum

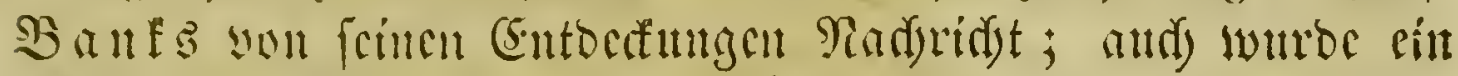

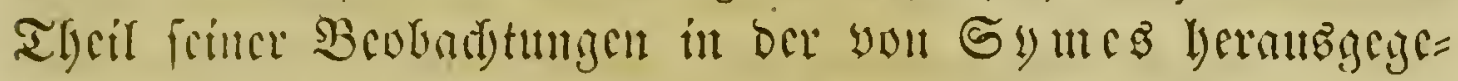

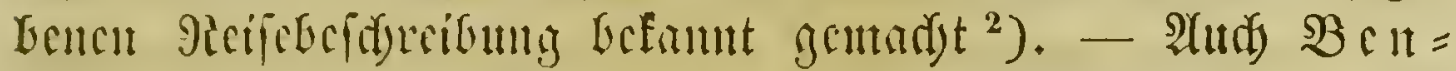

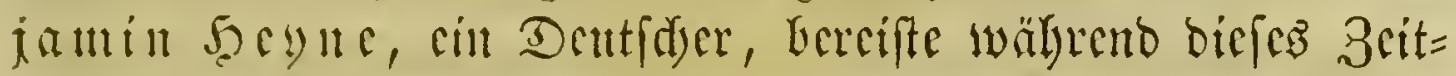

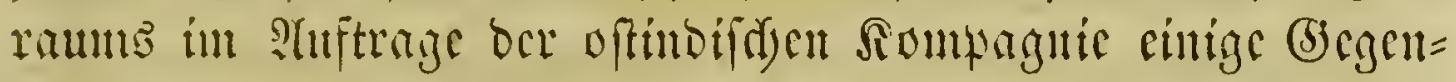

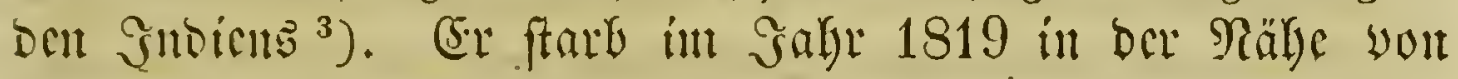

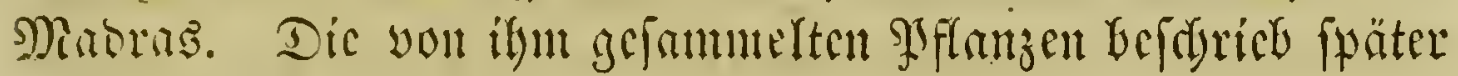

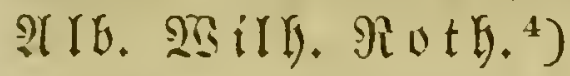

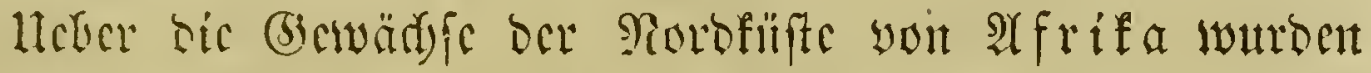

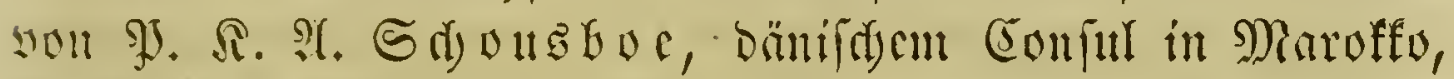
Marifridyten mitzethcilt. ${ }^{5}$ )

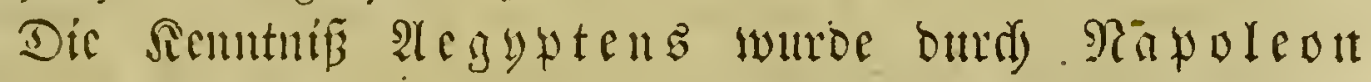

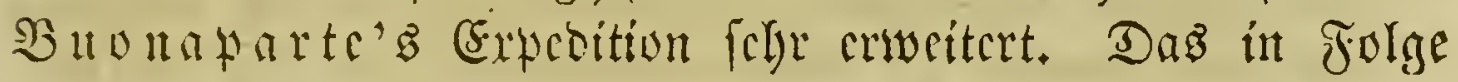

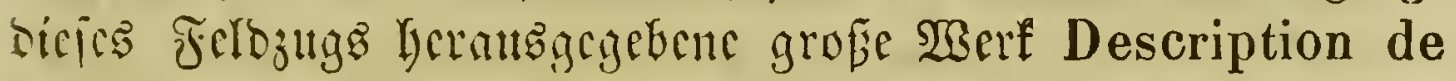
l'Egypte etc. (Paris 1813. Fol.) enthält audid viele Sotizent

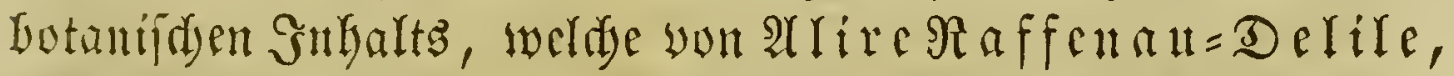

') Asiatic researches, Vol. II, p. 3 ł5 fi. 405 fi. Vol. IV, p. 229 fi. 237 fi.

$\Rightarrow$ An account of an embassy to the kingdom of Ava, senth by the Governor-General of India, in the year 1795 . London 1800. 4. 27 tab.

3) Historical and Statistical tracts on India. London 1804.4.

4) Novae plantarum species praesertim Indiae orientalis, ex collectione Dr. Benjamin IIeynii. Cum descriptionibus et observationibus. Halberstadii. 1821. 8.

5) Jagttagelser over Vextriget i Marokko: Förste Stycke. Kiobenharn 1800. 4. 7 tab. - Deut

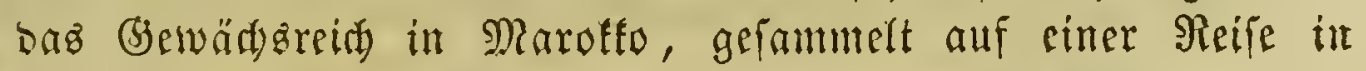
Den Sabren $1791-1793$. 1r Theil. $\mathfrak{A}$. D. Dänifden von 3. \{tmbrof. Marfuffen. Ropentagen u. Reipzig 1801. 8. 2 Iaf.

(5. 2 in đuler, Bridy. b. Bootanit.

24 


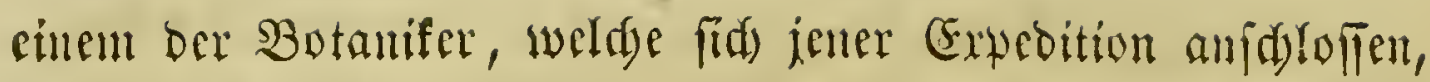

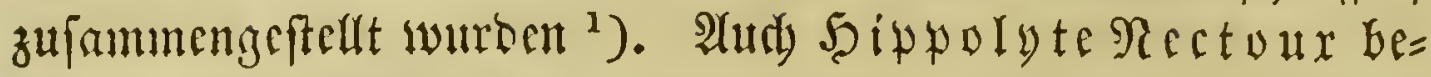
gleitete bic frauzüfifite Arme nad) A(egypten und veröffent=

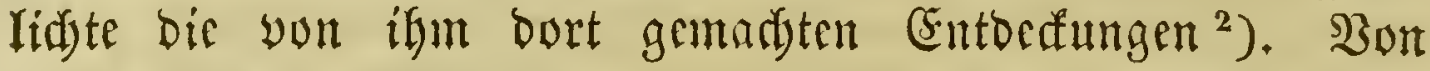

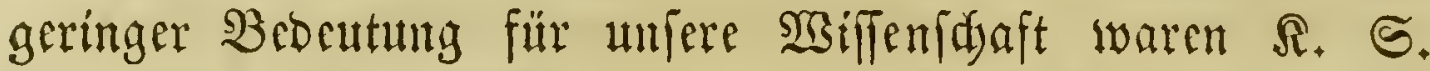

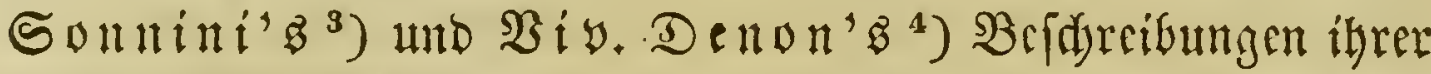

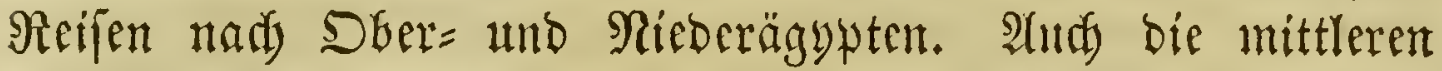

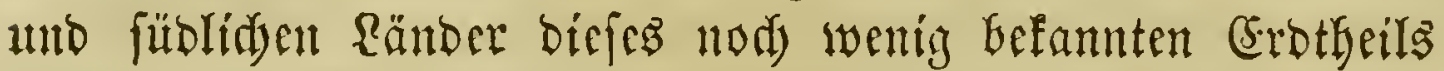
sourben bereift. $\mathfrak{B}$ ill. (5), Browne befudte rinige (biegent=

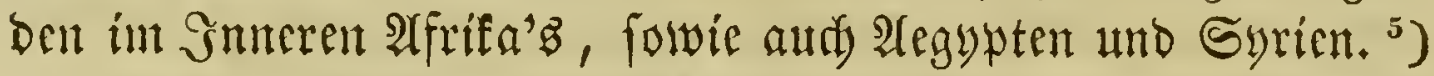

(3) uinea wurbe yon A. Afjelius ${ }^{\circ}$ ), Jjalifot de Beauyais ${ }^{7}$ ) (geftorben 1820) und Dem Dänifden (Etats=

1) Mémoires botaniques extraits de la ,Description de l'Egypte." Paris 1813. Fol. - I. Description du Palmier Doum de la Haute-Egypte, ou Crucifera thebaica. 1810. - II. Histoire des plantes cultivées en Egypte. 1813. - III, Mémoire sur les plantes qui croissent spontanément en Egypte. 1813. - IV. Florae aegyptiacae illustratio. 1813. - V. Flore d'Egypte. Explication des planches. 1813. 62 tab. botan.

$\left.{ }^{2}\right)$ Voyage dans la Haute-Egypte au-dessus des cataractes avec des observations sur les diverses espèces de Séné qui sont repandues dans le commerce. Paris 180s. Fol. 4 tab. col. ad Cassiam genus spectantes.

3) Voyage dans la Haute - et Basse-Egypte. Paris an VII. 1799. III voll. 8.38 tab. 4. - Deutíl : Eeipzig 1800. 2 Bbe. 8.

4) $\mathfrak{B} i$. Denon's Reife in Rieber = und Deerägypten. Berlin 1803. 8.

5) Travels in Africa. London 1799. 4.

-) Genera plantarum Guineensium revisa et aucta. Upsaliae 1804. 4. tab. - Remedia Guineensia. Upsaliae 1813 1817. 4. - Stirpium in Guinea medicinalium species novae. Upsaliae 1818. 4. - Fasc. II. Ibid. 1829. 4. - Stirpium in Guinea medicinalium species cognitae. D. I et II. Upsaliae 1825 . 4.

${ }^{7}$ ) Flore d'Oware et de Benin en Afrique. (Latine et gallice.) Paris 180\% - 1807. II_voll. Fol. 120 tab. col. 


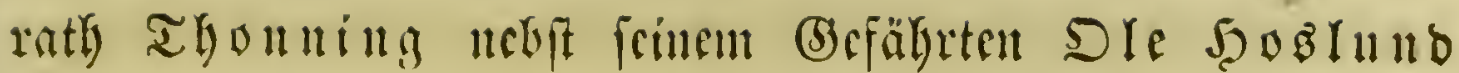

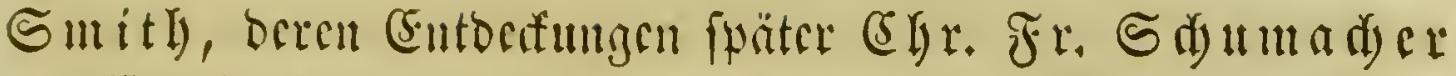

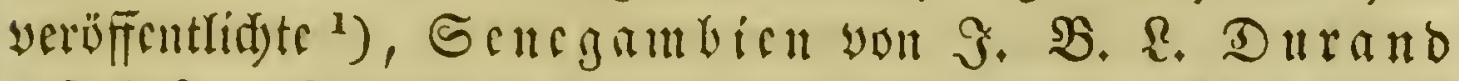
befudyt ${ }^{2}$ ). (5) riften Smith fanmelte einige PJflanzen ant oen 1 fern bes Congoftromes, weldye won $\Re$ obert $\mathfrak{B r o w n}$ befdrichen wuroen ${ }^{3}$ ). Şeinl. Ridytenftein, Shrofeffor in

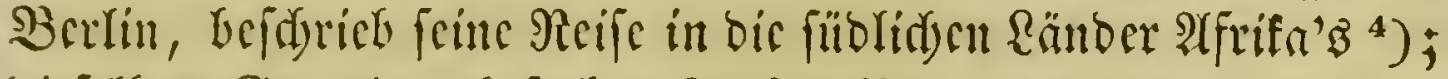

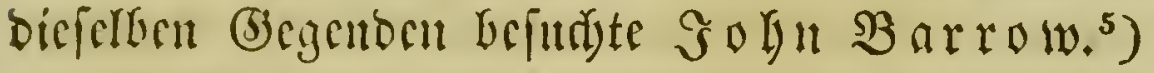

Dic PJflanzen ber fanarifden $\Im \mathfrak{n}$ feln wurben von

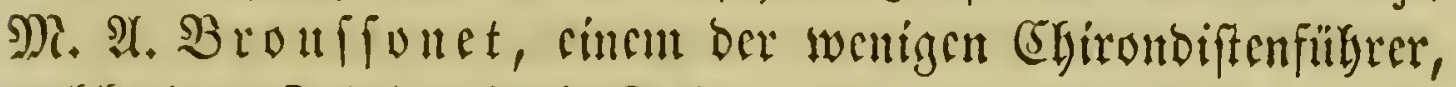
weldye bem Tob burd) dic (jutllotine cutgingen, geboren 1761, gefturben 1807 als Shrofeffor zu Montperfier, unterfudst; $\mathfrak{c r}$ felbft fdrieb nidytż über frine Entorfungen, theilte aber bie=

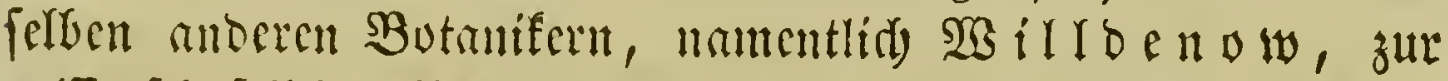

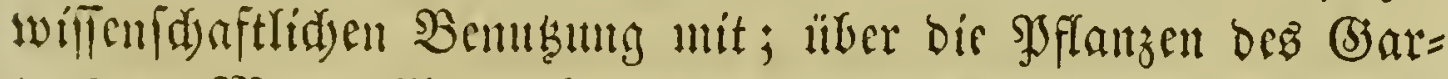

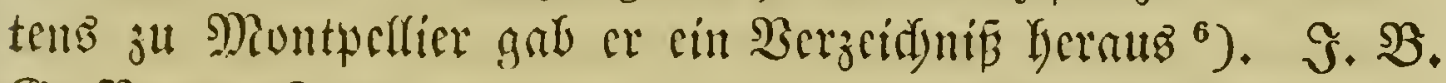
(3). Bory= Saint= Bincent, cin franzüfifder Dffizier, be=

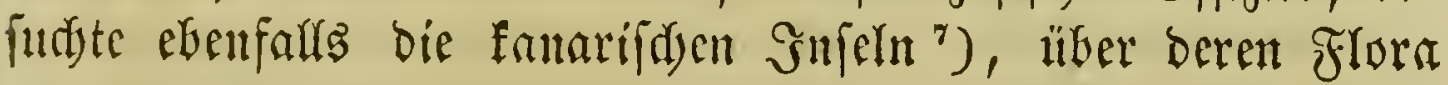

1) Beskrivelse af Guieniske Planter somere fundne af danske botanikere, isaer af Etatsraad Thonning. Kiöbenhavn 1827. 4.

2) Voyage au Sénégal. Paris 1802. II voll. 8. avec un Atlas in - 4. 43 tab. (Tafel $22,37,38,39,40,41$ unb 42 finto OPflanzen.) - Deutf

$\left.{ }^{3}\right)$ Observations systematical and geographical on the Herbarium collected by Professor Christian Smith in the vicinity of the Congo, during the expedition to explore that river under the command of Capt. Tuckey in the year 1816. London 1818. 4.

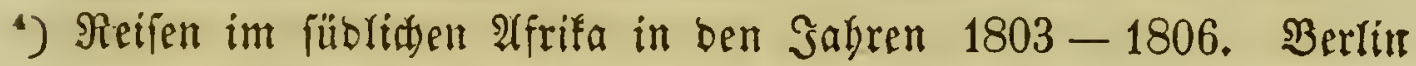
$1811-1812.2$ Thle. 8.

5) An account of travels into the interior of southern Africa. Lond. 1801. 2. Edit. 1804. 2 Bbe. 4.

-) S. oben 5. 327, Rote 4.

') Voyage dans les quatre principales îles des mers d'Afrique, fait par ordre du gouvernement pendant les années IX 


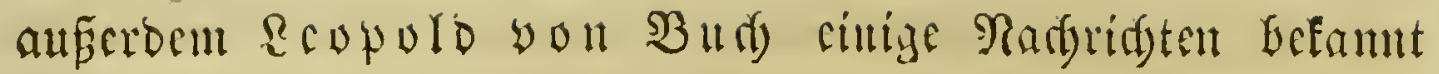
madjte.

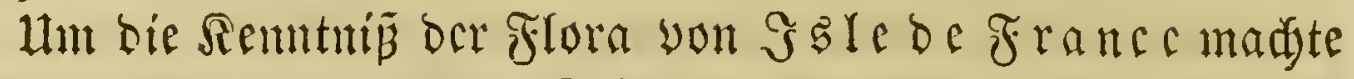

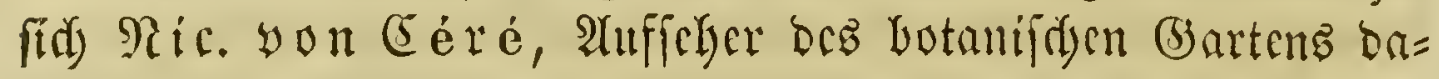
felbft, geftorben 1810, fehr verbient. (Fr madjte ez burd)

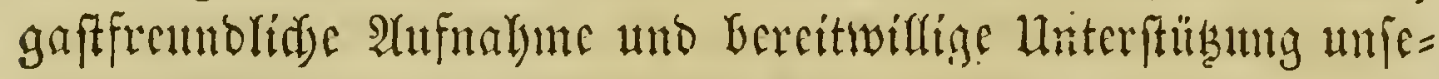

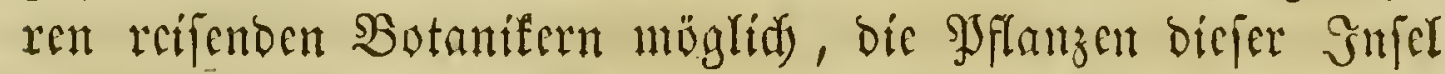

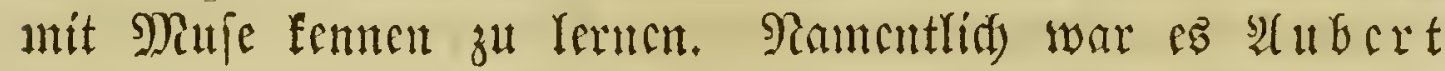

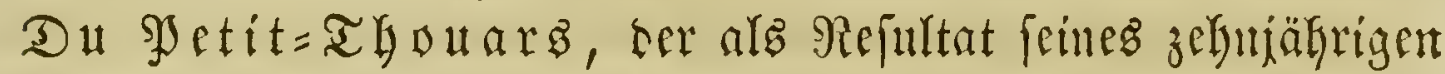

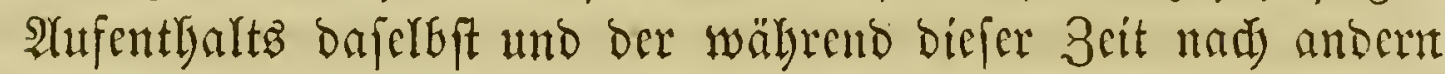

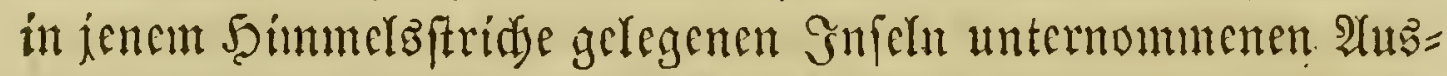

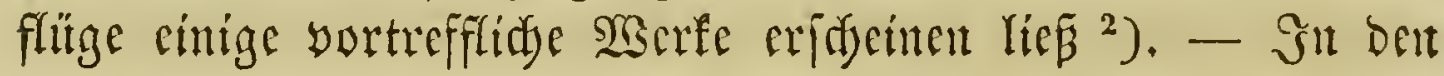

et $\mathrm{X}$ de la république (1801 et 1802), avec l'histoire de la traversée du Capt. B a udin jusqu'au Port Louis de l'isle Maurice. Paris 180\%. III voll. 8. - Atlas in-4..58 tab. - Deutid: Reife nad Den bier vornelmiten Snjeln ber afrifanifden Mere. 1r Theil. Reipjig 1805. 8. - Essais sur les isles fortunées et l'antique Atlantide ou précis de l'histoire générale de l'Archipel des Canaries. Paris an XI (1803). 4. 3 cartes. 7 tab.

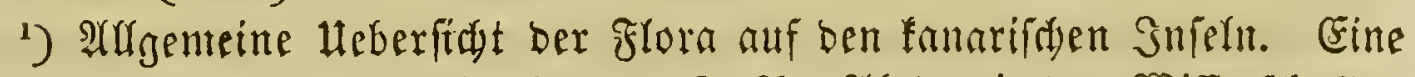
abbanbr., vorgelefen in ber $\Omega$. Pr. Afabemie ber Wiffenidaften zu Berlin in Snbre 181\%. Bertin 1819. 4. - Jjgyfifalifie Şefdreibung Der fanarifan Snfeln. . Berlin 1825. 4. 1 Tafel. Atraz in Folio. 9 Tafeln. (Pag. $105-199$ enthalten bie 1teker fidst ber Flora ber finarifien Sniflir.)

2) Histoire des végétaux recueillis sur les isles de France, La Réunion (Bourbon) et Madagascar. Première partie, contenant les descriptions et figures des plantes qui forment des genres nouveaux ou qui perfectionnent les auciens: accompagnées de dissertations sur différens points de botanique. Paris (1S0\%). 4. 10 tab. - Histoire des végétaux recueillis dans les isles australes d'Afrique. Première partie, contenant les descriptions et figures des plantes qui forment des genres nouveaux ou qui perfectionnent les auciens. Paris 1806. 4. 24 tab. col. Genera nova Madagascariensia secundum methodum Jus- 


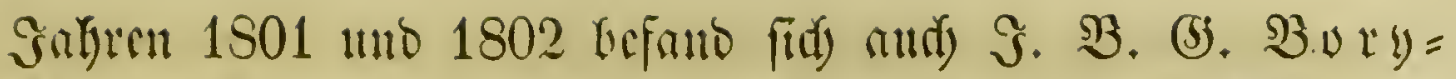
Saint= Bincent auf GBle de France und cutberite bort

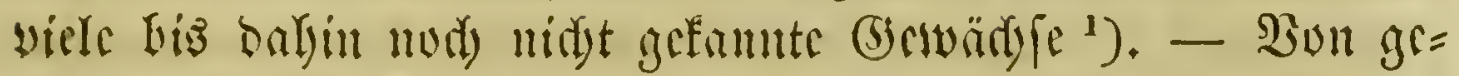

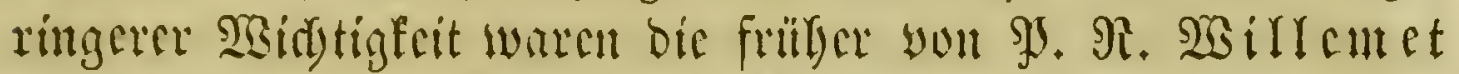

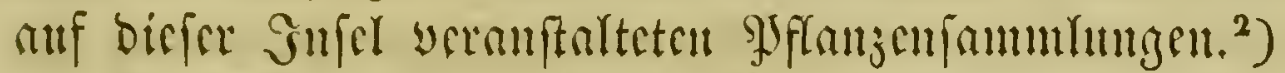

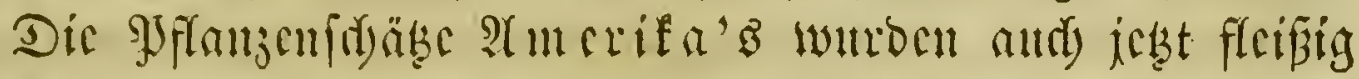

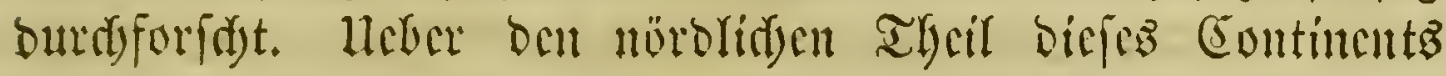

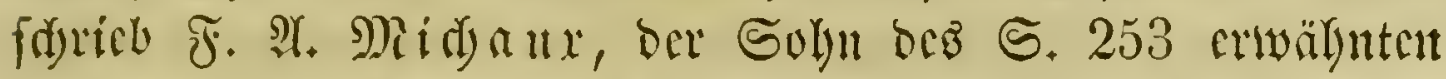

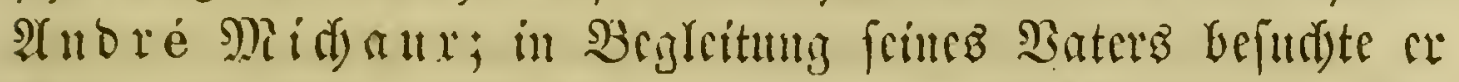

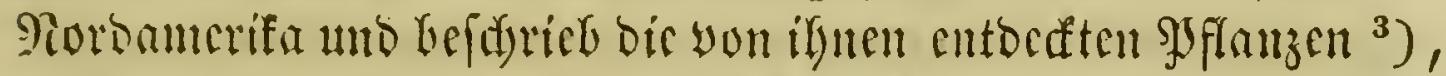

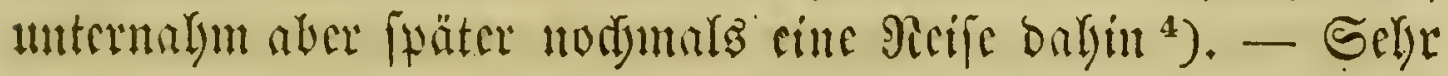

sieuanam disposita. (Paris 1806.) 8. - Extrait d'une mémoire sur les espèces de Pandanus observées aux îles de France, de Bourbon et de Madagascar. 4. (Bull. des sc. par la soc. philomatique, Août 1808.) Mélanges de hotanique et des voyages. Premier recuèil. Paris 1811. 8. 1 carte. 18 tab.

1) Voyage dans les principales îles des mers d'Afrique. Paris 180 \%.

2) Herbarium Nauritianum. Lipsiae 1796. 8. Mit einer $\mathfrak{B} 0 \mathrm{~d}=$

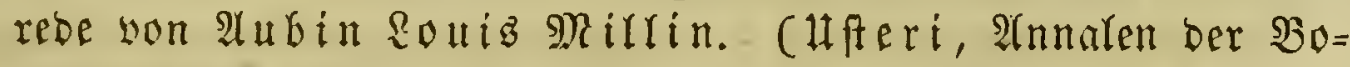
tanif, Stüư XVIII, p. $1-66$.)

$\left.{ }^{3}\right)$ Flora boreali-americana, sistens characteres plantarum, quas in America septentrionali collegit et detexit Andre as Michaux. Parisiis et Argentorati anno. XI. 1803. II voll. 8. 51 tah. col. - Ed. II. Parisiis 1820: II voll. 8.

4) Voyage à l'ouest des monts Alléghanys dans les Etats d'Ohio, du Kentucky et du Tennessée et retour à Charleston par les Hautes-Carolines efc. Paris 1804. 8. 1 carte. - Deltid): Reife in Das Gnnere Der norbamerifani=

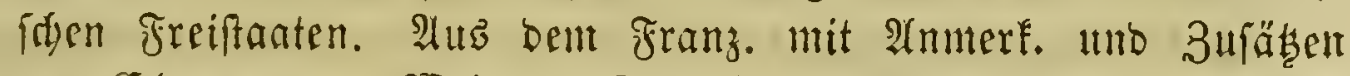
bon Eீbrmann. Şeimar 1805. 8. - Mémoire sur la naturalisation des arbres forestiers de l'Amérique septentrionale etc. Paris 1805. 8. - Notice sur les iles Bermudes et particulièrement sur l'île Saint-Georges, adressée a M. M. les professeurs du Muséum d'histoire naturelle. (Paris 1806). 4. (Extrait des Annales du Muséum d'hist. 
criprieflid war bie Reife, welde Meriwether Rewis, Stattbalter yon Dberlonifitana, und ber Rapitän Daniel (Elarf burdi) Rordamerifa unternahmen ${ }^{1}$ ). Die von ínen ge=

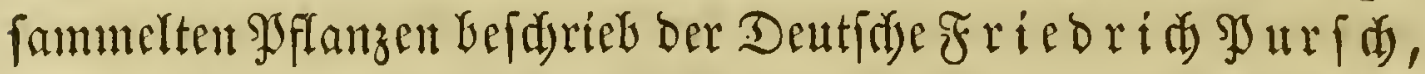
ber überbiez aud felbft viele (B)egenden Rorbanerifa's in ben Gabren 1799 - 1811 burdyanderte und nadj Beenoigutnis

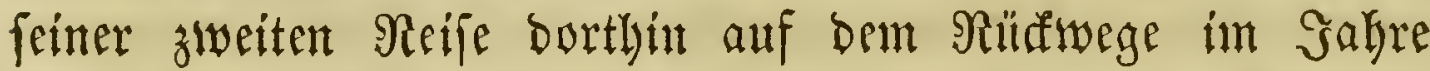

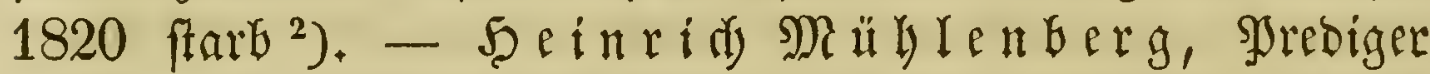
zu Rancafter in গুonfylyanien, gefturben 1815, verfäte

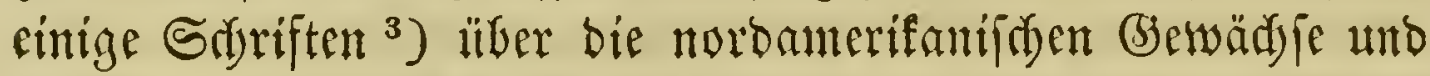
fodicte audi) biele (Exemplare biaber nod unbefannter arten

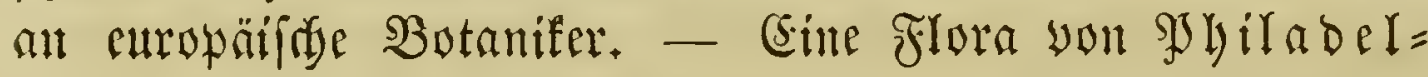
plia lieferte, $\mathfrak{B}, \mathfrak{B}$, (5., $\mathfrak{B} \mathfrak{a r t o n} \mathfrak{n}^{4}$ ), yon $\mathfrak{B} \mathfrak{d}$ fton $\mathfrak{J}$.

nat. vol, VIII). Histoire des arbres forestiers de l'Amérique septentrionale etc. Paris $1810-1813$. III voll. 4 . 145 tab. col. - Deutfd: Die Eiden ber vereinigten Staaten

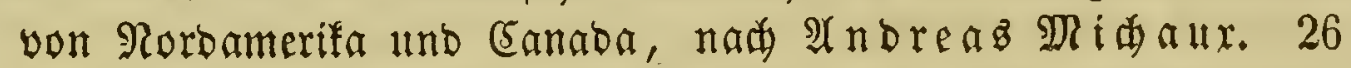
$\mathfrak{T a f e l n}$ mit ber nötrigen Erftärung uno Den botantiđaen, enge

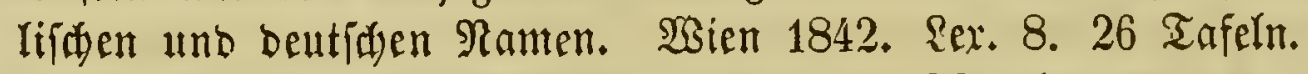

$\left.{ }^{2}\right)$ Voyage des capitaines Lewis et Clark en 1804 1806, rédigé par Gas, traduit par Lallement. Paris 1810. 4.

$\left.{ }^{2}\right)$ Flora Americae septentrionalis, or a systematic arrangement and description of the plants of North-America. London 1814. II voll. 8. 24 tab. col. - Edit. II. Ibid. 1816. 8. 24 tab. col.

3) Catalogus plantarum Americae septentrionalis hucusque cognitarum indigenarum et cicurum, or a Catalogus of the hitherto known native and naturalized plants of North-America, arranged according to the sexual system of Linnaeus. Lancaster 1813. 8. - Edit. II. Philadelphiae 1818. 8. - Descriptio uberior graminum et plantarum calamariarum Americae septentrionalis. Philadelphiae 1817. 8.

-) Florae Philadelphicae Prodromus; plantarum quae hactenus exploratae fuere, quaeque in ipso opere ulterius describentur, exhibens enumerationem, or Prodromus of 


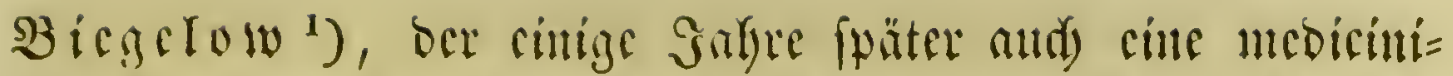

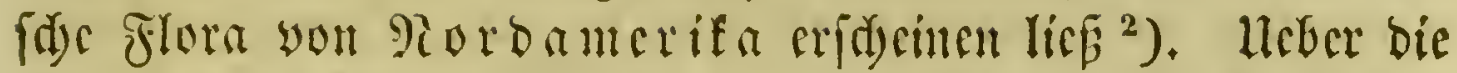

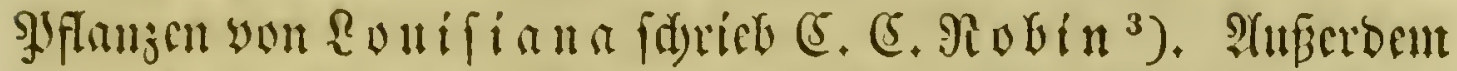

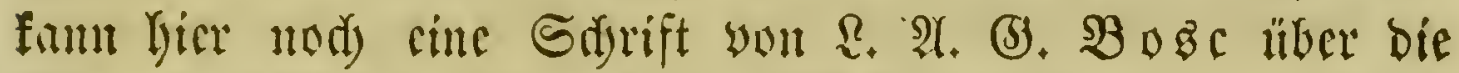

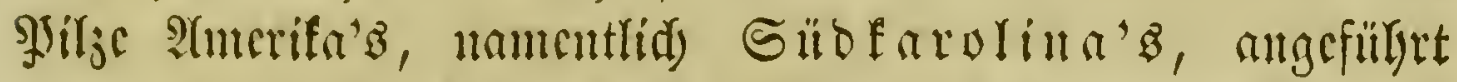

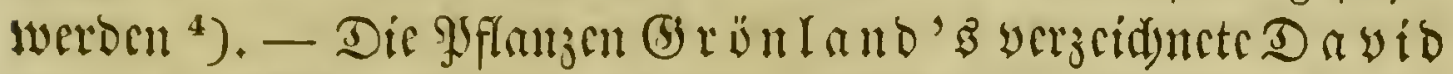

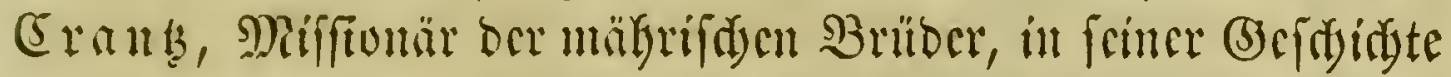

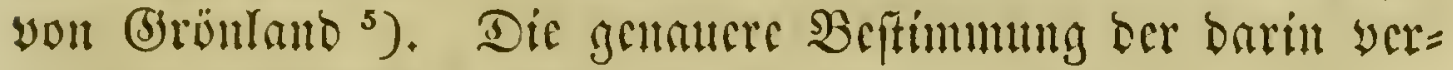

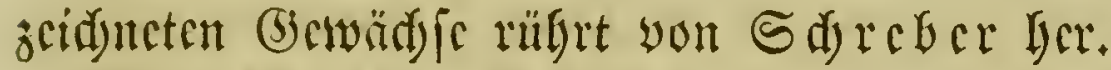

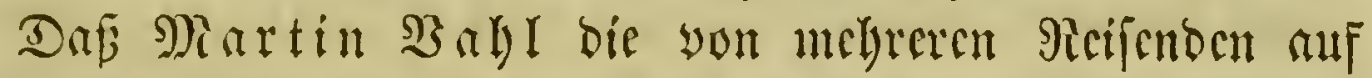

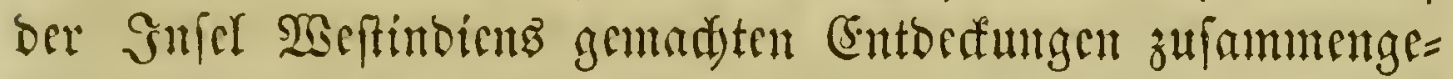

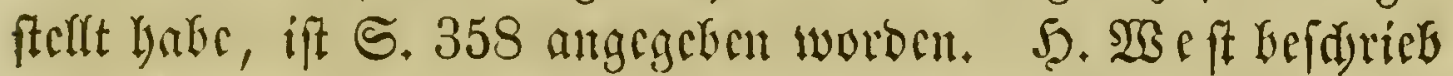
dif Syflumgen von St. (

the Flora Philadelphica, exhibiting a list of all the plants to be described in that work, which have as yet been collected. Philadelpliae 1815. 4.

$\left.{ }^{2}\right)$ Florula Bostoniensis. A collection of plants of Boston and its vicinity, with their generic and specific characters, principal synonyms, descriptions, places of growth and time of flowering and occasional remarks. Third edition enlarged and containing a glossary of botanical terms. Boston 1840. 8. - Edit. I. Ibid. 1814. 8. Edit. II. Ibid. 182\%. 8.

$\left.{ }^{2}\right)$ American Medical Botany, being a collection of the native medical plants of the United States etc. Boston 1817 - 1821. III voll. 4. min. 60 tab. col.

3) Voyage dans l'intérieur de la Lonisiane, de la Floride occidentale et dans les îles de la Martinique et de St. Domingue pendant les années $1802-1806$; suivi de la Flore louisianaise. Paris 1807. 3 Bbe. 8.

-) Némoire sur quelques espèces de champignons d'Amérique. Paris 1814. 4.

5) Şifforie yon Gröntanb. Barby 1765. 8. - Fortfestung ber Şiftorie yon Grönland. 1770. 2. 2(ufl. 1780.

-) Bidrag til beskrivelse over Ste. Croix, meden kort udsigt over St. Thomas, St. Jean, Tortola, Spanishtown og Crabeneiland. Kiöbenhavn 1793. 8. (Cap. II, pag. 259-336.) 
Anders Euphrajén bie von St. Barthelemy, St. (Euftade und St. (Shriftoply $^{1}$ ). St. Domingo tourbe

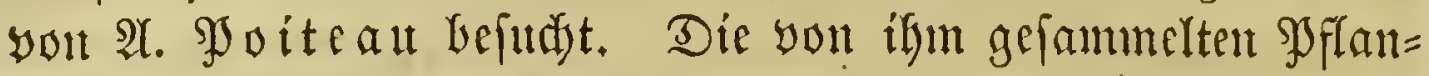

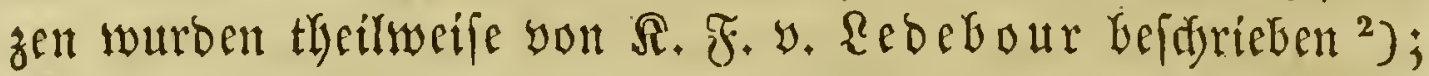

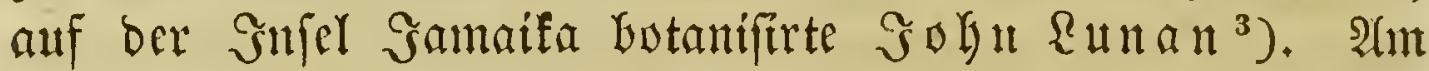

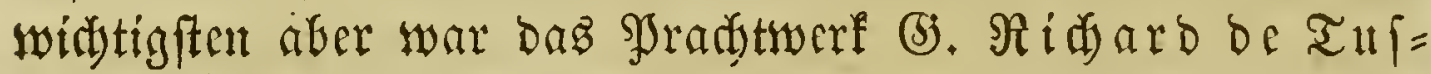
fac's liber bie Flora ber Antiflen, bas im Jahre 1808 be= gonnen, febodi erft 1827 becnoigt wurbe. ${ }^{4}$ )

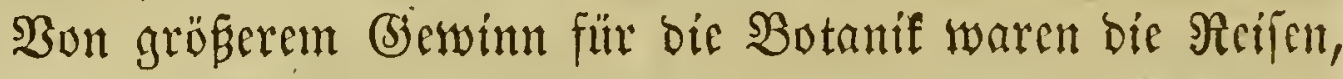
welde wälyrend diefes Zeitraums nad) Sild a inerif a unter=

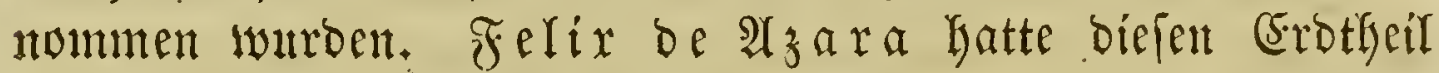

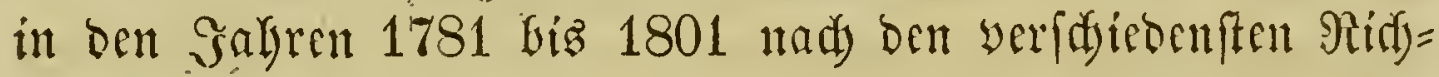
tungen lín durdwandert, aber bie yon ihm bort gcmadten, audi) für bie Botanif vielfadj widjtigen Beobaditungen war = Den erfit nad feinem Iobe veröffentlidet ${ }^{5}$ ), - Bon viel größe=

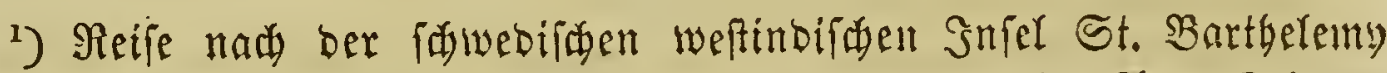

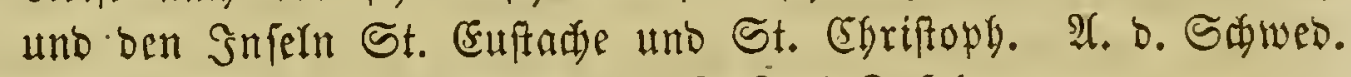
von $\mathfrak{B} \mathfrak{l}$ umb of. (3öttingen 1798. 8. 1 Tafer.

$\left.{ }^{2}\right)$ Dissertatio botanica sistens plantarum domingensium decadem. Gryphiae 1805. 4.

3) Hortus Jamaicensis, or a botanical description (according to the Linnean system) and an account of the virtues etc. of its indigenous plants hitherto known, as also of the most usefull exotics. Compited from the best authorities, and alphabetically arranged in two volumes. Jamaica 1814. 4.

") Flora Antillarum, seu historia generalis botanica, ruralis, oeconomica vegetabilium in Antillis indigenorum et exoticorum indigenis cultura adscriptorum; secundum systema sexuale Linnaei et methodum naturalem $J$ us sieui in loco natali elaborata, iconibus accuratissime delineatis et coloratis illustrata. Parisiis $1808-182 \pi$. IV voll. Fol. 138 tab. col.

$\left.{ }^{5}\right)$ Voyages dans l'Amérique méridionale depuis $1781-1801$, publiés par C. A. Walckenaer etc. Paris 1809. IV voll. 8. avec un atlas de 25 planches. 
rem Erfolge für unfere Biffendyaft aber war bie Reife, weldye

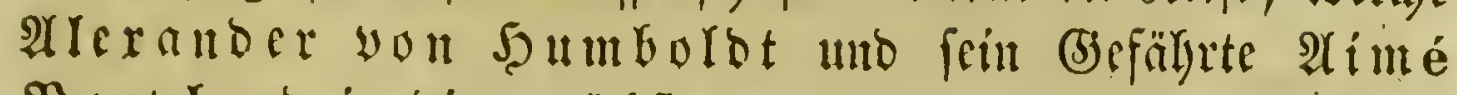

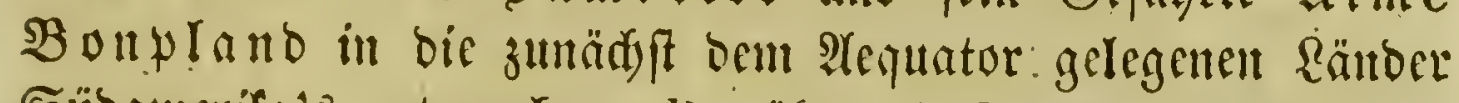
Sübamerifa's untermalymen ${ }^{1}$ ) ; therer bie Reiftungen biefer $\mathfrak{u}=$ ermilibliden forfidser bethalten twir uns jebods yor, in ber nädffen গুl borff, ber ben Rapitän Serufenfern auf feimer Reife tum bie SBalt begleitete, hielt fid) in Galye 1803 einige 3rit auf ber Gmiel $\subseteq$ t. Ratharina itt ber Räbe ber braftianifoten

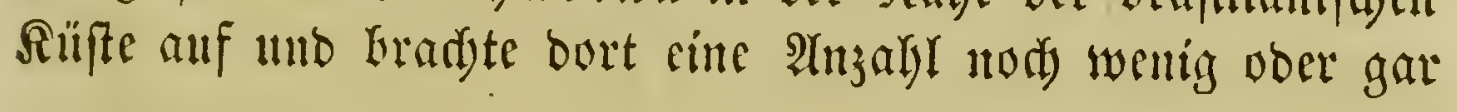

1) Plantae aequinoctiales, per regnum Mexici in provinciis Caracarum et Novae Andalusiae, in Peruvianorum, Quitensium, Novae Granatae Andibus, ad Oronoci, Fluvii nigri, fluminis Amazonum ripas nascentes. In ordinem digessit Amatus Bonpland. Parisiis 1805-1818. II voll. 17 fasciculi. Fol. 163 tab. - Monographia Melastemacearum continens plantas hujus ordinis hucusque collectas, praesertim per regnum Mexici in provinciis Caracarum et Novae Andalusiae, in Peruvianorum, Quitensium, Novae Granatae Andibus, ad Oronoci, Fluvii nigri, fluminis Amazonum ripas nascentes. In ordinem digessit Amatus Bonpland. Lutetiae Parisiorum 1806-1823. II voll. 24 fasciculi. Fol. 120 tab. col. - Nova genera et species plantarum, quas in peregrinatione orbis novi collegerunt, descripserunt, partim adumbraverunt A matus Bonpland et Alexander de Humboldt. Ex schedis autographis Amati Bonpland in ordinem digessit Carolus Siegesmund Kunth. Accedunt Alexandri de II umboldt notationes ad geographiam plantarum spectantes. Lutetiae Parisiorum 1815-182.5. VII voll. 36 fasciculi. Fol. 700 tab. col. - Mimoses et autres plantes Légumineuses du Nouveau Continent, recueillies par M. M. de Humboldt et Bonpland, décrites et publiees par Karl Siegesmund Kunth. Paris 1819. Fol, 60 tab. col. - F. $\mathfrak{A}$. 5 . von $\mathfrak{5} u m b o l o t$ uno $\mathfrak{A}$ imé Bonpland, Reife in bie 2Aequinoctialgegenden bez nellen Con. tinentz in ben Jagren 1799-180\%. Stuttgart 1815- 1832. 6 Theile. 8. 


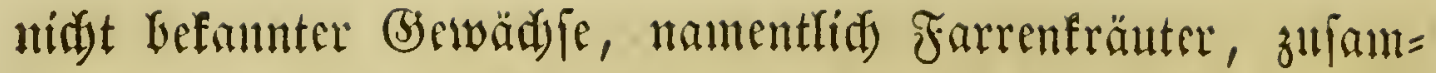
men; aud) gebülyt ihm bas Berbienti, auf bie rwutberbare

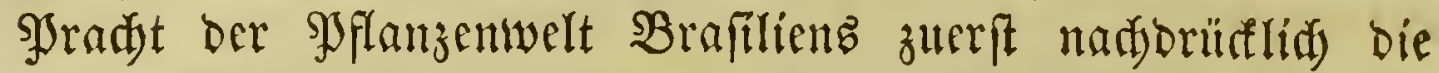

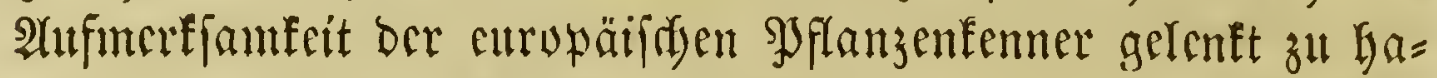

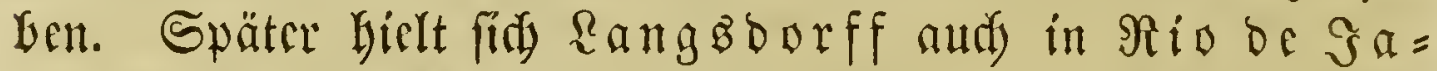

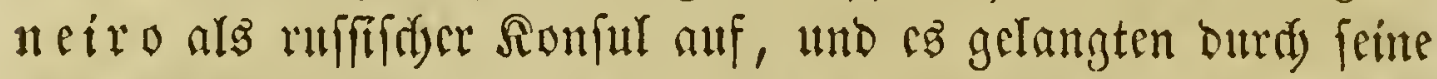
Şemülumgen vicle in ben bortigen (Begenden gefammelten SPfranzen nad) (5uropa herïber ${ }^{1}$ ). - (Begen bas Ente bicfer

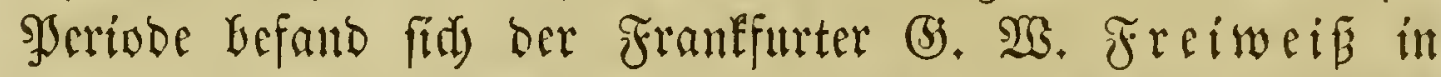
Brafilien; namentlid) bereifte or aud) bie Srovill Minas (5)eraës; obgleing ar felfit nidjts über feine Entbertungen be=

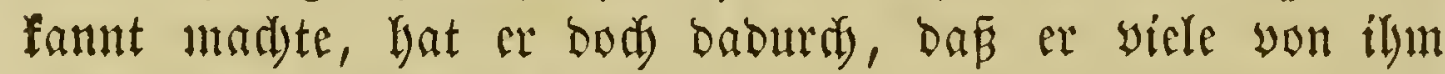

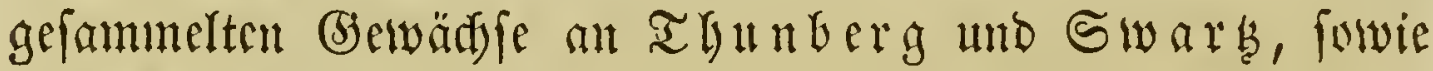

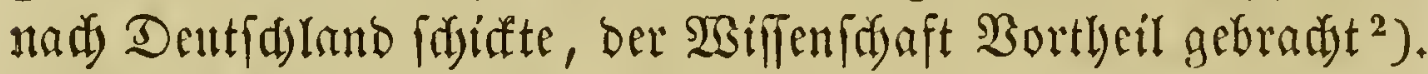

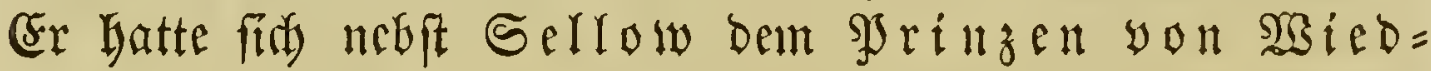

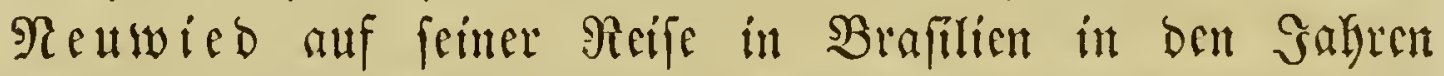

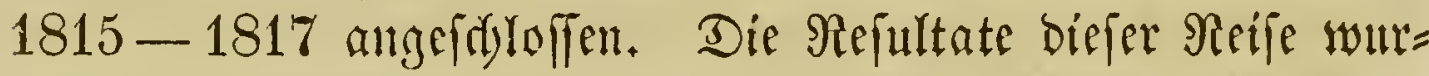
ben yon Drm Syinzen yon $\mathfrak{X}$ entwied felbft befant ge= madjt; aud benuste Martius fpäter in feiner brafilianifdent Flora ${ }^{3}$ ) bie bei biefer Expebition gefammelten Siflanjen. -

$\left.{ }^{1}\right)$ Plantes recueillies pendant le voyage des Russes autour du monde, expédition dirigée par M. de Krusenstern. Parties I et II. Icones filicum. Tübingen 1810-1818. Fol. 30 tab.

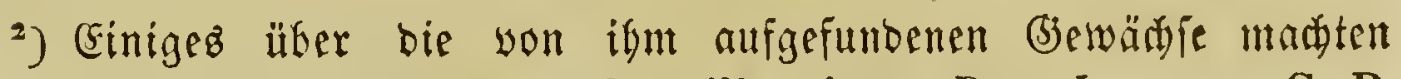
Thumberg (Plantarum brasiliensium. Dec. I. praes. C. P. Thunberg, prop. J. Billberg. Upsala 1817. - Dec. II. prop. C. G. Als lberg. Ibid. 1818) und Swark (K. Wetensk. acad. Handl. 1817) Gefinnt.

$\left.{ }^{3}\right)$ Flora brasiliensis, seu enumeratio plantarum in Brasilia tam sua sponte quam accedente cultura provenientium, quas in itinere auspiciis Maximiliani Josephi I. Bavariae regis annis $1817-1820$ peracto collegit partim descripsit; alias a Maximiliano Principe Wiedensi, Sellovio aliisque advectas addidit, communibus amicorum propriisque studiis secundum methodum naturalem 
Sn ben Snlyren 1815 utho 1816 hieftent fint audi) bie beiben

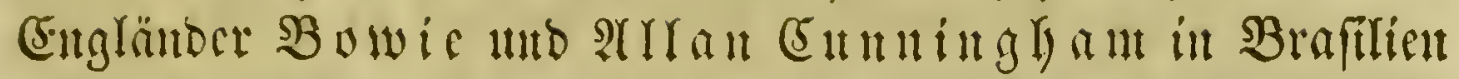

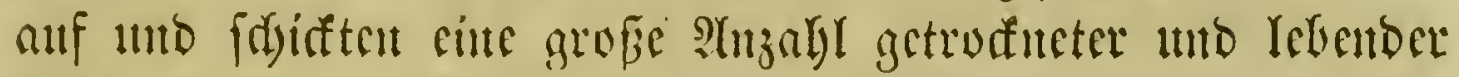

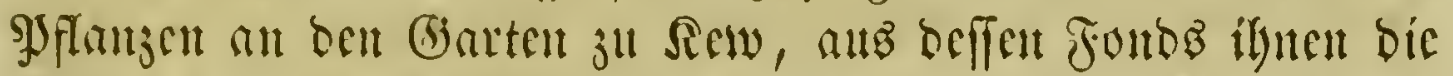

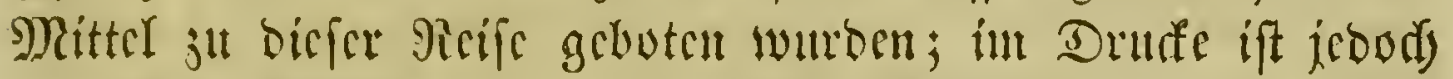

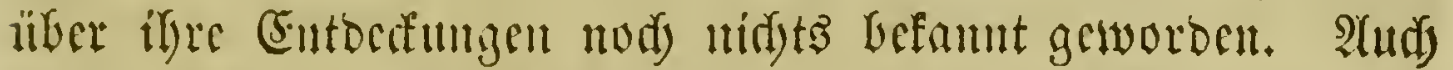

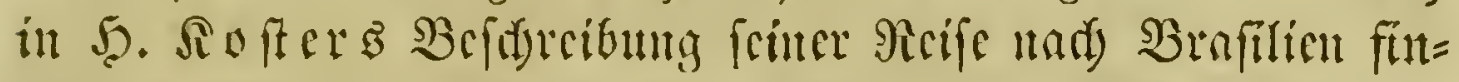

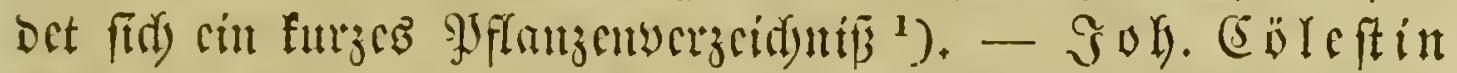

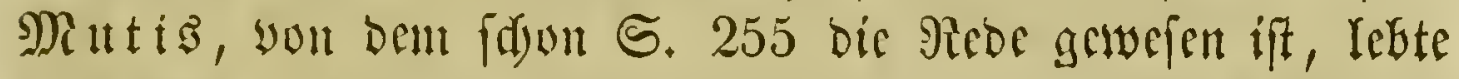

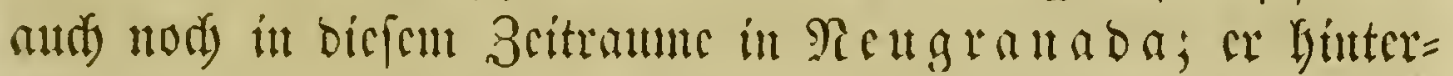

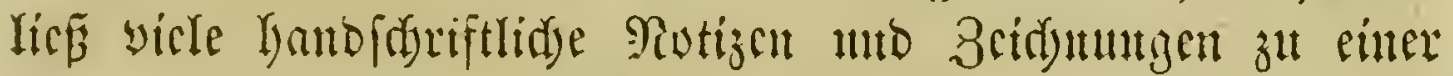

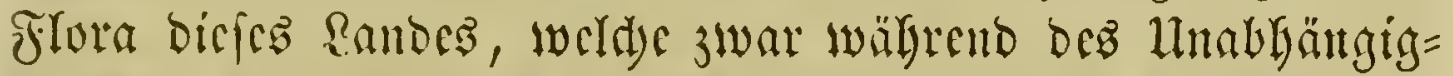

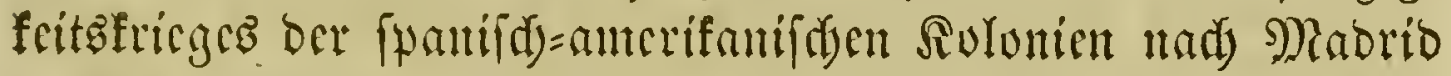

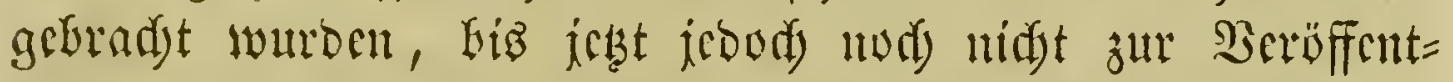

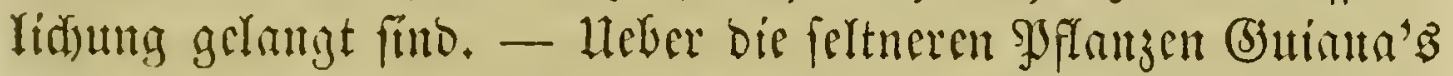

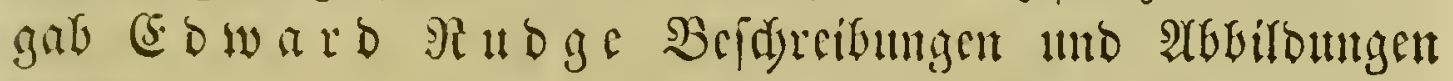
(yerants. ${ }^{2}$ )

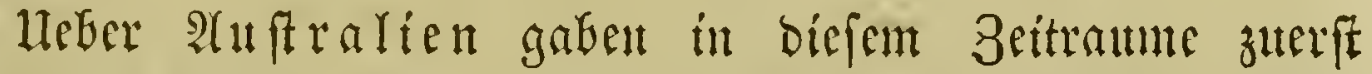

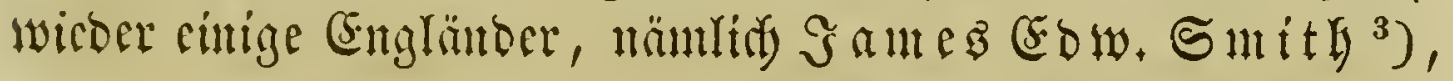

dispositas et illustratas edidit Karl Friedrich Philipp von Martius. Stuttgardiae et Tubingae 1829-1833. Vol. I. pars prima, et voluminis II pars prima. 8: I, 1: Algae, Lichenes, Hepaticae. Exposuerunt: Karl Friedrich Philipp von Martius, Franz Gerhard Eschweiler et Chr. Gottfried Nees von Esenbeck. II, 1: Gramineae. $\mathfrak{A}$ uf unter bem Titel: Agrostologia brasiliensis, seu descriptio Graminum in imperio brasiliensi hucusque detectorum auctore Christ. Gottfr. Nees von Esenbeck.

1) Travels to Brasil. London 1816. 4.

$\left.{ }^{2}\right)$ Plantarum Guianae rariorum icones et descriptiones hactenus ineditae. Vol. I. Londini 1805. Fol. 50 tab.

3) A specimen of the botany of New-Holland, fasc. I. London 1793. 4. - Transact. of the Linn. soc. Vol. 2. p. 346 seq. Vol. 6. p. 299 seq. Vol. 9. p. 294 seq. 301. 


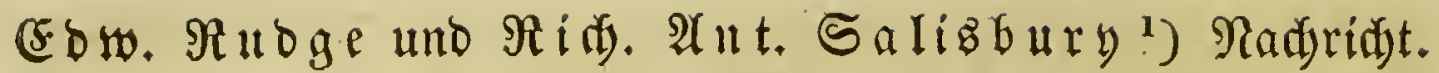

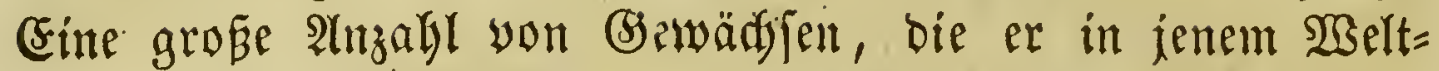

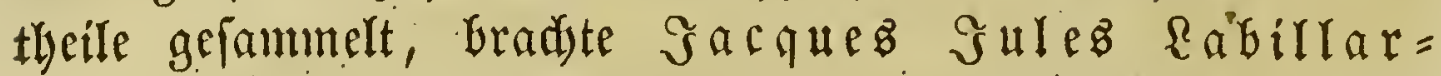

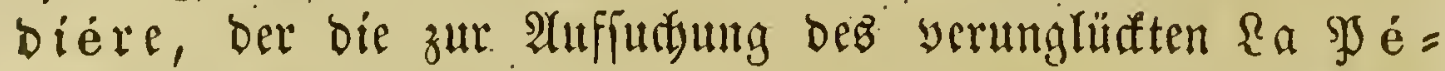

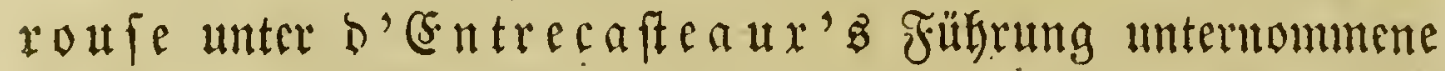
Expedition alz Botanifer begleitete, nady (Europa zutüa ${ }^{2}$ ). In feinen $\mathfrak{S e r f e n ~ b e m u t e ~ e r ~ a u d ~ b i e ~ f r u ̈ l e r ~ y o n ~ F e r b . ~ b e ~}$ Rovonha auf ben Shbilipinten gefammelten Pflanzen. Dis

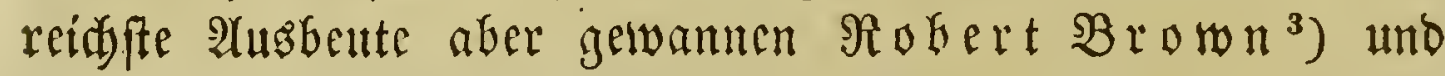
Der $\mathfrak{s f l a m j e m m a l e r ~ F e r d i n a n d ~} \mathfrak{B a u c r}{ }^{4}$ ) auf mebreren

") Transact. of the Linn. soc. Vol. 8. p. 291. seq. Vol. 9. p. 296 seq. Vol. 10. p. 283 seq.

2) Relation du voyage à la recherche de La Pérouse, fait par ordre de. l'Assemblée constituante pendant les années 1791 et 1792 et pendant la première et la seconde année de la république française. Paris an VIII (1799). II voll. 8. et Atlas in-Folio de 44 planches. Darunter 14

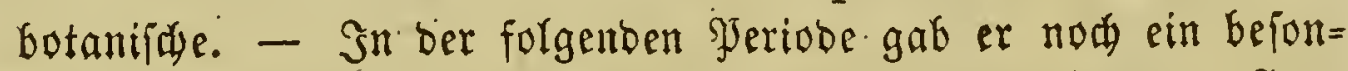

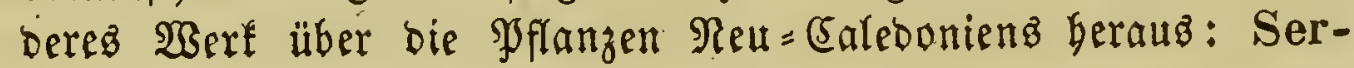
tum austro-caledonicum. Parisiis 182/-1825. II partes. 4. 80 tab.

3) Prodromus florae Novae Hollandiae et insulae van Diemen. Vol. I. London 1810. 8. Gin fegre feltenes $\mathfrak{B e r f}$. - Edit. nova 1821. 4. Edit. tertia: curis Chr. God of redi Nees ab Esenbeck. Norimbergae 1827. 8. - 2(ü in beflen

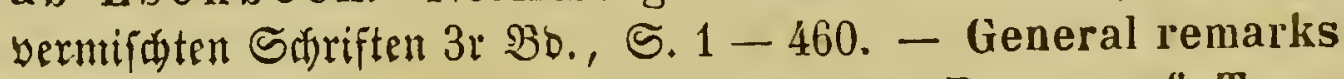
geographical and systematical on the Botany of Terra Australis. London 1814. 4. 10 tab. - $\mathfrak{2}$ (u) in beffen ver $=$

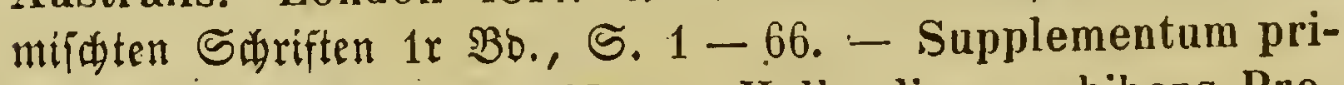
mum Prodromi Florae Novae Hollandiae, exhibens Proteaceas novas quas in Australis legerunt D. D. Baxter, Caley, Cunningham, Fraser et Sieber, et quarum e siccis exemplaribus caracteres elaboravit. Londini 1830. 8. - Hud in beffen werntifwten Sdriften $5 \mathfrak{r}$ Bb., S. $77-116$.

*) Illustrationes Florae Novae Hollandiae, sive Icones generum quae in Prodromo Florae Novae Hollandiae et insulae van Diemen descripsit Robertus Brown. Londini 


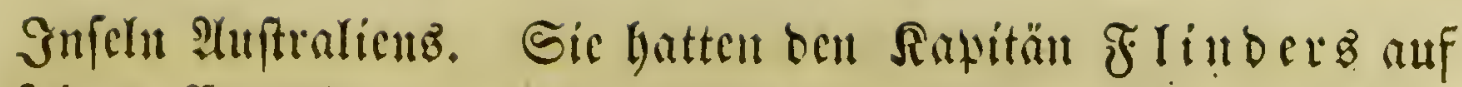
feiter Expedition in bic Silbjee in Jahje 1801 begleitet,

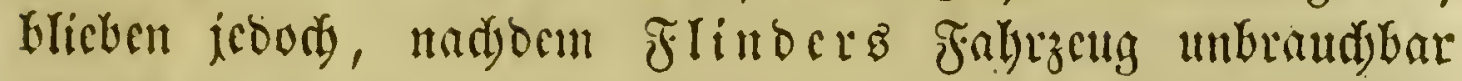
gelvorben แnb ar barmu genüthigt war, zแt J̧erbeifdaffung

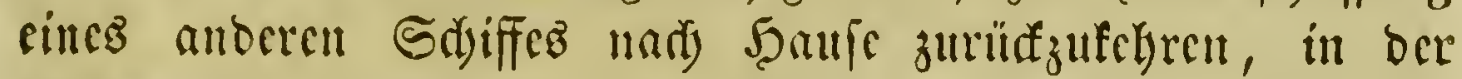
rinige 3cit vorker you ben Engläntocrn angelegten Solonie

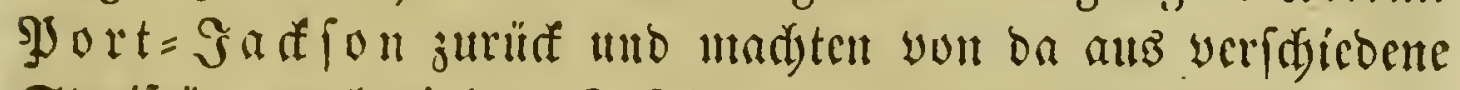

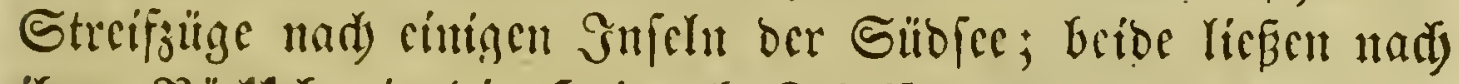

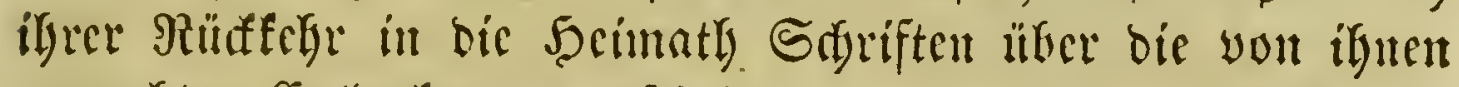
gemaditen (Enthedutgen eridjeinen.

(Fin jwar nidyt ueuer, afer bod, fiaber nur wentig beadi)= teter 3weig oer Botanif, die 35 fla in biciem 3citraume bic erfte wiflenidjaftlide Begrintoung.

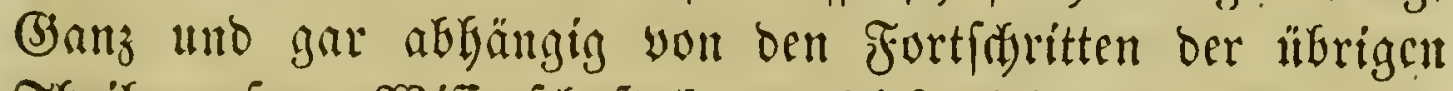

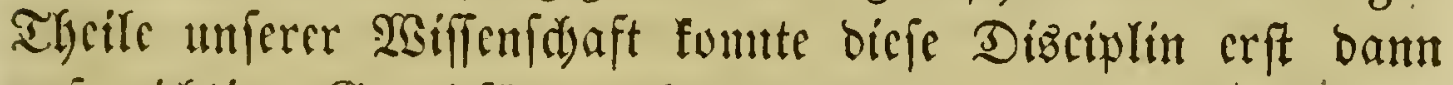
auf ridjtige (stumbjäłse gebaut worben, als namentlid) bie SWyytographic uno bic Selure yon ocr natürlidyen Berwandt=

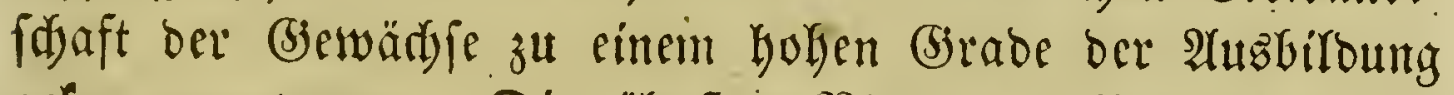
gefommen waren. Die älteften $\mathfrak{B a ̈ t e r}$ ber $\mathfrak{B o t a n i f e r , ~ o e n ~}$

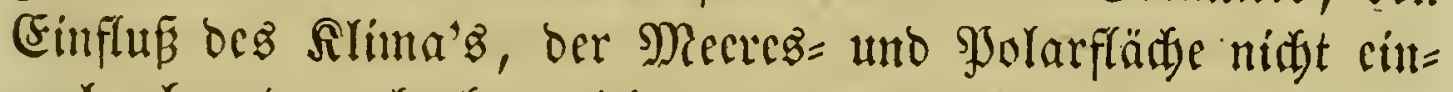
mal afnent, glaubten díc von Dioseorioes unto ben anderen Sdyrifteflern bes flaffiden âterthums angefülyrten IJflanzen (S)ricdenlanos und Эtaliens auth in ben übrigen \&än=

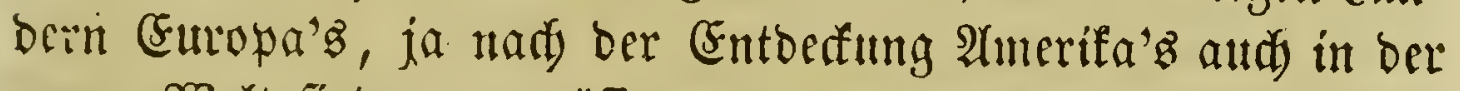
meucn $\mathfrak{B e l t}$ futtoen zu müffen unb erft nadjocm man fid lange vergeblid) abycmüht hatte, die Ramen uno Befdreibungen friilyerer Sifriftfteller ben neu aufgefunbenen Spflanzenarten

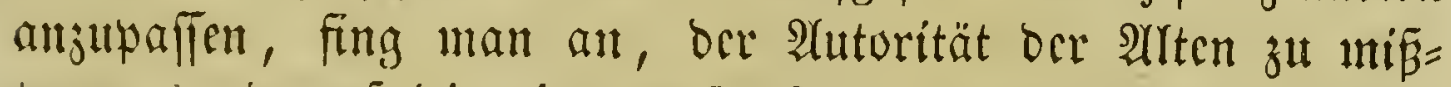
trauen uno auf bie eigenen Sräfte im Sirforfdyen ber vater=

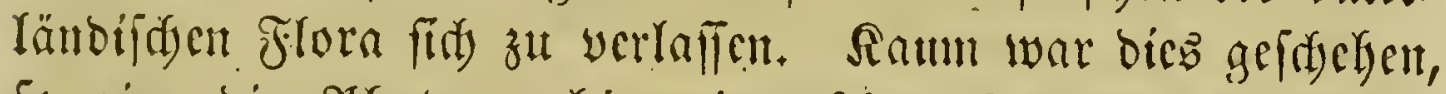
fo ging bie SJghtograwhie mit rafden Sdyritten yorwärts.

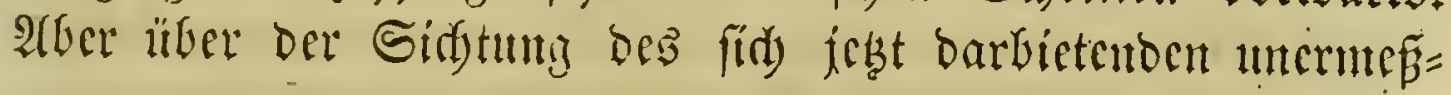

1813. Fol. max. 15 tab. col., von weldent $\mathfrak{W e r f e}$ indeffen mur 3 sefte erifhienen fint. 
lidjen Materials yerging wieberum ein ganzes gafrlumbert. Şährend biefer Zcit utb nod) lange nadyber muften ez bie Botanifer notgwendig für ifre hauptfädylidyfte Sorge halten, Durdi) Attfittllung eíner allgemein gültigen Terminologie utto ciner gecigneten Alaffifitation eine Heberfidyt über bie aufge= fundenen Sdjäze fid zu ermüglidsen, und wir haben gefeken,

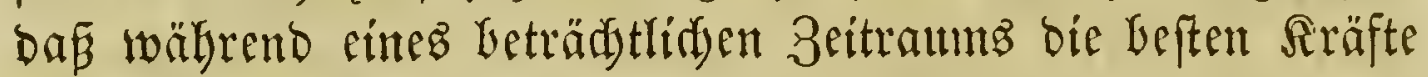

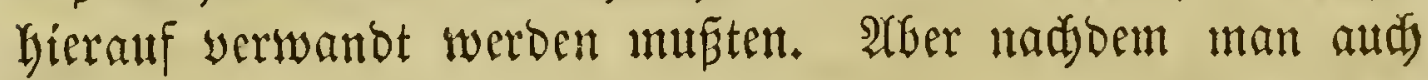
Gierin zut ciniger Bollfommentyeit gelangt war, uno nadjoem bie Botanif burd die von (F) rew und Malpighi gegen das ङnde bes 17. Jahrhunderts neu Gegrünbcte Disciplin

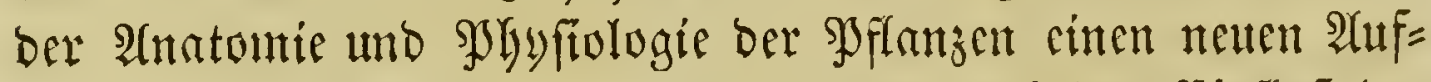

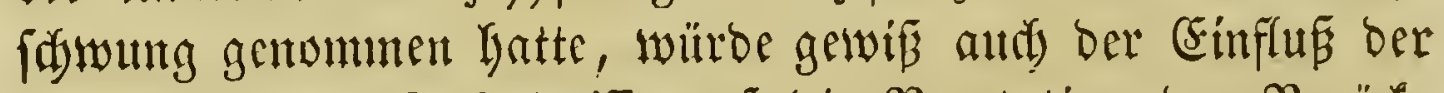

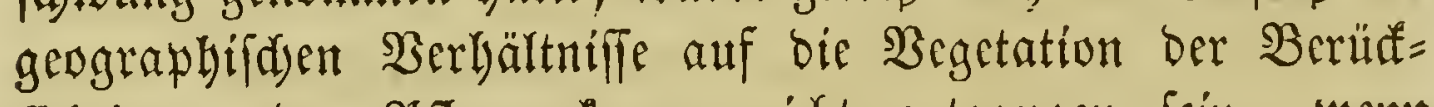
fidstigung ber splanzenfenter nidjt entgangen fein, wemu cútestbeilz gerade berienige Rändercomplex, ber hauptfädylid) 3u botanifden 3weaten burdforidst worben war, bezüglids

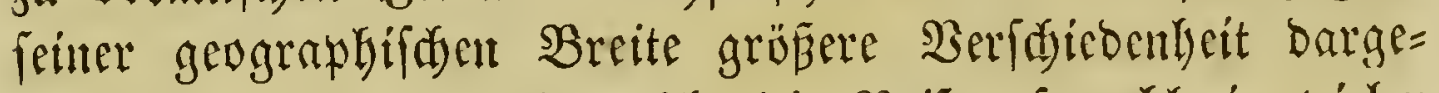
boten, und anderntleiliz nidyt die Reifen fowohl in viclent Ränbern (Europa'ż, als aud) namentlid) in ben überfeeificten (Eroftriden mit ben gröften Sdywerigfeiten yerbumben $g \mathfrak{c}=$ wefen wären. (Shriftian Meulat (S. 140), cin Mann,

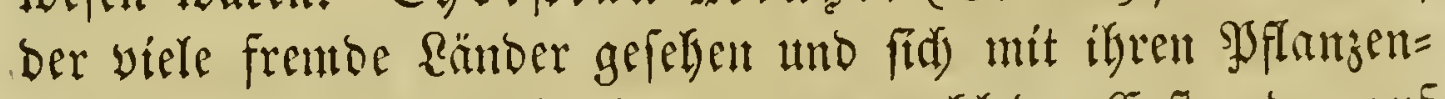
fadälen befaunt gemadyt batte, war wobl ber (Erfte, ber auf

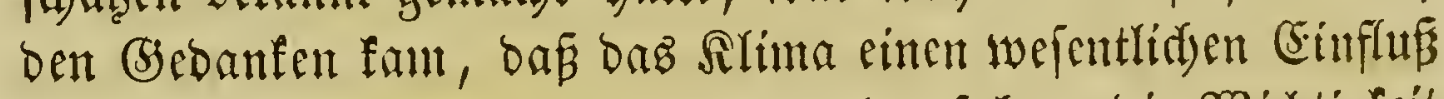

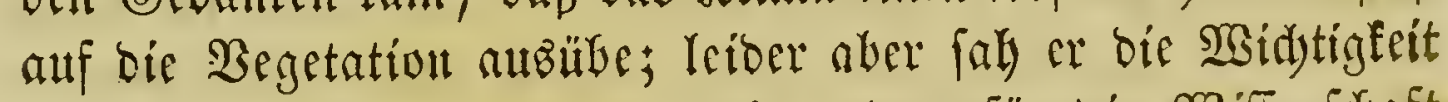

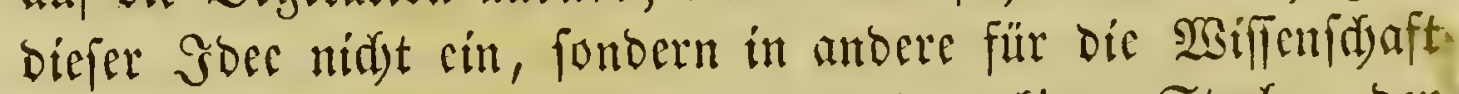
yiel weniger bebeutende, aber bem bamaligen Streben ber

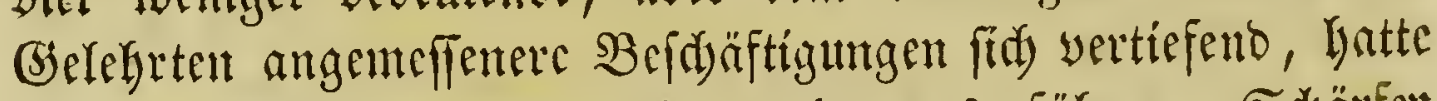

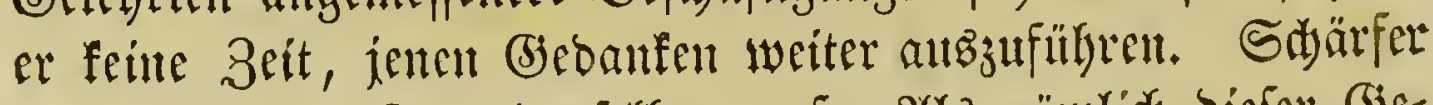

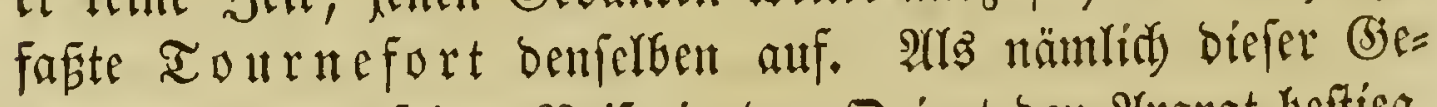
Jebrte wäkrent feiner Reife in ben Drient ben Rrarat beftieg, warbe er auf ben Unterifeico ber $\mathfrak{B} e g e t a t i o n$ in ben wer=

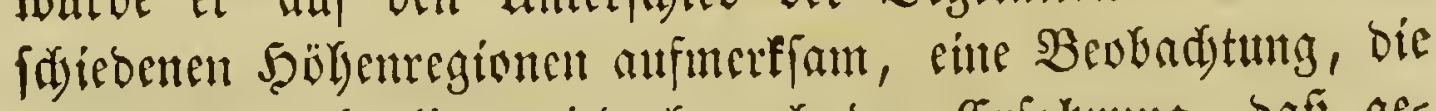

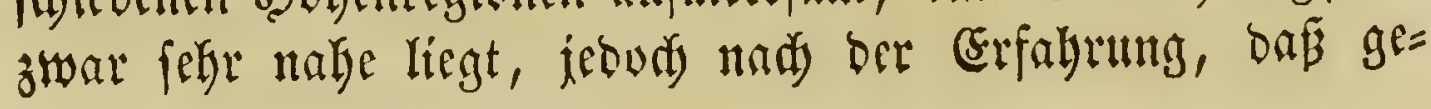




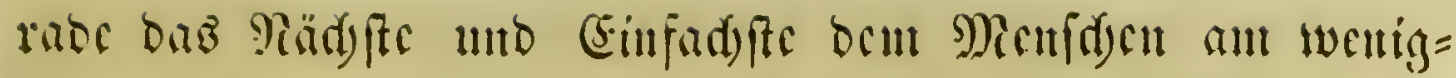

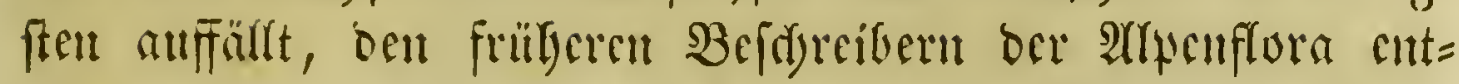

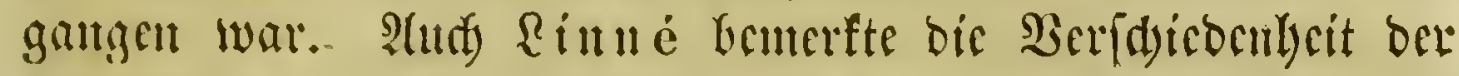

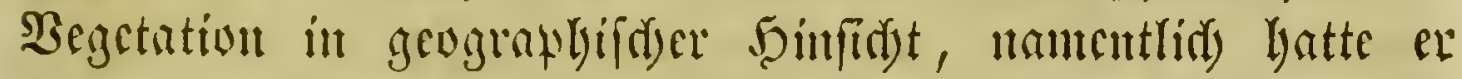

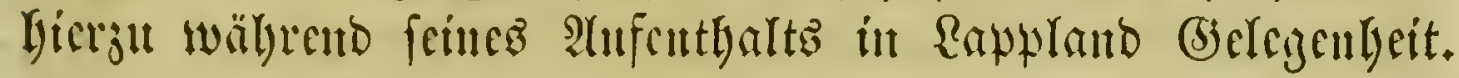
Sowohl in feiner Flora biefes Randes, als audi) in eintigen

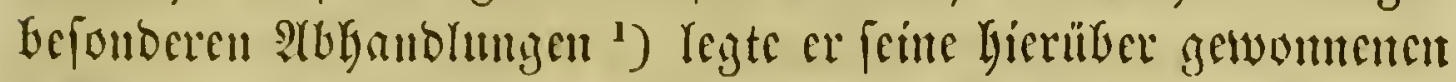

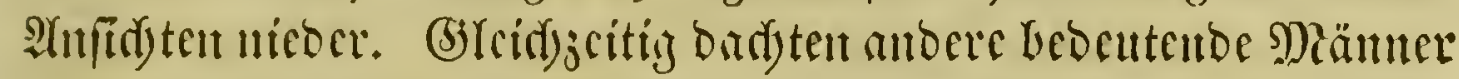

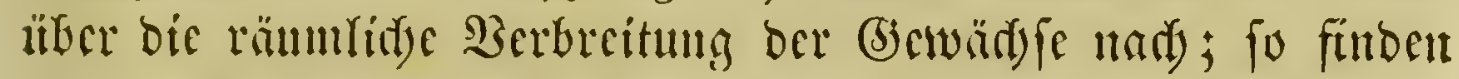

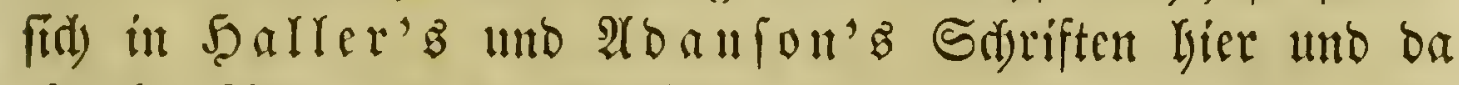

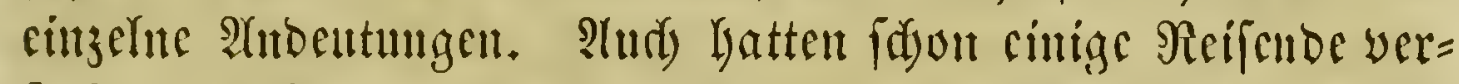
fudjt, bie (5)renzen zu beịtintuten, innerlyalb weldyer cintzelne Syflanjengattungen vorfommet, Slnbere, wie Reynier und Sauffure, hatten über ben Cinflup bez STimaz auf bie

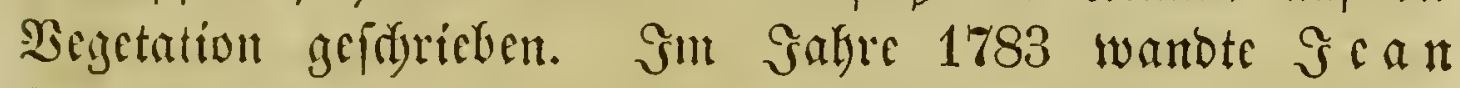
Rouis (b) iraub= Soulavic bie bisher aufgeftellten (strund=

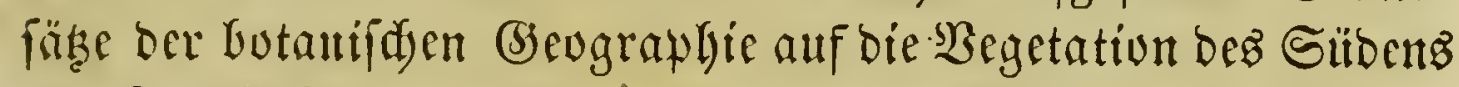
עon Frantreidy an und wagte fogar, biefes Rand in Syflanzent= regionen cinzutheilen ${ }^{2}$ ). Unter ben erften (jielegrten, weldye auf bic Goce yon bem engen Zujammentange ber Begetation mit ber phyfifd = geograwhifden $\mathfrak{B e f d}$ affenleit ber (Froober= flädse näher cingingen, ift aud) Fricbrid) Stromeyer lyerworzulefen, ber in einer Snauguraldiffertation widtige $\mathfrak{B} e=$ obadytungen über die (Grenzen ber Begetation befannt madyte ${ }^{3}$ ). SEeiter als er ging (5) ottfr. Reinly. Treviranus, indem

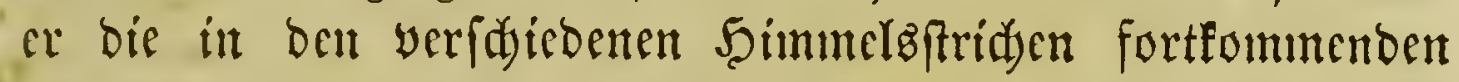
Fantilien zufanmenftelle unb Gierauf ben Berjud madjte, bie Begetation ber (Erdoberflädye unter $\%$ g. Saauptfloren zu brin= gen, b. Yy. in einige grofie IJflanjemegionen abzufdeiben. ${ }^{4}$ )

\footnotetext{
1) S. 258, Note 1.

2) S. 233, Note 2 .

3) Commentatio inauguralis sistens Historiae vegetabilium geographicae specimen. Goettingae 1800. 4.

4) Biologie ober Pghilofophie ber lebenten Ratur. 2r Banb. (3)bts tingen 1803. 8.
} 
Daz Berbienft aber, bie eigentlid) willemidaftlide $B \mathfrak{e}=$ bandiung oer Syflanzengeographie angebahnt zu haber, ge=

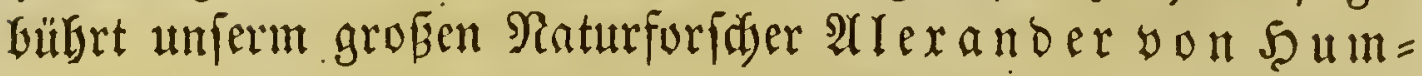
bolot. Diejer (B)lebrte, genuglam augerftattet mit geiftigen

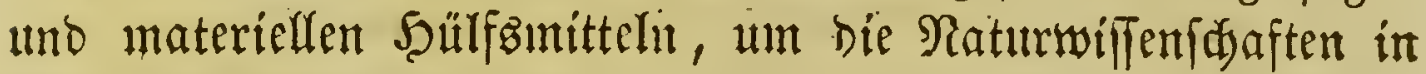

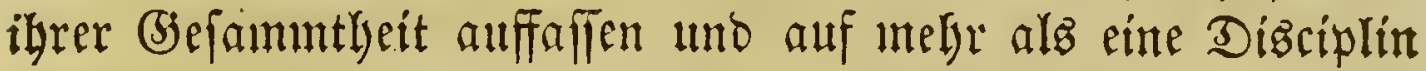
Derfelben erfolgreidi eimwirfen zu fünnen, war burds bie Vielfeitigfeit feines $\mathfrak{B i f f e n s}$ und burdy bie auf feinen Reijent crworbene Bertrautheit mit den verfdebenartigiten Rändern ber Eroe yor 2 tndern in ben Stant gefert, aud biejem Zweige oer Naturfunde eine fefte $\mathfrak{B a f i z}$ zu verleílen. (Fr fpradi zuerit flar und beftimmt ben Sals aub, dap bie $\mathfrak{B e r}=$

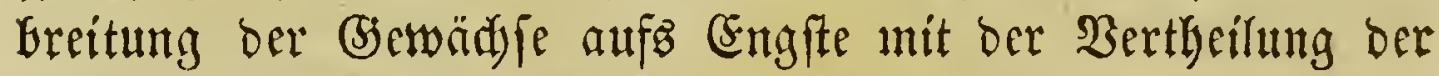

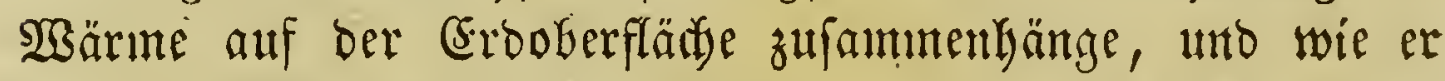

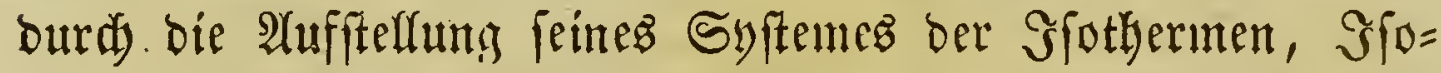
theren utto Sfordimenen ber Meteorologie cinen netten 2 Uuf=

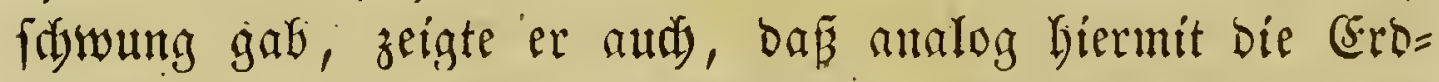

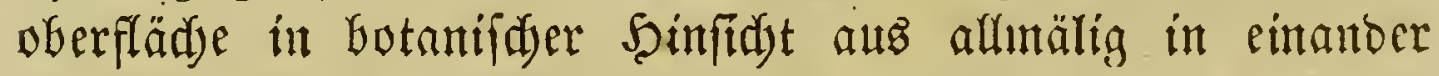

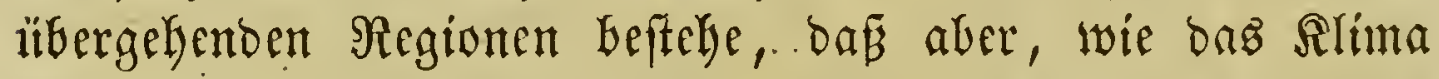
cines fueziellen Ranoez burd) örtlidye Unfadyen mantherlei

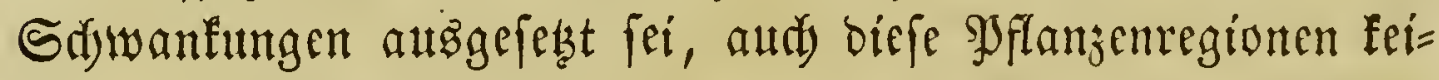
iteşwegg immer fósarf abgegrenzt werden fönnen, fonderit mannidafad) yariirent bem $\mathfrak{B}$ evbadjer oft mur unbeutlidje Spuren igres wirtliden Borkandenfeins aufweifen. In baz

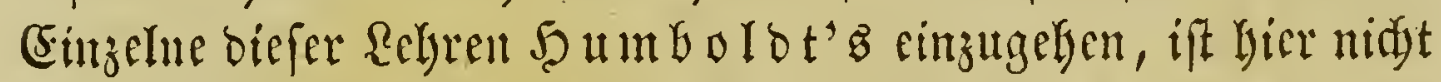
ber Drt, wair fülyren mur nod) ant; bafi er aus jenen ört=

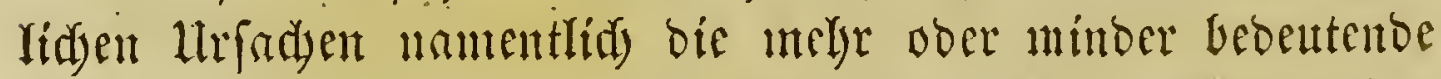

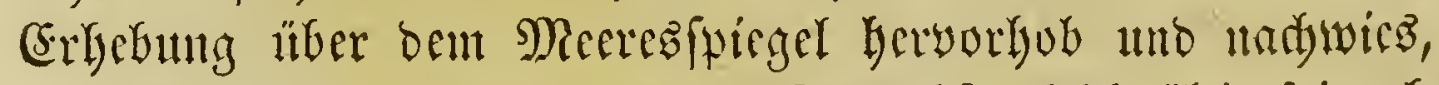

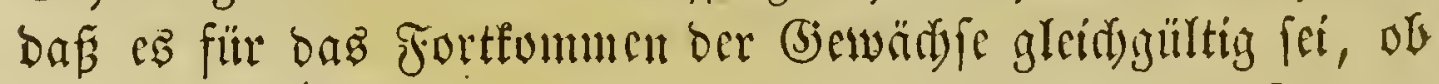
Die Dazu erforberlidye Säantemenge in Fulge ber Entfermuty

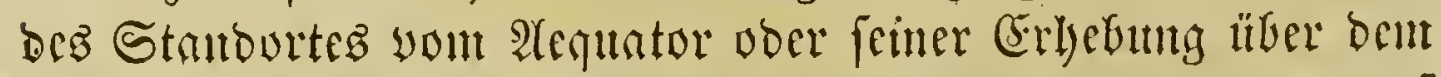

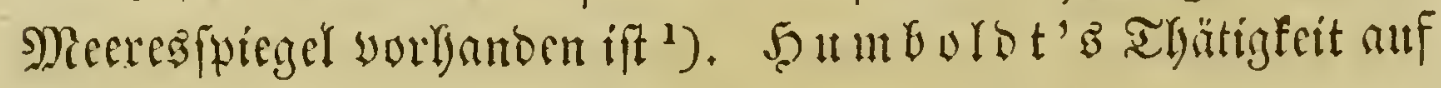

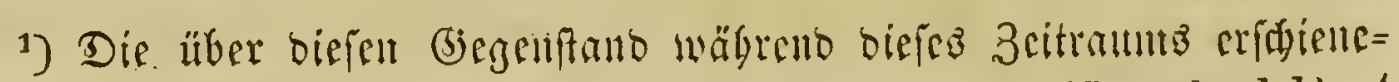
men Sariften bon SHmbolot find: F. A. v. Humboldt et 
bem (5) Chicte ber Botanif reidyt inbeffen nody in bie forgento

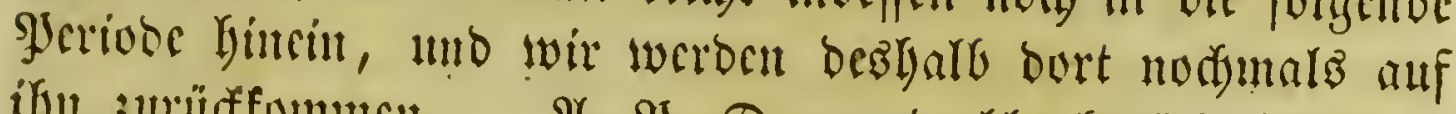

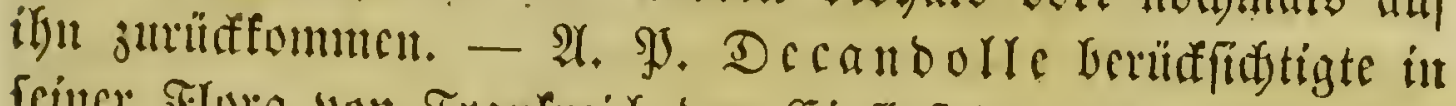

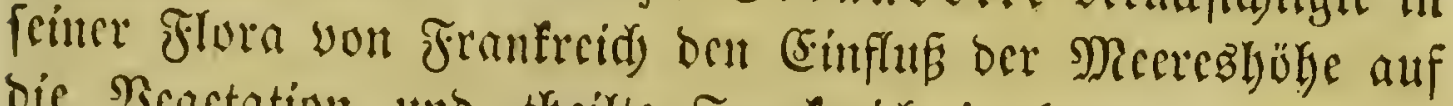
Die. Begctation und theilte Franfreids in butanifids=geogra=

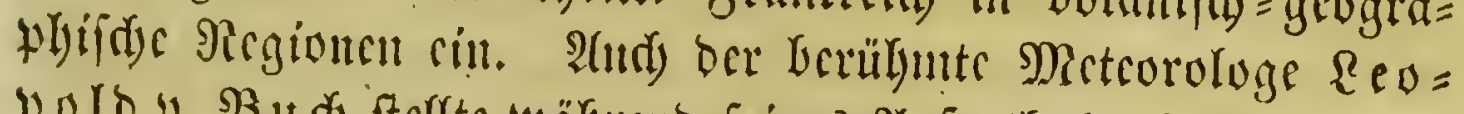

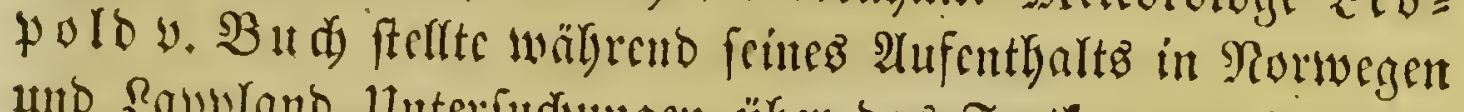
und Rnpwlano Unterfudjungen liber bas Fortfommen ber (je:=

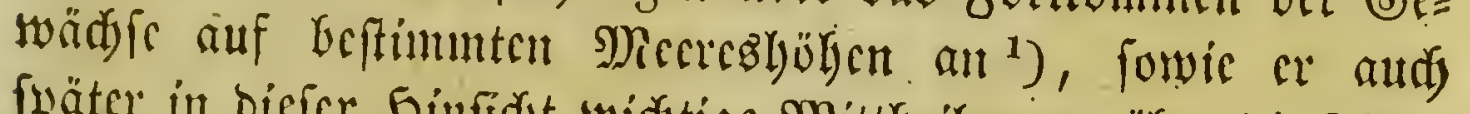
fwäter in biefer binfed)t widytige Mittbeilungen über bie Flora Der fanarifden Gufeln befannt madte ${ }^{2}$ ). Son ben $\mathfrak{B e r}=$

A im é Bonpland. Essai sur la géographie des plantes accompagné d'un tableau physique des régions équinoxiales, fondé sur des mesures exécutées depuis le dixième degré de latitude boréale jusqu'au dixième degré de latitude australe pendant les années 1799-1803. Paris an XIII. 1805. \%. maj. - Deut fih: Soeen full einer Bjeograpgie ber Yjlanzen nebft einem. Raturgemälde ber Tropen=. Yånber, auf Beobadjtungen und Meffitngen gegrünbet, welde. bom 10. Brabe nörblider bis zum 10. Brabe füblitjer Breite in ben Sabren $1799-1803$ angeftellt worben find. Searbeitet unb berausgegeben yon bem Erferen. Tübingen 1807. 4. 1 Taf. - Soeen zut einer Geograpbie ber SPfanzen. Mit ertäuternden

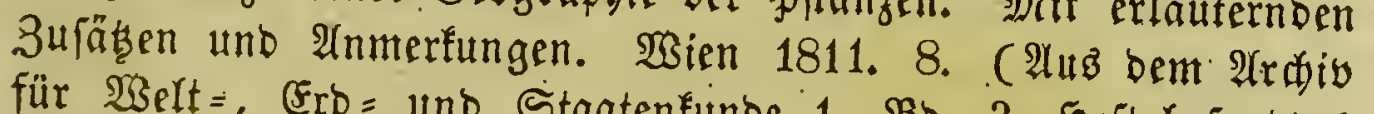

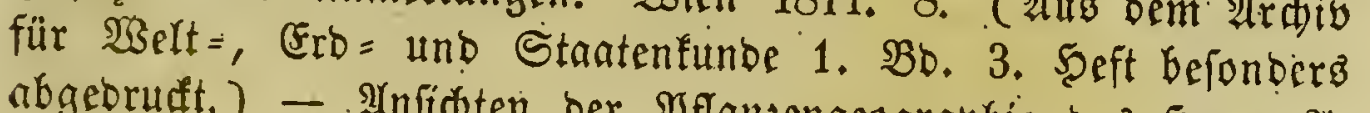

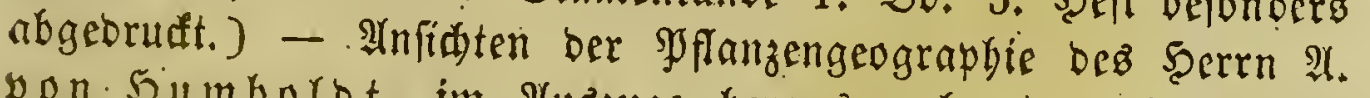

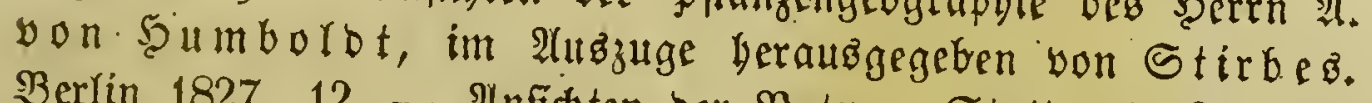
BerYin 1827. 12. - 2unfidten Der Ratur. Stuttgart 1808. 12. 2. 2uff. Daf. 1827. 2 Bbe. 12.

1) Reife Durd Rorwegen und Rappland. Bertin 1810. 2 Illle. 8. 2 Sarten.

2) AUgemeine Heberfidt ber Glora auf ben (Sanarifjen Snfetn. Cine

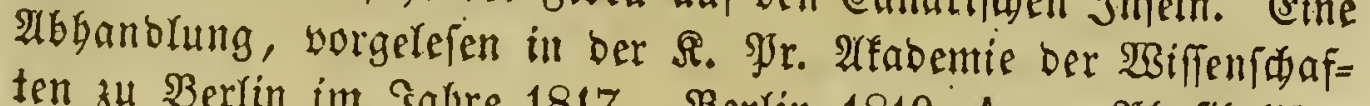

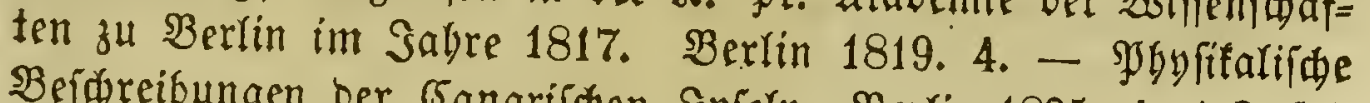
Befadreibungen ber Eanarif Ittras in Fol. 9 Iafeln. S. 105- 199 entbalten eine Heberfidt ber Flora ber Ganarif 


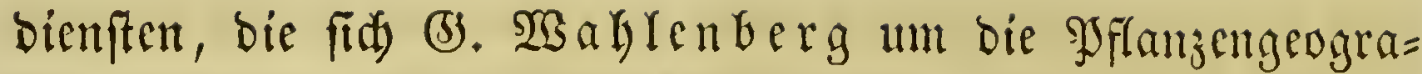
phie burd feine Flora Rapplands, dez mürdidyen Theilez der Sdyweiz and der Siarpathen erworben, ift fidon bie Rebe

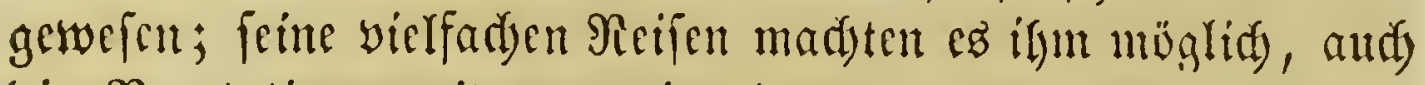
bie Begetation weit yon cinander getremter Giegenden zat vergleidjen; zugleidy war er ez, ber zuerif nuf bie Berjdicben= Jeit ber şflatzemwelt an ben Secfüften mind in. Den Bimnen= ländern himwieb ${ }^{1}$ ). - Robert $\mathfrak{B r o v n}$ fdrieb efrenfalle ïber bic Bertheilung Der SJflanzenfamilien auf ber Erboker=

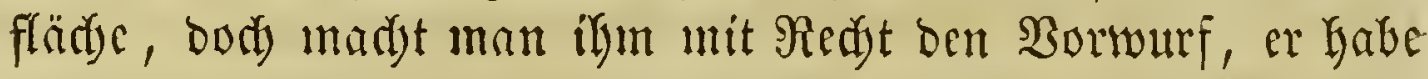

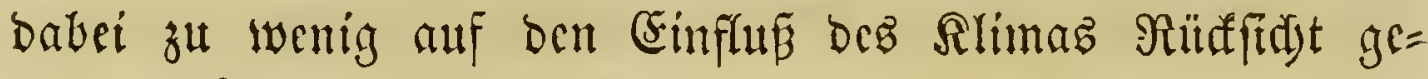
munumen. ${ }^{2}$ )

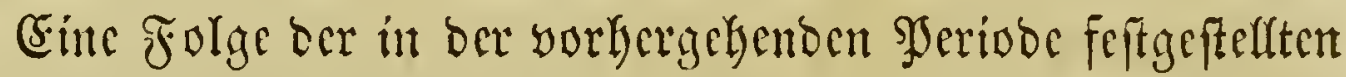

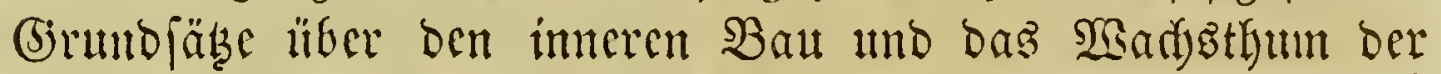

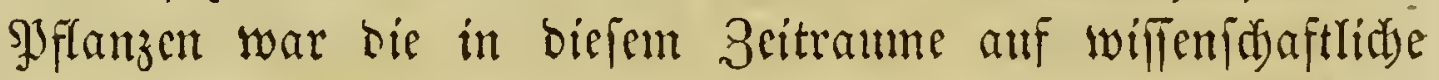

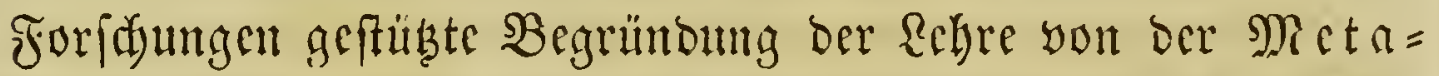

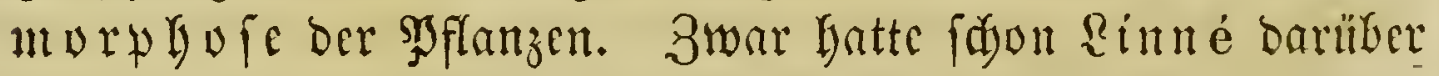

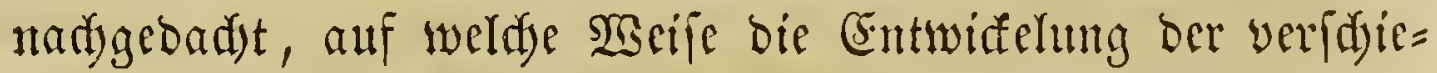
Denen Syflanzentyeile aus cinamor ertlärt werben fümne, uno feine $2\left(n\right.$ fidden bieribber befannt gemad)t ${ }^{3}$ ); aber cr war jut wenig Ânatom uno Sglyyfololog, als baß er hier ftetz bas

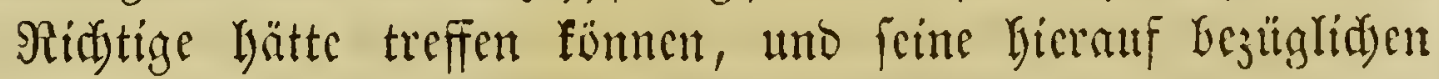

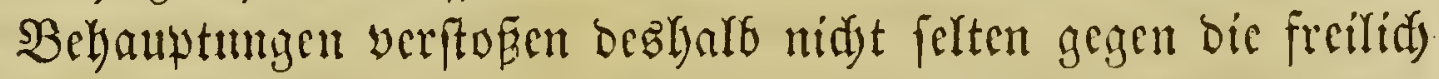

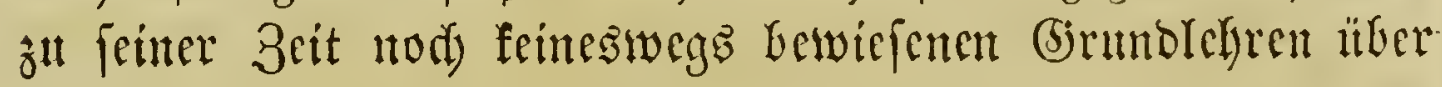

1) Samtidabafifde Raub= und Rebermuoje. (Mingaj. Der Befieffid. naturforichender Freumbe ju $\mathfrak{B} e r(i n .1811 .4$.)

$\left.{ }^{2}\right)$ On the natural order of plants called Proteaceae. London 1810. 4.; audf öl firben in Defifen vermifiten Edfriften B̧. 2, S. $53-246$. - General remarks geographical and systematical on the Botany of Terra Australis. London 1814. 4. 10 tab.; alth in befien yermifiten Edyriften BD. 1 , 5. $1-166$.

s) Metamorphosis plantarum sub praesidio Car. Linnaei proposita. a. N. E. D. Upsaliae 1755. (Amoen. acad. ed. Schreber vol. IV. p. $368-386$.) 
ben intueren Ban ber Getväd)

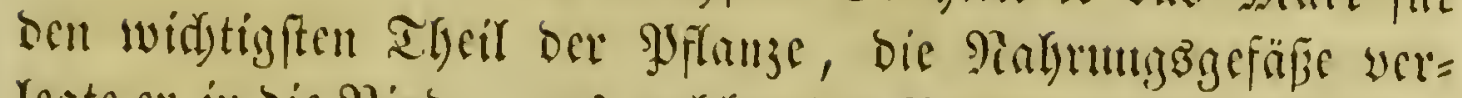

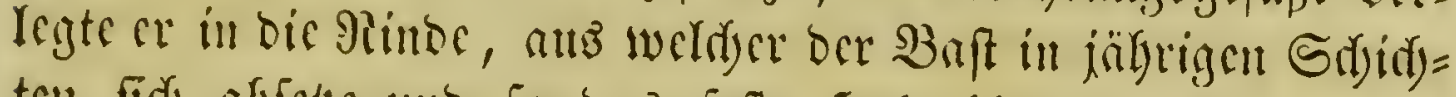
ten fid abferse unb fo bas fefte Jyolj bilde; atte ben eben

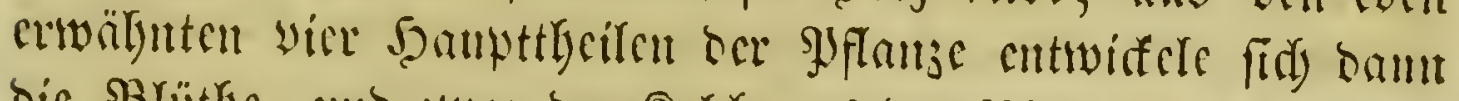

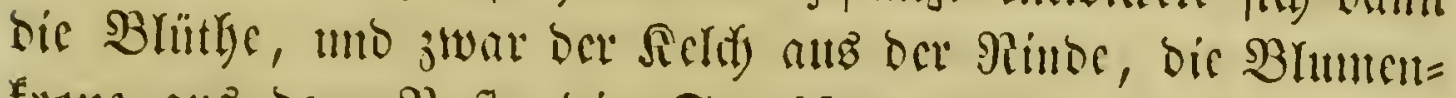
froul aus bem Baft, bie Staubfäben aus bem Seolze unb

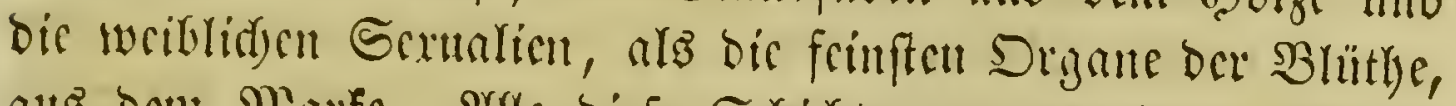

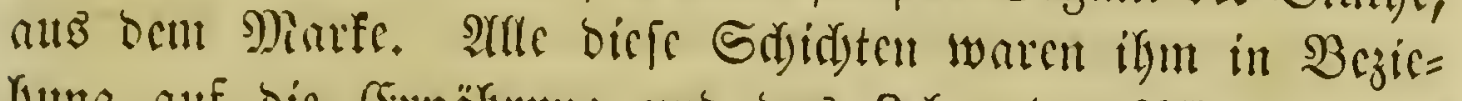
humg auf bie Crmäbrung utb bas Reben ber STftanzen yon

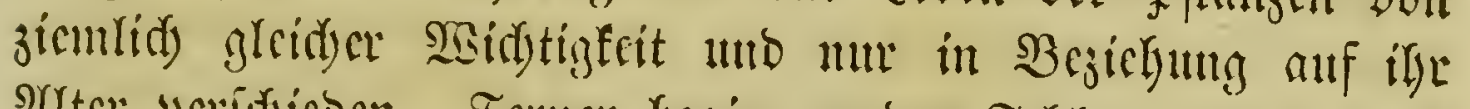

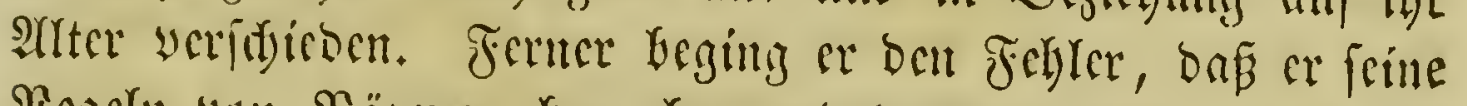

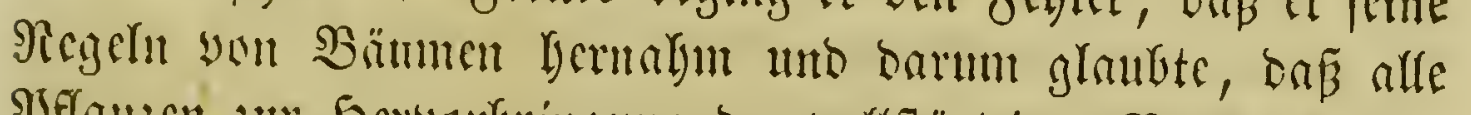

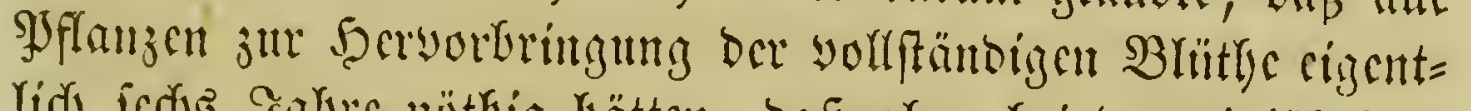

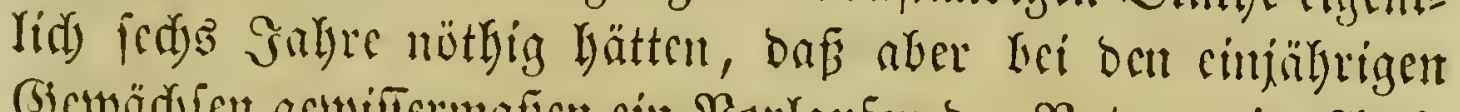
(G) cipation (Jrolewfis) ftattfänos. Sn ben zwei anbern Differ= tationen, welde cinige Gafre fwäter, als bie Metamorphosis

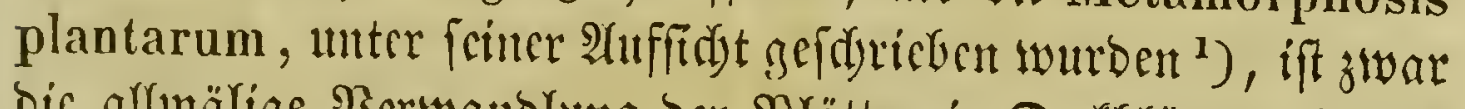
bic allmälige Berwanblung ber Blätter in Deffblätter, in ben Selds, bie Sorolfe zc. Geruiffidtiget, beffentungeadstet aber bie

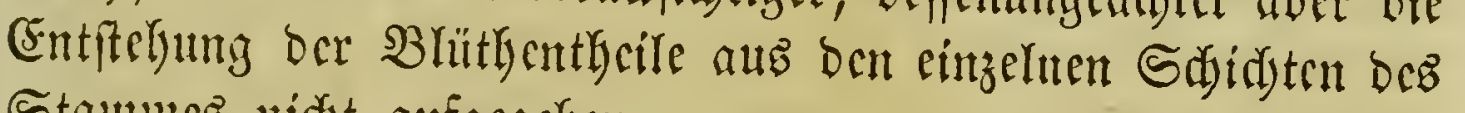
Strumues nidjt aufgegeben.

Biel beftimunter find bie (3runbfäbe, weldye $\mathfrak{x} a \mathfrak{s} p a r$ Jriebr. Ș olff über bie Entwidelung ber cinzelnen Syflanjen= theile auscinander aufftelfte ${ }^{2}$ ). Die $\mathfrak{B l a t f f o r m a t i o n ~ z u t ~ ( S ) ~}$

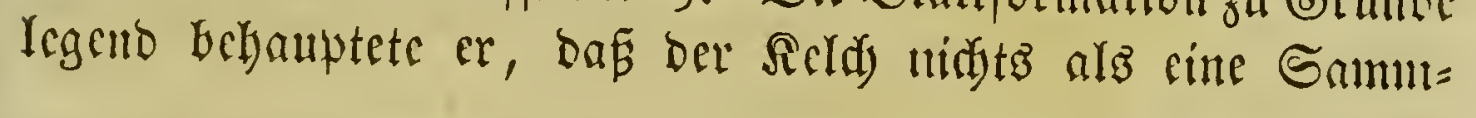

2) Prolepsis plantarum quam praeside Car. Linnaeo proposuit Henr. Ullmark. Upsaliae 1760. (Amoen. acad. vol. VI. p. $324-341$ ). - Prolepsis plantarum quam praeside C ar. von Lin né proposuit auctor Joh. J a c. Ferber. Upsal. 1763. (1. c. p. $365-383$ ).

2) Nov. comment. acad. petropol. Tom. XII, pag. 403. Tom. XIII, p, 478 et seq. 


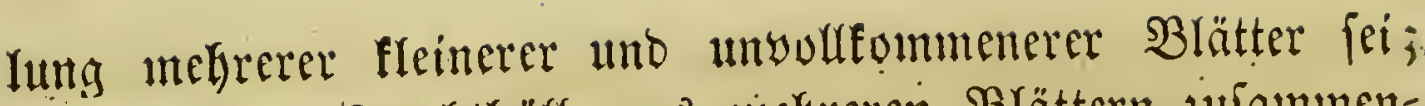

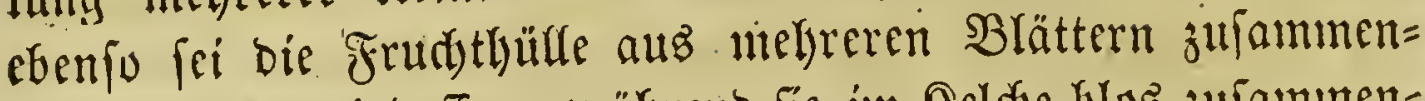

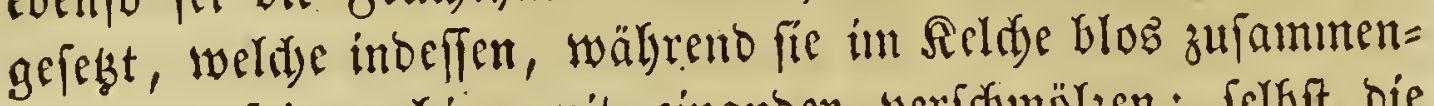
gebräugt feien, bier mit cinander verfidumölyen; felbft bie Samen beftänoen auz yerjdumolzenen Blättern; benn fobalo biefelben ber (Erbe auvertraut wülden, verwandelten fits bie unförunlidjen umb faftlojen Samenlappen in vollfommene, grüne, faftige Blätter; aber aud) bie Blumentrone fei aus Der Bereinigung mobificirter Bä̈tter entftanden, wab fidy

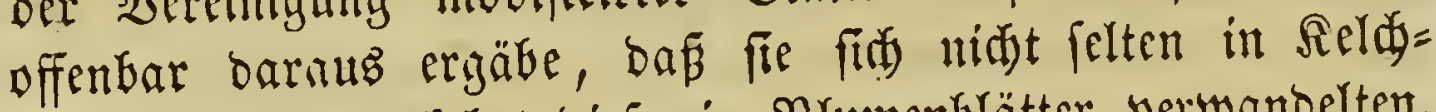
blätter und umgefehrt biefe in Blumenblätter verwanbelten.

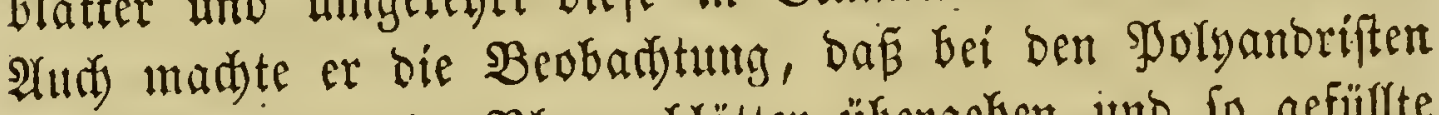
die Staubjäben in Blumenblätter übergeten uno fo gefüllte

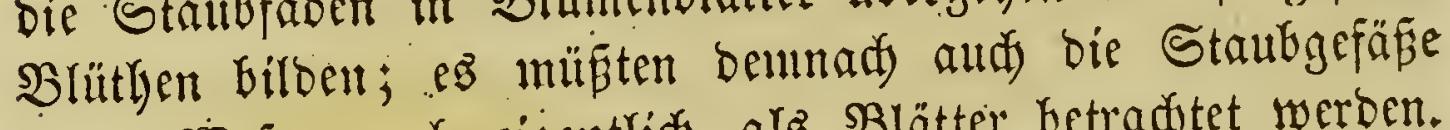

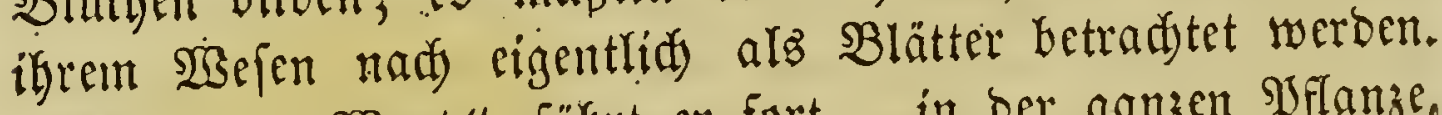
" Mit einem SSort", fäbrt er fort, "in ber ganzen MJflanze,

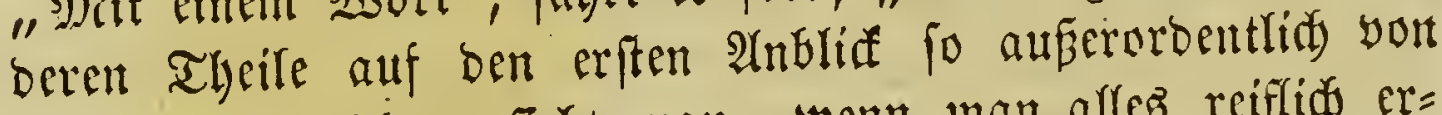

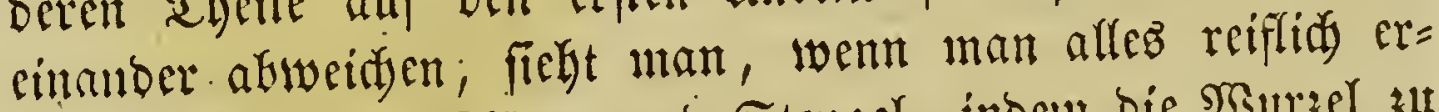

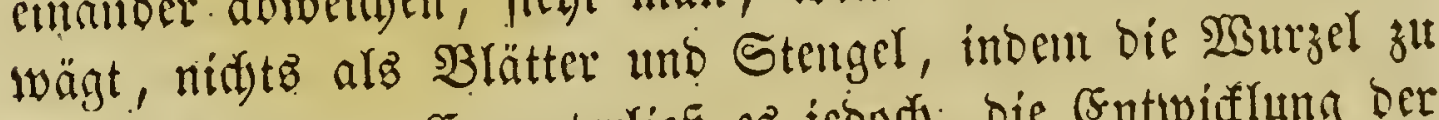

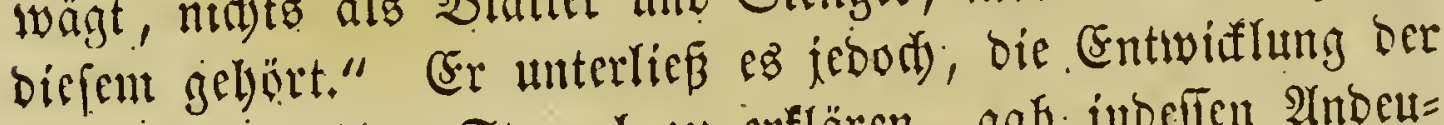
Silätter aus bem Stengel zu erflären, gab intoefen 2 (nbeu= tuingen, wie man bies and himnieberum bie (Entftellung bes

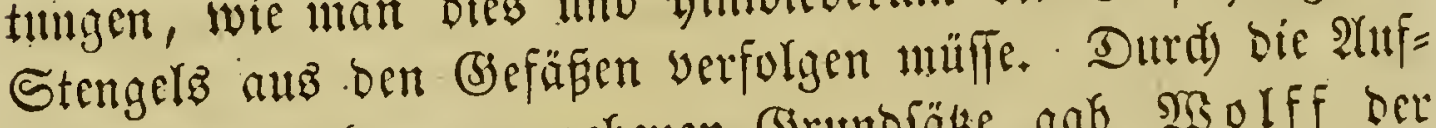

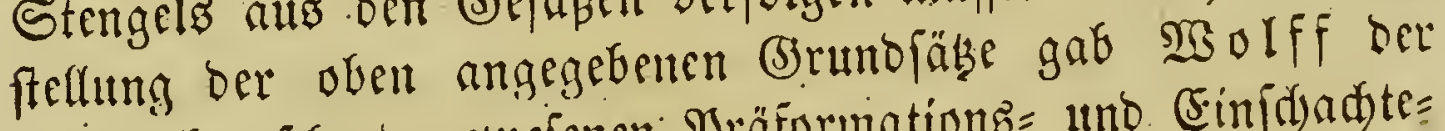
feither herrfdento gewerenen Sräformationg= uno. Einjdyades Iungstlyeorie cinen gewaltigen Stop. Dod beging er be:t

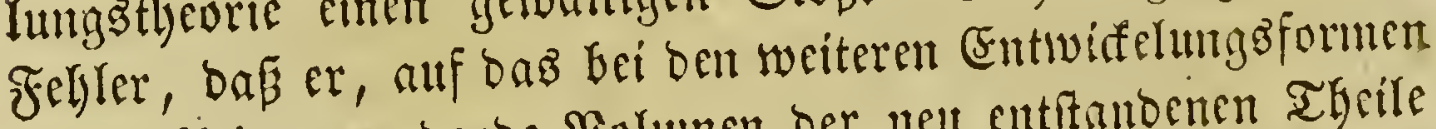
immer fleiner werbende $\mathfrak{B o l u n e n}$ ber neu entiftandenen $\mathfrak{T}$ heile

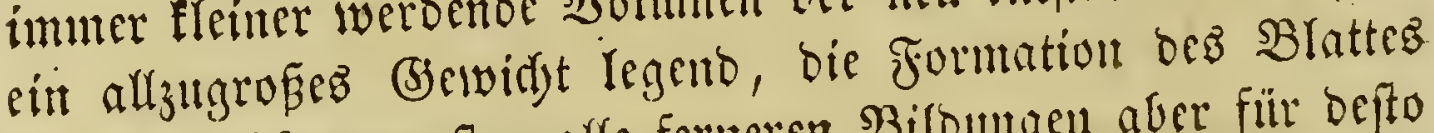
ałs bie yolffummenfte, alfe ferneren Bildumigen aber für befto unyolffommener bielt, je weiter fie fird you ber (seffalt bes eigentlidyen Blattez entfermen, umb nidyt beadytete, bar bie fpäteren Metamorkhofen immer feiner uno coler werben.

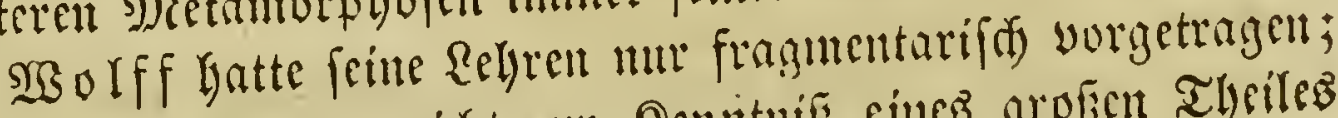

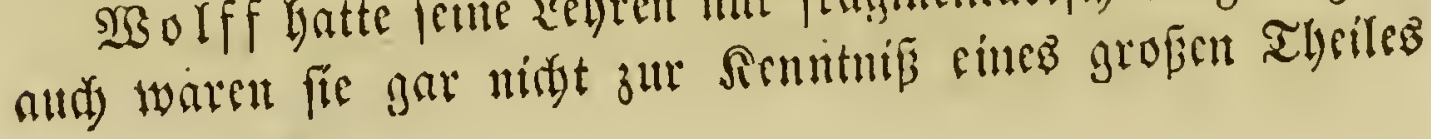


Der Botanifer gcfoumen. Son Bufammenlange aber, fdgün und anjieflent fülyrte unfer groper Didjter

\section{Goh. WOUlfgang you. (5) B̈the}

bic Mictamorthofe der Sylanzen auz ${ }^{1}$ ), und ift barmm alz

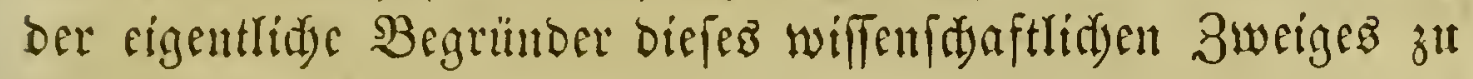

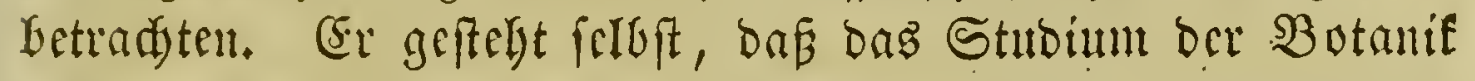

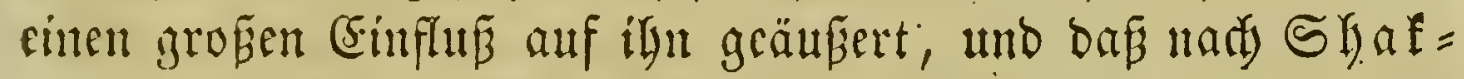
fpeare unto Spinoza bie gröpte Sairfung anf ihn yon

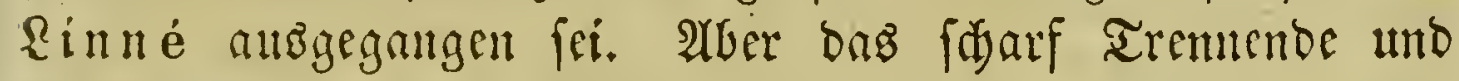

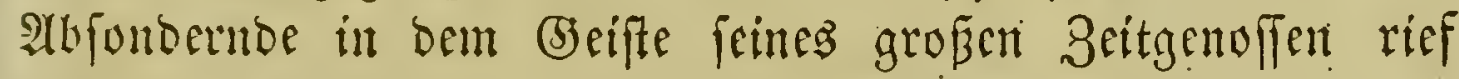

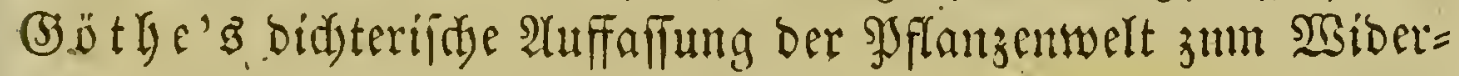
ftreite auf"; "Denu", fagter ferbit, "bas swas Rinné mit (5)e=

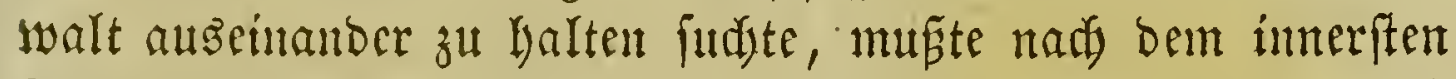

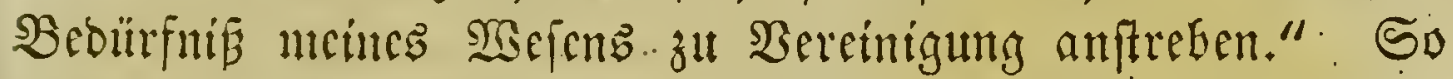

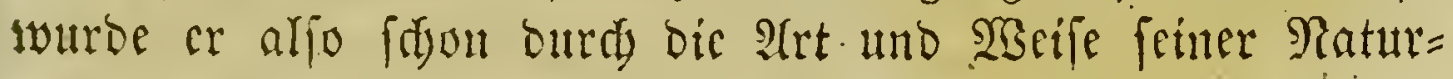

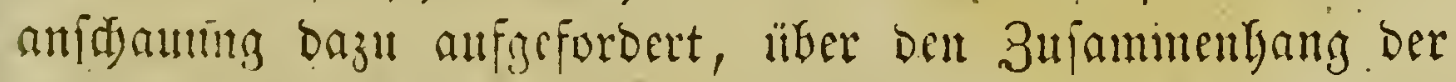

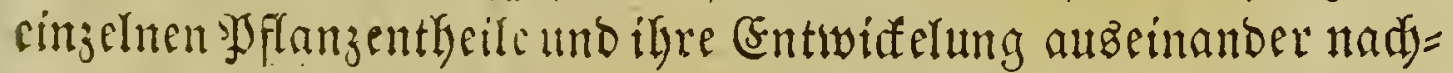

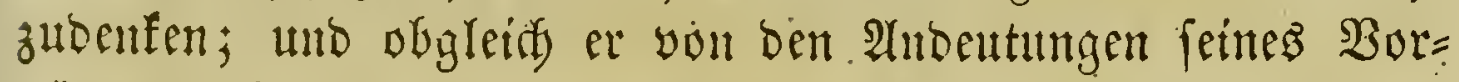

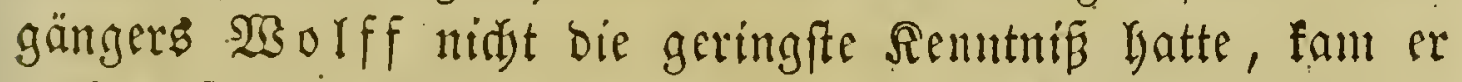

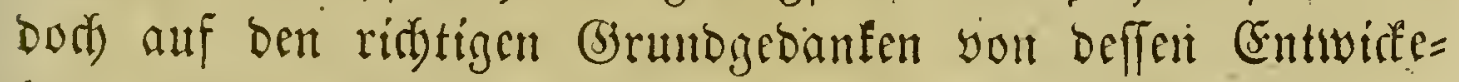
lungstheorie. H(ber er legte nidgt, wic $\mathfrak{B}$ olff, bie formation

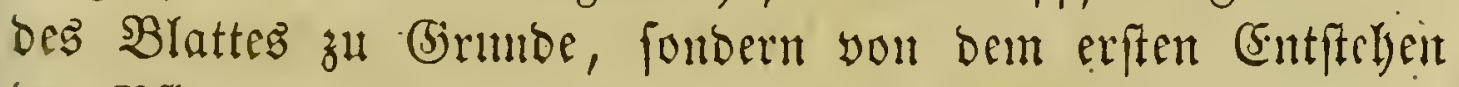
ber Wfflanzen, yon bem Servorfunmen ber Samenlappen an, werfolgte er bas fernere Sisadysthum bis zur yollftändigen (sitt=

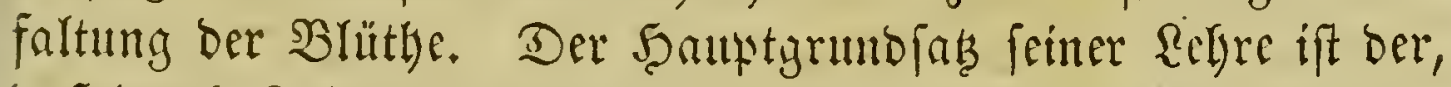

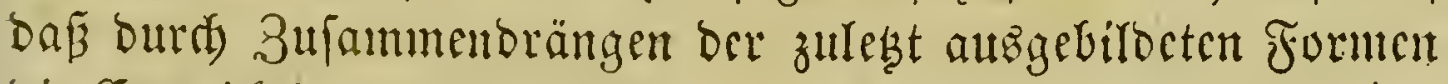

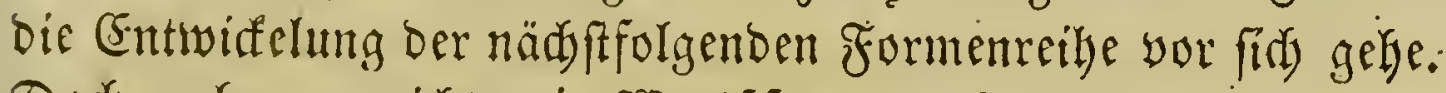

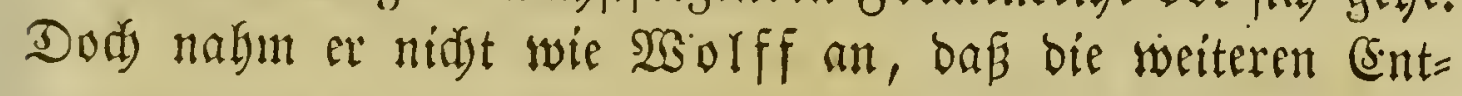

1) Berfuch, bie Metamorpgofe ber Mffanjen zu ertlären. Botba

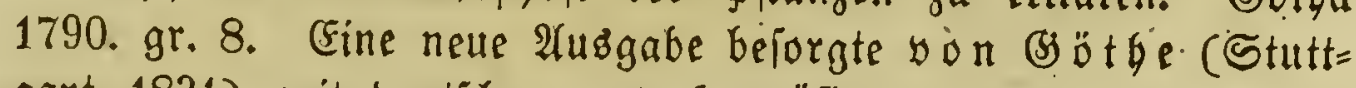
gart 1831) mit bentifdem und franjöfifidem $\mathfrak{I}_{\text {exte }}$ und mit ge=

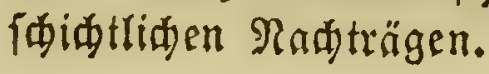




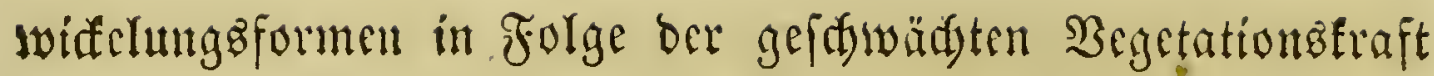
fid inmermebr an $\mathfrak{B o h m}$ en vermindern, fondern er ftelle ben Sals auf, onf die ergengenden Sin̈fte, yon ben rofyeren Stuffen

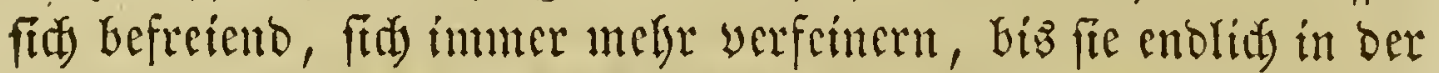

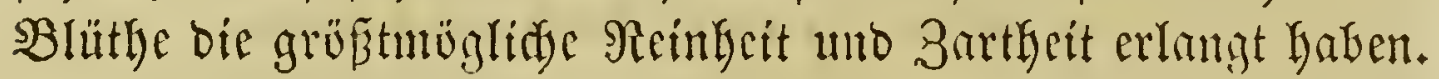

Die Botrnifer betradteten (s) öthe als Dilettanten uno

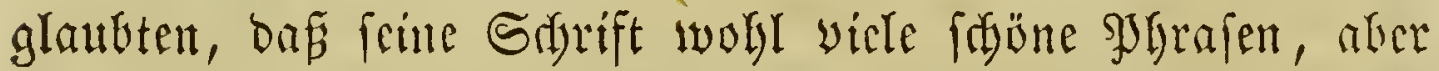

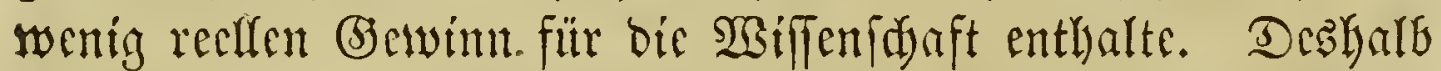

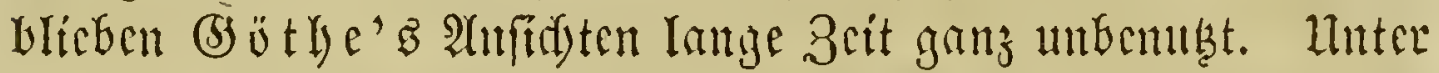

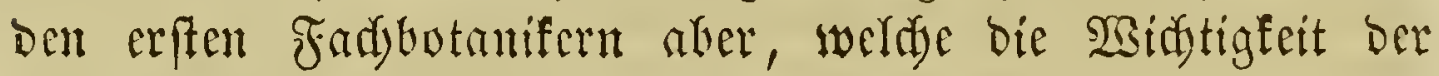
Metamorphofenlehre erfanten, iff Fricbridy Sicgmunt

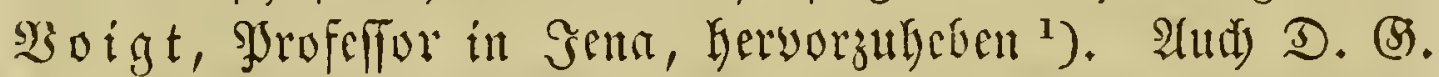

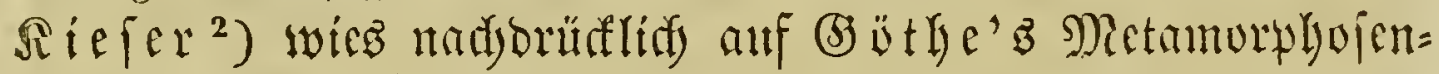

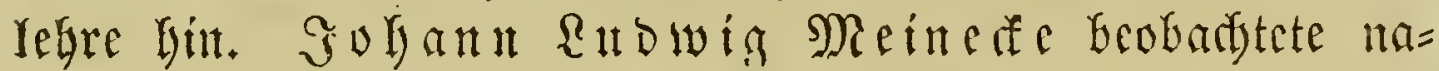
mentling bie Berivandififaft ser Staubfäben uno Blumenblät=

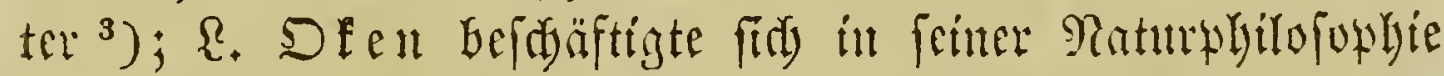

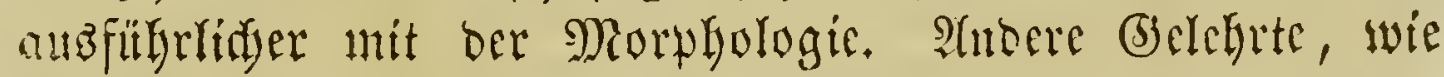

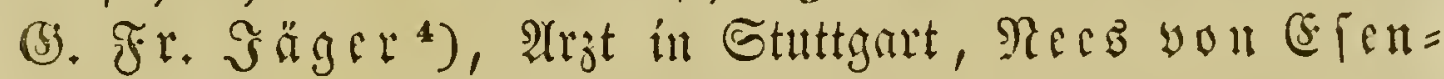

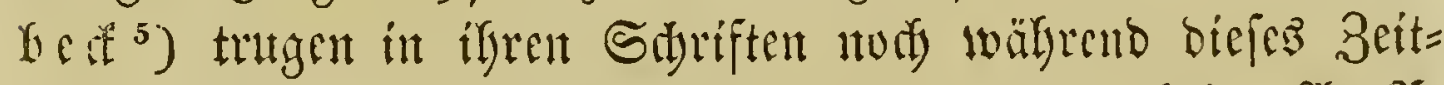

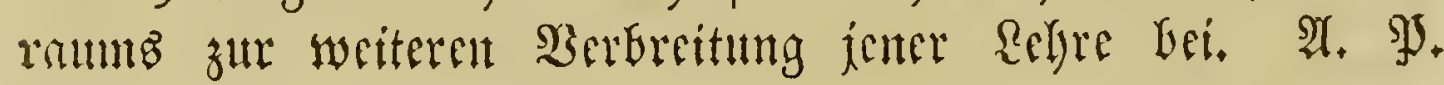

1) Syftem ber Botanif. Sena 180S. 8. 4 Tafelur. Sm Sabr 1827

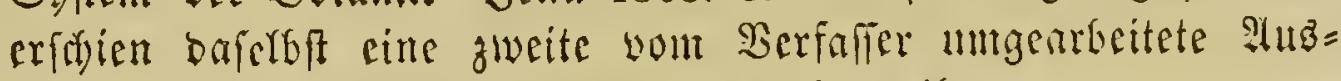
gabe unter bent Titel: "Pegrench Der Botanif."

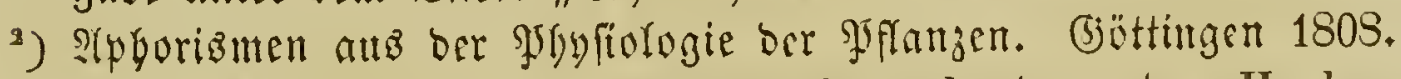
8. - Mém. sur l'organisation des plantes etc. Harlem

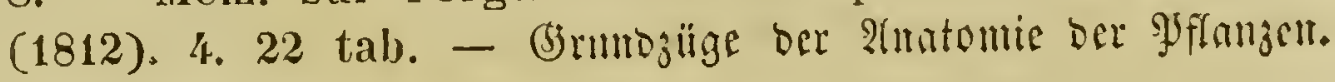
Jena 1815. 8. 6 Iafeln.

3) Iteber bas 3ablenverbärtmín in ben Fructificationsonganen ber

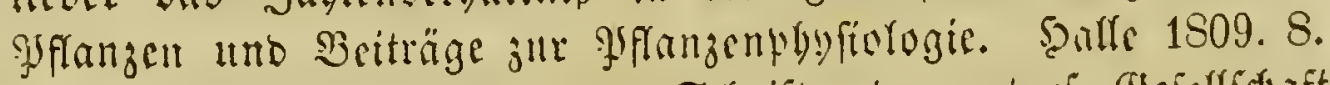

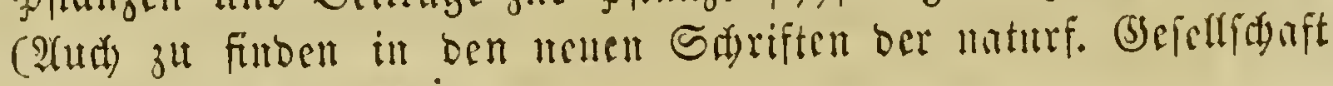
fit Saalfe illt 1. Soeft.)

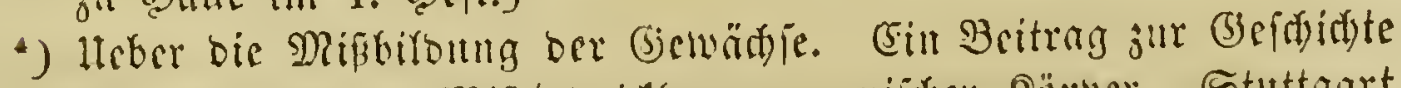
umb Theorie ber Mifiéntwitflung organiider Sïrper. Stutgart 1814. 8. $2 \mathfrak{T a f f r i t}$.

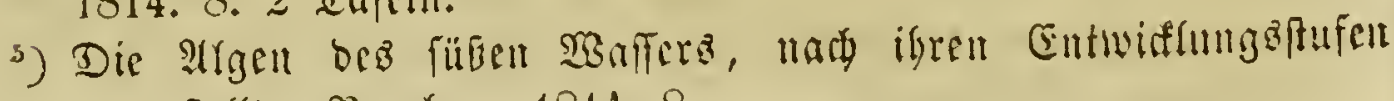
Dargeftert. Samterg 1814. 8. 


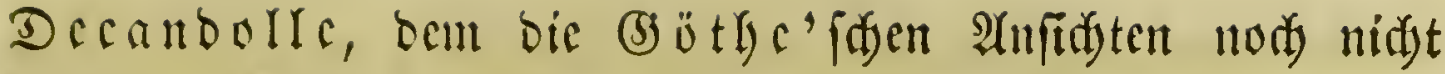
Gefannt geworocu waren, ftelfte in feincr Théorie élémentaire de la botanique ${ }^{1}$ ) S. $94-123$ dic Refre you ber Symmetric ber Sriganc auf; bic A(bweidumgen von biejer Symutric mannte er Dejenerescenjen (erreurs) mno makm als Mrjadic berjelben bas Feblidjlagen (avortement) und bas 3 crwadjfar (adhérence) ant. In feiner Organogra-

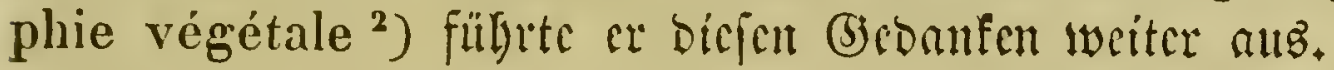

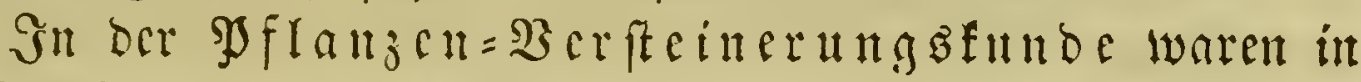
bicfun 3eitrame manentlid (5) ruft Friebrid) yon Sdlot=

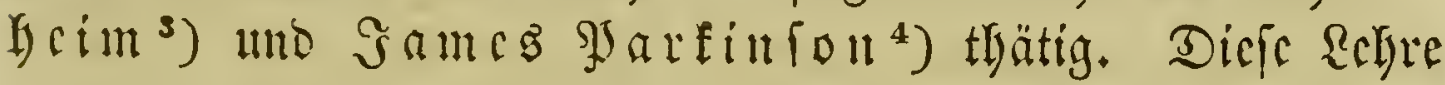

1) Théorie élémentaire de la botanique, ou exposition des principes de la classification naturelle et de l'art de décrire et d'étudier les végétaux. Paris 1813. 8. - Ed. II.

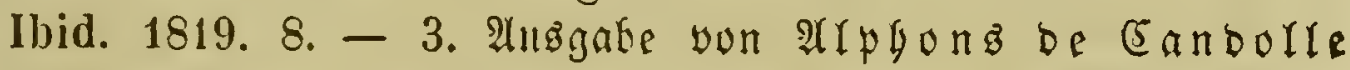

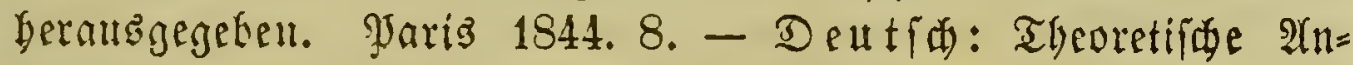

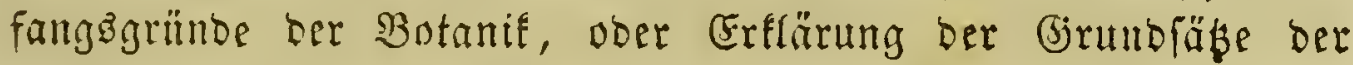

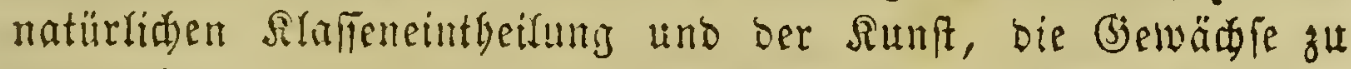

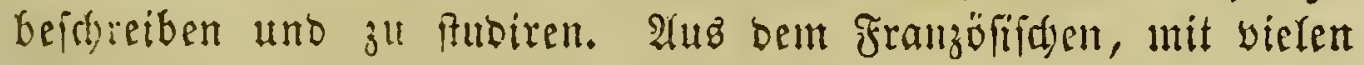

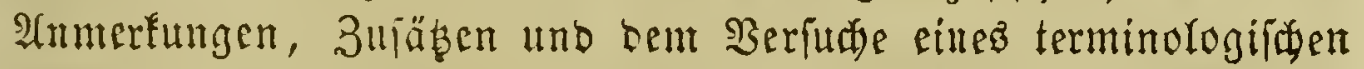

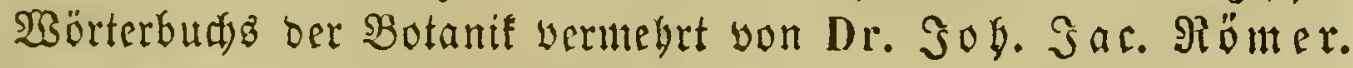
3ürid $1814-1815.2$ Bbe. 8. 1 Tafel.

2) Organographie végétale ou description raisonnée des organes des plantes, pour servir de suite et de développement à la théorie élémentaire de la botanique et d'introduction à la physiologie végétale et à la description des familles. Paris 1827. Il voll. 8. 60 tab. - Delltfd):

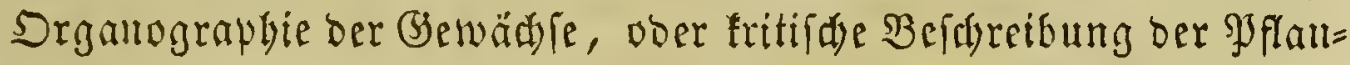

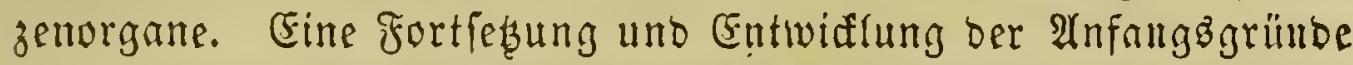

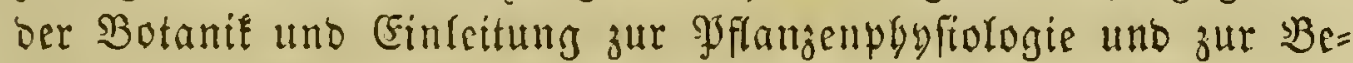

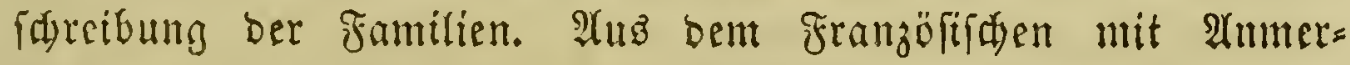
fungen yon $\Re$ arl Friebri申 Meisner. Stuttgart 1828. 2 Boe. 8. 60 Tafellt.

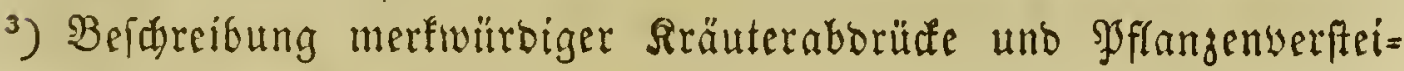
merungen. Cin Beitrag zur Slora ber Berwelt. Erfte Áthei= lung. Botba 1804. gr. 4. 14 Tafér.

4) Organic remains of a former world. London 1811. 3 voll. 4. 9 tab. col. 2 tab. nigr. 
wourbe jebod) erfit in folgenden Zeitraume ausigebiloet, uno wir werben barum bie Befdidde berfeleen bort in 3 ufammen= Jange darftelfen.

Butanifde (b) ärten wurben angelegt zu Roftod (1795), Rancy (1802), (5) enta (1802); Dorpat (1802),

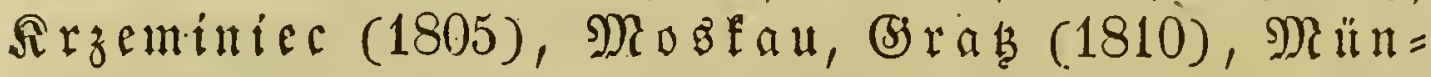

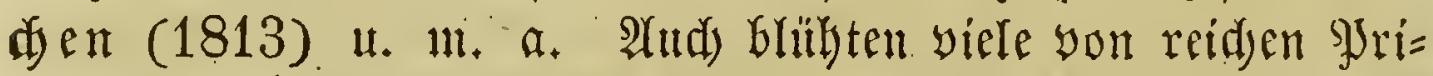
yaten unterbaltene (5ärten, yon benen fay mebrere erwähnt worben finb.

Unter ben Gelebrtenwereinen, weldye igre meifte IGätigfeit Dor Botanif zuwanden, ift yor allen bie fdjon $\subseteq$. 342 be=

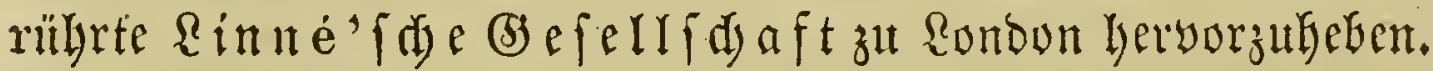
Seit 1805 beftand aud) eine (bartenbaugefellidaft ba=

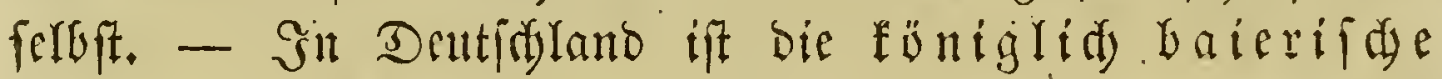

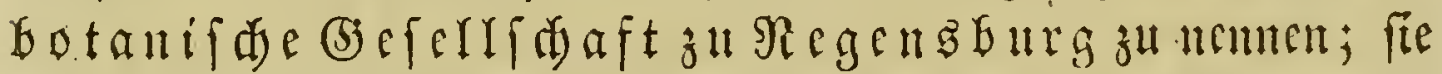

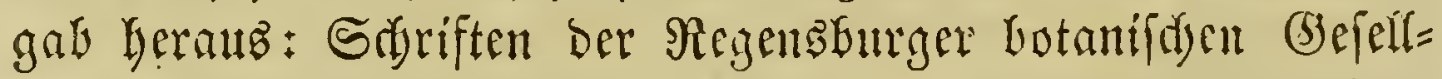

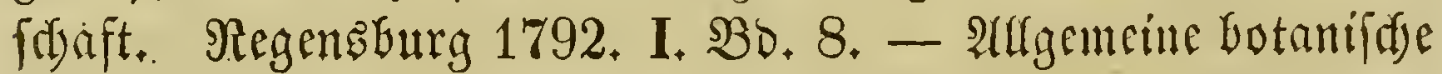

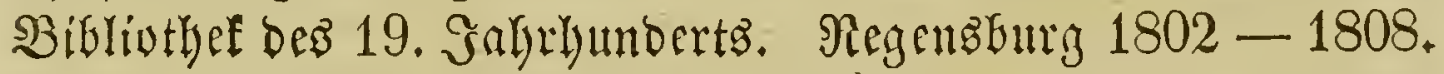

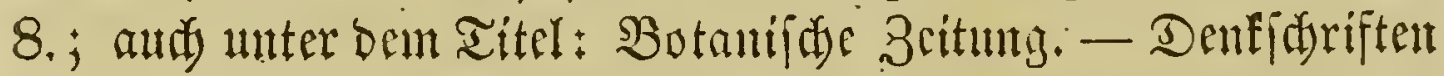

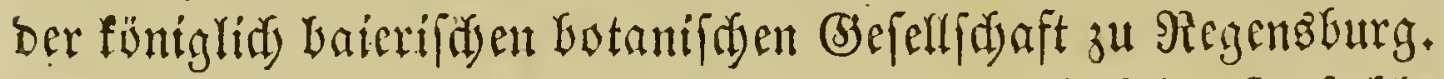
Regensburg 1815, 4. - Die whytographifde (5) efell=

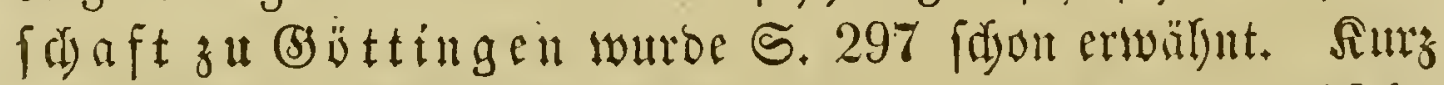
nad) berferben (int Jabre 1805) wurbe antí bie botanif be

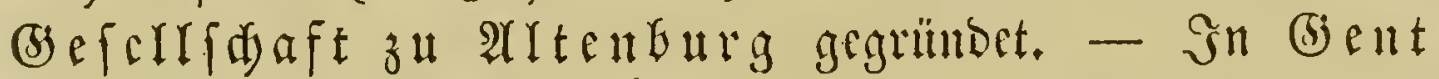
rirfocte fid bie Société botanique. - Bon ber phytogra=

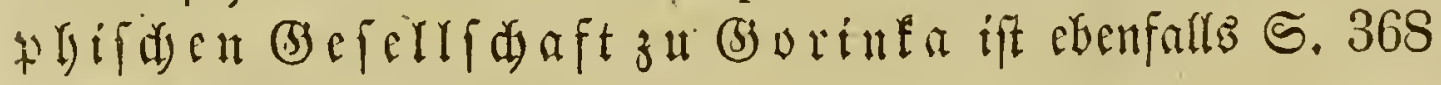
figon die Rebe getwefen.

Bon ben butanifden Zeitfidriften, weldye wälyreno biefez

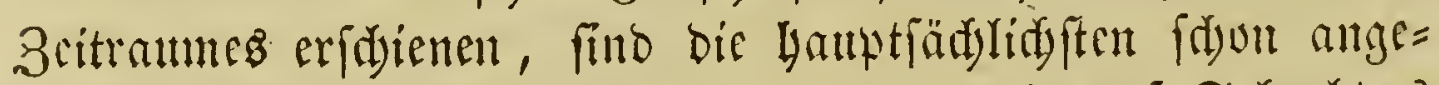

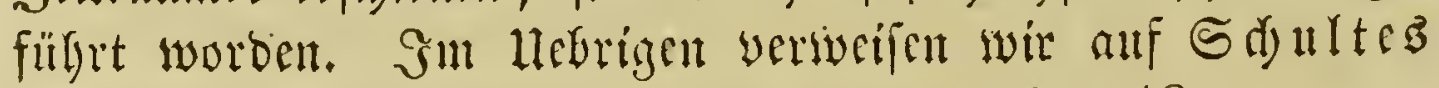
Berfud) ciner (Sefdyidte ber $\mathfrak{B o t a n i}$ S. $14-18$. 


\section{Die uturfite 3rit.}

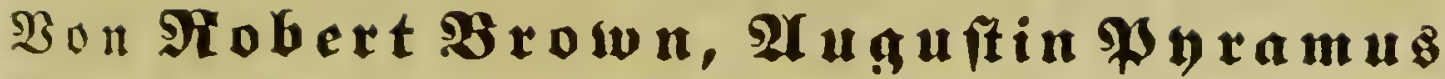 Decandolle und aletandevon sum: boldt bis auf die (5)genwart $(1817-1850)$.}

Scinc yon allen früberen \$scroben lyatte auf bie Botanif

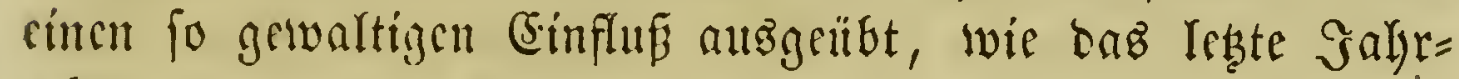

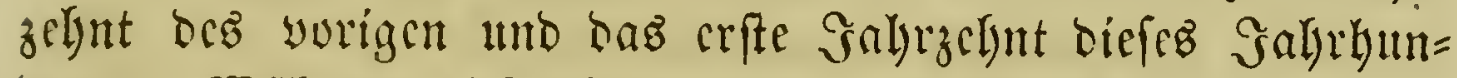

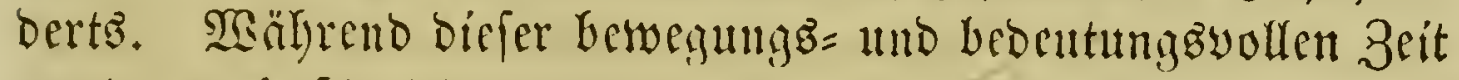

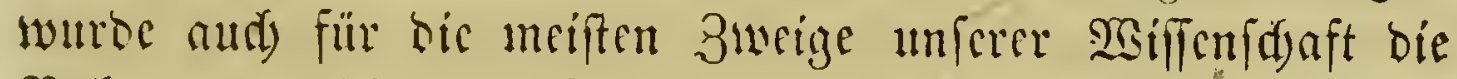
Bailn yorgezcidjnet, auf weld)er ihre jufimftige Beryolufomm= munj zu crzielen fein willde. Die Ridjtung, weldse bamals begounen wurbe, if nod frincsivegs abgeidloflen; biz allf bie ncuefte 3rit war es. Die Aufgabe der Botanifer, die $b a=$

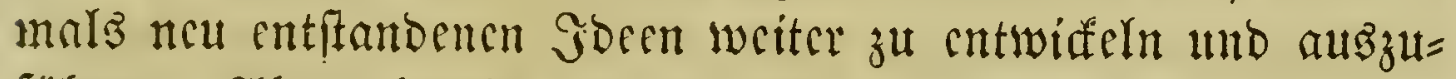

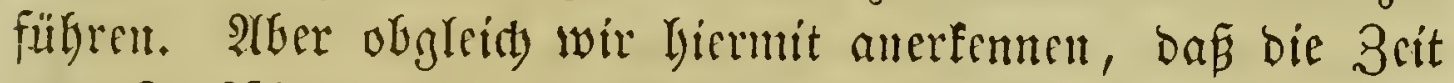
yon $\Im$ uffiea bis auf bie Giegentwart nur als cine cimzige unb ungethrilte Entwiffelumgsperivor ber Botanif angefehen wecrocn barf, laben wir es bod) für nüthig eradstet, ber be= nuemeren Ueberfidjt wegen béfflbe in zwei ungefähr gleidyat Sälften zu beljandeln, unb wir glaubten bicfe (Fintheilung nidjt auf würbigere $\mathfrak{S e i f e}$ bewerfitelligen zu fümen, als weun wir dic (Epodye oer lyauptfäd)lidjfen SBirfiamfeit ber brei grofent Raturforfder Robert $\mathfrak{B}$ rown, A. P. Defandorle und Alex. yon 5 umbolot, Der Repräfentanten ber nuf bem

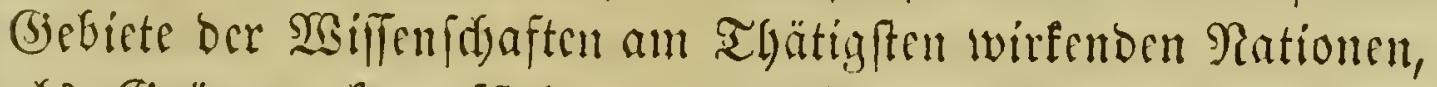
als Giränzıarfe auffellten. Die Berbienfte diefer Forider, swem aud) nur furz uno im Allgemsinen, zut witrobigen, foll bartun lier umfer nädjter 3wat fcin. 


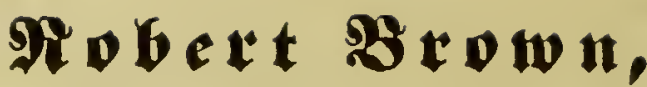

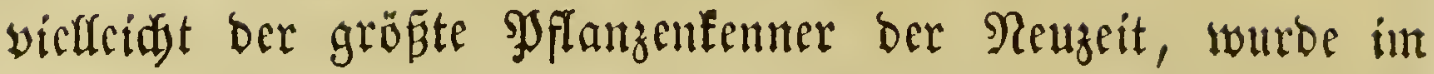
Jahre 1781 geboren. (Er fdeint fid fdyon als fegr junger Mann burd feine botantíd)en Renntniffe ausgezeidyet zu haben; benn foun elje er baz zwanzigite Rebengialjr erreidjt hatte,

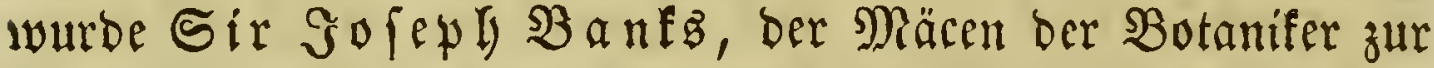
Damaligen 3 eit, auf ifn aufmerffam uno berwirfte, bas er zum Botanifer ber Expebition beftimmt wurbe, weldye unter Der Fülyrung Des Rapitän Flinbers im Galure 1801 bie

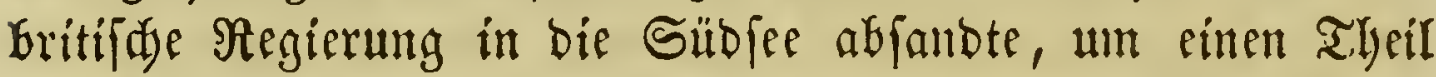
ber Rilfte Reufjolfanos zu unterfudyen. Da aber bas fabr= zeug ber. Expedition unbralld bar getworben war uno frin= Ders Dezhalb zur Serbeifdaffung einez anderen Sdiffes nady

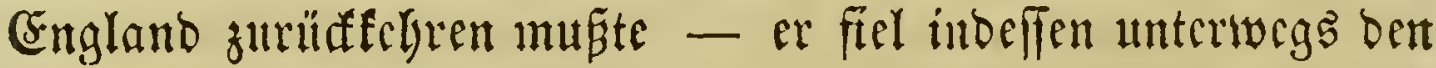
Franzofen in bie Şände und unutbe melgrere Jaljre lang itt Szle be France gefrngen gehalten, - fo blieb Brown int

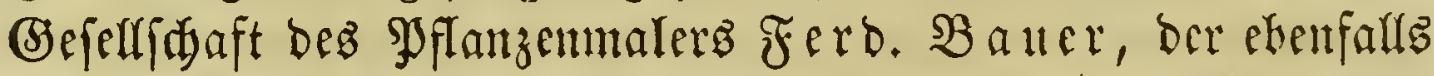
bie Expebition mitgemadyt lyatte, in Reufjollano zutüă, madyte

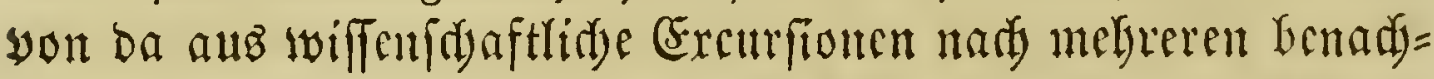

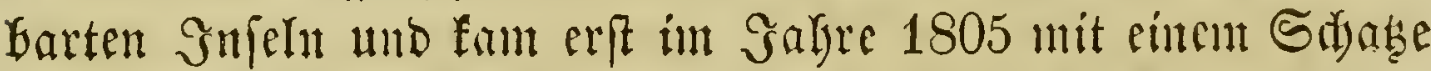

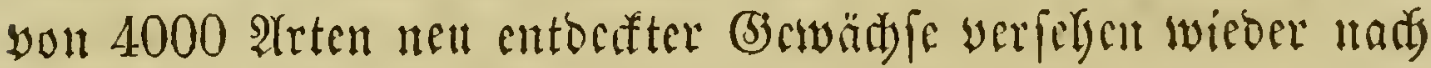

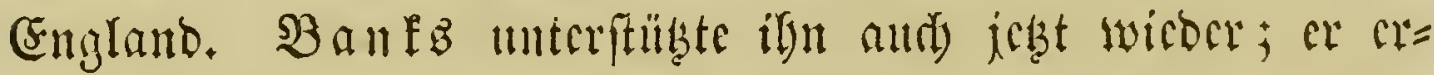

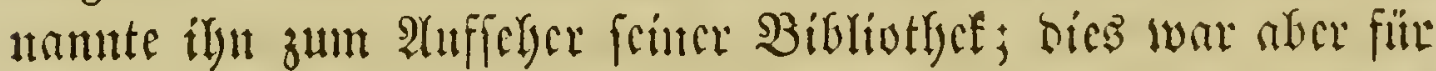

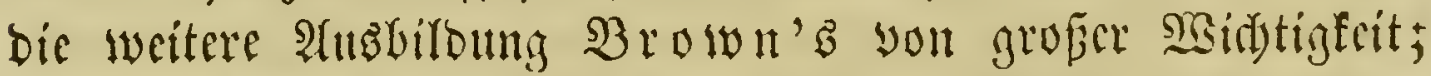
bemt in feiner antoren Stelfung bätten ify fo grope bullf: $=$ mittel zum Stubimm ber Botanif gevotent werbent fümen. Pind =

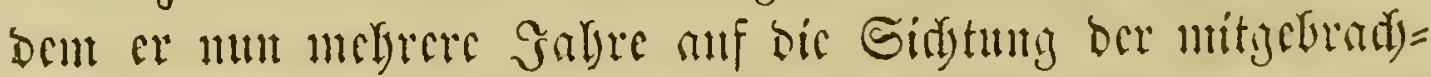

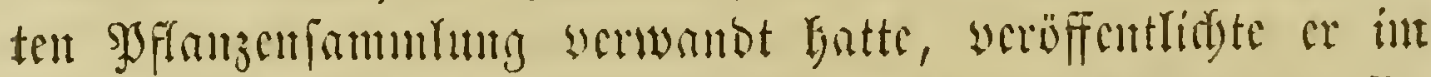
galjee 1810 f́ncu Prodromus florae Novae Hollandiae ${ }^{1}$ ).

*) Vol. I. Londini 1810. 8. ( $S e f r$ feftem.) Ed. nova (1S21). 4. - Edit. III curis Chr. Godofredi Nees ab Esenbeck. Norimbergae 1827. S. 


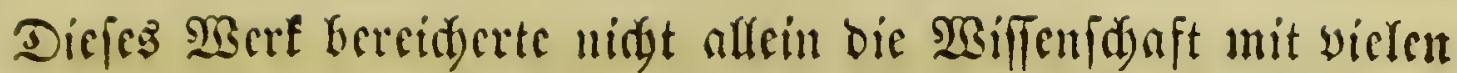
frither unlefannten झुflanjenarten, fondern ber Berfaffer be= gaun bamit aud) cine neuc Methode Der Mflanzenbefdreibung,

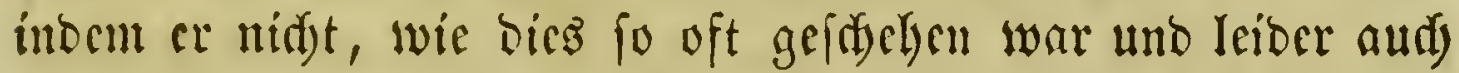
ject nod) oft gentig gejdyicht, eine Maffe yon Eingelnheiten

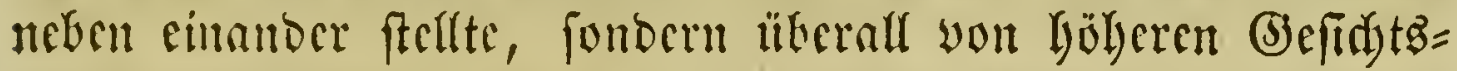

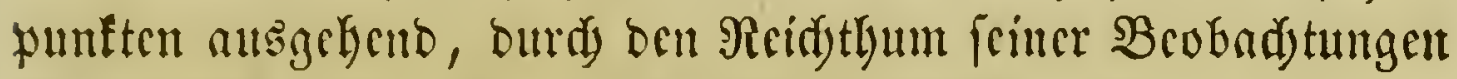

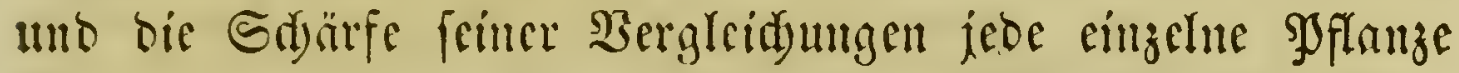

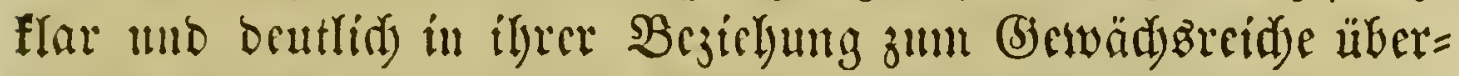
Gaupt auffät mo barfellt. Man fann barum mit Redjt be= Gaupten, baj dicje Sifurift ber \$ghytographie cine neue $B a h n$

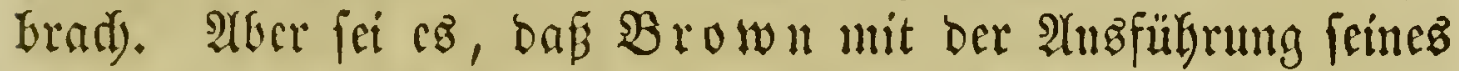

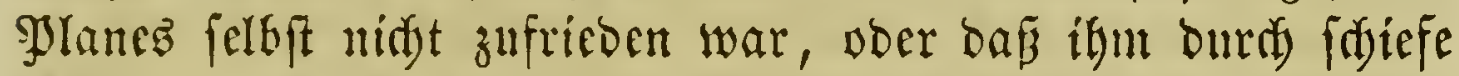

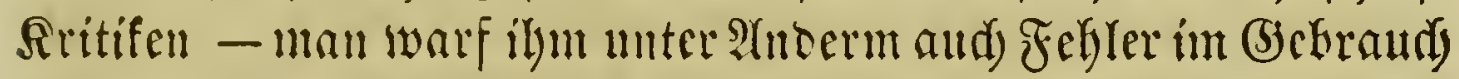
ber Inteinijden Spradje vor - wirflid) bie weitere Bearbeitung beffelben verleibet warbe: arft und cincm 3citraume von 25

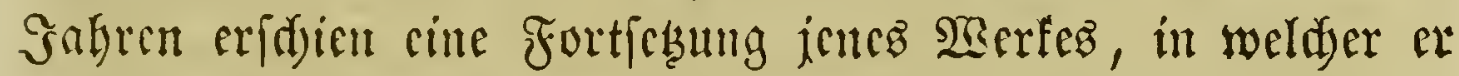

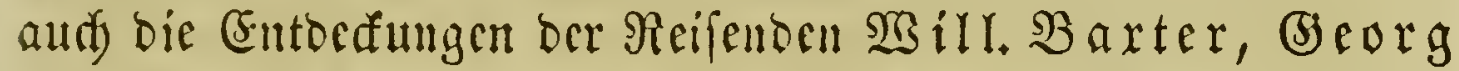

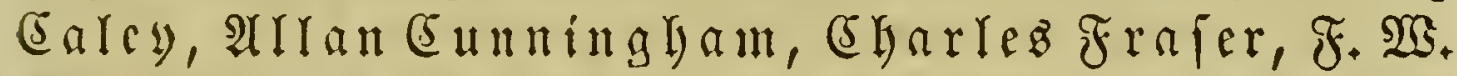
Sicber u. A. Gerüdfidtigte ${ }^{1}$ ), Șährent diefer 3eit abcr

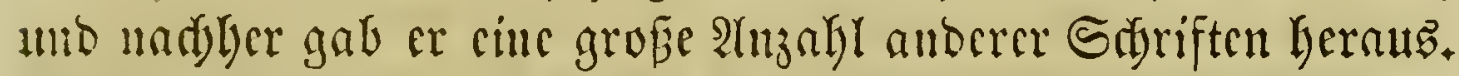
Faft alle bicje bejichen fid zivar zunäd) ant ausländifide

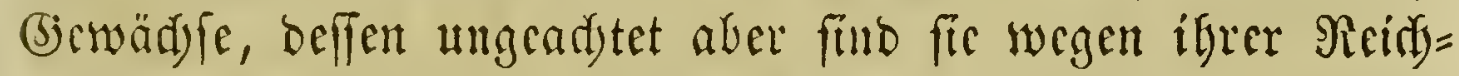

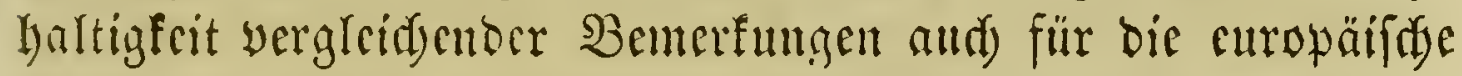
Flora yon groferer Beocutung. So befdrieb er bie won Fra fer am Sdwanemflutic ${ }^{2}$ ), dic won (Shriften Smith am

') Supplement. primum Prodromi Florae Novae Ilollandiae, exhibens Proteaceas novas quas in Australia legerunt DD. Baxter, Caley, Cunningham, Fraser et Sieber, et quarum e siccis exemplaribus characteres elaboravit, Londini 1830.8.

2) Character and description of Kingia, a new genus of plants found on the south-west coast of New-Holland: with observations on the structure of its unimpregnated ovulum; and on the lemale flower of Cycadeae and Coniferae. 
(congoftrome ${ }^{1}$, won Dubney, (S Iapperton uno Denham

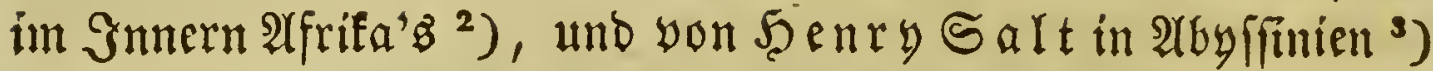
gefammelten Syflanzen; autid veröffentlid)te er bie von $\Re$ oB, IJarry, Giv. S'abine und Fifder auf ber Melwille's=

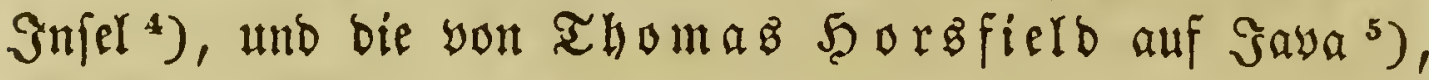

S. 1. 8. 1 tab. Finbet fí aud in Den vermifaten Sqriften $5 r$ Bb. S. $301-312$.

1) Observations systematical and geographical on the Herbarium collected by Professor Christian $\mathrm{Smith}$ in the vicinity of the Congo, during the expedition to explore that river under the command of Capt. T uckey in the year 1816. London 1818. 4. - Jranjöfif : Jarí 1818. 4.

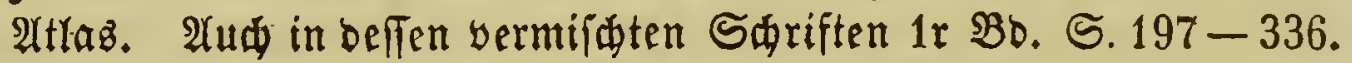

$\left.{ }^{2}\right)$ Observations on the structure and affinities of the more remarkable plants collected by the late Walter $\mathrm{Oud-}$ ney, M. D. and Major Denham and Captain Clapperto $n$ in the years 1822,1823 and 1824, during their expedition to explore Central Africa. London 1826. \%. $\mathfrak{A} u \mathfrak{d}$ in beffen vermifiten Sdriften $4 \mathfrak{r} \mathfrak{B} b$. S. $1-74$.

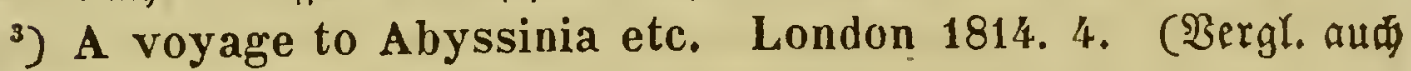
bie bot. 3eitung Jabrg. 1821. 1. BD. Beil. S. $61-64$.

-) Sermifite Squiften 1r $\mathfrak{B b}$. S. 551 - 558. - List of plants collected on the coasts of Baffins Bay and the Possession Bay. s. l. et a. 4. (From: A voyage of discovery in H. M. ships Is a bell a and Alexander, by John Ross. London 1819.) - Chloris Melvilliana. A List of plants collected in Melville Island in the year 1820 ; by the officers of the voyage of Discovery under the orders of Captain Parry. With characters and descriptions of the new genera and species. London 1823. 4. 4 tab. Bejon= bers abgebrutt aus: A supplement to the Appendix of Capt. Parry's Voyage for the Discovery of a north-west passage in the years $1819-1820$, containing an account of the subjets of natural history. London 182\%. 4. No. XI, p. CCLIX - CCCX et tab. 3-6.) Deutifi) Bon (5) uf ay Sunze in Flora 18'24. Bcilage p. $65-115$.

5) On Cyrtandreae. London. March 1838 - December 1839. Fol. $\mathfrak{n}$ Dr. Horsfield's „Plantae javanicae rariores." 
Imb vou $\mathfrak{A}$ f el in (Shita ${ }^{1}$ ) gemaditen (Entbedungen und war

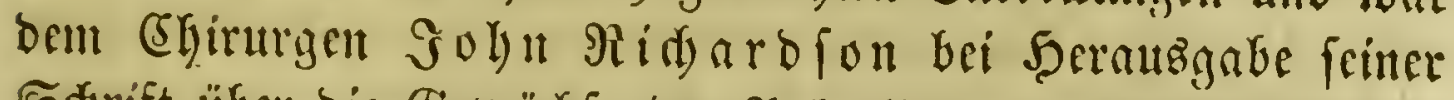

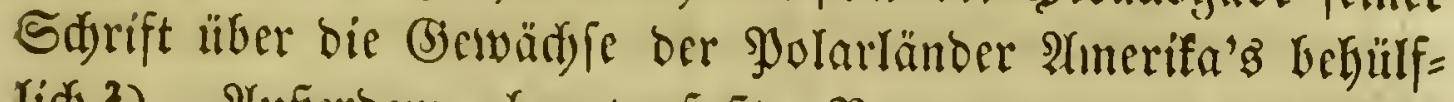

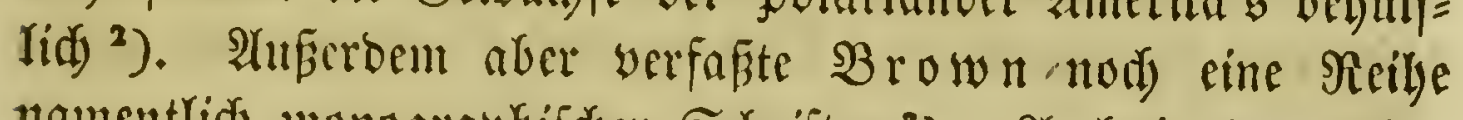
mamentlid) monographifder Sdjriften ${ }^{3}$ ). 2(ud) in ber \$ghy $=$

- Pterocymbium, with observations on Sterculieae, the tribe to wich it belongs. In Dr. Horsfield's ${ }_{n}$ Plantae javanicae rariores." London. June 4. 1844. Fol. p. 219238. 1 tab.

1) Characters and descriptions of three new species of plants found in China by Clarke Abel Esq.; selected from a small collection of specimens the only part of his Herbarium that escaped the wreck of the Alceste. London 1818. 4. 2 tab. - Bermilfte Sdriften 1r $\mathfrak{B D}$. S. $559-570$.

2) Bermifite Edriften 1r B.b. S. $551-558$.

$\left.{ }^{3}\right)$ On the natural order of plants called Proteaceae. London 1810. 4. (Transactions of the Linnean Society, vol. X. p. $15-226.2$ tab.) - On the Asclepiadeae (Edinburgh 1810.) 8. (Memoirs of the Wernerian Society, vol. I. $1808-1810$. p. $12-78$.) - On Woodsia, a new genus of ferns. London 1812. 4. (Transactions of the Linnean Society, 1812. p. $169-174$. 1 tab.) - Observations on the natural family of plants called Compositae. London 1817. 4. (Transactions of the Linnean Society, vol. XII. p. $75-142)$.- Characters and description of Lyellia a new genus of mosses with observations on the section of the order to which it belongs; and some remarks on Leptostomum and Buxbaumia. (Transactions of the Linnean Society, vol. XII. p. $560-583$.) - Of three species of the natural order Orchideae. London 1817. 4. 2 tab. - Select Orchideae. London. 4. (Journal of science and the arts.) - An account of a new genus of plants named Rafflesia. London 1821. 4. 1 tab. col. 7 tab. nigr. (Transactions of the Linnean Society, vol. XIII.) On the female flower and fruit of Rafflesia with observations on its affinities and on the structure of IIydnora. 8. (Linnean Society, June 17). - Remarks on the structure and 
fologie ber SIflanzen hat $\mathfrak{B}$ rown nidyt wenig geleiftet; bod

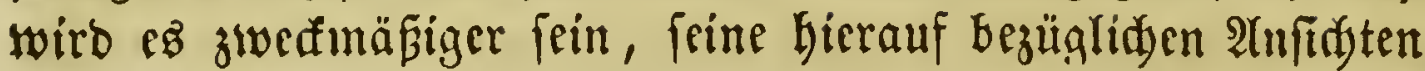
an ben betreffenden Stellen bes über biejen 3weig handelnden

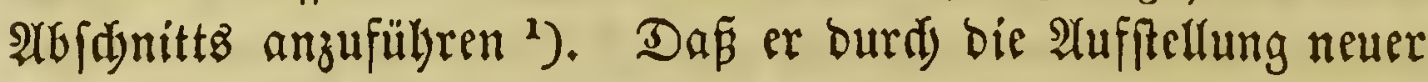

affinities of Cephalotus. (London and Edinburgh Philosophical Magazine, 1832 Septbr. p. $315-318$.) - Observations on the organs and mode of fecundation in 0rcbideae and Asclepiadeae. London 1831. 8. (Transactions of the Linnean Society 1833. 4. p. 685-745. 3 tab. col.) Observations on the organs and mode of fecundation in Orchideae and Asclepiadeae. London 1833. 4. (Transactions of the Linnean Society, p. $685-745.3$ tab. col.) - On the female flower and fruit of Rafflesia Arnoldi and on Hydnora africana. London 1844. 4. 9 tab. (Transactions of Linnean Society, vol. XIX. Part. III.) - On the plurality and development of the embryos in the seeds of Coniferae. London 1844. 8. 1 tab. (Annals and Magazine of natural history for Mai 1844). Brown lie= ferte aud bie Befirreibungen bes 4. Seftes bon Diffon's fryptogamifden (3ewäafen (S. 235, Rote 8) unb zum britten Theile yon Roxburgh's Flora yon Soromandel. - Seine Sarriften wurben yon (5) in SRerbinbung mit megreren anderen (belegrten ins Deutide überiegt: Mobert Brown, Bernifide botanifale Edrifter.

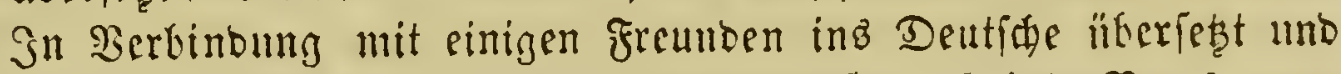
mit Stmerfungen yeriegen yon (5) ๔f fenbect. Rürnberg 1825-1834. 5 BBbe. 8. 10 Tafern.

2) On some remarkable deviations fiom the usual structure of seeds and fruits. London 1816. 4. (Transactions of the Linnean Society, vol. XlI. p. $143-151.1$ tab.) -- A brief account of microscopical observations made in the months of June, July and August 1827, on the particles contained in the pollen of plants; and on the general existence of active molecules. 18:9. 8. - Dentfd: $\mathfrak{R} i=$ froafopifor Beverdytungen, weldye in ben Mounten Suni, Sulfi unb 2(uguft 1827 gemadyt wurben üfer bic Thrild)en, melde int

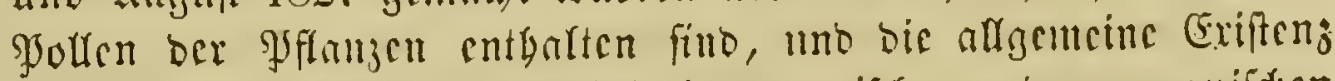

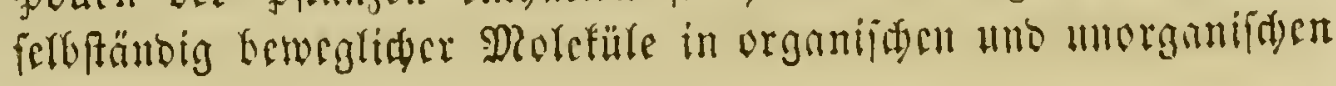




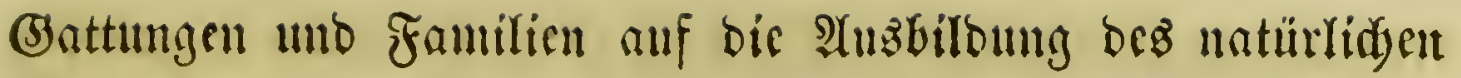
Syftems erfolgreidy cintwirtt, bedarf nady bem Dbigen mobl

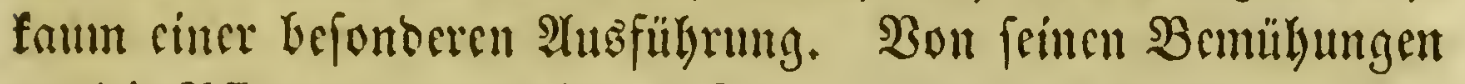

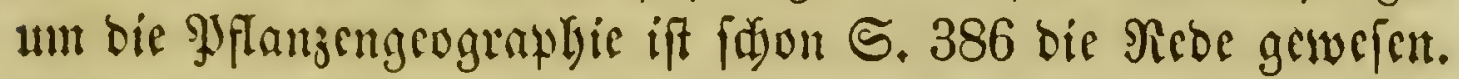

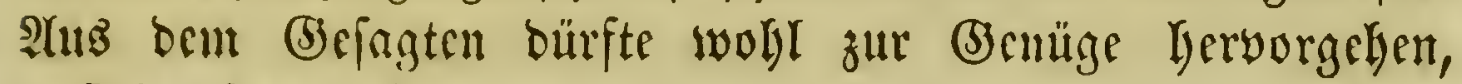

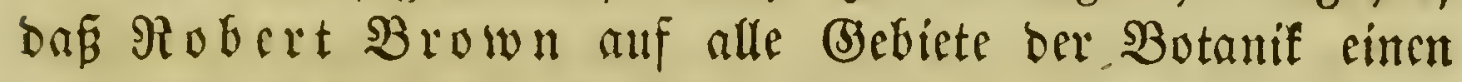

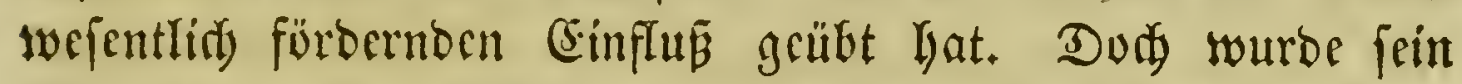
Rame lange 3eit nidyt fo berïlymt, wie man bies bätte er=

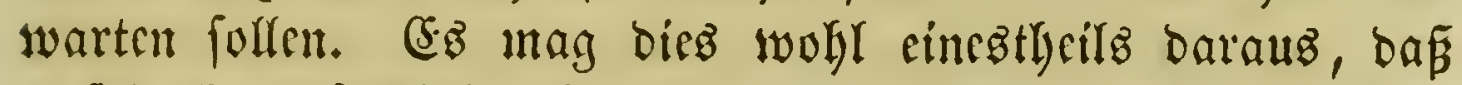

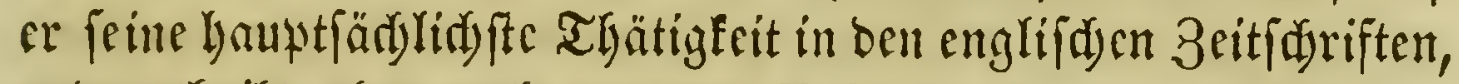

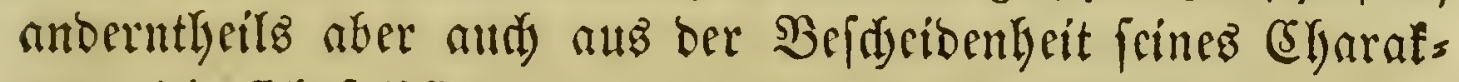
ters, bie fird felbft ba, wo fie baju beredtigt gewefen wäre, nidjt vorbrängte, fu erflären feín. (5) ïthe, ber ifn ben

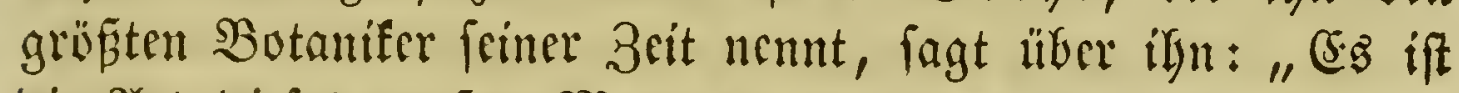
bie Art dicfes grofien Mannes, bie Grundwalgrheiten feiner Milferidjaft ferten im Munbe zu fülyren, währent ood jebe feincr 2 lrbeiten zrigt, wie innig er mit ihnen vertraut ift;

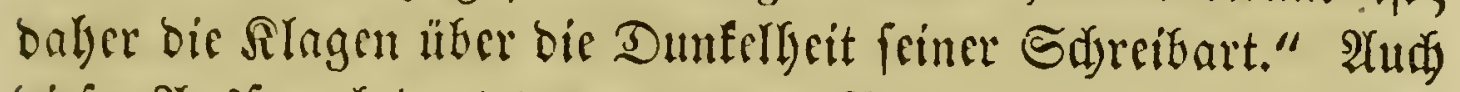

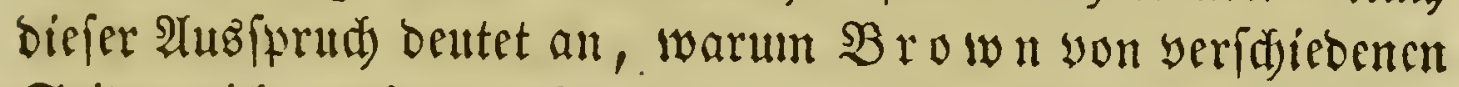
Seiten nidjt redyt anerfonnt wurbe. Jin Gabre 1849 wurbe

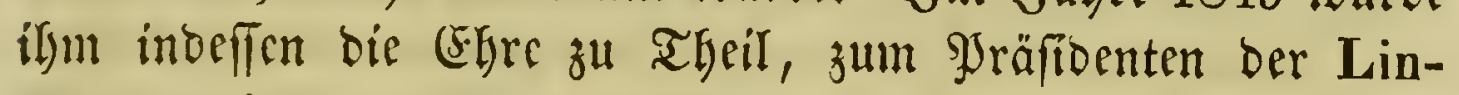
nean society crwäklt zu werben.

5Eenfalls in allen 3weigen ber Botanif ausgezcidunt wat

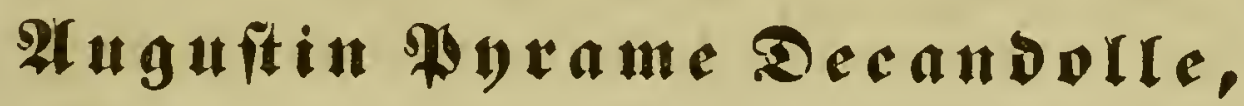

grboren zu bsonf int Gabre 1778.

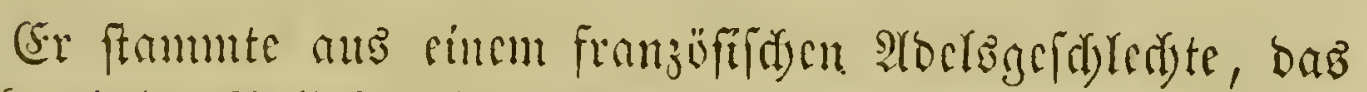

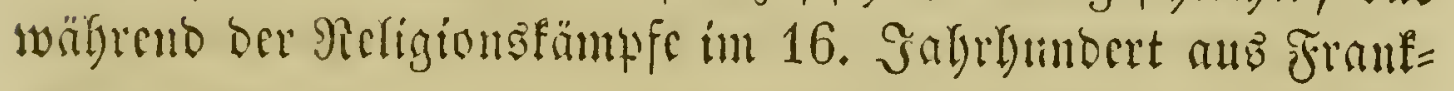

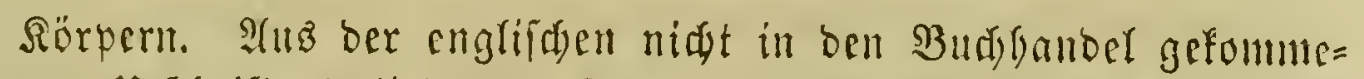

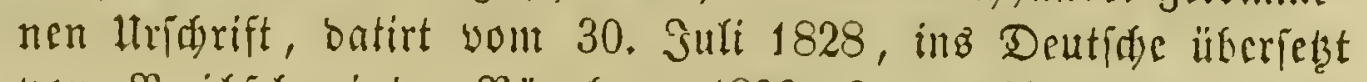
won Beilfd) micb. Nürnberg 1829. 8. - 2(ud) cinige von ben oben erwägnten Edyriften gegören tycitweife bierger. 
reid) augegewanbert war. Sbgleidy er in ber Sdyeiz geborent

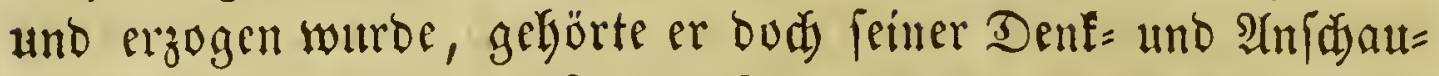
ungsiweife narb zu ber franzöfiffen Nation, uno wir haben

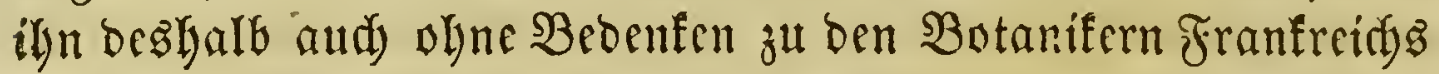
gezäblt. - Sdjon auf bem (5)ymnafium feiner Baterftabt zeid)= nete er firf vortheilgaft aus. Befonders bie liftorifden Stu=

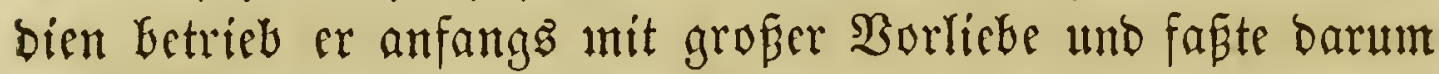

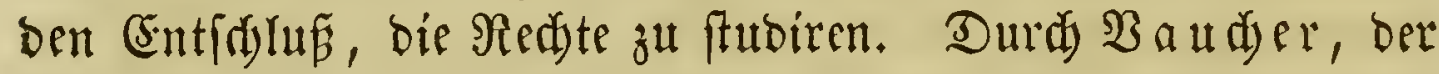
im Salyre 1796 zu (S)enf $\mathfrak{B u r l e f m g e n ~ G i e l t , ~ w u r b e ~ e r ~ z u e r i t ~}$ auf daz Sntereffe, welthes das Stubium ber Ratur gewährt, aufmertfam gemarbt, und narfoem er hierauf in Şaris meh= rele grofe Raturforfder gelört lyatte, wiomete or fid in Galue 1798 gänzlíd bem Stubium ber Micoicin. Bald madjte

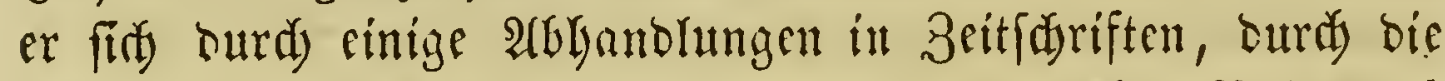
Historia plantarum succulentarum, fll $\mathfrak{w e l d}$ en $\Re$ e $b$ out é bie Abbilloungen rieferte, und burd) feine Astragalogia als

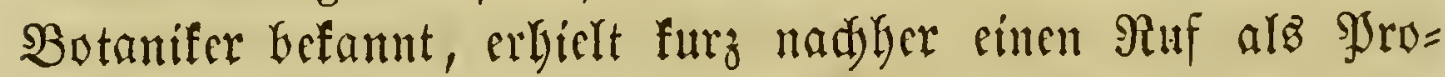
feffor an ber Ifabemie feiner Baterftabt, fdylug bemferben jebod) aut uno bielt $\mathfrak{B o r l e j u n g e n ~ a n ~ b e m ~ C o l l e ́ g e ~ d e ~ F r a n c e ~ z u ~}$ Sariz. Bon 1804 an begann er bie won ifm neu Kearbeitete

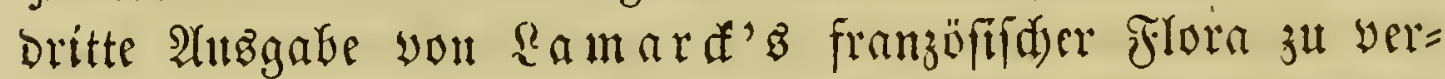
Bffentridyen, woburd) er ben (birund ju frinem $\Re u l$ un Iegte.

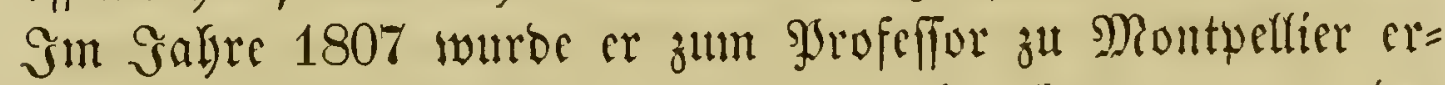
nannt. Sdjon im vorbergebenoen Gabre batte or yon ber

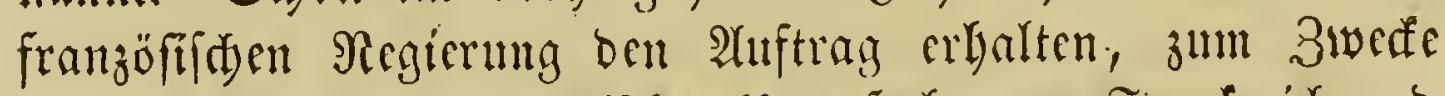

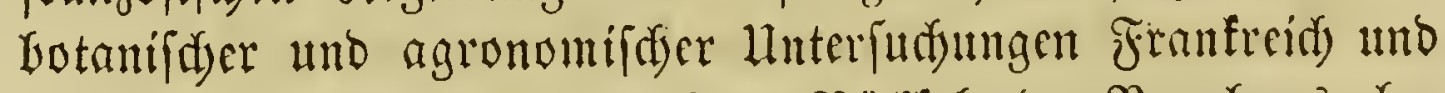

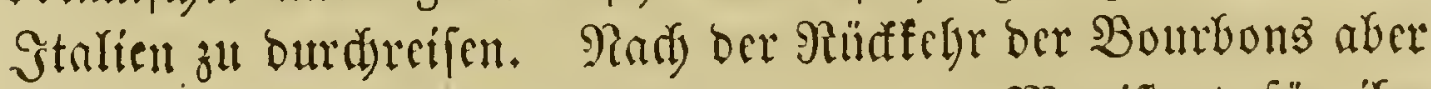
begab er fiti in feine Baterftabt, beren Magiftrat für if cine eigene \$Jofeffur erridytete. Dort begam er mun erfe redjt

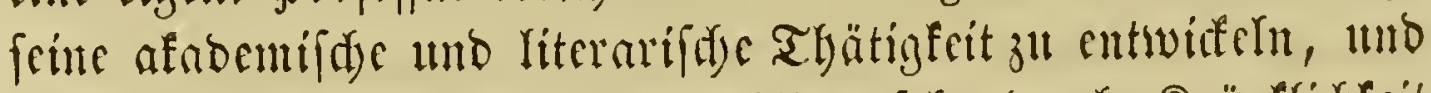
obgleid) or in feinem fpäteren âter feldr burd) Sränflidect

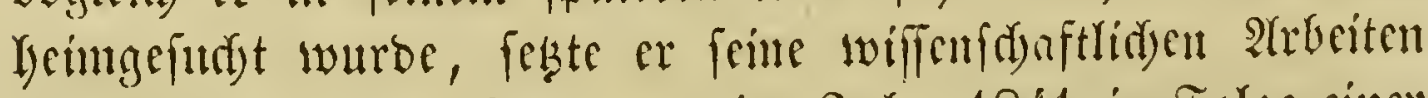

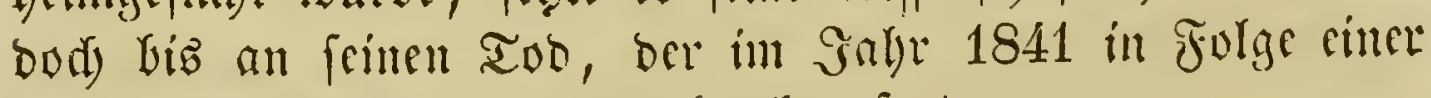
SEafferjudt erfolgte, unmenterbrodjen fort.

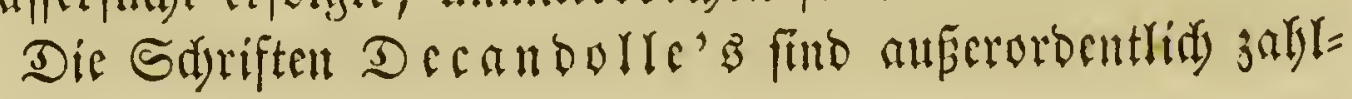




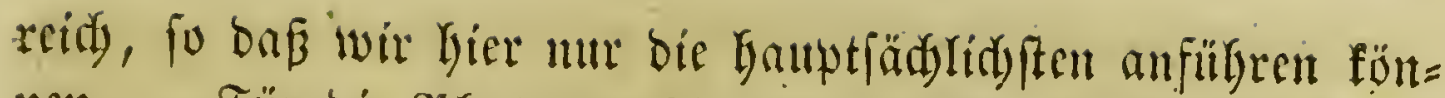

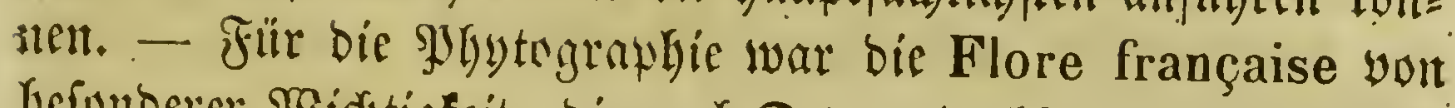
befonberer Midjtigfcit, bie mad) Decandorle'B Bcarbeitung

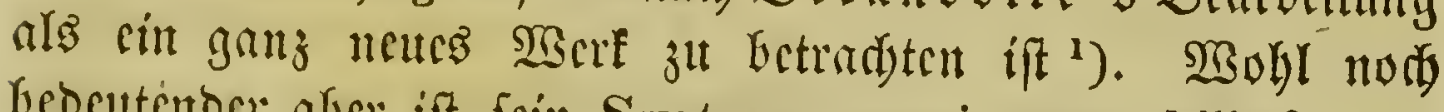
bebcutender aber ift fcin Systema regni vegetabilis ${ }^{2}$ ) und

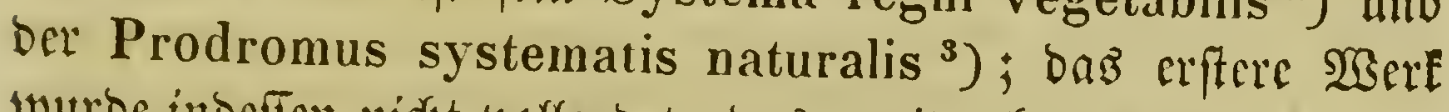
twurbe indeffer nidyt wollendet, ons zweite aber wirb nod) fort $=$ gefest. Decand orle swar für bie Bolfenoung bes Prodromus ferbft fo beforgt, baf cr bie fortectung befferben feinem

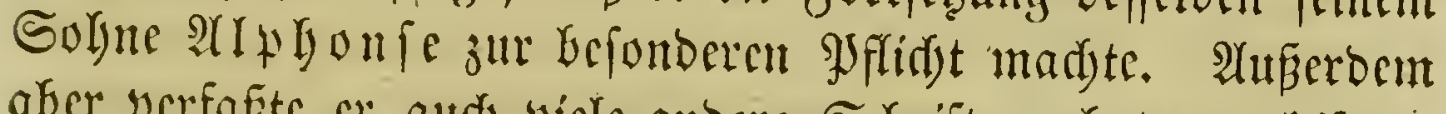
aber werfafite or aud) viele andere Sdyriften whytugrawhifdert

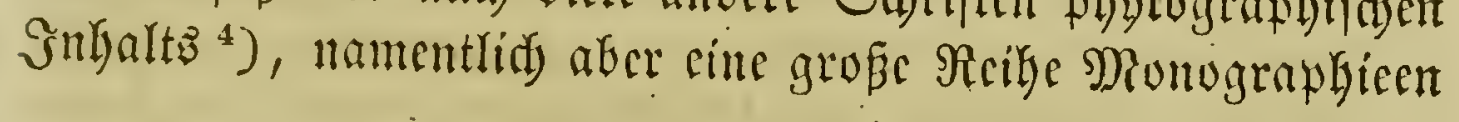

1) Flore française ou descriptions succinctes de toutes les plantes qui croissent naturellement en France, disposées selon une nouvelle méthode d'analyse et précédées par un exposé des principes élémentaires de la botanique. Troisième édition. Paris 1805. IV tomes. 8. 11 tab. - Bergleide aud : Synopsis plantarum in Flora gallica descriptarum. Parisiis 1806. 8. - Edit. II par J. C. D u by. Paris 1828 - 1830 . II voll. 8.

$\left.{ }^{2}\right)$ Regni vegetabilis systema naturale, sive ordines, genera et species plantarum secundum methodi naturalis normas digestarum et descriptarum. Parisiis 1818 - 1821. II voll. 8.

$\left.{ }^{3}\right)$ Prodromus systematis naturalis regni vegetabilis, sive enumeratio contracta ordinum, generum specierumque plantarum hucusque cognitarum, juxta methodi naturalis normas digesta. Parisiis $182 \%-1826 . \mathrm{X}$ partes. 8.

4) Plantarum historia succulentarum: Histoire des plantes grasses, avec leurs figures, en couleurs dessinées par P. J. Redouté. Paris 1799-1829. XXXI fasciculi. Fol. ( 185 tab. col.) 3u ben 4 erften Bänocn voun $\Re$ ebouté' Liliacées Yieferte er ben $\mathfrak{T} e x t$. - Astragalogia, nempe Astragali, Biserrulae et Oxitropidis, necnon Phacae, Coluteae et Lessertiae historia iconibus illustrata. Parisiis 1802. Fol. min. 50 tah. - Paris 1802. Fol. max. 50 tab. Icones plantarum Galliae rariorum nempe incertarum aut E. Bin äler, Befw. b. Botanil. 
einzelner (sattungen uno Familien ${ }^{1}$ ). - Bon nidst geringe= rem $\mathfrak{B e r t b e}$ finto feine Sdyriften

nondum delineatarum. Fasc. I. Parisiis 1808. 4. 50 tab. - Catalogus plantarum horti botanici Monspeliensis addito observationum circa species novas aut non satis cognitas fasciculo. Monspelii 1813. 8. - A. P. D e candolle et Alph. Decandolle, Rapports (ou Notices) sur les plantes rares, qui ont fleuri dans le jardin de Genève. No. I-IX. Genève 1824-1845. 4. 23 tab.

1) Observations sur les plantes Composées ou Syngenèses. Trois mémoires: Composées, Cynarocephales, Labiatiflores. (Annales du Muséum d'histoire naturelle de Paris. Vol. XVI. 1810. p. $135-158$, et 1 tab. - Vol. XVI. 1810. p. $181-208$, et $10 \mathrm{tab}$. - Vol. XIX. 1812. p. 59-72, et 5 tab. - Extrait: Bull. soc. phil. 1811. p. 223. - 1811. p. 240. - 1812. p. 166.) - Recueil des mémoires sur la botanique, contenant: Observalions sur les plantes Composées, la description de Chailletia, monographie des Ochnacées, Simaroubées et Biscutelles. Paris 1813. 4. $48 \mathrm{tab}$. - Mémoire sur la famille des Crucifères. (Paris 1821) 4. 2 tab. (Mém. du Muséum d'hist. nat. de Paris. Vol. VII. 1821. p. $169-252$, et 2 tab.) - Mémoire sur les différentes espèces, races et variétés de choux et de raiforts en Europe. Paris 1822. 8. Deutid: $\mathfrak{T}(13$ bent

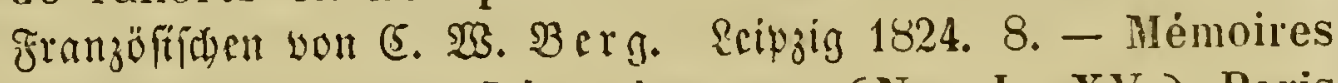
sur la famille des Légumineuses. (No. I-XV.) Paris 1825. 4. $70 \mathrm{tab}$, et 2 tableaux. - Mémoire sur la famille des Mélastomacées (Paris 1528. 4. 10 tab.), Crassulacées (Paris 1828. 4. 13 tab.), Onagraires (ibid. 1829. 4. 3 tab.), Paronychiées (ibid. 1829. 4. 19 tab.), Ombellifères (ibid. 1829. 4. 19 tab.), Loranthacées (ibid. 1830. 4. 12 tab.), Valerianées (ibid. 1832. 4. 5 tab.), sur quelques espèces des Cactées (ibid. 1834. 4. 12 tab.), Composées (ibid. 1838. 4. 19 tab.), Statistique de la famille des Composées (ibid. 1838. 4. 4 tab.). - Revue de la lamille des Cactées, avec des observations sur leur végétation et leur culture, ainsi que sur celles des autres plantes grasses. Paris 1829. 4. 21 tab. col. (Mém. du Muséum 


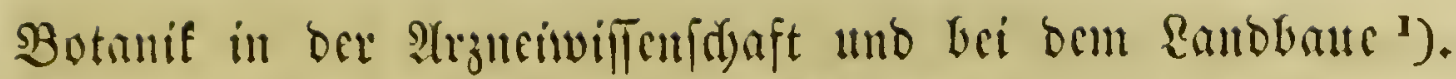

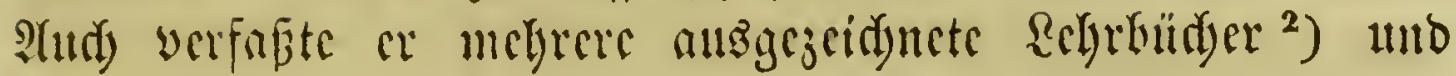

d'hist. nat. de Paris. Vol. XVII. p. 1-119. - Flora 18:29, p. 626, u. anberwärtż.) - Mémoire sur la famille des Myltacées. Ouvrage posthume, publié par les soins du fils de l'auteur (Alphonse Decandolle). Genève 1842. 4. 22 tab. (Mém. de la soc. de phys. et d'hist. nat. de Genève, vol. IX.) - Heber bie bier nidjt aufgefüfrten zaflreid)en

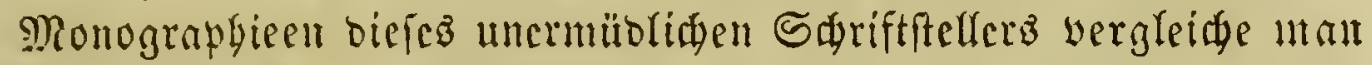
Jjrifel' Thesaurus literaturae botanicae, S. 58-62.

1) Essai sur les propriétés médicales des plantes comparées avec leurs formes extérieures et leur classification naturelle. Paris 1804. 4. Ed. II. Paris 1816. 8. - Deutfda:

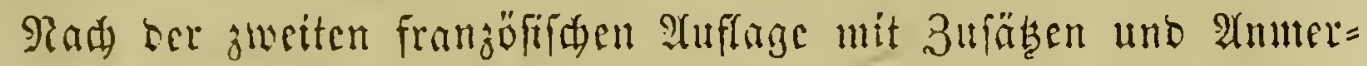

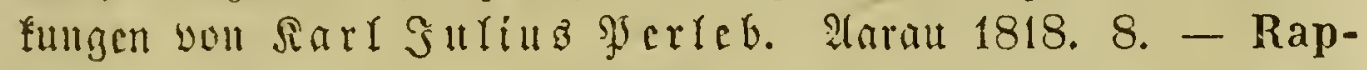
port sur les voyages botaniques et agronomiques faits dans les départements de l'empire d'après les ordres de S. E. le Ministre de l'intérieur. Paris 1813. 8.

2) Principes élémentaires de la botanique et de physique végétale. Paris 1805. S. (ㄷํ $\mathfrak{2} \mathfrak{4} \mathfrak{z}_{3} \mathfrak{u g}$ auz ber Flore française, 3. $\mathfrak{2}\left(\mathfrak{t} \mathfrak{g}_{\text {g. }}\right)$ - Théorie élémentaire de la botanique, ou exposition des principes de la classification naturelle et de l'art de décrire et d'étudier les végétaux. Paris 1813. 8. Ed. II. Paris 1819. 8. Ed. III, publiée par Alphonse Decandolle d'après les notes et les manuscrits de l'auteur. Paris 18\%4. 8. - Deutid): ?(uß bem granjöfifiden mit viefen 2(nmerfungen, 3ufäłen unb bem

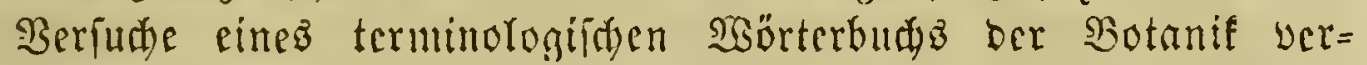

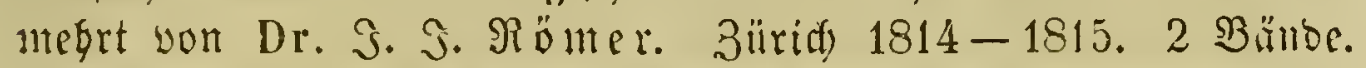
8. 1 Taffl. - Instruction pratique sur les collections botaniques à l'usage des voyageurs, qui sans avoir étudié l'histoire naturelle des plantes désirent être utiles à cette science. (Genève 1820.) 8. - Organographie végétale, ou description raisonnée des organes des plantes, pour servir de suite et de développement à la théorie élémentaire de la botanique et d'introduction à la plyysiologie végétale et à la description des familles. Paris 182i. II

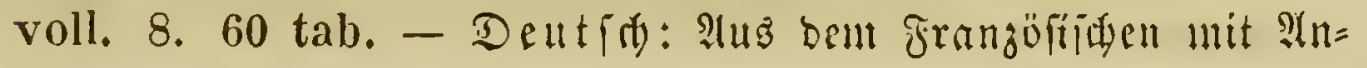




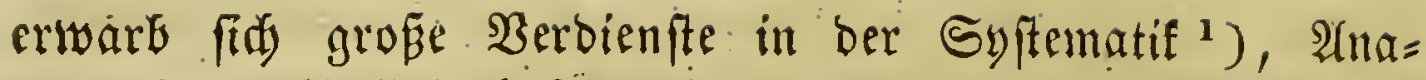
tomie ${ }^{2}$ ), Sghyfiologie ${ }^{3}$ ); (Steographie ${ }^{4}$ ) uno Morpholo=

merfungen von Rarl Friebr." Meisner. Stuttgart 1828. 2 BDe. 8. 60 rafeln.

1) Théorie élèm. etc. Prodrom. system. etc. Note sur la division du règne végètale en quatre grandes classes ou embranchemens. (Genève 1833.) 8. (Bibl. univers. de Genève. Vol. LIV. 1833. p. 259-268. - Deutí: Von Søledtendal in Linnaea 1835: p. 270.)

2) Organographie etc. unb in vielen anbern feiner Shriften.

$\left.{ }^{8}\right)$ Observations sur les plantes marines. (Extrait: Bull. soc. phil. de Paris. 1799. p. 171. 1 tab.) - Expériences relatives à l’influence de la lumière sur quelques végétaux. (Extrait: Bull. soc, phil. 1800. p. 138, unb anber= märţ̇.) - Mémoire sur les pores de l'écorce des teuilles. (Bull. soc. phil: 1801, u. a.) - Premier mémoire sur les lenticelles des arbres et le développement des racines, qui en sortent. Paris 1826. 8. 2 tab. col. - Physiologie végétale, ou exposition des forces et des fonctions vitales, des vẻgétaux, pour servir de suite à l'organographie végétale et d'introduction à la botanique géographie et agricole. Paris 1832. II voll. 8. - Deutid: Paflanzens whyfologie 2c. A. D. Franj. intit Inmerfungen verfeben won S. A.

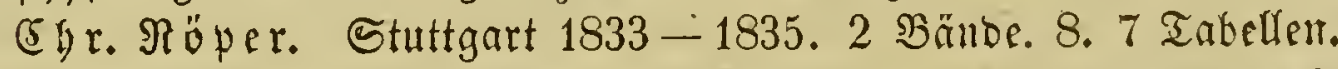

*) Rapports sur les voyages hotan, etc. - Géographie agricole et botanique. (Article du Nouveau, cours complet d'agriculture théorique et pratique, ou dictionnaire raisonné et universel d'agriculture. Vol. VI. 1809. p. 355. Ed. II. Ibid. Vol. VII. 1822. p. 303. - Essai élémentaire de géograplïe botanique. (Paris 1820) 8: - De l'influence de la température atmosphérique sur lè développement des arbres au printemps. Genève 1831. S. Notice sur la géngraphie botanique de l'Italie. Genève 1835. 8. (Bibl, univers, de Genève. Vol. LIX. 1835. p. 193-201.) - Flore française etc. - Mẻmoire sur la géographie des plantes de France, considérée dans les rapports avec la hauteur absolue. (Paris 1817.) 8. Mèmoire sur la famille des Crucifères. (Paris 1821.) 4. 2 tab. 
gie ${ }^{1}$ ) ber (b) treffentoen. Stellen ausfülyrlider reben fümten.

3u gleidjer 3eit mit biefen beiben gropen (3) feldrten. ent= iviffelte

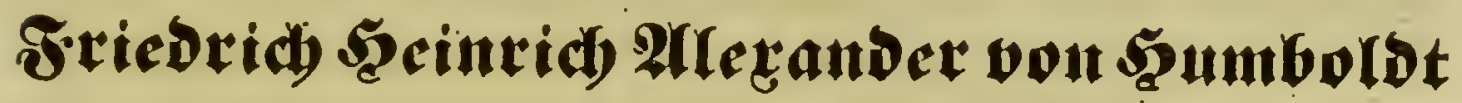

feine erfolgreidye Ilyätigfeit. Ser wurbe als ber jweite Sofhn bes Raumerberm uno Majors Alexander fas erg von Sumborbt am 14. September. 1769 zu Berlin geboren.

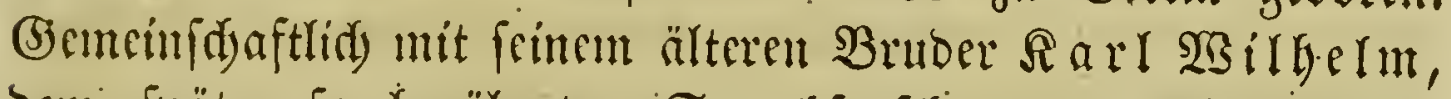

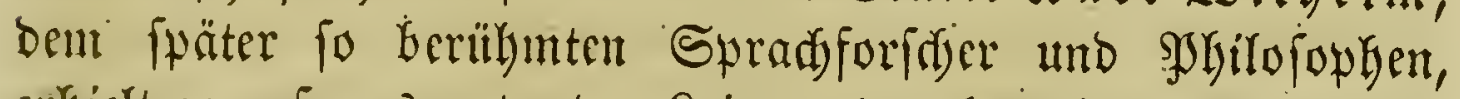
erbielt er anfangs unter ber Reitung bes befanten $\mathfrak{s}$ äbagogen

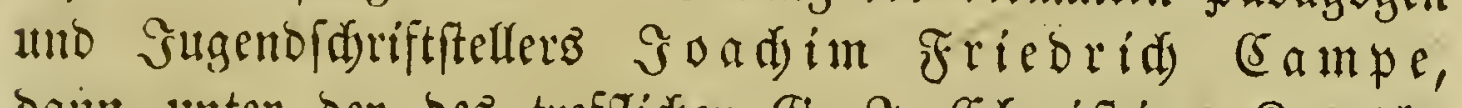
Dain unter ber bes treffliden (5). S. Chriftian $\Re$ unth, mit bem bie beiben Briiber audi in ifiren fpäteren Rebens= jafren in beun innigften Freund (d)aftsyerfältmiffe ftanden, feine erfte wiflenidyaftlidse Billoung. Entid)lolfen, die Rameral= willenidyaften zu ftudiren, bezog er im Galire 1786 die. uni= werfität Franffurt uno ging zivei Jahre fpäter nad) (Siöttingen,

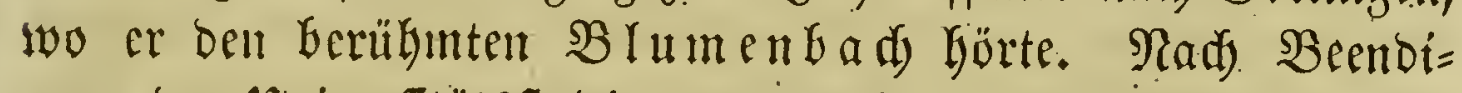
gung ber Univerfitätêftubien unternalym er eine Reife an ben

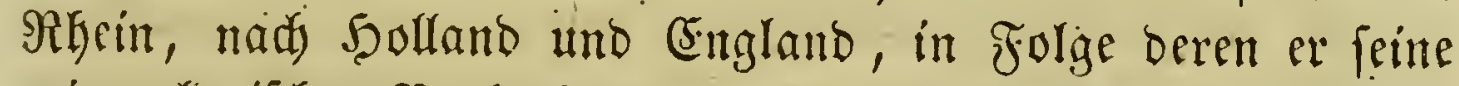
mineralogifden $\mathfrak{B}$ eobadytungen über einige $\mathfrak{B}$ ajalte aut $\Re$ bein

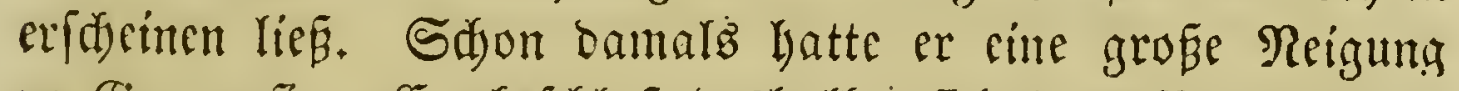
zu (5jegnnofie. (Fr befdlof beghalb; fid bem Bergbaue zu wiomen, bildocte fid auf oer 5andelsafabcmie zu Jamburg

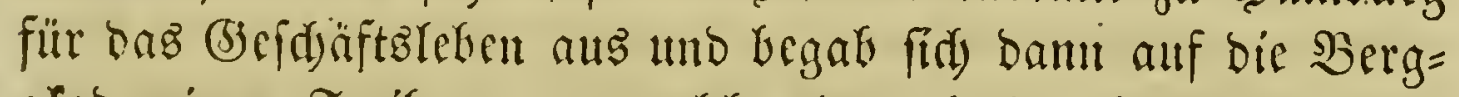
afabemí zu Freiberg, an welder bamals ber berhilymte (5iso=

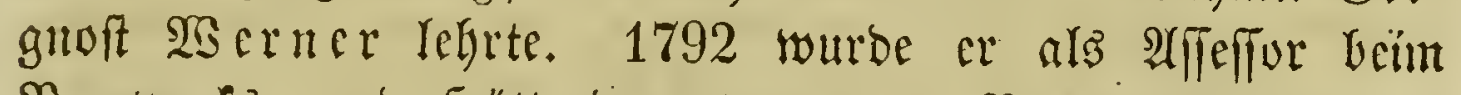

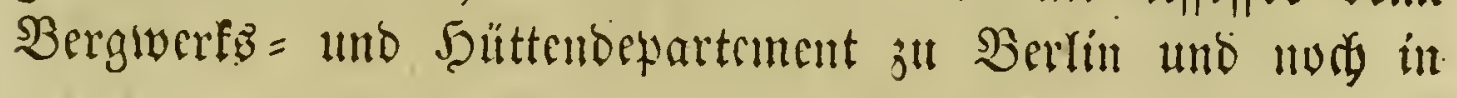

1) Théor. élément. etc. Organographie etc. 
Demfelben Gabre als Sberbergmeifter zu Baireuth angeftellt.

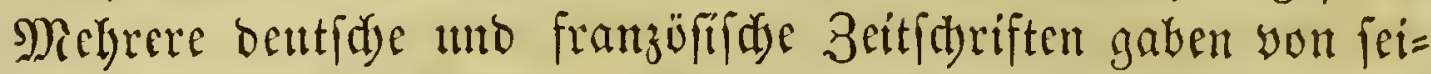

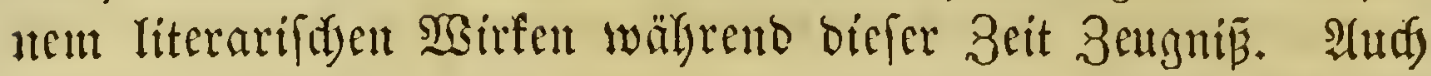
erfodien bamals bic fdyon frilyer angefillyrte Edrift über bie fryptogamifden (b) wäd)

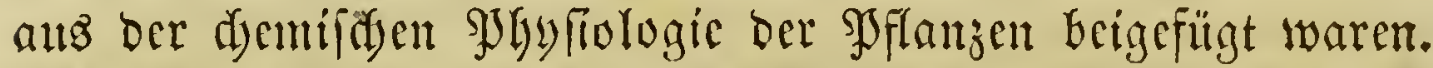
Şumbolot felfit fagt, baf er yon feincr erften Jitgento an eine brennente $\mathfrak{B e g i e r d e}$ empfunden habe, in entfernte, son (Furowäern wentig befudjte Ränder zu reifen. Diefe Begierbe

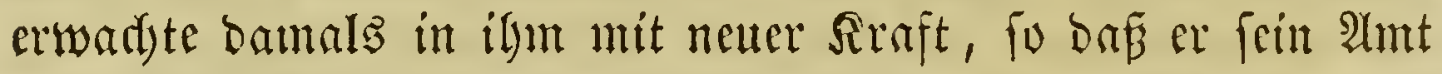
nieberlegte und fiti) nad) Saien begnd, um bie bortigen Samm=

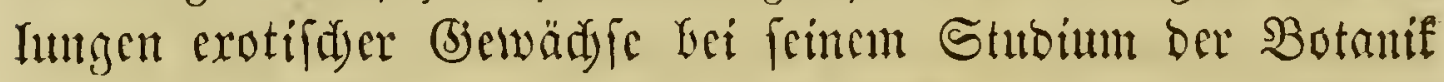

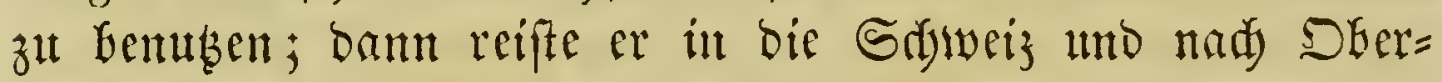

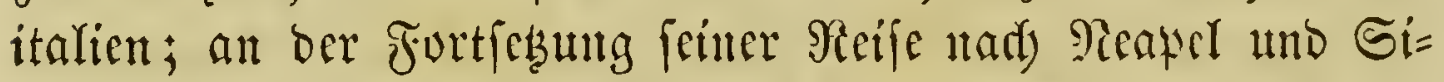
cilien wurbe er aber burd den baunaligen Niriegszutitand ge= bindert. Berjdiedener Familienturbältnifie wegen war er

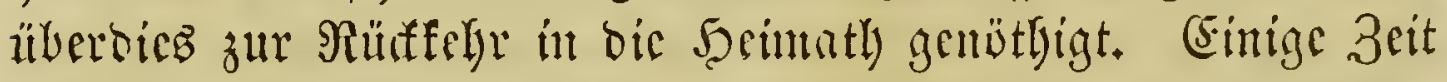

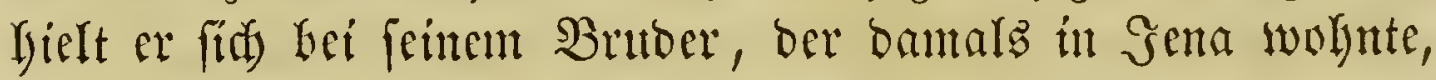

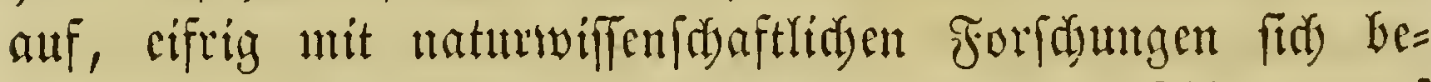

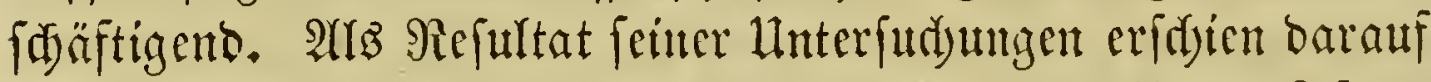

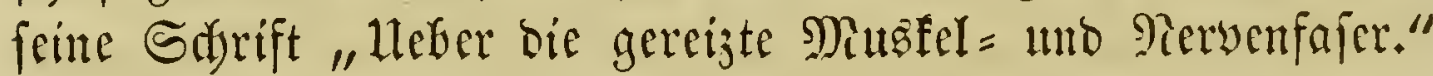

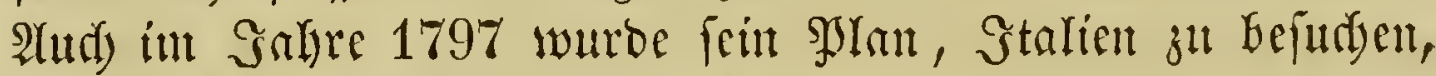

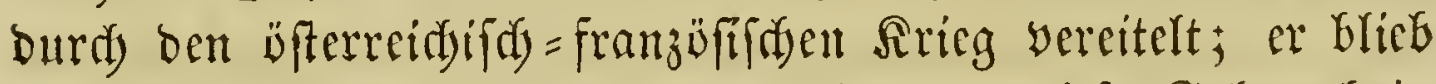

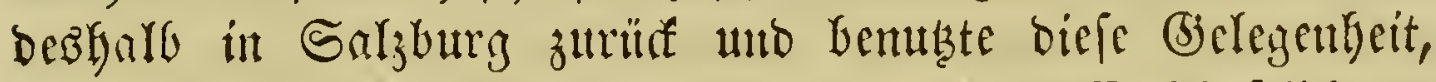
dis. (b)ebirge Saljutrgs und Stciermarts willenidaftlid) zut

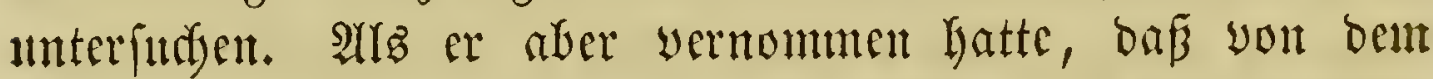
Rationalmuleum zu Şaris eine (expedition nad) ber filbliden

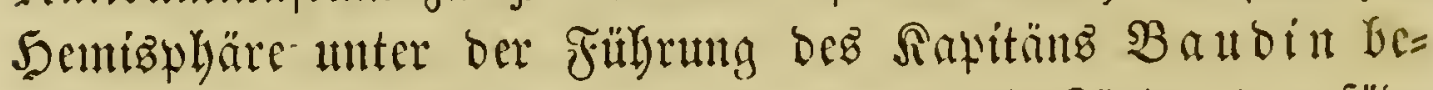
abfidtigt werbe, befdlofi er, on gerabe die Rältoer Der fill =

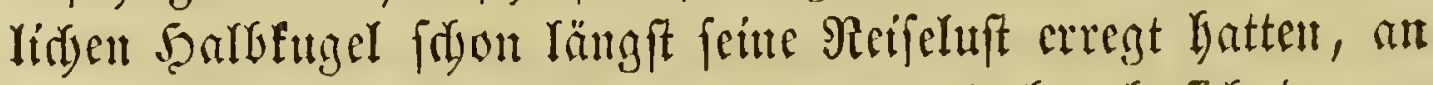

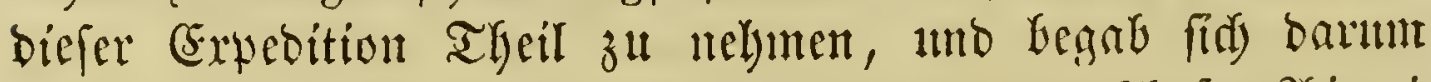

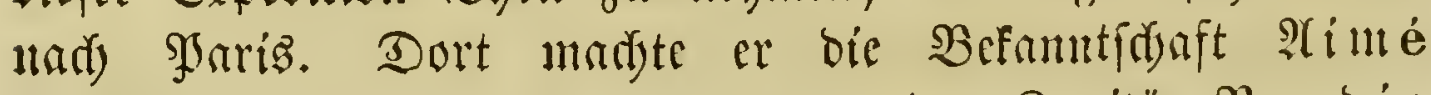

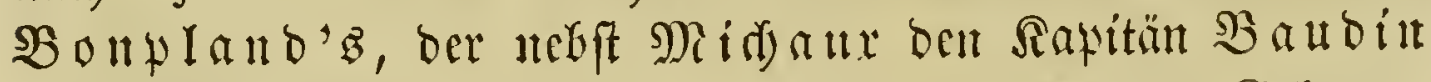
als Raturforfder begleiten forte; aud) batte er bort (S)legen= Geit, anbere Gerülunte Raturforfder fenten zu Yernen. Die 


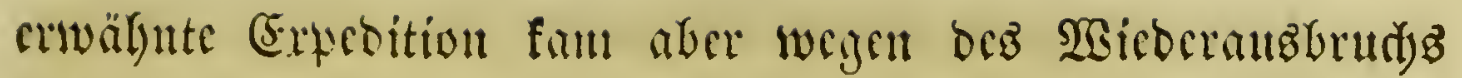

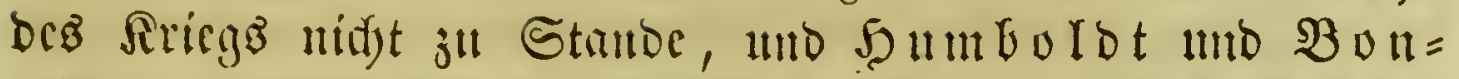

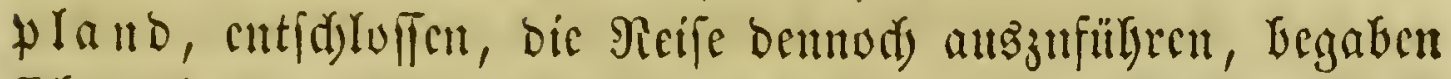

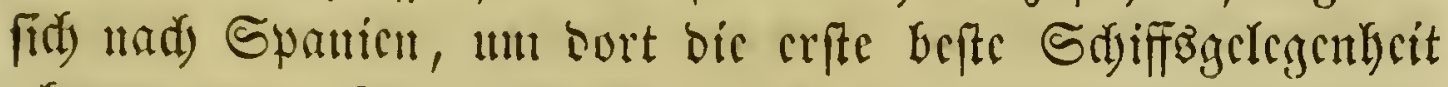

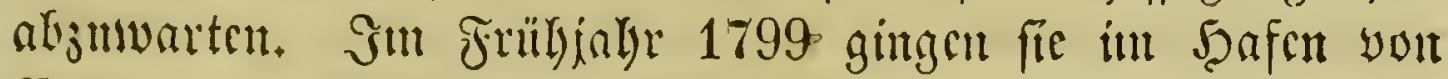
(5ormma an Bord ber (Borycte Syizarro, weldye nad) (5uba

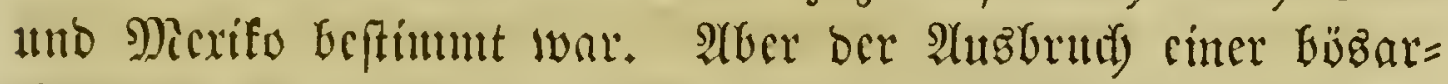

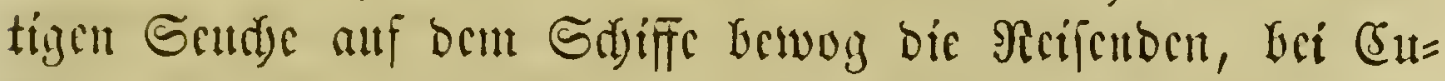
mani an ber Nurbfilfte yon Benejucla anb Rano zut gehen. Bon ba ats begamen fic baun ifre $\mathfrak{x a n b e r u n g e n ~ i n ~ b a s ~}$

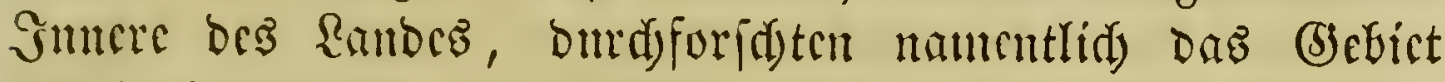
bez Drinufo anto Riu Regro, bumdjogen die Stepwen von Benejucla, hictten fidj cintige Zcit in Buba auf unb begaben

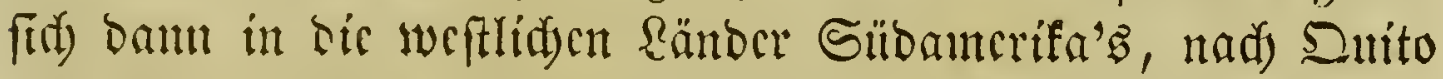
und Freru, yon ba festen fie ifre Reife uady Mcxifo fort, be= fudjten bie vercinigten Stanten und fdifften fid Dann nad) oer Scimatly cin, yon ber fie megr als fünf Gabre cntfernt

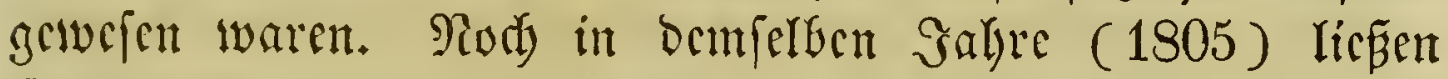

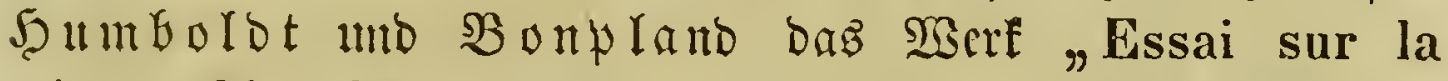
géographie des plantes" unb im barauffolgenden bie

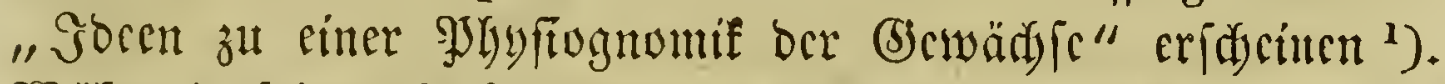
S⿱⺈⿻コ一心

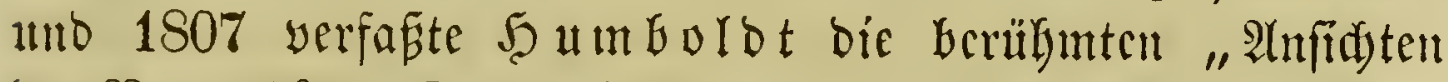

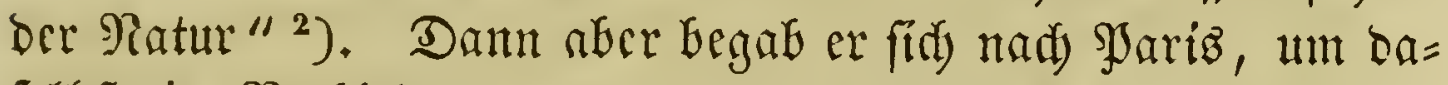

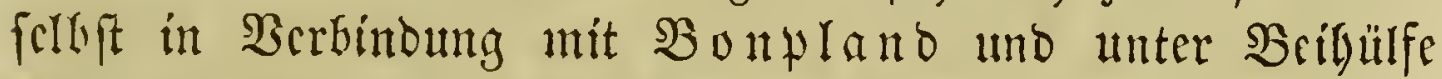

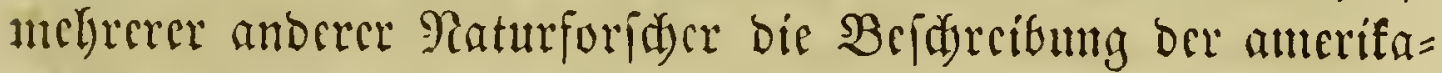

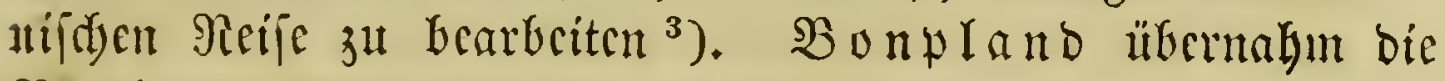
Bearbcitung ber in bie Botanif cinfdalagenden Furidungen ${ }^{4}$ );

1) Tübingen 1806. 8.

2) Stuttgart 1809. 12. - 2. YUżg. Stuttgart 182\%. 2 BDe. 12.

3) Reije in bie sequinoctialgegenden bez neuen (5ontinentż in ben Saldren $1799-1804$. Stuttgart 1815-1832. 6 Theile. 8.

4) Plantae aequinoctiales, per regnum Mexici in provinciis Caracarum et Novae Andalusiae, in Peruvianorum, Quitensium, Novae Granatae Andibus, ad Orinoci, Fluvii 
einen Theil bes gefammelten Materials aber übergab $5 \mathfrak{u} m=$ bold bem Srofeflor ber Botanif Rarl Siegesmuno

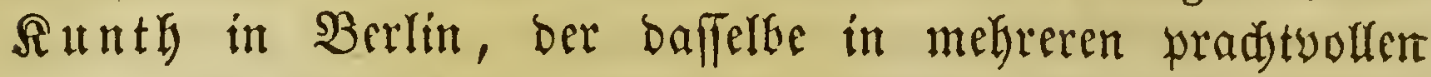

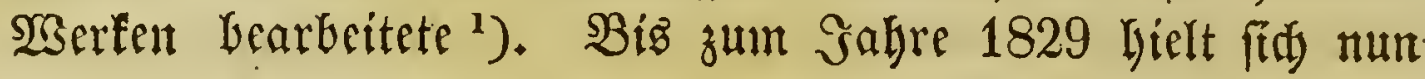

nigri, fluminis Amazonum ripas nascentes. In ordinem digessit Amatus Bonpland. Parisiis 1805-1818. II voll. 17 fasciculi. Fol. 143 tab. - Monographia Melastomacearum continens plantas hujus ordinis hucusque collectas, praesertim per regnum Mexici, in provinciis Caracarum et Novae Andalusiae in Peruvianorum, Quitensium; Novae Granatae Andibus, ad Orinoci, Fluvii nigri, fluminis Amazonum ripas nascentes. In ordinem digessit Amatus Bonpland. Lutetiae Parisiorum 1806-1823. II voll. 2/f fasciculi. Fol. 120 tab. col.

1) Nova genera et species plantarum, quas in peregrinatione orbis novi collegerunt, descripserunt, partim adumbraverunt Amatus Bonpland et Alexander de Humboldt. Ex schedis autographis Amati Bonpland in ordinem digessit .Carolus Siegesmund Kunth. Accedunt Alexandri de Humboldt notationes ad geographiam plantarum spectantes. Lutetiae Parisiorum 18151825. VII voll. 36 fasciculi. Fol. 700 tab. col. - Mimoses et autres plantes Légumineuses du Nouveau Continent, recueillies par M. M. de $\mathrm{Humboldt}$ et $\mathrm{B}$ on pland, décrites et publiées par Karl Siegesmund Kunth. Paris 1819. Fol. 60 tab. col. - Distribution méthodique de la famille des Graminées par Karl Siegesmund Kunth. Ouvrage accompagné dè deux cent vingt planclies représentant autant d'espèces nouvelles ou peu connues, dessinées par Madame Eulalie Delile. Paris 1835. II voll. Fol. 220 tab. - Die übrigen bierber gebörigen Shriften 5̧ 4 m=. bolot'b und $\mathfrak{B}$ onpland'b find: Sur les lois que l'on observe dans la distribution des formes végétales. Paris 1816: 8. - Nouvelles recherches sur les lois que l'on observe dans la distribution des formes végétales (Paris) 8. 1 tab. - De distributione geographica plantarum secundum coeli temperiem et altitudinem montium prolegomena. Lutetiae Parisiolum 1817. 8. 1 tab. col. - Deut d :

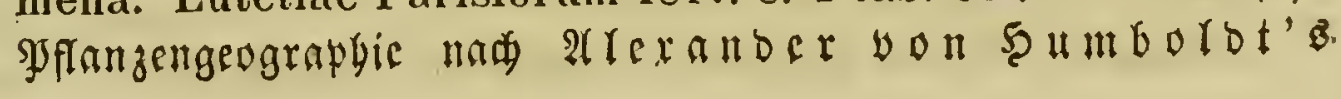




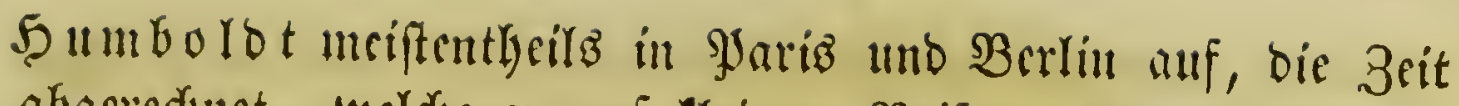

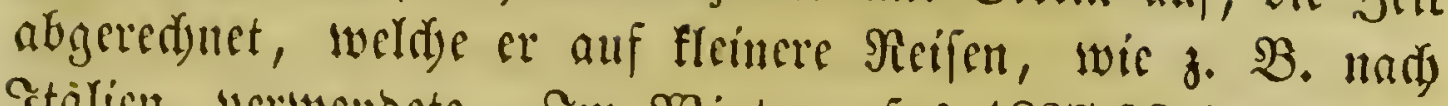
Stälicn, verwentete. Sin Sisintercurfus 1827/28 hielt er fut Berlin feine berilfumten Borlefungen liber phyfifde Welt= befdyreibung, welde bie Branblage zu feinem אosmos bilbe= ten. Sm Frilhiabre 1829 ater war er entlidy in ben Stand

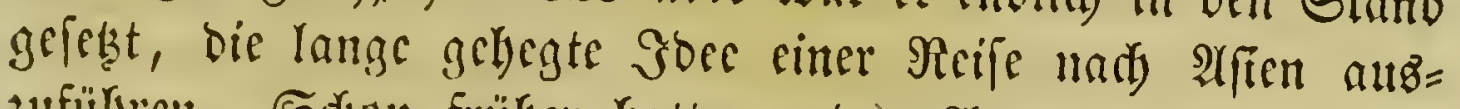
ouffülyten. Sidjon frilger hatte er ben atntrag ber ruffifden Regierung, an cincr wifferifyaftlidyen experition in bas $\Im_{11}=$ nere Rufianos Theil zu nelmen, angenommen, aber wegen

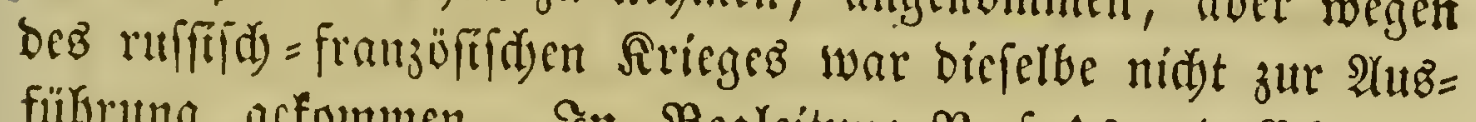
füfrung grformmen. In Begleitung $\mathfrak{R}$ ofe's und berg's yollentete er num diefe Reife in adyt und einem halbent Monate. Rad) friner Rüffebr befdaftígte ibn bie Benrbei= tung bes aud aif biefer Reife wieber gefammelten reidjal=

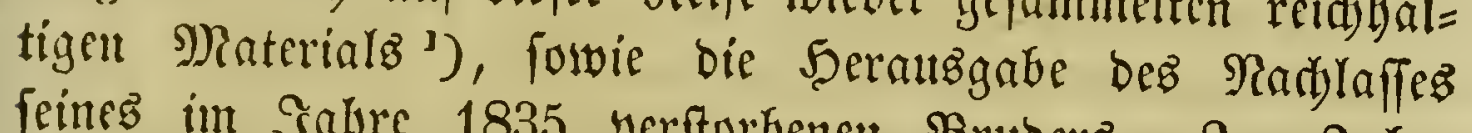
feines im Эahre 1835 verftorbenen Brubers. Sm Эahre 1845 aber begann er bie Jerauggabe feines Roginos, einez

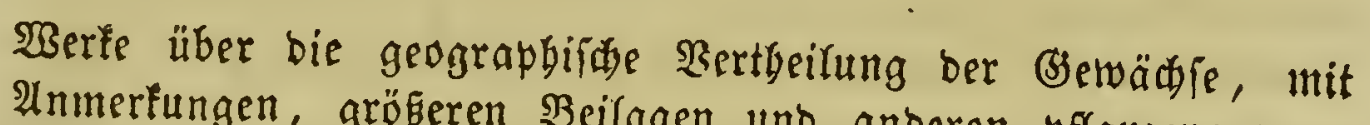
Anmerfungen, größeren Beilagen unb anberen pflanjengeogra prifdien Edriften unb einem Excure über bie bei pflanzengeo=

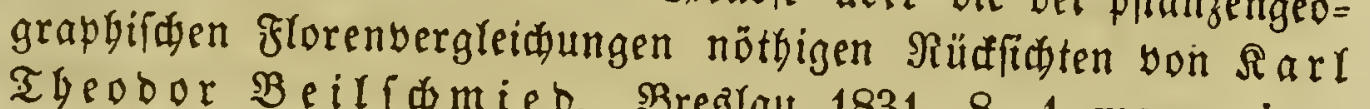
IGeobor Beilfdmieb. Brealau 1831. 8. 1 mapp. isogeotherm. - Rapport verbal fait à l'Académie des sciences sur un ouvrage de Mr. Auguste de St. Hilaire, intitulé: Plantes usuelles de Brasiliens. Paris 182\%. 8.

1) Fragmens de géologie et de climatologie asiatiques. Paris 1831. II voll. 8. 1 tab. - Deutid: Fragmente einer beo= logie uno Rlimatologie श(fienz. A. b. Franz. mit 2(nmerfungen von Juliub \&äwenberg. Berlin 1832. 8. (

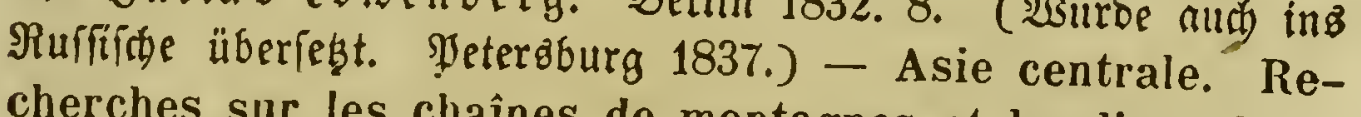
cherches sur les chaînes de montagnes et la climatolngie comparée. Paris 1843. III voll. 8. 3 cartes. - Deutifi:

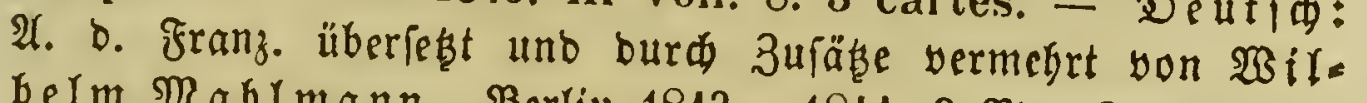

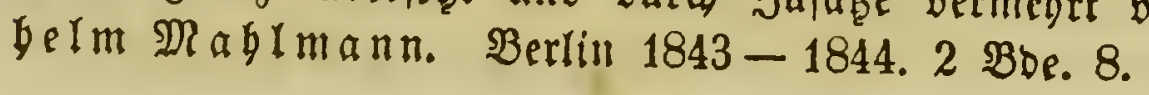




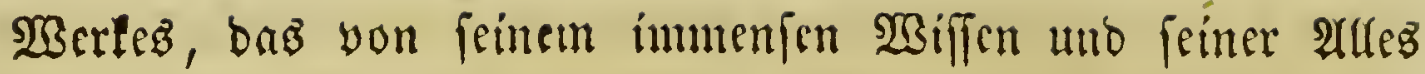

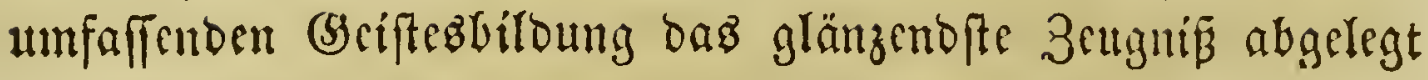
Gat. ${ }^{1}$ )

Die grobartigen $\mathfrak{B e r b i e n f t e ~} 5 \mathfrak{m m b}$ ord t' 8 in fo viclen

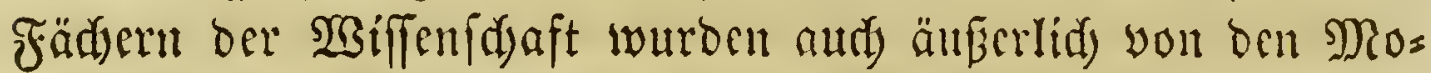
nardjen feines Baterlanbes anerfant. Fricoridy SBillyclim III.

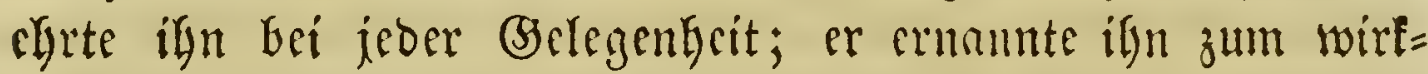

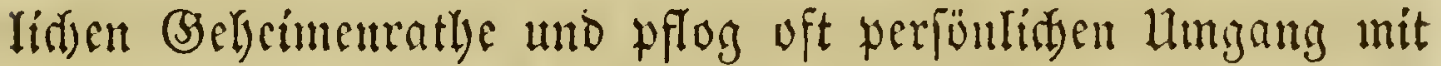
Dem lodygebildocten Maune. Alud) ber jekige Rönig wein ben

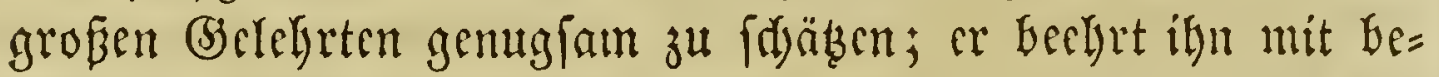

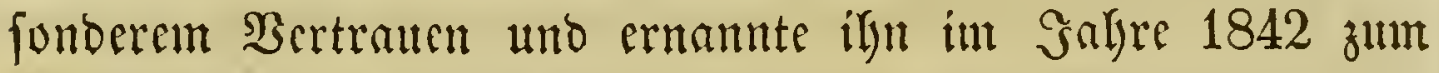
Sanjler ber Friedenstlaffe des Droens pour le mérite. So

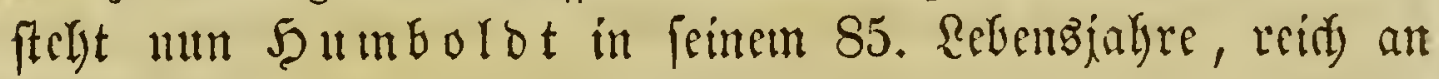
(Erfalyrung uno Siffen, wie feiner feiner Beitgenoffen, in allen Theilen ber gebilosten $\mathfrak{W e l t}$ gefannt tmo hodygeadstet, gleidy fémem Freunde (so ö the ciner ber wenigen Sterbliden, benent Das Sdjiffal vergönnt lyat, an ben Errfolgen ingers rulymbollen wno thatenreityen Revens als glüctidise (bireife fid zu erfreuen.

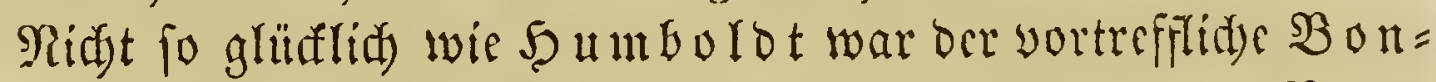
wland. (5r nalym 1818 ben $\Re$ uf als Profeffor ber Ratur=

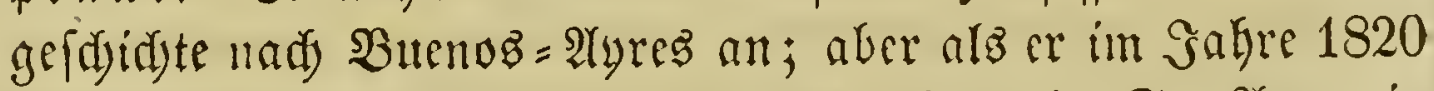
bie yon ifm gegründete indianifase folonie St. Atma in Saraguny befudste, wurbe er auf Scfchl bes bortigen Dic= tators Francia burd)aus wiberreditlití) gefangen genwmmen,

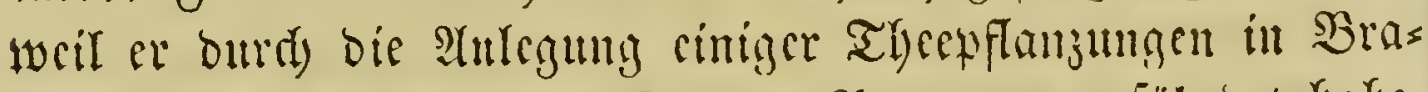

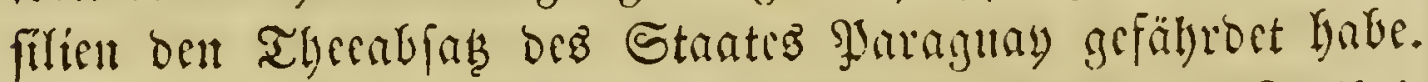
(5rift nady a(blauf mekrerer Gabre faut er wicber it Freifcit

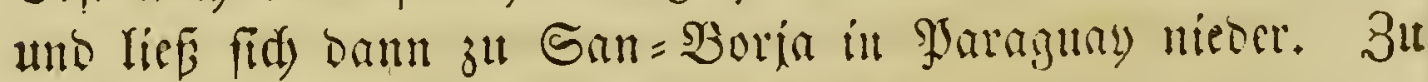

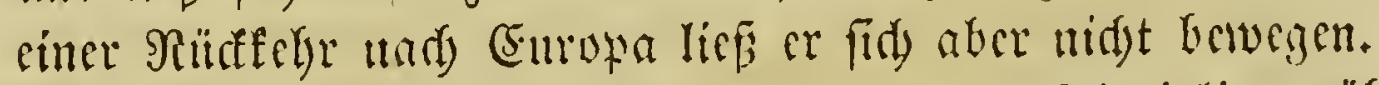

SWir gelyen nummegr zu ben cinjelnen Disciplinen über

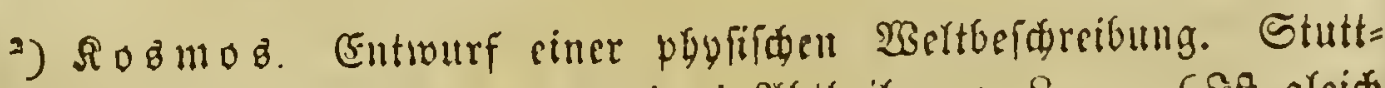
gart 1845-1852. 3 Bose. in 4 stbthcil. gr. 8. - (Sft gleid

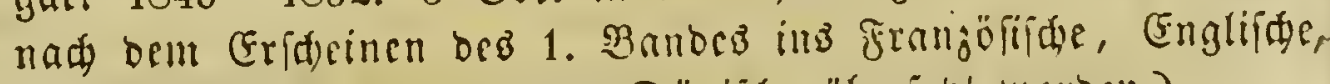

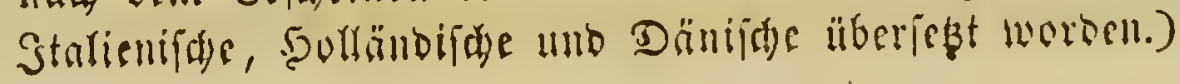




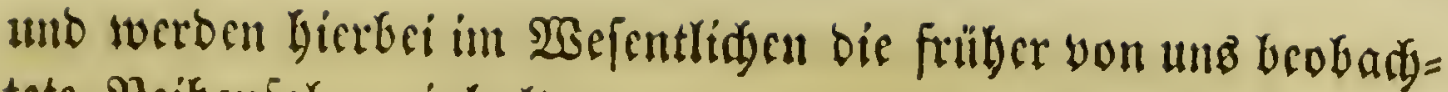
tete Reibenfulge sinbalten.

$\Im \mathfrak{n}$ ber Syftematif batte $\Im u f f i c u$ cine neue Babn gebruct)en. Aber bie Mängel f́inç̧ Syftemz layen balo zu flar aun Tage, als bafi man fíd bätte mit bomfelben begnügen

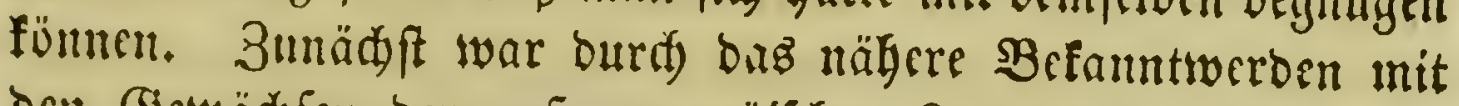

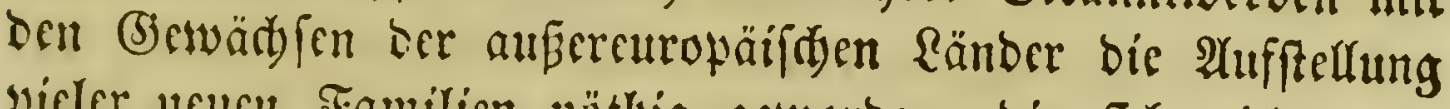
vicler ncucu Familion mötlig geworben, bie fidh nidjt whe

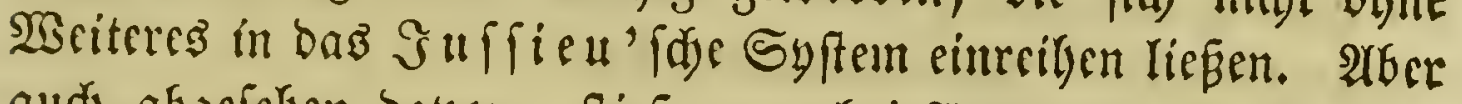
aud) abgeflyen bayon, friç man bei 2 tnwendung auf man= derlei Unvollfommenheiten beffelben. Ramentlich hatte fid

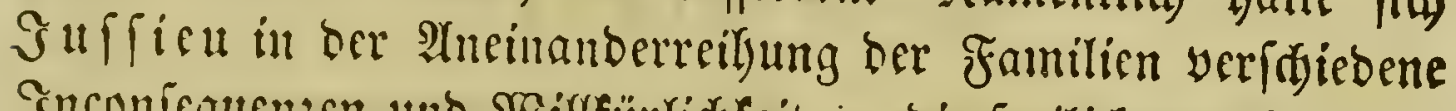

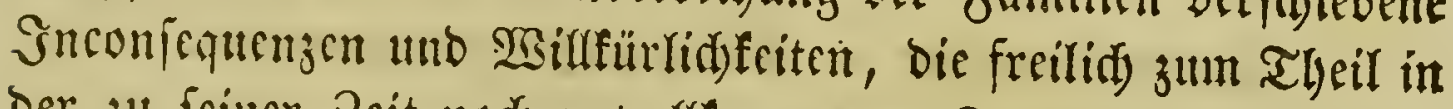
Der zul feiner 3rit nody unyolfommenen Renntnís ber Drgaine ibren (Sirund hatten, zu Sdulben fommen laflen; bie meifte

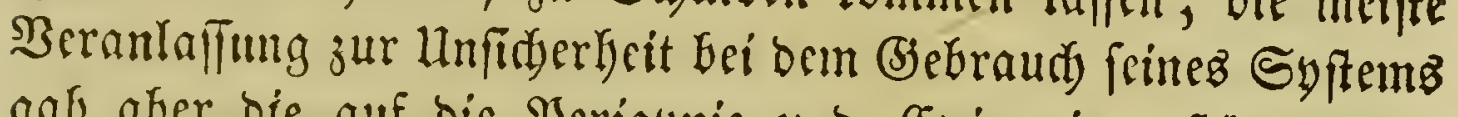
gab aber bie auf bie SJrrigynie und Epigynie geftübte Ein= theilung.

(5: บerfud)ten Darum bald nanhafte Botanifer biefe Män= gel zu entfernen. Unter biefen ift yorzüglich $\mathfrak{A}$. $\mathfrak{d}$. D $\mathfrak{f} \mathfrak{c a n}=$ bolle zu nennen, beffen Alenberungen fid) eines ausgebrei=

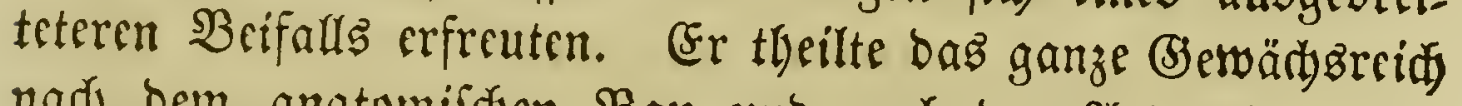
nad) bem anatomifden $\mathfrak{B a u}$ uno nad) ber 2 rtt uno Weife,

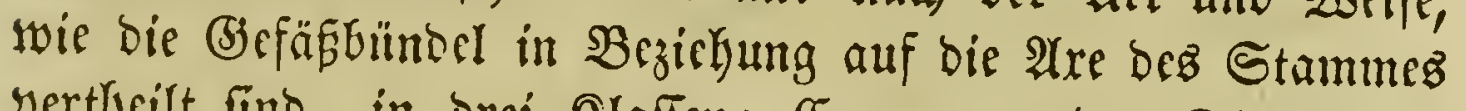
vertlycilt fino, in trei Rlaffen: Erogenen ober Difotylebo= nen, Embogenen oder Monofotylcbonen, 3elfenpflanzen ober Affutylebunen; bie beiden erften Slaffen begrcift er unter Dem Ramen (5) fäßpplanzen.

Die Difotylcoonen zerfallen wieber in zwei unterabthic lungen, is nadjocm sine bopwelte ober cinfad)e Blüthenthülfe yorbanben ift. Sei ben SPflanzen mit boppelter Blüthenkülle

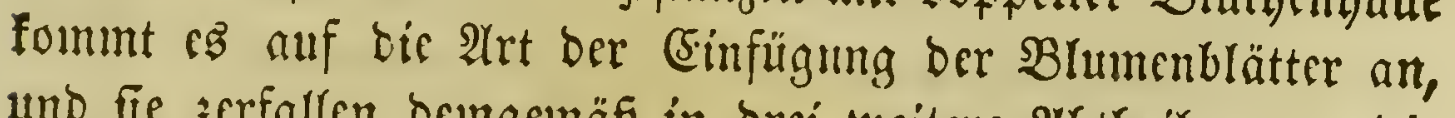
uno fie zerfallen bemgemäв in brei weitere 2Abtheilungen; bie SPlanjen mit einfadyer Blüthenhülle bildoen nur eine Untertlalfe. Die Enoogenen zerfallen in \$obanerogamen uno Sirytogamen; 
unter ben Iesteren find bie mit (Befäßen verielenen Sporen= pflanzen und die Rajabeen verftanden. Die erfte Unterabthei= lung Der 3ellenpflanzen entyält die Moofe, bie ztweite bie Fledten und bie übrigen angiofporen. Inter biefe Rlaffen bradte er anfangs 161, in ber zweiten Aluzgabe ber Théorie

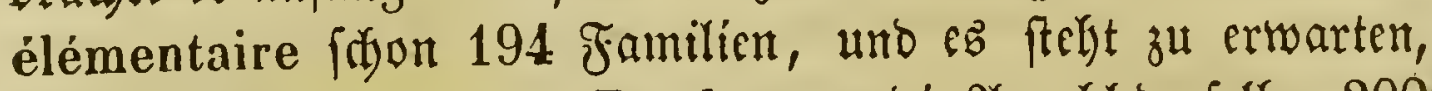

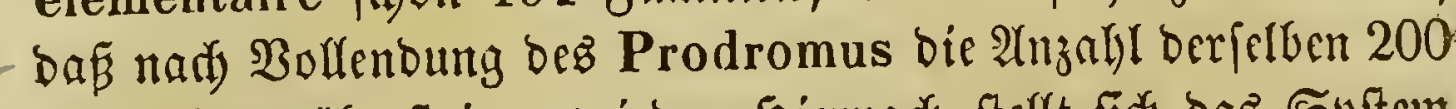
bei weitem üferfteigen wirb. Şiernady ftellt fidy bas Syltem Decandolle's folgendermafen bar:

\section{(5)te Siafie:}

\section{Exogenae s. Dicotyledoneae.}

Erfte Hutterflaffe: Thalamiflorae.

Erfte cogorte:

Carpella numerosa $v$. stamina petalis opposita.

Sronumg 1. Ranunculaceae.

"2. Dilleniaceae.

" 3. Magnoliaceae.

" 4. Annonaceae.
Drbnung 5. Menispermaceae.

6. Berberideae.

7. Podophyllaceae.

8. Nymphaeaceae.

3weite coborte:

Carpella solitaria aut connata, placentae parietales.

\section{Sronung 9. Papaveraceae.}

"10. Fumariaceae.

" 11. Cruciferae.

"12. Capparideae.

"13. Flacourtianeae.

"14. Bixineae.

" 15. Cistineae.
Srbnung 16. Violarieae.

17. Droseraceae.

18. Polygaleae.

19. Tremandreae.

20. Pittosporeae.

21. Frankeniaceae.

Dritte Cogorte:

Ovarium solitarium placenta centralis.

Sronung 22. Caryophylleae.

23. Lineae.

" 24. Malvaceae.
Dronung 25. Bombaceae.

26. Büttneriaceae.

27. Tiliaceae. 
Dronung 28. Elaeocarpeae.

29. Chlenaceae.
"30. Ternstroemiaceae
" 31. Camellieae.
32. Olacineae.
" 33. Aurantiaceae.
"3r. Hypericineae.
" 35. Guttiferae.
" 36. Mrgraviaceae.
" 37. Hippocrateaceae.
"38. Erythroxyleae.
"39. Malpighiaceae.

Drbmung 40. Acerineae.

41. Hippocastaneae.
" 42. Rhizoboleae.
43. Sapindaceae.
" 44. Meliaceae.
" 45. A mpelideae.
" 46. Geraniaceae.
" 47. Tropaeoleae.
" 48. Balsamineae.
"49. Oxalideae.
" 50. Zygophylleae.
" 51. Rutaceae.

Bierte Coborte:

Fructus gynobasicus.

Dronung 52. Simarubeae.

" 53. Ochnaceae.

Srbnung 54. Coriarieae.

\section{3rwcite Unterflaffe: Calyciflorae.}

Drbnung 55. Celastrineae.

" 56. Rhamneae.

" 57. Bruniaceae.

" 58. Samydeae.

" 59. Homalineae.
Srbnung 60. Chailletiaceae.

" 61. Aquilarineae.

" 62. Terebinthaceae.

" 63. Leguminosae.

unteroronung 1. Papilionaceae.

2. Swartzieae.

3. Mimoseae.

4. Caesalpinieae.

Srbnung 64. Rosaceae

" 65. Calycantheae. Sronung 76. Melastomaceae.

66. Granateae.

" 67. Nemecyleae.

" 68. Combretaceae.

" 69. Vochysieae.

" 70. Rhizophoreae.

"71. Onagrarieae.

72. Halorageae.

73. Ceratophylleae.

" 74. Lythrarieae.

1" 77. Alangieae.

" 78. Philadelpheae:

" 79. Myrtaceae.

" 80. Cucurbitaceae.

" 81. Passinoreae.

" 82. Loaseae.

" 83. Turneraceae.

" 84. Fouquieraceae.

" 85. Portulaceae.

" 86. Paronychieae.

" 87. Crassulaceae. 
Drbnung 88. Ficoideae.

" 89. Cacteae.

" 90. Grossularieae.

Hnteroronung 1. Orthospermae.

2. Campylospermae.

3. Coelospermae.

Dronung 93. Araliaceae.

94. Hamamelideae.

" 95. Corneae.

96. Loranthaceae.

97. Caprifoliaceae.

unteroronung

\section{"}

"
Dronung 103. Stylidieae.

"104. Lobeliaceae.

" 105. Campanulaceae.

I" 106. Cyphiaceae.

"107. Goodenovieae.

" 108. Roussaeaceae.

" 109. Gesneriaceae.

" 110. Sphenocleaceae.

1. Tubuliflorae.

2. Labiatiflorae.

3. Liguliflorae.
Drbnung 91. Saxifrageae.

" 92. Umbelliferae.
Dronung 98. Rubiaceae.

99. Valerianeae. 100. Dipsaceae. 101. Calycereae. 102. Compositae.

Dronung 111. Columelliaceae.

\section{Dritte Unterflaffe: Corolliflorae.}

Dronung 119. Myrsineae.

120. Sapoteae.

" 121. Ebenaceae.

" 122. Oleineae.

" 123. Jasmineae.

II 124. Strychneae.

" 125. Apocyneae.

" 126. Gentianeae.

" 127. Bignoniaceae.

"128. Sesameae.

" 129. Polemonieae.

" 130. Convolvulaceae.
Drbnung 131. Borragineae.

132. Solancae. 133. Antir rhineae. 134. Rlinanthaceae. 135. Labiatae.

136. Myoporineae. 137. Pyrenaceae. 138. Acantliaceae. 139. Lentibularieae. 140. Primulaceae. 141. Globularieae.

Bierte Unterflaffe: Monochlamydeae.

Drbnung 142. Plumbagineae. " 143. Plantagineae.
Sronung 144. Nyctagineae.

" 145. Amaranthaceae. 
Drbnung 146. Chenopodieae.

" 147. Begoniaceae.

"148. Polygoneae.

„ 149. Laurineae.

I 150. Myristiceae.

I 151. Proteaceae.

" 152. Thymeleae.

" 153. Santalaceae.
Dronung 154. Elaeagneae.

155. Aristolochieae.

156. Euphorbiaceae.

157. Monimiaceae.

158. Urticeae.

159. Piperiteae.

160. Amentaceae.

161. Coniferae.

\section{$3 \mathfrak{w e}$ ite $\mathfrak{R}$ taffe:}

\section{Endogenae s. Monocotyledoneae.}

Erfte Unterflaffe: Phanerogamae.

Dronung 162. Cycadeae.

163. Hydrocharideae.

164. Alismaceae.

165. Orchideae.

166. Drymirrhizeae.

167. Musaceae.

168. Irideac.

169. Haemodoraceae.

170. Amaryllideae.

171. Hemerocallideae

172. Dioscoreae.
Srbnung 173. Smilaceae.

174. Liliaceae.

175. Colchiaceae.

176. Junceae.

177. Commelineae.

178. Palmae.

179. Pandaneae.

180. Typhaceae.

181. A roideae.

182. Cyperaceae.

183. Gramineae.

3iweite Unterflaffe: Cryptogamae.

Dronung 18\%. Najadeae.

"185. Equisetaceae.

" 186. Marsiliaceae.
Sronung 187. Lycopodiaceae.

"188. Filices.

\section{Dritte $\mathfrak{R} \mathfrak{L}\{f \mathfrak{e}$ :}

\section{Cellulares s. Acotyledoneae.}

\section{Erfte Unterflaffe: Foliaceae.}

Drbnung 189. Musci.

Sronung 190. Hepaticae.

3ivcite Interflaffe: Aphyllae.

Drbmung 191. Lichenes.

"192. Hypoxyla.
Drbnung 193. Fungi.

" 194. Algae. 
DGgleita Decandolte auf dieje Weife cinige Mängel Dez $\Im$ uffie $\mathfrak{u}^{\prime}$ fiden Syftems glüflich entfernte, namentlid bie auf bic Epigynie uno Sorigynie gebaute Eintheilung unging, die Fantilien fdjärfer begrente und fie ifrer Berwandtidaft gemäfer aneitander reibte, fo leibet body audy fein Syftem an nint unbeträd)tlid)en Mängeln. Dá̧ bie 3u[ammenftellung

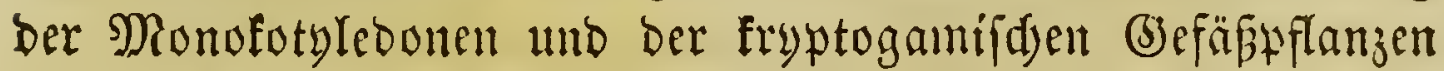

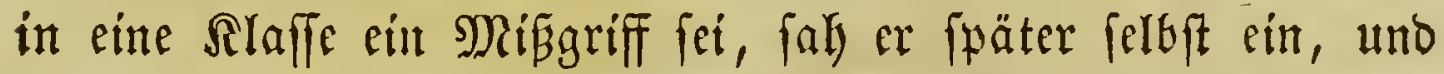
ftellte barum vier. Şauptelaffen auf ${ }^{1}$ ). 2Aber aud) bie (Einthei= Inng ber Monofotylebonen in Srfanzen mit buppelter und ein=

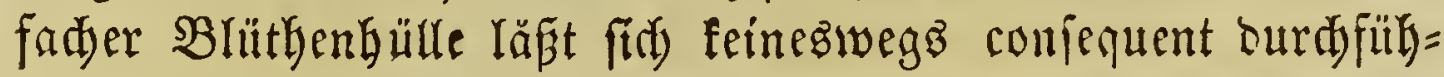
ren. Ebenfo läßt fith an ber âfeinanderfolge ber Frmilien

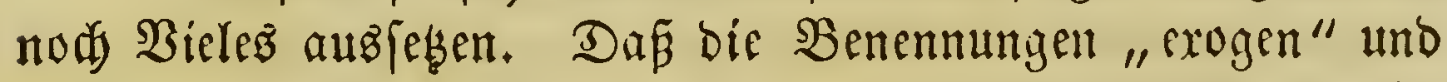
"endogen" in Dem Sinne, in bem fie Decrndorle aufapt, auf einem Srrthum beruben, Gebarf faum ber Grivälymng.

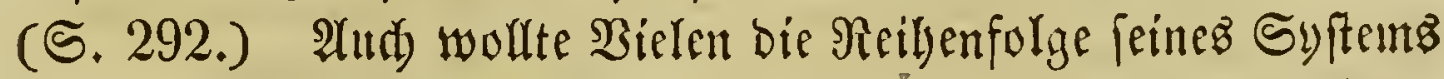
nidyt gefalfen, wail ez naturgemä̈er fei, yon cen unyolffum= minen (5) wäd) fen zut Den wolfommeren fortzuldreiten.

D. b. Sdjledtendal, auf Decallo olle's Sinthei=

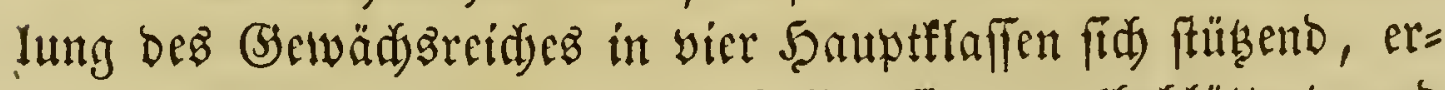
hob die Unterabtheilungen ber 3 ellemplanzen (beblätterte und brattlofe) ebenfallz zu Rlaffen uno erridstete nod eine fedjzte Slaffe für die plyanerogamifdyen 3 ellentflanzen. ${ }^{2}$ )

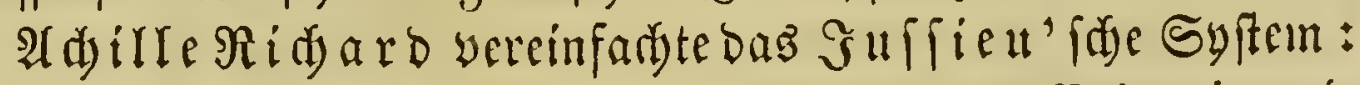
cr nahin 9 Rlaffen an, indem er bie nuf bie (Epigynie uno Sorigynic geftübste (Eintheilung verwarf. ${ }^{3}$ )

1) Note sur la division du règne végétal en quatre grandes classes ou embranchemens. (Genève 1833). 3. - Deutí:

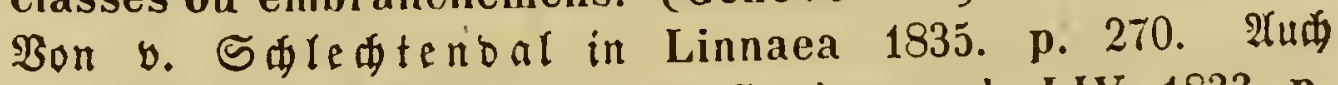
zu finben in ber Bibl. univ. de Genève. vol. LIV. 1833. p. $259-268$.

2) Linnaea S. $279-285$.

3) Botanique inédicale, ou Histoire naturelle et médicale des médicamens, des poisons et des alimens, tirés du règne végétal. Paris 18:3. II voll. 8. - Deut f中: MRit 3u[äben 


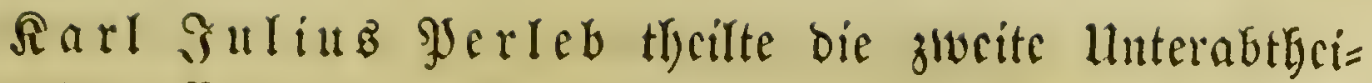
Iunty der Cintogenen Defandorle's (Calyciflorae) in

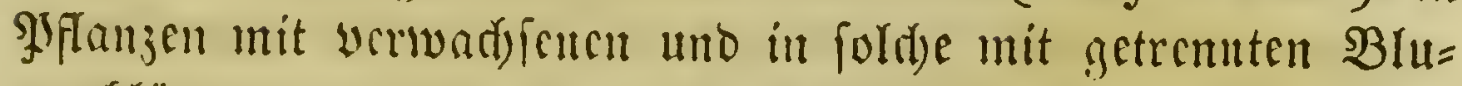
menblïttern unb trug and) fonft zur $\mathfrak{D e r b e f f e r u n g}$ bes $\mathfrak{D} \mathfrak{C}=$ candorfe'fdyen Syftems bri. ${ }^{2}$ )

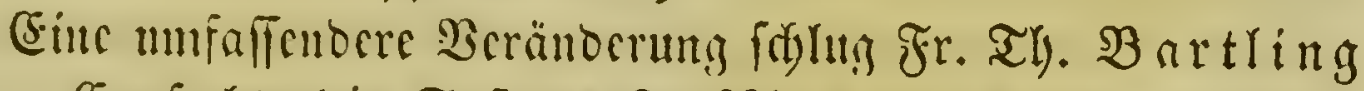
bor. Er fudyte dic Syfteme Suffien's unb Decandol=

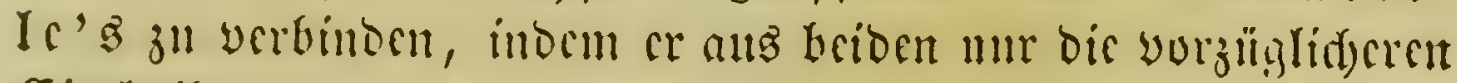

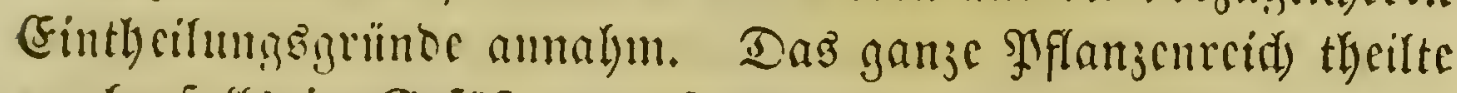

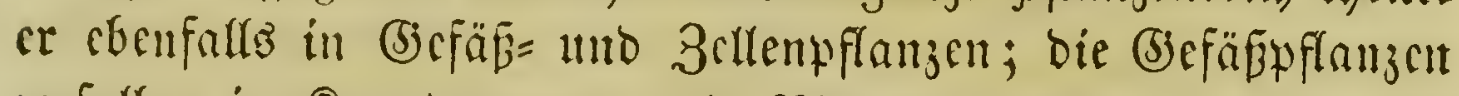
jerfallen in Siryntugamen uno sglyancrogamen, die Ietzeren in Nono= uno Afotylcooncn, fene wicrerum in büllfcimige (chlamydoblasta) uno nadffimige (gymnoblasta), uno biefe wisorrum in blumenlofe, cin= uno viclblumenblätterige; bie 3rufupflangen theilte er in gleidgfäbige (homonemea) uno ungleidjäbige (beteronemea), indem or ammahm, bas bei

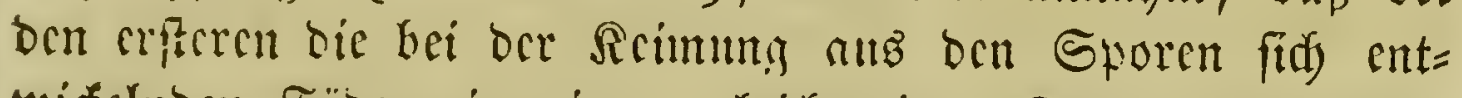

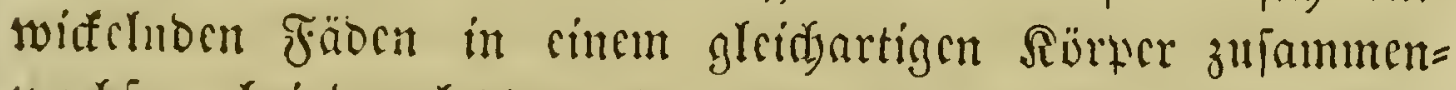
wwadjen, bei ben Iegteren bagegen entweser frei bleifen ober zu cincm unglcidartigen Rörper fid) verbinter. (5r nalym ferner 60 Droummgan als Mittelglieber zwifdyen ben STaffen

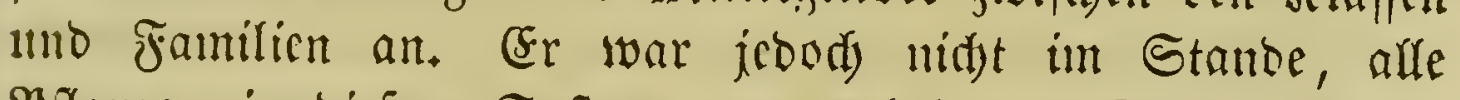
Bfflungen in biefom Syfteme unterjubringen, fügte vielmedr zu ben 246 eingereibten Familicn 9 antere uno auferecm nod)

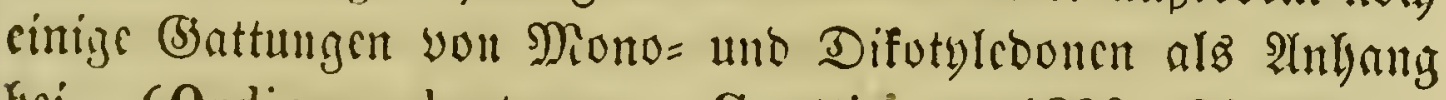
bei. (Ordines plantarum. Goettingae 1830. 8.)

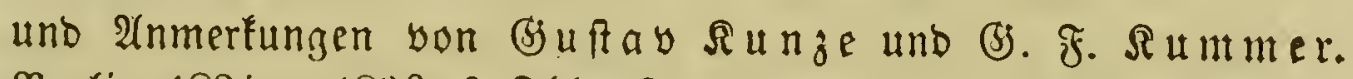
Berlin $1824-1826.2$ Thle. 8.

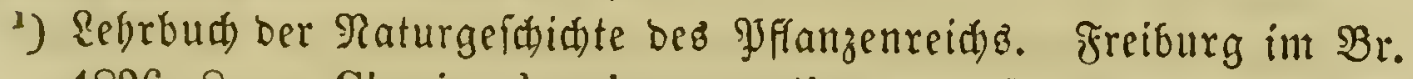
1826. 8. - Clavis classium, ordinum et familiarum, atque index generum regni vegetabilis. - Diugnoftiche $\mathfrak{H e b}$ erfictitz=

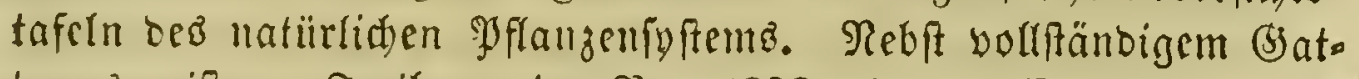
tungbregiffer. Frriburg im 33 . 1838. 4. - Er frfrieb aud über ben botanifden Garten zu Freiburg: De horto botanico Friburgensi. Friburgi Brisgoviae 1829, 4. 1 tab.

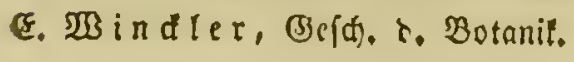




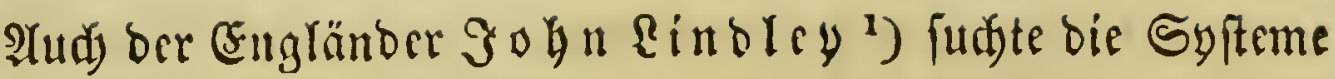

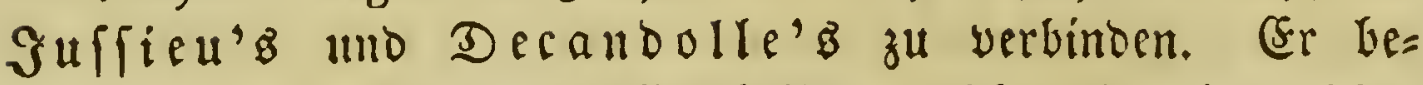

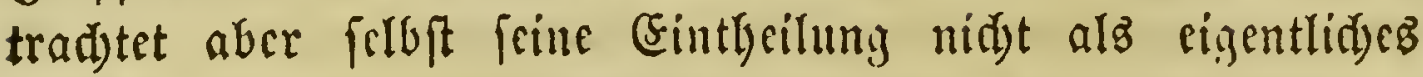

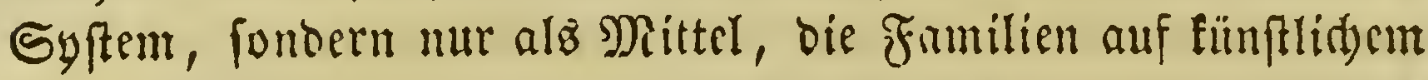
SBege aufzufinden. Aud) er bradtete bie Familien unter Mittel= gruppen (nixus) und dicje wieber unter böhere afbethrilungen (cohortes). SSBir fülyren feille Anfinten uid)t weiter aus, ba fie feine Berbrcitung fanten. ${ }^{2}$ )

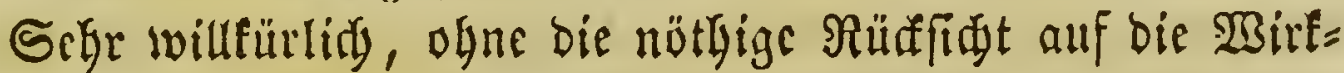
Iidffit, verfugr

\section{Rorenz $\mathfrak{D} \mathfrak{e}$ it,}

geboren zu Boblsbad in Squaben im 3abr 1779, geforben 1851 als Srofefior zu 3üriø,

bei Aufftellung frimes Şflanjenigftems. Er theilte das $\mathfrak{g e}=$

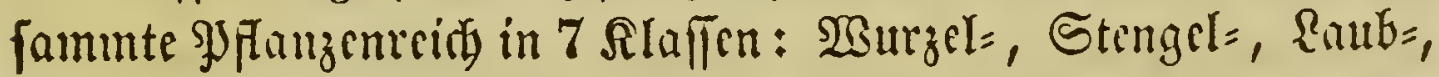
Samen=, Sröps=, Blumen= uno Frudtpflanjen. Sere diefer Slaffen zerfällte er nad den virr Şauptoryanen, SMurzel, Stengel, Raub uno Blume, in 4 Dromumien; fo theilte er

1) An introduction to the natural system of botany; or a systematic view of the organisation, natural alfinities and geographical distribution of the whole vegetable kingdom. London 1830. 8. - Ed. II London 1835. 8. 6 tab. - Ed. III London 1839. 8. - Deutíl: Beimar 1833. 8. - Sauptfennzeiden ber natürliden SYfanzenfamilien. Atus

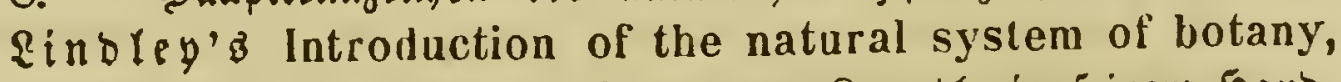
London 1830; georbnet naw ber von $\Re$ unth in feinem Sano= buclye ber Botanip, Berlin 1831, gewäblten Folge. 2 . D. Engl.

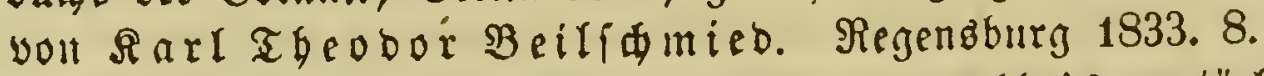

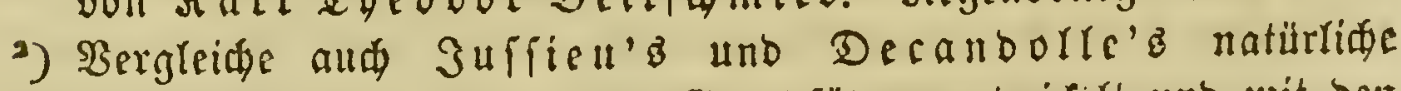

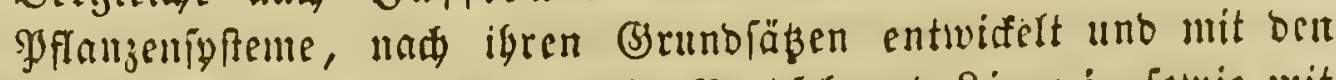

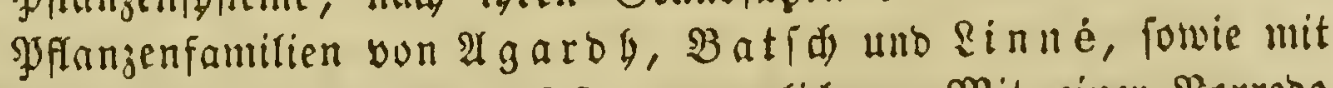

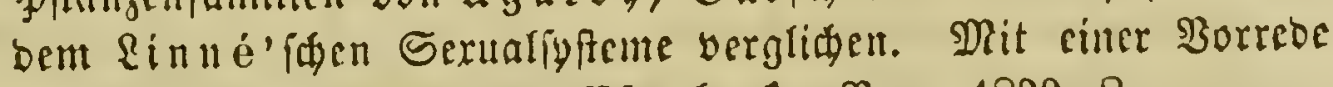

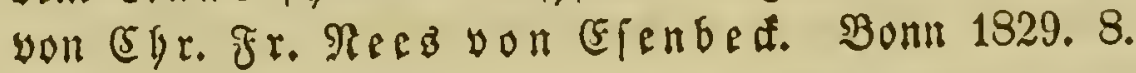




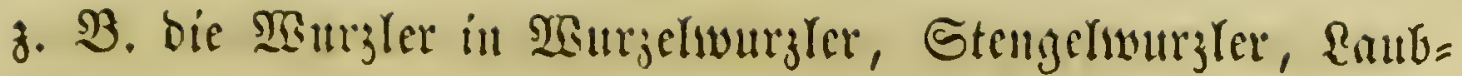

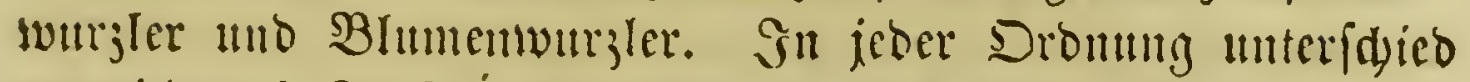
rr wieber 4 3ünfte, in jeoer 3unft 4 Sippfdjaften und it jeder Siptidyaft 4 Sippen ${ }^{2}$ ). (Er blicb jebod) biefer (Ein= theiluni nidgt getren, fondern inbem er fpäter ${ }^{2}$ ) bent feiner STaffencintlycilung ju Grumbe liegenten Drganen nod) bie $3 \mathrm{el}=$ Ien, ADcrn uno Druffeln mo fermer 4 Frudtformen (Nuf,

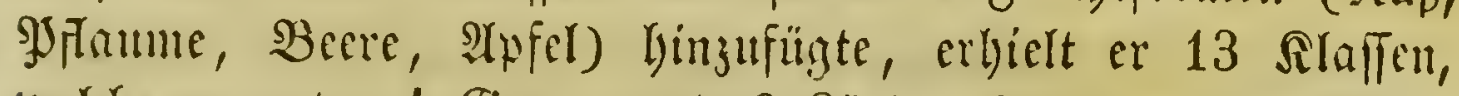
weld)e er unter 4 (jauen und 2 Ränder bradjte; jede SIaffe zerfällt bann wieber in 2 Stufen, 4 Dronungen and 13 3ünfte, jebe 3umft in 2 arbtheilungen, 4 Sipvidjaften uno 13 Sipwen. - 3u feiner 3eit bewumberte man ben Sdyarf= fim, ben $D$ fen bei ber Aluffellung bicfes Syftems entwiafelt babe; jeşt aber, wemn man audy ben woblthätigen (sinflus ber Raturphiloforlie auf bie Raturwillemidajten im (5)anjelt tilto (5rofen burd)aus nidyt in atbrebe ftellt, betradjtet mant

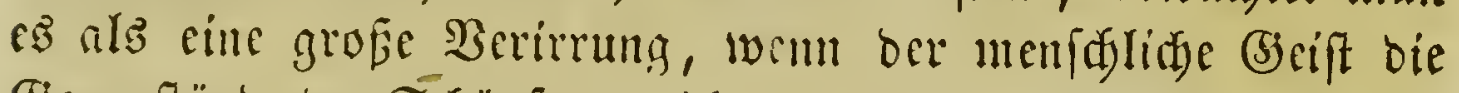

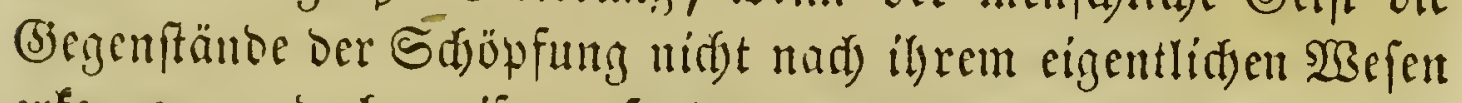
erfennen uno begreifer, fonbern nad) feinen cigenen flein= lidyen (5) rumbjägen mafiregeln uno bie Mängel bes willfürlity

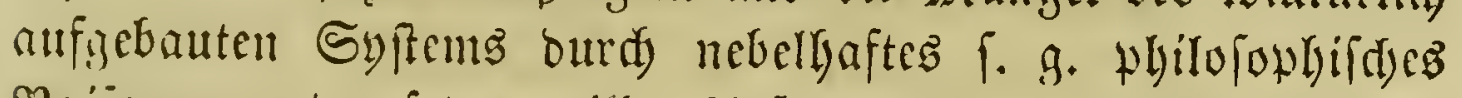
raijonnement exfegen will. Uuf ägulitye Siseife wie Dfen,

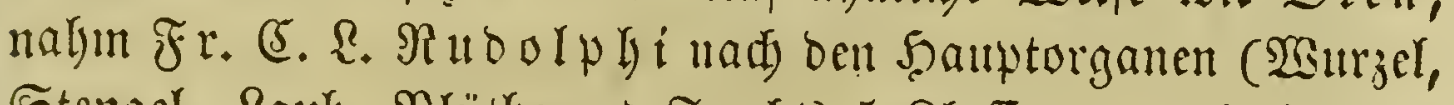

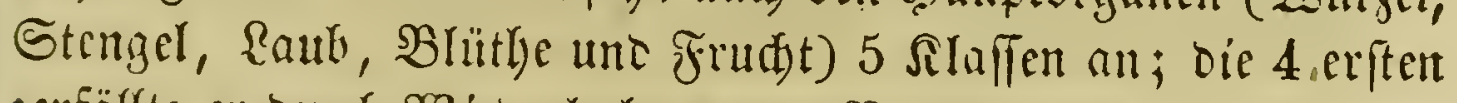
jerfällte er Durd) SBicoerbolun! und Berbinoung Diefer Drgane jere in 4, bie leste in 2 Dromungen, unter werd)e er baunt die familien cimrsilyte. ${ }^{3}$ )

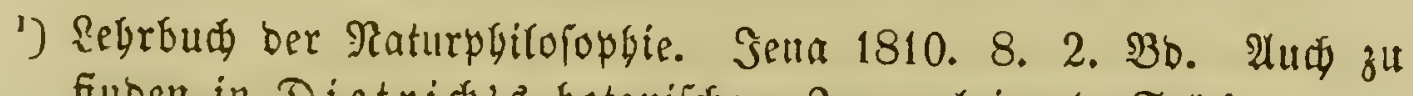
filloen in Dietrid,'s botaniffecut Sournal im 1. Stüd.

2) Segrbuch ber Raturgefdidyte $2 \mathfrak{r}$ Theil. SBotanif. Sena 1825 1826. 8. - Rugemeine Raturgeídidyte für alle Etänbe. Samb 2 unb 3, oder פotanif Bano 1 und 2. Etuttgart 1839-1841. 8. 2 ttras in 4.8 fol. Taferlu.

3) Systema orbis vegetabilium. Gryphiae 1830. 8. 


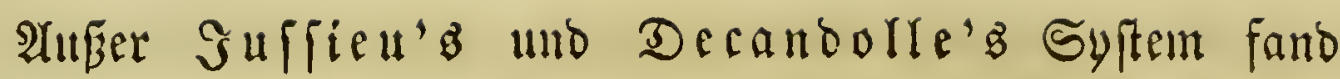
bas yon

\section{Sccinrid Sottlicb Rlubig Rcidbenbady,}

Director Dez fönigliden Raturalientabinets und Sprofeffor ber Ratur=

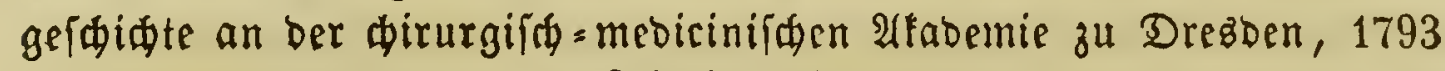

zu Reipzig geboren,

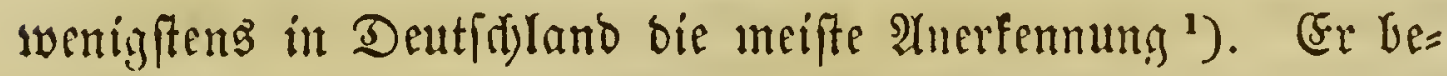
zweáte die Drganijationsftufen ober Entwidelungsmomente ber einjelnen wollendeten SSflanje in Der (Gejammtheit bes

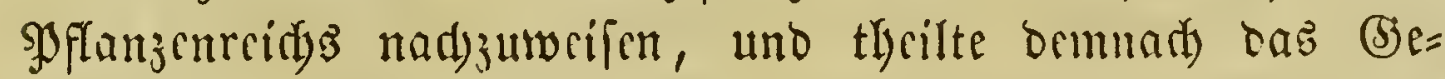

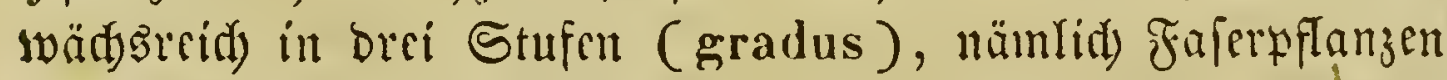
(inophyta), Stofpflanjen (stelechophyta) uno SBlithen= Frudbtpflumzen (antho-carpophyta). Siefe orei Stufen zer= fallen oamit naty ber Art und SSeife bes Reimens in vier Un= terabtlarilungen, weldye in adyt SIlafen nady folyenoem Sdyemn eingetbeilt fino:

\section{Erite Stufe: \\ Fajerpflanjen, Tnophyta.}

a. Rafteiner, Gymnoblastae.

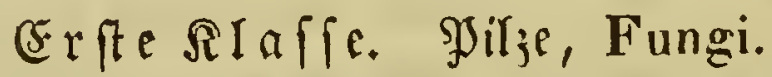

3 weite Ilaffe. Fledter, Lichenes.

\section{3weite Stufe:}

હtodfpflanjen, Stelechophyta.

b. Zelffeimer, Cerioblastae.

Dritte SIaffe. Srümplanjen, Chlorophyta.

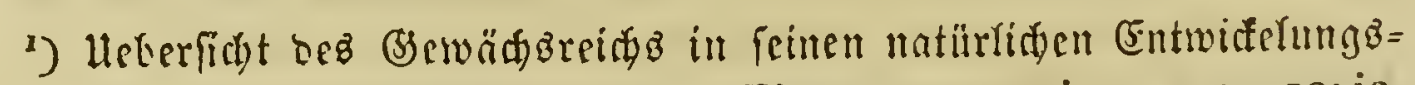
fufen. Scipjig 1828. 8. - Flora germanica excursoria, ex affinitate regni vegetabilis naturali disposita. Lipsiae

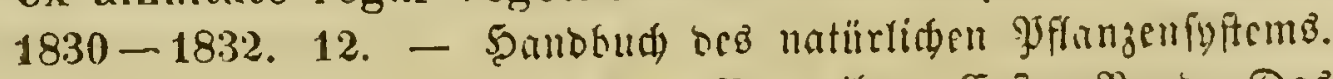
seipzig 1837. 4. - Der reutithe Botanifer. Eriter Şand: Das Serbarienbuć. Dres̄ben uno Reipjig 1841. 8. 
c. Spifteimer, Acroblastac.

Bierte $\mathbb{R}$ Iaffe. Sdecibenflanjen, Coleophyta.

d. Blattfeimer, Phylloblastae.

Fünfte RIaffe. 3weifalblumige, Synchlamideae.

Dritte Stufe:

\section{Blütben $=$ Fruchtpfingen, Antho - Carpo $=$ pliyta.}

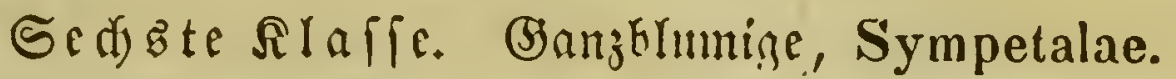

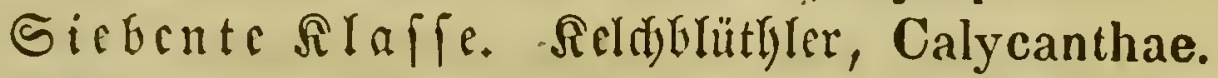
$\mathfrak{A}$ d) te $\mathfrak{S} \mathfrak{I} \mathfrak{a}\{\mathfrak{f}$. Stílblütfler, Thalamanthae.

Bon biefen 8 SIaffen zerfällt jebe in 3 Dromungen. Die Dromunisen ber erften uno die erfte Dromung Der zweitent Silaffe zerfallen jeoe in 3 Familien; alle librigen Dromungen aber werben in 2 Formationen und jebe Formation in 3 Fa= mifien cingetleilt. Bon ben unyolffommenen (B) wäd) fen aus=

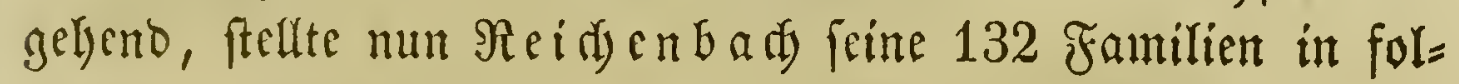
gentor Reilenfolige auf:

\section{Erite $\mathfrak{A l a f f e :}$}

\section{Fungi.}

(5ifte Oromung. Coniomycetes, Seimpilze.

1. Familie. Praeformativi, Urpilze.

2. " Uredinei, Sranopilze.

3. " Tubercularii, Marzenpilze.

3write Dronung. Hyphomycetes, Fabenpirze.

4. Fanilie. Byssacei, Mloberpilze.

5. " Mucedinei, Fafrrilize.

6. "Mucorini, Sdjimmelpilze. 
Dritte Dronung. Dermatomycetes, Şültpilge.

7. Familie. Sphaeriacei, Sdlauds)linge.

8. " Lycoperdacei, Strulinge.

9. " Hymenini, Şutpillje, Şutlinge.

\section{3 weite $\mathfrak{R}$ laffe: \\ Lielnenes, Fledten.}

Erfte Dronung. Coniopsorae, Staubfledten.

10. Familie. Leprariaceae, Fräğfledten.

11. "Variolariaceae, Blätterfledten.

12. " Arthoniaceae, Malfledjten.

3weite Dronung. Podediopsorae, Stielfledten.

Formation 1. Crateropsorae, Büđíenfletten.

13. Familic. Calycieae, Reldy fledten.

14. " Coniocarpicae, Staubfrudifledtett.

15. " Sphaerophoreae, Staubfugelfledten.

formation 2. Cephalopsorae, Ropffectent.

16. Familie. Isidieae, SJfrifenfledttcn.

17. "Lecideaceae, Stacifonfledten.

18. " Cladoniaceae, Ruopflifedten.

Dritte Dronung. Thallopsorae, SBedelfledter.

Formation 1. Gasteropsorae, Rernfledten.

19. Fomilie. Gasterothalamae, Balgfernfledten.

20. " Graphithalamae, Rimurufledten.

21. " Gyrothalamae, Rnaulfledyten.

Formation 2. Apotheciopsorae, Sdyüffeffledter.

22. Familic. Collemaceae, (Gaffertfled)tert.

23. "Usneaceae, Strumfflditen.

24. " Parmeliaceae, \&appenfledten. 


\section{Dritte $\mathfrak{R} \mathfrak{l}$ ffe:}

\section{Chlorophyta, Grünp flamen.}

Erfte Dronung. Algae, Argen.

gormation 1. Gongylnphycae, Inospenalgen.

25. Familie. Nostochinae, (Baflertalgen.

26. " Confervaceae, Fatmalgen.

27. "Ulvaceae, Sdjlautilgalgen.

Formation 2. Ascophycae, Balgalgen.

28. Fanilie. Ceramiaceae, (B) elcufirudytalgen.

29. " Sphaerococceae, Rermalgen.

30. " Fucoideae, Tangalgen.

3iveite Dronung. Musci, Movfe.

Formation 1. Thallobrya, Mebelmoofe, Rebermovie.

31. Familic. Ricciaceae.

32. " Jungermanniaceae.

33. " Marchantiaceae.

Formation 2. Phyllobrya, Raubmoofe.

34. Familie. Sphagnaceae, Torfmovfe.

35. " Andreaeaceae.

36. " Calyptrobrya, Müßemmovie.

Dritte Dronung. Filices, Farrn.

formation 1. Thryptopterides, Riffarrı.

37. Familie. Salviniaceae.

38. " Marsiliaceae.

39. - " Polypodiaceae.

Formation 2. Anoegopterides, Spaltfarrm.

40. Familie. Osmundaceae, Trubcufarm.

41. " Ophioglosseae, Ratteriungenfarrm.

42. " Cycadeaceae, Şalmenfarm. 


\section{Biexte $\mathfrak{R}$ affe:}

\section{Coleophyta, Echeidenpflanger.}

Erffe $D$ ronang. Rhizocole ophyta, $\mathfrak{B}$ urzer fideibcnpflanzen.

Formation 1. Limnobiae, Taudergewädíe.

43. Familie. Isoëteae, $\mathfrak{B r a d j [ c n f r a ̈ u t e r . ~}$

44. " Zosteraceae.

45. " Aroideae.

Formation 2. Helobiae, Sdilammwurgler.

46. Fannilie. Potamogetoneae, Raídferütter.

47. " Alismaceae.

48. " Hydrocharideae, Rixenfräuter.

3weite Dronung. Caulocoleophyta, Stamm= fdecidentlanzen.

Formation 1. Glumaceae, Spel żengemäăfe.

49. Framilie. Gramineae, (5)räicr.

50. " Cyperoideae, (Sypernräfer.

51. " Commelynaceae, હd)wertclgräjer.

Formation 2. Ensatae, Salvertelgewädáe.

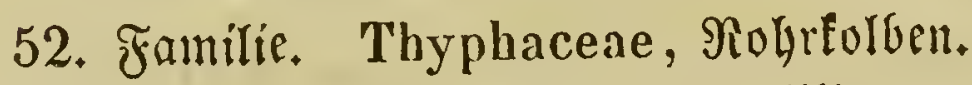

53. "Irideae, Sdytwertliticn.

54. " " Narcissineae, Narciffenidjucter.

Dritte Dronung. Phyllocoleophyta, Blatt= fdjcibcupflanjem.

Formation 1. Liliiflorae, Rifienblütbige.

55. Familic. Juncaceae, Simicniticn.

56. " Smilaceae.

57. " Liliaceae. 
Sormation 2. Orchiflorae, Drøisblütbige.

5S. Framilie. Orchidaceae.

59. " Scitamineae, 23anamen.

60. " Palmaceae, Palment.

Filnfte $\mathfrak{A l a f f e :}$

\section{Synchlamydeae, Bweifelblumige.}

(Erfte Drbung. Enerviae, Riphenlofe.

Formation 1. Najadeae, Rajabeen.

61. Framilie. Characeae, Âruleuditergenäduje.

62. " Ceratophylleae, Şurnblattgewäd)

63. " Podostemoneae.

Formation 2. Inbricatae, Sdupprer.

64. Fintlie. Lycopodiaceae, Bärlapue.

65. " Balanophoreae, Rolbenfdoffer.

66. " Cytineae.

3weite Dronung. Rigidifoliae, Steifbrätterige.

gormation 1. Inconspicuae, Sdledtbrütgige.

67. Familie. Equisetaceae, Srfarbtelfalme.

68. " Taxineae, (Fiben.

69. " Santalaceae.

Formation 2. Ambiguae, Dopperbeutige.

70. Fumilie. Coniferae, 3apfenbäume.

71. " Proteaceae.

72. " Tbymelaeaceae, Sribelit.

Dritte Dronung. Venosae, Aderblätterige.

Gormation 1. Incompletae, Misblütgige.

73. Familie. Myriaceae.

74. " Amentaceae.

75. " Urticaceae, Reffeln. 
Formation 2. Foliosae, Blattreide.

76. Familí. Aristolochiaceae.

77. " Nyctagineae.

78. " Laurineae, Rorbergewä̉ife.

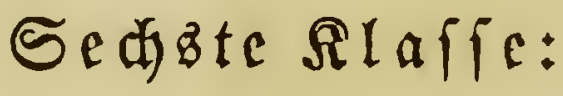

\section{Synpetalae, Gianjblumige.}

(5rfte Dronung. Tubiflorae, Röhrentüthige.

Formation 1. Aggregatae, 5̧äufelblütbler.

79. Familie. Dipsaceae.

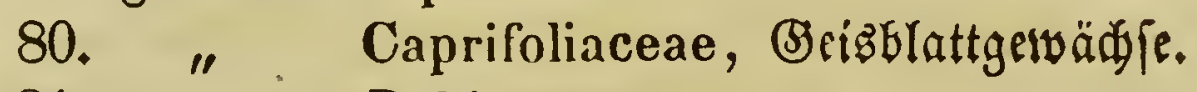

81. " Rubiaceae.

Formation 2. Campanaceae, Bjlođenblütbler.

82. Familie. Synantherae, Berwadjenbeutelige.

a. Compositae.

๙. Amphigynanthae.

3. Amphicenianthae.

r. Homoianthae.

b. Dispositae.

a. Ambrosieae.

ß. Iveae.

久. Calycereae.

c. Segregatae.

¿. Seriphieae.

ß. Echinopsideae.

$\gamma$. Bolandreae.

83. Familie. Cucurbitaceae, Rïrbisgct๖ähie. 84. " Campanulaceae, (j)

3weite Dronung. Fauciflorae, Sd) Formation 1. Tubiferae, Röbrenträger.

85. Familie. Labiatae, Riptenblütbler.

86. " Asperifoliaceae, Raubbrättrige.

87. " Convolvulaceae, Winbengeıäd 
Formation 2. Limbatae, Saumblütgler.

88. Familic. Globulariaceae.

89. " Personatae, Rarvenblütblex.

90. " Solanaceae, Radtidjatten.

Dritte Dronung. Limbiflorae, Saumblüthige.

Formation 1. Crateriflorae, Bederbrütbige.

91. Familie. Plumbagineae.

92. " Primulaceae.

93. " Ericaceae, ந̧eibegetwäd)

Formation 2. Stelliflorae, Sternblütbrer.

94. Familie. Asclepiadeae.

95. " Contortae, Drebblütbler.

96. " Sapotaceae.

\section{Siebeute SIaffe:}

Calyeantlae, Reldblütblex.

Erfte Dronung. Variflorae, Beríieben= blütbige.

Formation 1. Parviflorae, ATeinblütbige.

97. Familie. Umbelliferae, Doloengelväd fe.

98. " Rhamneae, Ireugborngewäd)

99. " Terebinthinaceae.

Formation 2. Leguminosae, Şülfenfrüntige.

100. Familie. Papilionaceae, Sdymetterlingåblütbige.

101. " Cassiaceae.

102. " Mimosaceae.

3weite Dronung. Confines, Aebnlidblütbige.

formation 1. Sediflorae, Seoumblütfige.

103. Familie. Corniculatae, Bebörntfrildytige.

104. " Loasaceae.

105. " Ribesiaceae. 
Forntation 2. Rosiflorae, Roienblütbige.

106. Familie. Portulaceae.

107. " Aizoideae.

108. " Rosaceae.

Dritte Dronung. Concinnae, (5) leidförmig= blütlige.

Formation 1. Onagriflorae, Rantferzenblütbige. 109. Familie. Halorageae.

110. " Onagraceae, Radtferzen.

111. "Lythrarieae, Seiberidggetwäd) pe.

Formation 2. Myrtiflorae, Myrtbenblittbige.

112. Familie. Polygalaceae.

113. " Myrtaceae.

114. " Amygdalaceae.

Adte $\mathfrak{R} \mathfrak{l} \mathfrak{a}\{\mathfrak{f}$ :

\section{Thalamanthae, Stielblütbler.}

(Erfite Dronumg. Thylachocarpicae, Şofl= frübtige.

Formation 1. Craciflorae, Rreuźbütţler.

115. Jamilie. Tetradynamae, Biermädtige.

116. " Papaveraceae, Mokngewäd)fe.

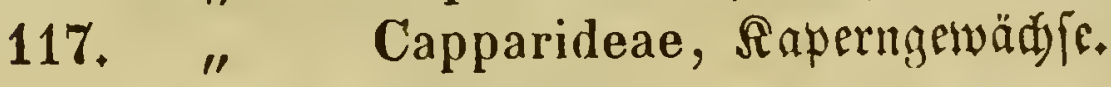

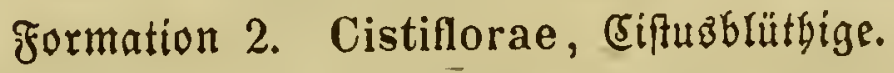

118. Familic. Violaceae, Sicildjengewädjé

119. " Cistineae.

120. " Bixaceae.

3weite Dronung. Schizocarpicae, Spalt= fril ditige.

Formation 1. Ranunculiflorae, Ranunferbrütbige.

121. Familie, Ranunculaceae.

122. " Rutaceae, Rautengctwädj

123. " Sapindaceae. 
Formation 2. Malviflorae, Malvenblütyige.

124. Familie. Malvaceae.

125. " Geraniaceae, Stord)

126. " Oxalideae, Sauterflergervädfe.

Dritte Dronung. Idiocarpicae, Säulfufrüdtige.

Formation 1. Tiliiflorae, \&inbenblütgler.

127. Familie. Caryophyllaceae, Melfengetwädje.

128. " " Theaceae.

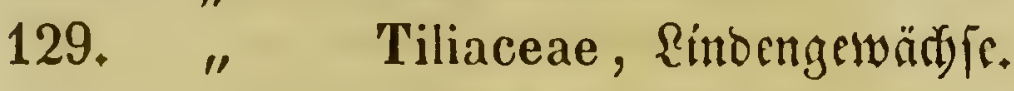

Forntation 2. Aurantiiflorae, Sorangenblütgler.

130. Familie. Hypericineae, Şartheugewäd)[e.

131. " Guttiferae.

132. " Hesperideae, Drangengewäbje.

Die grofien Mängel diefez Syftems fino leid)t zu erfen= nen; Der bebentendfte Febler befferben aber ift ber, baj fein

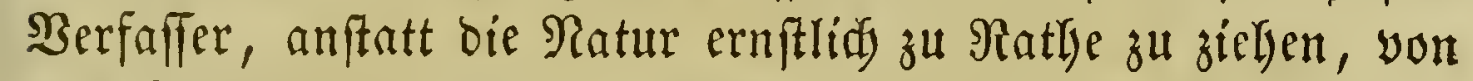
pliflofoplifiden Fictionen ausgelyt. So follen nady feiner $2(n=$ fidit bie einzelnen Şauptentwidelumgsperioden ber Syflanze

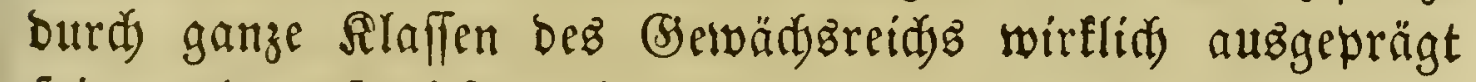
fein, und auf biefe bod, wie leidjt nadjulweifen ift, feines= Ivegs burd)zufülrenoe Ânalgme ift das ganze Syftem aufge=

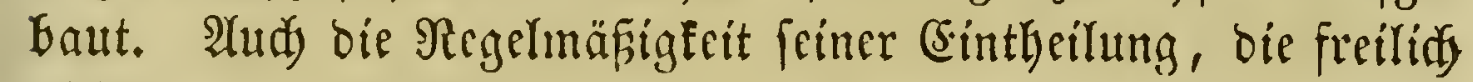
nidyt wenig zur Berbreitung feines Gyftems beigetragen baben

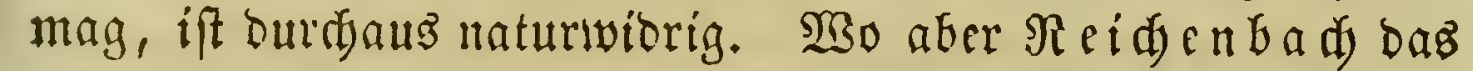

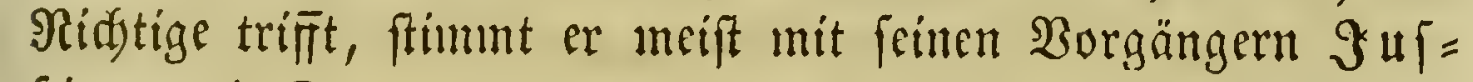
fieu unb Decandolle übersin, und wir finden bann nur yeridsiedene Ramen, nidyt aber yerfdicbene Dinge. 
Sine viel gräßere Beaditung verbient bas von

\title{
$\boldsymbol{F} \mathfrak{r a n z} \mathfrak{u} \mathfrak{g} \mathfrak{e r}$,
}

\author{
grofeffor in Bien,
}

aufgeftellte uno yon

\section{Ctepban dabislaus Onolider,}

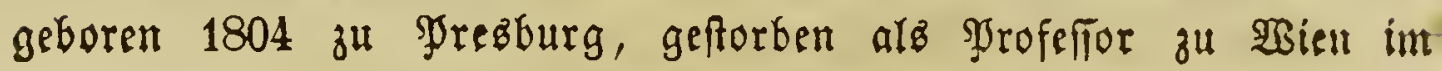
3abr 1849,

auşgefübrte natürlidye Syftem ${ }^{1}$ ). Nad) bemfelben zerfällt baz gefammte (setwäd)breidy in zwei Regionen, nämlid in axen= Ioje oder Raubgewäd)je (thallophyta), D. H. joldee, bei benen nod fein $\mathfrak{A}$ useinandertreten in $\mathfrak{A}$ re und $\mathfrak{B l a t t}$ ftattfindet und Deren Sïrper auf alfen Sunten eine 3unahme erleibet, und in $\mathfrak{A}$ ren = ober Stengelpflanjen (cormophyta), b. h. Syflan= zen, Die mit einer beutlid) auşgeprägten $2(r e$ uno mit $\mathfrak{B l a ̈ t t e r n ~}$

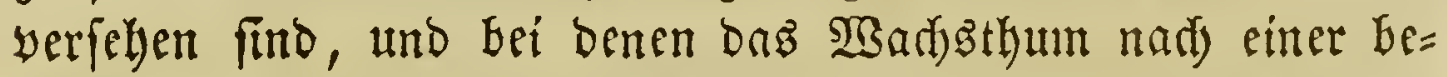

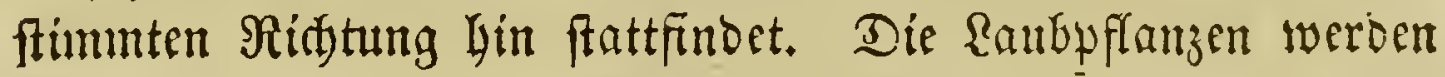
in zwei Sectionen eingetheilt, in urfprünglidje (protophyta, D. H. ÂIgen und Fledten) und in fecundäre (hysterophyta, D. b. SJilje, fo genant, weil fie wenigftens jun Theile aub

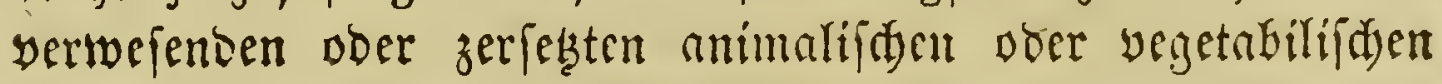
Subftanjen entfegen). - Die Irenyflanjen bagegen jerfalfent

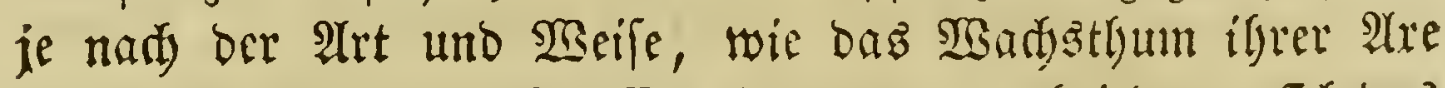
wor fid gelyt, in (entofproffer (acrobrya), bei benten fid baz

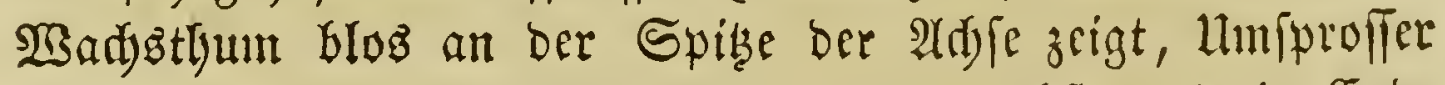
(amphibrya), Deren $\mathfrak{A}$ re in bie Diffe wäd)ft, und int (End = umpproffer (acramphibrya), bei benen biefe beiber Arten bes

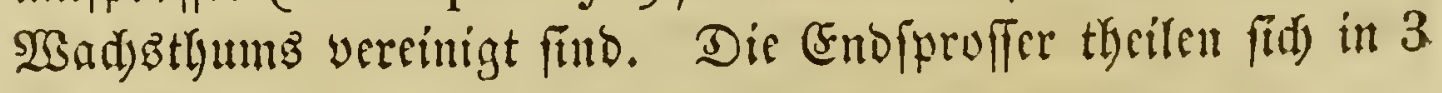

1) Genera plantarum secundum ordines naturales disposita. Vindobonae 1836 - 1843. 4. - Enchiridion botanicum exhibens classes et ordines plantarum. Lipsiae 1841. 8. 


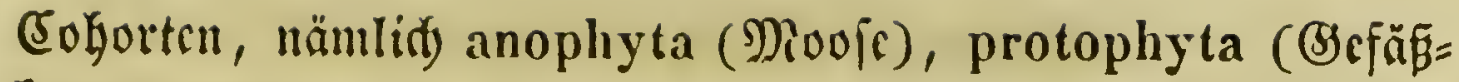

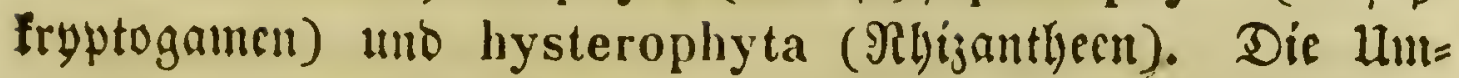
fproffer (MRonofutyledonen) bilben nur cine (Suborte, bie (End= umproffer bageyen $\dot{4}$, uämlid) gymnospermia (ङoniferen), apetala (Monod)lamioeen, Decand.), gamopetala (Eorolli= floren uno gamopetale (Salycifloren, Decand.) unb dialypetala (friopetale (Enlycifloren und Ihalamifloren, Decand.). Die Thallophyten enthalten 3, bie (Sormophyten 58 Rlaffen (Dronungen), benen 278 Dronumgen (Familien) nad) fol= gentem Sduana untergeoronet find:

\section{(5) fite slaffe: Algae.}

Dronung 1. Diatomaceae.

" 2. Nostochinae.

"3. Confervaceae.

" 4. Characeae.
Sronung 5. Ulvaceae.

6. Florideae.

7. Fucaceae.

\section{3tweite Rlaffe: Lichenes.}

Sronung 8. Coniothalami.

9. Idiothalami.
Dronung 10. Gasterothalami. " 11. Hymenothalami.

Dritte Rlaffe: Fungi.

Dronung 12. Gymnomycetes. Soronung 15. Pyrenomycetes.

"13. Hyphomycetes. "16. Hymenomycetes.

"14. Gasteromycetes.

Bierte RIaffe: Hepaticae.

Sronung 17. Ricciaceae.

" 18. Anthoceroteae.

" 19. Targioniaceae.
Dronung 20. Marchantiaceae.

" 21. Jungermanniaceac.

$$
\text { Füllfte Rlaffe: Musci. }
$$

Sronung 22. Andreaeaceae. Dronung 2\%. Bryaceae.

" 23. Sphagnaceac.

Sedfote Rlafie: Calamariae.

Dronulig 25. Equisetaceae. 
Siebente Rlaffe: Filices.

Dronung 26. Polypodiaceae.

27. Hymenophylleae.

" 28. Gleich eniaceae.

" 29. Schizaeaceae.
Dronung 30. Osmundaceae.

31. Marattiaceae.

32. Ophioglosseae.

Id te Rlaffe: Hydropterides.

Drbmung 33. Salviniaceae. Srbnung 34. Marsiliaceae. Reunte $\mathbb{R} \mathfrak{l}\{f \mathfrak{e}$ : Selagines.

Sronung 35. Isoeteae.

Dronung 36. Lycopodiaceae.

3efute RIaffe: Zamiae.

Sronung 37. Cycadeaceae.

(E) ilfte Rlaffe: Rhizantheae.

Sronung 38. Balanophoreae. Sronung 40. Rafflesiaceae.

" 39. Cytineae.

$3 \mathfrak{w}$ ölfte $\mathfrak{R} \mathfrak{I}\{f \mathfrak{e}:$ Glumaceae.

Srbnung 41. Gramineae.

Sronung 42. Cyperaceae.

Dreizehnte Rlaffe: Enantioblastae.

Sorbnung 43. Centrolepideae. Sorbnung 46. Xyrideae.

" 44. Restiaceae. "47. Commelynaceae.

" 45. Eriocauloneae.

Bierzehte SIaffe: Helobiae.

Sronung 48. Alismaceae. Sronung 49. Butomaceae.

Fünfzlinte Rlaffe: Coronariae.

Sronung 50. Juncaceae.

51. Philydreae.

" 52. Melanthaceae.

Sedizegnte Rlaffe: Artorrhizae.

Srbnung 56. Dioscoreae.

Sromung 53. Pontederaceae.

Siebenzlinte SIaffe: Ensatae.

Sronung 58. Hydrocharideae.

" 59. Burmanniaceae.

"60. Irideae.

. 61. Haemodoraceae.
Sronung 62. Hypoxideae.

Sronung 57. Taxaceae.

" 63. Amaryllideae.

" 64. Bromeliaceae. 
Ad ţellite $\mathfrak{R}$ Iaffe: Gynandrae.

Dronung 65. Orchideae. Dronung 66. Apostasieae. Reunzelnte Rlaffe: Scitamineae.

Dronung 67. Zingiberaceae. Sronung 69. Musaceae. " 68. Cannaceae.

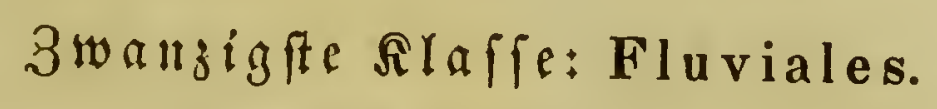

Drbnung 70. Najadeae.

Einunbzwanzigfte Rlaffe: Spadiciflorae. Drbuung 71. Aroideae.

"72. Typhaceae.

Dronung 73. Pandaneae.

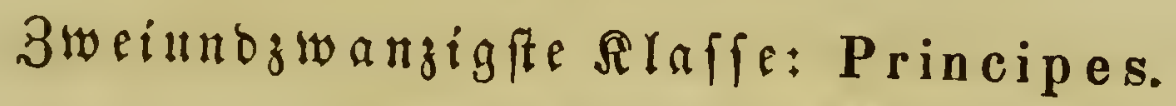
Dronung 7\%. Palmae.

Dreiund $z \mathfrak{w a n j i g f t e}$ Slaffe: Coniferae. Sronung 75. Cupressineae.

" 76. Abietineae. Dromung 77. Taxineae. " 78. Gnetaceae.

Bierundwanjigfte Rlaffe: Piperitae. Srbnung 79. Chloranthaceae. Srbnung 81. Saurureae. " 80. Piperaceae.

Fünfunozivanzigfte Nlaffe: Aquaticae. Srbnung 82. Ceratophylleae. Drbnung 84. Podostemeae.
" 83. Callitrichinae.

Sed saubjwanzigfte Rlaffe: Juliflorae. Sromung 85. Casuarineae.

" 86. Myriceae.

" 87. Betulaceae.

" 88. Cupuliferae.

" 89. Ulmaceae.

" 90. Celtideae.

" 91. Moreae.

" 92. Artocarpeae.

E. WB ind
Sronung 93. Urticaceae.

" 94. Cannabineae.

" 95. Antidesmeae.

" 96. Plataneae.

" 97. Balsamifluae.

"98. Salicineae.

" 99. Lacistemeae. 
Siebenunozwangigfte $\mathfrak{x}$ laffe: 0 leraceae. Sronung 100. Chenopodeae. Dronung 102. Polygoneae.

" 101. Amaranthaceae. "103. Nyctagineae. Id tunozwangigfite firffe: Thymeleae.

Sronung 10\%. Monimiaceae.

"105. Laurineae.

" 106. Gyrocarpeae.

" 107. Santalaceae.

" 108. Daphnoideae.
Sronung 109. Aquilarineae.

"110. Elaeagneae.

"111. Penaeaceae.

"112. Proteaceae.

Seunumbłanzigfte $\mathfrak{R}$ Iaffe: Serpentariae. Sronung 113. Aristolochieae. Dronung 114. Nepentheae.

Dreízigfe $\mathfrak{A} \mathfrak{l}$ aff: Plumbagines.

Sronung 115. Plantagineae.

Sronung 116. Plumbagineae.

(Finunobreifigfte $\mathfrak{A}$ laffe: Aggregatae.

Sronung 117. Valerianeae.

Sronung 119. Compositae.

118. Dipsaceae.

Erfte Unteroronung: Tabuliflorae.

3weite unteroronung: Labiatiflorae.

Dritte Hnteroronung: Liguliftorae.

Dronung 120. Calycereae.

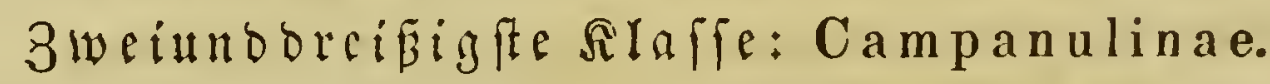

Sronung 121. Brunoniaceae.

122. Goodeniaceae.

" 123. Lobeliaceae.

Dreiundorefifigfe Siffe: Caprifoliaceae.

Sronung 126. Rubiaceae.

Sronung 127. Lonicereae.

Bieruluorefibigfe Rlaff: Contortae.

Sronung 128. Jasmineae.

"129. Bolivarieae.

" 130. Oleaceae.

" 131. Loganiaceae.

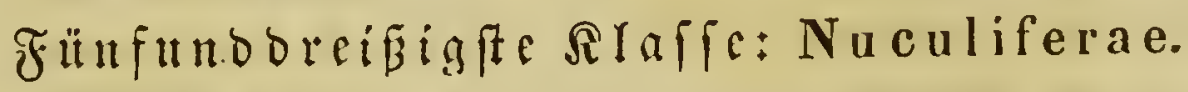

Sroming 132. Apocynaceae.

" 133. Asclepiadeae.

"134. Gentianeae.
Sronung 124. Campanulaceae.

"125. Stylideae. 
Dromung 139. Selagineae.

"140. Myoporineae.
Dromung 14.1. Cordiaceae. 142. Asperiloliae.

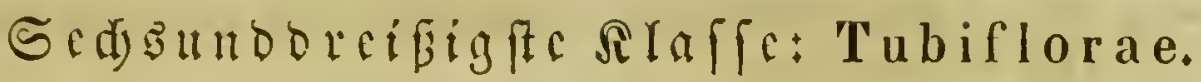

Sroming 143. Convolvulaceae. Sronung 146. Hydroleaceae.

"14'. Polemoniaceae.

147. Solanaceae.

"145. Hydrophylleae.

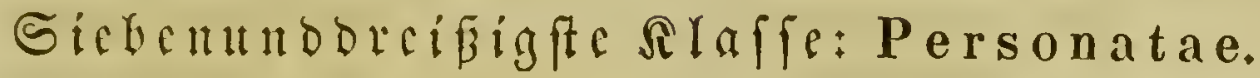

Sronung 148. Scrophularineae.

"149. Acanthaceae.

150. Bignoniaceae.
Droulng 151. Gesneraceae.

152. Pedalineae.

153. Orobancheae.

154. Utricularieae.

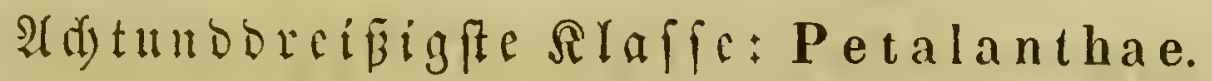

Sromung 155. Primulaceae.

" 156. Hyrsineae.

"15\%. Sapotaceae.

Rcumunobrefigife Rlaffe: Bicornes. Sromung 160. Epacrideae. Sromung 161. Ericaceae.

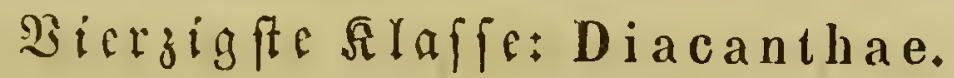

Sronung 162. Umbelliferae.

" 163. Araliaceae.

" 164. Ampelideae.

" 165. Corneae.

Sronung 158. Ebenaceae.

" 159. Styraceae.

Sronung 166. Loranthaceae.

(5imubyifrzigfte Rlaffe: Corniculatae. Sronung 169. Crassulaceae. Sronung 171. Ribesiaceae. "170. Saxiflagaceae.

3wciunduicrzigfte Raffe: Polycarpicae. Sronung 172. Menispermaceae.

173. Laŕdizabaleae.
" 174. Myristiceae.

"175. Anonaceae.

Dreiundyierzigfte RInffe: Rhoeades.

Dronung 181. Papaveraceae.

" 182. Cruciferae.

„183. Capparideae.
Dronung 176. Schizandraceae.

"177. Magnoliaceae.

" 178. Dilleniaceae.

" 179. Ranunculaceae.

"180. Berberideae. 
Bierundyierzigfte Rlaffe: Nelumbia.

Sronung 186. Nymphaeaceae. Dromung 188. Nelumboneae. " 187. Cabombeae.

Fünfunbvierjigfte Rlaffe: Parietales.

Sorbnung 189. Cistineae.

"190. Droseraceae.

" 191. Violarieae.

" 192. Sauvagesieae.

" 193. Frankeniaceae.

"1 194. Turneraceae.

"195. Samydeae.
Drbnung 196. Bixaceae.

" 197. Homalineae.

" 198. Passifloreae.

" 199. Malesherbiaceae.

"200. Loaseae.

" 201. Papayaceae.

Sediunoviergigfte Rlafle: Peponiferae. Sronung 202. Nhandirobeae. Sorbnung 204. Begoniaceae. " 203. Cucurbitaceae.

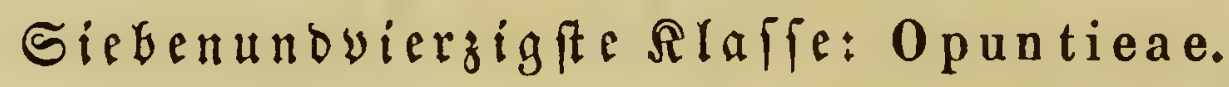
Soronung 205. Cacteae.

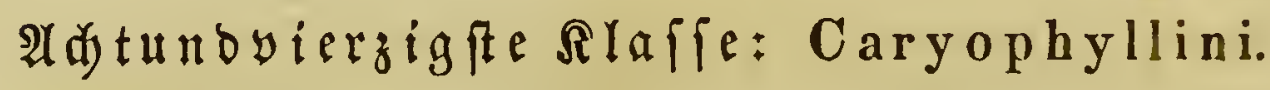

Sronung 206. Mesembryanthemeae.

" 207. Portulaceae.

Reun novierzigfte Rlaffe: Columniferae.
Sronung 208. Caryophylleae. 209. Phytolacceae.

Reunnobierzigfte Raffe: Columniferae.

Dronung 210. Malvaceae.

Sronung 212. Büttneriaceae.

211. Sterculiaceae. "213. Tiliaceae.

Füllfigfte $\mathfrak{R} \mathfrak{I}$ fffe: Guttiferae.

Dronung 214. Dipterocarpeae. Dromung 218. Marcgraviaceae

"215. Chlaenaceae. "219. Hypericineae.

" 216. Ternstroemiaceae.

" 217. Clusiaceae.

"220. Elatineae.

" 221. Reaumuriaceae.

" 222. Tamariscineae.

Einunbfünfzigfte Rlaffe: Hesperides.

Soronung 223. Humiriaceae.

" 224. Olacineae.

"225. Aurantiaceae.
Sronung 226. Meliaceae.

" 227. Cedrelaceae. 


\section{Biveiunofünfigfte Rlaffe: Acera.}

Sronung 228. Acerineae.

" 229. Malpighiaceae.

" 230. Erytroxyleae.
Sromung 231. Sapindaceae.

" 232. Rhizoboleae.

Dreiunbfünfigfte Rlaffe: Polygalinae. Drinung 233. Tremandreae. Sronung 23\%. Polygaleae.

Bierunofünf igfte Ifaffe: Frangulaceae.

Sronung 235. Pittosporeae.

" 236. Staphyleaceae.

" 237. Celastrineae.

" 238. Hippocrateaceae

Fünfunbfünfzigfte $\mathfrak{A} \mathfrak{I} f f e:$ Tricoccae.

Sronung 242. Empetreae.

" 243. Stackhousiaceae.

Srbnung 239. Ilicineae.

" 240. Rhamneae.

" 241. Chailletiaceae.

Sed)und

Sronung 245. Juglandeae.

" 246. Anacardiaceae.

" 247. Burseraceae.

" 248. Connaraceae.

"249. Ochnaceae.
Drbnung 250. Simarubaceae.

" 251. Xanthoxyleae.

" 252. Diosmeae.

" 253. Rutaceae.

" 254. Zygophylleae.

Siebenunbfünfzigfte $\mathfrak{R} \mathfrak{l}\{f \mathfrak{f}$ : Gruinales.

Sronung 255. Geraniaceae.

" 256. Lineae.

" 257. Oxalideae.
Sronung 258. Balsamineae.

" 259. Tropaeoleae.

" 260. Limnantheae.

Ad tunofünfzigfte $\mathfrak{R}$ Iaffe: Calyciflorae.

Srbnung 261. Vochysiaceae.

" 262. Combretaceae.

" 263. Alangieae.

" 264. Rhizophoreae.
Srounug 265. Philadelpheae.

" 266. Oenothereae.

" 267. Halorageae.

" 268. Lythrarieae.

Reununofünfzigfte Rlaffe: Myrtiflorae. Srbnung 269. Melastomaceae. Sronung 270. Myrtaceae. 
Sedjoigfte Rlaffe: Rosiflorae.

\section{Sronung 271. Pomaceae.}

272. Calycantheae.

" 273. Rosaceae.
Sronung 274. Amygdaleae.

" 275. Chrysobalaneae.

(Finunbfedfigfte Rlaffe: Leguminosae. Sromung 276. Papilionaceae. Sronung 278. Mimoseae. " 277. Swartzieae.

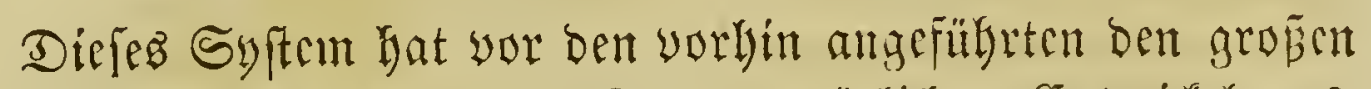

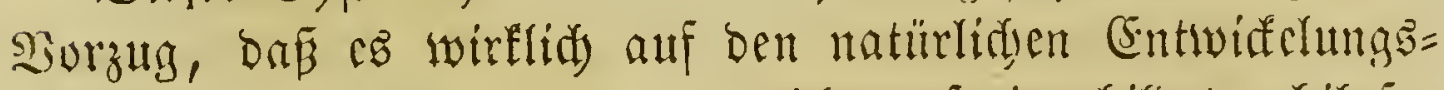
gang ber spflanzan gebaut und uidet auf cingebiloete whilojo=

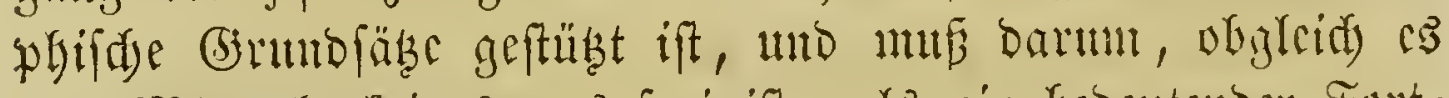

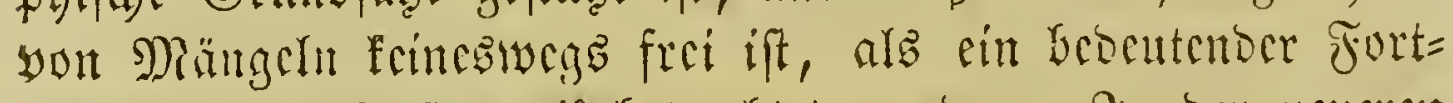

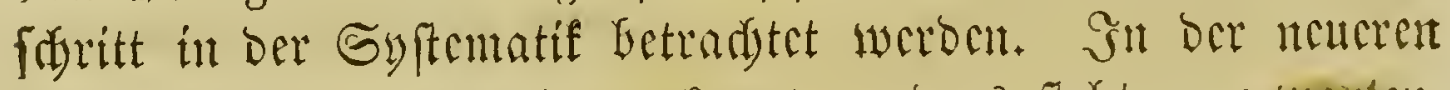
3eit hat man bicz aud auterfannt, who cs ftcht jut erwarten,

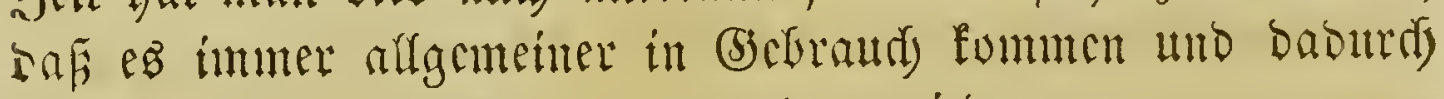
inmer mekr werwolfommat weroen wirb.

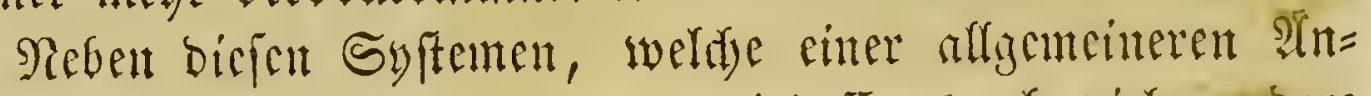

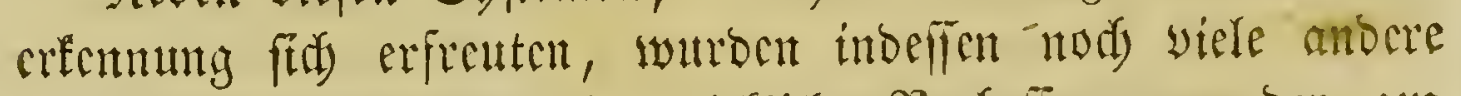
aufigeftert, bie theifweife wirflidye Berbeffermingen ber ant

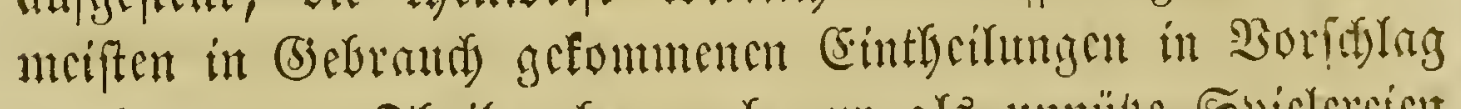

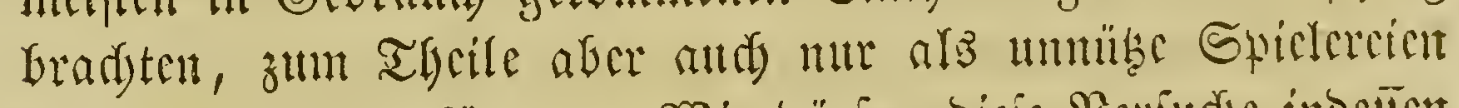

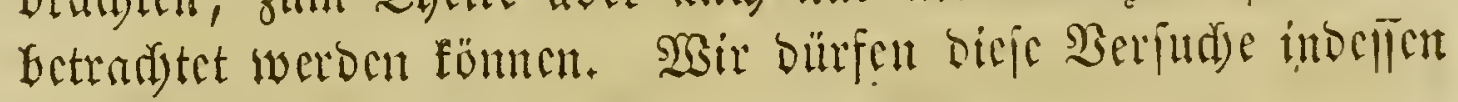
Gier mu furj anocuten.

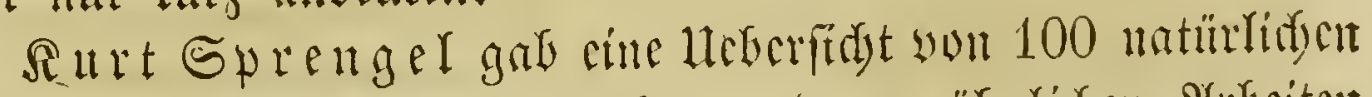

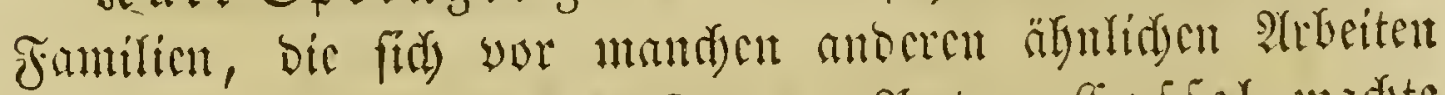

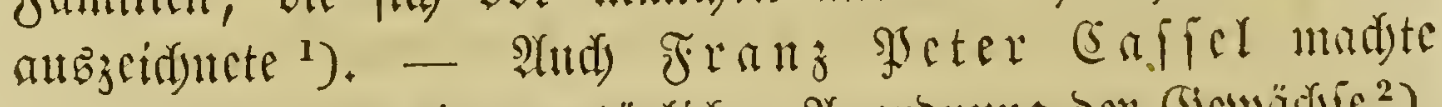

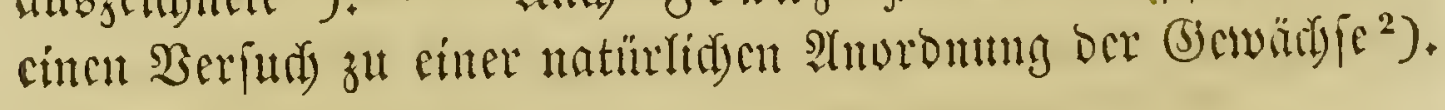

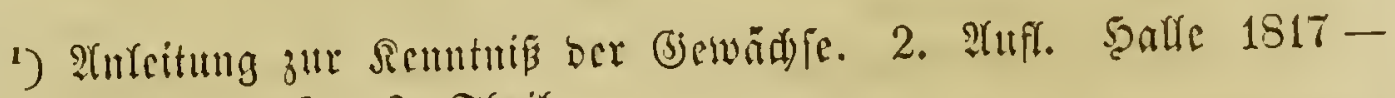
1818. 8. Sm 2. Theif.

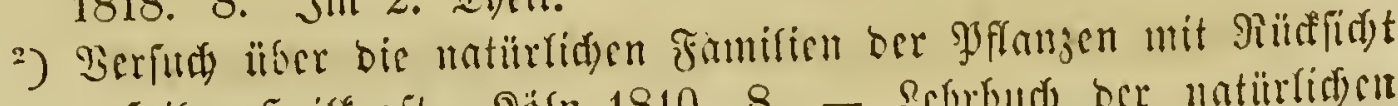

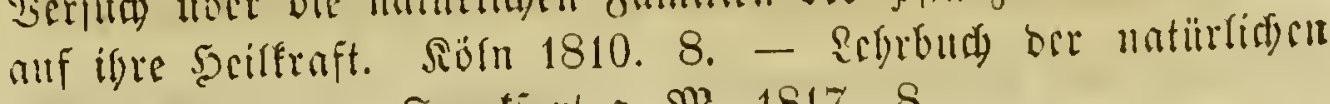

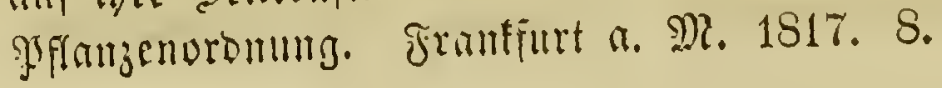




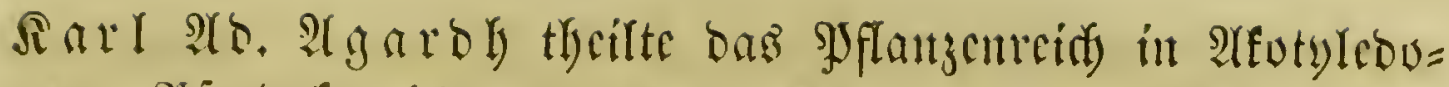

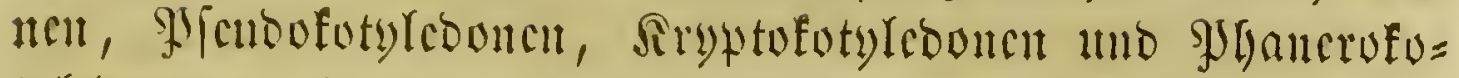

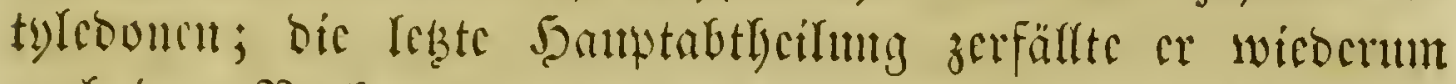

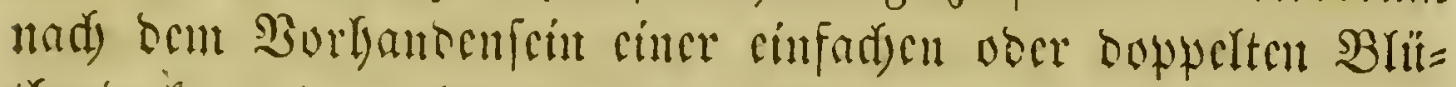
thembeife 1 mo nad) ber S3cidaffenlycit mo bem Stande ber

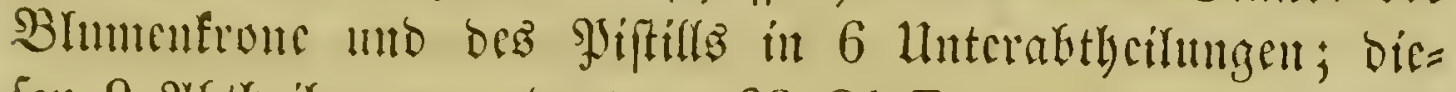
fen 9 stbthcilungen orbucte or 33 Sirafien unter ${ }^{1}$ ). Rorens

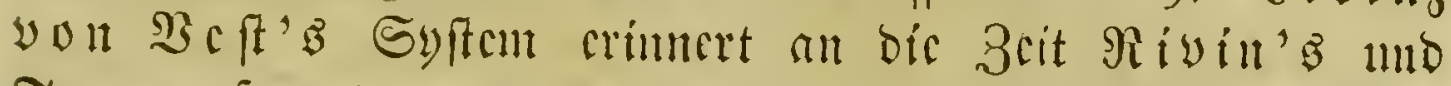
Tourucfort's; Dcm cB ftügt ferd auf Das Borbandenfcit

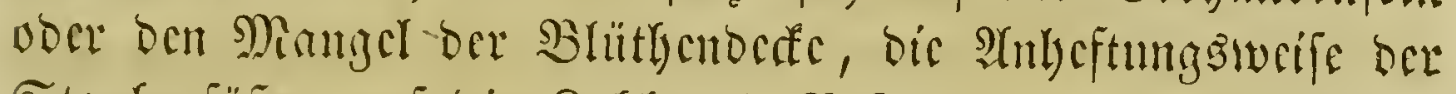

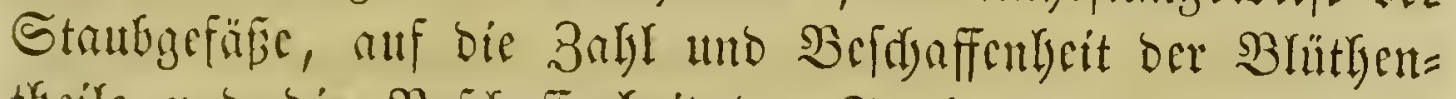

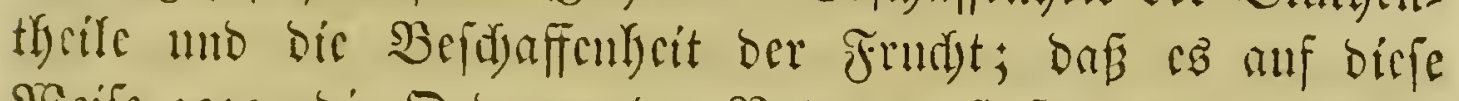

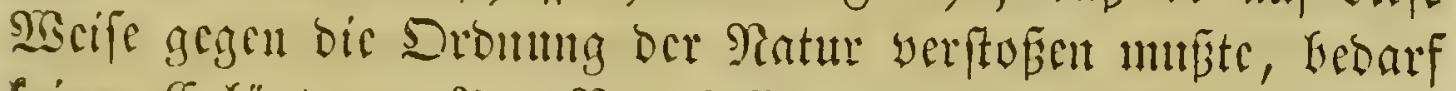

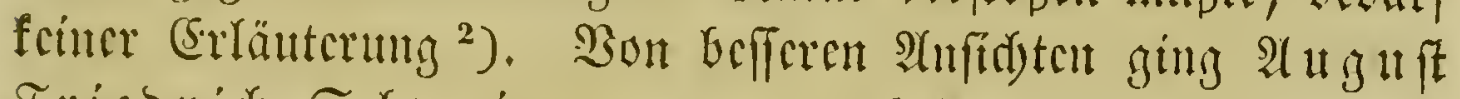

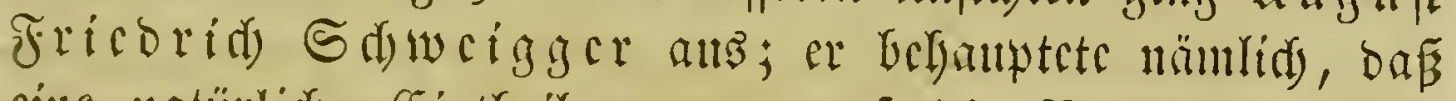
cine natiblidic Sintbeilunig nur anf bie Berglcidung ses Batte mo ber Funtionen ber cinjelnen Digane geftübt

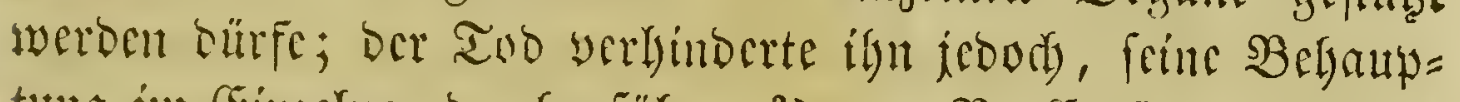

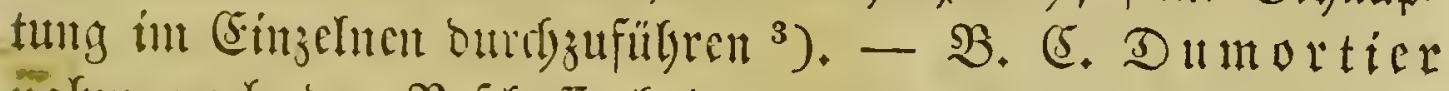

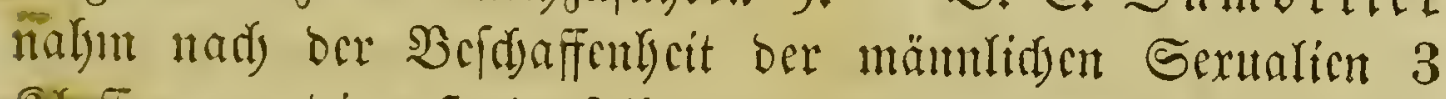

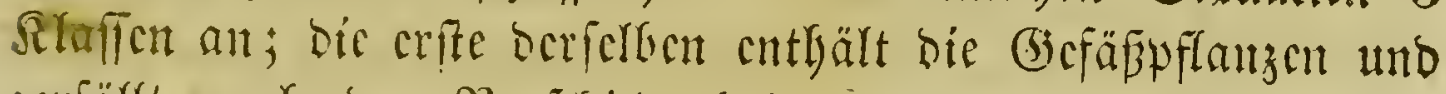

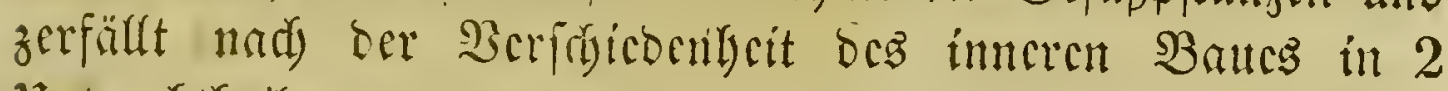

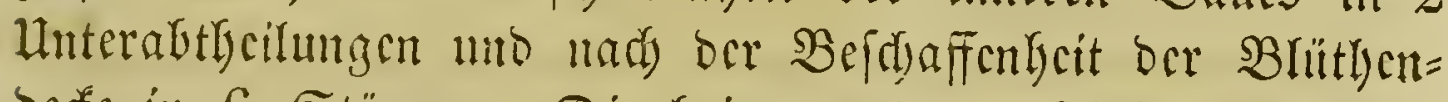
beffe in 6 Stämme. Die beiocn anberen Sifaffen entyalten die 3ellemflanzen und zerfallen fe nad) ocm Borbandenfein

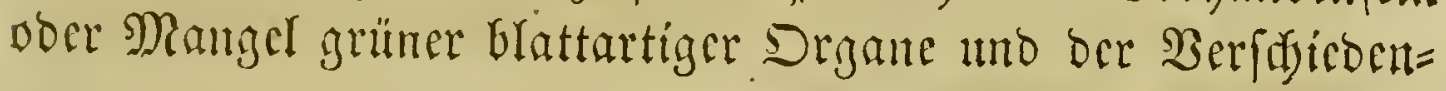

1) Aphorismi botanici. D. I-XVI. Lundae 1817-1825. 8. - Classes plantarum. D. I et II. Landae 182.5. 8. 1 tab.

$\left.{ }^{2}\right)$ Anteitung zum grünoliden Sturium ber Botanif. Mit einer Heberfidst über ben Bau naturbifforifaer ßiafififationsfyfteme, einer Sritif Des Suflieu'faen tho den Grunbzügen eines neten natürliden Syffems. ß̊ien 1818. 8.

$\left.{ }^{3}\right)$ De plantarum classificatione naturali, disquisitionibus anatomicis et physiologicis stabilienda commentatio. Regiomonti 1820.8 . 3 chart. 
Leit ber $\mathfrak{B e f r u d f t u n g s i w e r f} z$ euge in 5 Stämme. Unter biefe 11 Stämme find nady ben Berbältniffen ber Blütte uno ber Frudjt 30 Dronungen eingereifyt ${ }^{1}$ ). - Die yon (E I $i a$

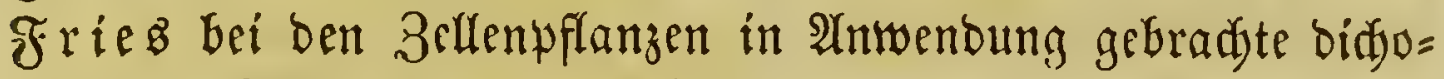

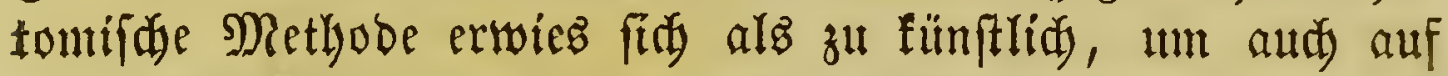

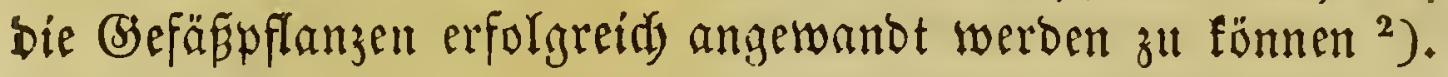

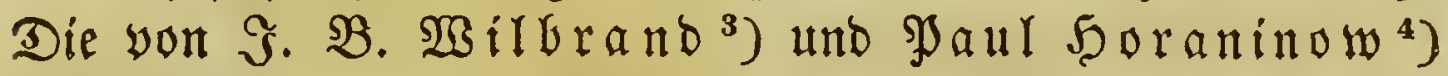
aufgeftellten Syfteme mögen hier nur erwähnt werben, ba fie feine weitere Alnwentung fanben. - Iarl Şeinrid

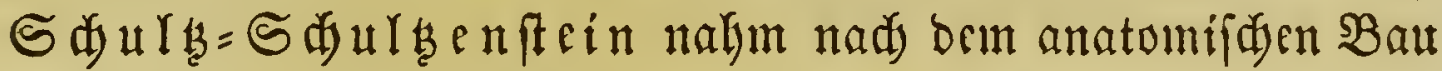
Der (Setwädje 3 Şauptabtheilungen, Homorgana, Synorgana unb Dichorgana, an, welife er vornchmlidy nadj bem Sorbandenfein unb ber $\mathfrak{B e f d j a f f e n l y e i t ~ b e r ~ B l u ̈ t h e ~ u n d ~ F r u d j t ~}$

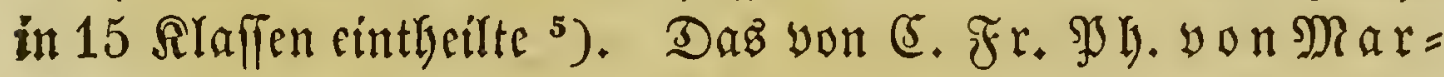
tius angetwandte, zwar aud bie Billoung ber Syflangen über=

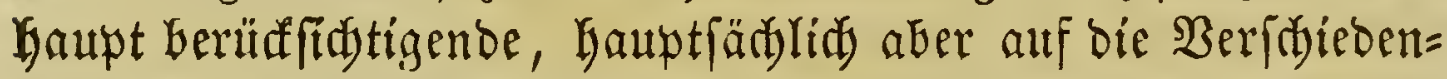
Weit bes Frudithaues geftüliste Syftem theilt das gefammte Şflanzenreid) in sine uriprünglide und fecunbäre $\mathfrak{B e g e t a t i o n ; ~}$ Die erftere zerfälut in 4 Sraffen: blüthenlofe (allotylebonen whe bie Silze), farägfaferige ober cinblatterimige (5) wädje (Monofotylebonen), פorenzefler (5ycabeen und Zapfentäume)

1) Commentationes botanicae (Observations botaniques). Tournay 1822 (1823). 8.

2) Systema orbis vegetabilis. Primas lineas novae constructionis periclitatur Elias Fries. Pars I. Plantae homonemeae. Lundae 1825. 8.

3) Die natürriden SPflangenfamilien in, ifren gegenfeitigen Stel= fungen, Sergweigungen uno Brruppirungen zu sinem natürliden SYflanzenfyfteme. Bießßen 1834. 8.

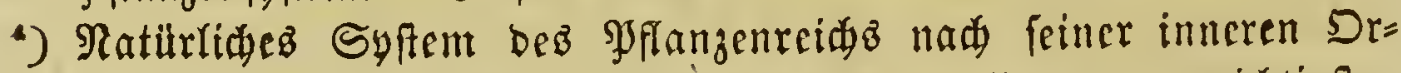
ganifation, nekft einer vergleidenden Darfellung ber widutigfen

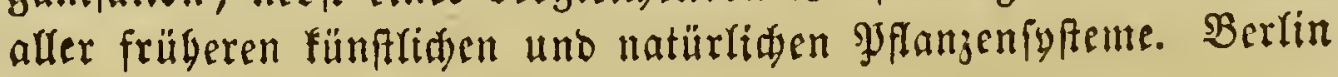
1832. 8. 1 infel.

s) Primae lineae systematis naturae, sexui naturali omnium evolutionique progressivae per nixus reascendentes superstructi. Petropoli 1834. 8. 1 tab. 


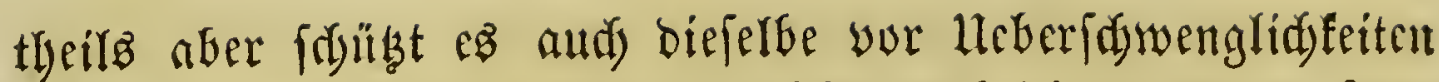
unb SBinbbeuteleien, welde fo leidyt burd) bie cutgegengefeste Ridytung lyerworgebradjt werben. Die am Anfange biefes

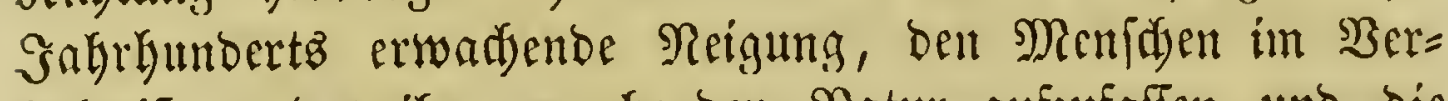

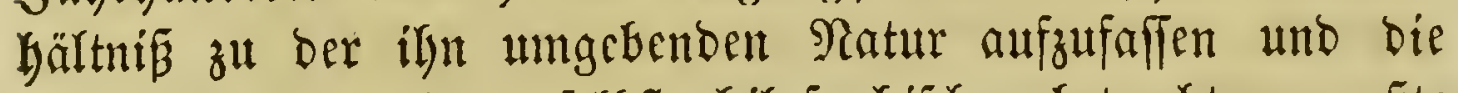
(5)egenftänoe ber satur felbft plyilofoplifid zu betraditen, muste natürlid) audi auf bie Botanif ibren (sinflus äuß̧ern. Ulno

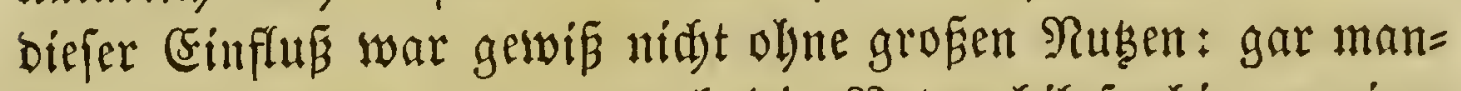
d)er Naturforfder mag turd) bie Raturphilufoplie zu einer höleren 2 uffaffung frimer $\mathfrak{B i f f e n j}$ aft hingeleitet worben fein. Alber aud bie forlimmen Folgen jener Neigung blieben midt

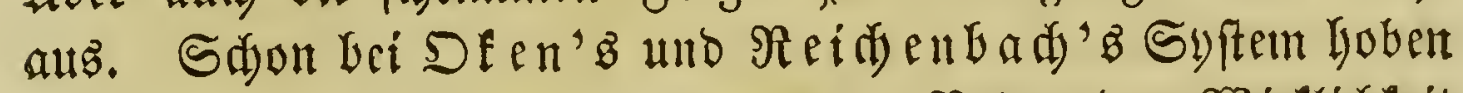

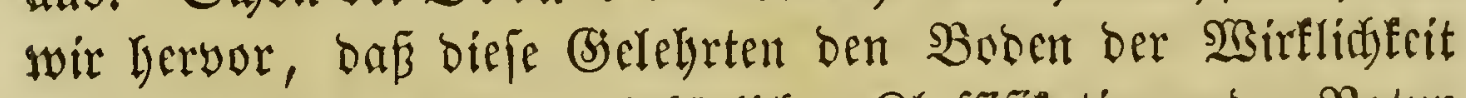

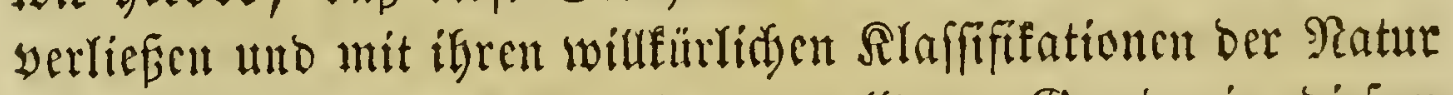
jeloft cine 3wangsiacte anlegen wollten. Berabe in biefem Sounte fanden aber biefe fonft fo trefflitisen Foridser bie mriftent

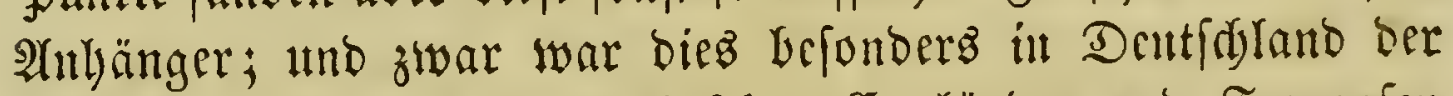

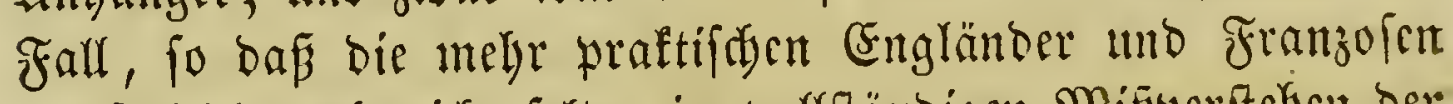

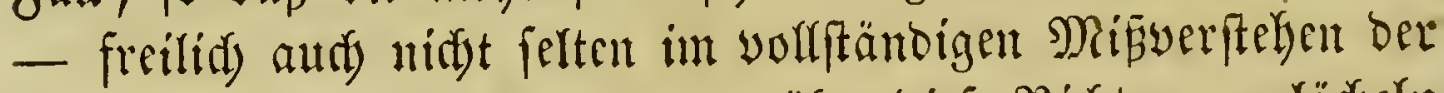

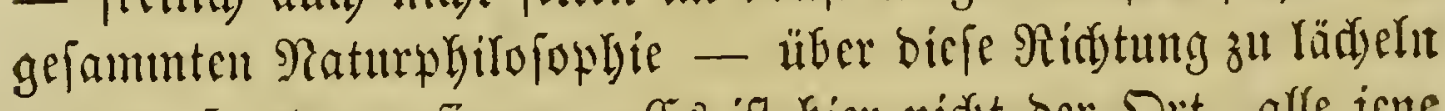
amb zu frotten anfingen. (5is ift hier nidyt ber Dort, alle jene Berfud)e zul erörtern, weldye cine $\mathfrak{A}$ nwentung ber Saturphi= Yojohlyí bei ber Aluffellumg won Sffamzenfyftemen anfrebten; nur einige wollen wir bes Beifpicls wegen fur's erwälynen.

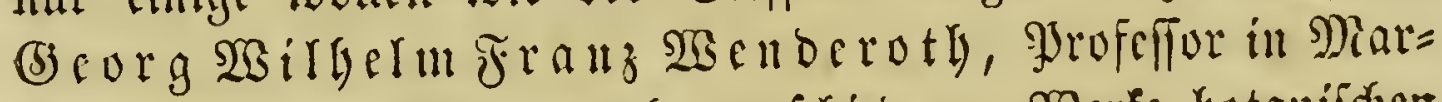

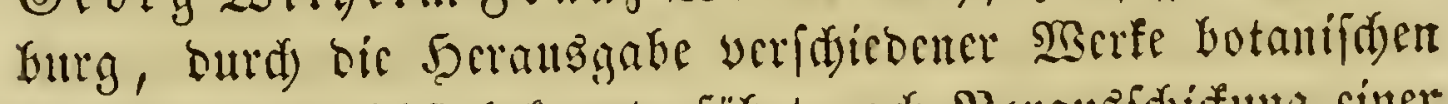

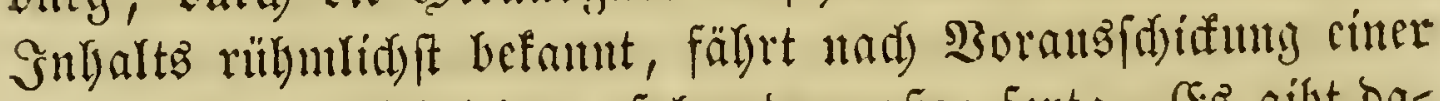

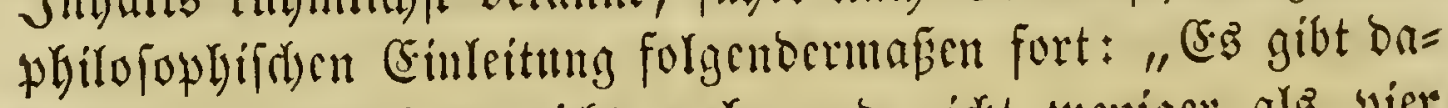

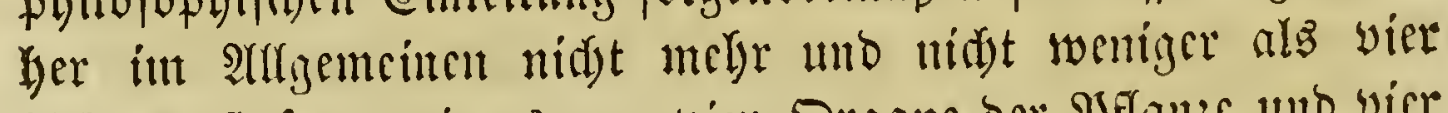
Şflanzenfufen, wie cas mur vier Drgane ber gyflange und yicr

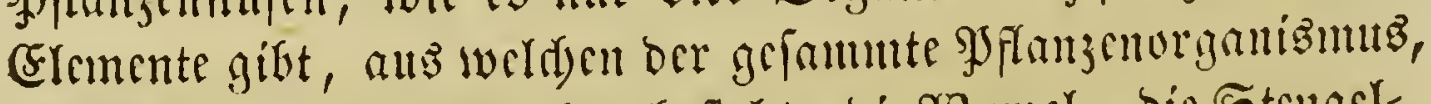

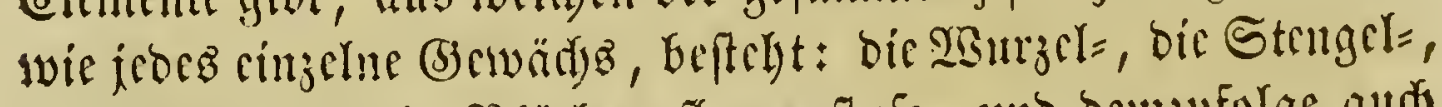

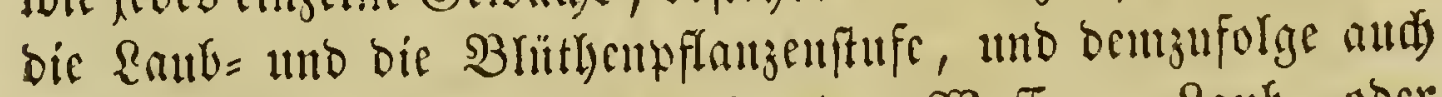

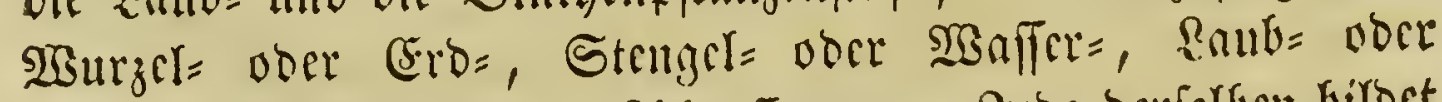

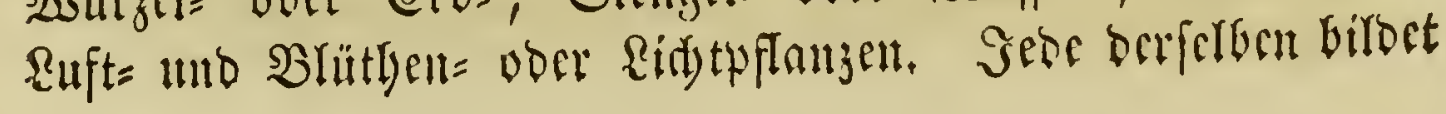


Seringe und (5) uilraro ${ }^{1}$ ), Antoine $\mathfrak{a} a$ urent (pporl.

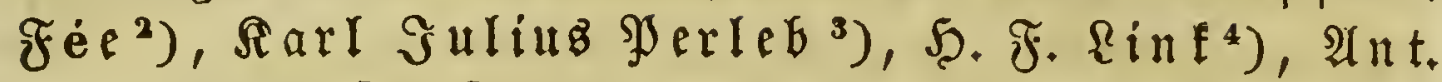
Fr. Spring ${ }^{5}$ ), Şerm. Reop. 3 und ${ }^{6}$ ), (sottl. Wirg.

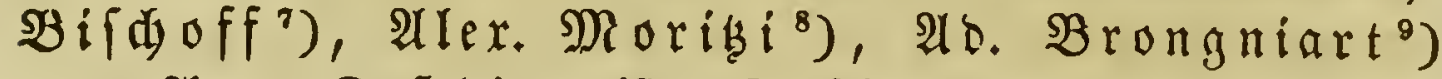
u. m. A. - Dấ bie meiften Forfdser, wenn audi mur indi= rect, zur Berbefferung ber Syftematif beitrugen, bebarf faum Der Erroäbnung.

Sn ber neueften 3eit hat Morig Sille om m, Srivat= bocent an ber Univerfität zu Reipzig, ben Borid)lag zut einem

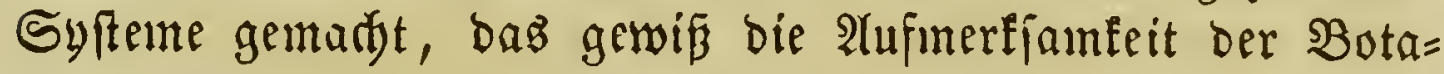
nifer verdient. Er theilt näulids die ganze Syflanzentwelt in

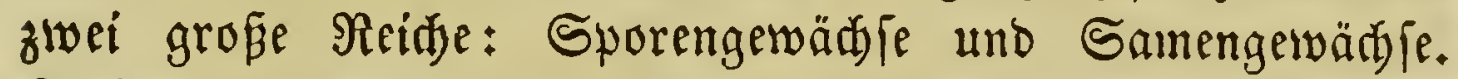
3u ben erfteren geliören bie Siryptogamen, zu ben Yezzteren Die SHGanerogamen \&inne' 'B. Bei ben Sporenplanzen fummt cz barauf an, ob bie Sporen entweber bis zu ifrer Tren= nung von ber Mutterpflange (in vielen Fällen aud) nod nadi

1) Essai de formules botaniques. Paris 1835. 4.

$\left.{ }^{2}\right)$ Les Jussieu et la méthode naturelle. Strap̧urg 1837. 8.

3) Clavis classium, ordinum et familiarum atque index generum regni vegetabilis. Freiburg i. $\mathfrak{B}$ r. 1838. 4.

4) Şanobud zur Erfennung ber nutbbarfen u. am bäufigften yor=

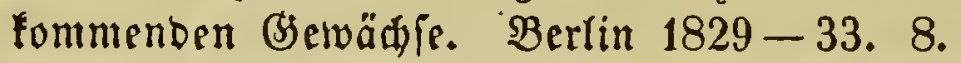

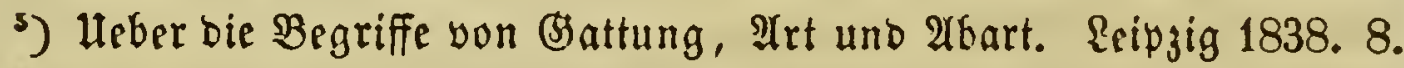

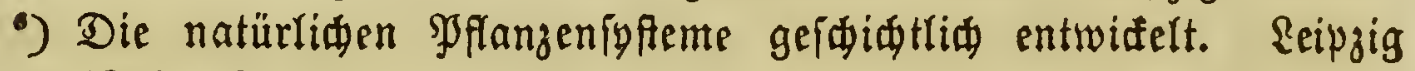
1840. 8.

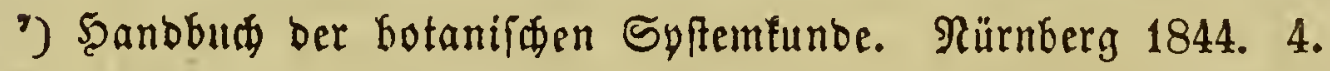

$\left.{ }^{3}\right)$ Reflexions sur l'espèce en histoire naturelle. Soleure 1842. 8.

-) Considérations sur la nature des végétaux, qui ont couvert la surface de la terre aux diverses époques de sa formation. Paris 1838. 4.- - Enumérations des genres de plantes cultivés au Muséum d'histoire nat. de Paris, suivant l'ordre établi dans l'école de botanique en 1813. Paris 1843. 8. - EGronologifde Heberfidt ber $\mathfrak{B} e g e=$

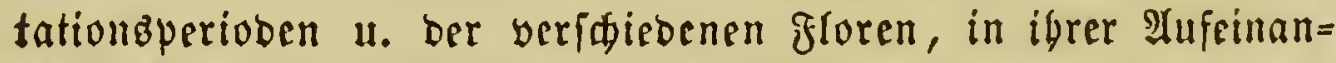
berforge auf ber Erboberfädde. 2. ๖. Iranz. (Annal. sc. nat.

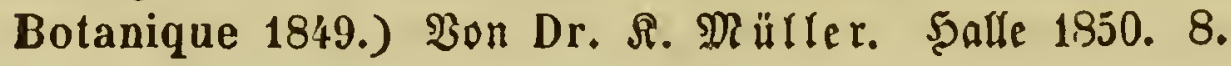




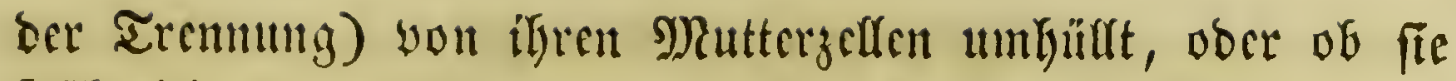
früfjectig burd) Reforption ber Muttergellen frei werben unb

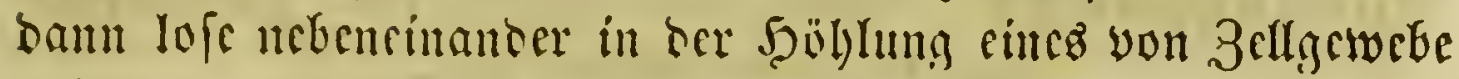
geGilocten Bebälterb (Sporenfrudst) ifolirt liegen, unt fie zerfallen bemigemä in werbülltiporige mo maftpporige Spo= rentlanjen. Dic Samengewäd)ie zerfallen in nattfamige und

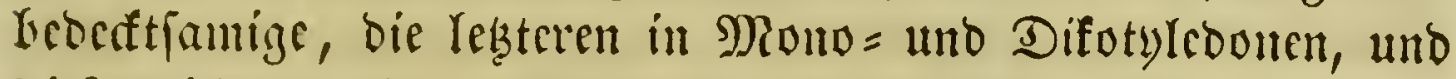

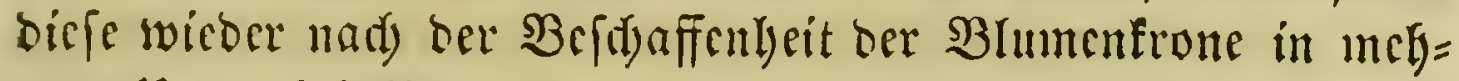

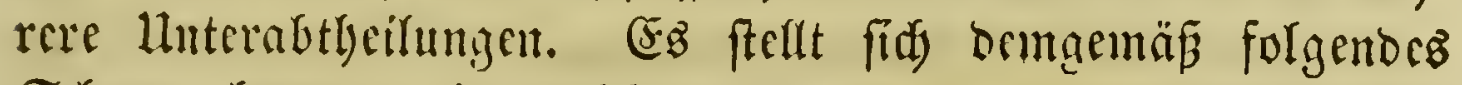
Sdjema heraus, in woldjes bie einjelnen Dronungen uno Familien eingefügt werben fümen:

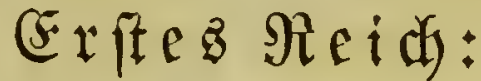

\section{Eporengewädie, Sporoplayta, plantae sporophorae.}

\section{Erfte Abtheilung:}

Bebeftiporige ober gefdredt pflanzen, Plantae angiosporae, Sporophyta agama.

Erfte $\mathfrak{A} \mathfrak{I}\{f \mathfrak{c}$ : Fabenzellige oder unvolffommene Angioipd = ren, Angiosporae fibro-cellulosae s. imperfectae (

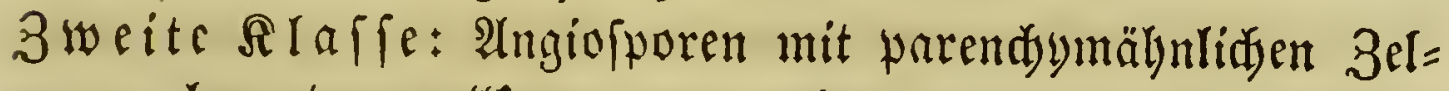
len obar yolffommencre; Angiosporae cellulis parenchymatoideis praeditae $s$, perfectiores ( $\mathfrak{A I}_{\mathfrak{g} \mathfrak{H})}$ ).

\section{3weite Albtheilurg:}

Raftiporige obergefdledtlide Sporenpflanzen,

Plantae gymosporae, Sporophytagamica.

Dritte $\mathfrak{I} \mathfrak{l}$ fife: Bellige (5jmmofporen, Gymnosporae cellulares (Sbaracen, Rebermovie, Raubmoofe).

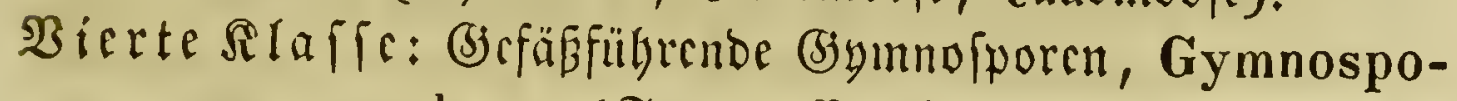
rae vasculares (Farrn, Equijetaceen, Rgizocarpeen, \{ycopodiaceen). 


\section{3 weitez $\mathfrak{l}$ eid \\ Gamengewäd fie, Spermatoplnyta, plantae spermatophorae.}

Erfte Abtheilumg:

Raft $\{\mathfrak{a m i g e , ~ G y m n o s p e r m a e . ~}$

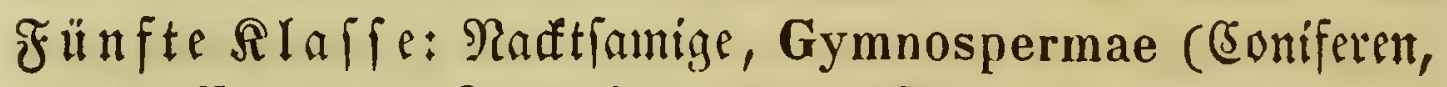
(5ycabcen, forantbacecn und (5netaceen [?]). ${ }^{1}$ )

\section{Bweite abtlscilung:}

Bebeftiamige, Angiospermae.

Sediste $\mathfrak{i l a} f(e:$ Monocotyledoneae.

Sifbente $\mathfrak{A}$ I ffe: Dicotyledoneae.

Erifte Uuterflaffe: Blumentronenlofe, Apetalae. 3write Unterlaffe: Ganjblumige, Gamopetalae.

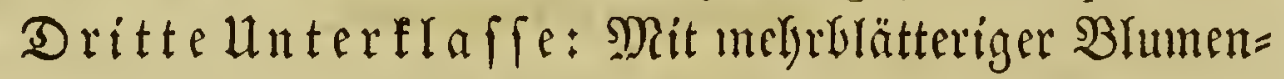
frone begabte, Pleiopetalae.

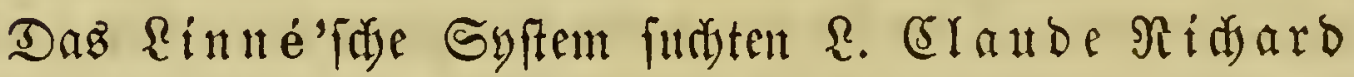
uno $\Re \mathfrak{u t}$ Sprengel zu verbeffern. Der Gritere licé bie 11. Rlaffe aus und bradste bic (S)ewädje Derfelfen in bie 12. umb 13, theilte aber biefe beioen Rlaffen in 3: Polyandria, Calycandria uno Hysterandria, ie mad) bem Stambe ber Staubgeräze unto banad), ob ber (Eicritof frei ober ange= wadjen ift; die 6. Srbung ber 19. SInffe crlob er fut

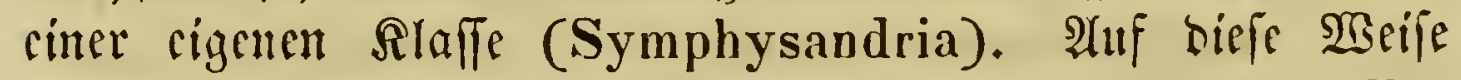
crlfielt er 25 Siaffert. Äuferbem veränberte er nod) bie $\mathfrak{B} e=$ nemungen einzelucr Rlaffen und Drbmungen ${ }^{2}$ ), 一 $\mathfrak{i} \mathfrak{r} \mathfrak{t}$

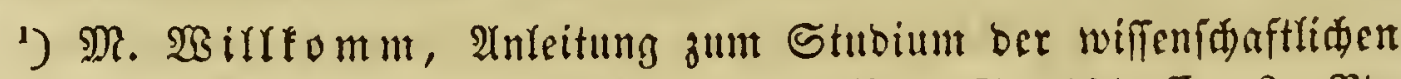
Botanif zc. Reipzig 1854. 8. 1. Bb. S. 141 ff. 2. $\mathfrak{B b}$. ธ. $78 \mathrm{ff}$.

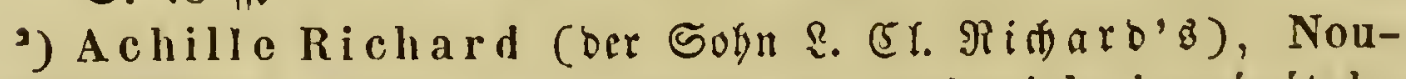
veaux éléments de botanique et de physiologie végétale. Paris 1819. 8. 8 tab. 7me édition, ibid. 1846. 8. Deutíf yon $\mathfrak{M} . \mathfrak{B}$. నittel, Rürnberg 1828. 1840. 8. 


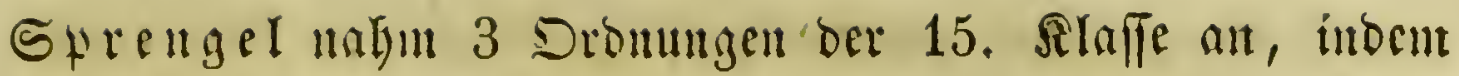

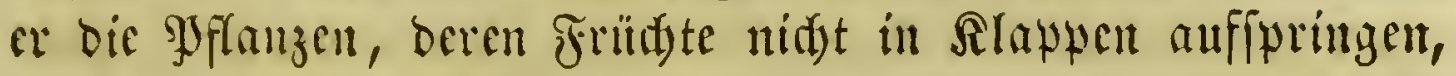
in ciner befonocren Drounutg (Synclystae) vereinigte, bie 19. Sraffe theilte er nady ber natillliden Berwantefduaft in 6 (3rupten (Cynareae, Eupatorinae, Perticeae, Radiatae, Cichoreae uno Desciscentes). Atus ber 21. Rlalfe madjte cr 2 Sectionen, nämlid Androgynia uno Diclinia;

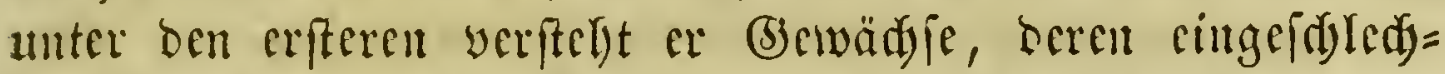

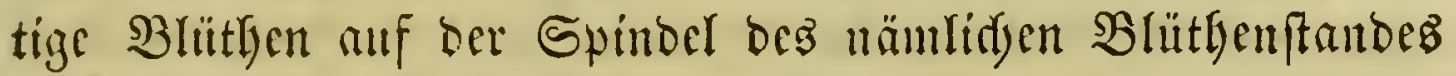
yorfoumen, unter Diclinia bagegen bicienigen, beren cinge $=$ fdjledjtige $\mathfrak{B l u ̈ t}$ then auf verfdjicoenen Spindeln fits befuben; bie Diclinia theilte er bann wieber it veridjicbene Dromun= gen. Dí 24. Slaffe \&inn é' zerfällte $\mathfrak{e r}$ in 5 Sectionen,

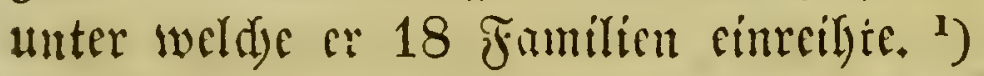

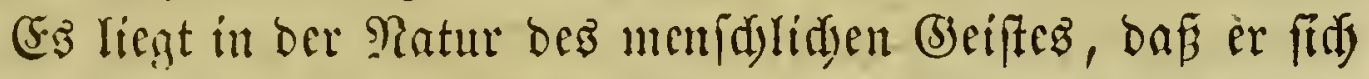

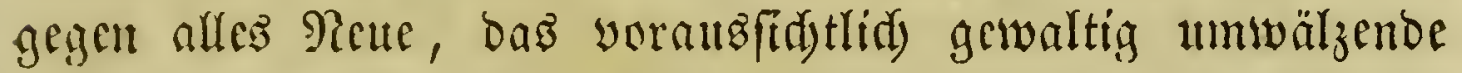
Folgen mait) fid) zithen wirb, mädtig fträubt; bem bickes

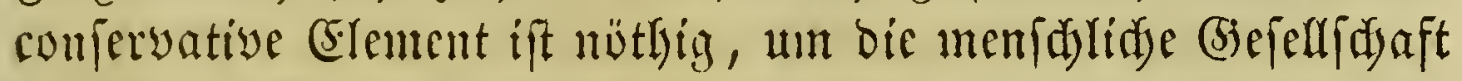
wor Heberftürgung und unheilbaren Sadbtheilen zu beswabren;

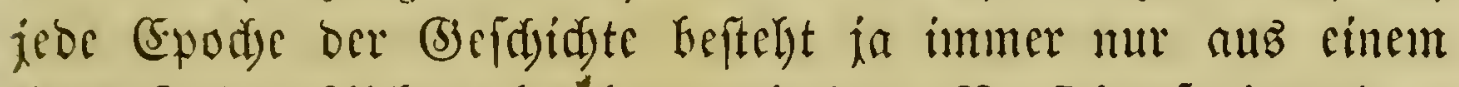

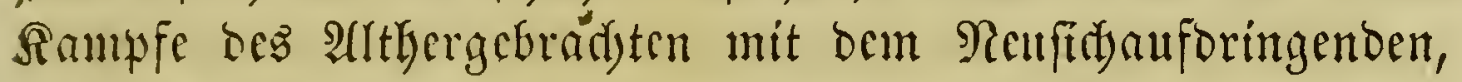

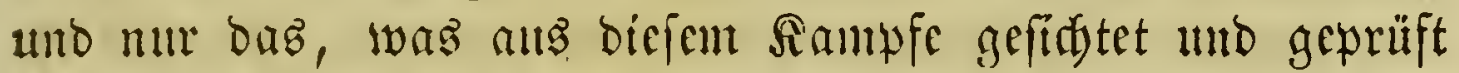
herworgelyt, wirb für bas jewcilige Menfdengeidsledst heilfant unto eriprieflidy frin. So ift es in ber Soolitif, fo in ber

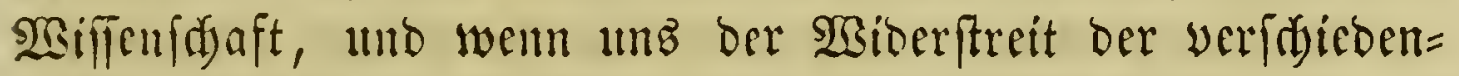
artigften (STemente in ber (S)egentwart oft mifmettyig madst und

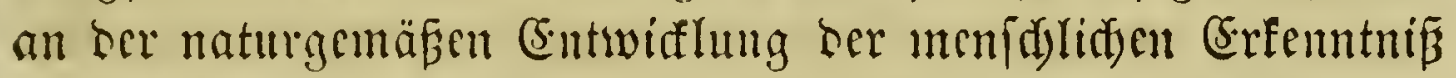

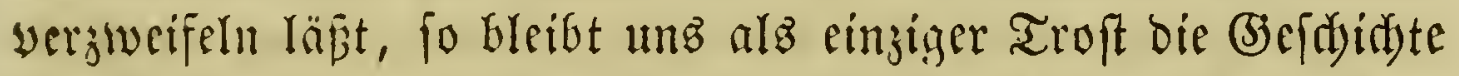

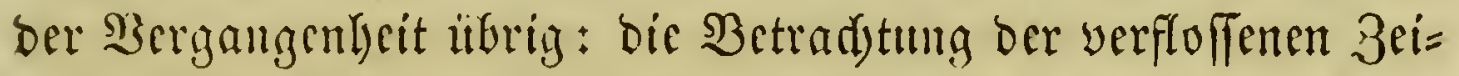
ten zeint uns flar, bafi trols ber heftigften Sämtre, weldye

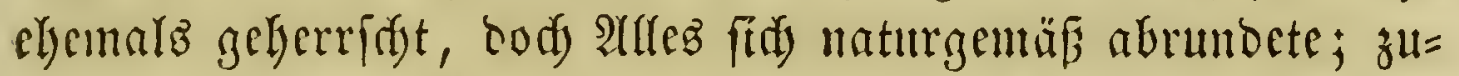
gleich aber beweift bieje Betradtung, dafi jebe 3citperiobe

2) Car. Linnaei systema vegetabilium. Editio XVI, curante K. Sprengel. Goetting. 1825-28, IV vol, vel V partes. 8. 
relativ Borghïglides geleiftet lyat, und daß̃ man feine einfäl= tigcre Eitelfit an ben Tag legen fann, als wenn man, ganz allein auf bie Furtidyritte ber (sicgenwart feheno, mit veräd)t=

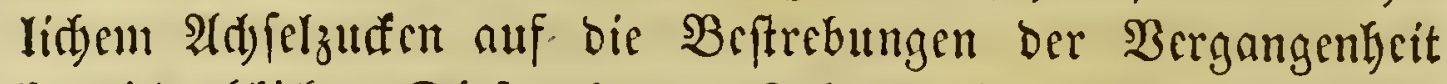
Germiederblifft. Diefer legtere Fefler wiro aber nidt felten aud) won Männern ber Sififenfdjaft begangen. Rann man fid) bod) beutzutage von cincr gewiffen Seite ber nidt genug=

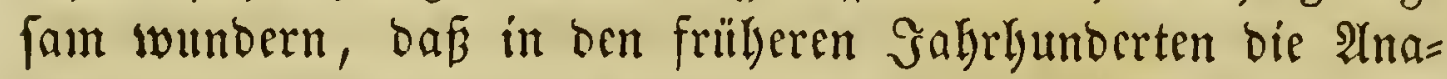

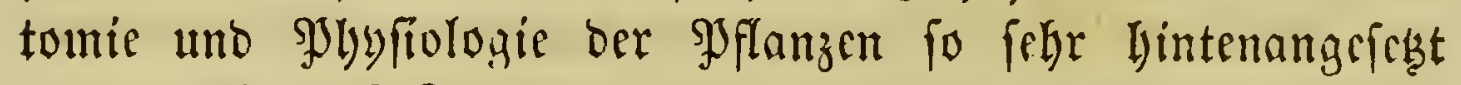
worben, ja baßj Rinné, bor gute Mam, fo bornirt gewricn fei, bie Şgytographic uno Syptematif jenen Disciplinen yor=

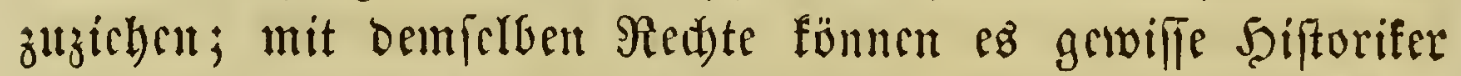
auffallent finoen, baß ber Simperator Rero feine Repräjen= tatioverfaffumg eingefülyrt habe, ober oafi Dfdyengib= (Ehalt fein $\Re$ epublifuner grwefen fei. - Die Reljre yon Dem Baue,

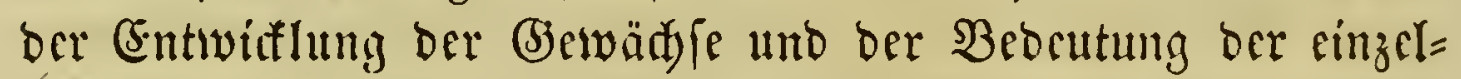

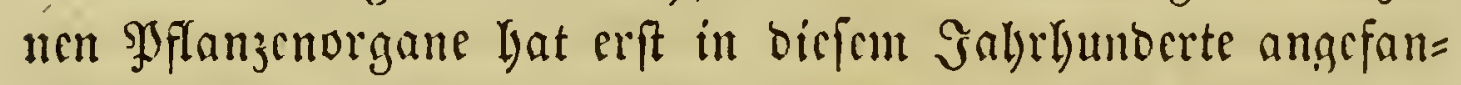
gett, wahrbaft wiffenfdyaftlid behanoelt zut werben; fie ift erfit

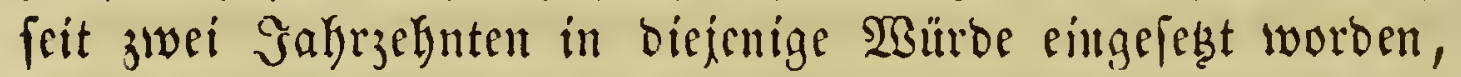

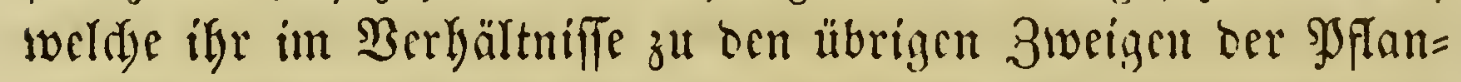
zenfunde gebülyrt; bic Fortfdyritte, weldye fie in bicfer furgen 3rit gomadyt, fint ftauncusiverth; bie grfammte Botanif be= ginut mumelse eine ganj andere (5icftalt anjunchmen, enblids nad) lanģen Rämpfen fann fie verlanisen, ben anderen Fäd)ern

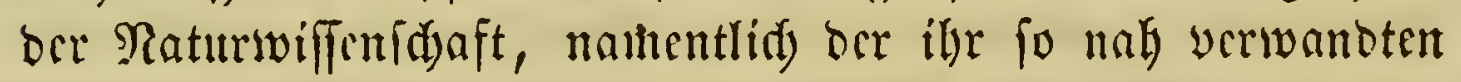
3oulogie an bie Seite gefest zu werben. A(ter bellentmgead)tet gezicme es fid nidft, bie librigen 3iveige oer Botanif im (5)e

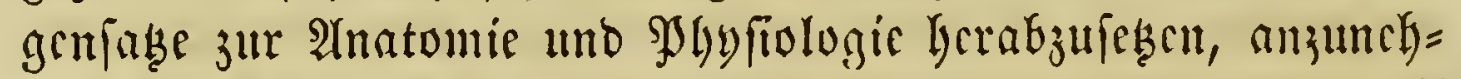
men, bẩ mur bicfe Dižciplinen die wiffenid)aftlidje Botanie

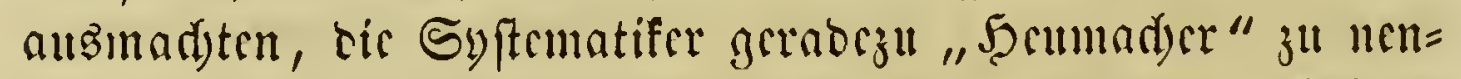

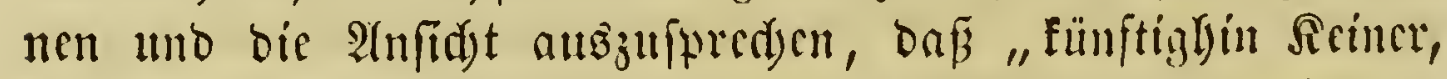

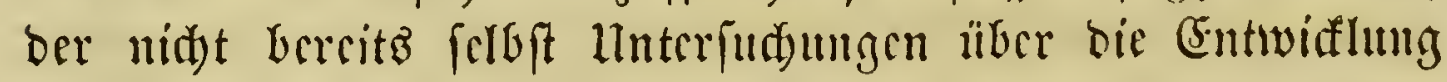
oer 3rifen gemadjt hat, ju ben Botanifern zählen werbc." Sair wolfen nidjt fragen, ob liberlyaut dic Anatomie uno

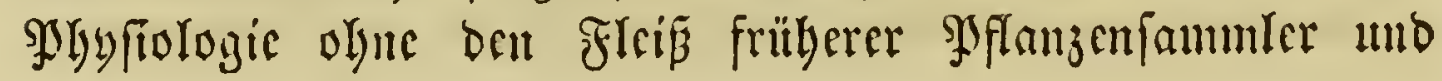


Syftematifer jemalz auf ifren lyeutigen bäbepunft bätte ge=

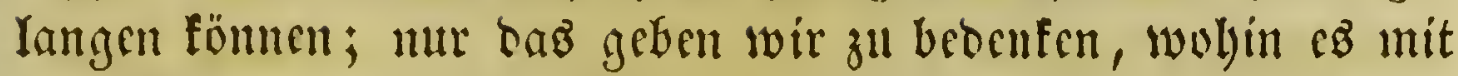
ber Sygytotomie unb Sुflanzenplyyfulogic fäme, in weldse unendidye Berwirrung fie gerathen wïrben, wenn man auf=

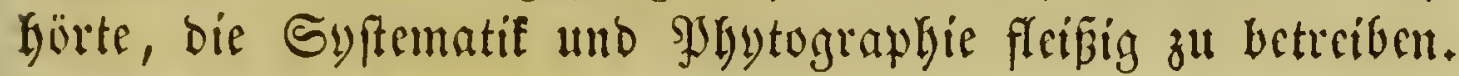
Suum cuique!

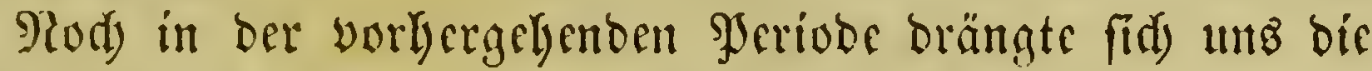
Bemerfung auf, baß̧ bie meiften Botanifer ilge Sräfte auf bie befrereibente Botanif verwenteten; in ber yorliegenden $\mathfrak{a b e r}$, namentlidy in bem Iesteren Theile berferten, ift $\mathfrak{e s}$ alt=

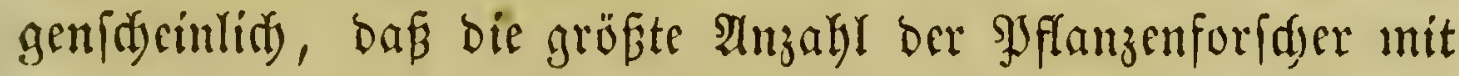
anatumifden uno whyfiologifon Unterfudungen fid befäaf= tigt. Die gefammte Sisiffenfdyaft ber Botanif lat mummelyr einen foldyen Llmfang gewonnen, daf ç cinem eingelnen Men=

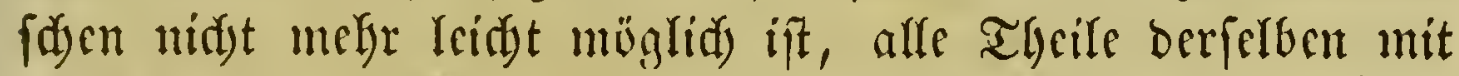

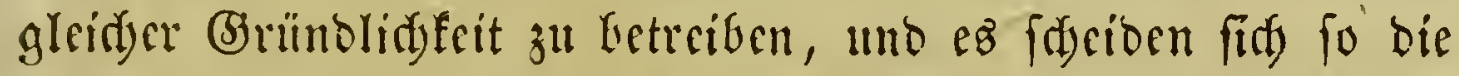

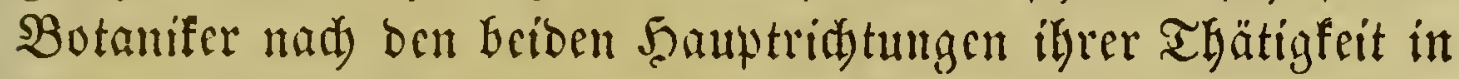
SJgytographen und \$ogyfwlogen, welde, wie wir bercitz oben anbeuteten, nidst felten über ben Borgug ifjer Disciplinen in Streit geratfen. Es fann mun nidyt unfere Aufgabe fein, bier sine yolffäntige uno grünblidye Darftellung yon ber (Entrviff= lung Der Anatomie uno SJbyfiologie Der (jeswäd)fe zu geben, fondern woir fönnen nur eine ganz furge und allgemeine $\mathfrak{l l} c b e r=$ fidft über bie hauptfäd)lidfiten Momente biefer Entwidflung yorfïfren und milffen in Uebrigen auf bie fpeziellen Gabrez= beridste über biefe Disciplinen yerweifen; wenn wir barum manden ber nod) lebenden foridjer nidyt namentlidy anführen, fo möge man biez mit bem biefem Compendinm zugcmeffenen

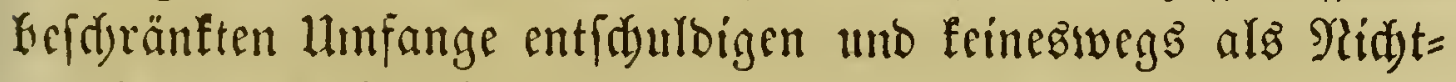
ancifennung wirflidjer Berbienfte betradten.

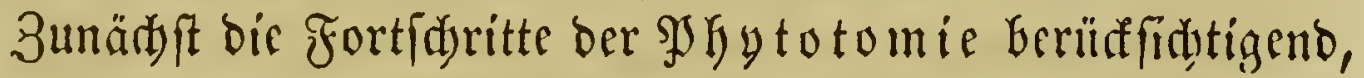
geben wir bas Şauptiäd)lidbfte liber bie Elementarorgane an. - Den Anfang Der vegetabilifiden Entwifflumb biloet sic 3elle. Ramentlid zroe berügmte Raturforider, 
und

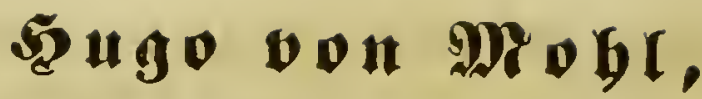

Jrofefifor in. Tübigen,

\section{Mattbias S. Edjleiden,}

Srofeffor in Sena,

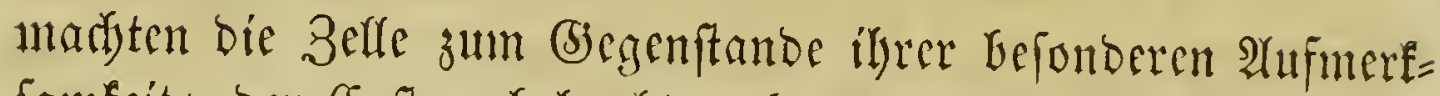

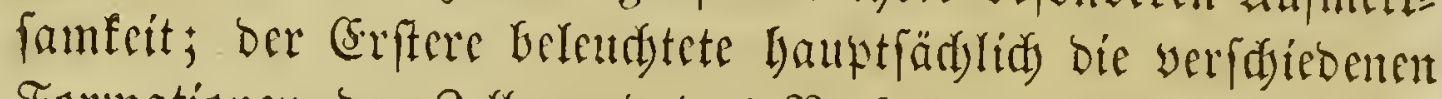
Formationen ber 3erle uno das Berbältnif́ berferfen zu cin=

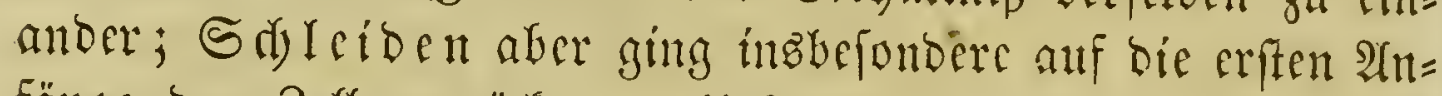

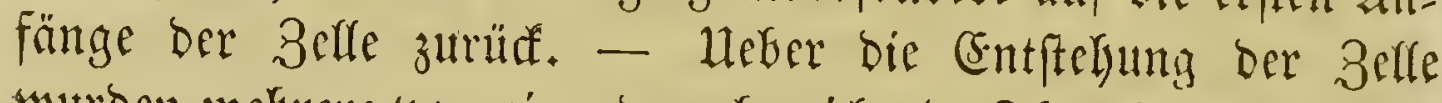

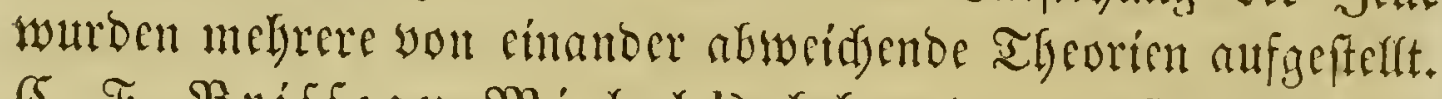

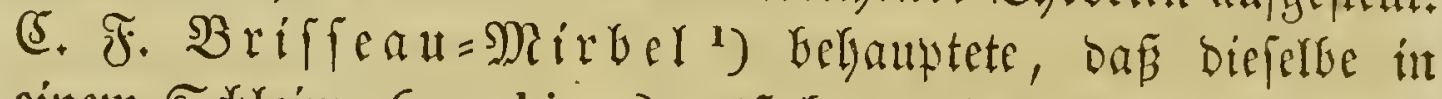

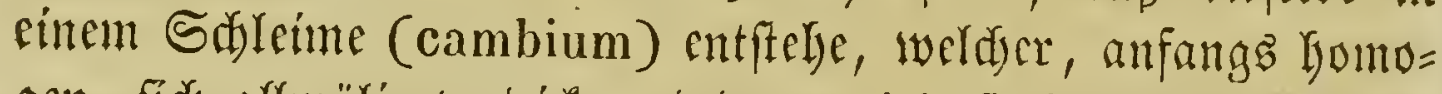
gen, fict) alfmälig werbiafe und bann viele Şöhlungen befomme;

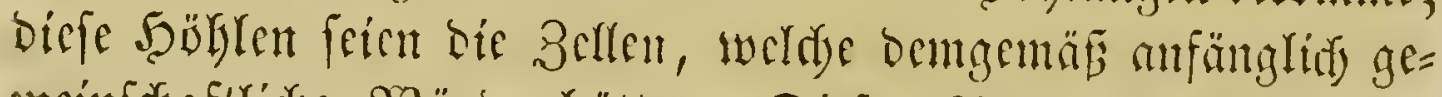

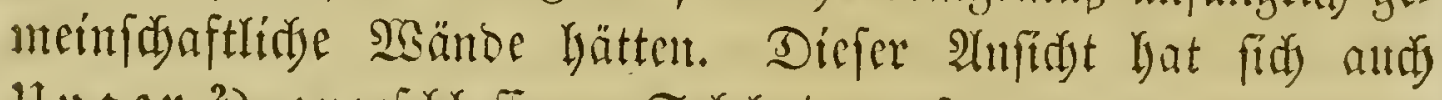

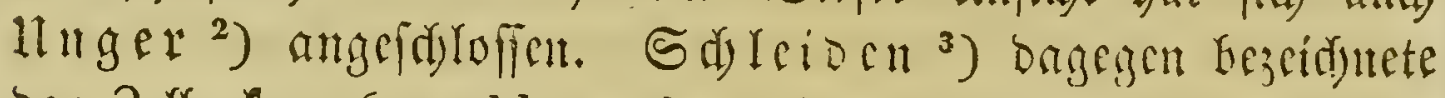
Den 3elfenfern (cytoblastus), weldyer zuerft yout $\Re$. $\mathfrak{B}$ rown

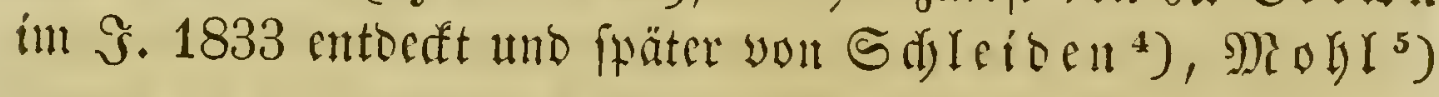

1) Nouvelles notes sur le cambium extraites d'un travail sur l'anatomie de la racine du dattier. Paris 18'2. 4. 12 tab. (Extrait du tome XVIII des Mém. de l'Acad. des sciences. - Archives du Maséum, tom. I. p. 303-335.)

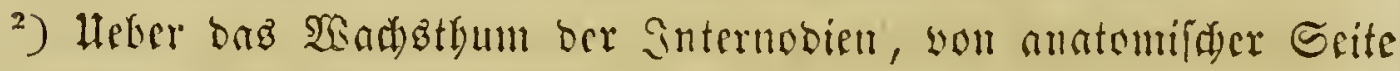
betradjtet. Sot. 3cit. Sp. 489 ff.

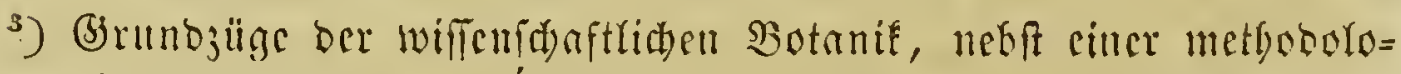

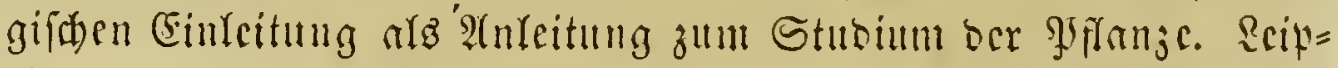

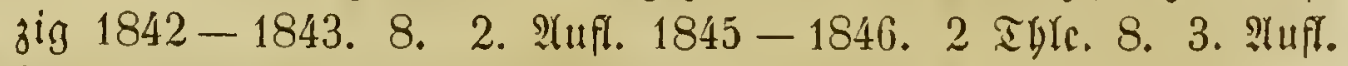

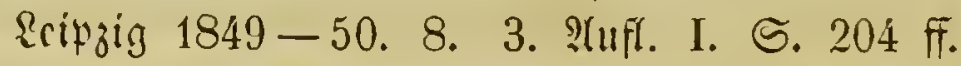

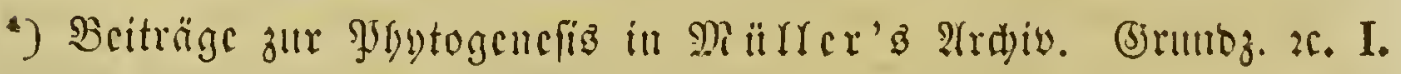
ธ. 207 ff. Salfrg. 1838.

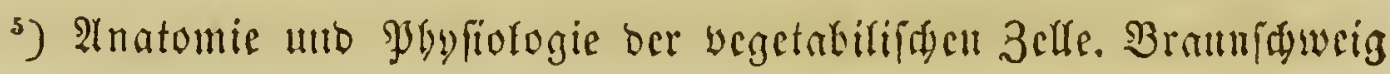
1851. 8. S. 42 ․ 45 f. 


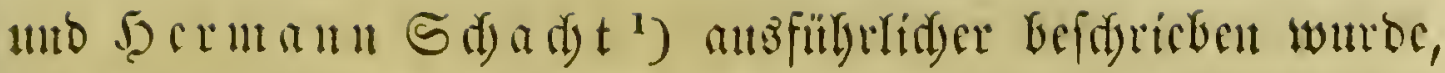

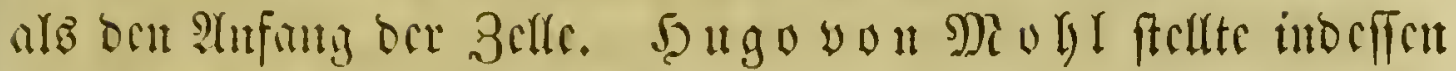

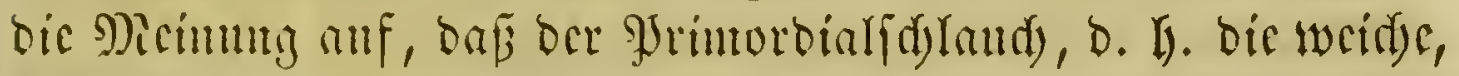

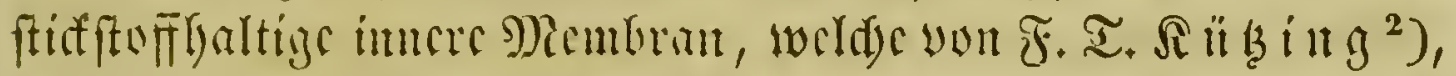

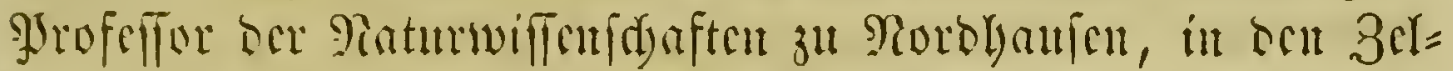

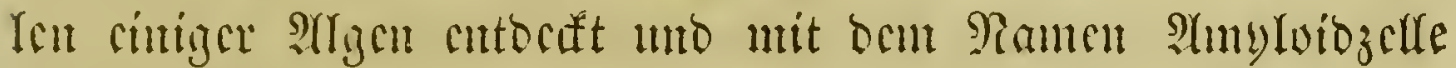

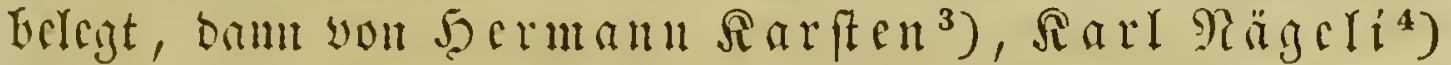

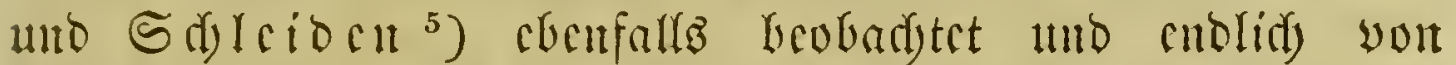
Moly ${ }^{6}$ ) mit jeurm Ramen bezcidyet wurbe, ocn Uriprung

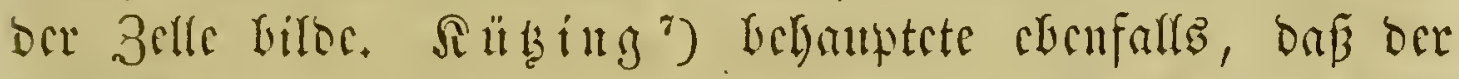

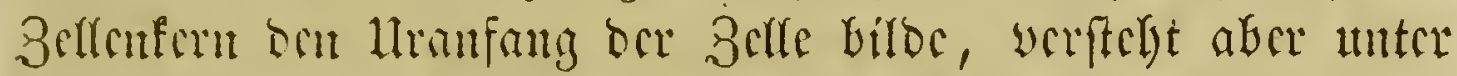
bicfer 3 cricmmmg nid)t ben Sd) lciben'fiden cytoblastus,

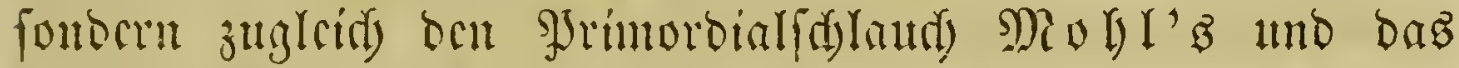

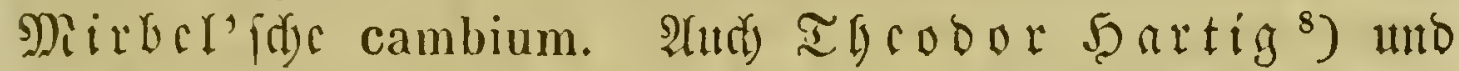

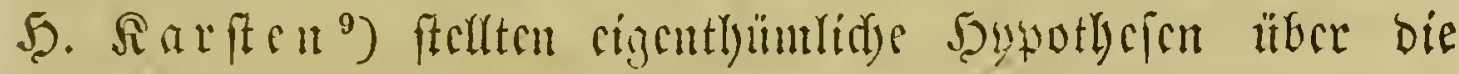

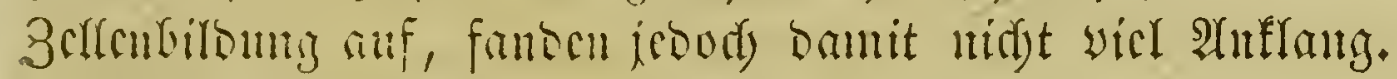
Heber bie printäe Belfubildung haben in ber neueren 3cit

1) SIbyfiologifue Botanif. 8. S. 30 ff.

2) Linnaea, 1841, હ. 546, unb Phycologia generalis, ober $2(n \mathfrak{n} a=$ tomie, S3Gyfiologie und Syftemfunde Der Tange. Seipzig 1843. 4. 80 tab. col. S. 38 .

$\left.{ }^{3}\right)$ Dissertatio de cella vitali. Berolini 1843. 8.

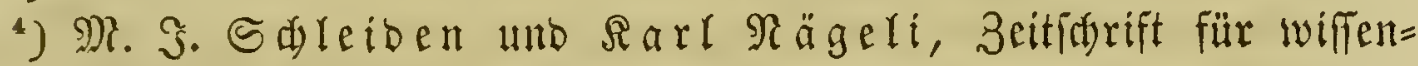
fdafttidje Botanif. (Bürid) 1844-1846. 8. 16 1ab.) Seft 1, S. 96.

5) Brundzüge ber wilīenidaftr. Botanif, S. 204.

-) Einige Bemerfungen über ben Bau Der vegetabitifaen Belle. Bot. 3eit. 1844, S. 273.

7) Şrundoüge ber philoiopgifaden Botanif. Reipzig 1851. 8. I. S. $232-258$, S. $291-333$.

B) Beiträge zur Entwieflungaggeididte ber Jflanzen. Berlin 1843.

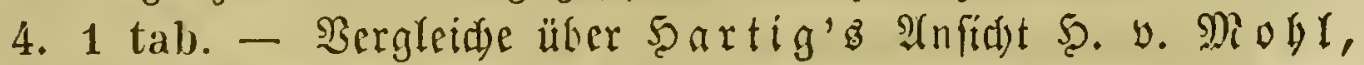

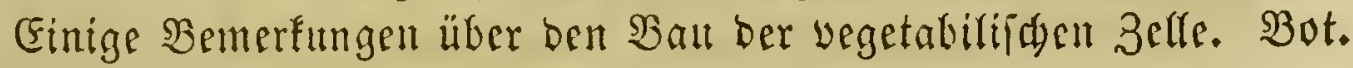
3eit. 1844, Sp. 307 ff.

') De cella vitali etc. - Die $\mathfrak{B}$ egetationzorgane Der Yalmen. 1847. 


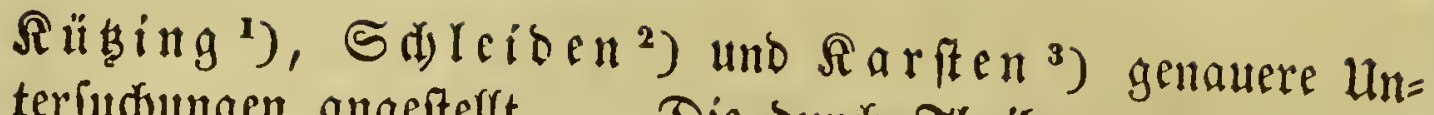
terfudungen angeftellt. - Die burd Theilung bez Shrimor= Dialldilauds ber Mutterzelfe vor fid gebende fecumbäre 3ellen= billoung wurbe zuerft 1833 von $B$ riffea $=$ Mirbel entbeaft; Dam warbe diefelbe yon Franz $\Im u l$. Ferd. Meyen ${ }^{4}$ ),

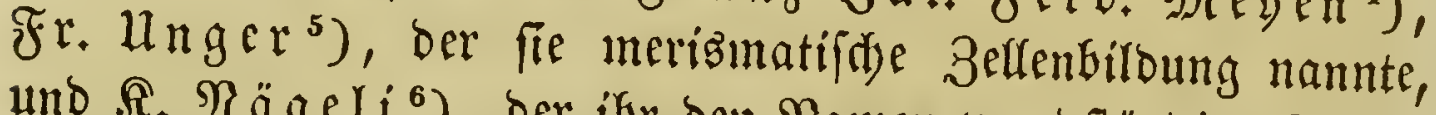

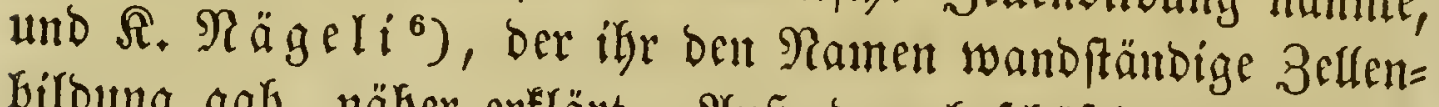
billoung gab, näher erflärt. 2(uferbem befdäftigten fid nod

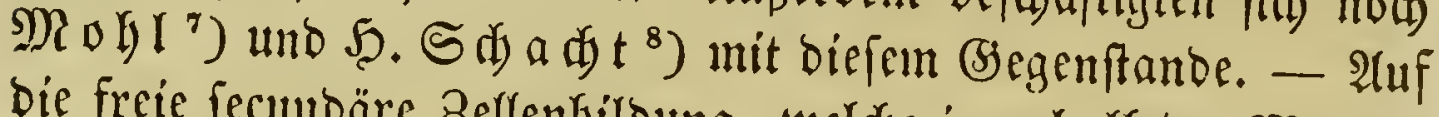
Die freie fecuntöre 3ellenfildung, weldye innerkalb ber Mutter=

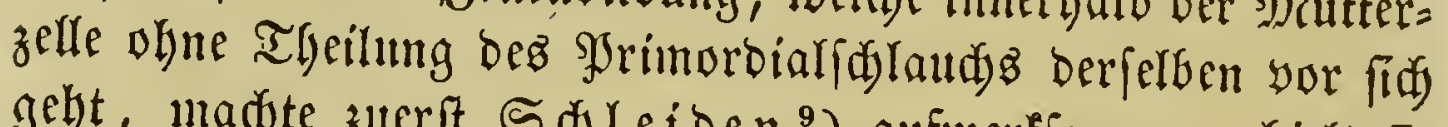
gebt, madyte zuerit Sdleiben ${ }^{9}$ ) aufmerffam; er lielt fie jebod fïr alfgemeiner verbreitet ${ }^{10}$ ), als fie nad den neueren

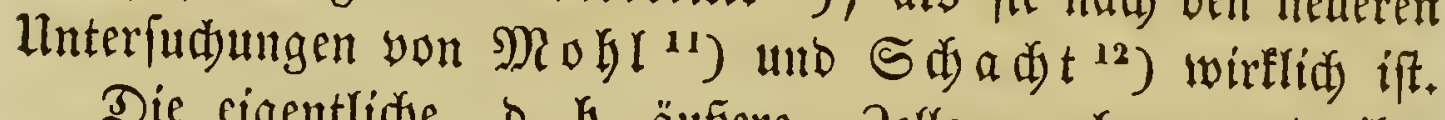

Die cigentlidse, b. h. äußere, Zetlemmenbram unb ifye verfdicbenen Berbiffungsfduid)ten wurben ebenfalls forgfăltig

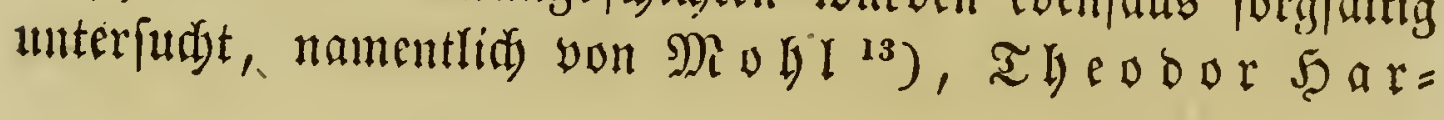

1) (Brunbzüge 2c. I. S. $230-240$.

2) (3rumbjitge 2.. I. S. 205 fi.

3) Die Hrjeugung. Bot. 3eit. 1848, S. 457 ff., 473 ff.

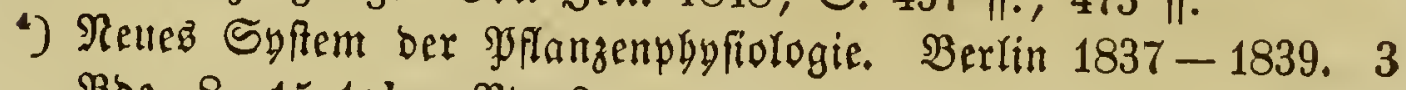
BDe. 8. 15 tab. $\mathfrak{B b}$. 2.

5) Heber baz $23 a d$ zthum ber Snternob. Bot. 3eit. 1844, S. 483 fi., 506 ff.

•) Beitjdrift für wififenidaftl. Botanif. 1846. Seft 3.

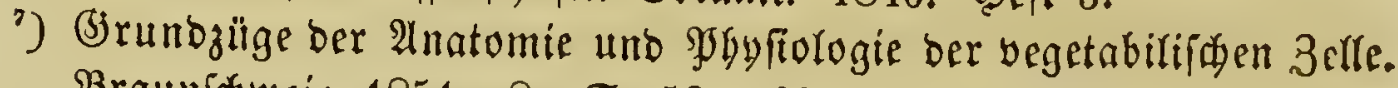
Braunโdweig 1851. 8. 5. $53-60$.

8) Bbyfiologifale Botanif. Berrin 1852. 8. S. 56-67.

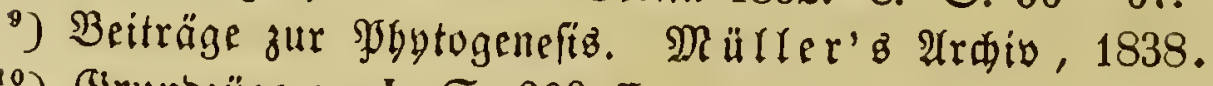

10) B̧rundzüge 2.. I. S. 209 ff.

1) Brunbzüge ber 2 (nat. und \$ghyfiolog. ber vegetab. Zelle 2c. S. 61.

12) SGyfiologifale Botanit. S. $50-56$.

$\left.{ }^{13}\right)$ Heber die Soren bes Planjenjellengetwebra. Tübingen 1828. 4. 4 Tafern. - Einige Bemertungen iiber Den Bau ber vegetabi=

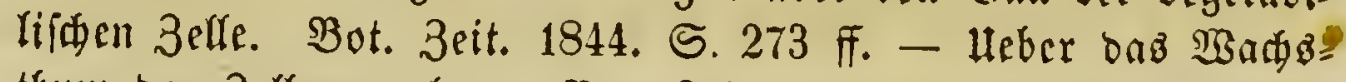
tgum ber 3cllenmembran. Bot. 3eit. 1846. S. 337 ff. - Unter= 


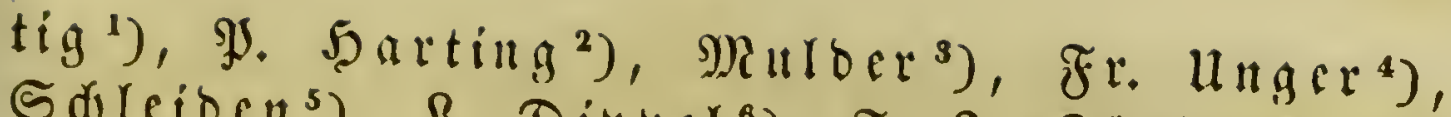

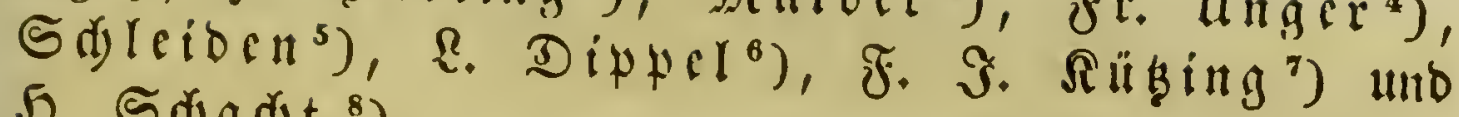
5.. Sकadt. ${ }^{8}$ ).

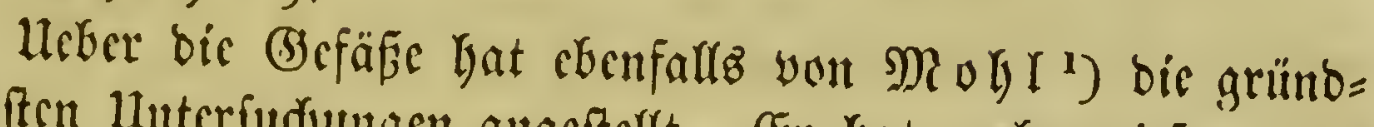

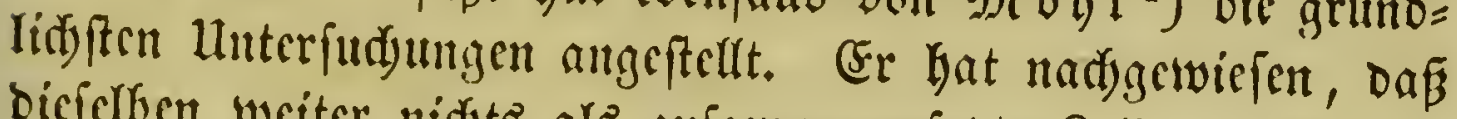
biefelben weiter nidytz alz zufamunengefeste Bellen finb, unb fritbem ift bicfe $\mathfrak{a n f i d y t ~ f a f t ~ a l l g e m e i n ~ a n g e n o u m m e n , ~ o b i g l e i d ) ~}$ Rübing behauptete, bẩ bie Spiral= und Ringgefäpe ur=

Fudungen ber frage: Bitbet bie Eelluloje bie Brunblage fämmt= lider vegetabilificer Membranen? Bot. 3eit. 1847. S. 497. -

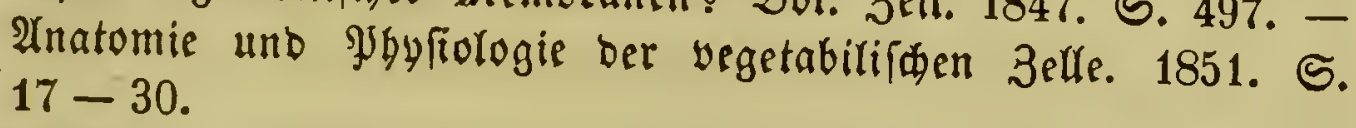

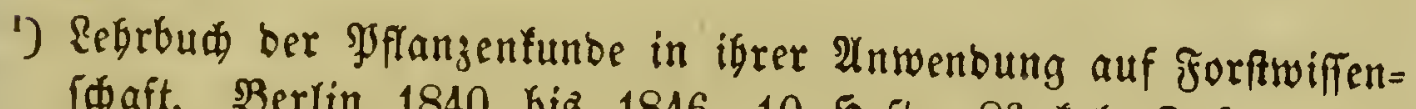

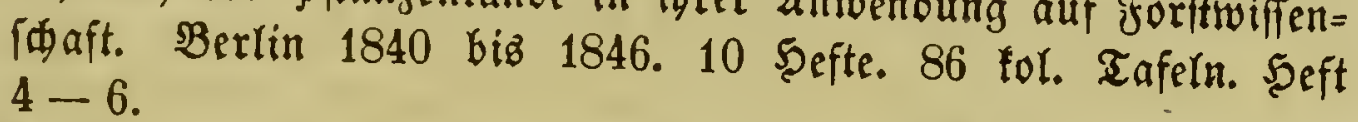

2) Mikrochemische onderzoekingen over den aard en de ontwikkeling van den plantaardigen celwand. $s$. l. et a. 8 tab. - Heberfegt in Sdledtendal'z Linnea $\mathfrak{F} b$. XIX. - Brief an 5. y. Mogl zur Beantwortung feines 2uffakez: Heber bą Waadsthum ber 3eflenmembran. Bot. 3eit. 1847. ज. 337 fi.

3) Berfud einer phyfologifden Gbemie. Heberfegt yon $\mathfrak{R o r e}=$ fidott. Rief. 4 u. 5.

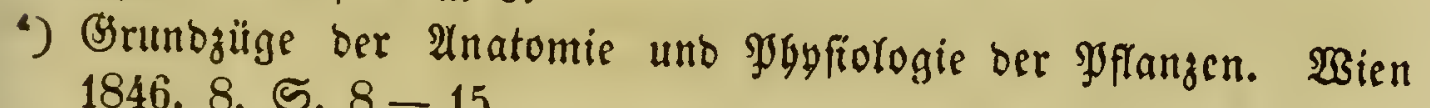
1846. 8. 5. $8-15$.

$\left.{ }^{5}\right)$ Brunbzüge ber wiffenfidaftl. Botanit. 1849. I. S. $225-243$.

-) Beiträge zur \&öfung ber Frage: Soinmt bie Belfenmembran bloz

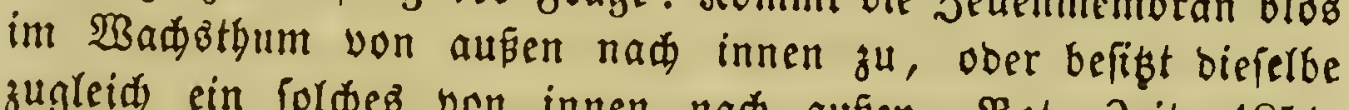
zugleidy ein foldes von innen nad ausen. Bot. Beit. 1851. S. $409 \mathrm{ff}$.

7) Sirunbzüge 2c. I. 1851. S. $230-292$.

8) Heber eigentbümlide, biòber nod nicht beobadtete Errdeinungen in ben Berbidungsididten geivifier Şorzzellen. Bot. Beit. 1850. S. 697 ff. - SSbyfol. Bot. 1852. S. $12-27$.

-) Heber ben Bau und bas Binben ber Ranfen unb Salingpflangen. Tübingen 1827. 4. 13 Tafeln. - Heber bie Yoren bez \$Plangen= zellgerwebes. Täbingen 1828.4.4 4 Tafeln. - 2 tnatomie unb Sybyliologie ber vegetabilifaen 3elle. S. 26 u. 27. 
fwrünglidye einfadye Zeffen mit unbegränztem Spibenwadya thume frient ${ }^{1}$ ). Die Anfidsten $B$ riffeau= Mirbel's über

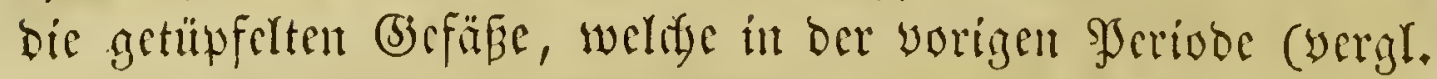
S. 282) Gejonders in Dentid)land Gartnäafig beftritten wor= Den waren, wurbe jest yon $M$ ol $l$ als ridutig crfannt; ex

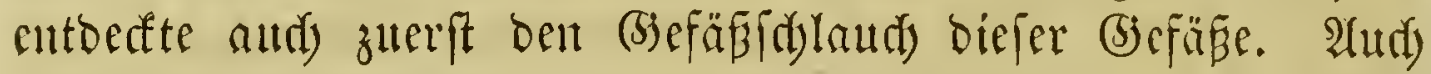

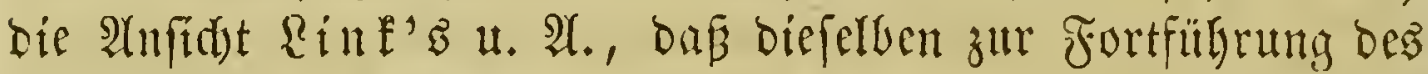
Syflangenfaftes bienten, wurbe in ber neueren 3eit wiber= Iegt. Alufer Molyl lyaben fid) nod) namentlid, Meyen ${ }^{2}$ ),

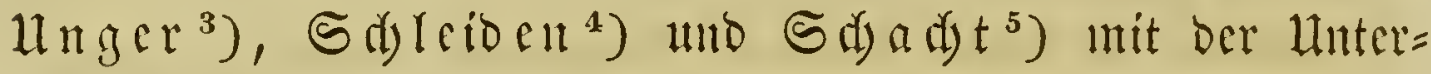

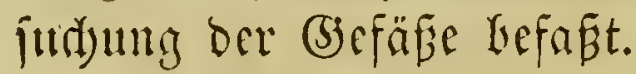

Die genautre Erforidumy bes Zellengervebes ift erit ein

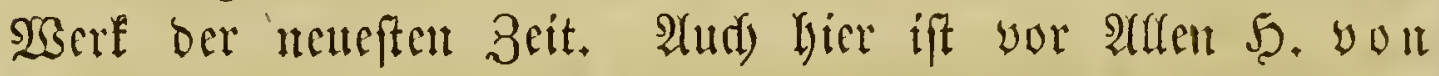

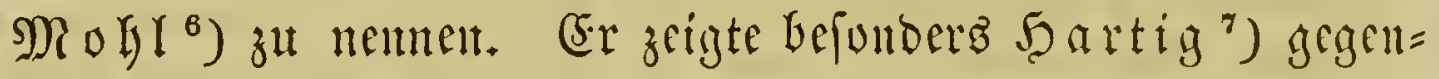
über, Der eine gemeinidjaftlidye Membran ber eillzelnen Zellent

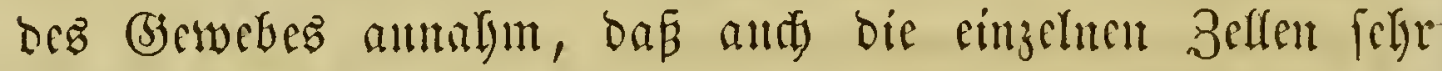
sidfter (b) ewebe von cinanber getrennt werben fümen; er ftellte aud) zuerft bie $\mathfrak{B}$ elyauptung auf, baß bie Sutercellularfubftanj

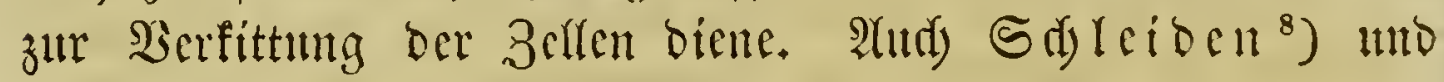

1) (3runozüge. I. S. 287. 288.

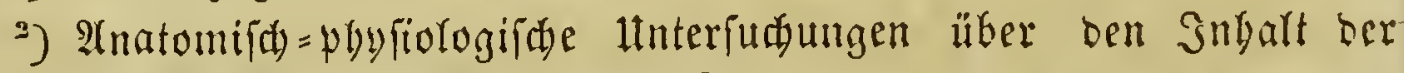
YJflanzenjellen. Berrin 1828. 8.

3) (3runbzüge 2r. S. 46 ff.

4) (birunbjïge 2 .

3) भुbyfiologifde Botanif S. 183 ff.

-) Bergl. Defifen Beiträge zur Intatomie uno \$Jbyfiologie ber (3ie=wädje. Şeft 1. Bern 1834. 4. 6 Tafech. - Heter bie Berkin= bung ber Zellen unter einnnber. Tübingen 1835. 4. 2 Tafeltr. - Erräuterung uno $\mathfrak{B e r t y c i b i g u n g ~ m e i n e r ~} 2$ tnfịten ber Strut=

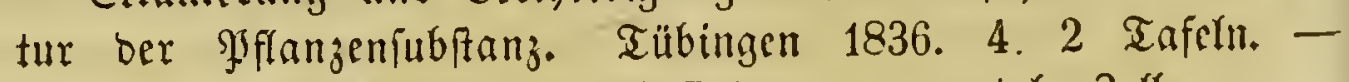
(3runbzüge oer Anatom. u. Mggfioleg. oer vegetab. Belle.

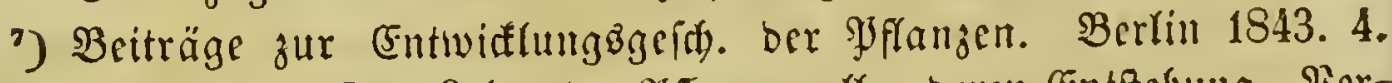

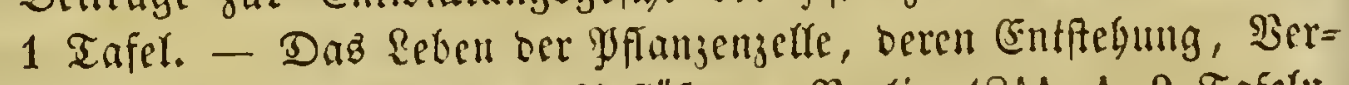

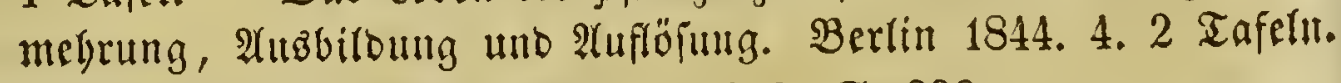

8) (Brundzüge ж.. 3. 2(ufl. Bant I. 1849. S. 330. 


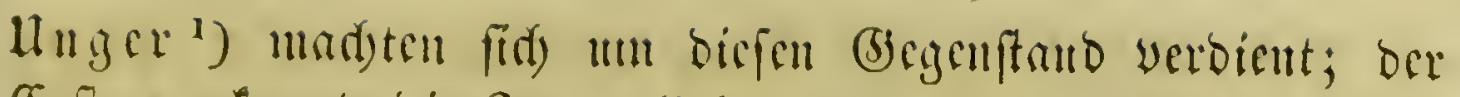

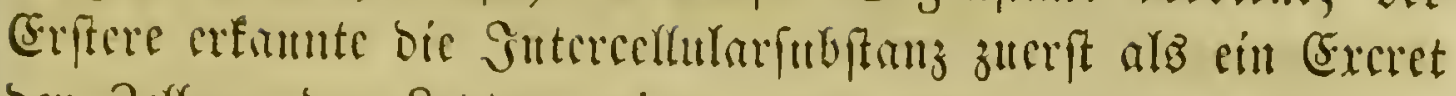

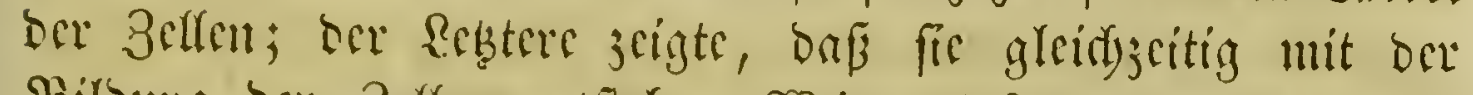

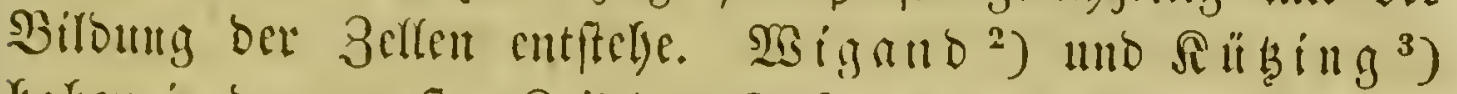

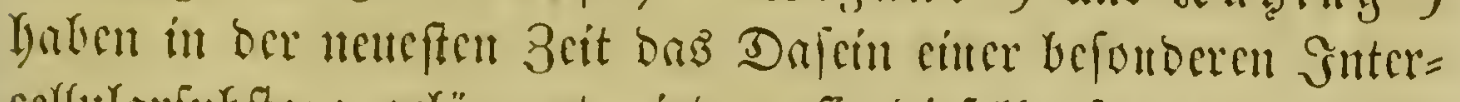
cellularfubftan; geläunnet, indem fie bicfelbe fïr cine Mobi=

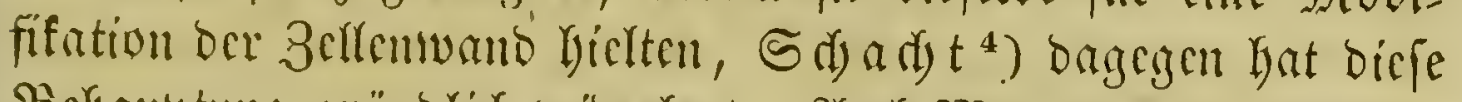

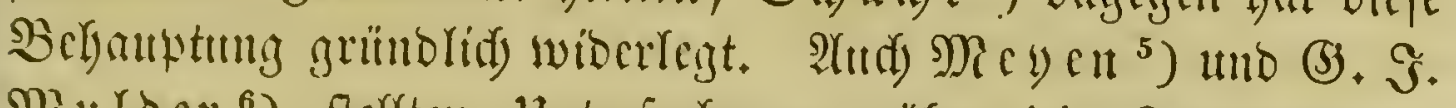

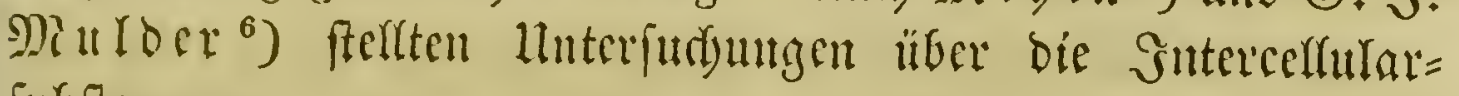
fubftanj ant.

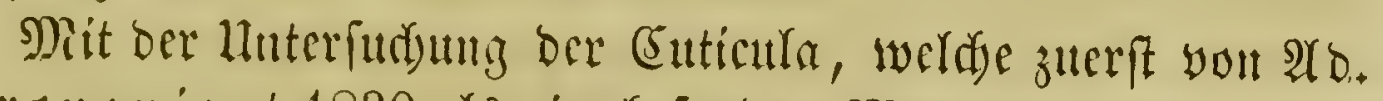
B rongniart 1830 als cine befondere Menteran erfennt wor"

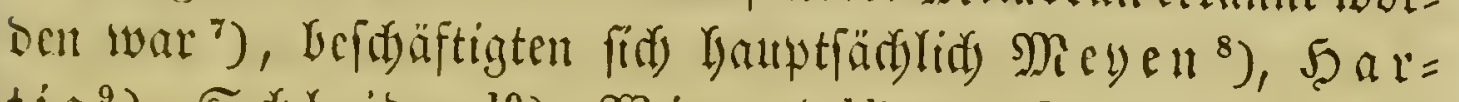

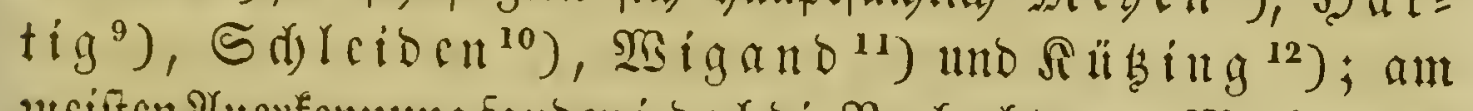

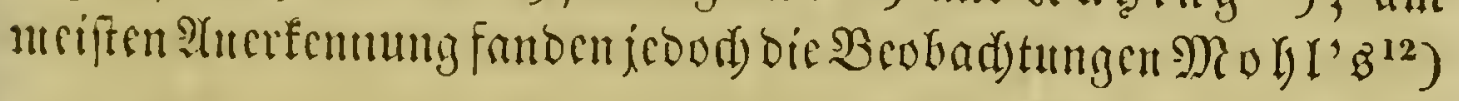

1) Şrunboüge 26. S. 18 fr. - Die Sntercellulariubftanz unb ifr Berbältni zur Zellenmembran bei Yjflanzen. Bot. Zeit. $184 \%$ 5. $289 \mathrm{fr}$.

$\left.{ }^{2}\right)$ Sntercellularfubfang u. Suticula. Braunfwiweig 1850.

$\left.{ }^{3}\right)$ (3rundızüge 2c. S. 300 ff.

3) Sybfiologitide Botanif. 1852. S. $76-86$.

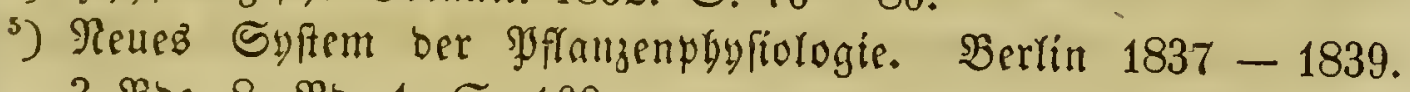
3 Bope. 8. Bo. 1. S. 160.

-) Berfud einer phyfiologifanen (Shemie. Braunfdrweig 1844. 8. S. 418.499.

7) Annales des sciences natur. tom. XVIII. p. $42 \%$

$\left.{ }^{8}\right)$ Eiete oben Mote 5.

๑) Beiträge zur Entwiålungägei 4. $1 \mathfrak{T a f}$.

$\left.{ }^{10}\right)$ (brunbzüge $2 c$.

$\left.{ }^{11}\right)$ Cifle oben Rote 2.

$\left.{ }^{12}\right)$ Sirunszüge I. S. 302 ff.

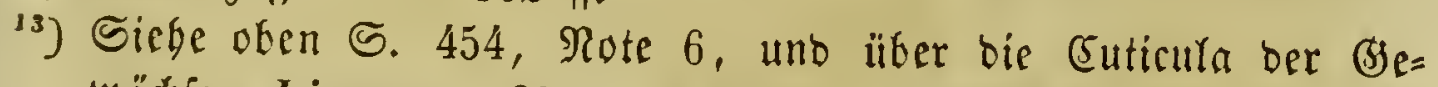
wädje, Linnaea 1842. - Heber bas Ginbringen ber (Suticula in bie Spartöfnungen. Bot. Beit. 1845. S. 1 ff. - Heber bie Suticula yon Viscum album. Bot. 3eit. 1849. S. 593 ff.

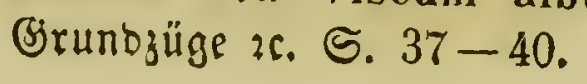




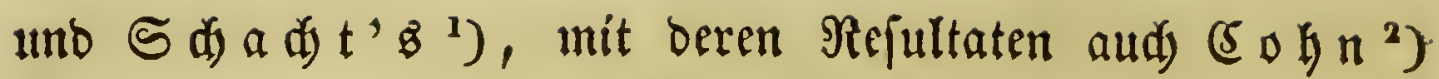
uibercinftiumte.

Uleber bie Gntercellulargänge war fdjon in früheren Zeiten Bielez gefdrieben worden, von grüßerer Widtigfeit waren je=

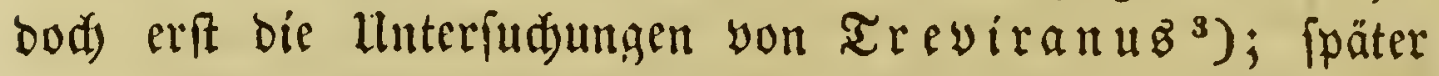

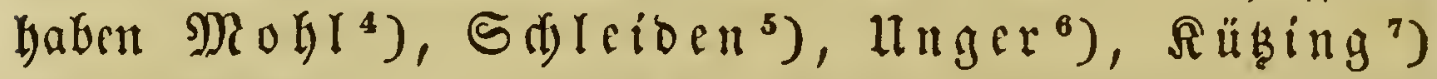

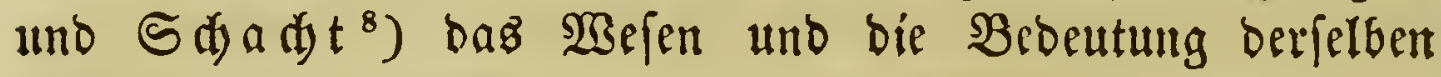
bollfänoiger erforidt.

Die Zufammenfezung bes 3efryetwebes zog fdon frül bie

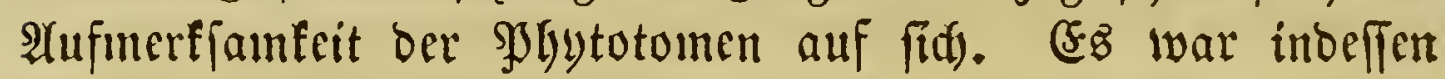

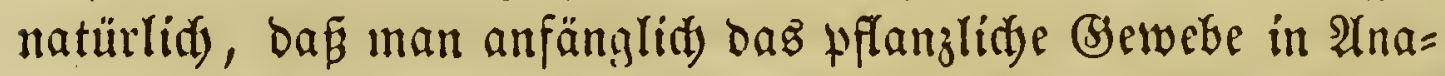
logie mit bem thierifden 3ellgetwebe bradjte uno annahm, baf $\mathfrak{C B}$ aus vielen in einaltber verwad) jenen fajern uno Blüthen

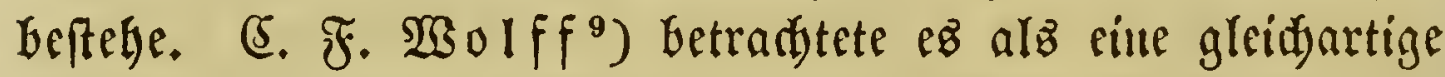
Maffe, bie von ciner Minge Ranäle und Rüfen burdzogen

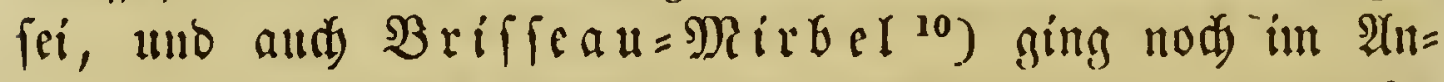

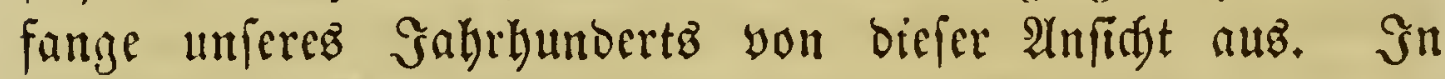
Beutfdiland fam man zuerft burd) bie Foridungen ber in ber vorigen Sarivo genannten berillunten Sbytotomen ber

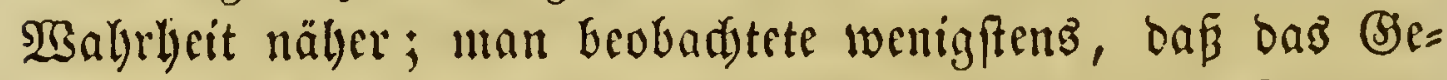
wobe aus einer groß̧en $2(n j a h) l$ fleinerer Drgane jufammen= gefegt fei, uno unterfdied nadi der Berfdjiedentheit biefer

1) Sbyfiologifide Botanit. 1852. S. 89-102.

2) De cuticula. Vratislav. 1850.

3) Shgyfiologie ber (łewä山fe. Bonn 1835-1838. 2 Boe. 8. 1. Bø.

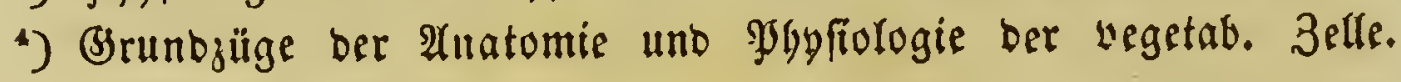
S. 36 .

3) (3)runbzüge 2c. I. S. 247 ff.

-) Brundzüge 2c. S. 20.

${ }^{7)}$ S)runbzüge жr. I. S. 315.

3) Śbyfiologifide Botanit. S. 87 ff.

9) Theoria generationis. Halae 1759. 4. 2 tab. - Ed. nova. Ibid. 1774. 8. 2 tab. - Deutid: Berlin 1764. 8.

10) 5. 282 . 


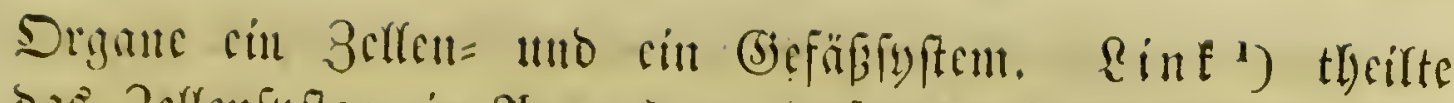

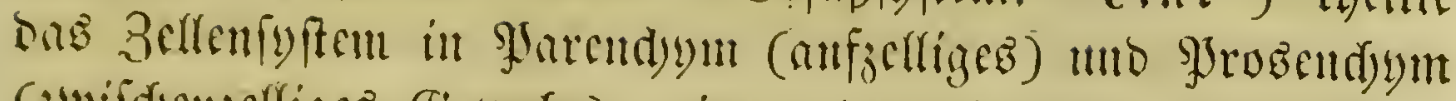

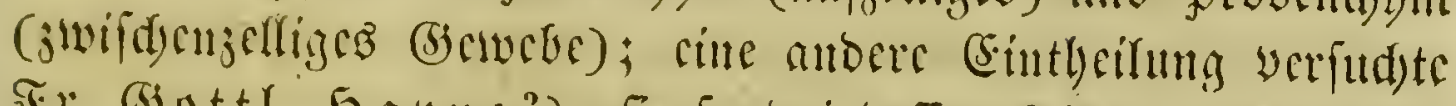
Fr. (5ottl. $5 a y \| c^{2}$ ), fic fand indeffen fciuc Atucrtemung.

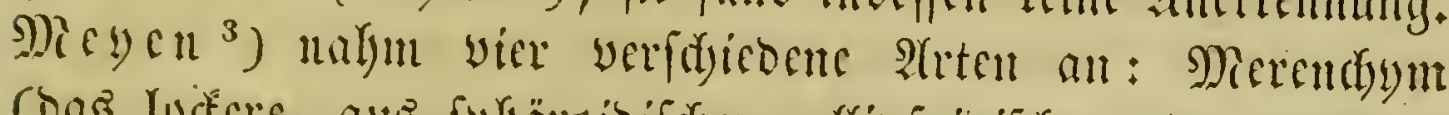

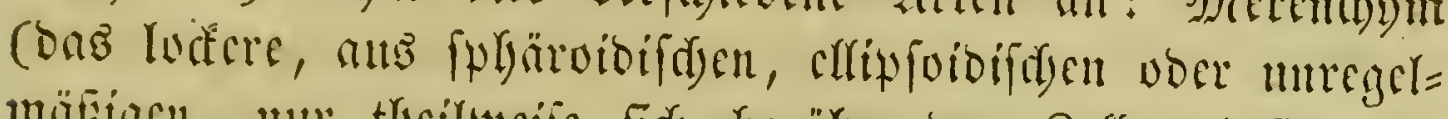

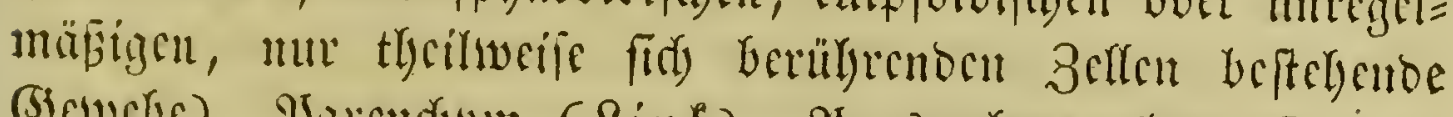

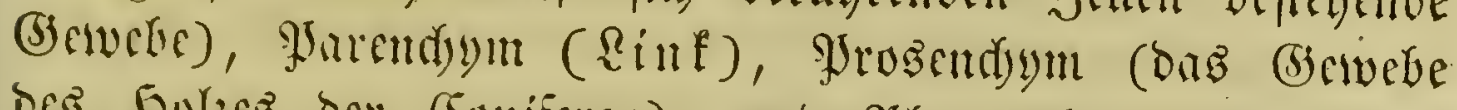

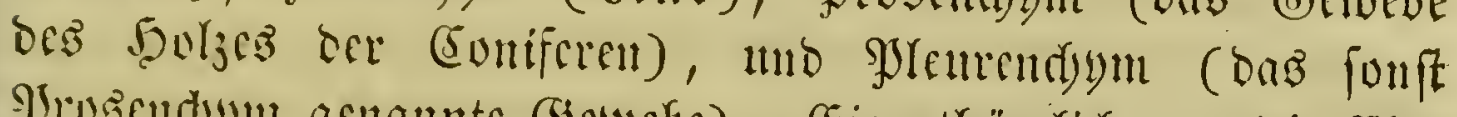

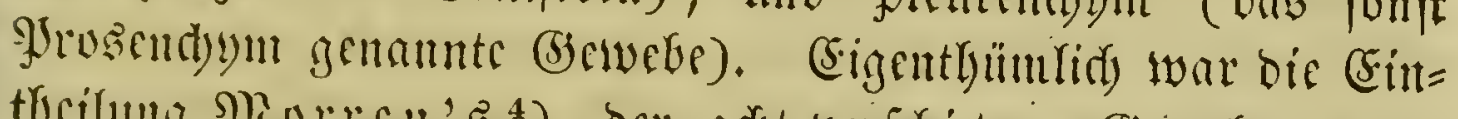

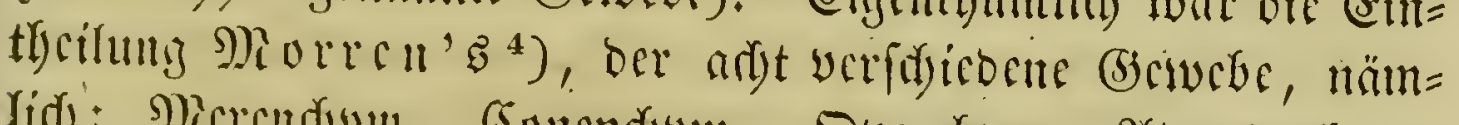

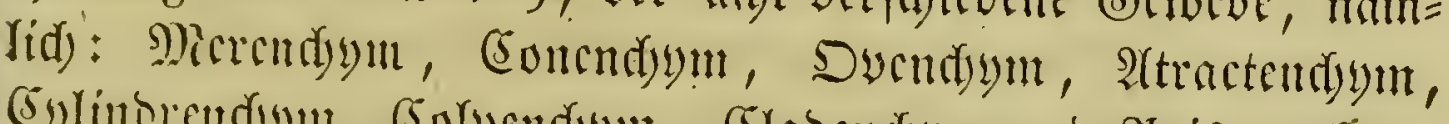
Eylintendym, Solpendym, Sladendym uno Sriencudium,

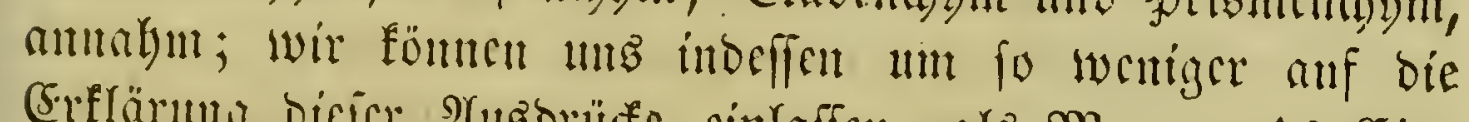

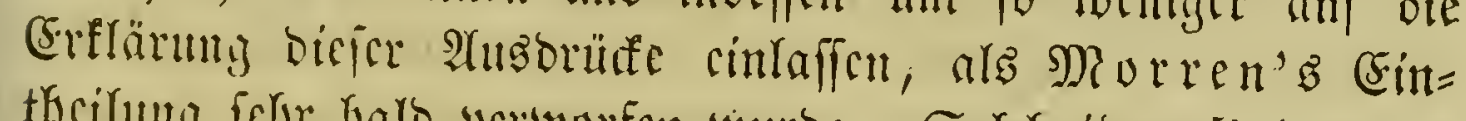

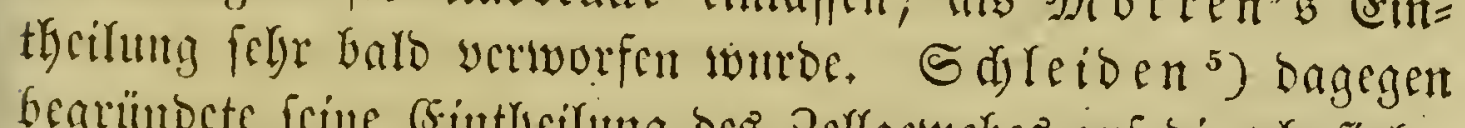
Gegrünocte feine sintlyeilung ocs 3crfgencbes anf bie why fiolo=

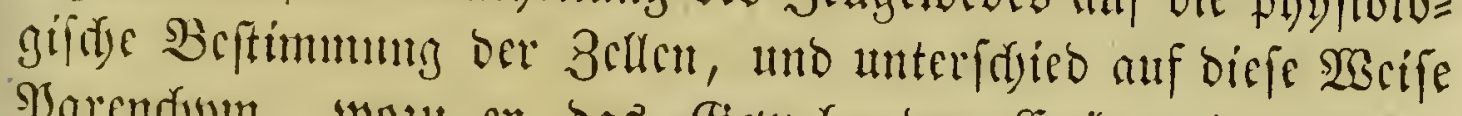

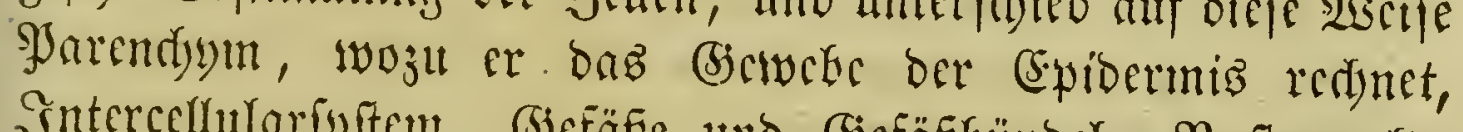

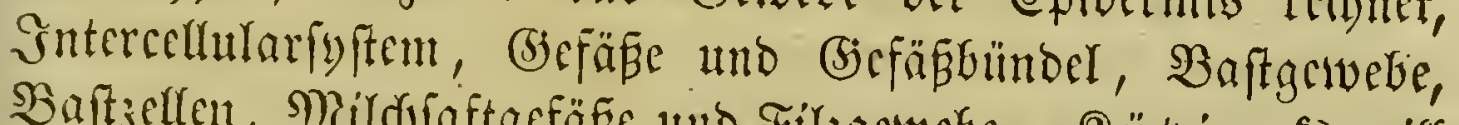

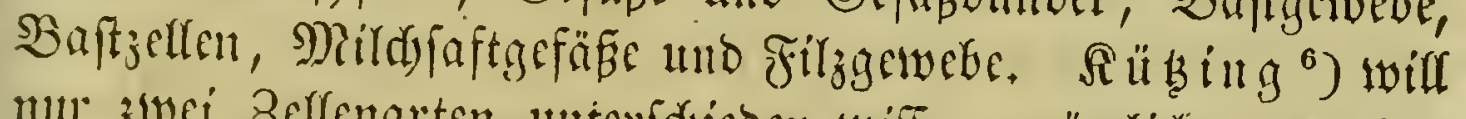
mul zivei Beffenarten unterfdjicben woiffen, nämlidj: getwöln

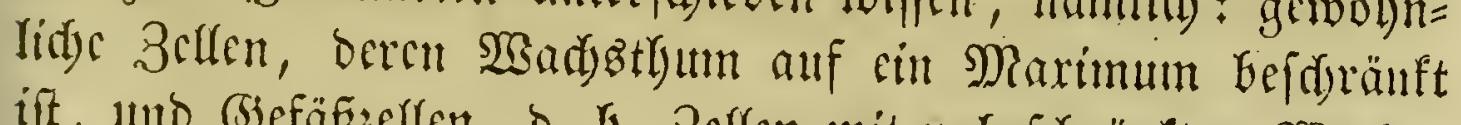

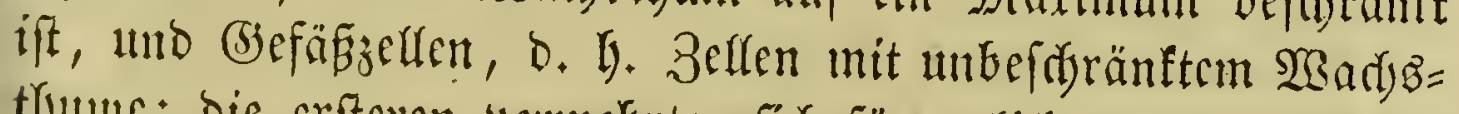

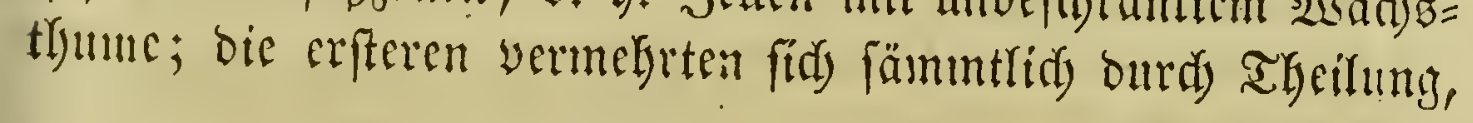

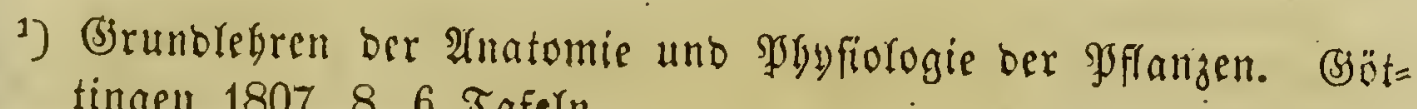
tingen 1807. 8. 6 Tafeln.

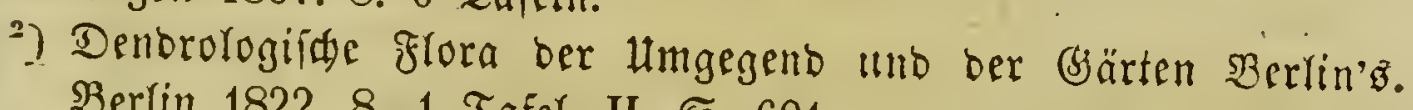
Bertin 1822. 8. 1 Iafer. II. S. 601.

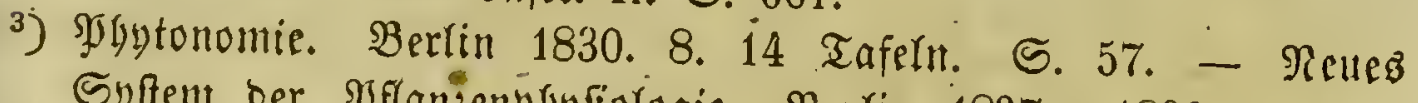

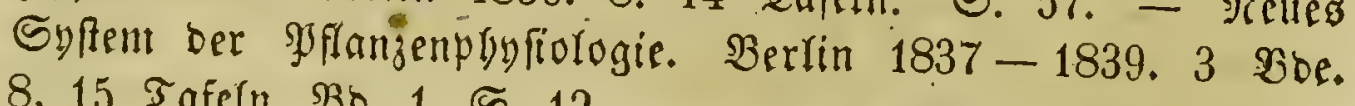

8. 15 Tafeln. BBo. 1. S. 12.

4) Bullet. de l'Acad. de Bruxelles. Tom. II. No. 3.

5) Brundzüge ber wiffenidaftl. Bot. I. S. 240 ff.

') Brunbzüge Der pgitoioph. Bot. I. S. 311. 
bie lekteren vergrö̈rerten fid nut olye Theilung, indem bet

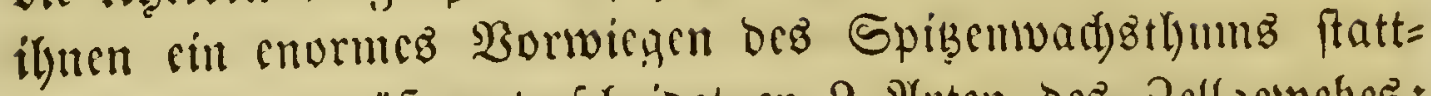

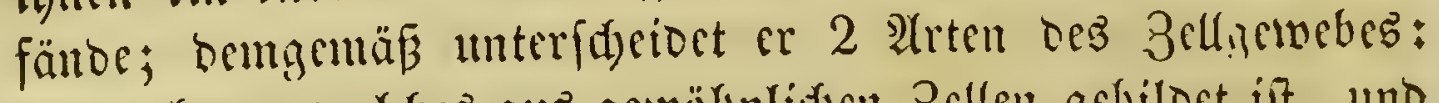
Şarendym, weldes aus gewöbnlidy 3enten gebiloct ift, uno

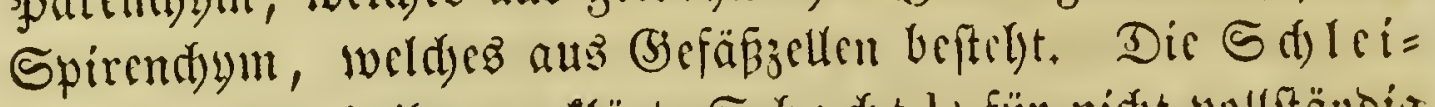

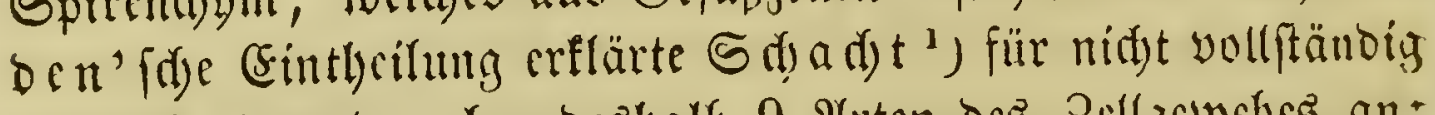

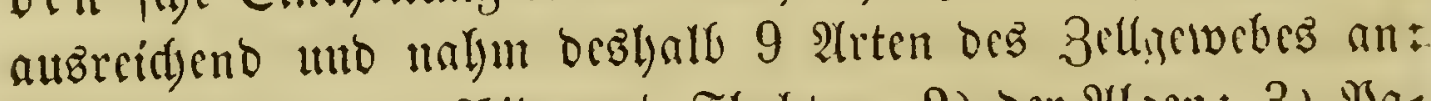

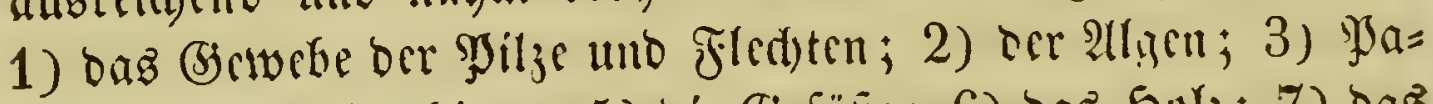

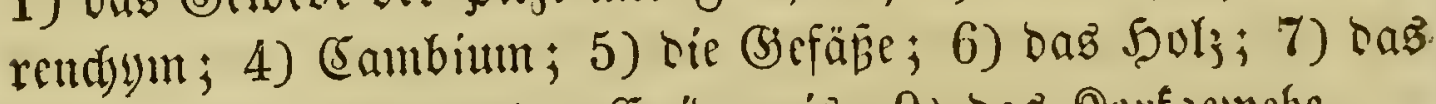

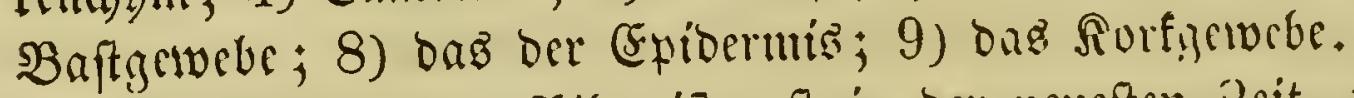

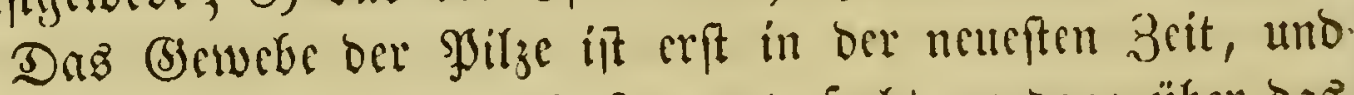
zwar befonders yon $S d) a d) t^{2}$ ), unterfudt morden; über bas ber Fledten ift nod) wenig befannt gemad)t worben. - Einer

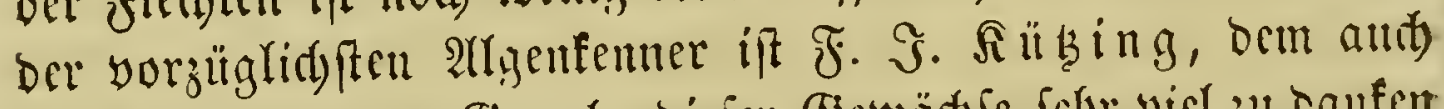

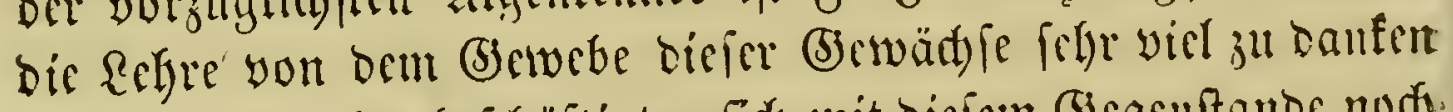

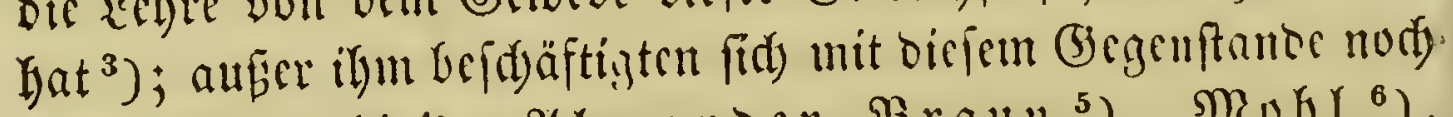

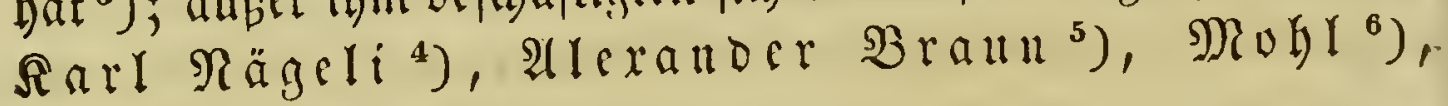
S(i) $a$ d) $\left.t^{7}\right)$ u. $\mathfrak{m} . \mathfrak{A}$.

Mit Den werfdeicbenen Arten ber 3urammenfegung res.

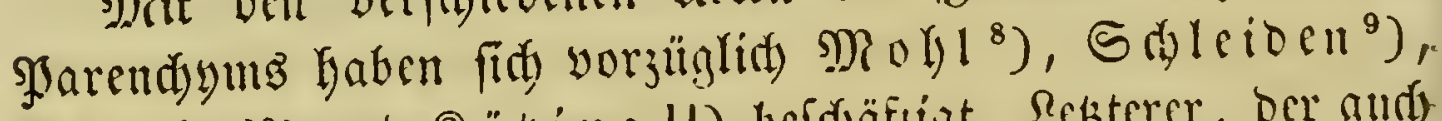

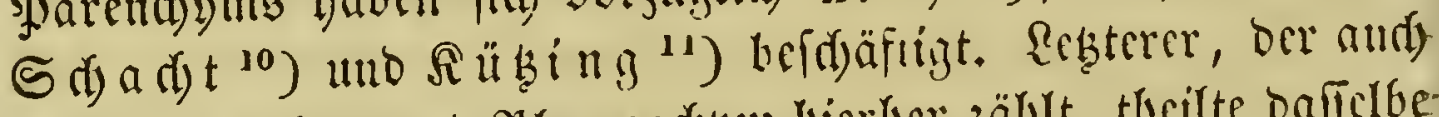

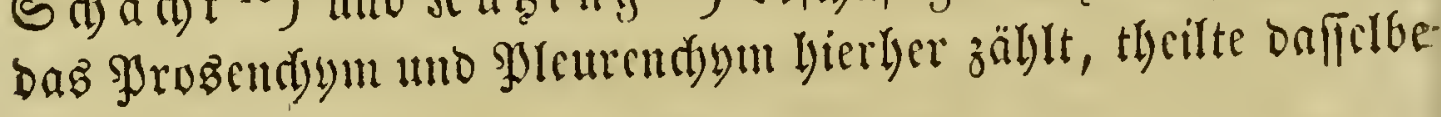

1) Şlygfiologirase Botanit. S. 105.

2) Sobyfiologifine Botanif. S. $134-147$.

s) Phycologia generalis etc. Reipzig 1843. 80 tol. Iafern. (3) rungozïge ber philoioph. Bot. II. S. $6-33$.

4) Die neueren Atrgenfyfteme 2c. उürí, 1847. 4. 10 Tafern. -

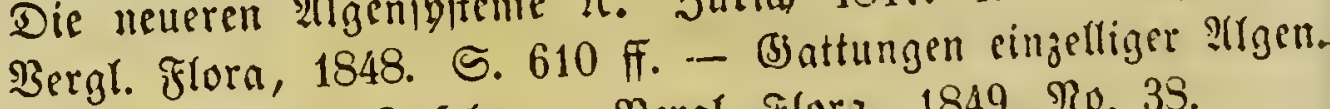
Ibid. 1849. 4. 8 Tafelt. - Bergl. Slori, 1849. Ro. 39.

3) Die Beriüngung in Der शatur. Berlin 1850.

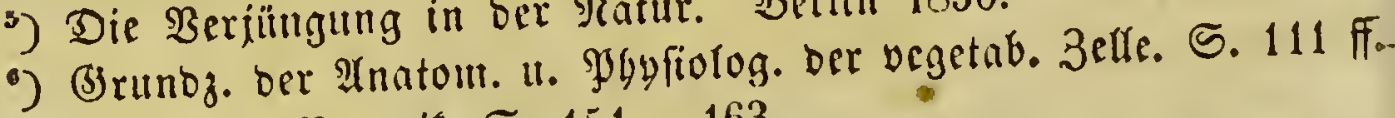

') Bgyfiolog. Botanif. S. $151-163$.

8) (3runbzüge 2c. S. 13 ff.

-) (stundzüge ber wifienidaftl. Botan. I. S. 245.

10) Jjoyfiologilde Botanif. S. $163-173$.

i) (3)untz. I. S. 312. 


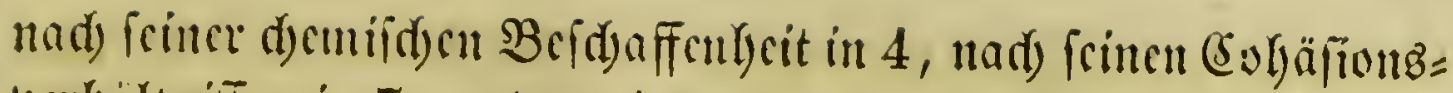

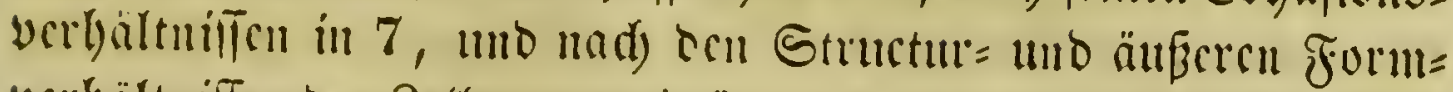

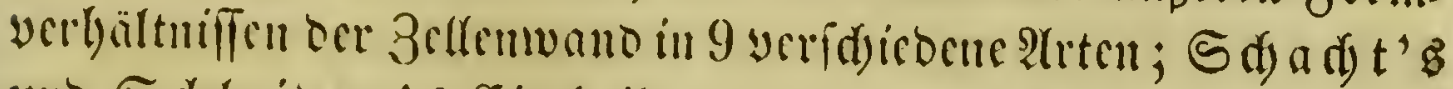

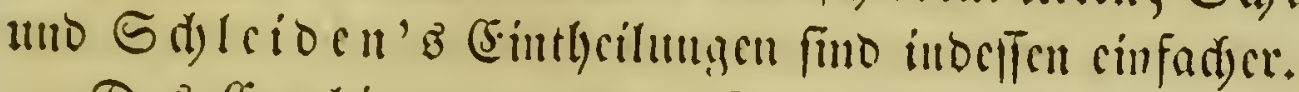

Dab Cambinm war jwar fdon friblyer beobaditet worben, rod) fabte man feine $\mathfrak{B}$ cftimmming falid) auf, inbcm man $\mathrm{cB}$ bloz alis cime gollertartinge Mafle betradtete, bie zut Scryor=

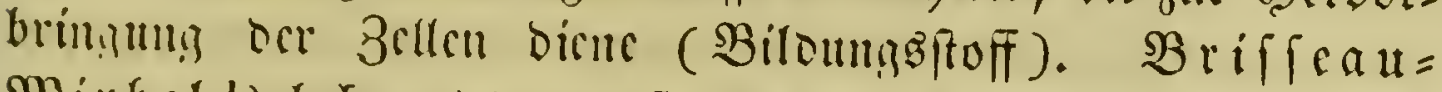

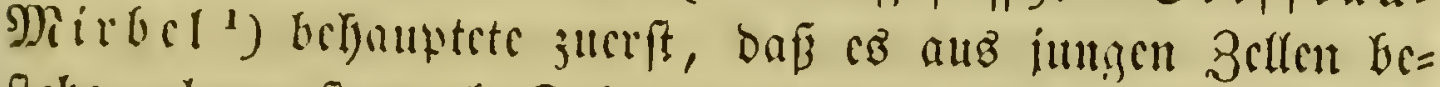
ftcle, aber crft curd) Sd) $\left(c i d e n^{2}\right.$ ) wurbe frime Bufanment=

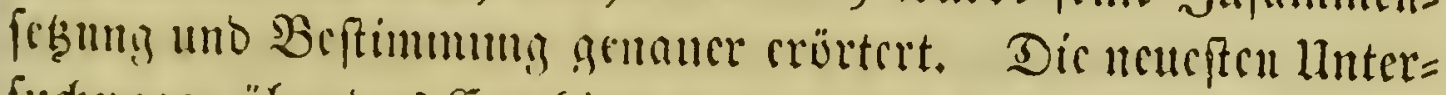

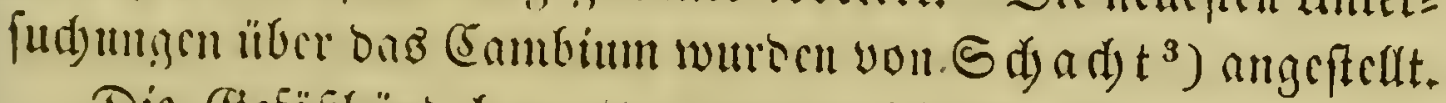

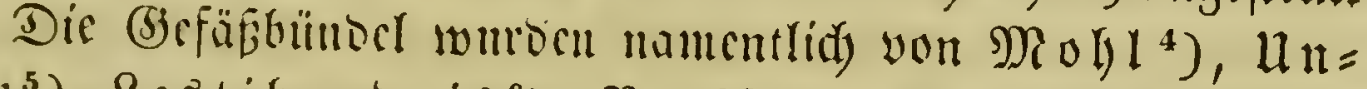
$\left.\mathfrak{g e r}^{5}\right)$, Rcstibundoig $\left.{ }^{6}\right), \mathfrak{B r i f f c a u =}$ Mitbel $\left.{ }^{7}\right), \mathfrak{M a r}=$ tiub $\left.{ }^{8}\right)$, S. ( rüger $\left.^{9}\right)$, Trecul $\left.{ }^{10}\right)$, Sd)leiden ${ }^{11}$ ) und

1) Comptes rendus de l'acad. des scienc. 1837. S. 295.

2) Brunos. Der wiffenidaftl. Botan. I. S. 253.

3) SPgyfiulog. Bot. S. $173-182$.

4) De palmarum structura. Monachii 1831. Fol. 16 tab.

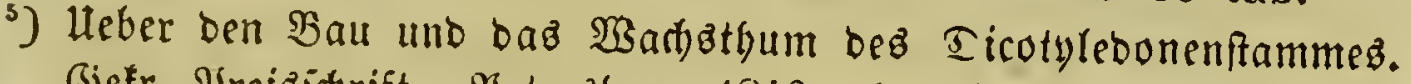
Bjefr. Sreizidrift. Weterzburg 1840. 4. 16 Taf. - Heber ben (3runo ber Bitoung ber Sabrezlagen bicotyler f̧olzpflanzen.

-) Etudes sur l'anatomie et la physiologie des végétaux. Paris 18\%0. 8. 21 tab. - Mémoire sur la structure des monocotylédonés. Lille 18:3. 8.

') Sur la structure da dattier. (Comptes rendus de l'académie des scienc. 1813.)

-) Historia natural. palmarum. Monachii 1823-1850. Fol. 2 it tab.

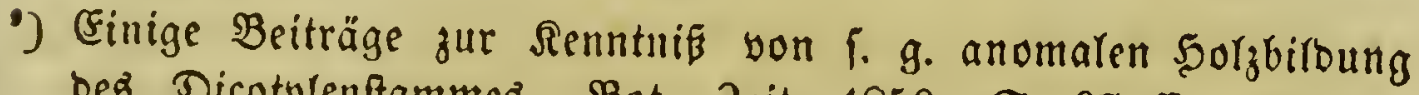
bez Dicotnlenftammez. Bot. 3eit. 1850. S. 97 ff., 121 ff., 137 ff., 177 ff ; 1851 . S. 465 ff., 481 ff.

10) Ohservatt, relatives à l'accroissement en diamètre des végétaux dicntylédonés. (Aunal. des scienc. nat. Tom. X VII. 18.22. No. 5.

ii) Brunbjînge 26. 


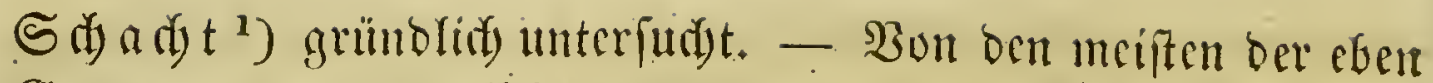

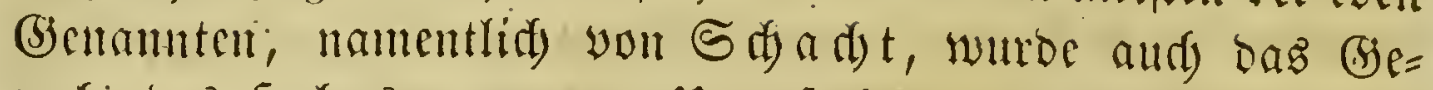

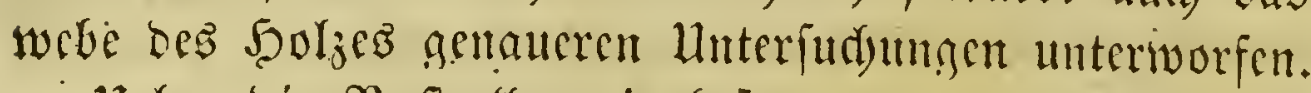

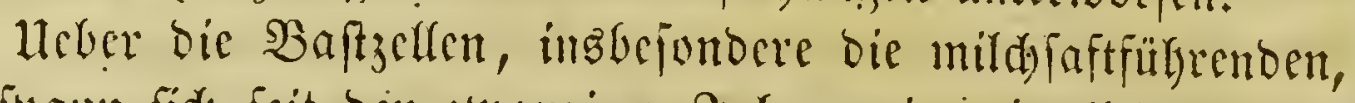
cutfipann fid) feit ben zwanziger Gabren sine ziemlid lebbafte Disfuffion. SBriffeau= Mirber ${ }^{2}$ ) erfannte fie zuerfit als Drgane, weldye mit cigenen Membranen verieben fund. Rad

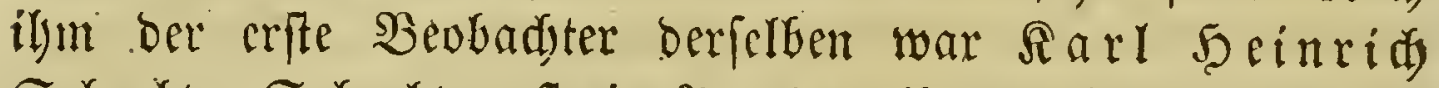

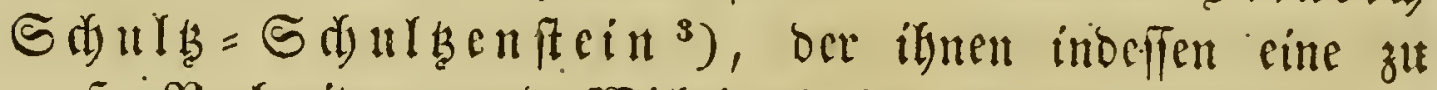
grofe Bevbrcitung uno Widthtigfeit it bcm Drgantizmus bci= Ingte, fie Rebensgefäße, ben Mildafaft Rebensiaft und bie $\mathfrak{B} e=$ wegung beffelbcu, weldye $\mathfrak{e r}$ als cine felbftändige Strömung beobadytet Gaben woulte, Bycloje nannte. Bald befidyätig=

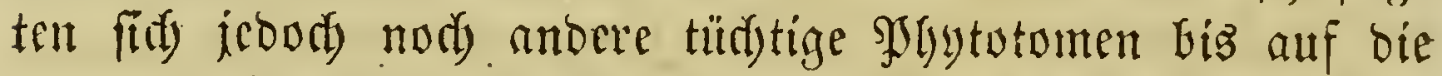
ncuteite 3cit mit biefon (Sogenftande, fo: Treviranus ${ }^{4}$ ),

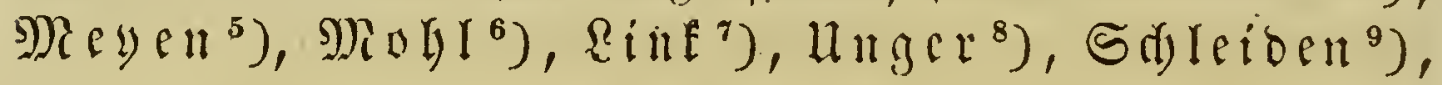

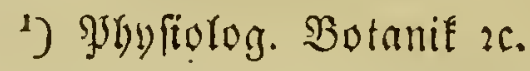

$\left.{ }^{2}\right)$ Eléments de physiologie végétale et de botanique. Paris 1815. III voll. 8. 72 tab. Vol. I. - Heber pie mildajaftfübren= Den Baftzellen ocr 21pocyneen. (Annal. des scienc. nat. 183.5.)

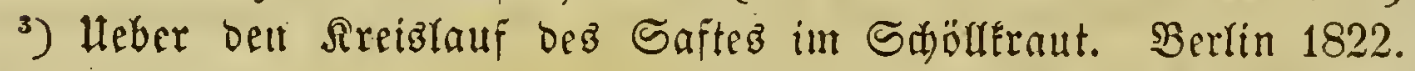
8. 1 \%ol. Tafel. - Heber ben Ireiglauf dez Saftez in ben YJfanz̧̨r. Grräuternde Bemerfungen. Bertiu 1824. 8. - Die

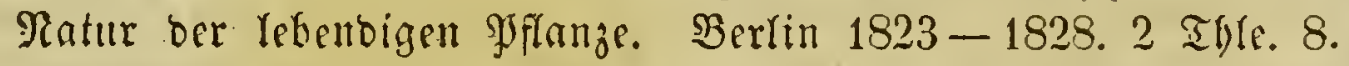
- Sur la circulation et sur les vaisseaux lactifères dans les plantes. Paris et Berlin 1839. 23 tab. - Dis Eyflufe

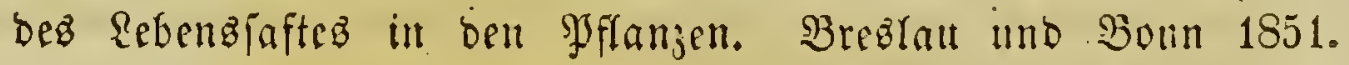
33 Iafeln.

4) SYyufiologie ber (3ewän fe. Bo. I. S. 75. 1835.

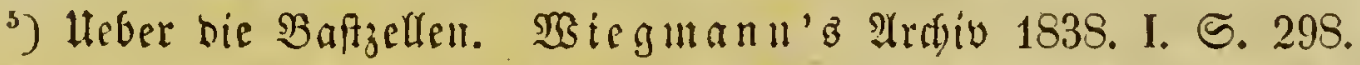

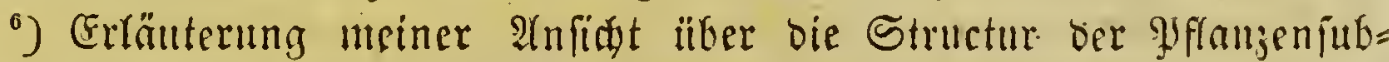
ftanz. Tübingen 1836. - Heber oen Mildy)aft uno peine Bewe= gutng. Sot. Beit. 1843. S. 553· ז. 593 fi.

7) Anatomia plantar. iconibus illustrata. Fase. I. Berrin 1843.

$\left.{ }^{8}\right)$ (3) S. 52 fi.

$\left.{ }^{9}\right)$ (3runojüge Der wiflenidaftl. Sot. I. 1849. S. 264 fi. 


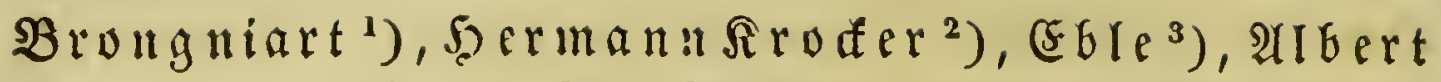

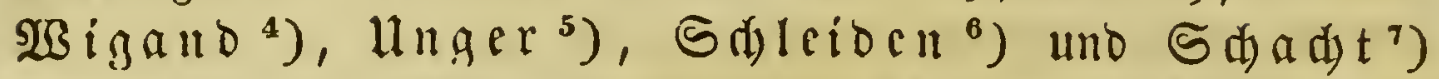

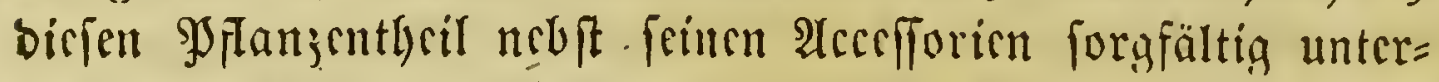
fudt. - Die Spaltüfnumgen oer (spidermiz unterfudtern vor=

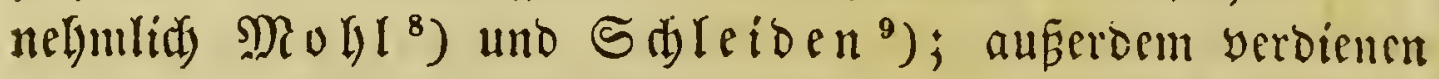

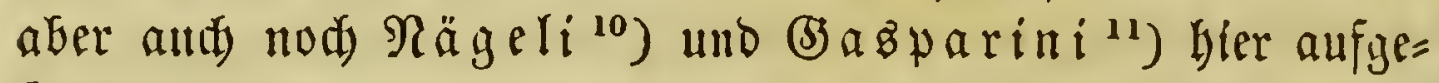
fülgrt 孔u werdent.

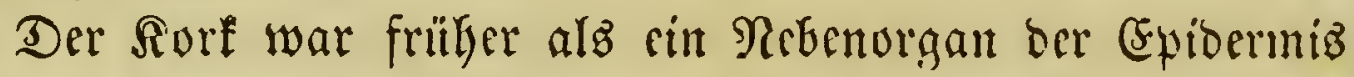

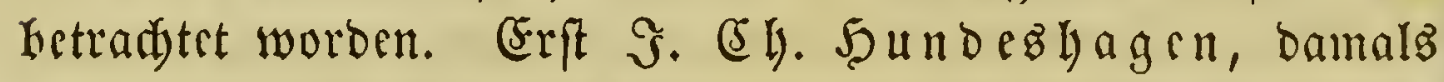

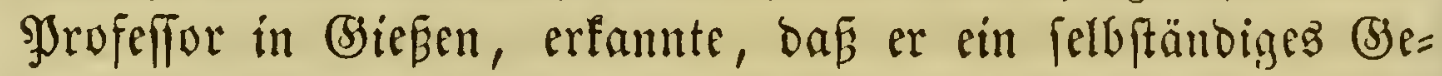
webe bilde, und feit biefer 3cit wurbe er bein von verfdie= Denen (3)elehrten, wie yon Mo $\mathfrak{h l}^{12}$ ), Döpping ${ }^{13}$ ), Mul=

1) Annal. des scienc. natur. tom XXI.

$\left.{ }^{2}\right)$ De plantar. epidermide. Vratislav. 1833. 4. 3 tab.

3) Die \{egre yon ben 5̧aaren. Wrien 1831. 8. Vol. I. S. 1-60.

4) Heber bie Soberflähe ber Semebe. Bot. 3eit. 1850. S. 409 ff. 441 ff.

5) Die Exantbeme ber \$flanzen. Wien 1833. 8. - (Erunbzüge ber

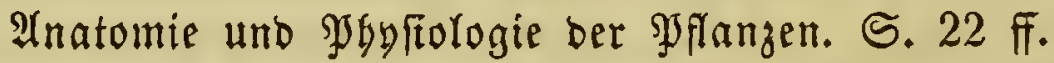

-) Broundzüge ber wiffenfdaftliden Botanif. I. S. 270-284.

7) SYgufiologifde Botanif. S. 223-236.

8) Heber bie Spaltöffnungen auf ben Şättern ber Yroteaceen (1833). Sn Deffen vermifden Squriften. Tübingen 1845. 4. -

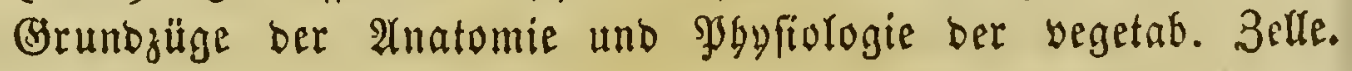
S. 37.

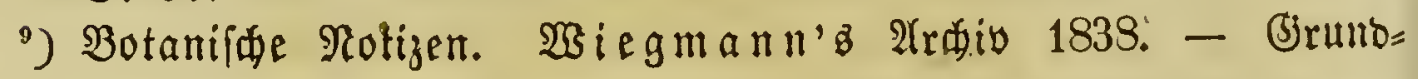
züge $2 x$.

$\left.{ }^{10}\right) \mathfrak{U}$ eber bie Spaltöffnungen. Linnaea, 1842. S. 237 ff.

$\left.{ }^{11}\right)$ Ricerche sulla struttura degli stomi. Napoli 1842. 4. 1 tab. - Nuovo ricerche sulla struttura dei cistomi. Ibid. 1844. 4. 2 tab. -

$\left.{ }^{12}\right)$ Itnterfudjungen über die Entwifflung bes Rorfes uno ber Borfe auf ber Minbe ber baumartigen Dicotylen. Tübingen 1830. 4.

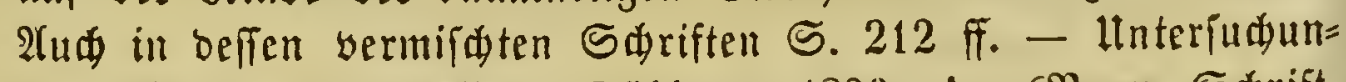
gen über bie Rentigellen. Täbingen 1836. 4. (B̧erm. Sabrift. S. 233 ff.)

13) S(muaten Der SGyemie 1843. S. 286. 


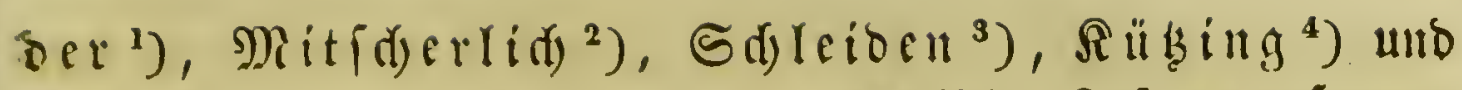

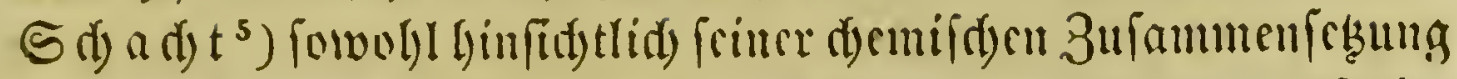
wois ber 2lit uno siscife feincr (5ntfechung forgfaner unterfudyt.

Unter ben jufanmenengefezten Drganen ift bie Saurzel un=

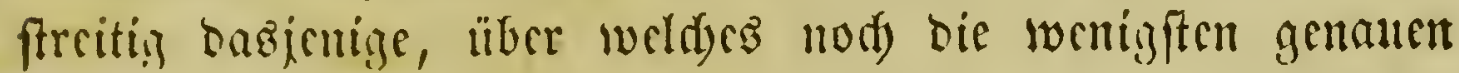
Radyforidyungen befaunt gemad)t worben futo. (5:B fdrie=

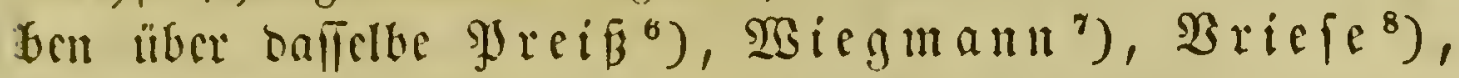
Miad and ${ }^{9}$ ), Moly $\mathfrak{l}^{10}$ ), Decaisue ${ }^{11}$ ), Moretti ${ }^{12}$ ),

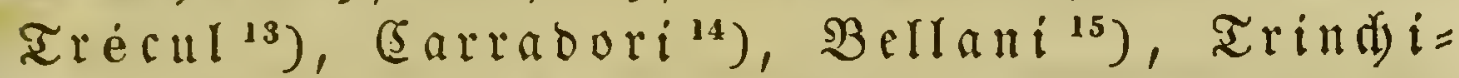
netti ${ }^{16}$ ), Martiug ${ }^{17}$ ) uno 50 ffmann ${ }^{18}$ ); wnter ben

1) Thy fiologirase (Shemie. S. 507.

2) Monatzberiøt ber Berliner Afabemie vom 18. Mai 1850.

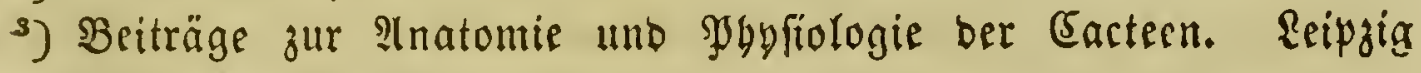
1842. 4. 10 Iafeln.

4) (๖runbzüge. II. S. 247 ff.

5) ŞGyfiolog. Botanif. S. $237-245$. - Heber baż velamen radi-

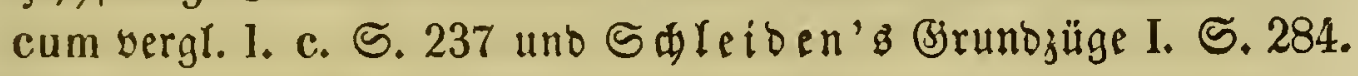

-) Mgizograpgie. MJrag 1823. 8.

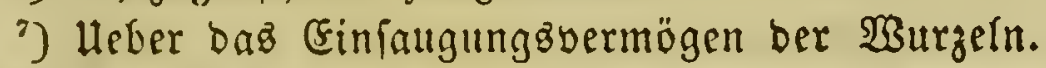

3) Quid hactenus ex plantar. physiologia de forma, directione, structura et functione radicum innotuerit? Groningae 18:29. 4.

$\left.{ }^{9}\right)$ De radicibus et vasis plantarum. Htredt 1830. 8.

$\left.{ }^{10}\right)$ De structura palmarum. Mündfen 1831. Fol. 16 Tafern. 2u山 in beffen vermiditen Sariften S. $129-185$.

${ }^{21)}$ Recherches anatomiques et physiologiques sur la garance. Bruxelles 1837. 4. - Sur l'organisation anatomique de la betterave à sucre. Paris 1839.8 .

$\left.{ }^{22}\right)$ De radicis vegetabilium officiis. Ticini 1837. 8.

$\left.{ }^{13}\right)$ Recherches sur l'origine des racines adventifs. Annal. des sc. nat. 1846.

$\left.{ }^{14}\right)$ Degli organi assorbenti delle radici. Tirenze s. a. 8.

$\left.{ }^{15}\right)$ Sulle funzione delle radici. Ililano 1813. 8.

16) Sulla facolta assorbente delle radici. Mil. 18't3. 4.

$\left.{ }^{17}\right)$ Ilistoria nat. palmar. Vol. III. Monachii 1850. 2(ud in bot. 3eit. 1852. S. 192.

18) Heber bie $\mathfrak{B} u r z e l n$ ber Dolbengetwädúe. Sn Flora 1849 Ro. 2, 46;

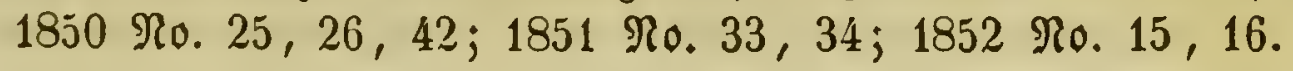




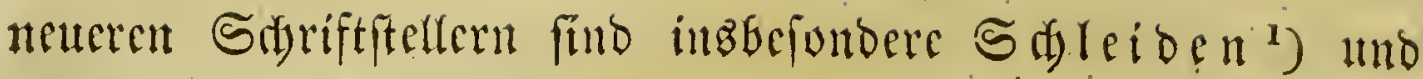
S (d) $\pi$ da $t^{2}$ ) berworzubebent.

Heber bie Structur bes Stammes eridjen in biefern Zeit=

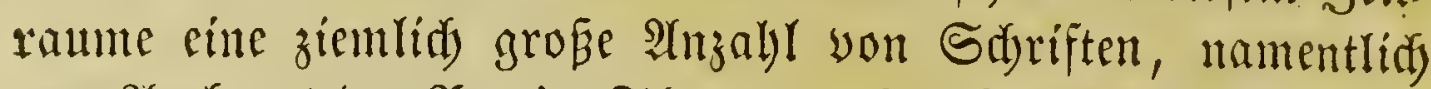
won $\mathfrak{A}$ bert bu Shetit= Thouara ${ }^{3}$ ), sestiboubois ${ }^{4}$ ),

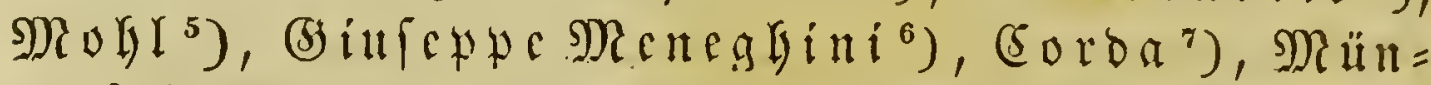
ter ${ }^{8}$ ), Meyer ${ }^{9}$ ), (fjöpert ${ }^{10}$ ), Roifeleur ${ }^{11}$ ), Mi=

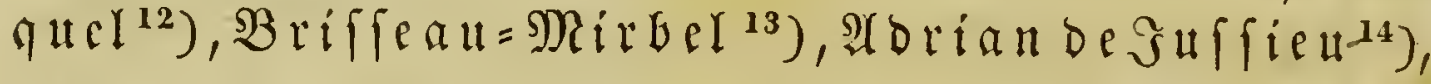

1) Borunbzüge ber wiffenidaftl. Botanif. II. 3. 2tufl. S. 123 开.

2) Soyviologifabe Botanif. S: 288 fr. 322 fi.

$\left.{ }^{3}\right)$ Sur la formation des arbres. Paris 1823. 8.

t) Mémoire sur la structure des monocotylédonés. Lille 1823. 8. - Etudes sur l'anatomie et la physiologie des végétaux. Paris 1840. 8. $21 \mathfrak{I a f e l n}$.

5) Heber sen Bau bez Sycrabenitammez (arbhandungg. ber f. bair.

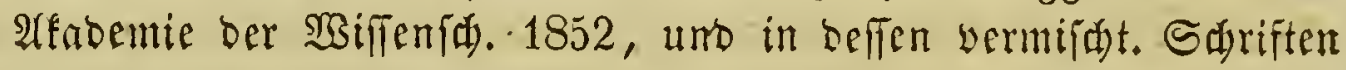
S. 195 ff.) - De palmar. structura (fiefle oben). - Hnter= futfungen über ben Mitterffod von Tamus Elephantipes. Tï= bingen 1836. 4. (Ŝn beffen vermifden Sdriften S. 186 ff.) -

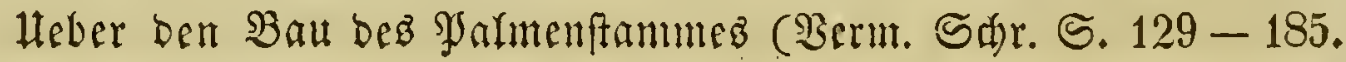

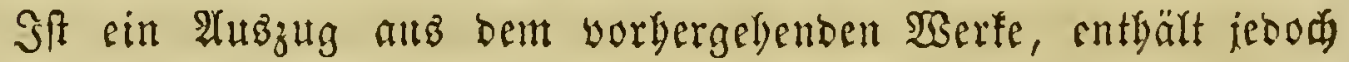

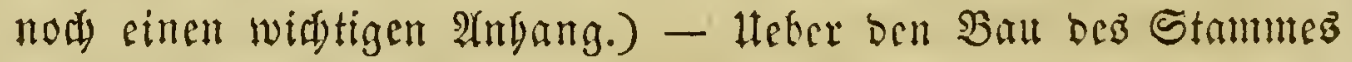
yon Isoetes lacustris (3erm. Sduriften S. 122-128).

$\left.{ }^{6}\right)$ Ricerche sulla struttura del caule nelle piante monocotyledoni. Padova 1836. 4. 10 tab.

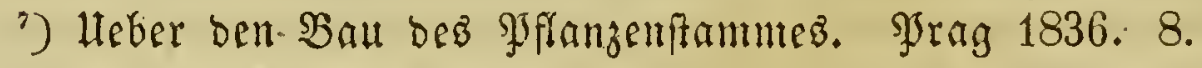

$\left.{ }^{8}\right)$ Observationes phyto-physiologice. Berolini 1841. 8 .

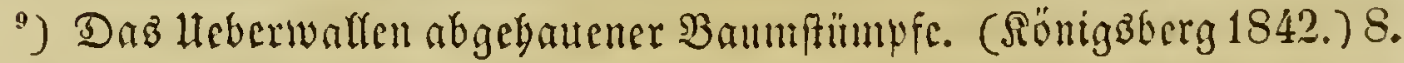

$\left.{ }^{10}\right)$ De coniferarum structura anatomica. Vratislaviae 18\%. 4. 2 tab. - Heber ben $\mathfrak{B a n}$ ber $\mathfrak{B}$ alanoproren. Nov. Act. Acad. C. L. c. nat. curios. Vol. XVIII. supplem. 1841. - Heber=

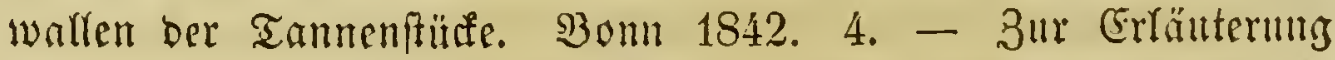

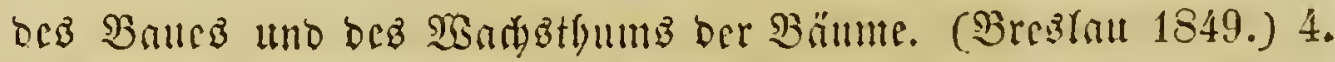

") Reflexions sur la formation du bois. Paris 184.3. 8.

13) Heber Dell $\mathfrak{B a u}$ ber Melocactecn. (Linnaea $9 B$ b. XVI. 1842.)

13) Sur la structure du dattier. (Comptes rendus de l'Acad. des sc. 1813.)

14) Monographie des Malpighiacées. Paris 1813. 4. 23 tab. 
Şartig ${ }^{1}$ ), Şarting ${ }^{2}$ ), Standins), Martiub ${ }^{4}$ ),

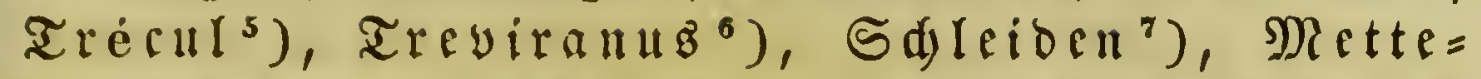

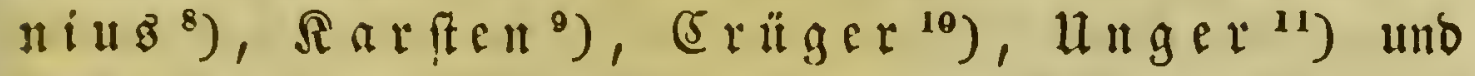

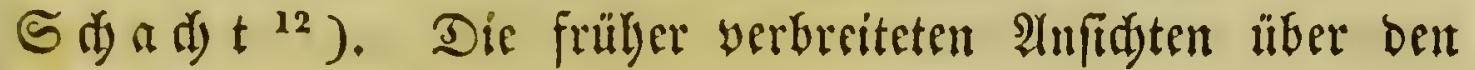

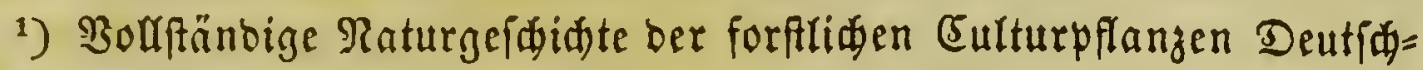
Iands. Berlill 1841-1850. 4.

$\Rightarrow$ Die Entwidflung Der Grementartbeile beả jägrliđen Stauma ber Difotylen. 5aalle 1847,8.

3) Heber ben 3wieberfo von Narcissus Pseudonarcissus. (Annales des scienc. nat. 184\%) Botanique S. $162-176$.

4) Historia nat. palmar. (Siebe oben.)

$\left.{ }^{5}\right)$ Recherches sur la structure et le développement du Naphar. luteum. (Annal, des scienc. nat. 1845.) - Observatt. relatives à l'accroissement en diamètre des végétaux dicotylédonés (Annal. des scienc. nat. Tom. XVII. 1852. No. 5.)

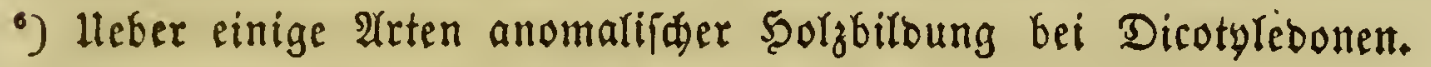
Bot. 3eit. 1847, S. 377 ff., 393 ff.

") (3rundzüge ber wiffenidaftl. Bot. $\mathfrak{B b}$. II. S. 141 ff., 155 ff., 159 ff. - Beiträge zur 2Anatomie ber Eacteen. Reipzig 1842. 4. 10 Iafeln.

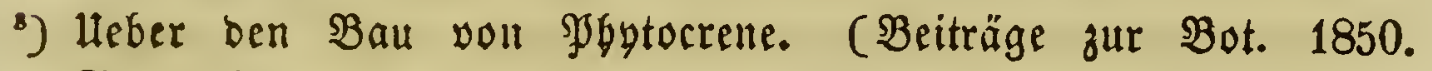
S. 50 fi.)

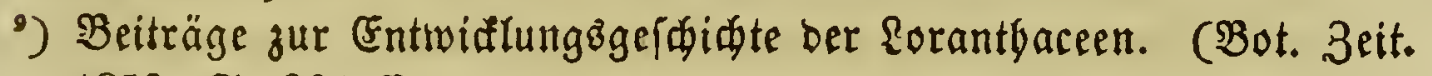
1852. S. 361 ff.)

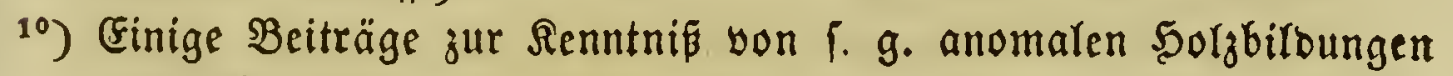
Des Difotylebonenftammes. (BBot. 3eit. 1850. S. 97 ff., 121 ff., 137 ff., 177 ff. 1851. S. 465 ff., 481 ff.)

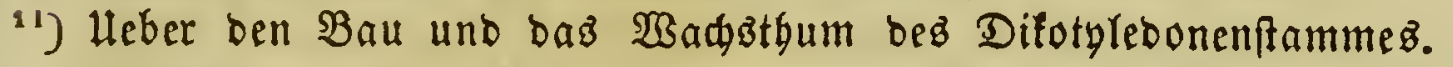
Peterz̧burg 1840. 4. 16 Taf. - Beiträge zur Renntniß ber

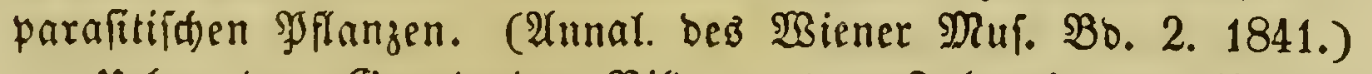
- Heber ben Bruno ber Bildung Der Sagrezlagen. biffotyler Solzpflangen. ('כot. 3eit. 1847. S. 265 ff.)

12) Sogbfiolog. Botanif. S. 180, 202，206，232，252 fi., 265-274, $275-288,318-322,326$ ff. - Der $\mathfrak{B}$ aum. Stubien aus bem SPflanzenteben. Berrin 1853. gr. 8. Mit adt Ritlyogra= phien, worunter vier mit Farbenbruaf, und mit vielen in ben Text eingebrudten 5olzidnitten.

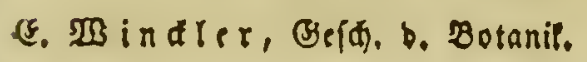


Unteridjed ber Entwidflung bes Mono= unto Difotylebonen= ftammes wurben in ber. neucften 3cit grünblid soiderlegt. Ramentlid ift es $\mathfrak{u} \mathfrak{n g e r}$, bem bie Rebre yon ben 2 xen ber

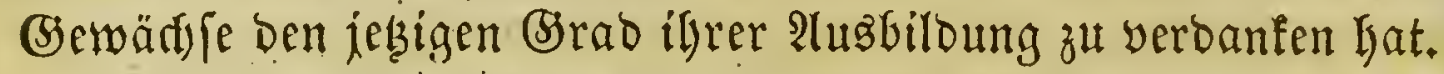

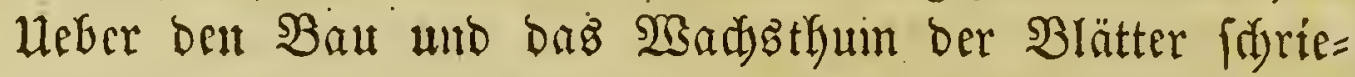

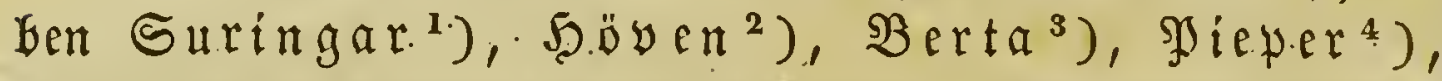

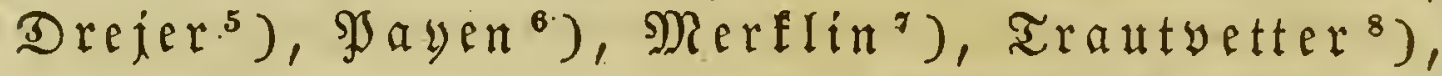

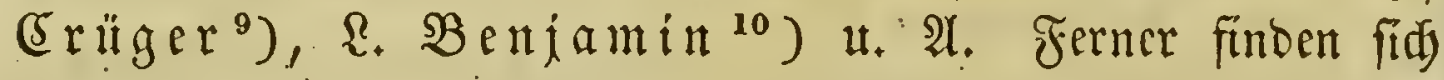
barüber wertigolle. Notizen in ben fdon oft citirten gröferen

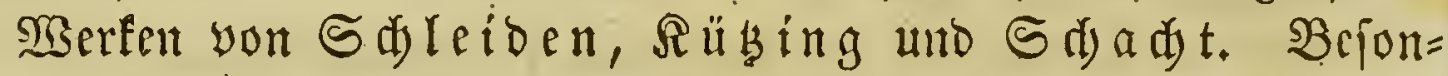
Dere 2lufimerffaunfeit aber. erregte bie Stelling Der Blätter, jiber welde mebrere Theorien aufgeftellt wurben. $\Omega$. $\mathfrak{F}$.

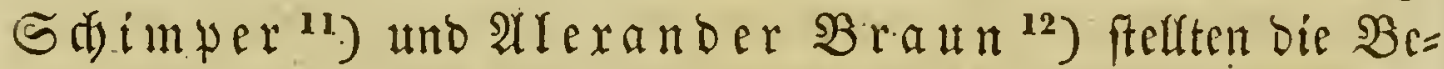

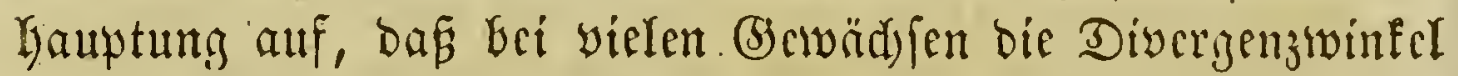

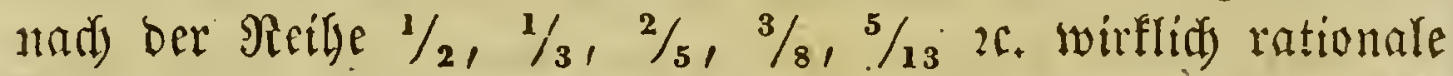
Ifleile beş Stengelumfangs feicn, aljo 180, 120, 144,

') De folior. ortu, situ, fabrica et functione. (Lugd: Batav. 18:20. 4.)

$\left.{ }^{2}\right)$ De folior plantar ortu, situ etc. Ibid. 1826. 4.

$\left.{ }^{3}\right)$ Iconographia di scheletri di diverse foglie. Parma 1828. 4. - Memoria sull anatomia della foglie delle piante. Ibid. 1829. 4. - Iconographia del sistema vascolare delle foglie. Ibid. 1830. 4.

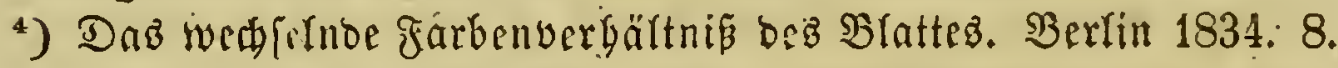

$\left.{ }^{5}\right)$ Elementa phyllologiae. Hafn. 1840. 8.

$\left.{ }^{\circ}\right)$ Essai sur la nervation des feuilles dans les plantes dicotylées. Paris 18\%0. 4.

7) 3ur Entwieflungşgei

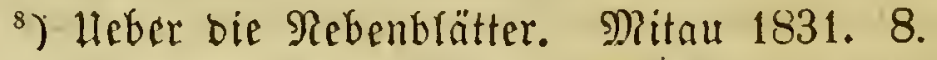

9) ?(re und Blatt. (- (9Bot: 3cit. 1851. S. 497 fi.)

10) 3ur SOg gtogenefiz. SBot. 3rit. 1851. S. 871 ff., 989 ff.

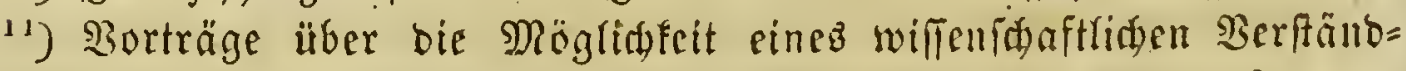
niffez ocr Brattfeflung. (Elora 1835. Mro. 10, 11 u. 12.)

$\left.{ }^{12}\right)$ Sergleidende unterịudungen über bie Sronung ber Eduppent an ben Tannemapfen. (Nov. Act. Acad. C. Li C. Nat, Cur. Tom. XV. Vol. I. S. $195-402$. 
135 2c. (5ratoe entyalten. Daraus reiteten fie confequent ben

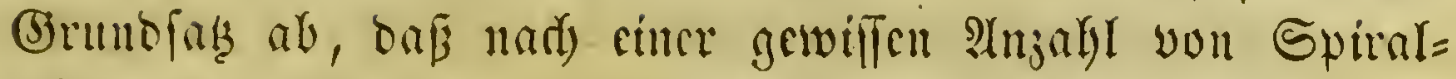

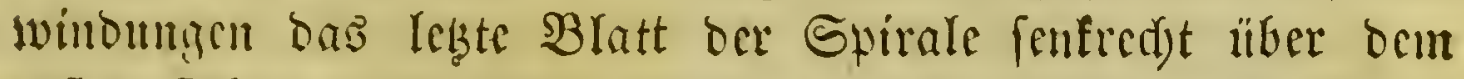

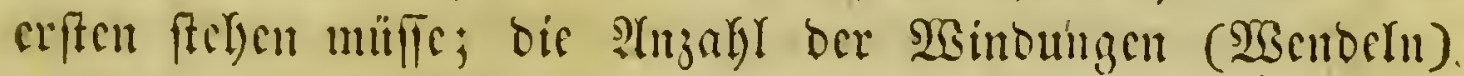

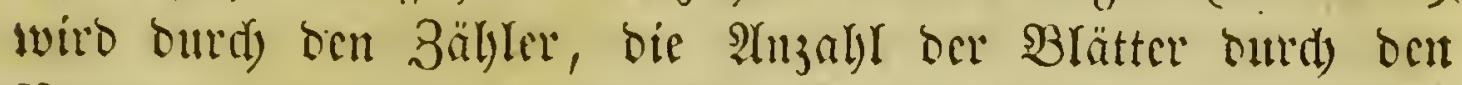

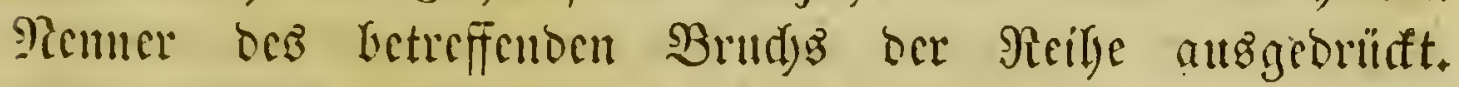

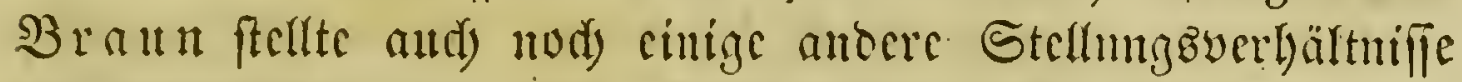

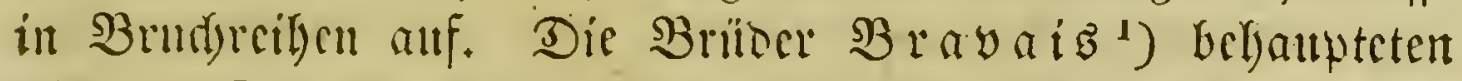
aber, baß́

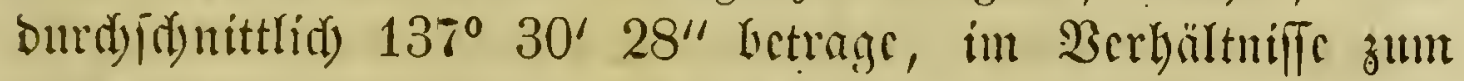
Stangelumfange cine irrationale $3 a b l$ fei, fo táp arfo nie

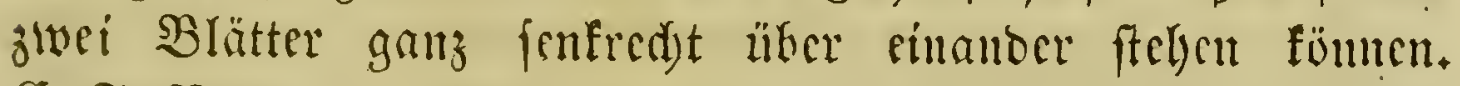

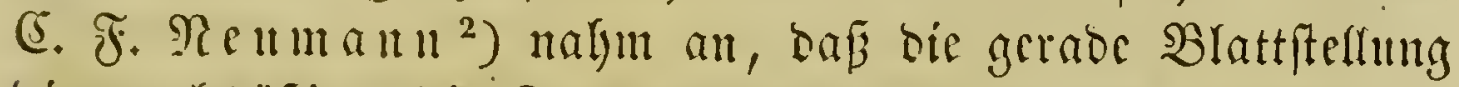

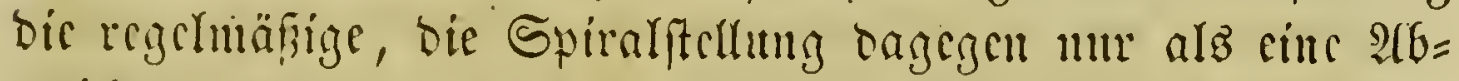

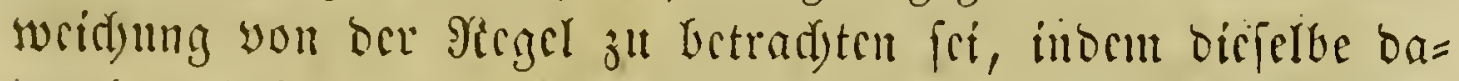

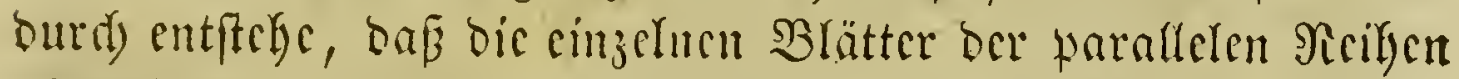

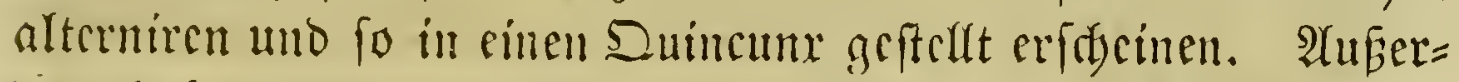

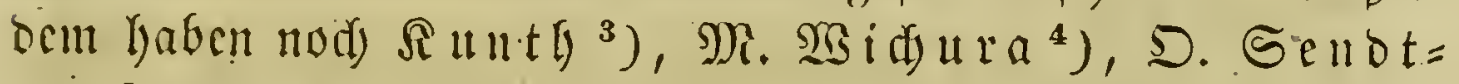

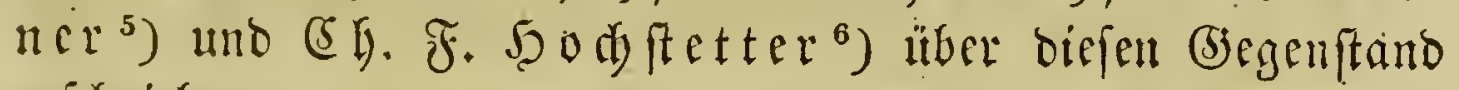
geidjrieben.

1) L. F. et A, Bravais, Mémoires sur la disposition géométrique des feuilles et des inflorescences, précédés d'un résumé des travaux de MM. Schimper et Braun sur le même sujet. Paris 1838, 8. 7 tab. - Dêt tha: Breşlau-1839. - Essai sur la disposition générale des feuilles rectisériées. Clermont 1839. 8.

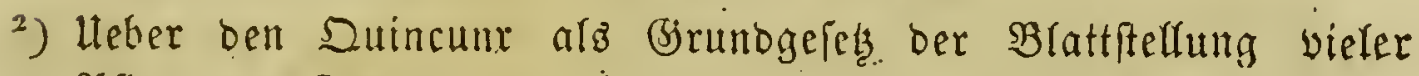
Bflanzen. Drešben uno Seipzig 1854. 8. 1 Taf.

$\left.{ }^{3}\right)$ Heber Blattifellung ber Difotyleoonen. Berrin 1843. 8.

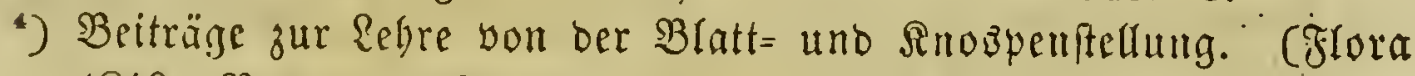
1840. Rro. 15, 16.)

5) Sritida Bergleidung ber Regren über sie Brattfferfung von S d im =

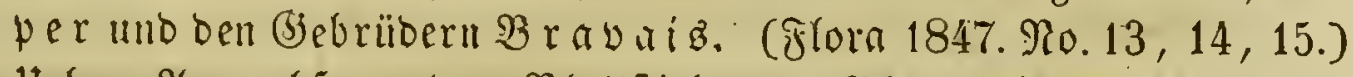

?) Heter 2(nwadflung ber Battfficle uno Brattidfeiden, 2(efte unb

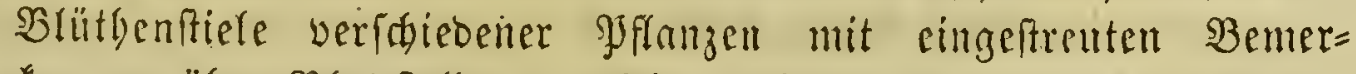

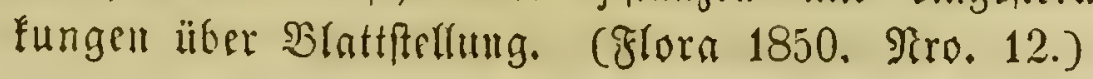


Die Regre von ben eigentlitfen Rnospen, ben Brutfnob= yen, 3wicbeln und Rnollen wurbe von be $\mathfrak{I r}^{2} \mathfrak{f t a n}^{1}$ ), $\mathbb{F}_{+}$

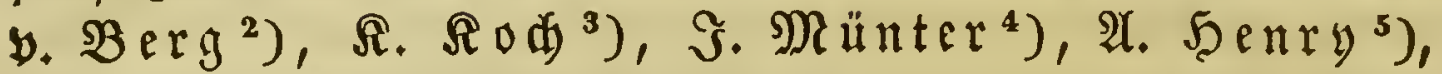

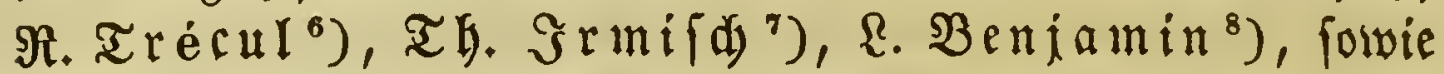
burd) bie fijon oft citirten auşführlidjeren Saerfe von Sdileiben, Sdad t und $\mathfrak{R}$ übing weiter geförbert.

Ueber bie einzelnen Iheile ber $\mathfrak{B l u ̈ t h e}$ lieferte biefe \$geriobe sine reidhaltige Riteratur, bie wir Gier nid)t volfftänoig an= fübren fönnen. Bon Widgtigfeit für die Renntnís bicfer $\mathfrak{D r}=$ gane waren bie unten yerzeiffneten Sdriften von $\mathfrak{M}$ urray ${ }^{9}$ ), $\mathfrak{D} \mathfrak{B} \mathfrak{y} \mathfrak{a} \mathfrak{x}^{10}$ ), $\mathfrak{B} \mathfrak{v} \mathfrak{e} \mathfrak{a} \mathfrak{u}^{11}$ ), Svyer = $\mathfrak{B}$ illemet ${ }^{12}$ ), $\mathfrak{D} \mathfrak{u}=$

1) Histoire des développements de quelques genres bulbifères et principalement de celles de Colchique. (Mém. de Mus. d'hist. nat. Tom. X. 1823. No. 36-56.)

$\left.{ }^{2}\right)$ Die Biologie ber 3wiebelgewä口) if. Renfrelit u. Reubran= Denburg 1837. 8.

3) Einige 230 rte über Rilienpflangen und 3wiebelbilbung. (Linnaea XXII. S. 213 fi.)

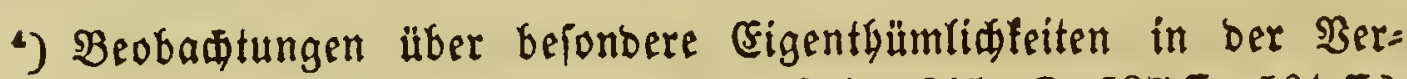
mebrungatweife ber Rnozpen. (Bot. 3eit. 1845. S. 537 ff., 561 ff.)

s) Beiträge zur Renntni L. C. Nat. Cur. Tom. XVIII. S. 1 f.,, Tom. XIX. S. 1 f.)

-) Recherches sur l'origine des bourgeons adventifs. (Annal. des scienc. nat. 1847.)

7) 3ur Morphologie ber monofotylifiden Rnollen = und 3wiebelges wäđje. Berlin 18j0. 8. 10 Taf.

8) Heber intrapetiolare Snozpenbildung. (Boot. 3eit. 1852, S. 201 fi., 217 fi.)

9) Experimental researches on the painted corolla of the flower. London 1824. 8.

10) Recherches sur les appareils sécrétoires du nectar. Paris 1826. 8.

11) Observatt. sur les enveloppes florales des végétaux monocotylédons. Paris 1827. 8.

12) Mémoire sur le nectaire. Paris 1826. 8. 


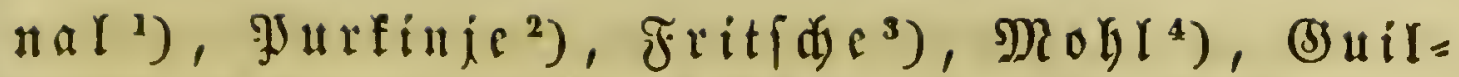

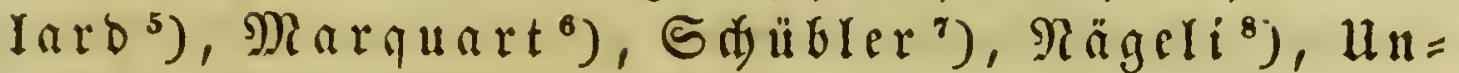

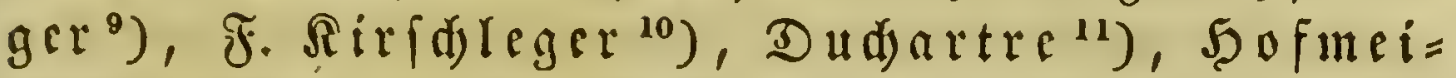

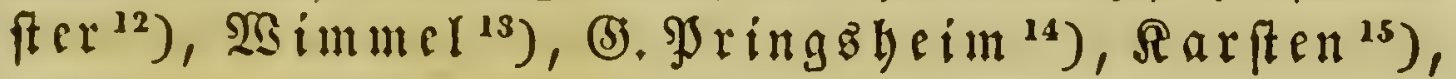

1) Considération sur les organes floraux glanduleux. Montpell. 1829. 4.

2) De cellulis antherarum fibrosis necnon de granorum pollinarium formis. Vratislaviae 1830. 4.

$\left.{ }^{3}\right)$ Beiträge zur Renntríß bez Pollen. 1. Seft. Berlin 1832. 4. 2 Iaf. - De plantar. polline. Berolini 1833. 8. - Heber ben Godren. Weterzburg 1837. 4. 13 Tafeln.

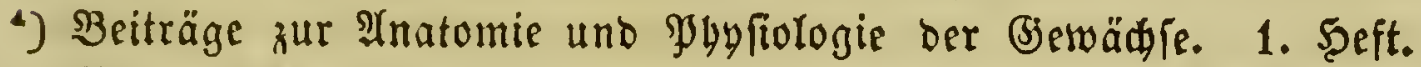
Bern 1834. 4. $6 \mathfrak{T a f e l n}$. - Heber bie fibrofen 3ellen ber $\mathfrak{A} n=$ theren. (B̧erm. Sadriften, II. S. $62-66$.) - Heber bie männ= liden $\mathfrak{B l u ̈ t b e n ~ b e r ~ ( 5 o n i f e r e n . ~ T u ̈ b i n g e n ~ 1 8 3 7 . ~} 8$.

$\left.{ }^{5}\right)$ Sur la formation et le développement des organes floraux. Paris 1835. 4.

-) Die Farben ber-Blütgen. Bonn 1835. 8.

") Hnterfu币ung über bie Bebeutung ber Rectarien. Stuttgart 1832.

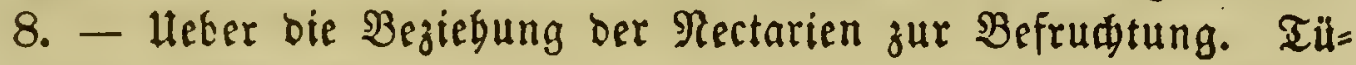
bingen 1833. 8.

8) 3ur Entwifelungżgef 3ürid 1841. 8. 3 I $\mathfrak{x}$ afeln.

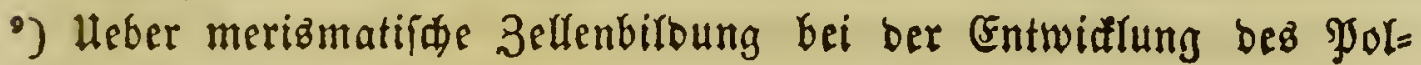
Ienz. s. 1. 1844. 4.

$\left.{ }^{10}\right)$ Essai sur les folioles carpiques ou carpidies dans les plantes angiospermes. Strasbourg 1846. 8.

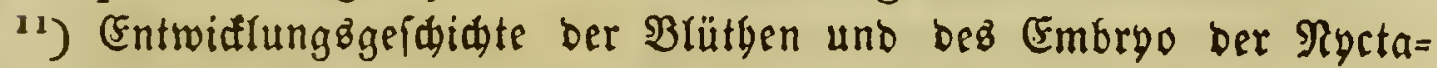
gineen. (Annal. des sc. nat. 1848. Mai.)

12) Heber bie Entwiaflung des Mollens. (Bot. 3eit. 1848. S. 425 ff., 649 f., 670 fi.) - 3ur (Entridtlungageididte ber 3oftera. (Ibid. 1852. S. 121 fi., 137 ff.)

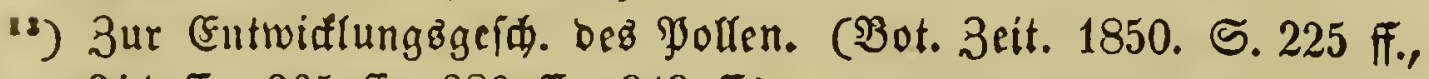
241 f., 265 ff., 280 f., 313 ff.)

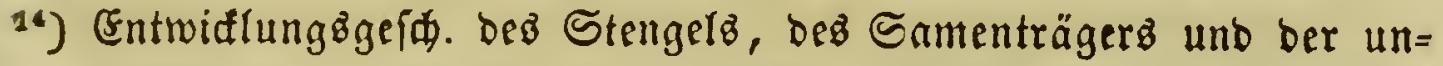
befru币teten Samenfnozpen von Mercurialis annua. (Bot. Zeit. 18j1. S. 97 ff., 113 ff.)

18) Beiträge zur (Entmiaflunge̊gei d. Der Rorantbaceen. (Bot. Beit. 1852. S. 305 ff., 321 ff., 337 ff., 361 ff.) 


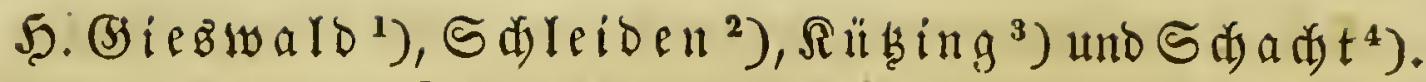
Bon Den Sexualfunctionen wirb weiter unten nody gerebet werben. 2luty die Regre von bem SBlüthenitande fano eine febr augfübrlidie Erörterung. Die erfte miffenfdaftlitie (Fin= theilung deffelben wurbe von $\Re$ öper ${ }^{5}$ ) verịtut. Die vbent erwähnten $\mathfrak{B e g r i n d e r ~ b e r ~ R e f r e ~ v o n ~ d e r ~ B l a t t f t e l l u n g ~ - ~}$

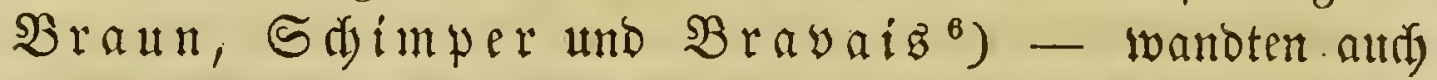
auf ben Blütyenftand ifre Theorien an, uno vbgleid fie aud hier, wie bort, in ber Alufferflung mathematifit genauter Regeln mandsmal zut weit gingen, baben fie bod viel zur 2lufflärung

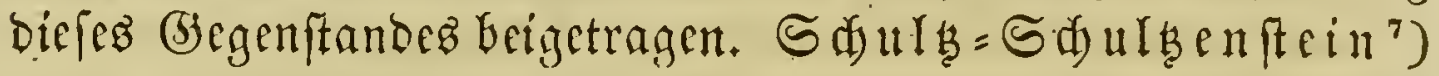

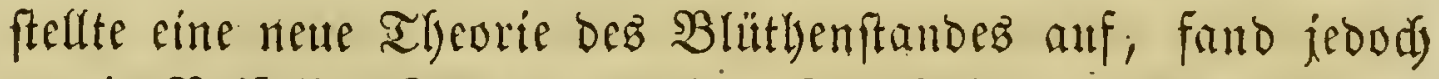

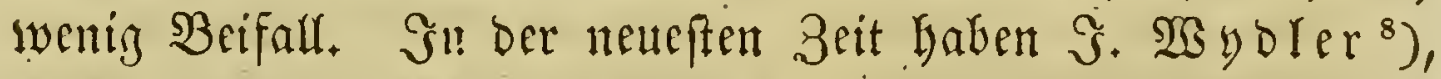

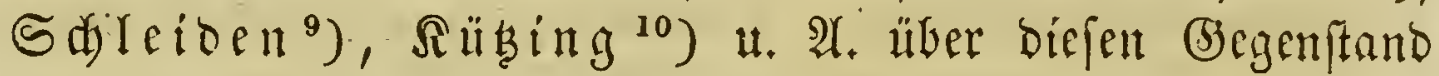
forgfältige lunterfuddungen angeftellt.

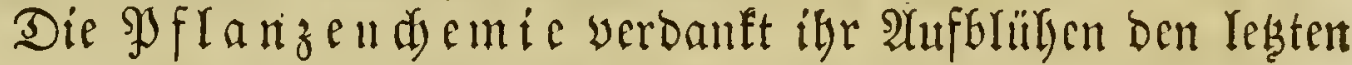

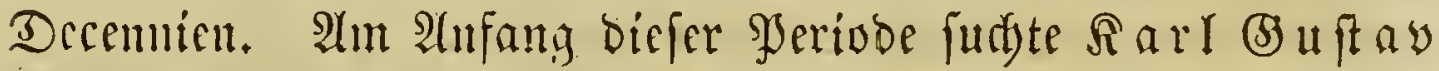
$\mathfrak{B}$ ifd off ${ }^{11}$ ), Şrofeffor zu Şon, unter Mitwirfung yon

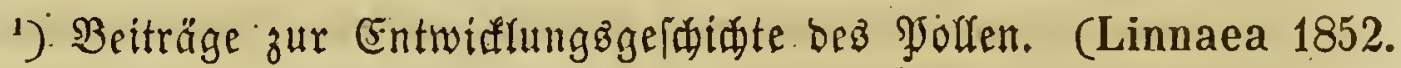
S. $81-157$.

2) Şrunozüge 2c. II. S. $239-355$.

3 ) (3) rundoüige zc. S. $188-214$.

4) WGyfiologifde $B$ otanif. S. 53 ff., 132 ff., 309 ff.

5) Observalt. sur la nature des fleurs et des inflorescences. (Seringe, Mélanges bot. Vol. II. Genève 1826. 8.)

6) S. 466 , Rote 11 u. 12, uno S. 467 , Rote 1.

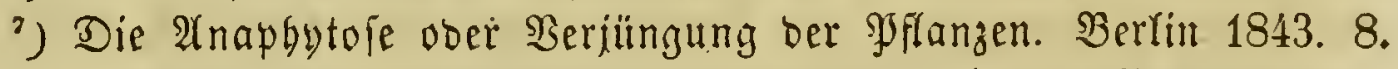
- 3ur natürr: Sygtematif und . Terminologie ber Bhütyenftände. (Flora 1840, Rro. 39.) - Reues Syftem ber Morplologie der Yflanzen. Şertin 1847. 8.

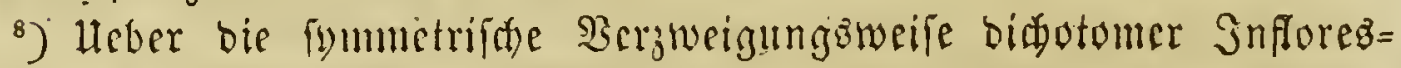
cenzrn. (Frora 1851, Rro. $19-28$.

9) (3rrmibzüge 2c. II. S. 225-239.

$\left.{ }^{10}\right)$ (3rumbjüge 2c. II. S. $171-188$.

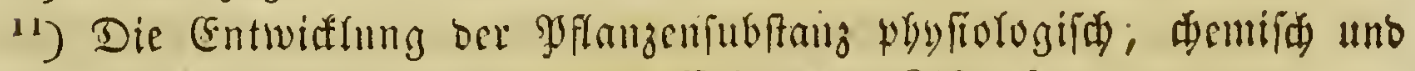

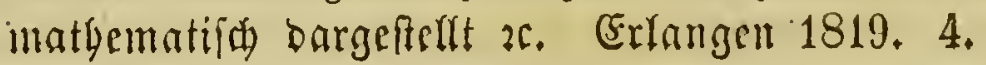




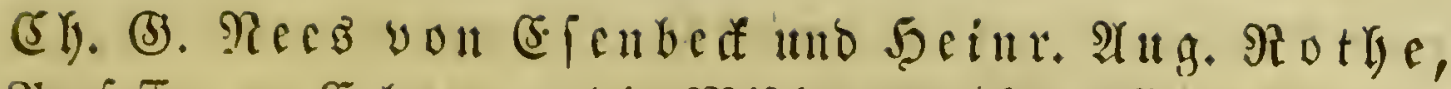

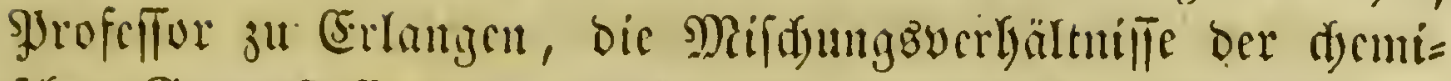

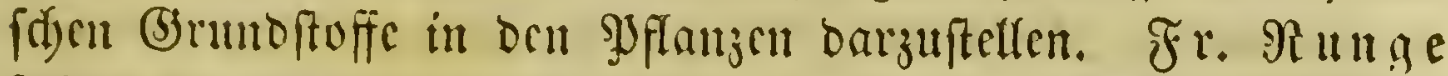

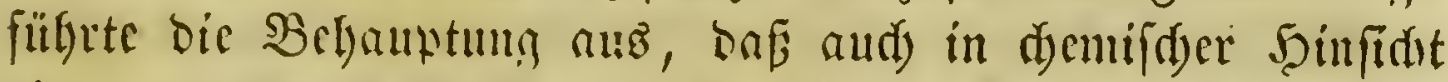

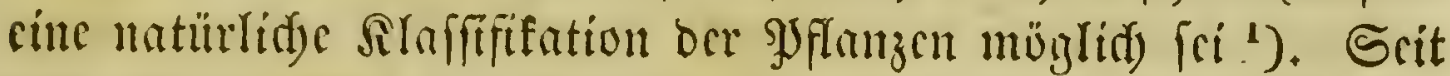
ben jwanziger Gnlyen erlangten bie d)entifden Unterfudyungen ber (5)

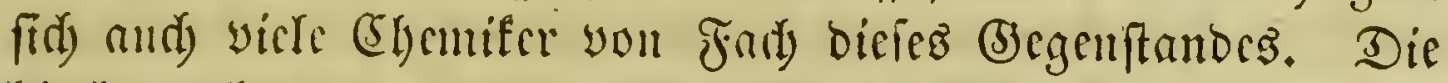

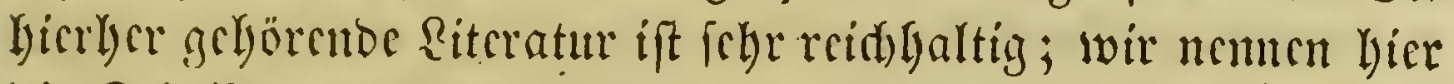
bie Edriften won gean Antoine (Slaubede (Shaptal ${ }^{2}$ ), Safob Berzeliub ${ }^{3}$ ), Guttay. Theobor Feducrat), (3) uftay Soltbler ${ }^{5}$ ), Antoine $\mathbb{R} a$ urent apollinaire

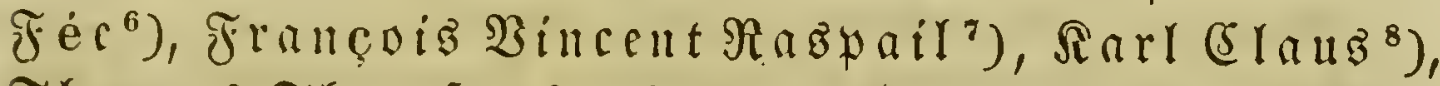

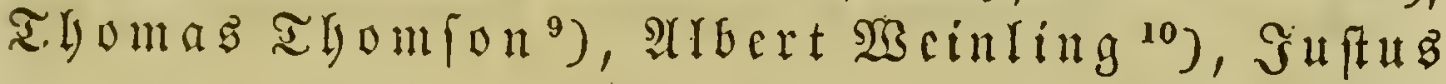

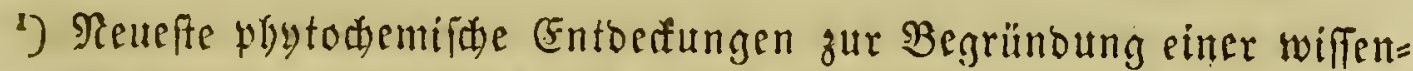

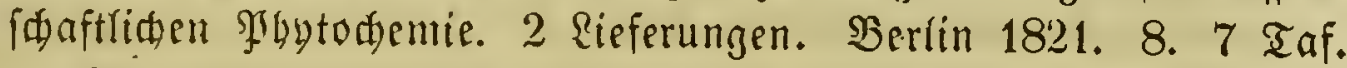
- De pigmento indico ejusque connubiis cum metallorum nonnullis oxydis. Berolini 1822. 8. - Refultate demifider Itnterfuchungen ber Şnareen, "Eupatorinen, Rabiaten, (Eid)oreen, Aggregaten, $\mathfrak{B}$ alerianeen und Eaprifolien in 2 uffindung und $\mathfrak{R a d}=$ weifung einez biefen: $\mathfrak{B}$ flanjenfamilien eigentgümliden Stoffez. Breảłau 1828. 4.

$\left.{ }^{2}\right)$ Chimie appliquée à lagriculture. Paris 1822.8. - Ed. II. ibid. 1829. 8.

3) Lärbok i Kemien. Stockholm 1826-1828. 8.

4) Sicjultate ber biz jeģt unternommenen Sj flanzenanalyjen. Reipzig 1829. 8.

5) Błrundiäbęe ber $\mathfrak{A} g r i f$ utturdemtie. Reipzig 1831. 8. Ibid. 1838. 8.

-) Examen de la théorie des rapports botano-chimiques. Strasb. 1833. 4 .

') Nouveau sy'stème de chimie organique. Paris 1833. 8.

$\left.{ }^{8}\right)$ Brunbjüge ter anafytifaen 95 ghtodemie. Dorpat 1837. 8.

- Chemistry of organic bodies. Vegetables. London 1838. 8.

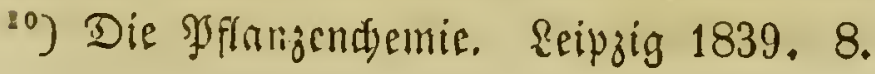




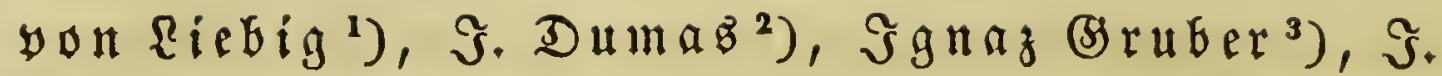

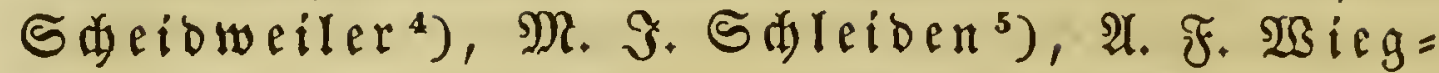

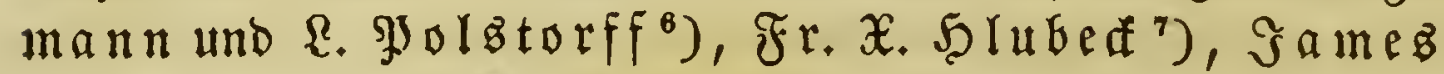

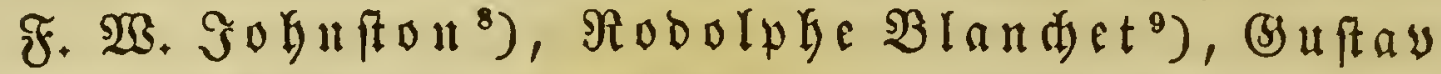
(5)

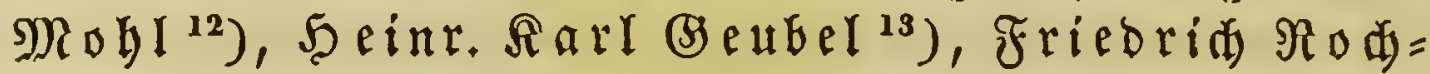

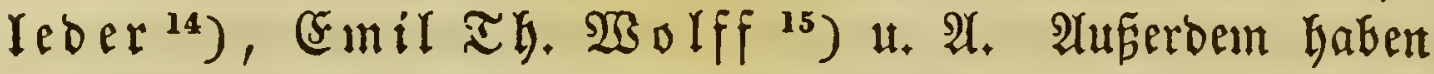
viele zur Riteratur ber eigentlidsen (Shemie gebörenden $\mathfrak{B}$ erfe,

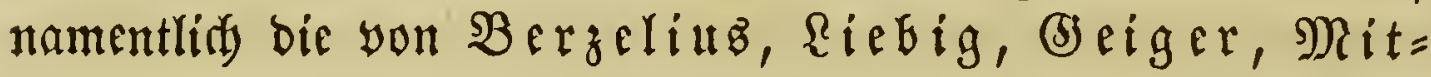

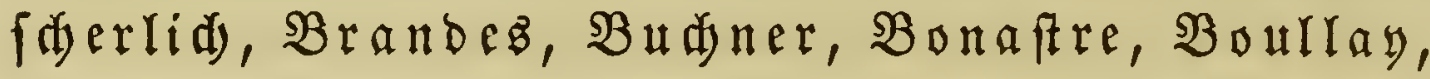

1) Die organif \$gyfiologie. Braunifweig 1840. 8. unto öfter.

2) Leçon sur la statique chimique des êtres organisés. Paris $1841-1842.8$.

3) Heber ben 3uftand ber neueren organifđen (Atgrifututur=) (5gemie. Wien 1841.8.

4) Cours raisonné et pratique d'agriculture et de chimie agricole. Bruxelles 1841-1843. 8.

5) Sffnez Sendidreiben an 3. Riebig. Reipzig 1842. 8. - Serr Suftus Riebig und bie গ̧flanzenphyfiologie. Reipzig 1842. 8.

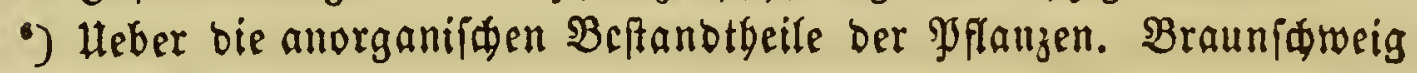
1842. gr. 8.

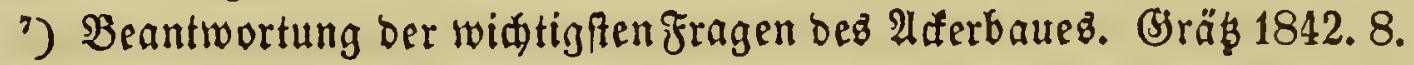

$\left.{ }^{8}\right)$ Lectures on agricultural chemistry. Ediuburgh 1842. 8. - Elements of agricultural chemistry. Edinburgh 1842. 8.

') Influence de l'ammoniaque sur la végétation. Lausanne 184.3. 8.

$\left.{ }^{10}\right)$ De causis naturae chemicae et efficaciae plantarum. Lipsiae 1843. 4.

11) Heber Bitbung und 3ujammeniekung Der organifden Berbins bungen. 3üri西 1843. 4.

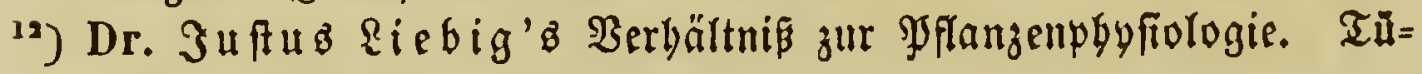
bingen 1843. 8.

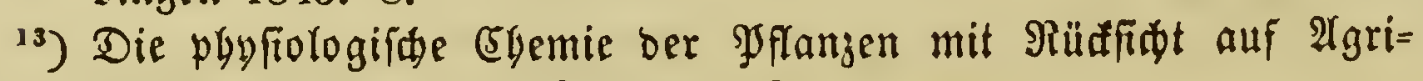
furtur. Franffurt a. $\mathfrak{R} .1845 .8$.

14) Beiträge zur $\mathfrak{3 g y t o d e m i e . ~ W B i e n ~ 1 8 4 7 , ~} 8$.

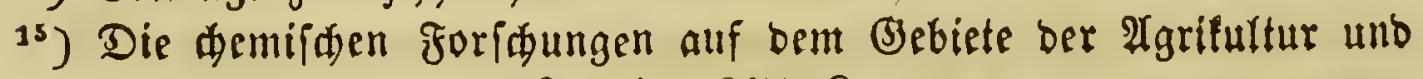
Yjolanzenphyfiologie. Reipzig 1847. 8. 


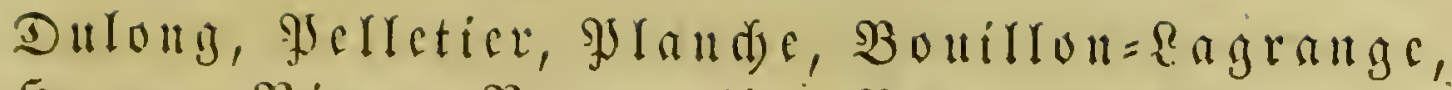
5cury, Birey, Bauqueriu, $\mathfrak{B}$ outrou=

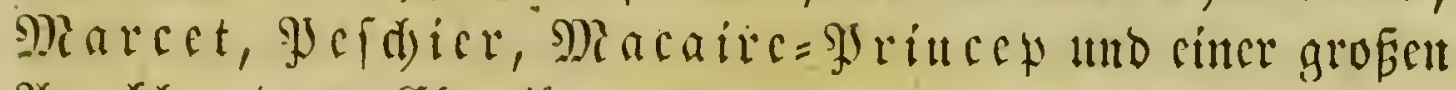

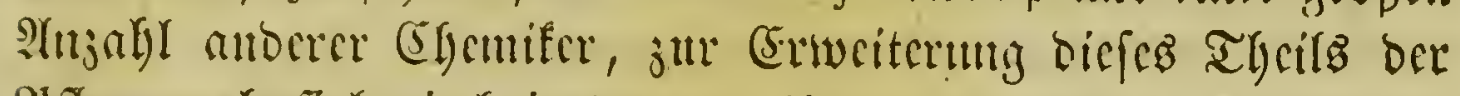

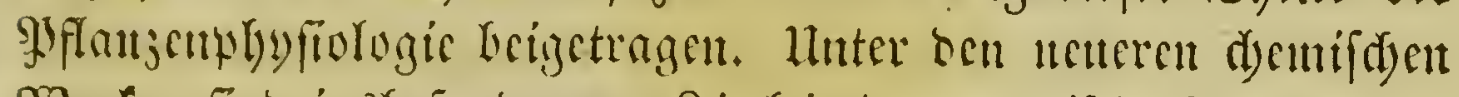

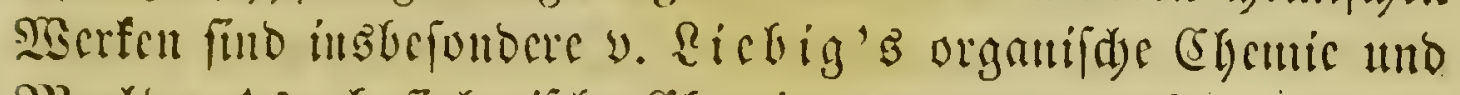

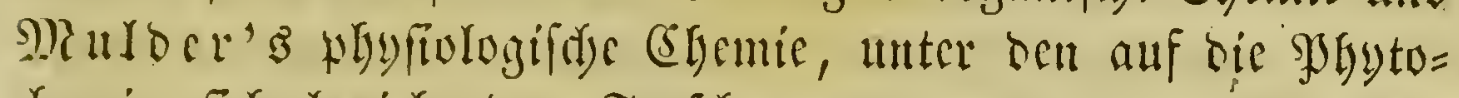

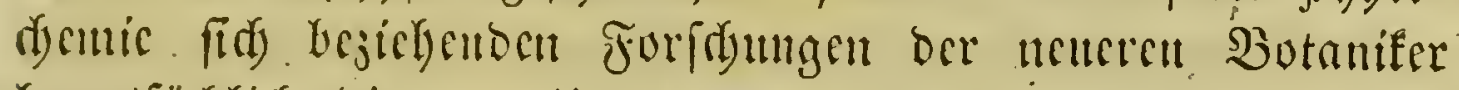

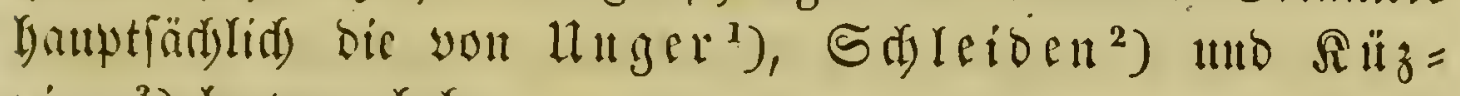
jittg ${ }^{3}$ ) lyerworjulfeben.

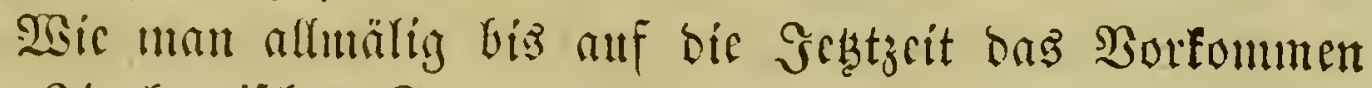

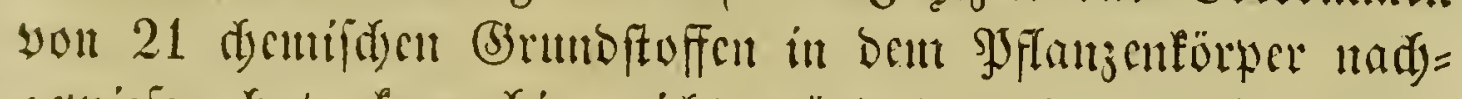

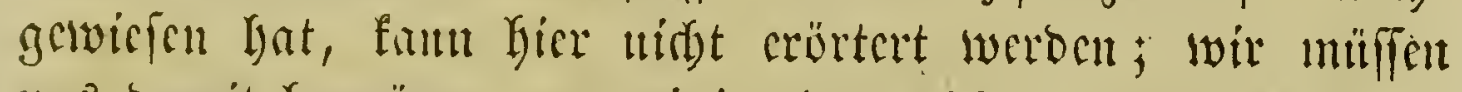

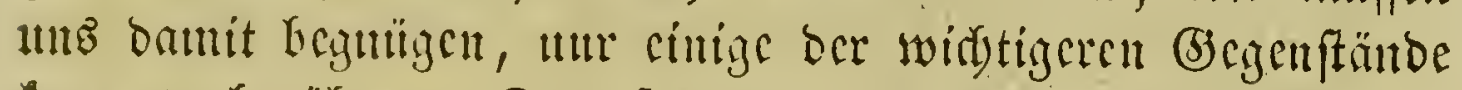

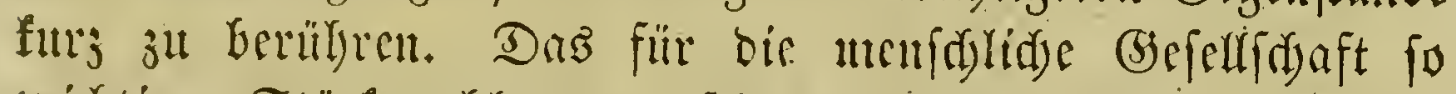

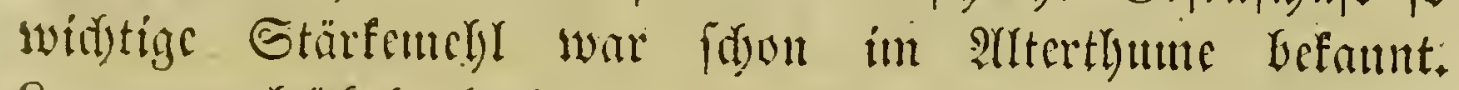

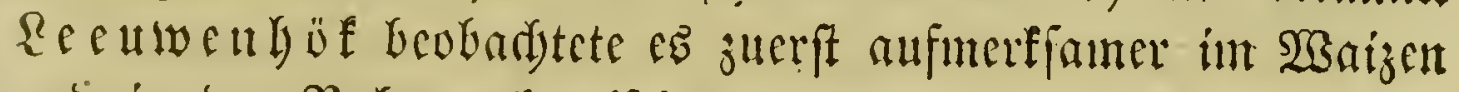

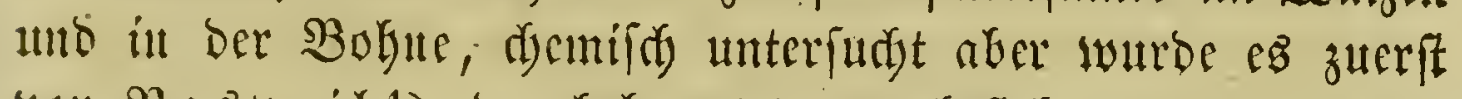

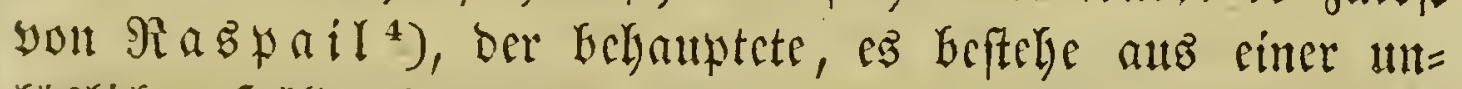

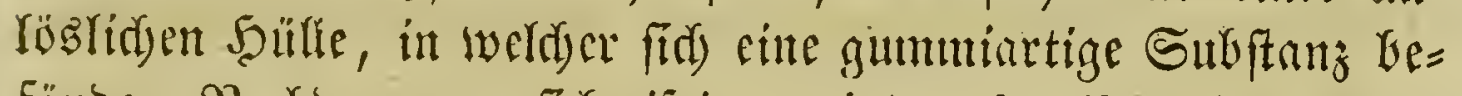

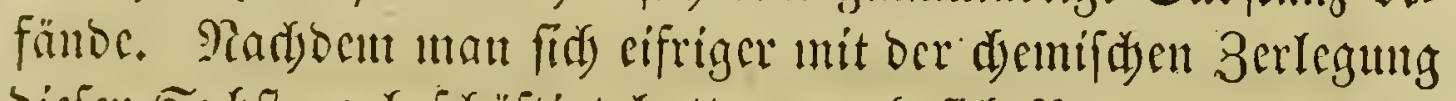

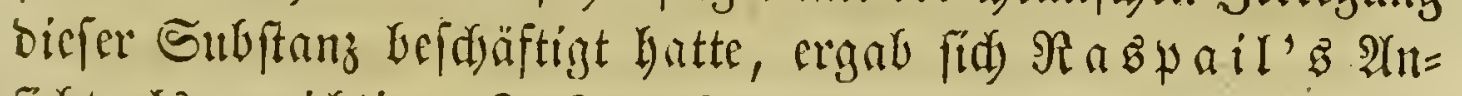

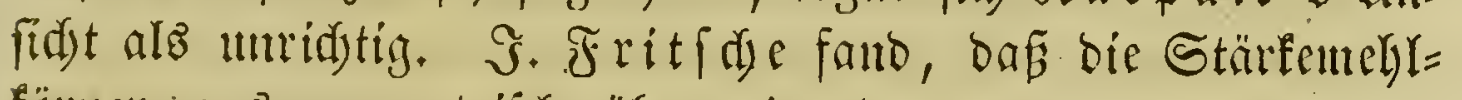

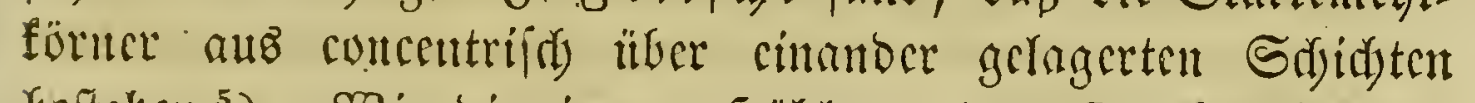

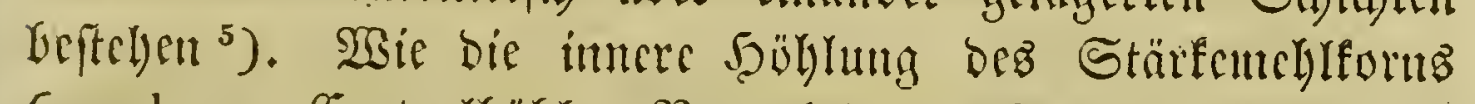
(nucleus, (sentralgüble, Bactule) zu crelärcu fei, ift twod)

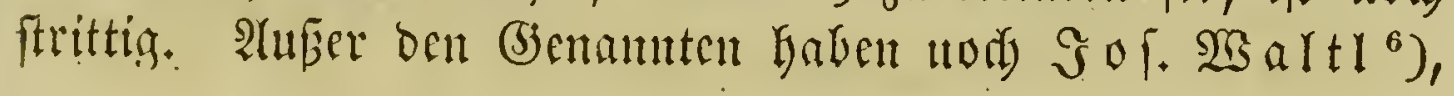

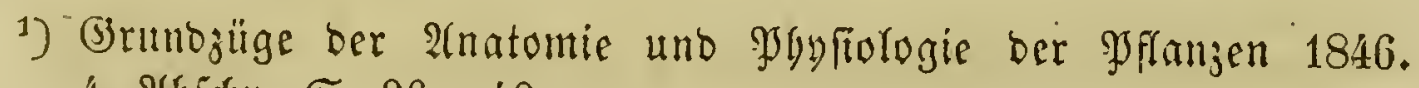
4. 216idn. S. $26-40$.

$\left.{ }^{2}\right)$ Bjrunbzüge ber wifīenidy. Botanif. I. 1849. S. 16j-203.

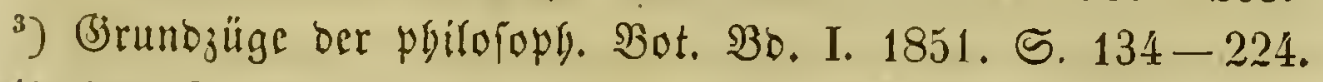

4) Annal. des sc. nat. T. VI. 1825. S. 384 , VII. 1826. S. 325.

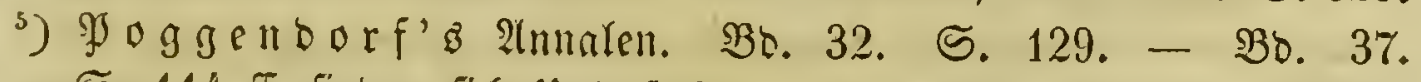
S. 114 fr. finben fid thnterfurfungen you gjoggenoorf ferbft.

6) Då̉ 2(mylon uno Snutiut. Rürnberg 1829. 8. 


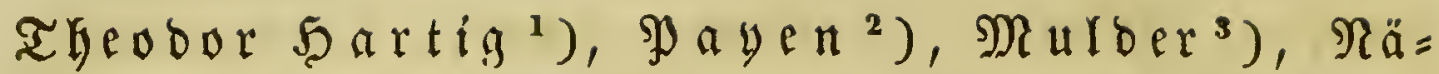

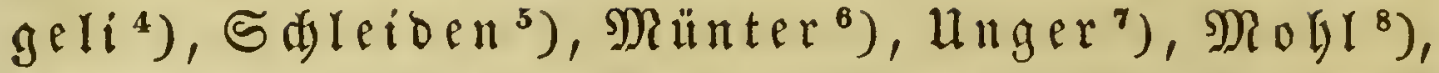

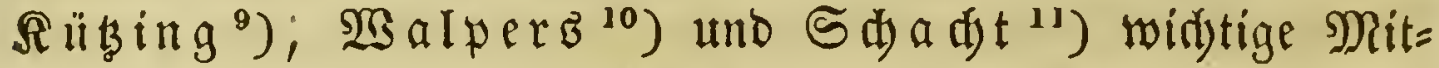
theilungen über bas Stärfemebl gemadt.

Das Ehlorophyll wurbe erft in ber neueren 3eit dhemifa unterjudst. Die eriten aubfülyrliden Forjdungen über calfelbe wurben yon $5, y, \mathfrak{M}$ oh $\mathfrak{l}^{12}$ ) angeftellt. Bann haben $\mathfrak{B} \mathfrak{e r}=$

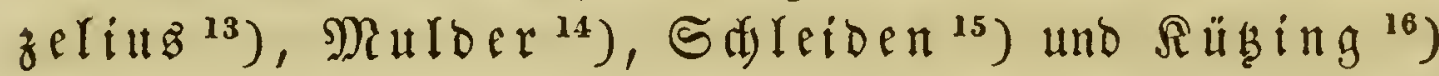
fid) mit ber Unterfurdung biefes Stoffes bejoäftigt. - Heber bie Farben ber SPflanzen itberbaupt uno bie fie bebingen=

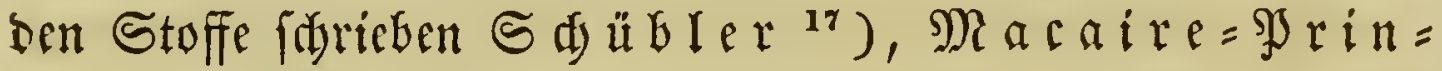

1) (Erbmann's und Shweigger= Seiber'z Sournal. 1835. Nro. 12.

2) Mémoire sur l'Amidon. (Annal. des scienc. nat. X. 1838. VIII. 209.)

3) SHbyfiolog. (SGemie, überf. von Molef由ott. S. 215 ff.

4) Beitfar. für miffenfdaftl. Botan. Seft III. জ. 117.

$\left.{ }^{5}\right)$ Brumbjüge 2f. I. S. $176-190$.

6) Heber bez Almylumt ber gloriosa superba. (B̧ot. 3eit. 1845. S. 193 fi.)

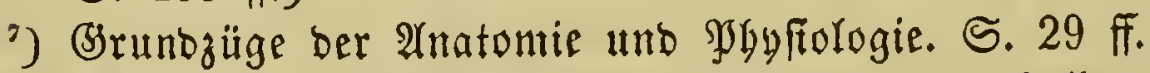

8) Atnatomie uno \$ुgnfiologie Der vegetabilifien 3elle. S. 48 ff.

9) Srunbzüge 2f. I. S. $183-189$; S. $261-266$.

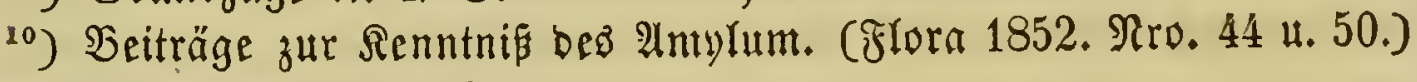

11) SSygfiolog. Sotanif.

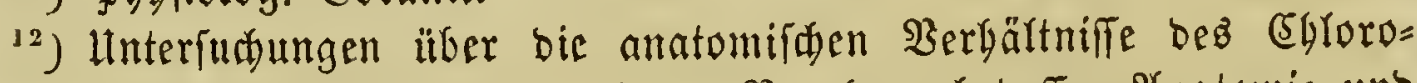
phyllas. Tilbingen 1837. 8. - Bergl. aud befien 2 natomie und Shysfiologie ber negetabitifaen 3elle. S. 45 if.

13) Regrbud Der Gremic ic.

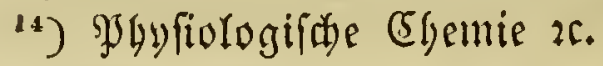

${ }^{15}$ ) Brrunbzüge I. S. 196.

$\left.{ }^{10}\right)$ (j)rundzüge ber pritof. Bot. I. S. 169 fr.

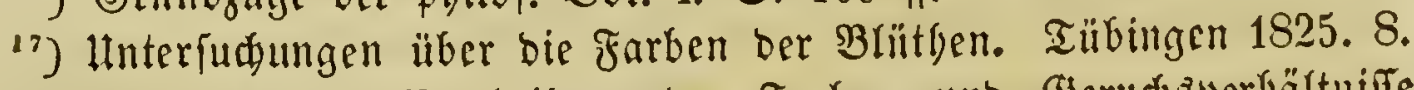
- Heber die Bertyeilung ber Farben uno Berudsuserbältuifife bei ben 2(aperifolien, Srimulaceen 26. Tǘbingen 1831. 8. -

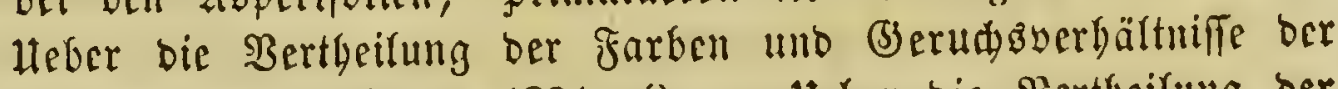
Rubiacen. Tübingen 1831. 8. - Heber bie Sertbeitung ber 


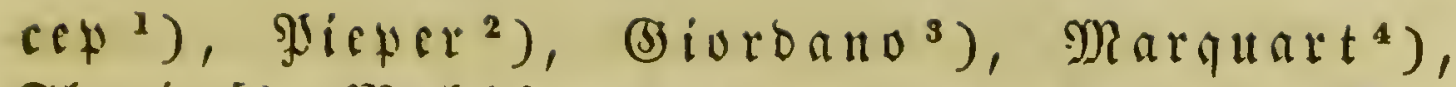

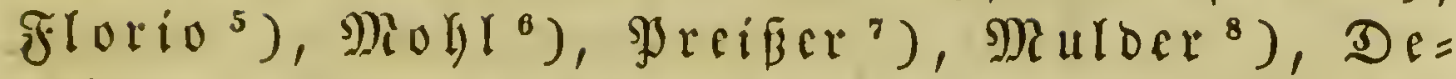
caisne ${ }^{9}$ ), Berzeliub ${ }^{10}$ ), $\mathfrak{R}$ ü̉iug ${ }^{11}$ ) u. $\mathfrak{A}$.

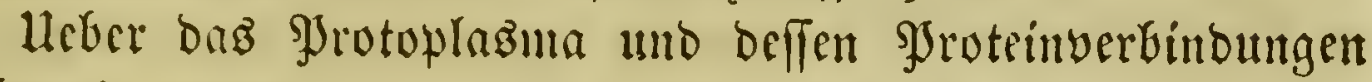

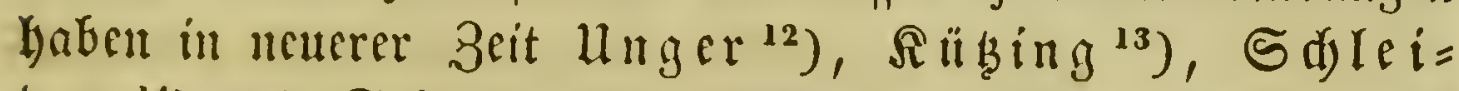

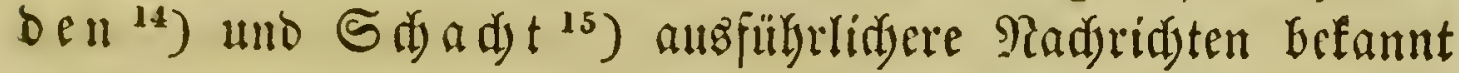
gemadit.

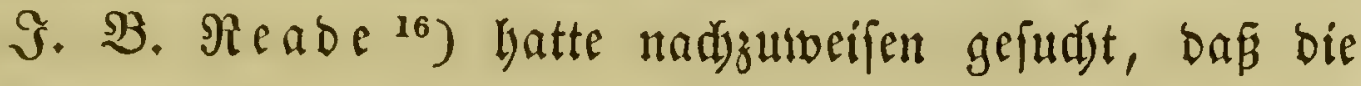

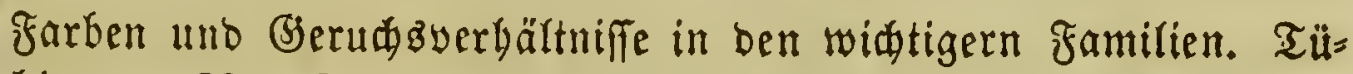
bingen 1831. 8. - Unterfuthungen über bie Farbenveränberu!= gen Der Blütben. Tübingen 1833. 8. - Heber bie Farbenver= Gältniffe in ben Blüthen ber Flora Franfreids. Tübingen 1833. 8.

1) Mlémoire sur la coloration automnale des feuilles. Genève 1828. 4.

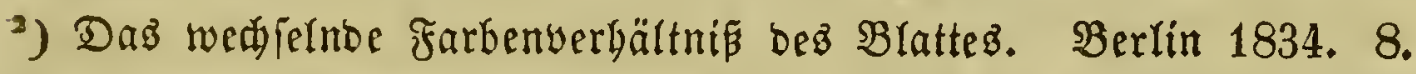

3) Cenno sulla decolorazione delle foglie in autumno. Torino 1835.8.

4) Die $\mathfrak{J}$ arben ber Blüthen. Bonn 1835. 8.

5) Sug'l innesti, sulla colorazione dei vegetabili e sulla fosforenza del ligno. Vigevano 1836. 8.

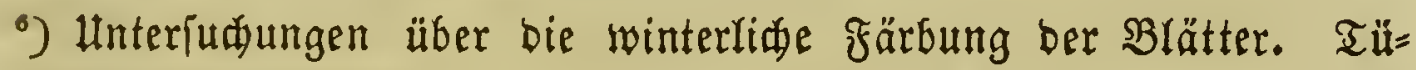
bingen 1837. 8.

') Sur l'origine et la nature des matières colorantes organiques. Rouen 1843. 8.

8) STgufiologifde (5hemie $2 c$.

$\left.{ }^{9}\right)$ Recherches anat. et physiol. sur le Garance etc. Bruxelles 1837. 4. (Extr. du tome 12 des mémoires couronnès par l'acad, royale de Brux.)

10) ITnnalen ber SSharmacie XXI. 1837. S. $257-264$.

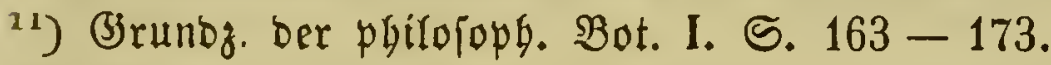

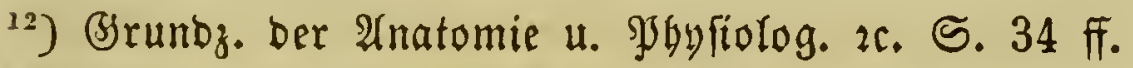

${ }^{23}$ ) (jrunbz. 2c. I. S. 214.

14) (3runoz. 2c. I. S. 193.

15) STgufiologifde. Botanif S. 27 ff.

$\left.{ }^{10}\right)$ The Lond. and Edinb. philos. mag. and journ. of sc. Nov. 1837. S. $418-424$. 
Beflemmembran nidjt iumer cine gleirfe dyemijdye 3ujamment=

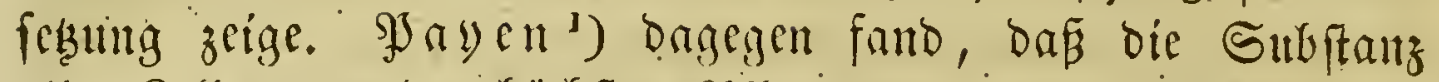

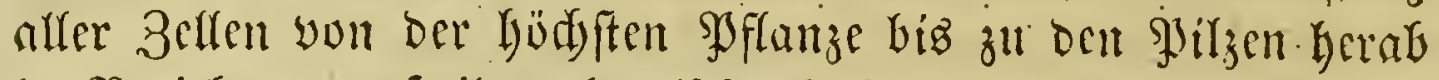

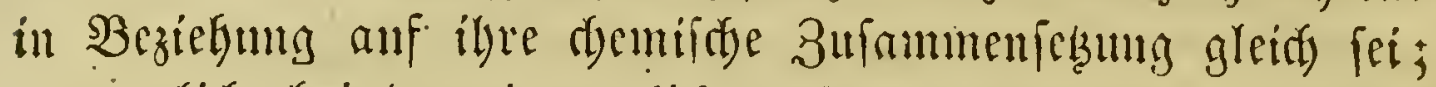
unmentlid) bei ben jugendidsen Mambranen laffe firt bies nad)weifen; die älteren bagegen erleiden burd) größzere ober geringere Berbindung mit fremben Stoffen veridjiedene $\mathfrak{B e r}=$ ärocrungen. Mulder ${ }^{2}$ ), der ïber diefen (biegenftrmo febr genalle Unterindyungen anfellte, ftimmte zwar barin, oafi bei

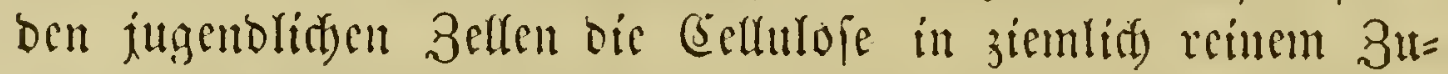
ftrabe fich befände, mit sos a yen uberein, bebautete jebods Ginfidtllidy ber Sicrbintung älterer Dienbranen mit fremben Stoffen, Daf cine beftimunte Sidityte cines EY Tementaroriganez, weldyes fids mit Sod uno Sdywefelfäure nidjt brau färbe, feine Seflulofe enthalte; fönne aber nadygewiefen werben, bafis Diefelbe Sdjidft fidjon in ber jugendidien Zelle ans (Seflulofe

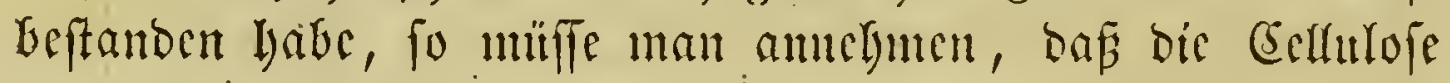
burd) andere Berbinsumigen verorängt worben fei; fönte bie

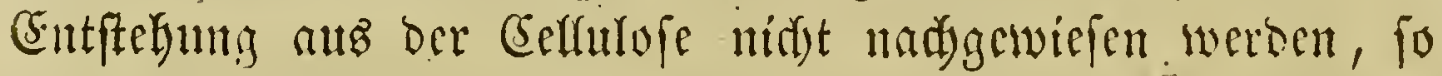

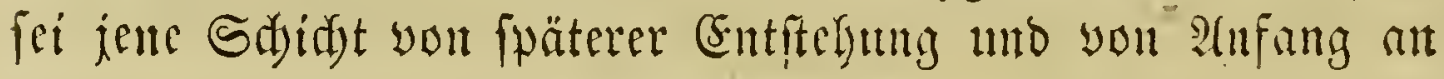
anters als bie (edfulofe zufanmengefegt. Mogr ${ }^{3}$ ) bagegent

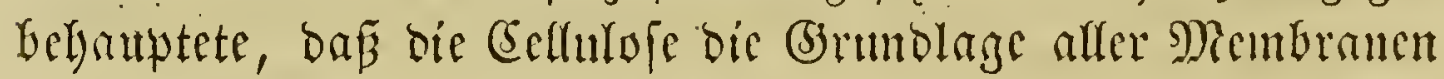

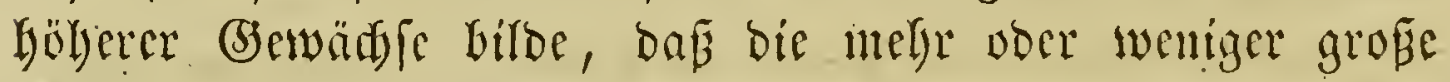

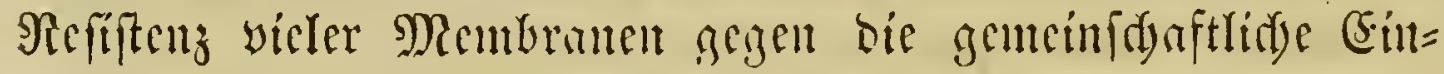
wirfung yon gob uno Sryuvefelfäure in cingeloigerten fremb= artigen Berbinoungen begrünoet fei, mo bas bie von $\Re$ Ml=

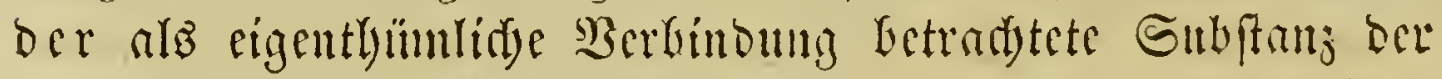

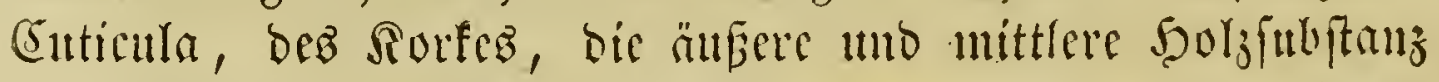
Berbindungen yon Eefluloje mit fremben Einlagermingen feicn.

') Mémoires sur les développements des végétaux. Paris 1812. 4. 16 tab. col.

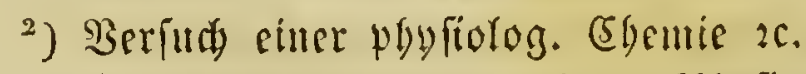

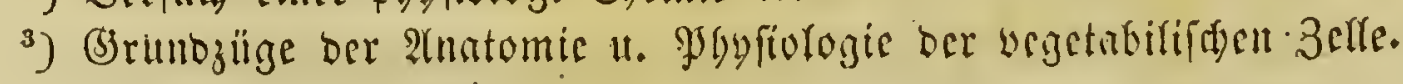
ธ. 30 f. 


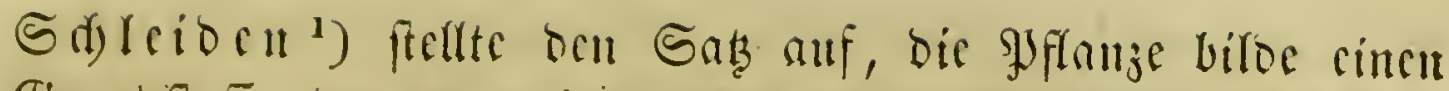

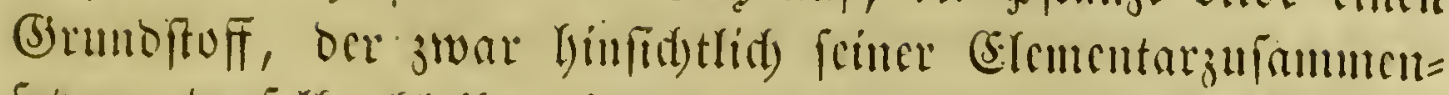

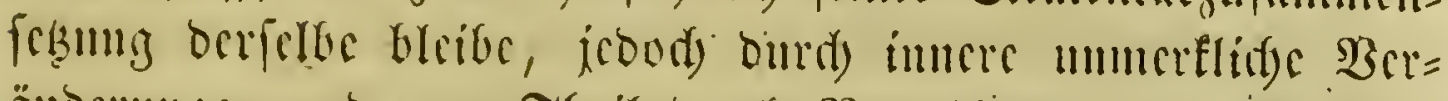

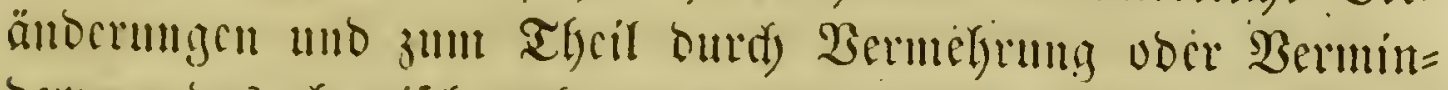

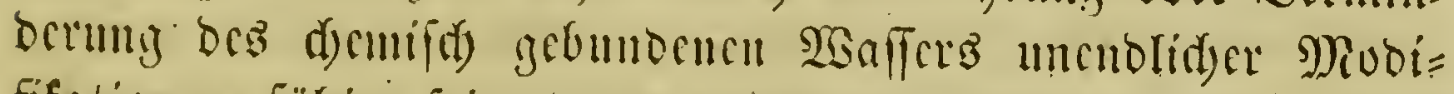

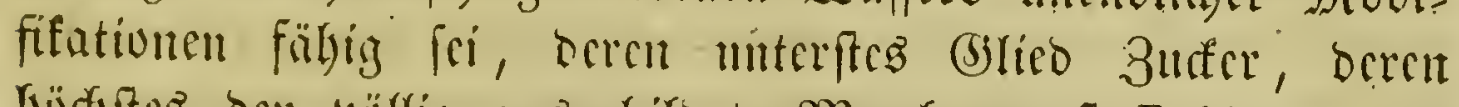

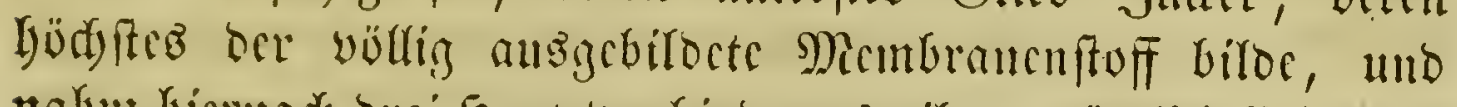

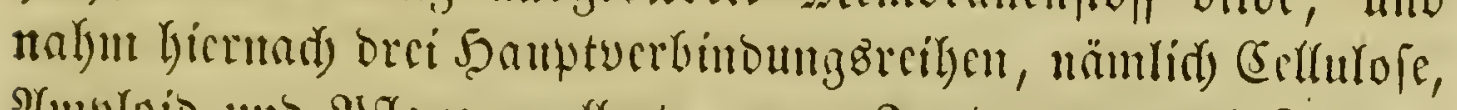

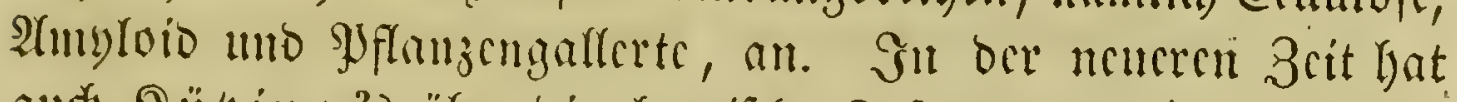

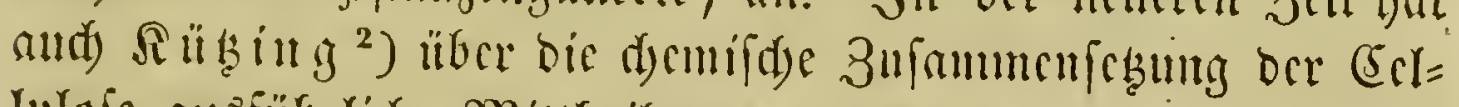
luloie ansfülgrlictye Mittlycillungen gcmadyt.

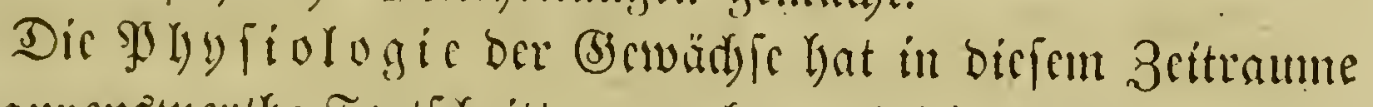

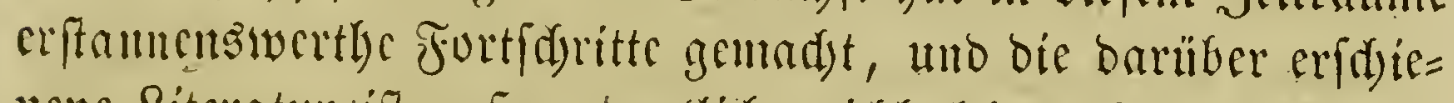

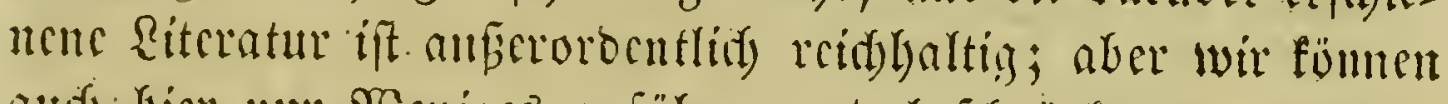

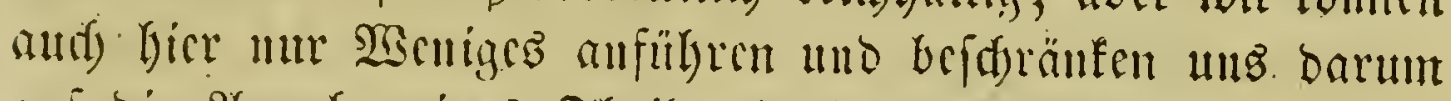
anf bic Angabe cincs Theiles bericnizen Sdyriften, welde

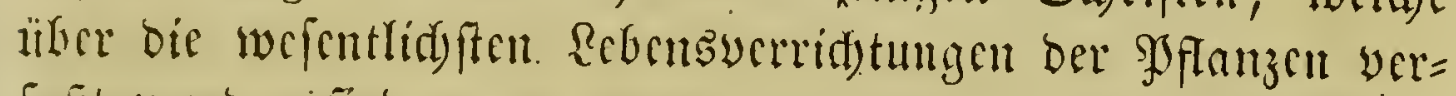
fajt worteri find.

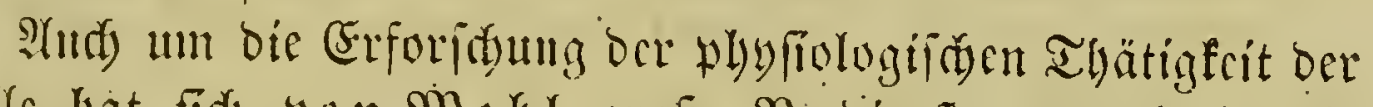

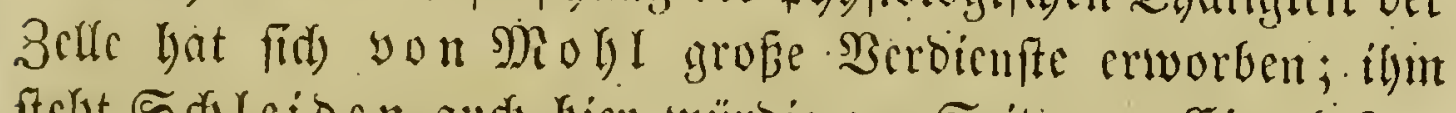

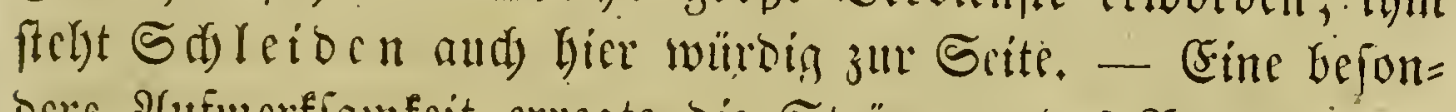
bere Aufuncrfianteit erregte die Strümung ors Srotakliasma in ocr neucreil 3eit. Dirfelbe war zwar fifon in vorigen

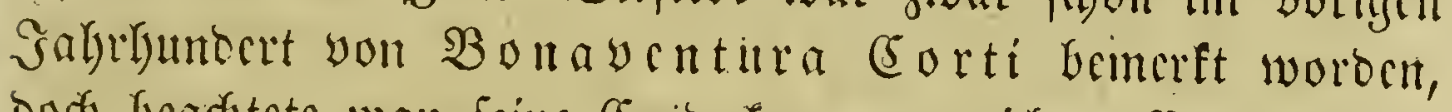

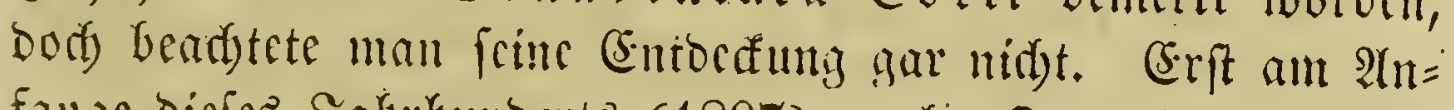
fange ticfez Sahrhumberts (1807) madjte Treviranus bic= filbe Bewbadinng bei oen (Sharcm: Man glaubte mun lange, jent Strümung fomme nur bei einigen : Barfferpflaujen vor; erft in ocr neneren 3cit hat man narbgewicfen, bar bicfelfe

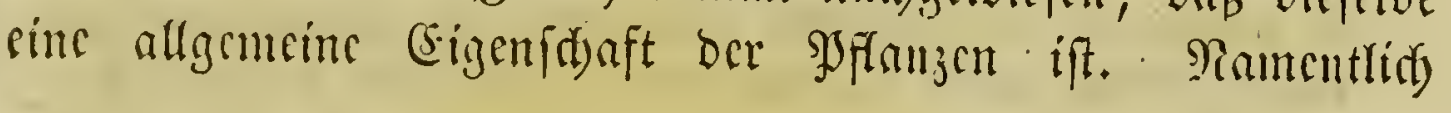

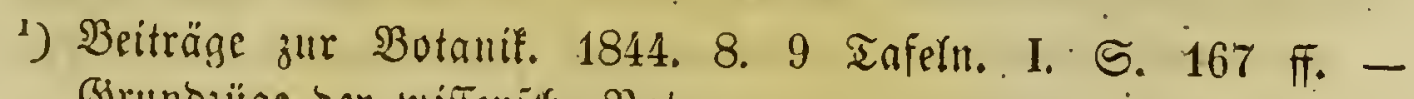
(3) runbzüge ber wifientidy. Bot. ic.

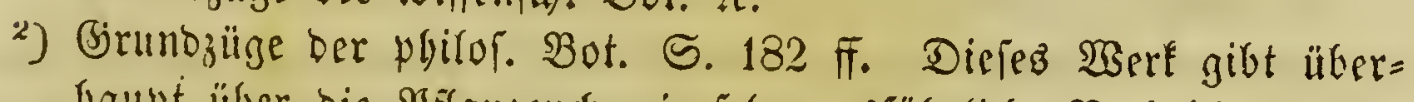

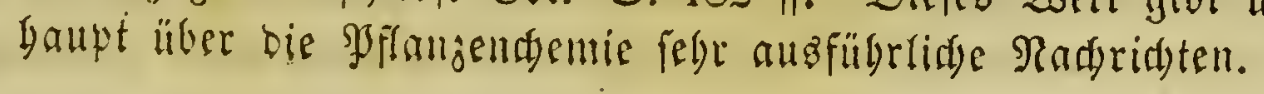




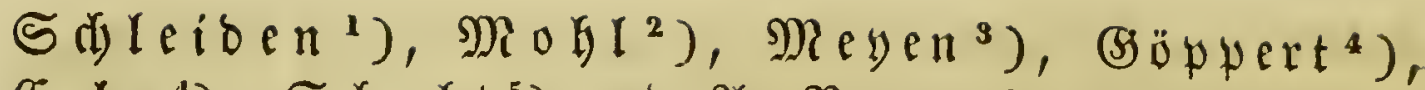

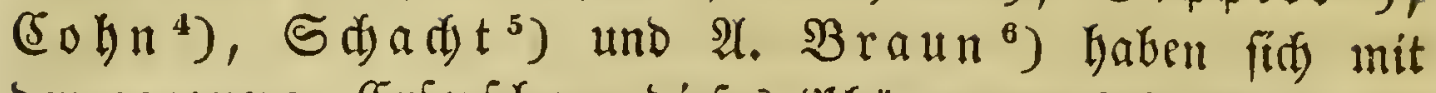
ber genaueren (Erforidyung biefes y্jyänomens beidäftigt.

Uleber bie (Entwifelung bes (5mbryo hatte fdon aegen bas (Enbe beb vorigen 3ritraums \&. (Sh. Treviranus ${ }^{7}$ ) fleisige Beobadytungen angeftellt. alber erfit in ben lesten Decennien ift tiefe Materie ausfülyrlicyer yon verfdiebenen Mrgyfologen

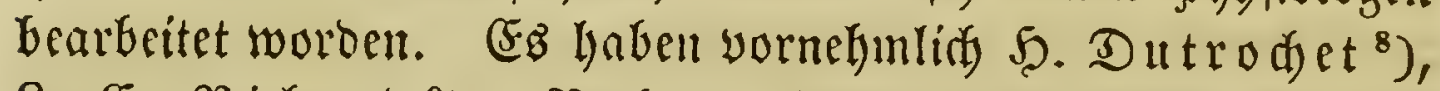

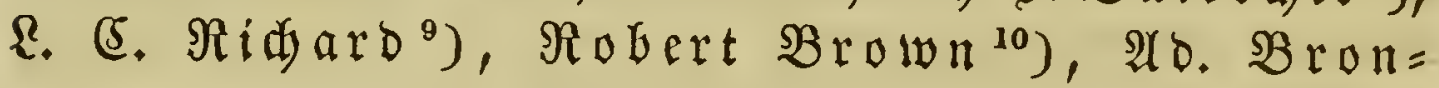

1) Beitrag zur Renntni位 ber (Seratopgyuleen. (Linnaea, 1837. ङ. 527.) - (3runbz. 2.. II. S. $304-313$.)

2) Heber bie Saftbewegung im Snnern ber 3ellen. (Bot. 3eit.

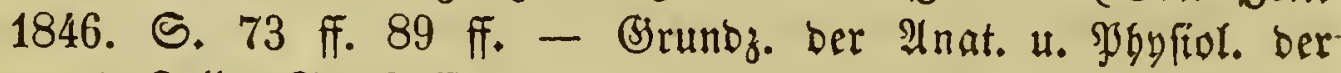
veget. Belle. S. 42 fi.

3) \$flanzenplyfiologie. II. S. 244 ff.

4) (S) öpert und (5ofn, Ueber bie Rotation bez 3elfaftż in Nitella flexilis. (Bot. 3eit. 1849. S. 665 ff. 681 ff. 697 ff. 713 fi.)

5) Sbyfiologiane Botanit S. $335-341$.

-) Heber bie Ridtungäberbältniffe ber Saftfrömung int ben Zellen

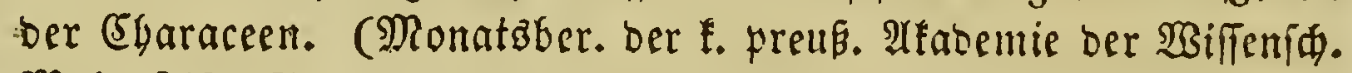
Mai 1852. S. $220-268$. Sanuar 1853. S. $45-76$.)

") Bon ber Entrwideclung bez (Embryo unb feinen Hmbülfungen im Sflanzenei. Berfin 1815. 4. - De ovo vegetabili ejusque mutationib. observationes rencensiores. Vratislav. 1822. 4.

$\left.{ }^{8}\right)$ Recherches sur l'accroissement et la reproduction des végétaux. Sect. IV. Du développement des ovules et des embryons séminaux dans les ovoires. (Mém. du mus. d'hist. nat. Tom. VIII. 1822. S. 241 ff. - Observatt. sur la forme et la structure primitive des embryons végétaux. (Nouv. ann. du mus. d'hist. nat. 1835. S. 163-212.)

') Commentatio botan. de Coniferis et Cycadeis, opus posth. ab Ach. Richard in lucem ed. Stuttgartia 1826. Fol. 30 tab.

$\left.{ }^{10}\right)$ Character and description of Kingia, with observations on the structure of its unimpregnated ovulum etc. (King's. 


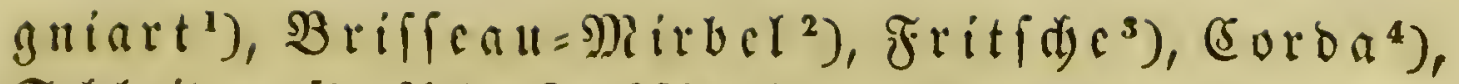

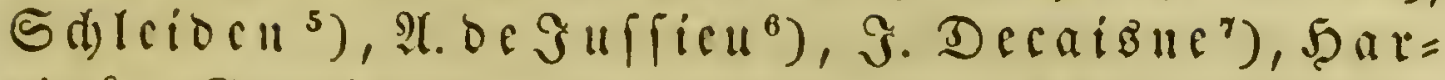

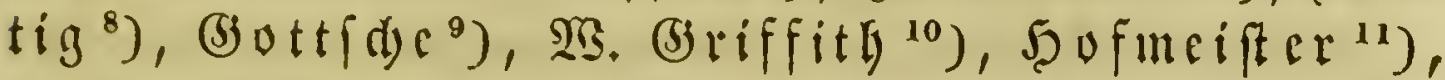

voyages of discovery etc. Vol. II. Append. B.; vergr. R. Brown'B werm. Sduriften BD. 4. S. $75-140$.) - Heber bie (Sorpuzcula ber Soniferen. (Annal. sc. nat. II. Tom. XX. 1834. S. 211 fi.)

1) Mémoire sur la génération et le développement de l'embryon dans les végétaux phanérogames. Paris 1827. 8.

$\left.{ }^{2}\right)$ Annal. des scienc. nat. Suli 1829. S. 302-318. ('Bergl. aud R. Brown'B yerm. Sdyriften $\mathfrak{B}$ D. 4. S. $515-534$.)

3) Heber bie Entwieflung bez Syflanzenteis in feinen früleffen $3 \mathfrak{l t =}$ Pänben und über bie Birtoung ber 5̧äute beffelben. (2Bieg= mann's $2(r d$ fiv 1835. Bo. 2. S. $229-232$.)

4) Beiträge zur Regre yon ber Befruđtung ber Mflanzen. (Nov. act. acad. caes. L. C. nat. cur. Tom. XVII. p. II. S. $599-614$.

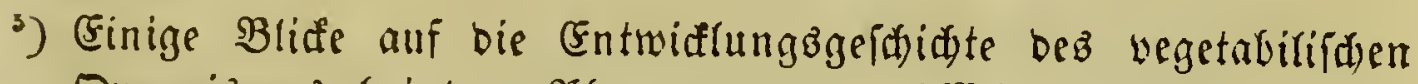

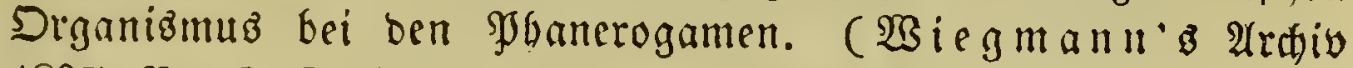
1837. 3 b. I. S. $289-320$ ) - Heber bie sBitoung bez (siđen'z unb (Entfel)ung des Gmbryo. (Nov. act. acad. caes. C. L. C. cur. Vol. XIX.) - Brunoz. ber wifienlaaftl. Botanif. II. S. $3{ }^{2}-380$.

-) Sur les embryons monocotylédonés. (Annal. des sc. nat. Juni 1839.)

') Mlémoire sur le développement du pollen, de l'ovule et sur la structure des tiges du Gui (viscum album). BruxelJes 1810. 4. 3 tab.

8) Regrbuch ber Pfanzenfunbe, in iGrer 2(nwendung auf Forftwiffen= iffaft. Berlin 1810-1846. 8. 38 Seft.

3) Unterfudungen ber Doula bei Coniferen unb (sycabeen. (Bot. 3eit. 1845 , S. 378 ff. 398 ff. 413 ff. 433 ff. 447 f.)

10) lleber bie Entwifflung ber Samenfnozpen bei 2 (twicennia. (Annal. des sc. nat. 18\%7. Januar. Flora 1847. Ro. 21.)

11) Die Entfel)ung bez (Embryo ber \$Jhanerogamen. Leipzig 1849. 4. 14 Iafetn. - Bergleidente Unteriustungen ber Reimung, Entfaltung und frudtbildung Gögerer Siryptogamen und ber 


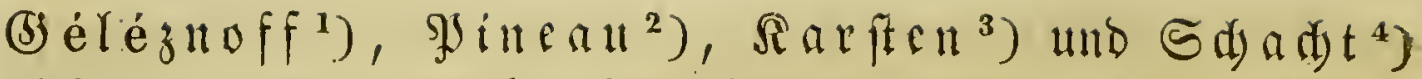
diefen (Segenftand näber beleudatet.

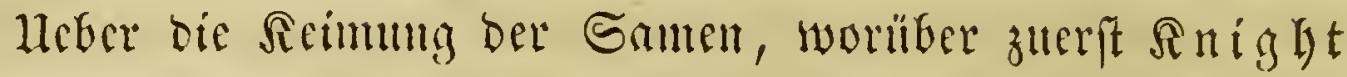
in ber vorigen Sheriode genauere Radjorfdumen angeftedt

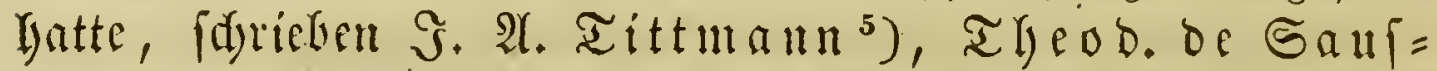

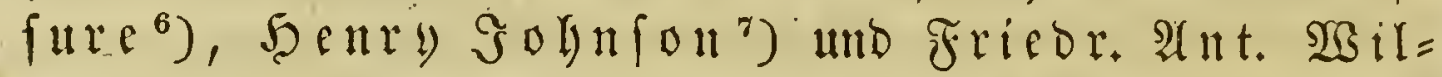

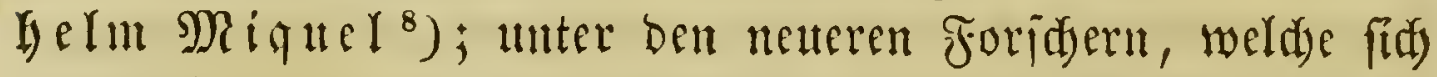
mit biefem (Gergenftande refdaftigt baben, find $F \cdot\left(50 h n^{9}\right.$ ),

Samenbiloung ber Coniferen. Reipzig 1851. 4. S. $126-138$. - 3ur Entwidlungegefdide Der Zostera. (B̧otan. 3eit. $18 j .2$. S. 121 ff. 137 fi.)

1) Sur l'embryogénie du Melèze. (Bullet. de la soc. impér. des natural. de Moscou 18.49. S. $50-605.2$ Tafeln.)

$\left.{ }^{2}\right)$ Heber bie (5mbryobilbung ber (5oniferen. (Annal, des sc. nat. III. Sèr. Tom. XI. 1849.)

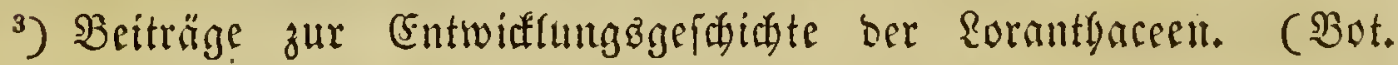
3rit. 1852 . S. 305 ff. 321 ff. 337 ff. 361 ff.

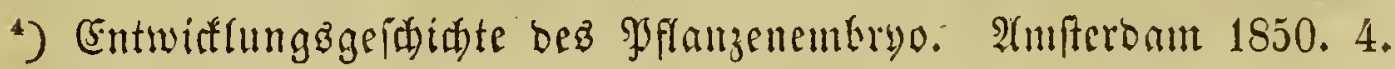
36 Tafeln. - Sglyfiolog. Bot. 1852. S. 292 ff.

5) Heber Den Embryo des Samentorng uno feimer Entwiaflung zur Sfflanje. Drezben 1817. 8. - Die Reimung ber Syflanjen Durd

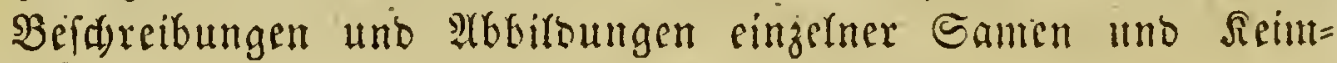
Yflangen erläutert. Ibid. 1821. 4.27 Tafeln.

$\left.{ }^{6}\right)$ Annal. des sc. nat. San. 1827. S. 86-93. - Mém. de la soc. de phys, et d'hist. nat. de Genéve. Tom. III. P. 2. ऽ. 1. - De l'altération de l'oie par la.germination et par la fermentation. (Biblioth. univers, de Genève 1834. $\subseteq$. 113 - 199.)

$\left.{ }^{7}\right)$ The unsatisfactory nature of the theories proposed to account for the descent of the radicles in the germination of seerls, shewn by experiments. (Edinb. new philos. Journ. Sctob. 1828, März 1829.)

s) Responsio ad quaestionem bot.: describatur germinatio plantarum, praemissa brevi disputatione de partibus fructus etc. Groningae 1832.

9) Symbola ad seminis physiologiam. Berol. 181\%. 8. (Deutít: in Flora 1849. शro. 31 แ. 32.) 


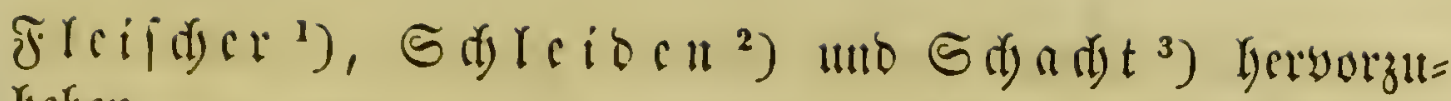
hyeren.

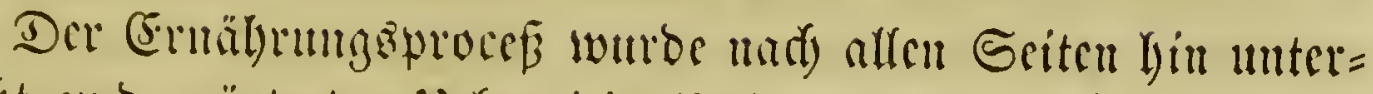

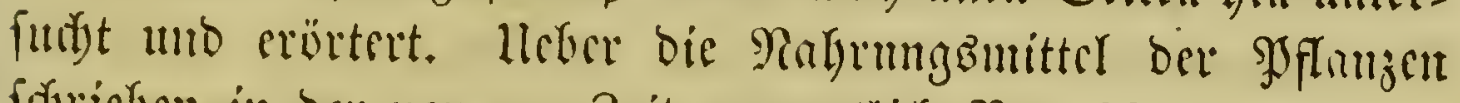

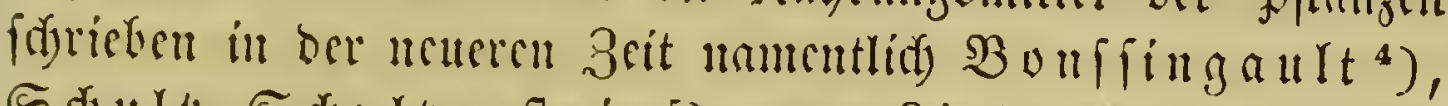

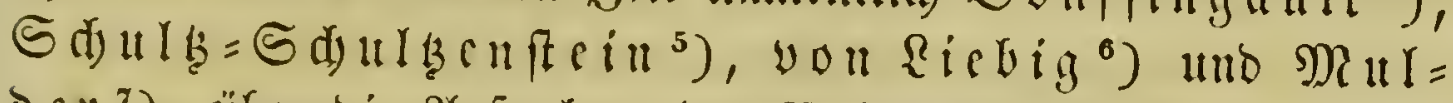

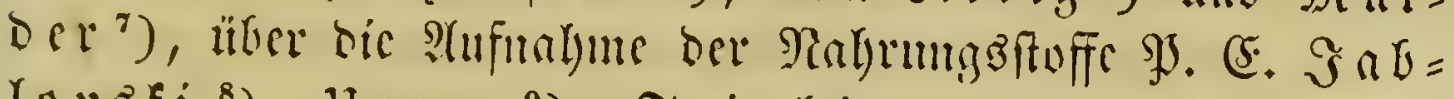

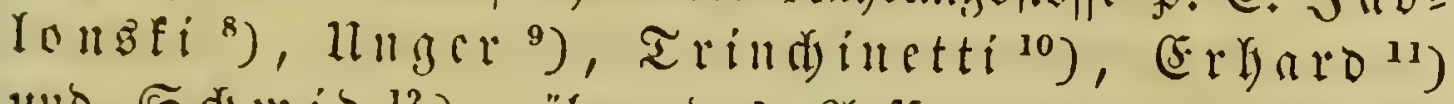

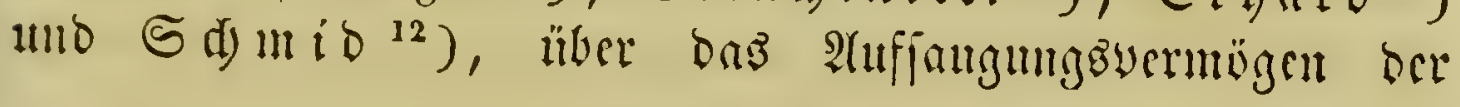

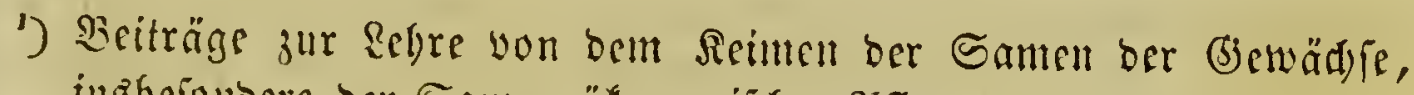

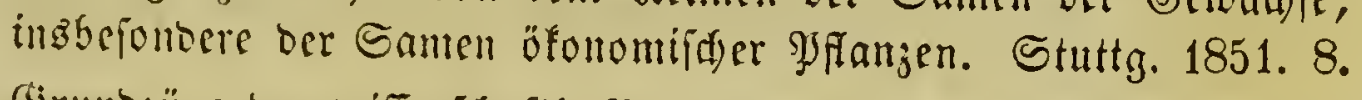

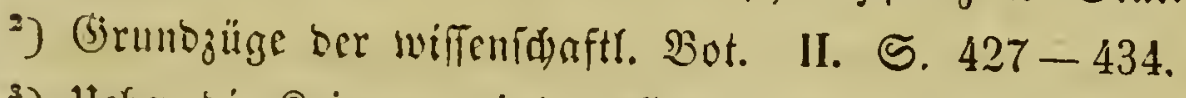

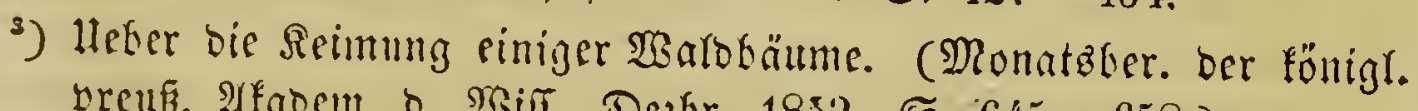

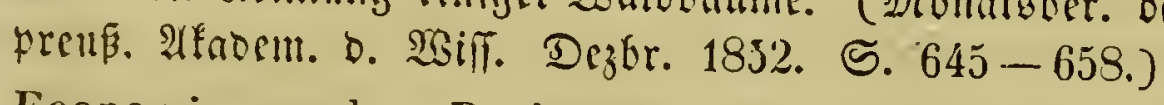

4) Economie rurale. Paris 1844. 8. - Die Ranbwirtbingaft in

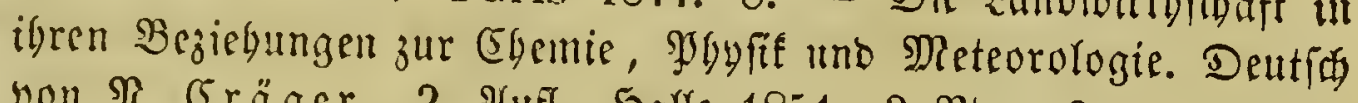

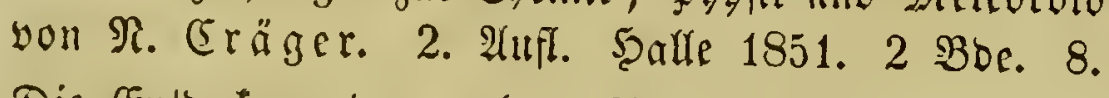

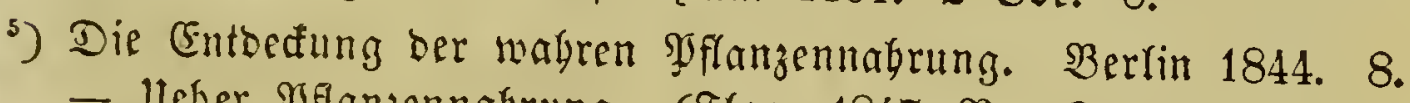

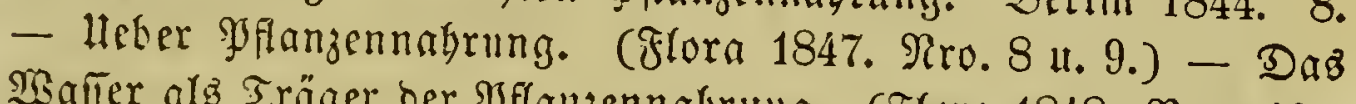

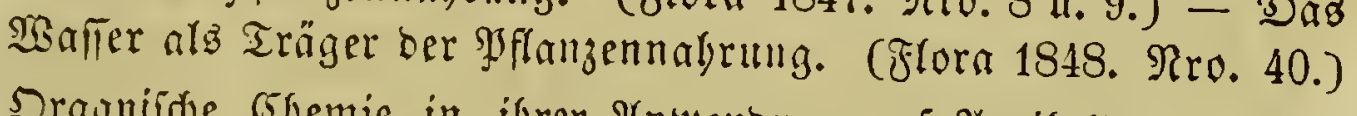

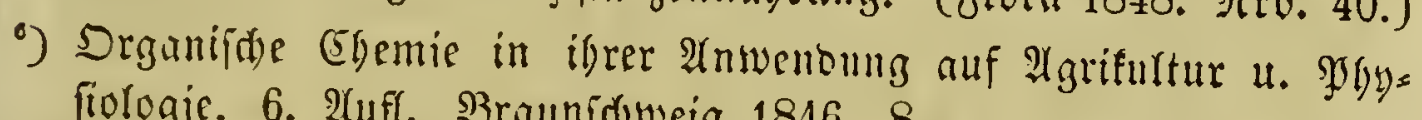
fiologic. 6. Yuff. Braunfatmeig 1846. 8.

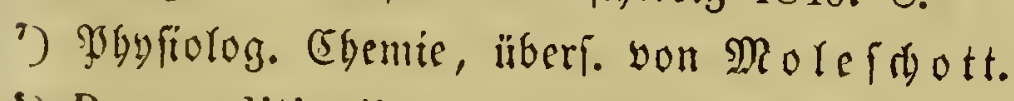

-) De conditionibus vegetationi necessariis quaedam. Berolini 1832. 8. - Beitrag zur \&ǘfung ber frage, of surd bent

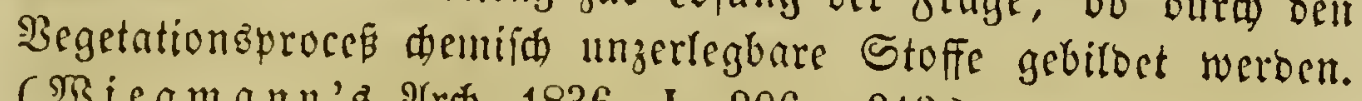

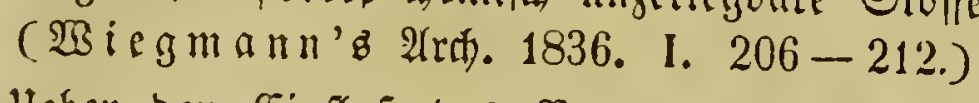

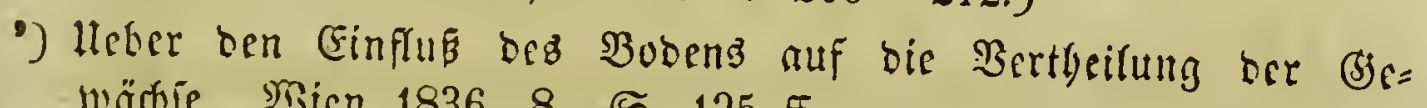
wäafje. Wisn 1836. 8. S. $125 \mathrm{ff}$.

$\left.{ }^{10}\right)$ Sulla facolta absorbente delle radici de vegetabili. Milano 1843. 4.

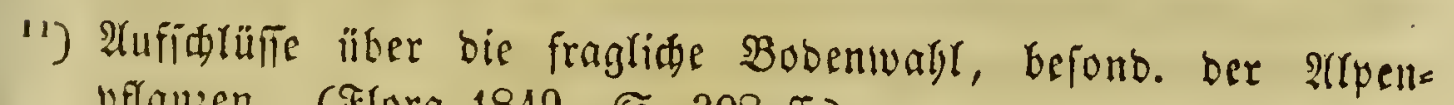
Fflamijen. (\$lora 1849. S. 303 ff.)

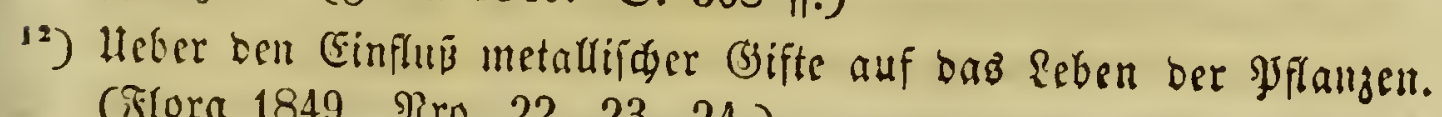
(\$Itorn 1849. Mro. 22, 23, 24.) 


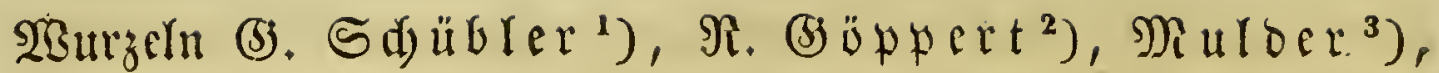

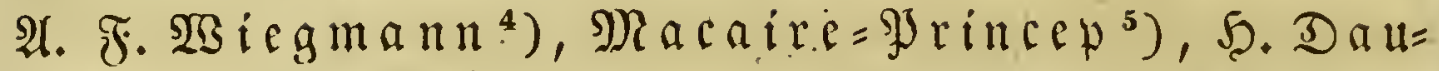

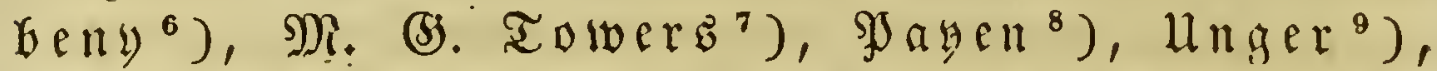

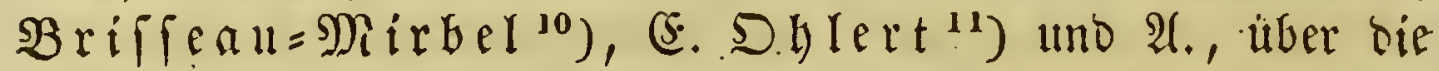

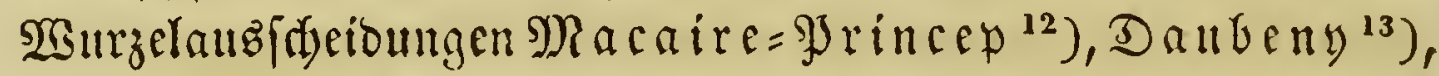
$\mathfrak{U n g e r}^{14}$ ), Meyen ${ }^{15}$ ), $\mathfrak{B r a c o n n o t}{ }^{16}$ ), $\mathfrak{Z}$ alter. ${ }^{17}$ )

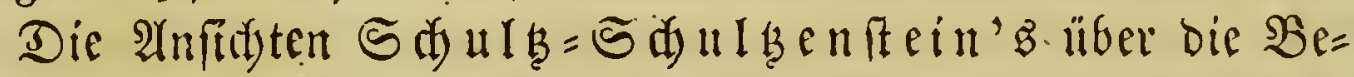

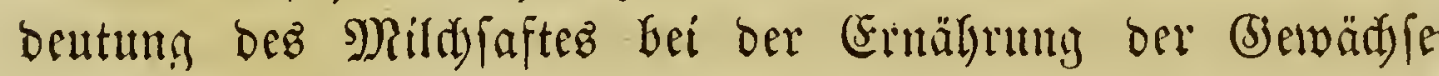

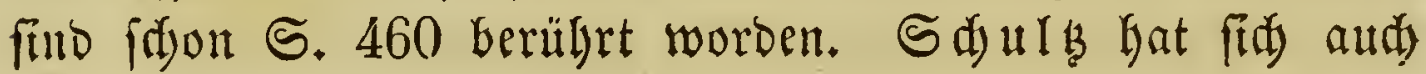

1) Unterfuđungen über bie Sintwirfung veridiebener Stoffe bes or= ganif Iitbingen 1826. 8.

$\left.{ }^{2}\right)$ De acidi hydrocyanici vi in plantas comment. Vratislaviae 18:27. 8.

3.) Over den invloed van vergiften op zongenaamd gevoelige en eenige andere planten. ( $v$. Hall, Vrolik en J. G. Mulde r's Bydr. tot de naturk. Wetensch. 2 Deel. 1827. S. 38. 3 Deel. 1828. S. 112.

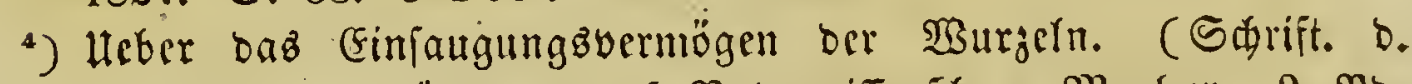

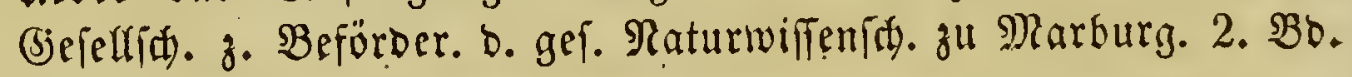
1831. S. 1.)

$\left.{ }^{5}\right)$ Mém. pour servir à lhist. des assolements. (Mém. de la soc. de phys. et d'hist. nat. de Genève 1832.)

$\left.{ }^{6}\right)$ Memoirs on the degree of selection exercided by plants etc. (Transact. of the Linn. soc. Vol. XVII. P. 2. 1835.)

") (Transact. of the hort. soc. of Lond. 2 ser. Vol. II. P. I. (5. 41.)

s) L'Institut. 1839. S. 936.

-) Heber den (ङinflus dez bुudens ze. S. 147.

10) L'Institut. 1837. S. 311.

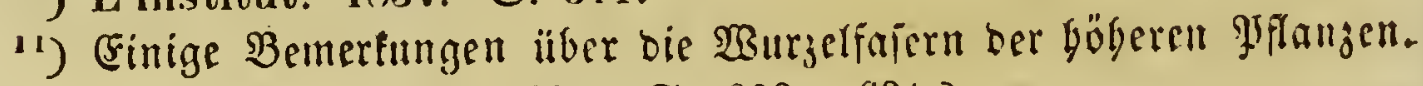
(Linnaea 11. 38. 1937. S. $609-631$. )

12) Mém. de la soc. de Genève. Tom. V.

${ }^{13}$ ) Siele oben Rote 6.

14) Ueber denl Ginflús bez Bodenz. S. 147 ff.

1s) $\mathfrak{B}$ ieg mann' 2trdib 1837. 2: Bo. S. 55.

10) Annal. de Chimique el de Physique. Tom. 72.

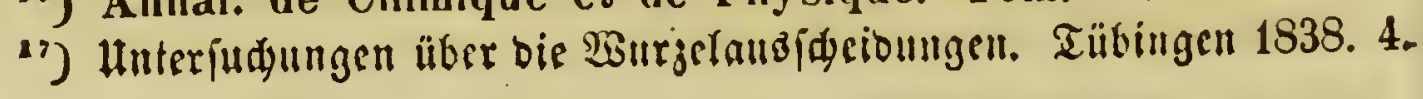


fouft melymalis burdy bie sufferlumg unbaltbarer, auf unge=

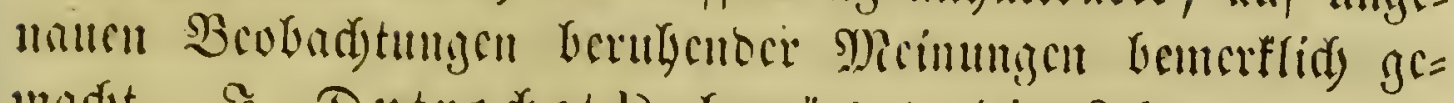
madyt. S. Dutrodyet ${ }^{1}$ begrünocte bie Refre you ber (5mbosmofe unb (5rosmofe und fudste burdy bicfelle bie $\mathfrak{B}_{c}=$

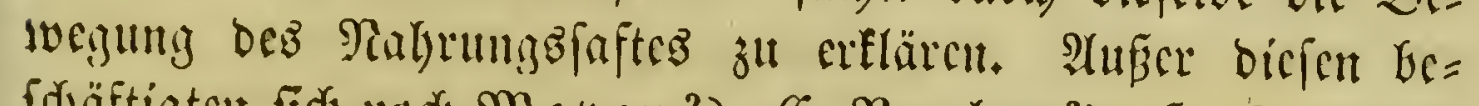

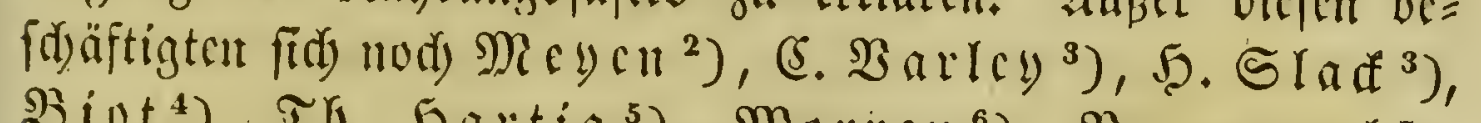

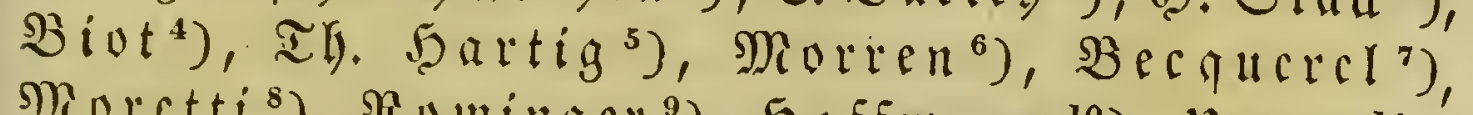
Noretti ${ }^{8}$ ), Ruminger ${ }^{9}$ ), $50 f f m a n n^{10}$ ), Hnger ${ }^{11}$ ),

1) Agent immédiat du mouvement vital. Paris 1826. Nouv. recherches sur l'endosmose. Ibid. 18:28. - Mém. pour servir à l'hist. anatomique et physiol. des végétaux et des animaux. Ibid. 1837. 2 3be. 36 Iaf.

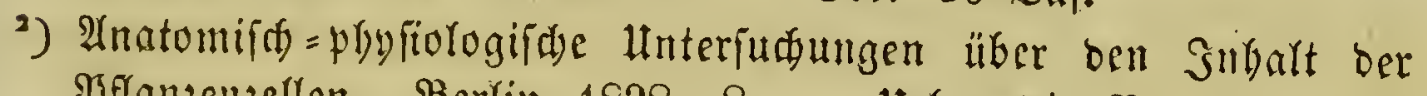
SJflnzenzellen. Bertin 182S. 8. - Heber die Betwegung Der

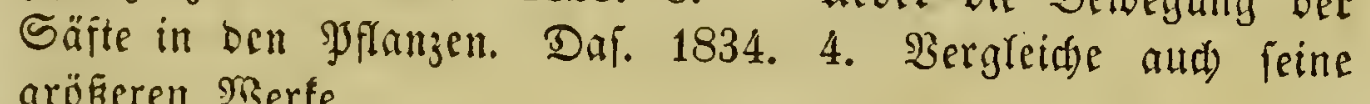
grö̈eren $\mathfrak{B e r f e . ~}$

3) Transact. of the soc. for encourag. of arts etc. Vol. 48.

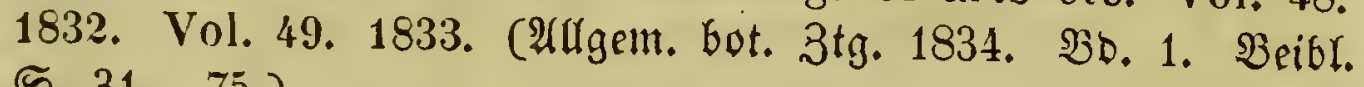
ธ. $31-75$.

4) L'Institut. 183\%. S. 66 .

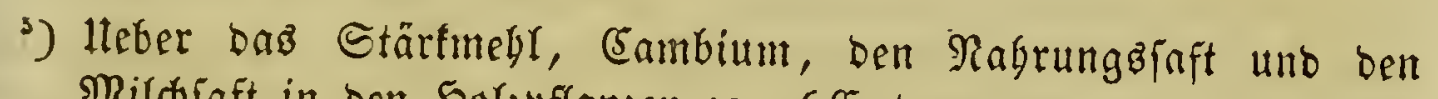

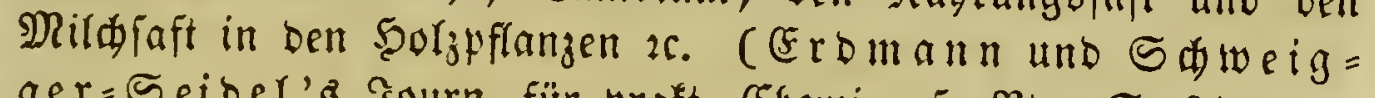
ger= Seibel's Sourn. für praft. (Elyemie. 5. Bb. S. 217.)

-) Considérations sur le mouvement de la sève des Dicotylédones. (Bullet. de l'acad. royal. de Bruxelles. Tom. IV. No. 7. - Notice sur la circulation observée dans l'ovule, la fleur et le ploranthe du Figuier. (Ibid. No, 12.)

") Influence de l'électricité sur la circulation du Chara. (Comptes rendus etc. 1837. S. 184.)

$\left.{ }^{8}\right)$ De retrogradu lymphae vegetabilis motu. Ticini 183!. 8.

') Berfudfe über bie Saftfǘrung Der Gefäße. (Bot. 3eit. 1843. S. 177 fi.)

${ }^{10)}$ Heber bie Ridutung ber Saftifrömung in ben YFlamjell. (Bot. 3eit. 1848. S. 377 ff.) - Heber bie Drgane ber Safterömung. (Ibid. 1850. S. 17 ff.) - Heber bie Saftwege in ben $\$$ Pfanjen. (ibid. S. 793 ff., 809 ff., 842 ff., 857 ff., 876 f.)

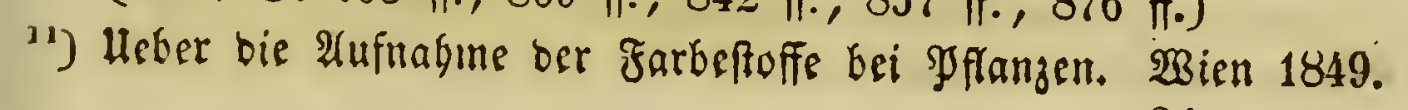




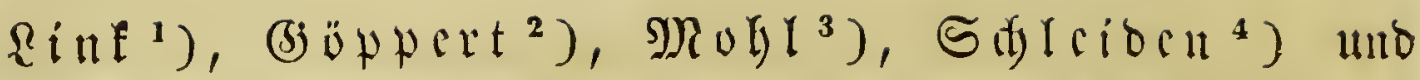

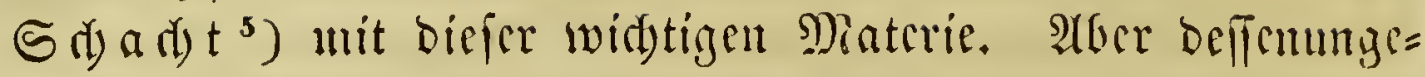
adjet ift man fid bis jegt weber ber llefade ter Saftberwe= glutg bewust, nod) hat man fich barilber vereinigen fümen,

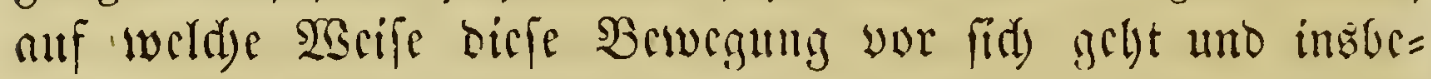

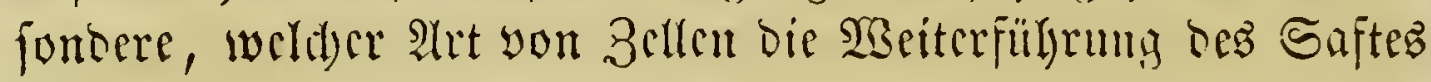
zufommt. Sad) ocr alteren, fdon von $\mathfrak{D}$ uhamel mo

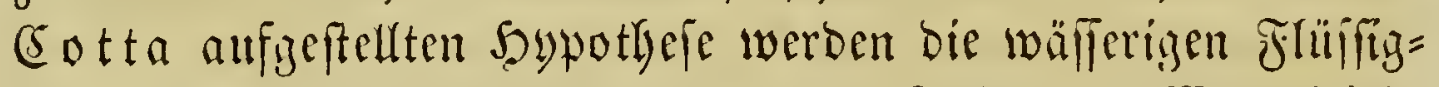

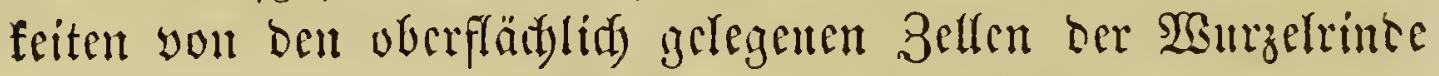

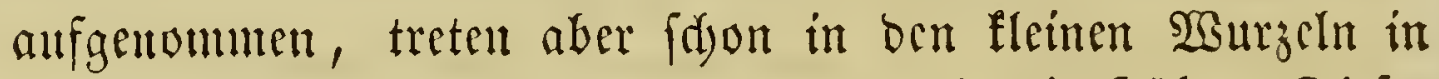

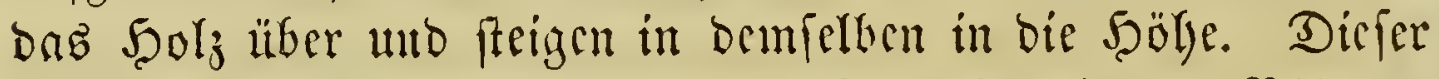
fo aufgenommene robe Ralyrungsiaft erleibet in ben Blättern

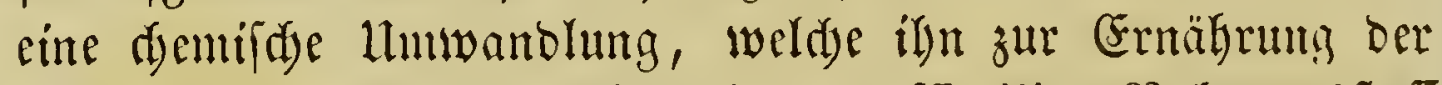

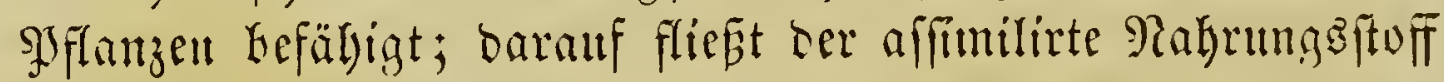

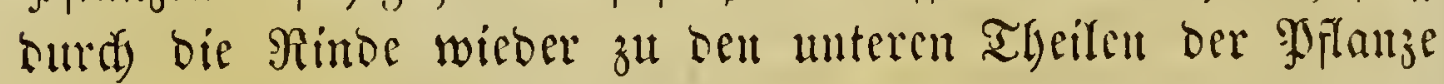
lerab. Yad) cben bicicr älteren Anfidst, bie naunentlid) in ber neueren 3eit you Miohl vertlycibigt wurde, fteigt ber Gaft in ben (befäpen cmpor. Subeflen batten fid fduon in

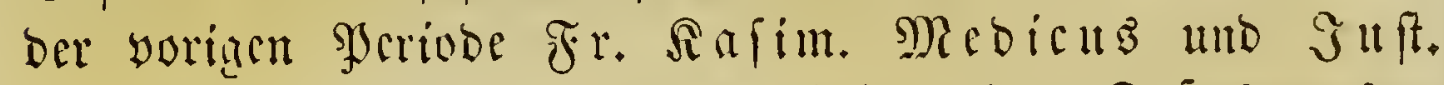

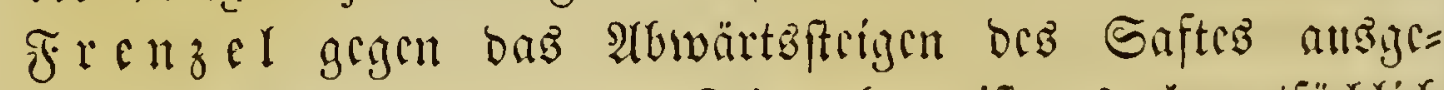

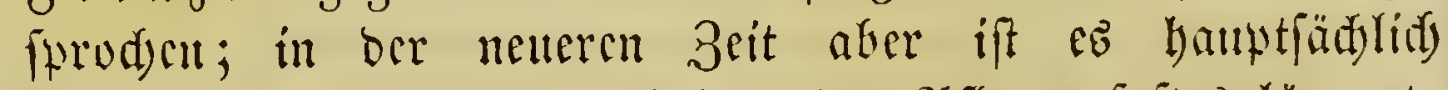

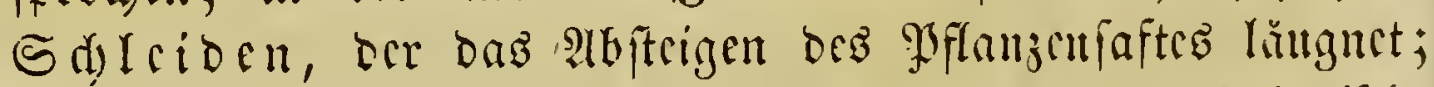

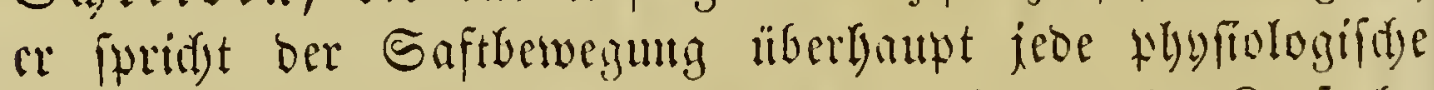

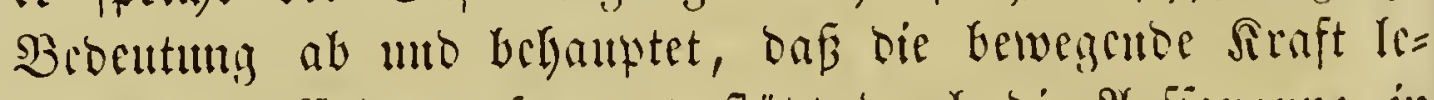

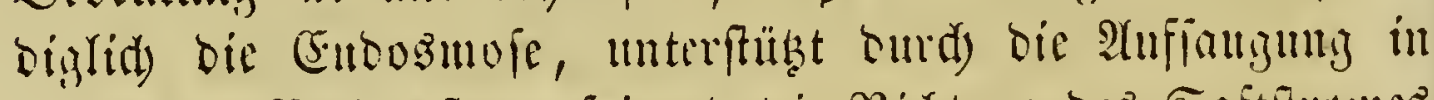

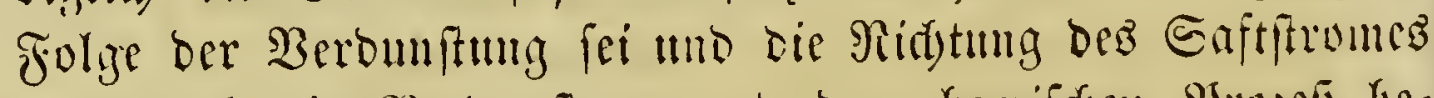

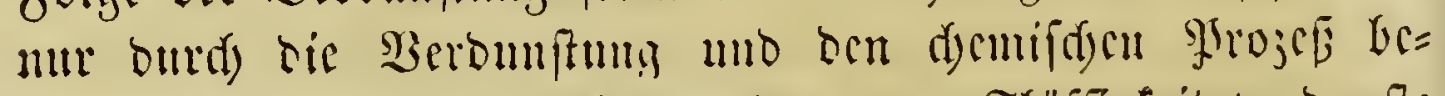

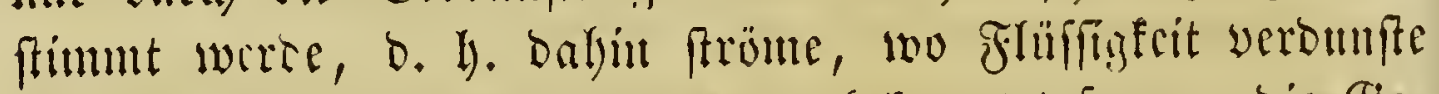

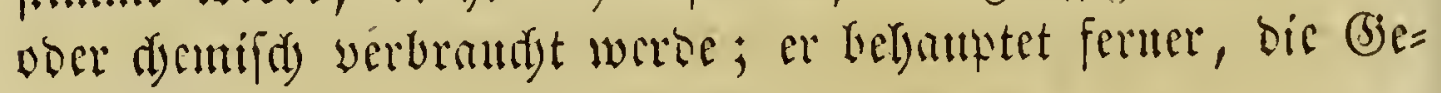

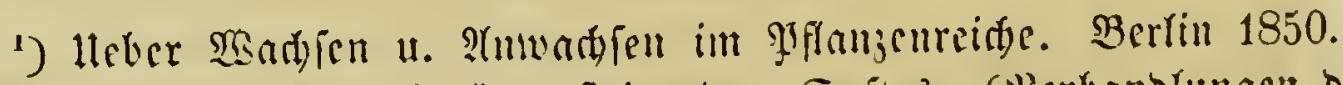

$\left.{ }^{2}\right)$ Exiffeng eincz abwärtz ffeigenden Gaftez. (Berbandungen bez fátef. Forfucrinz 1852. S. $355-360$.

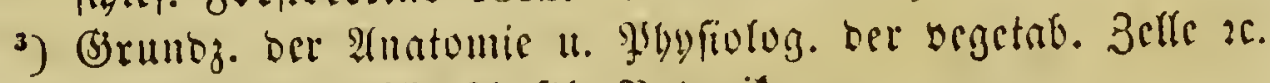

•) Srrunoz. Der milfenidtaftl. Sotanif ac.

s) Sbyufiulogifite sotrif ic. 


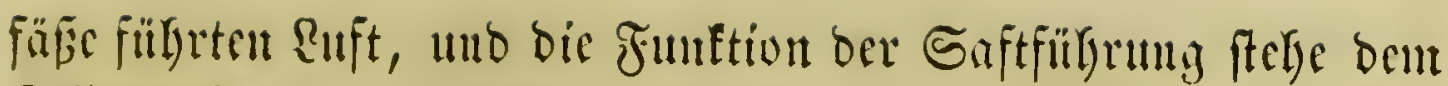

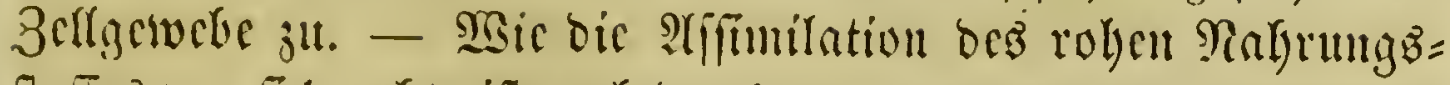

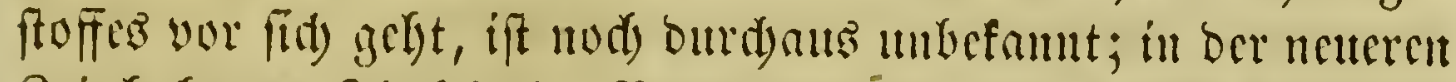

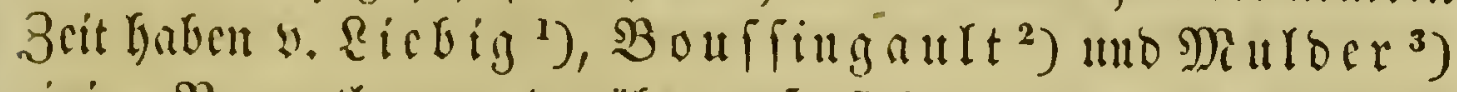

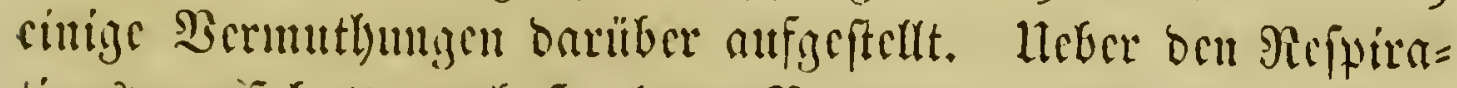

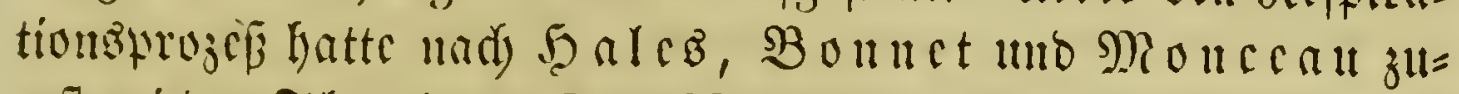
erit wieber Tlyeob. v. Sauffure vorteffflidye lluterfudjumgen

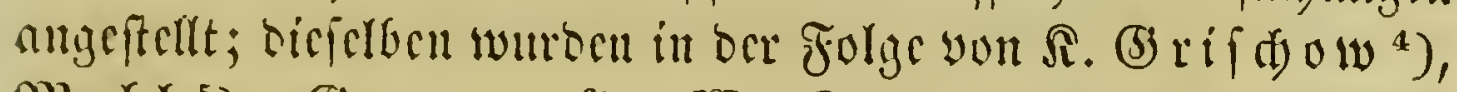

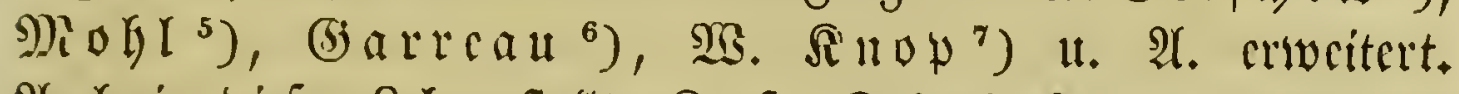

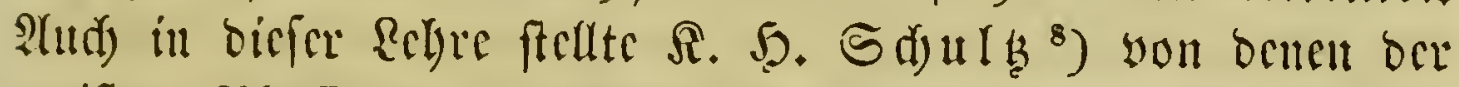

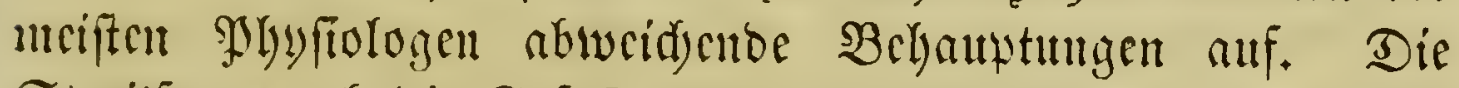
Streitfrage, ob tie (5icfäpe luft= vocr faftfügrento feien, libcr

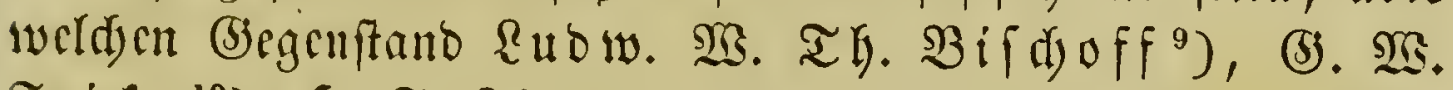

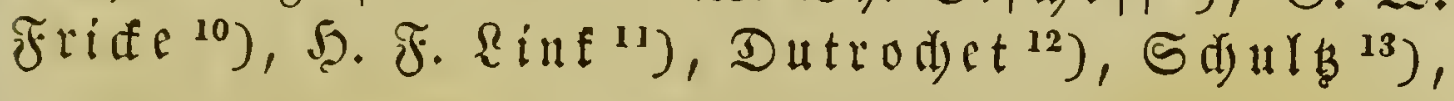

1) Seite 481, Note 6.

$\left.{ }^{2}\right)$ Seite 481, Note 4.

3) Seite 481, Note 7.

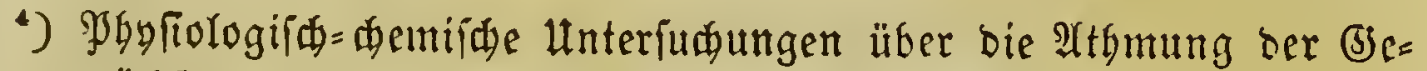
wädie und beren Einflus auf bie gemeine Ruft. Reipzig 1819. 8.

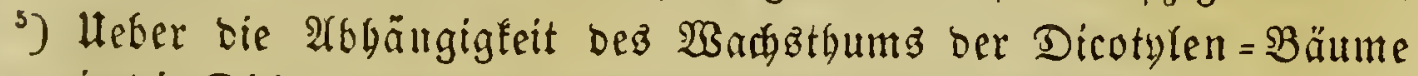
in bie Dife yon ber pgyfiulogif

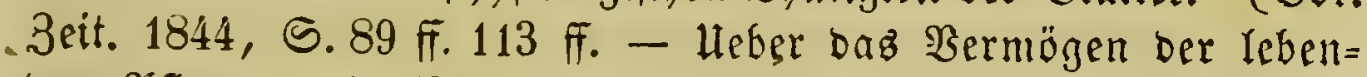

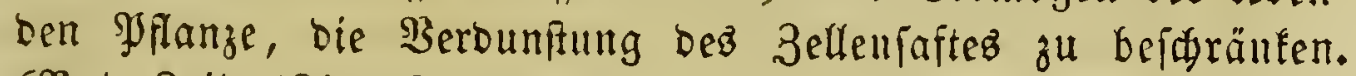
(Bot. 3eit. 1847. S. 321 fi.)

-) De la respiration chez les plantes. (Annal. des sc. nat. 18.50. Seeft 1.)

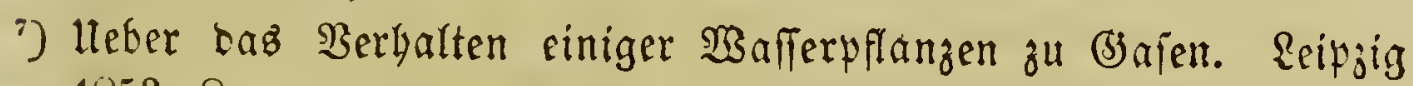
1853. 8.

8) Die wabre ஒrflangennabrung $2 c$.

') De vera vasorum plantarum spiralium structura et functione commentatio. Bonnae 1829. 8. 1 tab.

$\left.{ }^{20}\right)$ De respiratione vegetabilium. Heidelb. 1832. 4.

$\left.{ }^{11}\right)$ In feinen idjon öfters angefülrten Sdyriften.

12) Recherches sur les organes pneumatiques et sur la respiration des végétaux. (Şn belifen Mlémoires etc. S. $320-364$.)

${ }^{23}$ ) Siele when. 


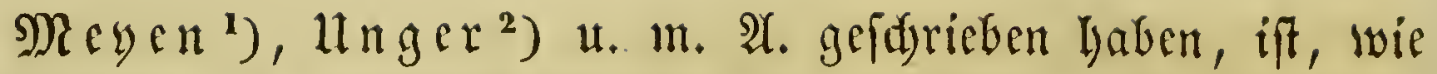
woir bereits bei (5elegenlyeit ber (jefd)idste der Saftberwegung andeuteten, bis jest nod) nidjt entidjieben.

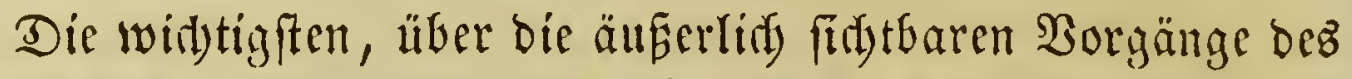

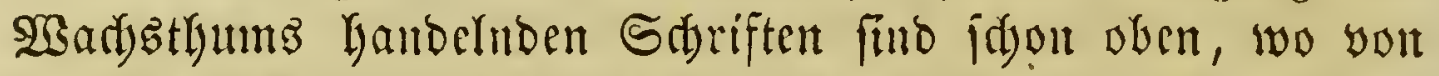

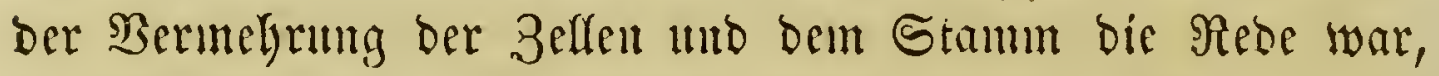

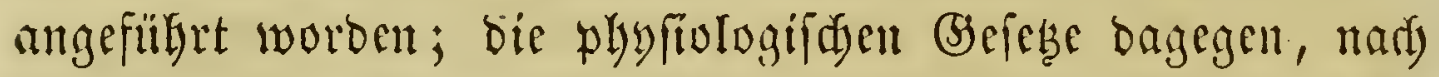

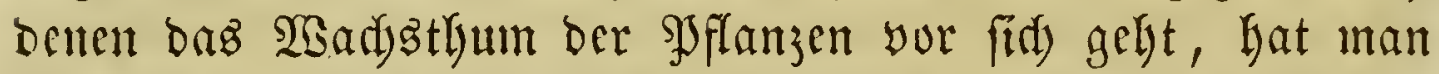
bis jest vergeblid) zu erforidyen gefurdt. Heber ben (Eimflur

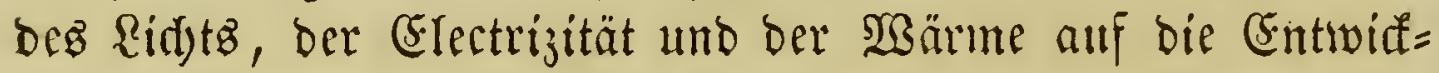

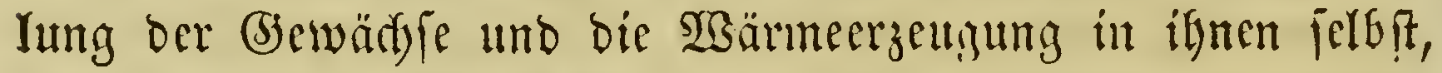
fint you viclen (Bielehrten fleifige Rad)forfdungen angeftellt

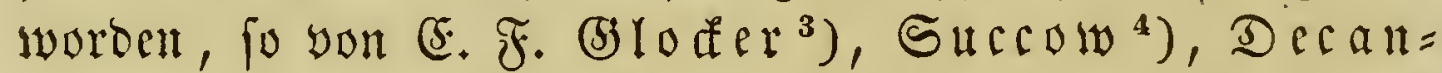

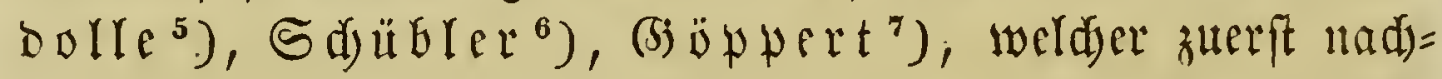

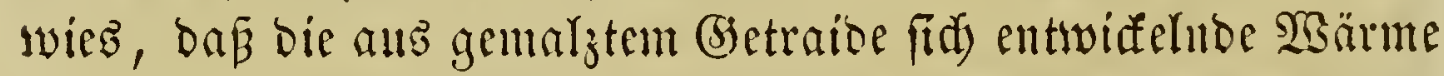

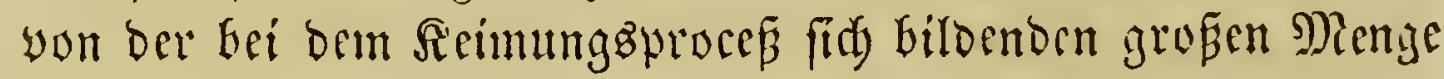

1) Siegre oben.

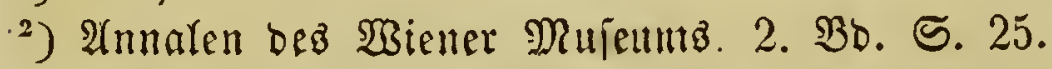

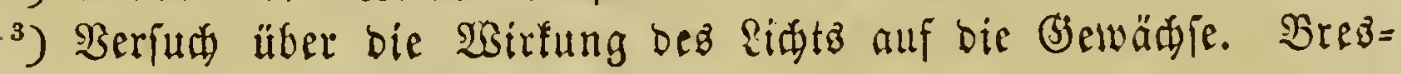
Iaut 1820. 8.

4) De lucis effectibus chemicis in corp. organ. Jenae 1828. 4.

${ }^{5}$ ). De l'influcnce de la température atmosphérique sur le développement des arbres au printemps. (Genève 1831). 8.

$\left.{ }^{6}\right)$ Bevbawtungen über bie Temperatur ber Begetabilien. Tübingen

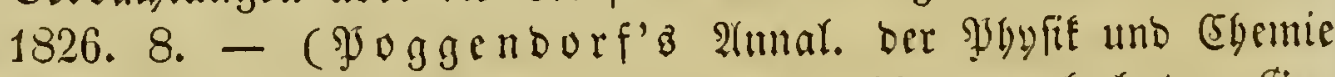
1827. BBo. 10. S. 561. - Bot. Siteraturblatt Der f. Gotan. Gie=

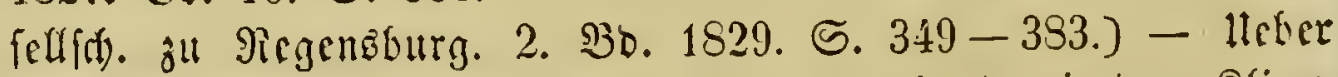
bie Temperatur, weldse Baum= unb Straudarten in bem Rima Deutioflanos alt ertrigen im Stalle find; mit einer tabella =

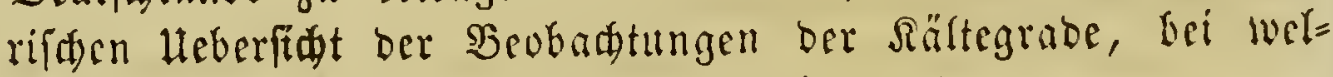
den uebrere berfatben erfrieren. (Tilbingen.)

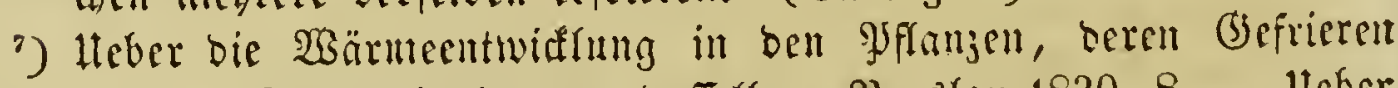

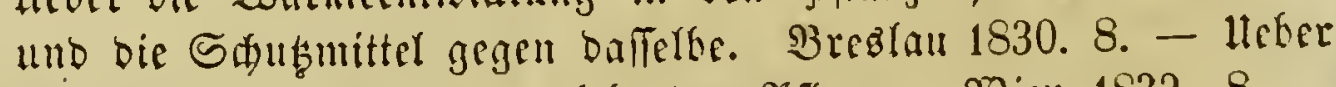
खärmeentwiatung in ber Irbenben Yflanje. Şsicn 1832. 8. -

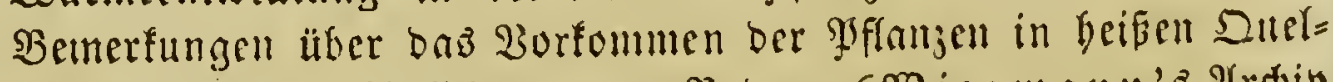

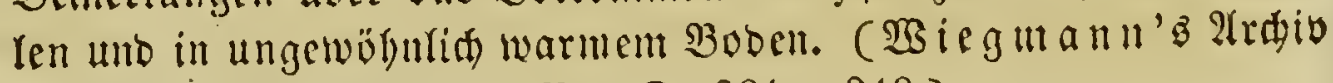
für Raturge [d. 1837. 1. 3. S. S. $201-210$.) 


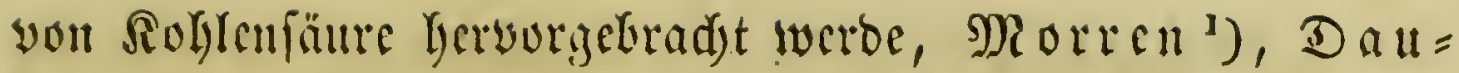

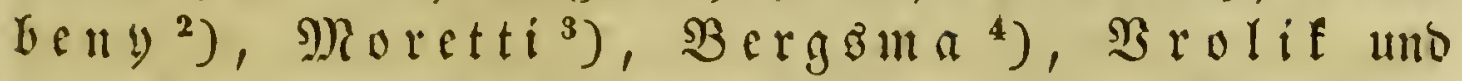

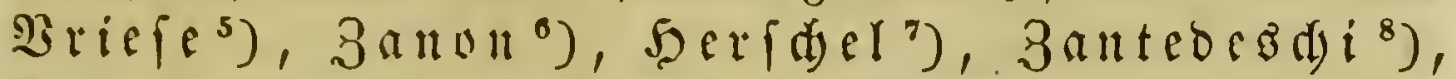

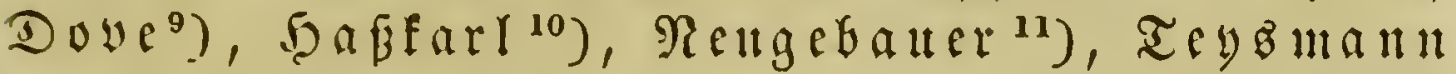
utto $\mathfrak{B}$ riefe ${ }^{12}$ ) t. $\mathfrak{A}$.

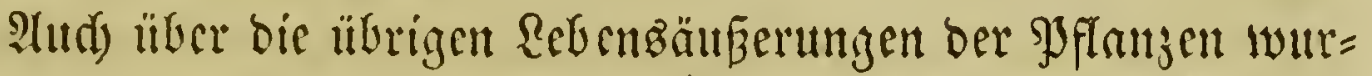

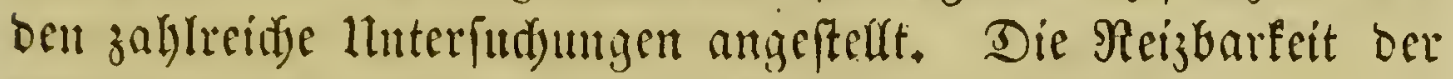

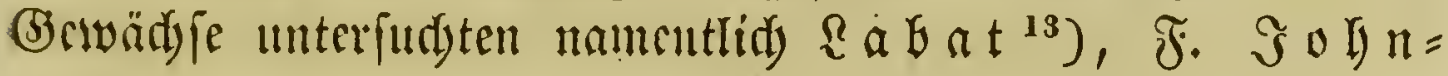

') Observations anatomiques sur la congélation des organes des végétaux. (Extr. des Bullet. de l'acad. roy. de Bruxelles, Tom. V. No. 3.)

$\left.{ }^{2}\right)$ On the action of light upon plants, and of plants upon the atmosphere. London 18:36. 4.

$\left.{ }^{3}\right)$ Sul influsso della luna nella vegetazione. Parma 1838. 8.

4) Observations thermo-électriques sur l'élévation de températion des fleurs du Colocasia odora. 1838.

5) Unterfudungen über bie Aroibeen. (Annal. des sc. nat. sec.

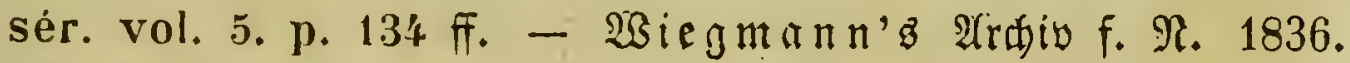
BD. 2. 5.95 ff.)

$\left.{ }^{6}\right)$ Sull' influenza elettrochimica delle terre sulla vegetazione. Belluno 1840. 8.

') On the action of the rays of the solar spectrum on vegetable colours. London 1842. 4.

s) Dell' influenza dei raggi solari rifratti dai vetri colorati sulla vegetazione. Venezia 1843. 4.

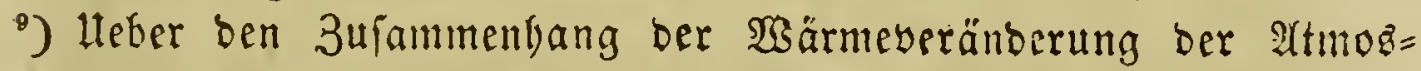
phäre mit ber Entrwitlung ber gfflanje. Berlin 1846. 4.

$\left.{ }^{20}\right)$ Heber bie Wä̈rmeentwiafung im Epabix ber Arcibern. (Flora 1847, No. 29.)

$\left.{ }^{11}\right)$ De calore plantar. Vratislaviae 1845. 8.

12) Heber bie erböbte Temperatur bei ber männliden Bräthe soir Cycas cricinnalis. (Nederlandsch Kruidkundig Archief. II Deel. $1-4$ stuck. Leyden $1849-1851$. p. $172-191$. 2(uฐ̊jug: Flora, 1851. S. 511.)

13) De l'irritabilité des plantes, de l'analogie qu'elle présente avec la sensilbilité organique des animaux et du rôle important qu'elle joue dans les diverses maladies des tissus végétaux. Paris 183\%. 8. 


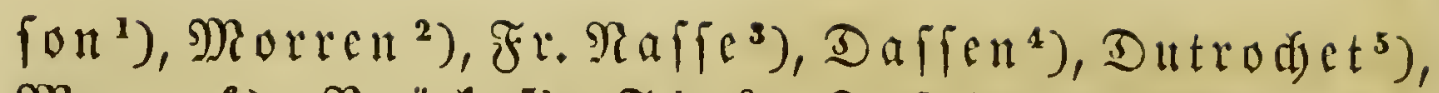

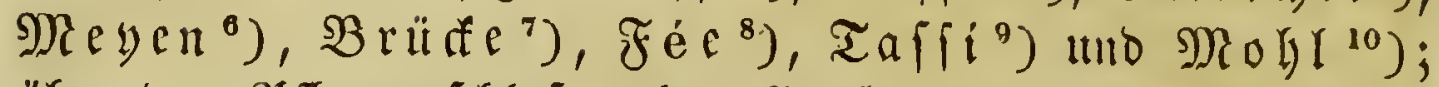

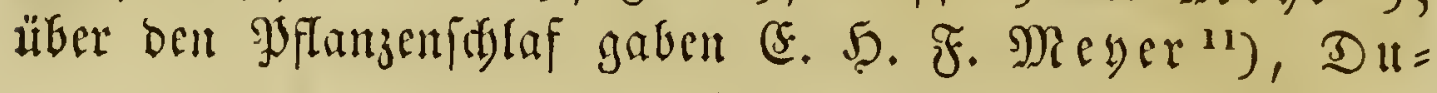

3) On the general existence of a newly observed on peculiar property in plants, and on its analogy to the irritability of animals. ( $(\$ n$ The Lond. and Edinb. philos. mag. Tom. VI. 1835. p. 16\%.)

2) Recherches sur le mouvement et l'anatomie du Stylidium graminifolium. Bruxelles 1838. 4. 1 tab. lithogr. - Recherches sur la Catalepsie du Dracocephalum virginianum. (Extr. des Bullet. de l'acad, róy, de Bruxelles 1836. No. 10.)

3) Heber die Reizbarteit der Staubfäben dez Błąffrautz unb ber Refiel, nebit cinigen Siemerkungen über bie äuseren Bebingungen

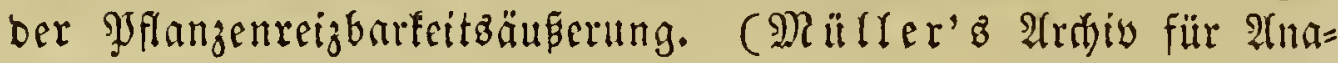
tomie 1835. S. 196.)

-) Natuurkundige Verhandel. van de hollandsche maatschapij der wetensch te Harlem 1835. Deel 22.

5) Mémoires pour servir à l'histoire anatomique et physiologique des végétaux et des animaux. Paris 1837. II voll. 8. 30 tab.

-) Sflanjenplyyfiologie ze.

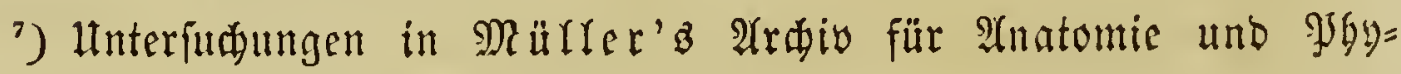
fiologie 1848. S. 434 ff.

$\left.{ }^{8}\right)$ Heber Mimosa pudica. (Compt. rendus de l'acad. franç. Séance du 21 Septbr. 1846.)

-) Heber bie Reizbarkeit ber Staubfäben bei Portulaca mucronata, speciosa etc. (Boorgeler. in ber bot. Section bei ber 5.

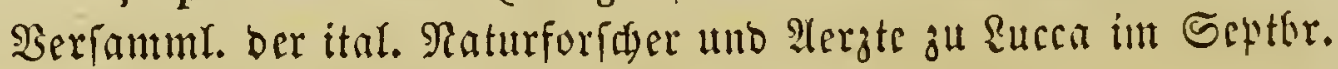

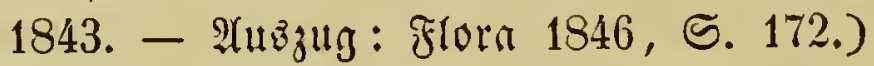

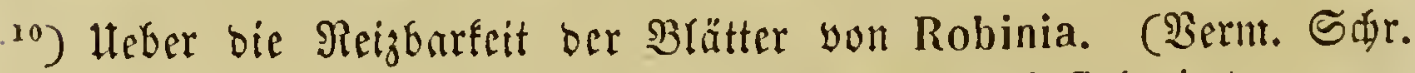

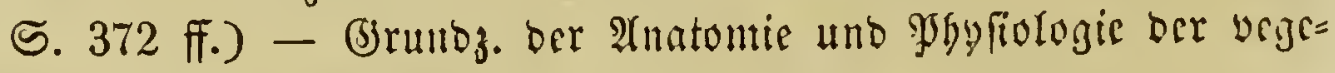
tab. Belle. S. 145 fi.

11) $\mathfrak{B}$ orträge auz bem (sebiete ber Raturwiffenfáaften unb Sofv=

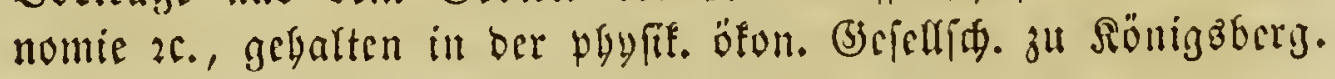

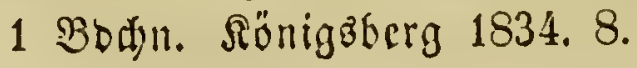




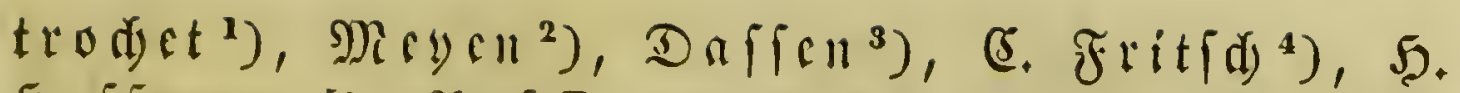

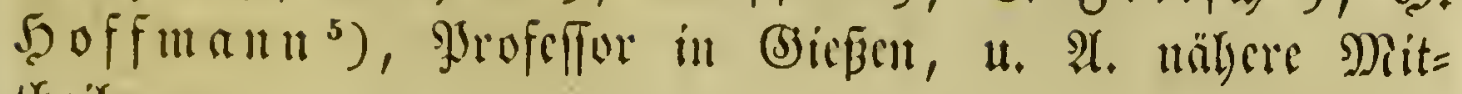
theilmigen.

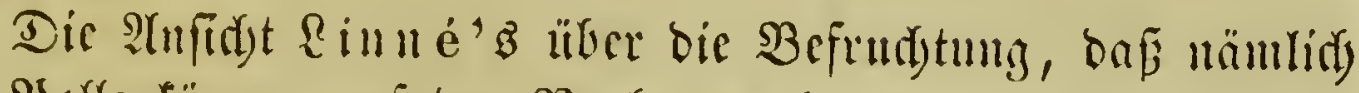

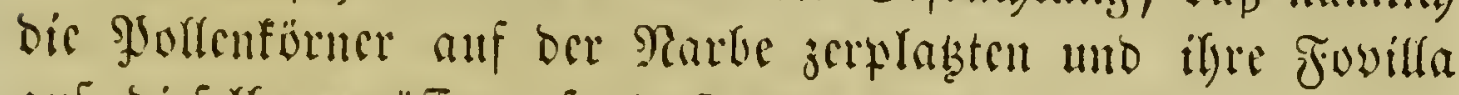

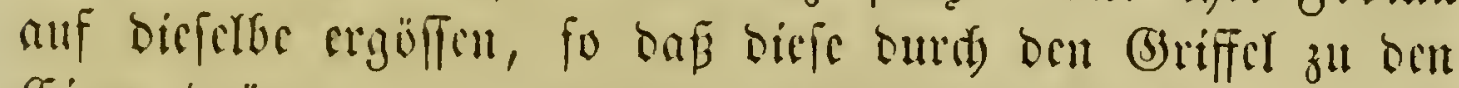
(sicrn bränge, war alligemein beibebalten worben, obgleids)

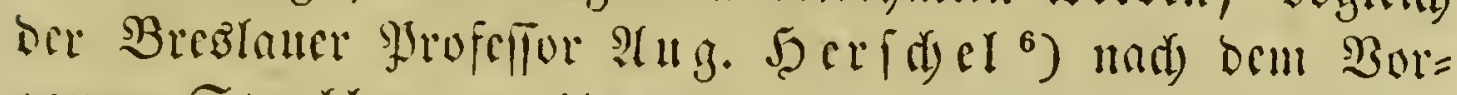
ganje Spaltanjani's mo Sdueluer's felbit nod in

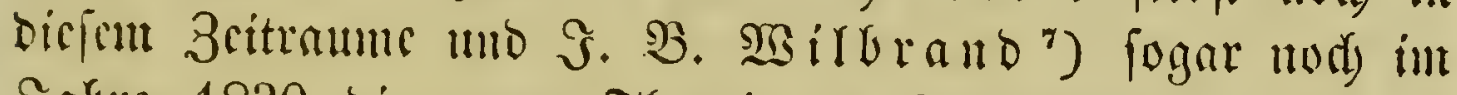
Saldre 1830 dic ganje Tleoric ser Sefrudtung in Albrebe

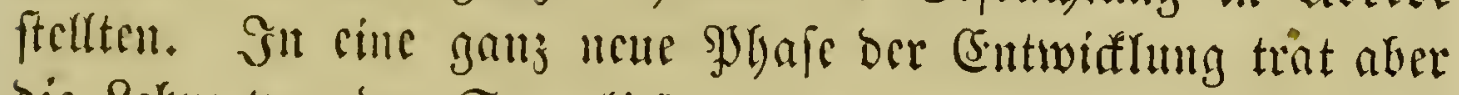

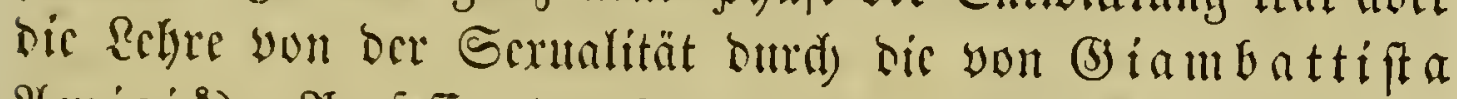

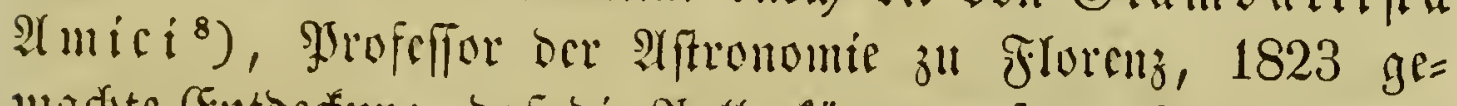

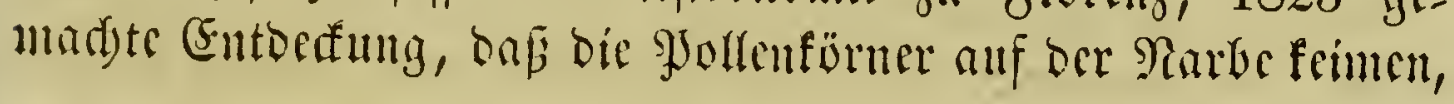

5) Du réveil et du sommeil des plantes. (Annal. des sc. nat. 1836. T. II. p. 177 - 189.) - Siebe aud oben S. 488, Rote 5. Mémoires etc.

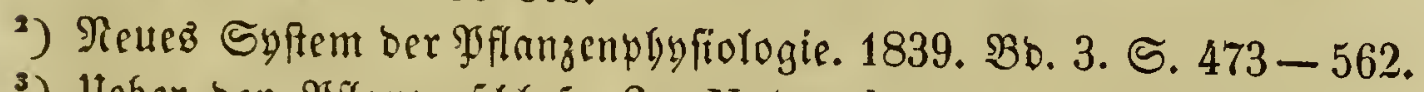

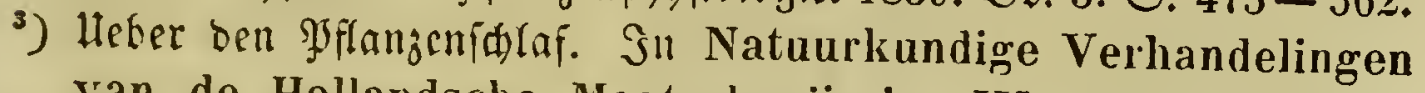
van de Hollandsche Maatschapij der Wetenschappen te Harlem. II Deel. 1835. S. $309-346$, uno Tijdschrift voor natuurlijgke Geschiedenis en Physiologie. 1837. S. 106 ปi 131.

4) Refultate melriälriger Beokad)tungen iiber jene Yflanzen, beren

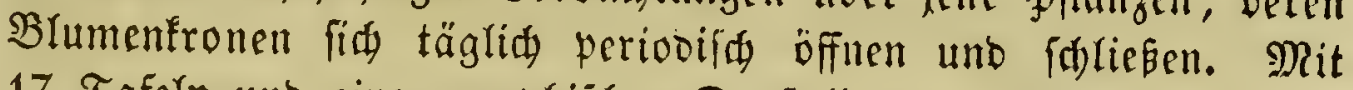
17 Tafeln uno einer grapbiicten Darfellung. SPrag 1851. Fol. (2118̊3ug: Silora 1850, ভ. 405 fi.)

5) Itnterfudungen itber ben Yfflamzenfiglaf. Bicéen 1851. 8.

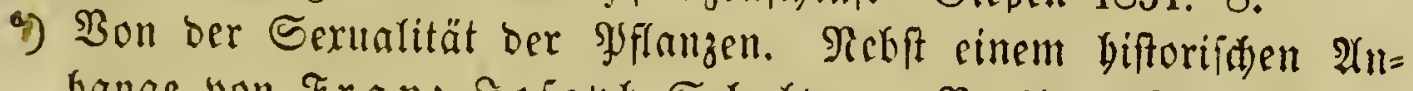
bange von franz Jofeph Sderver. Breslau 1820. 8.

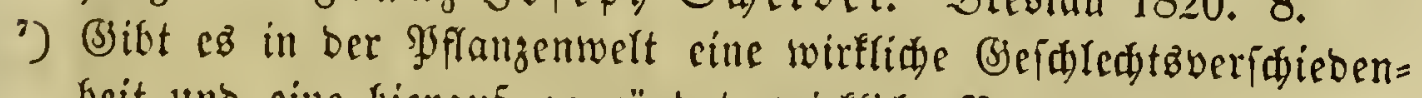
beit unb sine bicrauf gegrünbete wirflide Befrudtung? (Flora ober $\mathfrak{B o t}$. 3eit. 1830. BOo. II. S. $585-599,601-609$.

8) Heber die Wourenidläudje und bie Vicfrudtung. (Memor. di Societ. ital. Tom XIX. 1823. ङ. 253-257. - Annal. des sc. nat. Tom. XXI. 1830. S. 331.) 


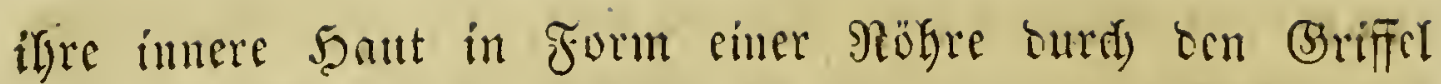
ins Dvarium Ginunter wäd)ft und mit ocm (sic in Berbinoung tritt. Balb wurbe bicfe (5ntocfmin burd) $\mathcal{A}$. Brongniart ${ }^{1}$ )

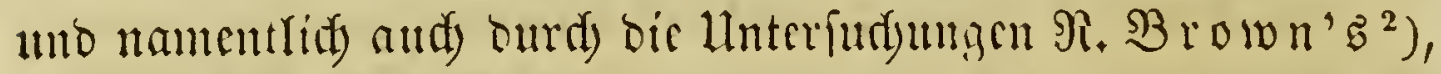

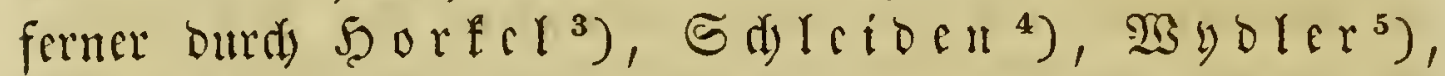

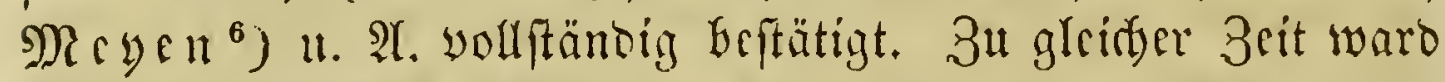
aud, wic fityon S. 478 fi. angegeticn wurbe, bic Bildung bes

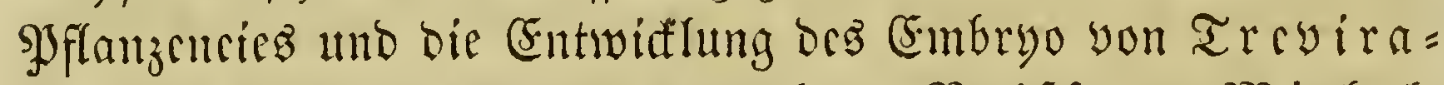

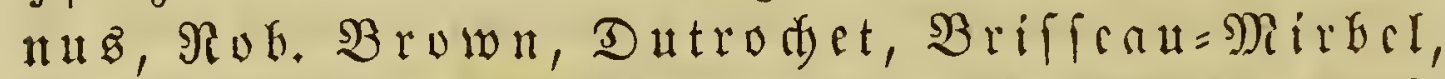
Brongniart, Fritfde, (sorba, Sd) reiben, Şof= meifter u. A. auf bas Sorgfältigfte unterfuddt. Sm Galyre 1837 ftellte (s) (eiden ${ }^{7}$ ) die $\mathfrak{B}$ chauptung auf, ber (Embryo

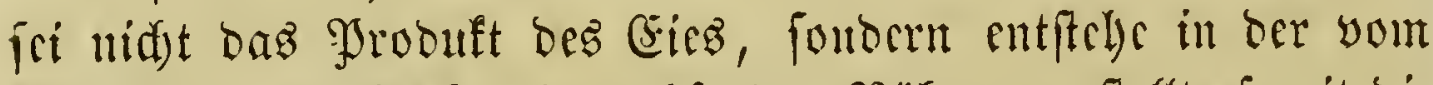

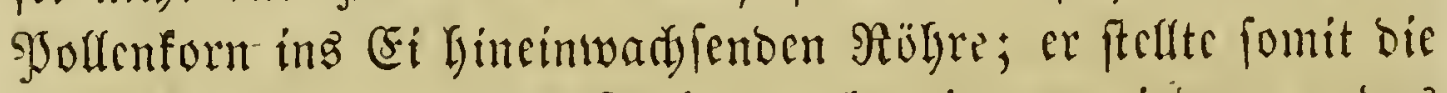

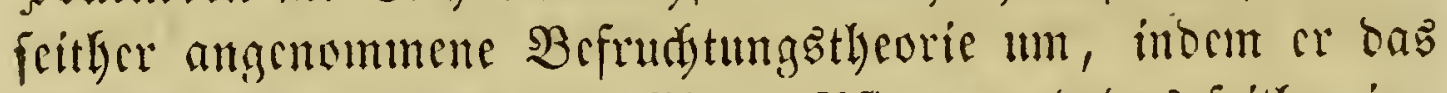
Solfenforn als bas waljre (5i der Syflanje uno bas feitler im=

1) Mémoire sủr la génération et développement de l'embryon dans les végétaux, phanérogames. Paris 1827. 8. 11 tab. - Deut $\{$ d: in Rob. Brown'ż Berm. Shriftell, beraubge= geben you Ree von Fented, Bo. IV.

$\left.{ }^{2}\right)$ Observations on the organs and mode of fecundation in Orchideae and Asclepiadeae. Lond. 1833. 4. - Deutí:

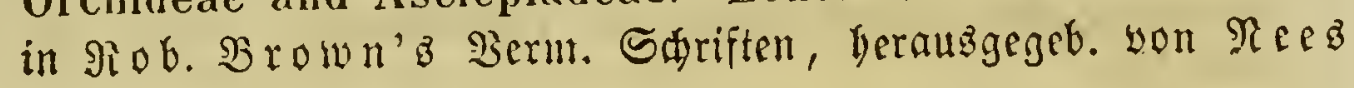
yon Fienbefi, BD. IV.

3) Iteber bie Sefrudtung. (Monatşnađridten b. Bertin. Affabemie. 1336, 2(uguft.)

4) Heber sifonng bes Fidens unb bie Entfebung bez Embryo ber

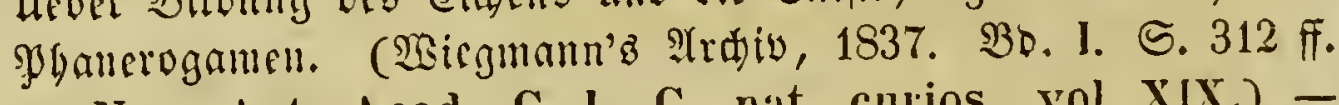
- Nov. Act. Acad. C. L. C. nat. curios. vol. XIX.) Dic neuen (sinwinfe gegen meine Regre you ber Befrudtung, alz

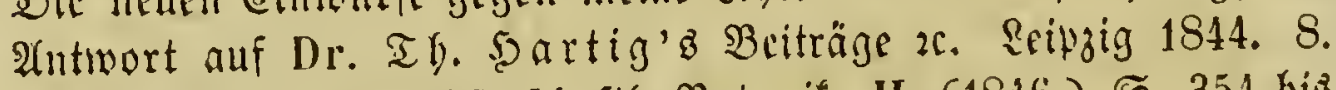
- (3rumbzüge ber wiffenforaftr. Botanit. II. (1846.) S. 354 bis 372. 3. 2ufl. (1850.) S. $355-372$.

5) Heber die $\mathfrak{B e f r u d}$ tung. (Bibliothèque universelle de Genève, Shtoberbeft 1838.)

-) Đrovitolog. Sootanif zf.

') Heber bie Birbung dez (5idend if. Sirle oben Rote 4. 


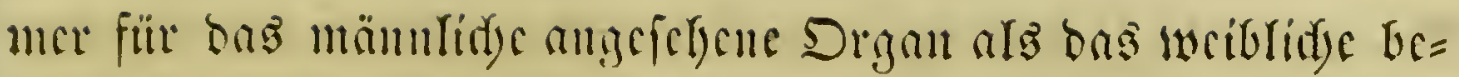

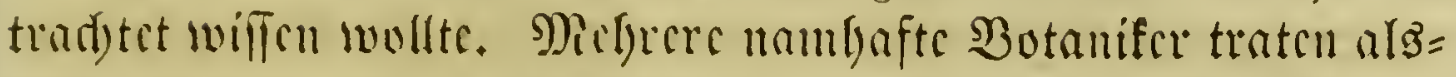

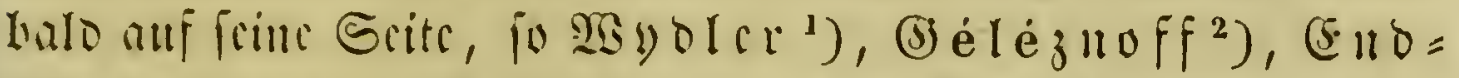

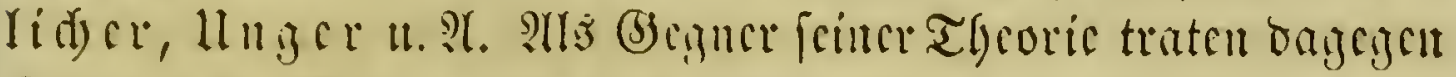

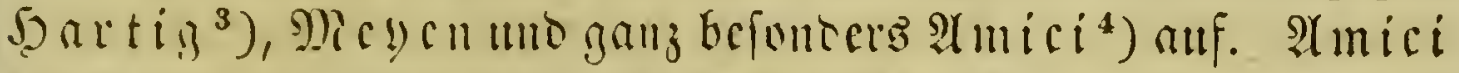

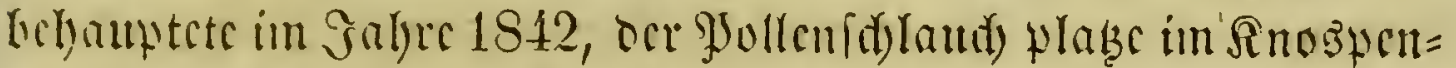

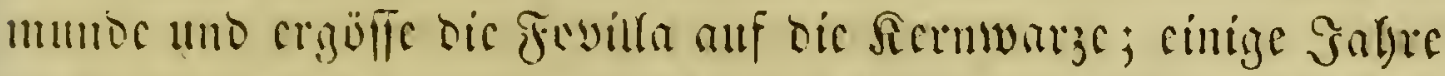

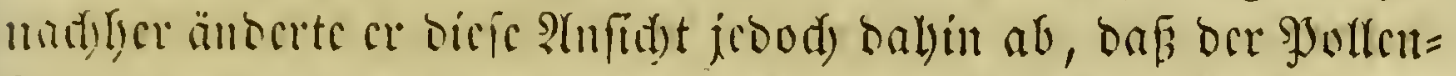

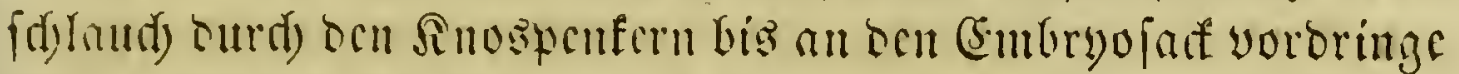

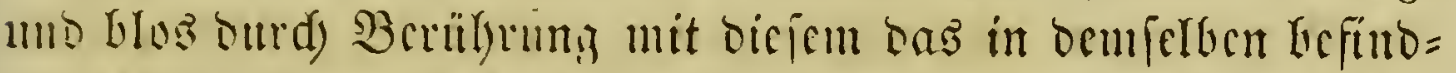

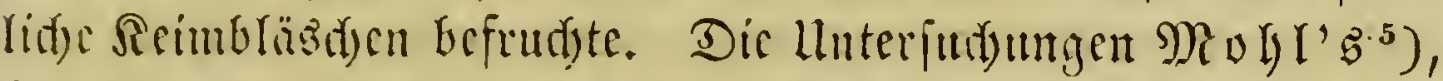

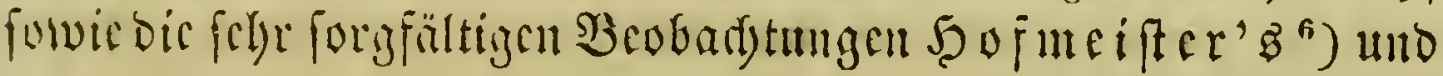

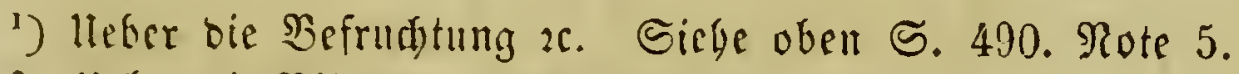

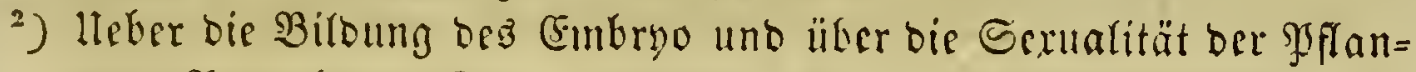

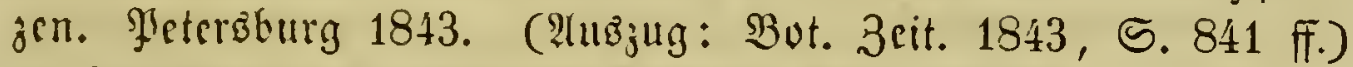
- Sur l'embryogénie du Melèze. 1849. 2 tab.

3) Reue Theorie ber Beirudutung ber צyflanzen. Braunfaweig 1842. 4. 1 Tafel. - Beiträge zur Entmif́lungảgeididte ber şflanzen. Berlin 1843. 4.

-) Heber bie befrudtung bei Cucurbita Pepo. (Sin bei bem Cont= grelife ber italien. Raturforíder zu গुabua 1842 gebaltener $\mathfrak{B o r}=$ trag. - Heberietzung: Flora 1843, S. 359. - Heber bie $\mathfrak{B} e=$ frudtung ber Drdibeen. Eine bei bem Songreffe ber italien. $\mathfrak{R a}$ turforfder zu Benua, im September 1846, yorgeléene 2Absand=

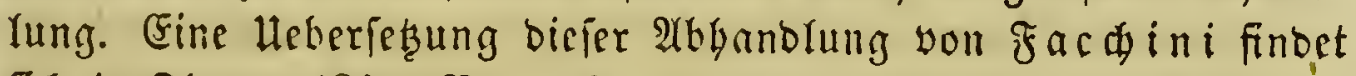

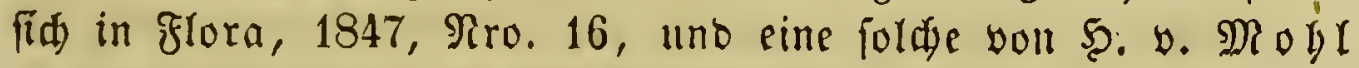
in $\mathfrak{B o t}$. 3eit. 1847, S. 364 fi., 381 ff.

5) Hcber bie Entwifflung Dea Embryo von Orchis Morio. (Bot. 3eit. 1847. 5. 465 fif.)

6) Unterfudungen beż Borgangez bei ber Befrudutung ber Sent= thercen. (Bot. Beit. 1847. S. 785 ff.) - Die (5ntferbung bes Embryo ber ßJancrogamen. Reipzig 1849. 4. 14 Tafeln. -

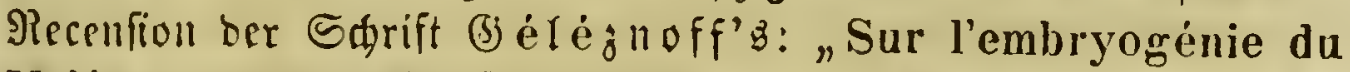
Melèze. 1819." (Sn Jlora 1850. S. 685 ff.) - Siecenfion ber

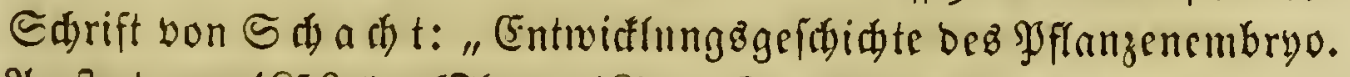
21mperbau 1850." (Flora 1851. S. 378 ff.) - 3ur Entwif*

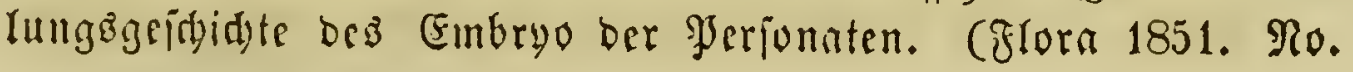




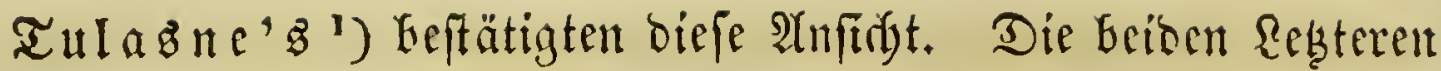

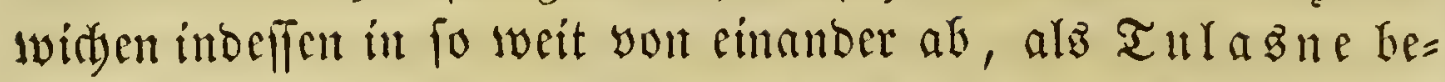
Jautptet hatte, bie 2 (nf

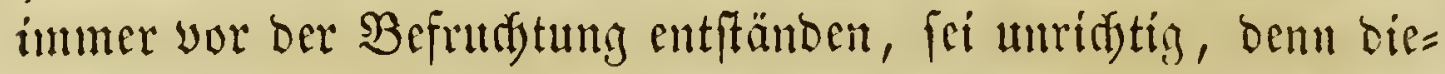
felben entftänden balo vor, bald währent, balo nadi ber $\mathfrak{B}_{e}=$

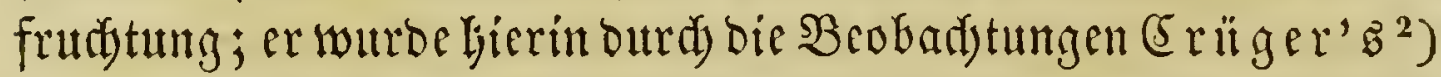
unterftübt. - Gn ber allermenteften 3eit lyat bie yorfin erwäbnte

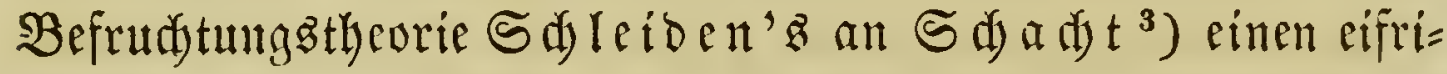
gen $\mathfrak{B e r t h e i b i g e r ~ g e f u m b e n ; ~ b a ~ a b e r ~ m e g r e r e ~ b e r ~ a u s i g e z e i f y e t ~ = ~}$ ften Shy frologen, namentlid) Shofmeifter und Mold, feine Bebauptungen für burdjaus irrig erflärt $\mathfrak{h a b e n , ~ f o ~ i f t ~ b i s ~ j e s t ~}$

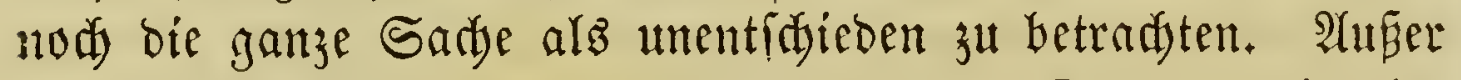
Den (Erwähnten haben aber aud (s) ärtner, (5) a

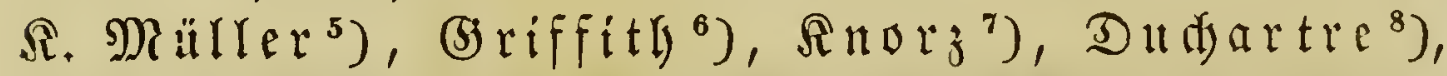

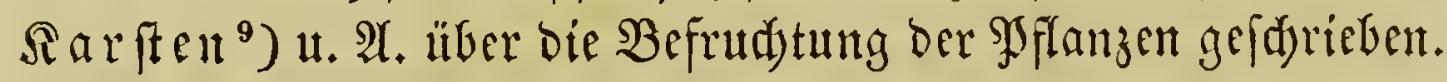

29.) - Bergleiflende $\mathfrak{u n t e r i u t u n g e n ~} 2$. Reipzig 1851. (Heber bie Samenbiloung ber Soniferen. S. $126-138$.)

1) Heber bie Befrudtung. (Compt. rendus. Tom. XXIV. [1847.] No. 24.)

2) Uteber Befrudtung bei Dell Srangen. (Bot. 3eit. 1851. S. 57 ff. 73 fi.)

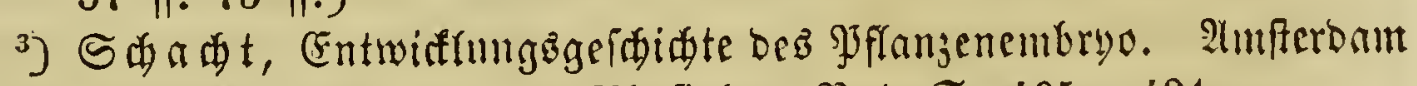
1850. 4. 36 Tafern. - 9j6yfiolog. $\mathfrak{B o t}$. S. $405-421$.

4) Heber bie Erzsugung Des Embryo in ben Samen ber phanero= gamifden Sffanzen. Eine ber Berjammlung itafienifaler Ratur= forfater zut Reapel 1846 vorgelegte 2lbganblung. Fine 1teter=

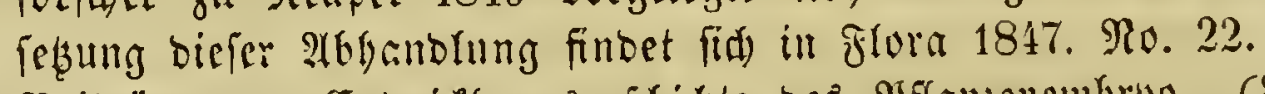

5) Beiträge zur Entwidung 3eit. 1847 . S. 737 ff. 753 ff. 769 fr.)

-) $\mathfrak{t} e \mathfrak{b e r}$ bie Entwifflung ber Samenfnozpell bei Avicennia. (Annal. des sc. nat. Janvier 1847.)

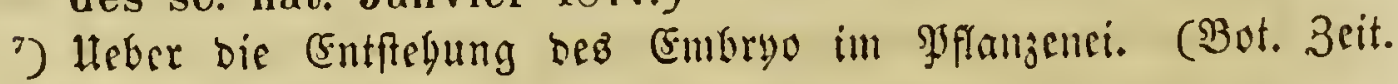
1848. S. 273 ff.)

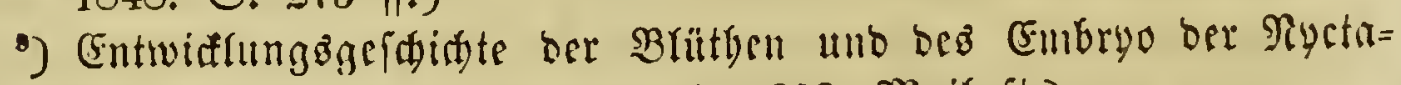
gineen. (Annal. des sc. nat. 1848. Maibeft.)

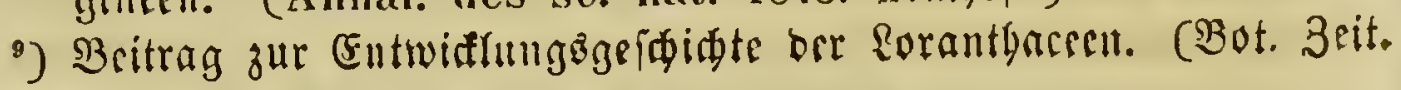
1852.) 


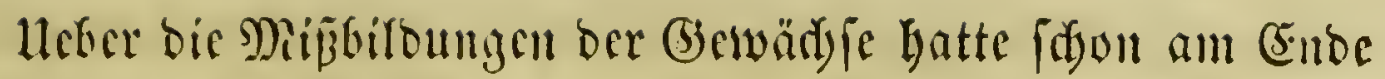

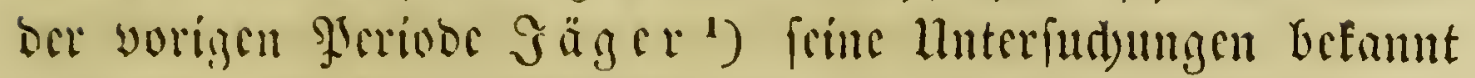

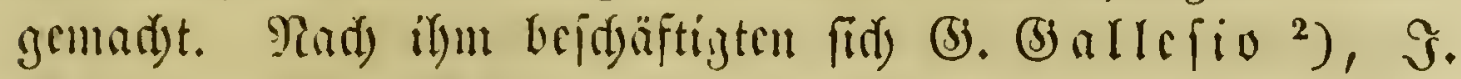
Ra

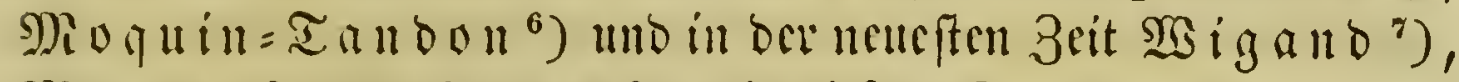

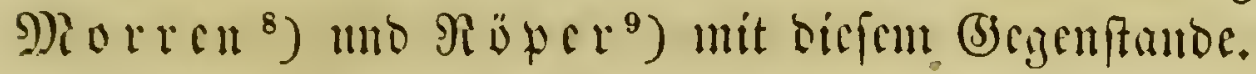

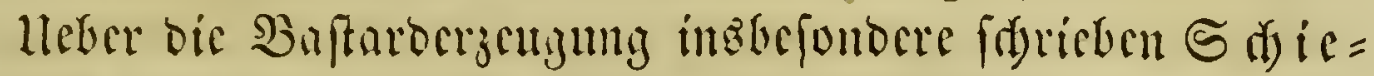

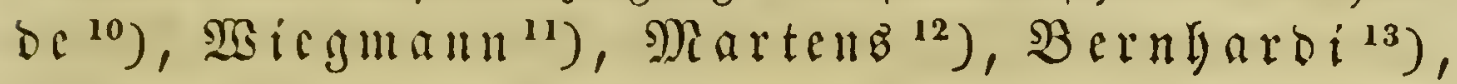

1) Heber bie Míbbiloungen ber (5ietwädje. Stuttgart 1814. 8. 2 Taf.

3) Teorica della reproduzione vegetabile e l'arte di ottenere fiori doppi e nuove sorta di frutta, ossia ricerche sopra la natura e le cause delle varieta e delle monstruosita. Vienna 1815. 8.

3) Observationes ad Peleoriarum indolem definiendam spectantes. Berolini s. a. 8. 1 tab.

4) Flora anomala. A general view of the anomalies in the vegetable Kingdom. Glasgow and London 1817. 8. 11 tab.

$\left.{ }^{5}\right)$ De Antholysi prodromus. Cum 93 iconibus in tabulis V. lithogr. Francofurt. a. MI. 1832. 8.

$\left.{ }^{6}\right)$ Elémens de tératologie végétale. Paris 1841. Deutfめ:

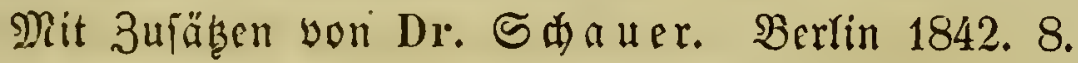

7) Grumblegung ber Siflanzenteratologie. Marburg 1850. 8.

8) Fuchsia et Lobelia, ou recueil d'observations de botanique etc. Bruxelles $1850-51.2$ Bbe. 8. - 2 uperbem finben fith viele 2lbbandlungen über bie Bifoungsabweidungen von $\mathfrak{M o r r e n}$ in ben Bulletins de l'Académie royale des sciences, des lettres et des beaux-arts de Belgique. 1848

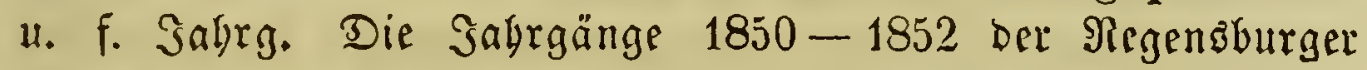

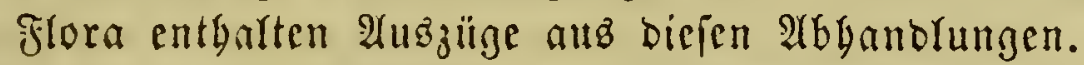

') Tlbnorme Rormalgeftaltungen. (Bot. 3eit. 185'. S. 185 ff.) Rormales und A(bnormis. (Bot. 3eit. 1852. S. 425 fi. S. 441 ff. S. 457 fi.)

$\left.{ }^{10}\right)$ De plantis hybridis sponte natis. Cassellis Cattorum 1825. 8.

") Heber bie Saftarberzengung im Pflangenreide. (Befrönte Jjreib= idrift. Braunidiveig 1828. 4. 1 Tafel.

12) Beobadytungen über Baftarbe. (Bulletin de l'Acad, roy. de Bruxelles 1837.)

"') Berllyarbi's Beobadytungen. (Dtto und Dietrid), Bar= tenzeitung 1840.) 


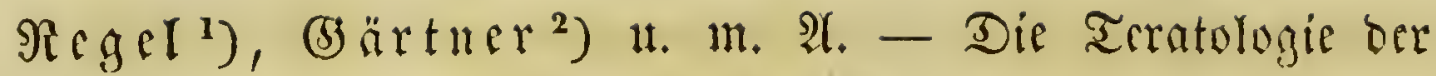

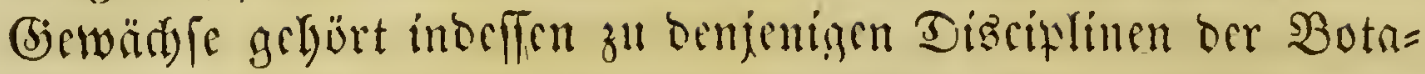
nif, werdise nody am wemigfen beleudstet find.

(5.benfo werbält es fids mit ber Reclere son ben Rrant=

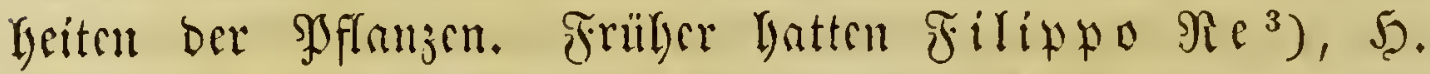

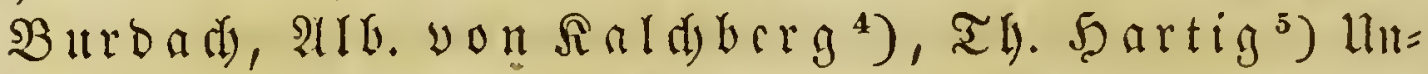
terfurdungen in bicfem Fad)e angeftellt; in ber neucren 3 cit

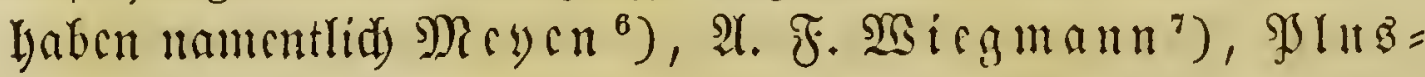

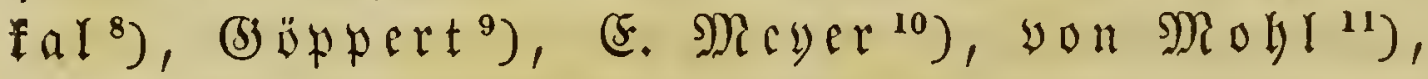

1) Bemerfungelt über Baftarbfarrn. (Bot. 3eit. 1843. S. 537 fi.)

2) Heber Baftarberzeugung im Siflamzenreidie. Stuttgart 1849. 8.

${ }^{3}$ S Saggio di nosologia vegetabile. Firenze 18:77. 8. - Saggio teoretico - pratico sulle malattie delle piante. Venezia 1807. 8. - Ed. II. Nilano 1817. 8.

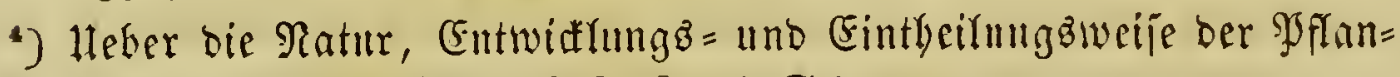

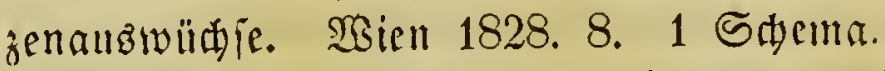

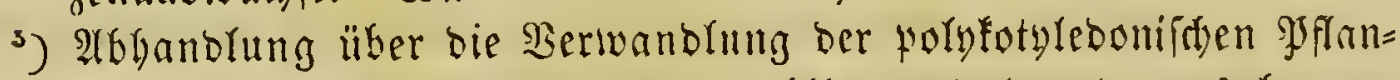

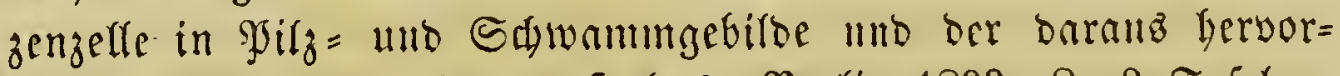

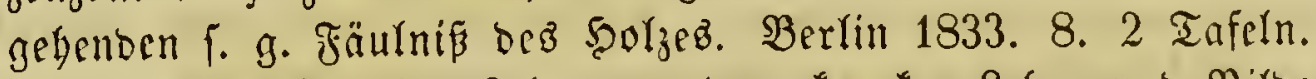

-) YSflam

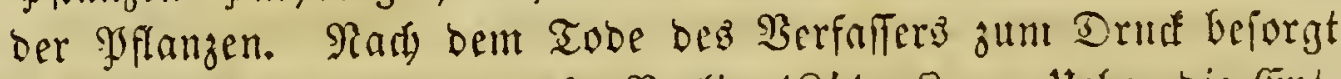
yon Ref yon Efenbeat. Berlin 1841. 8. - Heber bie Ent=

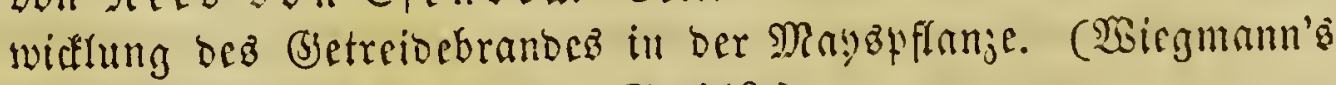

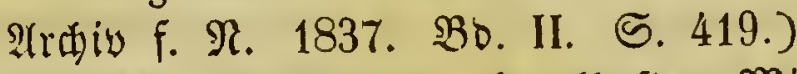

7) Die Siranfgeiten uno franflaften Misbiroungen ber (s)ewädie. Braunfdweig 1839. 8. 1 Infel.

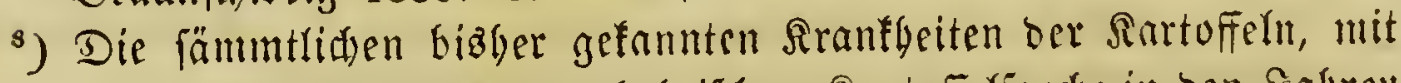

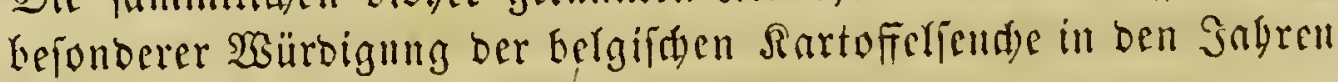
1845 und 1846. Brïnn 1847. 8.

9) Beobachtungent ither baz fogenamute theberwalfen ber Tanmen=

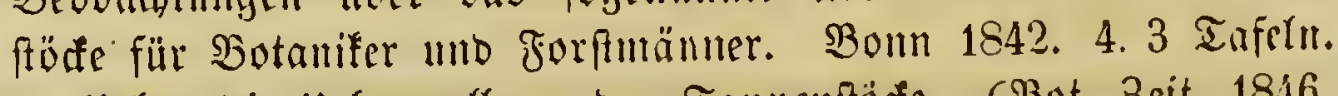
- Heber bis Heberwaflung ber Tanuenitöffe. (Bot. Zeit. 1846. (S. 505 ff.)

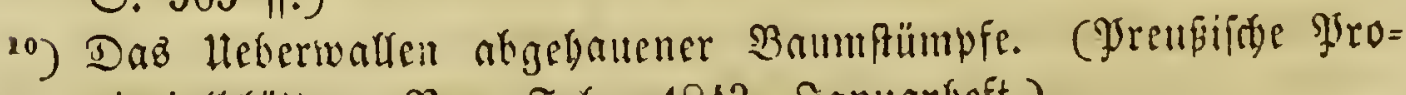
vinzialblätter. Reue Folge 1813. Sanuarlyeft.)

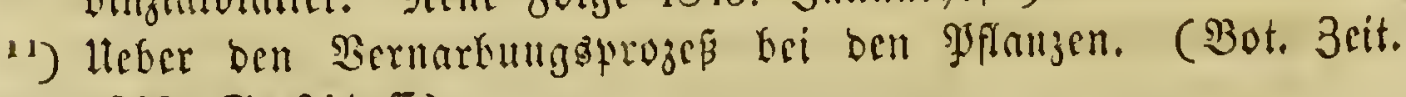
1849. S. 641 fi.) 


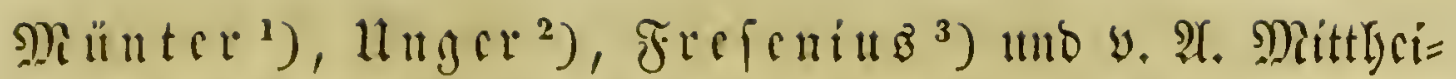

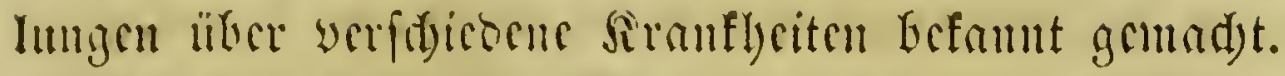

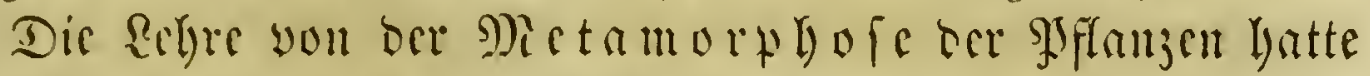

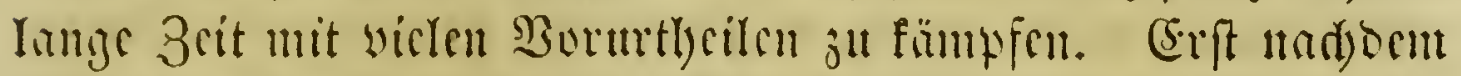

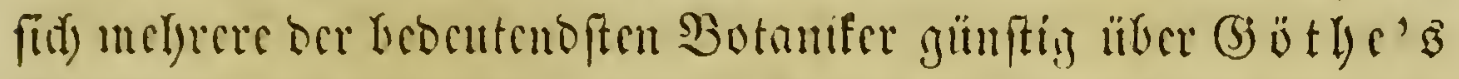

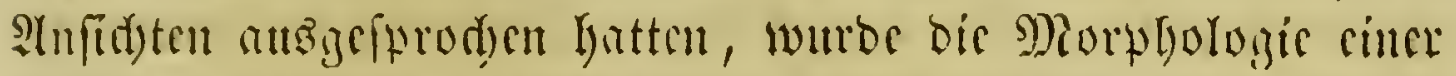

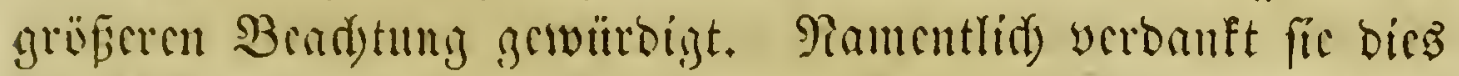

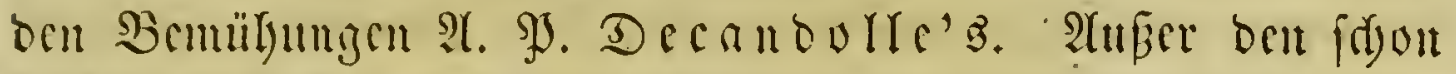

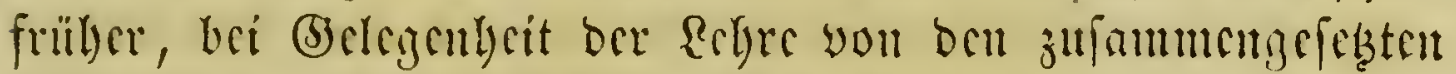
Drganen, genamuten Sdyrifteftern funo nod) bic Srbriften yon

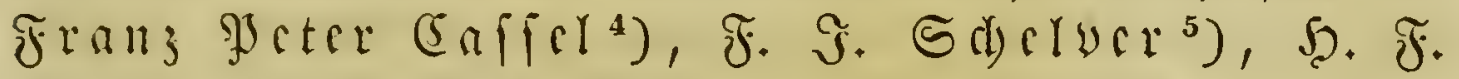

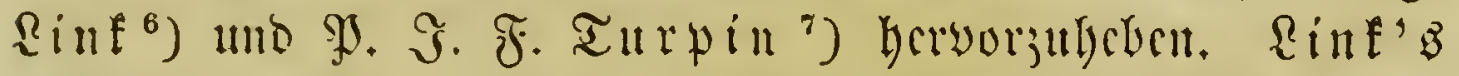

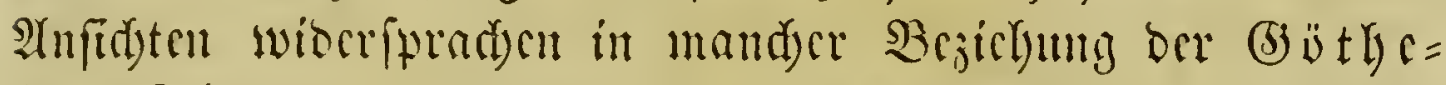

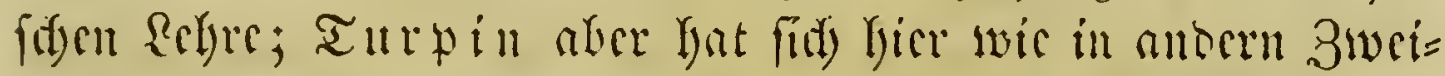
gan ber Shbyfologie nidyt felten burdi whantafiereidye Fiftionen

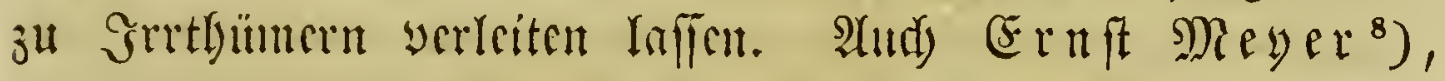

') Sur la maladie des pommes de terre. (Compt. rendus de l'acad. des sciences 1845. Séance du 3 Novembre.)

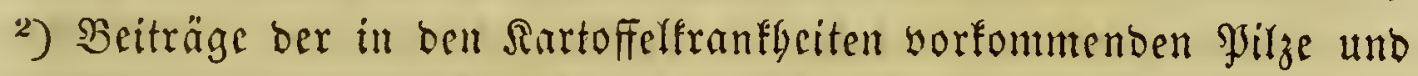
ber Urfatye ibres Entfegens. (Bot. 3tg. 1847. S. 305 ff.)

3) Sartoffelfranflycit und Rartofferpirge. (Jiora 1847. No. 1.)

*) Morphonomia botanica, sive observationes circa proportionem et evolutionem partium plantarum. Col. Agripp. 1820. 8. 1 tab.

5) Sritil ber Refre you ben (5ejd) ledtern ber gुflanze. Seeiberberg 1812. 8. Erfte Fortięzung. Daf. 1814. 8. 3weite Fortifetzung. Sartarube 1823. 8. - Rebens= uno Formgeididite ber Mfflanzen= welt. Erifter Banto. Scribelberg 1822. 8.

-) Elementa philosophiae botan. Berolini 1824. 8.

7) Essai d'une iconographie élémentaire et philosophique des végétaux avec un texte explicatif. Paris 1820. 8. 2 tab. - Organngraphie végétale. (Mém. du mus. d'hist. nat. T. XIV. 1827. p. $15-67$.)

3) Linnaea. 1832. $\mathfrak{3}$ ๖. 7. ․ 403 u. f. 


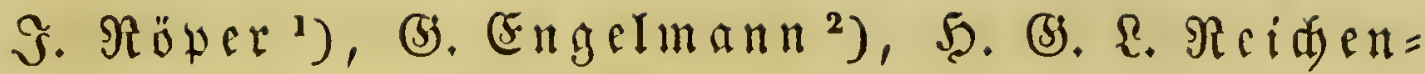

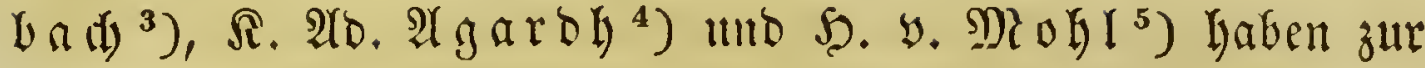
(5ruveiterutiz ber Eebre von ber Metamorwhofe beigetragen. Sill (England madyte juerif (bs ilbert $\mathfrak{T}$. $\mathfrak{B}$ urnett ${ }^{6}$ ) (Finigez

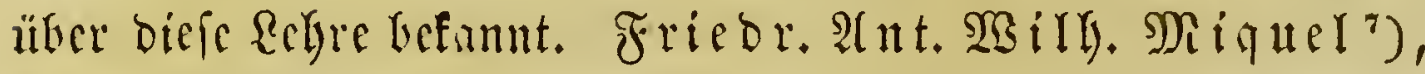

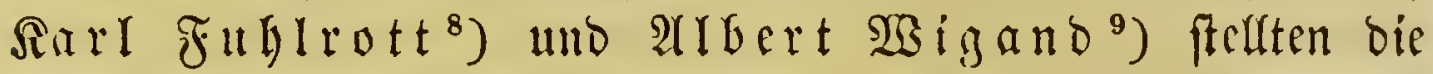
Refultate ber Metamorwlyojenlebre zufammen uno gaben eine

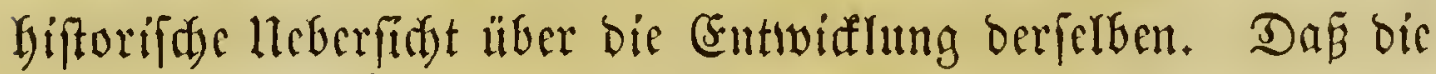

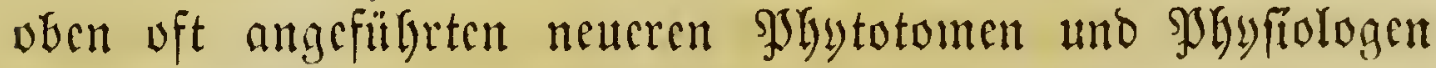
bie weitere Aluzbildoung ber Morphologie in ifren Sdriften fehr gefördert haben, bebarf faum einer bejonberen Erwäh= 11111!.

1) Enumeratio Euphorbiarum etc. 1824. - Observationes aliquot in florum inflorescentiarumque naturam. (Linnaea $\mathfrak{B}$ b. 1. $\subseteq . ~ 4: 33-466$.$) - De organis plantarum. Basi-$ leae 1828. 4. - De floribus et affinitatibus Balsaminearum. Basileae 1830. 8. 1 tab. (Linnaea BD. IX.)

$\Rightarrow$ De antholysi prodromus. Francof. a. M. 1832. 8.5 tab.

3) Botanif für Damen 2 .

4) Lärobok i Botanik. Första Afdelningen: Organografi. Malmo 1829-1830. 8. 4 tab. - Andra Afdelningen: Växt-Biologie. Nalmo $1830-1832$. 8. - Deutid): (Erfte $2 \mathfrak{d}$ th. von R. Meyer. Ropenthagen 1831. 8. 4 Tafern. 3weite $2(6$ th yon F. . 5. Ereplin. (3reifanarbe 1832. 8. 1 Tafel.

s) Heber bie Symmetrie ber \$gflanzen. Tübing. 1836. 8. - Beobad= tung über bie $\mathfrak{H}$ mwwanblung von $\mathfrak{A}$ ntheren in Carpelle. Tibbing. 1836. 8. - Hefeer bie männliḑen Blütלen ber Eoniferen. Täbing. 1837. 8. - Morplorogifase Betradtungen iiber baz Sporangium

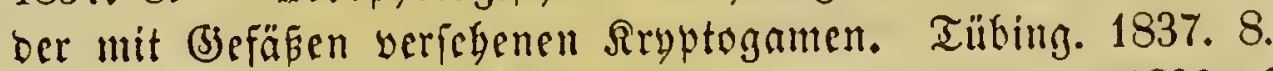

-) Bot. Riteraturblatt ber bot. (Jefellfa. zn Regengburg. 1829. BB. 2. S. 427.

7) Commentatio de organorum in vegetabilibus ortu et metamorphosi etc. praemio ornata. Lugd. Batav. 1833. 4. 2 tab.

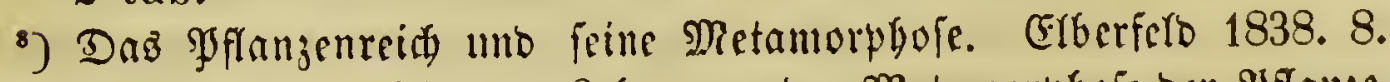

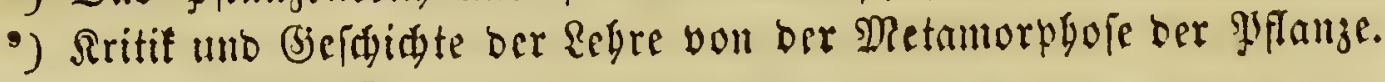
Reipzig 1846. 8. 


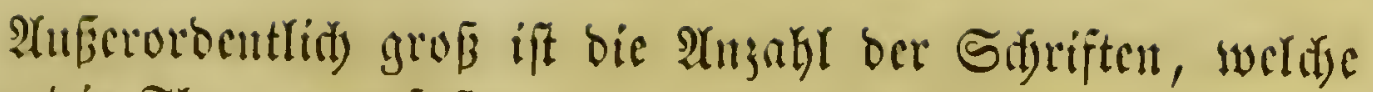

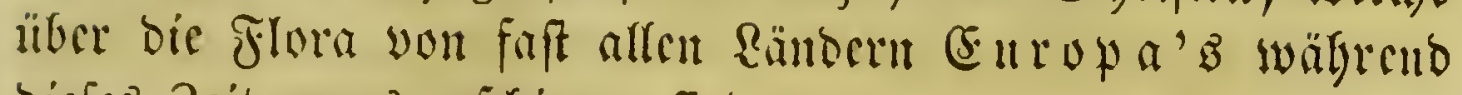
biefes Zritranms crifjicuen finto.

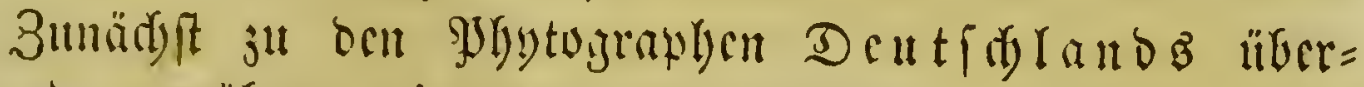

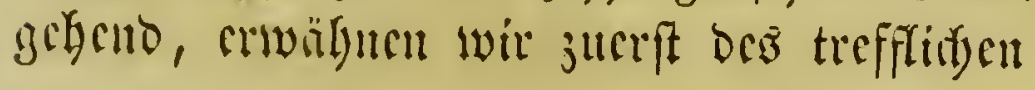

\section{Scittrid) Fricorid) Rillt,}

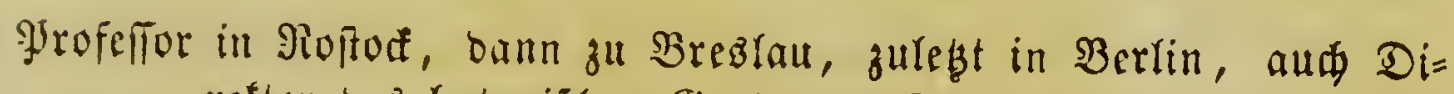
rettor bes botanifden (jartenz bajelbit, geft. 1850.

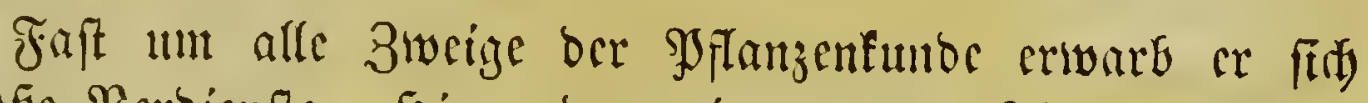
grofe Berbienfte. Sicr reben wir nur von feinen fflanzen=

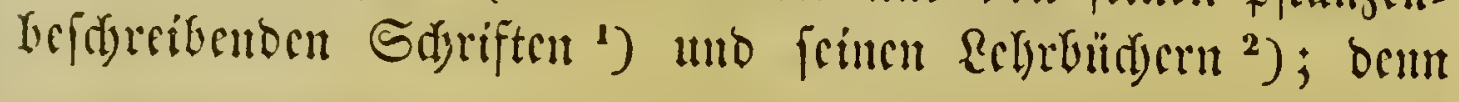

1) Eowobl allein als in Berbinoung mit Friebrid St to uno

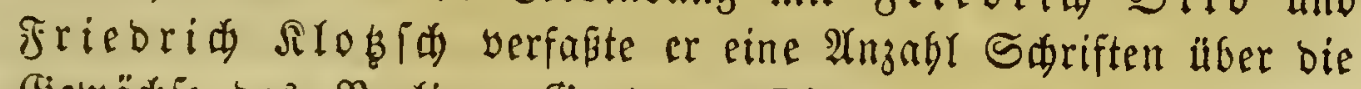
(Jelwäd) je bez Berliner (Bjartenz. Dissertationes botanicae, quibus accedunt Primitiae horti botanici et Florae Rostockiensis etc. Suerin 1795. 4. - Enumeratio plantarum horti reg. botan. Berolinensis altera. Berol. 1821 1822. II voll. 8. -- Icones plantarum selectarum horti regii botanici Berolinensis cum descriptionib. et colendi ratione. Fasc. I-X. Berol. 18:20-1828. 4. 60 tab. col., unb P. I. Fasc. I-VIII. Berol. 1828 (-1831). 4. 48 tab. col. - Heber bie Battungen Helocactus uno Echinocactus

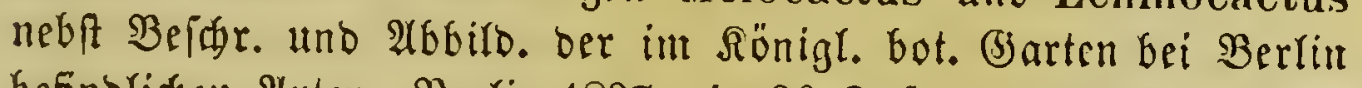
befindliden $\mathfrak{A}$ rten. Berfin 1827. 4. 26 Iaf. - Hortus regius botanicus Berolinensis descriptus. Berol. 1827 - 1833. II voll. 8. - Icones plantar. rarior. horti reg. bot. Berolinensis. Berol. 18't-18\%' 4. 126 tab. col. - Filicum species in horto regio botanico Berolinensi cultae. Berol. 1841. 8. - Abietinae horti reg. bot. Berolinens. cultae. Halae 1841. 8.

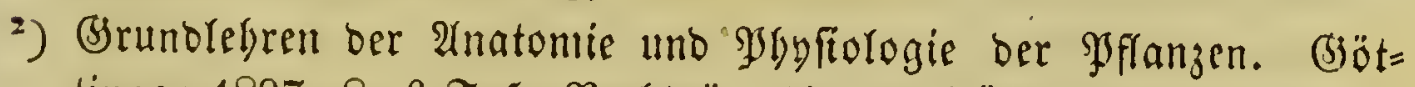
tingen 1807. 8. 6 Taf. Rađträge bier ̧̆u: (5ö̈ttingen 1809-1812. 2 Sefte. 8. - Elementae philosophiae botanicae. Berol. 1824. 8. Ed. II. Ibid. 1837. II voll. 8. 4 tab. - Şanbbuda

E. Binfler, Beff. b. Botanit. 
feime anatomifoen und whyfologifonen Forfatungen find bes reits wben getwïrbigt worben. Ramentlid) auf bie Befdyrei= bung ber Sroptogamen wande er feine 2ufmerfiameit, und inzbejondere bie Silje warben von ifm felge forgfältig belyan=

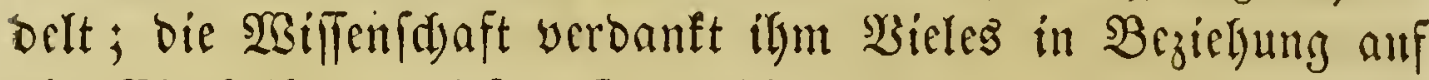
bie Sintbeilung bicjer (bicwäd) fe; megrere neue (b)attungen Der Rryptogamen wurben zuterft von ifm aufgeftellt.

Einer ber würbigften Beteranen unferer SBiflenjdaft ift

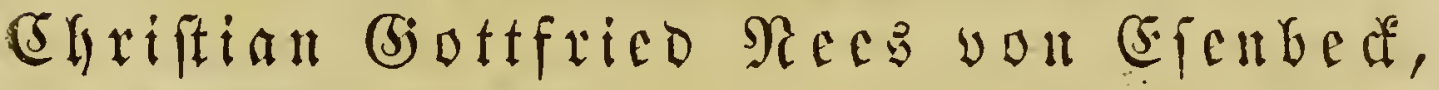

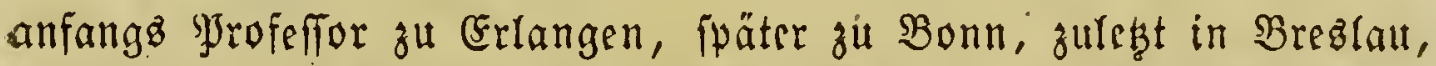

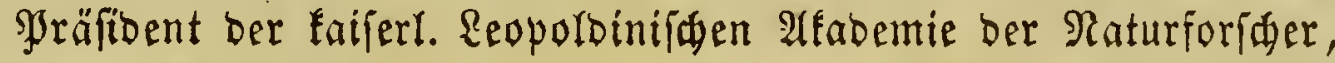

S. 309 fdon aufgefithrt. In biejer Syeriode fein erfolgreidjez

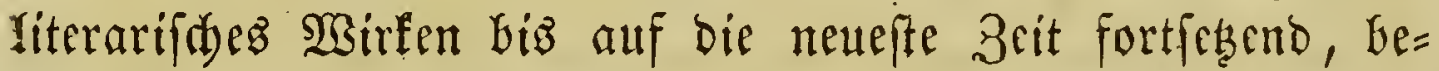
reidjerte er ben literarifaen Sdats oer Botanil burd) cine grofe Reife yorzügliduer Monographieen ${ }^{1}$ ), bie er zun Theil

zur Erfennung ber mutbarften unb ant bäufigften vorfommenben

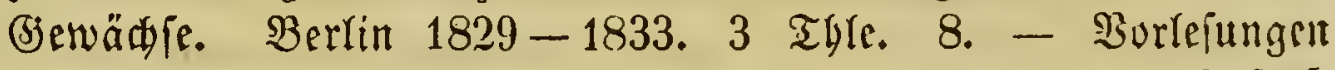
über bie Rräuterfunte I, 1. 2. Bertin $1813-1845$. 8. 3 Taf. - Einer befonberen Erwägnung verbienten feine Gabreaberidte

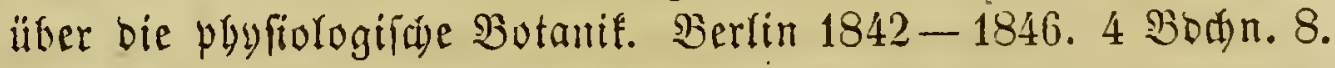

-) Synopsis specierum generis Asterum herbacearum, praemissis nonnullis de Asteribus in genere, eorum structura et evolutioni naturali. Exercitatio quae praelectiones suas, die IV Calendas Maji inchoandas indicit et simul monographiam Asterum herbaceorum mox edendam commendat. Erlang. 1818. 4. - Heber bie bartmürtbigen Enjian= artur. Erfang. 1818. 4. - Horae physicae Berolinenses collectae ex symbolis virorum doctorum II. Fr. Link, K. A. Rudolphi, F. Klug, Chr. Gottfr. Nees von Esenbeck, F. Otto, A. v. Chamisso, Chr. Fr. Hornschuch, D. Fr. Ludw. von Schlechtendal, Chr. G. Ehrenberg. Edi curavit Chr. Gottfr. Nees von Esenbeck. Bonnae 1820. Fol. 27 tab. - Agrosto- 
nllcin, fum Theil in Berbinbung mit anberen Forfdern Geraut= gab, nahm thätigen Antheil an ber von $\mathfrak{B} \mathfrak{Y}$ f f und $\mathfrak{F}$ inger $=$ b) ut weranftalteten Flora von Deutfolant, bearbeitete in $\mathfrak{B c r}=$ binoung mit (5)r. Fricbr. நornfduds unb Gafob

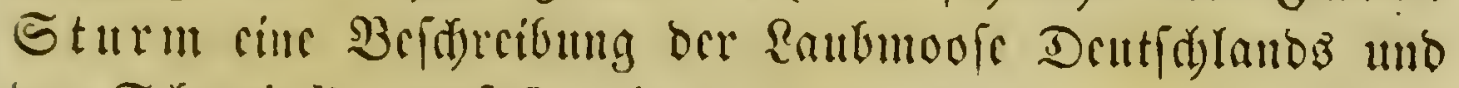
ber Edywcis ${ }^{1}$ ), verfafite cinc Naturgcidyidste ber curopäifden

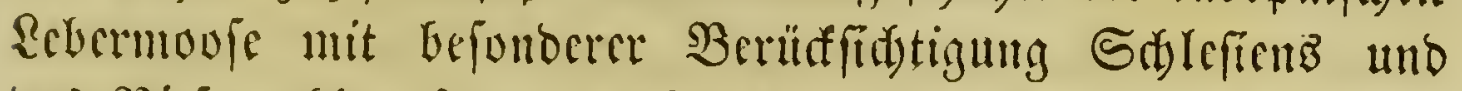

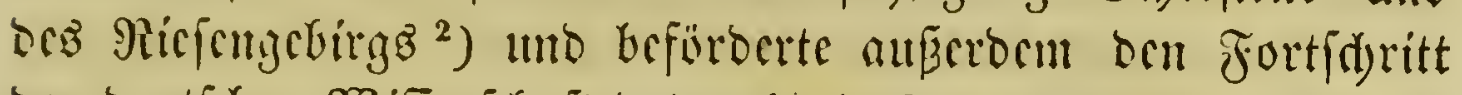

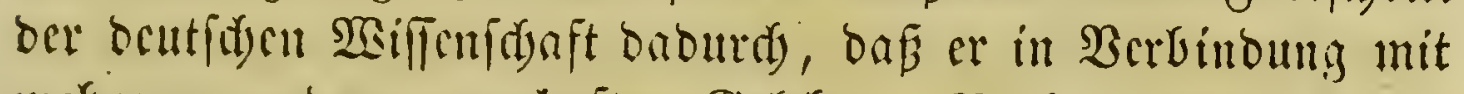

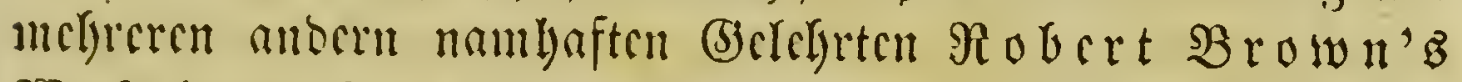

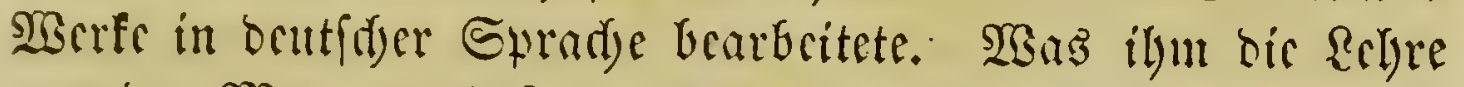

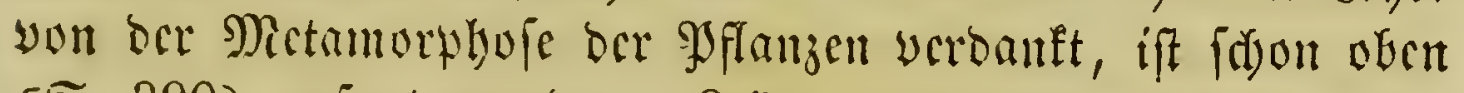
(S. 390) gefagt worben. Rciber wuthe diefer chrwürroige

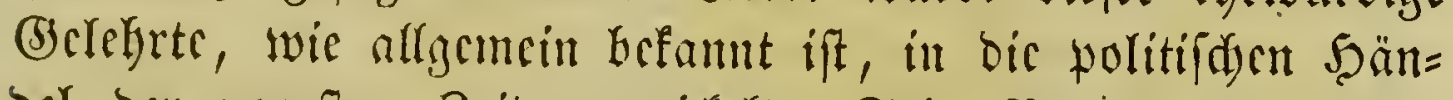

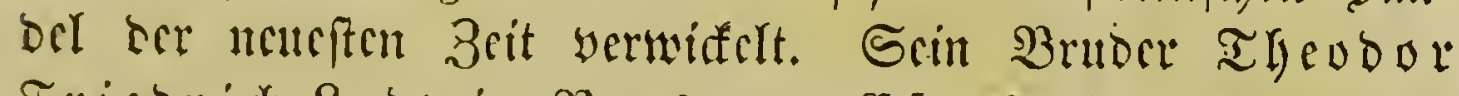
Fricorid) Rubivig Res von Eenbed, geftorben als

logia brasiliensis auctore C. G. Nees von Esenbeck. Stuttg. et Tubing. 1829. 8. - Enumeratio plantarum cryptogamicarum Javae et insularum adjacentium, quas a Blumio et Reinwardtio collectas describi edique curavit. Fasc. prior. IIepaticas complectens. Vralislav. 1830. 8. - Genera et species Asterearum. Vratislaviae 1832. 8. - Systema Laurinarum: Berol. 1836. 8. Cum charta distributionem geographicam exhibens. - Kamptzia, novum arborum Myrtacearum genus. Vratislaviae ad Viadr. 1840. Fol. 2 tab. - Florae Africae australioris monographicae. I Gramineae. Glogaviae 1841. 8. - Ad socios literae etc. Adjecta est Lepida gathidis, generis ex Acanthacearum ordine illustratio monographica. Vratislaviae ad Viadr. 1841. 4.

') Bryologia germanica. Püruberg 1823-1831. II voll. 8. 43 tab. col.

2) Raturgeídidte ber europäifden Rebermoofe. Bertin und Brestau 1833-1838. 4 Bbe. 8. 1 Taf. - Synopsis Hepaticarum. Conjunctis studiis scripserunt et edi curaverunt C. M. Gottsche, J. B. W. Lindenberg et Chr. Gottfr. Nees von Esenbeck. Hamburgi 1844. 8. 
Jrufellor zu Boum in Gahre 1837, war ein Kebeutender Siemer ber Siryptogamen ${ }^{1}$ ). Scine Splanzengattungen ber

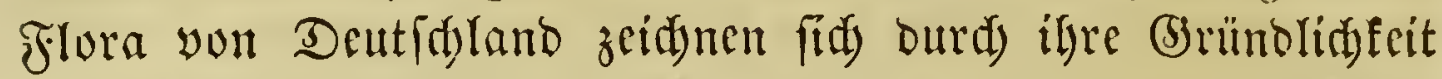
yor andern ähnlidien $\mathfrak{W e r f e n}$ aus ${ }^{2}$ ); von nidst geringerer

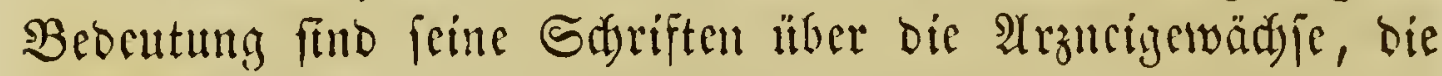
cr in $\mathfrak{B e r b i n d u n g ~ m i t ~ c i n i g e n ~} \mathfrak{A}$ (noen herausgab. ${ }^{3}$ )

Hnter ben Sefdreibern der Deutidyen Floea if der oben als Syftematifer borügrte Şeinrid Gottleb Rubivig Reidentady bejonders heryorzufeben. Seine phytographi=

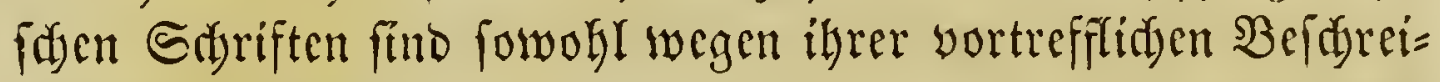
bungen, als audi beshalb, wcil barin vicle neue Gattungen uno $\mathfrak{A}$ rten aufgeftert fino, Gemerfenbiwerth ${ }^{4}$ ). (Fr war Mit=

1) De muscorum propagatione. Erlangae 1818. 4. 1 tab. col.

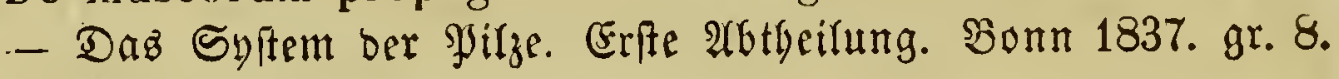
12 foldor. Taf.

$\therefore$ Genera plantarum florae germanicae, iconibus et descriptionibus illustrata. Bonnae 1833-1845. Fasc. I-XXIV.

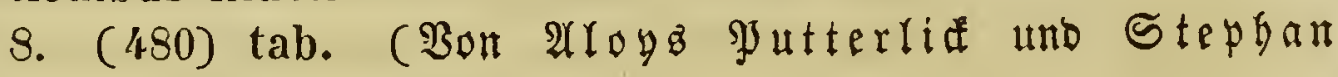
(Fnolici)er fortgeietst.)

3) Plantae officinales. Saumml. off. SYflanzen. Mit ritgographirten

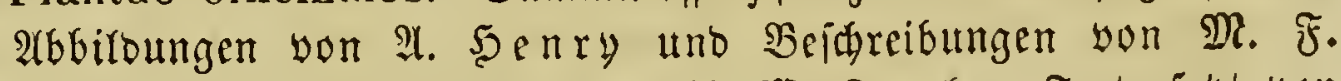

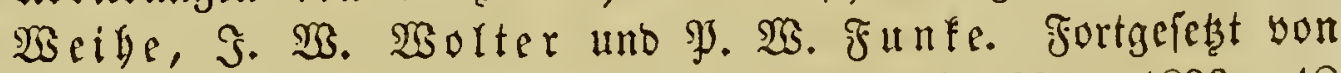

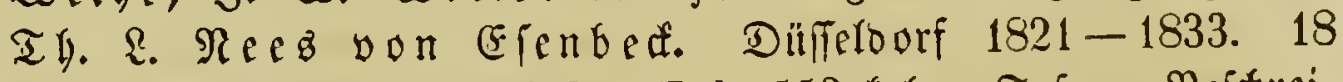
5efte unto 5 Supplementbefte. Fol. 552 foror. Taf. - Beffrei $=$

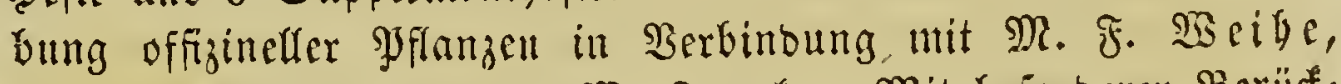

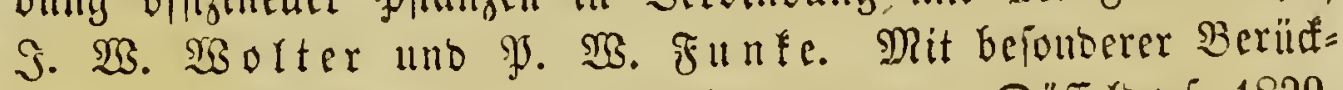
fidtigung ber fonigl. preus. \$Yharmacopoc. Düfteroorf 1829. gr. Fol. - Sanbfud ber mebicinifa) = prarmacentifaen Botanit.

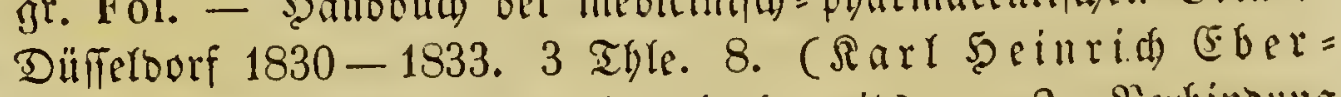
unaier arbeitete an biejeur Soanbbudse mit.) - Su Serbinoung mit 23 . Sillning bearbeitete er aud bie iajün blübenden (Be=

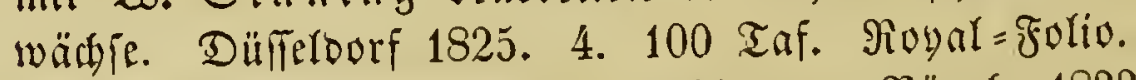

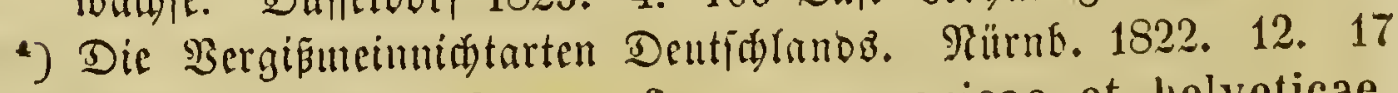
folor. Iafern. - Icones florae germanicae et helveticae. Cent. I-X. Lipsiae 18:34-1848. X voll, 4. 1036 tab, col. - Flora germanica excursolia, ex affinitate remni vegetabilis naturali disposita, sive principia synopseos plan- 


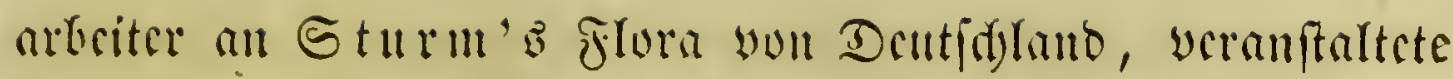

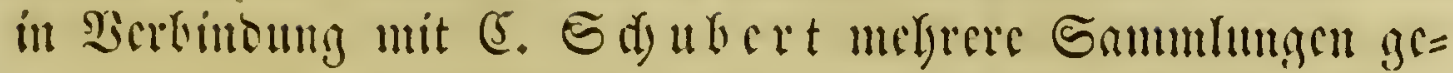

tarum in Germania terrisque in Europa media adjacentibus sponte nascentium cultarumque frequentius. Lipsiae $1830-$ 1832. 12. 2 tab. - Florae germanicae clavis synonymica. Lipsiae 1833. 12. - תupferfammlung zum praftifden beutiden Botanifirbudge. Grefte und einjige Rieferung. Enthält: Seimung und Sinospung und 294 (j)attungen ber beutiden Flora mit igren Inatyjen. Reipjig 1836. 8. 12 Iaf. - Der beutidae Botanifer.

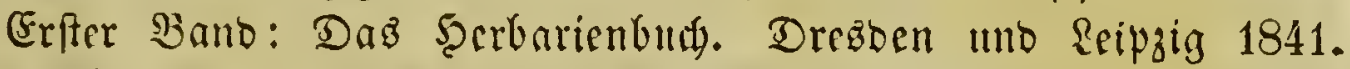

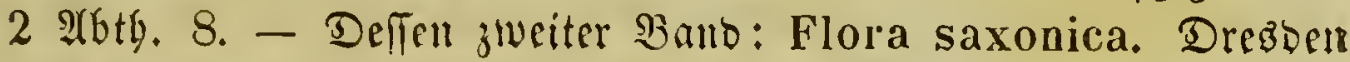

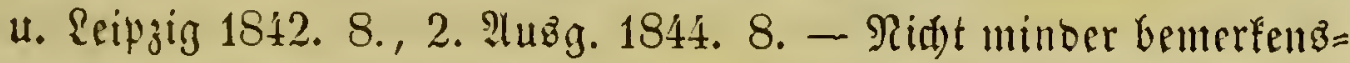
werth find feine Sdjriften, bie von bem geiammten Gewäd) Breide und ben exotídsen Pflanjen Gandeln: Iconographia botanica, seu Plantae criticae. Icones plantarum rariorum et minus rite cognitarum indigenarum exoticarumque, iconographia et supplementum, inprimis ad opera Willdenowii, Schkurii, Personii, Roemeri et Schultessii, delineatae et cum commentario succincto editae a H. G. Ludov, Reich enbach. Cent. I-X. Lipsiae 1823-1832. X voll. 4. 1000 tab. col. - Magazin ber äfthetifđen Botanif. Reipzig 1821-1826. 4. 96 folor. Iafeln. - Taffenbud für Bartenfrcunbe. Dreb̧oen 1827. 8. - Iconographia botanica exotica. Lipsiae 1827 - 1830. III voll. 4. 250 tab. col. - Conspectus regni vegetabilis per gradus naturales evoluti. Tentamen. P. I.

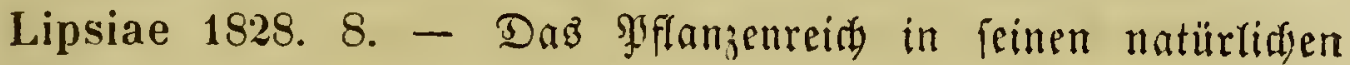
Silaten uno Familien entrvifelt uno burd megr als taufeno in

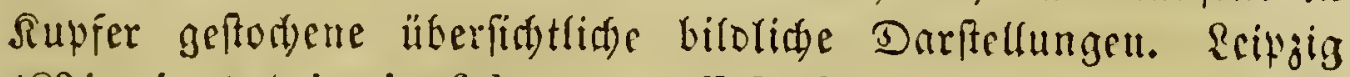
1834. 4. 1 tab. in fol. max. Erffe Fortipeţung. Reipzig 1835.

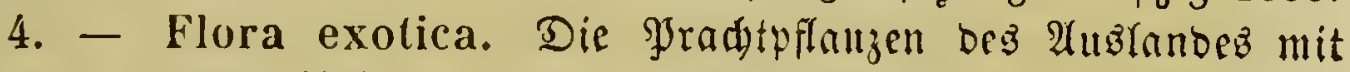
naturgetrenen 216biloungell ze. Reipzig 1834-1836. 5 B̉be. Fol.

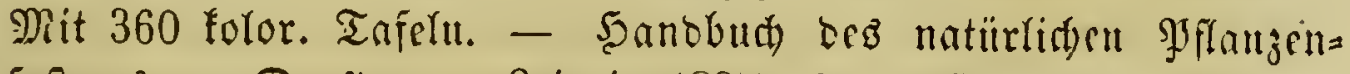
fyfems 2c. Dres̃ben 11. Reipzig 1837. 4. - Serbarien=(5tifetten.

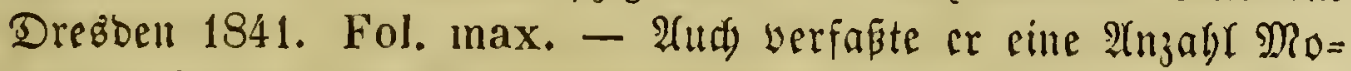

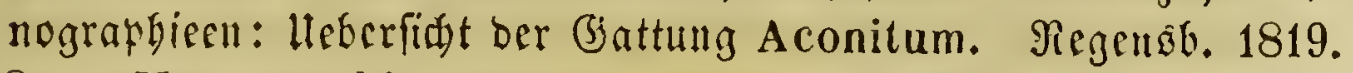
8. - Monographia generis Aconiti, iconibus omnium specierum coloratis illustrata, latine et germanice elaborata. Lipsiae 1820. II voll. Fol. 19 tab. col. - Amoenitates botanicae Dresdenses. Dresdae 1820. 8. - Illustratio spe- 
trocfucter (jocwäd)ie uno bejurgte bic netteren 9 Atflagen won

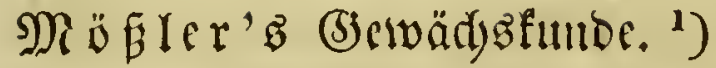

Einer of woüroigften Deutfdyen Botanifer war

\section{Rurt Sprengel,}

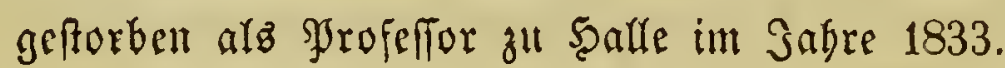

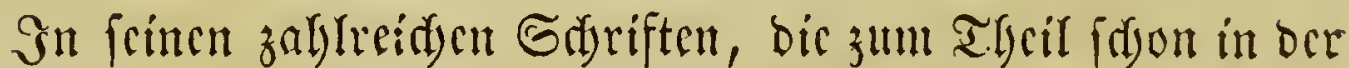
yorigen Serivoe angefïlyrt worben fitto, verbreitete or fich über faft alte Thaile ber Syflanjenfunde. Sn $\mathfrak{B}$ cziefunty auf feine Berbienfte un bic Sogytograplic ift namentlid) heryorgugeben, Dẩ or cic 16. 2luggabe yon Rinné'z Systema vegetabilium ${ }^{2}$ ) Geforgte und mohrere trefflidye Mlonographisen ver= faß̧te ${ }^{3}$ ). Sn Den Saliren 1804-1806 rebigirte er bie (5)ar= tenzeitung, gab in bon Galurcu 1818-1820 in Berbindung

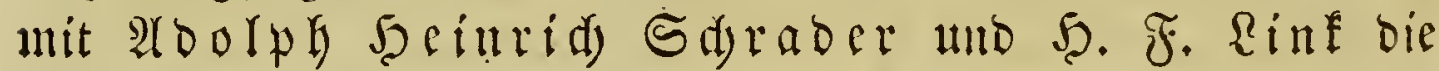

cierum Aconiti generis, additis Delphiniis quibusdam. Lipsiae 1823-1827. Fol. 72 tab. col. - $\mathfrak{A}$ uß̉er ben oben ge=

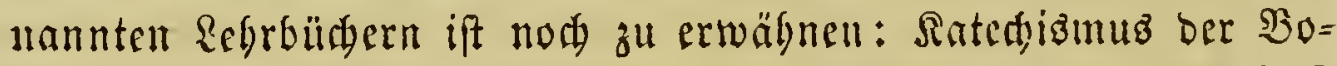
tanit. Reipzig 1820. 8. 7 Taf. 2. 2(uff. Daf. 18'5. 8. 7 Taf. (ift faft um bas Doppelte vermelert.)

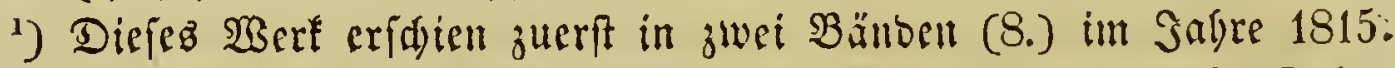

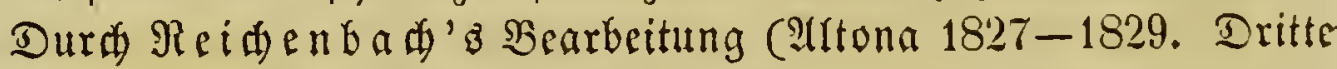
2tuffage, A(tona $1833-1834.3$ Bände. 8.) wurbe es ein fely braudbares 5̧anbbud.

$\left.{ }^{2}\right)$ Caroli Linnaei Systema vegetabilium. Edit. XVI. curante Kurt Sprengel. Goettingae $1825-1828$. IV voll. vel V partes. 8.

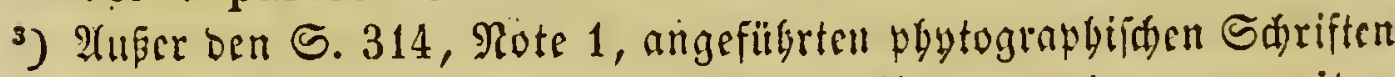
fino zu erwälnen: Species Umbellifarum minus cognitae illustratae. Halae 1818. 4. 7 tab. - Novi proventus hortorum academicorum IIalensis et Berolinensis. Centuria specierum minus cognitarum, quae vel per annum 1818 in lorto Ilalensi et Berolinensi floruerunt, vel siccae missae fuerunt. Ilalae (1819), 8, - Narcissorum conspectus. s. 1.1820 .8 . 


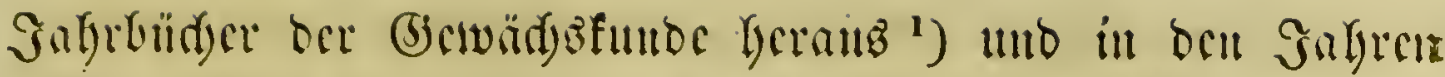
1820 - 1S22 cbirte cr bic nenen Entbeffungen im ganzen lum=

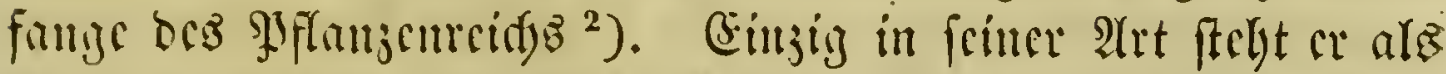

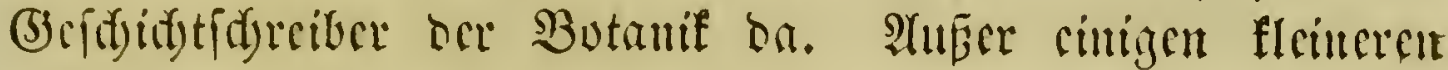

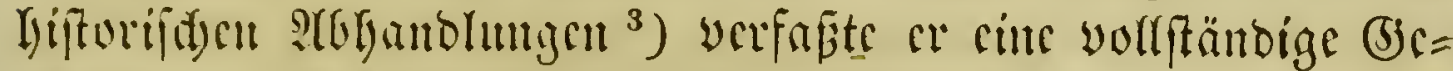

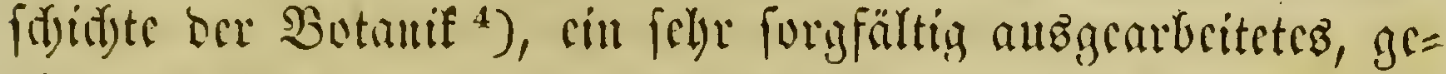
riegenes șerf, bas von oer wifferfdaftlidien Birdung unb

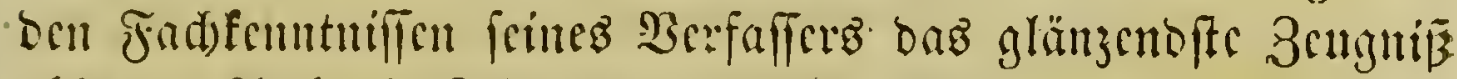
nblegte. Alud bie Relyrbüder ${ }^{5}$ ) Sprengel's waren zu ibrer

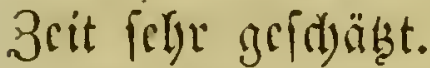

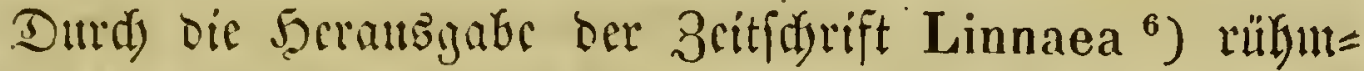

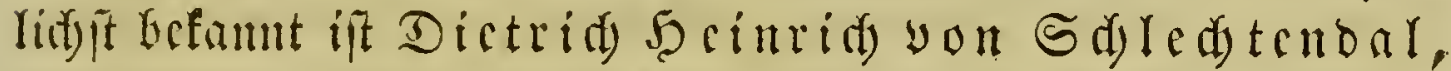

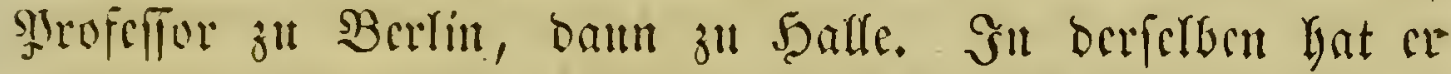

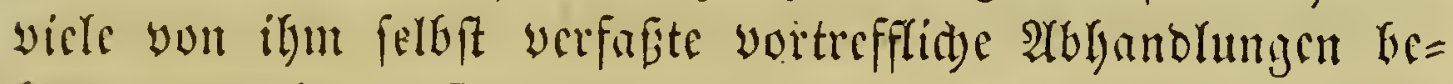
farmt grmedst; auferbem aber bewiez er fith aud burd feine Flora yon Scrlin uno cinige Monographieen ${ }^{7}$ ) als tüd)tiger 3rystograph.

1) Berlin. 3 Şefte. 8.

${ }^{2}$ Reipjig. 8.3 voll.

$\left.{ }^{3}\right)$ Antiquitatum botanicarum specimen primum. Lipsiae 1795. 4. 2 tab. - Dissertatio de germanis rei herbariae patribus. Mündfen 1813.4. - De frumentoruın maxime Secales antiquitatibus. Ilalae 1816. 4.

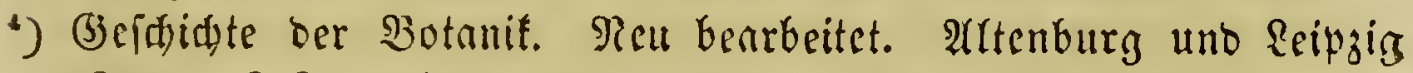
1817-1818. 2 Thle. 8. 8 folor. Tafeln. - Er ithericte nud

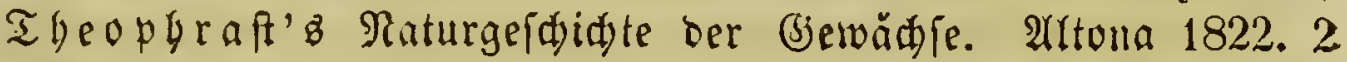
Thle. 8.

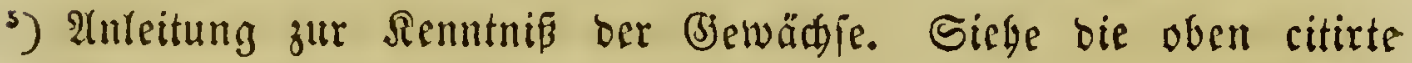

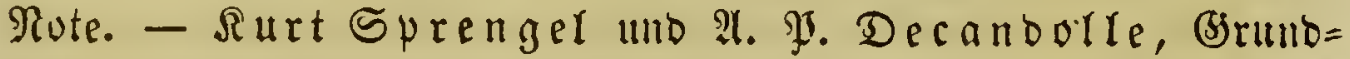

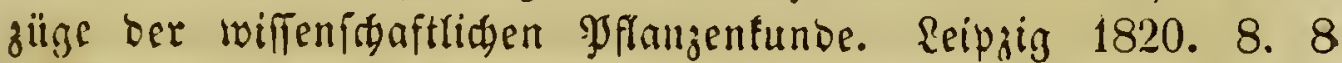
Tafeln. - Seime afabemifaen Sdyriften warben yon 3 uliuz

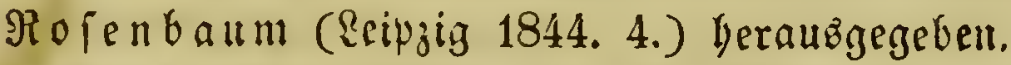

-) Linnaea. Cin Sournal für bie Botanif iut gangen llmfange. Bant I-IX. Berlin 1826 - 1834, banu Şalle 1 835 - 1851. XXIV voll. 8. - Sn Berbindung mit 55. von $\mathfrak{R o g l}$ gibt berielte bie botanif đe 3eitung Geraus. Berlin 1843-1853. 4. ') Animadversiones botanicae in Ranunculeas Candollii. 
3u oen tüd)tigften Floriften Deutidulando gebürt

\section{SBillelut Danicl Gofeply Rody,}

früber Bezirfzarzt zu Saiferglautern, gefrorben als গjofefior uno Director bes botanijden Gartenz zu Erlangen im Jabre 1849.

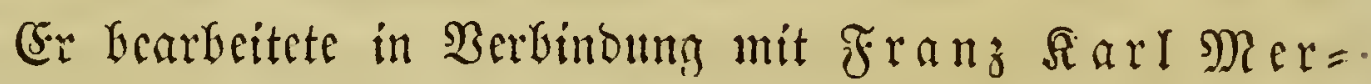

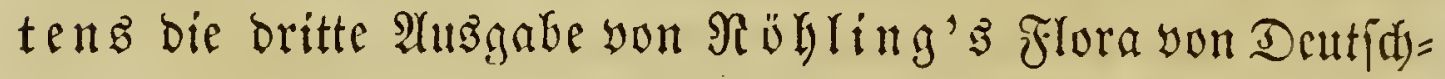
lano ${ }^{1}$ ), werfapte eille funoptifde Flora yon Dentidjlano uno

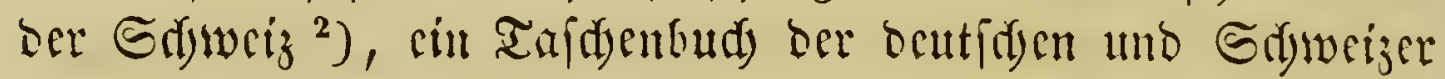
Flora ${ }^{3}$ ), licferte Siciträge zu Eturm'B Flora uno iatrieb mebrere Monographicen ${ }^{4}$ ) uno vicle werthwolle $2(6$ hand hungen.

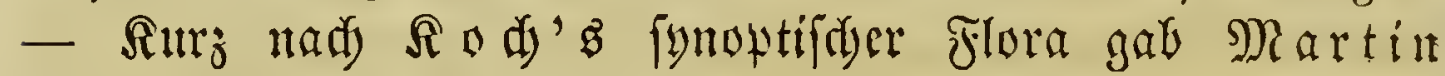

Berol. 1919-1820. 4. 6 tab. - Erineum Pers. Regen $8=$ burg 1821. 4. - Adumbrationes plantarum (Filices capenses) fasc. I-V. Berolini 1825 (-1832). 4. 30 tab. D. F. R. von Sd leditendal ullo B. (5. B̧oude, Heber bie wilte Sartoffel (Papa cimarron) von Merifo. Berlin 1833. 4. 1 Iafel, u. m. a.

1) Deutidlandz flora. Bremen 1796. 8. 2. 24ufl. Franffurt a. M. 1812-1813. 3 Bob. 8. - 3. Atuft. Deutfallanoz frora nach eincm veränderten uno crwéiterten MJane bearbeitet von fram;

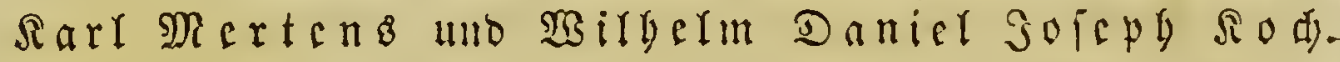
Franffurt a. M. $1823-1839.5$ Boe. 8.

2) Synopsis Florae germanicae et helveticae, exhibens stirpes phanerogamas rite cognitas, quae in Germania, Helvetia, Borussia et Istria sponte crescunt atque in hominum usum copiosius coluntur, secundum systema Candolleanum digestas, praemissa generum dispositione, secundum classes et ordines systematis Li nna e a $\mathrm{n}$ i conscripta. Francofurti ad Hoen. 1837-1838. 8. Fd. 2. Lipsiae 1843-1845. 8. - Deut Reipzig $1846-1847.8$.

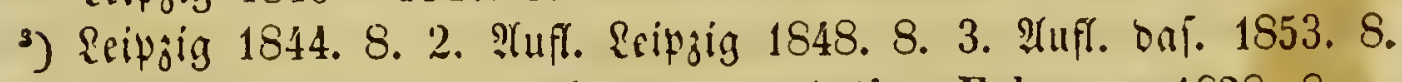

-) De Salicibus europaeis commentatio. Erlangae 1828. 8. De plantis labiatis, Erlangae 1833. 4. 
Balouin Rittel, Srofeffor num gycemm unb Rector ber

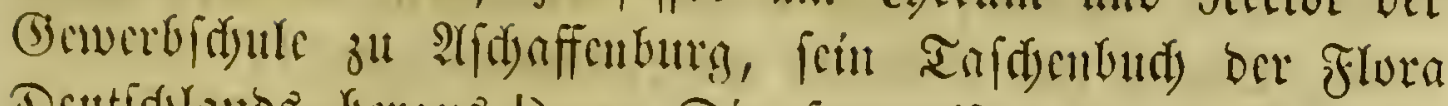

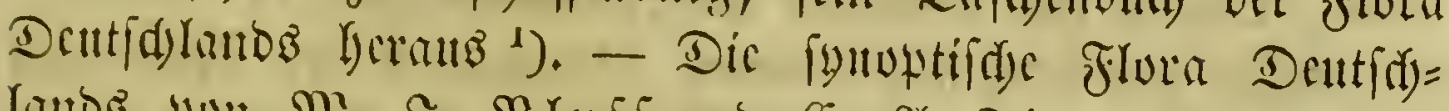

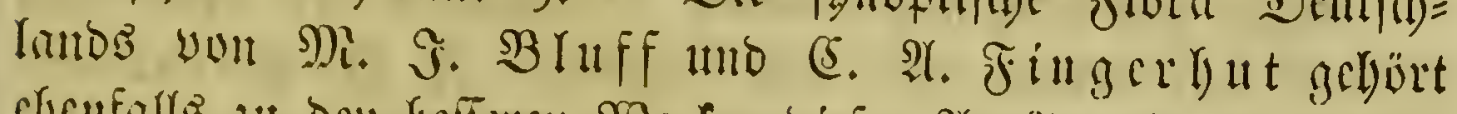

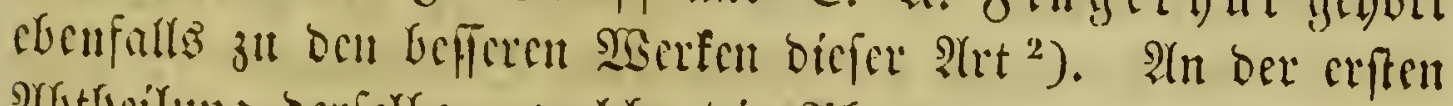

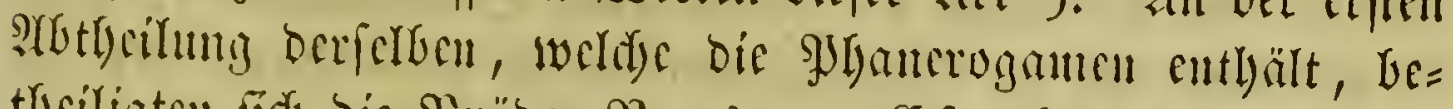

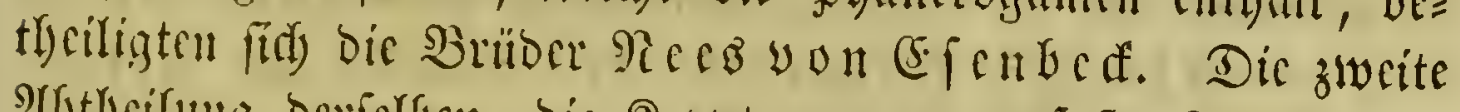

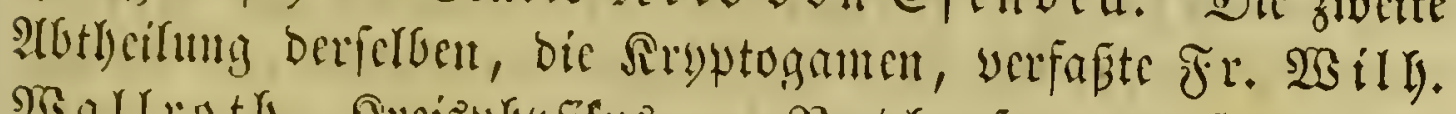

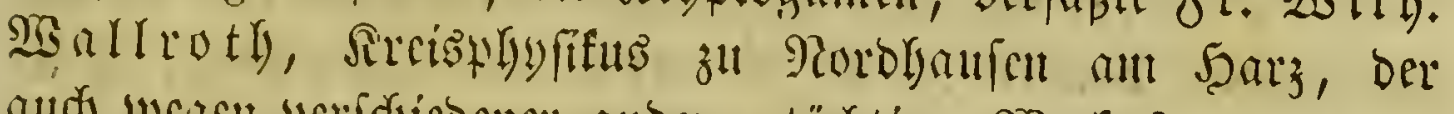
and weyen verfdyicbener antorer tïd)tiger $23 e r f e{ }^{3}$ ) zut nemen

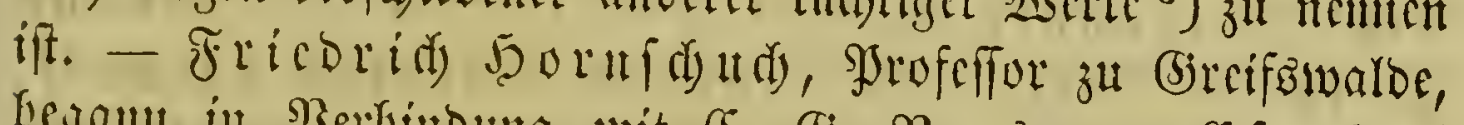

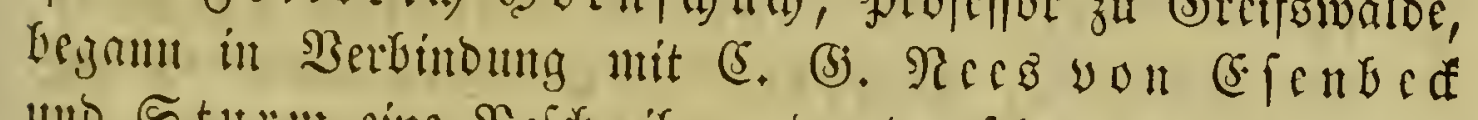

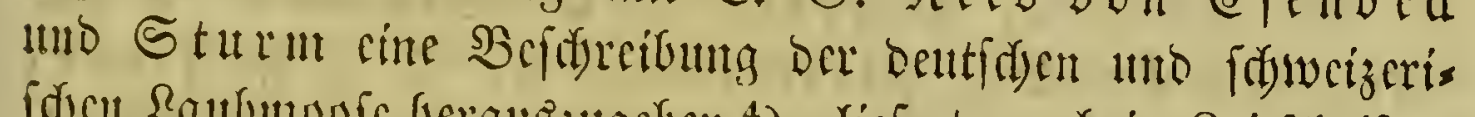
id)

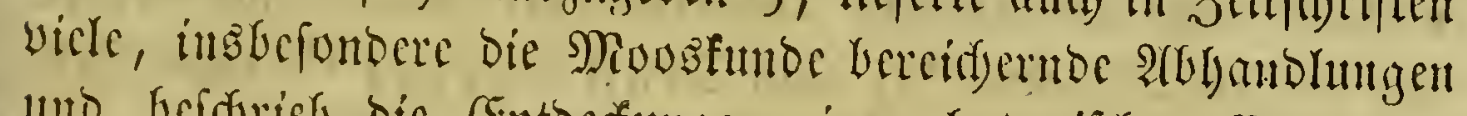
unt befdrieb bie Entocfungen siner botanifyen Excurfun,

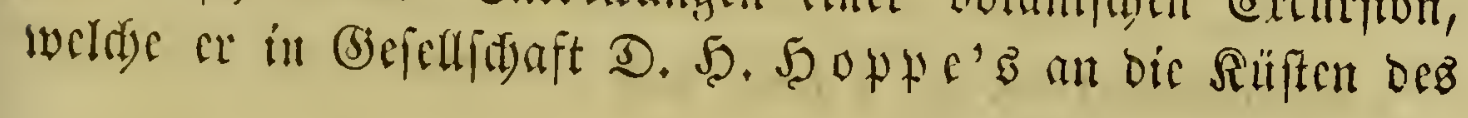

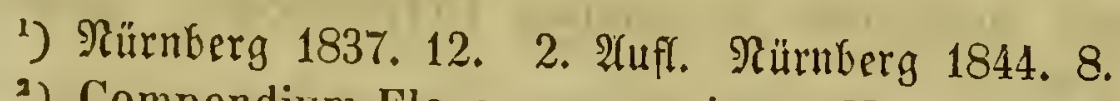

2) Compendium Florae germanicae. Norimbergae 1821-1833. IV tom. 12. - Edit. II. Ibid. 1836-1838. II voll. 12.

$\left.{ }^{3}\right)$ Orobanches generis Diaskeue. Ad Car. Mertensium epistola. Francofurti ad Moen. 1825. 8. - Raturgefdidte ber Fledten. Franffurt a. $\mathfrak{M} .1825-1827.2$ Sbe. 8. Rosae plantarum generis historia succincta, in qua Rosarum species tum suae terrae proventu tum in hortis natas suppositicias secundum normas naturales ad stirpium bessestres primitivos revocat inque speciminum ratorum fidem rhodologorum et rhodophilorum captui accommodat.

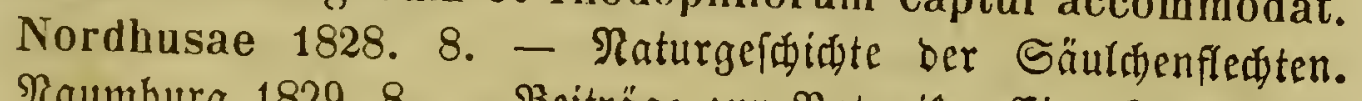
Raumburg 1829. 8. - Beiträge zur Botanif. Eine Sammlung monograplifier 2tbqanblungen über beionberz fdiwierige Be= wäđß̈gattungen ber Flura Deutidianbs. Banb I. Seft 1 u. 2. Scipzig 1842-1844. gr. 8. 3 folor. Taf. - Seine Sdriften über bie floren eingelner Begenden werben an ben betreffenben Stellen angefübrt werben.

4) Siebre oben S. 499, Rote 1. 
abriatifden Meereb, nad) Rrain, Ränthen, Tyrol, Galz= burg, SBaiern uno Bülymen unternommen hatte. ${ }^{1}$ )

Shufer Den yorhin genannten Bearbeitern ofr Flura yon

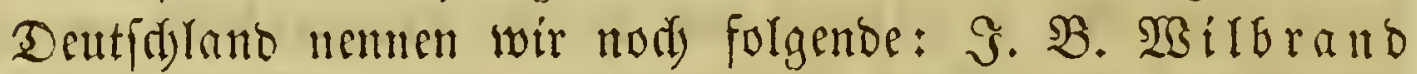
fdureb ciue Meberfidst oer $\mathfrak{B e g}$ etation Dentidjlandos ${ }^{2}$ ); über

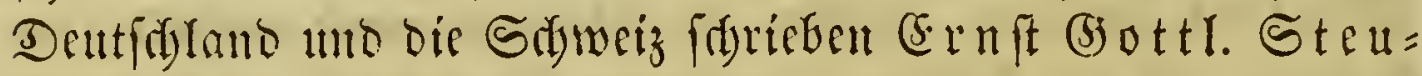

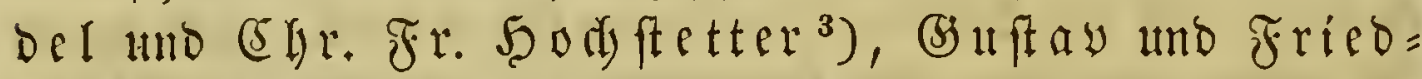
rid) Rorin $\left[\mathrm{er}^{4}\right.$ ); hiber Deutfdland überbaunt und die an=

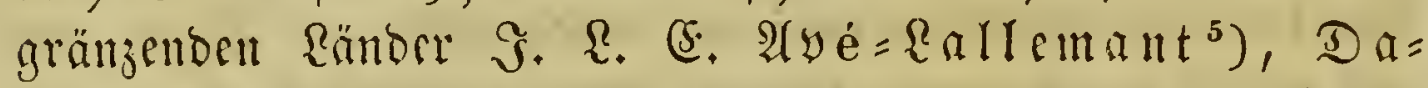
yis Satlanael Friebrid Dietrid) ${ }^{6}$ ), Golann

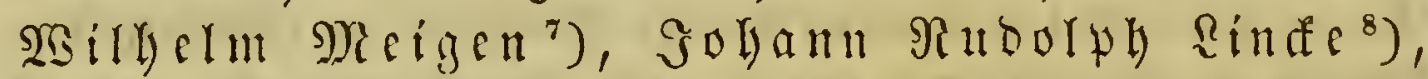

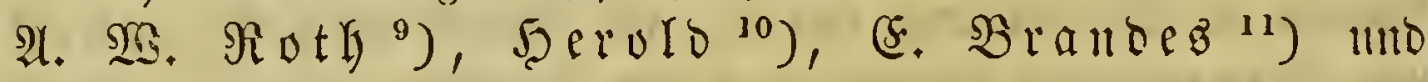

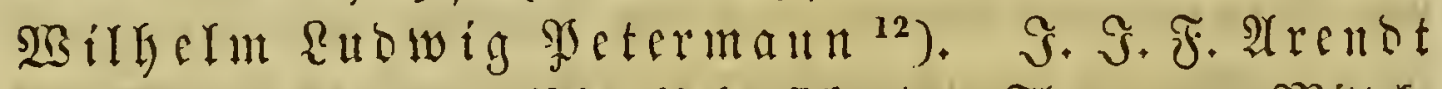

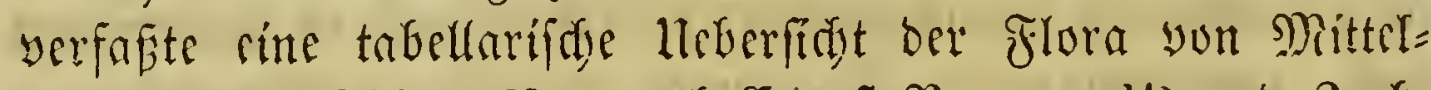

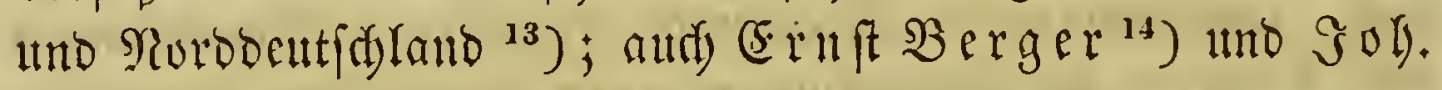

1) Regenzburg 1818. 8. 1 folor. Taf.

2) Regenşutrg 1824. 8.

3) Enumeratio plantarum Germaniae Helvetiaeque. Stuttgartiae 1826. 8.

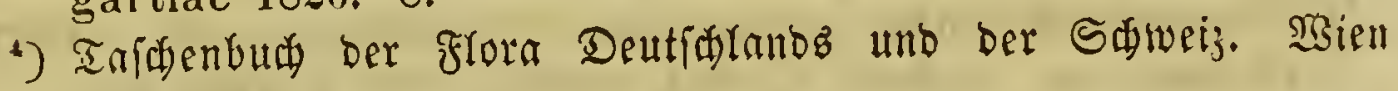
1847. 8.

5) De plantis quibusdam Germaniae australis. Berol. 1829. 4.

-) Deutfalanda flora. Sena 1833 - 1842. gr. 8.

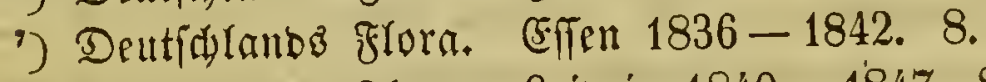

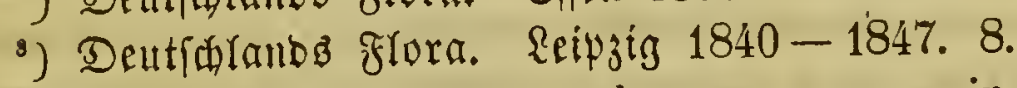

-) Enumeratio plantarum phaenogamarum in Germania sponte nascentium. Par's prima. Sectio prior. Classes I-V. Lipsiae 1827. 8. - Manuale botanicum peregrinationibus botanicis accommodatum, sive Prodromus enumerationis plantar. phanerogamar. in Germania sponte nascentium. Fasc. I-- III. Lipsiae 1830. 8.

$\left.{ }^{10}\right)$ Tafdentud ber beutiden fista. Rorblaufen 1845. 8.

11) Die Frora Deutfdrlando und ber angränzenden. Ränber. Stul= berg 1846. 12.

12) Deutfilanoz frora. Reipzig 1846-1849. 4.

13) D\&nabrillt 1831. Fol.

16) Catalogus herbarii. S2sitrours $1841-1846.12$. 


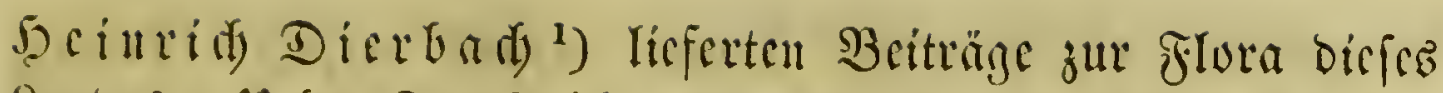

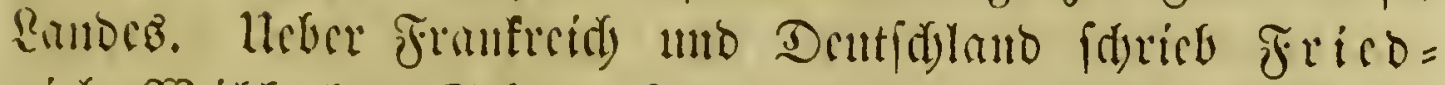

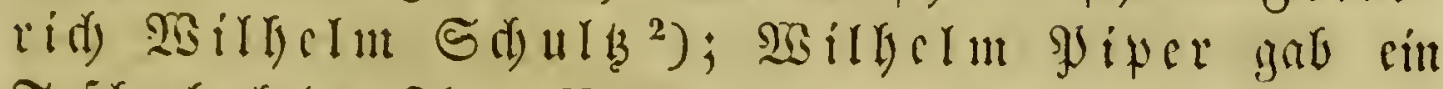

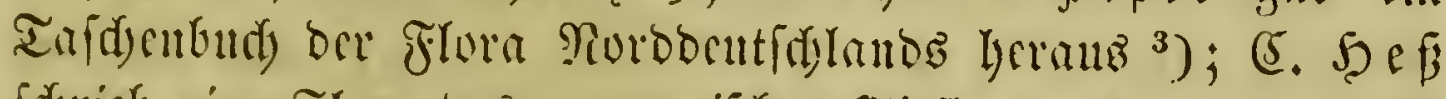

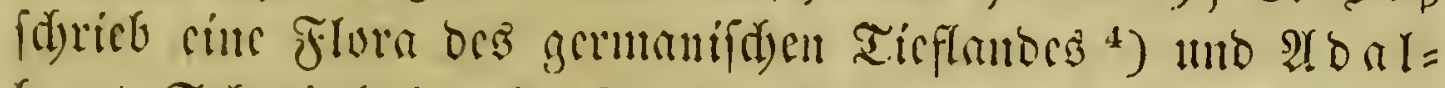

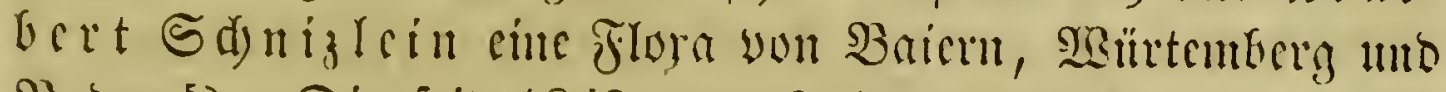

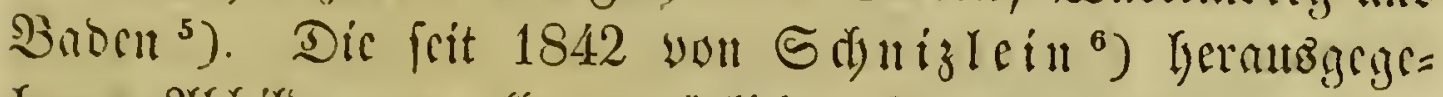

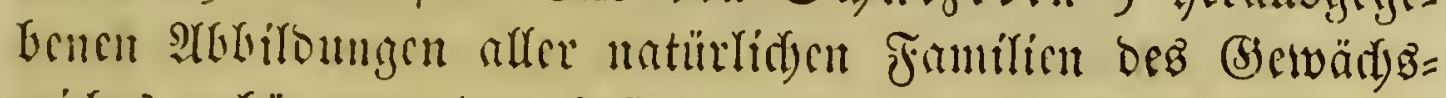

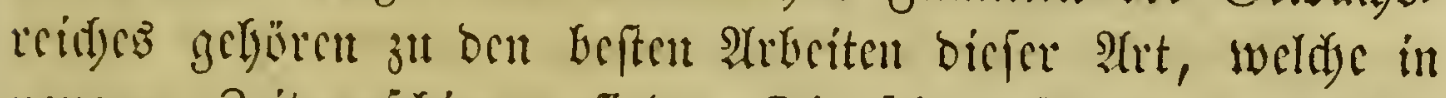

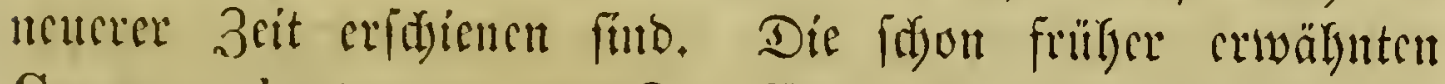
Genera plantarum von $S_{t}$. (5nolid $c r^{7}$ ) enthalten cine

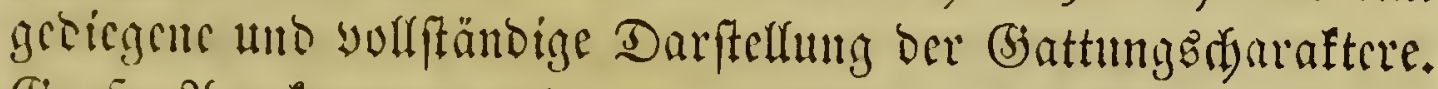

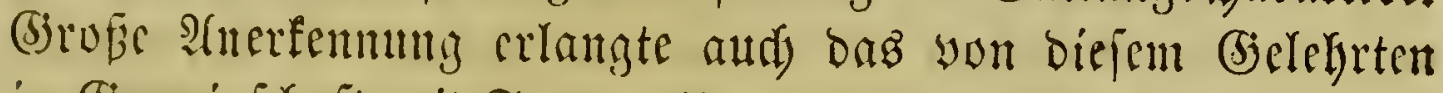
in (B) meinfdyaft mit Franz orr Botanif. ${ }^{8}$ )

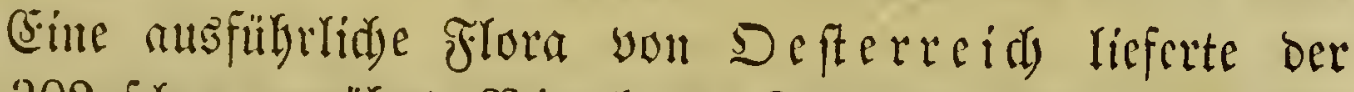
ธ. 302 (d)on crmähnte Ricola

1) Beiträge z̆ur Frora Deutichrandz. Seciberberg 1825-1833. 8.

$\left.{ }^{2}\right)$ Flora Galliae et Germaniae exsiccata. Cent. I - IV. Bitsche 1836-1840. Fol. Cent. V-X. Daf. 1841-1847. 8.

3) MRardin 1846. 8.

†) Entharten in befien "\$9lanzenfunbe." Berlin 1846. 8.

$\left.{ }^{5}\right)$ Grlangen 1847. 8.

-) Iconographia familiarum naturalium regni vegetabilis. 2(t6s

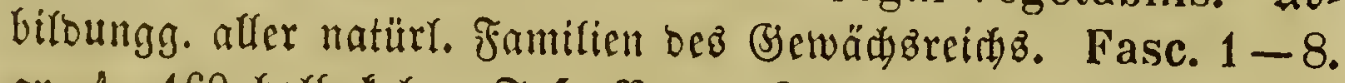
gr. 4. 160 barb folor. $\mathfrak{x a f}$. Bonn 1842-1852.

') Genera plantarum. Accedunt supplementa tria. Vindobonae 1836-1843. 4. - Iconographia generum plantar. Vindobonae 1838. 4. 125 tab. - Enchiridion botanicum exhibens classes et ordines plantarum; accedit nomenclator generum et officinalium vel usualium indicatio. Lipsiae 1841. 8. "- Die Mebicinarpflanzen ber ëferr. SPbarma. copoe. Wien 1842. 8.

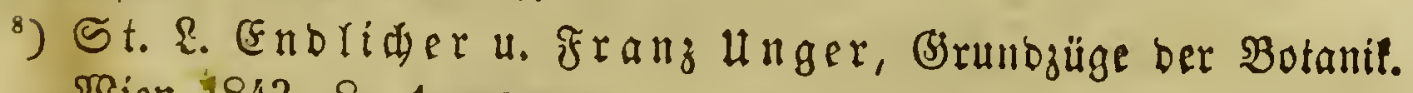
ESien 1843. 8. 1 mappa.

$\left.{ }^{\circ}\right)$ Flora austriaca. Viennae $1827-1831.2$ voll. 8. 


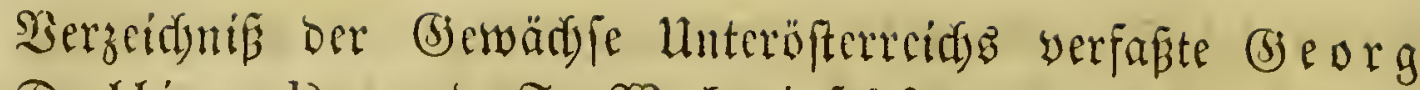

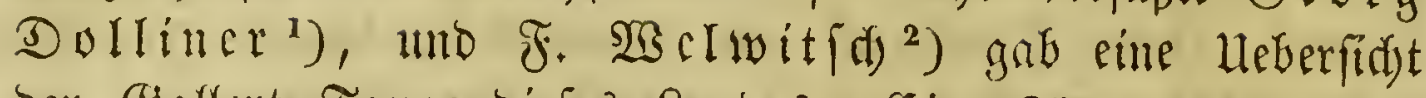
ber Ballert = Tange diefes Ranbez. Sine Flura yon Dber=

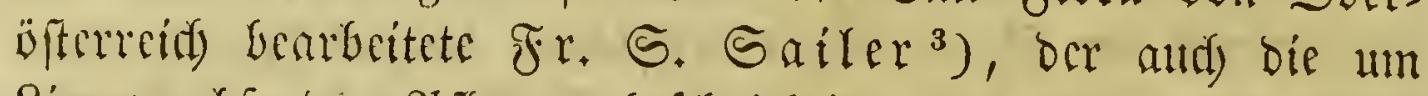

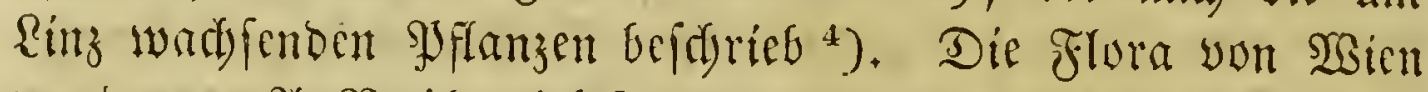

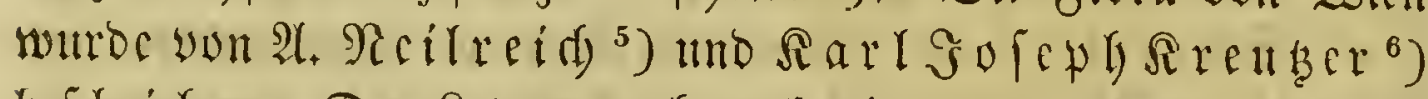
befdricben. Ser Rektere gab aud) cine Darfteflung ber (3ift=

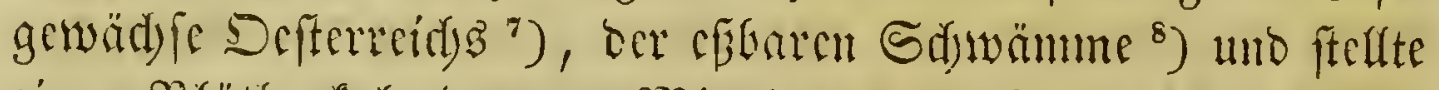

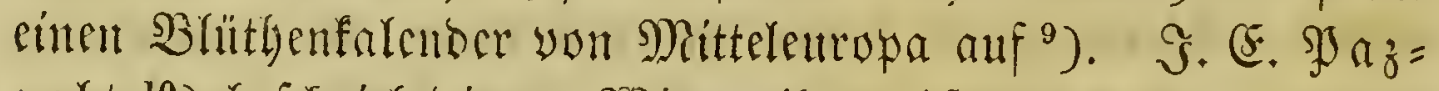

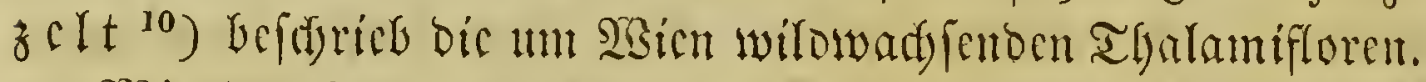

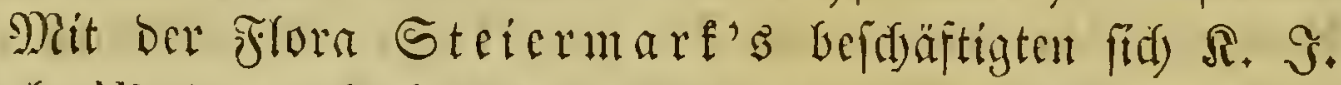

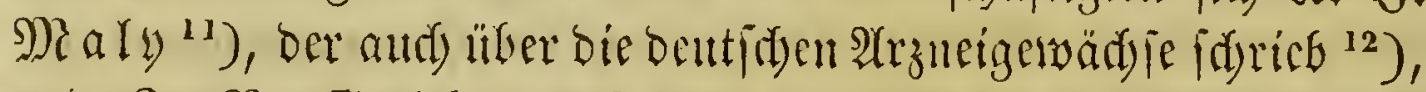

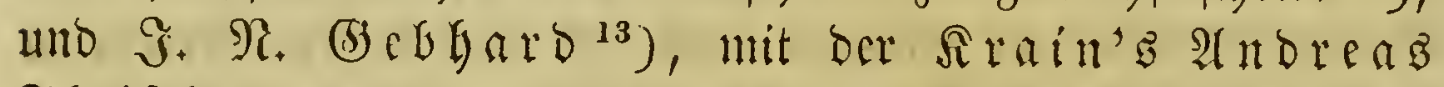

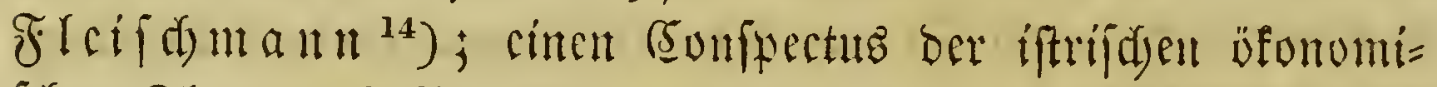
fdoct Flura gab $\mathfrak{B}$. Siajoletti. ${ }^{15}$ )

1) Enumeratio plantarum in Austria inferiori. Vindobonae 1812. 8.

$\left.{ }^{2}\right)$ Synopsis Nostochinearum Austriae inferioris. 2 Sien 1836. 8.

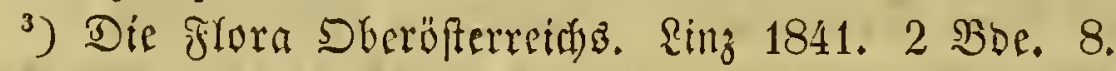

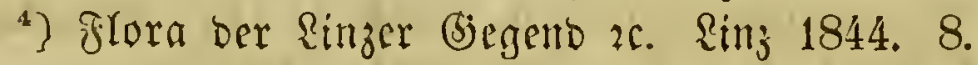

5) Flora yon wien. Wisten 1846. gr. 8.

') Prodromus Florae Vindobon. Sisien 1840. 8. - Blithen=

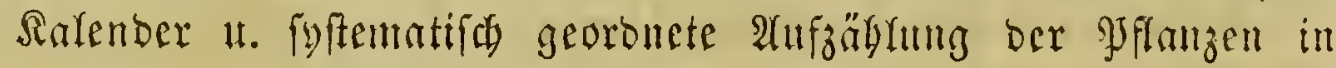

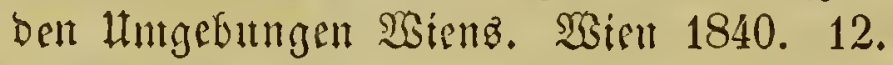

7) 秎ien 1838. 8.

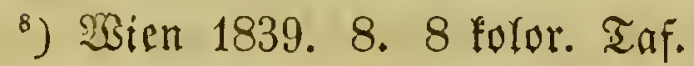

$\left.{ }^{\circ}\right)$ Anthochronologion plantar. Europae mediae. SBien 1840. 12.

10) 2 Siten 1842. 8.

11) Flora styriaca. (3rönt 1838. gr. 12.

13) (5räţ 1837. 8.

13) Şerjeiduifi ber bon bent Sabre 1804 bia 1819 auf meinen bor

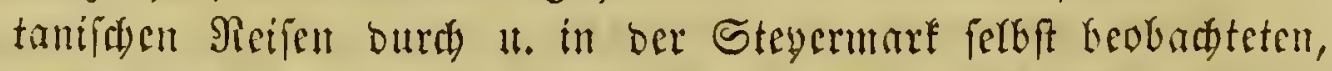
grímmelten unb, bis auf wentge, bereitz in meinen Eenturien getrodenet gelieferten gyflanjen; mit $\mathfrak{A}$ (ngabe ibret Standorte,

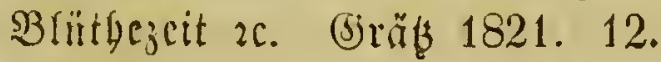

14) Heberficat ber Jlora Sirain'ß. Raibad) 1844. 8.

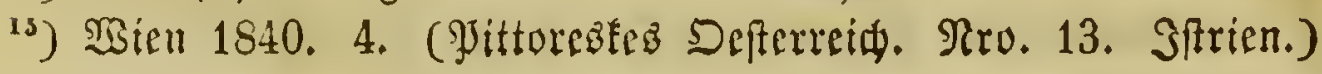




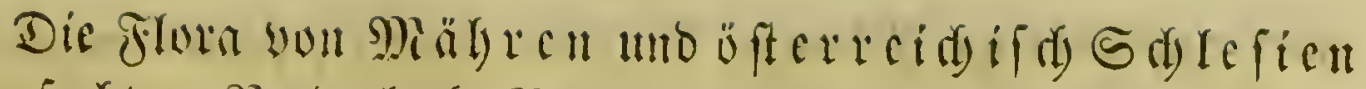

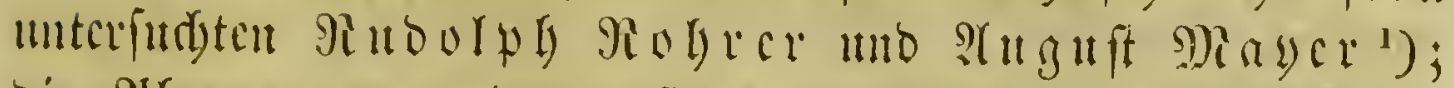

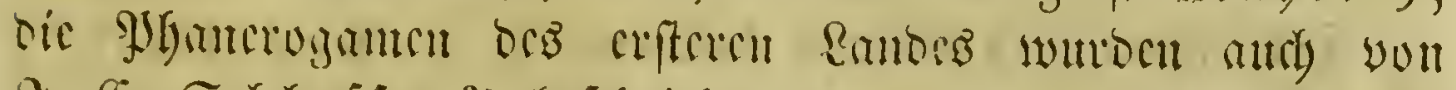

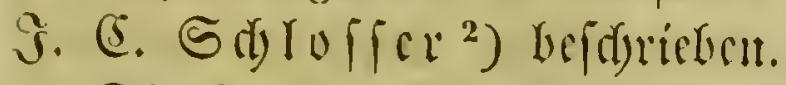

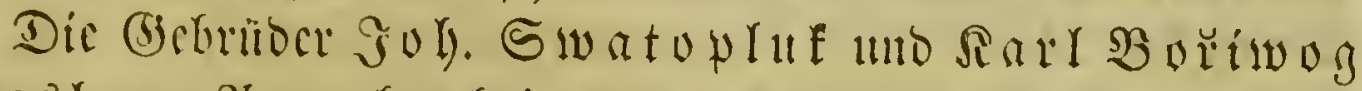

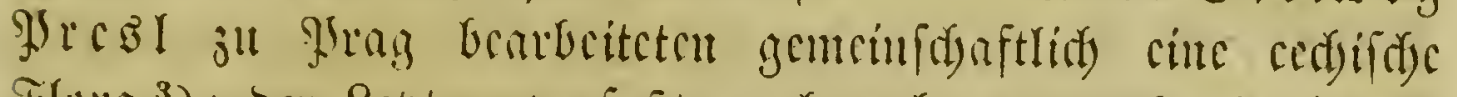

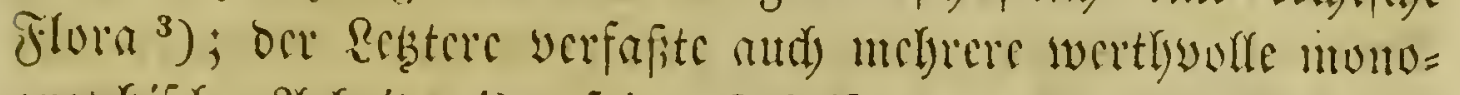

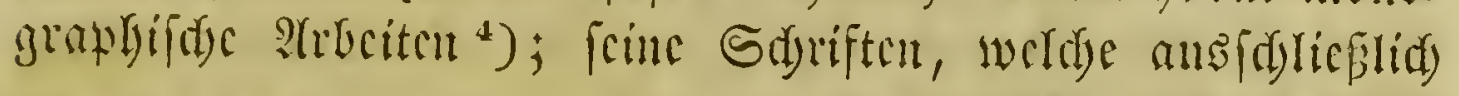

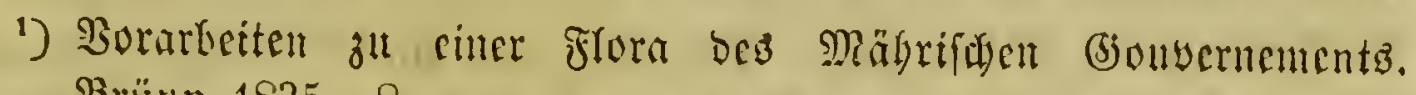
Brünn 1835. 8.

2) Anreituny, bie im Mälyrifhen (jonwernement wifowadgenben u.

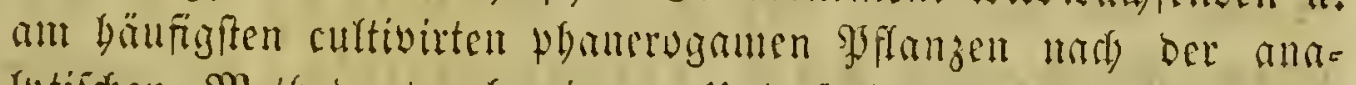

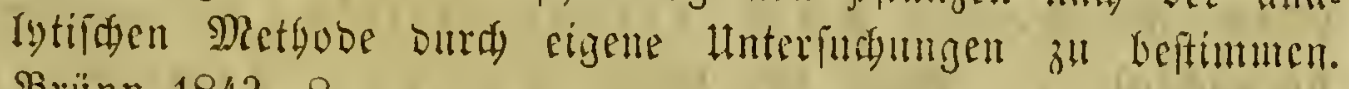
Briunn 1843. 8.

3) Jirag 1819. 8.

4) Bemertungen über ben Bau ber Bhhumen ber \$̧arfamineen.

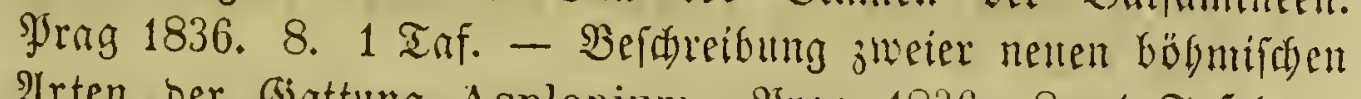
Irrten ber Battung Asplenium. Jrag 1836. 8. 1 Iafel. Prodromus monographiae Lobeliaceorum. Pragae 1836. 8. - Tentamen pteridographiae, seu genera filicacearum praesertim juxta venarum decursum et distributionem exposita. Pragae 1836. 8. - Hymenophyllaceae. Eine botan. HGbanbr. Jirag 1842. 4. 12 Taf. - Supplementum tentaminis pteridographiae, continens genera et species ordinun dictorum Marattiaceae, Ophioglossaceae, Osmundaceae, Schizaeaceae et Lygodiaceae. Pragae 1845. 4. - Er farrieb audf: Symbolae botanicae etc. Pragae 1832 -1833. II voll. (7 fasc.) Fol. 70 tab. - Repertorium botanicae systematicae. Excerpta e scriptoribus botanicis, continentia diagnoses generum et specierum novarum aut melius distinctarum, indicationes iconam, generum et specierum jam cognitarum et adnotationes succinctas botanicam systematicam spectantes, sistentia supplementum continuum Prodromi systematis naturalis Candollei, systematis vegetabilium $S c h u l t e s i i$ et $S$ prengelii. Vol. I. Pragae 1834. 8. - Bermifate botanifale $\mathscr{2}(u f=$ fäge. S. l. et a. 1 tab. 


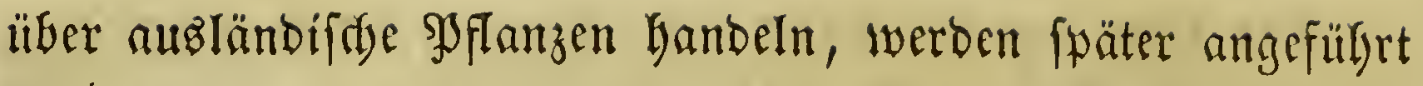
iwerden.

Bie Flora $\mathfrak{B}$ b̈hineng befdrieb $\mathfrak{B}$. F. Roftelegey ${ }^{1}$ ),

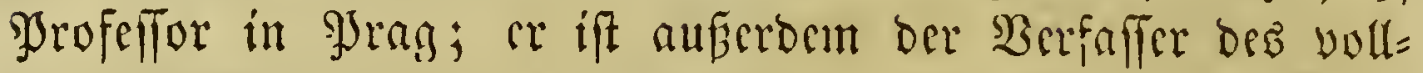
ftändigften $\mathfrak{X} \mathfrak{B} e r f e s$ über die offizinetlen $\mathfrak{S}$ flanzen ${ }^{2}$ ), - $\mathfrak{X} B . \mathfrak{B}$.

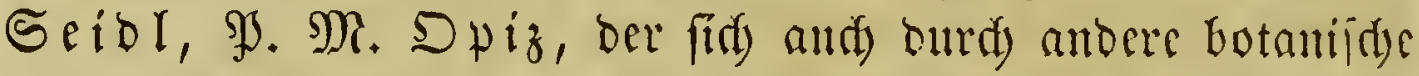
arbeiten ${ }^{3}$ ) befannt madste, Franz $\mathfrak{X}$ aer Fieber uno

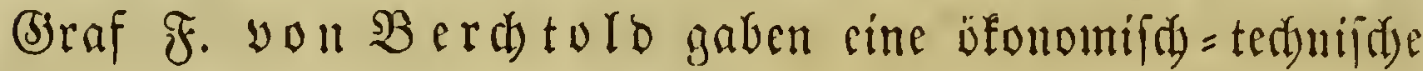
Flora ${ }^{4}$ ) you $\mathfrak{B u ̈ h m e n ~ h e r a u s . ~}$ A. Drtmann ${ }^{5}$ ) nuo ber

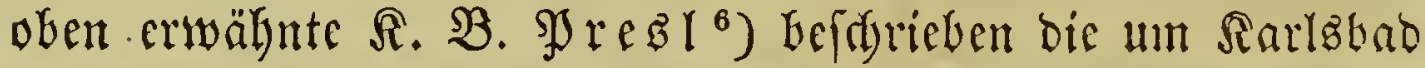

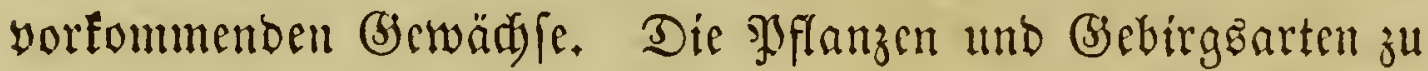
Marienbab unterjudten Friebrid) $\mathfrak{A} u g u f t$, Damals Shit=

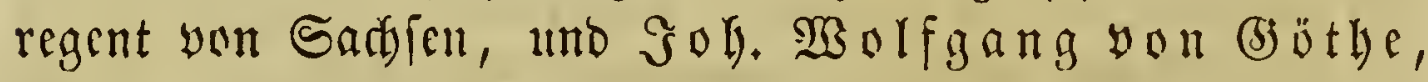

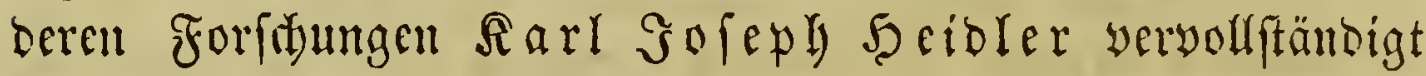

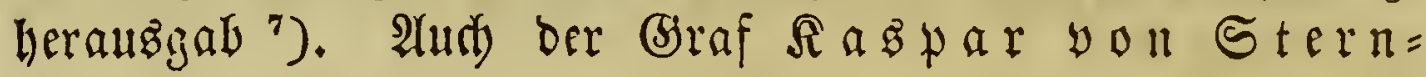

1) Clavis analytica in Floram Bohemiae phanerogamicam. ßjag 1824.8.

2) Allgemeine medicinif 6 Bop. 8.

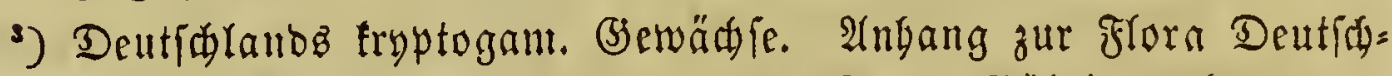
lanbs von $\Re$ ögling. $\mathfrak{g r a g}$ 1816. 8. - Böbeimb phanernga=

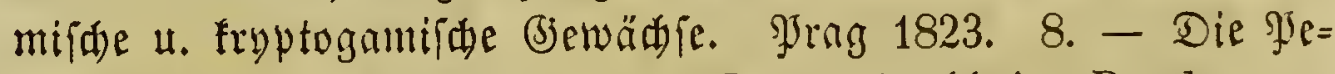

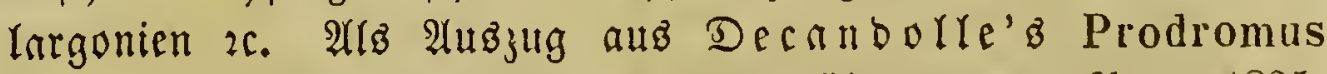
systematis naturalis inz Deutifhe übertragen. Wrag 1825. 8. $\min$.

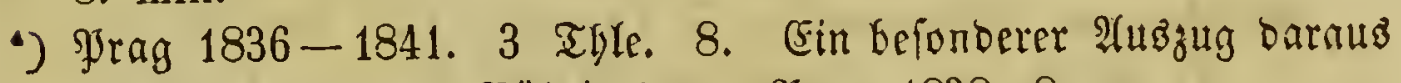
if: Die Rubiaceen $\mathfrak{B}$ b̆geims 2c. \$vrag 1838. 8.

s) Seopolo Fle

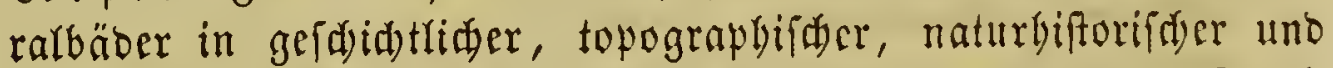
mebicinifaner Şinfint bargeftedut. Etuttg. 1838. 8. 1 infer. (Entyält eime flora von Sarlabad von $\mathcal{A}$. Drtmant.

-) John de Carro. Essay on the mineral waters of Carlsbad for physicians and patients. With observations on the microscopic animalcules about the hot springs of Carlsbad by A. J. C. Corda, and a Flora of Carlsbad by C. B. Presl. Prague 1835. 12. 6 tab.

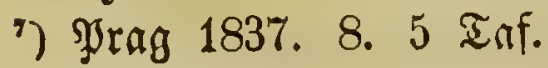




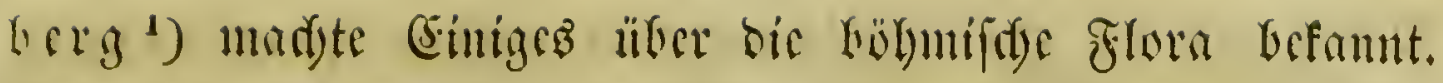

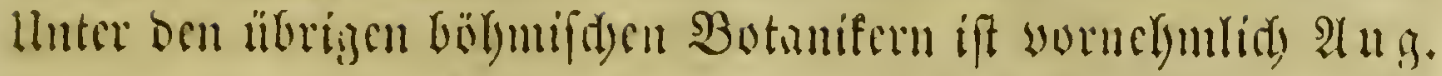

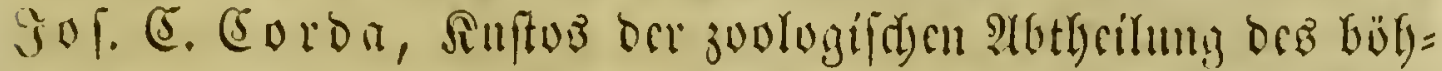

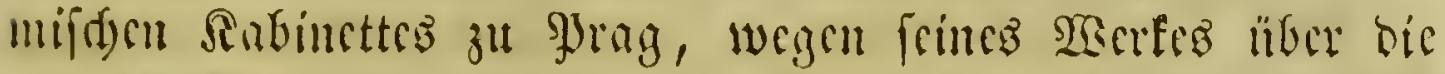

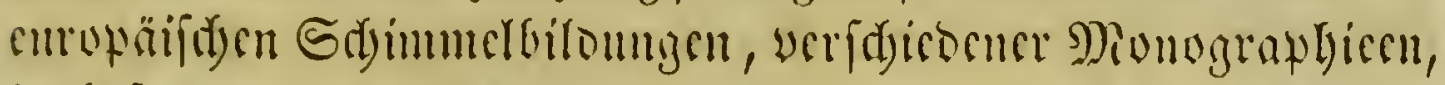

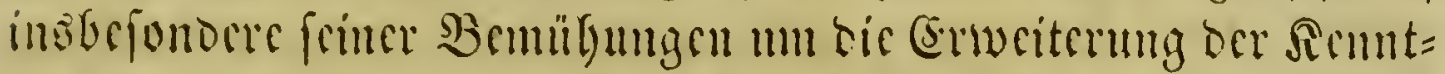

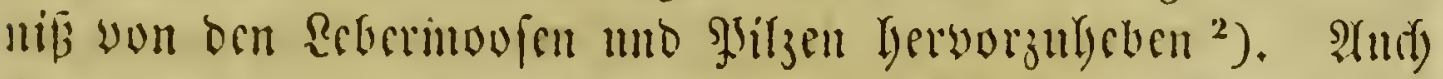

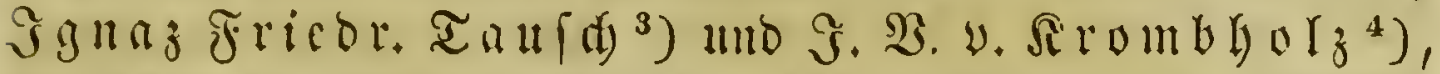

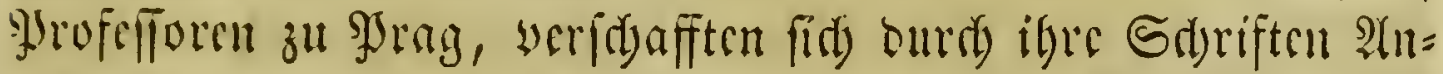
erfermung.

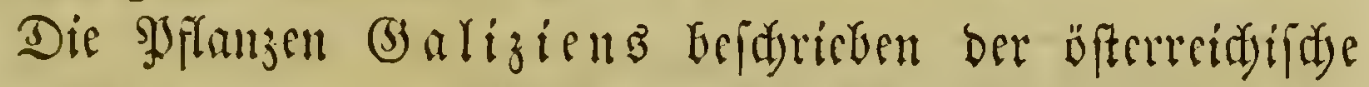

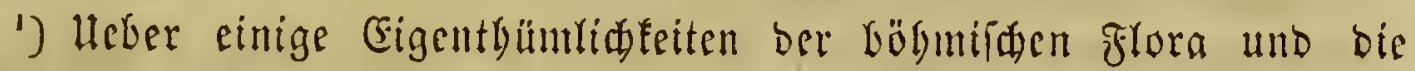

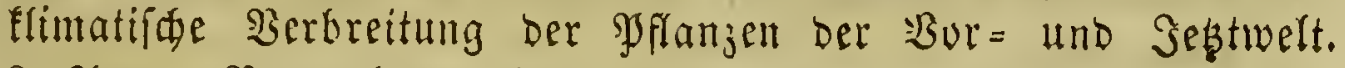

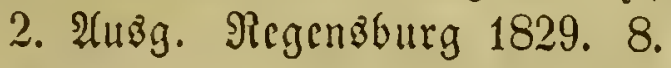

2) Jiradtflora europäiøder Sdimmelbirbungen. Reipsig u. Dreaben 1839. Fol. 25 for. Iaf. - Monographia Rhizospermarum et Hepaticorum. Erftes Şeft. Wrag 1829. 4. 6 Iaf. - Genera Hepaticarum. s. a. 8. (\{logcbr. aus $\mathfrak{P J}$. $\mathfrak{R}$. Spiz)

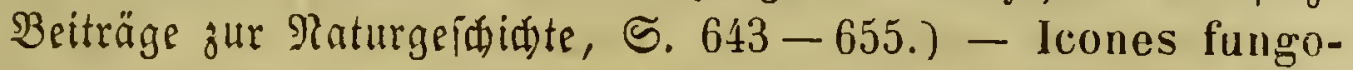
rum hucusque cognitorum. Pragae $1837-18$ '2. V voll. Fol. 44 tab. - PAnleitung zum Stubium ber $\mathfrak{R}$ yfologie, nebif fritiface Befdreibung aller befannten (ba)tungen und einer fur=

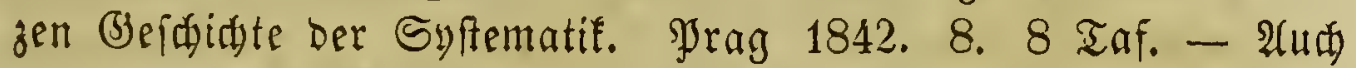
lieferte er biele 2 (brandrungen in Beitiffiften.

$\left.{ }^{3}\right)$ Index plantarum, quae in horto excellentissimi Comitis Josephi Malabaila de Canal coluntur. Prag. 1821. 4. - Hortus Canalius, seu plantar. rariorum, quae in horto botanico illustr. ac excell. J. M. Com. de C an al coluntur, icones et descriptiones. 'Tom. prim. Decas I. Pra-

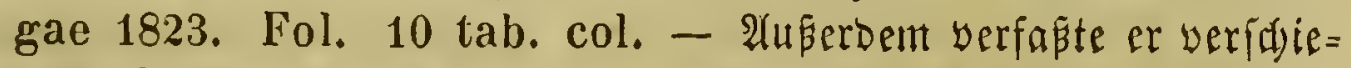
bene Monograplieen.

') Conspectus fungorum esculentorum, qui per decursum anni 1820 Pragae publice vendebantur. গJrag 1821. 8. -

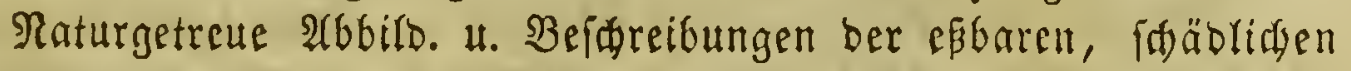

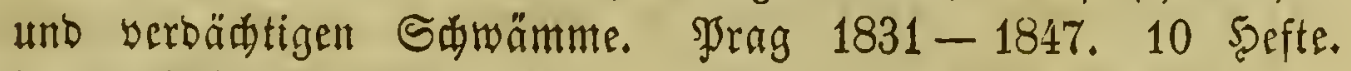
Fol. 78 \%ol. $\mathfrak{T a f}$. 


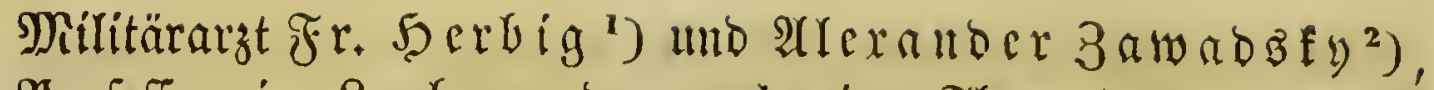
Jrofeffor in Remberg, ber and) cine Flora der Umgegento biefer Strot lieferte. ${ }^{3}$ )

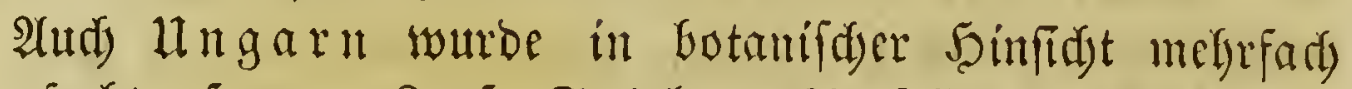

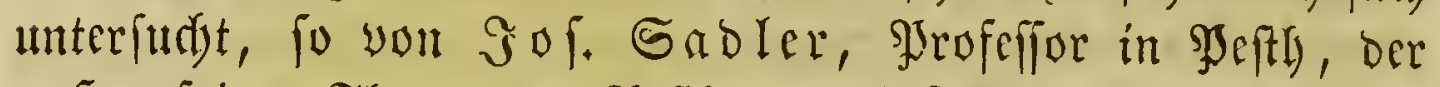
nuper feiner Flora vou grefth unt Dfen eite Befdreibung Feltener Spflanzen Ungarns, Siroatiens uno Siebenbürgens, fowie nudf cinige Monvgraphicen liber bic Farrn weröffent=

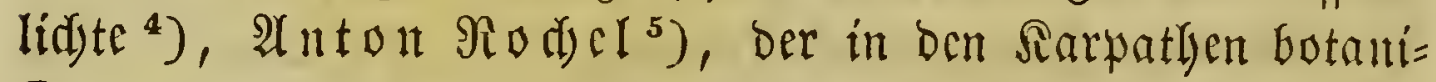

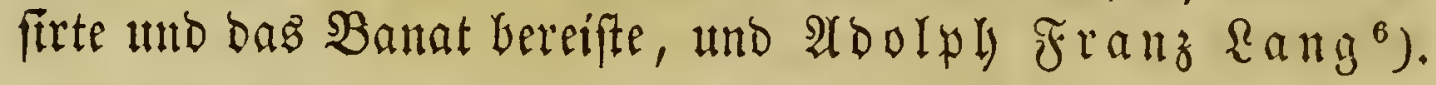

1) Additamentum ad Floram Galliciae. Leopoli 1831. 8. 1 tab. - Selectus plantarum rariorum Galliciae et Bucovinae. Czernovicii 1836. 4.

2) Enumeratio plantarum Galliciae et Bucovinae. Breß̊ı 1835. 8.

8) Flora ber Stabt Remberg. Remberg 1836. 8.

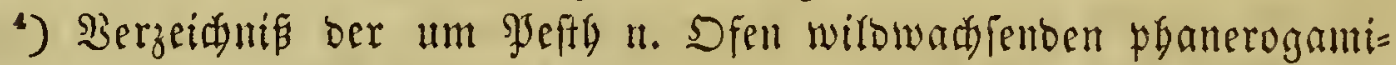

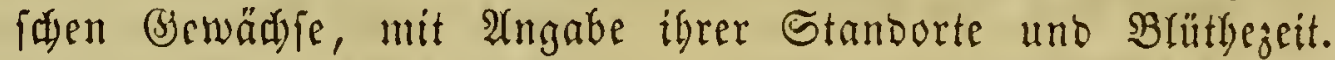
פefff . 1818. 8. - Descriptio plantarum epiphyllospermarum Hungariae et provinciarum adnexarum atque Transsylvaniae indigenarum. Pesthini 1820. 8. - De Stipa noxa. Pesthini 1825. 8. - Deutid: baf. 1825. 8. Flora Comitatus Pesthinensis. Pesthini 1825-1826. II voll. 8. - Ed. II. Flora Comitatus Pesthinensis in uno volumine comprehensa. Pesthini 1840. 8. - De Filicibus veris Hungariae, Transsylvaniae, Croatiae et Litoralis hungarici. Budae 1830. 8.

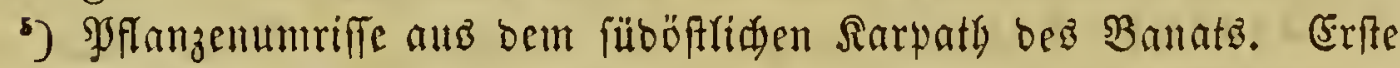

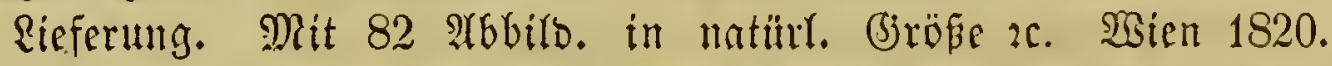
Fol. 1 Taf. - Raturbifurifde Misceflen über ben norbwęt= riden אarpath in Dberungarn. SJefth 1821. 8. 1 geogr. Sarts. - Plantae Banatus rariores, iconibus et descriptionibus illustratae. Pesthini 1828. Fol. 42 tab. - Botanifide Pieife in Das Bannat. im Sabr 1835, mebit Briegenlyeitabemerfungen

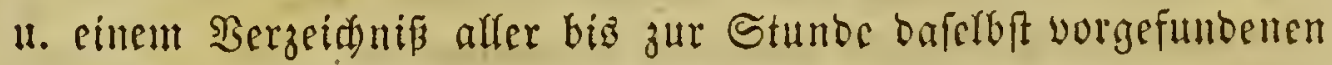

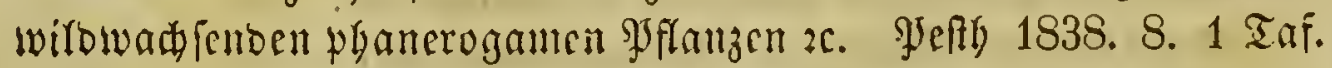

-) Enumeratio plantarum in Hungaria sponte nascentium, quas in usum botanicorum legit. Pesthini 1822. 8. 


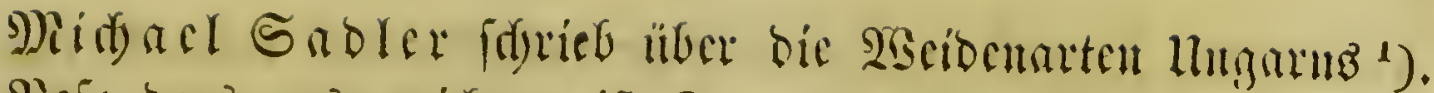

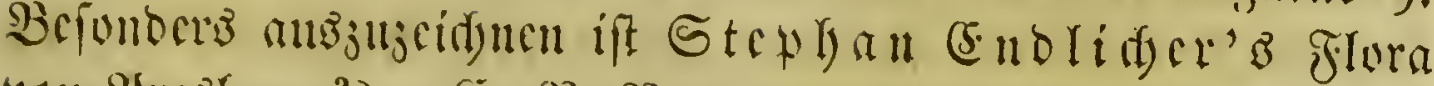

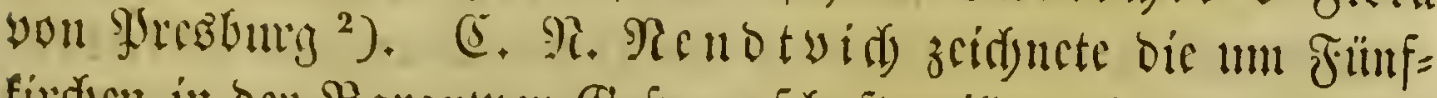

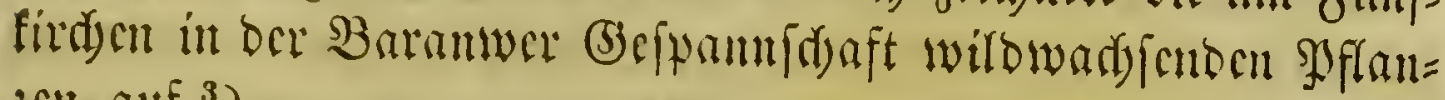
jen $\mathfrak{m} f^{3}$ )

3แ Baแmgartens S. 306 criväbnten Frora yon Sicben=

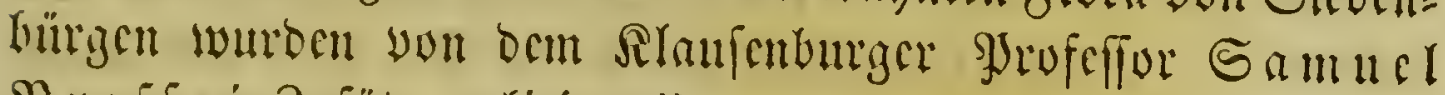
Braffa $\mathfrak{i}$ Zufäze gelicfert. ${ }^{4}$ )

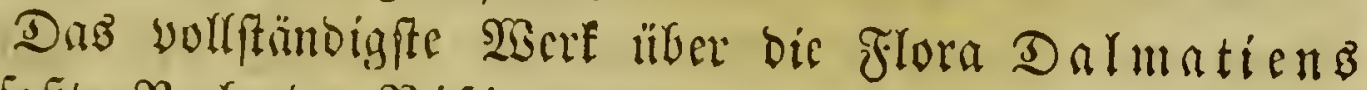
verfajite $\Re$ b. D \& Bifiani. ${ }^{5}$ )

Die Flora you $\mathfrak{B}$ aiern wurbe audi) in ber neueren 3cit fleifig unterfudt. Sofeph (5)ergarb Zucearini coirte cine Flora yon Mändan unl fdricb liber ben botanifden (5)arten bafelbft; aud) werfagte er cinige Sdriften liber Doutfd)=

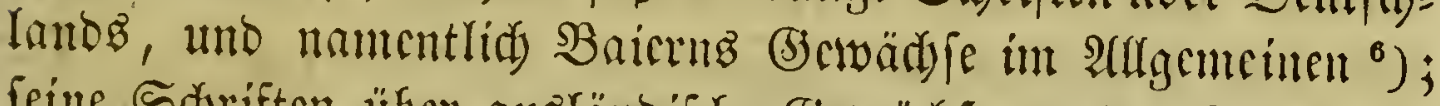

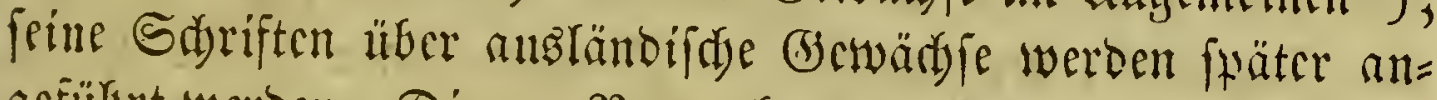

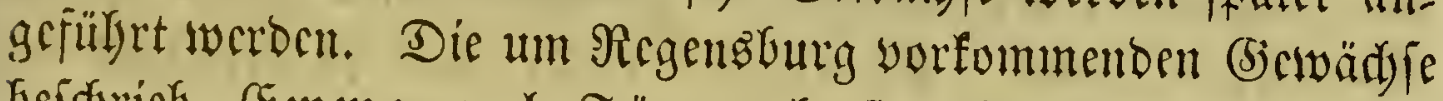
befaricb (Emmanuel Fürnrohr ${ }^{7}$; (5harles Seunet Duyal befdäftigte fid insbefondere mit ben Farrenfräutern, Raubmuofen und Ficdsten bicjer Gegeno uno verfafite cine

1) Synopsis Salicum Hungariae. Pesthini 1831. 8.

$\left.{ }^{2}\right)$ Flora Posoniensis. Posonii 1830. 8. 1 tab. col.

3) Dissertatio exhibens enumerationem plantarum in territorio Quinque-ecclesiensi sponte crescentium etc. Budae 1836. 8. 2 tab.

4) Af(rgemeine botanifdhe Zeitung 1838. B̧. 1. S. 305.

s) Flora dalmatica. Lipsiae 1840-1851. III voll. 4. 36 tab. col.

-) Flora ber (Gegend um Münden. T. I. Mhanerogamen. (Cl. I-XI.) Münd)en 1829. 8. - Egarafteriffif ber beutidyen

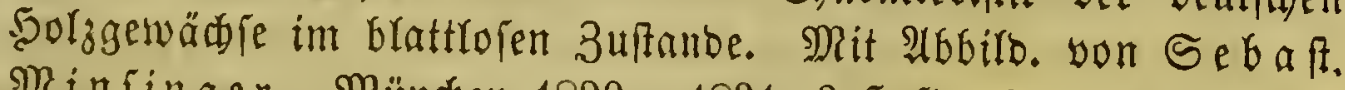
Minfinger. Münden 1829-1831. 2 Sefte. 4. 18 folor. Taf. - Heber bie Begetationżgruppen in Baiern. Münđen 1833. 4.

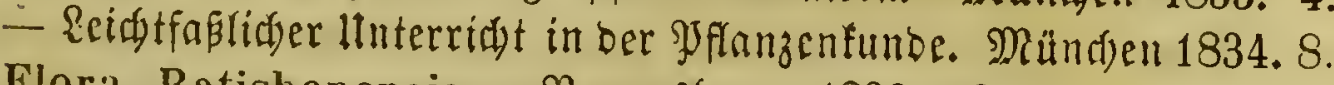

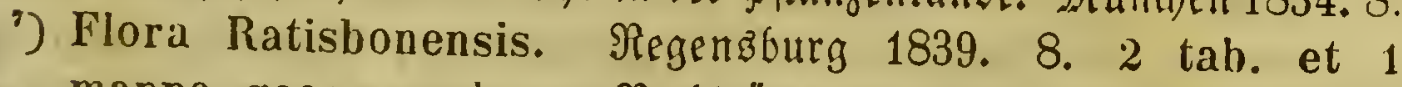
mappa geogn. col. - Rađträge und Beriđtigungen bierzu.

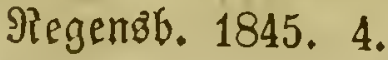




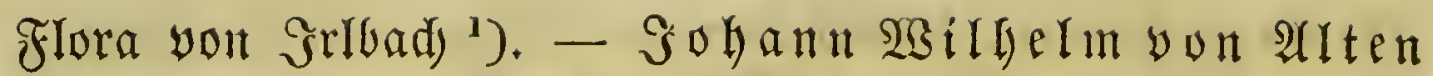

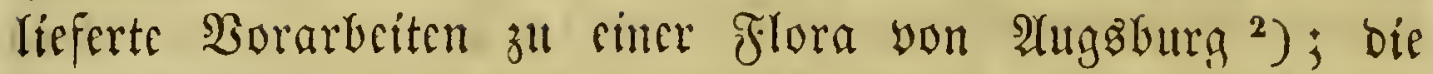

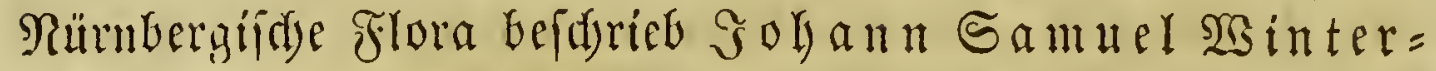

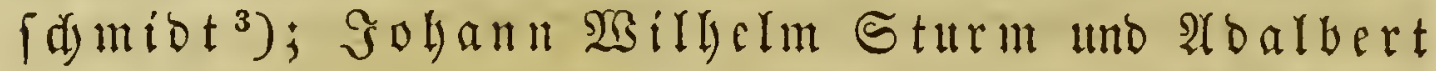
Sid nizlein werzeidyeten bie sybantrogamen uno froptoga=

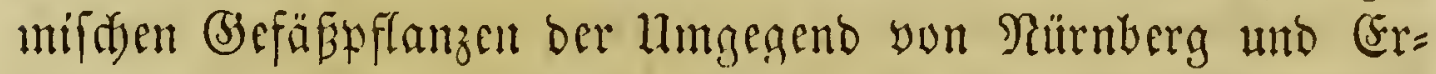

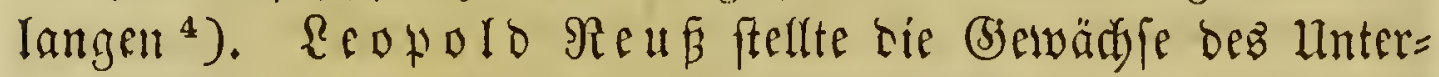
Donaufretfes zufammen und verfap̧te audi nod cine bejonocre Flora yon Salfau ${ }^{5}$ ). Der um bie Renntnif ber auslän=

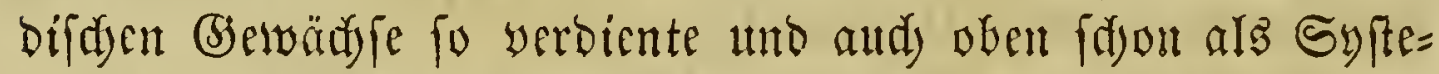

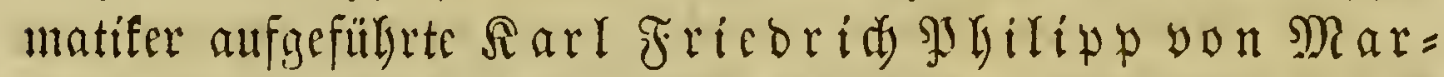
tiu bearbcitete bie Areptogamenflora yon Erlangen und gab

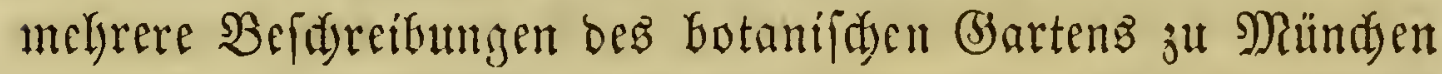
beraus; audd) verfapte er cine Reife tüdtiger Monographieen

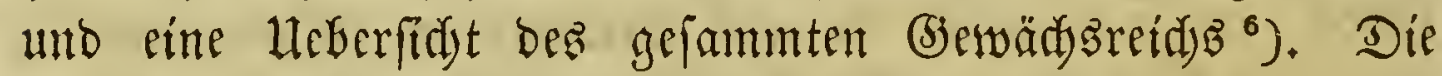
um Sngulfabt wilowadjemben Shanerogamen zählte $\mathfrak{R}$. F.

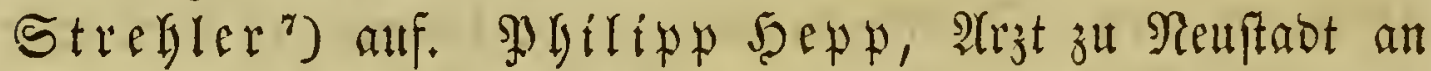

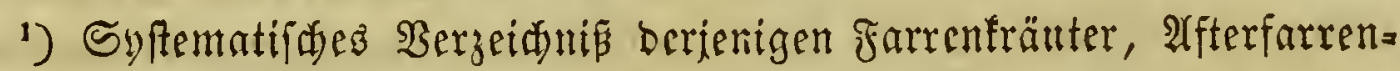

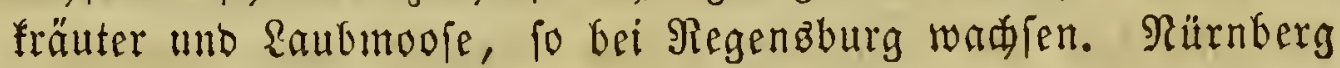
1806. 8. - Syfematifaez Berzeidnif Derienigen Fledten,

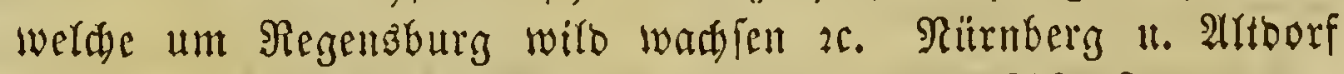

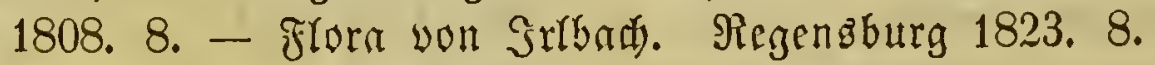

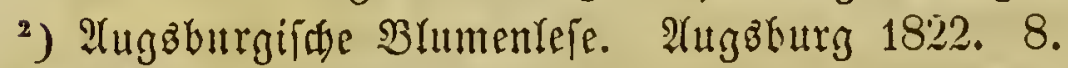

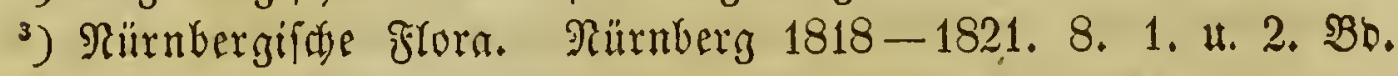
unt 3. Bandes 1. Şeft. 108 Iaf.

4) Errangen 1. Reipjig 1847. 8.

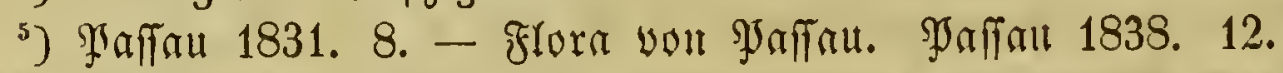

-) Flora cryptogamica Erlangensis. Norimbergae 1817. 8. 6 tab. pro parte col. - Hortus botanicus Regiae Academiae Monacensis. Monachii 1825. 4. 2 tab. - K. Fr. Ph. von Martius et Fr. von Paula Schrank, Hortus regius Monacensis. Müntfen u. Reipzis 1829. 8. - Amoenitates botanicae Monacenses. Froulfurt a. MR. 1829-1831. Fasc. I-IV. 4. 16 tab. col. - Heberfítht ber תraffer, Drb=

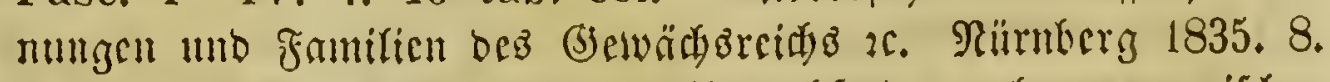

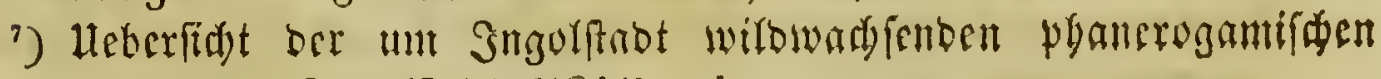
Yjflangen. Sulgolfabt (1841), 4. 


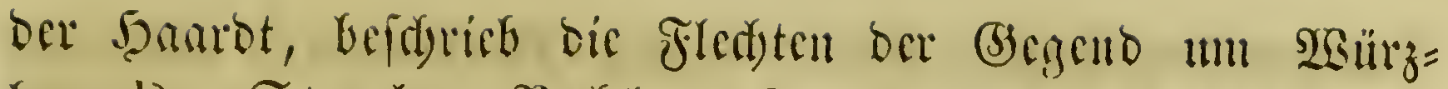

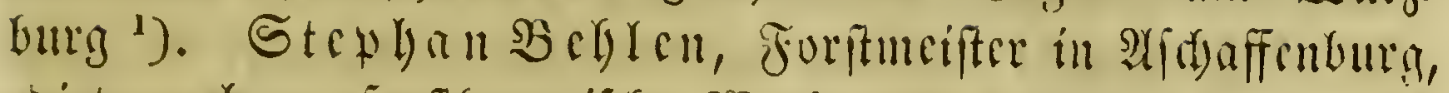

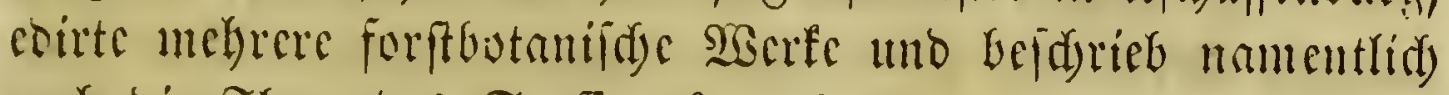

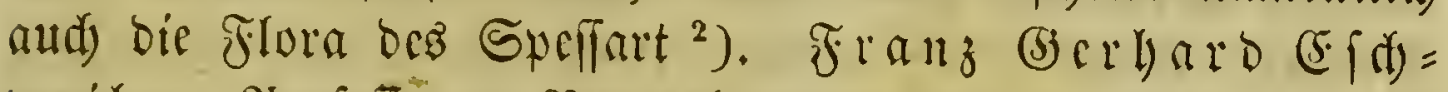
tweiler, Jjofeffor zu Negenşurg, geftorben 1833, resiginte in ben Jalyren 1828 - 1831 (Rärnberg 8.) bie Gotanifden Riteratmblätter uno verfafte cinige monograplifiche 2 (rbeiten

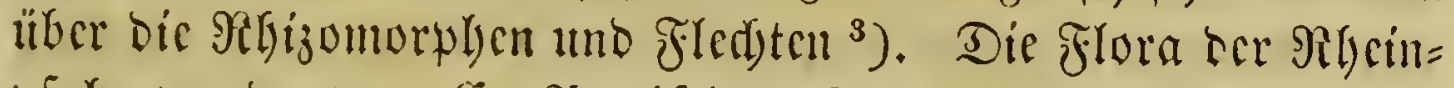

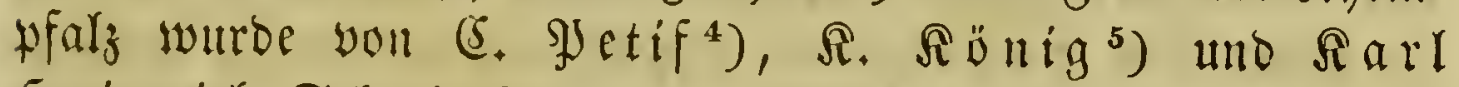

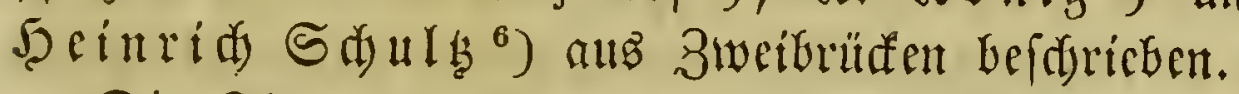

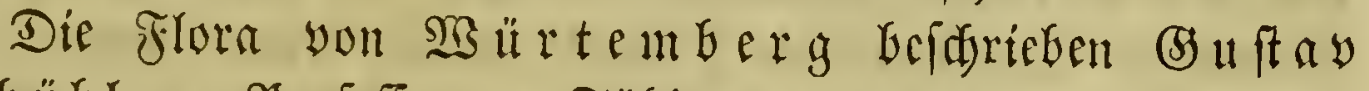
Sdübler, Srofeffor zlt Tulbingen, gefturben 1834, unb (3) erg von Martenb ${ }^{7}$ ); ber (Erftere unterfudte audy bie

1) Ridheneinflora son $\mathfrak{S}_{\text {Shrzburg. Mainz }}$ 1824. 8. 1 Tafer.

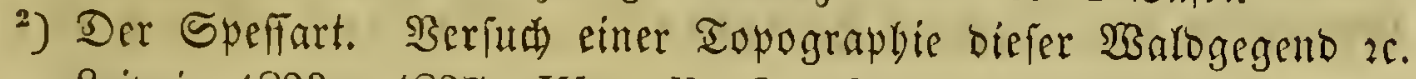
\{eipzig 1823-182\%. III voll. 8. (Sm 1. Baande S. $78-138$ finbet fid bie flora bes Epeffart.) - Eegrbud ber befareiben= Den Forftootanif. Franffurt a. M. 1824. 8. - Botanifdes

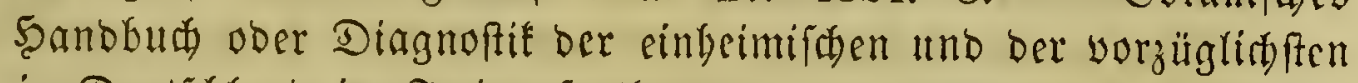
in Deutfaland in freien fortfommenden gorftgewädje, mit $\mathfrak{b}_{\mathfrak{e}}=$ fonberer sinweifung ruf ben Sdjönufd) bei 2(føaffenburg. Bam: berg 1824.8.

3) De fructiticatione generis Rhizomorphae commentatio. Accedit novum genus Hyphomycetum. Elberfeldiae 1822. 4. 1 tab. - Systema Lichenum, genera exhibens rite distincta pluribus novis adaucta. Norimbergae 18:4. 4. 1 tab.

4) Enumeratio plantarum in ditione Florae Palatinatus sponte crescentium. Post Pollichium, Kochium et Zizium denuo recensuit auxitque. Pars phanerogamica. Biponti 1830. 8.

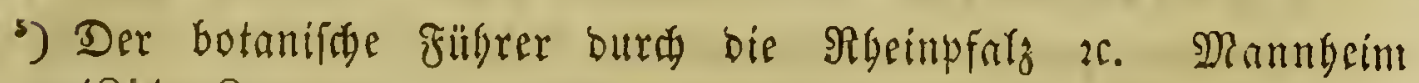
1841. 8.

') Analysis Cichnriacearum Palatinatus secundum systema articulatum. Landau 1841. 8.

") (5) berg. Tübingen 1834. 8. 1 mappa geograph. 
SPflanjen ber (S)egeno yon Tübingen ${ }^{1}$ ) und verfaßite auferbem

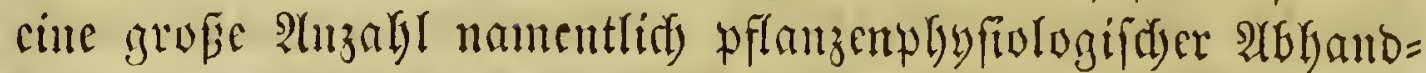

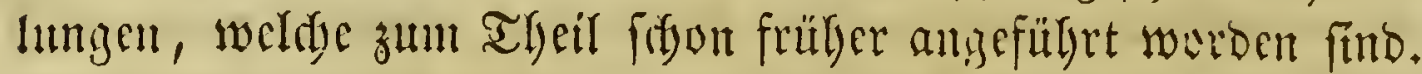

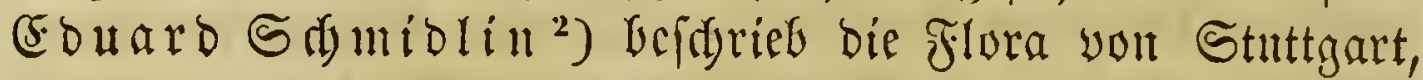

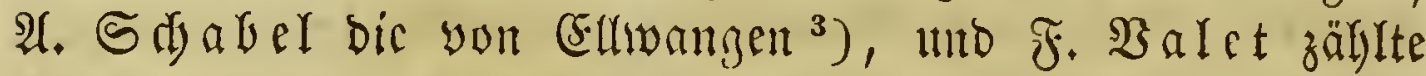
dic Sybancrognmen in ber Ungegend won 14 m auf ${ }^{4}$ ). (Fin

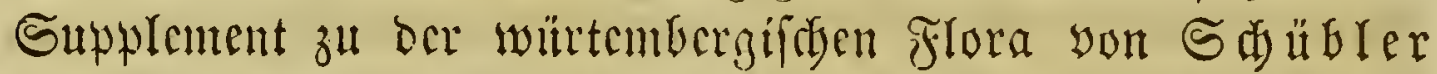
und Martens wurbe von Sallibalo Red ler ${ }^{5}$ ) geliefert.

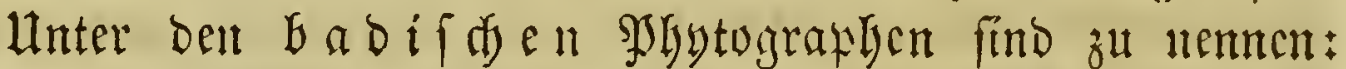
Friebr. Sillis. Rubw. Succow, wegen feiner Flora won Mannlyeim ${ }^{6}$ ), Sofrph Frant wegen feiner Flora von

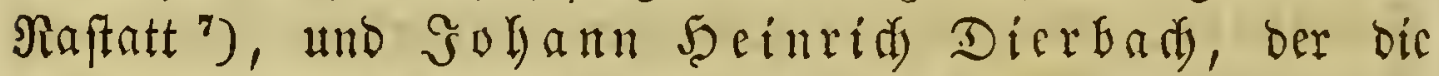
um Sceibelberg yorfommenocn (Serwäd) fe befdrieb ${ }^{8}$ ) und über= bies cinige Werfe liber bie Materia medica, über die (Jie=

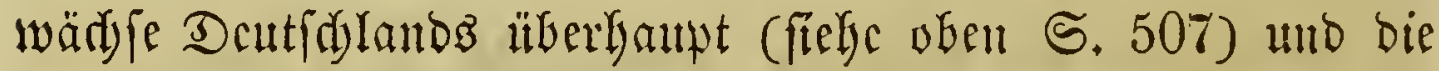

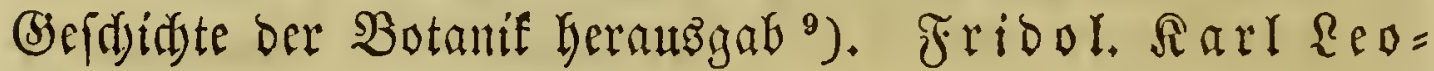

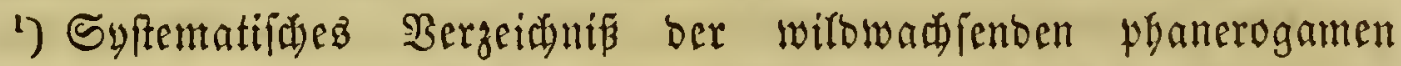

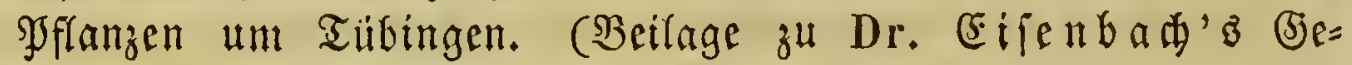

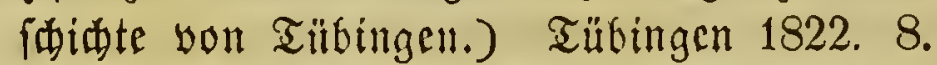

3) Flora yon Stuttgart. Stuttgart 1832. 12.

-) Flora von Errmangen. Stuttgart 1837. 8.

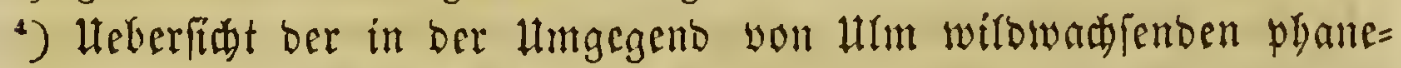

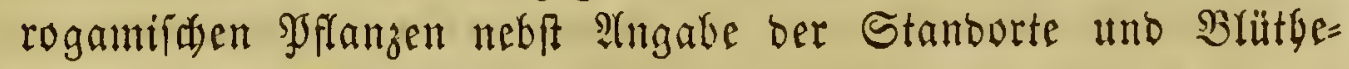
geit. 11tm 1847. 8.

s) Supplement zur Flora yon $\mathfrak{3}$ ärtemberg. Stuttgart 1844. 8.

-) Flora Mannhemiensis et vicinarum regionum cis et transrhenanum. Mannhem. 1822. Il partes. 8. 1 mapp geogr.

') Piaftatto Flora. 5̧riberberg 1830. 8.

3) Flora Heidelbergensis etc. secundum systema sexuale Linne a num etc. Heidelbergae $1819-1820$. II part. 12. c. mapp. geogr. - Sylfematifac Heterfint ber un beioetberg

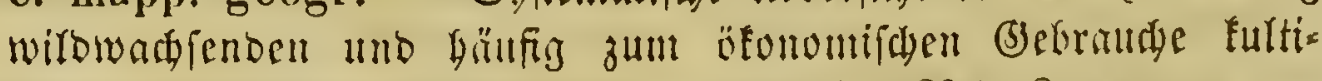
birten (3)

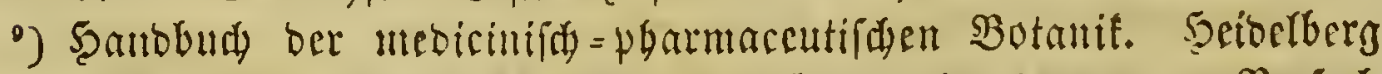

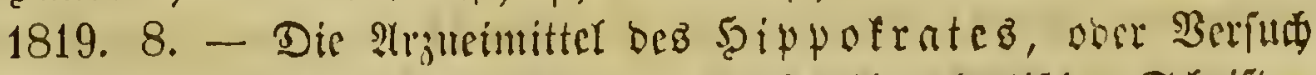

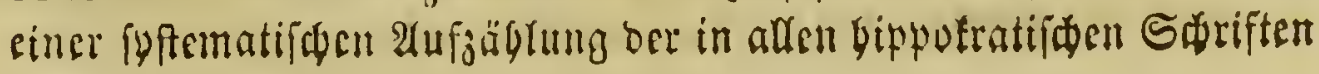




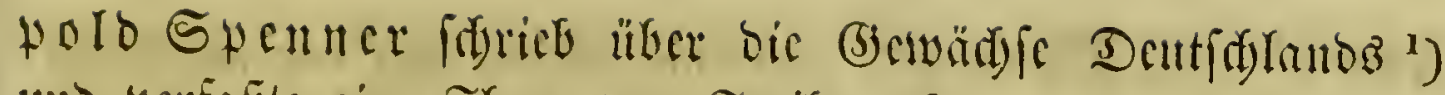
uno werfafite cine Flera won Freifurg. ${ }^{2}$ )

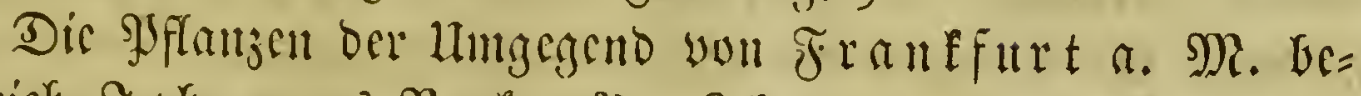

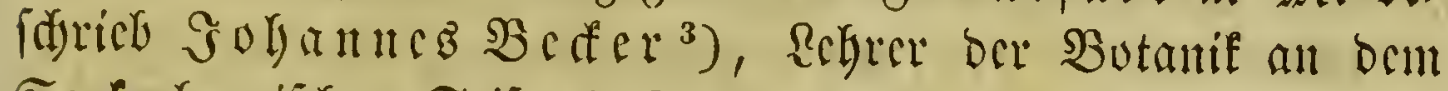
Senfenbergifden Stifte baferbit, jeftorben 1833, unb fein

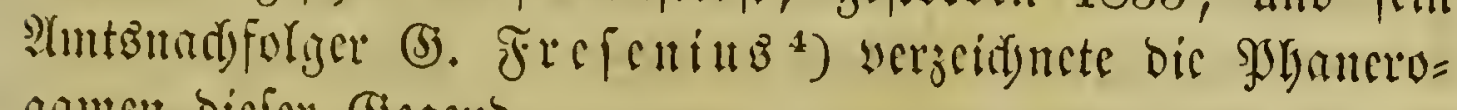
gammen bicfer (j)egculo.

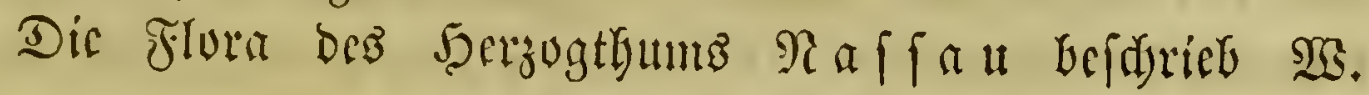

yorfonmenten Mcoifamente. Sciberberg 1824. 8. - Beiträge ju Deutialanbs flora, gefaummelt aus ben $23 e r f e n$ ber älteften beuticten \$fflanjenforider. 5ocibelferg 1825 - 1833. 4 Tale. 8.

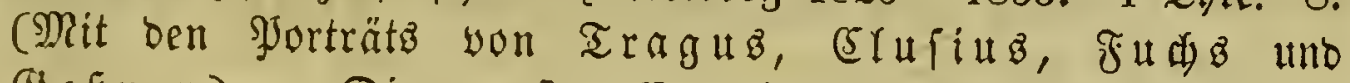
(3) ев́еr.) - Die neueften (Entberfungen in ber materia medica. Seeiberkerg 1828. 2 abtheifungen. 8. - 3weite biz auf

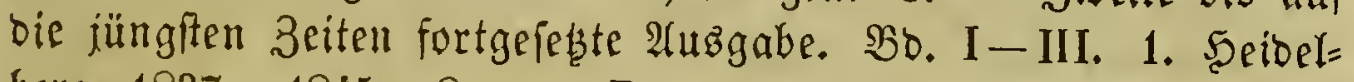
berg 1837 - 1845. 8. - Repertorium botanicum. \&emgo

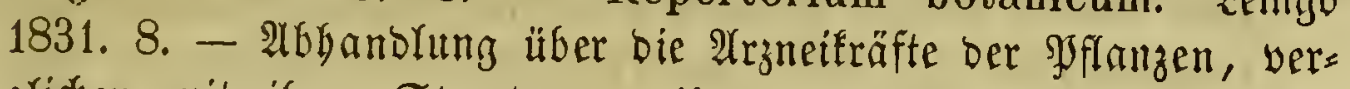
gliden mit ifrer Structur 4t. igren 中emifiden Beftandtyeilen. Remgo 1831. 8. - Flora Apiciana. ઉ̧in Beitrag zur näberen

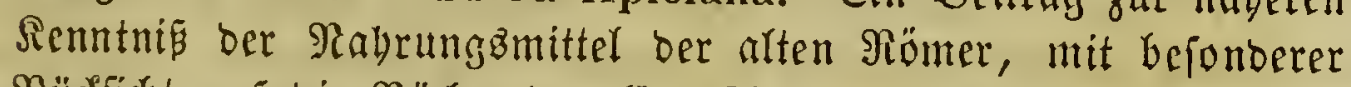

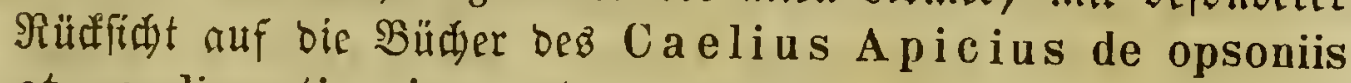
et condimentis sive arte coquinaria. Seeibefferg 1831. 8.

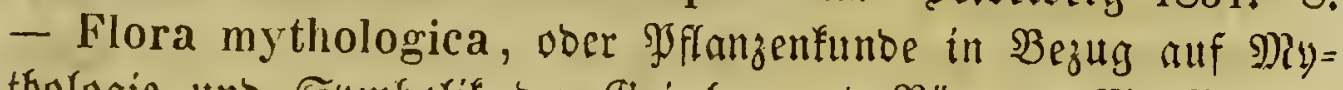
tbologie uno Symbolif Der Brricalen uns Riömer. CSin Beitrag zur älteften (Bjeididte ber Botanif, Agrifultur und Mebicin.

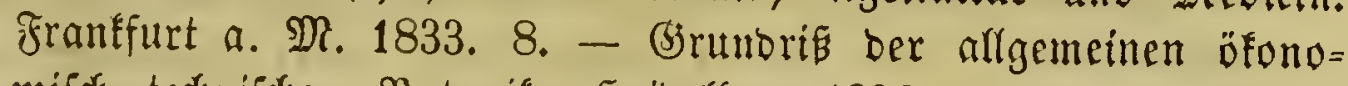

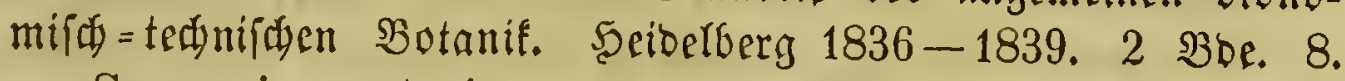
- Synopsis materiae medicae. Şaiberberg $1841-1842$. 2 Abthcilungen. 8.

1) Deutiølanbs planerogamifá Sfflanzengattungen 2 . Freiburg

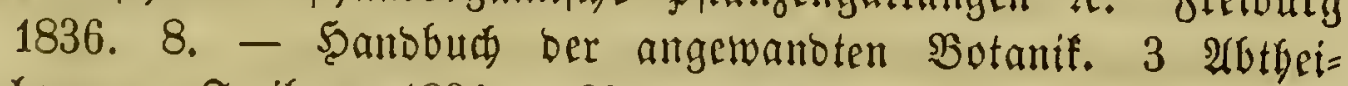
lungen. Freiburg 1834-1836. 8.

2) Flora Friburgensis et regionum proxime adjacentium. Friburgi Brisgoviae 1825 - 1829. III voll. 8. 3 tab.

3) Jrankfurt a. $\mathfrak{R} .1828 .2$ Albtgeilungen. 8.

4) Tafdenbud zum (3ebraudise auf botanifaten (Excurfionen in ber umgegeno yon franffurt a. DR. 2 Abtheilungen. Franlfurt a. M. $1831-1832.8$. 


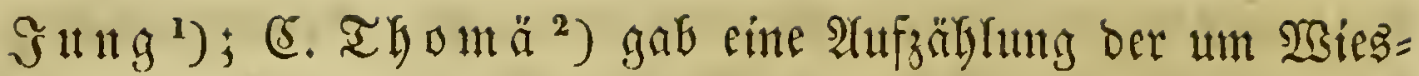

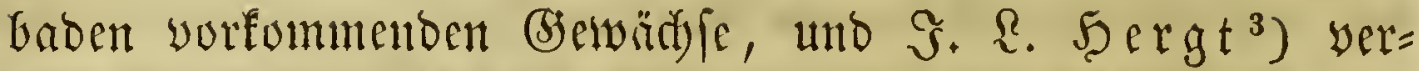
zeidinete die syflanzen der (jegento yon Şadamar.

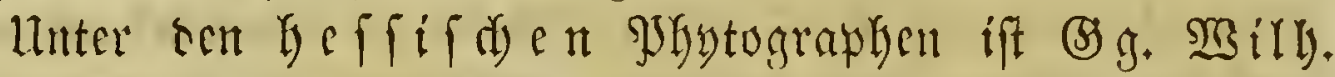

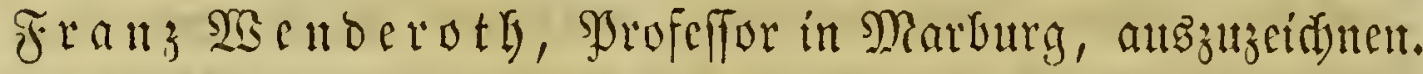
Er verfafte mebrere Sdyriften über bie Flora yon Sellen,

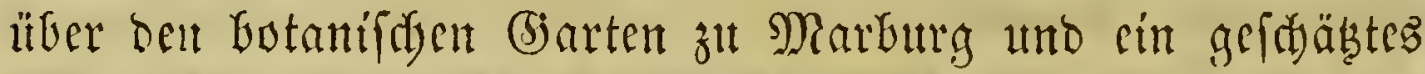

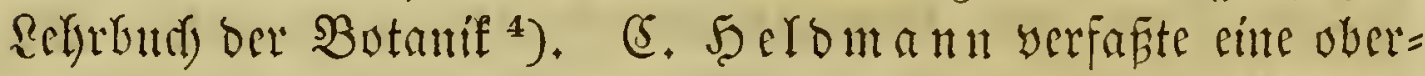

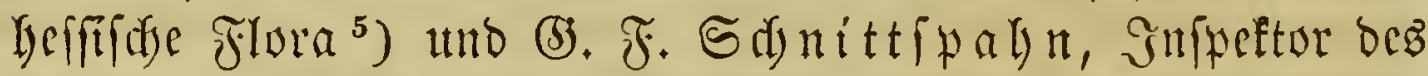
Gotanifden (B)artens und Rebrer ber Sootanif an ber lyöheren

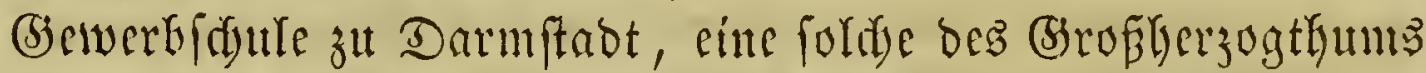

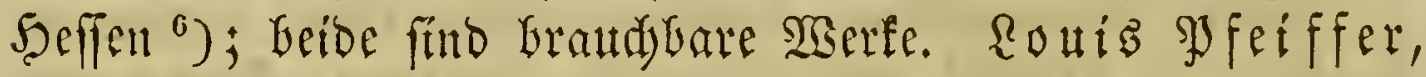

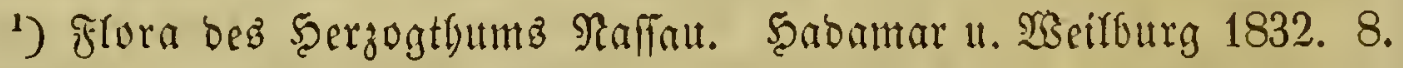

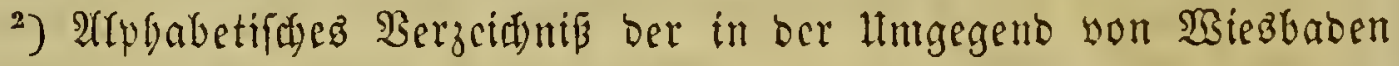

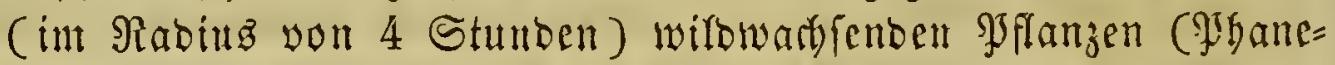

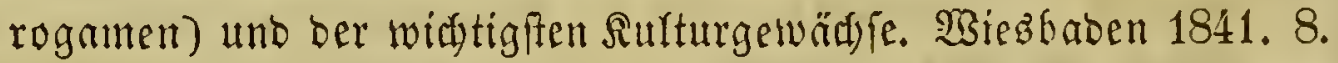

3) SBerfud einer glora yon Sabamar. Saabantar 1822. 8.

*) Beiträge zur Flora yon 5efilen. Marburg 1823. 8. - Serfurb

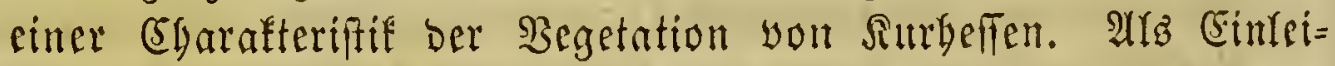
tung in bie flora biefes Rantbes. Saffer 1839. 8, 3 Taf. -

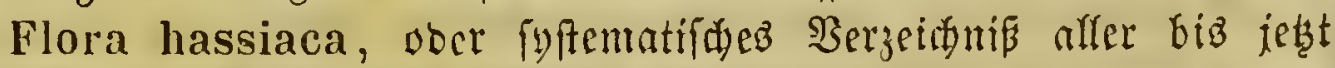
in Surbefien uno (binfichttich) ber fortneren) in ben näaft an=

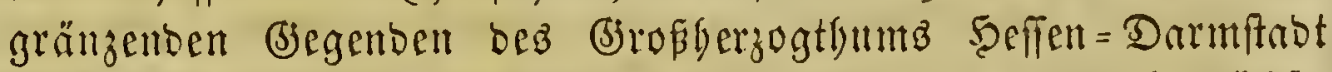

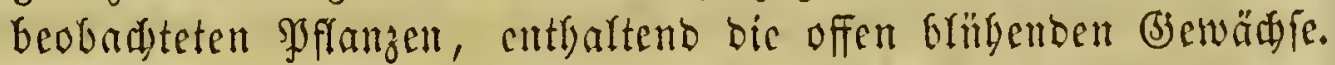
אaffel 1846. 8. - Index plantarum horti Marburgensis. Marburgi 1807. 8. - Einge פ̧emerfungen über veridsicheme neve Sfflanzenarten bes butanifacn Bartens in Marburg, nebit ciner Afbritoung ber Polygala depressa Wender. Mirturg

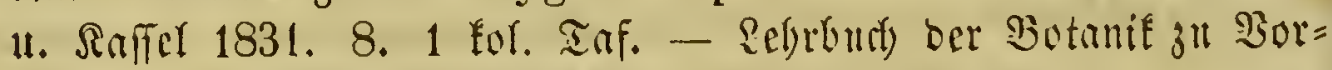
Kefungen unb zum Serbfftubium. Marturg 1821. 8.

5) Sberbeffifde Flora. Tafdenfurty zun (jebrauche auf botantifjen

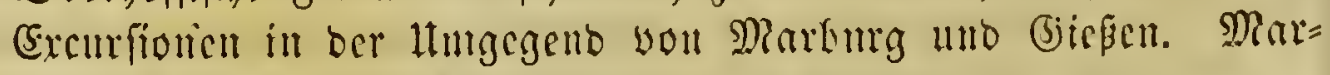
burg 1837. 8.

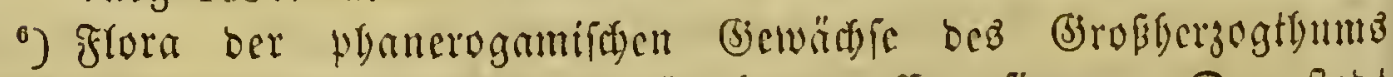

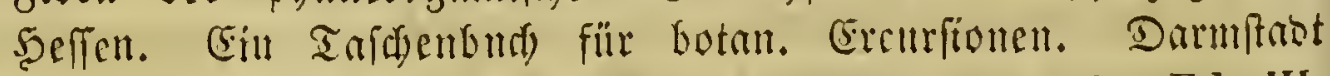
1839. 8. 1 mappa geogr. Ed. II. ibid. 1846. 8. Ed. III. ibid. 1854. 8 . 
ber unten aud) als Menugrawh zut ucumen ift, fdrieb ebenfartz

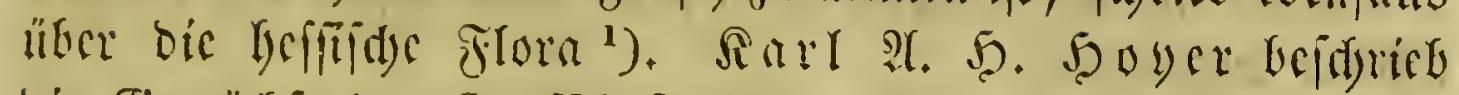

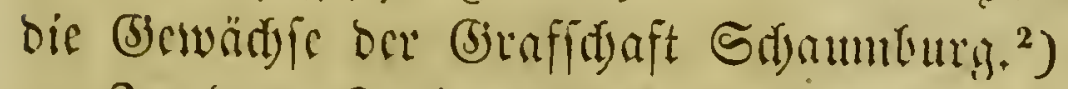

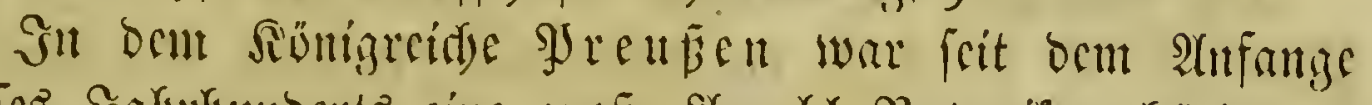

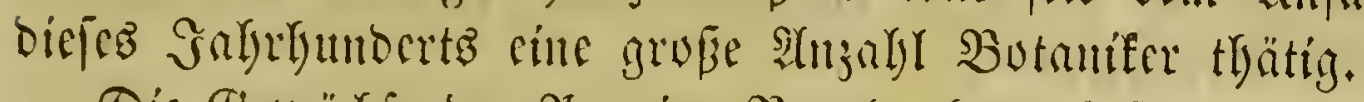

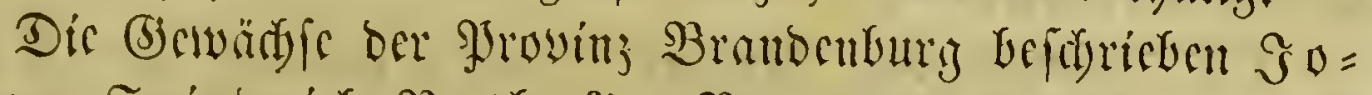

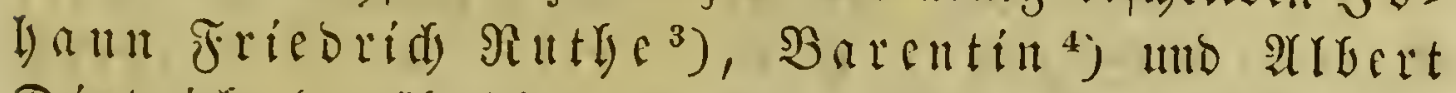

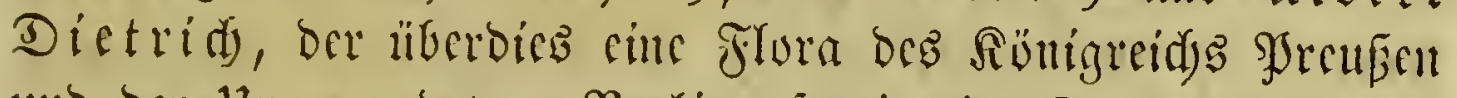
umb ber llmijegend yon Berlin, fotwic cine Icrminologie ber

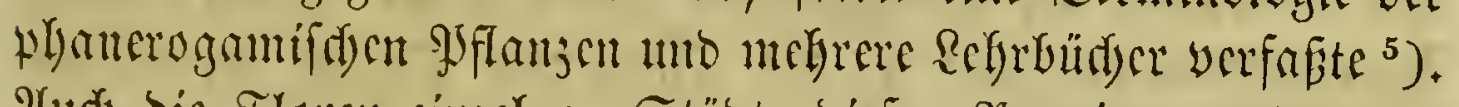
Audi) die Floren eimzelner Stäbte dicfer Jroving wurben be= arbeitct, fo bie Berlin's auper won Dictrid aud) nod) won

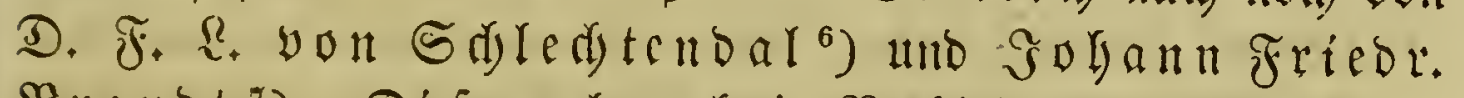

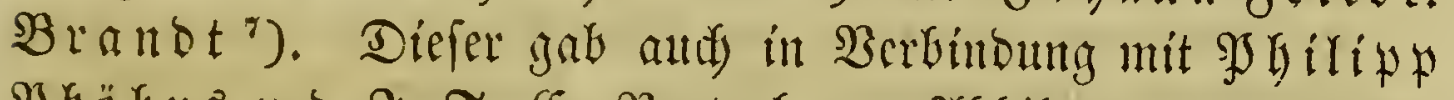
\$ु)

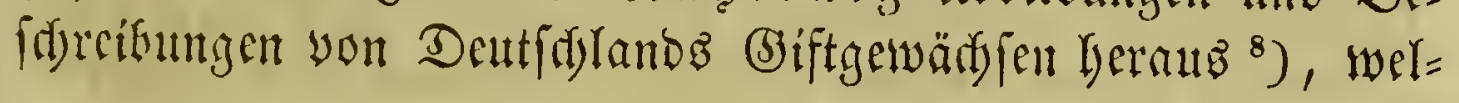

1) Heberfidt ber bisher in Surbefien beobadteten wirbwathenten unb eingebürgerten Sfflangen. Erffe 2tbtheifung. Saffel 1844. 8. - Flora yon Rieberbefien und Münben. 1. Bo.: Difotylebo= nen. Saftel 1847. 8.

$\left.{ }^{2}\right)$ Flora ber Braffdaft Sdaumburg unb ber lturgegend, mit befon=

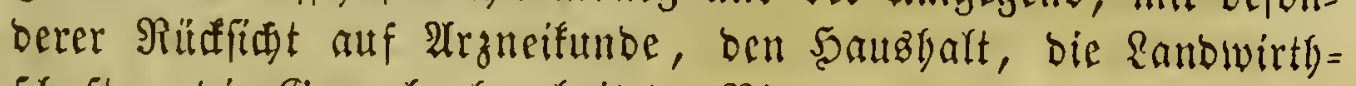

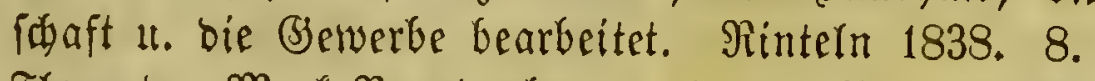

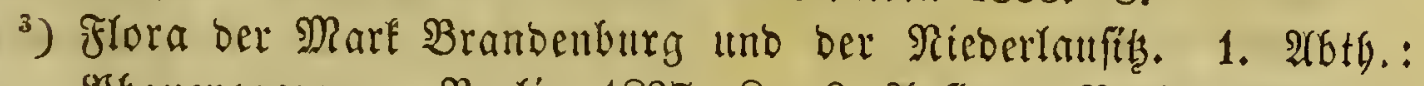
5jgauerogamen. Berlin 1827. 8. 2. 2uflage. Bertin 1834. 8. 2 Taf. (Entrält auta) bie ßroptogamen.)

4) Die $\mathfrak{B}$ egetation in ber Marf Brandenburg. Berrin 1840. 4.

5) Flora marchica. Boertin 1841. 8, - Flora regni Borussici. Bertin 1833-1844. Xll voll. 8. max. 86\% tab. col. Flora ber Begend um Berlin. 1. Thl.: Whanerogamen. Berrin 1824. 8. -- Terminologie ber phanerogamifden $\mathfrak{T f f a n z e n ~ b u r d ) ~}$ megre als 600 figuren ertäutert 2c. Bertin 1829. Fol. 8 Taf.

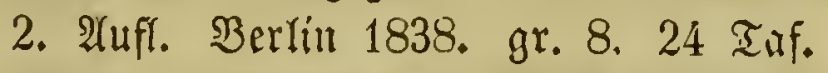

$\left.{ }^{6}\right)$ Flora Berolinensis. Berolini 1823-1824. II voll. 8 .

$\left.{ }^{7}\right)$ Flora Berolinensis. Berolini 1824. 12.

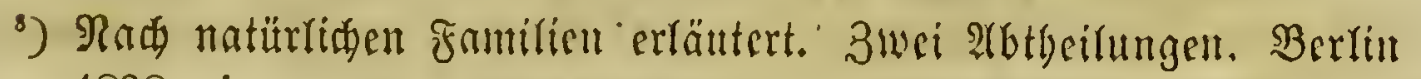
1838. 4. 


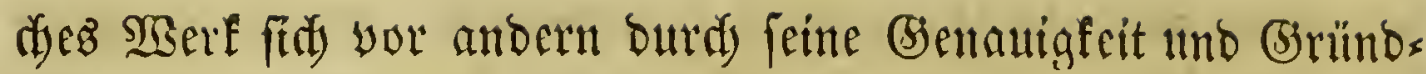
lict)êt nuşzeid)uet.

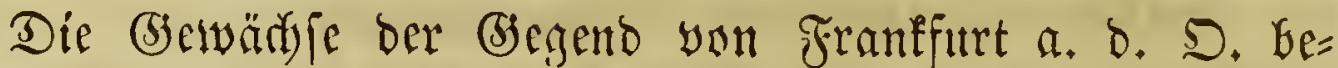

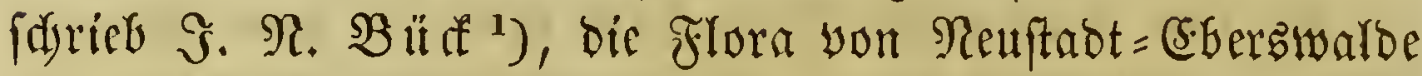

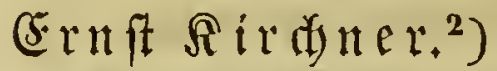

Die Sffrnzen ber Srovinz Sreufen wurben sout Rarl

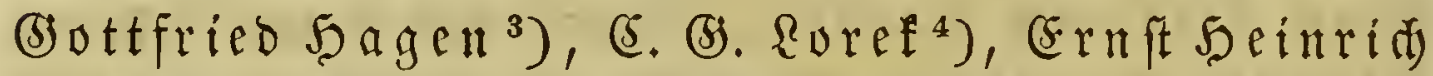

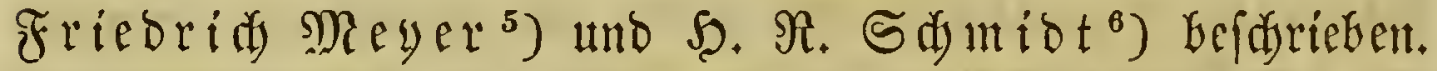

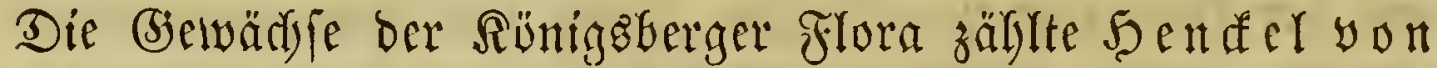
Donnersmarl auf ${ }^{7}$ ), bie Flora bon Danzig Gearbeitete

1) Hortus Frankofurtanus, Doer $\mathfrak{B e r z e i f f n i}$ ber in meittem (5)ar=

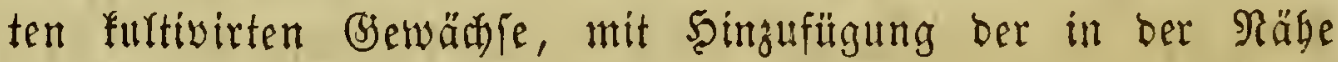

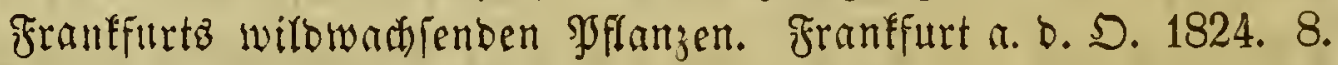

$\left.{ }^{2}\right)$ Heberficht ber wifienfwaftlidien Sfflanzenfunbe, nebfit eitrem Sortz=

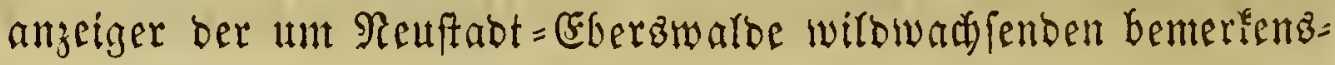
werthen Sffanzen. Berrin 1830, 8.

$\left.{ }^{8}\right)$ Tentamen historiae Lichenum et praesertim prussicorum. Regiomonti 1782. 8. 2 tab. col. - Commentatio botanica de Ranunculis prussicis. Regiomonti (1783). 4. - De Cardamine pratensi. Regiomonti 1785. 4. - Veronicarum prussicarum recensio. Regiomonti 1790. 4. - De plantis in Prussia cultis (Monandria-Triandria). Regio-

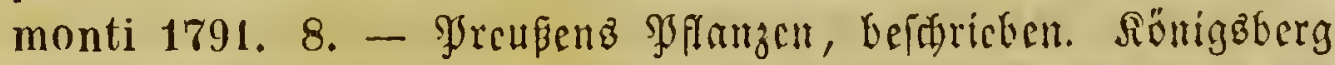
1818. 2 Bbe. 8. 2 Iaf. - Chloris Borussica. Regiomonti 1819. 12.

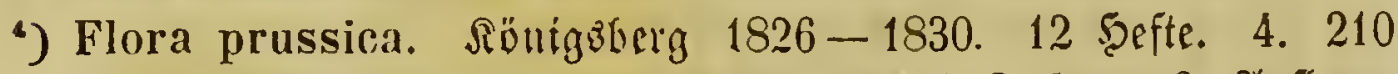
fol. Taf. - Nafitrag. Daf. 1837. 20 \%ol. Taf. - 3. Fluffige. Daf. 1846. 24 5effte. gr. 8.

$\left.{ }^{5}\right)$ Elenchus plantarum Borussiae indigenarum. (Regiomonti

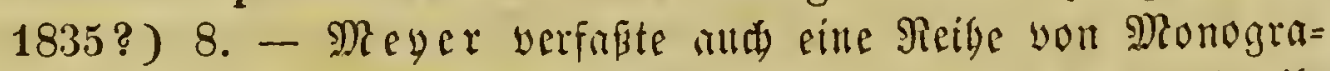

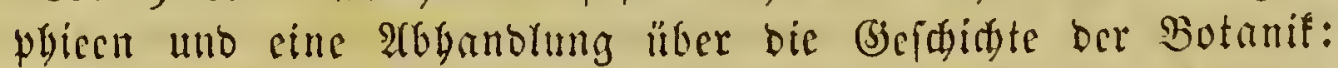
Die Entwifflung ber Botanif in igren Sauptmontenten. Sönigs: berg 1844. 8.

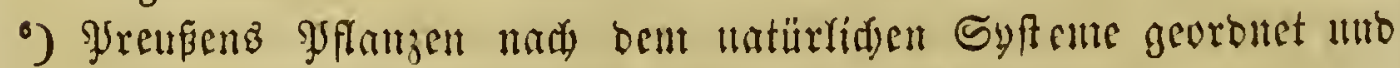
bejdrieben. Danzig 1843. 8.

') Enumeratio plantarum circa Regiomontum Borussorum sponte crescentium. Regiomonti 1817.8. 


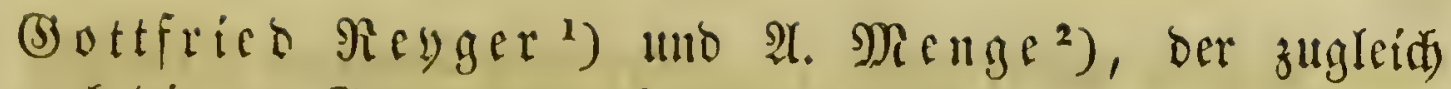
aud) bic um (Straubenj yorfommentoen Pftanzen berüafidstigte. গ) Braunsberg.

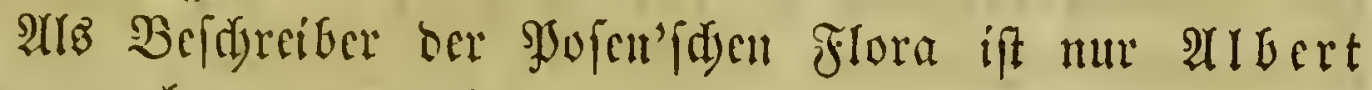

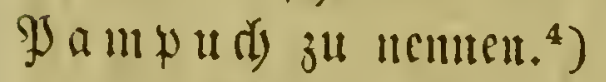

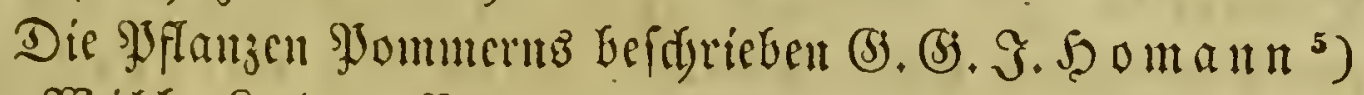

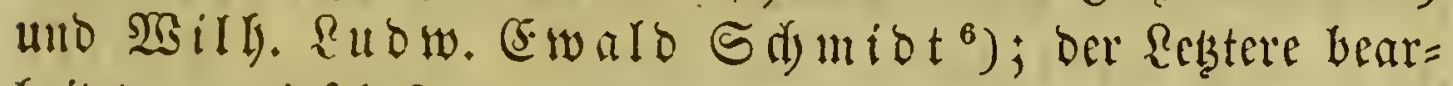

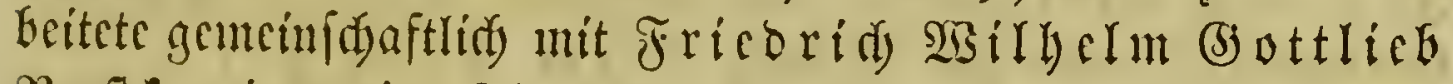
Roft oyius cime Flora yon Stctim. ${ }^{7}$ )

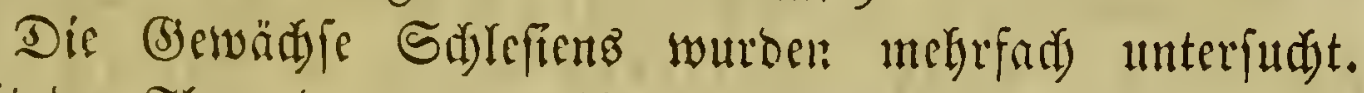

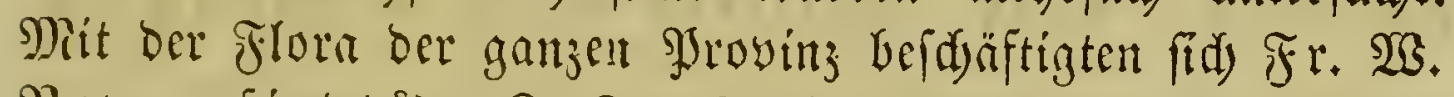

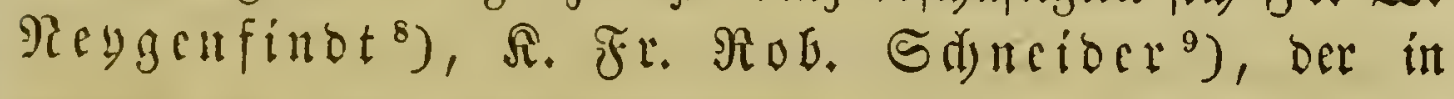

') Tentamen Florae Gedanensis methodo sexuali accommodatae. Dantisci 1764-1766. Il voll. 8. - Die um Danzig

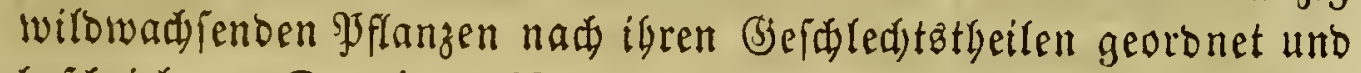
beidrieben. Danzig 1768. 8. Fine neue umgearbeitete Pluflage

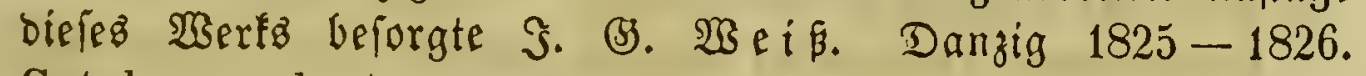

$\left.{ }^{2}\right)$ Catalogus plantarum phanerogamicarum regionis Grudentinensis et Gedanensis. Grudentiae 1839. 12.

$\left.{ }^{3}\right)$ Catalogus plantarum phanerogamarum circa Brunsbergam sponte crescentium elc. Brunsbergae (1846). 8.

t) Flora Tremesnensis. Trzemessno 1840. 8.

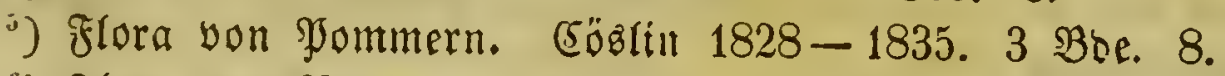

$\left.{ }^{6}\right)$ Flora yon Wommern unb Rügen. Stettin 1840. 8.

7) Flora Sedinensis, exhibens plantas phanerogamas spontaneas necnon plantas praecipuas agri Sevinemundii. Sedini 1824. 8. 2 tab.

$\left.{ }^{8}\right)$ Fnchiridium botanicum, continens plantas Silesiae indigenas, cui adjungitur in fine Calendarium botanicum. Misenae 1821. 8. 1 tab. - Ialenber ber fiflefifden Flora. Meípen 1822. 8.

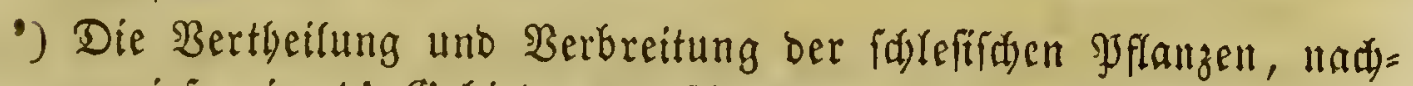

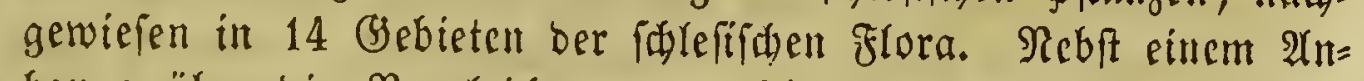
bange über bie Bergleidjung ber fidlefildsen mit ber britifden Jlora. Rebft eimer botanifich=geognoftifden Rarte von Bumblau. Breălau 1838. 8. 


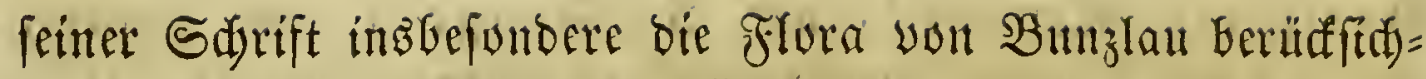

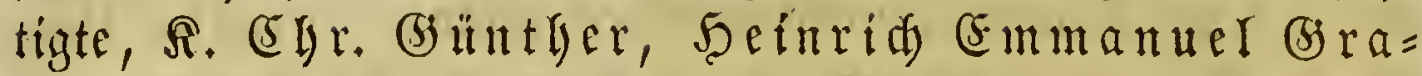
bowafi und Fr. 2 i immer ${ }^{1}$ ). Die (5)

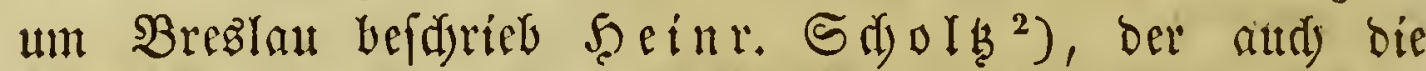

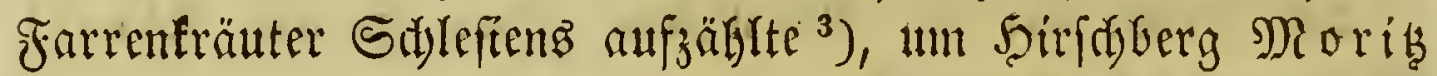

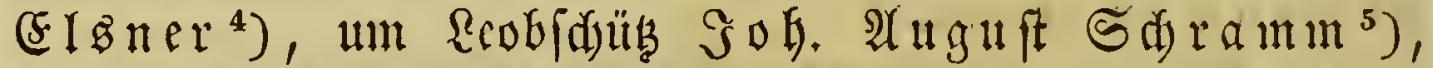

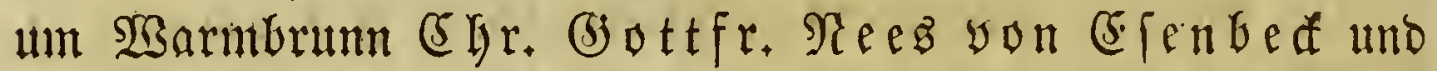

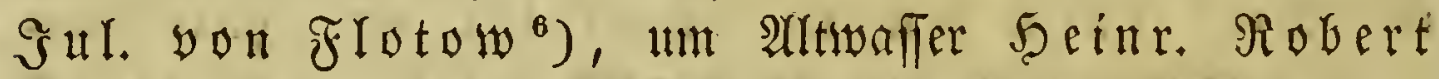

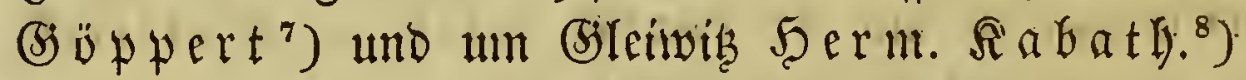

Ergänzungen zu R. Splengel'b Flora you Şalke lic=

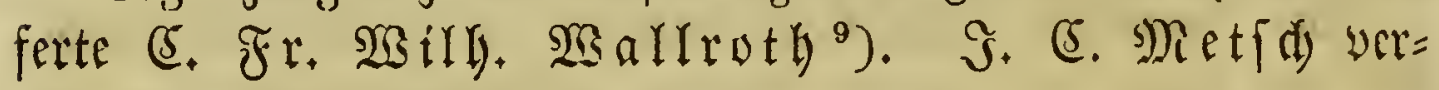

1) Enumeratio stirpium phanerogamarum quae in Silesia sponte proveniunt. Vratislaviae 1824. 8. - B $\mathfrak{r a b o w} \mathfrak{b} \mathfrak{i}$ farieb auferbem: Flora yon Sberidlefien u. Dem Befenfe mit

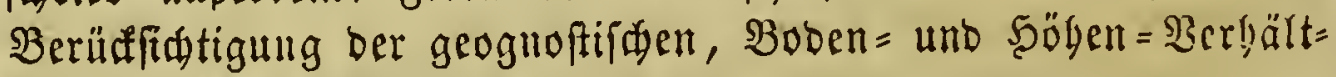
niffe. Brestau 1843. 8.

$\Rightarrow$ Flora ber umgegend yon Breblau. Breslau 1843; 8.

$\left.{ }^{3}\right)$ Enumeratio Filicum in Silesia sponte crescentium earumque de usu, additis Lycopodiaceis et Equisetaceis. Vratislaviae 1836. 8.

5) fiora von Sirføberg unb bem angränzenten Riefengebirge. Brezlau 1837. 8. - Synopsis Florae Cervimontanae. Praemissa est de speciei definitionibus quaestiuncula critica. Vratislaviae 1839. 8.

5) Die $\mathfrak{B f l a n z e n ~ b e s ~ R e o b i d u ̈ t ̦ e r ~ S t a b t w a l b e s . ~ R a t i b o r ~ 1 8 3 3 . ~} 8$.

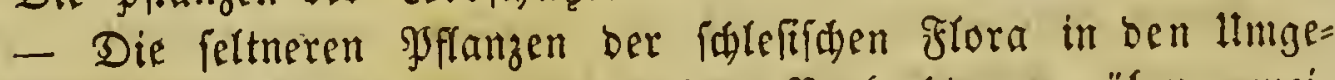
bungen von \&eobidübs, nebft einigen Beobadtungen über gemei= nere. \&eobidüb 1840.8.

-) Sobann Wendt, Die Thermen zu Warmbrum. Breşau 1840. 8. S. $115-169$.

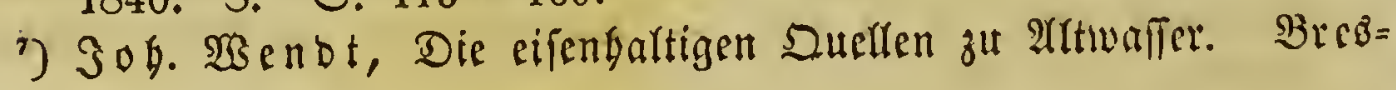
Ina 1841. 8.

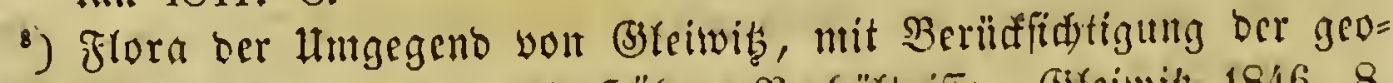

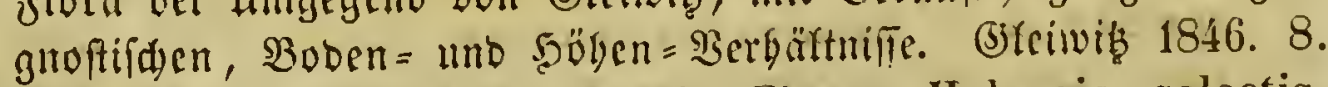

-) Schedulae criticae de plantis Florae Halensis selectis. Corollarium novum ad Sprengelii Floram Halensem. Tom. I: Phanerogamia. Halae 1822. 8. 5 tab. 


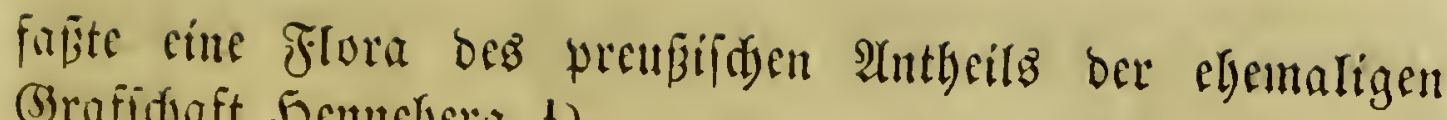
(3rafidaft 5emucberg. ${ }^{1}$ )

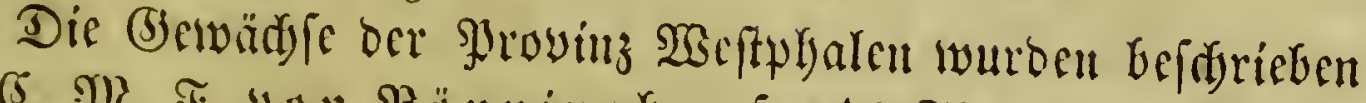

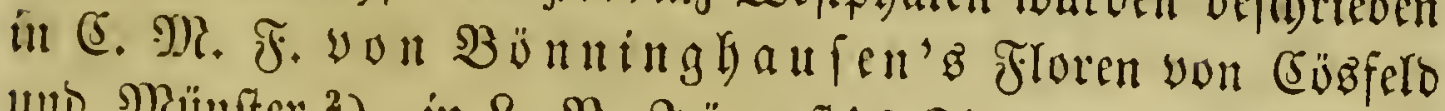

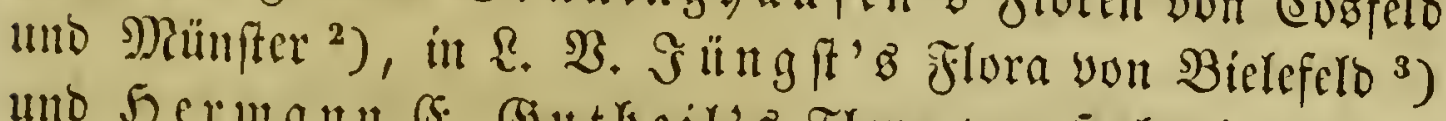

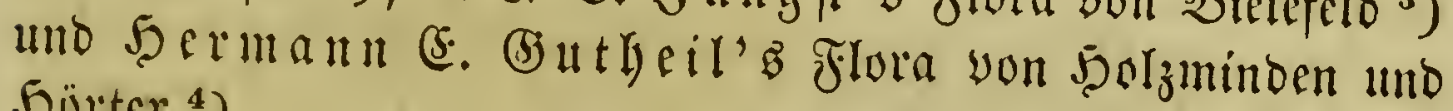
5. (üter. ${ }^{4}$ )

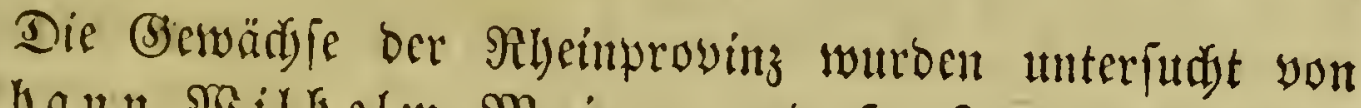

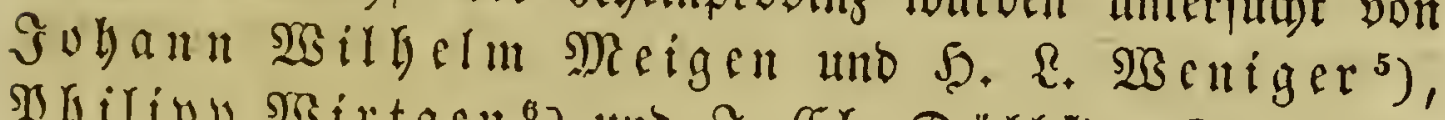

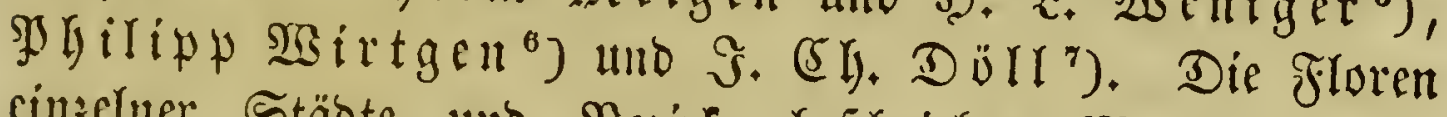

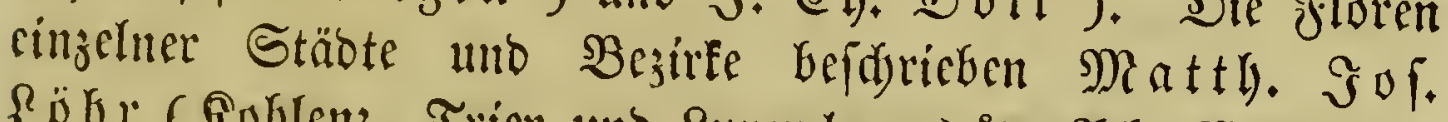

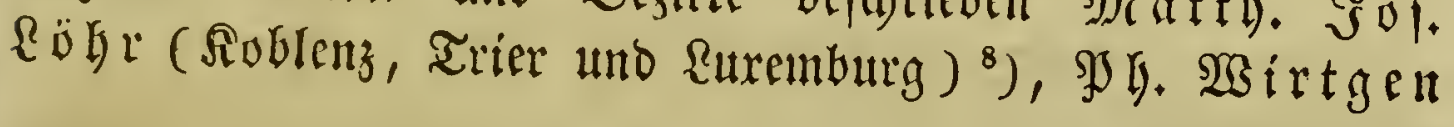

1) Flora Hennebergica. SWhYeuting

2) Nomenclator botanicus, sistens plantas phanerogamas in circulo Coesfeldiae Westphalorum inquilinas etc. Coesfeldiae (1821). 8. - Prodromus Florae Monasteriensis Westphalorum. Phanerogamia. Monasterii 1824. 8.

3) FIora ber näđdfften thmgebungen Bielefeldoz. Bicleferto 1833.8. - Flora bon Biecefeldo. Bieleferto uno Serforo 1837. 8.

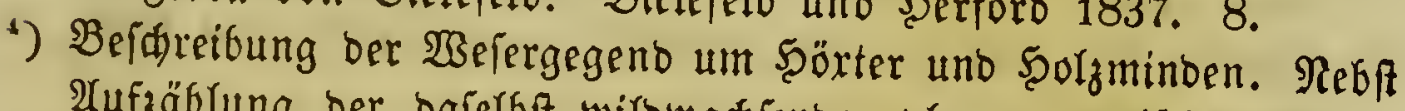

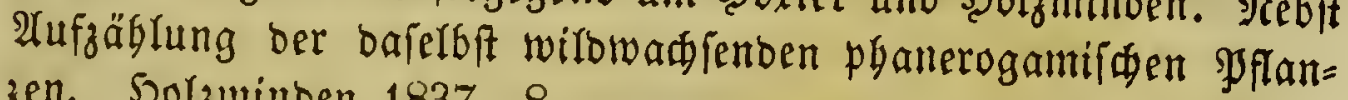
zen. S2orgminten 1837. 8.

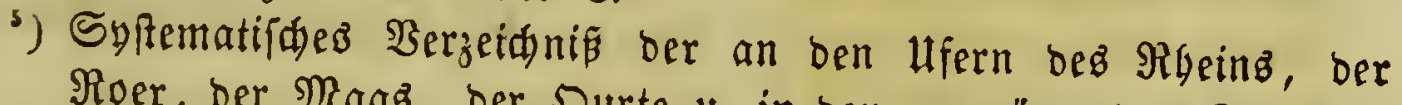
Roer, ber Maaz, ber Surte u. in ben angränzenden Bsegenden

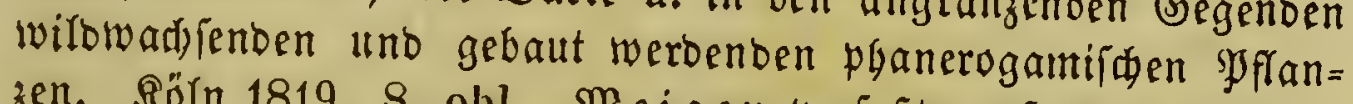
zen. Röln 1819. 8. obl. Meigen werfaß̧te auß̧erbem nod ein

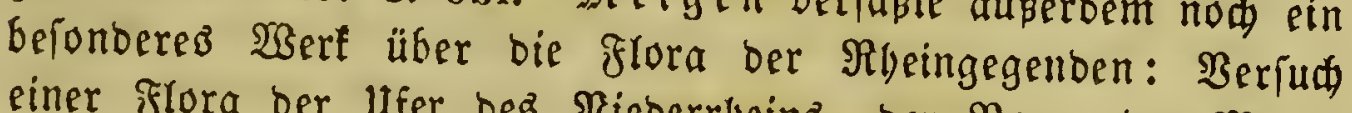

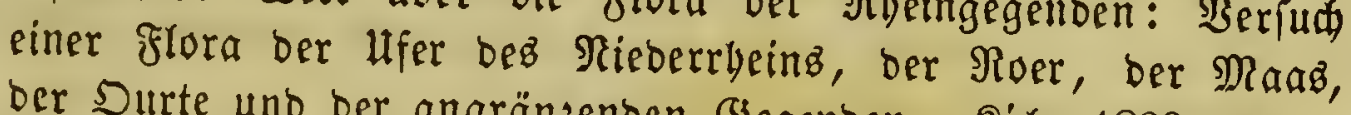
ber Sirte und ber angränjenben Begenben. Ró́n 1823. 12.

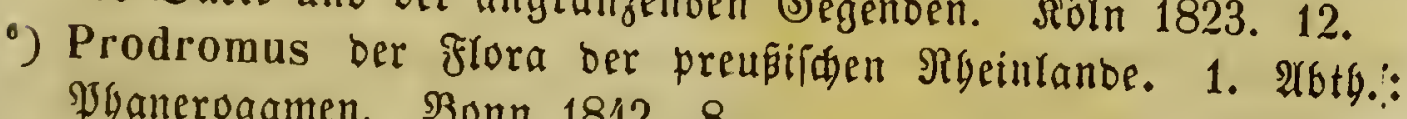
\$YGanerogamen. Bonn 1842. 8.

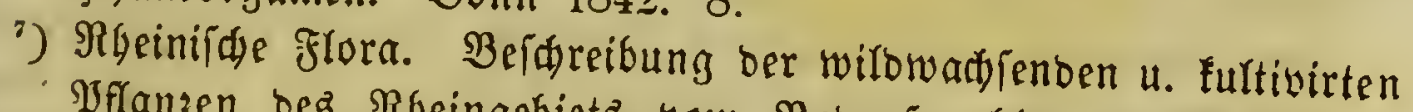

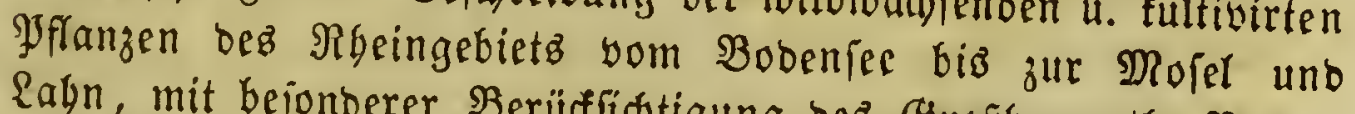

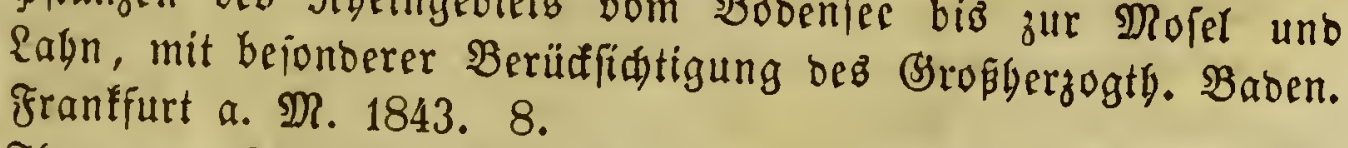

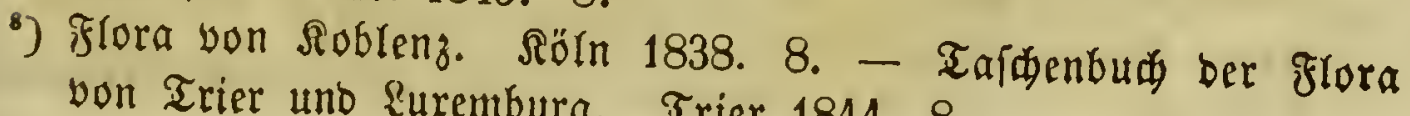
von Trier uno \&uxemburg. Trier 1844. 8. 
$\left(\right.$ Roblenz) ${ }^{1}$ ), Sofeth Müler (Hadien) ${ }^{2}$ ), M. Sdäfer

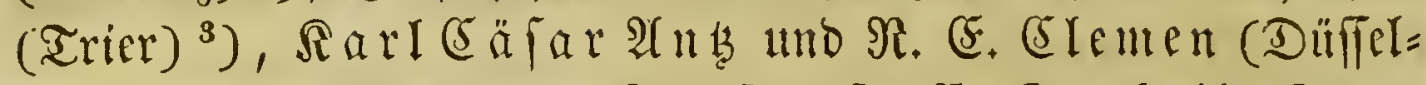

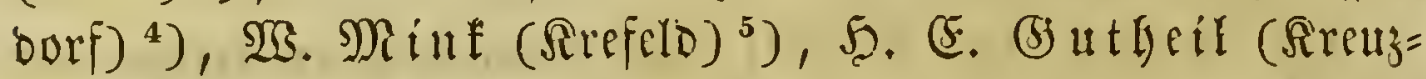

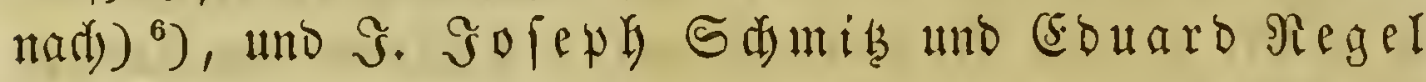
$\left.(\mathfrak{B o n n t})^{7}\right)$.

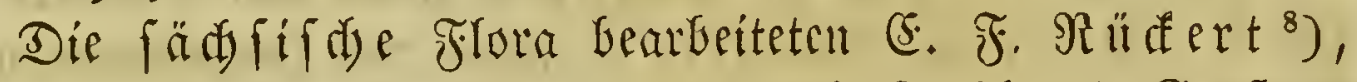

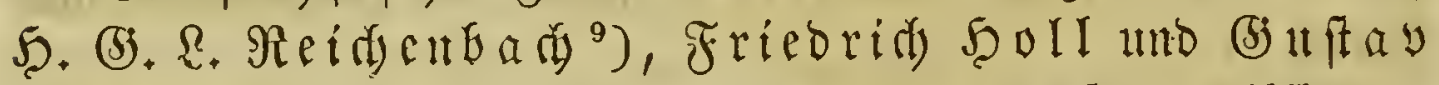
Scynlyolo ${ }^{10}$ ). Mit ben um Dresocn wadjenten SFlangen

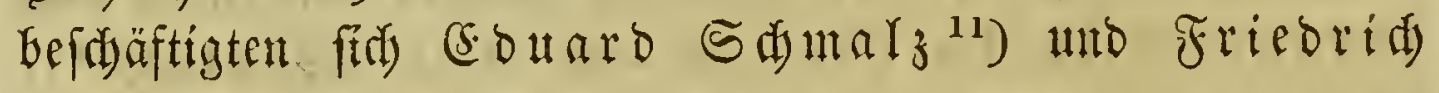

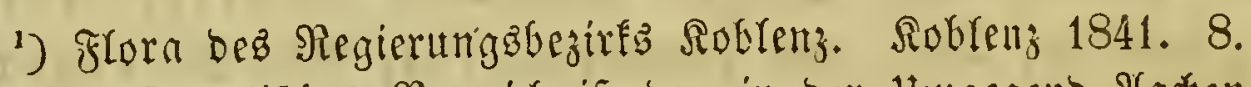

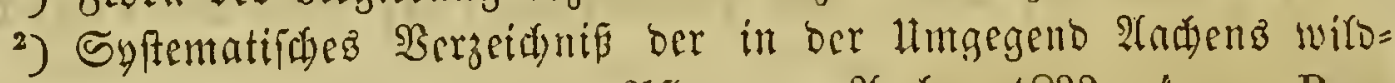
wadjenden phanerogament Pfflaljelt. Atrdhen 1832. 4. - Prodromus ber phanerogamijaen frora yon Fhaden. Deż oben

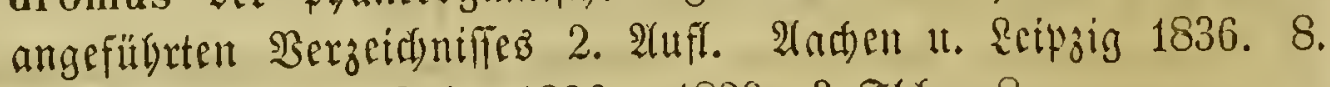

3) Irierifue frora. Trier $1826-1829.3$ Thle. 8.

4) Slora yon Dilffeloorf. Düffeldorf 1846. 8.

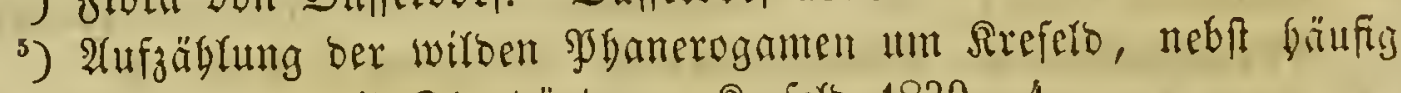
furtivirten, mit Stanbörtern. Sirefło 1839. 4.

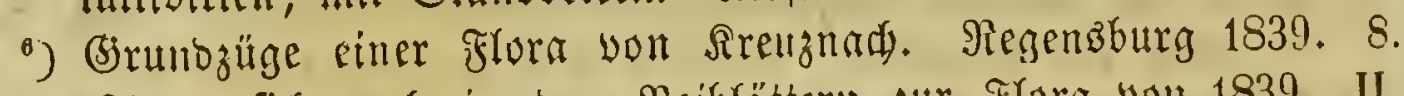
(Frindet fith alta in ben Beiblätterı jur flora yon 1839. II. (5. 1 -68.)

7) Flora Bonnensis. Praemissa est L. C. Trevirani, Prof, Bonn., Comparatio Florae Vratislaviensis et Bonnensis. Bonnae 18't1. 8.

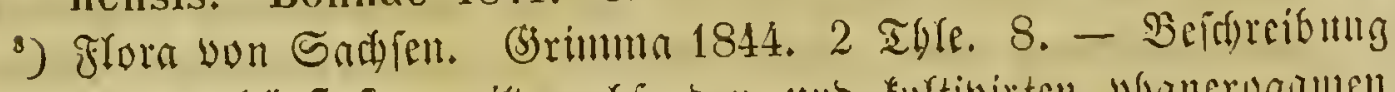
ber aun bälfigften wirbsadj/enden ulb fultivirten phanerugumen

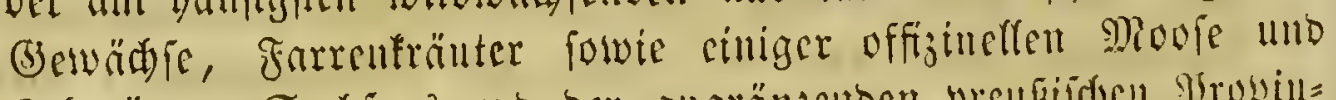

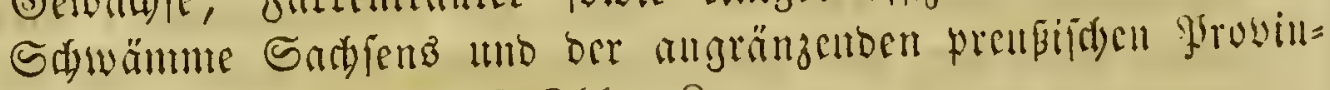
zen 2c. Reinzig 1840. 2 Tole. 8.

9) Siege Seite 501.

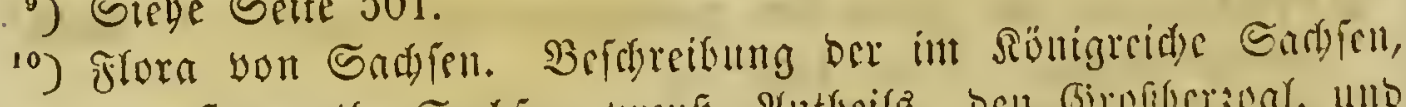

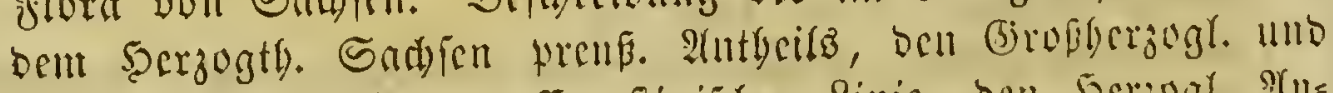

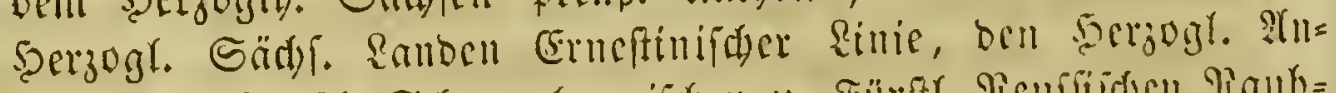

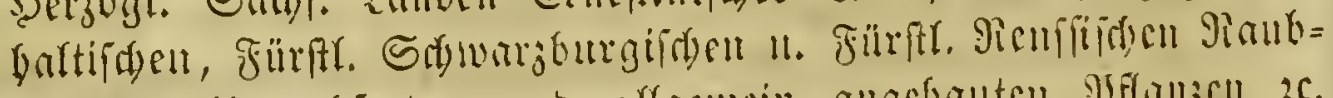

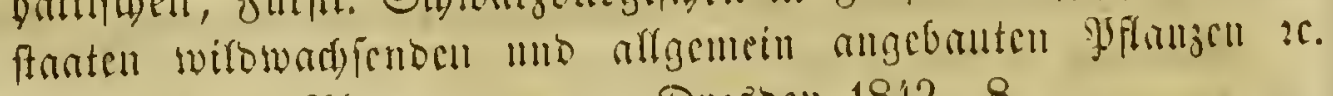

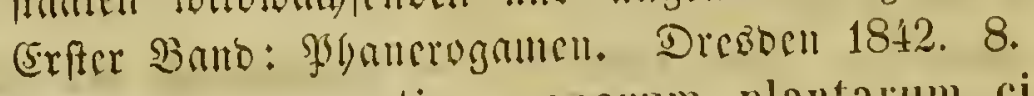

ii) Dispositio synoptica generum plantarum circa Dresdam 


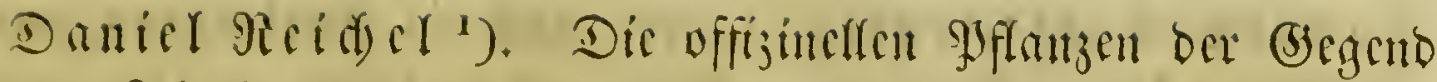

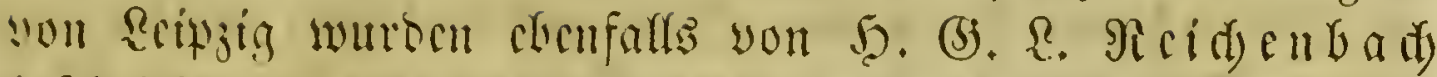

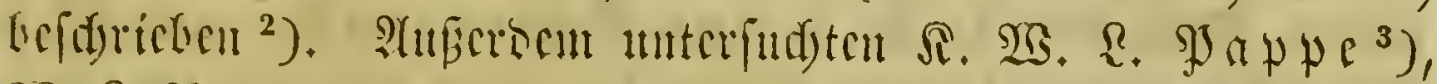

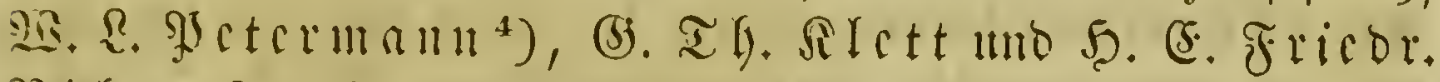

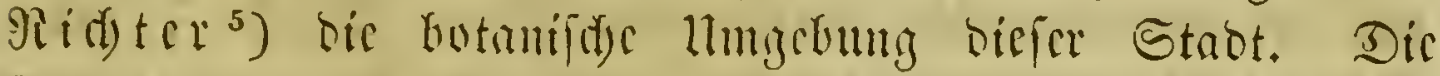

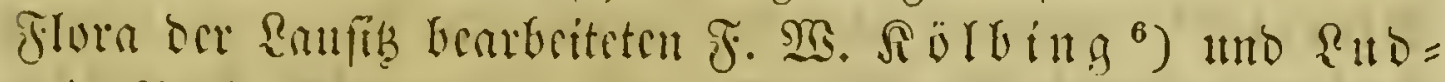

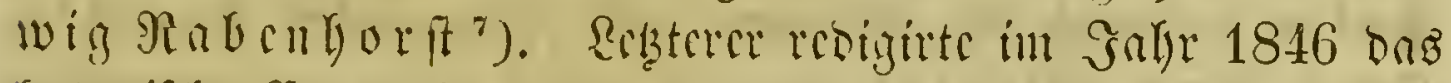
botanifde (Sontralbratt für Doutidyland ${ }^{8}$ ); als Siryptogamift

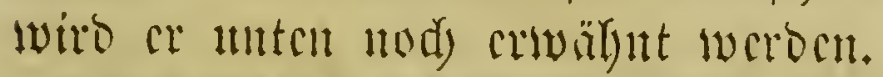

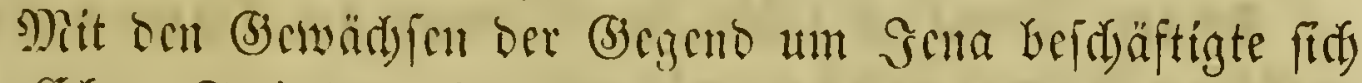

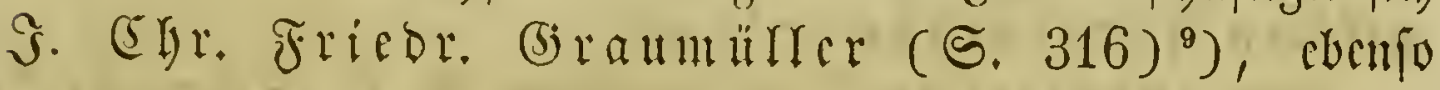

et sponte crescentium et in agris frequentius cultarum adjectis familiis naturalibus. Dreb̉on 1822. Fol.

1) Strnborte ber feltneren u. auzgejeidyneteren MJfanzen in ber Hungegent von Dresben. Drezben 1t. Reipzig 1837. gr. 16.

$\left.{ }^{2}\right)$ Flora Lipsiensis pharmaceutica etc. Lipsiae 1817. 8.

3) Enumeratio plantarum phaenogamarum Lipsiensium specimen. Lipsiae 1827. 8. - Synopsis plantarum phaenogamarum agro Lipsiensi indigenarum. Lipsiae 1828. 8.

‘) De flore gramineo, adjectis graminum circa Lipsiam tam sponte nascentium quam in agris cultorum descriptionibus genericis. Lipsiae 1835. 8. 1 Ed)ema. 1 Iafel. - Flora

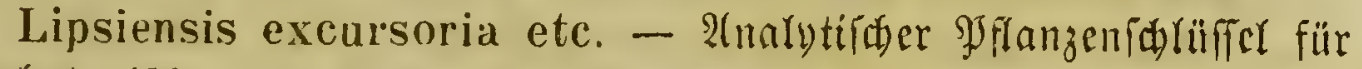
botanifite Excuriionen it ber lingegento yoll Reipzig. Reinzig 1846. 8. - Flora bez Bientis uno feiner Hungebungen. Mit

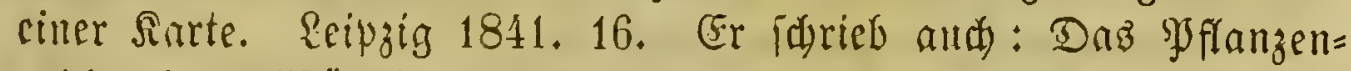
reid, in solfftänoigen Beidreibungen aller widhtigen Bewäd)

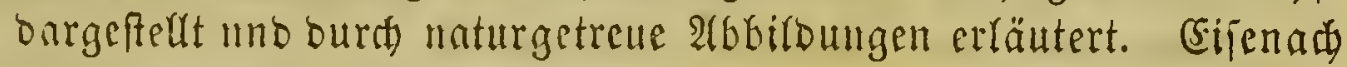
1845. gr. 8. 282 folor. Tafeln.

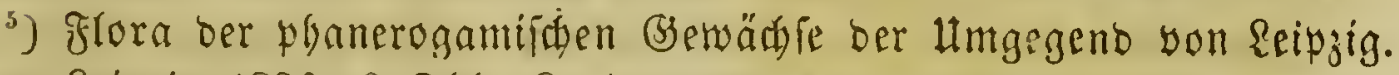
\{eipjig 1830. 2 Thle. 8.1 mapp. topograph.

-) Frora ber Deertimitit. (3örlig 1828. 8.

${ }^{3)}$ Flora lusatica etc. \&eipzig $1839-1840.2$ Boe. 8.

$\left.{ }^{8}\right)$ Eeipzig 8. 26 Rummern.

') Flora Jenensis etc. (Erfter Banb. (Cl. I - V.) Eifenberg 1824. 8. 
Gouath. Rarl 3 enferl), ber aud) in Berbindung mit (5. S (d) enf cime Flora von Thüringen verfäte, welde nad) feinem Tode you D. F. R. von S d leditendal und (shr.

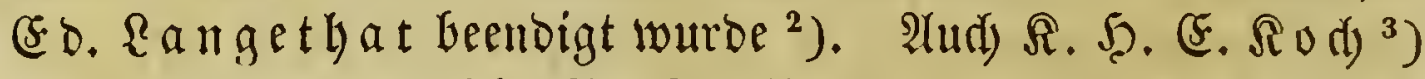
uno ber uneridöpflide Vielfdraber $\mathfrak{D} a \mathfrak{v}$. Nath. Friedr.

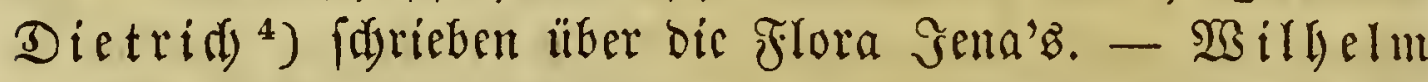
Aoler befdrieb die Sflanzen bes Ziegenrücter Rreifes ${ }^{5}$ ); (Ernft $\mathfrak{A} u g$. Nicolai bie un Armftabt ${ }^{6}$ ) vorfommenden (St)wäd)

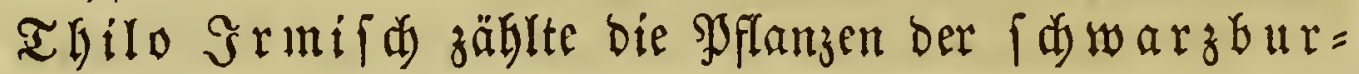
gifd) en Für fitenthümer ${ }^{7}$ ) auf.

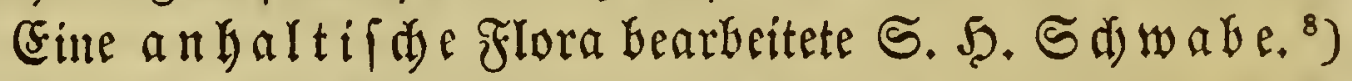
Die Sflanzen bes Fürftenthums $\mathfrak{B}$ ald eff und ber heffit fden Serrfdaft $\Im$ tter befdrieb $\Im$. $\mathfrak{B}$. Müller ${ }^{9}$ ) und die

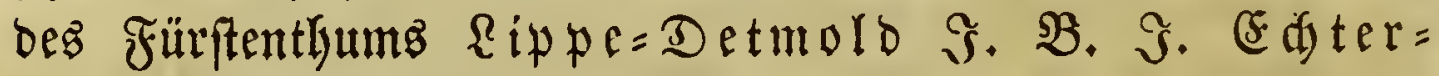
(ing. ${ }^{10}$ )

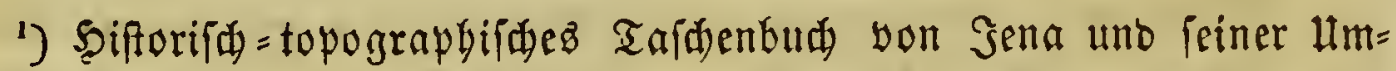
gegend 26. Sena 1836. 8. 2 Tafeln. (ङ. 258-286 entgalten bie Flora-yon Gena.)

') Flora von Thüringen uno ben angränzenten grrovingen. Seft 1-88. Sena 1836 - 1848. 8. 880 fol. Tafeln.

3) Daz natürlide Syftem bez sfflanzenrsidg, nad)gewiefen in ber Flora bon Sena. Erfte u. zweite 2abtgr. Sena 1839. 8.

- Flora Jenensis etc. Grfter Bano ober 2 Theile. Sena 1826. 8.

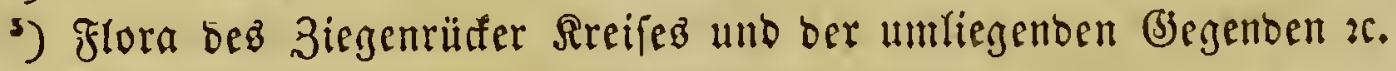
Renifabt unt 3iegenrüat 1819. 8.

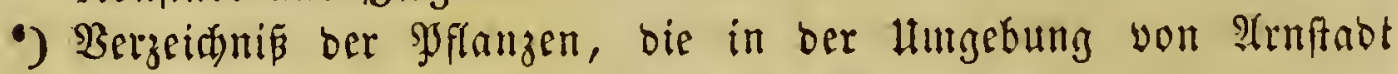
wilbuvadfen 2r. $\mathfrak{A} r n f a b t$ 1836. gr. 12.

') Syftematía

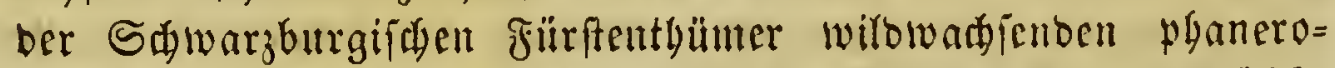

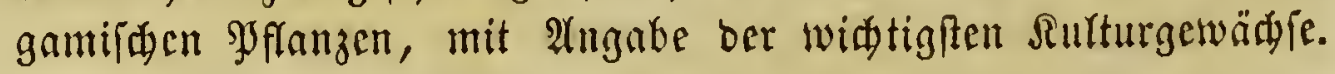
Soutbershanfent 1846. 8.

-) Flora Anhaltina. Berol. 1838-1839. Il voll. 8. 7 tab.

-) Flora Waldeccensis et Itterensis. Brilon 18\%1. 8.

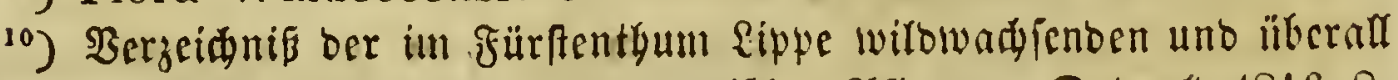

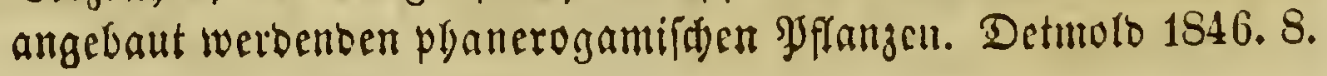


(3) J. Fricor. SBilh. Mcyer lieferte eine Aufzählung

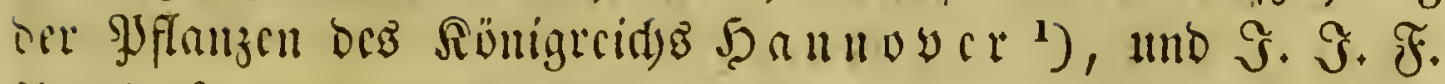

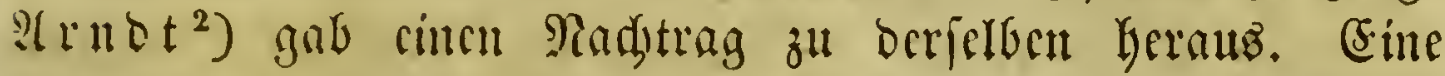

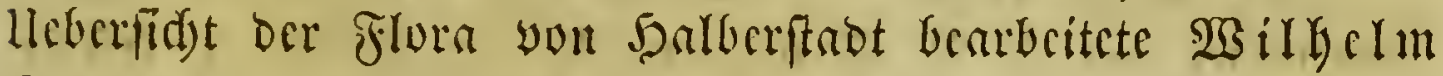

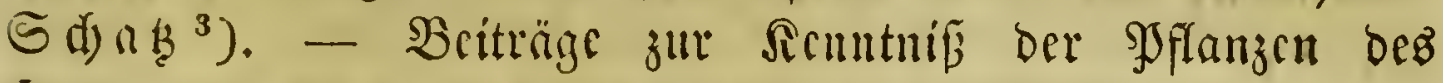

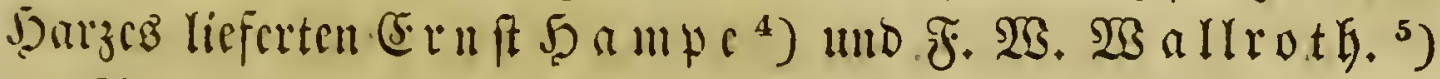
Alf Baffureiber bct Mefflenburgifden Flora fino

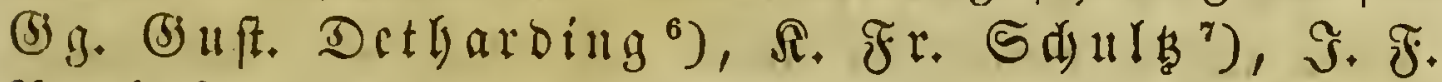

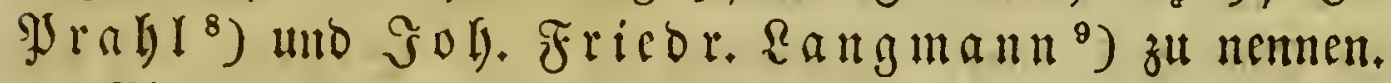

(Fine flora yon $\mathfrak{B} \mathfrak{r a} \mathfrak{n}\{$ d) weig bearbeitete $\mathfrak{S}$, $\mathfrak{X}$. $\mathfrak{R} \mathfrak{a}\left(\mathfrak{m} \mathfrak{m} \mathfrak{a} \mathfrak{n}^{10}{ }^{10}\right)$

') Chloris Ilanoverana etc. (3öttingen 1836. 4. - Beiträge zur dorograpbiīen Renntuís bez flusgebietz oer Snmerfte in Den Fürftentbümern (Srubenlyagent uno Silloezgeim zc. S5öttingen 1822. 2 Thle. 8. 1 fdwarze und 1 folor. Iafel.

$\left.{ }^{2}\right)$ Scholia Osnabrugensia in Chloridem Hannoveranam. Osnabruck 1837. 8.

3) Flora Halberstadensis excursoria. Salferfadot 1839. 8.

4) Prodromus Florae Hercyniae. Saalle 1836. 8. - ( $\mathfrak{N a d}=$

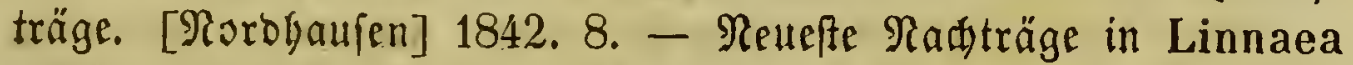

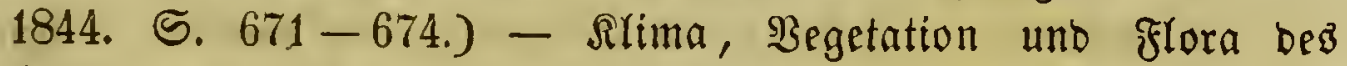
Sarzes. (

s) Erffer Beitrag zur Flora Hercynia. (Erffe Âtbtjeil.: ÂHgemeine Beridtigungen einiger in 5 a mpe' $\mathfrak{z}^{\prime}$ Prodromus Florae Her-

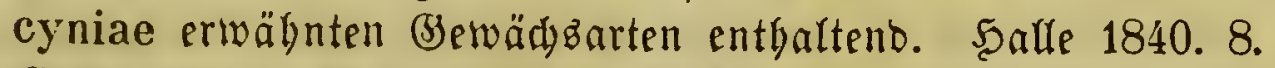

$\left.{ }^{6}\right)$ Conspectus plantarum magniducatum Megalopolitanorum phaneroganarum. Rostockii 1828. 8. 2 tab. Fol.

$\left.{ }^{7}\right)$ Prodromus Florae Stargardiensis, continens plantas in Ducatu Megapolitano-Stargardiensi seu Strelitzensi sponte provenientes. Berolini 1806. 8. - Supplementum Neobrandenburgi 1819.8.

$\left.{ }^{8}\right)$ Index plantarum, quae circa Gustroviam sponte nascuntur, phanerogamarum. Gustroviae 1837. 8.

-) flora ber beiben (Broş̧erzogtgümer Meălenburg zc. Reuftrelits 1841. 8.

10) Flora Brunsvicensis etc. Brauniøumeig 1827-1831. 2 Bbe. 8. 1 mapp. geogr. 5 tab. 


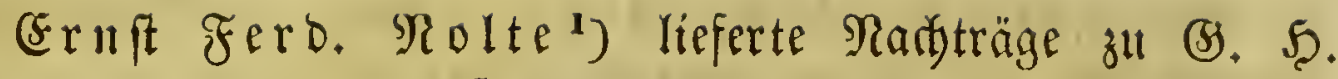
Beber'B Flora bun beolitein.

Aludi) bie (Geswäd) ber (5icgend yon 5 amburg wurben

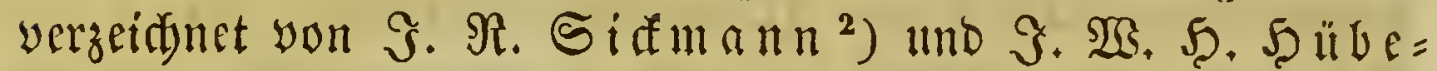
$n \in r^{3}$ )

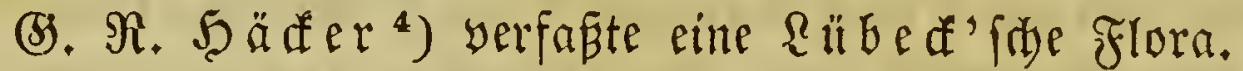

Bon den S. 319 erwähnten Botanifern ber Sdivciz

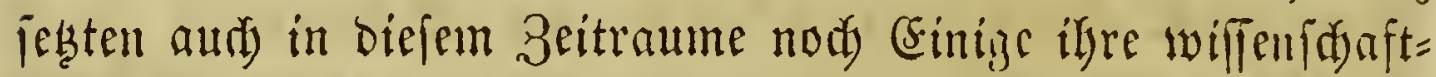

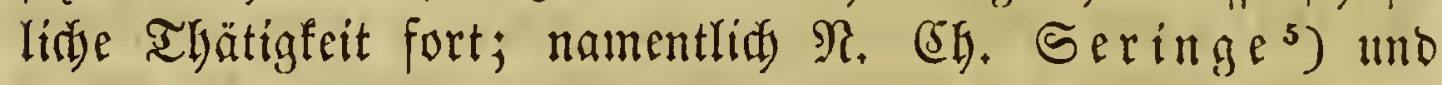

1) Novitiae florae holsaticae, sive supplement. alter. Primitiarum florae holsaticae G. H. W e beri. Kilonii 1826. 8.

$\left.{ }^{2}\right)$ Enumeratio stirpium phanerogamarum circa Hamburgum sponte crescentium. Hamburgi 1836. 8.

3) Frora ber Hmgegend von 5̧amburg 26. Şamburg 1846. gr. 8.

4) Rübectijøe Flora. Rübed 1844. 8.

$\left.{ }^{5}\right)$ Musée helvétique d'histoire naturelle (Partie botanique) ou Collection de mémoires, monographies, notices botaniques. Avec 16 planches. Tome I. Berne 1818. 4. Mélanges botaniques, ou Recueil d'observations, mémoires et notices sur la botanique. I vol. Ibid. 1818. 8. - Mémoire sur la famille des Cucurbitacées. Genève 1825. 4. 5 tab. - Bulletin botanique ou Collection de notices originales et d'extraits d'ouvrages botaniques, souvent accompagnées de gravures représentant des analyses d'organes importans de la fleur ou de fruit. Genève 1830. 8. Mémoire sur la culture et l'emploi des Céréales et de quelques autres Graminées. Lyon 1831. - Bon Scringe Geraugegebene Sammlungen: Herbier portatif des alpes 1-IV. Cent. 4. - Saules desséchés de la Suisse. 18051814. Fol. - Collection des Graminées, Cyperacées et Joncées de la Suisse. Centur. I et II. Fol. - Roses desséchées. Décade I-V. Fol. - Herbarium cereale, ou Collection des Blés, Seigle, Orges, $\Lambda$ voines, Maïs et Millets de la Suisse. Fol. - Descriptions et figures des Céréales européennes, telles qui orge, seigle, blé, nivièra, avoine, phalaris, riz, millet, maïs etc. Seconde édition, avec $30-35$ planches gravèes in 4 Quartlivraisons. Paris 1841-1847. gr.8. - Flore des jardins et des grandes 
Gean Fr. (5). Э̧ h. (5) a Anzagl Monographicen verfafite, aud burd) Seranftaltung

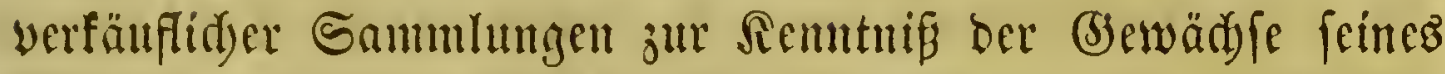
Baterlantez Dieles beitrug, (5) a ub in aber cine aubfübrlide Flora ber Sd)weiz nebft einer Synnpfis berjelben bearbeitete; Das lestere werf wurbe inteffen erft nadj feinem Tobe von

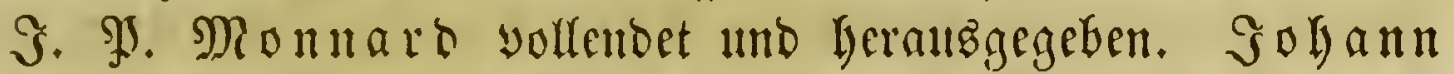

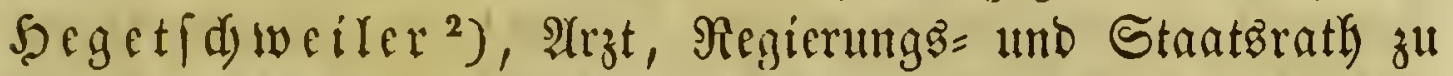
Zürid), werfafite ben 2Anfang einer Flora ber Sdjweiz, weld)e nad) feinem Tode yon $\mathfrak{D}$. Şeer fortgefegt und ebirt wurbe.

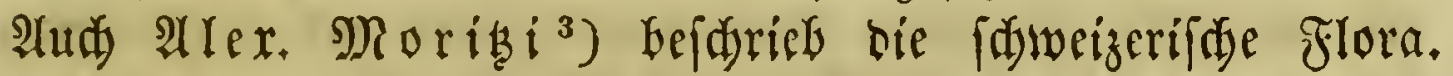

cultures, ou description des plantes des jardins, d'orangeries et des grandes cultures, leur multiplication, l'époque de leur fleuraison et de leur fructification et leur emploi. Tom. prem. Lyon 1845. 8. 11 tab.

') Flora helvetica. Turici 1828-1833. VII voll. 8. 28 tab. col. - Synopsis florae helveticae. Opus posthumum continuatum et editum a J. P. Monnard. Turici 1836. 8. - Introduction à la Flore helvétique de Mr. Gaudin par Ed. Chavannes. Lausanne 1830. 8.

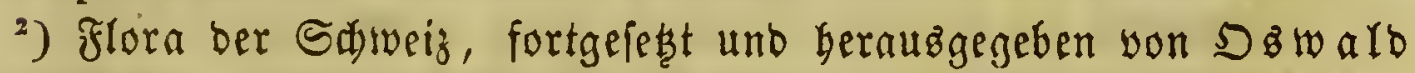

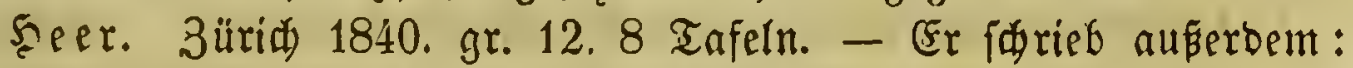
Supplement: Annalytifhe $\mathfrak{T a b e l l e n}$ zur Beftimmung ber phanero= gamifden Pflangengattungen ber Sdiweiz. 1840. - Neifen in

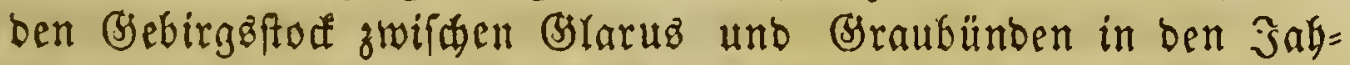
rell 1819-1822. Rebit einem botan. 2(nhang. 3ürid 1825. 8. $11 \mathfrak{T a f e I n}$. - Beiträge zu einer fritif pflanzen unb einer 2lbleitung ber Gelvetifaen $\mathfrak{3 f l a n}$ zenformen bon ben Einflüffen Der 2(upentwelt. 3üriđ 1831. 8. 1 tab. gèogr. bot. - Sammlung won Satweizerpflanzen. Bafel 1826-1834. 80 Sefte. 8. 480 tab. lithogr. col. - Die Biftpflanzen ber Saneiz (befdrieben won 3ob. Segetidweiler), gezeidnet you Э. D. Rabram, litgograplirt yon (5. Э. Brobtmann. 3ürich s. a. 3 Şefte. 4.18 tab. col.

3) Die Syflanzen ber Salmeiz. (5hur (3ürid) 1832. 8. 1 Tafel. -

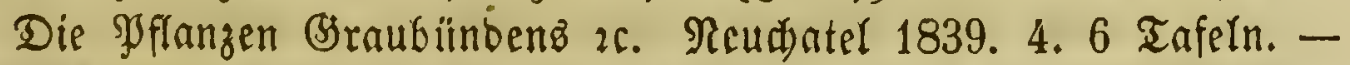
Reflexions sur l'espèce en histoire naturelle. Soleure

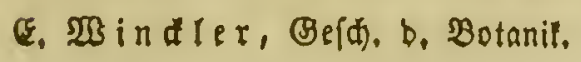




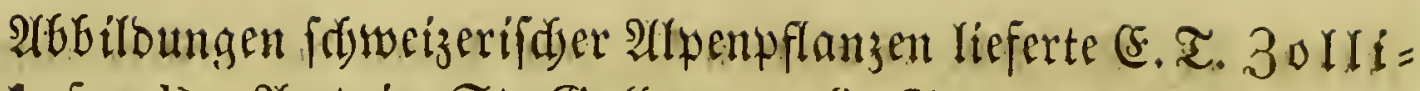

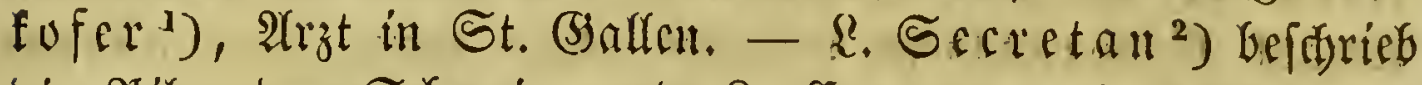
bie Syilze ber Sdyweiz, uno $\mathfrak{R}$ ( madyte fid um bie Renntnif ber Flerbten verbient. Die (be=

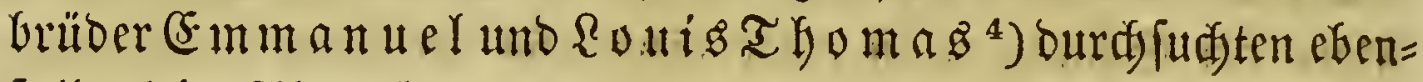
falls bie altpenflora uno veranftalteten verfäuflite Samm= lungen getrofineter Spflanzen. Sarl Friebr. Meißner ${ }^{5}$ ) befdrieb die (Befäßpplanzen unb lieferte eine gefdäzte Mono=

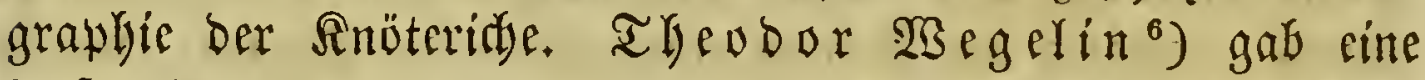

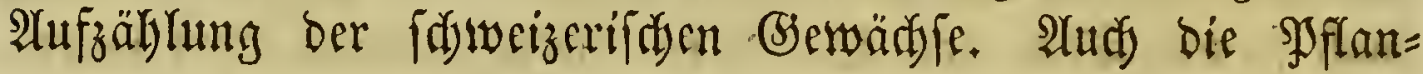
zen einzelner (Stegenden wurben unterfudt uno bejdrieten; wir nennen hier (5. F. Şagenbad) (Baajel) ${ }^{7}$ ), Johann

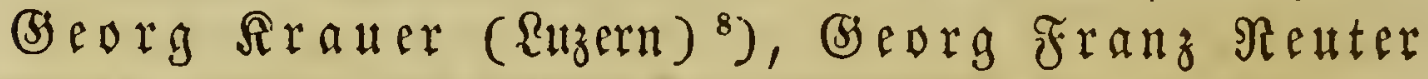

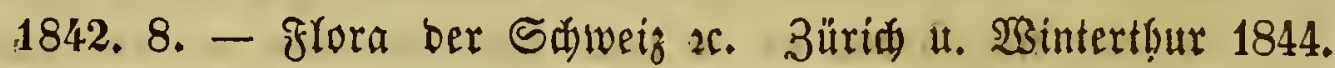
8. 1 mappa geologica. Reipzig 1847. 8. - Prospectus du Lexicon botanicum. s. l. et a. (1845) 4 .

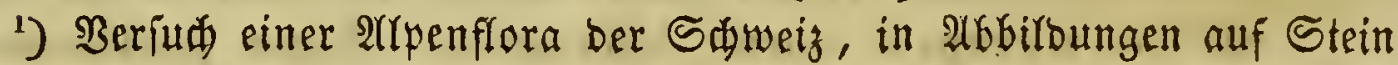
nadi ber Ratur gejeidnet uno beidrieben. Tentamen florae alpinae helvetiae. Seft I. St. (3aflen 1828. Fol. 10 tab. col.

$\left.{ }^{2}\right)$ Mycographie suisse, ou descriptions des Champignons qui croissent en Suisse. Genève 1833. 3 B̧be. 8.

3) Lichenum helveticorum exsiccatorum fasciculi. - Lichenum helveticorum spicilegium. Sect. I-VII, Lichenum exsiccatorum fascicul. I-XII. illustrant. Bernae 1823-1836. 4.

4) Catalogue des plantes suisses, qui se vendent chez Emmanuel Thomas a Bex, Canton de Vaud en Suisse. Lausanne 1818. 8. - 1837 8. - Strasbourg 1841. 8. (Enţält Die Aruptogamen.)

5) Monographiae generis Polygoni prodromus. Genève 1826. 4. 7 tah. - Plantarum vascularium genera secundum ordines naturales digesta eorumque differentiae et affinitates tabulis diagnosticis expositae. Lipsiae $1836-1843$. Fol.

-) Enumeratio stirpium florae helveticae secund. ordin. natural. disposita. Turici 1838. 8.

') Tentamen Florae Basileensis. Basileae $1821-3 \%$. II voll. 8. 2 tab. col. - Suppl. ibid. 1843. 8. 1 tab. col.

$\left.{ }^{8}\right)$ Prodromus Florae Lucernensis, Lucernae 1824, 12. 


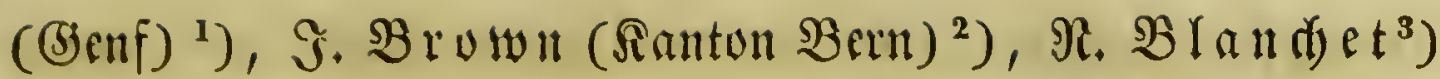
แmb D. Sapin ( Ranton Sandot) ${ }^{4}$ ), Arbert Röllifer

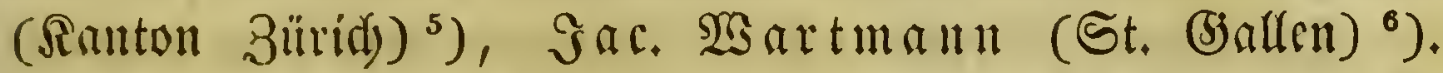

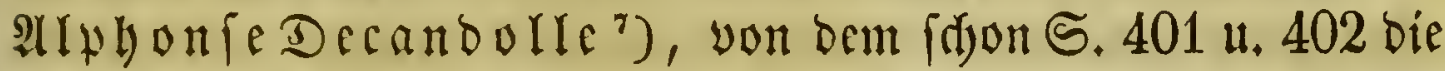
Nebe getvefen ift, fdrieb cinige Monographieen and ein ge=

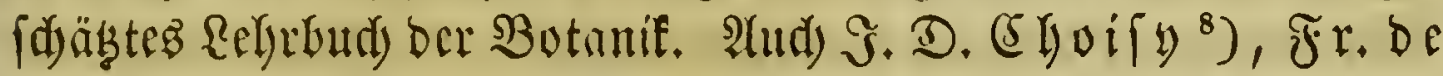

1) Catalogue détaillé des plantes vasculaires qui croissent naturellement aux environs de Genève. Genève 1832. 8. - Suppl. 1841. 8. 1 tab. (Arrabis hybrida Reut.) - Essai sur la végétation de la Nouvelle Castille. Genève 1843. 4. 1 tab. (Colmeira buxifolia Reut.)

2) Catalogue des plantes aux environs de Thoun et dans l'Oberland bernois. Thoune 1843. 8.

3) Catalogue des plantes vasculaires qui croissent naturellement dans le canton de Vaud. Vevey 1836. 8. - Influence de l'Ammoniaque et des sels ammoniacaux sur la végétation. Lausanne 1843. 8. - De l'épidémie des pommes de terre. (Lausanne 1845.) 8.

C) Le guide de botaniste dans le canton de Vaud. Lausanne 1842. 8.

5) Serzcidni ber phanerogamif 3ürid) 1839. 8.

-) Botanif für die weiblide 3ugend. St. Ballen 1841. 8. St. Ballifde Flor. St. Brallen 1847. 8.

') Monographie des Campanulèes. Paris 1830. 4. 20 tab. Mémoire sur la famille des Anonacées et en particulier sur les espèces du pays des Birmans. Genève 1832. 4. 5 tab. - Introduction à l'ètude de la botanique ou traité èlémentaire de cette science. Paris 1835. II voll. 8.8 tab. - Deutfd: Bearbeitet yon Dr. Alex. von Bunge. Reipzig 1838. 8. 3weite 2 ufl. brf. 1844. 8. 8 Iafelli.

8) Prodromus d'une monographie de la famille des Hypéri. cenées. Genève 1821. 4. 9 tab. - Mèmoire sur la famille des Selaginées. Genève 1823. 4. 5 tab. - Description des Hydrolèacées (Genève 1833). 4. 3 tab. - Convolvulaceae orientales, nempe indicae, napaulenses, birmanicae, chinenses, japonicae nec non et quaedam australasicae. (Genevae 1834.) 4. 6 tab. - De Convolvulacées. 


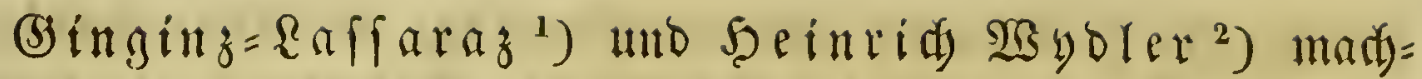
ten fid) alz $\mathfrak{M}$ (unographen bofaunt.

Dí Flura Frantreids ïberlyattpt warbe yon melyreren (5elebrten bebandelt. Gean (Eticune Duby bejorgte die

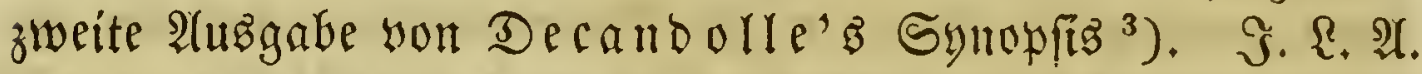

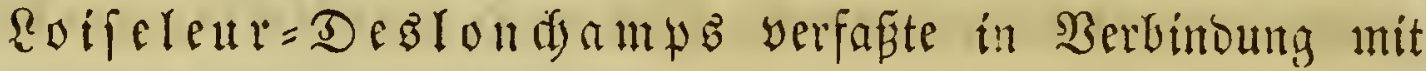
cinigen $2\left(n\right.$ tern eine allgemeine Flora von Franfreidy ${ }^{4}$ ); aud

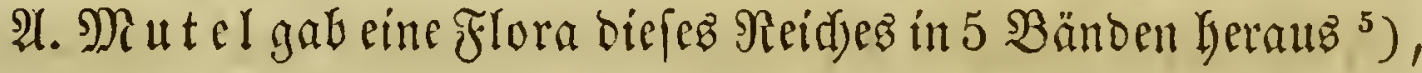

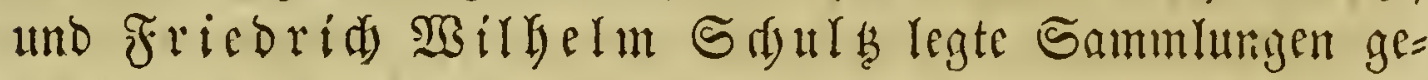
trodneter Syflanzen Franfecidys unb Deutfdylands an ${ }^{6}$ ). 2(udy

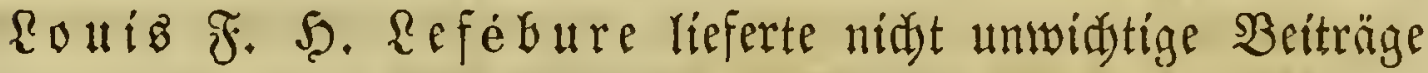
zur Flora yon Franfreidy ${ }^{7}$ ). Der fdon 5.322 angeführte Sean Şenry $\mathfrak{J a u m e ~ S a i n t = 5 ̧ i l a i r e ~ b a t ~ a u d ~ n o d ~ i n ~}$

Genève 1838. 4. 4 tab. - Genève 1841. 4. 5 tab. - Note sur les Convolvulacées du Brésil et sur le Marcellia, genre nouveau de cette famille. Genève 184\%. 4. 1 tab.

1) Mémoire sur la famille des Violacées. Genève 1823. 4. 2 tab. - Histoire naturelle des Lavandes. Genève 1826. 8. 11 tab. in-4.

$\left.{ }^{2}\right)$ Essai monographique sur le genre Scrophularia. Genève 1828. 4. 5 tab.

3) Sielye S. 401, Rote 1.

‘) Flore générale de la France etc. Paris 1828. 8. - Sieke ธ. 323.

5) Flore française. Paris 1834-1838. V roll. 8. Atlas in-4. obl. (95 tab.)

-) Flora Galliae et Germaniae exsiccata. Bitche et Deux-Ponts 1836-1840. Fol.

') Cours de promenades champêtres aux environs de Paris, en forme de bulletin, dit de Flore, au moyen duquel on apprend soi-même à signaler, reconnaître et classer les plantes d'après la théorie facile et la pratique sur nature du nouveau systeme floral. Paris 1826. 8. obl. 2 tab. L. F. H. Lefébure et Charles Leforestie:", Album floral des plantes indigènes de France etc. Paris 1829. 8. obl. 5 tab. - Flore de Paris. Paris 1835. 8. 
ber neueren 3eit über die Flora Franfleids gefdrietent ${ }^{\text {) }}$. Die

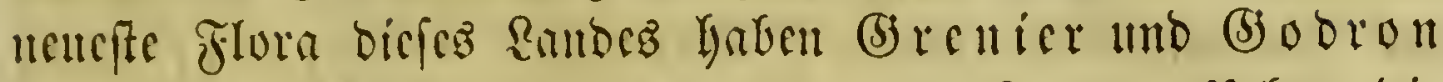
int Gafe 1848 lerauşugeben begummen $^{2}$ ), - Heber Die

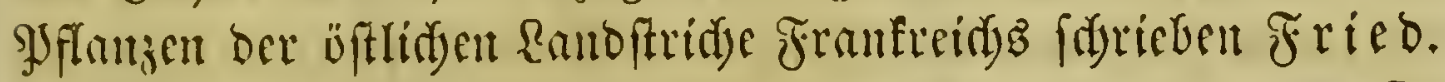

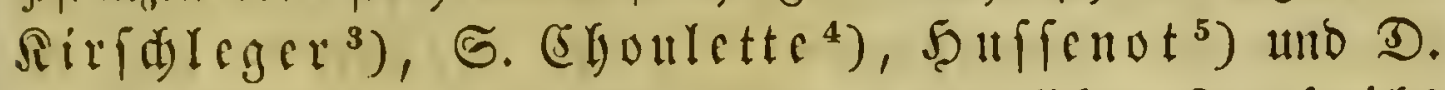

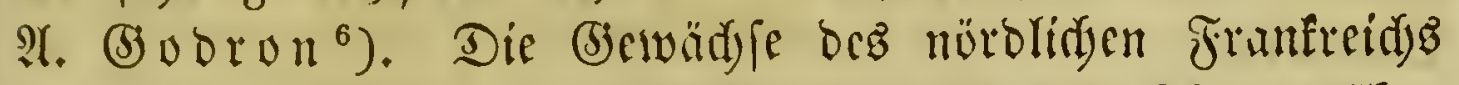
werben zum Theil in ben Sduriften bes foun S. 342 ermähn=

1) La Flore et la Pomone françaises etc. Paris 1828-1833. VI voll. Fol. 544 tab. col.

$\left.{ }^{2}\right)$ Flore de France. Paris 1848 - 1852. II voll. 8.

$\left.{ }^{3}\right)$ Liste des plantes les plus rares d'Alsace et de Vosges; impr. cum Aufschlaeger Description historique et topographique des deux départemens du Rhin. Strasbourg 1826. 8. - Statistique de la Flore d'Alsace des Vosges qui font partie de cette province. Mühlhausen 1831. 4. -- Prodrome de la Flore d'Alsace. Strasbourg 1836. 8. - Appendice au Prodrome de la Flore d'Alsace. Strasbourg 1838. 12. - Notice sur les violettes de la Vallée du Rhin, depuis Bâle jusqu'à Mayence, des Vosges et de la Forêt noire. Strasbourg 1840. 4. 3 tab.

4) Synopsis de la Flore de Lorraine et d'Alsace etc. Strasbourg et Paris 1845. 12.

5) Chardons Nancéiens ou prodrome d'un catalogue des plantes de la Lorraine; par le Docteur Huss e not, qui n'est rien, pas même médecin, membre d'aucune académie, corresp. d'aucune soc. savante; qui n'est ni de la soc. royale des sciences lettres en arts de Nancy, ni de la société centr. d'agriculture de la même ville; pas plus de la société d'émulation des Vosges que de celle philomathique de Verdun ou d'aucune de celles de Metz; directeur d'aucun jardin public ou particulier, conservateur d'aucune collection autre que la sienne, qui se mange des bêtes; rédacteur de rien du tout; enfin simple citoyen comme tout le monde hors qu'il n'est pas décoré. Premier fascicule. Nancy 1835. 8.

-) Flore de Lorraine (Meurthe, Moselle, Mense, Vosges). Nancy $1843-1844$. III voll. 8 . 


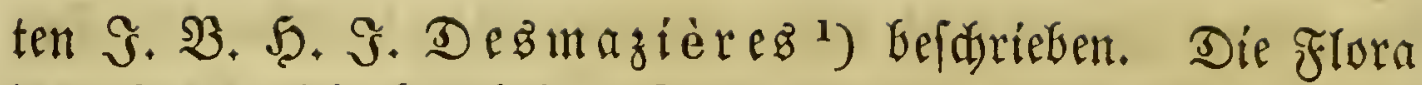
Der Normandie bearbeitete \&. Alphonfe de $\mathfrak{B r}$ ébiffon ${ }^{2}$ )

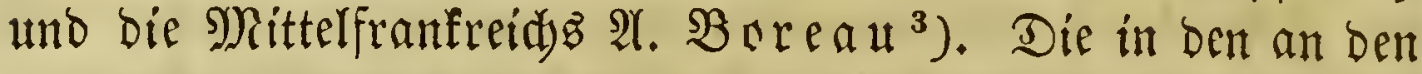
SJyrenäen gelegenen Randifridyen yortommenden (seswädje be=

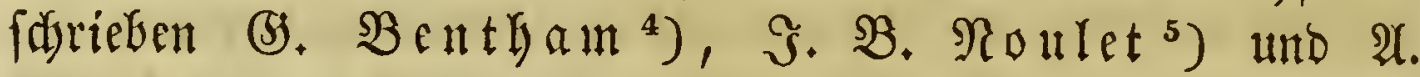
Da $\left\{\left\{\mathfrak{i e r}^{6}{ }^{6}\right\}\right.$

Seldr zahlreidy füto bie Sifriften, weldye über bie Flora Der cinzelnen Departementz währeno diefez Beitraumb eriđjes= nen find. Der 3weâ diejes Compendiums geftattet uns nid)t, mehr alz eine furze leberfidyt Der lyerher gelyörenton Sryrift= fteller zat geben. Sisir führen beshalb die Floriften ber ein= zelnen Departementz Der Reife nadi auf.

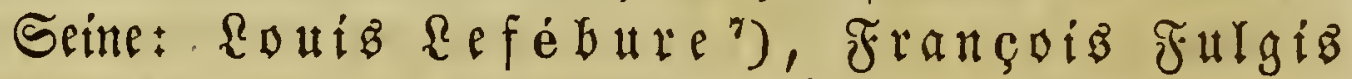

1) Plantes cryptogames du nord de la France. Fasc. I. Lille 1825. 4. Edit. II, Lille 1836-18.t5. 29 livraisons, 4.

$\left.{ }^{2}\right)$ Coup d'oeil sur la végétation de la Basse-Normandie, considérée dans ses rapports avec le sol et les terrains. Caën 1829. 8. - L. A. de Brébisson et Godey Algues des environs de Falaise, décrites et dessinées. Falaise 1835. 8. 8 tab. col. - Flore de la Normandie. Première partie. Phanérogamie. Caën et Paris 1836. 12.

s) Programme de la Flore du centre de la France suivi du catalogue des plantes observées dans le rayon de cette Flore et d'observations relatives a quelques plantes critiques. Nevers 1835. 8. - Flore du centre de la France etc. Paris 1840 . II voll. 8.

4) Catalogue des plantes indigènes des Pyrénées et du BasLanguedoc etc. Paris 1826. 8.

5) Flore du bassin sous-pyrénéen etc. Toulouse 1837. 8. Additions et corrections à la Flore du bassin sous-pyrénéen. Toulouse 1846. 8.

-) J. B. Noulet et A. Dassier, Traité des champignons comestibles suspectes et vénéneux, qui croissent dans le bassin sous-pyrénéen, orné de figures coloriées de grandeur naturelle. Toulouse et Paris 1838. 8, 42 tab. col.

') Cours de promenades champêtres aux environs de Paris etc. Paris 1826. 8. obl. 2 tab. - Flore de Paris. Paris 1835. 8. 


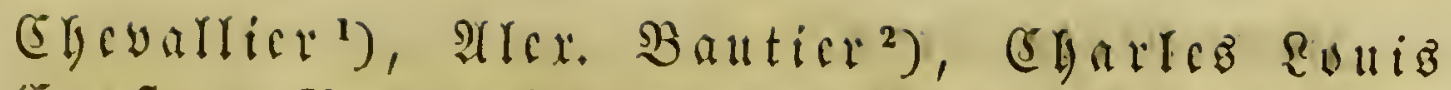

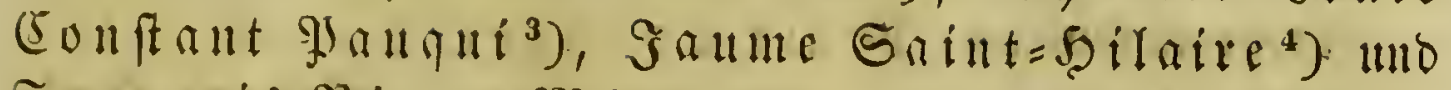
Jrauçuis Bictur Miérat. ${ }^{5}$ )

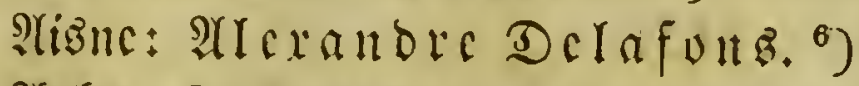

Fubc: Stanislab beg (5tanga.7

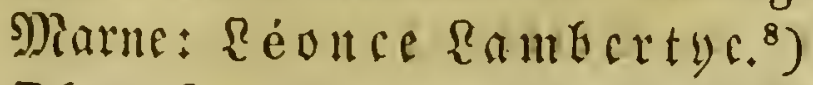

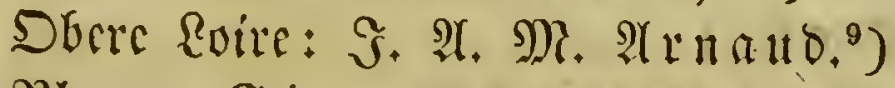

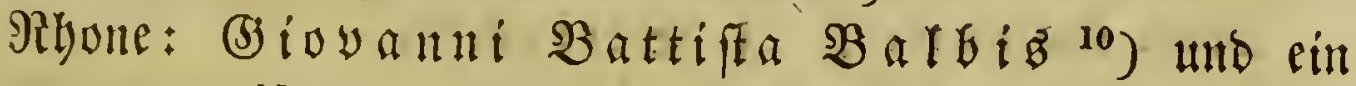

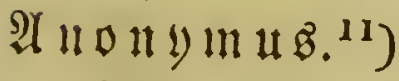

(Eôte D'Dr: Rorey uno Duret. ${ }^{12}$ )

1) Flore générale des environs de Paris. Paris 1826-1827. II voll. 8. 18 tab.

$\left.{ }^{2}\right)$ Tableau analitique de la Flore Parisienne etc. Paris 1827. 12. 1832. - 1836. - 1839. - 1845. 12.

s) Statistique botanique, ou Flore du Département de la Somme et des environs de Paris etc. Amiens 1831. 8. Paris 1834. 8.

t) Flore Parisienne. Paris 1835. 4. ic. plur. xylogr. i. e. nigr. et col. 1 carte.

5) Synopsis de la nouvelle Flore des environs de Paris. Paris 1837. 12

-) Prodrome de la Flore des arrondissements de Laon, Vervins, Rocroy et des environs de Noyon. Noyon 1829.8.

7) Notes sur quelques plantes observées dans le Dép. de l'Aube. Troyes (1841). 8. - Liste de noms populaires des plantes de l'Aube et des environs de Provins. Paris 1815.8.

3) Catalngue raisonné des plantes vasculaires, dans le Département de la Narne etc. Paris 1846. 8. 1 mapp. bot. geol.

') Flore du Département de la Haute-Loire. Puy 1825. 8. - Suppl. Puy 1830. 8.

$\left.{ }^{10}\right)$ Flore Lyonnaise. Lyon 1827 - 1828. II voll. 8. - Suppl. Lyon 1835. 8. 1 tab.

11) Analyse des plantes du Lyonnais et du Mont-Pilat. Lyon 1838. 12.

$\left.{ }^{12}\right)$ Catalogue des plantes, qui croissent naturellement dans le Département de la Côte d'Or. Dijon 1825. 8. - Flore de la Côte d'Or. Dijon 1831. II voll. 8. 7 tab. 


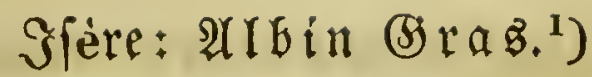

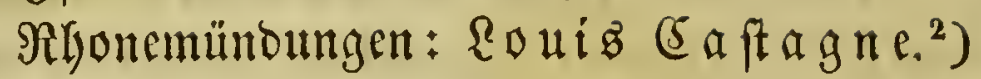

Sar: Serreymono uno Requien ${ }^{3}$ ), Arbert Soh. gुolferer ${ }^{4}$ ) unto $\Re$ obert. ${ }^{5}$ )

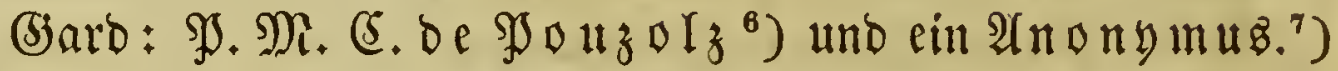
Serault: (Elyeyalier be Belleyal.8

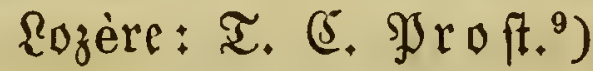

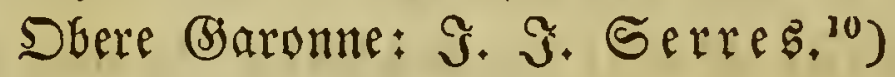

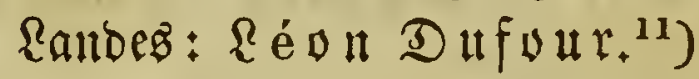

1) Statistique botanique du Département de l'Isère ou guide du botaniste dans ce Département. Grenoble 18\%. 8.

$\left.{ }^{2}\right)$ Observations sur quelques plantes acotylédonées de la famille des Urédinées et dans les sous - tribus des Nemasporées et des Aecidinées, recueillies dans le Dép. des Bouches - du-Rhône. No. I. Marseille 1842. 8. 1 tab. No. 2. Aix 1843. 8, 2 tab. - Catalogue des plantes qui croissent naturellement aux environs de Marseille. Aix 1845. 8. 7 tab.

$\left.{ }^{3}\right)$ Plantes phanérogames aux environs de Fréjus. Paris 1833. 8.

4) Hyéres in der Provence. Wien 1834. 8.

$\left.{ }^{5}\right)$ Plantes phanérogames, qui croissent naturellement aux environs de Toulon. Brignolles 1838. 8. 1 mapp. geogr.

") Catalogue des plantes qui croissent naturellement dans le Gard, pour servir à la formation de la Flore de ce Département. Nismes 1842. 8.

$\left.{ }^{7}\right)$ Synopsis analytique de la Flore du Gard. Nìmes 1847. 12.

$\left.{ }^{8}\right)$ Beautés méridionales de la Flore de Montpellier, par un ancien herboriste de cette ville. Montpellier 1826. 8.

9) Notice sur la Flore du Département de Lozère. Mende (1820.) 8. - Liste de mousses, hépatiques et lichens, observés dans le Département de la Lozère. Mende 1828. 8.

$\left.{ }^{10}\right)$ Flore abrégée du Toulouse. Toulouse 1836. 8.

11) Notice botanique et culinaire sur les champignons comestibles du Département des Landes. Mont-de-Marsan 1840. 8. 
Rot unb (5)aronne: Gean Florimont Boubon be Saint $\left.=\mathfrak{A} \mathfrak{M} \mathfrak{a} \mathfrak{B} .^{1}\right)$

Borbognte: (Eharle beg Moulinb. ${ }^{2}$ )

Tarn und (jaronne: $\mathfrak{R}, \mathfrak{B} a r \cup n^{3}$ )

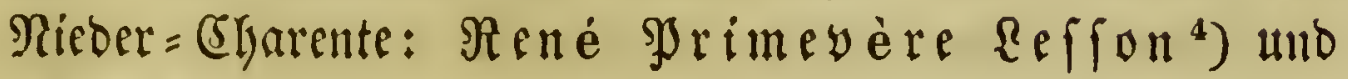
eít $\left.\mathfrak{A} \mathfrak{n} \cup \mathfrak{y} \mathfrak{m} \mathfrak{u} \mathfrak{s} .{ }^{5}\right)$

Sarthe und Mayente: $\mathfrak{N}$. DeBporteb $B^{\circ}$ ) unb cin $\mathfrak{A} \mathfrak{n}=$ ก) $\left.) 111 \mathfrak{B} .^{7}\right)$

Gnore unt Roire: Dufardit. ${ }^{8}$ )

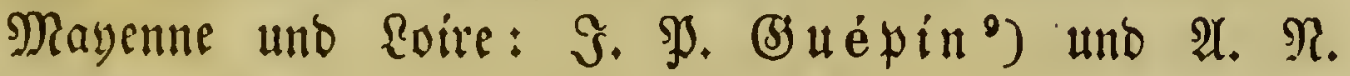
$\mathfrak{B} \in \mathfrak{s} \mathfrak{y} \mathfrak{a} x_{0^{10}}$ )

$\left.{ }^{1}\right)$ Flore Agenaise. Agen 1821. 8. - Le bouquet du Département de Lot-et-Garonne ou fascicule de quelques plantes de ce Département nouvelles, rares point ou mal figurées dans les ouvrages de botanique et décrites dans la Flore Agenaise. Agen 1821. 8. 12 tab.

2) Catalogue raisonné des plantes qui croissent spontanément dans le Département de la Dordogne. Première partie. Phanérogames. Bordeaux 1840. 8. - Suppl. 1846. 8.

3) Flore des Départemens méridionaux de la France et principalement de celui de Tarn et Garonne. Montauban 1823. 8.

4) Flore Rochefortine. Rochefort 1835. 8.

3) Catalogue de la Flore de la Charente-inférieure. La Rochelle 1840. 4.

-) Flore de la Sarthe et de la Mayenne (Maine). Le Mans 1838. 8.

') Catalogue des plantes du Dép. de la Mayenne. Laval 1838. 18.

-) Flore complète d'Indre et Loire publiée par la société d'agriculture, sciences, arts et belles-lettres. Tours 1833. 8. 2 tab.

-) Flore de Maine et Loire. Tom. prem. (Phanérogames). Angers 1530. 12. - 1838. 12. - Suppl. 1842. 8. - Edit. III. Angers 18\%. 8.

10) Observations sur les plantes des environs d'Angers. Angers 1818. 12. - Flore de l'Anjou. Angers 1827. 8. - 
Biente : (6. S. R. Delafte. $\left.{ }^{1}\right)$

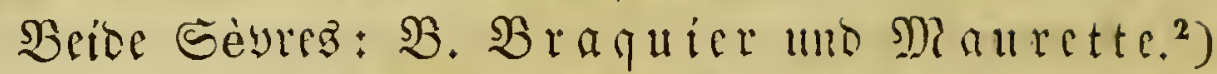

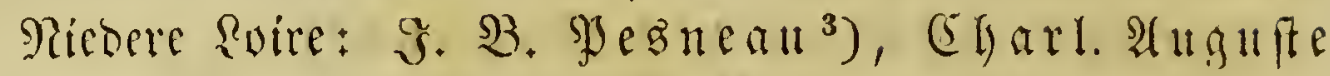

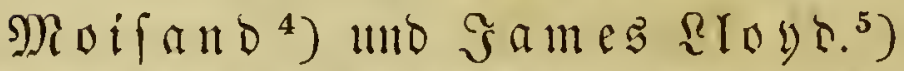

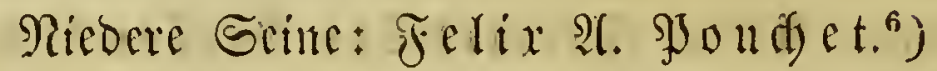

(sure: $\mathfrak{B}$ rou ard. ${ }^{7}$ )

Doubz: (5harles (5)eriter. ${ }^{8}$ )

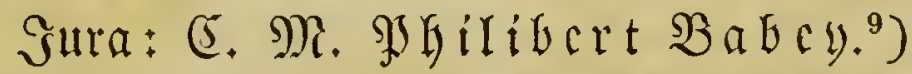

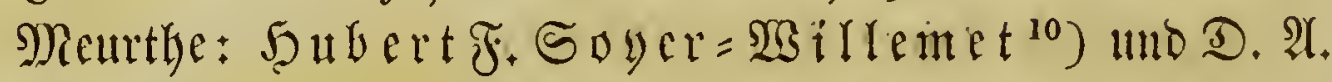
(5) od $\mathfrak{d} \mathfrak{H}^{11}$ )

Statistique naturelle de Maine et Loire. Angers 1834. 8. Programme du cours de botanique. Angers 1817. 8. Ed. Il. ibid. 1832. 8.

1) Aperçu statistique de la végétatión du Département de la Vienne. Poitiers 1835. 8. 1 tab. - Flore analytique et descriptive du Département de la Vienne avec Planches et vocabulaire. Paris et Poiticrs 1842. 8. 4 tah.

2) Tableau syuoptique des végétaux du Département des Deux - Sèvres. Saint-Maixent 1842. 18.

s) Catalogue des plantes recueillies dans le Département de la Loire-infërieure, classé suivant le système de Limnée. Nantes (Paris) 1837. 12.

s) Flore Nantaise. Nantes 1839. 8.

${ }^{8)}$ Flore de la Loire-inférieure. Nantes (Paris) 1844. 12.

-) Flore, ou Statistique botanique de la Seine-inférieure. Rouen 183\%. 8.

') Catalogue des plantes du Département de l'Kure. Evreux 1820. 12.

$\left.{ }^{8}\right)$ Catalogue des plantes phanérogames du Département du Doubs. (Besançon 1843.) 8. - Thése de géographie botanique du Département du Doubs, présentée à la faculté des sciences à Strasbourg. Strasb. 184.4. 8. 1 tab. géogre.

') Flore Jurasienne. Paris 18\%5. VI voll. 8.

${ }^{10}$ ) Observations sur quelques plantes de France, suivies du catalogue les plantes vasculaires des environs de Nancy. Nancy 1828. 8.

i') Catalogue des plantes cellulaires du Département de la 


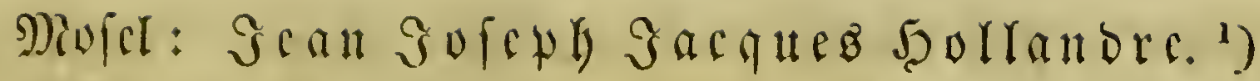

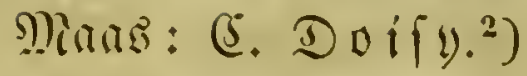

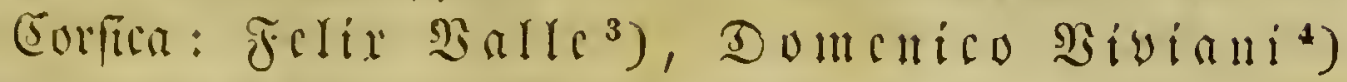
mo Uly

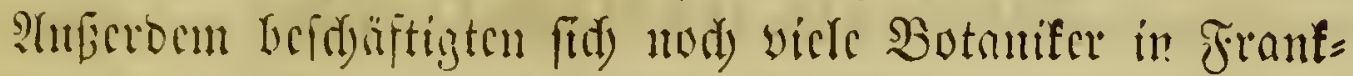

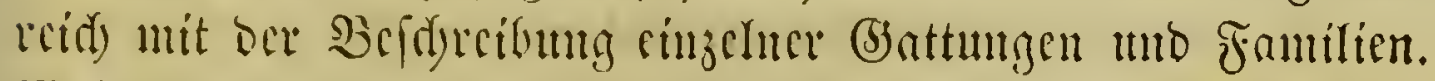

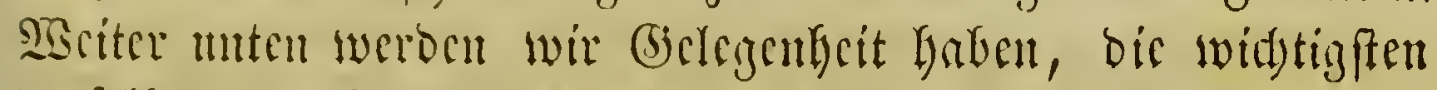
ocrfolben anjufüfren.

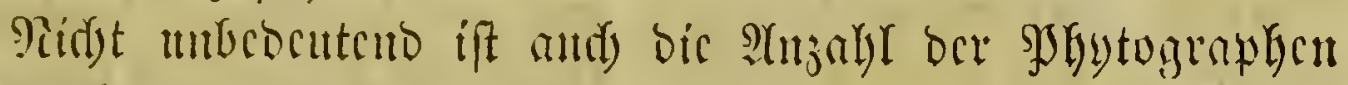

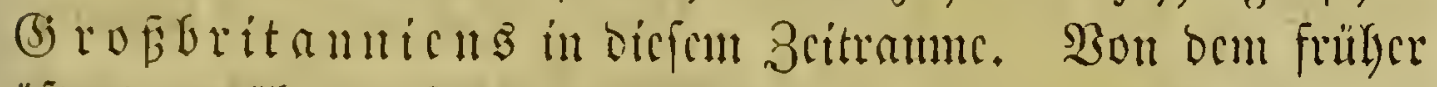

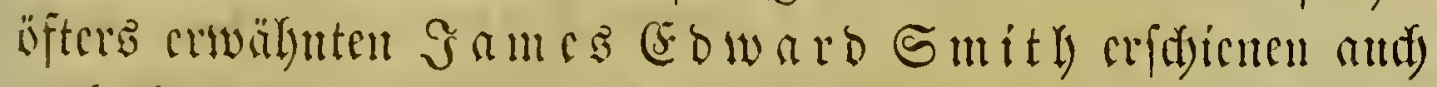

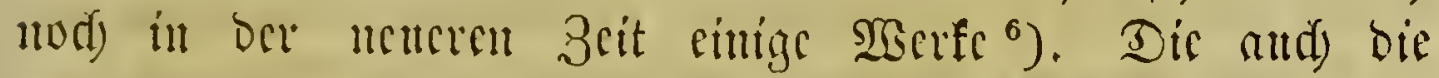

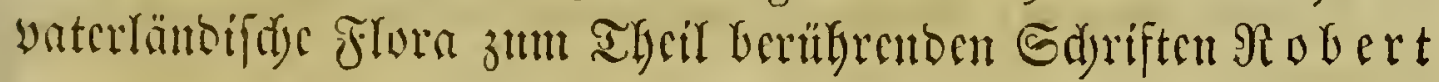

Meurthe. Nancy 1843. 8. - Monographie des Rubus, qui croissent naturellement aux environs de Nancy. Nancy 1843. 8.

1) Flore de la Moselle. Metz 1829. II voll. 8. -- Suppl. 1836. 8. - Nouvelle édit. 1842. II voll. 8.

$\left.{ }^{2}\right)$ Essai sur l'histoire naturelle du Département de la Meuse. Partie I: Flore. Verdun et Paris 1835. II voll. 16. 1 tab.

5) Florula Corsicae. (Misc. taur. II. 214-218. - Nov. Act. Acad. Nat. Cur. IV. App. 205-254.)

‘) Florae Corsicae etc. Genuae 182\%. 4. - Append. 1825. 4. 1 tab. - Append. altera 1830. 4. 2 tab.

s) AUlgemt. bot. 3cit. 1833. II. S. $449-461$. 1834. II. SBeibr. (5. 1 -86.)

3) A review of the modern state of Botany, with a particular reference to the natural systems of Linnaeus and Jussieu. London 1817. 4. - A grammar of hotany etc. London 1821. 8. 21 tab. col. - Ed. II. London 1826. 8. 21 tab. - Dellfif): 23 eimar 1822. 8. 21 Iafeln. - The English Flora. London 1824-1836. V voll. 8. - A Compendium of the English Flora. London 1836. 8. -- Memoir and correspondence of the late Sir James Edward Smith. Edited by Lady Smith. In two volumes. London 1832. 8. 
V̧rown's find bersits oben angefülyet worden. Unter ben

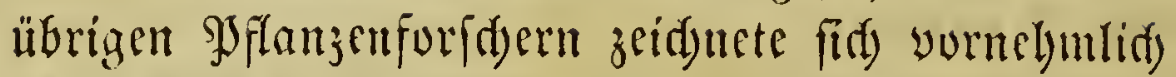

\section{William Gaffon Şoofer, \\ Şrofeffor ă (biagagow,}

aus '). ( Bergl. S. 340.) (Fr verfapte cine Rrife yout

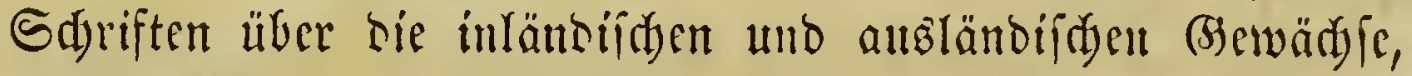
rebigirte in ben Galuren 1834- 1842 das Journal of Botany uno you 1842-1846 bas London Journal of Botany uno mad) te fird surd) bie Unterftilgnng veridsiebener Reifenden um

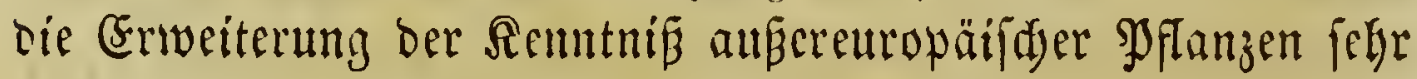
verbicut.

গeben ifym ift

\section{Solit Riubley,}

STrofefior in Ronbon,

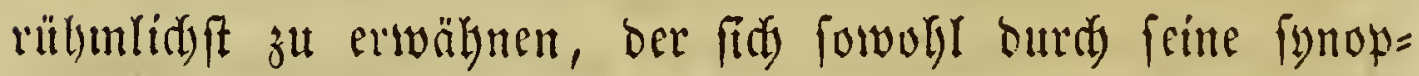
tifde flura von (Englano, wie burd) verfdaiedeme trefflide

') The british Flora, Vol. I. Phanerogamia. London 1830. 8. - The british Flora. Vol. II. Cryptogamia. London 1833-36. 8. - Botanical illustrations. Edinburgh 1822. Fol. obliq. 21 tab. col. - A catalogue of plants contained in the royal botanic garden of Glasgow in the year 1825. Glasgow 1825. 8. 1 tab. - Botanical Niscellany. London 1830 - 1833. III voll. 8. 153 tab. - The Journal of Botany. London 1834 - 42. IV voll. 8. 28 tab. pro part. col. - The London Journal of Botany. London 1842-1846. V voll. 8. 119 tab. - Characters of genera extracted from the British Flora of Will. Jacs. Hooker. Edinburgh 18:30. 8. - Companion to the Botanical Magazine. London 1835-1836. II voll. 8. 51 tab. - Icones plantarum etc. London 1837-1845. VIII voll, (XV parts.) 8. 750 tab. - Seine widtigften Monograpgieen uno feime Sdriften über auzländiføe (3ewädy fe werben fpäter angefübrt werben. 
Mlonographieen als tüd)tiger Sghytograph zeigte, auferbent aber and) cinige Refurbuldyer unt cin seerf liber bie forfite Flora (5) robibritamiens verfafte ${ }^{1}$; was $\mathfrak{a r}$ in ber Syftematif geleifet, ift frither angegelen worben.

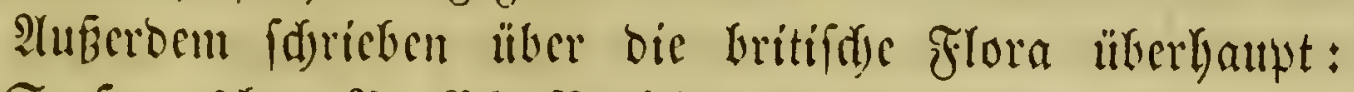

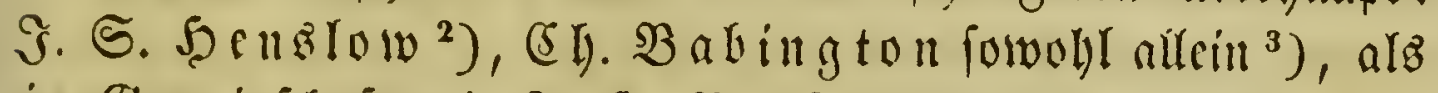

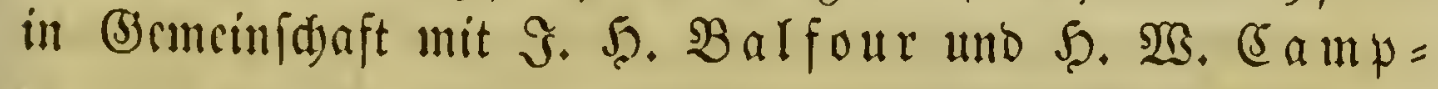

1) A synopsis of the British Flora. London 1829. gr. 12. Ed. II ibid. 1835. gr. 12. - Ed. III ibid 18'1. gr. 12. Flora medica. London 1838. 8. - The vegetable kingdom; or the structure, classification and uses of plants illustrated upon the natural system. With upwards of five hundred illustrations. London 1846. 8.1 tab. - An outline of the first principles of botany. London 1830. 12. 4 tab. - Ed. II ibid. 1831. 12. 4 tab. - Deutid: Beimar 1831. 8. 4 iaf. - Elements of botany. London 1841. 8. - Ed. V ibid. 1847. 8. - An introduction to the natural system of botany etc. London 1830. 8. - Edit. II ibid. 1835. 8. 6 tab. - Edit. III. London 1839. 8. -

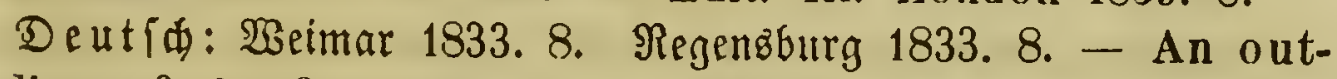
line of the first principles of horticulture. London 1832. 12. - Deutfil: Stuttgart 1833. 12. - The theory of horticulture, or an attempt to explain the principal operations of gardening upon physiological principles. London 1840. 8. - Deut 4 : 2 Bien 1842. 8. Ertangen 1843. 8. Ladies' botany etc. Edit. II. London s. a. 8. - Edit. III ibid. 1837. 8. - Deut tq: Bonn 1838. 8. 25 folor. Taf. A key to structural, pliysiological and systematical botany etc. London 1835. 8. - Nixus plantarum. Londini 1833. 8. - Deutid: Rürnberg 1834. 8. - A natural system of botany etc. London 1836. 8. - John Lindley and William Hutton, The fossil Flora of Great-Britain. London 1831 - 37. III voll. 8. 230 tab.

$\Rightarrow$ A catalogue of british plants. Cambridge 1829. 8.

3) Manual of british botany. London 1843. 8. - Synopsis of the british Rubi. London 1840. 8. - Monograph of the british Atripliceae. (From the Transact. Bot. Soc. Edinb. vol. I. 1840. 8.) 


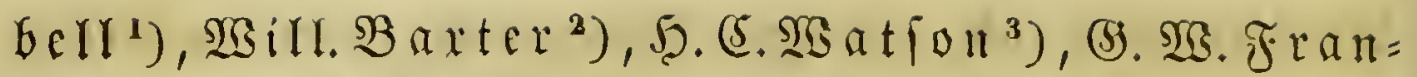

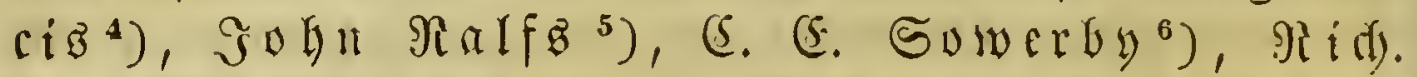

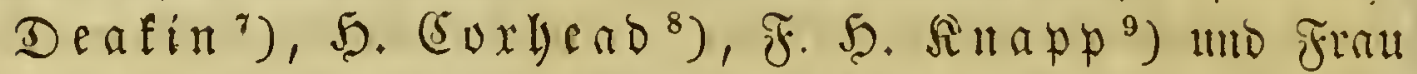

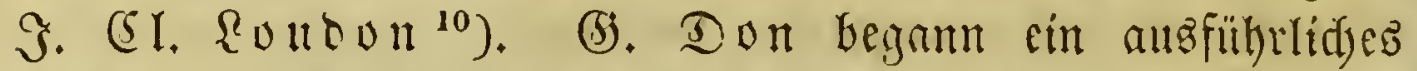
Trerf, worín alle bis jest befinnten SJflanzen befdrieben

1) Catalogue of british plants. Edinlurgh 18\%1. 8. (II. Ed.)

${ }^{2}$ ) British phaenogamous botany. Oxford 1834-184. VI voll. 8. 509 tab. col.

$\left.{ }^{8}\right)$ The new botanist's guide to the localities of the rarer plants of Britain. London 1835-37. II voll. 8. - Outlines of the geographical distribution of british plants etc. Edinburgh (1832). 8. - Remarks on the geographical distribution of british plants. London 1835. 8. - The geographical distribution of british plants. Third edit. Part. J. London 1843. 8. - Cybele britannica; or british plants and their geographical relations. Part. I. London 18\%?. 8.

4) A catalogue of british flowering plants and ferns. London 18:35. Fol. - London 1840. Fol. - The little english Flora. London 1839. 8. 14 tab. - An analysis of the british ferns and their allies. London 1837. S. 7 tab. Edit. II. 1843. 8. -- The grammar of botany; with engravings. London 1840.8.

s) The british phaenogamous plants and ferns. London 1839. S.

o) The illustrated catalogue of british plants. London 1811. 12. 8 tab.

7) Florigraphia britannica. London $1841-1845$. II voll. 8 . 170 tab. col. c. 1076 fig.

-) Catalogue of plants of Great Britain. London 1842. gr. 8.

9) The botanical chart of british plants. Bath. 1846. 8.

$\left.{ }^{10}\right)$ British wild-flowers. London 1846. 4. - Instructions in gardening for Ladies. London 1840. 8. - The Ladies' Flower-garden of ornamental annuals. London 1840. 4. 48 tab. - The Ladies' Flower-garden of ornamenta! bulbous plants. London 1841. 4. 58 tab. col. - 'The Ladies' Flower-garden of ornamental perennials. London $18 \%$. II voll. 4. - The first book of botany. London 18\%1. 12. - Botany for Ladies. London 1842. 8. - Ladies Companion to the Flower-garden etc. London 1841. 12. - 


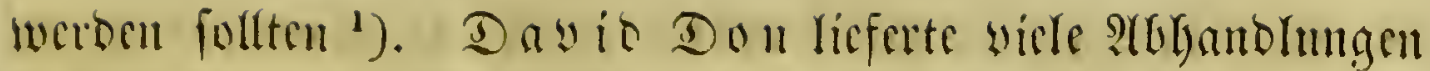

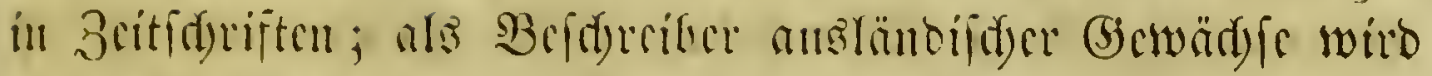

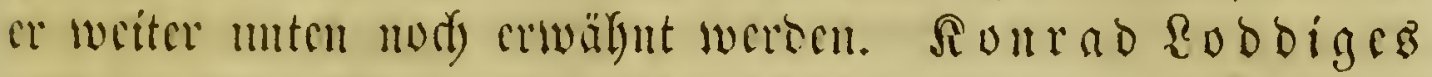

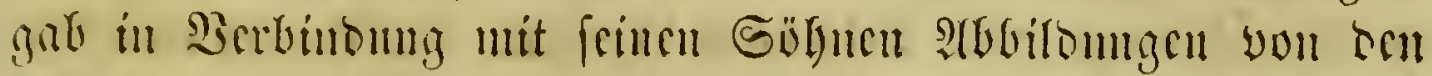

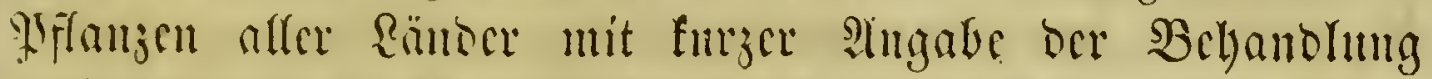
serfelben herans ${ }^{2}$ ). Robert Sweet befdricb bie (Gie=

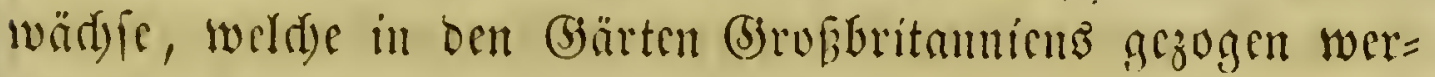

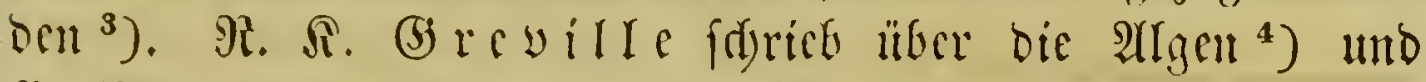

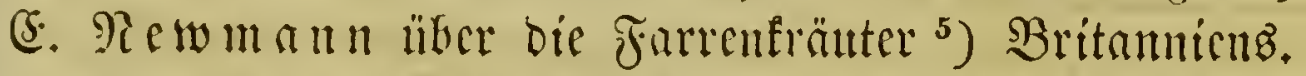

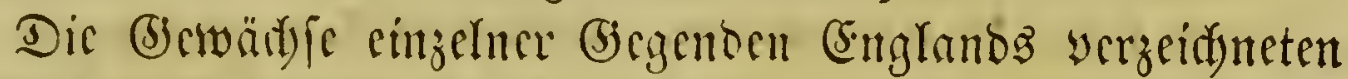

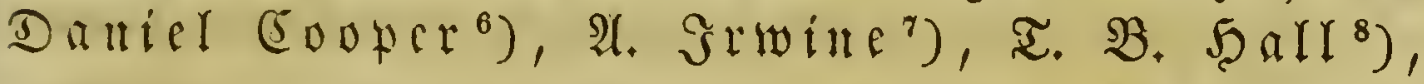

Edit. IV. London 1846. 12. - Tales about plants. London 1846. 12.

') A general History of the dichlamydeous plants comprising complete descriptions of the different orders etc. Preceded by introductions to the Linnean and natural systems, and a glossary of the terms used. Founded upon Miller's Gardener's Dictionary, and arranged according to the natural system. London $1831-38$. IV voll. 4.

$\left.{ }^{2}\right)$ The botanical Cabinet, consisting of coloured delineations of plants from all countries, with a short account of each directions for menagement etc. by Conr. Loddiges and Sons. London 1818-1833. XX voll. 4. 2000 tab. col.

3) Hortus suburbanus Londinensis etc. London 1818. 8. The british Flower - Garden. London 1823 - 1829. III voll. 8. 300 tab. col. - Series the second. London 1831 - 1838. IV voll. 8. 412 tab. col. - Swe et's Hortus britannicus, or a catalogue of plants cultivated in the Gardens of GreatBritain. London 1827. 8. - 1830. 8. - 1839. 8. - Robert Swe et and II. Weddel, British Botany No. 1. London 1831. 8. 2 tab. col.

") Algae britannicae etc. Edinburgh 1830. 8. 19 tab. col.

5) A history of british ferns and allied plants. London 1840. 8. 184 . 8.

-) Flora metropolitana. London 1837. 12.

') The London Flora. London 1838. gr. 12.

$\left.{ }^{8}\right)$ A Flora of Liverpool. London (1839). 12. 1 chart. geographica. 


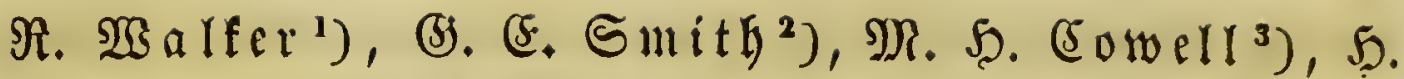

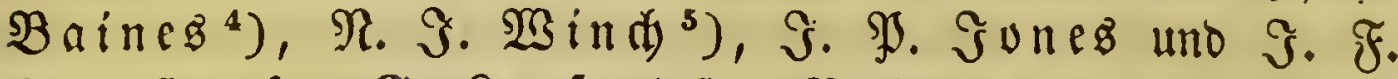
Ringfton ${ }^{6}$ ), (s). Ruxford ${ }^{7}$ ), $\mathfrak{B a b i n g t o n}$ allein ${ }^{8}$ ) unb in Berbinbung mit $\mathfrak{B}$ (oxam ${ }^{9}$ ), $\mathfrak{B}$. A. Reighton ${ }^{10}$ ),

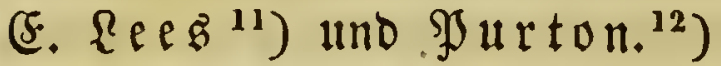

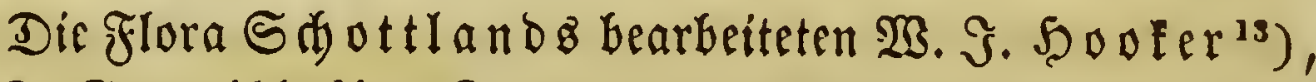

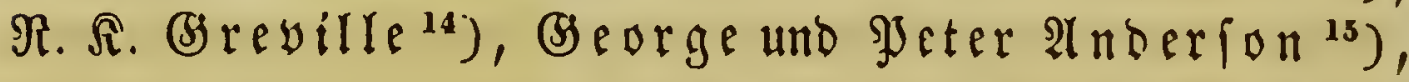

') The Flora of Oxfordshire. Oxford 1833. 8. 12 tab.

${ }^{2}$ ) Catalogue of rare plants collected in South-Kenth. London 1829. 8.

3) A Floral guide for East-Kenth. Faversham 1839. 8.

4) Flora of Yorkshire. London 1840. 8.

$\left.{ }^{3}\right)$ Flora of Northumberland and Durham. Newcastle 1831. 4. - Contributions to the Flora of Cumberland. Newcastle 1833. 4. - An essay on the geographical distribution of plants trough the counties of Northumberland, Cumberland and Durham. Newcastle 1819. 8. - Ed. II ibid. 1825. 8. - Deutíd: von $\mathfrak{i a r l}$ Iraugott $\mathfrak{B} e \mathfrak{l}=$ f́micb. (Flora 1837. J. p. $289-317$.)

-) Flora devoniensis. London 1829. 8.

') A Flora of the neighbourhood of Reigate, Surrey. London 1838. gr. 12. 1 mappa geographica.

-) Charl. C. Babington, Flora bathoniensis. London 1834. 12. - Suppl. ibid. 1839. 12. - Primitiae Florae Sarnicae. London 1839. 8.

-) Bloxam and Babington, Botany of the Charnwood Forest. Sn: Potter, The history etc. London 1842. 8.

$\left.{ }^{10}\right)$ A Flora of Shropshire. London 1841. 8.

${ }^{11}$ ) The botany of the Malvern Hills etc. London (1843). 8.

12) British plants of the Midland counties. Stratford-uponAvon 1817. III voll. 8. 24 tab. col.

is) Flora scotica. London 1821. II voll. 8.3 tab.

16) Scottish cryptogamic Flora. Edinburgh 1823-29. II voil. 8. 360 tab. col.

15) Guide to the Higlands and Islands of Scottland. London 1834. 8. 


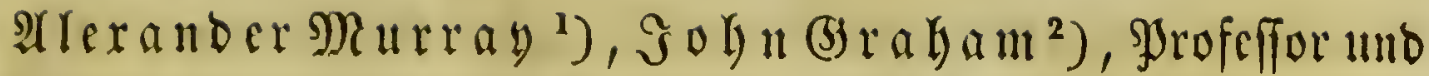
Director bes Kotanifden (3artenz zu ङ大inburg, geftorben 1839. Dic (B) enädje cinjelner Stäbte uno Sezirfe Sdjottlanbo unter= furdeten ber eben erwälunte (5) revill $\mathfrak{f}^{3}$ ), ber namentlid) bie Rryptogamen fleipig unterfudste, fermer $\Im . \mathfrak{B}_{0}$ ob for o ${ }^{4}$ ),

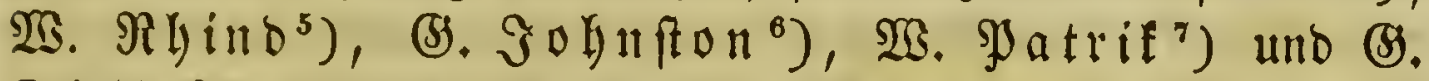

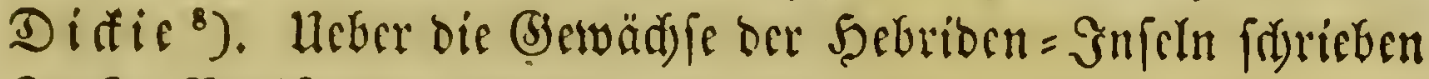
J. S. Balfour mo (5l). Babington. ${ }^{\circ}$ )

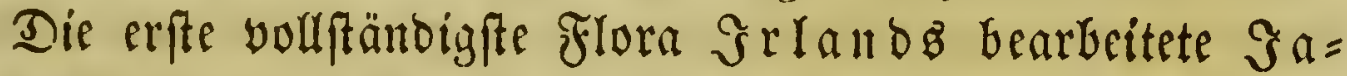

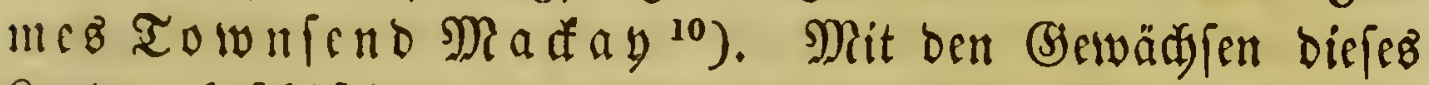
Runbe: befdäftigten fid auperbem nod (E. New mann ${ }^{11}$ )

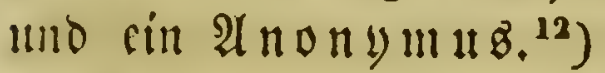

Unter ben nieberlänbifden Shytographen if zunädit Themiftocle \&eftiboubois, ber Soln des Seite $342 \mathrm{er}=$ wallnten Franç. SoF. Reftiboubois, wie frin Bater unb

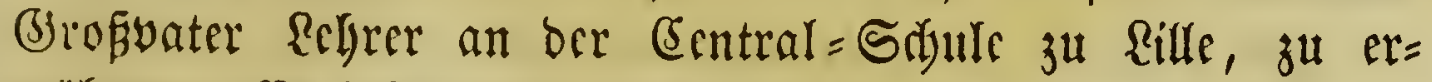

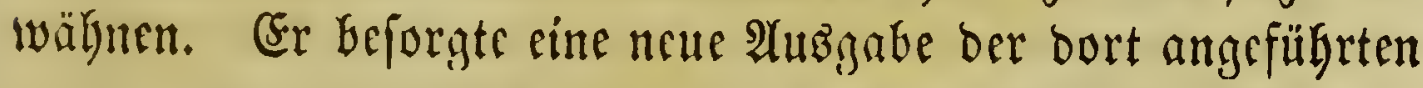

1) The northern (Scotland) Flora. Edinburgh 1836. 8 .

2) Seine Beiträge wurben in werfdiebenen 3eitfäriften mitgetbeilt.

3) Flora Edinensis. Edinburgh 1824. 8. 4 tab.

') Catalogue of plants growing in the neigbourhood of Edinburgh. Edinburgh 1824. 12.

s) Excursions. (Flora Edinensis). Edinburgh 1836. 12. - A catechism of botany. Edinburgh 1833. 12.

') A Flora of Berwick-upon-Tweed. Edinburgh 1829-1831. 8. 8 tab.

') Indigenous plants of Lanarkshire. Edinburgh 1831. 12.

3) Flora Abredonensis. Aberdeen 1838. 8.

-) An account of the vegetation of the outer Hebrides. (Edinburgh 1841). 8.

$\left.{ }^{10}\right)$ A catalogue of the plants found in Ireland. Dublin 1825. 4. - Flora hibernica. Dublin 1836. 8.

11) Notes on irish natural history. London 1840. 8. - A history of british ferns and allied plants. London 1840. 8. -1844.8.

12) The irish Flora. Dublin 184\%, 12.

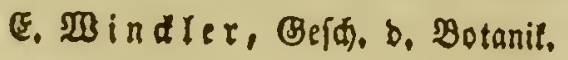


Botanographie belgique ${ }^{1}$ ), worill er bie Rryptogamen forg= fältiger befanoclte, bearbeitete cinige gute Monograplyieen und berfaß̈te ein Refrbud ber Botantif ${ }^{2}$ ). - Heber bie Flora Belgiens überlyaunt fdyrieben außerbem 2 . R. S. Rejeune mo R. (Sourtoib $\left.{ }^{3}\right), \mathfrak{B}$. (5. Dumortier $)^{4}$, S. (5hr.

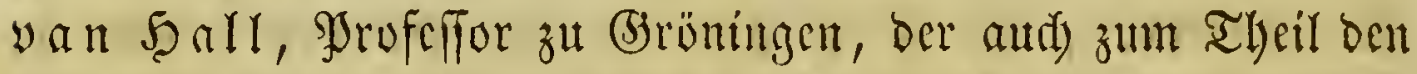
Text ber Seite 341 angefübrten Flora Batava Gearbeitete, fpäter bie Correfpondenz ciniger berülynter Raturforfder be=

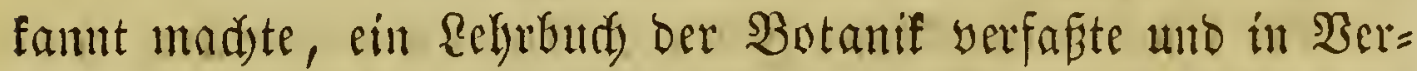
binoung mit $\mathfrak{Z}$. Brolif uno (b). Y. Mulder eine natur= wiffenidgaftlidje Zettfdrift Gegründete ${ }^{5}$ ); in Der neueften Zeit

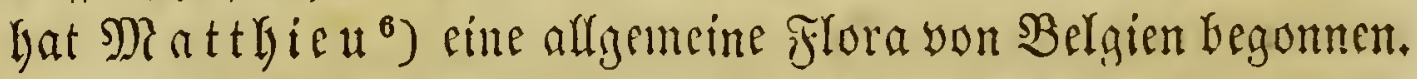

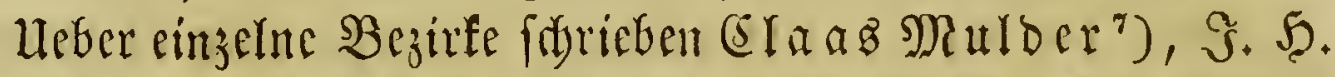

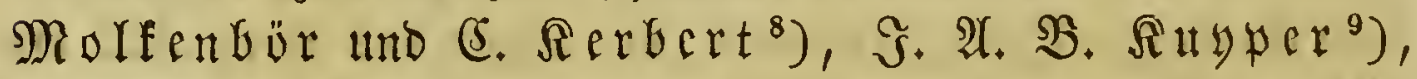

1) Lille 1827. II voll. 8. 22 tableaux.

3) Botanographie élémentaire. Lille 1826. 8.

3) Clowix des plantes de la Belgique. Liège 1826. Fol. tab. Compendium Florae Belgicae. Leodii 1828-1836. III voll. 8.

†) Florula belgica, operis majoris Prodromus. Staminacia. Tornaci Nerviorum 1827. 8.

s) Specimen botanicum etc. Trajecti ad Rhenum 1821. 8. 1 tab. - Flora Belgii septentrionalis etc. Vol. I. (Flora van Noord Nederland etc.) Amsterdam 1825. 8. - Flora Belgii septentrionalis etc. Vol. II. (Flora Batav.) Amsterdam 1832 - 1836. 8. - Epistolae ineditae Car. Linnaei; addita parte commercii litterarii inediti inprimis circa rem botanicam, J. Burmanni, N. L. Burmanni, Dillenii etc.; annis $1730-1793$. Ex litteris autographis edilit. Groningae 1830. 8. - Elementa botanices. Groningae 1834. 8. - Bydragen tot de natuurkundige Wetenschappen. Amsterdam 1826. 8.

-) Hore générale de la Belgique. Fasc. I. Bruxelles 1852. gr. 8.

') Elenchus plantarum, quae prope urbem Leidam nascuntur elc. Lugduni Batavor. 1818. 4.

3) Flora Leidensis. Lugl. Batav. 18\%0. 8.

$\left.{ }^{9}\right)$ Eerste naamlijst van zigtbaarbloijende plaanten weicke in de omstrekeu van Breda gefonden. Breda 1826. 8. 


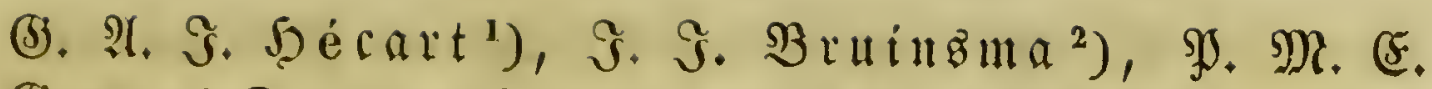

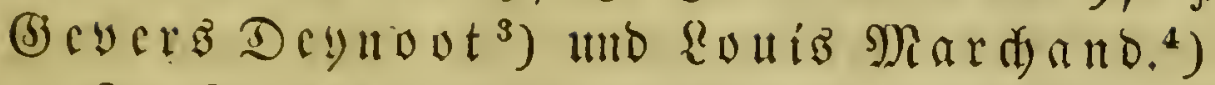

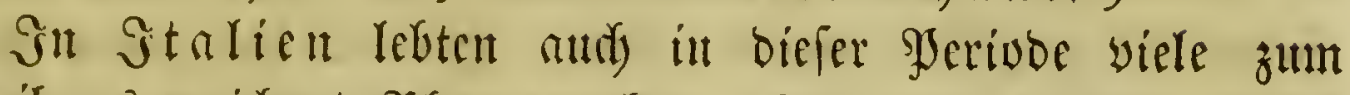

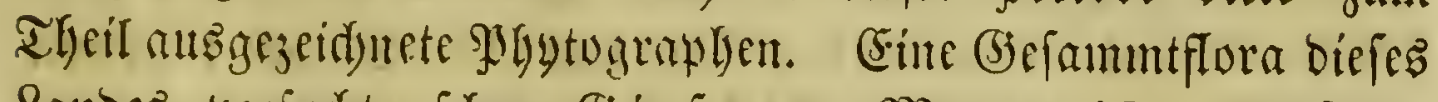

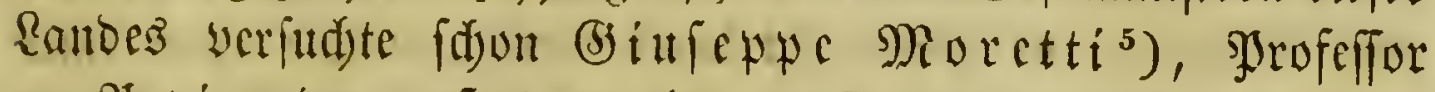

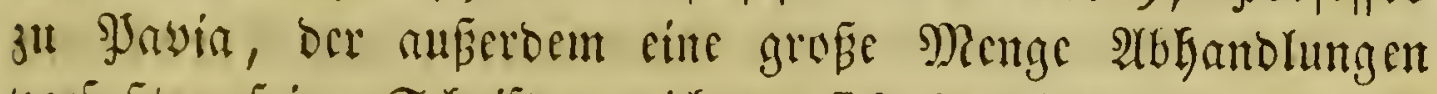
werfapte; feine Sdyriften zciduncm fid) jeood) nidst befonoers

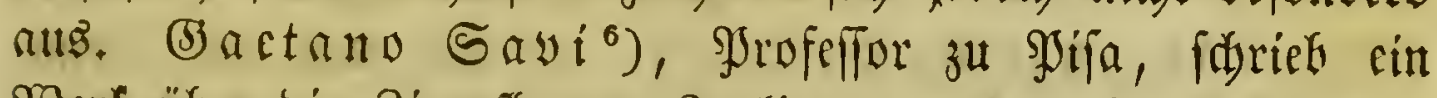

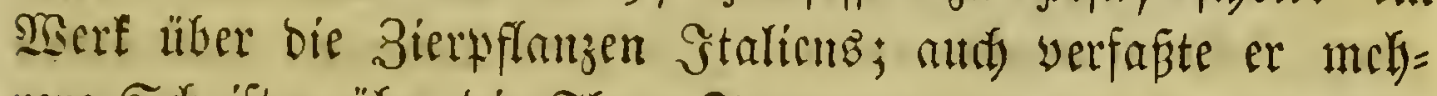
rere Sdyriften über bie Flora Toscrun's, weldye bereits Seite 349 angefülyrt woroen fint. 3u ben fleifigften Botanifern

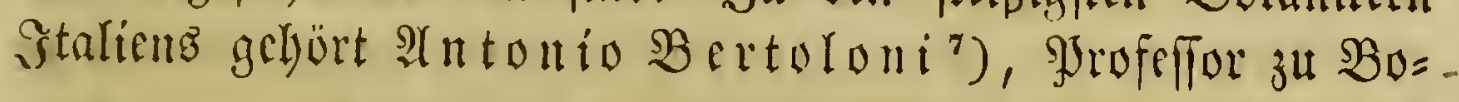

1) Florula Hannoniensis. Valencienues 1836. 8.

$\Rightarrow$ Flora Frisica. Leeuwarden 1840. 8.

3) Flora Rheno-Trajectina. Utrecht 1843. 8.

‘) Beiträge zur flora \&uremburgß̈. In Bydr, tot de nat. Wetensch. III. (1828).

5) Notizia sopra diverse piante da aggiungersi alla flora vicentina. Pavia 1815. 4. - Plantae italicae. 1822. Flora italica $s$. descriptio plantarum omnium quae in Italia sponte nascuntur e systemate sexuali distributarum. Pavia 1825.

') Flora italiana. Pisa 1818 - 1824. III voll. Fol. 120 tab. col.

') Amoenitates italicae sistentes opuscula ad rem herbariam et zoologiam Italiae spectantia. Bononiae 1819. 4. 6 tab. - Praelectiones rei herbariae et prolegomena ad Floram italicam. Bononiae 1827. 8. - Memoria sopra alcune produzioni naturali nel golfo della Spezia. Modena 1832. 4. 1 tab. col. - Mantissa plantarum Florae Alpium Apuanarum. Bononiae 1832. 4. - Florula Guatimalensis sistens plantas nonnullas in Guatimala sponte nascentes. Bononiae 18\%0. 4. 12 tab. col. - Iter in Apenninum Bononiensem. Bononiae 1841. 4. 2 tab. col. - Niscellanea botanica. Bononiae 1842-1846. V fasc. 4. 18 tab. col. Flora italica etc. Bononiae 1833-1846. VI voll. 8. Suserbem verfäte er mebrere Saliften üher ben botanifden (arten zu Bologna unb cinige tleinere AbGandlungen. 
logna; er hat cine nidjt geringe $\mathfrak{A}(\mathfrak{z}$ abll won Sdyriften über

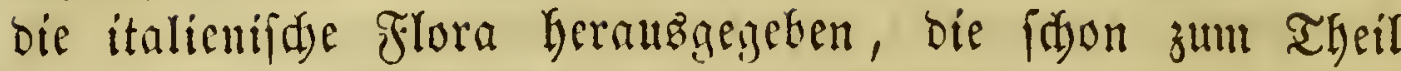
Seite 348 anjefüfrt worben find. Der tm bie Flora (sor= fica'z yerdiente Domenico Biviani ${ }^{1}$ ) (S. 539) lieferte aud) Briträge zur flora $̧$ tulienz liberhaupt uno war einer oer beften Monograplen feines Baterlantes; aud (5) irolamo

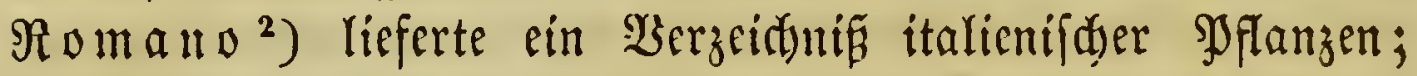
ebenjo Bincenzo be (sefati $i^{3}$ ), ber fid aud als Mono= graph befannt madjte uno ber Zeitjurift Linnaea Raduridten iiber ben Stano ber neueren botanifiden Riteratur Staliens mittbeilte. Filippo Parlatore $e^{4}$ ), ber (d)on frither mely= rere Sieiträge zur Flora Stalienz geliefert lyatte, begann in ber neueften Zeit cine bejamntflora Staliens gerauşugeben. Heber bie Flora einzelner (Segenten ber \&ombarbei fdrie=

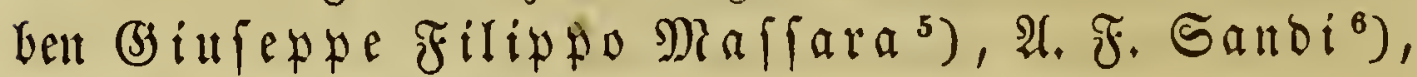

3) I funghi d'Italia e principalmente le loro specie mangereccie, velenose e sospette, descritte et illustrate con tavole disegnato e colorite dalvero. Genova 183\%. Fol. 50 tab. col.

2) Catalogus plantarum italicarum. Patavii 1820.8.

3) Stirpes italiacae rariores vel novae, descriptionibus iconibusque illus!ralae. Mediolani 18\%. Fol. elephant. 2:k tab. mit Text. (Fasc. I - III.) Linnaea. X Bd. ff.

4) Observations sur quelques plantes d'Italie. (Extrait des Annales des sc. nat. Cahier Mai 1841.) Paris 1841. 8. Plantae novae vel minus notae opusculis diversis olim descriptae, generibus quibusdam speciebusque novis adjectis iterum recognitae. Parisiis 1842. 8. - Giornale botanico italiano etc. Firenze 181.4-46. 8. - Flora italiana. Tom. I. Firenze 1850. 8. - $\mathfrak{A} u$ pererbem verfä̧te er mefrere Sariften über ben 3uftand ber Sotanif in 3talien unb einige Donograpgieen. Seine Sdriften über bie ficilianifde Flora wer= ben unten angefiulgrt werben.

s) Prodromo della Flora Valtellinese etc. Sondrio 1834. 8. 1 (ab. col.

-) Enumeratio stirpium plantarum phanerogamarum agri Bellunensis. Belluni 1837. 8. 
Bictor (araf yon Trevifan $)^{2}$, Eorenz Rota ${ }^{2}$ ), (B). $\Re \mathfrak{d} \mathfrak{i n g} \mathfrak{r r}^{3}$ ), Stcfano Moricano ${ }^{4}$ ), (5) $\mathfrak{g}$. yon

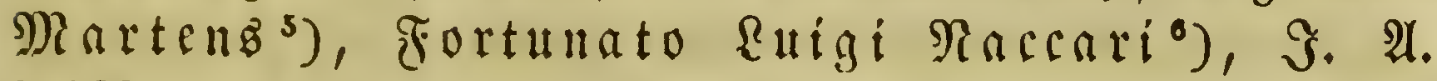

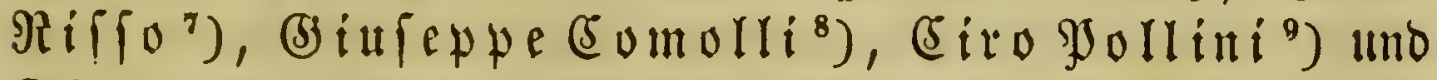
(B) irolamo $\Re$ omano ${ }^{10}$ ). Beiträge zur Renntnifi der Rryp= togamen biefes Randes lieferten Santo (jaroyaglio" ${ }^{11}$,

1) Enumeratio stirpium cryptogamicarum hucusque in provincia Patavina observatarum. Patavii 18\%0. 8. - Prospetto della Flora Euganea. Padova 1842. 8.

2) Enumerazione delle piante fanerogame rare della provincia Bergamasca. Pavia 1843. 8.

3) Flora dei Lidi Veneti. Venezia 1818. 8.

4) Flora Veneta etc. Vol. I. Phanerogamia. Genevae 1820. 8.

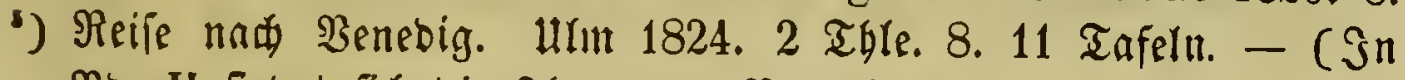
Bb. Il finoet fif bie filora von $\mathfrak{3 e n e d i g . )}$

-) Flora Veneta. Venezia $1826-1828$. Vl voll. 4. 1 tab.

') Histoire naturelle des principales productions de l'Europe méridionale et particulièrement de celles des environs de Nice et des Alpes maritimes. Paris $1826-1828$. V voll. 8. 46 tab. 2 mapp. geograph. - Flore de Nice, et des principales plantes exotiques naturalisées dans ses environs. Nice 1844. 8. tab.

8) Plantarum in Lariensi provincia lectarum enumeratio, quam ipse in botanophilorum usu atque comnodo exhibet uti prodromuin Florae Comensis. Novo-Comi 1826. 8. - Flora Comensis. Novo-Comi 1826. 8. - Flora Comense disposita secondo il sistema di Lin ne o. Como 1834-1836. III voll. 12.

-) Sulle Alghe vivente nelle terme Euganee, con un indice delle piante rinvenute sui colli Euganei, e un' appendice sopra alcune alghe della provincia Veronese, Lettera. Milano 1817. 8.1 tab. - Flora Veronensis. Veronae $1822-$ 1824. III voll. 8. 12 tab. - Heber feine übrigen $23 e r f e$ fieble Seite 345 u. 346.

10) Le piante fanerogame Euganee, per le auspicatissime nozze Meneghini-Fabris. Parlova 18:28. 8. Ed. III. Padova 1831. 8.

ii) Catalogo di alcune crittogame raccolte nella provincia di Como e nella Valtellina. Como 1837. 8. Milano 1838-1843. 


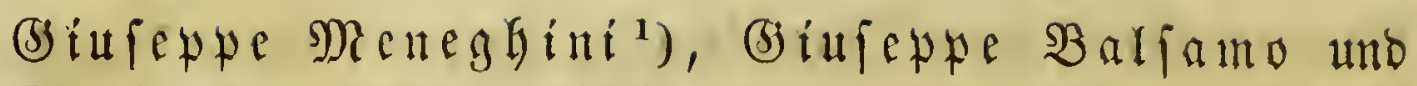
(3) illicple de PotariB. ${ }^{2}$ )

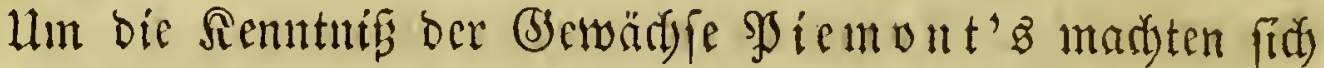

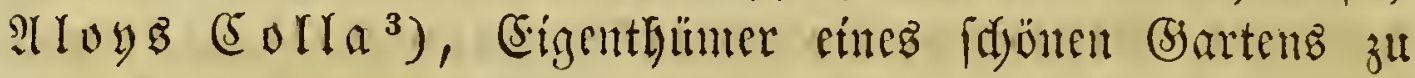

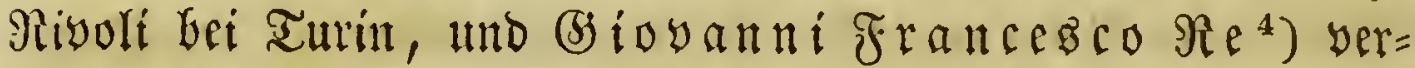

8. Paviae 1843. 8. III Partes. - Delectus specierum novarum vel minus cognitarum quas in collectionibus suis cryptogamicis evulgavit. Sectio II. Lichenes illustrans. Ticini 1838. 8. - Enumeratio muscorum omnium in Austria inferiore hucusque lectorum, adjecta indicatione loci eorum natalis, et temporis, quo fructum ferunt. Viennae $18 \% 0$. 8. - Bryologia austriaca excursoria tamquam Clavis analytica ad onnes in imperio austriaco hucusque inventos muscos facile et tuto determinandos. Vindobonae 1840. 8.

1) Conspectus algologiae euganeae. Patav. 183\% - Cenni sulla organografia e fisiologia delle Alghe. Ibid. 1838. 4. - Alghe italiane e dalmatiche illustrate dal Professore Giuse ppe II eneghini. Fasc. I-V. Padova 1842-1846. 8. 5 tab.

2) Algologiae maris ligustici specimen. ('Taurini 1842). 4. 7 tab. - Index seminum, quae hortus botanicus R. Archigymnasii Genuensis pro mutua commutatione offert amnis $1840-184.5 .8$.

3) Hortus ripulensis elc. Augustae-Taurinorum 1824. 4. 10 tab. - Illustrationes et icones rariorum stirpium quae in ejus horto Ripulis florebant anno 18:24, addita ad hortum ripulensem appendice I. (Inemorie della real Acad. delle scienze di Torino. Tom. 21.) 7 tab. - Illustrat. et icon. etc. anno 1825, add. ad h. ripul. appendice II. 9 tab. - Illustr. et icon. etc. anno 1826 , adtl. ad h. rip. appendice III. (Mem. T. XXXIII). 12 tab. - Herbarium Pedemontanum etc. Augustac-Taurinorum 1833-1837. VIII voll. 8. 97 tab.

') Ad Floram Pedemontanam Appendix (prima). Taurini 1821. 8. - Append. altera finbot firh in Men. della R. Acc. di Torino Tom. XXXI 18\%\%. S. 189-22\%. - Flora Torinese. Vol. I. (Classes Linn. I-XVI.) T'orino 1825. 8. 
bicnt, mb Domenico Rifa ${ }^{1}$ ) befd)äftigte fid mit bon un Tutin wadjenden Mroofen. - Dic Gnjel Sarbinten wurbc crit in bicfom 3citraume genauer unterfudit; wir yerbanfen

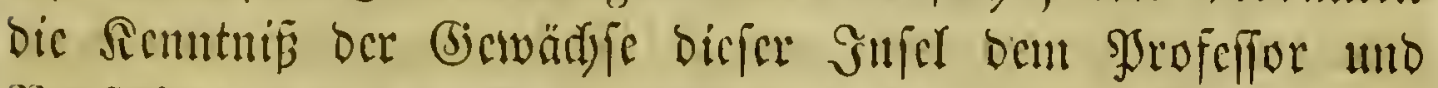

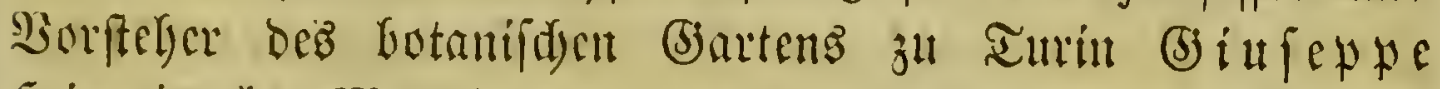
Siaciutlyo Moris. ${ }^{2}$ )

Dic Jungcrmanten Tosana's Gefdrieb (3) iufape $\Re \backsim b \delta i^{3}$ )

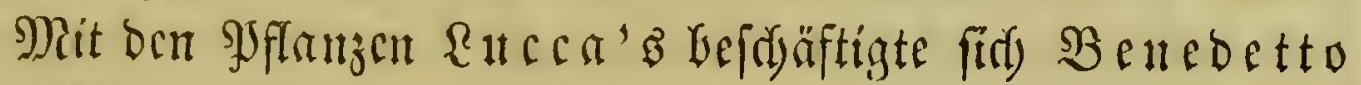

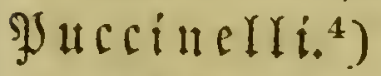

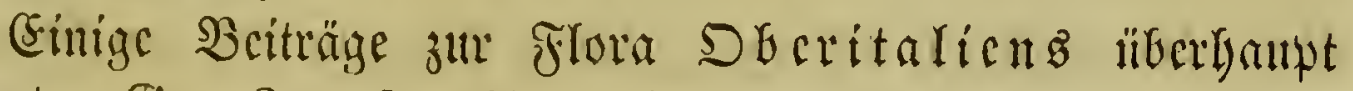

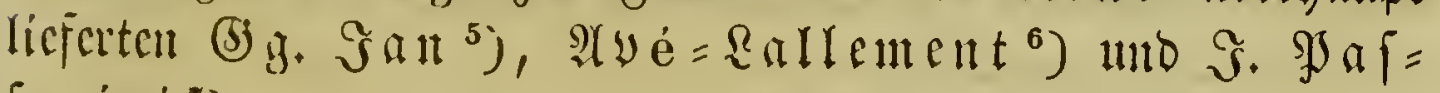
(crini. ${ }^{7}$ )

Antonio Sebaftiani ${ }^{8}$ ) rieferte atbriloumgen won spfan=

') Elenco dei muschi raccolti nei contorni di Torino. Torino 1837. 8.

2) Stirpium Sardoarum elenchus. Fascicul. I-III. Carali 1827-1829. 4. - Stirpes sardoae novae aut minus notae. (Taurini 1839.) 4. - Flora sardoa, Taurini 1837-1843. II voll, 4. 93 tab. 1 mapp. geographica. - (5r fdjrieb aud über ben (jarten zu Iurin: Enumeratio seminum regii horti botanici Taurinensis. Taurini 1831 - 1846. 8. - Illustrationes rariorum stirpium horti botanici univ. Taurinensis. (Taurini 1833), 4. 6 tab. G. G. Moris et G. De Notaris, Florula Caprariae. Taurini 1839. 4. 6 tab.

$\left.{ }^{3}\right)$ Jungermanniografia etrusca. (Memorie della società italiana delle scienze residente in Niodena, tom XVIIl. 1820). Bonnae 1841. 4. 7 tab.

4) Synopsis plantarum in agro Lucensi sponte nascent. (Fasc. I-III.) Lucae 1841 (-1843). 8. (9 tah.)

5) Catalogus complectens prodromum Florae Italiae superioris. Parmae 1832. Fol.

$\left.{ }^{6}\right)$ De plantis quibusdam Italiae borealis. Berolini 1829. 4.

${ }^{7)}$ Flora Italiae superioris. Thalamiforac. Mediolani 184t. 8.

8) Romanarum plantarum fasciculus primus. Romae 1813. 4. 4 tab. - Romanarum plantarum fasciculus alter. Accedit Enumeratio plantarum sponte nascentium in ruderibus 


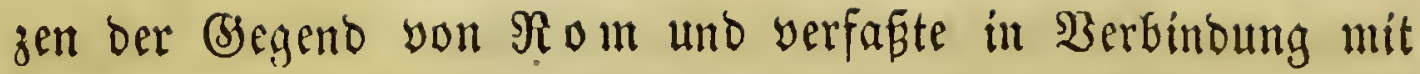
(5. Ma ari einte Flora von einem Theile bes Rirnenftaates. Aud) (s) iovanni Francesco Maratti ${ }^{1}$ ) beldrieb die Sylanjen diefes Ranbes uno Elifabetha, (s) räfin you Fiorini Miazzanti ${ }^{2}$ ) uno Soletro Sanguinettio ) lies

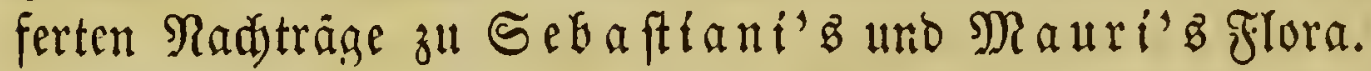

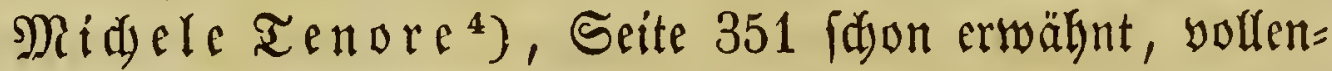
bete in biefem 3eitraume feine Flora yon $\mathfrak{R}$ eapel und lies

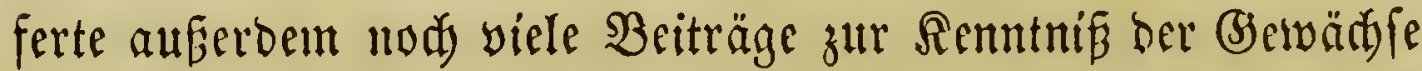

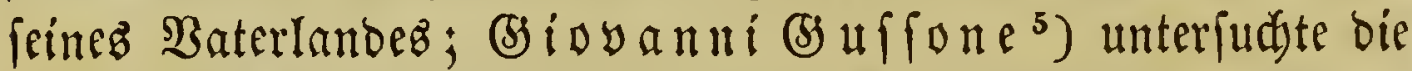
Flora ber Abruzzen und bez öflidien Rüftenlandes yon Reapel,

Amphitheatri Flavii. Romae 1815. 4. 6 tab. - A. Sebastiani et E. Mauri Florae Romanae Prodromus etc. Romae 1818. 8. 10 tab.

1) Flora Romana. Opus posthumum nunc primum in lucem editum (edidit Mauritius Benedictus Oliveri). Romae 1822. II voll. 8.

$\Rightarrow$ Specimen bryologiae romanae. Romae 1831.8. 1 tab. Ed. II. 1841. 8. - Appendice ad Prodromo della Flora Romana (aut. Sebastiani et Mauri.) s. l. et. a. 8.

$\left.{ }^{3}\right)$ Centuriae tres Prodromo Florae Romanae addendae. Romae 1837. 8.

4) Ad Florae Neapolitanae Prodromum appendix quarta. Neapoli 1823. 8. - Ad Florae Neapolitanae appendix quinta. Neapoli 1826. 4. -- Memoria sulle specie e varietà di Crocchi della Flora Napolitana. Napoli 1826. 4. 4 tab. col. - Cenno di geografia fisica e botanica del regno di Napoli. Napoli 1827. 8. 2 mapp. geograph. - Essai sur la géographie physique et botanique du royaume de Naples. Naples 1827. 8. 2 mapp. geograph. - Sylloge plantarum vascularium Florae Neapolitanae hucusque detectarum. Neapoli 1831. 8. (Cum Appendicib. I-V).

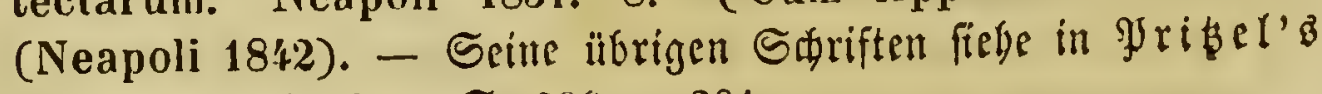
Thesaurus lit. bot. S. 290 u. 291.

•) Plantae rariores, quas in itinere per oras Jonii et Adriatici maris et per regiones Samnii et Apruttii collegit. Neapoli 1826. 4. 66 tab. 
uno Stefano belle (shiaje befdricb die âtgen uno

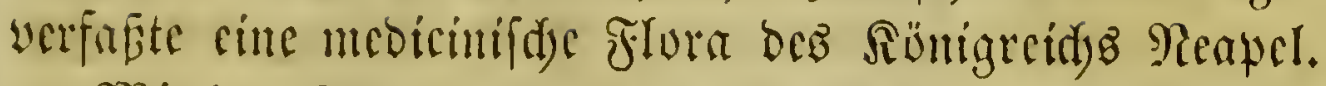

Mit ber Flura Siciriens befoüftigten fids Bincente

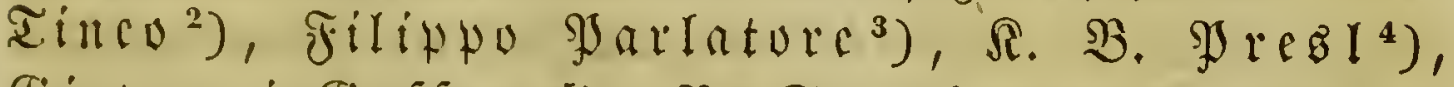

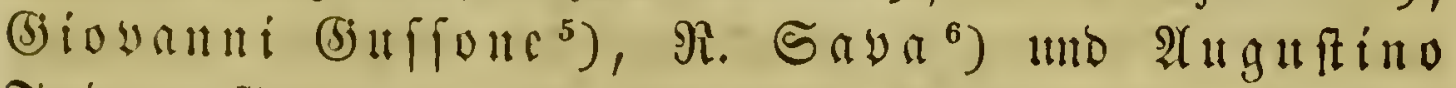
Iobar. $\left.0^{7}\right)$

3แr Flura Spaniens licferten (5) mono $\mathfrak{B}$ offfier ${ }^{8}$ ),

1) IIydrophytologiae regni Neapolitani icones. Neapoli 1829. Fol. 100 tab. col, - Iconografia ed uso delle piante medicinali ossia trattato di farmacologia vegetabile. Napoli 1824 - 1825. II voll. 8. et vol. 4. 119 tab. col. in 4. (A Paris 1845). - Flora medica. Napoli 1836. II vol. 8. 130 tab. in 4.

$\left.{ }^{2}\right)$ Plantarum rariorum Sicilia pugillus primus. Panormi 1817. 8. - Catalogus plantarum horti regii Panormitani ad annum 1827. Panormi 1827. 8.

3) Rariorum plantarum et haud cognitarum in Sicilia sponte provenientium fasc. I et II. Panormi 1838 - 1840. 8. tab. - Flora Palermitana. Vol. I. Firenze 1845. 8.

4) Gramineae siculae. Pragae 1818. 8. - Cyperaceae et Gramineae siculae. Pragae 1820. 8. - Flora sicula. T. I. Pragae 1826. 8.

5) Florae siculae prodromus. Neapoli $1827-1828$. II voll. 8. - Supplementum ad Florae siculae prodromum. Fasc. I et II. (CI. I - XVII). Neapoli 1832-1834. 8. - Flora sicula. Vol. I. Neapoli 1829. Fol. 5 tab. col. - Florae siculae synopsis exhibens plantas vasculares in Sicilia insulisque adjacentibus hucusque detectas, secundum systema Linne a 11 u dispositas. Neapoli $1842-1845$. II voll. 8.

') Lucubrazioni sulla Flora dell' Etna. Milano 1844. 8.

') Rariorum plantarum Siciliae decas I. s. l. (1845). 4. Orchideae siculae. Panormi 1842. 8. 2 tab.

$\left.{ }^{8}\right)$ Elenchus plantarum novarum minusque cognitarum, quas in itinere hispanico legit. Genevae 1838. 8. - Erfordiae 1840. 8. - Voyage botanique dans le midi de l'Espagne pendant l'année 1837. Paris 1839 - 1845. II voll. 4. 208 tab. col. - E. Boissier et Gg. Franc. Reuter, Diagnoses plantarum novarum hispanicarum, praesertim in Castella nova lectarum. Martio 1842. Genevae 1842. 8. 


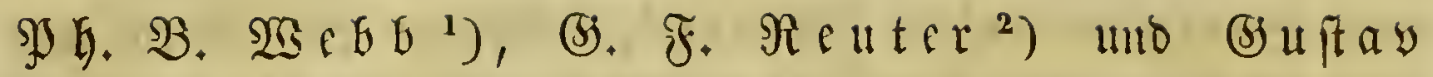

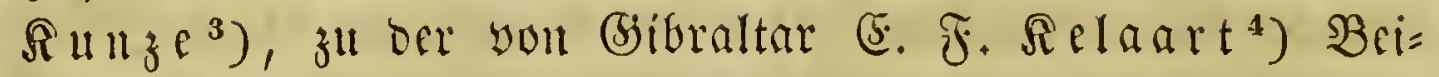
träge; Die alt ben $\mathfrak{B a l e a r e n ~ v o r f o m m e n t e n ~ P J f l a n z e n ~ v e r z e i d ) = ~}$ nete $\Im$. (5 a mbeffedes ${ }^{5}$ ), ber auch mefrere Monographicen

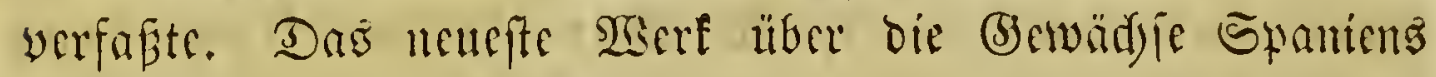

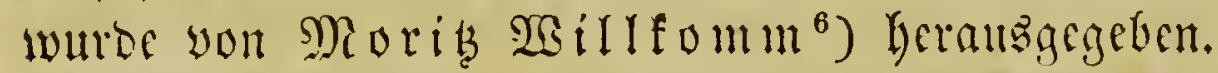

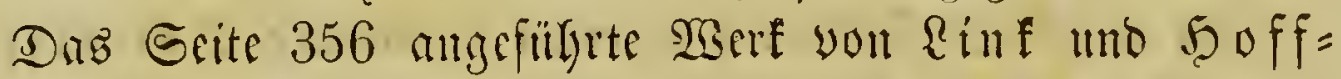
mannzegg über bic portugiefifde Flora ift bis jegt nod

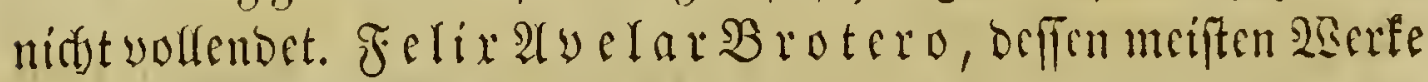
f(t)on früber angegeben wurben, lief aud it béefm Zeitraume

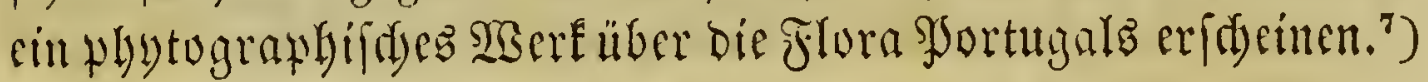

1) Iter hispaniense, or a synopsis of plants collected in the southern provinces of Spain and in Portugal, with geographical remarks, and observations on rare and undescribed species. Paris 1838. 8. - Otia lispanica, seu Delectus plantarum rariorum per Hispanias sponte nascentium. Pentas I-II. Parisiis 1839. Fol. 6 tab. - Otia hispanica seu Delectus plantarum rariorum aut nondum rite notarum, per Hispanias sponte nascentium. Parisiis 1853. Fol. min. 45 tab.

$\left.{ }^{3}\right)$ Essai sur la végétation de la Nouvelle Castille. Genéve 1843. 4. 1 tab.

s) Chloris austro-hispanica. E collectionibus Willkom$\mathrm{mianis}$ e mense Majo 184, ad finem mensis Maji 1845 factis composuit. Ratisbonnae 1846. 8 .

7) Flora Calpensis. London 1846. 8. 4 tab.

s) Enumeratio plantarum, quas in insulis Balearibus collegit, earumque circa mare mediterraneum distributio geographica. Parisiis 1827. 4. 9 tab.

") Icones et descriptiones plantarum novarum, criticarum et rariorum Europae-austro-occidentalis, praecipue Hispaniae (Sileneae). Lipsiae 1852-1853. Fasc. I-IV. 27 tab. col. in 4. unt Fol.

$\left.{ }^{7}\right)$ Flora lusitanica. Olisipone 1804. II voll. S. - Phytographia Lusitaniae selectior. Olisipone 1816-1827. II voll. Fol. mill. 181 tab. 


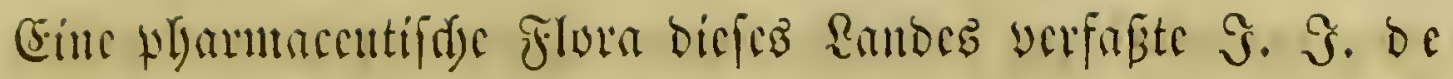
Jigucitcon. ${ }^{1}$ )

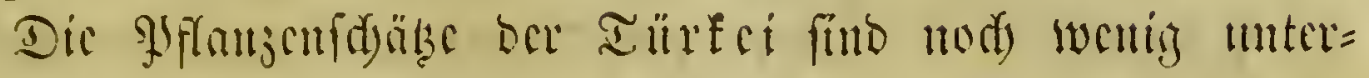

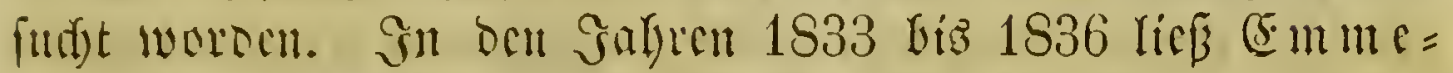

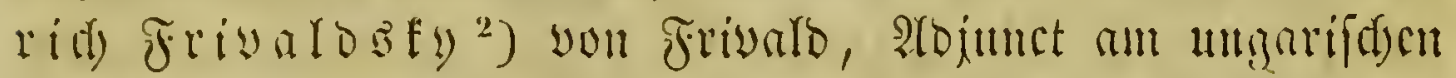

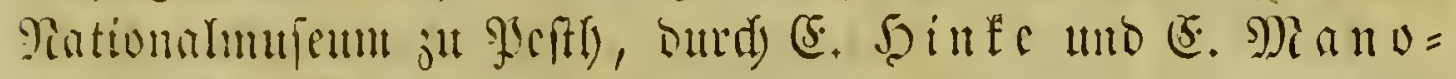

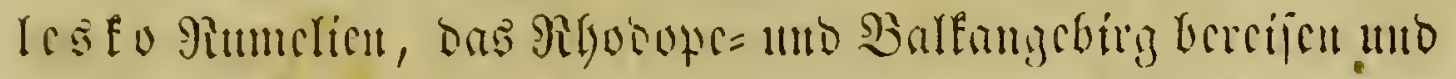

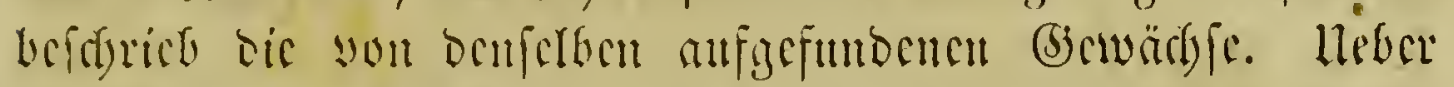

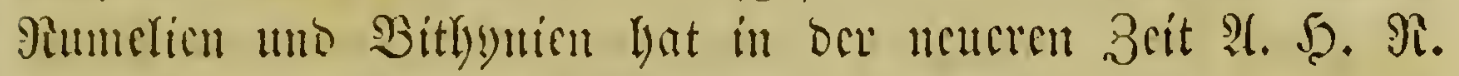

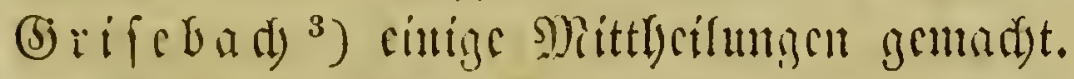

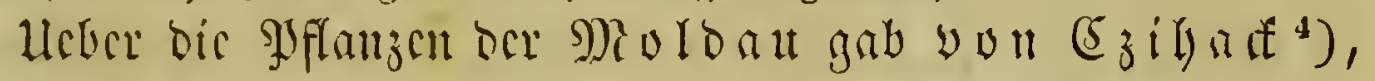

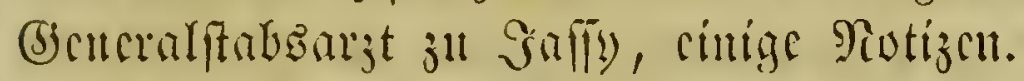

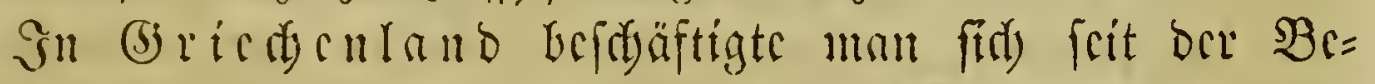

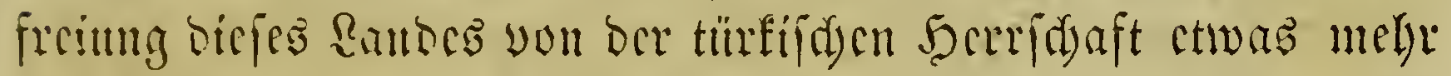

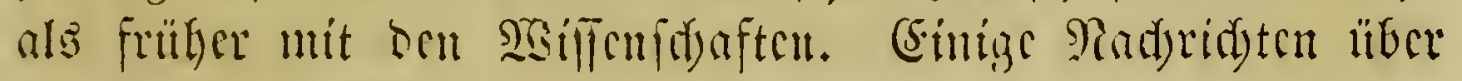

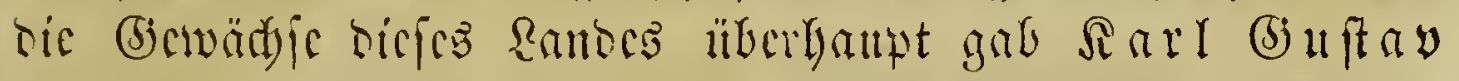

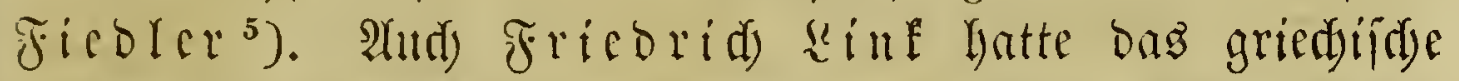

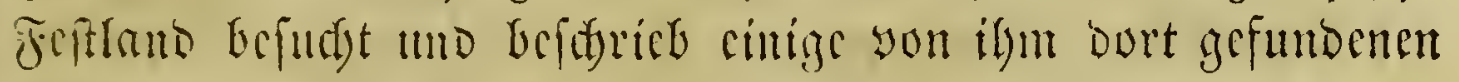

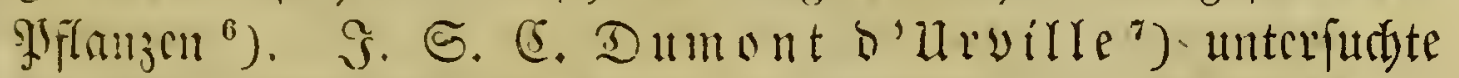

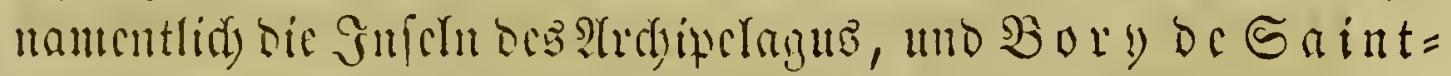

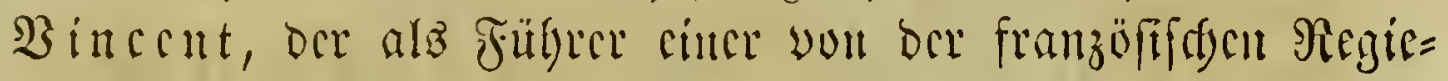

') Flora pharmaceutica e alimentar portugueza. Lisboa 1825. 8.

2) Succinctae diagnoses specierum plantarum novarum in Turcia europaea collectarum. (2Ulfgent. bot. 3eit. 1835. BD. 1, ธ. $311 .-1836.96$ ๖. 2 , S. 433.)

$\left.{ }^{2}\right)$ Spicilegium florae rumelicae et bithynicae. Brunsvigae 1843 - 184.5. II voll. 8 .

4) 2urgemeil. bot. 3cit. 1835. BD. 1, S. 44-46. - 1836. BBo. 2, Beibr. S. 58-74.

5) Reije burd) alle Iyeile bes Rünigreidy (jriedentand. Reipzig 1840-1841. 2 Thle. 8. 11 Taf. 1 fol. geognoft. Tnf.

') Symbolae ad floram graecam. (Linnaea $\mathfrak{b}$ b. 9, 1834. S. 129 - 141. (. 567 - 588.)

') Enumeratio plantarum, quas in insulis Archipelagi aut littoribus Ponti Euxini annis 1819 et 1820 collegit atque detexit. Parisiis 1822. 8. 


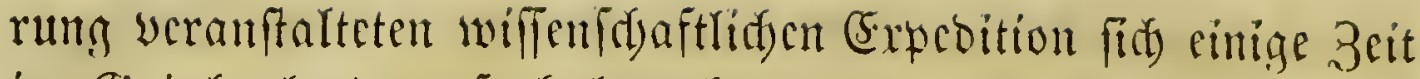
in Birictsenland aufichalten batte, yerfafite in Berbinoung mit (5)aubert cine Flora bes Pelopomejes uno ber Cylla

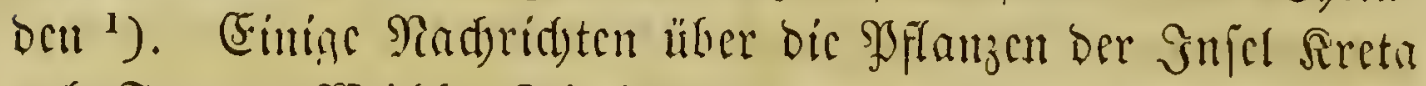
gab Franz Sairg. Siefcr. ${ }^{2}$ )

Heber dic Flora Der junifden Fnfeln fidricten $\Re$. $\Omega$.

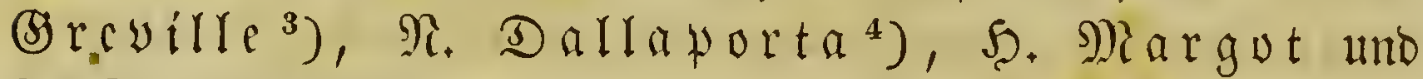

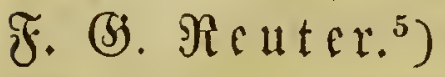

Uluter ocu oänifd en Botanifern biciç 3citraums ift oer ธ. 358 fidon gemante Scns 2 Bilfen Sornemann ${ }^{6}$ ) zu erwäbnen. Э. Ş. B rogic uno Botanif zu Soprnbagen, begann bie Berureitung

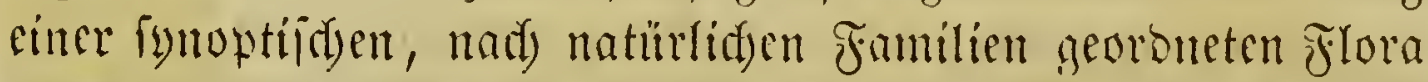

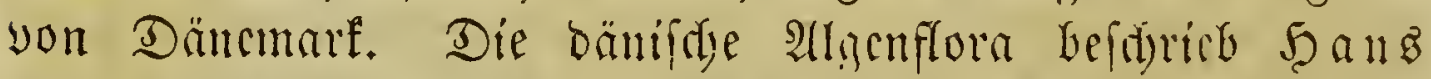

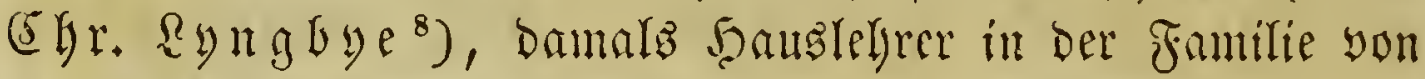

1) Expédition scientifique de Morée. Tome III, $2^{\theta}$ partie: Botanique. Paris 1832. 4. et Atlas in Fol. - Nouvelle Flore du Pélnponnèse et des Cyclades etc. Paris et Strasbourg 1838. 4 livraisons. Fol. 42 tab.

2) Reife nad ber Jnid Rreta. Reipzig 1823. 2 Bbe. 8. 11 Iaf. (Tathtrag: S) fer, Sfis, 1833. Seft 5, S. 456.)

${ }^{3}$ ) Some account of a collection of cryptngamic plants from the jonian islands. ('Transact. of the Linn. soc. of. Lond. vol. XV. p. Il. 1827.) 3 tab.

‘) Prospetto delle piante che si trovano nell' isola di Cefalonia, e che si possono adoperare a titolo di alimento o di remedio. Corfu 1821. 4.

5) Essai d'une Flore de l'île de Zante. Genève 1S'1.4.6 tab.

-) Nomenclatura Florae danicae emendata, cum indice systematico et alphabetico. Ilafniae 1827. 8. - 0m de indenlandske planter anvendte som zürplanter. Kiobenhavn 18:36. 8 .

7) Haandbog ved botaniske excursioner i Egnen om Soröe. Kiobenhavn 183' - 1835 .

8) Tentamen Hydrophytologiae danicae etc. Hafniae 1819. 4. 70 tab. 


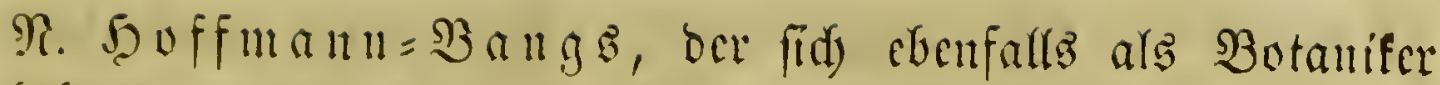

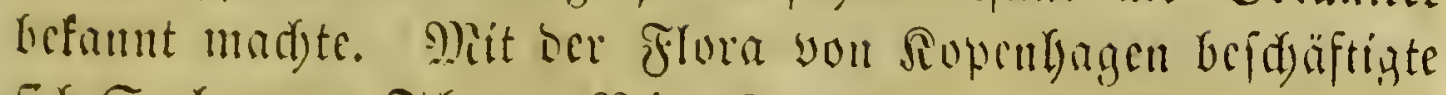

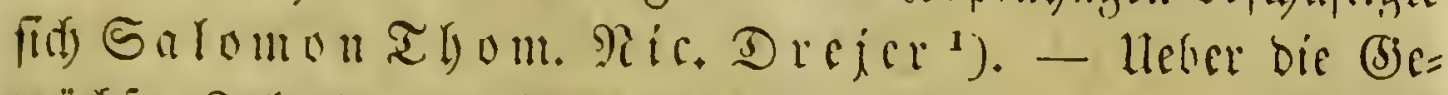

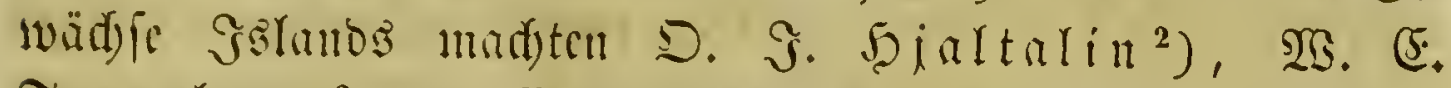
Ireyelyan ${ }^{3}$ ) mb (s. Robert ${ }^{4}$ ) cinize Mittbcilumgen.

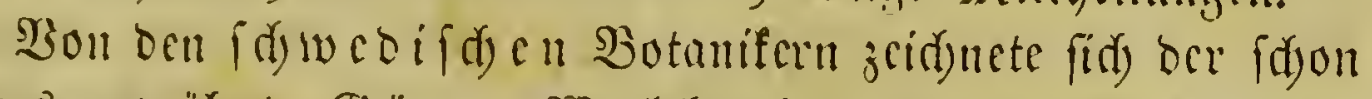

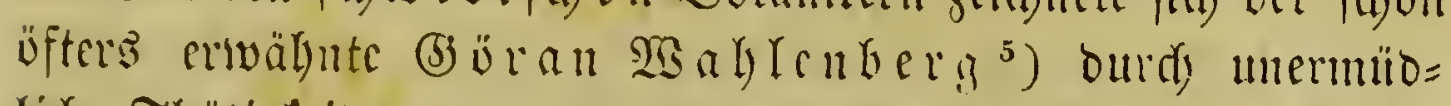
lide Ibätigfeit ans; namentlid) licferte or in ber neneren 3eit and) melyrere Serfe liber bie flora feincs Baterlanoes. (eten= fo thätin, befonsers auf ocm (bebicte ber Alycufunbe, zeigte fid)

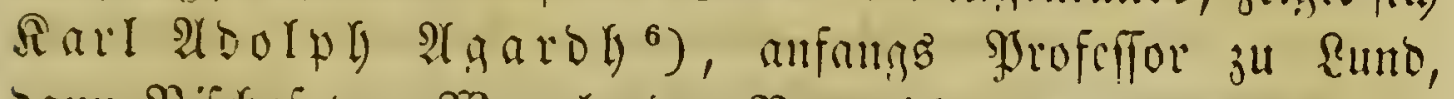
Dam Bifduf you Siscrmland. Bon nid)t geringer Recocutung

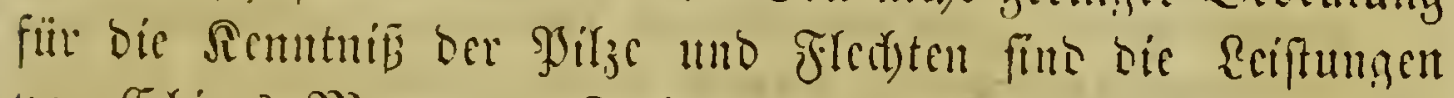

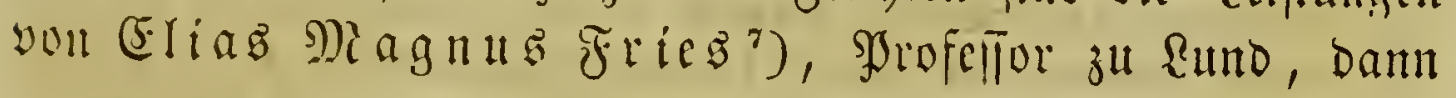

1) Flora excursoria Hafniensis. Hafniae 1838. 12.

${ }^{2}$ Islenzk Grasafraedi. Utgefin ad tilhlutun hins islenzka Bókmenta félagss. Kaupmannalıöfn 1830. 8.

3) Edinb. new philos. Journ. Oct. 183\%. - Jan. 1835. p. 154-164.

4) Observations sur la végétation en Islande etc. Paris 1811.8 .

$\left.{ }^{5}\right)$ Flora Upsaliensis etc. Upsaliae (Lipsiae) 1820. 8. 1 mapp. geogr. - Flora suecica etc. Upsaliae (Lipsiae) 1821-1826. II part. 8. - 1831-1833. II voll. 8. - Synopsis Florae gothlandicae. D. I et II. Upsaliae 1837. 8.

-) Dispositio Algarum Sueciae. D. I - IV. Lundae 1810-1812. 4. - Algarum Decades I-IV. Lundae 1812 - 1815. 4. 3 tab. - Synopsis Algarum Scandinaviae etc. Lundae 1817. 8. - Dissertatio de metamorphosi Algarum. Lund. 1820. 8. - Icones Algarum ineditae. Lundae 1920 - 1822. 4. 20 tab. - Species Algarum etc. Gryphiae 1823-1828. Il voll. 8. - Systema Algarum. Lundae 182\%. 8. - Icones Algarum europaearum. Leipzig 1828 - 1835. 8. 40 tah. col. - Aphorismi hotanici. D. I-XVI. Lundae 1817-1825. 8. - Stirpes agri Rotnoviensis. D. I. Lundae 1826. 8. Flora parochiae Bränkyrka. D. I-III. Upsaliae 1827. 8.

") Observationes mycologicae, praecipue ad illustrandam Floram suecicam. Haviliae $1815-1818$. II voll. 8. 8 tab. col. - 1824.8. 8 tab. col. - Systema mycologicum etc. Gryphis- 
zu Upfala; er licferte aud) wirbtige Beiträge zur (d)werbifden

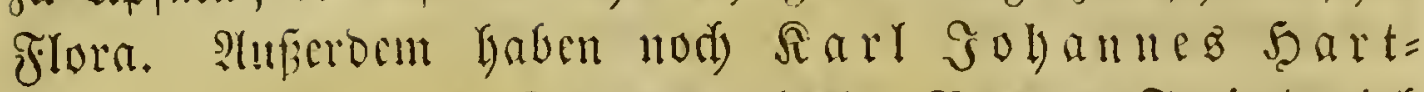
mann $n^{1}$, arzt in Sibdrmantano, Sheter Friebrids

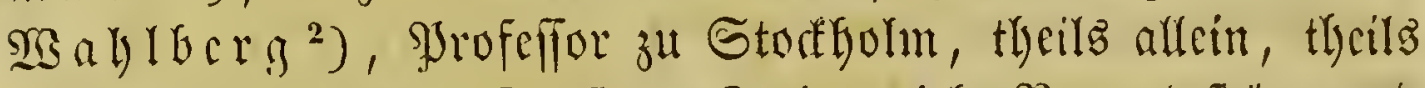

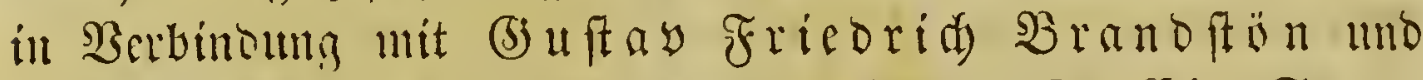

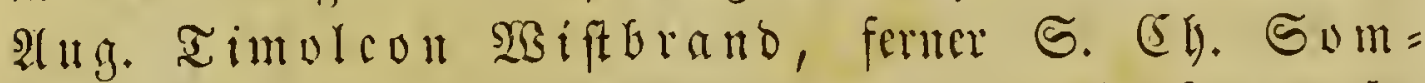

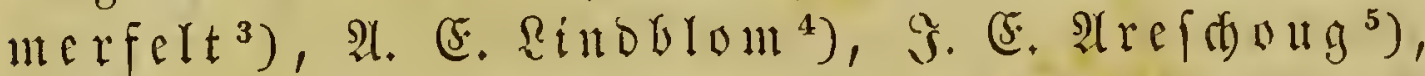

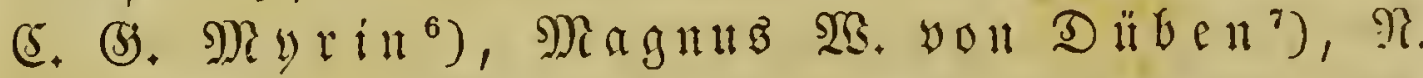

waldiae 1821-1829. IIl voll. 8, - Supplem. vol. I. ibid. 1830. 8. - Schedulae criticae de Lichenibus exsiccatis Sueciae. I-XIV. Londini 1824-1833. 4. - Blenchus fungorum etc. Gryphiae 1828. Il voll. 8. - Lichenographia europaea reformata. Lundae et Gryphiae 1831. 8. - Novitiae Florae suecicae. Lundae 1814-1823. \%. - El. II. Londini Gothorum 1828. 8. Fortgereft won $\mathfrak{N}$. R. BIytt. Suno u. Upfata 1832 - 1842. 8. - Flora hallandica etc. Pars prior. Lundae 1817 et 1818. 8. - Stirpium agri Femsoniensis index, observationibus illustrata. Lundae $1825-$ 1826. 8. - Flora scanica. Upsaliae 1835. S. - Botaniska Utflygter. Upsala 1843. 8. - Summa vegetabilium Scandinaviae etc. Holmiae et Lipsiae 1846. 8.

1) Handbok i Skandinaviens Flora etc. Stockholm 1820. 8. 2 tab. - 1832. 8. - 1838. Il voll. 8. 4 tab. - Svensí och Norsk Excursions Flora. Stockholm 1846. 12.

2 Flora gothoburgensis. Upsaliae 1820-1824. 8 .

3) Supplementum Florae lapponicae, quam edidit G. Wahl enberg. Christianiae 1826. 8.3 tab. col.

-) Stirpes agri Rotnoviensis. D. I - V. Lundae 1826- 1829. 8. - Bidrag till Blekings Flora. Stockholm 1831. 8.

5) Stirpes in regione Cimbritshamnensi sponte crescentes. D. I. Londini Gothor. 1831. 8. - Plantae cotyledoneae Florae Gothoburgensis etc. Londini Gothor. 1836. 8.

') Anmärkningar om Wermland's och Dalsland's regetation. Stockh. 1832. 8. (K. Wet. Ac. Handl. 1831. - 5 . 1 it $=$

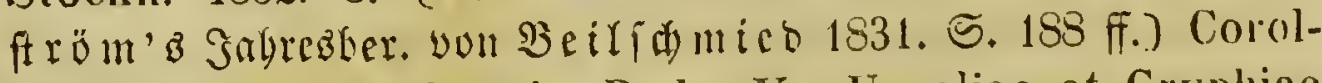
larium florae upsaliensis. P. 1-V. Upsaliae et Gryphiae 1833. 8. - Ilistoria rei herbariae in Suecia. P. I. Upsal. 4.

7) Conspectus vegetationis Scaniae D. Lund. 1837. 8. - 


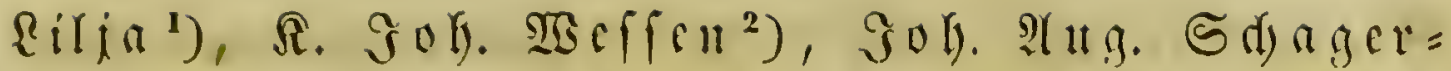

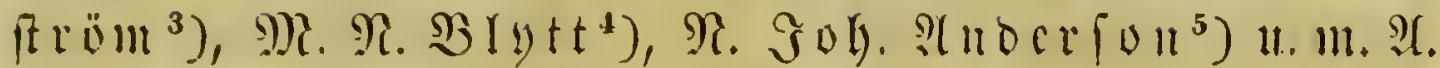

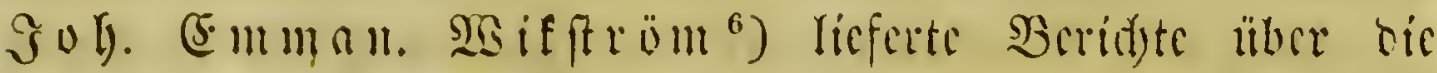

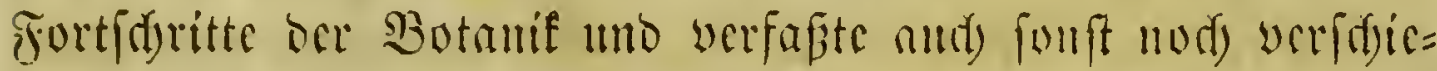

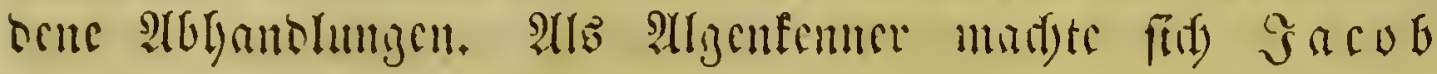

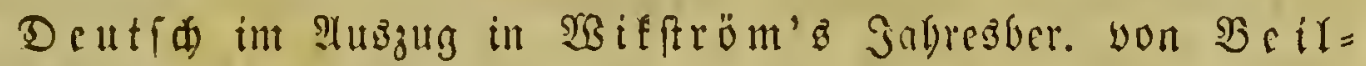
íd mieb, 1837. S. $321-326$.

1) Skănes Flora etc. Lund 1838. 8. - Flora öfver Sveriges odlade Vexter, innefattande de flesta pä frik Land odlade Vexter i Sverige, jemte de allmännare och vackrare fönster vexterna, med Kännetecken och Kort Anvisning om deras Odlingssätt. Stockholm 1839. 8. - Flora öfver Sveriges odlade Vexter. Första Supplementet. Stockholm 18ł0. S. - Handbok i de odlade Växternas Flora etc. Örebro 1842. 8.

2) Plantae cotyledoneae in paroecia Osthogothiae Kärna etc. Upsaliae (Lipsiae) 1838. 8.

$\left.{ }^{3}\right)$ Plantae cotyledoneae paroeciae Roslagiae Bro. D. Upsaliae 1839-1810. 8. - Conspectus vegetationis Uplandiae. D. Upsaliae 1845. 8. - Lärobok i Skandinaviens Växtfamiljes efter det Friesika systemet. Upsala 1846. 8.

4) Enumeratio plantarum vascularium, quae circa Christianiam sponte nascuntur. Christianiae 1844. 4.

3) Plantae vasculares circa Quickjock Lapponiae Lulensis quarum enumerationem proponit. D. Upsaliae. $1844-1845$. 8. - Salices Lapponiae cum figu:" XXVIII. specier. D. Upsaliae 1845. 8. 2 tab.

') Öfversigt af Botaniska Arbeten och Upptäckter', på Kongl. Vetenskaps-Akademiens befallning lemnad år 1821-1826 af Joh. Em. Wikström. Stockholm 1822-1826. 8. Ärs-Berättelse om Framstegen uti Botanik (om Botaniska Arbeten och Upptäckter) för åren 18:6 - 1842. Stockholm 1827 - 1844. 8. - Conspectus litteraturae botanicae in Suecia etc. Holmiae 1831. 8. - Öfversigt af Stockholmstractens naturbeskaffenhet. Stockholm 1839. 8. - Stockholms Flora. Stockholm 1840. 8. Appendix 1 mapp. geograph. 
(5) orga $\mathfrak{A g a r b}^{1}$ ), ber Soln bes vorfin crwähnten farl ADolpl, befount.

Unter ben Berrbeitern ber $\mathfrak{r}$ uffifden Flora ift $\mathfrak{R}$ arl

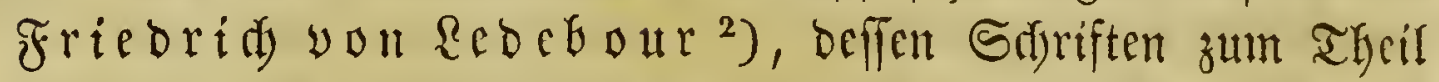
fdon S. 364 angefülert wurben, herworgulgeten. Ernft

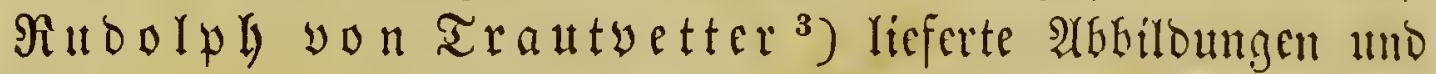

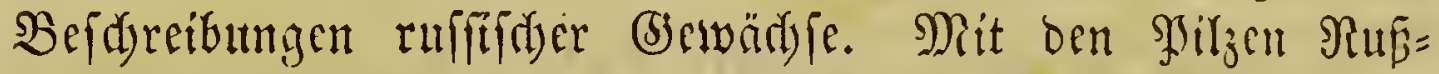

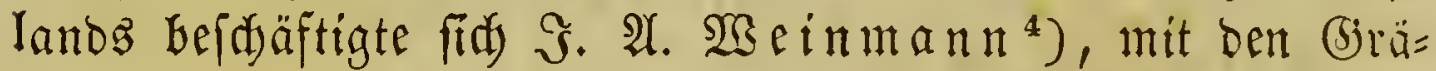

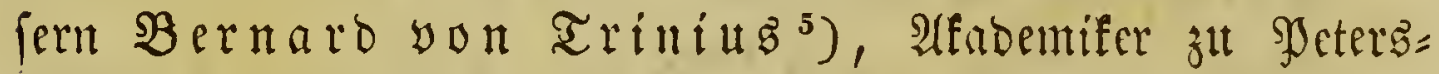

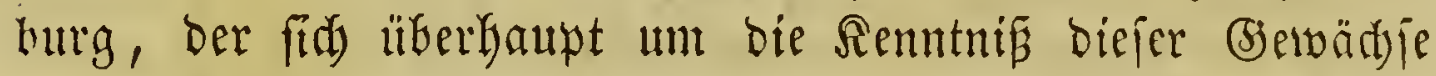

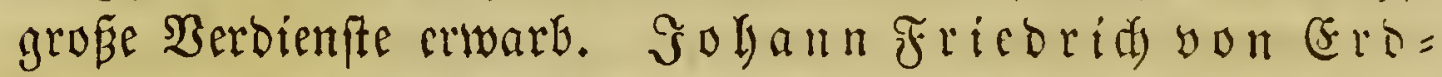
mann ${ }^{6}$ ) bereifte das Gnnere von Rufiland. Ahtd Ferbi= nand (E. R, yon Fifder und a arl Anton Meycr lieferten einige phytographifase Arbeiten. Csinige Radyridyten

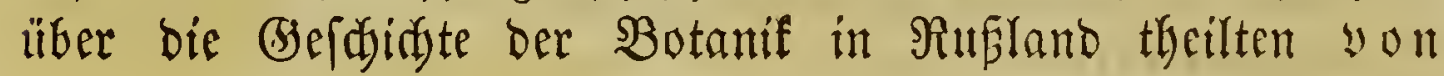

1) Novitiae Florae Sueciae ex Algarum familia. D. Lundae 1836. 8. - Algae maris mediterranei et adriatici etc. Paris 1842. 8. - In systema Algarum hodierna Adversaria. Lundae 1844. 8.

2) Icones plantarum novarum vel imperfectae cognitarum Floram rossicam, imprimis altaicam, illustrantes. Rigae 1829 - 1834. V voll. Fol. 500 tab. col. - Flora rossica etc. Stuttgartiae 1842-1852. III voll. 8.

3) Plantarum imagines et descriptiones Floram russicam illustrantes. Fasc. I - VIII. (Monachii) Stuttgartiae $1844-$ 1846. 4. 40 tab. col.

-) Hymeno- et Gasteromycetes hucusque in imperio rossico observatos recensuit. Pars prodromi Florae rossicae. Petropoli 1836. 8.

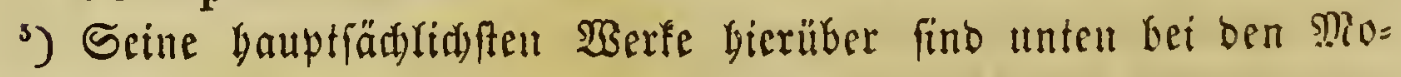
nograpgicen angefitibrt.

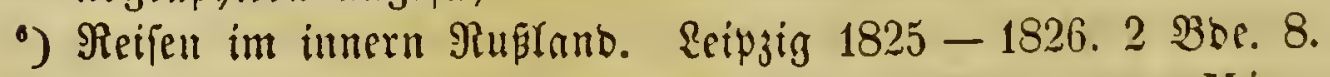

') Mém. de la soc. des naturalistes de Moscou. - Mém. de l'acad. imp. des sc. de St. Pétersb. F. E. L. a F is cher, Zygophyllaceae. Pars prodromi florae rossicae. Petropoli 1833. 8. 


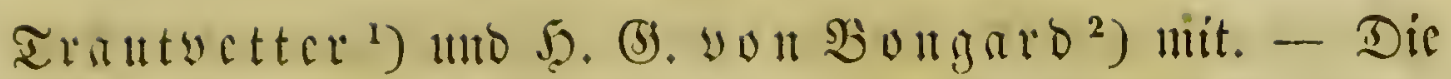

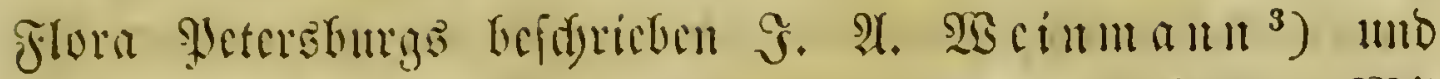

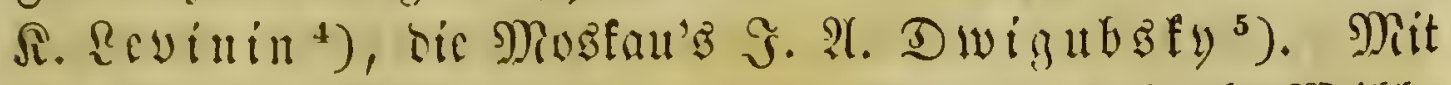

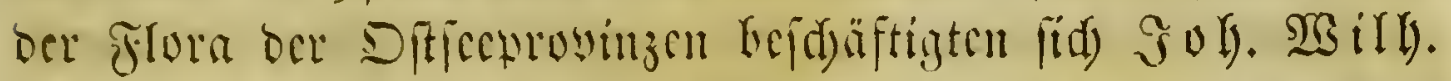

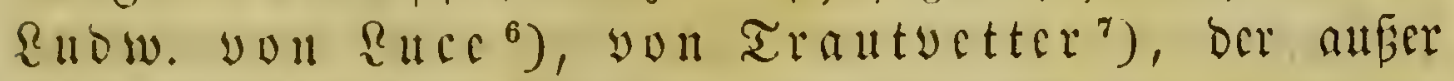

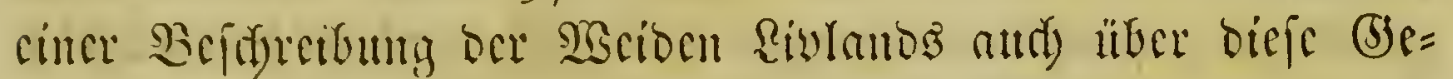

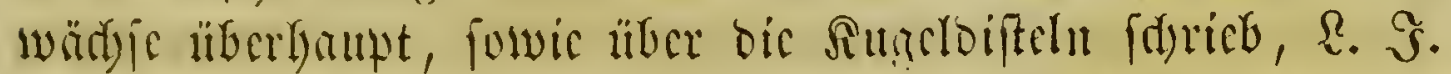

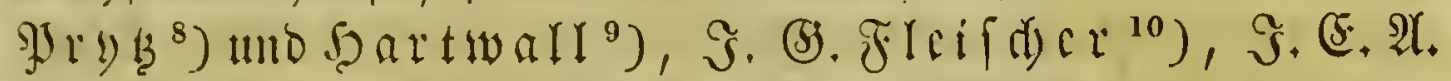

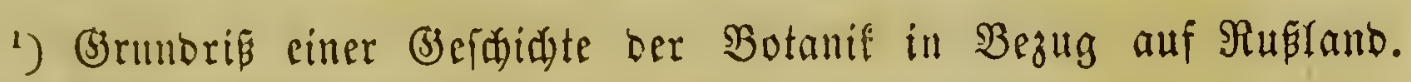
St. Tretersburg 1837. 8.

$\Rightarrow$ Exquisse historique des traxaux sur la botanique entrepris en Russie, depuis Pierre le Graild jusqu'à nos jours et de la part que l'Académie a lue aux progrès de cette science. 4. - (Recueil des Actes. 1834).

3) Elenchus plantarum horti imperialis Pawlowskiensis et agri Petropolitani. Petropoli 1824. 8. - Enumeratio stirpium in agro Petropolitano sponte crescentium etc. Petropoli 1837.8.

4) Icones Florae Petropolitanae. Petropoli 1836.

5) Methodus facicilis recognoscendi plantarum, quae sua sponte circa Mosquam enascuntur etc. Mosquae 1827. 8. - 1838. 8. - Flora Mosquensis etc. Mosquae 1828. 12. Icones plantar. medicinal. rossicarum etc. Mosquae 18281834. IV voll. 4.

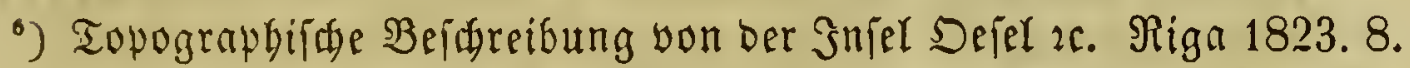

") De Salicibus livonicis. (Mém. de la soc. des nat. de Mosc. VIII p. 361 - 384). - De Salicibus frigidis Kochii (ibid. p. $279-318$, t. $4-27$.) - Salicetum s. Salicum formae, quae hodie innotuere. Fasc. I. 4 tab. - De Echinope genere capita II. Mitaviae 1833. 4. 1 tab.

8) Florae fennicae breviarium etc. D. I-VI. Åboe 1819 1821. 4.

$\left.{ }^{9}\right)$ L. J. Prytz et Hartwall, Florae fennicae breviarium. Ano 1821.8.

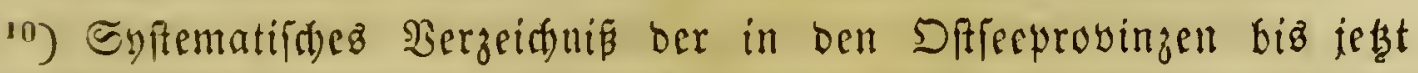
befannt gelwordenen Syanerogamen 2c. Mitau 1830. 4. - Flora

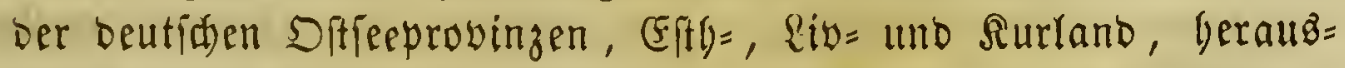
gegeben yon Esuaro Rindemann. Mitau u. Reipzig 1839. 8. (E. DBindler,; Beffit. D. Botanit. 36 
Mirzén ${ }^{1}$ ) und F. Rylanoer ${ }^{2}$ ). Die Spflanzen ber Sho= vinzen Bolbynien, Sodolien uno ber Ufraine verzeidnete $\mathfrak{S}$. S. S. SEe $\left\{\mathfrak{e r}^{3}\right.$ ); aud (5)

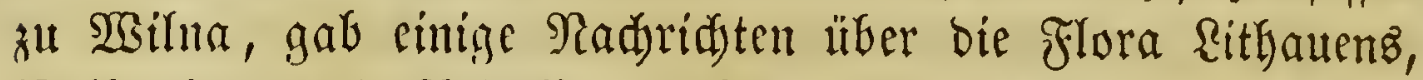

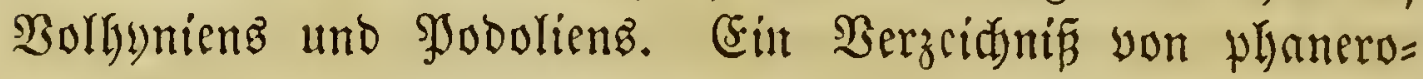
gamífden (Selwäd) fen Rapplands licferte $\Im a c o b ~ F e l l m a n n^{5}$ ).

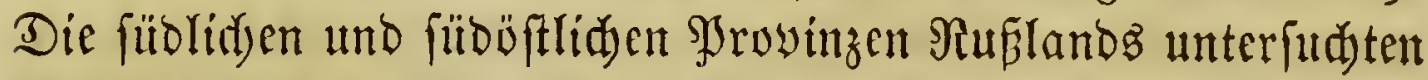
Friebrid Sarrot ${ }^{6}$ ), Jrofeffor zu Dorpat, (E. (5id)=

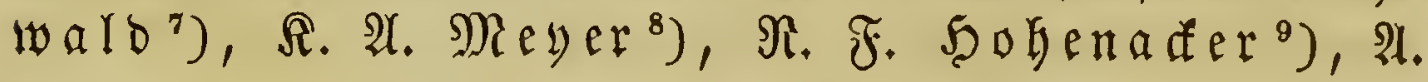

1) Prodromus Florae fennicae. D. I - II. Helsingforsiae 1843. 8.

2) Spicilegium plantarum fennicarum. D. Centuria I et II. Helsingforsiae $1843-1844.8$.

3) Enumeratio plantarum hucusque in Volhynia, Podolia, gub. Kiioviensi, Bessarabia, Cis-tyraica et circa Odessam collectarum, simul cum observationibus in Primitias Florae Galiciae austriacae. Vilnae 1821. 8. - 1822. 8.

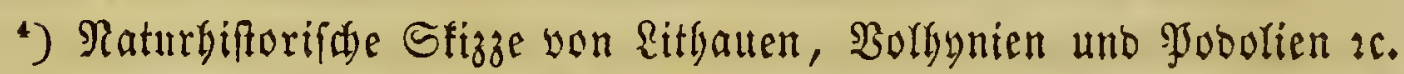
23itna 1830. 4. 3 Iaf.

$\left.{ }^{3}\right)$ Index plantarum phanerogamarum in territorio liolaënsi lectarum. (Bullet. de la soc. des nat. de Mosc. III. p. $299-328)$.

o) Fr. Sgarrot (unb Mor. v. (Engelgarbt), Reife in bie Rrym

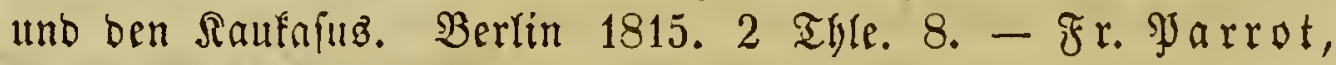
Reife zum \{trarat. Berlin 1834. 2 Thle. 8. 7 Taf.

?) Plantarum novarum v. minus cognitarum, quas in itinere caspiocaucasico observavit, fasc. I et II. Vilnae et Lipsiae 1831 - 1833. Fol. 40 tab.

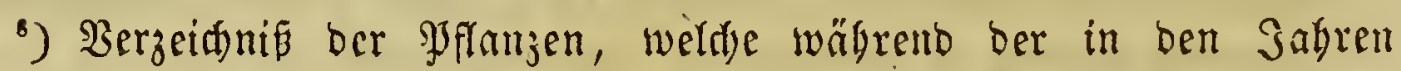
1829 und 1830 unternommenen Reife im Saufaftus unb in ben

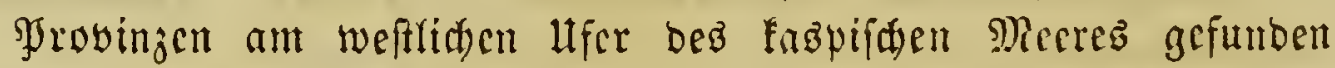
uno eingefammelt worben fino 2c. Setersburg 1831. 4.

-) Enumeratio plantarum e territorio elisabethpolensi et in provincia Karabach sponte nascentium. (Bullet. de la soc. des Natur. de Mosc. Tom. VI.) 1833. - Enumeratio plantarum quas in itinere per provinciam Talysch collegit. (1838. p. 239). 


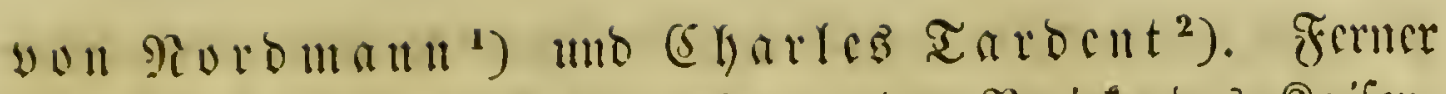

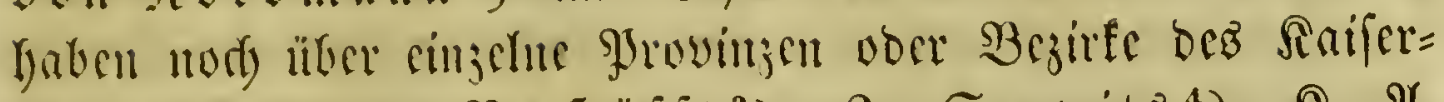

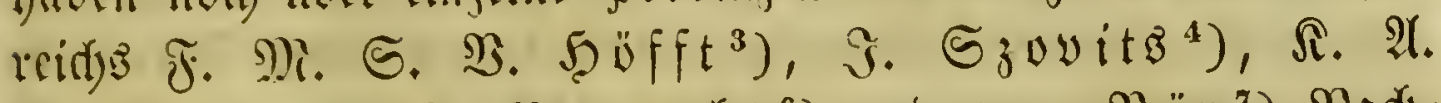

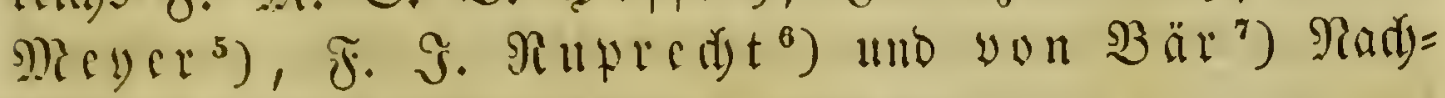
rididet igegeten.

Meflere Ränber $\mathfrak{A}$ ficus wurben in bicfom Bcitraume

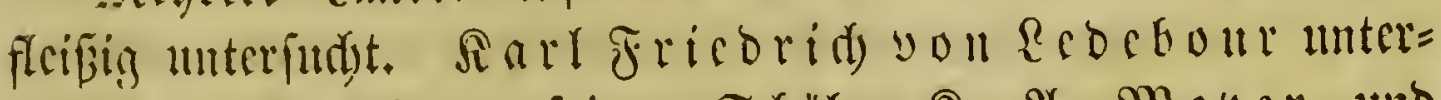

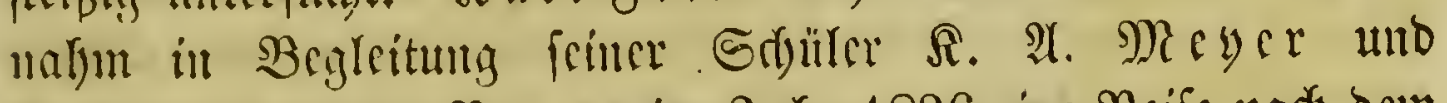

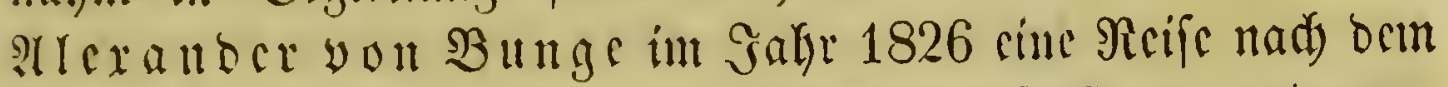
Sltai = (3)chirge und ber foongarifden Rirgifenfteppe unt ver= siffentlidyte medyrere Sdyriften $\ddot{b}$ ber bie bort gemadyten (5nt=

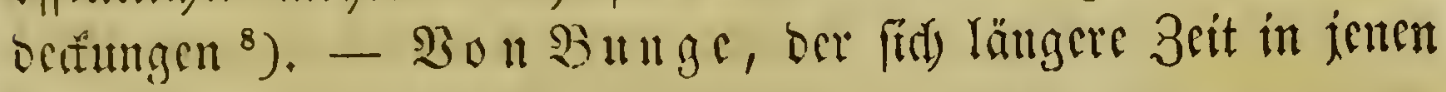

1) Borläufige Diagnden einiger, wälyeend since naturwiffenfdaft=

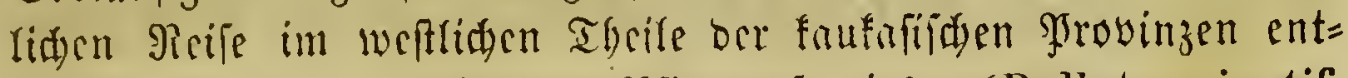
Defitcn uno alz ucu erfannten grflanzenipecies. (Bullet. scientif. de l'acad. des sc. de Pétersb. Tom. II. No. 20).

2) Essai sur l'histoire naturelle de la Bessarabie. Lausanne 1841. 8.

3) Catalogue des plantes, qui croissent spontanément dans le district de Dmitrieff sur la Svapa dans le gouvernement de Koursk. Moscou 1826. 8.

') J. Szovits et A. Fr. Lang, Herbarium Florae ruthenicae etc. Cent. I. (Bot. 3eit. 1827. Beil. S. 33-94).

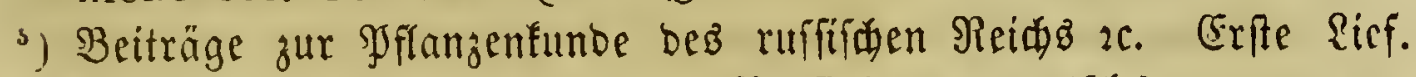

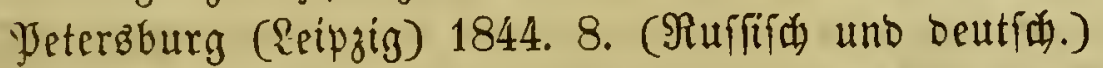

$\left.{ }^{6}\right)$ Flores Samojedorum cisuralensium. Petropoli (Lipsiae) 1845. 8. 6 tab.

7) Bulletin scientif. de l'acad. de Pétersb. Tom. II. No. 11. p. 172-173. - Premier rapport de Mr. de Bär sur l'expédition à Novaja Zémlia et en Laponic. (No. 20. p. $315-319$.)

8) Reife burd) baz Altai=(jestirge und bie foongarifate Rirgifen. feppe. Bertin 1829-1830.2 Tlle. 8. 2tttab. Fol. 12 Iaf. Flora altaica etc. Berolini $1829-1834$. IV voll. 8. Icones plantarum novam vel imperfecte cognitarum Floram rossicam, imprimis altaicam, illustrantes. Rigae 1829 1834. V voll. Fol. 500 tab. col. 
Sändern aufbiclt, uno aud nock veridsiebene andere (biegenden

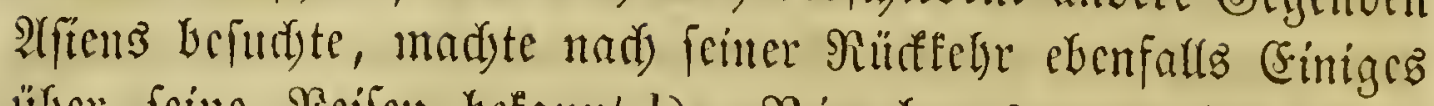
แ̈bcr frite Reifa befannt ${ }^{1}$ ). Nicolaus yon Turcza= ninow unterfutyte in ben Gafhern 1828 - 1835 bie (jiegen= ben un ben Baffalfee unt Davurien uno gab eine Flora

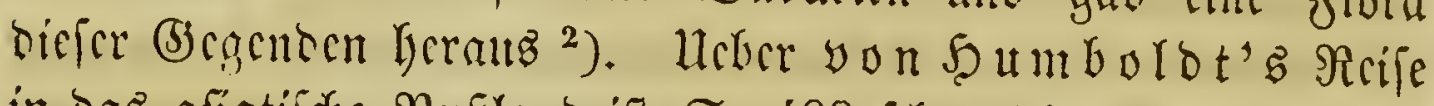

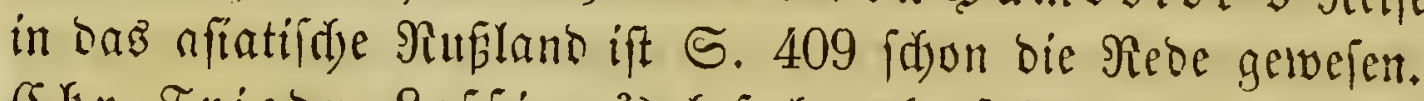

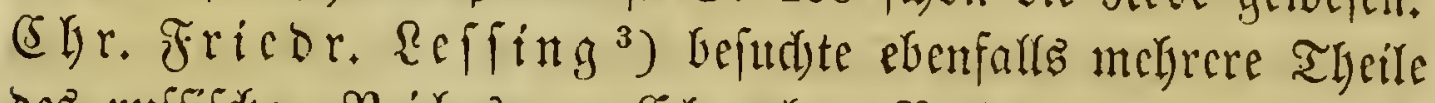

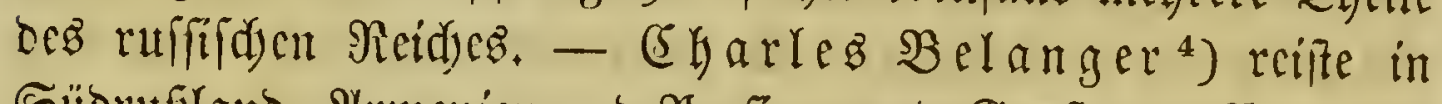
Silorufiano, Armenien uno Serften, uno (5) uftave (5oque=

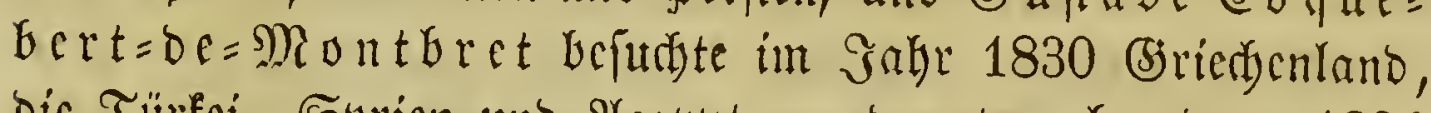
bic Titrfei, Syricn mo Alegypten uno unternahy bann 1834

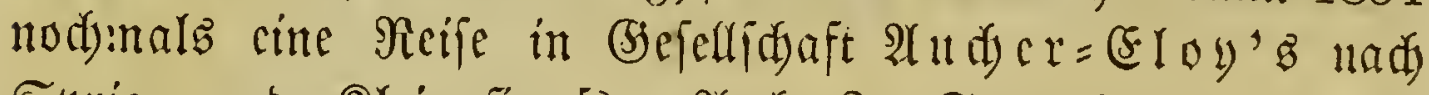

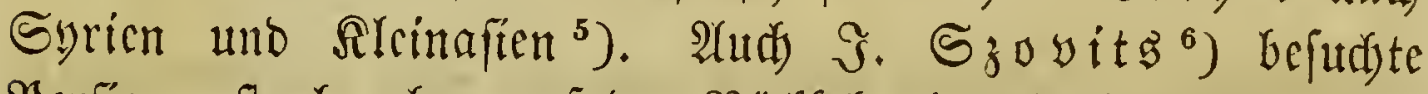

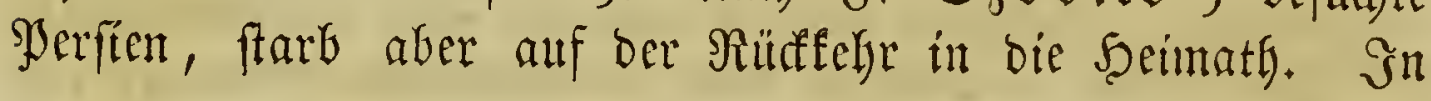

1) Enumeratio plantarum, quas in China boreali collegit. (Petropoli 1831.) 4. - Plantarum mongholico-chinensium Decas I. Casani 1835. 8. 3 tab. - $\mathfrak{B}$ erzeidjui ber im Safre

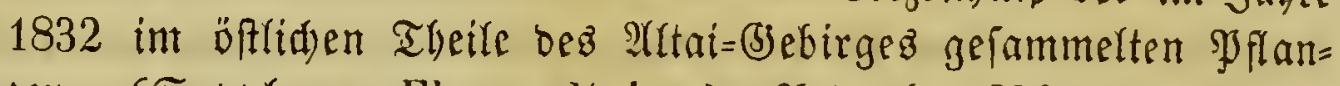
zen. (Suppl. zur Flora altaica.) Эeterz̧. 1836. gr. 8.

$\left.{ }^{2}\right)$ Catalogus plantarum in regionibus baikaleusibus et in Dahurica sponte crescentium. (Bullet. de la soc. des Nat. de Mosc. 1838.) - Flora baikalensi-dahurica etc. - Pars I. Mosquae 1842 - 1845. gr. 8.

8) Beitrag zur Frora bez fïbliden Utratz und ber Steppen. (Linnaea 30. 9: 1834. S. $145-213$ ).

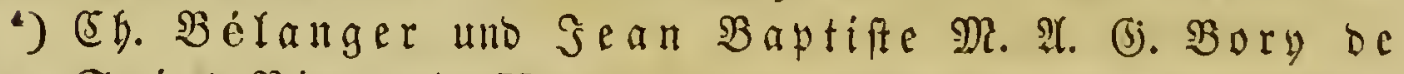
Saint= Bincent, Voyage aux Indes orientales pendant les années 1825-1829. Paris s. a. (Botanique. Phanérogamie 15 tab. 4.)

5) G. B ent h a m, Plantae orientales herbarii Montbretian i, s. Labiatarum species novae v. minus cognitae quas in Syria et Asia minore collegerunt G. Coquebert-deMontbret et Aucher-Eloy. (Annal. des sc. nat. Juill. 1836).

-) Herbarium florae ruthenicae, sistens plantarum rariorum in gobernio chersonesi sponte obviarum Centur. I. (Siege 


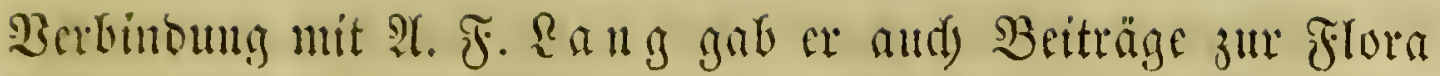

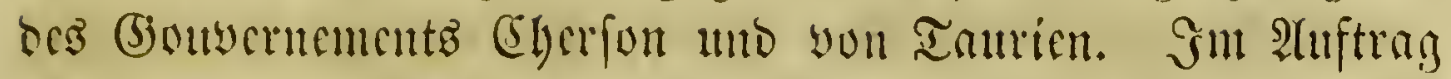

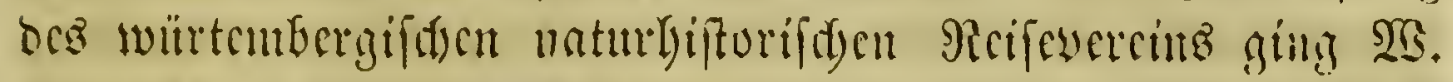
Sd) imfer ma Manubeim und) $2(e g y p t e n$ umb wou ba in ons peträifde strabien, wo er instefondere bie (5)ewäd) bes Barigez Sinai unterfudyte, brang banu bis in bas burbland

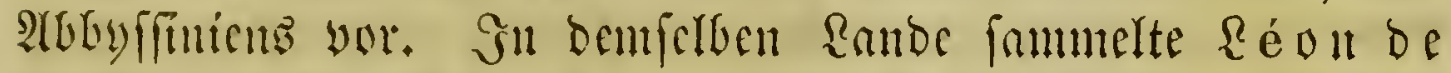
Raboroc. ${ }^{1}$ )

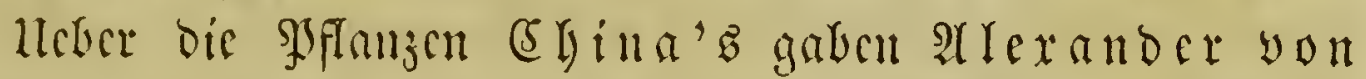

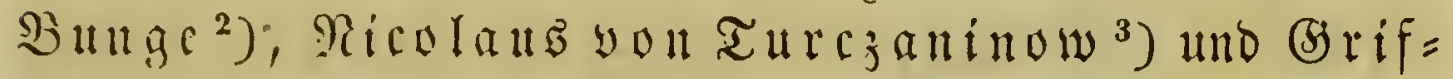
fith $\left.{ }^{4}\right)$ Padridjt.

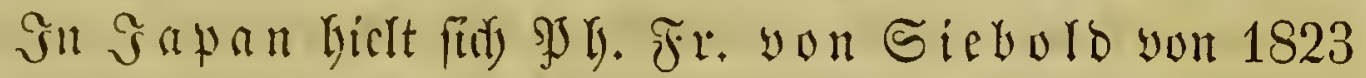

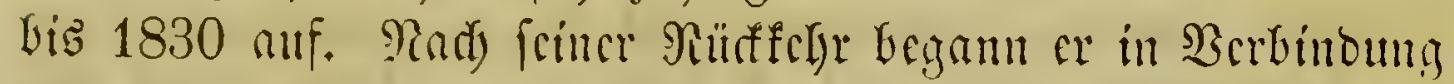
mit Э. (5). Zuccarint uno viclen anderen Botanifern cin

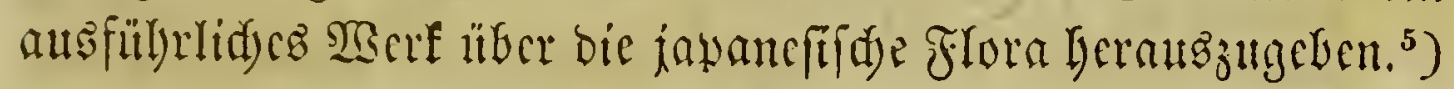

auch: L ang, Illustratio plantar. herbarii florae ruthenicae. Bot. 3cit. 1827. Beir. S. $33-9$ r.)

') Fragments d'une flore re l'Arabie pétrée. Plantes recueillies par Lé on de Laborde, nommées, classées et décrites par Delile. Paris 1830. gr. 4.

2) De relatione methodi plantarum naturalis in vires vegetabilium medicinales. Dorpati 1825. 8. - Enumeratio plantarum, quas in China boreali collegit. (Petropoli 1831.) 4.

${ }^{3}$ ) Decades tres plantarun novarum Chinae borealis et Mongoliae chinensis incolarum. (Bullet. de la soc. des Natur. de Mosc. Tom. V.) - Enumeratio plantar., quas in China boreali legit et mihi communicavit cl. medicus missionis rossicae Porphyrius Kirilow. (1837.)

4) Some account of the botanical collection, brought from the Eastward by Dr. Cantor. s. I. et a. 4.

$\left.{ }^{5}\right)$ De historiae naturalis in Japonia statu, necnon de augmento emolumentisque in decursu perscrutationum expectandis Dissertatio, cui accedunt spicilegia Faunae japonicae. Bataviae 1824. 8. - Tabulae synopticae usus plantarum. Dezima 1827. Fol. - Synopsis plantarum oeconomicarum universi regni japonici. (Dezima 1827.) 8. - Flora japonica etc. Lugduni Batav. 1835 - 1844. Fol. 127 tab. col. 
Befonders flcifing wurbe dic Flora ber beiden Sald

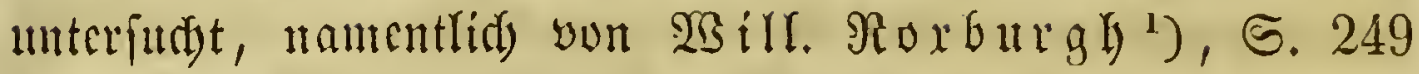

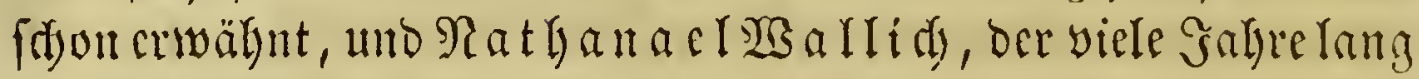

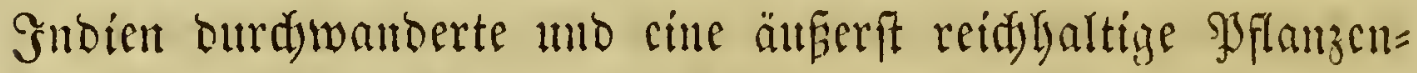

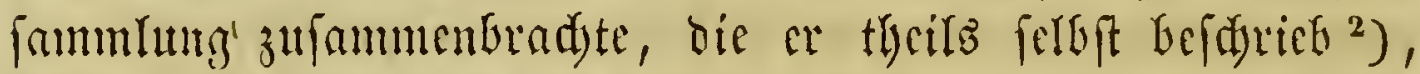

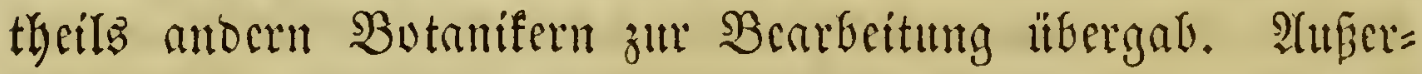
bem find nod) zat erwähnen 5 . Thom. (Solebrode ${ }^{3}$ ),

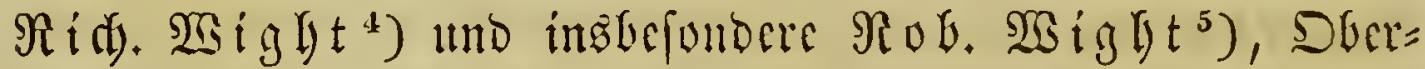

1) Hortus Bengalensis etc. Serampore 1814. 4. - A catalogue of plants described by Dr. Roxburgh in his mss. Flora indica, but not yet introduced into the botanical garden. Serampore 1813. 4. - Flora indica etc. Serampore 1820-1824. II voll. 8. - Flora indica etc. Serampore 1832. III voll. gr. 8. - The cryptogamous plants of Dr. Roxburgh, forming the fourth and last part of the Flora indica s. l. et a. 8.

$\Rightarrow$ Descriptions of some rare Indian plants. (Calcutta 1818). 4. (14) tab. - List of Indians wnods collected. London s. a. 8. - Tentamen Fiorae Napalensis illustratae etc. Calcutta and Serampore 1824-1826. Fol. 50 tab. - A numerical List of dried specimens of plants in the East India Companys Museum, collected under the superintendence of Dr. Wallich, of the Companys Botanic garden at Calcutta. London 1828. Fol. - Plantae asiaticae rariores ete. London 1830-1832. III voll. Fol. 300 tab.

$\left.{ }^{3}\right)$ Asiatic researches. Vol. IX, XII. - Transact. of the Linn. soc. of Lond. Vol. XII, XIII, XV.

t) Illustrations of Indian botany, being Supplement I. to the Bot. Miscell. London 1831. 4.

$\left.{ }^{5}\right)$ Illustrations of Indian botany etc. Glasgow 1831. 4. 32 tab. col. - Catalogue of plants of East India s. 1. 1833. 8. Prodromus Florae Peninsulae Indiae orientalis etc. Vol. I. London 1834. 8. - Contributions to the Botany of India. London 1834. 8. - Illustrations of Indian Botany etc. Madras 1838-1841. XIII parts. 4. 141 tab. col. - Icones plantarum Indiae orientalis etc. Mladras $1838-1847$. III voll. 4. 1162 tab. - Spicilegium Neilgherrense etc. Madras 1846-1847. II part. 4. 


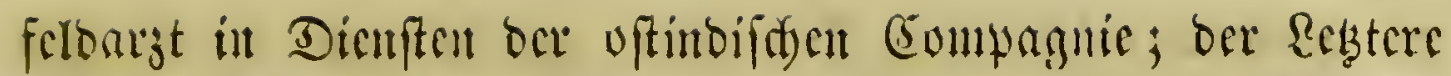

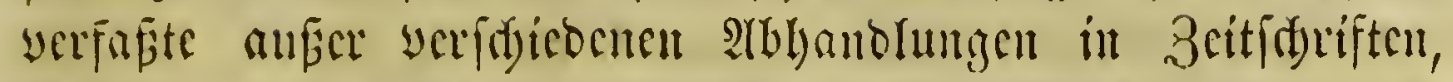

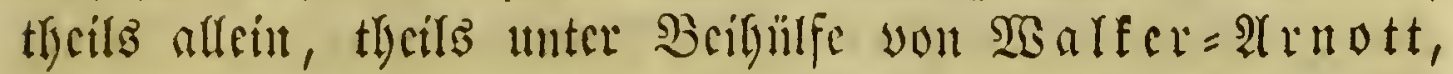

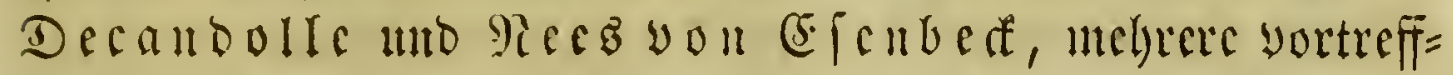

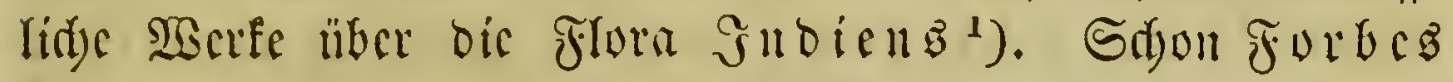

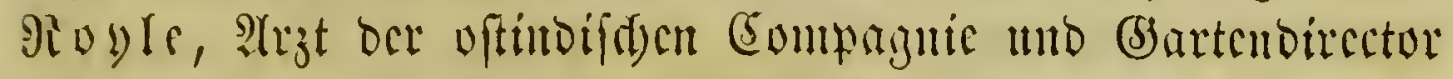

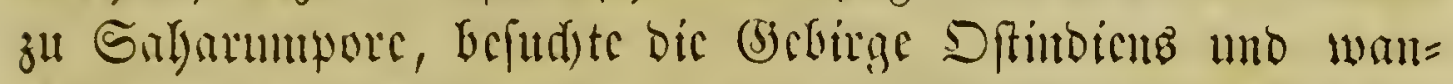

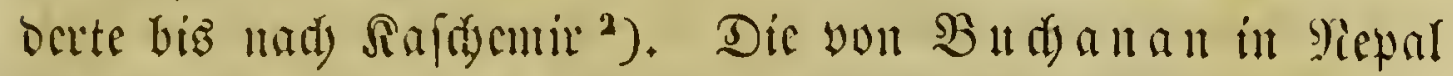

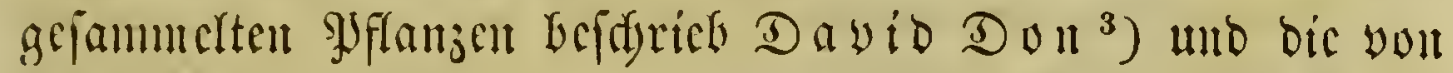

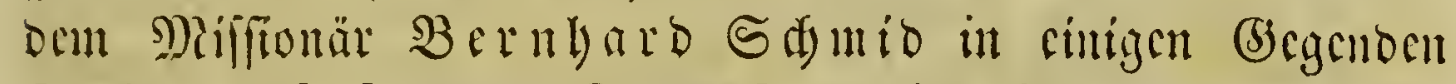

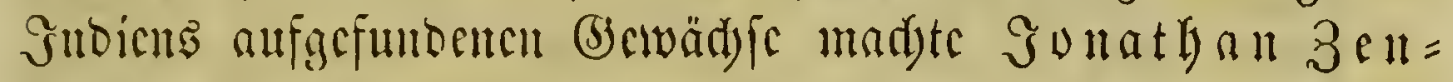
$\left.\mathfrak{f} \mathfrak{r}^{4}\right)$, Srofefior zu Jena, befamit.

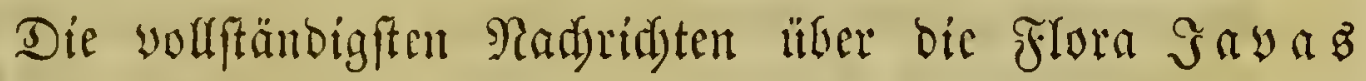

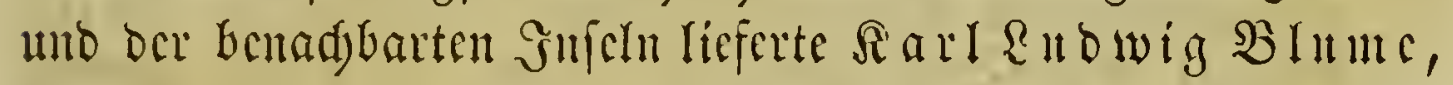
Shrofeffor zu Reiocu, ber fid) nem Jahre lautg bort aufgebal=

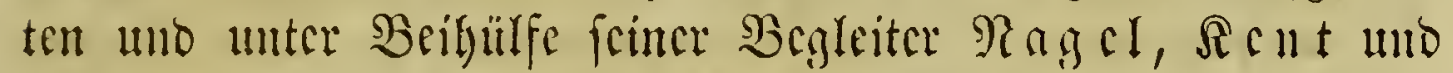

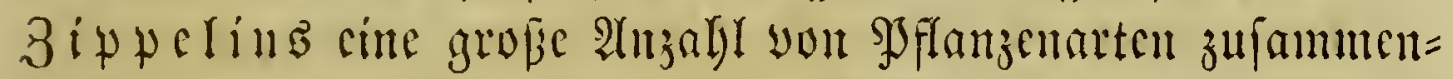

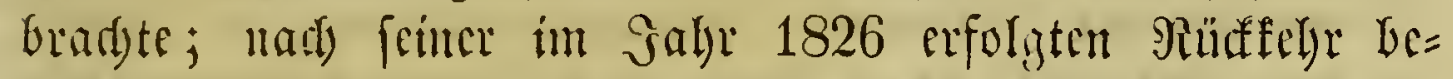

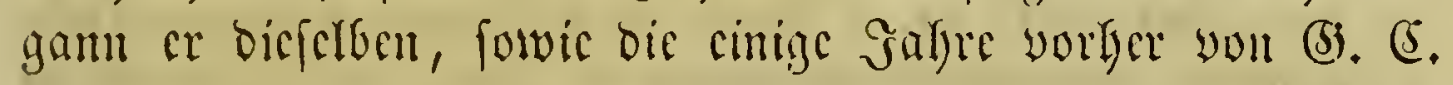

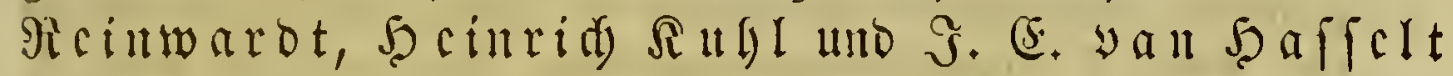

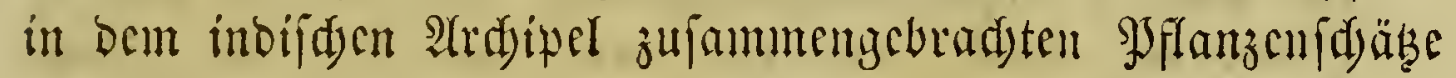

1) S. 566. Rote 5.

2) An essay on the antiquity of Hindoo medicine, inclading an introductory lecture to the course of Materia medica and Therapeutics, delivered at Kings College. London 1837. 8. - Illustrations of the botany and other branches of the natural history of the limalayan mountains and of the Flora of Cashmere. London 1839. II voll. Fol. 100 tab. col. - Essay on the productive resources of India. London 1840. 8.

$\left.{ }^{3}\right)$ Prodromus florae nepalensis etc. Londini 1825. 8.

') Plantae indicae, quas in montibus Coimbaturicis coeruleis, Nilagiri s. Neilgherries dictis, collegit rev. B. Schmid. Dec. I et Il. Jenae et Parisiis 1835. Fol. 20 tab. 


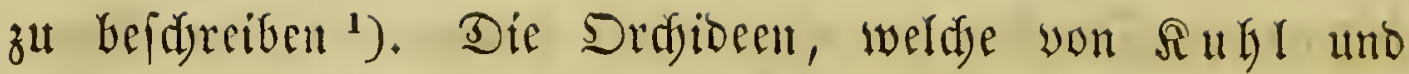
van $\mathfrak{5}$ affelt auf Gava gefrmmelt worben waren, bearbci=

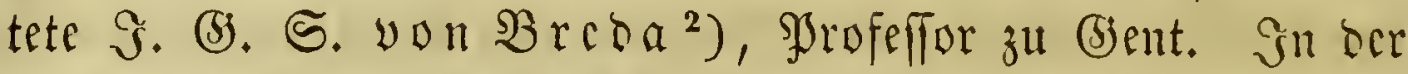

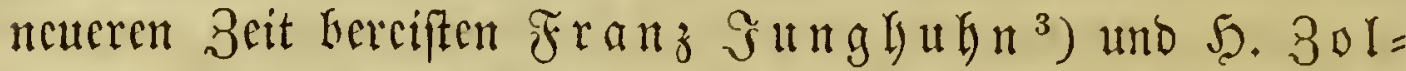
linger ${ }^{4}$ ) bie Gnicl Gava. Mit ber Flora Sumatra's

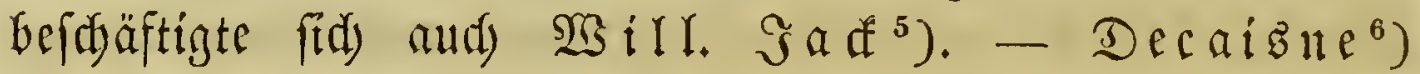

1) Catalogus van eenige der merkwaardigste zoo in- als uitheemsche gewassen, te vinden in's lands plantentuin te Buitenzorg. Bataviae 1823. 8. - Kruitkundige Waarnemingen. Bydragen tot de Flora van Nederlandech Indie. Batav. 1825. 17 Sefte. 8. Mit Abbito. - Florae Javae etc. Bruxellis 1828-1829. XX Fasc. Fol. Mit ‘itf. Tafeln. Enumeratio plantar. Javae et insularum adjacentium minus cognitarum vel novarum ex herbaris Reinwardtii, Kuhlii, Has seltii et Blumii. Fasc. I et ll. edit. novae. Hagae 1830. 8. - Rumplia, sive commentationes botanicae imprimis de plantis Indiae orientalis etc. Lugd. Batav. 1835 - 1838. 15 Riefer. Fol. Nit vielen Hbbiloungen. - Die yon ifm und $\Re$ einwarot gefanmelten Sryptogamen befarieb zum Theil (5)r. Fr. R. Rec you Efenbed: Enumeratio plantar. cryptogamicar. Javae et insularum adjacentium etc. Fasc. I. Hepaticas complectens. Vratislaviae 1830. 8. (Nov, act, acad. caes, nat. cur. tom. XI. (1823). tom. XIII. (1826.)

2) Genera et species Orchidearum et Asclepiadearum, quas in itinere per insulam Java collegerunt $\mathbf{H}$. K u h l et J. C. va I H a s s elt. Vol. I. Fasc. I - III. Gaudavi 1827. Fol. 15 tab. col.

$\left.{ }^{3}\right)$ Praemissa in Floram cryptogamicam Javae insulae. Fasc. I. Batav. 1838. 8. 15 tab. col. - Nova genera et species plantar. Florae javanicae. Leiden 1840. 8. 1 tab. - Iopo= graphifue uno naturwiffenfdaftriche Reifen burd Sava. Magoe= burg 1845. 8. 38 Taf. 2 Sirter. - Die Sattalältber auf Su= matra. Serlin 1847. 2 I Ilf. 8. 19 Iaf.

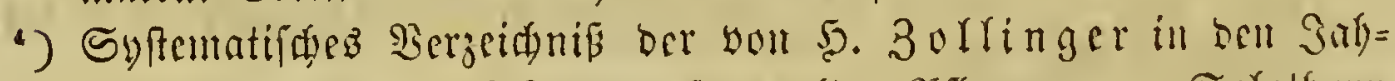
ren $1842-1844$ auf Sava gefanmelten grfanjen ze. Solotburn $1845-1846.8$.

${ }^{5}$ ) Description of Malayan plants. (Hooker, bot. miscell. Vol. I. p. 290. Vol. II. p. 60) 1828-1831.

') Nouv, ann. du mus. d'hist. nat. t. III. p. $333-501$. 


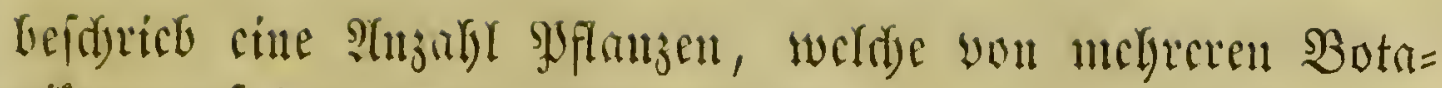

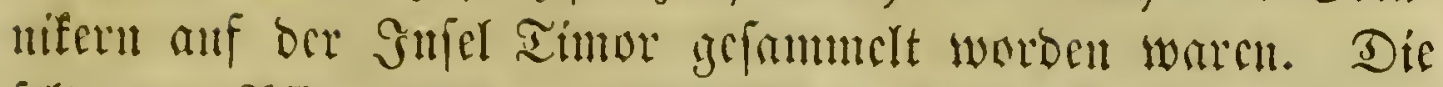

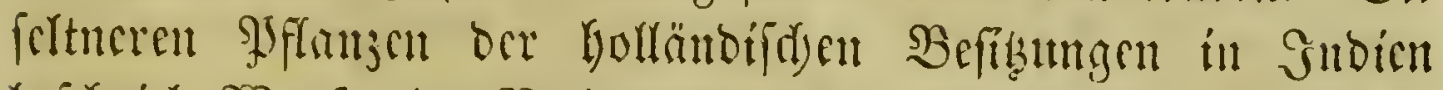

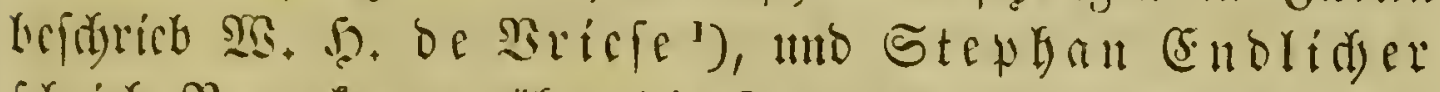
fdjreb Şemerfungen ilfer bie Flura ber Sübfceinfeln ${ }^{2}$ ). -

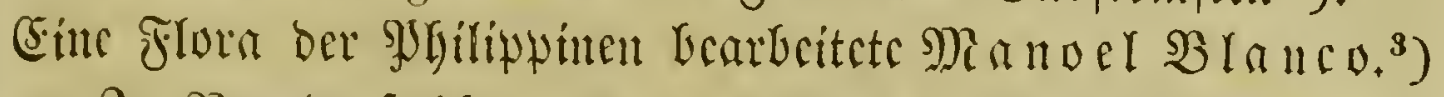

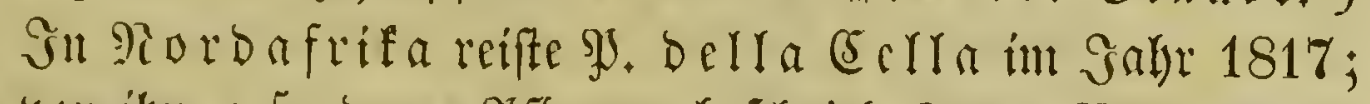

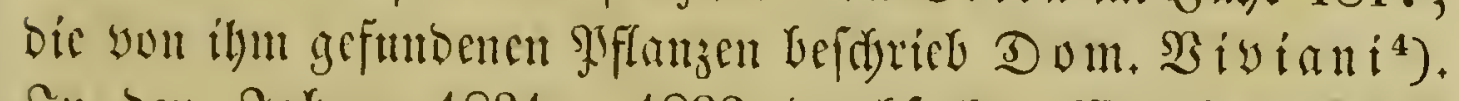

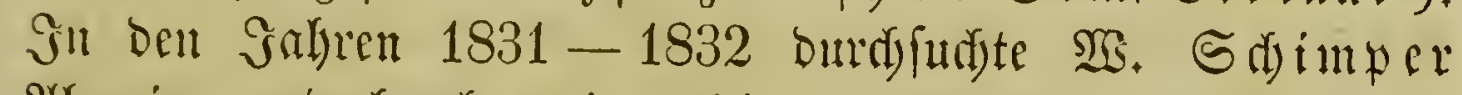

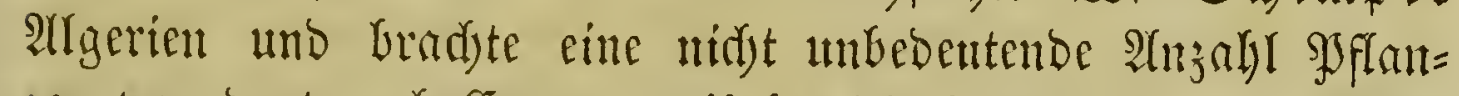

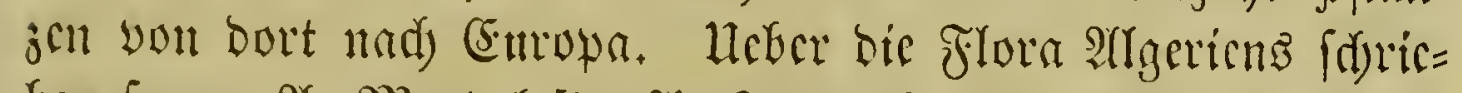

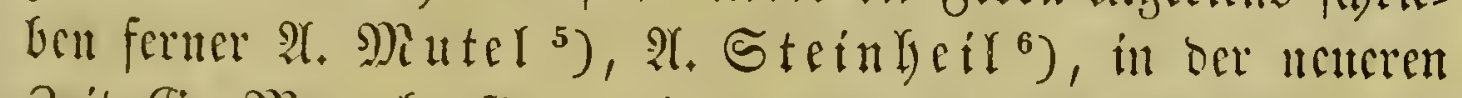

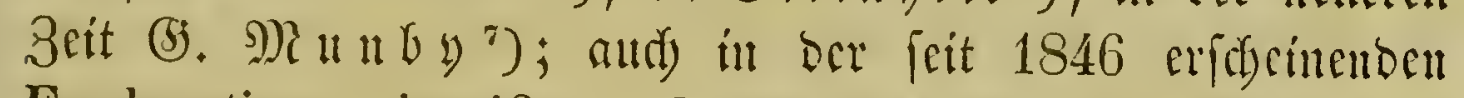
Exploration scientifique de l'Algérie. Paris 1846 sqq.

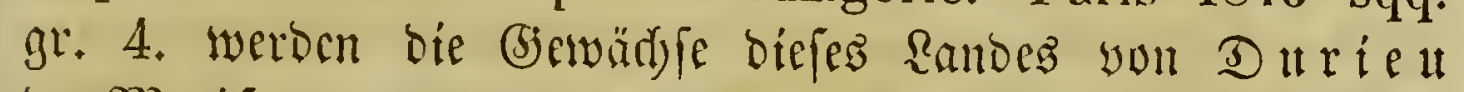

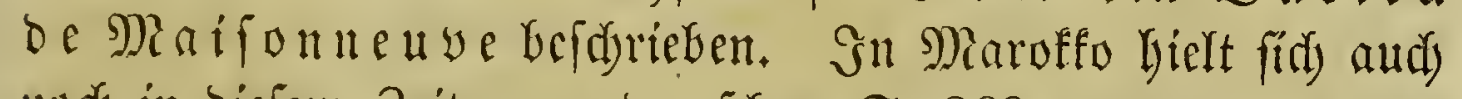

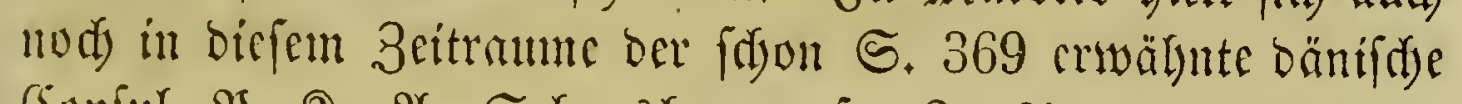

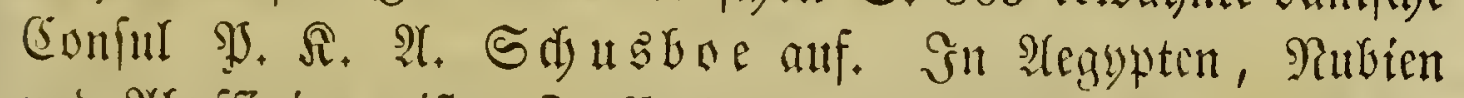

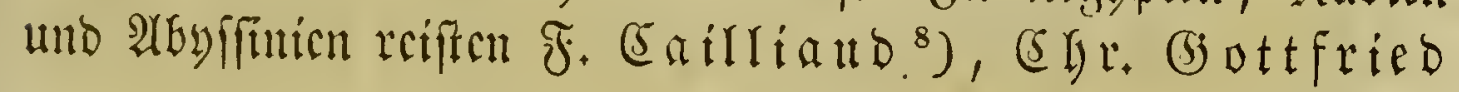

1) Plantae novae et minus cognitae Indiae batavae orientalis. Fasc. I. Amsterdam 1845. 4. max. 3 tab. col.

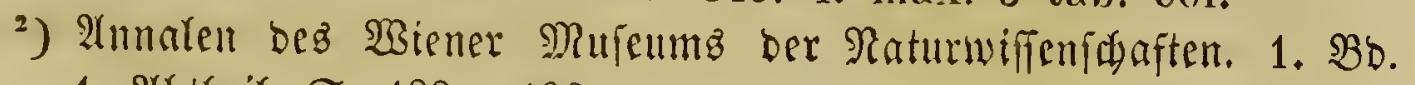
1. 2tbtgeit. S. $122-190$.

$\left.{ }^{3}\right)$ Flora de Filipinas. Manila 1837. 8.

$\left.{ }^{4}\right)$ Florae lybicae specimen etc. Genuae 1824. Fol. 27 tab. - Plartarum aegyptiarum Decades IV. Genuae 1830. 8. 3 tab.

$\left.{ }^{5}\right)$ Observations sur les espèces du genre Ophrys recueillies à Bone. (Mém. du mus. d'hist. nat. de Strasb. T. II. 1836. p. 1-6). - Flore fiançaise etc. Paris et Strasb.

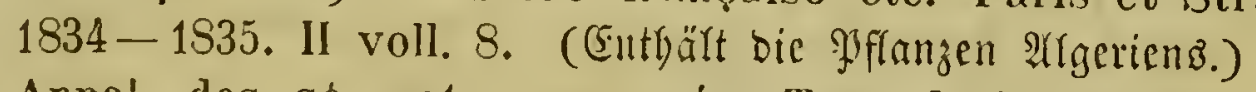

$\left.{ }^{6}\right)$ Annal. des sć. nat. nouv. sér. Tom. I. Bot. (1834.) p. $99-108$. p. $321-332$. p. $282-289$.

7) Flore de l'Algérie. Paris 1847. 8. 6 tab.

$\left.{ }^{8}\right)$ Centurie de plantes d'Afrique du voyage a Méroé, recueillies par Fr. Calliaud, décrites par R. Delile. Paris 1826. 8. 3 tab. 


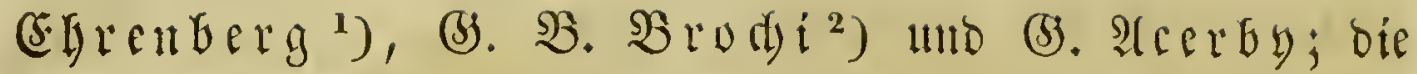

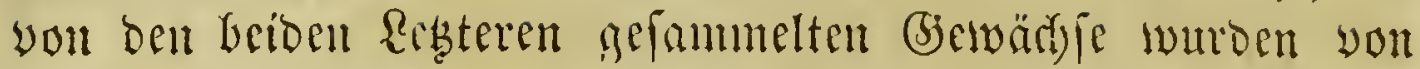
Robert De $\mathfrak{S}$ ifiani ${ }^{3}$ ) Gefdrieben. Der Franfurter Dr.

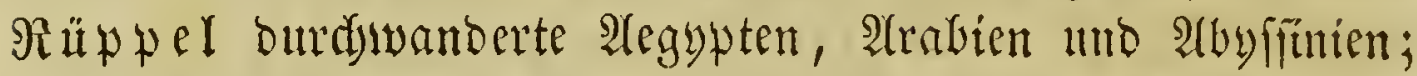

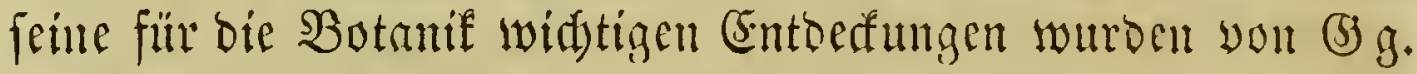

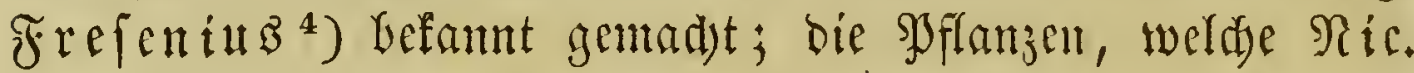

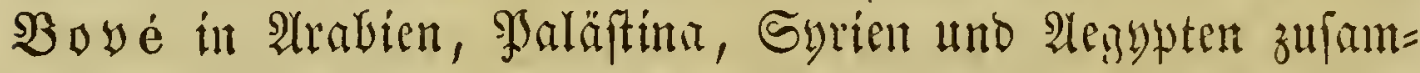
mengefradst hatte, wutron won Decrisne ${ }^{5}$ ) befarieben.

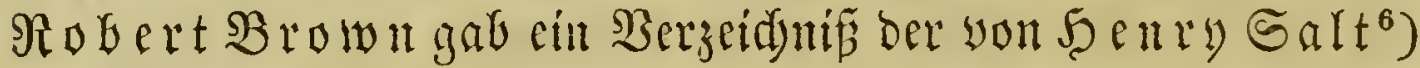

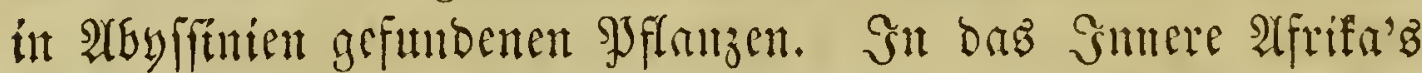

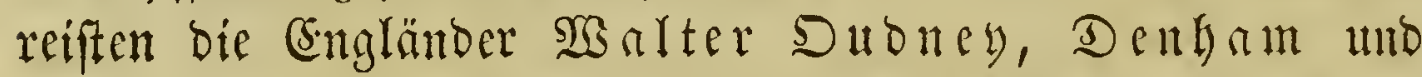
(SIapperton; über ben Srfolg biefer Reife in botanifider

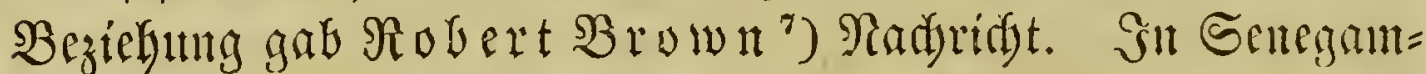
bien bielten fun Reprieur unb gserrotet ${ }^{8}$ ) in ben Gabren

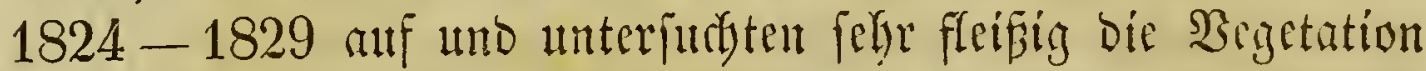

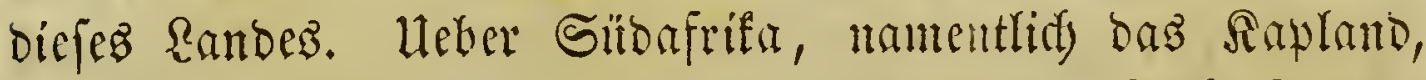

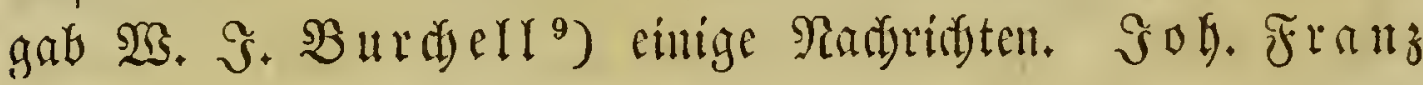

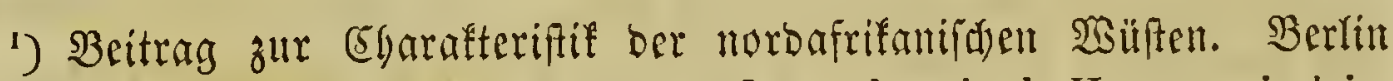
1827. 4. - De Myrrhae et Opocalpasi ab Hemprichio et $\mathrm{Ehr}$ enbergio in itinere per Arabiam et Habessiniam detectis plantis particulam primam offert. Berolini 1841. Fol.

2) Bibliotheca italiana. 1828.

s) Plantae quaedam Aegypti ac Nubiae enumeratae atque illustratae. Patavii 1836. 8. 8 tab.

4) Museum Senkenbergianum. 1833.

s) Ann. des sc. nat. nouv. sér. t. II. 1834. t. Ill. IV. 1835.

$\left.{ }^{6}\right)$ A voyage to Abyssinia etc. London 1814. 4. (Bot. 3eit. 1821. 1 B̧b. Beil. 5 . $61-64$.

i) Narrative of travels and discoveries in northern and central Africa in the years 182', 1823 and 1824. London 1826. 4. - Botanical appendix by Robert Brown. ( Brown, verm. Sdrr. Bo. 4. S. 1 - 74.)

$\left.{ }^{8}\right)$ Flore de Sénégambie etc. Paris 1831-1833. Vol. I.

-) Travels in the interior of southern Africa. London $1822-$ 1824. Il voll. 4. 20 tab. col. - The zoological and botanical index to Travels in the interior of southern Africa. London 1824. 4. 


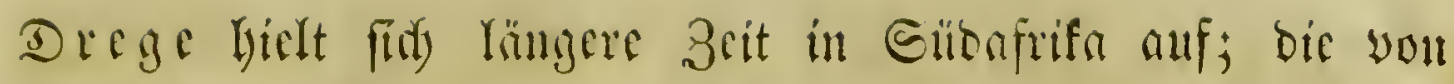
ifm gefammelten Syflangen bat zum Theil exnft 5 .

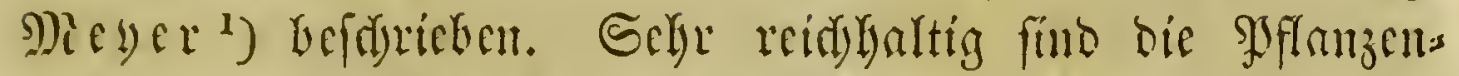

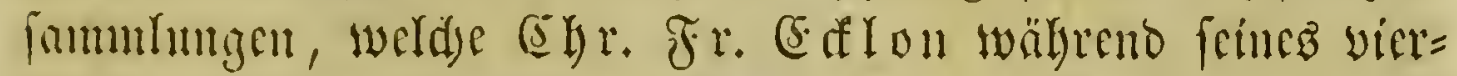

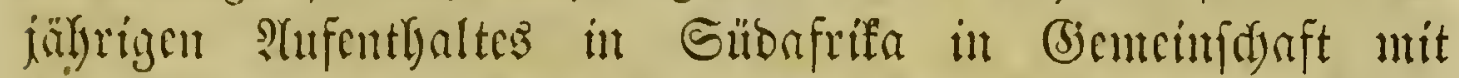

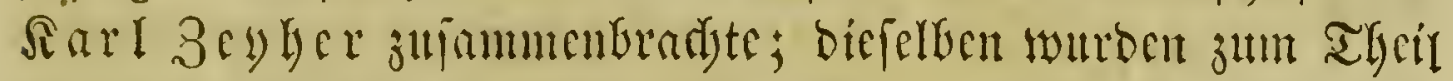

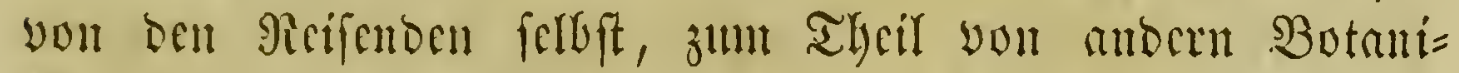

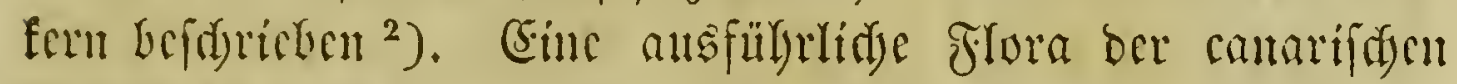

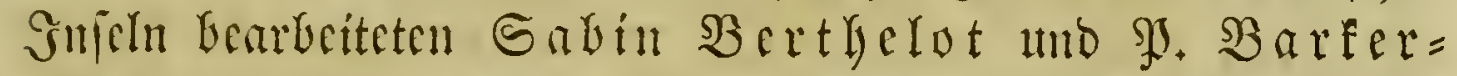

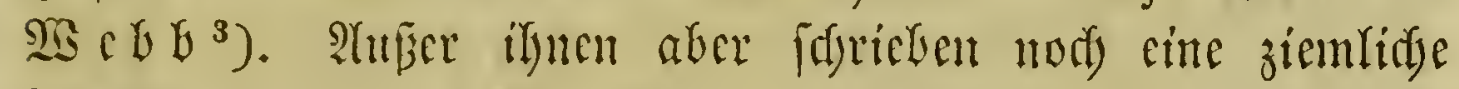

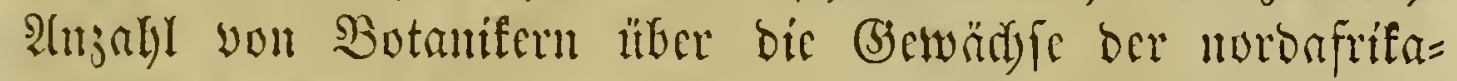

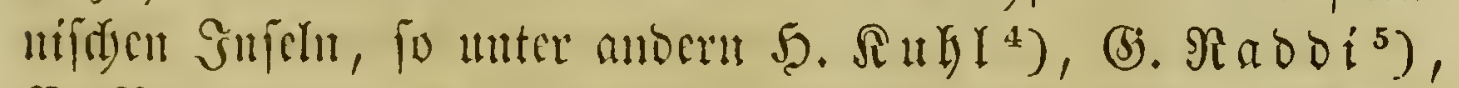

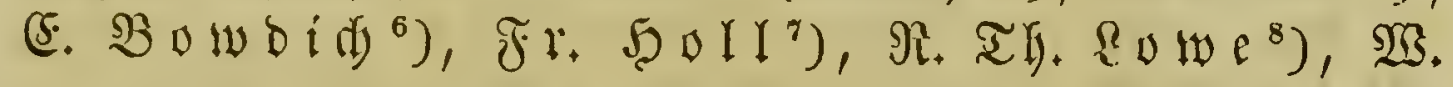

1) Commentariorum de plantis Africae australioris etc. Vol. I. Fasc. I et II. Lipsiae 1835-1837. 8.

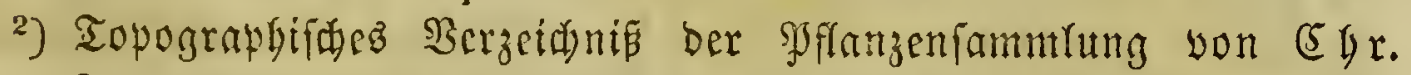

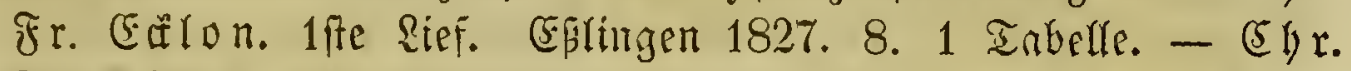

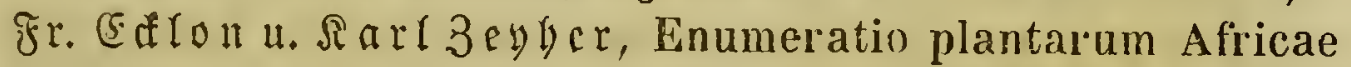
australis extra tropicae, quae collectae determinatae et expositae ab Ecklon et Z eyher. Pars I-III. Hamburgi 1834-1837. 8. - G. Kunze Acotyledonearum Africae anstralis extra tropicum sitae, inprimis promontorii bonae spei, recensio nova, e Dregei, Eckloni et Zeyheri aliorumque peregrinatorum collectionibus aucta et emendata. Particula I. Filices Linnaei complectens. Halae 1836. 8.

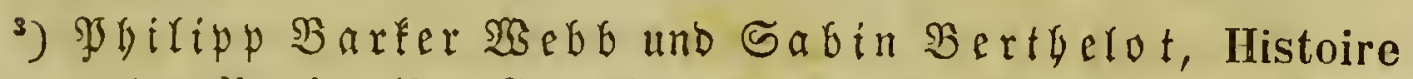
naturelle des îles Canaries. Tome III. (Botanique.) Paris 1836-1847. 4. Atlas 1838. Fol.

4) Bot. Beit. 1821. B̊. 1. S. $225-232$.

5) Breve osservazione sull' isola di Madera. Firenze 1821.8.

-) Excursion to Madcira and Porto Santo during the autumn of 1823. With an appendix containing zoological and botanical descriptions. London 1825. 4. tab.

') Bot. 3eit. 1830. BBo. 1. ․ $369-392$.

$\left.{ }^{8}\right)$ Primitiae faunae et florae Maderae et Portus sancti etc. Cambridge 1831. 4. 4 tab. 


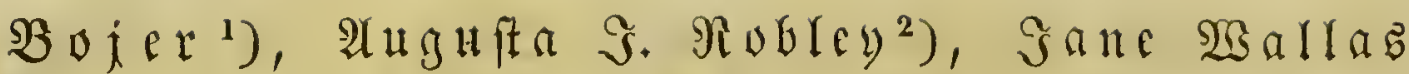

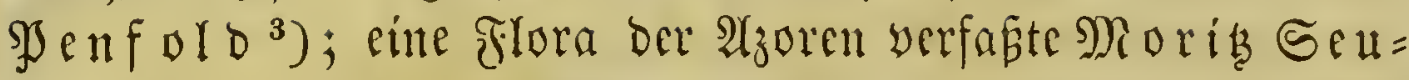

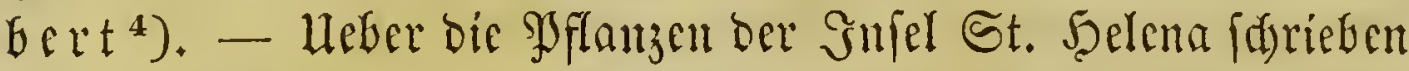

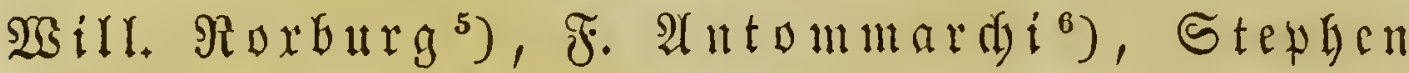

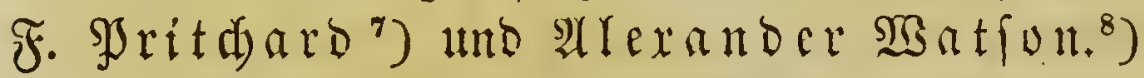

Die Sfflanzenfijätze $\mathfrak{A}$ merifa's wurben in ber neucren 3eit vielfady unterfutst. Heber bie Flora Poromerifa's fdrie=

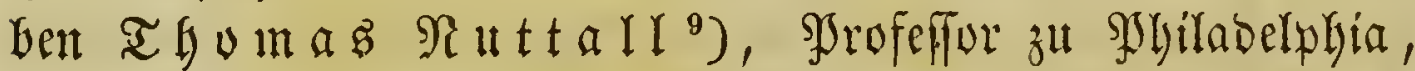

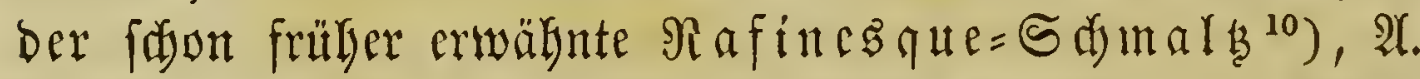

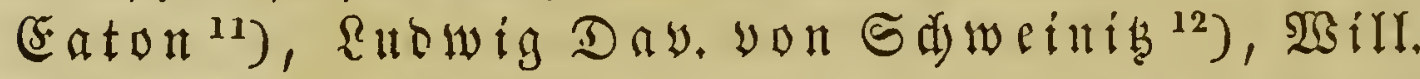

1) Description des plantes recueillies en Madagascar. (Bou ton, Rapports. Maurice 1839-1843.) 4.

2) A selection of Madeira flowers. London 1845. Fol.

$\left.{ }^{8}\right)$ A selection of Madeira flowers, fruits and ferns. London 1845. royal 4.

4) Flora azorica. Bonnae 1844. 4 .

5) List of plants from the island of St. Helena. London 1816. 4.

$\left.{ }^{6}\right)$ Esquisse de la Flore de St. Helène. Paris 1825. 8.

$\left.{ }^{7}\right)$ List of plants growing on the island of St. Helena. Capetown 1836. 8.

$\left.{ }^{8}\right)$ Flora Sta. Helenica. St. Helena 1825. 4.

') The genera of North-American plants etc. Philadelphia 1818. II voll. 8. - Descriptions of new species and genera of plants in the natural order of the Compositae, collected in a tour across the continent to the pacific, a residence in Oregon, and a visit to the Sandwich islands and upper California, during the years 1834 and 1835 (s. t.) 1840. (Transact. of the American Philosoph. Soc. 1841. p. $283-$ 453). - The North-American Sylva etc. Philadelphia 1842 sqq. III voll. 8. tab.

${ }^{10}$ ) Medical Flora, or Manual of the Medical Botany of the United States of Nortli-America. Philadelphia 1828-1830. II voll. 8. 100 tab. col. - New Flora and Botany of North-America etc. Philadelphia 1836. 8.

11) Manual of botany for North-America etc. Albany 1817. 12. - Ed. VIII. 1841.

12) Specimen florae Americae septentrionalis cryptogamicae, sistens Muscos hepaticos hucusque in America septen- 


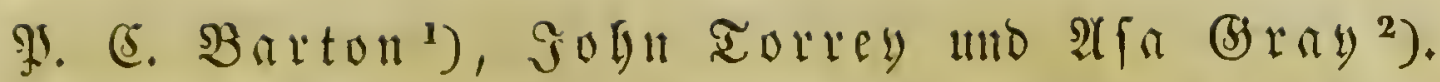
Iorey befidricb aud) bic gyflamen ber nürolidyen und mitt=

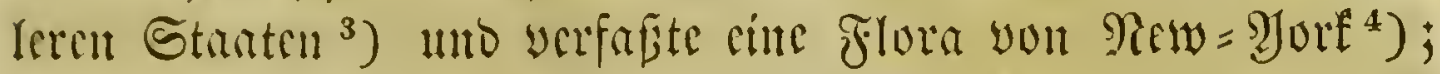

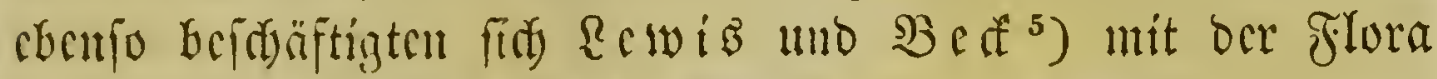
Der mürolifyen mo mittleren $3 \mathfrak{B}$ zinfe ber vercintigten Staten.

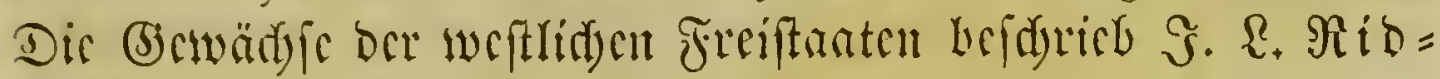

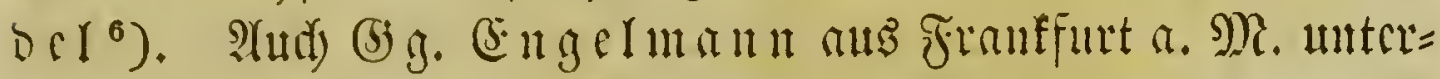

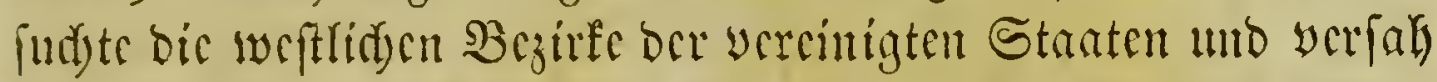
momentlict) Den becibelberger botanifden (5)arten mit Samen

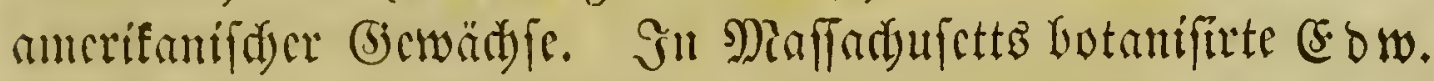

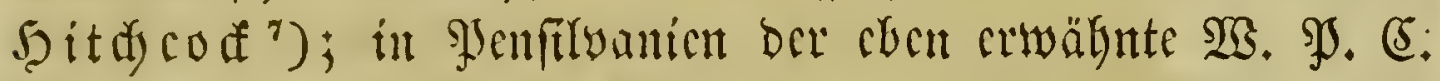
$\mathfrak{B a r t o n}{ }^{8}$ ) uno $\mathfrak{W}$ ill, Darlington ${ }^{9}$ ); in Sübfardina

trionali observatos etc. Raleigh 1821. 8. (Journ, of the ac. of Philad. Vol. II. [1821.] p. 361).

') Vegetable materia medica of the United states; or Medical botany. Philadelphia 1817-1818. II voll. 4. 50 tab. A Flora of North-America. Philadelphia 1820-1823. III voll. 4. 106 tab. col.

$\left.{ }^{2}\right)$ A Flora of North-America etc. New-York 1838- 1843. Il voll. 8.

3) A Flora of the northern and middle sections of the United States etc. Vol. I. (Cl. I-XII. Li inn.) New-York 1824. 8.

4) A Catalogue of plants growing spontaneousluy within 30 miles of the city of New-York. Albani 1819. 8. - A Flora of the State of New-York. Vol. I. Albany 1843.4. (72) tab. col.

$\left.{ }^{5}\right)$ Botany of the northern and middle Staates. Albany 1833. 12.

$\left.{ }^{6}\right)$ A synopsis of the Flora of the Western States. Cincinnati 1835.8.

') Report on the Geology, Mineralogy, Botany and Zoology of Massachusetts etc. P. IV. Catalogues of animals and plants. Amherst 1833. 8.

$\left.{ }^{8}\right)$ illora Philadelphicae Prodromus etc. Philadelphia 1815. 4. - Compendium florae Philadelphicae etc. Philadelphia 1818. II voll. 8. - Ibid. 1824.

$\left.{ }^{\circ}\right)$ Florula Cestrica etc. West-Chester, Pennsylvania 1826. 4. min. 3 tab. col. - Flora cestrica etc. West-Chester 1837. 8. 1 mapp. geogr. col. 
und Georgien Stephen (Elliott ${ }^{1}$ ); im Stant Dhio Gor. (5. Frand, beffen Sammlungen an ben würtembergifity

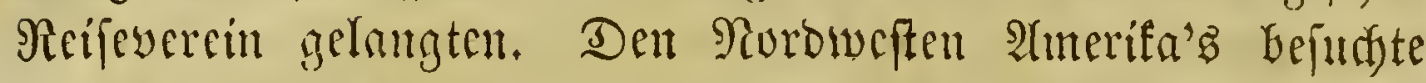
Dav id Douglas, beffen zallreidje Entbefungen von ver: fóficdenen Botanifern benutzt wurben. Diefelten Begenden,

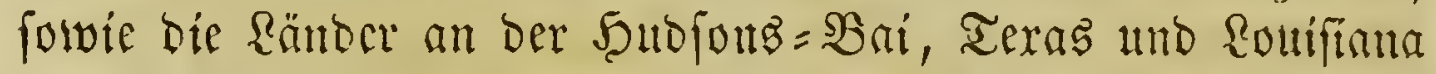
bereifte Sanes Drummond, yon deffar Sammlumen

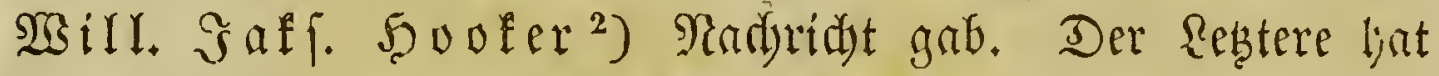

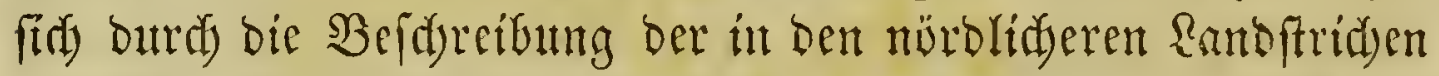

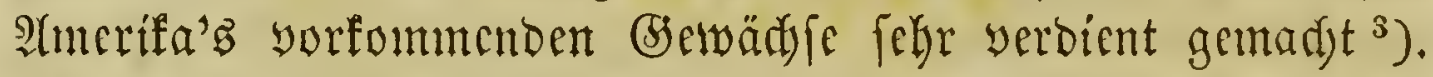

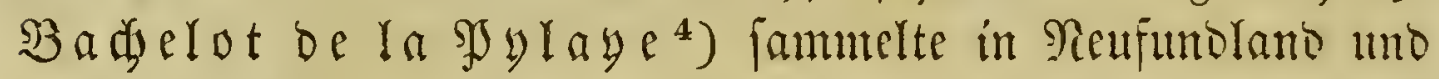

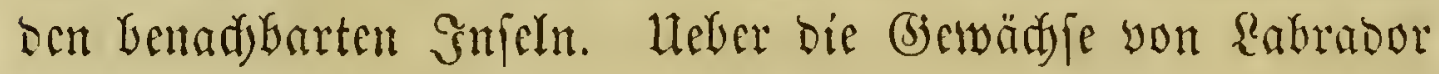
madjte (E) inf Me yer ${ }^{5}$ ) Mittheilungen, uno D. vou

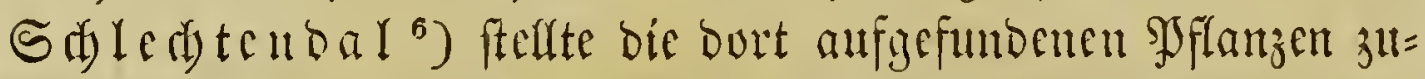
fammen. Die von bem jüngeren $\mathfrak{B}$ a $l$ I in Grönland gejam=

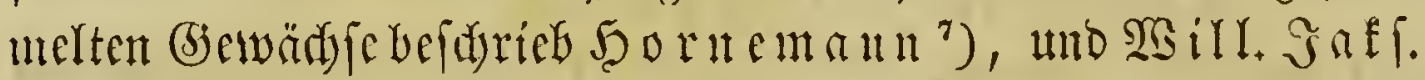

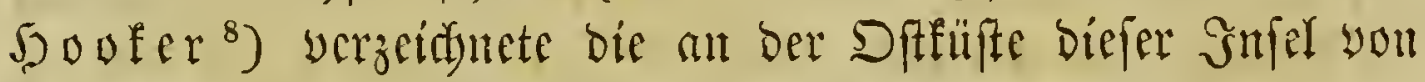

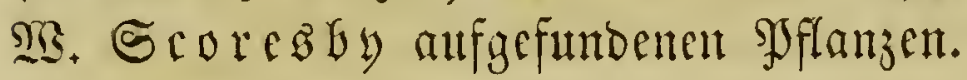

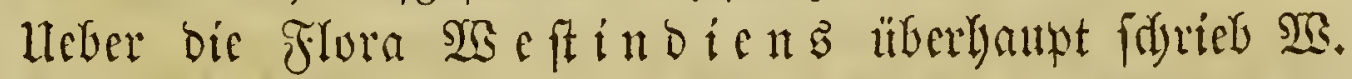

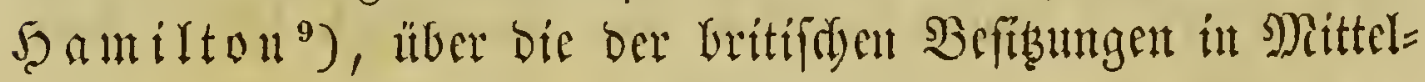

1) A sketch of the botany of South-Carolina and Georgia in two volumes. Charleston 1821 - 1824. II voll. 8. 12 tab.

2) Hooker's Journ. of bot. T. I. p. 183-202.

s) Flora boreali-americana etc. London 1833-1840. II voll. 4. 238 tab. 1 mapp. geogr.

t) Journ. de bot. T. IV. p. 269. T. V. p. 70. p. 130 etc. Flore de Terre-neuve et des îles St. Pierre et Miclon avec figures dessinées par l'auteur sur la plante vivante, Paris 1829. 4.

$\left.{ }^{8}\right)$ De plantis labradoricis libri III. Lipsiae 1830. 8.

o) Linnaea. Bd. X. 1835-1836. (S. 76-114).

7) Forsög til en dansk oeconomisk Planteläre. 3. $\mathfrak{A}$ tủ̧g. 1821 1836. 8.

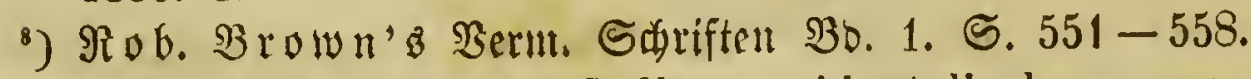

-) Prodromus plantarum Indiae occidentalis hucusque cognitarum tam in oris Americae meridionalis quam in insulis 


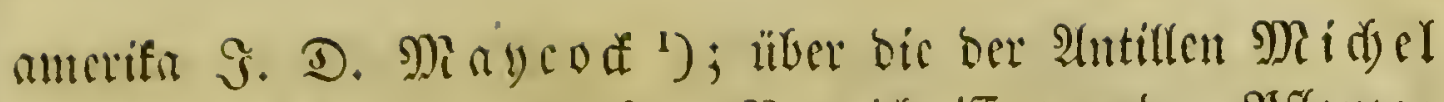

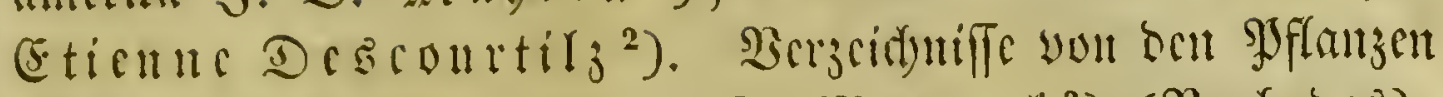
cinjcher Gufch licferten: S. D. Mi ayco $\mathfrak{t}^{3}$ ) (Barbabob),

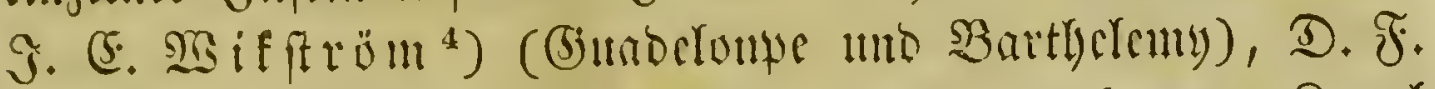

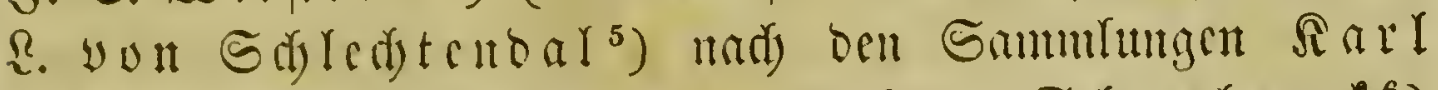

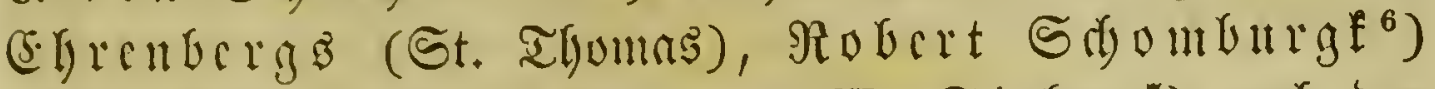

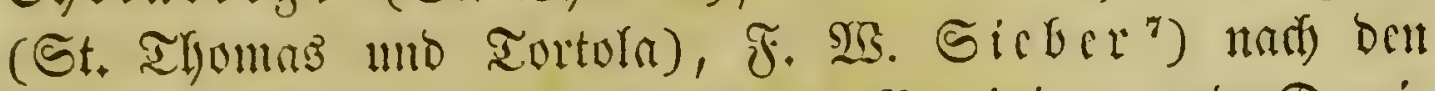

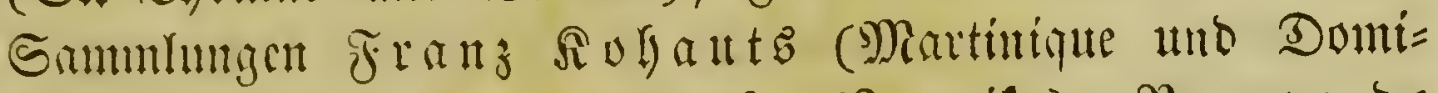

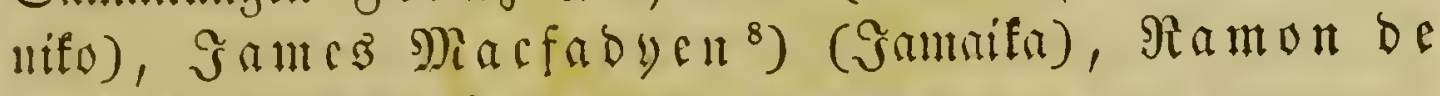
$\left.\operatorname{la} \subseteq \mathfrak{a} \mathfrak{g} \mathfrak{l}^{9}\right)(\mathfrak{\pi} \| \mathfrak{b})$.

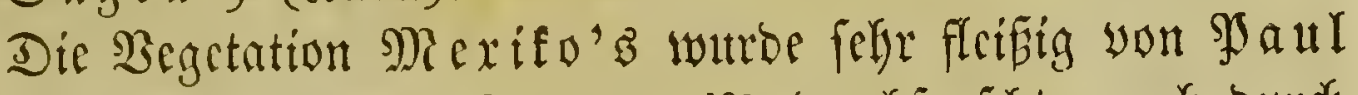

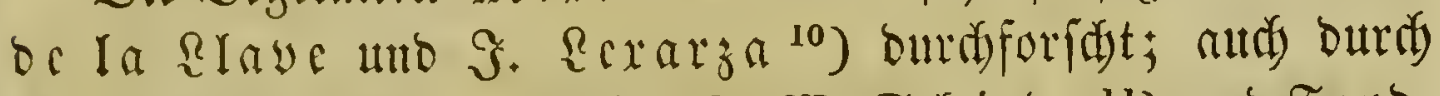

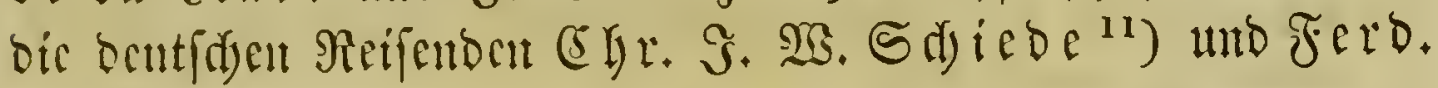

antillicis sponte crescentium aut ibi diuturne hospitantium; nova genera et species hactenus ignotas complectens. Londini 1825. 8. 1 tab. col.

1) $3 n$ : A ndrew II alliday's The West Indies ete. London 1S37. 8. 3 táb.

2) Flore médicale des Antilles etc. Paris 1821-1829. VIII voll. 8. 600 tab. col.

$\left.{ }^{3}\right)$ Flor'a Barbadensis etc. Lond. 1830. 8. 2 tab. geol.

*) Kongl. wetensk. acad. handl. 1826. p. 411. - 1827. p. 51.

5) Linnaea. Bd. III. 1828. (p. $251-276$. ) - Bd. IV. 1829. (p. 78-93.) - Bd. V. 1830. (p. 177-200.) - Bd. VI. 1831. (p. 722-772.)

$\left.{ }^{6}\right)$ Linnaea. Bd. VIII. 1833. (p. 229-244, 257-292.)

T) Herbarium florae martinicensis. Pragae 1822. Sect. I et II. - Herharium floculae dominicensis.

$\left.{ }^{8}\right)$ Hooker's bot. miscellan. Vol. II. 1831 (p. 110). Vol. III. 1833 (p. 76 seqq.). - The Flora of Jamaica etc. Vol. I. London 1840. 8.

$\left.{ }^{9}\right)$ Histoire physique, politique et naturelle de lîle de Cuba. Botanique. Paris 1838-1842. II voll. 8. 48 tab. Fol.

$\left.{ }^{10}\right)$ Novorum vegetabilium descriptiones. Mexici 1824-1825. II Fasc. 8.

11) Seine Entbefungen wurben beifrieben von Shledtenbal unb (5) ramiffo in: Linnaea. Bd. V. 1830. - Bd. XII. 1838. 
Deppe ${ }^{2}$ ) wutroc ciniges über biefelbe befannt gemadjt. Stephan Morifand ${ }^{2}$ ) veranftaltete 2 bbildungen über bie yon cinigen Nicifenten in Mexifo und anderen Ränbern Süb= amerifa's aufgcfmbencn (șciväd)je.

Jn Brafilien hiclt fid) Fr. Sellow anz Sotsobam, geftorben 1831, längere 3eit auf und bradte eine grope $\mathfrak{A}$ th= zahl won SJflanzen zufanmers, welde theifweife burd andere Botanifer ${ }^{3}$ ) befdricben wurben. Fn ben Gabren 1816-1822 bielt fich Augufe be Saint=Şilaire ${ }^{4}$ ) in Braftlien mo

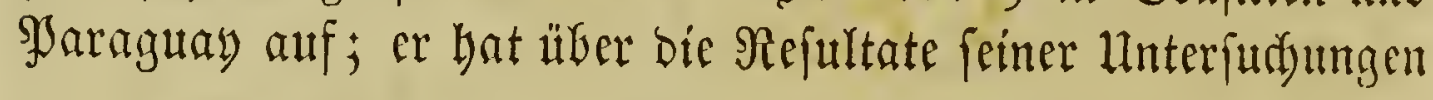

1) Linnaea. Bd. IV. 1829. (p. 205-236. p. 554-583.) Bd. V. 1830. (p. $463-477$.)

3) Plantae americanae rariores descriptae et iconibus illustratae etc. Genève 1830. Fol. 10 tab. - Plantes nouvelles d'Amérique. Genève 1833-1846. gr. 4.100 tab.

3) So von Rinf: Hort. berolin. 1821, 1827, 1833; yon (5ha= miffo unb you v. Sdledtenbar: Linnaea; 爪. Sprenger: Rcue Entbeffungen. 1820-1822. Sn feinem Systema vegetabil. 1825 - 1827 und in feinen Fleineren Sdriften; yon \&ef fing: Linnaea $\mathfrak{u}$. Synops. gen. composit,; von Defandofle: Prodrom. syst. regn. vegetab. Bd. V-VII, ; and fam ein

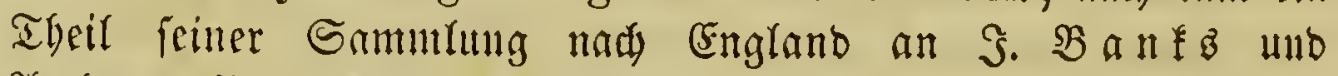
F(y) mer Bourfe Rambert.

4) Histoire des plantes les plus remarquables du Brésil et du Paraguay. T. I. Paris 1824. tab. - Plantes usuelles des Brasiliens. Paris 1824. 4. tab. - Flora Brasiliae meridionalis. Paris 1825 - 1832. Fol. - Voyage dans les provinces de Rio de Janeiro et de Mines Geraës. Par. 1830. 2 Sbe. 8. - Voyage dans le district des diamans et sur le Littoral du Brésil. Par. 1833. II voll. 8. - Tableau de la végétation primitive dans la province de Minas Geraës. (Annal, des sc. nat, t. XXIV.) - Seine botan. 2fbrblgg. fiefye in Bullet. de la soc. philomat. 1823-1826. - Mém. du mus. d'hisist. nat. t. II.) - A. F. C. SaintHilaire et Fr. de Girard, Monographie des Primulacées et des Lentibulariées du Brésil méridional et de la république argentine. Orléans 1840, 8, 2 tab. 


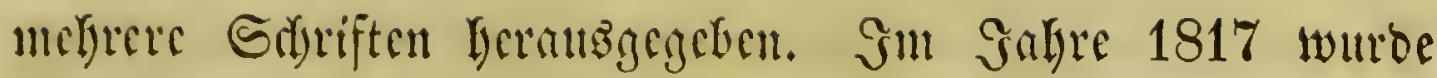

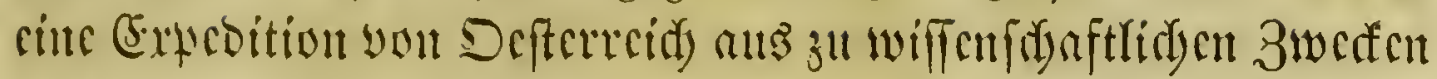
nad) Brafilicu unternommen; ant berferben nabmen $\mathfrak{S}$. (5h)

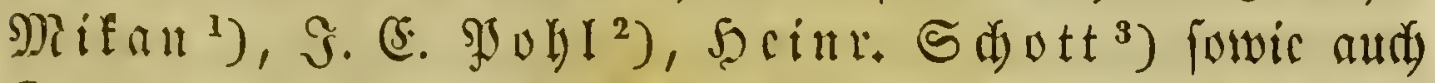

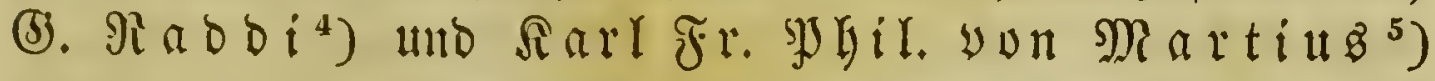

1) Sinber meiner Raune. 2. S(kt). Reife=:Notizen mus BrafilienS. 95-170. - Delectus florae et faunae brasiliensis. Vindobonae 1821 - 1822. Fol. 12 tab.

2) Plantarum Brasiliae icones et descriptiones hactenus ineditae. Vindobonae 1827 - 1831. II voll. Fol. 200 tab. col. -

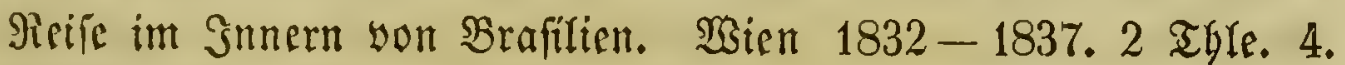
4. 2 Itlaz.

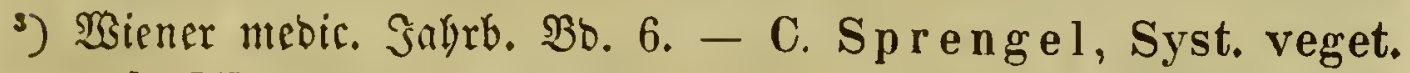
vol. IV. Append. (p. 403-418.) - Seine Tagebüder wutr=

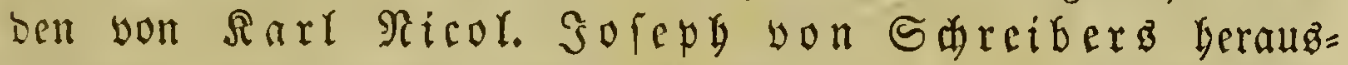

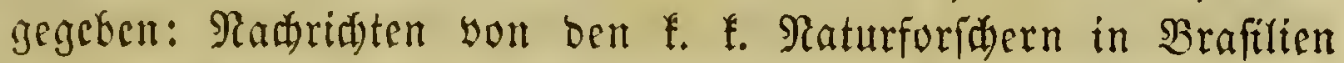
11. Den গefultaten igrer Betriekfantét. Brünn 1820-1822. 2 Şefte. 8. 2 Iaf.

4) Synopsis Filicum brasiliensium. (Opuscoli scient. di Bologna. T. III. 1819). Descrizione di quaranta piante nuove proveniente dal Brasile. Modena 1820. 4. (Mem. della soc. ital. V. 18.) - Plantarum brasiliensium nova genera et species novae v. minus cognitae. P. I. Filices. Florent. 1825. Fol. 86 tab. - Crittogame brasiliane raccolte e descritte. (Atti della soc. ital. delle sc. in Modena. T. XIX. 1826). Agrostographia brasiliensis etc. Lucca 1823. 8. 1 tab.

5) K. Fr. Ph. v. Martius et Joh. Bapt. Spix, Reife in Brafilien. Münden 1824-1831. 3 Bobe. 4. u. Átraż. Fol. K. Fr. Ph. v. Martius. Genera et spec. Palmar., quas in itinere per Brasiliam annis 1817 - 1820 collegit, descripsit' et iconibus illustravit. Monachii $1823-1845$. Fol. max. 219 tab. col. - (Fasc. I-VIII.) - Nova genera et spec. plantar., quas in itinere per Brasiliam annis $1817-1820$ suscepto collegit et descripsit. Monachii 1824-1832. III voll. Fol. 300 tab. - Die \$ygyfiognomie bes \$fflanzenreidyz in Brafllicn. Mündfen (1824). 4. - Specimen materiae medicae brasiliensis etc. (Nonachii) 1824. 4. 9 tab. - Icones planE. DBinfler, Gefid. b. Botanit. 


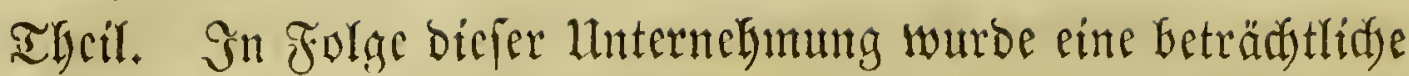
Anzabl forgfältiger Unterfuddutgen liber bie reidje $\mathfrak{B e g e t a t i o n}$ Braflicus veröffentlidst. Daburdy, oafs fcine Ränoer immer

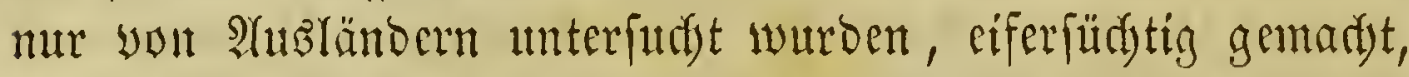
lief ber Saifer Don Spero burdi) Don Antonio ba $\mathfrak{A} r \mathfrak{r a}=$ fis a ${ }^{1}$ ), Biffyof yon Anemmía, Albbilloungen üter bie flora

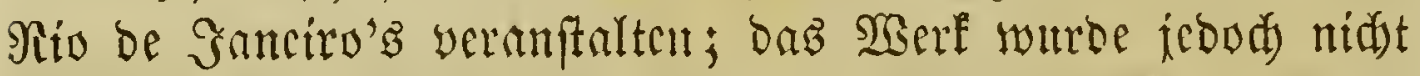
yollendet und jeigt überbies yon wentg Selbftändigfeit. Durrí) ben gewaltigen Berkegr mit Simerifa, ben bie Fortidjritte ber Snouftrie in ber neueften 3eit zu Sasge gebradtht haben, ift

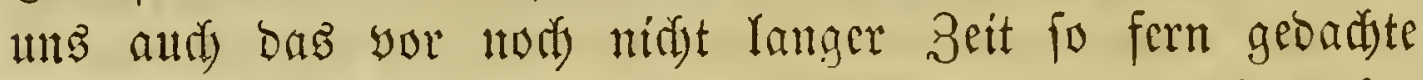

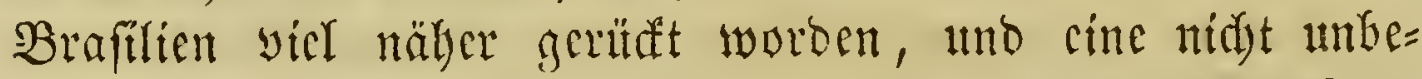

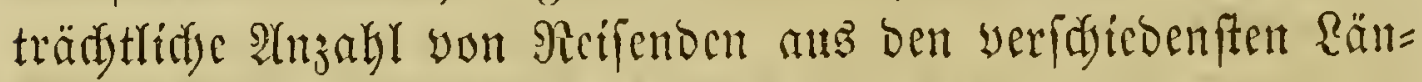
bern Garopa's Gaben bie Forfdumgen ber vorbin genannten Botanifer zut veryollftändigen gejud)t; body bleibt bet ber fo

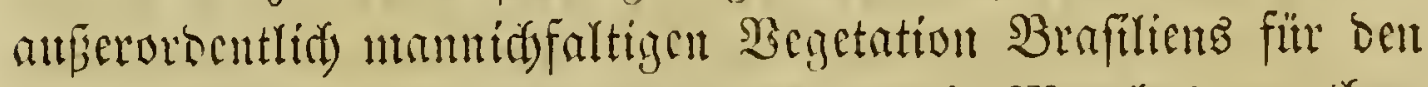

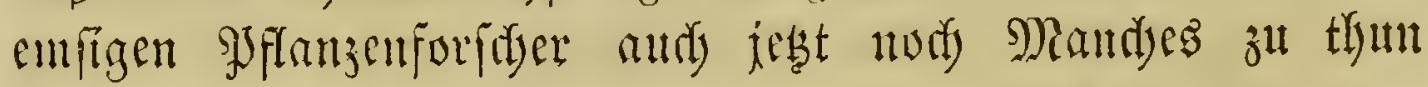
ilbrig.

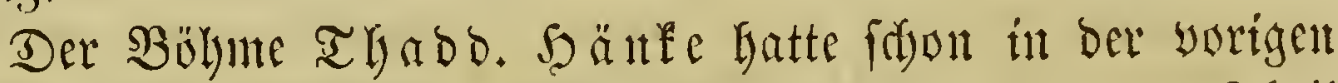

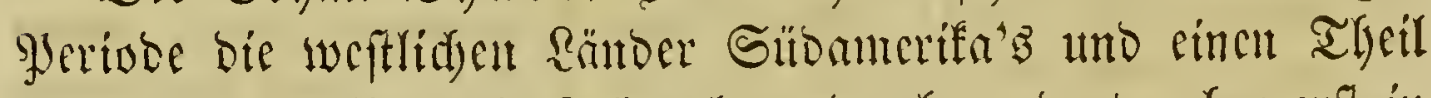

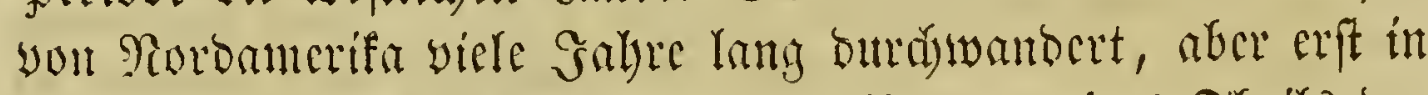

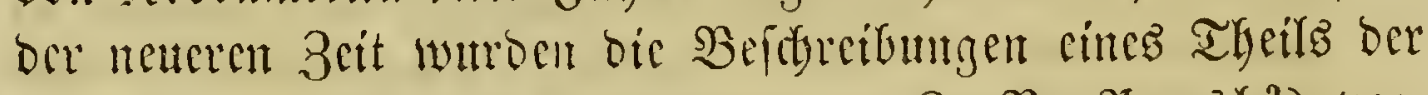

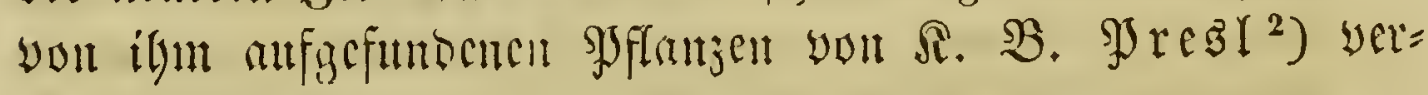

tarum cryptogamicarum, quas in itinere annis $1817-1820$ per Brasiliam instituto collegit et descripsit. Monachii 1828 - 1834. Fol. min. 76 tah. col. - Flora brasiliensis etc. Stuttgardiae et Tubingae 1829-1833. II voll. 8. -

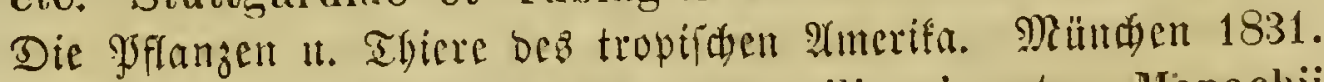
4. 4 Iaf. - Herbarium florae brasiliensis etc. Monachii 1837 -(1840). 8. - Systema materiae medicae vegetabilis brasiliensis. Lipsiae 1843. 8. - Palmetum Orbiguianum etc. Paris $1843-1846$. gr. 4. 29 tab.

1) Florae fluminensis icones, Paris 182\%, 11 Bbe. gr. Fol. 1639 Infeln.

2) Reliquiae Haenkean, etc. Prag. 1830 - 1836. II voll, Fol. 72 tab. 


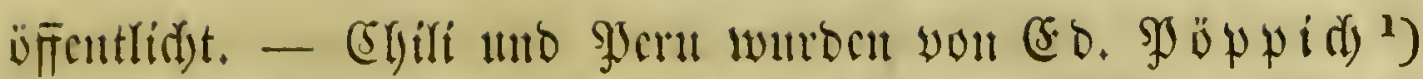

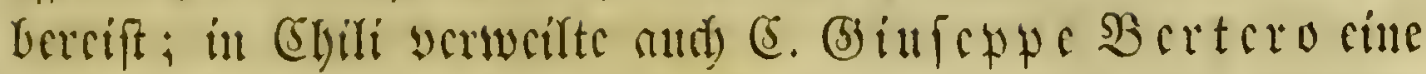

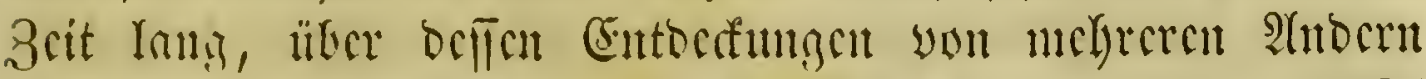

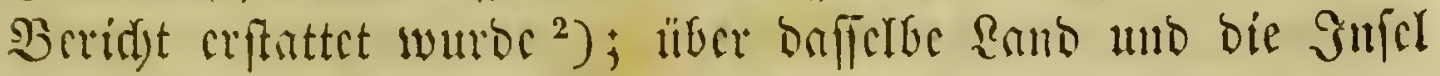

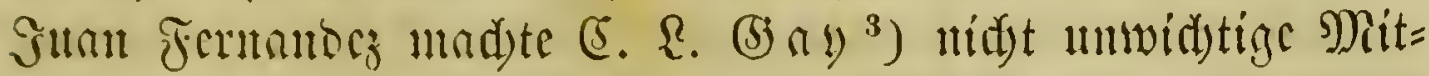

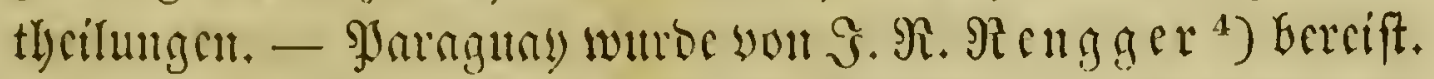

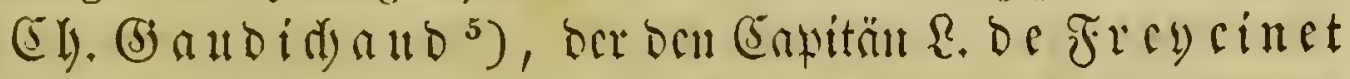

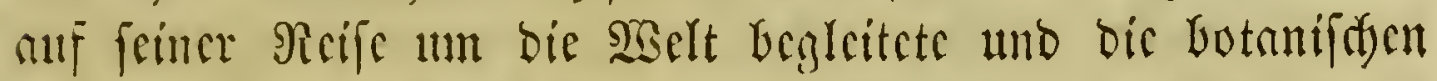

1) Fragmentum Synopseos Phanerogamarum ab auctore annis 1827 - 1829 in Chile lectarum. Lipsiae 1833. 8. - ^eife in

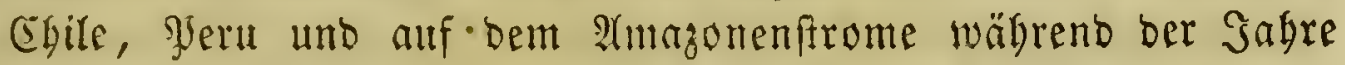
1827-1832. Rcipzig 1835-1836. 2 Bbe. 4. 16 Taf. 1 mapp. geogr. Fol. - Nova genera ac species plantarum, quas in regno Chilensi, Peruviano et in terra Amazonica annis 1827-1832 legit Ed. Poeppig et cum Stephano Endlicher descripsit iconibusque illustravit. Lipsiae $1835-$ 1845. III voll. Fol. 300 tab. - Die yon ibm aufgefundenen (3)äjer wurben yon B. v. Trin iuz befdrieben: Linnaea X, Bd. 1836. (p. $291-308$.)

2) Plantae rariores in regionibus chilensibus a Dre C. Ber tero nuper detectae et ab A. Colla in lucem editae. August. Taurinor. 1832 - 1833. (Mem. della acad. de scienze di Torino. t. 38. 1834.) - C. Montagne, Prodromus lorae fernandesianae. P. I. sistens enumerationem plantarum cellularium quas in insula $\mathbf{J u a n}$ Fernandez a cl. Bertero collectas describi edique curavit. (Extr. des ann. des sc. nat. 1835). - J. F. L elımann, Primae lineae Florae herbopolitanae. Wirceburgi 1809. 8.

$\left.{ }^{3}\right)$ Ilistoria fisica y politica de Chile etc. Paris 1845. 8.

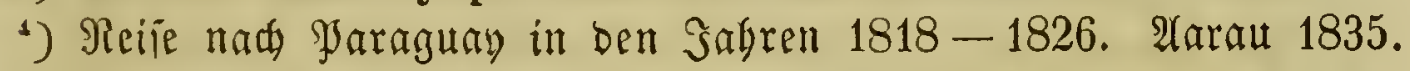

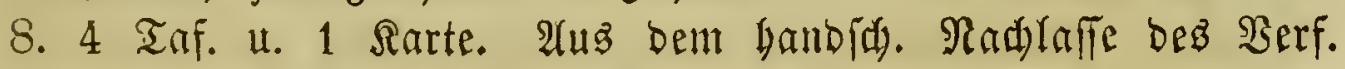
berauzgegeben von $\mathfrak{A}$. Rengger.

$\left.{ }^{5}\right)$ Voyage autour du monde, exécuté sur les corvettes l'Uranie et la Physicienne, sous les ordres du Cap. L. de Freycinet, en 1817-1820. Partie botanique; par Chr. Gaudichaud. Paris 1826. 4. 120 tab. Fol. - Sieke aแ由: Mirbel, Rapport sur la flore des îles Malouines par Gau di chaud. (Ann. des sc. nat. t. IV. 1825. p. 89. seqq.) 
Rotizen zu beffen Reifebefdreibung licferte, unterjudte aud die Flora oer Fetterlanbs = unto oer Falflanbsinfeln; cin $\mathfrak{B e r}=$

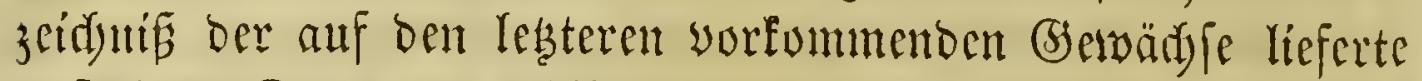
auferoem Dum ont o'uryille. ${ }^{1}$ )

Dic zallreidyen Entocafungen, weldye Robert $\mathfrak{B}$ rown

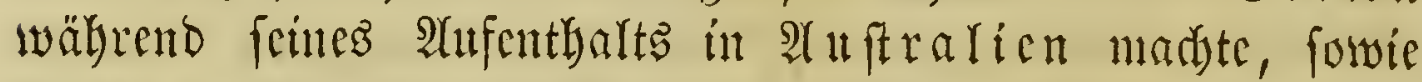

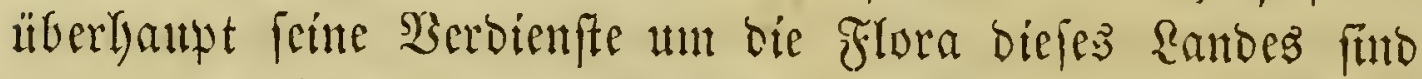

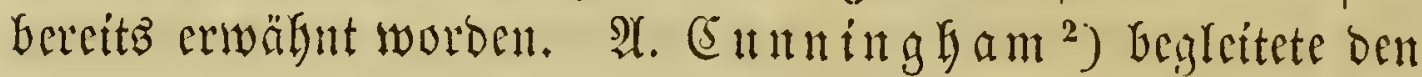

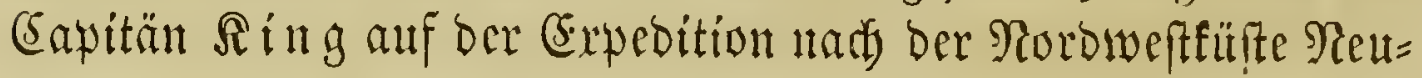
Hullands und befaricb bie Begetation biejer begent nament= lidy in gevigraplifider b̧infidyt. Ferner licferten Şeiträge zur

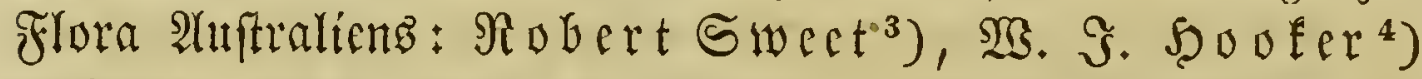

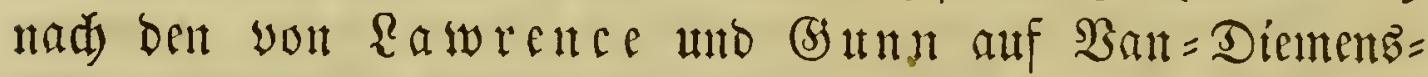

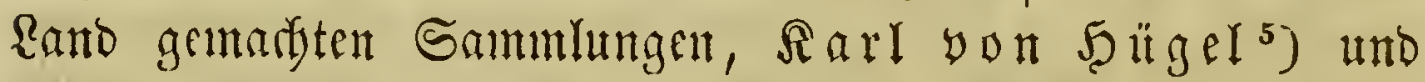

1) Flore des Malouines. (Mém. de la soc. Linn. de Par. T. IV. 1826. p. $573-621$.)

2) A specimen of the indigenous botany of the mountain country between the colony round Port Jackson and the settlement of Bathurst. (Fields Geographical Memoirs on New Sud Wales. London 1825. - Deutif: Linnaea 1827. S. $120-144$.$) - A few general remarks$ on the vegetation of certain coasts of Terra australis and more especially of its northwestern shores. (King, Narralive of a survey of the coasts of Australia. London $1 \times 27$.

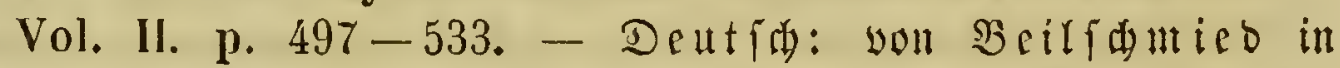
Flora Riteraturberidjt 1829. II. S. 1 -37.)

$\left.{ }^{3}\right)$ Flora australasica etc. London 1827-1828, gr. 8. 56 tab. col.

4) W. J. Hooker's Journal of botan. Vol. I.

$\left.{ }^{3}\right)$ Steph. Endlicher, Gg. Bentham, Ed. Fenzl et If ch. Schott, Enumeratio plantarum quas in Novae Ilollandiae ora austro-occidentali ad fluvium Cygnorum et in sinu Regis Georgii collegit Ka r I vo n II ü ge el. Vindobonae 1837. 8. - St. Endlicher, Stirpium Australasicarum Herharii Hügelian i decad. III. Vindobonae 1838. 4. ( $\mathfrak{A}_{\mathfrak{n} n a l .}$

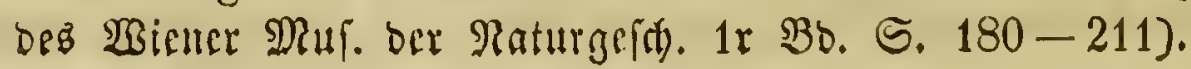




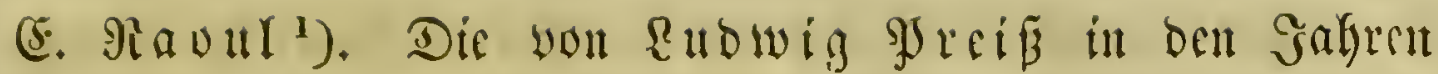

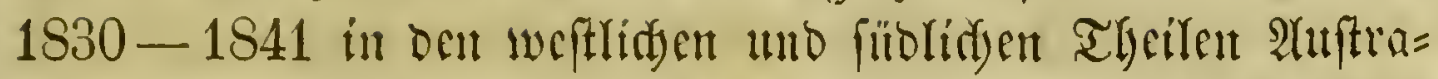
licus uen aufgefundenen \$fflanjen befdrieb goban (b) $\mathrm{g}$.

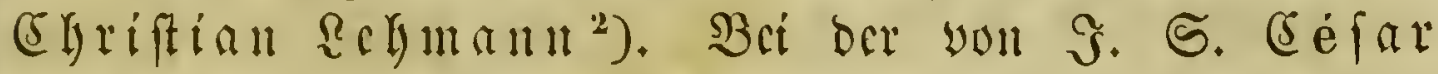

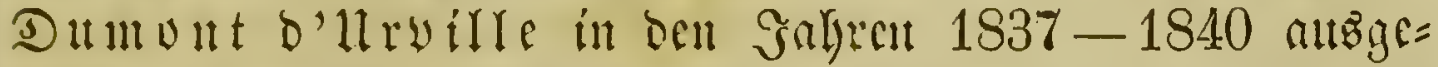

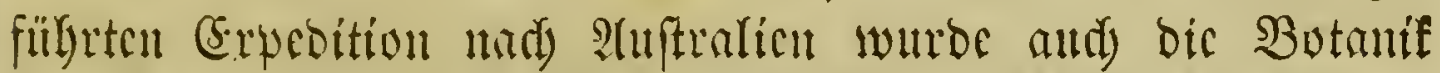

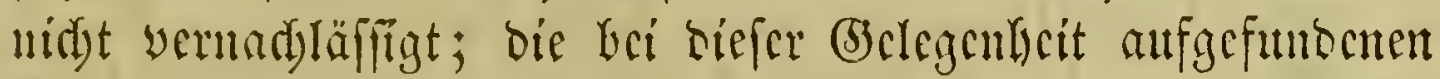

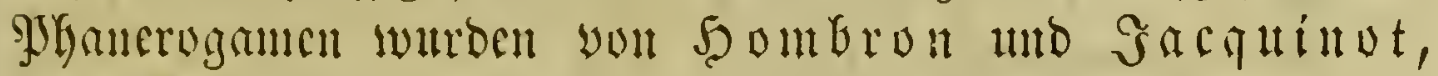
Dí Sigptoganen von פiontague ${ }^{3}$ ) befdrieben; l̈ber bie

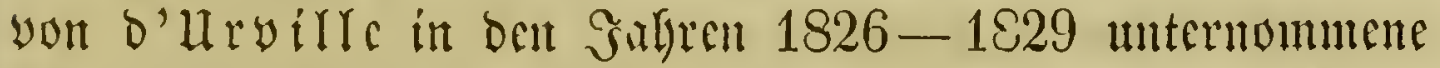

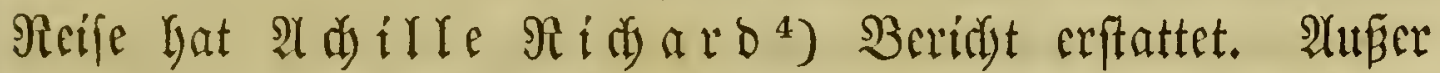

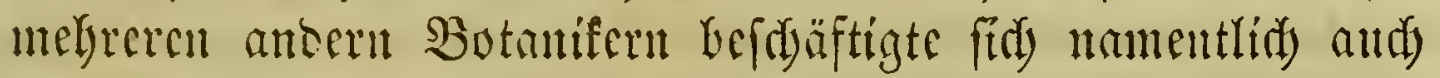

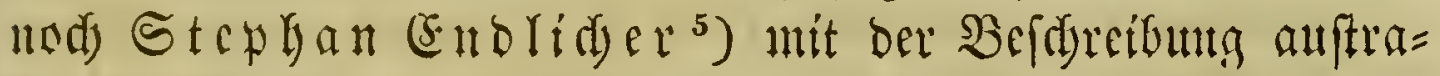

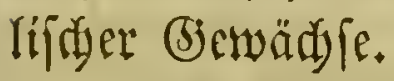

Эn bem Borbergegenden Gaben wir bie Befdreibungen cimzclner (5sittungen uno Familicn mur bciläuftg erwähnt, and ca wirb beshalb nöthig fein, hier cine 1 eberfint ber baupt= füblidyften Sdyriften biefer $\mathfrak{A}$ (rt folgen zu laffen. ${ }^{6}$ )

1) Choix des plantes de la Nouvelle-Zélande etc. Paris 1846. gr. 4.30 tab.

$\left.{ }^{2}\right)$ Plantae Preissianae etc. Hamburgi 1844-1847. II voll. 8.

$\left.{ }^{8}\right)$ Dumont d'Urville, Voyage au Pole Sud et dans l'Océanie sur les corvettes l'A strolabe et la Z élée, exécuté pendant les années 1837-1840. Paris 1841-1847. 8. 1 Atlas. Fol.

4) Voyage de découvertes de l'Astrolabe, exécuté par ordre du roi pendant les années 1826 - 1829 sous le commandement de Dumont d'Urville. Botanique par A. Less on et Achille Richard. Paris 1832-1834. Il voll. 8. 1 Atlas. Fol.

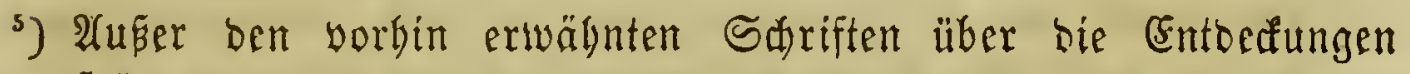
Sägel'z berfápte er aud bie Beidreibungen ber von Fert. Bauer in ben Sagren 1804 u. 1805 auf ber S̈llfet Rorfolf ge= fammelten gyflanzer.

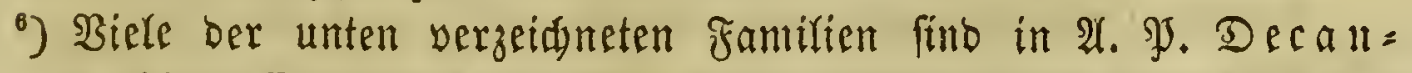
Dofle's Prodromus systematis regni vegetabilis, fortgééçt 


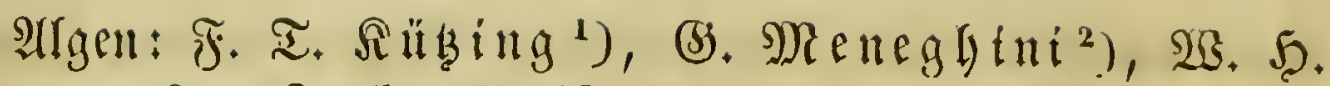

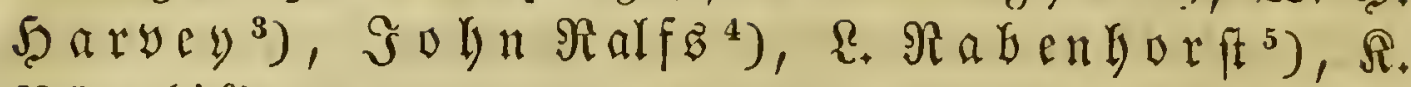
$\Re a ̈ g \in\left(i .{ }^{6}\right)$

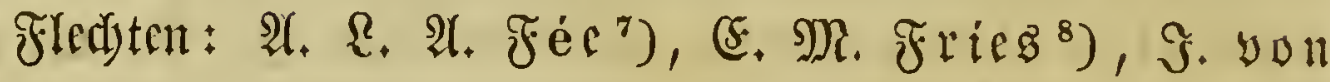

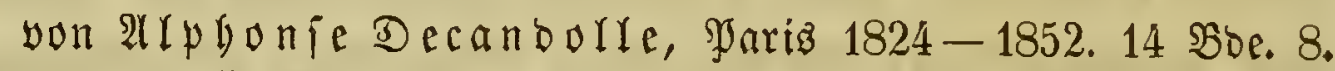

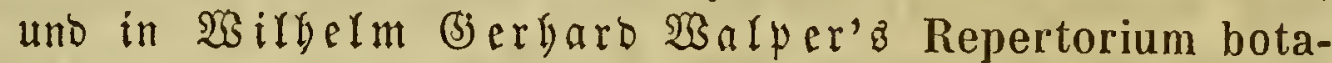
nices systematicae. Lipsiae 1842-1848. 6 BDe. 8., fowie in beflen Annales botanices systematicae. Lipsiae $1849-$ 1853. 3 BDoe. 8. befdrieben.

1) Synopsis Diatomacearum. Halle 1834. 8. 7 tab. - Phycologia generalis, Leipzig 1843. 4. 80 tab. col. - Phycologia germanica. Nordhausen 1845. 8. - Tabulae phycologicae. Nordhausen 1846-1850. III Hefte gr. 8. 30 tab. col. Species Algarum. Lipsiae 1849. 8. - Sammlung getrofineter Âtgen: Algarum aquae dulcis Germaniae. Dec. I-XVI. Halle 1833 - 1836.

$\left.{ }^{2}\right)$ Alghe italiane e dalmatiche illustrate dal professore. Fasc. I-V. Padova 1842-1846. 8.

$\left.{ }^{3}\right)$ Phycologia britannica. Fasc. I. London 1846. 4.

t) The british Desmidieae. London 1848. 8. 35 tab. col. The british Watel Algae. London 1848. 8. 33 tab. col.

$\left.{ }^{5}\right)$ Die Süpwaffer = Diatontaccen. Reipzig 1853. gr. 4. 10 col. Taf. - Sammlung getrodfueter Argen: Dic Algen Sadjens (Mittel= (5uropas). Dec. I-XXX. Dreảben 1850-1853. 8. - Dic Bacillarien Sadjens (Deutia)landä). Fasc. I-VII. Drešben 1850-1853. 8. - 5̧o henafer, Algae marinae siccatae.

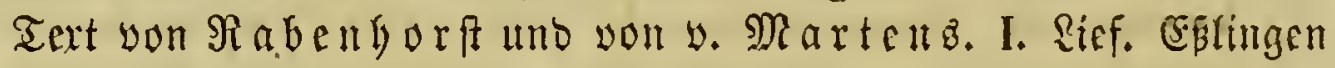
1852. Fol.

") Die meneren 2(rgenfyfteme 2c. 3ürid) 184\%. 4. 10 Inf. - (bat= tungen einzelliger 2 (rgen 2 . 3ürri 1849. 4. 8 Tafeln.

7) Essai sur les Cryptogames des écorces exotiques officinales, précéde d'une méthode lichénographique et d'un genre, avec des considérations sur la reproduction des agames. Paris 1824-1837. II voll. 4. 43 tab. col. - Mémoires lichénographiques. Bonne 1838. 4. 6 tah. col.

$\left.{ }^{8}\right)$ Lichenographia europaea reformata. Lundae 1831, 8. 


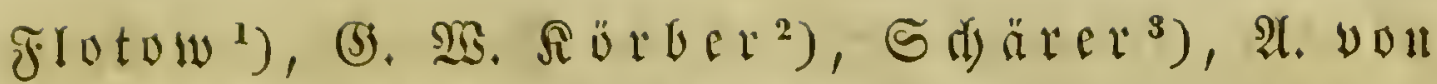

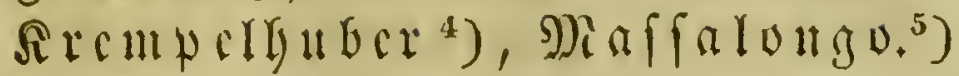

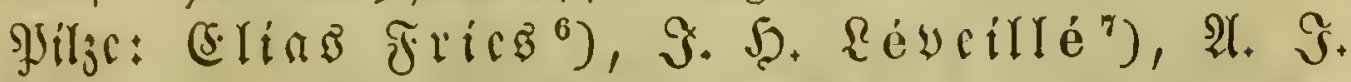

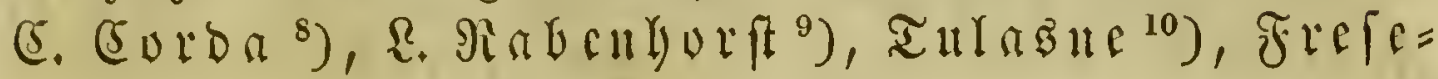

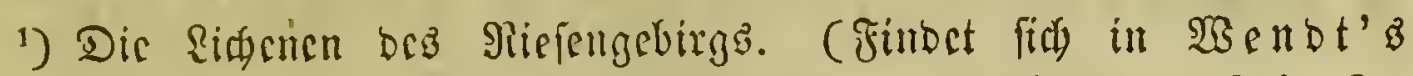

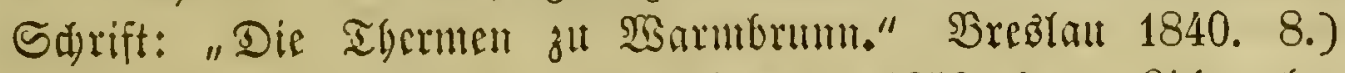
- Lichenes Florae Silesiae. Sorçlat 1850. 4. - Richendto= gifde Briträge łur Flora europaea. (Şot. 3cit. 1850. S. 537 ff. 553 fi. 569 ff.)

$\left.{ }^{2}\right)$ Lichenographiae germanicae specimen, Parmeliacearum familiam continens. D. Vratislaviae 1846. 4.

$\left.{ }^{3}\right)$ Lichenum europaeorum genera ex utraque methodo, arteficiali et naturali digerit. (Mittheil. Der naturforidenden

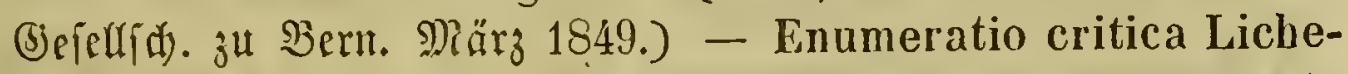
num europaeorum etc. Bernae 1850. 8. 10 tab. pro parte col. - Eamutung getroffneter fledten: Lichenes helvetici exsiccati etc. Fasc. I-XXVI. No. 1-600. 12 Ðtboc. Bern 1. Reips. 1849.

4) Diplotomma calcareum. (Flora 1853. No. 26 fi.)

$\left.{ }^{5}\right)$ Ricerche sull autonomia dei Licheni crostosi e materiali pella loro naturale ordinazione. Verona 1853. 8. 64 tab. (400 mifroffop. AHbbitoungen.)

$\left.{ }^{6}\right)$ Systema mycologicum etc. Gryphiswaldiae $1821-1832$. III voll. 8. - Suppl. vol. I. ibid. 1830. 8. - Elenchus fungorum etc. Gryphiae 1828. II voll. 8. - Epicrisis systematis mycologici etc. Upsaliae et Lundae 1836 - 1838. 8. - Summa vegetabilium Scandinaviae etc. Holmiae et Lipsiae $1846-$ 1849. 8. - Novae symbolae mycologicae. Fasc. I. Upsaliae 1851. 4. - Hymenomycetes in Suecia nuper detecti. (Öfversigt af Kongl. Vetenskaps-Akademiens Förhandlingar. Stockholm 1852.) 2(uşzug: (Flora 1853. S. 27 ff. S. 39 ff.)

7) Considérations mycologiques, suivies d'une nouvelle classification des Champignons. Paris 1846. 12.

$\left.{ }^{8}\right)$ 2(nteitung zum Stubium ber Myfologie ?c. \$rag 1842. 8. 8 Taf. Icones fungor. hucusque cognitor. Pragae 1837-1842. V voll. Fol. 44 tab. - פjradifflora europ. Sdinmelbiloungert. Reipzig uno Drezben 1839. Fol. 25 folor. Taf.

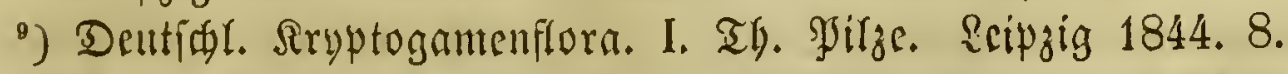

10) Fungi hypogaei. Paris 1851. Fol. 21 tab. 


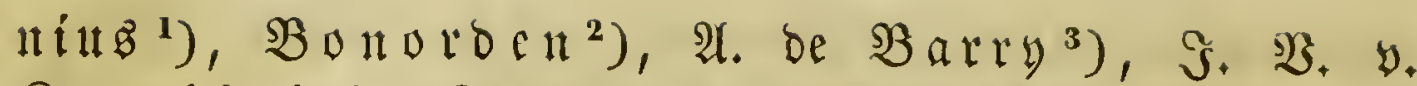

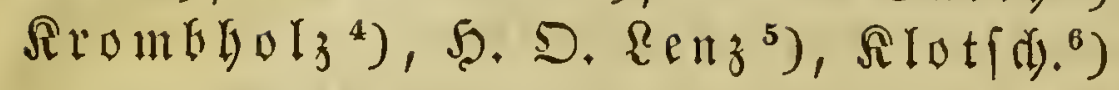

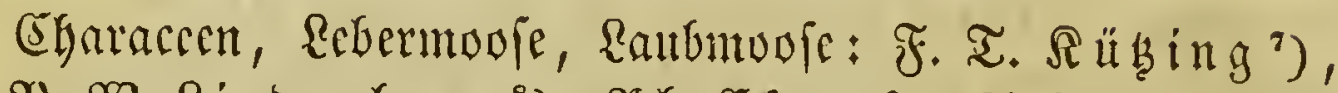

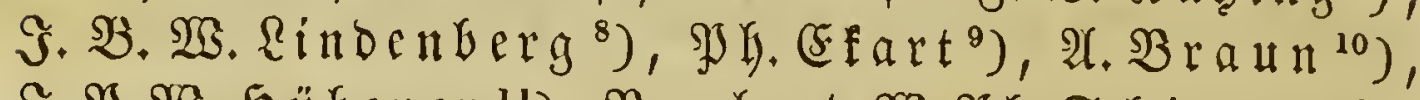

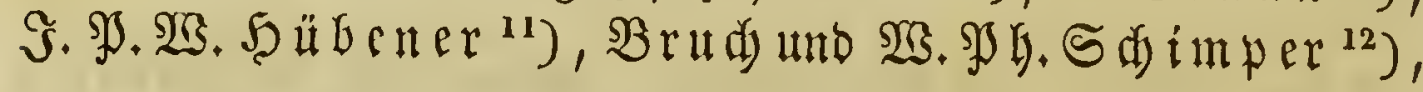

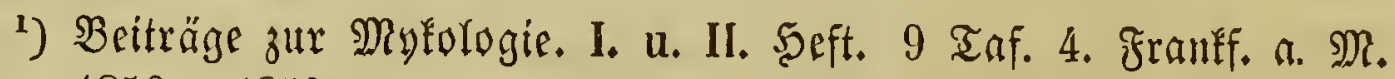
$1850-1852$.

2) Sandbud ber allgemeinen Myfologie. Stuttgart 1851. 8. 12 $\mathfrak{I a f e l n}$ in 4.

3) Hnteriudungen über bie Branopilze uno bie burdh fie veruriat)= ten Sranfleiten ber SPflanzen. Berlin 1853.8.8

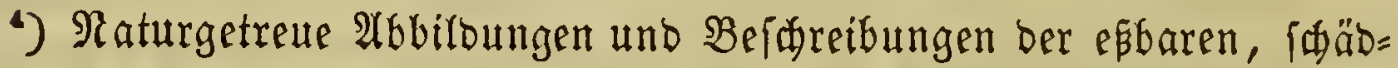

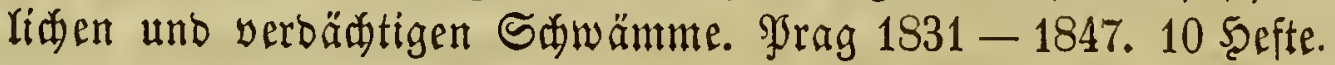
Fol. 78 col. Iaf.

5) Die müb̨ił 8. 16 color. Taf.

-) Sammlungen getrodneter 马ilze: Kl o ts c hii, Herbarium vivum mycologicum sistens Fungorum per totam Germaniam crescentium collectionem perfectum. Cent. I-III. cura Klotschii. Cent. IV - XVIII cura L. Rabenhorst. Dresdae 1842 - 1853. 4.

') Species Algarum. Fam. LI. Characeae. p. 513 seqq.

$\left.{ }^{8}\right)$ Synopsis Hepaticarum europearum. Bonnae 1829. 4. 2 tab. - Species Hepaticarum. Fasc. I - V. Bonnae 1839- 1844. 4. 33 tab. Fasc. VI. VII. Bonnae 1846-1847. 12 tab.

-) Synopsis Jungermanniarum in Germania vicinisque terris hucusque cognitarum figuris CXVI microscopico-analyticis illustrata. Coburgi 1832. 4. 13 tab.

$\left.{ }^{10}\right)$ Die faweizerifaen (Sharacen. (Nete Denfidrift ber alfge= meinen idweizerifaen Bejellfdaft f. b. gejammt. Raturwifienid. Bb. X. 1849.)

i1) Muscologia germanica. Reipzig 1833. 8.

12) Bryologia europaea. Stuttg. 1837 - 1851. IV voll. (46 fasc.) 4. 428 tab. 


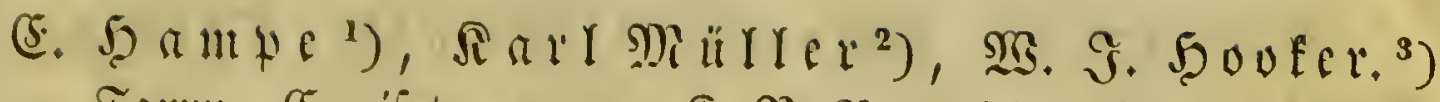

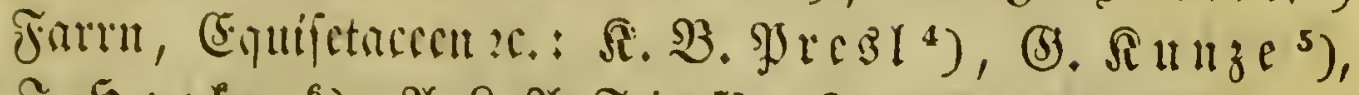

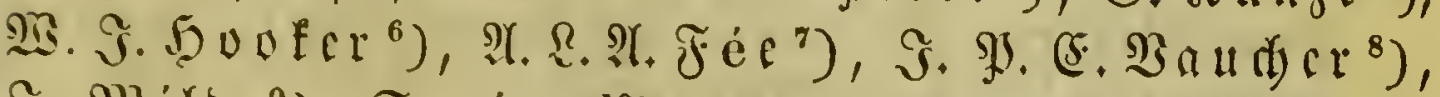
Э. Miritor ${ }^{9}$ ), Spring. ${ }^{10}$ )

(B)

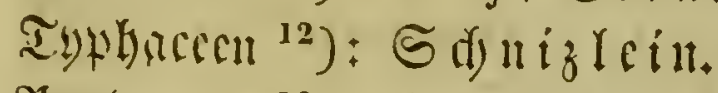

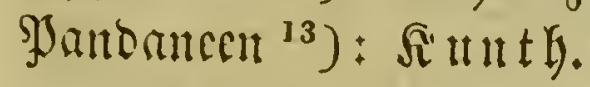

') Icones muscorum novorum vel minus cognitorum. Dec. I-III. Bonnae 1844. 8. 30 tab.

") Synopsis muscorum frondosorum omnium hucusque cognitorum. Bernlini 1849-18à. II voll. 8. - Deutfálanbs

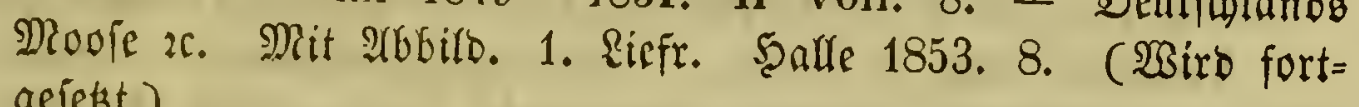
géerest.)

s) W. J. Hooker et Thom. Taylor, Muscologia britannica etc. London 1827. 8. 36 tab.

4) Tentamen pleridographiae etc. Pragae 1836. 8. - Hymenophyllaceae. Eime bot. Albbandr. Wrag 1842. 4. 12 Taf.

$5)$ Die Farrenfräuter in folorirten 2 (rbbirogg. naturgetreu erläutert uno beífrieben. ( zig $1840-1851.4 .140$ fol. $\mathfrak{T a f}$.

') Genera Filicum. Lond. 1842. Royal-8. 121 tab. col. Species Filicum. Part. I - V. Lond. 1846-51. 8. 90 tab. col.

') Mémoires sur la famille des fougères. Mém. I - IV. Strasb. 1844-1845 et Paris 1851-1852. Fol. 106 tab.

s) Monographie des Prêles (Equiseta). Genève 1822. 4. 13 tab.

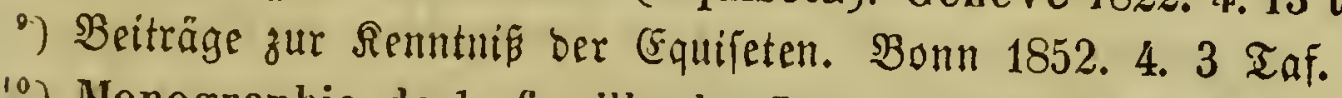

10) Monographie de la famille des Lycopodiacées, extraite des tom. XV et XXIV des mémoires de l'académie royale de Belgique. Bruxelles 1842 et 1849. 4.

i') Decandolle, Prodromus etc. - Neyer, Berfü einer Monograpgie ber Bjottung Epheora. St. Petersburg 1846. gr. 8. $8 \mathfrak{T a f}$.

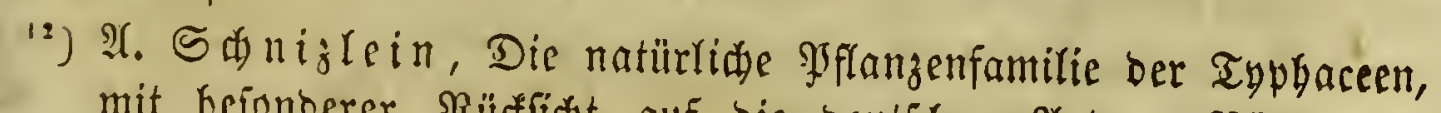

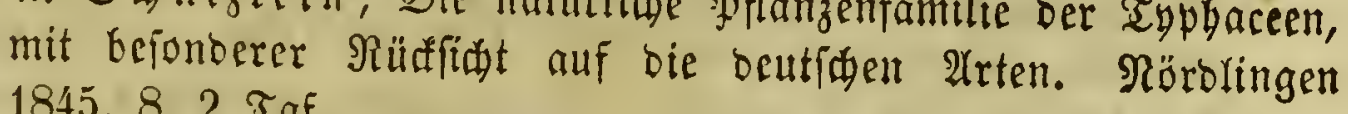
1845. 8. 2 Taf.

13) K. S. Kunth, Enumeratio plantar. omnium hucusque cognitar. Tom. III. Stuttg. et Tübing. 1841. 


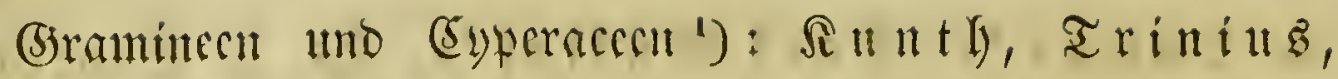

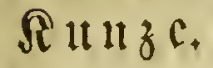

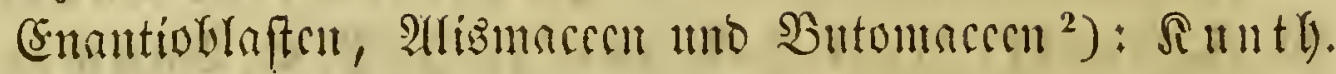
(Eriofoutsen ${ }^{3}$ ): won $2 \mathfrak{M}$ artius.

Sriocent ${ }^{4}$ ): $\Omega \mathfrak{R}, 5 \mathfrak{a}$ worth.

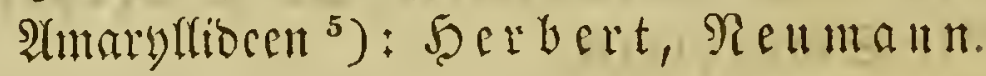

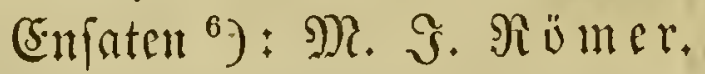

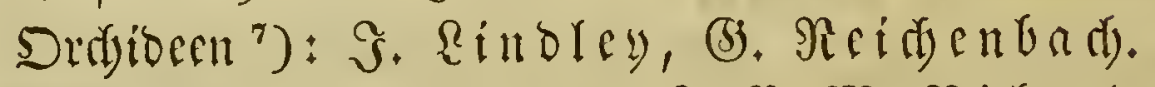

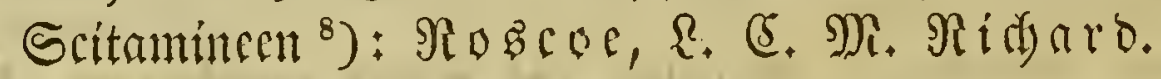

$\left.{ }^{1}\right)$ K. S. Kunth, Enumerat. plantar. Tom. I, II et III. (18331837), - K. B. v. Trini us, Fundamenta Agrostagraphiae. Viennae 1820. 8. 3 tab. - Species graminum, iconibus et descriptionib. illustr. Petropoli $1828-1836$. III voll. 4.

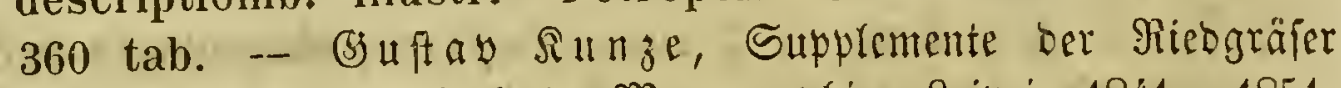

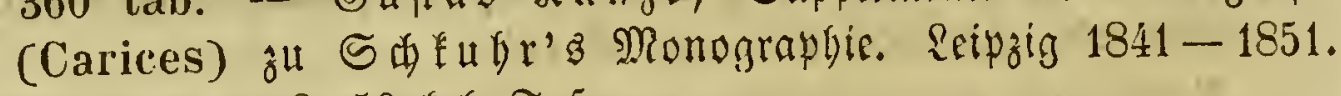
5 Rieferung. 8.50 \%ol. Taf.

$\left.{ }^{2}\right)$ K. S. K u n th, Enumerat. plantar. Bd. III et IV. (18'1 - 1843).

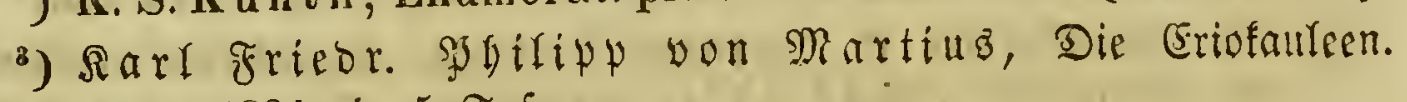
Bonn 1834. 4. 5 Taf.

)) J. B. Ker, Iridearum genera etc. Bruxellis 1827. 8. A. H. Haw orth, Narcissearum revisio. Londini 1819. 8. - Narcissearum monographia. London 1831. 8.

5) W. Herbert, Amaryllidaceae. London 1837. 8. 49 tab. -

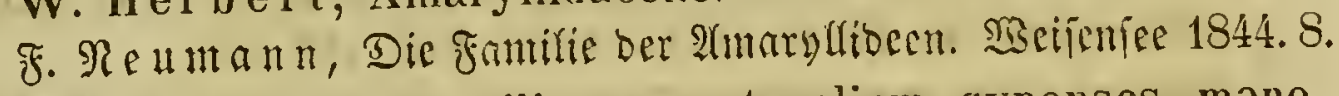

-) M. J. Römer, Familiarum naturalium synopses monographicae. Fasc. IV, Ensatae. Wimariae 1847. 8.

') John Lindley, lllustrations of orchidaceous plants. London 1830-1838. Fol. 20 tab. col. - The genera and species of orchidaceous plants. London $1830-1840$. VII voll. 8. - G. Reichenbach, Orchideae in Flora Germanica recensitae additis Orchideis Europae reliquae, reliqui Rossici imperii, Algerii etc. Lipsiae 1851.4. 170 tab. col.

$\left.{ }^{8}\right)$ William Roscoe, Monandrian plants of the order Scitamineae. Liverpool 1828. Fol. 112 tab. col. -- L. C. II. Richard, De Musaceis commentatio botanica, sistens characteres hujusce familiae generum. Op. postl. ab A. Rich ard editum. Vratislaviae el Bonnae 1831. 4. 32 tab. 


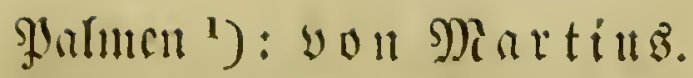

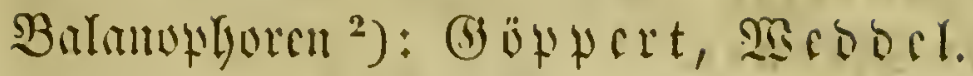

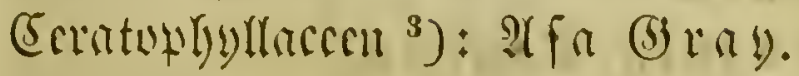

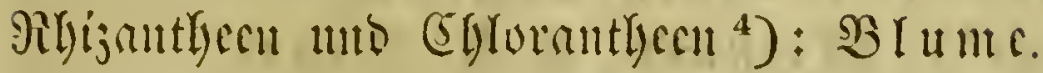

Bjiperaccen ${ }^{5}$ ): Si i iucl.

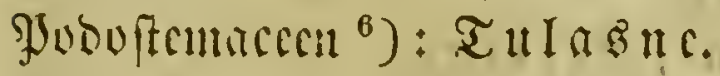

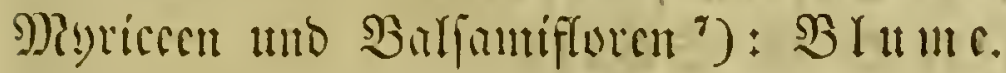

(Empuliferen ${ }^{8}$ ): F. A. Midi aux.

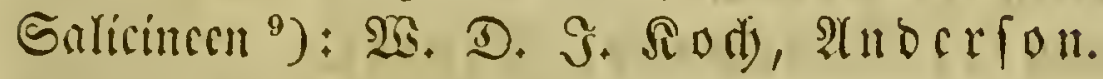

2(mentacen ${ }^{10}$ ): Th. \$artig.

') v. Martius, Historia naturalis Palmarum etc. Monachi $1823-1850$. Fol. 245 tab.

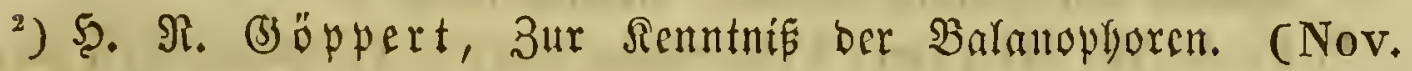
Act. Acad. C. L. C. Nat. Cur. Tom. XXII.) 1847. 5 tab. Weddel, Considérations sur l'organe reproducteur femelle des Balanophorées et des Rafflesiacées. (Annal, sc. nat. Botanique. Tom. XIV.) 1850.

3) Asa Gray, Remarks on the structure and affinities of the order Ceratophyllaceae. New-York 1837. 8.

s) Karl Ludwig B I ume, Rhizantheae et Chlorantheae. (Snl : Flor. Javae.) Bruxellis 18:28-1829. Fol.

s) F. A. W. Miquel, Systema Piperacearum. Roterodami 1843-1844. 8. - Illustrationes Piperacearum. (Nov. Act. Ac. C. L. C. Nat. Cur. XXI.) 1846. 92 tab.

") Tulasne, Podostemacearum synopsis monographica. (Annal. sc. nat. XI, S. 87 -114.) 1849.

i) F. A. W. Blume, Myriceae et Balsamiflorae. ( $3 n$ : Flor. Javae.) Bruxellis 1828-1829. Fol.

") F. A. II ichaux, Histoire des arbres forestières de l'Amérique septentrionale. Tom. II. (Cupuliferae). Paris 1810. 4.

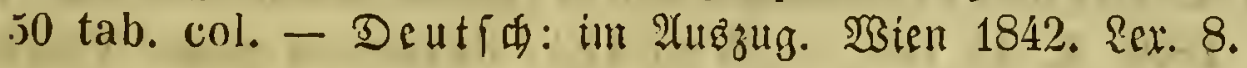

0) IVill. Dan. Jos. Koch, De Salicibus europaeis commentat. Erlangae 1828. 8. - Nicol. Joh. Anderson, Salices Lapponiae, cum figuris XXVIII specierum. Upsaliae 1845.

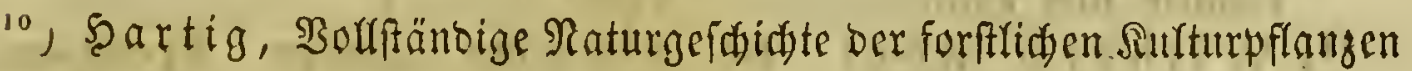
Deutidlandz. Berrin 1840-1846. 10 Şcfte 4.86 for. Taf. 
Moreen ${ }^{1}$ ): Moretti.

Ulrtifaccen ${ }^{2}$ ) : Miqu

(Shenopobeen ${ }^{3}$ ): Moquin= Tanoon.

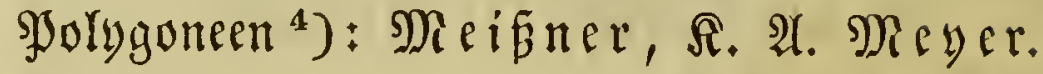

Dipfaceen ${ }^{5}$ ): (Soulter.

(Sompofiten $\left.{ }^{6}\right):($ Saffini, $\mathfrak{e}$ effing.

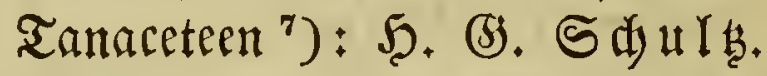

Robeliaceen ${ }^{8}$ ): $\mathfrak{P}$ ręl.

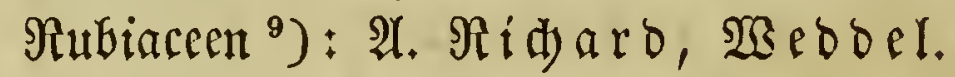

Slantagineen ${ }^{10}$ ): $\mathfrak{B} a \mathfrak{r}$ é oud.

SJlumbrgineen ${ }^{11}$ ): (Ebel, $\mathfrak{W}$ altroth, Boiffier.

1) Giuseppe Moretti, Prodromo di una monografia delle specie del genere Morus. Milano 1842. 8.

${ }^{2}$ ) F. A. W. Miquel, Urticaceae novae. (Commentarii phytographici tom. III). Lugd. Batav. 1810. Fol.

${ }^{8}$ ) A l fred Mo qu in-Tandon, Chenopodearum monographica enumeratio. Parisiis 1840. 8.

4) Karl Friedr. Meisner, Monographia generis Polygoni prodromus. Genevae 1826. 4. 7 tab. - $\mathfrak{R} \mathfrak{a} \mathfrak{I} \mathfrak{A} \mathfrak{n}$ ton Meyer, Finige Bemerfungen über die natürlide familie ber Jolygoneen. St. SJeterab. 1840. 4. 1 זaf.

5) Thomas Coulter, Mémoire sur les Dipsacées. Genève 1823. 4. 2 tab.

$\left.{ }^{6}\right)$ A. H. G. Graf von Cassini, Opuscules phytologiques. Paris 1826-1834. III voll. 8. - Less ing, Synopsis generum Compositarum. Berolini 1832. 8. 1 tab.

7) $\mathfrak{R}$ arl Şeinri申 SquI 1844. 4.

8) Karel Bo ̌i iwog Presl, Prodromus monographiae Lobeliacearum. Pragae 1836. 8.

-) A. Richard, Mémoire sur la famille des Rubiacées. Paris 1829. 4. 15 tab. - Weddel, Revue du genre Cinchona. (Annal. sc. nat. X) 1848. - Rectifications à la revue du genre Cinchona. (Ann. sc. nat. XI) 1849.

10) F. Marius Barnéoud, Monographie générale de la famille des Plantaginées. Paris 1845. 4.

11) Wilhelm Ebel, De Armeriae genere. Prodromus Plumbaginearum familiae. Regiomonti 1840. 4. 1 tab. - 


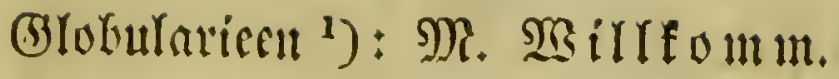

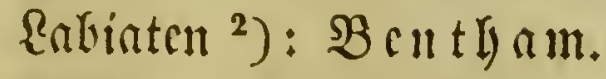

Stifbincen ${ }^{3}$ ): $\mathfrak{x} \mathfrak{u} t \mathfrak{h}$.

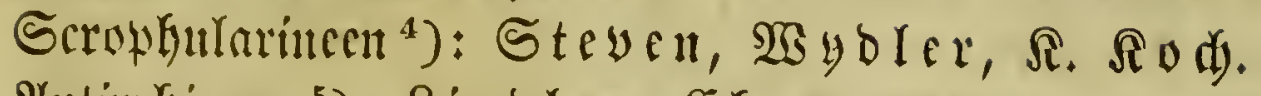

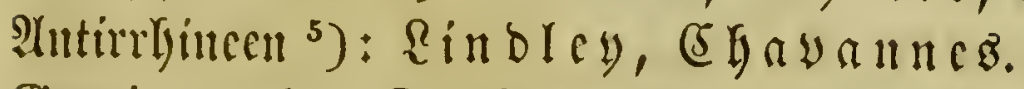

(5)entiance: ${ }^{6}$ ): (5) rifebad

Sybroleaceen "): (hotify.

Solnuen ${ }^{8}$ ): Fingerguth.

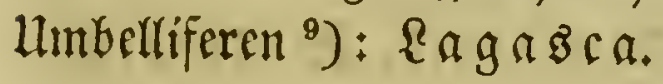

C. Friedr. Wilh. Wallroth, Monograpgie ber Battung

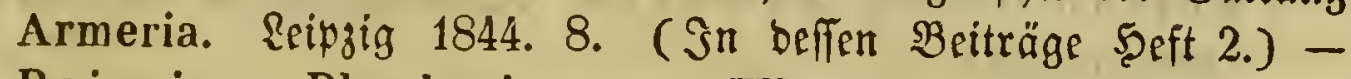
Boissier, Plumbaginaceae. (XII. $3 B_{0}$. Deß̉ Prodromus). Paris 1848.

1) M. Willkomm, Recherches sur l'organographie et la classification Globulariées. Leipsic 1850. gr. 4. 4 tab.

2) G. Bentham, Labiatarum genera et species. London $1832-1836.8$.

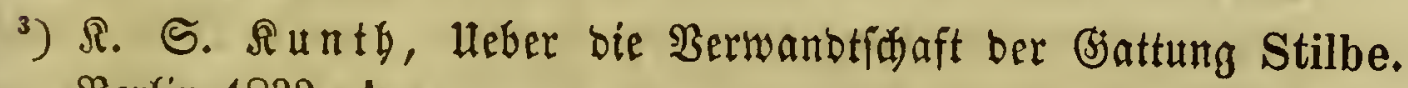
Berrin 1832. 4.

') C. Steven, Monographia Pedicularis. Petersb. 1822. 4. 17 tab. - Henry Wydler, Essai monographique sur le genre Scrophularia. Genève 1828. 4. 5 tab. - K. Koch, Monographia generis Veronicae. Wircehurgi 1833. 8.

5) John Lindley, Digitalium Monographia. Londini 1821. Fol. 28 tab. - Edouard Chavannes, Monographie des Antirrhinées. Paris 1833, 4. 11 tab.

-) A. II. R. Grisebach, Genera et species Gentianearum. Stuttgartiae 1839. 8.

i) Jacques Denis Choisy, Description des Hydroleacées. Genève 1833. 4. 3 tab.

$\left.{ }^{8}\right)$ Karl Anton Fingerhuth, Monographia generis Capsici. Düsseldorpii 1832. 8. 10 tab. col.

-) Ma ri a n o La gas c a, Dispositio Umbelliferar. carpologica. (Amenidades naturales de las Españas. Tom. I.) Madrid 1821. 4. - Observaciones sobre la familia natural de las plantas aparasoladas. (Umbelliferae). Londres 1826, 8. 


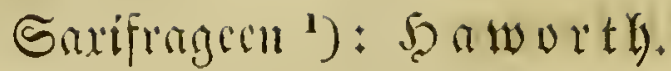

(broffularien ${ }^{2}$ ): Şerlandict.

(Sactcen ${ }^{3}$ ): Spfciffer, şfeiffer uno $\mathfrak{F}$. Dtto, MRi= ile er, Förfter.

(Sucurbitacen ${ }^{4}$ ): Seringe.

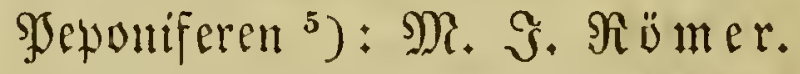

Melaftumaceen ${ }^{6}$ ): Seringe, (Sh. Randin.

Myrtacent ${ }^{7}$ ): Sdauer.

Rofacen ${ }^{8}$ ): Rindley, $\mathfrak{x}$ attinif, $\mathfrak{B a r t r o t h}$.

') Adrian Hardy Haworth, Saxifragearum enumeratio. Londini 1821. 8.

$\left.{ }^{2}\right)$ Jean Lou is Berlandier, Mémoire sur la famille des Grossulariées. Genève 1828. 8. 3 tab.

8) Routis פJfeiffer, Beforeibung und Synonymit ber in ben beutfden (3ärten vorfommenten Cancteen. Şerlin 1837. 8. Enumeratio diagnostica Cactearum hucusque cognitarum.

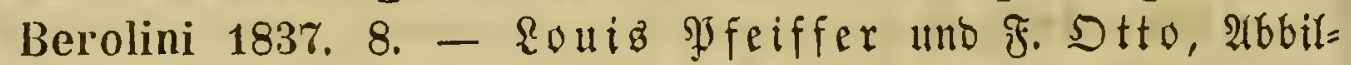
bung unb Beidreibung Glithenber Gacteen. Safiel 1842-1847. 2 3ibe. 4 . 45 \%ol. $\mathfrak{I a f}$. - F. A. W. Ml iquel, Genera Cactearum descripta et ordinata. Roterdami 1839. - $\mathfrak{R}$ arl Friebr. Förfter, Sandbud ber Eacteentunde in ibrem ganjen Hullfange 2f. Reipzig 1846. 8.

') Nic. Charl. Seringe, Mémoire sur la famille des Cucurbitacées. Genève 1825. 4. 5 tab.

3) M. J. Römer, Familiarum naturalium regni vegetabilis synopses monographicae. Fasc. II. Peponiferarum pars I. Wimariae 184.6.

") Nic. Charl. Seringe, Mémoire sur la famille des Mélastomacées. Paris 1828. 4. 10 tab. - N andin, Melastomacearum monographica descriptio. (Annal. sc. nat. Botanique. Tom XII, XIII et XIV.) $1849-1850$.

') Joh. Konr. Schauer, Monographia Myrtacearum xerocarpicarum. Sect. I. Chamaelauciearum hucusque cognitarum genera et species. Vratislaviae 1841. 4. 7 tab.

') John Lindley, Rosarum monographia etc. London 1820. 8. 19 tab. col, - Leopold Trattinik, Rosacearum monographia. Vindobon. $1823-1824$. IV voll. 8. - C. F. W. 


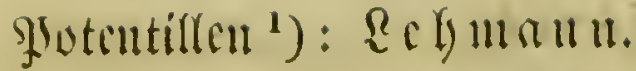

Epirem ${ }^{2}$ ): (5 a mbeffedes.

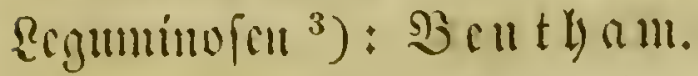

Teretinthaccon ${ }^{4}$ ): $\mathfrak{i} u t \mathfrak{h}$.

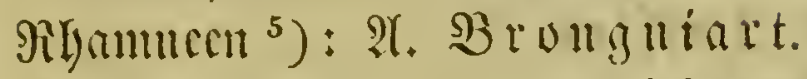

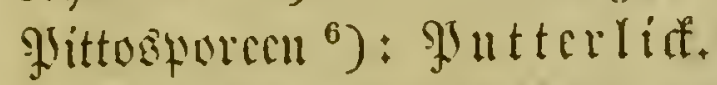

Divgmeen ${ }^{7}$ ) + D3artling mo 2 Ee

Putreen ${ }^{8}$ ): $\mathfrak{H}$ o o gufficu.

Dralioen ${ }^{9}$ ): 3 ucearini.

(5)eraniacen ${ }^{10}$ ): Sivert.

Mialpighiacrat ${ }^{11}$ ): A. be $\Im$ uffiet.

Wallroth, Rosae plantarum generis historia succincta. Nordhusae 1828. 8.

') J. G. Chr. Lehmann, Monographia generis Potentillarum. Hamburgi $1820-1835$. 4. 20 tab.

2) Jacques Cambessèdes, Monographie du genre Spiraea. Paris $182 \%$. 8. 7 tab.

3) George Bentham, Commentationes de Leguminosarum generibus. Vindobonae 1837. 4.

t) K. S. Kunth, Therebinthacearum genera. Paris 1824. 4.

5) A. Th. Brongniart, Mémoire sur la famille des Rhamnées. Paris 1826. 4. 6 tab.

') Aloys Putterlick, Synopsis Pittosporearum. Vindobonae 1839.

$\left.{ }^{7}\right)$ F. G. B artling et H. L. W end land, Diosmeae descriptae et illustratae. Goettingae 1824. 8. 2 tab.

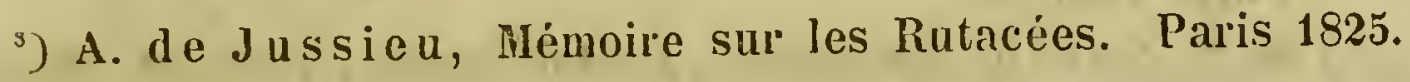
4. 16 tab.

-) Sor. Berbaro Zuccarint, Monograplie der amterifanifiden Dxariönten. Münd)en 1825.4.6 Taf. - Radytrag. München 1831. 4. 3 Iaf.

10) Robert Siveet, Geraniaceae. London 1820-1830. V voll. 8. 500 tab. col.

11) A. de Jussieu, Malpighiacearum synopsis. Paris 1840. 8. - Monographie des Malpighiacées. Paris 1843, 4. 23 tab. 
Sapilloacen $\left.{ }^{1}\right):(5 a m b e f j e ̀ d e b$.

(Erytroxileen ${ }^{2}$ ): $\mathfrak{v}$. Martiub.

Drangen ${ }^{3}$ ): Riffo und Soloteali.

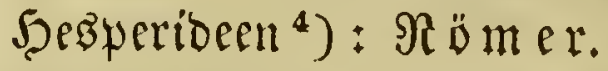

Meliaceen ${ }^{5}$ ): $\mathfrak{A}$. de $\mathfrak{\Im}$ uffifu.

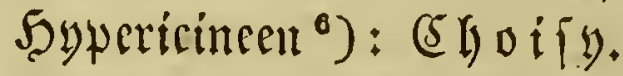

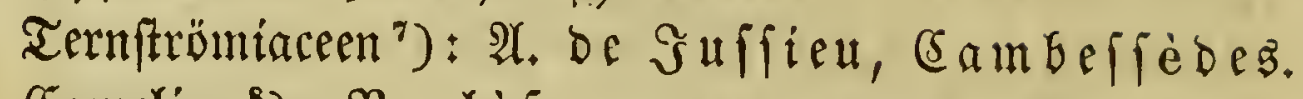
(5amelien ${ }^{8}$ ): $\mathfrak{B}$ erlè $j e$.

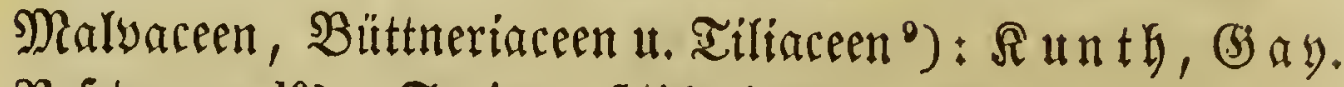
Refebacenn ${ }^{10}$ ): Saint=Şitaire.

') Jacques Cambessèdes, Mémoire sur la famille des Sapindacées. Paris 1831. 4. 3 tab.

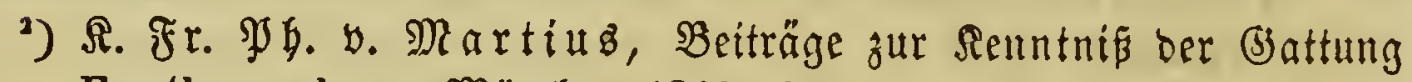
Erythroxylon. Münden 1840. 4. 10 Tafcln.

$\left.{ }^{3}\right)$ J. A. Ris so et A. Poit e a u, Histoire naturelle des orangers. Paris 1818-1819. Fol. 109 tab. col.

‘) M. J. Römer, Synopses regni vegetabilis monographicae. I. Hesperides. Wimariae 1846. 8.

$\left.{ }^{5}\right)$ A. de Jussieu, Mémoire sur la groupe des Méliacées. Paris 1830. 4. 12 tab.

-) J. D. Choisy, Prodrome d'une monographie de la famille des Hypericenées. Genève 1821. 4. 9 tab.

') A. de Jussieu, Revue des Ternstroemiacées. Paris 1824. 8. - Cambess èdes, Mémoire sur les familles des Ternstroemiacées et Guttifères. Paris 1828. 4. 4 tab.

8) La urent Berlèse, Monographie du genre Camellia. Paris 1840. 8.

-) K. S. Kunth, Malvaceae, Büttneriaceae, Tiliaceae, familiae denuo ad examen evocatae etc. Paris 1822. 8. Jacq. Gay, Fragment d'une monographie des viaies Büttnériacées. Paris 1823. 4. 4 tab. -- Monographie des cinq genres de plantes, que comprend la tribu des Lasiopétalées dans la famille des Büttnériacées. Paris 1821. 4. 8 tab.

$\left.{ }^{10}\right)$ A. F. C. S a int-Hil a ir e, Deuxième mémoire sur les Resédacées. Montpellier 1837. 4. 


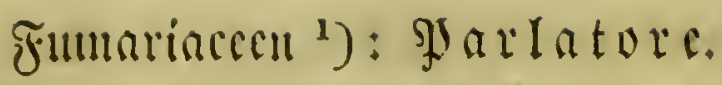

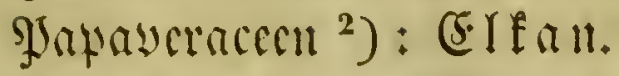

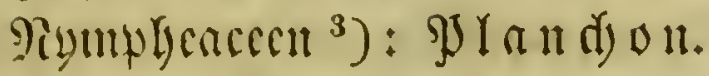

Ramunfulacren ${ }^{4}$ ) : $\mathfrak{g} r \mathrm{i}$ izel.

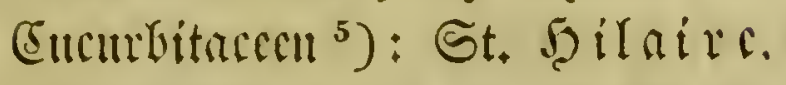

(Emplorbincen ${ }^{6}$ ): $\mathfrak{A}$, De $\Im$ uffieu, $\Re$ üper.

Die gofranzengeogranhie wurbe inglefonocre burd Dic Sdriften

\section{Gonfint Freterif Sdyan's,}

Jjrofefior ber Botanif zu Sopentagen,

meiter gefürocet ${ }^{7}$ ). (Ex ift nad yon 5 amborot bericnige, wildyer Durdy bie wifienfidaftlidje Begründung biefer Disci=

1) Filippo Parlatore, Monografia delle Fumariée. Firenze 1844. 8. 1 tab.

2) Ludwig Elkan, Tentamen monographiae generis Papaver. Regiomonti 1839. 4. 1 tab.

$\left.{ }^{3}\right)$ Planchon, Etudes sur les Nymphaeacées. (Annal. des sc. nat. Tom. XIX.) 1853.

t) Georg August Pritzel, Anemonarum revisio. Lipsiae 1842. 8. 6 tab.

5) A. F. C. St.-Hilaire, Mémoire sur les Cucurbitacées, les Passiflorées et le nouveau groupe des Nandhirobẻes. Paris 1823. 4.

${ }^{6}$ ) A. de Jussieu, De Euphorbiacearum generibus medicisque earundem viribus tentamen. Parisiis 1824. 8. 18 tab. - J. A. Chr. Röper, Enumeratio Euphorbiarum, quae in Germania et Pannonia gignuntur. Goettingae 1824. 4. 3 tab.

') Grundtraek til en almindelig Plantegeographie. Kiobenhavn 1822. 8. 1 mapp. bot. geogr. - Plantegengraphisk Atlas Henhörende till Sammes Grundtraek til en almindelig Plantegeographie. Kiöbenhavn 1824. Fol, 22 mapp. bot. 
Win fird bas meifte Berbienft arwurben gat. - F. A, yun

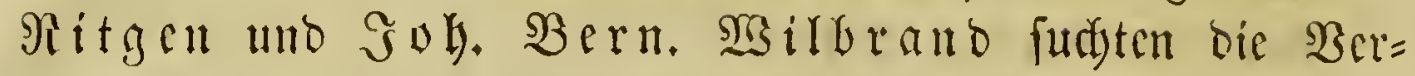

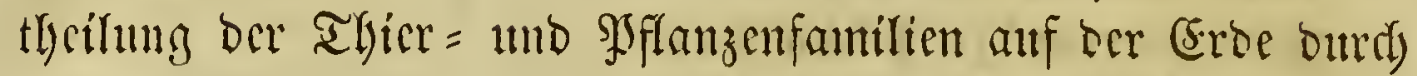
cine Sarte, weldyer fie cinc näbere Ereflärung beifügten, zu

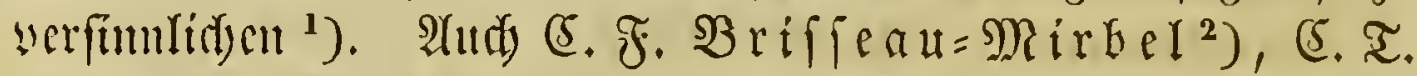

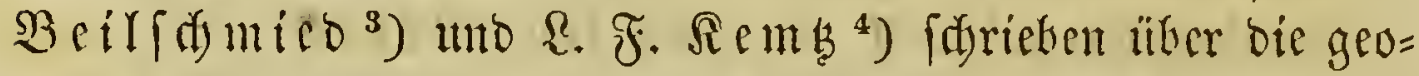

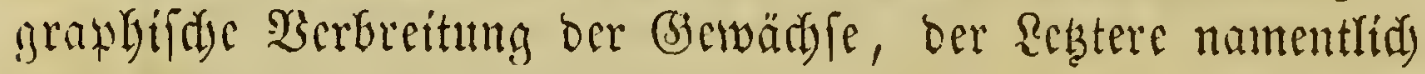
mudi) über bie cinfliffe, welde bas Sima, die Temperatur

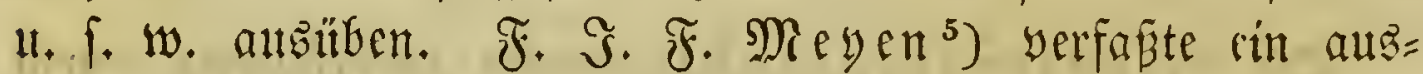

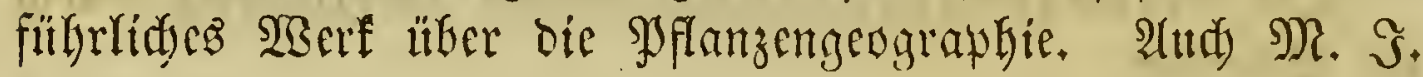

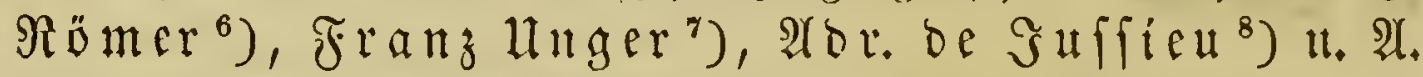

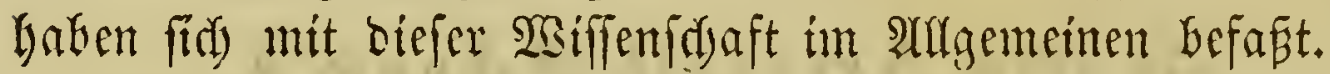

Dic geograwhifdse Berbreitung ber Syflanzen in eingelnen Rändern wurbe in vielen ber oben angefüfrten froren Gerï

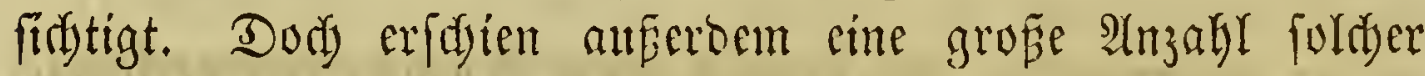

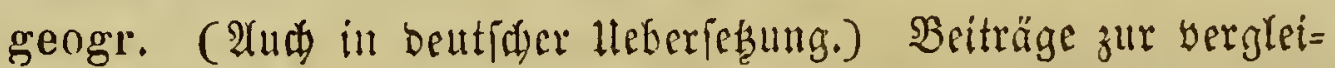

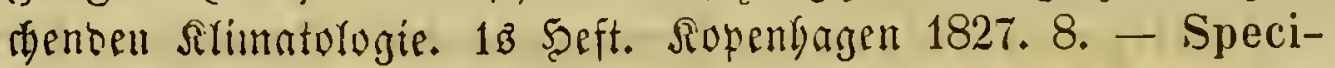
men geographiae physicae comparativae. Havniae 1828. 4. 3 tab. - Europa, en let fattelig Naturskildring. Kjöbenhavn 1832. S. - 1835. 8. Ilttaz mit 8 Iafelu. - Deutid: Sopentingen 1833. 8.

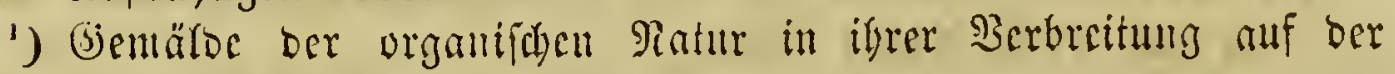
(Grbe. (Bïep̃en 1822.

$\left.{ }^{2}\right)$ Mém. du mus. d'hist. nat. tom. XIV. $182 \%$.

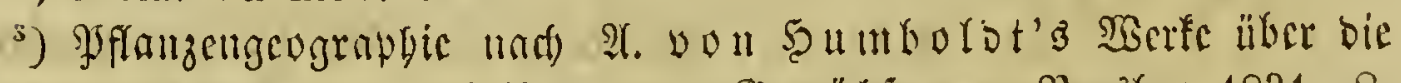

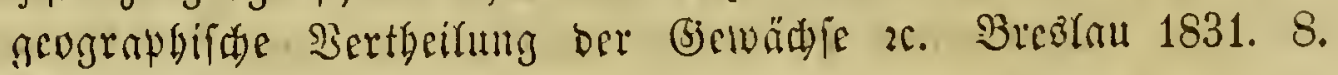
1 mapp. isogeotherm.

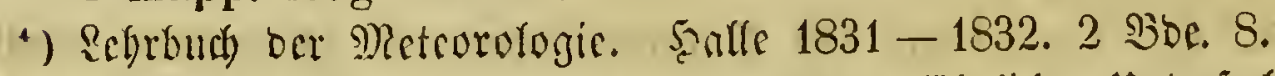

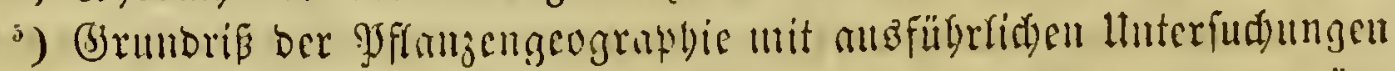

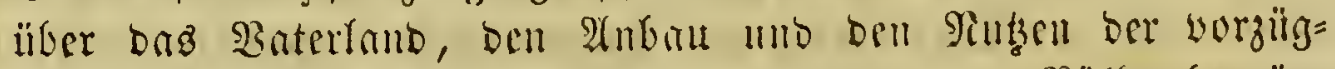

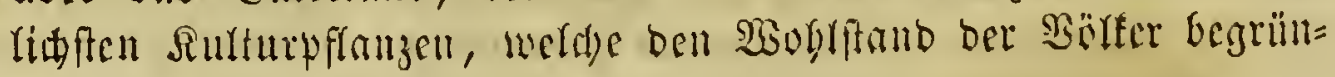
ben. Sierlin 1836. 8. 1 Iaf.

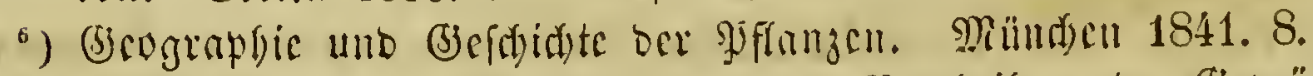

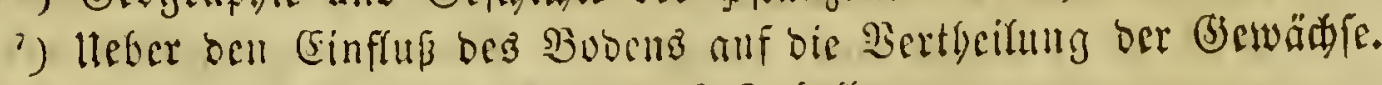
MBien 1836. 8. 2 Sarten unb 6 Tabellen.

8) Géographie botanique. Paris 1845. 8. 


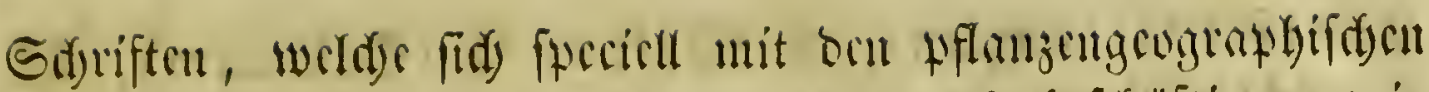

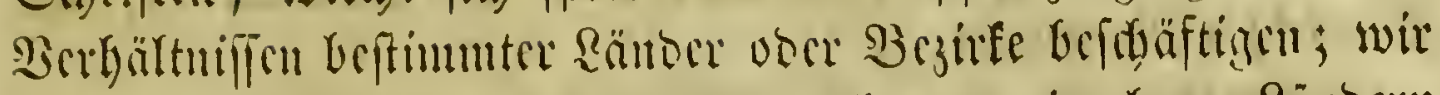

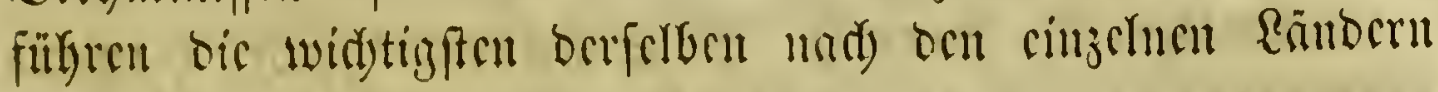
gevionet bier auf.

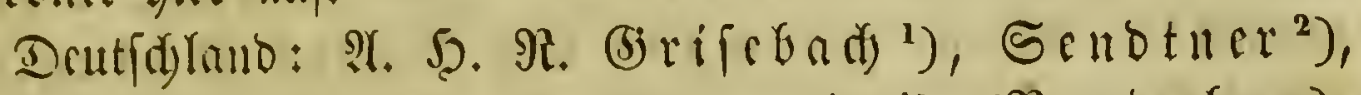

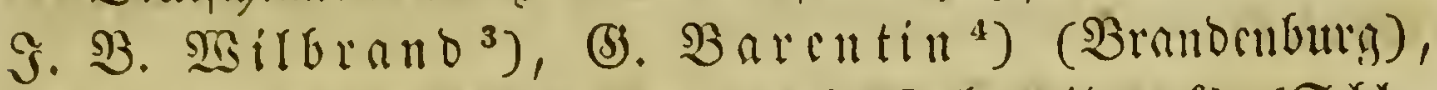

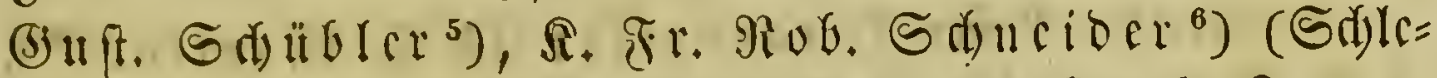

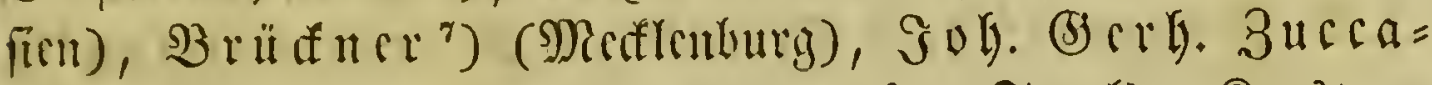

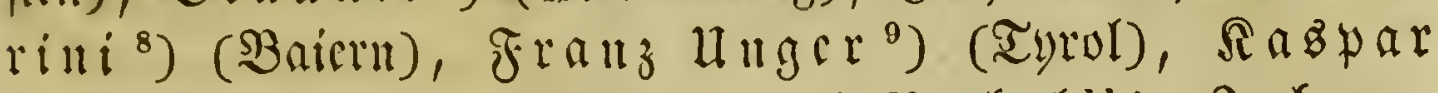

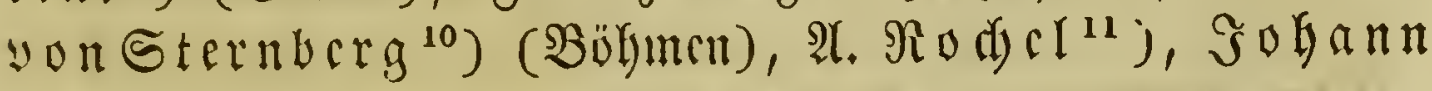

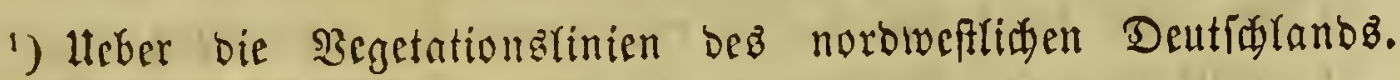
(j)̈̈ttingen 1847. 8.

$\left.{ }^{2}\right)$ Beobadtungen won 5öbengrenjen fordyer planerogamijalen Sflan= zen, werde in ben 5oderbenen Mitndens vorfomment in ben

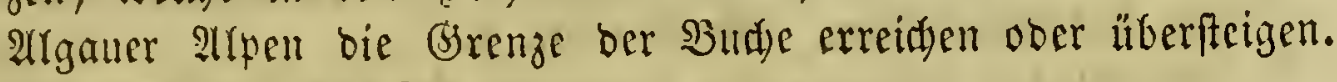
(fiora 1849. No. 8.)

3) Bot. 3eit. 1824. Beil. S. $1-74$.

') Die $\mathfrak{B}$ egetatiun ber Marf $\mathfrak{B r a m b e n b u r g . ~ B e r f i n ~ 1 8 4 0 . ~} 4$.

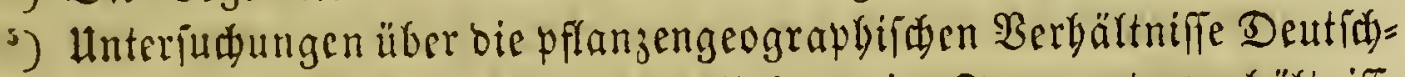
Ianos. Tübing. 1827. 8. - Heler bie Temperaturverlältniffe

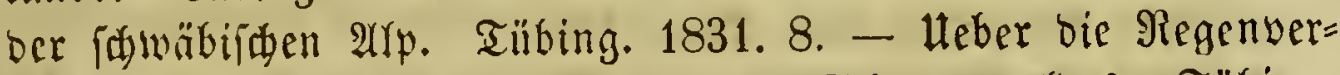

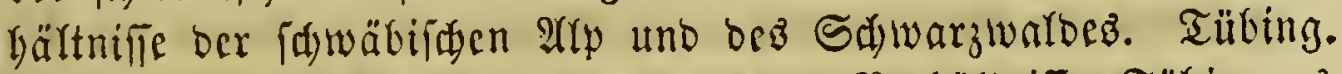
1832. 8. - Heber bie geognofif Tübing. 1832. 8.

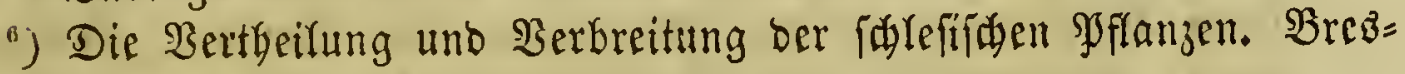
lau 1838. 8.

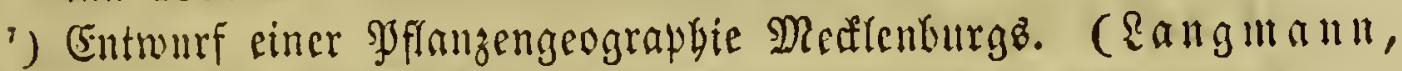
Slora von Medflenburg. Reuftrelit 1841. 8.)

$\left.{ }^{3}\right)$ Lleber bie Begetationżgruppen in $\mathfrak{B a i c r n .}$ Münden 1833. 4.

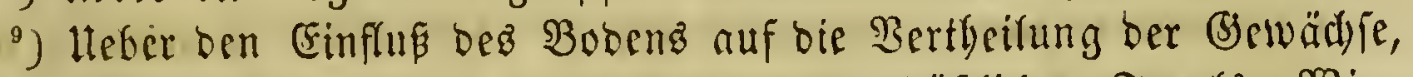

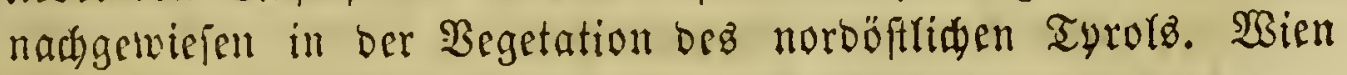
1831. 8.

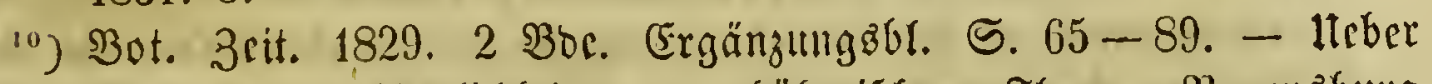

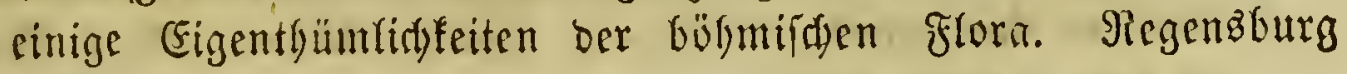
1829. 8.

1') Tractatus phytogengraphicus. (Plantae Banatus rariores.) Pesthini 1828. Fol. 


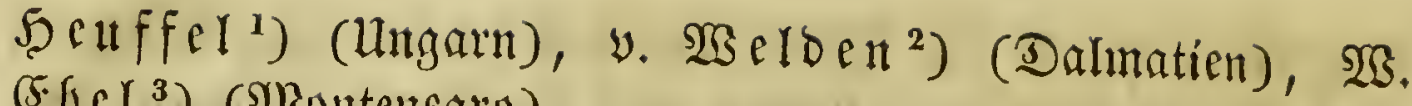

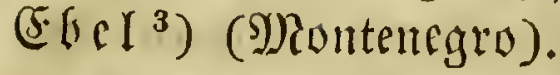

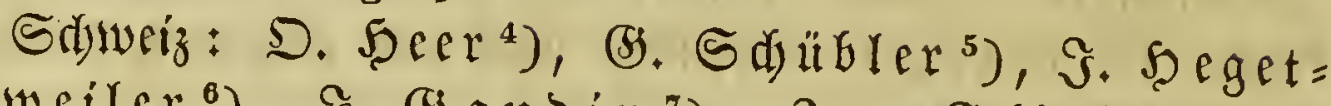

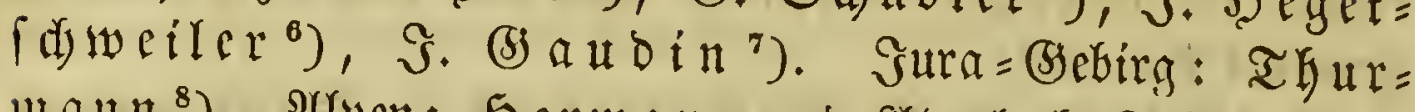
man ${ }^{8}$ ). SAlpen: Şermann mo Adolph Sdlagint= weit. ${ }^{9}$ )

Franfreidy: :Heper Decandorle: (5h. F. Martins ${ }^{10}$ ), $\left.\mathfrak{J} \cdot \mathfrak{B} . \mathfrak{M o u g e o t}{ }^{11}\right), \mathfrak{A} . \mathfrak{R}\left\{\int_{\mathfrak{o}^{12}}\right), \mathfrak{R} . \mathfrak{A}$. De $\mathfrak{B r}$ ébiffon $\left.{ }^{13}\right)$,

1) De distributione plantarum geographica per comitatum pestiensem. Pesthini 1827. 8.

$\left.{ }^{2}\right)$ Bot. 3eit. 1830. BD. I. (S. $193-206$. S. $214-221$ ).

3) Swoilf Trige auf Montenegro. II. Şeft. Rönigaberg 1844. 8.

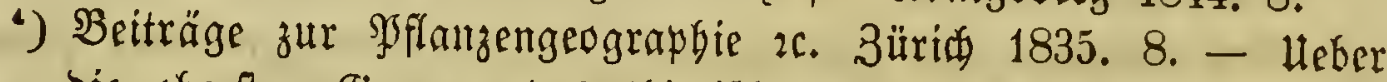
bie oberften Brenzen bes thierifuen und pflangliden Rebenz in ben Sdyeigrafper. Bürid 1845. 4.

3) Dissertatio inauguralis botanica de distributione geographica plantarum Helvetiae. Tübing. 1823.

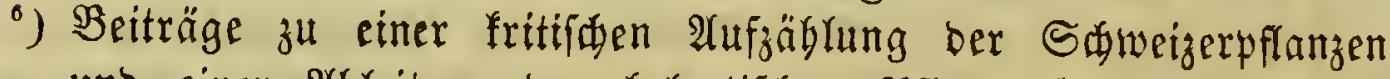
uno einer Ableitung ber Gerbetifaen Sfflanzenformen yon ben

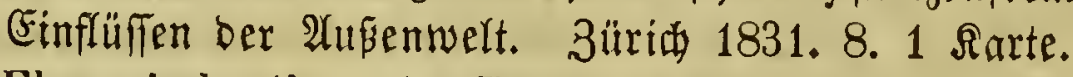

?) Flora helvetica etc. Tom. VII.

$\left.{ }^{8}\right)$ Essai de Phytostatique appliquée à la chaîne du Jura et aux contrées voisines. Berne 1849. II voll. 8.

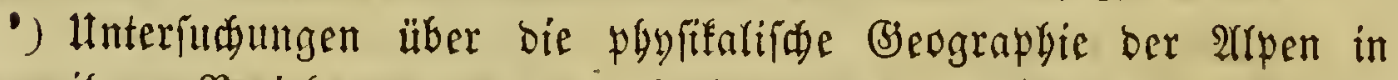

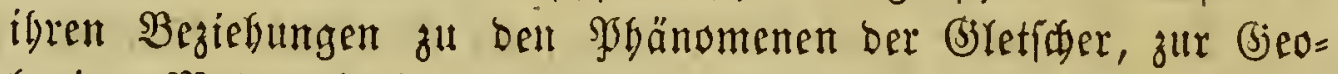
logie, Meteorologie und Sffanzengeograpbie. Reipzig 1850. 8. 11 Iaf. 2 Rarten.

1.1) Essai sur la météorolngie et la géographie botanique de la France. Paris 1845. 8.

11) Considérations gẻnérales sur la végétation spontanée du dép. des Vosges. Espinal 1845. 8.

13) Histoire naturelle des principales productions de l'Europe méridionale et particulièrement de celles des environs de Nice et des alpes maritimes. Paris 1826-1828. 5 B̧ø. 8. 46 tab. 2 cart. geol.

13) Coup d'oeil sur la végétation de la Basse-Normandie. Caean 1829. 8. 


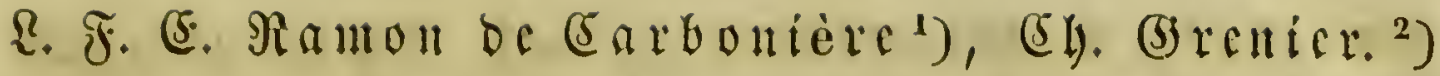

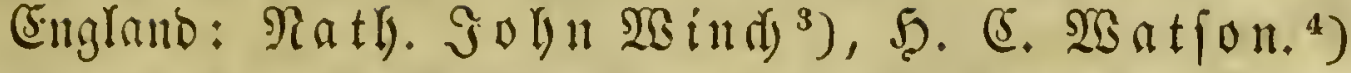

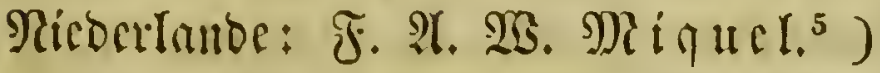

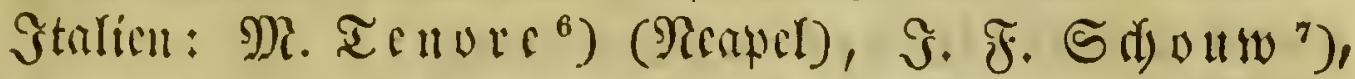
S. Scubcri $i^{8}$ ) (Sicilicu), A. N. Decandolle ${ }^{9}$ ) ( Stalicu

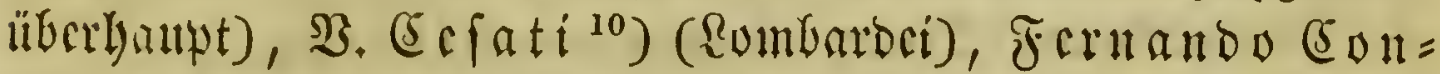

1) Voyage au mont Perdu et dans la partie adjacente des Hautes-Pyrénées. Paris 1811. 8. - 1teber bie Begetation Des Giłpfelz bez Yjic bu Midi in ben Yyyrenäen. (Mém. du mus. d'hist. nat. vol. XIII. 1827. p. 217.)

$\left.{ }^{2}\right)$ Tbèse de géographie botanique du dép. du Doubs. Strasbourg 1844. 8.

$\left.{ }^{3}\right)$ Essay on the geographical distribution of plants trough Northumberland, Cumberland and Durham. Newcastle 1819. 8. Ibid. 1825, 8. - Deutid von R. T. Beilfamieb. (Flora Bb. 1. 1837. S. $289-317)$.

t) Outlines of the geographical distribution of british plants. Edinburg (1832). 8. - Remarks on the geographical distribution of british plants. London 1835. 8. - De $\mathfrak{A} f \mathfrak{f}$ yon ふ. T. Beilf distribution of british plants. Ed. III. Part. I. London 1843. 8. - Cybele britannica: or british plants and their geographical relations. Part. 1. Lond. 1847. 8.

5) De plantarum regni batavi distributione. Lugdun. Bat. 1837. 8.

$\left.{ }^{6}\right)$ Cenno di geografia fisica e botanica del regno di Napoli. Napoli 1827. 8. 2 cart.

') Tableau du climat et de la végétation de l'Italie etc. Vol. I. Copenhague 1839. 4. 5 cart.

3) Trattato dei boschi dell Etna. (Atti dell' acad. Gioenia di sc. nat. t. I. 1825. p. $41-80$. p. $241-292$.)

-) Notice sur la géographie botanique de l'Italie. (Genẻve 1835.) 8.

$\left.{ }^{10}\right)$ Saggio su la geografia botanica della Lombardia. Milano 1844. 8. 
(cutinv $)$, (5. (b) cilient).

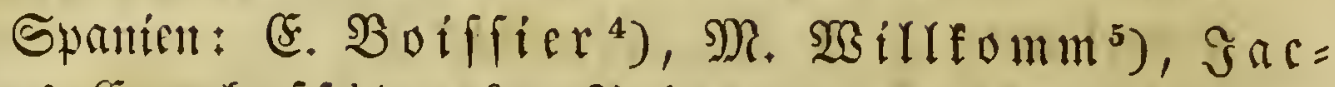
qué (5ambeffèdeg ${ }^{6}$ ) (2̧alearem).

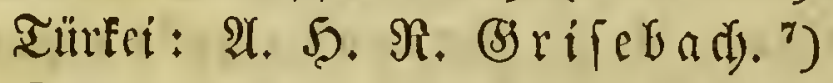

(Brictyenland: $B$ ory de Saint $=$ Bincent. ${ }^{8}$ )

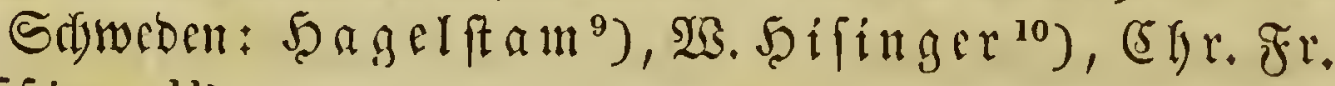
Refititg. $\left.{ }^{11}\right\}$

Norwegen: (Shy, Fr. Martinb. ${ }^{12}$ )

1) Saggio di topographia botanica della campagna detta l'Arena di Catania. (p. 148-170.)

$\left.{ }^{2}\right)$ Cenno sulla vegetazione di alcune piante a varie altezze ilel cono dell' Etna. (t. IV. 1830. p. 77-86.) 1 cart.

$\left.{ }^{3}\right)$ Iteber die Begetation deż 2 (etna. (Linnaea $\mathfrak{B}$. VII. 1832. S. 727 - 764.) 1 tab. col.

') Voyáge botanique dans le midi de l'Espagne. Paris 1839 1845. 4. tab. col.

5) Die Strand = und Eteppengebiete Der iberifwen Şaltinjel und Deren $\mathfrak{S e g e t a t i o n . ~ M i t ~ e i n e r ~ g e o g n o f t . ~ b o t . ~ R a r t e . ~ R e i p z i s ~ 1 8 5 2 . ~} 8$.

-) Knumeratio plantarum in insulis Balearibus earumque circa mare mediterraneum distributio geographica. Parisiis 1827.8.

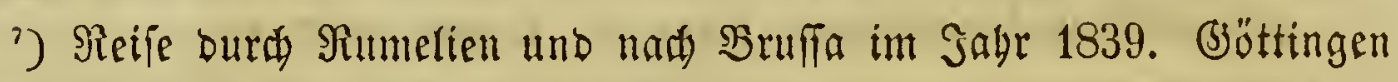
1841. 2 Bbre. 8.

${ }^{8)}$ Nouvelle flore du Péloponnèse et des Cyclades, entièreinent revue etc. Paris 1838. Fol, 42 tab.

") Heber die Region bez elwigen Sqneez in Rorwegen und Sawe= ben. (Bot. Riteraturbl. 36. II. 1829. S. 38-44).

${ }^{10}$ ) Antekningar i Physik och Geognosie under Resor uti Sverige och Norrige. 5 Häftet. Stockh. 1831. 8.

11) Reife Dura Rorwegen nad Den Roffoden, Durd Rapplano unb

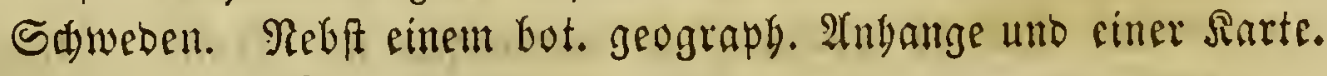
Berlin 1831. 8.

13) Voyage botanique le long des côtes septentrionales de la Norvège, depuis Drontheim jusqu'au Cap Nord. Paris 1845.8. 


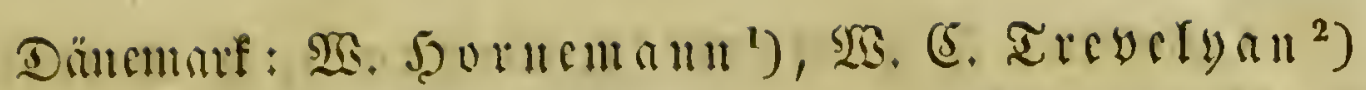

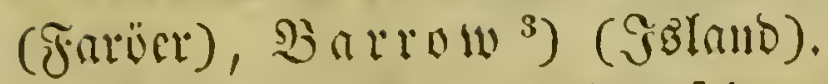

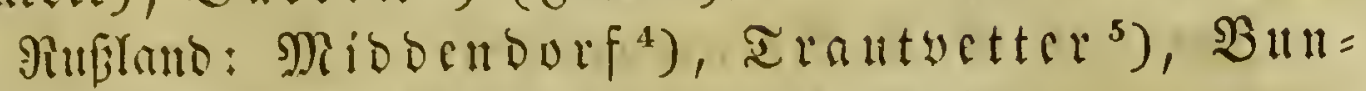

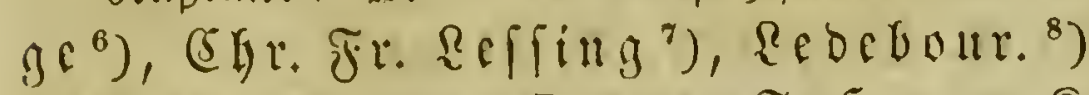

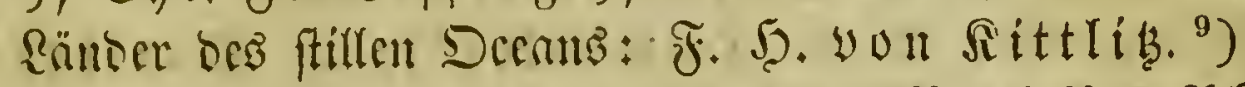

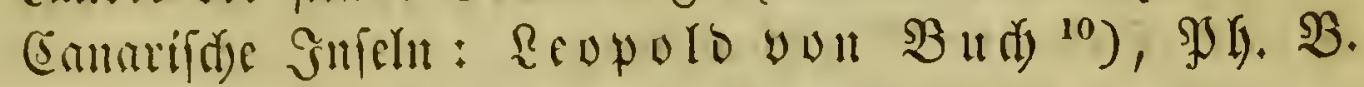

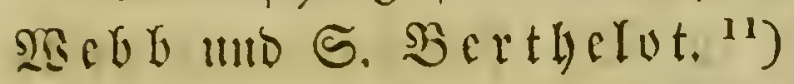

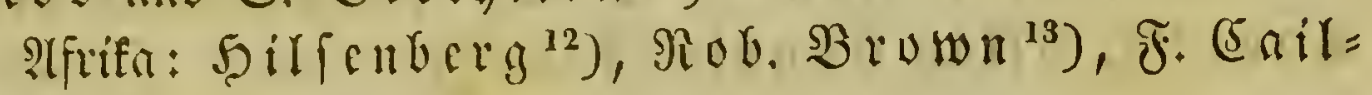

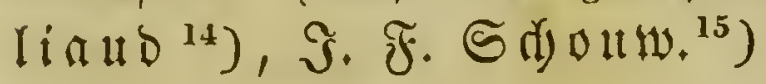

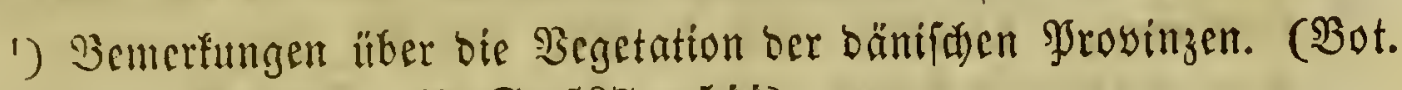
3eit. 1825. Sb. II. S. $537-544$ ).

$\Rightarrow$ On the vegetation and temperatur of the Faroe Islands. Florence 1837. 4.

$\left.{ }^{3}\right)$ Visit to Iceland in the summer of 1834 . London 1835.

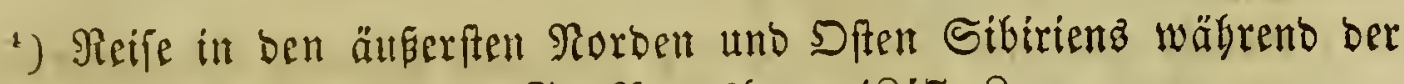
Sabre 1843-1844. St. Soeterßburg 1847. 8.

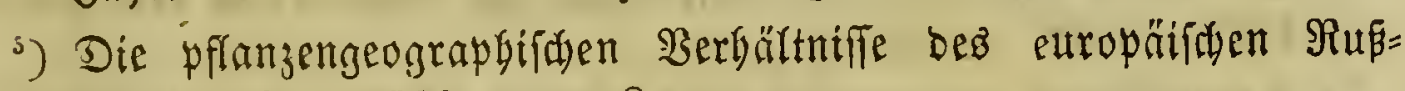
lanbz. Riga 1849 seqq. 8.

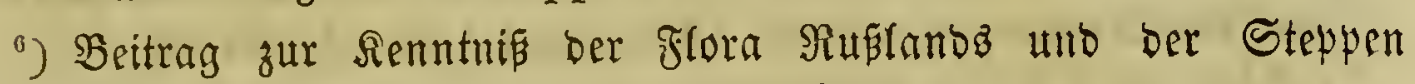
(Sentral =2 2fienz. Seteräburg 1851. 4.

¡) Linnaea. Bd. IX. 18:3\%. (S. 145-213.)

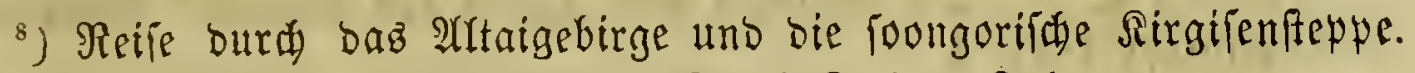
Berfin 1829 - 1830. 2 İfle. 8. 12 Taj. q. Fol.

9) Sierunbswanzig Begetationzanfithten yon Süfen und Snfeln bes frillen Sceans. Siegen 1844-1845. 4.

10) Autgemeine Heberfibt ber Flora auf Den canariftẹen Snjern. Bers lin 1819. 4.

i') Géographie botanique des îles Canaries. Paris 1840. 4. (1r Thgr.)

$\left.{ }^{12}\right)$ Nouv. annales des voyages. Flor. 1829.

13) Siege oben befien Sariften.

14) Voyage à Méroé, au fleuve blanc etc. Paris 1823-1827. 8. ( $4 \mathrm{r} \mathfrak{T} \mathfrak{l l}$.)

$\left.{ }^{15}\right)$ Naturbistorisk tidsskrift. 1836. (p. 1-9.) 


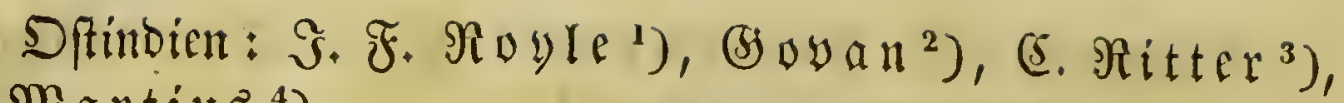

y. $\mathfrak{M} \mathfrak{a r}$ tius. $\left.{ }^{4}\right)$

Эaya: (5. (5. (5. Reiniwarbt. ${ }^{5}$ )

Rorbamcrifa: (5). Dubch ${ }^{6}$ ), $\mathfrak{T}$. Flint. ${ }^{7}$ )

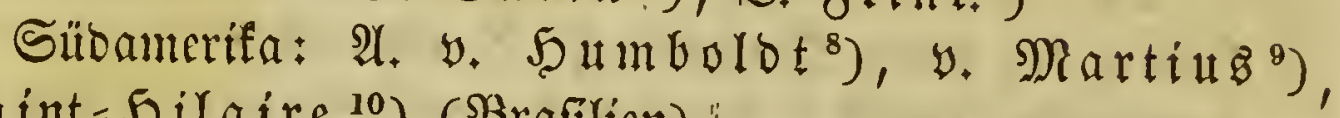
Saint $=5$ Silaire ${ }^{10}$ ) (B̈rafilicn)."

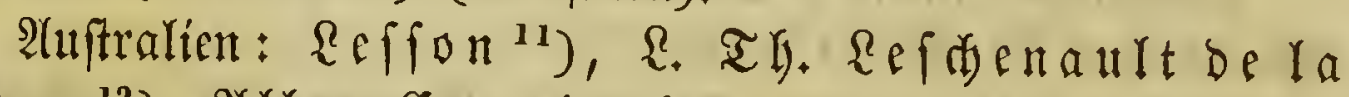

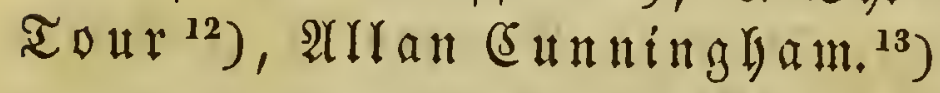

1) Illustrations of the botany and other branches of natural history of the Himalayan mountains and of the flora of Cashmere. London 1833. Fl. Fol. Mit fol. Taf.

2) Brewster's Edinb. journ. of science, Tom. II.

3) Grbfunbe von affien. 2r $\mathfrak{r}$ b. Berlin 1833.

4) Autgem. bot. 3eit. 1834. Bb. 1. (S. 1-16.)

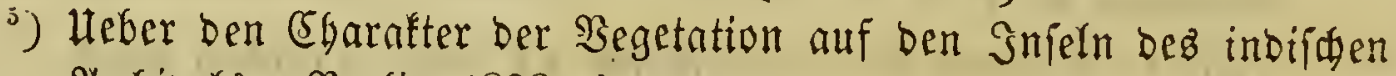
2trdjipels. Serlin 1828. 4.

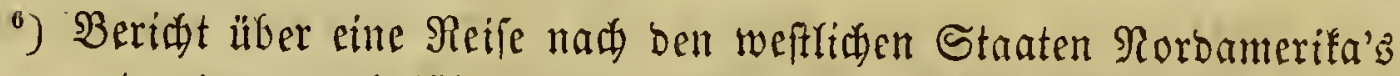
und einen melriäbrigen 2lufenthalt am Miffouri in ben Sabren 1824-1827. Estherfero 1829. 8.

') A condensed geography and history of the western states of the Missisippi valley. Cincinnati 1828. 2 Bbe. 8.

$\left.{ }^{8}\right)$ Siele oben befiten Sariften.

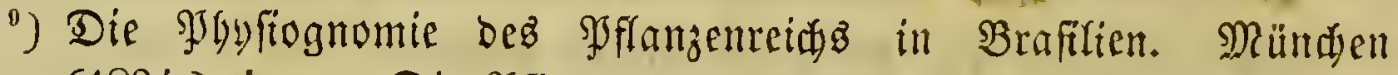

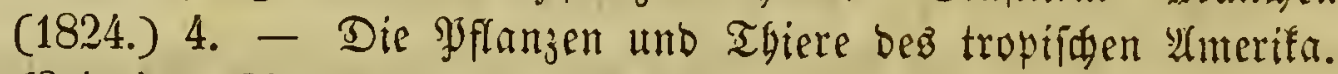
(Reipzig) 1831. 4.

10) Tableau de la végétation primitive dans la provincè de Minas Geraes. Paris 1837. 8.

11) Supplément à l'hist. nat. de Buffon. (Ann. des sc. nat. t. IV. p. 241.)

$\left.{ }^{12}\right)$ Notice sur la végétation de la Nouvelle-Hollande et de la terre de Diemen. Paris 1824. 8.

13) Botany of the mountain country between the colony round Port Jackson and the settlement of Bathurst. (Fields Geographical Memoirs on New Sud Wales. London 1825. 8. -Deut f h : Linnaea 1827.p. 120-144.) - General remarks on the vegetat. of Terra australis. (King: Narrative of a survey of the coasts of Australia. Lond. 1827. 8. - Dent fd : yon Beirfamied, flora, Riteraturberidt II. 1829. S. 1-37). 


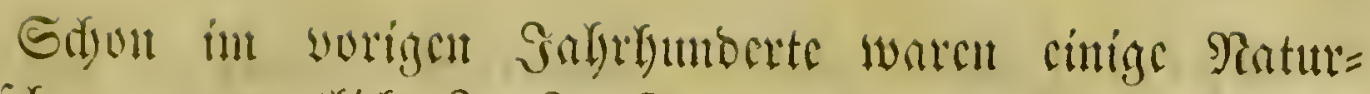

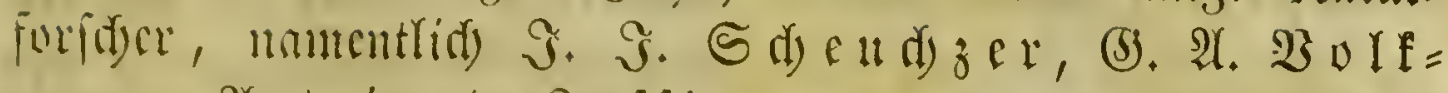

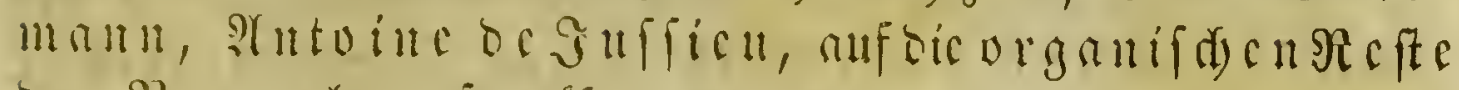

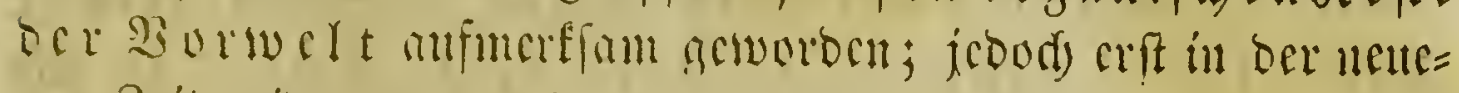

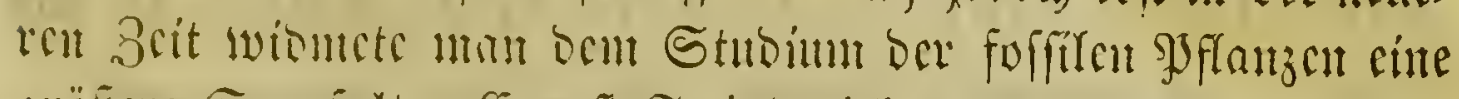

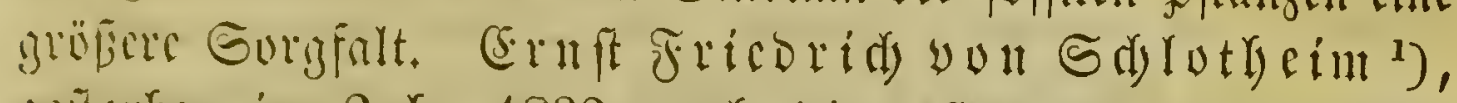

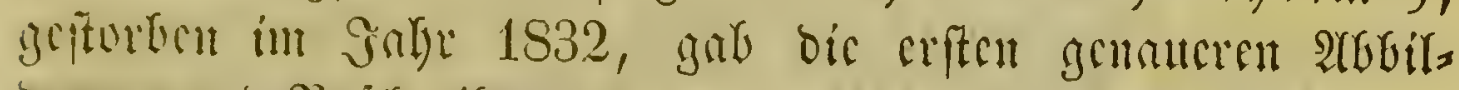

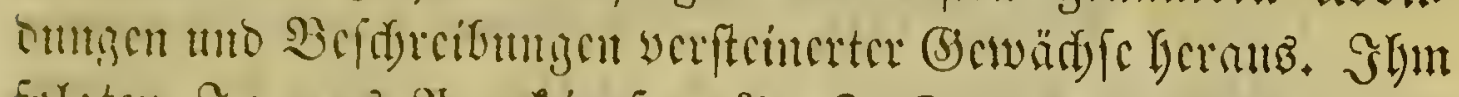

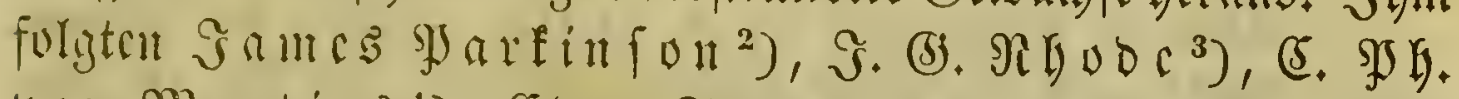

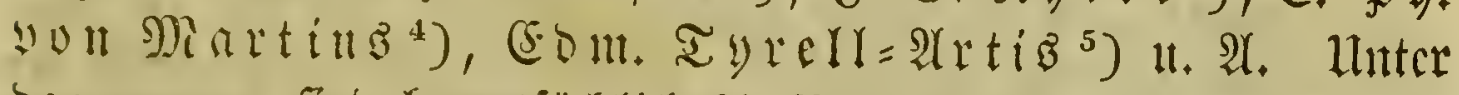

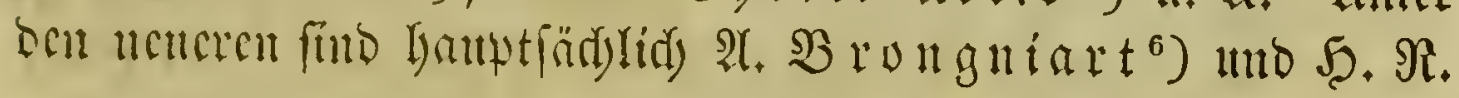

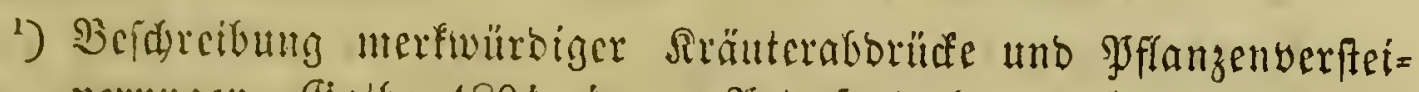
nerungen. (jotta 1804. 4. - SJetrefactenfunbe. (Sot)a 1820. 4.

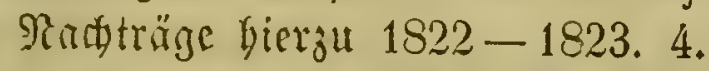

$\Rightarrow$ Organic remains of a former World. London 1811. 3 Bbe. 4. 11 tab.

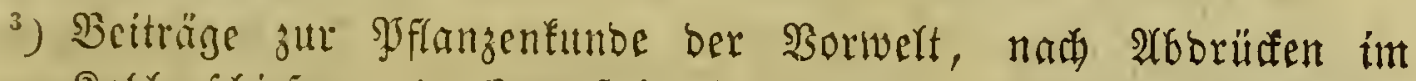
Soblenfdiefer uno Sanbftein in fajlefifden Steinfoblenwerfen. Reipzig 1820-1823. Fol. 10 for. Taf.

t) De plantis nonnullis antediluvianis, ope specierum inter Tropicos nunc viventium illustrandis. Ratisbonnae 1821, 4. 2 tab.

5) Antediluvian Phytology, illustrated by a collection of the fossil remains of plants, peculiar to the coal formation of Great Britain. London 1825. 4.

$\left.{ }^{6}\right)$ Sar la classification et la distribution des végétanx fossiles. Paris 1822. 4. 6 tab. - Observations sur les végétaux fossiles renfermés dans les grès de hoer en Scanie. Paris 1825. 8. 2 tab. - Considérations générales sur la nature de la végétation qui ćouvrait la surface de la terre aux diverses périodes de la formation de son écorce. Paris 1828. 8. - Prodrome d'une histoire des végétaux fossiles. Paris 1828. 8. - Histoire des végétaux fossiles ou recherches botaniques et géologiques sur les végétaux renfermés dans les diverses couches du globe. Paris 1828-1837. II voll. 4. 194 tab. - Consilérations sur la nature des végétaux, qui ont couvert la surface de la terr'e aux diverses époques de sa formation. Paris 1838. "4. 


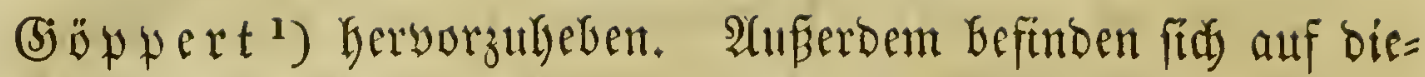
fen 3̧weig Der Botante fid bezieldende Mittheilutgen in ben

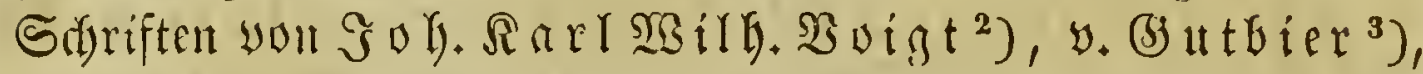

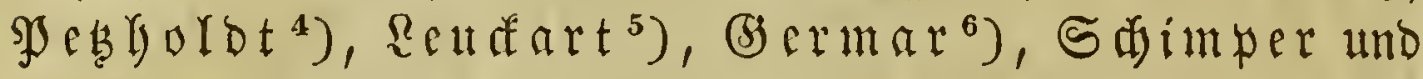

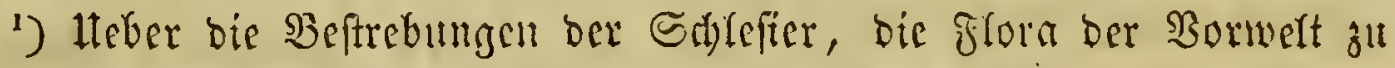
erräutern. Şreß̊la 1834. 8. - Systema Filicum fossilium. Breslau et Bonn 1836. gr. 4. 44 tab. - Heber ben 3uftand,

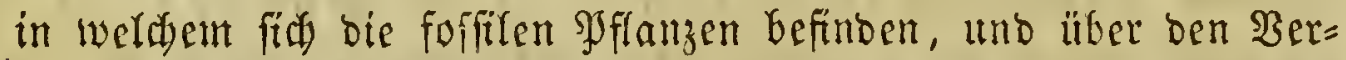

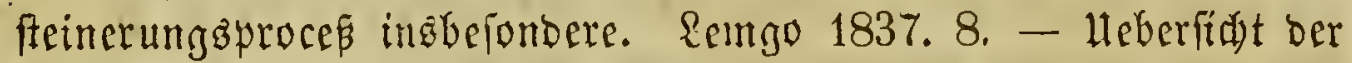

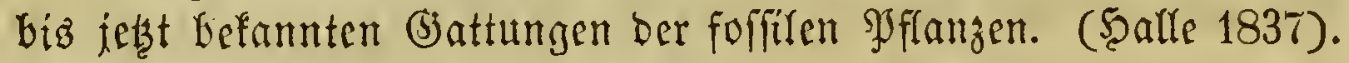
8. - De floribus in statu fossili. Commentatio botanica. Vratislaviae 1837. 4. 2 tab. - Heber bie foffite flora bes

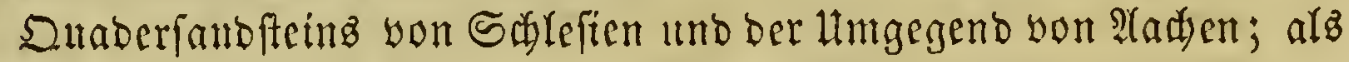
erffer und zweiter Beitrag zur Flora der Tertiärgebilbe. Breaglaut 1841. 4. 9 Taf. - Heber bie fofifie Flora ber (5)ypgformation

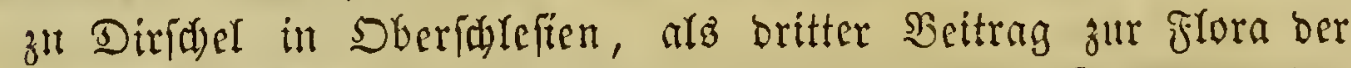
Tertiärgebifoe. B̧resłau 1842. 4. 2 Taf. - Die (3)attungen ber

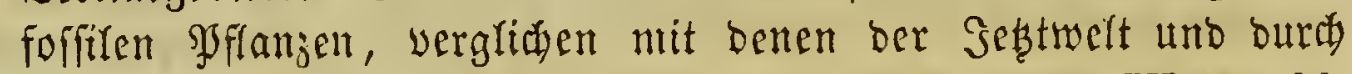
Nebbiroungen ertäutert. Bonn 1841 - 1845. Fasc. I - VI. 4. obl.

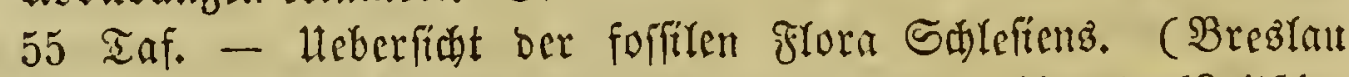
1844.) 8. - Heber bie filora bes Hebergangaggebirges. (Zeitianr. ber bentfit. geolug. (Befellifi. 1851. 5eft. 2.) - 3ur flora ber Bramfohlenformation. (B̧ot. 3eit. 1848. S. 161 ff.) $-\mathfrak{S n} \mathfrak{3 e r}=$

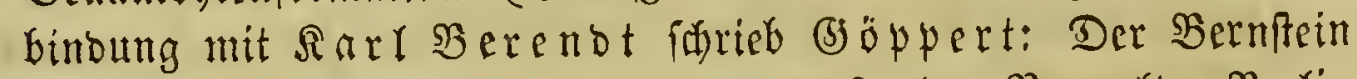

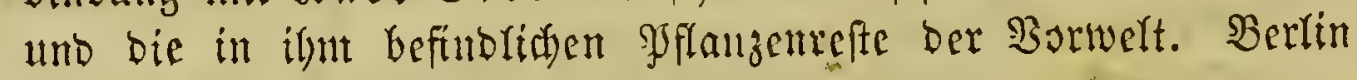
1845. Fol. 7 tab. pro parte col.

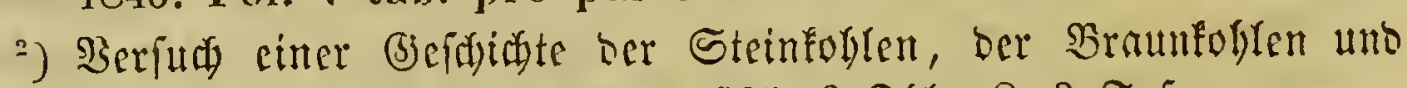
Des Torfa. TScimar $1802-1805.2$ Thle. 8. 3 Taf.

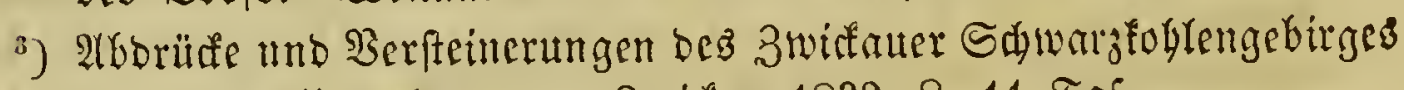

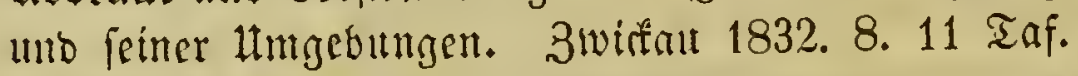

4) Heber Salamiten und Steinfollenbifoung. Dresben und Seipsis 1841. 8. 8 Iaf.

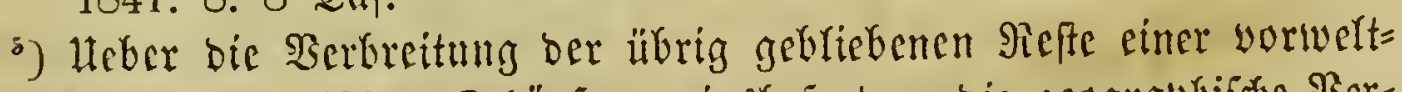
riden organifden Edyöpfung, inzbeionbere bie geographifase Ber= breitung berferben int Bergleid) mit ben nody icetert exiftirenden organifaen \$sefn. Freiburg im Breisgat 1835. 4.

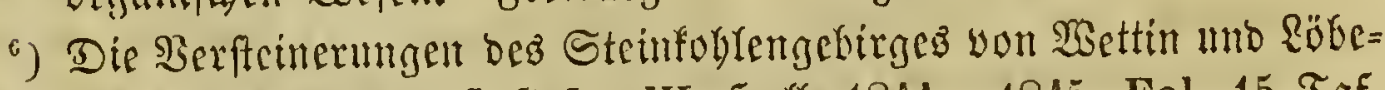
jüt im Saaffreiff. Sefft I - III. Şâfe 1844-1845. Fol. 15 Iaf. 


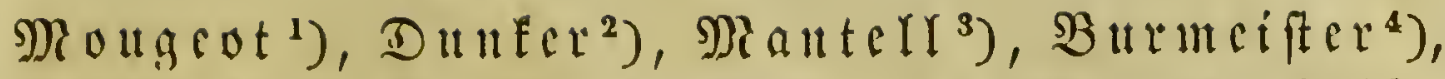

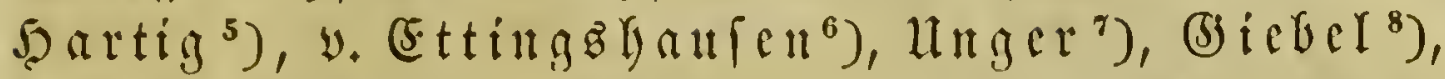

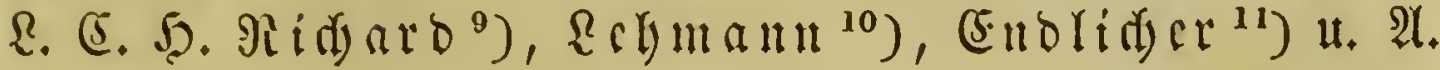

1) Monographie des plantes fossiles du grès bigarré ( $\mathfrak{B} u n t$. famb(trim) des Vosges. Leipzig 1844. 4. 40 tab. col.

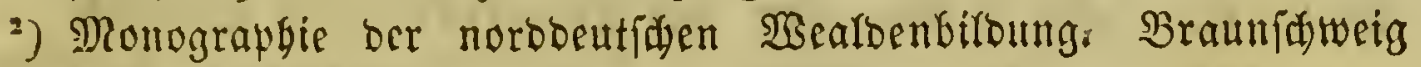
1846. 4. 6 Iaf.

3) The medals of creation etc. London 184\%. II voll. 8. Dentf由: Die Denfmünjer ber Sajopfing, ober erfter Hnter=

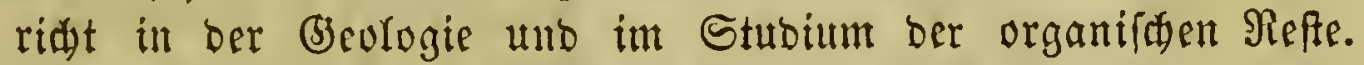

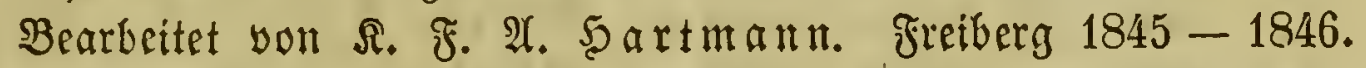
2 Bodin. 8.

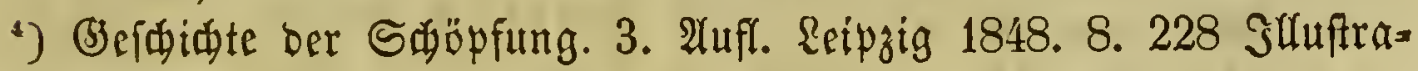
tionen.

s) Beiträge zur (Befđidjte ber Mflanzen und zur Renntnif ber norb= beutjayen Braunfoglenflora. (Bot. 3eit. 1848. S. 122 ff. 137 ff. 166 fif. 185 fi.)

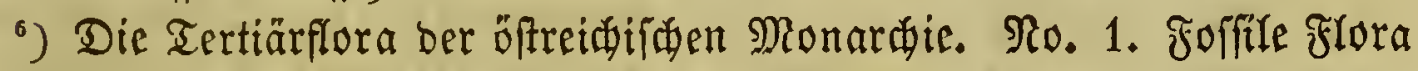
von \$sien. Wien 1851. Fol. 5 Taf.

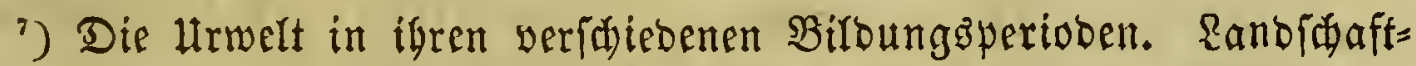
Yide Darftellungen mit erfäuterndem Tert. WBien 1850. gr. 4. Attaż: 14 Brätter quer fol.

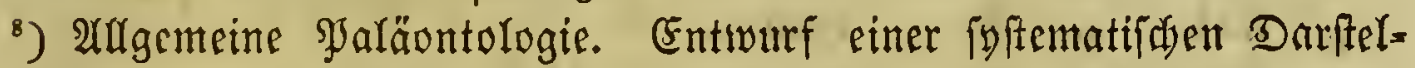
lung ber Fauna uno flora ber Borivelt. Leipzig 1852. gr. 8.

') Commentatio botanica de Coniferis et Cycadeis. Opus posthum. ab Achille Rich ard filio, perfectum et in lucem editum. Stuttgartiae 1826. Fol. min. 30 tab.

${ }^{10}$ ) De plantis Cycadeis, praesertim Africae australis. Hamburgii 1834. Fol. 5 tab. col.

i') Synopsis Coniferarum. Sangalli 1847. 8. 


\section{$\mathfrak{V} \mathfrak{e} \mathfrak{b} \mathfrak{e}\{\mathfrak{f} \mathfrak{x} \| \mathfrak{g} \mathfrak{u}$}

Seite 92, 3eile 2 yon oben lies francisco ftatt Franjizlo.

" 111 " 14 "unten "Dberftieutenants ft. Dber= lientenantis.

" $124 " 13$ " vben " Sacob fr. Socob.

" 154 " 4 " " "Bol famer fit. Bolfamer.

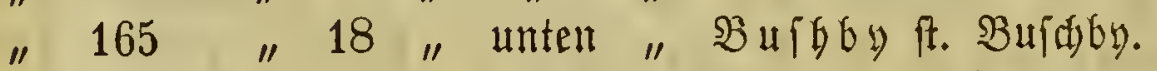

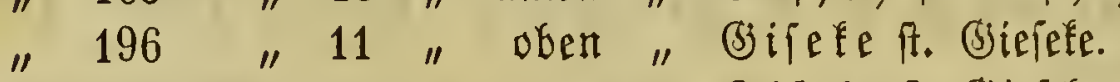

" 203 " 16 ". " "Bifefe fit. Bieféfe.

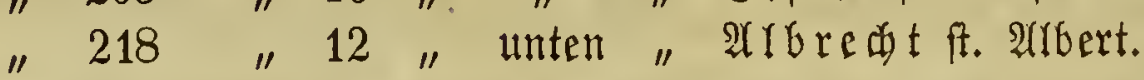

" $220 " 5$ " " 5 " umbelliferarum fr. umbellifarum.

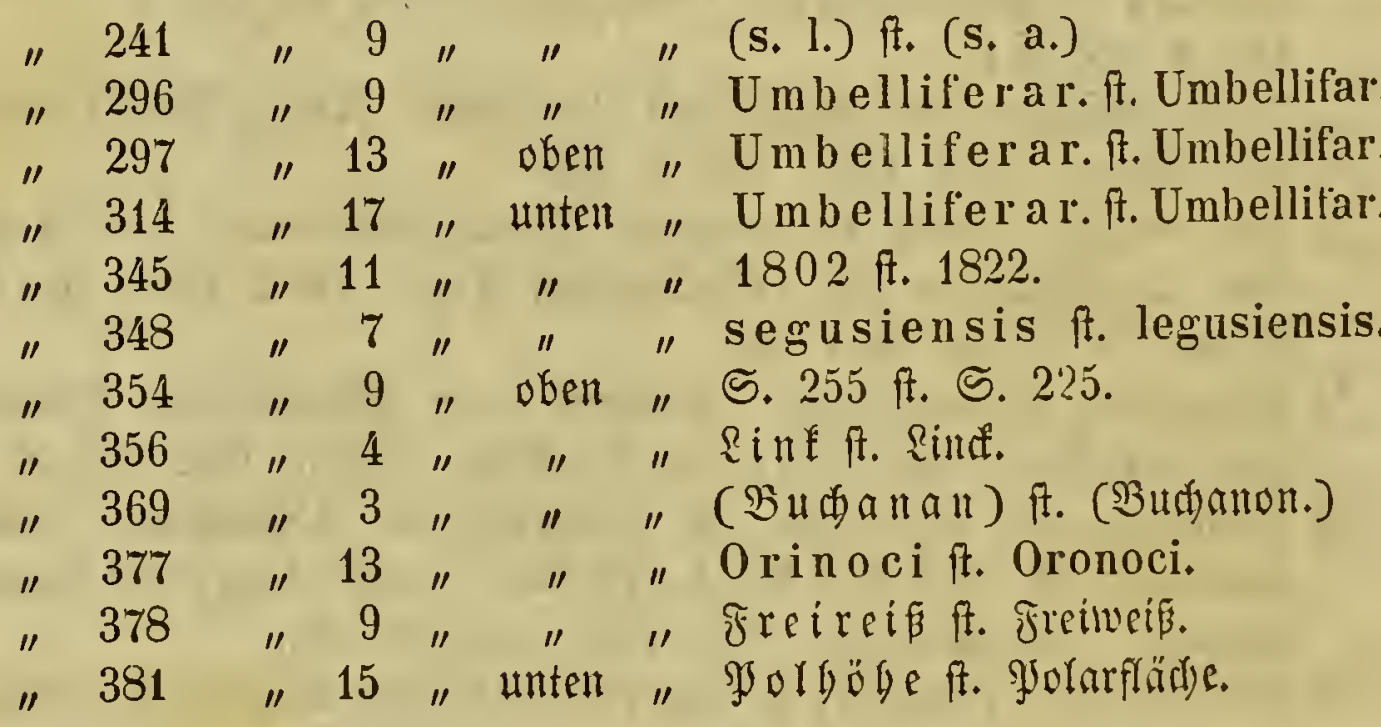




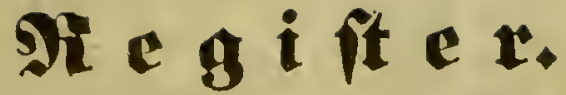

\section{1.}

26bot, 厄rart., flor. 337. Aborlatif ben Sufuf $\mathfrak{M} u=$

gam 5 ed 52.

$\mathfrak{A} \mathfrak{b} \mathfrak{e l}, \Re \mathfrak{R i f} .397$.

Abendrand, durift. $55-63$.

$\mathfrak{A} \boldsymbol{b} \in \boldsymbol{n}$, (j) u e fit 48,49 .

2) 6 u D f r ribrail 48.

abul gabli Sdierzita 49.

Stbyifinien, fitora yon, 250.

Acerby, (5j., Reifender 570.

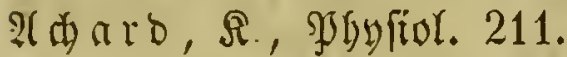

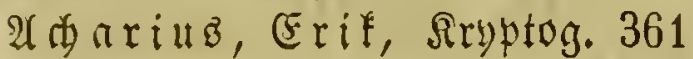

-362 .

$\mathfrak{A} \subset \mathcal{O}$ 代 $\mathfrak{a} 90$.

U⿻一丿

Abanjon, গR. 204-205, 250, 383.

Idoler, $\mathfrak{W}$, Flor. 526.

alegypten, ältefte Serifunture 2. ältefte Sultur 2.

flora $90,121,248-$

$249,367-370,570$.

Acmiliue Macer 31 .

2lesculap 7.

İëtiuz 41.

Ietna, Flora 109.

Afrifá, Flora 121, 167, 249-251,

$369-371,569-572$.

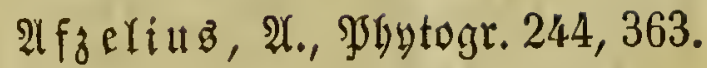
Reifend. 370.

A) garbb, 3. (3) 560 .

At garbh, R. A., Iryptog. 363, 557. Morplolog 496.

Syftem. 439.

I g oft $i$, Bittif. 237.

Aiton, $\mathfrak{x}$, sjogtogr. 338.

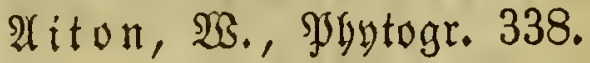

$\mathfrak{Z}(\mathfrak{i x}, \mathfrak{F l o r a}$ yon, 158.

arbertini, S. D. У., flor. 315.

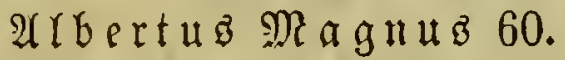

IYexander a u B Tralles 41.

$\mathfrak{U}$ fexander y. Sagles 60 .

भTeranbria 25, 26.

$\mathfrak{A} \mathfrak{Y} \mathfrak{i}$, Soln bes $\mathfrak{A} \mathfrak{b} \mathfrak{b} \mathfrak{a} \mathfrak{z} 50$.

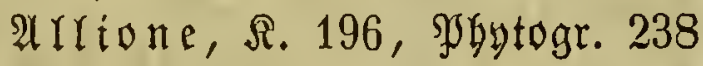
$-239,349$.

\{⿰亻弋乚 atploub, 5erzog yon Eftye 69. ITphonfo, Fürft von Effthe 93.

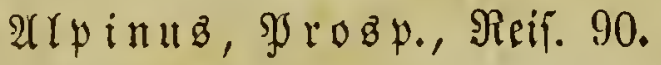

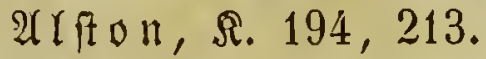

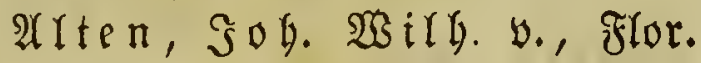
514.

Altenglano, flora yon, 234.

2Yitorff' flora 99, 100.

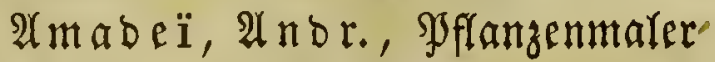

62.

$\mathfrak{A} \mathfrak{m} \mathfrak{m} \mathfrak{n} \mathfrak{n}, \mathfrak{s} .167$. 
$\mathfrak{A} \mathfrak{m} \mathfrak{a} \mathfrak{a} \mathfrak{n}, \mathfrak{P} \mathfrak{a} \mathfrak{u} \mathfrak{l}, \mathfrak{F l o r}, 102$, Syftem. 129.

$\mathfrak{A} \mathfrak{m} \mathfrak{a} \mathfrak{u} \mathfrak{z}\{\mathfrak{q} u \mathfrak{f}$ it $\mathfrak{a} \mathfrak{n} \mathfrak{\mathfrak { z }} 89$. Amerifa, flora yon, 91-92, 121 $-123,168-169,251-257$, $373-377,572-574$.

$\mathfrak{A}$ mici, (5., গুgyা. 489, 491. $\mathfrak{A} \mathfrak{H} \mathfrak{u} \mathfrak{c} \mathfrak{u x}, \mathfrak{J}$. S., Flor. 327. Amiterbam, Ssarten $\mathfrak{u}, 161$. $\mathfrak{A}$ แa $\mathfrak{x} \mathfrak{a}$ ơra 13. Anderfen, S., Jjyytogr. 343. Anderfon, (Sg., Flor. 544. A n berfon, Monograph 587.

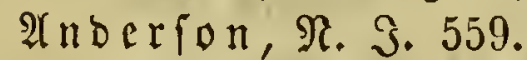
An Derion, $\mathfrak{P}$, , Flor. 544. A norews, 5. 5., SPflanzenmaler 337.

Anguirrara, 2.36 .71 . Fintoumardi, F., Flor. 572. An tonio be $\mathfrak{A r a b}$ ib a, $\mathfrak{0} .578$. Antonius cs aftor 38 .

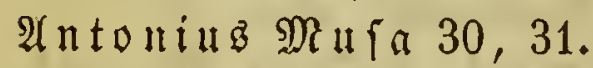

$\mathfrak{A} n$ s. R. (5., Flor. 525 .

Ipenninen, Flora Der, 110, 238. APollo 6.

Ұ中 น

Araber $46-54$.

Arabien, flora bon, 248.

$\mathfrak{A} \mathfrak{x} \mathfrak{a} \mathfrak{i}$, (⿷匚⿳丨コ丨 Betre 49.

$\mathfrak{A} \mathfrak{x} \mathfrak{i} \mathfrak{i n o}, \mathfrak{P} .237$.

A renot, $\mathfrak{~} . \mathfrak{J} . \mathfrak{F}$, Flor, 506.

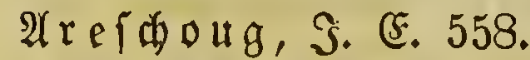

Arifteteles 20, 21.

Arnaแb, 马. $\mathfrak{A} . \mathfrak{D}$., Flor. 535.

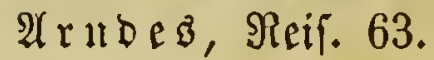

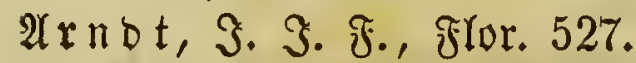

Afien, Flora von, 166, 246-249,

$368,563-564$.

Aสฺlepiab enorben 9.

Affo y bel $\Re$ io, F., Sognt. 241.
$\mathfrak{A}$ ttaluz $\mathfrak{s}$ bilometer 24.

A u b let, $\mathfrak{F}$., Reifend. 254.

$\mathfrak{A} u \mathfrak{b r i e t , ~} \mathfrak{P f l a n z e n m a l e r ~} 157$.

$\mathfrak{A} \mathfrak{u} \mathfrak{e} \mathfrak{r}=(\mathbb{E} \mathfrak{D} y, \mathfrak{R}$ eifend. 564 .

2luggburgz frora 514.

Aufralien, Flora bon, 256, 257,

$379-381,580-581$.

2lutorität ber $\mathfrak{A}$ ten 67.

भluvergne, Flora ber, 158.

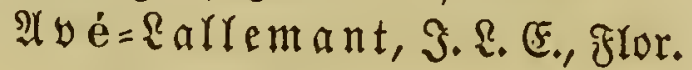
$506,551$.

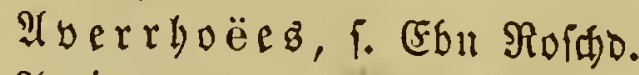

Avicenna, f. Ebn Sina.

$\mathfrak{A} \mathfrak{z} \mathfrak{x} \mathfrak{a}, \mathfrak{F e l . ~ D e , ~ R e i f e n d . ~} 376$.

Ajoren, Flora ber, 572.

$\mathfrak{A} \mathfrak{u} \mathfrak{n} \mathfrak{i}, \mathfrak{3} . \mathfrak{A} .$, Jjogtogr. 349.

\section{3.}

$\mathfrak{B} \mathfrak{a} \mathfrak{b} \mathfrak{e y , ~}$ (5. $\mathfrak{M} . \mathfrak{S} \mathfrak{l}$, , Flor. 538. $\mathfrak{B} \mathfrak{a} \mathfrak{b}$ ington, $\mathfrak{5} \mathfrak{y} .$, Flor. 541, $544,545$.

Badelot de la gyylaye 574 . $\mathfrak{B}$ aco, Roger 61 .

Babens Flora 100, 101, 224, 309 $-310,516,517$.

$\mathfrak{3} a ̈ r, \mathfrak{v} .563$.

Baierng Flora 99, 100, 222$223,306-309,513$.

$\mathfrak{B}$ a ine $\mathfrak{B}, \mathfrak{T}$, , Flor. 544 .

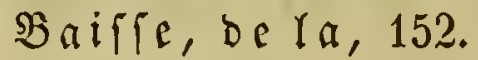
$\mathfrak{B} \mathfrak{a} \mathfrak{l b} \mathfrak{i} \mathfrak{B}$, (S). $\mathfrak{B} .$, Flor. 345,347 , 535.

Balda a ari, Spgytogr. 239. Baldo Monte, Flora Des, 109. $\mathfrak{B a l f o u r , ~ \Im . ~ S ̧ . , ~ F l o r . ~ 5 4 1 , ~} 545$. $\mathfrak{B a l o g}, \mathfrak{f l o r} .221$. $\mathfrak{B} \mathfrak{a}\{\mathfrak{f}$ mo, (3)., Siryptog. 550. $\mathfrak{B a n i f t e r , ~ R e i f e n d e r ~} 123$.

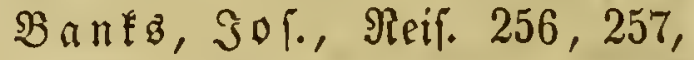
$369,394$.

B̧arbaboż, Flora von, 253. 
Barsutin, Flor. 519, Mflamjent= geogr. 595.

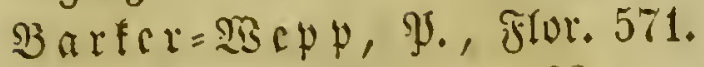
B̧arnéaub, Mionogr. 588 .

3 arou, 2 . , fror. 537.

Barrelicr, Sacq., gybytogr. 105. Sartere, গj., Flor. 255. গ̉arrow, S., গicif. 368, 371, Đyflangengeogr. 599.

Barry, $\mathfrak{A}$. De , Monogr. 584. 3artalini, B3., Flor. 238. Bartring, Fr. Th., Eyftema= tifer $41 \%$.

Barting, F. (3), Monogr. 591. $\mathfrak{B} \mathfrak{a r} \mathfrak{o n}, \mathfrak{B} . \mathfrak{B}$. $5 .$, Flor. 374 . $\mathfrak{B a r t o n , ~} \mathfrak{3}$. 9J. (5., Flor. 573. Bartram, J., Spbytogr., 253. Bartram, $\mathfrak{i s . , ~ S p y t o g r . , ~} 253$. Bafcls Flora 99.

$\mathfrak{B}$ a ffi , Ferd. 238.

$\mathfrak{B a t a r b}, \mathfrak{T} .$, flor. 325.

Bathe, Stepb., Flor. 101.

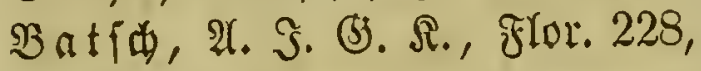

Syftem. 275.

B̧attarra, (3). $\mathfrak{A}$, Flor. 239.

$\mathfrak{B} \mathfrak{a} \mathfrak{u}$ Din, א. 406 .

Bauer, Fetb. 339 , Reif. 380, 394.

$\mathfrak{B}$ auer, $\mathfrak{F}$ r. , Spflanzenmaler, 339.

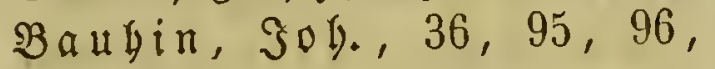
Flor. 99.

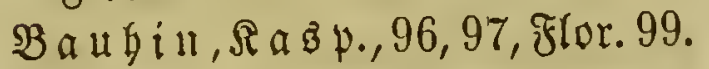
$\mathfrak{B} \mathfrak{a} \mathfrak{u m \mathfrak { c }}$, Flor. 328.

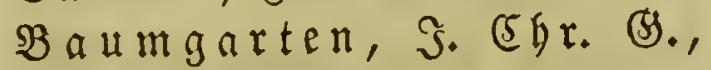
Flor. 306, 315.

$\mathfrak{B a t i e r , ~ 2 l . , ~ f l o r . ~} 535$.

$\mathfrak{B}$ axter, Rcif. 395, Flor. 542.

$\mathfrak{B}$ azin, (3. A., Jbyfiolog 209. Bèarn, Flora biefer Provillz 106. Be fá, Flor. 573.

Befer, S. F., SPlytogr. 317.
Beder, Э., Flor. 517.

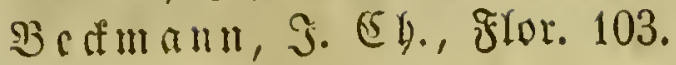

B̀ecquerel, গुbyfiur. 483.

B.b)

B̧cilidumics, (5. T., Mflanzen=

grogr. 594.

Bctanger, ḉ., Sicif. 564.

Bclgien, flora von, 546.

Beltani, Wbyfor. 463.

Berfardi, 5. A. R., Flor. 348.

Beffeval, (5). of, Flor. 536.

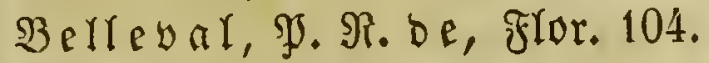

Berron, $\mathfrak{~}$, Reif. 90.

B̉enjamin, R., SJygfiol. 466, 468.

$\mathfrak{B c u} \mathfrak{B}, \mathfrak{s l o r .} 221$.

$\mathfrak{B}$ entban, (b). , Flor. 534, $\mathfrak{M} \mathfrak{v}=$

nogr. $589,591$.

Benzoni, Scieron. 92 .

Serd told, (s) $x$ af $\mathfrak{F}, \mathfrak{y}$, f Flor.

510.

$\mathfrak{B} \mathfrak{e r g}$, (્. v. , 468.

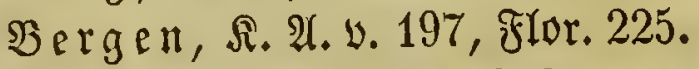

Bergeret, Э. , flor. 329.

Bergius, ஒJ. S., SPbytogr. 251.

Bergo ma, Jjhufítol. $48 \%$

Bering, 代eit, Neif. 246.

Bertyey, Job. Ie Francq. v.l 237.

Berlandier, $\mathfrak{~}$. 590.

Berlèfe, R., Monogr. 592.

Serlin, Flora biefer Stabt, 225, $311-312,519$.

Bernlyardi, S. S., Syftem. 279, 443, frlor. 314, Jjhyfiol. 282, 493.

Berta, Jygufior. 466.

Bertero, (5. (3). Nrif. 579.

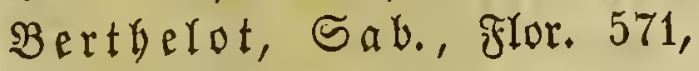
sfflangengeogr. 599.

Bertoloni, A., Flor. 348, 547. 


\section{8}

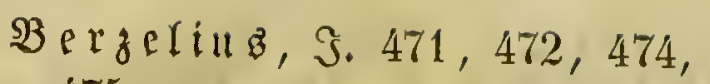
475.

Beß̊er, $\mathfrak{B}$ ז., Flor. 124.

$\mathfrak{B e f f e r , ~} \mathfrak{W}$. S. S. (3), Flor. 305, 562.

Biafoletti, 2 . 508.

Biblifde Botanif 4.

Bieberftein, F. A. v., Flor. 366, 367.

Biegefow, S., flor. 375.

B̧irfberg, (5). F., 364 .

Biot, grypitor. 483.

Biria, Э. A. S., Sjbytogr. 332.

Siroli, (3). 347 .

Bi i ceglie, $\mathfrak{B}$., Flor. 351.

$\mathfrak{B}$ ifdoff, (3). W3., Gyftem. 444.

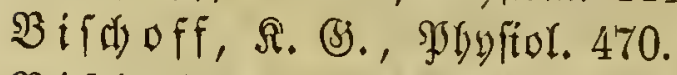

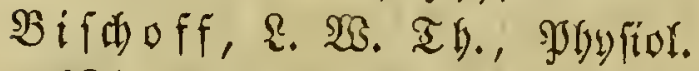
485.

Bivona $\mathfrak{B}$ ernarbi, $\mathfrak{A}$, Flor. 352.

Braffone, Soln, Flor. 234.

$\mathfrak{B} \mathfrak{I} \mathfrak{i} \mathfrak{x}, \mathfrak{J} \mathfrak{a} \pm \mathbf{x}, 145,149,152$,

Spgytogr. 161.

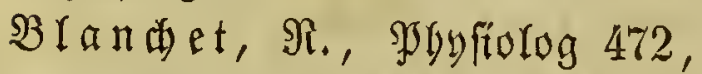

Flor. 531.

BIanco, M., Flor. 569.

BIandow, Jbytogr. 299.

$\mathfrak{B l o x a m}, \mathfrak{F l o r .} 544$.

BI $\mathfrak{f f f}$, Flor. $499,505$.

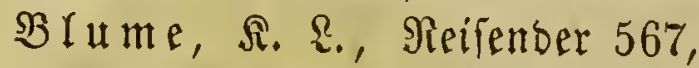

Monogr. 587.

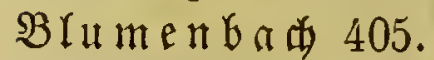

$\mathfrak{B}$ yt, $\mathfrak{N} . \mathfrak{R} .559$.

Bofcone, SJ., Pyytograph 105, $108,109$.

$\mathfrak{B} \cup$ df, $5.75,76$.

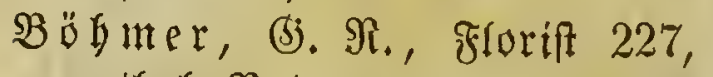

mythor. Bot. 7, Sbytotom 207, 209.

Böbmifde Flora $305,510-511$.

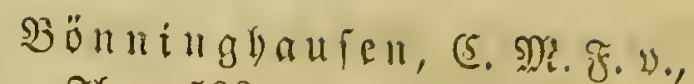
Flor. 523.

Boerly a ve, 5.., Jybutogr. 161, Syftem. 147.

Bojer, $25 .$, Flor. 572.

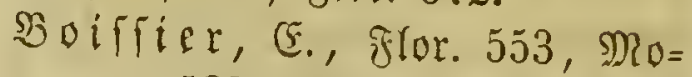
nogr. 588, Mflamgengeogr. 598. $\mathfrak{B}$ oiffie u, 5. B., Flor. 295.

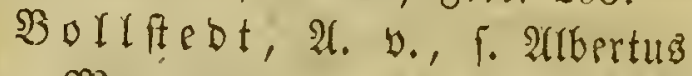
Maginus.

Bologna, (Sarten z̆l 162. Bolton, Sant. Fror. 235.

Sonamy, $\mathfrak{s}$ r. , Flor. 232. 3onaftre 3, 3jhyfiol. 473. Bonerri, (3)., whytogr. 239. Bonfigrioli, (3), Jjoytogr. 109. Bongarb, 5. (5) v. 560 .

B̉onnet, $\Omega$, Jjgufiol. 209, 485. Bonorden, Monogr. 584.

Bonprano, $\mathfrak{A} .330$, Aetr. 377, $406,407,410$.

Bontius, Sac., গeip. 117.

3oreau, Jgyfior. 468, Flor. 534 . $\mathfrak{B}$ orf a l fen, $\mathfrak{A}$. 3 ., Syftem. 278, Flor. 298, 310.

$\mathfrak{B}$ or $y=S$ aint $=\mathfrak{B}$ incent, S. $\mathfrak{3}$.

(3). Flor. 371,373 .

$\mathfrak{B} \cup \mathfrak{G}, \mathbb{R}$, flor. 355, Nivptog. 357.

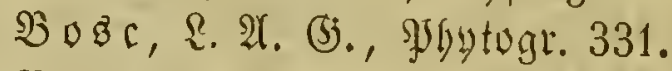

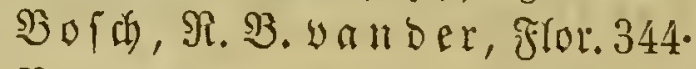

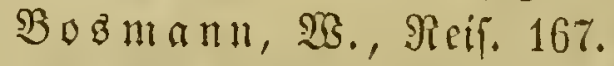

Botanifde (3ärten 93, 123, 124, $170,258,392$.

Butanifde (5efellidaften 141, 258. $3 \mathfrak{B}$ It d) er, S. 2A. (5). De, Flor. 325. Bouirron=?agrange, gjhyfior. 473.

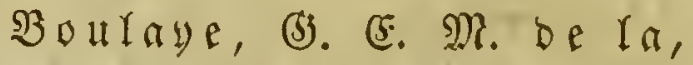
gror. 325.

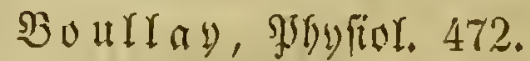

Boแfringaแrt, 3gy $481,485$. 


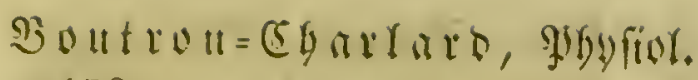
473.

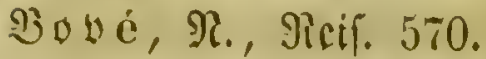

Bowbid, 巨., Flor. 571.

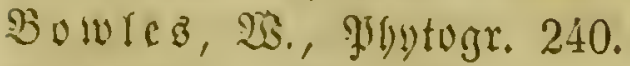

9oy 11, D?. Micif. 120.

Sir acoun ut, 5., গुbyfior. 288, 482.

Brabry, গ. 150, 152.

Srintonburg, flora ber Parf, 226.

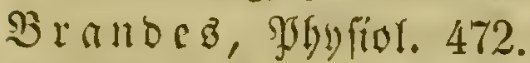

Branbez, ש., Flor. 506.

Brandfón, (5). F. 558.

Sranbt, Job. Friebr., Spysto= graply 519.

B̧raquicr, 3., fror. 538.

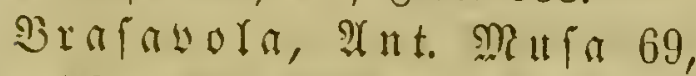
70.

Braftiten, Flora won, 122,255

$-256,377-378,576-578$.

B̉raifai, S., flor. 513.

$\mathfrak{B} \mathfrak{r} \pi \mathfrak{n}, \mathfrak{T} .$, Bgyfior. 458, 466, 467, 470, 478, Monogr. 584.

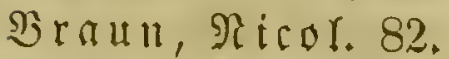

$\mathfrak{B}$ r ๙uा e, Fr. A nt. v., Flor. 304. Sormund)weigz flori 104, 527.

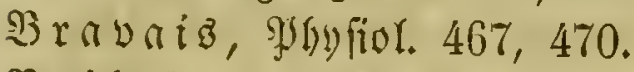
Brébiffon, ‥ A. De, Flor. 534,

Sfflanjengcogr. 596.

$\mathfrak{B r C D}$, S. (3). S. v., 568.

BreD Dorff, S. S., Flor. 556 . Breyn, $\mathfrak{s}$ c., Sjbytogr. 124.

Bribel=Briberi, S. (5. v.,

Iruptog. 321.

Briganti, $\mathfrak{B}$., Fror. 351 .

Brignoli, (5). , Flor. 304, 346. Briffeau = Mirbel, (5. F., $\mathfrak{d y y}=$ fitor. $282,284,322,450,452$, $454,456,459,460,464,479$, 482, 490, গjorlanjengedgr. 594. Britifate Flora 234.

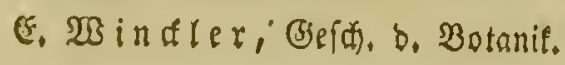

3rocdi, (3). B., Reif. 570.

Brollet, S., Flor. 116.

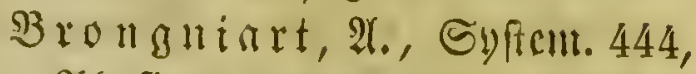

Jibufior. $455,462,479,490$,

Monogr. 591, 601.

Srotero, F. H., Flor. 355, 554 . 3̧rourto, Flor. 538.

Sroughtou, $\mathfrak{A}$. Fror. 235.

Şroulfonet, S. \&. 3., Flor. 327.

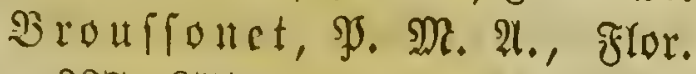

$327,371$.

Browart, Sol. 191.

Э̧rotvu, S., Fror. 531.

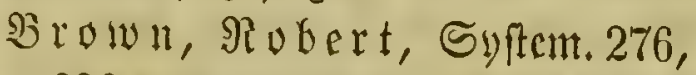

339 , gryytogr. 371, 539, 540,

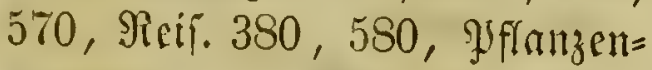

grogr. $386,393-399,599$,

3rtyufiur. $450,478,490,499$.

3rotune, $\mathfrak{s} .$, Flor. 253.

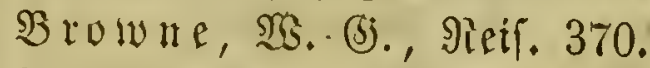

Bruce, S., গieif. 250.

$\mathfrak{B r u}$ u, Monogr. 584 .

$\mathfrak{B} r$ it df $e$, Jbyfior. 488.

Brĭ afm a n n, F. F., Whytog. 156. Brï ce̊ ner, $\mathfrak{A}$ D. Fr., Flor. 313. $\mathfrak{B} r$ ü af ner, PJflanzengeogr. 595.

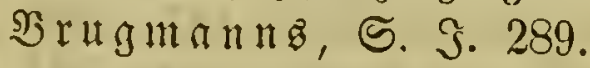

B̊ufels, $\mathfrak{t}$ to $, 74,75$.

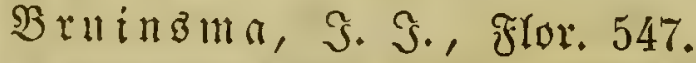
Siutere, (5). ?. De r'seri=

tier, Jjyytogr. 233.

Brutg, Dr. 342.

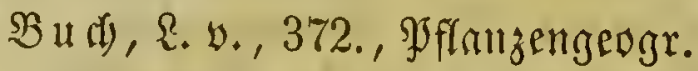

$385,599$.

$\mathfrak{B} \amalg$ a) a $\mathfrak{a}$ ศ. Franc. Şantilton.

$\mathfrak{B}$ u der, (5q). Traug., Flor.

315.

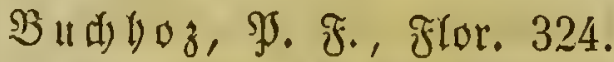

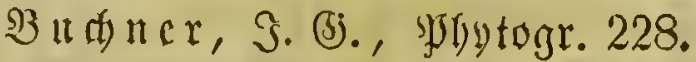

Buth ner, Jjyufiol. 472 .

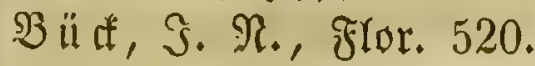




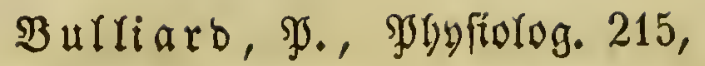
flor. 232.

$\mathfrak{B} u \mathfrak{n g e}, \mathfrak{A}$. ๖. 565 , Sfflauzen= geogr. 599, 凡eif. 563.

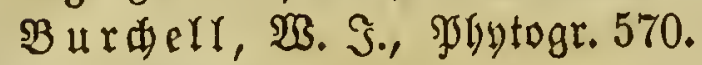
Buratgarbt, S. S. 148.

$\mathfrak{B u r b}$ a $\mathfrak{B} \mathfrak{u} \mathfrak{m a n n}, \mathfrak{S} \bullet \mathfrak{h} .119$, Jjhytogr.

$249,250$.

$\mathfrak{B} \mathfrak{i r m a n n}, \mathfrak{r} . \Omega_{0}$, Jyytogr. 239, $248,251$.

$\mathfrak{B}$ urmcifter 603.

Burnett, (\$s. T., Morphol. 496. $\mathfrak{B}$ univa, $\mathfrak{M}$. F. , Flor. 348 .

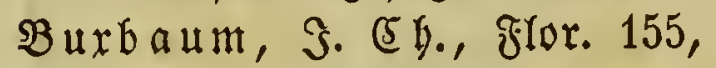
Reif. 168.

\section{(5.}

(cairliaub, F., Reifender 569, Sflanzengeogr. 599.

(5aley, (5)., Reif. 395.

Salifornien, Flora yon, 252.

(5 a mb effè be $\mathfrak{b}, \mathfrak{S}$., Monogr. 591, 592, ’jflanzengeogr. 598, SThytogr. 554.

Srmbrioge, Flora soll, 160. (5amerariuz, $\mathfrak{9} .80,81$.

(5amerarillz, $\Re$. S. 147-148. (5 ampbelt, Ş. W3., Flor. 541, 542.

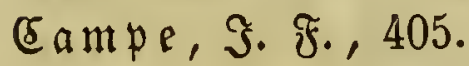

(campi, Balo a fore, Syytogr. 109.

(E ampi, $\mathfrak{M}$, , Spgytogr. 109. (5 appel, গ. F. \&., Flor. 229. (5arueiro, $\mathfrak{R} .117$.

Sarolina, Flora volt, 169.

(5 arpenter, $23 .$, bibl. Bot. 4. (5arrabori, গjgyfiol. 463.

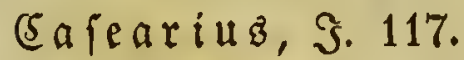
(5a $\{\mathfrak{f l}, \mathfrak{F}$. T. , Syftem. 276, 438, Morpbolog. 495.
(Saffini, Monogr. 588.

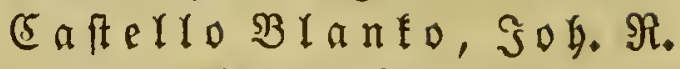

be, f. 2amatuz Rufitanuz.

Caftagne, \&., flor. 536.

c5afiglione, \&., flor. 253.

(5atezby, $\mathfrak{N}$., filor. 169.

(5atv, MR. Ş. $26,28$.

cavallini, F. গু

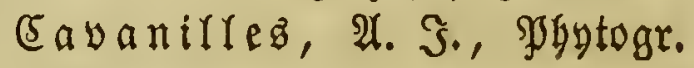
$240,257,353$.

巨ectifite flora 509.

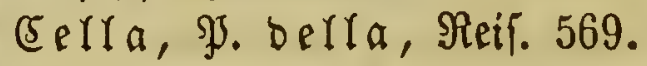

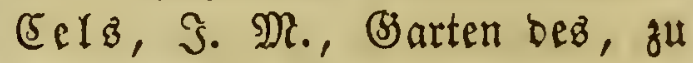
Pariz, 330.

(5elitub, 5., bibl. Bot. 4, Soby= togr. 165.

Sentaureum 7.

(5éré, গ. v. , Flor. 372.

Seiarpini, 4 . 36, Syftem. 72, $73,74$.

(5e fati, $\mathfrak{B}$. de, florift 548, Sffanjengeogr. 597.

(5efi, fr. 92.

(5eylon, flora von, 249.

(5りabré, D. 96 .

(5)albäer, äItefte Rultur, 3.

(5) a miffo, 2. y., flor. 313.

(5) aptal, S. A. (ET, De, Sbyfiol. 471.

(5)arbin, J., Reí. 120.

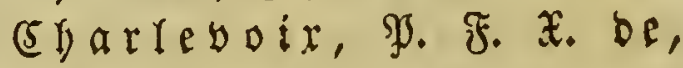

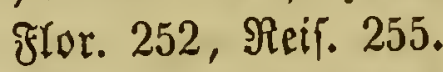

(5)artier, R. 40.

(5) a ubert 556 .

(5) ayannez,, Monogr. 589.

(5) emnis, S., flor. 104.

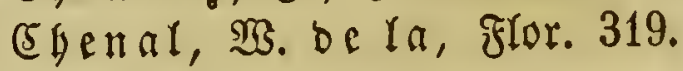

Egerter, 55. 3. 95.

(5)evallier, F. F., Flor. 535.

(5)iajo, St. Della, flor. 553. Egiti, flora von, 255-256. 
(5bina, flora von, 120, 247, 368, 565.

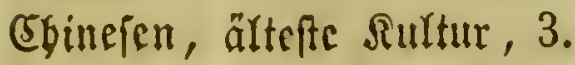

厄hir on, segrer ber Seiffunbe, 6.

çbiroltion 7.

(5) bify, S. D., Monogr. 589, 592, Jjhytogr. 531.

EGoulette, S., flor. 533.

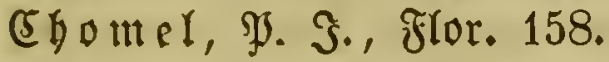

Cínfuego, $\mathfrak{B} .89$.

(5irillo, D., Flor. 239.

Clairbille, be, flor. 320.

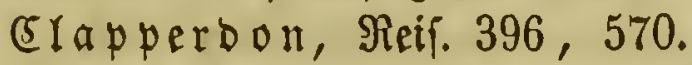

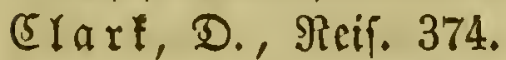

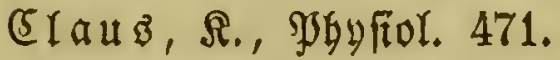

çrayton, S., flor. 252.

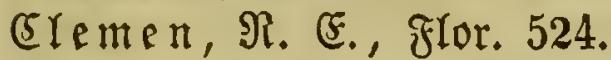

Cremente y Rubio, Don S.

be $\Re \mathfrak{X} \mathfrak{x} \mathfrak{B}, \mathfrak{F l o r} .355$.

Cleyer, $\mathfrak{A}_{0}$, Reif. 120.

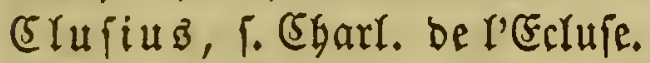

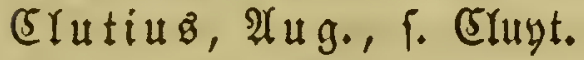

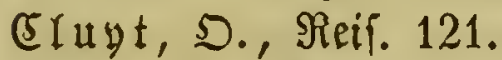

Sobo, B., Reif. $121-122$.

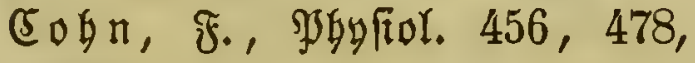
480.

çolben, (5., flor. 252.

Solden, S. 252.

colebroofe, 5.. Th., flor. 566. Eolla, $\mathfrak{A} .$, Jlor. 550 .

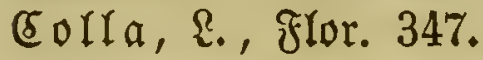

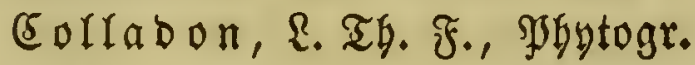
332.

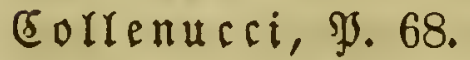

(5olfet, Sy h., flor. 158.

Colonna, Fab. 135, 136.

6olumella， \&. গ. $\mathfrak{M} .31,32$. (5ommeryn, Э., Flor. 107, 117, 118.

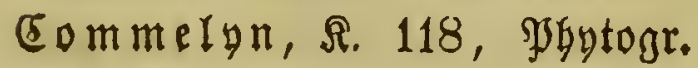
161. (5ommerfon, פ̧. 5ุ., Reif. 250. (5omorri, (3), Flor. 549.

somparetti, 2 ., grbyfrol. 281.

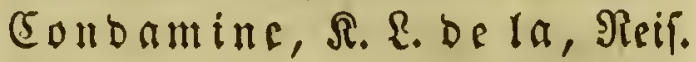
256.

Sonfentino, F., Sflanzengeogr. 598.

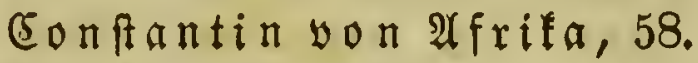

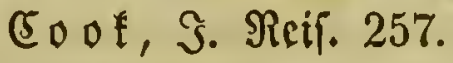

Eooper, D., Sflor. 543.

(5oquebert $=\mathfrak{b} \mathfrak{e}=$ Montbret, आcif. 564.

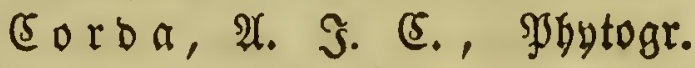

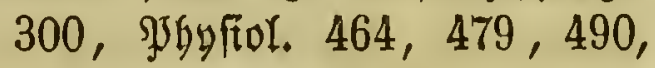
Iryptog. 511, Monogr. 583.

SorDo, S. DR, 61, 62 .

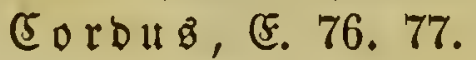

(5orðuB, $\mathfrak{B} .77$.

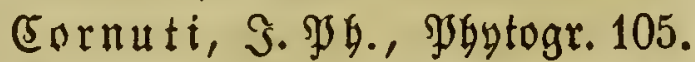
Goronarien 85.

Gorrea be Serra, 3. F., Syftem. 274.

(5orfífa, frora von, 239.

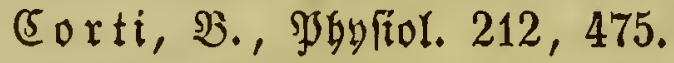
(5otta, 5., Sybyfior. 290, 484.

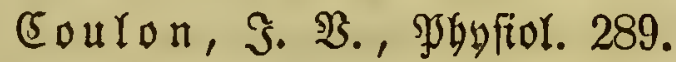
coulter, Monogr. 588.

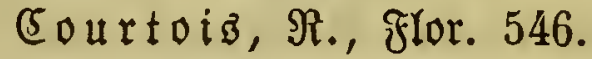
cowelt, M. S., flor. 544 . (5 oxbeab, 5., flor. 542 .

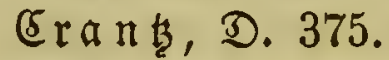

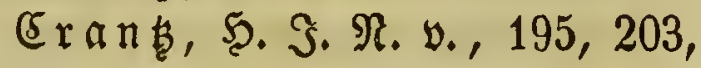
flor. 220.

Crateya

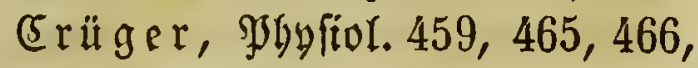
492.

(5 $\mathfrak{u} \mathfrak{b} \mathfrak{i} \mathfrak{i}, \mathfrak{f} \mathfrak{r}_{.}$, flor. 110.

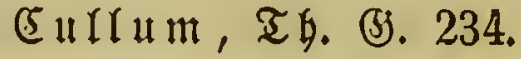

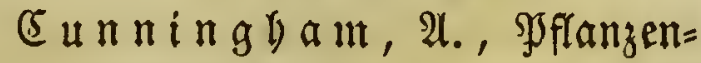

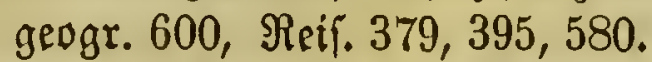
(5 unning 39. 


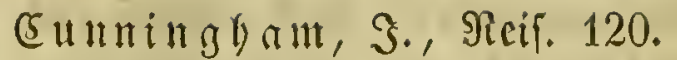

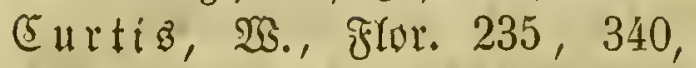
341.

ç子⿰亻⿻乚㇒ia 555 .

\section{D.}

Dänentarl, Bgytographen von, $114-115,241-242,318-$ $319,357-359,556-557$.

DaY T, A. 244.

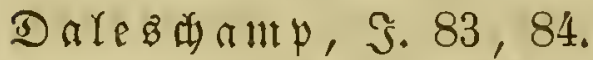

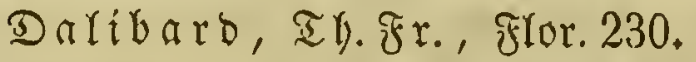
Dartaporta, R., Flor. 556 . Dafutatier, flora yon, 513. Dampier, 235 . Reif. 121. Danzig's frora 102, 226. Danz $\mathfrak{y} \| \mathfrak{A} \mathfrak{A} \mathfrak{i t}, \mathfrak{F} .36$. Darlington, $\mathfrak{3}$. 573.

Darwin, E., פJgyfidt. 292. Daffen, Shy fitol. 488, 489. Daffier, $\mathfrak{A}$., Fror. 534.

Daubeny, 5̧., Sygyfiot. 482, $48 \%$. Davies, ,̧., flur., 338.

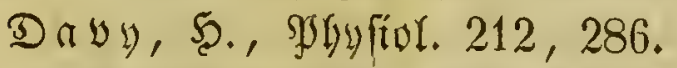
Dertin, R., Fror. 542.

Decaizine, Sygyidol. 463, 475, 479, 568, 3gytogr. 570.

Decandorte, Atragnie, 401, Bjgytogr. 531.

Decandolfe, itugut gुy SPlyyfor. 281, 286, 296, 322, 323, গfflanzengeogr. 385, 596, 597, Morplor. 391, 393, 399, $405,411,412-416,417,418$, 420, 486, Molugr. 567, 585.

Deering, (5garl., Flor. 236.

Defin, it., Fitor. 343.

Delafons, 2 ., filor. 535.

Defarbie, H., fror. 327.

Delafte, Demofit, 13.

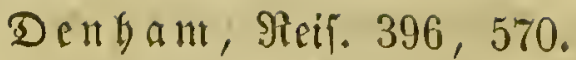

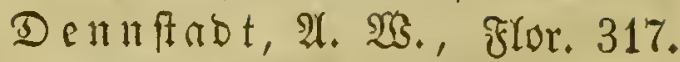

Denon, Biv., Reif. 370.

Denfus, 38.

D'Entrecafterux, Reif. 380.

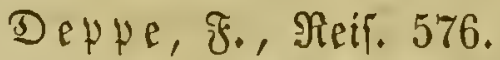

DeBCourtíz, M. E. 575 .

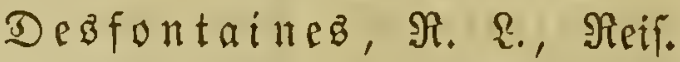
250, Jjbyfiof. 292, 3rytograph 331.

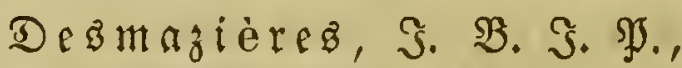
Flor. 342, 534 .

Desportes, R., Flor. 537.

DeBu氏 327, 330, 537, \$glyfiol. 468.

Detgarbing, (5). (5), Ffor. 317, 527.

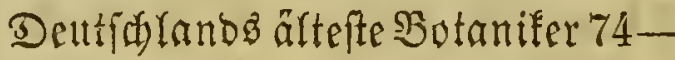
82.

Deutiflands Filora $99-104$, $152-156,218-219,296-$ $319,497-528$.

Dhiäboin, Aboallat bell

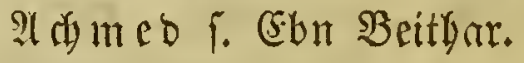

Diffie, (3), Flor. 545.

Diffion, Э., Aryptog. 235.

Dierban, S. S., Fitor. 507, 516.

Dictrid, $\mathfrak{A}$, fror. 519.

Dictrida, D. R. Fr, Flor. 506, 516.

Dijon, flora yon, 158.

Diflenilta, 30 f. Sac., 134, 135, 145, 3j6ytogr. 152, 153. Dirron, S. T., grgytogr. 241. Difrwy n, ‥ $\mathfrak{2}$., fitor. 338, 339. Diozluribez, gyedan. 32, 33, 381.

Dipper, ․, Mglaftel. 453.

Ditmar, \&. 9J. F., Flor. 299. Dobart, D., Jbyfiur. 139. 
Dodoeng, Sentert 84,85 .

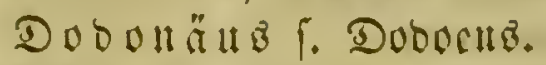

Dör, Э. (5)., ETur. 523.

Döpping, grgyfur. 462 .

Dörrien, 爪ath. Sgel. 224.

Döring, ת., Flur. 236.

Dotily, (5., flur. 539.

Dolliner, (3), firte 50 S.

Dombey, 3., গcif. 256.

Doningo, Jlora von Et., 254.

Don, D., Mbytogr. 543, 567.

Don, (3), Srytogr. 542.

Donati, $\mathfrak{A}_{0}$, Shytogr. 109.

Douati, $\mathfrak{B}$., MJyufiol. 217, MSyy= togr. 239.

Dondi, S. be 63.

Domep, (5) 5 . 5. De, $11 \%$

Doubois, filor. 326.

Douglabi, D., Ricif. 574.

Dove, Mryfiol. 487.

Drafenfeen, Şentiă yan RGede tot, 117.

Dregc, J. Fr., SReif. 571.

Dreier, Jhyfiol. 466, fitor. 557.

Dresben, Flora bon, 315.

Drümpelmann, (ซ. 203., Flor. 365.

Drumnond, $\mathfrak{S}_{\text {. }}$ Reif. 574.

Dryander, Jon, , Iroptog. 216.

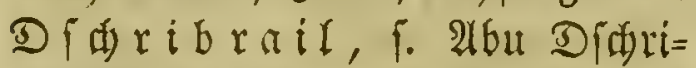
brail.

Dubourg, S. 3., flor. 230.

Duby, $\mathfrak{~}$.

Dudartre, Jygufiol. 469, 492.

Ducluzeau, S. $\mathfrak{A} . \mathfrak{Y}_{*}$, Flor. 327.

D u D en, G., gyflanzengeogr. 600. Düben, M. $\mathfrak{2}$. ๖. 5558 .

Dufour, ․, flor. 536 .

Dut amel, Ş. \&., SJgytogr. 323, 356y fiol. 484.
Dufirbin, Flor. 537.

Dufong, अhyfiut. 473.

Duma है, S., Jुbyfiol. 472.

Dumont b'llvifle 555, 580, 581.

Dumorticr, S. (5., Syftem. 439, filor. 546.

Dutat, M. F., S5ytogr. 332, Bjoyfiol. 469.

Dunfer 603.

Dupout, 3. D., flor. 324.

Durato, S. B. R., Reif. 371. DUrand, S. $\mathfrak{F} . \Re$, Flur. 232. Durante, (كaft., yjbytogr. 98. Duret, flor. 535.

Dutrodet, jhyyfur. 478, 483, $485,488,489,490$.

Duval, ç). S., filor. 513.

Duvertioy, (3), Flor, 154.

Dwigubsy, S., Jybytogr. 365, 561.

\section{(5.}

Eatoul, $\mathfrak{A l}_{0}$, fror. 572.

Éfel, Monogr. 588.

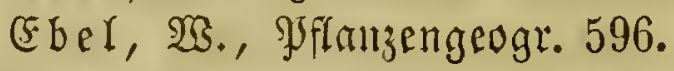

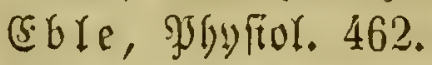

(5)

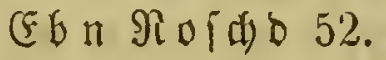

(5b) Sina 50,51 .

(E)

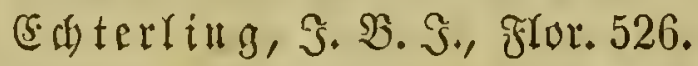

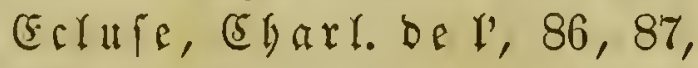
Frtur. 101.

๔ob

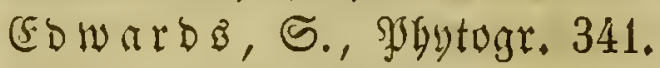

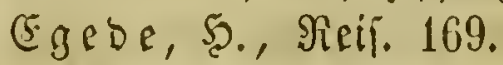

(E)

(5)

Ererenberg, ת. 575 .

(5́)rat, (3). Dionyf., Mal. 223. 
(E)

Erbart, Fr. 311.

(5) $\mathfrak{r m a n n}$, S. Cำ 106.

(Fi由lvald, E., flor. 562.

Finberf, Flora bolt, 156.

(Finkof, 5̧., פygyfiol. 286.

Efart, $\mathfrak{b}$ h., Monogr. 584 .

Elfan, R., Monogr. 593.

Ertiott, St. 574 .

Erminger, S., Jjhytogr. 332.

Eljấ, Flora diefer Sjrobinz, 106,

$158,329$.

(ElBhold, S. S., Fflor. 103.

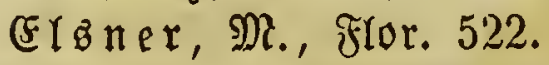

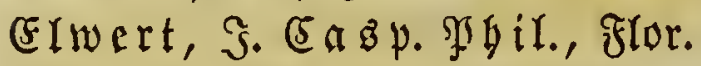

222.

Fimpedocles 12.

Enblider, St. R., Syftemat. 430-438, פjgyfiol. 491, Flor. $507,513,569,581,603$.

(Fngelmann, (3)., Sybyftor. 493, $496,573$.

England, beffen ältefte Botanifer, $88-89$.

England, frora volt, 160, 161, $234-235,333-342,539-$ 545.

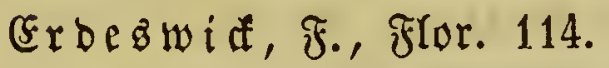
Fromann, Sob. Fricor. b., Reif. 560. Erfurt, Flora von, 225, 314. (Erbarb, Spgyfior. 481.

Ernoter, (5). 55., Flor. 154.

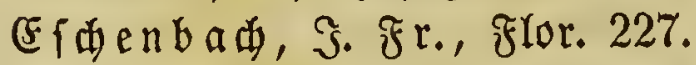

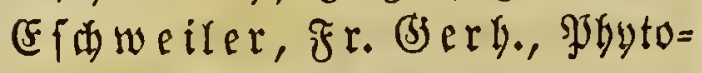
graph 515.

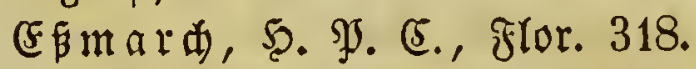
Etangba, Stanisl. Deb, flor. 535.

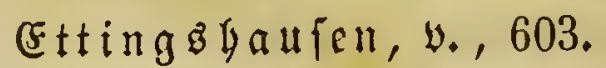

Eupatoria 24.
Euphorbia 31.

Fupborbus 31.

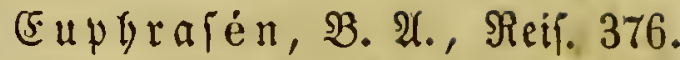
Furopa, über bie Flora diejes $\mathfrak{3 e l t t b e i l z , ~ 9 8 , ~ 9 9 , ~ 2 9 5 - 2 9 6 , ~}$ 497 ff.

\section{$\mathfrak{F}$}

$\mathfrak{F} \mathfrak{a} \mathfrak{b} \mathfrak{e g o u}, \mathfrak{M} ., \mathfrak{F l o r} .231$. Fabicius, ภ., Flor. 229 . $\mathfrak{F} \mathfrak{a b} \mathfrak{i} \mathfrak{i} \mathfrak{u}, \mathfrak{g} \mathfrak{b}$. R., 197.

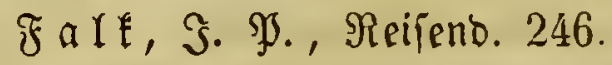
Falflambininfeln, Flora ber, 256. Fedner, (s. Th., Pbyfiol. 471 .

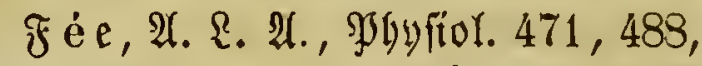
Syftem. 444, Sirgilifae Flora 30, Monogr. $582,585$.

Feiren, (s), Flor. 115.

Fellmann, $\mathfrak{J} a$ c., Flor. 562.

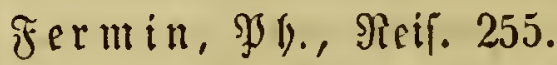

Ferrara, bot. (s)ärt. Daj., 69.

Feuillèe, R., Reif. 168.

Ficinub, S., Flor. 315.

Fieber, Fr. ł., Flor. 510.

Fieber, spgytogr. 299.

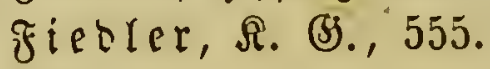

Figueirebo, S. S. De, flor. 555.

Fingerlut, Flor. 499, 505, Monogr. 589.

Fiorini $\mathfrak{R} a z \mathfrak{a n t i , ~ ( 5 . ~ ( S ) ~} \mathfrak{a} a$ fin von, 552.

Fif

Fifder, Ferd., Syftent. 276.

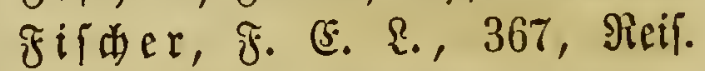
368,396 , Jyyutogr. 560 .

Fifder, (jotth., 287.

Flacourt, G. De, flor. 121. Fleifder, gygyfol. 481, Flor. 561.

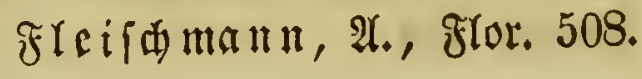




\section{5}

Frinberb , Capit., Reif. 381, 394.

Flint, $\mathfrak{x}$., gyflangengeogr, 600 .

Slörte, 5. (3., Rryptog. 317. Elora, foifite, $391-392,601-$ 603.

Floren, (3)arten 孔 164. floriba, flora von, 169.

Florta, SJgyifiol. 475.

Flo tow, 3. v., Sogntogr. 522, Monogr. 583.

Föroi, Son., Flor. 505.

Förfter, R. F., Monogr. 590. Fontenerre 206.

Forreft, $\mathfrak{T}$ \%., Reir. 257.

For

Forfer, (3), Reif. 257.

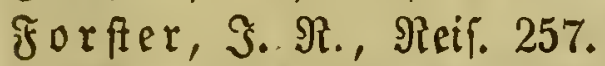

Forfter, $\mathfrak{2}$ 4. F., fror. 338.

Francia, Dict. 410.

Francib, (3.) W., Flor. 542 .

Frand, Sor. (5., 574 .

Francoeur, \&. B., frlor. 324. Francu , f. So\%. Franfe.

Franf, Э., Flor. 516.

Frante, Sok, fror. 102, Ter $=$ minolog 116.

Franffurt a. $\mathfrak{M}$., Flora biejer Stabt, 101, 224, 517.

Franffurt a. D. D., Flora biejer Stabt, 103, 155, 225, 520 .

Frantreidis erfe eigentlide $\mathfrak{B} \mathfrak{D}=$ tanifer 82,84 .

Jranfreide Şgytograpgen $104-$ $107,157-159,230-233$, $322-333,532-539$.

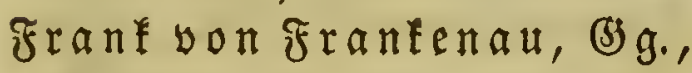
Spgtogr. 100, 101.

Frafer, Çgarl., Reif. 395.

Greemann, 厄yarl. 335.

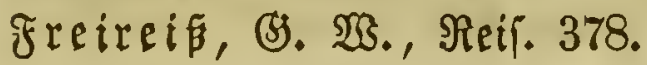

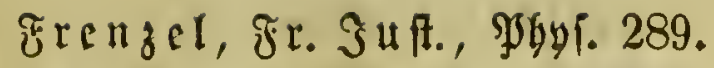
Frenzel, S. S. T., Jygutogr. 313.

Srenzer, S., Sgyyfior. 484.

Frefeniuz, (3), Florift 517, Sogyfiol. 495, 3rgytograph 570, Monogr. 584.

Freycinet, R. D., Reif. 579.

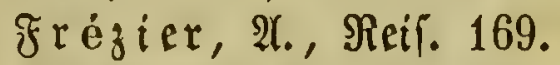

Friafe, (3. W., SJgyfior. 485.

Friebe, $\mathfrak{B}$. (5)., sybutogr. 365. Friebrid $\mathfrak{A} u g u f t$, Mitregent won Sadien, 510.

Fries, (E), ভyptem. 440.

Friez, ㅌ․ MR. 364, Rryptog.

557, Monogr. 582, 583.

fritestanto, fllora von, 236.

Frití, (5., SPGyfiol. 489.

Fritid, M. , 38.

Fritide, Э., Spgyfiol. 469, 473, $479,490$.

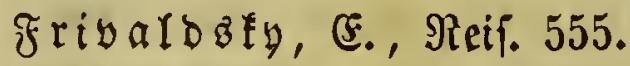

Fud b, \{eony., 78.

$\mathfrak{F} \mathfrak{u} \mathfrak{n}$, Sogytogr. 300 .

Fürnrokr, (飞., Flor. 513.

$\mathfrak{F}$ ublrott, R., Morphol. 496. Fuldoa, flora von, 224.

\section{(3).}

(3) ärtner, (5. Fo, Nogytugr. 310. (3) ärtner, Gottfr. SJgir., flor. 311 .

(3) ärtner, (3., filor. 311 .

(3) ärtuer, sof., 217, Syptem.

274, 275, Shgufiol. 294.

(3)ärtner, S., Sygytogr. 310, Sygufiol. $492,494$.

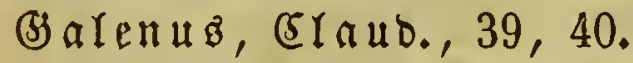

(3) alle fio, (5), spbyfiol. 493. (5)alizien, frlora yon, 305, 511. (3) alpine, S., flor. 336. 
(5) arciab ab $5 \operatorname{rta} 90$.

(3) arcin, \&., Bhytogr. 166.

(5) arioel, J., flor. 158.

(3) arouaglio, S., Siryptug. 549.

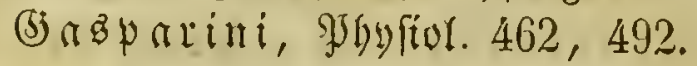

(3) atera, Flor. 327.

(3) attentof, sn., Fror. 224.

(5) aud (

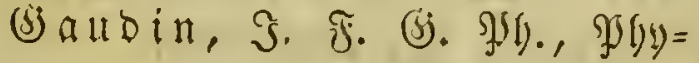
togr. 321, 529, Sfflanzengeogr. 596.

(3) ay, (5. ‥ 579 .

(5) a y, S., Monogr. 592 .

(5) ay étant, fror. 328.

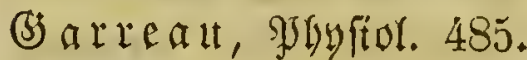

(3) $\mathfrak{b l a r d}, \mathfrak{S} . \Re .$, Flor. 508.

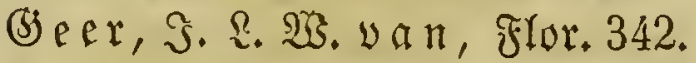

(3) ciger, \$ुbyfiol. 472.

(5) érézitoff, Jjgyfíor. $480,491$. (5) $\mathrm{em}$ elfaro, c5., Sflanjengeog. 598.

(b) enerfidy, Sallt., Flor. 306. Seograptie ber Spflmzen 140, $381-386,593-600$.

(3) e offrov), $5.3 ., 148$.

(S) P ffroy, (5. F., 148.

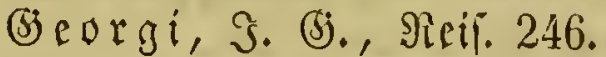

(Jiera, Flura biefer Stabt, 228.

(5) érard, Jol $\mathfrak{i}, 89$.

(5) érar b, ‥ 203, flor. 232.

(5)erard von cremoun 58.

(5) erber, Reir. 167.

(5) ermann, (3). 2. , Flor. 365.

(5) ermar 602.

(3) efiner, S., 4, 197.

(5) efüer, ת., 79. 80.

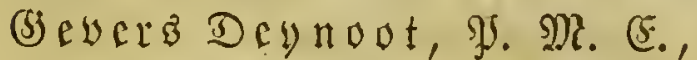
Flor. 547.

(3) $\mathrm{eubel}, 5$. R., Shgyfiol. 472.

(3) $\mathfrak{e}$ แ 237.
(3) bini, \&uc. 70.

(3) iebel 603.

(3) i (G) iefien's Flori 100, 153, 311.

(3)ilibert, J. (5., Flor. 245.

(5inanni, (5)

(5) inginz=saffaraz, $\tilde{s}$. D, Jjyytogr. 532.

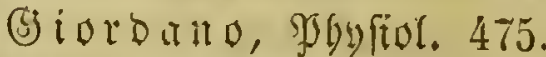

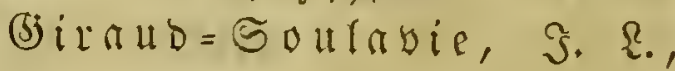
Sffratzengeogr. 383.

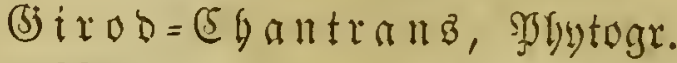
333.

(3) irtanner, (5) r., Jogyfiol. 212. (3) ifefe, Sout (D., 196, 203. (5) iulio, Sylyfiol. 212.

(5) ilf fppe, Matt., Reif. 108, 117.

(5) I $\mathfrak{n}$ vilfe, $\mathfrak{B} \mathfrak{a} \mathfrak{x} \mathfrak{b} \mathfrak{o l},, 62$.

(5) febitich), S. (5j., 191, 195, gybyfiol. 215.

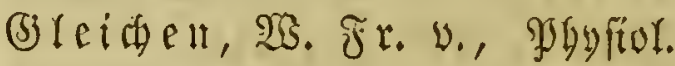
$214,217$.

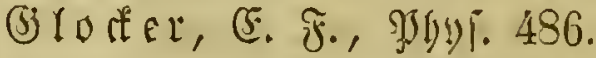

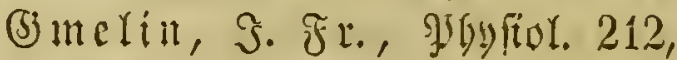
3hytogr. 223.

(5) me! it, S. (3), Jybytogr. 245, 246.

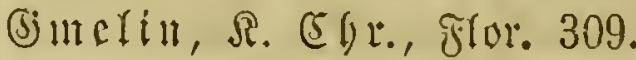

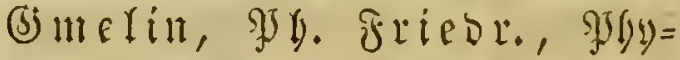
togr. 223.

(5) melill, Sam. (3) ottl. 217, Reif. 246, 247.

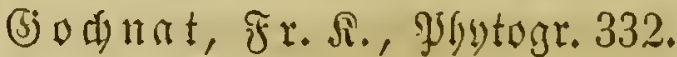
(5) ODivu, D. A., Flor: 533, 538.

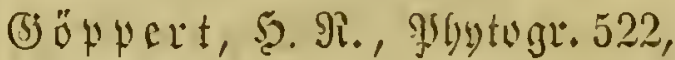
602.

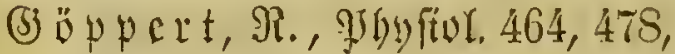
482, 484, 486, 494, Mono= girily 587. 
(3) iैtle, Sob. 2Bolfg. von, $359,390,510$.

(S)ittingen, Flora bicier Stabt, $228,319$.

(G)

(jorter, Dav. Dr, Flor. 237, $245,343$.

(5) otheแburg, flora won, 116.

(5) ottiche, gुbuftur. 479.

(3) ottidicb, S., Flor. 155.

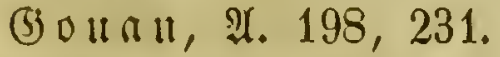

(5) o y a n, Sflanzengeogr. 600.

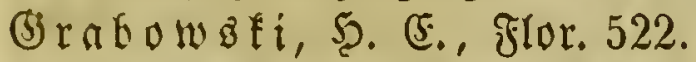

(5) raff, (5) b. (5) ottl., Flor. 313.

(3) rabam, S., flor. 545.

(5) $\mathfrak{r} \mathfrak{a} \mathfrak{b}, \mathfrak{A} .$, flor. 536.

(5) rateloup, S. IJ. A. (5), Flor. 327.

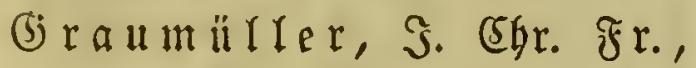
Flor. 316, 525 .

(3) $\mathfrak{x} \mathfrak{4}, \mathfrak{M} \mathfrak{a}, \mathfrak{f l o r} .573, \mathfrak{M} 0=$ nogr. 587.

(j) relf, R. y., Jhyfiol. 288.

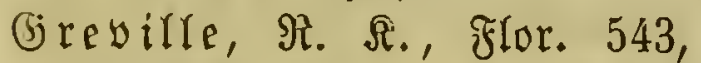
$544,545,556$.

(S) renier, (5)., Flor. 533, 538, Jjflanzengeogr. 597.

(5) retw, R., Sjbytonom 137.

(5iriedenland, Flora von, 90, 111, $241,357,555-556$.

(5)riedenlands ältepte Botanifer 5 -26 .

(3) riffith, Jjhyf. 479, 492, 565.

(5) rimm, S.. R. , Reir. 117.

(3) rinbel, D. S2., Flor. 365.

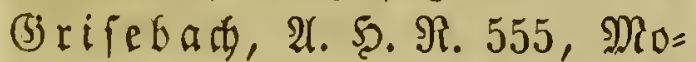
nogr. 589, Soflanzengeogr. 595, 598.

(5) rislev), (5) abr., Flor. 110. Grönland, Flora von, 169, 243, 375.

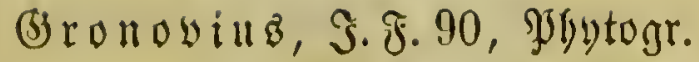
$251,252$.

(3rofbritannien, 3jgutographen von $111-114,159-161,234-$ $235,333-342,539-545$.

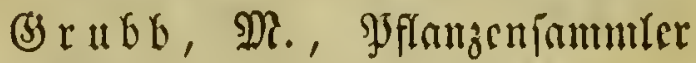
251.

(3) $\mathfrak{r} \mathfrak{b} \mathfrak{e r}, \mathfrak{F} r$. D. S., Flor. 319. (3) $\mathfrak{r} u b \mathfrak{c r}$, 3., Spgyfiol. 472. (3) uefit, r. Arben (3) uefit.

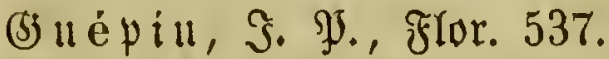

(3) ä $\mathfrak{n}$ th $\mathfrak{c r}, \Omega$. (5) r., Flor. 522.

(3) u érin, S., Flor. $32 \%$.

(3) uft $\mathfrak{a} \mathfrak{r}, \mathfrak{s}$. St., Spgyfor. 209, Flor. 232.

Guiana, flora von, 254.

(S) uiart, D. R. 145.

(3) uillaro, Sbyyfol. 469, Syftem. 444.

(5) uillemeau, Э. R. M., Flor. 326.

(5)uilea, Flora von, 250, 370371.

(5) ulbenftäbt, S. A., Reir. 247. (5) $\mathfrak{n} \mathfrak{n} 580$.

(3) unner, S. (5., frlor. 242.

(3) u flone, (3), Flor. $552,553$. (5) utbier, v., 602.

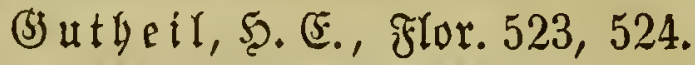

\section{న.}

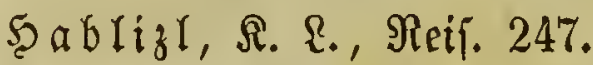
5̧acquet, $\mathfrak{B} .$, Flor. 221.

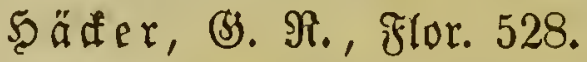
Şagelfam, Bjflanzengeogr. 598. Şagen, R. $\mathfrak{F}$. , Flor. 520.

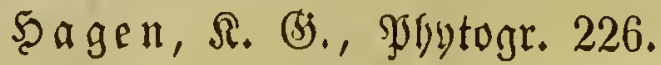

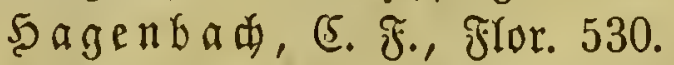
Şales, Steph., Shym. 151.

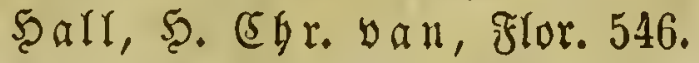

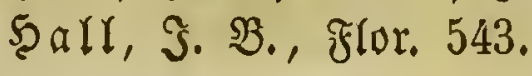


Şalle, Flora diefer Stadt, 103, $155,225,313-314$.

Scaller, A. v., $191-193$, flor. $228,230,319,333$.

5amburg, flora von, 528.

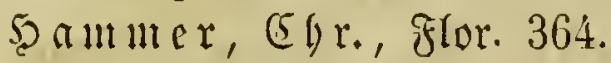

5amirton, Fr., গieir. 369, 567. 5amilton, $25 .$, flor. 574.

Sampe, nogr. 585.

Şanifi, $\mathfrak{A b}$ orrabman $\mathfrak{M} d=$ bamed ebn ati ebn $\mathfrak{A}$ a $=$ med 50 .

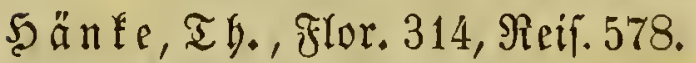
5annover, Flora voll, 156, 527. 5̧arbuin 38.

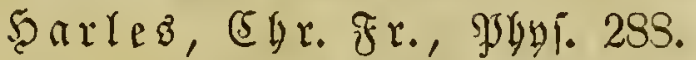
Scartig, Th., Sbyfiol. 451, 453, $454,455,465,474,479,483$, 491, 494, Mlonogr. 587, 603. 5earting, Ps., Bgyfiol. 453, 465 . Şartmann, צs. S., Flor. 225. 5̧artmann, న. S., 558 . 5ुatog, S., Reir. 249. 5artwalt, flor. 561.

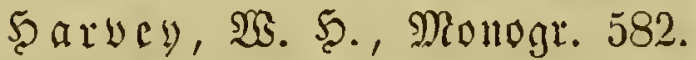
Şarj, Flora beffelben, 81. 5̧affelt, S. E. van, Reif. 567, 568.

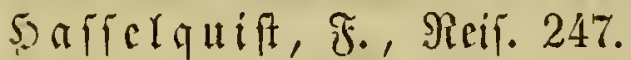

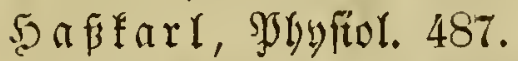

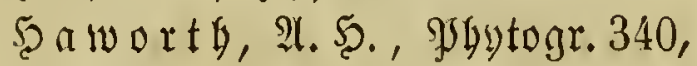
Monogr. $586,590$.

5ayne, Fr. (5ottr., Spgytogr. 312 , Jbyfior. 457.

Seberfteit, S. (5., 146. Sebribenimieln, Flora ber, 545. Şécart, (3. 2. S., Flor. 547. Scfer, Sol. Эur., Flor. 225. Sedwig, Joh., ghy fifol. 208, $215,217,218,280,281$.

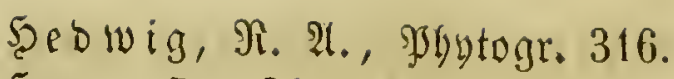
Şeer, S., fflor. 529, yjflanzen= geogr. 596.

Segetid weiler, S., flor. 529,

Wflangengeogr. 596.

Scriolberg's folora 100,224,516. Seioler, 凡. S., flor. 510.

5eim, (j) g. (5) r., Flor. 298. 5ecinzelmann, Reí. 167. Sefiter, R. , 193, 194.

Seldmann, א., Flor. 518. Seller, Fr. X̃a., Flor. 308. 5erriving, (5. A., Flor. 308. Selmftäbt, flora von, 229. 5ุenfel von Donnergitarf, flor: 520.

Senty, 2., Jुgyftol. $463,473$. 5enibam, ஒrbytonom 137. รุnำ

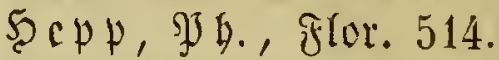

5̧erafitus 13.

5erberth, Monogr. 586 .

5ectig, Fr., flor. 512.

5̧erborn' flo flora 101, 224.

Scrgt, S. \&., Flor. 518.

5ermann, গJ., Flor. 107, Reif.

120, 249, Syftem. 129, 130.

Scermb ftäbt, S. F., Pुbyftul. 285.

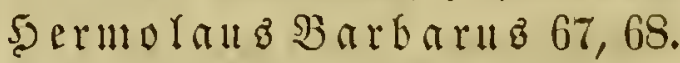

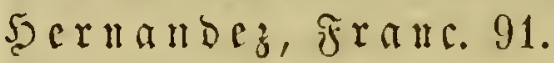

5erolo, flor. 506.

Scerfdel, $\mathfrak{H}$., Jyyfiol. $487,489$. Seffen, Flora yon, 224, 310,311, $518,519$.

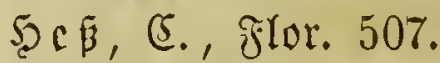

5euffer, J., Planzengedgr. 596.

5eydenberger 63.

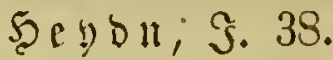

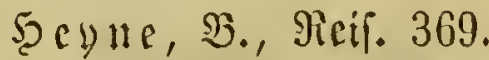

5eyntold, (5)., flor. 524.

5bonain cben 3 bat 48. 
Şialtarit, D. S., flor. 557. girbegardia so.

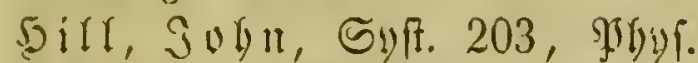
$209,213,215,217, \mathfrak{f l o r} .234$. 5iffenberg, \$flujecugeogr. 599. 5ippofrates 14, 16.

5ifinger, 羿, gftanzeng. 598.

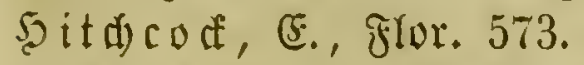

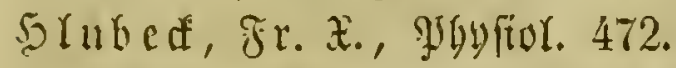

5odberg, Frgr. vou, (barten DCB, 305.

5odfetter, (5) 506, Jigyitor. 467.

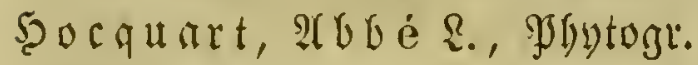
343.

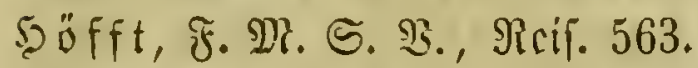
50 yen, \$gyftur. 466 .

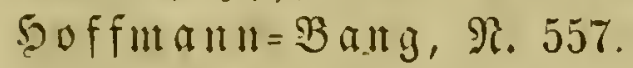

50 f f ntan, (3) g. Fr., Flor. 296, $367,368$.

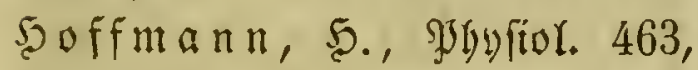
$483,489$.

5offutan, Mor., Flor. 100.

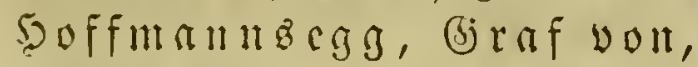
Sieif. 356,554 .

5o fmeifter, PGyfor. 469, 479, $490,491,492$.

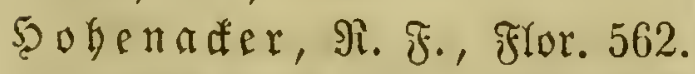
Solenwart, S. v., Nicif. 304. 5orr, $\mathfrak{g}$ r. , fror. 524, 571. Solland, firora yon, 237.

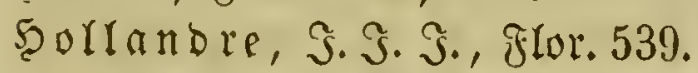
5olmffioro, Th. 5. v., SBby= togr. 359.

Souffein, Flora yon, 229, 528. $50 \mathrm{mbrou}$, sgytogr. 581.

5oukeney, (5.) A., flor. 219.

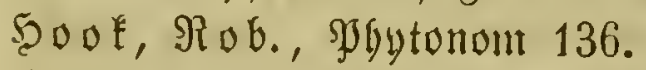
5oofer, $\mathfrak{3}$. S., Sygtogr. 340, 540, 544, 574, 580, Яeif. 364, Ronogr. 585.
Soptirk, Th., flor. 338, 9Jyy= fiolog 493.

5op\&c, D. 5., AReif. 505, 9yby= togr. 299, 308, 309.

5opHc, Tob. R., Flor: 228.

5oraninow, Sy., Syftent. 440.

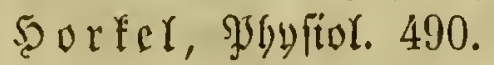

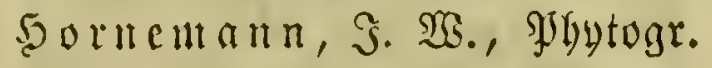
$242,358,556,574, \mathfrak{P f l a n} \mathfrak{z} \mathfrak{e n}=$ grogr. 599.

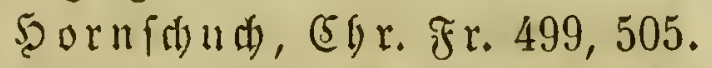
Sorrebow, Rirb, Sygntogr. 243. Sorri, IJ. MR. J. De, flor. 101. 5orafierb, 立h., Neif. 396. 5oft, Ric. IDom., Flor. 302, 303, 507.

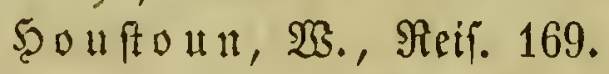

Souttuyn, Mart., $\mathfrak{d g y t .} 237$. 5ow, $\mathfrak{W}$ irf., flor. 114.

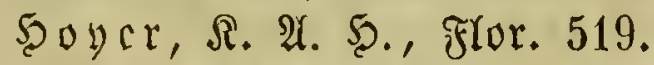

5ुuber, gre, gogyfur. 288.

5ุofon, 23., Flor. 234.

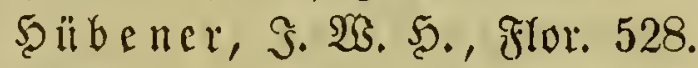

5̧übener, S. צJ. W., Monogr. 584 . 5ü $\operatorname{gel}, \Re$. y. 580 .

5ำ

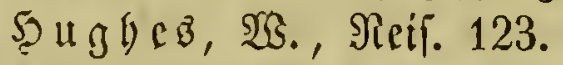

5̧ult, Joln, flor. 335.

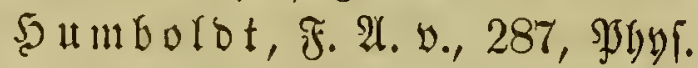

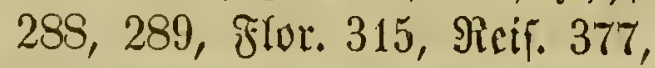
564, sjflanjengrogr. 384, 393, $405-410,593,600$.

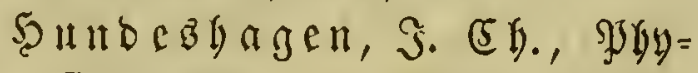
fiolog 462.

5̧unter, Atex. 210.

5utfenot, Fror. 533.

\section{I.}

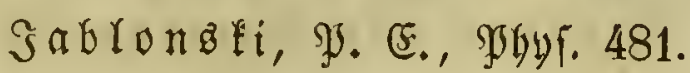
Sa af, $2 \mathfrak{s i n t}, \mathfrak{F l o r} .568$. Sacob, Foward, Flor. 236. 
Sacob Theobor bon $\mathfrak{B e r g}=$ zabern 81, 82 .

Sacquil, গ. S. v., spbytogr. 220, Sieif. 254.

Sacquint, gjgytogr. 581.

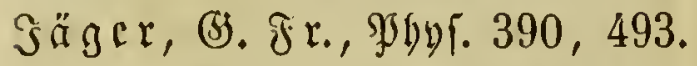
$\mathfrak{S a \mathfrak { n } ,}$ A. $\mathfrak{F}$ r. E., Flor. 227. San, (3) g., flor. 551 . Samaifa, Flora von, $253-254$.

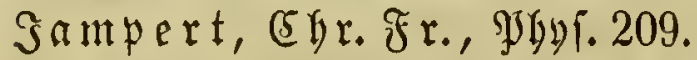
Sapanefífie Flora $247,565$.

Jaufiin, ‥ A., Sbytogr. 239. Sava, Flora von, 249, 567-568. Sena, Flora von, 155, 228, 525. Sentinion, S. 234.

Snbiens ältefte Siultur, 1.

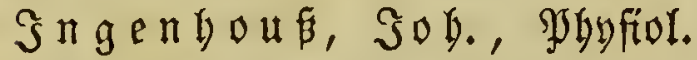
$211,212,287$.

Sngolfabt, Flora von, 100, 514, Sobann von caba 63 .

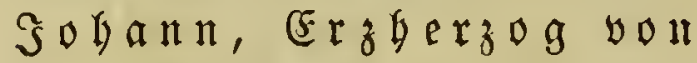

Seftecid, Sphytogr. 304. Johannes Actuariub 45.

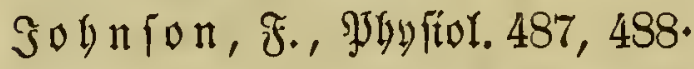
Soln non, 5., Jjgyfor. 480. Solynion, Th., Sogytogr. 111. Solntiton, (3), fror. 545.

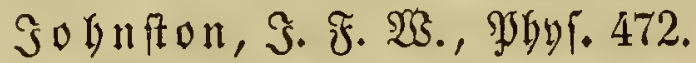

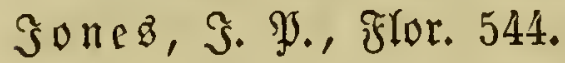
SoneB, WF., Reif. 369. Sonifde Snieln, flora beri. , 556. Solveniub , Mে. D., Flor. 155.

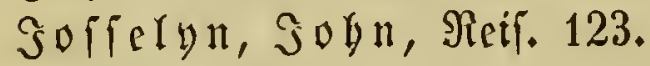
Srlano, Flora von, 160, 545. Srmifd), $\mathfrak{I}$ y., flor. 526, Jjgy $=$ fiolog 468.

Srivine, A., Flor. 543. Siert, গ]. E., Reif. 250. Síoorub aus carthagena 44.

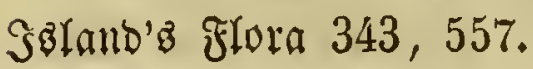

Sfrifide Flora 162, 508.

Stalien's erfte eigentr. Botanifer $67-74$.

Stalien, Spgytographen von, 108 $110,162-164,237-239$, $344-353,547-553$.

Suan Fernandez, Flora von, 256. Эuan, (3., Reí. 256.

Suben, älteite Sultur berf., 4.

Silngft, ‥ গ⿹. , Flor. 523.

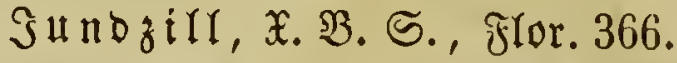

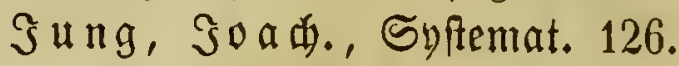
Sun $\mathfrak{g}$, $\mathfrak{W}$. , Flor. 518.

Sungermann, Soad., 81 . Singermann, \&., flor. 99.

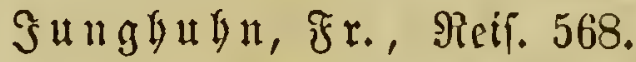
Sulfieu, $\mathfrak{A}$ or. oe, Şguftor. 464, 479, 601, Monogr. 591, 592, 593, grflarzengeogr. 594. Suffieu, $\mathfrak{B e r n a r d}$ de, 261.

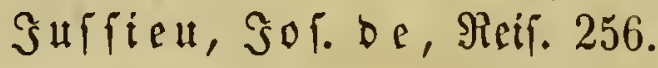
Sulfieu, \&aur. $\mathfrak{A}$ t. of, 106, $145,158,159,262,272,276$, $393,411$.

ร子yaf, f. Somain.

\section{凡.}

Rabatb, 5̧., Şatogr. 522 . Räbnlein, H. , Flor. 226.

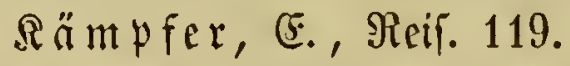
Rärntben, Flora von, 304. Räftuer, A. (5), ஒJgy 213.

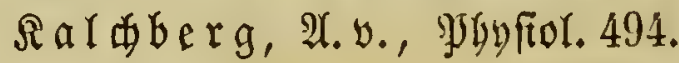

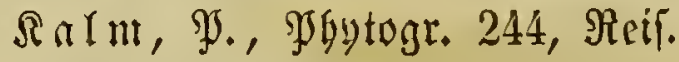
252.

Ramel, (j). S*, Reif. 121. Ranaba, flora uon, 253. Sanarifde Silieln, Flora Deri., $371,372,571$. Saplãubifá Flora 250, 251, 570. Rarläbab, flora von, 154. 
ภarlz bes (3rofen Berbicufte แแ bic Seriltumbe 57.

Simelina, flora woll, 252.

Sarfen, 5., Jhyfort. 451, 452, $465,469,480,492$.

Sartoffel, Anffinoung berielb. 92 . Sitfarina, flora won St., 92.

Sautrafidac frlora 247.

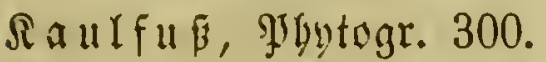

Reith, 多., ghbyfor. 293.

Relaart, F. F. Flor. 554 .

Rcm Rent, Reir. 567.

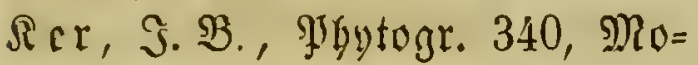

nogr. 586.

Serbert, C., Flor. 546.

Rerner, Sof. Sim. 223, Flor.

310.

Rew, botan. (B)rten baf. 88 .

Ri ifx, S., Flor. 343.

Ricier, D. (3)., Jbýf. 285, 390.

Rillg, Reif. 580.

Singiton, S. F., Flor. 544 .

Sirucnftant, Flora beflelben, 238,

$350,552$.

Rirduer, (5., Flor. 520.

Sirfdeger, Jjyftol. 469, fror.

533.

Ritaibel, S. Flor. 306.

Rittel, SR. B., Flor. 505.

Rittli 13, F. S. v., Pflanjeng. 599 .

Rlcimafien, Flora Deffelben, 90, $166,247,564$.

Rlett, (5. Th., Flor. 525.

Rlot $[$ d), Monogr. 584.

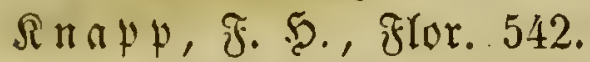

Snautb, Shriftian, Syft. 145.

snautb, sbriftoph, Flor. 103,

Sy)fent. 132.

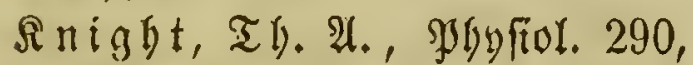
$293,480$. アnip丩of, S. S., 156.

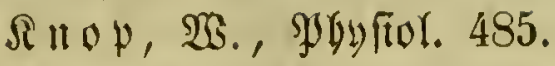

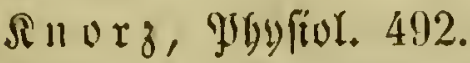

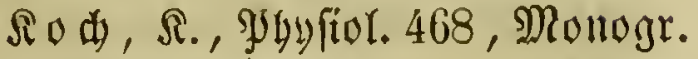

589.

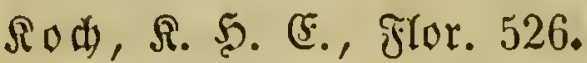

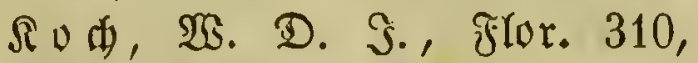

504, Monogr. 587.

R̋̈bing, F. $\mathfrak{W}$., Flor. 525.

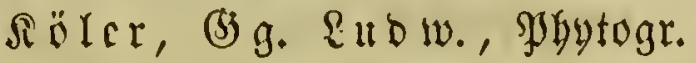

300.

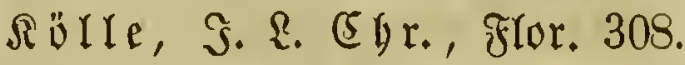

Rörtifer, $\mathfrak{A}$, flor. 531.

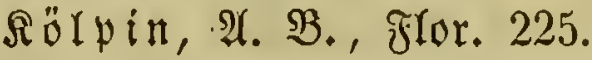

Sör $\mathfrak{i}$ at ter, S. (3)., Sogyfor. 214,

$215,217,295$.

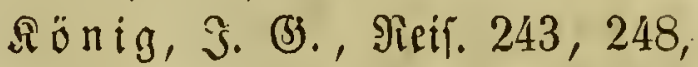

361.

Rönig，R., 341, fror. 515.

ヘ̈̈rber, (3). WH., Monogr. 583.

Rürte, f̧r., Sybtogr. 308.

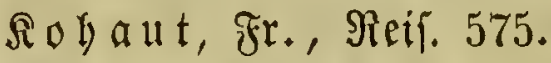

Ropentagen, flora von, 557.

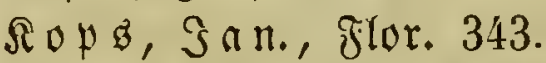

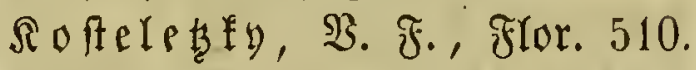

Rofter, Ş., Reif. 379.

Srain, Flora yon, 221, 304, 508.

Iramer, S. 5., Syft. 146.

Rramer, $\mathfrak{i s . ~ S . ~ , ~ F l o r . ~} 219$.

Srafdeninifow, St., Jieif.

246.

Rraucr, S. (3., Flor. 530.

Srempelfuber, $\mathfrak{A}$. y., $\mathfrak{M}_{\mathfrak{d}}=$

nogr. 583.

ภreuter, . S., Flor. 508.

S r o fer, $\mathfrak{A}$. S. , Flor. 226.

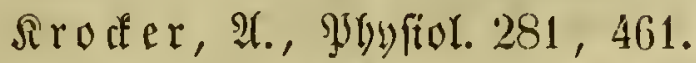

Srofer, 5., Jgyfitor. 462.

Sromblolz, S. $\mathfrak{B}$. v., Sigpt.

511, Monogr. 584.

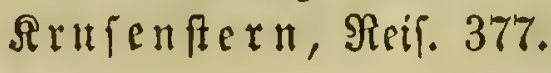




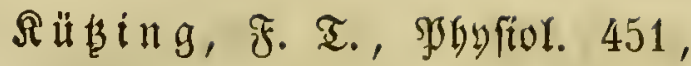
$452,453,455,456,457,458$, $461,463,466,468,470,473$, 474, 475, 477, Monogr. 582, 584.

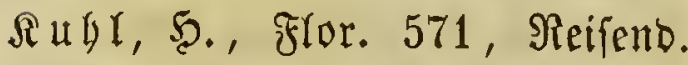
$567,568$.

爪unth, 凡. S., flor. 313, 408, Monogr. 585, 586, 589, 591, 592, 9sbyfiol. 467.

Runze, (S., Myfor. 316, Flor. 554, Monogr. 585, 586.

A uyper, (3). $\mathfrak{A}$. $\mathfrak{3}$., Flor. 546. Rylling, Jet., Flor. 116.

\section{\&.}

Zabat, S. S., Reif. 167, 169. Rabat, Shyfít. 487.

Rabillarbière, $\Im_{\text {. }}$ Э. Reir. $248,380$.

Rab OrDe, $\mathfrak{R} \mathfrak{C O N D C}, 565$.

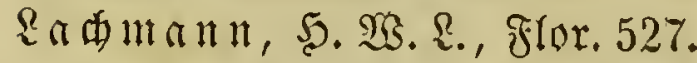
Ragaźa, R. A., Monogr. 589. \&agåaca, M., Sjbytogr. 354 .

\&爪guri, গ̧., Flor. 239.

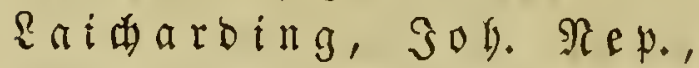
Flor. 295.

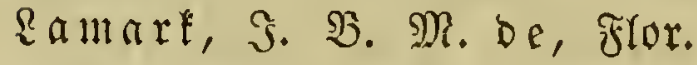
233, Syftemat. $272-73$.

Rambert, $\mathfrak{A} . \mathfrak{B} .$, Monogr. 341 . \&ambertye, R., flor. 535.

\&amoureux, Flor., 326.

\{amouroux, 3. 3. $\mathfrak{5} .333$.

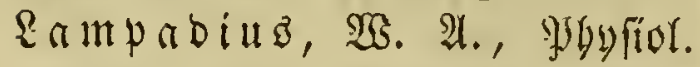
289.

Rancifi, $\mathfrak{R}, 151$.

\&ang, A. Fr., Sbytogr. 512, 565 . Rangetbat, (5br. (5), f Flor. 526.

\&angford, $F_{*}, \mathfrak{F l o r .} 114$. Rangmann, S. Fr., Flor. 527. \&anguedoc, Flore biefer Browind, 105.

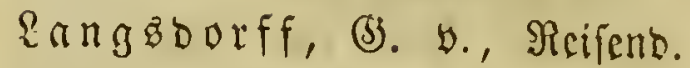
$377-378$.

\&a Ş érou $\{\mathfrak{e}$, Reif. 380.

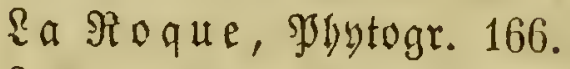

Raterrabe, S. $\delta$, flor. 328.

\&aunay, $\mathfrak{M}$. De, Phytogr. 323.

\&auremberg, 2ืirh. , Gyltem. 125.

Rauremberg, Syet., Syftem. 125.

Raurer, Sbfytogr. 300.

Raufiti, flora biefer Jrovinj, 102, 315.

\&avy, รean, flor. 348.

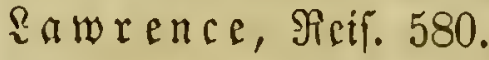

\&awfon, S., flor. 169.

Raxmann,

Rechler, Sib., flor. 516.

Rebeboll, R. Fr. von, Fior. $364,376,560,563$, Jjflan= zengeogr. 599.

Reerg, S. D., Flor. 224.

Rees, (5., fror. 544 .

Reentoentö, $\mathfrak{A}$ ton ban, 3hy fiol. 138, 473.

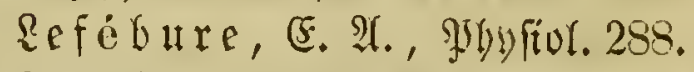
Reféburs, R. F. S., Flor. 532, 534.

\&elmann, Э. F., frlor. 308.

\&ebmann, S. (3). (5) r., 603, Monogr. 591, Jrygtogr. 581. Reiden, Flori von, 167, (5arten bar., 162.

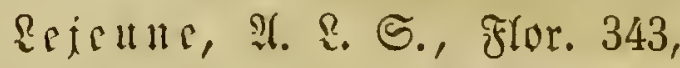
546.

Reighton, 然. A., Flor. 544. Reipzig' Frar 102, 155, 227, $315,525$.

Ren3, Ş. S., Monogr. 584 . 
SconicenแB, sicol. 68.

ecopolo, S. D., Flor. 154.

ecpedill, 3., glor. 246.

ectictir, Aicif. 570.

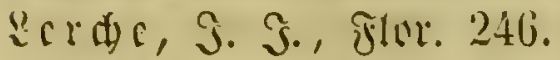

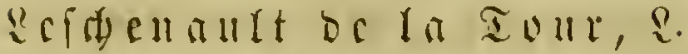

IY., Bfflanjengcogr. 600.

effiting, (5). Fr., Nonugr. 588,

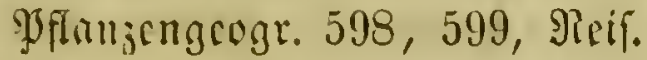
564.

Eefron, 9R. 3r., flor. 537,

Pfflanzengeogr. 600.

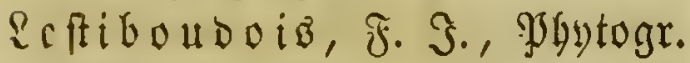

$342,545$.

\&cfiboubois, Э. B., Jjgnt. 342. Rcfiboubois, Them., Tyby

459,464 , gjhytogr. 545.

seudart, über bie foffiten (5)e

wäd je, 602.

Réveirré, \$. \$2., Monogr. 583.

Revinin, R., flor. 561.

\&ewiz, M., Reif. 374, Flor. 573.

Rexara, $\mathfrak{S}_{\text {. }}$ flor. 575.

eeyifer, Fr. Wirty. y., Flor. 225.

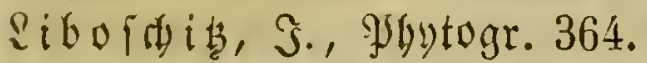

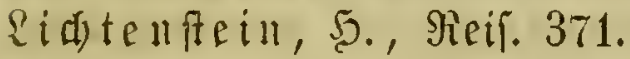

Sicblein, S. న., filor. 225.

siebig, S. v., 472, 473, 481,

485.

gightfoot, sobn, fror. 236.

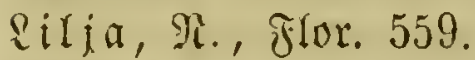

Eiljeblab, S., Eyftemat. 199,

fror. 360.

Riufe, Sol. $\Re$ ub., fror. 506

QinDblom, A. F., 558.

ainoenberg, S. B. 25 ., $\mathbb{N}_{0}=$ nogr. 584.

sitiber, S. v. Eindenfolpe,

Flor. 165.

Rindern, S. B., Flor. 158.

Rindley, S., Syftemat. 418, flor. 540, Mlonugr. 586, 589, 590.

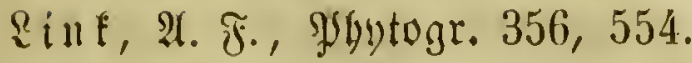

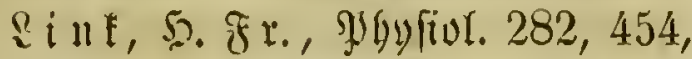

$457,460,48 \pm, 485,495$, firtor.

319, Syftemat. 444, Bgytogr.

497, 498, 502, Reif. 555.

Sillć, Rarl von, $171-176$,

$215,243,258,383,386,389$, $441,446,448,489$.

sinne, $\mathfrak{i} a \mathfrak{l}$ yon, Soln,

Jjhytogr. $243,244$.

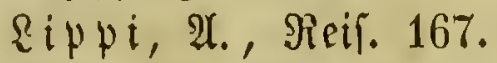

Sifa, D., Jruptog. 551.

¿ifter, $\mathfrak{M}$., Spgytun. 137.

Sityautiche Flora 245, 366.

Rivorno, flora yon, 162.

Rlave, গJ. be $\mathfrak{l} a$, Flor. 575.

Rloys, S., flor. 538.

Roberius, f. Sober.

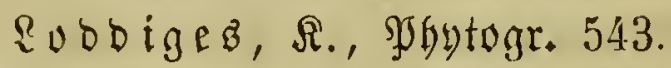

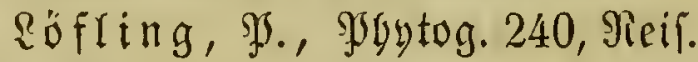

255.

Röhr, MR. F. , Flor. 523.

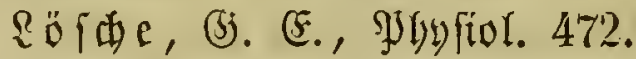

Röfel, Sol., flor. 102, 103.

Roew, 爪. F., Flor. 221.

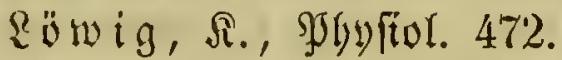

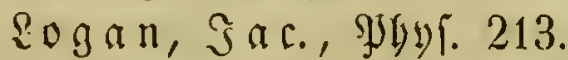

Roifeleur = Dezlondamp

R. S. 2., Fror. 323, 331, 532,

3jbyfiol. 464.

Sombarbei, flora ber, 237, 548, $5 j 0$.

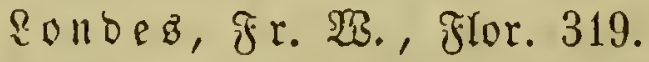

Eonoon, frora von, 235, 337, 543.

Roret, (5. (5), Flor. 520.

Rorey, frtor. 53 j.

Rorinier, Fricor., Fror. 506.

Rorinier, (3), Flor. 506.

Rotlyringen, flora wolt, 232, 326. 
Loubere, De Ia, פybytogr. 166. \&oudon, $\mathfrak{~}$. (5⿺., Şbytogr. 542. Roureiro, S. D. v., Reif. 247. $\mathfrak{R} \mathfrak{W} \mathfrak{w}, \mathfrak{R}$. $\mathfrak{T} \mathfrak{l} .$, Flor. 571.

\&uf $\mathfrak{a n a}, \mathfrak{A} .89$.

Rucca, Flora von, 551.

\&uce, S. WS. R. v., Flor. 561 .

\&ubivig, હ乌. (3., Syft. 146, 195.

\&über $\mathfrak{B}, \mathfrak{F}$. $\mathfrak{W}$. A. , Flor. 226. \&unniber, Steph., Flor. 305. Runan, Soln, Reif. 376.

\&uxford, (s., Flor. 544 .

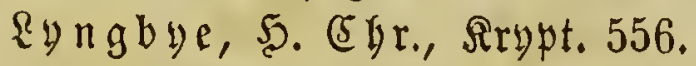
Ryon, flora yon, 231.

\{yonz, Sarael, Flor. 236.

\section{Mt.}

Macaire = Srincep, Sybyfol. $473,475,482$.

Macartney, Reif. 247.

Macfabyen, $\mathfrak{S}$, flor. 575.

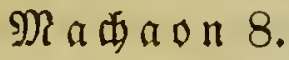

Ma a a y, S. D. , Flor. 545 .

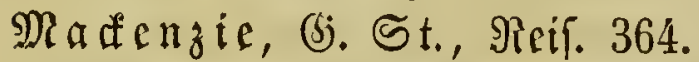
Mabagażcar, Flora yon, 121.

Mäbren, Flora von, 509.

Märtín, (3). Fr., Jyyfiol. 216. Märter, Fr. Sof., Flor. 219. Magnol, Wierie, Flor. 106,

Syftem. 133, 201, গुby. 139. Da a founeube, D. De, $\mathfrak{D b} y=$ togr. 569 .

Malpi glbi， M., SJbyton. 138. Malta, Flora bon, 110.

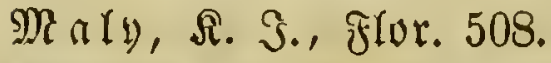

$\mathfrak{M a n a r b}$ แ $\mathfrak{B} 69$.

Manncim, Flora diefer Stabt, 516.

Mantell, übre bie forfflen (s)e wäd) $\{e, 603$.

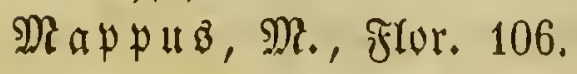

$\mathfrak{M} \mathfrak{a} \mathfrak{r} \mathfrak{a} t \mathfrak{t a}, \mathfrak{B} .70$.

Maratti, (3). F., 枹ufiol. 217, Spgytogr. 552.

Marceltus Empirifus 41 . Marcet, Şbyftol. 473.

Marcgraf, (G., Reif. 122.

Mard and, Sybyfiol. 463, fror. 547.

Marant， S., Sbyfiol. 151.

Mardant, $\mathfrak{i}$ ic., SWbytogr. 105. Margot, 5 . , fflor. 556 .

Mariotte, (5., Sybyfiol. 139.

Mariti, (s., Reir. 248.

Marf , Flora Derfelben, 103.

Marb ס $\mathfrak{n}, \mathfrak{W} .$, Shytogr. 249.

Marfball, 5ृ., Sjhytogr. 253. Marfigli, 尽. Marteng, $\mathfrak{F r}$, Reif. 123.

Martenz, (B) g. D., filor. 515, 516,549 , Jhyfior. 493.

Marterfted, S. (5), Jlor. 315. Martiniö, B. De, Flor. 164 .

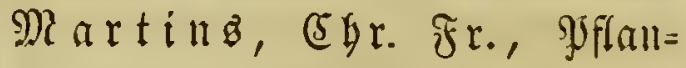
zengeogr. 596, 598.

Martius, 5̧. ע., Jjgytogr. 365 . Martiub, R. Fr. P $\mathfrak{g}$. von, Syftem. 440, Iryptogam 514,

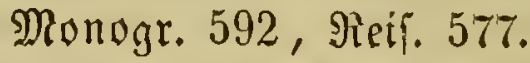

Xartiub， Jbyfiol. 458，463, 465, Mffangengeogr. 600, 9Mv= nogr. 586, 587-601.

Martyn, S., Jjbytogr. $160,161$. Martyn, Thom., Jybtogr. 336. Marquart, Pyyfior. , 469, 475. Marum, Mart. v., Jgyfiut. $212,289$.

Maruland, Flora von, 123.

Mara ar $i=$ Jencati, (5). , Flor.

345.

Darawaib ben 5 anted 52 . Maffalongo, Monogr. 583. 
$\mathfrak{M}$ ๓ा Mafion, Fr. Sict. 251.

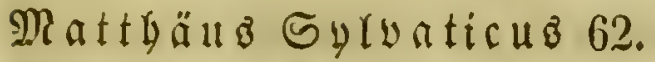
Mattlicu, Flor. 546.

Mattbioli, $\mathfrak{x}$. $.36,71,72$.

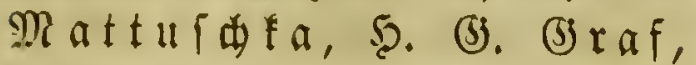
flur. 226.

Maurette, Flor. 538.

Rauri, E., filor. 552.

May cod, S. D., Flor. 575 .

Nayer, $\mathfrak{A}$. Flor. 509.

Mayerboffer, Э. R. 307.

Majzuc ato, G., Mcif. 304.

Medtenburg, flora yon, 229.

Mebicub, franz Raץ. 196,

अॄฯ 216, 280, 290, 291, 484. Meefe, ‥ 194, Whuftol. 215, Slor. 236.

Meigen, Sob. Mith., Flor. $506,523$.

Deinede, S. \&., Shbuful. 390. Mci $\sin \mathfrak{r}$, R. Fr., Jgytogr. 530 , Monogr. 588.

ReI a แp

Nenge, A., flor. 521 .

Menegbini, (5iur, Syby. 464,

Siruptog. 550 , Monogr. 582. Mentel, (5) r. Flor. 102,

Sflanjengeogr. $140,382$.

Menzel, Albert, flor. 100. Renzel, Brgilipp, Flor. 100. Menjieb, $\mathfrak{A}$, Flor. 253. Mérat, F. F., Flor. 324, 535. Mertin, Spyfiol. 466.

Merian, Mar. Syb., Reif. 122.

Meret, Ghr., Flor. 114.

Merten , Fr. R., Flor. 300 , 504.

Mefferifmis, D. (5. , Neti. 167.

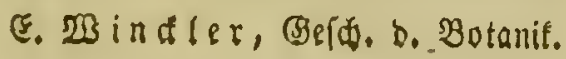

Mefuf o. S., 52 .

Metrumorpbofe ber Pflnnzen 386, 495.

Mcti何, S. (5., Flor. 522.

Rctteutud, Jbytiol. 465.

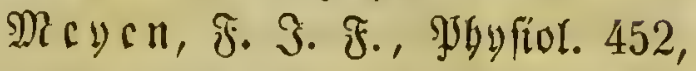
$454,455,457,460,461,478$, $482,483,486,488,489,490$, 491, 494, Pflanzengeogr. 594.

Meyenberg, S., Fior. 156.

Meycr, Bcrnb., Flor. 311.

Seyer, (5)r. Anor., Bgyftor. 208.

Meyer, (5. 5. F., Şbyfior. 464, 488, 494, 495, flor. 520, פghyt. 571, Reir. 574.

Meyer, (Sg. Fr. Wilf., Flor. 527.

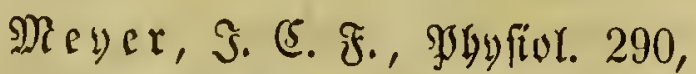
291.

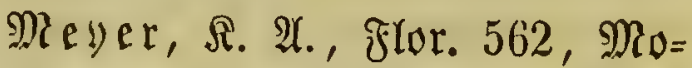
nogr. 585, 588, פJbyt. 560, 563. Mexifo, Syflanzen von, $575-576$. Mid acl 5 cotuz 59.

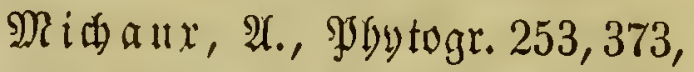
406.

Mi $\mathfrak{i} \mathfrak{a} u \mathfrak{x}, \mathfrak{F}$. $\mathfrak{A} .$, Flor. 373, Monogr. 587.

Michel, (F., Byytogr. 323.

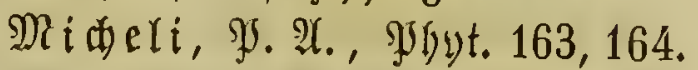
Mio bendorf, Pffanzengeograph 599.

Mifan, J. (5́nr., Reir. 577. Milde, S., Monogr. 585. Mirler, S., Sprytogr. 160. Milfer, $\mathfrak{J}$ h., Pygtogr. 159, 160. Miller, $\mathfrak{s}$ b., Mjoutogr. 224 . Mirlington, Thom., Sgyr. 137. Mirne, collin, flor. 335.

Minf, M., flor. 524.

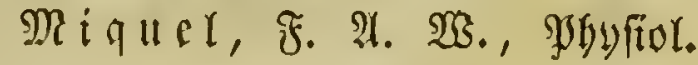
40 
464, 480, 496, Monogr. 587, 588,590, gflanzengeogr. 597. Mituell, 3., Flor. 252.

Mitgriont, Rönig y. Pontus, 24. Mitiderlid, gygyfiul. 463, 472. Mittelalter 42-66.

Mitterpader, R., Flor, 306. Mörter, (b) g. Fr., Phyfiol. 213. Mönd, నonr., flor. 224,

Syftem. 278.

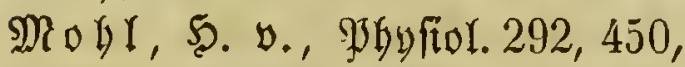
$451,452,453,454,455,456$, $458,459,460,462,463,464$, $469,474,475,476,477,478$, $484,485,488,491,492,494$, 496.

Moln , D. M. S. , Nryptog. 318, Flor. 364.

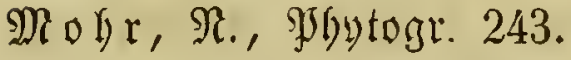

Moirano, (5). A. , flor. 538. Moldentawer, S. D. , Jhyfiot. 208.

Moldenlatwer, $\mathfrak{s}$. Phy fiol. $284,285$.

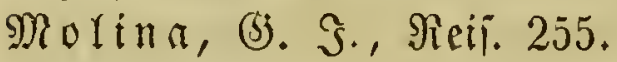

Molfenbör, S. S., Flor. 546.

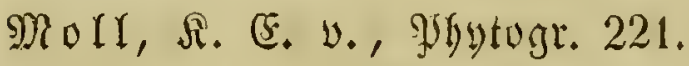
Monaroc $, \mathfrak{R} .90,91$. Monceau, S. ․ Dubamel Du, Pुgy 210, 233.

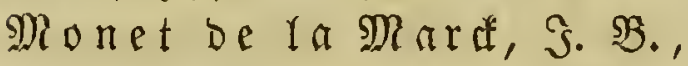

f. Ramart.

Mongolei, Flora Der, 247.

Monograpten 581 - 593 .

Montpellier, bot. (5iart. ju, 104, Flora woll, 106, 231.

Mont=Saint, Thollt., Fror. 104.

Montagne, Mrytogr. 581 .

Mout $i$, (5illieppe, Shatogr. 162.

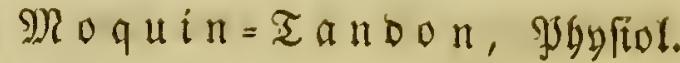
493, Monogr. 588.

Morland, Mgýfíl. 148.

Morplologie 258, 386-391, 495. Morre n, Shyfiol. 457 , 483, $487,488,493$.

Moretti， (5j., Flor. 345，547, Jyyfiol. $461,463,483,487$, Monogr. 588.

Moritand, St., Flor. 549, Pbytogr. 576.

Mori

Morifon, R. 108, Syft. 127 ff.

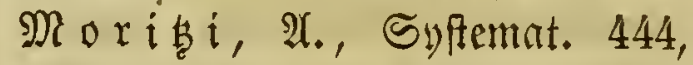
flor. 529.

Mo

Mou ge ot, $\mathfrak{S}$. $\mathfrak{B}$., Wflanzengeogr. $596,603$.

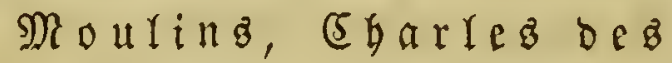

Flor. 537.

Mouton=Fontenire, S. F., Jjhytogr. 329.

Mülicnberg, 5., Jुgnt. 374. Mürler, S. $\mathfrak{B}$., Flor. 526.

Müller, Sof., flor. 524.

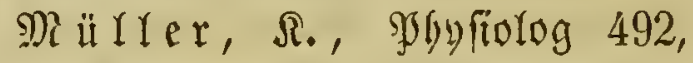

Monogr. 585.

Mürter, 5. Fr., Đogyfor. 216, Bgytogr. 242, 243.

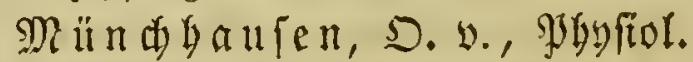
215.

Miinter, $\mathfrak{F}_{\bullet}$, grgyfiol. 464, 468, $474,495$.

Mำ Nurber, S. (5), Whytior. 453, $455,463,473,474,475,476$, $481,482,485$, Flor. 546.

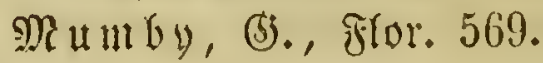

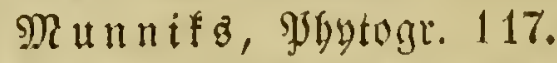
Murny, $\mathfrak{s}$ of. 初or. 198, Bryfiol. 210, flor. 229. 
Murxay, gुby . 468, Flor. 545. Murith, fror. 321.

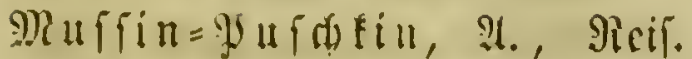
367.

Mufer, Phyfiol. 210.

Dutel, R., flur. 532, 569.

Mutis, 3. (5., Meif. 255, 379. Myrefifuz, Ricol. 45. Myril, C. (5). Fitor. 558. Mytbologidue Sotanif 7.

\section{গR.}

Taccari, গ⿱. Sägeri, R., Sobyfiol. 451, 452, 458, 462, 469, 474, Monogr. 582.

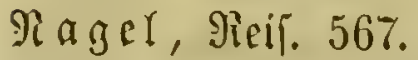

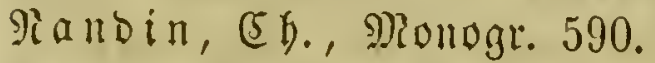
Rantea, Biflangen yon, 232.

Raा̄au, frlora עon, 224, 517, 518.

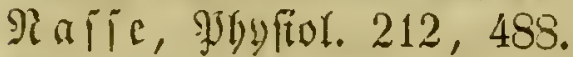

Reapel, Flora won, 239, 552. Reffer, Rat. Jof. v., Pbyfior. 216, 217, flor. 236.

Rectoux, S., Micif. 370.

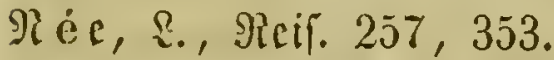

Nec bon E fenbed, (5)

(3) ottr., Bjbyfior. 390, 471, Jjoytogr. 300, 309, 495-500, $505,522,567$.

Rees you Éfenbet, Th. R, Siryptog. 499, 500, Bjbt. 505. Peilreid, $\mathfrak{A}$, fislor. 508.

Rendtuid, (5. R., Flor. 513. Refter, (5br. (3). Juytogr. 332. Neftorianer 48.

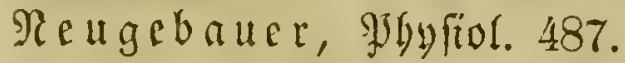
Reugranada, flora von, 255. Reu=(juinea, flora von, 257. Reubolland, flora von, 121, 256, $379,580$.

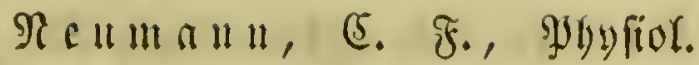
467, Monugr. 586.

গew = Serfey, Flura von, 252.

\{cwmann, F., fryptog. 543, Fisur. 545.

Relw=9yort, flora bon, 252.

Rcygenfinot, $\mathfrak{F r}$. $\mathfrak{W}$, filur. 521.

Niculai, ‥ A., Flor. 526.

Ricut, Scan 92.

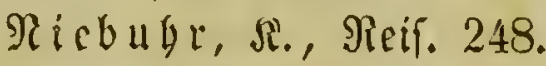

Rieberlande, erffe eigentl. Botanif biefes Ranses, 84, 87.

Nieberlälldifue Shytographen 107, $161-162,236,342-345$, $545-547$.

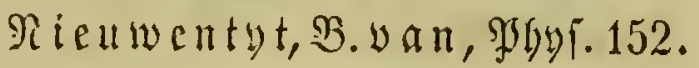
Rifander 24.

Rocfa, D. , Flor. $344,347$.

Rolfet, J. A., Jyyftol. 212.

Rolte, $5 . \xi_{5}$, Flor. 528.

Ronne, Sol. $\mathfrak{l}$ h., Flor. 226. গ⿺辶ก

Rorbafrifa, Bflanzen yon, 167 , $249,369,569-570$.

Norbamerika, frora vun, 123, $251-253,373,572$.

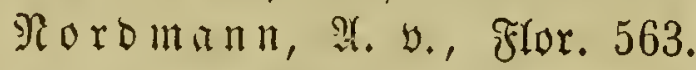
Roronba, ז5. De, Reif. 380 . Rormande, frura der, 325. Porwegens flora 242, 364. Rotariz, (5). De, Aryptog. 550. Roulet, S. B., Flor. 534 . Rürnberg, bot. Sarten, 81. Rürnberg, flora von, 100. Rubien, frlora von, 250.

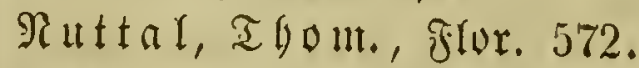
Rylanoer, F., Flor. 562.

\section{D.}

Sber, Matth. of $\mathfrak{l}, 85,86$. 40 . 
Scber, (5) g. (5gr., Syft. 203, 206, গPGy. 217, Sybytogr. 241. Delfafen, Ricol., Flor. 102. Sefreids flora 101, 219-220, $301-304,507-508$.

Detter, r. (5)r., Flor. 315.

Dblert, 巨., Sghyfiol. 482.

Sfen, $419,442$.

DIaffen,

Dlaffen, Dlaf, פjgutogr. 243.

SIeariub, ज̃ob. (s) ottfr., Flor. 103.

Slivier, (3). A., Reif. 368.

Dpiz, P. M., Flor. 510 .

STDOyแt, Th., Flor. 338.

Sribafiuz 41.

Drleanb, タ̧flanzen um, 232, 326. Drtega, (5. (3)., Jyytogr. 240, 354.

Drtmann, A., Flor. 510 .

Ortus sanitatis 63 .

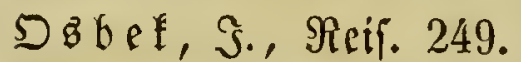

Sftimbien, Florn yon, $117-119$, 166, 248-249, 369, 566567.

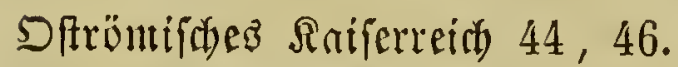

Stto, $\mathfrak{F} .$, Monogr. 590.

Dubuey, Reif. 396, 570.

Svibo yึaldes, Bonzalo รexnandez 91.

\section{\$.}

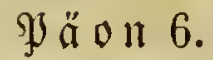

B̧alifot = Beauvaib, $\mathfrak{A}$. M. F. Э., গieif. 370.

J atmberg, Sol., Flor. 116. Şallab, Sinton, flor. 245.

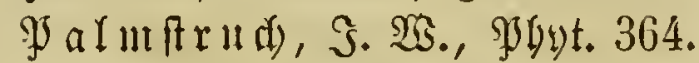

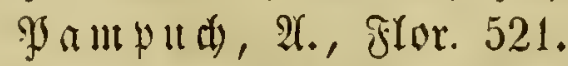

gran arolus , Dom., פ⿹byt. 109.
Janzer, (bg. Wolfgang $\mathfrak{F}$ r., Jjgytogr. 299, 309.

$\mathfrak{P} a p p e$, R. $\mathfrak{W}$. R., Flor. 525.

Paraguay, Flora yon, 255.

Jariō, Flora von, 105, 157, 230, $324,325,534$.

J̧ariz, , Hniverfität, 61.

Şa rifiu z, Sim., Whytogr. 109. Sarfinion, S., Spgtogr. 111,

$391,601$.

Sarlatore, F., Flor. 548, 553,

Monogr. 593.

$\mathfrak{S a r r o t}, \mathfrak{f r}$, , Flor. 562.

SJarry, Reif. 396.

Tyaffau, Flora biefer Stabt, 514. SP affy, $\mathfrak{F} .$, Flor. 343.

Şatrif, $\mathfrak{W}$, Flor. 545.

Satterfon, $\mathfrak{W}$. Reif. 251.

gs a let, virgilifie flora, 30.

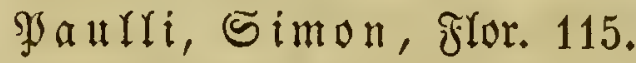
Saul von $\mathfrak{A}$ egina 42 .

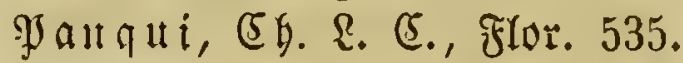
⿰马) a von, $\mathfrak{S}_{\circ}, \mathfrak{R e i f .} 255,354$.

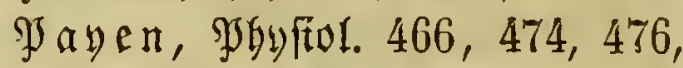
482.

Şazzelt, S. E., SJgytogr. 508. Şe đey, S., Şbytogr. 114.

Jjelletier, S., פ⿹bl. 287, 473. Jjena, Jierre 83.

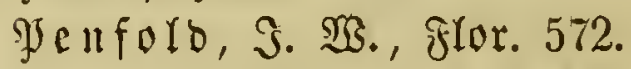
Spenfylyanien, frora won, 252.

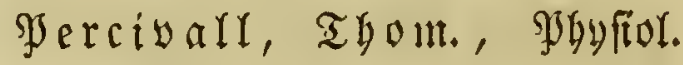
211.

Perey mond, Flor. 536. Serez, Rorenzo 89. Serleb, R. S., Syftemat. 417, 444.

Syeruetty, A. S., れeif. 256. Jerotti, 巨., Jjoyfiol. 293.

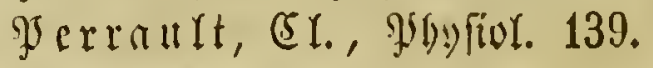
s]eriotet, Sieif. 570. 
Perfien, Flora von, 120, 247, 368, 564.

Jeru, flora von, 255-256, 579. gjeidicr, gogyfiol. 473.

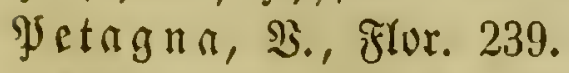

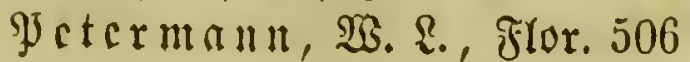
525.

Jetergaturg, Flora voll, 245, 561. Jeter von Sreacentia 60. Petif, 6., Flor. 515.

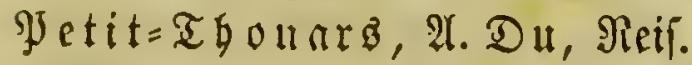
372, अbyfiol. 290, 291, 292, 464.

Sctiver, $\mathfrak{s}$, flor. 110,113, 161. Petalorot, über foffile (Sewäd) 602.

STfarz, Flora derielben, 100, 224. SJfeiffer, \&., flor. 518, $\mathfrak{M}_{\mathrm{D}}=$ nogr. 590.

Wflanjenanatomie 206, 280, 449. Jiflanzengeographie 257,381 $386,593-600$.

Sflanjenterfteinerungătunde 391 $392,601-603$.

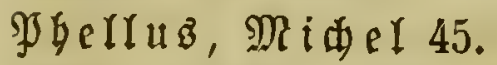

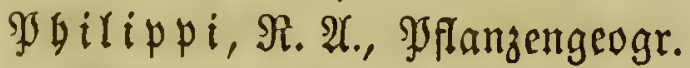
598.

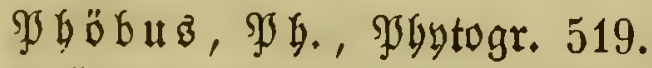

gjö̈nizier, ältefte Rurtur, 3.

Sjgufiologie $147-152,206-218$, $280-295,449-496$.

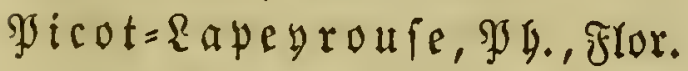
328.

Piemont, Flora von, 238, 550. sjieper, Bryyitol. $466,475$. Spieri, M. T. , Flor. 357. Silfer, $\mathfrak{M}$ atth., Flor. 305. Şirfetier, Razp., Flor. 107. sjineau, sybyfior. 480. Ş iper, 23 ilf., Frlor. 507. Sifa, (3)arten zu, 164.
Ji

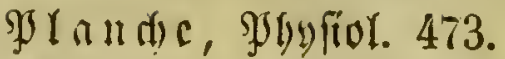

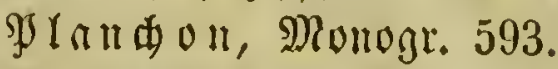

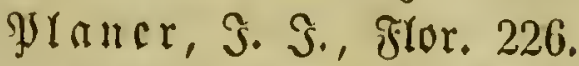

$\mathfrak{J} \mathfrak{i} \mathfrak{z}, \mathfrak{A} . \mathfrak{W}$. , 152.

Jiér, भ., flor. 325.

Jjéc, §., Flor. 325.

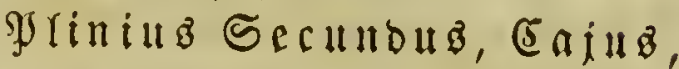

$36,37,38$.

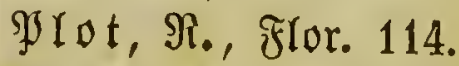

Srufenet,, , Sybytogr. 112, 113.

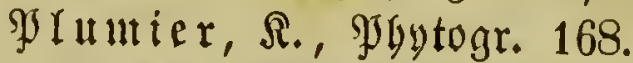

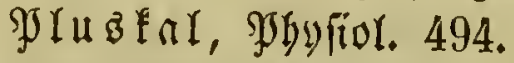

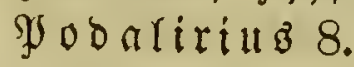

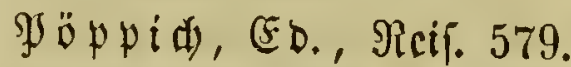

Jobl, Sof. Eman., Flor. 305, Reif. 577.

Soiret, S. R. M., Rcif. 250.

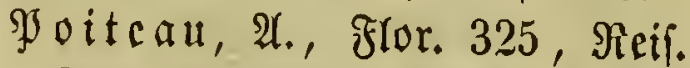

376, Monogr. 592.

SPoivre, SP. , 250.

Solti

sperrini, 厄., Splypitor. 291, flor. $345,346,549$.

Solferer, S. A. , Flor. 536 .

Solstroff, $\mathfrak{R}$, , Shy fiol. 472.

Jommern, Flora bon, $225,521$.

Pona, Franceáco 109.

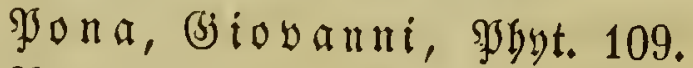
Joot, $\mathfrak{A} b$ rab. $\mathfrak{A} .117$.

Jontedera, Giuglio, 145,

150 , Spbytogr. 162.

Pontoppioan, F., Flor. 242. Sortugn, befien ältefte Botan. 89. Jortugar, Spyutogr. von, 98-116,

$152-169,241,355,356$, $554-555$.

Şojen, Flora von, 521.

Joudet, F5. 2A, fror. 538.

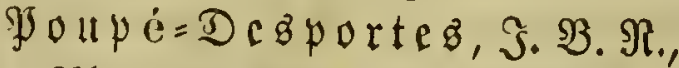

Pbytogr. 254. 
Pourlet, $\mathfrak{S}$. 2t., Fror, 327.

SDouzolz, W. M. C. De, Flor. 536.

J ovelfe แ, $\mathfrak{B}$, Reif. 243.

Jjabl, S. F., Flor. 527.

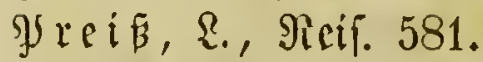

greif, Sylugtor. 463.

Preifer, Jjhyfor. 475 .

Şrezl, S. S., Fror. 509.

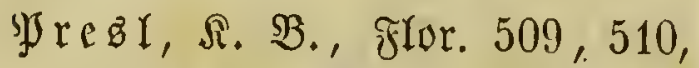

553, Mligtogr. 578, Monogr.

$585,588$.

Sreusens Flora $102-104,155$,

$225-226,311-315,519-524$.

Şreyoft, S., Fror. 106, 110.

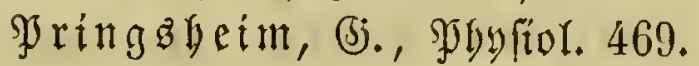

Situard, St. F., Flor. 572 .

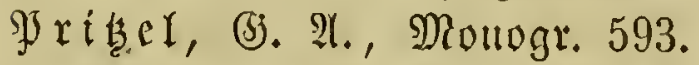
Sriftey, Sof., Jygntor. 211.

SProft, $\mathfrak{T}$. $5 .$, Flor. 536.

Jroyence, Flora Der, 158, 232. J ry 售, ?. S., Fror. 561 .

Ș c ciuclri, 3 . , flor. 551.

Juel, J., Flor. 328.

乌urfi $i$ e, Wryfiol. 469.

$\mathfrak{S}$ ur $\{\mathfrak{d}$, $\mathfrak{F}$ r. Tr., Flor. $315,374$.

Surtou, flor. 544.

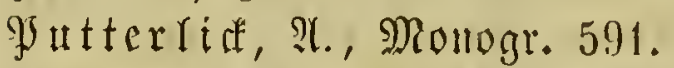

Şyrenäen, Flora ber, 231, 328, 329.

3ythagoräer 11.

Jy ytyagoras 10.

\section{Q.}

Dueniel, (5., gryytogl. 364 .

Ducry Martinez, S., Sुgy $=$ togr. 240.

\section{$\Re$.}

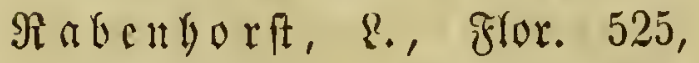
Monogr. 582, 583.

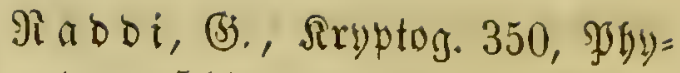
togr. 551, 571, ఇeif. 577.

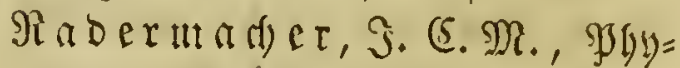
togr. 249.

Raffenau= Delile, $\mathfrak{A}$, Reif. 369.

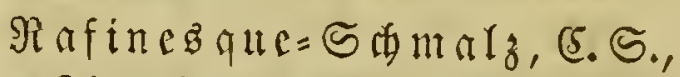
Flor. 352, 579.

R a f Flor. 318, 358.

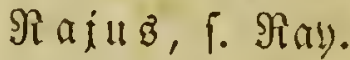

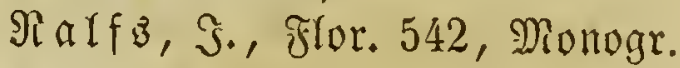
582.

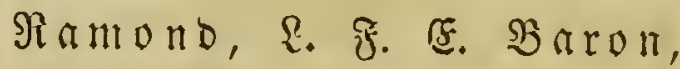
Flor. 329.

গ⿻

(5., Bjflanzengeogr. 597.

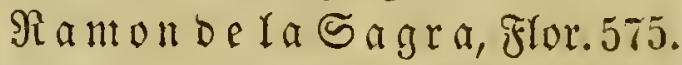

$\Re \mathfrak{m}$ ษ , $\mathfrak{S}_{.}$, flor. 242.

$\Re$ a o ul,

Napin, D. , frlor. 531.

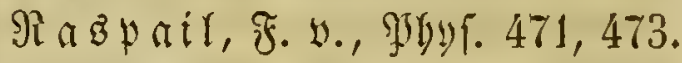
Raftatt, frora von, 516.

$\Re$ a 493, Jygtogr. 519.

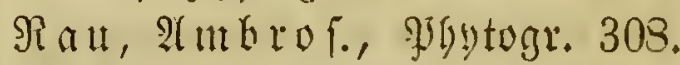

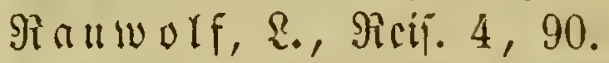

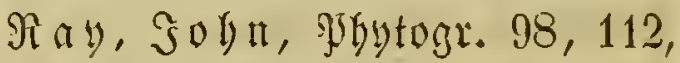

Syftem. 130 ff.

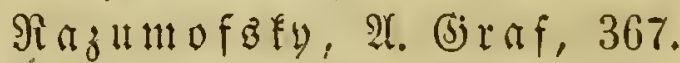

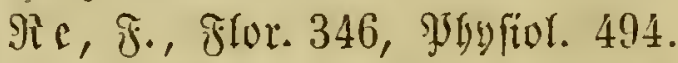
Re, (3). Fr., flor. 348, 550.

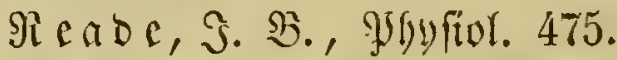

$\Re$ é a unu $\mathrm{r}, \Re$. श. De, 150, Sognfor. 217.

Rebentifd, Fr., Flor. 313.

Rebouté, গJ. S., Jुflamjemma = Ier 330.

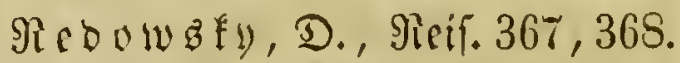

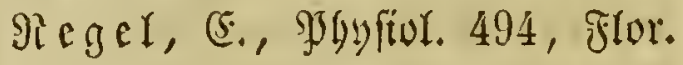
524. 
Regimen sanitatis Salerni 59. Selferto, 2t, flor. 155. Reidacl, Fr. Dan., firter. 525.

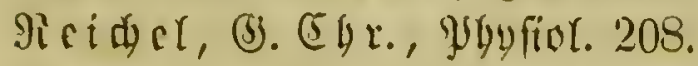
Re cidentrad, (3), Munegr. 586. Recidentady, 5. '(5). R, 299, Syftemat. 420-429, 442, Mive= phol. 496, flor. $500,502,524$, 525.

Micidenbad, Şerminevon, 95y)fiut. 461.

Meitier, Jof, Mirit. 304.

Misinuarot, (5. (3). (5., gyfan=

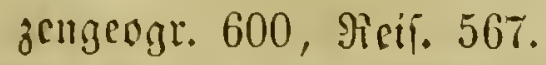

Mcintward, 5. (3). A., Slor. 344.

গecifenoe 89-92, 117-123, 245

$-257,366-381,562$ ff.

Reiffef́, S., Mryfior. 461.

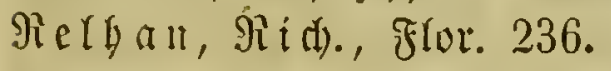

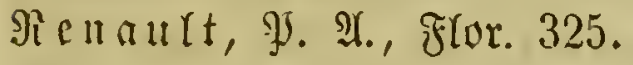

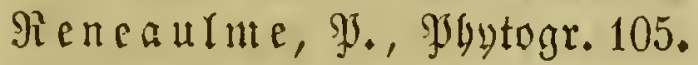

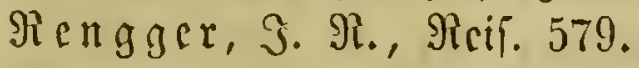
Requien, flor. 536.

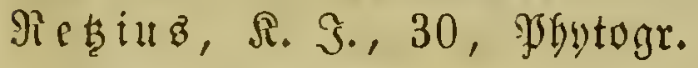
$244,243,361$.

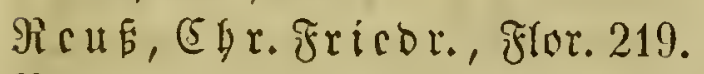
$\Re \mathfrak{A} n \tilde{B}, \mathfrak{R}$, Flor. 514.

Reuter, F. (3)., Flor. 556.

Reutcr, (S) g. Fr., Fror. 530, 554. Reyger, (5)., fitor. 226, 521. Neynier, 足, Flor. 319, 383.

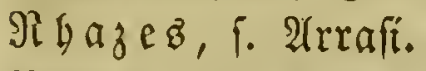

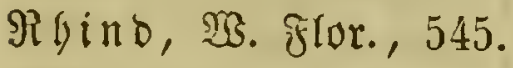

Rgizotomi 23.

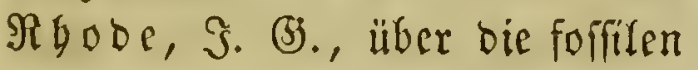
B̧ewuädje, 601.

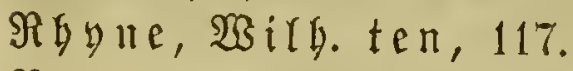

Ridard, \{., Eyftem. 416, 581, Monogr. 588.

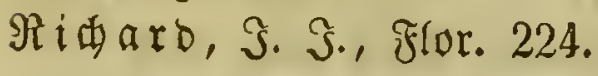

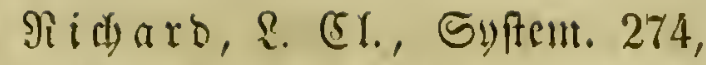
446, gigyfiol. 284, 478.

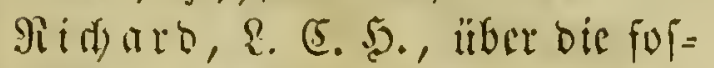
fiten (s)wädy je, 603.

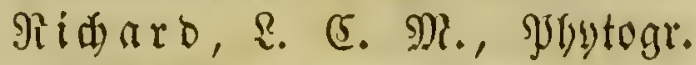

329, Nionogr. 586.

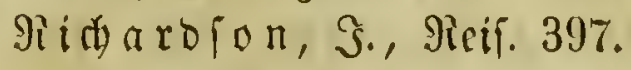

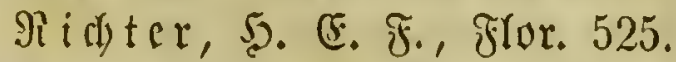

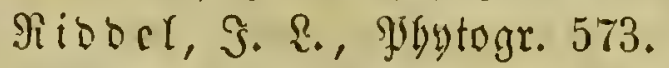

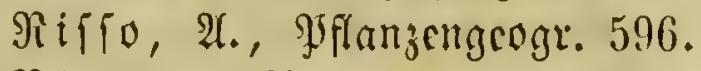
$\mathfrak{R}$ iffo, S. H., Flor. 549, Mo= nogr. 592.

$\Re$ itgen, 予. A. y., Syffemt. 443, Ifflanjertgengr. 594.

ritter, gybyfiol. 212, צjflangen= geogr. 600.

Rivin, $\mathfrak{A} . \mathfrak{D}$ u. Syftem. 133 ff. Roferg, grgytogr. 165.

Robert, frlor. 536 .

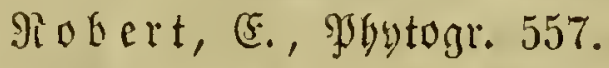

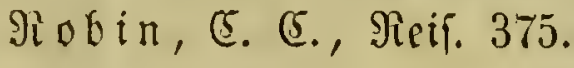

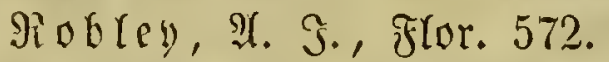

Robion, Stepr), Flor. 235.

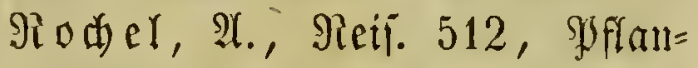
zengeogr. 595.

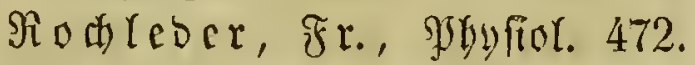

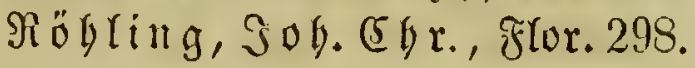

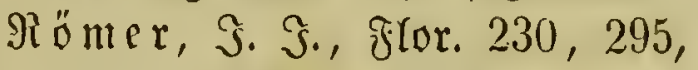
$296,301$.

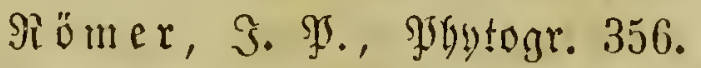
Römer， M. Э., Monogr. 586, 592, ģflantzengrogr. 594.

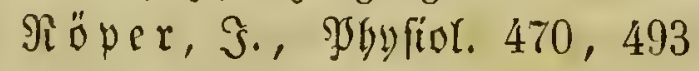
496, Monogr. 593.

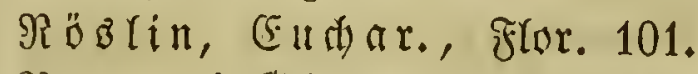
গioggeri, (b) i acomo, firor. 110. Mogr, Meif. 358.

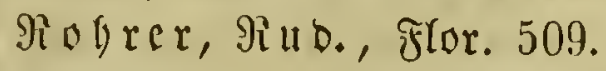

Siom, flura von, 109, 110, 552. Tiomano, (5j., glor. 548, 549. Rominger, grgyfiol. 483. 
Ronconi, $\mathfrak{A}$, Flor. 351.

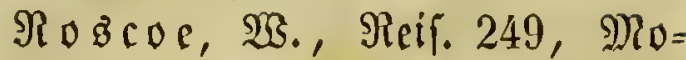
nogr. 586.

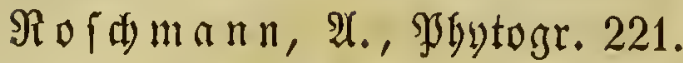

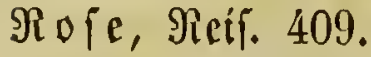

Rofé n, 5 , IJgytogr. 244.

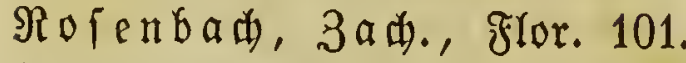

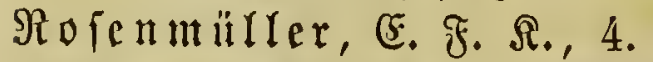

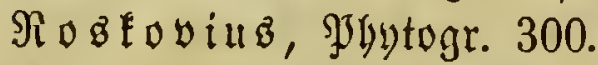

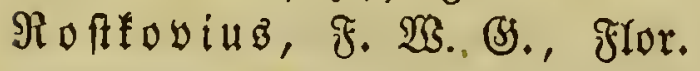
521.

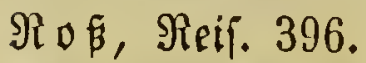

Rota,, , Flor. 549.

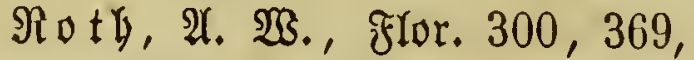
506.

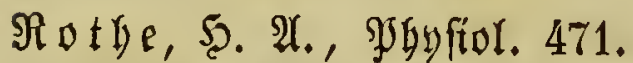

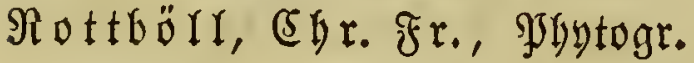
$243,248$.

Roucel, F. , Flor. 342.

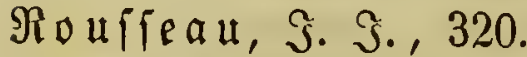

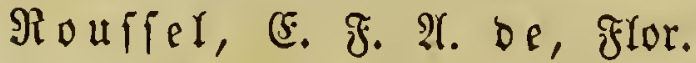
325.

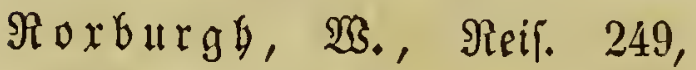
Flor. $566,572$.

Royen, A. van, 152, 203.

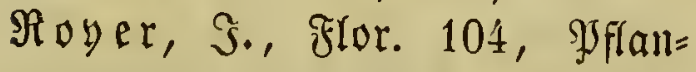
zengeogr. 600, Reif. 567.

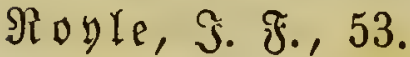

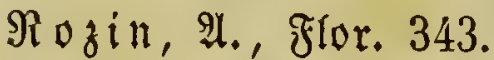

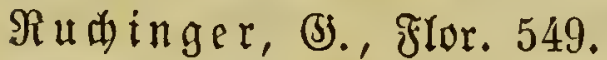

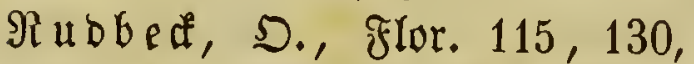

164.

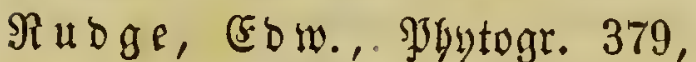
380.

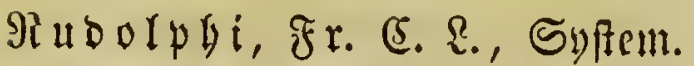
419.

Rubolpbi, J. 5., Flor. 228.

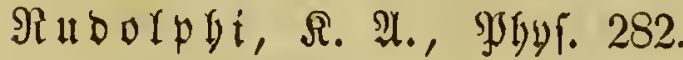
গuerte, S. 82.

Rüp pel, Dr., গicif. 570.

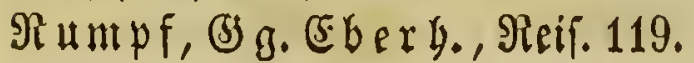

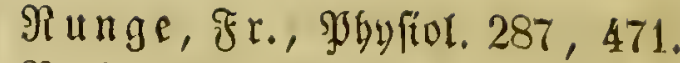

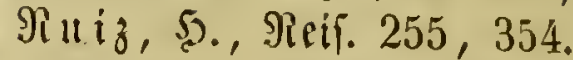
Rup , S. B. 146, Flor. 155. Rup redt, F. S., Flor. 563.

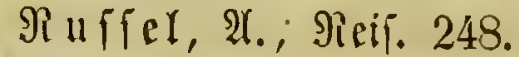

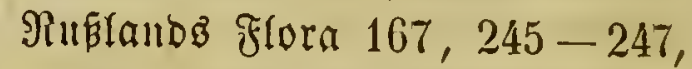
$364-368,560-563$.

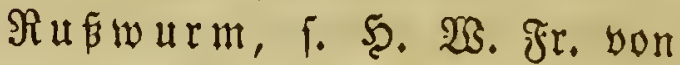
(S) reiden.

Ruthe, Sof. Fr., Flor. 519.

$\Re y a n$, Rcif. 358.

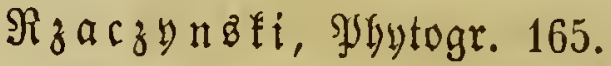

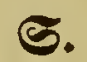

Sage, $\mathfrak{M}$. S., Flor. 521.

Sabbati, \&., Flor. 238.

Sabine, F., Reif. 396.

Sa⿱屮, 氶. S. R., Flor. 299.

Sadicn, Flora von, 155,227 , $278,315-317,524-526$.

Sabler, Sof., fror. 512.

Sidter, Mid., Flor. 513.

Sailer, Fr. S., Flor. 508.

Saint $\mathfrak{A} \mathfrak{A} a \mathfrak{a z}, \mathfrak{S}$. $\mathfrak{F} . \mathfrak{B}$. De, Flor. 328, 537.

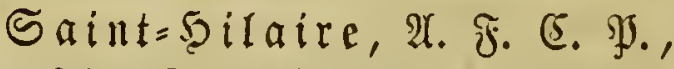
Flor. 324, Reif. 576, Monogr. $592,593$.

Saint=Şifaire, S., Syltell. 273, Jyytogr. 322, 532, 535, Spflanzengeogr. 600 .

Saint= Sincent, $\mathfrak{B}$. De, Reir. 555, grflanzengeogr. 598.

Salerno, Rlofter, 59.

Salizbury, 9i. A., Syptem. 276, SJyutogr. 336, 337, 340, 350 .

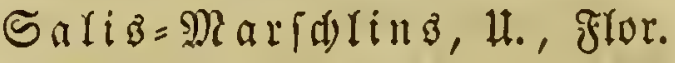
539.

Salmon, $\mathfrak{B} .$, Flur. 160. Salt, 5., গeif. 396.

Saljburg, Flora von, 304. 
Salt, 5., Raif. 570.

Saltri, I. ₹., fror. 548.

Sallguillatti, צy., Flor. 552.

Santi, (3), filur. 350.

Sarbinicu, Flora you, 550.

Sarrabat, 9j., f. Baitịc.

Sartori, Fr., Flor. 304.

Sauffure, 5. B. De, Jjgyiur. 209.

Sauffure, a q. v., अुgyfid. $285,383,450,485$.

ธauvagez, Fr. B., 194, flor. 231.

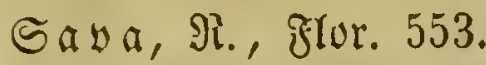

Savi, (3)g., flor. 349, 547.

Sbaraglia, (3). S. 206.

ভdy abcl, $\mathfrak{H}_{0}$, Flor. 516.

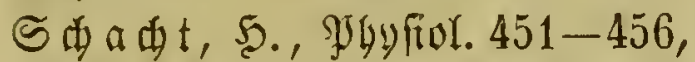
$458-466$ ，468，470，474，475, $478,450,481,484,492$.

ভđäfer, MR., flor. 524.

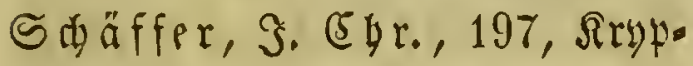
tog. 222.

S山üffer, R., Flor. 103.

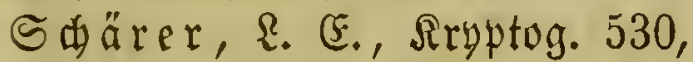
Monogr. 583.

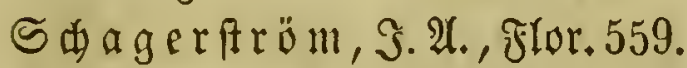

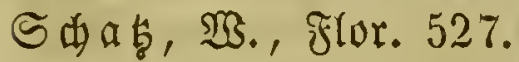

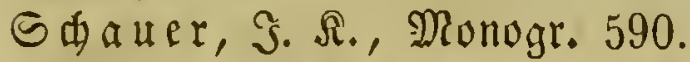

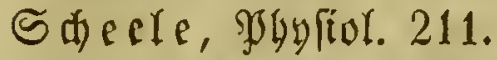

S申elgammer, (5)r. (3), flor. 104, 132.

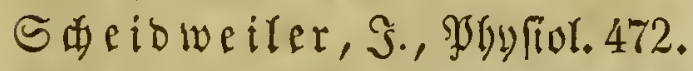
Saelver, gr. Sof., Sggyfiol. $295,489,495$.

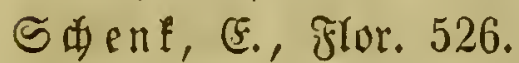
S中erbiub, Jol., flor. 311. ธdeudzer, Э. S. 156. 601. (Ed)euder, S. 157.

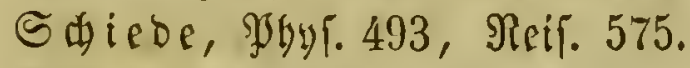
Sqiera, (3. M., 198.

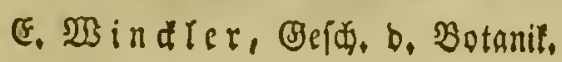

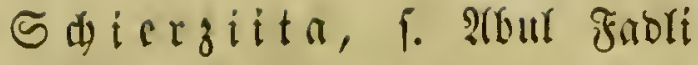
Sdjierjitita.

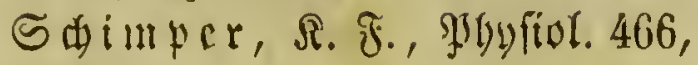
470.

Srimper, 25. 602, Monogr. 584, গicif. 565, 569.

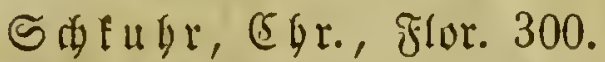

Shlagintweit, 5., Jflanjen= geugr. 596.

Sd) lagintwe it, $\mathfrak{A}$, Ffflauzen= grogr. 596.

Siledtendal, D. 5.. v., Syff. $416, \mathfrak{3 g y t o g r}$ 503, 519, 526 . Sqlentendal, D. F. \&. y., gjgytogr. 574.

Sdleider, J. (5. 320.

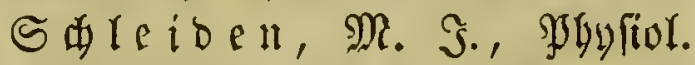
$450-460,462-466,470$, $472-475,477,478,481,484$, $490,492$.

Sdilefien, flora yon, 104, 226, $314,521$.

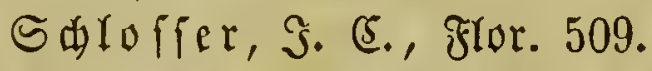

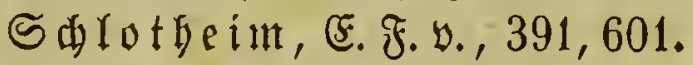

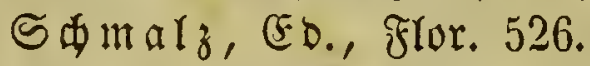
Samit, gogyfior. 481，567.

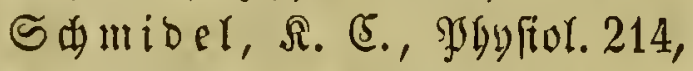
217, sblutogr. 222.

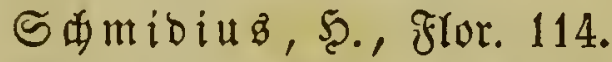
Sqmiblin, E.b., flor. 516. Sdmitot, Fr. 2 ilitib., flor. 305.

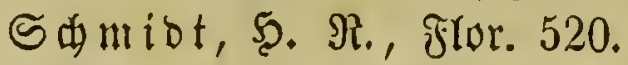
S中utibt, S. R., Myfolog 316.

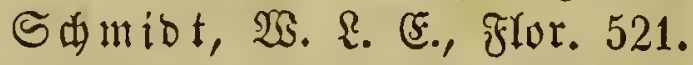
S4mi

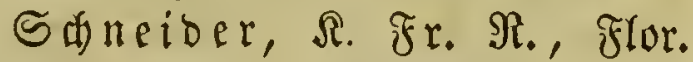
521, 522, अflanzengcogr. 595. Sanittipand, (3. F. 518 . Saniblein, 95gytogr. 299. Sditifleill, $\mathfrak{A}_{\text {. }}$ flor. 507, 514, Monogr. 585. 
Søuber, 35., Reir. 167.

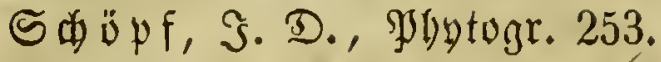
S由̈̈pfer, Fr. X., flor. 304. S d) oller, $\Im$. A. von, Flor. 226.

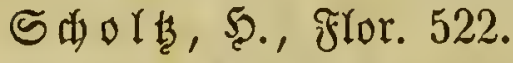

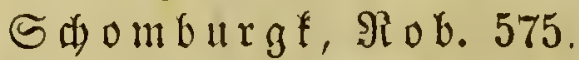

Sd) ott, 52., Sicif. 577.

Sduottland, Flora von, 114, 236, 544.

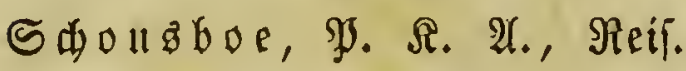
$369,569$.

Swoum, S. F., SPflangengeogr. $593,597,599$.

Sdraber, A. 5ூ. 502.

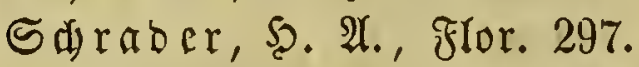

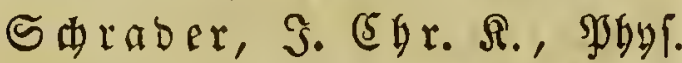
286.

Sqramm, Э. 2., flor. 522.

Sdrank, Franz be $\mathfrak{P} a u l a ，$ glyutogr. 221, Splyfiol. 281, 294, Flor. 304, 307.

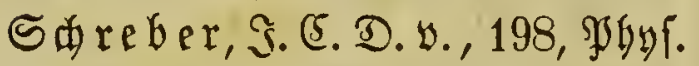
215, Flor. 227, 299, 375.

S中xe fenfein, $\mathfrak{F}$. $\mathfrak{B} . \Re$. v. flor. 310.

ธฯubert, 厄. 501.

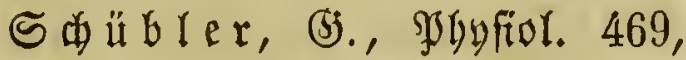
$471,474,482,486$, flor. 515, 516, গ̧flangengeogr. 595, 596.

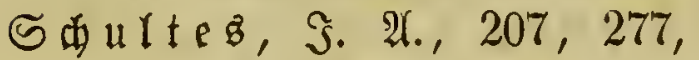
$279,301,302,307$.

Squrtez, \$. 5., Flor. 301.

S中ur

S屯ur

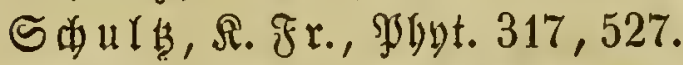

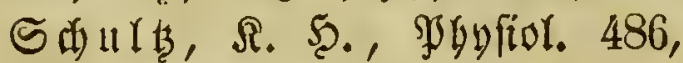
Flor. 515.

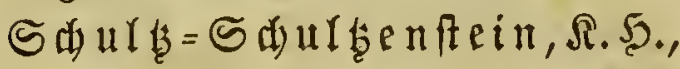

’jhy fiol. 460，470，481，482， Syftent. 440 .

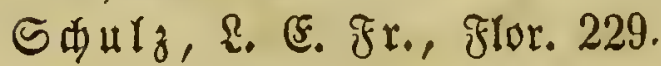

Squmader, (5qr. Fr., Reif. $359,371$.

Squabe, S. 5. 526.

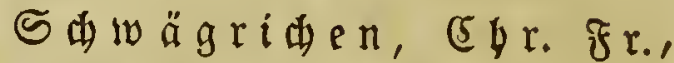
gjoytogr. 316.

Sdweben, Bgytogr. yon, 115$116,164,243,244,359-$ $364,557-560$.

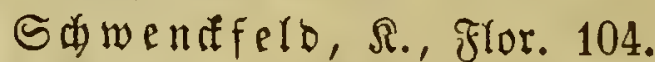

Sw weigger, A. F., flor. 307, Syftem. 439.

Sw weigger, S. S. (5. 7.

Schiveinit, \&. D. v., flor. $315,572$.

Shweizerifde Flora 99, 156, $229-230,319-321,528$.

Scopoli, S. A., 198, 204, Shy fior. 216, flor. 221.

Scoresby, $\mathfrak{2 0 . , ~ \Re e i f . ~} 574$.

Scotuz Miøael, F. Midael Scotur.

Scribonius sargub Defig= natianuв 38.

Scuberi, S., Sflangeng. 597. Spbaftiani, A., Şlgtogr. 350, $551,552$.

Secretan, 足, Sryptog. 530 . Seguier, Fr., Sglytogr. 237.

Seiol, $\mathfrak{3}$. B., Flor. 510. Seligmann, S. $\mathfrak{W}$. 208. Sellow, Reif. 378, 576.

Sendtner, S., গJbyfiol. 467, Sfflanzengeogr. 595.

Senebier, Э., Jgyfiol. 211, 280, $289,293$.

Senegambien, Flora von, 250. ธenż, fyora boit, 104. Sepp, Э. G., Flor. 343. Serapion, D. 3. 51. Seringe, R. (5)., Jjgytogr. 321, 528, Monogr. 590, Syftem. 444. 
Serra, correa or, flor. 356. Serreb, 3. 3., flor. 536.

Setbuв , Simon, 45.

Seubert, R., flor. 572 .

Sฤחw, Th., গieif. 167, 249.

Sberaro, $30.153,165,166$.

Sibbaro, R., flor. 114.

Sibirifac frlora 246, 247, 367, 368 . Sibthorp, 3., Bgytogr. 241, $337,357$.

Sianann, Э. R., flor. 528.

Sicilien, fflora yon, 109, 110, $239,553$.

Sicbcnbürgen, Floravon, 306, 513. Sieber, F. W., Reifend. 395, $556,575$.

Siebold, 9y. Fr. v., Meif. 565. Siegezbef, Э. (3). 190, flor. 245. Sieverb, J., Reif. 247.

Simonde Gordo 61, 62.

Simond, Srlinger, Flor. 336.

Sims, Sobn, 341.

Sla fi, গybyfior. 483.

Sloane, S., গeif. 122.

Smitb, 巨̧r., Reif. 371, 395.

Smith, (5). (5., Flor. 544.

Smith, S. F. 199, Flor. 296, $333,335,379$, 9ghyfiol. 293, 3ryytogr. 539.

Smith, 5. S., Seif. 371.

Sobolewży, çyr., Flor. 365. Sommerfelt, S. 5h. 558.

Sonnerat, গ1., Reif. 247, 249, 257.

Sonnini, א. S., Reif. 370.

Soulavie, 5b., Flor. 233, şflanzengeogr. 258.

Somerby, 巨. E., Flor. 542.

Sowerby, S., Flor. 334, 339. Soyer = Siltemet, Sygyfor. $468, \mathfrak{s l o r} .538$.
Spảatin, Rob.78.

Spartanzani, R., Jgyfiol. 214, 489.

Spanicn, die erften Sotanifer bieícz \&anoeż, 89.

Spanten, Sybtograpben bon, 110 , $239-241,353-355,553-$ 554.

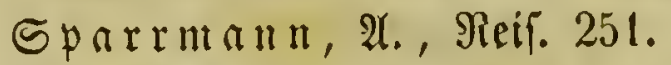
Spenner, \&., Jlor. 517. Sperting, 5. , Flor. 115. Spicgel, A., Sgyton. 136-156. Spielmann, S. R., Flor. 231. Spitbergen, Flora von, 123.

Sprengel, (5yr. Conrad, 3̧byfiol. 294.

Sprengel, $\mathfrak{i} u \mathfrak{r}, 207$, Syft. 276, 438, 446, 447, गפgy. 281, Flor. 301, 314, 502, 503, 522. Spring, $\mathfrak{A} . \mathfrak{F r}$, Syftem. 444, Monogr. 585.

Stachoule, S. 340 .

Standin, Shyfiol. 465.

Steiermarl'z Flora 508.

Steinbeil, $2 .$, Flor. 569.

Steflofen, 5. S., Flor. 344. Sterler, (3). W. , Meif. 246. Steplan, Fr., Jjhytogr. 365. Sterbef, frz. ע., Sghyt. 107. Sternberg, Razp. (J) raf ע., Flor. 299, 346, 511, Sfflan= zengcogr. 595.

Steudel, (5. (3., Flor. 506.

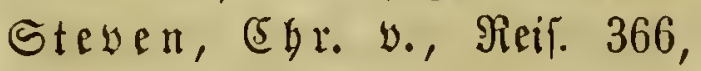
Monogr. 589.

St. Seclena, Spflanzen yon, 572. Steyermark's flora 304. Stieff, So4. (5., 197. Storz, Э. Ér., flor. 329. Strabo, $\mathfrak{B a l a f r i e b , ~} 57$. Strapburg'z Flora 231, 329. 
Strebler, R. F. , Flur. 514.

Striftand, S. S. 335.

Strobelberger, Sob. Steph. 107.

Ström, Ş., Flor. 242.

Strobmeier, Fr., Sflanzen= geogr. 383.

Sturm, Sac., flor. แ. Daler, 299, 499, 501.

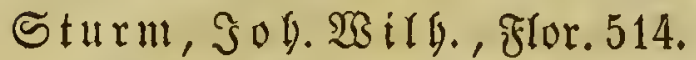
Stuttgart, Flora von, 516.

Succow, F. SE. R., Flor. 516 . Succow, (5), SJgyfiol. 486.

Suff ow, (3). A. 199, गुy以 212. Sübafrifa, bflamzen b., 570-572. Sübamerifa, Flora yon, 254-256. Suffien, M. De, Aeir. 304. Sumatra, Flora von, 249, 568. Surningar, Bhyfior. 466.

Suter, S. R., glor. 320.

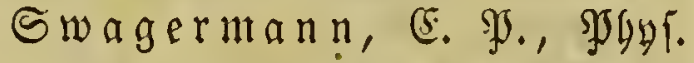
208.

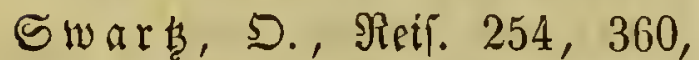
$364,378$.

Sweet, $\Re$ ob., Flor. 580, $\mathfrak{M l}_{\mathrm{v}}=$ nogr. 591, Spyytogr. 543.

Syen, A. 117.

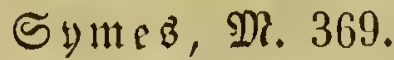

Syrien, Flora biefez Sanbes, 90 , $247-248,349$.

Syftemfunbe $83-96,124-135$, $142-147,171-206,261-280$, $411-447$.

Szorits, S., Reí. 563, 564.

Iabal 92.

\section{$\mathfrak{s}$}

Tabernaemontanus, . . Sac. Ibeob. woll Bergantern.

Tardent, çyarl., firlor. 563. Targionti= Tojetti, $\mathfrak{D}$, 349 . Taffi, 3yufiol. 488.
Tauf Ienore, M., Flor. 351, 532, Pflanzengeogr. 597.

Teyzmann, গjhyfiol. 487.

Thalı

Tyeoderid 55,56 .

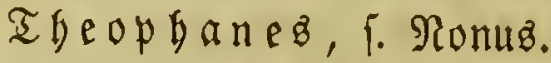

Theophraft $21,22$.

Thomä, 5. , flor. 518 .

Thoma , F., Flor. 530 .

I

Thoma bon $\mathfrak{A} \mathfrak{q}$ u $i$ no 60 .

Igomfon, Th. Sybyfiol. 471 .

Thonning, Reif. 371.

Tbore, S., Flor. 326.

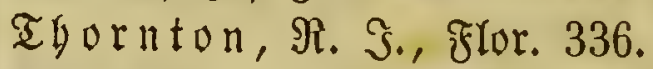

T)

Thulier, S. R., flor. 324.

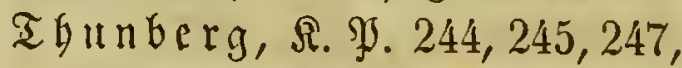

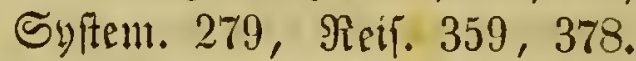

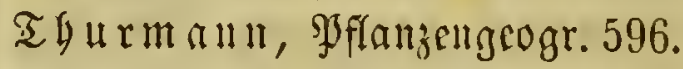

$\mathfrak{I} \mathfrak{i}=\{\mathfrak{a} n \mathfrak{z}, \mathfrak{F} \mathfrak{l}, \mathfrak{f l o r} .116$.

Tili, M. R., Jjhytogr. 164.

Tim m, soad. ธ上丨., slor. 229.

Iinfo, (5), fflor. 353.

Sineo, $\mathfrak{3}$., Flor. 553.

Iit $\mathfrak{1}, \mathfrak{A}$., Flor. 162.

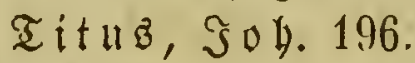

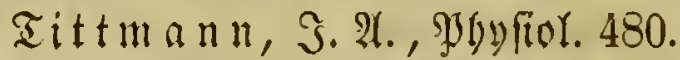

Toonro, A., Flor. 553 .

TODe, S. S., Mptolog. 317.

Iongue, (E., Jjgyfiol. 139.

Touning, 5., Jjbytogr. 242.

Torrey, S., flor. 573.

Tournou, D. S., Flor. 328.

Tobีanifar flora 238.

Iourette, çaret be la, fror. 232 .

Tournefort, Sol. Sitt. Oe, 142-145, Jbytogr. 157, গicif. 166, Pflanjengeogr. 3S2. 
Iowera, MR. (3), gyGyftul. 482.

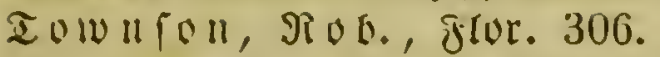

Iojetti, argioni, Bbioy, grbyfiol. 217, fror. 238.

Iojetti, Iargioni, D., grigutegr. 238.

Iragub, f. Ş. Bod.

Irattinif，足, Sylfemat. 276, flor. 303, Monugr. 590.

Irautuetter, Jjoyfor. 466,

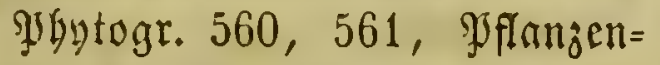
geogr. 599.

Trecul, Phyfidr. 459,463，465, 468.

Trerterb, R., flor. 160.

Irentepogl, 3. F., \$ghyt. 300. Treveryan, 2B. א., gyflanjen= geogr. 599.

Terelyan, 25. હ. 557.

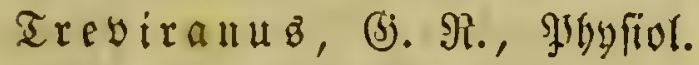
288, yflanjengeogr. 383.

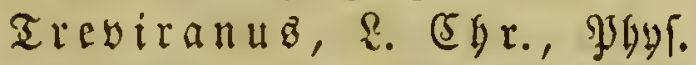
$283,284,290,294,460,461$, 465, 477, 478, 490, Flor. 299 . Trevifan, Bictor (3) rafon, flor. 549.

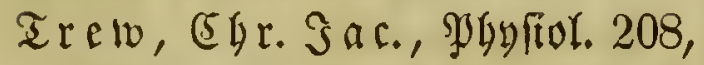
Slyytogr. 223.

Trient, Flora yon, 162.

Irindinetti, Jgyfiol. 463,481. Trinius, B. v., 560, Mondgr. 586.

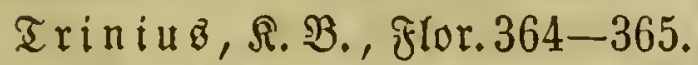
Triptolemuz 5 .

Triftan, $\mathfrak{s} u$ l. (B) $\mathfrak{r}$ af $\mathfrak{y}_{\text {, }}$ firor. 326, פ⿹勹冫fiof. 468.

Triumfetti, 3. B., 9hy f. 139. Iübingen, Flora von, 154, 516 . Türfei, Jiora ber, $241,357,555$.

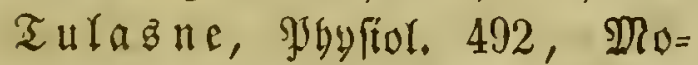
nogr. 583, 587.
Turczaninow, $\Re$. $564,565$.

Turuer, D., fror. 338, 339.

Turner, M. 114.

Turuer, S., গieí. 368.

$\mathfrak{I} \| \mathfrak{r}$ ยr $, \mathfrak{3} 3.88,89$.

Turpin, গু. Э. F., Flor. 325.

gjoyrtol. 495.

Turra, $\mathfrak{A}$ t. , flor. 238.

Tuffac, (3). R. De, flor. 376. Iyrell= $\mathfrak{A} \mathfrak{r t i}$, ED $m .601$.

Tyrol's filora 304.

\section{it.}

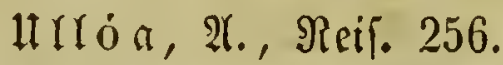

Hrm, flora yon, 154.

Ungarna flora 101, 221, 305$306,512-513$.

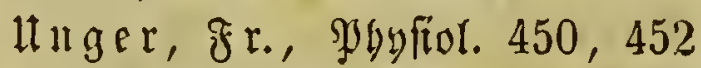
$-456,459,460,462,465$, $469,473,474,475,481,482$, 483, 486, 491, 495, flor. 507, Syftemat. 430,603, Pfflanzens geogr. 594, 595 .

Hpiala, ßjarten 孔ll, 115, glora yon, 165 .

$\mathfrak{H r b a n , ~ 5 e n r i f u z , ~ f . ~ C o r b u z , ~}$ ritr.

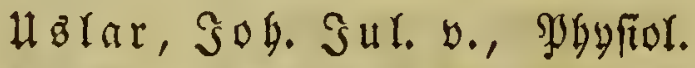
288.

Ufteri, P., Stor. 230, 295, 344.

\section{$\mathfrak{B}$.}

Bagl b. Süngere, Reir. 574.

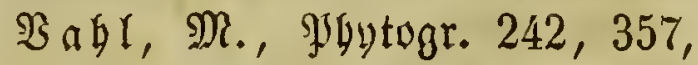
$358,375$.

Bailfant, Seb., 145， 149, Jgytogr. 157, 158.

Balentini, M. $\mathfrak{B}$, wghytogr. 154.

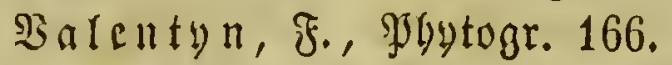

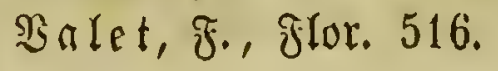


$\mathfrak{B}$ alle , F. , fflor. 239, 539.

Balliżncri, $\mathfrak{A}$, frlor. 162.

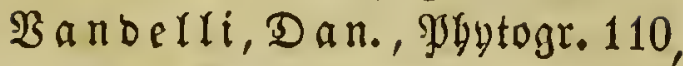

241 , Reif. 255.

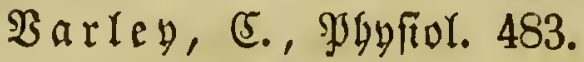

Barro, $\mathfrak{R} . \mathfrak{T}$. $28,29$.

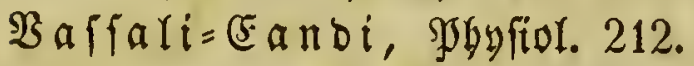
$\mathfrak{B a u \notin e r , ~ S . ~ S j . ~}$

321, Monogr. 585.

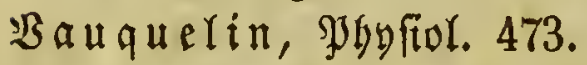

Bencoig, Flora bon, 109, 162.

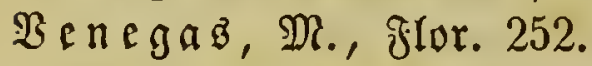

Bentenat, অ. Ş., Syitemat.

273, Spgtogr. 330.

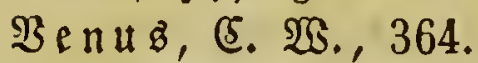

Bergirius Marcellus 36, 69.

Berona, flora von, 162.

Berrow, Reif. 123.

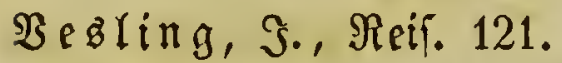

Beft, R. y., Flor. 300 , Syftem. 439.

Bicenja, Flora yon, 238.

Bigne, (s. Fr. be Ia, Flor. 298. Bigneux, $\mathfrak{A}$, Flor. 324 .

$\mathfrak{B}$ illar $\mathfrak{b}, \mathfrak{D a n}$, flor. 232, 321. Binceng, S. 5., Flor. 328.

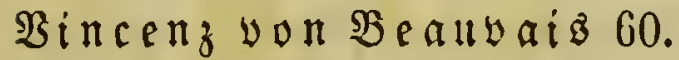
Birey, Jyyftol. 473.

Birgitifde Flora 30.

Birgiliu $\mathfrak{R}$ aro, $\mathfrak{s}$, , 29, 30. Birginien, flora von, 123, 169, 252.

Bifiani, $\Re$. De, Flor. 513, 570 . Biviani, D. , Flor. 348,539 ,

$548,569$.

$\mathfrak{B}$ it mann, $\mathfrak{F}_{\text {. , }} 238$.

3odenberg 63 .

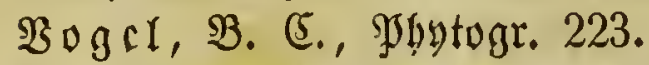

$\mathfrak{B} \cup \operatorname{gel}, \Re$. A., SJgy fiol. 212.

Boigt, Fr. S. 390 , Syft. 443.

$\mathfrak{B}$ oigt, S. R. $\mathfrak{B} .602$.
Boigtlands mertmürdige Pflanzen 228.

Boit, গ. अ. $\mathfrak{3}$., গJbytogr. 299, 308.

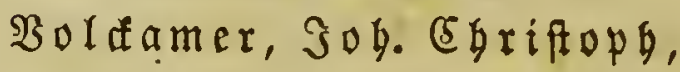
Sogtogr. 154.

Sol áamer, Soh. (3), Flor. 100.

$\mathfrak{B}$ ol f mann, (3). $\mathfrak{A}$, 601.

$\mathfrak{B}$ ol $\mathfrak{a} \mathfrak{a}$, Sgyfior. 212.

Briefe, SJgyftor. 463, 487, \$̧6y= togr. 569.

Brolit, (3)., Shbufiol. 293, 487. Brolit, $\mathfrak{B}$. , flor. 546.

\section{X3.}

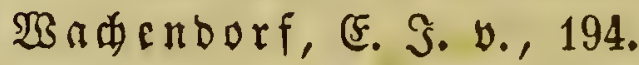
Ta abe, 28 alth., flor. 333.

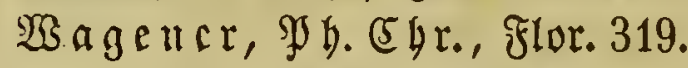

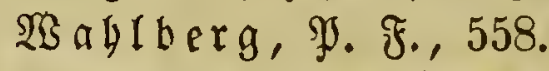

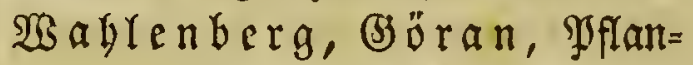
zengeogr. 320,386, flor. 306 , $362-363,364,557$.

Waldern, Flora yon, $10 \%$.

Walafried Strabo, f. Strabo. W alcot, Sobn, Flor. 235.

Wald fein= $\mathfrak{B a r t e m b e r} g, \mathfrak{F}$.

A. (अ) $\mathfrak{r} \mathfrak{f}, 306$.

$\mathfrak{B} \mathfrak{a} \mathfrak{l} \mathfrak{e} \mathfrak{r}=\mathfrak{A} \mathfrak{r}$ ott, $\mathfrak{J l o r} .567$.

$\mathfrak{B}$ alfer, $\Re$., Flor. 544.

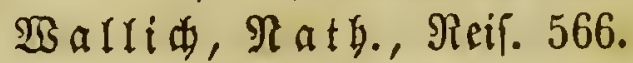

Walfroth， (5. Fr. Wilf., Flor. 314，505，522，527,

Monogr. 588, 590.

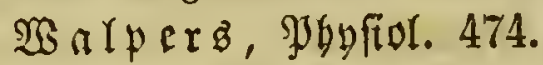

Ba a ter, gJgufiol. 482.

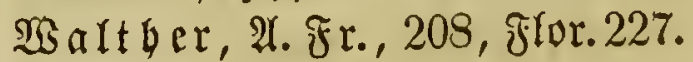

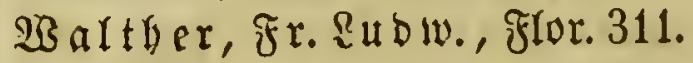
$\mathfrak{B a l t b e r , ~} \mathfrak{x}$ o om. , Flor. 252. isaltl, Sob., Jbyfiol. 473.

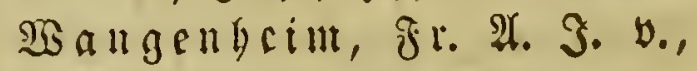
Jghtogr. 253. 


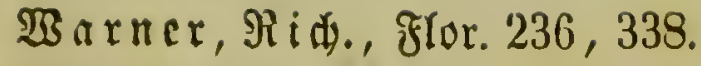
Wartmant, J., Flor. 531.

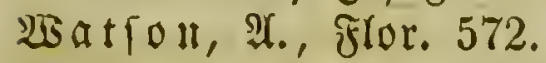

Watfon, 5.. (5., flor. 542, Syflanzengeogr. 597.

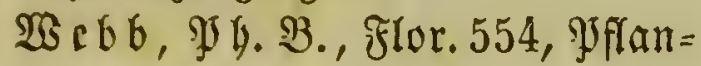
zengrogr. 599.

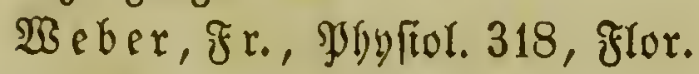
364.

$\mathfrak{e} \mathfrak{e} \mathfrak{e r}$, (3) g. Saeinr., flor. 229, 528.

Wed bel, Monogr. 587, 588. Wegelin, $\mathfrak{x}$ h., Pbytogr. 530. Brigel, (5)r. Egrenfr., flor. 225.

Beigel, sok. Alo. Ba l., Flor. 314.

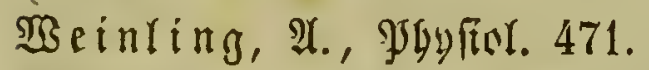

Weinmann, J. A., Flor. 561,

Rryptog. 560.

Beí, Fr. Wíth., flor. 229, Thy fitor. 216.

Eseizenbef, (5). 2l., flor. 222. Werden, v., Syflanzengedgr. 596. Wella, bot. Baart. baf., 88.

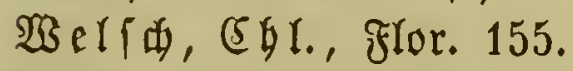
Weltwitid, S., Flor. 508. Benderoth, (G. $\mathfrak{B} . F_{.}$, Flor. 518, Syftem. 442.

Wendiand, 5. \&., Monogr. 591. Weniger, $\mathfrak{5}$. R., flor. 523.

Berner 505.

werner oe la çgenal, fylor. 230.

Wernefind, Fr., Flor. 315. Wernif山ef, Sar. 196.

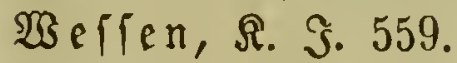
WSe ft, 5., Neif. 358, 375. Weftindien, Flora von, 122, 253 $-254,574-575$.

Befton, Ri由. 235.

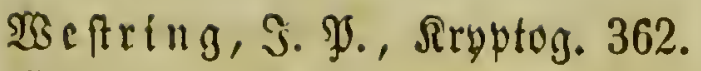
Whacler, (3). flor. 111.

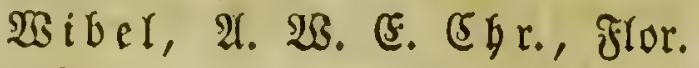
310.

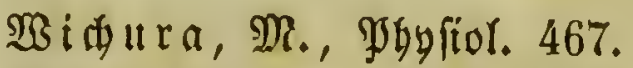
Wied = Reumieb, Mring von, Reit. 378.

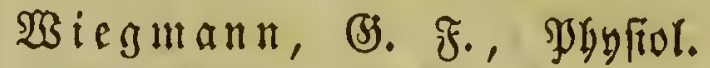
463, 472, 482, 493, 494. Wien, flora yon, 220, 508.

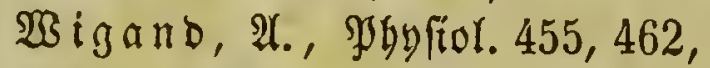
$493,496$.

\$igano, Sol., fror. 102. Wiggerz, F. 5., flor. 229.

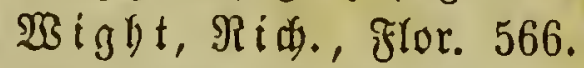
Wight, $\Re$ bb., flor. 566 .

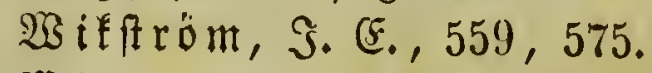
Birbrand, S. B., flor. 506, Shy fiol. 489, Syftemat. 440, Yjflanzengeogr. 594, 595. B̧il Sistroenow, R. ‥, Flor. 225, $311,312,371$.

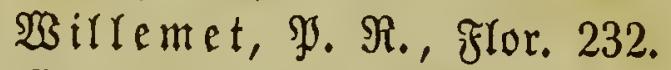

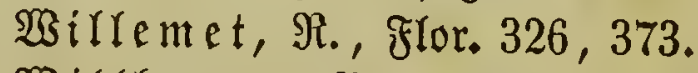
Wirlfom m, M., Syftem. 444 -446, Monogr. 589, Pflan= zengeogr. 598, Sbygtogr. 554. Birmer, B. 235.

Birfon, Sogn, Flor. 234. Wimmel, Spgufiol. 469. $\mathfrak{B i m m e r}, \mathfrak{F r}$, $\mathfrak{F l o r} .522$. Win zengeogr. 597.

Winterl, S., flor. 221. Winterímiot, S. S., flor. 514.

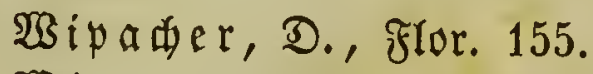
Birtgen, gybir., flor. 523.

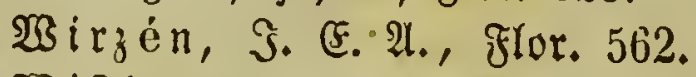
Wiftbrand, A. T. 558. 
Witlering, witr., Jior. 234, $-334$.

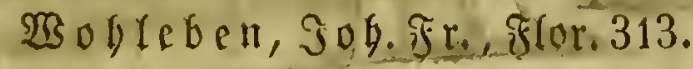
Wolff, ç) 150.

Wolff, (5. T)., Sobyfiol. 472. 2Bolff, R. ₹r., Spgyfít. 214, $387,383,389,456$.

3000 forbe, 3., Flor. 545.

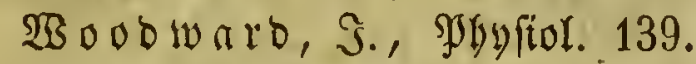

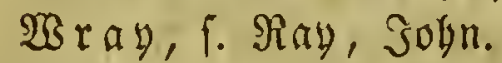

wrebow, S. c. R., frlor. 317.

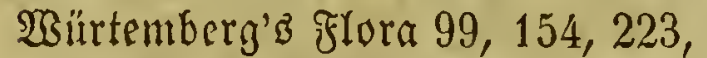
$309-310,515$.

23it nf Wît uneferd, F. S. 54.

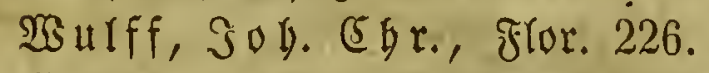

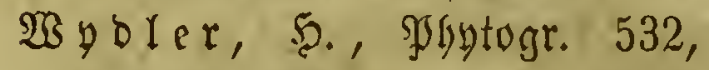
Monogr. 589.

Soybler, S., 9by 4 . 470, 490, 491.

$\mathfrak{X}$

Ximenคż, $\mathfrak{F r .} 92$.

\section{3.}

3afuzianzy bon 3 aluzian 135.

3anidierri, (3). J., Flor. 162. 3 a non, ysgyfior. 487.

3 a noni, A. (3). PJytogr. 108. 3 ante beschi, Sygyfiol. 487.

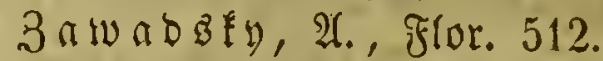
3enter, S. న., flor. 526, 567.

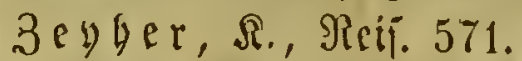
3 inn, 3. (3., Flor. 228. 3 ippeliuz, Reif. 567.

$3 i z$, 3. B., flor. 310. 3 oega, $\mathfrak{3}$, Solytogr. 243.

3 olrifofer, 5. T., Jjbytogr. 530. 3ollinger, 5. , Reif. 568. 3 uccagni, $\mathfrak{x} .350$. 3 uccarini, S. (5., Flor. 513, 565, Monogr. 591, Sflanjen= geogr. 595.

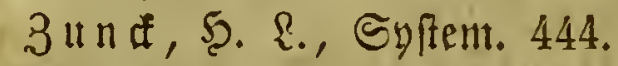




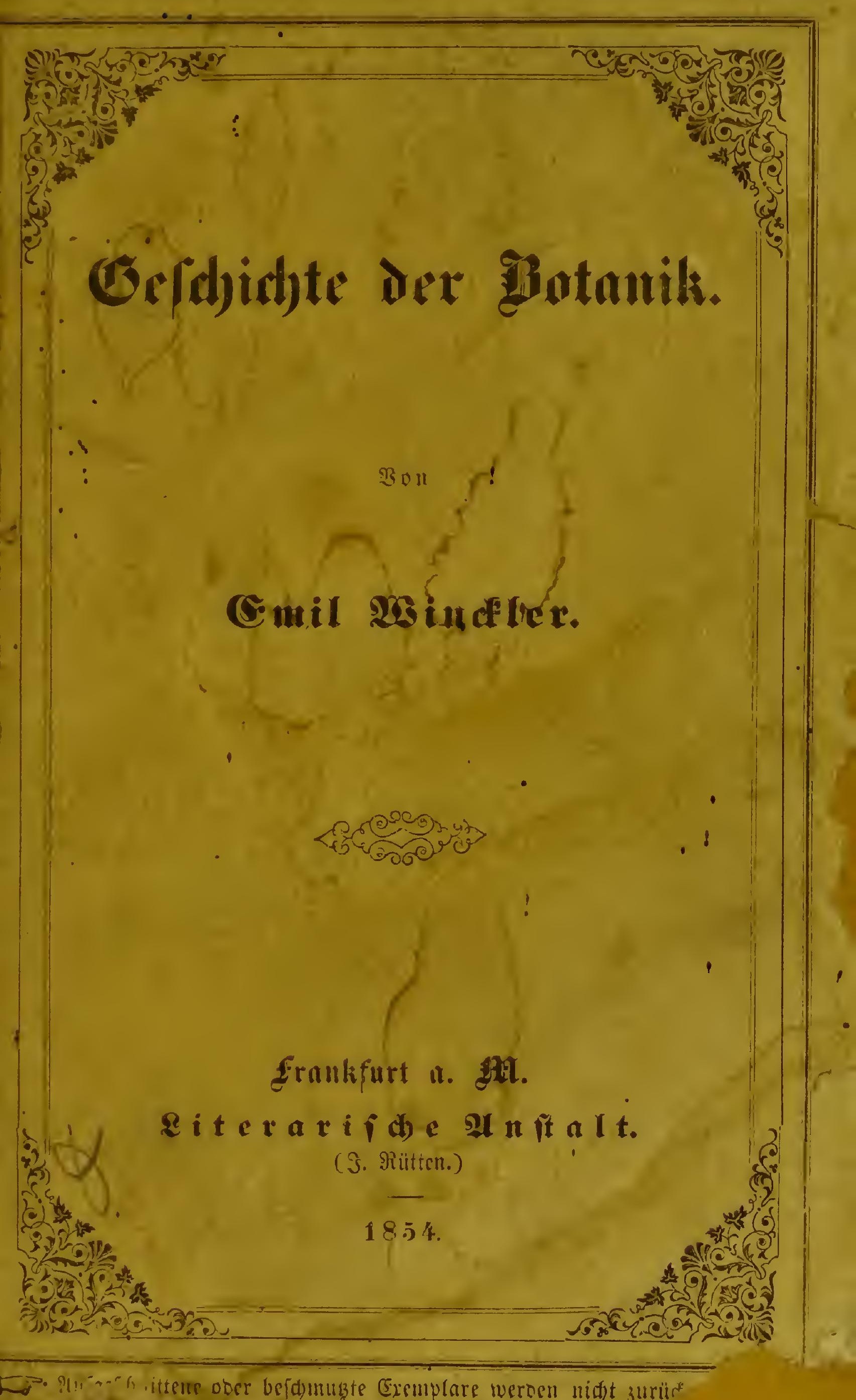




.

II 



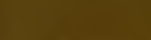

$+1$ 